\title{
Barāqish/Yathill (Yemen) 1986-2007
}

\author{
Volume 1: \\ Excavations of Temple B \\ and related research and restoration
}

Scavi del Tempio B e ricerche e restauri connessi

\author{
Edited by / A cura di \\ Sabina Antonini and Francesco G. Fedele
}





\section{Barāqish/Yathill (Yemen) 1986-2007}

Edited by / A cura di

Sabina Antonini and Francesco G. Fedele

Contributions by / Contributi di

Alessio Agostini, Sabina Antonini, Mounir Arbach, Vittoria Buffa, Christian Darles, Francesco G. Fedele, Solène Marion de Procé, Alessandra Paladino, Jérémie Schiettecatte, Saverio Bruno Scigliano, Rosario Valentini

\section{Volume 1: \\ Excavations of Temple $B$ and related research and restoration}

\section{Scavi del Tempio B e ricerche e restauri connessi}

Arabic translation of abstracts by / Riassunti in arabo di Khālid al-'Ansī 


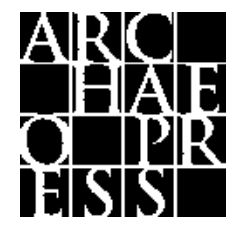

ARCHAEOPRESS PUBLISHING LTD

Summertown Pavilion

18-24 Middle Way

Summertown

Oxford OX2 7LG

www.archaeopress.com

ISBN 978-1-78969-470-3

ISBN (e-Pdf)

(C) Archaeopress and the individual authors 2021

Cover: View of Barāqish from the southeast after a major rainstorm (22 July 1992; cf. Chapter 1, section 3.3) (A. de Maigret 1992 @ MAIRY)

This book is available in print and as a free download from www.archaeopress.com 


\section{Contents}

\section{VOLUME 1}

Contents

Preface

Premessa...

Contributors

Dates and Arabic Names.

Barāqish: Reference Map and Plan.......

\section{Introductory Information}

Chapter 1

A History of Archaeological Research at Barāqish and in Its Area

Sabina Antonini and Francesco G. Fedele ${ }^{1}$

Chapter 2

Risultati della prima prospezione della Missione archeologica italiana a Barāqish nel 1986.

Sabina Antonini

\section{The Temple of 'Athtar dhu-Qabd (Temple B)}

Chapter 3

Il tempio di 'Athtar dhu-Qabḍ. Lo scavo

Alessio Agostini

Chapter 4

Il tempio di 'Athtar dhu-Qabd. Le iscrizioni

Alessio Agostini

Chapter 5

Il tempio di 'Athtar dhu-Qabḍ. Gli oggetti

Sabina Antonini

Chapter 6

An Obsidian Cache from Temple B

Francesco G. Fedele

Chapter 7

The Temple of 'Athtar dhu-Qabd. The Pottery

Vittoria Buffa

\section{Extramural Excavation at Recess R44/45 (Minaean Wall)}

Chapter 8

Lo scavo fuori mura in R44/45 a Barāqish

Sabina Antonini con Rosario Valentini

Chapter 9

Lo scavo fuori mura in R44/45 a Barāqish. Le iscrizioni

Alessio Agostini

\section{Architecture and Cult}

Chapter 10

L'architecture des Temples de Nakrah et 'Athtar dhu-Qabḍ à Barāqish

Christian Darles

Chapter 11

Le mobilier de culte dans le temple de Nakrah à Barāqish

Solène Marion de Procé 
Chapter 12

La brique de terre crue dans les fortifications de l'Arabie du sud. L'exemple de Barāqish. .270

Christian Darles

\section{Restoration: Temples A and B}

Chapter 13

Restauro conservativo e strutturale degli elementi architettonici della sala ipostila del Tempio di Nakrah (Tempio A) a Barāqish

Saverio Bruno Scigliano e Alessandra Paladino

Chapter 14

Restauro, movimentazione e messa in sicurezza degli elementi architettonici del tempio di 'Athtar dhu-Qabḍ (Tempio B) a Barāqish

Saverio Bruno Scigliano e Alessandra Paladino

\section{Barāqish/Yathill: Corings and Radiocarbon}

\section{Chapter 15}

Exploratory Coring at Barāqish, 1987 and 1990.

Francesco G. Fedele

Chapter 16

Radiocarbon Determinations 1987-2006: Corings, Temples A and B, Area D. A Survey and Reappraisal ........355 Francesco G. Fedele

Bibliography for Volume 1 .368

\section{MISSIONE ARCHEOLOGICA ITALIANA NELLA REPUBBLICA DELLO YEMEN}
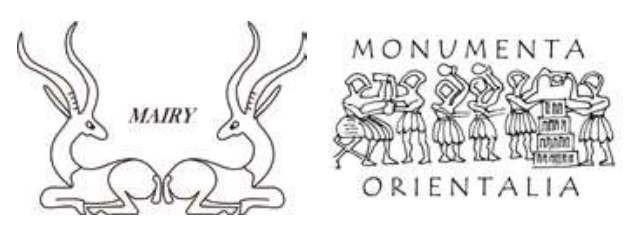

Unless indicated otherwise, the illustrations are from the archives of the Italian Archaeological Mission to Yemen (C) MAIRY).

The research for, and production of, the manuscript for this volume were made possible through a generous grant from The Shelby White and Leon Levy Program for Archaeological Publications (2017-2020). 
VOLUME 2

\section{Extramural Excavations in Area C}

Chapter 17

Excavations in Area C. Setting, Stratigraphy, and Geoarchaeology

Francesco G. Fedele

Chapter 18

Excavations in Area C. Chronology and the Historical Sequence

Francesco G. Fedele

Chapter 19

Excavations in Area C. Economy, Trade, and the Environment

Francesco G. Fedele

Chapter 20

The Area C Collection Catalogue and Related Works

Francesco G. Fedele

Chapter 21

Area C. The Objects

Francesco G. Fedele and Sabina Antonini

Area C. The Objects

Chapter 22

Area C. The Minaean Pottery

Vittoria Buffa

Chapter 23

Area C. The Sabaean Pottery: a Survey

Francesco G. Fedele

Chapter 24

Area C. Il materiale epigrafico

Alessio Agostini

\section{Ceramic Typology, Territory, and a Historical Outline of the Jawf}

Chapter 25

The Typological Classification of the Minaean Pottery from the Temple of 'Athtar dhu-Qabd and the Extramural Excavations in Area $\mathrm{C}$

Vittoria Buffa

Chapter 26

A Glimpse of 'Greater Yathill': Sabaean Settlement and Tell Evolution

Francesco G. Fedele

Chapter 27

Les inscriptions de Barāqish : apport à la connaissance de l'antique cité de Yathill et du royaume de Ma'in

Jérémie Schiettecatte avec la collaboration de Mounir Arbach

Chapter 28

Risultati di una prospezione archeologica nel sito di Darb al-Șabī

Rosario Valentini

Abstracts of Chapters.

Bibliography for Volume 2 
:三 


\section{Preface}

We considered it a duty to devote a substantial publication to Barāqish at the end of the archaeological works - surveys, excavations, restorations - conducted at this amazing and challenging site by Professor Alessandro de Maigret from 1986 to 2007. Readers will be able to understand the importance of this site in the Jawf from Chapter 1, dealing with the history of explorations carried out at Barāqish and its territory since 1870, until the first systematic survey by the Italian Mission (MAIRAY, afterwards MAIRY) in 1986. A site further investigated through excavations and restorations between 1989 and 2007, with major work at the temples of Nakrah (Temple A) and 'Athtar dhu-Qabd (Temple B) as well as in extramural areas.

Not only does the volume feature previously unpublished results and materials from reconnaissance and excavations, together with architecture studies and the MAIRY restoration projects, but, thanks to the generosity and determination of Professor Francesco Fedele - who deserves most of the credit for this publication - it also reveals a great deal of forgotten data alongside more recent and newly-acquired information. This has resulted in the acquisition of crucial knowledge about the history and economy of this splendid caravan city.

Access to Barāqish and the whole Jawf has not been allowed for security reasons since 2007, which is why the excavations and the study of collections came to a halt. For instance, we could not complete the excavation in the southern sector, beyond Temple B, or in the area between Temples A and B. This would have helped to understand how the two temples were connected, since Temple $B$ is situated about 2 metres above Temple A. Of course, we would have liked to bring to completion the study of all archaeological materials, including those of the Islamic period. We are therefore fully aware of some obvious limits in this publication.

As mentioned above, it was impossible to return to Barāqish after 2007. The archaeological material studied (objects, ceramics, inscriptions etc.) were deposited in storage rooms and in the 'antiquarium', which was built especially for that purpose by MAIRY in the southwestern area of the site. The rest of the material which was being studied at the time was left on shelves and tables in the laboratory. During my last stay in Șan' $\bar{a}^{\prime}$ in September 2013 I managed only to make sure that a small part of the material reached the capital, mostly the Islamic pottery that was still sealed in bags.

It ought not to be forgotten that during the current conflict in Yemen, which started in March 2015, the Barāqish site was bombed by Saudi Arabia as the leader of a coalition formed to stop the Houthi advance in Yemen. Part of the city wall was destroyed, the temple of Nakrah was virtually wiped out, and the Temple of 'Athtar dhu-Qabd was severely damaged. Recent satellite images show that all what had been built by the Italian Mission, including the storage rooms, the 'antiquarium', and the laboratory, is now just a pile of rubble and debris.

\section{Acknowlegements}

The excavations in Barāqish were directed by Professor Alessandro de Maigret, to whom this volume is dedicated. He was particularly fond of this site, so much so that his dearly-missed friend, Prime Minister 'Abd al-Karìm al-Iryānī, called Alessandro 'Abu Barāqish' in a speech on 10th December 2006, at Șan' ${ }^{(\bar{a})}$ University during the presentation of a book dedicated to qā

We would like to dedicate this book to our friend and colleague Mario Mascellani, who died on 11th September 2015. A CNR (National Research Council of Italy) researcher, Mario had collaborated with the Italian Mission in Yemen since 1985. His last topographic survey on the Gaymān site dates back to 2010. His scientific contribution in the field of archaeological discovery and environmental exploration is incomparable, and his production of high-resolution cartography is of great scientific value.

We would like to thank all collaborators who have taken part in the more recent excavation missions: the officials of GOAM (General Organisation of Antiquities and Museums): Khālid al-'Ansī, Șādiq Sa'īd 'Uthmān, Mabkhūt Muhtamm, Mana' Allāh Sārī al-Nașrī, Muḥammad Ḥajar, 'Abd al-Bașit Nu'mān, 'Īsa 'Alī al-Shaybānī, Jamāl Thābit, Aḥmed Shamsān; archaeologists Alessio Agostini, Francesco Di Grazia, Romolo Loreto and Rosario Valentini; epigraphists Christian J. Robin and Mounir Arbach; architects Jean-Marie Gassend and Ghislain Richoux; topographer Mario Mascellani; restorers Saverio Scigliano and Alessandra Paladino; nurse Patrizio Morlupi; and last but not least the students from the University of Naples 'L'Orientale' Danilo Mongiello, Serena Vessichelli, Marilena Scuotto, Gennaro Di Rosa e Stefano Javarone. The ceramics studied by Vittoria Buffa were drawn by Giuseppina Stelo, to whom we are grateful. A special mention goes to Laetitia Munduteguy, who made the plates of pottery and did the final drawings, from the original drafts, of the report on the excavation of the Temple of 'Athtar dhu-Qabd. 
My own special thanks go to Professor Francesco Fedele, who, with his detailed stratigraphic extramural excavations, has contributed greatly to the chronological reconstruction of the settlement.

We also want to thank GOAM's former President, 'Abdallāh Bāwazir, and the current President, Muhannad alSiyyānī, and the Director of Excavations for the Yemen, Muhammad al-Așbahī, for their support and collaboration with the Italian Mission.

We are also grateful to all the Yemeni soldiers who served in Barāqish, for protecting us and providing us with a feeling of stability for the length of our stay. Moreover, they safeguarded the site and the headquarters of the Italian Mission when we were not there.

Finally, we would like to thank the staff of the Italian Embassy in Șan' $\bar{a}$ ' with a special mention for Ambassadors Giacomo Sanfelice di Monteforte and Mario Boffo for their never-failing professional and altruistic assistance and support of the Italian Mission in the Yemen and, in particular, the more recent excavation and restoration projects in Barāqish.

The 2004-2005 and 2006 archaeological campaigns were funded by the Italian Ministry of Foreign Affairs and International Cooperation (Direzione Generale Sistema Paese) and by the Yemeni Ministry of Finance, supported by the then Istituto Italiano per l'Africa e l'Oriente (IsIAO) in Rome and by the University of Naples 'L'Orientale'.

The publishing of this volume would not have been possible without the generous support of The Shelby White and Leon Levy Program for Archaeological Publications (2017-2020), to which I extend my heartfelt thanks.

S. Antonini de Maigret

Perugia, 27 September 2019

Between 2005 and December 2007 - the last days of the Italian archaeological mission in the Jawf - I carried out a particular project of extramural investigations at Barāqish combining excavation, small-scale geological approaches, animal and plant residue retrieval, and limited site survey (alas very limited, due to security restrictions). The chapters in this volume that I suggested for inclusion, and my own, are intended as a tribute to a remarkable place, particularly at a time when Yemen's people and heritage are horribly suffering, and as a testimony to a marvellous experience both intellectual and human. My Yemeni coworkers at Area C in 2005 and 2006, soldiers in the Yemeni army, were often in my thoughts while I was writing in the comfort of a quieter and paler Europe.

It was a privilege, as well as a challenge, to work as a member of Alessandro de Maigret's mission at Barāqish. What I attempted to do, as a contribution to the mission's general objectives, was to disclose and understand the overall history of a settlement. A town-size settlement on Yemen's desert margin in particular. In the circumstances, sadly, only a minimal fraction of that lofty goal could be accomplished, confining the project to its designed limits of a first phase only - a simple beginning, and no more than a glimpse. The results are presented in this volume as a final report.

If the acquisitions from Area $C$ appear to overcome their limitations, it is only because they concur to show what the Baräqish site has in store for the future. And not merely within the bulk of the mound. There can be no doubt that a tremendous wealth of significant information is awaiting discovery all around its circumference: down in the adjacent plain, up the talus and flanks outside the magnificent wall. Just think - from Area C and the western sectors alone - of earliest Yathill, buried at a depth we cannot gauge; or of the relationships between the settlement and the first irrigated zone; or of the nature and extent of Karib'il the Great's walling. From the site as a whole, think of the record of early dromedary use which we can reasonably expect (Fedele 2017, 306). All that and much more had to remain terra incognita after 2007. To borrow from a reflection on Tell Brak (Matthews 2003a, 229), it can only be hoped that the wait for such historical treasures to be discovered will not prove endless.

F. G. Fedele

Turin, 4 October 2019 


\section{Premessa}

A conclusione di prospezioni archeologiche, scavi e restauri diretti dal Professore Alessandro de Maigret a Barāqish dal 1986 al 2007, abbiamo ritenuto doveroso dedicare una corposa pubblicazione a questo sito del Jawf, tanto stupefacente quanto complesso e impegnativo per tante ragioni. Di queste il lettore si renderà conto leggendo il Capitolo 1, che è consacrato alla storia delle ricerche archeologiche su Barāqish e sul suo territorio, condotte a più riprese da studiosi di diversi ambiti e competenze, sin dal 1870, e via via sino alla prima esplorazione della Missione archeologica italiana (MAIRAY, poi MAIRY) nel 1986; a seguire gli scavi e i restauri, discontinuamente, dal 1989 al 2007, del Tempio di Nakrah (Tempio A), del Tempio di 'Athtar dhu-Qabḍ (Tempio B), e gli scavi fuori dalle mura.

Nel volume non vengono presentati soltanto i risultati inediti di ricognizioni e scavi, i materiali, l'architettura e i restauri condotti dalla MAIRY; ma, grazie alla generosa disponibilità e alla tenacia del Professore Francesco Fedele - cui spetta gran parte del merito di questa pubblicazione - l'elaborazione di molti dati rimasti a lungo in sospeso accanto ad altri di più recente acquisizione. Ciò ha permesso di ottenere alcune informazioni cruciali sulla storia e l'economia di questa splendida città carovaniera.

Per ragioni di sicurezza, dal 2007 è stato proibito l'accesso nel Jawf e, nel caso specifico, a Barāqish, per cui furono interrotti gli scavi e lo studio dei materiali. Per esempio non riuscimmo a completare lo scavo né nel settore meridionale oltre il Tempio B, né nell'area compresa tra questo e il Tempio A, che avrebbe rivelato il raccordo tra i due templi rispetto al piano di calpestio dell'area sacra; il Tempio B si trova, infatti, ad una quota maggiore di circa $2 \mathrm{~m}$ rispetto al Tempio A. Avremmo voluto naturalmente che lo studio di tutti i materiali, inclusi quelli di epoca islamica, fosse completato. Siamo, dunque, consapevoli delle ovvie lacune che questa pubblicazione presenta.

Come accennato sopra, dopo l'ultima campagna di studio del 2007 è stato impossibile recarsi a Barāqish per problemi di sicurezza. Il materiale archeologico studiato (oggetti, ceramica ed iscrizioni) all'epoca fu sistemato nei magazzini e nell'antiquarium appositamente costruiti dalla MAIRY nell'area a sud-ovest del sito. Il resto del materiale che era in corso di studio fu disposto sugli scaffali e sui tavoli nel laboratorio. Durante il mio ultimo soggiorno a Șan'ā', nel settembre del 2013, riuscii a far arrivare nella capitale soltanto una parte dei materiali, e cioè la ceramica di epoca islamica che era ancora chiusa nei sacchetti.

È doveroso ricordare che durante il conflitto in Yemen, iniziato nel marzo del 2015, il sito di Barāqish è stato l'obiettivo dei bombardamenti aerei da parte dell'Arabia Saudita, che guida la coalizione formatasi per fermare l'avanzata degli Houthi nello Yemen. Un settore delle mura è stato distrutto, il tempio di Nakrah irrimediabilmente raso al suolo e il Tempio di 'Athtar dhu-Qabḍ fortemente danneggiato. Dalle recenti immagini satellitari si nota che tutte le costruzioni del campo della Missione, inclusi i magazzini, l'antiquarium e il laboratorio, sono solo un cumulo di macerie.

\section{Ringraziamenti}

Gli scavi a Barāqish sono stati diretti dal Professore Alessandro de Maigret, cui dedichiamo questo volume. Era nota la sua particolare passione per questo sito, tanto che il 10 dicembre del 2006, alla presentazione all'Università di Șan 'à del libro dedicato al qāḍī Ismā̄ill al-Akwa' (Robin e Jāzim 2006), l'amico e compianto Primo Ministro 'Abd al-Karìm al-Iryānī nel suo discorso definiva Alessandro 'Abū Barāqish'.

Dedichiamo questo libro anche all'amico e collega Mario Mascellani, scomparso l'11 settembre 2015. Ricercatore del CNR, Mario ha collaborato con la Missione Italiana in Yemen sin dal 1985. L’ultimo suo rilievo topografico nel sito di Ǵaymān è del 2010. Il suo contributo scientifico nel campo del rilievo delle emergenze archeologiche e dell'esplorazione ambientale è stato insostituibile, con la produzione di cartografia di grande precisione e valore scientifico.

Si ringraziano tutti i collaboratori che hanno partecipato alle più recenti campagne di scavo: gli ispettori del GOAM Khālid al-'Ansī, șādiq Sa'ìd 'Uthmān, Mabkhūt Muhtamm, Mana' Allāh Sārī al-Nașrī Muhammad Hajar, 'Ábd al-Bașit Nu'mān, 'Īsa 'Alī al-Shaybānī, Jamāl Thābit, Ahmed Shamsān; gli archeologi Alessio Agostini, Francesco Di Grazia, Romolo Loreto e Rosario Valentini; gli epigrafisti Christian J. Robin e Mounir Arbach; gli architetti Jean-Marie Gassend e Ghislain Richoux; il topografo Mario Mascellani; i restauratori Saverio Scigliano e Alessandra Paladino, l'infermiere Patrizio Morlupi e, infine, gli studenti 
dell'Università di Napoli 'L'Orientale' Danilo Mongiello, Serena Vessichelli, Marilena Scuotto, Gennaro Di Rosa e Stefano Javarone. I disegni della ceramica studiata da Vittoria Buffa sono stati eseguiti da Giuseppina Stelo, che ringraziamo. Un ringraziamento particolare va a Laetitia Munduteguy che ha composto le tavole di ceramica e messo in bella i disegni del rapporto di scavo del Tempio di 'Athtar dhu-Qabd. Un mio speciale ringraziamento è rivolto al Professore Francesco Fedele che, con il suo profondo ed esteso sondaggio stratigrafico eseguito fuori dalle mura di Barāqish, ha dato un grande contributo alla ricostruzione cronologica ed estensiva dell'insediamento.

Si ringrazia inoltre l'allora Presidente del GOAM, 'Abdallāh Bāwazìr e l'attuale Muhannad al-Siyyānī, e il Direttore degli scavi dello Yemen, Muhammad al-Așbahị per il sostegno e la collaborazione con la Missione italiana.

Particolare riconoscenza a tutti i militari yemeniti di stanza a Barāqish, che durante la nostra permanenza sugli scavi hanno garantito protezione e stabilità, e in nostra assenza salvaguardia del sito e della sede della Missione archeologica.

Vorremmo concludere ringraziando tutto il personale dell'Ambasciata d'Italia a Șan' $\bar{a}$. Un particolare grazie agli Ambasciatori Giacomo Sanfelice di Monteforte e Mario Boffo, che hanno assistito e supportato costantemente con professionalità e generosità l'attività della Missione Italiana in Yemen e, nello specifico, le più recenti campagne di scavi e restauri a Barāqish.

Gli scavi delle campagne 2004-2005 e 2006 furono finanziati dal Ministero italiano degli Affari Esteri e della Cooperazione Internazionale (Direzione Generale Sistema Paese) e dal Ministero yemenita delle Finanze, e con il patrocinio dell'allora Istituto Italiano per l'Africa e l'Oriente di Roma (ISIAO) e dell'Università di Napoli 'L'Orientale'.

La produzione di questo volume non sarebbe stata possibile senza il generoso sostegno da parte di The Shelby White and Leon Levy Program for Archaeological Publications (2017-2020), che ringrazio con tutta la mia riconoscenza.

S. Antonini de Maigret

Perugia, 27 settembre 2019

Tra il 2005 e il dicembre 2007 - gli ultimi giorni nel Jawf della Missione archeologica italiana - ho condotto a Barāqish un particolare progetto di indagini fuori-mura che ambiva a combinare scavo, geoarcheologia di piccola scala, recupero di residui animali e vegetali, e limitata prospezione del sito (ahimé molto limitata a causa delle restrizioni di sicurezza). I capitoli che ho suggerito di includere in questo volume, e i miei propri, intendono essere un tributo a un luogo straordinario, soprattutto in questo momento in cui la gente e il patrimonio dello Yemen soffrono in maniera orribile, e la testimonianza di una esperienza meravigliosa sia intellettuale sia umana. I miei collaboratori yemeniti del 2005 e 2006 nell'Area C, soldati dell'esercito dello Yemen, sono stati spesso nei miei pensieri mentre scrivevo queste pagine, nella quiete confortevole di un'Europa monotona e pallida.

È stato un privilegio e una sfida lavorare come membro della missione di Alessandro de Maigret a Barāqish. Ciò che ho cercato di fare, per recare un contributo agli obiettivi collettivi della missione, è stato di dischiudere e comprendere la storia complessiva di un insediamento. In particolare un insediamento urbano al margine del deserto dello Yemen. Purtroppo, nelle circostanze, si è potuta adempiere soltanto una minima parte di tanto elevato obiettivo, arrestandosi il progetto alla prima fase in programma - ossia un semplice inizio, e non più che uno sguardo. I risultati presentati in questo volume ne costituiscono il rapporto finale.

Se le acquisizioni ottenute a Barāqish Area $C$ sembrano superare i loro limiti, è solo perché concorrono a mostrare quanto il sito di Barāqish abbia in serbo per il futuro. E non semplicemente nel ventre del tell. Non c'è dubbio che un'enorme ricchezza di informazioni significative attende di essere scoperta tutt'intorno al suo perimetro: giù nella piana attigua, sui fianchi e sul talus all'esterno dello stupendo muro. Basti pensare - per limitarsi all'Area C e ai soli quadranti occidentali - alla Yathill delle origini, sepolta a profondità sconosciuta; o ai rapporti tra l'insediamento e la più antica zona irrigua; o alla natura e all'estensione del muro di cinta di Karib’īl il Grande. Circa il sito nel suo insieme, si pensi soltanto alla documentazione sull'uso incipiente del dromedario, quale è lecito attendersi da una Yathill (Fedele 2017, 306). Con il 2007 tutto ciò, e molto altro, è obbligatoriamente rimasto terra incognita. Per riprendere una riflessione dei recenti scavatori di Tell Brak (Matthews 2003a, 229), si deve e si vuole sperare che l'attesa di scoprire siffatti tesori storici non si riveli infinita. 
During the production of the book sad news were received of the sudden death of Muhannad al-Siyyāni (1962-2020), President of the General Organization of Antiquities and Museums of Yemen since 2012. Together with the authors, we wish to remember him not only as a sincere friend, but also as one of the best leaders of GOAM for its tireless commitment to the preservation of the cultural heritage of Yemen.

10 August 2020

أثناء إعداد و إنتاج المجلد, تلقينا الخبر المؤلم عن الوفاة المفاجئة لرئيس الهيئة العامة للآثار و المتاحف اليمنية مهدد أحمد السياني (1962 - 2020), و الذي

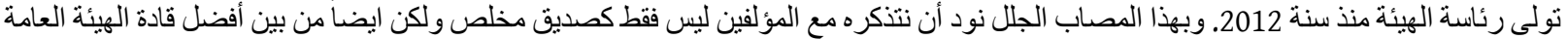

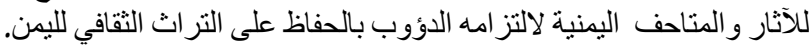

10 


\title{
Contributors
}

\begin{abstract}
Alessio Agostini is a researcher at the University of Rome 'La Sapienza', where he teaches Semitic Epigraphy and Philology. As a member of the Italian Archaeological Mission to Yemen since 2002 he has participated as archaeologistepigraphist to the excavations at Barāqish, Tamna' and Hayd ibn 'Aqīl. More recently he has conducted fieldwork in Oman and Ethiopia. Among his recent publications, 'The Jawf valley as a crossroad. Some observation about the tribe of Amir in South Arabia' in ARAM 30 (2018).
\end{abstract}

Sabina Antonini heads the Italian Archaeological Mission to Yemen c/o Monumenta Orientalia (Rome). Since 1984 she has taken part in archaeological surveys and excavations of prehistoric sites in Khawlān al-Ṭiāal and Ramlat al-Sabcatayn and of South Arabian sites, including Yalā, Tamna', H.̣ayd ibn 'Aqīl, and Barāqish. She is a specialist in South Arabian archaeology and history of art. Her contribution, 'The Italian Archaeological Mission at Šibām alGirās, Yemen', has appeared in Festschrift in honour of Professor Mikhail Piotrovsky (2019).

Mounir Arbach is director of research at the French National Centre for Scientific Research (UMR 5133 - Archéorient, Lyon). He is a specialist of languages and history of pre-Islamic South Arabia. He has been taking part to French and Italian archaeological missions in Yemen (1993-2009) and in Saudi Arabia (2006-2019). He is currently heading the Saudi-French archaeological Mission in the region of al-Fāw (Saudi Arabia). His recent publications include 'Premiers échos de l'expédition romaine d'Ælius Gallus dans la documentation sudarabique' (with J. Schiettecatte) in Académie des Inscriptions et Belles-Lettres, comptes rendus des séances de l'année 2017 (2017).

Khālid 'Alĩ al-'Ansī obtained a BA in Classical Archaeology at the University of Șan'ẫ' (1988) and specialized in Near Eastern Archaeology and Art at the Università di Napoli 'L'Orientale'. In 1988 he joined Yemen's General Organization for Antiquities and Museums, where he was director for the Province of Ibb (2002-2007) and since 2012 heads the Al-Bayda'a' office. He has done extensive fieldwork in Yemen, both for GOAM, including directorships of excavations, and as a participant in foreign archaeological missions, publishing widely on ancient Yemen.

Vittoria Buffa is a member of the Italian Mission of the University of Pisa to Oman, in this capacity conducting excavations at Khor Rori in Dhofār (Sultanate of Oman) since 2000. As a member of the Italian Archaeological Mission to Yemen she has participated in the excavations at Tamna' and Barāqish. She is a specialist in South Arabian archaeology and ceramic studies. A forthcoming publication is Sumhuram. The becoming of a town (V. Buffa, editor; 'L'Erma' di Bretschneider).

Christian Darles is an architect and archaeologist, honorary professor at the Ecole Nationale Supérieure d'Architecture (Toulouse) and research associate of several French institutions, including CNRS UMR 5608, ENSAToulouse, and CEFAS-Șan'ā'. Since 1976 he has been a member of both French and international archaeological missions to Yemen, Saudi Arabia, Oman, Tunisia, and Morocco, and an expert for the UNESCO's World Heritage city of Shibam. He is a corresponding member of the Académie d'Architecture and a Knight of the National Order of Arts and Letters.

Francesco G. Fedele has been Professor of Anthropology and Prehistoric ecology at the Università di Napoli 'Federico II', Naples, until retirement in 2011. As a member of the Italian Archaeological Mission to Yemen since 1984 he has conducted excavations in Khawlān al-Ṭiyāl and at Barāqish, with a particular focus on site geoarchaeology and archaeofaunas. His recent publications include 'New data on domestic and wild camels in Sabaean and Minaean Yemen' in Archaeozoology of the Near East 9 (2017).

Solène Marion de Procé specializes in the archaeology of the ancient Arabian Peninsula. She heads the SaudiFrench archaeological mission to the Farasān Islands in the southern Red Sea and is currently working on the Maparabia project (ANR-18-CE27-0015, dir. J. Schiettecatte). Her recent publications include 'Un petit temple inédit au sud de la mer Rouge' in Semitica et Classica 11 (2018) and 'What evidence for the 6th cent. conflict in the Farasān Islands?' in La guerre en Arabie antique (Geuthner, 2019).

Alessandra Paladino has been dealing since 1998 with conservation and restoration of stone artefacts, mosaics, and wall paintings of archaeological, artistic and architectural interest, for cultural heritage, in Italy and abroad. From 2003 to 2006 she took part in the restoration works of the Temples of Nakrah and 'Athtar dhu-Qabd at Barāqish for the Italian Archaeological Mission to Yemen. 
Jérémie Schiettecatte is a research fellow at the French National Centre for Scientific Research (UMR 8167 Orient et Méditerranée, Paris). He has an 18-year-long experience of both the archaeology and historical geography of the Arabian Peninsula, with field researches in Yemen, Saudi Arabia, Bahrain, and UAE. He is interested in the study of the Arabian settlement process, the land-use in arid environments, and the Late Antique to Early Islam transition. Among his latest publications, 'The political map of Arabia and the Middle East in the third century AD' (with M. Arbach) in Arabian Archaeology and Epigraphy (2016).

Saverio Bruno Scigliano has been dealing since 1998 with conservation and restoration of stone artefacts, mosaics, wall paintings, and canvas and wood of archaeological, artistic and architectural interest, in Italy and abroad. From 2003 to 2006 he was chief restorer for the Italian Archaeological Mission to Yemen, carrying out the project on the restoration of the Temples of Nakrah and 'Athtar dhu-Qabḍ at Barāqish.

Rosario Valentini is an archaeologist and topographer at the Università di Napoli 'L'Orientale'. He has taken part in archaeological surveys and excavations in Yemen - with a particular focus on Tamna' and Barāqish as a member of the Italian Archaeological Mission to Yemen since 1999 - as well as in Saudi Arabia, Oman, Turkey, Uzbekistan, and Italy. Among his recent publications, 'Trial Trenches at Koitepe, Samarkand Area (Sogdiana). Eighth Interim Report 2018' in Newsletter di Archeologia CISA, Ricerche e Studi (2019).

\section{Dates and Arabic Names}

Dates

Dates in the English-language chapters of this book will be expressed in the text as 'BCE' or 'CE', i.e., before or in the current era, respectively. However, following standard international practice, in the tables with chronological content the technical abbreviations 'BC' and 'AD' will be employed. Expanded as 'cal BC' or 'cal AD', cal meaning both calendar and calibrated, these latter abbreviations might also be used in text passages specifically concerned with radiocarbon dating.

\section{Arabic names}

In the transcription of Arabic names, unless indicated otherwise, the lam of the article al-is never assimilated with the initial letter of the following word, regardless of how it is pronounced. Both common and proper names will be so transcribed. 


\section{Barāqish: Reference Map and Plan}

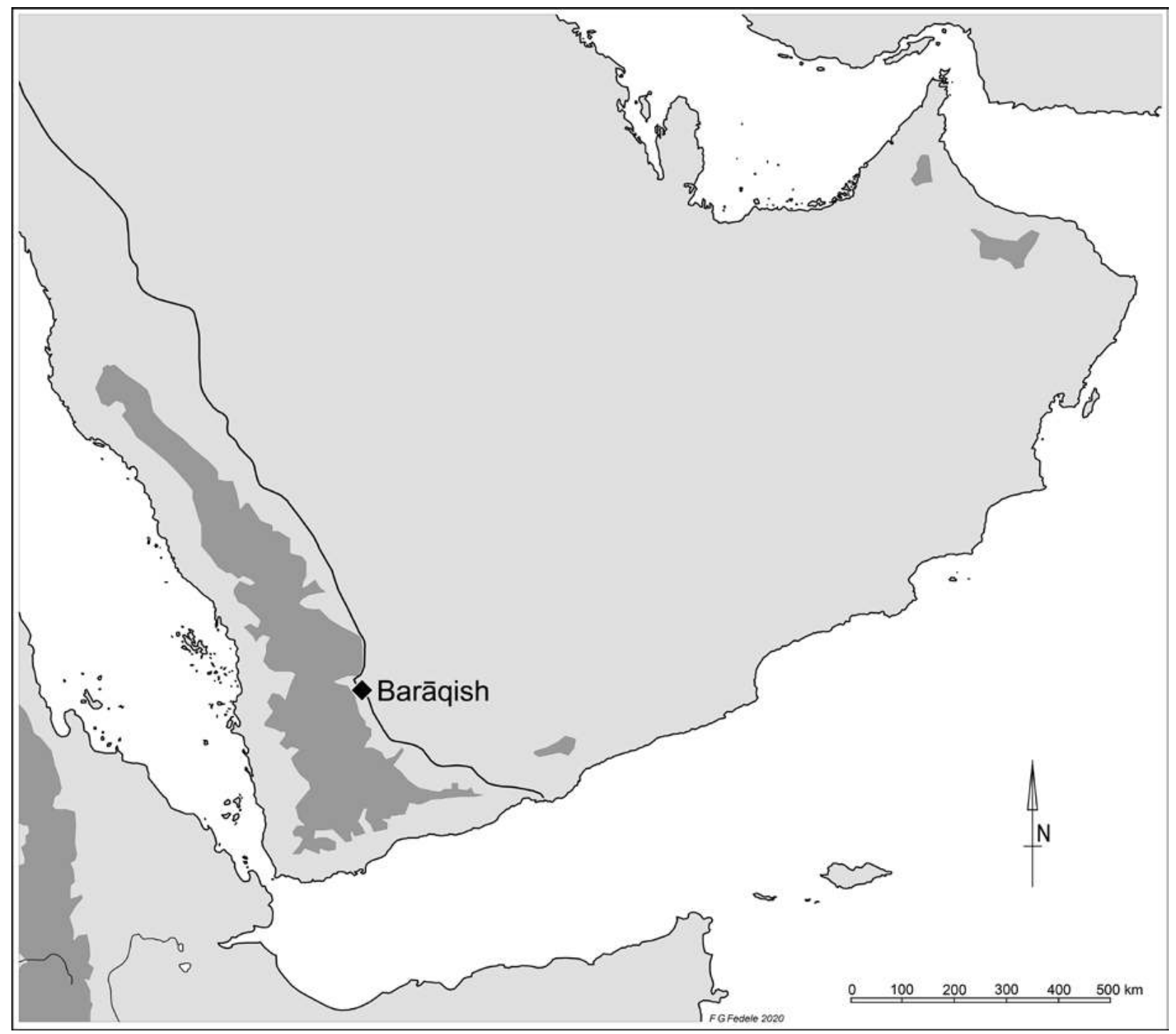

Map of Southern and central Arabia. Barāqish and the so-called 'incense' route. 

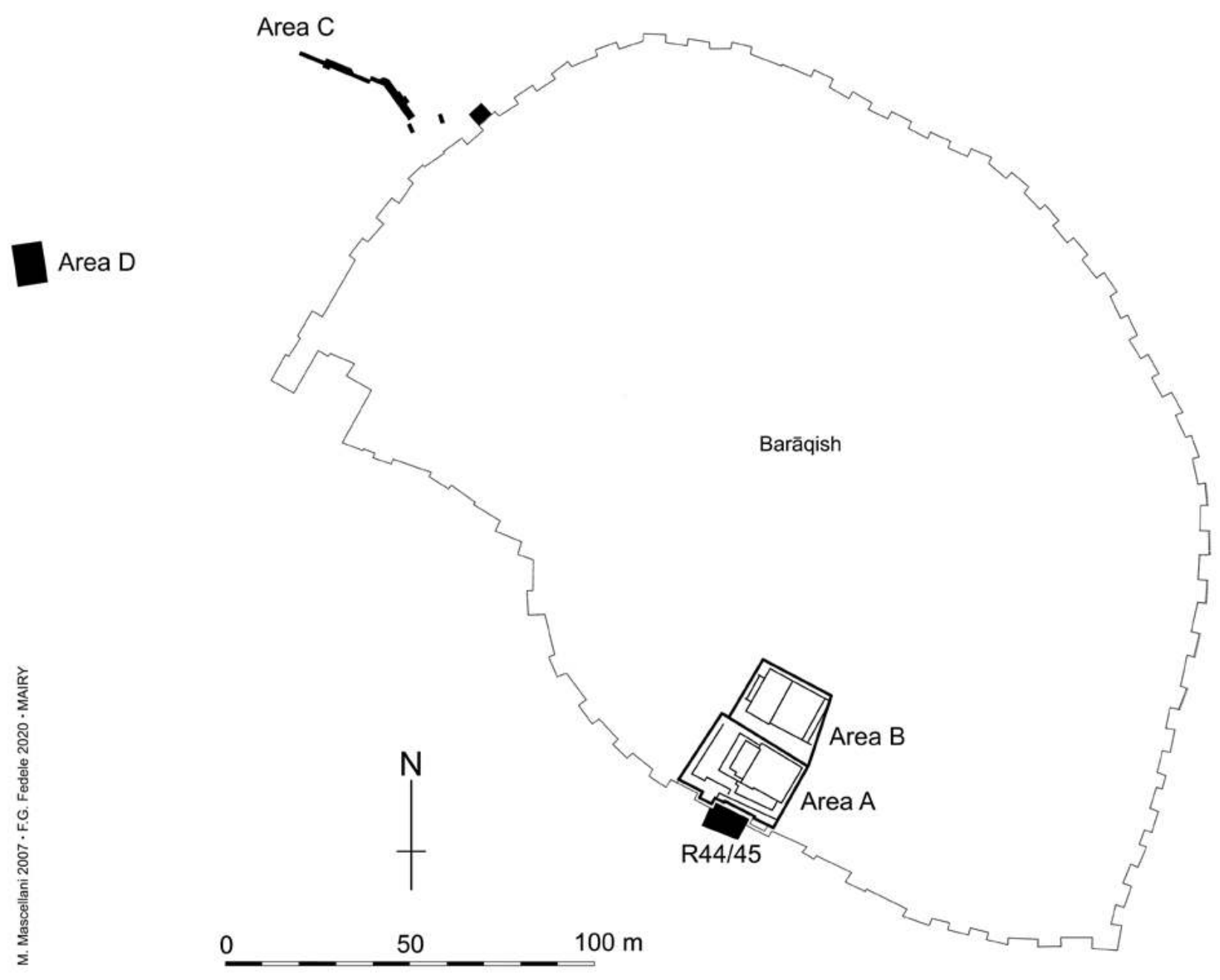

Plan of archaeological operations at Barāqish 1986-2007. 
$\vdots \equiv$ 


\title{
Introductory Information
}

\author{
Chapter 1
}

\section{A History of Archaeological Research at Barāqish and in Its Area}

\author{
Sabina Antonini and Francesco G. Fedele ${ }^{1}$
}

Barāqish as an archaeological site was brought to the attention of the wider world outside Yemen in the last decades of the 19th century. Further visits and reports were rare and only followed much later, due to the persistent difficulties the area presented (and still presents) to access and stay. Formal recording, mostly epigraphic, began in the late 1970s. However, it was only in 1986 that a sustained archaeological initiative could be arranged to bring Barāqish into focus and make its significance well known. This effort by the Italian Archaeological Mission to Yemen, led by A. de Maigret, developed in two phases until 2007, supported by prompt publication. Notable restoration work of the excavated monuments was also accomplished. The present volume contains a final report on the Italian project, mainly devoted to the unpublished records and to a detailed reappraisal of some previously presented information. Research at Barāqish proved impossible after 2007 because of mounting tension in the Jawf. A. de Maigret's death (2011) and war in Yemen (2015) contributed to make this halt permanent. In 2015 the Barāqish archaeological site was damaged by a Saudi Arabian attack and the Italian Mission's base was razed to the ground.

\section{Early visits and observations, $1870-1947$}

The first western observer to report about Barāqish 'in the lower Jawf' was the Jew erudite and great Semitist,

\footnotetext{
${ }^{1}$ This chapter is intended as both a narrative of archaeological research and an introduction to the contents of the two volumes comprising this book. It was proposed and outlined by FGF in consideration of - and as a complement to - the cataloguing of the archives of the Italian Archaeological Mission to Yemen which has been carried out by SA since 2016 and is being completed. The chapter was written in English by FGF in April-July 2018 with archival information and partial texts contributed by SA for sections 3.2-3.3 and 4.2-4.6; SA also drafted a preliminary bibliography on Barāqish (for previous bibliographies see Schiettecatte 2006a, 134-135; 2011, 51; 2019a). Sections 1, 2, 3.1, 4.1, and 5 were researched and written by FGF, who also copied and annotated the documents in Appendix A. The entire chapter underwent a final revision in October 2019. The reader is advised that in the transcription of Arabic proper names the lam of the article al- is never assimilated with the initial of the following name, regardless of how it is pronounced. This convention will be followed throughout the English-language chapters of this book.
}

Joseph Halévy (1827-1917), ${ }^{2}$ who in 1869 had been sent to Yemen by the Académie des Inscriptions et BellesLettres specifically to look for epigraphic sites and 'copy Sabaean or Himyaritic inscriptions'. ${ }^{3}$ He visited the area in the spring and torrid summer of 1870 with a younger Yemeni Jew from Șan' $(\bar{a})$ as his hired assistant, Hayyim Habshūsh, who was already personally interested in ancient inscriptions as well as magic. Carried out between February and some time in the late summer or autumn, their perilous mission was a great success, but by the time they returned to Șan' $(\bar{a})$ their relationship had become strained. The appearance in 1939 of Habshush's own version of the journey ${ }^{4}$ stirred

\footnotetext{
2 Halévy (ha-Levi) was most likely a Hungarian Jew (Verskin 2018b, 13 , note 33 ), who had been wandering for religious and social pursuits for most of his life. Although his career as a scholar took place largely in France, he only settled there in 1868 when he was already middle aged. See Verskin 2018b, 3, 13-25; Tobi 2005; both with further references.

3 As Halévy records $(1873,5)$, 'Ce voyage avait pour but de rechercher et de copier les textes des monuments épigraphiques des anciens Sabéens'. Cf. Halévy $1872 a[=1872 b]$, 5 , letter of 21 July 1871 to the Minister of Public education: 'Une mission dans le Yémen, afin de rechercher et de copier les inscriptions sabéennes ou himyarites existant dans le pays.' Behind Halévy's epigraphic mission was the Corpus Inscriptionum Semiticarum (CIS), the ambitious initiative launched by Ernest Renan and two colleagues in 1867. Renan's role in eventually choosing Halévy and shaping such a difficult mission was instrumental, as was his unfailing support of Halévy in the aftermath of the journey (Chevalier 2012, 56; Verskin 2018b, 20-22, 24). On Halévy's mission from the perspective of Sabaeology see, e.g., de Maigret 1996, 43-45; 2009a, 46-47 [from here onwards only this English edition of the book will be cited]; de Maigret and Robin 1993, 493 (Robin); Schiettecatte 2006a, 135; 2011, 51-52, and elsewhere; 2019a; Charloux and Robin 2016, 25-26; all with further references. The proceedings and results of the mission were made known in two complementary publications, issued in several instalments for a total of 381 printed pages: Halévy 1872a, reissued as a volume (1872b); 1873, with a large folding map in the July issue of the journal showing the itinerary; and 1877. The Rapport has been partly translated into Arabic (Halévy 1992). A landmark publication on 'Sabaean' philology followed in the same years (Halévy 1873-1874;
} reissued as a volume, 1875).

4 Habshūsh's remarkable travelogue, Ru'yat al-Yaman ('A vision of Yemen'), was written twenty-three years after the journey when the Austrian orientalist Eduard Glaser urged him to commit his recollections to paper. However, the manuscript was only rediscovered in 1936 and published in 1939 (Habshūsh 1939, in Hebrew; announced in Goitein 1938). For subsequent editions see Goitein 1941; Habshūsh 1976, 1983, 1992, 1995, 1998. The first English translation (Habshūsh 2018) has just appeared as part of a wider-ranging study (Verskin 2018a), and it will be followed here. For an interesting review of Ḥabshūsh 1976 see Müller 1980. 
a scholarly dispute about their respective accounts, reviving late 19th century criticisms of Halévy and lingering suspicions about the behaviour of both. ${ }^{5}$ This subject will be commented upon in some detail because it has a direct bearing on the archaeological discovery of Barāqish. ${ }^{6}$

As Jews who could count on the support of Jewish groups in an otherwise difficult land, Halévy and his companion set off towards Mārib taking a northern route from Șan' $\bar{a}$ ) into and across the Wādi Jawf depression. Undeterred by its descriptions as 'a problem area' and 'a real carnage for foreigners', Halévy had become attracted to the Jawf because of 'the appeal of the unknown', in addition to the tales of ancient cities provided by the classical authors and a personal ambition to retrace the steps of Aelius Gallus, the Roman prefect who reached Mārib. ${ }^{7}$ A highlight was the discovery and identification in this region of $\mathrm{Ma}^{\mathrm{C}} \mathrm{i} n$, the ancient Qarnaw or Qarnā of the Minaeans; another one was the so-called Banāt ' $\bar{A} d$ temple at Haram. ${ }^{8}$ Back in the Jawf in August, after a demanding excursion to Najrān in present-day Saudi Arabia, they were told of an ancient 'Jewish' city a little to the south, now uninhabited, which was in fact Barāqish. ${ }^{9}$ Halévy briefly described it: ${ }^{10}$

5 The respective roles of Habshūsh and Halévy in recording antiquities have repeatedly been debated without reaching total consensus. In fact, the dispute needs to be analyzed at a higher level and on different registers: as a character clash between two individuals with hugely different life histories and aims (see below); as emblematic of the collision between the cultures each of them represented, i.e., an issue in Orientalism (Verskin 2018b, 35-36; 2018c, 41-44); as contrasts and tensions within Judaism itself.

6 This section on Halévy and Habshūsh summarizes research on most of the original sources conducted between May 2018 and September 2019; on the controversy it reflects personal interpretation. [FGF]

7 By his own admission: Halévy 1872, 13-14. He often compares himself to the ancients who had been his only European predecessors in the Jawf or having dealt with the Jawf (Aelius Gallus, Strabo, Pliny). Classical memories feature repeatedly in Halévy's pages as a source of guidance and strength: e.g., Halévy 1872, 27-28 ('J'avais la certitude de fouler une terre classique, et je sentis revivre en moi une énergie assez grande pour braver les dangers de la situation'), 34-35, 43; 1873, 583, 600-604.

8 'One of the famous buildings to which the Arabs give the picturesque name of Binat Ad, the daughters of the patriarch Ad' (Halévy 1873, 583-584, translated). Habshūsh himself (2018, 134-135, 145) was well acquainted with ' $\bar{A} \mathrm{~d}$ as the forefather of a mythic tribe mentioned in the Qur'ān (cf. Verskin 2018a, 241, note 15; 244, note 4).

9 This is Halévy's version $(1872 b, 43)$. Habshūsh is completely silent about how the existence of Barāqish became known, in spite of having learned, from a Jewish graveyard 'close to the ruin', that his ancestors had lived there (Habshūsh 2018, 144-145). Furthermore, contrary to Habshūsh, Halévy places the 'discovery' of Barāqish on the return journey from Najrān, not during their stay in the Jawf two or three months earlier. This is only the most glaring discrepancy between the two versions of the proceedings of the journey, strangely overlooked by commentators; or the three versions, since there is disagreement on several details also between Halevy's Rapport and Voyage. But on matters of itinerary the reliable chronicler must be Halévy, as he alone was the undisputed leader of the expedition and was always behaving as such; in his eyes Habshūsh was a mere paid servant with no say in the choice of route or in scientific decisions.

10 Halévy 1872b, 85; an English translation in Schiettecatte 2019a. In
[Une] ruine fort imposante, quoique de moindre étendue que Mécîn $\left[\mathrm{Ma}^{\mathrm{c} i} \mathrm{i}\right]$. Le mur d'enceinte est en grande partie conservé et porte de nombreuses inscriptions. Des fragments de stèles se voient à profusion, aussi bien dans l'intérieur que hors de la ville. [11] Les édifices publics ne forment qu'un tas de décombres. On sent pourtant que c'était une ville religieuse par excellence, car les vestiges de temples, reconnaissables par les débris des portes et par la disposition des stèles, $\left.{ }^{12}\right]$ abondent de tous les côtés.

Whether Halévy ever saw Barāqish himself is not clear; in fact, it is to be doubted. ${ }^{13}$ In many instances he clearly only relied on what Habshūsh would report to him, as well as on the freshly copied inscriptions which his companion was bringing. Here lies the crux of the Habshūsh-Halévy debate, triggered by the former's revelations. ${ }^{14}$ The issue is particularly intriguing in

Halévy's Rapport (1872b), Barāqish is dealt with on pages 43-44 (discovery), 85-90 (list of inscriptions), 184-214 (original texts), and 254-260 (translations). On p. 43 Halévy cites an old written contract indicating that 'Berâqisch' - as he spells the place name - had been abandoned since no more than a century. A Jewish community 'close to Barāqish' is mentioned in a document of 1922 cited by Tobi (2005, 287).

11 This observation was echoed decades later by Ahmed Fakhrī: ‘[a] stela lying near the mosque, another stela outside the girdle-wall, and three fragments reused in the wall-restorations sic of the Arab period' (Fakhry and Ryckmans 1951-1952, I, 142). It is worth noting that Fakhrī (see below in this section) greatly admired Halévy's accomplishments, stating that the scope of Halévy's voyage remained unrivalled even in his own time (Verskin 2018b, 25, summarizing Fakhry and Ryckmans 1951-1952, I, 23).

12 By 'stèles' Halévy almost always referred to the tall stone blocks that constituted columns or beams, see footnote 25 . Identically Habshūsh 2018, 134.

13 As first revealed by Glaser (1913, 165; cf. Goitein 1941, 10), it appears that Halévy did not see Barāqish, nor did he work personally on a number of other sites (see, e.g., Philby 1938, 125; Calvet and Pic 1997, 79; Tobi 2005, 289, 290; Schiettecatte 2006a, 136, note 422, 'Il semble en realité que J. Halévy se soit contenté d'y envoyer son guide à en croire le récit de ce dernier'; 2011, 70, 74, 97). In comparison to the profusion of details about $\mathrm{Ma}$ 'in and Haram, sites he actually visited (cf. footnote 25), Halévy is laconic and banal about Barāqish precisely in the same way he was about Kamnā (Robin 1992, 149). Besides, Barāqish is wildly misplaced on Halévy's map, while in the text of Voyage it is not even mentioned. Habshūsh's account, on the contrary, is detailed and eloquent and rich in anecdotes (Habshüsh 2018, 142-147; notes in Verskin 2018a, 241), although the reader would hardly find an expression of wonder at the spectacle of Barāqish Habshūsh was no archaeologist, and when he reached the place he rather felt like a pilgrim. The likely inference is that Halévy did not visit Barāqish, or at least did not examine it, and certainly he did not copy inscriptions. At most, he might have caught a glimpse of the site accompanying Habshūsh on one brief occasion, when, after Najrān, his mind was now totally and characteristically focused on the next step (reaching Mārib), hence relatively distracted.

14 Nowhere in his reports does Halévy mention Habshūsh, or even admits that he had a partner throughout his journey. This was his inexcusable failing. Halévy's deliberate ignoring the contribution of his companion had possibly to do with his manifest disdain for the Jews of Yemen (Tobi 2005, 289) and eventually for Habshūsh as a person. But arguably no less impelling was an obligation towards himself and his sponsors to portray his journey as a solo feat and a great European success. Of this he was rightly proud, and since for his career he deemed it essential that his authorship of the copies was not doubted (cf. Halévy 1875, 237, here reproduced in footnote 17), he kept quiet about his companion's role accordingly (cf. Chevalier 2012, 56). 
the case of Barāqish, this being the site that produced about a quarter (22.6 per cent) of all Halévy's ancient inscriptions, ${ }^{15}$ besides being a remarkable archaeological site in itself.

Ḥayyim ibn Yahyā Ḥabshūsh (1839-1899) was a coppersmith by trade, and later a historian and community activist, for whom the encounter with Halévy was transformational. ${ }^{16} \mathrm{He}$ was taught to read and copy inscriptions in Old South Arabic, a script with which he was already superficially familiar because of his habit of melting ancient bronze plaques. ${ }^{17}$ During their journey Halévy would often send him off alone to inspect sites, particularly if these were difficult to reach or seemed too risky. It was Habshūsh who copied most of the inscriptions, especially during their long stay in the Jawf on the outward journey, and it is to him in particular that all the copies from Barāgish must be attributed. ${ }^{18}$ As he was paid by lines of copy, and the curtain wall of Barāqish was found to offer exceptionally long inscriptions, he matter-of-fact admits to secretly dividing the longer ones into shorter pieces to earn more money. ${ }^{19}$ Halévy's Rapport lists in

15 Of the total of 686 inscriptions (Halévy's raw count), Barāqish had produced 155 (nos 424-578; Halévy 1872b, 85-90). The Jawf as a whole had produced 467 inscriptions, or more than two thirds (68.2 per cent) of the total.

16 Verskin 2010. The encounter and mission with Halévy were for Habshūsh 'the journey of discovery and self-discovery of a [Yemen's] native son', observes Verskin (2018a, 4), and the same can be said of writing A vision of Yemen. On the Jews of Yemen, for perspective, see Klein-Franke 1988; Nini 1991; Tobi 1999, 1-108; Verskin 2018b, 20-21; $2018 c$.

17 Not just melting, but also reproducing? In 1872, soon after the 'Sabaean' texts in Halévy's Rapport had become known, Habshūsh was suspected of forgery in connection with several inscribed bronze plaques acquired by the British Museum, an accusation that Halévy when questioned - indeed endorsed (Tobi 2005; Phillips and Simpson 2007, 207-209; Verskin 2018b, 33-34). Wrote Halévy later in Études Sabéennes (1875, 237 ['Additions et corrections', referencing p. 50]): 'L'original du $n^{\circ} 157$ de mes textes est un de ceux qui m'ont été soustraits par mon guide de Șan'a, et qui ont servi à la fabrication des fragments [...], fragments que le falsificateur a imité, car cet homme ne savait pas lire le sabéen [...]. De quelques-uns des textes volés, je possède d'autres copies faites sur les lieux mêmes.'

18 Cf. Habshūsh 2018, 109, 116, 134-135, 139-140, 142-147 (Barāqish), 154. Halévy would take the texts copied by his guide and write them down again in his own hand (Habshūsh 2018, 143). Concerning the Jawf, Habshūsh (2018) claims that it was he and not Halévy who had made the vast majority of the transcriptions (p. 135), and even that Halévy barely left the house of his Jewish hosts: 'As for my teacher Joseph, he was so afraid during our sojourn in the Jawf that he did not venture out of home except to go to Ma'in and Banāt ' $\bar{A} d$ - and it was in the Jawf that we stayed the longest' (p. 154). See Verskin 2018b, 33. While such assertions have found acceptance with most critics, understandably there have been dissenters siding with Halévy (cf. Verskin 2018b, 34-35). Philby, for instance (1943), reacting to Goitein 1941, expressed outrage that Halévy's word could be doubted, and thought that Habshūsh had contrived part of his story from a later revisiting of the places (and copying inscriptions) by himself. More recently Bianchi $(2003 ; 2008,141-142)$ suggested that Habshūsh had belittled Halévy to please Glaser. Although 'inclined to believe Habshūsh's claim', Verskin $(2018 b, 35)$ concludes that 'the question cannot be definitively resolved on the basis of the available evidence'.

19 Stressing, however, that he behaved in this way only in the case of Barāqish (Ḥabshūsh 2018, 142). See Robin and de Maigret 1994, 49; de fact more individual texts from Barāqish than actually existed. ${ }^{20}$

The reader of Halévy's and Habshūsh's versions had better take an eclectic stance. In fact, both accounts are biased: both are at the same time reliable and unreliable, albeit in a complementary way depending on context and topic. Both men had a temperament as well as reasons to tell a subjective and often highly personal story of their journey together: Halévy, quietly and tactfully to advance his standing and reputation in Paris, and Habshūsh to get the record straight - to get back his moral due. Halévy was a driven and self-centred man, ${ }^{21}$ ambitious and secretive, single-mindedly striving for his one goal. Part character, part survival strategy, these personal qualities enabled him to carry out one of the remarkable exploration and archaeological feats of the 19th century. From this point of view the Académie could not have chosen better. On his part, Habshūsh was curious and adventurous, and tended to be boyishly cunning. But he can be trusted about what interested, affected, or impressed him more: the people and places and incidents of the journey; the work he did to his very best as an enterprising partner; and his respect for the intellectual stature of his 'master' and 'teacher', in spite of all their differences - Habshūsh had been imprinted by Halévy.

Ḥabshūsh's perseverance, directness, and spirit of observation thus played a greater role in understanding the antiquities of the Jawf than is still commonly admitted: his informations and opinions inevitably informed - uncredited - Halévy's own thinking and writing. In describing Barāqish, for example, he showed remarkable intuition when he recognized the site's successive strata: 'three discernible layers from the Islamic period on top of a Minaean layer', the very sequence - as de Maigret noted admiringly - that excavations revealed 120 years later. ${ }^{22}$ Another case

\footnotetext{
Maigret 2009a, 47-48.

20 As firstly noted by Goitein (in Habshūsh 1983, 112, note 52a). Robin, citing Halévy 1872a, mentions 154 inscriptions (de Maigret and Robin 1993, 493). For an independent assessment of their number cf. de Maigret's topographic listing compiled in 1986 (Appendix B, below) and Gushchina 2015 (see footnote 41).

21 'Indifferent' to the needs and merits of others: cf. W.F. Prideaux, letter of July 1872 to H.F. von Maltzan, as quoted in Phillips and Simpson 2007, 208. Prideaux had met Halévy in Aden in 1870 on this latter's return from his journey.

22 de Maigret 2009a, 48, from which the quotation is taken. In fact, Habshūsh described four layers or periods. In his own words (Habshūsh 2018, 145): 'After I had examined the ruin [= Barāqish], I discovered that it had been rebuilt and inhabited three times after it was first built.' This first building clearly was Minaean (one could think of Temple A): 'Through [a torn-down wall] I could see ancient and magnificently constructed buildings. I cannot begin to describe their grandeur and splendor, the size of their stones, and their craftsmanship and architecture. It was as though each stone was laid so close to a matching one that a hair could not fit between them. There was no plaster or mortar in the first building.' 'Once the first building had been destroyed and covered in earth, they had built
} 
in point is Halévy's claim that Barāqish, ancient YTL (Yathill), ${ }^{23}$ was 'a religious city without equal': at the origin of this idiosyncratic interpretation of Yathill ${ }^{24}$ was clearly the fact that Habshūsh had noticed quite a number of half-buried monolithic pillars similar to those characterizing the temples he and Halévy had seen at $\mathrm{Ma}^{\text {īn }}$ and Haram. ${ }^{25}$ Habshūsh seems to have inspected with keenest curiosity the cavernous, largely buried structure existing near the southern wall of Barāqish, which the Italian excavations in 1989-1990 would indeed reveal to be a temple dedicated to the patron god of the town. ${ }^{26}$

During the last decades of the 19th century the identification of Islamic Barāqish with ancient South Arabian Yathill became established. ${ }^{27}$ The extraordinary wealth of inscriptions from the wall of Barāqish, painstakingly copied by Habshūsh and reported with erudition by Halévy, was crucial to this effect.

No further archaeological research in the Jawf followed this pioneering episode until the 1940s, when imām Yahyah cautiously began to admit the occasional foreign scholar into the country. Two Egyptian scholars had then a chance briefly to inspect Barāqish on their way to Ma'in. ${ }^{28}$ The first was Muhammad Tawfíq, an entomologist and keen amateur archaeologist, in 1944 and 1945 . He had already been to Yemen as a natural scientist with the Egyptian University Expedition of 1936 led by Sulaymān Ahmad Huzayyin, a prehistorian. ${ }^{29}$ Although short and imperfect, Tawfiq's account reliably documented for the first time a number of Barāqish inscriptions and reliefs; the inscriptions were subsequently published in four instalments by Khalīl Nāmīi. ${ }^{30}$

another above it with bricks and also with some stones from the earlier building. Then, the second building had been destroyed and covered, and they had built above it a third, and when that had been destroyed and covered, they had built a fourth time.'

${ }^{23}$ Ițoul or Ițâl in Halévy's $(1872 b, 44)$ transliteration and vocalization. On Yathill as a place name cf. al-Sheiba 1987, 60.

24 A notion that was not only repeated in Halévy's own publications (1872b, 43, 85; this latter passage is reproduced above, see footnote 10), but also appeared in the encomium introducing the gold medal he was awarded for geographic discovery (Duveyrier 1872, 37): a text inspired, if not actually written, by Halévy himself.

25 Square-section colums and beams are standard architecture in the temples of the Jawf (cf. footnote 12), although not exclusively (Darles 2009b). Ma'in and Haram were the only two sites which, according to Habshūsh (see above), Halévy had personally visited.

26 The god Nakrah, see section 3.3 below; cf. de Maigret 2009a, 313. As to the state and appearance of this particular ruin - no less bewitching in the 1980s than it must have been for Habshūsh in 1870 - see footnote 68 .

27 E.g. von Müller 1896a, 1896b (YṬL vocalized Iathull).

28 de Maigret 2009a, 66-69.

29 Huzayyin 1937; cf. Zimmerman 2008, 150. Huzayyin's expedition contributed to inspire G. Caton Thompson's own mission to Hurayda the following year (Caton-Thompson 1938, 139).

30 Tawfíq 1951; Nāmī 1954, 1955, 1956, 1957. Notable among the reliefs are those of the so-called Banāt ' $\bar{A} d$ motifs in the extramural
In 1947 Barāqish was visited by Ahmad Fakhrī (19051973), professor of ancient history at Cairo University, during a three-month journey to Șirwāh, Mārib, and the Jawf. ${ }^{31}$ This was in many respects an institutional follow-up on the above mentioned Egyptian expedition of a decade earlier, Fakhri also personally following in the footsteps of Huzayyin. Fakhri's account tends to be impressionistic and often lacks precision, nevertheless his observations, drawings, and particularly photographs concerning Barāqish were a significant improvement on all previous records..$^{32}$ Among his many merits, Fakhrī documented Temple A and clearly recognized other similar monuments, still barely emerging from the ground. ${ }^{33}$ More generally, and more importantly in retrospect, this journey represented one of the first professional archaeological surveys ever conducted in Yemen, a field in which the pioneering role played by both Huzayyin and Fakhri deserves to be acknowledged. ${ }^{34}$

\section{The 'renaissance' of the 1970 s and work at Barāqish 1976-1986: epigraphy and architecture}

'Modern' archaeology commenced at Barāqish in the 1970s, and effectively only in the second half of the decade. This was an outcome of developments of a very particular time in both international politics and research. The 1970s witnessed a social and intellectual 'renaissance ${ }^{35}$ in the two new republics that now formed Yemen. In South Yemen the British had retreated in 1967 from the former Aden Protectorates, where they had set up - and left as an important legacy - the first Department of Antiquities in the Arabian Peninsula and

temple of Ma'īn/Qarnā , cf. footnote 8 (Antonini 2004, 37-38). M. Tawfīq visited the Jawf and other parts of Yemen to study the behaviour and migrations of grasshoppers (Robin 1992, 150; cf. Antonini 2004, 9).

31 Fakhry 1948; Fakhry and Ryckmans 1951-1952. As Fakhrī recounts, 'the famous Barakish' was reached on 15 May 'after six and a half hours' march [in] intense heat' (Fakhry and Ryckmans 1951-1952, I, 12); 'the traveller can see Barakish from a great distance, as it is quilt [sic: built] over a high ridge commanding the whole neighbourhood', and 'the bastioned wall is the best preserved in the northern Yemen' (I, 141).

32 Fakhry and Ryckmans 1951-1952, I, 141-142; III, plates XIII, LII-LV (pl. XIII mistakenly attributed to Șirwāh, see Van Beek 1958, 289, note 4 , acknowledging A. Jamme for the correction). For a balanced evaluation of Fakhrī's survey see de Maigret 2009a, 46, 67, 71, 313. Among the expressions of interest for Barāqish in the two decades following Fakhrī's publication, H. von Wissmann's is particularly worth mentioning (von Wissmann 1962, e.g. 200, fig. 7, about the town wall).

33 Fakhry and Ryckmans 1951-1952, I, plates LII (Temple A), LIV; II, 141; von Wissmann 1964, 230, fig. 12; Doe 1983, 171-172, fig. 55 (a sketch view of Temple A based on Fakhrīs photographs); de Maigret 2006, 81-82 (in reference to Temple B).

34 Almost all previous fieldwork in Yemen had focused on site excavation, not survey (C. Rathjens and H. von Wissmann, G. Caton Thompson, Major R.A.B. Hamilton), or had been more travel adventure than research (H.St J.B. Philby, a self-proclaimed 'common explorer', not an archaeologist - Philby 1938, 128). Only von Wissmann and D. Van der Meulen in 1930-1931, in Hadramawt, had set out to do field reconnaissance.

35 'Renaissance' is Robin's term $(2016,4)$. 
a new museum. ${ }^{36}$ In North Yemen the political situation seemed to have stabilised, and in 1969 a General Organization for Antiquities and Libraries had just been established to protect and supervise ancient heritage. ${ }^{37}$ This was soon followed by a professional appraisal of the archaeological collections in order to form the National Museum in Șan' $(\bar{a})$. On a suggestion from the Italian embassy, the task was entrusted to Paolo Costa, an Italian archaeologist with experience in Iraq. ${ }^{38}$

The museum opened in October 1971, while in 1972 an antiquities law, drafted under the guidance of Costa and aimed at the conservation and investigation of Yemeni cultural heritage, was promulgated. During his tenure, Costa was instrumental in securing to the National Museum a large number of objects from the Jawf, where the illicit digging of antiquities was already thriving. Truly exceptional among these finds - 'an unexpected surprise' - was the famous stone fragment inscribed in Latin and Greek (YM 605), reportedly coming from Barāqish. ${ }^{39}$

In this climate, a few individual scholars were allowed to travel to ancient sites and record inscriptions, including Italian semitist Giovanni Garbini ${ }^{40}$ and Soviet

36 Doe 1983, 6-10 (history of research in both South and North Yemen). Under Brian Doe's responsibility the Department carried out regular surveys in 1960-1967, following the impetus provided by $G$. Lankester Harding - 'an experienced field archaeologist' - during his single season at Aden in 1959-1960. The construction of a new Museum of antiquities was begun in 1966.

37 GOAL, founded by noted Yemeni historian and social activist qā Ismā'īl bin 'Alī al-Akwa' (cf. Daum 1988, 480). GOAL became 'General Organization for Antiquities, Museums and Manuscripts' (GOAMM) in 1990, and GOAM - without 'manuscripts' - after a further renaming in 2004; it will be cited with this last acronym in this chapter. For a Festschrift honouring qā

38 Costa 1972a, 1972b, 1978, 2000; Garbini 2000, 29-30; de Maigret 2009a, 111. Paolo M. Costa (1932-2019) served as archaeological adviser to the Yemen Arab Republic between 1970 and 1975 (Frenez 2019 , vii). A significant Italian presence in North Yemen was already assured by a respected team of medical doctors. Among them, Antonio E. Parrinello, and the Italian ambassador himself, Gualtiero Benardelli, were keen amateur archaeologists with an unusual interest in prehistory (Garbini 2000, 28-29; de Maigret 2009a, 117; D. Grébénart in Charloux and Schiettecatte 2016, 53-60). The head of the medical team, Mario Livadiotti, would personally support both the retrieval of South Arabian art, otherwise lost to the antiquities' market, and the sojourn and work of visiting scholars, including Garbini and Grjaznevič (see below).

39 Costa 1977; 1986; 2000, 35; cf. Beaucamp and Robin 1981, 61. About its provenance see footnote 78 , below; its association with Barāqish is circumstantial and has remained unproven to this day. YM 605 immediately attracted great interest by virtue of its hypothetical relationship with the Roman military expedition of 25 or $24 \mathrm{BCE}$, first reported by Strabo in a passage that significantly mentions 'A $A \rho \circ \nu \lambda \alpha$ : a place identified with Barāqish via its ancient South Arabian name of Yathill (cf. footnote 27). This issue is taken up and discussed elsewhere in this book (Chapter 18, section 3.3, and Chapter 27, both in Volume 2). During the 1970s, the evocative association of Barāqish/Yathill with 'A $A \rho \circ \nu \lambda \alpha$ or 'A $\theta \lambda$ ou $\lambda \alpha$, once briefly garrisoned by the Roman army, emerged as a subject of renewed, intense suggestion.

40 Garbini 2000, 29. Two missions to Yemen in 1969 and 1970 allowed him to publish a first corpus of Minaic inscriptions by the mid-1970s (Garbini 1974); he also sponsored the Italian translation of Habshūsh's archaeologist Pjotr Grjaznevič; this latter was able to visit Barāqish and the Jawf during his second mission to North Yemen in 1970-1971, accompanied by Costa. ${ }^{41}$ More significant in the long term was a parallel process: foreign scholars began to approach North Yemen with interest, extending collaboration on the behalf of their countries. German and French archaeologists and philologists were at the forefront of these essentially political and diplomatic overtures, and with the backing of their national institutions archaeological missions were quickly agreed and arranged. In 1978 the first two permanent research centres were set up in Șan' $(\vec{a})$ (the Șan' $\bar{a}$ ) branch of the German Archaeological Institute/DAI, and the American Institute for Yemeni Studies). Equivalent developments took place in South Yemen, where two missions, one Soviet and the other one French, were involved. ${ }^{42}$

A 'German Expedition' to North Yemen was established as early as 1970, but in a few years both field opportunities and a need for a more substantial involvement emerged. Jürgen Schmidt, then at DAIBaghdād, was sent to Yemen for a first visit in December 1975, during which he was offered German ambassador Günter Held's private aeroplane to fly over several major sites, including Barāqish and $\mathrm{Ma}^{\mathrm{C}} \mathrm{in} .{ }^{43}$ Fine, oblique aerial photographs of Barāqish were taken on that occasion. ${ }^{44}$ Schmidt made a second two-week visit in April 1977 to supplement the aerial observations with ground inspections and photographs of promising sites. A place of greatest interest was Barāqish, where the above-ground elements of two pre-Islamic temples buried among the city's later ruins were recorded in plan and briefly described, and several inscriptions examined..$^{45}$

A French initiative based on a diplomatic exchange in 1971 led to a French field season the following year, conducted by Jacqueline Pirenne together with Christian J. Robin and devoted to a highland survey. ${ }^{46}$ In

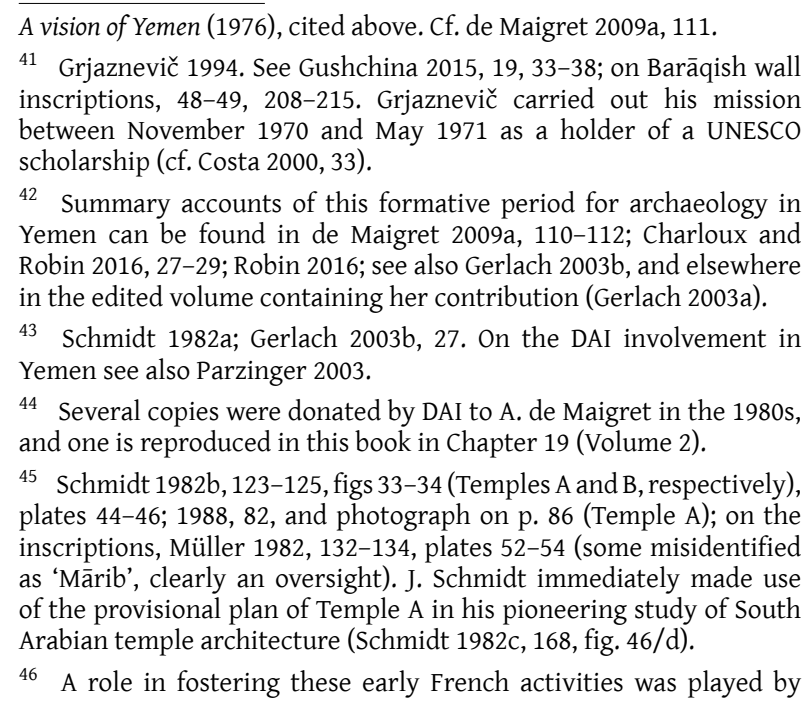


1973 Robin started his own programme of 'Prospections épigraphiques', which in 1976 allowed him a first visit to the Jawf and neighbouring sites, ${ }^{47}$ and convinced him of this region's outstanding potential. As a result, in January 1978 a full-fledged French mission was formed ('Mission archéologique et épigraphique française au Yémen du Nord', MAFRAY). ${ }^{48}$ Composed of Robin, Jean-François Breton and Rémy Audouin, the French mission's pre-Islamic team began its work at Barāqish in the late $1978,{ }^{49}$ with further operations in 1980 and $1981 .^{50}$

The French mission's theatre was in fact the whole Jawf, recognized as a geographic and historical unit, ${ }^{51}$ and the primary research focus was epigraphy. However, much work was devoted to architectural and topographic surveys, which besides being important per se were critical to effective epigraphic recording, as well as unavoidable in a region characterized by such a variety of sites, contexts, and preservation conditions. Studies aiming at the close integration of architecture and inscriptions were particularly needed at Barāqish and its satellite sites, and were carried out with alacrity. ${ }^{52}$ Two extramural cultic sites

Arabist and sociologist Joseph Chelhod. On French archaeological research in Yemen see particularly Charloux and Robin 2016, 27-29, 33-35 ('Tableau récapitulatif des missions archéologiques françaises au Yémen'); Robin 2016; Tuchscherer 2016 (about the French Centre for Yemeni Studies in Șan' $\bar{a}$ ') established in 1982 and later renamed); Darles 2017.

${ }^{47}$ Made possible by 'the acceptance of the Republican government by these regions' (Charloux and Robin 2016, 27). For useful archaeological maps of the Jawf in the South Arabian period see Schiettecatte 2006b; 2011, figs 8, 25-31; Fontaine and Arbach 2006, 86. 48 Constituted of two teams, respectively charged with Islamic and pre-Islamic research. This latter équipe operated in the Jawf - among other study areas - between 1978 and 1981, continuing intermittently until 1988.

49 Robin 1979a, 191-201 ('la mission s'est rendue à Barâqish, ville minéenne étonnamment bien conservée, au débouché du Gawf dans le désert', 193); 1979c; Robin et al. 1979, 425-427.

50 Robin 1981b, 152-153; see also Robin 1981a, 52-53; Breton et al. 1981. The archaeology, epigraphy, and history of Barāqish have been usefully summarized by Schiettecatte (2006a, 134-142; 2011, 51-57; 2019a), within the context of the early urbanization of the Jawf (2006b; 2011, 43-95). See also, e.g., Doe 1983, 127-128, fig. 40, plates $17 \mathrm{a}-\mathrm{b}$. It is appropriate to note here that the city plan in Schiettecatte 2011, fig. 15, while duly credited to MAIRAY, is based on a faulty drawing from Arabia Felix (de Maigret 1996, fig. 64; on p. 312 in de Maigret 2009a) and was incorrectly referenced.

51 Claiming the Jawf as an area for French research somehow harked back to ideal links with Halévy (see section 1 above). Furthermore, an aura of exceptionality and fascination had surrounded the Jawf - 'the sunken country' - since Halévy's arresting statement, pronounced after his great discovery of Ma'in of the Minaeans: 'The lower Djaouf and middle Djaouf contain, to my knowledge, more vestiges of antiquity than any other Arab country' (Halévy 1872, 32, translated).

52 Robin 1979b; 1987. Checking the texts from the curtain wall against the original edition by Halévy (from Habshūsh's copies) was among the first tasks of the mission (cf. Doe 1983, 128 and pl. $17 b)$. The curtain inscriptions still in situ containing references to the building of parts of the wall were particularly dealt with (Robin 1979b; de Maigret and Robin 1993, fig. 1; Breton 1994, 111-112, 156160). An update on the historical importance of the Barāqish wall inscriptions is provided by Schiettecatte and Arbach, Chapter 27, this within a $2.5 \mathrm{~km}$ radius from Barāqish were examined and surveyed..$^{53}$ At Barāqish itself, Breton exploited the exceptional preservation of masonry, wealth of in situ inscriptions, and personal familiarity with the site, to produce a first study of the town's curtain wall, in the framework of a comprehensive study of old South Arabian fortifications. ${ }^{54}$ The complicated social history of both wall and walling, in turn, contributed valuable insights towards an understanding of Minaean social organization. ${ }^{55}$ An additional outcome, published much later, was Jean-Claude Bessac's study of the stone building, cutting, and ornamenting techniques in the ancient Jawf. ${ }^{56}$

\section{The Italian Archaeological Mission: 1985-1992}

\subsection{A biographical-historical outline: de Maigret at Barāqish $^{57}$}

'The last word has still to be with archaeology', Sir Leonard Woolley remarked after R.A.B. Hamilton's talk about Shabwa at the Royal Geographic Society in $1942 .{ }^{58}$ This seemingly indifferent instruction encapsulates the essence of the quantum change that the Italian mission under A. de Maigret brought to Barāqish, and incidentally to archaeology in the Jawf. In this section, before a factual account of the fieldwork (sections 3.23.3), we think it appropriate to look at the Italian work at Barāqish against the background of both the Italian mission's own history and North Yemen's archaeology in the mid-1980s.

It is perhaps apt to recall that the Italian involvement in Yemen's archaeology, when it began anew in 1980, took a different route from the German and French ones during the preceding decade. In the Italian case, instead of being to a large extent a corollary of politics and diplomacy, the initiative was individual, and was

book (Volume 2); on their significance for South Arabian architectural lexicography see Agostini 2010.

53 Robin et al. 1981; Robin and Ryckmans 1988. These two sites, the hill complex at Darb al-Ṣabī and the temple at Shaqab al-Manașșa, will be treated in greater detail in section 5 of this chapter. R. Audouin's plan of the temple at Shaqab al-Manașsa was instantly included in Schmidt 1982c (fig. 46/e, labelled as 'Aš-S̆̉aqab').

54 Breton 1994: 109-113, 156-161; figs 5, 6, 10, 11, 26, 42; plates 15-18; with additional details in table 2 and on pages $3,5,7,12,16,18,21$, 23, 25, 29-31, 33-39, 45 (unnumbered table), 47-48, 50-51, 53-54, 67, $71,99,165,168,171$. Even a simple sketch derived from a pre-1975 air photograph (pl. 15; already employed in publications by von Wissmann 1976 and Robin 1979b, see footnote 79 below) provided for the first time a reliable topographic plan of Barāqish (Breton 1994, fig. 42 on p. 110).

55 Robin 1984; Breton 1994, 155-157.

56 Bessac 1998a.

57 This section is an edited version of part of 'Barāqish stratigraphy and Sabaean Yathill', a contribution to a memorial volume for de Maigret, written in winter 2014/2015 at the invitation of Università di Napoli L'Orientale and as yet unpublished. [FGF]

58 The Geographical Journal 100 (3), 122. The talk and subsequent public discussion took place on 20 April 1942. 
essentially framed as a research problem based on personal choice.

Alessandro de Maigret chose Yemen and its archaeology as his new field of study in 1980 on taking up his associate professorship at Naples' Istituto Universitario Orientale (as it was then called). Later that year, and again in 1981, he obtained a small grant from Rome's Istituto per l'Oriente to go and carry out survey in North Yemen. The groundbreaking results of those two field seasons on the Yemen Plateau concerning prehistory, together with the respect that his efficiency and integrity had won among the Yemeni archaeological authorities, allowed de Maigret to develop his budding operation into a major foreign mission, thanks to a long-term agreement between North Yemen and Italy under the aegis of the Istituto per il Medio ed Estremo Oriente (IsMEO, later IsIAO). ${ }^{59}$ Thus formally born in 1983, the 'Missione archeologica italiana nella Repubblica Araba dello Yemen', MAIRAY (MAIRY after Yemen's unification on 22 May 1990), aimed to promote pioneering, broad-spectrum work on Yemen's prehistory, and an unprecedented group of researchers and supporting technical specialists was assembled. ${ }^{60}$ However, it was no secret that de Maigret's most cherished goal was an investigation of the emergence of the state societies - and especially the Sabaean polity - in the Sayhad, Yemen's desert fringe. Furthermore, his fieldwork preferences pointed towards stratified sites with significant architecture, provided that there were archaeological or historical problems to solve. ${ }^{61}$

It was at this juncture that an interest in the cities of the Jawf began to surface, in 1985, and that MAIRAY was offered a chance to engage with Barāqish in 1986. In fact, as we shall see in the next section, the process was more circuituous. Towards the end of its first five-year cooperation programme, the Italian mission was given the possibility of undertaking excavations at a Sabaean town in the lowlands, Hajar al-Durayb, which had been found during a survey in 1985. The ruin is commonly referred to as Yalā/al-Durayb, or simply Yalā. This possibility marked the awaited shift from a phase of reconnaissance, mostly centred on prehistoric research, to one of excavation in urban-historical contexts, ${ }^{62}$ and was welcomed as a prelude to further developments. However, tribal contrasts made it impossible to pursue work at Yalā in 1986. An excavation would eventually take place only at the very end of the programme in

\footnotetext{
59 IsMEO was chaired by Iranist Gherardo Gnoli (University of Rome 'La Sapienza'); his presidency continued after the institute's transition into IsIAO.

60 With the creation of MAIRAY the Italians joined the other foreign archaeological missions in setting up a permanent research base in San' $(\bar{a})$, in 1983.

61 Fedele 2011b; S. Antonini de Maigret and C.J. Robin, 'Introduction', in de Maigret 2012, 5-7.

62 de Maigret 1991a, 3; 2005a, 16; 2009a, 173.
}

December 1987. And perhaps more significantly, de Maigret's dream site had become Barāqish. ${ }^{63}$

The General Organization of Antiquities (GOAM) had already asked the Italian mission to produce a conservation and study project on Barāqish in October 1986, and in order to draft an evaluation MAIRAY promptly carried out a number of data-gathering operations at the site and in the area in OctoberDecember that year. ${ }^{64}$ Just to mention one product, the topographic map of Barāqish made on that occasion, the first ever, would remain an invaluable tool for twenty years, until the total station and GPS surveys of 2006-2007. The project's original focus was the restoration of the walls and the unearthing and consolidation of partially buried structures, but, in recognition of MAIRAY's significant contribution to Yemen archaeology, by the end of the 1980s the plan agreed with GOAM was extended to allow for a fuller excavation and restoration of one of the temples. As de Maigret later wrote, 'in 1989 a new convention of cooperation was stipulated, [and] we were delighted when the General Organization of Antiquities proposed we embark on excavations in the stupendous Minaean city of Yathill, one of the real gems in the Yemeni archaeological heritage'. ${ }^{65}$

De Maigret's enthusiasm about Barāqish repeatedly shows in both his published and private writings. Barāqish, he says in Arabia Felix, is 'one of the archaeological marvels not just of Yemen, but of the entire Near East'. ${ }^{66}$ 'The ruins occupy a gloriously isolated position in the desert', he further notes in an often repeated passage. ${ }^{67}$ Even in ordinary conversation he never tired to observe how the remarkably wellpreserved wall encircling this ancient town was unparalleled in the Arabian peninsula, and, indeed, its sight from a distance could not fail to impress.

In the two previous sections we have briefly recalled that scholars had been familiar with the Minaean and Sabaean inscriptions from the walls and the town's environs since the late 19th century. Within the town, more inscribed blocks of similar age could be seen amidst the blanketing debris of the medieval settlement. The massive stone pillars of three preIslamic temples still emerged above ground, an

\footnotetext{
${ }^{63}$ This became quite clear - to the writer at least (FGF) - during the visit to Barāqish organized for several Italian colleagues by R. Audouin on 23 October 1985 (see next section). 'On that occasion de Maigret and I had a chance to talk over our prospects and aspirations, and I was impressed by finding him so utterly taken with the archaeological appeal of Barāqish' (FGF, personal archives YE-1985).

64 de Maigret 1986, 384-388; and cf. de Maigret 1991a, 3-4; 2009a, 313. See section 3.2 for details.

65 de Maigret 2005a, 18 (English), 21 (Italian).

66 de Maigret 2009a, 313-314.

67 de Maigret 1991a, 4; 2004a, 4; 2009a, 313 (Italian edition 1996).
} 
indication of great archaeological promise ${ }^{68}$ Clearly, the Islamic occupation had sealed and preserved a major Iron Age site just awaiting rediscovery. In two large-scale campaigns between December 1989 and September 1992, de Maigret and his team brought to light Temple A, dedicated to Nakrah, the tutelary god of the Minaeans. ${ }^{69}$ This monument and its architectural context helped cast vivid light on the Minaean society, and on the Jawf scene more generally, during the later first millennium BCE.

\subsection{Data gathering and evaluation: $1985-1987$}

The direct acquaintance with Barāqish began for the Italian mission in 1985. On 23 October a visit to Barāqish and the Al-Hazm area, the first for A. de Maigret and several MAIRAY members, was kindly arranged by the French mission's R. Audouin, then also head of the Centre Français d'Études Yéménites in Șan'ā’) (CFEY) (cf. Figs 1,9$).{ }^{70}$ On that occasion also the extramural temple of 'Athtar ('Attar) at Ma'īn was visited. Audouin intended to give the Italian colleagues an idea of both the work the French mission had accomplished and the considerable problems still open in the area, with a prospective view to a possible French-Italian cooperation. Three weeks later, on 16-17 November, the Islamist team of MAIRAY conducted by Umberto Scerrato visited Barāqish (Fig. 16), Ma`īn, and Hazm alJawf (often, briefly, Al-Hazm) in their systematic survey of Islamic architecture and archaeology. ${ }^{71}$ The mosque and other ruins were recorded ${ }^{72}$ and a collection of surface material was made. ${ }^{73}$

When these visits took place, Barāqish and a broad perimeter zone had recently been protected with a wire mesh fence. In all probability the measure had been

\footnotetext{
68 See footnote 45, above; and, e.g., Fakhry and Ryckmans 1951-1952, plates LII, LIV; Doe 1983, fig. 55; de Maigret 2004, 6, fig. 7. The surfacing roof structure of what was later identified as the temple of Nakrah had long been known to the sharif of Barāqish as al-siğn, 'the prison', a nickname borrowed by the MAFRAY archaeologists and rendered into French as le cachot or la geôle (e.g., Robin 1981b, 152; de Maigret and Robin 1993, 458, 460-461). This spot seems to have been the scene of some of Hayyim Habshūsh's observations and adventures in 1870 , see footnote 26 . On the sharif of Barāqish see footnote 78 .

69 de Maigret 1991a, 1991b, 1993; de Maigret and Robin 1993. See section 3.3 for details.

70 In addition to de Maigret, the participants on the Italian side included G. Gnoli, 'Chicca' Gaja, and the writer (FGF). On this landmark visit see already footnote 63 .

71 In addition to Scerrato the team was composed of Giovanna Ventrone Vassallo, Paolo Cuneo, young graduate Michael Jung, and Mario Mascellani in his double capacity of topographer and driver. We thank M. Jung, now at Rome's Museo delle Civiltà-Museo d'Arte orientale 'G. Tucci', for allowing the publication of the plan in Fig. 16.

72 The mosque is indicated as 'mausoleum/mosque' in Scerrato et al. $1985,394$.

73 Scerrato et al. 1985, 392, 395.
}

taken when GOAM opened its Mārib office, responsible for the Barāqish area, in the earlier part of $1985 .{ }^{74}$

The Italian involvement with Barāqish effectively began in 1986. It climaxed during a short, hectic period of that field season between 10 August and the late October. As summarized in section 2, the French had already been conducting epigraphic and architectural work in the Jawf for several years, but the region remained difficult because of local tensions, in spite of the alignment with the central government, and the MAFRAY operations had been losing frequency and effectiveness. The whole Jawf, Barāqish included, was MAFRAY's concession, but basically the French work had been restricted to above-ground observations and survey; also their idea of a cooperation with the Italian mission merely comprising a sondage and studies of pottery now appeared limited..$^{75}$ Ultimately it was $q \bar{a} d \bar{l}$ al-Akwa' who decided to entrust Barāqish to the Italian mission (October 1986), and the critical factor that tipped the balance in favour of MAIRAY was the Italians' offer of restoration, supported by competent ad hoc excavation. ${ }^{76}$

The immediate result has been outlined in the previous section: in a matter of days (21-25 October) MAIRAY was asked to undertake a conservation and study evaluation and was granted a permit to visit Barāqish for a photographic and topographic survey. Four successive operations at Barāqish were organized and conducted in October-December $1986 .{ }^{77}$ The first one was carried out between 26-30 October in the form of a systematic reconnaissance of the site for producing basic documentation, including professional photographic coverage by A. Solazzi (Fig. 2). ${ }^{78}$ As usual

\footnotetext{
74 The fenced area was extended in 1990. We thank Khālid al-`Ansī (GOAM) for contributing information on this subject.

75 This was among the discussion topics on 16-17 September 1986, when de Maigret, with the assistance of C.J. Robin as head of MAFRAY and R. Audouin as director of CFEY, once again could visit the Jawf and archaeologically appraise five of its major sites. The occasion allowed de Maigret - and probably all the participants - 'to form a better estimate of the archaeological position of Barāqish in Wādī Jawf' (de Maigret 1986, 388). Shortly afterwards de Maigret noted: 'Barāqish is beautiful, problematic - enormous, complete with Islamic' (personal diary, 21 October 1986).

76 These developments of August-October 1986 are precisely and vividly recorded in de Maigret's personal diary. In addition, one of us (Antonini) had first-hand knowledge of the context in which these facts unfolded. Fedele only caught a glimpse of the final stages and general excitement, having arrived in $\operatorname{San}^{(}(\bar{a})$ for his field season on 16 October, and already on the 18th being on his way for Wādì atTayylah, site WTH3. He learnt of the success concerning Barāqish when de Maigret visited the excavation on the 31st October. In the following pages of this chapter, for the sake of both neutrality and simplicity, the participation of the authors in the facts and events at and about Barāqish will be cited in the third person with our surnames.

77 Information after de Maigret's 'Exploration' notebooks and personal diary, 1986. For a thematic list of the 1986 operations see de Maigret 1986, 388.

78 de Maigret 1986. In addition to de Maigret and Antonini, the
} 
for MAIRAY, the creation of a topographic plan of the site was of paramount importance. This general plan (Fig. 3), the first professional mapping of the Barāqish mound, was accompanied by three topographic profiles (Figs 4-5) and an elevation view of the curtain wall (Fig. 6), all showing in realistic detail the monuments in the interior of the town.

Concerning the intra moenia ruins, the only Minaean structures emerging from the Islamic deposits were the monolithic pillars of three temples, already noted by previous researchers and visitors (see sections 1-2). These temples were now labelled ' $A$ ', from subsequent excavations identified as consecrated to god Nakrah (Figs 7-8); 'B', similarly identified as a temple to god 'Athtar dhu Qabḍ ('Attar dū-Qabḍ) (Fig. 9); and 'C' (Fig. 10). The visible pillars of temples $A, B$ and $C$ were clearly still standing in their original site. Three more prismatic monoliths could be seen within the precinct of the mosque (Figs 11-12), but in this case the non-uniform orientation of their faces suggested that a displacement had occurred. Some isolated blocks of similar appearance lying between Temple $C$ and the mosque represented re-employed material. Unsurprisingly, large numbers of Minaean stone elements including squared and ornamented blocks, inscriptions, basins, drainage spouts or gargoyles, stelae, etc., occurred as scatters on the surface as a result of reuse in Islamic masonry (Figs 13-15). In the general survey of the town's ruins the location and relative position of the Minaean architectural and epigraphic elements were recorded.

In the new plan of the site, the numbering of bastions in the curtain wall runs clockwise, whereas in the French provisional plans, derived from an aerial photograph, the numbering was counterclockwise. ${ }^{79}$

participants to the operation were architect Vincenzo Labianca, topographer-surveyor Mario Mascellani, photographer Antonio Solazzi, draughtswoman and artist Patricia Smith, and the GOAM inspector-archaeologist Ahmad Shuja (Fig. 2). An arresting photograph of an 'intact' Barāqish from this time, showing the southern wall and adjacent plain, can be seen in the exhibition catalogue, Yemen (Robin 2000, 118). It was during this first sojourn at Barāqish that MAIRAY learnt of the deep-rooted struggle between the two ashrāf families of Āl-Sālih and Jarfil - the families of the Jawf claiming descent from grandsons of the Prophet Muhammad who considered themselves sharif of Barāqish ('owners' of the site; Habshūsh 2018, 148, footnote [Verskin]; Verskin 2018a, 213, glossary; cf. de Maigret and Robin 1993, 458, note 12). Since both families laid claims to the place, GOAM would pay for six guards from each family. The feuds between Āl-Ṣālih and Jarfil affected MAIRAY's activities during all and each of the Barāqish campaigns of 1987-1992, often severely and indeed causing disruptions. On these families and the tribal situation of the Jawf see Robin 1979b, 102, notes 2-3. The title of sharif is restricted to the Jawf. The Latin-Greek bilingual stone YM 605 , allegedly from Barāqish (see footnote 39 ), had been found by a man of the banū ashräf (Costa 1977, 69).

79 Robin 1979b, fig. 1 on p. 109 ('croquis redessiné par M. Hirschi', p. 102); Breton 1994, pl. 15, and drawing of the plan on p. 110, fig. 42. The photograph was taken from von Wissmann 1976, pl. II between pages 488-489 (Robin 1979b, 107, note 5); in Breton 1994, 203, it was credited to the Swiss Technical Cooperation. Cf. footnote 54.
Bastion numbers were coded with a capital T, e.g. T5, from Italian torre, torrione (also bastione). Apart from the direction of counting, the discordance between the two systems is only noticeable in the area of the town gateway in the curtain's southwest corner, where the wall plan was complicated by alterations and foreparts: ${ }^{80}$ French bastion 2 (saillant 2 ) adjacent to the gateway did not receive any number in the Italian plan. Details of numbering notwithstanding, there are 56 distinct bastions altogether, intercalated with recesses, to which two foreparts to the gateway must be added.

The 1986 photographic survey systematically covered the town and its remarkable wall. An additional, particular focus was a photographic record of wall inscriptions, both in situ and reused. A total of 246 inscriptions was personally recorded by de Maigret, who admitted possible omissions, as blocks or fragments located high up in the shadow were not easy to be seen or ascertained. 27 inscriptions were or appeared to be in situ, and the 13 longest and most important had already been published in Répertoire d'Épigraphie sémitique (RES) ${ }^{81}$ However, the majority of the inscriptions had been reused and haphazardly embedded in Islamic re-walling, often rotated 90 degrees or turned upside down. The curtain wall inscriptions recorded in 1986 are listed with their positions in Appendix B.

In order to understand the plan and construction of the Minaean wall, a geomorphological study of the site and its area was considered essential. This survey was carried out by Bruno Marcolongo (CNR, Padua) together with Alberto Maria Palmieri (CNR, Montelibretti, Rome) during two trips on 9-10 and 21 November. The only point of the curtain wall where its foundations were partly exposed was at the southeast corner of the city (Fig. 17) ${ }^{82}$ but from the surface no information on the substratum on which the wall rested could actually be gleaned. Following Marcolongo, de Maigret argued that Barāqish rested on a north-dipping sandstone mesa - a tabular relief - similar to those present at some distance in the region (cf. Fig. 14) ${ }^{83}$ With an eye to future excavations in the town's interior, he made an elaborate drawing based on this reconstruction (Fig. 18), and readily sketched a series of propositions about the settlement's development and stratigraphy (Appendix

\footnotetext{
80 Breton 1994, 68, 109-110, fig. 26.

81 On this subject see Robin 1979b; de Maigret and Robin 1993, 430; Breton 1994, 67-68, 109-113; all with further references.

82 Cf. Breton 1994, fig. 6. Discussed in Fedele, Chapter 26 in Volume 2. 83 Marcolongo and Palmieri 1986, 462-463. The Barāqish relief was marked as such in Marcolongo's 'Geomorphological map of [the] Barāqiš area', 1986, unpublished, but presented at a smaller scale elsewhere (Marcolongo 1994, 1996, 2000). A different view was held by Vincenzo Francaviglia, who worked at Barāqish in 1987 ('Geoarchaeological survey at Barāqish, Y.A.R.', unpublished report in de Maigret et al. 1987). On this subject see Fedele, Chapter 26 in Volume 2.
} 
A, Document A1). In this writing he explicitly spoke of a 'Sabaean-Minaean occupation', which indicates his belief that stratified evidence for the Sabaean control and the epigraphically attested walling by mukarrib Karib’il Watār (c. 700-680 BCE) might exist. ${ }^{84}$

From an inspection of the collapsed curtain wall in the recess between bastions T43 and T44, de Maigret recognized 'a double layer, the upper one being the Islamic level, and the lower one a compact layer made of uniform, grey mud bricks which go down behind the Minaean outer face of the preserved city wall recess' (Fig. 19, with details); 'a row of blocks parallel to the outer face of the recess, but about $3 \mathrm{~m}$ towards the inside of the wall, might be the inner casing of the curtain' ${ }^{85}$ In 1992 and 2003-2004, the excavations of bastion T45 confirmed that such mudbrick indeed constituted the fill of the ashlar walling. Finally, de Maigret in his 1986 notes tried to figure out the defensive working of the Minaean curtain wall. An elaborate passage on this subject is here reproduced in Appendix A as Document A2, to be read in conjunction with Figs 20-22. Already J.-F. Breton in his 1994 monograph had come to the conclusion that the mudbrick fill of the wall probably supported a walkway. ${ }^{86}$

B. Marcolongo devoted most of his work in NovemberDecember 1986 to reconstructing the hydraulic features and neotectonic interference in the alluvial territory west and south of Barāqish, aimed at the town'sirrigation history and carried out by photointerpretation (Figs 23-24); ${ }^{87}$ unfortunately ground control, with Palmieri's assistance, could only be limited. An independent account of ancient irrigation at Barāqish was later published by geologist and geophysicist Vincenzo Francaviglia. ${ }^{88}$ The trip to Barāqish on 21 November was partly connected with an appraisal, by local firms, of the state of decay of the town's structures and of the works necessary to preserve them.

\footnotetext{
84 A long pre-Minaean occupation, although not precisely the 'levelling layer' hypothesized by de Maigret in 1986 ('livello pareggiante' in Document A1), was eventually revealed by Fedele in 2005 as a result of the extramural excavations in Area C (Fedele 2010; Chapter 17 in this book, Volume 2) and by de Maigret's deep sounding in front of Temple A in 2006 (de Maigret 2009b, 63-67; 2010a); see sections 4.4-4.5 below. Whether Wall F4 of extramural Area C is indeed Karib'il Watār's wall is best considered an open question (Fedele, Chapters 17, section 6.2, and 18, section 3.1, in Volume 2).

85 A. de Maigret, 1986 Explorations notebook, 'Barāqish': see Appendix A, Document A2.

86 Both de Maigret and Breton focussed on the only fully preserved Minaean bastion, T48 (= French saillant 11): see Breton 1994, 51-53; 1999, 78. Two rows of loopholes, or embrasures, can be seen in the bastion from the outside, located at heights of $10.0 \mathrm{~m}$ and $12.55 \mathrm{~m}$ (Figs 20-21); according to Breton the inner face of the mudbrick fill should not have exceeded a height of 7.0-7.7 m.

87 Marcolongo and Palmieri 1986, 462-463; Marcolongo 1994, 1996, 1997, 2000 .

88 Francaviglia 2002.
}

The fourth and last operation at Barāqish took place on 7-8 December and was a major expedition virtually involving all mission's members then present. ${ }^{89}$ On the occasion an Italian Television (RAI) team recorded the site and some of the activities for a documentary on the archaeology of Yemen. Chief scientific goals were the checking of the general topographic plan, the completion of the curtain wall records, and archaeobotanical sampling. A new survey for a distribution map of Sabaeo-Minaean and Islamic ceramics from the ground surface around Barāqish was also made, supplementing the collections begun on 2630 October.

This latter survey also encompassed a number of non-ceramic artefacts (cuboid burners, for instance). Conducted by one of the authors (Antonini), it was intended as a first approach to the extramural archaeologicalevidencewithinthe fencedarea of the site. In the eastern quadrants this evidence was emphasized by existing structures such as an extramural well (Fig. 25) and a weir (Figs 26-28; for topographic reference see Fig. 3). Four main collection spots coinciding with concentrations of artefacts were recognized: BARi, in gullies below bastions T4 and T5; BARii, on a small hill to the west of the Minaean gateway; BARiii, on a raised bank more than $100 \mathrm{~m}$ north-northeast of bastions T15-T18, where human bones were also surfacing; and BARiv, immediately inside the entrance to the fenced area near its northwest corner. Their plan and details are illustrated in Chapter 2, this volume (Antonini). The operations of 1986 and particularly the last one 'also led to the discovery of important satellite monuments around Barāqish', including probable Sabaean tombs in the northern sector (cf. findspot BARiii) and temples and dams associated with irrigation works in Wādi Shaqab to the southwest (Figs 29-32). ${ }^{90}$

Concerning archaeobotany, IsMEO's L. Costantini was able to sample both pottery sherds, for seed and fruit imprints, and dried and charred macroremains from sediments. The latter were particularly retrieved extramurally from an erosion gully below bastion T5 (cf. findspot BARi, above). Such a precise topographic identification was made possible three decades later by a comparison of the photographs of the sampling (1986)

\footnotetext{
89 Including, in addition to de Maigret and Antonini, G. Gnoli, assyriologist Giovanni Pettinato (University of Rome 'La Sapienza'), archaeobotanist Lorenzo Costantini, Palaeolithic archaeologist Maria Grazia Bulgarelli, architects V. Labianca and Edoardo Gatti, M. Mascellani, restorer Mario Picchi, and the GOAM inspectorarchaeologist Muhammad Halabi. The great enthusiasm that accompanied this first Italian season at Barāqish, on its completion, can perhaps best be read in Gnoli (1988, xii), writing from $\operatorname{San}(\bar{a})$ on 6 December 1986 to preface the first book-length publication of MAIRAY - another significant success.

90 de Maigret 1986, 388. On Wādì Shaqab, where on 8 December an important new inscription was found, see Gnoli 1986a, 1986b, 1993b; and section 5 below.
} 
with the detailed records afforded by the excavations in Area C (2005); in turn, a stratigraphic attribution of the plant material from in situ deposits became possible. The details, together with a list of identified plant remains, ${ }^{91}$ are given in Fedele, Chapter 19 in Volume 2.

The Italian mission continued its reconnaissance of Barāqish in 1987, the last season of the first five-year cooperation programme..$^{92}$ During this season a single operation was carried out, whose scientific return fully repaid the organizational investment: the subsurface testing of the town's deposits. The equipment and expertise were supplied by the Lerici Foundation (Rome) in conjunction with the National Research Council (CNR, Montelibretti, Rome), and the operation took place from 26 August to 3 September. ${ }^{93}$ An extraordinary series of difficulties and misadventures befell the team. ${ }^{94}$ In the end, however, a total of eight usable cores were obtained, made by mechanical drilling with continuous coring. For comparison, one of the drillings was actually made in the plain outside the southern city wall. Furthermore, geoelectric and magnetic prospections were performed, which were unsuccessful. ${ }^{95}$ A second coring operation would take place in January 1990 in conjunction with the 1989-1990 excavations of Temple A (see below). The results of both coring campaigns, and information on the geophysical

91 Original lists in Costantini 1986; Costantini and Costantini Biasini 1986, 362-363, figs 9-14; and a summary and evaluation already in Fedele 2010, 144-145.

92 de Maigret et al. 1987, an unpublished report. After 1986, unfortunately, the IsMEO journal East and West discontinued its 'IsMEO activities' section, which for a few years had been a customary and highly useful news vehicle. As a consequence, the MAIRAY/MAIRY operations at Barāqish in 1987 and 1989-1992 could not be speedily reported in print. Here, in addition to the above cited report, we are using information derived from de Maigret's 'Exploration' notebooks and personal diary for 1987.

93 The participants to the operation were V. Francaviglia and Dario Monna (CNR), Mauro Cucarzi and Franco Brancaleoni (Lerici), V Labianca, M. Mascellani, and the GOAM inspector-archaeologists 'Abd al-Ahad and Ahmad al-'Ațtab (from the central office) and Ahmad Abd' al-Rahman al-'Izzī from Mārib. Mascellani, Cucarzi and Labianca came back to Șan' $\bar{a}$ ) on 29 August; Mascellani returned to Barāqish on 31 August when de Maigret and several mission's members visited the site (including Antonini, G. Pettinato, A. Solazzi, and GOAM's Khālid al-'Ansī)

94 Here is a selection, as penned by de Maigret in his diary of 29 August after listening to the accounts by the returning team members: their car tyres went flat five times on the road to Mārib; at Barāqish, the heat was unbearable and the tools could not be touched with bare hands; the refrigerator and one of the two new generators broke; a sudden storm unhinged the communal tent; and the men of the village from which the site guards had not been chosen fired at night.

95 V. Francaviglia, 'Geoarchaeological survey at Barāqish, Y.A.R.', unpublished report dated 7 September 1987 in de Maigret et al. 1987. In his personal diary de Maigret records that Francaviglia once thought of letting himself descend into the Islamic well in the middle of Barāqish, to inspect it, but was dissuaded. Nor was this kind of investigation ever attempted subsequently. The depth and geology of the well would have provided information which we are still lacking about the deeper structure of the Barāqish mound (cf. Fedele, Chapter 26 in Volume 2). work more generally, are reported for the first time in this book (Fedele, Chapter 15, this volume).

The cores offered a glimpse of the sedimentary nature and cultural contents of the mound's deposits. Even an incense burner was found, but de Maigret welcomed with particularly eager attention the finding of ash and charcoal levels (Appendix A, Document A3), which suggested in situ occupation and promised chronometric data. The short campaign was indeed also important because it provided the first charcoal samples for radiocarbon dating, a novelty for Barāqish and the whole Jawf. ${ }^{96}$ Also these determinations are formally published for the first time in this volume (Fedele, Chapter 16).

Two more aspects greatly interested de Maigret, as they would have repercussions on future work. Barāqish was 'hollow' in the middle apparently because of the thinness of Islamic remains: therefore the Minaean levels, being nearer to the surface, would have been reached more easily with excavation. On the other hand, the local sociopolitical context was worrying (cf. footnote 78): 'The locals are difficult and want money, a lot of money, for everything. They cannot conceive what Barāqish is destined to become - the only thing that interests them is exploiting the present. This will give us trouble' (Appendix A, Document A3).

\subsection{Excavations: $1989-1992^{97}$}

In 1989 a new archaeological cooperation plan was signed between North Yemen and Italy. Eventually renewed, it actually became a four-year plan allowing for a sustained new cycle of archaeological education and research. In this framework, as mentioned in section 3.1, it was with great delight as well as sense of responsibility that de Maigret and the Italian mission accepted the offer of the Yemeni authorities to undertake excavations at Barāqish (cf. footnote 65). The full excavation and restoration of Temple A were the focus of the new programme.

The first season took place between 25 December 1989 and 31 January 1990, with the actual excavations at the temple running from 30 December to 25 January. ${ }^{98}$

\footnotetext{
96 de Maigret had acquired an awareness of the importance of immediately obtaining radiocarbon determinations, where critical historical issues were concerned, during his fellowship at the London's Institute of Archaeology, in the late 1970s (Fedele 2011b, xi). In Yemen he put this attitude to good use, starting in 1983, but in the case of Barāqish the radiocarbon measurements from 1987-1992 although mentioned and used - were never formally published.

97 Similarly to section 3.2, above, the information used here was extracted from de Maigret's excavation notebooks and personal diaries of the relevant years and campaigns. Concise, general accounts of this period can be found in de Maigret 2000a, 2000c, 2005a.

98 In addition to de Maigret and Antonini, the participants were E. Gatti, V. Labianca, M. Mascellani, Christian Robin, and the GOAM
} 
A small team carried out a further intervention at the end of February, as reported below (see footnote 108). A major diplomatic event at the beginning of the field operations was the visit of the then President of the Italian government, Hon. Giulio Andreotti, and his wife, accompanied by Gherardo Gnoli as President of IsMEO and by an Italian-Yemeni delegation. The visit entailed exceptional security measures and other special arrangements. ${ }^{99}$ The archaeological work continued in fits and starts for the next four weeks, punctuated by problems with and between the locals. The final results, however, were impressive..$^{100}$

Temple A, located near bastions T44 and T45 in the middle of the southern curtain wall, was partly brought to light and turned out to be a magnificent monument dedicated to the Minaean patron god Nakrah, as the numerous inscriptions revealed (Fig. 33). ${ }^{101}$ Preserved up to the roof, this temple was constructed with well hewn, marginally drafted, pecked limestone blocks. In plan, four longitudinal rows, each made of three monolithic pillars, subdivided the hypostyle hall into five naves, leading to five raised cellae at the far end (Fig. 34). The lateral naves contained three monolithic offering tables, $3.1 \mathrm{~m}$ long, sculpted at either end with a row of recumbent ibexes. The hypostyle hall was preceded by a propylaeum whose four pillars originally stood $5.6 \mathrm{~m}$ high (only a fallen pillar survived). The impressive entrance gateway comprised a platform with steps round three sides, culminating in a portico integrated with the stylobate and two flanking terraces (Fig. 35). Through a side door, the hypostyle hall communicated with a two-storey annex on the western side of the temple, the so-called 'sacristy'(Fig. 36). The 'sacristy' produced fragments of ceramic vessels, several inscriptions, and rare but significant objects, including

inspector-archaeologists Khālid al-Mindī, Khālid al-'Ansī, Jamāl alSharjabī, Ahmad Shuja' (from the central office), and Ahmad Abd al-Rahman al-'Izzī from Mārib. The Barāqish team was subsequently joined by G. Gnoli, Rome University's Mario Liverani and G. Pettinato, B. Marcolongo, E. Francaviglia, F. Brancaleoni (Fondazione Lerici), L. Costantini, A. Solazzi, P. Smith, student Monica Ricci of Naples University 'L'Orientale', and GOAM's Ahmad al-Rawdī. The operations at Barāqish represented the centrepiece of a much longer field season spanning several months between autumn 1989 and spring 1990.

99 The deployment of security was extraordinary: all the local inhabitants were disarmed and lined up for the reception; tankers of water were emptied to compact the road and allow the cars of the presidential procession to reach the Barāqish mound.

100 de Maigret 1991a.

101 de Maigret 1991a, 1991b. For a narrative in the popular press see de Maigret 1990b. A photograph of Temple A at the beginning of the excavations can be seen in Queen of Sheba 2002, 165, fig. 60. Many excavation results of 1989-1990 were amalgamated with those of 1992 in a number of final publications on Temple A, or about Barāqish/ Yathill in general, including de Maigret 1993, 1997a, 1998a, 1998b (a nonspecialist article), 2000b, 2004a; 2009a, 313-324 (Italian edition, 1996, 289-303); de Maigret and Robin 1993; Robin and de Maigret 1994. The architecture of Temple A soon fostered comparisons with the 'Grand temple' at Yeha', Ethiopia, see Robin and de Maigret 1998, 775-780; de Maigret 2010b. plaster human figures (Fig. 37), ${ }^{102}$ two stone incense burners, and a plaster jar sealing. ${ }^{103}$ The topographic and architectural relationships between the temple and the curtain wall appeared to be most interesting, although the wall was only excavated in small part that season. In 1992 a small passageway would be found that directly linked the temple to a postern in the curtain wall (recess R44/45). ${ }^{104}$

At the end of the campaign, de Maigret could already sketch a four-phase history for the temple's architecture, tentatively suggesting a timeframe from perhaps the 5th century BCE to the 1st century CE (see footnote 100). With the support of the subsequent excavations and radiocarbon determinations, three architectural phases were eventually suggested, underpinning a long continuum of cultic life (cf. references in footnote 101): Minaean C (7th or 6th-5th centuries BCE), B (4th-3rd centuries BCE), and A (2nd century BCE to 1st century CE).

Epigraphers Gnoli and Robin could take care of a wealth of new texts generated by Temple A. ${ }^{105}$ In the Barāqish area, additional geomorphological elements for a study of ancient irrigation were recorded, ${ }^{106}$ and short archaeological and epigraphic observations were made at the satellite sites of Shaqab al-Manașșa (Figs 27-29) and Darb al-Șabī ${ }^{107}$ On 28 February 1990, a few hundred metres from al-Darb (or Darb al-Ashrāf) in the irrigated floodplain to the south of Barāqish, Gnoli inspected and Antonini photographed in situ a bifacially inscribed stela in the Sabaean dialect, of considerable interest because of both its antiquity and textual content (a ruling on irrigation rights, including a rare mention of local plantations). ${ }^{108}$

Retrospectively, however, the most significant field operation besides the excavations was a new coring campaign, after the 1987 operation described above. An arresting sentence from de Maigret's personal diary serves as a suitable epigraph to this campaign: 'Barāqish è antichissima', 'Barāqish is ancient indeed' (Appendix A, Document A4). This time the coring was conducted in close connection with the works at the temple, and

\footnotetext{
102 de Maigret 1993, figs 13-15; Antonini 1999.

103 de Maigret 1991a, 14; 1991b, 164, fig. 7; Marion de Procé, Chapter 11, this volume; the plaster jar sealing also in Costa 1991, 43, fig. 10. For the association with radiocarbon dates see Fedele, Chapter 16, this volume.

104 See footnote 114 below.

105 Gnoli 1991, 1996b.

106 Marcolongo 1994, 1996, 1997, 2000 (cf. footnote 87).

107 On both sites see section 5, below.

108 Texts Y.90.DA.1-2. Gnoli and Robin 1992; Sima 2000, 186, no. 10 (where the stela is attributed to the 8th century BCE), 377, 402. Of interest in text 1 , lines $10-11$, is the record of a plantation of 'ilb trees, i.e. sidder or Ziziphus spina-christi (see Fedele, Chapter 19, section 4.2, in Volume 2).
} 
it was decided that F. Brancaleoni should drill right outside the back wall of the temple of Nakrah, as well as within the 'sacristy' (Fig. 38). ${ }^{109}$ Two cores were taken, one as long as $7.5 \mathrm{~m}$ and reaching as deep as possible into deposits never examined before - yet without any hint of virgin soil or bedrock at the bottom (see Fedele, Chapter 15 , this volume).

A second excavation campaign at Barāqish could only be carried out in 1992. This two-year-long suspension of activities was essentially caused by security conditions. Yemen's unification on 22 May 1990 had unleashed a new surge of tribal and political tensions in several areas. Furthermore, there were commitments in Italy, connected with studies and publications awaiting completion, as well as with the organization by IsMEO of the First International Conference on the Conservation and Exploitation of the Archaeological Heritage of the Arabian Peninsula. This major conference eventually took place in Rome, at Palazzo Brancaccio, on 28-30 May 1991, and Yemen and MAIRY featured prominently. Following the Rome conference de Maigret, who in 1990 had become a full professor at Naples University 'L'Orientale', was elected president of the newly formed 'Arabia Antiqua' Association. However, for de Maigret and his closest collaborators a return to Barāqish remained a pressing priority. ${ }^{110}$

The field season of 1992 was long and complicated. At Barāqish the operations could eventually begin on 28 April and be closed on 10 September. ${ }^{111}$ They were discontinuous, however. A major interruption occurred when, in May, the repeated 'peace' agreements were disregarded and serious fighting both between local factions and with the military garrison at Barāqish broke out. During the night of 26-27 May, shootings and machine-gun fire forced the researchers daringly to escape into the inside of the town and find shelter among the ruins. On the next morning the MAIRY team

\footnotetext{
109 Supposedly with advice from de Maigret (cf. de Maigret 1993, 15). The drilling was carried out by F. Brancaleoni with assistance from V. Francaviglia. The attribution of these cores to 1992, cursorily made years later (Robin and de Maigret 2009, 60; de Maigret 2010a, 68), was a lapse of memory.

110 For archaeological reasons, and not discounting the personal, intellectual side: for de Maigret Barāqish had more than ever become a prize site, destined to remain his personal favourite project over the years (cf. Fedele 2011b, xii, based on personal records).

111 de Maigret 1993, 3 (but the digging operations were closed on 3 September; see Barāqish 1990 and 1992 excavations notebook, p. 244). In addition to de Maigret and Antonini, but generally only present for shorter periods, the participants were C.J. Robin as mission's epigrapher; M. Mascellani, also in charge of the camp organization and administration; archaeologists Vittoria Buffa, Marilia Poli, Barbara Davidde and Patrizia De Socio; E. Gatti; architects-restorers Giuseppe Tilia and Angela Bizzarro; cultural anthropologist Roberto Malighetti; and GOAM's inspector-archaeologists Khālid al-'Ansī, Jamāl al-Sharjabī, 'Abd al-Hakīm Shayf and Ahmad al-Rawdị, together with photographers Khālid al-Mindī and Ibrahīm al-Hudīd. Dr Aḥmad Billah efficiently coordinated the Yemeni team.
}

left for $\operatorname{San}^{\left(\bar{a}^{\top}{ }^{112}\right.}$ The works were resumed on 22 June. In July, the summer monsoon hit with all its force, with sandstorms day and night that made normal life at the camp difficult and hindered the excavations. This culminated on the evening of 27 July with a terrible rainstorm. The camp was flooded by the swirling and muddy water that descended in torrents from below the town wall and from the hillocks nearby. Those in the camp, de Maigret wrote in his diary, had barely time 'to salvage the cameras, drawings, archaeological finds, computers, and cigars': 'a challenge from Nakrah?' (Appendix A, Document A5). The photograph on the cover of this volume refers to that event.

However, the mission coped. The results were again impressive and effectively completed those obtained in 1990. The temple of Nakrah and its surroundings were unearthed completely, including the nearby portion of the curtain wall corresponding to bastions T44 and T45 (Fig. 39). ${ }^{113}$ A highlight of the campaign, on the penultimate day of excavations (31 August), was the discovery of a postern in the wall recess between T44 and T45, allowing direct access between the temple and the outside of Yathill. The next day, completely freeing this narrow passage of the debris, the arm of a wooden statue was discovered at the base of the staircase leading to the postern. ${ }^{114}$ Also the retrieval of epigraphic material was considerable, in fact greater than in $1989-1990 .{ }^{115}$ Finally, some restoration work was begun in 1992 on the most precarious outer walls of the temple; the roof truss (Fig. 40) was partly removed for a future and more substantial restoration project.

\footnotetext{
112 Already on 4 May, on the road between Al-Hazm (Hazm al-Jawf) and Barāqish, one of the cars of the mission had been attacked and all its contents stolen, leaving the occupants on foot.

113 de Maigret 1993; de Maigret and Robin 1993. For accounts of the season's results, including popular articles, see the references in footnote 101.

114 The field journal records that on 31 August 1992 the excavations of staircase L12 brought to light 'a small passageway that allowed the access to L12 from the outside of town', a finding signalled by de Maigret with a rare exclamation mark (Appendix A, Document A6, p. 241). On the 1st September both the staircase and passageway were completely exposed, allowing a complete view of the postern (p. 242), whose architecture became clearer on the 3rd when de Maigret after a forced trip to Șan' $\bar{a}$ ) and before closing the dig - was able to carry out a preliminary restoration (p. 244). In Minaean times, as far as we know, this was the only passage in the curtain wall besides the town gateway. On the extramural excavation in the area of wall recess R44/45 see Antonini, Chapter 8, this volume.

115 de Maigret and Robin 1993, 458-489 (C.J. Robin); see also Gnoli 1993a, 1993b, 1996a, 2009; Agostini 2014. Overall, the excavations connected with the temple of Nakrah produced almost a hundred new inscriptions (de Maigret 2000a), of which no less than 66 resulting from the temple alone (Gnoli 1993a, 23).
} 


\section{The Italian Archaeological Mission: 2002-2007}

\subsection{Return to Barāqish: an outline $e^{116}$}

The archaeological activity at Barāqish was resumed in 2002-2003 after an interruption of more than a decade. Several successive factors were responsible for such a stop. In 1992 A. de Maigret was appointed by the Ministry of Foreign Affairs as archaeological counsellor to the Italian Embassy in Riyadh, and took on his duties the following year, completing his tenure in 1997.117 By that time, it was clear that the tribal and political instability in the Barāqish area, combined with the lack of funds necessary to face the massive restoration of the temple of Nakrah, did not allow to pursue the expected archaeological work. Therefore, temporarily, in 1999, the Italian mission asked and obtained to excavate at Tamna', the Qatabanian capital, in collaboration with the French mission headed by Christian Robin. ${ }^{118}$ Only in 2002 did the Italian mission return to Barāqish, the most serious obstacles now in the process of being resolved. This time, besides sponsorships by the Ministry of Foreign affairs and IsIAO ('Istituto Italiano per l'Africa e l'Oriente', heir to IsMEO after a merger with Istituto italiano per l'Africa), MAIRY was officially supported by Naples University 'L'Orientale'.

A new agreement with the Yemen government had permitted the construction of living and storage facilities under military protection near the ancient town, in the plain immediately south of the mound. This would form the mission's base at Barāqish. In 2002-2003 MAIRY was engaged in this task, and several houses, a laboratory, and storage rooms for the archaeological finds were constructed: these rooms were destined to become part of a small onsite museum (Fig. 41). ${ }^{119}$ Thus in October 2003 the excavations could be fully resumed and the planned restoration work was commenced. By February 2004 a state-of-the-art restoration of the temple of Nakrah was completed (see Scigliano and Paladino, Chapter 13, this volume).

Between 2004 and 2006 a range of new excavations were undertaken by the Italian mission: the temple of 'Athtar dhu Qabd (Temple B), a deep sounding outside the temple of Nakrah, and two extramural operations. These operations included a Minaean cemetery (Area D), under the direction of Antonini, and an attempt at comprehensive testing across the Barāqish mound,

\footnotetext{
116 Portions of this section derive from the same contribution to a memorial volume for de Maigret mentioned in footnote 57 (FGF, 'Barāqish stratigraphy and Sabaean Yathill').

117 Antonini 2009, xxii; and, unsigned, in de Maigret 2012, 10.

118 de Maigret and Robin 2016.

119 Most of this work was supervised, and beautifully accomplished, by veteran Mario Mascellani. The rooms intended for the museum were eventually completed in December 2007 (see below).
}

or tell, accompanied by geoarchaeological and bioarchaeological studies (Area C, Fedele's subproject). Once again de Maigret typically immersed himself in the programme with vision and tireless energy. But in 2007 he was diagnosed with cancer and prevented for medical reasons from a return to the field. Coincidentally, new tensions were mounting in the Jawf. With fieldwork out of the question, the excavation plans were changed to a study season, which was highly successful but was to be the last at Barāqish. ${ }^{120}$

After the great excavation exploit of 2006, de Maigret was looking forward to doing more testing of the large Sabaean settlement lying beneath Minaean Yathill, while towards the same goal Fedele had agreed to broaden the investigations outside the western Minaean wall and into the plain. Other team members were ready to deal with other challenges. For instance, Sabaean cemeteries were also eagerly expected (like the one supposed to exist at findspot BARiii, 1986; see section 3.2, above). ${ }^{121}$ The subsequent events, however, made fieldwork at Barāqish impossible, due to de Maigret's death in February 2011 and, four years later, war in Yemen. Before war started, Antonini as director of the Italian mission was able to arrange with the officers at GOAM the transfer of part of the archaeological collections from Barāqish to Șan' $\bar{a}$ '. ${ }^{122}$ As mentioned at the beginning of this chapter, in 2015 the Barāqish site was damaged and both the temple of Nakrah and the Italian mission's base were razed to the ground. ${ }^{123}$ Like at Mārib or Șirwāh, targeting Barāqish for destruction was - in a peculiar way - a recognition of its cultural significance and of the outstanding value of the archaeological work performed on the site.

\subsection{October 2003-February 2004}

The aims and operations of the five field seasons that took place at Barāqish between 2003 and 2007 will be described only briefly, because they already form the core of the subsequent parts of this book (Chapters $3-11,13-14,17-26$, and 28). The first campaign was

\footnotetext{
120 Fedele 2011b, xii.

121 The expectation of a Sabaean cemetery was mentioned by de Maigret in one of his last writings, the foreword to A Minaean necropolis (Antonini and Agostini 2010a, 8). Early the same year, 2010, issue no. 4 of Arabia - Revue de Sabéologie appeared. This was the journal de Maigret had founded with C. Robin, and in 2008 he had personally assembled issue no. 4 in order to showcase major stratigraphic projects in Yemen, because comparative stratigraphy was a need he felt strongly about (see de Maigret's preface to Arabia 4, 9-10, dated October 2009). Significantly, two of the three reports in the volume featured Barāqish: de Maigret 2010a and Fedele 2010. (About this latter and its historical contribution see Robin and de Maigret 2009, 63-72.) The third article, opening the volume, was by J.-F. Breton and collaborators on Shabwa.

122 In September 2013. The collections rescued from Barāqish were housed at the National Museum of Yemen in the storerooms of the Yemeni-Italian Centre for Archaeological Research (YICAR).

123 Cf. Fedele 2017, 311 ('Update April 2016’).
} 
carried out between 21 October 2003 and 6 February 2004. Eleven years had elapsed since the previous field season. A team of both veterans and newcomers was formed, several of them also engaged at Tamna ${ }^{c, 124}$ and the following operations were conducted:

- the long-planned restoration of the temple of Nakrah ${ }^{125}$ (see Scigliano and Paladino, Chapter 13 , this volume);

- the excavation and subsequent terracing of the area in front of the temple of Nakrah, for the safeguarding of the exposures in the temple's sector;

- the excavation of the Islamic structures resting on bastion T45, in order to expose its mudbrick fill and the related masonry bodies;

- and the extramural excavation in the area of wall recess R44/45 and bastion T45 (see Antonini, Chapter 8, and Agostini, Chapter 9, this volume).

\subsection{December 2004-January 2005}

With the completion of works at the temple of Nakrah, the priority tasks had now become the excavation of the intervening area between it and Temple B, and of course the unearthing of this latter temple. To this effect, a relatively short campaign was carried out between 10 December 2004 and 13 January 2005, ${ }^{126}$ during which the following operations were conducted:

- the partial excavation of Temple $\mathrm{B}^{127}$ whose consecration to the Minaean god 'Athtar dhu Qabd has already been mentioned (see Agostini, Chapter 3, this volume);

- the partial excavation in the interval between Temples A and B, occupied by a thick and complicated stratification of Islamic residential

\footnotetext{
124 Besides A. de Maigret, these were M. Mascellani; three recent graduates in archaeological disciplines from Naples University 'L'Orientale' (Romolo Loreto, Rosario Valentini) and the University of Florence (Alessio Agostini); restorers Saverio B. Scigliano and Alessandra Paladino (Rome); 'L'Orientale' students Danilo Mongiello and Marta Passarelli; and GOAM's inspector-archaeologists Ahmad Billah and Jamal al-Tāait. Barāqish was now guarded by a resident garrison of 24 soldiers. For an inscription resulting from the 2003 season see Agostini 2014.

125 de Maigret 2004a, 2005b.

126 Besides A. de Maigret, the mission's core was formed by M. Mascellani, A. Agostini, R. Loreto, and R. Valentini, with the participation of a student of Naples University 'L'Orientale', Serena Vessichelli. C.J. Robin and Jean-Marie Gassend paid visit to the mission for a few days. The GOAM's inspector-archaeologists were Șādiq Sa'īi 'Uțmān, Mabkhūt Muhsyin Muhtamm, Muhammad Hajar, Mana 'Allāh Sarī al-Nașrī, Murad Ghalib, all from the Mārib office.

127 de Maigret 2006. The results of this excavation were amalgamated with those of the subsequent campaigns in several interim publications on Temple B, including de Maigret $2009 \mathrm{~b}$ and Agostini 2011, 2012, 2015. See also de Maigret 2010b (comparisons with Yeha', Ethiopia). On the architectural typology of both Barāqish temples see Breton 1998, 74-78; Darles 2009b; 2014, 126, 128-131; and Chapter 10, this volume.
}

deposits, a painstaking work contributing to Yemen's medieval archaeology;

- limited, further work in front of Temple A;

- the continuation and completion of the extramural operation at R44/45.

\subsection{November 2005-January 2006}

The return to the field in November 2005 was characterized by a relatively marked shift in the activities at Barāqish. The defining innovation was the start of two major extramural operations, both located to the west of the city and thus confronting entirely unknown topographic and sedimentary contexts. These locations were called Areas C and D (Areas A and B being those of the excavations in the temple precinct). At the same time, the maximum effort was dedicated to the works connected with the temple of 'Athtar dhu Qabd, for fear that the relatively good conditions that were allowing fruitful excavations in the Jawf might not last much longer. The 2005-2006 field season at Barāqish took place between 23 November and 6 January ${ }^{128}$ and saw the following operations:

- the further excavation of the temple of 'Athtar dhu Qabd;

- concomitant interventions by the restorers to ensure the stability and safety of this building (see Scigliano and Paladino, Chapter 14, this volume);

- the further excavation of the area between the temples of 'Athtar dhu Qabd and Nakrah;

- the first campaign of the extramural project in Area C, consisting in an interrupted, stepped trench through the western flanks and talus of the Barāqish tell outside bastions $\mathrm{T} 6$ and $\mathrm{T} 7$, between the Minaean wall and the dirt road, which measured at the end $52 \mathrm{~m}$ in length and $14 \mathrm{~m}$ in depth, or height ${ }^{129}$ (Fig. 42; see Fedele, Chapter 17 in Volume 2);

- a preliminary, total-station topographic survey of the western wall and talus of Barāqish (by R. Loreto);

- the partial excavation of the Minaean cemetery in Area D (Fig. 43). ${ }^{130}$

128 Besides de Maigret, the participants were Antonini, for the project at Area D; Fedele, for the project at Area C and palaeoecology; A. Agostini and R. Valentini; R. Loreto, present part-time since mainly engaged at Tamna'; Patrizio Morlupi, a nurse from Perugia in charge of both medical care and photography; draughtswoman Giuseppina Stelo; restorer S.B. Scigliano; architect Ghislain Richoux; 'L'Orientale' students Marilena Scuotto, Paola Pagano, Micol Cappelli, and Marco Lo Sardo (part-time since also employed at Tamnac). The GOAM's inspector-archaeologists were 'Abd al-Bașit Nu'mān, 'Isa al-Sha'ibānī (mostly with Fedele in Area C), and Jamal al-Țābit, while Ahmad Shamsan, director of the Mārib office of GOAM, took part to work in Area D.

129 Fedele 2010.

130 Antonini and Agostini 2010a, $2010 \mathrm{~b}$. 
Concerning Area $\mathrm{C}$, a brief theoretical justification is in order. The immediate aim of the operation was to obtain a comprehensive stratigraphy from Barāqish, together with a stratified series of associated plant and animal samples. The operation was attempted extramurally by exploiting the eroded talus where the layers of the mound appeared to be more easily approachable or even exposed. More precisely, the project formulated in 2005 in consultation with A. de Maigret had the two main aims of understanding ' $i$ ) the earliest and early settlement in the Barāqiš area' and '(ii) aspects of the Barāqiš economy, especially animals'. ${ }^{131}$ The strategy would be 'to map the extent and type of the earlier occupation history at Yathill [through] soundings and surface prospections outside the walls, in close cooperation with de Maigret's own study of early Barāqišs'. 'Surface observations over a wider area are expected to add vital information on the context in which the settlement had its origin and grew, with or without precursors.' Point ii would imply 'specific recovery of animal and plant material from the soundings, as an approach to the Minaean and preMinaean economy as well as an attempt to outline the environmental context through time, in relation to people'.

Once in the field, it soon became apparent that prospecting a wider area was simply not feasible, due to considerations of personal safety. The core of the programme, however, could be launched immediately, and on 6 December a first test trench was started on the northwest slope of the Barāqish mound, where it rises about $15 \mathrm{~m}$ above the surrounding surfaces and is conspicuously scarred by old erosion gullies. ${ }^{132} \mathrm{~A}$ distinct contribution of Area $C$ was to confirm the existence of a substantial Sabaean settlement and offer a glimpse of the horizontal extent and vertical growth of the pre-Minaean tell. That the Sabaean occupation had already formed a tell was now completely clear. It was recognized that Sabaean Yathill here extended horizontally far outside the area later walled by the Minaeans. The dry-stone base of a wall apparently

131 After a mutual loss of exchanges for more than a decade, Fedele had been contacted by de Maigret in May 2002. In June de Maigret made a general proposal to the effect of working again together in Yemen, now in anticipation of a new research phase at Barāqish, but as a prehistorian Fedele pointed out difficulties with that prospect. However, a more cogent invitation, supported by a detailed illustration of the work being accomplished at Barāqish, was extended by de Maigret in 2004 and again in February 2005. This time the proposal to join the Italian team at Barāqish was accepted, with the proviso that a project of mutual interest was identified; de Maigret's invitation was totally open in that respect. Such a project was 'Activities to be carried out in Yemen in 2005 as a contribution to the Italian Archaeological Mission', drafted in May 2005 (Fedele, 1 page), from which the present quotations are taken. A. de Maigret 2010a, 68, mentions how this project fitted in MAIRY's goals.

132 The same gullies already mentioned in connection with findspot BARi and the sediment sampling for archaeobotany in 1986 (see section 3.2 , above) delimiting this Sabaean occupation was also found (Wall F4). ${ }^{133}$

\subsection{November 2006-January 2007}

The 2006-2007 field season at Barāqish took place between 9 November 2006 and 3 January 2007, with the overall aim of completing as far as possible the projects of the previous season and furthering the study of finds. ${ }^{134}$ The following operations were carried out:

- a third excavation season at the temple of 'Athtar dhu Qabd;

- concomitant works to ensure the stability and safety of this temple, as during the previous season;

- the almost complete excavation of the area between the temples of 'Athtar dhu Qabd and Nakrah;

- a deep sounding in front of the steps of the temple of Nakrah, labelled A/S1;

- a second excavation campaign in extramural Area $C$, during which the sounding along bastion T7 begun the previous season was completed (to a depth of $8 \mathrm{~m}$ ) and a test pit was made in the plain at a distance from the Barāqish talus; ${ }^{135}$

- the further excavation of the cemetery in Area D;

- a total-station topographic survey of the curtain wall of Barāqish (by R. Loreto).

Concerning A/S1, this sounding was carried out in the space just off the base of the staircase leading up to the temple's entrance (Fig. 44), taking a total of 14 days between 18 November and 19 December. It was $3 \times 3 \mathrm{~m}$ in plan and reached a depth of $6.4 \mathrm{~m}$ below the ground level of the temple. ${ }^{136}$ Such a vertical probe, supplying direct artefactual data and a series of radiocarbon determinations, ${ }^{137}$ confirmed and expanded the evidence for a very long pre-Minaean occupation of Barāqish/Yathill, already gleaned from the cores

133 The possible significance of Wall F4 was mentioned in footnote 84. By 'Sabaean' occupation we intend a phase defined by the use of Sabaean pottery (see Fedele, Chapters 18 and 23 in Volume 2).

134 Besides de Maigret, Antonini, and Fedele, the participants were A. Agostini, R. Loreto, P. Morlupi, G. Stelo, G. Richoux, restorers S.B. Scigliano and A. Paladino, the graduates of the two Naples universities Gennaro Di Rosa ('L'Orientale') and Francesco Di Grazia ('Federico II'; this latter as Fedele's assistant for Area C and for laboratory work on the related finds), and a student from 'L'Orientale', Marcella Giobbe. Christian Robin paid visit to the mission for a few days. The GOAM's inspector-archaeologist was 'Abd al-Bașit Nu'mān. Fedele wishes to record that his 2005-2006 excavations in Area C owe a great debt to the dedicated assistance of 'Ali ' $A$ bduh 'Abdallah, a soldier-accountant in the Yemeni army.

135 Fedele 2010, 2011a.

136 de Maigret 2010a.

137 de Maigret 2010a, table 3; and Fedele, Chapter 16, this volume. 
taken during the earlier campaigns and more fully demonstrated by the Area C excavations of 2005 .

The successful unearthing of the base of the Minaean wall was the highlight of this second round of excavations in Area C. Rather surprisingly, in correspondence of bastion T7 and certainly for a much more extended stretch on both sides of it, the Minaeans had built their imposing wall on top of the latest Sabaean deposits, not on virgin terrain or bedrock (nowhere to be seen in Area C). Furthermore, the excavation revealed that important Minaean activities took place along the base of the wall, most of them apparently connected with trading, and that the upper talus had repeatedly seen the stationing of donkeys and dromedaries. ${ }^{138}$ This still represents the most direct archaeological evidence for trading at ancient Yathill. The stratified findings from the base of the talus, in 2005, now supplemented by the test pit in the plain, however limited $(2 \times 2 \mathrm{~m})$, concurred to outline a picture of persistent Sabaean and Minaean camping and trading in the plain to the west of the tell. ${ }^{139}$

\subsection{November-December 2007}

As mentioned above, the excavation plans for 20072008 had to be suppressed and the campaign at Barāqish was turned into a study season. This intensive, dedicated period was fruitful although rather short (24 November-17 December 2007). ${ }^{140}$ Studies were carried out on the Minaean ceramics (V. Buffa) and animal bones (Fedele), ${ }^{141}$ while the photographic record for the Area $\mathrm{C}$ artefactual and ecofactual collections was completed and their catalogue was updated. ${ }^{142}$

In connection with the bone work, a small zooarchaeological laboratory was set up at the Barāqish camp, where several thousand animal finds were examined and identified to species, in what might have

\footnotetext{
138 Fedele 2010, 142-144; 2011a; 2014; 2017; 2019.

139 Fedele 2010, 147-148; 2014; and Chapter 19 in Volume 2.

140 Besides R. Loreto, acting as de Maigret's deputy, and Fedele, the team was composed of Antonini (two days only, 28-29 November, as she was engaged at Tamna'), M. Mascellani, archaeologist Vittoria Buffa, G. Stelo, and 'L'Orientale' graduates Gennaro Di Rosa and Stefano Iavarone. The GOAM's inspector-archaeologist was again 'Abd al-Bașit Nu'mān, assisted by 'Abd al-Tawāb (a.k.a 'Abdu Taūb) and another senior colleague from the central office. After the hurried departure of the mission's team from Barāqish on 18 December, A. de Maigret was able to join the group later that day in Șan' $\bar{a}$ ') for the usual reporting to GOAM and a collective return of the mission to Rome on 22 December.

141 In addition, Fedele managed to finish his zooarchaeological study of the faunal collection from Yalä/al-Durayb, which had been transferred from Șan' $\bar{a}^{\prime}$ to Barāqish, for this purpose, the previous year.

142 Supervised by Fedele, G. Di Rosa and S. Iavarone provided valuable assistance in the photography, cataloguing, and storage of the Area C material. The photographic sessions covered other groups of finds as well (see Chapters 5-7, this volume).
}

been the most detailed analysis of a Sabaean-Minaean fauna yet carried out in Yemen. In the case of Area C, the information from bones was co-ordinated with information from both pottery and sediment geology in order to get a detailed picture of the economic and ecological history of the area as recorded outside of the western wall. The bone collection from the 2006 sounding along bastion T7, numbering about 2500 pieces, was completely studied, and the 2005 collection was partly re-examined as well. These analyses gave definitive indication that Minaean Yathill concentrated heavily on husbandry, of sheep and goats in particular, alongside a significant use of camels and donkeys in pack transport and caravan trade.

Laboratory studies, however, were not the sole activity of this season. Topographer M. Mascellani, assisted by R. Loreto, was able to carry out a general GPS survey of Barāqish and its main fenced complex, including a contour-line survey of the western talus and outlying 'hills'. ${ }^{143}$ This plan, the first by GPS technology for the Jawf, is presented in Fig. 45. It will serve in this volume as the reference plan for the reporting of all the archaeological operations conducted at Barāqish: Areas A, B, C, D, and R44/45. Finally, in December 2007, the rooms that would accommodate the small onsite museum at Barāqish were completed (see footnote 119): the use of two of them as living and laboratory space for one of the authors in 2006-2007 (FGF in connection with work on Area C) had come to an end.

\section{Investigations in the Barāqish territory}

Contemporary research at Barāqish not only focused on the city, but also - from the beginning - on two ancient sites located within a radius of $2-2.5 \mathrm{~km}$ to the west and south, and these investigations were integral to the historical understanding of the city itself. Both sites have briefly been mentioned in previous parts of this chapter (e.g., footnote 53). Their great interest depends on three main characteristics: their unsually high chronology, since both sites were established in the 8th century BCE, as epigraphically determined; their subsequent long duration; and their ideological connotation of tribal religious centres. ${ }^{144}$

Darb al-Ṣabī (often Darb aș-Ṣabī in the literature) comprises a group of cultic structures and installations within a symbolically delimited precinct (haram) consecrated to god Nakrah. It occupies a $300 \times 500$ $\mathrm{m}$ surface on a low rocky relief less than $2 \mathrm{~km}$ west

\footnotetext{
143 This plan includes the Italian-Yemeni archaeological camp and an outline of the talus surrounding the tell. The recording of the talus was ground-checked with Fedele, at whose suggestion it had been included in the GPS survey. The new general plan was used in a publication for the first time in Fedele 2010, fig. 128, and reproduced in its full extent - but unrevised - in Agostini 2015, fig. 2.

144 Schiettecatte 2011, 55.
} 
of Barāqish. The site was visited by the French archaeological mission in $1976,{ }^{145}$ and the architectural and epigraphic investigations were comprehensively published; over forty buildings have so far been inventoried on the site. ${ }^{146} \mathrm{~A}$ re-examination of the locality was carried out by the Italian mission during the field seasons of 2005 and 2006. ${ }^{147}$

Also Shaqab al-Manașsa, located in Wādī al-Shaqab 2.5 $\mathrm{km}$ to the south-southwest of Barāqish, was first visited and investigated by the French mission in 1976-1978. ${ }^{148}$ Subsequent observations and discoveries, mostly epigraphic, were made by the Italian mission, following an initial contact with the site on 8 December 1986 (see section 3.2, above). ${ }^{149}$ Both the French and Italian studies have focused on the ruins and inscriptions of two temples or sanctuaries (Figs 27-29), located close to each other on the top of a sandstone outcrop bordering the ancient irrigated floodplain. However, other remains are known to exist in the surrounding area, in addition to a large number of agricultural and hydraulic features (weirs, wells, garden plots and associated sediments). ${ }^{150}$ Furthermore, Shaqab al-Manașșa and Darb al-Șabī are not necessarily the only satellite sites existing in the Barāqish territory, where exploration was never easy and total prospecting could not be conducted.
145 Robin 1976, 1979a; Robin et al. 1979; and his foreword to Gnoli 1993b. Cf. already Tawfīq 1951.

146 Robin et al. 1981; Robin and Ryckmans 1988. See also, on epigraphy, Robin 1981a, 52; Ryckmans J. 1981, 260-261; Arbach 1994; and on the site and its archaeology, Breton et al. 1981; Cleuziou 1986 (unpublished report); Robin 1995; de Maigret 2009a, 263, 287; Schiettecatte 2011, 49, 52, 54-55, 63; 2019b; Darles 2014, 126.

147 Loreto and Valentini 2012; and Valentini, Chapter 28 in Volume 2. On epigraphy see also Agostini 2012.

148 Robin 1976; 1979a, 193-201, pl. 4; 1995; Robin et al. 1979, 425-427 (cf. de Maigret 2009a, fig. 58); Schmidt 1982c, 168, fig. 46/e (courtesy R. Audouin, cf. footnote 53, above); 1988, 82 ('a hypostyle forest of pillars'); Breton 1998, 73-74, figs 15-16; Darles 2001, 45; 2014, 128; Schiettecatte 2011, 52, 54-55, 61, 64; 2019c. Different names are reported for the wādi near whose bed the site is located.
149 Gnoli 1986a, 1986b (a previously unseen Minaean inscription, Y.86.SHQ/1; cf. Gnoli 1991, 17), and 1993b, a comprehensive edition of the site and its inscriptions. See also Jung 1988; de Maigret 2009a, 295-296.

150 Marcolongo 1994 (with map, fig. 14), 1996, 1997, 2000 (with map on p. 139); cf. Gnoli 1993b, pl. 4a. For a regional perspective see Cleuziou et al. 1992. 


\section{Appendix A. Personal documents}

\section{Document A1 \\ (A. de Maigret, 1986 Explorations notebook, 'Barāqish', unnumbered pages following page $21\left[^{[a}\right]$ )}

[page 22] Per capire l'impianto delle mura è necessario conoscere dove esse poggiano. Purtroppo in nessun punto è possibile vedere la fine, in basso, delle fondazioni, che, per altro, appaiono soltanto nell'angolo SE della città. Lo studio geologico del comprensorio mostra l'esistenza intorno a Baraqish ${ }^{\text {sic }}$ ${ }^{[}$] di tabulati di arenaria pendenti verso il Ğawf, ciò in accordo alla sinclinale in cui scorre appunto il W. Ğawf. Barāqish poggia, e segue con le mura (soprattutto nella sua parte sud), su uno di questi brevi tabulati pendenti ('mesa') in arenarie dette di 'Medjzir', che affiorano a poca distanza e paralleli al W. Ğawf. In particolare il fronte sud, rettilineo, delle mura deve seguire la 'questa' [c] di tale breve mesa, e anzi la rottura di tale linearità nella metà ovest, deve essere imputata alla mancata linearità di tale andamento naturale. A nord le mura seguono invece un andamento circolare, che è geometricamente la forma più adatta per 'frenare' sulla pendenza della 'mesa'. A seconda dell'entità di tale pendenza (probabilmente $4^{\circ}-5^{\circ}$ ) le mura dovrebbero avere maggiore o minore alzato, se si vuole ricostruire una cinta che abbia, se vista dall'esterno, | [page 24] una stessa altezza di coronamento. [Fig. 18 was here. ${ }^{\text {d] }}$

Il maggiore alzato delle mura a sud è oggi nascosto dall'accumulo dei rifiuti gettati dalle mura nei periodi mineo (ceramica di questo periodo si è raccolta in fondo ai calanchi $\left[{ }^{e}\right.$ ] che a tratti segnano il terrapieno) e islamico. La pendenza del livello roccioso d'impianto fa supporre l'esistenza di un 'livello pareggiante' all'interno della città (Fig. 18: H), che dovrebbe aumentare di spessore via via che si raggiunge la cinta a nord. Si potrebbe pensare che, se vi fosse un insediamento anteriore a quello mineo, una eventuale occupazione più antica potesse ubicarsi in questa zona nord della città. Su questo livello di pareggiamento si impostava l'insediamento sabeo-mineo (Fig. 18: I). Si potrebbe pensare che ' $\mathrm{H}$ ' non esistesse e che 'I' andasse a scendere, nel suo impianto verso $\mathrm{N}$, ma l'insediamento islamico (Fig. 18: J), che straborda dalle mura a N, come da quelle a S, sembra indicare un uguale spessore degli strati I + J in tutta la città, e quindi suggerire l'esistenza di un inzeppamento $\mathrm{H}$. La forma concava dell'interno della città sembra mostrare la preferenza delle varie occupazioni ad insediarsi presso le mura, lasciando libera una vasta piazza centrale. Il livello di questa si deve essere via via alzato perché in essa confluiscono i sedimenti dilavati dai livelli presso le mura. Si notano infatti numerosi | [page 26 ${ }^{\mathrm{f}}$ ] e profondi calanchi che segnano il pendio tra le mura e la piazza centrale (in tutte le direzioni, ma soprattutto a O e a N).
L'insediamento islamico, o meglio medievale e recente (fine XVII secolo) deve essere spesso diversi metri, dato che questi calanchi, che sono scavati nelle terre del disfacimento dei mattoni delle costruzioni lungo le mura, non raggiungono mai il livello mineo sottostante. Le sole strutture minee che affiorano sul livello islamico sono quelle monolitiche di alcuni templi, già noti nella letteratura archeologica (A. Fakhrī, J. Schmidt, B. Doe), e da noi per ora denominati 'tempio A', 'tempio B' e 'tempio C'. Altri 3 monoliti squadrati compaiono presso la moschea, o meglio dentro la moschea, ma il loro non allineamento tra le facce sembra indicare la loro posizione non in situ. Altri monoliti (tra il tempio C e la moschea) dovrebbero essere solo materiali di riutilizzo. Molto altro materiale mineo (blocchi dalle mura, iscrizioni, bacini, gronde, stelisic, etc.) sono del resto abbondantemente sulla superficie, dato che furono riutilizzati nelle costruzioni più tarde. $\left.{ }^{[}\right]$

[a] Pagination and subdivision in paragraphs added by the editor [FGF]; de Maigret's text is running continuously.

[b] And identical, simplified spelling in the rest of the document.

[c] Correctly cuesta, a geomorphological term: de Maigret was quoting by ear an unfamiliar term learnt from B. Marcolongo (FGF, based on personal records).

[d] This felt-pen coloured sketch is intercalated as folding page 23. The subsequent references to details in this drawing (e.g., 'Fig. 18: H') are by de Maigret himself. [e] Calanco, plural calanchi, is central-Italian for erosion gully. Notable examples could be seen on findspot BARi (Chapter 2, this volume) and in the talus sector of Area C (Chapter 17 in Volume 2); cf. main text, footnote 132. [f] Page 25 is an intercalated folding sheet with a photocopy of the aerial photograph of Barāqish repeatedly employed by the French authors (cf. main text, footnote 79), onto which the numbering of bastions and the positions of the three temples were hand-penned.

[8] 'L'imponente paramento esterno della cinta fu in gran parte abbattuto alla fine del periodo mineo. Esso fu ricostruito con la prima occupazione islamica, ma con blocchi più piccoli e con una tecnica più modesta. Al suo interno s'innalzarono da allora numerose sovrapposizioni abitative che, con il loro peso, hanno col tempo indebolito le cortine esterne e causato, in diversi punti della cinta, il crollo di torrioni e riseghe.' / 'The substantial outer façade of the walls was largely demolished at the end of the Minaean period. It was rebuilt when the city was reoccupied by Islamic settlers, but using smaller blocks of stone and less proficient building techniques. From this time onwards numerous dwellings were put up inside the walls, often 
on top of one another. This gradually weakened the external façades, leading to the collapse of towers and the curtain wall in various places round the circuit.' de Maigret 2004a, 16 (English), 19 (Italian).

\section{Document A2}

(A. de Maigret, 1986 Explorations notebook, 'Barāqish', in continuation of Document A1 [a])

[page 26] Dietro la cortina di facciata delle mura è difficile immaginare la struttura completa delle mura antiche. La rientranza tra il torrione 15 e 16 (Francesi), o 43 e 44 (nostri), | [page $28^{\mathrm{b}}$ ] è crollata ed è possibile vedere dietro la cortina mancante un doppio livello, di cui il superiore corrisponde al livello islamico e l'inferiore ad uno strato di mattoni crudi grigi omogenei, che si infossa dentro la cortina minea della rientranza conservata in basso. [Fig. 19 was here.] Tali mattoni costituiscono evidentemente il corpo interno delle mura. Un filare parallelo alla cortina e più interno di $\mathrm{c}$. $3 \mathrm{~m}$. potrebbe essere, se non è una struttura islamica, il contenimento interno in pietra delle mura.

[page 29] L'altro dato che abbiamo sull'interno delle mura si ricava dall'osservazione del bastione 48 (Fr[ancesi] 11), quello cioè l'unico in cui l'alzato giunge sino al coronamento. [Fig. 20.] A parte un riempimento posteriore che si addossa alla cortina in basso, nulla copre l'opera in pietra nella parte alta, che si erge così libera, sostenuta sino ad oggi soltanto dall'accuratezza con cui sono sovrapposti i blocchi e dalle angolarità con le riseghe. $\left.{ }^{[}\right]$Non si può pensare che il nucleo in mattoni giungesse sino in alto perché altrimenti non avrebbero avuto ragione di esistere le due file di quattro feritoie in facciata e le due file di feritoie nelle riseghe. [Fig. 21.] La rozzezza della rifinitura dei blocchi all'interno lascia tuttavia perplessi: o non se ne curavano, o erano coperti da malta (asfalto). [d] Forse il corpo del muro in mattoni giungeva sino a creare un camminamento che permettesse di vedere attraverso la fila più bassa di feritoie. [e] Su questo doveva poggiare una impalcatura (in legno?) per permettere l'osservazione dalle feritoie più alte. [Fig. 22.] Solo lo scavo potrà dire se il corpo delle mura seguiva, nella sua faccia interna, l'andamento spezzato [delle mura].

[a] Unnumbered pages: pagination added by the editor [FGF].

[ ${ }^{b}$ Page 27 contains a glued sheet of paper with de Maigret's drawing here reproduced as Fig. 22.

[c] The outer side walls of the bastion.

[d] Asfalto (asphalt, tar) was added in a note with an asterisk.

[e] 'La sommità del nucleo in mattoni rappresentava il piano di camminamento di ronda, protetto dall'alzato della cortina esterna.' / 'A parapet walkway ran round the top of the brick core, protected by the external façade.' de Maigret 2004a, 16 (English), 19 (Italian).

\section{Document A3 \\ (A. de Maigret, personal diary)}

[31 August 1987] Brancaleoni con i carotaggi ha scoperto un livello di bruciato a 2-3 $\mathrm{m}$ sotto la piazza centrale con cocci minei, che testimonia la presenza di strutture in questa parte cava del sito. La forma a conca di Barāqish si deve quindi agli insediamenti islamici lungo le mura. Ciò faciliterà lo scavo al centro.

[3 September 1987] Tornano da Barāqish Francaviglia, Monna, Brancaleoni e Mascellani. Hanno fatto altri sondaggi, 9 in tutto. Le carote sono interessanti e includono cocci, un incensiere, ecc. Sono venuti a casa con uno sharîf di Barāqish, un certo Omar Sharīf, capoguardiano da Darb al-'Ashrāf. Non vi sono state più sparatorie ma i locali sono difficili. Vogliono soldi, e tanti, per tutto. Non hanno idea di cosa diventerà in futuro Barāqish: pensano solo a sfruttare quello che gli si offre oggi. Sarà in futuro un affare serio!

\section{Document A4}

(A. de Maigret, Barāqish 1990 and 1992 excavations notebook [a]; and personal diary)

[Thursday 18 January 1990, excavations notebook, page 52] In Lbe si è scesi ormai al di sotto del livello di fondazione del tempio (ma i suoi grossi blocchi ancora non terminano). Si ferma lo scavo e si decide che in questo punto, domani, effettueremo un carotaggio per capire quali sono i livelli archeologici sottostanti.

[Friday 19 January 1990, personal diary] Sveglia con cielo plumbeo [...]. Alle 7 arrivano i 4 operai che abbiamo tenuto per i carotaggi. [...] Vado su a vedere Enzo F. [Francaviglia] e Franco [Brancaleoni] che perforano la zona adiacente al tempio: risultato: cocci, apparentemente sabei quasi $5 \mathrm{~m}$ al di sotto della base del tempio mineo. Barāqish è antichissima, e ancora il carotaggio non è finito.

[Saturday 20 January 1990, personal diary] Comunque il lavoro va avanti, anche se i pericoli di crolli mi assillano. Il sondaggio di Brancaleoni mi ha messo davanti un quadro diverso di Baraqish ${ }^{\text {sic: è una città }}$ importante anche dal punto di vista stratigrafico. Stiamo galleggiando col nostro tempio in livelli tutto sommato superficiali. [. . .] Brancaleoni è arrivato alla fine delle sue aste per la sonda $(6,50 \mathrm{~m})$. Abbassiamo il livello [del suolo] per permettergli di scendere ancora un po'. Ma dubito che arriveremo al terreno (o roccia) vergine.

[20 January, excavations notebook, pages 57-58] In Lbe, dopo avere per tutto il giorno continuato la 


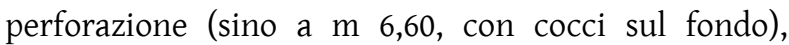
si decide di approfondire il sondaggio in modo da permettere alla sonda di scendere più in basso (hanno finito le aste di prolungamento). Si scende per una 70ina di $\mathrm{cm}$ (mettendo un pezzo di tubo a sigillare il foro), e così facendo si scoprono sotto la soglia di Mbh (ormai demolito) almeno 5 filari di blocchi, che a prima vista farebbero pensare al basamento del tempio, ma che, guardati con più attenzione, si rivelano i blocchi delle riseghe (visti in M1) consumati e rovinati dal salnitro.

[Sunday 21 January 1990, excavations notebook, page 59 - excavations in the so-called 'sacristy'] Si continua a pulire, raggiungendo il pavimento in tutto L3. Il pavimento non è, comunque, un gran che: terra appena pressata. | [page 60] Si scende ancora in Lbe e si continua la perforazione sino a c. 7,50 m. Forse si arriva al suolo vergine.

[Monday 22 January 1990, excavations notebook, page 61] Riduciamo a 27 operai. [. . . Finiamo di svuotare la terra in L3, sino ad arrivare alla pietra su cui poggia il plinto della stele. [ ${ }^{\mathrm{b}}$ ] A questa altezza si contano 6 riseghe in M1. [c] Non sono sicuro di aver raggiunto, però, il pavimento originale. Rifiniamo la sezione che divide [...] L3 da L6. Essa mostra con la sua sommità l'inizio dei livelli minei e alla sua base un segno di un pavimento biancastro, che è quello sul quale ci fermiamo in L3. | [page 62] In L3, quindi, abbiamo sfondato per qualche $\mathrm{cm}$ il pavimento relativo alla scala $\mathrm{M} 7$, ma non si è raggiunto quello, più basso, relativo a M5 ed M6. Se faremo - come da programma - un carotaggio in questo punto, si vedrà se esistono questi due pavimenti più antichi.

[end of page 62] 'Quote: L3: 1,04'. [']

[a] The Barāqish 1990 and 1992 excavations notebook, although headed 'Barāqish 1990 scavi', in fact comprises the excavation journals of both campaigns, forming two distinct but consecutive sections.

${ }^{[}$] Y.90.B.A 3: not a stela, but a reused slab (possibly a bench) placed vertically.

$[c]$ The southwestern wall of the temple's hypostyle hall. [d] Quote ('elevations'): i.e., excavation elevations at the end of the day, as de Maigret used to record.

\section{Document A5}

(A. de Maigret, personal diary, 27 July 1992)

Sbigottiti per tanta spaventosa rapidità siamo corsi con l'acqua alle caviglie (col pericolo della corrente elettrica) a mettere in salvo tutto (macchine fotografiche, disegni, materiale archeologico, sigari e computer). Sotto le sferzate del vento e della grandine, in macchina siamo corsi a cercare di aprire un varco al lago che, enorme, si era formato. Con lo scavatore i militari e gli operai alla fine abbiamo creato un condotto, ma l'acqua usciva troppo lenta. Intanto le case, le tende, le valige, gli armadi tutto marciva. Io sono corso su per vedere il tempio. Perfetto. Una sfida di Nakrah? Alle due, stremati, allucinati siamo andati a dormire, alcuni sui letti con $20 \mathrm{~cm}$ sopra l'acqua.

\section{Document A6 \\ (A. de Maigret, Barāqish 1990 and 1992 excavations notebook, pages 241-244)}

[page 241] 31/8/1992 | Si approfondisce L12. [a] Si trova una scala che occupa tutto l'ambiente e che scende verso la base esterna delle mura. Scendendo si trova un'iscrizione su lastra (Y.92.B.A/50) [ ${ }^{\mathrm{b}}$, ed una lastra di bronzo. Si prova a scavare dall'esterno delle mura nell'angolo tra $\mathrm{T} 45$ e la risega che va al T44 [c], e si trova lo stipite di una porticina che consentiva l'ingresso a L12 dall'esterno della città (!).

[page 242] Y.92.B/143 | 1/9/1992 | Si scava all'esterno della cinta nell'angolo tra T45 e la risega con T44 e si trova la soglia della porta in L12. Si finisce lo scavo di L12. La scala termina in un pianerottolo lastricato sul quale girava la porta. Si trova qui un braccio di statua in legno. [d]

[page 243] 2/9/1992 | Noi siamo a Sana [= Șan(ấ)], e gli operai lavorano solo allo scarico della terra di riporto.

[page 244, the last page of the notebook] 3/9/1992 | Si ricostituisce l'architrave nella porta sull'esterno di L12. Lo stipite $\mathrm{N}$ recava ancora l'alloggiamento per l'architrave e quindi si è sicuri dell'altezza della porta. | [new paragraph] Lo scavo a questo punto è terminato e si procede ai lavori di pulitura, di restauro, di rilievo, di fotografia, di ordine e di recinzione delle aree scavate.

[a] A narrow passage descending from courtyard D towards the curtain wall, to the southwest of the temple.

$\left.{ }^{[}\right]$Underlined in the original, as de Maigret used to do with inscriptions.

[c] Risega, an Italian architectural term, here means the wall recess between bastions T45 and T44.

[d] For this find, the forearm of a wooden statue, see de Maigret 1993, 16, fig. 17. 


\section{Appendix B. Barāqish curtain wall inscriptions}

\begin{tabular}{|c|c|c|c|c|c|c|c|c|c|c|c|}
\hline$\dot{z}$ & 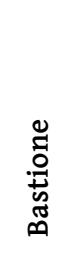 & 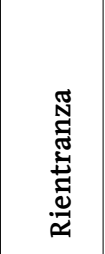 & 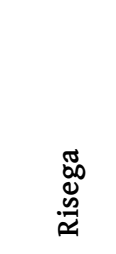 & 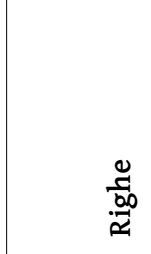 & 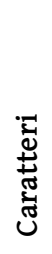 & 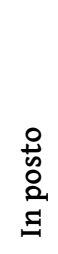 & 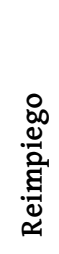 & 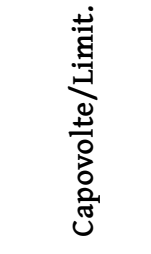 & :̊ & $\begin{array}{l}\stackrel{\mathbb{N}}{N} \\
\stackrel{ \pm}{ \pm} \\
\end{array}$ & 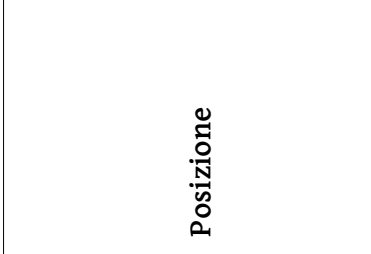 \\
\hline 1 & & $1 / 2$ & & & & & $\mathrm{R}$ & & & Basso & Sinistra \\
\hline 2 & & $1 / 2$ & & & & & $\mathrm{R}$ & & & Basso & Sinistra \\
\hline 3 & 2 & & & 3 & & & $\mathrm{R}$ & & & Basso & Centrale \\
\hline 4 & 2 & & & 1 & & & $\mathrm{R}$ & & & Basso & Centrale (sotto N. 3) \\
\hline 5 & 2 & & Sinistra & 3 & & & $\mathrm{R}$ & & & Alto & Centrale \\
\hline 6 & & $2 / 3$ & & 1 & & & $\mathrm{R}$ & & & $\begin{array}{l}\text { Basso } \\
\text { (terra) }\end{array}$ & Destra \\
\hline 7 & & $2 / 3$ & & 1 & & & $\mathrm{R}$ & & & Alto & Sinistra \\
\hline 8 & 3 & & & 1 & & & $\mathrm{R}$ & & & Alto & Centrale \\
\hline 9 & 4 & & & 4 & & & $\mathrm{R}$ & & & Alto & Destra \\
\hline 10 & 4 & & & 2 & & & $\mathrm{R}$ & & & Alto & Destra (sotto N. 9) \\
\hline 11 & 4 & & & 1 & & & $\mathrm{R}$ & & & Alto & Destra (sotto N. 10) \\
\hline 12 & 4 & & Sinistra & Rovin. & & & $\mathrm{R}$ & & & Basso & Centr./Sinistra \\
\hline 13 & & $4 / 5$ & & 2 & & & $\mathrm{R}$ & & & Basso & Centrale \\
\hline 14 & 5 & & Sinistra & $2 ?$ & & & $\mathrm{R}$ & & & Alto & Tutta \\
\hline 15 & & $5 / 6$ & & 4 Rovin. & & $?$ & & & & Basso & Destra \\
\hline 16 & & $5 / 6$ & & 2 Rovin. & & & $\mathrm{R}$ & & & Basso & Destra (sotto N. 15) \\
\hline 17 & & $10 / 11$ & & $2 ?$ & & & $\mathrm{R}$ & & & Basso & Destra \\
\hline 18 & 11 & & Sinistra & 1 & & & $\mathrm{R}$ & & & Basso & Centrale \\
\hline 19 & & $11 / 12$ & & 1 & & $\mathrm{P}$ & & & & Alto & Centrale \\
\hline 20 & 13 & & & 1 & & & $\mathrm{R}$ & & & Basso & Centrale \\
\hline 21 & 14 & & Sinistra & 3 & & & $\mathrm{R}$ & & & $\begin{array}{l}\text { Medio- } \\
\text { Alto }\end{array}$ & Destra \\
\hline 22 & 15 & & Destra & 3 & & & $\mathrm{R}$ & & & Alto & Sinistra (estrema) \\
\hline 23 & 15 & & & 3 & & & & Capovolta & & Alto & Destra \\
\hline 24 & 15 & & & 3 & & & $\mathrm{R}$ & & & Alto & $\begin{array}{l}\text { Destra (sotto filare a sinistra } \\
\text { di N. 23) }\end{array}$ \\
\hline 25 & 15 & & & 3 & & & $\mathrm{R}$ & & & Alto & A sinistra di N. 24 \\
\hline 26 & 15 & & & 3 & & & $\mathrm{R}$ & & & Alto & Sotto N. 25 \\
\hline 27 & & $15 / 16$ & & 1 & & & $\mathrm{R}$ & Capovolta & & Basso & Centrale \\
\hline 28 & 16 & & Destra & 1 & & & $\mathrm{R}$ & & & Alto & Destra \\
\hline 29 & 16 & & Destra & 2 & & & $\mathrm{R}$ & Capovolta & & Medio & Centr./Sinistra \\
\hline 30 & 16 & & & 3 & & & $\mathrm{R}$ & & & Basso & Destra \\
\hline 31 & 16 & & & 3 & & & $\mathrm{R}$ & & & Basso & Sinistra \\
\hline 32 & 16 & & & 3 & & & $\mathrm{R}$ & & & Basso & Sinistra (sotto N. 31) \\
\hline 33 & 16 & & & 4 & & & $\mathrm{R}$ & & & Basso & Sinistra (sotto N. 32) \\
\hline 34 & & $16 / 17$ & & Rovin. & & & $\mathrm{R}$ & & & Alto & Destra (estrema) \\
\hline 35 & 18 & & & Rovin. & & & $\mathrm{R}$ & & & Basso & Sinistra (estrema) \\
\hline 36 & & $18 / 19$ & & 4 & & $\mathrm{P}$ & & & & Basso & Tutta (M 283 = RES 3060) \\
\hline 37 & & $18 / 19$ & & 2 & & $\mathrm{P}$ & & & & Basso & Sopra N. 36 \\
\hline 38 & & $18 / 19$ & & 1 & & $\mathrm{P}$ & & & & Alto & Centro \\
\hline 39 & & $20 / 21$ & & 1 & & & $\mathrm{R}$ & $\mathrm{L}$ & & Alto & Centro \\
\hline
\end{tabular}




\begin{tabular}{|c|c|c|c|c|c|c|c|c|c|c|c|}
\hline$\dot{z}$ & 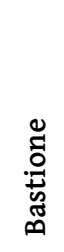 & 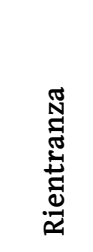 & 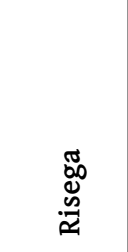 & $\frac{\mathscr{g}}{\infty 0}$ & 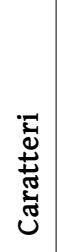 & 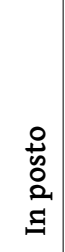 & 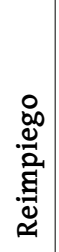 & 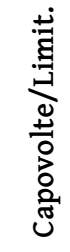 & ஜ̊ & $\begin{array}{l}\stackrel{\mathbb{N}}{N} \\
\stackrel{ \pm}{ \pm} \\
\stackrel{+}{<}\end{array}$ & 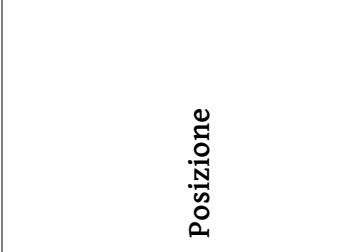 \\
\hline 40 & 21 & & & 3 & & & $\mathrm{R}$ & & & Medio & Sinistra \\
\hline 41 & 23 & & Destra & 1 & & & $\mathrm{R}$ & & & Alto & Destra \\
\hline 42 & 23 & & & 3 & & & $\mathrm{R}$ & & & Alto & Destra \\
\hline 43 & 23 & & & 3 & & & $\mathrm{R}$ & & & Alto & Destra (sotto N. 42) \\
\hline 44 & 23 & & & 1 & & & $\mathrm{R}$ & $\mathrm{C} / \mathrm{L}$ & & Basso & Centrale \\
\hline 45 & 23 & & & 3 & & & $\mathrm{R}$ & C & & Basso & Sinistra \\
\hline 46 & 23 & & & 3 & & & $\mathrm{R}$ & C & & Basso & $\begin{array}{l}\text { Sinistra (sopra) (parte di } \\
\text { N. 45?) }\end{array}$ \\
\hline 47 & 23 & & & 2 & & & $\mathrm{R}$ & & $90^{\circ}$ & Basso & Sinistra (sopra N. 46) \\
\hline 48 & 23 & & & 3 & & & $\mathrm{R}$ & & & Alto & Sinistra (estrema) \\
\hline 49 & 23 & & & 3 Rovin. & & & $\mathrm{R}$ & & & Alto & Centr./Destra \\
\hline 50 & 23 & & Sinistra & 1 & & & $\mathrm{R}$ & $\mathrm{L}$ & & Basso & \\
\hline 51 & 23 & & & 1 & & & $\mathrm{R}$ & $\mathrm{L}$ & & Alto & Destra \\
\hline 52 & & $23 / 24$ & & 1 & & & $\mathrm{R}$ & $\mathrm{L}$ & & Basso & Sinistra \\
\hline 53 & & $23 / 24$ & & 1 & & & $\mathrm{R}$ & $\mathrm{L}$ & & Alto & Destra \\
\hline 54 & & $23 / 24$ & & 1 & & & $\mathrm{R}$ & C & & Alto & Sinistra \\
\hline 55 & 24 & & Destra & 3 & & & $\mathrm{R}$ & & & $\begin{array}{l}\text { Medio- } \\
\text { Alto }\end{array}$ & Sinistra \\
\hline 56 & 24 & & Destra & 3 & & & $\mathrm{R}$ & & & Basso & Centro \\
\hline 57 & 24 & & Destra & 1 & & & $\mathrm{R}$ & $\mathrm{L}$ & & Basso & Destra \\
\hline 58 & 24 & & & 3 & & & $\mathrm{R}$ & & & Alto & Destra (estrema) \\
\hline 59 & 24 & & & 1 & & & $\mathrm{R}$ & $\mathrm{L}$ & & Basso & Centro \\
\hline 60 & 24 & & & 1 & & & $\mathrm{R}$ & $\mathrm{L}$ & & Alto & Sinistra \\
\hline 61 & 24 & & Sinistra & 3 & & & $\mathrm{R}$ & C & & Alto & Centro \\
\hline 62 & 24 & & Sinistra & 1 & & & $\mathrm{R}$ & $\mathrm{L}$ & & Alto & Centro (sotto N. 61) \\
\hline 63 & & $24 / 25$ & & 1 & & & $\mathrm{R}$ & $\mathrm{L}$ & & Basso & Centro \\
\hline 64 & & $24 / 25$ & & 1 & & & $\mathrm{R}$ & $\mathrm{L}$ & & Basso & $\begin{array}{l}\text { Centro (sopra a sinistra di } \\
\text { N. 63) }\end{array}$ \\
\hline 65 & 25 & & Destra & 3 & & & $\mathrm{R}$ & C & & Alto & Destra \\
\hline 66 & 25 & & Destra & 2 & & & $\mathrm{R}$ & $\mathrm{C}$ & & Alto & Sinistra \\
\hline 67 & 26 & & & 3 & & & $\mathrm{R}$ & C & & Alto & Sinistra (estrema) \\
\hline 68 & 26 & & & 1 & & & $\mathrm{R}$ & C & & Alto & Sinistra (sotto N. 67) \\
\hline 69 & 26 & & & 1 & & & $\mathrm{R}$ & $\mathrm{L}$ & & Basso & Centro \\
\hline 70 & & $26 / 27$ & & 1 & & & $\mathrm{R}$ & & & Basso & Centro \\
\hline 71 & 27 & & Destra & 1 & & P? & & & & Basso & Sinistra \\
\hline 72 & 27 & & & 1 Rovin. & & & $\mathrm{R}$ & & & Alto & Destra \\
\hline 73 & & $27 / 28$ & & 3 & & & $\mathrm{R}$ & & & & Sinistra \\
\hline 74 & 28 & & & & 2 & & $\mathrm{R}$ & & & Alto & Sinistra \\
\hline 75 & 28 & & & 1 & & & $\mathrm{R}$ & & & & Sinistra \\
\hline 76 & 28 & & Sinistra & 1 & & & $\mathrm{R}$ & & & Alto & Centro \\
\hline 77 & & $28 / 29$ & & 3 & & & $\mathrm{R}$ & & & Alto & Centro \\
\hline 78 & & $28 / 29$ & & 1 & & & $\mathrm{R}$ & $\mathrm{C}$ & & & Sinistra \\
\hline 79 & 29 & & & 1 & & & $\mathrm{R}$ & & & Alto & Sinistra \\
\hline 80 & 30 & & Sinistra & 1 & & & $\mathrm{R}$ & & & & Centro \\
\hline 81 & & $30 / 31$ & & 3 & & & $\mathrm{R}$ & & & Alto & Centro \\
\hline
\end{tabular}




\begin{tabular}{|c|c|c|c|c|c|c|c|c|c|c|c|}
\hline$\dot{z}$ & 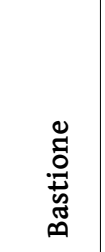 & 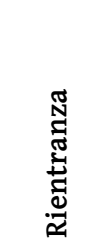 & 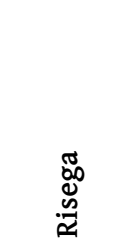 & 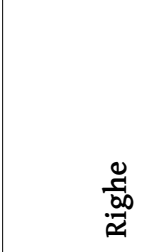 & 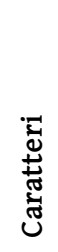 & 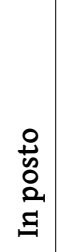 & 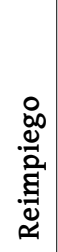 & 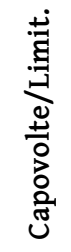 & ஜ̊ & $\begin{array}{l}\stackrel{\mathbb{N}}{N} \\
\stackrel{N}{ \pm} \\
\stackrel{ \pm}{4}\end{array}$ & 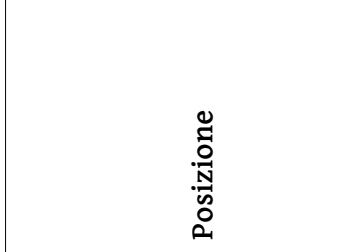 \\
\hline 82 & & $30 / 31$ & & 2 & & & $\mathrm{R}$ & & & Alto & Sinistra \\
\hline 83 & & $31 / 32$ & & 2 & & & $\mathrm{R}$ & $\mathrm{C}$ & & & Centro \\
\hline 84 & 32 & & & 2 & & & $\mathrm{R}$ & & & Alto & Sinistra \\
\hline 85 & 32 & & & 5 & & & $\mathrm{R}$ & & & Alto & Sinistra (sotto N. 84) \\
\hline 86 & $\begin{array}{r}32 \mathrm{bis} \\
(=33 ?)\end{array}$ & & & 2 & & & $\mathrm{R}$ & C & & Alto & \\
\hline 87 & 34 & & & 2 & & & $\mathrm{R}$ & $\mathrm{C}$ & & Alto & Sinistra \\
\hline 88 & 34 & & Sinistra & 2 & & & $\mathrm{R}$ & $\mathrm{C}$ & & Alto & Centro \\
\hline 89 & & $34 / 35$ & & 2 & & & $\mathrm{R}$ & C & & Alto & Destra (estrema) \\
\hline 90 & 35 & & Sinistra & 5 & & & $\mathrm{R}$ & & & Alto & Sinistra \\
\hline 91 & 35 & & Sinistra & 5 & & & $\mathrm{R}$ & & & Alto & $\begin{array}{l}\text { Sinistra (sopra a destra di } \\
\text { N. 90) }\end{array}$ \\
\hline 92 & & $35 / 36$ & & 1 & & & $\mathrm{R}$ & & & Alto & Sinistra (2 pezzi) \\
\hline 93 & & $35 / 36$ & & 1 & & & $\mathrm{R}$ & & & Alto & $\begin{array}{l}\text { Sinistra (più bassa a destra } \\
\text { di N. 92) }\end{array}$ \\
\hline 94 & 36 & & Destra & 2 & & & $\mathrm{R}$ & & & Alto & Centro (2 pezzi) \\
\hline 95 & 36 & & & 1 & 4 & & $\mathrm{R}$ & & & Alto & Destra \\
\hline 96 & 36 & & & 2 & & & $\mathrm{R}$ & & & Alto & Centro \\
\hline 97 & 36 & & & 2 & & & $\mathrm{R}$ & & & Alto & Sinistra (estrema) \\
\hline 98 & 36 & & Sinistra & 2 & & & $\mathrm{R}$ & & & Alto & Centro \\
\hline 99 & & $36 / 37$ & & 2 & & & $\mathrm{R}$ & & & Alto & Centro \\
\hline 100 & & $36 / 37$ & & 2 & & & $\mathrm{R}$ & & & Alto & Centro (sotto N. 99) \\
\hline 101 & 37 & & & 1 & & & $\mathrm{R}$ & & & Alto & Centro \\
\hline 102 & 37 & & & 2 & & & $\mathrm{R}$ & & & Alto & Centro (sopra N. 101) \\
\hline 103 & 37 & & & 1 & & & $\mathrm{R}$ & & & Alto & $\begin{array}{l}\text { Centro (sopra N. 202, } 3 \\
\text { pezzi) }\end{array}$ \\
\hline 104 & 37 & & & 1 & & & $\mathrm{R}$ & & & Alto & Centro (sopra N. 103) \\
\hline 105 & 37 & & & 5 & & & $\mathrm{R}$ & & & Alto & Centro (sopra N. 104) \\
\hline 106 & 37 & & Dietro & 1 & & & $\mathrm{R}$ & & & Alto & Destra \\
\hline 107 & 37 & & Dietro & 1 & & & $\mathrm{R}$ & & & Alto & Destra (sotto N. 106) \\
\hline 108 & 37 & & Dietro & 2 & & & $\mathrm{R}$ & & & Alto & Destra (sotto N. 107) \\
\hline 109 & & $37 / 38$ & & 2 & & & $\mathrm{R}$ & & & Alto & Destra (estrema) \\
\hline 110 & & $37 / 38$ & & 2 & & & $\mathrm{R}$ & & & Alto & $\begin{array}{l}\text { Destra (sotto a sinistra di } \\
\text { N. 109) }\end{array}$ \\
\hline 111 & & $37 / 38$ & & 2 & & & $\mathrm{R}$ & & & Alto & Sinistra \\
\hline 112 & & $37 / 38$ & & 2 & & & $\mathrm{R}$ & & & Alto & Sinistra \\
\hline 113 & & $37 / 38$ & & 2 & & & $\mathrm{R}$ & & & Alto & $\begin{array}{l}\text { Sinistra (sotto a sinistra di } \\
\text { N. } 112\end{array}$ \\
\hline 114 & & $37 / 38$ & & 3 & & & $\mathrm{R}$ & & $90^{\circ}$ & Alto & Destra \\
\hline 115 & 38 & & Destra & 2 & & & $\mathrm{R}$ & & & Alto & Sinistra \\
\hline 116 & 38 & & Destra & 2 Rovin. & & & $\mathrm{R}$ & & & Alto & Sinistra (sotto N. 115) \\
\hline 117 & 38 & & & 2 & & & $\mathrm{R}$ & C & & Alto & Destra \\
\hline 118 & 38 & & & 2 & & & $\mathrm{R}$ & C & & Alto & Centro \\
\hline 119 & & $38 / 39$ & & 2 & & & $\mathrm{R}$ & & & Alto & Centro (3 pezzi) \\
\hline 120 & & $38 / 39$ & & 2 & & & $\mathrm{R}$ & C & & Alto & Centro/Sinistra \\
\hline
\end{tabular}




\begin{tabular}{|c|c|c|c|c|c|c|c|c|c|c|c|}
\hline$\dot{z}$ & 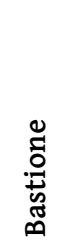 & 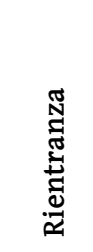 & 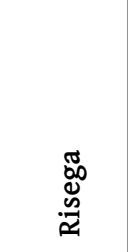 & 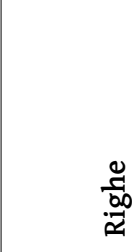 & 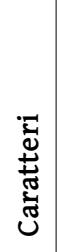 & $\begin{array}{l}\circ \\
\stackrel{+}{0} \\
\stackrel{2}{\varrho} \\
\Xi\end{array}$ & 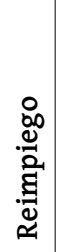 & 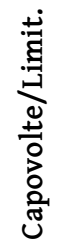 & ஜ̊ & 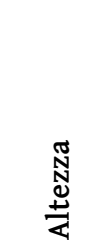 & 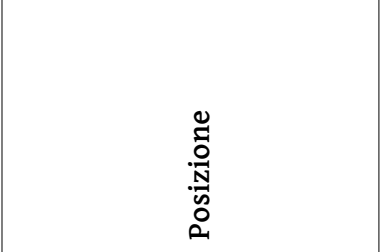 \\
\hline 121 & 39 & & Destra & 2 & & & $\mathrm{R}$ & $\mathrm{C}$ & & Alto & Destra \\
\hline 122 & 40 & & & 1 & & & $\mathrm{R}$ & & & Alto & Centro \\
\hline 123 & & $40 / 41$ & & 4 & & $\mathrm{P}$ & & & & Basso & $\begin{array}{l}\text { Centro (2 blocchi) }(\text { M } 222= \\
\text { RES 2999) }\end{array}$ \\
\hline 124 & 41 & & Destra & 3 & & & $\mathrm{R}$ & & & Alto & Centro (2 blocchi in due file) \\
\hline 125 & 41 & & Destra & 2 & & & $\mathrm{R}$ & & & Alto & Centro (sotto N. 124) \\
\hline 126 & 41 & & Destra & $1 / 2$ & & & $\mathrm{R}$ & & & Alto & Centro (tra N. 124 e N. 125 ) \\
\hline 127 & 41 & & Destra & $1 / 2$ & & & $\mathrm{R}$ & & & Alto & Centro (a destra di N. 126) \\
\hline 128 & 41 & & & 2 & & $\mathrm{P}$ & & & & M & Tutto il bastione \\
\hline 129 & 41 & & & 3 & & & $\mathrm{R}$ & & & Alto & Destra \\
\hline 130 & 41 & & & 1 & & & $\mathrm{R}$ & & & Alto & Destra (sotto N. 129, 2 pezzi) \\
\hline 131 & 41 & & & 2 & & & $\mathrm{R}$ & & & Alto & $\begin{array}{l}\text { Destra (sotto a sinistra di } \\
\text { N. 130) }\end{array}$ \\
\hline 132 & 41 & & & 3 & & & $\mathrm{R}$ & & & Alto & Centro (2 pezzi) \\
\hline 133 & 41 & & & 2 & & & $\mathrm{R}$ & & & Alto & Sinistra \\
\hline 134 & 41 & & & 3 & & & $\mathrm{R}$ & $\mathrm{C}$ & & Alto & Sinistra (sotto N. 133) \\
\hline 135 & 41 & & & 2 & & & $\mathrm{R}$ & & & Alto & $\begin{array}{l}\text { Sinistra (sotto a destra di } \\
\text { N. 134) }\end{array}$ \\
\hline 136 & 41 & & Sinistra & 2 & & $\mathrm{P}$ & & & & Medio & Continuazione di N. 128 \\
\hline 137 & 41 & & Sinistra & 2 Rovin. & & & $\mathrm{R}$ & & & Alto & Centro \\
\hline 138 & 41 & & Sinistra & 2 Rovin & & & $\mathrm{R}$ & & & Alto & Centro (sotto N. 137) \\
\hline 139 & & $41 / 42$ & & 2 & & $\mathrm{P}$ & & & & Medio & \begin{tabular}{|l} 
Destra (estrema) \\
Continuazione N. 128+N. 136 \\
\end{tabular} \\
\hline 140 & & $41 / 42$ & & 2 & & & $\mathrm{R}$ & & $90^{\circ}$ & Alto & Destra \\
\hline 141 & & $41 / 42$ & & 2 & & & $\mathrm{R}$ & & $90^{\circ}$ & Alto & Destra (a sinsitra di N. 140) \\
\hline 142 & & $41 / 42$ & & 2 & & & $\mathrm{R}$ & & & Alto & Centro (2 blocchi) \\
\hline 143 & & $41 / 42$ & & 3 & & & $\mathrm{R}$ & & & Alto & Centro \\
\hline 144 & & $41 / 42$ & & 2 & & & $\mathrm{R}$ & & & Basso & Centro \\
\hline 145 & & $41 / 42$ & & 5 & & & $\mathrm{R}$ & & & Alto & Centro/Sinistra (3 blocchi) \\
\hline 146 & & $41 / 42$ & & 2 & & & $\mathrm{R}$ & & & Alto & $\begin{array}{l}\text { Centro/Sinistra (sotto a } \\
\text { destra di N. 145) }\end{array}$ \\
\hline 147 & & $41 / 42$ & & 3 & & & $\mathrm{R}$ & & & Alto & Sotto a sinistra di N. 146 \\
\hline 148 & & $41 / 42$ & & 3 & & & $\mathrm{R}$ & & & Alto & Sinistra \\
\hline 149 & & $41 / 42$ & & 1 & & & $\mathrm{R}$ & & $90^{\circ}$ & Alto & Sinistra di N. 148 \\
\hline 150 & & $41 / 42$ & & 1 Rovin. & & & $\mathrm{R}$ & & & Alto & $\begin{array}{l}\text { Sinistra (sotto a sinistra di } \\
\text { N. 149) }\end{array}$ \\
\hline 151 & & $41 / 42$ & & 3 & & & $\mathrm{R}$ & & & Medio & Sinistra (2 blocchi \\
\hline 152 & & $41 / 42$ & & 1 & & & $\mathrm{R}$ & & & Medio & Sinistra (vicino a N. 151) \\
\hline 153 & & $41 / 42$ & & 1 & & & $\mathrm{R}$ & & $90^{\circ}$ & Medio & Sinistra (sotto N. 152) \\
\hline 154 & & $41 / 42$ & & 7 & & & $\mathrm{R}$ & & $90^{\circ}$ & Alto & Sinistra (estrema) \\
\hline 155 & 42 & & Destra & 1 Rovin. & & & $\mathrm{R}$ & & & Alto & \\
\hline 156 & 42 & & Destra & 2 & & $\mathrm{P}$ & & & & Basso & \\
\hline 157 & 42 & & & 2 & & $\mathrm{P}$ & & & & Basso & $\begin{array}{l}\text { Tutto il bastione (continua } \\
\text { N. 156) }\end{array}$ \\
\hline 158 & 42 & & & & 3 & $\mathrm{P}$ & & & & Basso & Sopra N. 157 \\
\hline 159 & 42 & & & 2 & & & $\mathrm{R}$ & & & Alto & Destra \\
\hline
\end{tabular}




\begin{tabular}{|c|c|c|c|c|c|c|c|c|c|c|c|}
\hline$\dot{z}$ & 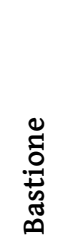 & 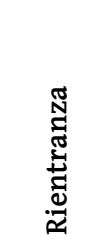 & 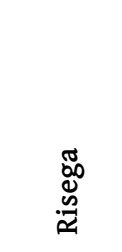 & 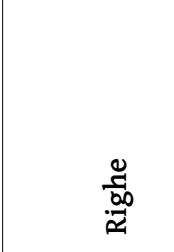 & 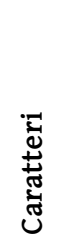 & 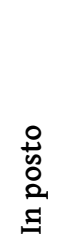 & 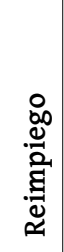 & 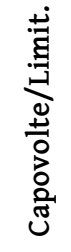 & ஜ் & $\begin{array}{l}\text { N } \\
\stackrel{N}{ \pm} \\
\stackrel{+}{4}\end{array}$ & 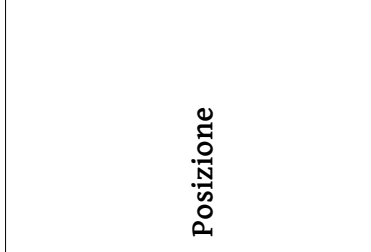 \\
\hline 160 & 42 & & & 2 & & & $\mathrm{R}$ & & & Alto & $\begin{array}{l}\text { Destra (sotto, a destra di N. } \\
159)\end{array}$ \\
\hline 161 & 42 & & & 2 & & & $\mathrm{R}$ & & & Medio & Centro \\
\hline 162 & 42 & & Sinistra & 2 & & & $\mathrm{R}$ & & & Medio & Centro \\
\hline 163 & & $42 / 43$ & & 6 & & & $\mathrm{R}$ & $\mathrm{C}$ & & Medio & Destra \\
\hline 164 & & $42 / 43$ & & 6 & & & $\mathrm{R}$ & & & Basso & Centro \\
\hline 165 & & $42 / 43$ & & 1 & & & $\mathrm{R}$ & & & Alto & Centro/Sinistra \\
\hline 166 & & $42 / 43$ & & 3 & & & $\mathrm{R}$ & & & Alto & Sinistra \\
\hline 167 & & $42 / 43$ & & 3 & & & $\mathrm{R}$ & & & Basso & Sinistra (estrema) \\
\hline 168 & 43 & & Destra & 4 Rovin. & & & $\mathrm{R}$ & $\mathrm{C}$ & & Basso & Destra \\
\hline 169 & 43 & & Destra & 4 & & & $\mathrm{R}$ & & & Basso & Destra \\
\hline 170 & 43 & & Destra & 4 & & & $\mathrm{R}$ & & & Basso & Destra (sotto N. 169) \\
\hline 171 & 43 & & Destra & 1 & & & $\mathrm{R}$ & $\mathrm{L}$ & & Basso & Destra (sopra N. 169) \\
\hline 172 & 43 & & Sinistra & 4 & & & $\mathrm{R}$ & & & Basso & Centro \\
\hline 173 & 43 & & Sinistra & 3 & & & $\mathrm{R}$ & & & Alto & Centro/Sinistra \\
\hline 174 & 43 & & Sinistra & 3 & & & $\mathrm{R}$ & C & & Alto & Centro \\
\hline 175 & 43 & & Sinistra & 3 & & & $\mathrm{R}$ & & & Alto & Centro (sommità) \\
\hline 176 & & $43 / 44$ & & 4 & & $\mathrm{P}$ & & & & Medio & Destra (estrema) \\
\hline 177 & & $43 / 44$ & & 3 Rovin. & & & $\mathrm{R}$ & & & Medio & Vicino a N. 176, a sinistra \\
\hline 178 & & $43 / 44$ & & 1 & & & $\mathrm{R}$ & & & Medio & Vicino a N. 177, a sinistra \\
\hline 179 & & $43 / 44$ & & ? (interrata) & & & $\mathrm{R}$ & & & Basso & Centro \\
\hline 180 & 44 & & & 4 & & & $\mathrm{R}$ & $\mathrm{C}$ & & Basso & Destra \\
\hline 181 & 44 & & & 1 Rovin. & & & $\mathrm{R}$ & & & Alto & Destra (sotto al N. 180) \\
\hline 182 & 44 & & & 1 & & & $\mathrm{R}$ & $\mathrm{L}$ & & Medio & Centro \\
\hline 183 & 44 & & & 4 & & & $\mathrm{R}$ & & & Basso & Sinistra (interrato) \\
\hline 184 & 44 & & & 1 & & & $\mathrm{R}$ & & & Basso & Destra \\
\hline 185 & & $44 / 45$ & & 2 & & & $\mathrm{R}$ & $\mathrm{L}$ & & Medio & Destra \\
\hline 186 & & $44 / 45$ & & 1 & & & $\mathrm{R}$ & & & Alto & Centro \\
\hline 187 & 45 & & & 3 & & & $\mathrm{R}$ & C & & & Destra (estrema) \\
\hline 188 & 45 & & & 4 & & & $\mathrm{R}$ & & $90^{\circ}$ & & Sotto a sinistra di N. 187 \\
\hline 189 & 45 & & Sinistra & 5 & & & $\mathrm{R}$ & & & Basso & Destra \\
\hline 190 & & $45 / 46$ & & 5 & & & $\mathrm{R}$ & & $90^{\circ}$ & Basso & Centro/Destra \\
\hline 191 & & $45 / 46$ & & 1 & & & $\mathrm{R}$ & $\mathrm{L}$ & & Alto & Centro/Sinistra \\
\hline 192 & 46 & & Destra & 1 & & & $\mathrm{R}$ & & & Basso & Centro \\
\hline 193 & 46 & & Destra & 1 & & & $\mathrm{R}$ & $\mathrm{L}$ & & Alto & Centro \\
\hline 194 & 47 & & & 3 & & & $\mathrm{R}$ & & & Alto & Destra (estrema) \\
\hline 195 & 47 & & & 3 & & & $\mathrm{R}$ & & & Medio & Centro \\
\hline 196 & 47 & & & 1 & & & $\mathrm{R}$ & & & Medio & Centro (a sinistra di N. 195) \\
\hline 197 & 47 & & & 5 & & & $\mathrm{R}$ & $\mathrm{C}$ & & Medio & Sinistra (estrema) \\
\hline 198 & 47 & & Sinistra & 1 & & & $\mathrm{R}$ & $\mathrm{L}$ & & Basso & Sinistra \\
\hline 199 & & $47 / 48$ & & 5 & & $\mathrm{P}$ & & & & Medio & $\begin{array}{l}\text { Tutta la lunghezza (M } 347= \\
\text { RES 3535) }\end{array}$ \\
\hline 200 & & $47 / 48$ & & 1 & 4 & $\mathrm{P}$ & & & & Medio & $\begin{array}{l}\text { Sopra N. } 199 \text { (M } 404 \text { = Nami } \\
\text { 32) }\end{array}$ \\
\hline 201 & & $47 / 48$ & & 1 & 2 & $\mathrm{P}$ & & & & Medio & Sopra a sinistra di N. 200 \\
\hline
\end{tabular}




\begin{tabular}{|c|c|c|c|c|c|c|c|c|c|c|c|}
\hline$\dot{z}$ & 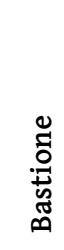 & 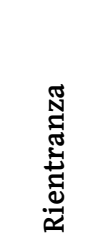 & 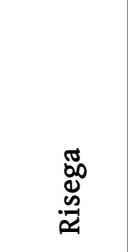 & 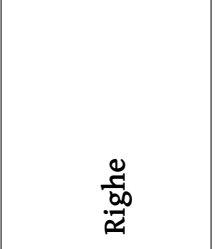 & 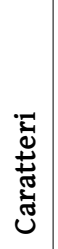 & 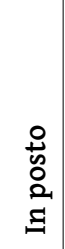 & 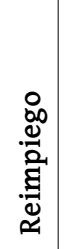 & 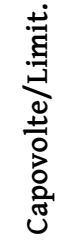 & ஜ̊ & $\begin{array}{l}\stackrel{\mathbb{N}}{N} \\
\stackrel{ \pm}{ \pm} \\
\stackrel{+}{<}\end{array}$ & 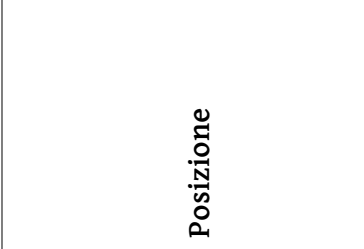 \\
\hline 202 & 48 & & & 4 & & $\mathrm{P}$ & & & & Basso & $\begin{array}{l}\text { Tutta la lunghezza (2 filari) } \\
\text { (M 185 = RES 2965) }\end{array}$ \\
\hline 203 & 48 & & Sinistra & 3 & & $\mathrm{P}$ & & & & Medio & Destra \\
\hline 204 & & $48 / 49$ & & 3 & & $\mathrm{P}$ & & & & & Destra (estrema) \\
\hline 205 & 50 & & & 3 & & $\mathrm{P}$ ? & & & & Basso & Destra \\
\hline 206 & 50 & & & 2 & & & $\mathrm{R}$ & $\mathrm{C}$ & & Basso & Sinistra (sopra N. 205) \\
\hline 207 & 50 & & & 1 Rovin. & & & $\mathrm{R}$ & & & Basso & $\begin{array}{l}\text { Sinistra (subito a sinistra di } \\
\text { N. 206) }\end{array}$ \\
\hline 208 & 50 & & Sinistra & 3 & & & $\mathrm{R}$ & & & Medio & Destra \\
\hline 209 & & $50 / 51$ & & 1 & & & $\mathrm{R}$ & $\mathrm{L}$ & & Basso & Centro \\
\hline 210 & 52 & & & 3 & & & $\mathrm{R}$ & & & Alto & Destra \\
\hline 211 & 52 & & & 1 & & & $\mathrm{R}$ & & & Alto & Sinistra \\
\hline 212 & 52 & & & 3 & & & $\mathrm{R}$ & & & & Sinistra (sopra N. 211) \\
\hline 213 & 52 & & & 3 & & & $\mathrm{R}$ & C & & & Sinistra (sopra N. 212) \\
\hline 214 & 52 & & & 1 & & & $\mathrm{R}$ & & & & Sinistra (sopra N. 213) \\
\hline 215 & 52 & & & 4 (rimartellata) & & & $\mathrm{R}$ & & & & Sinistra (sopra N. 214) \\
\hline 216 & 54 & & Destra & 2 & & & $\mathrm{R}$ & $\mathrm{C}$ & & Basso & \\
\hline 217 & 54 & & Destra & 2 & & & $\mathrm{R}$ & & & Basso & A terra \\
\hline 218 & 54 & & & 2 & & & $\mathrm{R}$ & $\mathrm{C}$ & & Basso & Destra \\
\hline 219 & 54 & & & 3 & & $\mathrm{P}$ & & & & Basso & $\begin{array}{l}\text { Tutta la lunghezza (2 filari) } \\
\text { (M 193 = RES } 2971 \text { bis b) }\end{array}$ \\
\hline 220 & 54 & & & 1 & & & $\mathrm{R}$ & $\mathrm{L}$ & & & Sopra N. 219 \\
\hline 221 & & $54 / 55$ & & 4 & & $\mathrm{P}$ & & & & & $\begin{array}{l}\text { Tutta la lunghezza (2 filari) } \\
\text { (M 196 = RES 2974; M } 247= \\
\text { RES 3022) }\end{array}$ \\
\hline 222 & 55 & & Destra & 3 & & & $\mathrm{R}$ & & & & Destra \\
\hline 223 & & $55 / 56$ & & 3 & & & $\mathrm{R}$ & & & Alto & Sinistra \\
\hline 224 & 56 & & & 3 & & & $\mathrm{R}$ & & & Medio & Centro (tra porta e spigolo) \\
\hline 225 & 56 & & & 3 & & & $\mathrm{R}$ & C & & & Sopra N. 224 (a sinistra) \\
\hline 226 & 56 & & & 2 & & & $\mathrm{R}$ & $\mathrm{L}$ & & & A sinistra di N. 225 \\
\hline 227 & 56 & & & 2 & & & $\mathrm{R}$ & & & & Vano richiuso della porta \\
\hline 228 & 56 & & & 2 & & & $\mathrm{R}$ & & & & Sopra, a sinistra di N. 227 \\
\hline 229 & 56 & & & 4 & & & $\mathrm{R}$ & & & & Sopra, a sinistra di N. 228 \\
\hline 230 & 56 & & & 3 & & & $\mathrm{R}$ & & & & Sopra, a snistra di N. 229 \\
\hline 231 & 56 & & & 2 & & & $\mathrm{R}$ & & & & Sopra, a sinistra di N. 230 \\
\hline 232 & 56 & & & 5 & & $\mathrm{P}$ & & & & Basso & $\begin{array}{l}\text { Dalla porta, dove entra, } \\
\text { all'angolo sinistro (M } 246= \\
\text { RES 3021) }\end{array}$ \\
\hline 233 & 56 & & & 3 & & $\mathrm{P}$ & & & & & $\begin{array}{l}\text { Sopra N. } 232 \text { (M } 200=\text { RES } \\
\text { 2978) }\end{array}$ \\
\hline 234 & 56 & & & 2 & & $\mathrm{P}$ & & & & & $\begin{array}{l}\text { Sopra N. 234 (M 234 = RES } \\
3011 \text { + simboli divini) }\end{array}$ \\
\hline 235 & 57 & & & 3 & & & $\mathrm{R}$ & & & Basso & Destra \\
\hline 236 & 57 & & & 2 & & & $\mathrm{R}$ & & & & Sopra N. 235 \\
\hline 237 & 57 & & Sinistra & 3 & & & $\mathrm{R}$ & & & Basso & Centro \\
\hline 238 & & $57 / 58$ & & 4 & & & $\mathrm{R}$ & & & Basso & Destra (con simbolo) \\
\hline
\end{tabular}




\begin{tabular}{|c|c|c|c|c|c|c|c|c|c|c|c|}
\hline$\dot{z}$ & 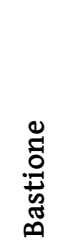 & 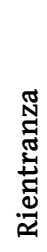 & 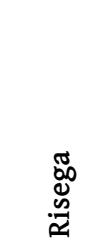 & 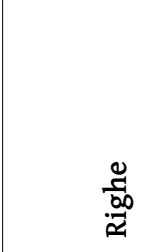 & 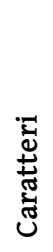 & 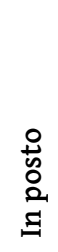 & 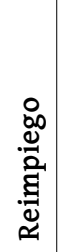 & 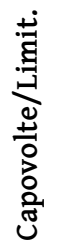 & ஜ̊ & 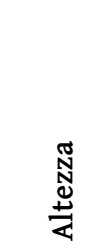 & 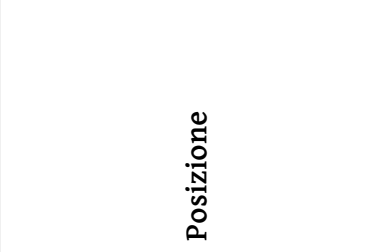 \\
\hline 239 & 58 & & & 6 & & $\mathrm{P}$ & & & & Basso & $\begin{array}{l}\text { Tutta la parete (M } 236=\text { RES } \\
\text { 3012) }\end{array}$ \\
\hline 240 & 58 & & & 2 & & & $\mathrm{R}$ & & $90^{\circ}$ & Alto & Destra (estrema) \\
\hline 241 & 1 & & Dietro & 9 & & $\mathrm{P}$ & & & & Medio & $\begin{array}{l}\text { Tutta la parete (su } 5 \text { filari) } \\
\text { (M } 197=\text { RES 2975) }\end{array}$ \\
\hline 242 & 1 & & Dietro & 1 & & & $\mathrm{R}$ & & $90^{\circ}$ & & Sopra N. 241 \\
\hline 243 & 1 & & Destra & 2 & & & $\mathrm{R}$ & & & Alto & Destra \\
\hline 244 & 1 & & Destra & 1 & & & $\mathrm{R}$ & & & Alto & Centro \\
\hline 245 & 1 & & Destra & 3 & & & $\mathrm{R}$ & & & Medio & Sinistra (estrema) \\
\hline 246 & 1 & & Destra & 3 & & & $\mathrm{R}$ & & & Alto & Destra \\
\hline & & & & \multicolumn{8}{|c|}{$156+157+128+136+139=$ M $151(=\operatorname{RES} 2929)+$ M $163(=$ RES $2941+2945+2946)$} \\
\hline
\end{tabular}

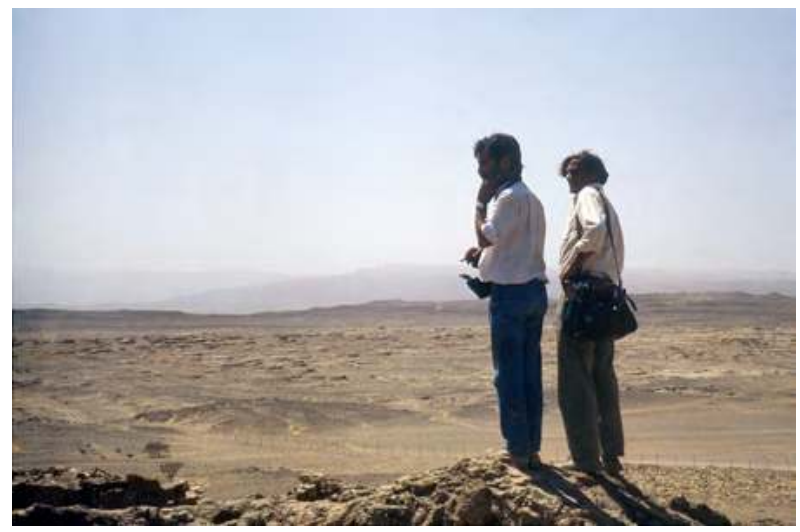

Figure 1. Alessandro de Maigret and Rémy Audouin at Barāqish on 23 October 1985. (Photograph F.G. Fedele)

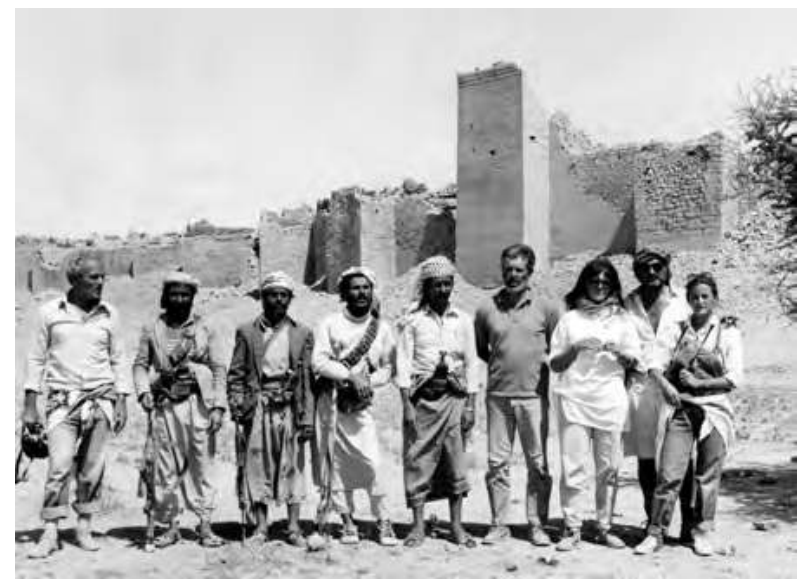

Figure 2. Barāqish, October 1986. From the left, Italian mission's staff photographer Antonio Solazzi, three of the twelve local guards, GOAM's inspector Ahmad Shujac, mission's director Alessandro de Maigret, draughtswoman

Patricia Smith, topographer Mario Mascellani, and archaeologist Sabina Antonini. In the background is Minaean bastion T48, preserved in its entirety.

(V. Labianca 1986 @ MAIRY) 


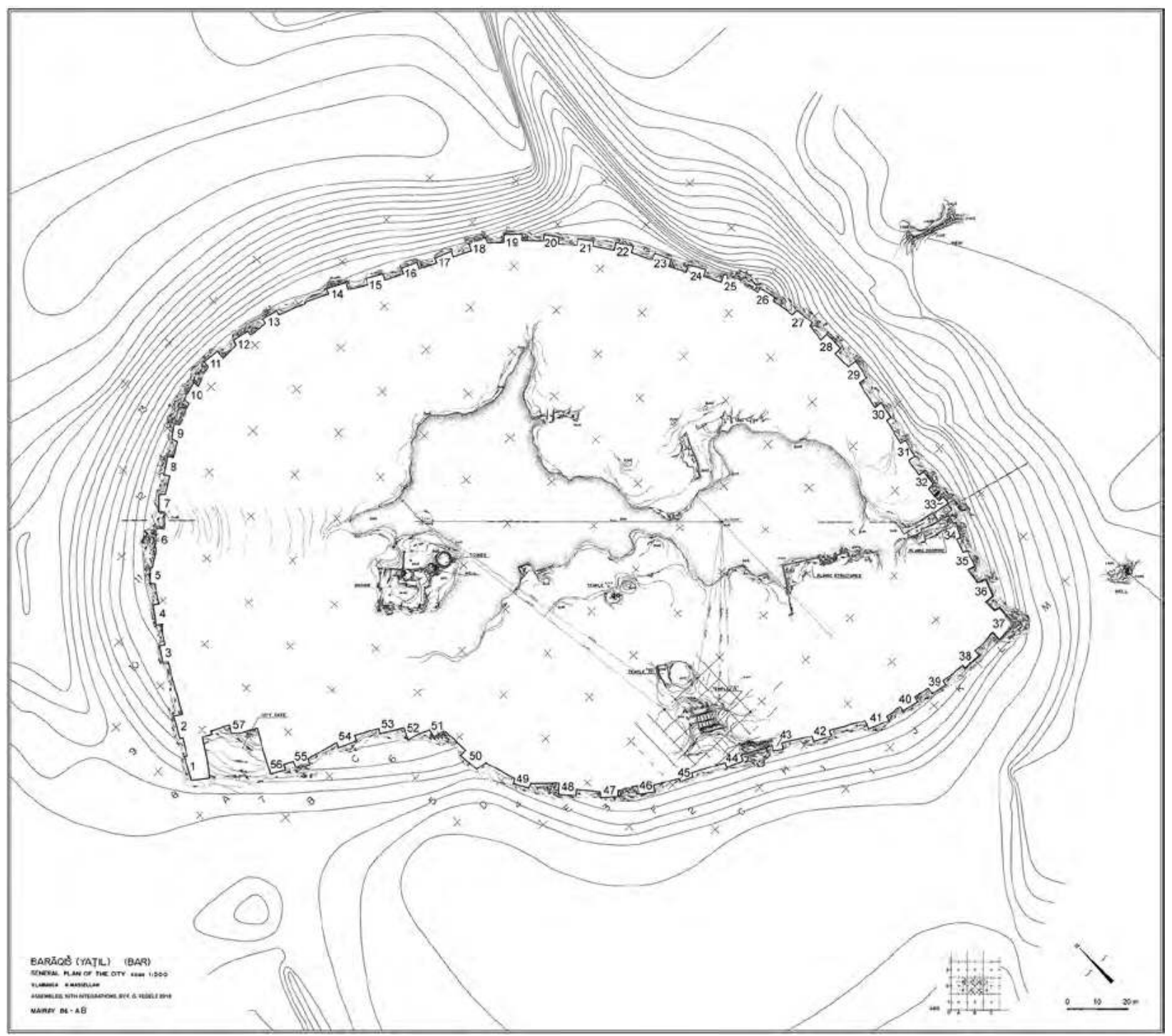

Figure 3. General plan of Barāqish, surveyed and drawn by V. Labianca and M. Mascellani, 1986 (assembled from a two-sheet original, with integrations, by F.G. Fedele, 2018). The curtain wall bastions are numbered clockwise. (@ MAIRY) 
Figure 4. Southeast-northwest topographic profile of Barāqish, from the talus below bastion T34 to bastion T6, viewed from the NE. (V. Labianca 1986 C MAIRY) View on-line at http://doi.org/10.32028/9781789694703-Ch1Fig4
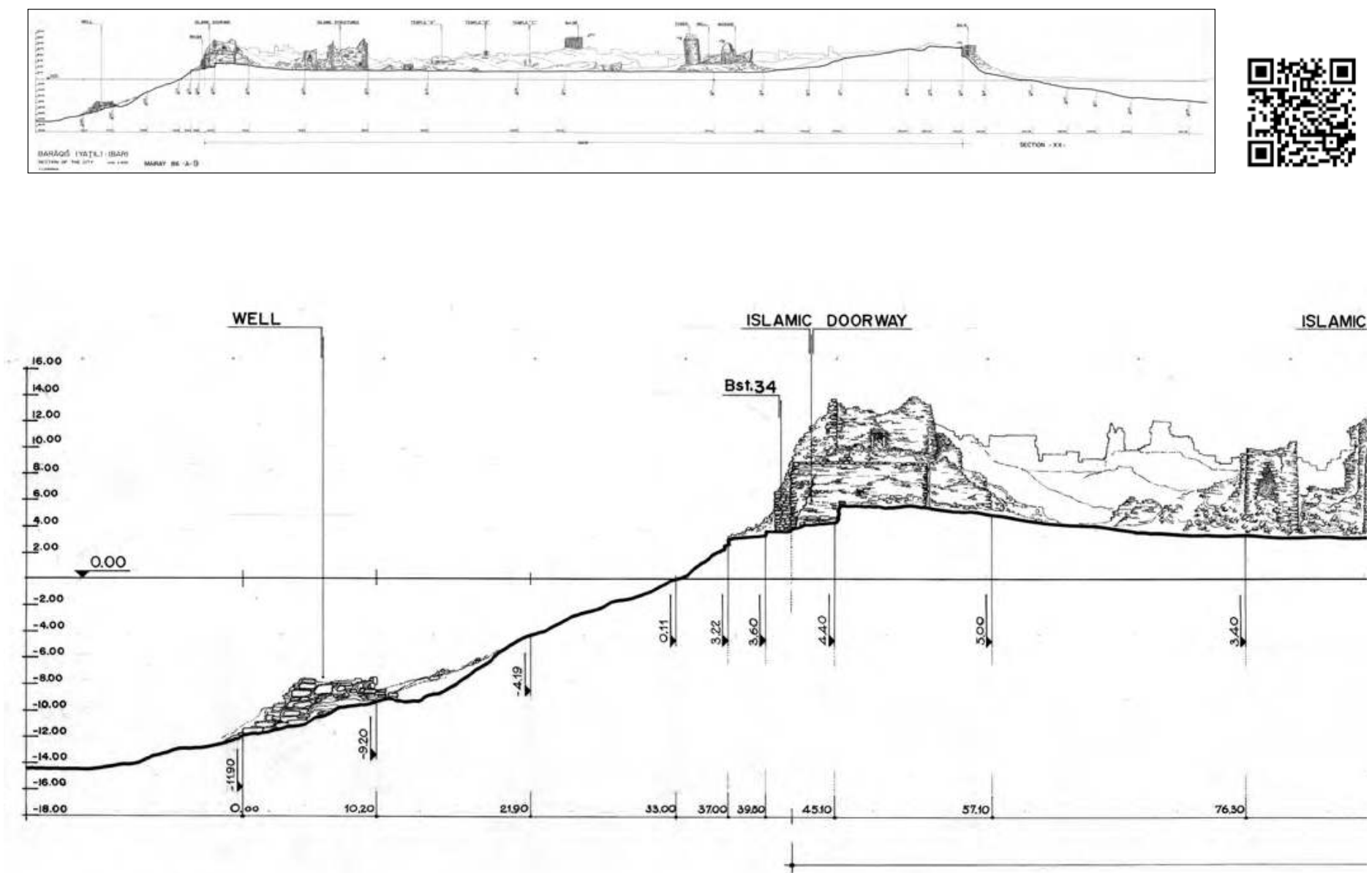

BARĀQIŠ (YATIL) - (BAR)

SECTION OF THE CITY scale 1:200

V.LABIANCA

MAIRAY $86-A-9$

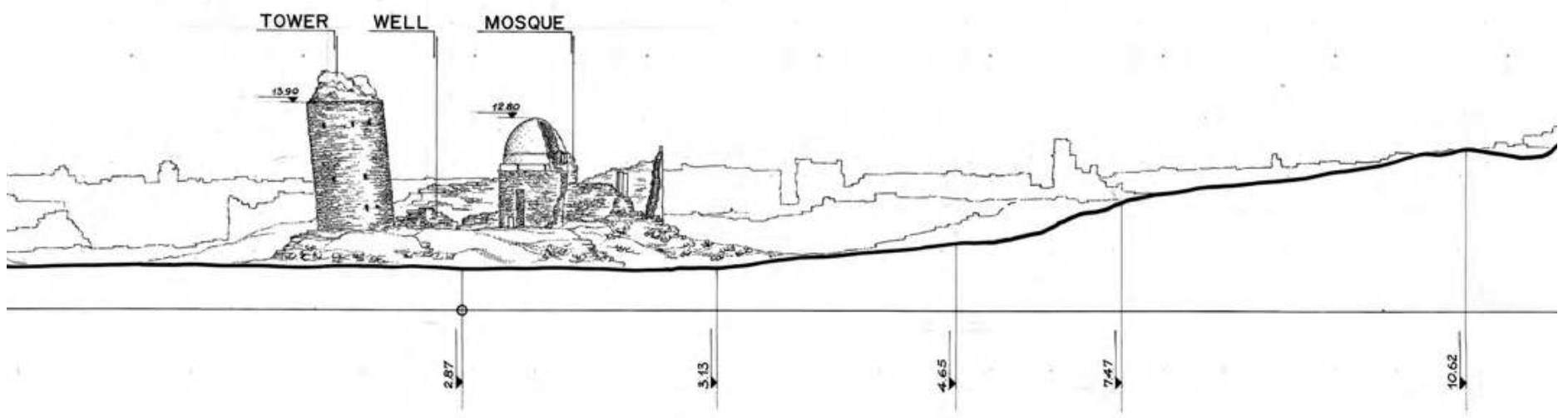

217.00 .

234.06

250.06

251.06

284.06 .

292 

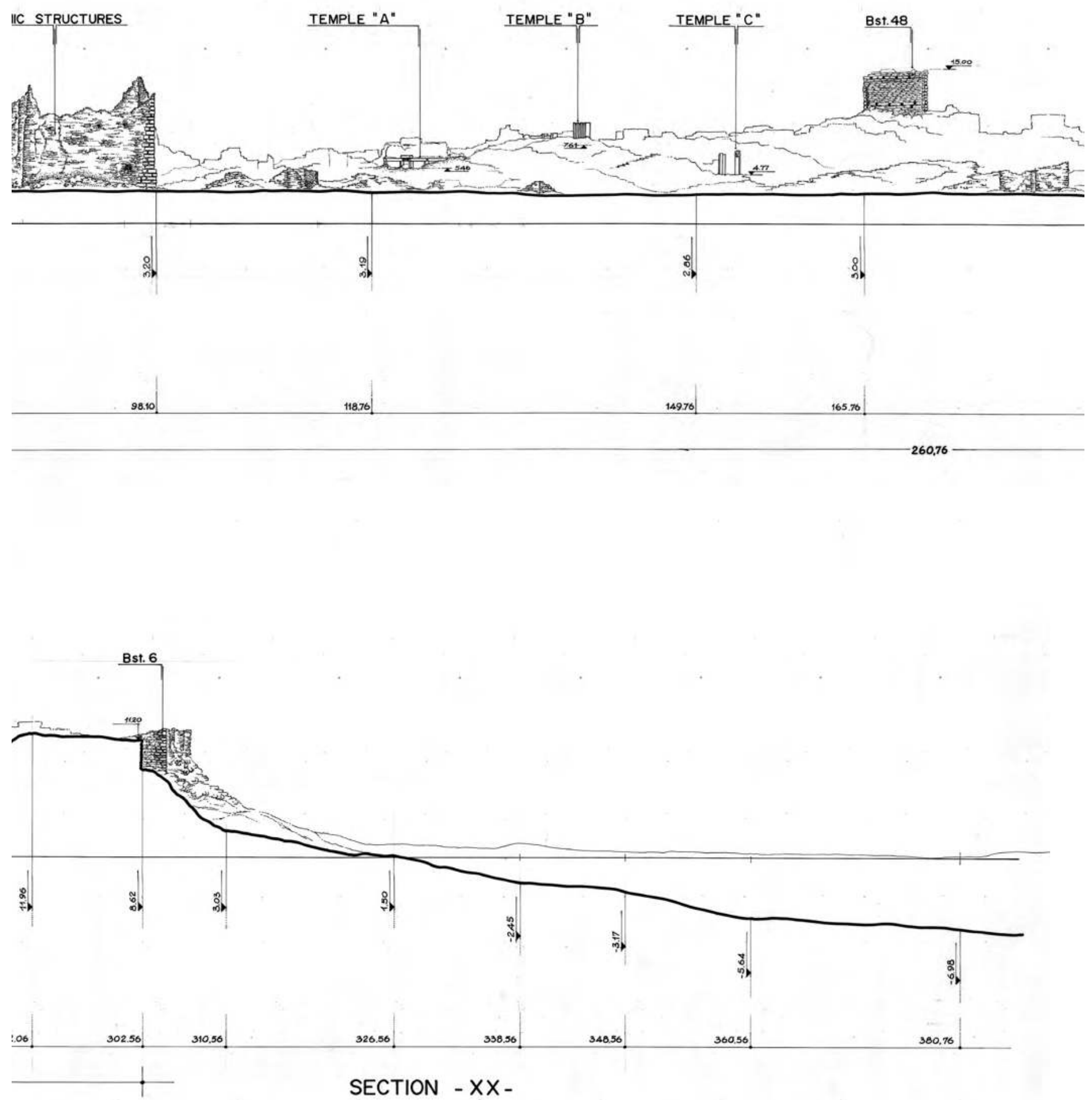
Figure 5. Northeast-southwest topographic profile of Barāqish between bastions T24 and T48, viewed from the NW ('section YY') and from the SE ('section JJ'; 'Bst 4’ at the right end of profile is a mistake for bastion T24). (V. Labianca 1986 @ MAIRY). View on-line at http://doi.org/10.32028/9781789694703-Ch1Fig5
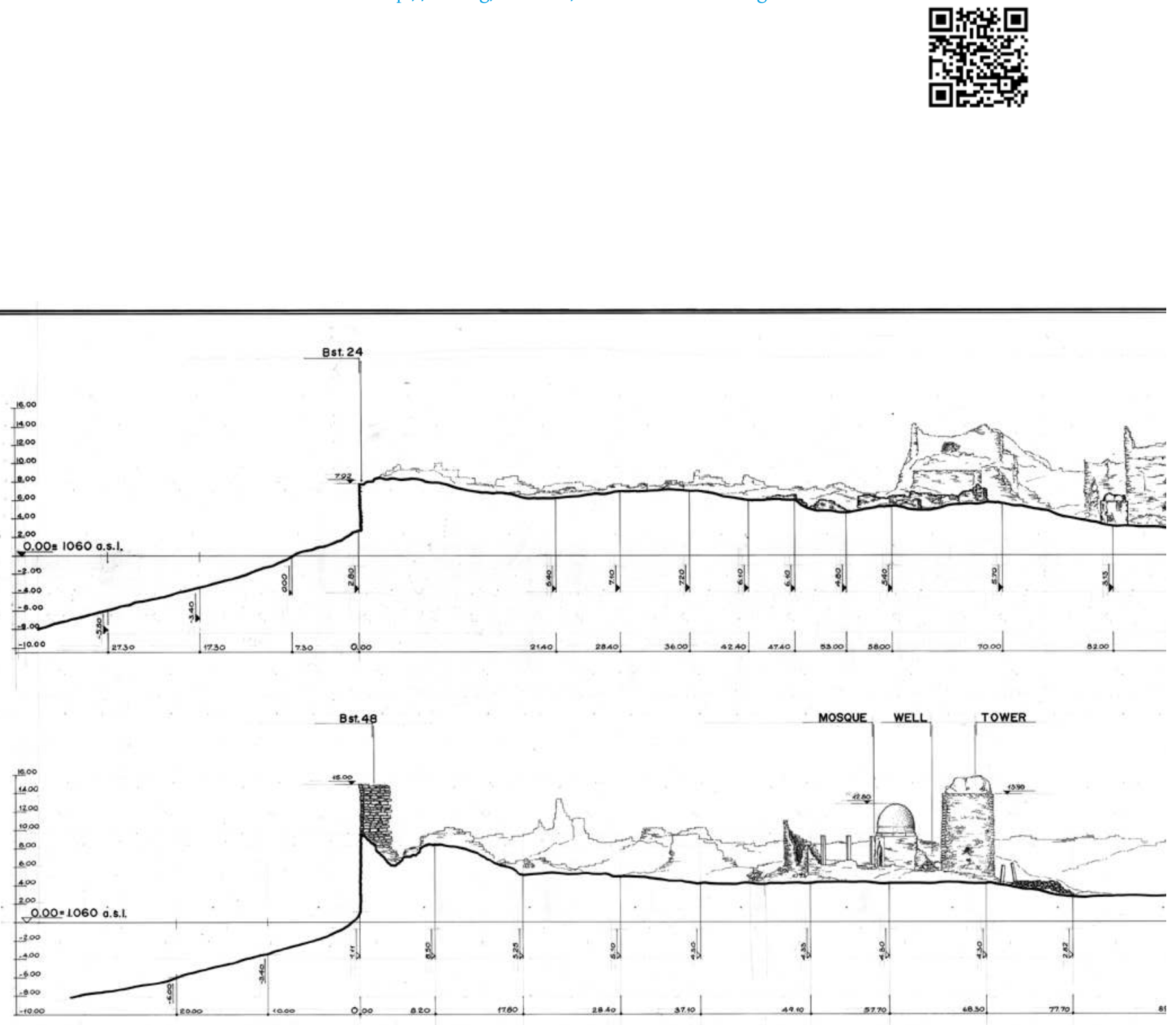

BARĀQIŠ (YATIL) - (BAR)

SECTIONS OF THE CITY scale I:200

v. LABIANCA

MAIRAY $86-A-10$ 


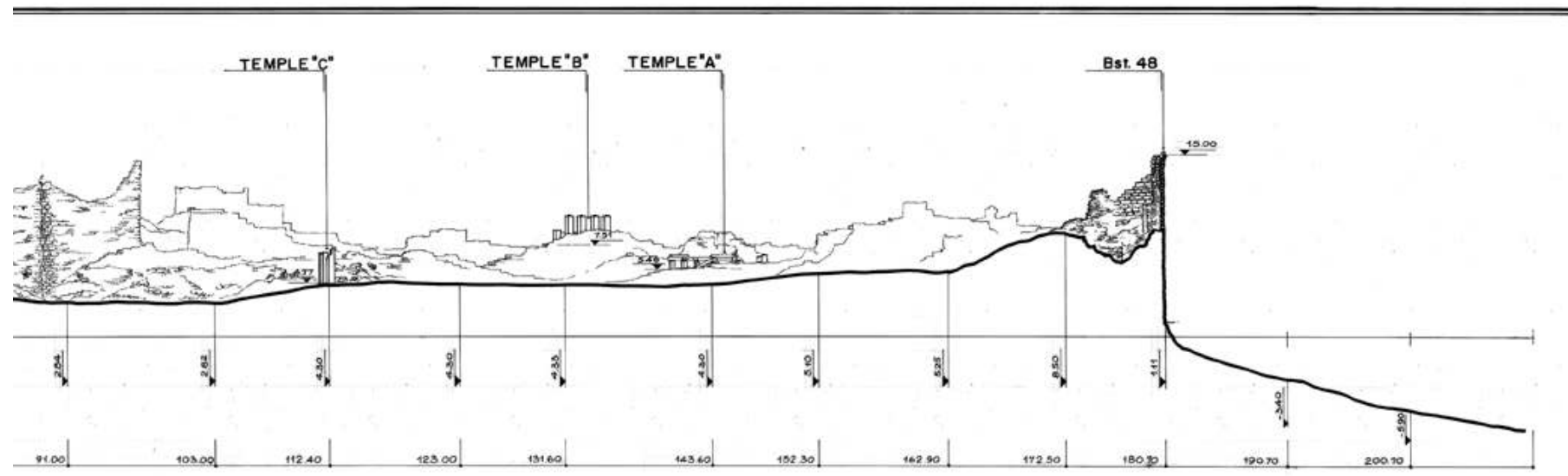

SECTION - YY -

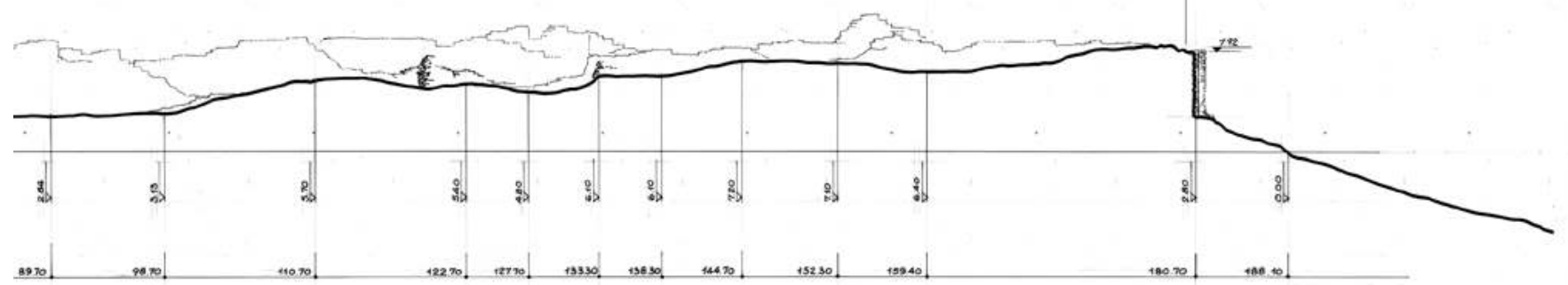

$$
\text { SECTION - JJ - }
$$

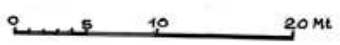


Figure 6. The Barāqish city wall: elevation view from the southwest. (E. Gatti 1986 @ MAIRY) (pages 34-41)

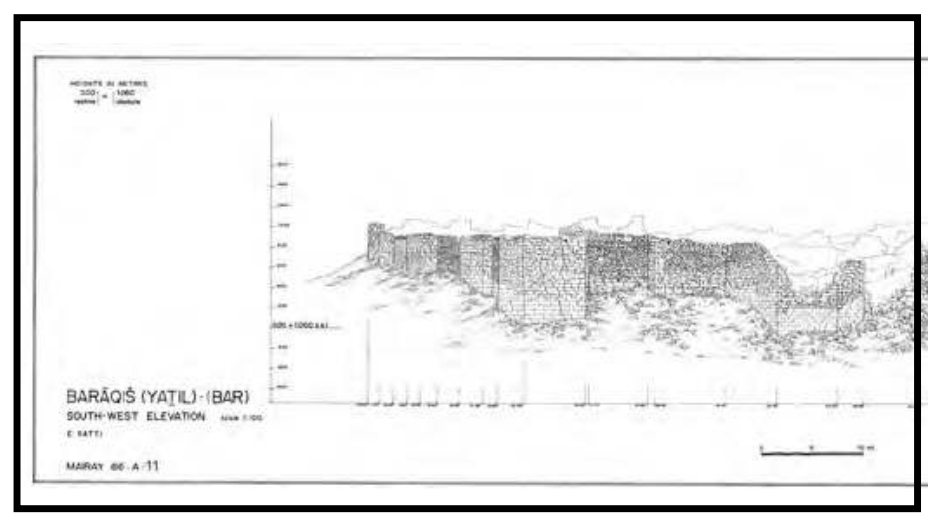

$$
\begin{gathered}
\text { HEIGHTS IN METRES } \\
\begin{array}{r}
0.00 \\
\text { relative }
\end{array}|\equiv| \begin{array}{l}
1.060 \\
\text { absolute }
\end{array}
\end{gathered}
$$

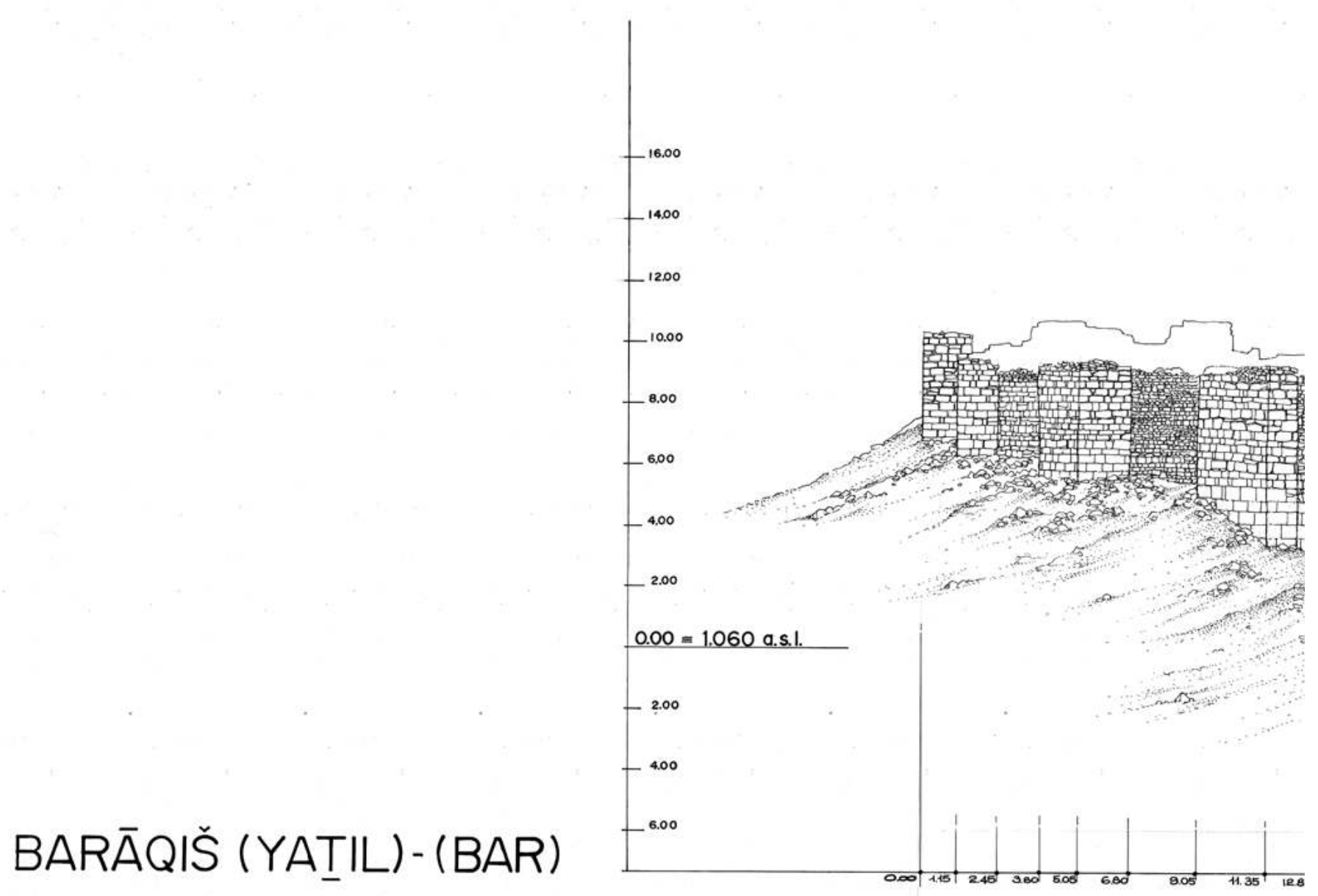

\section{SOUTH-WEST ELEVATION scale 1:100}

E. GATTI

MAIRAY 86-A-11 

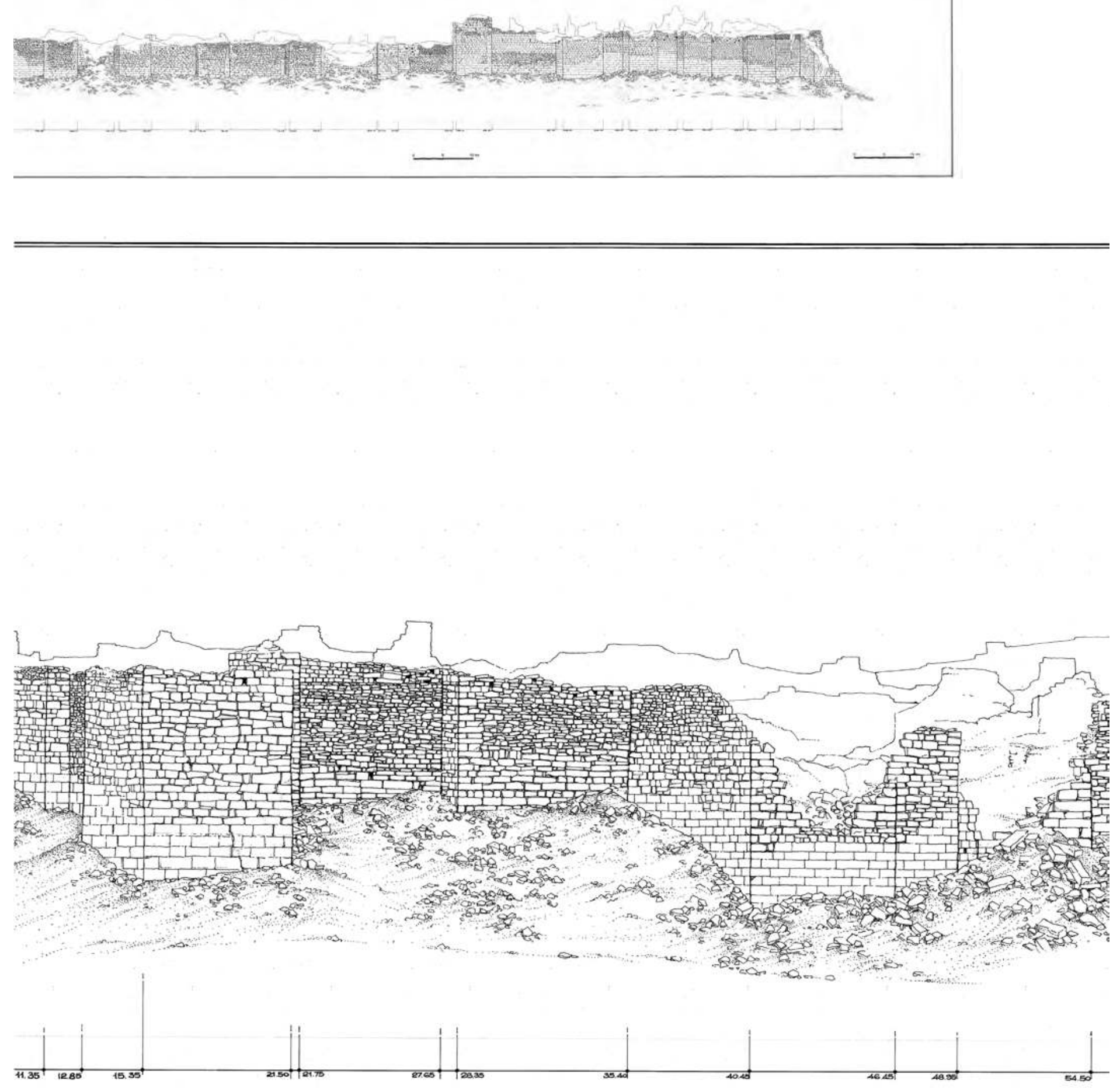

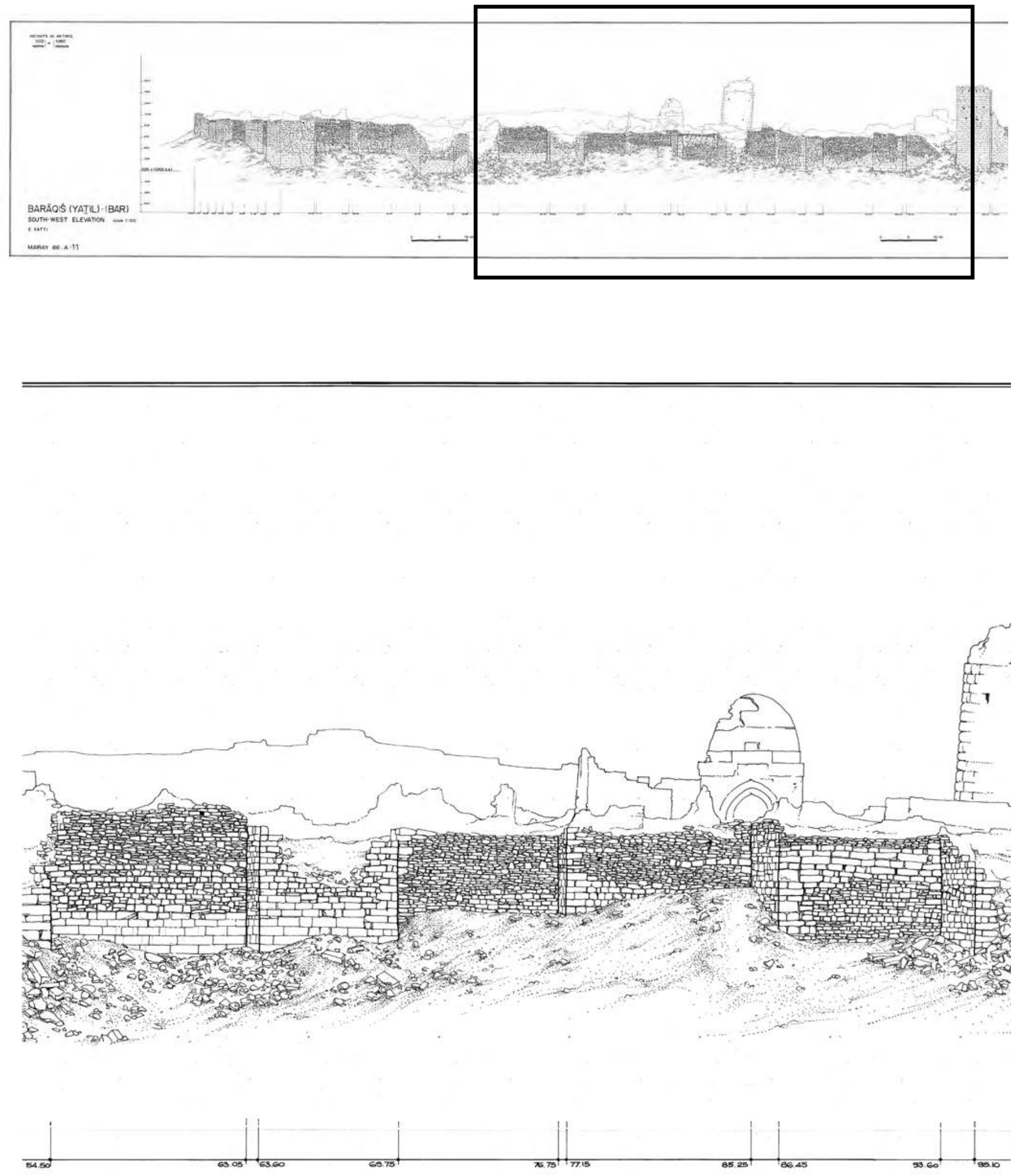

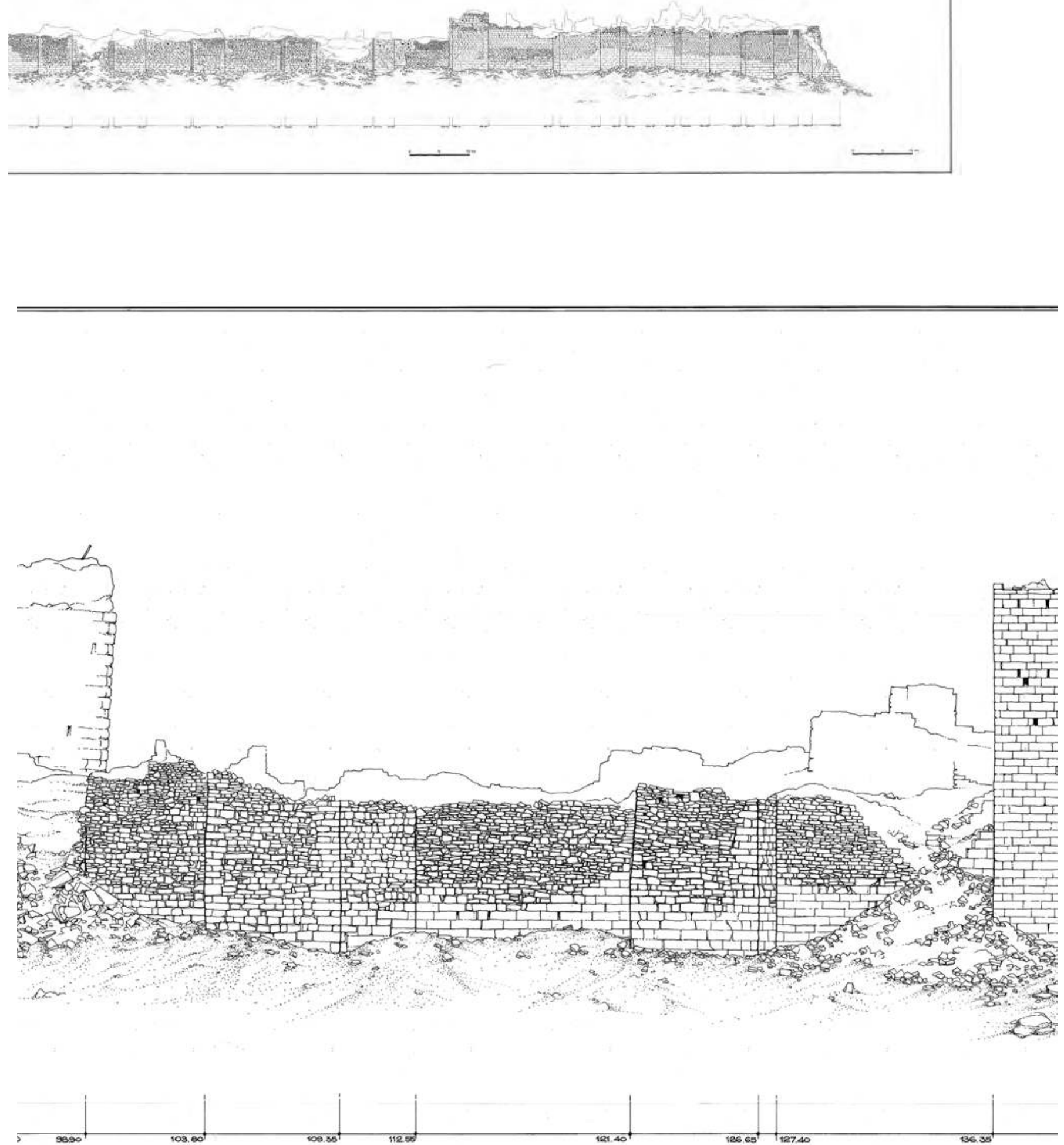

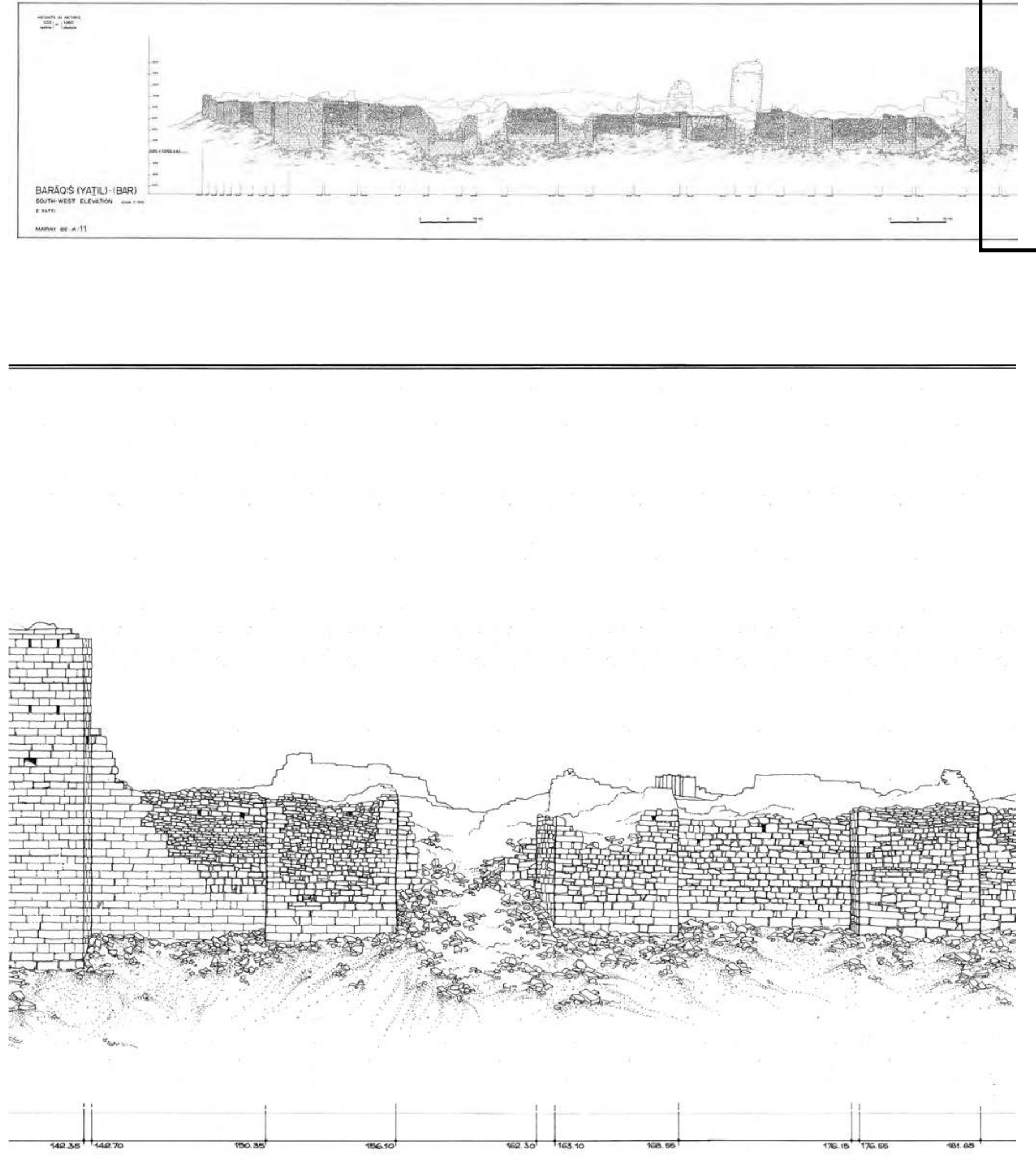

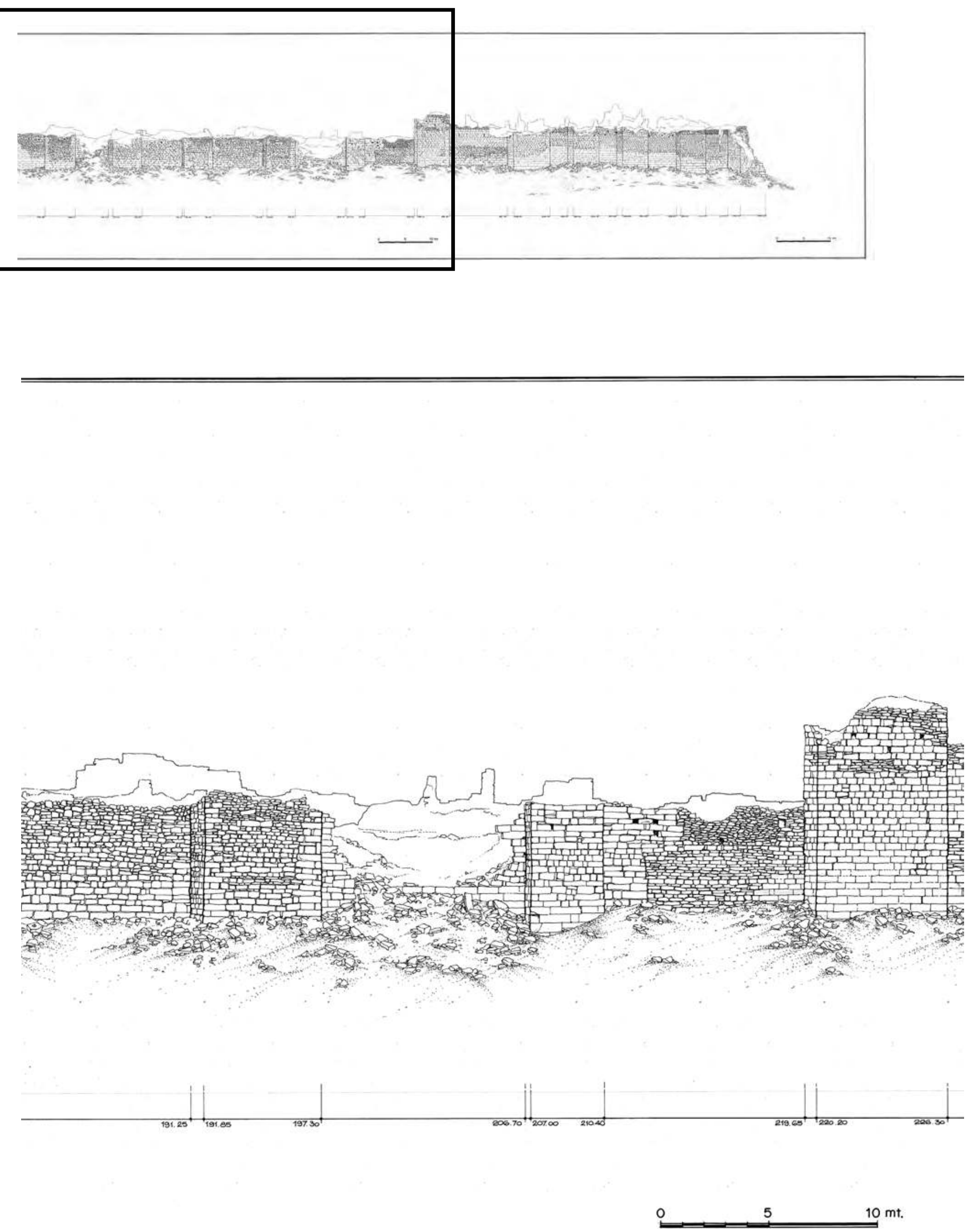

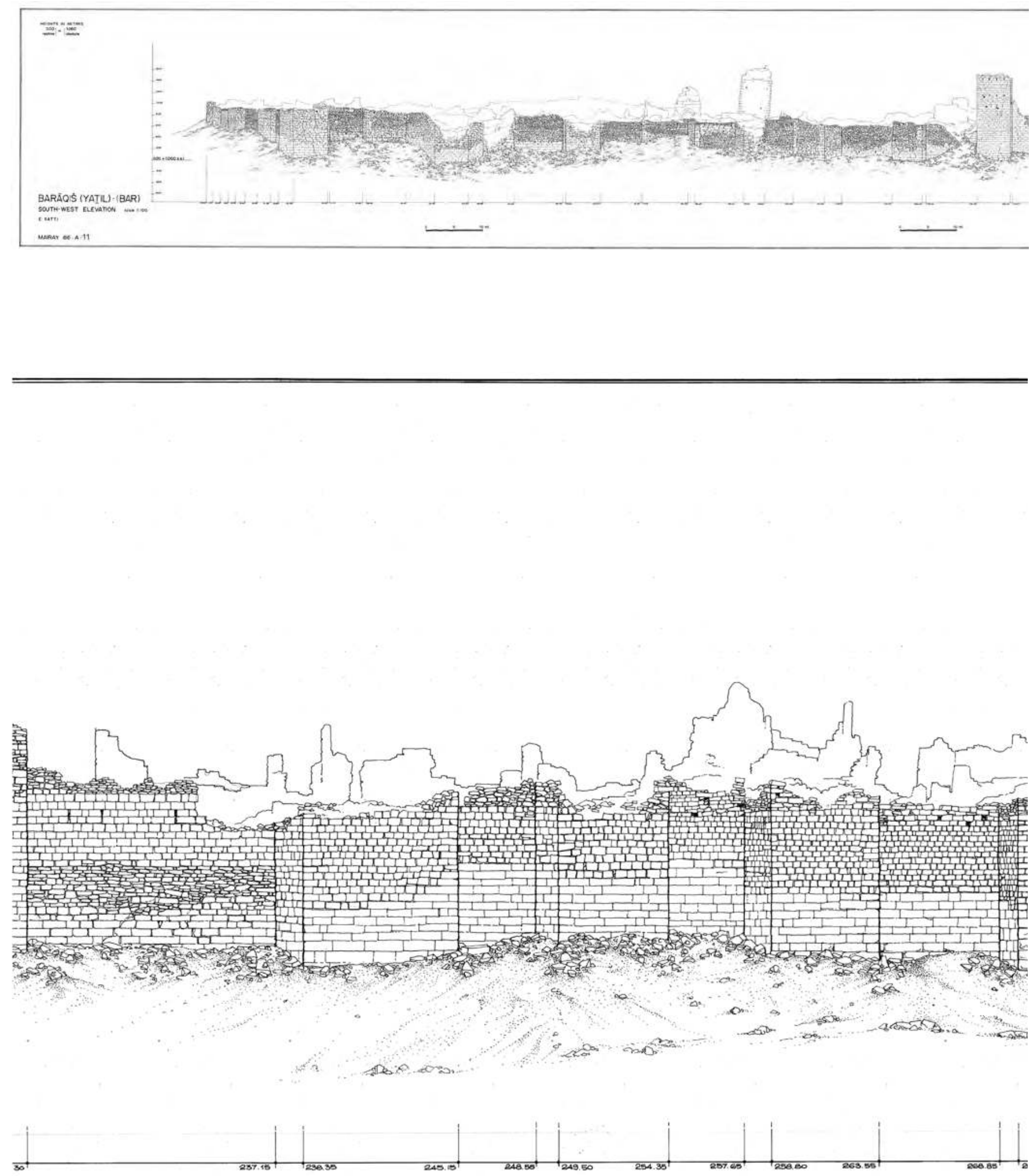

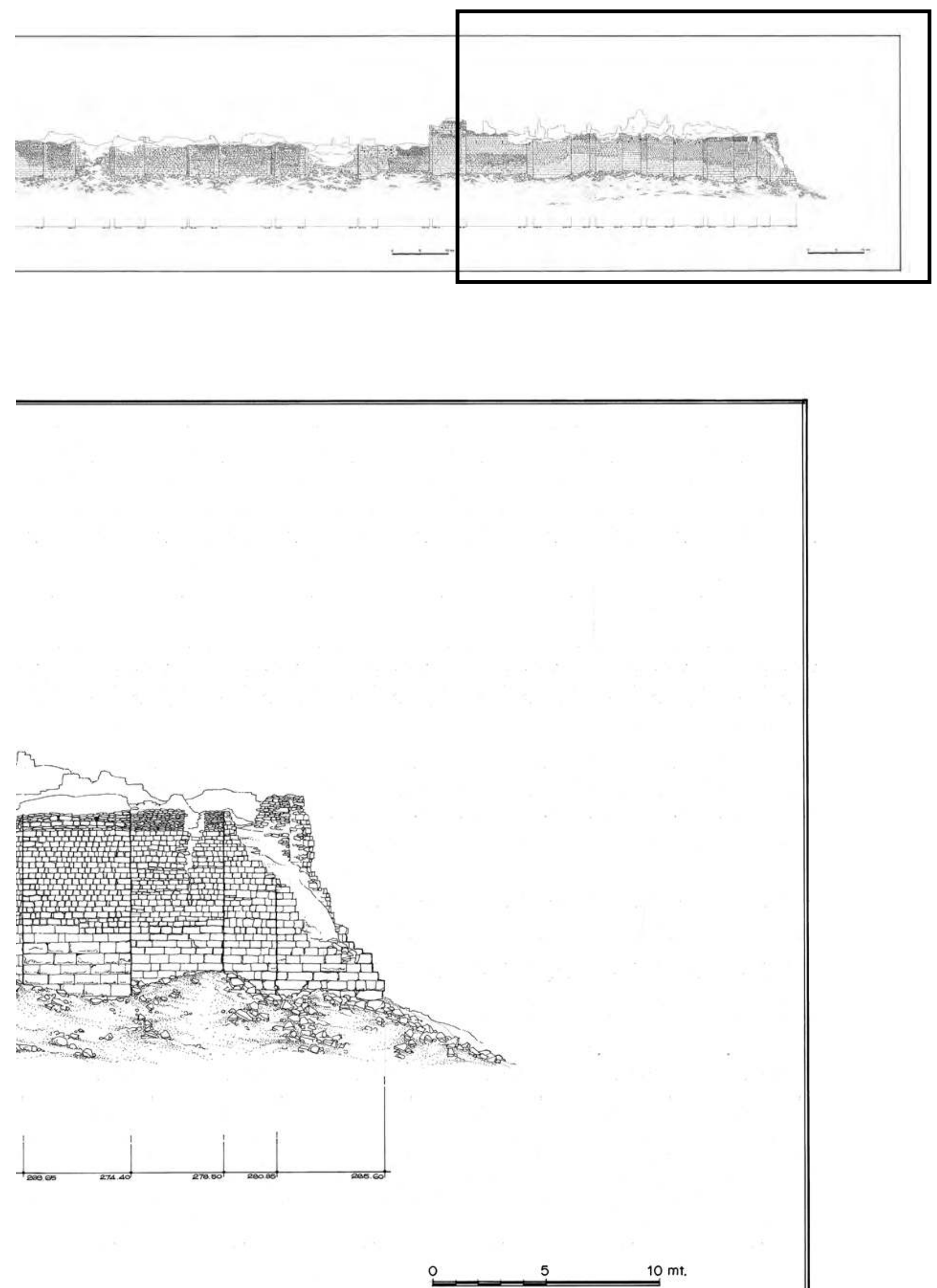


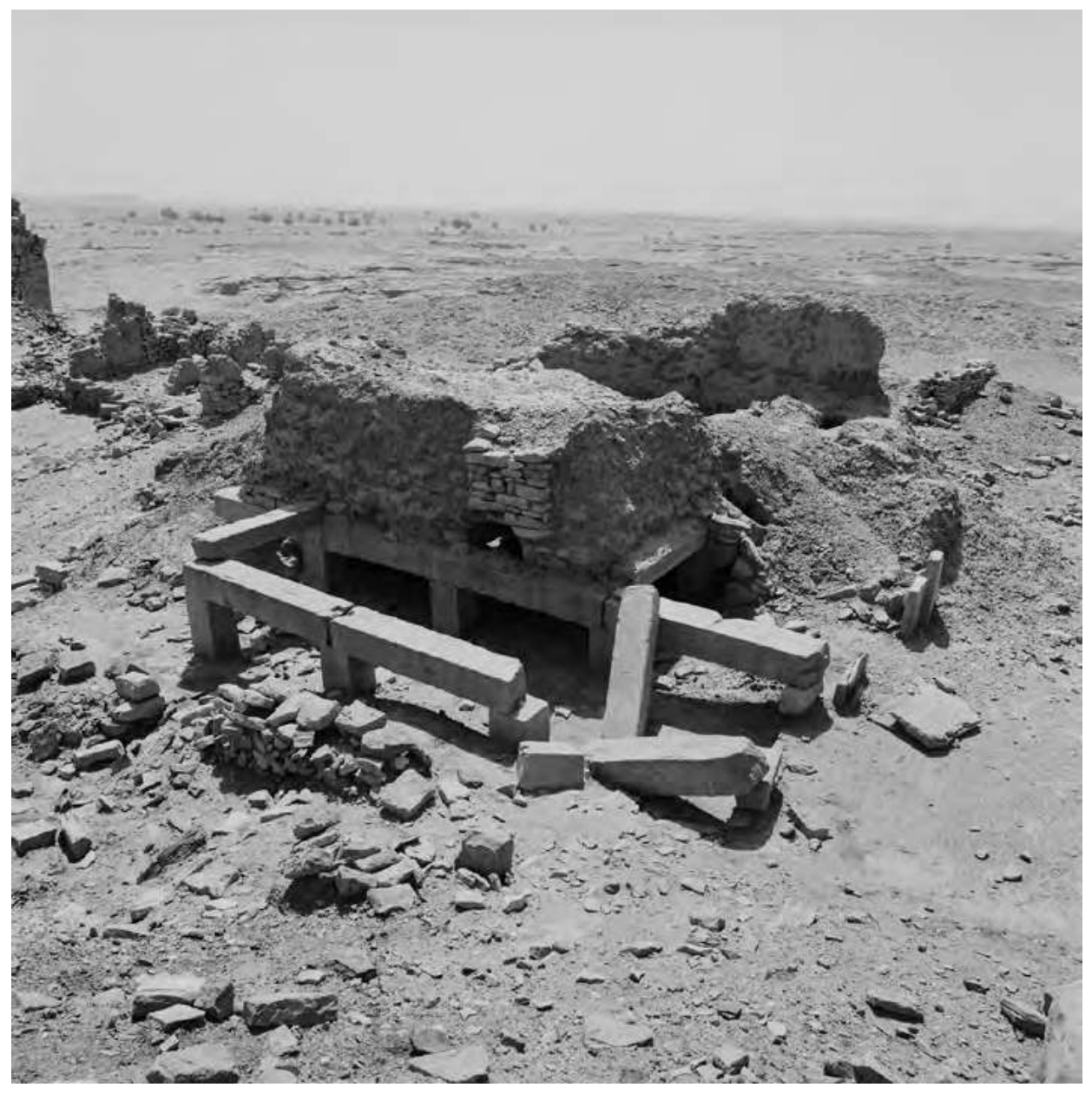

Figure 7. Temple A, dedicated to Nakrah, viewed from the north before excavation. (A. Solazzi 1986 @ MAIRY)

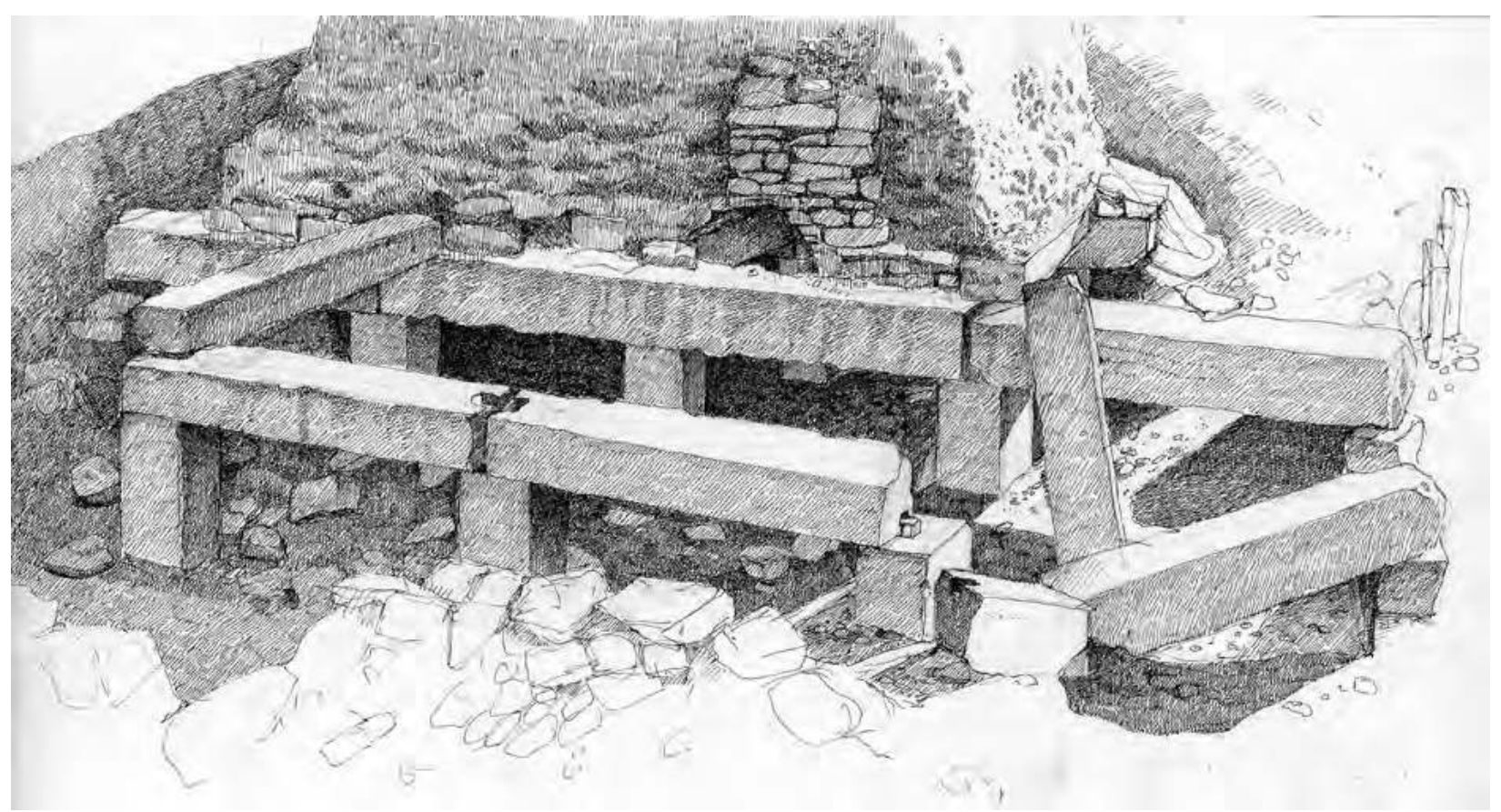

Figure 8. An ink sketch of Temple A before excavation. (P. Smith 1986 ○ MAIRY) 


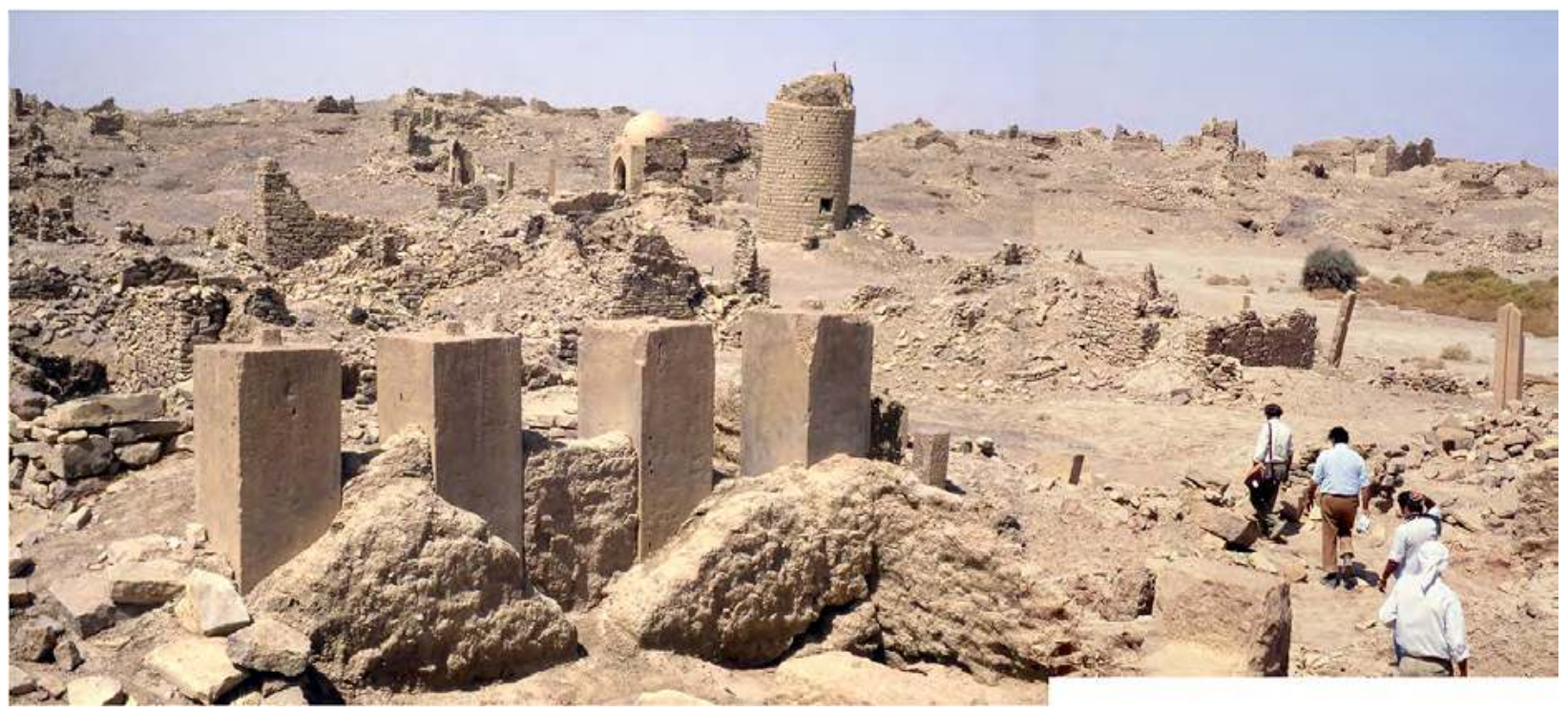

Figure 9. The central and northwestern sectors of Barāqish as seen during the visit of 23 October 1985: in the foreground the propylaeum pillars of Temple B, dedicated to 'Athtar dhu Qabd, viewed from the southeast, and in middle distance the Islamic complex of tower and mosque. (Photograph and montage F.G. Fedele, 1985 and 2018)

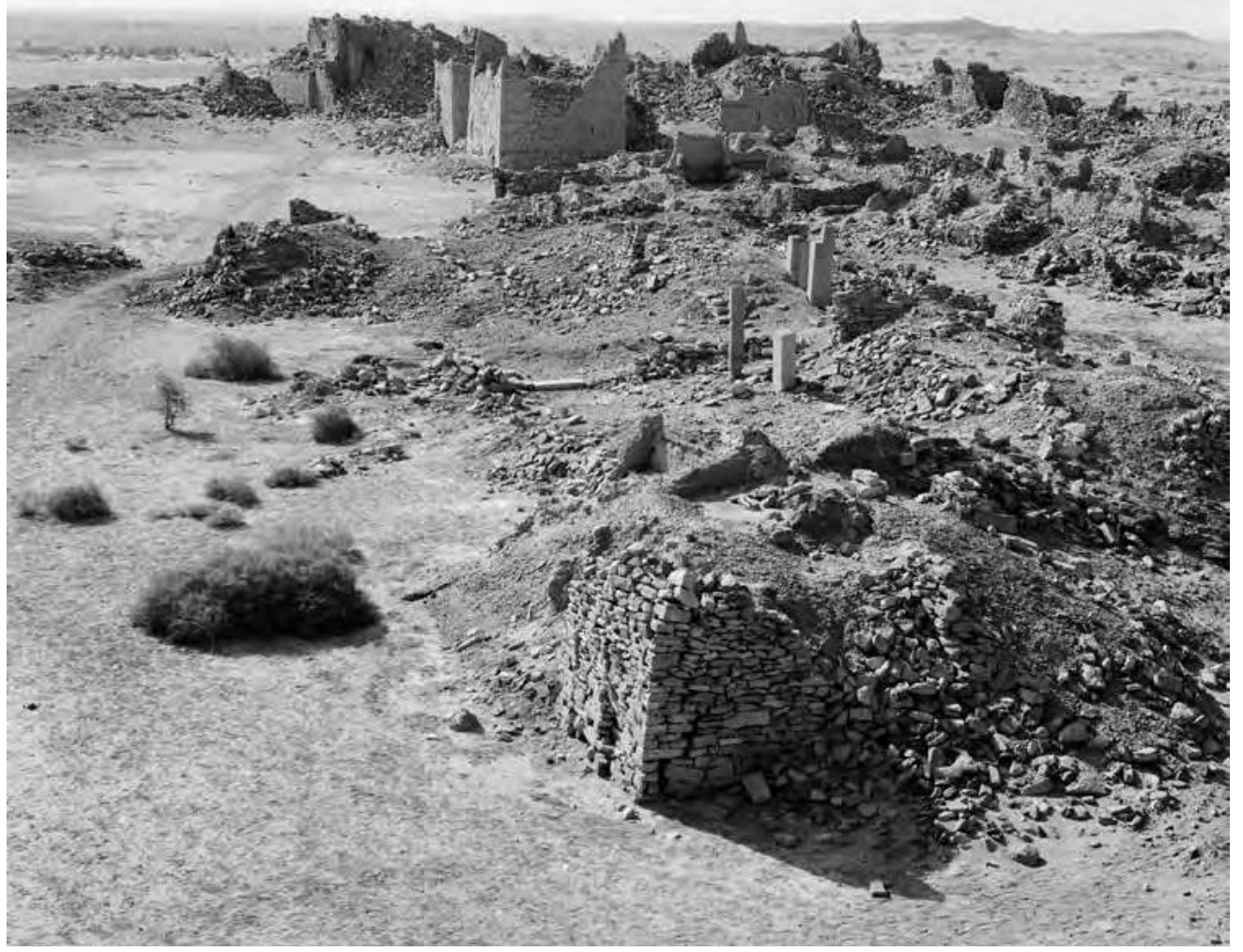

Figure 10. View of the Barāqish ruins and the entrance of Temple $C$, from the north.

(A. Solazzi 1986 C MAIRY) 


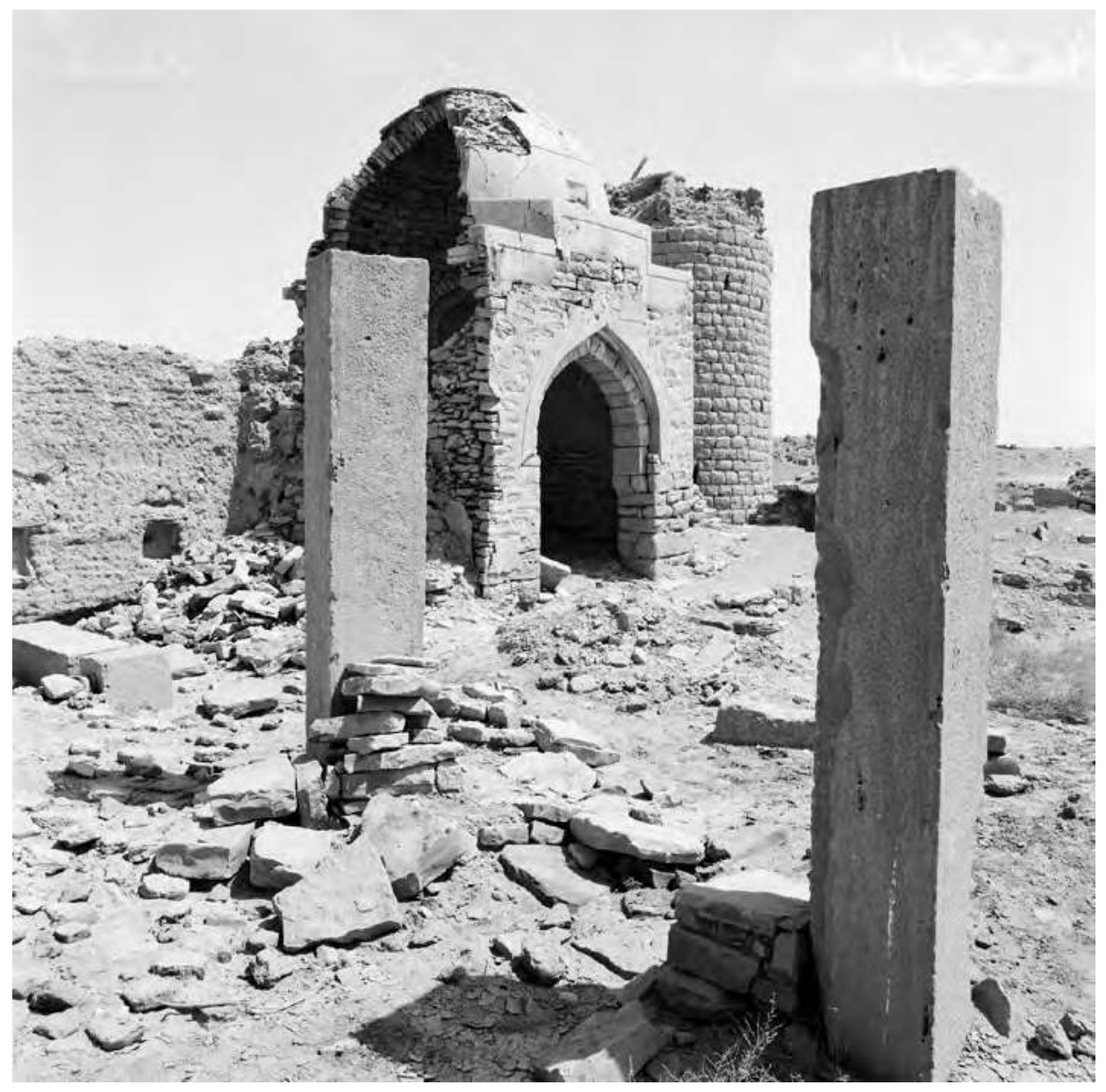

Figure 11. The pillars of a Minaean temple re-employed in the courtyard of the mosque. (A. Solazzi 1986 @ MAIRY)

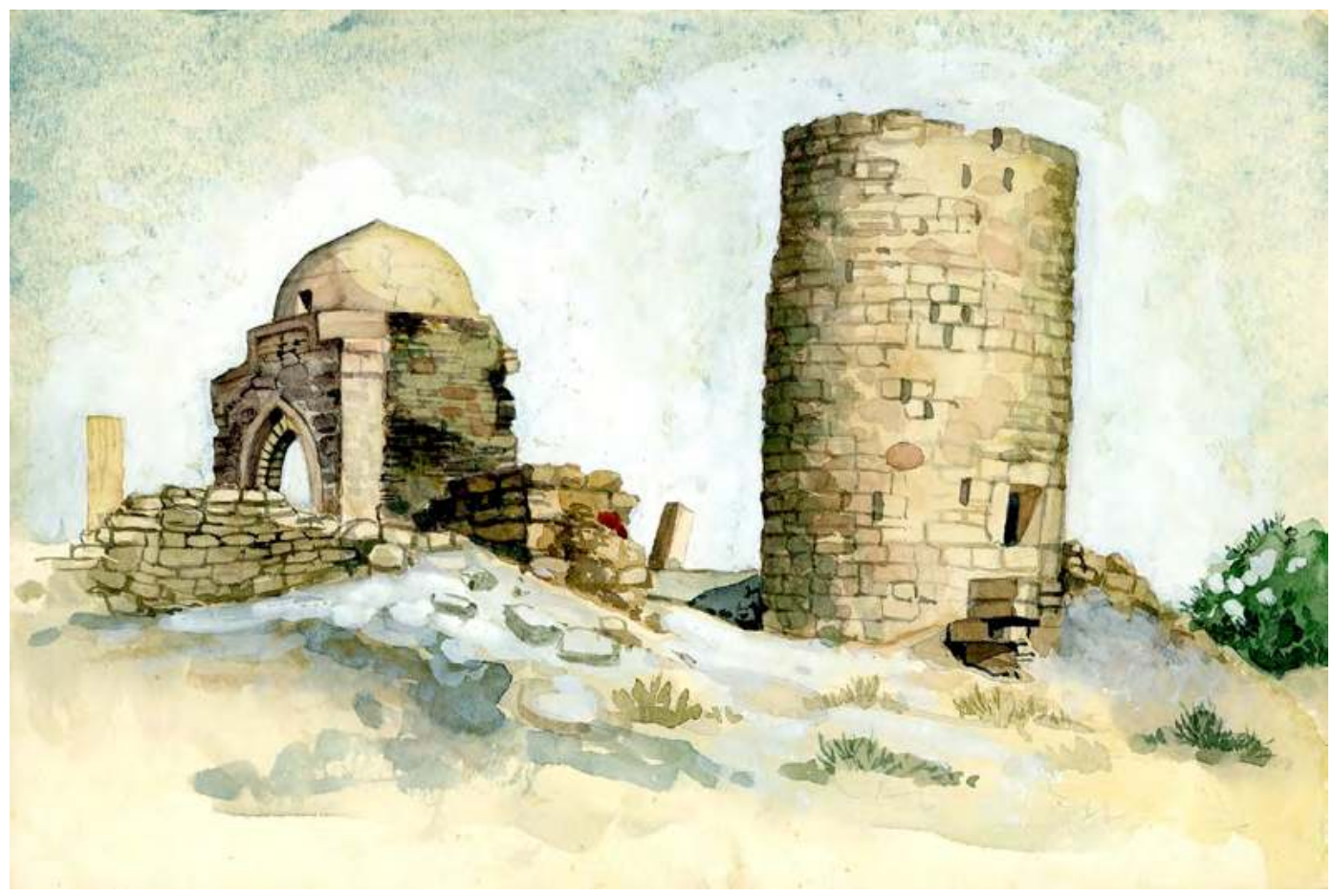

Figure 12. The Barāqish mosque and tower, from the south, in a watercolour by P. Smith, 1986 (৫ MAIRY). 


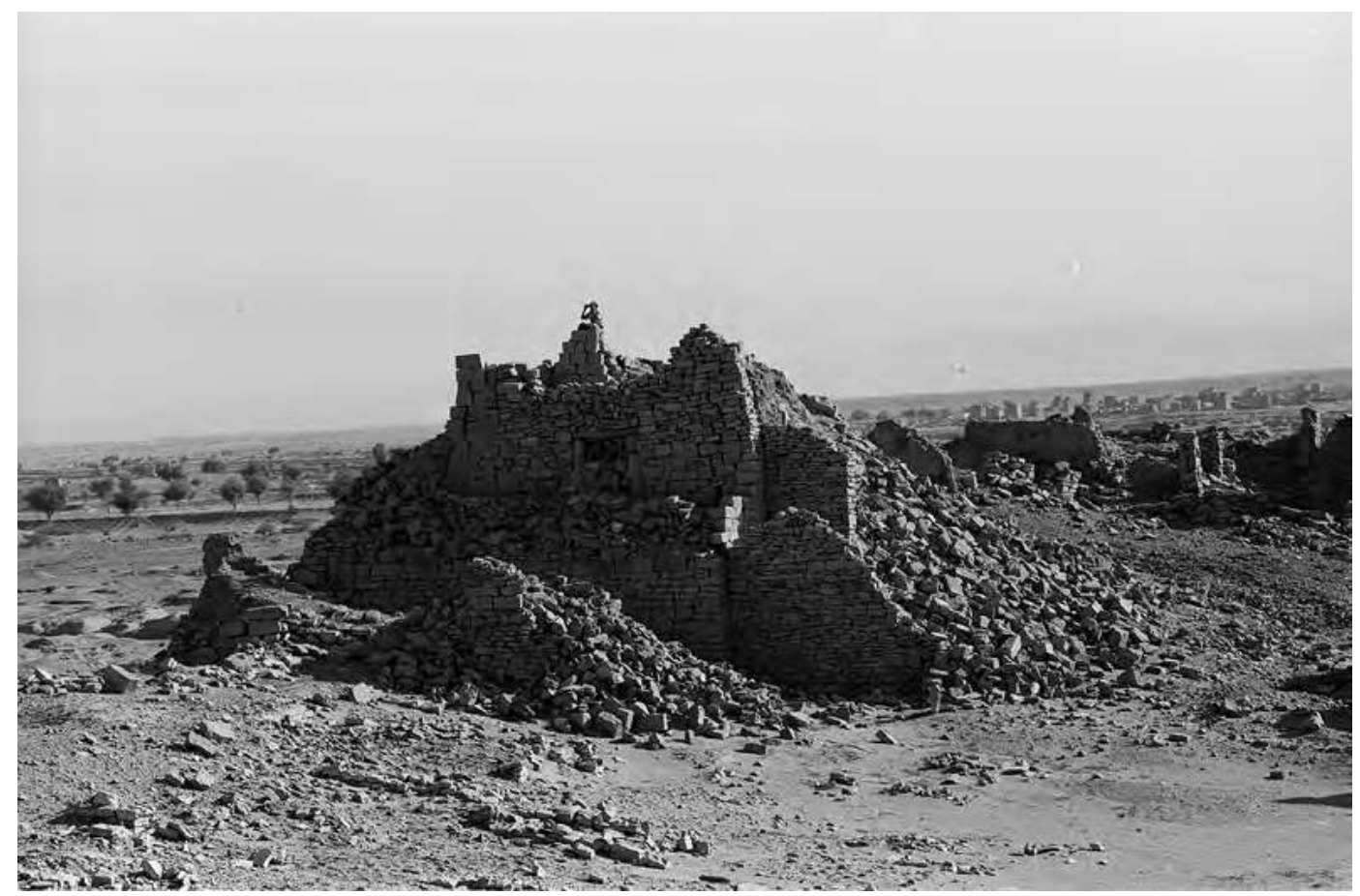

Figure 13. Ruins of Islamic buildings in the southeastern part of the city near the Islamic gateway. (A. Solazzi 1986 C MAIRY)

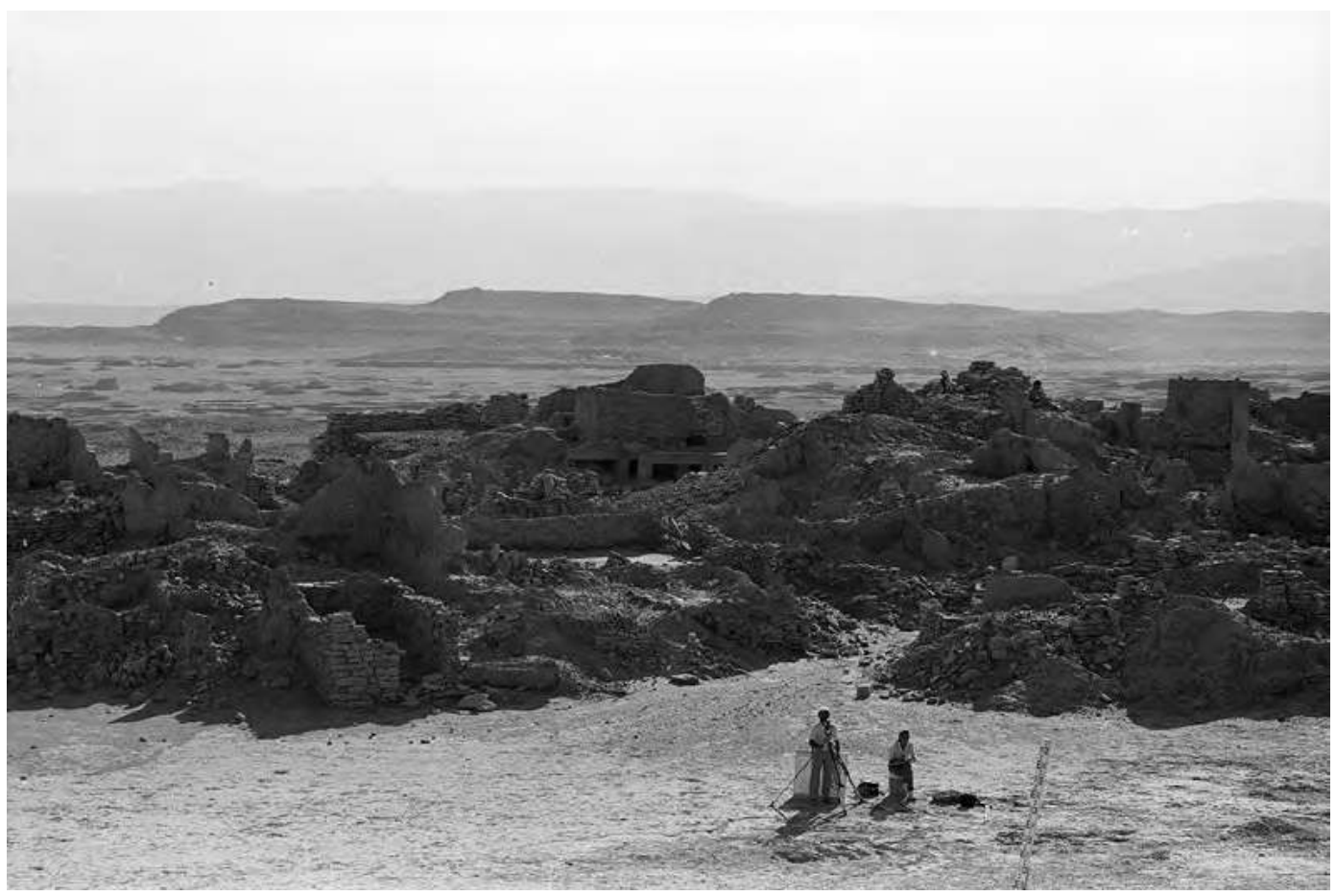

Figure 14. View of the Islamic ruins of Barāqish and Temples A (on the left) and B (on the right), from the northeast. The mesas and the Plateau to the southwest can be seen in the background.

(A. Solazzi 1986 ( ) MAIRY) 


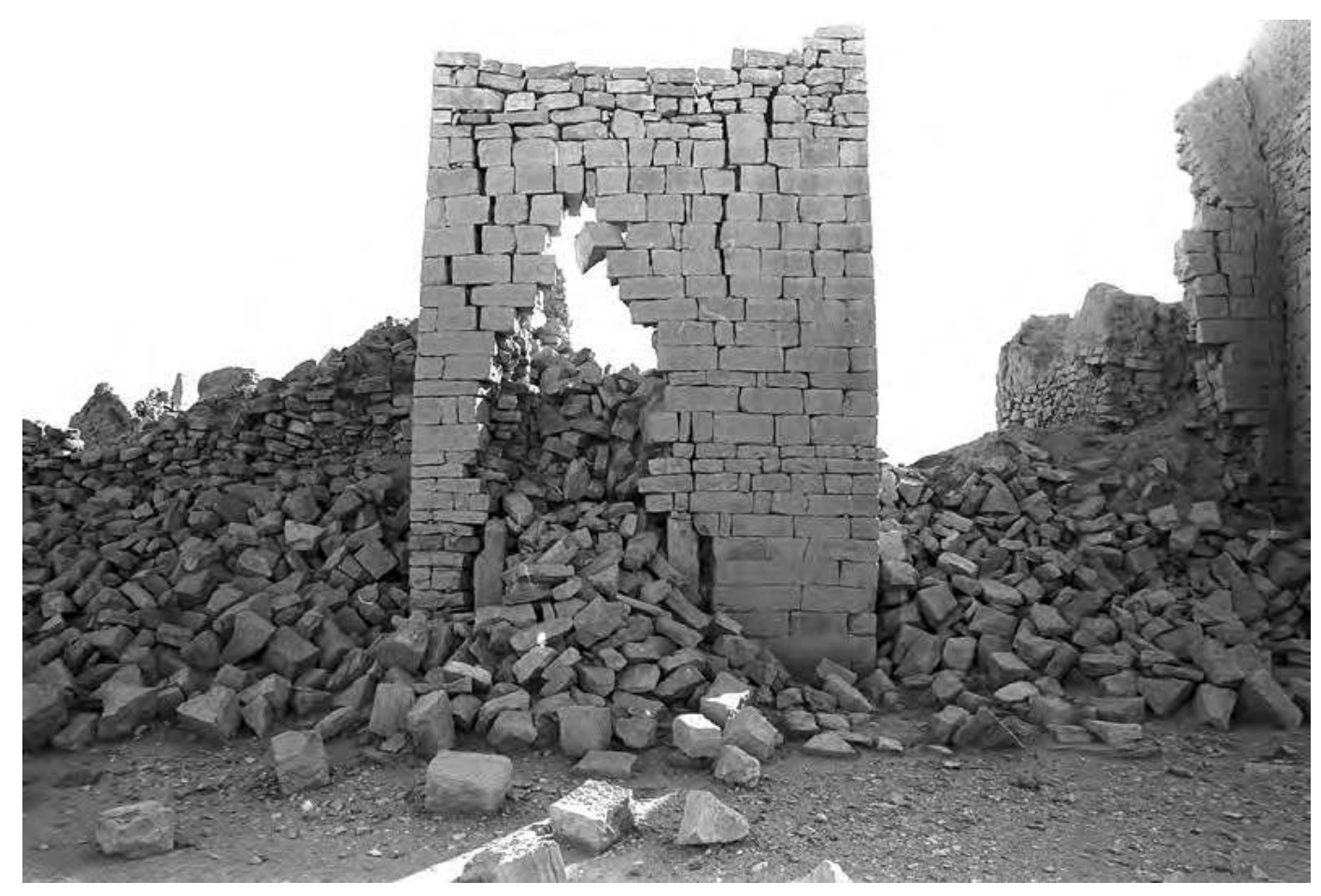

Figure 15. Ruins of an Islamic house in the central part of Barāqish. (A. Solazzi 1986 C MAIRY)
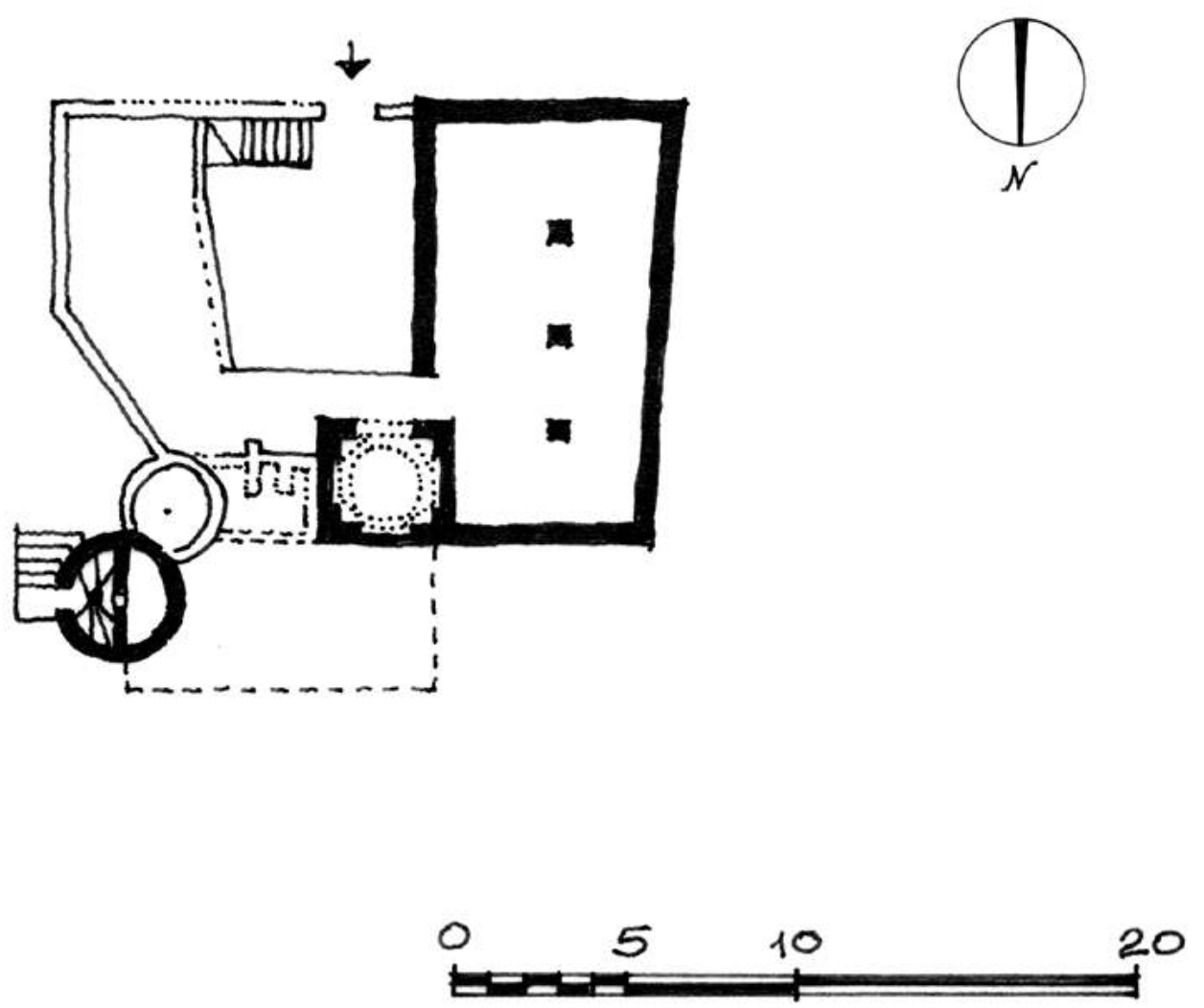

Figure 16. Plan of the Barāqish mosque. (P. Cuneo 1985 @ MAIRY). 


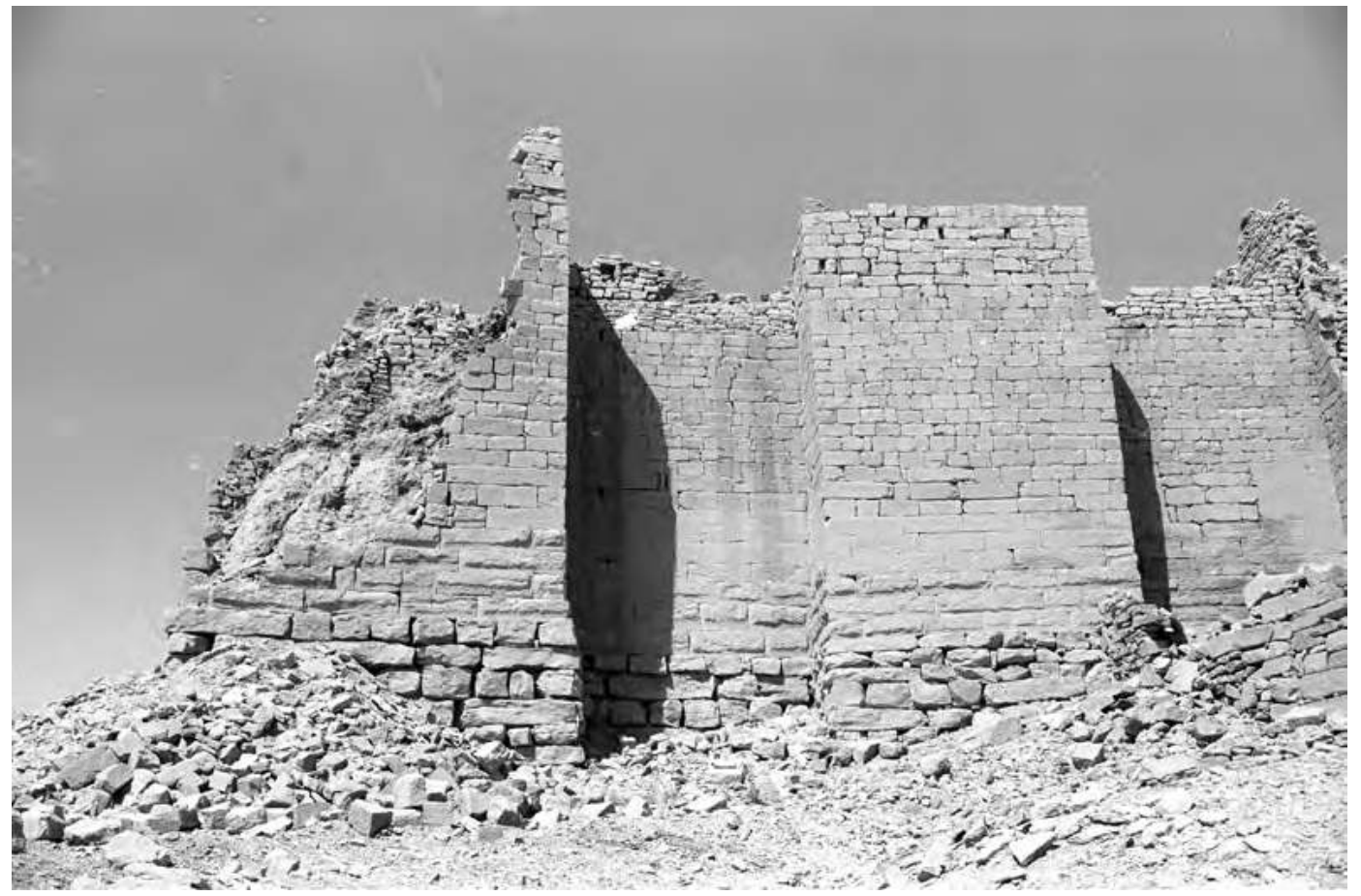

Figure 17. The foundations of bastions T36 and T37 of the city wall, from the south. (A. Solazzi 1986 C MAIRY)

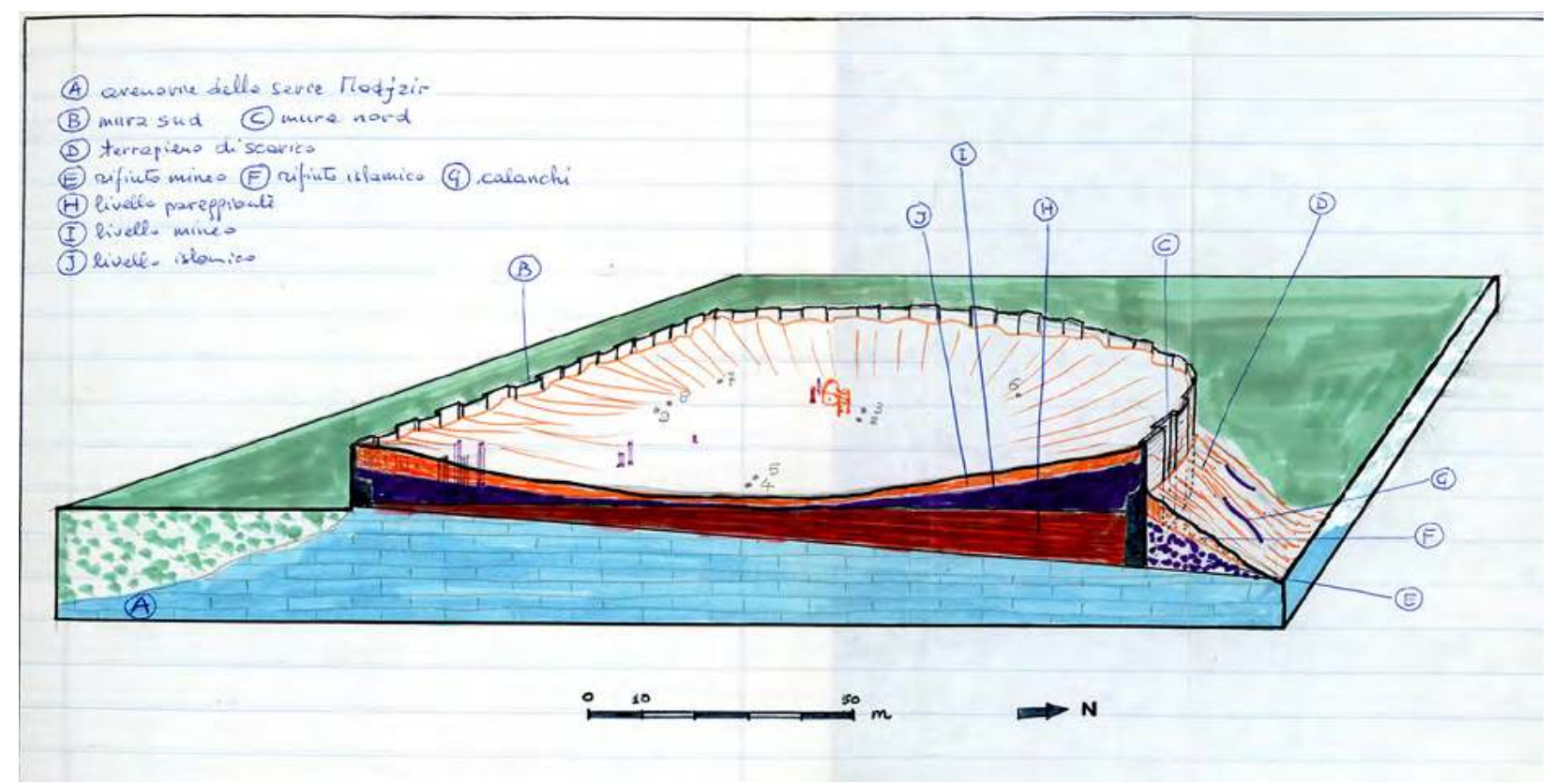

Figure 18. A hypothetical section and axonometric view of Barāqish, reflecting the reconstruction of geology and local substratum as put forward in 1986 (felt-pen coloured sketch by A. de Maigret, 1986). The numbers, added subsequently, refer to the mechanical corings within the city made in 1987. (৫ MAIRY) 


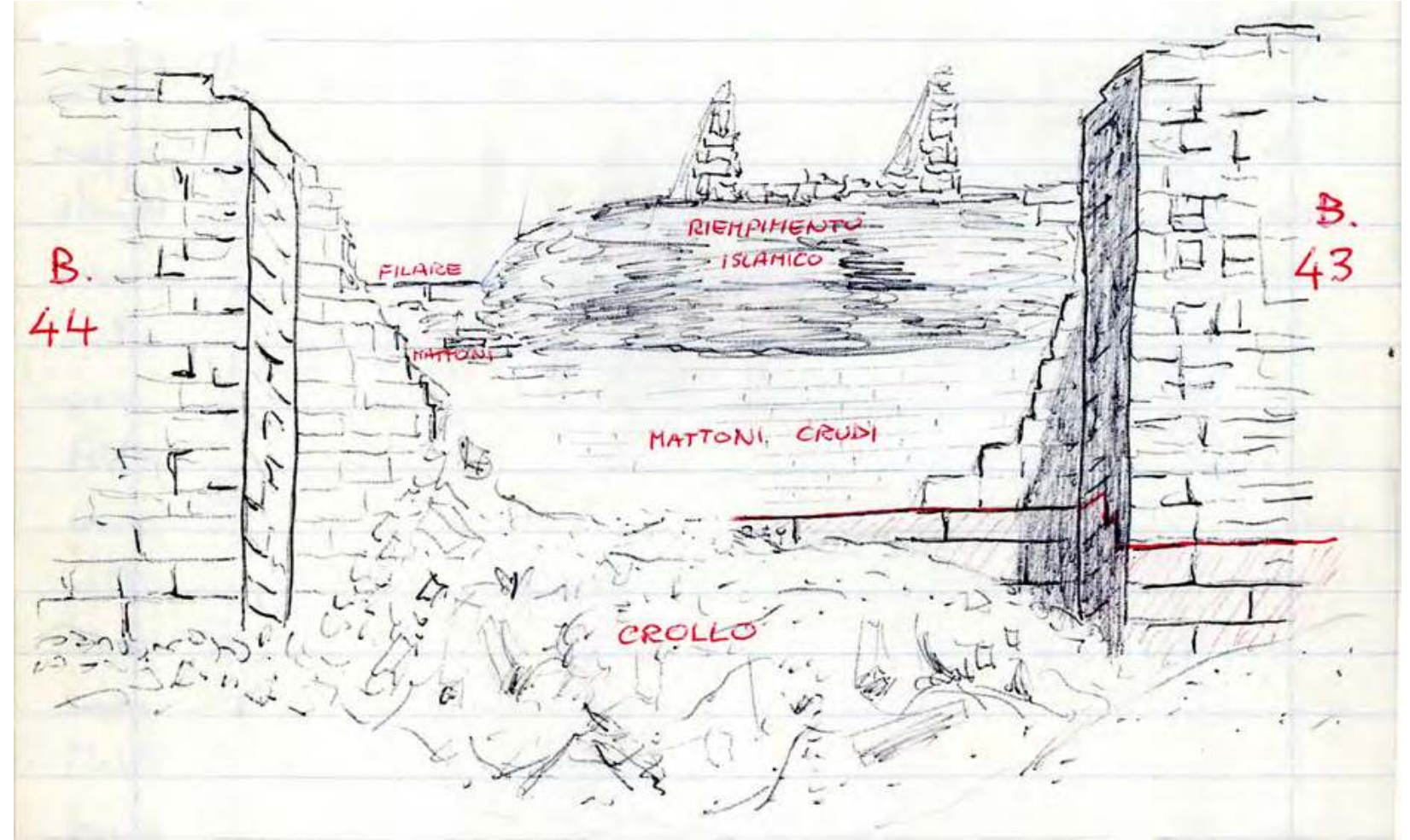

Figure 19. A sector of collapsed curtain wall between T43 and T44, where the Islamic levels above the Minaean mudbrick masonry can be observed; a remnant of a mudbrick wall in the left background is in all probability the inner face of the Minaean walling. Note that bastions were initially designated with a 'B', here B.43 and B.44.

(Sketch by A. de Maigret 1986 ○ MAIRY)

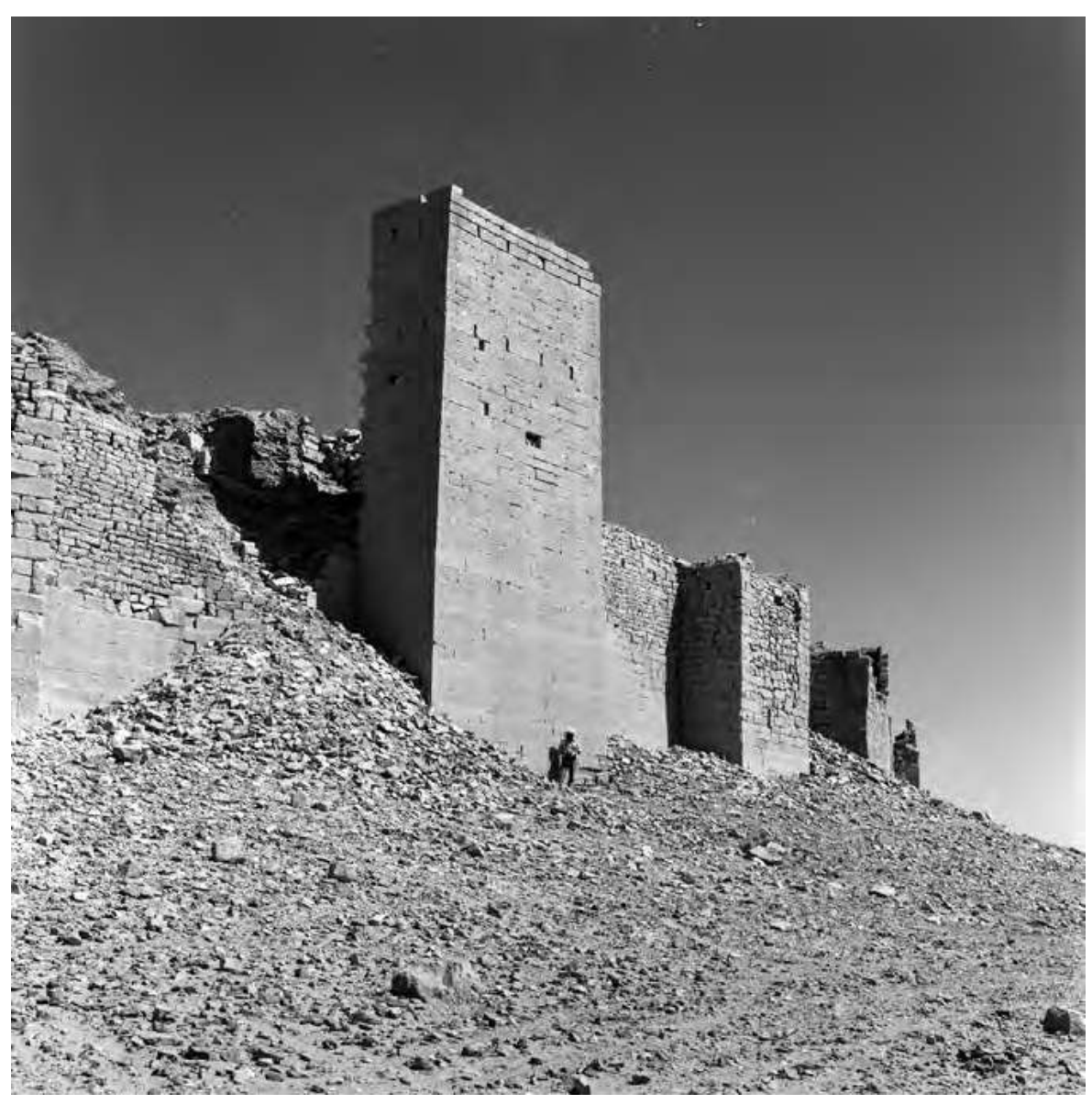

Figure 20. Bastion T48 from the west. (A. Solazzi 1986 (C) MAIRY) 


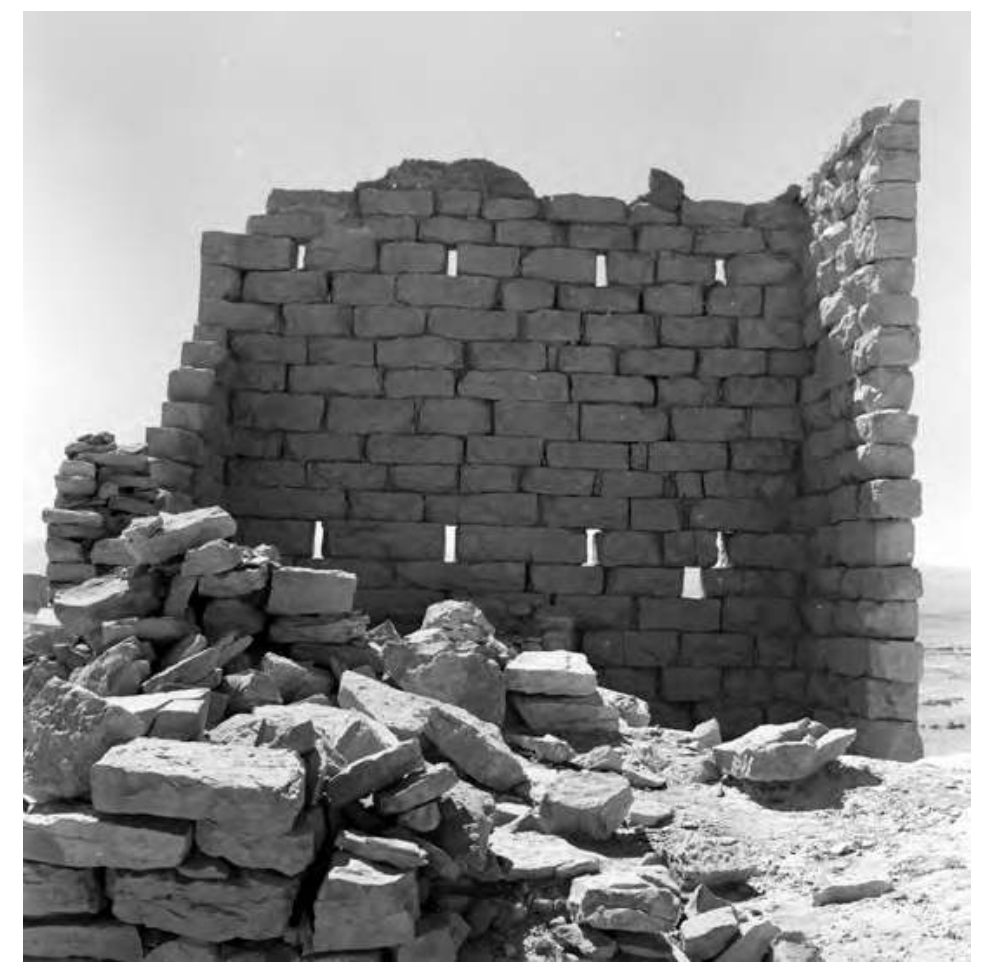

Figure 21. Inside view of the upper part of bastion T48, with two rows of loopholes, or embrasures. (A. Solazzi 1986 C MAIRY)

Figure 22. A hypothetical reconstruction of the mudbrick wall walkways (or allures) around the Barāqish curtain. (Sketch by A. de Maigret 1986

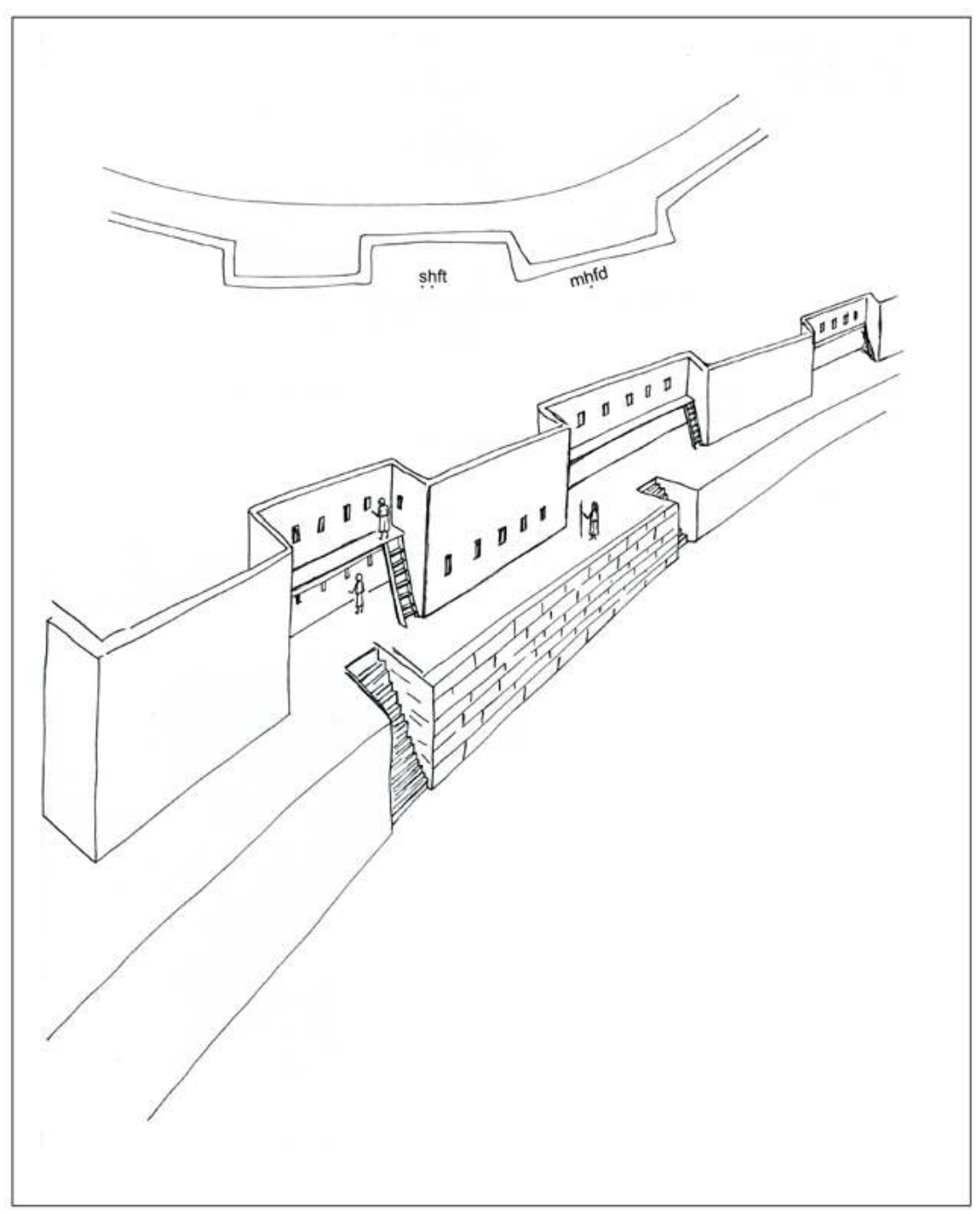




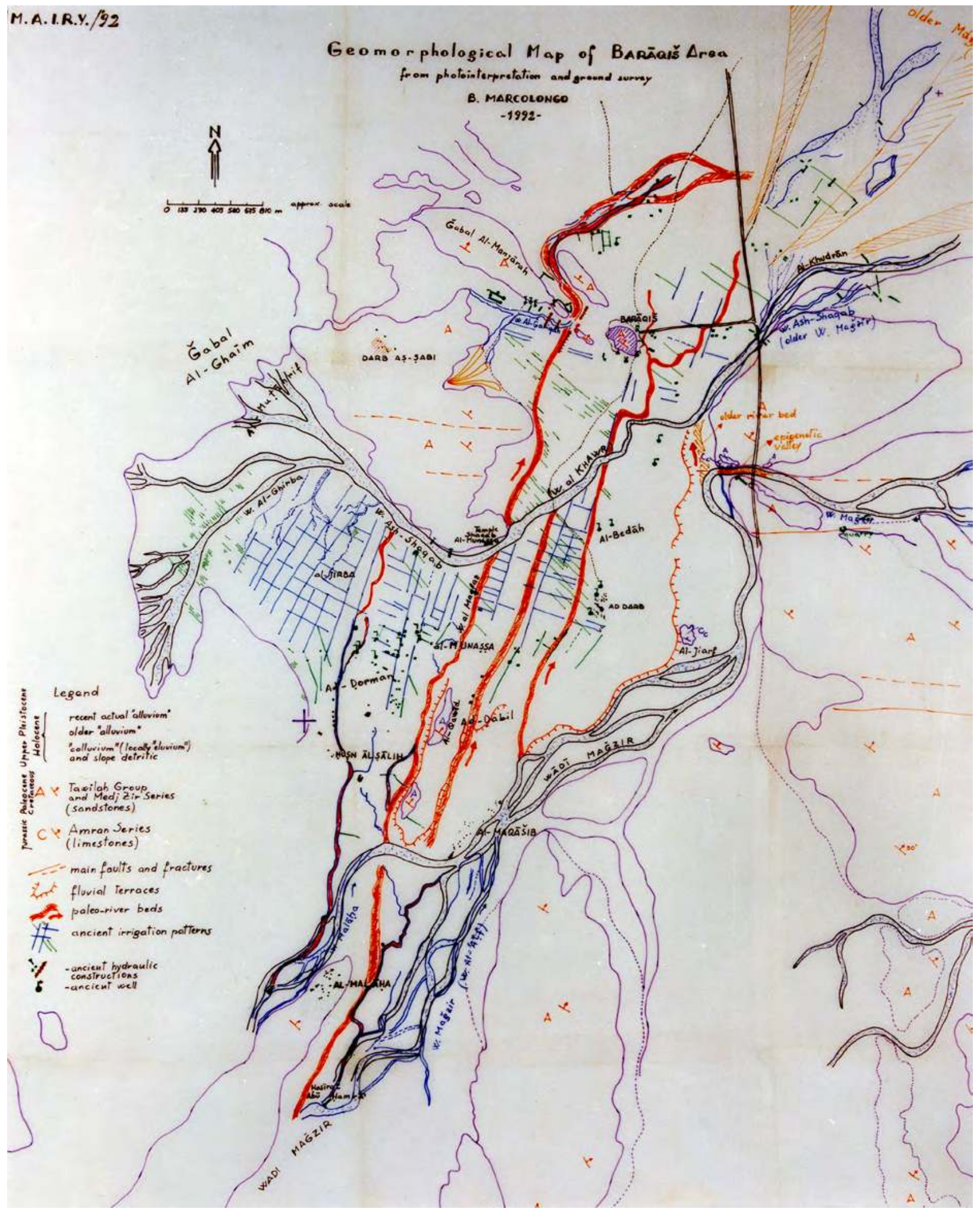

Figure 23. 'Geomorphological map of [the] Barāqish area from photointerpretation and ground survey', colour version, 1992 (B. Marcolongo, unpublished (C MAIRY). 


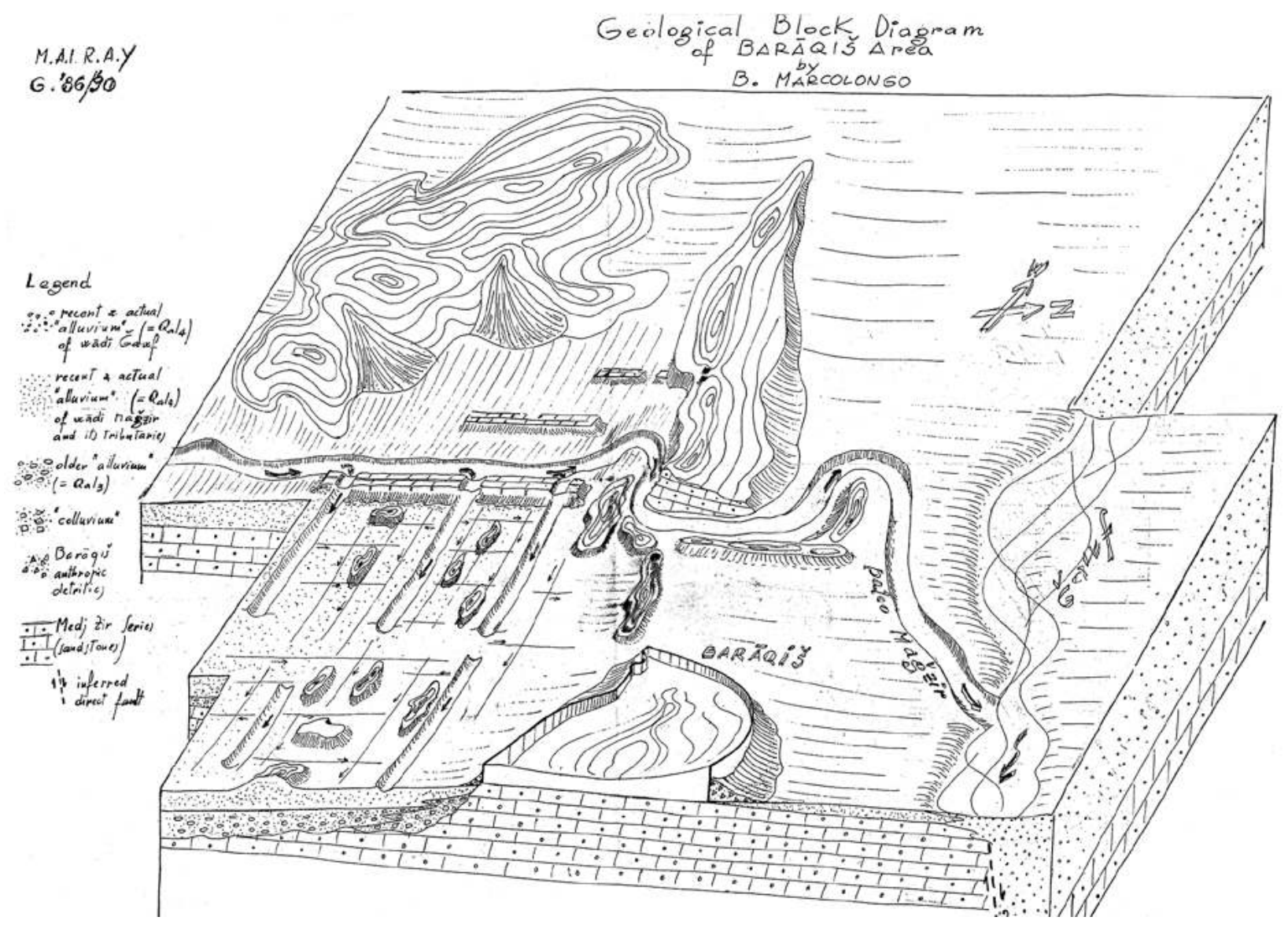

Figure 24. 'Geological block diagram of [the] Barāqish area', 1986-1990 (B. Marcolongo, unpublished @ MAIRY).

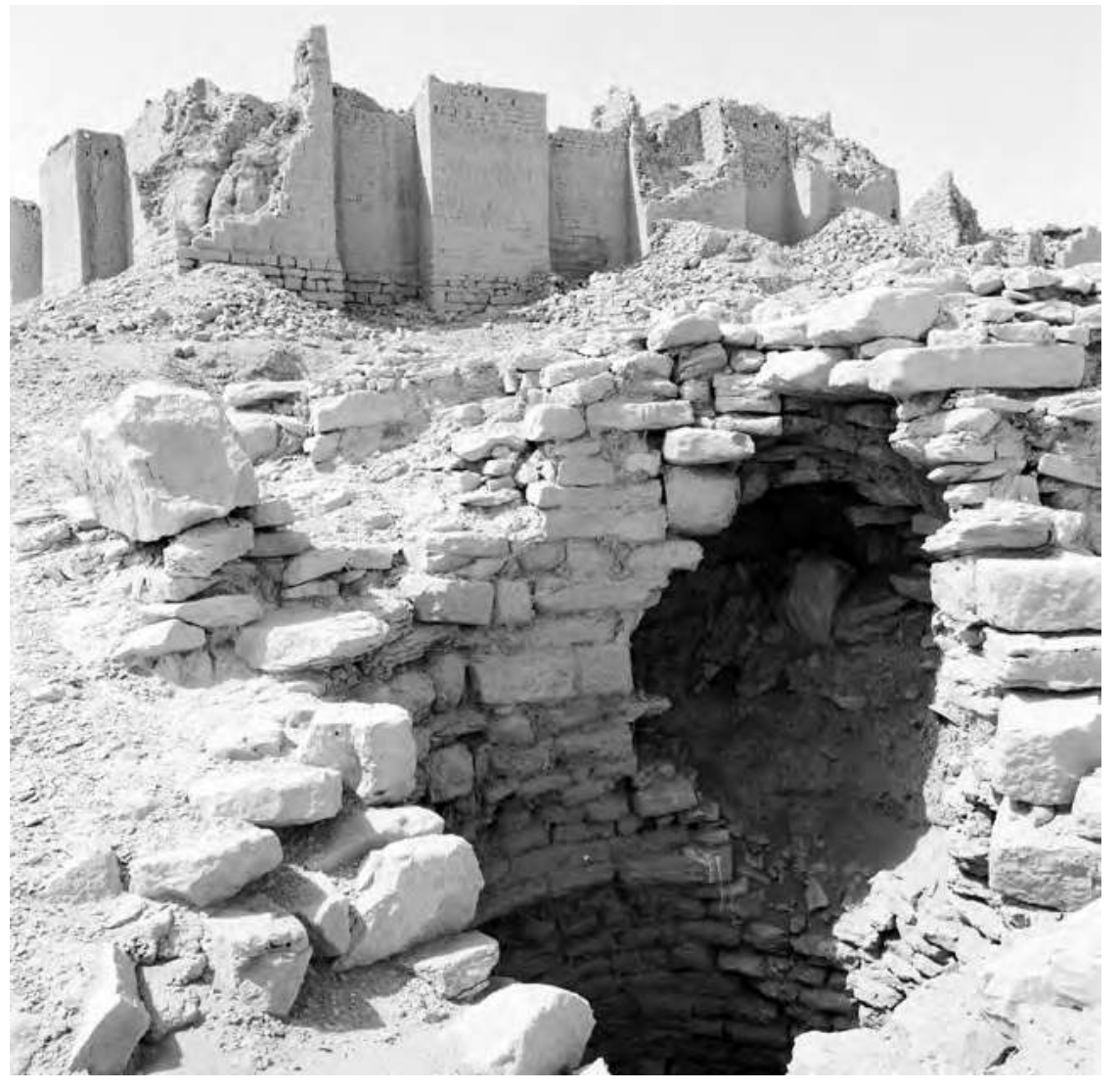

Figure 25. The well to the southsoutheast of Barāqish, from the south. (A. Solazzi 1986 @ MAIRY) 


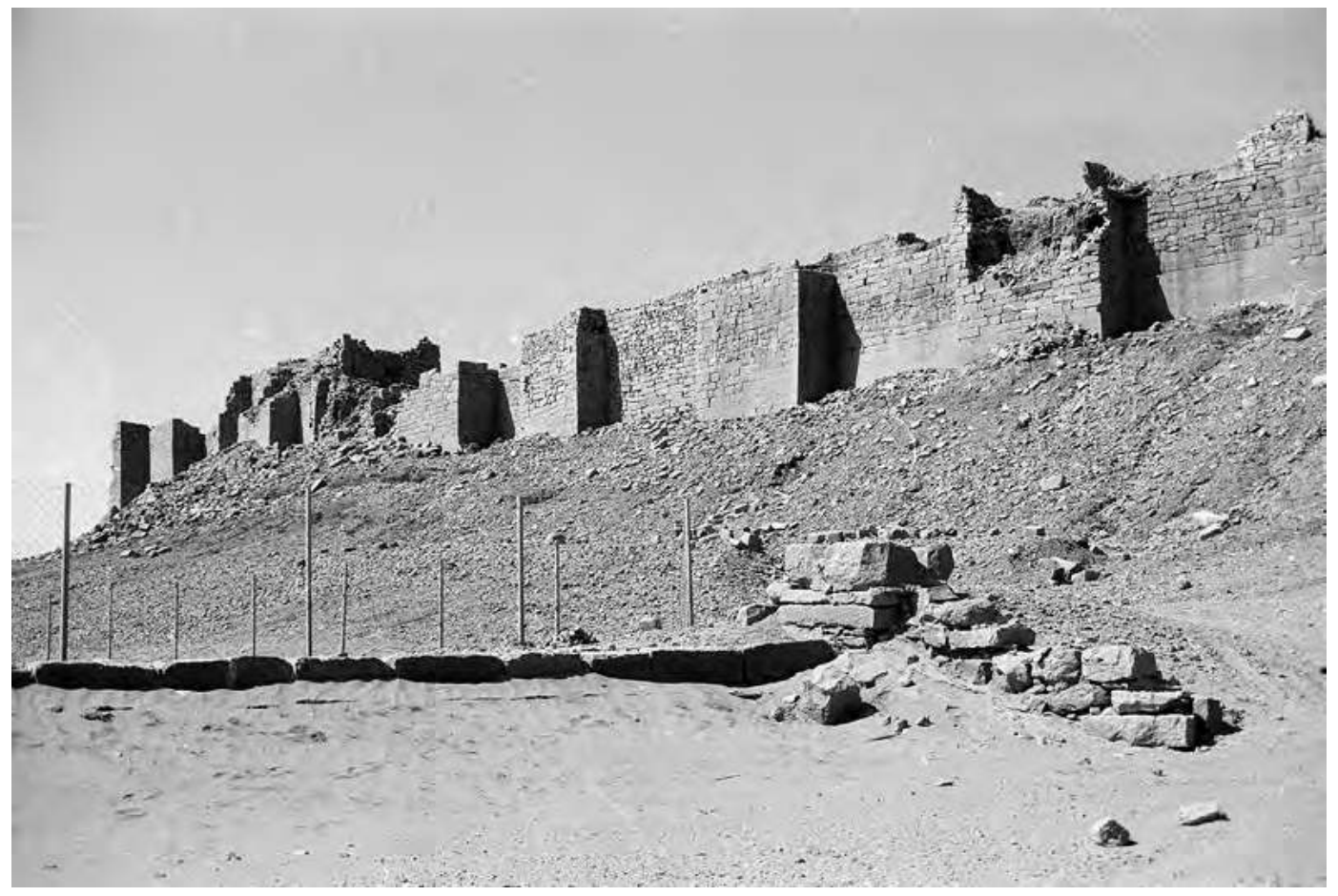

Figure 26. The weir to the east of Barāqish: the western wall. (A. Solazzi 1986 @ MAIRY)

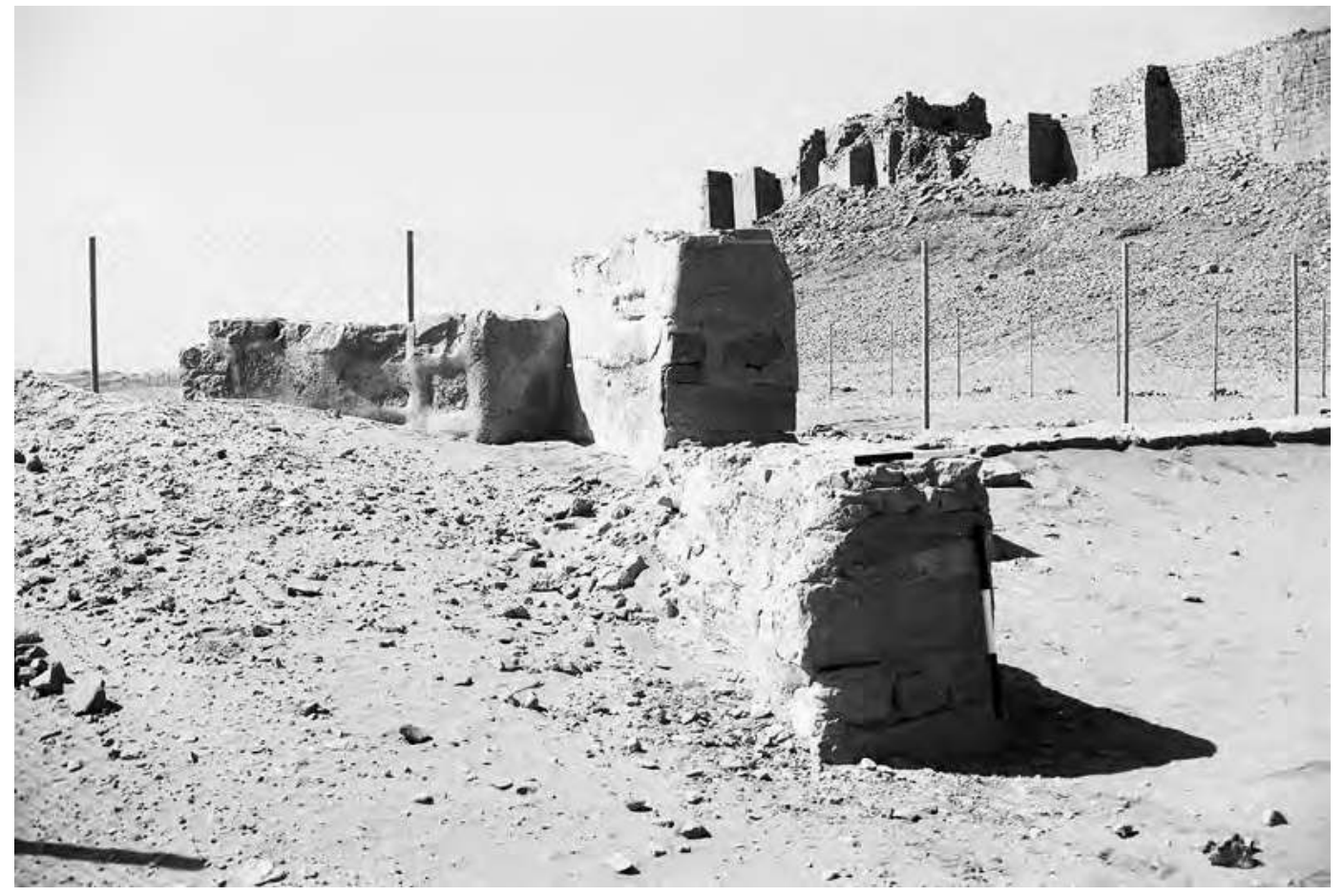

Figure 27. The weir to the east of Barāqish: the eastern wall. (A. Solazzi 1986 @ MAIRY) 


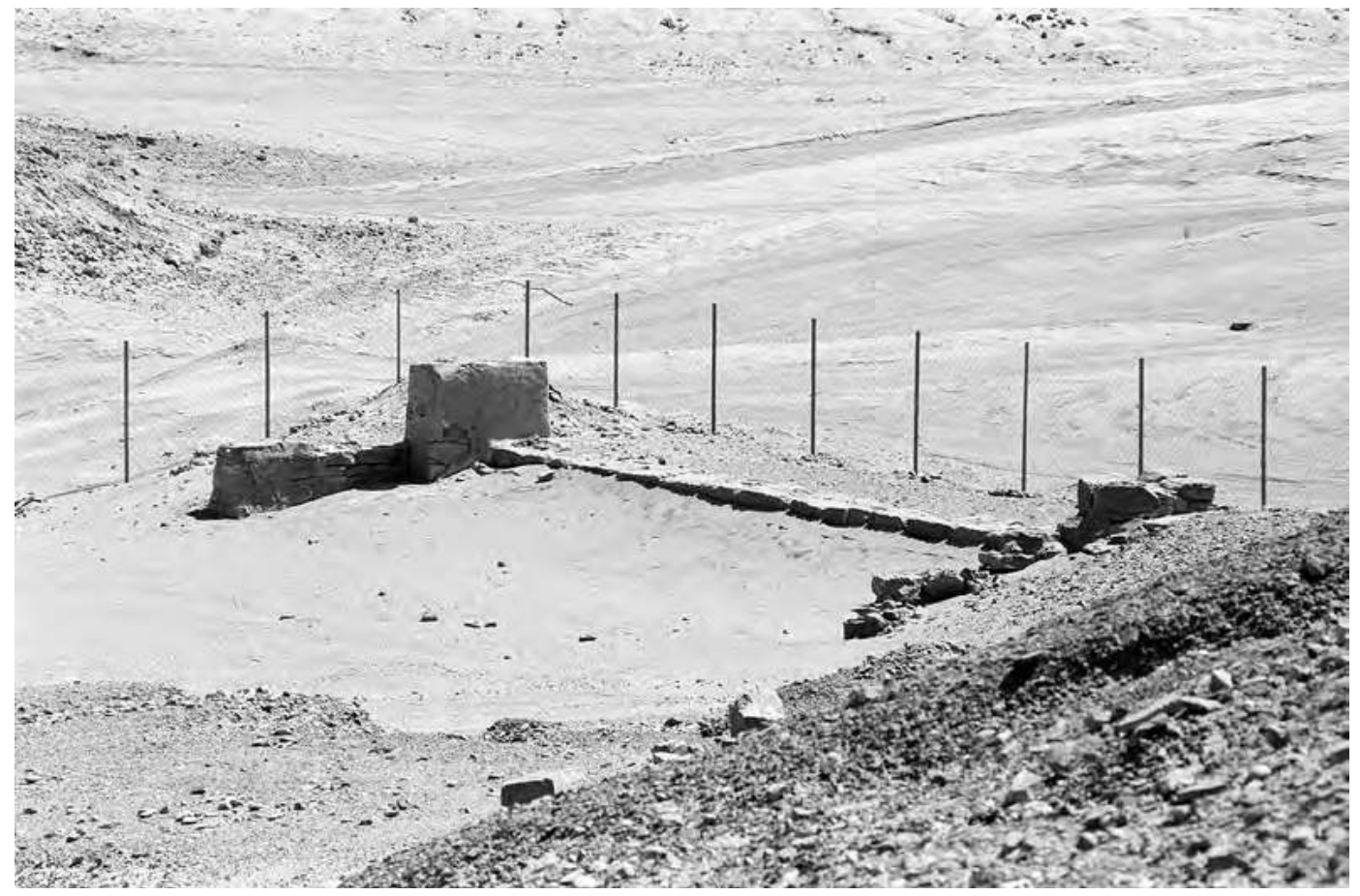

Figure 28. General view of the weir to the east of Barāqish, from the northwest. (A. Solazzi 1986 C MAIRY)

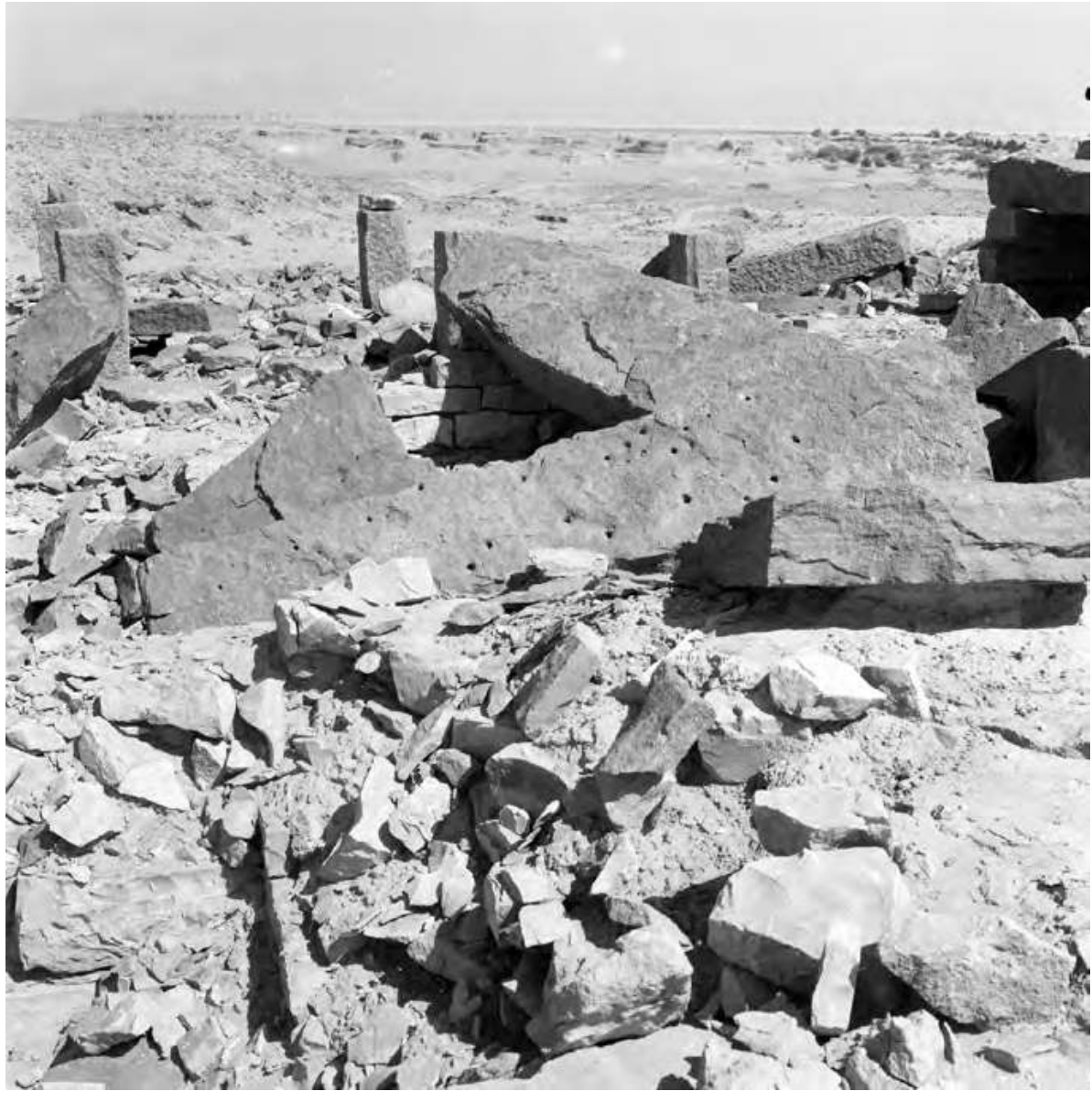

Figure 29. Beams and pillars of a temple at Shaqab al-Manașa; Barāqish in the background. (A. Solazzi 1989-1990 @ MAIRY) 


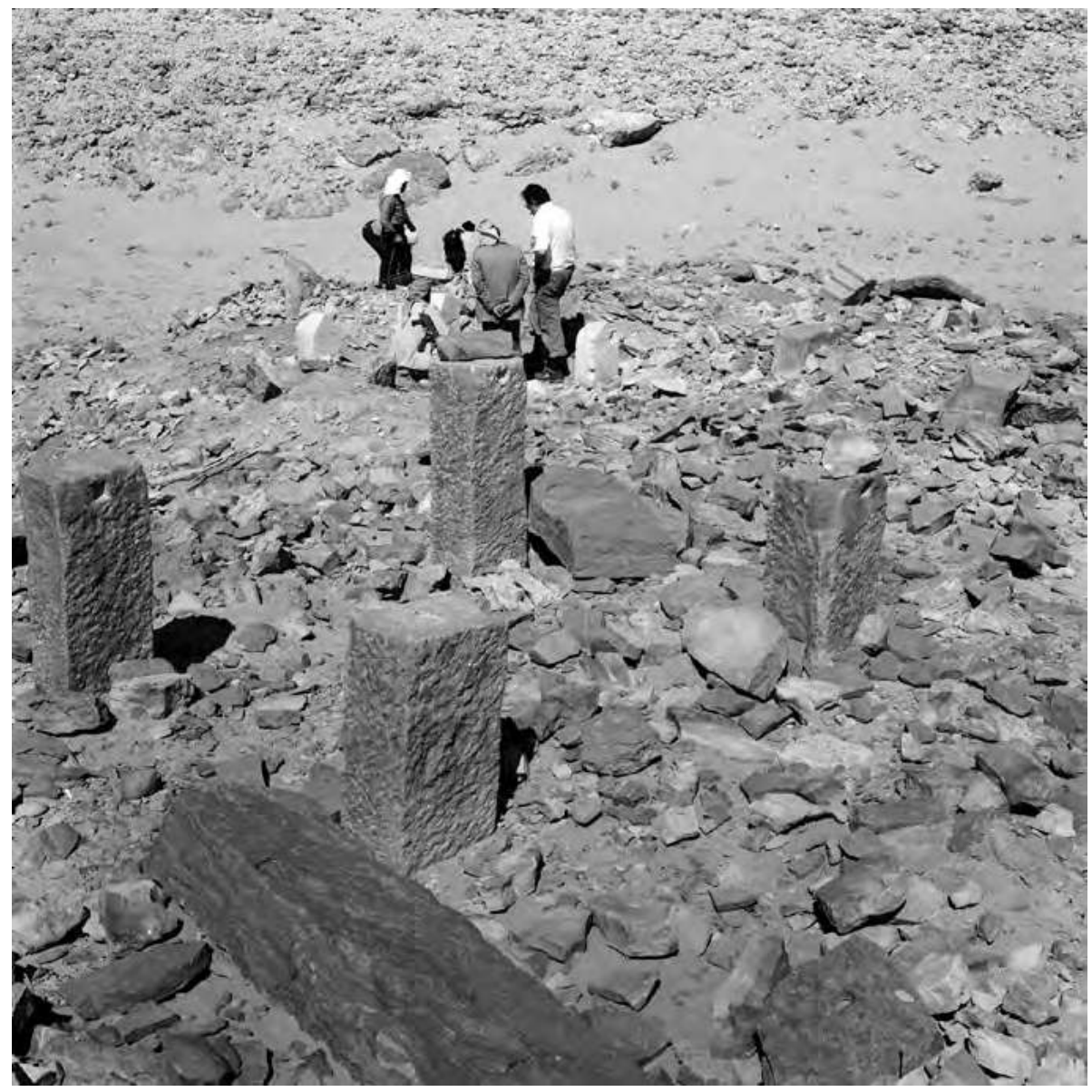

Figure 30. Pillars of a building, probably a temple, at Shaqab al-Manașșa. (A. Solazzi 19891990 @ MAIRY)

Figure 31. Inscribed pillars of a temple at Shaqab alManașsa, cf. Figure 30. (A. Solazzi 1989-1990 @ MAIRY)

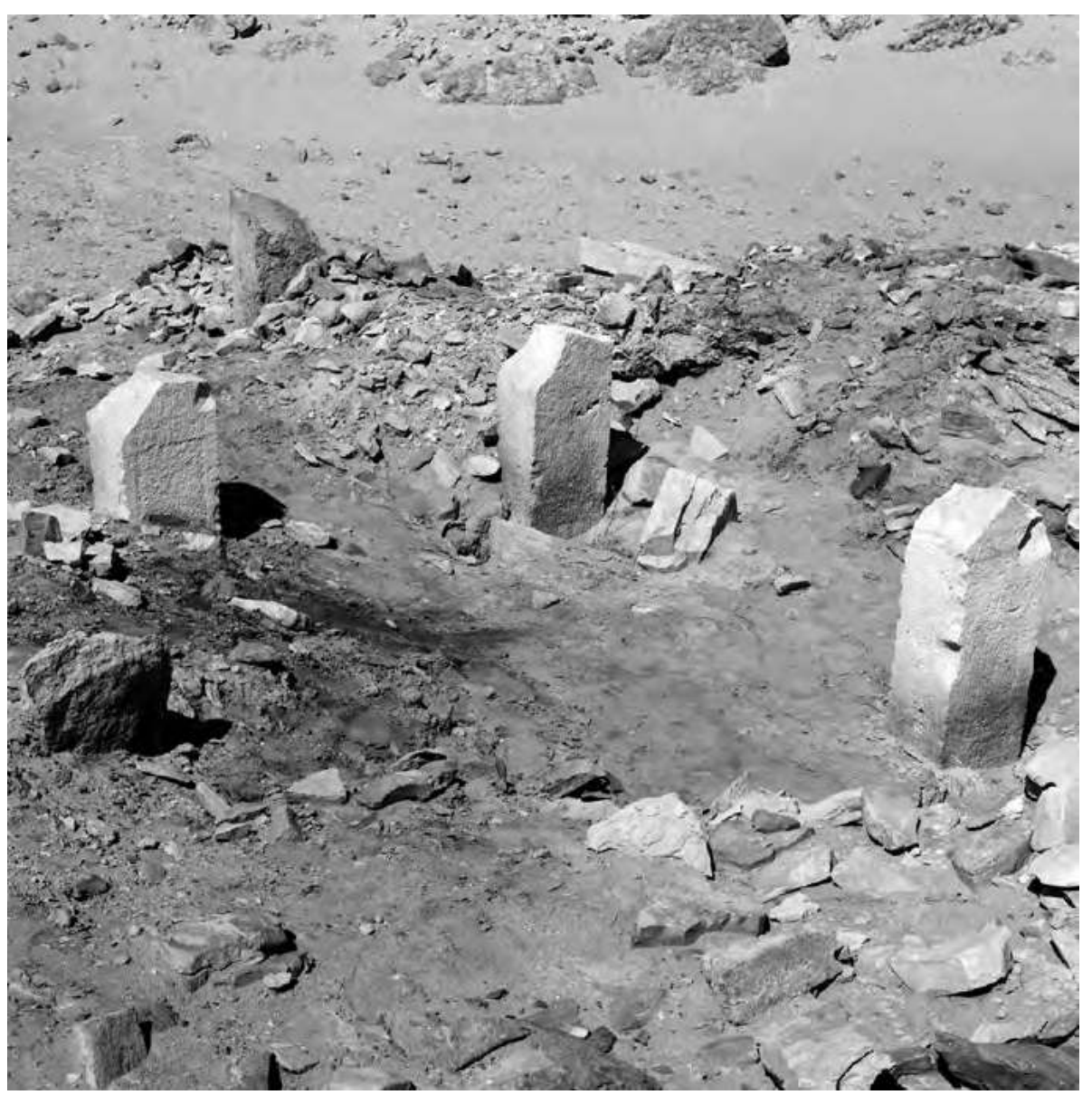




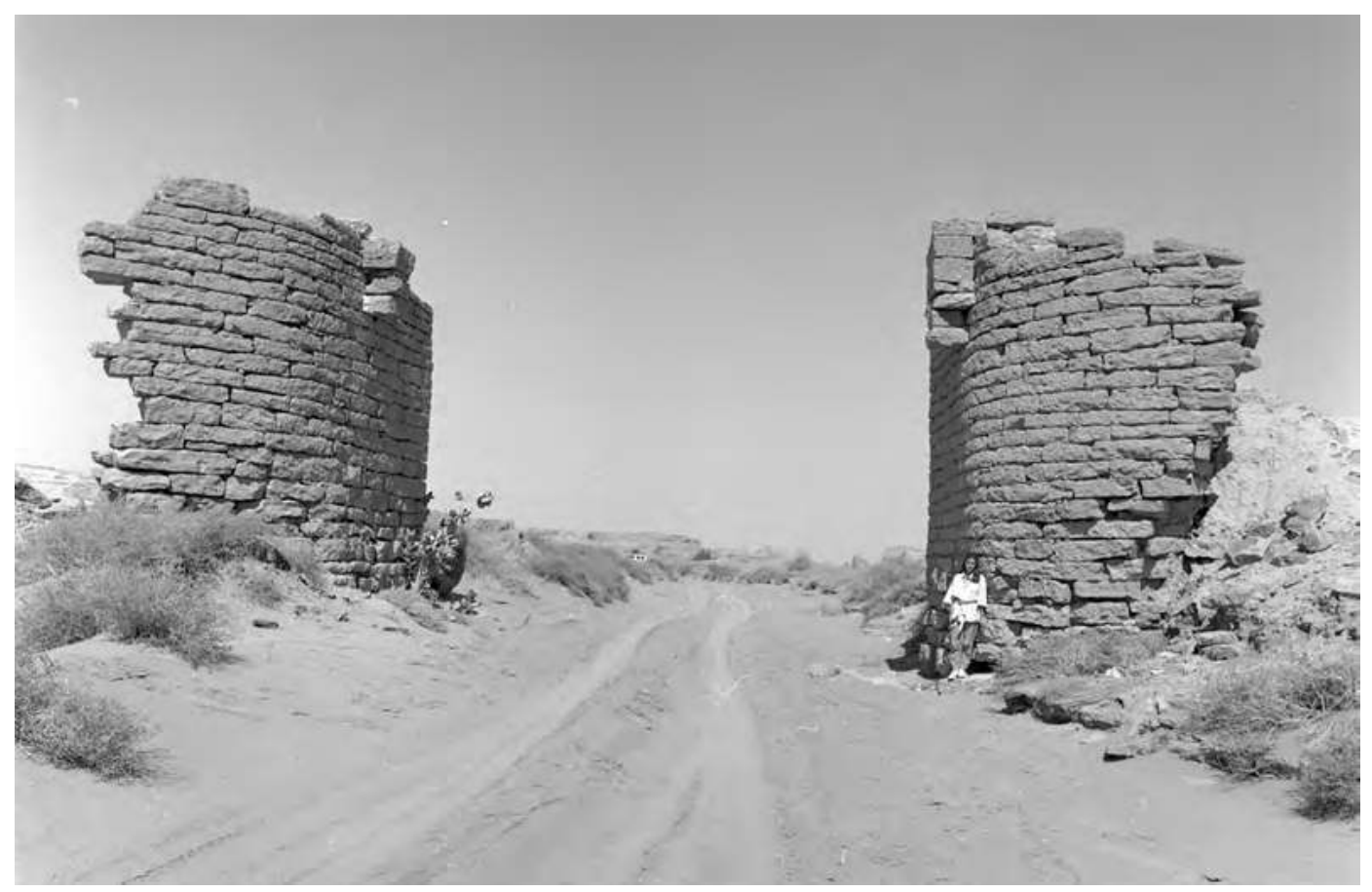

Figure 32. A monumental hydraulic structure in Wādī Shaqab, today reportedly destroyed. (A. Solazzi $1986 @$ MAIRY)

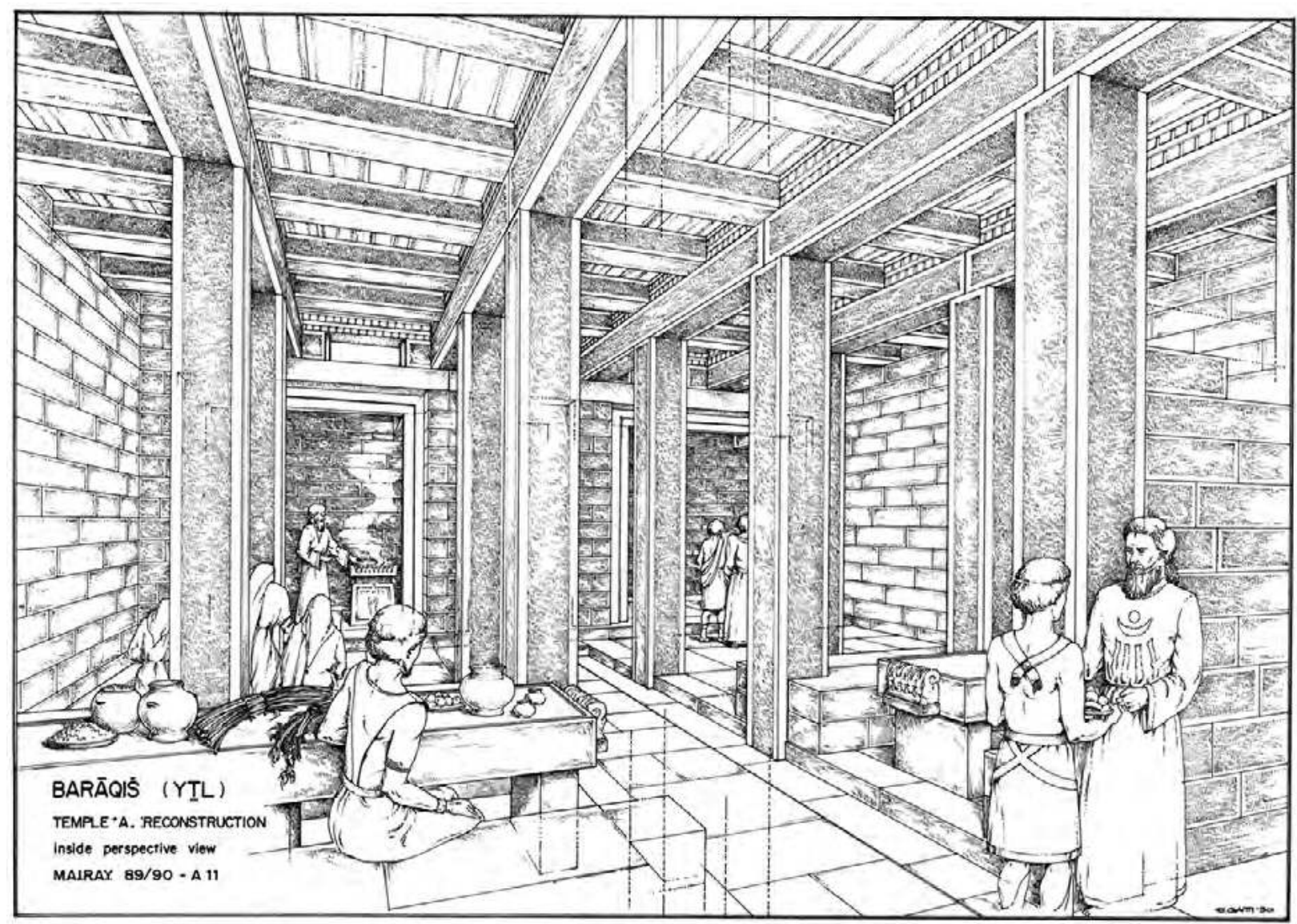

Figure 33. The hypostyle hall of the temple of Nakrah at Barāqish, in an atmospheric drawing by mission's architect E. Gatti. (1989-1990 @ MAIRY). 
BARĀQIŠ (YTL)

TEMPLE'A. :RECONSTRUCTION - Generol axonometrical view E. GATT

MALRAY 89/90-A6

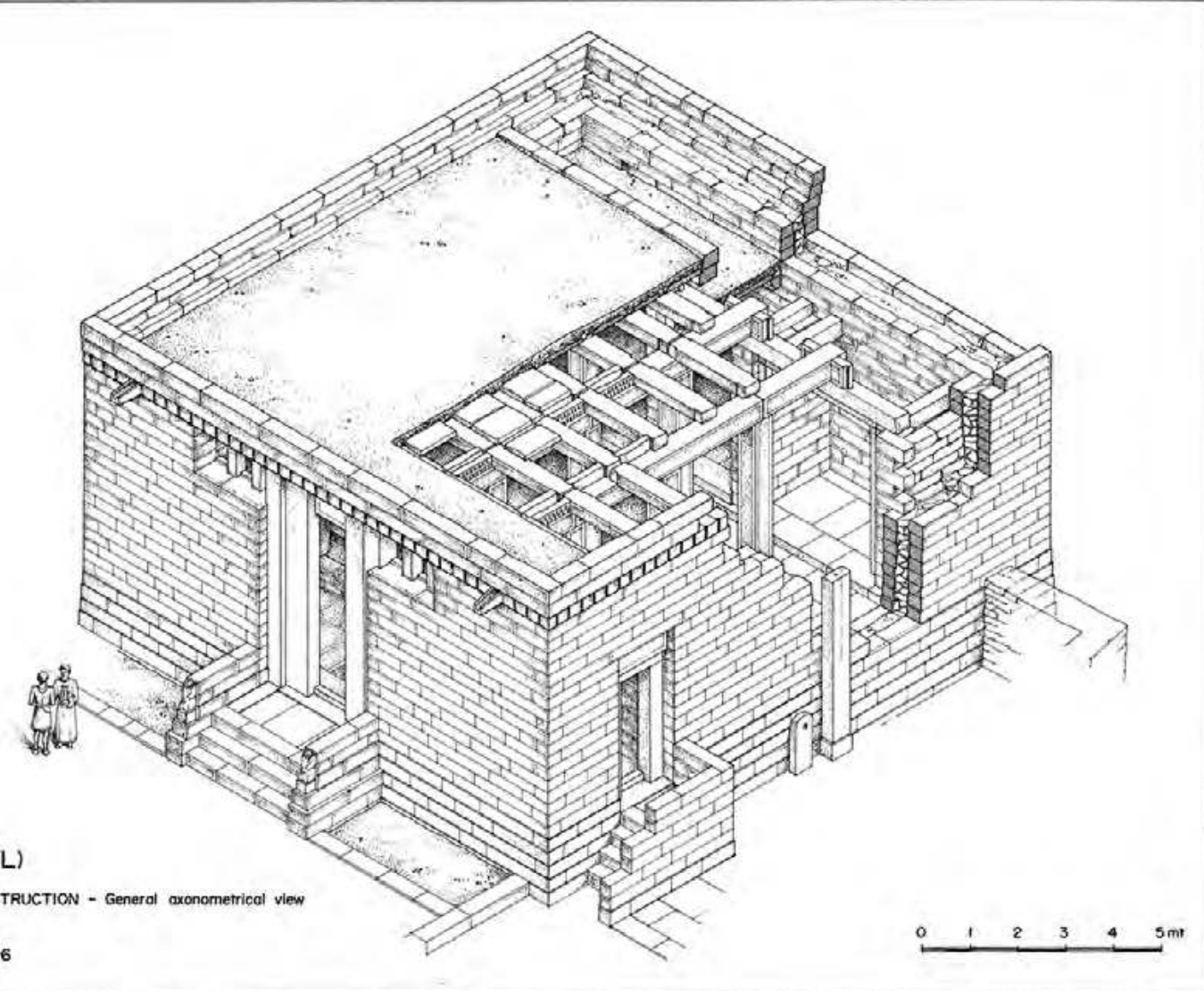

Figure 34. An axonometric reconstruction of the temple of Nakrah before the discovery of the tetrastyle propylaeum and staircase. (E. Gatti 1989-1990 @ MAIRY)

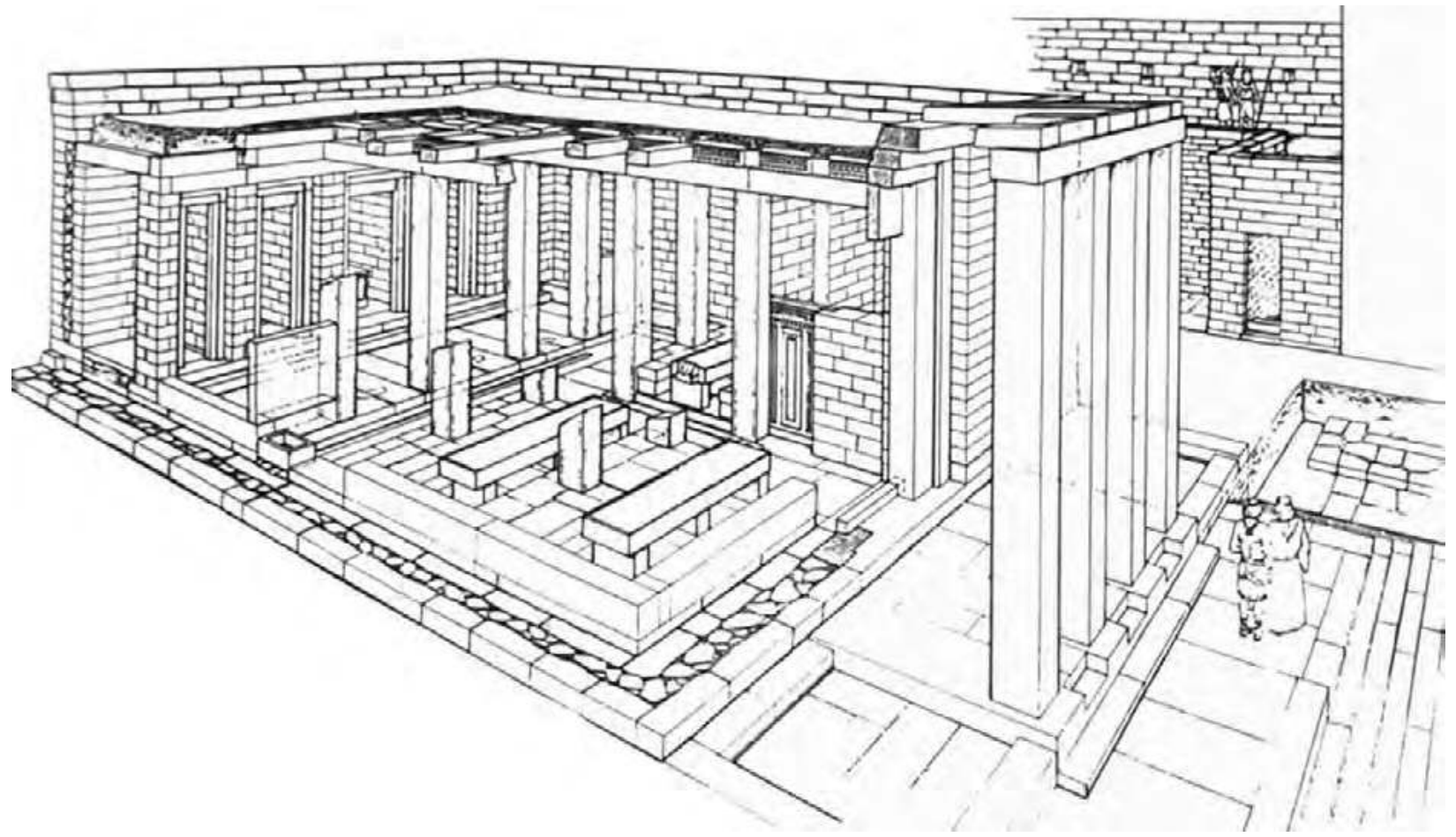

Figure 35. An axonometric reconstruction of the temple of Nakrah from the north, with the city wall and postern in the background. (E. Gatti 1992 @ MAIRY) 


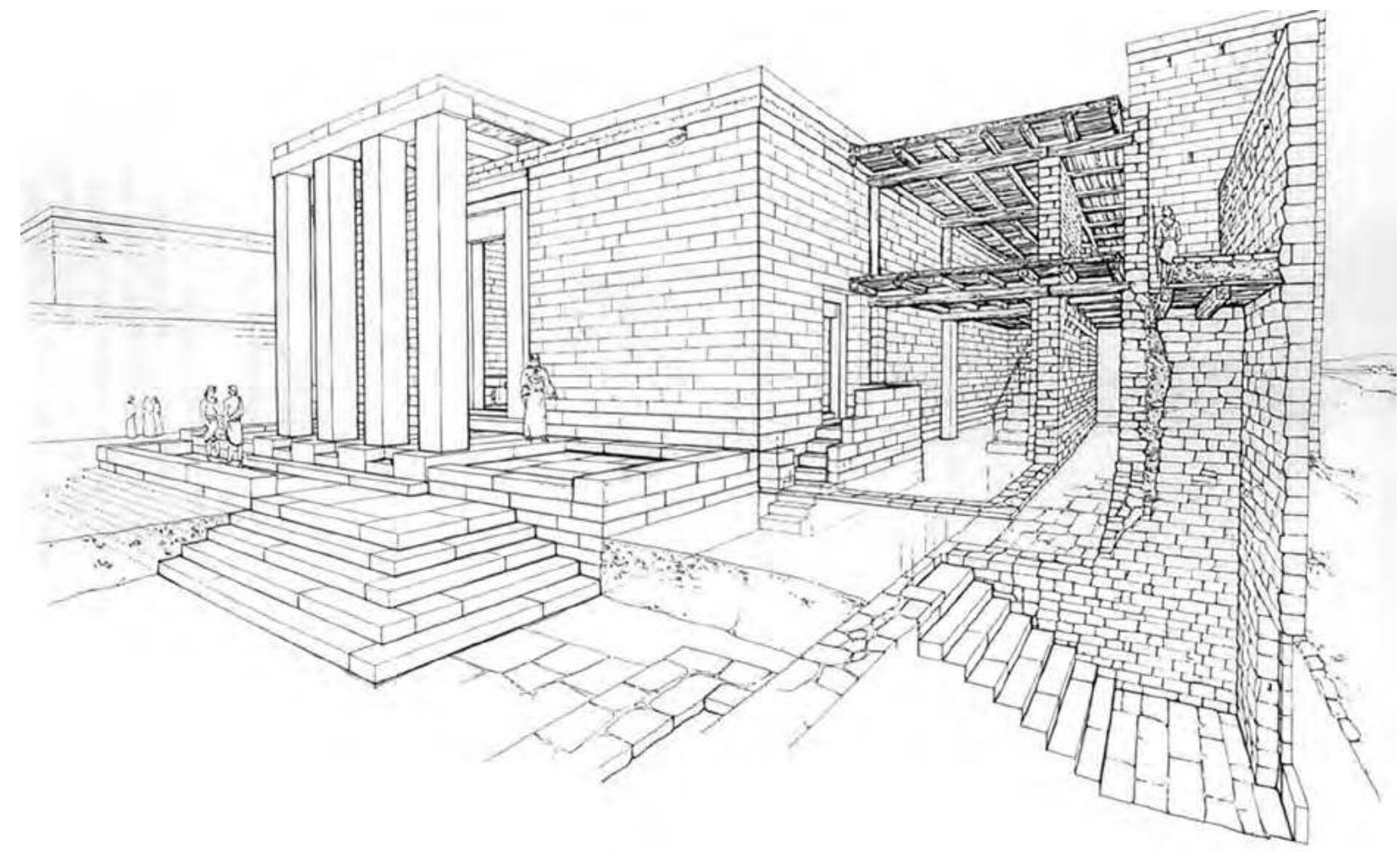

Figure 36. An axonometric reconstruction of the temple of Nakrah. On the right the so-called 'sacristy', the city wall, and the staircase to the postern, in the left background the wall of Temple B. (E. Gatti 1992 @ MAIRY)

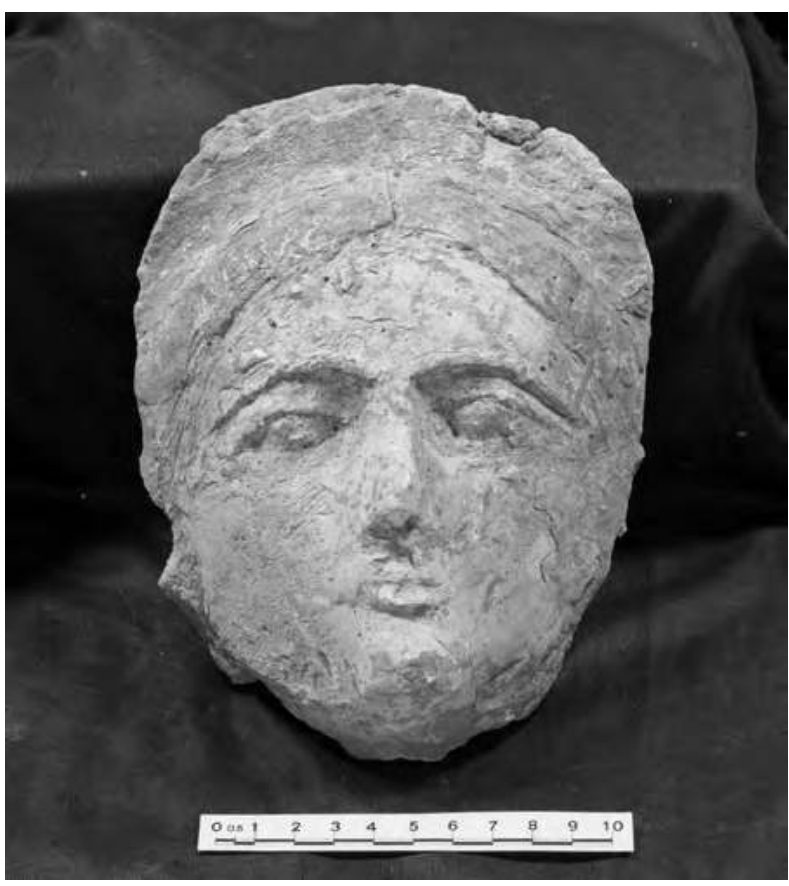

Figure 37. Barāqish: a plaster female face from the so-called 'sacristy', first century CE. (A. de Maigret 1990 @ MAIRY)

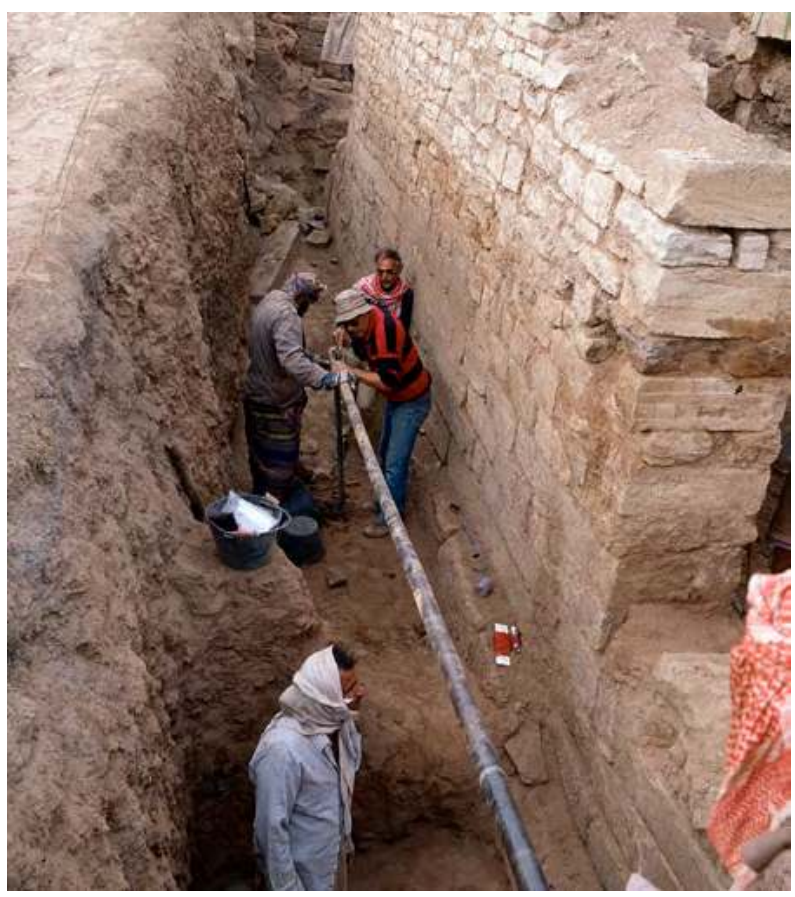

Figure 38. Mechanical coring outside the SE wall of the temple of Nakrah in January 1990; behind drilling specialist F. Brancaleoni is geologist V. Francaviglia. (A. de Maigret 1990 ○ MAIRY) 


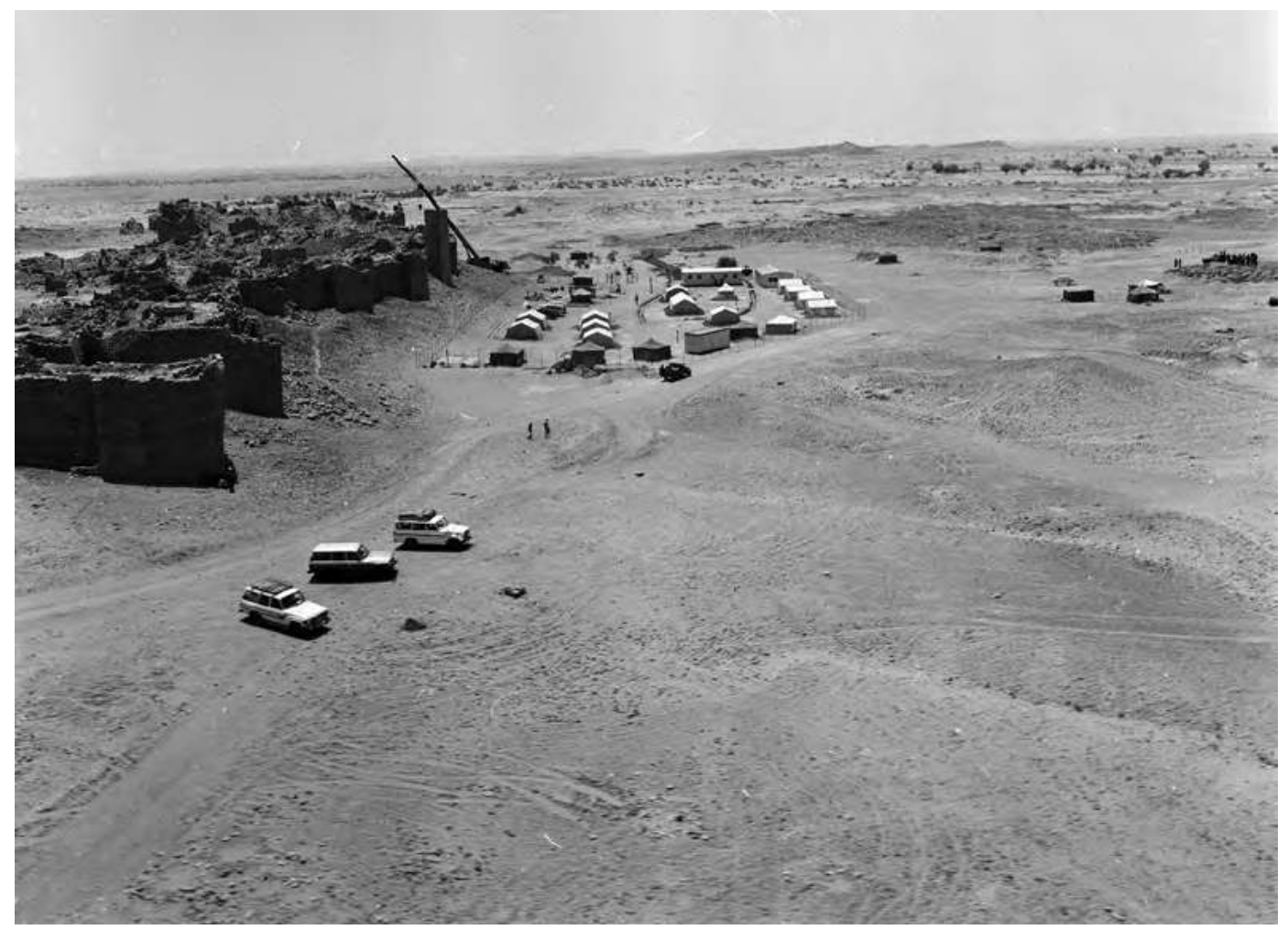

Figure 39. A bird's eye view of the MAIRY camp and excavations at Barāqish in 1992, from the northwest, featuring the prominent crane arm. (A. de Maigret 1992 ( ) MAIRY)

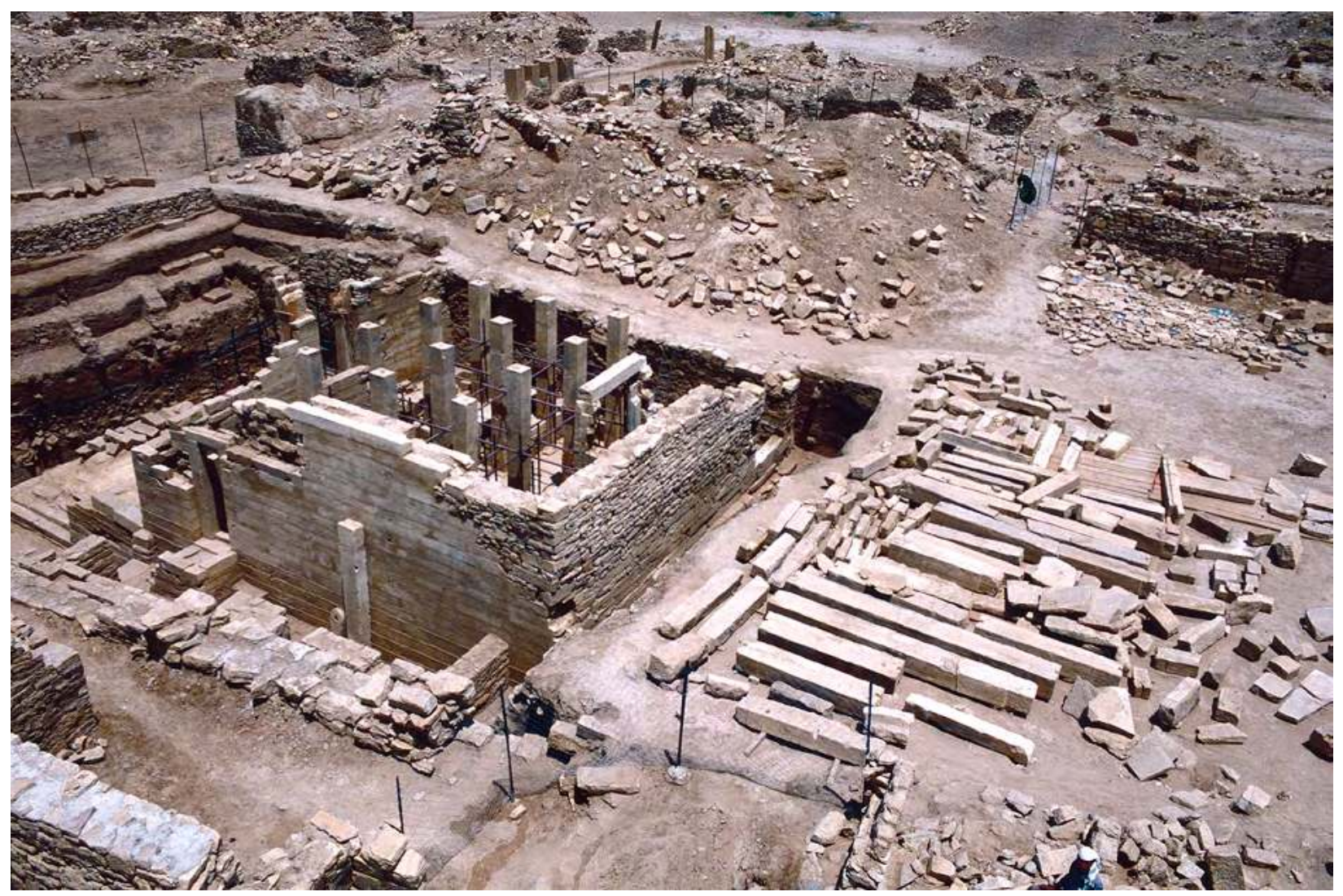

Figure 40. View of the temple of Nakrah from the crane arm: the temple's roof has been disassembled and the beams have been laid down on the southeast side of the building. (A. de Maigret 1992 @ MAIRY) 

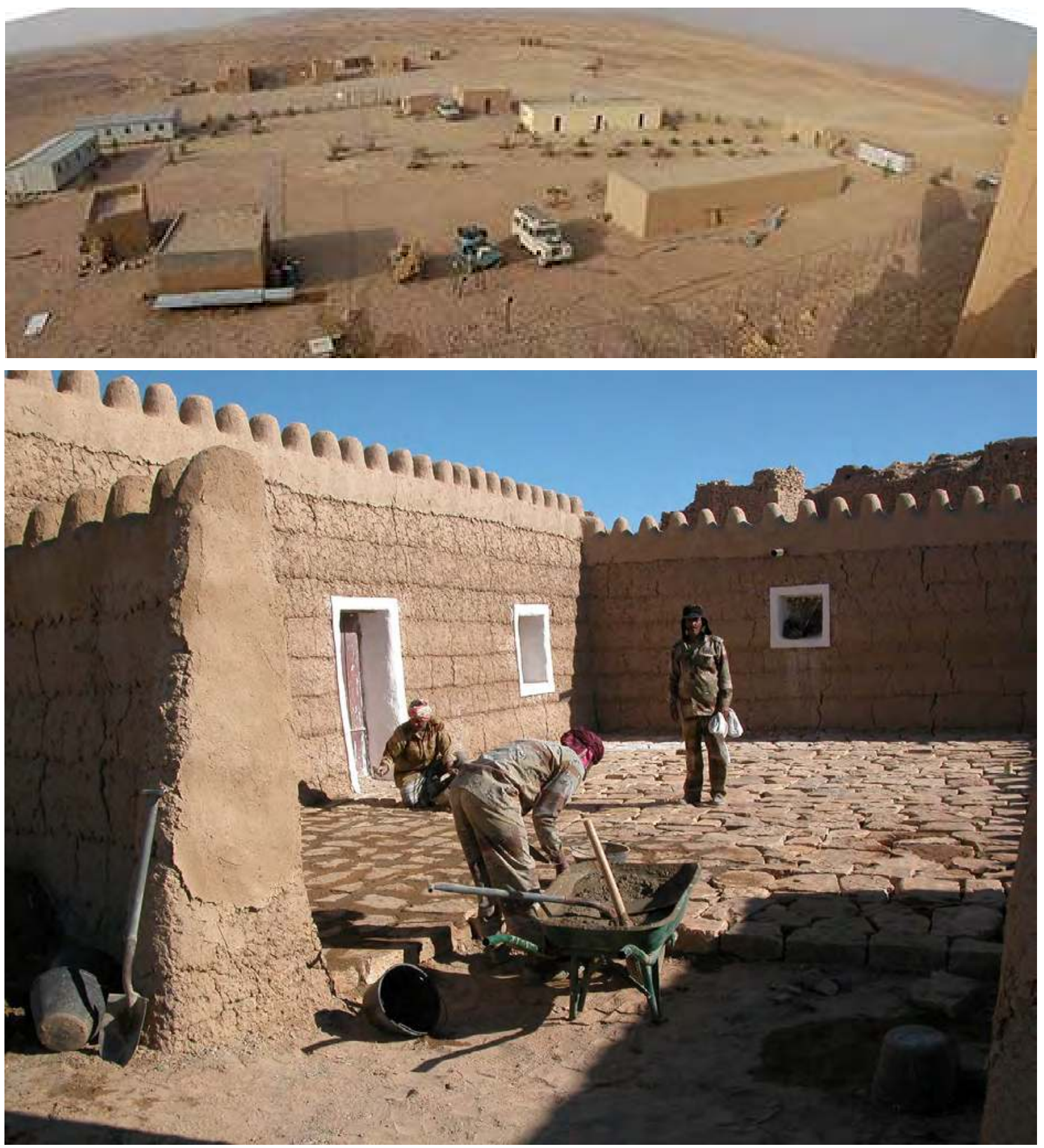

Figure 41. Barāqish: the Italian-Yemeni archaeological base in 2005 (above) and the museum compound reaching completion in 2007 (below). (P. Morlupi/S. Antonini @ MAIRY) 

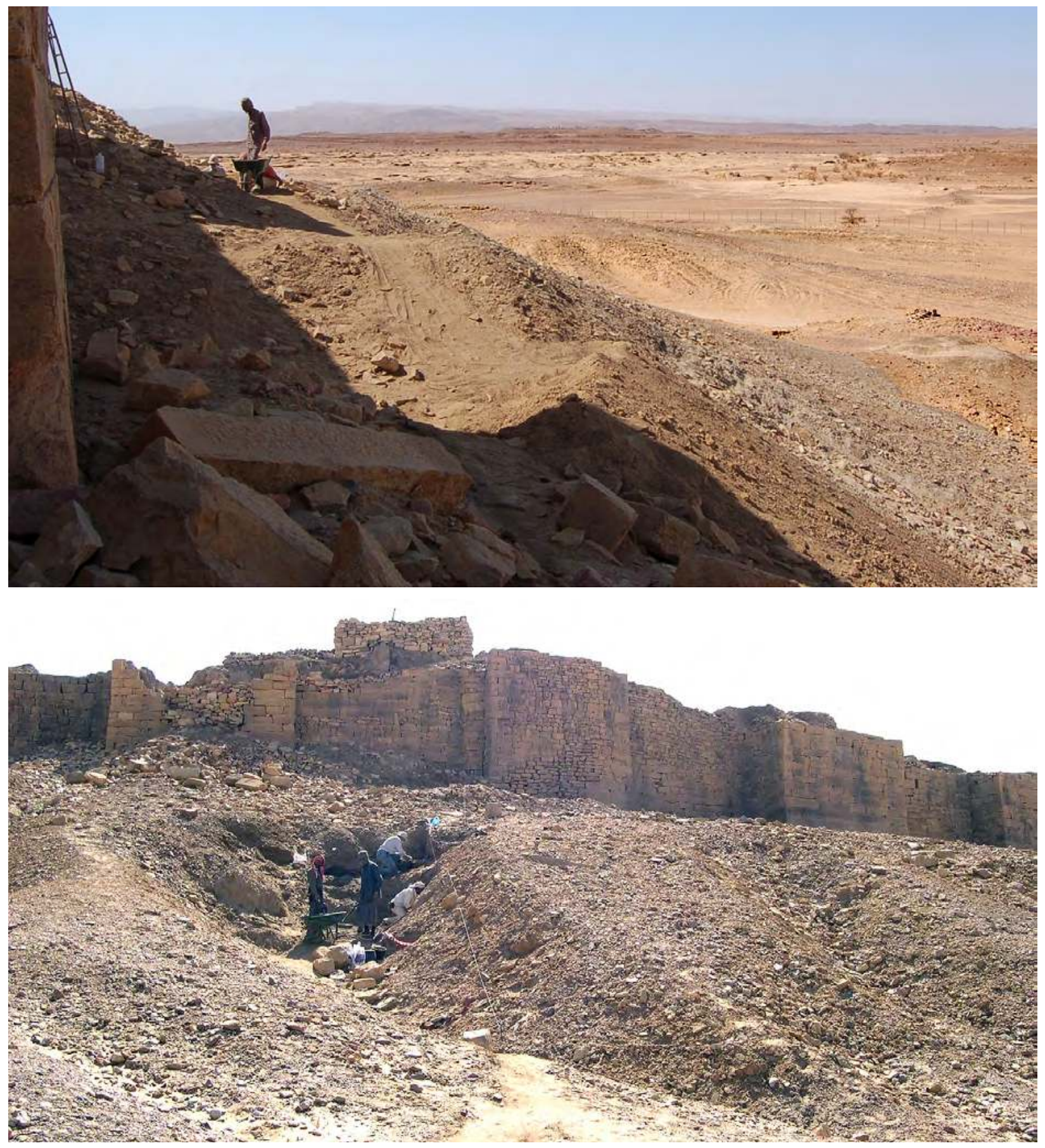

Figure 42. Extramural Area C: (above) a view from bastion T8, with excavation in progress at T7, showing the talus and immediate plain covered by the excavations of 2005-2006; (below) an initial phase of the stepped trench below bastions T5-T6 in 2005. (P. Morlupi 2005-2006 @ MAIRY) 

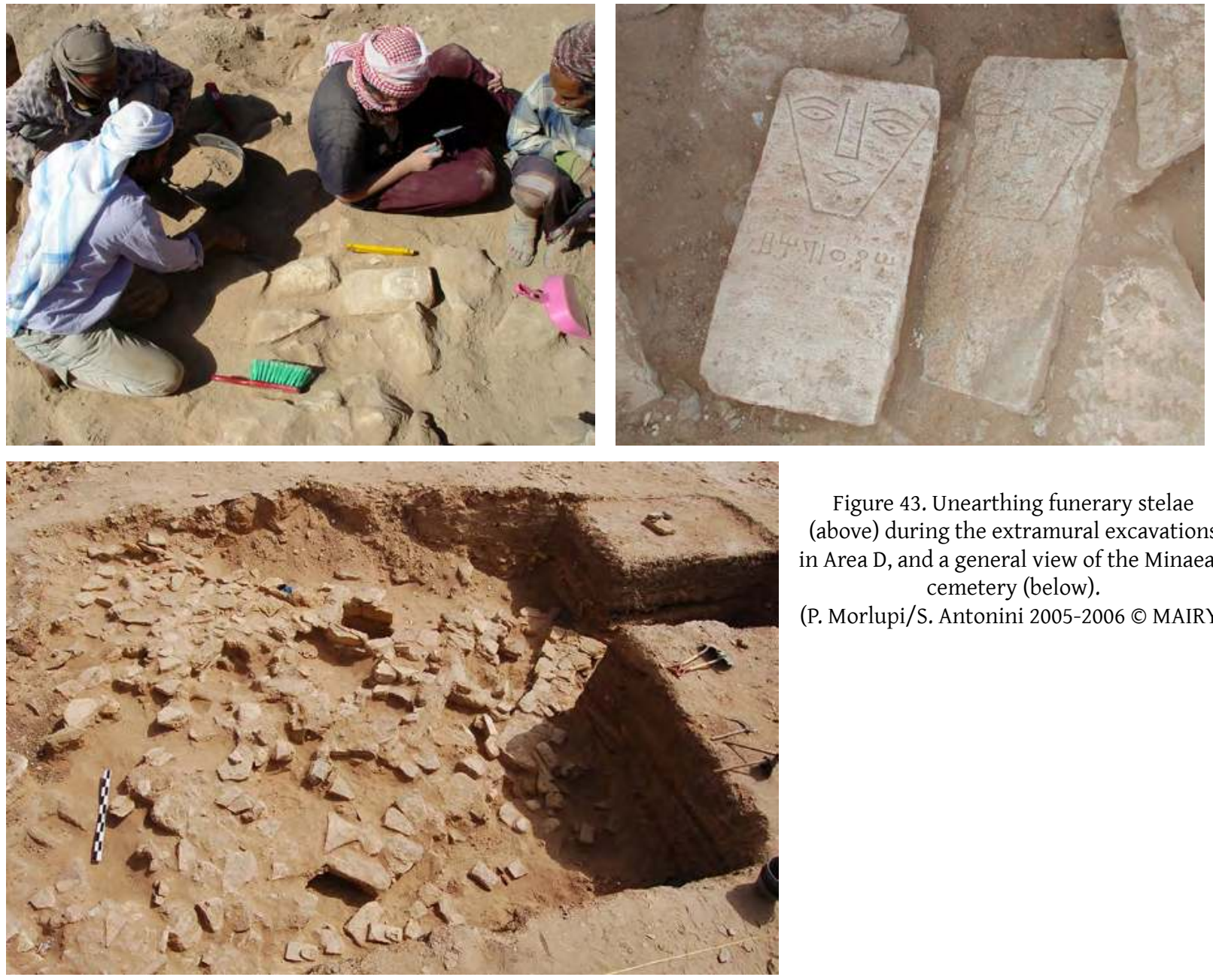

Figure 43. Unearthing funerary stelae (above) during the extramural excavations in Area D, and a general view of the Minaean cemetery (below).

(P. Morlupi/S. Antonini 2005-2006 @ MAIRY)

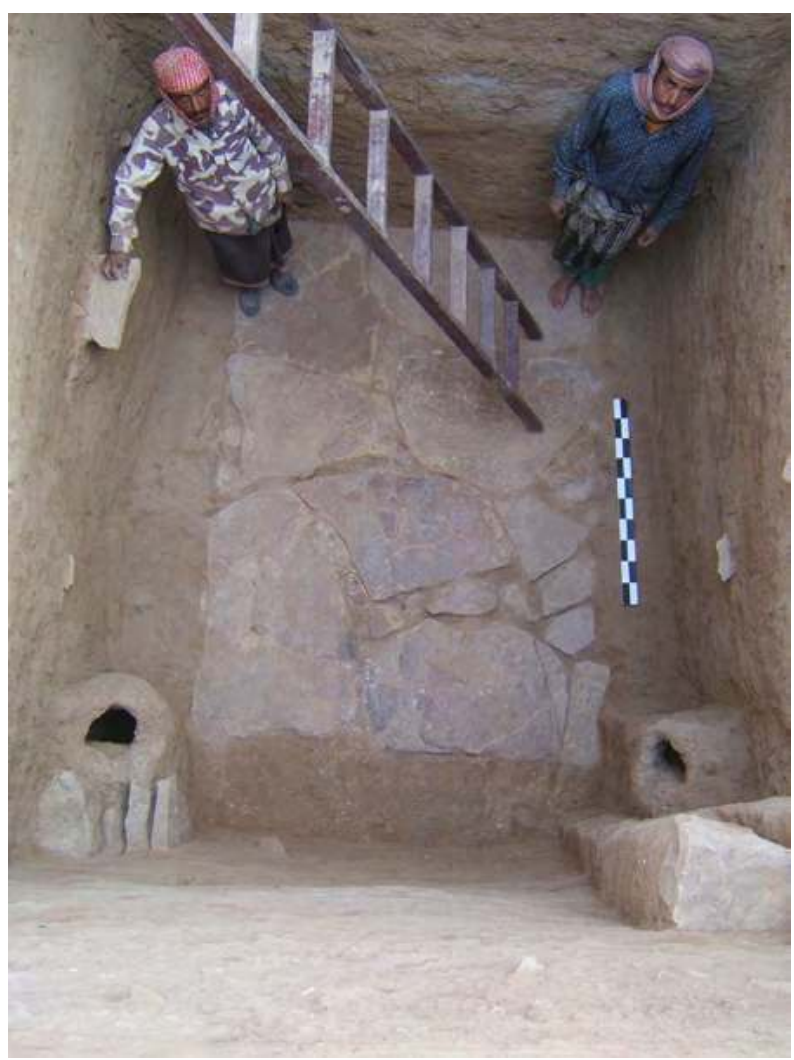

Figure 44. A Sabaean paving (L1000) encountered in Sounding S1 in front of Temple A, 2006; and Yemeni workers. (A. de Maigret @ MAIRY) 


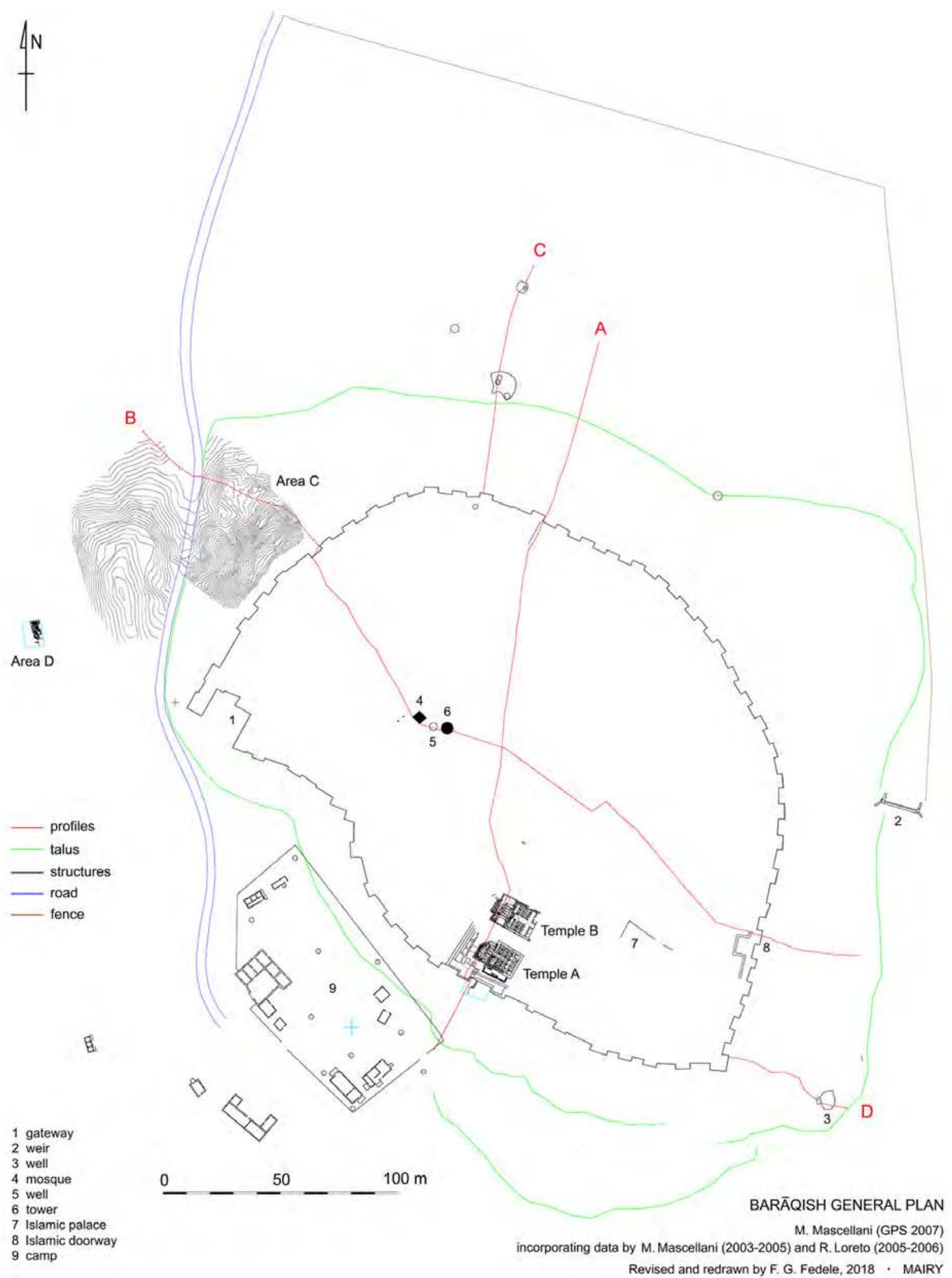

Figure 45. Barāqish general plan 2007, based on GPS survey (M. Mascellani) and incorporating the total station records from 2003-2006 (M. Mascellani, R. Loreto); revised and redrawn by F.G. Fedele, 2018. The revision was chiefly necessitated by a correction of the planimetric relationships between the morphological plan of Area $\mathrm{C}$ and the curtain wall, based on independent ground checks (see Chapter 17, section 1, in Volume 2), and by the substitution of a realistic plan of the excavation camp as actually built. Imprecisions in the original plan were caused by the fact that the various parts of Barāqish - the camp, the city wall, and Area C - had to be assembled from separate, differently conducted topographic surveys.

(๑ MAIRY) 


\title{
Chapter 2
}

\section{Risultati della prima prospezione della Missione archeologica italiana a Barāqish nel 1986}

\author{
Sabina Antonini
}

\section{Premessa}

Tra il 26 e il 30 ottobre del 1986, il prof. Alessandro de Maigret insieme a chi scrive condusse una prima sistematica ricognizione sul sito di Barāqish, sia all'interno della città ${ }^{1}$ che al di fuori delle mura (fig. 1). Qui, in quattro zone differenti, venne raccolta una cospicua campionatura di ceramica ed alcuni oggetti che presentiamo qui di seguito. Per una determinazione cronologica dei materiali provenienti dalla raccolta di superficie, abbiamo dato priorità all'analisi comparativa con i materiali trovati negli scavi della stessa Barāqish.

\section{BAR o BARi}

Con questa sigla, BAR o BARi, ci si riferisce alla campionatura di materiali provenienti dai solchi di erosione formatisi nel talus in corrispondenza dei torrioni T4 e T5, nel settore occidentale delle mura di Barāqish (v. Antonini e Fedele, capitolo 1 in questo volume, fig. 3). La ceramica proveniente da questo contesto è ascrivibile, sia per quanto riguarda le forme vascolari che i trattamenti delle superfici, alla produzione sabea. I confronti sono stati individuati tra la ceramica rinvenuta in stratigrafia nel sondaggio B.A.S/1, condotto da A. de Maigret nell'area prospiciente il tempio di Nakrah. ${ }^{2}$ Le corrispondenze vascolari sono state individuate prevalentemente negli Strati C-B, datati ai secoli VIII-VI a.C. Alcuni frammenti trovano corrispondenze nella ceramica dagli Strati E-F (X secolo a.C.).

\section{Tipologia ceramica}

Tipo 1 (fig. 2/1): giara con orlo spesso, leggermente estroflesso, piatto all'interno, adatto generalmente per l'alloggiamento del tappo in pietra ricoperto in gesso e con impronta di sigillo; argilla rossa. Questa giara rientra nel Tipo VI.D.10 della tipologia ceramica di Tamnac ${ }^{3}$

\footnotetext{
Si notò sin da allora che dalla ricognizione all'interno della città affiorava soltanto materiale attribuibile ad epoca islamica.

2 Cfr. de Maigret 2010a.

3 Antonini e Buffa 2016, 469-470; 546-549, figg. 34-35, e relativa bibliografia. Questo tipo di giara da trasporto è stata trovata anche nello scavo della necropoli; cfr. Antonini 2010, fig. 3, n. 10; fig. 7, nn. 2-9.
}

Tipo 2 (fig. 2/2): giara globulare, con orlo leggermente estroflesso, labbro lievemente rigonfio, scanalature sul collo; argilla rossa. Giare di questo tipo sono state trovate nello Strato C del sondaggio B.A.S/1 di Barāqish. ${ }^{4}$ Tipo 3 (fig. 2/3): giara con orlo leggermente svasato, labbro rigonfio; argilla nocciola-rosata con ingubbiatura esterna rossa, lustrata. Giare simili a questa da BARi sono state trovate nello Strato $\mathrm{C}$ del sondaggio B.A.S/1 di Barāqish. ${ }^{5}$

Tipo 4 (fig. 2/4-6): giare con orlo sottile e lievemente svasato; argilla nocciola-rosata, con ingubbiatura esterna rossa, lustrata. Queste giare per tipologia, oltre che per il trattamento delle superfici, trovano confronti con alcuni esemplari dalla stessa Barāqish, nello Strato B (VIII sec. a.C.) del sondaggio B.A.S $/ 1 .^{6}$

Tipo 5 (fig. 2/7): piccola giara con orlo svasato, spalla carenata, corpo cilindrico e fondo piatto; argilla nocciola-rosata, ingubbiatura esterna rossa, lustrata. Il pezzo trova confronti specifici con ceramiche provenienti dallo scavo della Casa A di Yalā. ${ }^{7}$

Tipo 6 (fig. 3/1): giara con orlo espanso; argilla di colore beige-rossiccio, ricoperta di ingubbiatura rossa, lustrata.

Tipo 7 (fig. 3/2): giara medio-grande, a parete dritta, con argilla di colore beige-rossiccio, ricoperta di ingubbiatura rossa, lustrata; trova un puntuale confronto tra la ceramica di Yalā. ${ }^{8}$

Tipo 8 (fig. 3/3-5; fig. 4/1-2): giare medio-grandi a parete dritta e orlo arrotondato e variamente espanso, con costolatura orizzontale; si prelevarono 12 frammenti, con argilla di colore beige-rosata. Alcune ingubbiature lustrate sono a chiazze bruno-violacee. Queste si ritrovano nello Strato A (VII secolo a.C.) del sondaggio B.A.S/1 di Barāqish. ${ }^{9}$

\footnotetext{
4 Cfr. de Maigret 2010a, 231, fig. 106, nn. 9-10. Si ritrovano anche a Yalā (de Maigret 2003, 224, tav. 19), e nel livello 3 del sondaggio A.00/ S2 di Tamna' (de Maigret 2004b, 254, fig. 9, A84:10).

5 Cfr. de Maigret 2010a, 231, nn. 14-15. Un altro confronto viene da Yalā (de Maigret 1988, fig. 22, n. 9).

6 Cfr. de Maigret 2010a, 234, fig. 109, n. 3. Confronti puntuali si ritrovano anche a Yalā: per il pezzo Y.86.BAR/60, cfr. de Maigret 1988, fig. 22, n. 2; per un confronto di Y.86.BAR/55, v. de Maigret 2003, 225, tav. 20, nn. 1 e 5; per il pezzo Y.86.BAR/59, cfr. de Maigret 2003, 234, tav. 29, n. 2. Questi ultimi hanno il fondo piano.

7 Cfr. de Maigret 2003, 225, tav. 20, nn. 7-8, con un'iscrizione sulla spalla.

8 Cfr. de Maigret 1988, fig. 21, n. 3 (dalla superficie); de Maigret 2003, 236, tav. 31, n. 4 (dallo scavo della Casa A).

9 Cfr. de Maigret 2010a, 234, fig. 109, nn. 14-15. Si trovano paralleli
} 
Tipo 9 (fig. 4/3-4): giare medio-grandi con orlo espanso e appiattito esternamente, pareti leggermente svasate; argilla beige-rosata, superficie esterna con ingubbiatura rossa scura, lustrata. La tipologia è documentata nello Strato B del sondaggio B.A.S/1 di Barāqish. ${ }^{10}$

Tipo 10 (fig. 5; fig. 6/1): coppe profonde a parete dritta, con orlo naturale e scanalature (singola o doppia) incise sotto il labbro. Si contarono 23 pezzi con argilla beigenocciola, con ingubbiatura rossa interna ed esterna, lustrata, alcune con tracce brunite; 4 frammenti hanno una decorazione incisa ondulata sulla parete, al di sotto del bordo (fig. 5/6-9). Anche queste coppe a parete dritta con decorazione ondulata sono state trovate nello Strato C del sondaggio B.A.S/1 di Barāqish. ${ }^{11}$

Tipo 11 (fig. 6/2): coppa profonda a pareti sottili e dritte con due scanalature orizzontali che inquadrano una decorazione a cerchi impressi entro triangoli incisi. Argilla beige-nocciola, con ingubbiatura lustrata interna.

Tipo 12 (fig. 6/3): coppa polilobata, con scanalatura sotto l'orlo, decorazione ondulata doppia sulla pancia, e superfici non trattate. ${ }^{12}$ Sebbene non disponiamo di una completa descrizione del frammento da BARi (argilla, colore, etc.), notiamo che il profilo dell'orlo differisce dal classico tipo cosiddetto di Bayhān, caratterizzato da un orlo piuttosto sottile e svasato (v. le coppe da BARii, fig. 14).$^{13}$ Possiamo, infatti, confrontare questa coppa con un esemplare trovato nel sondaggio fuori le mura, che presenta una scanalatura sotto l'orlo e una decorazione ondulata sulla pancia. ${ }^{14}$ Questo, come gli altri frammenti di coppe ondulate trovati nel sondaggio fuori le mura, provengono da un livello della fine dell'occupazione sabea (VII-VI sec. a.C.). ${ }^{15}$

Tipo 13 (fig. 6/4-5): coppe emisferiche, con orlo naturale; argilla beige-nocciola, ingubbiatura rossa lustrata interna ed esterna.

Tipo 14 (fig. 6/6-7): coppe profonde con orlo naturale e scanalature sotto l'orlo. Argilla nocciola, prevalentemente ingubbiate e lustrate su entrambe le superfici. Si raccolsero 14 frammenti. I confronti con

anche tra la ceramica di Yalā (de Maigret 1988, fig. 21, n. 6; de Maigret 2003, 236, tav. 31, nn. 1 e 5).

10 Cfr. de Maigret 2010a, 233, fig. 108, n. 7. Anche queste giare trovano paralleli nella produzione ceramica di Yalā, dalla raccolta di superficie e dallo scavo della Casa A (rispettivamente de Maigret 1988, fig. 21, n. 4; de Maigret 2003, 236, tav. 31, n. 3).

11 Cfr. de Maigret 2010a, 230, fig. 105, nn. 24-27. Esemplari del tutto simili a queste coppe sono stati trovati durante la prospezione a Yalā (de Maigret 1988, fig. 18, nn. 12-14).

${ }_{12}$ Per questa tipologia vascolare e la diffusione in Arabia Meridionale rimandiamo a Antonini e Buffa 2016, 459-461.

${ }_{13}$ Cfr. Antonini e Buffa 2016, 459-461, tavv. 5-8.

14 Fedele 2010, fig. 144 (200.01).

15 Fedele 2010, 105-106; '... the end of the Later Sabaean occupation, Stratum L, possibly continuing into the End-Sabaean.' (fine VII/VI secolo a.C.; Fedele 2010, 127, tabella II). Sono stati trovati 6 frammenti, di cui sono state individuate 3 varianti (A, B, C); la variante C è quella che si avvicina al tipo 'Bayḥān bowls', e le varianti A e B sono coeve (c. 600 a.C.). queste coppe provengono dal sondaggio B.A.S/1 di Barāqish, sia dallo strato $\mathrm{F}$ che dallo strato $\mathrm{B} .{ }^{16}$

Tipo 15 (fig. 6/8): coppa piuttosto bassa, con labbro evidenziato da scanalatura; l'argilla è nocciola, ingubbiata e lustrata su entrambe le superfici, interna ed esterna. Il pezzo trova confronti provenienti dal sondaggio B.A.S/1 di Barāqish, dagli Strati F e C. ${ }^{17}$

Tipo 16 (fig. 7/1-3): coppe basse o ciotole, con parete dritta e fondo piano, argilla di colore nocciola, con ingubbiatura rossa, lustrata sulle superfici interna ed esterna. Un parallelo certo viene dallo strato B del sondaggio B.A.S $/ 1,^{18}$ e puntuali confronti sono stati trovati nello scavo della Casa A di Yalā. ${ }^{19}$ Questo tipo di ciotola si ritrova anche in contesti più tardi, come per esempio a Tamnac. ${ }^{20}$

Tipo 17 (fig. 7/4-10): coppe più o meno profonde con orlo rientrante. I nn. 8-10 hanno il labbro sottolineato da scanalatura. Argilla nocciola, con superfici ingubbiate e lustrate. Si ritrovano nella stessa Barāqish, in diversi strati del sondaggio B.A.S/1. ${ }^{21}$

Tipo 18 (fig. 8): coppe basse a parete rientrante, con orlo inspessito e labbro sottolineato da scanalatura; si raccolsero in tutto 33 frammenti, di cui 5 conservano la lustratura, e due hanno ingubbiatura marrone-violacea lustrata. Un solo confronto al nostro tipo 18 viene dallo Strato F del sondaggio B.A.S/1.22

Tipo 19 (fig. 9): coppe carenate, argilla nocciola-beige, ricoperta da ingubbiatura rossa, lustrata. Si raccolsero 26 frammenti, di cui 11 caratterizzati da scanalature sotto l'orlo. A Barāqish queste coppe sono documentate negli Strati D-B del sondaggio B.A.S $/{ }^{23}$ ma sono comuni in tutta l'Arabia Meridionale e diagnostiche per il periodo sabeo (dal IX alla metà del VI secolo a.C.). ${ }^{24}$

Tipo 20 (fig. 10/1-4): fondi con piede ad anello; 12 frammenti, quasi tutti con tracce di ingubbiatura rossa, lustrata.

Tipo 21 (fig. 10/5): base di 'Torpedo jar' con fondo a piede anulare; argilla sabbiosa di colore rossiccio. Alcuni frammenti di questo genere di giara sono stati

\footnotetext{
16 Cfr. de Maigret 2010a, 224, fig. 99, n. 16 (dallo Strato F); de Maigret 2010a, 233, fig. 108, n. 4 (dallo Strato B, con varianti nella forma del labbro).

17 Cfr. de Maigret 2010a, 224, fig. 99, nn. 7 e 11 (dallo Strato F); 230, fig. $105, n$. 21 (dallo Strato C). Un puntuale confronto viene dalla raccolta di superficie di Yalā (de Maigret 1988, fig. 20, n. 7).

18 Cfr. de Maigret 2010a, 232, fig. 107, n. 13.

19 Cfr. de Maigret 2003, 226, tav. 21, nn. 1-4.

20 Antonini e Buffa 2016, fig. 15, nn. 2 e 3, tipo III.C.1.

${ }_{21}$ Cfr. de Maigret 2010a, 86, tab. 2, col. 2; de Maigret 2010a, 224, fig. 99, n. 13 (dallo Strato F); 227, fig. 102, nn. 10-11 (dallo Strato E); 229, fig. 104, nn. 2 e 8 (dallo Strato D).

22 Cfr. de Maigret 2010a, 224, fig. 99, n. 12.

23 V. tab. 2 in de Maigret 2010a, 86.

24 Per la diffusione di questo tipo di coppe carenate in Arabia Meridionale cfr. Antonini e Buffa 2016, 463 e le relative note bibliografiche; v. inoltre Antonini e Buffa 2016, 514, fig. 15, nn. 6-10, tipo III.E.1; de Maigret 1988, fig. 18, nn. 1-11; de Maigret 2003, 218, tav. 13; de Maigret 2004b, 246, 250 fig. 5, dal sondaggio A.00/S2, level $2 \mathrm{da}$ Tamna', e relativa bibliografia.
} 
trovati negli Strati D e B del sondaggio B.A.S $/ 1,{ }^{25} \mathrm{e}$ alcune pareti anche dallo Strato E. ${ }^{26}$

Tipo 22 (fig. 10/6): fondo leggermente umbonato che potrebbe appartenere ad una forma aperta. Argilla beige e superfici ingubbiate e lustrate.

Tipo 23 (fig. 10/7): coperchio leggermente concavo, con presa apicale a due digitazioni; argilla rossiccia, con superfici non ingubbiate. Confronti puntuali si ritrovano a Yalā, dallo scavo della Casa A. ${ }^{27}$

Tipo 24 (fig. 10/9): coperchio con alto bordo verticale e probabile presa apicale. Anche questo genere di coperchio ricorre frequente nella tipologia vascolare di Yalā. ${ }^{28}$

Tipo 25 (fig. 10/8): ansa ad anello posta sul labbro della coppa; superficie interna ed esterna con ingubbiatura rossa, lustrata. Un esemplare simile viene dallo Strato $\mathrm{F}$ del sondaggio B.A.S/1.29

Tipo 26 (fig. 10/10-12): pareti decorate, di cui una con tre costolature parallele (n. 10), una con ondulazioni incise (n.12), e l'ultima con decorazione (frammentaria) a listelli compositi (n. 11).

\section{Catalogo degli oggetti}

Gli oggetti trovati in quest'area di prospezione sono di diversa natura e materiale. Vasetti in alabastro (nn. 1-2), una figurina di animale in terracotta (n. 3), un piccolo cucchiaio in bronzo (n. 4), un piede di statuetta umana in bronzo (n. 5), due tappi rotondi in pietra calcarea (diam.c. $11 \mathrm{~cm}$ ), sbozzati a percussione diretta centripeta per ottenere la forma e le dimensioni volute, frammenti di contenitori in steatite, il frammento di un incensiere cubico in arenaria (h tot. $5,5 \mathrm{~cm}$ ), e un incensiere iscritto, cubico quasi completo in arenaria (n. 6).

1. Y.86.BARi.O/1 (fig. 11): bicchierino in alabastro (h $3,8 \mathrm{~cm}$; diam. $5,9 \mathrm{~cm}$; spess. $0,4 \mathrm{~cm}$ ), a parete dritta, con linea incisa al di sotto dell'orlo naturale.

2. Y.86.BARi.O/2 (fig. 12): coppetta in alabastro (h 3,7 $\mathrm{cm}$; diam. orlo 7,0 cm; diam. base 5,6, cm; spess. 6,0/7,0 $\mathrm{cm}$ ), di forma troncoconica con orlo naturale e base piatta. Tracce di levigatura interne ed esterne della parete.

3. Y.86.BARi.O/4 (fig. 13): frammento di animale in terracotta (lungh. $6,1 \mathrm{~cm}$; spess. medio $1,9 \mathrm{~cm}$ ), probabilmente la rappresentazione di una iena, di cui sono conservati la testa e il collo. La breve criniera è rappresentata da una serie di linee a spina di pesce

\footnotetext{
${ }^{25}$ Cfr. de Maigret 2010a, 82, 230, fig. 105, n. 7; 84, 234, fig. 109, nn. 7-9. Per dei confronti da Yalā, v. de Maigret 1988, fig. 23, n. 15; de Maigret 2003, 238, tav. 33, nn. 10-11.

${ }^{26}$ Cfr. de Maigret 2010a, 81 .

27 Cfr. de Maigret 2003, 239, tav. 34, nn. 1-3, 5.

${ }_{28}$ Cfr. de Maigret 1988, fig. 20, n. 3; de Maigret 2003, 240, tav. 35, nn. $2,4-6$.

${ }^{29}$ Cfr. de Maigret 2010a, 225, fig. 100, n. 13.
}

incise lungo la parte superiore del collo; muso squadrato, orecchie larghe sporgenti, occhi circolari ottenuti mediante impressione.

4. Y.86.BARi.O/5 (fig. 14): cucchiaino in bronzo (diam. $1,4 \mathrm{~cm}$; h $0,6 \mathrm{~cm}$; spess. $0,2 \mathrm{~cm}$ ), di forma emisferica con labbro sporgente, in origine con manico (lungh. conservata $0,4 \mathrm{~cm}$ ).

5. Y.86.BARi.O/6 (fig. 15): piede di statuetta umana in bronzo (lungh. 4,4 cm; largh. media $2,3 \mathrm{~cm} ; \mathrm{h}$ max. conservata $2,5 \mathrm{~cm}$; diam. 1,7/2,1 cm). Ottenuto mediante la tecnica della cera persa, il piede, la cui superficie presenta incrostazioni dovute all'ossidazione del metallo, è piuttosto schematico con superficiali indicazioni delle dita. L'altezza totale della statuetta poteva essere $c .30 \mathrm{~cm}$.

6. Y.86.BARi.O/13 (fig. 16): incensiere cubico in arenaria (h tot. $10 \mathrm{~cm}$, largh. $11 \mathrm{~cm}$, h delle lettere $5 \mathrm{~cm}$ ). Su ogni faccia è scolpito il nome di una resina: qsț, drw, rnd, h. $\underline{d k}$. In base alla paleografia, l'incensiere viene datato al IVIII secolo a.C. ${ }^{30}$

\section{BARii}

Con questa sigla, BARii, si definisce un piccolo rilievo o collinetta situata a ovest del torrione T1 (all'interno della recinzione metallica che circonda il sito). Qui fu notata abbondante ceramica e furono annotati diversi oggetti di materiale vario, che fecero supporre trattarsi di un edificio di una certa importanza, di cui, tuttavia, non vi è traccia di strutture affioranti. Peraltro, si trova non lontano, a sud dalla necropoli da noi parzialmente scavata nel 2005 e nel 2006. ${ }^{31}$ Di tutta la ceramica raccolta, fu selezionata una campionatura per il disegno.

\section{Tipologia ceramica}

Tipo 1 (fig. 17): giare con orlo spesso ed estroflesso, a volte appiattito all'interno per ricevere il tappo in pietra ricoperto in gesso con la sigillatura impressa; si contano in tutto 17 frammenti, di cui 7 frammenti sono in argilla giallo-verdastra e 10 in argilla rossiccia. Le superfici non mostrano tracce di ingubbiatura e lustratura. Queste giare, che rientrano nel tipo VI.D.10 della tipologia di Tamna ${ }^{\text {, }}{ }^{32}$ sono state trovate anche nell'area della necropoli di Barāqish. ${ }^{33}$

Tipo 2 (fig. 18/1-7): giare con orlo sottile ed estroflesso; si contarono in tutto 12 frammenti, di cui 7 in argilla giallo-verdastra, 4 in argilla beige-rossiccia e un frammento in argilla marrone-grigiastra. Sono senza ingubbiatura e lustratura e $\mathrm{i}$ pezzi beige-rossicci hanno le superfici più abrase. I nn. 2 e 8 hanno l'orlo

\footnotetext{
30 Antonini 1988, 133, 141, fig. 1, tav. IVa-d.

31 Antonini e Agostini 2010a.

32 Antonini e Buffa 2016, 469-470; 544-548, figg. 32-35.

33 Antonini 2010, fig. 7, dal Livello 1 (tardo mineo), e fig. 9, n. 9, dalla superficie.
} 
piatto internamente. Il tipo, che si è trovato anche in superficie nell'area della necropoli scavata nel $2005 \mathrm{e}$ nel $2006,{ }^{34}$ potrebbe rientrare nella tipologia VI.D.3a, o VI.D.5a delle giare (senza decorazioni, senza iscrizioni) trovate negli scavi di Tamna ${ }^{\mathrm{c}}{ }^{35}$

Tipo 3 (fig. 18/8-9): giare con collo dritto del tipo VI.C.1.b o VI.C.3 da Tamna ${ }^{\text {c }}{ }^{36}$ Un frammento è di argilla beige, senza ingubbiatura e lustratura.

Tipo 4 (fig. 18/10): grande giara con orlo naturale obliquo; il tipo comprende un solo frammento di colore rossiccio, senza ingubbiatura e lustratura.

Tipo 5 (fig. 19): coppe polilobate, con orli sottili e svasati. Si raccolsero 26 esemplari, di cui 18 in argilla giallo-verdastra e 8 in argilla beige-rosata. Coppe polilobate di questo tipo sono state trovate nello scavo della necropoli di Barāqish, ${ }^{37}$ e in entrambi i templi, di Nakrah e 'Athtar dhu-Qabd. Queste sono del tipo di coppa cosiddetto di Bayhān, trovate negli scavi di Tamna' (III.B.2). ${ }^{38}$ La grande produzione e diffusione delle coppe polilobate avviene dal III secolo a.C. al I/ II secolo d.C.

Tipo 6 (fig. 20/1): piccola coppa profonda a pareti sottili e dritte, in argilla rossa, con ingubbiatura rossa, lustrata, del tipo II.1 da Tamnac. ${ }^{39}$

Tipo 7 (fig. 20/2, 4): piccole coppe a pareti sottili e oblique; argilla rossa, con ingubbiatura rossa, lustrata, del tipo III.A.1 dagli scavi di Tamna ${ }^{40}$

Tipo 8 (fig. 20/3): coppa con orlo svasato e leggermente incavato all'interno per ricevere il coperchio; argilla rossa.

Tipo 9 (fig. 20/5): coppa emisferica media, argilla rossa, lustrata.

Tipo 10 (fig. 20/6-8; fig. 21/1): coppe medio-grandi aperte con orlo espanso; furono raccolti in tutto 35 frammenti, di cui 17 in argilla di colore beige-verdastra e 18 in argilla rossiccia; di questi ultimi soltanto due hanno tracce di ingubbiatura rossa, lustrata, del tipo III.A.4.a dagli scavi di Tamnac.41

Tipo 11 (fig. 21/2-6; fig. 22/1-2): coppe mediograndi profonde con labbro inspessito e appiattito superiormente e parete leggermente rientrante; argilla giallo-verdastra e un frammento in argilla rossa. Questa tipologia, che si è trovata anche nello scavo delle tombe

\footnotetext{
34 Antonini 2010, fig. 9, nn. 6-7.

35 Antonini e Buffa 2016, 468-469; 536, fig. 28; 538, fig. 29.

36 Antonini e Buffa 2016, 466; 530, fig. 24, nn. 2-4; 532, fig. 25, n. 1.

37 Antonini 2010, 28-29, fig. 2, n. 12; 30-32, fig. 6, nn. 4-6, fig. 9, nn. 3-4.

38 Per la diffusione nel territorio sudarabico delle coppe polilobate, cfr. Antonini e Buffa 2016, 459-461, tavv. 5-8 e tutta la relativa bibliografia.

39 Antonini e Buffa 2016, 458; 491, fig. 2.

40 Antonini e Buffa 2016, 458; 492, fig. 3.

41 Antonini e Buffa 2016, 459; 492, fig. 3.
}

di Barāqish, ${ }^{42}$ potrebbe rientrare nel tipo III.B.7 dagli scavi di Tamnac.43

Tipo 12 (fig. 22/3-5): coppe medio-piccole emisferiche con labbro rigonfio e parete leggermente rientrante; argilla rossiccia, ingubbiata e lustrata. Queste coppe, con alcune varianti nella forma del labbro, che rientrano nella tipologia III.B.1 di Tamnac, ${ }^{44}$ sono state trovate nello scavo della necropoli di Barāqish. ${ }^{45}$

Tipo 13 (fig. 22/6-8): coppe basse o ciotole, piccole e medie, con orlo naturale e rientrante; argilla rossa con ingubbiatura lustrata interna ed esterna.

Tipo 14 (fig. 23/1): coppa profonda, orlo naturale e dritto; argilla rossiccia, ingubbiatura interna rossa, lustrata. Questa coppa rientra nel tipo III.B.8 di Tamnac ${ }^{4} 6$ Tipo 15 (fig. 23/2-5): coppe carenate, alcune con scanalature sotto il bordo; 4 frammenti, di cui uno in argilla beige e 3 in argilla rossastra. Questi ultimi sono ingubbiati e lustrati (tipo III.E.1 di Tamna). ${ }^{47} \mathrm{Il}$ frammento di orlo a parete dritta con scanalature, argilla beige ricoperta da ingubbiatura rossa lustrata, potrebbe far parte di una coppa carenata.

Tipo 16 (fig. 23/6): coppa profonda con orlo estroflesso, espanso e appiattito; argilla di colore marrone-grigio. Questo particolare tipo di coppa è stato trovato negli scavi di Tamna' (III.G.1). ${ }^{48}$

Tipo 17 (fig. 23/7, 9): giara con orlo inspessito; argilla beige-rossastra carica, con ingubbiatura e lustratura esterna. Si ritrovano a Barāqish, dallo scavo della necropoli. ${ }^{49}$

Tipo 18 (fig. 23/8): giare a parete dritta con doppia scanalatura esterna; argilla beige-rossastra ingubbiata e lustrata esternamente.

Tipo 19 (fig. 23/10): recipiente a parete sottile con orlo rientrante. Coppe simili a questa sono state trovate nello scavo delle tombe a Barāqish, ${ }^{50}$ e negli scavi di Tamna' (III.B.11.a). ${ }^{51}$

Tipo 20 (fig. 23/11): coppa con orlo naturale rientrante e ansa a presa con foro verticale.

Tipo 21 (fig. 24): fondi con piedi ad anello: piccoli, 10 frammenti di argilla giallo-verdastra, senza lustrature. Il n. 6 trova confronti con alcuni fondi del tipo IX.B.3 trovati negli scavi di Tamna ${ }^{c}{ }^{52}$ Fondi di medie dimensioni, 23 frammenti, di cui 14 in argilla rossa, scura, e 9 in argilla beige-rosata. Spesso le superfici interne sono ricoperte di ingubbiatura rossa, lustrata.

42 Antonini 2010, fig. 5, nn. 7-12 (dal Livello 1)

43 Antonini e Buffa 2016, 461-462; 506, fig. 11.

44 Antonini e Buffa 2016, 459; 494, fig. 4.

45 Antonini 2010, fig. 2, n. 10 (dal Livello 3).

46 Antonini e Buffa 2016, 462; 508, fig. 12, n. 3.

47 Antonini e Buffa 2016, 463; 514, fig. 15, nn. 6-10.

48 Antonini e Buffa 2016, 463; 514, fig. 15, nn. 14-15.

49 Antonini 2010, fig. 6, nn. 7-8 (Livello 1)

50 Antonini 2010, fig. 3, nn. 1-2 (Livello 3).

51 Antonini e Buffa 2016, 462; 512, fig. 14, n. 10.

52 Antonini e Buffa 2016, 474; 586, fig. 61, nn. 5, 7, 9. 
Fondi di grandi dimensioni, 15 pezzi, di cui 13 in argilla rossiccia, 2 in argilla giallognola.

\section{Catalogo degli oggetti}

Per quanto riguarda gli oggetti provenienti da BARii, come accennato in precedenza, in quest'area è stato rilevato un numero cospicuo di materiale relativo ad attività di culto, come tavole sacrificali in calcare, blocchi oblunghi di pietra, più o meno squadrati, con scanalatura longitudinale, terminanti a testa taurina..$^{53}$ Inoltre, da qui provengono frammenti di recipienti in steatite,$^{54}$ conchiglie, frammenti di coppette in alabastro (fig. 25), un frammento di incensiere e un bacino, entrambi in arenaria, ${ }^{55}$ un piede di statua umana in alabastro (lungh. $3 \mathrm{~cm}$ ), una figurina in terracotta (fig. 26a-b) e, infine, un'iscrizione frammentaria che riporta il nome di 'Athtar (' $\underline{t} t r / \underline{d}[\ldots .]$.$) .$

Riportiamo qui di seguito una descrizione di tutti gli oggetti da noi raccolti e inventariati, nonostante non vi siano fotografie e disegni di tutto il materiale numerato.

1. Y.86.BARii.O/1: frammento di tavola offertoria o gronda, costituito da un blocco di arenaria a sezione piano-convessa, con scanalatura scavata longitudinalmente lungo la faccia superiore; su un lato corto in origine era il gocciolatoio o doccione a testa di toro (h 8,6/7,2 cm; largh. 10,2/7,9 cm; lungh. $14,1 \mathrm{~cm}$; largh. media canaletta $1,8 \mathrm{~cm}$ ).

2. Y.86.BARii.O/2: frammento di tavola offertoria o gronda, costituito da un blocco di arenaria a sezione rettangolare; la faccia superiore su cui è stata scavata la scanalatura è piatta e levigata, mentre la faccia inferiore è appena sbozzata $(\mathrm{h} 6,3 / 5,5 \mathrm{~cm}$; largh. 8,1/6,7 $\mathrm{cm}$; lungh. $13 \mathrm{~cm}$; largh. canaletta 2,3 cm).

3.Y.86.BARii.O/3:frammento oblungo ditavola offertoria o gronda, con canaletta scavata longitudinalmente lungo la faccia superiore (h 5,4/4,1 cm; largh. 8/4,5 cm; lungh. $11,9 \mathrm{~cm}$; largh. canaletta 2,3 cm).

4. Y.86.BARii.O/4: frammento di tavola offertoria o gronda, formato da un segmento cilindrico di arenaria, scanalato longitudinalmente sulla faccia superiore, terminante a testa taurina; le fattezze dell'animale sono poco visibili, poiché la superficie è piuttosto abrasa (h 6,8/6,1 cm; largh. 7,7/5,7 cm; lungh. $15 \mathrm{~cm}$; largh. canaletta $2,3 \mathrm{~cm}$ ).

5. Y.86.BARii.O/5: tavola offertoria frammentaria in arenaria, formata da una lastra quadrangolare $(13 \mathrm{x}$ 12,2 x 7,9 cm; lo spessore varia da 3,6 cm lungo i margini a $1,7 \mathrm{~cm}$ verso il centro della lastra; il bordo è spesso 4,8 $\mathrm{cm})$.

\footnotetext{
53 Per questo genere di materiali cfr. per esempio de Maigret 2016, 218-221.

54 Come esempi v. de Maigret 2016, 235-238.

55 Per il recipiente in arenaria come esempio v. de Maigret 2016, 242, fig. 174, n. 3.
}

6. Y.86.BARii.o/6: piede cilindrico di oggetto in arenaria (diam. 4,2 cm; lungh. 5,5 cm).

7. Y.86.BARii.O/7: frammento di pentola in steatite (diam.c. $36 \mathrm{~cm}$; lo spessore varia da 1,1 cm dell'orlo a 1,6 $\mathrm{cm}$ della parete; $\mathrm{h} 8,7 \mathrm{~cm}$ ). Una sporgenza orizzontale alta $1,8 \mathrm{~cm}$ e larga $2,3 \mathrm{~cm}$, forse un'ansa, è presente a 4,5 $\mathrm{cm}$ al di sotto dell'orlo.

8. Y.86.BARii.O/8: frammento di pentola in steatite

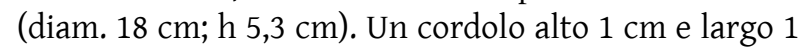
$\mathrm{cm}$ è presente $\mathrm{a} 1,5 \mathrm{~cm}$ al di sotto dell'orlo. La superficie interna e l'orlo della pentola sono levigati; la superficie esterna al di sotto del cordolo è marcata da profonde incisioni oblique.

9. Y.86.BARii.O/9: ansa in gesso a presa allungata, con tracce di colorazione rosso-arancio (lungh. $8 \mathrm{~cm} ; \mathrm{h} \mathrm{2,5}$ $/ 1 \mathrm{~cm}$ ). Una sporgenza alta $1,8 \mathrm{~cm}$ e larga $2,3 \mathrm{~cm}$, forse un'ansa, è presente a $4,5 \mathrm{~cm}$ al di sotto dell'orlo.

10. Y.86.BARii.O/10: frammento di conchiglia bivalve $(2,5 \times 3,8 \mathrm{~cm})$.

11. Y.86.BARii.O/11: conchiglia del genere conus (lungh. $3,5 \mathrm{~cm})$.

12. Y.86.BARii.O/12: frammento di vasetto in alabastro, di cui è conservato soltanto l'orlo (lungh. $3,5 \mathrm{~cm}$; h 1,2 $\mathrm{cm}$; largh. orlo $0,5 \mathrm{~cm})$.

13. Y.86.BARii.O/13 (fig. 25): frammento di coppetta in alabastro, con orlo lievemente estroflesso e piatto superiormente; la parete esterna è decorata con incisioni verticali parallele a distanza costante. Le incisioni si trovano sul punto di maggiore espansione del corpo del recipiente (diam. $6 \mathrm{~cm}$; h 3,9 cm; spess. $0,4 / 1 \mathrm{~cm})$.

14. Y.86.BARii.O/14: frammento di coppetta in alabastro, con orlo lievemente svasato e piatto superiormente; la parete e l'orlo sono piuttosto spessi (diam. esterno 4,2, interno $2,6 \mathrm{~cm} ; \mathrm{h} 4,8 \mathrm{~cm}$; spess. $1,6 / 1,8 \mathrm{~cm}$ ).

15. Y.86.BARii.O/15: frammento di coppetta in alabastro, con orlo naturale; la parete si inspessisce progressivamente dall'orlo verso il fondo, che nella parte conservata sembra piatto (diam. $5 \mathrm{~cm} ; \mathrm{h} 4 \mathrm{~cm}$; spess. 0,7 / $1 \mathrm{~cm}$ ).

16. Y.86.BARii.O/16: piede si statua in alabastro, rettangolare senza dettagli anatomici (lungh. $3 \mathrm{~cm}$;

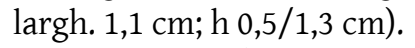

17. Y.86.BARii.O/17: frammento di recipiente rotondo in arenaria con base piatta. Il bordo è naturale, ma diventa spesso e piatto in corrispondenza dell'ansa (diam. 8/9,5 $\mathrm{cm}$; h $3,5 \mathrm{~cm}$; spess. $1,5 \mathrm{~cm}$; largh. orlo $0,9 / 1,8 \mathrm{~cm}$; ansa $2,5 \times 2,5 \times 3 \mathrm{~cm})$.

18. Y.86.BARii.O/18: porzione di un incensiere cubico in arenaria (h totale $10,1 \mathrm{~cm}$; lungh. pareti conservate 7,5 $\mathrm{x} 7,7 \mathrm{~cm}$; spess. bordo $1,4 \mathrm{~cm}$; spess. parete $0,3 \mathrm{~cm}$; piede $4,5 \times 4,5 \mathrm{~cm})$.

19. Y.86.BARii.o/19: blocco in arenaria di forma triangolare con iscrizione frammentaria su tre righe (lungh. max. 13,5 cm; h max. 10,7 cm; spess. 4,2 cm; largh. cornice $2,7 \mathrm{~cm}$; h lettere $3,1 \mathrm{~cm}$ ); nella riga centrale si legge ${ }^{\mathrm{t}} \mathrm{tr} / \underline{\mathrm{d}}[\mathrm{c..}]$. 
20. Y.86.BARii.O/20: frammento di tavola offertoria o gronda, formato da un blocco di arenaria a sezione piano-convessa, scanalato longitudinalmente sulla faccia superiore, terminante a testa taurina; il muso è piatto alla base, ed è conservato un solo occhio (h 4,4/6,1 cm; largh. 5/8,1 cm; lungh. 13,5 cm; largh. canaletta $2 \mathrm{~cm}$ ).

21. Y.86.BARii.O/21 (fig. 26a-b): figurina fittile frammentaria (h 8,6 cm; largh. 5,8/7,4; spess. 2,7/4,1). È conservato il torso di una figura femminile seduta, i cui dettali sono indicati solo sulla parte anteriore; si notano, dall'alto, un cordolo intorno al collo e più in basso 6 brevi incisioni verticali, probabilmente la rappresentazione di una collana, e 3 pieghe della pancia indicate con solcature orizzontali; sotto la seconda piega l'ombelico è indicato con un foro oblungo. Al di sotto della terza piega due fori incisi indicano il triangolo pubico. La figurina è piatta inferiormente. La testa era probabilmente modellata insieme al corpo. ${ }^{56}$

Una figurina acefala in terracotta del tutto simile a questa di Barāqish è stata trovata in superficie nella città di Mārib. ${ }^{57}$ Altri esemplari della stessa tipologia provengono da scavi illegali nei siti del Wādī Jawf (alBayḍā', al-Sawdā'), e sono conservati presso il Museo del Dipartimento di Archeologia dell'Università di $\operatorname{San}^{(} \bar{a}{ }^{3} \cdot{ }^{58} \mathrm{C}$. Rathjens datò questo genere di figurine al II secolo a.C. ${ }^{59}$ Questa potrebbe essere una congrua datazione anche per l'esemplare da BARii. La datazione è confermata dalla tipologia della ceramica raccolta nello stesso contesto e datata, grazie allo studio comparativo come abbiamo visto sopra, agli ultimi secoli del I millennio a.C.

\section{BARiii}

Il terzo punto di campionatura fu effettuato in un'area rilevata, chiamata BARiii, situata circa $100 \mathrm{~m}$ a $\mathrm{N}$ delle mura, di fronte ai bastioni T15 e T18. Dal momento che si notarono frammenti di ossa umane assieme a scarsa ceramica pre-islamica, l'area fu interpretata come cimiteriale, nonostante non vi fossero evidenti resti di strutture emergenti e alcun frammento di stele funerarie. Per questo fatto e per il tipo di ceramica rossa, compatta, de Maigret suppose che si trattasse di tombe di epoca sabea (fig. 27). Purtroppo non ci fu modo di eseguire degli scavi in quell'area.

\footnotetext{
56 In una figurina femminile in terracotta, ma ricoperta di gesso e dipinta, proveniente dalla cosiddetta sacrestia del tempio di Nakrah, la testa era eseguita separatamente ed applicata al corpo per mezzo di un bastoncino; cfr. Antonini 1999, 59, fig. 4.

57 Cfr. O'Neill 2014, 352, tav. 9, MT8.

58 Yasseen et al. 1996, 289, fig. 2; 292-294, figg. 3-5.

59 Rathjens 1955, 40-60.
}

\section{Tipologia ceramica}

A parte 5 frammenti di pareti di vaso e un'ansa a presa con due digitazioni (fig. 28/12), la raccolta si compose esclusivamente (e curiosamente) solo di fondi con piede ad anello, di cui se ne raccolsero 34, e ne furono disegnati 11 (fig. 28/1-10)..$^{60}$ I piedi ad anello sono medi, sottili e slanciati, per cui potrebbero appartenere a coppe, piuttosto che a giare, i cui piedi anulari sono bassi e spessi. Un piede (fig. 28/11) potrebbe essere del Tipo IX.D.1 della tipologia ceramica di Tamna ${ }^{c}{ }^{61}$ Le superfici sono abrase per l'esposizione e dunque la lustratura è poco conservata.

\section{BARiv}

La quarta zona dove fu effettuato un sopralluogo si trova a destra dell'ingresso all'area del sito, all'interno della recinzione metallica. Qui furono raccolti alcuni oggetti, ma non fu prelevato alcun campione di ceramica sudarabica diagnostica (orli, fondi e anse). Spicca, al contrario, un frammento di parete di ceramica con impasto molto depurato beige, con superfici, interna ed esterna, nero-lustrate, identificata allora come ceramica 'a vernice nera' di importazione (fig. 29). Alcuni frammenti di ceramica simili a questo furono trovati nello scavo nel sito di Tamna' (fig. 34a-b). ${ }^{62}$ In entrambi $\mathrm{i}$ casi questi frammenti appartengono a forme aperte.

\section{Catalogo degli oggetti}

1. Y.86.BARiv/4 (fig. 29): un frammento di parete, leggermente concava, di ceramica con argilla fine beige,

60 Anche nello scavo delle tombe a ovest della porta nord-occidentale della città di Barāqish, furono rinvenuti numerosissimi fondi ad anello (ben 124 nel Livello 3), molti dei quali con tracce di combustione, probabilmente utilizzati come lampade ad olio (v. Antonini 2010, 28).

61 Antonini e Buffa 2016, 474; 586, fig. 61.

62 Questi frammenti furono trovati nello scavo delle strutture nordoccidentali del tempio di Athirat a Tamna', più specificamente nello scavo in L22 (de Maigret 2016, 159; 161, fig. 96). Lo scavo non è proceduto oltre in questo edificio - delimitato da M40 e M31 - a sud del tempio, e quindi non possiamo conoscere dettagli dell'ambiente L22 e di altri eventuali ambienti attigui. Le strutture nell'area a sud del tempio di Athirat sono attribuite alla Fase B (de Maigret 2016, 158-163). Per quanto riguarda il materiale proveniente da L22, cfr. de Maigret 2016, 189, fig. 133, n. 4; 235, n. 4; 251, n. 11. La ceramica della fase B di Tamnac è datata tra il II /I secolo a.C. e il I secolo d.C. (de Maigret 2016, 183). Tuttavia, quei frammenti di ceramica d'importazione trovati a Tamna' sembrerebbero attribuirsi ad un periodo più antico, se fosse vero che potrebbe trattarsi di 'ceramica attica a figure rosse'; apparterrebbero ad una forma aperta, con figurazioni sulla superficie esterna, in cui si intuisce il panneggio di un abito (V-IV secolo a.C.). Si ringrazia il dott. Andrea D'Andrea (Università di Napoli 'L'Orientale') per questa preziosa expertise. Probabilmente i frammenti venivano da un rimaneggiamento del terreno in quel punto, a ridosso delle mura. Non conosco le ragioni per cui A. de Maigret abbia omesso di pubblicare questi frammenti con la ceramica d'importazione, ossia con la sigillata (v. de Maigret 2016, 183-184; 196-197, figg. 140-141), nel suo rapporto di scavo del tempio di Athirat. Data l'unicità di tale ritrovamento, ritengo sia estremamente importante presentarli in questa occasione. 
depurata e compatta, realizzata con il tornio $(\mathrm{h} 1,8 \mathrm{~cm}$, largh. 3,6 cm, spess. 0,3 cm); entrambe le superfici, interna ed esterna, sono ricoperte di 'vernice nera'.

2. Y.86.BARiv.O/1 (fig. 30): olletta in alabastro giallino (h cm 3,9 cm; diam. $6,0 \mathrm{~cm}$; spess. $0,5 \mathrm{~cm}$ ); orlo rigonfio e piatto superiormente, ansa a presa verticale con foro passante, posta a metà della pancia. ${ }^{63}$

3. Y.86.BARiv.O/2 (fig. 31): coppetta bassa e aperta in alabastro biancastro (h $1,4 \mathrm{~cm}$; diam. 12,0 cm; spess. parete $0,3 \mathrm{~cm}$ ); orlo fortemente espanso (largh. 2,0 $\mathrm{cm}$ ), piatto superiormente, e pareti sottili. La coppetta trova un confronto puntuale con un'altra trovata nel cosiddetto Timna ${ }^{\mathrm{C}}$ Temple 1 (TT1) a Tamnac ${ }^{64}$

4. Y.86.BARiv.O/3 (fig. 32): coppetta a parete $\operatorname{dritta}$ (h 1,2 $\mathrm{cm}$; largh. $2,1 \mathrm{~cm}$; spess $0,2 / 0,4 \mathrm{~cm}), 65$ orlo evidenziato da due incisioni parallele; sulla parete esterna la decorazione consiste in triangoli lisci alternati a triangoli a linee incrociate incise. ${ }^{66}$

5. Y.86.BARiv.O/5 (fig. 33): anellino in bronzo ( $1,4 \times 0,9$ $\mathrm{cm}$; spess. $0,3 \mathrm{~cm}$ ), formato da una barretta a sezione quadrangolare piegata a formare un ovale, con le estremità distanziate.

\section{Conclusioni}

Dall'analisi dei materiali provenienti dalle diverse quattro zone dell'area archeologica fuori dalle mura di Barāqish, possiamo affermare che BARi e BARii hanno fornito la maggiore quantità di ceramica, da cui si è ricostruita una ricca tipologia vascolare. Il risultato più rilevante è che si tratta di due produzioni ceramiche differenti per forme, impasti, e trattamenti delle superfici.

La ceramica da BARi rientra appieno nella produzione sabea, di cui i tipi 16-19 e 21 sono i più caratteristici; a parte le 'torpedo jars' (Tipo 21), tipiche per le forme e l'argilla sabbiosa e pesante, gli impasti sono beige o rossi, e le superfici sono ricoperte da ingubbiatura rossa e bruno-violacea, lustrata. La ceramica da BARi trova confronti specifici con quella proveniente dal sondaggio B.A.S/1 effettuato nell'area antistante la gradinata del tempio di Nakrah, $\mathrm{e}$, come ho accennato in precedenza, soprattutto dagli Strati C-B, datati tra l'VIII e il VI secolo a.C.

La zona di BARiii sembra relativa a questo periodo insediamentale più antico di Barāqish.

La ceramica raccolta in BARii appartiene ad una facies diversa. La ceramica è del tutto simile a quella rinvenuta nello scavo delle tombe (che si trovano un po' più a nord); prevalgono gli impasti rossiccio e gialloverdognolo e le superfici non sono sempre trattate con ingubbiatura. Le tipologie vascolari peculiari sono: il Tipo 1 che, essendo un tipo di giara da trasporto, si trova disseminato in tutto il Sudarabia ${ }^{67}$ e diffuso tra il I secolo a.C. e il I/II secolo d.C.; e il Tipo 5, ossia le coppe polilobate, che si trovano distribuite in tutto il territorio sudarabico e in tutti i contesti, domestico, funerario e cultuale. Queste da BARii, soprattutto per gli impasti, sembrano potersi attribuire tra il III secolo a.C. e il I secolo d.C.

I ritrovamenti archeologici di superficie a BARii sembrano relativi ad una struttura dove si svolgevano attività cultuali, e per questo non possiamo escludere che qui sorgesse una cappella per i rituali funerari, considerata la vicinanza con la necropoli.

Per quanto riguarda BARiv, abbiamo pochi materiali e nessuna struttura. Il frammento di vaso n. 3 fa parte di una produzione qatabanita peculiare, per il materiale utilizzato e per lo stile cosiddetto di Shukac, dal nome della necropoli nella regione di aḍ-D̄âlic ${ }^{68}$ dove sembra fosse ubicato il centro di produzione. Le opere, prevalentemente statuaria e vasellame, sono diffuse tra il I secolo a.C. e il II secolo d.C.

Il frammento ceramico 'a vernice nera' è sicuramente d'importazione dal Mediterraneo. Se fosse dello stesso tipo di quei frammenti di ceramica attica trovati a Tamna' (v. sopra e nota 62), allora potrebbe risalire almeno al IV secolo a.C.

\footnotetext{
63 Per il tipo, cfr. per esempio Antonini 2016, 358: nn. 13-14.

64 Loreto 2016, 320, n. 26, fig. 38,4.

65 Per il tipo di materiale cfr. Antonini 2013, 22; Hitgen 2002 (idrossidobicarbonato di magnesio).

${ }_{66}$ Cfr. de Maigret 2016, 238, fig. 170, n. 1.
}

\footnotetext{
67 Antonini e Buffa 2016, 469-470.

68 Antonini 2013.
} 


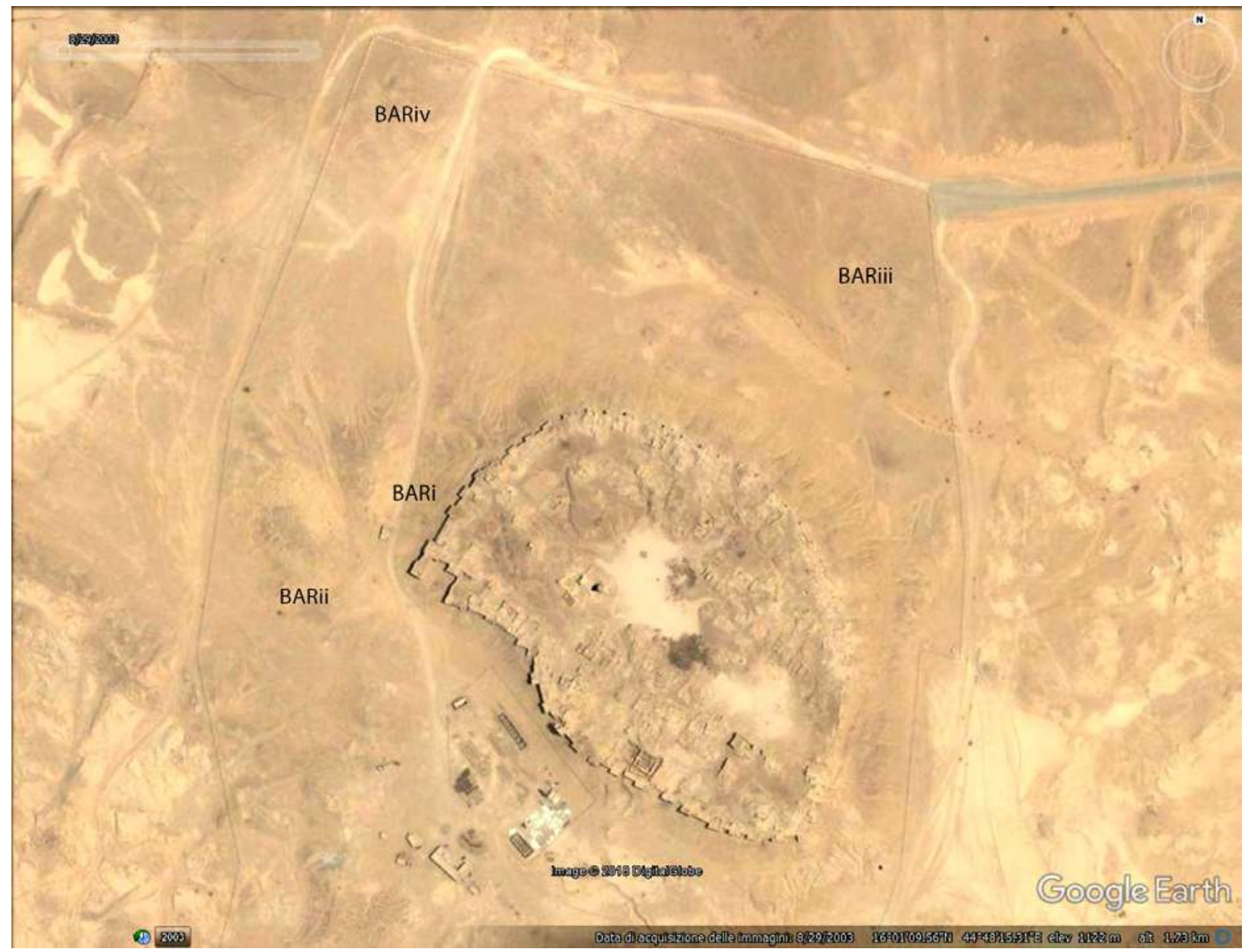

Figure 1. I punti di prelievo della prospezione archeologica condotta a Barāqish nel 1986 riportati sulla foto satellitare Google Earth del 29 agosto 2003. (Elaborazione della base fotografica di F.G. Fedele) 

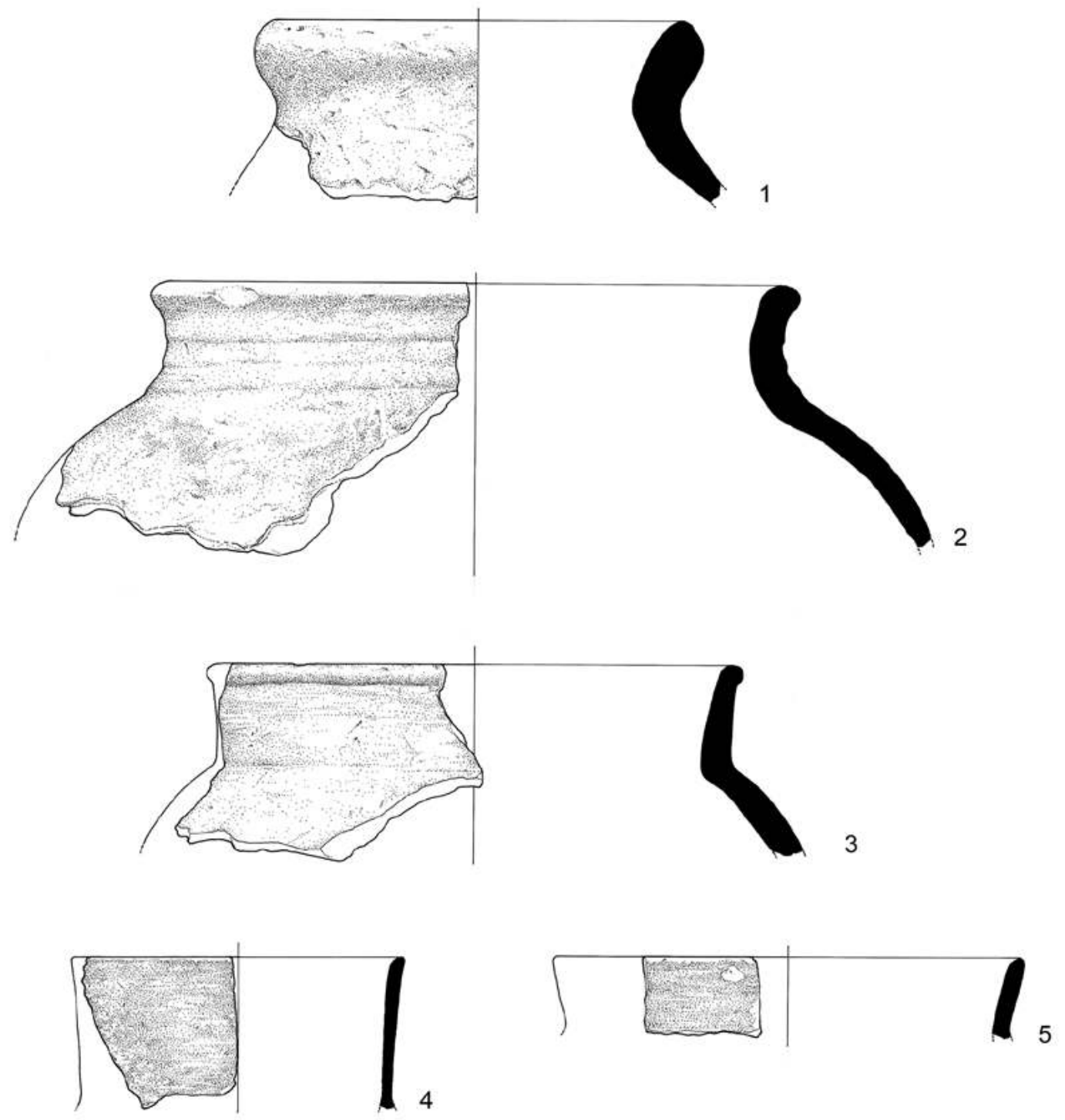

4
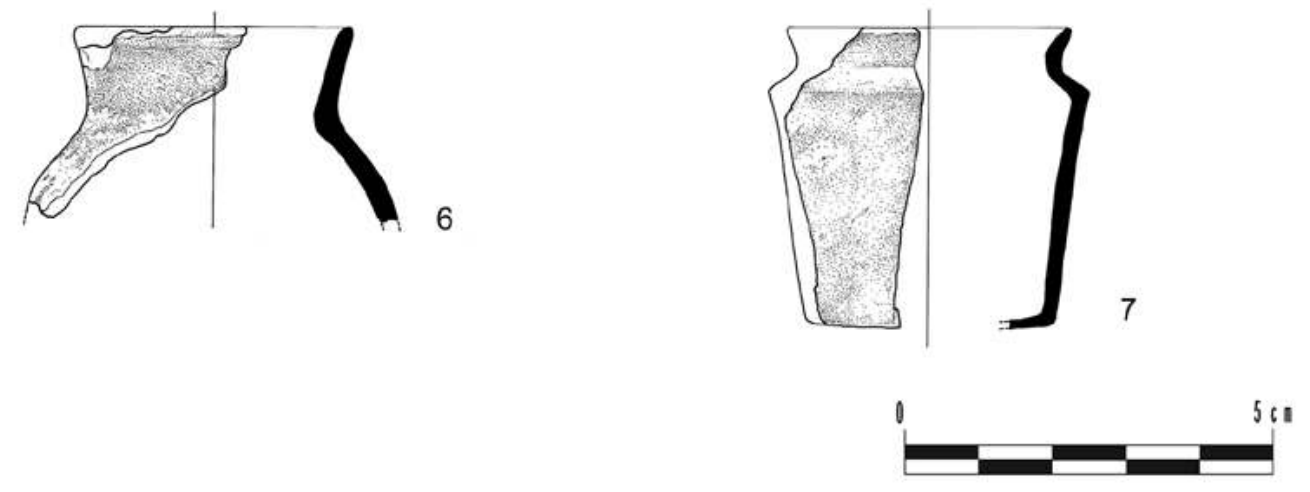

Figure 2. 1: Y.86.BAR/67; 2: Y.86.BAR/68; 3: Y.86.BAR/69; 4: Y.86.BAR/59; 5: Y.86.BAR/60; 6: Y.86.BAR/55; 7: Y.86.BAR/74. (E. Gatti 1986 CMAIRY) 


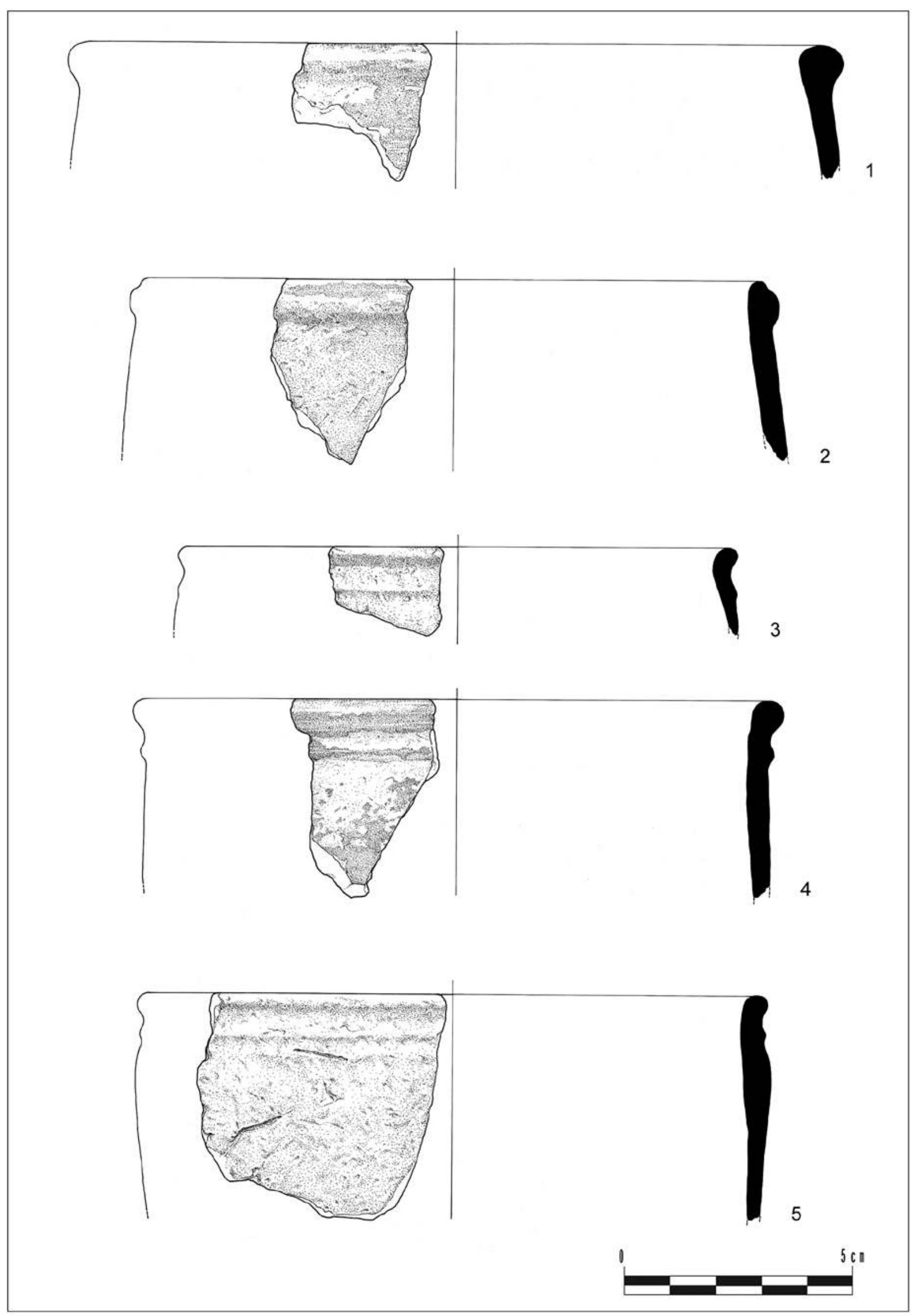

Figure 3. 1: Y.86.BAR/48; 2: Y.86.BAR/40; 3: Y.86.BAR/47; 4: Y.86.BAR/43; 5: Y.86.BAR/46. (E. Gatti 1986 OMAIRY) 

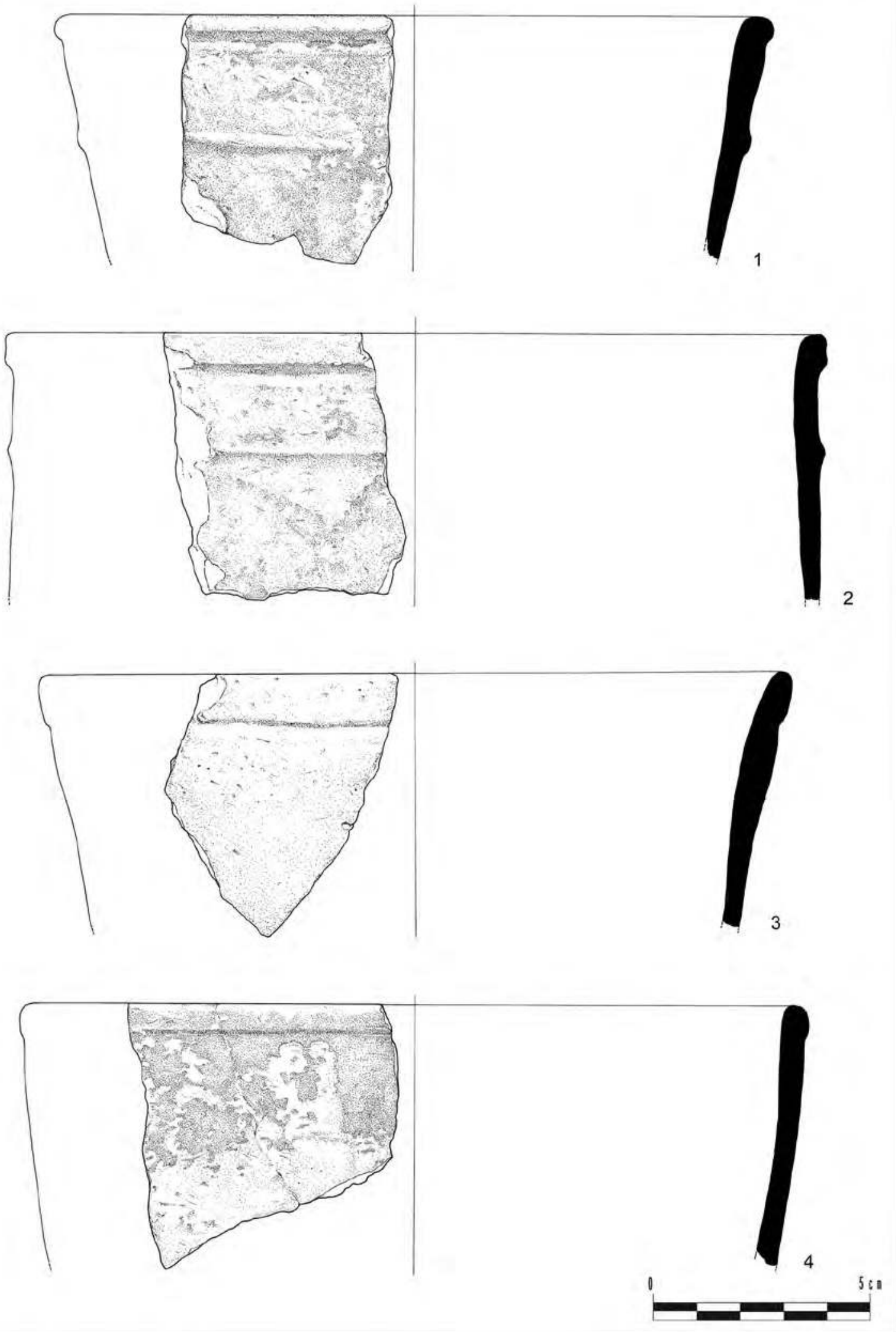

Figure 4. 1: Y.86.BAR/42; 2: Y.86.BAR/45; 3: Y.86.BAR/41; 4: Y.86.BAR/44. (E. Gatti 1986 OMAIRY) 

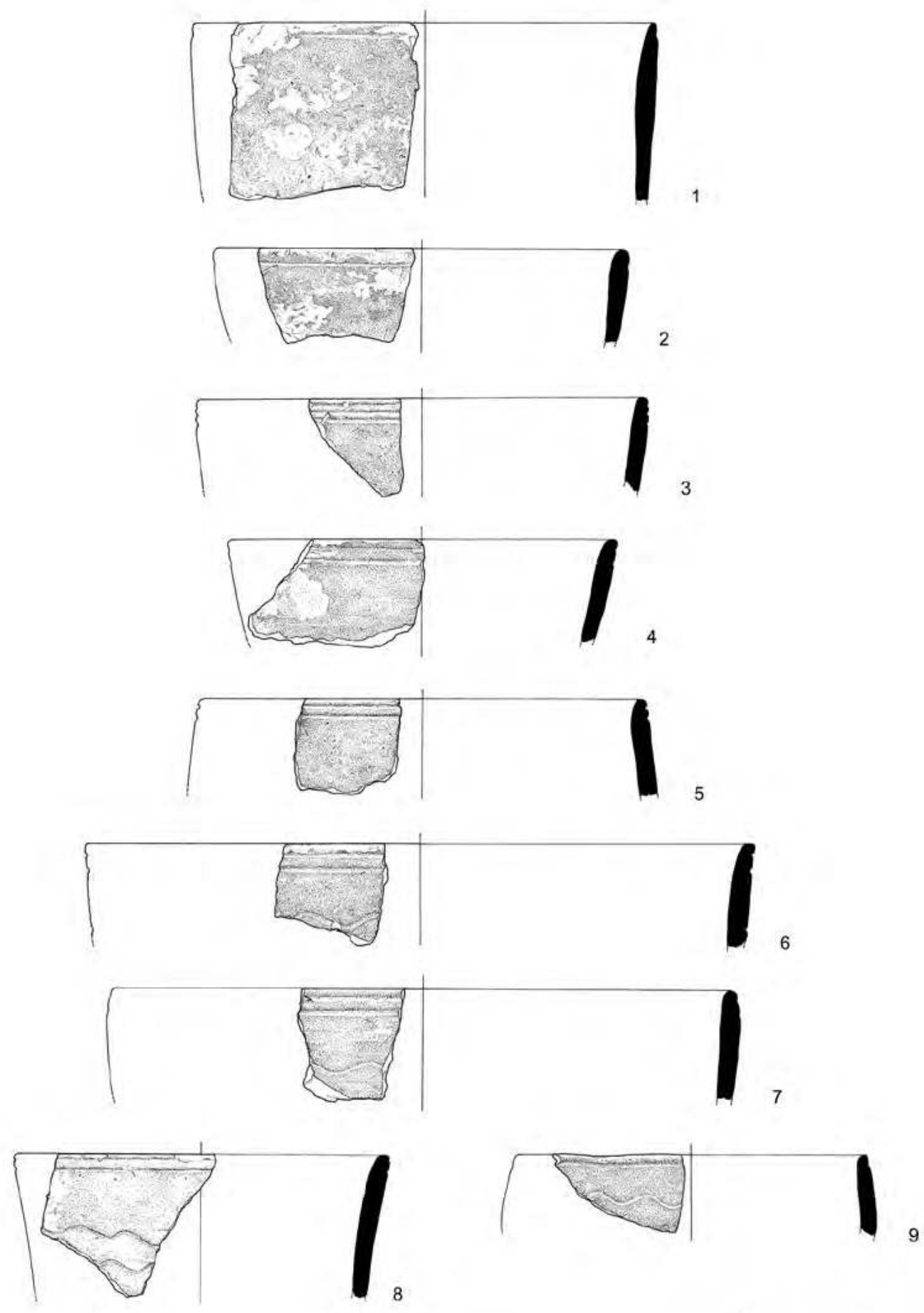

8

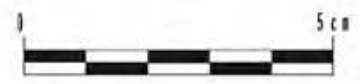

Figure 5. 1: Y.86.BAR/63; 2: Y.86.BAR/65; 3: Y.86.BAR/61; 4: Y.86.BAR/56; 5: Y.86.BAR/57; 6: Y.86.BAR/54; 7: Y.86.BAR/51; 8: Y.86.BAR/53; 9: Y.86.BAR/52. (E. Gatti 1986 CMAIRY) 


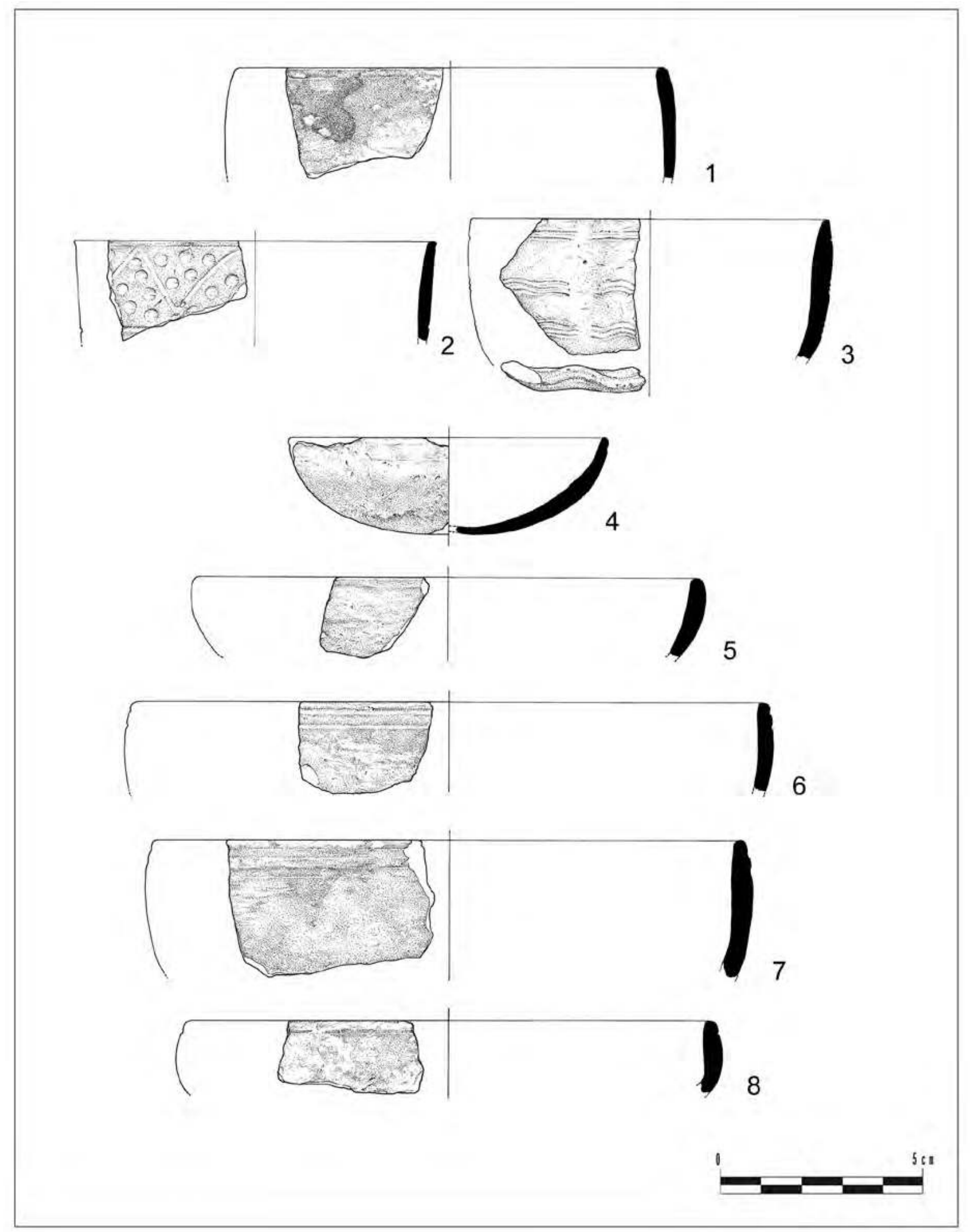

Figure 6. 1: Y.86.BAR/18; 2: Y.86.BAR/71; 3: Y.86.BAR/73; 4: Y.86.BAR/31; 5: Y.86.BAR/14; 6: Y.86.BAR/36; 7: Y.86.BAR/58; 8: Y.86.BAR/9. (E. Gatti 1986 CMAIRY) 

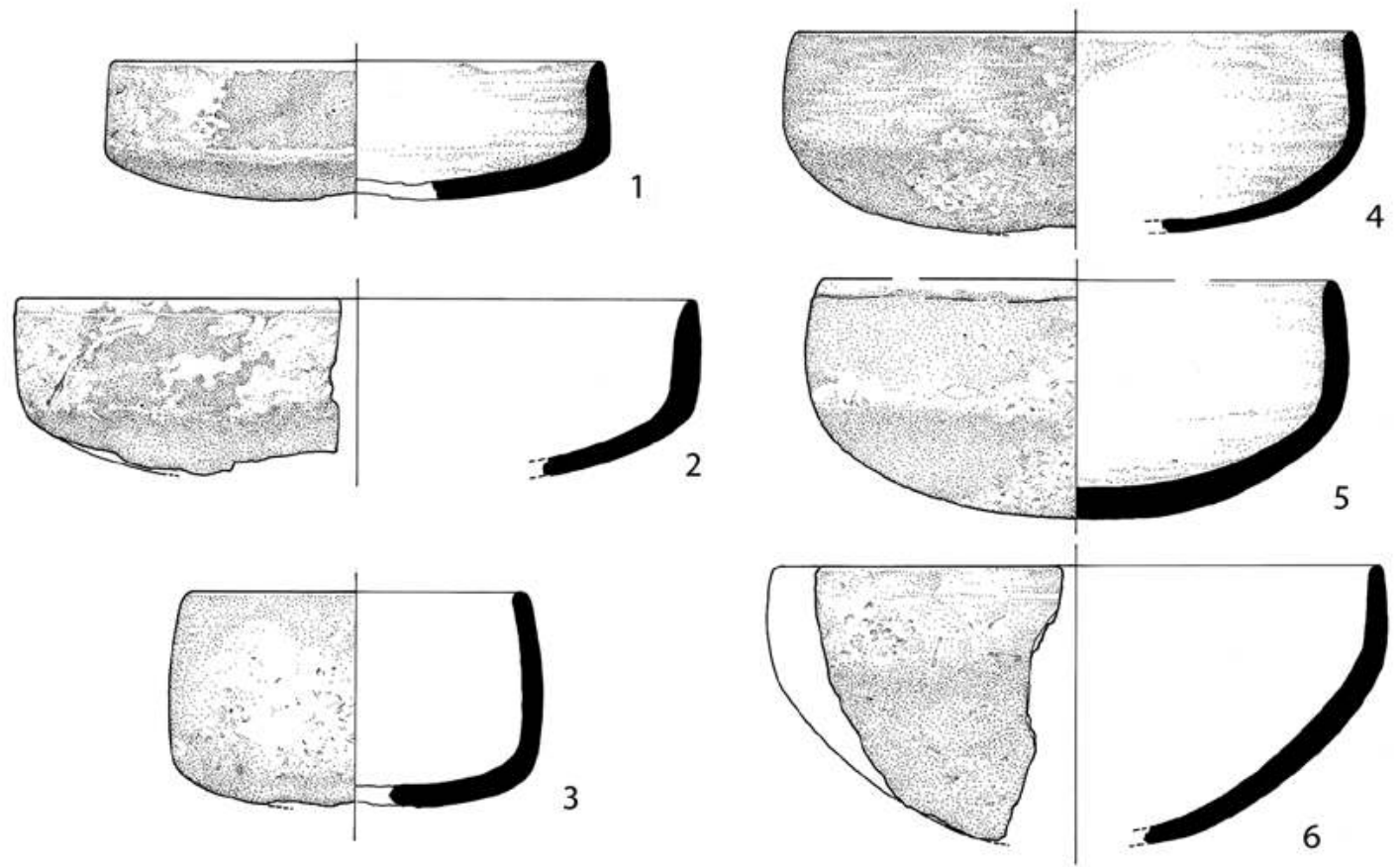

\section{3}
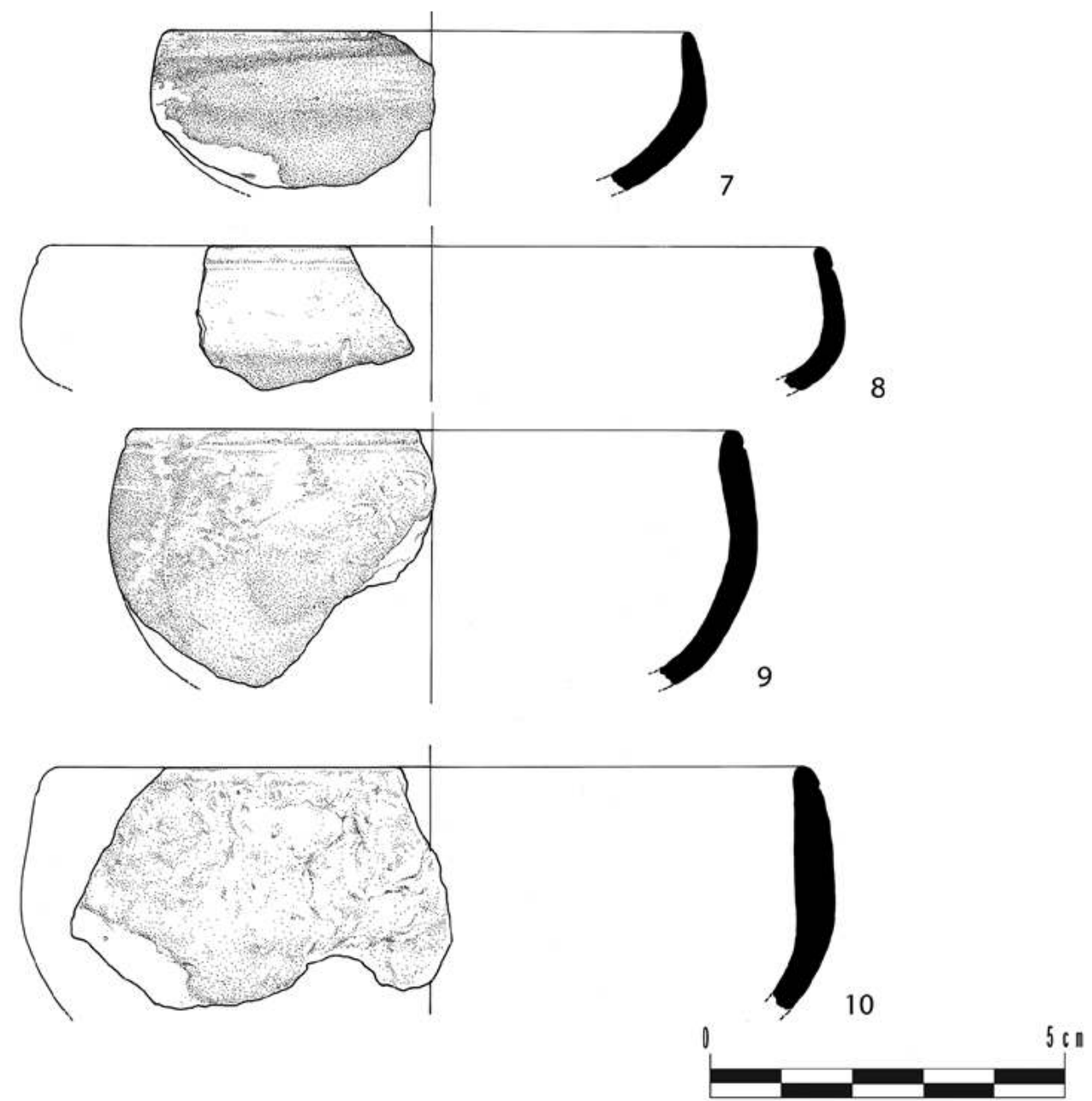

Figure 7. 1: Y.86.BAR/13; 2: Y.86.BAR/5; 3: Y.86.BAR/15; 4: Y.86.BAR/39; 5: Y.86.BAR/2; 6: Y.86.BAR/27; 7: Y.86.BARi/19; 8: Y.86.BARi/11; 9: Y.86.BARi/34; 10: Y.86.BARi/29. (E. Gatti 1986 CMAIRY) 


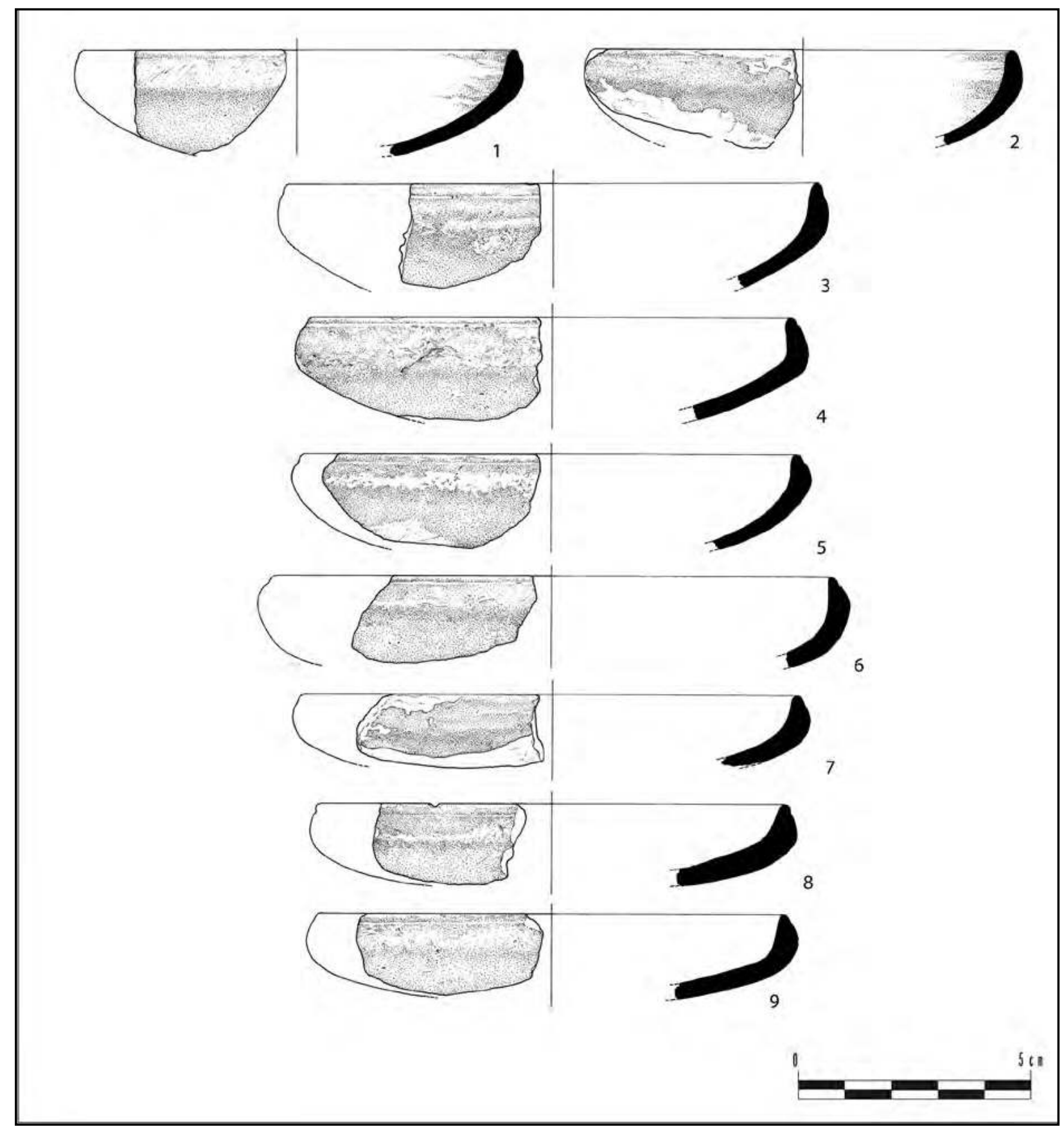

Figure 8. 1: Y.86.BAR/6; 2: Y.86.BAR/7; 3: Y.86.BAR/24; 4: Y.86.BAR/1; 5: Y.86.BAR/4; 6: Y.86.BAR/12; 7: Y.86.BARi/8; 8: Y.86.BARi/3; 9: Y.86.BARi/10. (E. Gatti 1986 CMAIRY) 


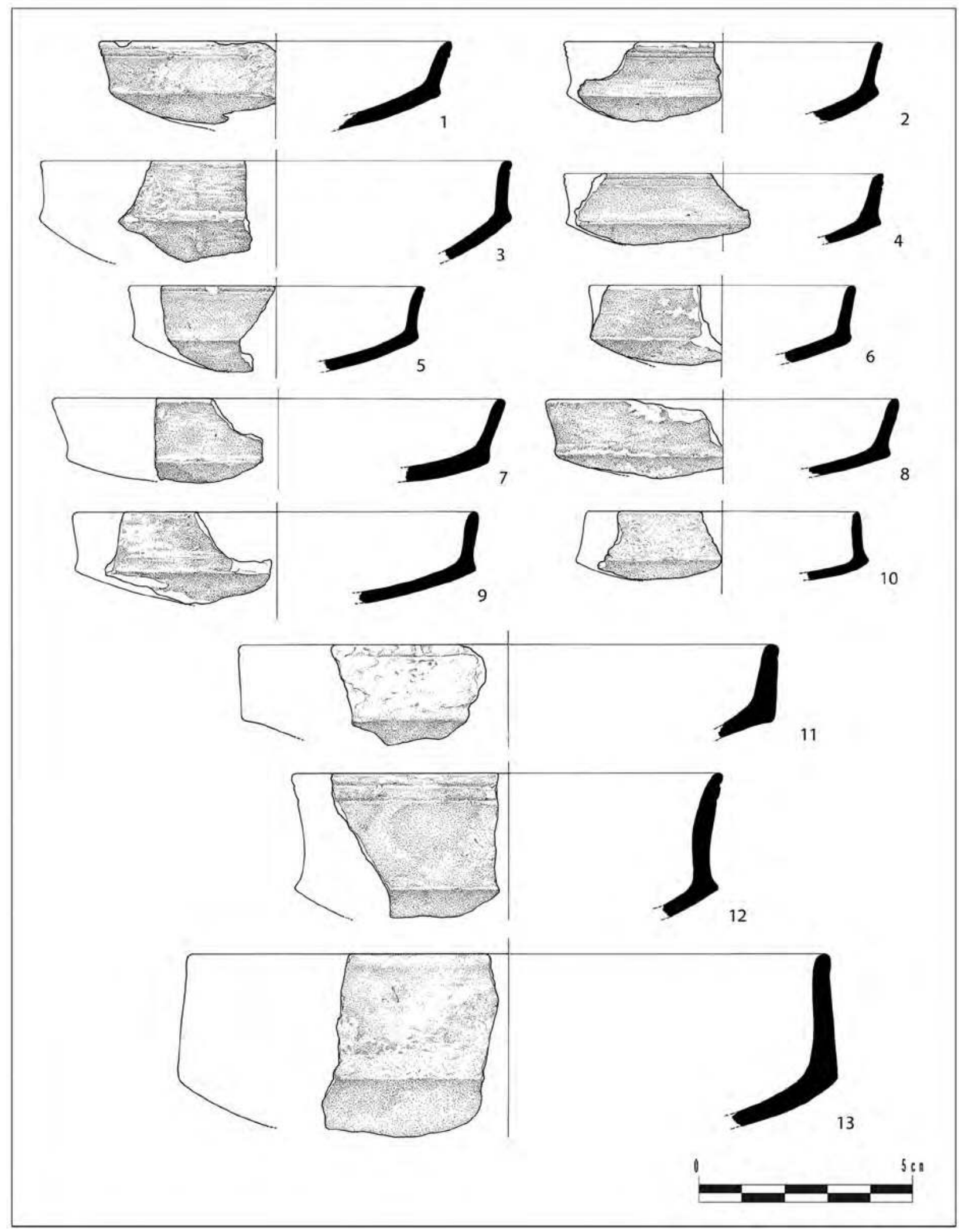

Figure 9. 1. Y.86.BAR/20; 2: Y.86.BAR/26; 3: Y.86.BAR/22; 4: Y.86.BAR/32; 5: Y.86.BAR/35; 6: Y.86.BAR/17; 7: Y.86.BAR/38; 8: Y.86. BAR/16; 9: Y.86.BAR/21; 10: Y.86.BAR/28; 11: Y.86.BAR/23; 12: Y.86.BAR/30; 13: Y.86.BAR/36. (E. Gatti 1986 OMAIRY) 


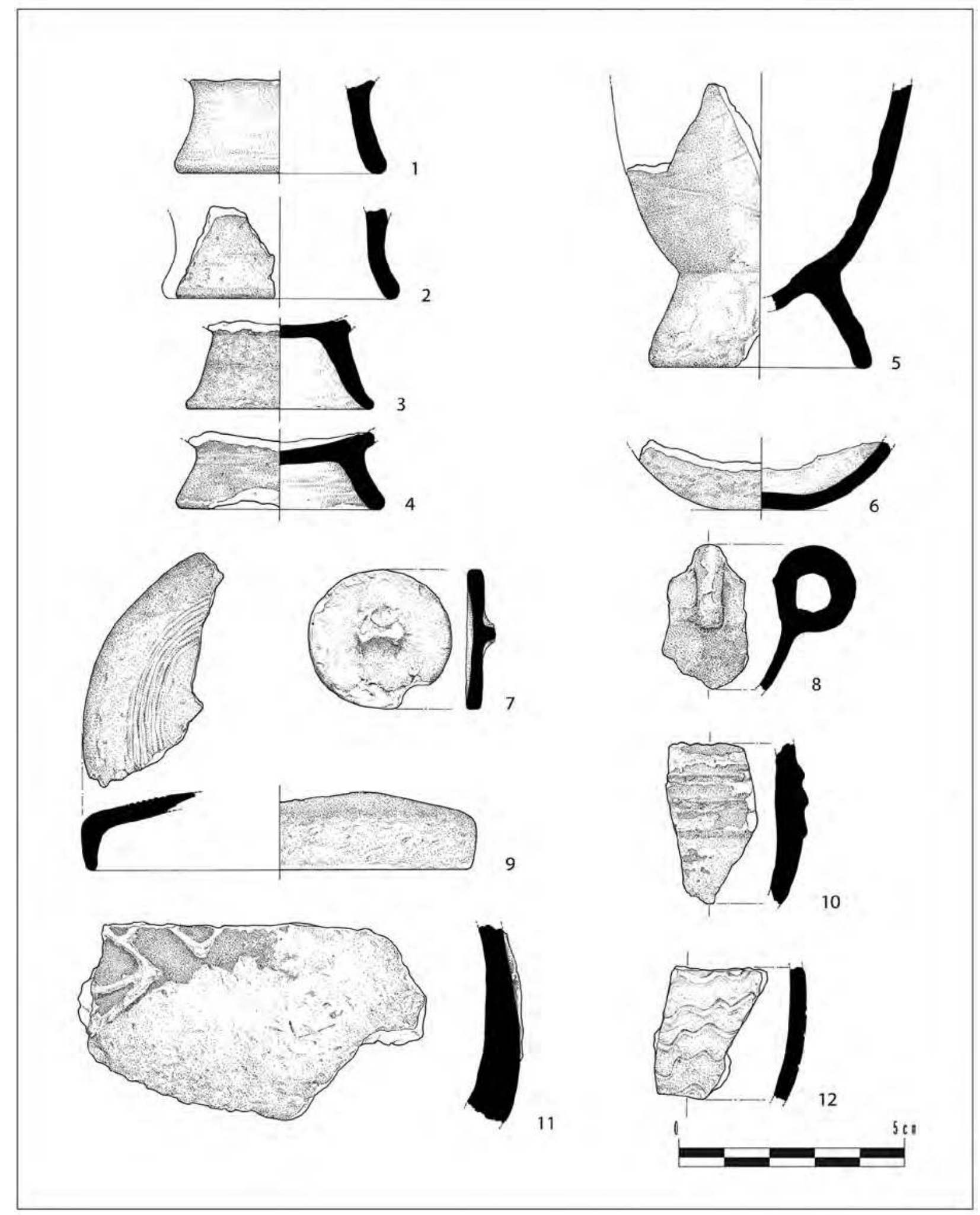

Figure 10. 1: Y.86.BAR/75; 2: Y.86.BAR/49; 3: Y.86.BAR/64; 4: Y.86.BAR/62; 5 Y.86.BAR/66; 6: Y.86.BAR/33; 7: Y.86.BAR/76; 8: Y.86. BAR/77; 9: Y.86.BAR/25; 10: Y.86.BAR/50; 11: Y.86.BAR/70; 12: Y.86.BAR/72. (E. Gatti 1986 OMAIRY) 


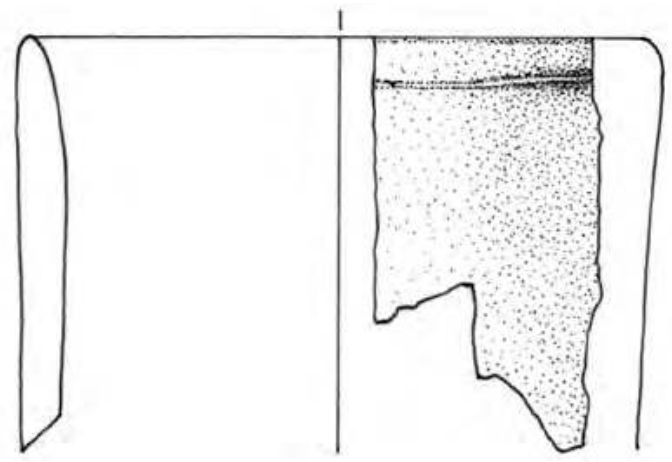

Figure 11. Bicchierino in alabastro (Y.86.BARi.o/1). (P. Smith 1986 CMAIRY)

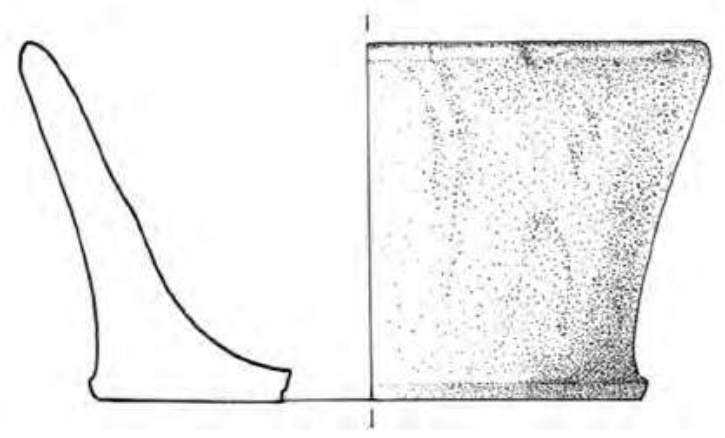

Figure 12. Coppetta in alabastro (Y.86.BARi.O/2). (P. Smith 1986 OMAIRY)
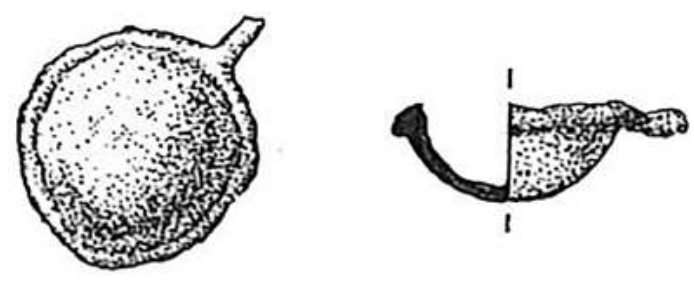

Figure 14. Cucchiaino in bronzo (Y.86.BARi.O/5).

(P. Smith 1986 CMAIRY)
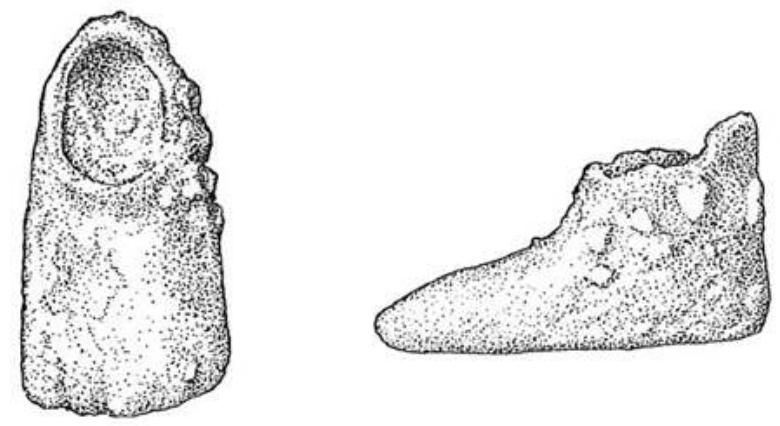

Figure 15. Piede di statuetta umana in bronzo (Y.86.BARi.O/6). (P. Smith 1986 CMAIRY)
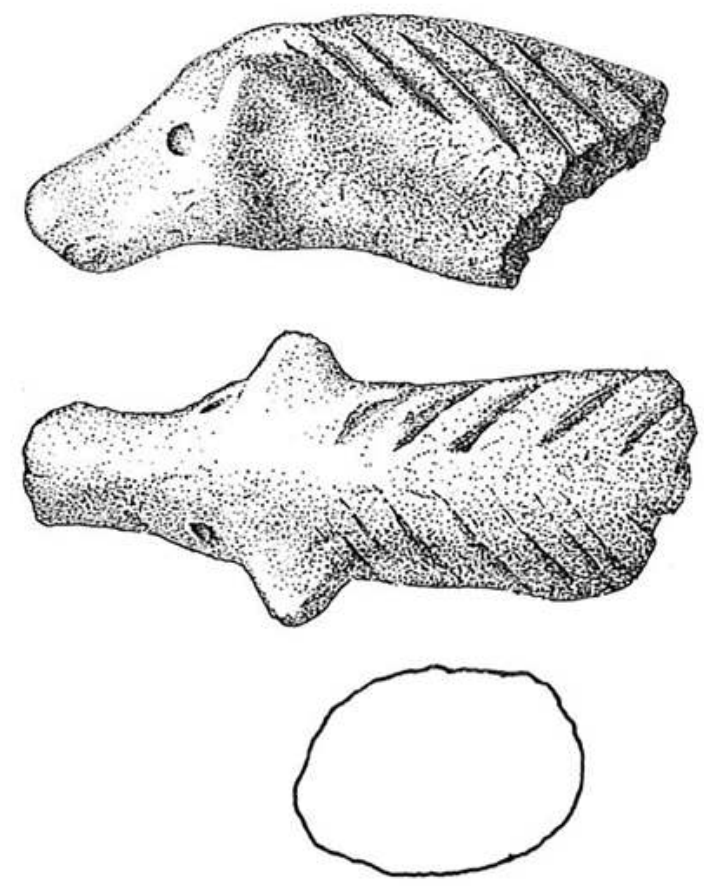

Figure 13. Frammento di animale in terracotta (Y.86. BARi.O/4). (P. Smith 1986 CMAIRY) 
a

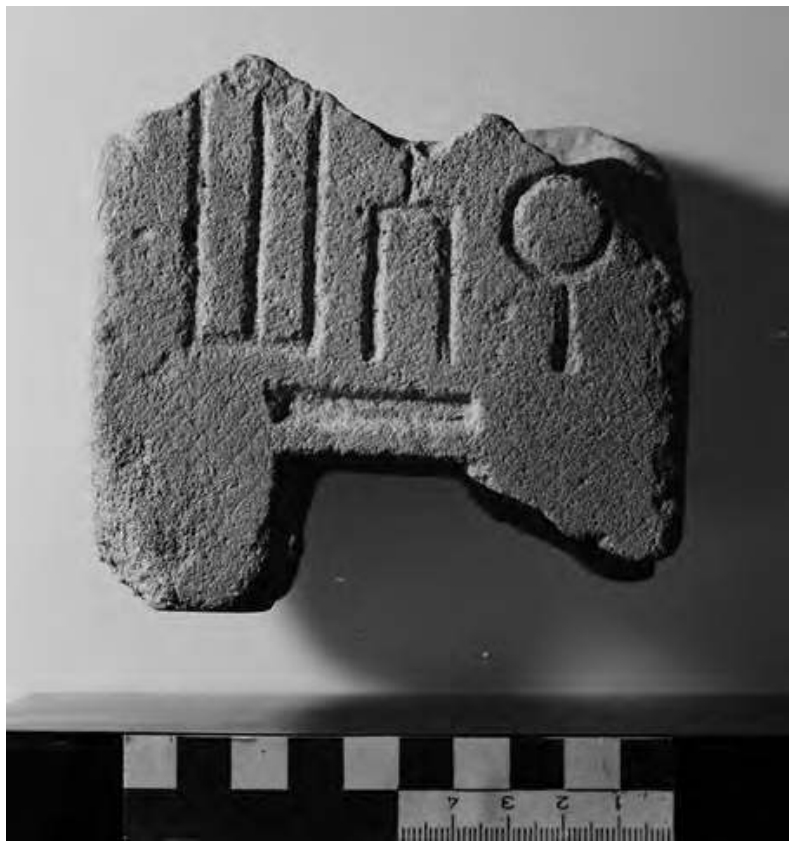

C

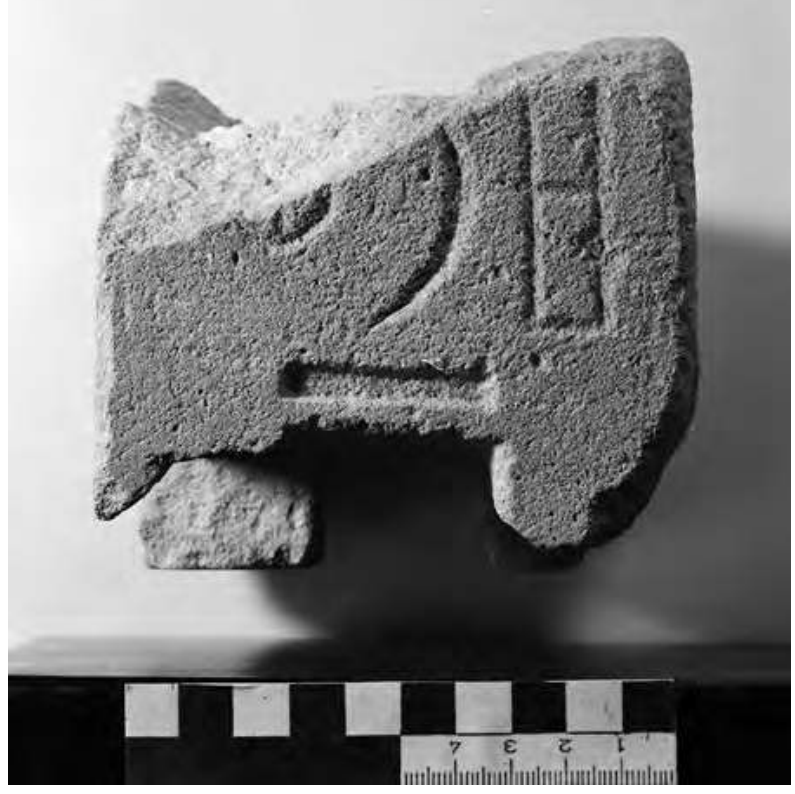

$\mathrm{b}$

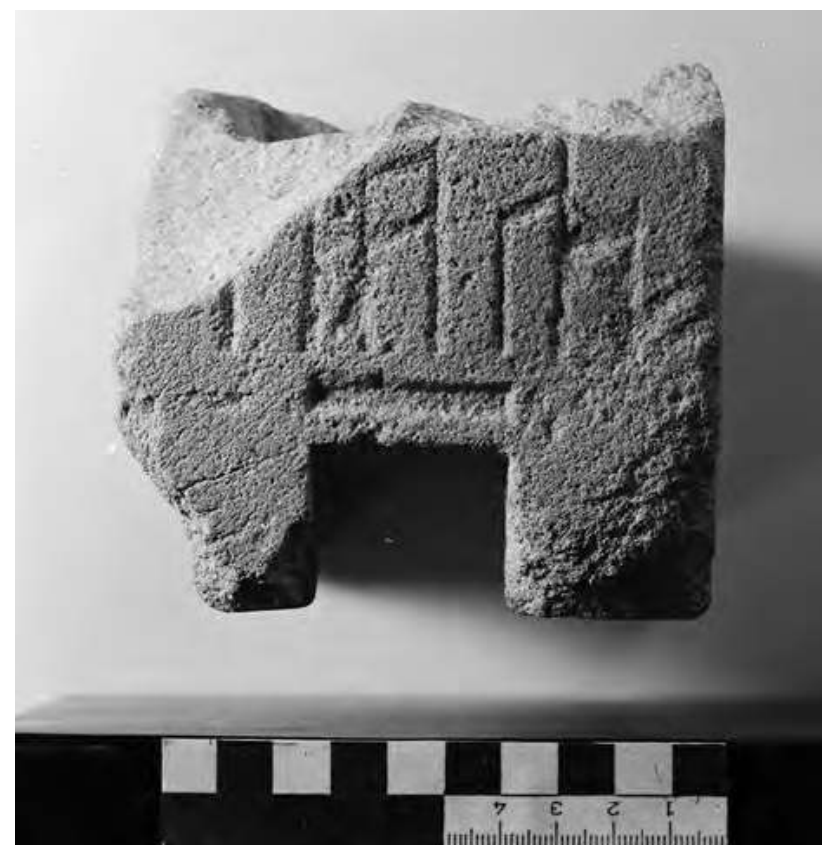

$\mathrm{d}$

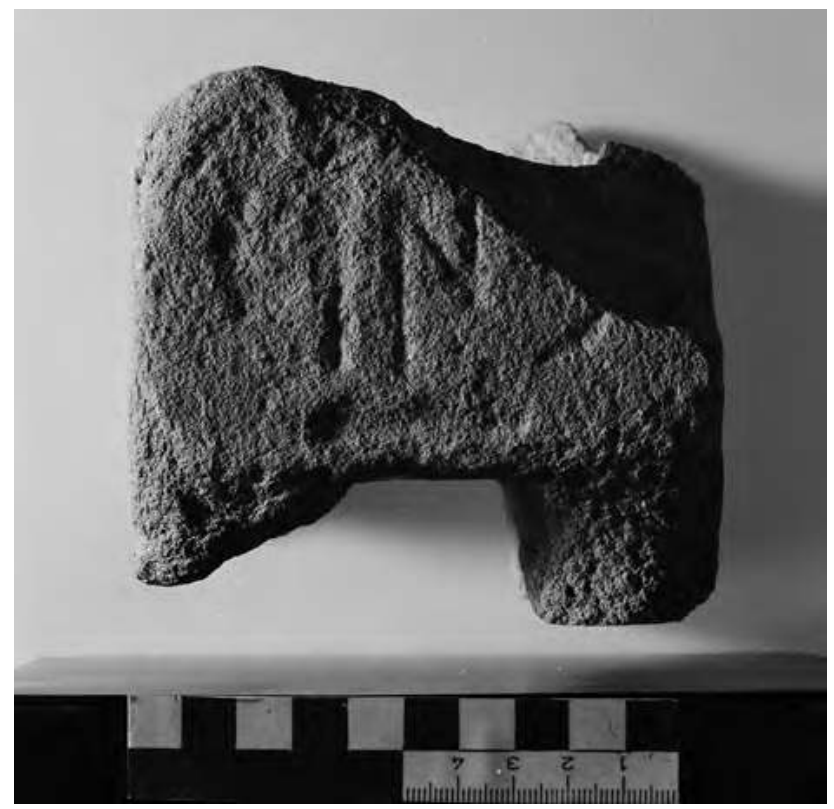

Figure 16. Incensiere cubico in arenaria (Y.86.BARi.O/13). (A. de Maigret 1986 CMAIRY) 


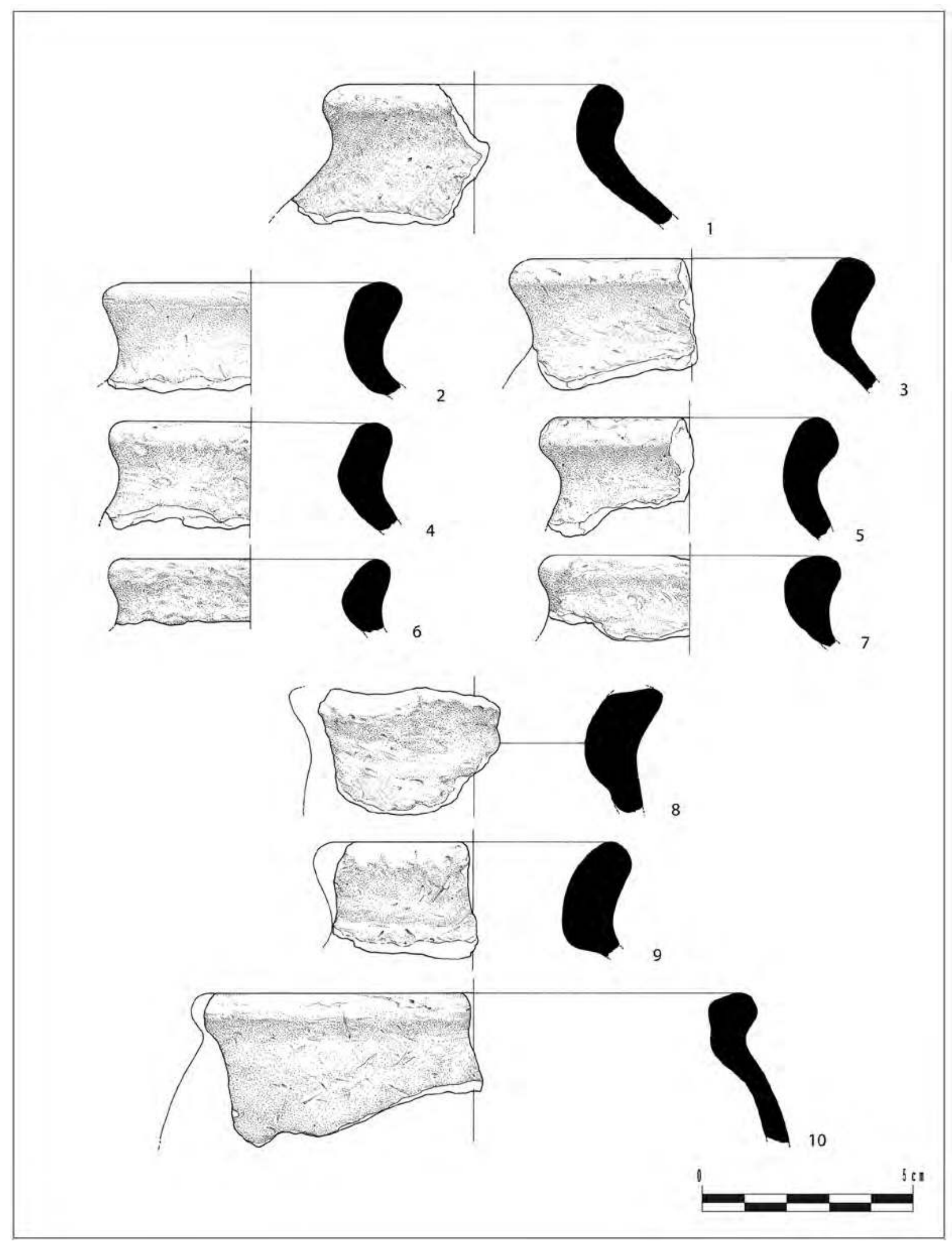

Figure 17. 1: Y.86.BARii/68; 2: Y.86.BARii/69; 3: Y.86.BARii/61; 4: Y.86.BARii/63; 5 Y.86.BARii/64; 6: Y.86.BARii/62; 7: Y.86. BARii/67; 8: Y.86.BARii/66; 9: Y.86.BARii/70; 10: Y.86.BARii/46. (E. Gatti 1986 CMAIRY) 


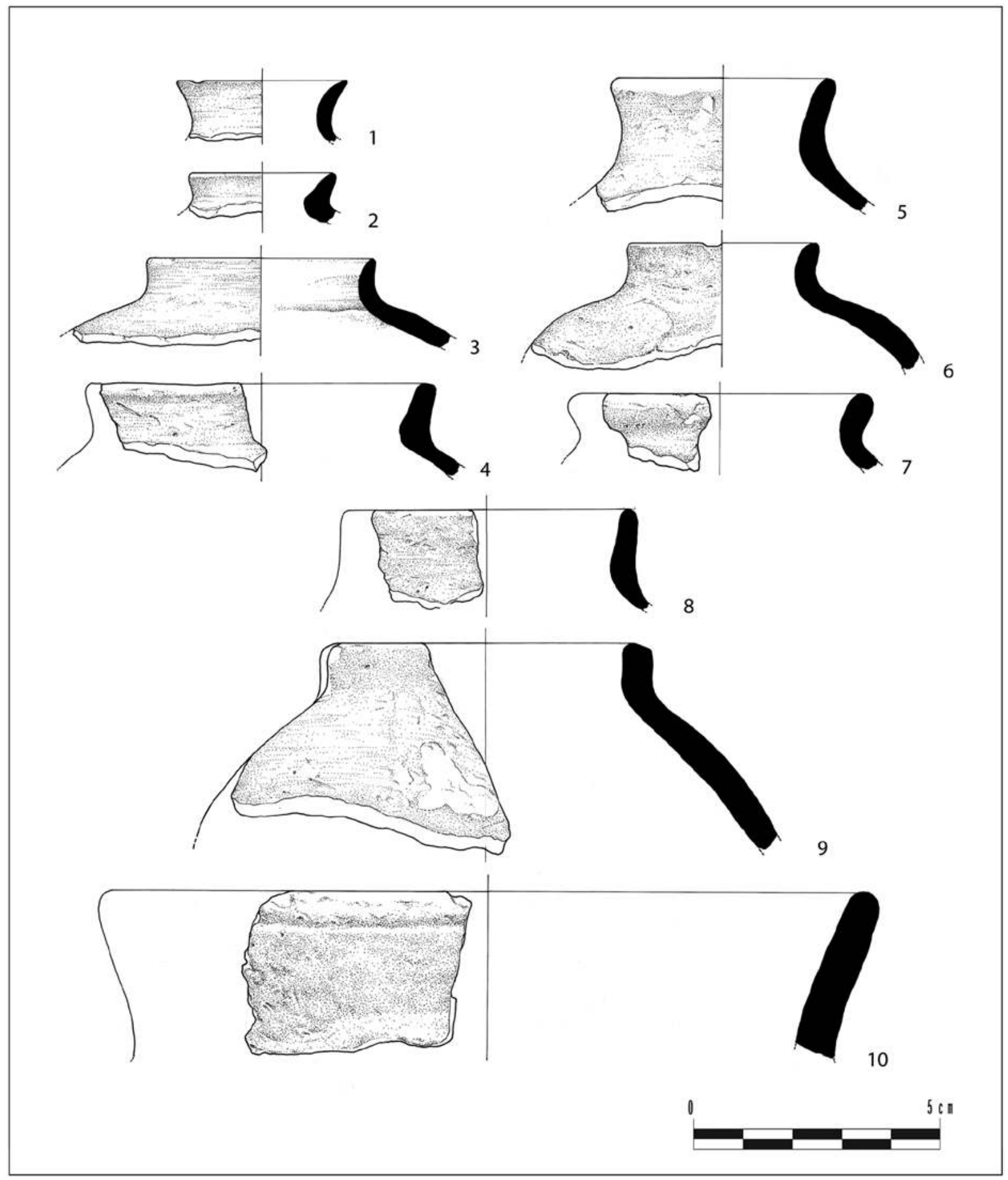

Figure 18. 1: Y.86.BARii/25; 2: Y.86.BARii/27; 3: Y.86.BARii/23; 4: Y.86.BARii/24; 5 Y.86.BARii/30; 6: Y.86.BARii/29; 7: Y.86. BARii/31; 8: Y.86.BARii/32; 9: Y.86.BARii/28; 10: Y.86.BARii/42. (E. Gatti 1986 OMAIRY) 

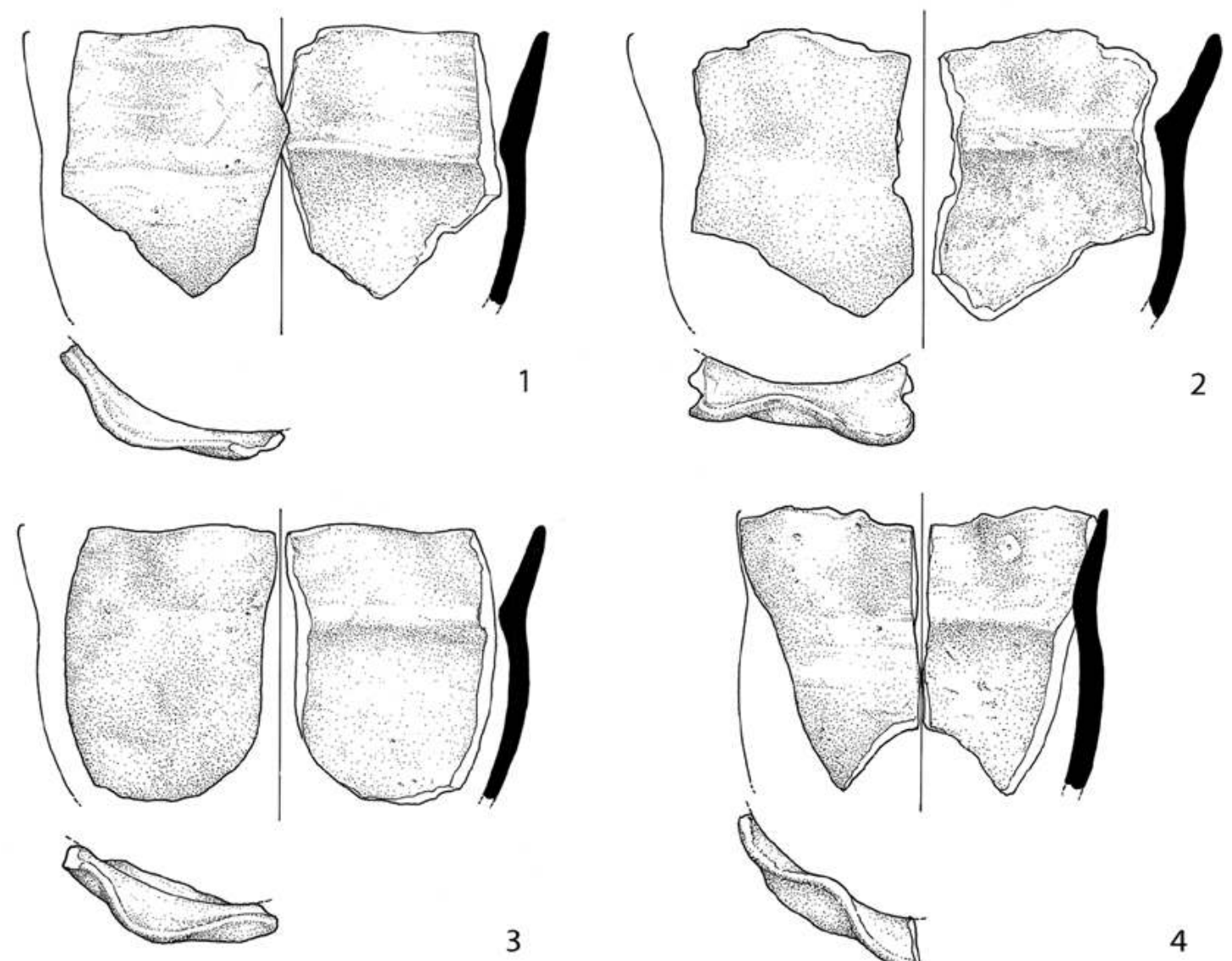

3
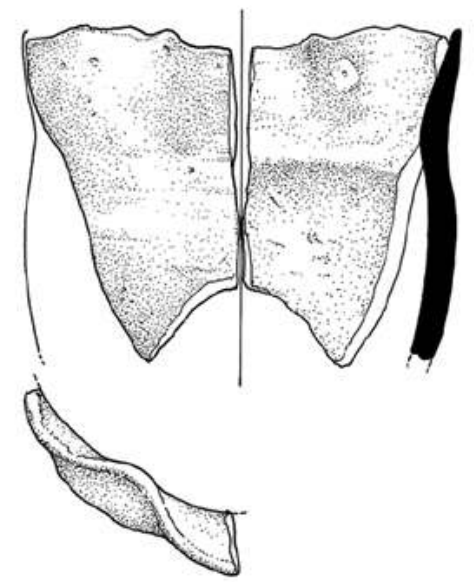

4
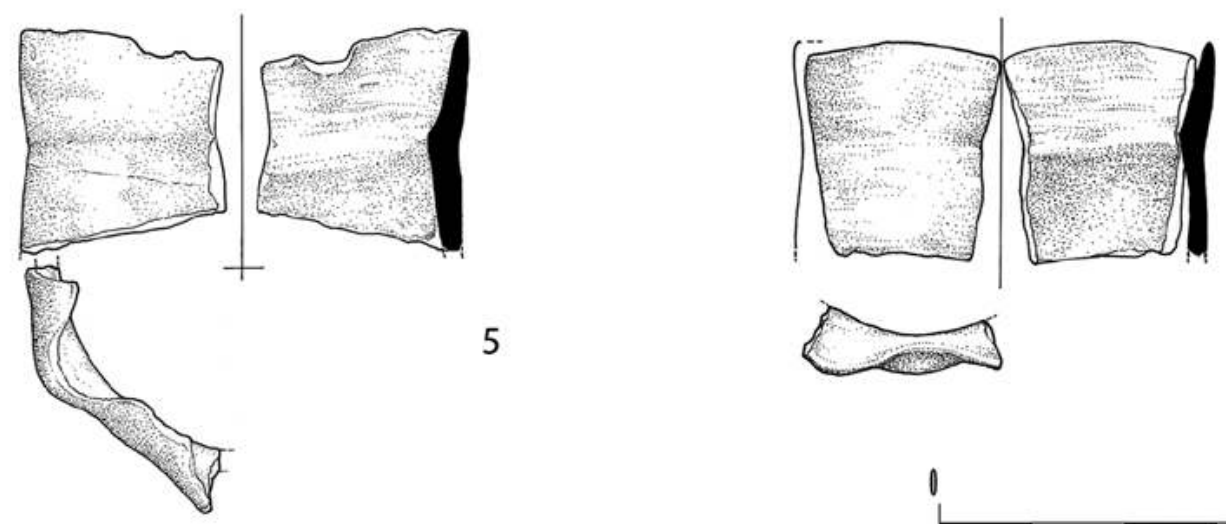

6

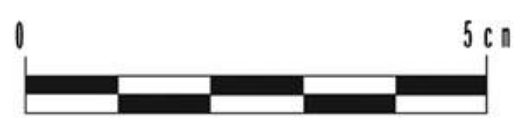

Figure 19. 1: Y.86.BARii/4; 2: Y.86.BARii/1; 3: Y.86.BARii/3; 4: Y.86.BARii/2; 5 Y.86.BARii/5; 6: Y.86.BARii/6. (E. Gatti 1986 OMAIRY) 


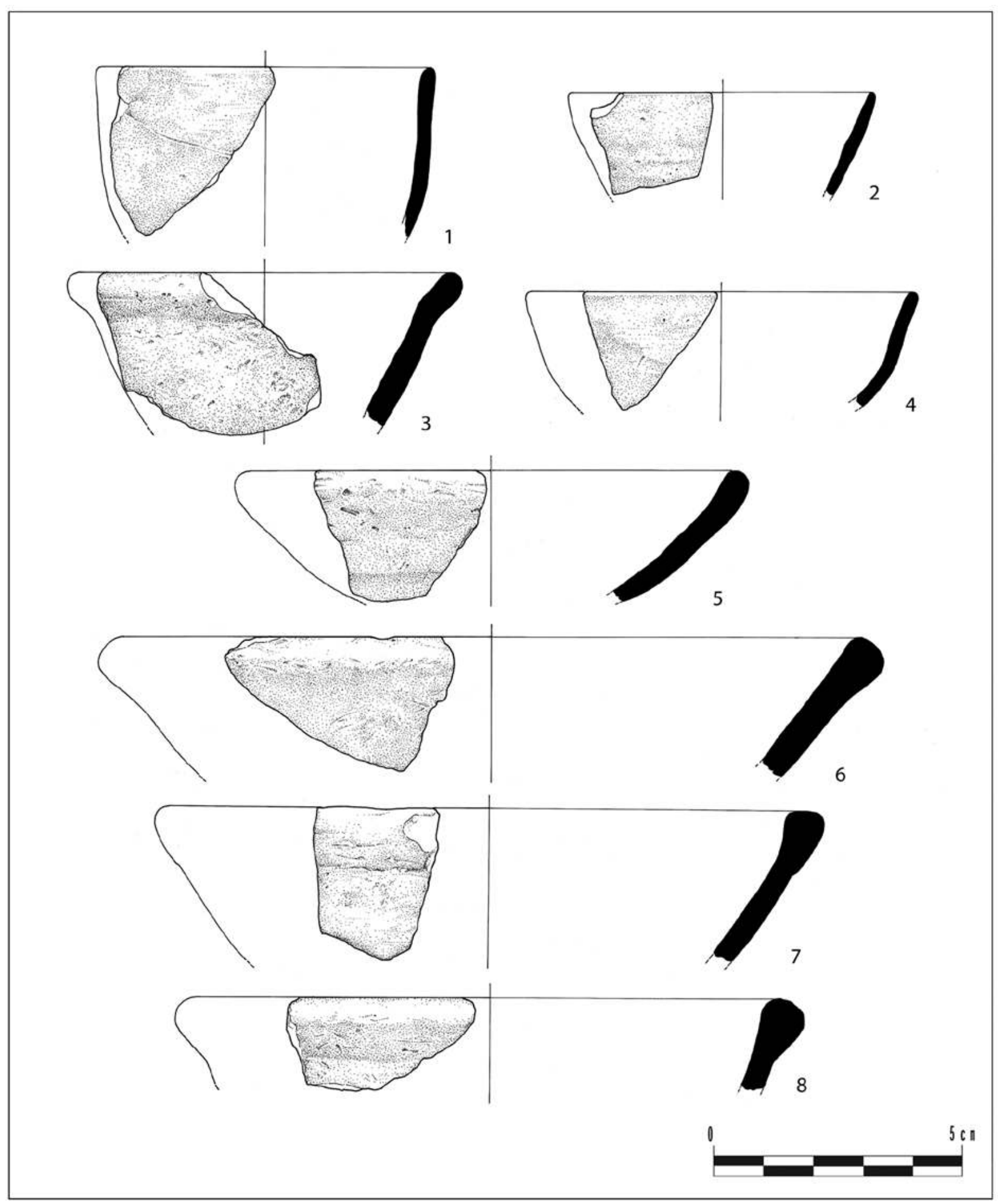

Figure 20. 1: Y.86.BARii/12; 2: Y.86.BARii/8; 3: Y.86.BARii/55; 4: Y.86.BARii/14; 5 Y.86.BARii/44; 6: Y.86.BARii/57; 7: Y.86.BARii/54; 8: Y.86.BARii/45. (E. Gatti 1986 CMAIRY) 

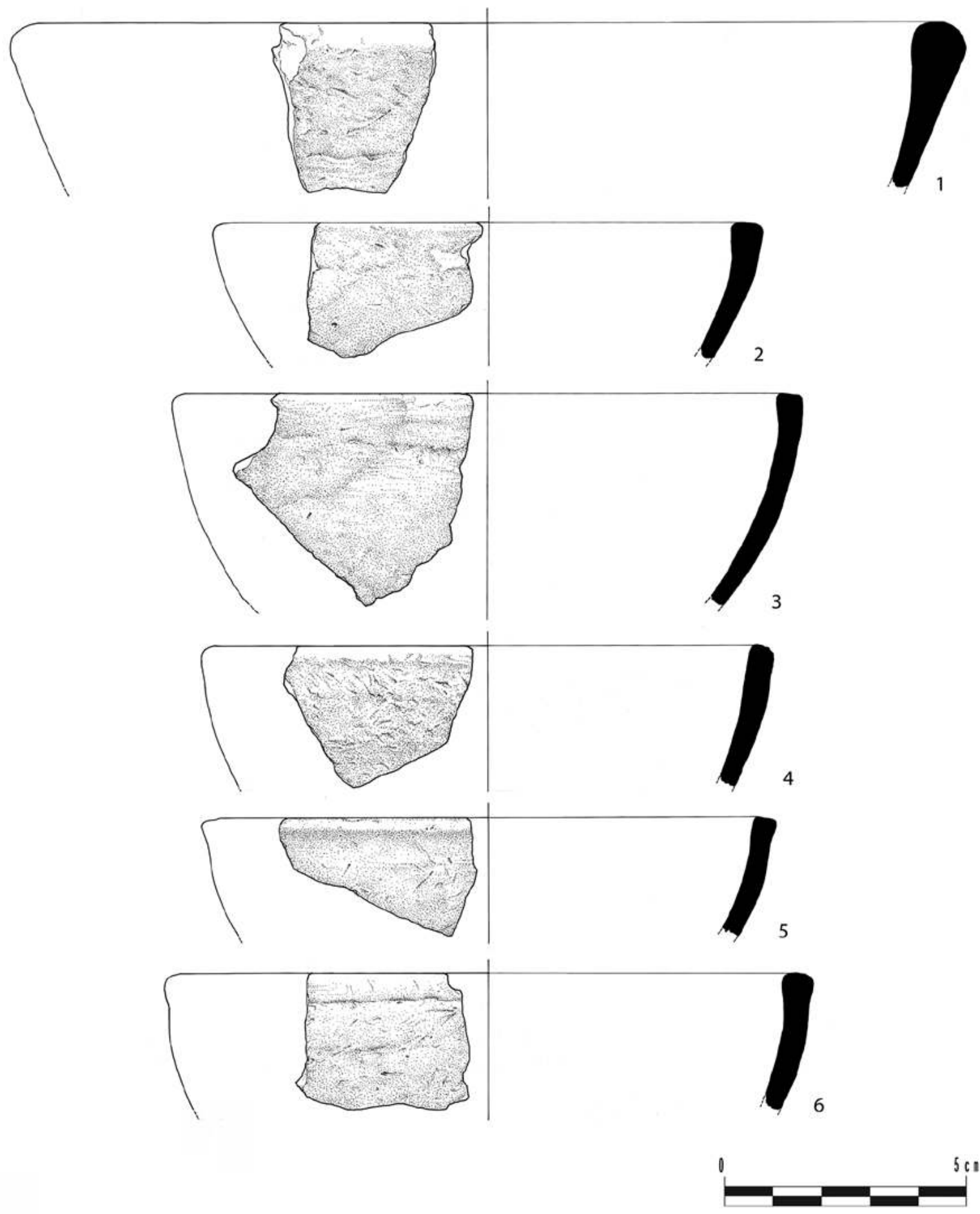

Figure 21. 1: Y.86.BARii/59; 2: Y.86.BARii/60; 3: Y.86.BARii/47; 4: Y.86.BARii/43; 5 Y.86.BARii/52; 6: Y.86.BARii/56. (E. Gatti 1986 CMAIRY) 


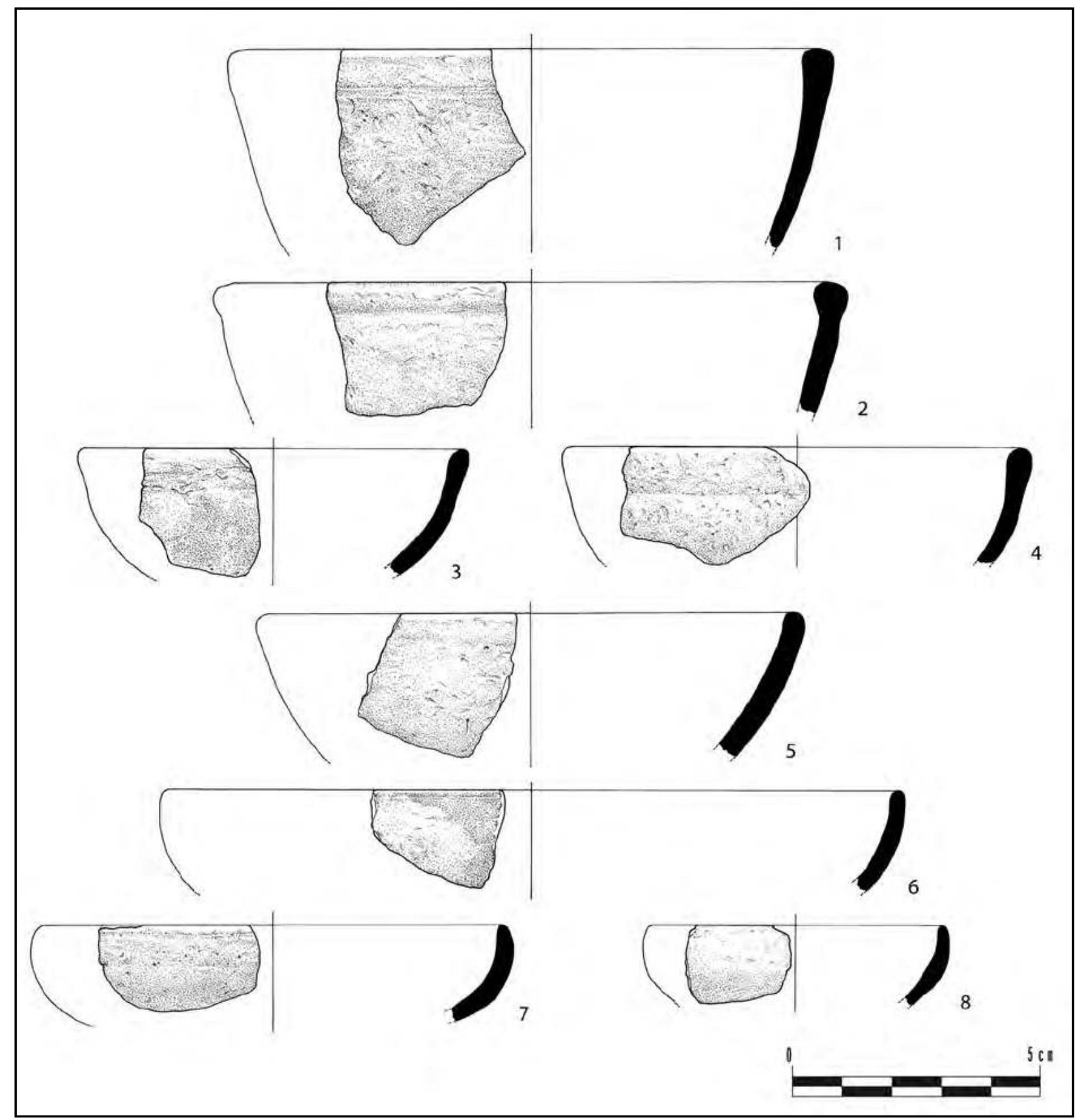

Figure 22. 1: Y.86.BARii/51; 2: Y.86.BARii/50; 3: Y.86.BARii/9; 4: Y.86.BARii/11; 5 Y.86.BARii/53; 6: Y.86.BARii/18; 7: Y.86.BARii/17; 8: Y.86.BARii/13. (E. Gatti 1986 CMAIRY) 

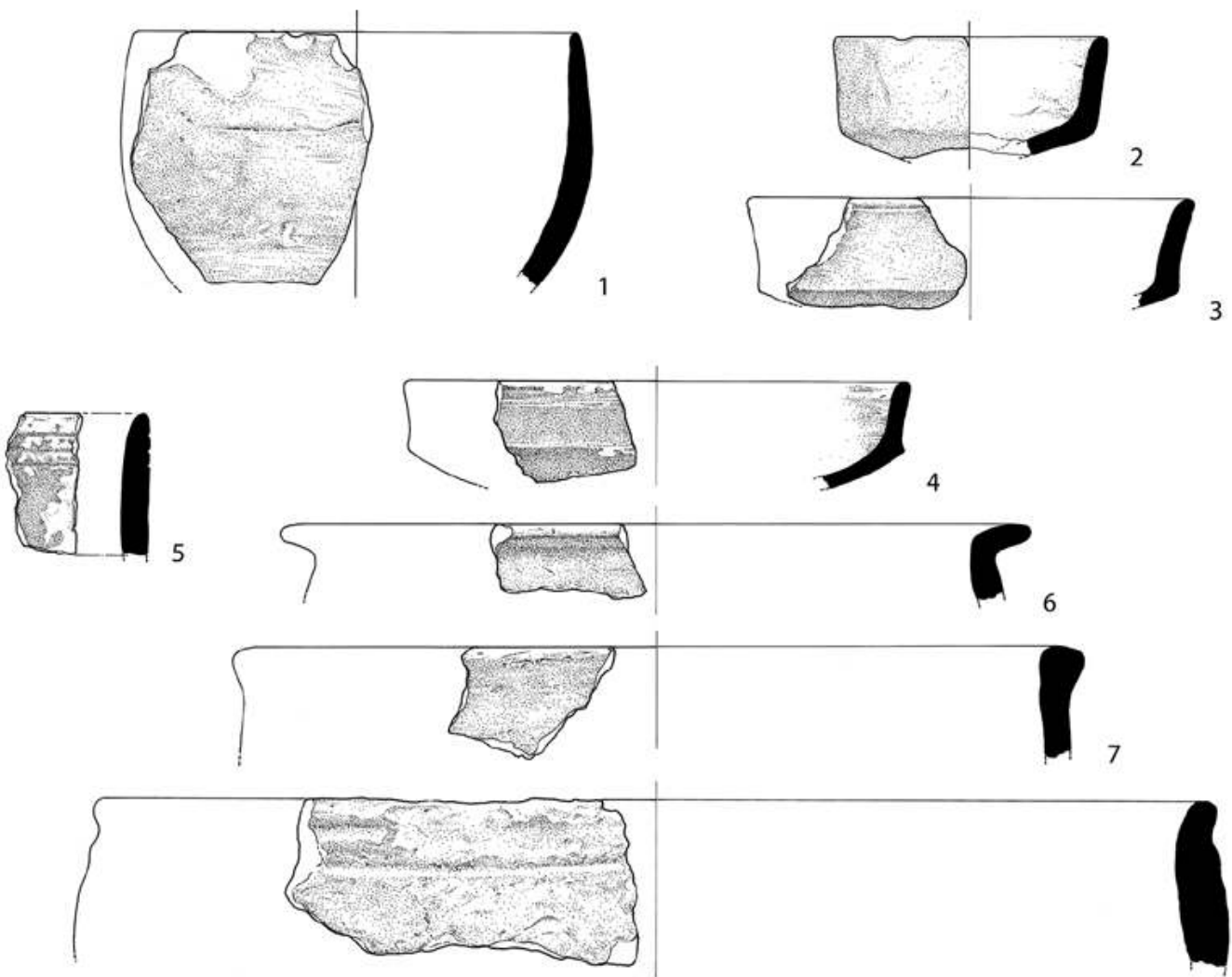

7
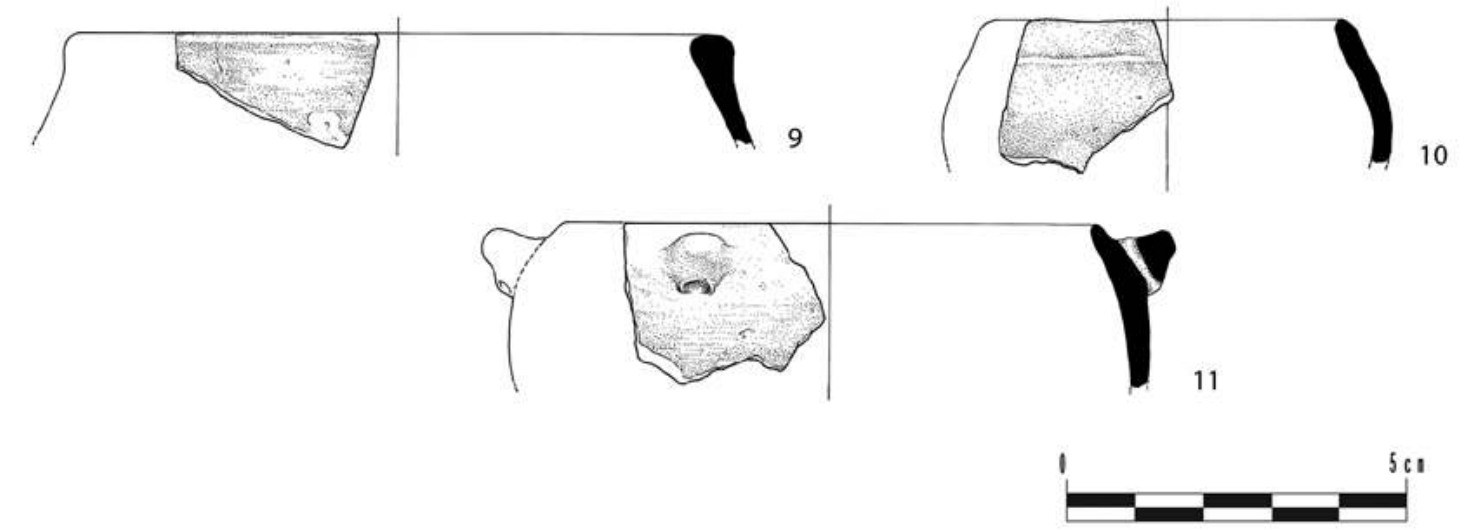

Figure 23. 1: Y.86.BARii/7; 2: Y.86.BARii/16; 3: Y.86.BARii/20; 4: Y.86.BARii/19; 5: Y.86.BARii/58; 6: Y.86.BARii/33; 7: Y.86.BARii/49; 8: Y.86.BARii/65; 9: Y.86.BARii/48; 10: Y.86.BARii/15; 11: Y.86.BARii/10. (E. Gatti 1986 CMAIRY) 

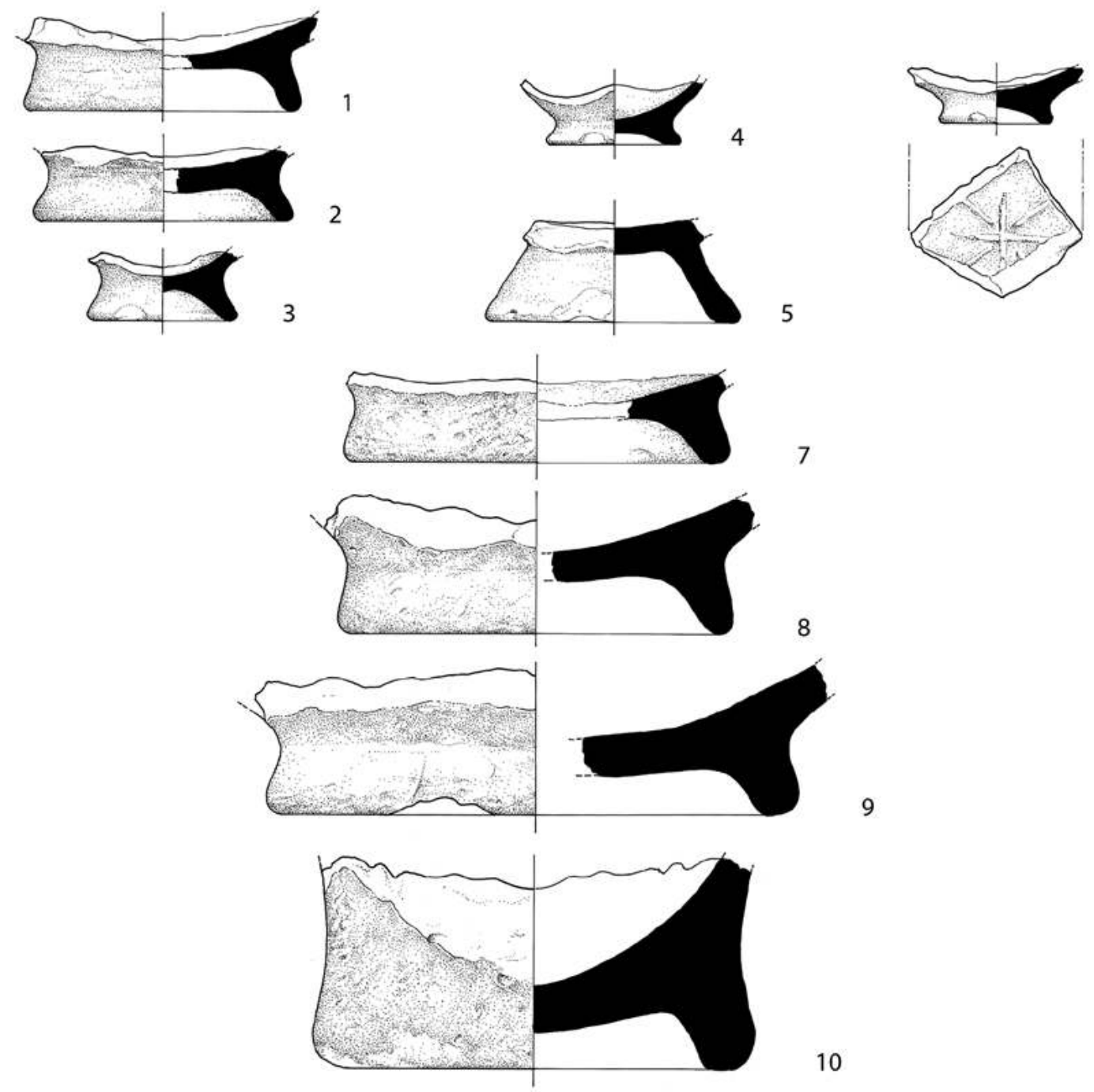

10

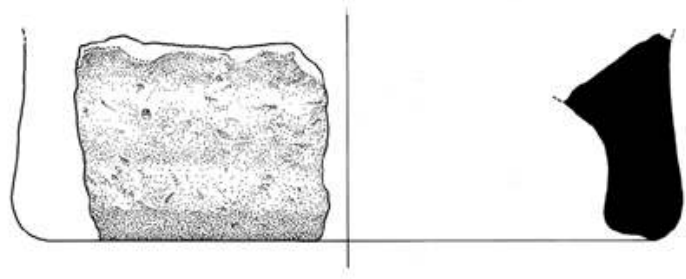

11

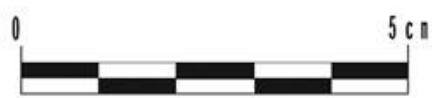

Figure 24. 1: Y.86.BARii/35; 2: Y.86.BARii/39; 3: Y.86.BARii/21; 4: Y.86.BARii/22; 5 Y.86.BARii/36; 6: Y.86.BARii/26; 7: Y.86. BARii/34; 8: Y.86.BARii/40; 9: Y.86.BARii/37; 10: Y.86.BARii/41; 11: Y.86.BARii/38. (E. Gatti 1986 CMAIRY) 


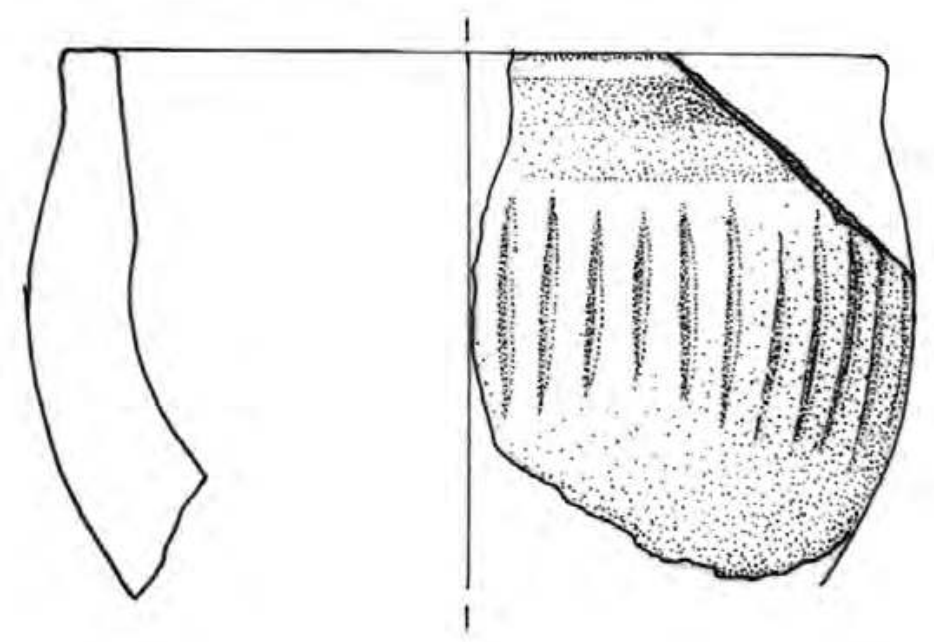

Figure 25. Coppetta in alabastro (Y.86.BARii.O/13).

(P. Smith 1986 @MAIRY)

a

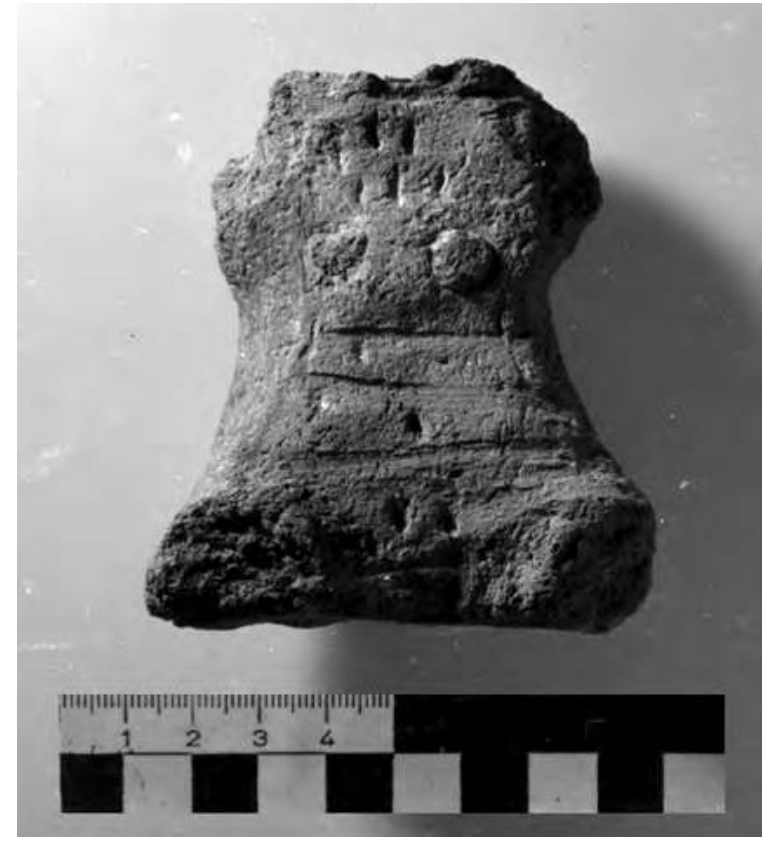

b
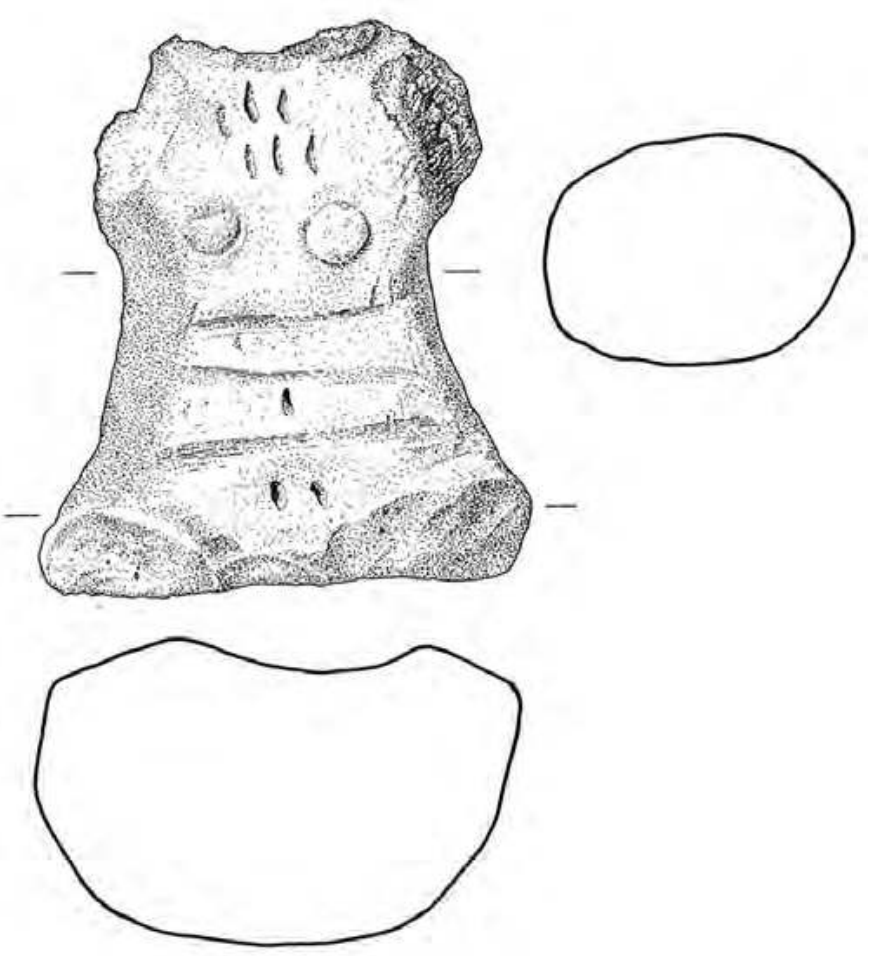

Figure 26a-b. Figurina fittile frammentaria (Y.86.BARii.O/21). (P. Smith 1986 CMAIRY) 


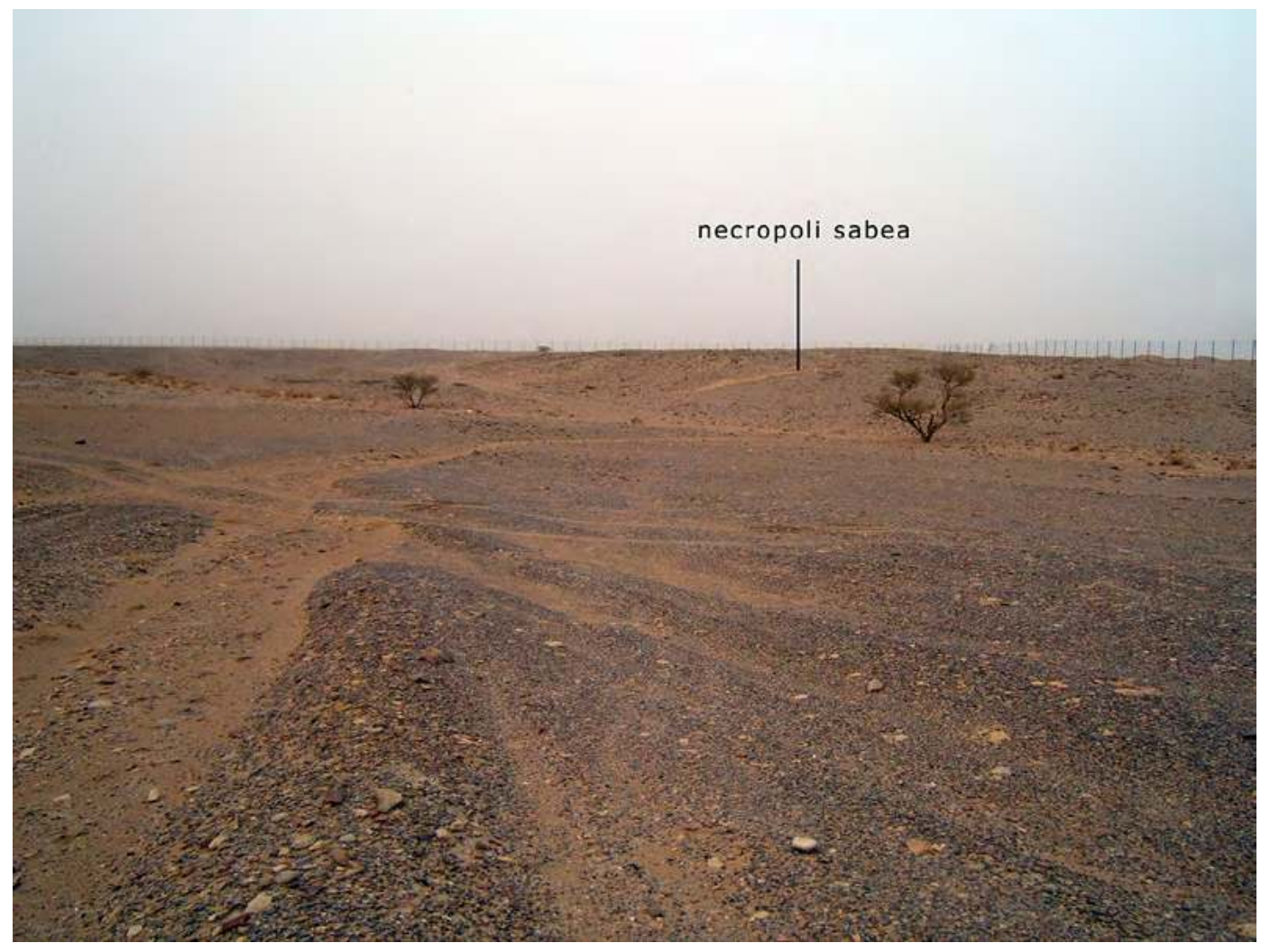

Figure 27. Probabile localizzazione della necropoli sabea di Barāqish, c. $100 \mathrm{~m}$ a N delle mura, di fronte ai bastioni T15 e T18, compresa nella moderna recinzione. (A. de Maigret 2006 CMAIRY) 


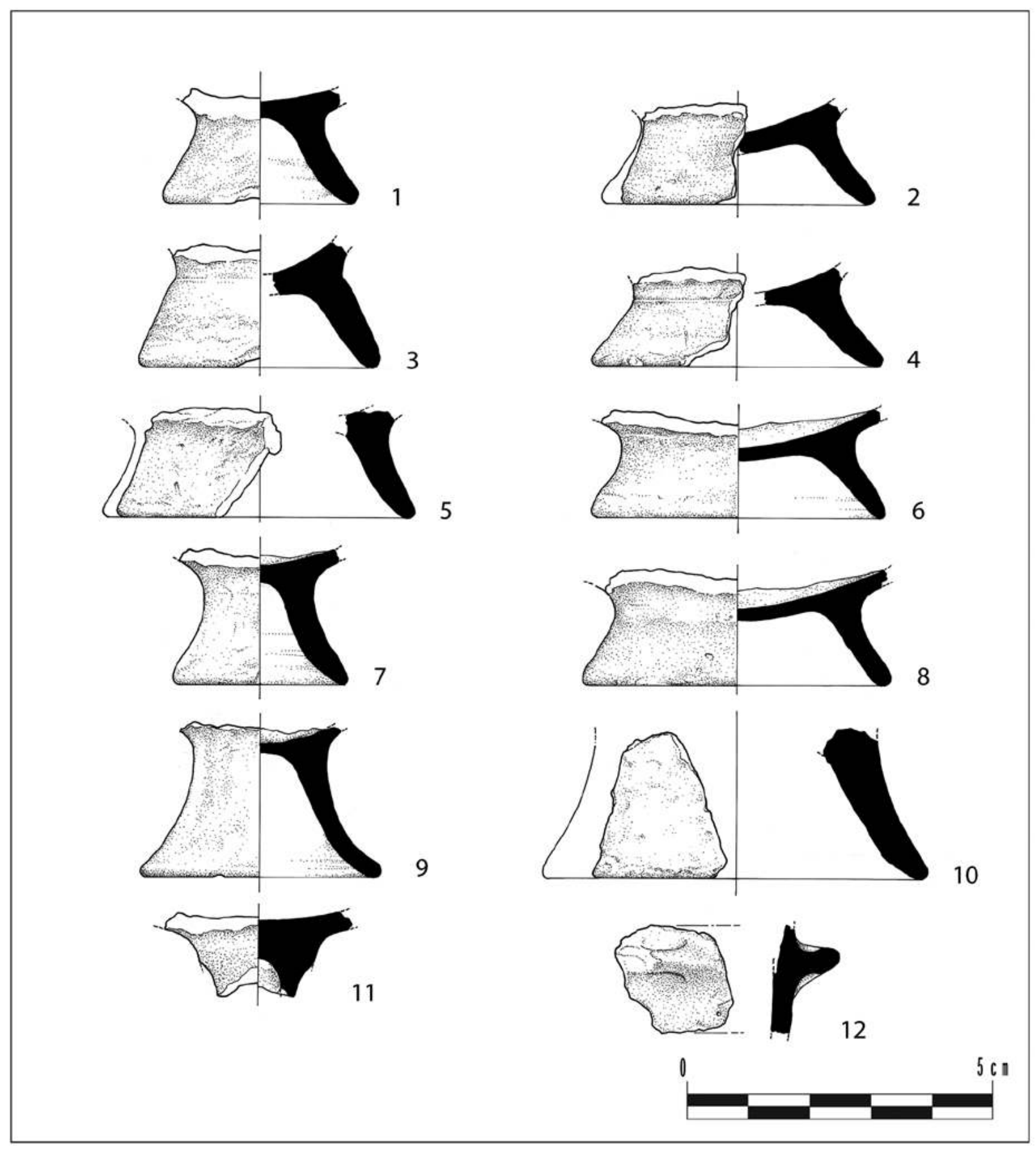

Figure 28. 1: Y.86.BARiii/8; 2: Y.86.BARiii/7; 3: Y.86.BARiii/5; 4: Y.86.BARiii/2; 5 Y.86.BARiii/1; 6: Y.86.BARiii/9; 7: Y.86.BARiii/12; 8: Y.86.BARiii/3; 9: Y.86.BARiii/11; 10: Y.86.BARiii/6; 11: Y.86.BARiii/4; 12: Y.86.BARiii/10. (E. Gatti 1986 CMAIRY) 

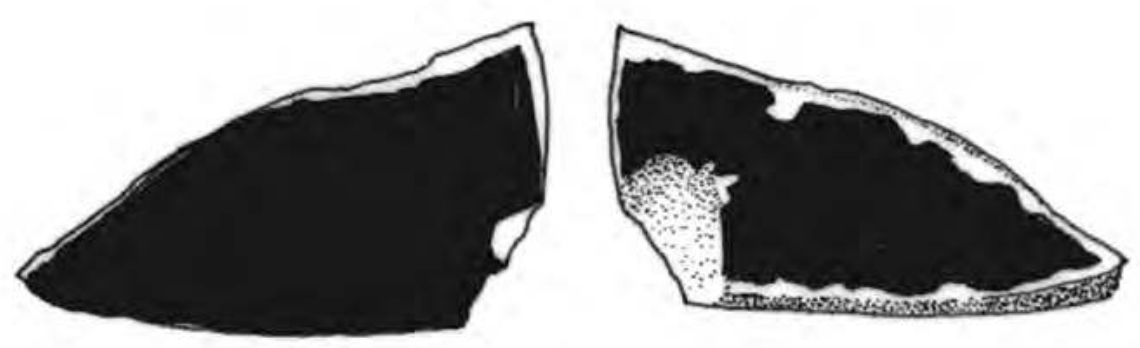

Figure 29. Frammento di ceramica 'a vernice nera' di importazione (Y.86.BARiv/4). (P. Smith 1986 CMAIRY)

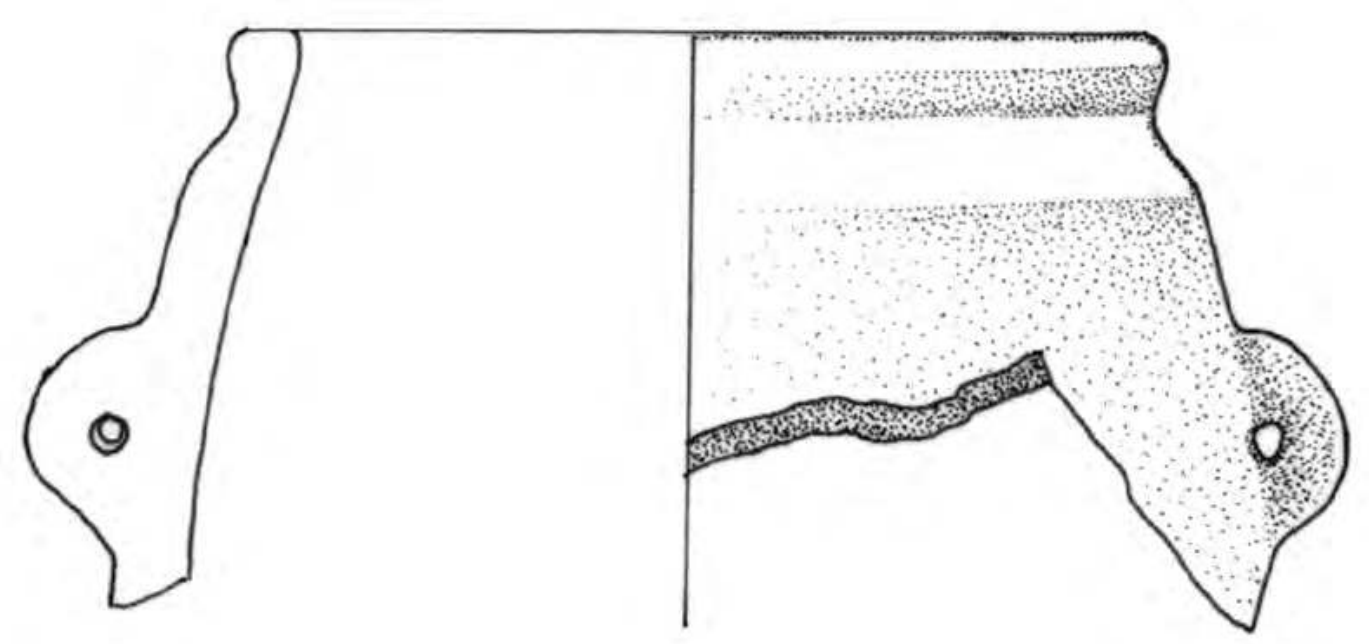

Figure 30. Olletta ansata in alabastro (Y.86.BARiv.O/1). (P. Smith 1986 CMAIRY)

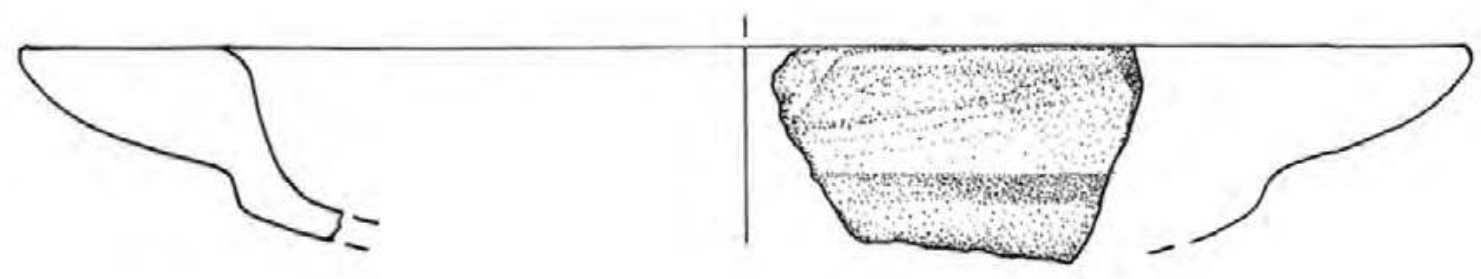

Figure 31. Coppetta con orlo espanso (Y.86.BARiv.O/2). (P. Smith 1986 CMAIRY) 


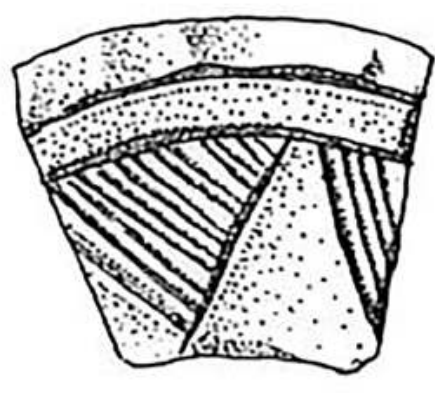

Figure 32. Coppetta a parete dritta decorata (Y.86.BARiv.O/3). (P. Smith 1986 CMAIRY)

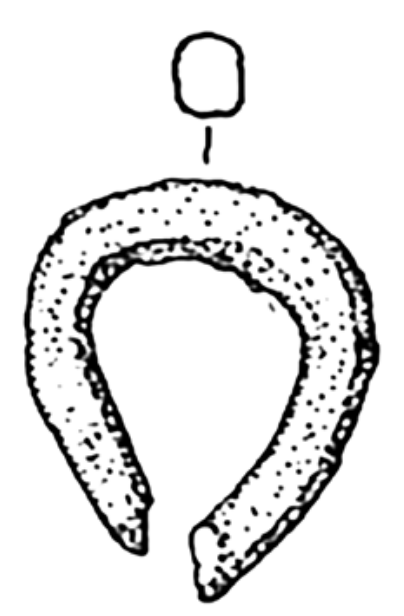

Figure 33. Anellino in bronzo (Y.86.BARiv.O/5). (P. Smith 1986 OMAIRY) a

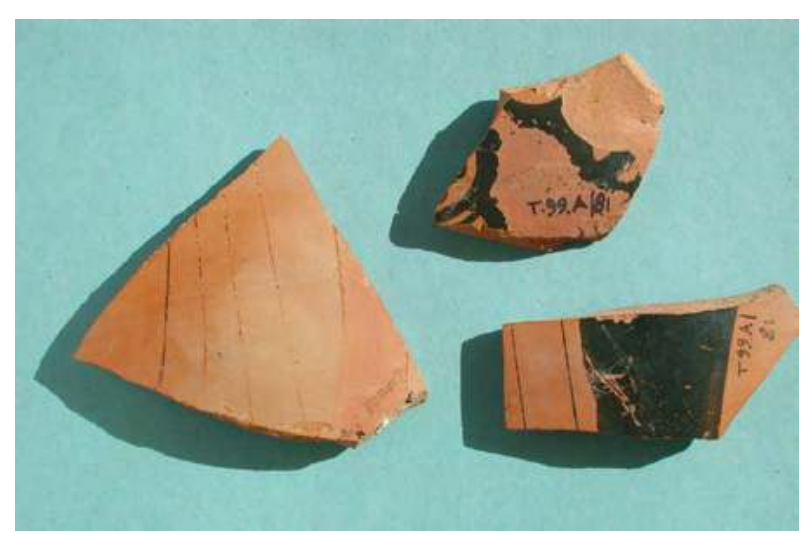

b

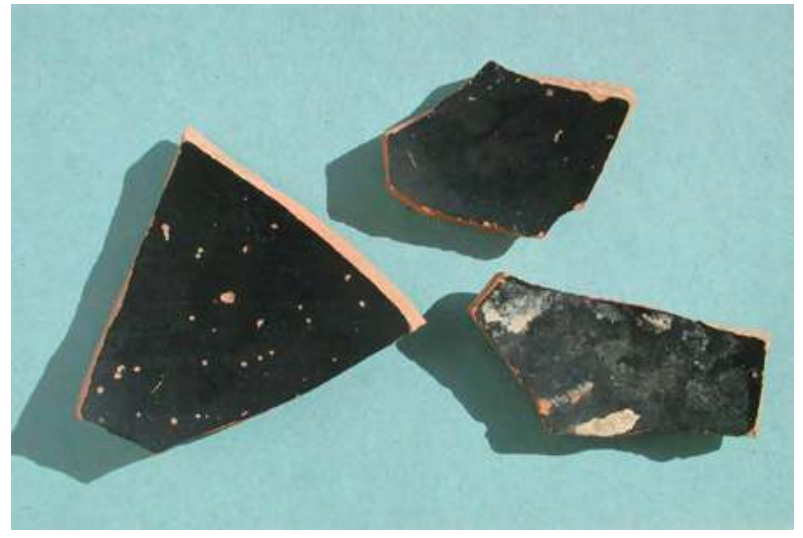

Figure 34a-b. Frammenti di ceramica a 'vernice rossa' d'importazione (V-IV secolo a.C.) trovati nello scavo delle strutture nord-occidentali del tempio di Athirat a Tamnac. (A. de Maigret 2000 CMAIRY) 


\title{
The Temple of 'Athtar dhu-Qabd (Temple B)
}

\author{
Chapter 3 \\ Il tempio di 'Athtar dhu-Qabd. \\ Lo scavo
}

Alessio Agostini

\section{Introduzione}

Lo scavo del tempio B dell'area sacra di Barāqish è iniziato nel dicembre del 2004 sotto la direzione di Alessandro de Maigret e si è sviluppato nel corso di tre campagne, ${ }^{1}$ riuscendo a portare alla luce l'intera sala ipostila e l'avancorpo d'accesso con la sua scalinata monumentale. ${ }^{2}$ Alcuni interventi di consolidamento hanno poi permesso di mettere in sicurezza alcune parti dell'edificio e di restaurare alcuni elementi del mobilio rimasto in posto. ${ }^{3}$ Questo scavo è stato successivo a quello del Tempio A, dedicato al dio Nakrah, lavoro pressoché portato a termine negli anni $1989-1992,{ }^{4} \mathrm{e}$ poi ripreso nel 2002-2003 solo per alcune parti dell'area esterna all'ingresso, in concomitanza con gli interventi di restauro che hanno interessato l'intero edificio. ${ }^{5}$

Le iscrizioni rinvenute hanno permesso di determinare che questo Tempio B era dedicato al dio 'Athtar dhuQabḍ, divinità suprema del pantheon mineo e che il suo nome proprio doveva essere Qabdum. ${ }^{6}$ Per comodità d'esposizione, continueremo a riferirci al tempio di

\footnotetext{
1 Le informazioni che seguono sono tratte dai diari di scavo da me tenuti durante le tre campagne in qualità di capo-cantiere, sotto la supervisione del capo-missione Alessandro de Maigret. Sabina Antonini, che ringrazio sentitamente, ha messo a disposizione anche i diari di scavo di de Maigret, i quali hanno consentito utili verifiche e approfondimenti. Altri documenti presenti nell'archivio della Missione hanno permesso ulteriori integrazioni, recuperando anche alcuni risultati di laboratorio che il Direttore non aveva avuto il tempo di considerare pienamente. Per ulteriori dettagli sull'organizzazione di queste campagne e sui partecipanti, si veda il capitolo 1 in questo volume. Si ringrazia infine Francesco Fedele per i suoi commenti a una versione preliminare del presente lavoro.

2 Alcune informazioni preliminari sono state pubblicate in de Maigret 2006, de Maigret 2009b, e Agostini 2015.

3 Scigliano e Paladino, capitolo 14, in questo volume.

${ }_{4}$ Relativamente allo scavo del tempio di Nakrah, v. de Maigret 1991a; 1991b; 1993; 2004a e de Maigret e Robin 1993.

${ }_{5}$ Cfr. de Maigret 2004a; v. Scigliano e Paladino, capitolo 13, in questo volume.

6 Cfr. Agostini 2011 e capitolo 4, in questo volume.
}

Nakrah come Tempio A e al tempio di 'Athtar dhuQabd come Tempio B. I due edifici si trovano affiancati e distanziati tra loro circa sette metri. Il Tempio A è localizzato più a sud-est, prospiciente le mura cittadine, in prossimità dei bastioni T44 e T45 e della postierla; mentre il Tempio $B$ si trova più verso il centro della città. Entrambe le strutture sono pressoché allineate secondo la direttrice nord-ovest/sud-est, parallelamente quindi all'asse longitudinale dell'insediamento.

A giudicare dalle vestigia ancora emerse, l'area sacra doveva comprendere anche un terzo edificio di culto, Tempio C, probabilmente dedicato al dio Wadd secondo quanto suggeriscono alcune iscrizioni; ma di questo si nota al momento solo l'affioramento dei due stipiti dell'entrata principale, il che farebbe ritenere che il corpo dell'edificio si trovi in un pessimo stato di conservazione; ciò nonostante, la posizione dell'entrata permette di stabilire un orientamento perpendicolare rispetto ai Templi A e B. Il Tempio $\mathrm{C}$ non è stato ancora oggetto di indagini specifiche.

Mentre il Tempio A fu facilmente identificato dall'affioramento di parte della trabeazione della copertura, sulle cui lastre s'impiantarono alcune recenti casupole islamiche oramai in stato di abbandono, il Tempio B si riconosceva dall'affioramento di una porzione del portale d'ingresso e delle parti sommitali di quattro grandi pilastri relativi al propileo frontale dell'edificio, tratto distintivo di molta architettura sacra nell'Arabia meridionale (figg. 1-2). Gli elementi della complessa trabeazione, che doveva connettere il propileo alla facciata dell'edificio, erano ormai perduti, ma ciò che restava era comunque in ottimo stato di conservazione. In particolare, si poteva notare come il tipo di calcare utilizzato per queste strutture fosse del tipo oolitico, quindi di natura più compatta rispetto a quello 'a lumachelle' impiegato nelle corrispondenti strutture d'ingresso del Tempio A, il quale, invece, per la sua tendenza a esfoliare, aveva richiesto attenti 
interventi di consolidamento. L'affioramento di questi pilastri tra le recenti strutture islamiche spiega l'appellativo di 'Propylaeum Temple' che talvolta si incontra nella letteratura anteriore in riferimento a questo edificio. ${ }^{7}$ Il Tempio B si inserisce quindi all'interno della tipologia architettonica del tempio ipostilo intra-muros di ambito mineo, ${ }^{8}$ arricchendola di ulteriori particolarità finora inedite.

\section{Nota metodologica}

La metodologia di scavo utilizzata è stata quella consueta della MAIRY, che prevede il riferimento a una numerazione progressiva di zanābill, secondo la quantità di materiali di volta in volta rinvenuto, e secondo la progressione dei livelli stratigrafici, distinti per ciascun ambiente o locus. Ogni zanbil [zanbil, cestino, contenitore] è pertanto associabile a uno strato in maniera univoca, ma il materiale pertinente a un singolo strato, se particolarmente abbondante, può essere contenuto anche in più zanābill. Tali livelli sono da considerarsi quindi più propriamente come strati archeologici indipendenti e non come levée. Per un elenco degli zanābìl pertinenti alle sole fasi preislamiche si veda la Tabella 2 .

Ogni locus e ogni muro è distinto da un numero univoco, distinguendo a loro volta quelli pertinenti al periodo di vita mineo (con prefisso L e M, fig. 3) da quelli relativi alle fasi islamiche (Li e Mi). Per i livelli islamici sono stati utilizzati intervalli numerici diversi in base alle aree di scavo parallelamente attive (questo solo per la prima campagna, 2004/2005: zona A e zona B) e utilizzando nuovi intervalli per ciascuna campagna successiva, al fine di evitare ripetizioni. Per i livelli minei la numerazione di loci e muri è stata fatta partire da 100 per mantenere una chiara distinzione da quella usata a suo tempo durante lo scavo del Tempio A. ${ }^{9}$

\section{Il livello mineo: il tempio di 'Athtar dhu-Qabḍ}

I livelli che gravavano sul tempio mineo hanno presentato densità differenti che in parte hanno influito sulla conservazione della struttura sottostante, e questo ha naturalmente condizionato anche l'andamento dello scavo. Uno strato di sabbia molto fine è filtrato durante il periodo di abbandono attraverso le strutture,

\footnotetext{
7 Cfr. Jung 1989, 190 (n. 16, fig. 6, tavv. I, IIa e IIb); Schmidt 1982b, 125 (fig. 34, tavv. 44b e 45a).

8 Schmidt 1997; Breton 1998; Darles 2014; Arbach e Darles 2019.

9 Zona A (direzione sud-est), muri: Mi 1-199/M 100-149; loci: Li 1-199/L 100-149. Zona B (nord-ovest), muri: Mi 200-399/M 150-199; loci Li 200-399/L 150-199. Il muro Mi200, allineato a sua volta con M101, segna la divisione tra le due zone di scavo, di tale suddivisione si è però tenuto conto solo durante la prima campagna, esclusivamente per i livelli islamici. Si ricorda inoltre che le strutture islamiche del Tempio A erano state indicate da M o L, seguite da una successione consonantica progressiva.
}

ma non si tratta di un livello ovunque omogeneo. Siamo propensi a interpretare questo strato come deposito eolico, analogamente a quanto supposto durante le indagini del Tempio A e coerentemente con la situazione archeologica generale. ${ }^{10}$ L'accumulo diseguale di questo strato può essere dovuto alla presenza di strutture superstiti che possono averne limitato la deposizione; è anche possibile che in alcuni punti sia stato in parte rimosso in antico - ipotesi pure da tenere in considerazione, specie se pensiamo alla necessità di realizzare qualche fossa di fondazione per i muri in pietra durante il primo momento islamico. In ogni caso, la spoliazione del materiale lapideo del tempio mineo ha certamente contribuito a disturbare $\mathrm{i}$ depositi precedenti, sia perché si è andati a smantellare le strutture intatte, sia perché si era pescato sul crollo (v. oltre).

Alla fine della messa in luce di tutta la sala ipostila, si è dovuto constatare che il tempio si presentava meglio conservato nei quadranti meridionali, quelli cioè più vicini al Tempio A, mentre i muri perimetrali a nord-est e parte di quelli a nord-ovest si presentavano pressoché rasati fino ai primi filari. Anche all'interno della sala gli alzati sono solo parzialmente conservati e solo quattro dei dodici pilastri che vi erano in origine sono rimasti intatti e in posto; nonostante questo, la planimetria e l'organizzazione interna sono ancora perfettamente leggibili (fig. 4). Tutta la struttura d'ingresso, invece, che comprende la scalinata, la terrazza e il propileo, si è meglio mantenuta (fig. 5). Possiamo quindi affermare che la situazione si presenta in modo speculare a quella incontrata nel Tempio A, dove è la sala ipostila a essersi ben conservata, fino a parte della sua copertura con tutti i dodici pilastri di sostegno ancora in posto, mentre a essere carente è il dispositivo di accesso, anche a causa del diverso materiale impiegato.

\subsection{L'avancorpo}

La facciata nord-ovest dell'edificio è stata completamente messa in luce solo durante la terza campagna di scavo, cioè dopo aver messo in sicurezza tutto il propileo. Una scalinata monumentale, della larghezza di 5,46 m, si trova in asse con l'entrata ed è costituita da un'unica rampa al centro. Si è potuto mettere in luce una fila di sette gradini, dalle pedate e alzate un poco irregolari (fig. 6). ${ }^{11}$ L'area di appoggio della scala non è stata scoperta estensivamente, pertanto non si può escludere che il numero fosse

\footnotetext{
10 Questo strato ha raggiunto lo spessore di $1 \mathrm{~m}$ nella sala ipostila del Tempio A; cfr. de Maigret e Robin 1993, 440. Il prof. Fedele consiglia una maggiore cautela, dato che 'l'attribuzione di questo deposito e dei consimili all'azione eolica è stata inferita a vista e non su base sedimentologica, sia pure soltanto qualitativa, e può quindi essere imperfetta' (comunicazione personale).

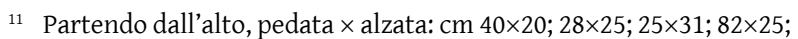
$25 \times 26 ; 30 \times 22 ; 25 \times 24$.
} 
maggiore, benché di poco. A più livelli a partire dalla base della scalinata sono state individuate delle lenti di terra più compatta, mista a frammenti di carbone, gesso e pietrame sparso, con poca ceramica, che quindi possono essere associate all'ultimo periodo di vita del tempio (ultima Fase Minea oppure Fase Intermedia - v. sotto).

I lati della scalinata sono protetti da due ali laterali (M132 e M134) e tutta la struttura si aggancia alla terrazza antistante per $2,5 \mathrm{~m}$ di altezza. Questa terrazza misura in larghezza $13 \mathrm{~m}$ e corrisponde pertanto alla larghezza dell'intero lato della facciata. Su di essa poggiano i sei grandi stilobati su cui svettano i possenti pilastri del propileo, il quale è a sua volta fiancheggiato da due piccole aree aperte laterali larghe ciascuna circa $3 \mathrm{~m}$; due balaustre, alte $1 \mathrm{~m}$, le incorniciano specularmente, ed entrambe presentano il filare superiore esterno decorato con il consueto fregio a dentelli, tratto tipico del coronamento architettonico sudarabico. Un blocco realizza un fronte allineato con la testa degli stilobati verso la terrazza (M131), che manca però specularmente nella porzione nord-ovest, tra L127 e L123 - ambienti peraltro molto mal conservati fino al livello del lastricato. Le due porzioni laterali delle terrazze, L125 e L127, erano probabilmente fornite di sedili laterali che incorniciavano i lati interni, dato che le murature interne presentano i filari inferiori solo sbozzati, quindi non destinati a essere esposti, almeno in origine.

Il basolato della terrazza si è conservato solo parzialmente, dato che le singole lastre sono di un materiale calcareo molto friabile. Il piano della terrazza presenta una sensibile inclinazione verso nord-ovest, come tutto l'avancorpo, fenomeno ulteriormente accresciuto dal fatto che le sue murature non sono state cucite con quelle del corpo della sala ipostila. Il muro laterale sud-ovest della terrazza, M128, presenta una struttura solida e compatta, ma appunto slegata dal muro perimetrale sud-ovest del tempio, M102, il che ha prodotto un distanziamento in alto di circa $20 \mathrm{~cm}$; i suoi filari sono tuttavia perfettamente predisposti per addentellarsi con gli aggetti dei filariinferiori di M102. La situazione si presenta naturalmente speculare in L123, tra M129 e M124. Un ulteriore slittamento è ravvisabile in direzione sud-ovest: la base di Pf, ad esempio, si trova ben $8 \mathrm{~cm}$ al di sotto dalla quota su cui si impostano gli stilobati di $\mathrm{Pa}$ e $\mathrm{Pb}$, che sembrano invece essere restati in posto. La frequente inclinazione verso nord-ovest di molte strutture indagate, ben visibile anche nel Tempio $\mathrm{A},{ }^{12}$ può essere stata provocata da movimenti tellurici di cui sono state notate tracce pure nel riempimento islamico a tratti fessurato. I registri riportano almeno tre eventi sismici che hanno interessato lo Yemen in

${ }_{12}$ Nel Tempio A la misura di questa pendenza era $3^{\circ} 20^{\prime}$; v. de Maigret 1991b, 161. epoca medievale. ${ }^{13}$ In effetti, la stabilità delle strutture superstiti del Tempio A e dell'avancorpo del Tempio B è stata possibile solo grazie al riempimento accumulatosi durante le fasi islamiche.

L'entrata del tempio era in origine schermata da un imponente portico aggettante, con propileo esastilo. All'interno del muro anteriore M103 s'incuneano i sei massicci stilobati o basamenti longitudinali $(\mathrm{Ba}$; $\mathrm{Bb} ; \mathrm{Bc} ; \mathrm{Bd} ; \mathrm{Be} ; \mathrm{Bf})$ su cui erano alloggiati i pilastri del propileo (fig. 7). La testa a vista degli stilobati del pronao si presenta lavorata con la consueta picchiettatura e cornice lisciata, tipica delle strutture murarie più monumentali. Questi plinti sono larghi 87 $\mathrm{cm}$ e possiamo ipotizzare che abbiano una lunghezza complessiva di circa $3,10 \mathrm{~m}$; sono inoltre distanziati tra loro da interstizi della larghezza di $30 \mathrm{~cm}$ e riempiti con lastre ribassate. Tra i plinti Bd e Be è inserito un blocco lungo e squadrato che serviva da gradino aggiuntivo sul piano di L101. I pilastri distano invece da M103 per 2,35 m. Da questa quota base dei plinti abbiamo quindi misurato l'altezza totale dei pilastri anteriori, che è 6,15 m.

Solo iquattro pilastricentrali sono integri $(\mathrm{Pb} ; \mathrm{Pc} ; \mathrm{Pd} ; \mathrm{Pe})$ e ancora in posto, anche grazie al deposito islamico che li ha progressivamente sommersi. Per la completa messa in luce dei pilastri integri si è dovuto prima procedere a una stabilizzazione con un'impalcatura metallica, per via della loro leggera ma regolare inclinazione verso nord-ovest che li avrebbe resi troppo instabili una volta liberati, essendo privi della trabeazione superiore. Tali pilastri, infatti, dovevano essere in origine fermati da un architrave longitudinale e poi con delle grosse travi perpendicolari, che avrebbero dovuto a loro volta agganciarsi in alto all'architrave dell'entrata, nello stesso M103. È possibile che questa travatura non fosse parallela ai plinti sottostanti, ma inclinata verso il basso in direzione del portale d'ingresso, come dimostra il ben conservato pronao del tempio extra-muros di 'Athtar dhu-Qabd a Qarnaw. ${ }^{14}$

Il sesto pilastro Pf, quello all'estremità sud-ovest, è stato rinvenuto spezzato in due tronconi, con la metà inferiore ancora alloggiata in posto, mentre la metà superiore era adagiata verso sud-ovest, inglobata nei livelli islamici successivi, ma ancora allineata alla sua base. Del pilastro di nord-ovest, $\mathrm{Pa}$, abbiamo rinvenuto solo alcuni frammenti ai piedi della scalinata, compresa la parte superiore con il tenone. Lo stilobate $\mathrm{Ba}$, destinato al sostegno di questo pilastro, era quindi

\footnotetext{
${ }_{13}$ Un terremoto risulta registrato nel 1072, e altri fenomeni tra il XIV e XV sec. Cfr. National Geophysical Data Center / World Data Service (NGDC/WDS): Significant Earthquake Database. National Geophysical Data Center, NOAA. doi:10.7289/V5TD9V7K [consultato il 14.09.2018]. 14 Grohmann 1963, 158-159, 162. Cfr. anche Breton 1998, 63-66, 7577.
} 
libero e si può notare che la mortasa di alloggiamento è profonda poco più di $1 \mathrm{~cm}$, il che rivela una grande maestria costruttiva, dato che questi pilastri, pesanti ciascuno circa sei tonnellate, si reggevano sul loro peso e sull'incastro assicurato dalla trabeazione sovrastante.

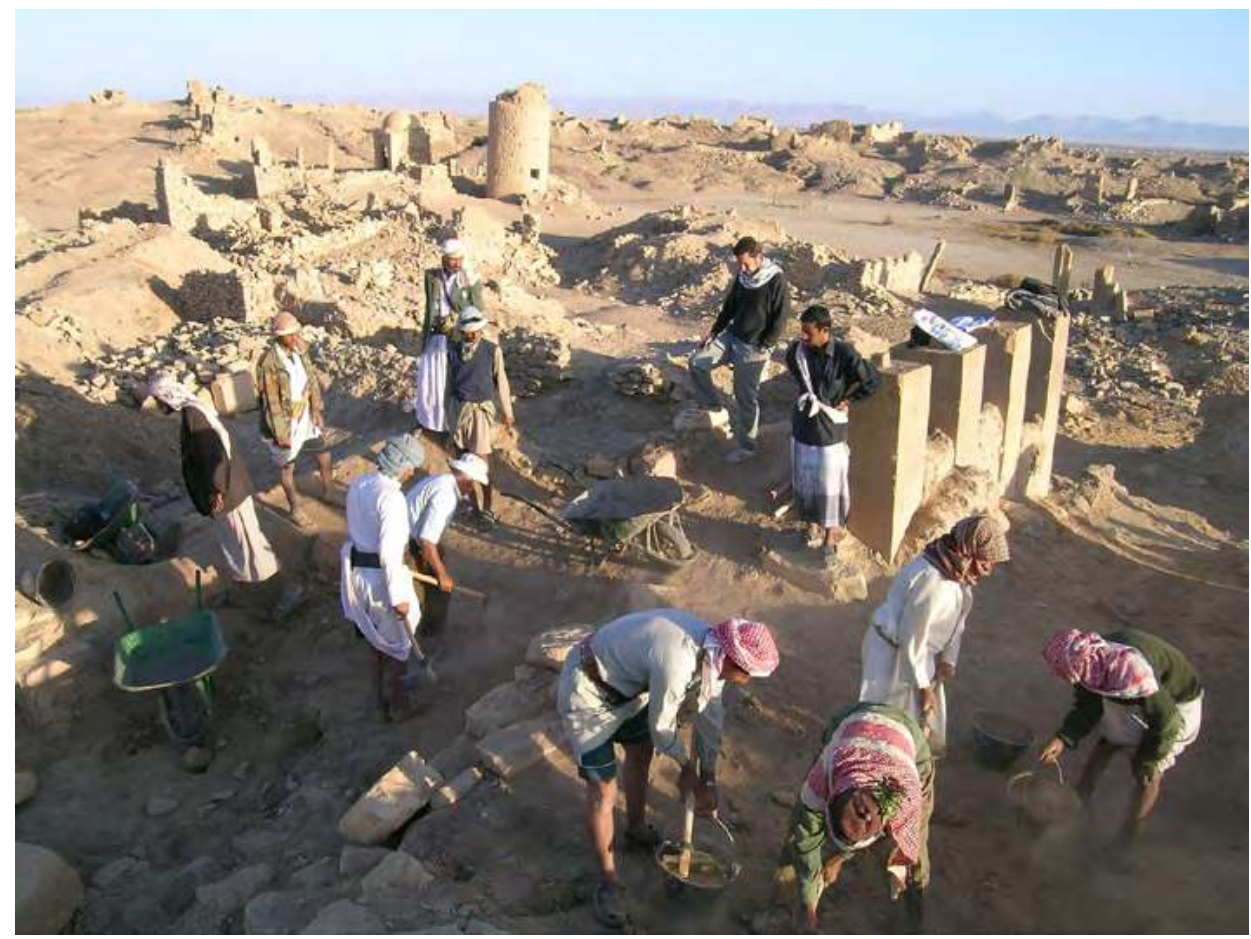

Figure 1. Inizio delle operazioni di scavo sull'area del Tempio B. (A. de Maigret 2004 @MAIRY)

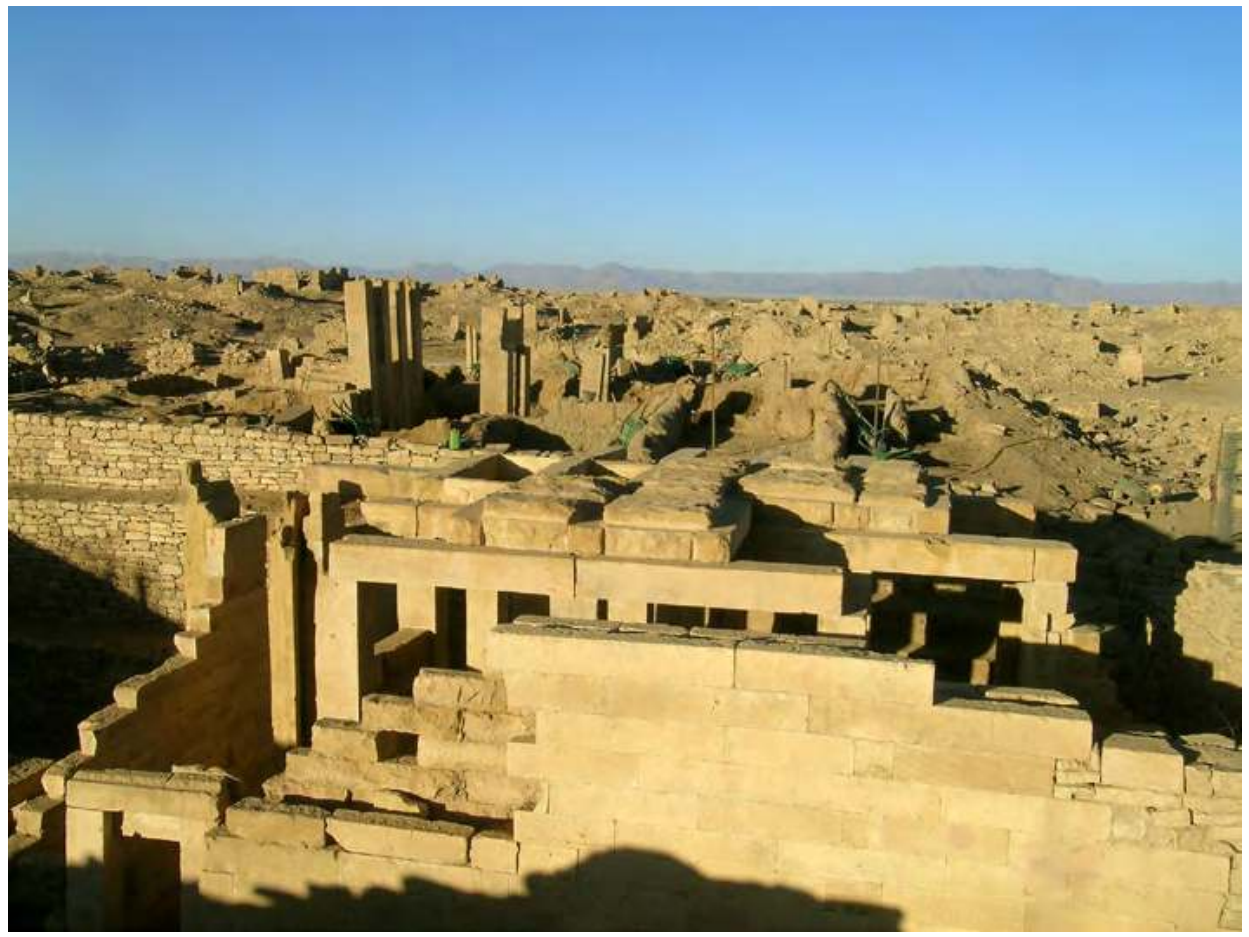

Figure 2. L'area sacra di Barāqish da sud-est; in primo piano il tempio di Nakrah. (A. de Maigret 2006 CMAIRY) 


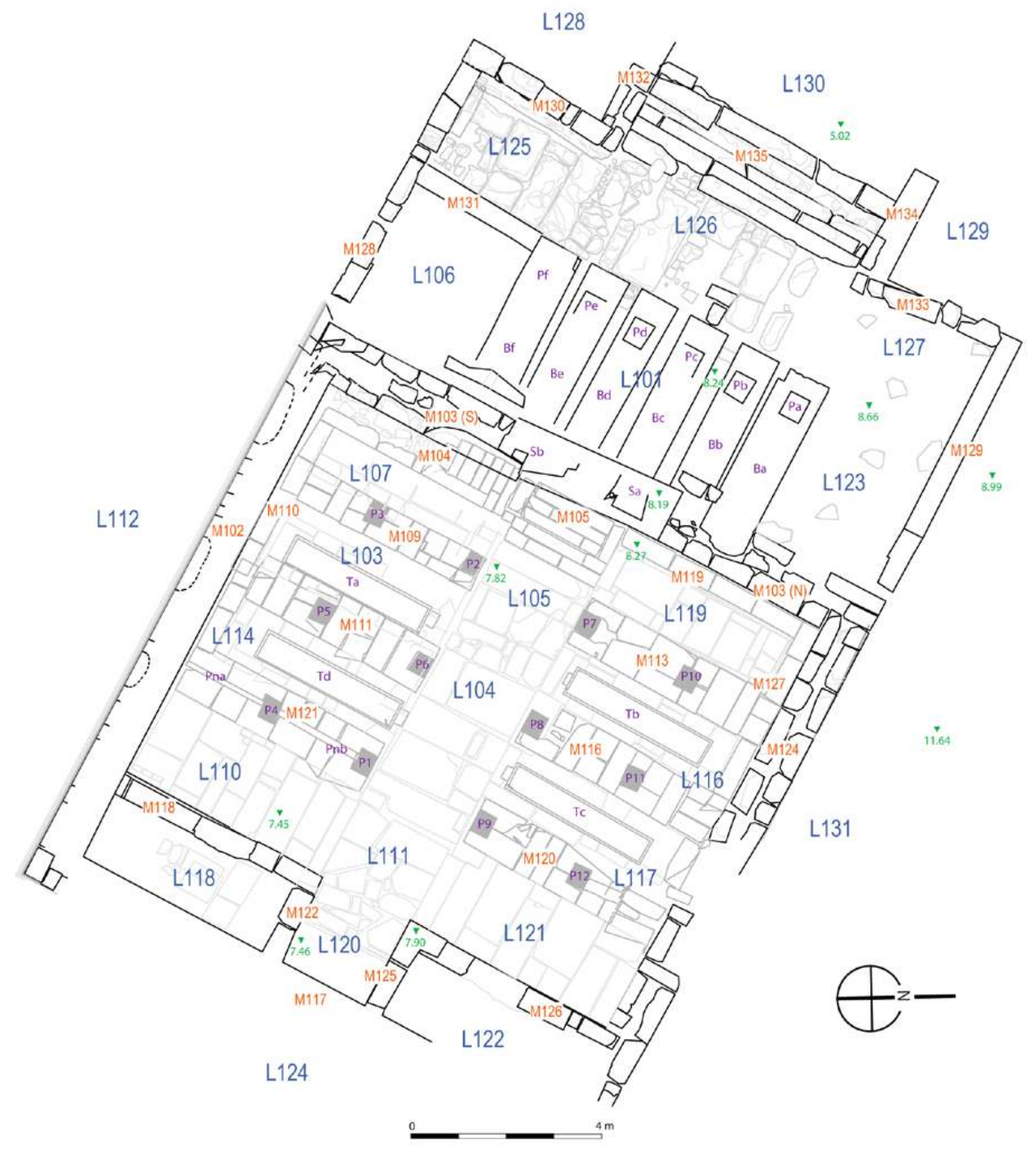

Missione Archeologica Italiana

Barāqish 2006

Rilievo planimetrico del Tempio B

Romolo Loreto; adattato da Laetitia Munduteguy (2018)

Figure 3. Planimetria del Tempio B, con indicazioni dei muri e dei loci. (Rielaborazione di L. Munduteguy e A. Agostini da rilievo di R. Loreto 2019 OMAIRY) 


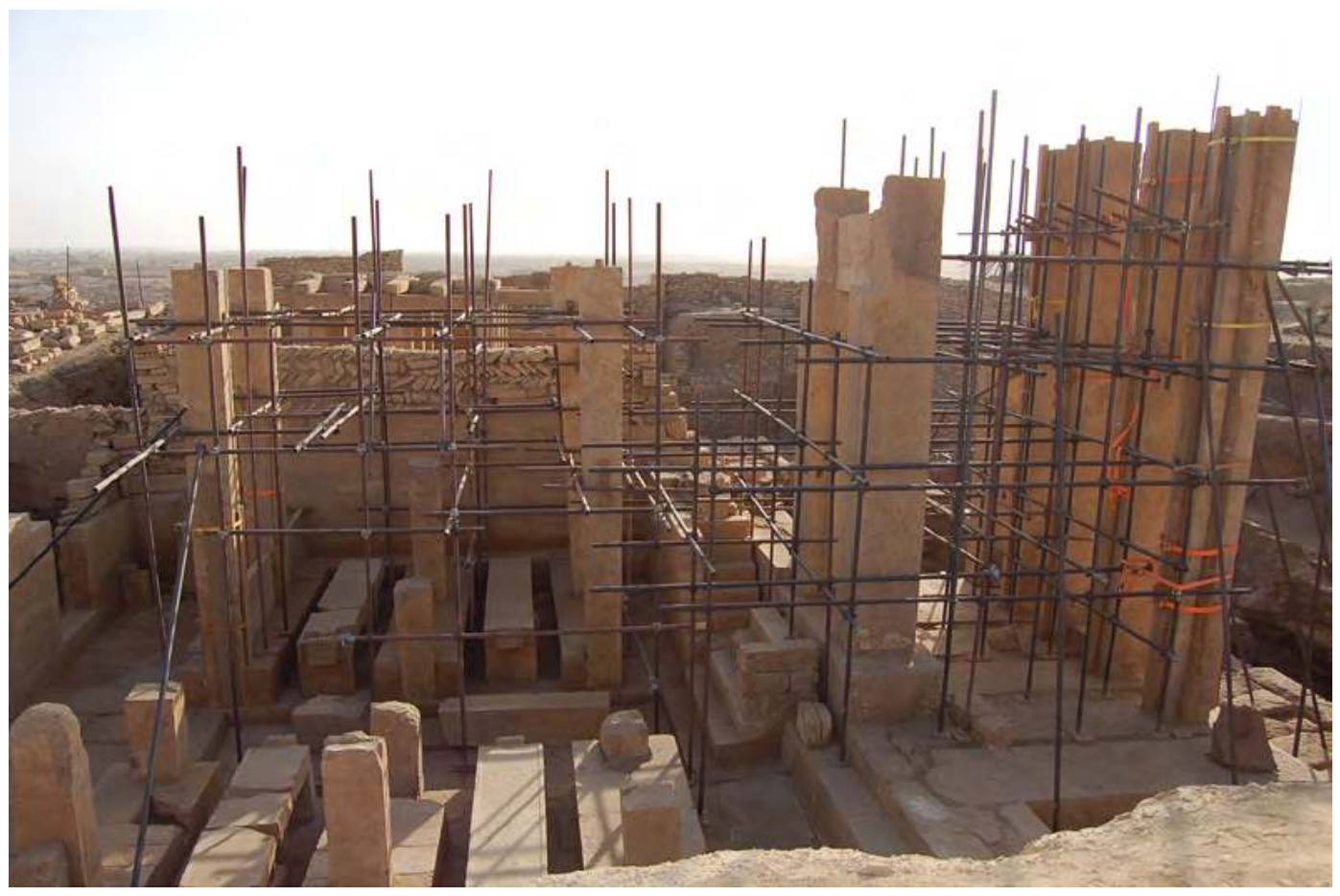

Figure 4. Il tempio di 'Athtar dhu-Qabḍ dopo le operazioni di scavo, da nord-est. (R. Loreto 2006 @MAIRY)

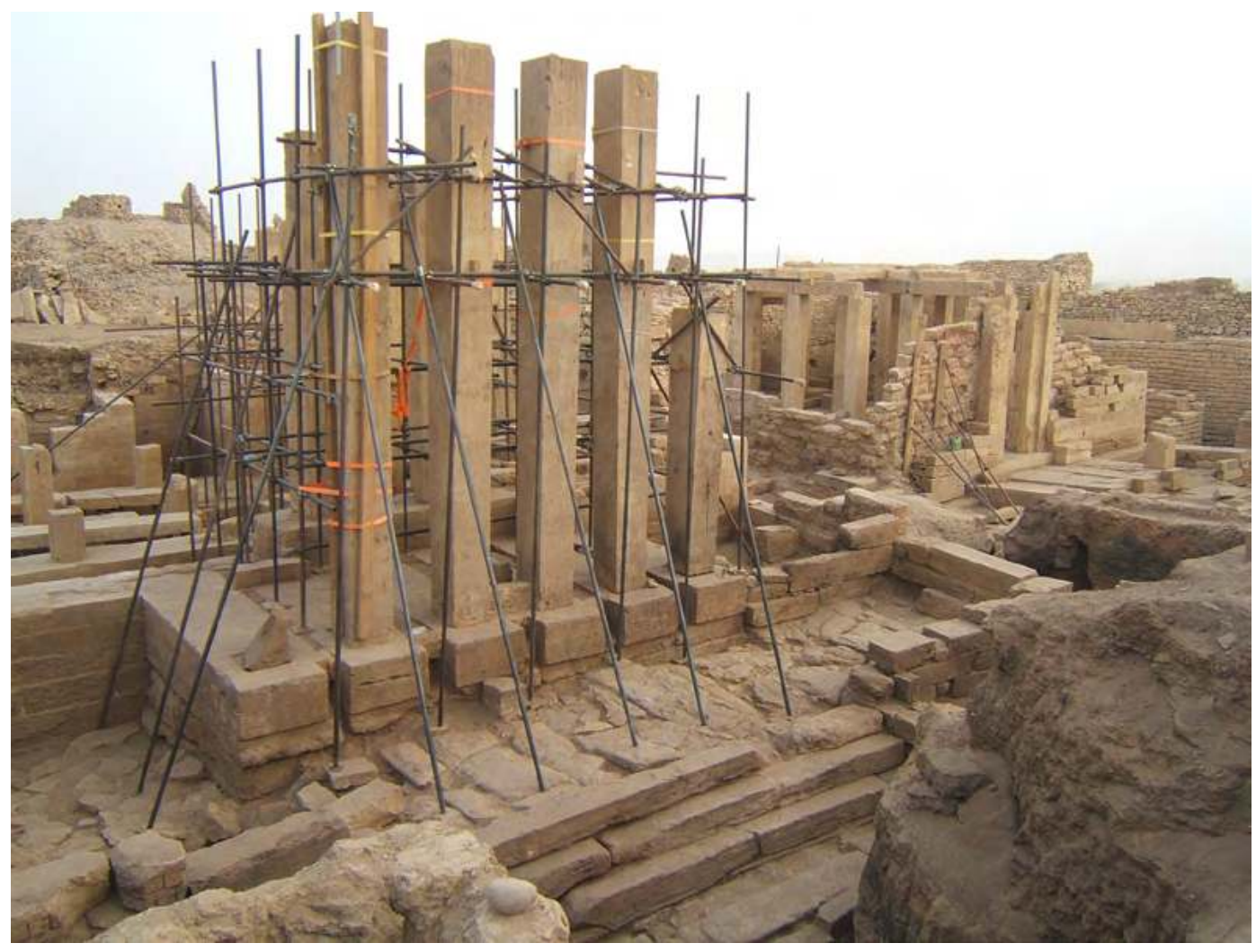

Figure 5. L'area di accesso al tempio di 'Athtar dhu-Qabd dopo le operazioni di scavo, da nord-ovest. (R. Loreto 2006 @MAIRY) 


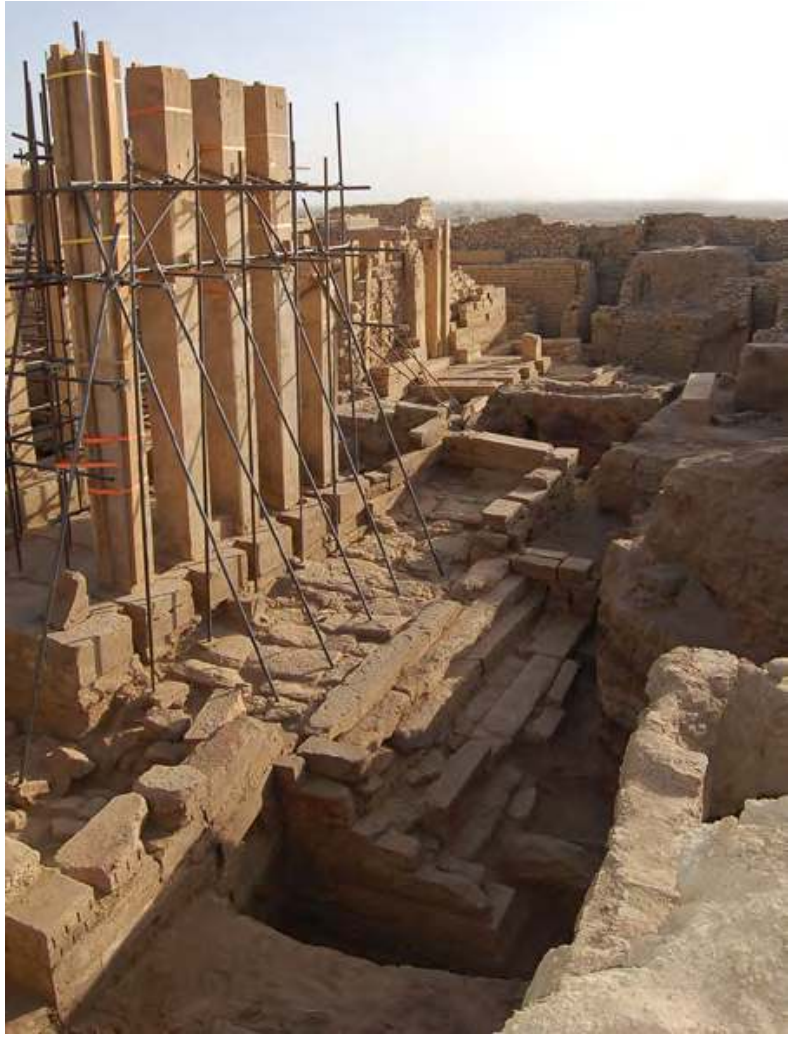

Figure 6. La scalinata e la terrazza del tempio di 'Athtar dhuQabd dopo le operazioni di scavo, da nord. (R. Loreto 2006 OMAIRY)

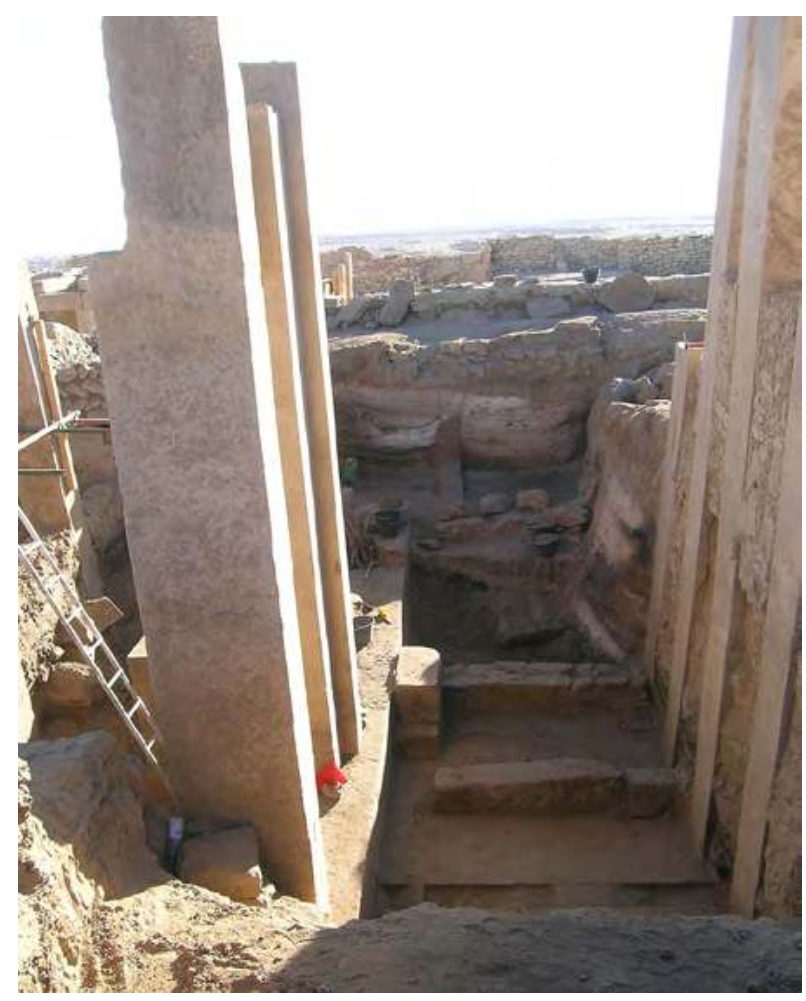

Figure 7. L101, tra il propileo e il portale d'ingresso al tempio, da nord-est. (A. de Maigret 2005 @MAIRY)

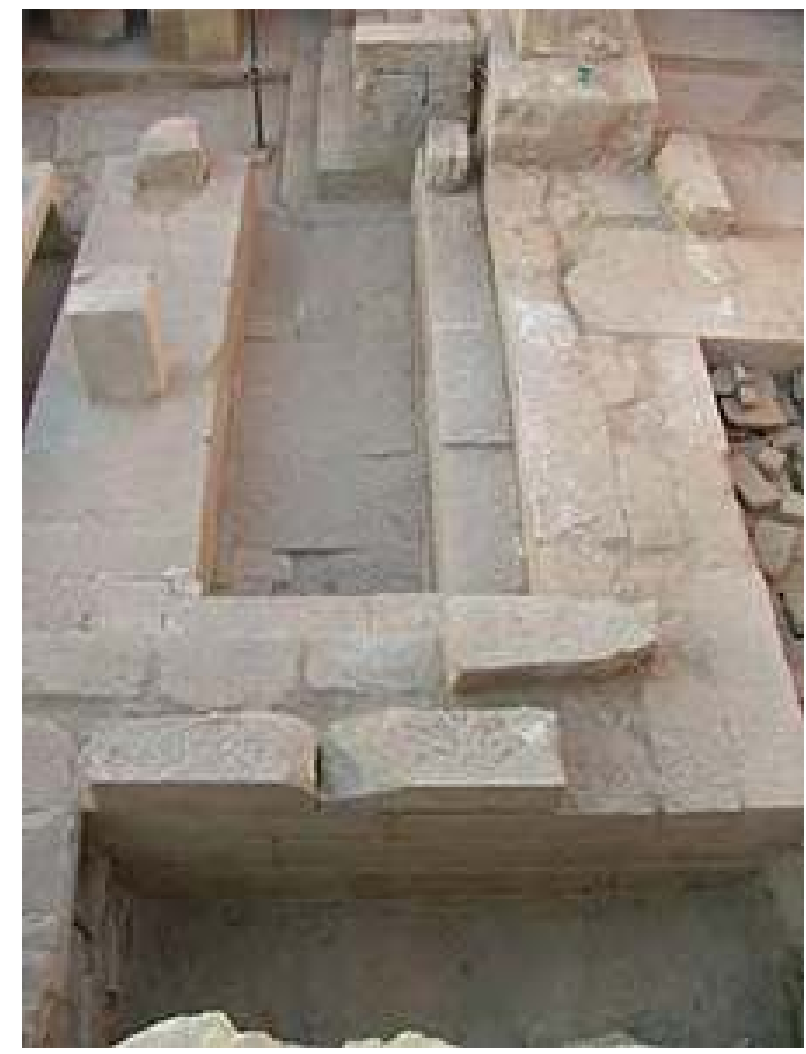

Figure 8. Il muro perimetrale del tempio nell'angolo nord, che racchiude L119. (A. de Maigret 2005 CMAIRY) 


\subsection{La sala ipostila}

I quattro muri perimetrali della sala sono realizzati a doppia cortina, con uno spessore complessivo di circa $1,10 \mathrm{~m}$, all'interno dei quali si trova della terra mista a poco pietrame sciolto (fig. 8). La faccia a vista di ciascun blocco in calcare è decorata con la consueta leggera picchiettatura centrale e cornice liscia. ${ }^{15}$ I primi sette filari inferiori esterni, che emergono subito sopra il piano di calpestio, presentano la tipica messa in opera con leggero aggetto ad andamento progressivo verso il basso: i blocchi a filo presentano uno spessore medio di circa $22-25 \mathrm{~cm}$, mentre quelli della base arrivano fino a $40 \mathrm{~cm}$ circa. In prossimità dell'angolo sud-ovest esterno del tempio, all'intersezione tra M102 e M128, troviamo la porzione del muro perimetrale meglio conservata: in M102 si contano ancora 14 filari fino a un'altezza massima di 3,30 m. I filari conservati di M102 diminuiscono progressivamente verso sud-est, tanto che avvicinandosi all'angolo con M117 si riducono a soli due filari.

Gli stipiti, Sa e Sb, del portale d'ingresso (M101) sono perfettamente conservati e ci appaiono oggi molto imponenti, ulteriormente slanciati dalla pressoché totale assenza del muro della facciata (M103), che è stato quasi integralmente spoliato (cfr. fig. 4). Gli stipiti poggiano a loro volta su un grosso blocco spesso $50 \mathrm{~cm}$ inglobato nella base di M103 e che fa anche da soglia. I due stipiti racchiudono in alto un'ampia lastra, la cui faccia esterna è perfettamente lisciata come quella degli stipiti, e che si trovava subito al di sotto dell'architrave, ormai perduto. Anche questa lastra superiore era visibile al di sopra del deposito islamico. Gli stilobati che si trovano in corrispondenza degli stipiti (M101) sono di dimensioni maggiori rispetto agli altri (larghezza 1,08 $\mathrm{m}$, spessore $55 \mathrm{~cm}$ e lunghezza 3,60 m). Nell'angolo di Sa, verso l'interno del tempio, vi è ancora traccia di un cardine bronzeo sul quale ruotava la porta minea, che di conseguenza doveva essere composta di una singola anta, mancando tracce analoghe su Sb. L'apertura dell'ingresso risulta infatti relativamente stretta $(85 \mathrm{~cm})$, mentre si sviluppava in altezza per circa $5 \mathrm{~m}$, conferendo a questa porta un aspetto elegante e slanciato.

Uno degli aspetti più inconsueti di questa sala ipostila è la quota ribassata di $-1 \mathrm{~m}$ del suo piano interno rispetto al piano esterno all'ingresso, L101, e questo spiega la presenza di una piccola scala di cinque gradini (M105), che si appoggia a M103 e al grande blocco della soglia (figg. 9-10); il lato nord-est di questa scaletta è anche rifinito da un piccolo muretto (M106). Subito a destra di questa scala, verso l'interno, se ne avvia un'altra

${ }_{15}$ Si tratta della cosiddetta marginally drafted, pecked masonry per la quale si rimanda all'ormai classico lavoro di van Beek 1958; cfr. anche Darles, capitolo 10, in questo volume, fig. 24.
(M104) che sale verso sud-ovest. Anche questa struttura rappresenta un'assoluta novità nel disegno dei templi ipostili sudarabici, perché indica l'accesso a un livello superiore. Entrambe queste scale si appoggiano al muro della facciata e non rappresentano dunque un'unità strutturale col resto dell'edificio, benché probabilmente coeve all'impianto del tempio (fig. 11). La scala M104 è lateralmente chiusa verso sud-est da un muro che si imposta a partire dal suo terzo gradino inferiore.

La scarsità delle strutture rimaste e la natura insufficiente del crollo non consentono di farsi un'idea chiara di come fosse realizzato un ipotetico piano superiore: se fosse cioè a forma di balconata interna o ballatoio, oppure di un piano continuo che copriva tutta la sala. Un'altra possibilità è che la scala M104 servisse semplicemente per accedere al tetto. In realtà, tutte queste ipotesi presentano delle difficoltà. Dobbiamo anzitutto rilevare che i fianchi dei quattro pilastri integri all'interno della sala non presentano tracce di appoggio di un piano o di una balaustra a una quota intermedia. La possibilità che tale piano di sviluppasse sopra la quota sommitale dei pilastri ci pare d'altronde confliggere proprio con l'altezza di questi, di circa 5,5 m: un ulteriore alzato avrebbe quindi impresso all'edificio un'eccessiva sproporzione verso l'alto, con conseguenti problemi di pesantezza strutturale e di staticità. Se la scala M104 serviva per accedere al piano del tetto, ipotesi che ci pare al momento preferibile, doveva comunque raggiungere la quota sommitale dei pilastri. Un dislivello di quasi sei metri è però difficilmente raggiungibile se questa scala avesse mantenuto una pendenza uniforme, se cioè tutti i suoi gradini avessero avuto le stesse dimensioni dei cinque gradini superstiti - cosa che non siamo in grado di verificare.

In questa porzione della sala ipostila, cioè in L107, L103 e parte di L104, è stato intercettato un consistente crollo di pietre minee, tra cui alcune metope a dentelli pertinenti alla parte sommitale delle murature, che sono state poi rimosse con l'ausilio di una movimentazione meccanica. Sotto di queste era un abbondante deposito di sabbia fine, riconoscibile per la consistenza impalpabile, nonché per il colore marrone chiaro. In questa parte della sala, quindi, il livello islamico si è necessariamente impostato a una quota più alta, il che è comprensibile proprio per la presenza di questo ingombrante crollo (fig. 12). È infatti ragionevole pensare che non tutte le aree siano state subito rioccupate, né che lo siano state in modo tra loro omogeneo.

La faccia del muro sud-est di M104, verso l'interno della sala, presenta in alto un'ampia iscrizione che si caratterizza per una grafia piccola e densa (Y.04.B.B.5). Un'altra iscrizione in situ (Y.04.B.B.6), analoga per grafia e tenore del testo, è presente poco distante anche sulla 
faccia interna del muro perimetrale M102, ma risulta purtroppo mancante della parte iniziale, incisa sui filari superiori del muro che sono stati asportati. Entrambe sembrano riguardare disposizioni di natura legale e rituale. Le porzioni di muro su cui sono incise entrambe queste iscrizioni presentano tracce di pigmentazione rossa, che però non copre l'incisione dei singoli caratteri, e si può quindi pensare che la superficie destinata all'iscrizione venisse pitturata prima di procedere all'incisione, in modo da dare maggior risalto alle lettere.

I pilastri interni alla sala poggiano su un pavimento rialzato di $20 \mathrm{~cm}$ rispetto a quello del corridoio centrale (L104) su cui scende la scala centrale M105. Sono conservati integralmente solo i pilastri P1, P2, P3 e P4, che sono alti 5,5 m (misura basata su P4). La base dei pilastri è inglobata all'interno della muratura dei sedili che formano i cenacoli attorno alle quattro tavole offertorie, con un'organizzazione dello spazio interno del tutto analoga a quella del Tempio A; solo la faccia laterale dei pilastri che delimitano il corridoio centrale risulta del tutto scoperta (figg. 13-14). Tutte le loro facce presentano la stessa decorazione a leggera picchiettatura e cornice, come i blocchi delle murature. Il pilastro P1 ha una breve iscrizione incisa sulla sua faccia di nord-est (Y.05.B.B.14).

La prima tavola a essere stata messa in luce è quella sud-ovest in L103 (Ta). Il lato corto verso il corridoio centrale si caratterizza per un fregio aggettante decorato da sette stambecchi recumbenti, sotto di essi è una fascia incorniciata con l'iscrizione Dyt (Y.04.B.B.11), mentre alla destra degli stambecchi è il monogramma certamente riferibile al nome familiare Ġazīr (Gzr, cfr. fig. 12). Quella affrontata in L116, la $\mathrm{Tb}$, ha solo sei stambecchi nel fregio e sotto presenta l'iscrizione $D \underline{t}^{\prime}$ (Y.05.B.B.1), mentre Tc (in L117, a nordest) ha l'iscrizione $\operatorname{Hrf}$ (Y.05.B.B.9). Per ultima abbiamo individuato $\mathrm{Td}$ (in L114, a sud-est), con l'iscrizione $Y \dot{g} l$ (Y.05.B.B.10) accompagnata da un altro monogramma, che si può sciogliere nel nome proprio Bi'athtar $\left(B^{3} t\right.$ tr) ${ }^{16}$ Il piano di ciascuna tavola ha un leggero bordo rilevato, largo un paio di centimetri, con un piccolo scolatoio nel lato corto anteriore. Le ultime due sono quelle ad aver subito i danni maggiori dal crollo, ma sono stati tuttavia individuati quasi tutti i frammenti pertinenti e avrebbero quindi potuto beneficiare di un restauro integrativo.

\footnotetext{
$16 D t^{\prime}$ è generalmente associato con la stagione primaverile (termine che ricorre anche in una delle tavole del Tempio A: Y.92.B.A.38), mentre Hrf con quella autunnale (cfr. iscrizione Y.92.B.A.39 dal Tempio A). Per Dyt cfr. Y.92.B.A.40, sempre dal Tempio A, associabile all'estate. La quarta tavola con iscrizione $Y \dot{g} l$, indicante con ogni probabilità l'inverno, non trova riscontro nel Tempio $\mathrm{A}$, poiché qui le tavole superstiti erano solo tre. Per una più completa trattazione degli aspetti epigrafici si rimanda al capitolo 4, in questo volume, e ad Agostini 2020a.
}

Come già anticipato, la spoliazione delle strutture è stata particolarmente devastante nei quadranti settentrionali del tempio, ravvisabile anche nella minore entità del crollo. Parte della porzione nordovest della banchetta M116 è stata asportata e pure i pilastri di questa metà della sala sono stati interessati da gravi manomissioni, quasi certamente da ascrivere alla prima fase islamica, tanto che oggi si presentano assai frammentari o pressoché rasati (cfr. P7, fig. 15). Se osserviamo il mausoleo Osmanide, ${ }^{17}$ che sorge verso il centro di Barāqish, ci accorgiamo che è stato realizzato in parte col reimpiego di alcuni pilastri di epoca minea, forse in larga parte provenienti dal più vicino Tempio $C$, ma non è escluso che qualcosa provenisse anche dal Tempio B, dato che le dimensioni delle basi dei pilastri che si trovano nel mausoleo coincidono con quelle registrate in questo tempio $(c .48 \times 39 \mathrm{~cm})$.

Dallo scavo della navata centrale L104 provengono alcune lastre con decorazione a pannello, una tavola offertoria con gocciolatoio a testa di toro in un calcare a grana molto fine, ${ }^{18}$ un'altra testa di toro sbozzata e una lamina in argento. ${ }^{19}$ La ceramica è piuttosto grossolana e certamente pertinente all'ultima fase di frequentazione del tempio. ${ }^{20}$ L'abbondante gesso rinvenuto in quest'area potrebbe essere dovuto alla rimozione di parte delle strutture minee avvenuta in epoca islamica antica.

Le ultime due file di sedili sostenevano alcuni pannelli verticali, incastrati nell'ultima fila di pilastri verso sud-est, che dovevano schermare i lati del transetto agli occhi di chi entrava. Di nuovo la situazione è meglio conservata solo nella metà meridionale del tempio (fig. 16). Su M121, tra il muro perimetrale $\mathrm{M} 102$ e $\mathrm{P} 4$, vi è un pannello rimasto in situ (Pna) con un'iscrizione (Y.05.B.B.12) rivolta verso l'ingresso, che per grafia si presenta molto diversa rispetto alle iscrizioni su M104, M102 e P1, dato che qui i caratteri sono di dimensioni sensibilmente maggiori e dalle proporzioni più slanciate. Questa iscrizione è la parte finale di un testo che iniziava in un pannello che doveva essere collocato superiormente e che non è stato trovato in posto. Accanto a questa, tra $\mathrm{P} 4 \mathrm{e}$ $\mathrm{P} 1$, vi è un pannello speculare, ancora in posto, ma anepigrafo (Pnb). Entrambi questi pannelli presentano la superfice perfettamente lisciata e due fasce laterali in rilievo. Dallo scavo del transetto L110 è emersa la metà superiore di un pannello, franata sul suo lato posteriore e fratturata in ordinati frammenti; questa porzione presenta un'iscrizione (Y.05.B.B.13), dello stesso tenore della precedente. La parte superiore del pannello è

\footnotetext{
17 Fontana 2016.

18 Per tutti gli oggetti preislamici citati si faccia riferimento a Antonini, capitolo 5, in questo volume. Catalogo degli oggetti, n. 5.

19 Catalogo degli oggetti, n. 24.

20 Zanbil Y.05.B./20 e cfr. Buffa, capitolo 7, in questo volume.
} 
decorata con un doppio dentello che contiene al centro un motivo a persiana bipartita. Il suo ritrovamento alle spalle del pannello anepigrafo farebbe ritenere che la sua collocazione originaria potesse essere al di sopra di questo Pnb e il fatto che si trovasse al di sopra alcuni centimetri del riempimento sabbioso suggerisce che sia franata in un momento successivo all'abbandono. Tuttavia, l'andamento del testo farebbe propendere per una collazione reciproca di questi due testi, una possibilità non in contrasto con le misure del supporto, nonostante il luogo di ritrovamento di Y.05.B.B.13 suggerisca una certa cautela. Entrambe queste iscrizioni sono di fondamentale importanza per la collocazione storica della costruzione del tempio (v. qui sotto, $\S$ 1.5 e capitolo 4 , in questo volume). I pannelli erano dunque composti ciascuno di due lastre sovrapposte e nascondevano le due ali laterali del transetto. Dobbiamo pensare che la situazione fosse analoga anche tra L117 e L121, dove tra M124 e P12 abbiamo rinvenuto solo un piccolo moncone di una delle lastre inferiori ma senza iscrizione (fig. 17).

Tutto il transetto costituito da L110-L111-L121 è a una quota superiore rispetto alla navata centrale L104 e allo stesso livello dei cenacoli laterali. Un campione di carbone (Bar.05.B/2a) prelevato dal livello di pavimentazione di L110, in prossimità di M118 e in angolo con M122, è stato ritenuto idoneo per un'analisi radiometrica al ${ }^{14} \mathrm{C}$, restituendo una datazione tra il VI e V secolo a.C. ${ }^{21}$ Tracce di piccoli travetti lignei sono anche in L111, ma difficilmente attribuibili a elementi del mobilio mineo - come vedremo tra breve, questo ambiente è stato molto disturbato in antico. Sia in L110, sia in L111, è stata raccolta abbondante ceramica di periodo sudarabico preislamico, frammista a un deposito sabbioso forse di natura eolica. ${ }^{22}$

Tra la ceramica si segnala un interessante vaso, a pareti spigolose e a base pressoché quadrata, di probabile funzione cultuale, ricostruito sulla base di alcuni frammenti rinvenuti nel livello Mineo B di L121 (zanbil B.05.B./58), insieme ad altri da L111, ma provenienti dal livello Intermedio successivo (B.05.B./74). ${ }^{23}$ È possibile che la sua utilizzazione si sia protratta nel tempo, ma si deve anche tener presente che gli ultimi strati preislamici di L111 sono stati sensibilmente disturbati da un saccheggio che già in antico aveva interessato il quadrato proprio di fronte alla cella, come si evince

\footnotetext{
${ }^{21}$ Questo risultato è discusso nella sezione $\S 1.5$ (v. qui sotto) e da Fedele, capitolo 16, in questo volume.

${ }^{22}$ Cfr. zanbil B.05.B.58; B.05.B.59. Preferiamo in questo caso parlare di ceramica genericamente 'sudarabica', dato che è possibile che sia piuttosto da associare alla frequentazione amirita post-minea, anche se le due fasi non sembrano presentare significative differenziazioni a livello di produzione ceramica. Cfr. Buffa, capitolo 7 , in questo volume.

${ }^{23}$ Cfr. sotto, $\S 2$ e Buffa, capitolo 7, in questo volume, fig. 4, n.10 e fig. 9 .
}

chiaramente dalla sistematica e regolare asportazione delle lastre pavimentali in tutta la superficie del locus - alcune di queste lastre sono state poi rinvenute accatastate disordinatamente in L110 e nella camera laterale L118. ${ }^{24}$ Lo stesso L118 ha subìto una parziale rottura e rimozione del suo lastricato, specie in prossimità dei suoi muri laterali M102 e M122 - dove sono poi stati realizzati dei piccoli ricettacoli (v. oltre). La soglia di questo vano in $\mathrm{M} 118$ è ben rialzata rispetto a L110 e non presenta tracce di cardini, ma si nota che gli stipiti laterali hanno degli incavi centrali longitudinali in cui doveva essere inserita l'imbotte della porta, presumibilmente in legno. La faccia interna dei blocchi delle due camere laterali L118 e L122 è solo sbozzata: questi non dovevano infatti essere visibili, dato che queste stanze erano tenute chiuse e poco accessibili, ed è possibile che fossero usate come sacrari (fig. 18).

Il tempio presenta quindi un'unica cella centrale (L120) che si trova a sud-est, opposta all'entrata, in fondo al corridoio centrale. I muri laterali M122 e M125 presentano dei fori di sezione quadrangolare. Si nota inoltre che la lavorazione di uno dei filari dei blocchi della faccia interna alla cella non si presenta uniforme: il filare in basso è solo sbozzato, con una fine cornice esterna, ma con bugnatura interna più grossolana; segue un filare dalla superficie totalmente liscia, e al di sopra di questo si ha la consueta lavorazione con cornice liscia e leggera picchiettatura interna. La pavimentazione della cella non è conservata, ma sono emerse delle lastre calcaree irregolari poste di taglio, in corrispondenza grossomodo con la linea mediana del vano; una delle lastre laterali più piccole sembra sia in posto, quella più grande che doveva essere posta al centro è invece stata rinvenuta un poco scalzata verso l'interno, ma è ancora ben visibile la spessa malta che le legava reciprocamente e con il blocco della soglia (fig. 19). Non è chiara la loro funzione: sostenevano forse un piano rialzato in altro materiale, ad esempio un podio di legno? La presenza di un podio rialzato di circa $30 \mathrm{~cm}$ sul piano del transetto è coerente con la quota alla quale corre il filare dalla superficie liscia, che disegnerebbe quindi una sorta di elegante fascia in corrispondenza del piano del podio; i piccoli aggetti dei filari sottostanti, ben visibili in M122 e M117 (stranamente assenti però in M125), ben si configurano come ulteriori sostegni per questo possibile piano rialzato. A livello di questi aggetti si trova nel vano un livello di mattoni ben compatti. Cosa dovesse sostenere questa struttura può essere oggetto di molte speculazioni: dobbiamo pensare a un'istallazione cultuale, sulla cui forma e aspetto non abbiamo però al momento nessun confronto (ma si faccia attenzione ai frammenti di ossidiana rinvenuti nel saggio che ha interessato questo vano: v. sotto, §

\footnotetext{
24 A fine scavo queste lastre sono state riposizionate in L111, il cui pavimento visibile nelle foto è quindi da considerare una integrazione.
} 
1.4). ${ }^{25}$ Viene tuttavia naturale pensare che questa parte del tempio non fosse lasciata totalmente esposta, ma è possibile che fosse schermata (forse con l'ausilio di una tenda?). Certo è che tutto questo podio, con il suo sostegno e parte del suo riempimento, sono stati divelti al momento della spoliazione del tempio.

\subsection{Tempio A e Tempio B a confronto}

Ci pare utile offrire in questa sede una rapida disamina delle principali similarità e delle più evidenti differenze che emergono da un'osservazione in parallelo di questi due contigui edifici di culto. Limitandoci agli aspetti più macroscopici, possiamo rilevare che i due templi condividono la scelta dei materiali, anche se diversamente utilizzati nella varie strutture, una stessa tecnica costruttiva e l'impianto generale del tempio ipostilo. ${ }^{26}$

Le strutture esterne del Tempio B presentano significativi elementi di novità. Si nota anzitutto il diverso disegno della scalinata d'accesso, non su tre lati come nel Tempio A, ma che s'imposta al centro del lato della facciata, in asse con l'entrata, e si compone di almeno sette gradini, contro i cinque del Tempio A - il quale comunque si imposta a una quota inferiore di $1,70 \mathrm{~m}$ rispetto al Tempio $\mathrm{B} \cdot{ }^{27} \mathrm{La}$ presenza di un propileo esastilo, rispetto a quello a quattro pilastri del Tempio $A$, è certamente uno degli aspetti che conferisce al Tempio $\mathrm{B}$ una maggiore monumentalità, ulteriormente esaltata anche dalla sua quota più elevata, e tutto ciò poteva essere coerente col fatto che questo secondo edificio fosse dedicato a 'Athtar dhu-Qabd, la suprema divinità del pantheon mineo. Gli stessi pilastri del propileo sono anche di dimensioni maggiori nel Tempio B: sono alti infatti $6,15 \mathrm{~m}$, mentre quelli del Tempio A arrivano a 5,60 $\mathrm{m}$. Da ciò consegue che anche l'entrata $\mathrm{e}$ gli stipiti che delimitano l'ingresso sono più imponenti nel Tempio $B$; per questi è stato oltretutto utilizzato un calcare di qualità migliore rispetto al Tempio $\mathrm{A}$ (oolitico invece di quello 'a lumachelle'). Il Tempio B si presenta di dimensioni più ampie rispetto al Tempio $\mathrm{A}$ e la sala ipostila è di forma quadrata $(13 \times 13 \mathrm{~m}$ all'esterno $)$, rispetto a quella pressoché rettangolare dell'altro tempio $(11 \times 12 \mathrm{~m})$. I muri perimetrali del Tempio $\mathrm{B}$ sono più spessi rispetto al Tempio $\mathrm{A}(110$ contro $90 \mathrm{~cm})$. I pilastri della sala ipostila sono più alti nel Tempio $B$, 5,50 $\mathrm{m}$ invece di $4 \mathrm{~m}$.

Come si è detto, le differenze più notevoli che riguardano il Tempio B sono la quota ribassata del

\footnotetext{
25 Sul problema della rappresentazione delle divinità nel contesto delle culture arabiche preislamiche è ancora in corso un vivace dibattito, si vedano pertanto i vari contributi raccolti da Sachet e Robin 2012 per un più aggiornato status quaestionis.

26 Si veda anche il contributo di Darles, capitolo 10, in questo volume.

27 de Maigret 2006, 88.
}

piano della sala rispetto al piano esterno e l'accesso a un piano superiore. Anche se questo piano superiore fosse semplicemente il tetto della sala, ipotesi che ci sembra da prediligere, è comunque significativo che per accedervi fosse stata concepita una scala in muratura, con la stessa tecnica costruttiva dell'intera cella. Se si vuole accettare la presenza di un secondo piano coperto - o di un ballatoio interno - si potrebbe guardare all'architettura sudarabica del Tigray etiopico, dove il tempio di Yeha fornisce il confronto più evidente. ${ }^{28} \mathrm{Si}$ ricordi, tuttavia, che anche la 'Sagrestia' del Tempio A aveva una scala interna per un accesso al piano superiore, ma certamente era un vano di dimensioni e altezza inferiori rispetto a quelle della sala ipostila.

L'organizzazione e l'orientamento degli spazi interni della sala ipostila sono tra i due templi assolutamente similari, specie per quanto riguarda la presenza dei dodici pilastri interni, che dividono lo spazio in cinque 'navate' e per la presenza dei quattro cenacoli con relative tavole offertorie stagionali - benché, com'è noto, queste siano state ridotte a tre nel Tempio A in un secondo momento, per una riorganizzazione dello spazio interno e la creazione del passaggio verso la 'Sagrestia'. ${ }^{29}$ Osservando più nello specifico le tavole offertorie e la loro denominazione si vede che entrambi i templi hanno sulla navata sinistra la tavola $D t^{2}$ e $H r f$, osservando dall'entrata, mentre sulla destra il Tempio B ha Dyț e poi verso il transetto si trova la tavola Y $\dot{g} l . \mathrm{Nel}$ Tempio $\mathrm{A}$, invece, la riorganizzazione di cui si è detto ha portato alla soppressione della tavola $Y \dot{g} l$ al cui posto è stata collocata quella denominata Dyț. Un'ulteriore similarità si riscontra per la presenza di alcuni pannelli lapidei, talvolta iscritti, inseriti verticalmente tra il muro perimetrale e i pilastri laterali verso il fondo della sala in direzione sud-est, e che servivano a schermare le ali laterali del transetto. ${ }^{30}$

Le differenze tornano invece a essere rilevanti nell'area dell'adyton, che entrambi i templi hanno opposta all'entrata e quindi orientata verso sud-est. Il Tempio A presenta tre celle al centro, con due vani chiusi alle estremità laterali, mentre nel Tempio B abbiamo un'unica cella centrale, che pure corrisponde alla larghezza del corridoio al centro, e i vani laterali sono ancora due, ma ciascuno occupa la larghezza delle due navate laterali. Il transetto del Tempio B (L121L111-L110) si presenta al livello dei cenacoli laterali. L'assenza del lastricato nella porzione di transetto di fronte alla cella (L111) non permette di verificare se anche qui fosse stato ricavato un bacino nel pavimento per raccogliere liquidi sacrificali, come i tre di fronte

\footnotetext{
28 de Maigret 2010b.

29 Agostini 2020a.

30 Nel Tempio A abbiamo un unico pannello iscritto (Y.92.B.A.21+30), con una concezione decorativa del tutto simile a quella dei pannelli rinvenuti nel Tempio $\mathrm{B}$.
} 
alle celle del Tempio A; le lastre certamente pertinenti a quest'area, rinvenute dislocate poco lontano, tenderebbero tuttavia ad escludere la presenza di simili incavi nel pavimento. Quindi, l'assenza di canalette di scolo e di ricettacoli, che sono invece ben visibili nel Tempio A lungo il transetto e verso l'esterno (a nordest), farebbe ritenere che ci fosse pure un'importante differenza a livello di pratica rituale tra i due edifici. La cella del Tempio B ci risulta aperta sul corridoio e, come abbiamo visto, doveva essere caratterizzata da una sorta di podio che doveva presumibilmente contenere una istallazione, forse un simulacro, qualunque forma questo avesse. Nelle tre celle centrali del Tempio A si aveva una pavimentazione lastricata, al centro della quale era un alloggiamento per delle basi risultate

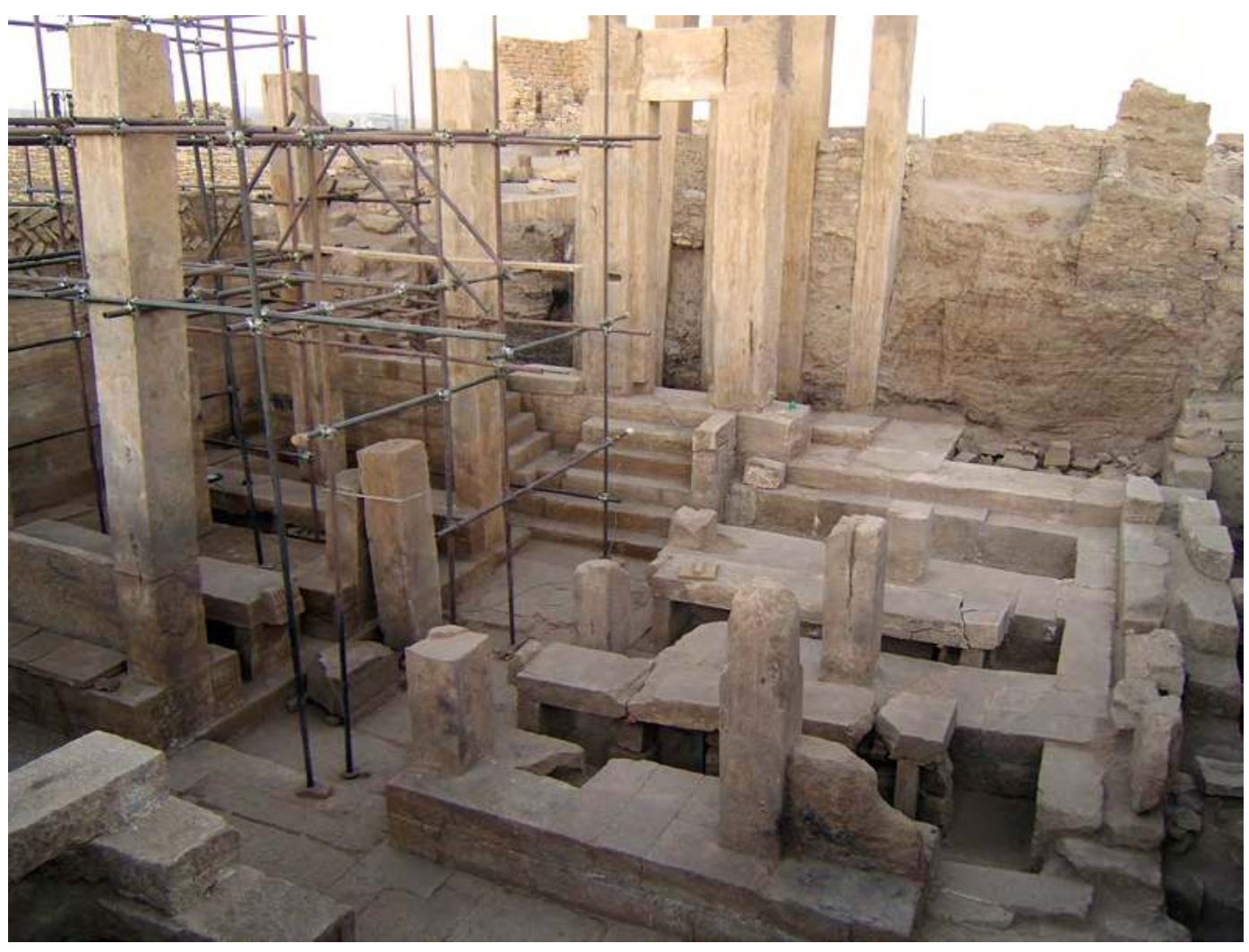

Figure 9. La sala ipostila dopo le operazioni di scavo, da est. (A. de Maigret 2005 @MAIRY) 


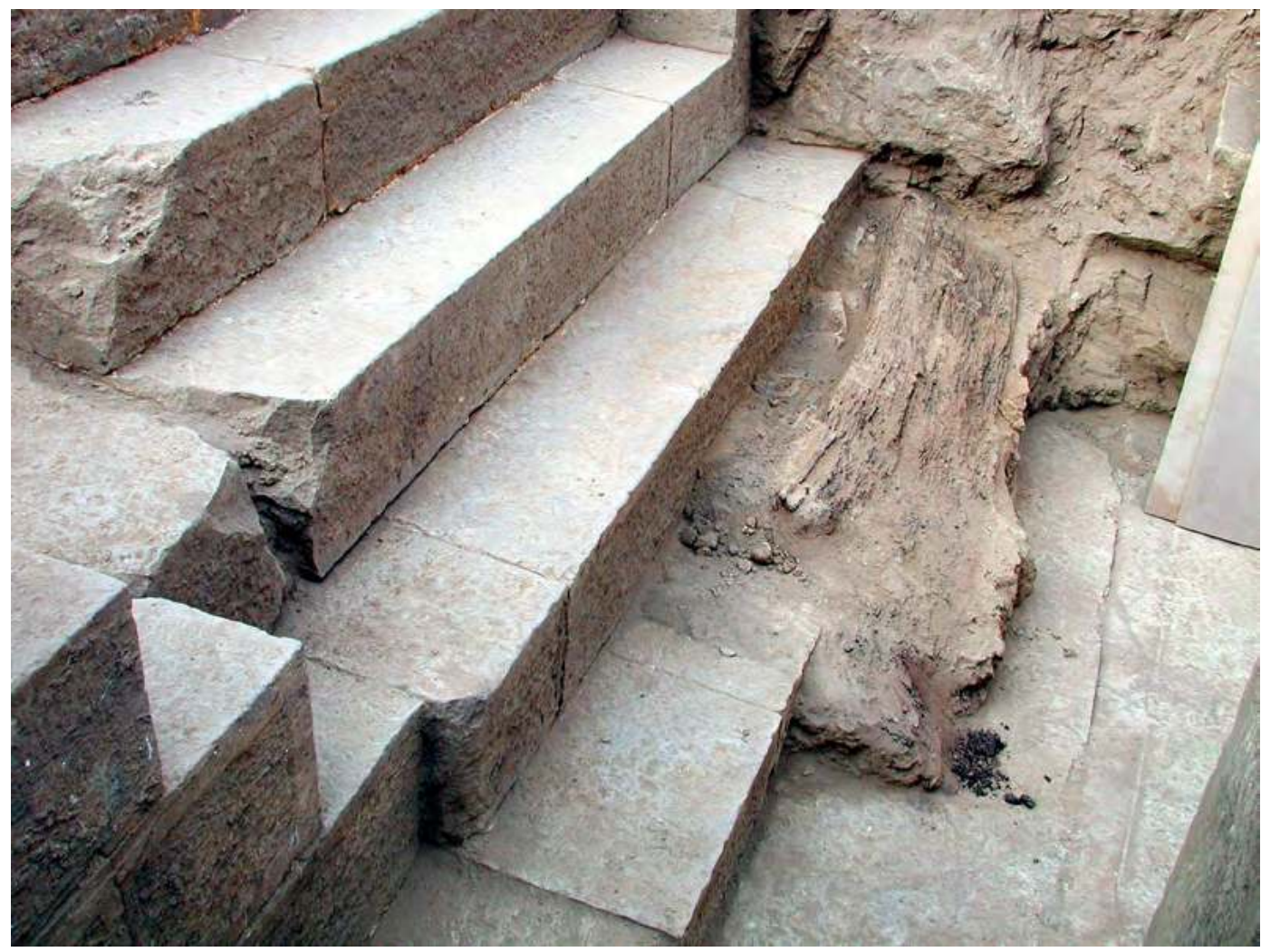

Figure 10. L'area d'impostazione delle scale M105 e M104 all'entrata del tempio, con i resti di un asse ligneo forse pertinente alla porta, da sud. (A. de Maigret 2004 OMAIRY)

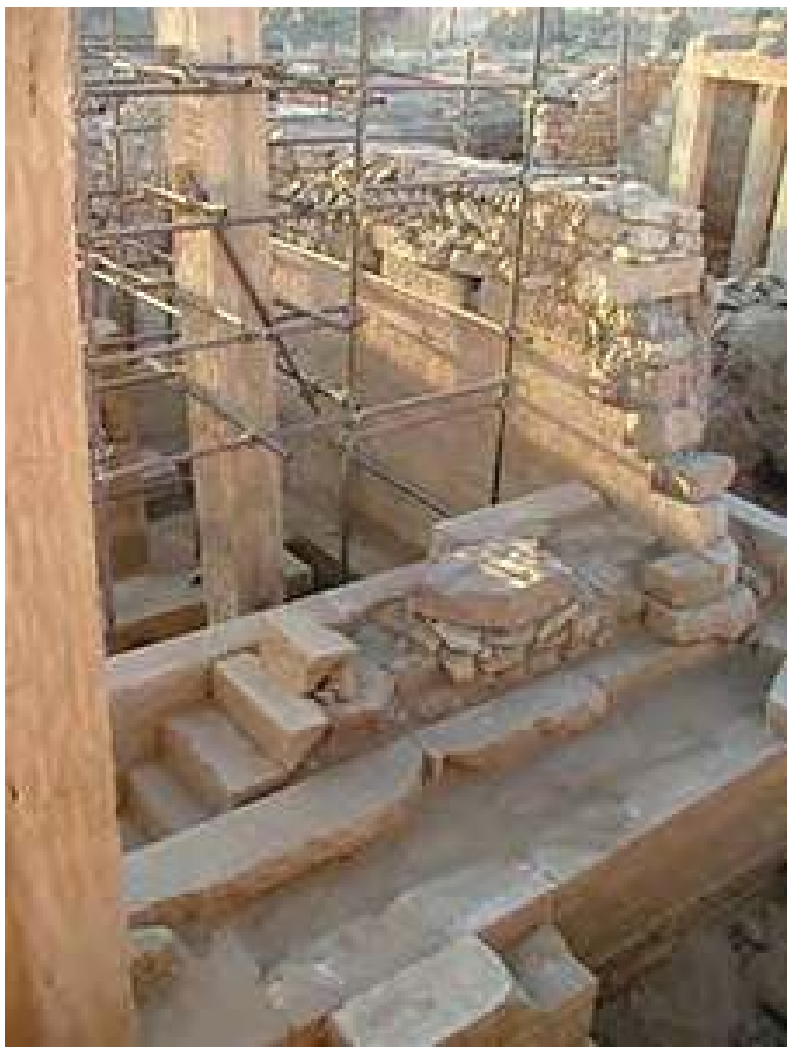

Figure 11. La scala M104 che si appoggia alla porzione sud del muro perimetrale M103, da nord.

(A. de Maigret 2005 OMAIRY) 


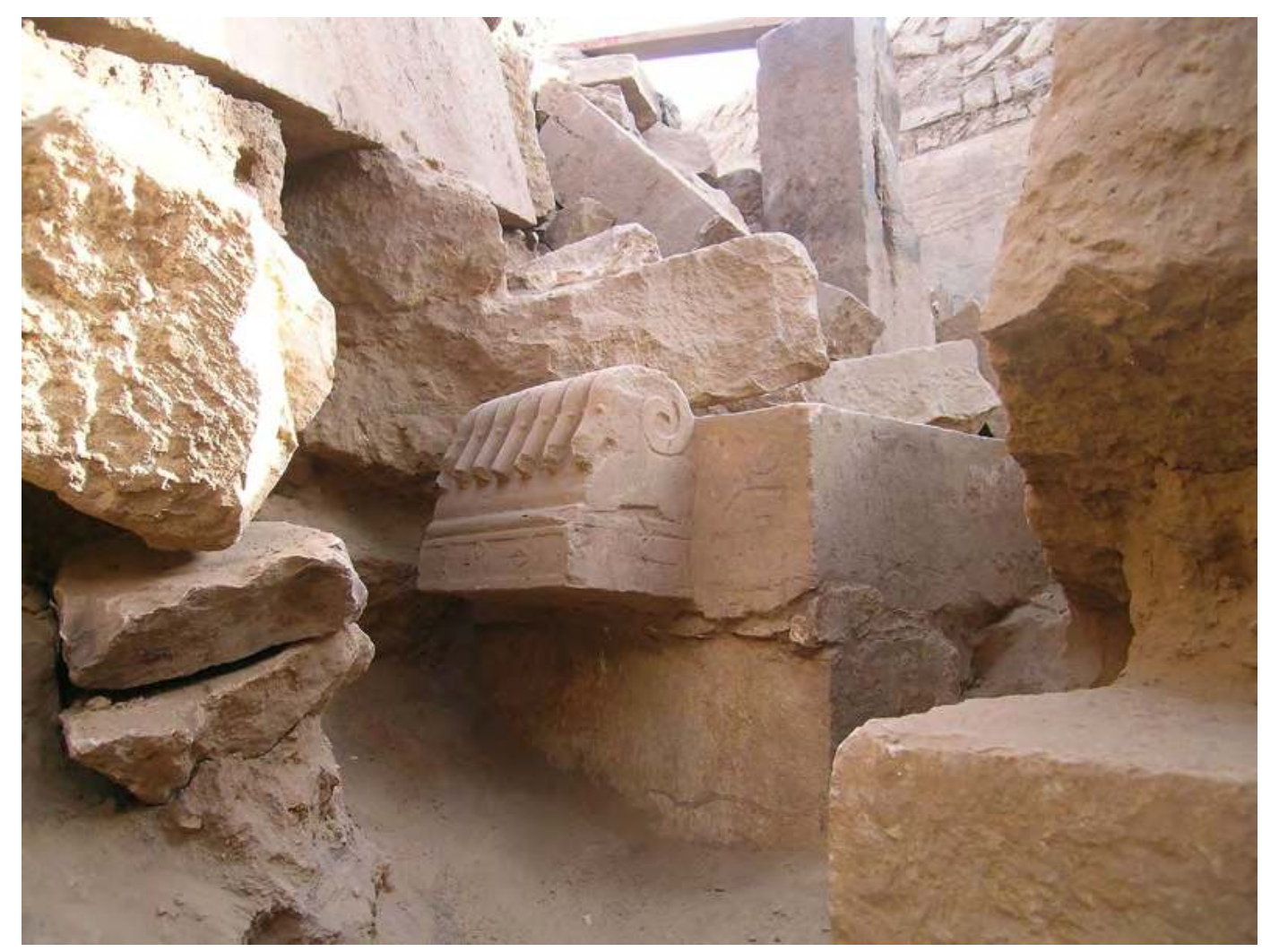

Figure 12. Il rinvenimento della tavola offertoria Ta sommersa dal crollo, da nord. (A. de Maigret 2004 CMAIRY)

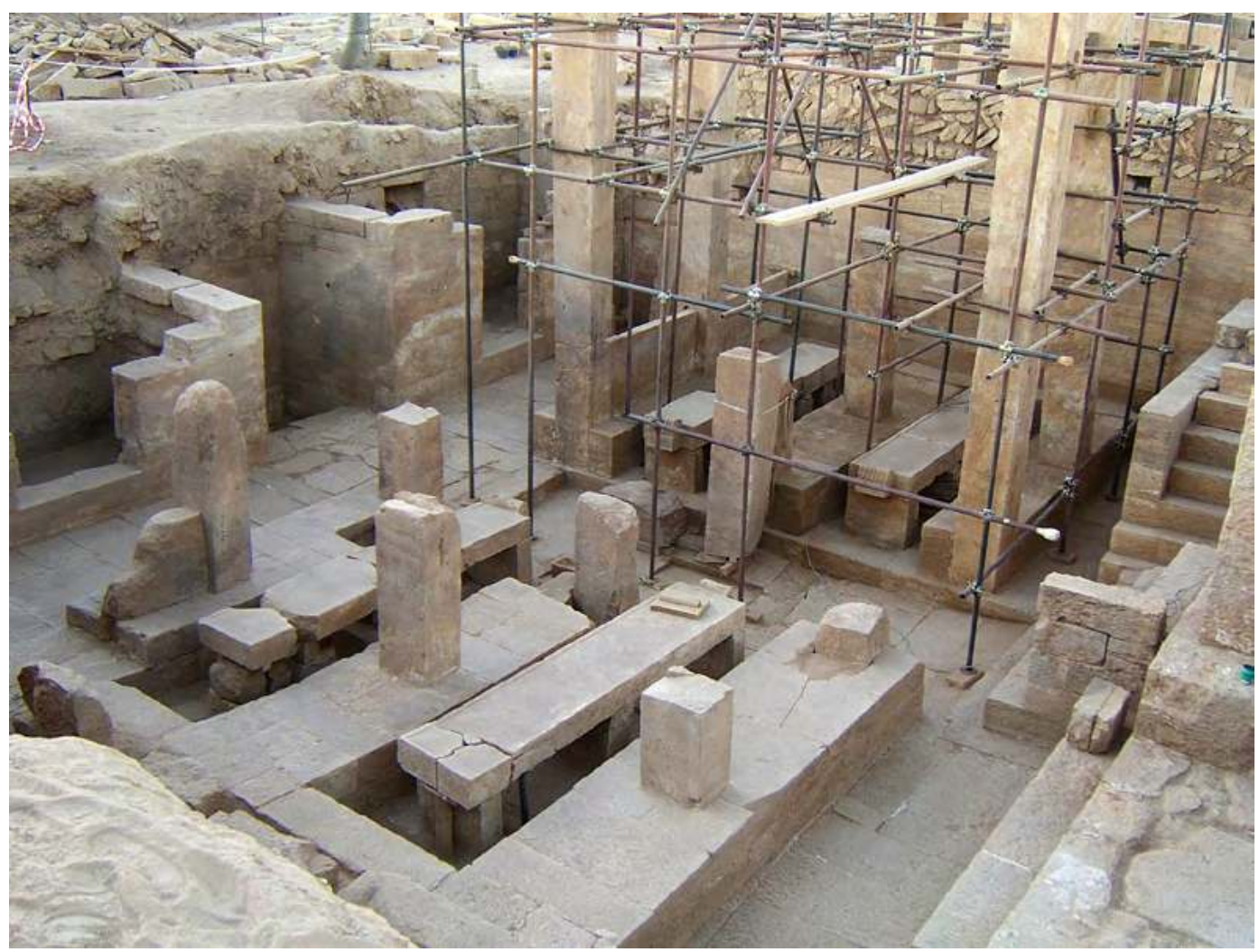

Figure 13. La sala ipostila dopo le operazioni di scavo, da nord. (A. de Maigret 2005 CMAIRY) 


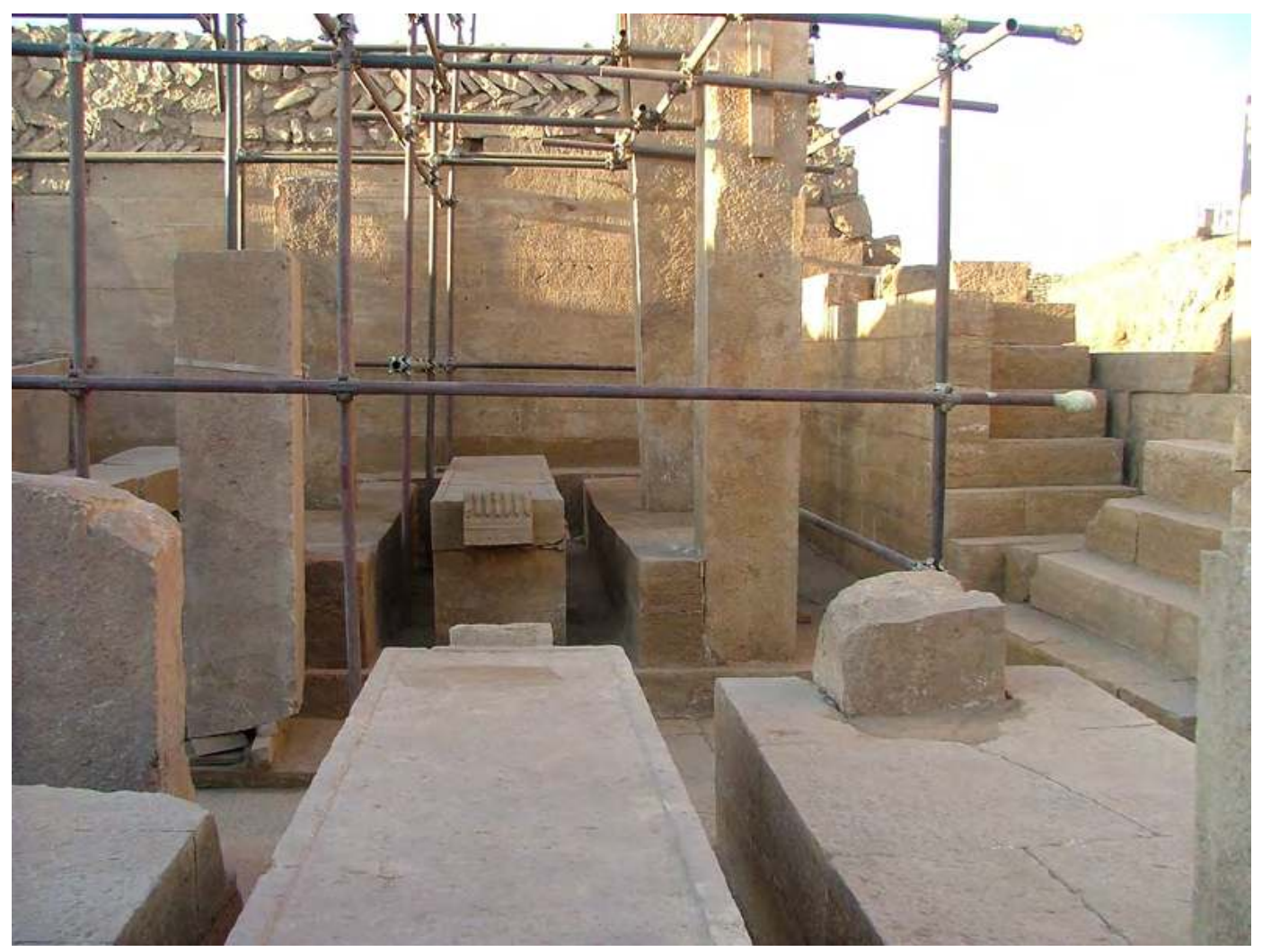

Figure 14. La tavola offertoria $\mathrm{Tb}$, in primo piano, e Ta, affrontate, da nord-ovest. (A. de Maigret 2005 OMAIRY)

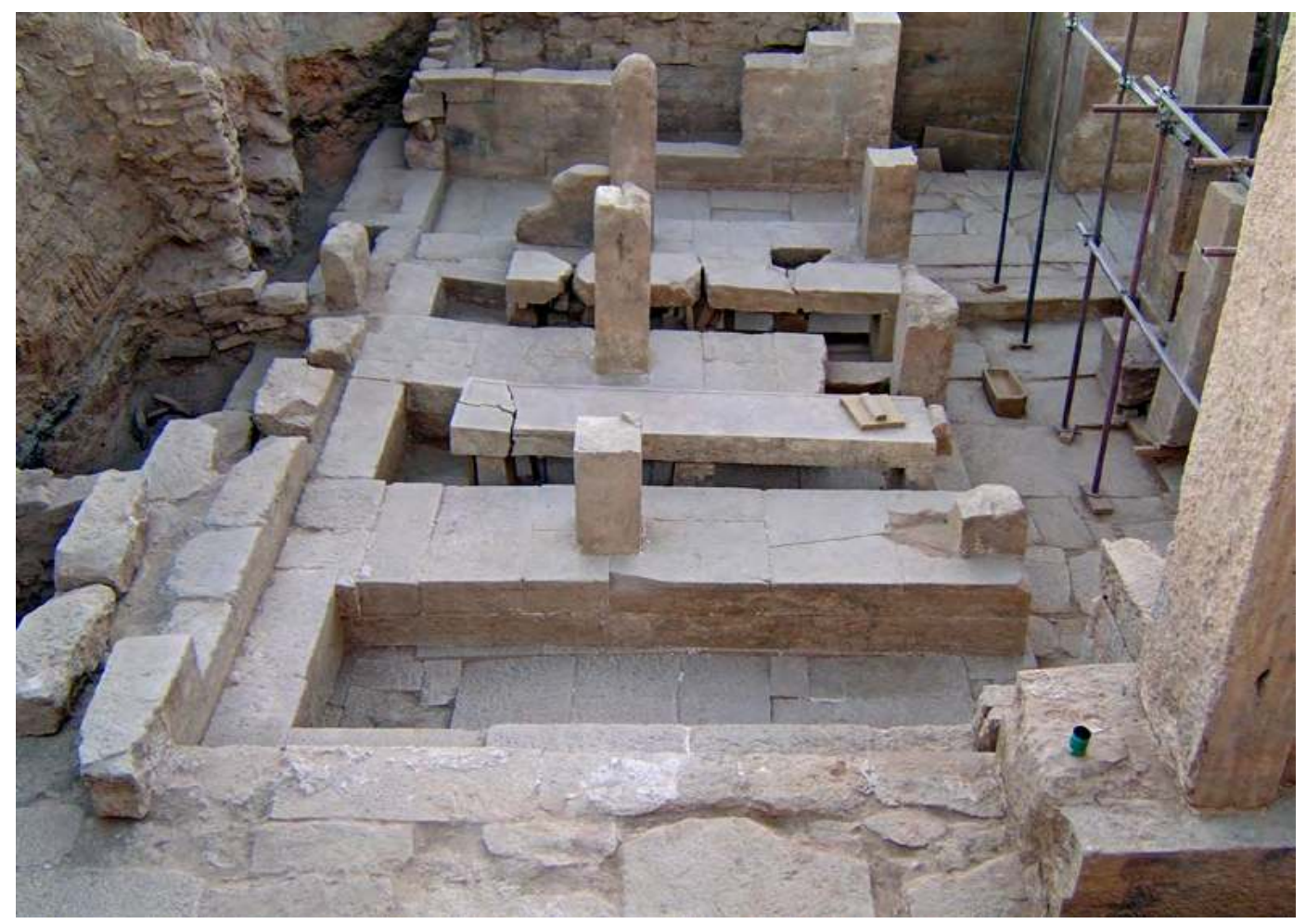

Figure 15. L'area dei cenacoli nella porzione nord-est della sala ipostila. (A. de Maigret 2005 CMAIRY) 


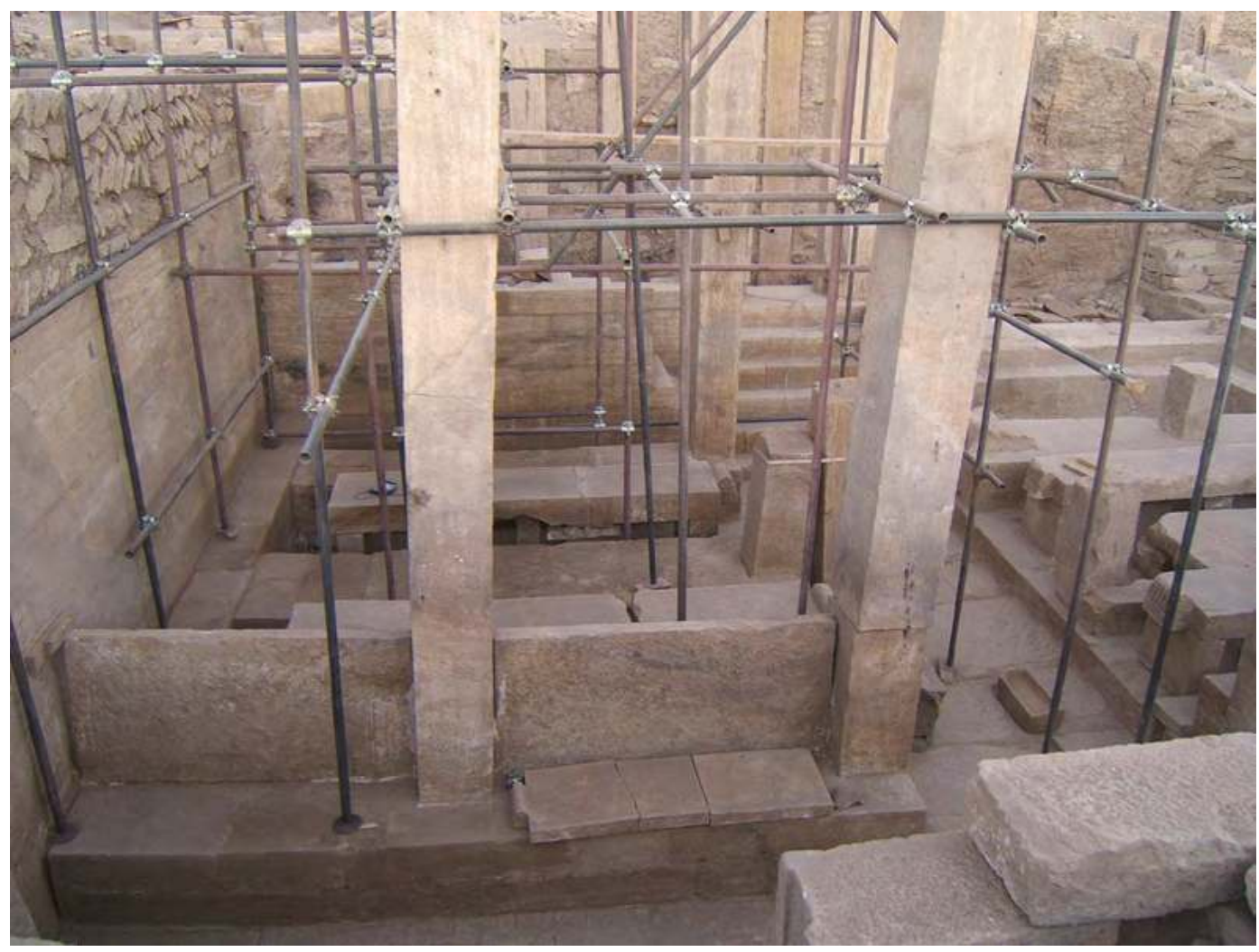

Figure 16. L'area dei cenacoli nella porzione sud-ovest della sala ipostila, in primo piano il retro dei due pannelli Pna e Pnb. (A. de Maigret 2005 CMAIRY)

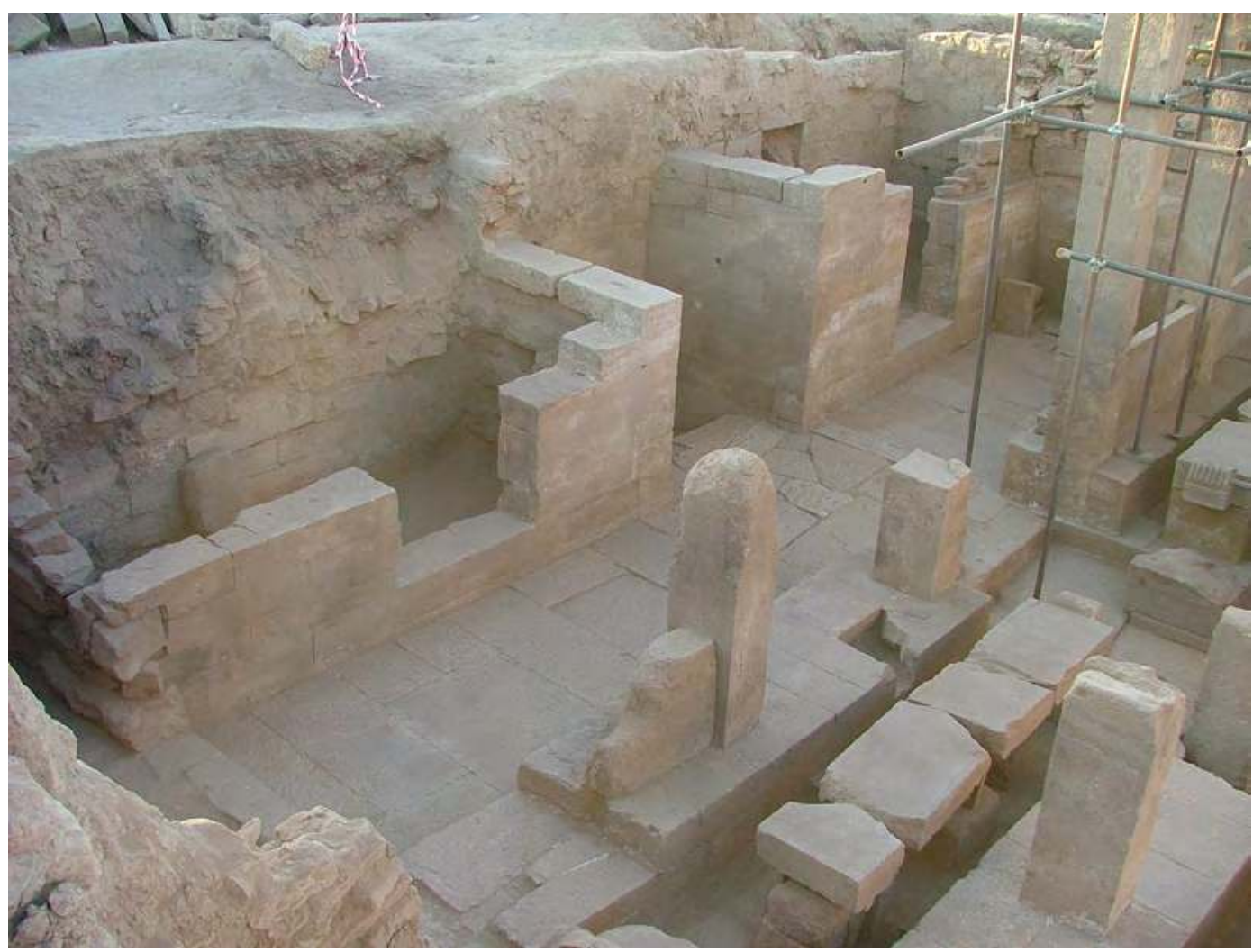

Figure 17. L'area del transetto e dei vani di fondo L122 e L118, con al centro la cella L120, da nord. (A. Agostini 2005 CMAIRY) 


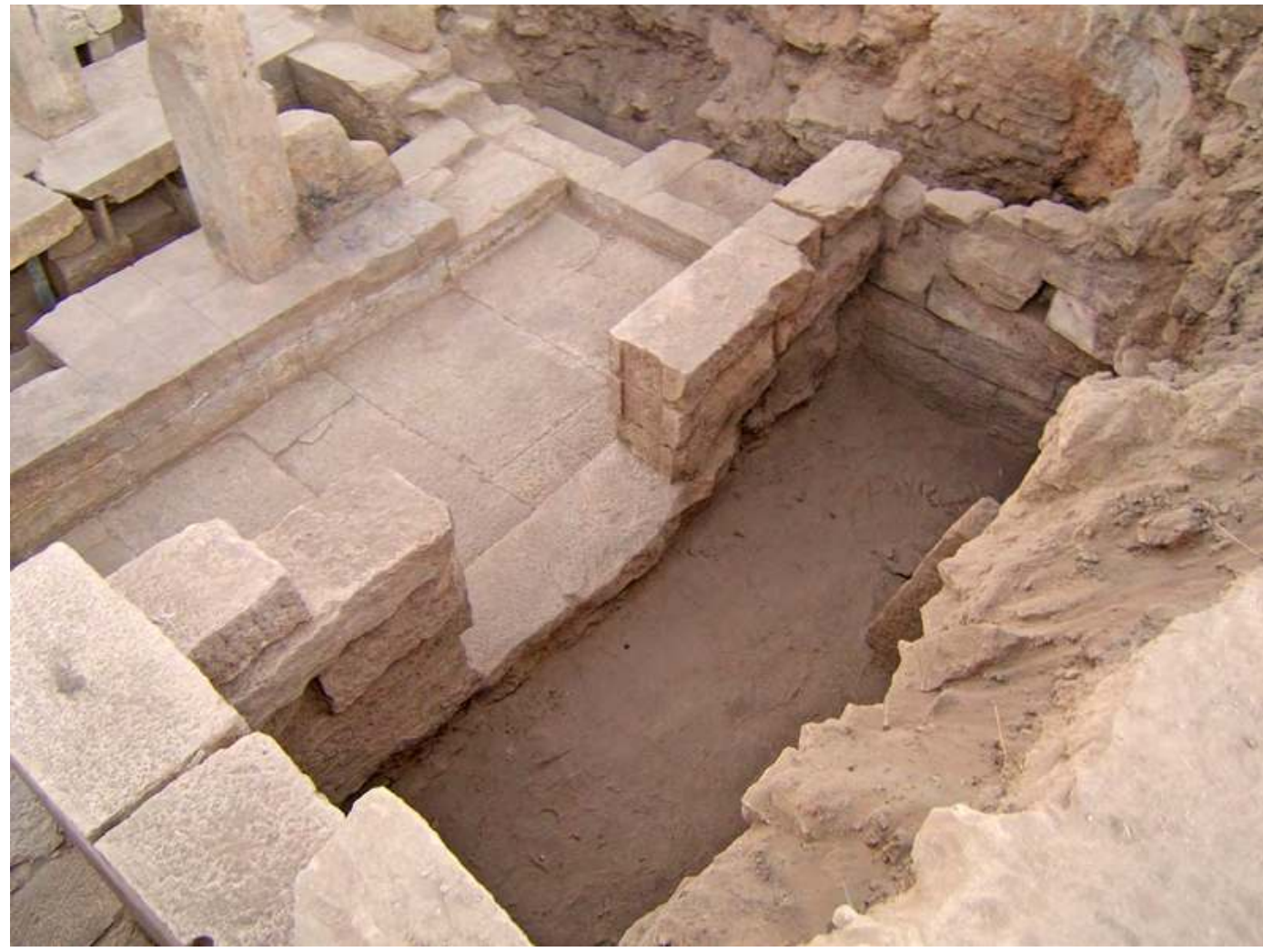

Figure 18. L'interno del vano laterale L122 dopo le operazioni di scavo, da sud. (A. de Maigret 2005 OMAIRY)

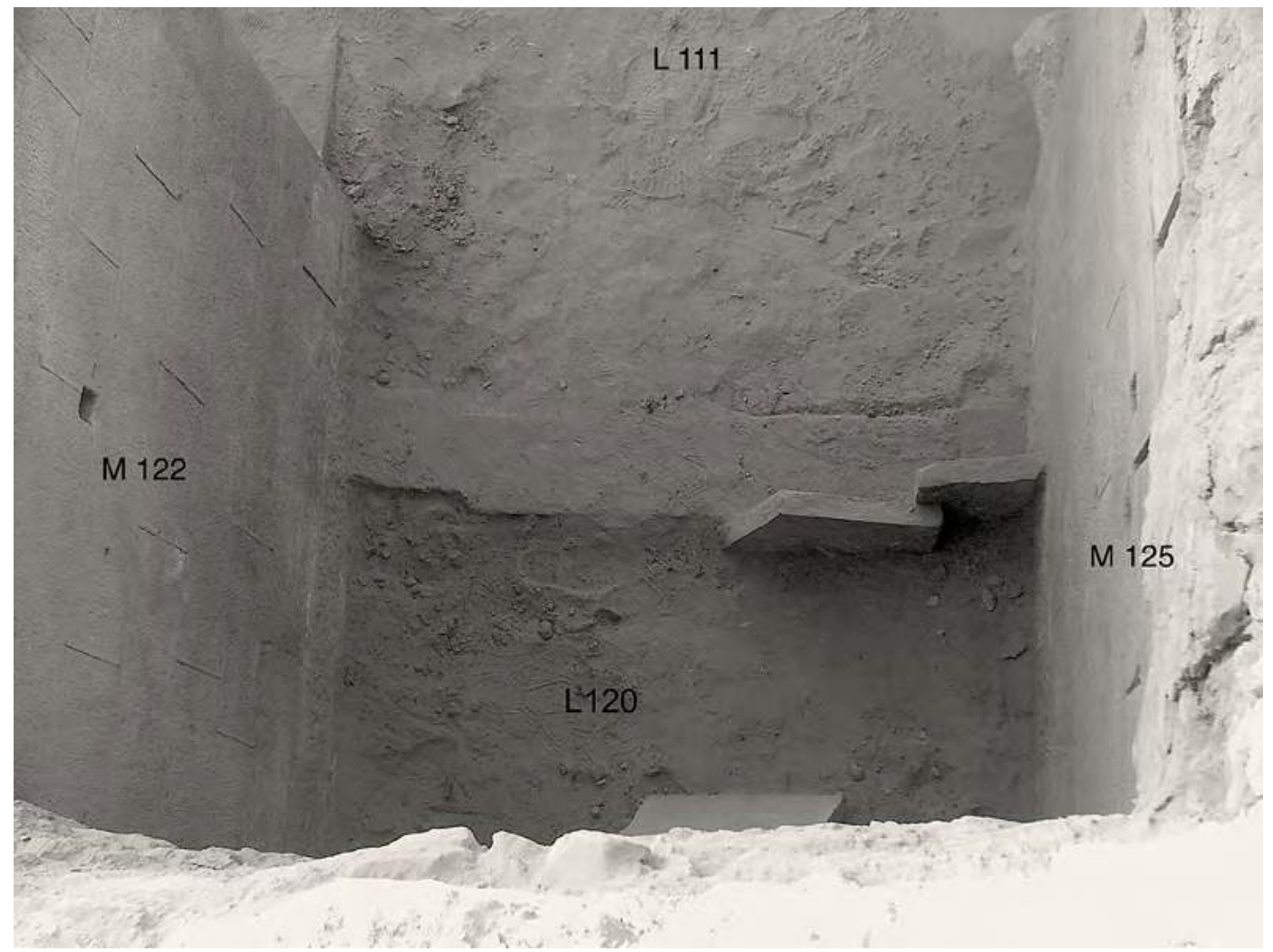

Figure 19. La cella L120, da sud-est. (A. Agostini 2005 @MAIRY) 
mancanti, poiché anche in quel caso tutto è stato asportato in fase di saccheggio.

\subsection{Sondaggi effettuati all'interno del tempio}

Dopo la messa in luce della sala ipostila nel suo livello mineo finale, si sono effettuati due brevi sondaggi, resi possibili dall'assenza del lastricato di pavimentazione originario in alcune porzioni della sala. Questo è stato quindi possibile all'interno di L111-L120 e in una piccola porzione della navata centrale L104 (quadrato tra P2-P6-P8-P7, fig. 20).

In L111 è stato possibile evidenziare una sequenza stratigrafica, qui descritta dall'alto in basso in riferimento alla sezione sud-ovest:

1. riempimento sabbioso molto fine che si interrompe a circa $-50 \mathrm{~cm}$ dalla soglia di L120;

2. riempimento siltoso misto a pietre di piccolo taglio, sciolte e frequenti - questo riempimento prosegue per $1,25 \mathrm{~m}$ al di sotto della sabbia;

3. base in mattoni crudi molto compatta che interessa tutta l'area del sondaggio.

In alcuni punti i mattoni sono ben squadrati, ma generalmente il tutto risulta assai compatto; in direzione est tra il limo e il livello in mattoni è stato visto un sottile strato di pietrame sciolto molto piccolo.

Nella sezione nord-est, che di fatto coincide con la linea P9-M125, si è potuto osservare (fig. 21):

1. il blocco monolitico della soglia di L120;

2. livello della pavimentazione di L121, ma mancante in L111;

3. i blocchi di fondazione della cella lasciati a grezzo, riconoscibili dagli aggetti a questa quota in M125 e M126.

Tutte queste strutture si legano tra loro e dimostrano che i muri perimetrali del tempio, i due vani laterali e la cella al centro sono stati concepiti in un'unica fase costruttiva.

L120: anche qui ritroviamo dapprima un riempimento sabbioso; questo potrebbe essere dovuto sia a deposito eolico depositatosi nella fossa di spoliazione, sia essere originario, ed essere servito come versatile alloggiamento per strutture più leggere (del tipo di un podio ligneo, di cui abbiamo detto). Sotto di questo rinveniamo uno strato più compatto in mattoni. I muri perimetrali, scoperti a questa quota, presentano un aggetto particolare, che ci pare diverso rispetto alle solite riseghe dei livelli di fondazione; da notare, inoltre, l'abbondante presenza di gesso. Il ritrovamento più significativo viene dal riempimento sabbioso $e$ sono i tre grossi elementi di ossidiana, di cui uno di considerevoli dimensioni $($ c. $20 \mathrm{~cm})$. Dato il contesto disturbato dalla spoliazione, non è possibile essere sicuri su quale fosse la collocazione originaria di questi pezzi, se cioè fossero stati originariamente collocati al di sopra del podio della cella o se invece fossero già al di sotto. Dobbiamo tuttavia ritenere che, per la loro collocazione nell'ambiente più sacro del tempio, potevano essere investiti di un ruolo votivo o cultuale (betili?). Purtroppo, non è stato possibile sottoporre questi pezzi a più precise analisi petrografiche prima della conclusione dei lavori. ${ }^{31}$

L104 (quadrato tra P2-P6-P8-P7): qui il lastricato della pavimentazione è risultato particolarmente mal conservato anche a causa dell'impatto del crollo. La caduta di una trave ha provocato nel punto di impatto un'inclinazione delle lastre della pavimentazione e questo ha creato le condizioni per una breve indagine nel riempimento sottostante, da cui affioravano frammenti di ceramica minea (fig. 22). ${ }^{32}$ Sono pertanto emerse le fondazioni a reticolo, in corrispondenza della divisione degli ambienti della sala ipostila. Si è visto in particolare che due grosse travi sovrapposte sostengono i due pilastri P2 e P6, mentre altre due parallele a queste sono sotto P7 e P8, tutte sono quindi in asse nord-est/sud-ovest. Nello spazio tra esse compreso si è incontrata della terra di un colore nocciola chiaro, con molti frammenti di ceramica e pietre di piccolo taglio, miste ad altre più grandicelle, tra queste vi erano anche alcuni frammenti di una tavola offertoria, che doveva essere ormai in disuso e perciò scaricata nello spazio alla base del pavimento in L104..$^{33} \mathrm{Si}$ è potuto arrivare a scavare fino a una profondità di $-1 \mathrm{~m}$ dal livello del pavimento della navata centrale, quando si sono trovati dei mattoni e una grossa pietra messa di piatto, in corrispondenza della quale ci siamo dovuti arrestare (fig. 23). La robusta trabeazione di fondazione che abbiamo individuato doveva quindi essere speculare a quella della copertura del tetto che, come ha dimostrato il Tempio A, era realizzata con un reticolo di travi sovrapposte. La struttura in basso era destinata a sorreggere i punti di scarico principali, cioè le basi d'appoggio dei pilastri interni.

\subsection{Collocazione storica della fondazione del tempio}

I documenti epigrafici rinvenuti in situ durante gli scavi del Tempio B forniscono dati del massimo interesse ai fini di una collocazione storica dell'edificio, soprattutto considerato che alcuni di questi testi riguardano esplicitamente la fondazione del tempio. In alcuni casi ciò consente anche di precisare la cronologia di alcuni

\footnotetext{
${ }_{31}$ Per una più accurata analisi di questi pezzi si rimanda a Fedele, capitolo 6 , in questo volume.

32 Zanbil B.05.B.77.

${ }_{33}$ Cfr. il catalogo degli oggetti, n. 6.
} 
momenti chiave della storia minea ${ }^{34} \mathrm{Ci}$ pare dunque opportuno ripercorrere il contesto storico di questi documenti insieme ad alcuni dei dati archeologici appena presentati. ${ }^{35}$

Particolarmente rilevanti sono le due iscrizioni incise sui pannelli che fanno da schermo per l'area del transetto. L'iscrizione Y.05.B.B.13 indica chiaramente che il tempio è stato costruito al tempo del sovrano mineo Waqih’il Riyām, che sappiamo essere figlio del re

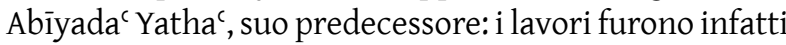
diretti e completati dalle 'fondazioni fino alla sommità' da Ya'ws'il figlio di Yisma ${ }^{\left({ }^{\prime} i l ~ d h u-G ̇ a z i ̀ r ~ S a h ̣ f a ̄ n, ~ c o n ~ i l ~\right.}$ favore del sovrano. Come si è detto, l'iscrizione è stata rinvenuta in frammenti nella zona del transetto, alle spalle del pannello anepigrafo rimasto in posto. Dal testo si evince che il tempio denominato Qabdum era stato dedicato al dio supremo mineo 'Athtar dhu-Qabd. Questo testo va letto in parallelo, se non integrato, con l'iscrizione Y.05.B.B.12, rinvenuta ancora in posto nella navata adiacente. ${ }^{36}$ In ogni caso, è opportuno rilevare che in questo secondo testo ricorre lo stesso soggetto Ya'ws'il, e si menziona nuovamente il re Waqih'il Riyām, ma qui il sovrano è citato insieme al figlio Aws'il come suo coreggente (che non figurerà poi come suo successore, almeno non con questo nome). L'indicazione di questa coreggenza potrebbe suggerire due testi diversi, cronologicamente consecutivi, ma non possiamo escludere che nello stesso testo ci si riferisca a due momenti successivi (cfr. M 172 e Ma'īn 7). In ogni caso, dobbiamo ritenere che i lavori per il tempio Qabdum si sono conclusi in un momento avanzato del regno di Waqih'il Riyām.

Questi testi si inseriscono in uno dei momenti meglio documentati della storia minea e certo uno dei più floridi, dato che sono molte le opere pubbliche che sono state promosse in quest'epoca, specialmente a Yathill. Il re Abīyada' Yatha', padre di Waqih'il Riyām, è il sovrano menzionato nella celeberrima RES 3022, incisa sul lato meridionale delle mura cittadine di Barāqish e nella quale si trova menzione del cosiddetto 'sincronismo mineo-persiano', ampiamente analizzato per la possibilità che potrebbe offrire ai fini di un ancoraggio assoluto all'interno della storia sudarabica antica. ${ }^{37}$ Nell'iscrizione delle mura si cita una 'rivolta' ( $m r d$ nel testo mineo) avvenuta in Egitto (Mșr) contro i Persiani (Mdy) di cui alcuni Minei sarebbero stati testimoni durante uno dei loro viaggi commerciali - fatto che hanno poi ricordato in questo testo,

\footnotetext{
34 Agostini, 2020b.

35 Per una trattazione più specifica della documentazione epigrafica si rinvia al capitolo 4, in questo volume; cfr. anche Agostini 2011.

36 Cfr. sopra $\S 1.2$ e capitolo 4, in questo volume.

37 Lemaire 1996, 44-47; Lemaire 2010, 381-383. Per una recente sintesi del dibattito attorno a questo testo si veda anche Multhoff 2019.
}

commissionato dopo il loro ritorno in patria. Un tale evento storico è però di difficile collocazione, anche per la consueta asciuttezza con la quale viene presentato, e molte sono quindi le possibilità di identificazione. Questa circostanza potrebbe dunque inserirsi tra i tumulti seguiti alla conquista dell'Egitto da parte di Cambise (525 a.C.) e l'invasione persiana di Artaserse III Oco, avvenuta nel 343 a.C. - ed escludendo fin da subito la battaglia di Raphia del 217 a.C., perché la data sarebbe eccessivamente bassa. ${ }^{38}$ Tuttavia, all'interno del lasso di tempo 525-343 a.C. sono avvenuti pure altri fatti di minore entità, che potrebbero ugualmente essere associati all'evento ricordato nella RES 3022. Se consideriamo un naturale passaggio generazionale tra Abīyada' Yatha' e il figlio Waqih’il Riyām, ecco che quest'ultimo potrebbe quindi collocarsi in un qualsiasi momento all'interno dell'intervallo temporale compreso tra tutto il V e il IV secolo a.C. In questo periodo dovremmo quindi anche inserire la costruzione del Tempio B. In termini relativi, la costruzione del Tempio B è avvenuta dopo quella del tempio A, dato che per questo edificio sono documentati interventi di manutenzione già durante il regno di Abīyadac Yatha', grazie al supporto finanziario Basîl bin $\mathrm{Ma}^{\mathrm{c}} \mathrm{s}^{39}$ e da 'Ammīsami' bin Awsān dhu-Balah ${ }^{40}$ (altri restauri verranno condotti anche successivamente). ${ }^{41}$

A questo panorama storico possiamo ora aggiungere un dato di estrema importanza dallo scavo del Tempio B. Un campione di carbone (Bar.05.B/2a), rimasto purtroppo isolato, è stato prelevato alla quota del pavimento di L110, vicino a M118, in angolo con M122 (v. sopra $\S 1.2$ ) e ha potuto essere sottoposto a un'analisi radiometrica del ${ }^{14} \mathrm{C}$ presso il laboratorio CIRCE. ${ }^{42}$ Il risultato calibrato restituisce un intervallo tra il 591 e il 408 a.C., con una probabilità relativa del $68 \%$. L'estremo superiore è un po' alto rispetto ai dati storici che abbiamo a disposizione, ma il V secolo si troverebbe invece ad essere indicato congiuntamente sia dalla deduzione storico-epigrafica, sia dall'analisi del dato archeologico, con un risultato da considerarsi sufficientemente solido, anche solo come terminus post quem. Non sappiamo a cosa dovesse essere pertinente questo legno carbonizzato, forse a un elemento di arredo, o della porta del sacrario di destra, ma certo deve essere rimasto in uso fino all'ultimo periodo di vita mineo, a giudicare dalla posizione del suo ritrovamento. Una certa cautela potrebbe essere raccomandata dal fatto che l'ambiente L110 è stato in parte disturbato da alcune istallazioni mobili, da ascrivere con ogni

\footnotetext{
38 Gnoli 1996b; Gnoli 2009.

39 Cfr. la tavola offertoria Y.90.B.A.7.

40 Pannello con iscrizione Y.92.B.A.21+30.

${ }^{41}$ Cfr. gli ampi interventi ricordati nel testo M 203.

42 Cfr. anche sopra nella sezione $\S 1.2$ per il contesto archeologico e Fedele, capitolo 16, in questo volume. Il dato non era stato ancora reso disponibile durante la redazione di Agostini 2015.
} 
probabilità a un periodo immediatamente successivo al piano di vita mineo (si veda qui sotto, Fase Intermedia). Si tratta tuttavia di un dato di grande rilievo, che ci consente di dedurre che la costruzione del Tempio B sotto Waqih’il Riyām possa essere stata iniziata nella seconda metà del V secolo a.C. Come conseguenza di questo, dobbiamo pure secondariamente innalzare di circa un secolo l'identificazione dell'evento alla base del sincronismo mineo-persiano, almeno rispetto alla data del 343 a.C., che ultimamente era quella a raccogliere maggiori consensi. ${ }^{43}$ Alla luce di questo, appare dunque da prendere in seria considerazione la prima delle due possibilità avanzate da André Lemaire per arrivare all'identificazione del sincronismo mineo-persiano, cioè il momento delle rivolte sotto Inaros (463-454 a.C.) e quelle al tempo di Amirteo (405-398 a.C.). ${ }^{44}$

Come abbiamo appena visto, i sondaggi praticati all'interno della sala ipostila non sono stati sufficientemente profondi da poter rivelare eventuali livelli edificati sottostanti, su cui questo tempio può essersi impiantato. La quota maggiore del Tempio B rispetto al Tempio A potrebbe essere coerente con una tale ipotesi; oltretutto, la possibilità che il sito di Barāqish si sia sviluppato su un affioramento roccioso, che avrebbe potuto dare un profilo irregolare all'insediamento, sembra ora da escludere, nonostante sia stata una teoria supportata in passato. ${ }^{45}$ Sulla presenza di eventuali strutture sottostanti il Tempio $\mathrm{B}$ non abbiamo però al momento nessun'altro dato archeologico o epigrafico. ${ }^{46}$

Per limitarci alle strutture emerse, possiamo dire che la costruzione e la dedica di un tempio così imponente al dio 'Athtar dhu-Qabd ci pare coerente con quel programma d'interventi promosso dai sovrani minei particolarmente attivi attorno al V secolo a.C., con lo scopo di dare a Yathill strutture adeguate e un ruolo di primo piano in una zona così strategica, al confine col regno sabeo.

\section{Fase Intermedia}

Dopo la fase minea e prima di cadere nel lungo periodo di abbandono, in cui la struttura del tempio dovette dare i primi segni di cedimento e di crollo, è possibile che tutta l'area abbia cominciato a subire una prima depredazione, forse limitata alla sola ricerca di oggetti di pregio. Contestualmente, si nota chiaramente che l'edificio è stato riutilizzato, ancora a scopo cultuale, da

\footnotetext{
43 Agostini, 2020b.

44 Lemaire 2010, 383.

45 Robin e de Maigret 2009, 70-72; Fedele 2010, 101 (n. 22); Fedele 2011a, 106; cfr. anche Fedele, capitolo 26, volume 2.

46 Per la situazione relativa alle fasi anteriori all'impianto del Tempio A si vedano gli importanti risultati del sondaggio effettuato alla base della scalinata (de Maigret 2010a).
}

gruppi etnicamente e culturalmente distinti dai Minei, gruppi che si erano infiltrati nel sito verso la fine del periodo mineo e che i dati emersi ci permettono di identificare con alcuni membri della tribù degli Amīr. ${ }^{47}$ In questa fase, le strutture minee dovevano trovarsi ancora in buono stato e saranno state riadattate alle nuove esigenze con un minimo sforzo. Segni di questa riutilizzazione sono emersi a più riprese e sono in parte coerenti con alcuni dati che erano stati rinvenuti durante lo scavo del Tempio A, seppur in maniera meno chiara e più sporadica. Indichiamo questo periodo come Fase Intermedia, collocandola poco dopo la fine del periodo di vita mineo e prima del definitivo abbandono. Possiamo far iniziare questo periodo agli albori del nuovo millennio, al più tardi, momento in cui il regno mineo ci pare già fortemente disgregato, ${ }^{48}$ come dimostra l'incontrastato passaggio di Elio Gallo nel 24 a.C. presso Athrula - Yathill, che rivela una città ormai in stato di forte decadenza. ${ }^{49}$

Questa riutilizzazione è emersa chiaramente in più settori di scavo, in special modo nella zona del transetto e della cella; qualcosa è forse emerso anche sulla terrazza anteriore, ma in modo più vago (v. oltre). Queste tracce si collocano a un livello di poco superiore a quello della messa in luce del pavimento mineo e sottostante, o al massimo frammisto, al deposito eolico - specie se il livello è stato particolarmente disturbato. Dalla pulitura di L110, durante la messa in luce di tutta la banchetta M121 nell'angolo con M102, è emersa una lastra infissa verticalmente che ha creato un piccolo spazio in questo angolo; all'interno si è trovata una pietra con tre incavi rettangolari poco profondi, la quale avrebbe potuto quindi fungere da sostegno per una stele aniconica rinvenuta nei pressi, stele che presenta un piccolo monogramma composto da Bā', 'Ayn, Mīm. Si tratta quindi chiaramente di installazioni mobili, che fanno pensare a una effimera riutilizzazione, in un'area del tempio laterale, peraltro nascosta già durante la fase minea (fig. 24).

Frammisto al riempimento eolico di L111 sono stati rinvenuti alcuni frammenti di piccole barrette bronzee a sezione circolare e contestualmente anche un exvoto su un blocco oblungo di calcare, spezzato in due frammenti, con un'inusuale iscrizione a pittura rossa; la dedica alla divinità Halfān rivela chiaramente che è stata redatta per un membro della tribù di Amīr (Y.05.B.B./16). ${ }^{50}$ Si ricorda che anche nel Tempio A era stata trovata un'iscrizione con dedica a un'altra divinità amirita, cioè dhu-Samāwī (Y.92.B.A.20). ${ }^{51}$ La

\footnotetext{
47 Sulla presenza degli Amīr in Arabia meridionale e sulla loro infiltrazione nel sito di Barāqish si veda anche Agostini 2018a.

48 Robin 1998.

49 Si veda Fedele, capitolo 18, volume 2 .

50 Agostini 2015, 9-11 e capitolo 4 in questo volume.

51 de Maigret e Robin 1993, 475.
} 
presenza di queste due iscrizioni offre un valido motivo per avanzare l'ipotesi che tutta l'area sacra sia stata occupata dagli Amīr in un secondo momento e che i due templi siano stati ridestinati alle loro proprie divinità: quello di Nakrah a dhu-Samāwī e quello di 'Athtar dhu-Qabḍ a Halfān. Viene poi da domandarsi se anche l'asportazione del lastricato in L111, L118, e parte dello smantellamento del podio in L120, sia da attribuire agli stessi Amīr, o piuttosto al primo periodo dell'abbandono, quando dovettero verificarsi i primi tentativi di saccheggio.

Dal livello Intermedio di L111 provengono anche alcuni frammenti del vaso cultuale poi risultati pertinenti ad altri rinvenuti nel livello Mineo B di L121 (cfr. sopra, $\S 1.2$ ). Si può quindi affermare che il vaso sia in prima istanza da ascrivere alla fase minea, ma è possibile che sia stato utilizzato anche successivamente, durante la frequentazione da parte degli Amīr (o forse distrutto in questo momento?).

Ci pare di poter attribuire a questa fase anche un piccolo bacino che è stato rinvenuto nei pressi della tavola Tc: questo piccolo oggetto si presenta di fattura piuttosto grossolana e di forma irregolare. Originariamente doveva essere collocato in un alloggiamento poco profondo scavato nella pavimentazione della navata centrale, di fronte a Tc, un poco decentrato rispetto all'asse centrale della navata (cfr. fig. 16). Questo incavo presente nel lastricato corrisponde perfettamente alla forma della base del piccolo bacino, il che ci permette di confermare questa sua collocazione. È opinione di chi scrive che debba essere ascritto a una fase successiva a quella minea, proprio per la sua fattura più modesta rispetto ai raffinati arredi minei. Se questa ipotesi fosse corretta, dovremmo pure ritenere che questo adeguamento sia stato dovuto ad esigenze rituali diverse rispetto a quelle in uso in epoca minea.

La situazione si è presentata più incerta sul piano della terrazza antistante il propileo, L125. Qui è stato individuato un pavimento chiaramente pertinente a un livello successivo alla fase minea, pertanto nominato sul momento Li415, chiuso verso nord-ovest da un modesto muretto, Mi480, e caratterizzato da un piano in terra battuta su cui era adagiato un finissimo strato di terra scura e morbida, mista a paglia. Nel limite sud-ovest del locus, in prossimità di M128, sono state trovate tracce di una effimera pavimentazione a piccole pietre - che non sembra in fase col lastricato mineo della terrazza - e di una fossa poco profonda del diametro di circa $25 \mathrm{~cm}$ (figg. 25-26). Questo livello si impostava direttamente sul piano della terrazza minea e siamo dunque propensi a collegarlo con delle sporadiche utilizzazioni successive alla fase minea. Ci mancano al momento elementi che ci possano permettere di associare con chiarezza questa frequentazione a una fase immediatamente post-minea (amirita?) oppure relativa al periodo post-abbandono, nel primo momento dell'Islamico Antico - ipotesi che ci pare in questo caso più probabile. Dobbiamo infatti anche tenere presente che qui il deposito eolico del lungo abbandono può essere stato assente, poiché il suo accumulo si sarà concentrato a partire dal livello di impostazione della scalinata d'accesso e può quindi aver lasciato libero questo piano che si trova a una quota sensibilmente maggiore. Tale deposito eolico è infatti stato individuato fino al livello del secondo gradino della scalinata M135 partendo dall'alto.

Va da sé che questaFase Intermedia è archeologicamente assai evanescente e molto difficile da individuare a livello stratigrafico, dato che le azioni che dovrebbero configurarla saranno state piuttosto di natura negativa - vale a dire connesse con la rimozione di leggeri strati di abbandono preesistenti - ; più probabilmente, si sarà posta in totale continuità con la fase minea precedente, tanto da poter essere individuata solo grazie a oggetti 'parlanti', come l'ex-voto chiaramente ascrivibile a un ambito culturale amirita, oppure da integrazioni nell'arredo templare che difficilmente si sposano con la concezione dello spazio tipica della fase di frequentazione minea (cfr. il piccolo bacino in L104). A questo si aggiunga che il rimaneggiamento avvenuto in epoca islamica, con l'impostazione di alcuni muri per i quali saranno state scavate alcune fosse di fondazione, avrà certamente contribuito a disturbare questo livello in più punti. È proprio la constatazione che questo livello post-mineo non possa ovunque ricevere una chiara identificazione culturale o etnica a farci propendere per una definizione più neutra, quale quella di 'Intermedia'. ${ }^{52}$

\section{I livelli islamici}

Analogamente a quasi tutto il sito, anche questa zona di Barāqish presenta un'abbondante stratificazione, esito di un'intensa e prolungata occupazione che pare essersi protratta almeno fino al XVIII secolo della nostra era. Non si può tuttavia escludere che alcuni nuclei abitativi sparsi abbiano continuato a insistere sul sito, seppur sporadicamente, fino a tempi più recenti, anche volendo dar credito ad alcune informazioni riportate

\footnotetext{
52 Dato che questa fase non ha presentato una autonomia stratigrafica altrettanto chiara durante gli scavi del Tempio A, siamo propensi a implicarla come parte finale dell'ultimo periodo mineo (Mineo A), al quale sarebbe dunque da ascrivere l'iscrizione amirita Y.92.B.A.20. Questo ci pare ancor più plausibile alla luce della rivalutazione delle datazioni al radiocarbonio che riguardano il Tempio A, discusse da Fedele, nel capitolo 16, in questo volume (cfr. nota 31 e nota a alla Tabella C): qui Fedele propone una definizione 'Minaean-Arab' per il Mineo A, che quindi sarebbe parzialmente da correlare con la nostra Fase Intermedia - tuttavia, per le motivazioni sopra esposte, si ritiene preferibile una definizione meno connotata dal punto di vista etnico-politico. Tale fase potrebbe inoltre avere una contiguità teorica anche con alcuni livelli individuati nell'Area C da Fedele, in particolare all'interno della fase 'Later Minaean' e 'Post-Minaean' (strata F-E-D): Fedele 2010, 137-139, Tab. 2.
} 


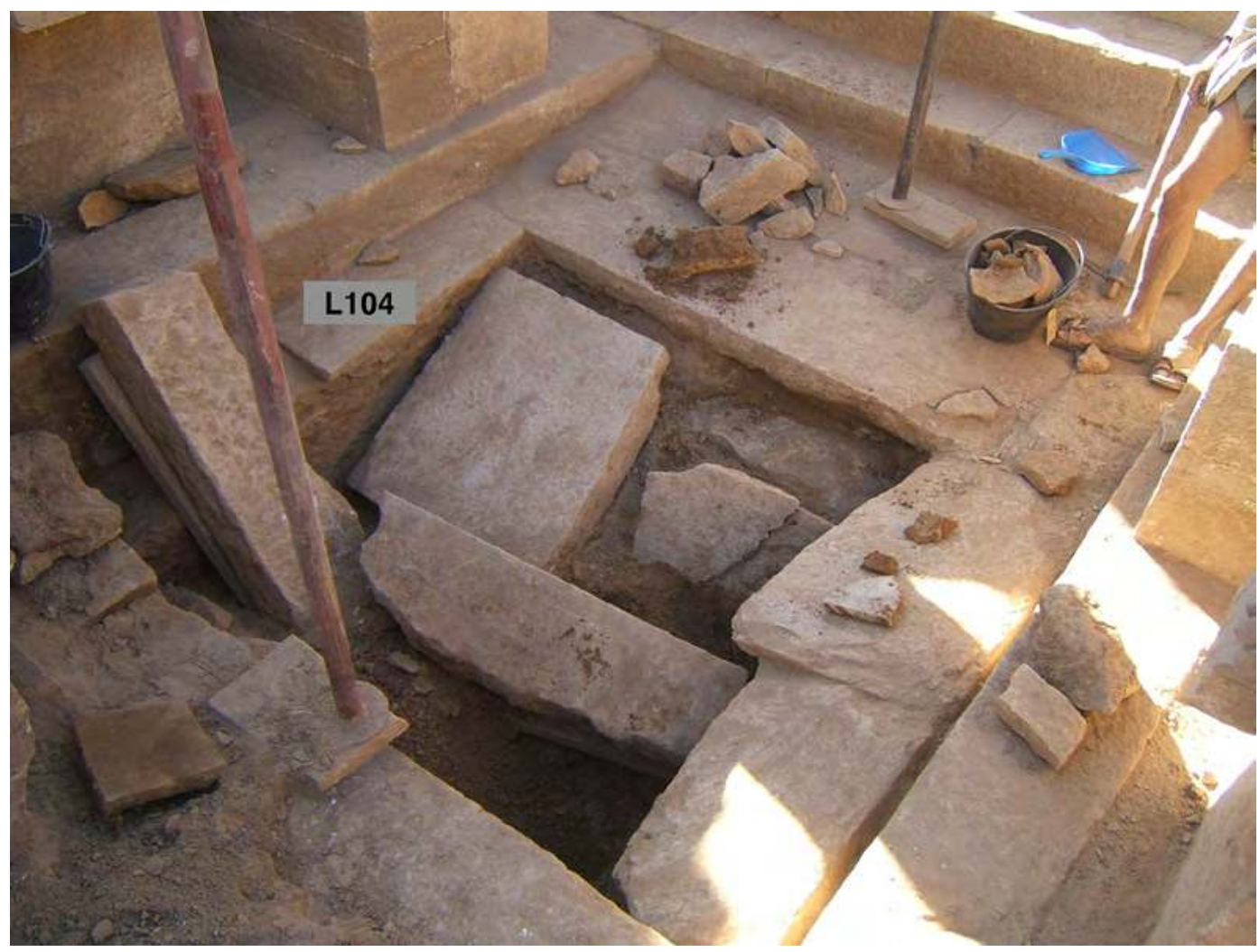

Figure 20. La condizione del lastricato in L104 prima del sondaggio esplorativo, da nord-est. (A. de Maigret 2005 CMAIRY)

dagli abitanti del luogo. Questo lungo periodo di vita ha lasciato un deposito che ha raggiunto uno spessore medio di circa $5 \mathrm{~m}$ sopra l'ultimo piano di calpestio mineo, il che ha reso le operazioni di scavo molto laboriose - una situazione naturalmente del tutto analoga a quella affrontata nel Tempio A.

Si ritiene importante dare conto qui anche di questa lunga fase islamica, specie per quanto riguarda le strutture murarie principali che insistevano nella nostra area di scavo, confidando che uno studio approfondito dei materiali a esse associati possa essere condotto in un futuro non lontano da specialisti del settore, in grado quindi di valorizzare una produzione materiale, per quanto attiene sia alla ceramica sia agli oggetti mobili, che potrebbe diventare un punto di riferimento imprescindibile per lo studio del medioevo islamico yemenita, e non solo.

Già da un'osservazione delle strutture esistenti, chiaramente pertinenti all'ultimo recente periodo di vita dell'insediamento, si è potuto individuare quale potesse essere in linea di massima l'area occupata dal tempio antico che si voleva intercettare. Si sono pertanto individuate tre strade (Strada 1 in direzione nord-ovest, Strada 2 a nord e Strada 3 a nord-est) che, insieme al limite sud-est in corrispondenza dell'area già scavata del Tempio A, disegnavano un'area pressoché quadrata, e sembrava plausibile che questa potesse coincidere con l'ipotetico perimetro del Tempio B. Come già verificato nel caso del Tempio $\mathrm{A}$, infatti, le strutture islamiche più antiche hanno in parte seguito, per distribuzione e allineamenti, le precedenti strutture minee, trasmettendo spesso questi stessi orientamenti anche alle strutture più tarde (figg. 27-28). Quando ciò è avvenuto in maniera più decisa, si poteva ragionevolmente sperare che le strutture antiche sottostanti fossero meglio conservate rispetto al caso, pure frequente, in cui queste siano state invece spoliate per ricavarne materiale edilizio. Gli stessi pilastri emergenti del propileo (M100) e la parte sommitale dell'entrata (M101) del tempio mineo, infatti, hanno perfettamente assolto a questa funzione di 'appoggio' fino all'ultima fase.

Dallo scavo del riempimento che gravava sopra l'area del tempio, si sono potute riconoscere tre grandi fasi sopra quel lungo abbandono (Fase IV) che è seguito all'utilizzazione del tempio sudarabico. Si designano pertanto come Islamico Antico (III), Islamico Medio (II) e Islamico Recente (I) - in alcuni casi con varie sotto-fasi, non sempre omogenee ed estese. ${ }^{53}$

53 Questa periodizzazione è stata quella da ultimo adottata anche dallo stesso de Maigret (2009b, 55-56). Nel Tempio A erano state dapprima riconosciute tre fasi islamiche, poi ampliate a 

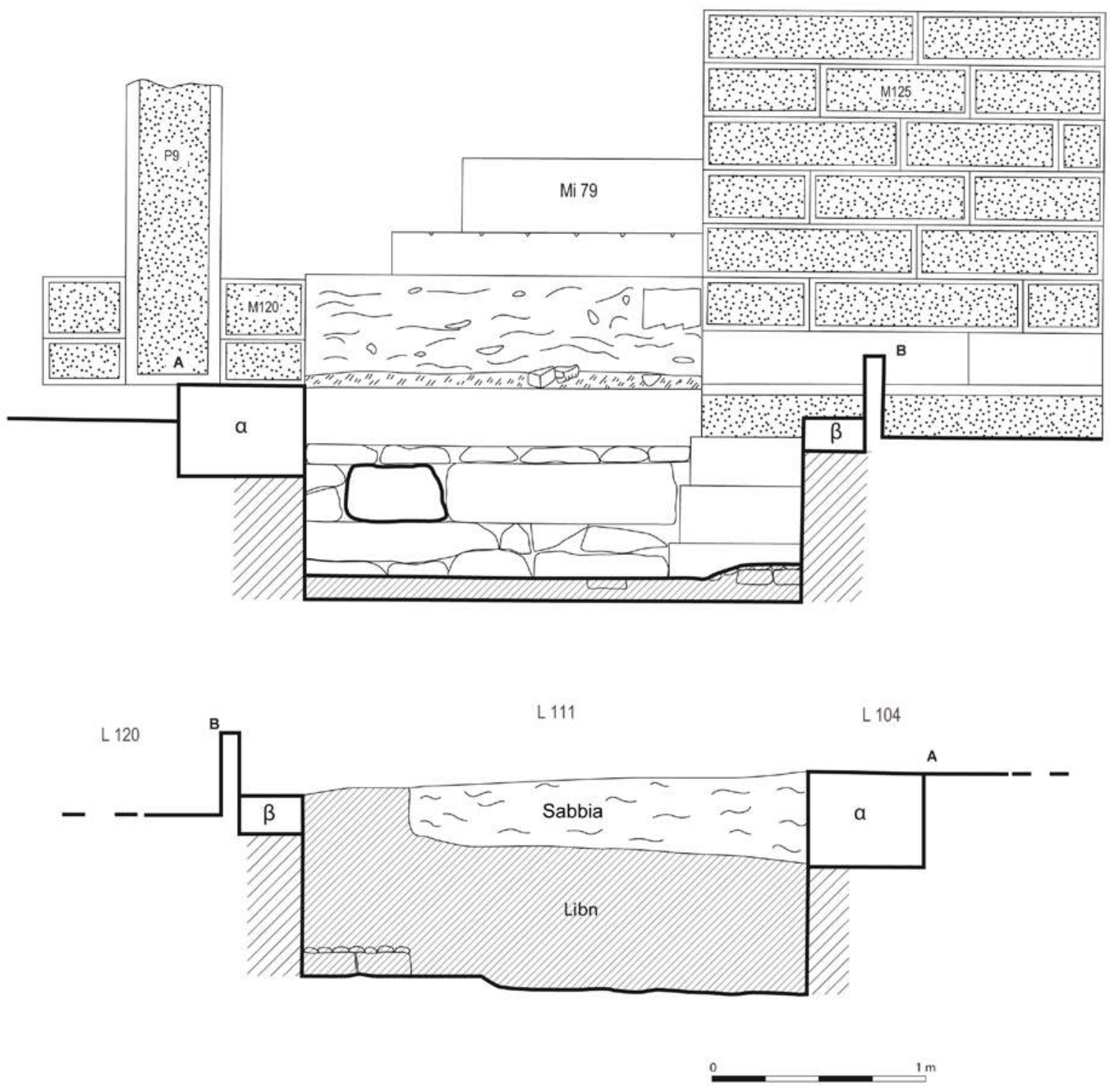

Figure 21. Sondaggio in L111, sezioni nord-ovest/sud-est In alto, sezione vista da sud-ovest; in basso, sezione parallela vista da nord-est. (Rielaborazione di L. Munduteguy da schizzo originale di A. Agostini 2019 @MAIRY) 


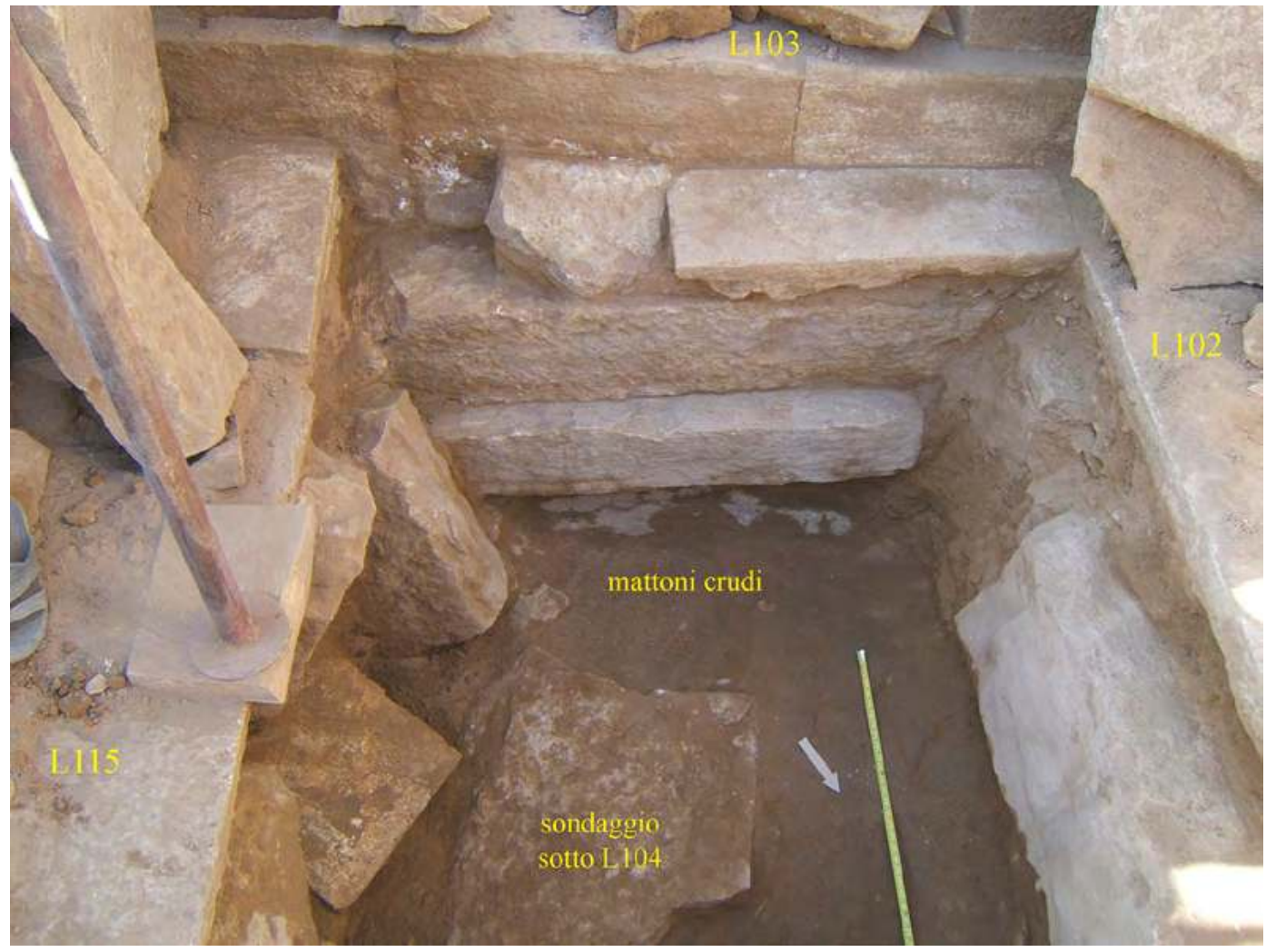

Figure 22. Sondaggio in L104, da nord-est. (A. de Maigret 2005 CMAIRY)

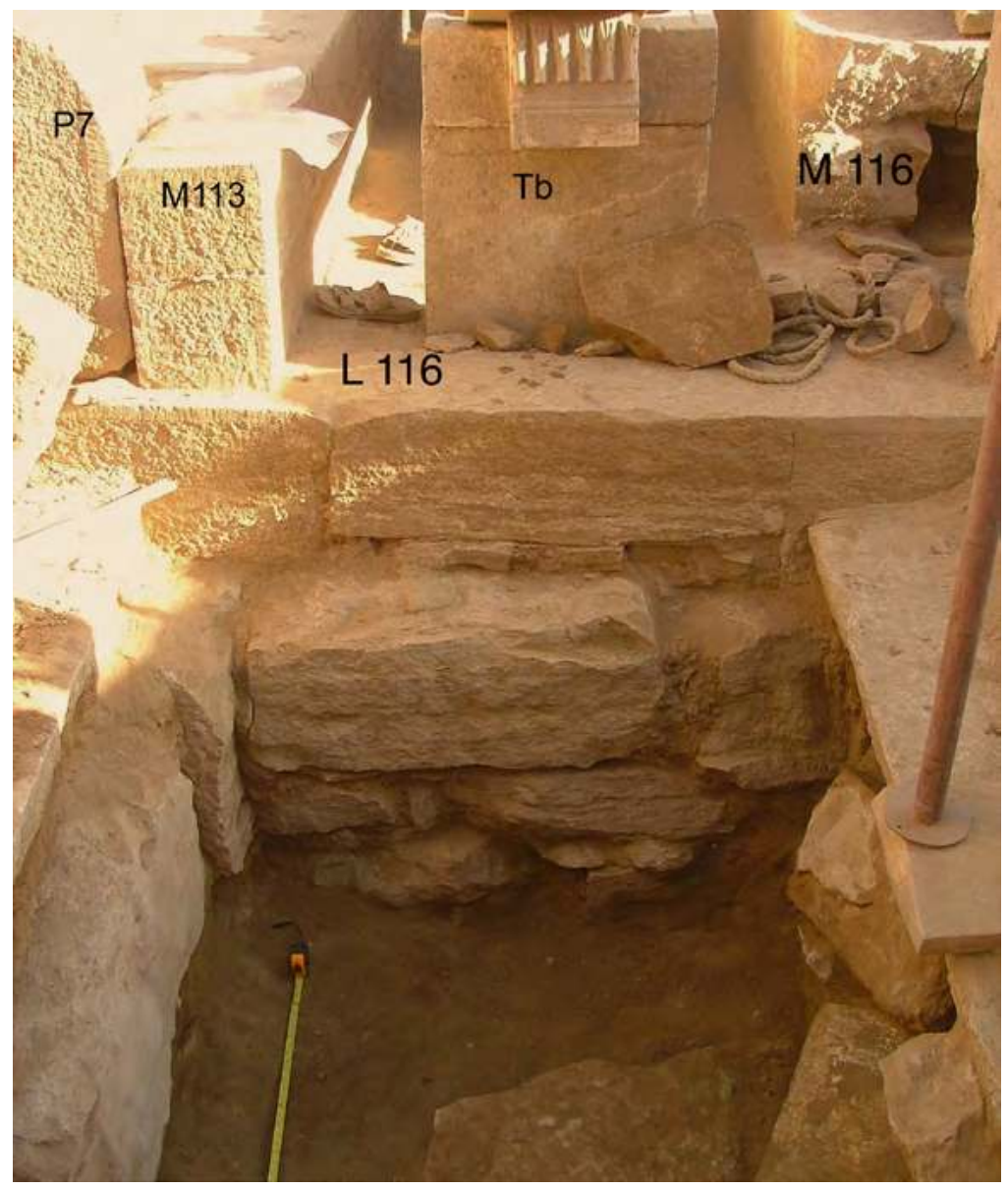

Figure 23. Sondaggio in L104, da sud-est. (A. de Maigret 2005 CMAIRY) 


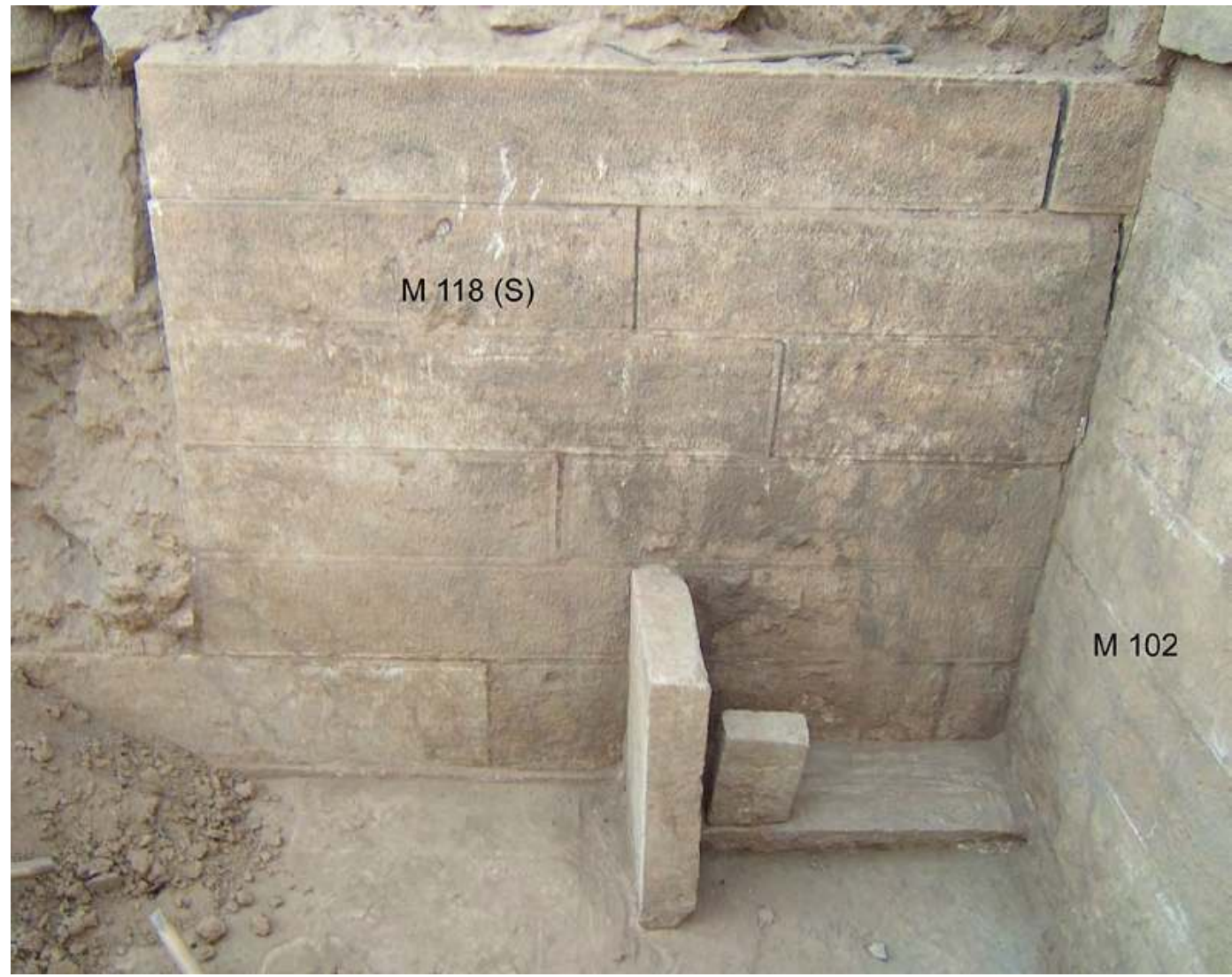

Figure 24. L'installazione realizzata nell'angolo sud est del L110. (A. Agostini 2005 CMAIRY)

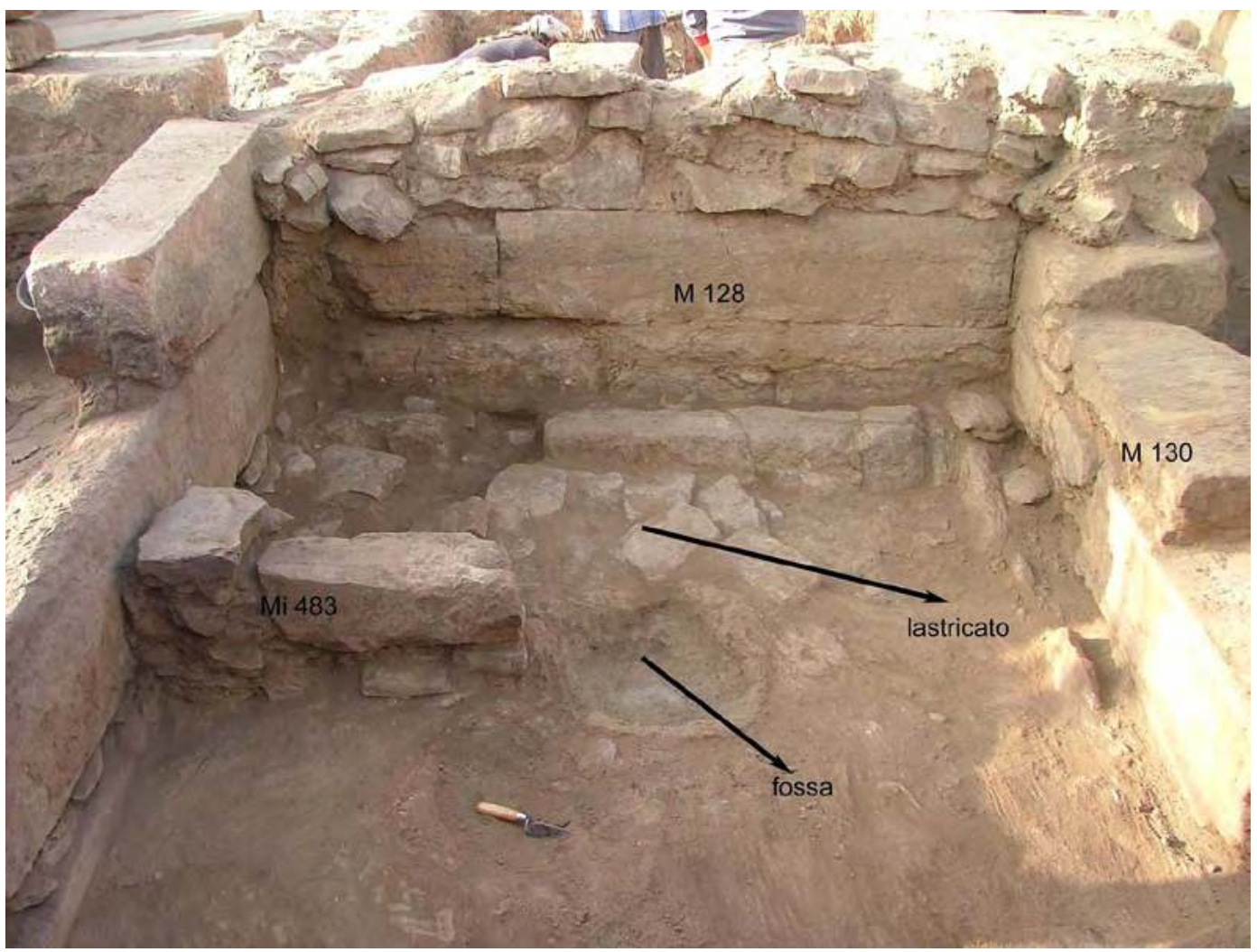

Figure 25. L'installazione in L125, da nord-est. (A. Agostini 2006 @MAIRY) 


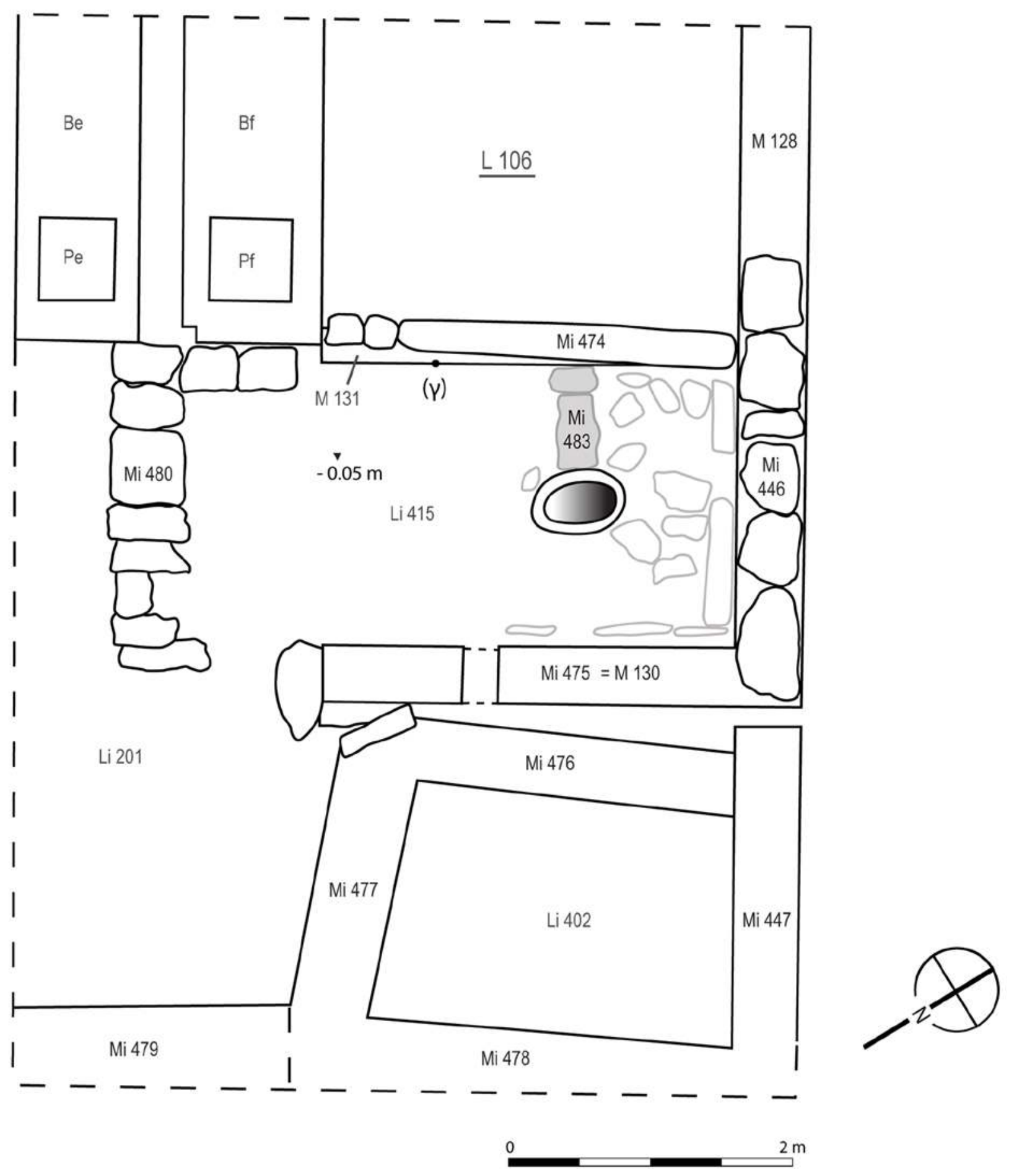

Figure 26. Particolare dell'installazione in L125 (Islamico Antico IIIb?). (Rielaborazione di L. Munduteguy da schizzo originale di A. Agostini 2019 CMAIRY) 

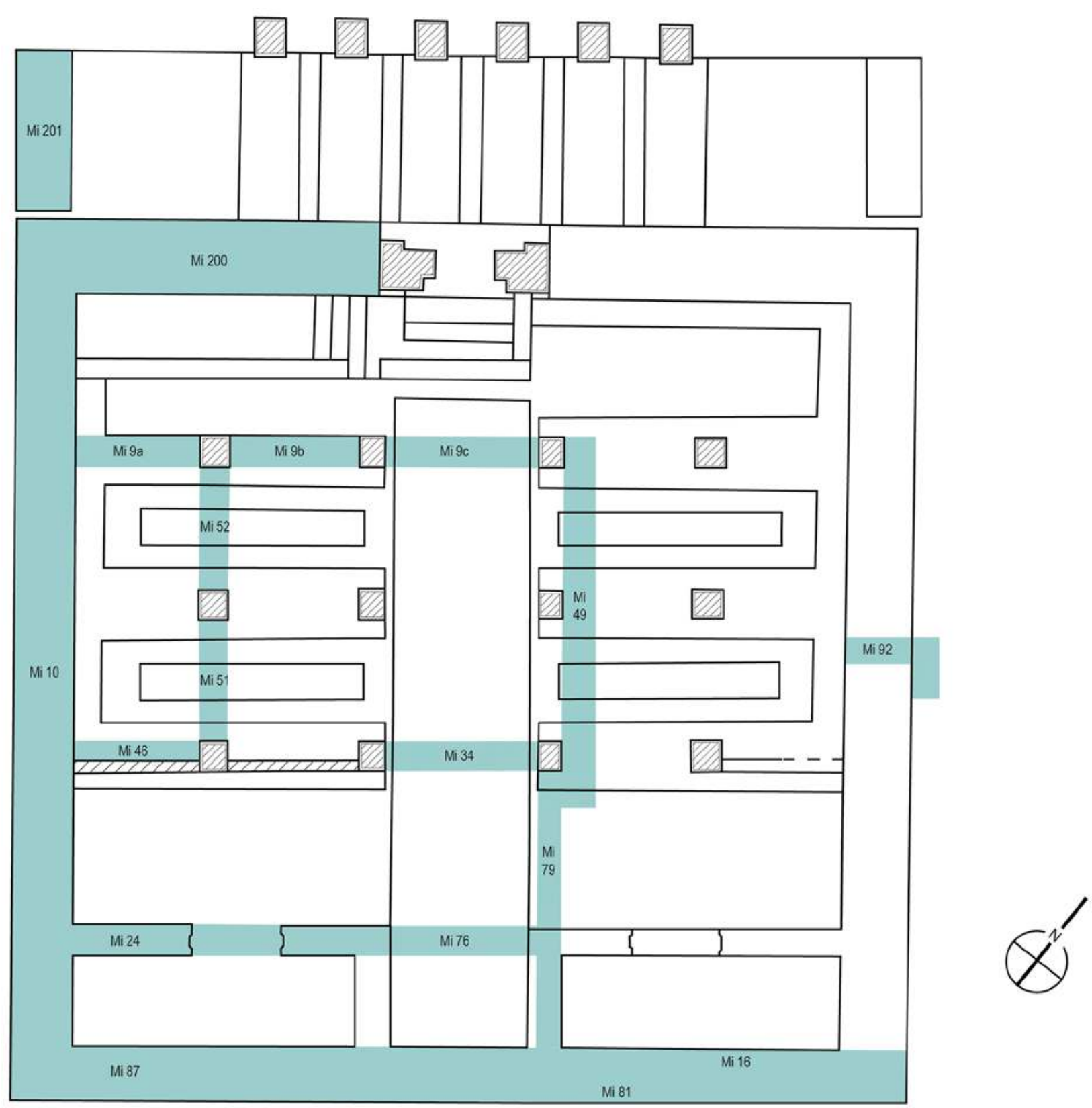

Figure 27. Principali strutture islamiche impiantate a contatto con le strutture minee superstiti del tempio. (Rielaborazione di L. Munduteguy da schizzo originale di A. Agostini 2019 CMAIRY) 


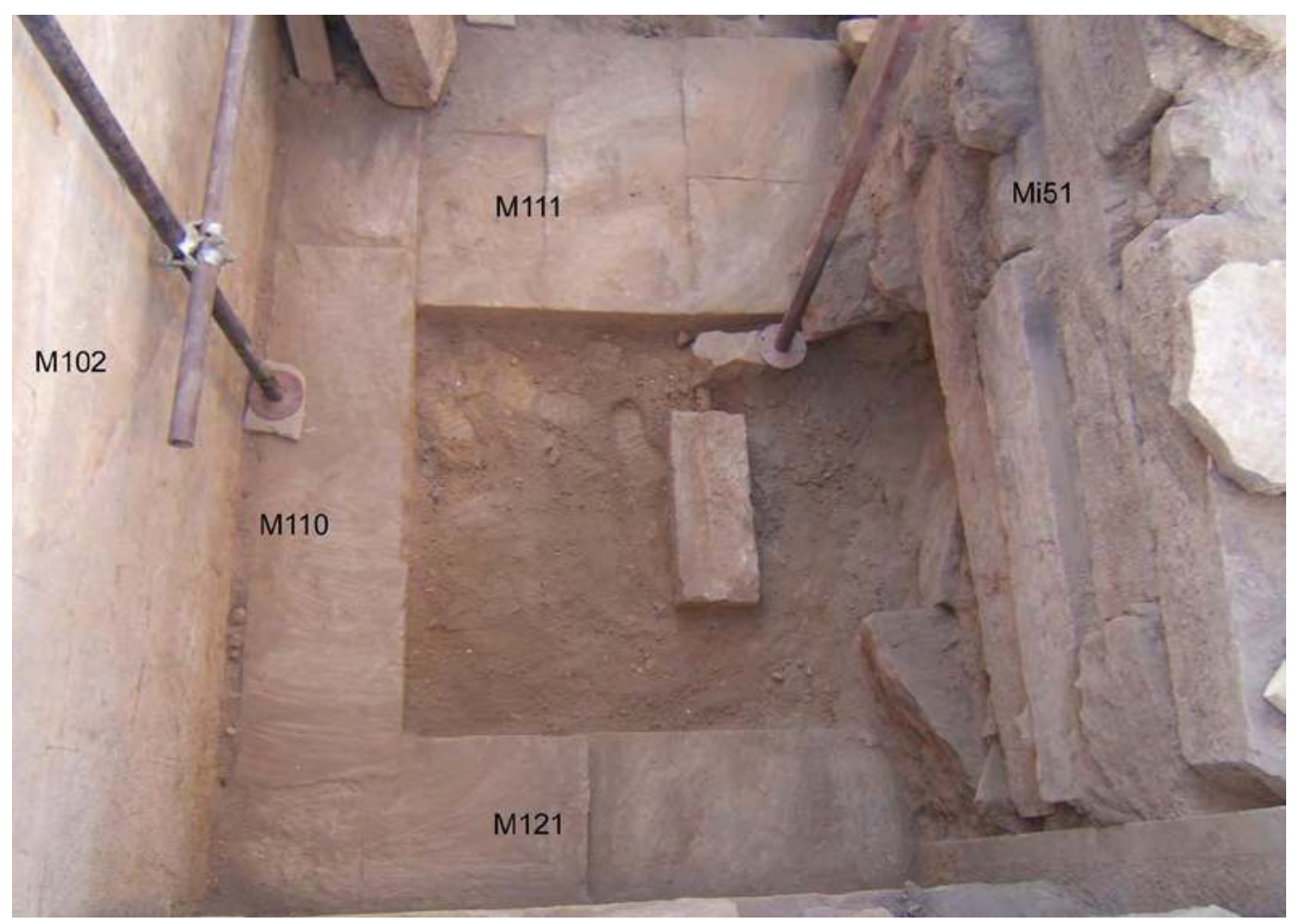

Figure 28. L'area del cenacolo in L114, con l'impostazione del muro islamico Mi51, da sud-est. (A. Agostini 2005 CMAIRY)

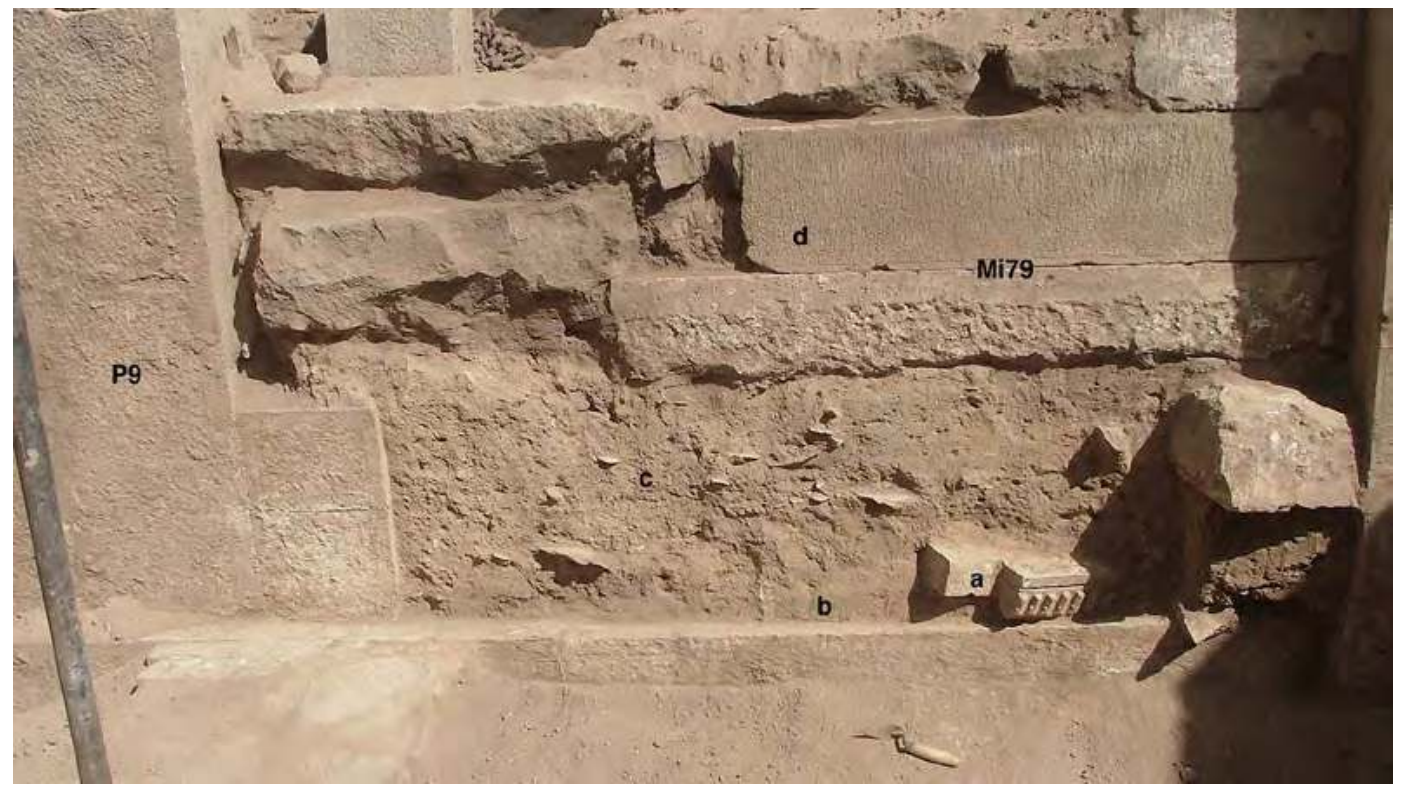

Figure 29. Stratigrafia relativa ai momenti del saccheggio, abbandono e primo periodo islamico su testimone in L111-L121, da sud-est. (A. Agostini 2005 OMAIRY) 
Il testimone che abbiamo lasciato nella linea P9M125, durante il saggio effettuato in L111 (v. sopra), ci consente di osservare meglio l'andamento delle varie fasi attorno a questo importante momento di passaggio e ci introduce nella fase di rioccupazione islamica (cfr. anche fig. 21). La devastazione dopo la fase minea e intermedia è ben rappresentata in sezione da un aggetto decorato a stambecchi pertinente a una tavola offertoria riversa poco sopra il livello del pavimento (fig. 29a), all'interno di uno strato terroso compatto (fig. 29b). Al di sopra del livello del pavimento di L121 è infatti ben visibile lo strato, friabile ma denso, di deposito eolico che si è lungamente accumulato dopo l'abbandono del tempio (fig. 29c). L'inizio del reimpiego della struttura è ben chiaro invece con l'impianto dei primi muri islamici che fanno uso di alcuni grossi blocchi minei, rimossi dalle strutture esistenti o semplicemente già crollati (fig. 29d): uno di questi muri corre proprio in corrispondenza di questa linea (Mi79) e ha come base un blocco con fregio dentellato mineo (cfr. anche fig. 27).

Più in generale, occorre premettere che le quote delle strutture pertinenti al primo momento islamico sembrano tutt'altro che omogenee e in taluni casi anche a diretto contatto con l'antico piano mineo. Questo perché l'area doveva presentare situazioni assai diversificate: alcune zone erano forse piuttosto libere, altre invece gravate da un abbondante crollo e pertanto poco accessibili, e altre ancora erano sotto un più abbondante strato sabbioso depositatosi durante il lungo abbandono. Da questo potrebbe conseguire che non tutta l'area del tempio sia stata occupata durante l'Islamico Antico e che alcune zone siano state riabitate solo dall'Islamico Medio, cioè quando l'innalzamento del livello aveva pressoché livellato zone in precedenza su quote diverse. In taluni casi, oltre che per la qualità della tecnica muraria, l'unico indizio in grado di far propendere per l'attribuzione all'Islamico Antico è stato proprio il denso strato di cenere che lo sigilla dopo la sua distruzione, prima del passaggio al Medio. ${ }^{54}$

\subsection{Islamico Antico}

La prima ampia fase di rioccupazione è preannunciata qua e là da alcuni sporadici passaggi, che possiamo distinguere dalla Fase Intermedia, perché in generale si collocano al di sopra del deposito sabbioso che associamo al lungo momento di iato, ma che non ci pare possano essere del tutto coerenti neanche con l'Islamico Antico pieno. Pertanto, ci pare utile distinguere l'Islamico Antico in due momenti: IIIb e IIIa,

quattro relativamente a una differenziazione ulteriore all'interno dell'Islamico Medio (de Maigret 1991a; de Maigret 1993). Cfr. anche Fedele, capitolo 26, volume 2.

54 Una più completa analisi dei materiali associati a questi livelli potrà in futuro chiarire meglio la successione e i rapporti cronologici tra le varie fasi. la cui reciproca distanza cronologica deve essere ancora pienamente precisata (fig. 30 ).

La sotto-fase IIIb non è individuabile estensivamente, ma le strutture che la caratterizzano sono in generale piuttosto effimere e sembrano in taluni casi impostarsi a una quota di poco superiore al piano mineo. La fattura di queste strutture, oltre ai materiali ad esse pertinenti, permette tuttavia di associarle al periodo islamico.

All'interno di L118, per esempio, notiamo una sorta di suddivisione interna realizzata con alcune pietre poste verticalmente e infisse nel deposito eolico: si tratta di un intervento che si realizza quando la fase di abbandono era già avanzata, ma che ci pare utile distinguere dalla sequenza dei più decisi interventi di riorganizzazione avvenuti nell'Islamico Antico IIIa (fig. 31).

Nella zona che corrisponde all'area antistante alla cella, cioè L111, è stato messo in luce un piccolo ambiente (Li303), delimitato lateralmente da piccoli muretti e caratterizzato da un ribassamento interno di cui non è chiara la funzione; il muro Mi79 che lo chiude verso nord-est si appoggia in parte direttamente sul mineo M125 (fig. 32). Anche in Li1 un pavimento in battuto di una prima rioccupazione è stato rinvenuto a una quota molto bassa, e in questo stesso vano si era pure visto una sorta di 'giaciglio' formato da un intreccio di foglie, forse di palma, il quale s'inserisce addirittura parzialmente sotto Mi49 e copre direttamente il deposito sabbioso: anche per questo si potrebbe dunque ipotizzare un'attribuzione a questo periodo IIIb, caratterizzato da questo tipo di installazioni piuttosto labili (figg. 33-34-35).

Per quanto riguarda l'area che insiste sulla parte antistante il tempio, dobbiamo ricordare anche il breve piano di vita post-mineo sulla porzione sud-ovest della terrazza L125, il quale potrebbe essere con una certa probabilità collocato in questo momento. Qui la situazione è complicata dal fatto che la quota della terrazza potrebbe aver impedito alla sabbia eolica di depositarsi e questo, come detto, ci priva del più chiaro indizio archeologico che potrebbe consentirci di dirimere tra la Fase Intermedia e un primo impianto dell'Islamico Antico.

Gli stessi piccoli muretti islamici di mediocre fattura che hanno cominciato ad impostarsi sulla scalinata (ad es. Mi486; Mi479 e forse anche l'intero Li427) possono forse cautamente essere ascritti alla fase IIIb, dato che subito al di sotto di questi si nota il solito fine deposito sabbioso. Tale fase ci appare tuttavia a tratti disturbata, e forse rimaneggiata proprio durante $\mathrm{i}$ momenti immediatamente successivi (IIIa), tanto che la ceramica islamica si rivela a tratti a contatto col livello del pavimento mineo. 
La fase dell'Islamico Antico più maturo ed esteso (IIIa) si caratterizza invece per strutture di dimensioni piuttosto ampie, che sono costituite da muri solidi e imponenti, specie negli spazi più liberi da precedenti strutture 0 crolli - come nella zona tra i due templi. Naturalmente, è pure frequente anche la riutilizzazione di alcune pietre già preparate, ricavate dalla struttura del tempio mineo, sia per spoliazione, sia per recupero dal crollo. Svariati sono anche i blocchi con iscrizioni minee reimpiegati in questa fase (fig. 36). I frammenti ceramici assegnati a questo periodo sono, a differenza della fase precedente, piuttosto abbondanti e presentano una discreta varietà di forme e decorazioni. Tra le più caratteristiche ci sono delle coppe e delle piccole giare dall'impasto abbastanza compatto e con fondo piatto (button bases), alcune delle quali presentano una decorazione a pittura rossa con linee oblique intersecanti - un motivo che sembra diagnostico per questo periodo. ${ }^{55}$ Queste strutture e i relativi materiali possono essere attribuiti al periodo attorno al XIII secolo d.C. cioè al tempo in cui Barāqish ha iniziato ad essere di nuovo intensamente occupata. In questo momento abbiamo certamente molti degli interventi che hanno recuperato alcune delle antiche strutture minee in stato di abbandono o parzialmente crollate, a cominciare proprio dalla cinta muraria cittadina. Alcuni degli edifici più imponenti e di migliore fattura - e lo sono certo soprattutto in confronto a quelli delle successive fasi islamiche - sono relativi al momento in cui il celebre Imām zaidita 'Abd Allāh ibn Hamza (1166-1217) si rifugiò temporaneamente a Barāqish, eleggendola a sua dimora. Il palazzetto che si trova nell'area est del sito, vicino alla porta secondaria, è infatti a lui ricollegabile; prova inconfutabile che l'Islamico Antico di Barāqish è da inserire in questo orizzonte cronologico viene poi dalla moneta rinvenuta durante lo scavo del Tempio A proprio sulla terrazza anteriore del tempio mineo. ${ }^{56}$ Questa fase termina con un denso strato di cenere scura, rinvenuto anche durante lo scavo del Tempio A, a testimonianza di un ampio incendio che deve aver interessato gran parte del sito alla fine di questo periodo (fig. 37).

Tra le strutture che caratterizzano meglio questa fase ci sono $i$ tre grandi vani (di circa $7 \times 5 \mathrm{~m}$ ) che occupavano lo spazio tra i Templi A e B, distanziati appunto tra loro per $7 \mathrm{~m}$ (fig. 38). La funzione di questi vani non è ancora del tutto chiara. Si tratta di Li2, Li10 e Li20, i cui alzati sono stati realizzati sfruttando in parte i due muri perimetrali paralleli dei due templi in direzione nordovest/sud-est, poi rialzati con integrazioni di epoca islamica: il limite sud-est è determinato da $\mathbf{M d}$, che è l'innalzamento di M8, muro perimetrale dei quadranti settentrionali del Tempio A, con la sua prosecuzione Mcf che si affila con Md verso nord-ovest (fig. 39); il

\footnotetext{
55 de Maigret 2009b, 56.

56 de Maigret e Robin 1993, 434, fig. 11.
}

limite nord-est di questi vani è disegnato da Mi10 che si imposta sul muro perimetrale sud-est del Tempio B, M102. I muri di raccordo inseriti tra i due templi, che corrono paralleli in direzione nord-est/sud-ovest, sono invece realizzati interamente nell'Islamico Antico: si tratta di mura possenti e di ottima tecnica costruttiva, che utilizzano pietre irregolari di piccolo e medio taglio, ma ben disposte a spina di pesce, con alcuni conci orizzontali a intervalli regolari e tenuti insieme da abbondante malta (fig. 40). Partendo da sud-est abbiamo Mi15, Mi14 e Mi42, il quale si appoggia su Mcf. Li2 è in comunicazione con Li10 attraverso un'alta porta in Mi14. Il livello di camminamento in questi ambienti, relativo all'slamico Antico, quindi presumibilmente all'epoca di 'Abd Allāh ibn Ḥamza, era pressappoco al livello del piano mineo dei templi. Questo può significare che quest'area era rimasta piuttosto libera da strutture, ad eccezione del crollo di una parte del propileo del Tempio A (fig. 41), il che potrebbe aver permesso una sua rioccupazione con poca difficoltà (figg. 42-43). Bisogna ricordare che anche lo stesso Mcf si impostava direttamente sul piano della terrazza minea antistante all'ingresso del Tempio A. Mi42 risulterà di un'altezza di $4 \mathrm{~m}$ sulla sua fondazione e potremmo quasi considerare sia Mi73, sia Mcf, come dei suoi contrafforti di sostegno. In Li2 e Li10 è stato messo in luce un pavimento in terra battuta dopo la rimozione dello strato cineroso, che come sappiamo chiude la fase dell'Islamico Antico (figg. 44-45); una pavimentazione analoga è emersa anche in Li218. ${ }^{57}$

Ancora nell'area che corrisponde allo spazio tra il Tempio A e il Tempio B, verso ovest, è emersa una struttura composita a sei vasche di forma quadrangolare (Li418 - Li419 - Li421 - Li422 - Li423-Li424), ciascuna con lati lunghi poco più di $1 \mathrm{~m}$ (figg. 46-47). Sono apparse sigillate da uno strato argilloso compatto di colore giallo e ciascuna era riempita da un deposito cineroso, piuttosto disomogeneo. Un deposito giallo terroso è quello che è affiorato una volta che le vasche sono state svuotate. Dobbiamo rilevare che questa struttura si impianta a una quota più bassa rispetto al livello Islamico Antico che abbiamo rinvenuto nella zona direttamente antistante il tempio (v. qui sotto), ma siamo propensi a ricondurre tutto a una medesima fase, perché risulta essersi impostata su un unico livello di crollo, a sua volta sopra lo strato sabbioso relativo all'abbandono. D'altra parte, una differenza di quota

\footnotetext{
57 Durante le operazioni di rimozione di questi livelli, sono emersi alcuni frammenti pertinenti al pilastro nord-est del Tempio A, rinvenuto in tre frammenti al di sotto del deposito eolico postabbandono. Al momento del crollo, il pilastro deve essere franato verso nord, adagiandosi ai piedi della scalinata esterna e in seguito ricoperto dai sedimenti. Su questo deposito si sono poi impostati i primi muri di epoca islamica (Mi42, Mi73 e Mcf, cfr. figg. 41, 43). Il moncone principale del suddetto pilastro era stato riportato alla luce durante gli scavi del Tempio A, ma poi spostato sul camminamento delle mura perché non creasse intralcio durante il lavoro nell'area della scalinata.
} 
doveva essere presente già in origine, poiché l'area si trovava più libera da strutture, e difatti la scala racchiusa dai muri Mi450 e Mi451 poteva in effetti servire da raccordo per questi piani diversi.

L'area corrispondente alla zona dell'avancorpo e alla parte anteriore del tempio è occupata nella fase dell'Islamico Antico da un complesso intreccio di strutture. Il nucleo di tale organizzazione sembra essere il piccolo ambiente Li413, di forma pressoché quadrata e senza accessi, il che lo configurerebbe come una sorta di vasca di deposito $o$, più probabilmente, di scarico (figg. 48-49-50). Altri ambienti potevano essere in effetti destinati all'immagazzinamento di derrate e alcuni di questi forse anche alla loro lavorazione, trasformazione e cottura. A questa area si poteva dapprima accedere attraverso due porte in Li201, poi entrambe chiuse a un livello di accumulo successivo; un'altra entrata che rimarrà più a lungo disponibile è quella in Mi401, che verrà chiusa solo nell'Islamico Medio. Da qui si accedeva alla zona con vasche di maggiori dimensioni (Li402). Tutta l'area era sigillata dall'abbondante strato di cenere che chiude questa fase. Tale passaggio in questa particolare zona sembra essere tuttavia più sfumato che altrove, e d'altronde la presenza di strati di cenere non è sempre ed ovunque riconducibile ad azione distruttiva, ma si deve tenere conto anche di un accumulo naturale per quei vani destinati alla cottura, e qui ne abbiamo individuati diversi, ben rappresentati da vari tannūr, come in Li403 (fig. 51). Bisogna inoltre rilevare che la ceramica proveniente da questo livello ci è parsa piuttosto omogenea, motivo per cui sarebbero utili ulteriori approfondimenti per una diagnosi più puntuale. Per il momento basti dire che le forme aperte sono nettamente prevalenti e tra queste molto abbondanti sono le coppe. Gli impasti appaiono depurati e compatti, tanto da lasciare fratture nette e pulite. Molta di questa ceramica ha però subìto

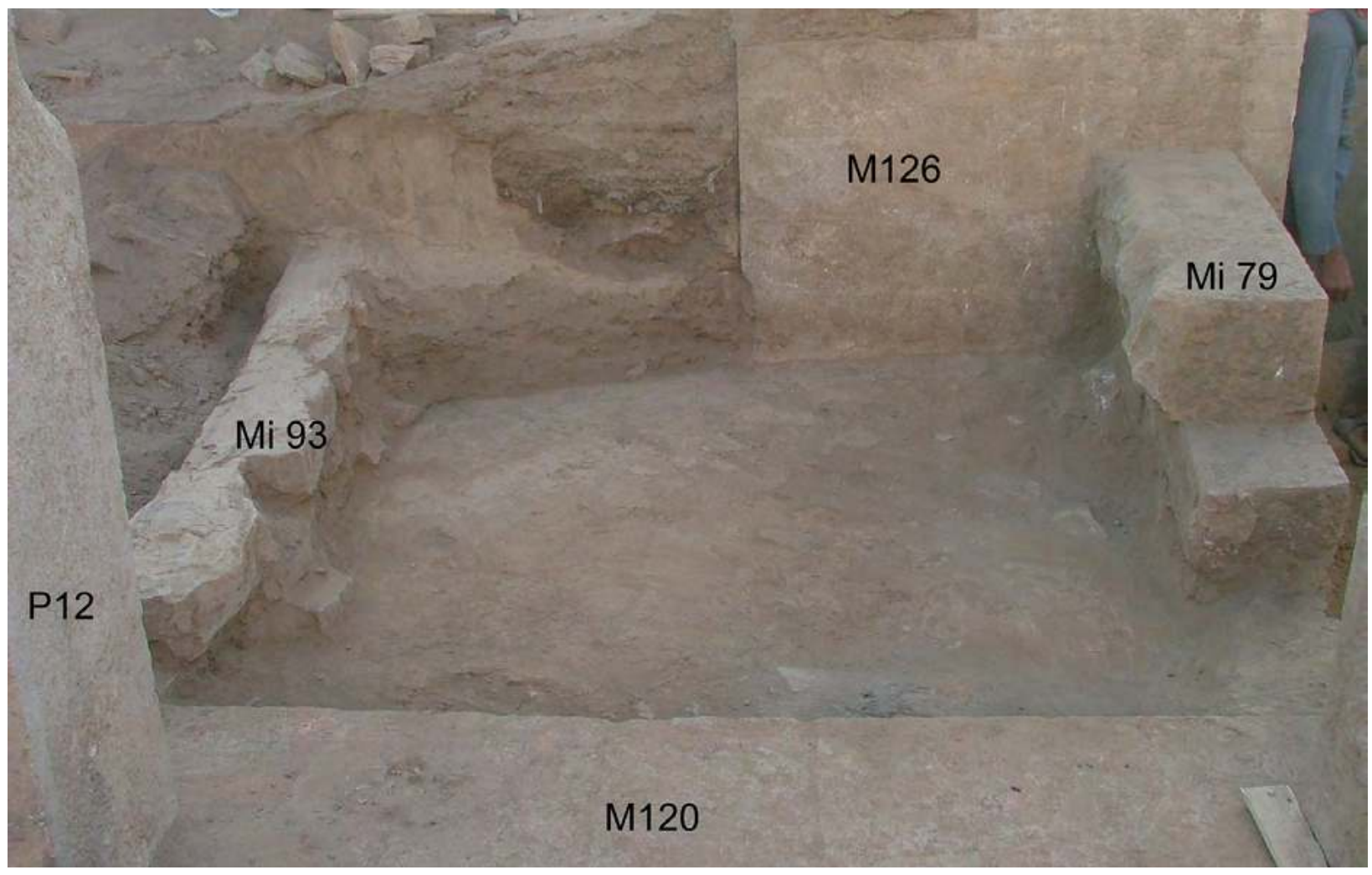

Figure 30. Strutture dell'Islamico Antico sull'area del transetto, da nord-ovest. (A. Agostini 2005 @MAIRY) 


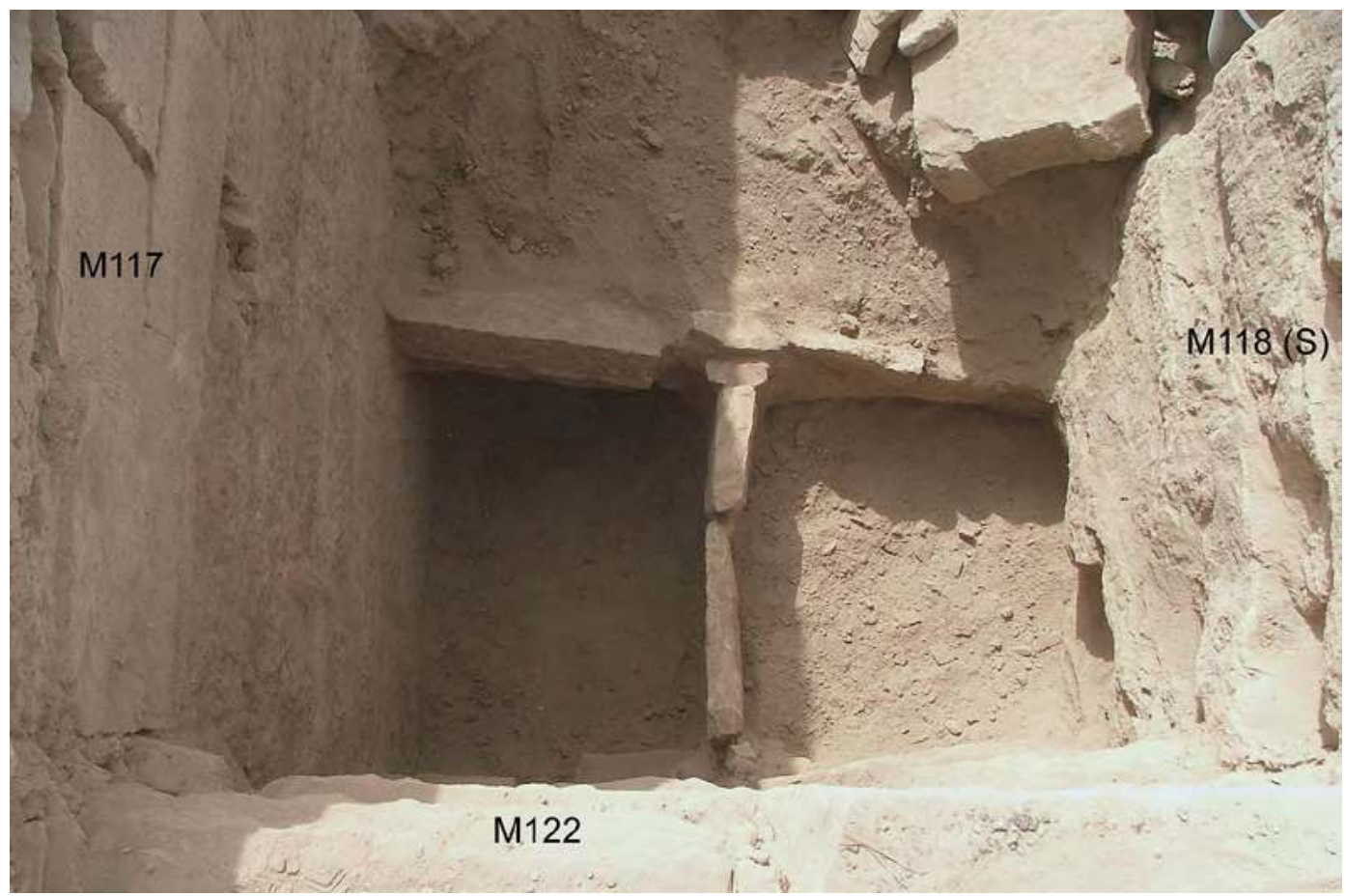

Figure 31. Ricettacoli realizzati all'interno di L118 durante la rioccupazione islamica, da nord-est. (A. Agostini 2005 CMAIRY)

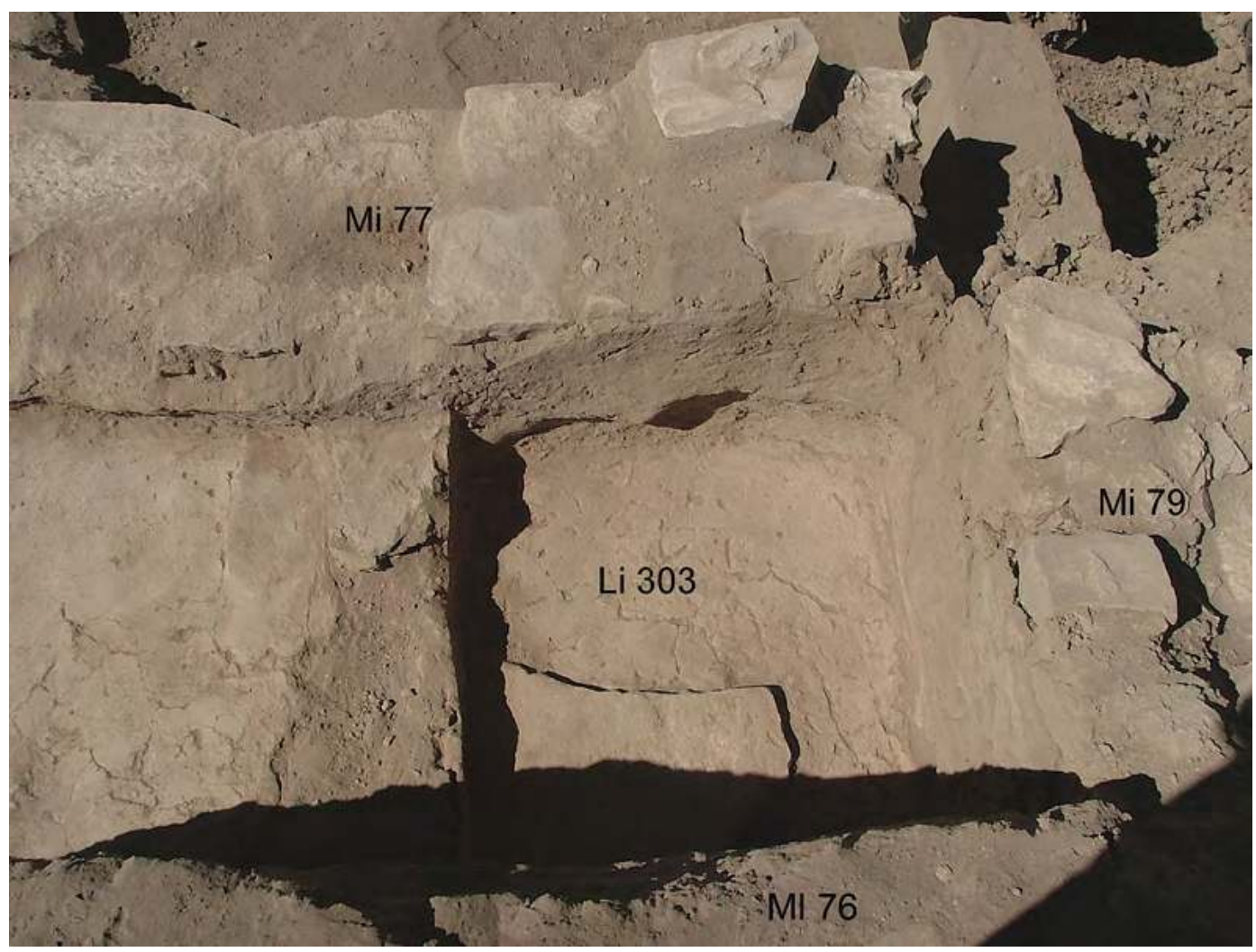

Figure 32. Li303 da nord-ovest. (A. Agostini 2005 @MAIRY) 


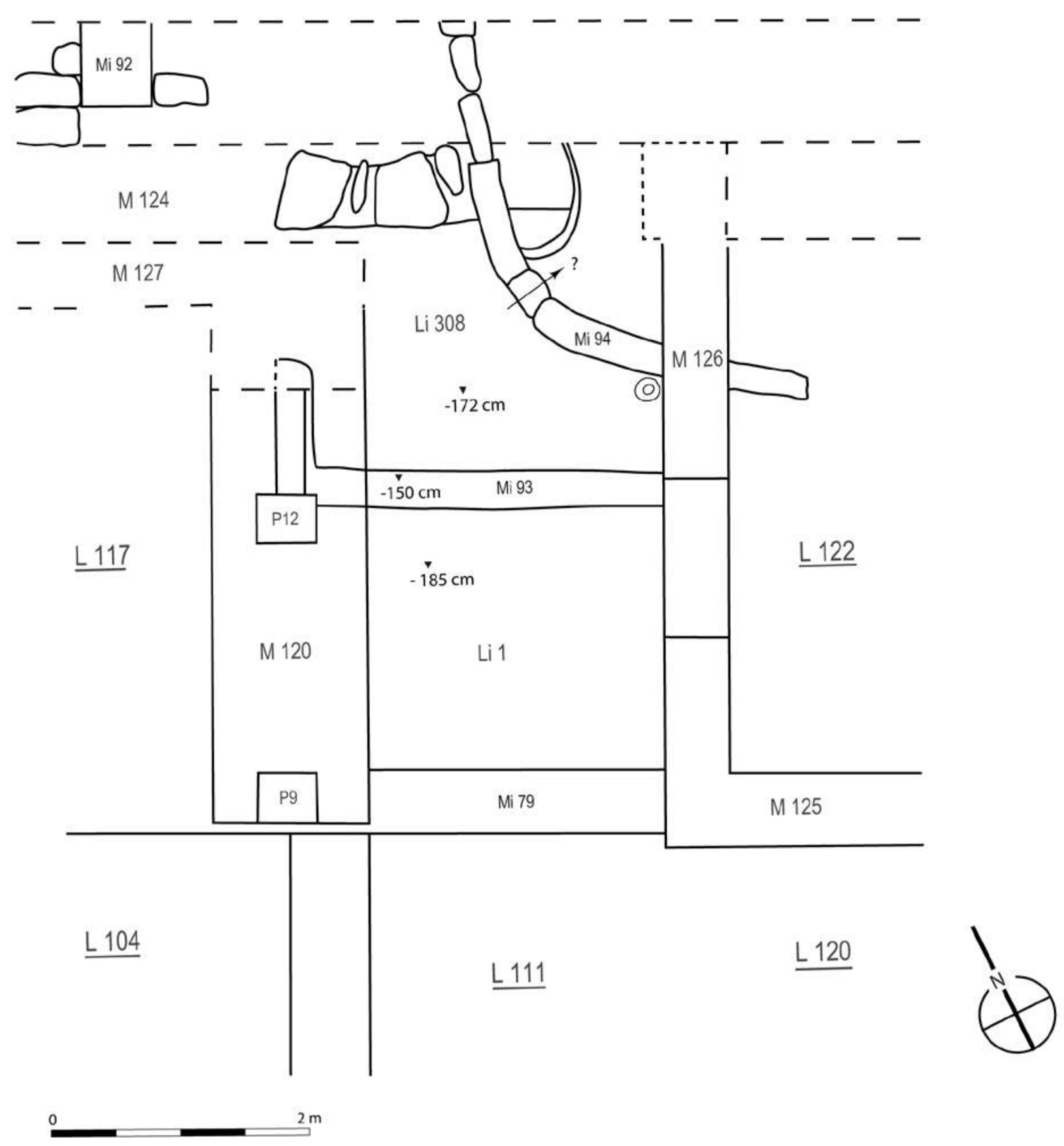

Figure 33. Islamico Antico IIIb su area sala ipostila; quote da cima P12. (Rielaborazione di L. Munduteguy da schizzo originale di A. Agostini 2019 CMAIRY) 


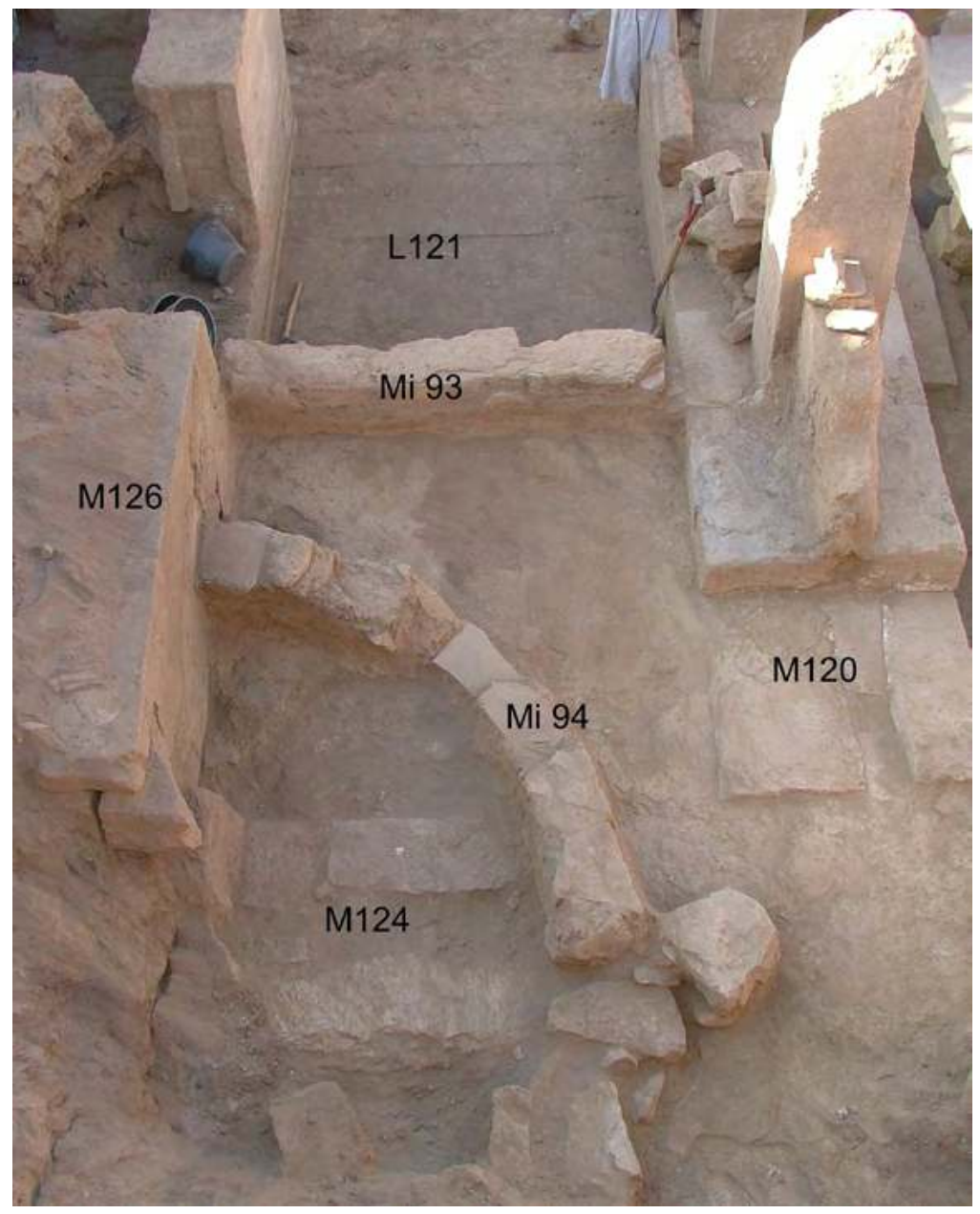

Figure 34. Li308 da nord-est. (A. Agostini 2005 CMAIRY)

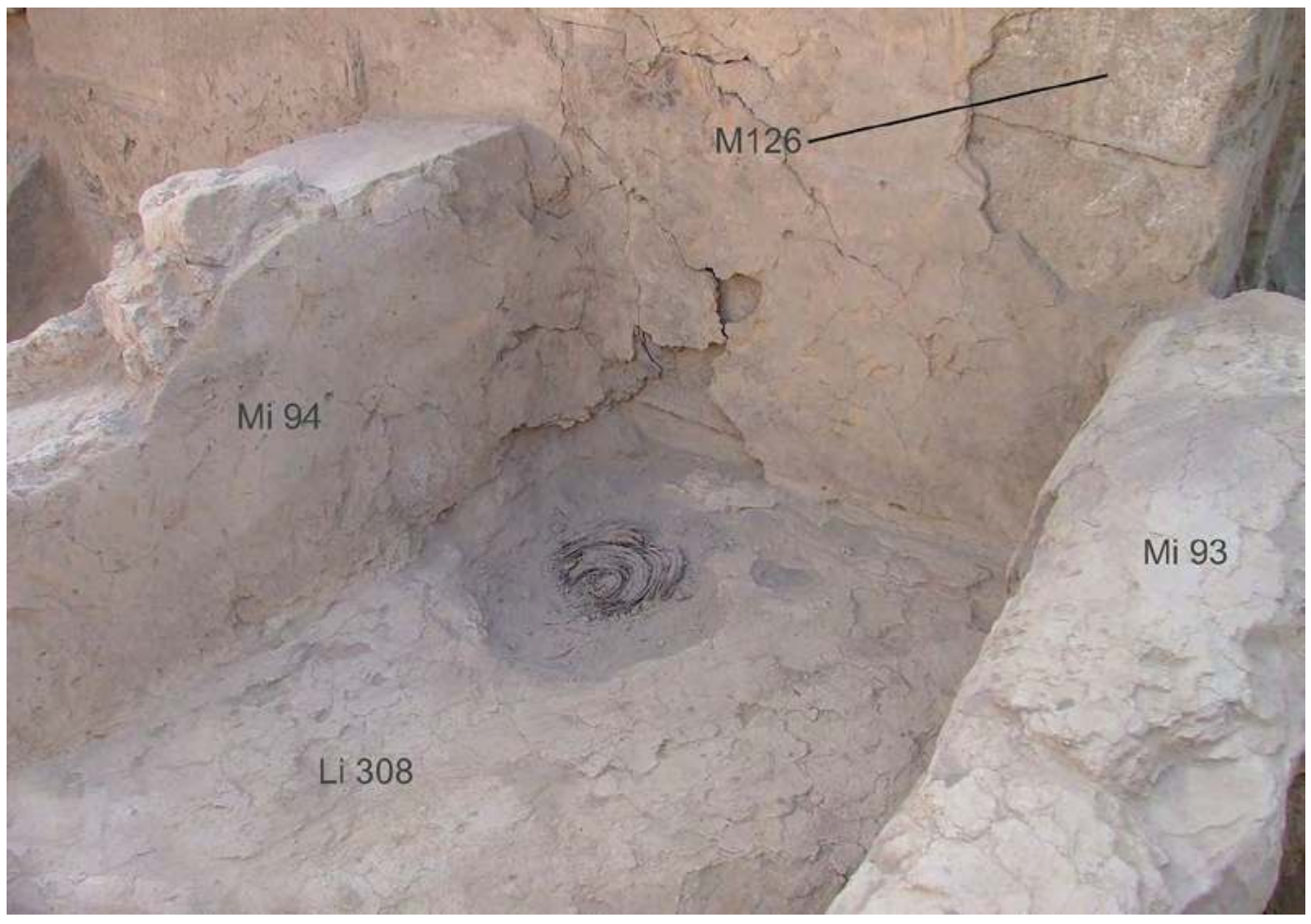

Figure 35. Li308 da ovest. (A. Agostini 2005 OMAIRY) 


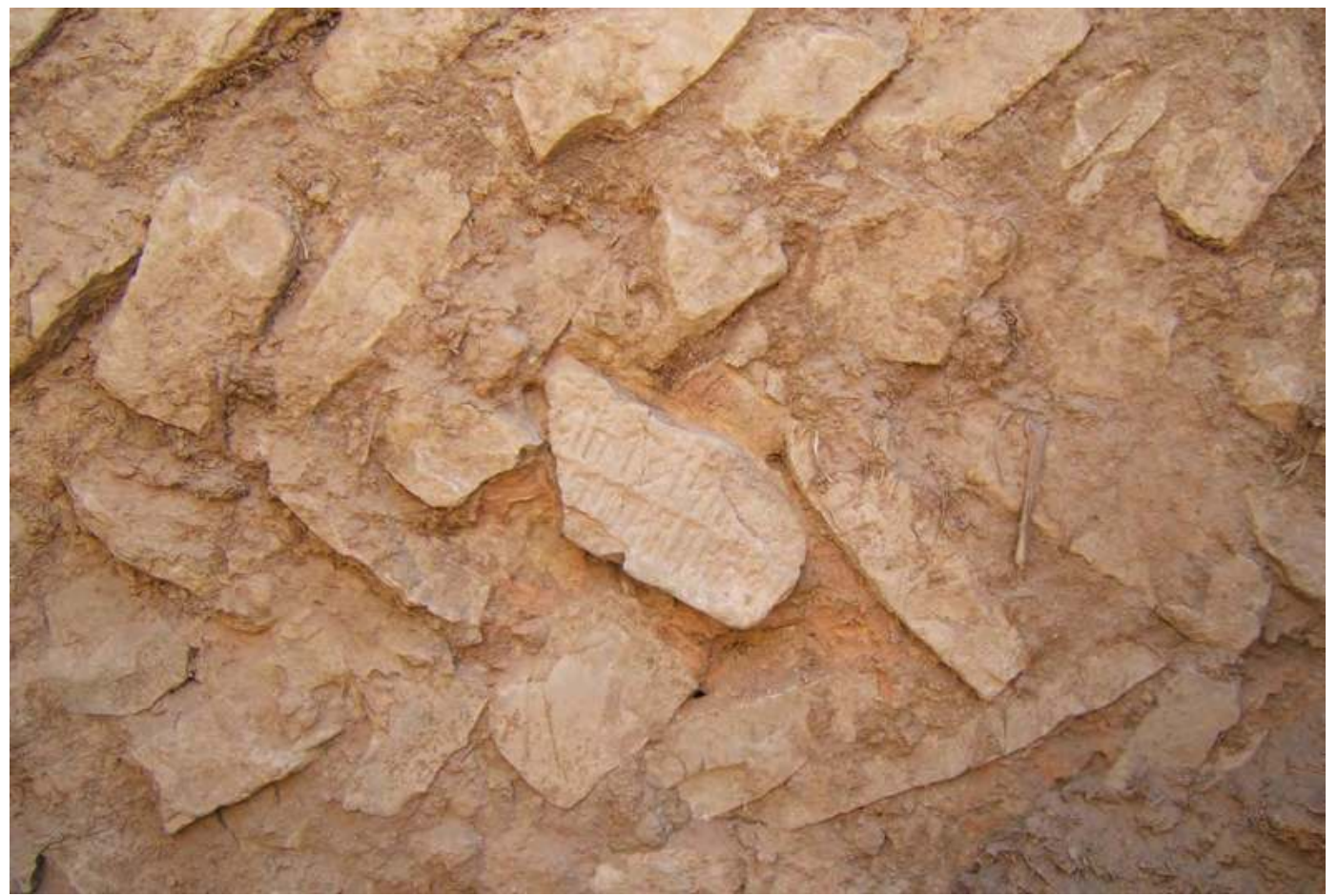

Figure 36. L'iscrizione Y.05.B.B.11 reimpiegata nel muro Mi15 di Li10. (A. Agostini 2005 CMAIRY)

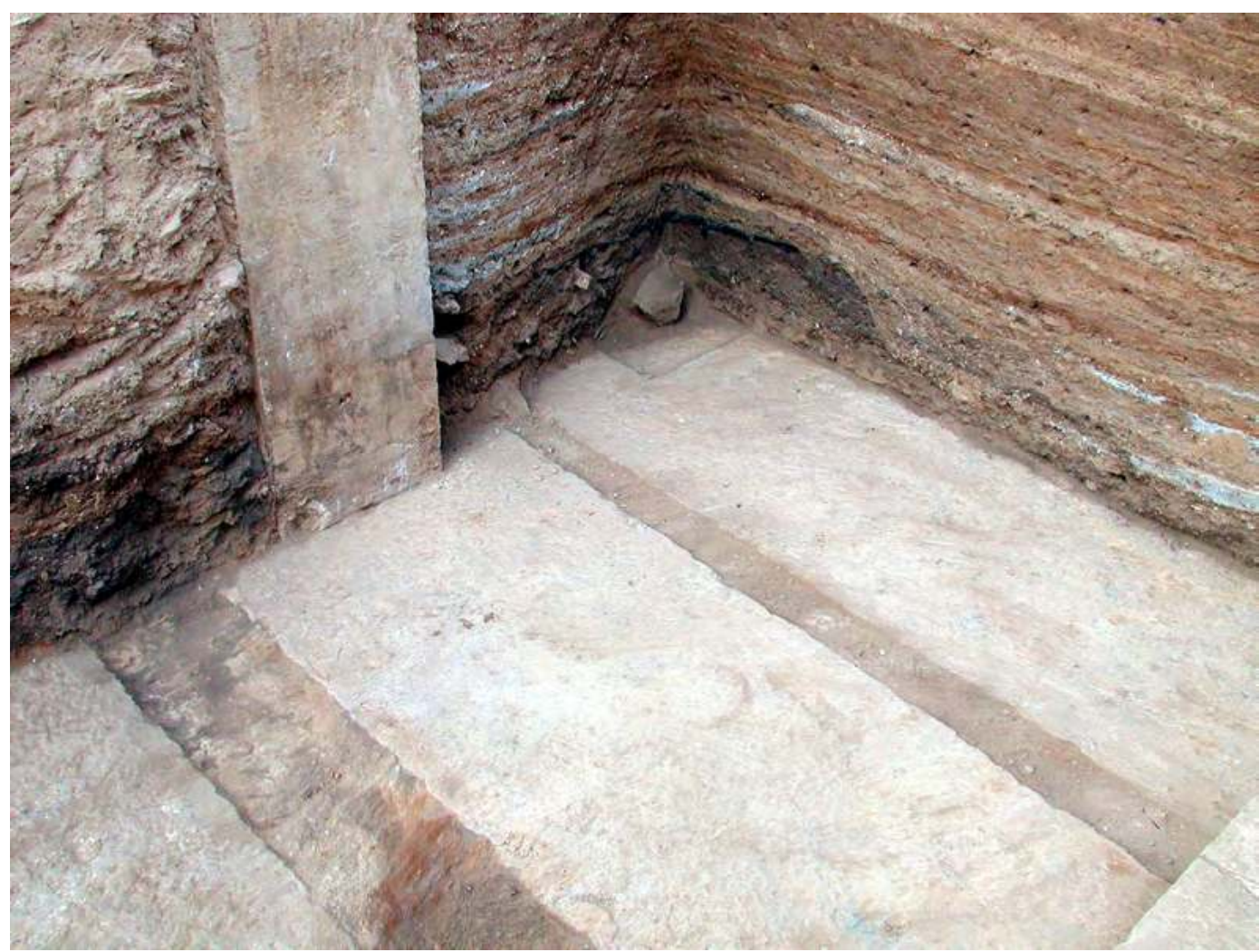

Figure 37. Stratificazione dell'accumulo in L101, da sud-est. (A. de Maigret 2005 OMAIRY) 


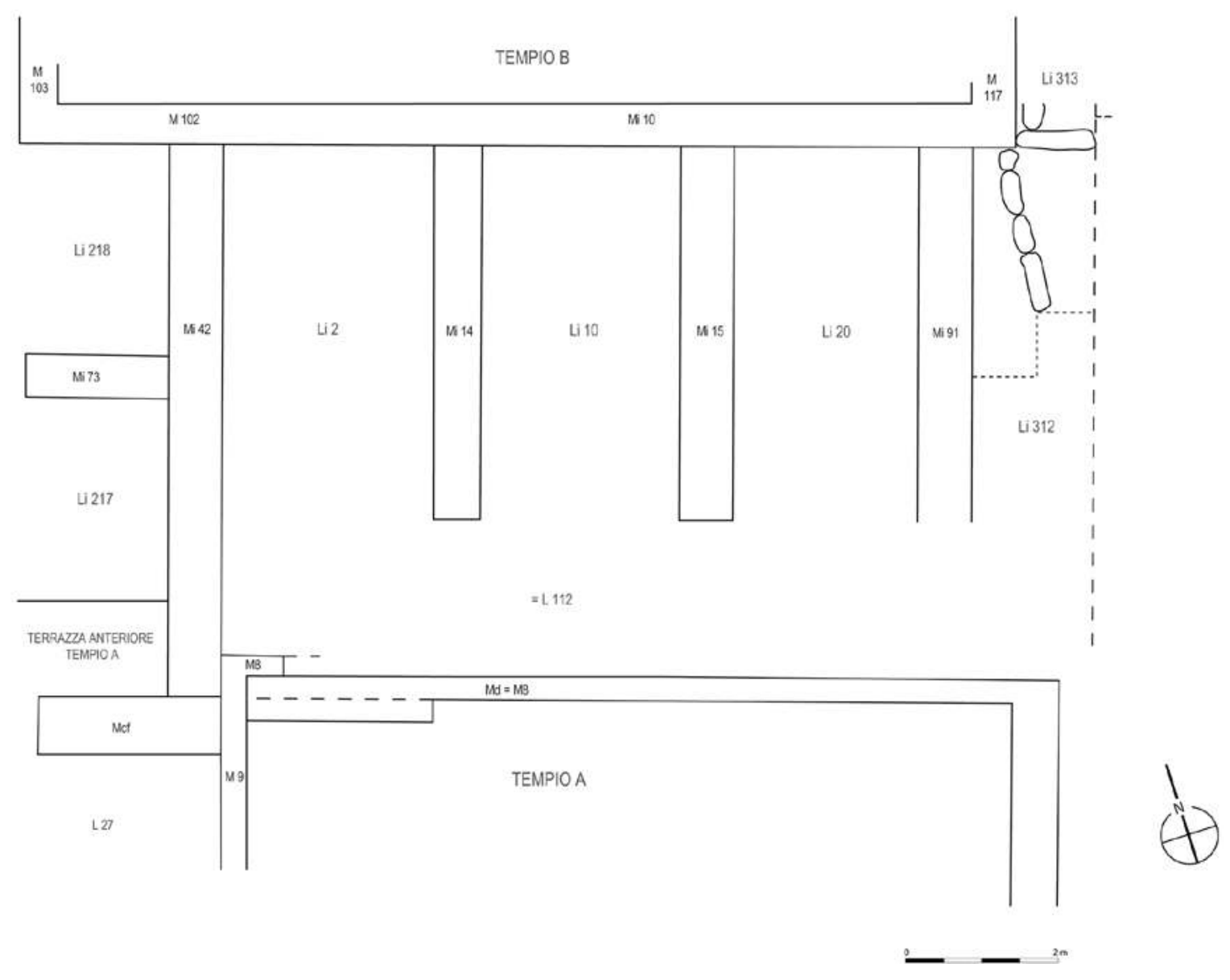

Figure 38. Islamico Antico IIIa, area tra i due templi, da sud-est. (Rielaborazione di L. Munduteguy da schizzo originale di A. Agostini 2019 @MAIRY)

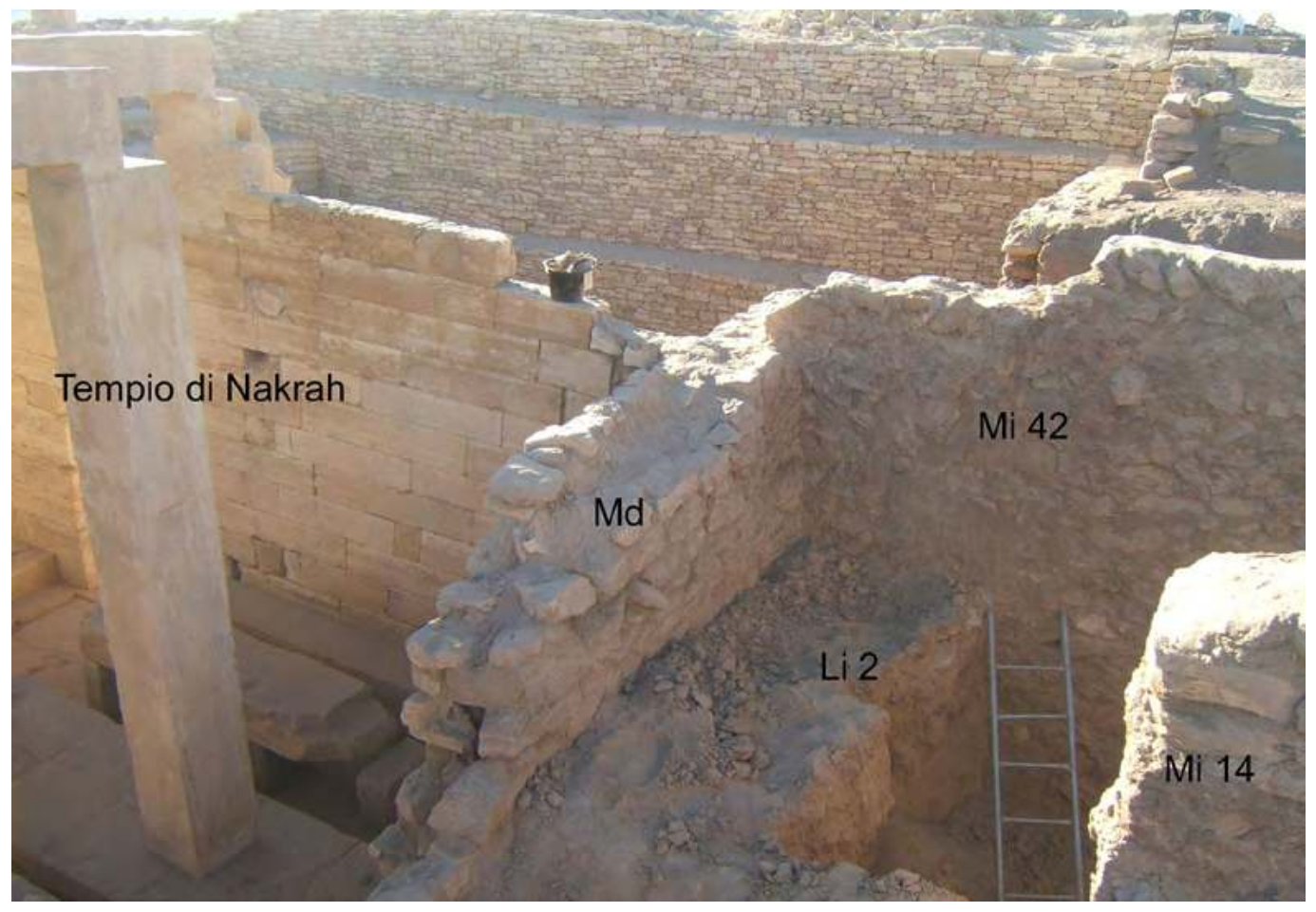

Figure 39. Li2 in appoggio al lato nord-ovest del Tempio A. (A. de Maigret 2006 CMAIRY) 


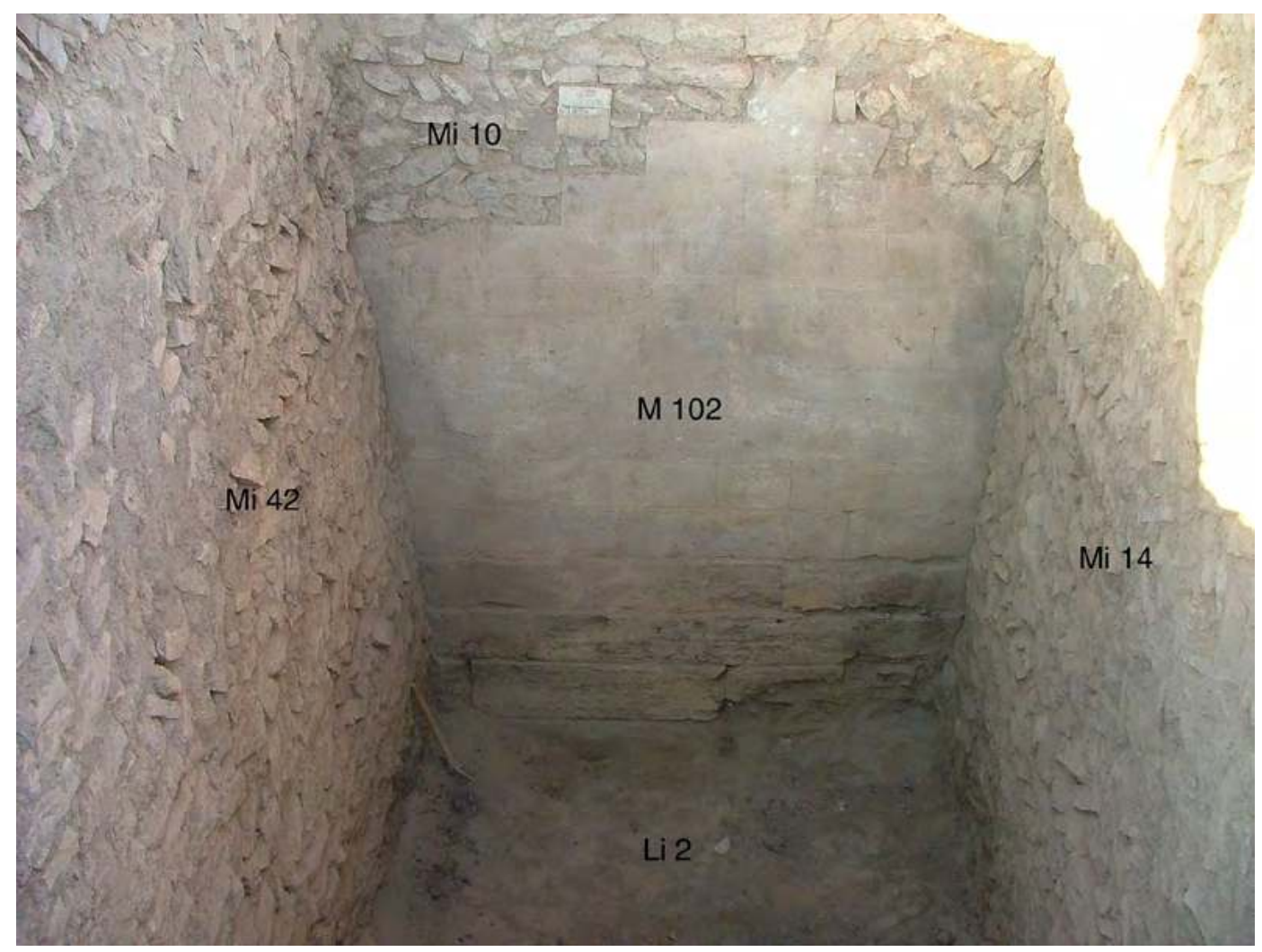

Figure 40. Li2 da sud-est. (A. Agostini 2006 CMAIRY)

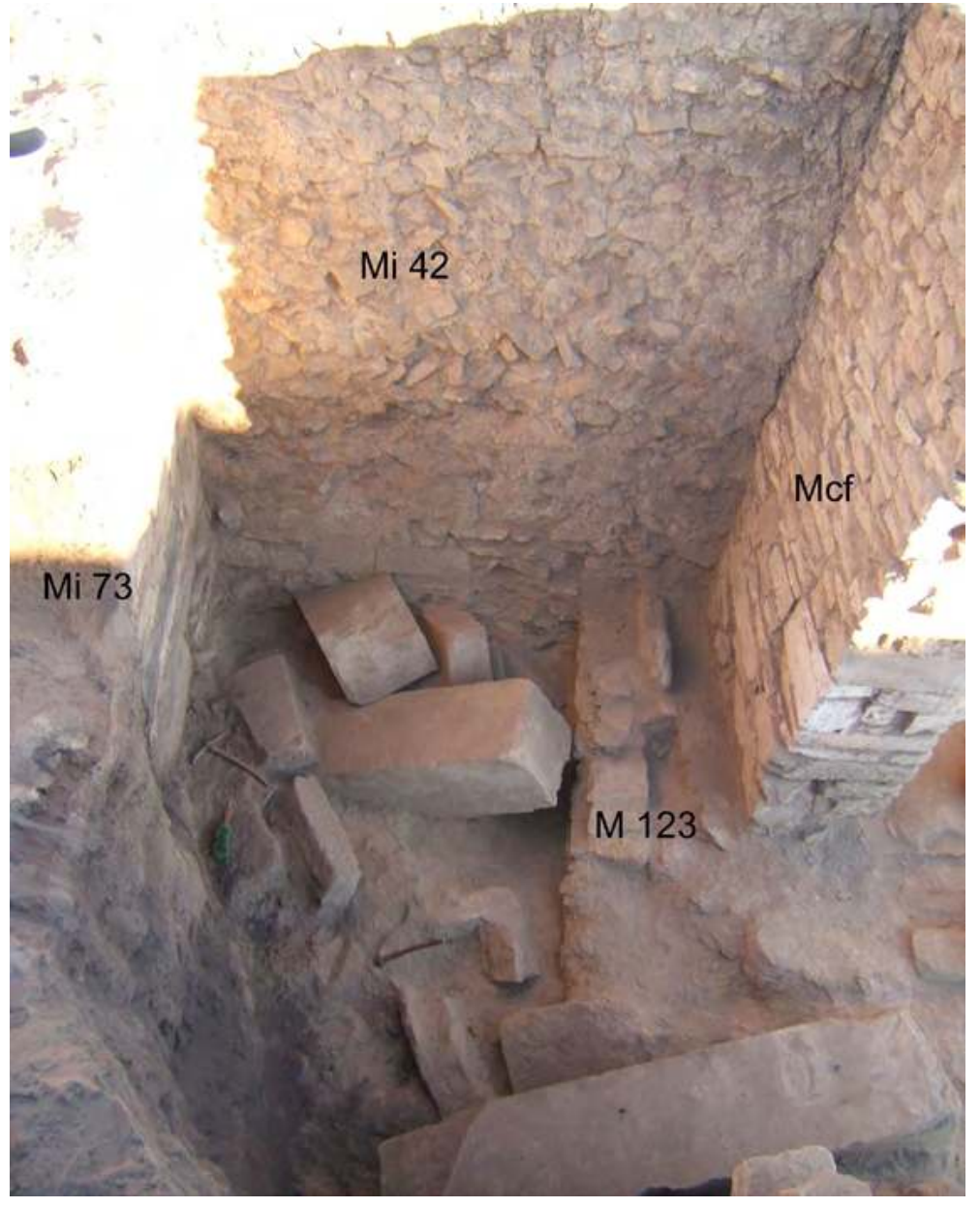

Figure 41. Parte del crollo pertinente al propileo del Tempio A in Li218, da ovest. (A. de Maigret 2006 @MAIRY) 


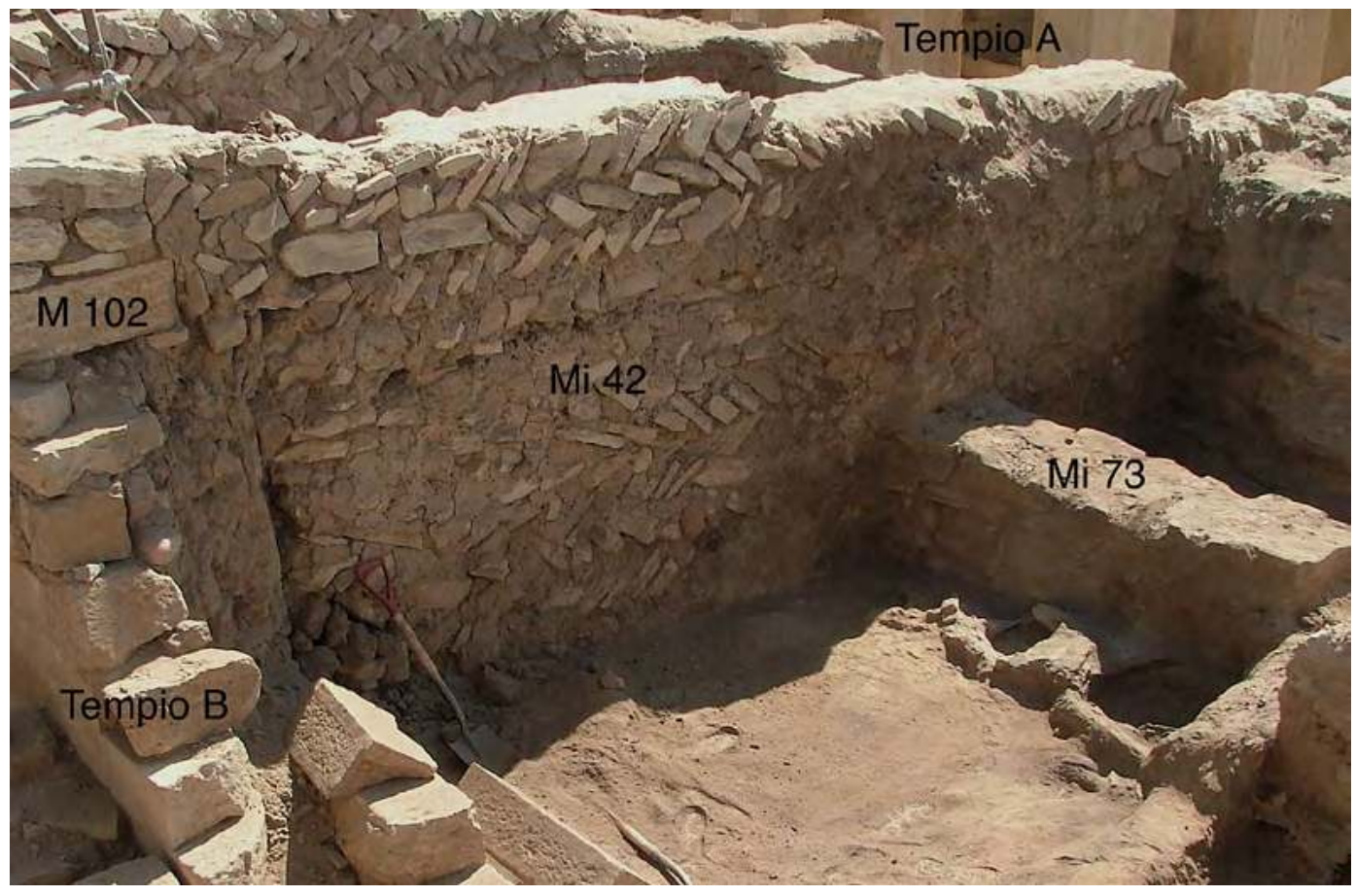

Figure 42. Parte delle strutture islamiche realizzate nell'area tra il Tempio A e il Tempio B, da nord. (A. Agostini 2006 CMAIRY)

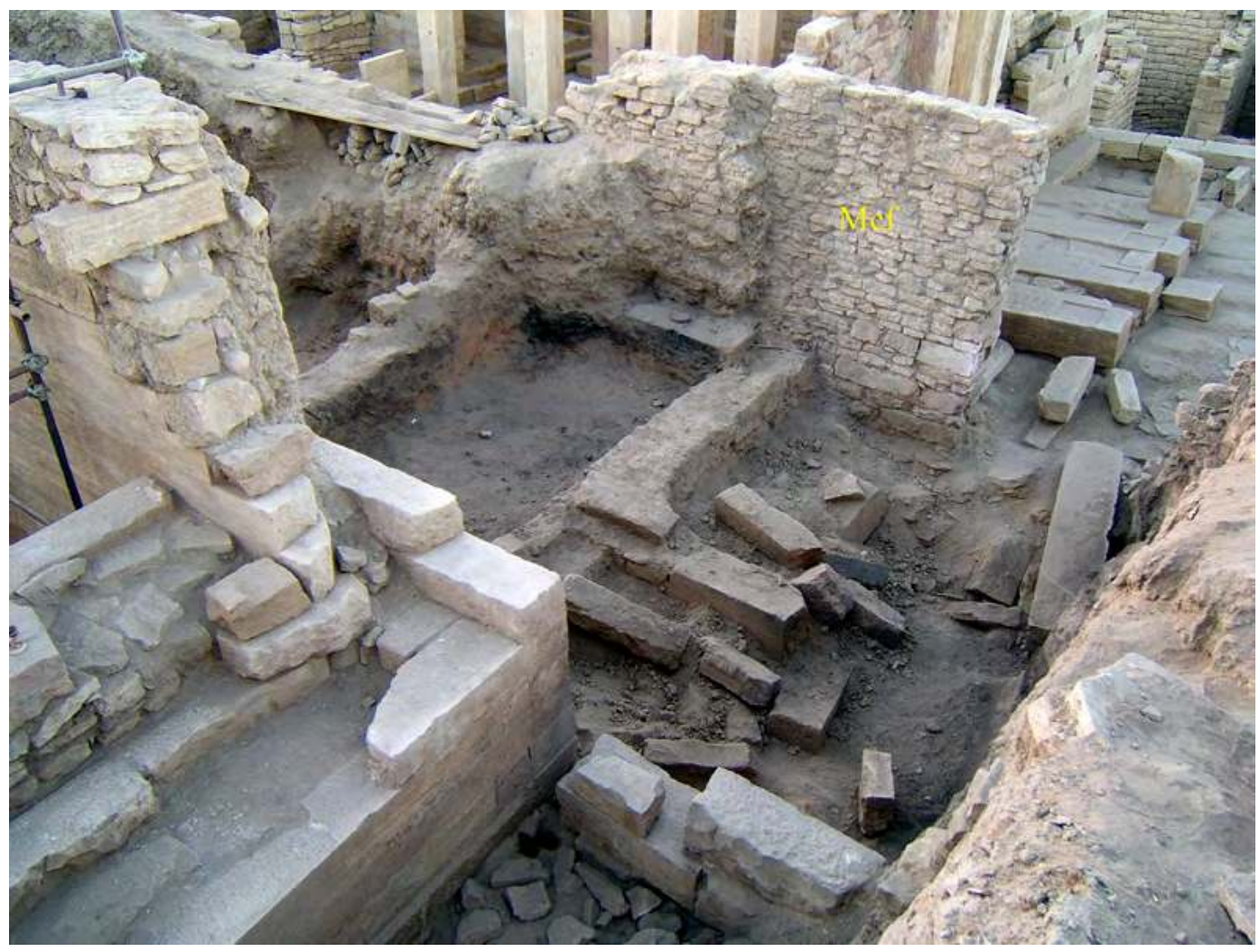

Figure 43. Messa in luce del crollo di alcuni elementi pertinenti al propileo del Tempio A, al di sotto delle strutture islamiche più antiche, da nord. (A. de Maigret 2006 OMAIRY) 


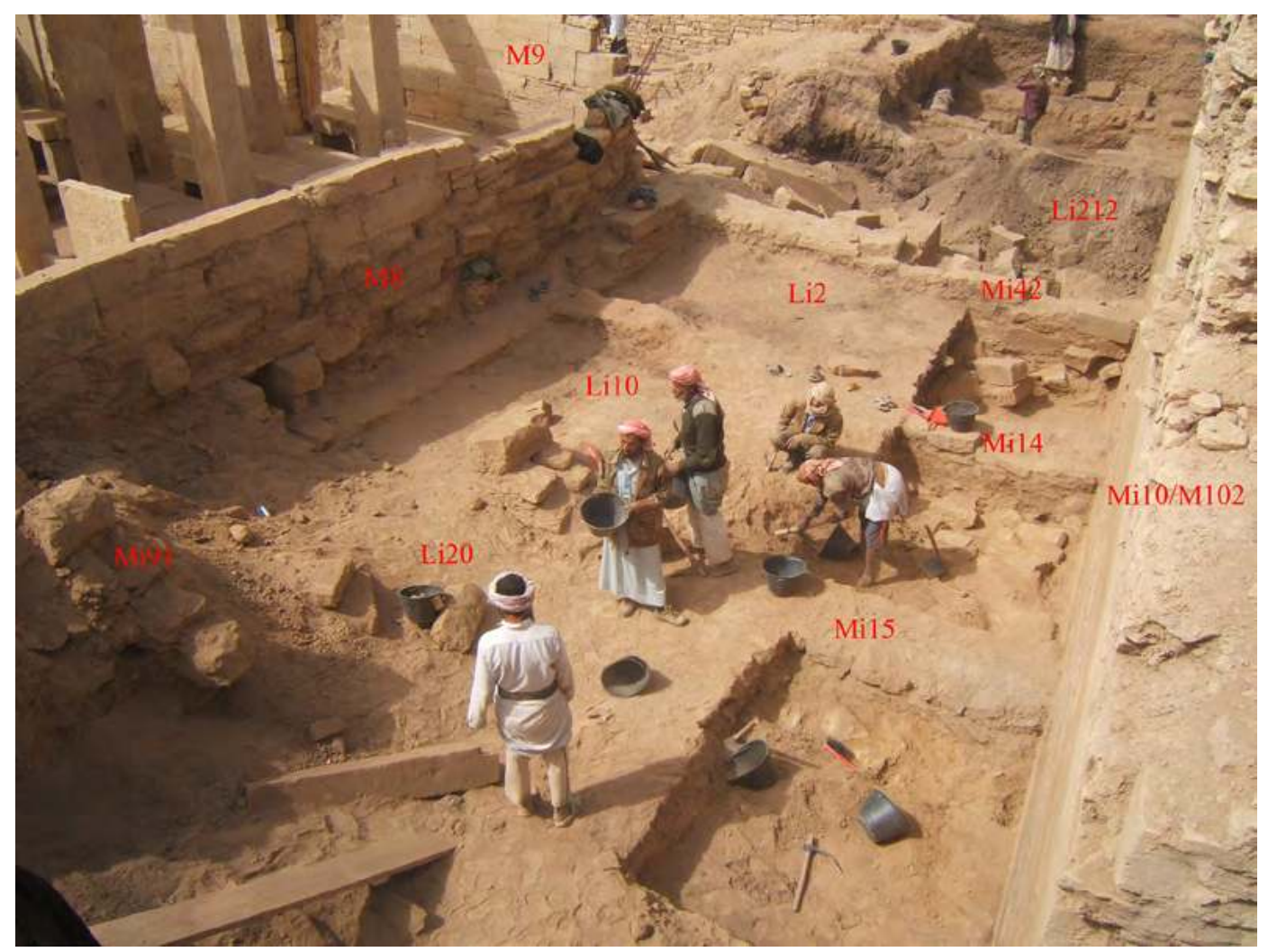

Figure 44. L'area tra i due templi durante lo smantellamento dei muri islamici che delimitavano i grandi vani, da nord-est. (A. de Maigret 2006 @MAIRY)

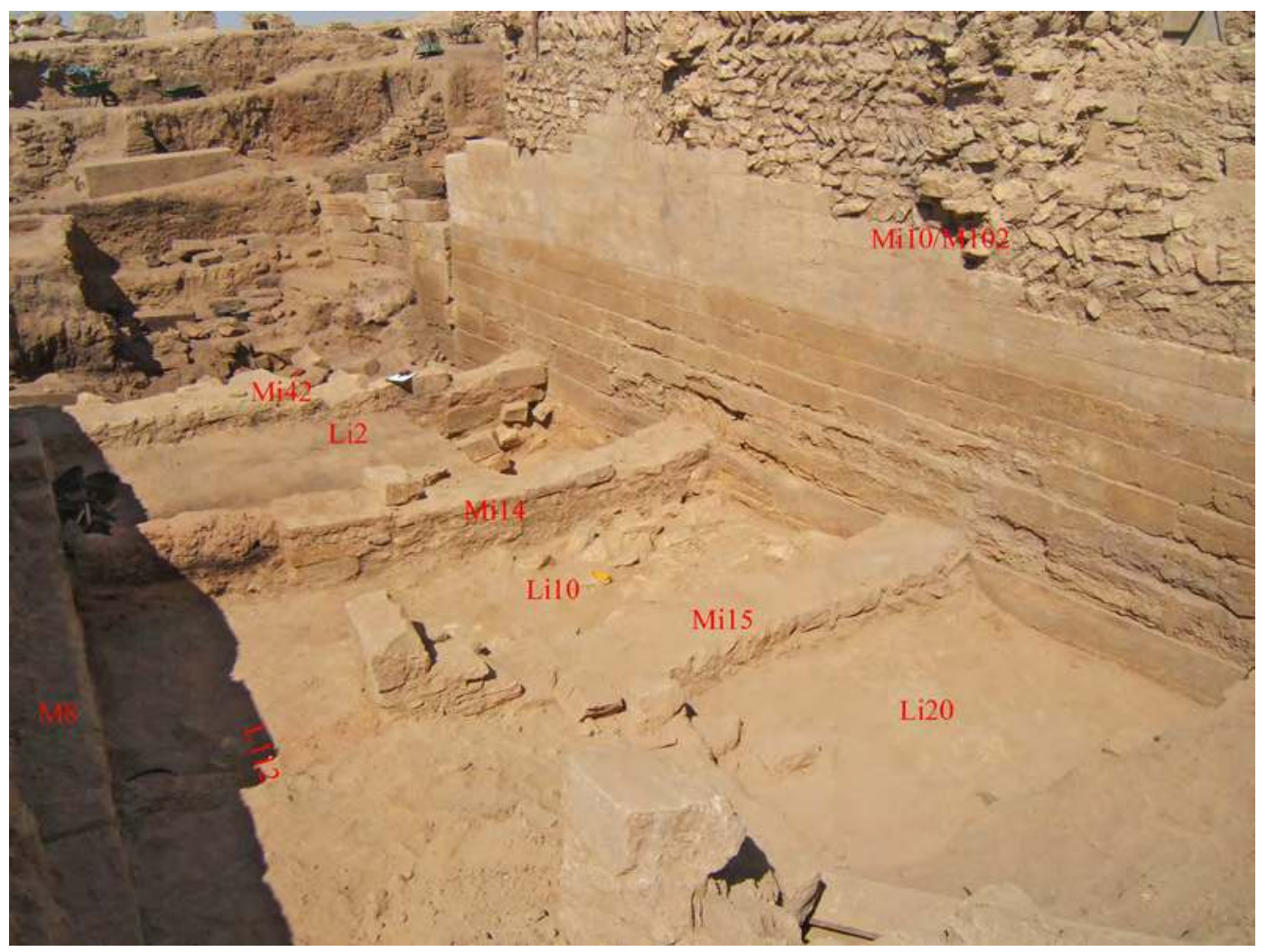

Figure 45. L'area tra i due templi durante lo smantellamento dei muri islamici che delimitavano i grandi vani, da sud. (A. de Maigret 2006 CMAIRY) 


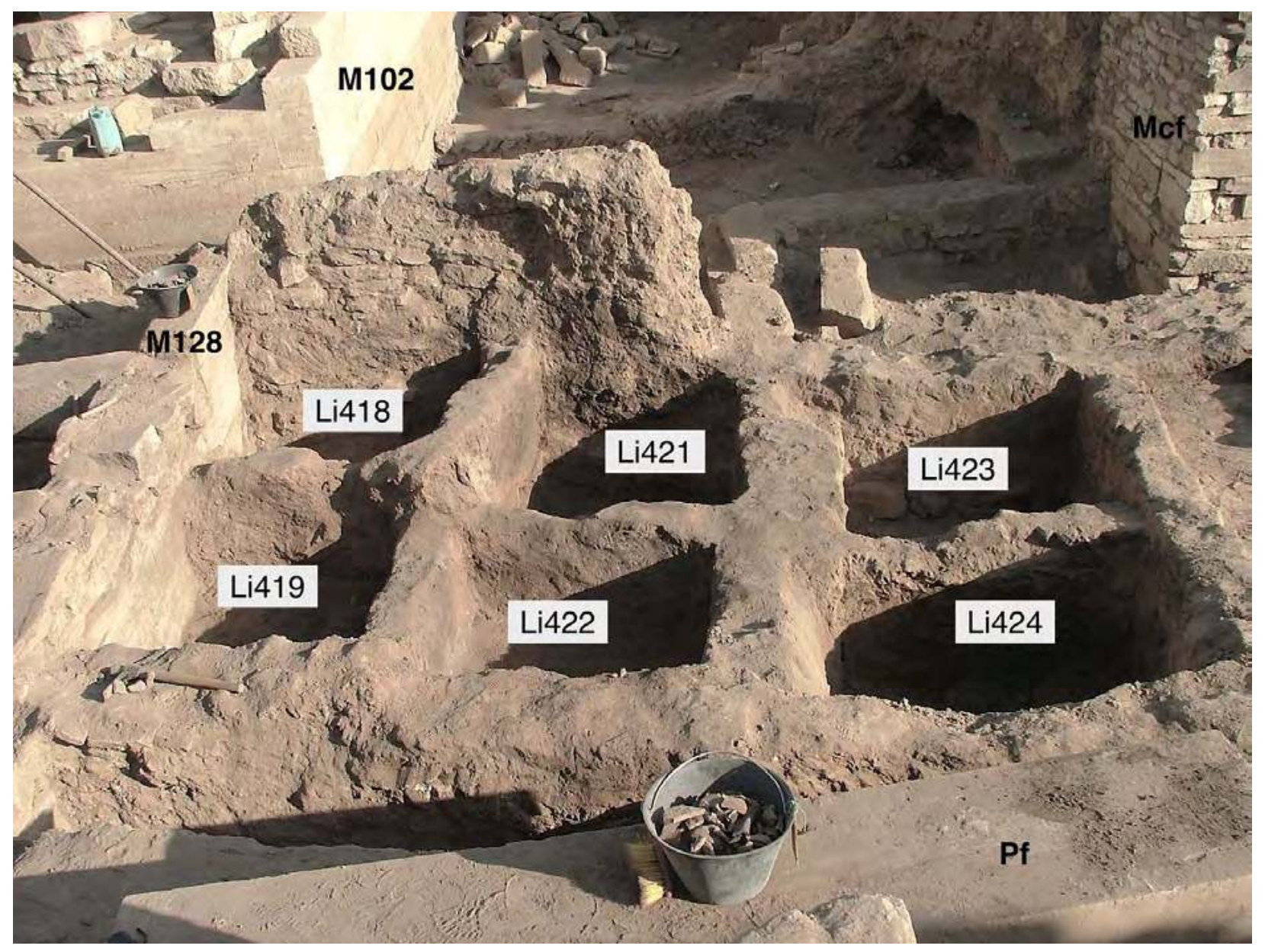

Figure 46. La struttura a vasche nell'area inter-templare occidentale, da nord-ovest; in primo piano il frammento del pilastro Pf crollato. (A. Agostini 2006 CMAIRY) 


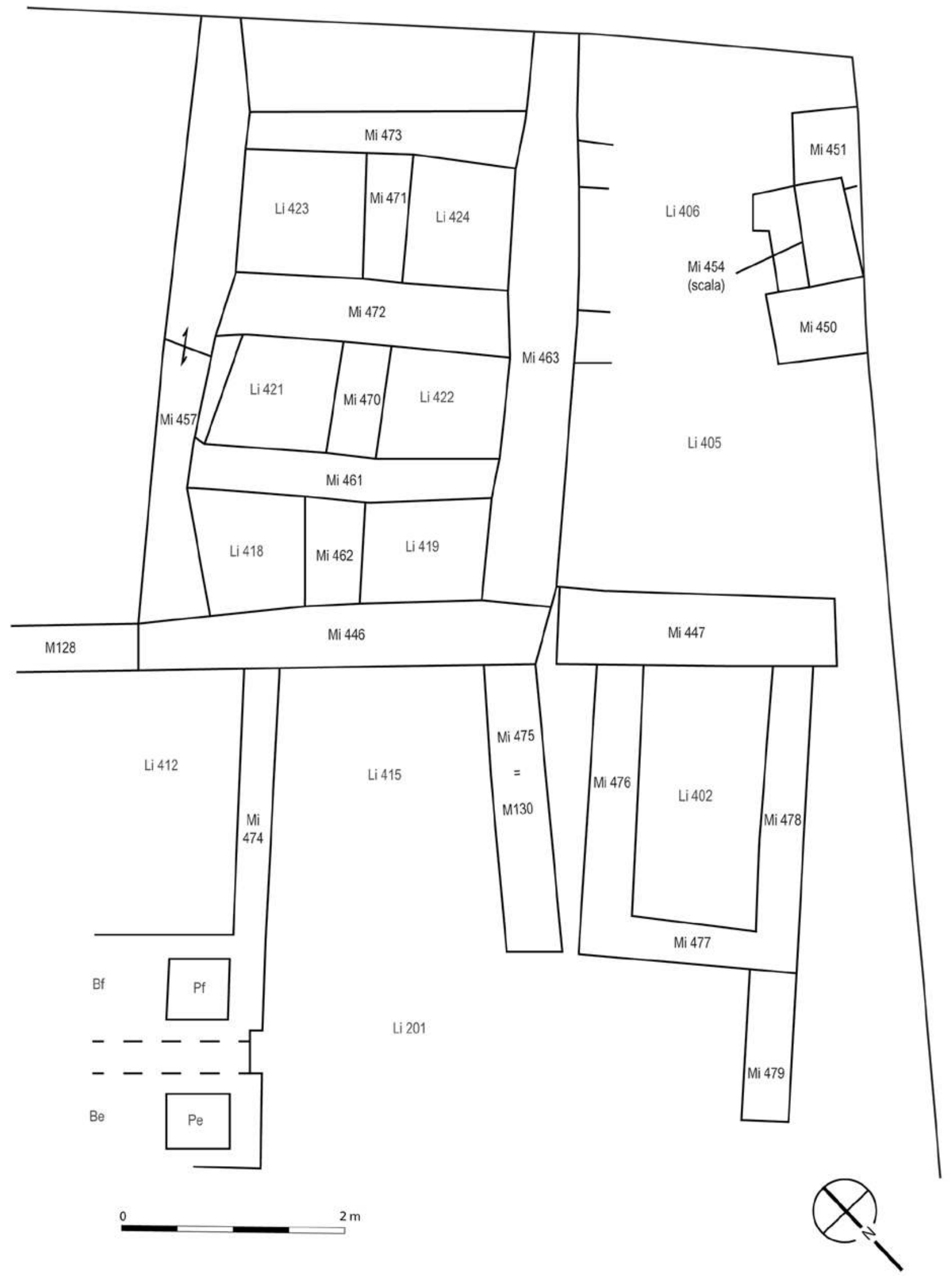

Figure 47. Islamico Antico IIIa, area inter-templare sud-ovest. (Rielaborazione di L. Munduteguy da schizzo originale di A. Agostini 2019 (MAIRY) 


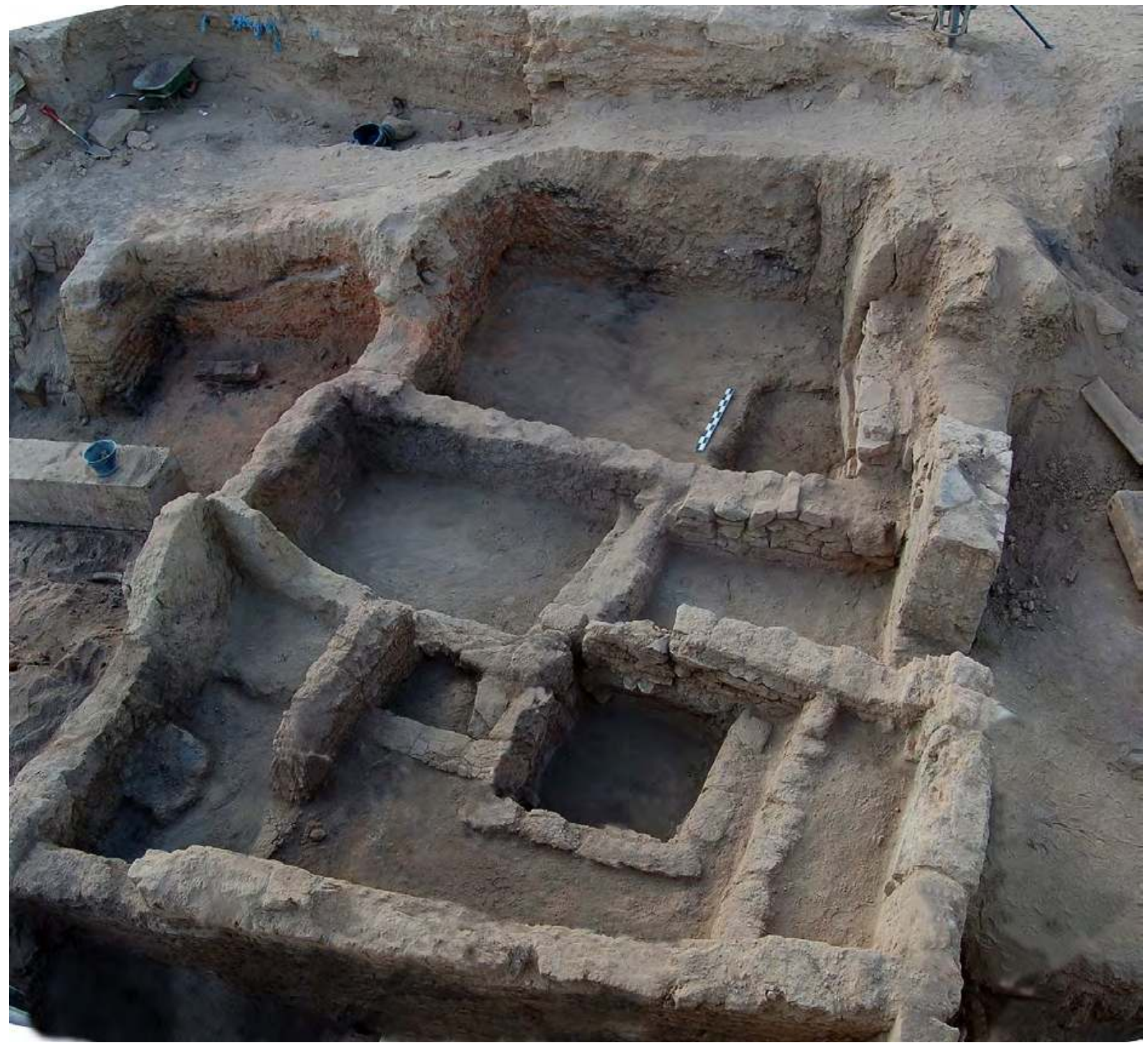

Figure 48. Le strutture dell'Islamico Antico che insistevano sull'area dell'avancorpo, da sud-est. (A. Agostini 2006 CMAIRY) 


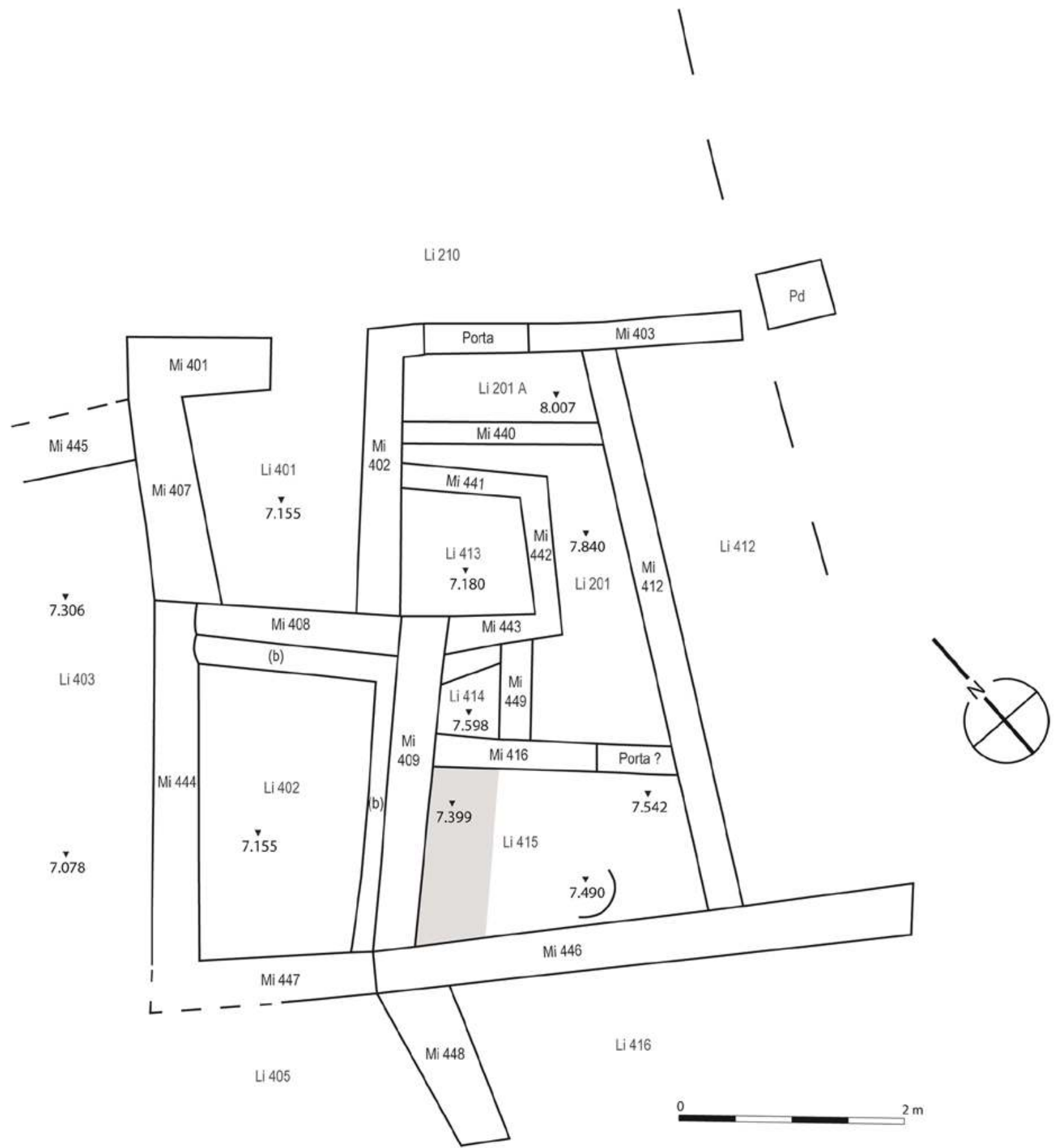

Figure 49. Islamico Antico IIIa, su area avancorpo; quote da Stazione E. (Rielaborazione di L. Munduteguy da schizzo originale di A. Agostini 2019 (MAIRY) 


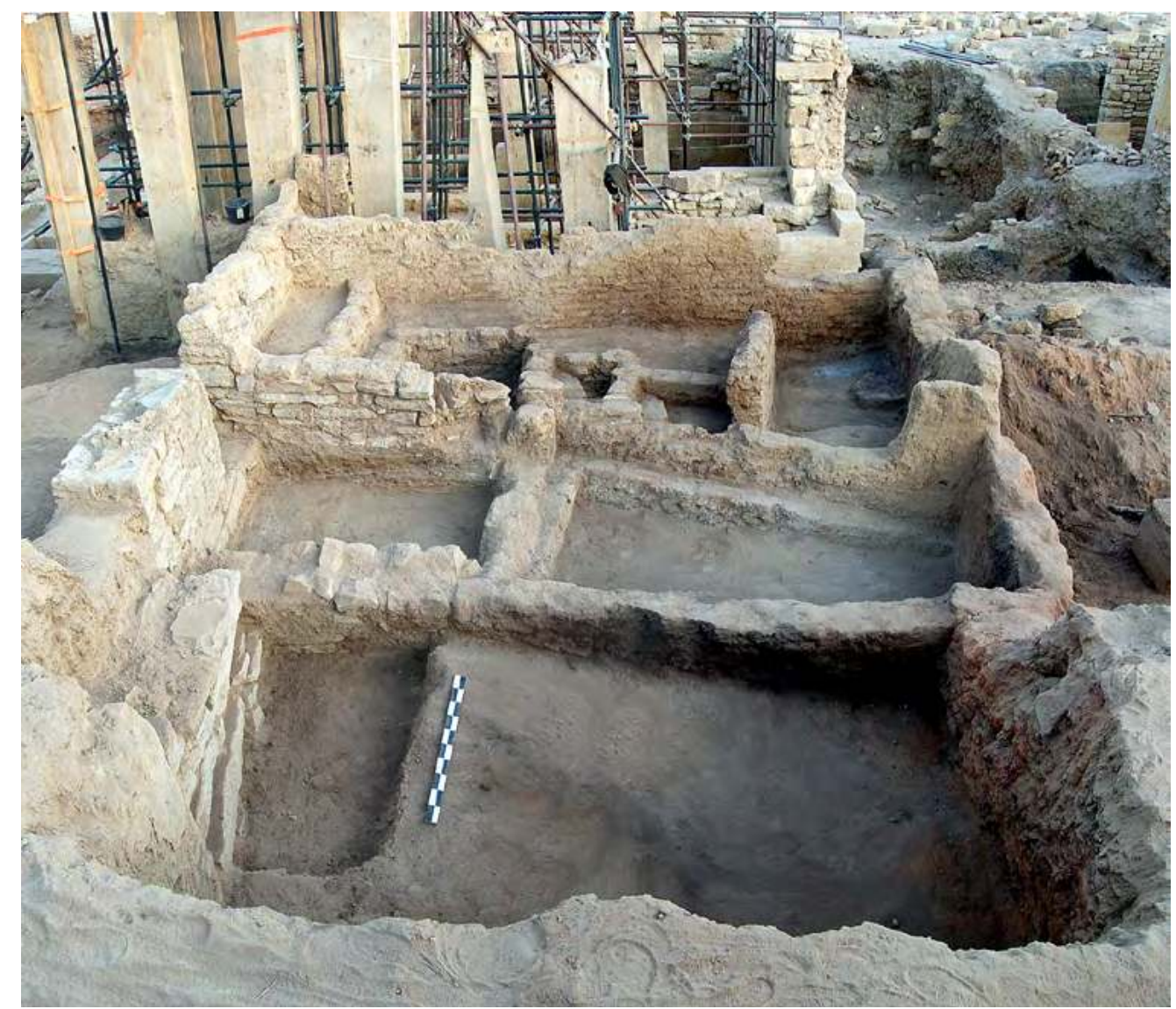

Figure 50. Le strutture dell'Islamico Antico che insistevano sull'area dell'avancorpo, da nord-ovest. (A. Agostini 2006 CMAIRY)

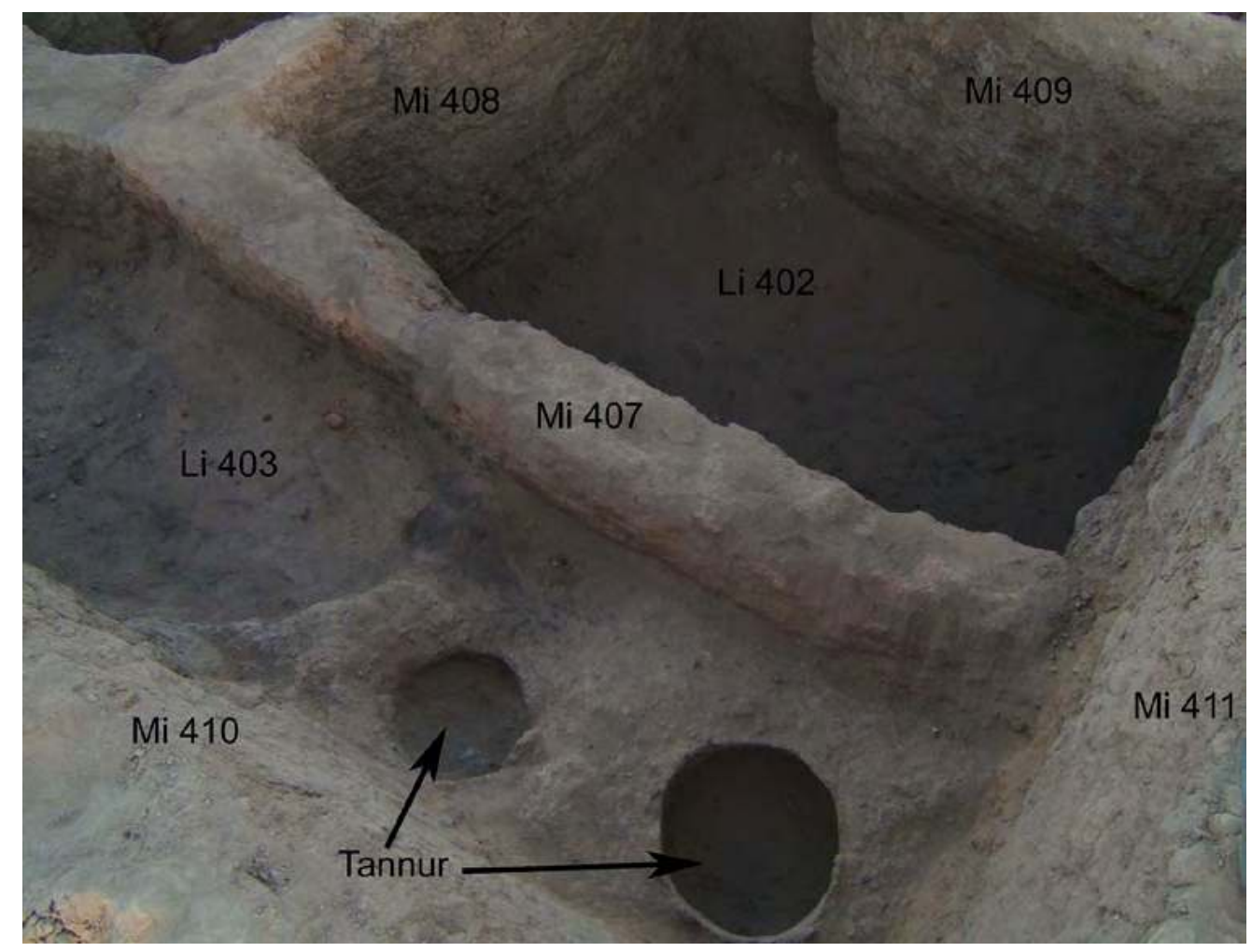

Figure 51. L'area dei tannūr in Li403, da sud-ovest. (A. Agostini 2006 OMAIRY) 
bruciature come conseguenza del vasto incendio che ha interessato la fine di questo livello.

Birka (Li310)

Nell'area che insiste sulla sala ipostila minea abbiamo rinvenuto una delle strutture più caratterizzanti per questa fase, ma con un periodo di vita probabilmente piuttosto lungo: si tratta del grande bacino in muratura e qadā d rinvenuto in corrispondenza del portale, un poco spostato verso nord-est. Il lato meridionale, e i due lati di nord-ovest e sud-est, sono costituiti da pietre irregolari disposte in allineamento continuo e in una forma quasi semicircolare (Mi82), il lato settentrionale è invece chiuso da una serie di strutture murarie più regolari (fig. 52). Affiora il muretto Mi71 e una struttura composita, Mi83, formata da moduli piccoli in mattoni, disposti su piani diversi; tutta la struttura è però nel suo insieme un tutto unico e coerente, ben compatto, che racchiude un piccolo vano con ciottoli sparsi di piccolo taglio e che potrebbe essere un bacino di decantazione. Verso sud-est s'intravede una piccola canaletta di scarico, che ben presto si perde. Mi82 è a doppia cortina, presenta un'incamiciatura esterna con pietre di dimensioni medio-piccole, legate tra loro con un'abbondante colatura di argilla. La cortina più interna invece è costituita da pietre più grandi che sono alloggiate di taglio. Vista dalla sezione messa in luce dalla sala ipostila, la parete esterna di questa struttura è alta $1,90 \mathrm{~m}$, e sempre da questa stessa sezione è possibile notare gli effetti delle prolungate infiltrazioni d'acqua all'interno del deposito sabbioso sul quale è stata impostata la cisterna. Viene da pensare che tutta questa area dovesse essere libera da case, e doveva quindi essere, certamente in questa fase, un'area a cielo aperto, di cui la cisterna era uno dei nuclei principali.

Con il suo svuotamento è stato possibile osservare la struttura interna, che è molto ben conservata e rivestita di un qadād (intonaco impermeabile) di buona fattura (figg. 53-54-55-56). Il bordo nord-ovest della struttura, che coincide con la cresta di Mi71, è anch'esso intonacato, e sul lato orientale si imposta, partendo da questo muretto, una piccola scaletta di quattro gradini, i primi due in direzione meridionale e gli altri due, girando a gomito, in direzione occidentale. Sul lato occidentale della vasca vi è una sorta di pedana longitudinale che occupa tutta la larghezza della vasca. Tutto l'interno, gradini compresi, è foderato di qadāad, che arriva a uno spessore di circa $1,5 \mathrm{~cm}$. In alcuni punti questo intonaco si presenta brunito dalle concrezioni calcaree dovute al ristagno idrico. La vasca è profonda al suo interno 1,60 m (larghezza 1,10 e lunghezza 2,66 m). All'interno del riempimento molto compattato si è potuto notare una frattura molto evidente che corre in direzione nord-ovest/sud-est: è possibile che sia da ascrivere a uno dei movimenti sismici storicamente registrati per questa regione (v. sopra). Per la solidità di tutta la struttura della vasca, per i rifacimenti che si sono evidenziati, e per la sua quota piuttosto elevata, non è possibile escludere che tale bacino sia stato in uso anche durante l'Islamico Medio.

Nell'area di scavo orientale si sono potute individuare chiaramente alcune strutture, tra le quali emerge in particolare Li303, delimitato dai muretti Mi76, Mi77, Mi78 e Mi79 (fig. 57). Si consideri pure Li304, ben definito da Mi34. I due vani continuano tuttavia a presentare riempimenti cinerosi e anche le stesse murature presentano evidenti tracce dell'azione del fuoco. I muri che compongono questi ambienti hanno delle basi leggermente aggettanti, ma l'alzato è in mattoni crudi, ad eccezione di Mi78 e Mi79 che sono tutti in pietra. Li16 è occupato in direzione sud da tre gradini pertinenti a una scala (Mi88), realizzata con grossi blocchi pertinenti al muro perimetrale del tempio; uno di questi si presenta fittamente iscritto con uno stile grafico molto simile a quello riscontrato nelle iscrizioni delle pareti nord-ovest e sud-est del tempio (v. sopra, fig. 58). ${ }^{58}$

Qualche interrogativo è stato suscitato dall'apertura individuata all'interno del muro perimetrale sud-est del tempio (M117), che quindi apriva un varco verso l'esterno della sala ipostila (fig. 59). Si tratta con ogni probabilità di una piccola porta, o finestra, realizzata secondariamente, benché allineata con la porta minea del vano L118, dato che si nota un taglio malamente realizzato sulle pietre del muro mineo. Considerando che è stata realizzata quando il muro di fondo del tempio era già in parte crollato, è abbastanza naturale attribuirla alla riutilizzazione della struttura durante l'Islamico Antico, parallelamente alla sigillatura della precedente apertura minea del vano. La pavimentazione secondaria che rinveniamo in questo vano, cioè Li19 corrispondente alla superfice di L118, è a una quota piuttosto bassa, il che ulteriormente suggerisce che vi sia stata una ripulitura e una riutilizzazione di questa camera una volta chiusa e resa accessibile dall'esterno del tempio.

\subsection{Islamico Medio}

Questa è la fase più lunga e complessa che ha vissuto quest'area dopo la fine del periodo mineo. Si è già visto che il passaggio dall'Islamico Antico al Medio è segnato da un diffuso incendio, già riscontrato durante lo scavo del Tempio A. La cesura tra il periodo Medio e l'Islamico Recente non sarà invece altrettanto netta.

\footnotetext{
58 Y.05.B.B./5. Un altro frammento quasi certamente ad essa pertinente è stato rinvenuto presso Mi35, si tratta solo di uno spigolo (Y.05.B.B./6) di cui manca un importante elemento intermedio in grado di assicurare la collazione con l'iscrizione precedente; un ulteriore frammento è comparso con la rimozione di Mi88, tutti questi blocchi sono stati danneggiati dall'azione del fuoco che ha interessato tutta l'area alla fine di questa fase.
} 


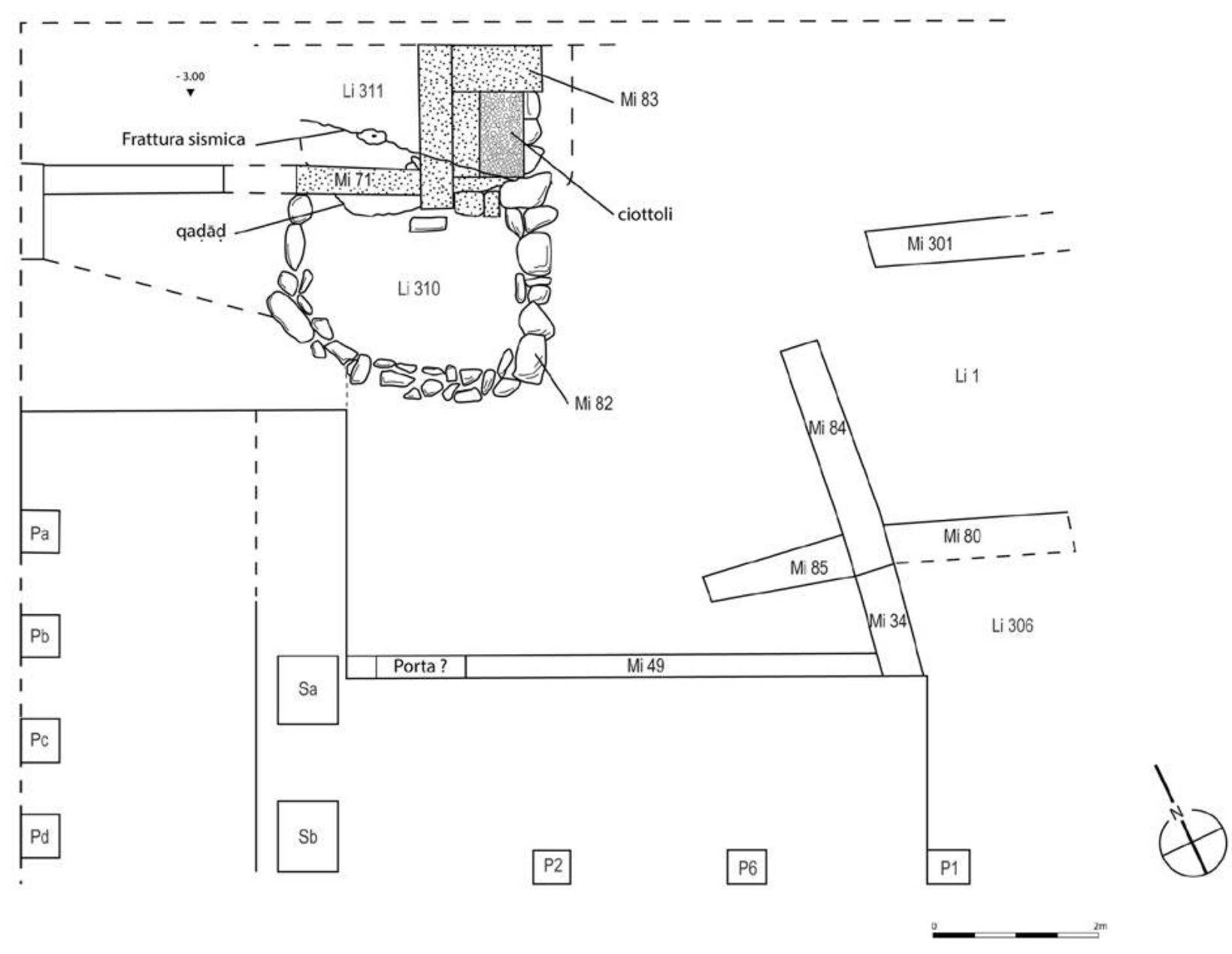

Figure 52. Islamico Antico IIIa, localizzazione delle strutture emergenti della Birka sull'area della sala ipostila; quote da B [P1]. (Rielaborazione di L. Munduteguy da schizzo originale di A. Agostini 2019 @MAIRY) 


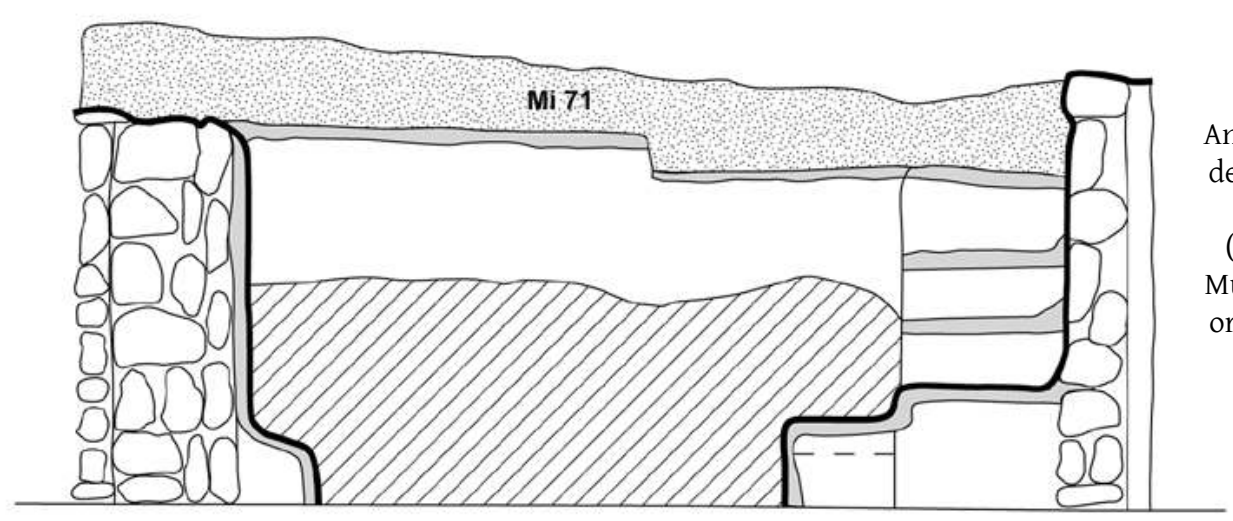

Figure 53. Islamico Antico IIIa, Li310, Birka, dettaglio planimetrico; quote da B [P1].

(Rielaborazione di L. Munduteguy da schizzo originale di A. Agostini 2019 (MAIRY)
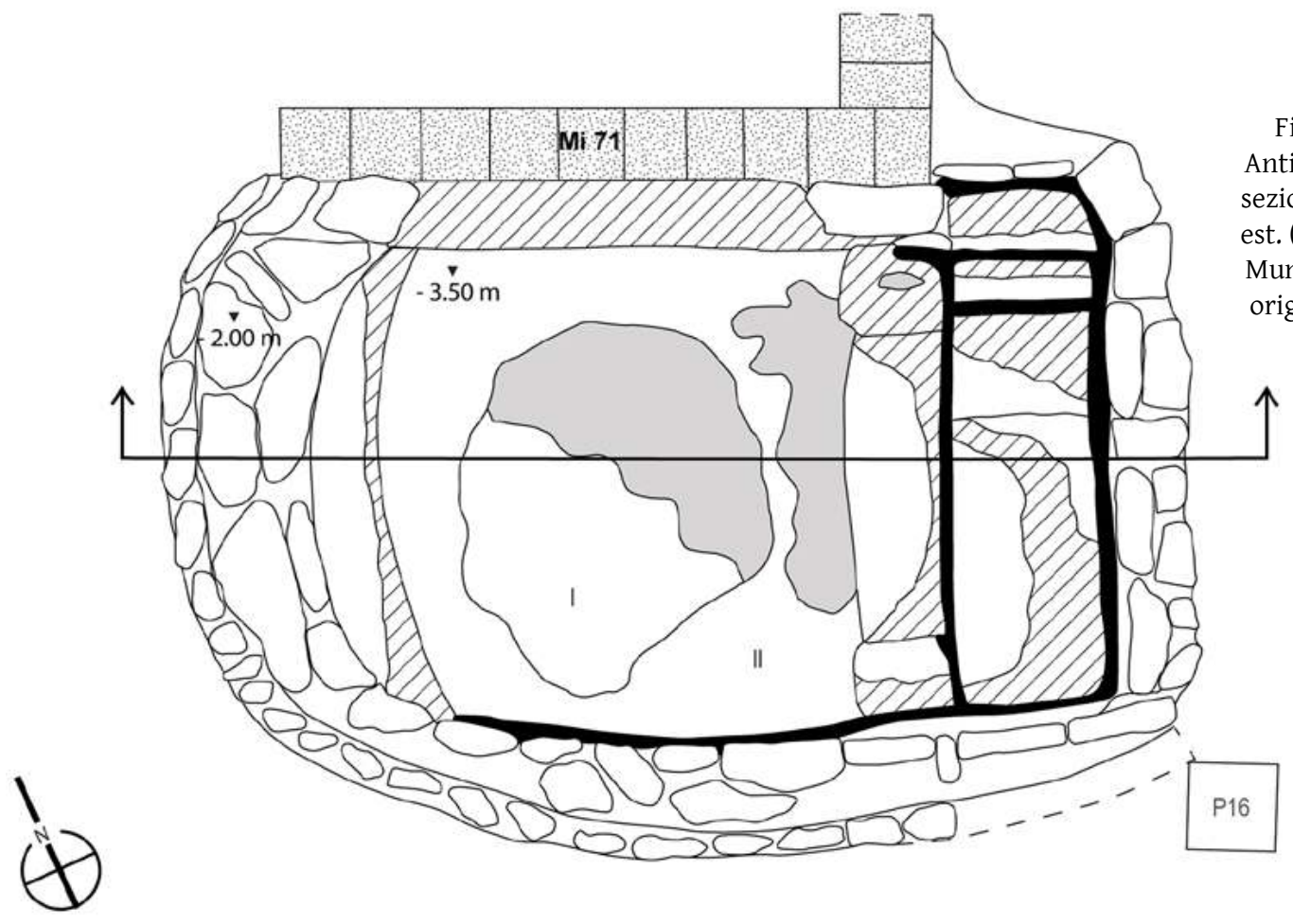

Figure 54. Islamico Antico IIIa, Li310, Birka, sezione nord-ovest/sudest. (Rielaborazione di L. Munduteguy da schizzo originale di A. Agostini 2019 (MAIRY)

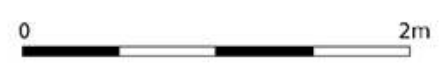

Libn

VIA Intonaco

Qaḍạ̣ in sezione

Intonaco marrone chiaro

I-II Livelli di rifacimento intonaco 


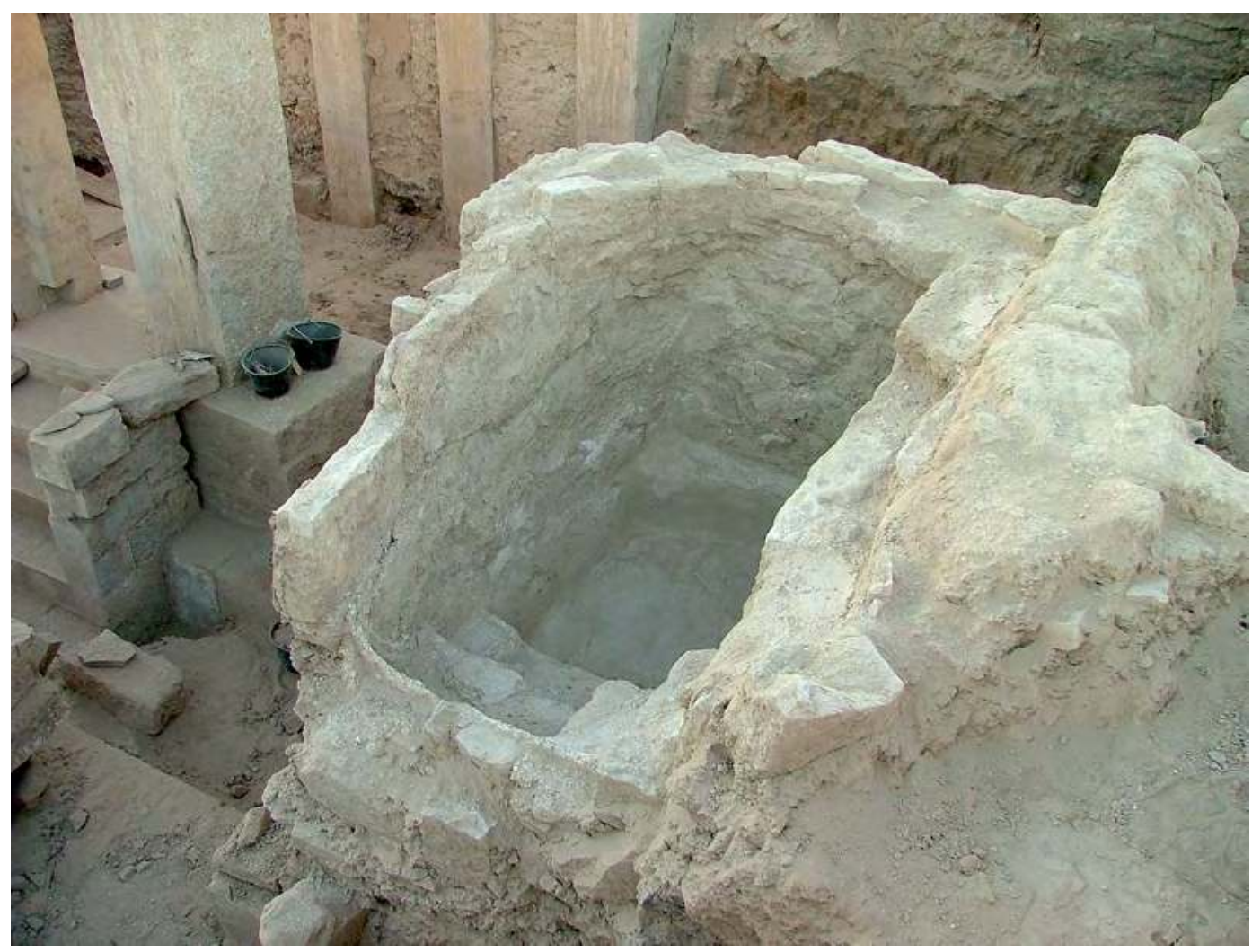

Figure 55. Islamico Antico IIIa, veduta della Birka, da est. (A. Agostini 2005 CMAIRY)

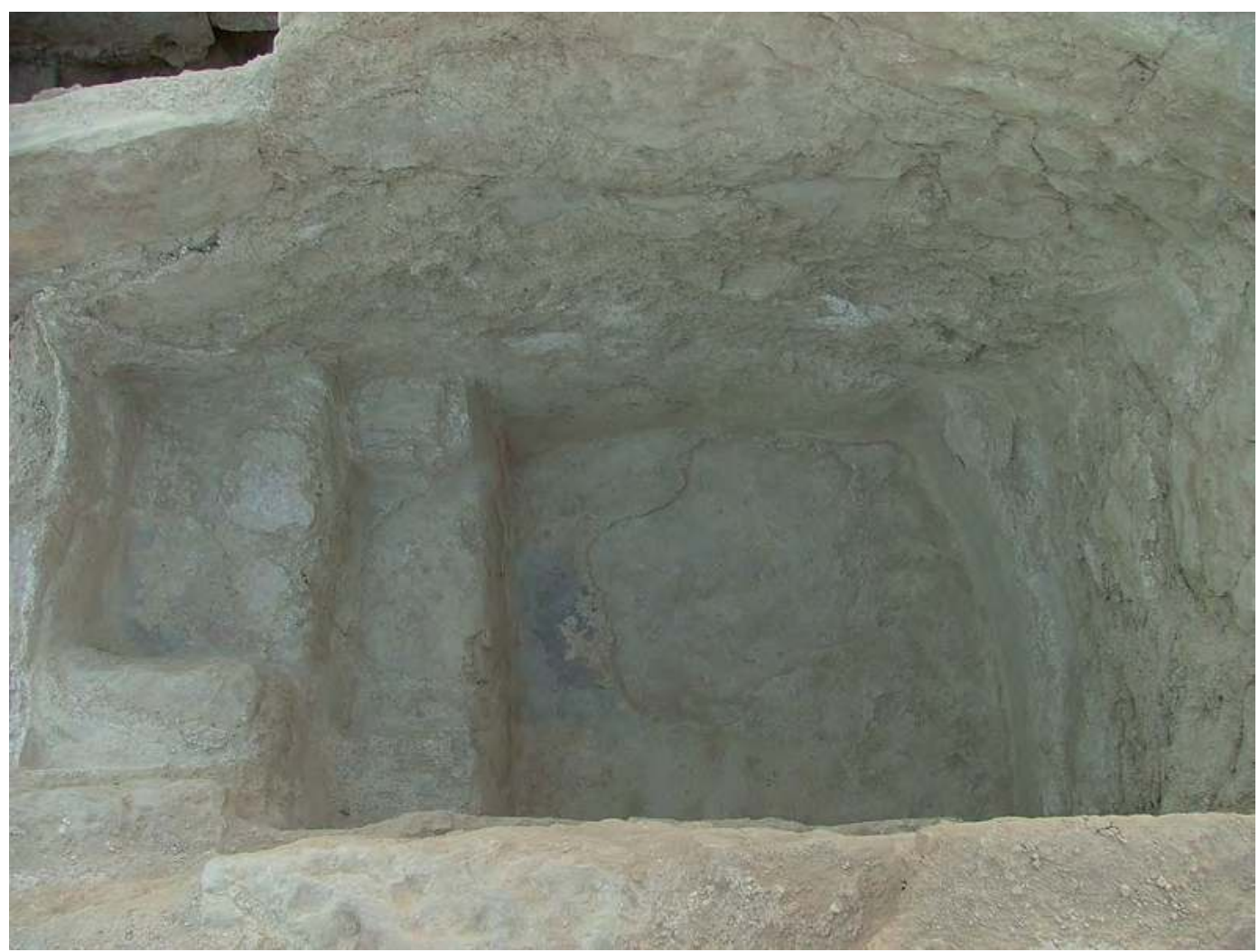

Figure 56. Islamico Antico IIIa, particolare della Birka, da nord-est. (A. Agostini 2005 @MAIRY) 
L1
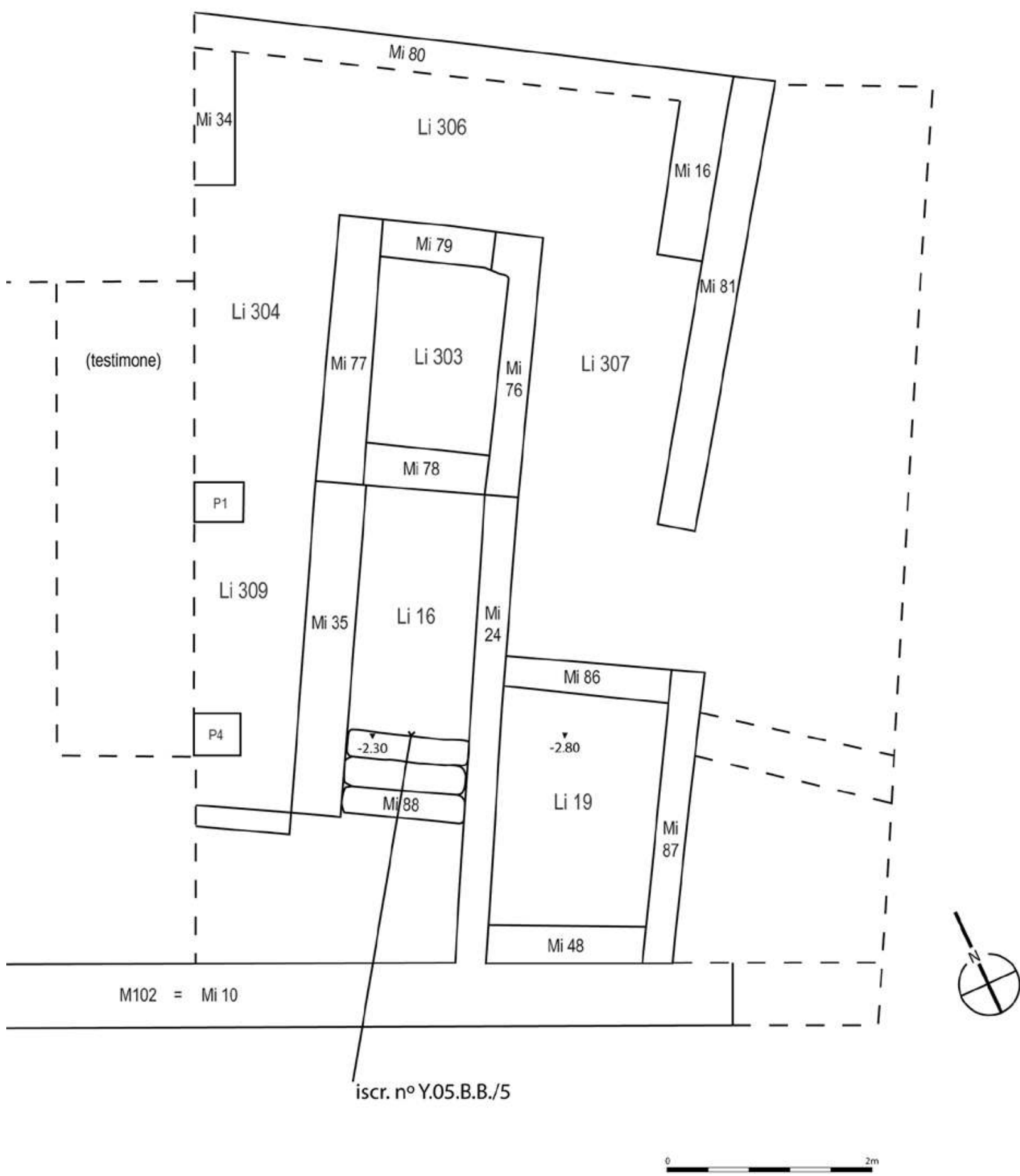

Figure 57. Islamico Antico IIIa, su area orientale della sala ipostila; quote da B [P1]. (Rielaborazione di L. Munduteguy da schizzo originale di A. Agostini 2019 CMAIRY) 


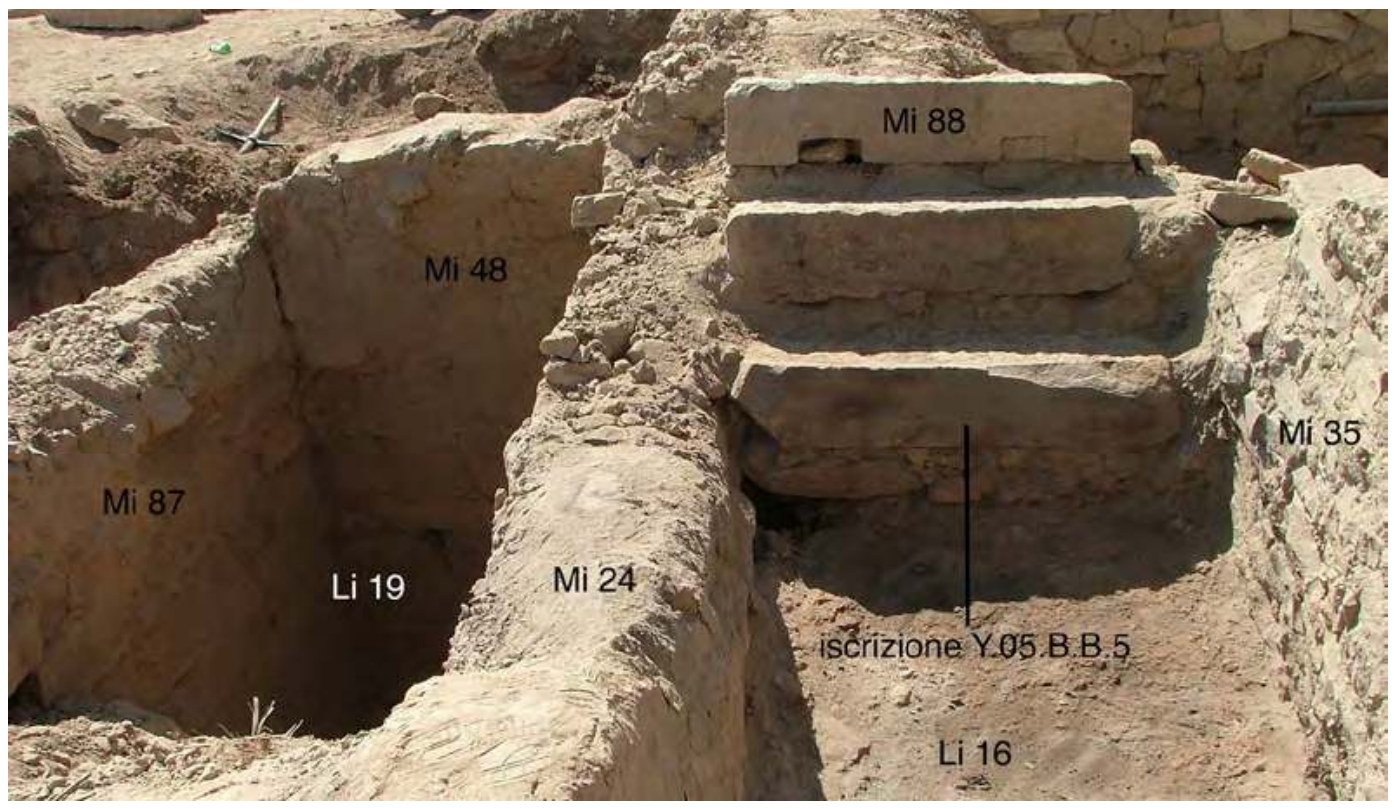

Figure 58. Islamico Antico IIIa, i piccoli vani Li16 e Li19, con particolare della riutilizzazione di un blocco mineo iscritto, Y.05.B.B.5. (A. Agostini 2005 OMAIRY)

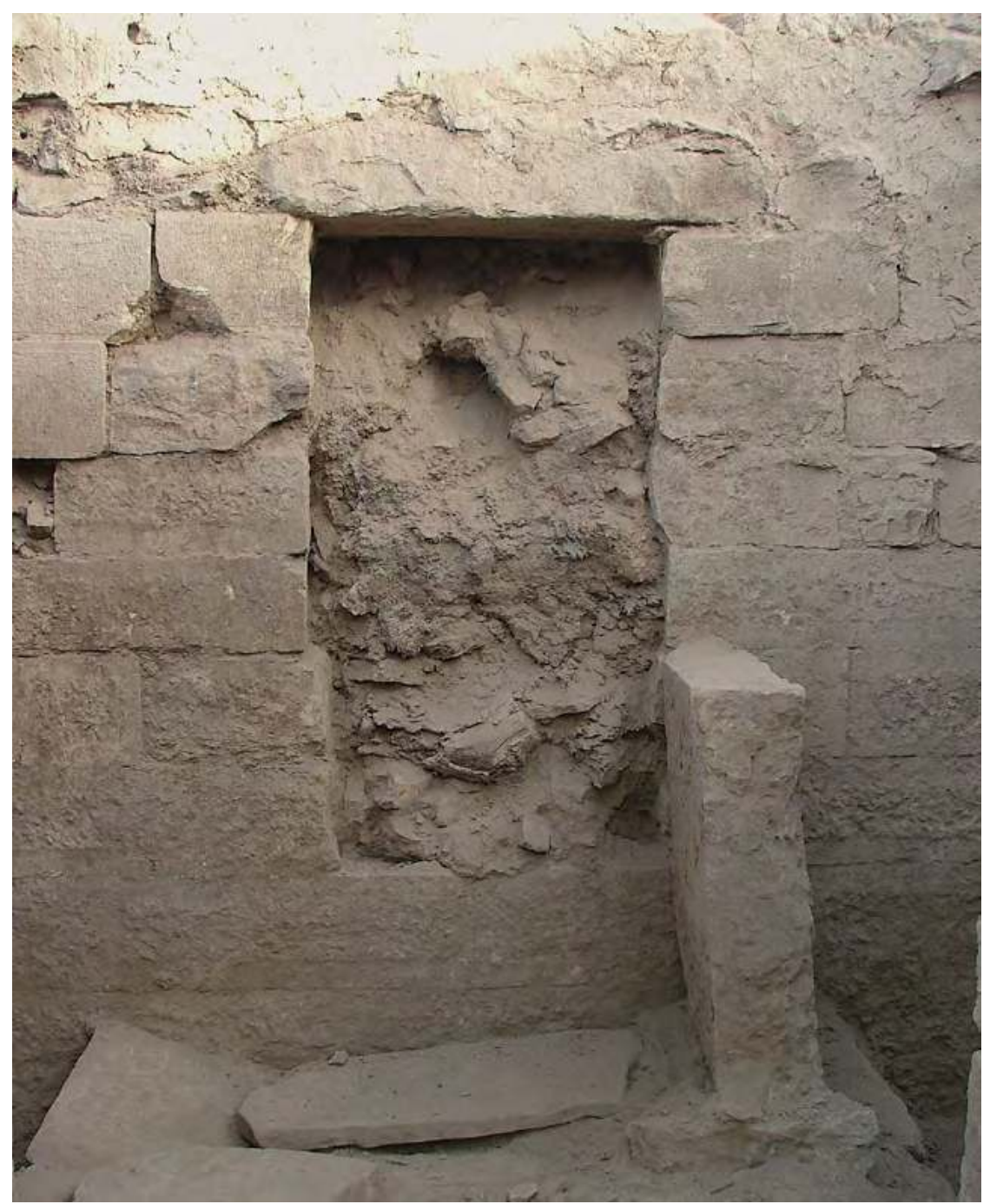

Figure 59. Porta realizzata in epoca islamica sul muro perimetrale di fondo del tempio, M117, da nordovest. (A. Agostini 2005 @MAIRY) 
Si può certamente notare che nell'Islamico Medio le strutture cominciano ad essere di fattura più grossolana, ma sono mediamente più solide rispetto $\mathrm{a}$ quanto avverrà in seguito. Il piano delle pavimentazioni costituisce una guida piuttosto attendibile per individuare la quota generale di questa fase (fig. 60). Rispetto all'Islamico Antico, i muri cominciano a essere costituiti per la maggior parte in mattoni, ma i basamenti sono ancora in buona parte in pietra, di fattura però diseguale. Un intonaco bianco più raffinato è talvolta utilizzato per rifinire le parti inferiori dei muri interni agli ambienti e la presenza di un paio di scale, qui dalla struttura in pietra con rivestimento in malta, indica l'esistenza di un secondo piano (ad es. Mi229). L'alto grado di specializzazione funzionale che avevamo associato a molte delle strutture dell'Islamico Antico si mantiene solo parzialmente in questa fase, per poi ulteriormente sfumare nella fase Recente. Aumentano le strutture destinate al ricovero per animali, precedentemente confinate nei vani in prossimità della Strada 1; altre stanze sono invece destinate all'immagazzinamento. Alcuni livelli si caratterizzano in questa fase per l'abbondante strato di stallatico che in alcuni punti ha raggiunto il ragguardevole spessore di $95 \mathrm{~cm}$ (ad es. Li210). Questo lento accumulo è andato progressivamente a occultare la prima pavimentazione pertinente a questa fase e talvolta ha richiesto adeguamenti delle strutture in alcuni momenti successivi, che sono particolarmente chiari nella sigillatura di porte, la cui luce era già in parte occupata da densi accumuli (ad es. Mi401). È plausibile che alcuni degli ambienti incontrati fossero destinati alla lavorazione dei materiali poi stoccati nei vani attigui, pensiamo soprattutto a sementi e granaglie; probabilmente era ancora in uso anche la grande cisterna del periodo antico (cfr. sopra, birka). In questa lunga fase, le modifiche, le ristrutturazioni e la riorganizzazione interna degli ambienti sono stati molteplici, e si sono succeduti con una tale continuità da rendere poco immediata la distinzione delle varie fasi intermedie che necessariamente s'incontrano. Sulla scorta di un confronto del corrispondente livello del Tempio A, notiamo che tra la ceramica spiccano degli esemplari di coppette invetriate di colore giallognolo. ${ }^{59}$ Ci sembra tuttavia di individuare almeno tre sotto-fasi principali, che possiamo distinguere in Medio Islamico A (IIa), Medio Islamico B (IIb) e Medio Islamico C (IIc) - s'intende che queste sotto-fasi non sono visibili ovunque.

La zona compresa tra il propileo e il portale del tempio è quella che ha rivelato maggiori rifacimenti e intensità di utilizzazione, con una considerevole concentrazione di vita e funzioni per l'ambiente Li216, che in parte scherma la faccia dei pilastri minei con l'aggiunta della fodera Mi202. Mi200 e Mi27 rivelano una maggiore continuità e stabilità. Li215 si trova gravato da un riempimento cineroso grigio con striature rossastre, peraltro localizzato solo in questo ambiente. Li216 è occupato da quattro vasche perfettamente intonacate, due piccole quadrangolari affiancate verso sud-est (I e II) e altre due di forma più rettangolare verso nordovest, quella più settentrionale tra le due (IV) presenta un'apertura sul suo muretto di contenimento verso sud (Mi243) di andamento lievemente circolare (figg. 61-62). La vasca III ha rivelato un riempimento di granaglie ed è quindi possibile che tutto il vano fosse stato suddiviso in vari siloi in muratura. Un blocco riutilizzato blocca il passaggio tra gli stipiti dell'entrata del tempio ( $\mathrm{Sa}$ e $\mathrm{Sb}$ ), che in quest'epoca erano ancora in buona parte emersi. Esso metteva in comunicazione la stanza-granaio in Li216 con gli ambienti Li5 e Li6, i quali a loro volta si trovano sopra L2, L7 e L8 della fase minea.

Il piano di calpestio del livello islamico medio è stato posto in luce abbastanza chiaramente almeno in Li4, Li5 e Li6. In Li6, presso Mi38, è inoltre emerso un forno con piano intonacato su cui poggia vasellame da cucina, delimitato da tre bassi e stretti muretti in mattoni crudi di appena quattro filari; sul suo pavimento in terra battuta si sono trovate anche alcune monete in bronzo. ${ }^{60}$ Già durante questa fase, Li15 aveva la sua funzione di stalla, poi mantenuta. Nel corso dei lavori di scavo in Li13 sono comparsi dei frammenti di blocchi chiaramente pertinenti ai pilastri della sala ipostila: uno è posto in posizione eretta, ma lievemente inclinato rispetto al punto atteso di alloggiamento di P6; l'altro è crollato a quota $-3,90 \mathrm{~m}$ da P2, quindi durante l'ultima fase di abbandono del tempio, quando il livello di crollo precedente era già piuttosto consistente. Pertinente a questa fase è pure la parte superiore del buon muro islamico Mi10, realizzato con alcuni filari di blocchi montati a spina di pesce, che a sua volta è stato poggiato direttamente sul muro perimetrale $\mathrm{S}$ della sala ipostila (M102).

Nell'area corrispondente alla sala ipostila hanno continuato a emergere zone destinate alla cottura, come quella compresa tra i due piccoli muretti paralleli Mi24 e Mi35, verso sud-est, dove si trovano ovviamente ampi riempimenti cinerosi di colorazione chiara e molta presenza di elementi concotti. Nell'area delimitata da Mi35 e Mi34, pure paralleli, abbiamo di nuovo rinvenuto tracce di cottura, ma qui la cenere era più compatta, di colore scuro, e comprendeva numerose ossa animali di taglio medio grande; potremmo quindi pensare a più forni tra loro contigui, ma utilizzati per funzioni diverse. In corrispondenza di questa zona, ma verso nord-ovest, è affiorata una scala in muratura, 
Li305, compresa tra i muretti Mi33 e Mi23: la scala s'imposta su Li300 e si sviluppa a gomito verso ovest. In Li300 e Li302 sono state individuate con una certa facilità le relative pavimentazioni; in Li300 una seconda pavimentazione è emersa a una quota inferiore di circa $50 \mathrm{~cm}$, il che quindi fa pensare a una delle sottofasi interne (IIb o IIc): è importante notare che questo pavimento copre tutto il vano, compresa la zona che sarà occupata dalla scala Li305, la quale andrebbe quindi attribuita a un ultimo rifacimento (IIa). In Li1 la pavimentazione si trova a una quota leggermente superiore rispetto alla seconda di Li300.

Verso il limite sud-ovest dell'area di scavo, cioè in Li218 a nord del Mi73, è pure presente una zona con forni, la cui azione ha particolarmente indurito i mattoni superiori del suddetto muretto. Dallo scavo in Li19 è emersa parte del muro di fondo del tempio, M117.

Mi49 è un muretto di fattura apparentemente piuttosto modesta, ma si è rivelato invece di lunga durata; si trova quasi al centro dell'area che insiste sulla sala ipostila e corre in direzione sud-est/nord-ovest in corrispondenza dello stipite Sa della porta dell'edificio templare, la sua base si imposta direttamente sul crollo mineo, di cui riutilizza alcune pietre e s'impostava direttamente su di un frammento del pilastro P8 che era stato alloggiato orizzontalmente, a sua volta poggiato sulla parte terminale di una tavola offertoria $(\mathrm{Tb})$ e di una banchetta, sull'allineamento immediatamente a nordest rispetto ai pilastri P7-P9. Rappresenta dunque una sorta di spina dorsale muraria che è stata impiantata già nell'Islamico Antico, ma dalla quale si dipaneranno molte delle strutture attive ancora nell'Islamico Medio (cfr. fig. 27).

\subsection{Islamico Recente}

Le strutture esistenti in superficie, ripulite e messe completamente in luce una volta rimossi i crolli, sono pertinenti all'ultima fase di vita dell'insediamento, che chiamiamo Islamico Recente. Si tratta in generale di piccoli edifici costruiti con una tecnica assai modesta. Da un'osservazione generale si sono potuti individuare circa tre o quattro nuclei, che potremmo chiamare 'quartieri', attorno ai quali si addensano strutture più piccole tra loro interrelate senza che sia possibile riconoscere un impianto ordinato. Anche la separazione tra gli stessi quartieri non è sempre chiaramente percepibile. I muri si presentano di due tipi: alcuni realizzati con una tecnica mista, ma assai grossolana, con basi in pietre di piccolo taglio e irregolari, su cui s'impostano alzati in mattoni crudi, anch'essi di dimensioni piuttosto irregolari (in media questi mattoni misurano $30 \times 25 \times$ $7 \mathrm{~cm}$ circa), altri invece sono composti esclusivamente di mattoni crudi, talvolta irrobustiti con l'inserzione di travicelli lignei al loro interno. Queste strutture murarie si sono conservate fino a un'altezza media di circa $1 \mathrm{~m}$. I livelli di crollo, che erano composti anche da sporadici travicelli e sterpaglie, potrebbero indicare delle soffittature piuttosto leggere. All'interno dei vani sono state individuate varie aperture, tutte di dimensioni molto anguste (a volte alte solo $40 \mathrm{~cm}$ ) e in taluni casi sigillate, il che suggerisce quindi un periodo d'uso piuttosto lungo che ha portato ad alcuni minori rimaneggiamenti interni. I depositi interni rinvenuti in alcuni di questi ambienti, misti al crollo, sono pressoché interamente costituiti da un mescolamento di paglia e terra impalpabile; in alcuni ambienti si è particolarmente concentrato uno strato di stallatico molto compatto, che aveva raggiunto un consistente spessore. La zona è dunque chiaramente occupata da modeste abitazioni con magazzini, cui si collegano stalle o piccoli ricoveri per animali, il che può spiegare anche le ridotte dimensioni di alcune aperture. La ceramica, così come in genere gli altri reperti mobili, risultano nel complesso scarsi e assai poveri.

Lo stallatico si è particolarmente concentrato in Li1, che presenta muri intonacati di fango e un piano in battuto; all'interno di questo ambiente sono stati rinvenuti frammenti di carta scritta in caratteri arabi ed ebraici, che potremmo associare all'ultimo periodo di vita, attorno al XVIII secolo. ${ }^{61}$ Negli ambienti in direzione del Tempio A, cioè in Li2 e Li10, il riempimento era composto da uno strato cineroso dal colore grigio brillante, pure questo misto a stallatico, con corde e qualche sporadico straccio.

Lo smontaggio di alcuni muretti, che delimitavano i piccoli ambienti in quest'area orientale dello scavo, ha fatto fin da subito emergere le cime di quattro pilastri ancora integri della sala ipostila minea, la cui sezione superiore mostra ancora il tenone (ad eccezione di P4 che è stato lisciato). P1 si trova all'intersezione di Mi1 e Mi3, P2 è compreso tra Mi9 e Mi26, e lungo Mi9 si trova anche P3, mentre P4 è lungo l'allineamento di Mi27, verso sud-est. Questo ha confermato che molti dei muri in direzione nord-est/sud-ovest, specialmente Mi1, Mi9, oltre a Mi200 e Mi202, hanno continuato a seguire la griglia dei pilastri contenuti nella sala ipostila sottostante fino a questo periodo recente (fig. 63).

In Li4 si sono trovate quattro vaschette, probabilmente adibite alla conservazione di liquidi o sementi, in modo analogo a quanto riscontrato nei livelli islamici che insistevano sul Tempio A. Il muro Mi10, che delimita a sud-ovest i due vani dell'Islamico recente Li4 e Li8, è stato fornito di una piccola finestra e aveva una base in pietra di buona qualità, risalente al periodo Islamico Antico, nonostante l'alzato in mattoni fosse invece molto precario (Mi10a); questo muro si appoggiava a sua

61 Come è noto, almeno fin verso il XIX secolo, a Barāqish risiedeva una comunità ebraica, come testimonia lo stesso Hayyīm Habshūsh $(1976,95-96)$. 


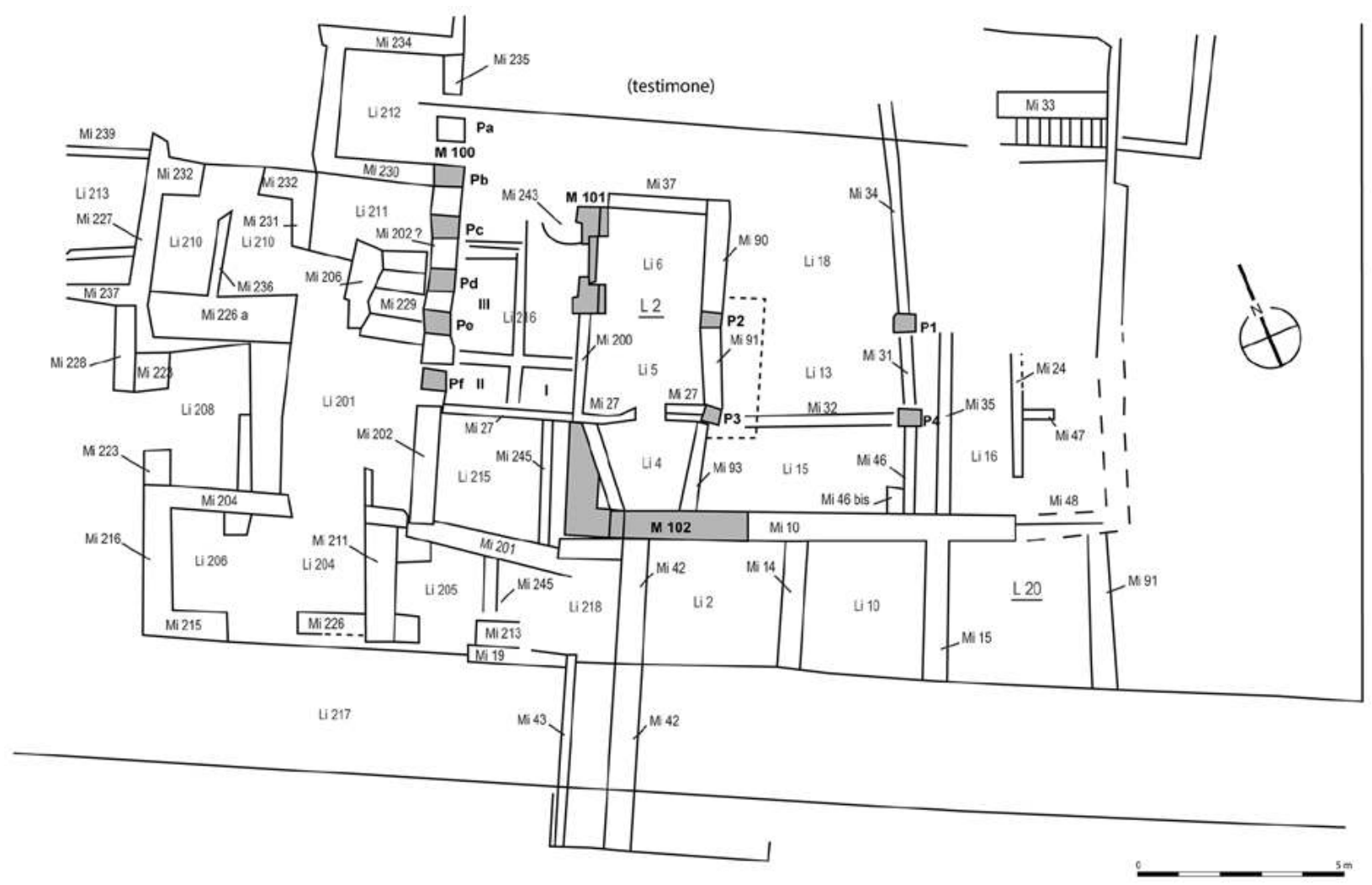

Figure 60. Islamico Medio IIb-c, planimetria generale. (Rielaborazione di L. Munduteguy da schizzo originale di A. Agostini 2019 (OMAIRY)

volta sul muro perimetrale sud-ovest del Tempio B, uno dei più conservati dell'edificio mineo, analogamente a Mi200 che si è impostato sulla stessa direttrice del muro di facciata e a Mi16 che stava sul muro posteriore del tempio.

Mi202 è uno spesso muro realizzato in tecnica mista che prosegue nell'allineamento disegnato dal propileo d'ingresso al tempio, in direzione nord-ovest/sud-est, inglobando i pilastri; questo muro è stato a sua volta foderato con mattoni crudi sulla facciata orientale, coprendo quindi gli stessi pilastri e separando due grandi ambienti, Li200 a sud-est e Li201 a nord-ovest, messi in comunicazione da una porta. Entrambi questi vani hanno presentato un pavimento in terra battuta e un buon intonaco in tiin: è possibile quindi che fossero un po' il centro di questa casa. È dalla demolizione di Mi202 che è emersa la sezione fratturata della metà inferiore del pilastro Pf del propileo.

\section{Conclusioni}

Lo scavo del Tempio B ha permesso di chiarire alcune dinamiche che in parte erano emerse anche durante lo scavo del Tempio $\mathrm{A}$, ma in modo più sfumato. Queste considerazioni sono per forza di cose limitate all'area sacra, perché è l'unica intra muros finora indagata archeologicamente, ma si vede che sono in parte coerenti con i risultati delle indagini condotte fuori le mura, ${ }^{62}$ il che ci consente quindi di estenderle in via preliminare e ipotetica a tutto il sito. L'esistenza di condizioni diversificate nelle varie parti del sito e della città dovrà essere ovviamente confermata con il prosieguo e con l'estensione degli scavi.

Il Tempio B rientra pienamente nella tradizione architettonica del tempio ipostilo mineo, presentando molti elementi di somiglianza col contiguo Tempio A, sebbene il piano ribassato della sala e la presenza di una connessione con un livello superiore rappresentino novità significative. Il periodo di vita mineo dovrebbe coprire tutta la seconda metà del I millennio a.C. È possibile infatti situare la fondazione di questo tempio in termini assoluti nella seconda metà del $\mathrm{V}$ secolo a.C. e questo anche grazie al supporto delle analisi radiometriche. A questo periodo va dunque ascritto anche il sovrano Waqih'il Riyām, figlio del re Abìyadac Yatha', che ha promosso l'iniziativa e che l'ha vista realizzata in una fase avanzata del suo regno, quando era in coreggenza con il figlio Aws'il. Il re Waqih'il Riyām andrebbe dunque collocato in una fase anteriore di circa un secolo rispetto a quanto finora ammesso,

62 Fedele 2010; Fedele 2011a. 


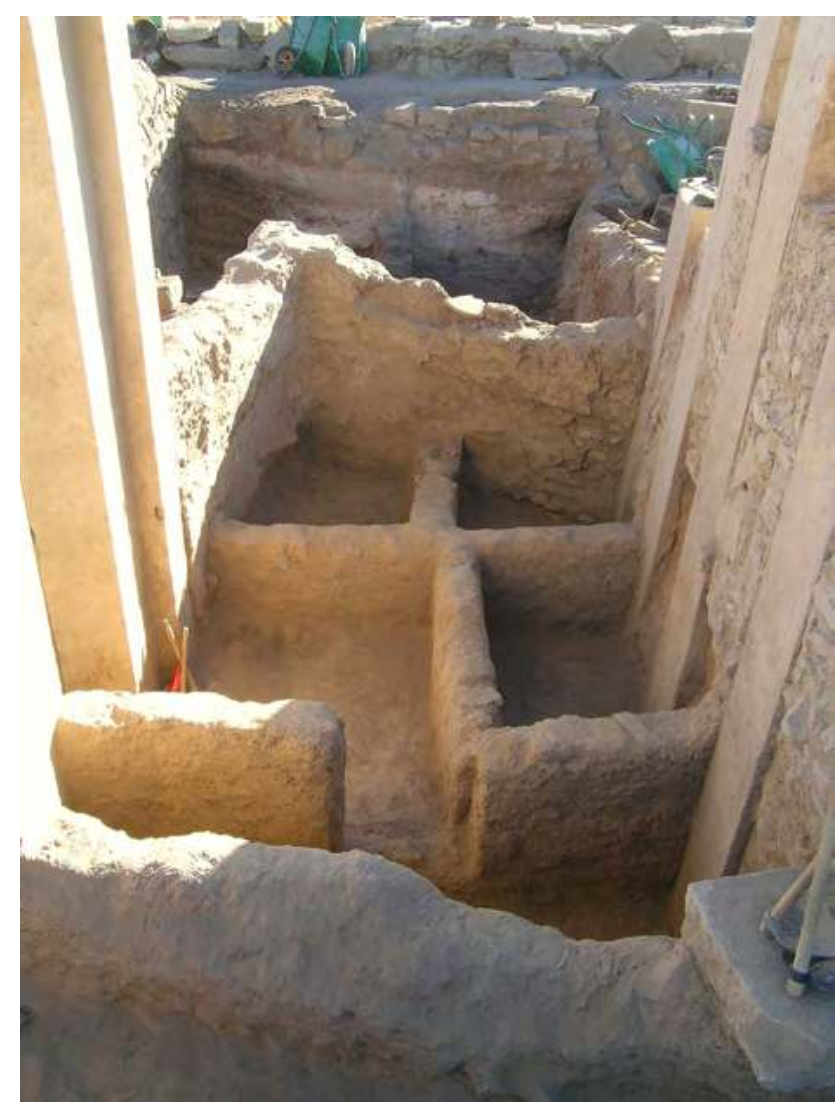

Figure 61. Islamico Medio IIb-c, localizzazione delle vasche in Li216, da nord-ovest. (A. Agostini 2004 @MAIRY)

Figure 62. Islamico Medio IIb-c, particolare dell'area sul propileo e dell'entrata del tempio; quote da P2. (Rielaborazione di L. Munduteguy da schizzo originale di A. Agostini 2019
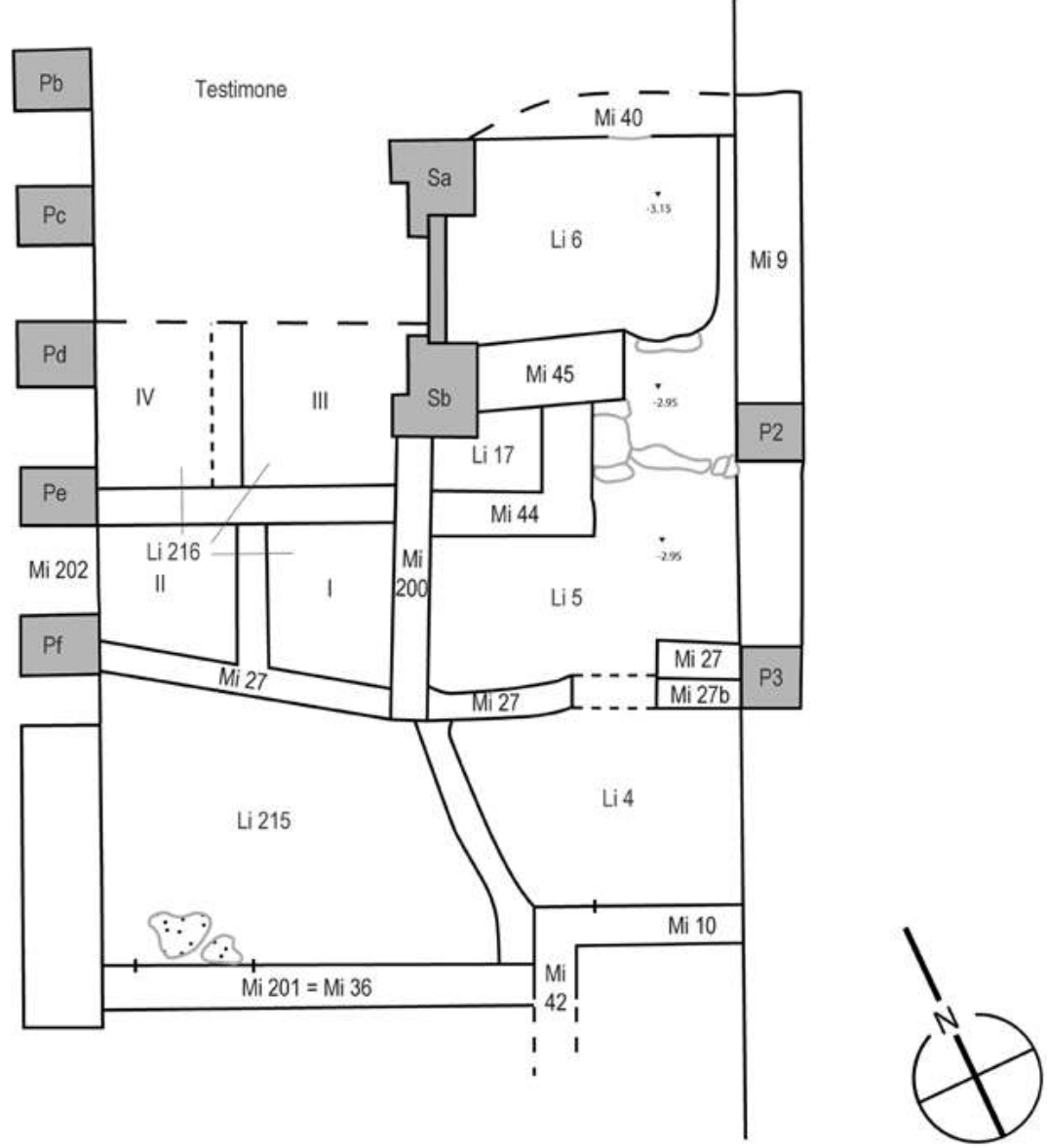
CMAIRY) 


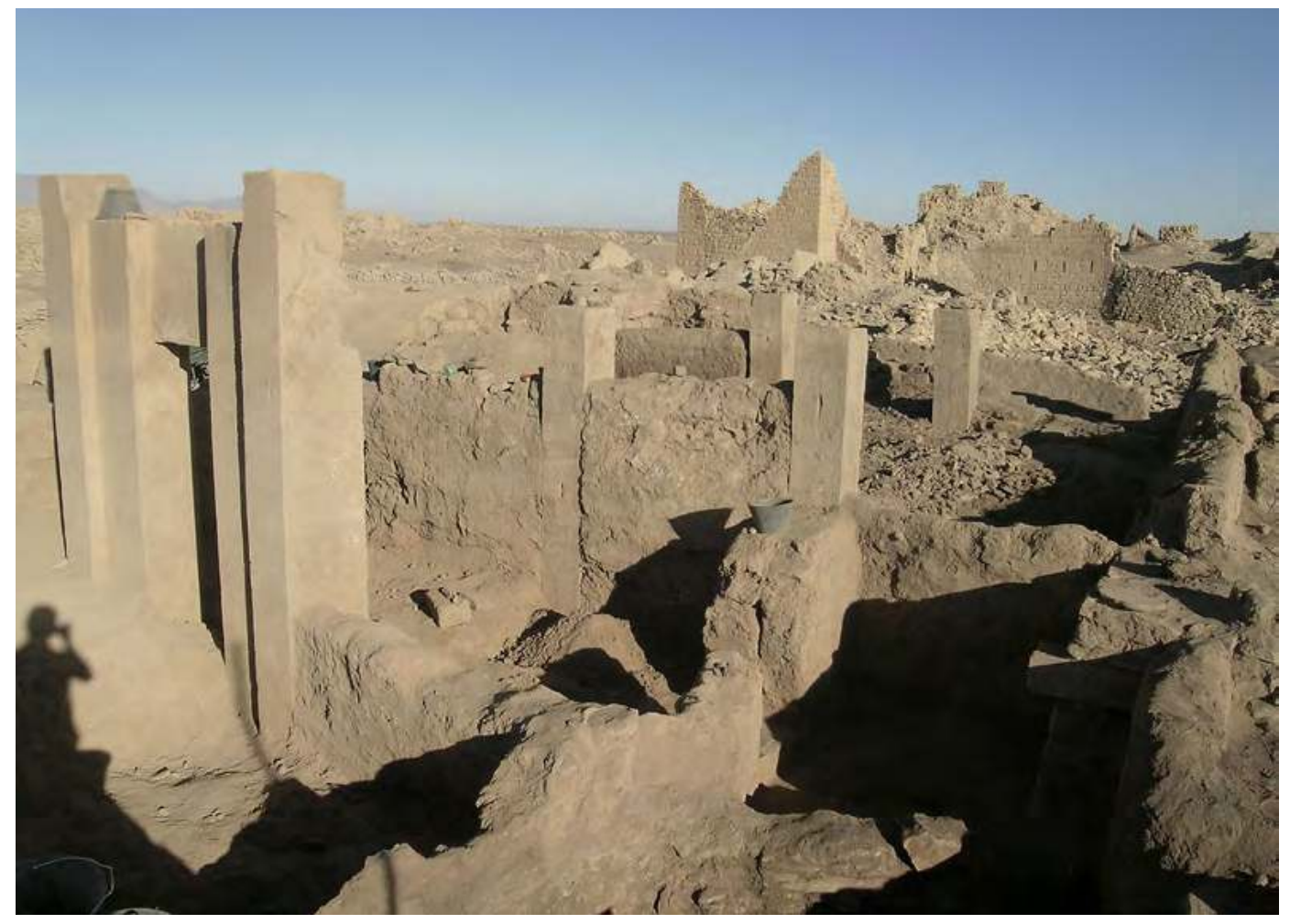

Figure 63. Strutture islamiche superiori che inglobano le strutture minee ancora emergenti del Tempio B, da ovest. (A. Agostini 2004 OMAIRY)

almeno sulla base della connessione con la RES $3022 \mathrm{e}$ della sua interpretazione più accreditata, che possiamo invece oggi riconsiderare alla luce di questi nostri dati archeologici ed epigrafici. Con la fine del periodo mineo, che possiamo grosso modo datare all'inizio del I secolo d.c., il tempio ha subito una depredazione, probabilmente solo limitata alla ricerca di oggetti di pregio, senza aver provocato grave danno alle strutture. Sembra inoltre ormai chiaro come il tempio abbia vissuto una breve riutilizzazione, sempre a scopo religioso, grazie all'occupazione da parte degli Amīr, precedentemente dislocati in aree più settentrionali del Jawf, come il sito di Haram e il wādī Shudayf. Questo gruppo ha lasciato inequivocabili tracce scritte, sia nel Tempio A sia nel Tempio B, e ha probabilmente fatto qualche piccolo adattamento negli arredi del tempio, secondo le proprie esigenze cultuali. A questa fase postminea che chiamiamo Intermedia, segue un periodo di abbandono, piuttosto lungo a giudicare dallo spessore di quello strato di sabbia fine che ci pare realistico associare a un deposito eolico, e concentratosi soprattutto in alcuni dei punti più esposti verso l'esterno. Si ritiene che in questo momento le strutture abbandonate abbiano cominciato a presentare segni di cedimento, con il conseguente verificarsi dei primi crolli.
La fase dell'Islamico Antico si annuncia dapprima con qualche sporadico intervento localizzato, sia nella sala ipostila, sia nella zona della scalinata d'accesso, che riteniamo possa essere stato in parte distruttivo verso alcuni depositi preesistenti. Nella fase piena dell'Islamico Antico, le strutture del Tempio B, forse già più degradate rispetto a quelle del Tempio $\mathrm{A}$, cominciano a essere sempre più sistematicamente spoliate, sia attingendo al crollo, sia smontando murature ancora intatte. In alcune aree più libere, come quella tra $\mathrm{i}$ due templi, si impiantano strutture assai imponenti; altre aree del tempio sono invece via via occupate da un intreccio di piccole costruzioni dalla funzione altamente specializzata, prive però di connessione con la pratica religiosa delle fasi antecedenti. La si interpreta come un'area destinata all'immagazzinamento e alla lavorazione di prodotti. Collateralmente, alcune strutture risultano adibite al ricovero degli animali. Sia gli ambienti con tale funzione, sia quelli destinati alla cottura e allo stoccaggio, subiscono un ampliamento nella fase dell'Islamico Medio. La fase dell'Islamico Recente vede infine la continuazione e l'intensificarsi della presenza animale, in associazione a nuclei abitativi di assai modesta entità. 
Tabella 1: Successione delle fasi archeologiche, cronologia e descrizione.

\begin{tabular}{|l|l|l|l|}
\hline Fasi principali & Sotto-fasi & Orizzonte cronologico & DescRIzIone \\
\hline \multirow{2}{*}{ Islamico Recente } & I & XVIII-XIX d.C. & Casupole e stalle superficiali \\
\hline \multirow{3}{*}{ Islamico Medio } & IIa & XIV-XVII d.C. & $\begin{array}{l}\text { Nuclei abitativi sparsi, aree di lavorazione e } \\
\text { stoccaggio }\end{array}$ \\
\cline { 2 - 4 } & IIb & & Grandi vani a sud - Birka \\
\cline { 2 - 4 } Islamico Antico & IIc & XII-XIII d.C. & Prima riutilizzazione 'leggera' \\
\hline \multirow{2}{*}{ Abbandono } & IIIa & XI d.C.? & Deposito eolico; crolli \\
\hline \multirow{2}{*}{ Fase Intermedia } & IV & III-X d.C.? & Frequentazione post-minea (Amï) \\
\hline \multirow{2}{*}{ Mineo } & A & I-II d.C. & Piano di vita del tempio \\
\hline
\end{tabular}

(a) La successione delle tre fasi A-B-C per il periodo sudarabico antico vuole agganciarsi a quella proposta da A. de Maigret per il tempio A (cfr. spec. de Maigret 1993, 17-22), aggiornandola sulla base dei dati archeologici emersi con lo scavo del Tempio B e delle relative valutazioni storiche.

Tabella 2: Zanābìl pertinenti alle fasi preislamiche.

\begin{tabular}{|c|}
\hline Livelli di crollo e abbandono (IV) \\
\hline B.05.B./32: M 105 \\
B.05.B./33: L 110 \\
B.05.B./39: L 104-L 111 \\
B.05.B./44: L 117 (M 120) \\
B.05.B./46: L 114 \\
B.05.B./51: L 110 \\
B.05.B./54: L 111 (Li 303) \\
B.05.B./56: L 117-L 121 \\
B.05.B./57: L 112 (Li 218) \\
B.05.B./68: L 116 \\
B.05.B./69: L 120 \\
B.05.B./71: Li 1 \\
B.06.B./41: Li 201-Li 412 \\
B.06.B./50: Li 402 \\
B.06.B./51: M 135 \\
B.06.B./53: L 129 \\
B.06.B./54: L 129 \\
B.06.B./55: M 135 \\
\hline B.05.B./58: L 111 \\
B.05.B./59: L 110 \\
B.05.B./60: L 111 \\
B.05.B./62: L 111 \\
B.05.B./63: L 111 \\
\hline
\end{tabular}

\begin{tabular}{|l|l|}
\hline Mineo B & \\
\hline & B.04.B./25: L 101 \\
& B.04.B./30: L 105 \\
& B.05.B./18: L 104 \\
B.05.B./20: L 104 \\
B.05.B./26: L 104 \\
B.05.B./28: L 103 (Ta) \\
B.05.B./31: L 103 (Ta) \\
B.05.B./43: L 101 \\
B.05.B./64: L 104 \\
B.05.B./72: L 103 (Ta) \\
B.05.B./74: L 121 \\
B.05.B./75: L 121 \\
B.05.B./78: M 124 \\
B.06.B./56: L 127 \\
B.06.B./57: L 127 \\
\\
\\
Mineo C & B.05.B./70: L 111 \\
\hline & B.05.B./73: L 120 \\
& B.05.B./76: L 104 \\
B.05.B./77: L 104 \\
\hline
\end{tabular}

(a) Si ascrivono alla Fase Intermedia solo quegli zanābïl per i quali sia chiara una connessione con la frequentazione amirita. 


\title{
Chapter 4 \\ Il tempio di 'Athtar dhu-Qabḍ. \\ Le iscrizioni
}

\author{
Alessio Agostini
}

\section{Introduzione}

Lo scavo del tempio Qabdum, dedicato al dio 'Athtar dhu-Qabd (Tempio B), ha permesso di riportare alla luce un abbondante materiale epigrafico di varia natura, ma in uno stato di conservazione molto diversificato. La maggior parte delle iscrizioni è stata rinvenuta in deposizione secondaria: dato il lungo periodo di vita dell'edificio, molto materiale lapideo è stato infatti molto spesso riutilizzato nelle strutture erette o rimaneggiate durante le fasi islamiche. In alcuni casi, durante questa riutilizzazione è stato dato risalto alla parte iscritta a fini decorativi, altre volte invece questo aspetto è stato ignorato e le epigrafi sono state reimpiegate come semplice materiale da costruzione. In generale, la situazione presenta alcuni elementi di continuità con quella rinvenuta negli scavi del Tempio A, ma le tipologie testuali sono diversamente concentrate tra i due edifici - un dato che può essere semplicemente dovuto alla casualità di ciò che si è conservato e che è stato poi ritrovato. ${ }^{1}$

Si presenta in questa sede parte della documentazione epigrafica rinvenuta, con particolare attenzione ai documenti che consentono di chiarire la collocazione storica del tempio e a quelli relativi all'organizzazione dello spazio cultuale. Due delle tre iscrizioni di costruzione rinvenute, una perfettamente in situ (Y.05.B.B.12) e l'altra di poco dislocata (Y.05.B.B.13), riguardano direttamente la fondazione dell'edificio avvenuta durante il regno di Waqih'il Riyām figlio di Abiyadac Yathac e consentono quindi una collocazione cronologica relativa abbastanza solida, che può verosimilmente concentrarsi in termini assoluti nella seconda metà del V sec. a.C. sulla base della ricostruzione storica generale e dell'analisi radiometrica. ${ }^{2}$ Un'altra iscrizione di costruzione (Y.06.B.B.6), pur contemporanea alle precedenti, è stata rinvenuta in deposizione secondaria e non sembra aver attinenza con l'edificazione del tempio.

\footnotetext{
1 La documentazione epigrafica rinvenuta durante gli scavi del Tempio A è stata in parte edita in de Maigret e Robin 1993 (spec. pp. 458-489); una presentazione sommaria del nuovo materiale epigrafico era stata offerta anche da Gnoli in appendice alle due conferenze IsMEO (de Maigret 1991a, de Maigret 1993).

2 Si veda la sintesi storica in Agostini, capitolo 3, § 1.5, in questo volume e Agostini 2020b; edizione preliminare in Agostini 2011.
}

Le iscrizioni dedicatorie sono in numero piuttosto ridotto e tra queste emerge senza dubbio la dedica al dio amirita Ḥalfān (Y.05.B.B.16), che ha consentito di individuare con una certa chiarezza il passaggio del gruppo degli Amīr verso la fine del periodo mineo - altrimenti evanescente sulla base della sola documentazione archeologica. ${ }^{3}$ Altre tipiche iscrizioni dedicatorie minee sono purtroppo in condizioni estremamente frammentarie e non offrono elementi di particolare rilievo alla discussione.

Benché molto brevi, significativi sono i testi che accompagnano alcuni degli arredi cultuali. Tra questi emergono in primo luogo gli arredi fissi, quindi le quattro tavole offertorie trovate ancora in posto, seppur in parte danneggiate dal crollo. Sulla base di questa loro collocazione, si è potuto notare che le tavole del settore nord-est della sala ipostila, cioè quelle individuate dai nomi $D \underline{t}^{3}$ e $H r f$, si trovano nella stessa posizione delle omonime tavole rinvenute nel Tempio A. La tavola Dyt si trova invece nel settore di sud-ovest nel Tempio B, nel primo cenacolo a destra dopo l'entrata, mentre è collocata nel cenacolo sud-est del Tempio A, nella parte della sala prospiciente le celle. In questo Tempio B abbiamo una quarta tavola, relativa a Yg்l, che invece era mancante nel Tempio A e che si trova nella stessa posizione che nel Tempio A è occupata dalla tavola Dyț. Ci sembra possibile ipotizzare che il numero originario delle tavole fosse quattro anche nel Tempio A e che la tavola $Y \dot{g} l$ sia stata sacrificata al momento in cui il primo cenacolo a destra era stato smantellato per creare il passaggio verso la 'Sagrestia'. Questo cenacolo, poi dismesso, doveva contenere in origine la tavola Dyt se, come ci pare plausibile, la collocazione delle tavole non sia stata casuale, ma analoga a quella riscontrata nel Tempio B. Durante la risistemazione della sala ipostila del Tempio A, la tavola Dyt deve essere stata traslata nel cenacolo adiacente, dopo che era stata eliminata la tavola Yg்l, che non è mai stata ritrovata (Agostini 2020a).

Tra gli oggetti mobili a carattere cultuale abbiamo alcuni incensieri, piccoli altarini e una stele. La presenza di questa stele (Y.05.B.B.27) all'interno di un edificio sacro, apparentemente simile a quelle in uso

Agostini, capitolo 3, §2, in questo volume; Agostini 2018a. 
Tabella 1: Sovrani attestati nei documenti epigrafici trattati nel presente capitolo 4 e nel capitolo 9.

\begin{tabular}{|c|c|c|}
\hline Sovrani & $\begin{array}{c}\text { Nuove attestazioni da scavo Tempio B } \\
\text { (Capitolo 4) }\end{array}$ & $\begin{array}{c}\text { Nuove attestazioni dal settore delle mura - R44/45 } \\
\text { (Capitolo 9) }\end{array}$ \\
\hline $\begin{array}{c}\text { Abīyadac Yathac } \\
+ \\
\text { Heyyawum }\end{array}$ & - & Y.03.B.R44-45.2bis + Y.03.B.R44-45.2ter + Y.03.B.R44-45.2 \\
\hline $\begin{array}{c}\text { Waqih'il Riyām } \\
\text { Waqih'il Riyām } \\
+ \\
\text { Aws'il }\end{array}$ & $\begin{array}{c}\text { Y.05.B.B.13 } \\
\text { Y.06.B.B.6 }\end{array}$ & - \\
\hline Ilyafac Yafash & Y.05.B.B.12 & - \\
\hline Ilyafac (1) $^{c}$ & Y.06.B.B.11 & Y.04.B.T45.1 \\
\hline
\end{tabular}

(1) L'identificazione di questo individuo come sovrano non è del tutto sicura (cfr. commento al testo).

in ambito funerario, potrebbe sollevare la questione di una possibile differenziazione funzionale per questo tipo di manufatti, dunque funeraria e votiva, ma si tenga presente che questo pezzo non è stato rinvenuto in situ e quindi potrebbe essere stato trafugato da un contesto funerario già in antico; in ogni caso, per il momento, siamo impossibilitati a indagare questa possibile duplice specializzazione funzionale in assenza di un campione più significativo, dato che la maggior parte di queste stele è solitamente fuori contesto.

Le iscrizioni di natura legale costituiscono una categoria documentaria particolarmente abbondante in questo tempio e che presenta testi insolitamente lunghi e articolati. Qui presentiamo quei documenti che ci sono parsi avere più diretta attinenza con l'uso dello spazio del tempio e la sua storia. Il breve testo inciso in un riquadro su una delle facce del pilastro P1 sembra offrire indicazioni per la preparazione di oggetti cultuali in occasione di una festa religiosa (Y.05.B.B.14). Altre due iscrizioni di ambito legale sono purtroppo frammentarie e riguardano disposizioni sulle donazioni (Y.06.B.B.10), la gestione di alcune pratiche agricole e i relativi tributi (Y.06.B.B.11 - questo testo è interessante per la menzione del re di Ma'īn, Ilyafa' Yafash, la cui collocazione cronologica rimane ancora assai incerta, cfr. Tabella 1).

Il resto della documentazione legale è costituito da due ampie iscrizioni ancora in situ incise sulla parete interna del muro perimetrale del tempio, nel lato sud (Y.04.B.B.6) e nel lato ovest (Y.04.B.B.5), di cui manca la parte iniziale (per la localizzazione di queste e delle altre iscrizioni in situ, cfr. fig. 1). Vari altri blocchi contengono porzioni frammentarie di testi di natura legale e sono stati ritrovati reimpiegati nelle strutture islamiche che insistevano sull'area sacra, ma si tratta anche in quel caso di pietre certamente pertinenti al muro perimetrale interno. La grafia di queste iscrizioni risulta omogenea e farebbe dunque pensare a una coerenza scrittoria, e forse cronologica, per questa produzione di ambito legale. Lo studio preliminare su questa documentazione, condotto in collaborazione con Khaldun Nouman, ha permesso di evidenziare un lessico ricorrente, ma in larga parte poco attestato negli altri testi minei appartenenti alla stessa categoria, offrendo aspetti stilistici e problemi di natura interpretativa che richiederanno un approfondimento in altra sede. $\mathrm{Si}$ deve sottolineare che il Tempio A, invece, ha restituito iscrizioni di natura legale in numero assai ridotto: tra il materiale edito si ricorda la Y.92.B.A.15, che documenta l'esistenza di particolari disposizioni circa il transito degli animali nell'area sacra. I documenti legali del Tempio B sembrano invece per la maggior parte di natura prescrittiva: questo farebbe quindi intravedere una particolare specializzazione del Tempio B, probabilmente da ricondurre a determinati attributi del dio 'Athtar dhu-Qabḍ, divinità suprema del pantheon mineo. Si potrebbe inoltre sollevare la questione se la costruzione di questo tempio sia diretta conseguenza di un nuovo consolidamento della posizione di Yathill all'interno della compagine politica del regno di Ma'īn, che raggiunse il suo apogeo proprio intorno al $\mathrm{V}$ secolo a.C. - come dimostra anche la straordinaria attività edilizia che interessa le mura cittadine proprio in questo periodo.

Infine, sempre durante le operazioni di scavo delle strutture islamiche che insistevano sull'area occupata anticamente dal Tempio B, ma specialmente durante la ripulitura dello spazio tra i due templi, sono emerse nuove epigrafi pertinenti al rito di espiazione, per il quale era già stata messa in luce una serie di documenti durante gli scavi del Tempio A negli anni Novanta, e rimasti da allora inediti. ${ }^{4}$ Le ultime campagne hanno permesso di integrare questa classe di documenti, che

${ }^{4}$ Un'iscrizione espiatoria dal Tempio A (Y.92.B.A.29) è stata edita in Gnoli 1996a, una seconda proveniente dalla ripulitura dello spazio tra i due templi (Y.05.B.A.1) in Agostini 2012. 


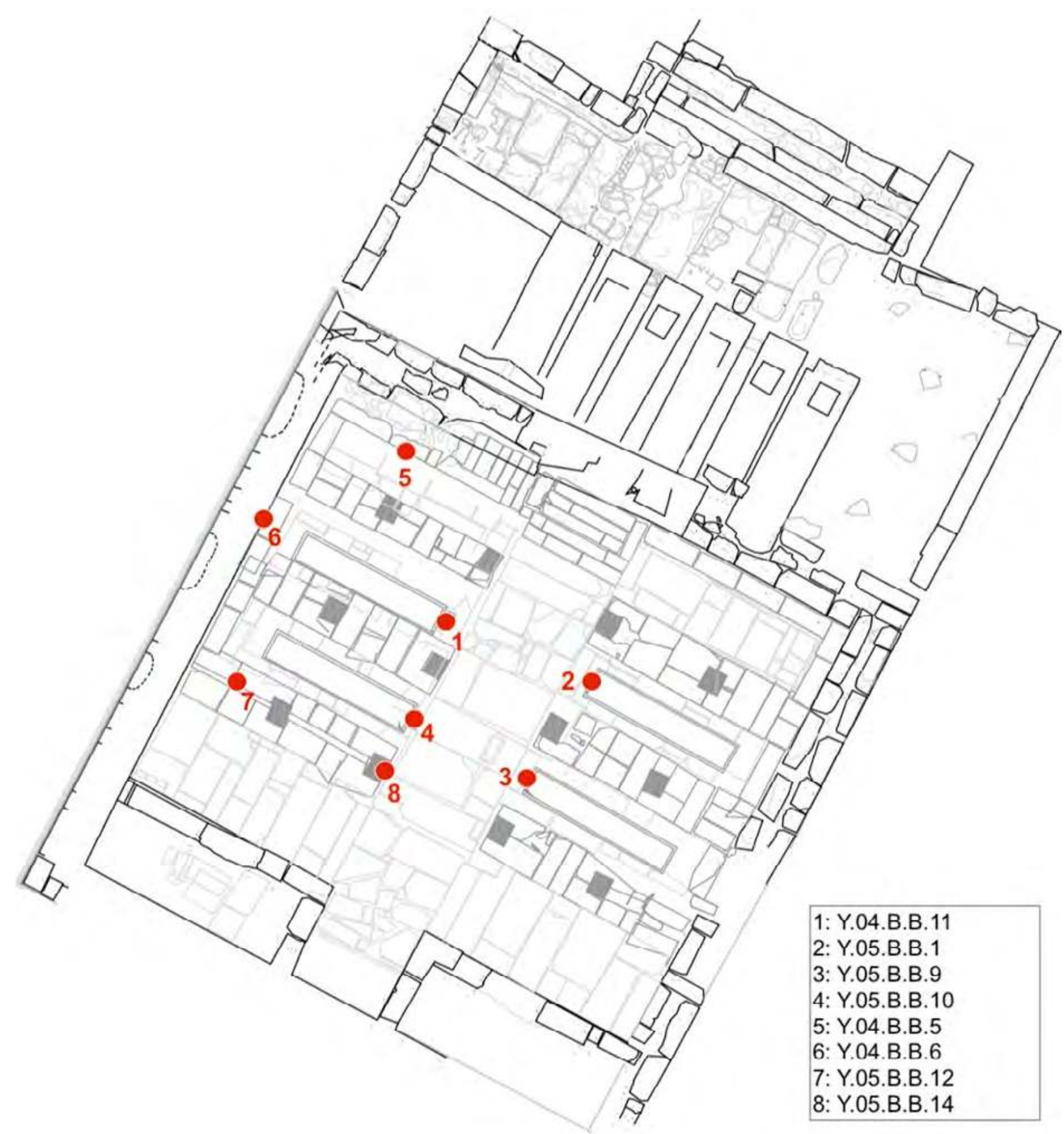

Figure 1. Localizzazione delle iscrizioni in situ della sala ipostila del Tempio B. (A. Agostini e L. Munduteguy 2019 CMAIRY)

per la maggior parte provengono dall'area esterna al Tempio B, tutti in deposizione secondaria. Tuttavia, sembra ormai di poter affermare che la pratica espiatoria non fosse connessa in modo esclusivo col dio Nakrah, come finora ritenuto, ma che potesse estendersi anche al dio 'Athtar dhu-Qabḍ, 'Athtar dhuYahriq e ad altre divinità minori del pantheon mineo, seppure in maniera più contenuta (Agostini 2012). Anche questa classe documentaria farebbe in definitiva parte dei testi di natura legale, specie in considerazione della particolare natura che questo rituale ha rivestito in seno alla società minea, come riparazione non solo di trasgressioni riguardanti le norme di purità, ma anche e soprattutto di infrazioni avvenute in ambito civile, il che ci permette di assimilare questi testi alla redazione di atti formali in seguito a un pubblico processo. ${ }^{5}$

La Tabella 1 ha lo scopo di evidenziare le nuove attestazioni di sovrani emerse dalla documentazione

\footnotetext{
5 Cfr. Agostini 2014; Agostini 2018b. Tutto il materiale che riguarda questo rito è in fase di lavorazione ai fini di un'edizione che raccoglierà $i$ testi espiatori provenienti dal Tempio A, quelli rinvenuti nei pressi del Tempio B, oltre ad altri documenti di varia provenienza coerenti con questa tipologia testuale.
} 


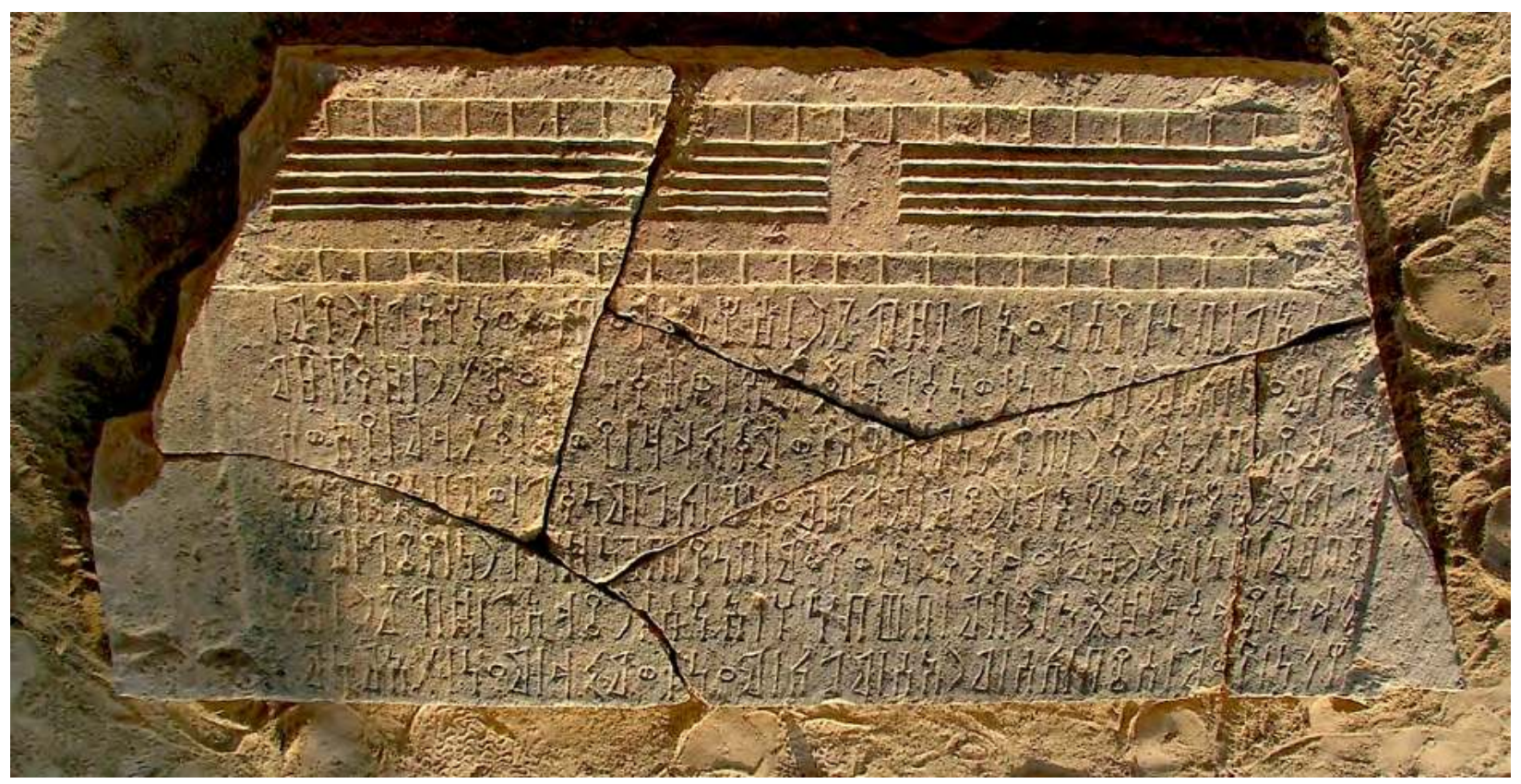

Figure 2. Y.05.B.B.13. (2005 @MAIRY)

epigrafica qui presentata, considerando anche quella proveniente dallo scavo in prossimità delle mura ( $\mathrm{v}$. capitolo 9).

\section{Avvertenze}

Contrariamente alle intenzioni, per motivi di contingenza politica, non è stato possibile effettuare un'ultimacampagnadistudiodedicataal completamento della catalogazione della documentazione epigrafica, per questo motivo alcuni pezzi sono privi di alcune informazioni. I pezzi di dimensioni contenute furono collocati alla fine delle varie campagne di scavo nel magazzino della Missione all'interno del nuovo edificio destinato al Museo/Antiquarium, e questa è la collocazione che si è di volta in volta indicata nelle schede dei vari oggetti, ma si dovrà tener conto che tutto il campo della Missione a Barāqish, compreso questo museo, ha subito gravi danneggiamenti durante i recenti avvenimenti bellici che hanno interessato la regione.

Ogni iscrizione è inserita nella periodizzazione storica di massima secondo quanto stabilito nel Digital Archive for the Study of pre-Islamic Arabian Inscriptions (DASI); quando possibile, si suggerisce anche un'identificazione dello stile grafico secondo la paleografia di Jacqueline Pirenne (1956); infine, si propone una datazione in termini assoluti solo laddove vi siano ulteriori elementi a supporto.

Nelle traduzioni, si vocalizzano solo i nomi propri personali e i toponimi più ricorrenti, tenendo però presente che tale vocalizzazione è puramente convenzionale e non necessariamente aderente a quella originale.

\section{Catalogo delle iscrizioni}

\section{A. Iscrizioni di costruzione}

\section{Y.05.B.B.13 (fig. 2)}

Provenienza: Barāqish, Tempio B, crollato in L110, alle spalle del pannello Pnb (aneprigrafo)

Collocazione: già Barāqish magazzino del Museo

Materiale: calcare oolitico

Dimensioni: larghezza pannello max.: c. $160 \mathrm{~cm}$; altezza lettere: $c .6,5 \mathrm{~cm}$

Conservazione: pannello rinvenuto in sei frammenti, ma la lastra è integralmente ricomponibile.

Bibliografia: Agostini 2011

Descrizione: il pannello presenta due fasce laterali in rilievo ed è decorato in alto con un fregio a persiana bipartita, inserito tra fasce orizzontali decorate a dentelli. Periodo B. Stile grafico E2. V-IV secolo a.C.

\section{Testo:}

1. $\left[Y^{3} w\right]\left(s^{1}\right)^{\prime} l$ bn $Y s^{1} m^{(c)} d-\dot{G} z r S^{1} h(f n)\left({ }^{\circ}\right) b d$ Wqh'l Rym /

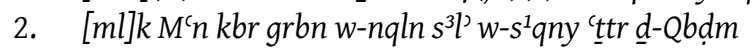

3. kl mșrbt qrar bytn Qbdm w-mqldn ywm qtdm $Y^{2} w s^{1}-$

4. 'l k-mr'h-s' Wgh'l Rym mlk M'nm kl mnql w-mbny bytn 
5. Qbdmbn ${ }^{2} s^{2} r s^{1} m{ }^{\prime} d s^{2} q r n w-y w m$ bny $b-g n^{\prime}(h) g r n Y t \underline{t}$ $m h-$

6. fdn Șdqn $\underline{d}-s^{3} n S^{2} b m b-t b n h h ' h-s^{1} R t d^{\prime} l \underline{d}-\dot{G} z r S^{1-}$

7. hfn ywm $s^{1} \underline{t} b k-s^{1} m r^{3}-s^{1} m l k M^{c} n w-m s^{3} d M^{C} n t^{3} m n m$ $[\ldots \ldots]^{2}$

\section{Traduzione:}

8. Ya’ws'il figlio di Yisma ${ }^{\circ} i l$ dhu-Ġazir Saḥān, servo di Waqih'il Riyām

9. re di Ma'īn, supervisore del cantiere e della cava, ha dedicato e offerto a 'Athtar dhu-Qabdum

10. tutte le tavole offertorie della sala del tempio Qabdum e il bacino, quando Ya'ws'il ha diretto

11. per il suo signore Waqih’il Riyām re di Ma`īn ${ }^{\text {um }}$ tutto lo scavo e la costruzione del tempio

12. Qabdum dalle fondazioni alla cima, e quando ha costruito sulle mura della città di Yathill la

13. torre Șidqān, quella vicino a Shibām, nella proprietà di suo fratello Rathid'il dhu-Ġazir

14. Saḥfān, quando il suo signore il re di $\mathrm{Ma}^{\mathrm{c} i n}$ e l'Assemblea di Ma'in gli hanno accordato gratitudine. $[\ldots . . .]^{?}$

Note:

L.1: $\quad Y^{2} w s^{11} l$ bn $Y s^{1} m^{(1)} \underline{d}-\dot{G} z r S^{1} h f n$ : la famiglia dhuGazir è attestata in M 106 (da as-Sawdā') e in M 198 (con formula onomastica estesa: $\underline{d}-\dot{G} z r S^{1} h f n$ ). In M 198 è probabilmente menzionato lo stesso Rathid'il dhu-Ġazir, citato anche qui alla linea 6, come fratello del soggetto della presente iscrizione. Il monogramma della famiglia dhu-Ġazir è presente in due delle tavole offertorie della sala (cfr. qui sotto: Y.04.B.B.11 e Y.05.B.B.1).

Wqh'l Rym: il sovrano Waqih’il Riyām (cfr. Tab. 1) è il figlio e successore del re di Ma'inn Abiyada' $Y^{\prime} \operatorname{ctha}^{c}$, menzionato nella RES 3022; dall'identificazione del sincronismo mineo-persiano ivi contenuta, consegue anche la collocazione cronologica di questo documento epigrafico; in questa sede, sulla scorta dell'analisi dei dati storico-epigrafici e archeologici, si propende per una datazione di Waqih’il Riyām verso la fine del V sec. a.C. (cfr. commento storico, capitolo 3, § 1.5; Agostini 2020b).

L.2: $\quad$ gbrn: la radice GBR ricorre anche nel Sabeo d'Etiopia in riferimento a una classe professionale di muratori (RIÉth 7).

nqln: la radice NQL si riferisce ad operazioni di estrazione di materiale lapideo e del suo trasporto, specialmente da cava, significato che è condiviso anche con il Sabeo (SD, p. 97). Altra attestazione minea di contesto analogo è in YM 10598.

L.3: $\quad m s r b t$ : questo termine plurale indica le 'tavole offertorie'; è in stato costrutto col termine che segue e si riferisce presumibilmente alle tavole offertorie fisse collocate all'interno del tempio. Questa identificazione è ulteriormente rafforzata dalla presenza del monogramma di famiglia dhu-Ġazir, che si riferisce al soggetto della presente iscrizione, su due di queste tavole (v. commento sopra alla linea 1). Il termine mssrb è diffuso in tutto il Sudarabico per indicare un oggetto di natura cultuale (cfr. paralleli in SW).

qrar: il termine ricorre come termine architettonico anche in riferimento al tempio di Nakrah (M 203), ma non era chiaro a quale spazio si riferisse; in questa attestazione si dichiara che grqr contiene le tavole offertorie (cfr. qui sopra) e ciò ci consente quindi di identificarlo con la 'sala ipostila'.

bytn Qbdm: in questo caso l'epiteto del dio, Qabdum, è utilizzato come apposizione del termine per tempio, bytn, ed è quindi chiaro che Qabdum era anche il nome proprio del Tempio B, come Barān $(B r n)$ era il nome del Tempio A.

mqldn: il termine ricorre anche nell'epigrafe minea MAFRAY-Darb aș-Ṣabī 3, dove indica chiaramente un 'bacino', accezione che accogliamo anche in questo contesto, senza che sia stato possibile identificare questo oggetto archeologicamente. Un'accezione analoga è presente anche in Sabeo (cfr. ad es. RES 4197bis, Robin az-Zāhir 1).

L.6: Șdqn: una struttura architettonica omonima è menzionata nel testo coevo Y.90.B.ext.2, dove però si riferisce a una abitazione.

$S^{2} b m$ : come nome proprio riferito a una struttura architettonica di una cinta muraria urbana ricorre anche in M 163 (ma il riferimento al contesto è dubbio) e in M 242 (dove una struttura omonima è appunto presente lungo le mura di Barāqish, non chiaro però se si riferisce a una cortina o a un bastione).

\section{Y.05.B.B.12 (fig. 3)}

Provenienza: Barāqish, Tempio B, M121 (L114) = Pna

Collocazione: in situ

Materiale: calcare oolitico

Dimensioni: larghezza pannello: $170 \mathrm{~cm}$; altezza lettere: c. $6,5 \mathrm{~cm}$

Conservazione: frammentaria

Bibliografia: Agostini 2011

Descrizione: lastra inferiore rinvenuta in posto tra P4 e M102, parte di un pannello di cui manca la metà superiore. È presente una doppia fascia ai lati che delimita la parte centrale iscritta, analogamente a Y.05.B.B.13. Periodo B. Stile grafico E2. V-IV secolo a.C.

Testo:

$[\ldots \ldots]$

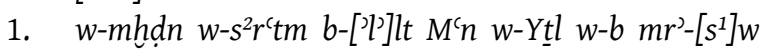
Wqh'-

2. l Rym $w-b n-s^{1}{ }^{2} w s^{11} l$ mlky $M^{(} n m w-b s^{2\left(b h-s^{1}\right.} M^{(} n m$ $w-\underline{d} Y-$ 


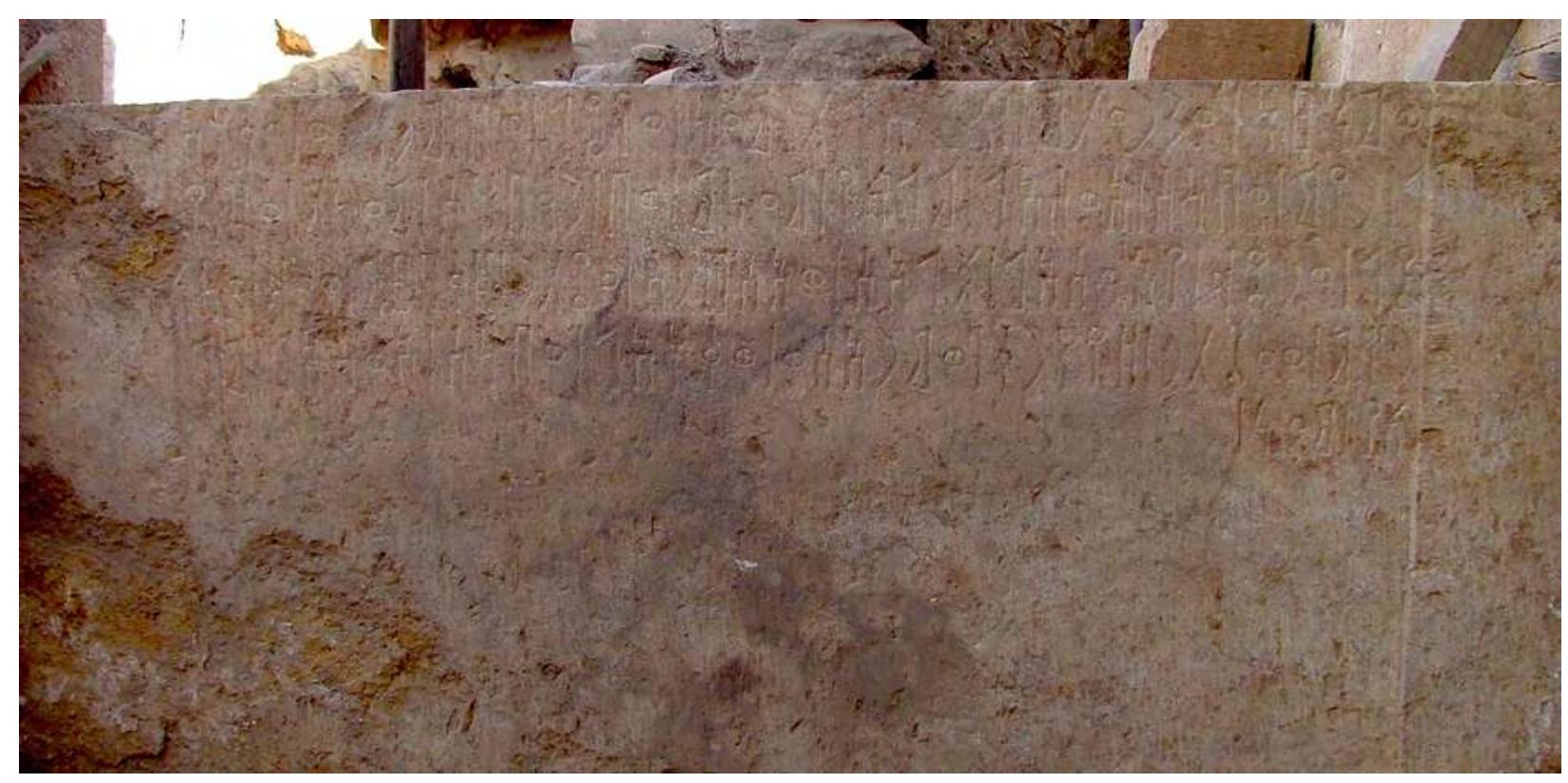

Figure 3. Y.05.B.B.12. (2005 @MAIRY)

3. tll w-rțd $Y^{3} w s^{11} l s^{3} l^{3}-s^{1} w^{-} s^{1} t r-s^{1}(\underline{t} t r \underline{d}-Q b d m w-W d$ $w-N k-$

4. $\quad r h m w-\underline{t} t r \underline{d}-Y h r q w-m r^{3}-s^{1} w$ Wqh'l $w-b n-s^{1}{ }^{2} w s^{17} l$ $m l-$

5. $k y M^{c} n$

\section{Traduzione:}

[.......]

1. e la concessione e un'onorificenza; per le divinità di Ma'īn e Yathill e per i suoi signori Waqih'il

2. Riyām e suo figlio Aws'il i due re di Ma ${ }^{C} \overline{i n}^{\text {um }}$ e per la sua tribù di Ma ${ }^{c} i n^{u m}$ e quella di Yathill;

3. e Ya'ws'il ha affidato la sua dedica e le sue iscrizioni a 'Athtar dhu-Qabdum, Wadd,

4. Nakrahum, 'Athtar dhu-Yahriq e i suoi signori Waqih'il e suo figlio Aws'il i due

5. re di Ma'īn.

\section{Note:}

L.2: $\quad m h d n$ : questo termine va inteso insieme a quello seguente ed entrambi sembrano essere utilizzati con un'accezione di tipo legale/burocratico. Questi due vocaboli sono attestati insieme, benché in posizioni invertite, anche nella Ja 555; le due radici sono accoppiate inoltre nella Demirjian 1, dove però MHुD è allo schema causativo. Il termine $m$ hidn è presente in ambito mineo nelle M 347, Maīn 1 e Kamna 26, dove si riferisce alla concessione o assegnazione di un bene materiale (in genere un terreno).

$s^{2} r^{c} t m$ : il termine è attestato nella frammentaria iscrizione minea M 442. La radice $S^{2} R^{c}$ in Sabeo sembra assumere sfumature che l'avvicinano all'ambito legale, potendo quindi forse indicare ciò che è pertinente a qualcuno o qualcosa. Cfr. anche l'attestazione del termine nelle iscrizioni sabee Ja 555 e Demirjan 1 dove $s^{2} r^{\prime}$ tm viene inteso come 'equipaggiamento' oppure 'decorazione'. L'accezione di 'decorazione, onorificenza' sembra ora quella più accreditata. Per il Mineo si considerino anche le forme verbali causative in $\mathrm{Ma}^{\mathrm{c} i n} 1$ e Ma'in 7. Esclusiva di una fase tarda sembra invece l'accezione di 'grondaia', che quindi va certamente esclusa in questo caso, anche perché siamo probabilmente di fronte a una radice omografa (SD, p. 133-134). Per un'ampia disamina dei contesti in cui questo termine compare in coppia col precedente, parallelamente alla situazione sabea, si veda Multhoff $(2019,8)$ che traduce con '[gave him] a [honorific] present and a decoration'.

$m r^{3}-s^{1} w$ : ricorre anche alla linea 5. La forma ampliata del pronome suffisso $\left(-s^{1} w\right)$ si riscontra in associazione con sostantivi di numero duale o in plurale esterno (Beeston 1962, 44). Nel caso presente il termine $m r^{3}$ va inteso come un duale in quanto si riferisce alla coppia di sovrani in coreggenza. Costruzione simile ricorre anche in Qatabanico (cfr. $\left.-s^{1} w w\right)$.

L.3: ${ }^{2} w s^{11} l$ : ricorre anche alla linea 5. Il nome di questo coreggente non è noto da altre fonti in riferimento al sovrano Waqih'il Riyām, per il quale invece era precedentemente nota un'altra coreggenza con Huffān Șādiq (M 266 + M 265 + M 274B; M 276 + M 277). Il successore di Waqih'il Riyām sembra essere stato invece Abīkarib Șādiq (cfr. Shaqab 4; Robin-Barāqish 80), che fino ad ora non è attestato come coreggente.

Il nome personale Aws'il non è mai stato utilizzato in ambito regale, mentre è piuttosto frequente nell'onomastica personale comune. Si potrebbe dunque 
ipotizzare che dietro questo nome si celi Ḥuffān Șādiq oppure lo stesso Abīkarib Șādiq, tenendo conto della possibilità che uno dei due sia stato qui indicato prima che assumesse il nome regale; si può inoltre pensare anche a un altro coreggente poi detronizzato o morto prematuramente prima di salire al trono singolarmente. Dobbiamo comunque ritenere che ci sia stato un avvicendamento e un cambiamento, per cause ignote, nella successione dinastica verso la fine del regno di Waqih’il Riyām (cfr. anche Agostini 2011, 50, 52).

\section{- Possibile collazione tra Y.05.B.B.13 e Y.05.B.B.12}

Si ritiene che una collazione tra i due testi appena presentati sia molto probabile, ma neanche del tutto sicura. ${ }^{6}$ Un elemento che induce a una certa cautela è essenzialmente il contesto archeologico del ritrovamento della lastra su cui è incisa Y.05.B.B.13, ritrovata franata in L110, tra P1 e P4, alle spalle del Pnb anepigrafo, con cui quindi verrebbe naturale riconnetterlo, mentre Y.05.B.B.12 è stata rinvenuta in posto tra P4 e il muro perimetrale della sala M102 (cfr. capitolo 3, §1.2, in questo volume). Alcuni degli aspetti contenutistici fanno invece apparire la collazione molto plausibile, si consideri ad esempio l'unione della linea 7 di Y.05.B.B.13 con la linea 1 di Y.05.B.B.12, che realizzerebbe la seguente frase: (...) ywm $s^{1} t b k-s^{1} m r^{3}-s^{1}$ $m l k M^{\prime} n w-m s^{3} d M^{\prime} n t^{2} m n m+w-m h d n w_{-1}^{2} r^{c} t m b-\left[l^{2}\right] l t$ $M^{\prime} n w-Y t l l(.$.$) , molto simile a quella che troviamo nella$ Ma'in 7, alla linea 8-9: (... w)-(ywm)[ $\left.s^{1} \underline{\underline{t} b} k-s^{1}{ }^{\prime} l\right] y f^{c}$ Rym $m l k M^{c} n w-m s^{3} w d M^{c} n+b-m s^{3} w d m(n)^{c} n t^{2} m n m w-\left(s^{1}\right)\left[s^{2}\right] r^{c}$ (...). Bisogna però anche tenere presente che qualunque sia stata la parte iniziale di Y.05.B.B.12, questa doveva essere in ogni caso molto simile, per contenuto e formulario, alla Y.05.B.B.13 e ciò potrebbe dunque trarre in inganno. Un ulteriore argomento che avrebbe potuto sconsigliare una collazione dei due testi non appare molto forte: il fatto che nella Y.05.B.B.13 il sovrano Waqih’il Riyām compaia citato come solo regnante, mentre nella Y.05.B.B.12 in coreggenza col figlio non è un dato sufficiente a considerare questo secondo testo come più recente, poiché nella stessa $\mathrm{Ma}^{\mathrm{c} i n} 7$ l'indicazione della coreggenza non è costante (si cfr. la linea 8-9 citata sopra con $\mathrm{Ma}^{c} \mathrm{i} n$ 7/2: 'lyf $\mathrm{Rym}^{\mathrm{w}} \mathrm{w}-b n-\mathrm{s}^{1}$ $H w f^{\prime} t t$ t $\left.m l k y M^{\prime} n\right)$. Una stessa incongruenza è ravvisabile anche nell'iscrizione M172 di alcuni anni precedente ai nostri due testi (linea 1: $\left(^{\prime} b y\right) d^{c}(Y t)^{c} w$-Wqh'l $R(y)[m$ mlk] y $M^{c} n$, contro la linea 4: $w$-ywm $s^{1} m h d w$-whb 'byd $Y t^{c}$ $\left.m l(k)[M]^{`} n w-M n n\right)$. È d'altronde possibile che all'interno dello stesso testo ci si possa riferire a momenti diversi e quindi l'individuazione della collazione non cambia in alcun modo l'interpretazione storica, ed è pertanto naturale pensare che il progetto di costruzione del tempio sia stato concepito sotto Waqih'il Riyām, e

${ }^{6}$ Multhoff $(2019,8)$ considera sicura la continuazione di Y.05.B.B.13 in Y.05.B.B.12, solo sulla base di valutazioni testuali.

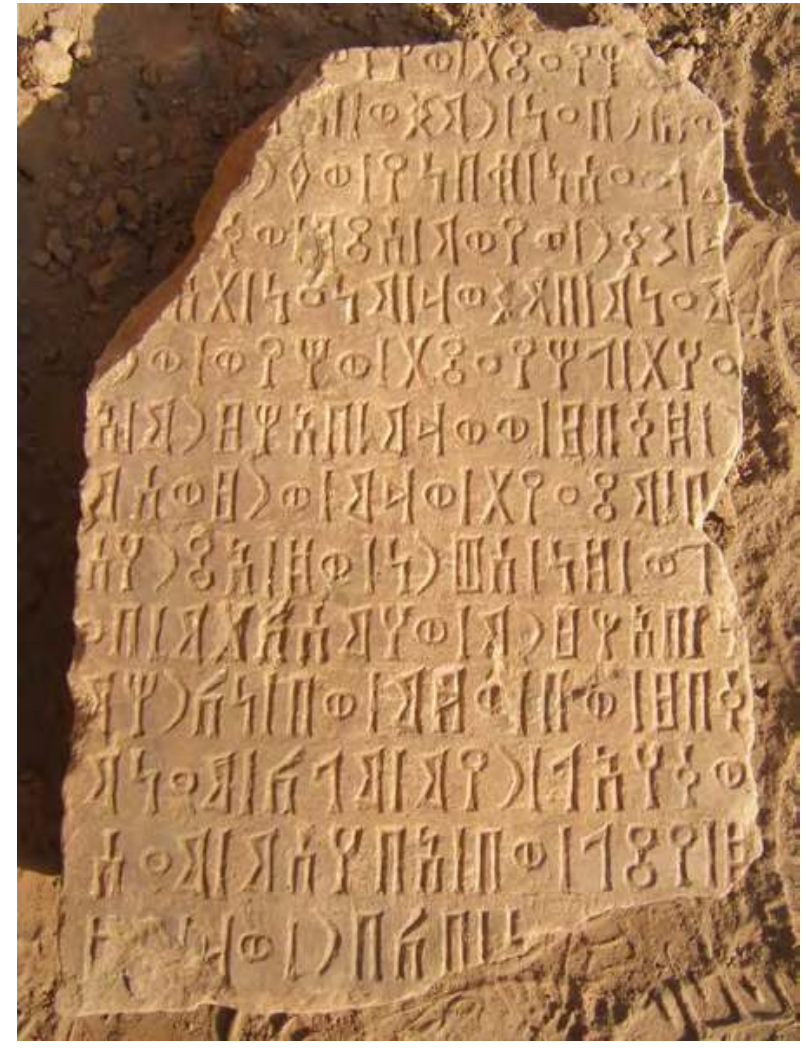

Figure 4. Y.06.B.B.6. (2006 CMAIRY)

gestito da Ya'ws'il, mentre la conclusione dei lavori sia stata realizzata quando Waqih'il Riyām si era ormai associato al trono il figlio Aws'il.

\section{Y.06.B.B.6 (fig. 4)}

Provenienza: Barāqish, Tempio B, Mi88

Collocazione: già Barāqish magazzino del Museo

Materiale: calcare oolitico

Dimensioni: altezza lettere: $c .3,5 \mathrm{~cm}$

Conservazione: frammentaria

Descrizione: l'iscrizione è su supporto ben preparato ed è stata redatta con una grafia molto accurata, si nota tuttavia che vi sono state varie incertezze durante la redazione del testo, con conseguenti correzioni (cfr. linee 3 e 11 - dittografia e linea 10, forse per un lapsus calami). La superficie presenta tracce di una diffusa pigmentazione rossastra. Il testo è frammentario, e non è possibile determinare dal suo andamento l'estensione del testo mancante (l'integrazione tra le linee 4-5 e tra le linee 10-11 potrebbero far intendere che la porzione mancante sia piuttosto ridotta). Periodo B. Stile grafico E2. V-IV secolo a.C.

\section{Testo:}

1. [... L] hyy ttt w-Hyw [...]

2. $[. .] w-.(b) r b c n R^{3} m s^{3} w(b) n[\ldots]$ 
3. $[\ldots .].(z) w-s^{1} n\{b\} w-b n y w-f r(r)\left[c^{c} \ldots\right]$

4. [...]d $s^{2} q r w-y w m s^{1} t(b) W q[h l$ Rym]

5. $[m l k] M^{c} n m b-m s^{3} w d m n^{i} n t\left({ }^{(}\right)[m n m ~ . .$.

6. [...] ht Lhy'tt w-Hyw w-r[...]

7. $\quad[. . . t t] r \underline{d}-Q b d w-W d m b-h d r m{ }^{\prime}[. .$.

8. [...wh]b $m t^{t} y t w d m w-r d w-s^{1} m[. .$.

9. [... n]gw dn $s^{1} \operatorname{trn} w-\underline{d}{ }^{2} \operatorname{trh}-s^{1}[m . .$.

10. [...]n b-' hdrm w-hms ${ }^{1}(\mathrm{kt}) m((\mathrm{kzm})) \mathrm{b}-\mathrm{c}[\mathrm{ttr}]$

11. [d-]Qbd $w-b W\{b\} d m w-b$ Nkrhm [...]

12. [... w-b-]Wgh'l Rym mlk M'nm [...]

13. $[\ldots w-] d \underline{t} Y \underline{t} w-b{ }^{3} b h-s^{1} m M^{c} s^{1}[\ldots]$

14. $[\ldots . . .] n b-.k b r W d[.] d.[. .$.

\section{Traduzione:}

1. [... La]hiy'athat e Hayyaw [...]

2. [...] e presso (?) il quartiere $\mathrm{Rms}^{3} \mathrm{w}$ da [...]

3. [...]. e ha posto le fondazioni e costruito ed eretto [...]

4. [...fi]no alla sommità e quando ha accordato Waq[ih'il Riyām]

5. [re di] $\mathrm{Ma}^{\mathrm{C}} \mathrm{in}^{\mathrm{um}}$ nel Gran Consiglio gra[titudine ...]

6. [...].. Lahiy'athat e Hayyaw e .[...]

7. [...'Athta]r dhu-Qabd e Waddum durante le festività .[...]

8. [...fe]cero offerte a Wadd ${ }^{\text {um }}$ e ne fu soddisfatto [...]

9. [... ha no]tificato questo documento e quello dei loro discendenti [...]

10. [...]. durante le festività $w-h m s^{1}(k t) m$ (?) per 'A[thtar]

11. [dhu-]Qabd e per Wadd ${ }^{u m}$ e per Nakrah ${ }^{\text {um }}$ [...]

12. [... e per] Waqih’il Riyām re di Ma'īn ${ }^{u m}[. .$.

13. [... e] di Yathill e per loro padre $\mathrm{Ma}^{\mathrm{C}} \mathrm{s}[. .$.

14. [.......]n durante il kabirato di Wadāad’il] d- $-[. .$.

\section{Note:}

L.1: Lhy'tt w-Hyw: entrambi i nomi propri sono molto comuni in ambito mineo: laddove il contesto sia chiaro, sono entrambi di genere maschile.

L.2: $\quad r b{ }^{`} n R s^{3} w$ : l'espressione ricorre nella Ma'īn 1 dove il toponimo $\mathrm{Rms}^{3} \mathrm{w}$ pare riferirsi a un quartiere di Qarnaw.

L.3: $\quad$ frr': cfr. Ma'īn 7.

L.4: 'd $s^{2}$ qr: porzione di una delle formule molto ricorrenti nelle iscrizioni di costruzione, si potrebbe integrare anteriormente con $b n^{2} s^{2} r s^{1}$ 'dalle fondazioni', ma le molteplici varianti con cui compare tale frase non permette una scelta univoca.

\section{$s^{1} t(b):$ cfr. Y.05.B.B.13.}

L.5: $\quad b-m s^{3} w d m n^{n} n t^{2} m n m$ : espressione che ricorre anche nella $\mathrm{Ma}^{\mathrm{c} i n} \mathrm{n}$ e nella $\mathrm{M}$ 230, ma in modo più frammentario. Cfr. anche Y.05.B.B.13.

L.8: [wh]b $m t^{c} y t$ : questa espressione si ritrova in varie iscrizioni minee ( $\mathrm{M}$ 151; $\mathrm{Ma}^{\mathrm{C} i n}$ 7; $\mathrm{Ma}^{\mathrm{c} i \mathrm{in}}$ 85), un'altra possibile integrazione, con significato analogo, avrebbe potuto essere con ['r $r] b m t^{C} y t$ (cfr. as-Sawdā' 5 ).

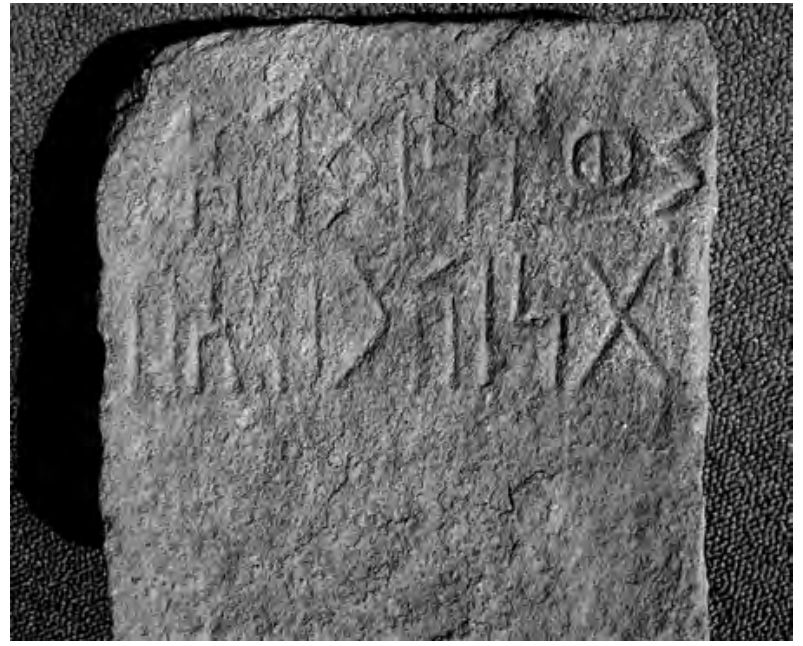

Figure 5. Y.04.B.B.10. (2004 @MAIRY)

L.13: $[w$ - $] \underline{d}$ Ytl: possibile pensare a un'integrazione anteriore secondo la formula $w-b s^{2 c} b h-s^{1} m M^{c} n$ : 'e per la loro tribù di Ma'īn e di Yathill'.

$M^{\mathrm{T}} \mathrm{s}^{1}$ : questo nome è attestato in Mineo come nome familiare del ben noto Basil dhu-Ma's, citato nelle iscrizioni del tempio di Nakrah. Come secondo nome è attestato anche nella stele funeraria minea YM 26687.

L.14: $\quad W d[. .$.$] : si tratta probabilmente della porzione$ iniziale di un nome proprio di persona, detentore della carica, da integrare forse con Wadād'il.

\section{B. Iscrizioni dedicatorie}

\section{Y.04.B.B.10 (fig. 5)}

Provenienza: Barāqish, Tempio B, Mi24

Collocazione: già Barāqish magazzino del Museo

Materiale: calcare

Dimensioni: altezza lettere: $c .4 \mathrm{~cm}$

Conservazione: frammentaria

Descrizione: sulla base dell'andamento del testo, si deve supporre che questa lastra fosse composta da altri due pezzi laterali mancanti. Si tratta di una tipologia di offerte alla divinità designate dal termine bht di cui si hanno vari esempi in ambito mineo, molto spesso si tratta di pezzi lapidei che si sviluppano in orizzontale, con pochi elementi decorativi.

Testo:

1. $\quad[\ldots.] s^{2} w y n s^{3} l\left[{ }^{2}[. .]\right.$.

2. $\quad[. . b](h) \operatorname{tn} k r b\left(s^{1}\right) b[r r]$

\section{Traduzione:}

1. [... . . $s^{2} w y n$ ha dedicato a [...]

2. [... la] lastra, come offerta (che) ha adempiuto. 
Note:

Il primo termine non presenta confronti in questa forma, neanche in ambito onomastico, benché si tratti con ogni probabilità della parte terminale di un nome proprio, forse familiare o di gruppo, con un'uscita in nisbe. Dopo il verbo mineo di dedica $\left(s^{3} l^{2}\right)$ doveva trovarsi il nome della divinità a cui questa offerta era destinata. Le integrazioni proposte alla linea 2 seguono un modello testuale abbastanza diffuso per questo tipo di dediche e sono coerenti con le tracce visibili (cfr. ad es. DhM 384, MȘM 4350).

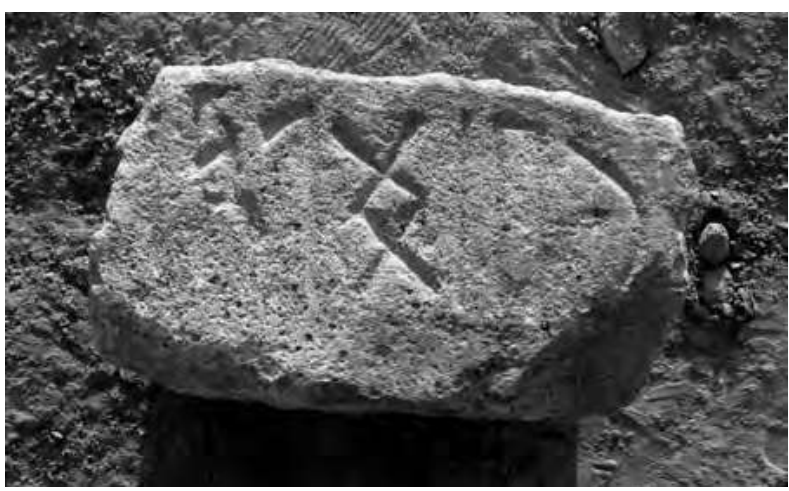

Figure 6. Y.05.B.B.8. (2005 @MAIRY)

\section{Y.05.B.B.8 (fig. 6)}

Provenienza: Barāqish, Tempio B, Li217

Collocazione: già Barāqish magazzino del Museo

Materiale: calcare

Dimensioni: altezza lettere: ND

Conservazione: frammentaria

Descrizione: piccolo frammento di un blocco calcareo, probabilmente pertinente a una muratura.

Testo:

$[\ldots] r b s^{3} l^{p}[\ldots]$

Traduzione:

[...]rb ha dedicato $[. .$.

6. Y.05.B.B.11 (fig. 7)

Provenienza: Barāqish, Tempio B, reimpiegata in Mi15 (Li10)

Collocazione: già Barāqish magazzino del Museo

Materiale: calcare

Dimensioni: altezza lettere: non disponibili

Conservazione: frammentaria

Descrizione: l'iscrizione, estremamente frammentaria. presenta alcune incertezze nell'incisione, come l'ultimo segno della linea 1 (esitante tra una $\langle\bar{c}$ e una $\langle\underline{T}\rangle$ ) e l'inizio della linea 2 , con sovra incisione di un fașel e di

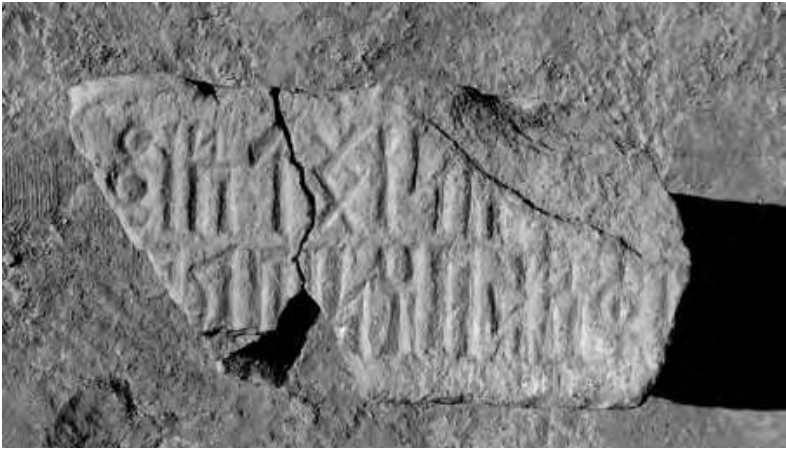

Figure 7. Y.05.B.B.11. (2005 @MAIRY)

un $\langle\mathrm{W}\rangle$. Da un punto di vista paleografico si notano gli angoli acuti particolarmente marcati della $\langle\mathrm{N}\rangle$.

Testo:

1. $\quad[\ldots] n s^{3} \pm p^{3}(t)[\ldots]$

2. $w^{-2} d b h n \pm b m[. .$.

\section{Traduzione:}

1. [...]n ha dedicato (.)[...]

2. w-'dbhn bm[...]

\section{Note:}

L.2: 'dbhn: il termine è forse da ricollegare con il sabeo ' $d b$ che indica un tipo di costruzione non ben identificato (cfr. Ja 540; Ja 541). È pure attestato come elemento onomastico. Data la frammentarietà del contesto non è possibile identificare con sicurezza la funzione del termine.

\section{Y.05.B.B.16 (fig. 8)}

Provenienza: Barāqish, Tempio B, L111 (B.05.B/58). Collocazione: già Barāqish magazzino del Museo Materiale: calcare e gesso

Dimensioni: altezza lettere: $c .4,5 \mathrm{~cm}$

Conservazione:supporto fratturato tra la linea $6 \mathrm{e} 7$, testo integro, ma la parte finale dell'iscrizione è fortemente decolorata. La lettura è basata sull'osservazione diretta al momento del ritrovamento.

Bibliografia: Agostini 2015, 11.

Descrizione: il testo è realizzato a pittura rossa. Gli elementi culturali, in primis onomastici e religiosi, insieme a quelli di tipo linguistico (forma dei prenomi suffissi e dello schema verbale causativo), permettono di ascrivere questo testo al gruppo amirita. Paleograficamente si nota come alcune linee verticali evolvano verso forme più circolari (cfr. spec. i segni $\langle B\rangle$, $\langle\mathrm{H}\rangle,\langle\mathrm{H}\rangle)$. Periodo C. I secolo a.C. - II secolo d.C. 


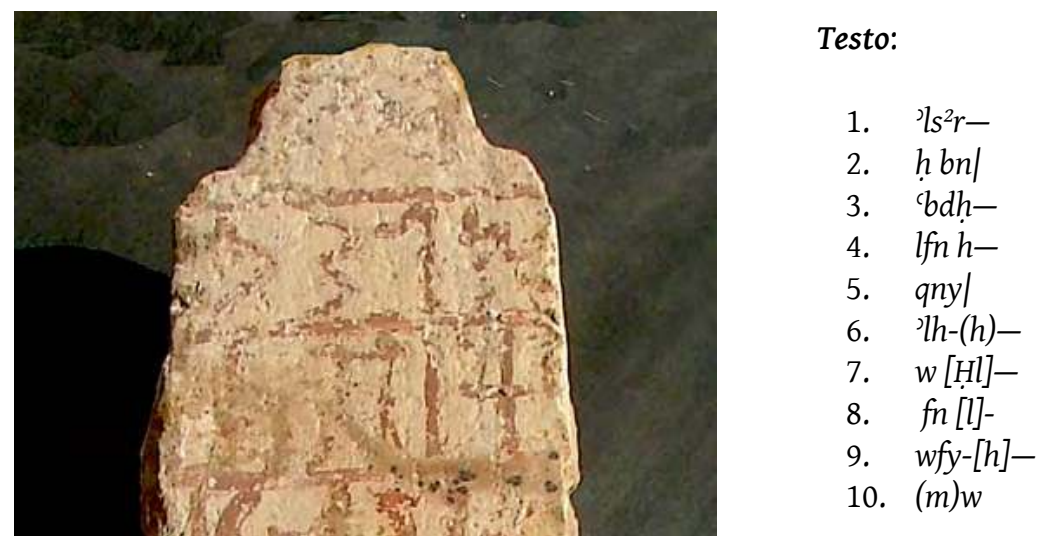

\section{Traduzione:}

1. Jlsharah,

2. figlio di

3. 'Abdha-

4. lfān,

5. ha dedicato

6. al suo dio

7. Halfān

8. Per la

9. loro

10. salvezza.

\section{Note:}

L.1-2: ' 'ls²h: questo nome proprio personale è molto diffuso, specie in ambito sabeo e qatabanico; nella $\mathrm{M}$ 185 si ha un'attestazione anche per l'ambito mineo.

L.3-4: 'bdhlfn: questo patronimico non presenta al momento confronti; il teonimo che lo compone è di chiara pertinenza amirita. Non si può escludere anche una restituzione più letterale, quindi con 'figlio del servo di Halfān'.

L.4-5: hqny: verbo di dedica allo schema causativo, di forma 'sabea' $(h-)$, in questo caso pertinente alla variante linguistica dello Amirita, anche per le considerazioni di tipo culturale e religioso che emergono da questo testo (v. sotto).

L.6-7: ' $h$ - $h w$ : il pronome suffisso di 3 maschile singolare (-hw) è di forma sabea (Amirita).

L.7-8: Hlfn: il culto del dio Halfān è specifico del gruppo degli Amîr, ed è infatti ben attestato in vari documenti provenienti dal sito di Haram, dove doveva essere presente anche un tempio a lui dedicato (tempio ' $r t t m$, cfr. Haram 8 e Haram 10). Si vedano le considerazioni di tipo storico e archeologico (capitolo 3, \$2) per le implicazioni del ritrovamento di questa dedica alla divinità amirita, anche in associazione con la dedica al dio dhu-Samāwī precedentemente rinvenuta nel tempio di Nakrah (Y.92.B.A.20).

L.8-10: l-wfy-hmw: il pronome suffisso plurale, anch'esso di forma sabeo-amirita, si riferisce probabilmente al soggetto e implicitamente anche al

Figure 8. Y.05.B.B.16. (2005 @MAIRY) suo entourage familiare. 


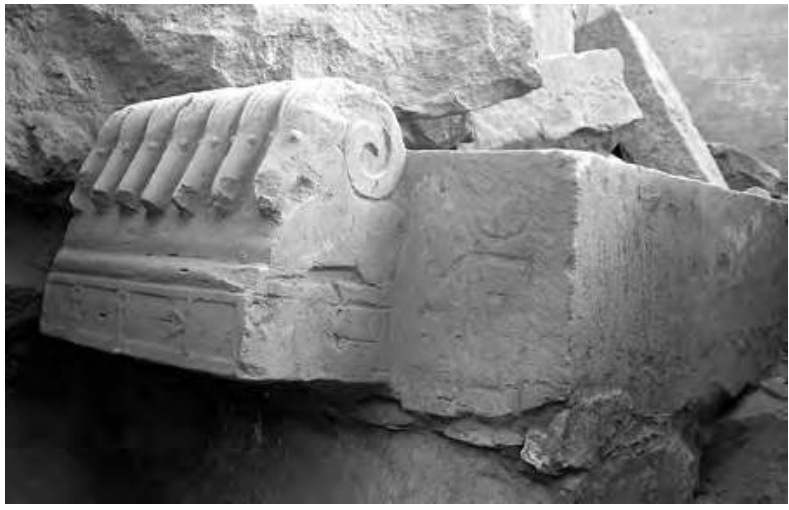

Figure 9. Y.04.B.B.11. (2004 @MAIRY)

\section{Iscrizioni relative ad arredi cultuali}

\section{Y.04.B.B.11 (fig. 9)}

Provenienza: Barāqish, Tempio B, L103 (Ta)

Collocazione: in situ

Materiale: calcare

Dimensioni: altezza lettere: $6 \mathrm{~cm}$

Conservazione: integra

Bibliografia: Agostini 2020a

Descrizione: tavola offertoria. La testa della tavola in aggetto si presenta decorata da una teoria di sette stambecchi recumbenti. Sul rientro del lato destro vi è un monogramma che possiamo sciogliere in Ġazìr ( $\dot{G} z r)$. Periodo B. V-IV secolo a.C.

\section{Testo:}

Dyt

Note:

Il termine è attestato in Mineo e in Sabeo specialmente in ambito agricolo, laddove indica il 'terreno livellato'. Lo stesso termine compare anche in una tavola offertoria del Tempio A (Y.92.B.A.40). Un termine omografo è presente anche in una iscrizione minea da Shaqab alManașșa all'interno di una lista di divinità destinatarie di una dedica (Shaqab 2); DASI lo interpreta come toponimo sulla scorta della attestazione sabea in RES 3943 che si riferisce ai due territori $(\underline{d} b h)$ di Yathill (Dyt e $S^{2} \mathrm{~mm}$ ). Sulla base del presente contesto si preferisce intenderlo come riferimento alla 'stagione della trebbiatura', cfr. anche Ar. dōs ed Eb. dayiš ('threshing season' HALOT, p. 221). Si può quindi ipotizzare un riferimento alla stagione estiva. Altri termini collegati con la stagione estiva possono essere più specializzati in ambito agricolo, per indicare determinati tipi di raccolti, ad es. $s^{1 c} s^{1 c}$, ben noto in Sabeo, ma cfr. infra Y.06.B.B.11 per la prima attestazione di questo termine anche in Mineo.

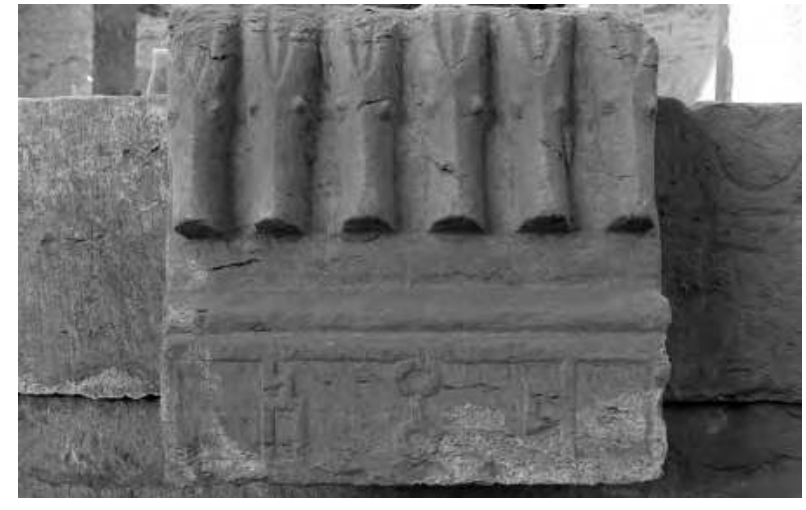

Figure 10. Y.05.B.B.1. (2005 @MAIRY)

Il nome Ġazìr, con cui possiamo sciogliere il monogramma presente a lato, è chiaramente un riferimento al nome familiare del supervisore dei lavori di costruzione del tempio, Ya'ws'il figlio di Yisma('il dhu-Ġazīr Sahfān, il quale dichiara esplicitamente di avere dedicato anche le tavole offertorie (mșrbt) nella iscrizione Y.05.B.B.13 (v. alla linea 2: $s^{3} l^{\text {' }} w$-s $s^{1}$ qny 't $t$ tr d-Qbọdm kl mșrbt qrqr bytn Qbḍ).

\section{Y.05.B.B.1 (fig. 10)}

Provenienza: Barāqish, Tempio B, L116 (Tb)

Collocazione: in situ

Materiale: calcare

Dimensioni: altezza lettere: $6 \mathrm{~cm}$

Conservazione: integra

Bibliografia: Agostini 2020a

Descrizione: tavola offertoria. La testa della tavola in aggetto si presenta decorata da una teoria di sei stambecchi. Sul rientro del lato di destra vi è un monogramma che possiamo sciogliere in Ġazir ( $\dot{G} z r)$. Periodo B. V-IV secolo a.C.

\section{Testo:}

$D \underline{t}^{3}$

Note:

Il termine è stato rinvenuto anche in una delle tavole offertorie del Tempio A (Y.92.B.A.38), la cui installazione è pure commemorata nell'iscrizione Y.90.B.A.7 insieme a quella della tavola Hrf. Il termine è frequentemente attestato nella documentazione sabea proprio in opposizione alla stagione autunnale Hrf, e può quindi riferirsi al periodo primaverile, anche sulla scorta dei confronti comparativi: Acc. daš $\bar{u}$, 'erba, primavera'; Ug. dttt ('spring grass', DULAT, p. 283); Eb. ďs' (HALOT, p. 233 e sg.); Ar. data'iyy (cfr. anche dathiathum [Plinio, Naturalis Historia, XII, 60]). Sulla presenza del monogramma per Ġazīr, cfr. Y.04.B.B.11. 


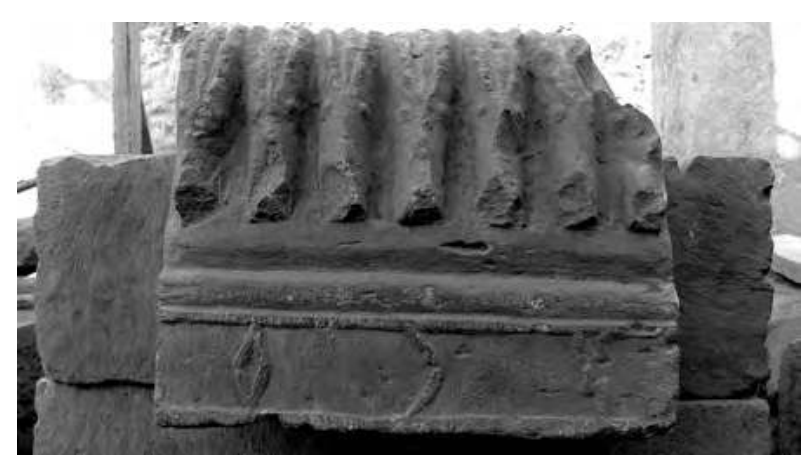

Figure 11. Y.05.B.B.9. (2005 @MAIRY)

10. Y.05.B.B.9 (fig. 11)

Provenienza: Barāqish, Tempio B, L117 (Tc)

Collocazione: in situ

Materiale: calcare

Dimensioni: altezza lettere: $6 \mathrm{~cm}$

Conservazione: integra

Bibliografia: Agostini 2020a

Descrizione: tavola offertoria. La testa della tavola in aggetto si presenta decorata da una teoria di sette stambecchi. Periodo B. V-IV secolo a.C.

\section{Testo:}

Hrf

Note:

Il termine è associato al periodo autunnale ed è stato rinvenuto anche in una tavola offertoria del Tempio A, Y.92.B.A.39, la cui installazione è commemorata nell'iscrizione Y.90.B.A.7 insieme a quella della tavola 'primavera' (cfr. sopra). Il termine è citato anche da Plinio il Vecchio come carfiathum (Plinio, Naturalis Historia, XII, 60).

\section{Y.05.B.B.10 (fig. 12)}

Provenienza: Barāqish, Tempio B, L114 (Td)

Collocazione: in situ

Materiale: calcare

Dimensioni: altezza lettere: $6 \mathrm{~cm}$

Conservazione: integra

Bibliografia: Agostini 2020a

Descrizione: tavola offertoria. La testa della tavola in aggetto si presenta decorata da una teoria di sei stambecchi. Sul rientro del lato di destra vi è un monogramma che possiamo sciogliere verosimilmente nel nome proprio Bicathtar (B'trtr). Periodo B. V-IV secolo a.c.

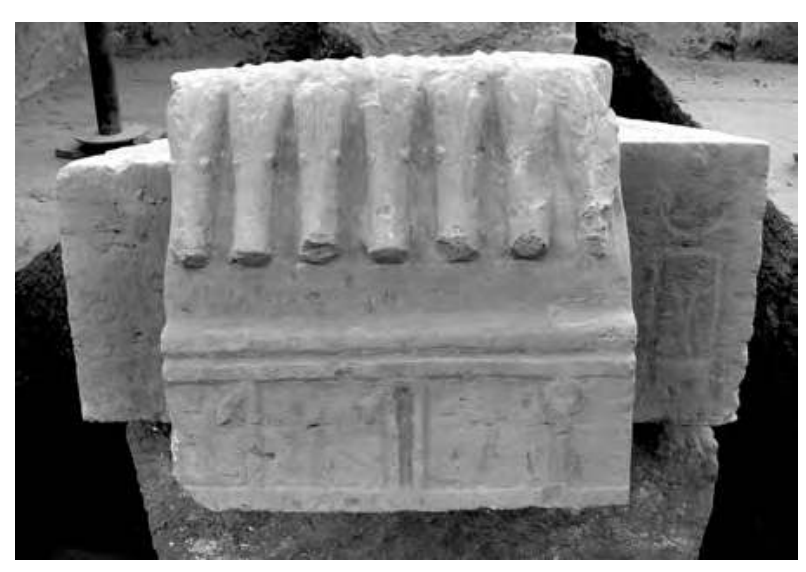

Figure 12. Y.05.B.B.10. (2005 @MAIRY)

Testo:

$Y \dot{g} l$

Note:

Il termine ricorre in tutto il Sudarabico come nome proprio di costruzione: in Mineo designa anche uno dei torrioni di Yathill (M 236). In Qatabanico il suo uso in contesto onomastico si estende all'ambito personale (ad es. secondo nome regale), oltre che in ambito religioso, come epiteto del dio 'Athtar (es. Ja 122, Ja 1096 e Ja 2195), ma è possibile che si tratti di omografi. Le attestazioni sudarabiche del termine non sembrano quindi strettamente collegate al calendario stagionale. Dal punto di vista comparativo notiamo invece che in Ugaritico yǵl indica la 'terra non coltivata' (DULAT, p. 959-960), quindi si potrebbe anche estendere a quella lasciata a riposo in determinati periodi dell'anno, come avviene nella pausa invernale. Rimane incerta una originaria connessione etimologica con la radice ${ }^{*} W G \dot{L}$ attestata in arabo: nelle fonti arabo-islamiche wägil è anche il decimo oppure ottavo mese del calendario islamico (Robin 2016c, 321; cfr. anche Robin 2017, 343-352). Per esclusione rispetto alle stagioni indicate dalle altre tavole offertorie, si può pertanto avanzare l'associazione con la 'stagione invernale'.

\section{Y.05.B.B.21 (fig. 13)}

Catalogo oggetti: B.05.B.0.38

Provenienza: Barāqish, Tempio B, L104

Collocazione: già Barāqish magazzino del Museo

Materiale: arenaria

Dimensioni: altezza lettere: $3 \mathrm{~cm}$

Conservazione: integra

Descrizione: incensiere. Periodo C. Datazione I secolo a.C.- I secolo d.C. 


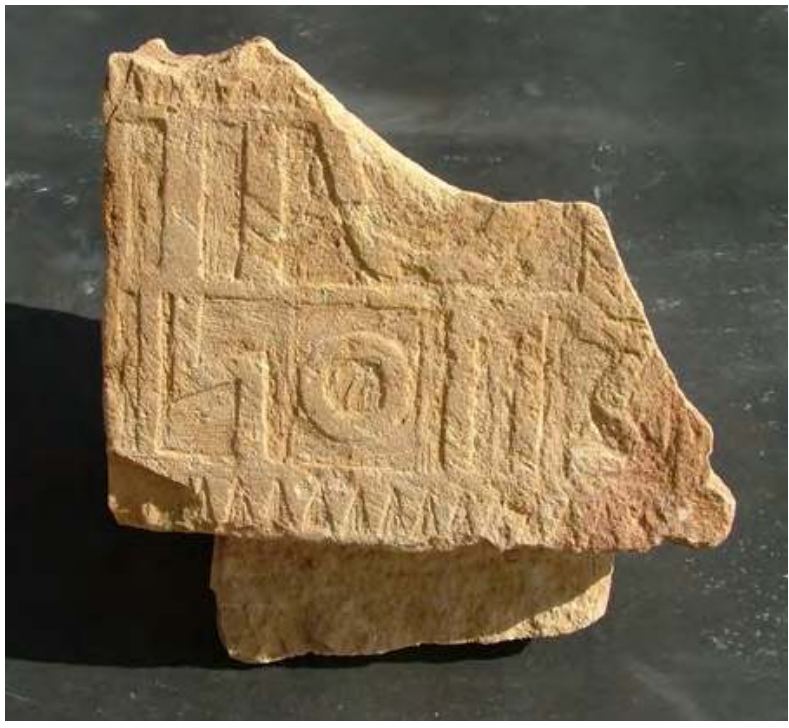

Figure 13. Y.05.B.B.21. (2005 @MAIRY)

Testo:

$S^{2} b{ }^{c} n$

Note:

Il termine nella forma con mimazione è attestato in Mineo nel ben noto altare decorato a motivi architettonici Șan ('̄a)-MM 3630, dove potrebbe indicare sia un nome proprio, sia il nome comune dell'oggetto stesso. Entrambe le possibilità potrebbero sussistere anche in questo caso, nonostante si tratti di un oggetto molto diverso, per funzione, dimensioni e decorazione. $S^{2} b^{c} n$ ricorre inoltre come nome proprio di un bacino ( $m$ 'h $\underline{d n}$ : Shaqab 18), oltre che all'interno di un elenco di tre nomi propri in Ma'īn 41, dove è pure possibile che si riferisca a una categoria di oggetti non ben identificata. Si può quindi ritenerlo un nome proprio particolarmente utilizzato per oggetti di diversa natura, specie di uso cultuale.

\section{Y.05.B.B.23 (fig. 14)}

Catalogo oggetti: Y.05.B.0.54

Provenienza: Barāqish, Tempio B, L121

Collocazione: già Barāqish magazzino del Museo

Materiale: calcare

Dimensioni: altezza lettere: c. $2 \mathrm{~cm}$

Conservazione: integra

Descrizione: incensiere. Periodo B-C. Datazione IV secolo a.C. - I secolo d.C.

Testo:

Dyt

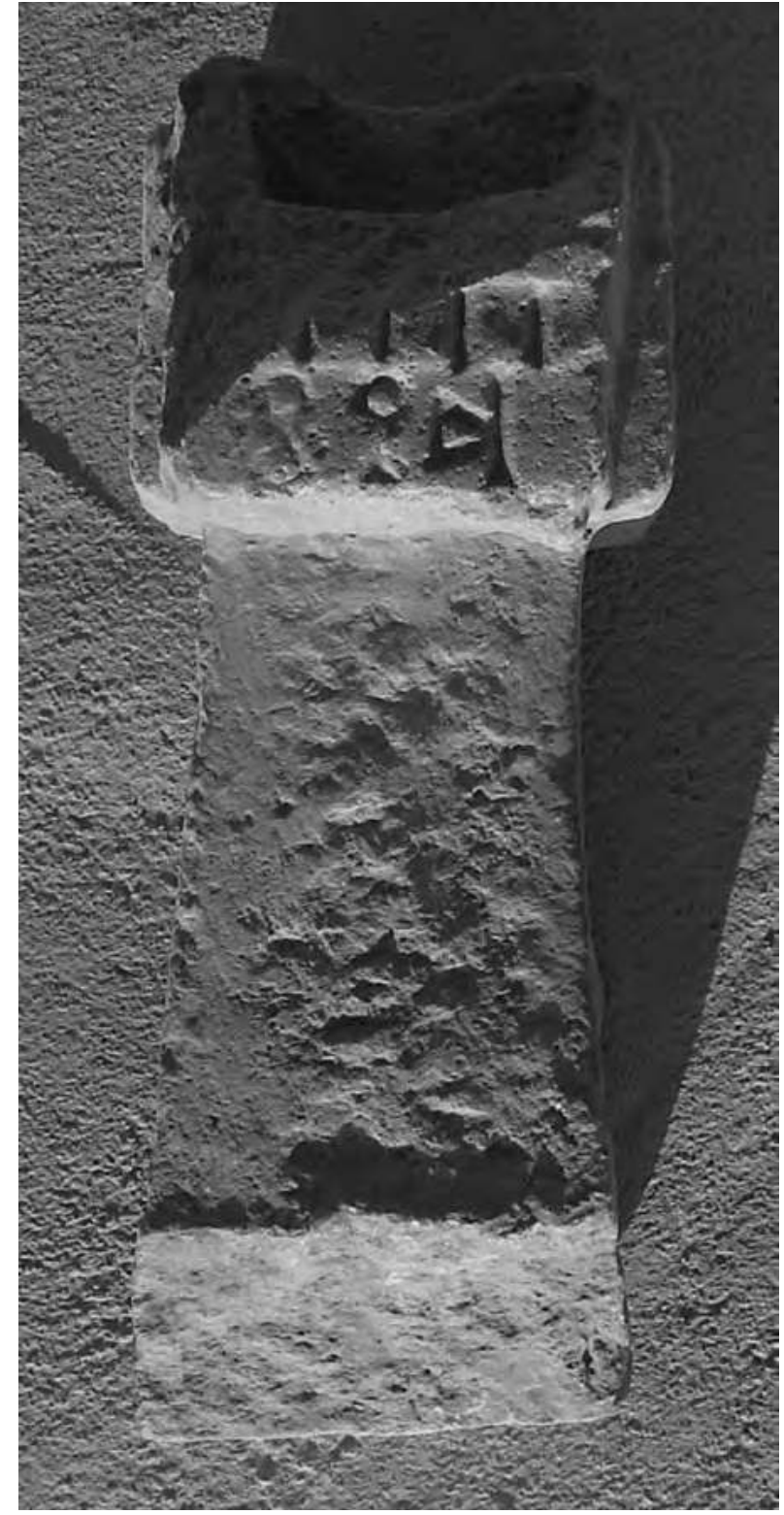

Figure 14. Y.05.B.B.23. (2005 @MAIRY)

Note:

Cfr. supra Y.04.B.B.11.

\section{Y.05.B.B.27 (fig. 15)}

Catalogo oggetti: Y.05.B.0.55

Provenienza: Barāqish, Tempio B, Li20

Collocazione: già Barāqish magazzino del Museo

Materiale: calcare

Dimensioni: altezza lettere: $c .4 \mathrm{~cm}$

Conservazione: integra

Descrizione: stele votiva. Incisione delle lettere molto profonda. Periodo C. I secolo a.C. - I secolo d.C. 


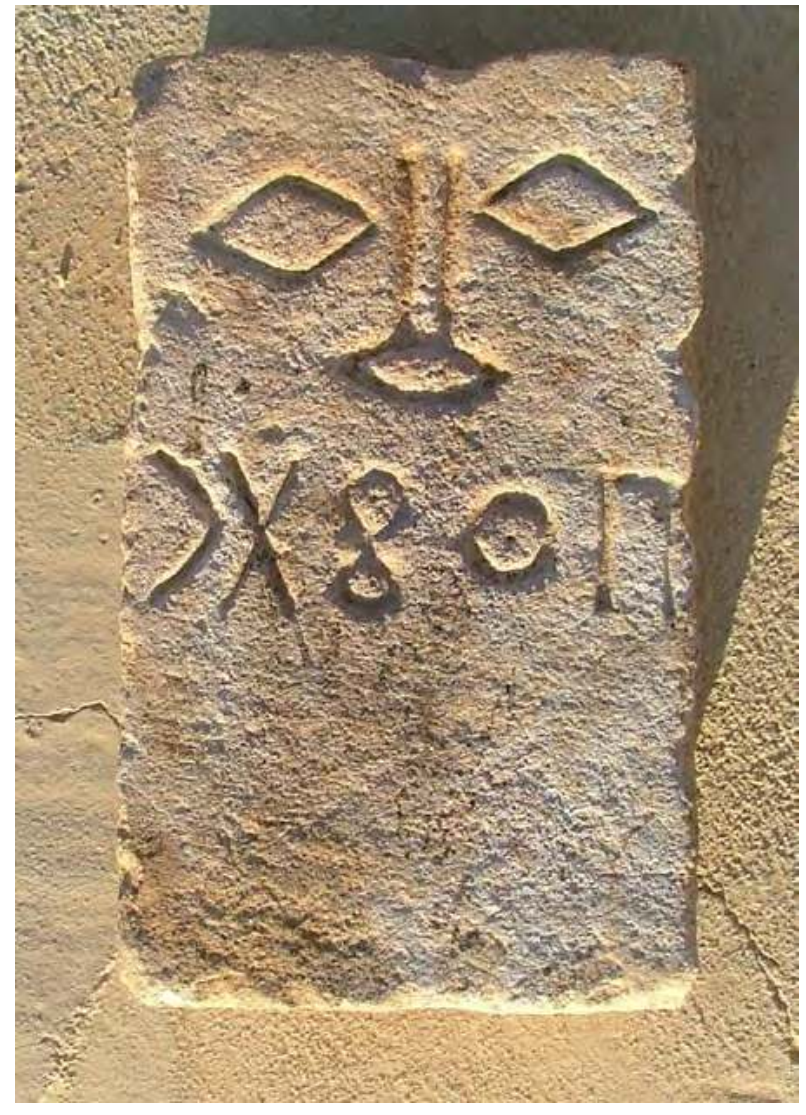

Figure 15. Y.05.B.B.27. (2005 CMAIRY)

Testo:

$B^{c} t$ tr

Note:

Il nome proprio teoforo, composto col nome divino 'Athtar, è ben attestato sia in Sabeo, sia in ambito madhabieno/mineo, pure in contesto regale. La presenza di questa stele individuale in ambito cultuale potrebbe far pensare a un uso votivo per questa classe di oggetti, quindi non necessariamente funerario. Dato il ritrovamento in livelli di epoca islamica antica, non si può tuttavia neanche escludere una deposizione secondaria in seguito alla spoliazione di un'area funeraria, possibile quindi che provenga dalla piccola necropoli extra-muros (Antonini e Agostini 2010a). Questo nome proprio è pure riconoscibile nel monogramma presente nella tavola offertoria $Y \dot{g} l$ (cf. Y.05.B.B.10)

\section{Iscrizioni legali (selezione)}

\section{Y.05.B.B.14 (fig. 16)}

Provenienza: Barāqish, Tempio B, P1, faccia nord-est Collocazione: in situ

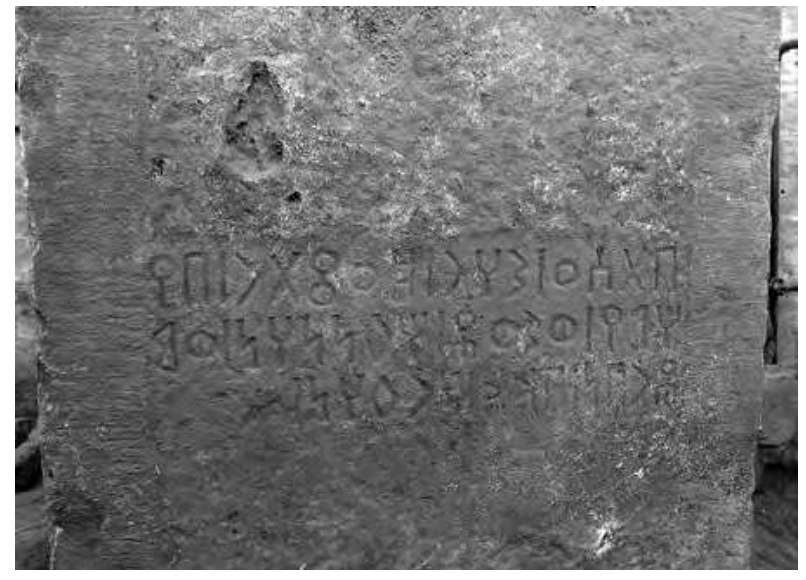

Figure 16. Y.05.B.B.14. (2005 CMAIRY)

\section{Materiale: calcare}

Dimensioni: altezza lettere: $c .3,5 \mathrm{~cm}$

Conservazione: integra

Bibliografia: Agostini 2020a

Descrizione: il testo è inciso al centro della facciata nordorientale del pilastro P1 della sala ipostila, uno dei quattro integri, e si sviluppa su tre linee regolarmente incise tra le due fasce che decorano verticalmente le estremità laterali del pilastro. Linguisticamente, si hanno pochi elementi diagnostici, soprattutto a causa della brevità del testo; la forma verbale byhly potrebbe in effetti confermare la pertinenza al settore mineo, ma vi sono alcune scelte stilistiche, sia lessicali (cfr. l'uso del termine $s^{2} h r$ per indicare il 'mese'), sia grammaticali (cfr. il plurale hrfhn), che potrebbero far pensare a un livello linguistico forse più cristallizzato o arcaicizzante, anche per ragioni cultuali. Dal punto di vista paleografico si nota una certa ampiezza degli elementi circolari delle lettere e la forma angolare della $\langle\mathrm{R}\rangle$. Si propone pertanto una datazione al I secolo a.C.- I secolo d.C.

\section{Testo:}

1. $b-t s^{1 \epsilon} s^{2} h r \underline{d}-{ }^{-} \underline{t} t r b y=$

2. hly $w-s^{2} w s$ h $f$ nnhn $w-m=$

3. șrbn bdd hrfhn

\section{Traduzione:}

1. Il 9 del mese di 'Athtar si forni-

2. scano e si preparino (?) i due oggetti-hfn e la

3. tavola offertoria, (per) la durata degli anni (a venire).

Note:

L.1: $\quad t s^{1 c}$ : prima attestazione del numerale cardinale 9 in Mineo. 
$s^{2} h r$ : in Sudarabico il termine indica il 'novilunio', quindi il primo giorno del mese. Questa accezione è nota anche in Mineo: cfr. i testi su bastoncino L 128 (Drewes e Ryckmans 2016, 88) e ATHS 52 (Maraqten 2014, 305-307). Qui è chiaramente utilizzato con l'accezione di 'mese', che è invece ben nota nel Corano e probabilmente anche nel testo mineo settentrionale da Dedān, M 356. È possibile che si tratti di una precisa scelta stilistica, per la quale si è evitato di usare il termine più comune in Sudarabico per indicare il 'mese', cioè wrh.

byhly: la costruzione dell'incompiuto col prefisso b-, ben nota in Qatabanico, presenta qualche parallelo pure in Mineo (Beeston 1962, 25). Sembra di poter ravvisare una certa prevalenza di questa costruzione verbale in contesti normativi, come in questo caso e nella Y.92.B.A.15 dal Tempio di Nakrah, quindi con una possibile sfumatura modale. La radice HLY è nota in Mineo, dove in qualità di sostantivo indica dei 'beni' (LM, p. 48), in Sabeo indica anche un tipo di 'donazione' (SD, p. 68), come forma verbale cfr. MB 2002 I-28/33 ('prendersi a cuore di').

d-'ttr: come nome di mese era finora attestato in Mineo solo in un testo su bastoncino (L 128: Drewes e Ryckmans 2016, 88), ma si veda anche la possibile integrazione alla linea 4 di Y.06.B.B.10 (qui sotto); è un mese invece ben noto nei calendari in uso a Saba' e presso gli Amīr (cfr. Robin 2017, 344, 346). Tale nome dovrebbe corrispondere al mese novembre/ dicembre (per le ragioni che hanno permesso questa identificazione, v. Agostini 2020a).

L.2: $\quad s^{2} w s:$ termine non attestato in Sudarabico in questa forma, la posizione sintattica farebbe propendere per una formazione verbale all'infinito in coppia col verbo precedente, che è coniugato all'incompiuto. Non sembra del tutto convincente un avvicinamento di questa radice debole con il termine con media reduplicata, $s^{2} s$, , presente in Sabeo con il significato 'essere effettivo, operativo' (cfr. SD, p. 135). Più efficace per il presente contesto è forse una connessione con l'arabo šws che ha il significato di 'sistemare qualcosa', 'strofinare', 'pulire', 'lavare' (Lane 1863-1893, I.4, p. 1618); cfr. anche il Lisān al-'arab (al-šawșu: al-ġaslu wa-ltanzîfu).

hfnnhn: termine determinato con terminazione duale, dalla radice HFN. Frequente in ambito onomastico, come nome comune è invece attestato raramente. Nel testo mineo Moussaieff 22, dove compare pure al duale, indica chiaramente le due appliques bronzee a forma di leone su cui è presente il testo. Nella RES 4930 da Najrān indica un tipo di offerta non ben identificato. Anche in questo caso si potrebbe pensare a un tipo di oggetto usato con funzione cultuale, ma non abbiamo alcun elemento archeologico che possa aiutare a definirne meglio la natura e l'aspetto. Da un punto di vista comparativo, la radice ${ }^{*} \mathrm{HPN}$, riscontrata in Semitico Nord-Occidentale, indica anche una misura di capacità (DNWSI, p. 395), e in arabo hafana indica il 'donare un pugno di qualche cosa', ma anche 'a piene mani’ (Biberstein-Kazimirski 1960, I, 462), similmente all'etiopico.

mșrbn: il termine indica generalmente la 'tavola offertoria' (cfr. sopra Y.05.B.B.13). In questo caso è probabile che non ci si riferisca a una delle quattro tavole offertorie in posizione fissa all'interno della sala ipostila, bensì a una tavola mobile di dimensioni più ridotte (cfr. Marion de Procé, capitolo 11, figg. 1-3 in questo volume).

L.3: $\quad b d d h r f h n: i l s e c o n d o t e r m i n e v a q u i$ interpretato con l'accezione di 'anno', in quanto il nome della stagione autunnale con la stessa radice non compare mai ampliata. La terminazione $-h n$ pone però qualche problema: una forma analoga rinvenuta in alcuni testi minei da Dedān (cfr. RES 3705 e spec. RES 3700) era stata interpretata da Beeston come un duale (Beeston 1962, 33), che tuttavia mal si accorda al presente caso, anche in virtù della chiara forma duale che compare alla linea precedente (hfnnhn); ci pare dunque più probabile una forma di plurale in stato assoluto, che potrebbe indicare una non meglio definita estensione temporale (e una forma analoga è ora attestata anche in un testo su bastoncino, L 128: Drewes e Ryckmans 2016, 88).

\section{Y.06.B.B.10 (fig. 17)}

Provenienza: Barāqish, Tempio B, L127

Collocazione: area antistante Tempio B

Materiale: calcare

Dimensioni: altezza lettere: $c$. $3,5 \mathrm{~cm}$

Conservazione: frammentaria

Descrizione: l'iscrizione presenta molti elementi di somiglianza, sia a livello grafico, sia di contenuto, con la as-Sawdā' 27. Periodo B. La grafia del testo appare certamente più evoluta della E2 e si può proporre una datazione intorno al III-II secolo a.C.

\section{Testo:}

1. [...] $\underline{d} Y \underline{t} l w^{\prime} \underline{d} n n w-m s^{3} w d \underline{d}-Y \underline{t} l w-W d d^{\prime} l \underline{d}-F^{\prime} d w-W d d^{\prime} l$ d-S $-S^{2} y d h w l[. .$.

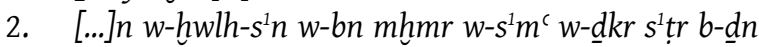
rbbn 'hly r'[...]

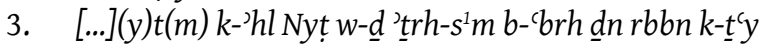
$m h m r[. .$.

4. [...] ykwn $k^{-}$'hl Nyt mnfam $w$-ms $s^{3} h l m$ wrh $s^{1} m^{c} n$ w-gzytn $\underline{d}-{ }^{c}\left[\right.$ ttr $\left.^{?} . ..\right]$

5. [... $\underline{d} n s^{1}$ trrn $w$-wf $h n w f y \mid$

\section{Traduzione:}

1. [...] di Yathill e l'autorità e l'Assemblea dhuYathill e Wadād'il dhu-Fa'd e Wadād'il dhuShayd, amministratori [...] 


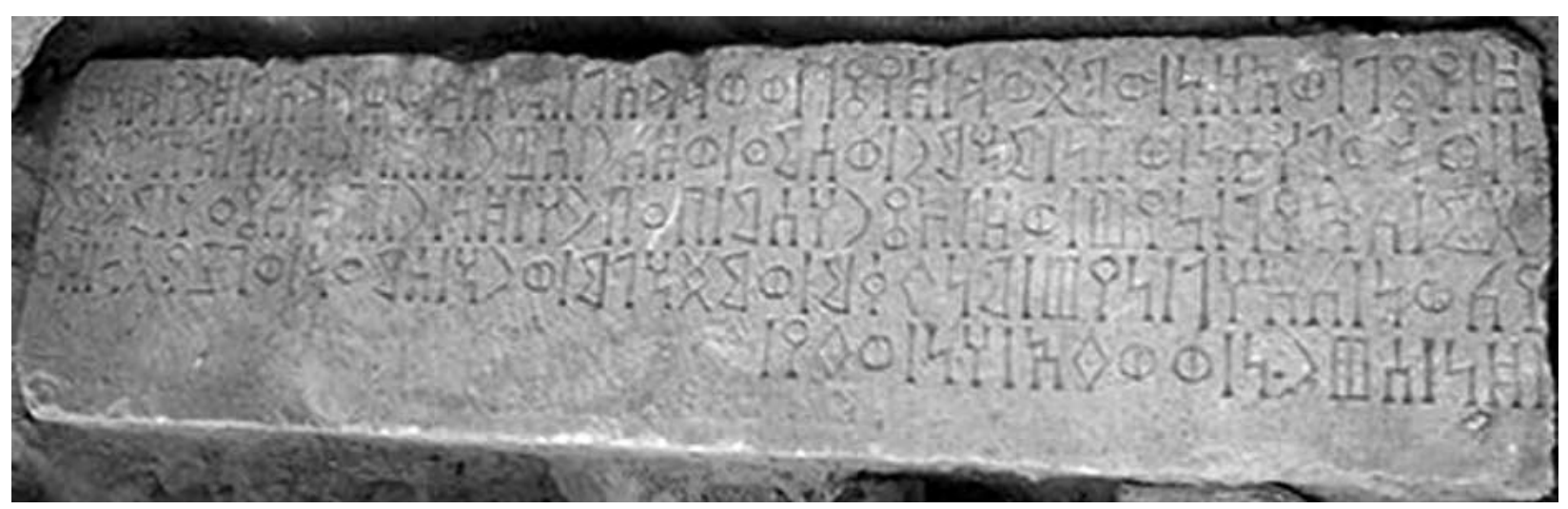

Figure 17. Y.06.B.B.10. (2006 CMAIRY)

2. .. e il loro amministratore e a partire dalla concessione, il decreto e la rendicontazione per questa raccolta (?), i beni ...

3. [...] $(y) t(m)$ per la tribù Nayt e dei loro successori nei confronti di questa raccolta, per la $t^{\zeta} y$ (?) della concessione [...]

4. [...] sia stabilito per la tribù Nayț un atto vincolante ed esecutivo. Mese dell'atto e del decreto, dhu-'A[thtar? ...]

5. [...] questo documento ed è dato quanto accordato.

Note:

L.1: huwl: il termine nei contesti in cui compare sembrerebbe indicare una particolare carica ('amministratore'); nell'unica attestazione minea (MȘM 3634) il contesto non è chiarificatore, ma sembra anche qui rimandare a un ambito legale: si può pensare a una forma di 'tutela legale', anche rivolta verso individui.

L.2: $\quad m h m r$ : attestato in Mineo settentrionale nel testo M355, dove G. Ryckmans lo considera un participio passato 'donatore'. Ricorre anche in Qatabanico sempre come termine di natura legale (ATM 866). La radice HMR è ben attestata in Sabeo, 'ottenere per cessione, favore o donazione’ (SD, p. 61).

$s^{1} m^{c}$ : 'testimonianza' (LM, p. 82): si preferisce in questo caso un'accezione più astratta piuttosto che il riferimento a una possibile carica individuale.

$\underline{d} k r s^{1} t r$ : si può intendere questa espressione come riferita a una funzione burocratica, come quella prerogativa del 'notaio', incaricato della redazione di un atto ufficiale.

rbbn: la radice compare sia in Mineo, sia in Sabeo, dove è connessa con il 'possesso', anche forzoso, di un bene, oppure come unità di misura. Avanzini traduce con 'possedimento' nel contesto similare, ma molto lacunoso, della as-Sawdā’ 27; si può anche pensare a una 'raccolta' di beni o donazioni.

L.3: Nyț: la tribù Nayt è attestata specialmente nella documentazione di as-Sawdā') (cfr. as-Sawdā' 20 e di nuovo as-Sawdā’ 27). $b$ - $b r h$ : per questa costruzione cfr. MAFRAYDarb aș-Ṣabī 30.

$t^{c} y$ : in Mineo è presente solo in uno schema nominale derivato: $m t^{t} y t$ 'libagione', che mal si accorda al presente contesto. Le altre attestazioni del termine $t^{t} y$ sono in contesti troppo lacunosi e non chiarificatori (es. M33; M310). Il termine sabeo derivato, $t t^{c} y$, è stato associato con un atto di 'diffamazione' (SD, p. 149).

L.4: $\quad m n f q m$ : termine giuridico attestato in Sabeo, col senso di un particolare documento (SD, p. 92: 'binding document' - cfr. CIH 600 e Gl 1200).

$\mathrm{ms}^{3} \mathrm{hlm}$ : termine strettamente collegato con quello precedente, la radice è attestata in Sabeo dove indica un vincolo esecutorio, cfr. $s^{3} h l$ 'legally binding, effective' (SD, p. 137-138).

$s^{1} m^{c} n$ w-gzytn: questi due termini coordinati si potrebbero intendere come un'endiadi: 'emanazione del decreto'.

\section{Y.06.B.B.11 (fig. 18)}

Provenienza: Barāqish, Tempio B, Mi457 (parte sud) Collocazione: area antistante Tempio B

Materiale: calcare

Dimensioni: altezza lettere: $c .3,8 \mathrm{~cm}$

Conservazione: frammentaria

Descrizione: grande blocco certamente pertinente a una muratura, sembra tuttavia differenziarsi per grafia a quelli relativi alle mura perimetrali del tempio. Periodo B.

\section{Testo:}

1. [...]n mlk $M^{c} n w-s^{2 c} b-s^{1} M^{c} n w-s^{2 c} b-s^{1} \underline{d}-Y \underline{t} l w-b h n y$ $m[\ldots]$

2. $[\ldots] w-s^{1 c} s^{1 c} w-s^{2} t t{ }^{\prime} t m r Y h n^{\prime} w-F l^{c} w^{-} h l Y s^{1 c}[\ldots]$

3. [...]ym w-thfm 'tr hn y'ly $\underline{d} r^{\prime} w b l w-m^{2} d-s^{1} m n w[. .$.

4. [...]n $\underline{d}-y k w n k$-tmr $b-{ }^{(} b r-s^{1} w$ mwd $d^{\top} w-r z^{3} w-l y s^{12} t w$ (m) $[\ldots]$

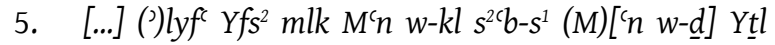
$w$-bh[ny ...] 


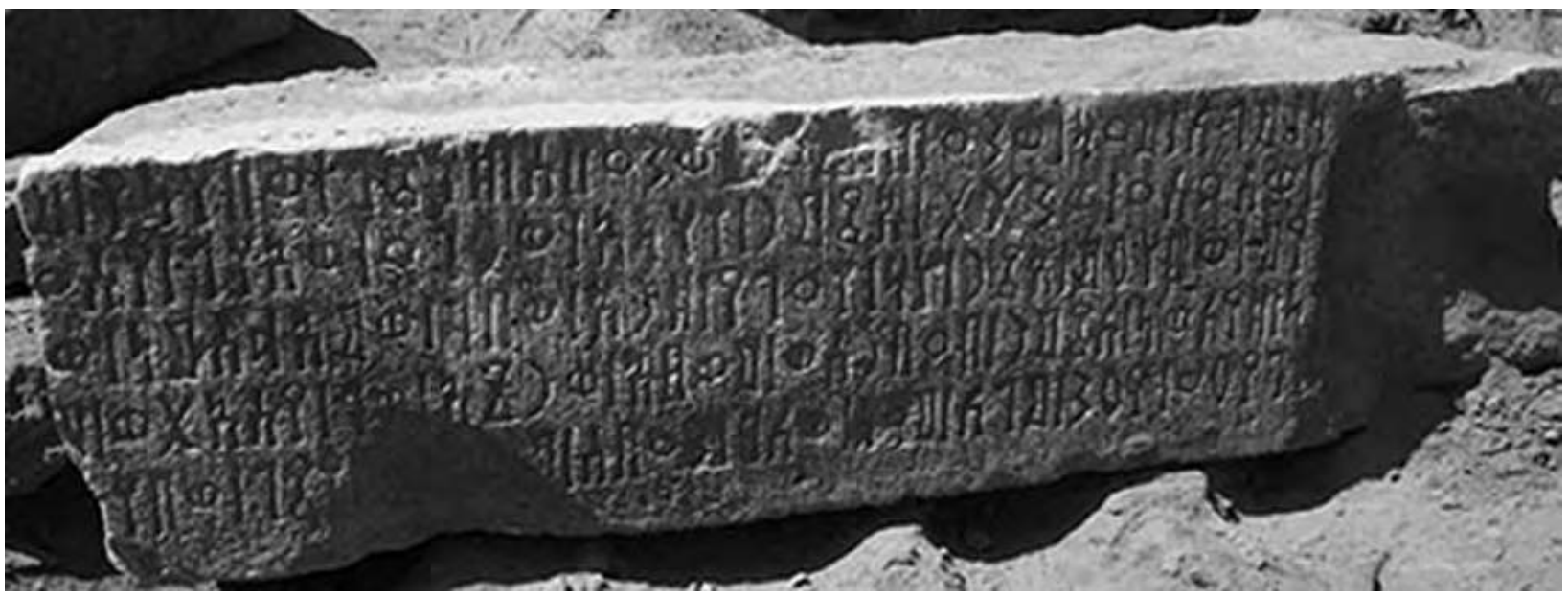

Figure 18. Y.06.B.B.11. (2006 CMAIRY)

\section{Traduzione:}

1. [...]n re di Ma'īn e la tribù di Ma'īn e la sua tribù dhu-Yathill e i figli M[...]

2. [...] e (il raccolto) estivo e oltre ai raccolti di Yhn' e Fl' $^{\mathrm{c}}$ e la tribù $\mathrm{Ys}^{1 \mathrm{c}}[. .$.

3. [...]ym w-thfm, dopo di che si aumenti la semina (sottoposta a) tassazione e in aggiunta a queste due cose $[. .$.

4. [...] che ci siano per il raccolto, a suo carico, imposte e spese, e che si arrivi a produrre [...]

5. [...] Ilyafa' Yafash re di Ma'īn e tutta la sua tribù $\mathrm{Ma}$ ['in e dhu-] Yathill e i fi[gli ...]

Note:

L.2: $\quad s^{1 c} s^{1 c}$ : termine finora non attestato in Mineo; in Sabeo compare con mimazione e indica la stagione estiva. Possibile che ci si riferisca a una particolare categoria di raccolto estivo. L'estate è indicata nelle tavole offertorie di questo tempio dal termine Dyt (cfr. sopra, Y.04.B.B.11 e Y.05.B.B.23).

$s^{2} t t$ : cfr. $s^{2} t y$ in YM10886 da Kamna, che Robin traduce in maniera ipotetica con 'invece di', senza escludere una possibile resa con un avverbio di tempo 'prima, dopo', che pure potrebbe adattarsi anche a questo contesto (Robin 2002, 200). Dal punto di vista grammaticale, potrebbe essere uno stato costrutto col termine che segue, formalmente un collettivo/plurale (possibilmente di genere femminile).

L.4: $\quad$ mwdיd': cfr. mwd'th in as-Sawdā'39.

rz': cfr. as-Sawdā'28.

$y s^{13} t w$ : verbo in costruzione iussiva e allo schema causativo dalla radice ${ }^{\mathrm{T}} \mathrm{TW} / \mathrm{Y}$ ben attestata anche in ambito agricolo (cfr. anche SD, p. 9).

L.5: $\quad$ 'lyf $f^{c} Y f^{2}{ }^{2}$ mlk $M^{c} n$ : un re con questo nome ed epiteto è citato nella M 18 da Haram, come coreggente di Huffan Șadīq, e nella M 205 da Barāqish, entrambe molto frammentarie. Kitchen lo colloca poco prima di Abìyada' Yatha' (Kitchen 1994, 51-56), ma in realtà finora mancano elementi certi anche per una sua collocazione relativa all'interno della successione dei Re di Ma'in. Il confronto paleografico tra queste attestazioni è impedito dall'assenza di immagini per M 18 e M 205. Un sovrano omonimo è citato adesso anche nella Y.04.B.T45.1, rinvenuta durante le indagini che hanno interessato le mura, la quale in effetti presenta alcune diversità di stile grafico con la presente iscrizione (cfr. Agostini, capitolo 9, in questo volume). Si tenga tuttavia presente che la diversa tipologia testuale (legale questo, probabilmente dedicatorio Y.04.B.T45.1), potrebbe spiegare questa diversità formale.

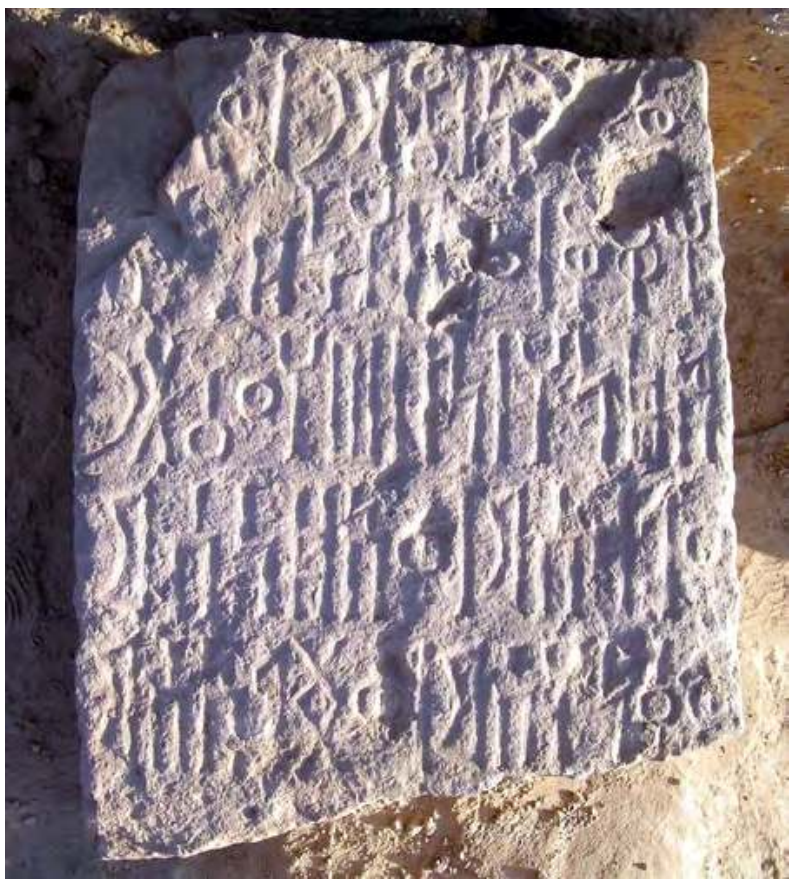

Figure 19. Y.04.B.B.2.bis. (2004 @MAIRY) 


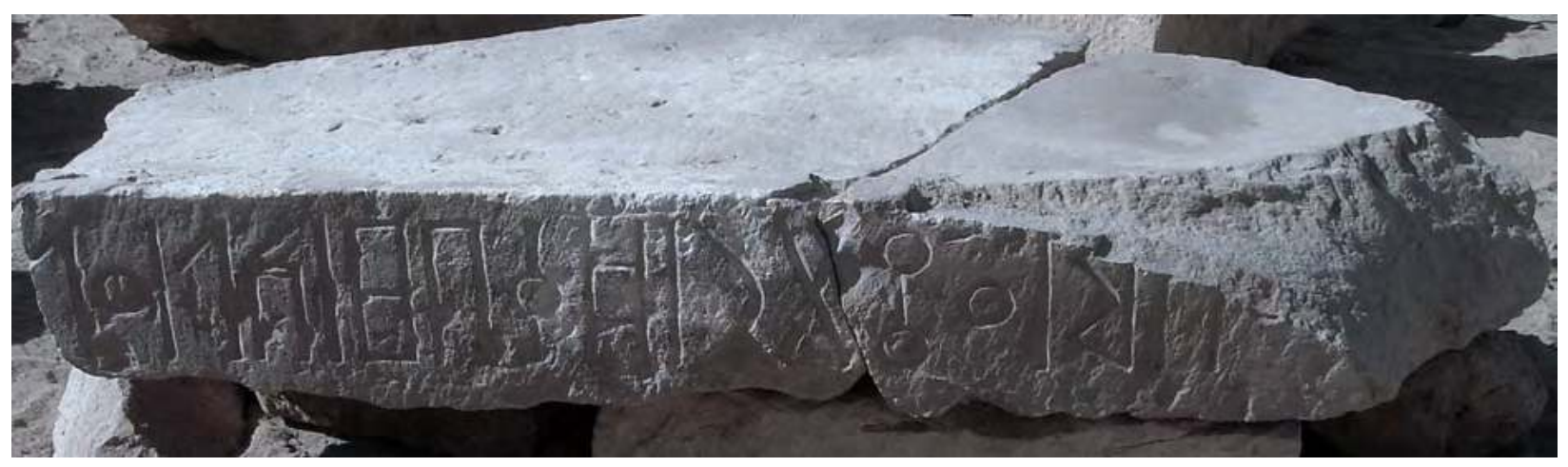

Figure 20. Y.05.B.B.3+18. (2005 CMAIRY)

\section{E. Iscrizioni frammentarie e di natura indeterminata}

\section{Y.04.B.B.2.bis (fig. 19)}

Provenienza: Barāqish, Tempio B, fuori contesto Collocazione: già Barāqish magazzino del Museo Materiale: calcare

Dimensioni: altezza lettere: non disponibili Conservazione: frammentaria

Descrizione: concio di forma squadrata originariamente inserito in una muratura monumentale non identificata. È probabile che l'iscrizione dovesse estendersi sui blocchi contigui della parete. Il testo presenta alcune incertezze di scrittura, cfr. spec. alla linea 2. Le lettere si presentano di forma allungata. Periodo B.

\section{Testo:}

1. $\quad w[] r n t m r w-.(t)[\ldots]$

2. hyw $((h w w)) w-b-h n[. .$.

3. 'dnh Nbth't trtr

4. $w$ ld $-s^{1} m w^{-} d \underline{d} n-s^{1} m$

5. $w$-qnh-s $s^{1} m-s^{3} l^{2}-s^{1} m$

\section{Traduzione:}

1. $[. .$.$] ... il raccolto ... [...]$

2. [...] (?) e poiché $[\ldots]$

3. [...] l'autorità di Nbth'thtrtr $[. .$.

4. [...] i loro figli e la loro autorità $[. .$.

5. [...] e le loro proprietà e la loro dedica.

\section{Note:}

L.2: hyw: non è chiara quale fosse l'intenzione dello scriba nella correzione apportata alle ultime due lettere della parola, e se quindi ci si volesse rifarsi a una radice HYW (in tal caso anche come possibile elemento onomastico), a HWW, oppure alla radice HWY.

L.3: Nbth'ttr: sulla base del contesto si ritiene il termine un nome proprio personale, ma non risulta avere confronti in ambito sudarabico. Si notino la presenza dell'elemento suffissale $\mathrm{H}$ e del teonimo 'Athtar non abbreviato, come avviene invece di frequente nelle composizioni onomastiche con questo nome di divinità $(-\underline{t} t)$.

\section{Y.05.B.B.3 + Y.05.B.B.18 (fig. 20)}

Provenienza: Barāqish, Tempio B, Mi73 + Mi42 Collocazione: terrazza a est del Tempio A Materiale: calcare

Dimensioni: altezza lettere: $c .7 \mathrm{~cm}$

Conservazione: frammentaria

Descrizione: porzione di tavola offertoria mobile in due frammenti, con iscrizione incisa su uno dei lati lunghi. Periodo B. VI-V secolo a.C.

Testo:

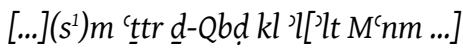

Note:

Con ogni probabilità si tratta di una porzione di un'iscrizione dedicatoria, di cui sono rimaste solo le invocazioni rivolte a 'Athtar dhu-Qabd e a tutte le divinità di Ma'īn.

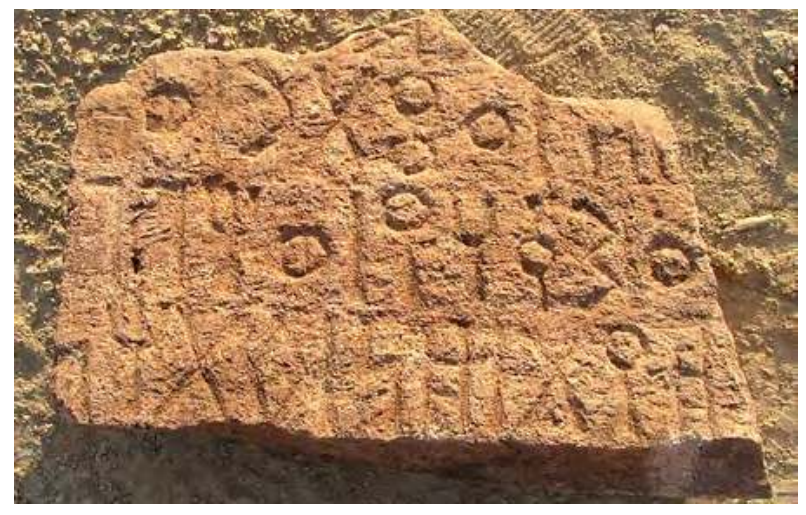

Figure 21. Y.05.B.B.17. (2005 CMAIRY) 


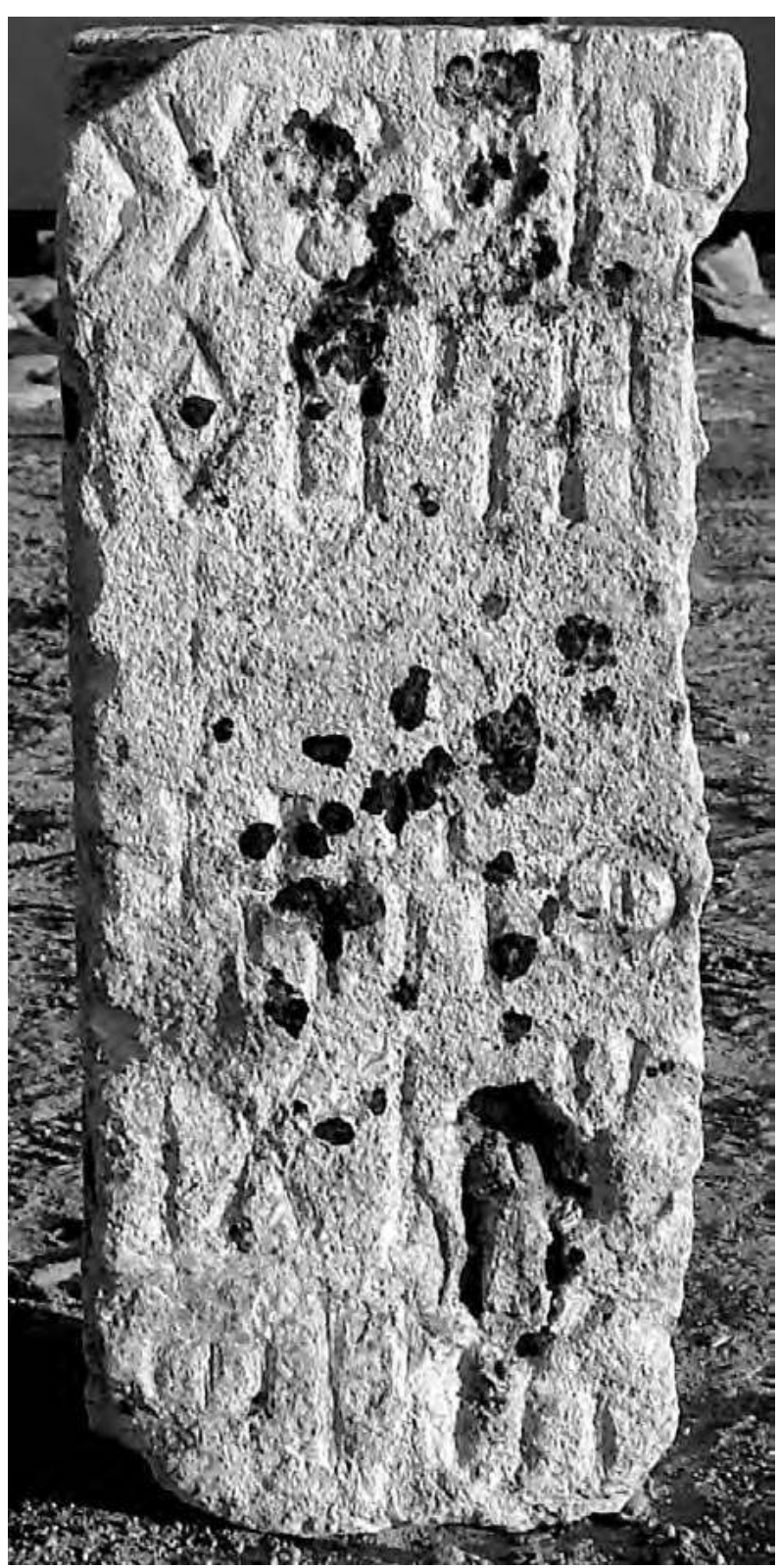

Figure 22. Y.05.B.B.19. (2005 CMAIRY)

20. Y.05.B.B.17 (fig. 21)

Provenienza: Barāqish, Tempio B, Mi73

Collocazione: già Barāqish magazzino del Museo Materiale: arenaria

Dimensioni: altezza lettere: non disponibili Conservazione: frammentaria

Testo:
1. $[\ldots](\ldots)[\ldots]$
2. $\quad[\ldots](..) \operatorname{tatr} w\left(s^{1}\right)[\ldots]$
3. [.]' $s^{2} q h y w-h b(b)[\ldots]$
4. [...] $d y t \underline{d} n f t h(n)[. .$.

Note:

La presenza del termine fth alla linea 4 farebbe propendere per un contesto di tipo legale, ma la frammentarietà del testo non permette ulteriori interpretazioni.

\section{Y.05.B.B.19 (fig. 22)}

Provenienza: Barāqish, Tempio B, Mi42

Collocazione: già Barāqish magazzino del Museo

Materiale: calcare

Dimensioni: altezza lettere: non disponibili

Conservazione: frammentaria

Descrizione: tra la linea 2 e la 3 è presente una fascia libera da incisione epigrafica. Potrebbe trattarsi di una intenzionale separazione tra due testi distinti, ma le dimensioni ridotte del frammento non consentono di risolvere la questione.

\section{Testo:}

1. $\quad[. .]. h \mathrm{c} t \operatorname{tr}[. .$.

2. $[\ldots .] d-.N(d) f[\ldots]$

3. $[\ldots ..] w^{-} s^{1}[\ldots]$

4. $[\ldots](h)[].(l) t[\ldots]$

5. $[\ldots](k) . . w[. .$.

\section{Note:}

L.2: $\quad$-Ndf: come nome di famiglia è attestato in asSawdā’ 40 A; Haram 42 e YM 28980.

\section{Y.05.B.B.26 (fig. 23)}

Provenienza: Barāqish, Tempio B, Mi42

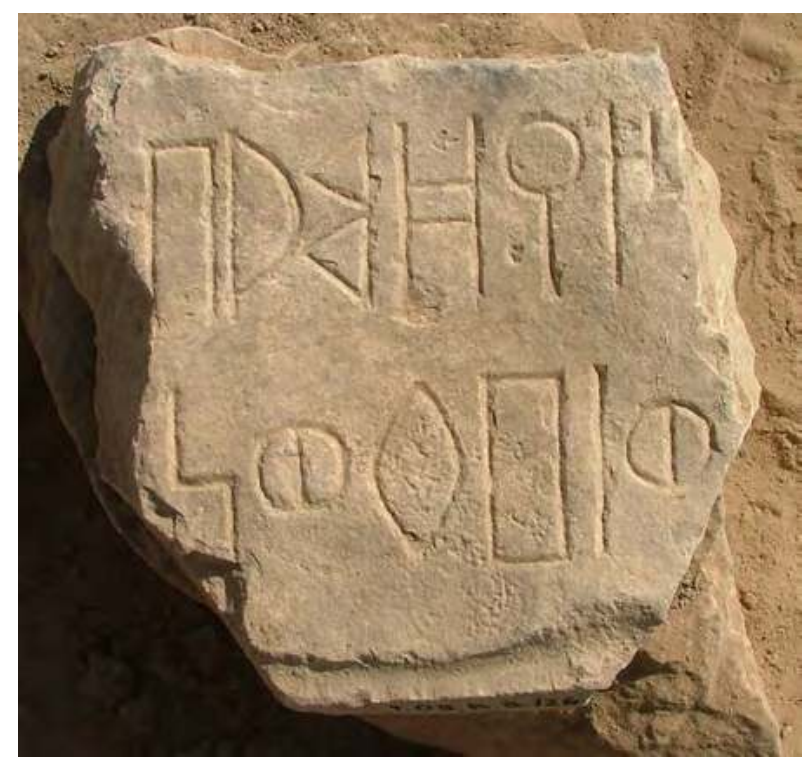

Figure 23. Y.05.B.B.26. (2005 @MAIRY) 
Collocazione: già Barāqish magazzino del Museo Materiale: calcare

Dimensioni: altezza lettere: $c .6 \mathrm{~cm}$

Conservazione: frammentaria

Descrizione: la grafia è di tipo arcaico, ma non vi sono sufficienti elementi grammaticali superstiti per individuare la lingua sabea, che potrebbe essere plausibile proprio su base paleografica. Particolarmente interessante la forma del segno $\langle\mathrm{D}\rangle$. Periodo A. Stile grafico A2. VIII-VII secolo a.C.?

\section{Testo:}

1. [...]. $y \underline{d} m r b[\ldots]$

2. [...]w dfwn [...]

\section{Note:}

L.1: $\quad y \underline{d} m r$ : la radice DMR è attestata in contesto giuridico sia in Mineo, sia in Sabeo, con l'accezione di 'intentare un'azione giudiziaria nei confronti di qualcuno' (LM e SD, s.v.).

L.2: dfwn: la radice DFW nei contesti minei sembra essere collegata ai concetti di 'abbondanza' e 'pienezza' (LM, p. 30); in Sabeo, la forma verbale derivata si specializza nel senso di 'inondare'.

\section{Y.06.B.B.4 (fig. 24)}

Provenienza: Barāqish, Tempio B, Mi410

Collocazione: già Barāqish magazzino del Museo

Materiale: calcare

Dimensioni: altezza lettere: non disponibili

Conservazione: frammentaria

Descrizione: blocco di altezza ridotta, possibile una sua pertinenza a una struttura muraria.

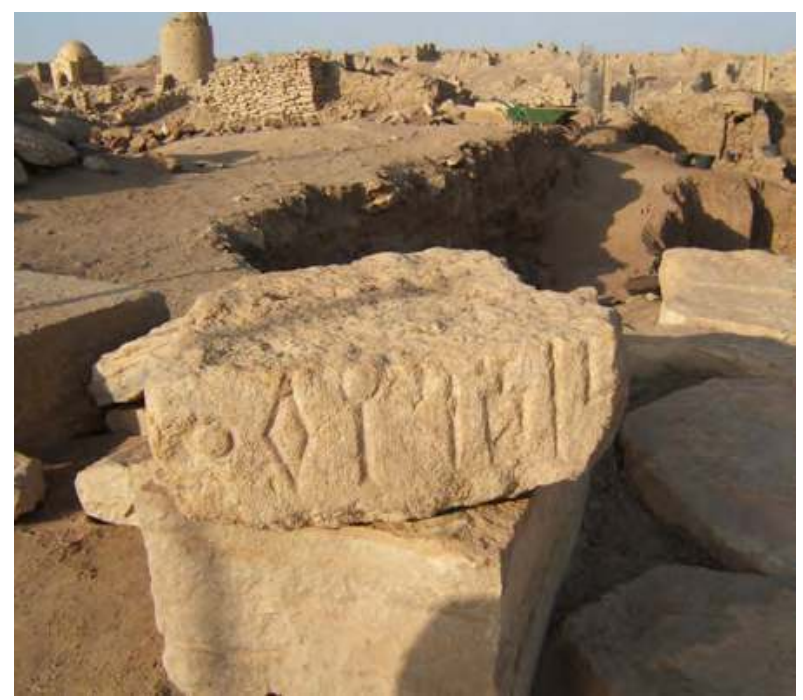

Figure 24. Y.06.B.B.4. (2006 CMAIRY)

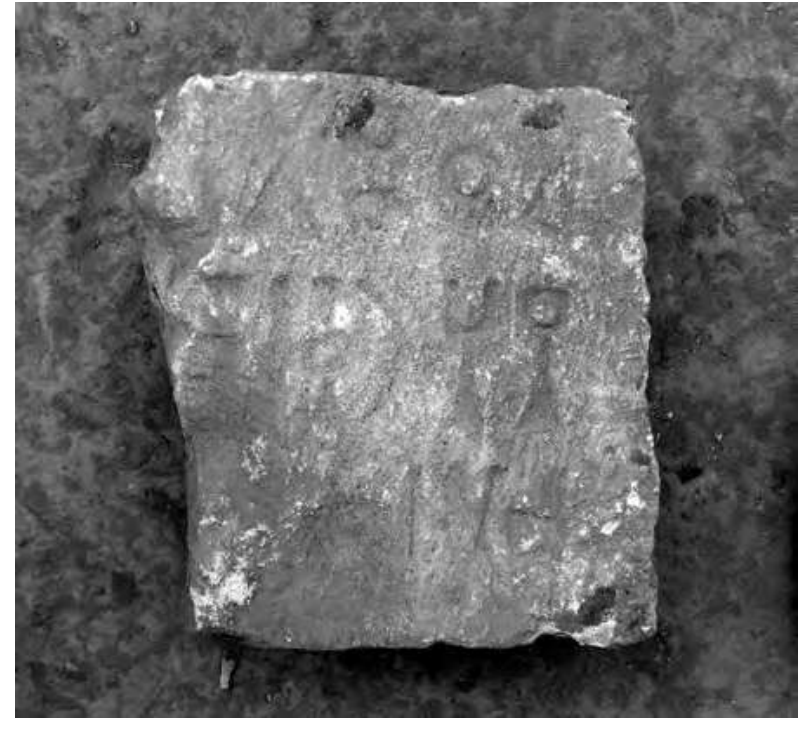

Figure 25. Y.06.B.B.7. (2006 CMAIRY)

Testo:

\section{$[\ldots .$.$] n \operatorname{lyf}[[. .]$.}

Note:

Il nome Ilyafa' è quasi esclusivo dell'onomastica regale minea (cfr. sopra, Y.06.B.B.11, e Kitchen 1994, 58), ed è quindi probabile che anche in questo caso ci si riferisca a un sovrano, il contesto assai mutilo induce tuttavia a una certa cautela. In ogni caso, l'assenza di epiteto e di titolatura non consente di proporre ipotesi integrative o identificazioni. Periodo B. V secolo a.C.

\section{Y.06.B.B.7 (fig. 25)}

Provenienza: Barāqish, Tempio B, Mi490

Collocazione: già Barāqish magazzino del Museo

Materiale: calcare

Dimensioni: altezza lettere: $c .4 \mathrm{~cm}$

Conservazione: frammentaria

Descrizione: dato il contesto estremamente limitato si considerino le integrazioni proposte come estremamente ipotetiche. Ė possibile che si tratti di un frammento pertinente a un'iscrizione dedicatoria.

\section{Testo:}

1. $\quad[\ldots H] m^{c} t t[\ldots]$

2. $\quad[\ldots . . t \operatorname{tg} \underline{d}]-Y h r q().[\ldots r t]-$

3. $d t^{c} t[t r . .$.

Note:

L.1: $\quad H] m^{\prime} t \underline{t}$ : l'integrazione è piuttosto plausibile sulla base della terminazione presente. 


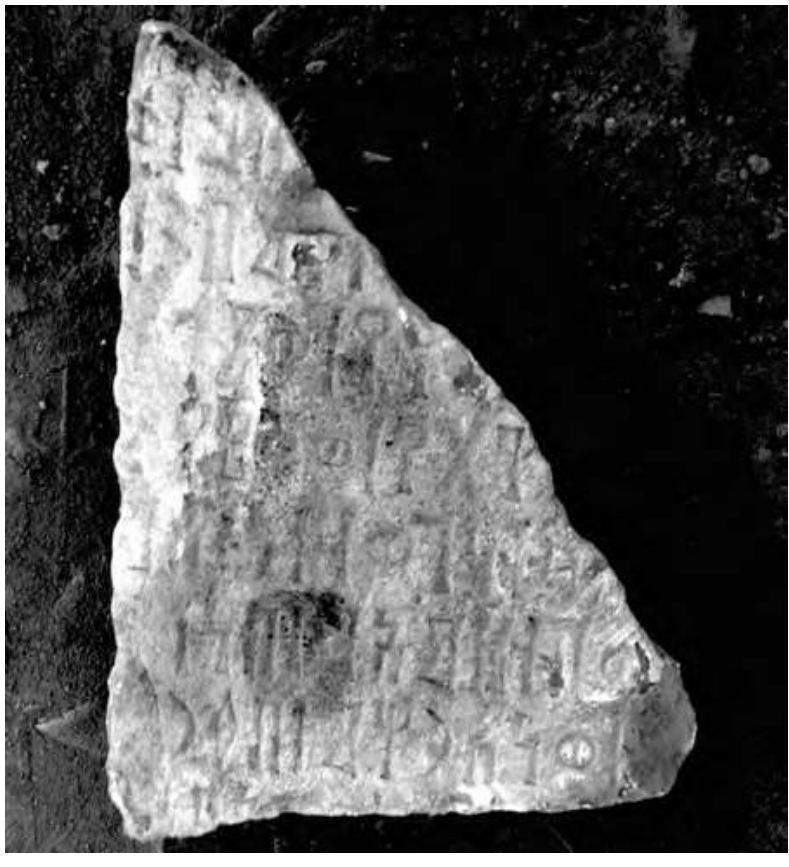

Figure 26. Y.06.B.B.8. (2006 @MAIRY)

L.2: L'integrazione del termine rțdt è estremamente ipotetica.

\section{Y.06.B.B.8 (fig. 26)}

Provenienza: Barāqish, Tempio B, Mi457 Collocazione: già Barāqish magazzino del Museo Materiale: calcare

Dimensioni: altezza lettere: $c .2,5 \mathrm{~cm}$

Conservazione: frammentaria

Descrizione: frammento di una lastra iscritta, di cui si conserva solo lo spigolo in basso a destra. Grafia piccola e compatta. Periodo B. III-II secolo a.C.

Testo:
$[\ldots \ldots .$.
1. $\quad[. .] m.().[. .$.
2. $[\ldots] \mathrm{mbs}^{2}[. .$.
3. $[\ldots](h) y w-(z) l[t . .$.
4. [...]hty $w-(c) d(h)[\ldots]$
5. [...]d $n g w(\underline{d}) n s^{1} t \underline{r}[n \ldots]$
6. $\quad[\ldots] w-(b) d-m^{\prime}(d) b n\left[y d h-s^{1} . ..\right]$
7. [...] $w-N k r h m b-f r\left[{ }^{\circ} f^{c}{ }^{c} \ldots.\right]$
8. $[\ldots \ldots . .$.

\section{Traduzione:}

$$
\begin{aligned}
& {[\ldots \ldots]} \\
& \text { 1. }[\ldots . . . .[\ldots] \\
& \text { 2. }[\ldots] \text { ?... [..] } \\
& \text { 3. }[\ldots] \ldots \ldots[\ldots] \\
& \text { 4. [...].. e il legno (di) [...] } \\
& \text { 5. [...]. ha notificato questa iscrizi[one ...] } \\
& \text { 6. [...] e con quello che ha aggiunto dalle (sue? } \\
& \text { mani) [...] } \\
& \text { 7. [...] e Nakrah }{ }^{u m} \text { con le primi[zie offerte ...] } \\
& \text { 8. }[\ldots . . . .]
\end{aligned}
$$

\section{Note:}

L.2: $\quad m b s^{2}[. .$.$] : si potrebbe pensare a un'integrazione$ con $m b s^{2} r t$ 'tipo di installazione', sulla scorta del Qatabanico (cfr. Lahj n. 61).

L.4: [...]hty: sono possibili due integrazioni, una con il termine mdbhty 'altari sacrificali', oppure, meno verosimilmente, con șrhty 'vestiboli', ipotizzando in entrambi i casi uno stato costrutto duale.

L.5: $\quad n g w d n s^{1} t r n:$ costruzione abbastanza ricorrente, cfr. Al-Jawf 04.28, M 236, Ma'īn 44, YM 28981.

L.6: $\quad w-b \underline{d}-m^{\prime} d$ bn $y d h-s^{1}$ : si tratta di una frase già nota dalle iscrizioni minee, cfr. M 197, M 406, Ma'īn 1; data la frammentarietà non è possibile stabilire il numero dei soggetti coinvolti.

\section{Abbreviazioni:}

DASI: Digital Archive for the Study of pre-Islamic Arabian Inscriptions: www.dasi.cnr.it

DNWSI: Dictionary of North-West Semitic Inscriptions (Hoftijzer e Jongeling 1995)

DULAT: Dictionary of Ugaritic Language in the Alphabetic Tradition I-II (Del Olmo Lete e Sanmartín 2003)

HALOT: Hebrew and Aramaic Lexicon of the Old Testament (Köhler e Baumgartner 1994-2000)

SD: Sabaic Dictionary (Beeston et al. 1982)

LM: Lexique Madhabien (Arbach 1993)

SW: Sabäisches Wörterbuch (http://sabaweb.uni-jena. de/sabaweb) 


\title{
Chapter 5 \\ Il tempio di 'Athtar dhu-Qabd. Gli oggetti
}

\author{
Sabina Antonini
}

Durante le campagne archeologiche del 2004/2005, 2005/2006 e 2006/2007 condotte nel tempio di 'Athtar dhu-Qabd e nell'area compresa tra questo e il tempio di Nakrah, è stato trovato abbondante materiale relativo alle diverse fasi di occupazione islamica dell'area. I reperti, che sono di diversa origine e natura - legno, carta, pergamena, vetro, metallo, cuoio e ceramica -, non vengono qui presentati, poiché meritano uno studio appropriato, per il quale si rinvia a futura e specifica pubblicazione.

In questa sede presentiamo esclusivamente gli oggetti sudarabici, alcuni dei quali sono stati trovati in contesti di epoca islamica, e altri in contesti relativi all'ultima fase di occupazione pre-islamica, ma tutti, naturalmente non in situ. Fanno eccezione le quattro lunghe e pesanti tavole per libazioni della sala ipostila, decorate su un lato corto da una teoria di stambecchi recumbenti scolpiti ad alto rilievo, che si trovano in posto all'interno del tempio - Ta in L103, Tb in L116, Tc in L117, Td in L114 -, due per ciascun ambiente laterale, tra i pilastri della sala ipostila, e perpendicolari al corridoio centrale (L115) (v. Agostini, capitolo 3, fig. 3 in questo volume).

Tra i materiali minei che componevano l'arredo cultuale del tempio, annoveriamo i gocciolatoi terminanti a testa taurina, che dovevano far parte sia di doccioni di gronde (B.05.B.O/31), sia di tavole sacrificali (B.05.B.O/32; B.05.B.O/33, B.05.B.0/34, B.05.B.O/41). Come doccioni di gronde in origine erano inseriti nella struttura di coronamento e della copertura dell'edificio templare.

Dal punto di vista iconografico, queste sculture di toro rientrano nella tipologia delle più antiche rappresentazioni sudarabiche di tori (VIII-VII secolo a.C.), in cui vi riconosciamo uno stile semplificato e geometrico. Nelle statue taurine a tutto tondo, come anche nelle tavole sacrificali del periodo formativo, le caratteristiche formali sono: testa compatta e cilindrica, muso con base piatta e occhi a bottone; le corna sono piccole e coniche, e le orecchie sono rappresentate con due protuberanze rotonde, dietro e in linea con le corna.
Tuttavia, dal punto di vista propriamente stilistico, queste sculture da Barāqish appaiono da una parte meno schematiche delle opere del periodo formativo, ma dall'altra non del tutto realistiche come le opere prodotte nel III d.C., quando tutte le caratteristiche dominanti di questo animale vengono estremamente enfatizzate: la testa si restringe in corrispondenza del muso, dove sono marcate le narici sormontate da due o tre plastiche pieghe di pelle; i grandi occhi sono contornati da spesse palpebre e pieghe di pelle a rilievo; sulla fronte viene rappresentata la peluria in forma triangolare, e, infine, in alcune opere sono incise le lunghe ciglia degli occhi dell'animale.

Le teste taurine da Barāqish, dunque, si collocano nella fase intermedia tra quella formativa e la fase più recente. In definitiva, considerando il periodo compreso tra la costruzione del tempio di 'Athtar dhu-Qabd, e il suo abbandono, potremmo datare in particolare: l'opera B.05.B.O/41 al V-IV secolo a.C., poiché conserva tratti arcaicizzanti; le opere B.05.B.O/32 e B.05.B.O/34, che hanno lo stesso stile scultoreo, e la scultura B.05.B.0/31 ad un periodo posteriore al IV secolo a.C.

Queste considerazioni stilistiche che riguardano le sculturebovine sonovalideanche perlerappresentazioni di stambecchi scolpiti sulle tavole offertorie, sugli altari, sui troni, ecc. Le peculiarità dell'iconografia dello stambecco del periodo più antico sono: testa tozza e squadrata, con lieve costolatura centrale longitudinale, muso piatto alla base, barbetta squadrata e piatta, occhi globosi e sporgenti, orecchie allungate e ritte e corna ricurve. Il corpo è tozzo e tornito, e la coda piccola e rialzata. Una iconografia codificata dello stambecco in uno stile astratto e stilizzato - formatosi all'inizio del I millennio a.C., e che, proprio per la sua natura religiosa, perdura nel tempo. Una tendenza ad uno stile più naturalistico si coglie in alcune opere a tutto tondo in bronzo del IV secolo a.C., che culmina nelle opere di I-III secolo d.C.

Tra i materiali trovati nel tempio di 'Athtar dhu-Qabd a Barāqish, vi sono le suddette tavole offertorie fisse, decorate su un lato corto da una teoria di stambecchi accucciati, che conservano quelle caratteristiche formali dell'antica iconografia, e che possiamo ragionevolmente 
attribuire, anche grazie alla paleografia delle iscrizioni che le accompagnano, al periodo di costruzione del tempio (v. Agostini, capitolo 4 in questo volume, figg. 9-12). Del tutto simili sono state trovate in posto nel vicino tempio Barran di Nakrah (v. Darles, capitolo 10 in questo volume, figg. 14-16). ${ }^{1}$

Dello stesso genere di rappresentazione è il fregio a rilievo di una tavola offertoria, B.05.B.O/42, con una serie di 6 stambecchi accostati. Questo tipo di tavola offertoria è più piccola e più leggera rispetto alle tavole fisse trovate in posto all'interno di entrambi i templi di Barāqish, ed alcuni esemplari iscritti furono trovati intorno al tempio di Nakrah (v. Marion de Procé, capitolo 11 in questo volume, figg. 1-3). È molto probabile che fossero utilizzate in particolari circostanze, o al di fuori del tempio, anche per la mancanza di spazio al suo interno. Anche il frammento di una testa di stambecco a rilievo, B.05.B.O/35, poteva appartenere a un altare ${ }^{2} \mathrm{O}$ tavola offertoria.

Tra gli oggetti relativi alle pratiche religiose vanno annoverati gli incensieri B.05.B.0/38, B.05.B.0/39, B.05.B.O/40, tutti realizzati in calcare. Tra questi si distingue l'esemplare B.05.B.O/54 a doppio scomparto su alta base a gradini, purtroppo frammentario. Gli incensieri sono di due tipi, cubici e su piede troncopiramidale, similmente a quelli trovati nello scavo del tempio di Nakrah (v. Marion de Procé, capitolo 11 in questo volume, figg. 6-9, 11-13)

Tra gli oggetti di uso quotidiano, sono stati trovati un mortaio in arenaria, B.05.B.O/36, un recipiente rettangolare in granito, B.05.B.0/37, forse un vassoio per le offerte, e frammenti di vasetti in alabastro, B.05.B.O/46, B.04.B.O/136, B.04.B.O/137 e B.04.B.O/140.

Tra i materiali di epoca pre-islamica trovati nell'area templare, annoveriamo una statuetta in alabastro di toro, B.04.B.O/139, frammentaria e piuttosto usurata, e tre stele, di cui due funerarie B.04.B.O/28, B.06.B.O/102. La stele B.05.B.O/55, su cui è inciso il nome 'Athtar, potrebbe essere votiva e provenire dal tempio stesso se si tratta del nome della divinità, oppure, se si tratta di un nome proprio, dalla vicina necropoli, in parte scavata dalla stessa missione italiana. ${ }^{3}$ La stele B.06.B.0/102 proviene dallo scavo condotto nello spazio compreso tra i due templi, a ridosso del tempio di Nakrah. Dal punto di vista formale, tutte e tre le sculture rientrano nella tipologia delle stele tipicamente jawfite, rettangolari con fattezze umane incise in modo sintetico e a volte piuttosto sommario nella metà superiore, e con il nome proprio del defunto inciso nella metà inferiore.

\footnotetext{
de Maigret 2004a, 12-13.

2 Cfr. per esempio l'esemplare dal Jawf conservato al Museo Militare di Șan' $(\bar{a})$, MiM 120, in Antonini de Maigret 2012, 50, fig. 38.

3 Antonini e Agostini 2010a.
}

Numerosi sono i confronti che provengono sia dalla necropoli di Barāqish, ${ }^{4}$ sia dagli scavi illegali nelle necropoli del Jawf yemenita. ${ }^{5}$

Infine, utensili e oggetti metallici, che provengono dallo strato mineo del tempio. Si tratta di asticelle e chiodi in bronzo, B.05.B.O/28, B.05.B.O/49, B.05.B.O/50, B.05.B.O/51, e un frammento di placca informe in argento, B.05.B.0/9.

Si segnala un gettone in bronzo, B.04.B.O/43 e una moneta, B.04.B.O/121, quest'ultima di non facile lettura, trovati negli scavi di strutture di Periodo Islamico Medio e Antico rispettivamente. Il token, che presenta una incisione a croce su una faccia e a raggera sull'altra faccia, non ha finora confronti. Che fosse una sorta di moneta di scambio minea?

Per quanto riguarda la datazione di questi materiali, essi sono tutti attribuibili al periodo compreso tra il $\mathrm{V}$ secolo a.C. e il I secolo d.C.; il periodo corrisponde alla data di costruzione del tempio di 'Athtar dhu-Qabd fino all'abbandono (v. Agostini, capitolo 3 in questo volume, Tabella 1).

\section{Catalogo degli oggetti}

\section{Arredo}

\section{Doccione a testa taurina (fig. 1a-d)}

\section{Catalogo: B.05.B.O/31}

Provenienza: L104, Periodo Mineo

Collocazione: già Barāqish magazzino del Museo

Materiale: calcare

Dimensioni: lungh. max. cm 56; largh. max. cm 34; spess. $\mathrm{cm} 8$; canaletta: largh. media $\mathrm{cm} 3$

Conservazione: frammentario; le corna del toro sono spezzate alla base

Descrizione: elemento architettonico appartenente al tempio. La gronda è costituita da una sezione rettangolare - che era inserita nel coronamento del muro del tempio - e dal gocciolatoio, o doccione, formato dal collo a sezione piano-convessa, con scanalatura superiore longitudinale, terminante a testa taurina. Il muso dell'animale è squadrato e piatto alla base, dove è incisa la bocca con un tratto retto; sul margine sono indicate le narici tramite due fossette speculari semilunate; gli occhi sono due leggere protuberanze delimitate sul lato interno da pieghe concentriche lievemente rilevate. Le orecchie sono a tutto tondo. Lateralmente la mandibola è rappresentata tramite un leggero sottoquadro. Si notano nel muso del toro, tra gli occhi, due scanalature verticali poco

\footnotetext{
4 Antonini 2010, tavv. $20-27$.

Arbach e Schiettecatte 2006, tavv. 43-60; Arbach et al. 2008, 72-170.
} 
a

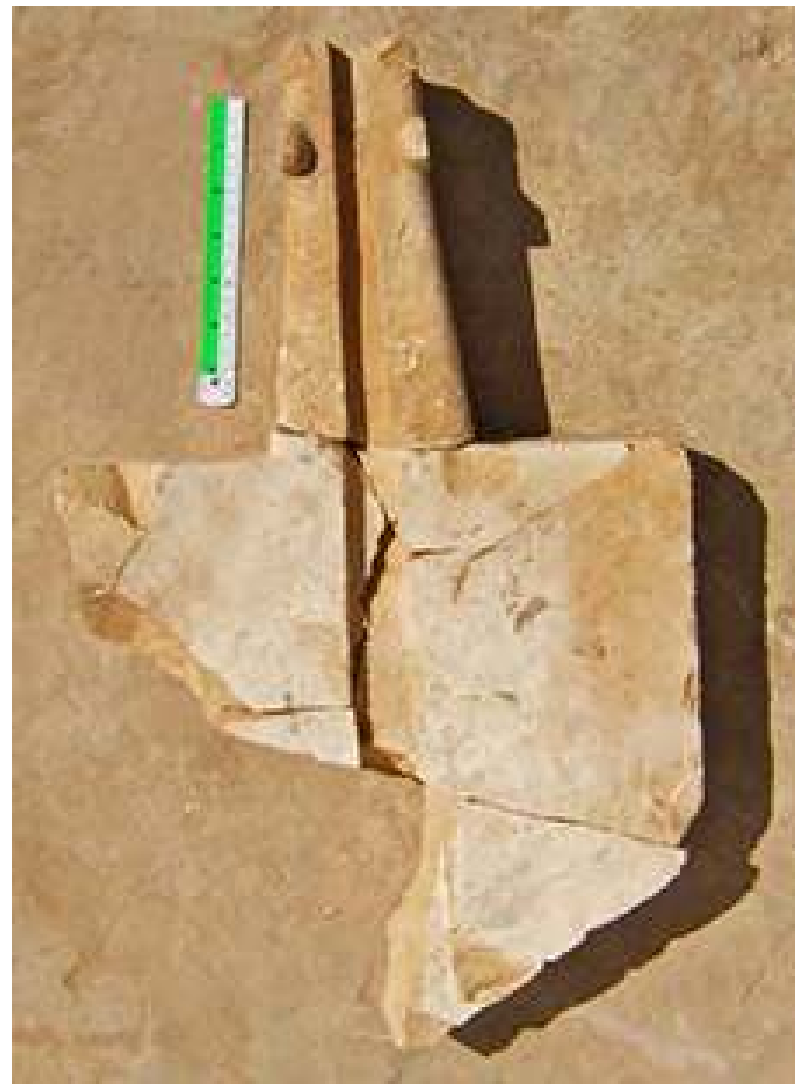

b

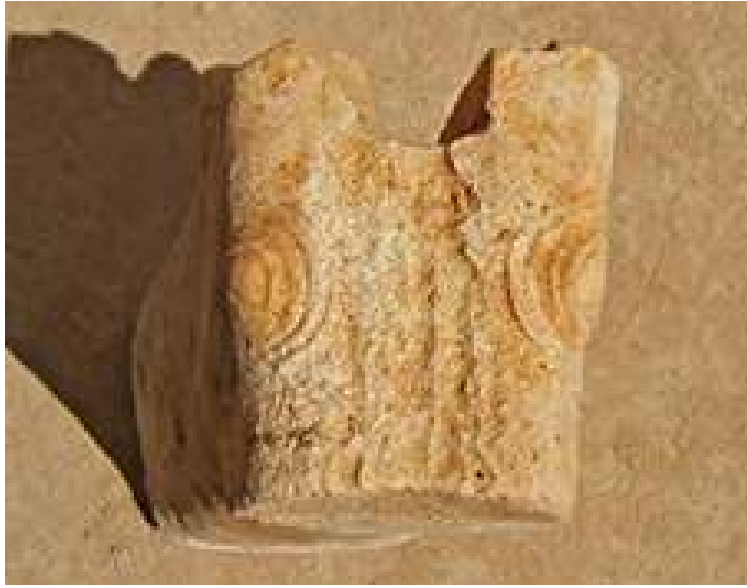

C

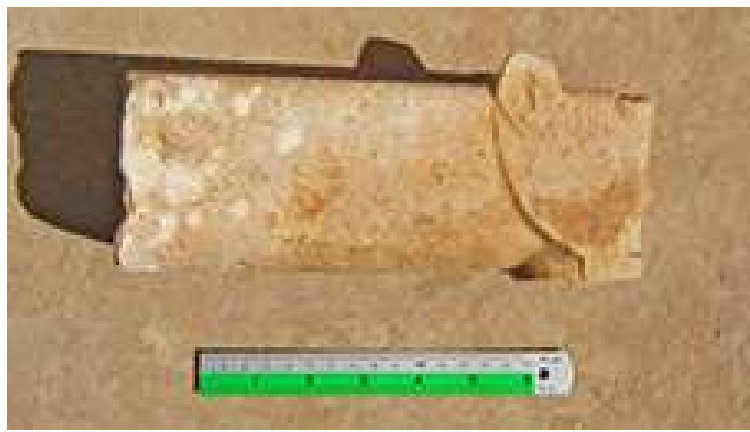

d

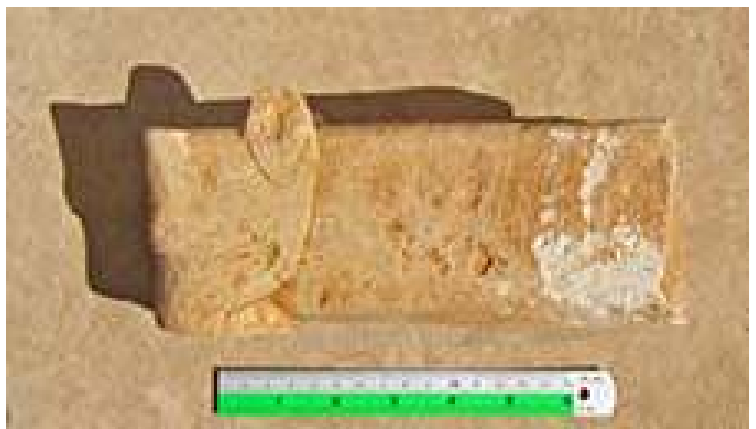

Figure 1a-d. Doccione a testa taurina (B.05.B.O/31). (R. Valentini 2005 CMAIRY)

profonde, in corrispondenza della canaletta superiore; l'usura della pietra è dovuta all'azione dell'acqua. Per i confronti si veda, per esempio, un esemplare completo in alabastro, conservato al Museo Militare di Șan' $\bar{a}$ ', MiM 365 (Antonini de Maigret 2012, 51, fig. 47); un altro confronto completo viene dagli scavi del tempio di Athirat a Tamna' (de Maigret 2016, 220, fig. 149); inoltre, si veda l'esemplare da Shabwa, dove lo stile scultoreo della testa taurina è più realistico e plastico rispetto agli esemplari minei, e risale al III secolo d.C. (Dentzer-Feydy 2009, 137, 155, fig. 18, e 156, fig. 19).

Data: IV secolo a.C. - I secolo d.C.

\section{Gocciolatoio a testa taurina (fig. 2)}

Catalogo: B.05.B.O/32

Provenienza: L104, Periodo Mineo

Collocazione: già Barāqish magazzino del Museo

Materiale: calcare

Dimensioni: lungh. max. cm 14,5; largh. max. $13 \mathrm{~cm}$; canaletta: largh. media $\mathrm{cm} 3$

Conservazione: frammentario; le corna del toro sono spezzate alla base

Descrizione: gocciolatoio costituito dal collo e dalla testa taurina. La testa è squadrata e piatta con occhi sporgenti 


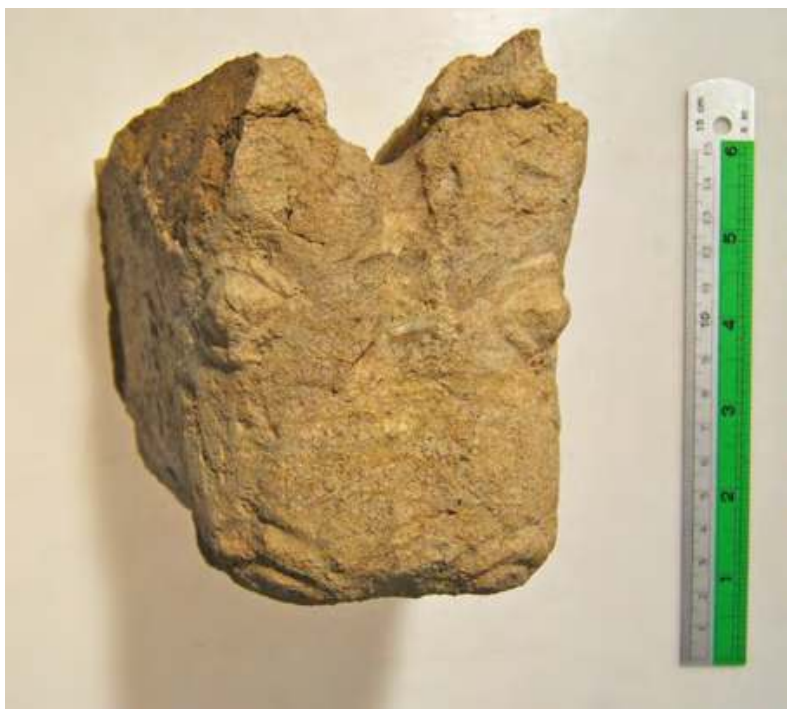

Figure 2. Gocciolatoio a testa taurina (B.05.B.O/32). (R. Valentini 2005 @MAIRY)

messi in evidenza da spesse palpebre a rilievo. Alla base del muso sono scolpite le narici, evidenziate da due pieghe della pelle, e la bocca, resa con una linea incisa ondulata. Lateralmente, la mandibola è rappresentata tramite un leggero sottoquadro. Sulla superficie frontale della testa taurina, in corrispondenza della canaletta scavata lungo la faccia superiore del collo, è un solco verticale poco profondo, causato dall'usura. Per quanto riguarda questo particolare, si veda, per esempio, l'esemplare in calcare dell'VIII secolo a.C. conservato al Museo Militare di Șan' $\bar{a}$ ), dove la corrosione ha scavato un profondo solco, provocando un ammanco notevole di materiale lapideo (Antonini de Maigret 2012, 51, fig. 46).

Data: IV secolo a.C. - I secolo d.C.

\section{Gocciolatoio a testa taurina (fig. 3)}

Catalogo: B.05.B.O/33

Provenienza: zanbil B.05.B.35, dallo smontaggio di Mi 80, Periodo Islamico Antico

Collocazione: già Barāqish magazzino del Museo

Materiale: calcare

Dimensioni: lungh. max. cm 14; largh. $\max . \mathrm{cm} \mathrm{8}$; canaletta: largh. media 1,5

Conservazione: frammentario e superficie erosa

Descrizione: gocciolatoio costituito da un collo, con scanalatura longitudinale, terminante a testa taurina. Di quest'ultima è conservato soltanto l'occhio destro. Data: IV secolo a.C. - I secolo d.C.

\section{Gocciolatoio a testa taurina (fig. 4)}

Catalogo: B.05.B.0/34

Provenienza: zanbil B.05.B.20, sul pavimento di L 104, Periodo Mineo

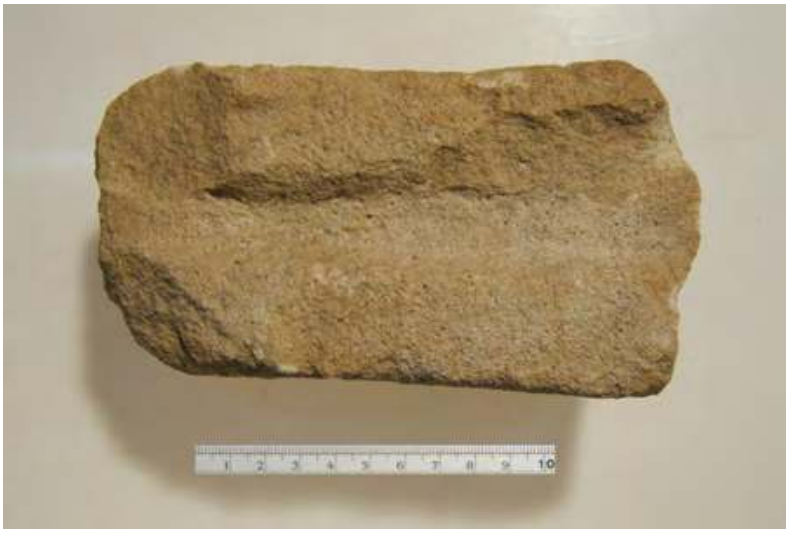

Figure 3. Gocciolatoio a testa taurina (B.05.B.0/33). (R. Valentini 2005 CMAIRY)

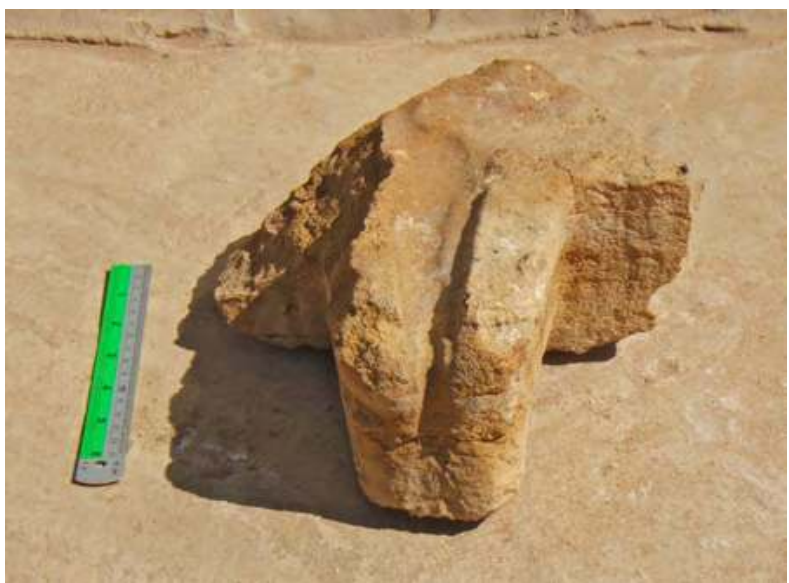

Figure 4. Gocciolatoio a testa taurina (B.05.B.O/34).

(R. Valentini 2005 @MAIRY)

Collocazione: già Barāqish magazzino del Museo Materiale: calcare

Dimensioni: lungh. max. cm 30; largh. $\max . \mathrm{cm} \mathrm{22;}$ canaletta: largh. media $\mathrm{cm} 3$

Conservazione: frammentaria e superficie fortemente erosa

Descrizione: il pezzo è formato da una piccola porzione del corpo rettangolare, da cui sporge il collo scanalato terminante a testa taurina, che costituiva il gocciolatoio vero e proprio. Il muso è squadrato e piatto alla base: sono evidenti gli occhi, con bulbo globulare sporgente, e le palpebre leggermente a rilievo, le narici rese con due cerchi concentrici incisi, e la bocca, anch'essa resa tramite una linea ondulata incisa. Dal punto di vista stilistico questo pezzo è molto simile al gocciolatoio B.05.B.0/32 (Fig. 2)

Data: IV secolo a.C. - I secolo d.C.

\section{Tavola sacrificale (fig. $5 \mathrm{a}-\mathrm{d}$ )}

Catalogo: B.05.B.0/41 
a

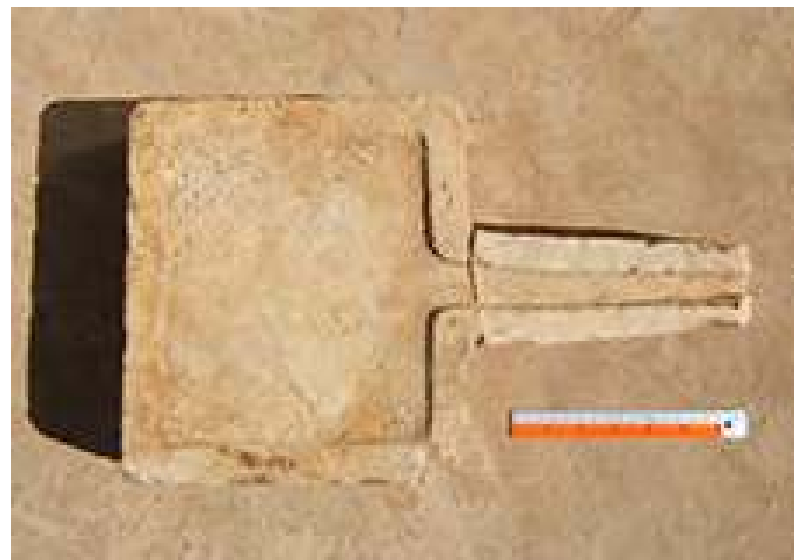

C

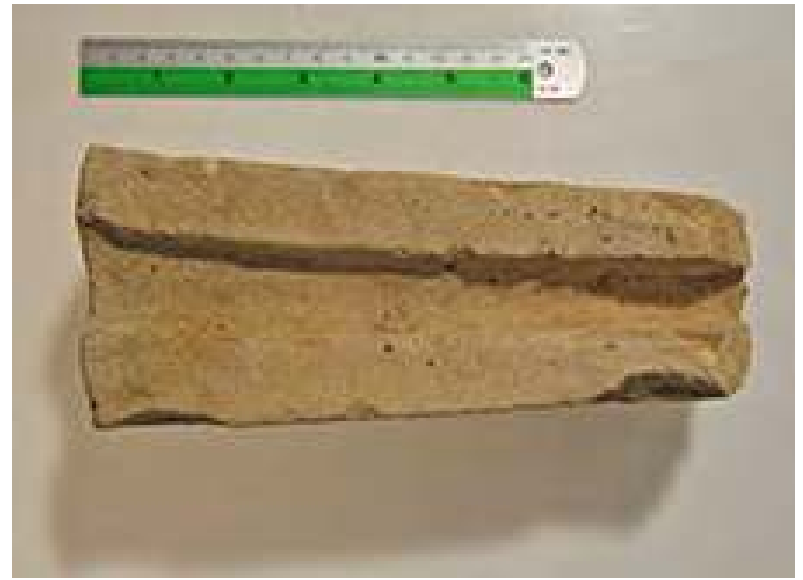

Figure 5a-d. Tavola sacrificale (B.05.B.O/41).

(R. Valentini 2005 OMAIRY) b

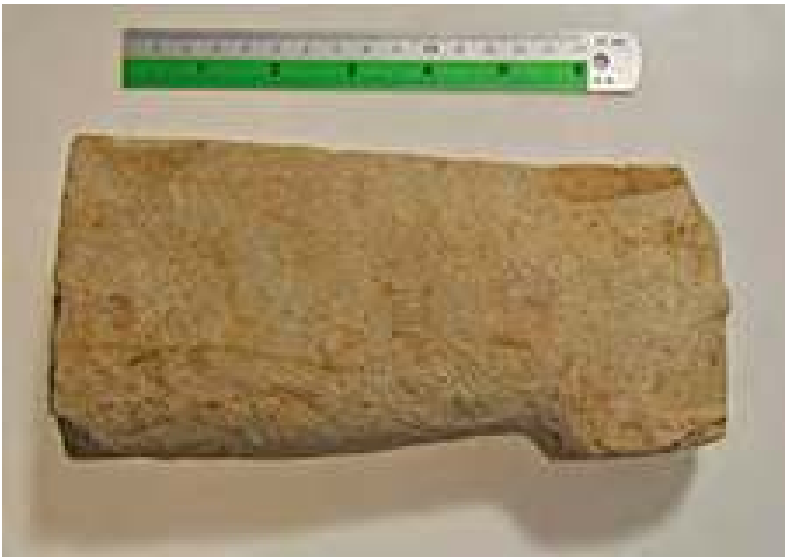

d

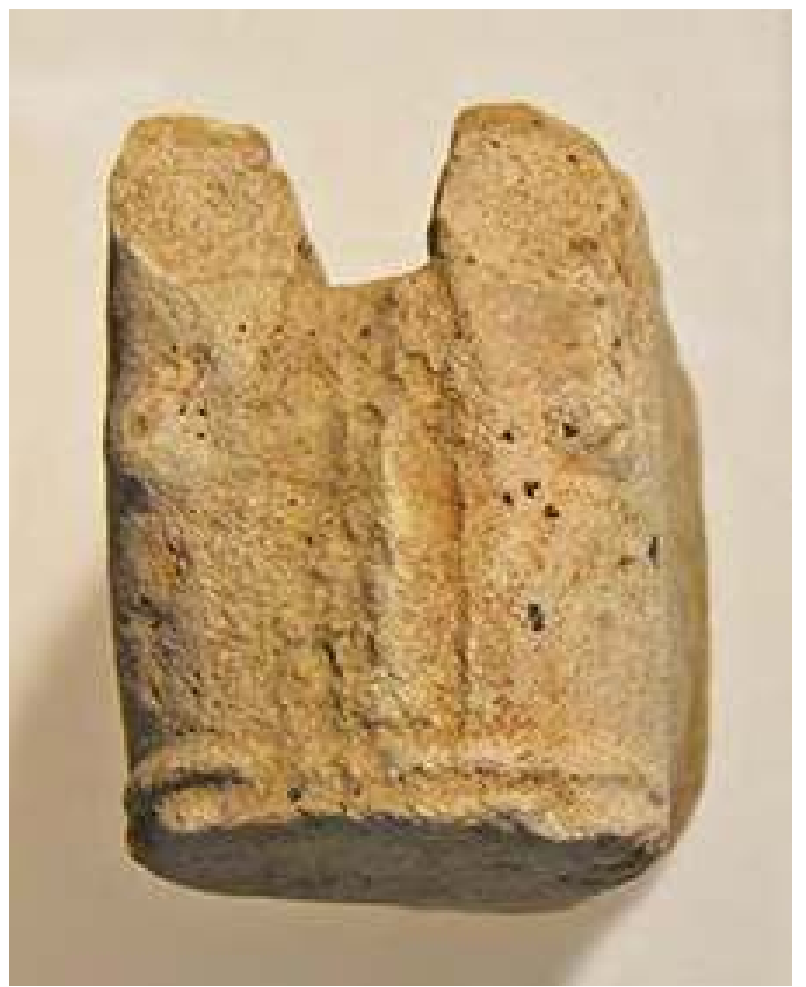

Provenienza: zanbil B.05.B.63, L111, pavimento, Periodo Mineo

Collocazione: già Barāqish magazzino del Museo Materiale: calcare

Dimensioni: piatto: $\mathrm{cm}$ 22,5 x 25,5 x 11; collo e testa del toro: lungh. cm 19; largh. max. cm 8; largh min. cm 5,5; spess. $\mathrm{cm}$ 9; scanalatura: largh. media $\mathrm{cm} 2$

Conservazione: completa, composta di due frammenti; spezzati gli orecchi e le corna del toro.

Descrizione: la tavola è formata da un 'vassoio' rettangolare e un gocciolatoio formato dal collo, con scanalatura longitudinale, e dalla testa di toro, scolpiti in un unico blocco di pietra. Il 'vassoio' è leggermente ribassato rispetto al bordo, quest'ultimo largo $\mathrm{cm} \mathrm{2,5}$. Tutte le superfici sono levigate, tranne quella inferiore.
La testa dell'animale è cilindrica e il muso, con base piatta, è delimitato in basso da un cordolo orizzontale a rilievo. Al di sotto, lungo il margine inferiore, è disegnata la bocca tramite una lieve linea ondulata a rilievo. Gli occhi sono rappresentati con due semplici protuberanze. Sulla superficie frontale della testa taurina, in corrispondenza della canaletta scavata lungo il collo, la pietra presenta erosioni verticali. Questa rappresentazione di toro, rispetto alle altre di questa stessa collezione trovata nel tempio di 'Athtar dhu-Qabd, ha tratti arcaicizzanti riconoscibili nella resa formale degli occhi e nella mancanza dei dettagli del muso.

Data: V-IV secolo a.C. 


\section{Frammento di tavola sacrificale (fig. 6a-b)}

Catalogo: B.05.B.O/43

Provenienza: zanbill B.05.B.69, L 120, deposito eolico, Periodo Mineo

Collocazione: già Barāqish magazzino del Museo Materiale: alabastro

Dimensioni: largh. max. cm 12; lungh. max. cm 13; spess. cm 6,5; bordo: largh. min. $\mathrm{cm} \mathrm{2,5;} \mathrm{largh.} \mathrm{max.} \mathrm{cm}$ 4 ; spess. cm 0,3

Conservazione: frammentaria

Descrizione: il frammento costituisce un angolo di una tavola sacrificale. Le superfici sono levigate, eccetto quella inferiore che reca i segni della lavorazione e un

\section{a}

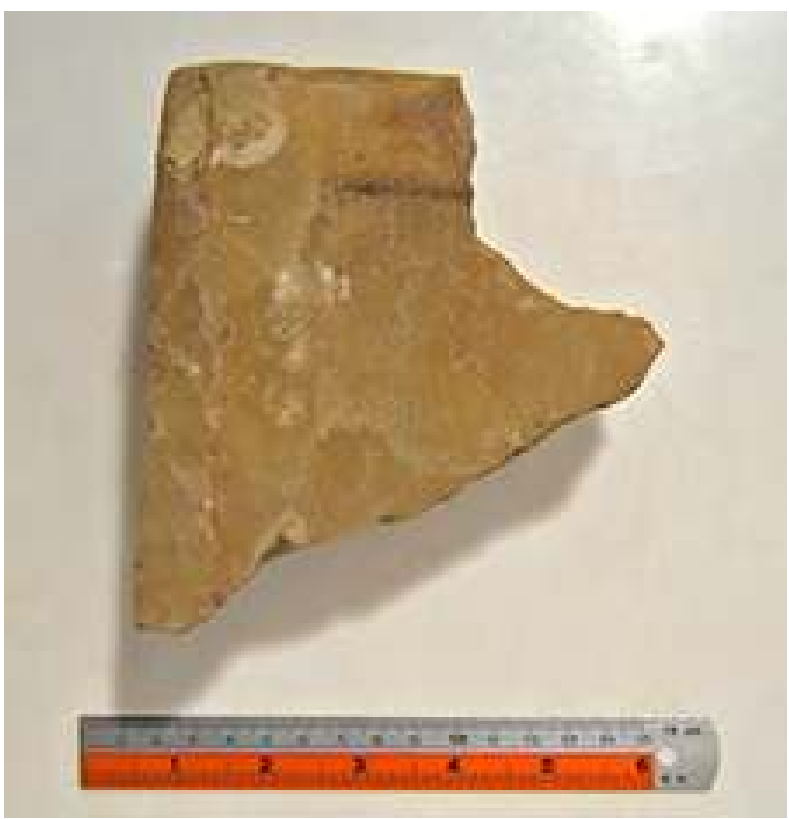

\section{b}

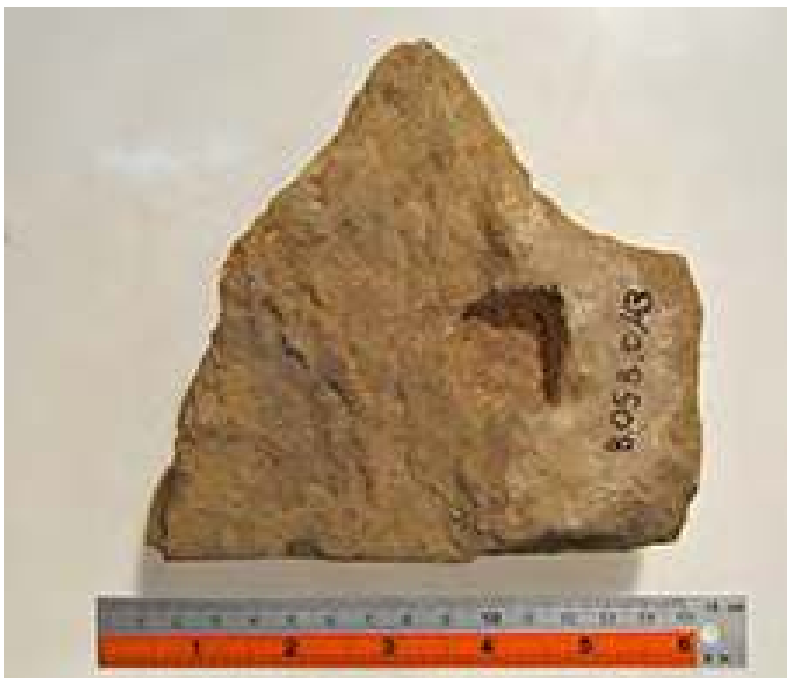

Figure 6a-b. Frammento di tavola sacrificale (B.05.B.O/43). (R. Valentini 2005 CMAIRY) incavo quadrato ( $\mathrm{cm} 2 \times 2$, profondo $\mathrm{cm} 0,5)$, che serviva forse per l'incastro su una superficie per tenere salda la tavola.

Data: IV secolo a.C. - I secolo d.C.

\section{Fregio con stambecchi a rilievo (fig. 7)}

Catalogo: B.05.B.O/42

Provenienza: zanbil B.05.B.32, L 119, Periodo di Abbandono

Collocazione: già Barāqish magazzino del Museo

Materiale: calcare

Dimensioni: h totale $\mathrm{cm} \mathrm{15}$; largh. $\mathrm{cm} \mathrm{10}$; spess. $\mathrm{cm} 12,5$ Conservazione: frammentaria

Descrizione: fregio di tavola offertoria decorato da una teoria di sei teste di stambecco a rilievo. I musi sono oblunghi con occhi sporgenti e corna ricurve, apprezzabili da una visione laterale. Una modanatura dal profilo arrotondato è scolpita $2,5 \mathrm{~cm}$ al di sotto degli stambecchi.

Data: V-IV secolo a.C.

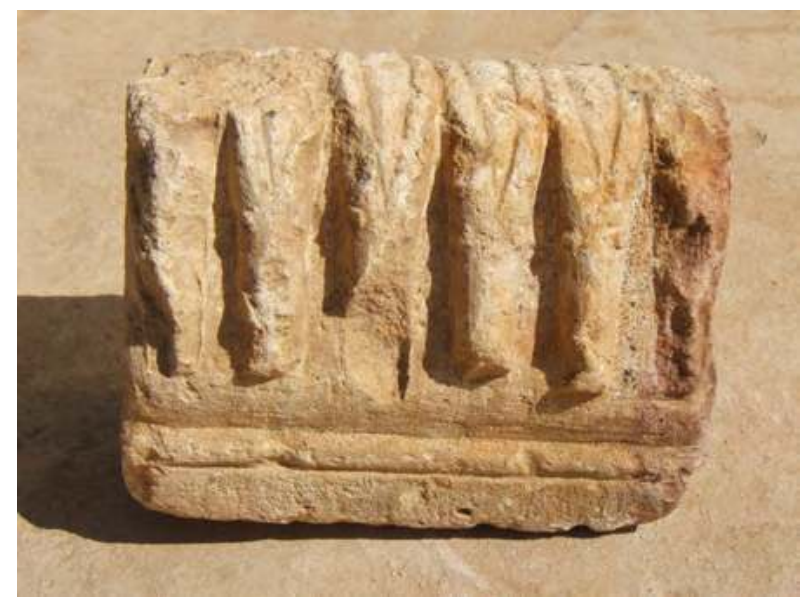

Figure 7. Fregio con stambecchi a rilievo (B.05.B.0/42). (R. Valentini 2005 @MAIRY)

\section{Frammento di stambecco a rilievo (fig. 8)}

\section{Catalogo: B.05.B.O/35}

Provenienza: zanbil B.05.B.30, Islamico Medio

Collocazione: già Barāqish magazzino del Museo Materiale: calcare

Dimensioni: $\mathrm{h} \mathrm{cm} \mathrm{10,5;} \mathrm{largh.} \mathrm{cm}$ 9; spess. medio $\mathrm{cm} 4$ Conservazione: frammentaria

Descrizione: il frammento è del tipo di stambecco recumbente, con occhi sporgenti e ampie corna ricurve, ben visibili lateralmente. Sulla parte destra dello stambecco si nota il corno sinistro dello stambecco a fianco. Teorie di stambecchi generalmente decoravano coronamenti di templi, tavole offertorie, altari e incensieri. 


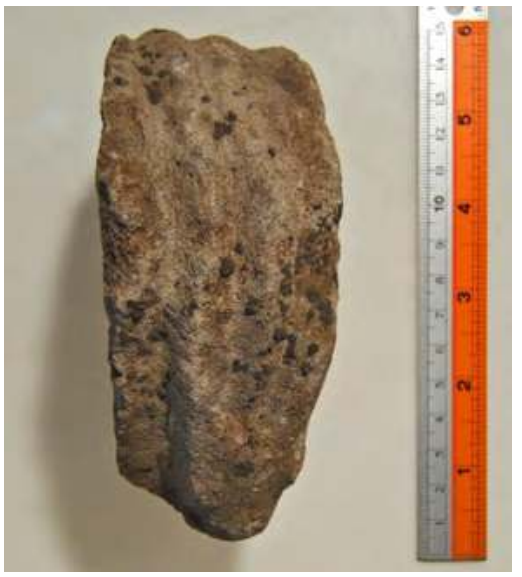

Figure 8. Frammento di stambecco a rilievo (B.05.B.O/35). (R. Valentini 2005 @MAIRY)

Data: IV secolo a.C. - I secolo d.C.

\section{Incensiere (fig. 9)}

Catalogo: B.05.B.O/40

Collocazione: già Barāqish magazzino del Museo

Materiale: calcare

Dimensioni: $\mathrm{h}$ totale $\mathrm{cm} \mathrm{21}$; base $\mathrm{cm} 14$ x 9,5; largh. del bordo $\mathrm{cm} 1,3$

Conservazione: orlo frammentario

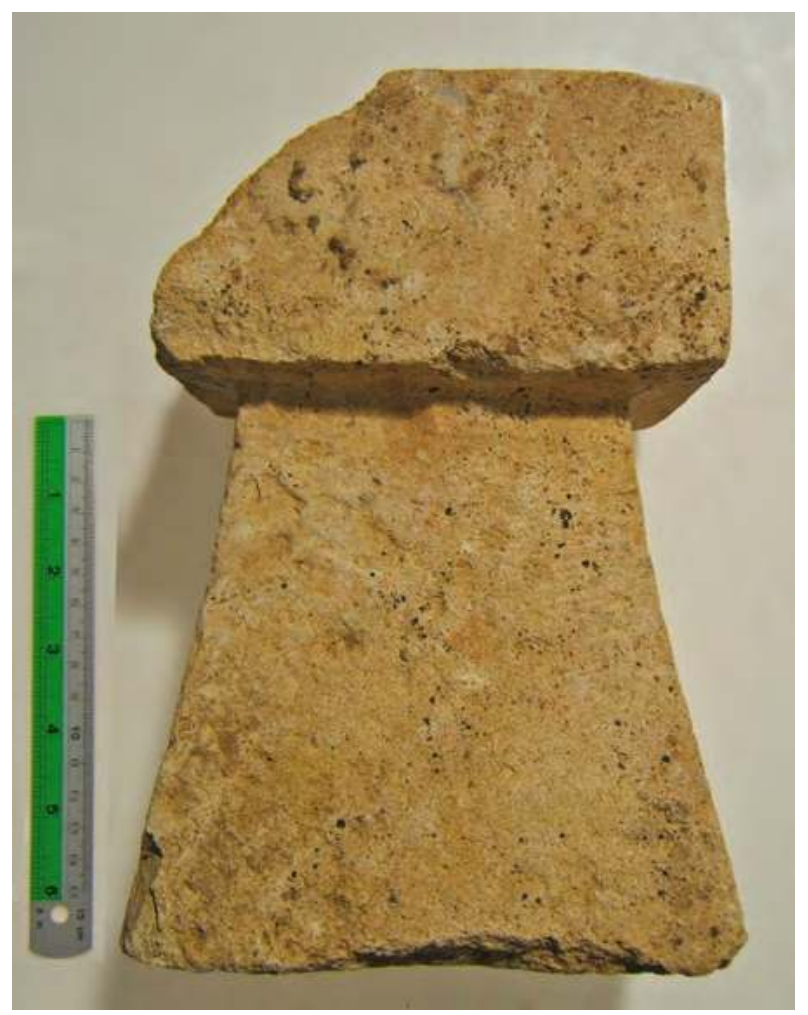

Figure 9. Incensiere (B.05.B.0/40).

(R. Valentini 2005 CMAIRY)
Descrizione: incensiere quadrato su base troncopiramidale. Su una faccia è scolpito a basso rilievo il simbolo religioso della falce di luna. Tracce di combustione all'interno.

Data: IV secolo a.C. - I secolo d.C.

\section{Incensiere a doppio scomparto (fig. 10a-c)}

Catalogo: B.05.B.O/54 (iscrizione Y.05.B.B./23, v. Agostini, capitolo 4 in questo volume, fig. 14)

Provenienza: zanbil B.05.B.75, L 121, sotto Mi 93; sul pavimento, Periodo Mineo

Collocazione: già Barāqish magazzino del Museo

Materiale: calcare

Dimensioni: $\mathrm{h}$ totale $\mathrm{cm}$ 25; piede: $\mathrm{h} \mathrm{cm} \mathrm{17,5;} \mathrm{largh.} \mathrm{max.}$ $\mathrm{cm} 9,5$; largh. min cm 6. Scomparti: maggiore $\mathrm{cm} 7 \times 9$ $\mathrm{x} 9,8$; minore $\mathrm{cm} 6,8 \times 8,4 \times 6$; spess. medio della parete $\mathrm{cm} 1,5$

Conservazione: frammentario

Descrizione: incensiere formato da due scomparti pressoché quadrati, il maggiore dei quali è sorretto da un piede tronco-piramidale, decorato alla base da tre gradini. Entrambi gli scomparti sono decorati esternamente da un motivo semplificato a false finestre e dentelli. Su una faccia del comparto minore è scolpita l'iscrizione di tre lettere (Dyt).

La faccia inferiore del secondo scomparto evidenzia una frattura che fa presupporre la presenza di un ulteriore piede. Tre facce del piede tronco-piramidale sono lisciate, mentre la quarta, quella non a vista, è sbozzata. Sono conservate tracce di pittura rossa.

Data: IV secolo a.C. - I secolo d.C.

\section{Incensiere iscritto (fig. 11)}

Catalogo: B.05.B.0/38 (iscrizione Y.05.B.B./21, v. Agostini, capitolo 4 in questo volume, fig. 13)

Provenienza: zanbil B.05.B.54, L 114, davanti a Ta, Periodo di Abbandono

Collocazione: già Barāqish magazzino del Museo

Materiale: calcare

Dimensioni: lungh. max. cm 14,5; largh. max. cm 11,7; spess. del bordo $\mathrm{cm} \mathrm{2,3}$

Conservazione: frammentario

Descrizione: dell'incensiere è conservata parzialmente una faccia, su cui sono scolpite, a basso rilievo entro riquadri, la falce di luna e, al di sotto, tre lettere di un'iscrizione $\left(\check{s}^{c} b\right)$. Il bordo inferiore è decorato a triangoli a rilievo con i vertici in basso. Il piede doveva essere del tipo tronco-piramidale e forse l'incensiere era a doppio scomparto.

Data: I secolo a.C. - I secolo d.C.

\section{Piede di incensiere (fig. 12)}

Catalogo: B.05.B.O/39

Provenienza: zanbil B.05.B.64, L 114, a est, Periodo Mineo Collocazione: già Barāqish magazzino del Museo 
$a$

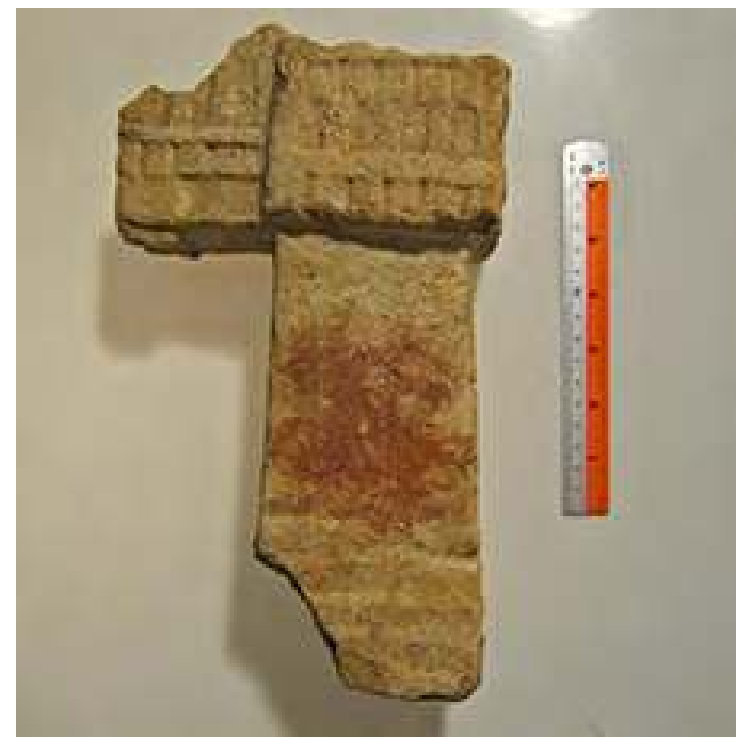

C

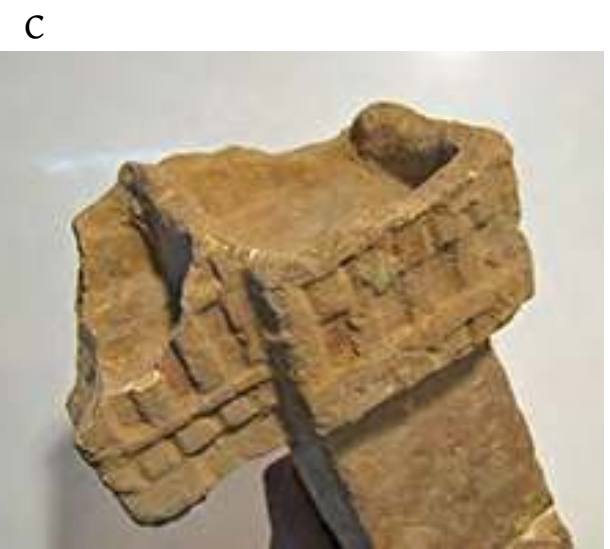

Figure 10a-c. Incensiere a doppio scomparto (B.05.B.O/54). (R. Valentini 2005 OMAIRY)

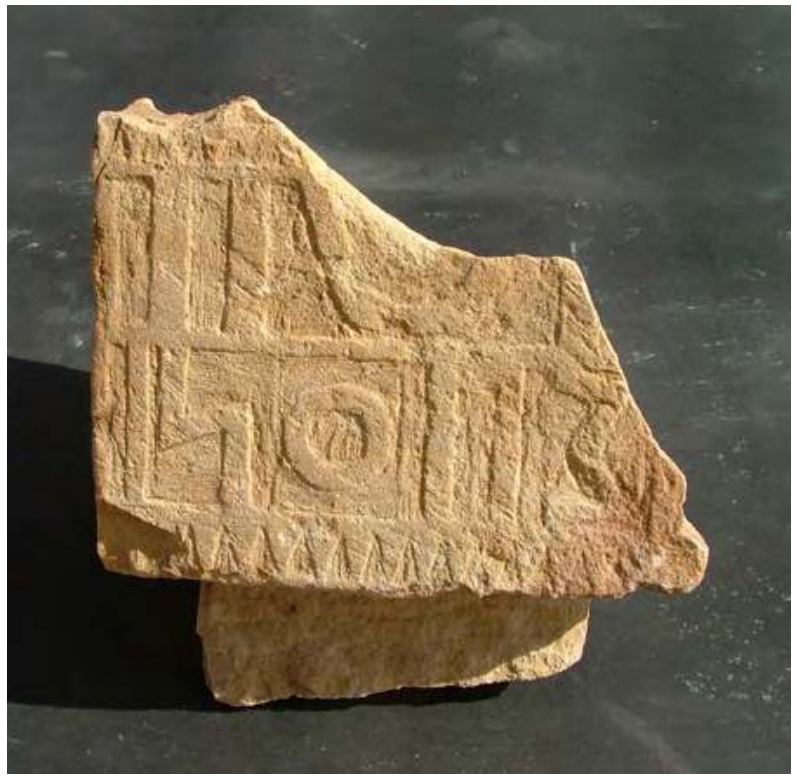

Figure 11. Incensiere iscritto (B.05.B.0/38). (R. Valentini 2005 OMAIRY) b
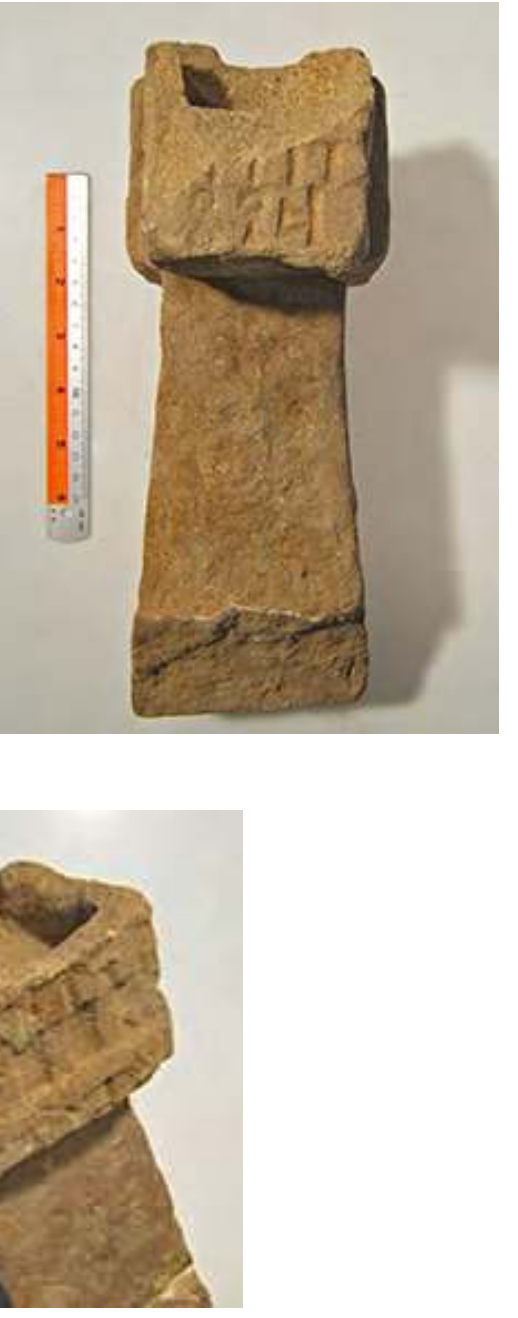
Materiale: calcare

Dimensioni: h max. conservata cm 17; base cm 13 x 13,6

Conservazione: frammentaria

Descrizione: base tronco-piramidale di incensiere.

Data: IV secolo a.C. - I secolo d.C.

\section{Incensiere cubico (fig. 13a-b)}

Catalogo: B.05.B.O/15

Provenienza: zanbil B.05.B.4, casa nord (Li 308), Periodo Islamico Recente

Collocazione: già Barāqish magazzino del Museo

Materiale: arenaria

Dimensioni: cm 5 x 6,3 x 7,5

Conservazione: frammentaria

a

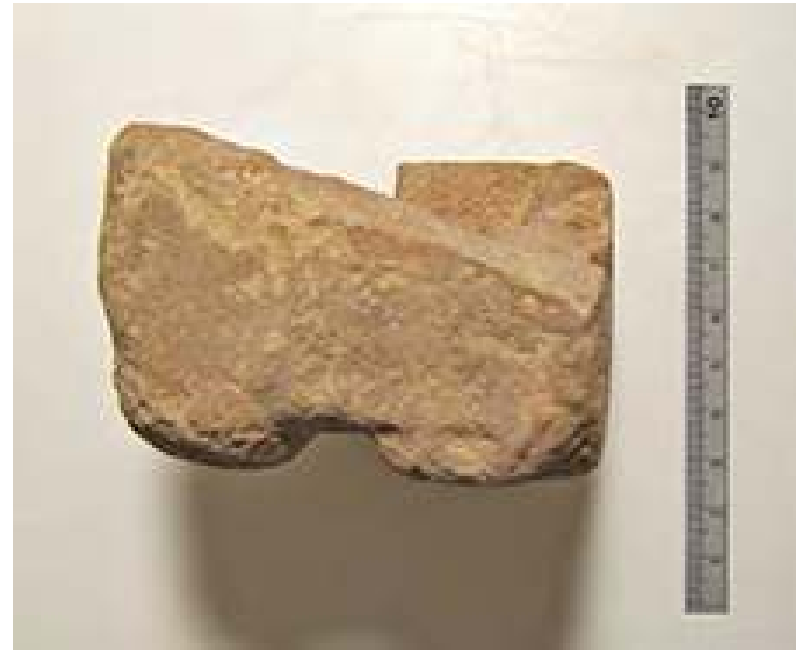

b

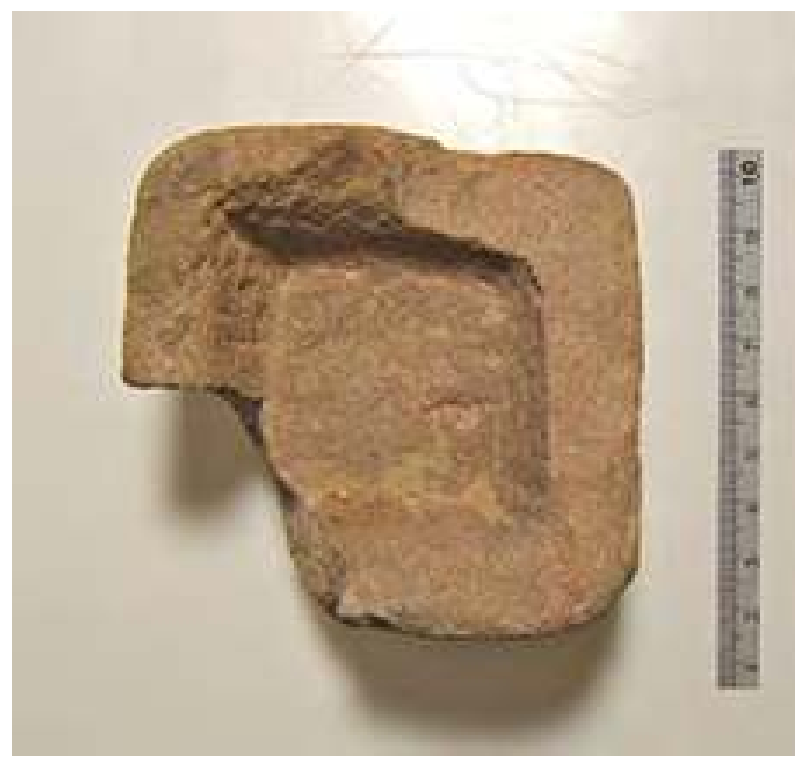

Figure 13a-b. Incensiere cubico (B.05.B.O/15).

(R. Valentini 2005 OMAIRY)
Descrizione: piccolo incensiere cubico con 4 piedi angolari a sezione quadrata.

Data: IV secolo a.C. - I secolo d.C.

\section{Contenitori}

\section{Tavola con 4 piedi angolari (fig. 14a-b)}

Catalogo: B.05.B.O/37

Provenienza: zanbil B.05.B.49, Li 308, Periodo Islamico Medio

Collocazione: già Barāqish magazzino del Museo

Materiale: granito

Dimensioni: h cm 10,5; largh. cm 26; lungh. cm 38; largh. cornice $\mathrm{cm} 4,5$

Conservazione: integra

Descrizione: tavola di forma rettangolare, con quattro piedi angolari a sezione rettangolare. Contenitori simili a questo, in granito e calcare, sono stati trovati nello scavo del tempio di Athirat a Tamna' (cfr. de Maigret 2016, 242, fig. 174, n. 2, da L15), e in miniatura nelle tombe di Hayd bin 'Aqīl (cfr. Antonini 2016, 361, nn. 28-29).

Data: I secolo a.C. - I secolo d.C.

a

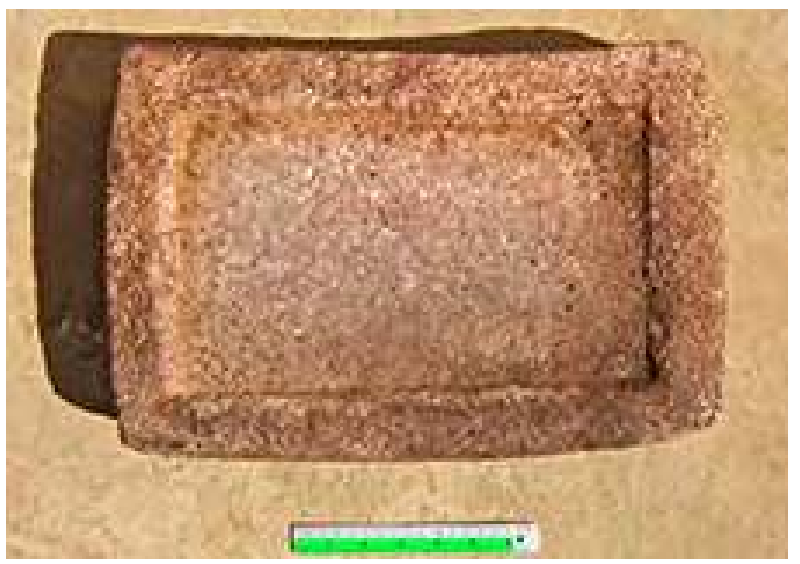

b

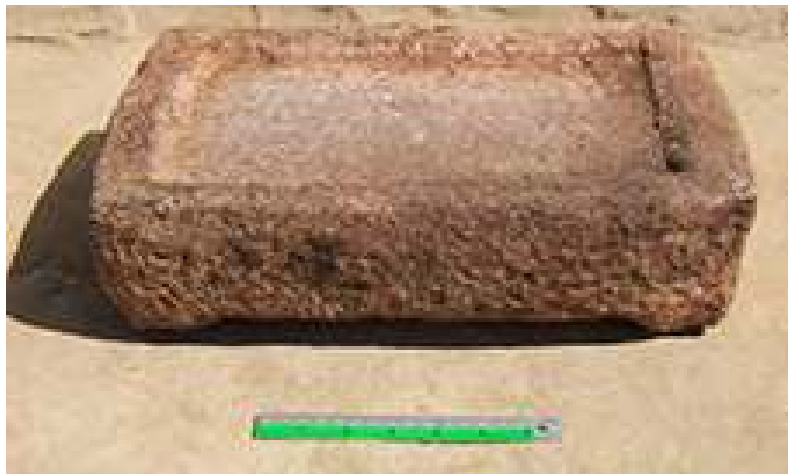

Figure 14a-b. Tavola con 4 piedi angolari (B.05.B.0/37). (R. Valentini 2005 CMAIRY) 


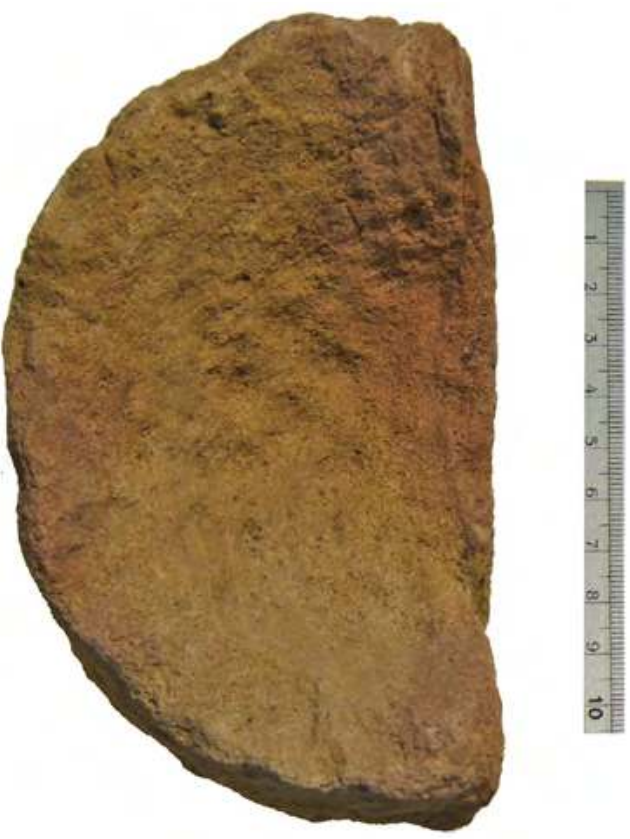

Figure 15. Mortaio (B.05.B.0/36). (R. Valentini 2005 @MAIRY)

\section{Mortaio (fig. 15)}

Catalogo: B.05.B.0/36

Provenienza: L104, Periodo Mineo

Collocazione: già Barāqish magazzino del Museo

Materiale: arenaria

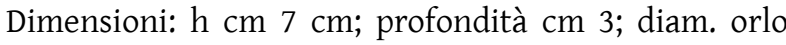
esterno $\mathrm{cm} \mathrm{13}$; spess. parete $\mathrm{cm} \mathrm{1,5;} \mathrm{spess.} \mathrm{fondo} \mathrm{cm} 3$ Conservazione: frammentario

Descrizione: recipiente rotondo, probabilmente a tre piedi, con pareti svasate e fondo piano. Le pareti interne recano i segni di lavorazione o di utilizzo. Il colore rosso dell'arenaria è dovuto alla combustione. Un esemplare del tutto simile a questo viene dallo scavo del tempio di Athirat a Tamna' (cfr. de Maigret 2016, 242, fig. 174, n. 3, da L16)

Data: I secolo a.C. - I secolo d.C.

\section{Recipiente in alabastro (fig. 16)}

Catalogo: B.05.B.0/46

Provenienza: zanbil B.05.B.63, L 111, sul pavimento, Periodo Mineo

Collocazione: già Barāqish magazzino del Museo

Materiale: alabastro

Dimensioni: lungh. max. $\mathrm{cm} \mathrm{11;} \mathrm{largh.} \mathrm{max.} \mathrm{cm} \mathrm{9;} \mathrm{h} \mathrm{cm}$ 6; spess. parete e fondo $\mathrm{cm} \mathrm{2,5}$

Conservazione: frammentario

Descrizione: recipiente rotondo, a fondo piano; generalmente questo tipo di recipiente ha tre piedi e reca una decorazione a dentelli alla base, nello spazio compreso tra un piede e l'altro; cfr. l'esemplare trovato

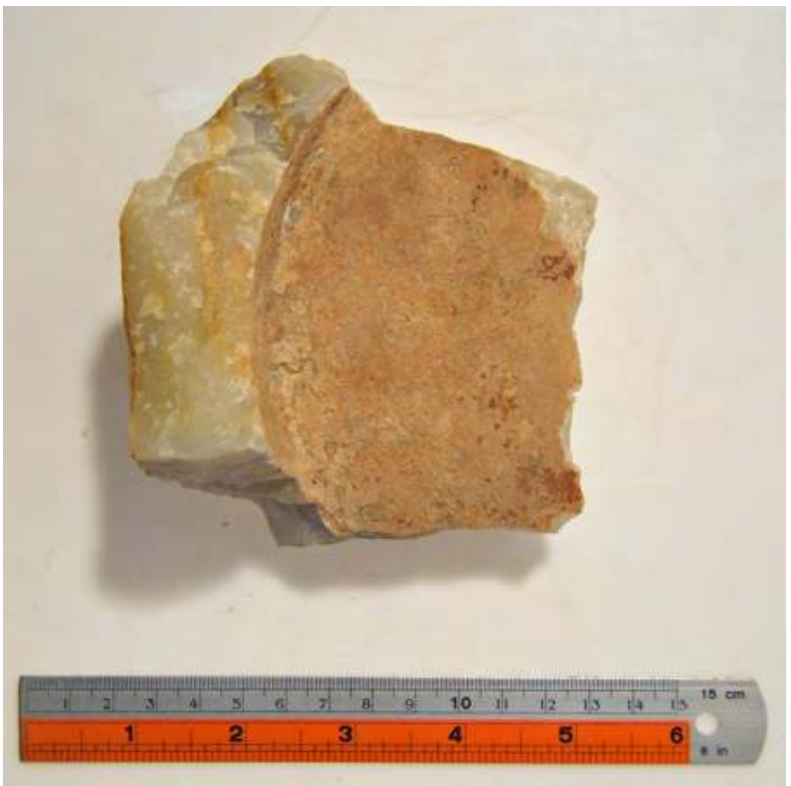

Figure 16. Recipiente in alabastro (B.05.B.O/46). (R. Valentini 2005 CMAIRY)

nello scavo del tempio di Athirat a Tamna' (de Maigret 2016, 234, fig. 167, n. 1, da L16), e altri due miniaturistici dallo scavo delle tombe si Hayd bin 'Aqil (Antonini 2016, 374, nn. 51-52).

Data: I secolo a.C. - I secolo d.C.

\section{Frammento di coppetta in alabastro (fig. 17)}

Catalogo: B.04.B.O/136

Provenienza: zanbill B.04.B.22, Li 13 - Li 18, Periodo Islamico Medio

Collocazione: già Barāqish magazzino del Museo Materiale: alabastro

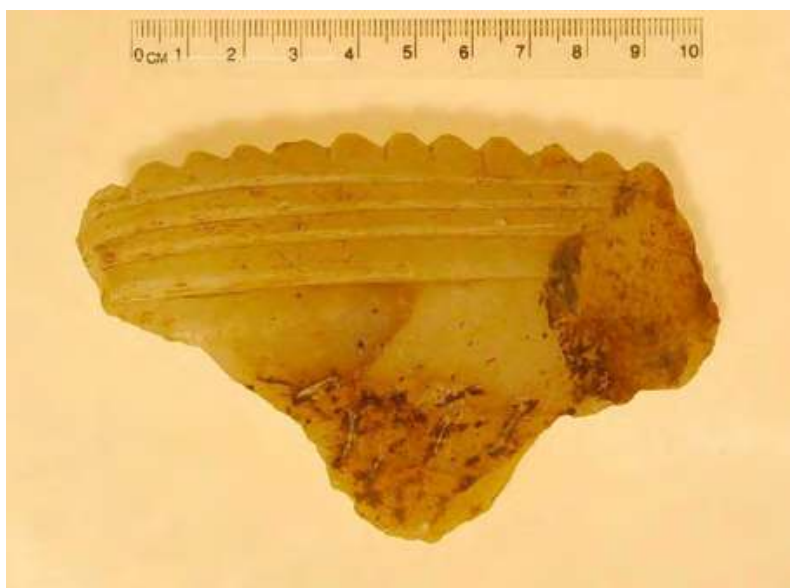

Figure 17. Frammento di coppetta in alabastro (B.04.B.0/136). (R. Valentini 2005 CMAIRY) 
a

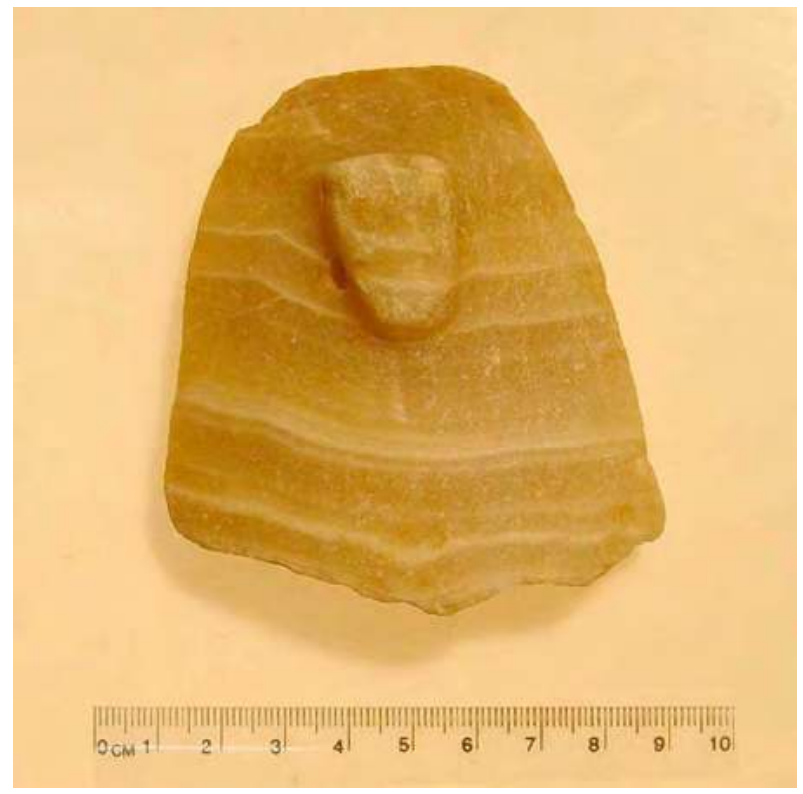

b

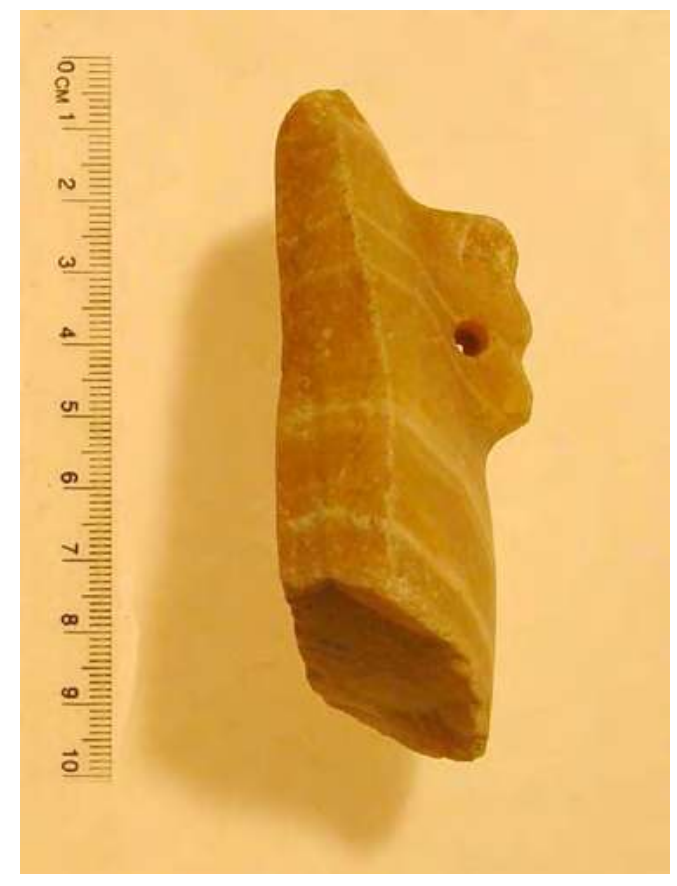

Figure 18a-b. Frammento di vasetto in alabastro (B.04.B.O/137). (R. Valentini 2005 @MAIRY)

Dimensioni: $\mathrm{h} \mathrm{cm} \mathrm{7,1}$

Conservazione: frammentaria

Descrizione: coppetta con labbro dentellato e quattro scanalature sotto l'orlo. Sulla pancia quattro lettere incise di non facile lettura.

Data: I secolo a.C. - I secolo d.C. a

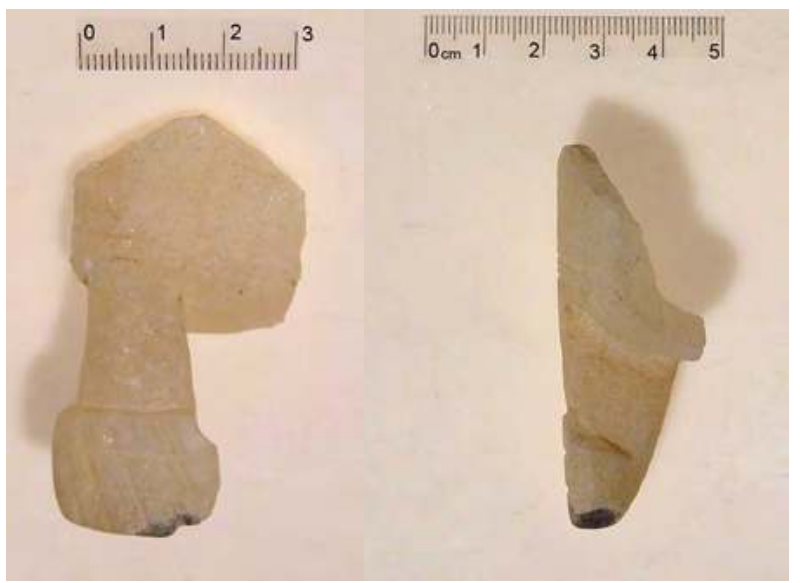

Figure 19a-b. Frammento di recipiente con alto piede (B.04.B.O/140). (R. Valentini 2005 CMAIRY)

\section{Frammento di vasetto in alabastro (fig. 18a-b)}

Catalogo: B.04.B.O/137

Provenienza: zanbil B.04.B.23, Li 4, Periodo Islamico Antico

Collocazione: già Barāqish magazzino del Museo

Materiale: alabastro

Dimensioni: $\mathrm{h} \mathrm{cm} \mathrm{8,3;} \mathrm{spess.} \mathrm{cm} \mathrm{1,5}$

Conservazione: frammentaria

Descrizione: vasetto in alabastro con ansa a forma ti testa di toro con foro passante; la parete è più spessa verso la base. Questo recipiente dovrebbe essere del tipo 'beehive-shaped', comune in Arabia Meridionale (cfr. Hassel 1997, 250, fig. 3, D1-D2, 269, fig. 16).

Data: I secolo a.C. - I secolo d.C.

19. Frammento di recipiente con alto piede (fig. $19 a-b)$

Catalogo: B.04.B.O/140

Provenienza: zanbil B.04.B.23, Li 4, Periodo Islamico Antico

Collocazione: già Barāqish magazzino del Museo

Materiale: alabastro biancastro

Dimensioni: h cm 6,3

Conservazione: frammentaria

Descrizione: frammento di piccolo recipiente a parete sottile decorata da una fascetta orizzontale alla base; è conservato un alto piede con spessa base incisa a reticolo.

Data: I secolo a.C. - I secolo d.C.

\section{Statuetta e stele}

\section{Statuetta di toro (fig. 20)}

Catalogo: B.04.B.O/139 

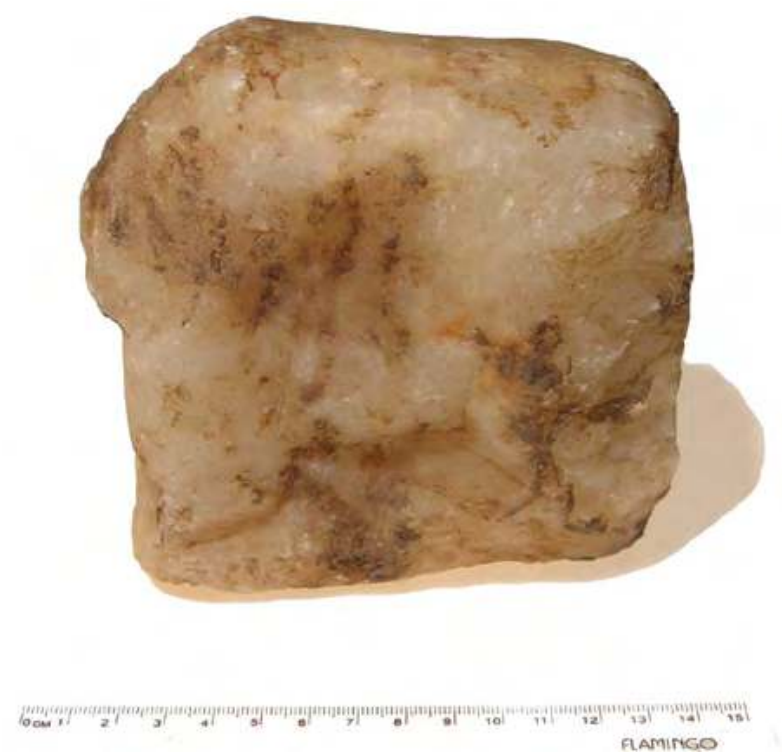

Figure 20. Statuetta di toro (B.04.B.O/139). (R. Valentini 2005 CMAIRY)

Provenienza: zanbil B.04.B.26, Li 18, Periodo Islamico Medio

Collocazione: già Barāqish magazzino del Museo Materiale: alabastro

Dimensioni: cm 13 x 12,5 x 6,5

Conservazione: frammentaria

Descrizione: statuetta acefala di toro, con il corpo delineato da un lieve sottosquadro.

Data: IV secolo a.C. - I secolo d.C.

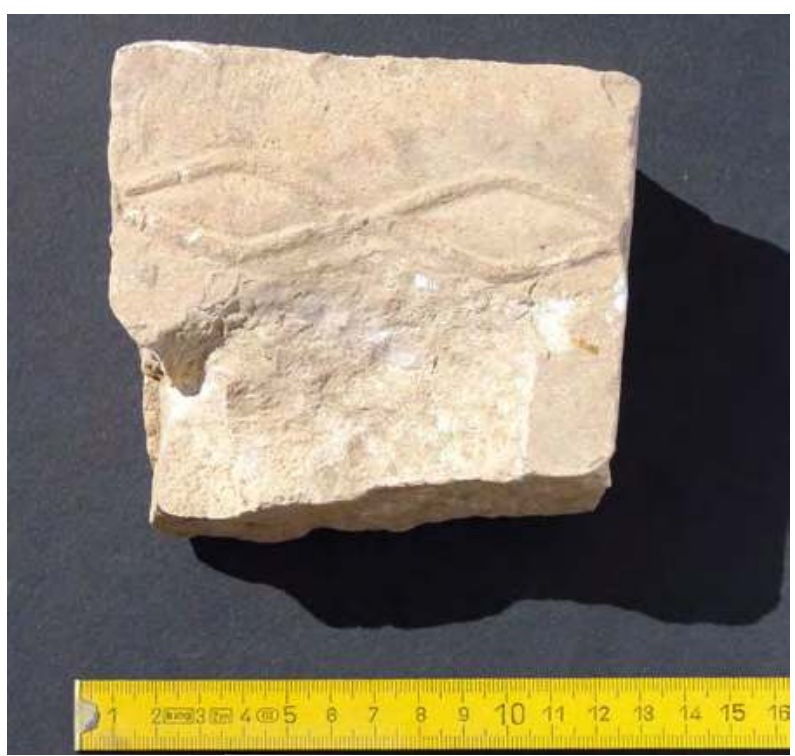

Figure 21. Frammento di stele (B.04.B.O/28).

(R. Valentini 2005 CMAIRY)

\section{Frammento di stele (fig. 21)}

Catalogo: B.04.B.0/28

Provenienza: zanbīl B.04.B.200, Li 200, Periodo Islamico Recente

Collocazione: già Barāqish magazzino del Museo

Materiale: arenaria

Dimensioni: cm 11 x 10 x 6,2

Conservazione: frammentaria

Bibliografia: Antonini 2005, 308-309, tav. 1c.

Descrizione: porzione superiore di stele funeraria rettangolare con occhi a losanga, scolpiti a rilievo piatto.

Data: V secolo a.C. - I secolo d.C.

\section{Stele funeraria (fig. 22)}

Catalogo: B.06.B.O/102

Provenienza: nello scavo tra il Tempio A (Nakrah) e il Tempio B ('Athtar dhu-Qabḍ)

Collocazione: già Barāqish magazzino del Museo Materiale: calcare

Dimensioni: $\mathrm{cm} 30$ × 20 × 8,5

Conservazione: quasi integra

Descrizione: stele funeraria rettangolare con volto umano inciso nella porzione superiore della lastra di pietra. Sono rappresentati sommariamente il contorno del volto, gli occhi ovali e le sopracciglia, e il naso rettangolare. Nella porzione inferiore si intravedono alcuni segni incisi che componevano il nome del defunto.

Data: I secolo a.C. - I secolo d.C.

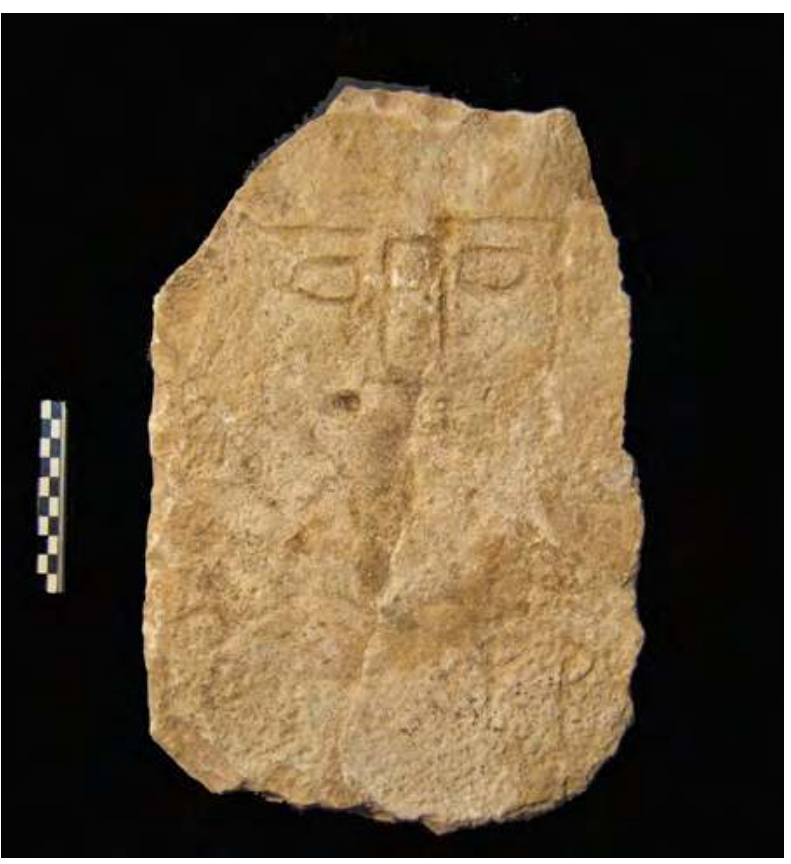

Figure 22. Stele funeraria (B.06.B.O/102). (R. Valentini 2005 OMAIRY) 


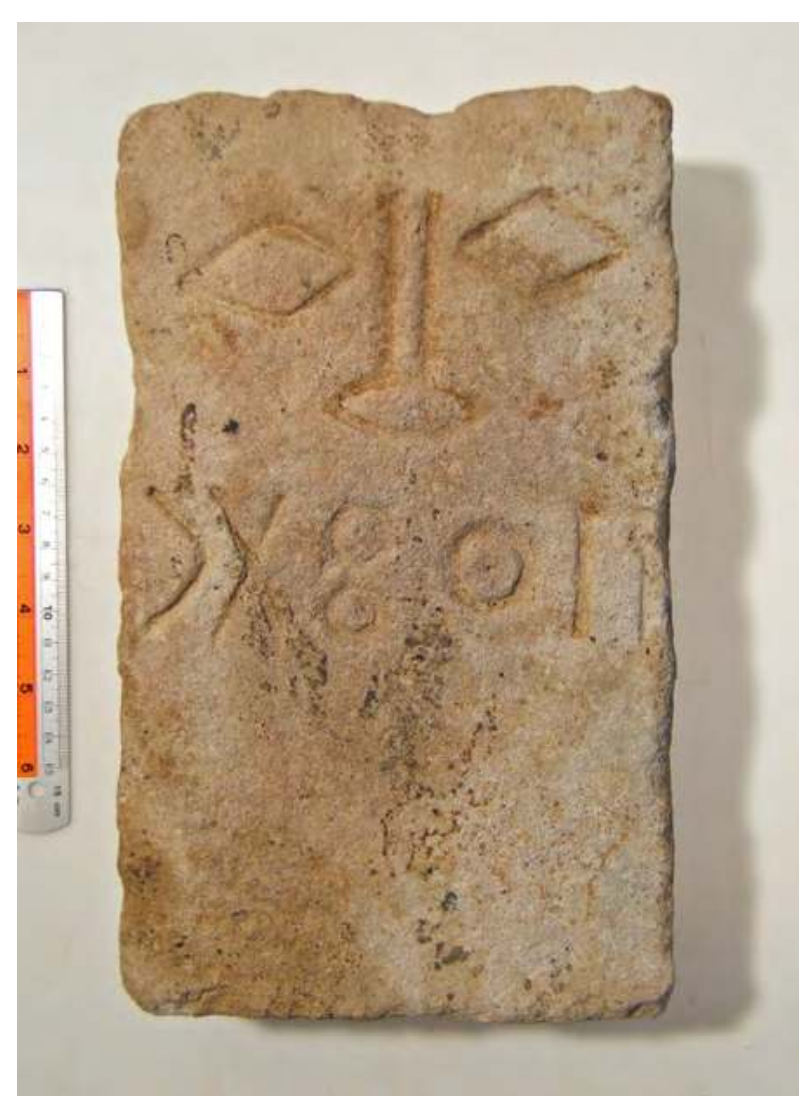

Figure 23. Stele di 'Athtar (B.05.B.O/55).

(R. Valentini 2005 CMAIRY)

\section{Stele di 'Atthar (fig. 23)}

Catalogo: B.05.B.O/55 (iscrizione Y.05.B.B./27, v. Agostini, capitolo 4 in questo volume, fig. 15)

Provenienza: zanbil B.05.B.55, Li 20, Periodo Islamico Antico

Collocazione: già Barāqish magazzino del Museo

Materiale: calcare

Dimensioni: cm 26 x 15,5 x 5,7

Conservazione: integra

Descrizione: stele votiva (o funeraria) di forma rettangolare. Sulla faccia anteriore, piatta e ben levigata, sono incise le fattezze di un volto umano: gli occhi a losanga, il naso con due linee verticali parallele e la bocca ovale. Al di sotto è inciso il nome Bicathtar. Le facce laterali sono levigate e recano i segni obliqui dello strumento di lavorazione. La faccia posteriore è semplicemente sbozzata.

Data: I secolo a.C. - I secolo d.C.

\section{Oggetti in metallo}

\section{Lamina in argento (fig. 24)}

Catalogo: B.05.B.0/9

Provenienza: Tempio B, L 104, sul pavimento, Periodo Mineo
Collocazione: già Barāqish magazzino del Museo Materiale: argento

Dimensioni: lungh. $\mathrm{cm} \mathrm{11;} \mathrm{spess.} \mathrm{cm} \mathrm{0,8}$

Conservazione: frammentaria, fortemente ossidata Descrizione: lamina rettangolare, con superficie irregolare e ripiegata, e foro passante.

Data: V secolo a.C. - I secolo d.C.

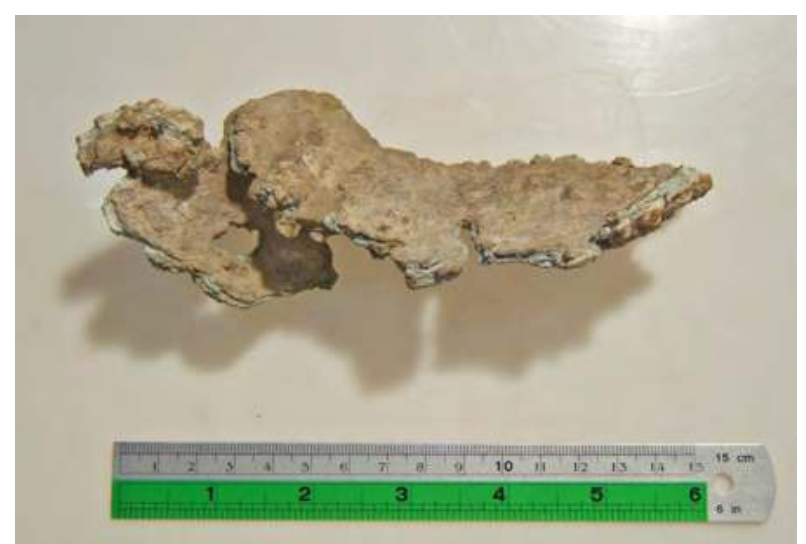

Figure 24. Lamina in argento (B.05.B.O/9).

(R. Valentini 2005 @MAIRY)

\section{Asticella (fig. 25)}

Catalogo: B.05.B.O/28

Provenienza: zanbill B.05.B/50, Li 303, Periodo Islamico Antico

Collocazione: già Barāqish magazzino del Museo Materiale: bronzo

Dimensioni: lungh. cm 13,8; diam. cm 0,6

Conservazione: integra e ossidata

Descrizione: asticella a sezione circolare, di spessore decrescente in prossimità della punta arrotondata.

Data: V secolo a.C. - I secolo d.C.

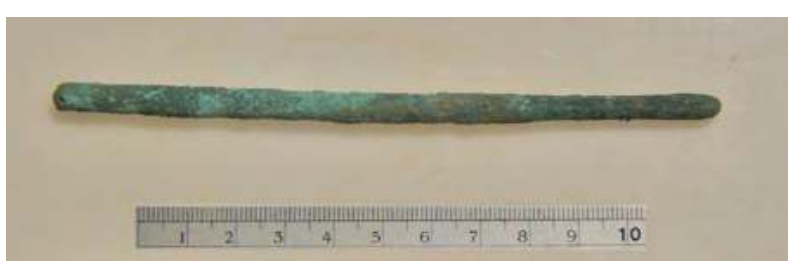

Figure 25. Asticella in bronzo (B.05.B.O/28).

(R. Valentini 2005 @MAIRY)

\section{Asticelle (fig. 26)}

Catalogo: B.05.B.0/49

Provenienza: zanbīl B.05.B/62, L 111, sul pavimento, Periodo Mineo 
Collocazione: già Barāqish magazzino del Museo Materiale: bronzo

Dimensioni: lungh. a) $\mathrm{cm} \mathrm{7,5;} \mathrm{b)} \mathrm{cm} \mathrm{8,8;} \mathrm{c)} \mathrm{cm} 9$ Conservazione: frammentaria e ossidata Descrizione: tre asticelle a sezione rotonda. Data: V secolo a.C. - I secolo d.C.

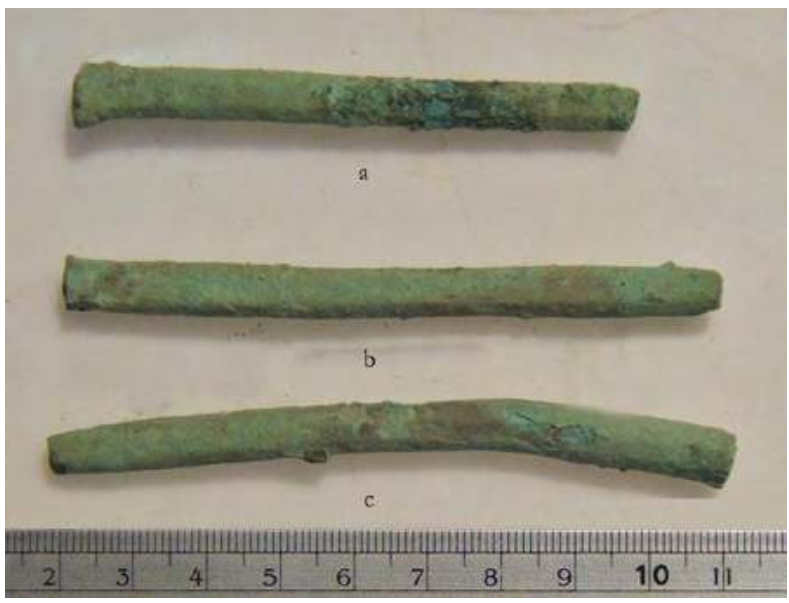

Figure 26. Asticelle in bronzo (B.05.B.0/49). (R. Valentini 2005 CMAIRY)

\section{Asticella (fig. 27)}

Catalogo: B.05.B.0/51

Provenienza: zanbil B.05.B/66, Li 1, Periodo Islamico Antico

Collocazione: già Barāqish magazzino del Museo

Materiale: bronzo

Dimensioni: lungh. cm 7; diam. cm 0,5

Conservazione: frammentaria, con superficie fortemente ossidata e con incrostazioni

Descrizione: asticella con una estremità a punta. La sezione è rotonda.

Data: V secolo a.C. - I secolo d.C.

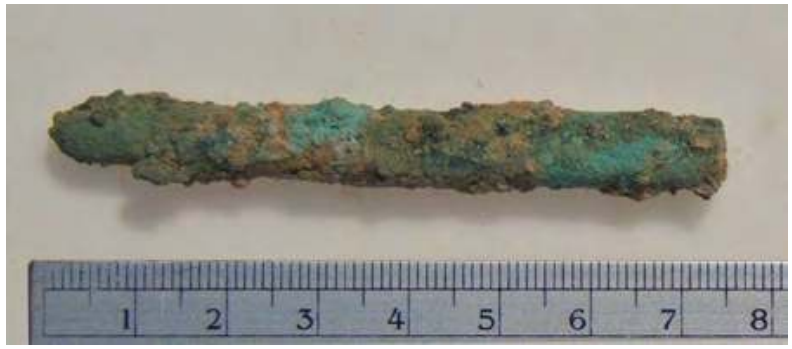

Figure 27. Asticella in bronzo (B.05.B.0/51).

(R. Valentini 2005 @MAIRY)

\section{Chiodi (fig. 28)}

Catalogo: B.05.B.O/50

Provenienza: zanbil B.05.B/38, Li 311, Periodo Islamico Antico

Collocazione: già Barāqish magazzino del Museo

Materiale: bronzo

Dimensioni: lungh. $\mathrm{cm} \mathrm{2;} \mathrm{diam.} \mathrm{testa} \mathrm{cm} \mathrm{0,5;} \mathrm{spess.} \mathrm{cm}$ 0,4

Conservazione: completi (?) e ossidati

Descrizione: chiodini con gambo a sezione quadrata e testa arrotondata e piatta. L'altro elemento in bronzo è una placchetta informe.

Data: V secolo a.C. - I secolo d.C.

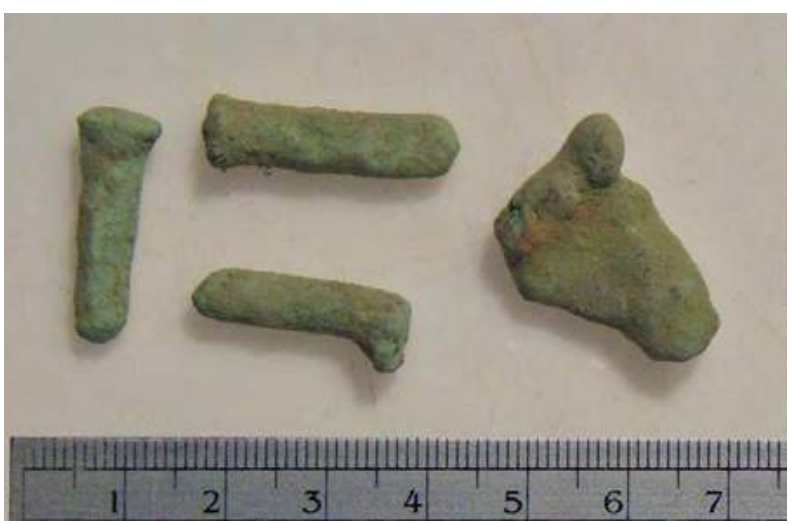

Figure 28. Chiodi in bronzo (B.05.B.O/50).

(R. Valentini 2005 CMAIRY)

\section{Gettone? (fig. 29a-b)}

\section{Catalogo: B.04.B.0/43}

Provenienza: zanbil B.04.B.11, Li 4, Periodo Islamico Medio

Collocazione: già Barāqish magazzino del Museo Materiale: bronzo

Dimensioni: diam. cm 2,4; spess. $\mathrm{cm} 1$

Conservazione: integro, con superficie ossidata

Descrizione: oggetto discoidale con incisione profonda cruciforme su una faccia; sull'altra faccia profonde

a

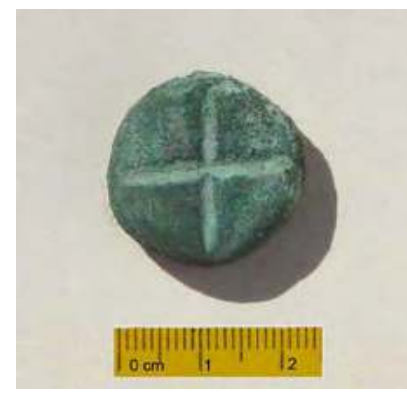

Figure 29a-b. Gettone (?) in bronzo (B.04.B.O/43).

(R. Valentini 2005 OMAIRY) b
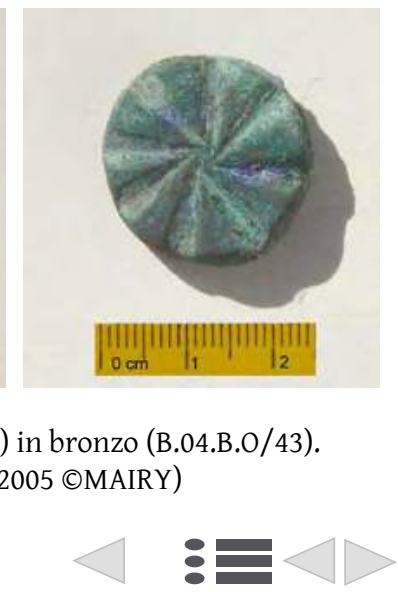

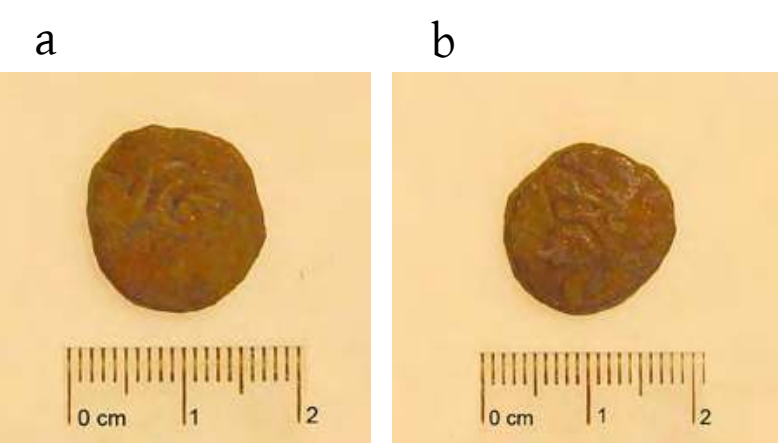

Figure 30a-b. Moneta in bronzo (B.04.B.O/121). (R. Valentini 2005 (MAIRY) incisioni formano una serie di 8 spicchi irregolari disposti a raggera.

\section{Moneta (fig. 30a-b)}

Catalogo: B.04.B.O/121

Provenienza: zanbil B.04.B.21, Li 6, Periodo Islamico Antico

Collocazione: già Barāqish magazzino del Museo Materiale: bronzo

Dimensioni: diam. cm 1,7; spess. mm 3,5

Conservazione: integra 


\title{
Chapter 6
}

\section{An Obsidian Cache from Temple B}

\author{
Francesco G. Fedele
}

\section{Introduction and context}

The discovery of what appears to be a cache characterized by a large obsidian piece in Temple B, in 2005, deserves attention because of its especially charged ideological context. ${ }^{1}$ Significantly, the cache was found in the area of the innermost and presumably most sacred part of the temple, the cella, and its scattered elements were assembled from the cella itself and its immediate surroundings (see Agostini, Chapter 3 above, for the relevant details). ${ }^{2}$ Although noted in the field, ${ }^{3}$ no mention of the discovery was made in the progress report on Temple B compiled at the end of the three excavation campaigns. ${ }^{4}$ From its very first stages, the planning of the present book eventually provided both an opportunity and a framework for bringing this unique finding to the consideration of the scholarly community. ${ }^{5}$

As will be described below, the finding consists of a large obsidian block and several smaller elements. The block, B.05.B/73 (B/73 for short), was found inside the cella, L120, contained in a layer of sand that either was a constructional fill or a post-spoliation sediment. As

\footnotetext{
1 In agreement with Sabina Antonini, this point was first made in an oral intervention (FGF) at the 21èmes Rencontres Sabéennes held in Toulouse (8-10 June 2017), following a paper by Lamya Khalidi on obsidian sources in Ethiopia and the Afro-Arabian contacts. Until then the finding from Temple B had remained unannounced, except for a brief mention by A. Agostini $(2015,7)$.

2 Particularly sections 1.2 (excavation proceedings) and 1.4 (test in transept in front of the cella). These details will be summarized below.

3 Alessio Agostini, personal communication 13.2.2015 (cf. below). The finding was made during the second campaign of excavations at Temple B in November-December 2005.

${ }^{4}$ de Maigret 2009b. At the time of the first interim report (de Maigret 2006, dealing with the first campaign) the cella of the temple had not yet been excavated.

5 This group of obsidian artefacts caught my attention in 2007 during the photography sessions by G. Di Rosa and S. Iavarone devoted to the finds of Temple B, which I was supervising. I was unaware of such material from the temple. The obsidians were photographed and examined on 6 December. What were they, and how had such an unusual cluster ended up in a cultic setting? I raised the subject during our first collegial meeting for the present book, held in Rome on 13 February 2015. Indeed, the initial guidelines for this chapter emerged from the stimulating, impromptu discussion that followed. Immediately afterwards I circulated among the colleagues my copy of the 14 digital photographs, and Agostini managed to insert a mention of the obsidians in his article in PSAS at the stage of proofs (cf. footnote 1, above).
}

to the smaller elements, a limited dispersion out of the cella had occurred. The floor of the cella, and the supposed low podium that had been made on its floor, had in effect been removed around the end of the temple's lifespan, together with the flagstones paving the transept immediately in front of the cella (locus L111). Therefore it cannot be determined whether the obsidian elements were originally placed on the floor - and possibly on the podium - or concealed below it. There is no doubt, however, about their association with the cella and having originally formed a cluster. We are dealing with a cluster that from circumstantial evidence can be construed as a cache, in spite of postdepositional perturbation and scattering. From the same evidence and with additional support provided by the outsize block, the original location of this cache can be traced to the cella. ${ }^{6}$

Here is a recapitulation of the excavation contexts involved: ${ }^{7}$

- B/73: from L120 (the cella); subphase Minaean C;

- B/18: from L104 (central nave); subphase Minaean B;

- B/51: from L110 (transept); subphase IV 'Abandonment';

- B/20+64: from L104 (central nave); subphase Minaean B;

\footnotetext{
${ }^{6}$ Here I use the term 'cache' on the basis of the above assumptions: a cache is the most parsimonious interpretation of the available evidence. In common language, a cache is a secret place for keeping provisions or valuables, as well as the contents of this place. In archaeology, any deposit of hidden objects may be considered a cache. The term and its meanings were repeatedly discussed by Schiffer (1996, 79-80, and elsewhere; Fogelin and Schiffer 2015), who gave a definition of 'ritual cache', in particular, at the same time observing that cache can encompass multiple types of ritual and nonritual deposition. In a recent review, considering that ritual and nonritual caches can be archaeologically distinguished, MacLellan (2019, 1249-1250) includes in the former such cases as 'periodic depositions in special locations', 'offerings associated with episodes', dedicatory and 'termination offerings', and in the latter - for instance the caches made of 'objects stored for future use'. All represent theoretical possibilities for our case from Temple B. Sometimes, it is also appropriate to note (cf. Bradley 1982), cached items were expressly taken out of active service - decommissioned - or were clearly intended as unsuitable for utilitarian use.

7 After Agostini, Chapter 3, Tables 1 (phasing) and 2 (zanäbïl); registration prefix 'B.05' omitted. Throughout this chapter this simplified designation will be employed.
} 
- B/58: from L111 (transept, in front of cella); subphase A 'Intermediate (Amirite)'.

\section{Material}

The six chipped-stone objects comprising the cache (Fig. 1) are all made of opaque black obsidian, representing a fairly uniform rock type. The rock shows occasional, negligible translucence only along the thinnest margins. There is no reason to think of a provenance from outside Yemen, since major sources of visually identical obsidian are known from the Yemen Plateau, to the west of Dhamār and in the Dhamār-Radāc volcanic field. ${ }^{8}$ The following description of the lithics is based on the autoptic examination of December 2007 (mentioned in footnote 5) and the photographs. ${ }^{9}$ It was not possible to weigh the objects.

B.05.B/73 (Fig. 1/a). Large piece of excellent raw material in the shape of a thick orange segment, probably a core just ready for exploitation. $19 \times 13.9 \times$ $14 \mathrm{~cm}$. The cortex, preserved for about one third of the 'back' of the segment, combines the cortical attributes of finds nos B/18 and B/20+64: a polyhedral suite of flat surfaces intermittently pockmarked with little holes, these latter often grouped in narrow bands. Plain areas predominate. At one end the cortex is scarred by thin, parallel furrows reminiscent of no. B/51. The overall characteristics suggest for this block of obsidian a proximate origin from a large - or very large - nodule or cobble, collected from a wādī-bed or scree.

B.05.B/18 (Fig. 1/b). Large, elongated piece of raw material, irregularly triangular in section and with pointed opposite ends, probably employed as a de facto core. $8.4 \times 7.9 \times 3.3 \mathrm{~cm}$. Two main faces flaked, the third one mostly cortical. Several scars suggest the intentional removal of blades. The cortex is slightly angular and pockmarked with little holes, some almost alveolar in appearance. These and other hollows retain an adhering matrix of yellow medium sand, likely

\footnotetext{
8 Overstreet et al. 1988b, 373-391, fig. 12.01; Francaviglia 1990; Fedele 1990c; Khalidi et al. 2010; Lewis et al. 2010, 220-222. The obsidian from Temple B is visually indistinguishable from variants of opaque, dark black obsidian amply recorded at Neolithic and Bronze Age sites on the eastern Yemen Plateau (e.g., Fedele and Zaccara 2009; Fedele in press; and personal observations 1984-1990), now precisely sourced to the highland central region (Khalidi et al. 2010, 2012; Barca et al. 2012). Whether obsidian sources also exist in southwest Hadramawt (Caton Thompson 1944, 135-136; cf. Queen of Sheba 2002, 188) is uncertain. The meticulous overview by Overstreet et al. (1988b, 390391) covers the southeastern and eastern parts of Yemen - as well as Saudi Arabia - only briefly, but is sufficient to remind us that the Temple B obsidian might have been brought in by caravan parties from distant locations in the Arabian Peninsula (cf. section 3, below). Without geochemical provenancing of the Barāqish finds there is no point in trying to elaborate on this matter.

9 Lithic terminology essentially follows Andrefsky 2005. Some suggestions were adopted from a fine study by Conolly (2003, 364369).
}

derived from the enveloping sediments (cf. 'sandy filling' of locus L120; Agostini, Chapter 3).

B.05.B/51 (Fig. 1/C). Roughly prismatic piece of raw material, triangular in section, unexploited. $9 \times 5.2 \times 3.8$ $\mathrm{cm}$. Two main faces flattish, one of which marginally scarred; the third face entirely cortical. The cortex shows parallel fluting from deep, interrupted furrows which retain a beige silty matrix with a fraction of yellow medium sand (cf. no. B/18). The surface appearance of the rock in this specimen is dark grey rather than black, i. e., slightly paler than in the rest of the finds, but as full-black obsidian transpires in the deeper scars we are clearly dealing with a combination of cortical weathering and surface patina. The rock falls within the natural variability of opaque black obsidian.

B.05.B/20+64 (Fig. 1/d). Broad, primary cortical flake, tabular in general appearance. $3.8 \times 2.9 \times$ c. $1.4 \mathrm{~cm}$. Its dorsal surface coincides with a flat patch of cortex, characterized by a scatter of deep pits $(2-3.5 \mathrm{~mm}$ in diameter) in combination with plain areas showing faint striations. The ventral surface is irregularly convex from hard-hammer percussion, and characterized by a bulb of force associated with localized lines of impact (striae). The broad, thick, flat striking platform has a striking angle of about $45^{\circ}$.

B.05.B/58, including B/58a and B/58b (Fig. 1/e). This register number (zanbil 58) includes two pieces which will be described as nos B/58a and B/58b. No. B/58a $(4.8 \times 2.7 \times$ c. $2 \mathrm{~cm})$ appears to be a nearly - or fully? - exhausted polyhedral core, roughly 'naviform' in shape, its main surfaces displaying multiple removals from different directions. An alternative interpretation is a facetted flake from core rejuvenation. This piece retains a cm-sized patch of cortex at one of its ends. No. $\mathrm{B} / 58 \mathrm{~b}(3.2 \times 2.3 \times \mathrm{c} .1 .2 \mathrm{~cm})$ is a fragment of a primary cortical tablet (no flake attributes) showing a convex dorsal surface, with very irregular cortex. From their similarity in lithology as well as type of cortex nos $\mathrm{B} / 58 \mathrm{a}$ and $\mathrm{B} / 58 \mathrm{~b}$ might be closely related products.

It transpires from the above analysis that the cache does not include any tool. Nor does it contain waste smaller than about $3 \mathrm{~cm}$. No piece suggests a connection with the production of geometric microliths (see sections 3-4, below), a theoretical possibility that, however, cannot entirely be excluded. It is quite possible that at least the two largest pieces (nos B/73 and B/18) are spatially close chunks from a single, bigger block of raw material.

\section{Discussion and a search for parallels}

This lithic assemblage, composed of two or three cores and a small series of related debitage, gives the overall impression of either being raw material for 
a

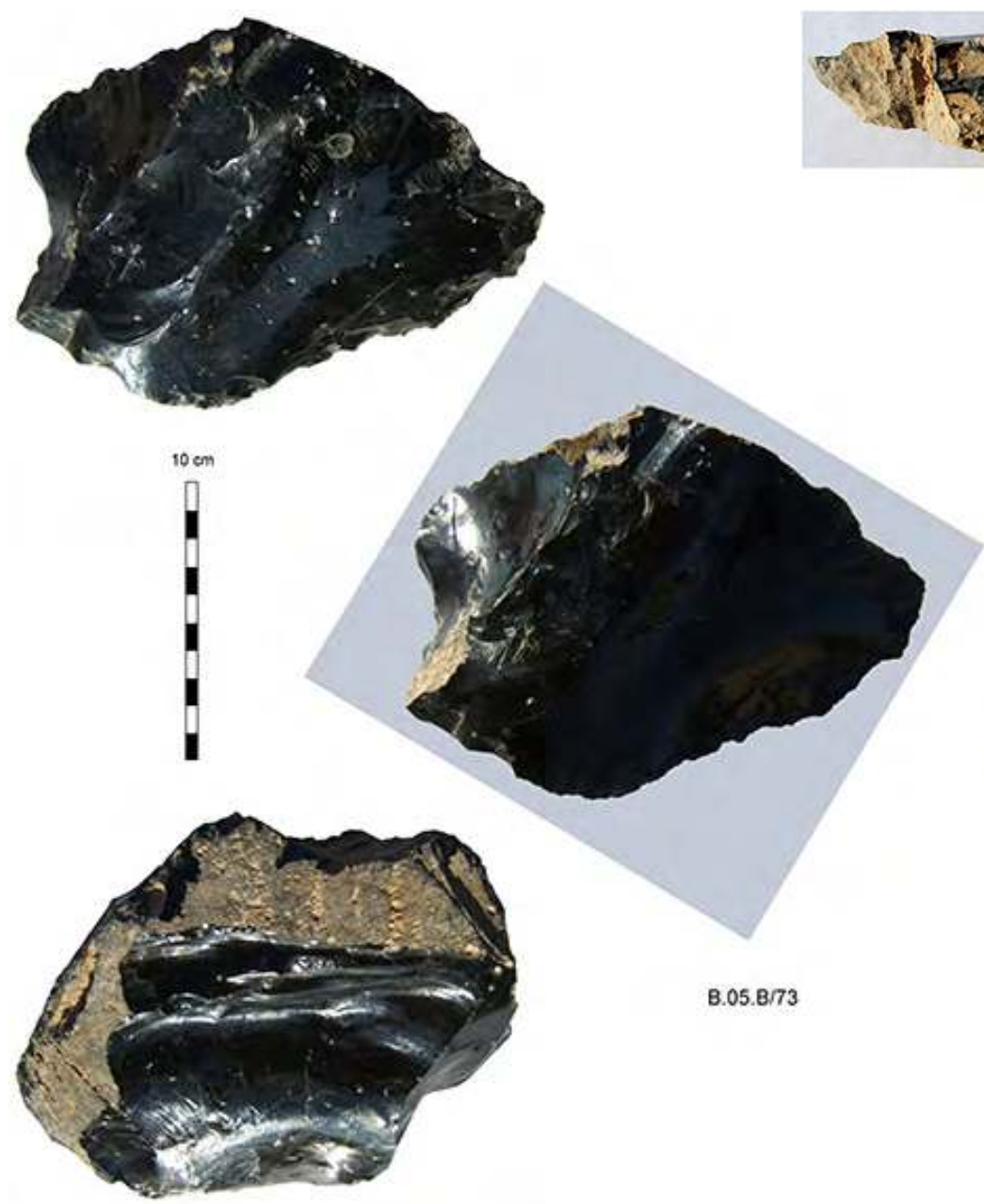

b
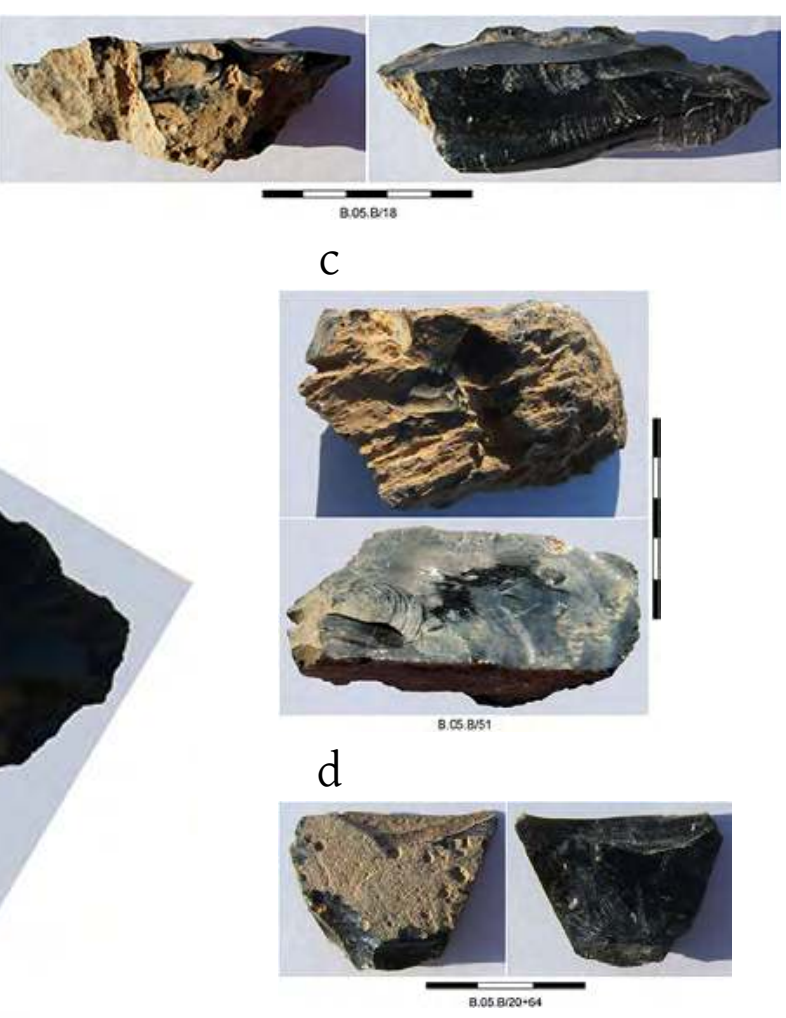

e

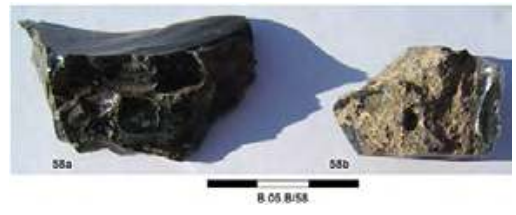

Figure 1. Barāqish, Temple B: obsidian elements in the cache from L120. Scale in cm. (G. Di Rosa and S. Iavarone 2007 C MAIRY, arranged and optimized by F.G. Fedele 2019)

future use, or - as a less parsimonious but equally admissible alternative - a residual lot from some kind of utilization or function. This is the intuitive standpoint. Whichever the case, according to this line of interpretation this obsidian would have been intended for making tools, hence, possibly, tools used in temple life or service, for example in a liturgy. If so, quite a number of hypothesis or even scenarios involving specific functions could be entertained, all, alas, now untestable. ${ }^{10}$

10 If making liturgical tools were indeed the purpose, a possibility inspired by Near Eastern and Egyptian analogies could be the manufacturing of obsidian knives for sacrificial use. Just for the record, a pressure-flaked bifacial knife made from chert, resembling the Egyptian types and - as such - possibly unparalleled inYemen, was obtained from a 'bedouin' at Hurayda in the Hadramawt (Caton Thompson 1944, 67, 144, pl. LXI/8; interpretation mine). Indeed, obsidian continued to be recommended in Early Islamic literature for slaughtering tools, in unison with the indication of using obsidian and chert tools as strike-a-lights (Miller 1984; cf. Queen of Sheba 2002, 188; also Caton Thompson 1944, 136).
An alternative and equally untestable line of interpretation would involve ideology. This again can be manifold, and the following is a random sample of vignettes:

- a general or a votive offering, possibly occasional and individual;

- a dedication inspired by some special episode, or incident, or encounter, in which a specific piece of obsidian had taken on a symbolic or commemorative role;

- a termination offering (cf. footnote 6), e.g., the decommissioning of obsidian that not only had been liturgically exploited (see above), but had acquired special meaning because of its use.

- Is this obsidian the simple recording of an episode, and in this case, considering the exotic status of obsidian at a site in the Jawf, an episode that had occurred far away, for instance during travel, caravan trade, or diplomatic mission (cf. footnote 8)? 
- Is the cache primary, in this case a 'structured deposition' connected with its temple-life phase? Or is it secondary, i.e. the hoarding and disposing of material whose uselife had expired?

- Or again, is it the concealment of objects at the moment in which the temple was abandoned by its original ministers, adherents, and/or users?

It should be noted that the above interpretations may overlap in part, as is often typical of ideology.

Whether an object such as B/73, almost 20 centimetre long, could be a symbolic stone or even a sacred effigy (a mașsebā or 'baetyl') cannot be determined on present evidence. ${ }^{11}$ It is sufficiently well known how natural stones which are for us inanimate, as well as stones turned into portable artefacts, in other cultures and times were imbued with life. ${ }^{12}$

Like each and every other archaeological find, this obsidian from Temple B has a 'biography' (life-history, uselife), of which only the very terminal and somewhat confusing part is archaeologically observable. How time-deep this biography can be, we do not know. We would like to uncover the mental and social meanings embedded in these artefacts and/or manuports, if any. The comments inspired by some special, non-lithic findings from the cella of an Upper Mesopotamian temple - in spite of their distance in space and time - are perhaps apposite here. To paraphrase Roger Matthews, ${ }^{13}$ the fact that these lithics were not left behind in the temple at its abandonment, or somehow ignored after their presumable uselife, but were apparently deposited and concealed, suggests that they were of significance to the people in the context of cult, and likely therefore to have been precious and valuable generally. It still is true, however, that the nature of this obsidian remains a mystery.

Going beyond the mystery, when and if geochemical sourcing of the Temple B obsidian is possible, ${ }^{14}$ would require careful use of an analytical protocol for interpretation. This is attempted here in Table 1. The table presents a systematic series of interrelations and 'pathways' inspired by systems theory, combined with a behavioural and 'biographical' approach to material culture. ${ }^{15}$ It merely provides a heuristic device,

\footnotetext{
11 At the time of examination, regrettably, it did not occur to test whether $\mathrm{B} / 73$ could stand upright by itself.

12 For recent treatments - from a copious literature - see Fogelin and Schiffer 2015 (e.g. 815, 'archaeologists have recognized that some objects are animate in ways similar to people'); Bradley 2017, e.g. chapter 8. In an Arabian context, cf. a passage about the Ka'ba in section 5 , below.

13 Matthews 2003c, 112-113 (speaking of clay sealings at Tell Brak).

14 Or, even better, laboratory obsidian sourcing (cf. footnote 8) coupled with renewed fieldwork at Barāqish and in the Jawf.

15 On the analysis of the cultural biography of artefacts see, e.g.,
}

basically a formalization of questions to be asked: a toolbox for dealing with the trajectory of acquisition, transformation, and deactivation of this obsidian over an unknowable timescale. While the table outlines a conceptual framework for analysis, both a theoretical justification and a detailed exploration of its pathways are outside the scope of the present chapter. Admittedly, only a few pathways could be pursued successfully at present, and these more or less correspond to what has been informally suggested in the above paragraphs of this section.

Needless to say, a considerable impasse in dealing with the case of Temple B is represented by the uniqueness of this finding. Until comparanda from other temple contexts of Iron Age Yemen become available, it will be difficult to argue further, and impossible to explore the case by analogy. However, one step back in time, an equally unique Bronze Age find from the Yemeni Tihāma might be pertinent to our temple-related obsidians. This remarkable finding (1997) from a controlled context at Al-Midamman, a megalithic ceremonial site, is well known: a cache of copper-base tools and weapons originally placed beneath the footing of a now-toppled stone pillar, containing a single, large obsidian block. ${ }^{16}$ This block - a core according to Lamya Khalidi - is cubical and has a maximum diameter of about $15 \mathrm{~cm}$. The term cache for this assemblage was used by Edward Keall, the discoverer. ${ }^{17}$

It cannot be doubted that the core was placed individually, as an integral part of the assemblage and its only non-metal component. And not only that: the single, intact cache of copper artefacts was 'deliberately centred around the large hunk of obsidian'. ${ }^{18}$ From this particular setting at site HWB 36, 'the major surviving standing stone alignment of Monumental Phase $1^{\prime},{ }^{19}$ as well as circumstantial evidence from other occurrences, the megalithic monuments of AlMidamman have been understood as commemorative sites. This interpretation can probably be applied to

Gosden and Marshall 1999 (170, 'thinking biographically'; 174-176, 'performing meaning'); Meskell 2004, particularly chapter 2; Fogelin and Schiffer 2015. The seminal work was Hoskins 1998. More subtly, we need to attempt 'an understanding of the ways that some objects take on, or are given, attributes of life, [of] the rites of passage of objects and the people who interact with them', in order to 'assess differences in the specific qualities of object and human agency', and by such approaches 'interpret enigmatic deposits such as caches, hoards and offerings' (Fogelin and Schiffer 2015, 815).

16 Keall 1998, particularly 141-145, fig. 7; 2004, 2005; Giumlia-Mair et al. 2002, 196-198, fig. 3; Khalidi 2005; 2009a, 361-363; 2009b; Weeks et al. 2009, 579-580, fig. 2; see also Buffa 2007, 200-201. Surprisingly Durrani $(2005,58-61$, etc.) ignores the obsidian. Al-Midamman - a general name for the locality - lies within $2 \mathrm{~km}$ of the Red Sea, and the site in question, HWB 36, is part of Area HWB, locally called AlManāsīb.

17 'The cache', 'the main cache': Keall 1998; Weeks et al. 2009, 579-580.

18 Keall 1998, 144 (emphasis mine), 142; Weeks et al. 2009, 579.

19 Weeks et al. 2009, 579. 
Table 1. An analytical protocol for the investigation of the obsidian cache from Temple B. (F.G. Fedele)

General

'Biography' of the find if treated as a cluster:a

A. previous history ('ante-temple'), i.e. before reaching the temple at Yathill:

A1. geological provenance

A2. human agency, including (a) material aspects, (b) ideological aspects

B. temple-phase biography

B1. association with temple (placement in temple):

a. time of initial association or placement

b. reason(s) of association or placement, i.e. 'function(s)'

B2. active uselife - see section below

B3. deactivation (decommissioning), i.e. cessation of use $\mathrm{b}^{\mathrm{b}}$

B4. deposition(s), i.e. 'sedimentation' in the cella:

a. time(s) of deposition(s)

b. reason(s) of deposition(s)

B5. postdepositional disturbance or reworking?

\section{B2. Active uselife analysis}

B2 corresponds to this question: What kind(s) of use, i.e. 'function' or 'functions'?

F0 [TECHNOLOGY]. ' 'mere' tool-making: hence $\rightarrow$ what tools?

a. raw material intended for future use?

b. actually exploited material?

F1 [IDEOLOGY]. ${ }^{c}$ ideological properties, i.e. meanings and values:

a. general (ontological), i.e. inherent in obsidian as a kind of material

b. specific ('cultic'), i.e. as objects (an object?) connected with the temple:

b1. for liturgy/in liturgy?

b2. as an offering, votive or else?

b3. other? - including as an object or objects of worship?

- Important: material is - or was - always imbued with both technological and ideological properties (or attributes). This means that F0 and F1 are two non-exclusive functions, i.e., they do not constitute two opposites (a polarity) but are connected to each other in a graded interplay (F0 $\leftrightarrow \mathrm{F} 1)$.

${ }^{a}$ If not, this analytical protocol is to be applied to each of the elements constituting the cluster.

${ }^{b}$ Deactivation (as well as deposition) as a cluster, or piece by piece individually? In principle, the next steps of the analysis depend on the answer to this question, or at least, more realistically, on addressing this question.

c ‘Technology' and 'Ideology' (the socio-cultural subsystem) after D. Clarke's 'Material culture subsystem' and 'Religious

subsystem', respectively (Clarke 1968, 101-126, figs 13,17).

similar monolith arrangements across the Tihāma. ${ }^{20}$ At least in one instance, for some unknowable specifics, a block of obsidian imbued with meaning became integral part of a 'commemoration'.

Interpretation aside, at Al-Midamman we are dealing with a specialized deposit, and the case of Yathill's Temple B might not have been dissimilar. What uniquely distinguishes the obsidian finds from the two sites is their exceedingly large size - or the size of one individual piece ${ }^{21}$ - combined with what clearly

\footnotetext{
20 E.g. Khalidi 2009a.

21 Clearly at Al-Midamman, only a mere possibility at Temple B, the cache was a 'structured deposition' from the point of view of being
}

is a particular, non-domestic and non-economic archaeological setting - a 'non-ordinary' context. ${ }^{22}$ No matter what the specific reason associated with the obsidian might have been in each case, the context per se was, so to speak, ideological. It is indeed this analogy that allows us to perceive an equivalence between the two occurrences in terms of meaning, purpose, or both.

informed by the centrality of a large block of obsidian.

22 Unless detailed qualifications can be made, such a term as 'ritual' is best avoided, and also 'cultic' and 'symbolic' must be used with great circumspection. For an introduction to the notion of 'ordinary' vs 'non-ordinary' in archaeological contexts, and how the 'ritual' could be constructed out of the materials of everyday life (in our case, obsidian), see Bradley 2005 (the whole Part I, including 'Conclusion', 119-120). 
In conclusion, it appears that there were moments and places during the Yemeni prehistory and protohistory when obsidian seems to have attracted sustained ideological interest, as an ontological entity in general or because of particular specimens and their associations. Whether that was dictated by mere curiosity, or instead derived from obsidian being endowed with conceptual or symbolic meaning, is impossible to tell: about such an elusive subject we simply need to know more.

Interestingly, at Al-Midamman the obsidian-centred cache and obsidian microliths co-occur, geometric microliths particularly. 'The area is grossly deflated, but the extensive surface scatters of pottery are consistently intermixed with copper alloy tool fragments and obsidian microliths. ${ }^{23}$ These microliths find a reasonable parallel in a vast number of finds from Iron Age contexts in other parts of Yemen, notably the desert margins and the Hadramawt. This, and the original case of the Tihāma, will be further considered in the next section. Geometric microliths are evoked here for the theoretical possibility mentioned at the end of section 2 , above.

\section{Obsidian as both everyday and special material}

A brief digression on obsidian as a cultural material in Yemen is apposite here. If Al-Midamman and Yathill's Temple B obviously represent special cases, obsidian was otherwise frequently used throughout the Neolithic, the Bronze Age, and the South Arabian Iron Age. In fact, its utilization appears to have decreased only during the pre-Islamic centuries of the current era, and have eventually stopped much later. This phenomenon the unexpectedly 'late' occurrence of a formal obsidian production in Yemen - was first outlined during the 1930s in the Hadramawt, where the presence of obsidian artefacts as surface finds was unusually common and had long been noticed. ${ }^{24}$ However, not until Gertrude Caton Thompson recovered obsidian microliths from tombs at Hurayda, in early 1938, was the chronology of those occurrences established. Providing context and dating was Hurayḍa's distinct contribution.

\footnotetext{
23 Giumlia-Mair et al. 2002, 196. See also Khalidi 2005, 119-121, 123124, fig. 10 ('obsidian geometric microliths have been recovered in large numbers on and around sites in the Tihāmah coastal plain, [...] and occasionally on sites of the desert fringe in Yemen').

24 The rare researchers and other visitors who observed how obsidian objects seemed to abound on the ground in the Hadramawt included - in this order - H. von Wissmann and D. Van der Meulen (1930-1931), W.H. Ingrams, S.A. Huzayyin with the Cairo University Expedition (1936), and G. Caton Thompson and E.W. Gardner (winter 1937-1938, from the surface of Hurayda and four lesser preIslamic sites). See, for its particular interest, Caton-Thompson and Gardner 1939, 31-32, 35. As Caton Thompson later reported after her excavations at Hurayda, 'On the irrigated plain, [...] the area was strewn with those obsidian microliths, cores, and waste which the tombs and Temple so vigorously proclaim to be their contemporaries' (Caton Thompson 1944, 15; also xi, 134 [with references in footnote 2], 135).
}

The pages about the obsidian finds retrieved from controlled contexts at Hurayda provide a landmark treatment of archaeological obsidian from Yemen. ${ }^{25}$ The study not only dealt with the obsidian in the burial equipment from two tombs, A5 and A6, ${ }^{26}$ but with several non-tomb and non-burial finds: notably, a core and two chips found deep down in the deposits beneath the pavement of the Moon Temple, ${ }^{27}$ and a large obsidian piece supposedly from 'near tomb A5'. Bought from one of her workers, this $12.6-\mathrm{cm}$-long carinated core or 'push-plane', ${ }^{28}$ may be the only published find that is comparable to the largest one from Yathill's Temple B (B/73; Fig. 1/a), in both kind (raw obsidian) and size. Also a relatively large core or 'scraper-core' from tomb A5, with a maximum length of $9.2 \mathrm{~cm},{ }^{29}$ offers a parallel. The dating for the obsidian specimens from Hurayda was only assured by tombs A5 and A6: they appeared to cover the 7th-5th (or 4th) centuries BCE, ${ }^{30}$ a time span which can be broadly retained today. ${ }^{31}$

From her observations at Hurayda, Caton Thompson argued that 'obsidian tools still formed the normal equipment of everyday life in [Hadramawt] a few centuries or less before the Christian era, when more advanced countries had ceased to use them'; 'they were absent at old Arab sites I searched'. ${ }^{32}$ Although coloured by the prejudiced assumptions of the period, Caton Thompson's deduction about the use of obsidian tools is still valid. Particularly noteworthy is the statement that, despite the presence in grave goods, obsidian was part of daily life and mundane equipment.

More recently, along the same lines but focusing on chronology, Keall observed: 'It seems to be standard these days to accept the thought that obsidian may have continued to be used through the Iron Age, even until pre-modern times, so that none of the traditional chronological attributions should be taken for granted in Yemen'. ${ }^{33}$ Regionally, time depth was important. In parts of East Africa, including the Horn and the Ethiopian Plateau, obsidian microlithic artefacts continued in use until early in the second millennium

\footnotetext{
25 Caton Thompson 1944, 134-136, 'Stone objects from tombs A5 ad A6', plates LVIII-LX.

26 In addition to the illustrations in Caton Thompson's monograph (1944), a fine photograph of obsidian geometric microliths from tomb A5 is in Queen of Sheba 2002, 188.

27 From -4 and $-4.30 \mathrm{~m}$ below pavement, reached through a sounding (Caton Thompson 1944, 37 [table], 134-135 [study]).

28 Caton Thompson $1944,134,135$, pl. LIX/4. The object presumably came from a destroyed cave tomb near A5.

29 Caton Thompson 1944, 134, 135, pl. LIX/1.

30 Caton Thompson 1944, 93, 136.

31 See, e.g., Queen of Sheba 2002, 186-190 (St J. Simpson); Vogt 2002, 181.

32 Caton Thompson 1944, 134.

33 Keall 1998, 145.
} 
of our era. ${ }^{34}$ This is replicated throughout Yemen and apparently the neighbouring regions, including the Tihāma coastal plain of southwestern Arabia. However, the Tihāma was a particular case ${ }^{35}$ always representing a different world because of its regular interactions across the Red Sea and with the Horn of Africa: a process which involved both Ethiopian obsidian and East African lithic traditions, prominent among these the geometric microliths. ${ }^{36}$

Selective use of obsidian for the making of specialized chipped-stone tools was particularly common in many periods and cultures, and prehistoric and Iron Age Yemen is no exception. In addition to geometric microliths proper, that is, those resulting from standardized geometric production (whose appearance in South Arabia would postdate the Neolithic, as mentioned), also the production of sharp-edged, 'informal' microlithic elements for composite tools is well documented in Yemen. ${ }^{37}$ Concerning the old Sabaean period - end-2nd and 1st millennia BCE - a fine contribution to elucidating both the overall time span and the repertoire of obsidian use has been provided by the American work of the 1980s in Wādi al-Jūbah, to the southwest of Mārib..$^{38}$

At Barāqish/Yathill itself, but associated with completely different stratified contexts, the finding from Temple B is supplemented by obsidian chips and flakes from the excavations in Area C. This small number of Sabaean and Minaean finds is illustrated in Volume 2, Chapter 21.

\section{The Black Stone at Mecca: a parallel?}

Confronting a cache of black obsidian from a temple, it was perhaps unavoidable to think intuitively of the 'Black Stone' preserved within the Ka'ba in Mecca, Saudi Arabia. However, can the sacred stone at Mecca be obsidian, and a large piece of obsidian especially? It does not seem so, in spite of the identification as obsidian having been voiced once or twice, with no

34 Phillipson 1977; 2005, particularly 208, 232, 233 (with further references). Also Barca et al. 2012, 603-604.

35 Cf. end of section 3, above.

36 E.g. Inizan and Francaviglia 2002; Khalidi 2005, 119-124; 2009b, 284 (a 'late' appearance of geometric microliths as part of a bipolarflaking package and in the context of increased, specialized obsidian exchange, can presumably be traced to an African origin); Barca et al. 2012, 610-612 (Fedele).

37 Rahimi 1985, 1987; Fedele and Zaccara 2005. For Edens and Wilkinson $(1998,97)$ the 'concentrated evidence for production of geometric microliths from obsidian bladelets' at sites such as Ḥurayḍa and those of Wādī al-Jūbah (see below) 'may reflect (semi-) specialized $^{\text {sic }}$ craft production'.

38 In addition to survey (comprehensive data in Overstreet and Grolier 1988a, 1988b, 1996), this project included testing at Hajar alTamrah and Hajar al-Rayhānī. See Rahimi 1985, 129-132, figs 49-50 (Hajar al-Tamrah); 1987, 140 (Hajar al-Rayhāāī); 1996 (from survey). supporting evidence stated. ${ }^{39}$ In fact, a petrographic determination of the Black Stone is hard to come by, and indeed it may not have been attained or not be definitive. ${ }^{40}$ Considering the vicissitudes of the object itself this is not surprising. According to tradition, the original stone $e^{41}$ got smashed into three fragments during a conflict in $64 \mathrm{AH} / 683 \mathrm{CE}$ (the Umayyad Caliphate's siege of Mecca), eventually ending up in a fire; it has undergone innumerable manipulations since. ${ }^{42}$ The present colour of the Stone is reddish black with red and yellow particles. ${ }^{43}$

From a variety of attributes, some probably illusory, the lithology of the Stone has been identified as basalt, agate ${ }^{44}$ obsidian (see above), impactite (impact or 'natural' glass), even pumice. ${ }^{45}$ Following the credence that the Stone had fallen from heaven, it has been widely considered by commentators a stony meteorite, to the point of having been listed as a probable example in Prior and Hey's Catalogue of Meteorites. ${ }^{46}$ However, 39 For Dietz and McHone (1974, 175), on the basis of the Stone's
colour 'obsidian might qualify; but obsidian probably is too brittle
and easily weathered to survive the handling accorded the Kaaba
Stone'. Nearest to Mecca, obsidian could be obtained from volcanic
fields in the western Arabian Shield (e.g., Overstreet et al. 1988b, 390-
391). Incredibly, the identification of the Black Stone's lithology with
obsidian was presented as certain in a recent novel by Alex Berenson
(2015, no pagination given): 'He closed his eyes [...] and found himself
dreaming of the Kaaba, the forty-three-foot-high cube at the heart
of the Grand Mosque in Mecca, tall black granite walls set on a
marble base. The Kaaba protected al-Hajar al-Aswad, the Black Stone,
a smooth piece of obsidian that was sometimes thought to have come
from a meteorite'.

40 '[Its] real nature is difficult to determine' (Wensinck and Jomier 1978, §1; I thank Christian Robin for readily supplying this reference - FGF via S. Antonini). There might be specialist publications in Arabic, in which case I would take the blame for their ignorance. Dietz and McHone $(1974,175)$ cite - presumably from personal correspondence - 'the observations of a highly qualified, but, by his own choice, anonymous, Arab geologist who made the Hajj (pilgrimage to Mecca) and examined the stone carefully', to the effect that the Stone would show a banding indicative of agate.

41 Set intact into the Ka'ba's wall by Prophet Muhammad five years before his first revelation.

42 See details in Wensinck and Jomier 1978, §§1-2. Today - compiling from various sources - the Stone consists of seven or eight fragments, the largest one being the size of a date, which have been cemented together and mounted in a silver frame c. $30.5 \mathrm{~cm}$ across (the Stone's exposed face measures c. $20 \times 16 \mathrm{~cm}$ ); six additional pieces are reported to exist in Istanbul. Cf. 'The Black Stone, front and side views', an image from William Muir's The Life of Muhammad, 1912, page 29 (a multi-volume work published in London between 1858 and 1864; Wikipedia 2018)

43 Wensinck and Jomier 1978, \$1.

44 Dietz and McHone 1974.

45 Cf. Wikipedia 2018; a longer search would perhaps produce more.

46 E.g. - from an ample literature - Kahn 1938; Dietz and McHone 1974, 173; Burke 1991, 221-223. Dietz and McHone (cited) rightly point out that an 'object from heaven', as claimed for the Stone in Muslim tradition, may refer to a supernatural rather than a natural origin, and therefore does not imply per se an origin in extraterrestrial space. More recently, students have demoted the Stone to the rank of a pseudometeorite, a terrestrial rock mistakenly attributed to a meteoritic origin (Grady 2000, 263). A meteoritic origin had been first proposed in 1857 by Paul M. Partsch, the curator of the AustroHungarian imperial collection of minerals in Vienna. 
most reports are insufficiently referenced and amount to no more than personal opinion.

The emblematic colour itself, black, is not beyond doubt, and a reliable source reporting its original colour and size is apparently unknown. Several centuries after its insertion in the $\mathrm{Ka}^{\mathrm{c}} \mathrm{b}$ a the Stone was described as a 'black stone' $46 \mathrm{~cm}$ long (by a 10th-century CE observer), and was depicted as a cobble of black rock, some $30 \mathrm{~cm}$ in size, in a folio manuscript of 1315 CE from the Jami al-Tawarikh. ${ }^{47}$ This, however, is no guarantee that the stone was black originally, or indeed jet or pitch black as it would befit obsidian; ${ }^{48}$ moreover, the alteration to colour caused by the fire of $64 \mathrm{AH}-$ if the event is accurate - can only be conjectured. In fact, an equally significant strand of Islamic tradition holds that the initial colour of the Stone is white: in some stories it is described 'as white as yogurt', in others, 'white as though it were silver', ${ }^{49}$ A fragment of the Stone removed by Muhammad 'Ali in 1817 and inspected by the Austrian consul-general in Egypt, reportedly revealed a pitchblack exterior and a silver-grey, fine-grained interior in which tiny cubes of a bottle-green material were embedded..$^{50}$ It thus seems that the issue of the initial colour might remain endlessly problematic.

The only interesting information for our purposes, perhaps, is that the Black Stone as a revered rock predates Muhammad's actions. Possibly this is also the most reliable 'fact' about the object. The Stone, or an ideology-charged stone anyway, was venerated at the Ka'ba before Muhammad. It had long been associated with the Ka'ba - how long is not known. The Ka'ba, or a precursor, was built in the pre-Islamic period and might have been in existence as early as the 2 nd century CE. ${ }^{51}$
It held 'idols' of the Meccan gods, hence possibly one or more unusual stones related to worship. ${ }^{52}$ Unfortunately the accounts of the campaign of Abraha, which suggest the existence of the $\mathrm{Ka}^{\mathrm{C}} \mathrm{ba}$ as a sacred site in the 6th century CE, 'tell us nothing of its appearance or equipment', including cultic stones or the Stone. ${ }^{53}$ At this date, however, and in any case before Muhammad's time, a stone destined to become the Black Stone was there. It follows as a likely possibility that the Stone is the memory of an ancient litholatry, whatever its rock type or nature.

A last element of potential interest for our case from ancient Yathill: according to a prophetic tradition, touching the Black Stone had a connection with the expiation for sins.$^{54}$ Not perhaps the expiation itself, but the public confession of sins, was a well-known social practice of the Minaeans, closely linked with particular gods and their temples. ${ }^{55}$ At Yathill it would be the patron god Nakrah, hence Temple A rather than Temple $B$, nevertheless one can wonder whether the truly black stone eventually cached in the cella of Temple B might have been itself involved in that ideology.

In the end, the finding from the temple of 'Athtar dhuQabd at Yathill is not only problematic, but intriguing and challenging, since it is unique and lacks elucidation from accompanying evidence. The origin, function, and hypothetical symbolism of Temple B's obsidian will not be properly understood until comparable data from other temple contexts of the same general period have been recovered from Yemen. ${ }^{56}$ At the moment it seems impossible further to argue about its nature and significance.

\footnotetext{
47 'The compendium of chronicles' or 'The universal history'. For a reproduction of the illustration - Muhammad and the Meccan clan elders lifting the Black Stone into place - see Wikipedia 2018, from a copy in the Edinburgh University Library, Special collections and archives.

48 Contra, e.g., Dietz and McHone $(1974,174,175)$, who accept that jet black was the initial colour of the stone.

49 After Muslim scholars' information cited in Dietz and McHone (1974, 177-178).

50 Burke 1991, 221-223.

51 Wensinck and Jomier 1978, §2.
}

\footnotetext{
52 E.g. Glassé 2001, 245. And Wensinck and Jomier 1978, §5: 'It cannot be denied that the cult of the $\mathrm{Ka}^{\mathrm{C}} \mathrm{ba}$ in the pagan era reveals traces of an astral symbolism'; at the same time, 'no tradition suggests that the Black Stone [in fact, any 'sacred' stone - FGF] was connected with any particular god'.

53 Wensinck and Jomier 1978, §2; at the same time it is clear that this sanctuary had involved 'a carefully regulated cult several generations before Muhammad'.

54 Cited in Wikipedia 2018, with references: 'Touching them both (the Black Stone and al-Rukn al-Yamani [the opposite corner of the $\left.\mathrm{Ka} \mathrm{a}^{\mathrm{b}} \mathrm{a}\right]$ ) is an expiation for sins.'

55 Specifically investigated by Alessio Agostini (2012, 2014, 2018b).

56 Cf. mention in section 3, above. The last sentence was inspired by Phillipson 2005, 127.
} 


\title{
Chapter 7 \\ The Temple of 'Athtar dhu-Qabd. The Pottery
}

\author{
Vittoria Buffa
}

\section{Introduction}

The pottery assemblage from the excavation of the temple dedicated to the god'Athtar dhu-Qabd comprises 94 diagnostic fragments. They are catalogued here following the stratigraphic sequence illustrated above by Alessio Agostini in Chapter 3, Table 1, this volume.

Mineo C: represents the sounding below the floor of the cella (locus 120); it is the only sounding that yielded diagnostic pottery (B.05.B./73). ${ }^{1}$

Mineo B: relate to the last frequentation of the various rooms of the temple (B.05.B./74, B.05.B./20+64, B.05.B./18, B.05.B./72).

Fase Intermedia: is described by Agostini as a frequentation post-Minaean, possibly to be related to the presence of the tribe of Amīr in Barāqish (B.05.B./58 and B.05.B./59).

Deposito eolico e crolli: represent the phase of abandonment and collapse of the temple and the formation of aeolian deposits over the ruins (B.05.B./46, B.05.B./51, B.05.B./54, B.05.B./56, B.05.B.57, B.05.B./68).

The description of pastes is illustrated in Chapter 22; the attribution to a type refers to the typological classification illustrated in Chapter 25, Volume 2.

\section{Catalogue}

\section{B.05.B./73, locus 120}

1. (Fig. 1/1). Cup with tronconical profile; flaring sides; thinned rim above a thickened of the wall. Rim diameter $14 \mathrm{~cm}$. Rather fine paste 1 with some straw temper and grits; weak red burnished slip on both surfaces. Type II.4.b.

2. (Fig. 1/2). Shallow carinated bowl. Medium compact paste 1 with some grits and straw temper; burnished red slip on both surfaces (10R 5/6). Type III.A.4.a.

\section{B.05.B./74, locus 121}

3. (Fig. 1/3). Tronco-ovoid jar with vertical thickened, squared rim. Rim diameter $21 \mathrm{~cm}$. Rather fine paste

\footnotetext{
1 For the zanābil numbers see Agostini, Chapter 3, Table 2, this volume.
}

5 with some grits and straw temper; exterior wet smoothed. Type V.A.3.a.

7. (Fig. 1/4). Barrel shaped dolium with two horizontal ridges. Maximum diameter $24 \mathrm{~cm}$. Medium compact paste 6 with some grits and straw temper; interior coated with weak red slip (10R 5/4), exterior smoothed. Type VI.3.

8. (Fig. 1/5). Base with omphalos. Rather fine paste 2 with some black grits; exterior smoothed. Type VII.A.1. 1. (Fig. 1/6). Low ring base with flaring, convex foot. Base diameter $14 \mathrm{~cm}$. Medium compact paste 2 with some grits and straw temper; exterior wet smoothed. Type VII.B.3.

4. (Fig. 1/7). Low ring base with flaring, convex foot. Base diameter $11.5 \mathrm{~cm}$. Medium compact paste 2 with some grits and straw temper; exterior wet smoothed. Type VII.B.3.

\section{B.05.B./20, locus 104}

8. (Fig. 1/8). Large shallow bowl with convex profile sides and flaring rim, rounded lip. Rim diameter $26 \mathrm{~cm}$. Very compact paste 2 with some grits and straw temper; exterior and upper interior surfaces wet smoothed. Type III.B.1.

6. (Fig. 1/10). Deep wavy rim bowl with vertical sides. Very compact paste 5 with some black grits; surfaces smoothed. Type III.A.5.

5. (Fig. 1/9). Jar with everted rim, squared lip. Rim diameter $23 \mathrm{~cm}$. Medium compact paste 4 with some grits; exterior wet smoothed, interior coated with light reddish brown slip (2.5YR 6/4). Type V.B.1.a.

4. (Fig. 1/12). Small jar with curving, everted rim; sloping shoulder. Rim diameter $12 \mathrm{~cm}$. Medium compact paste 6 with black and white grits, some large inclusions, some red (chamotte?), straw temper; interior coated with light reddish brown slip (5YR 6/4), exterior wet smoothed. Type V.B.3.a.

7. (Fig. 1/11). Jar with curving, everted rim, sloping shoulder. Rim diameter $12 \mathrm{~cm}$. Very compact paste 2 with black and white grits, some large red inclusions and straw temper; exterior smoothed. Type V.B.3.b.

2. (Fig. 2/1). Low ring base with flaring foot. Base diameter $8 \mathrm{~cm}$. Fine paste 5 with few black grits; exterior wet smoothed, interior smoothed. Type VII.B.2. 


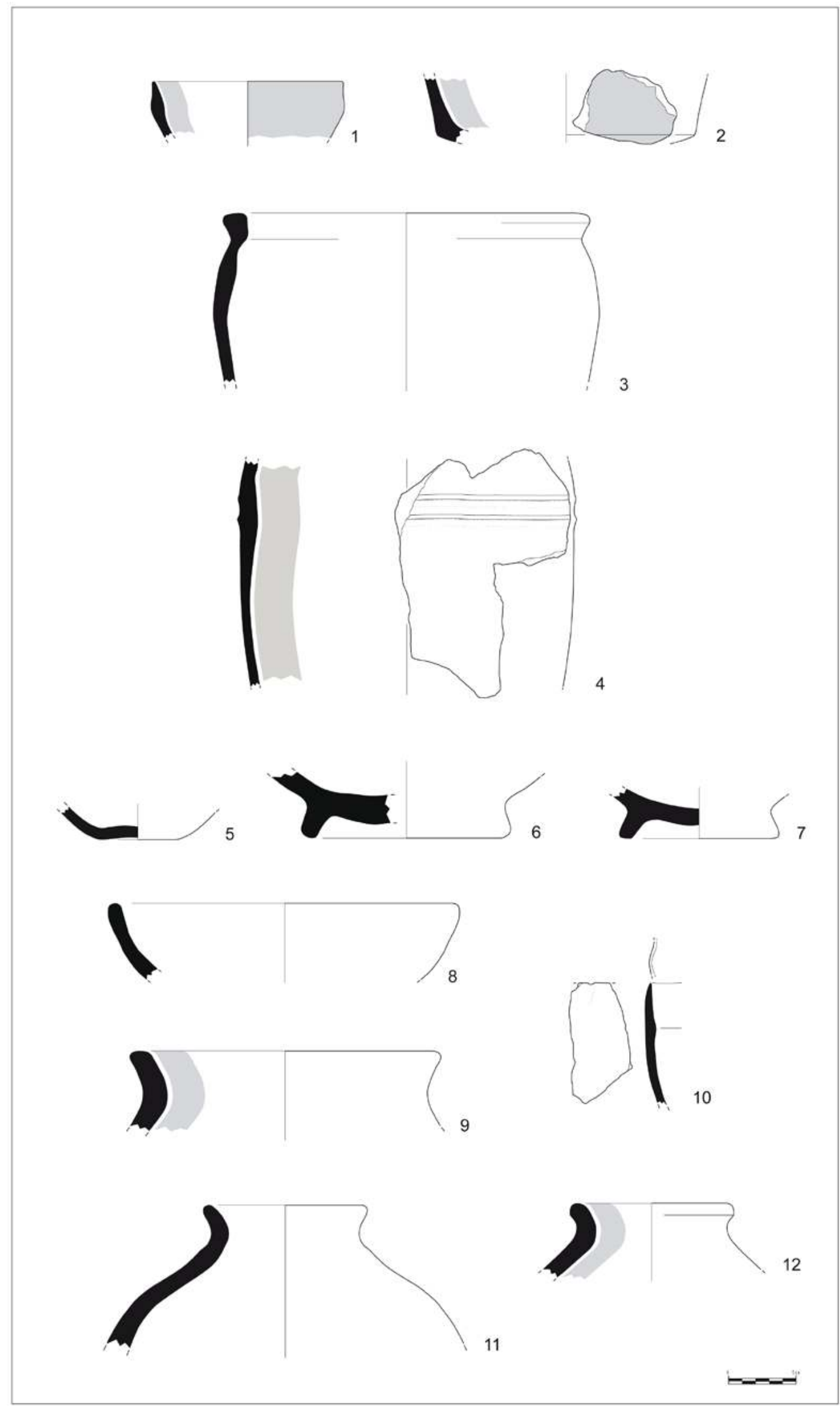

Figure 1. 1: B.05.B./73,1; 2: B.05.B./73,2; 3: B.05.B./74,3; 4: B.05.B./74,7; 5: B.05.B./74,8; 6: B.05.B./74,1; 7 : B.05.B./74,4; 8: B.05.B./20,8; 9: B.05.B./20,5; 10: B.05.B./20,6; 11: B.05.B./20,7; 12: B.05.B./20,4. (G. Stelo 2005 CMAIRY) 
3. (Fig. 2/2). Ring base with cylindrical foot. Medium compact paste 2 with many grits and straw temper; exterior wet (?) smoothed. Type VII.B.5.b.

\section{B.05.B./18, locus 104}

9. (Fig. 2/3). Tronconical bowl with straight sides, rim thickened, squared. Fine paste 1 with some grits and straw temper; surfaces covered with red slip (10R 5/6). Type III.A.2.a.

7. (Fig. 2/4). Shallow bowl of large dimensions, flaring rim, convex profile. Rim diameter $27.5 \mathrm{~cm}$. Compact paste 2 with few grits and a quantity of straw temper; exterior wet smoothed. Type III.B.1.

14. (Fig. 2/5). Jar with ovoid, squatted body; rounded rim. incised line below the rim. Rim diameter $17 \mathrm{~cm}$. Compact paste 2 with some grits and straw temper; exterior wet smoothed. Type V.A.8.

3. (Fig. 2/8). Ovoid jar with everted rim, sloping shoulder. Rim diameter 23 . Very compact paste 1 with some grits and straw temper; interior covered with red slip (10R 5/6), exterior light red slip (2.5YR 6/6). Type V.B.1.a.

5. (Fig. 2/6). Small jar with sharply incurving shoulder and almost vertical rim; thinned lip. Rim diameter $9 \mathrm{~cm}$. Rather fine paste 2 with some grits and straw temper, exterior wet smoothed, interior of rim smoothed. Type V.B.3.b.

6. (Fig. 2/7). Small jar with short vertical neck, thickened, rounded rim. Rim diameter $9 \mathrm{~cm}$. Compact paste 5 with some grits and straw temper; exterior wet smoothed, interior smoothed. Type V.C.1.b.

1. (Fig. 2/9). Low ring base with flaring foot. Base diameter $11.5 \mathrm{~cm}$. Fine paste 6 with some grits and straw temper; exterior wet smoothed, interior covered with a thin slip (7.5YR 7/4). Type VII.B.2.

2. (Fig. 2/10). Low ring base with flaring, convex foot. Base diameter $13 \mathrm{~cm}$. Fine paste 6 with few black grits and mica; exterior burnished over a thin wash. Type VII.B.3.

11. (Fig. 2/11). High ring base with cylindrical foot. Base diameter $20 \mathrm{~cm}$. Medium compact paste 2 with many grits and straw temper; exterior wet smoothed. Type VII.B.5.b.

8. (Fig. 2/12). Vertical loop handle with oval section. Paste 6 with some black grits, surface smoothed. Type VIII.1.c.

10. (Fig. 2/13). Fragment of wall decorated with an incised wavy line. Medium compact paste 4 with a quantity of straw temper and grits; exterior wet smoothed, interior covered with a red slip (7.5R 5/6). Type IX.A.2.

\section{B.05.B./76, locus 104}

9. (Fig. 3/1). Deep cup/beaker on low foot with concave, flaring sides. Base diameter $5.5 \mathrm{~cm}$. Fine paste 5 with some black grits and mica; surface smoothed. Type II.5. 13. (Fig. 3/2). Small tronconical bowl with strait, flaring sides; rim externally thickened. Medium compact paste 5 with some grits and some straw temper, surfaces wet smoothed. Type III.A.1.b.

8. (Fig. 3/4). Large shallow bowl with rim strongly thickened. Rim diameter $31 \mathrm{~cm}$. Compact paste 5 with some straw temper and grits; exterior roughly smoothed. Type III.B.2.

4. (Fig. 3/3). Deep tronconical bowl of large dimensions with upper sides thickened. Rim diameter $21.5 \mathrm{~cm}$. Compact paste 2 with some grits and straw temper; exterior wet smoothed, interior smoothed. Type III.B.4.a.

5. (Fig. 3/5). Basin with thickened rim, with flaring, straight sides. Rim diameter $31 \mathrm{~cm}$. Medium compact paste 2 with some grits and a quantity of straw temper; exterior smoothed, interior roughly smoothed. Type IV.4.b.

6. (Fig. 3/6). Basin with rim strongly thickened outside and inside; straight, flaring sides. Rim diameter $21 \mathrm{~cm}$. Compact paste 2 with some grits and straw temper. Type IV.4.b.

2. (Fig. 3/7). Jar with globular (?) body with tronconical collar. Rim diameter $17 \mathrm{~cm}$. Compact paste 6 with some grits and straw temper. Type V.A.7.

7. (Fig. 3/8). Small jar with curving, vertical rim. Rim diameter $8 \mathrm{~cm}$. On the shoulder two ASA letters. Fine paste 6 with some black grits. Type V.B.3.b.

10. (Fig. 3/9). Low ring base with flaring, convex foot. Base diameter $6.5 \mathrm{~cm}$. Medium compact paste 5 with some black grits. Type VII.B.2.

3. (Fig. 3/10). Low ring base with flaring, convex foot. Base diameter $14 \mathrm{~cm}$. Rather fine paste 5 with some grits and straw temper; exterior wet smoothed, interior smoothed. Type VII.B.3.

1. (Fig. 3/11). Ring base with high cylindrical foot; thick walls. Medium compact paste 3 with some black grits and mica; exterior smoothed. Base diameter $15 \mathrm{~cm}$. Type VII.B.5.b.

15. (Fig. 3/12). Ring base with high cylindrical foot; thick walls. Base diameter $15 \mathrm{~cm}$. Compact paste 2 with grits, some large inclusions, also red (chamotte), and straw temper; exterior wet smoothed. Type VII.B.5.b.

\section{B.05.B./72, locus 103}

2. (Fig. 4/1). Deep bowl with vertical thickened upper sides, rounded rim. Medium compact paste 2 with many grits and straw temper; exterior wet smoothed. Rim diameter $15.5 \mathrm{~cm}$. Variant of type III.B.4.a.

1. (Fig. 4/2). Basin with flaring, straight sides, thickened rim. Rim diameter $37.5 \mathrm{~cm}$. Coarse, flaking paste 3 with a quantity of straw temper and grits; exterior wet smoothed. Type IV.4.a. 


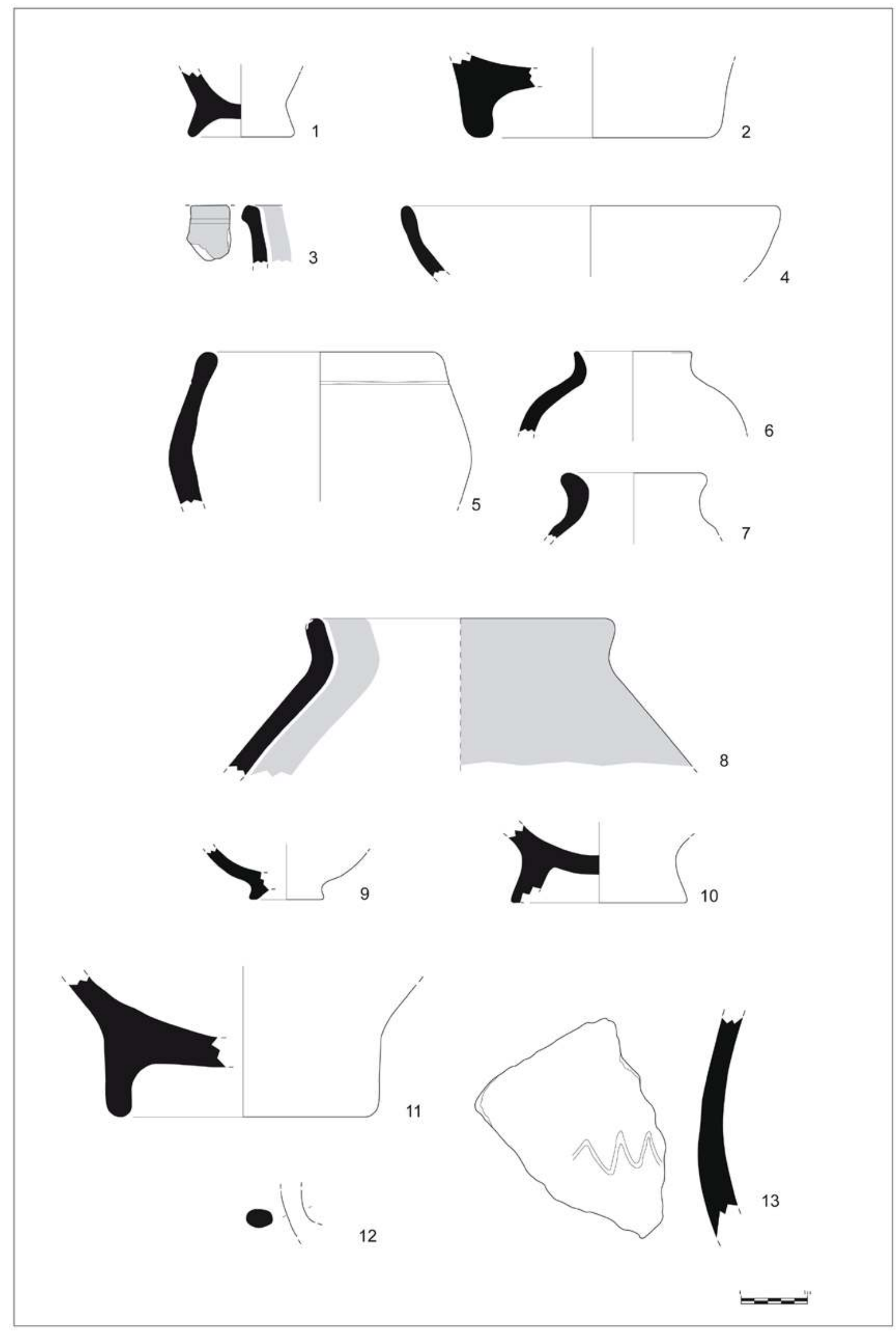

Figure 2. 1: B.05.B./20,2; 2: B.05.B./20,3; 3: B.05.B./18,9; 4: B.05.B./18,7; 5: B.05.B./18,14; 6: B.05.B./18,5; 7: B.05.B./18,6; 8: B.05.B./18,3; 9: B.05.B./18,1; 10: B.05.B./18,2; 11: B.05.B./18,11; 12: B.05.B./18,8; 13: B.05.B./18,10.

(G. Stelo 2005 @MAIRY) 

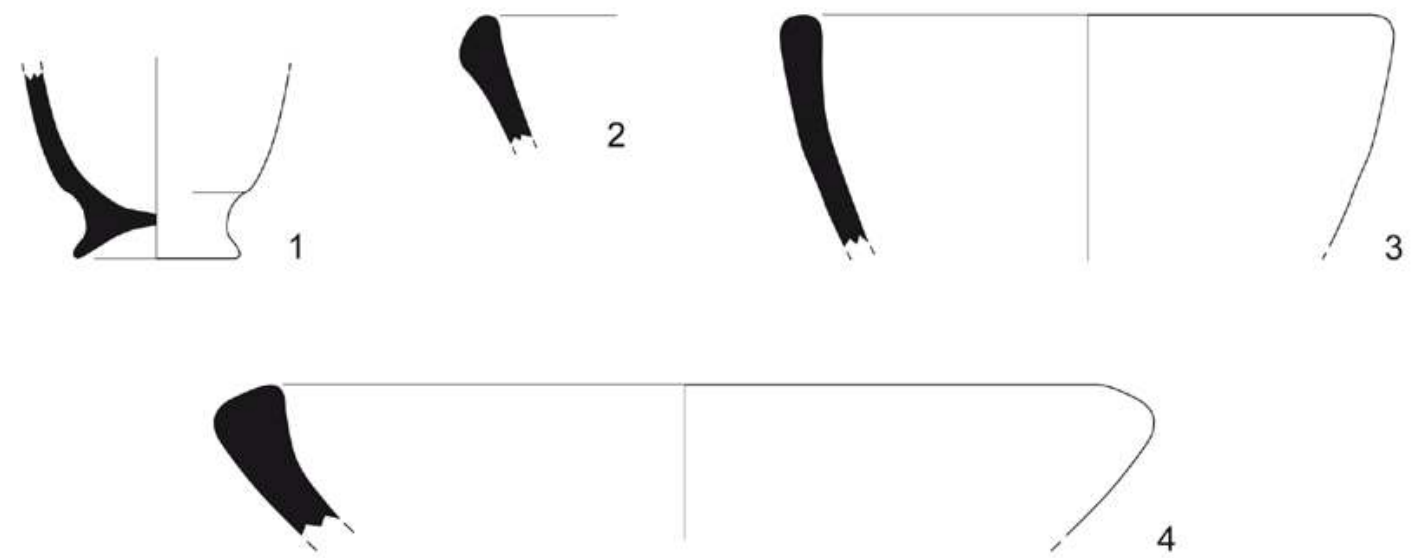

4
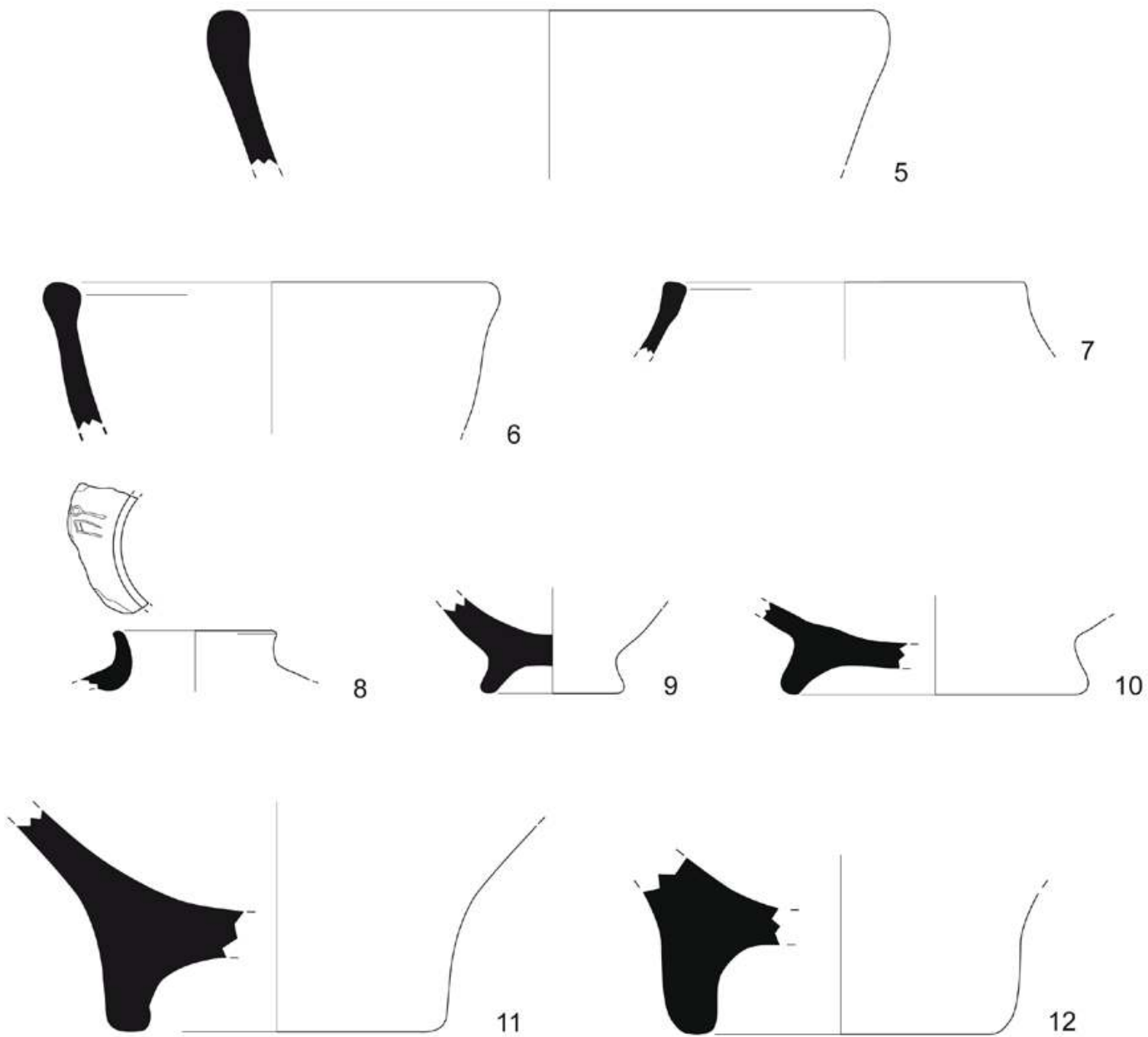

Figure 3. 1: B.05.B./76,9; 2: B.05.B./76,13; 3: B.05.B./76,4; 4: B.05.B./76,8; 5: B.05.B./76,5; 6: B.05.B./76,6; 7: B.05.B./76,2; 8: B.05.B./76,7; 9: B.05.B./76,10; 10: B.05.B./76,3; 11: B.05.B./76,1; 12: B.05.B./76,15. (G. Stelo 2005 @MAIRY) 


\section{B.06.B./57, locus 127}

1. (Fig. 4/3). Large plate with short, straight vertical sides, rounded rim. Rim diameter $33.5 \mathrm{~cm}$. Medium compact paste 1 with some black grits; interior coated with red slip (10R 5/6), interior smoothed. Type I.1.

\section{B.05.B./58, locus 111}

10. (Fig. 4/4). Deep cup/beaker on low foot with concave, flaring sides. Base diameter $5 \mathrm{~cm}$. Fine paste 5 with some black grits and mica; surface smoothed. Type II.5.

23. (Fig. 4/6). Cup? with tronconical profile. Rim diameter $9 \mathrm{~cm}$. Fine paste 6 with some grits and straw temper; surfaces smoothed. Type III.A.1?

16. (Fig. 4/7). Deep tronconical bowl with straight, flaring sides. In inner surface there is a thickened below the rim (to hold a lid?). Rim diameter $17 \mathrm{~m}$. Fine paste 5 with few grits and some straw temper; surfaces smoothed. Type III.1.A.a.

25. (Fig. 4/5). Deep tronconical bowl with straight, flaring sides; upper side thickened outside. Rim diameter $17.5 \mathrm{~cm}$. Medium compact paste 2 with some straw temper and grits. Type III.A.1.b.

11. (Fig. 4/9). Shallow bowl of large dimensions with flaring sides; thickened rim. Rim diameter $27.5 \mathrm{~cm}$. Compact paste 6 with some grits and some straw temper, surfaces smoothed. Type III.B.2.

19. (Fig. 4/8). Bowl of large dimensions with rounded flaring sides, medium depth. Rim diameter $23.5 \mathrm{~cm}$. Medium compact paste 3 with few grits and some straw temper; interior covered with red slip (2.5YR 5/4), exterior smoothed. Type III.B.3.b.

14+15. (Fig. 5/1). Deep, large tronconical bowl with rim thickened, lip flattened. Rim diameter $26 \mathrm{~cm}$. Compact paste 2 with many grits and some straw temper; exterior wet smoothed. Type III.B.4.a.

17. (Fig. 5/4). Bowl with angular profile, vertical upper sides, curving toward the base. Rim diameter $21 \mathrm{~cm}$. Medium compact paste 5 with black and white grits and straw temper; exterior wet smoothed. Type III.C.2.

12. (Fig. 5/2). Deep bowl with incurving rim, with convex profile. Rim diameter $24 \mathrm{~cm}$. Medium compact paste 5 with few grits and some straw temper; surfaces smoothed. Type III.C.5.

9. (Fig. 5/3). Basin with flaring, straight sides; rim thickened. Compact paste 2 with some straw temper and few grits; surfaces smoothed. Rim diameter $36 \mathrm{~cm}$. Type IV.4.b.

21. (Fig. 5/5). Jar with ovoid shape, everted, bevelled rim. Rim diameter $18 \mathrm{~cm}$. Compact paste 6 with some mica and little straw temper; grey core; surfaces smoothed. Type V.B.1.b.

18. (Fig. 5/7). Small jar with curving, everted rim. Rim diameter $11.5 \mathrm{~cm}$. Very compact paste 2 with some straw temper and few grits; surfaces smoothed. Type V.B.3.a.
20. (Fig. 5/6). Small jar with curving, everted rim and sloping shoulder. Compact paste 2 with some grits and straw temper; interior smoothed, exterior wet smoothed. Type V.B.3.a.

1. (Figs 4/10; 9). Large shaped barrel dolium, square transverse section with rounded edges; small horizontal rib below the rounded rim. Rim diameter 40 $\mathrm{cm}$. Compact paste 1 with some grits and straw temper; red slip on exterior. Type VI.2.

2. (Fig. 5/8). Very low ring base with thick foot. Base diameter $5 \mathrm{~cm}$. Very compact paste 2 with some grits and straw temper; surfaces smoothed. Type VII.B.1.

8. (Fig. 5/9). Low ring base with flaring, concave foot of small size. Base diameter $7.5 \mathrm{~cm}$. Very compact paste 2 with some grits and straw temper; exterior wet smoothed, interior smoothed. Type VII.B.2.

5. (Fig. 5/10). Low ring base with flaring, convex foot. Base diameter $12 \mathrm{~cm}$. Medium compact paste 6 with some grits and a quantity of straw temper, exterior wet smoothed, interior smoothed. Type VII.B.3.

3. (Fig. 5/11). Low ring base with flaring, convex foot. Base diameter $13 \mathrm{~cm}$. Medium compact paste 2 with few grits and some straw temper; exterior wet smoothed, interior smoothed. Type VII.B.3.

7. (Fig. 6/1). Low ring base with flaring, convex foot. Base diameter $14.5 \mathrm{~cm}$. Medium compact paste 6 with a quantity of straw temper and some grits; surfaces smoothed. Type VII.B.3.

1. (Fig. 5/12). Low ring base with flaring, convex foot. Base diameter $13 \mathrm{~cm}$. Very compact paste 6 with some grits and straw temper; exterior wet smoothed, interior smoothed. Type VII.B.3.

6. (Fig. 6/2). Medium high ring base with cylindrical foot. Base diameter $13 \mathrm{~cm}$. Medium compact paste 2 with some grits and straw temper; exterior wet smoothed. Type VII.B.5.a.

4. (Fig. 5/13). High ring base with cylindrical foot; foot incurving at base on the inner surface. Base diameter $14.5 \mathrm{~cm}$. Medium compact paste 5 with some grits and a quantity of straw temper; exterior wet smoothed. Type VII.B.5.b.

\section{B.05.B./59, locus 110}

6. (Fig. 6/3). Basin with flaring, straight sides, thickened rim. Rim diameter $20.5 \mathrm{~cm}$. Medium compact paste 6 with some black grits; surfaces smoothed. Type IV.4.b.

5. (Fig. 6/4). Globular jar with flaring collar with rounded rim. Rim diameter $13.5 \mathrm{~cm}$. Compact paste 2 with some grits and straw temper; exterior and inner collar wet smoothed, interior smoothed. Type V.B.4.

7. (Fig. 6/5). Jar with flaring collar with rounded rim. Rim diameter $12.5 \mathrm{~cm}$. Compact paste 5 with some grits and straw temper; surfaces wet smoothed. Type V.B.4.

4. (Fig. 6/7). Low ring base with flaring, concave foot. Base diameter $9.5 \mathrm{~cm}$. Medium compact paste 2 with many grits and some straw temper; light reddish brown paint on exterior (2.5YR 6/4). Type VII.B.2. 


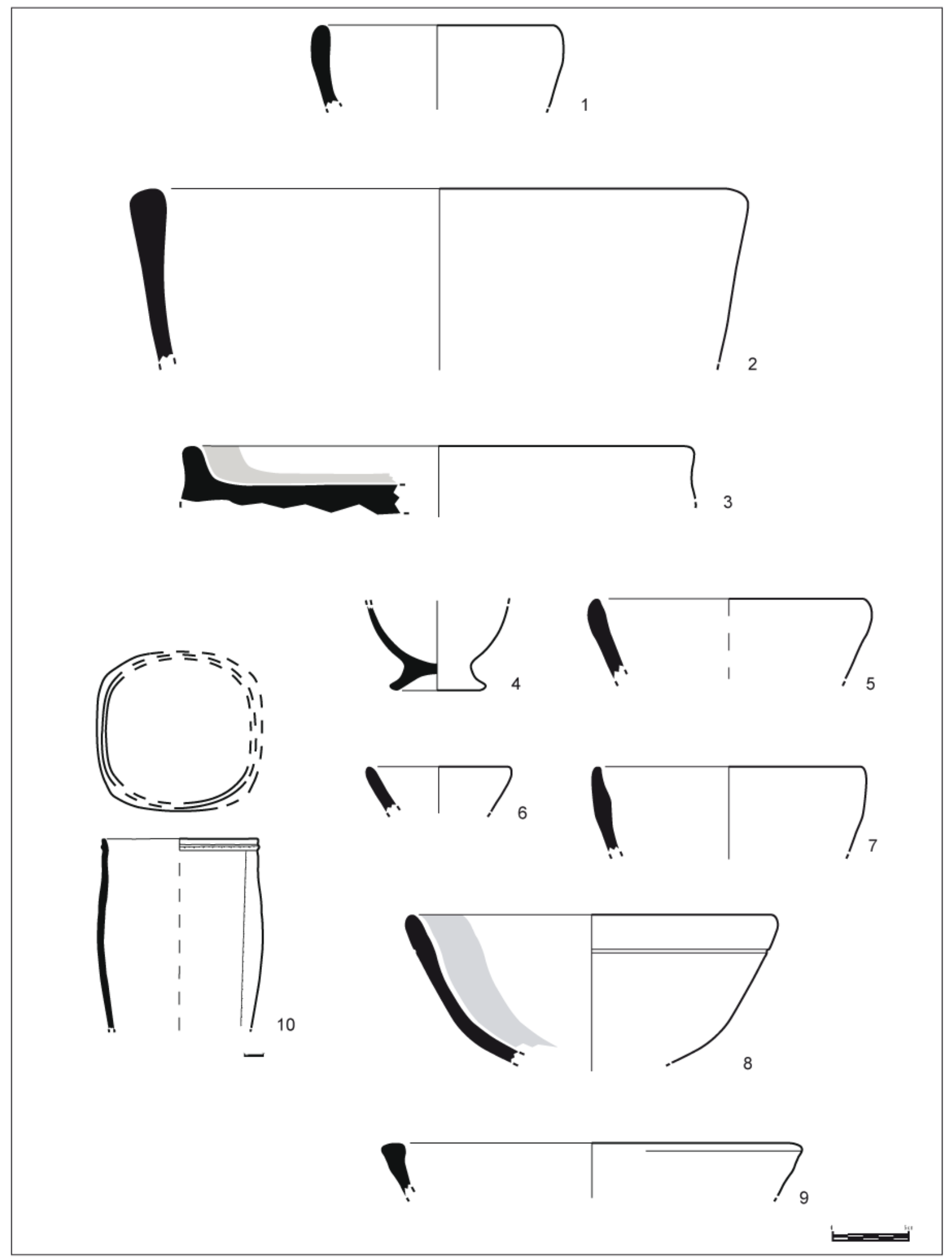

Figure 4. 1: B.05.B./72,2; 2: B.05.B./72,1; 3: B.06.B./57,1; 4: B.05.B./58,10; 5: B.05.B./58,25; 6: B.05.B./58,23; 7: B.05.B./58,16; 8: B.05.B./58,19; 9: B.05.B./58,11; 10: B.05.B./58+74,1. (G. Stelo 2005 @MAIRY) 


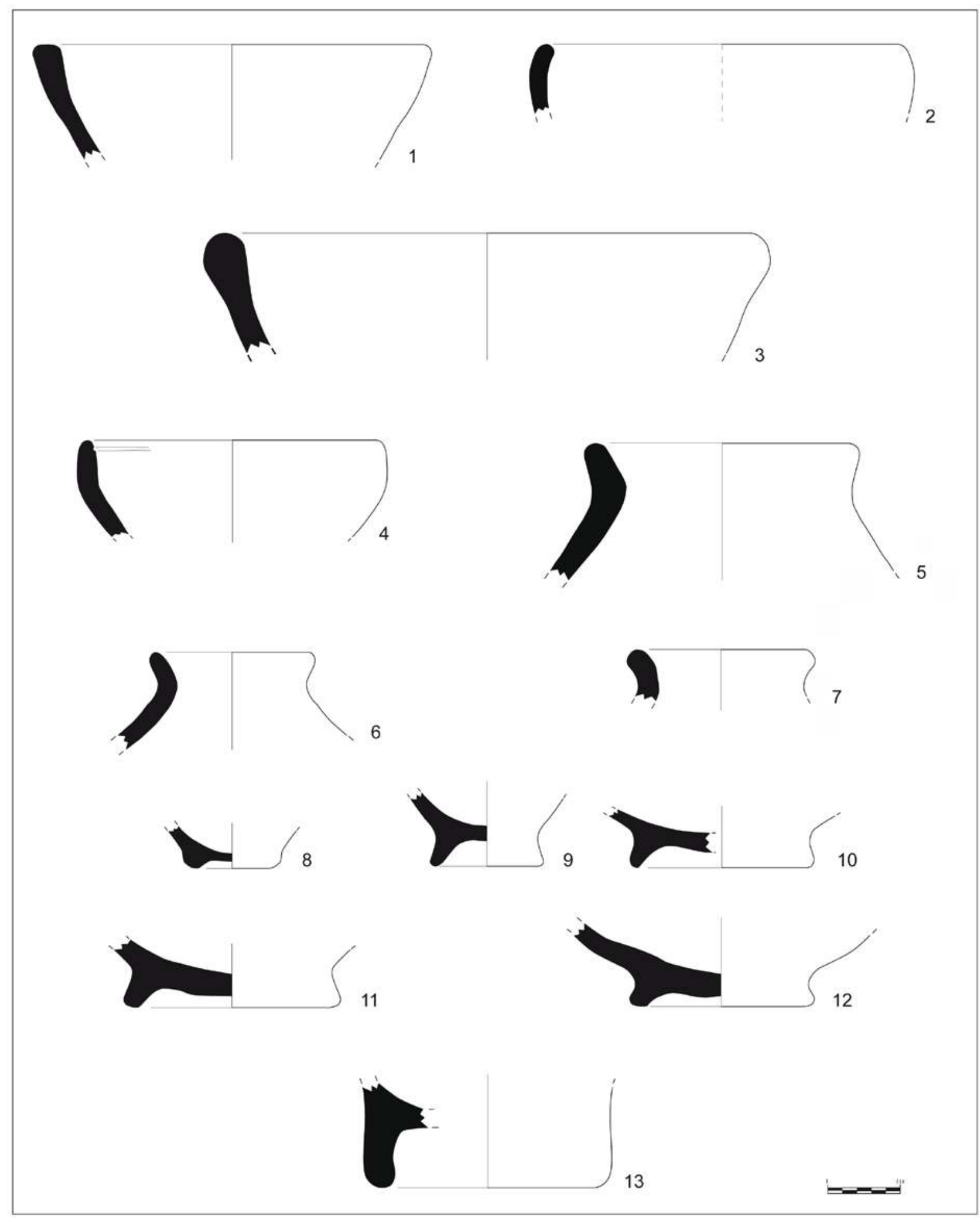

Figure 5. 1: B.05.B./58,14+15; 2: B.05.B./58,12; 3: B.05.B./58,9; 4: B.05.B./58,17; 5: B.05.B./58,21; 6: B.05.B./58,20; 7: B.05.B./58,18; 8: B.05.B./58,2; 9: B.05.B./58,8; 10: B.05.B./58,5; 11: B.05.B./58,3; 12: B.05.B./58,1; 13: B.05.B./58,4. (G. Stelo 2005 CMAIRY) 
3. (Fig. 6/8). Low ring base with flaring, convex foot. Base diameter $11 \mathrm{~cm}$. Medium compact paste 2 with some grits and straw temper; exterior wet smoothed, interior smoothed. Type VII.B.3.

1. (Fig. 6/6). High ring base with cylindrical foot. Base diameter $14 \mathrm{~cm}$. Coarse paste 3 with black and white grits, some large inclusions, some red and straw temper; exterior wet smoothed, interior smoothed. Type VII.B.5.b.

\section{B.05.B./51, locus 110}

4. (Fig. 6/9). Deep, large bowl with slightly curving sides, rim slightly thickened outside, lip flattened. Rim diameter $23.5 \mathrm{~cm}$. Medium compact paste 6 with some grits and straw temper; surfaces smoothed. Type III.B.4.b.

3. (Fig. 6/10). Basin with convex profile sides, slightly flaring; rim strongly thickened, rounded lip; decoration of a horizontal incised line below the rim. Rim diameter $30 \mathrm{~cm}$. Medium compact paste 2 with a quantity of grits and some straw temper; exterior wet smoothed, interior smoothed. Type IV.2.

2. (Fig. 6/11). Barrel shaped dolium with thick walls, rounded rim. Rim diameter $39 \mathrm{~cm}$. Medium compact paste 6 with a quantity of straw temper and grits; surfaces smoothed. Type VI.1.

1. (Fig. 6/12). Ovoid jar with thickened, everted rim. Rim diameter $15.5 \mathrm{~cm}$. Compact paste 6. Type V.B.2.

5. (Fig. 6/13). Ring base with flaring, concave foot. Base diameter $7.5 \mathrm{~cm}$. Very compact, fine paste 7 with some black grits; exterior covered with a pale brown slip. Type VII.B.2.

\section{B.05.B./54, locus 111 (Li 303)}

7. (Fig. 7/1). Cup with convex flaring sides. Compact paste 4 with some grits and straw temper; interior coated with weak red slip (10YR 7/3), exterior smoothed. Type II.4.a.

11. (Fig. 7/2). Cup with tronconical profile with slightly convex sides, bevelled rim. Rim diameter $10 \mathrm{~cm}$. Medium compact paste 1 with some black grits; interior and exterior coated with burnished weak red slip. Type II.4.a.

12. (Fig. 7/5). Large bowl with everted rim. Rim diameter $30.5 \mathrm{~cm}$. Fine paste 8 with mica and a little of straw temper; surfaces polished. Type III.B.5.

6. (Fig. 7/4). Bowl with vertical upper sides, incurving rim. Rim diameter $25 \mathrm{~cm}$. Coarse, porous paste 3 with a quantity of grits and straw temper; surfaces roughly smoothed. Type III.C.1.

10. (Fig. 7/3). Bowl with incurving upper sides, rounded profile. Rim diameter $19 \mathrm{~cm}$. Compact paste 1 with some straw temper and grits; interior and exterior covered with light red slip (2.5YR 6/6). Type III.C.4.

1. (Fig. 7/6). Tronconical basin with flaring, straight sides, slightly thickened rim. Rim diameter $27 \mathrm{~cm}$.
Medium compact, porous paste 2 with some straw temper and grits; surfaces smoothed. Type IV.4.a.

5. (Fig. 7/7). Tronconical basin with flaring, straight sides; rim strongly thicken inside and outside. Rim diameter $27 \mathrm{~cm}$. Medium compact paste 3 with some grits and straw temper; exterior wet smoothed. Type IV.4.b.

9. (Fig. 7/10). Cylindrical jar with vertical rim. Rim diameter $18.5 \mathrm{~cm}$. Compact paste 2 with some grits and straw temper; exterior wet smoothed. Type V.A.1.

3. (Fig. 7/11). Jar with cylindrical profile, rim thickened, slightly converging rim. Rim diameter $13 \mathrm{~cm}$. Compact paste 2 with some grits and straw temper; pale brown wash on exterior, interior smoothed. Type V.A.2.

4. (Fig. 7/9). Small jar with curving, everted rim. Rim diameter $13 \mathrm{~cm}$. Very compact paste 3 with some grits and straw temper, surfaces smoothed. Type V.B.3.b.

2. (Fig. 7/8). Jar with short, vertical neck, everted, thickened rim. Rim diameter $18 \mathrm{~cm}$. Compact paste 2 with some grits and straw temper; exterior wet smoothed, interior smoothed. Type V.C.1.b.

8. (Fig. 8/1). Wall with decoration of three superimposed incised wavy lines. Compact paste 2 with tiny black grits, a quantity of straw temper, some mica; exterior wet smoothed. Type IX.A.2.

\section{B.05.B./56, loci 117-121}

5. (Fig. 8/2). Deep tronconical bowl, straight, flaring sides, upper sides thickened. Rim diameter $19 \mathrm{~cm}$. Compact paste 4 with some grits and straw temper; red slip on interior and over the rim (10R 5/6), exterior smoothed. Type III.A.2.a.

4. (Fig. 8/3). Barrel shaped jar, slightly rounded profile. Rim diameter $19 \mathrm{~cm}$. Medium compact paste 3 with black and white grits, some large inclusions, some red, and straw temper; surfaces smoothed. Type V.A.4.

1. (Fig. 8/4). Jar with everted, curving rim, lip bevelled. Rim diameter $12 \mathrm{~cm}$. Medium compact paste 3 with some grits and straw temper. Type V.B.1.a.

2. (Fig. 8/5). Small globular (?) jar with everted, curving rim. Rim diameter $7.5 \mathrm{~cm}$. Very compact paste 2 with some grits and straw temper; exterior and inner rim smoothed. Type V.B.3.b.

\section{B.05.B./46, locus 114}

1. (Fig. 8/6). Low ring base with flaring foot. Base diameter $6.5 \mathrm{~cm}$. Fine paste 5 with very few black grits; surfaces smoothed. Type VII.B.2.

\section{B.05.B./68, locus 116}

2. (Fig. 8/7). Low ring base with flaring foot. Base diameter $9.5 \mathrm{~cm}$. Rather compact paste 5 with black and white grits, some large red inclusions and straw temper; exterior smoothed. Type VII.B.3. 


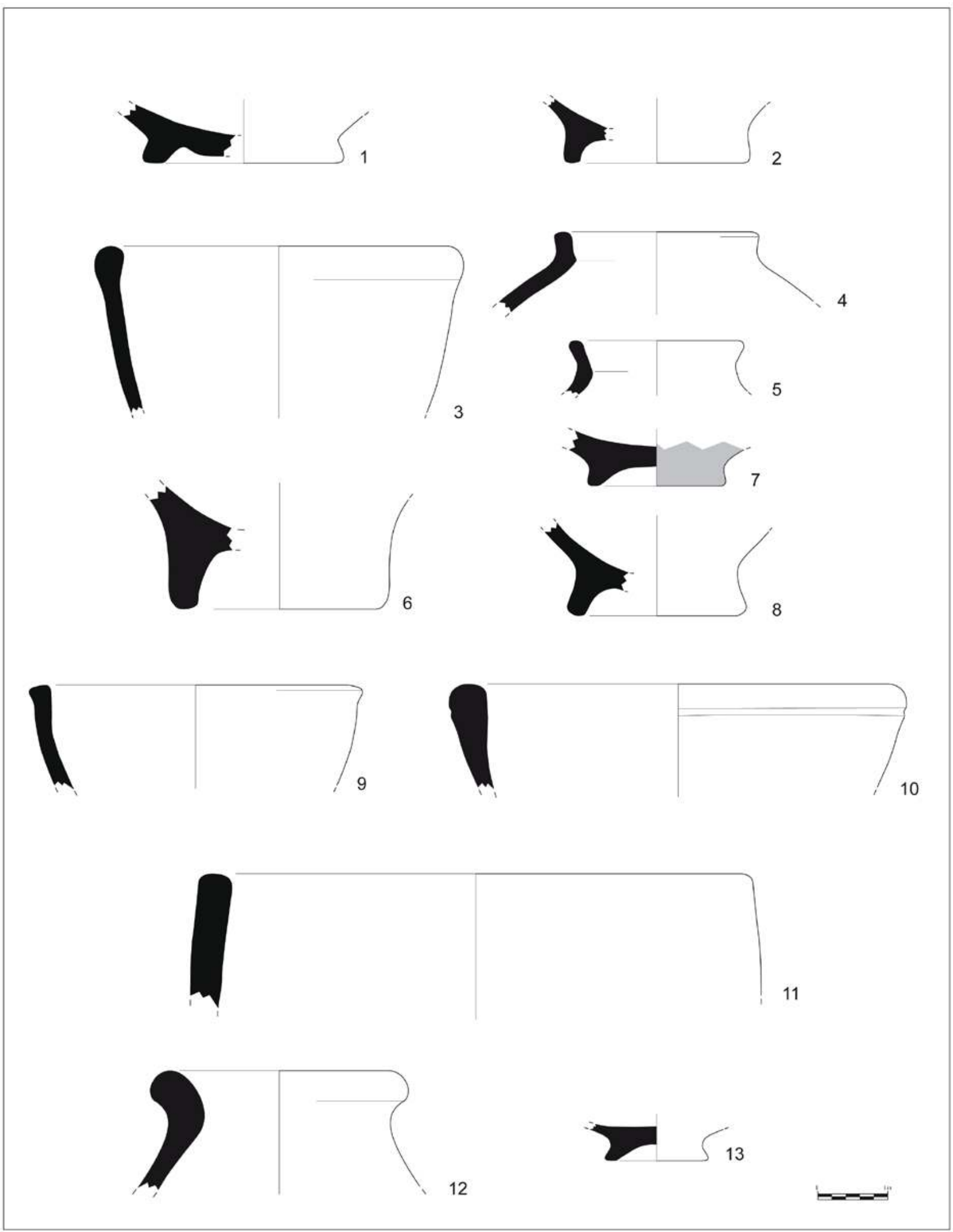

Figure 6. 1: B.05.B./58,7; 2: B.05.B./58,6; 3: B.05.B./59,6; 4: B.05.B./59,5; 5: B.05.B./59,7; 6: B.05.B./59,1; 7: B.05.B./59,4; 8: B.05.B./59,3; 9: B.05.B./51,4; 10: B.05.B./51,3; 11: B.05.B./51,2; 12: B.05.B./51,1; 13: B.05.B./51,5. (G. Stelo 2005 OMAIRY) 
VITTORIA BufFA: THE TEMPLE OF `ATHTAR DHU-QABḌ. THE POTTERY

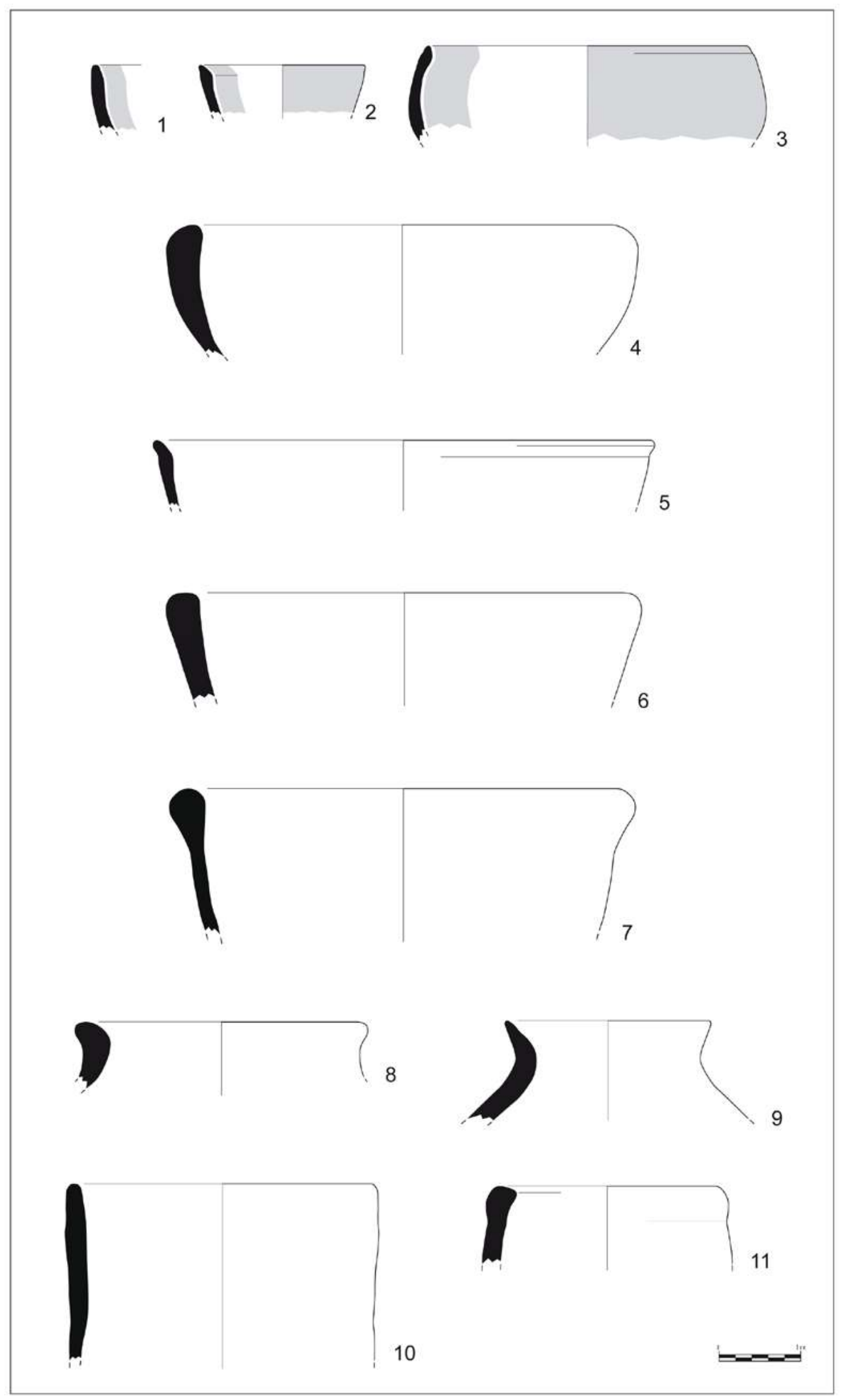

Figure 7. 1: B.05.B./54,7; 2: B.05.B./54,11; 3: B.05.B./54,10; 4: B.05.B./54,6; 5: B.05.B./54,12; 6: B.05.B./54,1; 7: B.05.B./54,5; 8: B.05.B./54,2; 9: B.05.B./54,4; 10: B.05.B./54,9; 11: B.05.B./54,3. (G. Stelo 2005 @MAIRY)

205 

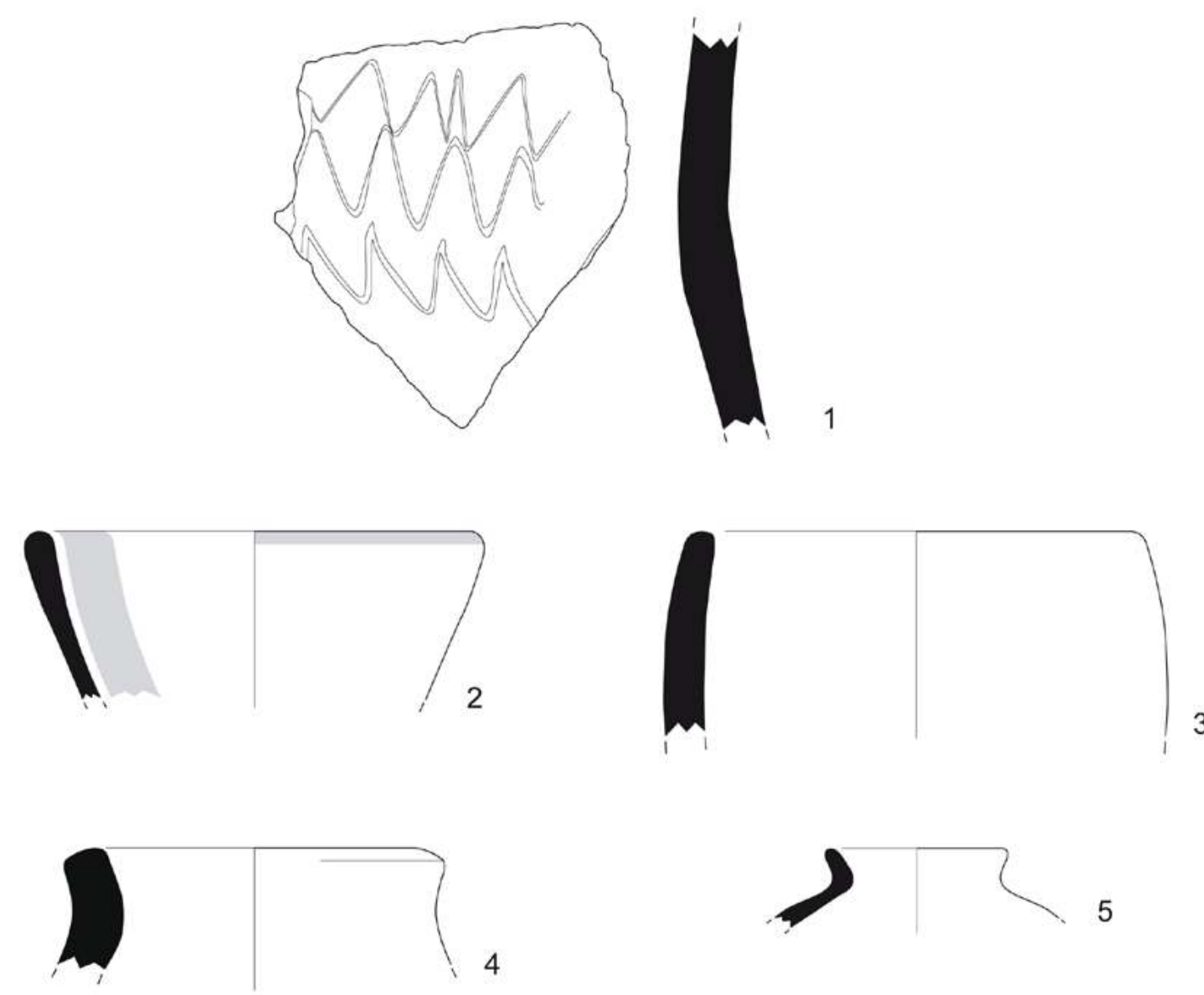

4
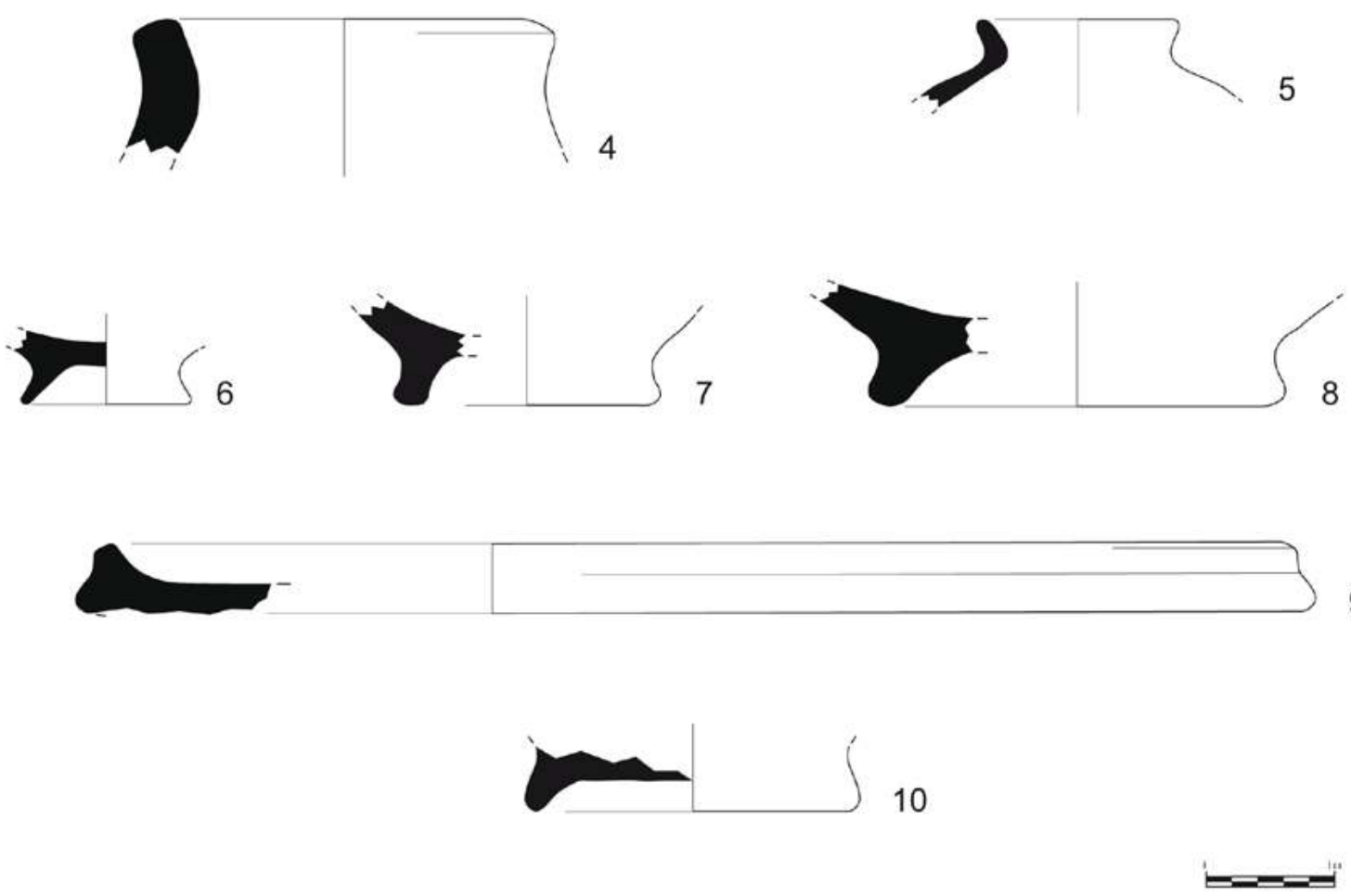

Figure 8. 1: B.05.B./54,8; 2: B.05.B./56,5; 3: B.05.B./56,4; 4: B.05.B./56,1; 5:B.05.B./56,2; 6: B.05.B./46,1; 7: B.05.B./68,2; 8: B.05.B./68,1; 9: B.05.B./78,2; 10: B.05.B./78,1. (G. Stelo 2005 @MAIRY) 


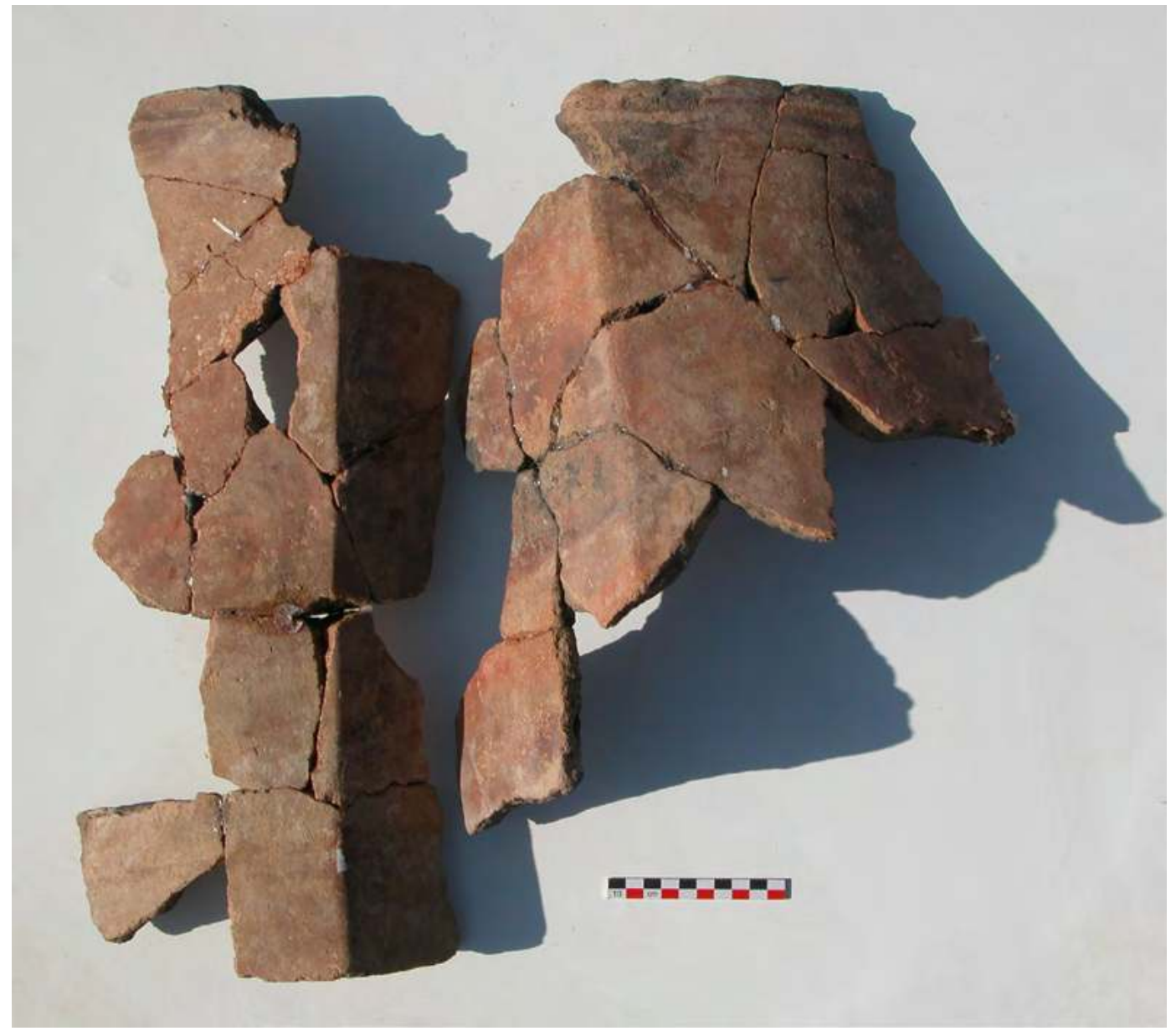

Figure 9. Large dolium, square transverse section with rounded edges, found in L111.

(F.G. Fedele 2006 CMAIRY)

1. (Fig. 8/8). Low ring base with flaring foot. Base diameter $15 \mathrm{~cm}$. Rather compact paste 5 with some grits and straw temper; exterior wet smoothed. Type VII.B.3.

\section{B.05.B./78, M 124}

2. (Fig. 8/9). Large plate with short straight vertical sides; bottom left unfinished. Rim diameter $62 \mathrm{~cm}$. Inclusions not visible. Type I.1.
1. (Fig. 8/10). Low ring base with flaring foot. Rather fine paste 6 with several grits and some straw temper. Type VII.B.3. 


\title{
Extramural Excavation at Recess R44/45 (Minaean Wall)
}

\author{
Chapter 8 \\ Lo scavo fuori mura in R44/45 a Barāqish
}

\author{
Sabina Antonini \\ con la collaborazione di Rosario Valentini
}

\section{Introduzione}

Questo rapporto sullo scavo eseguito fuori dalle mura di Barāqish, nello spazio compreso tra i torrioni o bastioni 44 e 45 (in sigla T44 e T45) (fig. 1), è l'elaborazione degli appunti del diario di scavo tenuto da Alessandro de Maigret e da Rosario Valentini durante le campagne archeologiche del 2003 e del 2004-2005. Abbiamo ritenuto importante includere in questo volume $\mathrm{i}$ risultati di questo saggio di scavo sia per un desiderio di completezza, sia perché fu il primo intervento all'esterno della cinta muraria. Lo scavo non ebbe in sé origine a scopo archeologico, ma fu reso necessario da ragioni tecniche, durante il restauro del tempio di Nakrah. Infatti, per poter smontare e poi rimontare la trabeazione e i pilastri danneggiati del tempio, nel 1992 e poi nel 2003, risultò indispensabile avvicinare il più possibile alle mura della città il carro-gru (fig. 2), il cui braccio potesse raggiungere il tempio all'interno delle mura (fig. 3). ${ }^{1}$ Con la casuale messa in luce, nel 1992, di una struttura muraria che fronteggiava le mura in corrispondenza della rientranza tra T44 e T45 (in sigla $\mathrm{R} 44 / 45)$, nelle campagne archeologiche 2003 e 20042005 si estese lo scavo per comprendere il sistema di accesso alla posterla che conduceva direttamente al Tempio di Nakrah e all'area sacra in generale (fig. 4).

Manterremo la medesima denominazione delle strutture adottata da A. de Maigret nel suo diario di scavo, in quanto la loro numerazione è connessa - in successione - con quella dello scavo del tempio di 'Athtar dhu-Qabd all'interno delle mura (Tempio B). Purtroppo non vi fu il tempo né di proseguire lo scavo in tutta l'estensione della pendenza del tell sino alla sua base, né di analizzare i materiali rinvenuti in quest'area di scavo. ${ }^{2}$

\footnotetext{
1 Si è trattato quindi, inizialmente, di uno scavo funzionale, non di un sondaggio estensivo come quello condotto da Francesco Fedele nell'Area C all'esterno del torrione T7. Cfr. Fedele 2010; Fedele 2011a; Fedele, capitolo 17 nel Volume 2.

2 Questi materiali, per lo più ceramica del periodo di occupazione
}

\section{Lo scavo}

Come accennato, già nel 1992 fu necessario aprire uno scavo nella zona esterna alle mura, sul lato meridionale di queste, nel tratto rientrante $\mathrm{R} 44 / 45$ compreso tra $\mathrm{i}$ torrioni T44 e T45 (cfr. fig. 1). La rientranza coincide, in termini di siglatura degli elementi murari, con il muro M39, compreso tra M12, muro ovest di T44 (lungo m 2,00) e M29, muro est di T45 (lungo m 2,00). Nel muro M39, all'angolo con M29, nel 1992 fu scoperta una piccola porta o posterla, M39P, larga c. $60 \mathrm{~cm}$, relativa all'epoca delle mura minee (fig. 5) e tamponata in epoca islamica (fig. 6). Essa permetteva la comunicazione diretta tra l'esterno della città e il Tempio di Nakrah e, più in generale, l'area sacra (fig. 7).

Varcata la porta M39P dall'esterno, un passaggio (L12) costituito da una scala di 7 gradini in pietra (fig. 8), compresi nello spessore delle mura (M15, M39 e M28-M29 di T45) (fig. 9), permetteva di salire al livello di calpestio del tempio di Nakrah, in L10. Lo spessore sia delle mura che dei torrioni è determinato da una massicciata di mattoni crudi compresa tra i due paramenti (figg. 10-11). ${ }^{3}$ Il paramento interno è costituito di conci di pietra calcarea, di piccole e medie dimensioni, con superficie scheggiata e non rifinita, ma disposti in filari regolari (fig. 12). ${ }^{4}$ Il paramento esterno è la facciata stessa della cinta muraria di Barāqish, i cui blocchi con la faccia a vista sono accuratamente squadrati e lavorati con lo scalpello. La faccia a vista di ciascun blocco è decorata scalpellando in modo irregolare un'area squadrata della superficie compresa entro una cornice che, al contrario, mostra i segni

islamica, furono sistemati all'epoca (2003-2005) nei magazzini appositamente costruiti dalla Missione italiana ai piedi del sito. Nel 2013, durante un breve soggiorno di lavoro a Șan'ā', la scrivente ottenne di potere trasportare i materiali nella capitale, che furono depositati nei locali dello Yemeni-Italian Centre for Archaeological Research (YICAR) presso il Museo Nazionale dello Yemen.

3 de Maigret 2005b, 35.

${ }^{4}$ Cfr. il paramento interno della Torre 38 di al-Baydā' (in taille éclatée) in Bessac 1998a, 184 e 213, fig. 16. 
regolari, paralleli e ravvicinati dello scalpello a punta larga, e perpendicolari alla lunghezza del blocco. ${ }^{5}$

Nella campagna di scavo del 1992, nell'impossibilità di portare il carro-gru all'interno della città, si vide di avvicinare il più possibile il mezzo meccanico alla base delle mura in corrispondenza del tempio di Nakrah. Fu durante le manovre e un limitato sbancamento al di fuori delle mura che venne messo in luce, verso valle, un tratto di muro in pietra, quasi parallelo a M39, e da questo distante c. $7 \mathrm{~m}$.

Durante la campagna di scavo del 2003, ${ }^{6}$ lo stesso muro, denominato M50 (fig. 13), venne di nuovo scoperto per tutta la lunghezza in corrispondenza della rientranza della cinta tra T44 e T45, cioè per m $10,30 .^{7} \mathrm{Il}$ muro si colloca più in basso rispetto alla soglia della posterla M39P (il dislivello è di $\mathrm{m}-2,90$ ), ed è meglio conservato in direzione est: la massima altezza superstite è di $\mathrm{cm}$ 60. M50 fu inizialmente chiamato da de Maigret 'muro esterno' delle mura di Barāqish: un muro di contenimento di un terrapieno (come si vedrà in seguito nel dettaglio) che interesserebbe l'intera cinta, se fosse appurato che esso costituisce una specie di rinforzo della base delle mura minee. Non è escluso, secondo de Maigret, che questo rinforzo esterno sia così imponente $-c .7 \mathrm{~m}$ di larghezza, come accennato - soltanto in corrispondenza dei punti più deboli della cinta muraria, ossia nei punti del tell più soggetti all'erosione, specialmente in periodi di forti precipitazioni o di inondazione del wādī.

Al di sopra della struttura conservata M50, nello spazio compreso tra M50 e M39, si osservava una stratigrafia costituita dai detriti accumulatisi a ridosso delle mura nel lungo periodo di occupazione islamica, e in seguito al disfacimento dell'alzato delle mura stesse di periodo islamico e degli edifici in mattoni crudi che vi erano costruiti contro, all'interno della città (fig. 14). Al di sopra del muro M50, nella parte orientale più conservata, si rilevava uno strato di $80-90 \mathrm{~cm}$ di terra compattata beige (a) frammista a schegge di pietra calcarea. Questo strato a era interrotto verso ovest da fosse di periodo islamico (b) che lacerarono il muro M50. Questo muro è meglio conservato, quindi, sulla faccia meridionale. Accumuli di cenere a lunghe lenti, in uno spesso strato di terra molto scura con carboni, materiale organico e ceramica (c), arrivavano quasi sino alla cima del colluvio. Li tagliava una fossa evidentemente più tarda $(d)$. Questo strato $b-d$ non era

\footnotetext{
5 Cfr. Bessac 1998a, 188-191, figg. 19-20.

6 Lo scavo venne aperto in questo punto dal 5 al 15 novembre del 2003, e ripreso dal 21 dicembre 2004 all'11 gennaio 2005 (v. Antonini e Fedele, capitolo 1 in questo volume).

7 de Maigret 2005b, 36. Le sezioni e le piante sono i disegni originali in scala desunti dal diario di scavo di A. de Maigret, messi in bella da M. Frondini e ritoccati da F.G. Fedele; gli scatti fotografici sono di A. de Maigret e R. Valentini.
}

altro che l'accumulo dell'attività abitativa di Barāqish durante l'occupazione islamica.

Il fatto che sia lo strato a, sia il muro M50 che lo conteneva fossero poco conservati nella parte ovest dell'area di scavo, ossia in corrispondenza della porta M39P, fece supporre che forse in epoca islamica ci fu un rimaneggiamento di questo ingresso a Barāqish. In realtà non sappiamo quando la posterla M39P venne chiusa: forse durante la prima occupazione in epoca islamica, ossia al tempo di 'Abd Allāh bin Hamza (periodo Islamico D, XII-XIII secolo), oppure nel corso delle occupazioni successive. ${ }^{8}$ È certo che la soglia della posterla originale, ossia minea, era più bassa. Infatti, da un primo e piccolo sondaggio effettuato al di sotto della soglia attuale (fig. 15) emerse una lastra quadrata di arenaria ben lavorata (cfr. fig. 23, d), probabilmente la base di uno o due gradini adatti per una precedente e più bassa soglia di epoca minea. In un secondo momento poi quando l'apparato d'entrata, che vedremo più oltre nel dettaglio, era ricoperto, l'altezza della porticina fu ridotta, con l'aggiunta di una grossa lastra posta verticalmente, alzando di fatto la soglia di $c .35 \mathrm{~cm}$.

Lo strato a, alto come si è visto $c .80 / 90 \mathrm{~cm}$ al di sopra del muro M50 che lo conteneva, si estendeva uniforme verso $\mathrm{N}$, venendo a formare il terrapieno L50 (fig. 16). Con il prosieguo dello scavo, asportando gran parte del colluvio e del livello 'beige chiaro di accumulo e crollo' di pietrame caduto dalla cinta muraria, si raggiungeva un piano di pietre medio-piccole $(p)$, digradanti verso est, che poggiavano sopra uno strato compatto di 50-60 $\mathrm{cm}$ di terra nera con carboni e cenere (q). Questo strato q diminuiva progressivamente di potenza verso est, fino a uno spessore di $20 \mathrm{~cm}$ (fig. 17). Oltre a ceramica di periodo islamico, esso conteneva l'iscrizione minea Y.03.B.R44/45.1 (v. Agostini, capitolo 9 in questo volume, fig. 1). ${ }^{9}$ A ovest del blocco iscritto si trovavano i resti di due gradini mal conservati (g), forse di epoca islamica, che sembravano condurre da L50 verso le mura. Un frammento compatto di intonaco (i) compariva ai piedi del colluvio (fig. 18).

Il muro M50 non è parallelo a M39, ma converge sul muro di cinta in direzione est (fig. 18). Si torna su questa osservazione più oltre, nelle conclusioni.

Nell'angolo tra M39 e M12 (T44), dove l'accumulo di detriti islamici raggiungeva il punto più alto $(+2,70 \mathrm{~m}$ dal piano di calpestio della soglia della posterla M39P), si scoprivano, inoltre, una mezza dozzina di blocchi grandi, caduti evidentemente dalla parte superiore di T44 (fig. 19). Una volta rimossi questi blocchi, veniva

\footnotetext{
8 de Maigret e Robin 1993, 454, Phot. 11, e 458.

9 R44/45 nella sigla si riferisce ovviamente alla citata rientranza muraria tra T44 e T45.
} 
messo in luce il terrapieno L50 in tutta la sua larghezza (fig. 20).

Con l'asportazione della terra di colluvio e dei grossi blocchi che coprivano una parte della facciata di M39, in questo tratto di mura vennero messe in luce due iscrizioni, entrambe reimpiegate in epoca islamica (cfr. fig. 22). La prima, di due righe, è composta di tre blocchi (Y.03.B.R44/45.2; v. Agostini, capitolo 9 in questo volume, figg. 2-4), che furono posati sull'ultimo filare originario mineo di M39; dei tre blocchi iscritti, uno è capovolto. La seconda iscrizione, di quattro righe, è scolpita in un blocco reimpiegato al di sopra dello stesso filare originale mineo, ma più verso est (Y.03.B.R44/45.3; v. Agostini, capitolo 9 in questo volume, fig. 5). Una terza iscrizione, di una sola riga, è stata messa in luce nel muro M12 del torrione T44 (Y.03.B.R44/45.4; v. Agostini, capitolo 9 in questo volume, fig. 6).

Al di sotto del filare con le iscrizioni Y.03.B.R44/45.2 e Y.03.B.R44/45.3 sono stati messi in luce sei filari in ashlar dell'originaria cinta muraria minea. Una progressiva rientranza del paramento $($ di $1 \mathrm{~cm})$ si osservava dopo ogni coppia di filari, una tecnica comunemente usata negli alzati delle costruzioni di epoca pre-islamica. ${ }^{10}$ Nelle mura di Barāqish essa è stata minuziosamente registrata altresì nell'Area $\mathrm{C}$, torrione $\mathrm{T} 7 \mathrm{.}^{11}$

E veniamo alle strutture murarie che compaiono davanti alla piccola porta M39P. Una sorta di piattaforma, siglata L51, rettangolare, larga $\mathrm{m}$ 3,40 (E-O) e lunga $\mathrm{m}$ 2,80 (NS), è delimitata dai muretti M51 e M52 (fig. 21). M51 è formato da un solo filare di blocchi parallelepipedi di arenaria, alti c. cm 40, larghi da 50 a $60 \mathrm{~cm}$. Il blocco che si appoggia a M39 è lungo $\mathrm{cm} 68$, il blocco centrale $\mathrm{cm} 73$. Il blocco più meridionale, frammentario, che fa angolo con M52, è il più lungo e misura $\mathrm{m} \mathrm{1,40.} \mathrm{Le} \mathrm{fondazioni}$ di M51 e M52, che penetrano nel terreno per c. $20 \mathrm{~cm}$, sono costituite da blocchi piatti sbozzati, regolarmente aggettanti di una decina di $\mathrm{cm}$, e si impostano entro L50: il terrapieno L50 è stato tagliato per impostare le fondazioni di M51 e M52.

I muretti M51 e M52 racchiudenti L51 sembrerebbero delimitare appunto una piattaforma che si estendeva sino a M39, e che poteva servire di accesso alla porta dopo che la soglia fu rialzata (fig. 22). Resti di mattoni crudi si notarono sopra questi due muretti, e può darsi che si trattasse di una spalletta che si alzava oltre il piano di L51.

\footnotetext{
10 Questa tecnica costruttiva è impiegata non solo sulle mura cittadine, ma anche negli edifici civili e religiosi: a Barāqish, per esempio, è altresì visibile nei muri perimetrali del tempio di Nakrah. Cfr. Breton $(1994,35)$, il quale, tuttavia, parla di 2-3 cm ogni tre o quattro filari, e ogni tre nel torrione T48 (= T11 dei Francesi).

11 Fedele 2010; Fedele 2011a; Fedele, capitolo 17 nel Volume 2.
}

Osservando la porta M39P (v. fig. 15 e fig. 23), si vede che la sua soglia attuale è costituita da una lastra $a$ e da una lastra più piccola $\mathrm{b}$, che insieme rialzano di $41 \mathrm{~cm}$ una originaria soglia costituita da uno dei blocchi del muro M39 (denominato c nella fig. 23). La soglia a è una lastra spessa c. cm 15, rifinita e decorata all'esterno e rozza e irregolare all'interno. Essa e il suo sostegno b non sono altro che un rialzo aggiunto più tardi, come dimostra anche - e soprattutto - il fatto che gli stipiti della porta, con gli incavi per l'alloggio dei cardini, continuano in basso per l'intera estensione di $\mathbf{a}+\mathbf{b}(41 \mathrm{~cm})$.

Precedentemente avevamo accennato al ritrovamento di una lastra a $-55 \mathrm{~cm}$ sotto la base della soglia b, lastra di $\mathrm{cm} 47 \times 49$ denominata d nella figura 23. Il livello formato dalla lastra $\mathrm{d}$ doveva essere il piano originario mineo di salita alla soglia $\mathrm{c}$, che, come si è detto, è costituita da un filare delle mura stesse.

\section{Conclusioni}

Lo scavo condotto all'esterno e a ridosso delle mura di Barāqish, in corrispondenza della rientranza R44/45 nel cui muro M39 si apre la porta M39P, ha messo in luce quello che abbiamo chiamato un terrapieno (L50), contenuto verso valle dal muro M50. La larghezza di questo terrapieno è di $c .7 \mathrm{~m}$, e, quanto alla sua altezza, esso è conservato per c. $80-90 \mathrm{~cm}$ al di sopra del muro di contenimento M50, quest'ultimo conservato per un'altezza massima di $60 \mathrm{~cm}$ (fig. 24). Il terrapieno L50 fu in origine designato da A. de Maigret come 'contrafforte', tradotto in inglese con counterfort. ${ }^{12}$ Esso è formato da strati di terra compatta, mista a scaglie di pietra calcarea (dello stesso genere delle mura) e mattoni crudi.

Nell'interpretazionedi A.de Maigret,esso probabilmente serviva per rinforzare la base delle mura della città, e, forse con ampiezza variabile, doveva circondare tutto il perimetro della cinta $($ c. $770 \mathrm{~m})$. La pur modesta convergenza, in pianta, notata più sopra tra M50 e M39 suggerisce che il muro M50 segue più in generale l'andamento delle mura della città, piuttosto che solo l'andamento di M39, il che si accorda con l'ipotesi che l'opera, di cui M50 è parte, circondasse l'intera cinta muraria. Inoltre, una sequenza sedimentaria interpretata come un tratto del medesimo tipo di terrapieno è stata descritta al torrione T7 nell'Area C. ${ }^{13}$

\footnotetext{
12 de Maigret 2004a, 6-7; de Maigret 2005b. Il termine è stato utilizzato da Fedele (2010, 132; ma in una variante ad hoc virgolata, 'counter-fort', in Fedele 2011a, 114, fig. 3).

13 Fedele 2010, 132-133, fig. 138; Fedele 2011a. Per l'ulteriore discussione dell'argomento si rinvia a Fedele, capitolo 17 nel Volume 2. Non è chiaro se e quanto sia avvicinabile a L50 di Barāqish la struttura rilevata a Tamna' durante gli scavi della American Foundation for the Study of Man (1950-1951), addossata alla faccia esterna delle mura a lato del bastione nord-est della 'South gate' (porta sud-occidentale) della città: 'un glacis en pierres grossièrement taillées et incliné a 45 degrés supportait le mur extérieur de la ville, dont il ne reste que
} 


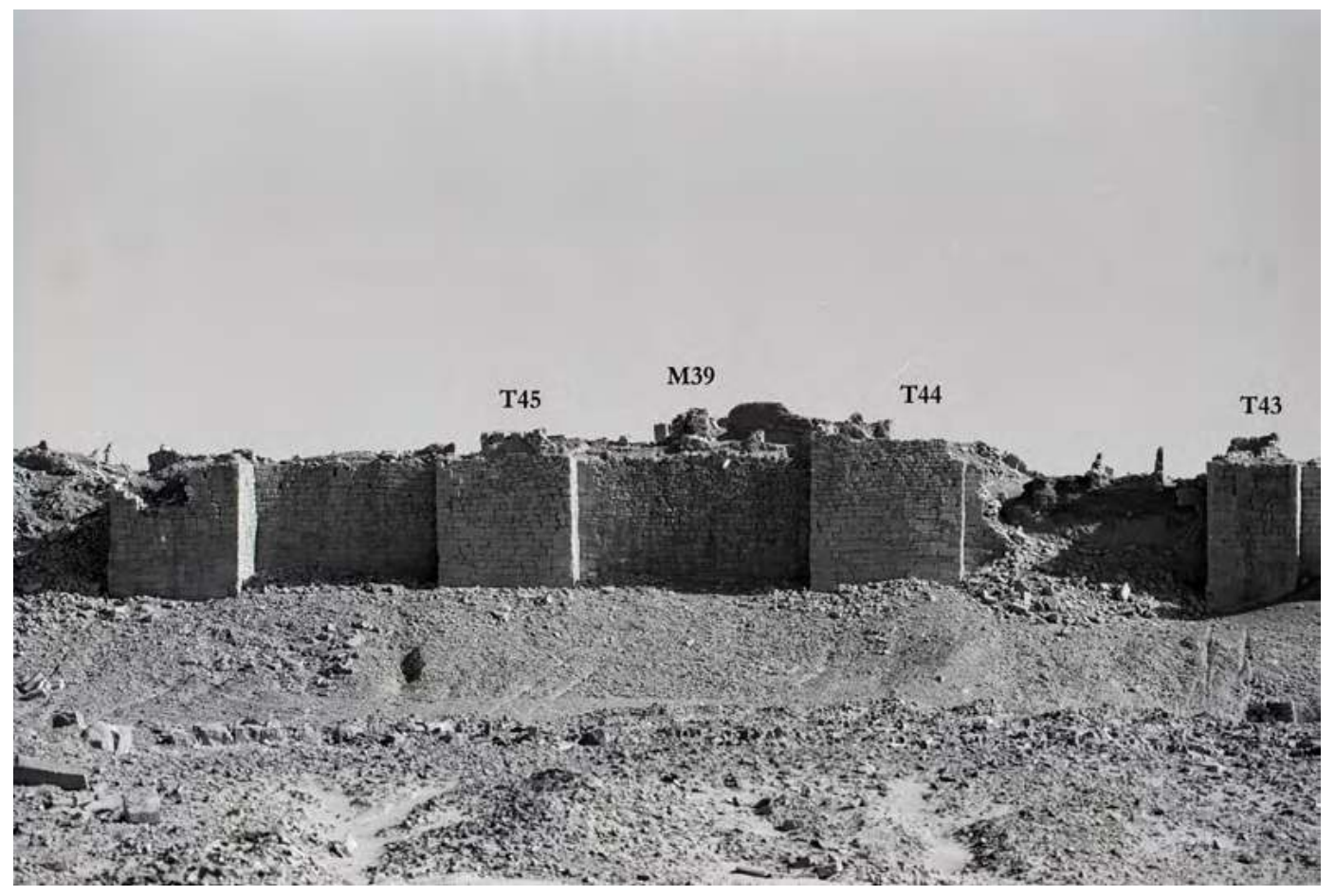

Figure 1. Vista del tratto meridionale delle mura di Barāqish, con i torrioni T44 e T45 che delimitano la rientranza R44/45. (A. de Maigret 1986 OMAIRY)

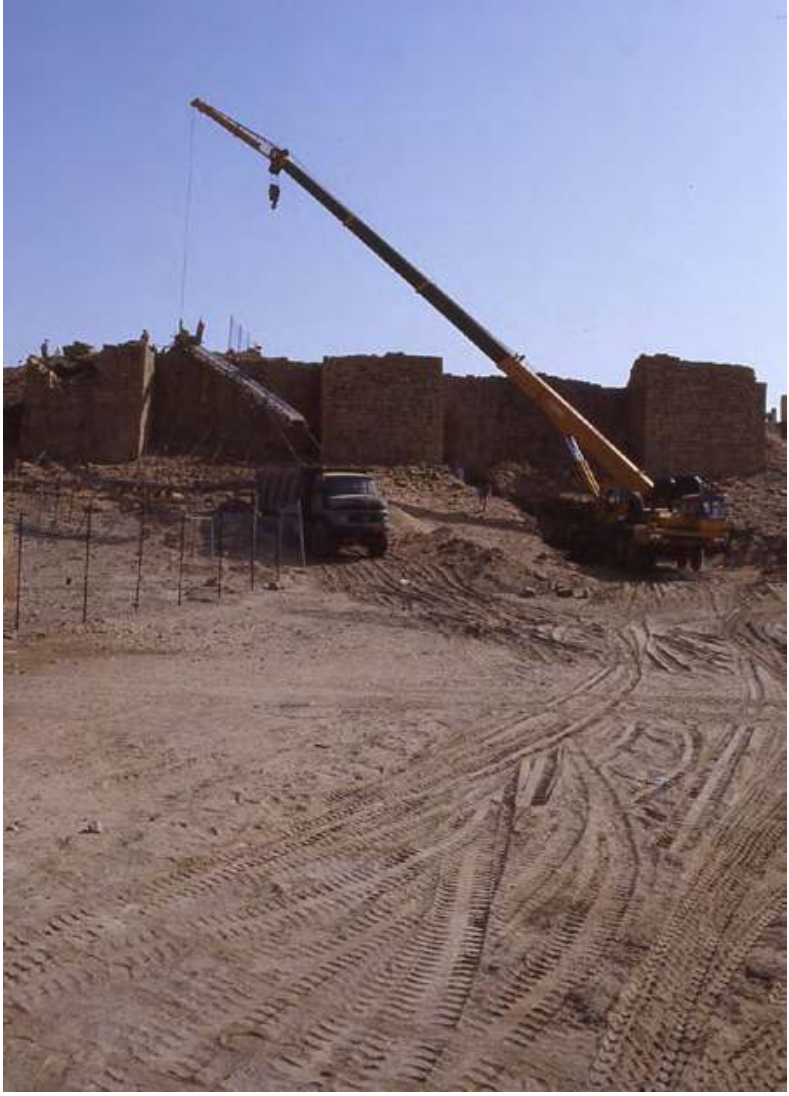

Figure 2. Il posizionamento della gru a ridosso delle mura, in corrispondenza della rientranza R44/45. (A. de Maigret 1992 CMAIRY)

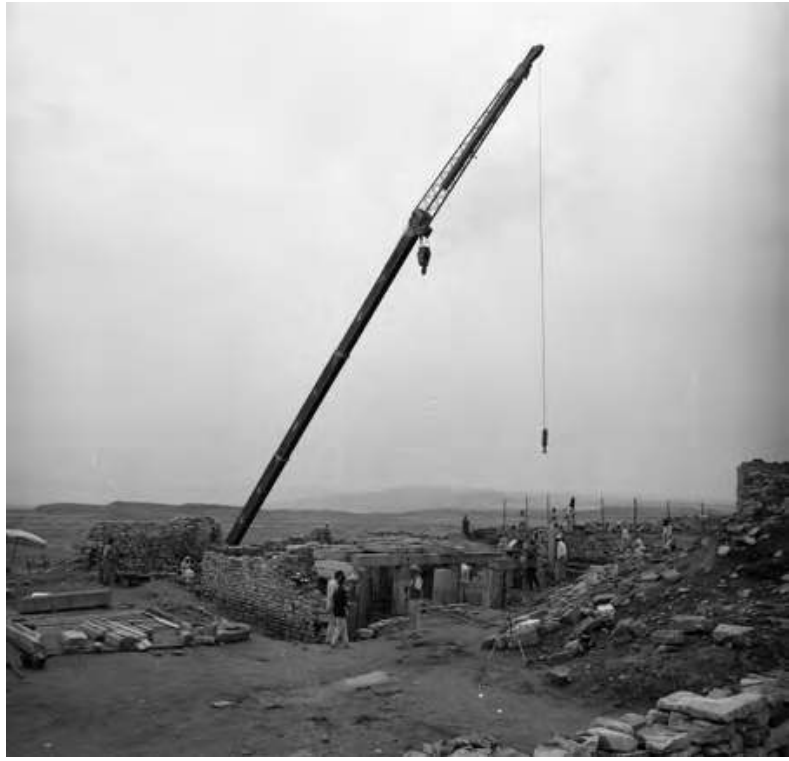

Figure 3. Il braccio della gru sporge all'interno delle mura in corrispondenza del tempio di Nakrah. (A. de Maigret 1992 @MAIRY) 


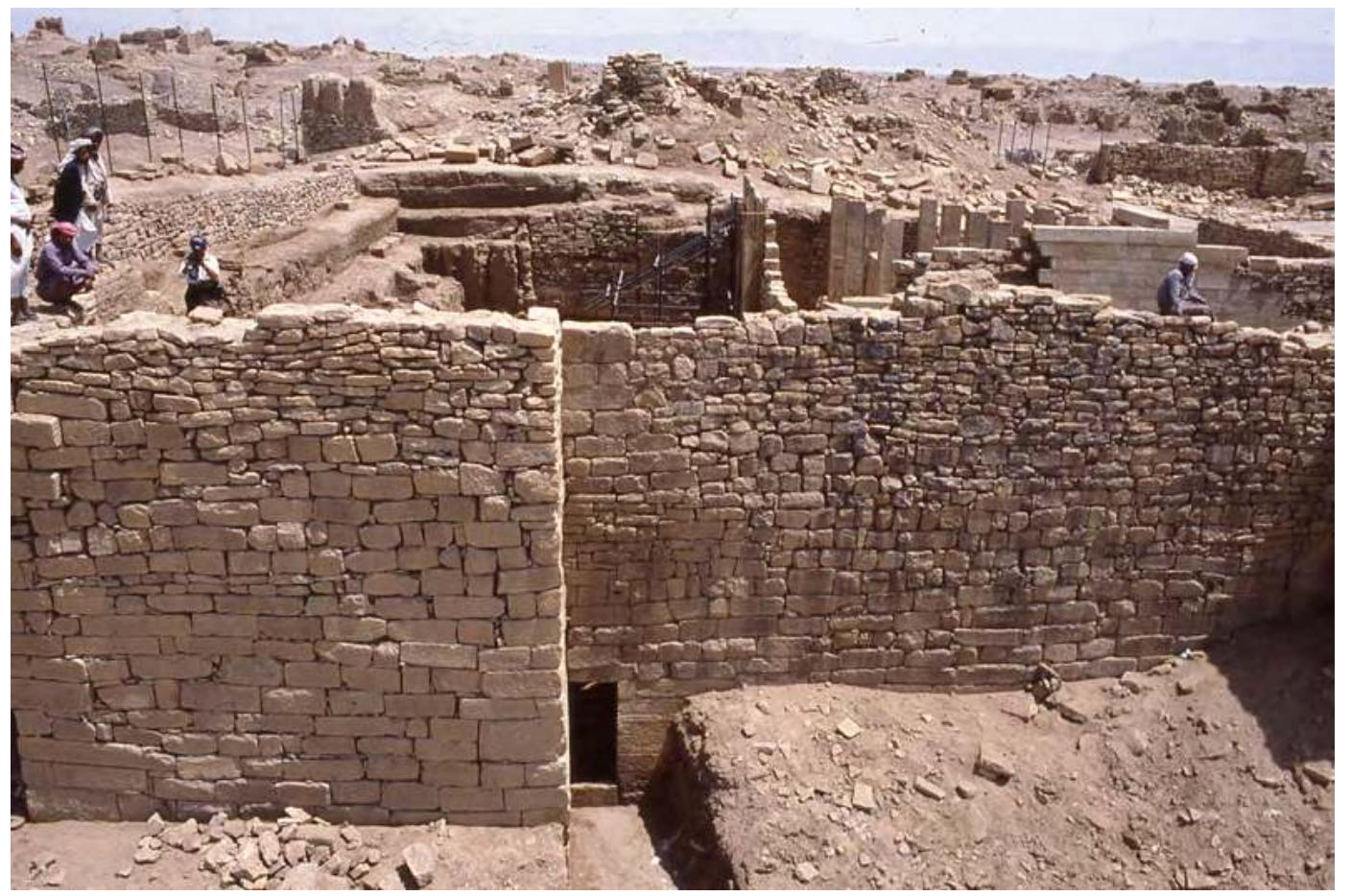

Figure 4. La posterla nel muro M39 (porta M39P) fotografata dal braccio della gru. (A. de Maigret 1992 OMAIRY)

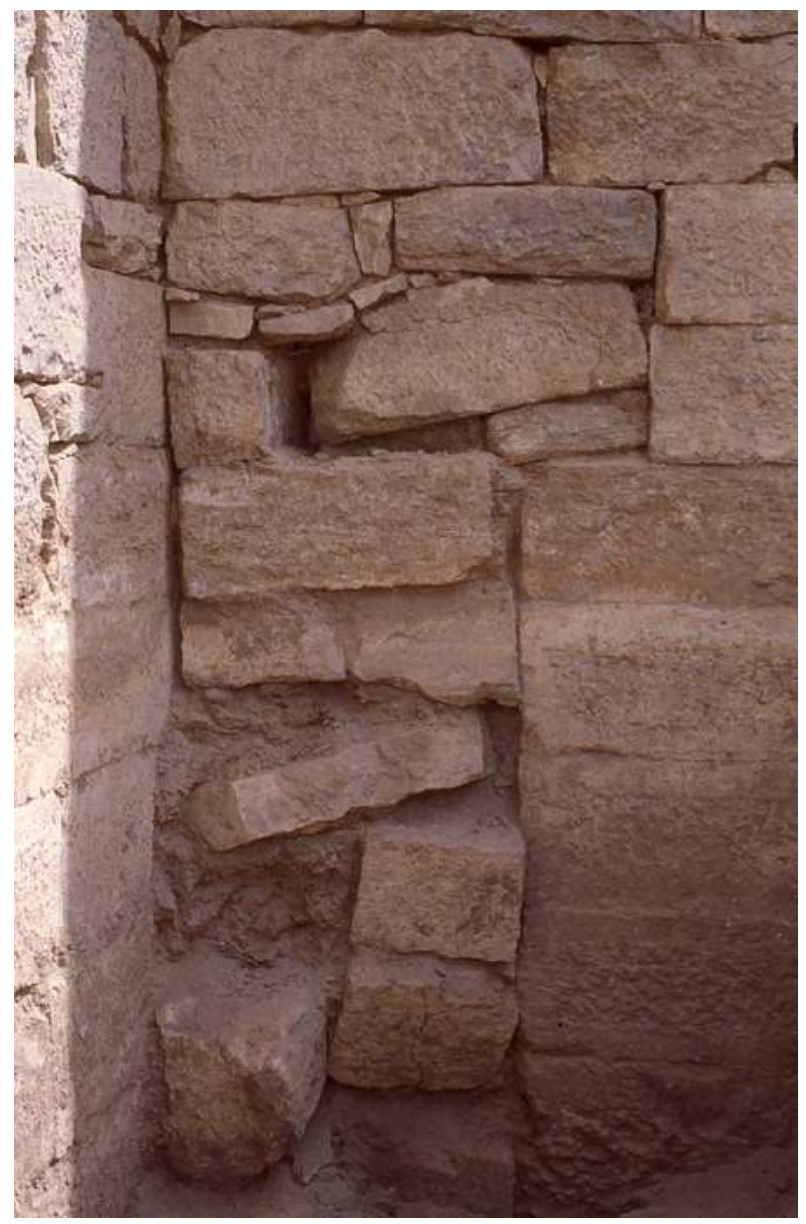

Figure 5. La porta M39P tamponata, vista dall'esterno. (A. de Maigret 1992 CMAIRY)

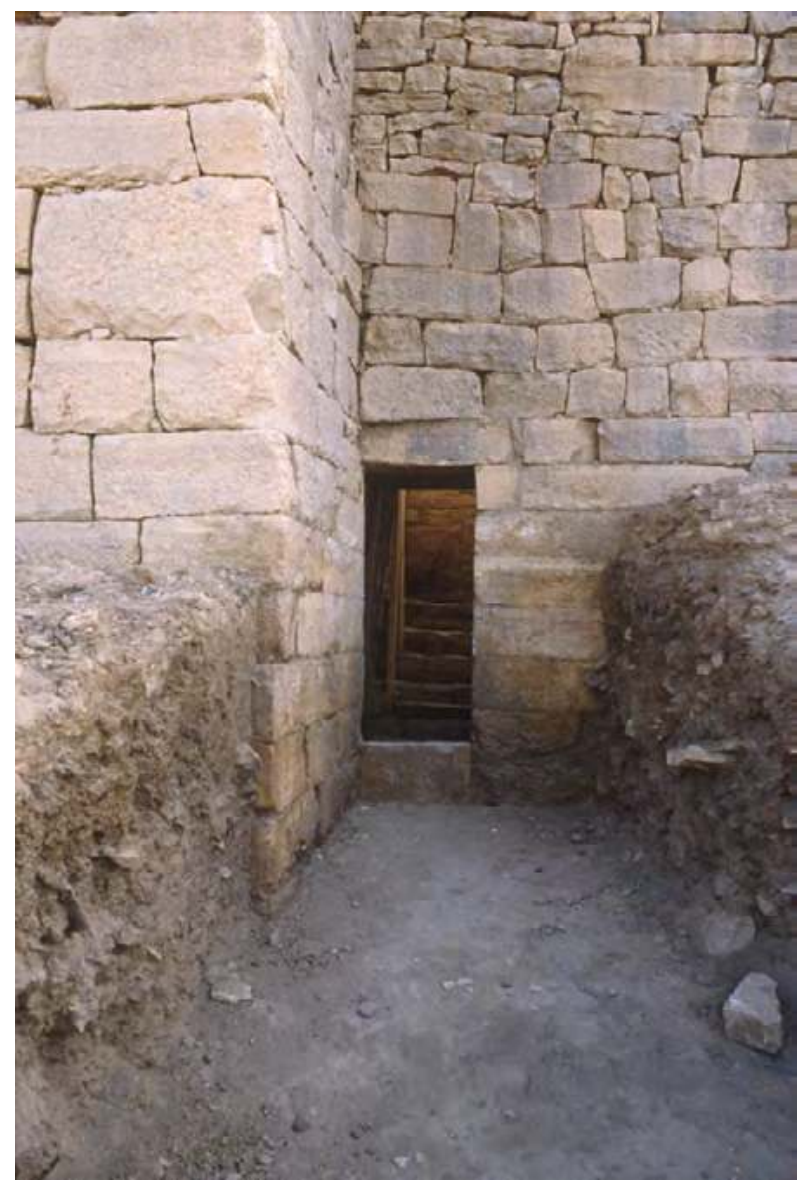

Figure 6. La porta M39P liberata dei blocchi di otturamento, vista dall'esterno. (A. de Maigret 1992 CMAIRY)

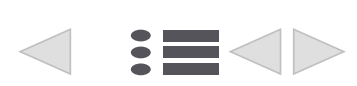




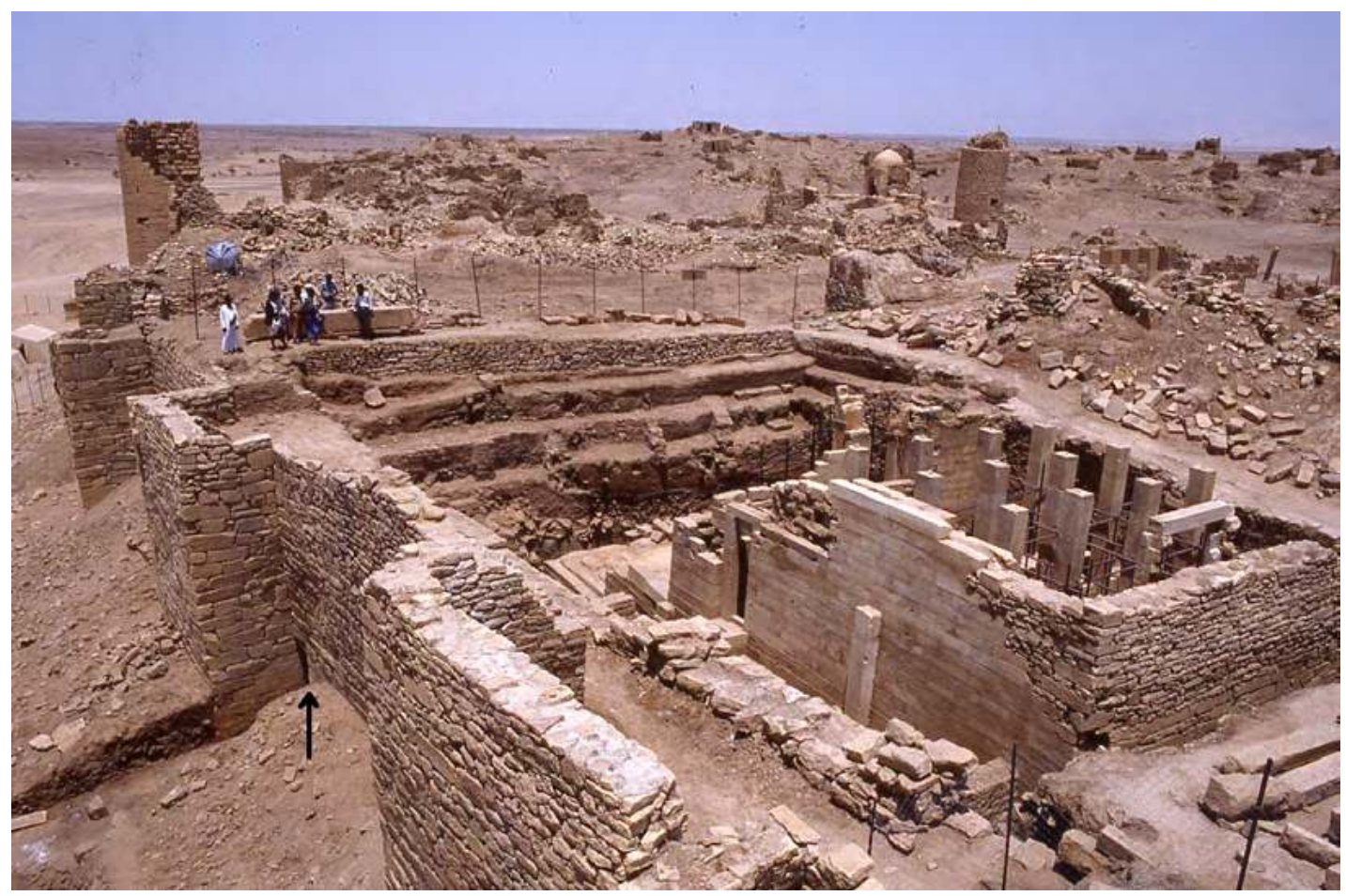

Figure 7. Panorama sulle mura di Barāqish con la porta M39P (a sinistra, indicata dalla freccia) e il tempio di Nakrah (a destra). (A. de Maigret 1992 CMAIRY)

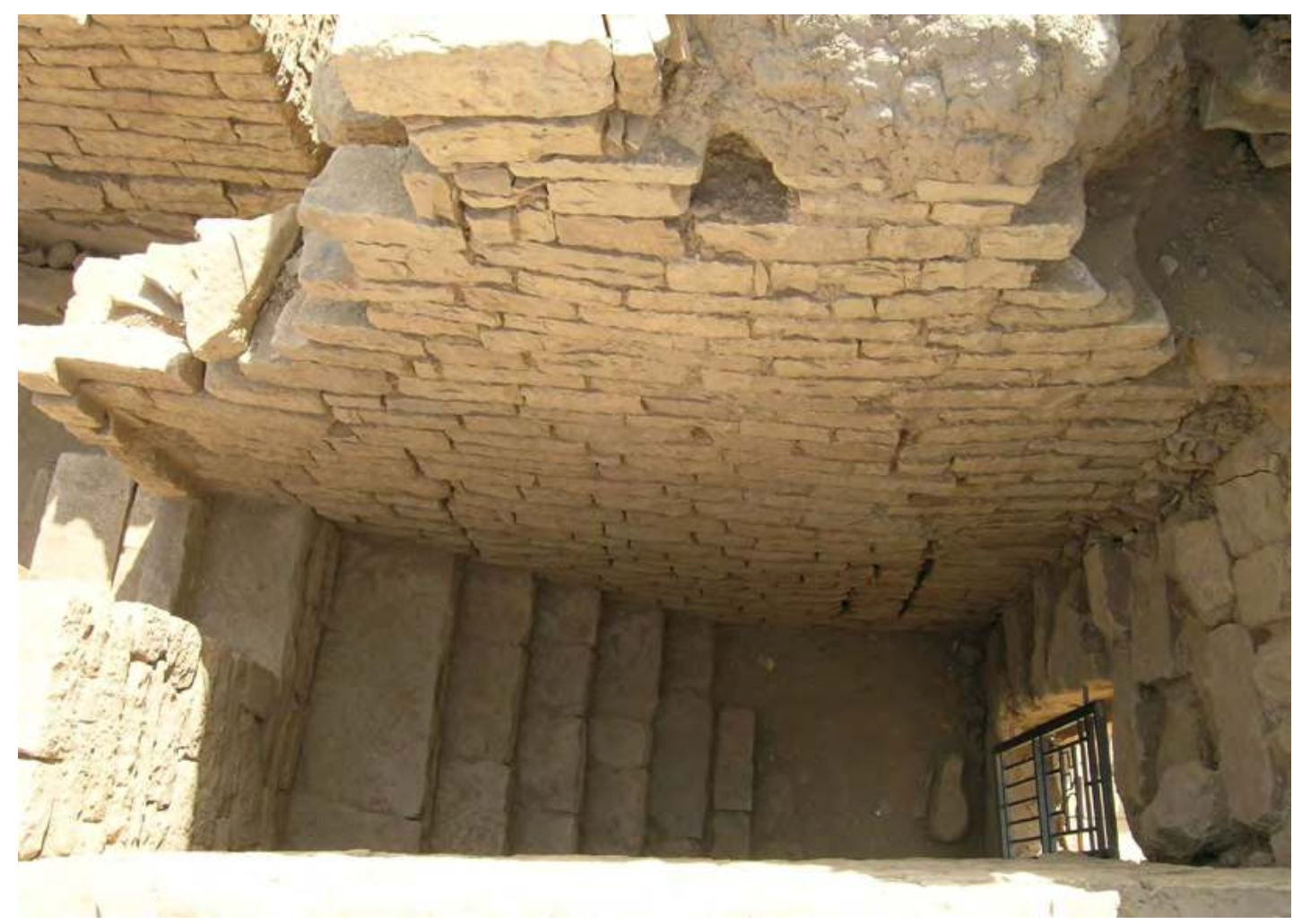

Figure 8. Il passaggio (L12) costituito da una scala di 7 gradini che tramite la porta M39P mette in comunicazione l'esterno delle mura con l'interno della città, presso il tempio di Nakrah.

(A. de Maigret 2004 CMAIRY) 


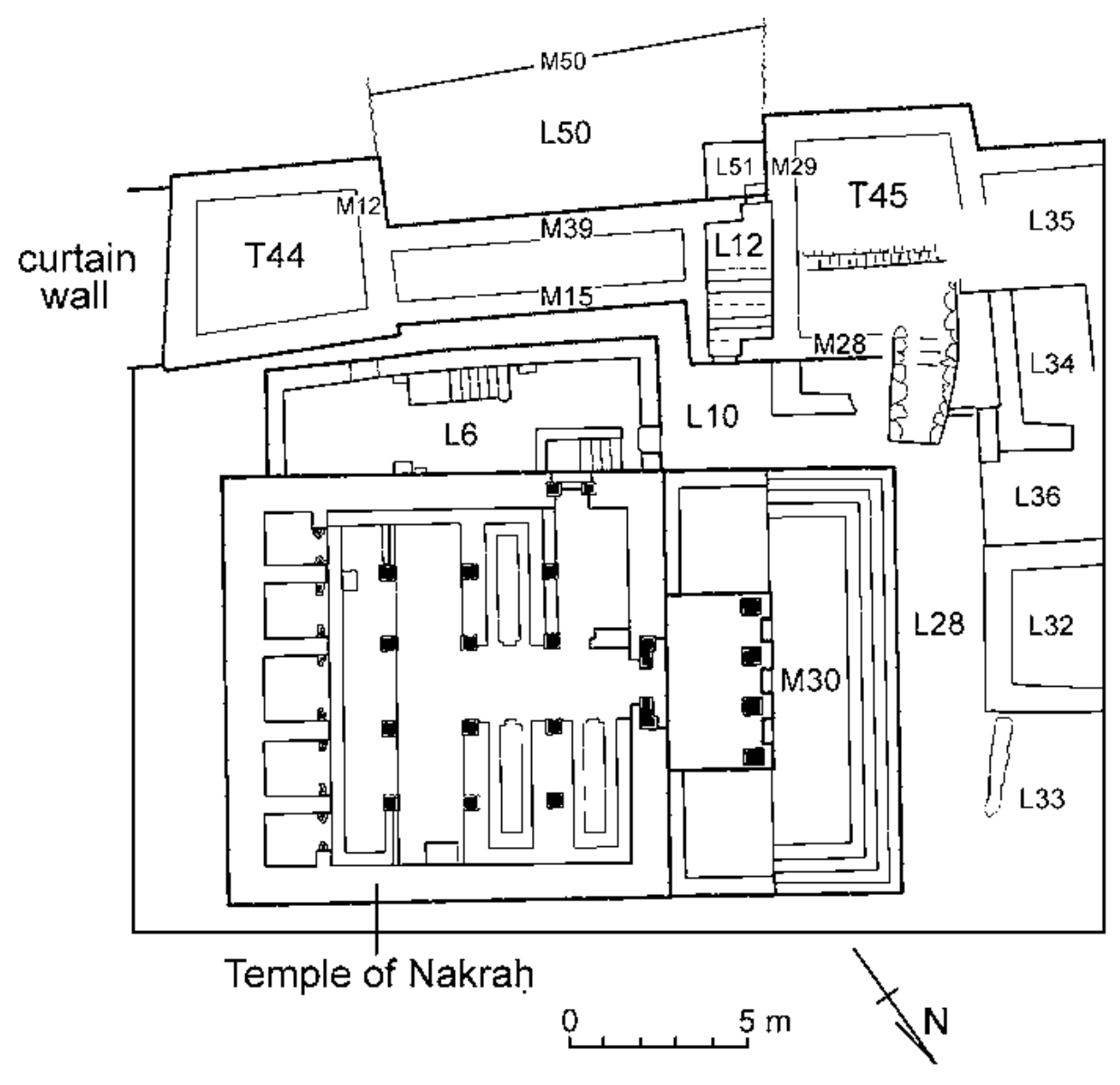

Figure 9. I loci intorno al Tempio di Nakrah. Il passaggio L12 con i gradini è compreso tra due porte: quella superiore dà in L10, quella inferiore è la porta M39P del muro M39 all'angolo con T45. (A. de Maigret 2005 OMAIRY)

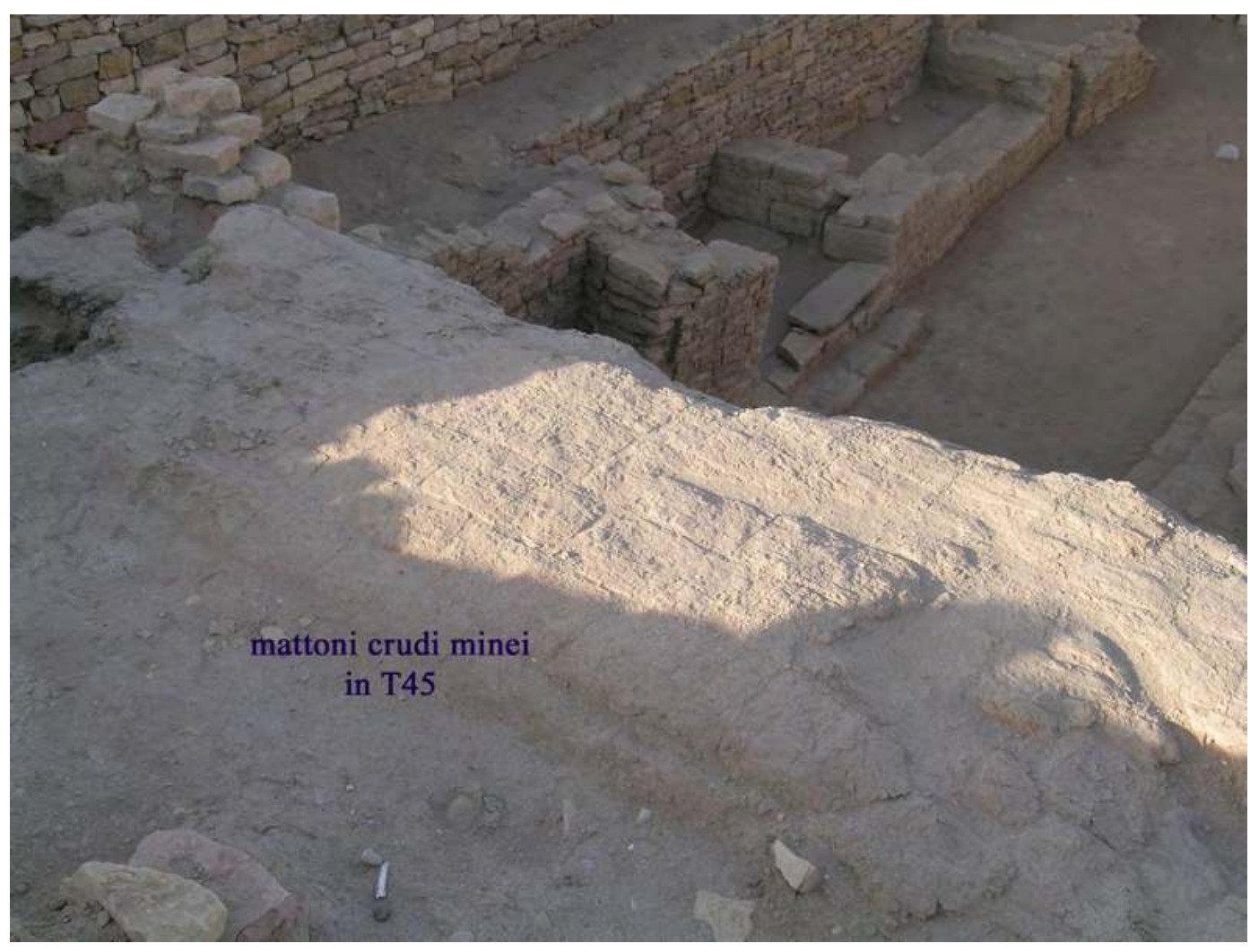

Figure 10. Massicciata di mattoni crudi in T45, dettaglio dall'alto. (A. de Maigret 2005 CMAIRY) 


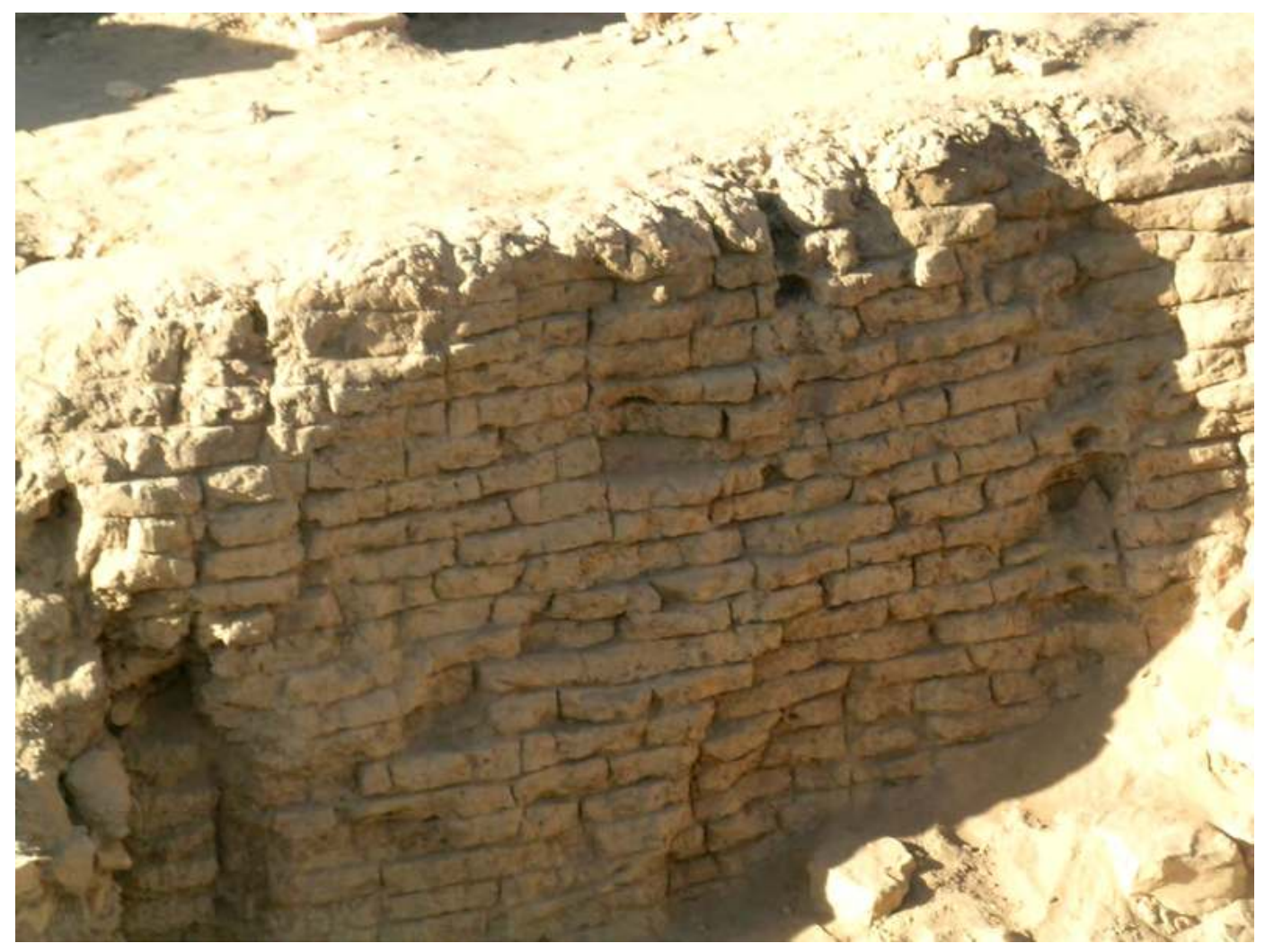

Figure 11. Massicciata di mattoni crudi in T45, dettaglio da SE. (A. de Maigret 2005 CMAIRY)

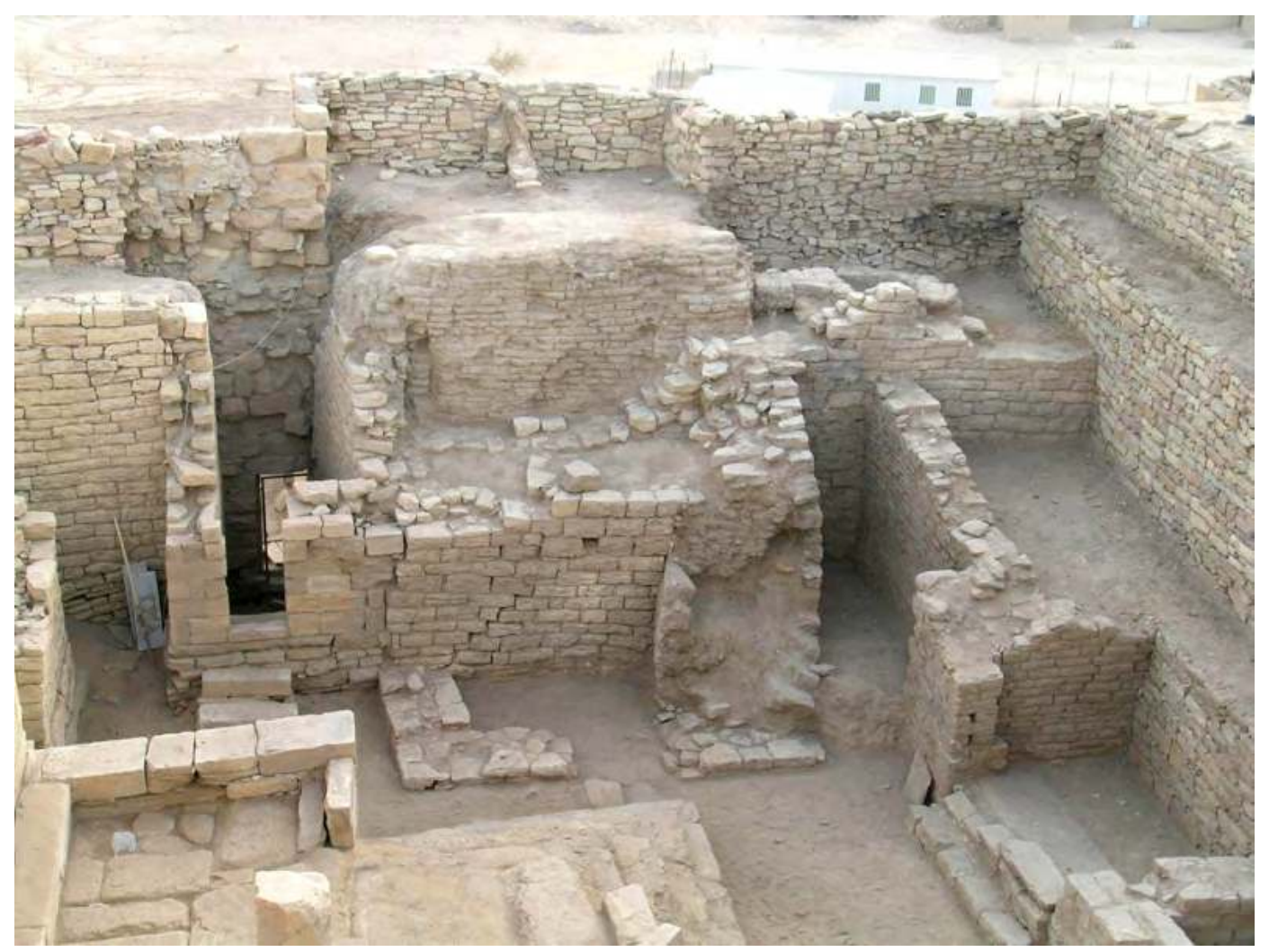

Figure 12. Massicciata di mattoni crudi in T45, racchiusa tra il paramento interno delle mura e quello esterno del torrione T45, vista da N. (A. de Maigret 2004 OMAIRY) 


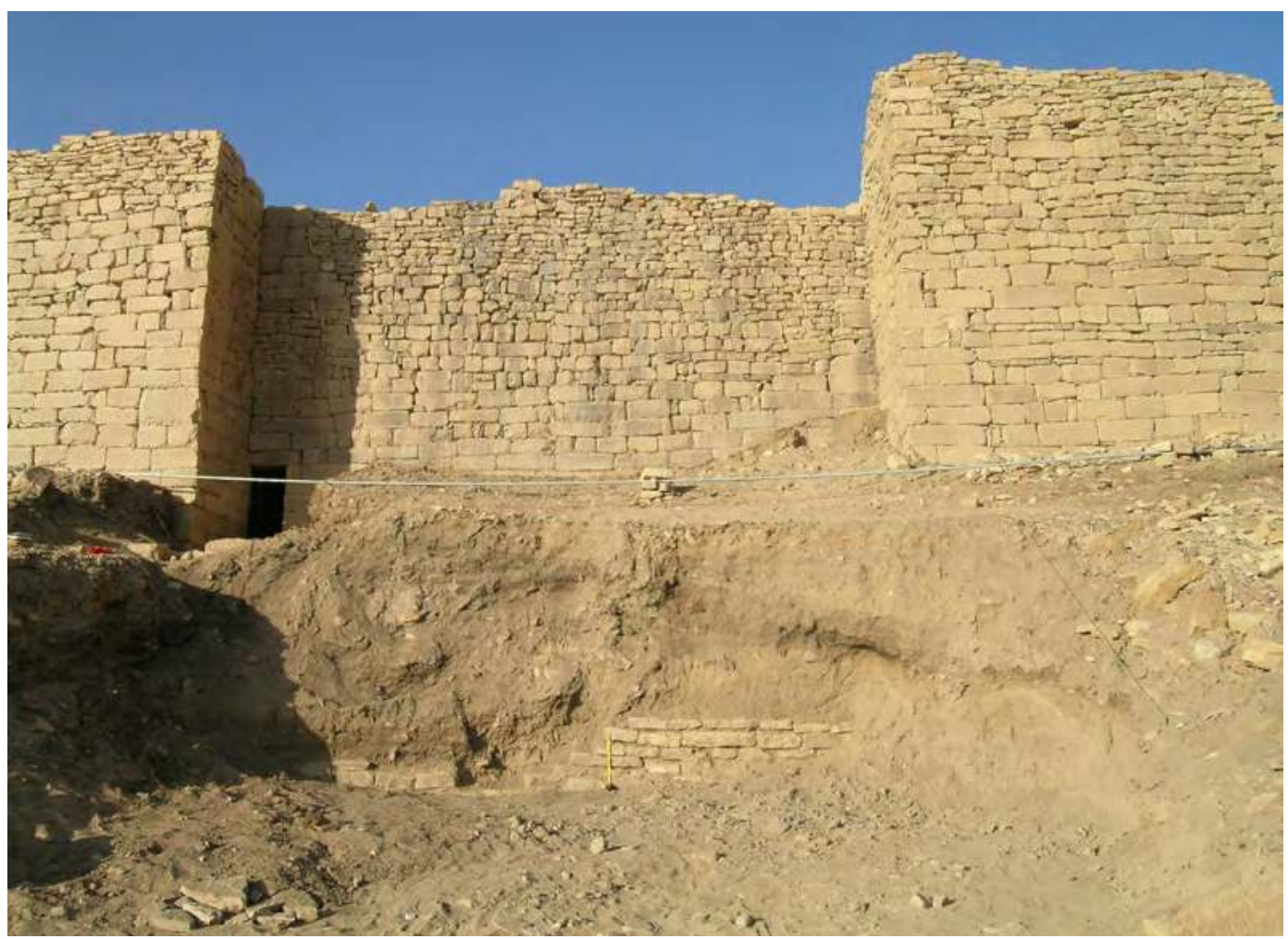

Figure 13. La sezione dello scavo davanti alla rientranza R44/45: in primo piano il lacerto di muro M50, messo in luce avvicinando il carro-gru alle mura. (A. de Maigret 2003 OMAIRY)

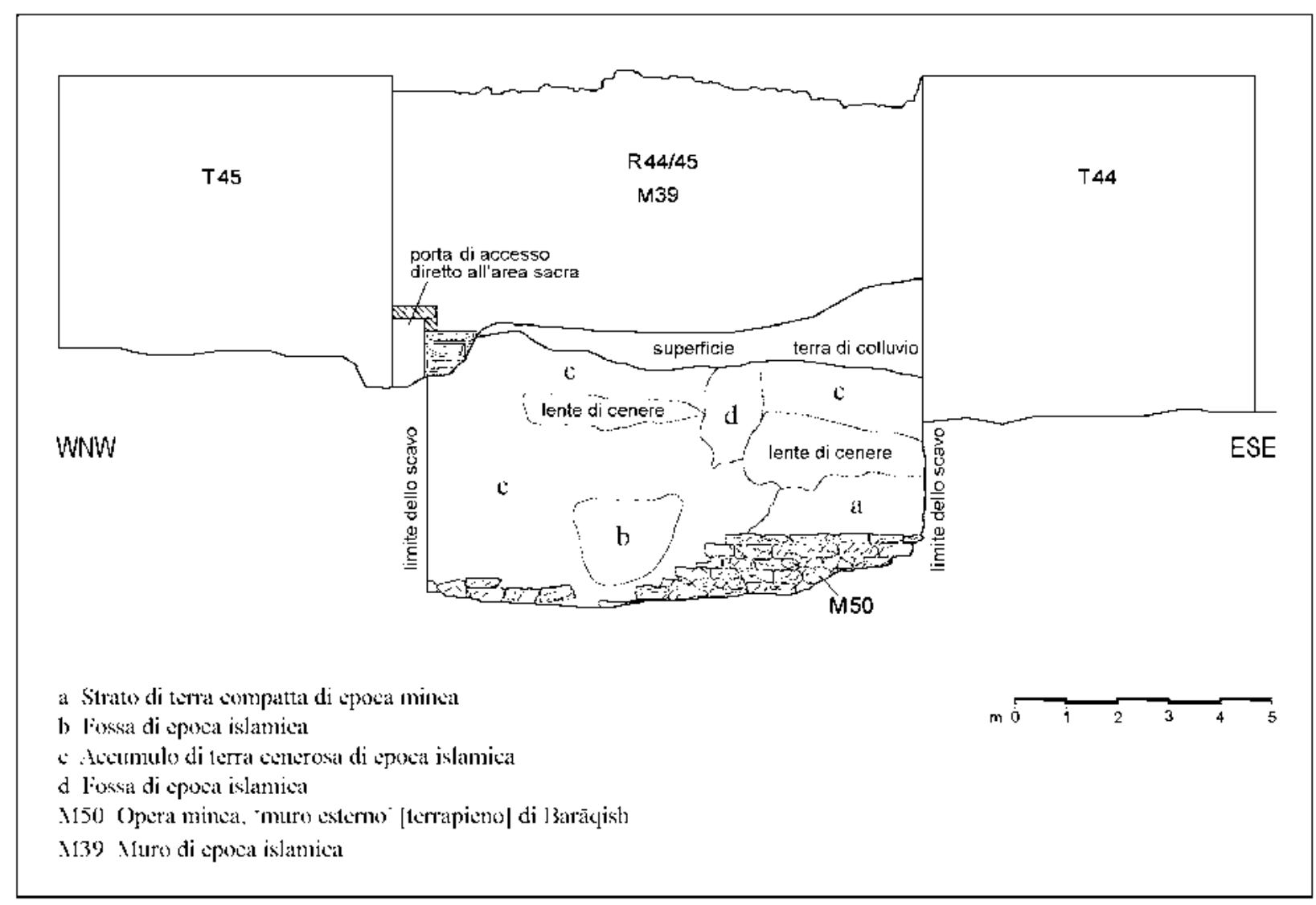

Figure 14. Sezione schematica dello scavo effettuato nella rientranza R44/45 davanti a M39. (Rielaborazione di M. Frondini e F.G. Fedele da schizzo originale 2003 di A. de Maigret, 2017 CMAIRY) 


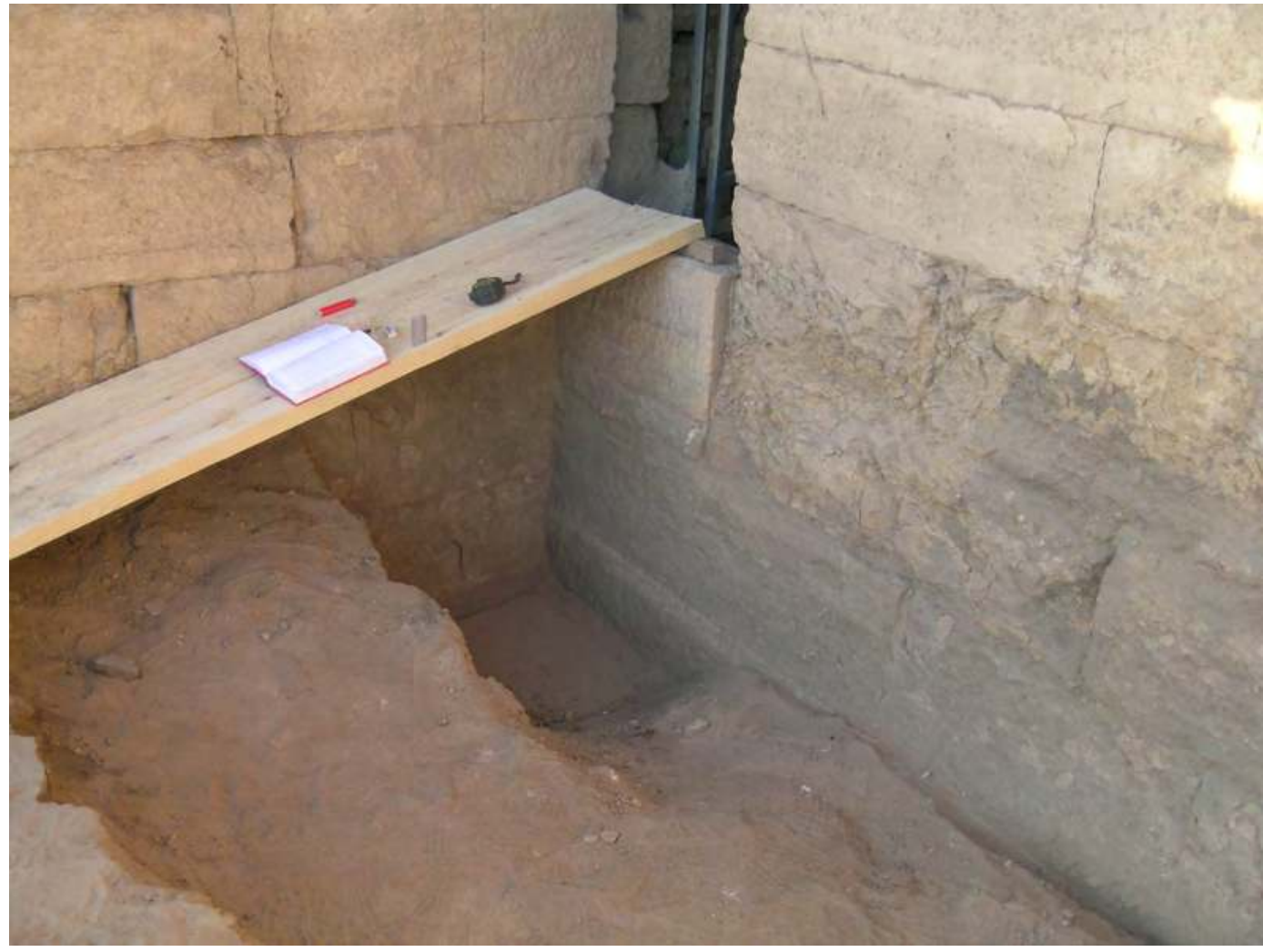

Figure 15. Nel sondaggio effettuato al di sotto della soglia della porta M39P si nota alla base una lastra quadrata di arenaria, probabilmente relativa ad una soglia minea più antica e più bassa rispetto a quella attuale. (A. de Maigret 2003 CMAIRY)

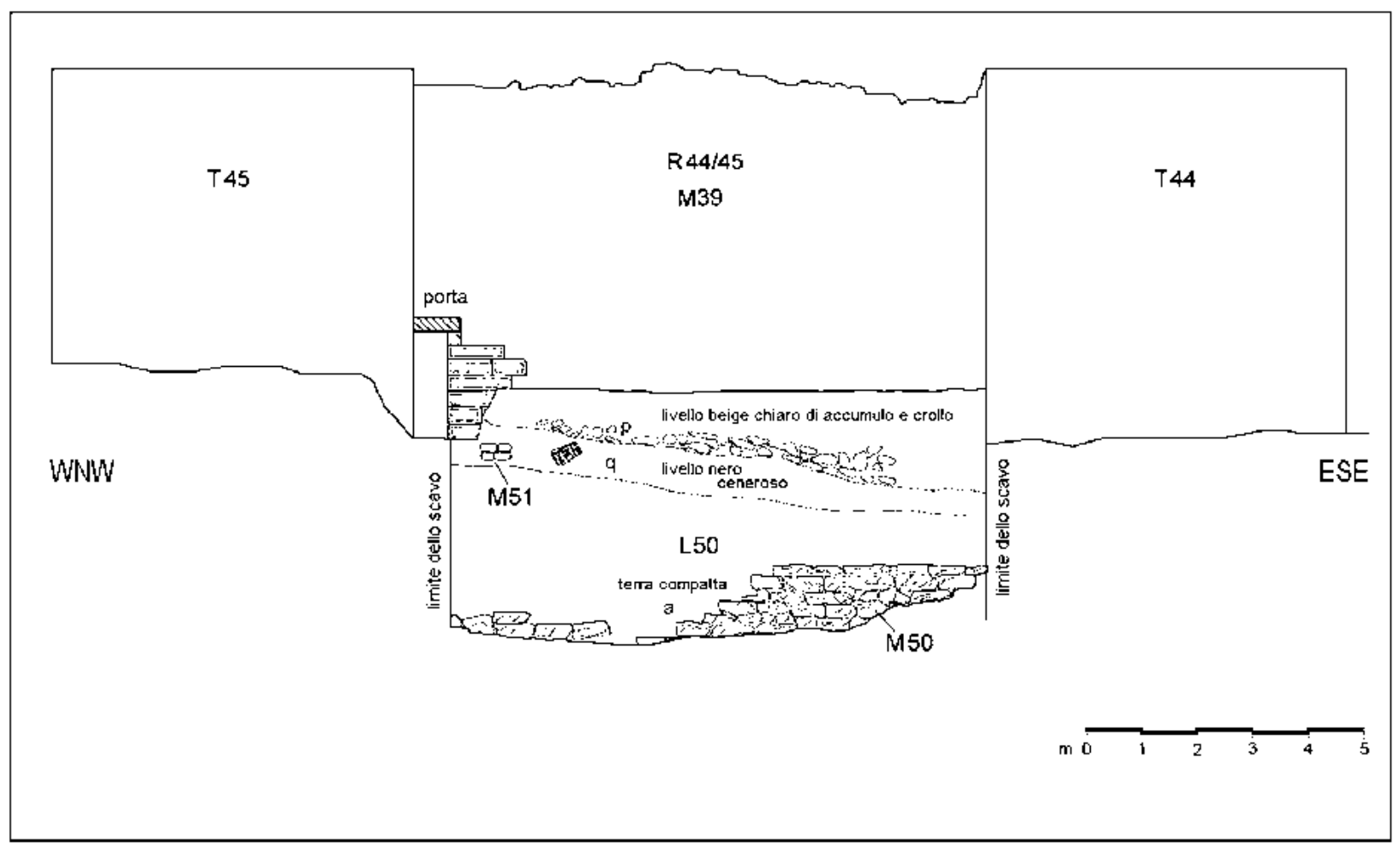

Figure 16. Sezione schematica degli strati di epoca islamica accumulatisi al di sopra del terrapieno L50. (Rielaborazione di M. Frondini e F.G. Fedele da schizzo originale 2003 di A. de Maigret, 2017 CMAIRY) 


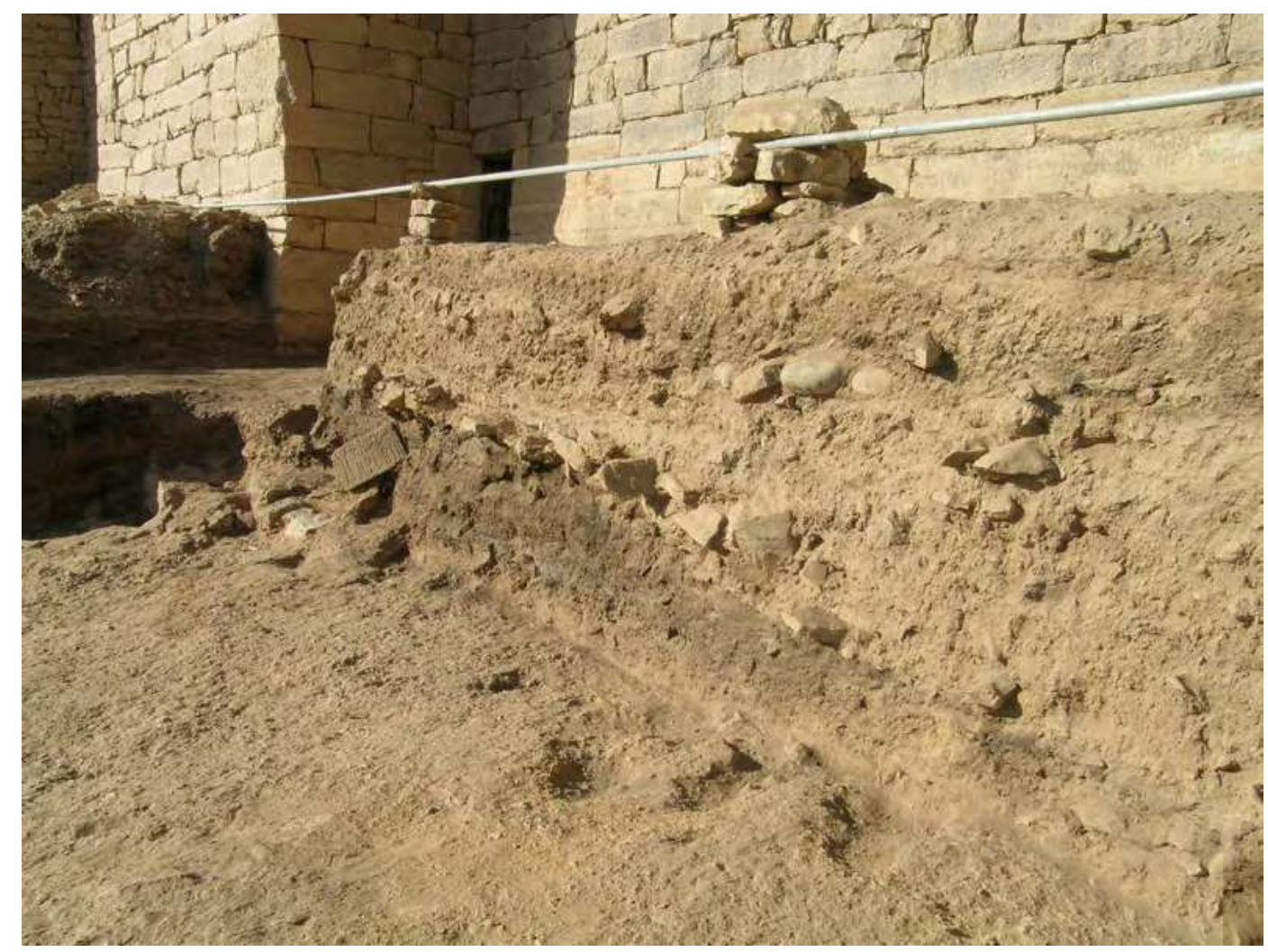

Figure 17. Vista da SE dell'accumulo di detriti di epoca islamica al di sopra di L50. (A. de Maigret 2003 CMAIRY)

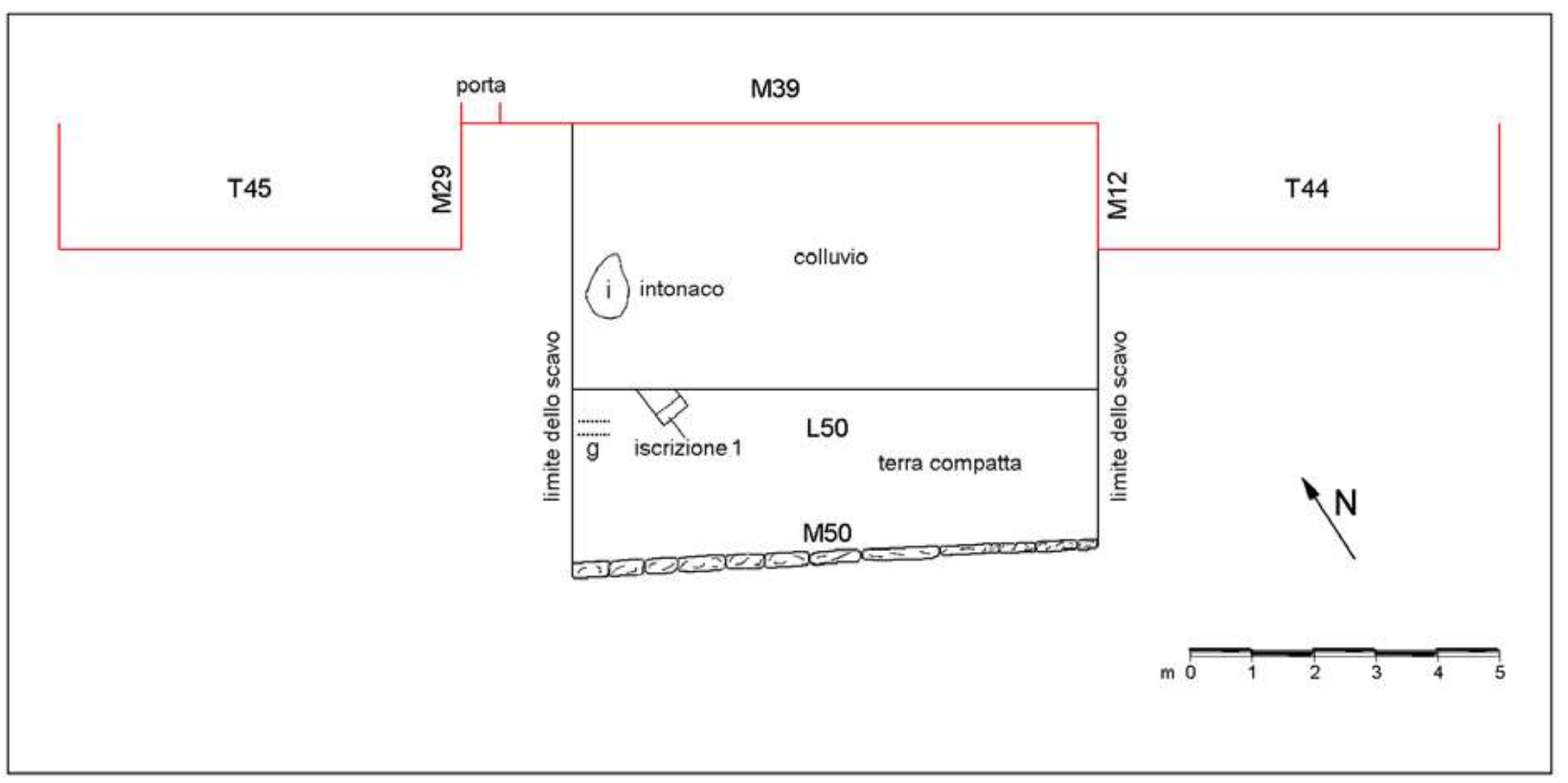

Figure 18. Pianta schematica dello scavo delimitato a N da M39 e a S da M50: situazione temporanea 2003. (Rielaborazione di M. Frondini e F.G. Fedele da schizzo originale 2003 di A. de Maigret, 2017 OMAIRY) 


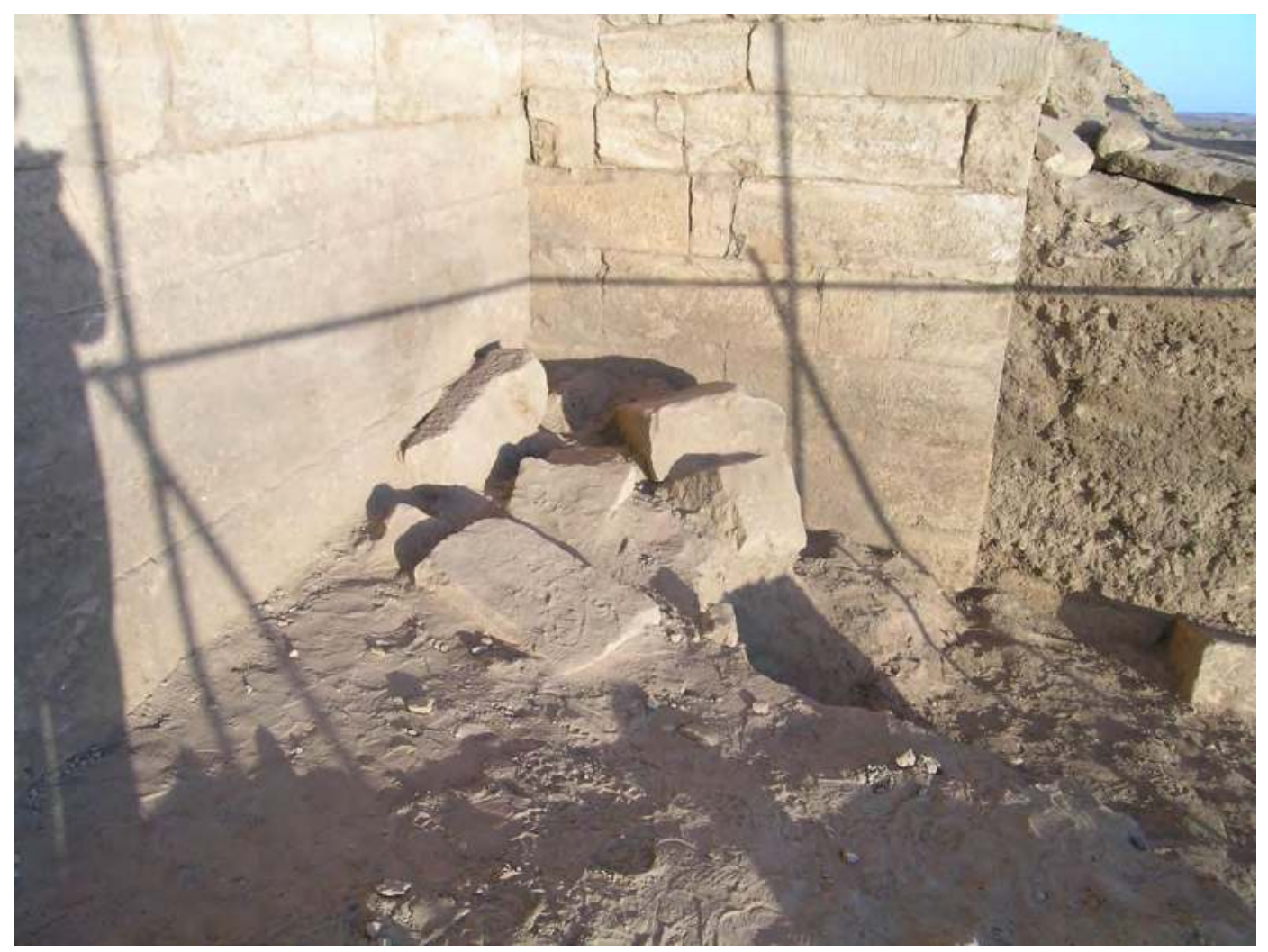

Figure 19. Blocchi squadrati in calcare rinvenuti nell'angolo tra M39 e M12 di T44, caduti dalla parte superiore di T44. (A. de Maigret 2003 CMAIRY)

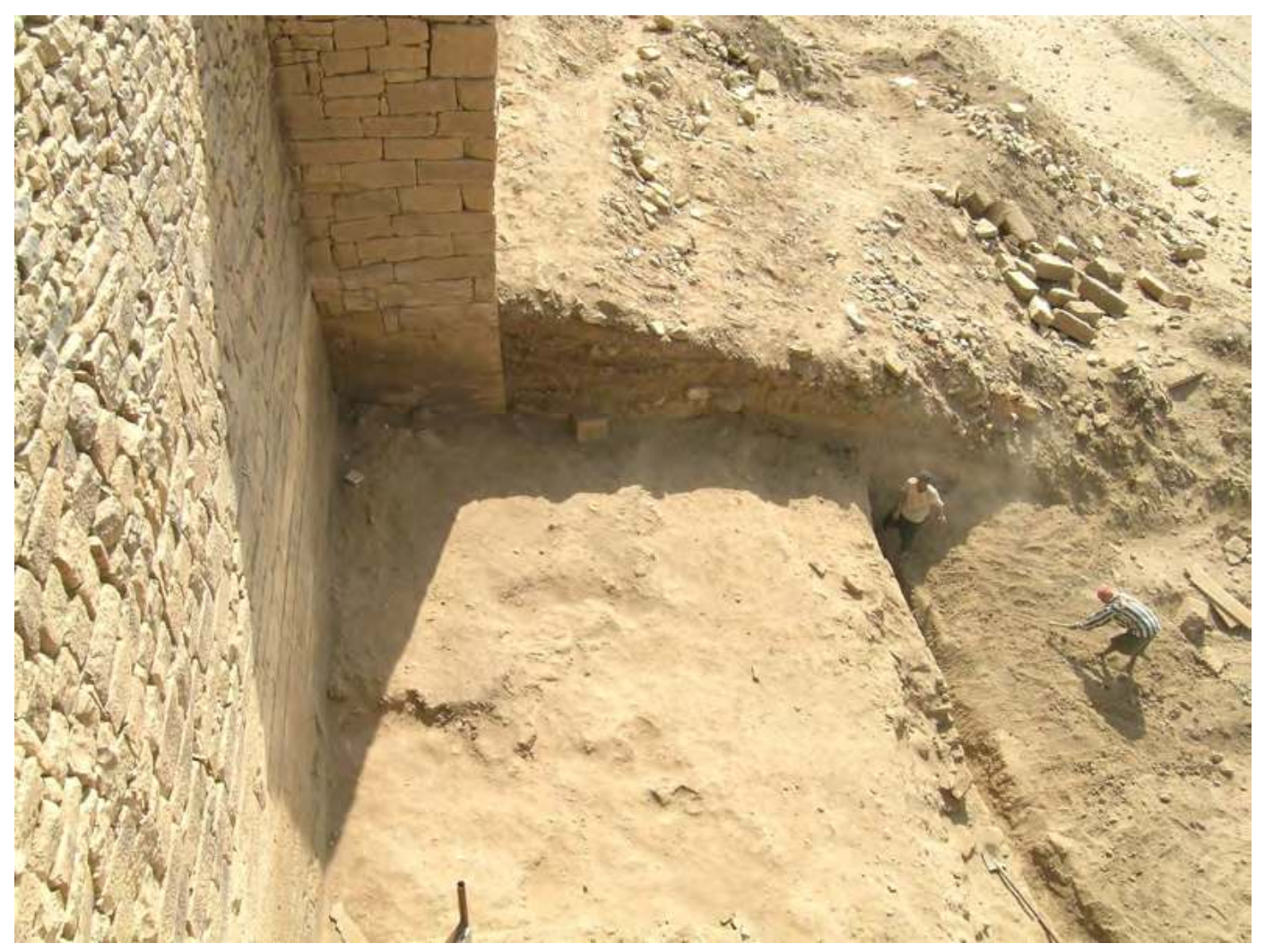

Figure 20. Vista del terrapieno L50 in tutta la sua ampiezza (da M50 a M39), dalla cima di T45.

(A. de Maigret 2004 OMAIRY) 


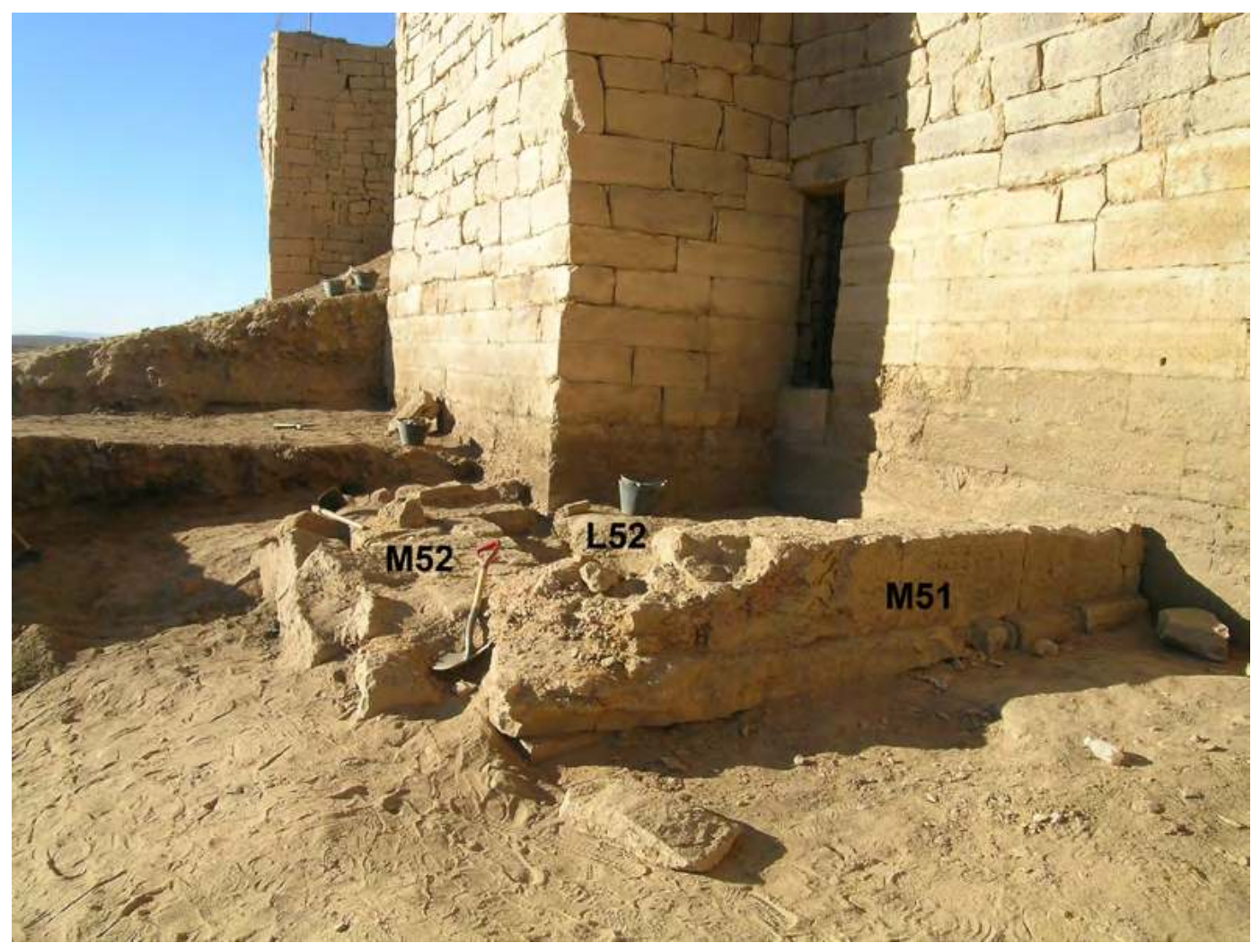

Figure 21. Il muretto est M51 della piattaforma L51 è formato da un filare di blocchi di arenaria che poggiano sulla risega di fondazione. (A. de Maigret 2003 OMAIRY)

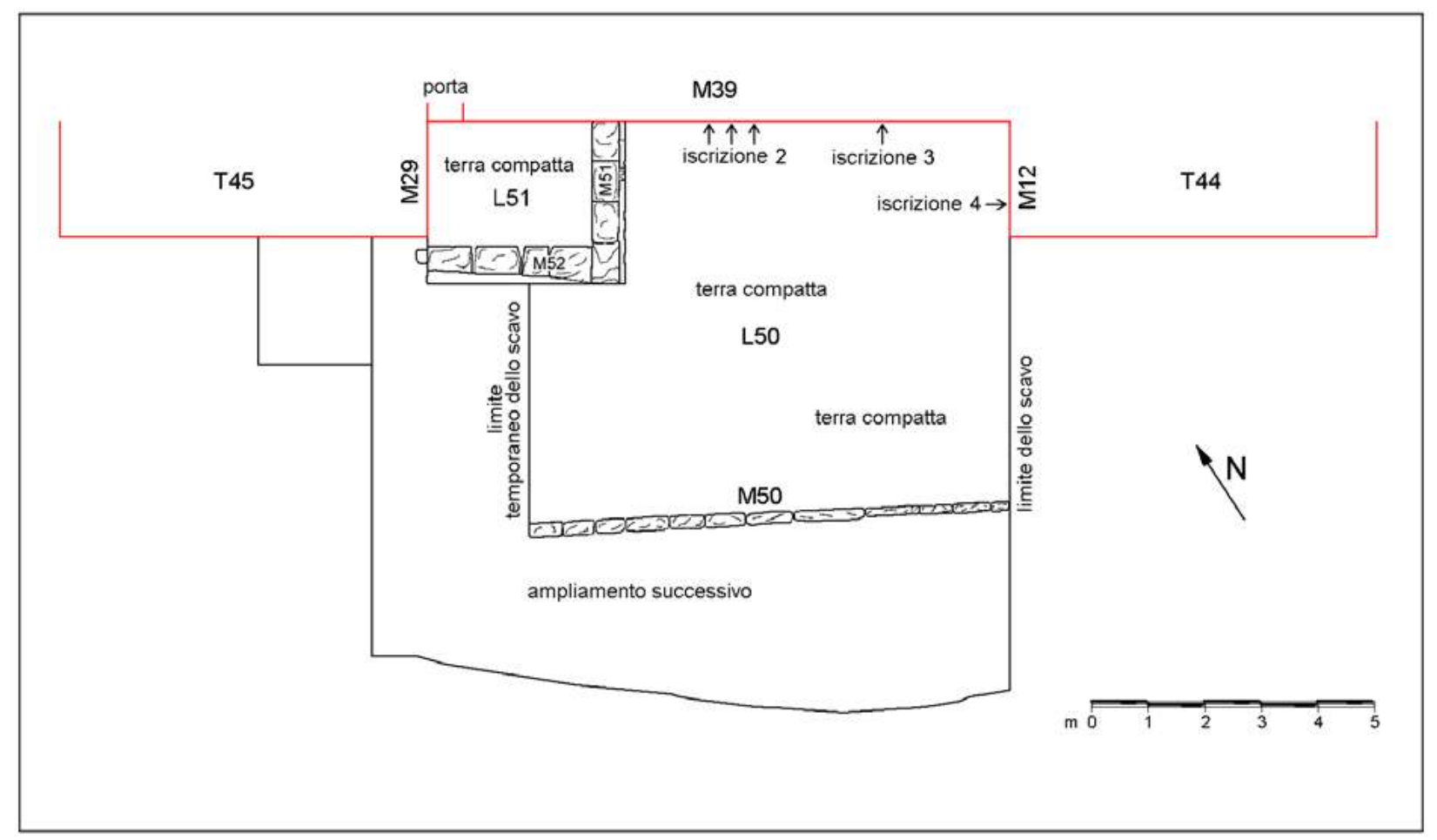

Figure 22. Pianta schematica della piattaforma L51 delimitata da M51 e M52. Questi muretti sono ospitati in una fondazione che ha tagliato L50. (Rielaborazione di M. Frondini e F.G. Fedele da schizzo originale 2003 di A. de Maigret, 2018 CMAIRY) 


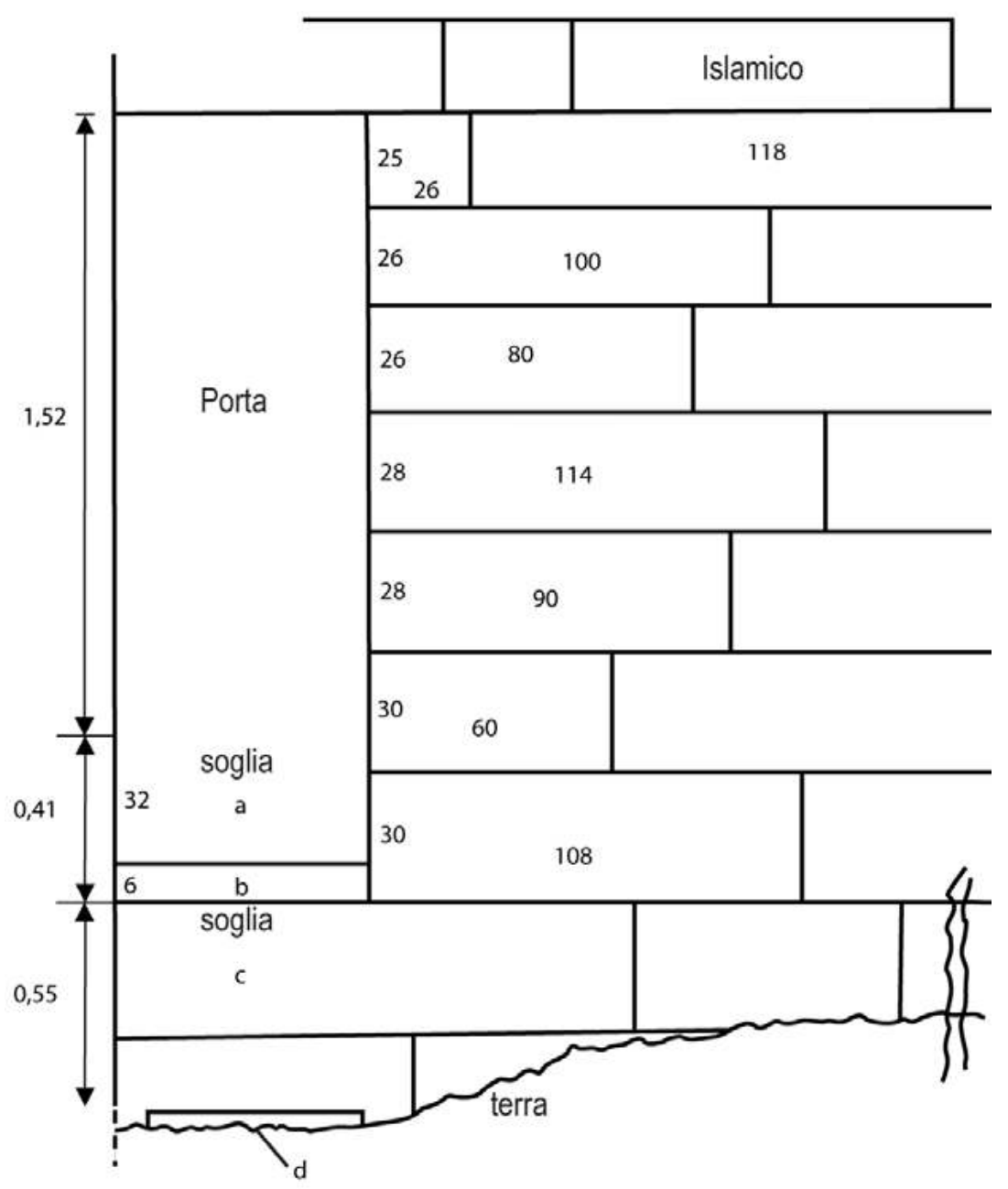

Figure 23. Schema della posterla M39P, con la soglia originale c e la soglia attuale rialzata a. Il livello del lastricato è di c. $60 \mathrm{~cm}$ più basso della soglia della porta M39P. (Rielaborazione di L. Munduteguy da disegno originale 2003 di A. de Maigret, 2019 (MAIRY)

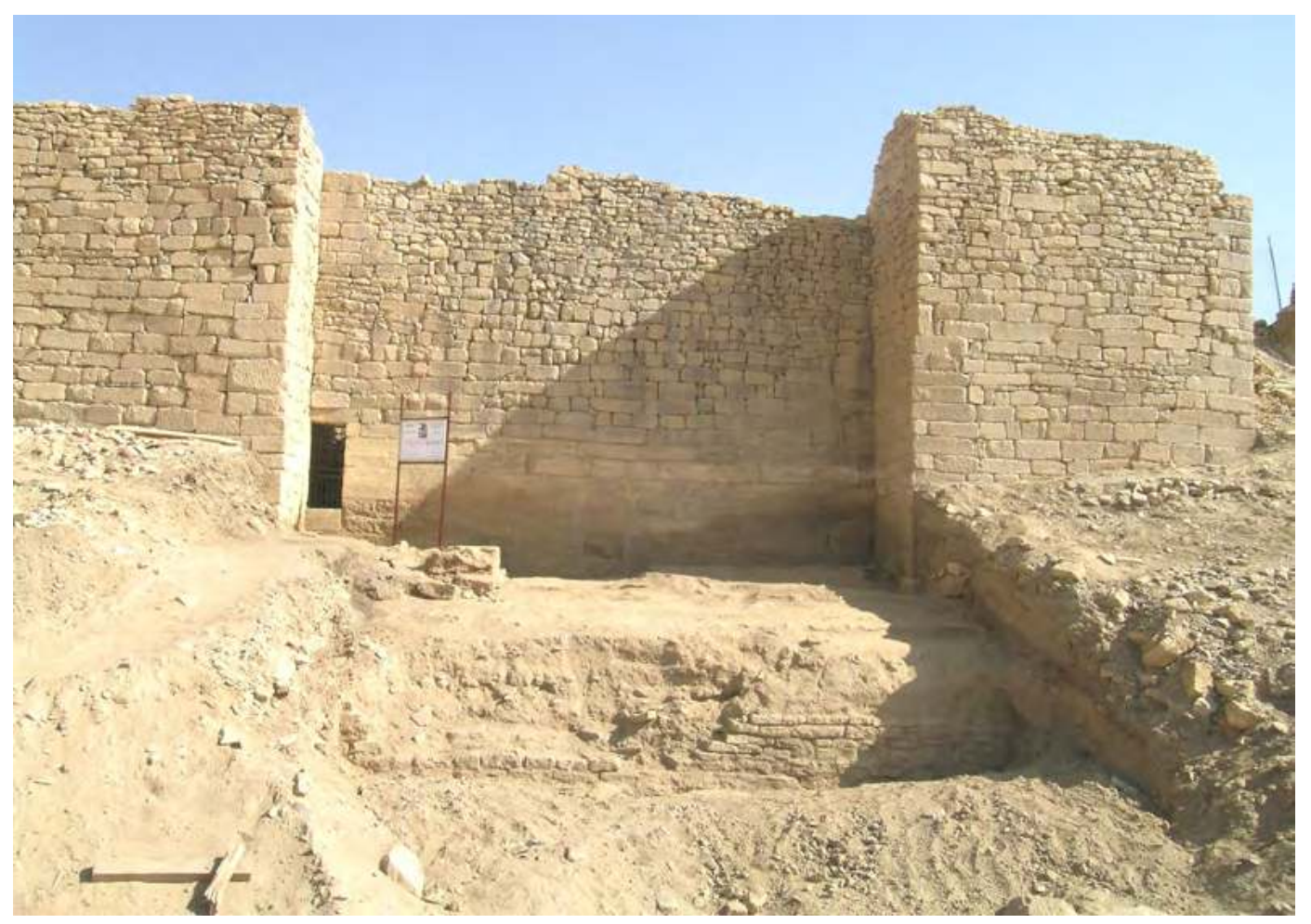

Figure 24. Vista dell'Area R44/45 e della struttura L50 a fine scavo, 2004, da S. (A. de Maigret 2004 OMAIRY) 


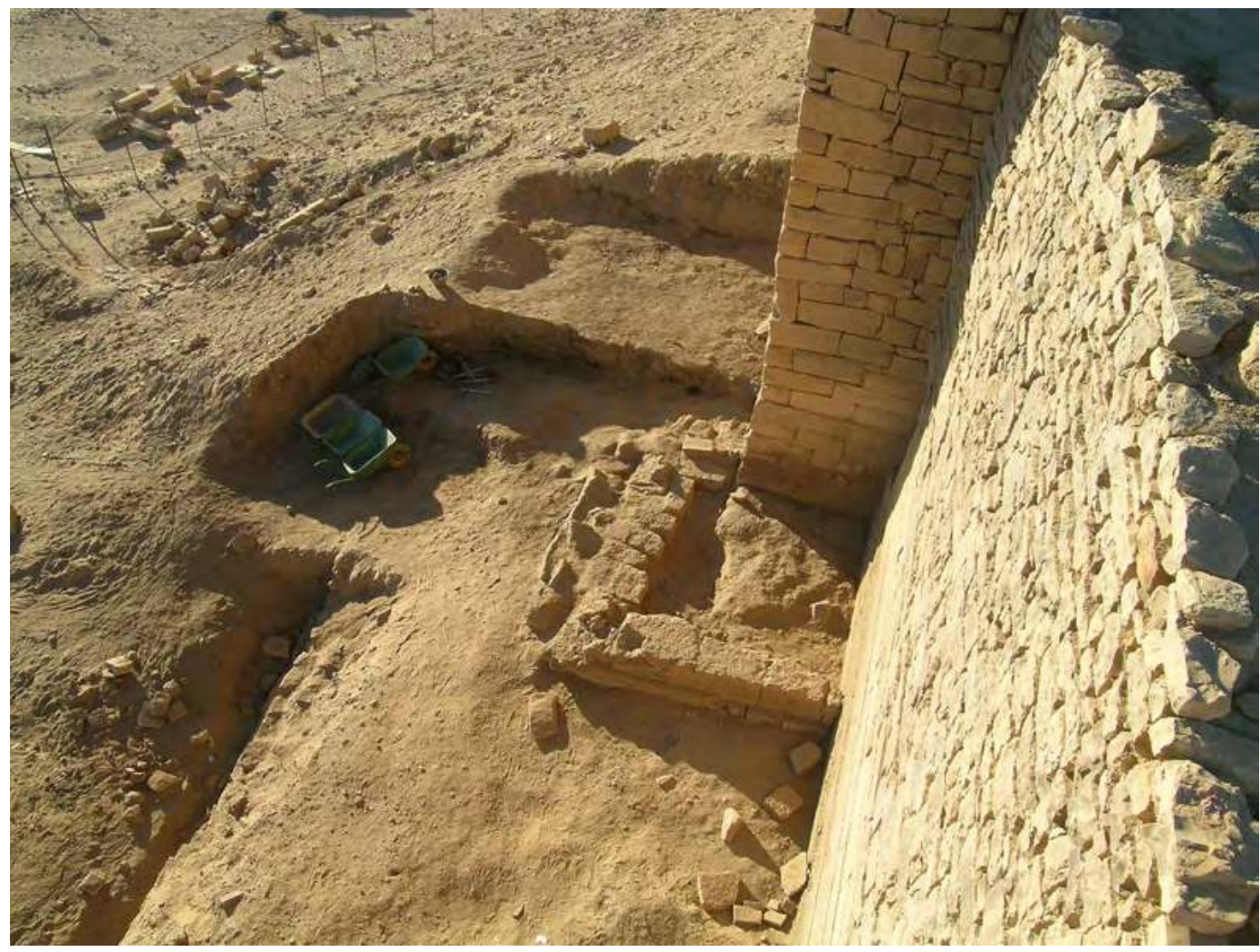

Figure 25. La piattaforma L51 dinanzi alla porta M39P, e la metà ovest dell'area di scavo, viste dalla cima di M39. (A. de Maigret 2003 CMAIRY)

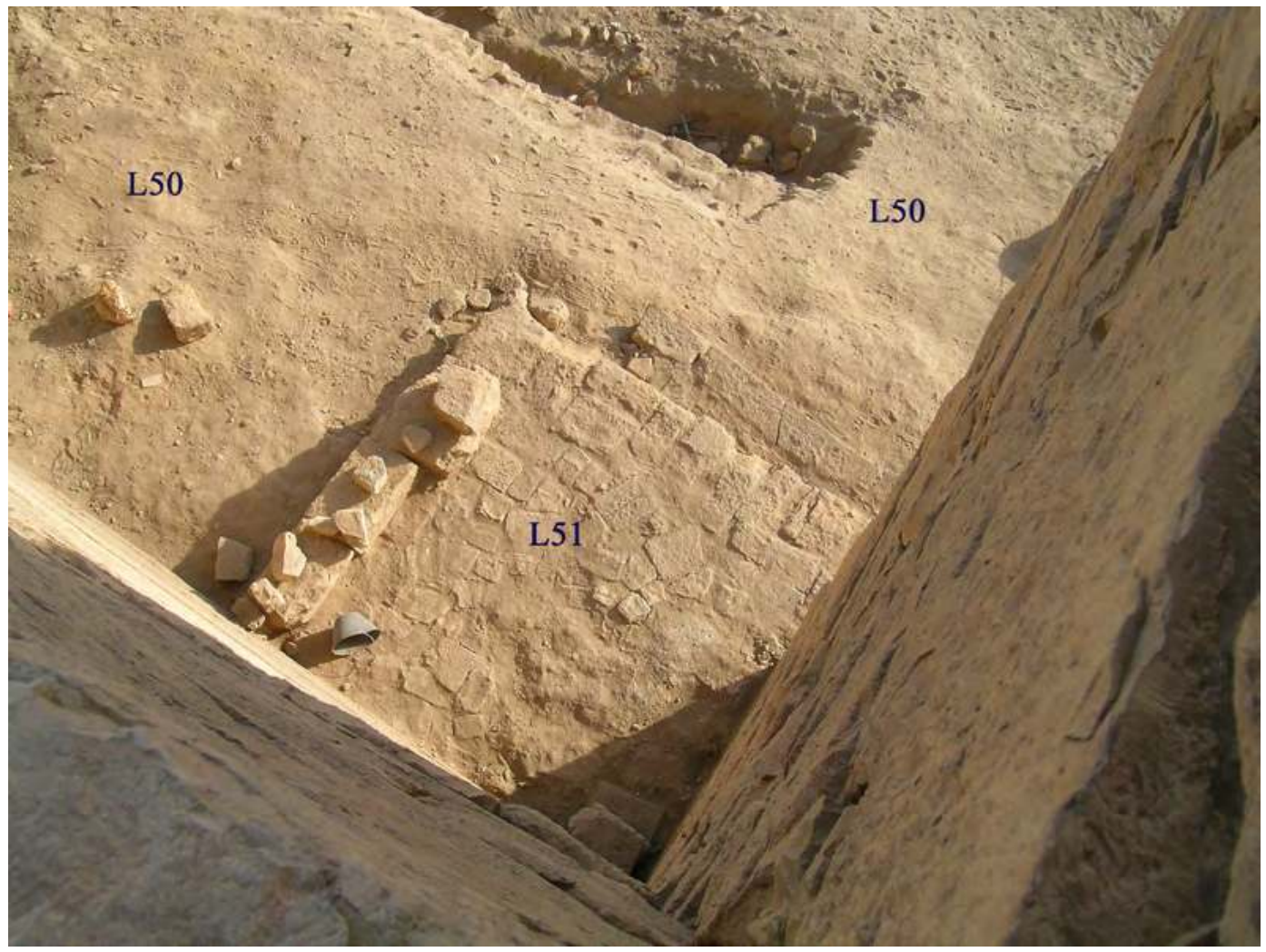

Figure 26. A fine scavo, gli spazi vuoti in L51 vengono colmati di terra e coperti di lastre di pietra. (A. de Maigret 2004 CMAIRY) 
Alessandro de Maigret non escludeva che all'interno del talus L50 ci fossero altri muri di rafforzamento, a nord di M50 e a esso paralleli.

Davanti alla porta M39P, nell'angolo compreso tra M29 e M39, fu messa in luce una piattaforma di terra compatta (L51) delimitata da due muretti (M51 e M52), le cui fondazioni, visibili sul lato orientale, tagliano L50. La piattaforma L51 era probabilmente ricoperta da lastre, come sembrano dimostrare le poche ritrovate, di fattura mediocre. Questa piattaforma, una sorta di pianerottolo (fig. 25), permetteva l'accesso alla rampa di scale in L12, dopo un rimaneggiamento, ossia l'innalzamento della soglia della porta M39P. ${ }^{14}$ Infatti, la soglia era in origine più bassa, come è dimostrato non soltanto dai fori per l'alloggiamento dei cardini lungo gli stipiti, ma anche dalla presenza di una lastra di antesoglia (d) scoperta al di sotto della piattaforma L51.

Ma qual era il raccordo tra il piano di campagna a sud del tell e il terrapieno L50 o la piattaforma L51? A fine scavo, A. de Maigret aveva osservato che 'il talus (terrapieno L50) copriva il muro M50 di contenimento,e, scendendo gradatamente e regolarmente, si raccordava al livello esterno di campagna, formando un ampio piano inclinato. Non vi era quindi bisogno di una scala per superare il dislivello e accedere alla posterla, dato che tale declivio non era, per la salita, eccessivamente, ripido'. Apparentemente ricoperto di terra compatta, il terrapieno avrebbe, cioè, potuto formare un piano inclinato graduale - un glacis - atto a raccordare il piano di campagna circostante con la posterla M39P (fig. 26). Queste restano, al momento, le sole osservazioni e considerazioni disponibili.

Tre iscrizioni minee sono state trovate reimpiegate nell'alzato di epoca islamica dei muri M39 e M12. Altre 4 iscrizioni sono state scoperte nello scavo lungo il fronte di T45: l'iscrizione Y.04.B.T45.1 (v. Agostini, capitolo 9 in questo volume, fig. 7), reimpiegata nell'alzato di epoca islamica di T45, e le tre iscrizioni frammentarie Y.04.B.T45.2, Y.04.B.T45.3 e Y.04.B.T45.4, fra le pietre di crollo su M52 (v. Agostini, capitolo 9 in questo volume, figg. 8-10).

L'indagine archeologica che era stata intrapresa lungo il fronte di T45 aveva lo scopo di seguire l'andamento del terrapieno L50 e del suo muro di contenimento M50 verso ovest. Purtroppo, gli scavi, interrotti a Barāqish nel 2007, non sono stati sino ad oggi più ripresi. Nella primavera del 2015 questo tratto di mura è stato irrimediabilmente distrutto dai bombardamenti dell'aviazione saudita, così come i templi di Nakrah e di 'Athtar dhu Qabd che la Missione archeologica italiana aveva messo in luce e restaurato. 


\title{
Chapter 9
}

\section{Lo scavo fuori mura in R44/45 a Barāqish. Le iscrizioni}

\author{
Alessio Agostini
}

\section{Introduzione}

Lo scavo della zona extra-muros in prossimità dei bastioni T44 e T45, e della cortina muraria tra essi compresa (v. Antonini, capitolo 8, in questo volume), ha riportato alla luce alcuni blocchi iscritti in larga misura pertinenti ai filari delle mura difensive urbane. Alcuni sono stati rinvenuti nel materiale di crollo via via rimosso, altri sono stati scoperti sulla faccia esterna del muro di cinta fino a quel momento coperta dal riempimento. Quest'ultimi risultano comunque non propriamente in situ, dato che sono stati riposizionati durante il restauro delle mura in epoca islamica, come si evince dalla non perfetta aderenza dei blocchi con l'opera muraria circostante e dal ricollocamento in posizione capovolta di un blocco. Si può tuttavia ritenere che questi elementi siano stati ricavati dal materiale di crollo e riposizionati grosso modo in prossimità della loro collocazione originaria; per questo, alcuni di questi pezzi si preferisce considerarli in loco. Le iscrizioni presenti permettono di aggiungere dati significativi all'abbondante documentazione epigrafica già nota dalla cinta muraria di Barāqish. In modo particolare, la collazione del testo Y.03.B.R44-45.2 ha rivelato una coreggenza finora ignota del re Abiyada' Yatha' con Hayyawum (cfr. anche capitolo 4, in questo volume, Tabella 1).

\section{Catalogo delle iscrizioni}

\section{Y.03.B.R44-45.1 (fig. 1)}

Provenienza: da crollo in prossimità di R44-45, tra M39 e M50, in uno strato di terra compatta in L50.

Collocazione: già Barāqish magazzino del Museo

Materiale: calcare

Dimensioni: non disponibili

\section{Conservazione: frammentaria}

Descrizione: a sinistra del testo è presente il Tor-Symbole o simbolo della 'porta' (Grohmann 1914, 52-55; Gajda 2012, 448), che si estende in altezza lungo entrambe le righe iscritte del blocco. Il simbolo è notoriamente associato al dio 'Athtar dhu-Qabd. L'incisione delle lettere è regolare e profonda. Periodo B. Stile grafico E2. V secolo a.C.

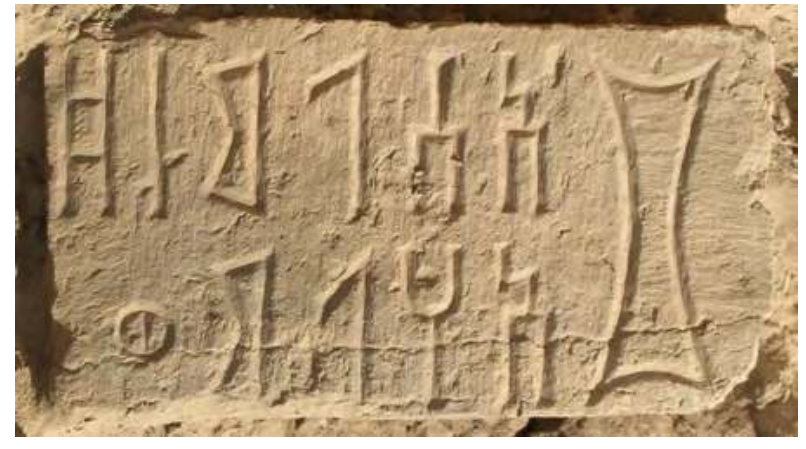

Figure 1. Y.03.B.R44-45.1. (A. de Maigret 2004 CMAIRY)

Testo:

1. ' $\mathrm{s}^{1} \operatorname{lm} \underline{\mathrm{d}}[\ldots]$

2. $h l m w[. .$.

Note:

L.1: il nome proprio Aslām è frequente in ambito mineo come primo nome personale maschile e come patronimico.

\section{Y.03.B.R44-45.2 (fig. 2)}

Provenienza: ricollocata nella cinta muraria sud (M39). Collocazione: in loco

Materiale: calcare

Dimensioni: non disponibili

Conservazione: frammentaria

Descrizione: Periodo B. Stile grafico E2. V secolo a.C.

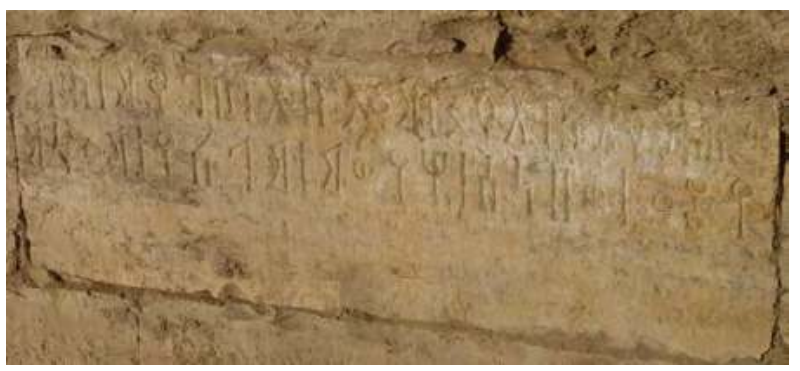

Figure 2. Y.03.B.R44-45.2. (A. de Maigret 2004 CMAIRY) 
Testo:

1. [...] $w$-ș (hf)tn $T f^{2}{ }^{2} m^{r} r b t b l q m$ ' $n[f . .$.

2. [...] Y $\underline{t}^{c} w-b n-s^{1}$ Hywm mlky $M^{\top} n m$ [...]

\section{Y.03.B.R44-45.2 bis (fig. 3)}

Provenienza: ricollocata nella cinta muraria sud (M39). Collocazione: in loco

Materiale: calcare

Dimensioni: non disponibili

Conservazione: frammentaria

Descrizione: Periodo B. Stile grafico E2. V secolo a.C.

Testo:

1. $\quad\left[\ldots{ }^{c} \underline{t} \operatorname{tr} \underline{d}-Q\right](b) d m w-W d m w-N k r h m w-\underline{t} t r \underline{d} \underline{d}-[Y] h[r q$ ...]

2. $\quad[\ldots b-\underline{t} t r] \underline{d}-Y h r q w-b \underline{d} t N s^{2} q m w-b k l\{\{\} l[l t \ldots]$

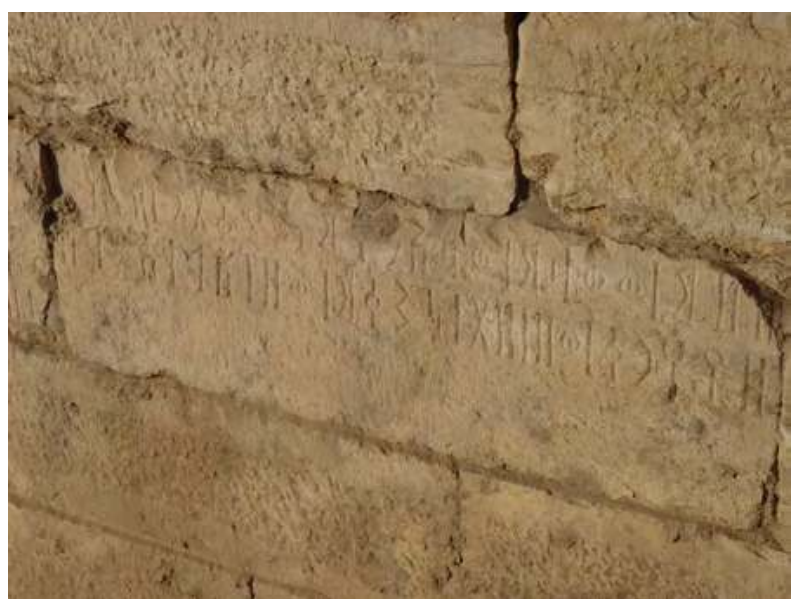

Figure 3. Y.03.B.R44-45.2 bis. (A. de Maigret 2004 @MAIRY)

\section{Y.03.B.R44-45.2 ter (fig. 4)}

Provenienza: ricollocata nella cinta muraria sud (M39). Collocazione: in loco

Materiale: calcare

Dimensioni: non disponibili

Conservazione: frammentaria

Descrizione: il blocco è stato riposizionato capovolto.

Periodo B. Stile grafico E2. V secolo a.C.

\section{Testo:}

1. $\quad[. .] q.(k) l(m b) n y m h f d n \underline{d}-N d b n[. .$.

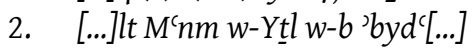

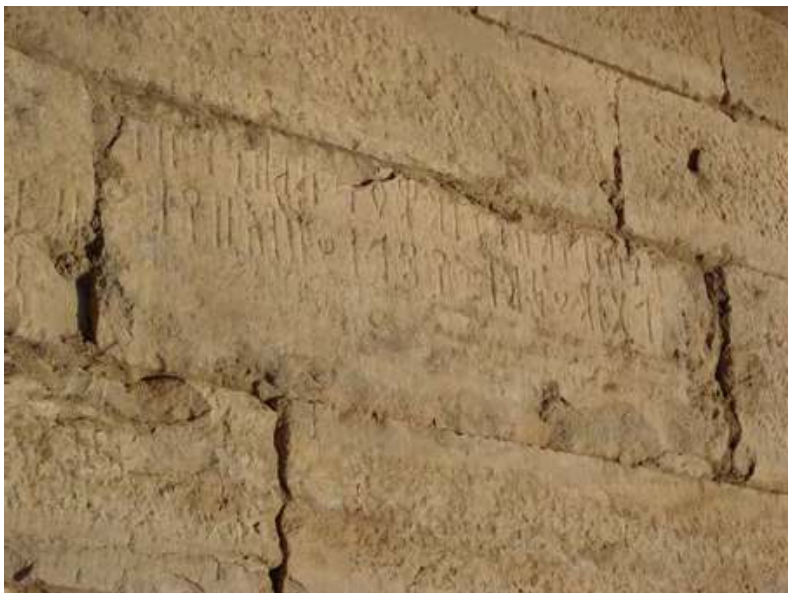

Figure 4. Y.03.B.R44-45.2 ter. (A. de Maigret 2004 CMAIRY)

- Collazione: Y.03.B.R44-45.2bis + Y.03.B.R4445.2ter + Y.03.B.R44-45.2

Testo:

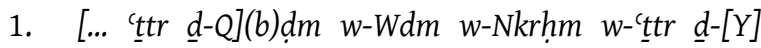
$h[r] \pm q(k) l(m b) n y$ mhfdn $\underline{d}-N b d n \pm w-s(h f) t n \quad T f s^{2}$ m'rbt blqm 'n[f...]

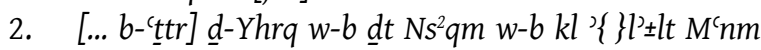
$w-Y \underline{t} l \underline{w}-b^{\prime} b y d^{`} \pm Y \underline{t} \underline{t}^{c} w-b n-s^{1}$ Hywm mlky $M^{c} n m[. .$.

\section{Traduzione:}

1. [e (ha dedicato) ad 'Athtar dhu-Qa](b)dum e a Wadd ${ }^{u m}$ e a Nakrah ${ }^{\text {um }}$ e a 'Athtar dhu-[Ya]h[ri]q tutta la costruzione della torre dhu-Nabdān e la cortina Tafish, in blocchi di calcare (per) la faccia[ta ...]

2. [... per 'Athtar] dhu-Yahriq e per Dhat Nashqum e per tutte le divinità di $\mathrm{Ma}^{\mathrm{C}} \mathrm{in}^{\mathrm{um}}$ e Yathill e per Abìyada' Yatha' e suo figlio Hayyaw ${ }^{\text {um }}$, i due re di $\mathrm{Ma}^{\mathrm{C}} \mathrm{i}^{\mathrm{um}}[\ldots]$

Note:

Si tratta con ogni probabilità di una iscrizione dedicatoria e di costruzione, combinazione testuale tipica dei testi minei relativi a opere pubbliche finanziati da privati.

L.1: $\quad \underline{d}-N d b n$ : questo nome di costruzione è già attestato a Barāqish nella M 185 (da ascrivere al tempo di Abīkarib Șādiq), dove potrebbe forse indicare una cortina, contigua alla torre Bqrn, dunque localizzata più a ovest rispetto alla posizione di questa iscrizione.

$T f s^{2}$ : questo nome, non attestato finora in Mineo, è invece noto in Sabeo, dove è pure utilizzato per indicare costruzioni: nella RES 3946 è il nome di una struttura non ben identificata ( $\left.{ }^{1} s^{1} n n\right)$ costruita da Karib'il Watar in Adhanat; nella MM 10 è riferito invece a una fortezza $\left(m \operatorname{șn}^{c} t\right)$. 


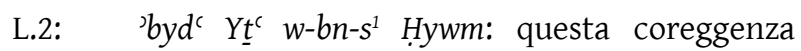
non era finora nota. La combinazione di Abiyada'con l'epiteto Yatha' è il risultato della collazione proposta, che sembra del tutto sicura, ed è pertanto plausibile un'identificazione con il sovrano omonimo della RES 3022, padre di Waqih'il Riyām con cui è pure coreggente per un certo periodo prima della successione di quest'ultimo. Ci sentiamo di escludere un caso di omonimia e, senza postulare un Abiyadac Yathac II, dobbiamo ammettere un nuovo caso di coreggenza plurima, come è stato possibile individuare proprio per lo stesso Waqih’il Riyām, con Aws'il (Y.05.B.B.12) e con Huffān Șādiq (v. Agostini, capitolo 4, in questo volume, e Agostini 2011). Proprio come per Aws'il, però, anche Hayyawum è un nome non di ambito regale e potrebbe dunque far pensare che sia stato utilizzato il nome di nascita del coreggente e non quello ufficiale (se questo fosse il caso, Hayyawum potrebbe essere il nome di Waqih'il Riyām). L'identificazione del primo sovrano di questo testo con lo Abiyada' Yatha' della RES 3022 sembra ulteriormente sostenuta da una vicinanza paleografica tra le due iscrizioni, entrambe nello stile E2 di Pirenne. Il contesto archeologico ed epigrafico relativo a Waqih'il Riyām, chiarito con lo scavo del Tempio B, consentono di posizionare il padre Abiyadac Yatha' nel pieno $\mathrm{V}$ sec. a.C. (cfr. capitolo 4, in questo volume e Agostini 2020b).

\section{Y.03.B.R44-45.3 (fig. 5)}

Provenienza: ricollocata nella cinta muraria sud (M39). Collocazione: in loco

Materiale: calcare

Dimensioni: non disponibili

Conservazione: frammentaria

Descrizione: il blocco si trova contiguo alla destra di Y.03.B.R44-45.2. Non sembra tuttavia pertinente all'iscrizione precedente, soprattutto in considerazione del diverso contenuto (si tratta della costruzione di

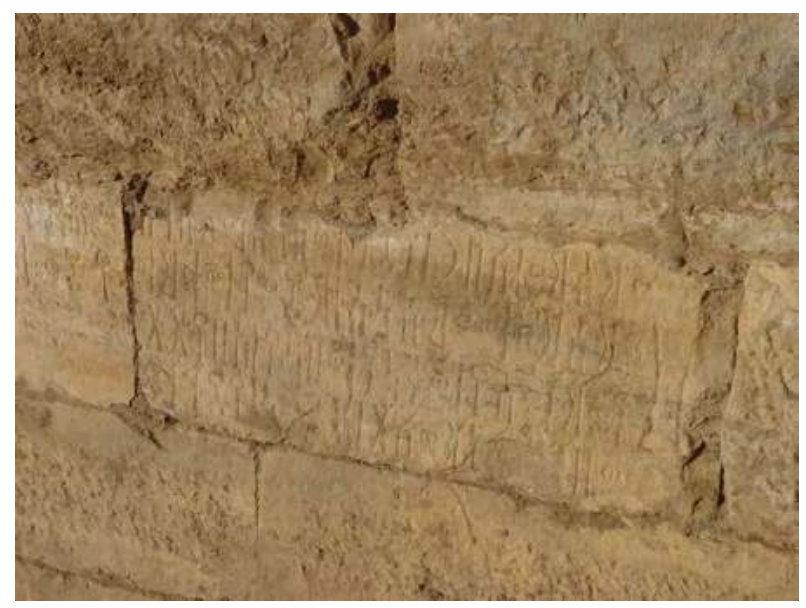

Figure 5. Y.03.B.R44-45.3. (A. de Maigret 2004 CMAIRY) case e non di opere difensive) e per il suo sviluppo su quattro linee. A destra, in corrispondenza delle due linee mediane del testo, si trova il Tor-Symbole. Periodo B. Stile grafico E2. V secolo a.C.

\section{Testo:}

1. ' $m s^{1} m^{c} k b r$ Ytl $w-b\left(n-s^{1}\right)^{c} m\left({ }^{\prime} n s^{1}\right)[\ldots]$

2. ${ }^{c} m s^{1} m^{c} w-{ }^{c} m^{2} n s^{1} m t^{t} y W d m w-[\ldots]$

3. $y w m^{\prime} s^{1} y w$-qny $w$-bny 'bytt [...]

4. $w-b(t)[..] s^{3} w k t h g(r) n Y \underline{t l}[. .$.

\section{Traduzione:}

1. 'Ammīsamic kabīr di Yathill e suo figlio 'Ammïanas [...]

2. 'Ammīsami' e 'Ammī'anas (hanno fatto) offerte a Waddum e [...]

3. quando hanno fatto e acquisito e costruito le case (?) [...]

4. .. (.)[..] assedio della città di Yathill [...]

\section{Note:}

L.1: ' $m s^{1} m^{c}$ : un 'Ammīsamic kabīr di Yathill è già noto dalla M 179 e dalla RES 3022 ('Ammīsami' dhuBalih), dove risulta contemporaneo di Abiyada' Yatha', dunque è possibile che si tratti dello stesso soggetto data la vicinanza paleografica dei testi.

L.3: 'bytt: l'ampio spettro semantico della radice BYT, utilizzata invariabilmente per edifici di tipo domestico e religioso, non permette di essere più precisi circa l'identificazione della costruzione che viene commemorata, anche in ragione della frammentarietà del testo. Si propende per costruzioni di tipo domestico, visti il numero plurale e la rivendicazione di proprietà espressa dal verbo qny (linea 3).

L.4: $\quad s^{3} w k t$ : un assedio di Yathill durante il periodo della dinastia di Abīyada' Yatha' (V secolo a.C.), che sembra la collocazione cronologica più plausibile per questo testo, non era finora noto. Precedentemente, Yathill fu vittima di un assedio imposto da un mukarrib sabeo, come ricordato nella RES 3943/3.

\section{Y.03.B.R44-45.4 (fig. 6) = M $180=$ RES 2960}

Provenienza: ricollocata nello spigolo sud-ovest T 44 (M12).

Collocazione: in loco

Materiale: calcare

Dimensioni: non disponibili

Conservazione: frammentaria

Descrizione: dal punto di vista paleografico, il testo presenta interessanti confronti con la M 222 che risente fortemente dello stile grafico qatabanico e che si colloca nella parte finale della Yathill minea. Fine periodo B inizio C. II-I secolo a.C. 


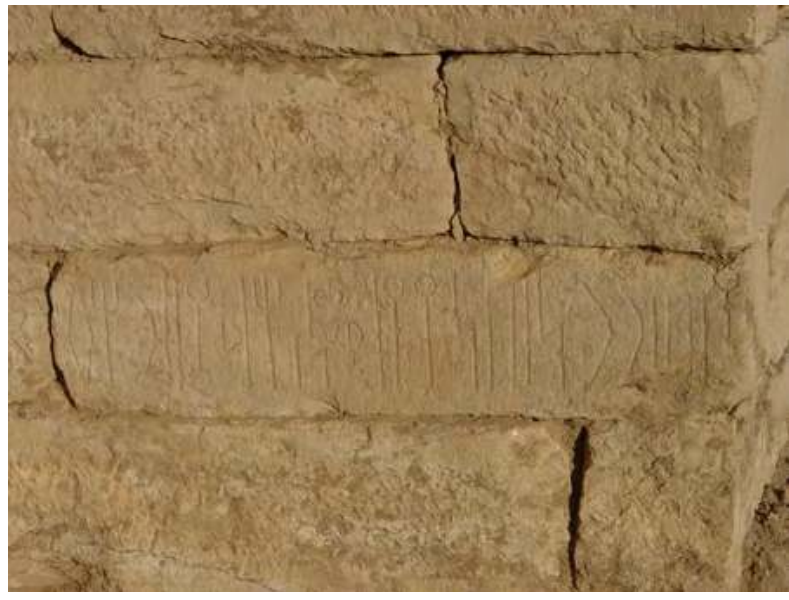

Figure 6. Y.03.B.R44-45.4. (= M $180=$ RES 2960)

(A. de Maigret 2004 CMAIRY)

Testo:

\section{1. [...]t $\underline{d}-M r n$ bnyy $w-s^{1} h d \underline{t} m h f[d t ~ \ldots .$.}

\section{Traduzione:}

1. [...]. dhu-Marān, hanno costruito e posto le fondazioni della tor[re ...]

Note:

d-Mrn: una lettura del nome come Dmrn potrebbe essere ugualmente possibile (cfr. Qatabanico RES 3566, benché integrata).

\section{Y.04.B.T45.1 (fig. 7)}

Provenienza: ricollocata in T45 (M29).

Collocazione: in loco

Materiale: calcare

Dimensioni: non disponibili

Conservazione: frammentaria

Descrizione: Periodo B. Stile grafico E2. IV secolo a.C.?

\section{Testo:}
1. [...] $y^{\prime} l y f^{c} Y f s^{2} d-H[. .$.
2. [...] Y $\underline{d} k r^{\prime} l m t^{c} y W d m[. .$.
3. [...]mw-s $s^{2} y m h-s^{1} m \mid$

\section{Traduzione:}

1. [...]. Ilyafa' ${ }^{\prime}$ Yafash dhu-H[...]

2. [...] Yadhkar'il (ha fatto) offerte a Wadd ${ }^{\text {um }}[. .$.

3. [...]. e (per) il loro patrono.

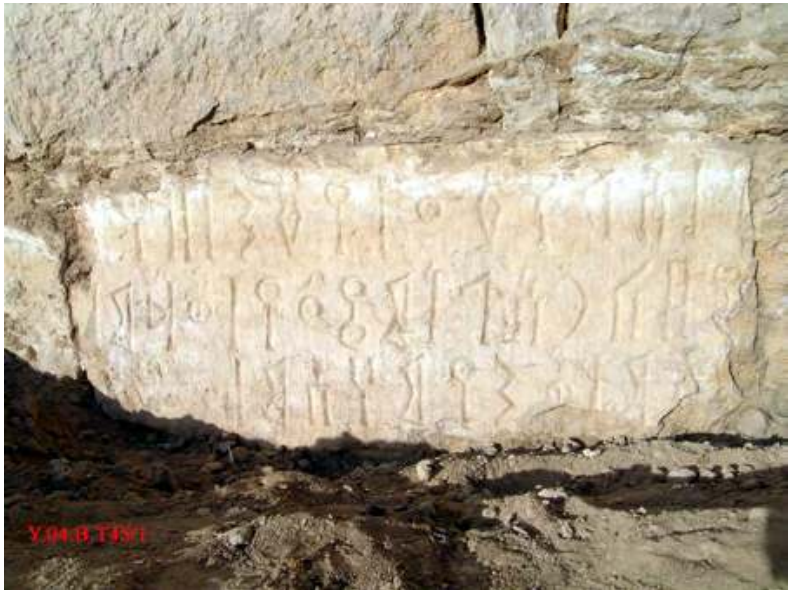

Figure 7. Y.04.B.T45.1. (A. de Maigret 2004 @MAIRY)

\section{Note:}

L.1: $\quad$ 'lyf $\mathrm{YfS}^{2}$ : un sovrano con questo nome ed epiteto è noto da M 205 sempre da Barāqish ma molto frammentaria e da M 18, dove sembra essere coreggente di Ḥuffān Șādiq. Secondo Kitchen, Ilyafa ${ }^{c}$ Yafash potrebbe essere uno degli immediati predecessori di Abiyada' Yatha' (Kitchen 1994, 53, 176, 238), ma al momento mancano dati certi. Cfr. il testo Y.06.B.B.11 dove si trova un'altra attestazione di un sovrano omonimo (cfr. Agostini, capitolo 4, in questo volume).

$d-H[. .$.$] : in via del tutto ipotetica, una possibile$ integrazione potrebbe essere con $\underline{d}-H d \underline{t}$, che è associato a un santuario (un tempio di 'Athtar, cfr. M 199 da Barāqish), ricorre inoltre come nome di un clan al quale appartenevano alcuni membri della classe sacerdotale (cfr. GOAM 315), sulla cui assegnazione sembra talvolta essere intervenuto anche il potere regale (cfr. as-Sawdä) $30)$.

\section{Y.04.B.T45.2 (fig. 8)}

Provenienza: da crollo prospiciente T45.

Collocazione: già Barāqish, magazzino

Materiale: calcare

Dimensioni: non disponibili

Conservazione: frammentaria

Descrizione: Periodo B. La superficie del supporto appare in più punti notevolmente abrasa. IV-III secolo a.C.?

\section{Testo:}

1. $\quad[\ldots \ldots . .] m.[\ldots \ldots . .$.

2. $\quad[. .] d m w.[. .] m w-.{ }^{c} t \operatorname{tr}(\underline{d}-)[Q b d . .$.

3. [...] b-gn' hgrn Qrnwt[...]

4. [...] $w-\underline{d}-\underline{t} t[r] h-s^{1} m y d(q) n[. .$.

5. [...] $w-[\underline{t} t] r \underline{d}-Y h r q w-[. .$. 


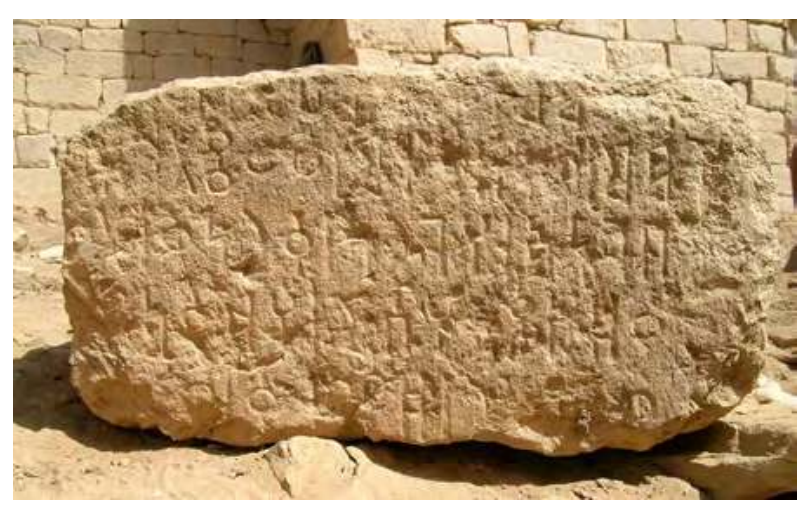

Figure 8. Y.04.B.T45.2. (A. de Maigret 2004 @MAIRY)

\section{Traduzione:}

1. $[\ldots \ldots . . . . . . .$.

2. [...] ...[...]. e 'Athtar dhu-[Qabd...]

3. [...] sulle mura della città di Qarnaw .[...]

4. [...] e dei loro discendenti ydqn (?)[...]

5. [...] e ['Athta]r dhu-Yahriq e [...]

\section{Y.04.B.T45.3 (fig. 9)}

Provenienza: da crollo prospiciente T45.

Collocazione: già Barāqish, magazzino

Materiale: calcare

Dimensioni: non disponibili

Conservazione: frammentaria

Descrizione: la natura simile del supporto lapideo e le caratteristiche paleografiche fanno ritenere questo pezzo pertinente a Y.04.B.T45.4, senza che sia stato possibile offrire una collazione reciproca. Periodo B. VIV secolo a.C.?

\section{Testo:}

1. $\quad[\ldots] s^{1} m[\ldots] m[\ldots]$

2. $\quad[. .]. m s^{3} w r t s^{1}[[. .]$.

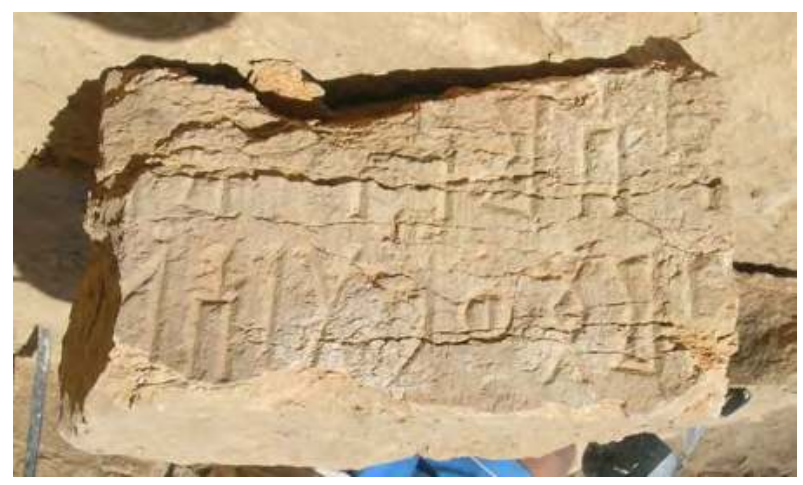

Figure 9. Y.04.B.T45.3. (A. de Maigret 2004 CMAIRY)
Note:

L.2: $\quad m s^{3} w r t:$ il termine indica un tipo di struttura idraulica, forse una canalizzazione.

\section{Y.04.B.T45.4 (fig. 10)}

Provenienza: da crollo prospiciente T45.

Collocazione: già Barāqish, magazzino

Materiale: calcare

Dimensioni: non disponibili

Conservazione: frammentaria

Descrizione: la natura simile del supporto lapideo e le caratteristiche paleografiche fanno ritenere questo pezzo pertinente a Y.04.B.T45.3, senza che sia stato possibile offrire una collazione reciproca. Periodo B. VIV secolo a.C.?

\section{Testo:}

1. $\quad[\ldots . .$.$] ghlt \operatorname{ct} t r[\ldots \ldots]$

2. $[\ldots \ldots . ..] \operatorname{th}[\ldots . .].[\ldots \ldots]$

\section{Note:}

L.1: $\quad$ ghlt 't $t$ tr: 'congregazione di 'Athtar'.

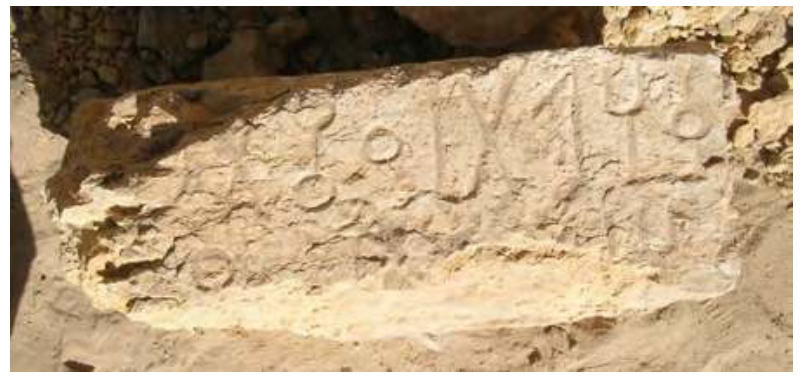

Figure 10. Y.04.B.T45.4. (A. de Maigret 2004 @MAIRY) 


\title{
Architecture and Cult
}

\section{Chapter 10 \\ L'architecture des Temples de Nakrah et 'Athtar dhu-Qabḍ à Barāqish}

\author{
Christian Darles
}

\section{Introduction: généralités architecturales et implantation}

$\mathrm{Au}$ cœur de la ville de Yathill, aujourd'hui Barāqish, à proximité immédiate de l'enceinte, au sud, a été édifiée une aire sacrée comprenant plusieurs temples et leurs annexes bâties. Durant plusieurs années, deux d'entre eux ont fait l'objet de fouilles minutieuses et d'études archéologiques par la mission archéologique italienne dirigée par le professeur Alessandro de Maigret. Ces recherches ont été complétées par des sondages stratigraphiques et un dégagement partiel du rempart adjacent. Ces deux temples ont la même orientation sud-est - nord-ouest et sont séparés d'à peine sept mètres. Ils peuvent être considérés comme deux variations d'un type architectural présenté et défini par les archéologues en tant que " temples hypostyles minéens ». Le temple de 'Athtar dhu-Qabḍ est légèrement plus grand que celui de Nakrah : $13 \mathrm{~m}$ par $21 \mathrm{~m}$ hors tout et $11 \mathrm{~m}$ sur $11 \mathrm{~m}$ à l'intérieur pour le premier ; $12 \mathrm{~m}$ par 18,50 hors tout et $10 \mathrm{~m}$ sur 10,50 $\mathrm{m}$ à l'intérieur pour le second. Les mesures hors tout comprenant les escaliers d'accès et les propylées (v. Antonini et Fedele, chapitre 1 dans ce volume, fig. 45).

Létude des inscriptions ${ }^{1}$ et celle des résultats donnés par les sondages archéologiques notamment celui réalisé au pied de l'escalier d'accès au temple de Nakrah, ont permis, outre des datations au $\mathrm{C}^{14}$, de proposer une chronologie relative. Le temple de 'Athtar dhu-Qabd a été construit alors que le temple de Nakrah avait déjà subi un certain nombre de transformation, et lui est donc légèrement postérieur. Ces deux sanctuaires offrent la particularité d'avoir été recouverts et scellés par des niveaux d'habitat islamique qui les ont relativement bien protégés jusqu'aux études archéologiques de la fin du XX ${ }^{e}$ siècle. ${ }^{2}$

\footnotetext{
1 Ces textes donnent le nom des divinités vénérées dans ces sanctuaires dont celle de 'Athtar dhu-Qabd, principale divinité du royaume de Ma'īn (de Maigret 2006 ; Agostini 2015, 1-14;).

2 Un troisième temple, peut-être celui dédié à Wadd, nommé dans les inscriptions, émerge légèrement de ces niveaux islamiques au
}

Des travaux d'anastylose ont été rendus relativement aisés grâce à la régularité de l'architecture et de par la nature des vestiges bâtis découverts in situ et en grand nombre. Les archéologues, durant leur fouille des niveaux médiévaux, ont pu récupérer une grande partie des blocs antiques réemployés durant les occupations tardives. Une importante campagne de restauration a permis de redonner à ces temples leur élévation d'origine (v. Scigliano et Paladino, chapitre 13 dans ce volume). Malheureusement les désastres récents, imputables au conflit qui ensanglante le pays, ont vu l'anéantissement de l'ensemble de ces efforts.

Le rempart tout proche, qui a subi des ajustements avec la transformation du temple de Nakrah, est percé par une poterne qui permettait tout particulièrement aux étrangers à la ville de pénétrer dans cette zone sacrée intra-muros (v. Antonini, chapitre 8 dans ce volume, fig. 6). Cet accès était doté de deux portes successives, de part et d'autre de l'épaisseur de l'enceinte.

Constructivement et architecturalement les deux édifices sont similaires, même si la nature de la pierre calcaire employée pour leur maçonnerie n'est pas identique. Plusieurs carrières d'extraction, proches et faciles d'accès, ont pu fournir les différents matériaux de construction nécessaires pour chacun d'eux. ${ }^{3}$

La description architecturale de ces deux monuments se fonde sur la somme importante des documents de la mission italienne; il s'agit d'une part d'une couverture photographique systématique, d'autre part de nombreux relevés architecturaux en plans, coupes et élévations. Plusieurs articles ont également rendu compte des résultats des diverses campagnes, ils font partie intégrante de notre documentation de base. Signalons l'importance du rapport consacré à l'étude

\footnotetext{
nord des deux monuments étudiés. Son implantation est différente, il est orienté nord-est - sud-ouest.

3 Ces carrières n'ont pas été identifiées par l'équipe italienne.
} 
des roches mises en œuvre et à la restauration de l'édifice.

Dans une première partie consacrée aux principes architecturaux et aux dispositifs constructifs, nous décrirons alternativement les deux édifices dans l'ordre de leur étude archéologique; puis nous tenterons de proposer un état comparatif. Nous consacrerons une troisième partie aux techniques de construction qui précèdera une conclusion sous forme d'hypothèses plausibles.

\section{Le temple de Nakrah}

\subsection{L'organisation du plan du temple et les dispositifs architecturaux mis en cuvre}

Le temple minéen dédié à Nakrah présente trois phases principales de construction rattachées à plusieurs

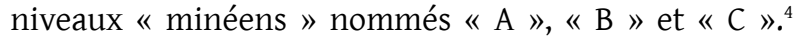
Un niveau sabéen antérieur a été identifié sous ces constructions. Le dispositif d'accès par des escaliers latéraux a été ainsi progressivement modifié et un bâtiment annexe a pu être implanté entre le monument et le rempart occasionnant des transformations notables de ce dernier.

L'ensemble se présente sous la forme d'un espace sacré, clos, entouré d'un mur extérieur épais de près d'un mètre. Le temple est disposé sur un podium surélevé auquel on accède par un dispositif d'escaliers disposé sur la face occidentale (v. Scigliano et Paladino, chapitre 13 dans ce volume, fig. 6). Ce podium est bâti avec des assises en retrait vers le haut; le nu de la face du haut du soubassement s'aligne avec celui de l'élévation. Un porche avec quatre piliers permet, à l'ouest, d'accéder à une salle hypostyle comportant des tables de libations et des banquettes, au fond cinq cellas, ou chapelles, sont adossées au mur oriental. Au sud, une porte latérale donne directement dans la salle hypostyle ; un vestibule tardif a été créé ultérieurement pour servir d'espace intermédiaire entre l'intérieur et l'extérieur (fig. 1).

\subsection{Les dispositifs d'entrée}

Létat primitif du monument « minéen $\mathrm{C}$ » $\left(\mathrm{VII}^{\mathrm{e}}-\mathrm{VI}^{\mathrm{e}}\right.$ siècle av. n. è.) présente une plateforme d'entrée accessible par deux escaliers latéraux accolés à la façade ouest. Peu de temps après, dans le dernier état (« minéen $\mathrm{A} »)$, un escalier monumental à quatre marches et cinq hauteurs donne sur les trois côtés

\footnotetext{
4 Tels que définis par A. de Maigret (de Maigret 1991b). Les datations sont : niveau sabéen : avant le $\mathrm{VII}^{\mathrm{e}} \mathrm{s}$. av. J.-C.; niveau minéen $\mathrm{C}$ : VII ${ }^{\mathrm{e}}-$ $\mathrm{VI}^{\mathrm{e}}$ s. av. J.-C. ; niveau minéen $\mathrm{B}: \mathrm{V}^{\mathrm{e}}-\mathrm{IV}^{\mathrm{e}}$ s. av. J.-C. ; niveau minéen A : III $^{\mathrm{e}}-\mathrm{II}^{\mathrm{e}}$ s. av. J.-C. Du XII ${ }^{\mathrm{e}}$ au XIX ${ }^{\mathrm{e}}$ s. ap. J.-C. L'ensemble a subi des réoccupations médiévales avec quelques interruptions momentanées.
}

de la plateforme "A2 », nommée estrade par les archéologues, elle mesure 8,50 m par 2,00 m. Cet avantcorps (plateforme) est bâti avec douze grandes dalles qui donnent la mesure de sa largeur et de sa profondeur. Un emmarchement de deux degrés et de trois hauteurs permet d'atteindre la terrasse " A1 », entourée au nord et au sud, de deux terrasses « $\mathrm{A} 3 \mathrm{a}$ » et « $\mathrm{A} 3 \mathrm{~b}$ » de 2,30 $\mathrm{m}$ par 2,50 $\mathrm{m}$, construites au-dessus des deux escaliers latéraux primitifs. La terrasse «A1 » est dotée d'un propylône avec quatre emplacements de piliers qui sont encastrés dans des mortaises quadrangulaires peu profondes. Il ne reste que les fragments du pilier sud.

La hauteur des piliers du propylée est estimée à 5,60 $m$ grâce à la présence d'un fragment cassé du pilier sud retrouvé sur le dallage de la terrasse " A2 ». Ces monolithes étaient dotés, en partie supérieure, de tenons de pierre destinés à recevoir une architrave munie de mortaises, puis, au-dessus, des poutres longitudinales reliaient le dispositif au mur de façade, enfin des dalles permettaient de recouvrir ce porche (fig. 2-3, fig. 4a-e).

L'emmarchement de trois degrés pour $0,60 \mathrm{~m}$ de dénivelé est disposé entre les quatre piliers posés dans des réservations de deux centimètres de profondeur creusées dans un stylobate bâti avec quatre grandes dalles de 2,90 $\mathrm{m}$ de long sur 0,80 $\mathrm{m}$ de large espacées de $0,45 \mathrm{~m}$. Ces grands monolithes mesurent la profondeur de la plateforme supérieure « $\mathrm{A} 1$ ».

\subsection{La salle hypostyle}

On pénètre dans la salle hypostyle par une porte, avec seuil, dotée de hauts chambranles monolithes qui possèdent deux décrochés vers l'extérieur et une importante feuillure orientée vers l'intérieur (fig. 5). ${ }^{5}$ Elle comprend cinq nefs et quatre travées définies par trois rangées de quatre piliers monolithes. La paroi extérieure, épaisse d'un mètre et continue, est bâtie en moyen appareil avec des blocs longs de 0,50 $\mathrm{m}$ à 1,50 m. Il s'agit d'un mur composite à deux faces de carreaux un mur à double parement bien connu en Arabie du Sud - avec un remplissage en tout-venant composé d'éclats de taille. Seules les faces visibles sont ornementées et des boutisses relient régulièrement les deux faces afin de renforcer la cohésion du mur. Cette paroi supportait également les monolithes de la couverture des nefs périphériques.

Cette salle hypostyle possède cinq nefs ( $« \mathrm{a} »,\|\mathrm{~b}\|$, 《 $c »,\langle d$ » et « $e$ ») : la centrale (c) est légèrement plus grande, $1,75 \mathrm{~m}$, les autres mesurent $1,50 \mathrm{~m}$. Cinq travées

\footnotetext{
5 Nous renvoyons ici aux études architecturales menées par JeanMarie Gassend de l'Institut des recherches sur l'architecture antique (IRAA) du CNRS français qui a particulièrement compris dans sa restitution les assemblages créés par les bâtisseurs antiques.
} 
scandent le parcours. Les quatre premières («1», «2», « 3 » et « $4 »)$ correspondent à la salle hypostyle. Les travées « 1 », « 2 » et « 3 » mesurent 2 m de largeur entre piliers, la suivante (« $4 »)$, entre la dernière file de piliers et les cellas mesure $1,50 \mathrm{~m}$. Ces cinq pièces (cellas ou chapelles) alignées avec les nefs occupent cette travée orientale (travée « 5-B2 »). Ces pièces sont dotées de portes et peuvent être hiérarchisées, la centrale ( B2C ») est plus large, elle est encadrée par deux autres symétriques (« B2b » et « B2d )). Ces trois chapelles sont précédées par des emplacements réservés à des sacrifices. Les pièces situées aux extrémités nord et sud ( B2a » et « B2e ») étaient difficilement visibles depuis la salle. En effet, les travées « 3 » et « 4 » sont séparées partiellement par des dalles, de type chancels, mises en œuvre dans les travées « a » et « e ». Les cellas étaient obturées par des menuiseries dont des traces de feuillure ont pu été observées. La cella centrale conserve encore un linteau posé sur la tête des deux murs de cloisonnement.

La salle « B1 » comporte plusieurs travées séparées par des piliers au nombre de douze d'une hauteur de $4 \mathrm{~m}$ et de 0,45 m de section carrée. Cette salle «B1», qui correspond aux quatre premières travées ( 1 1», « 2 », «3-B1a », et « 4-B1b»), est entourée par une banquette périphérique.

Travée "1-B1a1»: cette partie de la salle hypostyle (nefs « $a$ » et « $b$ », au sud) correspond à une pièce qui n'existait pas dans la phase initiale et qui a été disposée avec l'implantation d'un cloisonnement tardif pour créer un vestibule, fermé par une porte pour un accès secondaire à la salle hypostyle. Au nord (nefs « d » et " e ») on trouve une table et des banquettes pour les repas rituels sacrificiels.

Travée « 2-B1a2»: cette travée possède au sud (nefs « a » et $« \mathrm{~b} »)$ et, au nord (nefs « $d$ » et « e ») deux grandes tables ornées de frises de bouquetins. Des banquettes destinées aux collations rituelles complètent ce dispositif à leurs extrémités.

Travée «3-B1a3» : cette travée est libre; dans son dallage une rigole transversale a été creusée à l'emplacement des nefs $\langle\mathrm{b} »,\langle\mathrm{c} »,\langle\mathrm{~d}$ » et « e »; elle donne dans un exutoire complexe qui traverse le mur nord en « 3-c ».

Travée «4-B1b» : nommée ante-cella (niveau + 0,20) elle correspond, semble-t-il, à l'emplacement des rituels liés aux sacrifices. De petites rigoles ont été aménagées dans le sol des nefs « $\mathrm{b}$ », « $\mathrm{c}$ » et « $\mathrm{d}$ » pour amener les liquides - le sang et l'eau de nettoyage - vers la rigole de la travée « 3 ». Des plaques de chancel séparent les travées « 3 » et « 4 » à hauteur des nefs « a » et « e ». Les plaques qui forment cette séparation, au nord, entre les travées « 3 » et « 4 », étaient, face aux cellas, inscrites avec une dédicace à Nakrah décorée de denticules.
On peut envisager qu'une pièce similaire était située symétriquement dans la partie sud. Les archéologues pensent que ces deux dalles masquaient les cellas correspondantes des nefs extérieures «a » et « e ».

Travée " 5-B2 » : elle fait fonction de " paroi épaisse » et correspond à l'emplacement des cinq chapelles à un niveau supérieur de $0,60 \mathrm{~cm}$ accessible par deux marches. Ces petites pièces sont encore dotées des chambranles des hautes portes monolithes posées dans des feuillures aménagées dans les cloisons maçonnées. Les parois de ces petites pièces avaient un rôle structurel en supportant le plancher supérieur. L'accès à la cella centrale conserve un linteau. Au centre des trois pièces une petite cavité quadrangulaire, profonde de 6 à $7 \mathrm{~cm}$, indique l'emplacement probable d'autels dont les bases étaient protégées par une petite dalle verticale.

\subsection{Les sols, pavements, canalisations d'écoulement et la gestion des fluides}

Les niveaux des différentes " pièces » ne sont pas rigoureusement plats et possèdent d'importants dénivelés relevés par l'équipe des restaurateurs en charge de la mise en valeur du temple (v. Scigliano et Paladino, chapitre 13 dans ce volume, fig. 94). Ils notent que l'épaisseur des dalles peut avoisiner 0,50 m. La troisième travée («3-B1a3 ») (fig. 6) est libre et suivie d'une marche d'accès à la quatrième travée («4-B1b») qui correspond à l'aire de sacrifice surélevé de deux marches $(+0,40)$ qui précède les chapelles de la cinquième travée.

Au pied de la marche entre « 3-B1a3 » et « 4-B1b », il existe une rigole d'écoulement (fig. 7-8), qui fait toute la largeur du temple et qui traverse le mur nord pour se déverser à l'extérieur. Il faut noter la présence d'un bassin sur une base quadrangulaire inscrite de dédicace au dieu Nakrah. La banquette périphérique n'existe plus à cet emplacement.

Face aux trois chapelles centrales, l'aire de sacrifice possède trois traces d'évidement. Ces creux correspondent aux emplacements des sacrifices (fig. 9). De là, de petites rigoles axiales, orientées vers le nord, rejoignaient la grande tranchée transversale, mais peu profonde, située dans la travée « 3 ». Aussi bien le sang des animaux que l'eau pour le nettoyage des lieux étaient ainsi éloignés à l'extérieur du lieu de culte.

\subsection{Les escaliers secondaires}

Trois escaliers existent en plus de l'accès principal. Le premier a été construit, dans l'état final, pour atteindre l'annexe ( $C$ ») depuis la petite pièce cloisonnée dans l'angle sud-ouest de la salle hypostyle (ensemble « B »). Une petite porte, positionnée dans l'axe du mur, obture un passage étroit et permet l'accès à un palier d'où on 
descend ensuite vers l'ouest. Dans cette salle annexe un escalier intérieur a été construit (fig. 10), il est adossé au mur sud et permet d'atteindre un niveau supérieur, étage ou toiture (?), en direction de l'est. Enfin un escalier ( E3 ») a été installé au pied de la terrasse sud («A3a ») pour descendre vers le sud, depuis l'espace dégagé et dallé « $\mathrm{D}$ », et ensuite traverser les murailles de la ville («E4»), vers l'extérieur de la ville (v. Antonini, chapitre 8 dans ce volume, fig. 8). A cet effet, une poterne, dotée d'une fermeture intérieure et d'un autre côté extérieur, perce la fortification afin d'en permettre le franchissement pour les fidèles extérieurs à la cité.

\subsection{La structure porteuse}

La structure porteuse de la couverture fonctionne par empilement et descente de charge, on peut distinguer quatre catégories de monolithes : piliers, architraves, poutres et dalles. L'ensemble s'appuie sur les murs extérieurs et sur des piliers qui supportent des architraves (dans l'axe des temples) surmontées par des poutres transversales recouvertes de grandes dalles. La destruction de la couverture en périphérie semble prouver que c'est l'effondrement des parois extérieures qui a occasionné sa chute (fig. 11-12).

Les douze piliers sont dotés de tenons en pierre à l'exception de deux d'entre eux (v. Scigliano et Paladino, chapitre 13 dans ce volume, fig. 70). Leur hauteur est de $4 \mathrm{~m}$ et leur section régulière est de $0,45 \mathrm{~m}$ par 0,45 $\mathrm{m}$. Les architraves, de même section, sont posées dans l'axe de l'édifice et sont rendues solidaires de l'ossature verticale par un jeu de tenons et mortaises, elles sont liées entre elles par des tenons en bois disposés dans des mortaises en queue d'aronde. Ces pièces monolithiques horizontales sont en appui de vingt centimètres en moyenne. Leur longueur peut atteindre $4,40 \mathrm{~m}$; en général leur dimension correspond à celle de l'entraxe des piliers.

Des poutres de section $0,35 \mathrm{~m}$ par $0,35 \mathrm{~m}$ sont posées perpendiculairement aux architraves. Leur longueur est de deux mètres. Ces pièces monolithiques sont calées par des entretoises en pierre posées au-dessus des architraves et en empêchent le dévers. Certaines poutres reposent directement sur elles à l'appui des piliers et des poutres intercalaires, de mêmes sections, divisent la portée des dalles en deux en reposant, maladroitement, au milieu des architraves (v. Scigliano et Paladino, chapitre 13 dans ce volume, fig. 75). Cette technique montre bien que le principe employé correspond à une interprétation des charpentes en bois. Alors que le bois est capable de résister à des efforts de cisaillement et de flexion, le calcaire n'autorise que difficilement ce type de répartition des forces. De fait, les bâtisseurs ont pallié à ce problème en surdimensionnant de manière importante l'ensemble des pièces horizontales monolithiques qui s'appuient sur deux points porteurs.

Les entretoises n'ont aucun rôle de contreventement. Elles sont plutôt réalisées pour éviter des basculements et, surtout, également dans un but décoratif. Elles sont renforcées par des métopes sculptés et décorés de deux rangées de denticules qui rappellent le chevronnage des plafonds en bois (v. Scigliano et Paladino, chapitre 13 dans ce volume, fig. 76-77, 82).

Les dalles de couverture sont épaisses de 0,25 $\mathrm{m}$ en moyenne et leurs dimensions, constantes en longueur, correspondent aux largeurs des travées additionnées $\mathrm{du}$ recouvrement des poutres, elles sont cependant de largeurs variables. Les nefs latérales sont couvertes par trois dalles alors que la nef centrale l'est par quatre. Elles étaient uniquement posées sur les poutres, en s'adaptant finement aux défauts des pierres, et sommairement scellées au plâtre. Elles occupaient la totalité de la superficie de la salle et des chapelles. Leur extrados est très irrégulier, et pourrait indiquer qu'un épais enduit de plâtre recouvrait l'extérieur du sommet du complexe bâti (fig. 13). Cet enduit, outre son rôle d'étanchéité permettait de rendre la toiture monolithique en assurant la continuité des efforts sur la totalité du plan horizontal.

\subsection{Les tables de libations et les banquettes}

Le temple possède trois tables de libations monolithes de 3,10 m de long, certaines sont décorées et possèdent des inscriptions sur leurs tranches. Elles sont édifiées dans le cadre géométrique de principe qui a présidé à la composition du bâtiment. Les deux tables de libations des nefs nord sont installées dans les travées « 1 » et « 2 » (fig. 14); la table d'offrande, côté sud, est positionnée dans la nef « 2 ». Le long de la nef centrale, les monolithes ont leurs extrémités ornées d'une rangée de sept bouquetins sculptés en relief (fig. 15-16). Chaque dalle tabulaire est soutenue par deux pierres verticales taillées en orthostate. Celles qui sont situées sous les frises de bouquetins sont dotées d'inscription gravées. Les deux tables nord ont des inscriptions rapportant une dédicace par un personnage nommé Bāsil Ibn Ma's. Sous les bouquetins, on lit les mots qui signifient « automne » et « printemps ». ${ }^{6}$ Sous les bouquetins de la table située au sud, un mot est inscrit mais aucun sur la dalle de support. Les banquettes sont d'une part construites contre les parois périphériques excepté à l'emplacement de l'exutoire de la rigole, et sont disposées entre les piliers des deux premières travées. Elles permettent de s'asseoir, comme dans un triclinium, face aux trois tables destinées aux repas rituels, peut-être saisonniers.

\footnotetext{
6 de Maigret et Robin 1993, 437.
} 


\subsection{Les bâtiments annexes et le traitement des abords}

On peut accéder à la zone sacrée du sanctuaire par une poterne («E3») située dans la courtine «E4 » située entre les tours du rempart de la ville « T44» («E2 ») et « T45» («E1»). L'aménagement du bâtiment annexe a eu pour conséquence une transformation et un aménagement de la morphologie des fortifications : les faces nord intérieures de la tour « T44 » et la courtine « E4 » ont été alignées pour permettre la construction nouvelle. Ce bâtiment annexe est construit durant la dernière phase au sud du temple. Il est en communication par la petite porte annexe. Un escalier de plusieurs marches (L12), encore conservées, permet de rattraper les niveaux. Cet édifice possède un étage où semblent avoir été stockés de nombreux exvotos. L'importance des travaux engagés pour réaliser cet ensemble complémentaire au temple de Nakrah indique que son rôle était fondamental dans la conduite des cultes.

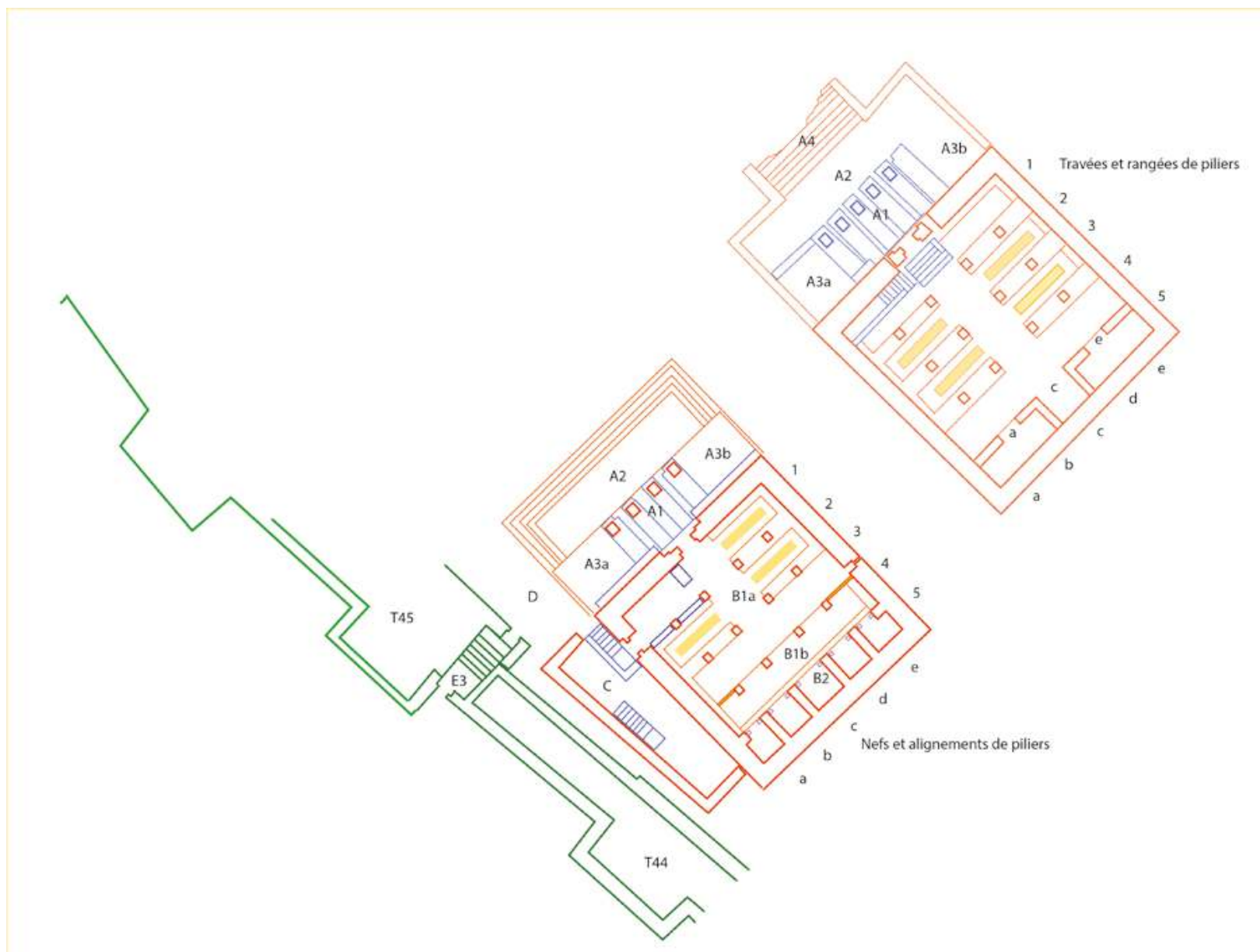

Figure 1. Plan général des deux temples et de leur proche environnement avec la numérotation des différents espaces ainsi que le repérage des nefs, des alignements, des travées et des rangées de piliers. Le nord est situé vers le haut de l'illustration.

(M. Mascellani adapté par C. Darles 2019 @MAIRY) 


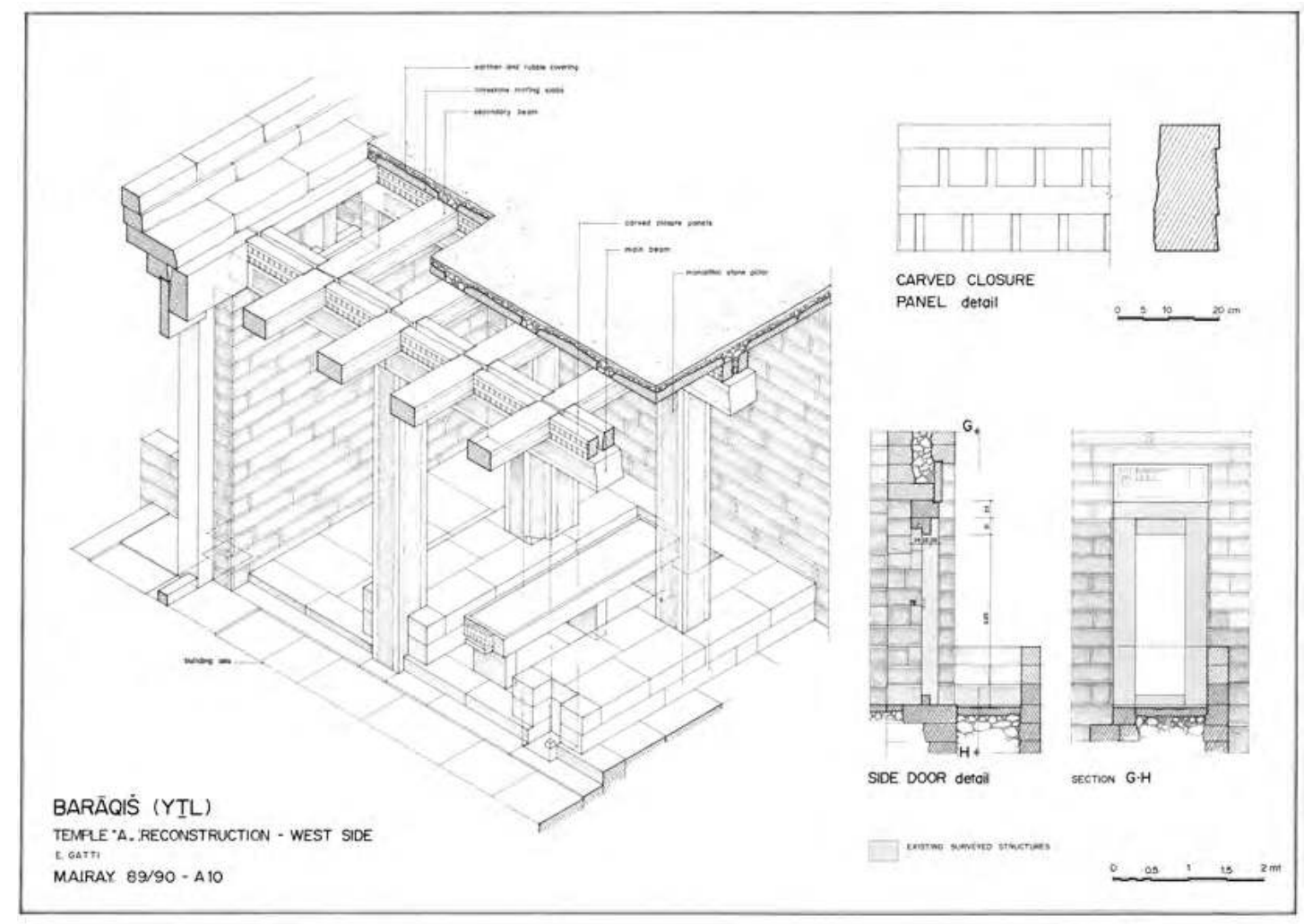

Figure 2. Reconstruction axonométrique de la partie nord-est de la salle hypostyle «B1a » du temple de Nakrah. (E. Gatti 1989-1990 @MAIRY)

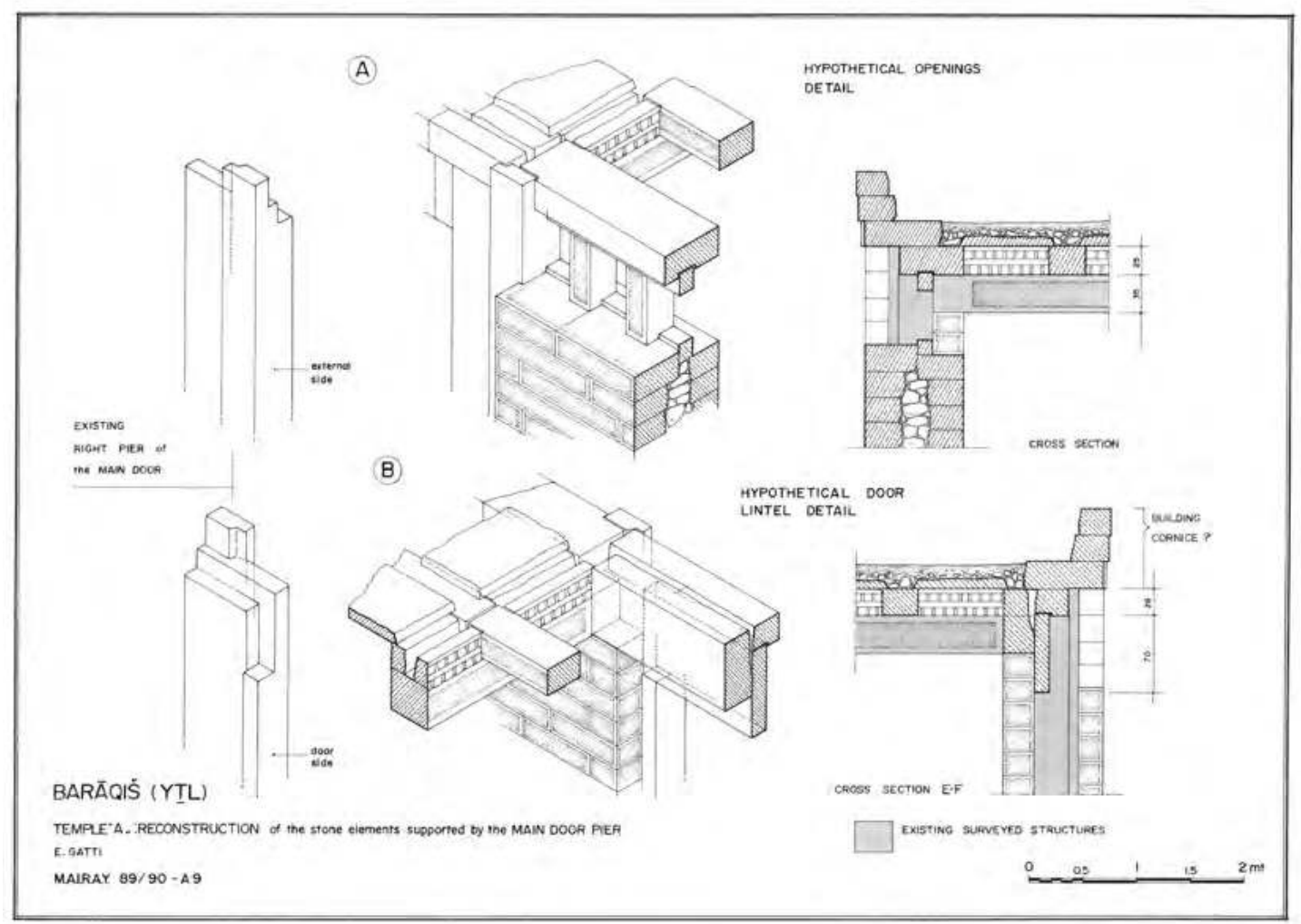

Figure 3. Reconstruction des détails d'assemblage des maçonneries en pierres appareillées de la porte du temple de Nakrah. (E. Gatti 1989-1990 CMAIRY) 


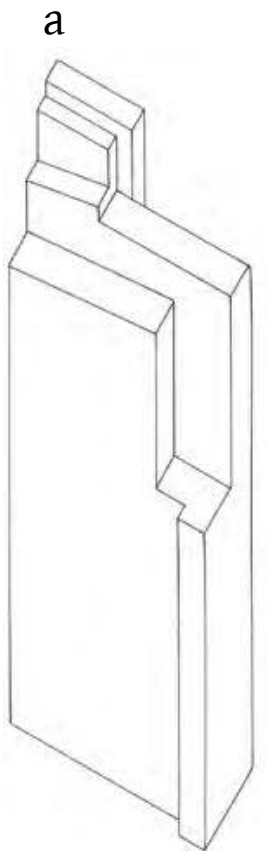

C

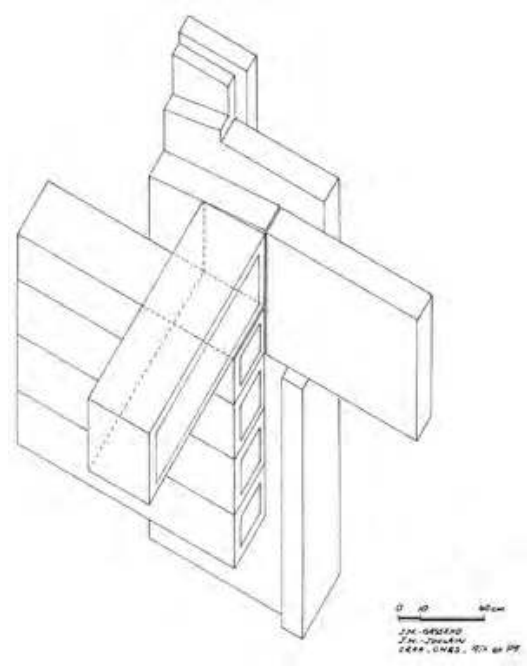

b

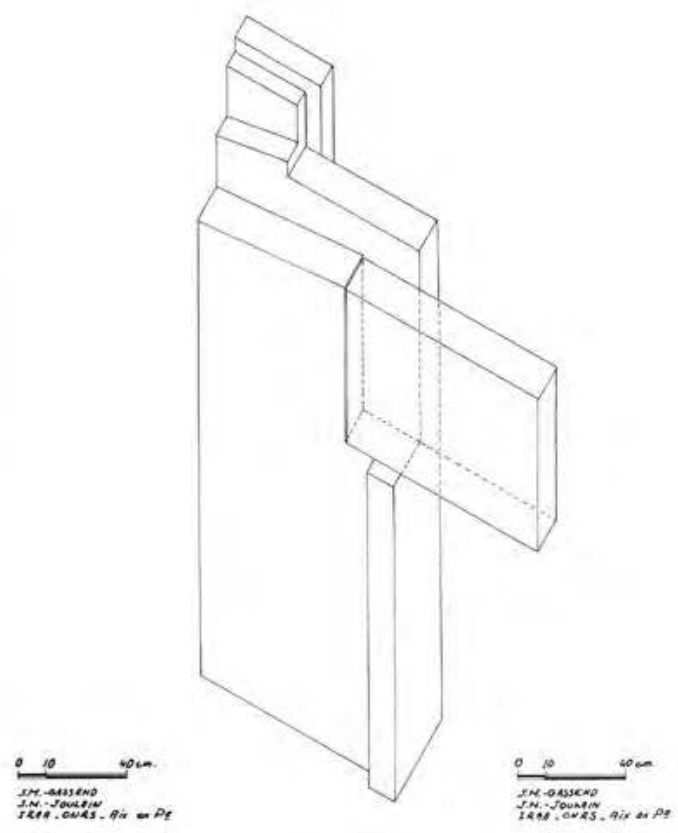

d

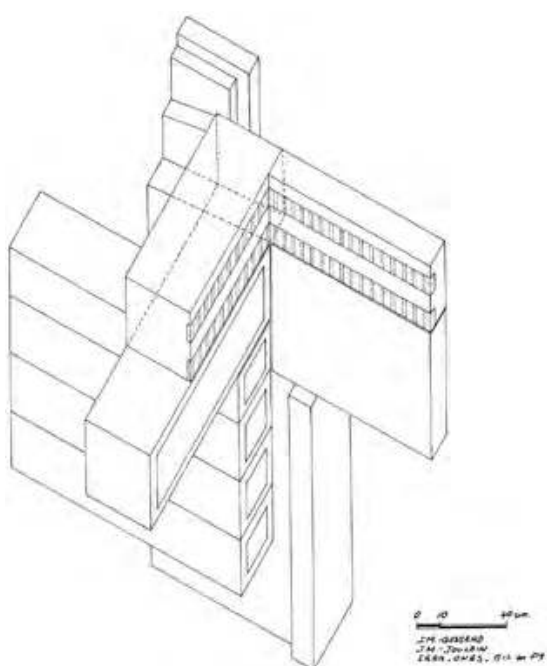

$\mathrm{e}$

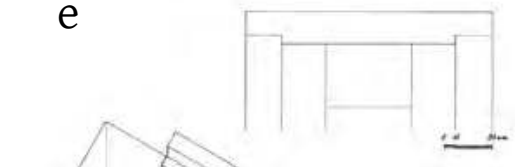

Figure 4a-4e. Restitution des assemblages de blocs de la porte du temple de Nakrah. (J.-M. Gassend 2004-2005 OMAIRY) 


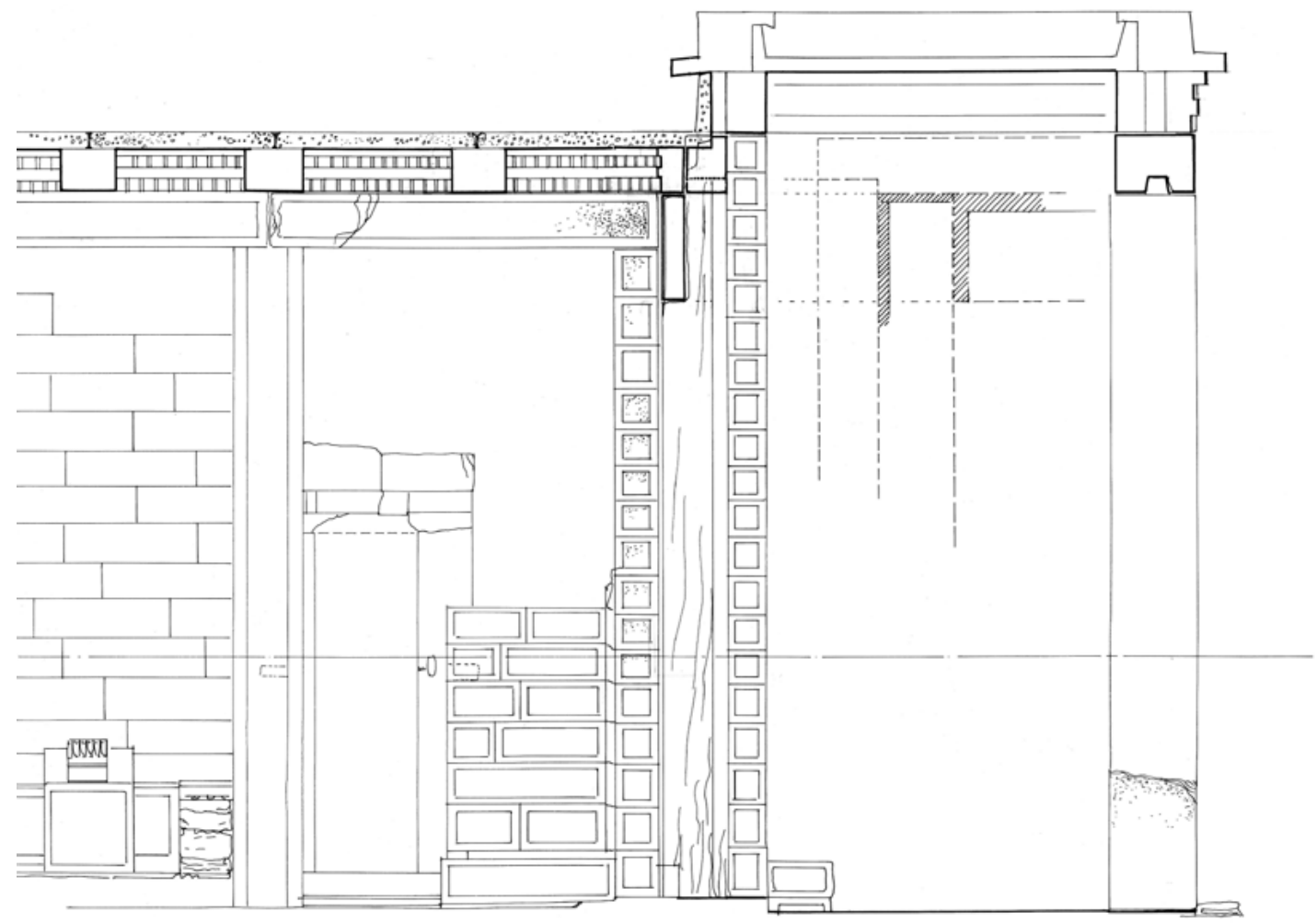

Figure 5. Coupe restituée sur l'entrée du temple de Nakrah, vue vers le sud-ouest et la porte qui permet d'atteindre la salle annexe « C». (J.-M. Gassend 2004-2005 @MAIRY)

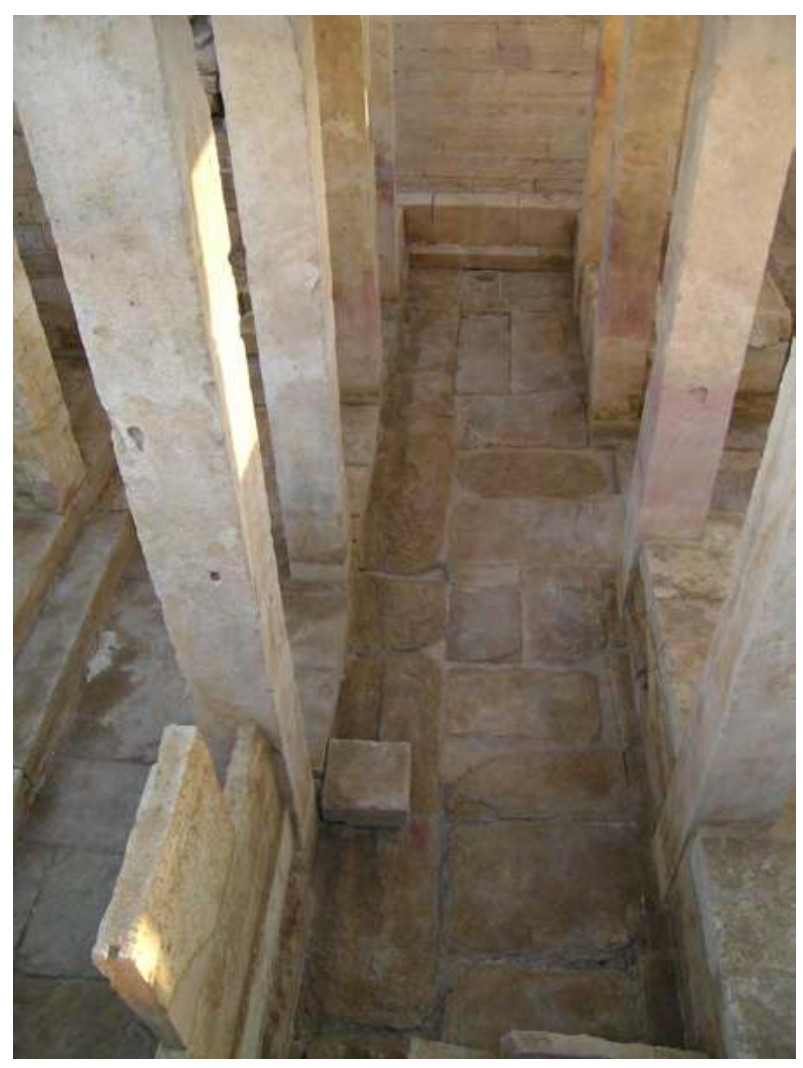

Figure 6. Vue de la travée « 3 » en direction du sud-ouest, avec la rigole de collecte des liquides située contre la travée « 4 » du temple de Nakrah.

(A. de Maigret 2005-2006 CMAIRY)

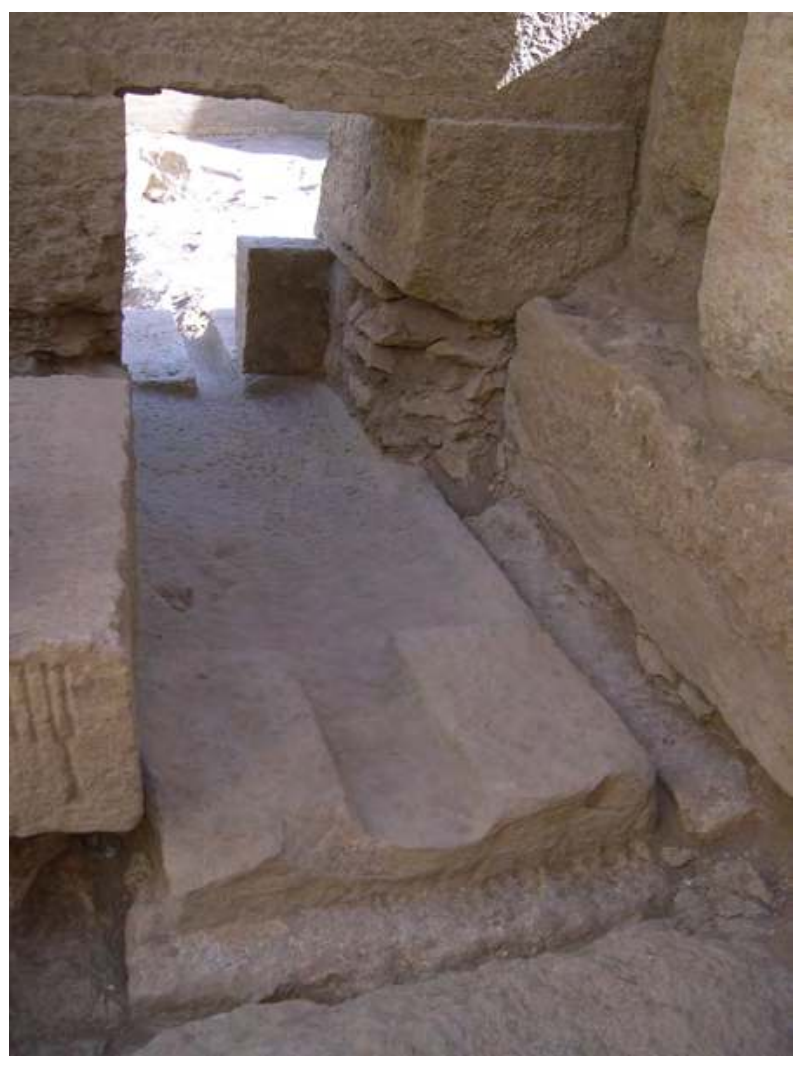

Figure 7. Exutoire des effluents collectés dans la rigole de la travée « 3 », vue depuis l'intérieur vers le nord-est du temple de Nakrah. (G. Richoux 2005-2006 CMAIRY) 

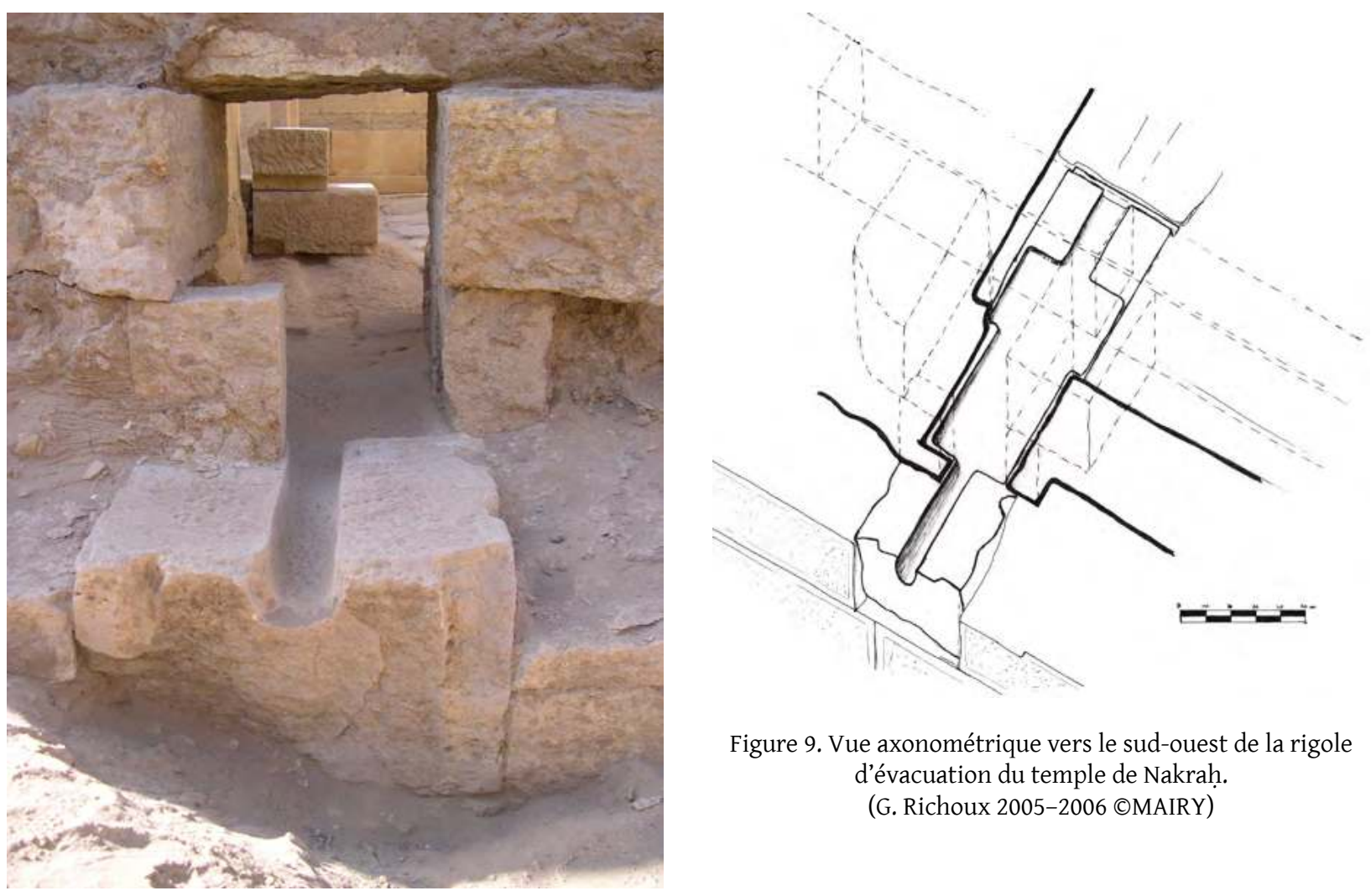

Figure 9. Vue axonométrique vers le sud-ouest de la rigole d'évacuation du temple de Nakrah.

(G. Richoux 2005-2006 @MAIRY)

Figure 8. Vue depuis l'extérieur du débouché nord-est de la rigole de la travée « 3 » du temple de Nakrah.

(G. Richoux 2005-2006 @MAIRY)
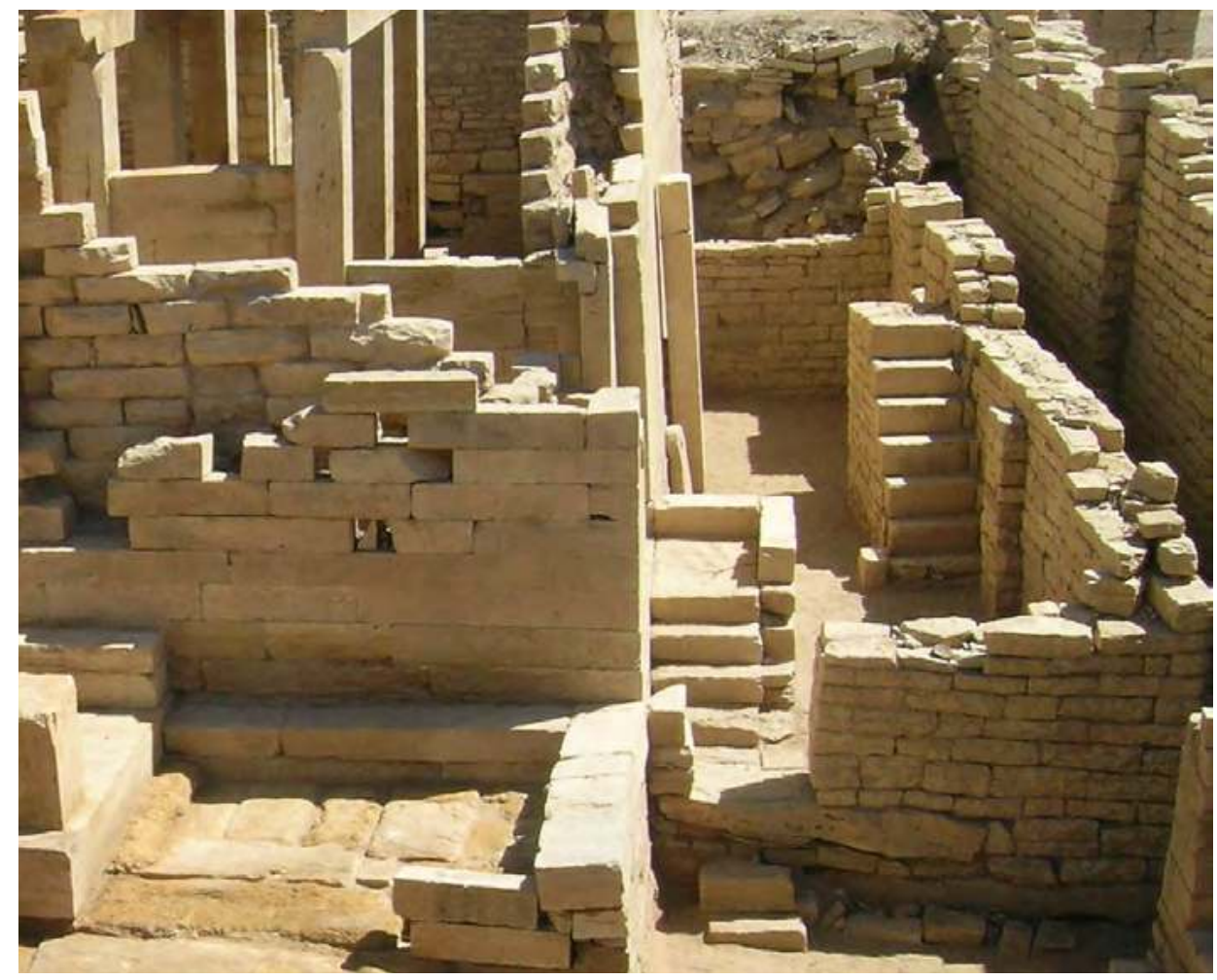

Figure 10. Temple de Nakrah. Au premier plan, à droite de l'illustration, la zone « D » qui permet d'atteindre l'annexe « $C$ » située, avec l'escalier d'accès à la travée « 1 » de la salle « B1a », au second plan l'escalier qui indique la présence d'un niveau supérieur.

(A. de Maigret 2003-2004 CMAIRY) 


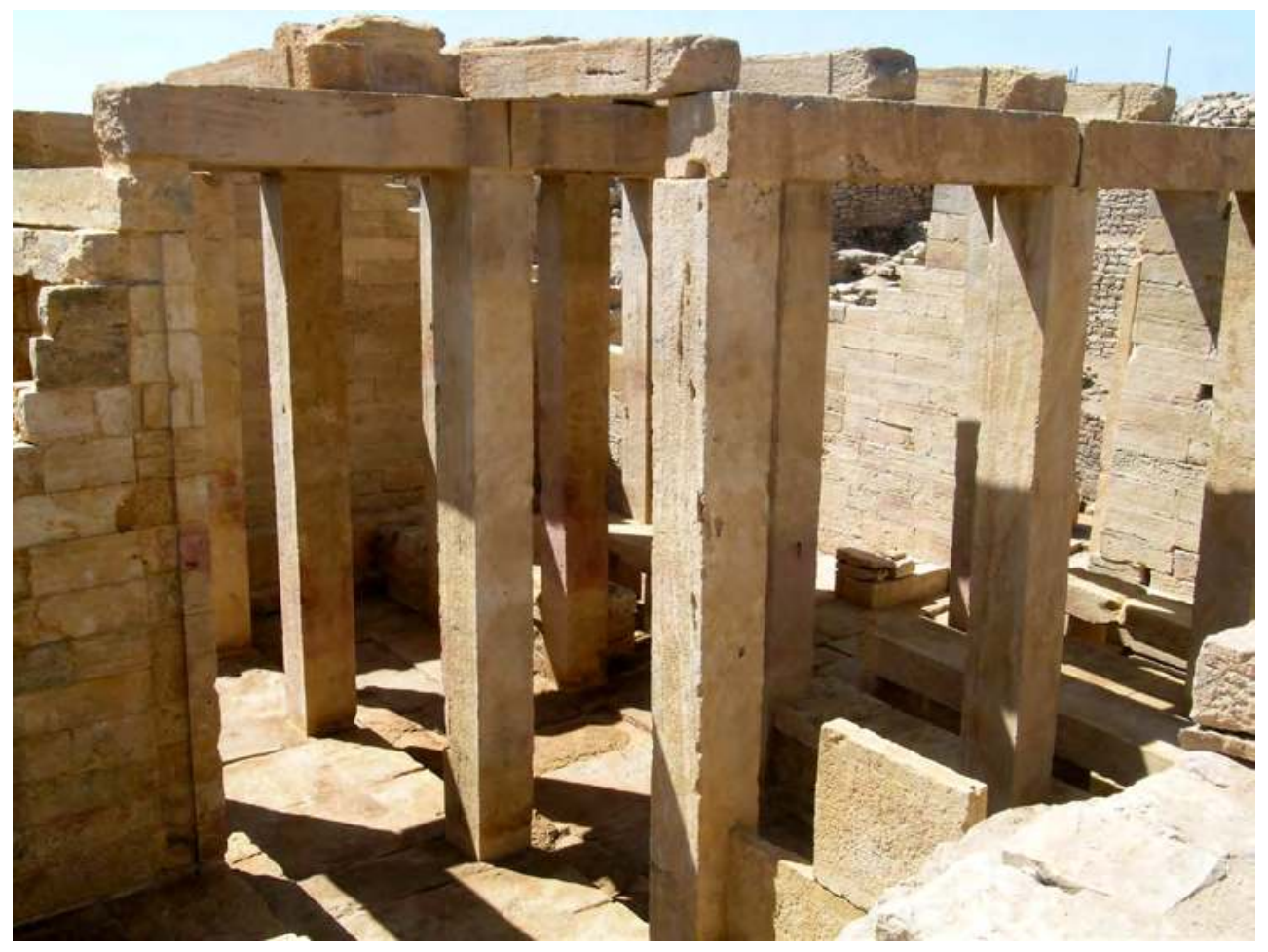

Figure 11. Vue de la salle hypostyle du temple de Nakrah, depuis l'angle oriental en direction de la porte d'entrée principale. (A. de Maigret 2003-2004 CMAIRY)

BARĀQIŠ (YTL)

TEMPLE 'A. RECONSTRUCTION

REAR PORTALS AND COVERING ( inside axonometrical view )

E.GATTI

MAIRAY $89 / 90 \cdot A 8$

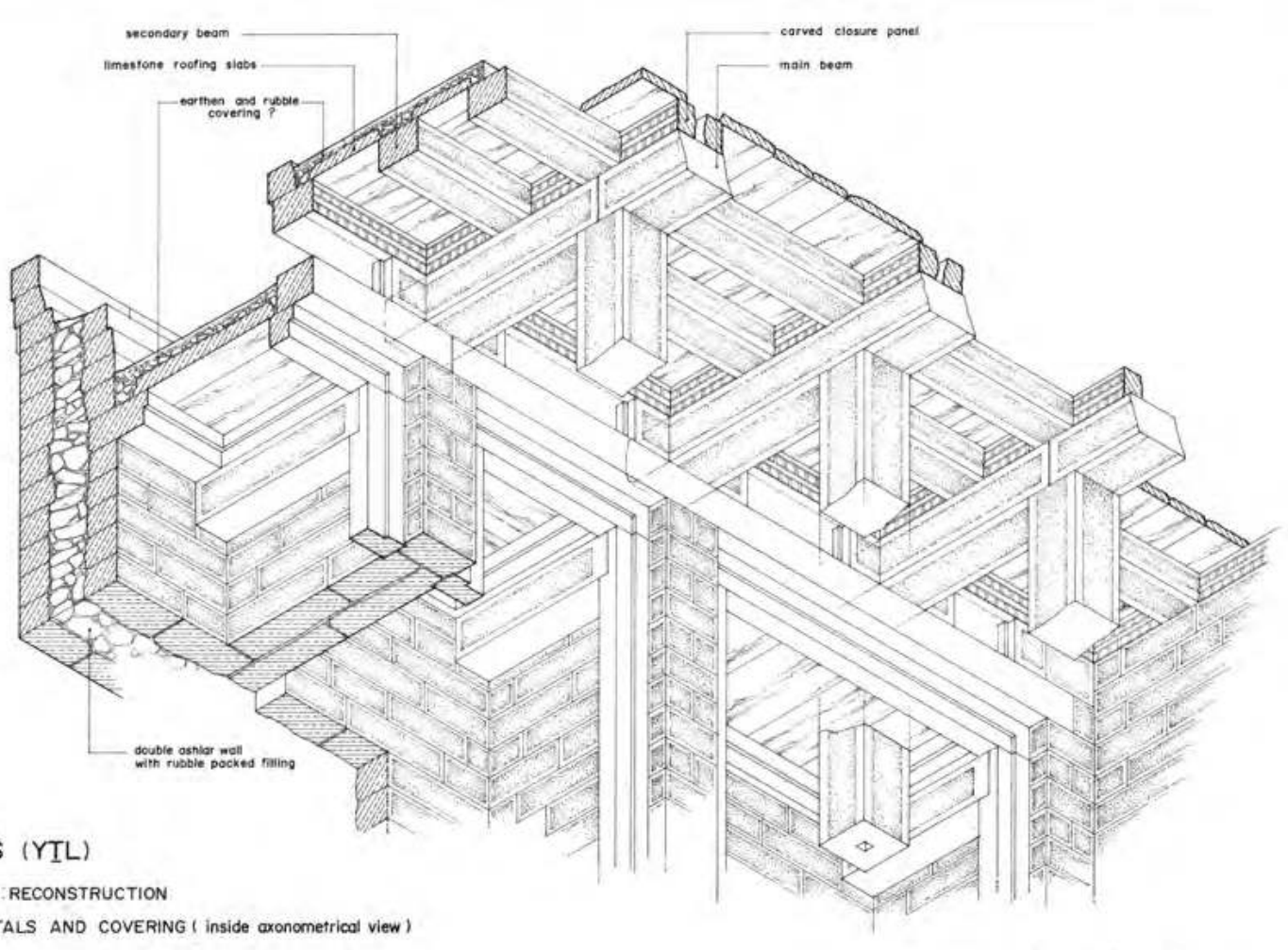

(ant

Figure 12. Vue axonométrique en contre-plongée de la structure constructive de la couverture du temple de Nakrah. (E. Gatti 1989-1990 OMAIRY) 


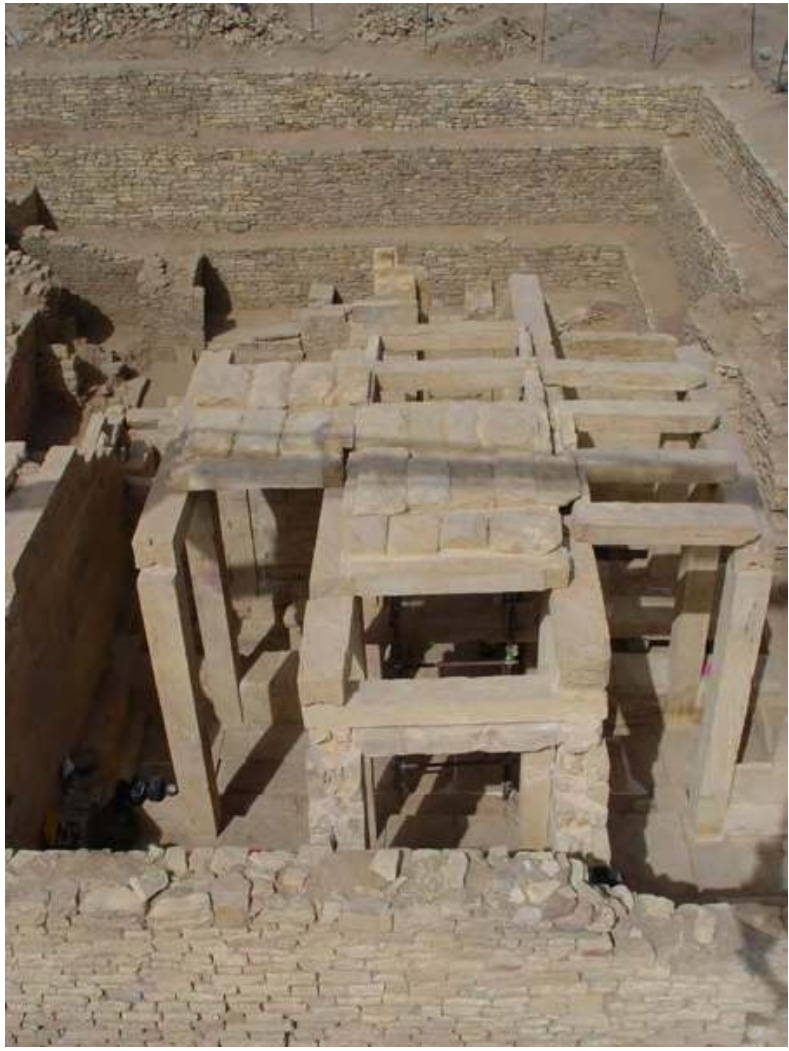

Figure 13. Vue axiale depuis le sud-ouest des ruines du temple de Nakrah montrant bien la destruction périphérique de la couverture. L'extrados des dalles de couvertures est très irrégulier et semble avoir été recouvert d'une épaisse couche d'enduit étanche. (A. de Maigret 2003-2004 CMAIRY)

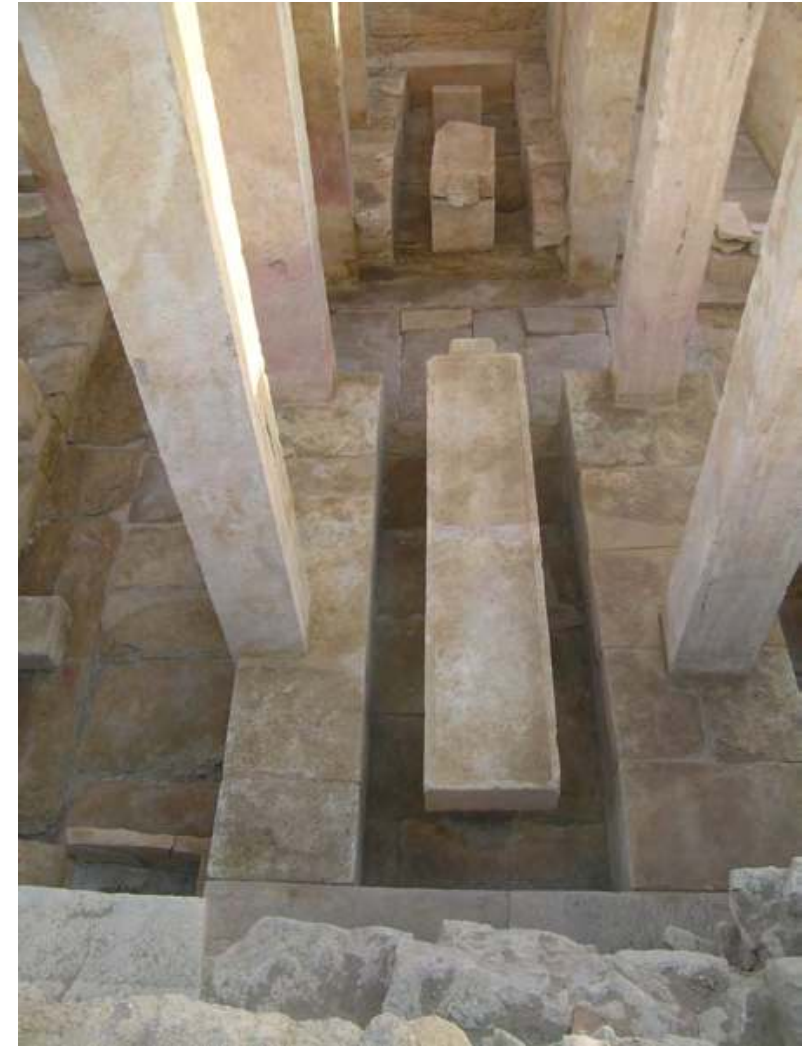

Figure 14. Travée « 2 » de la salle hypostyle « B1a » du temple de Nakrah, vue vers le sud-ouest. (A. de Maigret 2003-2004 OMAIRY)

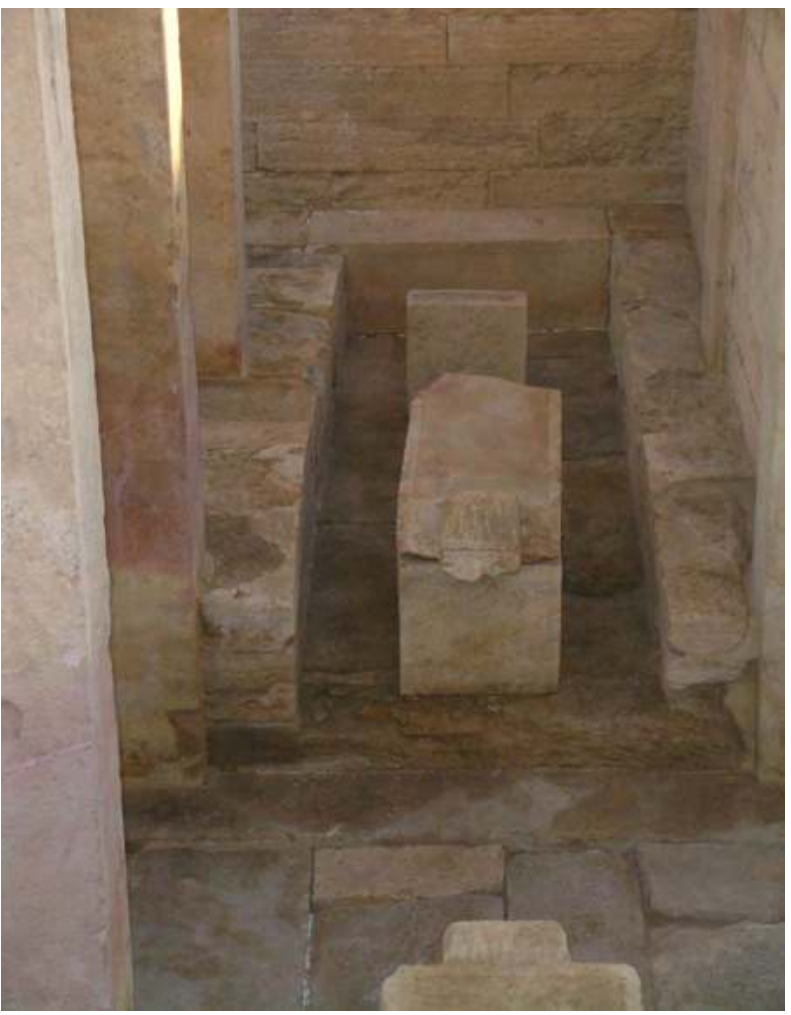

Figure 15. Table de libation sud de la travée « 2 » du temple de Nakrah, avec la décoration du nez du monolithe. (A. de Maigret 2003-2004 CMAIRY) 


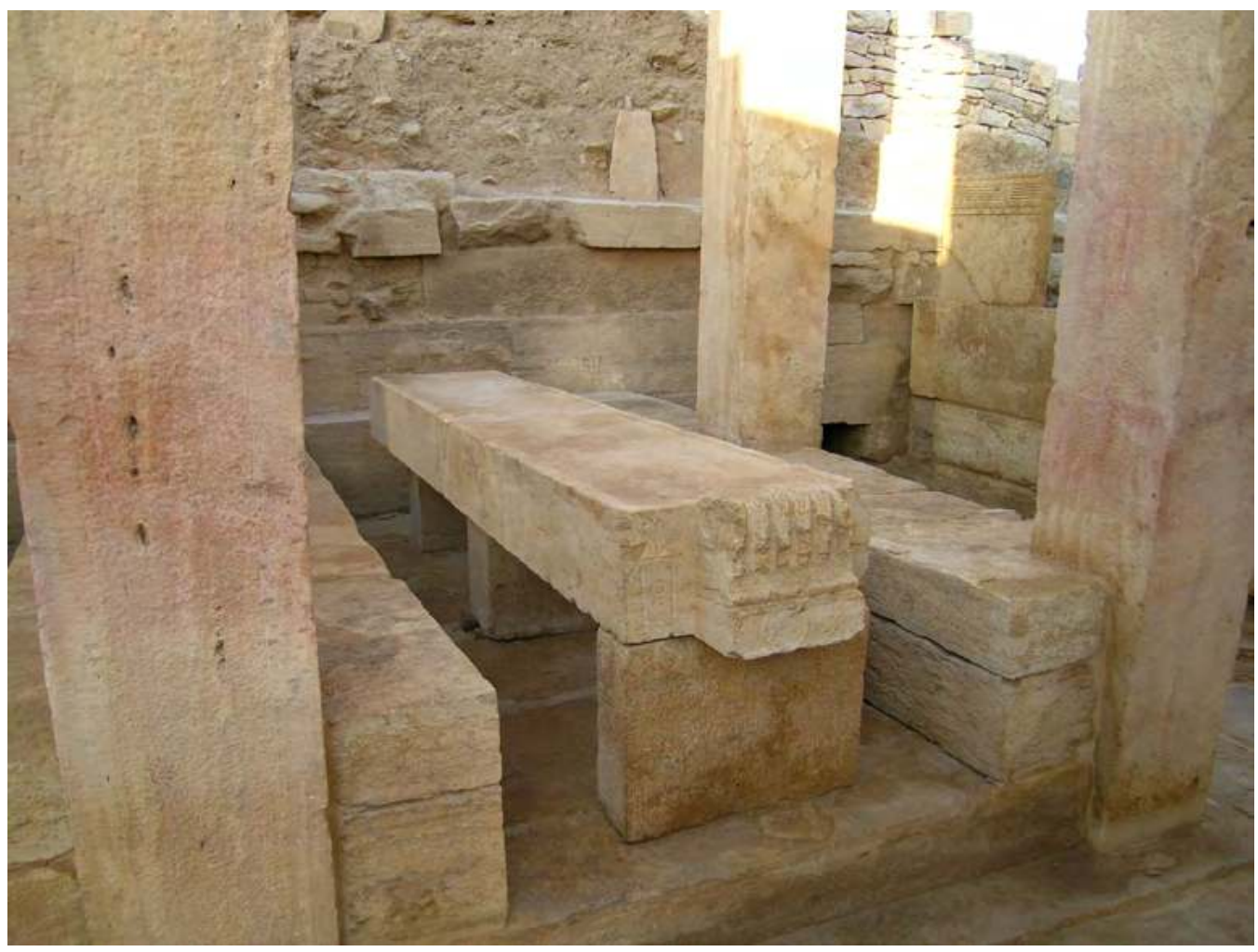

Figure 16. Table de libation nord de la travée « 2 » du temple de Nakrah, avec la frise sculptée de bouquetins. En arrière plan, on peut apercevoir au-dessus du trou de l'exutoire de la rigole, la dalle de chancel décorée qui, dans la nef « e », sépare la travée « 3 » de la travée « 4 ».

(A. de Maigret 2003-2004 @MAIRY)

\section{Le temple de 'Athtar dhu-Qabd}

Ce temple hypostyle est de même facture que le temple Nakrah, il en possède des dimensions relativement proches et une orientation identique (v. Agostini, chapitre 3 dans ce volume, fig. 3). Il a été édifié alors que des réfections importantes avaient été réalisées dans la morphologie du dispositif d'accès et des aménagements des abords de son voisin immédiat. Ce lieu de culte semble donc pouvoir être daté d'une période légèrement plus récente, même s'il reste représentatif d'une architecture religieuse de type " minéen ». Quelques différences notables le particularisent et le singularisent par rapport à son voisin. L'architecture de son principe d'entrée est différente de par la présence d'un propylée de six colonnes, et non plus quatre, accessible par un escalier frontal pris entre deux antes. Le monument est implanté sur un soubassement $(1,70$ $\mathrm{m}$ plus haut que celui du temple de Nakrah) depuis lequel on redescend dans la salle hypostyle. Il possède un escalier qui nous amène à penser qu'un niveau supérieur aurait pu être accessible (v. Agostini, chapitre 3 dans ce volume, fig. 9). Ce soubassement possède des assises en légères saillies qui diminuent vers le haut pour s'aligner avec l'élévation. Le parcours religieux offre donc des particularités certaines d'autant plus que la paroi orientale ne serait dotée, d'après les archéologues, que d'une seule cella accessible, prise entre deux pièces latérales plus refermées.

\subsection{L'organisation du plan et les dispositifs architecturaux}

Lédifice principal ( B ») est quadrangulaire, d'une forme proche du carré, avec un dispositif d'entrée en importante saillie («A ») (fig. 17-20).

L'escalier frontal « A4 » in antis donne sur une plateforme « $\mathrm{A} 2$ » de plus de deux mètres de profondeur. On accède alors à un propylée de six piliers avec deux terrasses latérales de trois mètres de profondeur (" $\mathrm{A} 3 \mathrm{a}$ » et « A $3 \mathrm{~b} »)$. La hauteur des piliers du propylée est de 6,15 m (« A1»). Ce sanctuaire semble avoir dominé le paysage urbain environnant, montrant son importance cultuelle et celle de la divinité au sein de l'espace sacré de la ville. Huit inscriptions in situ ou découvertes dans les déblais posés sur le sol de la grande salle ; elles attestent un culte rendu à la divinité la plus honorée du panthéon minéen.

\subsection{Les dispositifs d'entrée}

Lescalier axial, de 5,50 m de large, comprend sept marches, soit huit hauteurs, et estencadrépar deux antes bâties avec des murs à double parement (v. Agostini, 
chapitre 3 dans ce volume, fig. 6). Il débouche sur un palier de 2,15 $\mathrm{m}$ de profondeur et de treize mètres de large ( «A2 ). On monte ensuite quelques degrés situés entre les grandes dalles du stylobate «A1 » en passant entre les piliers hauts de 6,15 m. Ces six piliers, dotés de tenons à leur sommet, qui constituent les propylônes, ou propylées, forment un dispositif indépendant. Ils sont encastrés de $1,5 \mathrm{~cm}$ dans des réservations taillées dans autant de grandes dalles alignées selon l'axe du bâtiment. Ces monolithes horizontaux forment le stylobate large de $6,60 \mathrm{~m}$ sur 3,00 $\mathrm{m}$. Ces réservations de faible profondeur ne servent qu'à empêcher les déplacements éventuels lors de la pose des monolithes verticaux ; ils peuvent aussi contribuer à un ensemble de mesures antisismiques prévues par les bâtisseurs. Ces dalles sont espacées entre elles, en moyenne d'une vingtaine de centimètres. Ces piliers offrent la particularité d'avoir, à la base une section de 0,50 $\mathrm{m}$ de large par 0,60 $\mathrm{m}$ en profondeur et, en partie haute, une section bien plus importante respectivement de $0,70 \mathrm{~m}$ par $0,85 \mathrm{~m}$.

Après avoir franchi le seuil surélevé de $0,65 \mathrm{~m}$, on redescend cinq marches, soit six niveaux, l'équivalent de $1,20 \mathrm{~m}$ en dénivelé, pour atteindre le sol de la nef centrale de la salle hypostyle. On remonte ensuite d'une marche dans les nefs latérales et dans la travée libre « 4 » parfois appelée «transept » par les archéologues. Le seuil de 3,60 m sur 1,10 m est constitué d'une pierre monolithe en calcaire oolithique dans laquelle sont encastrés deux jambages (montants) imposants, à feuillure avec des tenons sur leur lit d'attente supérieur (fig. 21). Ce sont eux-mêmes des monolithes en calcaire oolithique qui font office de chambranle pour supporter un linteau monobloc également à feuillure. Ils mesurent 4,40 $\mathrm{m}$ de haut avec une section en plan de $0,80 \mathrm{~m}$ par $0,72 \mathrm{~m}$ (v. Scigliano et Paladino, chapitre 14 dans ce volume, fig. 9).

\subsection{La salle hypostyle}

Organisée comme celle du temple de Nakrah, la salle hypostyle de cet édifice comporte cinq nefs ( $« \mathrm{a} », \ll \mathrm{b} »$, 《 $\mathrm{c}$ », « d » et « e ») et cinq travées («1», « 2 », « 3 », « 4 » et « 5 ») (v. fig. 1). La salle correspond aux quatre premières définies par les trois rangées de quatre piliers monolithes de 5,50 $\mathrm{m}$ de haut qui supportait à l'origine l'ossature horizontale composée d'architraves, de poutres et de dalles qui composent le plancher haut (v. Agostini, chapitre 3 dans ce volume, fig. 9). La travée orientale « 5 », adossée à la paroi extérieure, comprend une cella centrale encadrée de deux pièces latérales de type chapelles, fermées par des portes en bois. Cette cella est vide et ne contient pas d'autel, de podium ou de socle pour d'éventuelles statues. Les archéologues

7 Cette particularité se retrouve également sur le temple Bacrān à Mārib. ont cependant trouvé vers le fond plusieurs dalles alignées en calcaire poli, ils supposent de fait que le sol de cette petite pièce était, à l'origine, surélevé de trente centimètres par rapport à la nef centrale. De nombreux témoignages de l'occupation de cette cella ont ainsi disparu.

Seuls quatre piliers étaient véritablement in situ. La nef centrale mesure 2,20 $\mathrm{m}$ de large et les nefs latérales 2,00 $\mathrm{m}$. Les piliers s'organisent sur une trame quadrangulaire carrée régulière : les nefs latérales et les travées ont la même dimension. Les parois extérieures sont épaisses d'un mètre en moyenne, si on considère le mur ouest, le mieux conservé, comme référence. Elles comprennent un blocage de tout venant pris entre deux rangées de blocs finement piquetés (parements) avec une marge ciselée définie par une incision linéaire. Ce type de maçonnerie est bien connu dans toute l'architecture de l'Arabie antique et on le retrouve aussi bien en Ḥaḍramawt, dans le Jawf ou à Mārib.

\subsection{Les sols et pavements}

Les niveaux des différentes "pièces ", comme dans le temple de Nakrah, ne sont pas rigoureusement plats et possèdent des dénivelés sensibles. Les dalles sont posées avec régularité dans l'organisation géométrique de l'édifice, en alternant les joints. L'homogénéité de l'ensemble témoigne également de choix esthétiques. Plusieurs monolithes ont été utilisés pour le sol du dispositif d'entrée (v. Agostini, chapitre 3 dans ce volume, fig. 5), tout particulièrement la pierre de seuil, de plusieurs mètres carrés, correspond au niveau le plus haut du propylée «A1 » par rapport au sol extérieur sensiblement plat qui est situé à près de deux mètres au-dessus du niveau du sol extérieur à l'enceinte. Vu depuis une certaine distance, le temple de 'Athtar dhuQabḍ, bâti au-dessus d'un soubassement important complété par les murs de soutènements des terrasses "A2 » et «A3 », est beaucoup plus imposant que son voisin immédiat. Il est donc surprenant de constater que depuis le seuil, à 3,50 m au-dessus du sol environnant, on redescend dans la nef centrale de la salle hypostyle de près de $1,25 \mathrm{~m}$, soit cinq marches ou six niveaux. De cette nef on remonte ensuite d'un degré dans les nefs latérales et dans la cella centrale. On enjambe un seuil surélevé pour pénétrer dans les chapelles latérales. De ce fait les niveaux des deux salles hypostyles sont sensiblement les mêmes.

\subsection{Les escaliers secondaires}

La présence d'un étage ou d'une terrasse accessible semble être attestée, selon les archéologues, par l'existence d'un escalier intérieur d'une seule volée conservé sur huit marches (fig. 22). Il s'appuie sur le mur extérieur occidental et débouche contre le 
mur sud (« M104»). Le mur d'échiffre oriental est soigneusement construit avec un appareil isodome de blocs soigneusement piquetés. Nous ne possédons pas les vestiges d'une deuxième volée qui aurait pu, éventuellement, être réalisée en bois. Il est difficile de savoir si, dans le cas d'un accès à un étage, il s'agissait d'une simple galerie périphérique de type balcon ou d'une pièce complète. Dans l'hypothèse de la restitution d'un escalier à simple volée, le plancher aurait été environ à une hauteur de 4,20 m-4,50 m tout au plus, soit plus d'un mètre sous le niveau défini par la hauteur de 5,50 $\mathrm{m}$ des piliers. De plus les piliers intérieurs ne comportent aucune trace d'un accrochage quelconque d'un plancher intermédiaire.

On peut également proposer que seule la terrasse de l'édifice ait été accessible, uniquement pour les fidèles autorisés à pénétrer dans le monument. De nombreux exemples existent au Proche-Orient, tout particulièrement en Syrie et en Arabie du Sud, plusieurs temples du Hadramawt possèdent des escaliers intérieurs situés dans des pièces annexes proches de l'entrée principale. Cependant la toiture-terrasse devait se trouver au minimum à $6,70 \mathrm{~m}$ de haut soit deux mètres au-dessus de l'arrivée hypothétique de l'escalier. D'où la nécessité d'une deuxième volée.

Dernière option envisageable, cet escalier n'aurait pu servir qu'à atteindre une tribune occupant partiellement la première travée, face à la cella. En effet la largeur de l'escalier correspond à la moitié de la largeur de la première travée ; il faudrait donc envisager hypothétiquement cette deuxième volée en bois qui reviendrait vers la nef centrale. Cet escalier peut ne pas être tardif - éventualité que proposent les archéologues - car sa réalisation ultérieure aurait nécessité des transformations importantes de l'ossature de l'édifice, plus particulièrement le démontage de l'architrave et de la toiture de la première travée située entre les nefs « $a »$ et $« b »$.

\subsection{La structure porteuse}

La charpente utilise, comme dans le temple de Nakrah, le principe de l'empilement. Elle s'appuie sur les murs extérieurs, sur les murs des chapelles de la travée orientale « 5 » et sur douze piliers monolithes. Ces piliers sont dotés de tenons et supportaient des architraves dotées de mortaises et positionnés dans l'axe d'entrée du monument. L'ensemble rigide, piliersarchitrave, est peu ancré dans le sol mais est stabilisé par le calage des blocs qui constituent les banquettes centrales. Cette ossature primaire était surmontée par des poutres transversales recouvertes de grandes dalles posées en appui simple. Les poutres comme les architraves, chacune à leur niveau, étaient liées entre elles de manière à assurer une continuité linéaire horizontale. Les assemblages des pièces composant la couverture étaient réalisés par des tenons de bois en queue d'aronde disposés dans des mortaises taillées dans la face supérieure des blocs contigus.

\subsection{Les tables de libations et les banquettes}

Les banquettes et les tables d'offrandes sont fréquentes dans les lieux de culte et bien connues de l'Arabie du Sud antique (v. Marion de Procé, chapitre 11 dans ce volume). Elles peuvent être de nature différente, en briques crues, maçonnées ou bien sous forme de monolithes, on les retrouve aussi bien dans les royaumes de Saba qu'en Hadramawt, dans le Jawf ou sur les hauts plateaux. Les tables de libations monolithes des deux temples de Barāqish présentent une marge polie en légère saillie par rapport au plan de la table. Elles sont posées sur des dalles posées de chant et sont décorées à leur extrémité côté nef centrale d'une frise de sept bouquetins.

Les banquettes du temple de 'Athtar dhu-Qabd (v. Scigliano et Paladino, chapitre 14 dans ce volume, fig. 7-8) englobent les piliers et participent de leur stabilité. Elles sont également liées constructivement à la banquette périphérique qui parcourt le périmètre intérieur des parois extérieures. 


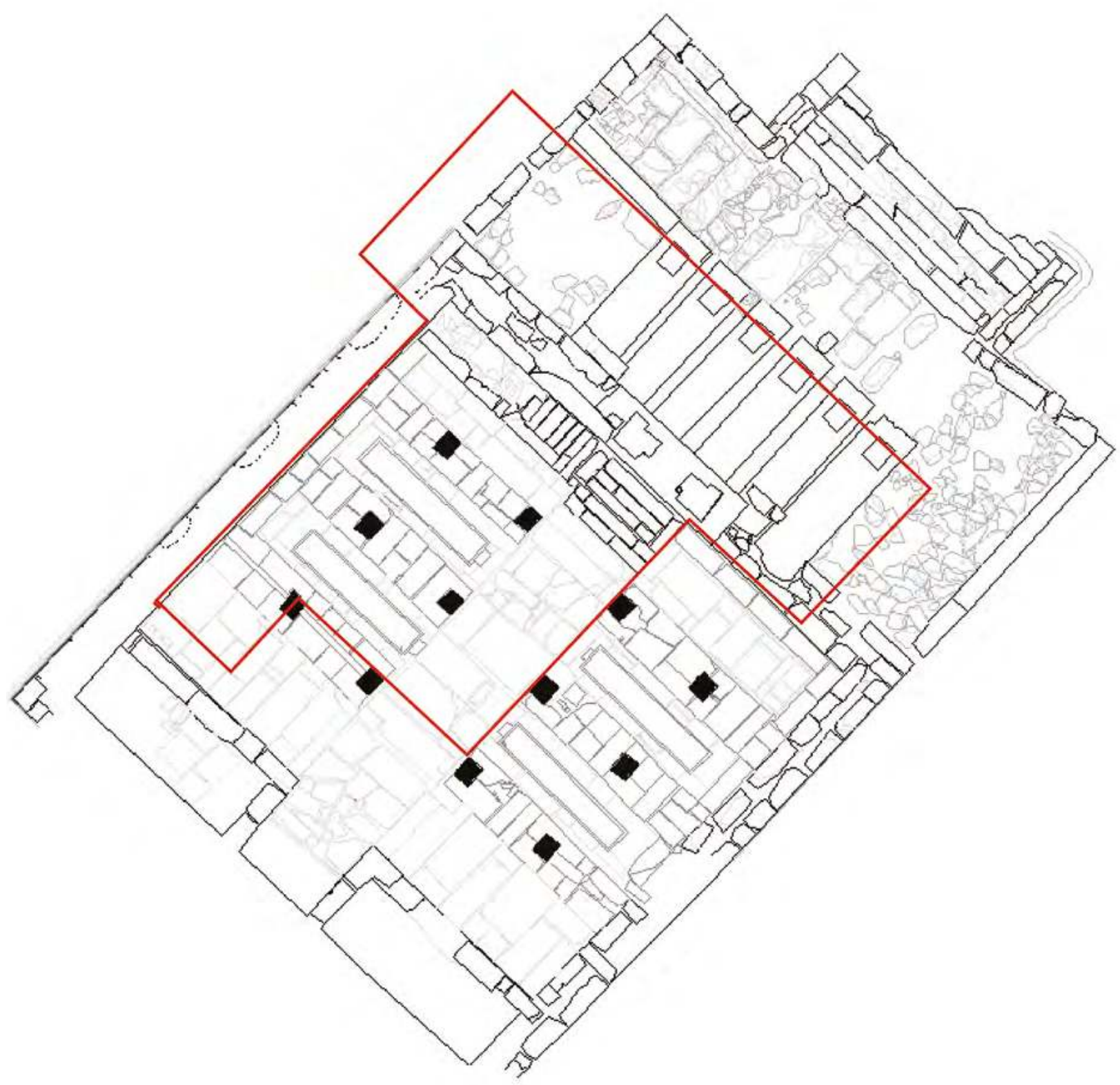

Figure 17. Plan final du temple de 'Athtar dhu-Qabḍ. (R. Loreto 2006-2007 OMAIRY) 


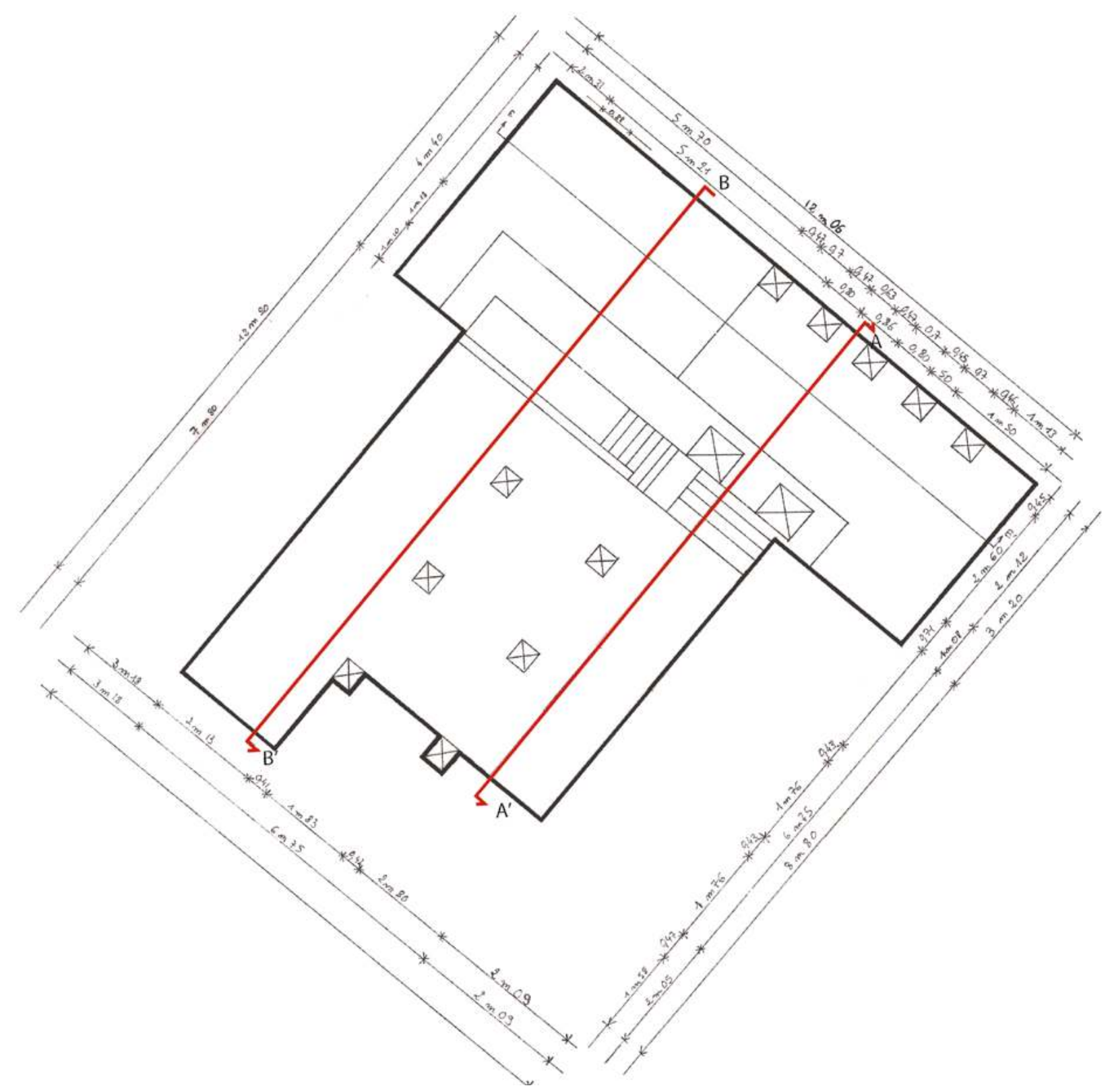

Figure 18. Plan de la fouille en cours du temple de 'Athtar dhu-Qabḍ, avec indication en rouge des deux coupes relevées. (G. Richoux 2005-2006 OMAIRY) 


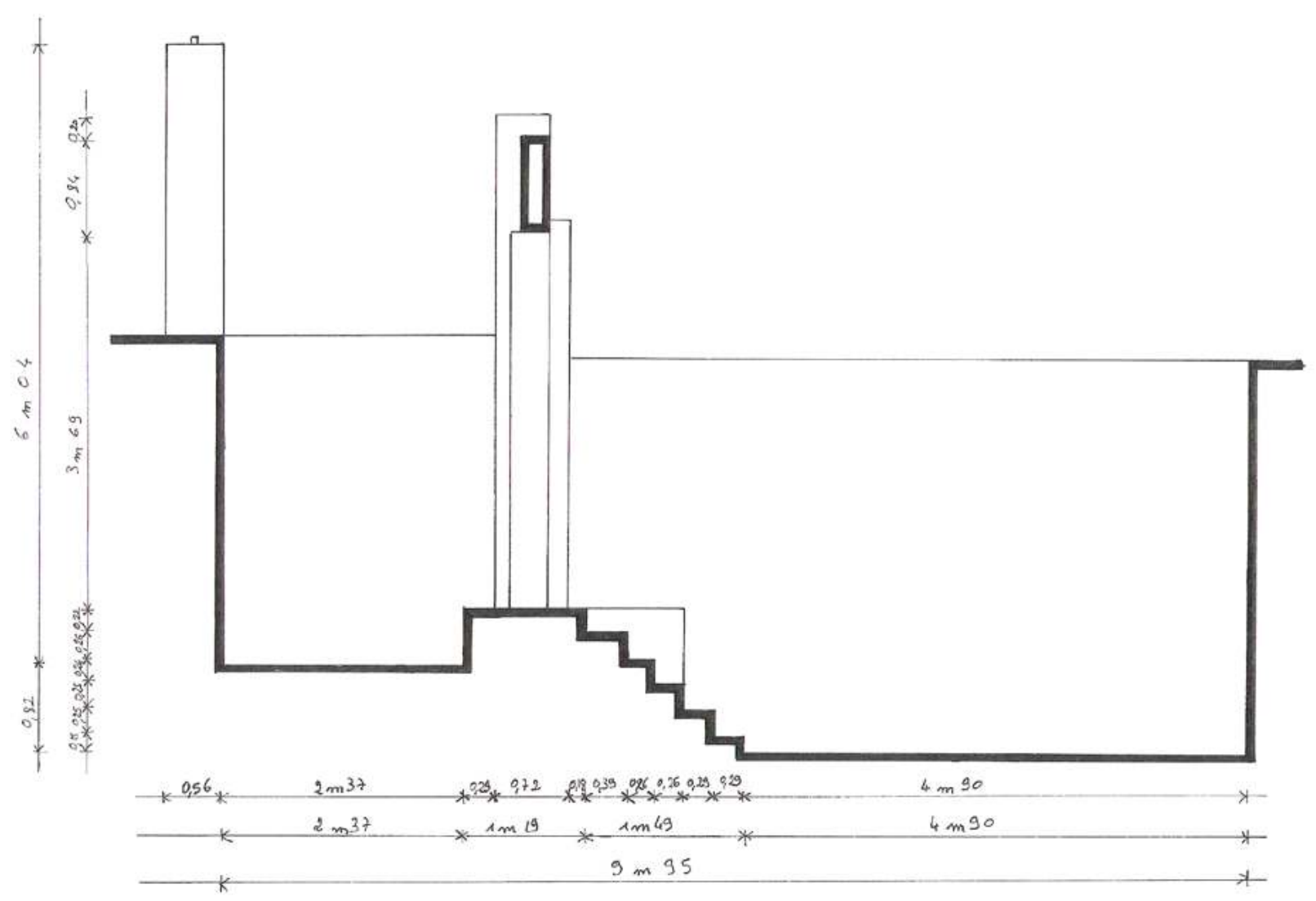

Figure 19. Coupe AA' du temple de 'Athtar dhu-Qabḍ. (Échelle 1:50; G. Richoux 2005-2006 OMAIRY)

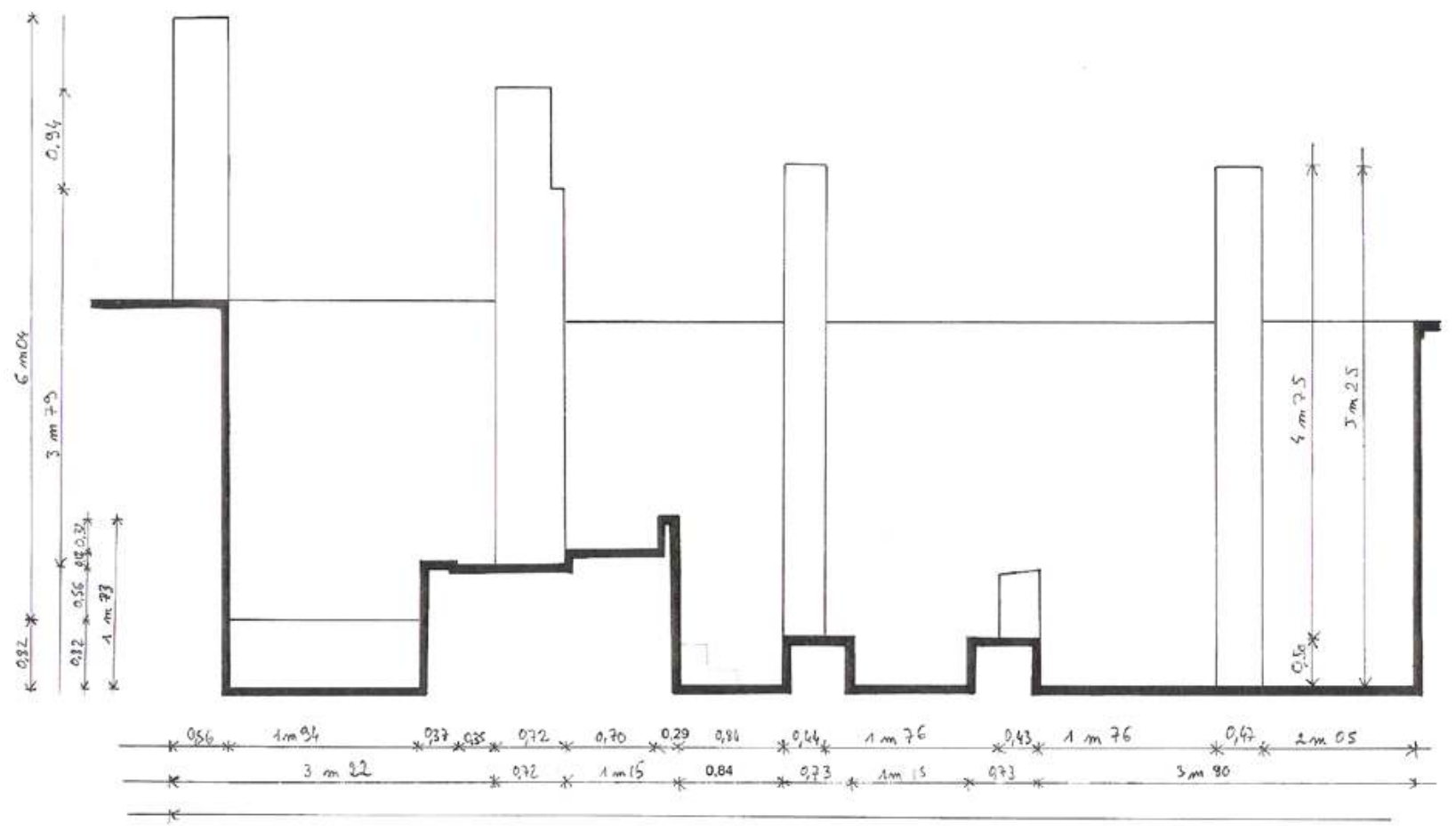

Figure 20. Coupe BB' du temple de 'Athtar dhu-Qabḍ. (Échelle 1:50; G. Richoux 2005-2006 OMAIRY) 


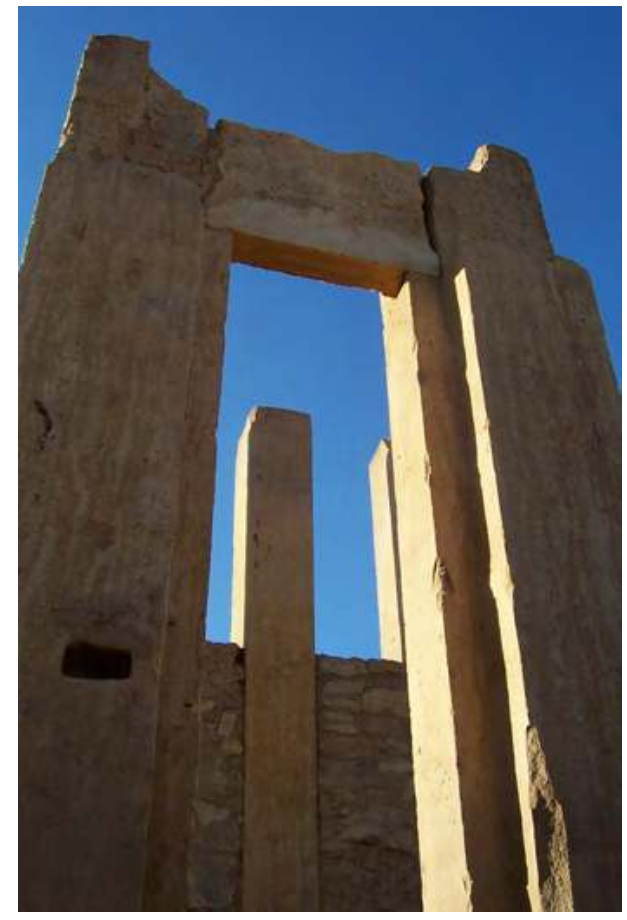

Figure 21. Porte d'accès, depuis la salle hypostyle du temple de 'Athtar dhu-Qabd vers les propylées « A1». (S.B. Scigliano 2005-2006 CMAIRY)

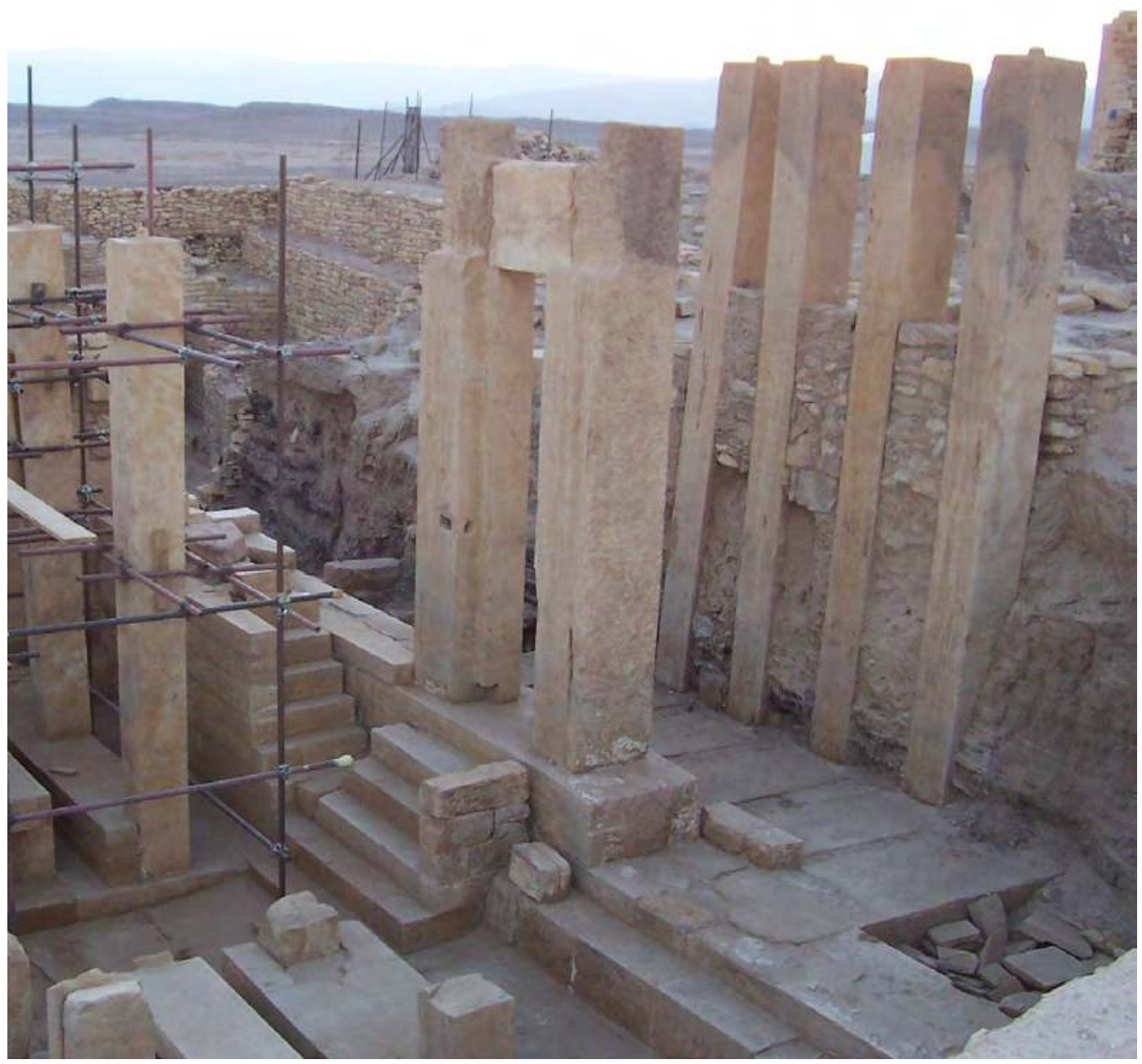

Figure 22. Vue depuis l'est vers l'accès de cinq niveaux qui descend dans le temple de 'Athtar dhu-Qabḍ et l'escalier qui mène à un niveau supérieur. (A. de Maigret 2004-2005 CMAIRY) 


\section{Constats pour une étude comparative}

Ces deux temples correspondent à une même catégorie architecturale, celle regroupant les temples à salle hypostyle que l'on peut différencier des temples plus anciens dotés d'une cour centrale entourée d'un portique dont un des meilleurs exemples est le temple extra-muros de 'Athtar dhu-Rișāf à al-Sawdā' / Nashshān. L'étude constructive indique bien que plusieurs procédés constructifs similaires ont été utilisés pour la construction de la maçonnerie des parois extérieures, avec un remplissage interne inséré entre deux rangs de blocs de parement finement piquetés et entourés d'une marge ciselée délimitée par une incision continue. De même l'ossature fonctionne en utilisant le principe de descentes de charges maitrisées par des empilements liaisonnés avec des tenons et mortaises pour les poteaux et architraves, par ancrages longitudinaux horizontaux pour les poutres et par simple superposition pour les dalles de couverture.

L'apparente homogénéité de la construction est peutêtre due à l'édification d'un édifice hyperstatique posé sur un socle. Aucun encastrement avec le sol n'est observé, cas des structures isostatiques. Cependant les parois périphériques sont, elles, liées au sol par leur poids et les forces de réaction. C'est d'ailleurs à leur jonction avec la toiture que les bâtiments ont vécus les premiers désordres structurels. Cet aspect d'une architecture hyperstatique est d'ailleurs confirmé en Arabie du Sud par la présence de chaînes d'angle à double boutisses. Faut-il y voir une tentative de créer une architecture parasismique?

La présence de tables d'offrande et de banquettes témoigne de l'existence de repas rituels, suivant le rythme des saisons, dont les inscriptions sur les tables de libations des deux monuments et les rigoles du temple de Nakrah témoignent. Nous notons cependant qu'aucune tranchée d'évacuation des effluents en rejet n'a été découverte dans le temple de 'Athtar dhu-Qabd.

Nous notons, malgré tout, des différences importantes entre les deux édifices.

- Tout d'abord il est nécessaire de noter l'importance attribuée au dispositif d'accès. Le temple de 'Athtar dhu-Qabd est doté d'un portique à six piliers au lieu de quatre pour le temple de Nakrah. Ce dernier est situé à $1,70 \mathrm{~m}$ en contrebas du temple de 'Athtar dhu-Qabd

- L'emmarchement du temple de Nakrah, dans son état tardif, est composé d'un escalier disposé sur trois côtés et à degrés rectangulaires alors que celui de 'Athtar dhu-Qabḍ est à simple volée axiale pris entre deux antes.
- Le temple de Nakrah possède un accès secondaire à la salle hypostyle, ce qui n'est apparemment pas le cas pour le temple de 'Athtar dhu-Qabd.

- On redescend dans le temple de 'Athtar dhuQabḍ alors que l'on est de plain-pied dans le temple de Nakrah.

- Le temple de Nakrah possède cinq cellas hiérarchisées, celui de 'Athtar dhu-Qabḍ n'en possède qu'une encadrée de deux chapelles fermées (v. Agostini, chapitre 3 dans ce volume, fig. 17).

- Le temple de 'Athtar dhu-Qabd possède un escalier intérieur dont il est difficile de comprendre l'exacte destination.

L'ensemble de ces différences importantes dans la disposition des dispositifs architecturaux semble pouvoir être attribué à des usages et des pratiques cultuelles diversifiés. Le soin mis à édifier ces deux bâtiments avec justesse et rigueur, ainsi que leurs caractéristiques typologiques, témoignent d'un savoirfaire affirmé et d'une culture architecturale raffinée que l'on retrouve dans l'ensemble du Jawf.

\section{Les techniques de construction mises en œuvre dans les temples de Barāqish}

Une première remarque s'impose, elle a été déjà formulée : les deux monuments utilisent les mêmes procédés de construction et correspondent à deux variantes d'un même type : le temple « minéen » à salle hypostyle. Au chapitre précédent nous avons noté les différences concernant la morphologie architecturale des deux monuments. Nous allons ci-dessous noter au sein des techniques de construction employées les nuances et les alternatives constructives proposées par les bâtisseurs antiques.

\subsection{Les roches}

Nous ne connaissons pas les carrières d'où sont extraites les pierres mises en œuvre. Les constructeurs ont utilisé deux grandes variétés de roche calcaire : le calcaire lumachellique (fig. 23) et le calcaire oolithique (fig. 24), ce dernier correspond à la pierre la plus utilisée dans l'ensemble de la région du Jawf. Le calcaire à lumachelles contient un grand nombre de fossiles entiers ou brisés, il a l'aspect du marbre sans en avoir la cristallisation métamorphique.

Le temple d'Athtar dhu-Qabd est construit dans sa totalité avec cette pierre alors que le temple de Nakrah est principalement construit avec du calcaire oolithique composé de nombreux petits fossiles sphériques noyés dans un ciment de carbonate de calcium. Seuls les montants de la porte d'entrée sont en calcaire à lumachelles. Les deux approvisionnements en roches témoignent de l'homogénéité et de la proximité des 
bancs d'extraction. Aucune donnée n'est fournie par les documents rédigés par les archéologues sur la nature pétrographique du troisième temple (dédié à Wadd ?) présent à proximité, au nord, et dont seuls les sommets des piliers du propylée dépassent des niveaux islamiques.

Le calcaire à lumachelles que l'on rencontre à Barāqish est très dense et les coquilles sont le plus souvent fragmentées et incluses dans un ciment qui donne la couleur beige parfois un peu rosée à cette roche. C'est une pierre classée comme dure dont la compacité permet de prendre un poli souvent nécessaire pour les champs épigraphiques. ${ }^{8}$ Cette pierre particulièrement compacte et homogène malgré quelques vacuoles calcifiées a été utilisée pour la taille des grands monolithes du temple d'Athtar dhu-Qabd, qui sont posés en délit pour les éléments verticaux, certaines architraves et poutres et en lit pour les dalles de couverture. On retrouve cette pierre sur les sites de Kharibat Hamdān, d'al-Sawdā'

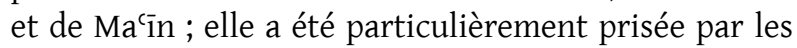
bâtisseurs du Jawf durant la première moitié du $I^{\text {er }}$ millénaire av. J.-C.

Le calcaire oolithique est une roche ferme, parfois dure; il correspond à la pierre la plus utilisée dans cette région de l'Arabie du Sud. C'est elle qui, à Barāqish, est employée pour les fortifications et dans le temple de Nakrah où la nature des fossiles sphériques est assez grossière. Vu sa nature homogène, on la trouve aussi bien en lit qu'en délit et est régulièrement exploitée en fonction de la hauteur des bancs naturels de son lieu d'extraction. Elle a fourni le matériau de construction des grands monolithes utilisés pour les propylées et l'ossature du temple ainsi que de sa couverture dallée. On retrouve cette roche utilisée avec des formats beaucoup plus petits dans la maçonnerie en petit appareil des parois extérieures du temple de Nakrah. On peut donc en conclure que le calcaire à oolithes présente des bancs fracturés de diaclases et de lithoclastes très fines et des bancs beaucoup plus homogènes de plusieurs décimètres de hauteur.

Il est difficile, en l'absence d'une étude des carrières d'extraction de la roche, de connaître exactement l'outillage des carriers lors de l'extraction et le débitage des blocs pour l'approvisionnement des chantiers. Ce calcaire oolithique dur se présente parfois en bancs, bien souvent très fracturés, de 5 à $15 \mathrm{~cm}$ de hauteur ; il a fourni la matière première pour le petit appareil en utilisant les joints naturels de la roche. Seules quelques retouches sur les faces visibles permettaient une utilisation rapide de cette pierre.

Aucune trace d'emboîture, liées à l'extraction avec des coins métalliques, sur les arêtes des monolithes

\footnotetext{
8 Voir Bessac 1998a, 175.
}

des deux temples n'a été mentionnée par les archéologues. Les carriers ont utilisé le plus souvent les fractures naturelles qu'ils ont donc régularisées. Plus généralement, on peut estimer que l'outillage nécessaire pour l'extraction a dû se limiter à quelques coins métalliques, à des percuteurs lithiques en calcaire froid, puis à des leviers et des rouleaux en bois dur pour la manutention des blocs.

Les outils nécessaires pour la taille de préparation des blocs à pied d'œuvre comprennent des instruments à percussion comme des masses et percuteurs lithiques ; ces outils correspondent au travail d'ébauche et de dégrossissage des pierres de construction.

L'étude de la taille des blocs permet d'affirmer que les tailleurs de pierre utilisaient des ciseaux métalliques soit relativement larges, jusqu'à $2 \mathrm{~cm}$ de tranchant, soit plus pointus (fig. 25). Ils sont alors nommés gravelets et ont une extrémité qui varie entre 0,2 et $0,5 \mathrm{~cm}$. Utilisés pour le piquetage des champs des blocs, ils sont utilisés également pour la taille des inscriptions. ${ }^{9}$

On trouve dans la maçonnerie des deux temples plusieurs exemples de polissage de la roche, soit pour un champ épigraphique soit pour la régularisation de marges ciselées ou des grands aplats des monolithes. On doit en conclure la présence d'abrasifs comme du sable fin légèrement humecté et "véhiculé par un tampon souple $» .^{10}$

\subsection{La taille}

Les opérations complexes de taille peuvent se diviser en deux catégories : les tailles fonctionnelles et les tailles ornementales. On peut aussi différencier les tailles à pied d'œuvre de celles effectuées au ravalement.

La taille fonctionnelle peut correspondre à des blocs bruts d'extraction qui subissent un minimum de retouches. Cette taille est soit une " taille dite éclatée » soit une " taille de dégrossissage » plus élaborée qui va permettre ultérieurement une finition au ravalement en taille pointée ou ciselée. Cette taille ornementale s'exécute à la fin du chantier alors que les blocs sont positionnés en œuvre. La recherche d'effets de texture avec un jeu d'accroche de la lumière par le grain de la pierre semble recherchée par les tailleurs de pierre du Jawf pour qui ce travail semble issu d'une longue tradition partagée avec celles des royaumes de Saba et d'Hadramawt.

La taille ornementale ciselée est la plus fréquente, tout particulièrement avec le calcaire à lumachelles utilisé pour cet appareil quasi-isodome. C'est un travail mené

\footnotetext{
9 Voir Bessac 1998b.

10 Bessac 1998a, 180.
} 
en oblique légère sur la face du bloc avec des impacts serrés. En général cette taille est réservée pour une ciselure périmétrique ornementale qui délimite un champ qui est ensuite travaillé perpendiculairement avec un gravelet plus fin. Ces ciselures sont taillées perpendiculairement aux arêtes des blocs et ne correspondent pas aux ciselures de réglages qui servent à positionner et à orienter les blocs lors de leur mise en œuvre. Cette dernière, irrégulière, n'est taillée que sur une, deux ou exceptionnellement trois arêtes afin d'indiquer l'orientation du bloc au bâtisseur en tenant compte de la disposition des lits et de la préparation du travail de pose du bloc suivant. Les ciselures visibles sur les blocs de façades, intérieures et extérieures, des deux temples sont régulières et souvent plus large que le tranchant de l'outil - ce qui nécessite un travail beaucoup plus important et une volonté d'un choix esthétique indubitable.

La taille pointée avec un gravelet occupe entièrement le centre de la face visible des blocs. Elle est délimitée par le cadre ciselé. La percussion verticale de l'outil métallique, par rapport au plan de la face du bloc, peut être très dense et donner ainsi un aspect de «pelure d'orange ». Cette taille se rapproche de celle reconnue à Tamna' sur le granit, sur les façades du bâtiment 8 de Shabwa et sur celles d'un des tombeaux de la nécropole de Mārib. Ce parement piqueté (fig. 24) est réalisé plus particulièrement sur les faces des blocs en calcaire oolithique ferme.$^{11}$ La manière de séparer cette texture piquetée de la marge ciselée qui l'entoure présente deux variantes : avec ou sans incision linéaire.

Les blocs mis en œuvre dans le temple de Nakrah et de 'Athtar dhu-Qabd témoignent tout particulièrement du soin mis à séparer ces deux zones par une incision en ligne droite continue. Cette technique est employée sur les blocs de parement des parois ainsi que sur les grands monolithes verticaux en calcaire oolithique du temple de Nakrah, mais pas sur ceux en calcaire à lumachelles du temple de 'Athtar dhu-Qabd.

La taille polie est réalisée tout particulièrement sur le calcaire à lumachelles employé dans le temple de 'Athtar dhu-Qabd. Le polissage, plus ou moins fin, est réalisé, totalement ou en partie, après une taille préparatoire ciselée perpendiculaire aux arêtes des monolithes. Les champs épigraphiques, quel que soit la nature de la roche, sont préparés avec un polissage destiné à recevoir les textes gravés.

\subsection{Les appareils}

Le petit appareil, relativement allongé, d'une hauteur d'assise de 0,10 à $0,15 \mathrm{~m}$ et long de 0,20 à $0,50 \mathrm{~m}$ semble

\footnotetext{
11 Ginouvès et Martin 1985, 130.
}

correspondre, d'après les archéologues, à des travaux tardifs même si on le retrouve fréquemment dans la maçonnerie des parois des fortifications de la ville. Ces blocs sont exploités comme matériau de construction, à peine dégrossis depuis leur lieu d'extraction. Le moyen appareil correspond à des blocs hauts de 0,15 à $0,40 \mathrm{~m}$ et longs de 0,30 à $0,70 \mathrm{~m}$, il reste le plus fréquent et est plus consciencieusement travaillé. Quant au grand appareil, fréquemment employé dans ces deux monuments, il se distingue par des hauteurs régulières $(0,30 \mathrm{~m}$ environ) et par des longueurs pouvant atteindre 1,50 $\mathrm{m}$, tout particulièrement avec l'utilisation du calcaire à oolithes. Dans le rempart d'al-Baydā', ville toute proche, des bocs atteignent 2,95 $\mathrm{m}$ de long. Les pierres utilisées en grand appareil sont mises en œuvre aussi bien en lit qu'en délit.

Les monolithes utilisés en grand nombre occupent une place prépondérante soit en éléments porteurs verticaux de la toiture soit en ossature du plafond de la salle hypostyle. On les retrouve utilisés pour les grandes dalles de couverture des deux temples et sont également mis en œuvre pour l'encadrement de la porte principale de chaque édifice. Leur utilisation semble dérivée de la charpente traditionnelle souvent dotée de pièces linéaires de bois de fortes sections. ${ }^{12} \mathrm{~A}$ titre de comparaison, dans les temples du Hadramawt ${ }^{13}$ et à Shabwa ${ }^{14}$ n'étaient utilisés que des éléments porteurs verticaux (et horizontaux) en bois. Faut-il voir dans ce phénomène de pétrification une influence venue d'Afrique et plus particulièrement d'Egypte ? L'état des études sur la construction dans cette région des deux rives de la mer Rouge n'en est qu'à ses débuts et il nous semble prématuré de tirer des conclusions qui n'en seraient que trop hâtives.

\subsection{Les techniques constructives utilisées pour les murs et les parois}

Les maçonneries utilisées par les constructeurs pour la réalisation de ces deux temples sont de trois types :

1. des murs à double parement avec un remplissage interne ;

2. des murs en parpaings disposés en carreaux ;

3. des séparations avec des dalles d'orthostates verticales.

Les parois composées horizontalement de deux rangées de pierre de taille avec un remplissage de débris divers correspondent aux murs périmétriques des deux monuments. Ces parois ont été réalisées avec soin, réutilisées à l'époque médiévale, et possèdent des

\footnotetext{
12 Darles 2009b.

13 Sedov 2005.

14 Seigne 1992.
} 
assises de même hauteur, intérieures et extérieures, qui correspondent. L'appareil est quasi isodome avec une très grande régularité dans la hauteur des assises. Les deux faces sont régulièrement reliées par des boutisses traversantes qui confèrent à la paroi une grande tenue et une stabilité accrue. La cohésion de l'ensemble permet d'éviter des effets de flambement et de gonflement de la paroi.

Les murs à une seule rangée de pierre de taille, en général des carreaux disposés en parpaings mis en œuvre dans un appareil quasi isodome sont réalisés pour la confection des parois internes, porteuses ou non. Dans les temples de Nakrah et de 'Athtar dhu-Qabd les parois des deux travées 5 , celles où sont édifiées les cellas et les chapelles, possèdent ce type de mur ainsi que le mur d'échiffre de l'escalier interne du sanctuaire d'Athtar dhu-Qabdi. Les parpaings sont soigneusement piquetés.

La présence de chancels est attestée dans les deux temples ; certains fragments d'entre-eux restent encore en place. Il est possible d'affirmer que ces cloisonnements de séparation, destinées sans nul doute à différentes catégories de participants, étaient limités en hauteur afin de former un garde-corps. Ils sont construits avec des dalles d'orthostate verticales utilisées en délit.

Les murs qui constituent les deux antes de l'escalier d'accès sont bâtis avec deux rangées de blocs sans remplissage, alors que les murs de soutènement des terrasses latérales sont édifiés avec des parpaings larges d'une quarantaine de centimètres qui assurent le parement du massif de remplissage de ces terrasses.

\subsection{La mise en cuvre des monolithes}

L'utilisation de monolithe dans les structures constructives de l'Arabie du Sud antique est généralisée ; elle est tout particulièrement présente dans les bâtiments à usage cultuel, quelles que soient leurs dimensions, même si certains palais semblent l'avoir adoptée comme à Tamnac ou à Shabwa. Cette technique de construction ne dépend ni de la situation géographique des édifices, ni des divinités honorées, ni des entités politiques, royaumes ou cités-états où elle a été employée. ${ }^{15}$

Ces pierres imposantes pèsent des centaines de kilogrammes, parfois plusieurs tonnes (v. Scigliano et Paladino, chapitre 13 dans ce volume), et ont dû nécessiter des choix délicats dans les bancs des

\footnotetext{
15 Darles 2009b
}

carrières souvent proches et maîtriser des techniques d'extraction et de transport éprouvées. Une fois à pied d'œuvre, les mégalithes étaient préparés afin d'assurer leur exacte destination. Les principes de levage sont inconnus mais ont dû faire appel, comme en Egypte, en Ethiopie ou au Liban, à des spécialistes de la répartition des forces qui utilisaient une machinerie souvent issue des techniques en usage dans la marine.

Ces mégalithes sont utilisés soit en éléments linéaires, piliers pour les verticaux, architraves, linteaux et poutres pour les horizontaux, soit en élément planaires, dalles de stylobates ou dalles de couverture. Certains dispositifs particuliers ont fait appel à des blocs monolithiques particulièrement homogènes, tout particulièrement les encadrements de portes dont la taille est particulièrement sophistiquée.

La qualité de ces monolithes témoigne d'une rigueur importante dans le travail des ouvriers tout particulièrement dans leur maîtrise de la géométrie (rectitude des arêtes, planéité des faces). Leurs assemblages dans les deux temples fouillés par la mission italienne à Barāqish témoignent de plusieurs principes de liaisonnement destinés à rigidifier la structure porteuse contre les tassements différentiels et les effets destructeurs des séismes (fig. 26). Ces assemblages sont surtout nécessaires durant le temps du chantier. Une fois le bâtiment terminé, la construction devient hyperstatique et massive, les liaisons et les articulations n'ont alors que peu d'importance, étant en surabondance. Seules les différences d'homogénéité entre les ensembles vont occasionner la destruction de certaines parties comme la couverture, par exemple. L'effondrement des grandes dalles de pierre des travées latérales semble prouver que c'est l'effondrement des parois qui a occasionné leur chute (voir supra).

L'assemblage par tenons en pierre et mortaises carrés est relativement fréquent et permet une pose exacte des blocs horizontaux sur les piliers sans possibilité de déplacement lors de la construction des temples. Les tenons sont taillés dans œuvre dès la fabrication du pilier, ils sont réservés dans le lit d'attente du sommet du pilier et les mortaises sont disposées dans le lit de pose des architraves.

L'assemblage par réservation de feuillures latérales (horizontales) ou longitudinales (verticales) est utilisé pour certains raccords de dalles et de poutres ainsi que pour les jambages monolithes des portes monumentales.

L'assemblage à « mi-bois » par refouillement d'un ressaut dans la masse du support ne semble pas avoir été utilisé à Barāqish contrairement à Ma'īn ou al-Sawdā’) 
villes où il est utilisé pour assurer la cohésion entre un support vertical et une pièce linéaire horizontale.

Les poutres et architraves étaient liées entre elles par des tenons, en bois sans nul doute, insérés dans des mortaises en queue d'aronde disposés sur les faces supérieures. Ce principe de liaison linéaire est bien connu en Egypte durant toute la période pharaonique. ${ }^{16}$

L'assemblage par simple empilement, par superposition sans ancrage est le plus fréquent pour les poutres et les dalles de couverture. Il est possible que du mortier ait été utilisé pour sceller et fixer ces lourdes pierres.

\section{Conclusion}

Ceux temples sont représentatifs d'un type bien précis : le temple minéen à salle hypostyle qui fait suite à des édifices plus anciens (VIII ${ }^{e}$ s. av. J.-C.) dotés d'une cour centrale et d'une galerie périphérique. Les procédés constructifs sont déjà largement maîtrisés lors de la réalisation des temples de Nakrah et de 'Athtar dhuQabd, et témoignent d'un savoir-faire contrôlé. Dès le début de la chaîne opératoire, le choix des lieux d'extraction, jusqu'à la taille décorative, les bâtisseurs utilisent les roches les plus performantes pour leur projet d'architecture, ils utilisent des outils choisis parfaitement adéquats et assurent une géométrie précise tant pour le plan de l'édifice que pour la taille des blocs et l'organisation de la pose.

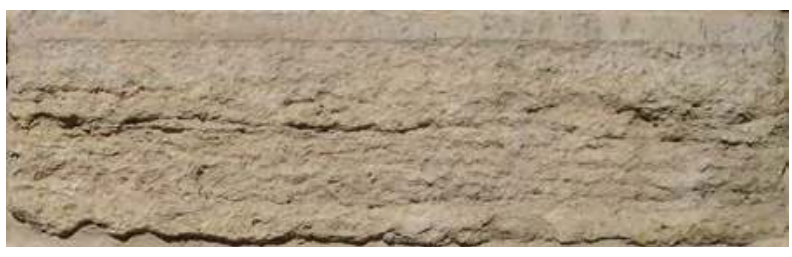

Figure 23. Bloc de calcaire à lumachelle avec une ciselure supérieure périmétrique. (A. de Maigret 2004-2005 @MAIRY)

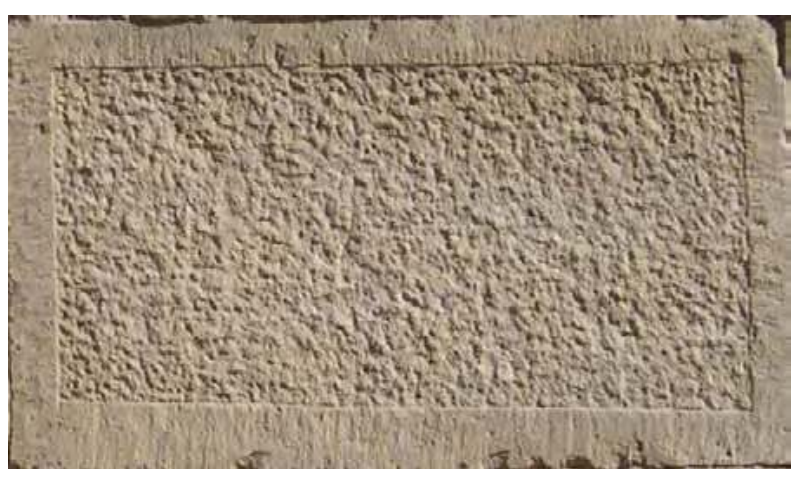

Figure 24. Bloc piqueté au ciseau à bout rond, de calcaire oolithique avec une ciselure périmétrique.

(G. Richoux 2004-2005 @MAIRY)
Ces deux édifices sont représentatifs d'une architecture qui ne connait pas les systèmes de couvrement en pierres appareillées et clavées. Ils ne connaissent ni la plate-bande, ni l'arc ni la voûte. Leur connaissance de la résistance des matériaux, totalement empirique, leur permet de compenser leurs difficultés en statique. Ces édifices, quoique très élaborés et maîtrisés dans leur plan et leur composition, sont encore primitifs et antérieurs aux inventions que le bassin méditerranéen va développer comme les arcades et les voûtes en plein cintre. Ils ne connaissent pas, non plus, au Yémen, la voûte à encorbellement en tas-de-charge qui utilise les porte-à-faux ni la voûte dite " en chevrons » pourtant utilisée dès le III millénaire av. J.-C. en Egypte. On peut supposer avec J.-C. Bessac que les constructeurs ont volontairement évité ce système constructif peut-être en raison des séismes. ${ }^{17}$ Cependant la pétrification des ossatures n'est pas du seul domaine du sud de la Péninsule arabique, on la retrouve par exemple en Syrie du Sud.

L'étude architecturale détaillée a été réalisée par les architectes, topographes et archéologues qui se sont succédés de 1989 à 2007. Ce chapitre est une synthèse exécutée sur la base des notes et des dessins de A. de Maigret, E. Gatti, M. Mascellani, J.-M. Gassend (fig. 2729), R. Loreto et de G. Richoux.

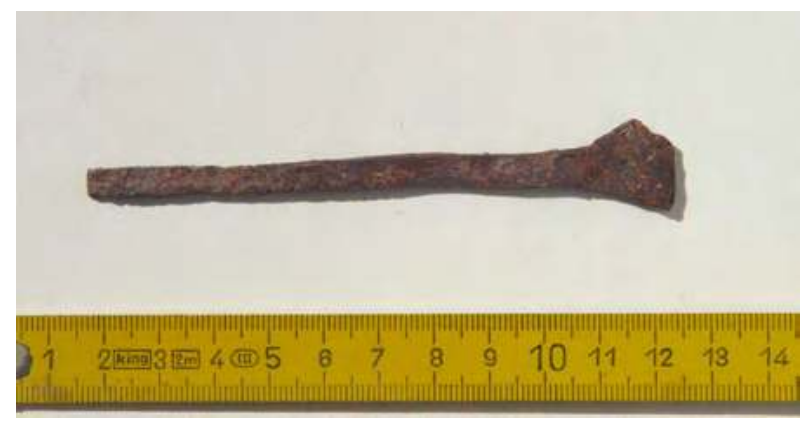

Figure 25. Outil de taille en fer de type ciseau à tranchant, pour la taille des marges ciselées (B.04.B.O/34). (R. Valentini 2004-2005 OMAIRY)

16 Golvin et Goyon 1987, 112. 


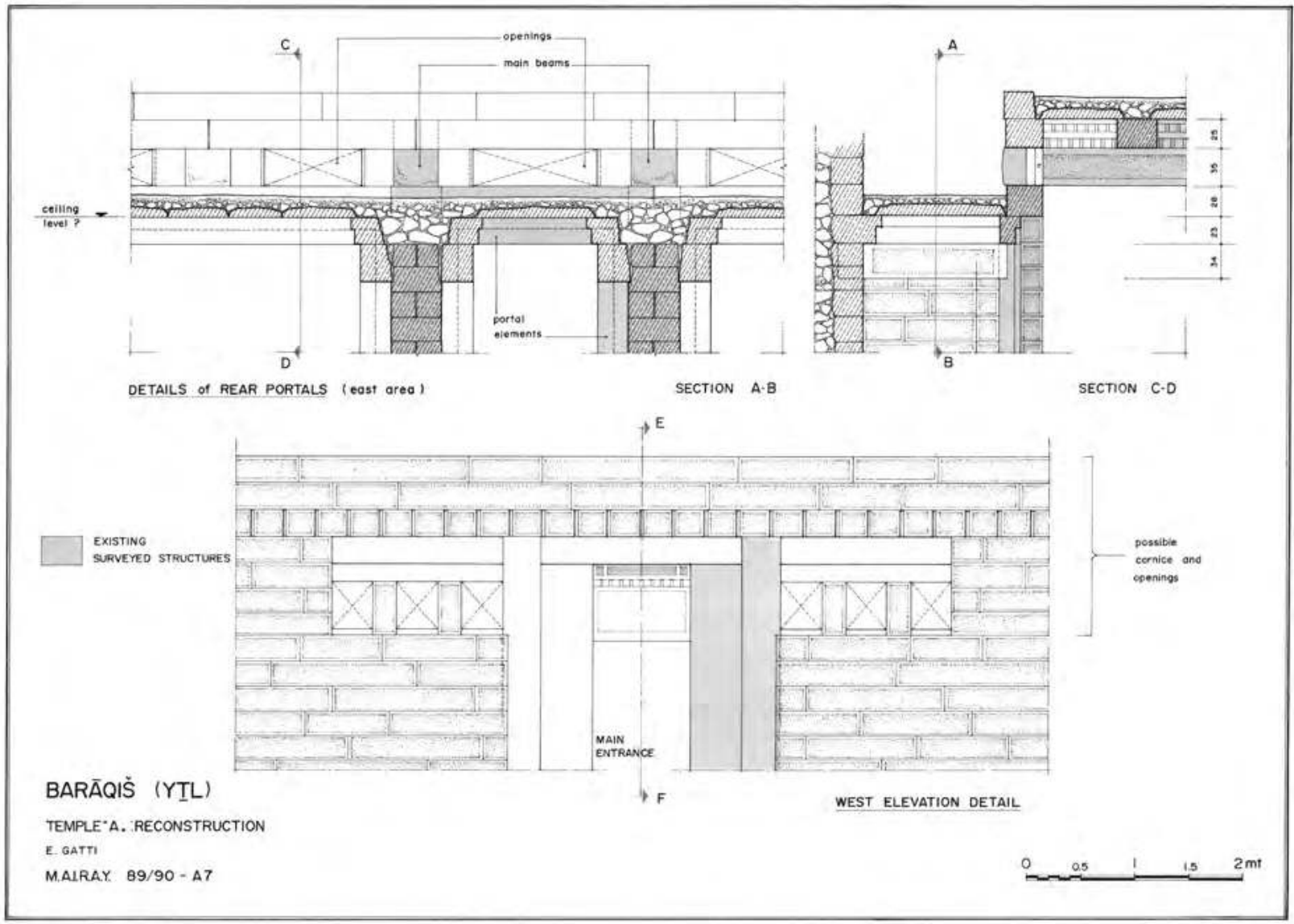

Figure 26. Détail des assemblages des monolithes de la couverture du temple de Nakrah. (E. Gatti 1989-1990 OMAIRY)

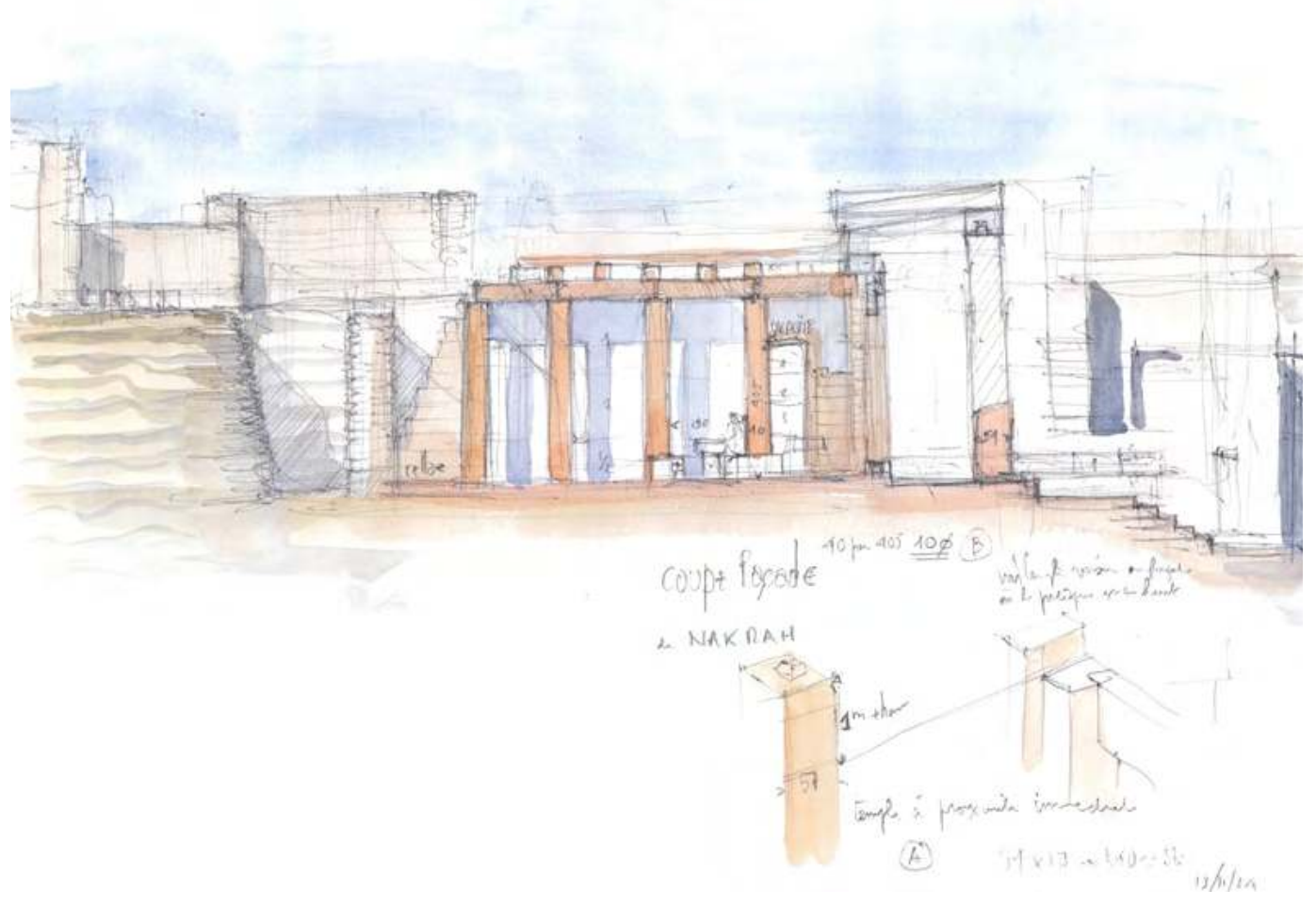

Figure 27. Dessin aquarellé de la coupe longitudinale du temple de Nakrah (J.-M. Gassend 2004-2005 @MAIRY) 


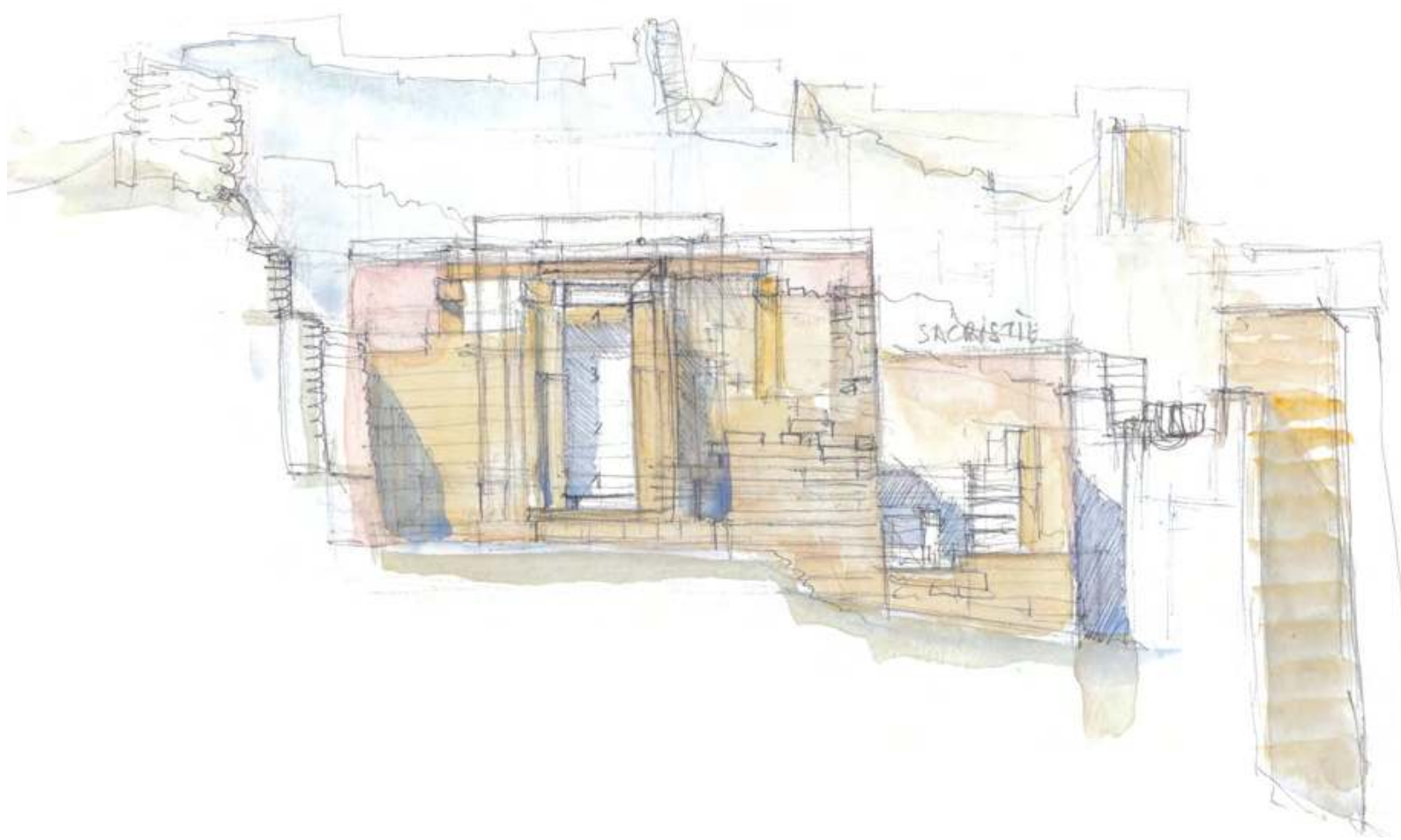

Figure 28. Vue aquarellée de la façade principale du temple de Nakrah. (J.-M. Gassend 2004-2005 @MAIRY)

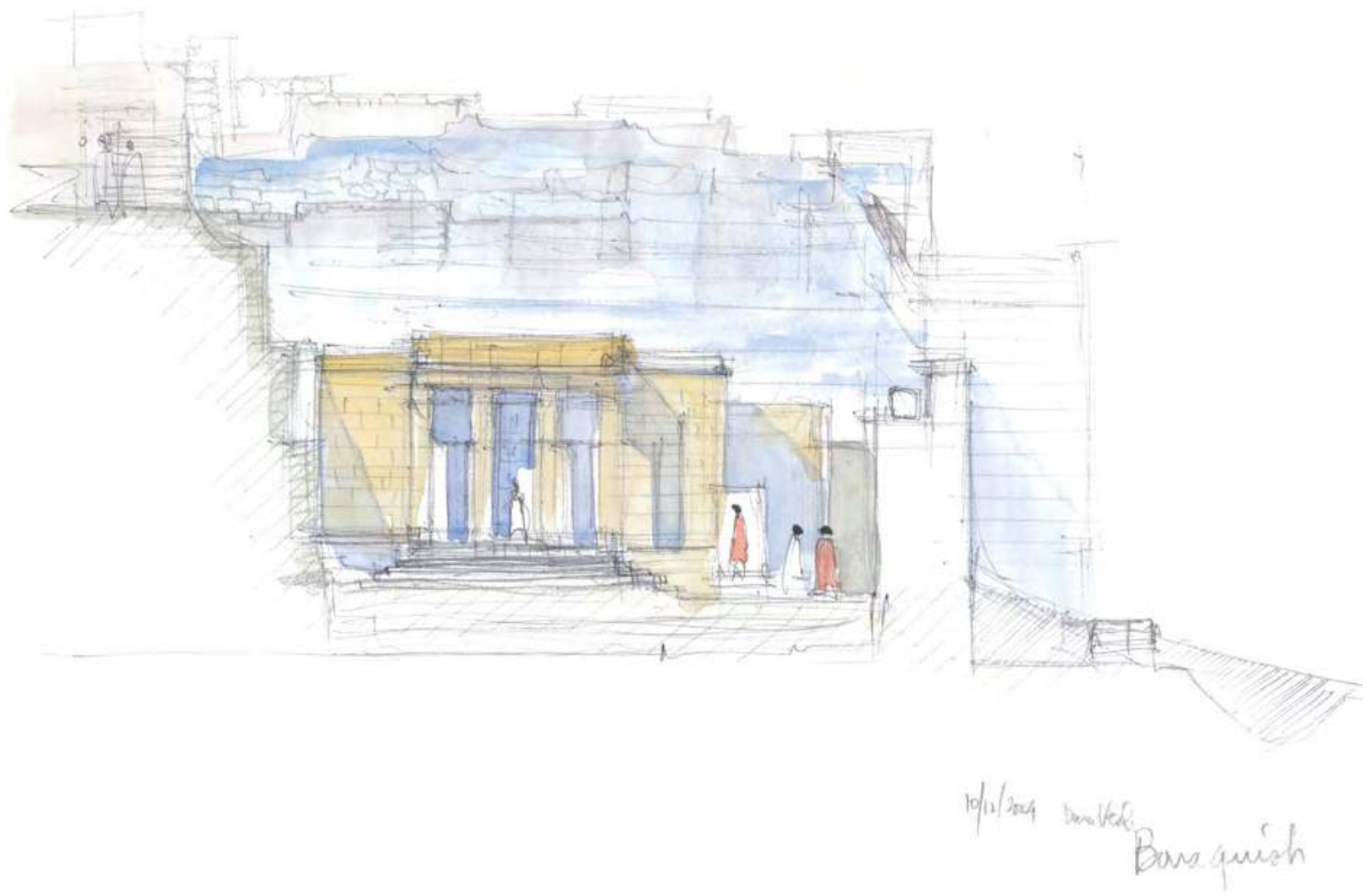

Figure 29. Evocation aquarellée de la restitution de la façade du temple de Nakrah. (J.-M. Gassend 2004-2005 OMAIRY) 


\title{
Chapter 11
}

\section{Le mobilier de culte dans le temple de Nakraḥ à Barāqish}

\author{
Solène Marion de Procé
}

\section{Introduction}

Les rituels réalisés dans les temples d'Arabie du Sud sont très peu connus : en effet, peu de textes les mentionnent et ces rares mentions ne sont jamais explicites quant à leur déroulement. Des éléments demeurent toutefois, découverts par les archéologues en surface des lieux de culte ou plus rarement dans leur contexte initial lors de fouilles archéologiques. Ces objets, qui constituent le mobilier de culte des temples, font partie intégrante de l'expérience religieuse et permettent de mettre en lumière, au moins en partie, ces rituels. Plusieurs types d'objets existent: des autels et des tables d'offrandes, des brûle-encens, de la vaisselle, ou encore des figurines et statuettes déposés dans les temples. Il faut ici distinguer les objets qui desservent une fonction rituelle (autels et brûle-encens destinés à être utilisés dans le cadre du culte) de ceux qui sont offerts à la divinité en son temple par un particulier (offrandes et ex voto). Dans le premier cas, ce mobilier est destiné à servir à plusieurs reprises, il fait partie des biens du temple, il y « vit ». Dans le second cas, l'objet offert ne semble pas réutilisé après l'offrande par le fidèle : il peut être exposé mais ne dessert pas une fonction liturgique.

Cette contribution traitera du mobilier cultuel découvert dans le temple de Nakrah, à la lumière des découvertes de la région de Barāqish. En seconde partie de l'exposé, on trouvera une présentation synthétique du mobilier cultuel sudarabique. Dans la catégorie des autels, on inclura les éléments destinés à recevoir une action rituelle ou bien une offrande. Les brûleencens, de par leurs formes caractéristiques, seront quant à eux présentés à part. Les statues et figurines à caractère religieux seront enfin brièvement évoquées. Il s'agit donc ici de présenter les différents types d'objets cultuels et leur contexte. La majorité des objets ne provient cependant pas de contextes scellés, leur position d'origine et leur datation sont donc inconnues pour la plupart.

2. Le mobilier cultuel à Barāqish : le temple de Nakrah

Le site de Barāqish a livré plusieurs exemplaires d'objets cultuels, lors des prospections dans la ville intra-muros et dans la nécropole, mais également à l'occasion des fouilles réalisées dans le temple de Nakrah («temple A ») puis dans le temple de 'Athtar dhu-Qabd (« temple B »). Certains objets ont été découverts in situ et renseignent sur leur rôle dans la liturgie ; d'autres - qui constituent la majorité - proviennent de niveaux de destruction. La présente contribution s'attachera principalement à présenter les objets destinés au culte dans le temple de Nakrah. Les objets votifs seront néanmoins évoqués, de même que l'on aura recours à des parallèles d'objets découverts dans la ville, dans la nécropole et dans le temple voisin ( « temple B ») dédié à 'Athtar dhu-Qabḍ. ${ }^{1}$

\section{Contexte}

Les travaux menés dans les deux temples voisins ont livré une quantité inégale d'objets. Les premiers travaux de l'équipe d'Alessandro de Maigret à Barāqish se sont concentrés sur le temple Barān, dédié à Nakrah («temple A ») au début des années 1990. Ces fouilles ont livré des objets de culte, parfois découverts à leur emplacement d'origine. Le deuxième temple, dédié à 'Athtar dhu-Qabḍ (« temple B ») a quant à lui été fouillé dans les années $2000 .^{2}$ Quelques objets de culte ont été exhumés à cette occasion, mais les réoccupations, à l'époque islamique notamment, ont considérablement altéré l'état des niveaux anciens.

On présentera tout d'abord les types d'autels à offrande (ou tables d'offrande) découverts dans le temple A, puis les brûle-encens révélés par les fouilles. De courtes présentations seront ensuite faites des indices matériels liés aux activités liturgiques au sein de l'espace du temple puis des ex voto découverts dans les niveaux d'effondrement de l'annexe C.

\section{Les tables d'offrande}

\section{1. À frises de bouquetins}

Parmi les découvertes les plus significatives du temple de Nakrah, on trouve les grandes tables d'offrande disposées dans les vaisseaux de l'édifice de part et d'autre de la nef centrale et perpendiculaires à celleci. L'espace intérieur du temple de Nakrah est pourvu

\footnotetext{
1 Une étude du mobilier cultuel de ce temple est proposée dans le rapport de fouilles, cf. Antonini, chapitre 5 dans ce volume.

2 Voir la contribution consacrée à la fouille de ce temple dans ce volume, Agostini, chapitre 3 dans ce volume.
} 
de trois tables, ${ }^{3}$ chacune dotée de deux banquettes parallélépipédiques portant parfois une inscription. Le temple de 'Athtar dhu-Qabḍ est quant à lui pourvu de quatre tables, réparties symétriquement dans l'espace hypostyle de manière analogue au temple de Nakrah. ${ }^{4}$ Dans ce dernier, la longueur des tables d'offrande $(3 \mathrm{~m})$ permettait à plusieurs personnes de prendre place. ${ }^{5}$ Larges de $60 \mathrm{~cm}$, elles présentent une épaisseur de $26 \mathrm{~cm}$. L'extrémité de chacune de ces tables, donnant sur la nef centrale, était ornée d'une frise de six bouquetins stylisés ainsi que d'une inscription sudarabique, dont deux comportent un nom de saison : " printemps » et « automne », soit deux saisons de récolte. Il est probable que des offrandes étaient réalisées selon un calendrier suivant les saisons.

Les fouilles réalisées en 1992 ont livré des fragments similaires de tables d'offrande. L'objet Y.92.B.O/392 est une table d'offrande fragmentaire en calcaire (fig. 1). Sa longueur maximale atteint $30 \mathrm{~cm}$ pour $35 \mathrm{~cm}$ de largeur et $11,5 \mathrm{~cm}$ d'épaisseur. Si l'on ignore sa longueur d'origine, ses dimensions (épaisseur et largeur) sont de moitié inférieure à celles des grandes tables découvertes in situ. Sur le petit côté, une frise en haut relief de sept bouquetins stylisés est encore visible. Sous celle-ci, on trouve un bandeau plat, surmontant un petit bourrelet puis un autre bandeau plat légèrement saillant. Un deuxième objet similaire (Y.92.B.O/427) comporte six têtes de bouquetins, à l'instar des tables de l'espace intérieur du temple (fig. 2). Sa longueur maximale conservée $(118,5 \mathrm{~cm})$ et sa largeur $(54,4 \mathrm{~cm})$ évoquent un module similaire à ces dernières. Du point de vue de l'épaisseur, cet objet est comparable au précédent $(11 \mathrm{~cm})$, tandis que sa largeur est légèrement supérieure $(54,4 \mathrm{~cm})$. Il comporte un registre inscrit d'un mot sudarabique sous un bandeau plat séparant les têtes de bouquetins du texte. Ces deux tables d'offrande ont été découvertes dans les niveaux d'occupation islamiques. Un troisième et dernier exemple a été exhumé des niveaux minéens entre L3 et L6 (Y.92.B.O/472, fig. 3). ${ }^{6}$ Ses dimensions sont très proches du précédent exemple (longueur maximale : $60 \mathrm{~cm}$; largeur : $52 \mathrm{~cm}$; épaisseur : $12 \mathrm{~cm}$ ). Il comporte également six bouquetins, au dessus d'un bandeau plat, surmontant lui-même un registre légèrement saillant arborant une inscription sudarabique.

\footnotetext{
3 de Maigret et Robin 1993, 435-436, fig. 2. Les textes portent les numéros Y.92.B.A/38 (" printemps »), Y.92.B.A/39 (" automne ») et Y.92.B.A/40 ([dyt]) (de Maigret et Robin 1993, 462-464, phot. 14, 15 et 16).

${ }^{4}$ Voir le plan du temple B dans ce volume, Agostini, chapitre 3, fig. 3, et chapitre 4, fig. 9-12.

${ }^{5}$ On ignore toutefois si des officiants ou fidèles venaient y célébrer des banquets. Ces tables pourraient tout aussi bien avoir été réservées à des convives divins.

6 V. le plan du temple avec les loci, Agostini, chapitre 3, fig. 3 dans ce volume.
}

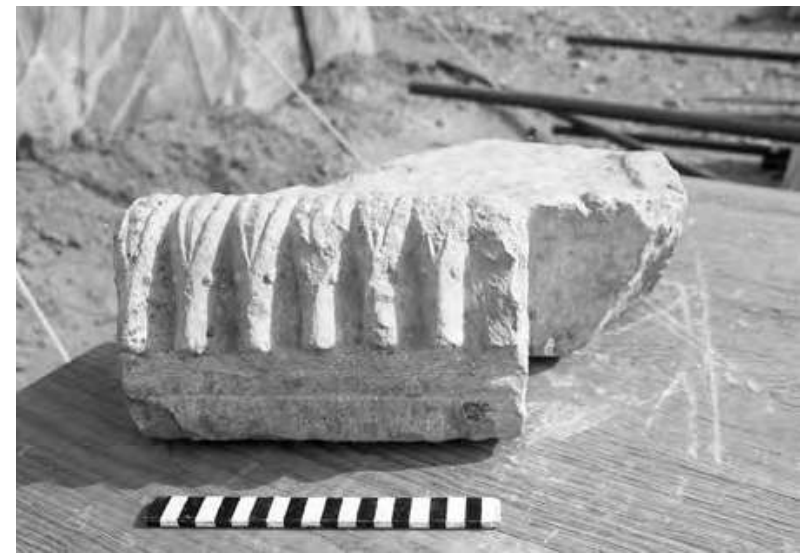

Figure 1. Fragment de table d'offrande en calcaire représentant sept bouquetins (Y.92.B.O/392).

(A. de Maigret 1992 CMAIRY)

Une table d'offrande conservée dans le musée national de Șan $\bar{a} \bar{a}^{\prime}$ provient probablement de la région de Barāqish et présente des caractéristiques similaires aux exemples mentionnés ci-dessus. Al-Jawf 04.44 est une table d'offrande arborant un texte dédicatoire à la divinité Nakrah courant les côtés. ${ }^{7}$ L'objet adopte une forme parallélépipédique dont la face supérieure est légèrement surcreusée et pourvue d'une bordure de $4,5 \mathrm{~cm}$ sur les quatre côtés, l'un des petits côtés arbore une frise de cinq bouquetins en haut-relief. Les dimensions de cet objet (longueur : $146 \mathrm{~cm}$; largeur : $45 \mathrm{~cm}$; épaisseur : $13 \mathrm{~cm}$ ) sont tout à fait comparables à celles des tables découvertes lors des fouilles du temple.

Ces quatre exemples semblent ainsi reproduire le module de table d'offrande visible dans la salle du temple, une longue table parallélépipédique présentant une face supérieure légèrement surcreusée et une frise de bouquetins stylisés saillants au milieu d'un petit côté surmontant deux bandeaux non décorés. Le premier exemple (Y.92.B.O/392) s'en différencie par le nombre de têtes de bouquetins, par l'absence d'inscription et par ses dimensions, presque moitié moindres que celles des grandes tables. Quant aux deux autres exemples (Y.92.B.0/427 et Y.92.B.0/472), si leur épaisseur est également plus petite de moitié que celles des grandes tables d'offrande du temple, ils s'en rapprochent par le nombre de bouquetins, par les lettres sudarabiques visibles et par leur largeur. Enfin, le dernier objet, qui proviendrait de Barāqish (AlJawf 04.44), est tout à faire similaire.

\section{2. À tête de taureau}

Lemobilier exhumélors defouilles dutemple deBarāqish comporte également des fragments de gouttières en

Arbach et Schiettecatte 2006, pl. 15/45. 


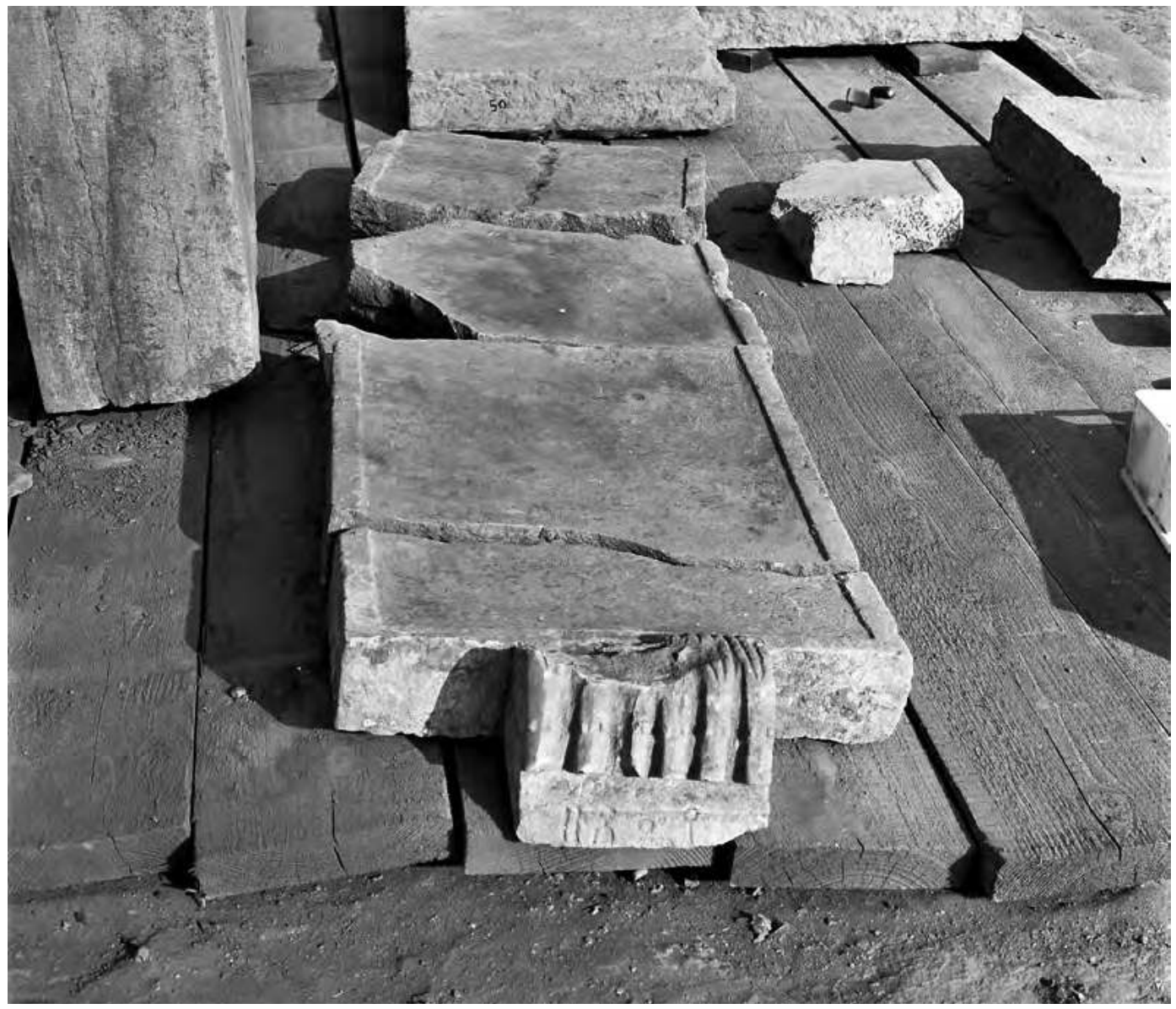

Figure 2. Table d'offrande en calcaire représentant six bouquetins (Y.92.B.O/427). (A. de Maigret 1992 @MAIRY)

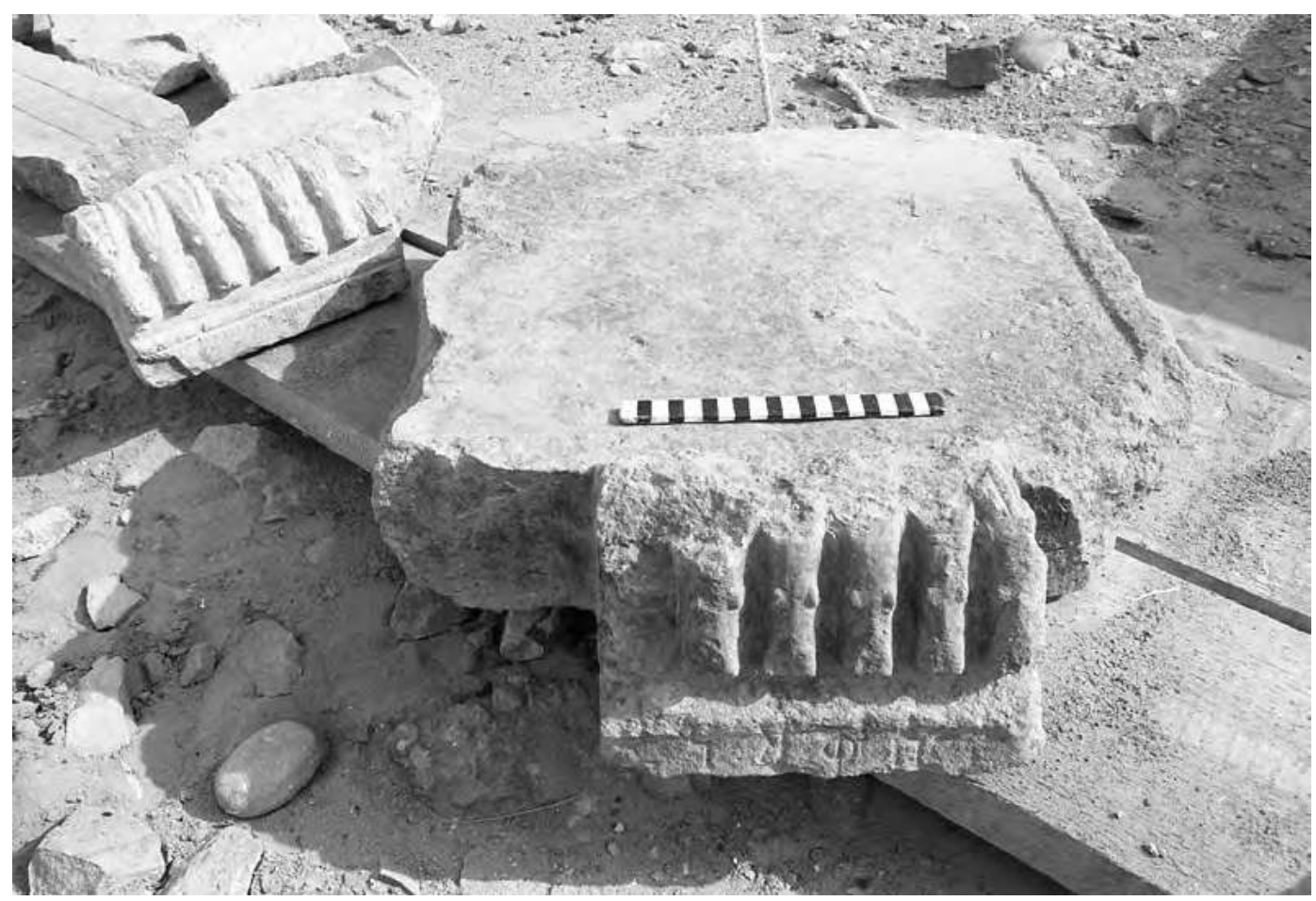

Figure 3. Table d'offrande représentant six bouquetins (Y.92.B.O/472). (A. de Maigret 1992 @MAIRY) 


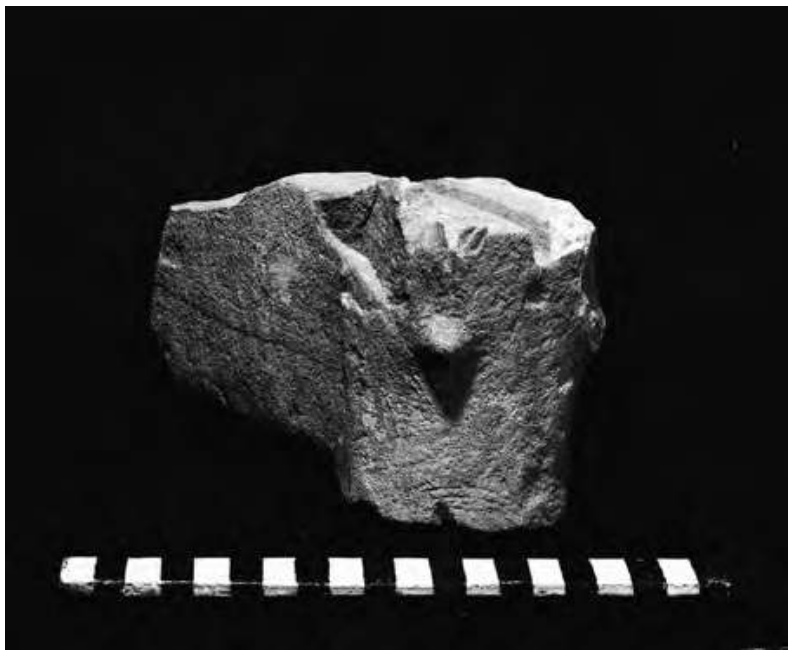

Figure 4. Gouttière en forme de tête de taureau (Y.92.B.O/8). (A. Solazzi 1992 @MAIRY)

forme de tête de taureau. Ceux-ci pourraient avoir fait partie de tables d'offrande présentant une ou deux gouttières. Le premier exemple (Y.92.B.O/8, fig. 4) est une tête de taureau stylisé en grès mesurant $16 \mathrm{~cm}$ de longueur, 7,5 cm de largeur et $10 \mathrm{~cm}$ d'épaisseur. Un petit canal est visible sur la partie supérieure de la tête. Trois lignes courbes parallèles représentent le museau, les yeux sont matérialisés par un bouton protubérant. Les oreilles et les cornes ont été arrachées. L'objet a été découvert dans les niveaux d'époque islamique. Une deuxième gouttière (Y.92.B.O/130, fig. 5), également issue des niveaux islamiques, présente des dimensions comparables : $13 \mathrm{~cm}$ de longueur, $7 / 8 \mathrm{~cm}$ de largeur et $8 \mathrm{~cm}$ d'épaisseur. La tête de taureau paraît plus stylisée encore que l'exemple précédent.

Le temple voisin de 'Athtar dhu-Qabd a livré des éléments de comparaison, notamment une table d'offrande complète (B.05.B.O/41, voir Antonini, chapitre 5 , fig. 5) de forme parallélépipédique et à l'aspect similaire. La hauteur de l'objet est du même ordre que les exemples du temple de Nakrah. La tête de taureau est stylisée, notamment les yeux qui prennent la forme de boutons protubérants sans bourrelets pour marquer les paupières. Un second objet sur lequel on devine une bordure caractéristique pourrait avoir constitué une table d'offrande (B.05.B.O/34, voir Antonini, chapitre 5, fig. 4). En revanche, des exemples de têtes de taureau ont été découverts associés à des blocs de couronnement de l'édifice et constituaient des gargouilles. Étant donné l'état de conservation des exemples du temple de Nakrah, il est difficile de dire s'il s'agissait de tables d'offrandes ou bien de vestiges d'un système de couronnement du bâtiment. Les dimensions des têtes (hauteur de $8 \mathrm{~cm}$ environ) sont comparables et ne permettent pas de trancher. Du point du vue du style, les objets du temple de 'Athtar sont légèrement

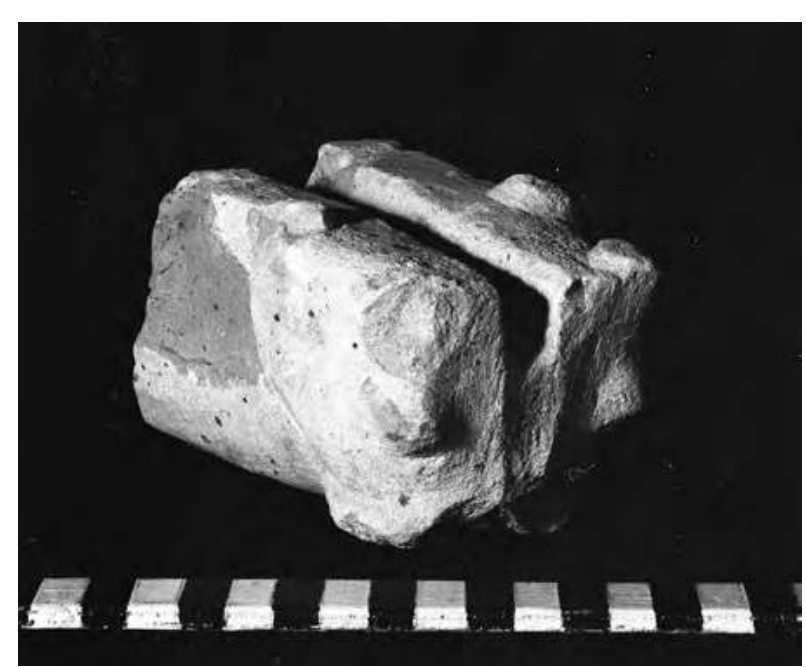

Figure 5. Gouttière en forme de tête de taureau (Y.92.B.O/130). (A. Solazzi 1992 CMAIRY)

plus naturalistes, avec des petits bourrelets autour des yeux représentant les paupières.

À titre de comparaison supplémentaire, on peut évoquer ici une table d'offrande conservée au musée national de Șan'(a) $\left(Y M\right.$ 28988) ${ }^{8}$ et peut-être originaire de Barāqish au vu du contenu de l'inscription qui l'orne. L'objet est complet et constitue une table d'offrande parallélépipédique dont la face supérieure est pourvue d'une bordure sur les quatre côtés. Sur l'un des longs côtés, deux têtes de taureaux, disposées symétriquement, font office de canalisation. Les têtes de taureau sont très stylisées (museau schématique et yeux matérialisés par un bouton protubérant) et évoque les deux exemples découverts dans le temple de Nakrah. L'épaisseur de la table, seule valeur comparable, est similaire à la hauteur des têtes fragmentaires (env. $10 \mathrm{~cm}$ ). Une seconde table d'offrande très fragmentaire est conservée dans le musée national de Șan' $\bar{a}^{\top}$ (al-Jawf 04.46). ${ }^{9}$ La tête de taureau, très érodée, est extrêmement schématique ; la hauteur de la table $(9 \mathrm{~cm})$ et l'origine proposée autorise le rapprochement des deux objets. Enfin, notons qu'une table fragmentaire a été découverte lors des fouilles de la nécropole de Barāqish (B.06.D.O/25). ${ }^{10}$ La tête de taureau est manquante et ses dimensions sont inférieures aux exemples évoqués cidessus (épaisseur de $6 \mathrm{~cm}$ ). Notons enfin que d'autres exemples mettent en évidence l'utilisation de ces objets en contexte funéraire. ${ }^{11}$

\footnotetext{
8 Arbach et Audouin 2007, 67.

9 Arbach et Schiettecatte 2006, 60, pl. 16/50, qui proposent Barāqish comme site d'origine de l'objet.

10 Antonini et Agostini 2010a, 23-24, pl. 34a.

11 Voir Antonini et Agostini 2010a, 23-24, pl. 34, 36.
} 


\section{Les brûle-encens}

Dans le cadre des fouilles du temple de Nakrah, sept brûle-encens ont été découverts. Ceux-ci peuvent être répartis en deux catégories : les brûle-encens cubiques et les brûle-encens sur base pyramidale tronquée.

\subsection{Les brûle-encens cubiques}

Quatre des brûle-encens provenant des fouilles du temple de Nakrah sont de type cubique. Il s'agit de petits encensoirs monolithes, généralement en grès, pourvus de quatre petits pieds de section carrée aux angles. La face supérieure est légèrement surcreusée (d'environ $2 \mathrm{~cm}$ ) afin de contenir les résines aromatiques destinées à être brûlées. Un décor géométrique orne parfois les faces latérales; on trouve en outre sur plusieurs exemples un ou plusieurs mots sudarabiques gravés, indiquant le nom de résines.

Le premier exemple (Y.92.B.0/9, fig. 6) issu des fouilles a été découvert dans les niveaux minéens (L4). Son état de conservation est assez mauvais : les quatre pieds angulaires ont disparu. On observe sur la face supérieure une patine noirâtre, probablement un indice de son utilisation dans le cadre de rites au sein du temple. Un décor de ligne horizontale en zigzag (ou bien de triangles) est encore visible dans le registre inférieur des quatre faces. Sur l'une d'elles, on peut encore lire $h d k$ (nom d'une résine). Ses dimensions sont $8 \times 8 \mathrm{~cm}$, sa hauteur conservée est de $3,9 \mathrm{~cm}$ et l'épaisseur des bordures est d'1,2 cm.

Un deuxième exemple (Y.92.B.0/103, fig. 7), est en meilleur état de conservation. Il provient également des niveaux minéens d'occupation (L4). L'objet a été réalisé dans un bloc de grès et présente des dimensions similaires à l'objet précédent $(8 \times 8 \mathrm{~cm}$, épaisseur des bordures : $1 \mathrm{~cm}$ ). La profondeur de l'évidement de la face supérieure est de $2 \mathrm{~cm}$. Trois des quatre faces présentent un décor de trois séries horizontales de triangles surmontant une ligne en zigzag dans le registre inférieur. La quatrième face arbore quant à elle une inscription mentionnant la résine rnd, à la place des deux séries centrales de triangles. L'observation de l'objet a en outre révélé des traces de combustion dans l'évidement supérieur.

Le troisième objet provenant des fouilles (Y.92.B.0/104, fig. 8), en grès et dont les quatre pieds ont disparu, est aussi issu des niveaux minéens (L4). Ses dimensions sont comparables aux brûle-encens présentés ci-dessus (hauteur : $6 \mathrm{~cm}$, largeur : $8,5 \mathrm{~cm}$, profondeur : $2 \mathrm{~cm}$, épaisseur des bordures : 1,2 cm). Le décor consiste en un motif de quatre fausses fenêtres, caractéristiques de l'art sudarabique, sur trois des quatre faces. On trouve une série horizontale de six triangles gravés au dessus et en dessous de ce motif. Ces mêmes séries de triangles

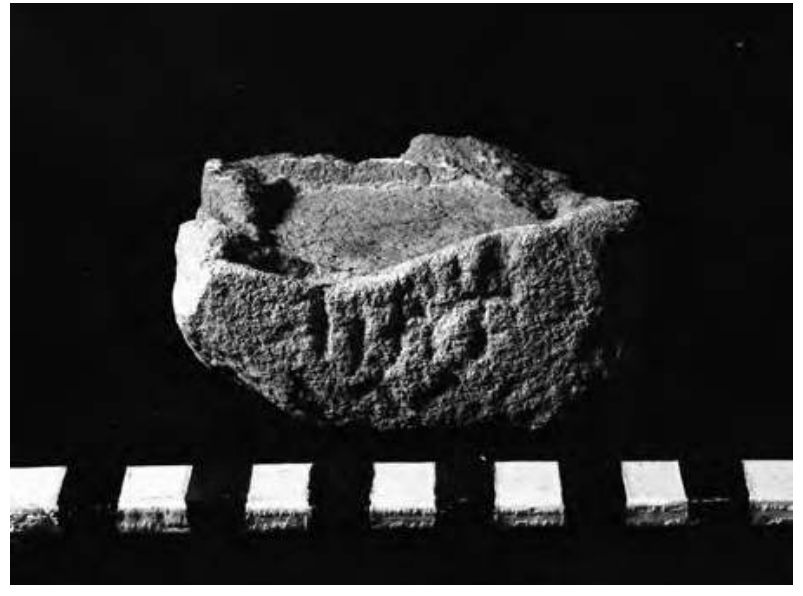

Figure 6. Brûle-encens inscrit (Y.92.B.O/9).

(A. Solazzi 1992 CMAIRY)

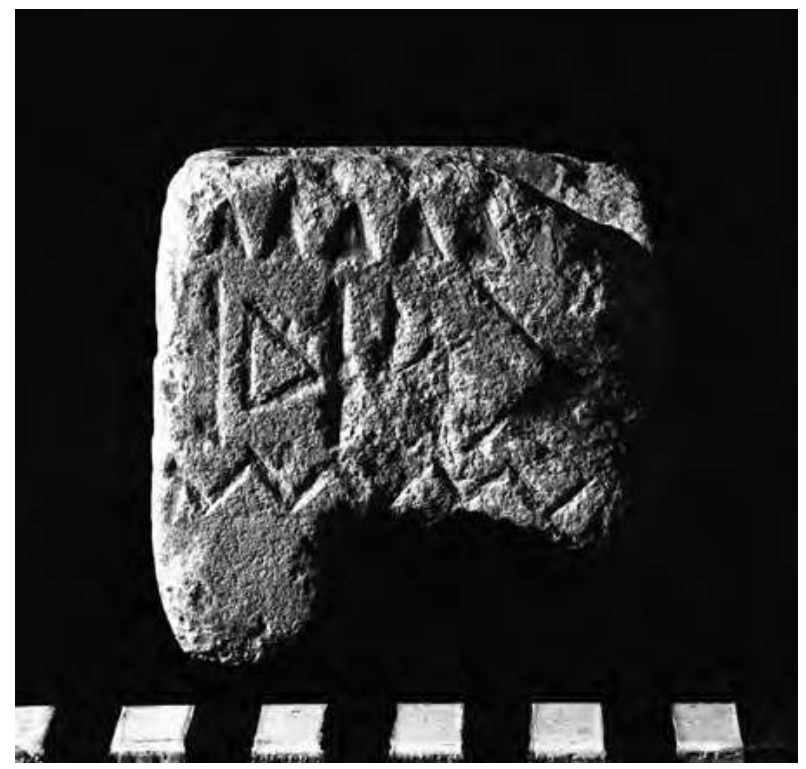

Figure 7. Brûle-encens quadripode inscrit (Y.92.B.O/103). (A. Solazzi 1992 @MAIRY)

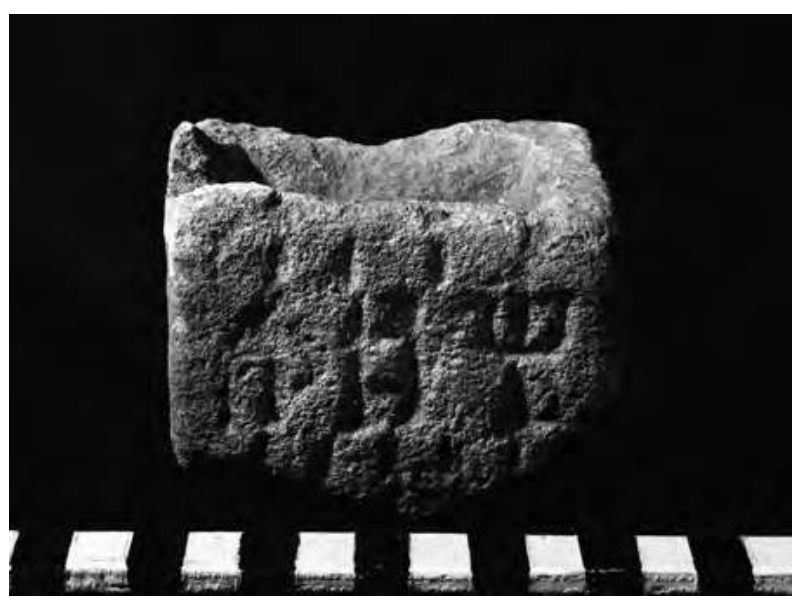

Figure 8. Brûle-encens inscrit décoré (Y.92.B.O/104).

(A. Solazzi 1992 @MAIRY) 


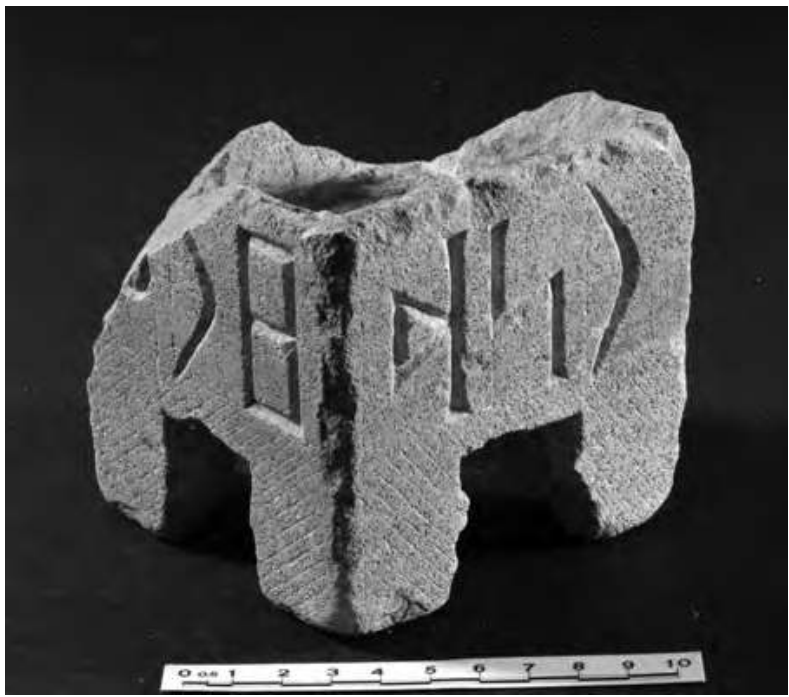

Figure 9. Brûle-encens inscrit décoré de croisillons (Y.90.B.O/2). (A. Solazzi 1990 CMAIRY)

se poursuivent sur la quatrième face, laquelle arbore le nom de résine hadk à la place du motif des fausses fenêtres. Enfin, cet objet a, comme les précédents, conservé des traces de combustion dans la cavité.

Le dernier brûle-encens monolithe cubique, en grès, (Y.90.B/2, fig.9), est également issu des niveaux minéens (L6) du temple de Nakrah. Ses dimensions sont très légèrement supérieures à celles des objets présentés cidessus (hauteur : 9,2 cm, largeur : 9,5 cm ; épaisseur des bordures : $1,5 \mathrm{~cm}$, l'évidement supérieur est de $2 \mathrm{~cm}$, comme les autres objets). Son état de conservation est plutôt bon du point de vue des surfaces conservées mais deux angles ont été cassés dans leur partie supérieure. Les quatre pieds aux angles sont de section triangulaire. Le décor se limite à des lignes parallèles diagonales s'entrecroisant et formant un motif de croisillons qui occupe la surface extérieure des pieds jusqu'à la base des lettres. Sur les quatre côtés, le bloc a été taillé de sorte à sculpter une barre reliant les pieds entre eux. Seule une de ces barres est conservée, on les devine toutefois sur les autres faces grâce aux cassures (visible sur la fig. 9). Chacune des faces de l'objet arbore trois lettres sudarabiques de très belle faction (haut. $4,2 \mathrm{~cm}$, larg. $2 \mathrm{~cm}$, épaiss. de la hampe :0,9 cm), dont on voit encore les fines lignes de préparation, et qui désigne une résine : $r n d, d r w, h d k$, $l d n$.

Les brûle-encens cubiques sont communs dans la sphère sudarabique et la région de Barāqish en a livré plusieurs, mis à part ceux du temple de Nakrah. Un exemple (Y.92.B.civ./2, fig. 10), a été découvert en surface à l'intérieur des murs de la ville. L'objet, réalisé en grès, présente de petits pieds cubiques et un décor de deux séries horizontales parallèles de triangles le long de la bordure supérieure et de la base. La

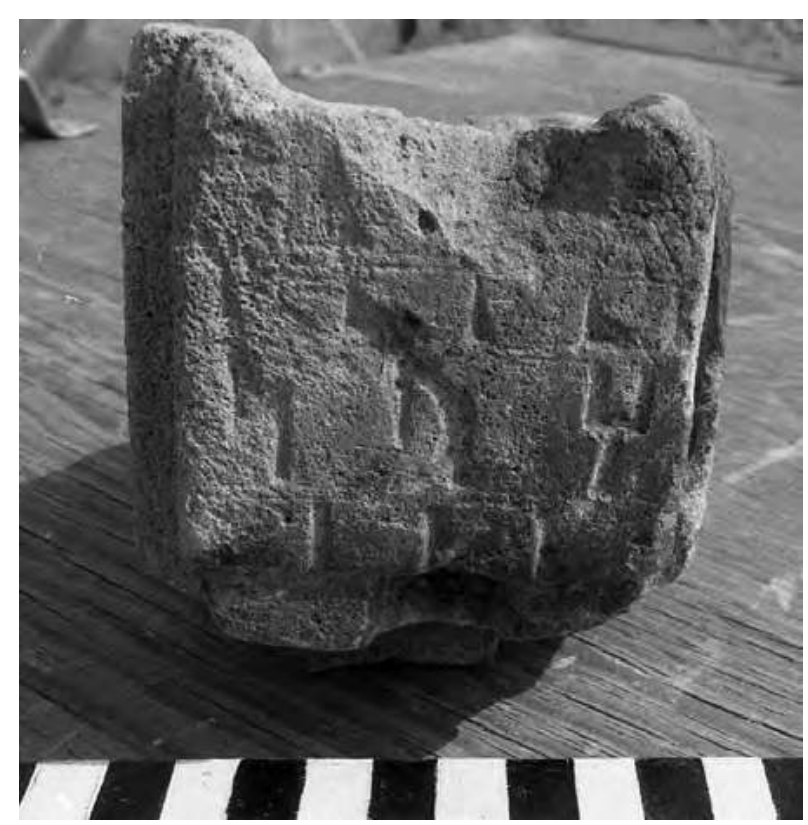

Figure 10. Brûle-encens quadripode décoré de triangles (Y.92.B.civ.2). (A. de Maigret 1992 CMAIRY)

quatrième face est saillante de $2 \mathrm{~cm}$ et arbore un décor de denticules le long de la bordure supérieure et de la base. Entre ces deux séries se trouvent trois lettres : $h r n$. Un deuxième objet (Y.86.BAR/13) peut être évoqué à titre de comparaison. Il s'agit d'un petit brûle-encens cubique découvert à la surface du site, à l'extérieur des remparts occidentaux de la ville. ${ }^{12}$ Ses dimensions sont proches de celles des exemples découverts dans le temple (hauteur : $7 \mathrm{~cm}$, largeur : $11 \mathrm{~cm}$, épaisseur : $11 \mathrm{~cm})$. L'objet ne porte pas de décor mais quatre noms de résines sont inscrits sur ses quatre faces : qsț, $d r w$, $r n d, h \underline{d} k$, dont trois se retrouvent sur les brûle-encens du temple de Nakrah.

Les recherches menées dans la nécropole, mais également certains objets de la région de Barāqish mais dont la provenance précise est inconnue ${ }^{13}$ ont permis de mettre au jour des brûle-encens similaires, tant par leur style que par leurs dimensions, et offrent des éléments de comparaisons avec les exemples mis au jour dans le temple. Les décors varient légèrement : on trouve par exemple des motifs de croisillons (B.05.D.O/34) ${ }^{14}$ et des traces de couleur rouge (MAIRY.05/11) ${ }^{15}$ - non attestés dans le temple de Nakrah - mais les motifs de denticules

\footnotetext{
12 Antonini 1988, 133, fig. 1. Cf. aussi Antonini, chapitre 2, fig. 16 dans ce volume.

13 Ceux-ci portent le sigle MAIRY (Missione Archeologica Italiana nella Repubblica dello Yemen) après avoir été enregistrés par l'équipe de fouille. Ils sont présentés dans Pagano 2010.

14 Antonini et Agostini 2010a, 23-24, pl. 36f.

15 Pagano 2010, 81, pl. 50 a-d.
} 


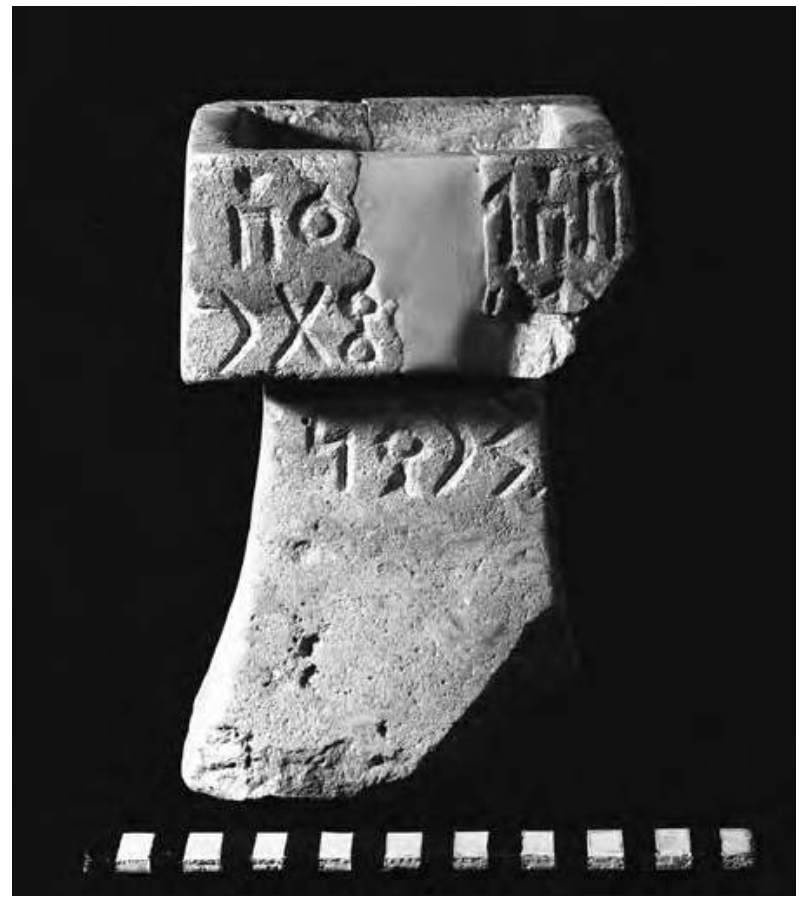

Figure 11. Brûle-encens inscrit à base pyramidale tronquée (Y.92.B.O/13). (A. Solazzi 1992 @MAIRY)

(B.05.D.O/35; ;6 MAIRY.06/4) ${ }^{17}$ et les séries de triangles (MAIRY.05/11) évoquent les objets présentés plus haut. Plusieurs arborent des noms inscrits tels que ceux évoqués ci-dessus (hd dk : MAIRY.05/11; MAIRY.06/4). Enfin, des traces de combustion ont été observées dans plusieurs cas (B.05.D.O/37; $; ;^{18}$ MAIRY.06/4 ; MAIRY.05/11). Celles-ci témoignent de l'utilisation de tels objets dans le cadre de rites funéraires dans le cas de B.05.D.O/37.

\subsection{Les brûle-encens sur base pyramidale tronquée}

Trois brûle-encens pourvus d'une base pyramidale tronquée ont été découverts dans le cadre des fouilles du temple de Nakrah. Ce type d'encensoir est de plus grandes dimensions que le type cubique, les décors qui les ornent sont différents de même que le type d'inscriptions qu'ils arborent.

Le premier exemple issu des fouilles (Y.92.B.O/13, fig. 11), ${ }^{19}$ provenant des niveaux minéens (L10), est réalisé en calcaire. La hauteur totale de l'objet s'élève à $20 \mathrm{~cm}$ (pied : $13 \mathrm{~cm}$; vasque : $7 \mathrm{~cm}$ ). La vasque mesure $11,5 \times 13 \times 4 \mathrm{~cm}$ et les bordures ont une épaisseur de $1,5 \mathrm{~cm}$. Le pied, évasé vers le bas, mesure $12,5 \mathrm{~cm}$ de côté à la base et $8,5 \mathrm{~cm}$ sous la vasque. L'objet porte une

\footnotetext{
16 Antonini et Agostini 2010a, 25, pl. 37a.

17 Pagano 2010, 81, pl. 49 a-e.

18 Antonini et Agostini 2010a, 25, pl. 37b.

19 de Maigret et Robin 1993, 484, photo 10.
}

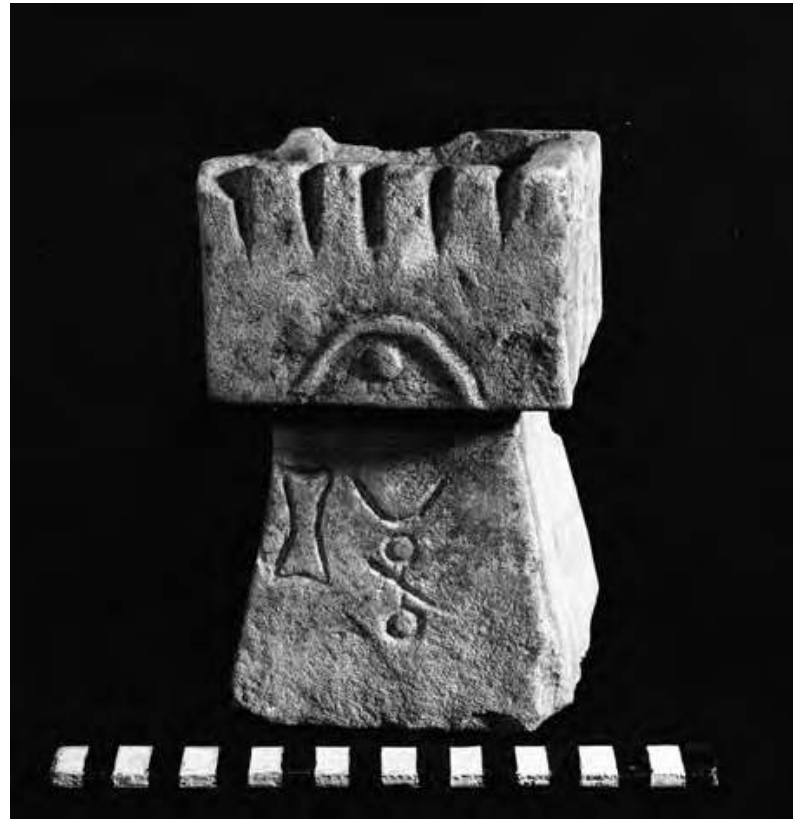

Figure 12. Brûle-encens inscrit et décoré à base pyramidale tronquée (Y.92.B.O/106). (A. Solazzi 1992 OMAIRY)

dédicace sudarabique à la divinité 'Athtar Shariqān, ${ }^{20}$ mais n'arbore aucun motif décoratif.

Le deuxième objet de cette catégorie découvert lors de la fouille est Y.92.B.0/106 (fig. 12). Il provient également d'un niveau minéen (L4). Il est réalisé en grès et sa hauteur atteint $17,7 \mathrm{~cm}$; son pied est de $11 \mathrm{x} 13 \mathrm{~cm}$ à la base et la vasque mesure $10,5 \times 13 \mathrm{~cm}$, les bordures sont épaisses d'1,2 cm et la profondeur mesurée varie entre $2,2 \mathrm{~cm}$ (face arrière) et $3 \mathrm{~cm}$ (face principale). L'objet porte une inscription sudarabique gravée sur le pied qui consiste en un monogramme (au centre) et un symbole divin attribuable à la divinité 'Athtar (à gauche). ${ }^{21}$ Le principal élément décoratif se trouve sur la face inscrite de l'objet, au niveau de la bordure supérieure de la vasque, plus élevée de ce côté. Il s'agit d'un motif crénelé occupant toute la largeur de la bordure. Un motif de disque et croissant (orienté vers le bas) en bas relief est en outre visible dans la partie inférieure de la vasque. Enfin, l'état de conservation de l'objet a permis d'observer des résidus d'encens à l'intérieur.

Un troisième brûle-encens taillé dans un même bloc de grès et de forme similaire est Y.92.B.O/1 (fig. 13). Découvert dans un excellent état de conservation dans le niveau minéen du locus L6, l'objet mesure $15,5 \mathrm{~cm}$ de hauteur pour $5,5 \times 8 \mathrm{~cm}$ à sa base. La vasque supérieure a pour dimensions $8 \times 8 \mathrm{~cm}$ de côté, 1,5 $\mathrm{cm}$ d'épaisseur

\footnotetext{
20 Sigle du texte : Y.92.B.A/46.

21 de Maigret et Robin 1993, 11, fig. 16.
} 


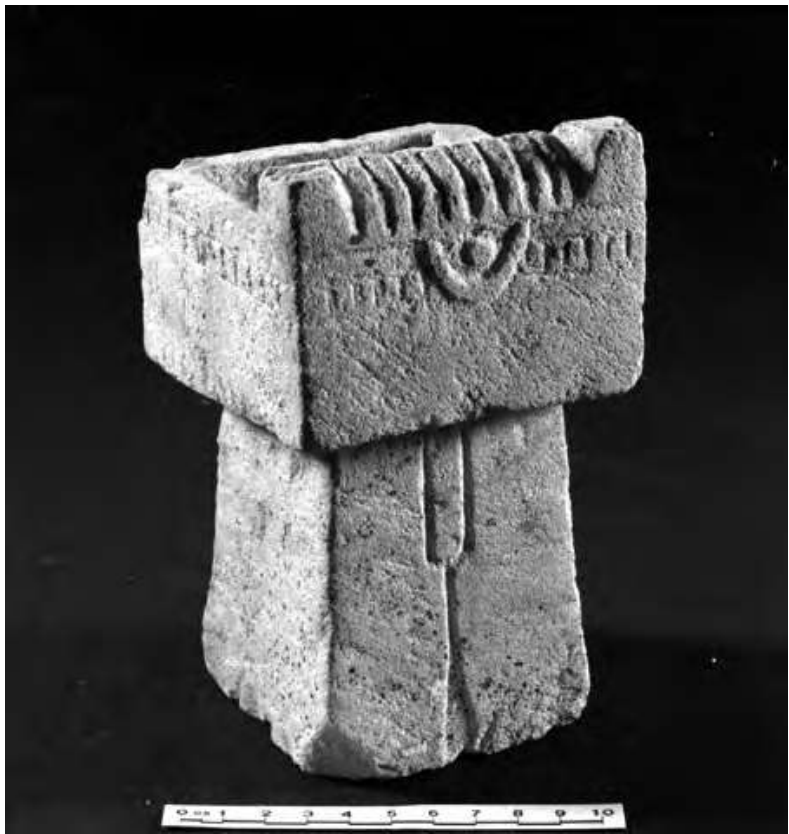

Figure 13. Brûle-encens inscrit et décoré à base pyramidale tronquée (Y.90.B.O/1). (A. Solazzi 1990 CMAIRY).

des parois, $5 \mathrm{~cm}$ de hauteur pour $2 \mathrm{~cm}$ de profondeur. La hauteur de son pied évasé s'élève à $7,5 \mathrm{~cm}$. Sous le bord de la vasque, une série de denticules gravés court sur les quatre faces. Cette série s'interrompt au milieu de la face principale pour laisser place à un symbole représentant un disque et un croissant orienté vers le haut. Sur cette même face, la vasque est plus haute $(6,6 \mathrm{~cm}$ contre $5 \mathrm{~cm}$ pour les trois autres) et arbore un décor sur son bord supérieur. Celui-ci consiste en une série de petits créneaux verticaux arrondis et étirés vers l'intérieur du bassin (qui évoque une forme très stylisée de bouquetins observées notamment sur les tables d'offrandes de Barāqish). Les deux angles sont laissés lisses et sans décor sur une largeur d'1,5 cm. Enfin, on observe un symbole sudarabique gravé sur la base de l'objet, dont il occupe toute la hauteur.

Le temple voisin dédié à 'Athtar a livré des objets similaires. Ceux-ci, tous réalisés en grès, sont de dimensions comparables aux brûle-encens du temple de Nakrah. L'un des objets semble par ailleurs arborer un croissant de lune (B.05.B.O/38) 22 $^{22}$ au-dessus d'une inscription. Enfin, on remarque également des traces de combustion dans l'un d'eux (B.05.B.0/40). ${ }^{23}$

22 Cf. Antonini, chapitre 5, fig. 11 dans ce volume.

23 Le dernier élément de ce type découvert lors de ces fouilles (B.05.B.O/39) pourrait avoir appartenu au premier objet B.05.B.O/38 ; voir Antonini, chapitre 5, fig. 9 dans ce volume.

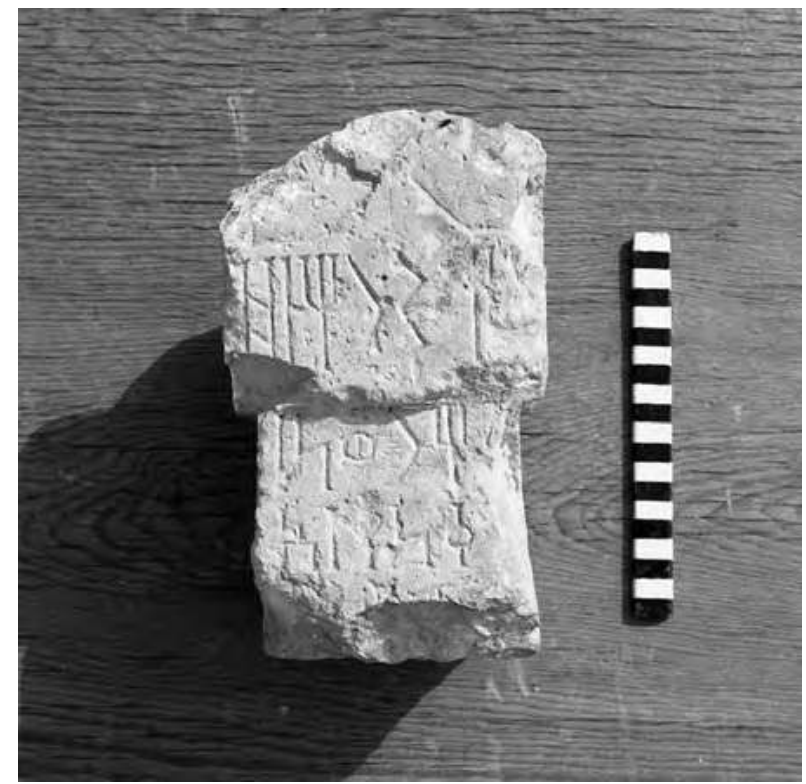

Figure 14. Brûle-encens fragmentaire à base pyramidale tronquée arborant une inscription (Y.92.B.civ.6).

(A. de Maigret 1992 OMAIRY)

Un autre exemple de brûle-encens inscrit du même type est connu..$^{24}$ L'objet en calcaire (Y.92.B.civ./6, fig. 14) mesure $24 \mathrm{~cm}$ de hauteur conservée. La vasque mesure $14 \times 11 \times 13 \mathrm{~cm}$, le pied s'élève à $10 \mathrm{~cm}$ et mesure 12 x $11,5 \mathrm{~cm}$. Une inscription sudarabique, inédite, a été gravée sur l'une des quatre faces et sur toute la hauteur conservée de l'objet. Dans la partie supérieure de la vasque, au dessus du texte, on remarque enfin un croissant de lune représenté en bas-relief.

Enfin, un brûle-encens provenant de la région de Barāqish (MAIRY.05/14) légèrement différent. Ses dimensions sont plus importantes que les exemplaires présentés ci-dessus avec une hauteur de $48 \mathrm{~cm}$. Son pied, fragmentaire, conserve une largeur comprise entre $16 \mathrm{~cm}$ et $19 \mathrm{~cm}$. Celui-ci ne présente pas une section tronco-pyramidale mais parallélépipédique, il est également beaucoup plus haut. Du point de vue du décor enfin, la face principale est ornée d'un serpent horizontal gravé dans la partie supérieure de l'objet. ${ }^{25}$

Comme les petits brûle-encens cubiques, les brûleencens à base pyramidale tronquée sont bien connus dans le mobilier cultuel du Yémen ancien. Leur répartition chronologique et géographique est également très vaste. Les exemples découverts à Barāqish permettent d'attester leur usage dans le

\footnotetext{
24 Ce brûle-encens, apporté aux archéologues par les bédouins et supposément trouvé en surface de Barāqish, ne provient probablement pas du site : le texte ne semble pas être rédigé en minéen, mais qatabanique, et l'objet est taillé dans du calcaire, contrairement à tous les autres exemples du site, taillés dans du grès. 25 Pagano 2010, 81, pl. 51 a.
} 


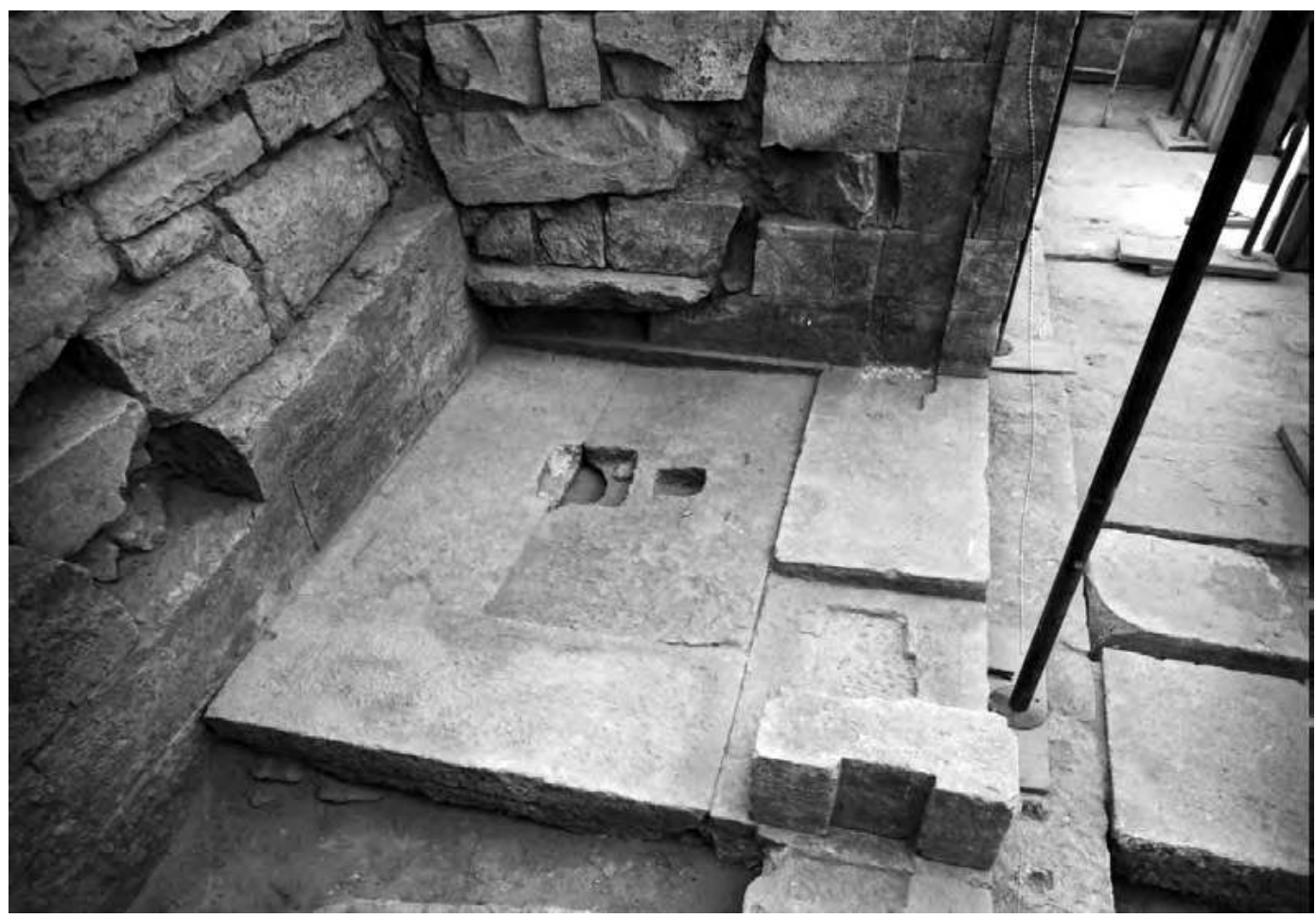

Figure 15. Cavités dans le sol de la cella pour ficher un objet. (A. de Maigret 1992 OMAIRY)

temple, mais également dans d'autres secteurs de la ville et notamment dans la nécropole, grâce aux traces de combustion conservées. Leur localisation au sein même de l'espace sacré n'est pas toutefois établie en raison des perturbations postérieures à l'abandon du temple.

\section{Quelques indices concernant le mobilier cultuel disparu et les pratiques rituelles}

Au sein du temple de Nakrah, l'extrémité orientale était occupée par cinq cellae. Devant les trois cellae centrales, des cavités étaient reliées entre elles par des rigoles permettant d'évacuer les liquides vers le mur nord. ${ }^{26}$ Dans ces mêmes cellae centrales, trois cavités rectangulaires de 6 à $7 \mathrm{~cm}$ de profondeur permettaient de ficher un objet dans le sol (fig. 15). Autour de celles-ci, des évidements moins profonds devaient recevoir des dalles destinées à cacher le socle des objets. Des fragments ont en effet été retrouvés dans ce secteur de l'édifice. Le négatif de ces objets, dont la base est dissimulée, permet d'en imaginer la forme et la dimension générale ainsi que sa présentation aux fidèles. Ce dispositif constitue un témoignage extrêmement rare sur la place, le type et la présentation des objets de vénération au sein des temples minéens.

Le dégagement des phases anciennes du temple A de Barāqish a également livré un bloc qui sera brièvement

\footnotetext{
26 Voir Darles, chapitre 10 dans ce volume, fig. 6-9.
}

évoqué ici. Ce long bloc, à l'aspect d'une « stèle », a été découvert adossé au mur méridional M1 du temple de Nakrah, dans le niveau minéen du locus L6. Une inscription indique que celle-ci a été dédiée par un notable, dont le nom est récurrent dans le corpus des inscriptions du temple. ${ }^{27} \mathrm{La}$ forme de ce bloc est parallélépipédique avec l'apex arrondi dans lequel un orifice est percé. Un exemple similaire est connu dans l'enceinte du grand temple de Șirwāh ${ }^{28}$ où se tenaient, comme à Barāqish, des rites de sacrifices et de banquets rituels. On peut envisager que ce bloc desservait à Barāqish la même fonction qu'à Șirwāh : attacher les bêtes destinées au sacrifice dans le cadre de rites tenus dans le temple. Si son emplacement ne se prête pas bien à cet usage - le bloc est trop près du mur pour pouvoir y passer une longe -, c'est qu'il ne s'agit vraisemblablement pas de son emplacement originel. Il se trouve en effet à côté d'un long bloc inscrit originellement aménagé dans le temple, également remployé ici (fig. 16).

\section{Mobilier votif}

Mis à part le mobilier proprement cultuel, il faut mentionner ici les petites têtes de personnages en

27 Il s'agit de Bs ${ }^{1} 1 \underline{\mathrm{d}}-\mathrm{M}^{\mathrm{c}} \mathrm{s}^{1}$, voir le texte Y.90.B.A/18 (de Maigret et Robin 1993, 482, photo 17).

28 Ce bloc est d'ailleurs interprété comme une pierre servant à attacher les bêtes prêtes à être sacrifiées dans la cour du temple de Șirwāḥ (voir Schmidt 2007, 217 et pl. 8/4, 8/5 et 9/1). 


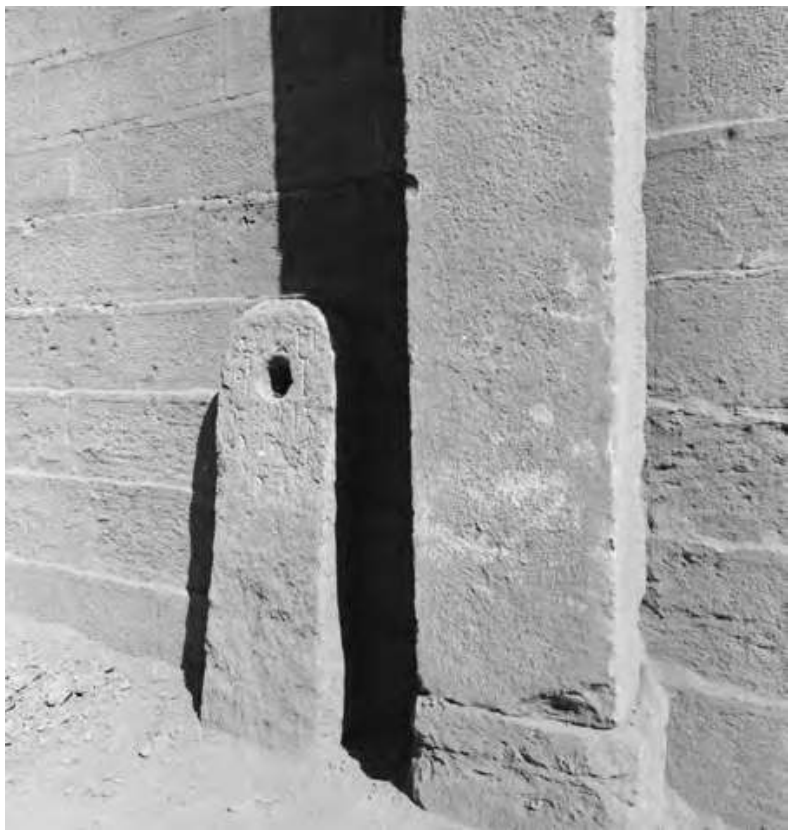

Figure 16. Bloc à l'apex arrondi dans lequel un orifice est percé probablement pour attacher les bêtes destinées au sacrifice. (A. de Maigret 1992 CMAIRY)

plâtre, ${ }^{29}$ plus rarement en bronze, découvertes dans des niveaux d'effondrement de l'annexe L6 du temple, ainsi que le bras droit d'une statuette en bois (Y.92.B/470, fig. 17), mis au jour au pied de l'escalier en L12 menant à la poterne. ${ }^{30}$ Le style tardo-hellénistique d'une tête en plâtre et celui des figurines parallèlement à des datations de charbon permettent à S. Antonini de les dater du Ier s. av. J.-C. / Ier s. apr. J.-C., période qui constituerait la dernière occupation du lieu avant son abandon et atteste donc de la continuité de fréquentation du temple de Nakrah alors même que le royaume de $\mathrm{Ma}$ 'īn connait un fort déclin à la fin du IIe s. av. J.-C. en raison des incursions menées par la tribu 'Amīr. Cette même annexe, qui servait probablement à entreposer des objets de culte aux côtés des ex voto, contenait également des fragments de vases cultuels décorés d'animaux, des brûle-encens, des inscriptions sudarabiques et de la céramique.

Ajoutons enfin que malgré l'absence de statues dans le mobilier archéologique exhumé, il faut imaginer que des représentations anthropomorphiques plus grandes que les figurines découvertes dans l'annexe ornaient l'espace intérieur des temples. Un socle en pierre découvert à Barāqish présente en effet l'empreinte des pieds dans laquelle était vraisemblablement placée une statue en bronze aujourd'hui disparue (fig. 18). ${ }^{31} \mathrm{Il}$

\footnotetext{
29 Cf. Antonini 1999.

30 de Maigret et Robin 1993, 16, fig. 17.

31 de Maigret et Robin 1993, 471, phot. 21, 484.
}

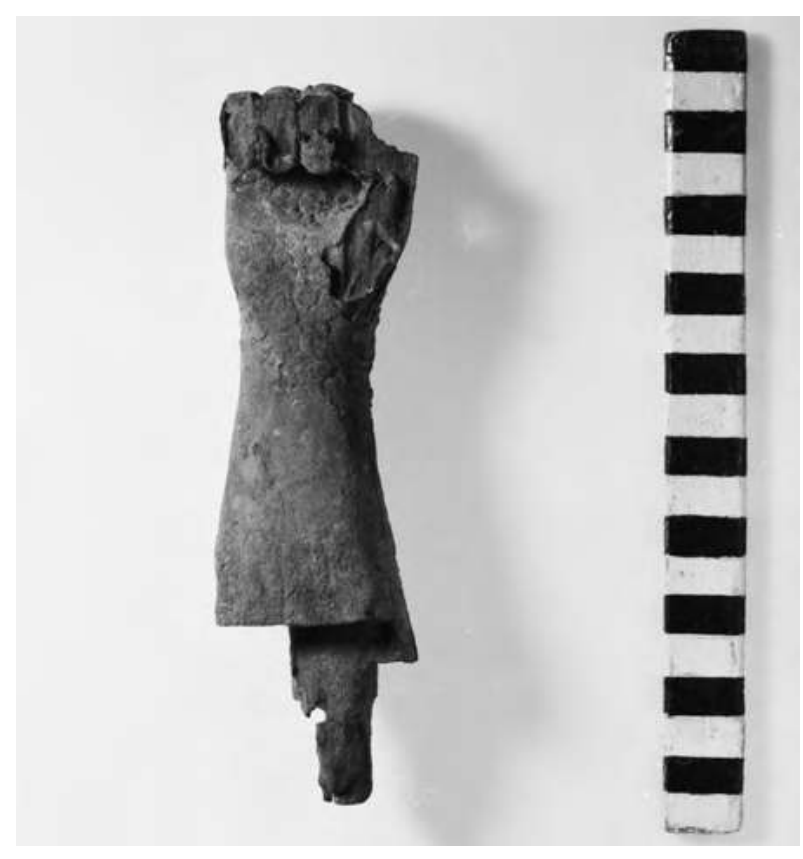

Figure 17. Bras droit d'une statuette en bois découvert lors des fouilles (Y.92.B.O/470). (A. Solazzi 1992 CMAIRY)

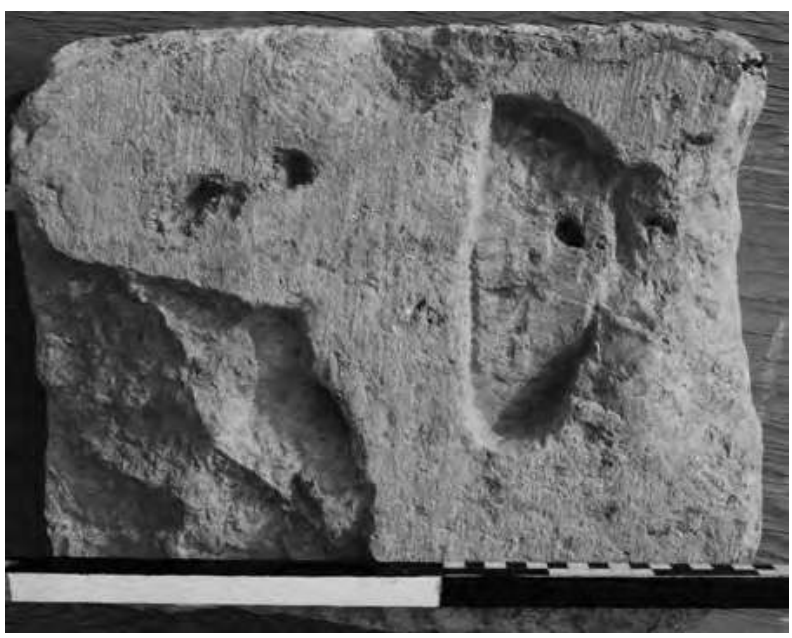

Figure 18. Face supérieure d'une base inscrite de statue qui n'était pas en place, découvert à Barāqish; l'empreintes des pieds de personnage est encore bien visible (Y.92.B.A./20).

(A. de Maigret 1992 OMAIRY)

pourrait s'agir de statues offertes par des particuliers en guise d'ex voto, pratique attestée dans d'autres temples sudarabiques (voir ci-dessous).

La présentation du mobilier cultuel du temple de Nakrah de Barāqish et de ses environs (temple de 'Athtar, dans la ville et mobilier exhumé lors des fouilles de la nécropole) révèle la nature relativement homogène des objets de culte de ce site, tant au niveau des formes adoptées que des motifs décoratifs. Celles- 
ci sont révélatrices des rites qui se déroulaient dans ce temple : combustion d'encens, offrandes diverses sur les tables d'offrandes dont certaines devaient être collectives (sur les grandes tables) et d'autres plus communautaires ou familiales (exemples plus petits), mais également de rites sacrificiels réalisés à proximité du temple qui pouvaient se poursuivre à l'intérieur de l'édifice par le biais d'offrandes de sang ou de pièces de viandes découpées (orifices creusés devant les cellae, tables d'offrandes à gouttières et bloc pour attacher les bêtes non loin du bâtiment de culte).

Afin de replacer les objets présentés ci-dessus dans un contexte plus général, le mobilier cultuel du Yémen ancien sera à présent rapidement exposé.

\section{Le mobilier cultuel sudarabique}

Les recherches menées au Yémen depuis les années 1970 ont permis la découverte d'un important corpus d'objets associés aux activités cultuelles. Ce matériel est principalement constitué d'autels, comprenant des tables d'offrandes, dont les formes et les fonctions varient, de brûle-encens et de quelques exemples de statues.

\subsection{Autels}

De nombreux exemples d'autels sont connus, mais en raison de l'absence de contexte archéologique dans la majorité des cas, les travaux typologiques sur le mobilier cultuel sudarabique demeurent très rares. Il existe plusieurs types d'objets communément désignés comme " autels » et la terminologie pose problème lorsqu'il s'agit de définir précisément tel ou tel type d'objet tant les formes et les fonctions de ces objets sont proches. Une des premières synthèses sur ce mobilier fut réalisée par Marina Forte qui présentait en 1967 une étude sur l'origine des autels sudarabiques. ${ }^{32}$ Ceux-ci représentent des éléments centraux de l'acte liturgique : on y réalisait des sacrifices et des offrandes à la divinité du temple. Certains exemplaires peuvent toutefois constituer des ex voto, offerts par des particuliers, non destinés à être utilisés dans le cadre de rituels. Des distinctions formelles permettent d'identifier différents types :

A. Les autels monumentaux ;

B. Les autels simples, sans gouttières, aux formes variées, principalement cylindriques et parallélépipédiques, présentant parfois un décor architectural ;

C. Les autels à gouttière, pourvus d'une canalisation. Ces éléments sont suffisamment significatifs pour les inclure dans une seconde catégorie, leur

\footnotetext{
32 Forte 1967. L'auteur y traite alors des autels portatifs, et non des autels monumentaux.
}

présence renvoie en effet à une nécessité qui les distingue des autels simples.

\subsection{A. Les autels monumentaux}

Il faut mentionner un type d'autel qui ne sera pas traité ici en raison de sa monumentalité, qui l'intègre de fait directement à l'architecture religieuse plutôt qu'au mobilier cultuel à proprement parler. Ces autels consistent en des structures monumentales faisant partie intégrante du lieu de culte. De rares exemples ont été découverts in situ. C'est le cas dans la cour du temple sabéen Bar’ān à Mārib ${ }^{33}$ ou encore dans le temple découvert à Wuqro $^{34}$ dans le Tigray éthiopien. Ce dernier a livré un exemple unique d'autel encore en place, composé de plusieurs dalles de calcaires décorées de motifs géométriques et architecturaux formant un élément cubique dans lequel sont maçonnés plusieurs autels à gouttières. Des orifices permettent de restituer un mécanisme de maintien ou de versement d'une offrande liquide. ${ }^{35}$ Dans la région du Hadramawt, une des caractéristiques des lieux de culte (partagée avec certains édifices de Qatabān et d'Awsān) est le podium : l'élément central des temples, généralement adossé au mur de fond du temple. Des objets et offrandes devaient être disposés dessus et l'on peut considérer que ces structures maçonnées remplissaient donc de fait la fonction d'autel.

\subsection{B. Les autels à offrandes simples}

Dans cette catégorie d'autels simples, deux types sont à distinguer. Tout d'abord, on présentera les exemplaires cylindriques connus dans le monde sudarabique, puis les exemplaires parallélépipédiques, beaucoup plus nombreux, découverts en contexte cultuel.

\section{a. Cylindriques}

Des autels cylindriques ont été découverts dans les régions du Hadramawt et du Jawf, mais ce type est assez rare. Trois sites ont livré de tels objets, tous datés de la deuxième moitié du Ier millénaire av. J.C. ${ }^{36}$ Grâce aux inscriptions qui les ornent, on sait que

\footnotetext{
33 Voir Vogt et al. 2000, phot. 15.

34 Wolf et Nowotnick 2010, fig. 3 et 4.

35 Voir les hypothèses de restitution proposées par M. Schnelle (Schnelle 2015). L'auteur privilégie un système de soutien d'un chaudron duquel du liquide s'écoulerait, il juge cette hypothèse plus plausible que le sacrifice d'un animal sur cet autel, dont la taille ne permettait pas d'y placer les bêtes (bouquetins, taureaux) associées à Almaqah.

36 Le premier exemple provient du temple extra-muros de Nashshān dédié à 'Athtar dhu-Rișāf (Breton 2011 (ed.), fig. 134). Trois autres exemples, de forme plus simple, proviennent du Hadramawt (Huraydah : Caton Thompson 1944, pl. LXII, 2 ; Raybūn VI : [Rb VI/04 altar 1] et [Rb VI/04 altar 2] sur le site internet Digital Archive for the Study of Pre-Islamic Arabian Inscriptions, ci-après DASI; et Jūja : Im Land Saba 1999, 334, cat. 203).
} 
ceux-ci sont des offrandes dédiées par des particuliers. La place centrale de l'exemple monolithe découvert à Nashshān dans le Jawf indique qu'il était utilisé dans la liturgie. Il pourrait avoir été inspiré par un autel cylindrique simple, tels ceux du Hadramawt, et placé sur une base cylindrique à degrés. De tels autels cylindriques sont connus à la même époque dans le monde méditerranéen, particulièrement gréco-romain. À la différence des exemplaires sudarabiques, ceux-ci sont toutefois beaucoup plus ornés, de motifs végétaux notamment, et desservent une fonction funéraire.

\section{b. Parallélépipédiques}

Ce type d'autel, ou tables d'offrande, est attesté partout en Arabie du Sud. Ces blocs monolithes ${ }^{37}$ ont une hauteur variable, de quelques centimètres à plusieurs dizaines de centimètres pour les plus imposants. La face supérieure peut être évidée ou plane. En termes de décor, certains sont seulement inscrits de textes explicitant parfois leur fonction, d'autres arborent un décor architectural ou bien une série de bouquetins stylisés, centrée sur un côté. Les Hauts-Plateaux en ont livré plusieurs exemples, le symbole principalement employé dans cette région est le disque et le croissant mais certains arborent une tête de taureau en bas-relief. ${ }^{38}$ Dans le Jawf, on notera la présence d'autels, en pierre ou en bronze, dotés de quatre pieds zoomorphes. ${ }^{39}$ Les autels parallélépipédiques découverts en Arabie du Sud sont parfois pourvus d'une base, solidaire de la partie supérieure, mais ils sont le plus souvent découverts sans leur base. Il est rare de connaître leur position d'origine au sein de l'espace sacré : les exemples découverts dans les temples de Barāqish sont, à ce titre, remarquables. Mentionnons enfin des blocs monolithes, découverts sur le site de Tamna', capitale du royaume de Qatabān, ressemblant à des autels simples à bases mais dont la face supérieure est incurvée. ${ }^{40}$

Une variante qui peut être distinguée dans cette catégorie est celle des autels, sans base pour la plupart, qui arborent un décor composé de motifs géométriques et de détails évoquant l'architecture sudarabique. Certains représentent des bâtiments caractérisés par une base à degrés, des fausses fenêtres et des frises de denticules dans la partie supérieure. Le contenu des textes qui les ornent parfois et le contexte cultuel de

\footnotetext{
37 Des exemples existent aussi en bronze.

38 Voir par exemple DhM 172 (GOAM) sur le site internet DASI (tête de taureau schématique en bas-relief) et Costa 1978, pl. XIII, a (double gouttière en forme de tête de taureau).

39 Trois objets de ce type sont connus à Nashshān : deux sont en bronze, (voir Caubet et al. 2003) et un en pierre (voir Arbach et Audouin 2007, $\left.n^{\circ} 15\right)$. Ceux-ci sont interprétés comme des trônes par M. Jung (Jung 2012).

40 Voir Arbach et al. 2001, pl. 20. La forme de ces autels évoque par ailleurs celle d'objets représentés sur une stèle inscrite découverte dans le Wādī Huirr (Avanzini et al. 1994, pl. 13).
}

découverte révèlent qu'il s'agit là de représentations de temples. ${ }^{41}$ Le décor des autels monumentaux évoqués plus haut est d'ailleurs similaire. La réalisation d'objets miniatures, notamment pour accompagner les défunts dans leurs tombes, est attestée en Arabie du Sud. ${ }^{42}$ Une miniaturisation analogue des lieux de culte dans le cadre d'activités cultuelles n'est donc pas à exclure.

\subsection{Les autels à gouttières}

Un autre type très répandu dans le mobilier cultuel il est attesté dans toutes les régions d'Arabie du Sud, à l'exception pour l'instant de Qatabān et du littoral - est celui des autels à gouttière. Ceux-ci sont tous de forme parallélépipédique et généralement sans base. Les exemplaires découverts, le plus souvent hauts de quelques centimètres, ne permettent pas de restituer leur place au sein des lieux de culte. Beaucoup sont des offrandes de particuliers. Ces autels peuvent toutefois faire partie d'autels monumentaux, comme celui de Wuqro en Éthiopie, évoqué ci-dessus. Les gouttières peuvent être simples ou prendre la forme d'une tête de taureau stylisée. Des autels à double gouttière sont également connus, notamment dans le Jawf (objet qui pourrait provenir de Barāqish), ce type est toutefois beaucoup plus rare. L'évidement de la face supérieure est peu profond, indiquant une faible quantité de liquide. Enfin, les cavités observées sur plusieurs exemples résultent probablement de l'érosion due aux liquides versés dans le cadre d'une utilisation rituelle.

Dans son étude, Marina Forte établit des parallèles entre les exemplaires sudarabiques et des objets similaires découverts dans la région syro-palestinienne. ${ }^{43}$ Elle parvient notamment à identifier des parentés entre le mobilier sudarabique et des exemples découverts au Proche-Orient. Les tables d'offrandes seraient ainsi des formes inspirées du mobilier cultuel provenant de cette région, celui-ci serait lui-même en partie dérivé d'exemples égyptiens. Les développements stylistiques propres à la sphère syro-hittite auraient largement contribué à la production d'objets dont on retrouve l'influence dans les exemples sudarabiques. ${ }^{44}$

\footnotetext{
41 Voir l'exemple découvert à Kamna (Șan(ā), MM 3630 sur le site internet DASI) ou encore celui présenté dans Jemen 1998, 317, n²24.

42 Voir notamment les exemples exhumés dans la nécropole du sanctuaire Awwām à Mārib par l'équipe du Deutsche Archäologische Institute (Gerlach 2002, pl. 16 à 29).

43 Forte 1967, 109.

44 Cette parenté stylistique avec le monde syro-hittite est selon nous également mise en évidence par les statues féminines découvertes en Éthiopie, dont les attributs évoquent celles mises au jour dans le temple de Hazor (Yadin 1958), ou encore par les petits objets tripodes issus d'une tombe de Lakish, identiques à des exemples sudarabiques (comparer l'exemple publié dans Tufnell 1953 et celui présenté dans Arbach et Schiettecatte 2006, fig. 79). Les liens commerciaux liant le Proche-Orient et le sud de la péninsule arabique expliquent aisément ces influences stylistiques, non limitées à de simples similitudes fortuites.
} 
Les autels, tels que nous les avons réunis ici, se présentent sous plusieurs formes qui remplissent vraisemblablement différentes fonctions. ${ }^{45}$ D'après le corpus des autels du Yémen ancien connu actuellement, ces formes varient très peu dans le temps, la majorité des changements stylistiques s'opérant lors des trois premiers siècles de l'ère chrétienne. La datation par le style des autels sudarabiques est donc très hasardeuse. On peut toutefois noter que dès les phases les plus anciennes de la période sudarabique (viIIe s. av. J.-C.), les autels à gouttière sont très sobrement décorés, arborant seulement une tête de taureau schématique, une série de quelques bouquetins et parfois un texte sudarabique gravé sur les parois extérieures ${ }^{46}$ Vers le tournant d'ère et jusqu'au IVe s. ap. J.-C., les formes ne varient pas et l'on observe une persistance des formes adoptées pour ces autels. ${ }^{47}$ Hors contexte archéologique, seules les formes caractéristiques du début de l'ère chrétienne ou la paléographie d'une inscription ornant l'objet peuvent aider à le dater. En contexte religieux, on trouve donc des autels monumentaux, rapidement évoqués plus haut, ainsi que des autels de taille plus modeste, dédiés par des particuliers à la divinité dans son temple. La majorité des objets conservés sont en pierre, mais il existe des exemples en bronze. L'observation des différentes formes laisse penser que la base, souvent solidaire de la partie supérieure, pourrait être une évolution, une fusion de deux éléments auparavant séparés. Un exemplaire d'autel découvert à Gobochela en Éthiopie présente en effet une haute base à degrés en pierre sur laquelle était disposée un autel parallélépipédique simple (ou table d'offrande) en albâtre. ${ }^{48}$ Ajoutons enfin que des coffrages en bronze ornés de motifs figuratifs (sphinx de face et bouquetins de profil) découverts dans les Basses-Terres ${ }^{49}$ semblent avoir recouvert des autels simples afin de mettre l'objet en valeur ou bien de le protéger.

\subsection{Les brûle-encens}

Les brûle-encens constituaient un élément récurrent dans le mobilier liturgique du Yémen ancien, il s'agit du type d'objet le plus répandu dans le monde sudarabique. Certains ont pu servir de supports à l'offrande de résines parfumées dans les temples. Beaucoup des exemplaires qui nous sont parvenus semblent toutefois

\footnotetext{
45 La terminologie permet parfois d'identifier ces fonctions, voir Maraqten 1994.

46 L'exemple décoré de Kamna (DASI, Șan'ā' 3630) et celui de Nashshān (Yémen 1997) font office d'exception en ce qu'ils représentent des lieux de culte miniaturisés.

47 Jemen 1998, 324, cat. 238; et pour le IVe s. apr. J.-C., voir l'exemple originaire de Baynūn sur le site DASI (BynM 15).

48 Leclant 1959, pl. XXXI.

49 Voir notamment BM $135323+4$ sur le site internet DASI et le fragment de coffrage présenté dans Costa 1978, 43, pl. 23 (tous deux provenant vraisemblablement de Mārib).
}

être des ex voto offerts, ${ }^{50}$ qui n'ont pas nécessairement servi. L'usage de ces objets n'étaient toutefois pas réservé aux temples et aux édifices religieux publics. De nombreux brûle-encens ont en effet été trouvés en contexte domestique ou funéraire.

Dans un catalogue des autels de Shabwa classés selon leurs formes et leurs décors, J.-F. Breton et A. Bațayāa ont établi trois catégories, dont deux concernent des autels à encens et recouvrent la majorité des formes rencontrées. ${ }^{51}$ Notons que ceux-ci proviennent de contextes funéraires et domestiques ou bien de ramassages de surface, et non de contextes cultuels avérés.

\subsection{A. Les brûle-encens cubiques quadripodes}

Les petits autels à encens cubiques quadripodes, découverts en contexte cultuel comme en contexte domestique, pourraient trouver leur origine en Arabie du Sud selon les auteurs. Lors des fouilles du temple de Sayīn à Hurayḍa dans le Hadramawt, G. Caton Thompson a découvert de nombreux exemplaires décorés de lignes incisées, qu'elle comparait à ceux mis au jour sur le site de Gezer (Levant Sud). ${ }^{52}$ Cette comparaison est reprise par M. Forte, pour qui les exemples découverts au Proche-Orient, datés de la première moitié du Ier millénaire av. J.C., auraient été inspirés par des modèles sudarabiques. ${ }^{53}$ Rémy Audouin, dans une étude parue en 1994, indique également que les décors géométriques et animaliers connus sur les exemplaires sudarabiques se retrouvent en Palestine, en Mésopotamie, en Crète ou encore à Délos. ${ }^{54}$

\subsection{B. Les brûle-encens à base pyramidale tronquée}

Il existe également une forme de brûle-encens très répandue pourvus d'une base pyramidale tronquée. Les motifs décoratifs rencontrés sontle disque et le croissant, les denticules et les motifs architecturaux comme les fausses fenêtres. Des motifs animaliers (bouquetins ou têtes de taureau), bien plus rares, peuvent également orner ces objets. Le manque de données chronologiques interdit malheureusement toute tentative de classification typo-chronologique. Il semble toutefois qu'à l'instar des modèles architecturaux et des canons stylistiques sudarabiques, la longévité des motifs et des formes caractérise également les brûle-encens. Dès le début du Ier millénaire av. J.C., la majorité des formes sont développées et paraissent déjà abouties.

\footnotetext{
50 Concernant les différents termes employés dans les dédicaces d'objets, ainsi que la typologie de Muhammad Maraqten, fondée sur la terminologie, voir Maraqten 1994.

51 Breton et Bațayā` 1991.

52 Caton-Thompson 1944, 153.

53 Forte 1967, 119-120.

54 Audouin 1994.
} 
On retrouve ainsi des brûle-encens parallélépipédiques simples à décor de denticules, des autels à encens inscrits présentant des reliefs sur la face principale et à base pyramidale ou tronconique tronquée. Le disque et le croissant et les motifs architecturaux sont déjà développés dans plusieurs régions. ${ }^{55}$ Ces motifs seront employés jusqu'aux premiers siècles de l'ère chrétienne (Ier - IIIe s. apr. J.C.). Dans les variantes observées, on peut noter la présence d'angles surélevés dans les motifs architecturaux ainsi que l'emploi fréquent de merlons sur le bandeau supérieur des exemples des Hautes-Terres. Les décors de ces derniers illustrent également le développement de motifs figuratifs (végétaux) caractéristiques des premiers siècles de l'ère chrétienne. Du point de vue des origines, ce type de brûle-encens, à l'instar des exemplaires cubiques présentés ci-dessus, aurait été développé localement ; il ne connait d'ailleurs pas de diffusion en dehors de la sphère culturelle du Yémen ancien (s'étendant à l'Éthiopie et l'Érythrée modernes). ${ }^{56}$

\section{Figurines et statues}

L'espace cultuel est occupé par de nombreux objets et dispositifs religieux. Les fouilles ont livré de nombreuses statues, bases de statues ou encore de figurines provenant de contextes cultuels avérés ou supposés. La plupart de ces objets sont des offrandes et des ex voto déposés par des fidèles. Les plus fortunés sont vraisemblablement les dédicants de grandes statues en bronze telles celles découvertes à Mārib dans le temple Awwām tandis que les fidèles les plus modestes seraient à l'origine des dépôts des petites figurines en bronze, en pierre ou encore en terracotta. ${ }^{57}$

\subsection{Les figurines}

Des figurines anthropomorphes ont été découvertes dans le Jawf (al-Sawdā') / Nashshān, Barāqish / Yathill), dans les Basses-Terres (Șirwāḥ, Mārib : dans les temples Bar’ān et Awwām), à Qatabān $\left(T^{2} a^{c}\right)$ et dans le Hadramawt (Bi'r Hamad). Dans le Tigray, un trône miniature est représenté avec un personnage assis à l'intérieur, dont seule la silhouette est esquissée. ${ }^{58} \mathrm{Il}$ évoque des représentations grandeur nature de tels modèles ainsi que les statues de personnages féminins connus sur le site même de Meqaber Ga'ewa et dans la région..$^{59}$ Les figurines sudarabiques représentent des hommes comme des femmes, le plus souvent dans

\footnotetext{
55 Notamment dans le Jawf, les Basses-Terres, en Éthiopie / Érythrée et en Arabie.

56 Forte 1967, 119-120.

57 Sur celles-ci voir notamment O’Neill 2014.

58 Wolf et Nowotnick 2010, fig. 10.

59 Notamment le trône de Hawlti-Melazo (de Contenson 1962), celui d'Addi Gelamo (Caquot et Drewes 1955, pl. VI) et les statues de Wuqro (Wolf et Nowotnick 2010, fig. 6) et de Hawlti (Leclant 1959).
}

une position d'orant (les bras tendus vers l'avant) ou assis. Plus rarement, ils figurent des prisonniers, ${ }^{60}$ des musiciens ${ }^{61}$ ou des guerriers en armes. ${ }^{62}$ Ces figurines semblent donc être caractéristiques de la sphère cultuelle, mais elles se retrouvent en contexte funéraire aux côtés d'objets cultuels miniatures ${ }^{63} \mathrm{Ce}$ sont des objets apportés dans le temple et disposés là en offrande à la divinité. Les exemples en bronze sont d'ailleurs pourvus d'un tenon destiné à placer l'objet sur un support. La fouille du temple extra muros de Nashshān (dédié à 'Athtar dhu-Risāâf) a permis de découvrir une figurine fichée dans le mur d'enceinte entre deux assises. ${ }^{64}$ Un texte du même site indique en outre que les cinq cavités creusées sur la face supérieure d'une base devaient recevoir cinq figurines représentant les frères offrant l'inscription à la divinité Aranyadac.$^{65}$

Ces figurines évoquent tout à fait celles, mentionnées plus haut, découvertes dans le temple de Nakrah à Barāqish. Dans ce cas précis, il s'agit surtout de femmes réalisées en stuc et en terracotta peintes de couleur vive. ${ }^{66}$ Une figurine en bronze représentant une citharède et le bras en bois en proviennent également. ${ }^{67}$ Ces objets étaient vraisemblablement entreposés à l'étage de l'annexe après avoir été offerts par des fidèles. ${ }^{68}$ La nature guérisseuse du dieu Nakrah incite $\mathrm{S}$. Antonini à y voir des ex voto offerts suite à des guérisons obtenues grâce aux faveurs de la divinité (le lien entre la protection de la santé des femmes enceintes et la fertilité serait par ailleurs indiqué par les nombreuses figurines de femmes). ${ }^{69}$

Au-delà des motifs anthropomorphes, il existe de nombreuses figurines représentant des animaux tels que le taureau, le bouquetin ou encore le dromadaire. Ce type se retrouve dans le Jawf, les Basses-Terres (à Mārib et Șirwāḥ), à Qatabān, en Arabie Saoudite à Najrān et Qaryāt al-Fāw) et enfin en Éthiopie et en Érythrée (taureaux, mais également sphinx et félins)..$^{70}$ Ces figurines proviennent de contextes cultuels ainsi

\footnotetext{
60 Arbach et Audouin 2007, n 87-90; Schiettecatte 2006c.

61 Voir la statuette de citharède, dans de Maigret et Robin 1993, phot. 8.

62 Arbach et Audouin 2007, $\mathrm{n}^{\circ} 91$.

63 Voir Gerlach 2002, pl. 24 à 27.

64 Breton 1992, 445, nº 23.

65 Schiettecatte 2006c, 186-187 (voir Queen of Sheba 2002, 226, n 175, sur cette base).

66 Sur les signes découverts sur certaines statuettes féminines sudarabiques, voir Antonini 1996.

67 'Alī 'Aqīl et Antonini 2007, 38 et 135.

68 Voir Antonini 1999.

69 Antonini 1999, 66.

70 Voir par exemple les figurines de bouquetins dans Arbach et Audouin 2007, $n^{\circ} 95$ à 98, ou de serpent (Arbach et Audouin 2007, n ${ }^{\circ}$ 99 et 100), Jemen 1998, cat. 243 et suiv., ou encore al-Ghabban et al. 2010.
} 
que de contextes funéraires où elles accompagnent le défunt.

Les figurines peuvent être réalisées en bronze, en pierre (calcaire, calcite, albâtre), en stuc, en bois ou encore en terracotta et mesurent jusqu'à $15 \mathrm{~cm}$ de hauteur. La chronologie est difficile à préciser dans la plupart des cas mais des analogies stylistiques permettent de situer certains objets dans le temps. ${ }^{71}$ Les figurines zoomorphes accompagnant le défunt pourrait revêtir une symbolique liée à des rituels destinés à être accomplis par le défunt.

\subsection{Les statues}

Les lieux de culte abritaient parfois des statues (et statuettes) aux dimensions plus imposantes. À l'instar des figurines, celles-ci représentent des personnages ou bien des animaux. Les grandes statues nous sont plus rarement parvenues du fait de leur taille : l'emploi du bronze pour plusieurs d'entre elles a entraîné une récupération de matériaux qui n'a laissé que peu d'exemples à découvrir. Enfin, le bois a également été employé pour la réalisation de statues mais le temps a certainement détruit la plupart des exemplaires qui auraient orné les lieux de culte. Certains fragments nous sont parvenus, comme cela a été vu plus haut; par ailleurs les statues en bois pouvaient être recouvertes de métal ou encore de stuc peint.

De beaux exemples de statues anthropomorphes ont toutefois été découverts, notamment dans les BassesTerres et dans le Jawf sabéen (Mārib, Șirwāḥ, al-Bayḍā̄ / Nashq). Dès 1958, F. Albright publiait des exemples de ces statues découvertes dans le temple Awwām. ${ }^{72}$ Hauts de près d'un mètre, les personnages masculins sont représentés armés et torse nu, l'un d'eux porte une peau de lion sur le dos et une coiffure typique de style sudarabique. Des exemples de statuettes de femmes de faible hauteur ont également été mis au jour dans le hall péristyle de ce même sanctuaire. Le site de Kamna dans le Jawf a livré une statue fragmentaire en bois d'une soixantaine de centimètres de hauteur représentant un personnage féminin de style Banāt 'Ād, il semble que celle-ci était recouverte de peinture (YM 2401). ${ }^{73}$ La région de Qatabān a également livré un exemple de $80 \mathrm{~cm}$ de hauteur en bronze, réalisé à la cire perdue. La tête et les extrémités des membres ont disparu. Le personnage masculin est torse nu, vêtu d'un pagne sur lequel est inscrit un texte, il porte une dague à la ceinture et les mains semblent avoir été tendues vers

\footnotetext{
71 Notamment dans le cas de Barāqish.

72 Bowen et Albright 1958, cat. 11 à 13.

73 Arbach et Audouin 2007, cat. 125.
}

l'avant. Il s'agit d'un ex voto dédié à la divinité 'Amm dhu-'Awratum (' $m \underline{d}-{ }^{-}$wrtm $) .^{74}$

Les sites de Qaryāt al-Fāw (Arabie) et Jabal al-c'Awd (Hauts-Plateaux) ont tous deux livré une collection exceptionnelle d'objets représentant des êtres mythologiques et des divinités en bronze datés du début de la période himyarite. Les modèles et le style sont clairement d'influence gréco-romaine (Harpocrate, Artémis, Héraklès), indiquant soit un artisanat importé, soit la présence d'artisans étrangers. ${ }^{75}$ Ces objets, bien que figurant des personnages divins issus du monde méditerranéen, ne proviennent toutefois pas de contextes cultuels avérés. Leur date tardive peut également militer en faveur d'éléments de décor de palais. Enfin, ledit «Grand Temple » de Shabwa, dont seul le dispositif d'entrée est conservé, arborait en façade une série de statues représentant des hommes grandeur nature.

Il faut enfin mentionner les exemples de statues féminines découvertes en Éthiopie et en Érythrée. Celles-ci représentent des personnages féminins corpulents en position assise, vêtus d'une longue tunique, parfois à frange. Ces femmes, pieds-nus, peuvent avoir les deux mains posées sur les cuisses, ou bien tenir des objets (des coupes ?) reposant sur un support plat. Les statues reposent sur des bases à degrés portant une inscription. Les fouilles allemandes du temple d'Almaqah de Meqaber Ga'ewa ont permis de découvrir un exemple de statue féminine disposé à l'extrémité orientale, près de stèles et "bétyles ", qui ne constitue probablement pas l'emplacement original de la statue. ${ }^{76}$ Les textes accompagnant ces statues indiquent qu'il s'agit ici aussi de représentations de dédicantes. ${ }^{77}$

Les socles sont bien souvent le seul vestige de l'emplacement de ces statues au sein de l'espace cultuel. La cella du temple Bar'an est dotée d'un socle présentant quatre cavités correspondant selon toute vraisemblance aux quatre pieds d'une statue zoomorphe. Un exemple similaire, quoiqu'apparemment placé à l'extérieur des murs du lieu de culte identifiés par des archéologues saoudiens, est connu à Najrān. De même à Șirwāḥ, un socle pourvu de cavités en forme de sabots de bovidés a été découvert non loin des deux grandes inscriptions du grand temple dédié à Almaqah. ${ }^{78}$ Ces exemples pourraient avoir soutenu des représentations associées

\footnotetext{
74 Antonini et Agostini 2013.

75 Voir Hitgen 2013.

76 Wolf et Nowotnick 2010, 372.

77 Voir RiÉth 52 et MG 2 DAI 'Addi Akawəh 2008-3. Les inscriptions invoquent la divinité afin qu'il donne un enfant à la dédicante, une certaine Ymnt, dans les deux cas.

78 Ces éléments ont été présentés par I. Gerlach lors des XIIIe Rencontres Sabéennes tenues à Paris en juin 2009.
} 
à la divinité, mais la majorité des socles découverts dans les sanctuaires et temples sont des offrandes ainsi que l'indiquent les textes inscrits sur les bases.

Ces statues et figurines peuvent donc être anthropomorphes (représentant le dédicant ou bien un personnage offert à la divinité : personnel, prisonniers capturés lors de conflits) ${ }^{79}$ ou zoomorphes. Dans ce dernier cas, les animaux les plus couramment représentés sont les taureaux, les bouquetins et les dromadaires mais les inscriptions révèlent que l'on pouvait également offrir une représentation de cheval, de jument ou d'âne. Il peut s'agir d'un hommage à l'animal symbolique de la divinité honorée, d'un symbole se substituant à un sacrifice (taureau ou bouquetin) ou bien d'une figuration en lien avec le souhait formulé à l'intention du dieu (bétail, animaux de transports).

\section{Conclusion}

Les recherches archéologiques menées à Barāqish ont mis au jour un mobilier de culte essentiellement constitué de brûle-encens et de tables d'offrandes ; il s'agit de découvertes de surface, de trouvailles dans le cadre des fouilles dans la ville antique et dans la nécropole. Les tables d'offrandes découvertes sont pour une part intégrée à l'architecture du temple (grandes tables disposées dans les vaisseaux) ou bien de taille imposante; d'autres exemples fragmentaires ne permettent pas d'apprécier les dimensions d'origine de l'objet. Les décors rencontrés sont exclusivement animaliers (tête de taureau ou frise de bouquetins).

Dans la catégorie des brûle-encens, de nombreux exemples sont de type cubique, quadripode et parfois ornés d'un décor géométrique (un motif de denticules sur la partie supérieure en bas relief ou encore des triangles), certains sont enduits de couleur rouge et portent des inscriptions mentionnant des noms d'aromates. Ce type d'assez petite taille (une vingtaine de centimètres de largeur pour une dizaine de centimètres de hauteur tout au plus) est notamment très représenté dans la nécropole. Le deuxième type présent dans cet ensemble est celui des brûle-encens à base pyramidale tronquée, orné de décors géométriques ou architecturaux et parfois de textes ou de symboles. Enfin, les découvertes effectuées lors des fouilles du temple de Nakrah offrent également des indices sur les rites réalisés au sein de l'espace sacré (sacrifices, libation, offrandes liquides et non liquides) et sur les types d'ex voto déposés par les fidèles.

Du point de vue de l'utilisation des objets cultuels présentés (principalement les tables d'offrandes et les brûle-encens), des résidus d'encens dans le mobilier de Barāqish attestent leur usage au sein du temple. De nombreuses interrogations demeurent toutefois sans réponse, notamment l'emplacement de ces objets offerts par des particuliers dans l'espace sacré ou encore la durée d'utilisation de ces mêmes brûle-encens (s'agitil d'un acte récurrent? Ou bien l'offrande de l'objet s'accompagne-t-elle de la combustion d'encens une fois seulement, au moment du dépôt dans le temple?).

On remarque que les objets de culte découverts à Barāqish sont représentatifs du mobilier cultuel sudarabique. Ce rapide aperçu aura tenté d'en présenter toute la richesse. Malgré la difficulté d'établir une typo-chronologie de ce mobilier, des parallèles stylistiques permettent néanmoins de situer dans le temps l'apparition de certains motifs. Il est toutefois remarquable d'observer une telle constance dans les motifs et les formes adoptées dans le mobilier cultuel sudarabique sur près de quatorze siècles. Les découvertes réalisées lors de fouilles archéologiques, et plus particulièrement à Barāqish, contribuent à affiner la chronologie. L'épigraphie, par l'étude de la paléographie des inscriptions qui ornent ces objets peut également apporter des marqueurs chronologiques qui permettraient de dater ce mobilier, bien souvent découvert hors contexte.

\footnotetext{
79 Tout comme certaines statuettes représentent une version symbolique de l'offrande (d'une personne par exemple, substituée par une statue ou figurine de la personne offerte), les figurines d'animaux pourraient symboliser une offrande d'un animal. Par ailleurs, les figurines anthropomorphes ne représentent pas toujours le dédicant. Certaines figurent des prisonniers et se substituent donc à l'offrande d'un butin de guerre (voir Schiettecatte 2006c).
} 


\title{
Chapter 12
}

\section{La brique de terre crue dans les fortifications de l'Arabie du sud. L'exemple de Barāqish}

\author{
Christian Darles
}

\section{Introduction}

De nombreuses agglomérations de l'Arabie du Sud antique possèdent des ensembles fortifiés imposants. Paradoxalement peu d'entre eux ont été étudiés du point de vue de l'architecture en brique. A côté de l'ouvrage de synthèse de J.-F. Breton ${ }^{1}$ seules les fortifications de Khawr-Rūrī, ${ }^{2}$ de Șirwāh ${ }^{3}$ et de Shabwa ${ }^{4}$ ont fait l'objet d'études approfondies, sans insister pour autant sur la présence de la brique de terre crue. Quelques articles sont également consacrés au rempart de Mārib, ${ }^{5}$ à celui de Naqab al-Hajar ${ }^{6}$ et à ceux des villes du Jawf.

Les dernières recherches menées à Barāqish, lors d'un sondage stratigraphique extra-muros, ont permis de retrouver le rempart sabéen primitif du VIIe s. av. n. è. ${ }^{8}$ Ce site longtemps parcouru, fouillé et étudié par Alessandro de Maigret et son équipe possède une des plus belles murailles du nord du Yémen, dans le Jawf. Emblématique, cette fortification semble immémoriale, pourtant elle n'a pas cessé d'évoluer et de se transformer. Pour l'archéologue l'analyse des techniques de construction, des phases de dégradation des indices de réfections et des immanquables reconstructions est d'une grande richesse d'enseignement qu'il est nécessaire de mettre à profit.

Ces quelques lignes vont tenter, à travers l'emploi de la terre et plus particulièrement de la brique crue, de démontrer que la construction de ces fortifications n'est jamais élaborée sans le souci de l'usure et de la réfection. Les murailles de ces cités n'ont jamais cessé de se transformer. Cependant, sur le plan historique, se pose le problème de l'interprétation des faits observés.

\footnotetext{
1 Breton 1994.

2 Darles 2011.

3 Schnelle 2007.

4 Darles 2003 ; Darles 2008 ; Bessac 1998b.

5 Finster 1986.

6 Breton et Robin 1987.

7 Bessac 1998a ; Breton et Bessac 2002, 149-150. Les archéologues ont pris l'habitude de parler de remparts en pierre avec un bourrage de brique crue. Je leur opposerai l'expression de « remparts en briques crues parementés de pierre ».

8 Fedele 2010 ; Fedele 2011a.
}

Les exemples cités incluront tout particulièrement la ville antique de Yathill et d'autres cités du Jawf. ${ }^{9}$

\section{Généralités architecturales}

Dans certaines régions du monde, la construction des remparts a pu faire appel à un matériau privilégié sans pour autant qu'il soit systématiquement le seul employé - par exemple la terre en Mésopotamie ou en Asie centrale. ${ }^{10}$ Dans d'autres environnements la disponibilité des matières premières a permis une construction mixte, en occident, le " murus gallicus », parfois parementé en pierre, où le bois en ossature se combine avec la terre, de même en Egypte hellénistique. ${ }^{11}$ Dans son précieux ouvrage, A. Orlandos précise bien que dans le monde grec l'usage simultané de plusieurs matériaux permettait une meilleure stabilité et un meilleur maintien des remparts. ${ }^{12}$ Longtemps l'architecture classique a partiellement occulté l'usage de la terre crue - la terre cuite au soleil - et des ouvrages comme celui de $\mathrm{R}$. Martin restent très discret avec ce matériau. ${ }^{13}$ C'est cependant dans le monde grec, dès le Ve s. av. n. è. jusqu'à l'époque hellénistique et au monde gréco-romain, qu'il faut tenter de rechercher quelques comparaisons d'ordre typologique ou morphologique. ${ }^{14}$

Frederick E. Winter dans son ouvrage majeur sur les fortifications grecques ${ }^{15}$ classe les remparts en trois catégories : les remparts constitués d'un mur de briques sur un socle de pierre, comme le rempart du Pirée décrit par Thémistocle, ${ }^{16}$ ceux qui consistent en un soubassement de pierre plus ou moins haut surmonté

\footnotetext{
9 L'usage de parois composites qui utilisent la terre crue associée au bois et à la pierre est connu dans le monde anatolien dès le $\mathrm{II}^{\mathrm{e}}$ millénaire av. n. è (Naumann 1971). En Mésopotamie l'usage de la terre pour des raisons géologiques a été de tout temps privilégié (Margueron 1982).

10 Un des plus beaux exemples de fortifications en briques crues est celui de de la ville hellénistique d'Aï Khanum sur les bords de la Koksha dans le nord de l'Afghanistan (Leriche et Callot 1986).

11 Spencer 1979.

12 Orlandos 1966.

13 Martin 1965.

14 Nous faisons référence ici à Adam 1982 ; Ginouvès et Martin 1985 ; Leriche et Treziny 1986, ainsi que Winter 1971 et Lawrence 1979.

15 Winter 1971, 69-90; v. aussi Winter 1986.

16 Lawrence 1979, 216.
} 
par une construction mixte en bois et en briques, enfin ceux qui sont totalement en pierre.

\section{Arabie du Sud}

Il n'y a pas de réseau d'irrigation sans maison, écrivait $P$. Gentelle en parlant des terres agricoles des basses terres du pourtour du Ramlat al-Sab'atayn. ${ }^{17}$ Il n'y a pas de construction sans la présence d'un système d'irrigation pourrait-on ajouter. L'argile des briques crues (ou plutôt « cuites au soleil ») ${ }^{18}$ est issue des dépôts limoneux qui constituent les champs. A chaque crue, une couche très fine de terre fertile recouvre la parcelle. Pierre Gentelle ajoutait, "c'est l'eau qui fait le champ ». Cette terre est peu onéreuse et sa transformation en matériau de construction est facile à mettre en œuvre. Les deux inconvénients sont la durée de la fabrication d'une part et le nombre de briques produites d'autre part. Le grand avantage est la proximité de la matière première et celle des ateliers de production qui peuvent être rattachés au chantier.

Cependant il n'existe pas de fortifications bâties uniquement en briques, en pisé ou en bauge. La terre est toujours associée à d'autres matériaux dans des formules architecturales complexes et toujours originales. La particularité de la construction de ce type d'édifices en Arabie du Sud, datés entre le VIIIe siècle av. n. è. et le IIIe siècle de notre ère, est la réalisation d'ouvrages composites où chaque matériau est utilisé au maximum de ses performances. Sur un massif de fondation composé de lits de briques cuites au soleil, un mur est édifié, bâti en briques simultanément avec un parement extérieur de pierres appareillées, lié au massif par des boutisses qui s'enfoncent profondément. ${ }^{19}$ Cette particularité n'est pas sans parallèles; quelques exemples identiques ont été relevés par F. E. Winter dans le monde grec à Velia en Italie du Sud, ${ }^{20}$ à Smyrne et Demetrias ${ }^{21}$ ainsi qu'à Gortys en Arcadie, ou bien par A. W. Lawrence à Drymaea en Phocide. ${ }^{22}$ Les parties supérieures sont composites soit une paroi en blocs disposés en parpaings et rigidifiés en arrière par une charpente et des étages en bois, soit une paroi mixte en ossature bois avec des remplissages en terre.

Ainsi à un empilement de diverses couches tel que décrit par Winter, les bâtisseurs du Yémen antique

\footnotetext{
17 Gentelle 2003, 119-120. « La maison habitée caractérise le réseau d'irrigation... elle disparait, l'irrigation cesse et la récolte meurt, le champ s'assèche et le canal disparaît... il ' $\mathrm{y}$ a plus que de l'eau qui coule, déshumanisée ».

18 Voir Vitruve sur l'estimation de la durée de la fabrication des briques.

19 R. Martin cite ce type de construction avec des boutisse pour les murs de soutènement d'Eleusis (Martin 1965, 374).

20 Winter 1971, 148.

21 Winter 1971, 130 ; Lawrence 1979, 212.

22 Lawrence 1979, 218.
}

dans la continuité - parfois en simultanéité - ont réalisé un ouvrage en " pelure d'oignon » ou les couches verticales s'additionnent tout en étant liées entre-elles. Bien entendu l'empilement est respecté et bien souvent les superstructures mixtes, de pierre et de bois ou de briques crues et de bois ne sont pas ou peu visibles depuis l'extérieur des villes renforçant par là-même la monumentalité de l'édifice.

\section{L'argile comme matériau de construction des fortifications}

Les auteurs grecs et romains vantent l'usage de la brique pour l'édification des fortifications parce que, comme le dit Pausanias, ${ }^{23}$ les briques crues sont plus résistantes aux attaques des machines de guerre de type béliers même si ces constructions manquent de tenue contre l'action destructrice de l'eau. ${ }^{24}$ Il n'est pas douteux que les premiers enclos ont consisté dans cette région à empiler des blocs de roches et à les couronner d'épineux et que les premières enceintes ressemblèrent à des clôtures pour le bétail. Dès la structuration des villes, un effort a été développé pour la réalisation de ces enceintes en privilégiant l'aspect défensif sans négliger le prestige de la communauté et la vanité des financeurs qui ne se privent pas de graver leurs actes sur les parois. A la suite de programmes semblables, fixés par les dirigeants et les responsables politiques et religieux, la maîtrise d'œuvre a dû composer avec la compétence des bâtisseurs, la proximité des matières premières et la nature du substrat géologique. La terre, présente, a été privilégiée autant que la pierre, calcaire, grès ou granite. ${ }^{25}$

\subsection{Les briques de terre crue « cuites au soleil »}

Une fois foulée et mélangée avec un dégraissant comme la paille des graminées, l'argile était moulée directement sur un sol légèrement sableux. ${ }^{26} \mathrm{Ce}$ séchage, en principe, se déroulait à l'ombre pour éviter des cassures. Vitruve conseillait même qu'il se poursuive pendant deux ans, à partir du printemps ou de l'automne. ${ }^{27}$ Dans les faits, en Arabie du Sud, la réalisation des briques était sûrement beaucoup plus rapide..$^{28}$

\footnotetext{
23 Pausanias, Periegesis, Voyage de l'Arcadie, VIII, 7 et 8.

24 Vitruve, De Architectura, II, chap. 8, 9 et 16.

25 Nous tenons compte ici des définitions données par O. Aurenche dans son dictionnaire multilingue (Aurenche 1977).

26 De nos jours au Sud du Yémen, le mélange une fois préparé est disposé, sur un sol sablé ou paillé, en gros boudins par un premier ouvrier, un autre sépare ce boudin en mottes grossières puis un troisième pose un cadre sans fond (souvent double) et tasse la terre dedans en soignant les angles. Il modèle le dessus en rendant la brique convexe et en y laissant ses traces de doigts. Le cadre est immédiatement soulevé puis déplacé. Les briques obtenues sont ainsi moulées sur leurs quatre faces latérales et modelées sur leur face supérieure. Voir Darles 2018.

27 Vitruve, De Architectura, II, 3, 2.

28 De nos jours, au Yémen, le séchage de ces briques moulées ne dure
} 
Les modules des briques moulées diffèrent selon les ateliers de fabrication. Elles peuvent aussi avoir des dimensions particulières selon leur destination ou suivant les époques. Le format peut aller du carré au rectangle allongé et les épaisseurs sont variables. Quand, dans un même bâtiment, les modules sont différents, on peut soupçonner que les provenances sont multiples ce qui implique souvent des réemplois possibles. On peut donner quelques mesures en centimètres relevées dans des fortifications d'Arabie méridionale (la longueur par la largeur sur l'épaisseur) : 28 × 24 × 8, 26 × 18 × 9, 51 x $31 \times 8$, donc des dimensions très proches de la brique lydienne, ${ }^{29}$ pour Shabwa, $45 \times 27$ x 9, à Barāqish, 44 x 27 x 8, à Hajar Yahirr, 48x29x8, 30 x 25 x 9, et à Mārib 25 x $20 \times 9$.

\subsection{Les liants}

Les briques possèdent une face supérieure légèrement convexe. Sur chaque assises réglée horizontalement les bâtisseurs posent un lit de terre mélangée à de la paille de graminée destinée à recevoir l'assise suivante. Le mortier de liaison est généralement constitué d'argile délayée. Utilisée en coulinage, elle garni les interstices entre les briques au fur et à mesure de leur pose. Les maçonneries de pierre peuvent ne pas être liaisonnées avec du mortier de chaux mais avec de l'argile comme à Kharibat Sacūd ou al-Asāhil. Les parements des remparts de Barāqish, ceux d'al-Bayḍā’ Ma'īn ou alSawdā’ semblent ne pas avoir été hourdés avec du mortier de terre, mais la disparition des massifs en brique disposés derrières eux pourrait indiquer que le coulis d'argile, fragile et pulvérulent dans le temps, était initialement présent en quantité. Les mortiers à la chaux se retrouvent aussi dans le petit temple de BāQuṭā daté du IVe s. av. n. è. en Huadramawt, ${ }^{30}$ ou dans le grand-temple de Shabwa et à Raybūn. Son usage généralisé à Mārib renforce le principe de liaison des angles en complétant l'usage des doubles boutisses alternées. ${ }^{31}$

\subsection{Les enduits}

Peu de données archéologiques nous sont parvenues relatives à la présence d'enduits de terre. La raison en est simple - la relative absence de vestiges des superstructures en terre. Cependant l'emploi de la

pas plus de trois semaines. Les briques sèchent d'abord à plat (entre 6 h et 3 jours), puis elles sont redressées de chant (de 5 à 15 jours). Elles peuvent ensuite être utilisées ou stockées selon l'état d'avancement du chantier. En Arabie, de nos jours, on les entrepose plusieurs mois (Aurenche 1981, 66 et Guest-Papamanoli 1978, 9, note 38).

29 Vitruve (De Architectura, II, 3, 3) décrit la dimension des briques tantôt carrées tantôt rectangulaires. La lydienne mesure un pied et demi sur un pied, la pentadoron un pied un quart (soit cinq palmes) et la tetradon un pied (soit quatre palmes). L'épaisseur est d'une palme soit huit centimètres.

30 Breton 1979, 186-189.

31 Bessac 1998a, 194. terre massive comme celui de la brique crue, hier comme aujourd'hui, nécessitent une protection contre l'humidité, contre les rares eaux de ruissellement et contre les affouillements créés par les effets éoliens et l'humidité du sol qui remonte par capillarité..$^{32}$ Les enduits de terre, qui ont pu recouvrir les tours et les courtines maçonnées en pierre, ont rapidement été remplacés par des enduits à la chaux comme à Shabwa ${ }^{33}$ ou à Khawr-Rūrî. ${ }^{34}$ On note également la présence de mortier de chaux " de mauvaise qualité » pour les réfections tardive de la porte occidentale de $\mathrm{Ma}^{\mathrm{C}} \mathrm{i} n{ }^{35}$

\section{Les principes constructifs mis en œuvre et les dispositifs architecturaux : courtines, tours et portes}

La brique joue un rôle important dans les dispositifs de fondation sous forme d'un massif équilibré destiné à recevoir la construction à venir. Ce dispositif est général et se retrouve pour d'autres types d'édifices comme le Palais royal de Shabwa. Cette semelle de répartition, en brique, est épaisse de près d'un mètre et pouvait être débordant vers l'extérieur. ${ }^{36}$ Le soubassement en pierre qui repose sur elle a généralement été visible ; le parement soigné de l'élévation n'apparaissant qu'au-dessus. On ne connait malheureusement pas suffisamment la nature des fondations des fortifications par absence de fouilles et de sondages. ${ }^{37}$ Les études archéologiques s'étant cantonnées généralement aux vestiges visibles. Cependant l'affouillement des parois, à Ma'in comme à al-Sawdā’ par exemple indique bien la présence de tels massifs sur lesquels sont disposés des soubassements successifs, grossiers en bas, puis à bossage et enfin en assises régulières. ${ }^{38}$

\subsection{Liaison entre le parement et le massif de briques cuites au soleil}

La brique de terre crue est le matériau principalement utilisé également pour la construction de massifs importants qui constituent l'âme des fortifications. Ce massif est solidement lié avec le parement extérieur par l'intermédiaire de boutisses régulièrement espacées. En fait il constitue le rempart proprement dit. La pierre n'est ici qu'en parement, souvent sur deux épaisseurs, comme à Ma'īn, Kamna ou Shabwa. ${ }^{39}$

\footnotetext{
32 Margueron 1985.

33 Darles 2008, 147.

34 Darles 2011, 67.

35 Bessac 1998a, 193.

36 Breton 1994, 29-30. L'épaisseur peut atteindre plusieurs mètres.

37 Bien souvent les archéologues se sont arrêtés aux soubassements des parois sans atteindre le substrat rocheux quand le monument s'appuyait dessus comme à Naqb al-Hajar (Breton 1994, 135) ou les parties les plus basses des ouvrages implantés sur des tells existants.

38 Breton 1994, 49. La figure 8 représente une coupe de la courtine orientale conservée jusqu'à son couronnement.

39 Nous notons une différence de nature du calcaire employé dans le
} 
Le mur peut ne comprendre qu'une série de carreaux alternés régulièrement avec des boutisses traversantes qui s'ancrent dans le massif arrière. Le massif de brique est également parementé à l'intérieur. Les exemples représentatifs sont rares car les fouilles de l'intérieur des villes n'ont pas ou peu été réalisées. On ne connait bien que le secteur du temple de Nakrah à Yathill et les abords de la «Citadelle » du troisième rempart de Shabwa. L'étude du rempart de Șirwāh par Mike Schnelle nous montre une paroi épaisse à deux parements et à caissons sur une partie du périmètre de l'enceinte qui se rapproche de l'enveloppe qui entoure l'aire sacré du temple Awwām à Mārib. ${ }^{40}$ Cependant le blocage interne de type "emplecton", en opus caementicium, est plus proche des structures construites pour les môles nord et sud de la grande digue de Mārib.

L'organisation de la hiérarchie des assises de la façade parementée peut correspondre à des impératifs techniques mais peut aussi indiquer des phases de travaux différenciées ou l'intervention de d'équipes distinctes ; on peut aussi ajouter l'importance de l'approvisionnement et le poids du financement des nombreuses parties du monument. A Barāqish, par exemple, la tour $n^{\circ} 22,{ }^{41}$ numérotée T37 par la mission italienne, comporte une fondation de sept assises visibles de près de trois mètres de haut surmontée par, avec un léger retrait de vingt centimètres, un soubassement comprend quatre assises ${ }^{42}$ sur $1,70 \mathrm{~m}$ de haut. La question est de savoir si ces fondations en blocs grossièrement taillés étaient vues ou non. En général, au-dessus des fondations, un soubassement en saillie était destiné à recevoir l'élévation, elle-même en léger retrait. Cette élévation correspond à une fine pellicule de pierre, soigneusement travaillée et largement dotée, parfois, comme à Barāqish, de champs épigraphiques correspondant à des dédicaces de construction gravées pour le compte de membres influents de la ville. Le couronnement de ces monuments est peu connu si ce n'est à Ma'īn, al-Bayḍ̄ā' et Șirwāh où des frises de denticules ou d'ibex ornent leurs sommets.

Les remparts de briques crues avec un simple parement de pierre sont nombreux ; nous citerons ceux de al-Baydā') d'al-Sawdā', de Barāqish, de Barīra, de Ğidfir ibn-Munayhir, de Mārib et de Shabwa. Ils sont essentiellement construits avec des carreaux souvent en appareil pseudo-isodome, parfaitement parementé au ravalement. Les blocs sont légèrement amaigris en queue pour donner l'impression d'une absence de mortier. Les joints sont parfois courbes et ont nécessité

Jawf ou à Shabwa. La face non vue, à l'intérieur, est soit bâtie avec des moellons polyédriques comme à Shabwa, soit construite avec un calcaire de moins bonne qualité, à Kamna par exemple. A Ma'īn, les deux parois sont parementées de manière similaire.

40 Schnelle 2007.

41 Breton 1994.

42 Breton 1994, 29. l'emploi onéreux d'une règle malléable. Tous les trois mètres environ des chaînes de boutisses débordantes assurent, en partie basse, la liaison avec le massif intérieur en briques de terre crue ${ }^{43}$ elles sont disposées telles de véritables jambes harpées. ${ }^{44} C^{\prime}$ 'est à Ma'īn que ce type d'appareil a été le mieux cerné par J.-F. Breton, R. Audouin et C. J. Robin dans un premier temps puis ensuite par J.-C. Bessac. ${ }^{45}$ L'étude des édifices de Shabwa et de ses fortifications confirme l'emploi généralisé de ce principe constructif. Dans les parties supérieures des parois, au-dessus du massif de briques crues, les parois à deux épaisseurs de rangs de pierres possèdent aussi des boutisses, posées en parpaing, qui assurent la liaison entre les deux parements.

Jean-François Breton dans son commentaire sur les dimensions respectives des tours et des courtines fait remarquer que plus on avance dans le temps plus la dimension des courtines diminue en longueur. Ces dernières sont beaucoup plus longues à l'époque archaïque $^{46}$ et tendent aux alentours du IIIe s. av. n. è. à avoir les mêmes dimensions que les tours. La normalisation des mesures des différentes parties de ces fortifications, saillants (tours) et rentrants (courtines), semble prouver qu'elles ont été montées et surtout commanditées de manière autonome, ce dont différentes inscriptions témoignent. On sait par ailleurs que plusieurs rois successifs de Ma'in sont intervenus dans la construction des murailles de Barāqish. Les plus anciennes parmi les trois cents inscriptions, in situ ou en réemploi, se trouvent dans les parois qui entourent l'accès du sud-ouest de la ville. Les constructeurs commençaient apparemment l'édification des enceintes fortifiées par les portes. ${ }^{47}$

\subsection{La présence du bois}

De nombreuses dédicaces de construction témoignent de la présence massive de bois dans les superstructures des fortifications de l'Arabie méridionale antique, notamment à Ma'īn ou à Tamnac' La porte sud de ce dernier site a possédé une superstructure réalisée avec une ossature en bois et un remplissage de briques crues. Ce type de construction n'utilise pas le principe de la triangulation pour garantir la stabilité de la structure mais celle des encastrements. Aussi sophistiquées qu'elles soient, ces liaisons ont nécessité la mise en œuvre simultanée de l'ossature et de son

\footnotetext{
43 Sur le môle nord de la grande digue de Mārib on peut également voir des séries de boutisses à crossettes qui font saillies à l'extérieur.

44 Bessac 1998a, 193.

45 Bessac 1998a, 195-196.

46 Breton 1994, 45.

47 Cette caractéristique se retrouve dans le monde grec et le monde romain. Ce sont les portes qui telles de véritables « arcs de triomphe » sont érigées en premier.
} 
remplissage en terre. ${ }^{48}$ Le bois a également été utilisé en tant que chaînage pour solidifier les parois, il l'a été aussi pour la construction des échafaudages. C'est avec les aménagements intérieurs et les charpentes des parties supérieures des tours et des courtines que son utilisation est la plus originale..$^{49}$ Les traces d'encastrement de ces pièces de bois dans les parois maçonnées en pierre indiquent que la stabilité de la charpente qui n'est donc pas isostatique (à la stabilité indépendante) mais hyperstatique. La charpente ne peut pas tenir sans le mur et le massif de briques crues qui la soutiennent. ${ }^{50}$ Ces constructions ont aujourd'hui disparu, fragilisées par leur exposition à l'air ambiant et par leurs assemblages. ${ }^{51}$ On peut penser qu'elles ont été excessivement fréquentes pour garantir aux défenseurs l'accès aux niveaux supérieurs des fortifications. C'est grâce à leurs liaisons avec les massifs de briques qui garantissaient les encastrements en pied et les accrochages dans la paroi de pierre que ces structures pouvaient être garantes de la solidité de cette charpente. Il faut aussi se rappeler que l'usage $\mathrm{du}$ bois était très fréquent pour les structures planes horizontales de type planchers ou plafond ${ }^{52}$ ainsi que pour les menuiseries des portes et des fenêtres.

\subsection{Les tours et les angles}

Les boutisses qui assurent la liaison entre le massif de briques crues et le parement en pierres appareillées sont aussi employées différemment, comme le précise

48 Cette superstructure est attestée par les deux textes RES 3880 et RES 3881. Les différentes fouilles menées à Tamnac par Alessandro de Maigret et les archéologues italiens ont bien montré l'usage généralisé de pièces de bois modulaires (Loreto 2011, 104, 145-146 et de Maigret et Robin 2006, 51). On connait de nombreux exemples de ce type de construction dans l'architecture civile des « BassesTerres ». D'excellents exemples ont également été dégagés en Hadramawt à Masghra, Raybūn et Shabwa par exemple (Breton et al. 1981b, Darles 1998, Loreto 2011 ; Seigne 1982 et Seigne 1992), puis dans le royaume d'Awsān dans le wādī Dura' (Breton 1997), ainsi qu'à Sirwāh (Gerlach 2012 ; Japp et al. 2011), et à Mārib dans le temple Awwām (communication personnelle de Mohamed Maraqten et de Carl Phillips).

49 Les nombreux trous de boulins qui n'apparaissent qu'au-dessus de la hauteur sommitale du massif arrière en brique ont été utilisés pour loger des pièces horizontales en bois qui supportaient des planchers (Breton 1994, 51-52, fig. 10).

$50 \mathrm{Si}$ on considère que l'architecture monolithique des temples du Jawf, par exemple, est issue de la pétrification de charpentes en bois (Darles 2010 et Darles 2012), il faut constater que cette architecture à base de grands modules de pierre est également hyperstatique, en témoignent les tenons et mortaises que l'on retrouve dans les liaisons entre piliers, architraves et poutres.

51 Les structures charpentées qui s'organisaient avant tout sur le mode de l'encastrement dépensaient beaucoup de matières ligneuses et de pièces de bois surdimensionnées. Les pièces de bois utilisées en compression qui sont sujettes au flambement sont toujours trop grosses. Les charpentiers ne se souciaient que peu des sections (beaucoup de pièces ne sont que des troncs grossièrement équarris); par contre un de leurs soucis était la longueur disponible dans des troncs souvent sinueux.

52 Les stèles d'Aksum sont démonstratives de ces savoir-faire. Voir aussi Darles 2009a où nous démontrons la complexité du système menuisé de la porte principale du Palais royal de Shabwa.
J.-C. Bessac, afin de renforcer les angles saillants des tours comme des portes..$^{53}$ Cet assemblage consiste en l'imbrication de deux séries de boutisses alternées qui renforcent les angles en s'enfonçant dans le massif de briques crues, c'est le cas quasi généralisé à Ma'īn, à Shabwa et dans d'autres fortifications des marges du désert. Afin d'éviter la cassure de ces boutisses par suite de tassements différentiels, les intervalles sont partiellement garnis avec des blocs qui assurent une rigidité encore plus grande. La raison de ce dispositif est encore aujourd'hui discutée. On ne le rencontre nulle part ailleurs en dehors de l'aire de l'Arabie méridionale antique, ni en Egypte, ni en Syrie ou en Perse. Un procédé constructif assez proche semble toutefois présent dans les parties supérieures des fortifications de Doura-Europos, ${ }^{54}$ sur les bords de l'Euphrate. L'absence de diffusion de ce type d'assemblage pose des questions auxquelles seules de nouvelles découvertes pourront répondre. On peut cependant proposer un dispositif technique d'ordre parasismique.

\subsection{Le problème de la couverture des passages.}

Les seuls exemples qui nous sont donnés sont à Shabwa dans le dispositif de l'entrée monumentale du bâtiment «A » du Palais royal, ${ }^{55}$ à Șirwāh dans la structure porteuse du " Five Pillars Building $\|^{56}$ et à Mārib, dans la poterne occidentale du temple Awwām. ${ }^{57}$ Les prospections menées en 1980 et 1981 dans le Jawf, à Kamna, par J.-F. Breton et C. J. Robin ont également permis la découverte de boiseries qui correspondaient à une menuiserie monumentale, certes difficilement rattachable au système défensif mais témoin d'une activité qui n'a pas laissé beaucoup de traces.

\section{Barāqish}

La ville de Barāqish, avec ses 770 mètres de périmètre et sa superficie de 4,5 hectares environ, ne devait abriter que l'élite de la tribu minéenne, seule cette élite, semble-t-il, avait le privilège de résider à l'intérieur des parois fortifiées de Yathill. ${ }^{88}$

Comme la plupart des enceintes du Jawf, la composition des courtines et des tours de cette enceinte fait appel largement à un massif de brique crue de plus de deux mètres de large et de près de sept mètres de haut (v. Antonini, chapitre 8 dans ce volume, fig. 10-12). Cette mesure correspond à la moitié de la hauteur totale du rempart qui est de 14,00 m. Le parement en pierre

\footnotetext{
53 Breton et Bessac 2002, 152.

54 Bessac 1998a, 194.

55 Darles 2009a.

56 Gerlach 2012, fig. 14a et 14b. Japp et al. 2011, 152, fig. 7.

57 Communication personnelle de Carl Phillips.

58 Voir de Maigret dans Robin et de Maigret 2009, 59.
} 
ne comporte qu'une seule rangée de carreaux et de boutisses (fig. 1) ; il a été réalisé simultanément avec le massif de brique comme peuvent en témoigner les lits de déchets de taille qui alternent avec les assises de briques crues (fig. 2). Aux alentours du temple dédié à Nakrah, une poterne a été découverte, elle menait depuis l'extérieur de la ville jusqu'à l'intérieur d'un espace de type temenos dont la paroi ouest de son enclos, perpendiculaire à l'enceinte, a été dégagée par les archéologues. La face interne du rempart a été également fouillée, il s'agit d'une paroi de pierres disposées sur deux épaisseurs et large de soixante centimètres environ. ${ }^{59}$ Le vide urbain entre le temple et cette paroi a été occupé par ce que les archéologues nomment une " sacristie » dont l'étage était accessible par un escalier (fig. 3). Il est possible de restituer un aménagement en relation avec les niveaux supérieurs de la fortification (v. Antonini et Fedele, chapitre 1 dans ce volume, fig. 22 et 36 ).

Nous notons ici le remarquable travail de la mission italienne qui tout en menant une fouille minutieuse de deux temples majeurs ont également dégagé un secteur de la ville en contiguïté avec l'enceinte nous permettant du même coup de mieux connaitre le rempart dans toute son épaisseur.

D'après $F$. Fedele, ${ }^{60}$ qui a réalisé un sondage majeur à l'extérieur des murailles visibles de Barāqish, la muraille minéenne (tour T7) commencée au VIe-Ve s. av. n. è. a été construite (Area A, Strato N) sur un aménagement du tell sabéen. Les fondations ont été construites en tranchée et la muraille se fonde ainsi sur un massif compact de briques crues agglomérées, mais non construit, résultant de la stratification de la ville antérieure dont la datation est du VIIIe s. av. n. è. ${ }^{61}$

\section{Conclusion}

Ces remparts emblématiques du Sud de l'Arabie, celui de Barāqish en est un des plus prestigieux exemples, apparaissent de loin comme massivement bâtis en pierre. En fait leur construction est beaucoup plus complexe. Derrière le prestige de ces parois de blocs parfaitement appareillés et ravalés, se cache une technicité importante nécessitée par l'art poliorcétique. Ces murailles ont servies et sont bâties pour la défense comme pour la peur. Impressionner les ennemis, proches ou éloignés, est bien ce qui résulte de ces centaines d'inscriptions qui décrivent

59 de Maigret 2004a, 24, fig. 24.

60 Fedele 2010, 248-250, fig. 136 et 138 ; Fedele 2011a, 109, fig. 7, la tour T7 est encastrée dans les couches de terre du tell sabéen primitif. Voir aussi A. de Maigret dans Robin et de Maigret 2009, 70.

61 A. de Maigret fait fort justement remarquer que les couches supérieures du tell sabéen ont été aménagées et que cette date du VIII ${ }^{\mathrm{e}}$ siècle ne correspond pas à celle de l'érection de la muraille minéenne, plus tardive, Robin et de Maigret 2009, 71.

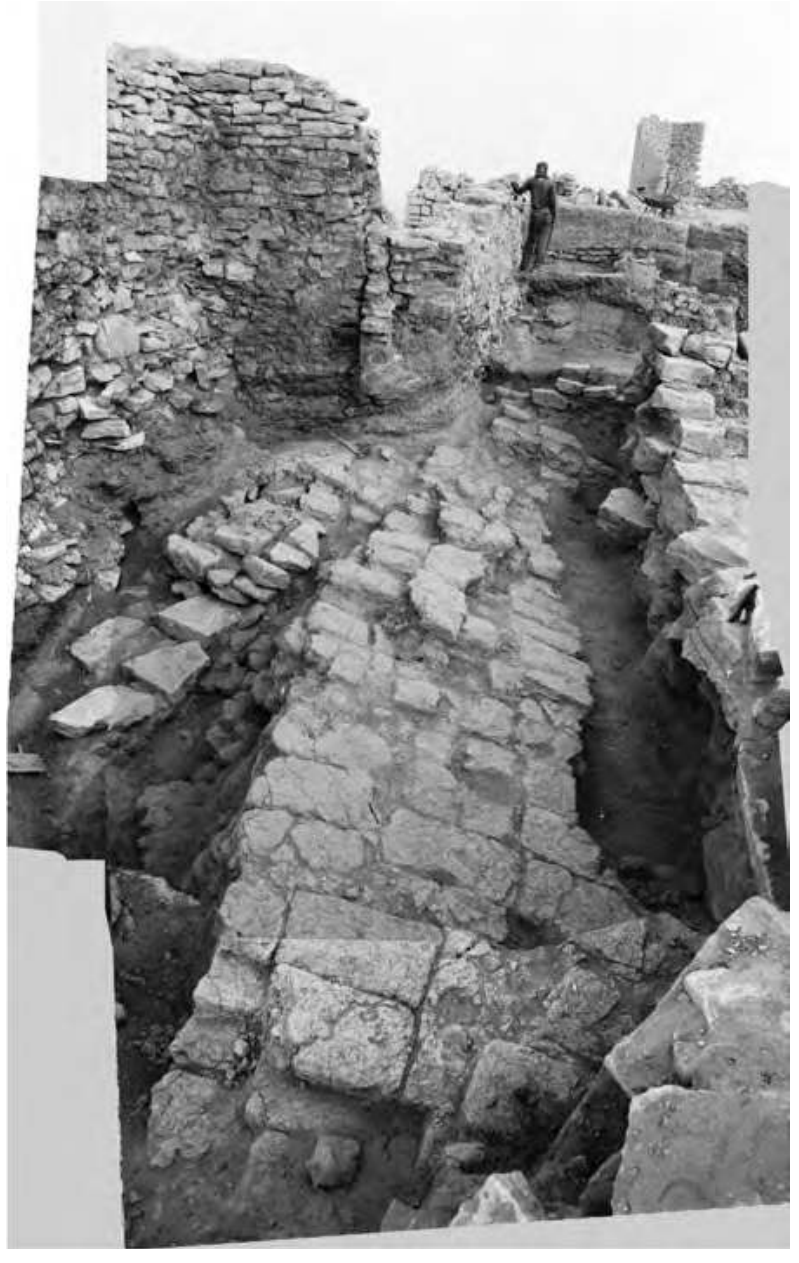

Figure 1. Vue longitudinale de la fortification de Barāqish, avec le sommet du massif de briques crues et ses deux parements de pierre intérieur (à droite) et extérieur (à gauche). (Assemblé par F.G. Fedele à partir de deux photos originales de Maigret 1989-1990, 2019 CMAIRY)

les noms et les ordres des commanditaires ainsi que les travaux réalisés. ${ }^{62}$ Il s'agit de fortifications dont l'âme construite, cachée, est construite en briques. Une énergie couteuse en homme a été nécessaire pour réaliser les millions de briques cuites au soleil qui ont permis de réaliser ces massifs impressionnants. La composition des murailles fait appel, certes, à plusieurs matériaux, terre crue, pierre et bois ${ }^{63}$ indissociables dans leur mise en œuvre, mais c'est par la variété des dispositifs architecturaux que se distingue ce type de construction. Il n'existe pas deux enceintes identiques, chaque ville a réalisé des variantes d'un type luimême assez vague dans ses définitions. On retrouve partout des combinaisons différentes entre courtines, tours et portes. On peut s'accorder sur le fait que la

\footnotetext{
62 Robin $1979 b$.

${ }^{63}$ Le bois a été largement utilisé pour la réalisation des échafaudages dont on retrouve les traces en négatif dans de nombreux trous de boulins.
} 


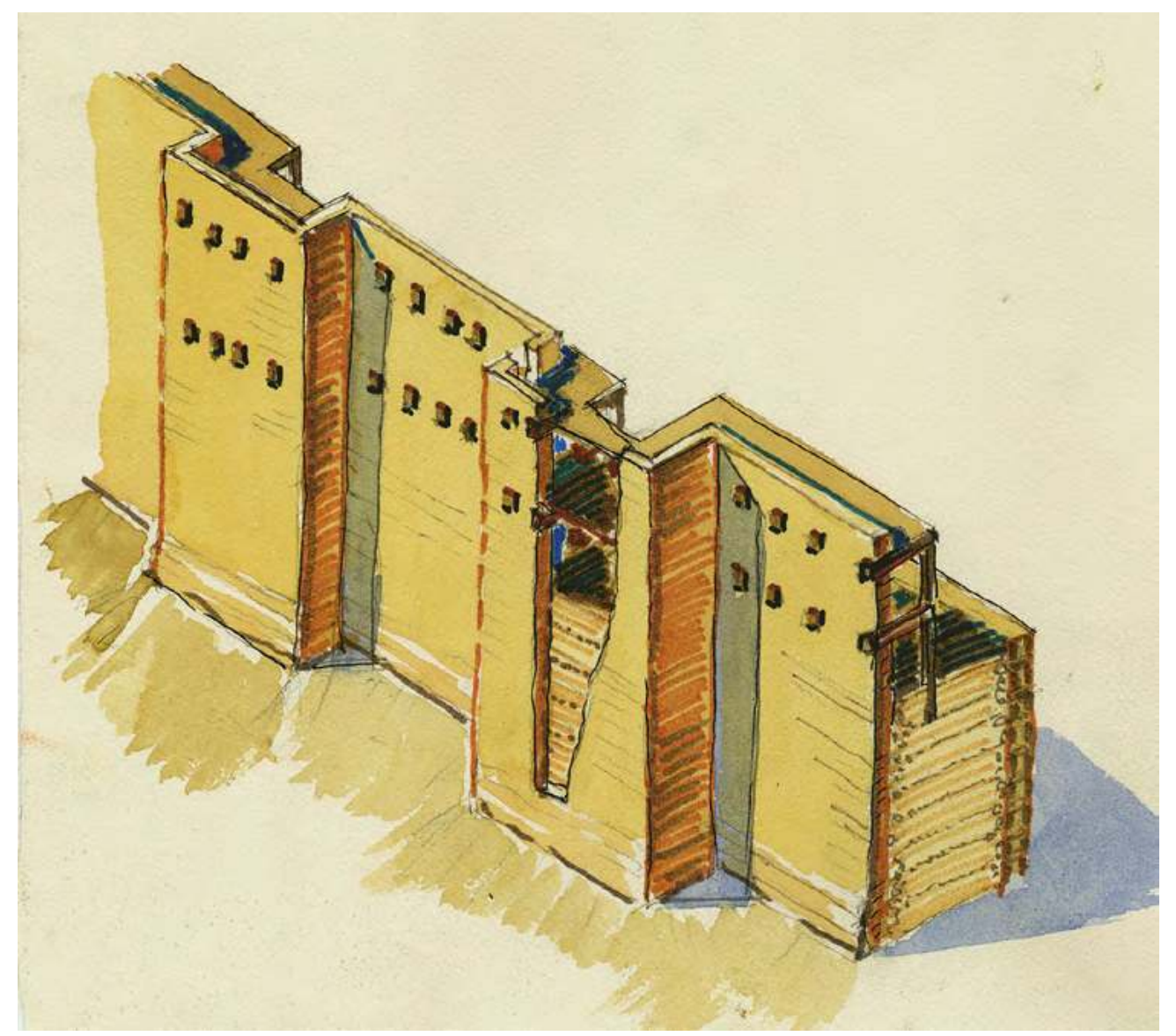

Figure 2. Hypothèse d'une vue extérieure restituée en écorché de l'enceinte de Barāqish avec le massif interne en brique crue et la superstructure en bois du couronnement. (C. Darles 2019)

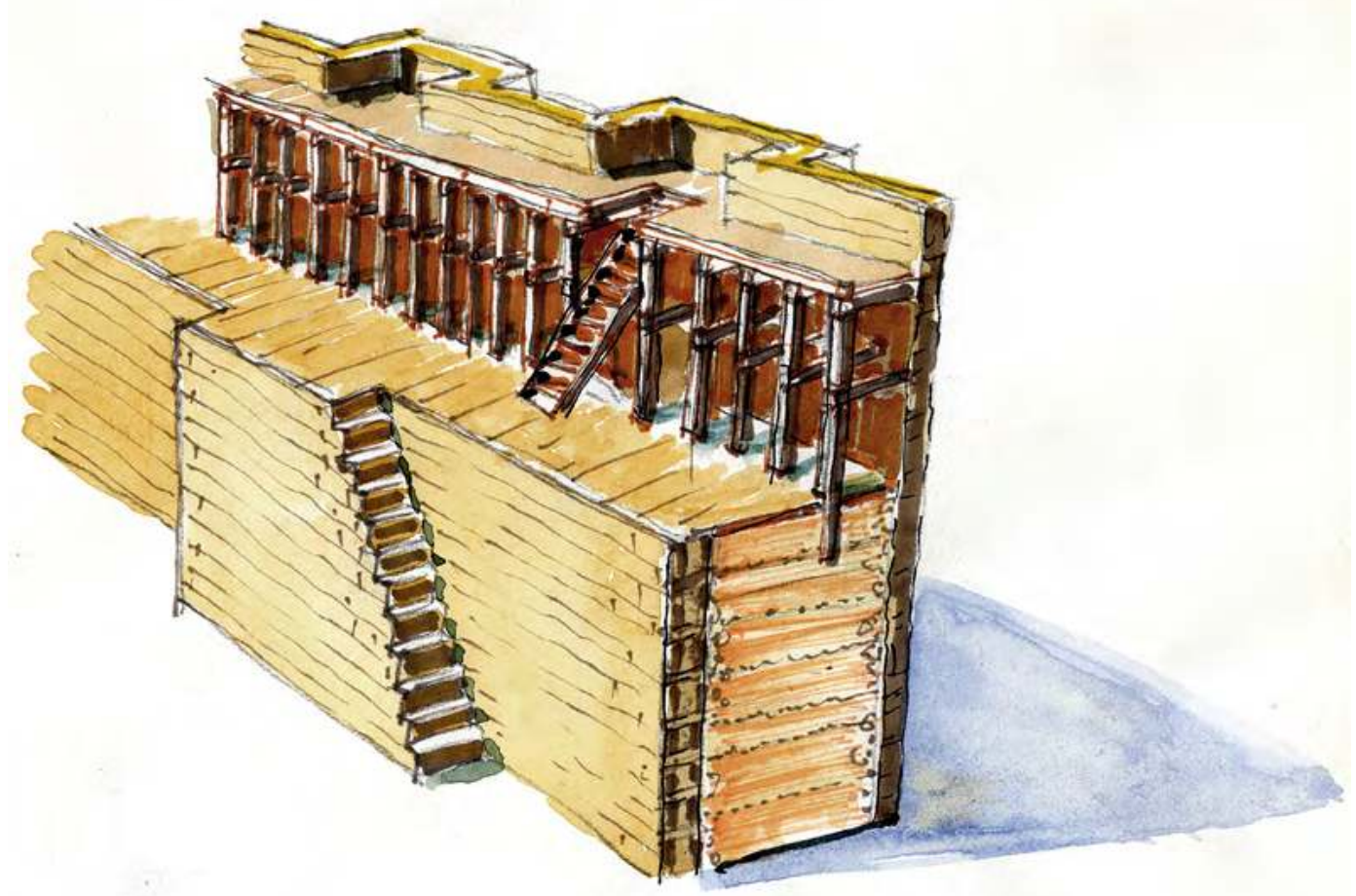

Figure 3. Hypothèse d'une vue intérieure restituée en écorché montrant les principes constructifs. Le rempart est avant tout construit avec des briques crues parementées en moyen appareil de pierre. Le couronnement est bâti avec des pièces de bois ancrées dans le massif de terre. (C. Darles 2019) 
topographie des sites choisis pour implanter les cités a influé sur la forme des enceintes et l'emplacement des dispositifs également que les dimensions ont pu changer au fil des siècles. ${ }^{64} \mathrm{Il}$ n'en reste pas moins que la hauteur des tours, le couronnement des courtines et la forme des portes et poternes correspondent à des choix locaux et à des initiatives personnelles de commanditaires particulièrement au fait. Les ouvrages eux-mêmes ont été bâtis par des constructeurs experts. Les parallèles qu'entretient l'architecture militaire avec celle des lieux de dévotion et de «l'habitat de luxe » sont manifestes. Les travaux sont effectués avec des matières premières sélectionnées transformées en matériau de construction de qualité eux-mêmes mis en œuvre pour des programmes complexes par des ouvriers experts. Les temples sont souvent cernés par un enclos fortifié porteur de longues inscriptions comme le temple Awwām à Mārib ou comme celui d'Almaqah à Șirwāh dont la décoration en frise d'ibex se retrouve régulièrement aux sommets de nombreux édifices comme le temple de Yeha. ${ }^{65}$
64 A Shabwa, plusieurs enceintes ont été édifiées en s'adaptant à l'agrandissement des zones à protéger (Darles 2003 et Darles 2008). A Barāqish, les archéologues italiens ont bien démontré que la ville minéenne est plus petite en surface que la ville protégée par le souverain sabéen Karib'īl Watār (Fedele 2010 et Fedele 2011a, C. Robin dans Robin et de Maigret 2009, 76 et suiv.)
65 Gerlach 2012. 


\title{
Restoration: \\ Temples A and B
}

\author{
Chapter 13
}

\section{Restauro conservativo e strutturale degli elementi architettonici della sala ipostila del Tempio di Nakrạ̣ (Tempio A) a Barāqish}

\author{
Saverio Bruno Scigliano e Alessandra Paladino
}

\section{Introduzione}

Nei mesi compresi tra ottobre 2003 e febbraio 2004 sono stati realizzati i lavori di restauro strutturale e conservativo degli elementi architettonici della sala ipostila del Tempio di Nakrạ a Barāqish.

Il tempio si trova presso il lato meridionale della cinta muraria della città, orientato secondo l'asse NO-SE. L'intero complesso architettonico occupa un'area di circa $15 \mathrm{~m}$ in larghezza e $19 \mathrm{~m}$ in lunghezza, compresi il propileo e la scalinata di accesso.

Il tempio, al momento del nostro intervento di restauro, si presentava ben leggibile, nonostante una parte degli elementi architettonici fosse andata perduta. L'edificio è costituito da una sala ipostila e da un'area antistante l'ingresso principale, dove un'ampia scalinata porta sulla piattaforma del propileo. Longitudinalmente al perimetro SE, tra la sala ipostila e le mura della città, si delimita la cosiddetta 'sacrestia', comunicante con l'interno del tempio attraverso una porta laterale e per mezzo di una scaletta in blocchi di pietra. L'accesso alla sala ipostila dalla sacrestia è ricavato da una porta alta e stretta, costituita da due stipiti in pietra calcarea, incassati alle due pareti frontali in blocchi di pietra, decorati a picchiettatura all'interno di una cornice liscia. ${ }^{1}$

Sullo stipite d'ingresso principale poggiavano gli elementi della copertura del tempio - purtroppo andati perduti - che costituivano il portico d'ingresso del propileo.

La sala ipostila è divisa in cinque navate longitudinali (v. fig. 6), ripartite in quattro triple file di pilastri in monoblocchi di pietra calcarea. La larghezza della

\footnotetext{
1 Per questo tipo di lavorazione, 'marginally drafted, pecked masonry', cfr. Van Beek 1958.
}

navata centrale è di $\mathrm{m}$ 1,70 circa, mentre le navate laterali risultano più strette di $20 \mathrm{~cm}(\mathrm{~m} \mathrm{1,50)}$.

I dodici pilastri, insieme al perimetro murario in blocchi di pietra, costituiscono la struttura di sostegno dell'articolata copertura in materiale lapideo. I pilastri, perfettamente squadrati e decorati a picchiettatura, raggiungono un'altezza media di $4 \mathrm{~m}$, con una sezione di $40 \mathrm{~cm}$.

Percorrendo la navata centrale, nel primo ambiente a $O$, tra la parete esterna frontale ed una parete interna che ingloba i primi due pilastri, vi è un corridoio per mezzo del quale si accede alla 'sacrestia'. Nella navata $\mathrm{E}$, su di un piano rialzato è posta una delle tre tavole offertorie corredate di panche in blocchi di pietra. Nelle navate laterali, poco più avanti si sono conservate altre due tavole offertorie in pietra calcarea, decorate frontalmente a stambecchi recumbenti, mentre al di sotto è un'iscrizione.

L'area delle navate a seguire si mantiene sullo stesso piano pavimentale del corridoio centrale. In quest'area, tra i cenacoli e il piano più rialzato della cella centrale avvenivano i rituali, testimoniati dal sistema di canalette di scolo dei liquidi che confluivano nella canaletta principale, verso la parete esterna orientale del tempio (v. Darles, capitolo 10 in questo volume, figg. 6-9).

Su un piano rialzato, nell'area meridionale della sala ipostila, si aprono in tutto cinque ambienti: due loci su ciascun lato della cella centrale. Di questi ambienti, è rimasta parzialmente conservata solo la cella centrale, larga come la navata centrale, costituita dal muro esterno ricostruito in epoca islamica e da due pareti laterali, allineate ai pilastri della navata centrale. All'ingresso della cella centrale rimane conservato lo stipite di sinistra verticale e quello superiore orizzontale, in pietra calcarea, oltre ad un architrave sostenuto dai due muri laterali. 
All'interno della cella, nel pavimento si nota ancora l'incavo nel quale si presume alloggiasse un altare.

Tutta la sala ipostila era completamente coperta da un sistema articolato di pesanti travi principali e secondarie (simili per lavorazione ai pilastri), intervallate da metope, sulle quali poggiavano le lastre di pietra calcarea della copertura.

Purtroppo l'edificio sacro rimase compromesso da un grave e generale cedimento del piano della costruzione verso il lato NE, avvenuto in epoca ancora imprecisata. Come verrà specificato più dettagliatamente nel capitolo sullo Stato di conservazione, l'inclinazione del piano di $c .5^{\circ}$ verso NE coinvolse tutti gli elementi architettonici, in particolar modo i dodici pilastri in pietra calcarea che sostenevano gli elementi della copertura (travi principali, travi secondarie, metope e lastre di copertura).

Le precarie condizioni statiche e strutturali dei pilastri inclinati costrinsero, nel 1992, la direzione dei lavori a rimuovere provvisoriamente tutti gli elementi della copertura, per poter continuare i lavori di scavo.

Si rese dunque necessario alleggerire i dodici pilastri dal peso della copertura per eliminare la terra contenuta all'interno del tempio, che ricopriva i pilastri fino a tre quarti circa dell'altezza. Tutti gli elementi della copertura furono in quel frangente rimossi e collocati provvisoriamente fuori dal tempio (v. Antonini e Fedele, capitolo 1 in questo volume, fig. 40), dove rimasero fino al nostro intervento di restauro e ricostruzione dell'intera struttura nel 2003.

I dodici pilastri della sala ipostila vennero messi in sicurezza all'interno di una struttura di tubi metallici appositamente portati dall'Italia (tipo 'Innocenti').

Nel febbraio del 2003 è stato possibile effettuare un primo sopralluogo nel tempio per stabilire le reali condizioni di degrado del monumento architettonico. In quella occasione è stata realizzata una dettagliata documentazione fotografica delle tipologie di degrado, finalizzata alla imminente realizzazione di un progetto tecnico di restauro.

La situazione più preoccupante apparsa fin dal primo sopralluogo era costituita dall'inclinazione di tutto l'edificio verso l'angolo NE, imputabile al cedimento del piano pavimentale (fig. 1). Probabilmente gran parte dei danni riscontrati nella struttura e nei singoli elementi architettonici sarebbero riconducibili al movimento monodirezionale, dovuto forse a movimenti tellurici che in passato avrebbero compromesso gli equilibri di staticità del tempio. Ad impensierire erano soprattutto le gravi fratture passanti, con distacco totale che interessavano quattro dei dodici pilastri, ed una trave principale, oltre che la precaria stabilità della cella centrale e gli stipiti d'ingresso particolarmente danneggiati.

Altri aspetti importanti da tenere in considerazione erano le condizioni climatiche ed ambientali, le elevate temperature, le variazioni termo-igrometriche, l'irraggiamento del sole, l'azione erosiva del vento e della sabbia, cui furono - e sarebbero stati - continuamente esposti sia il materiale costitutivo originale, sia i prodotti di restauro (adesivi, perni, malte, consolidanti e protettivi). ${ }^{2}$

Nei mesi successivi, fino a settembre del 2003, fu redatto un meticoloso progetto tecnico di restauro che prevedeva il seguente piano di interventi:

1. Rilievi grafici delle dimensioni e delle quote di tutti i pilastri in relazione al piano pavimentale inclinato, da effettuare per mezzo di una Stazione Totale di rilevazione;

2. Consolidamento coesivo della superficie lapidea interessata da fenomeni di polverizzazione e disgregazione;

3. Risanamento dei pilastri fratturati e lesionati mediante adesione e imperniazione;

4. Correzione dell'asse verticale dei pilastri mediante la rimozione provvisoria degli stessi con l'ausilio di un carro-gru, la realizzazione di una corretta base d'appoggio artificiale in piano orizzontale e la successiva ricollocazione in perfetto asse verticale;

5. Risanamento delle fratture e delle aree disgregate degli stipiti del portale del tempio;

6. Verificadella funzionalità statica e risistemazione della cella centrale;

7. Risanamento delle fratture della trave principale e integrazione lapidea dell'architrave della cella centrale;

8. Riconoscimento e numerazione, in base alle foto di scavo, di ogni singolo elemento della copertura precedentemente rimosso, in funzione della ricollocazione nell'esatta posizione originale;

9. Ricollocazione di tutta la copertura nella sede originale;

10. Risistemazione di due iscrizioni;

11. Restauroeconsolidamentodella pavimentazione;

12. Presentazione estetica e trattamento con protettivo finale.

Attraverso un primo progetto, è stato possibile realizzare una lista quantitativa e qualitativa dei

\footnotetext{
2 A questo proposito, vorrei sottolineare che interventi di restauro di opere architettoniche in stato di protratto abbandono, con problematiche così gravi, in condizioni ambientali così estreme, non possono essere considerati risolutivi di per sé e che un attento controllo ed una assidua manutenzione sono assolutamente indispensabili per la sopravvivenza delle opere stesse.
} 
materiali di consumo e dell'attrezzatura specialistica per il cantiere di restauro. Tutti i prodotti specifici per il restauro non reperibili nello Yemen sono stati ordinati a Roma ed inviati nel mese di aprile 2003 con un container per via mare.

Le varie fasi d'intervento, prima, durante e dopo, sono state documentate fotograficamente e in mini video digitali.

Gli interventi di restauro descritti in questa relazione furono finalizzati principalmente a risolvere le gravi problematiche strutturali della sala ipostila, in funzione della ricollocazione nella sede originale degli elementi della copertura, precedentemente rimossi. Attraverso le immagini degli interventi effettuati è possibile comprendere più chiaramente il lavoro complessivo svolto, mirato al recupero dell'edificio templare.

I restauri effettuati al tempio di Nakrah, oltre ad aver valorizzato ulteriormente l'aspetto storicoarchitettonico di notevole interesse archeologico, permisero di rendere merito alla sua unicità, caratterizzata dall'articolata copertura, ancora conservata quasi integralmente.

\section{Ringraziamenti}

Gli interventi di restauro del tempio di Nakrah furono realizzati sotto l'attenta direzione del Prof. Alessandro de Maigret, capo della Missione Archeologica Italiana nella Repubblica dello Yemen. A lui esprimiamo tutta la nostra stima per il supporto scientifico, per la perfetta organizzazione logistica e per il reperimento del personale specializzato yemenita (del GOAM e i militari di stanza a Barāqish), che con competenza ha collaborato al cantiere di restauro.

Al topografo Mario Mascellani manifestiamo la nostra gratitudine, oltre che per tutta l'organizzazione del campo di Barāqish, per il supporto tecnico-scientifico di rilevazione con la Stazione Totale, indispensabile per la riuscita del lavoro. Ad entrambi, scomparsi (14 febbraio 2011 e 11 settembre 2015), rivolgiamo un nostro affettuoso ricordo.

Ringraziamo la dott.ssa Sabina Antonini, Direttrice del Centro Italo-Yemenita per le Ricerche Archeologiche (YICAR) a Șan'ā', per il suo contributo storico-artistico, e per tutto il supporto logistico e organizzativo a Șan $(\bar{a})$. Si ringraziano, inoltre, gli archeologi dott. Rosario Valentini, dott. Romolo Loreto e dott. Alessio Agostini ed ai due allora studenti in archeologia dell'Università di Napoli 'L'Orientale' Danilo Mongiello e Marta Passarelli che parteciparono all'esecuzione dei lavori.

Un ringraziamento particolare agli allora Ambasciatori nello Yemen, Giacomo Sanfelice di Monteforte e Mario Boffo, e a tutto il personale dell'Ambasciata d'Italia per il calore con il quale ci accolsero e resero più gradevole la nostra permanenza nello Yemen.

\section{Stato di conservazione}

\subsection{Sala ipostila}

Il Tempio di Nakrah versava in gravissime e preoccupanti condizioni di degrado, sia di natura strutturale che statica. Appariva evidente il cedimento del piano pavimentale e la rotazione di tutti gli elementi architettonici in direzione NE (muri perimetrali portanti, pareti interne, pilastri, arredi e pavimentazione). L'ipotesi di un movimento monodirezionale verso NE dei vari componenti architettonici è accreditabile ad una forte scossa sismica con spinta orizzontale che ha provocato di conseguenza il cedimento del terreno sottostante.

I risultati di alcuni carotaggi eseguiti fino ad una profondità di $8 \mathrm{~m}$ (v. Fedele, capitolo 15 in questo volume), hanno documentato una lunga frequentazione della città in epoca sabea. Questi dati furono in seguito confermati dal sondaggio stratigrafico condotto da Alessandro de Maigret ai piedi della scalinata del tempio di Nakrah. ${ }^{3}$ Ciò avvalorerebbe la tesi di assestamenti sottostanti provocati durante una scossa sismica di forte entità che spiegherebbe in questo modo lo 'slittamento' violento verso un unico punto a NE e la consistente inclinazione di $c .5^{\circ}$ di quasi tutto l'edificio.

Tale slittamento è testimoniato anche nella parete frontale di sinistra della controfacciata. Osservando la parete a destra della porta d'ingresso, dall'interno (fig. 2), possiamo notare che la parete a partire dal quarto blocco di pietra dal basso è scivolata verso l'angolo a NE, mentre lo stipite verticale si è soltanto inclinato autonomamente. Le conclusioni più probabili sono che un tale slittamento non deve esse avvenuto gradatamente, ma tramite una sollecitazione violenta ed intensa dovuta forse a più fattori concomitanti.

Abbiamo voluto soffermarci su questo particolare per rendere più chiara la gravità dei danni scaturiti dall'abbassamento del piano pavimentale e della conseguente inclinazione di tutte le strutture portanti verso NE.

Oltre alle serie problematiche strutturali e statiche imputabili al cedimento del piano pavimentale (che hanno comunque rappresentato le difficoltà maggiori in funzione della risistemazione della copertura), il monumento era soggetto a tipologie di deterioramento del materiale costitutivo, legato a fenomeni atmosferici,

\footnotetext{
3 de Maigret 2010a.
} 
climatici e ambientali più comuni, oltre che alla naturale alterazione del materiale lapideo.

Per descrivere più dettagliatamente le condizioni di degrado in cui versava il tempio prima del restauro, abbiamo ritenuto opportuno trattare singolarmente e per tipologie gli elementi architettonici.

\subsection{Pilastri}

I dodici pilastri, come tutta la struttura architettonica del tempio, dal pavimento ai muri, agli stipiti, alle tavole offertorie e ai sedili in blocchi di pietra, si presentavano inclinati verso NE. Dai rilevamenti effettuati con la Stazione Totale è stato riscontrato un errore dell'asse verticale da $5^{\circ}$ a $6^{\circ}$. Inoltre, dai grafici restituiti dalle misurazioni con uno strumento al laser, attraverso la Stazione Totale si è potuto osservare che le sovrapposizioni delle sezioni superiori a quelle inferiori, anziché essere combacianti, risultavano notevolmente sfalsate tra loro (fig. 3). ${ }^{4}$

Le rilevazioni hanno consentito di verificare la differenza di quote delle sezioni superiori dei pilastri, e di conseguenza lo stato di fatto del piano orizzontale, sede della copertura. I tre pilastri della navata di sinistra (NE), pur avendo le stesse dimensioni, denotavano un dislivello delle sommità da $20 \mathrm{~cm}$ fino a $30 \mathrm{~cm}$ rispetto ai tre pilastri della navata di destra (SO). Tale differenza era dovuta alla conseguente inclinazione di tutto il piano pavimentale della sala ipostila verso NE che ovviamente si ripercuoteva anche sul piano superiore della copertura. Tutti i pilastri si presentavano, dunque, con una inclinazione tale da non poter consentire una corretta funzione statica, né autoportante, né strutturale nei confronti degli elementi della copertura da sorreggere.

I pilastri, oltre ad avere una precaria stabilità di natura statica, si presentavano compromessi da un

\footnotetext{
4 Il procedimento, eseguito da Mario Mascellani, è stato quello di effettuare un rilievo plano-altimetrico delle basi dei dodici pilastri a livello del pavimento; quindi, attraverso uno sviluppo poligonale, è stata lanciata una stazione topografica esterna al tempio che ha permesso il rilievo della parte superiore degli stessi pilastri. Nella fase di elaborazione dei dati, la sovrapposizione dei due rilievi ha creato un modello di facile interpretazione, sia per il calcolo dell'inclinazione dei pilastri, sia per lo spessore da aggiungere agli stessi, al fine di ottenere una quota omogenea dell'intera struttura. La verifica del lavoro è avvenuta con il rilievo di alcuni pilastri, presi a campione, e calcolando tutte le loro dimensioni. Di questi è stato fatto anche un rilevamento verticale per ricavarne la pendenza. La stessa metodologia è stata applicata per la messa in opera delle travi. Ogni singola trave, infatti, dopo essere stata misurata, è stata sovrapposta ai vari pilastri e realizzato un modello virtuale in AutoCAD dove veniva visualizzata l'intera struttura oggetto del restauro. Il rilievo topografico è stato realizzato con una Stazione Totale Elettronica PENTAX serie $315 \mathrm{~N}$ con un distanziometro laser fino a $220 \mathrm{~m}$. I dati sono stati elaborati con il software topografico GEOWIN della Veronesi di Bologna. I vettoriali, infine, ricavati e trattati con AutoCAD 14 e AutoCAD 2002.
}

punto di vista strutturale. Ben otto dei dodici pilastri presentavano, infatti, lesioni orizzontali e verticali, fratturazioni parziali che coinvolgevano due o tre lati. Quattro pilastri versavano in uno stato di degrado peggiore, con fratture passanti e conseguente distacco totale; due di questi con doppia frattura e distacco totale.

In queste condizioni di estremo degrado, sia da un punto di vista strutturale, sia per la 'scorretta' posizione verticale, completamente fuori asse, i pilastri rappresentavano il problema principale per il ripristino della configurazione architettonica completa, cioè la possibilità di ricollocare tutti gli elementi della copertura originale, documentata e rimossa dal Professore Alessandro de Maigret e dell'Architetto Giuseppe Tilia durante la campagna di scavo del 1992.

Per quanto riguarda lo stato di degrado del materiale costitutivo degli elementi architettonici, composto da pietra calcarea, si può dire che nel complesso lo stato di conservazione era buono. È stato riscontrato un lieve e disomogeneo fenomeno di decoesione ed esfoliazione superficiale, fortunatamente solo su alcuni pilastri. Sette dei dodici pilastri evidenziavano un particolare fenomeno di ossidazione, di colore rossiccio (ossido di ferro), forse dovuto ad alcune lampade ad olio appese ai pilastri, o forse per incendi avvenuti durante l'occupazione in epoca islamica, testimoniati dalle sezioni stratigrafiche di scavo, che coinciderebbero, in altezza, alle aree dei pilastri interessati da questo fenomeno.

\subsection{Stipiti del portale d'ingresso}

Anche i due stipiti del portale d'ingresso sono costituiti di pietra calcarea di formazione sedimentaria con inclusi organici (calcare 'a lumachelle') (v. Darles, capitolo 10 in questo volume, fig. 23). Gli stipiti presentavano un diffuso segno di decoesione ed un avanzato e grave deterioramento del materiale costitutivo con esfoliazione accentuata, ma soprattutto un preoccupante fenomeno di disgregazione di particellato lapideo, in modo particolare sulle aree superiori degli stipiti. Su alcuni lati degli stipiti erano visibili venature verticali di colore giallo-ocra scuro; si è notato, inoltre, che il materiale costitutivo di queste venature era particolarmente più fragile e di consistenza più tenera rispetto al resto. Il fenomeno di disgregazione riscontrato soprattutto sulle parti superiori degli stipiti si presentava in forme analoghe in prossimità delle venature precedentemente descritte. Da queste considerazioni abbiamo dedotto che la disgregazione riguardava soprattutto la presenza di stratificazioni di pietra più tenera, rafforzata dal fatto che la pietra dove si disgregava era di colore giallo-ocra scuro. 
Le aree maggiormente colpite da questo fenomeno di degrado erano le parti superiori che si presentavano con quattro o cinque strati di materiale lapideo disgregato e ricompattato all'interno di più fessurazioni. Alcune di queste fessurazioni, con all'interno materiale lapideo disgregato, evidenziavano uno spessore fino a $7 \mathrm{~cm}$, profonde circa $1 \mathrm{~m}$ e interessavano la larghezza totale della parte superiore dello stipite. La presenza di fratture in prossimità delle fessure farebbero credere che siano state in parte causate dal crollo di alcuni elementi della copertura del propileo. In seguito, l'esposizione all'erosione del vento ha contribuito a disgregare ulteriormente il materiale lapideo, così come la rara ma letale azione dall'acqua piovana ha determinato la formazione di piccoli canali interni alla pietra. Il materiale lapideo all'interno di queste falde si presentava completamente frammentato, disgregato, di consistenza simile ad una pietra arenaria molto tenera, con almeno il 50\% di materiale costitutivo andato perduto.

Nella parte superiore dello stipite sinistro era evidente una frattura quasi totale, con dislocazione di una porzione considerevole di materiale lapideo con pericolo di crollo. Nella parte interna dello stipite sinistro, a metà altezza circa erano presenti quattro fratture parziali, orizzontali.

Le parti basse degli stipiti presentavano esfoliazione superficiale, qualche lieve frattura, otre a piccole parti disgregate con perdita di particellato originale. Parte della superficie complessiva degli stipiti era interessata da un antico attacco biologico di colore nero, puntiforme (probabili licheni).

Anche i due stipiti, come tutti gli altri elementi architettonici del tempio erano stati compromessi dal cedimento del piano pavimentale verso $\mathrm{NE}$, evidenziando una forte inclinazione di circa $5^{\circ}$, provocando di conseguenza tutte le fratture riscontrate e descritte.

\subsection{Cella centrale}

La cella centrale posta nell'area meridionale del tempio è l'unica dei cinque ambienti ancora in gran parte conservata. Sono sopravvissuti parzialmente i due muri divisorî, costituiti da 14 file orizzontali in blocchi di calcare, decorati a picchiettatura. Nella parte superiore dei due muri, in prossimità delle cinque file più in alto, rimanevano conservate solo due o tre blocchi di pietra per ogni fila. Molti dei blocchi di pietra nella parte superiore dei due muri presentavano fratture multiple e alcune con distacco. Le condizioni strutturali e la funzione statica delle due pareti erano alquanto precarie.
Alti circa m 3,70 e con una sezione di circa $40 \mathrm{~cm}$, i due muri sopravvivevano con l'asse verticale inclinato di $5^{\circ}$ verso NE. Le due fragili pareti sostenevano ancora una trave in pietra calcarea, simile agli elementi della copertura. Su di essa poggiavano le estremità di due travi principali, che a loro volta sostenevano gli altri elementi della copertura (smontati provvisoriamente nel 1992). I due muri, dunque, avrebbero dovuto svolgere una funzione strutturale non indifferente.

La parte bassa del muro di destra era stata integrata con blocchi di pietra di diverso taglio e diversa lavorazione, probabilmente in epoca islamica.

All'interno delle due pareti che dividono la cella centrale era ancora conservata la cornice verticale di sinistra dello stipite, mentre l'architrave della cornice era stata rimossa dopo gli scavi del 1992. Anche la cornice seguiva l'andamento inclinato del muro est sul quale poggiava.

Essa evidenziava, oltre ad un fenomeno di decoesione superficiale, anche una frattura orizzontale nella parte in basso, risanata da un intervento di restauro eseguito nel 1992.

\subsection{Copertura}

Gli elementi della copertura del tempio (travi primarie, travi secondarie, metope e lastre di copertura) rimossi nel 1992 e collocati provvisoriamente fuori dal tempio (v. Antonini e Fedele, capitolo 1 in questo volume, fig. 40), versavano in uno stato di conservazione tutto sommato buono. Solo una delle due travi primarie, lunga $\mathrm{m} \mathrm{4,5}$, si presentava fratturata in due parti già prima dello scavo. Tutte le altre travi primarie ed anche le secondarie non riscontravano problemi di carattere strutturale. Il materiale costitutivo, come per i pilastri, si presentava in buono stato di conservazione, tranne qualche lieve fenomeno di esfoliazione e di decoesione poco diffusa su qualche singola trave in particolare.

Le metope ritrovate perfettamente integre nelle dimensioni originali erano circa una decina, alcune delle quali si presentavano con piccole parti mancanti; altre metope erano conservate solo in frammenti. Siamo riusciti ad individuarne soltanto 14 da poter ricollocare successivamente.

Delle 22 lastre di copertura, ancora in buono stato di conservazione e con delle dimensioni idonee per la sicura ricollocazione, 3 si presentavano fratturate in due parti, mentre una soltanto con una lesione trasversale.

\subsection{Iscrizioni}

Dei molti elementi degli arredi presenti nella sala ipostila del tempio, ci siamo potuti occupare soltanto 
della risistemazione di due importanti iscrizioni rinvenute durante lo scavo del 1992.

Una lastra di forma rettangolare iscritta è stata collocata in basso, tra un pilastro ed una banchetta verso il muro orientale, in prossimità del 'transetto', nell'area adiacente la zona della canaletta di scolo per i rituali. Una seconda lastra più piccola e quadrata è stata sovrapposta alla prima. Quest'ultima, sulla parte superiore, è delimitata da una decorazione con un motivo geometrico a listelli orizzontali (cosiddetto motivo 'a persiana'), e dentelli. La lastra più grande si era conservata bene nel complesso, mentre la seconda evidenziava la perdita di una porzione consistente di materiale lapideo in prossimità dell'angolo inferiore sinistro. Le due lastre iscritte erano state rinvenute durante gli scavi del 1992, sul pavimento nell'area della canaletta di scolo, adiacente al piccolo bacino scavato nella pietra. Lo stato di conservazione delle due lastre era piuttosto buono; il materiale costitutivo mostrava una lieve erosione generalizzata e qualche area interessata da una leggerissima decoesione superficiale.

\subsection{Pavimentazione}

La pavimentazione della sala ipostila è costituita da lastre in pietra calcarea più o meno della stessa natura degli altri elementi costruttivi del tempio. Le lastre hanno dimensioni in larghezza disuguali con uno spessore anche di $50 \mathrm{~cm}$. A parte le lastre sottostanti i pilastri, che hanno la funzione di ammortizzare la pressione di carico dei pilastri e della copertura, le rimanenti lastre svolgono, al contrario, solo una funzione pratica di calpestio.

Come si può immaginare, il cedimento dell'edificio verso $\mathrm{NE}$ con conseguente inclinazione ha interessato in primo luogo la pavimentazione in tutta la sua complanarità. La pavimentazione era interessata da cedimenti differenziati, dove in alcune aree sono visibili lunghe lesioni con una leggera divaricazione, imputabile alla rotazione e al cedimento dell'edificio.

Nel 1992 fu fatto un intervento provvisorio di consolidamento di alcune aree della pavimentazione, tra gli interstizi delle lastre, effettuato con una malta cementizia bianca, a vista, in prossimità delle celle. In questa area del tempio e nel corridoio della navata centrale è stata rilevata la mancanza di tre lastre pavimentali. Molte erano le singole lastre che versavano in stato di disgregazione con esfoliazione e perdita di gran percentuale di materiale costitutivo, soprattutto nella zona antistante le celle. L'avanzato fenomeno di disgregazione era però più presente in alcune lastre che denotavano una minore compattezza già in origine e di conseguenza più predisposte a questo tipo di degrado. Molte altre lastre mostravano un generale ma più lieve fenomeno di decoesione, polverizzazione ed esfoliazione su quasi tutta la superficie pavimentale.

\subsection{Stilobate e scalinata}

Dell'area del propileo erano ancora conservati i quattro grandi blocchi monolitici orizzontali che sorreggevano i relativi pilastri dell'ingresso principale del tempio, oltre a tutta la struttura della scalinata su tre lati. I quattro grandi blocchi orizzontali mostrano ciascuno un quadrato ribassato di un paio di $\mathrm{cm}$ che costituisce la base per l'alloggiamento di ciascun pilastro monolitico del propileo. Nella fig. 4 ne sono visibili 3; nel quarto è alloggiato il pilastro frammentario conservato in situ.

I grandi blocchi lapidei pavimentali dello stilobate - le basi dei quattro pilastri del propileo, del piano superiore della scalinata e dei gradini perimetrali - si presentavano in uno stato di conservazione differenziato, con fenomeni di degrado disomogenei.

I quattro grandi blocchi orizzontali si presentavano, da un punto di vista strutturale, in buono stato di conservazione. Mentre per quanto riguarda tutti gli altri elementi dello stilobate, i grandi blocchi del piano alto della scala, compresi quelli laterali e i gradini perimetrali denotavano un fenomeno di degrado avanzato di decoesione, fino a livelli di disgregazione di materiale costitutivo, purtroppo non solo superficiale.

I fenomeni di degrado più gravi sono stati riscontrati sui blocchi del piano alto della scala, la terrazza antistante l'ingresso del tempio ed i blocchi dei gradini centrali dei lati nord ed est. I blocchi compromessi erano interessati da una preoccupante ed evidente disgregazione che ne ha alterato la morfologia squadrata dei blocchi stessi. Infatti, i blocchi di pietra si presentavano con gli spigoli completamente stondati e consumati, con fenomeni di esfoliazione e scagliatura.

Purtroppo solo uno, e frammentario (la porzione inferiore), dei quattro pilastri del propileo era stato rinvenuto in posizione originale (v. fig. 4); tuttavia, nell'area antistante l'ingresso del tempio era presente a terra un grande pilastro incompleto. Solo in seguito, durante le fasi di scavo è stato ritrovato il secondo elemento mancante e combaciante, che ha consentito di calcolare l'altezza originaria di $m 5,6$. Successivamente, per consentire il proseguimento degli scavi fuori dal tempio e del contemporaneo restauro del tempio stesso, il grande pilastro fu movimentato e collocato a ovest del tempio, lungo M39, ossia la rientranza delle mura di Barāqish, tra i torrioni T44 e T45 (fig. 5, e per la collocazione esatta v. Antonini e Fedele, capitolo 1 in questo volume, fig. 3). 


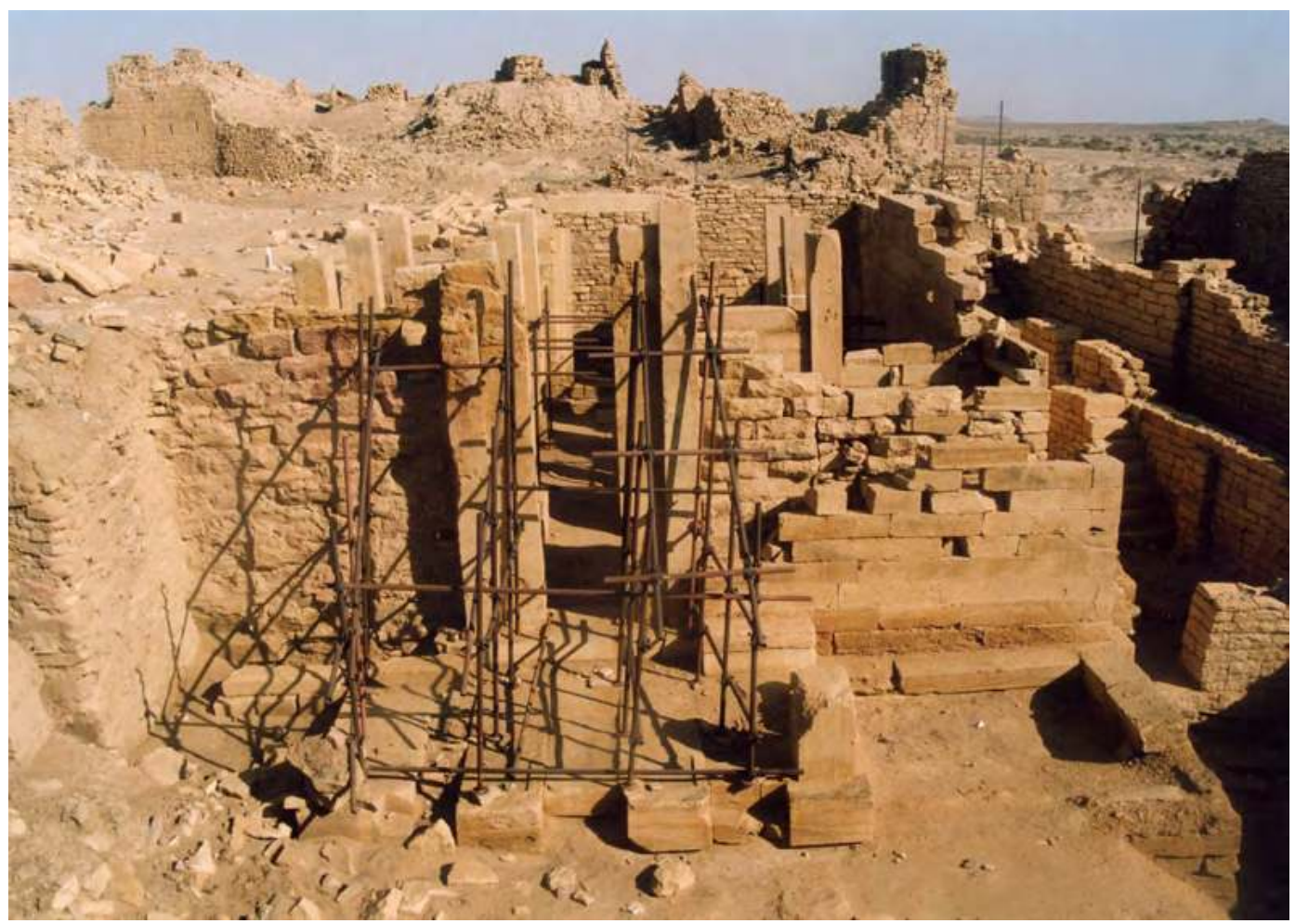

Figure 1. Vista del tempio di Nakrah prima del restauro. Evidente è l'inclinazione verso NE. (S.B. Scigliano 2003 @MAIRY)

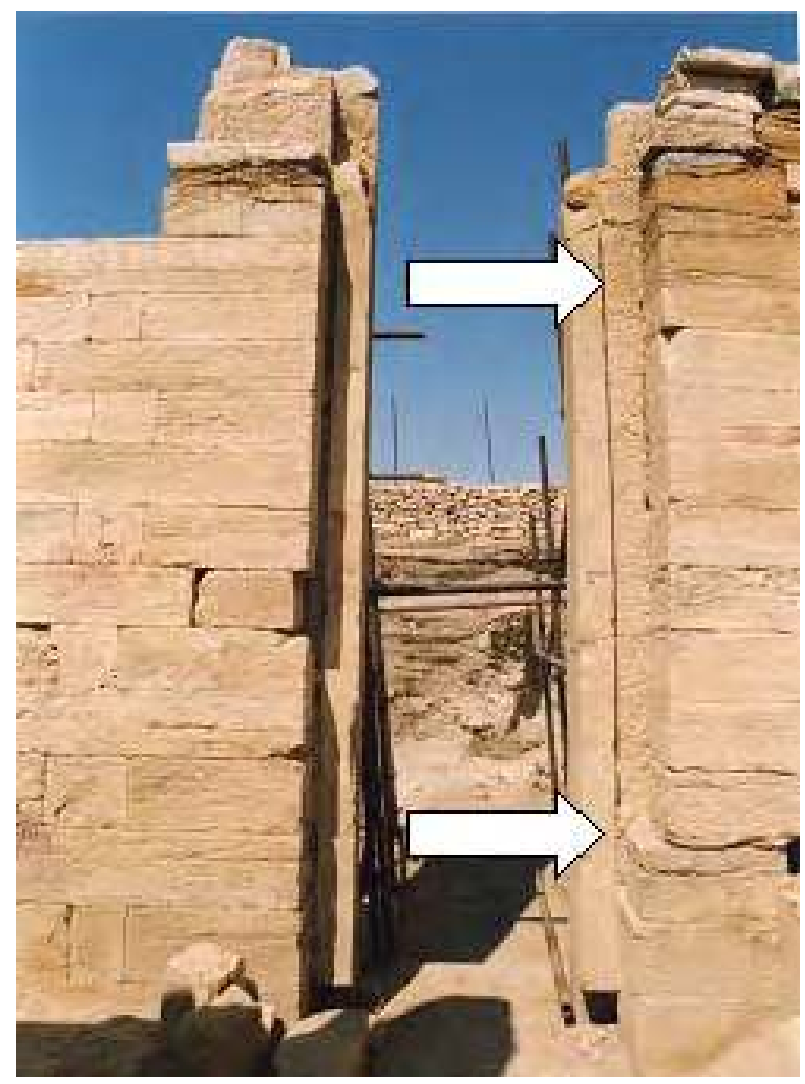

Figure 2. Portale del tempio di Nakrah visto dall'interno. La parete a partire dal quarto blocco di pietra dal basso è scivolata verso l'angolo a NE, e lo stipite verticale è inclinato verso l'interno. (S.B. Scigliano 2003 CMAIRY)

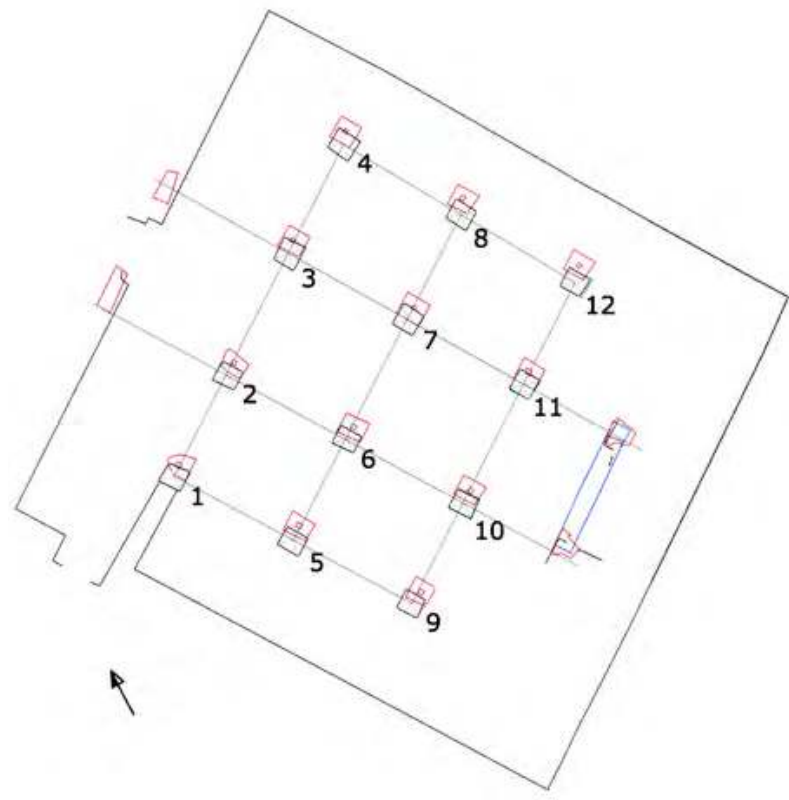

Figure 3. Nella figura si può notare come la sovrapposizione della base superiore (rossa) con quella inferiore (nera) evidenzi non solo una inclinazione del piano verso NE ma anche un ulteriore slittamento verso $\mathrm{N}$, punto dove è avvenuto il maggiore sprofondamento dell'intera struttura. (M. Mascellani 2003 CMAIRY) 


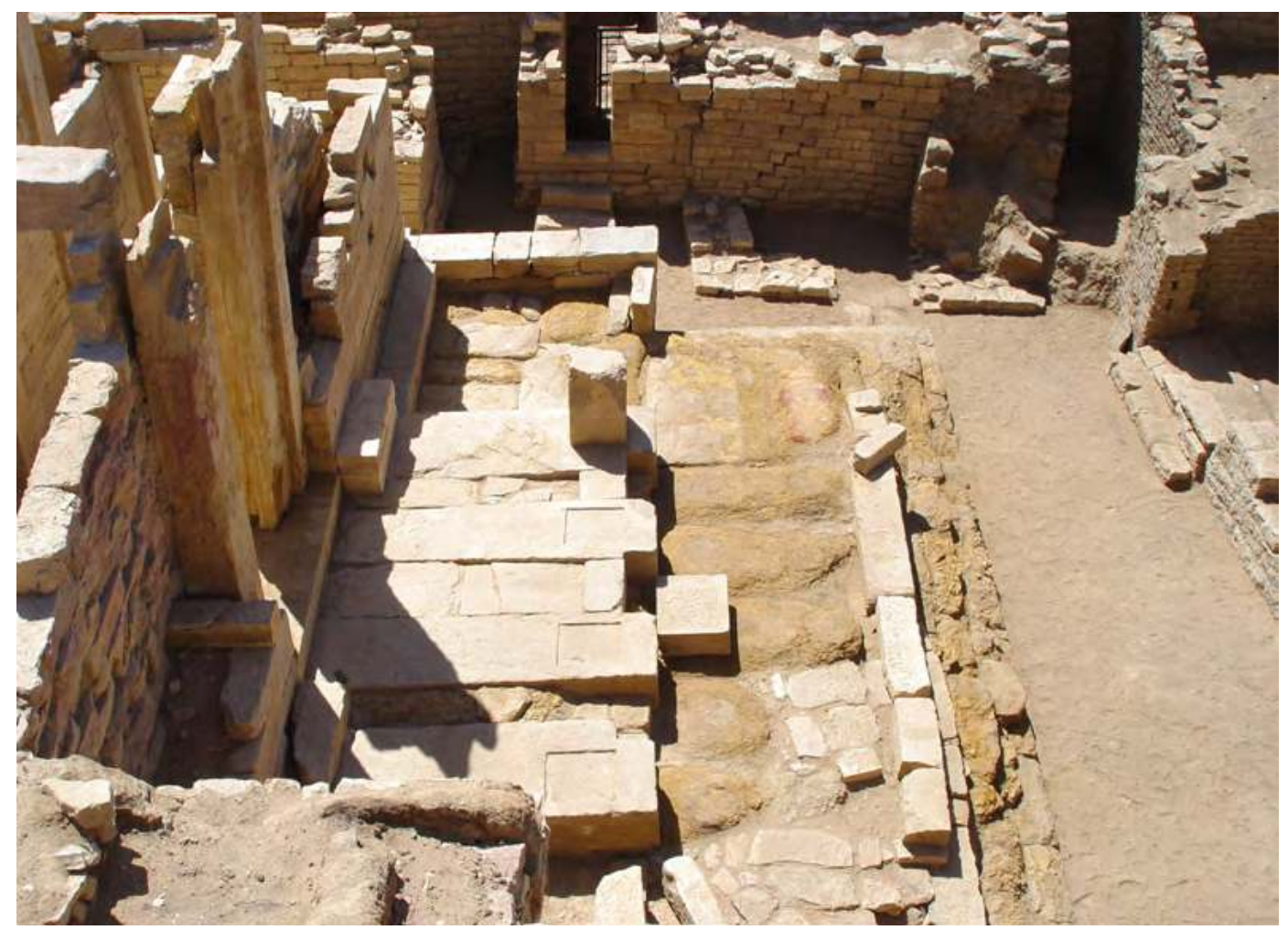

Figure 4. I quattro grandi blocchi orizzontali mostrano ciascuno un quadrato ribassato di un paio di $\mathrm{cm}$ che costituisce la base per l'alloggiamento di ciascun pilastro monolitico del propileo del tempio. Dei quattro pilastri, ne è conservato in situ soltanto uno frammentario. (S.B. Scigliano 2003 @MAIRY)

\section{Interventi di restauro}

\subsection{Descrizione delle fasi di intervento}

La totale eliminazione di depositi superficiali incoerenti - sabbia, terra e materiali inorganici sedimentati sulle strutture per oltre $30 \mathrm{~cm}$ - è stata effettuata accuratamente per mezzo di una spolveratura mediante pennelli di setola morbida e aspirapolvere.

A seguito della pulitura preliminare a secco degli elementi architettonici e degli arredi, si è intervenuti con una pulitura con acqua, previa una disinfezione con un trattamento biocida.

Qui di seguito le fasi e le modalità dei trattamenti di restauro.

A. È stato possibile procedere al trattamento di disinfezione del materiale lapideo, interessato da antichi attacchi biologici a carico di microrganismi (licheni). È stata applicata su tutte le superfici interessate una soluzione biocida di Preventol R80 prodotto da Bayer (preparato contenente Alchildimetilbenzilammoniocloruro), in soluzione al $3 \%$, effettuata mediante nebulizzazione. Successivamente le superfici trattate con biocida sono state lavate con acqua e spazzole di nylon morbide.

B. Le aree più degradate ed interessate da fenomeni di decoesione sono state trattate prima degli interventi con un consolidante a base di silicato di etile (soluzione di silicati organici) Rhodorsil RC 70, della Rhône Poulenc. L'applicazione è stata effettuata su tutte le superfici per impregnazione, mediante imbibizione a pennello e per nebulizzazione.

C. Dopo gli interventi di restauro conservativo, al fine di completare il risanamento delle aree interessate da problematiche di decoesione e come intervento propedeutico, tutte le superfici lapidee sono state trattate con un protettivo idrorepellente. È stato utilizzato il BS 290 della Wacker, concentrato a base di silano/silossanici, diluito in solvente organico White spirit all' $11 \%$ in volume, applicato mediante nebulizzazione con irroratore pneumatico a bassa pressione. Le proprietà di questo prodotto idrorepellente sono di ridurre sensibilmente l'assorbimento dell'acqua dall'esterno, senza tuttavia influire, o quasi, sulla permeabilità del vapore acqueo dall'interno.

Questo sistema di pulitura preliminare e i successivi trattamenti biocida e di consolidamento, nonché il trattamento finale con protettivo idrorepellente 


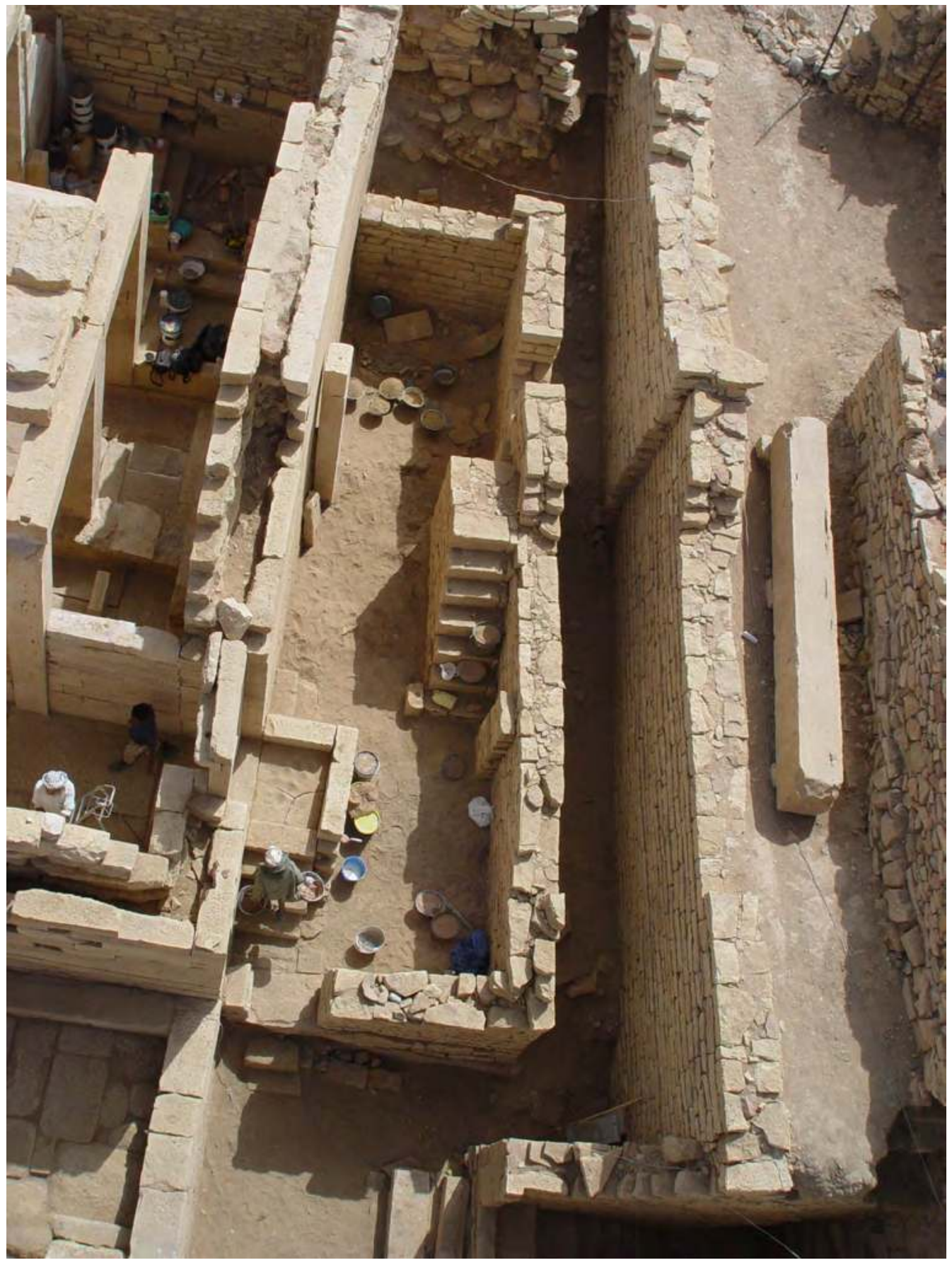

Figure 5. Nella fotografia il pilastro è posto parallelo alla rientranza M39 delle mura di Barāqish, tra T44 e T45. (A. de Maigret 2003 OMAIRY)

sono stati applicati a tutti gli elementi architettonici interessati al restauro, ossia ai pilastri della sala ipostila del tempio, agli stipiti del portale d'ingresso, alle strutture della cella centrale, a tutti gli elementi del tetto (travi, metope e lastre di copertura), alle iscrizioni, e, infine, alla pavimentazione.

Vediamo ora nel dettaglio i trattamenti specifici effettuati sui differenti elementi architettonici che necessitavano ciascuno di differenti interventi di restauro.

\subsection{Pilastri}

Su otto dei dodici pilastri sono state riscontrate lesioni e fratture parziali e totali, sia nel senso verticale, ma soprattutto nel senso orizzontale (fig. 6). Dopo un'accurata indagine, è stato possibile verificare la natura, la profondità e la gravità sia delle lesioni che delle fratture con distacco. Dove le lesioni erano di piccole entità $(\mathrm{P} 1, \mathrm{P} 3, \mathrm{P} 6, \mathrm{P} 10)$, si è potuto procedere al riempimento delle microfratture con resina epossidica bi-componente a bassa viscosità ad alto potere adesivo 
(LY 554 con indurenteHY 956 della CIBA GEYGY), caricata con quarzite super ventilata. ${ }^{5}$ Dopo aver accuratamente praticato dei forellini con trapani a mano, sfruttando la fessura della frattura, la resina epossidica è stata infiltrata con l'ausilio di siringhe e tubi a sonda (spiralini) per poterla penetrare in profondità (fig. 7). Se le fratture ponevano delle problematiche di gravità maggiore, dove si è ritenuto necessario (P3, P6, P10), sono state inserite barre d'acciaio inox del diametro di $10 \mathrm{~mm}$ o $15 \mathrm{~mm}$, lunghe fino a $35 \mathrm{~cm}$, in modo da risanare strutturalmente il distacco con un sistema d'imperniatura 'passante' (dall'esterno verso l'interno, trasversalmente rispetto alla frattura). Le barre in acciaio inox hanno una funzione strutturale, vengono fatte aderire all'interno del foro con resina epossidica ad alto potere adesivo, caricata con quarzite super ventilata. Sulla parte dove è stato inserito il perno verso l'interno, rimarrà solo un piccolo foro opportunamente stuccato in maniera mimetica con una malta avente colore e aspetto materico simile alla pietra.

I pilastri P1, P5, P7 e P11 evidenziavano problemi strutturali di maggior gravità, compromessi da fratture con distacco totale, ognuno con caratteristiche e tipologie di distacco diverse, da affrontare ciascuno in modo differente.

Dalla restituzione grafica di rilevazione fu riscontrato che vi erano considerevoli differenze, da 20 a $30 \mathrm{~cm}$, delle quote verticali fra i pilastri. Ad esempio il P1 posto sul lato destro risultava più in alto di $30 \mathrm{~cm}$ rispetto al $\mathrm{P} 4$ posto sul lato sinistro, pur avendo le stesse dimensioni in altezza di $4 \mathrm{~m}$ circa. Tale differenza era dovuta all'inclinazione dell'edificio proprio in direzione del P4 che si trovava nel punto di maggiore cedimento della pavimentazione. Dopo una serie di considerazioni e di calcoli, si è deciso di intervenire per livellare quanto più possibile le quote delle sezioni superiori dei pilastri, in proiezione della ricollocazione degli elementi della copertura, studiando soluzioni e compromessi accettabili. Dopo diverse analisi, abbiamo ritenuto che il miglior modo fosse d'intervenire sulle basi d'appoggio dei pilastri per correggerne le quote verticali.

È stato realizzato un programma d'intervento relativo alle quote da correggere, basandoci sullo stato di fatto generale, prima degli interventi, per poi decidere quali modifiche dovevano essere apportate. Purtroppo i 30 $\mathrm{cm}$ di differenza delle quote verticali tra P1 e P4 erano tanti. Abbiamo ritenuto, dunque, che la soluzione ideale fosse un compromesso che non stravolgesse troppo l'impianto originale della sala ipostila, mantenendo un minimo di dislivello tra la navata centrale e quella di

\footnotetext{
${ }^{5}$ D'ora in poi si ometterà di ripetere il nome $L Y 554$ con indurente $H Y$ 956 della CIBA GEYGY della resina epossidica ad alto potere adesivo, poiché più volte nel testo si farà sempre riferimento a questo prodotto.
}

sinistra, riducendo la differenza del piano delle quote dei pilastri, da 30 a $10 \mathrm{~cm}$ circa. La navata centrale e quella di destra, al contrario, dovevano essere riportate ad un piano superiore orizzontale ottimale.

Le correzioni avrebbero interessato i pilastri nel seguente ordine: due pilastri dovevano essere abbassati di 3 e $4 \mathrm{~cm}$; quattro pilastri sarebbero rimasti invariati; mentre gli altri sei dovevano essere rialzati a seconda delle diverse quote, da 6 fino a $15 \mathrm{~cm}$.

Per intervenire e risolvere le problematiche strutturali e statiche, era necessario rimuovere tutti i pilastri singolarmente, correggere il piano d'appoggio, risanare quelli interessati da fratturazioni parziali e totali ed infine ricollocarli in perfetto asse verticale.

Il P7 evidenziava una doppia frattura totale con distacco, nel senso orizzontale, nella parte centrale, caratterizzandosi come una delle situazioni più gravi (fig. 8). Il pilastro, compromesso da due fratture orizzontali è stato rimosso in tre parti, prima la parte superiore seguita dalla parte centrale ed infine da quella inferiore.

Con le cinghie a sistema auto-bloccante sono stati fissati dei travetti di legno ( $\mathrm{cm} 8 \times 8$ di spessore), ai quattro lati della parte superiore del pilastro. Con questo sistema di imbracatura è stato possibile proteggere il monoblocco di pietra per la successiva movimentazione. In questo modo, e con l'ausilio di un carro-gru, avente un braccio aggettante fino a $38 \mathrm{~m}$, con capacità di carico di quattro tonnellate, posto al di fuori delle mura della città, è stato possibile rimuovere prima la parte superiore e successivamente le altre due parti del pilastro fratturato.

Le tre porzioni del pilastro sono state collocate provvisoriamente fuori dal tempio, per poter intervenire in posizione orizzontale e praticare $\mathrm{i}$ fori per l'inserimento di una barra in acciaio inox, all'interno del pilastro, in prossimità delle fratture. Nella sezione della parte centrale, lunga $50 \mathrm{~cm}$ circa, è stato praticato un foro passante, del diametro di $25 \mathrm{~mm}$, perpendicolare alla sezione, perfettamente al centro e parallelo ai quattro lati, mediante l'ausilio di livelle con sistema 'a bolla', di cui una collocata in orizzontale sopra un lato del blocco da forare, ed un'altra sopra al trapano a rotazione Hilti (fig. 9). Questa metodologia ci ha consentito di realizzare dei fori combacianti 'a dima' tra le parti da riassemblare, cioè dei fori perfettamente allineati (fig. 10). Un altro foro, del diametro di $25 \mathrm{~mm}$ e profondo $28 \mathrm{~cm}$, è stato praticato nella sezione della frattura della parte superiore di P7, perfettamente combaciante e continuo con quello della parte centrale (fig. 11). Un terzo foro, della stessa profondità e diametro, è stato praticato nella sezione di frattura 
della parte inferiore, anch'esso 'a dima' con le altre due parti.

A questo punto, con l'ausilio del carro-gru, è stato possibile fare una prova di riassemblaggio in orizzontale delle tre parti spezzate, dopo aver inserito all'interno delle tre sezioni la barra in acciaio inox del diametro di $20 \mathrm{~mm}$ e lunga $1 \mathrm{~m}$. La prova ha confermato un esito positivo, le tre parti combaciavano perfettamente.

Nel caso del P7, è stata creata una base di appoggio artificiale, della stessa ampiezza della sezione inferiore del pilastro, in resina epossidica ad alto potere adesivo, caricata con quarzite super ventilata, alta $8 \mathrm{~cm}$, perfettamente in bolla orizzontale. È stato realizzato prima un cordolo perimetrale, con malta idraulica con bassissimo contenuto salino (conglomerato LEDAN C30, grassello di calce e polvere di pietra fina $1: 2$ ), di consistenza plastica, spesso circa $3 / 4 \mathrm{~cm}$, alto $8 \mathrm{~cm}$ nel punto più a monte rispetto all'inclinazione. Quando la malta aveva completato la presa, il giorno successivo, abbiamo versato la resina epossidica caricata con la quarzite in un rapporto anche 1: 1, all'interno del perimetro circoscritto dal cordolo di contenimento. Era necessario che la resina fosse abbastanza fluida da essere autolivellante, consentendoci di realizzare un piano perfettamente orizzontale e in bolla. Durante le varie fasi di 'colata', all'interno della nuova base sono state inserite ed inglobate nella resina alcune scaglie di pietra di diverse dimensioni (da 2 fino a $10 \mathrm{~cm}$ di larghezza, di diverso spessore), per avere più struttura e resistenza meccanica. Sopra l'ultimo strato della nuova base d'appoggio artificiale è stato realizzato uno strato d'ancoraggio, mediante la stesura di uno strato sottile di resina epossidica su cui è stata fatta cadere una graniglia di pietra (da $3 / 5 \mathrm{~mm}$ ) (fig. 12). Lo strato d'ancoraggio era indispensabile ad aumentare l'adesione con la malta idraulica da applicare sopra, per la successiva ricollocazione del pilastro.

Con l'ausilio della gru è stata ricollocata e riposizionata la parte inferiore del P7, sulla nuova base d'appoggio artificiale, rialzata di $8 \mathrm{~cm}$, con uno strato di malta idraulica a bassissimo contenuto salino. Tra la base d'appoggio e la sezione inferiore del blocco di pietra è stato introdotto un perno in acciaio inox del diametro di $20 \mathrm{~mm}$ e lungo $38 \mathrm{~cm}$ (fig. 13). La parte inferiore del P7, dopo essere stata riallettata, è stata posizionata perfettamente in verticale, mediante livelle con sistema a bolla, infine fissata per 24 ore con cinghie auto-bloccanti ai tubi metallici di sicurezza, precedentemente predisposti.

Successivamente, per migliorare l'ancoraggio della parte inferiore del P7 ai muretti del sedile in pietra, tra le connessure, è stata colata malta idraulica fluida, con caratteristiche tixotropiche (ledan MTX con graniglia di pietra) previa stuccatura di sigillatura e di contenimento.

In seguito, è stata effettuata una seconda prova di assemblaggio provvisoria, in verticale, con le altre due parti del pilastro, per una ulteriore verifica. Rassicurati dal risultato della verifica, è stato possibile procedere alla ricollocazione definitiva.

Con la resina epossidica, caricata con quarzite super ventilata, è stata fissata la lunga barra di acciaio inox all'interno del foro predisposto nella sezione superiore, della parte inferiore del P7. Abbiamo sovrapposto la parte centrale del P7, introducendo all'interno la barra in acciaio passante verticalmente. Infine, anche la parte superiore è stata assemblata definitivamente insieme alle altre due parti, mediante un unico perno. Le tre parti dunque, assemblate con un perno centrale del diametro di $20 \mathrm{~mm}$ e lungo $1 \mathrm{~m}$, sono state incollate con la resina epossidica caricata con quarzite ventilata per poi essere fissate ai tubi metallici con cinghie di sicurezza (fig. 14), in perfetta posizione verticale (fig. 15).

Il P11, a $50 \mathrm{~cm}$ circa dalla base, presentava una frattura orizzontale con distacco totale (fig. 16); la parte inferiore del pilastro, inoltre, era coinvolta da una seconda frattura trasversale con distacco, che interessava lo spigolo dell'angolo ovest (fig. 17).

Dopo essere stato imbracato con travetti di legno e cinghie auto-bloccanti (come per il P7), il P11 è stato rimosso in tre parti. Prima la parte superiore, alta quasi m 3,50, successivamente la piccola parte inferiore, compreso l'angolo completamente distaccato. Il pilastro in tre parti, dopo essere stato collocato provvisoriamente in orizzontale, fuori dalla sala ipostila, è stato predisposto per la foratura ed il risanamento strutturale mediante imperniazione. Come per gli altri pilastri fratturati, è stato effettuato un consolidamento coesivo e propedeutico sulla superficie delle sezioni delle fratture (due trattamenti di Paraloid B72 al 5\% in solvente al nitro, ed un trattamento al $10 \%$, mediante impregnazione a pennello) per favorire una migliore adesione ed una maggiore reversibilità in futuro.

La parte dell'angolo staccata è stata fatta aderire con la parte inferiore del P11, mediante l'applicazione a contatto tra le sezioni con resina epossidica ad alto potere adesivo, caricata con quarzite super ventilata. Per avere una migliore adesione e la minima divaricazione, le due parti sono state legate forzatamente con cinghie auto-bloccanti. Successivamente, sono stati praticati alcuni fori del diametro di $15 \mathrm{~mm}$ e profondi $33 \mathrm{~cm}$, che attraversavano trasversalmente le sezioni delle due parti fratturate, dove, per sicurezza, sono state inserite due barre in acciaio inox, del diametro di $10 \mathrm{~mm}$ e lunghe $30 \mathrm{~cm}$, dall'esterno verso l'interno (fig. 18). 


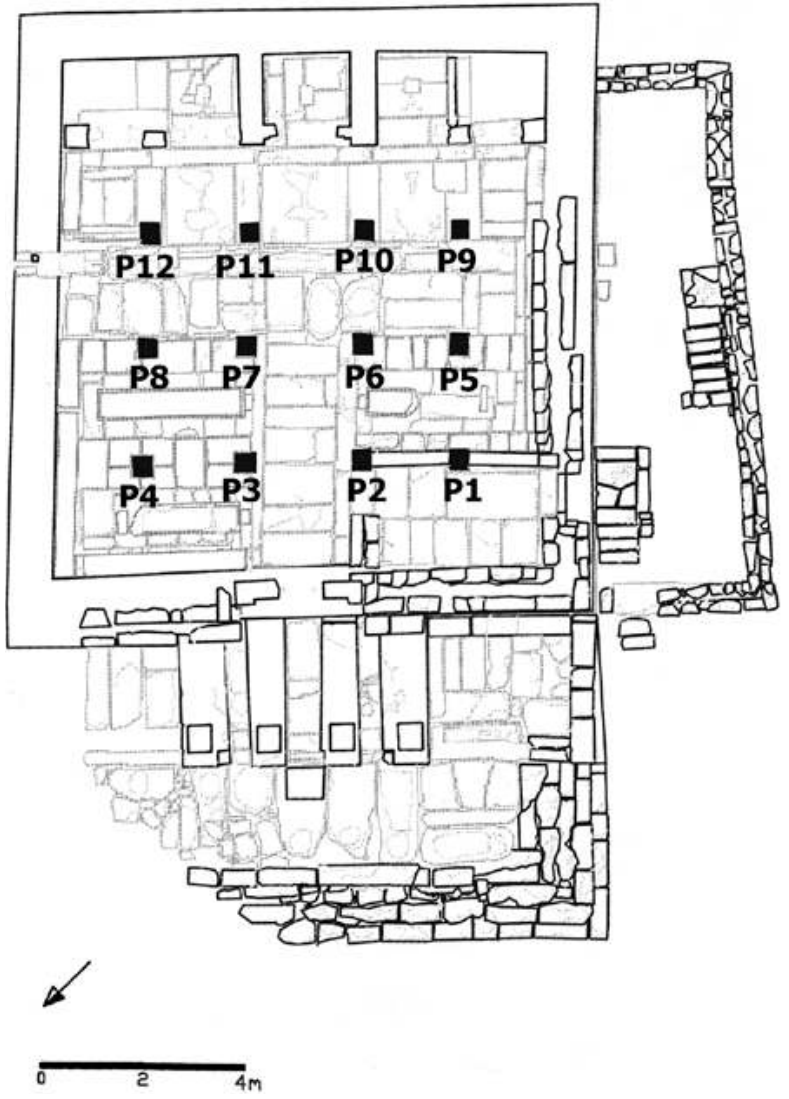

Figure 6. Pianta del tempio di Nakrah con i pilastri della sala ipostila numerati. (Rielaborazione di S. Antonini da rilievo di R. Loreto 2006, 2018 @MAIRY)

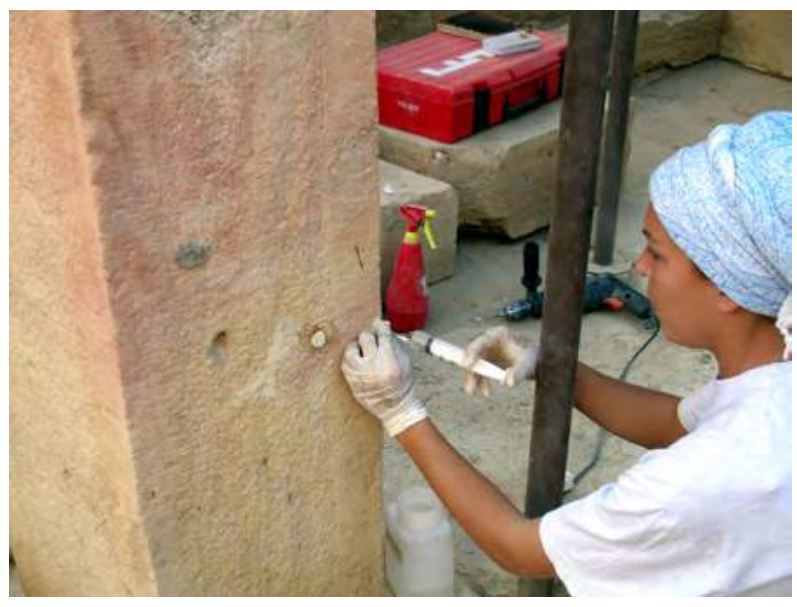

Figure 7. Alessandra Paladino inserisce con la siringa la resina epossidica nelle microfratture di un pilastro della sala ipostila del tempio. (S.B. Scigliano 2003 CMAIRY)

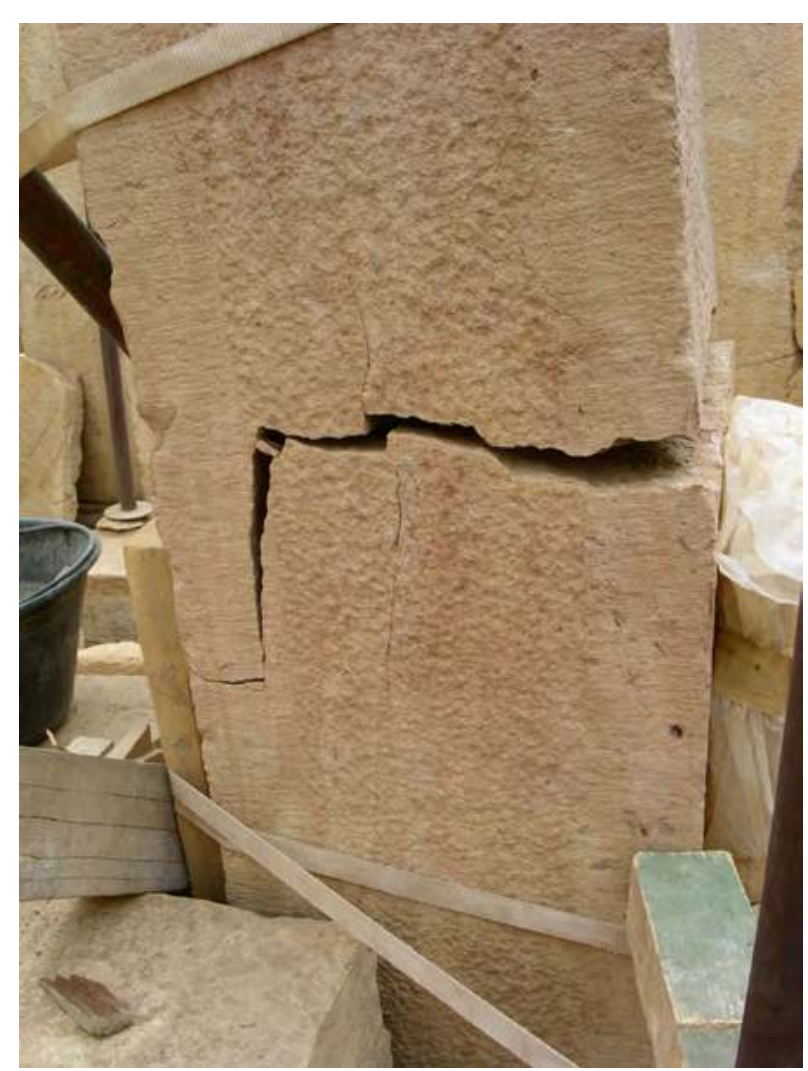

Figure 8. Il pilastro P7 con duplice frattura, orizzontale e verticale. (A. Paladino 2003 @MAIRY)

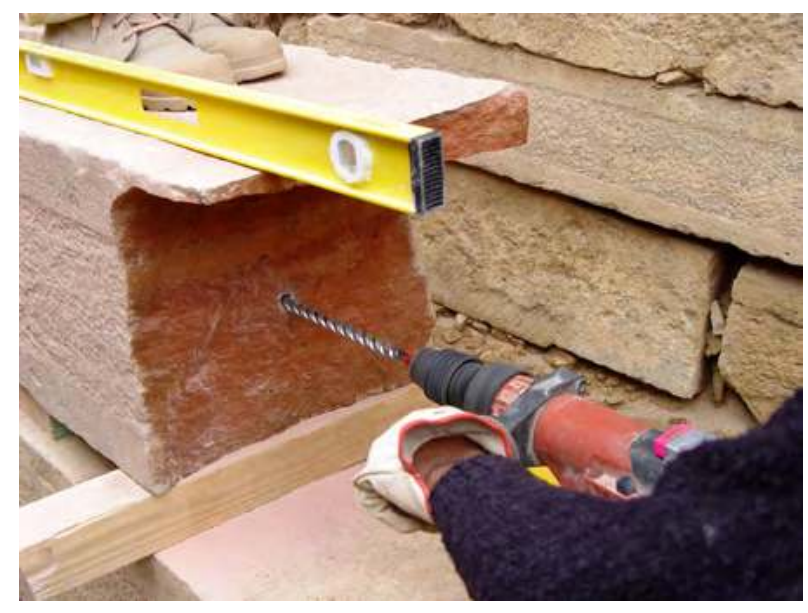

Figure 9. Foro praticato al centro del pilastro P7 per l'inserimento di una barra in acciaio inox. (A. Paladino 2003 CMAIRY) 


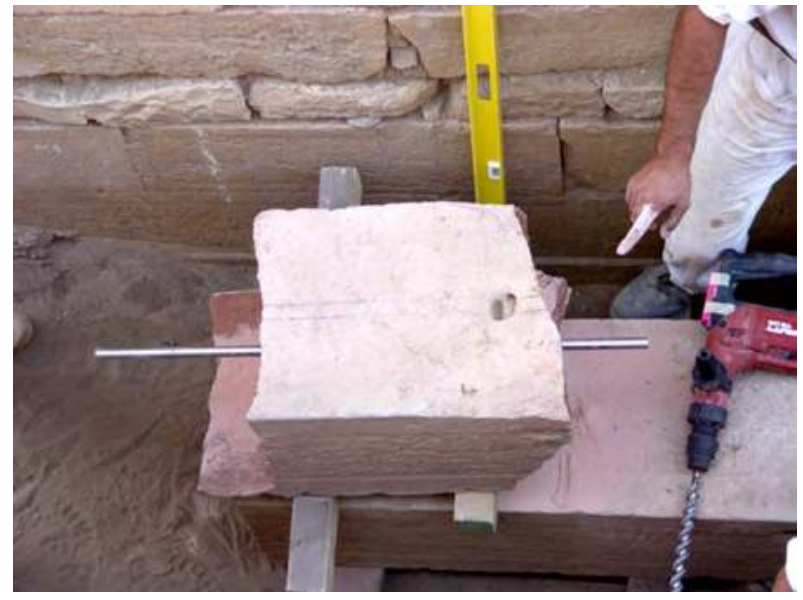

Figure 10. La barra d'acciaio attraversa tutta la sezione centrale del pilastro P7. (A. Paladino 2003 @MAIRY)

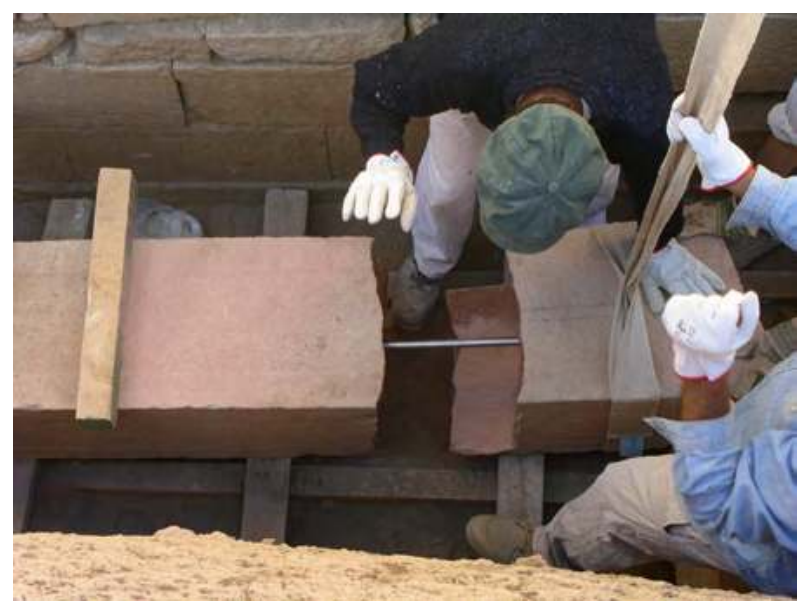

Figure 11. Foro praticato nella sezione della frattura della parte superiore di P7, combaciante e continuo con quello della parte centrale. (A. Paladino 2003 OMAIRY)

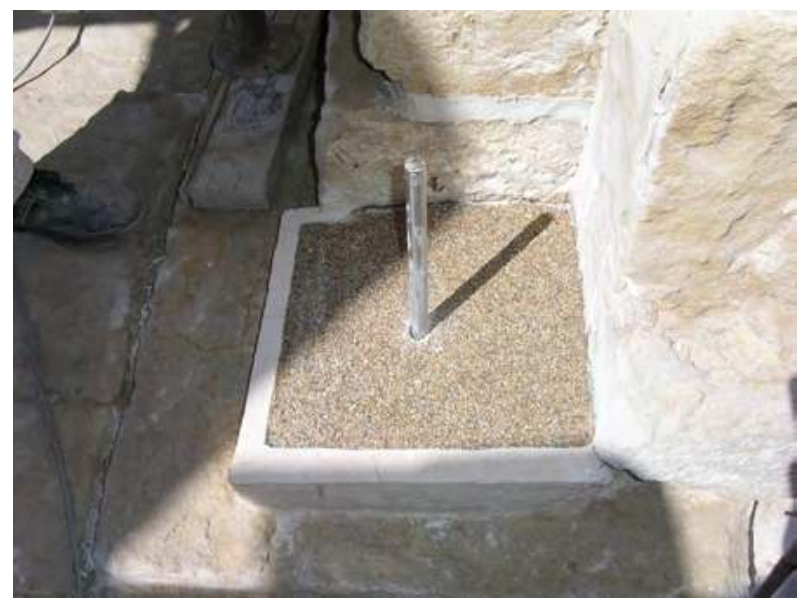

Figure 12. Base d'appoggio artificiale del P7 formata da un cordolo di malta idraulica, all'interno del quale è stato versato uno strato d'ancoraggio composto di resina epossidica e graniglia di pietra. (A. Paladino 2003 CMAIRY)

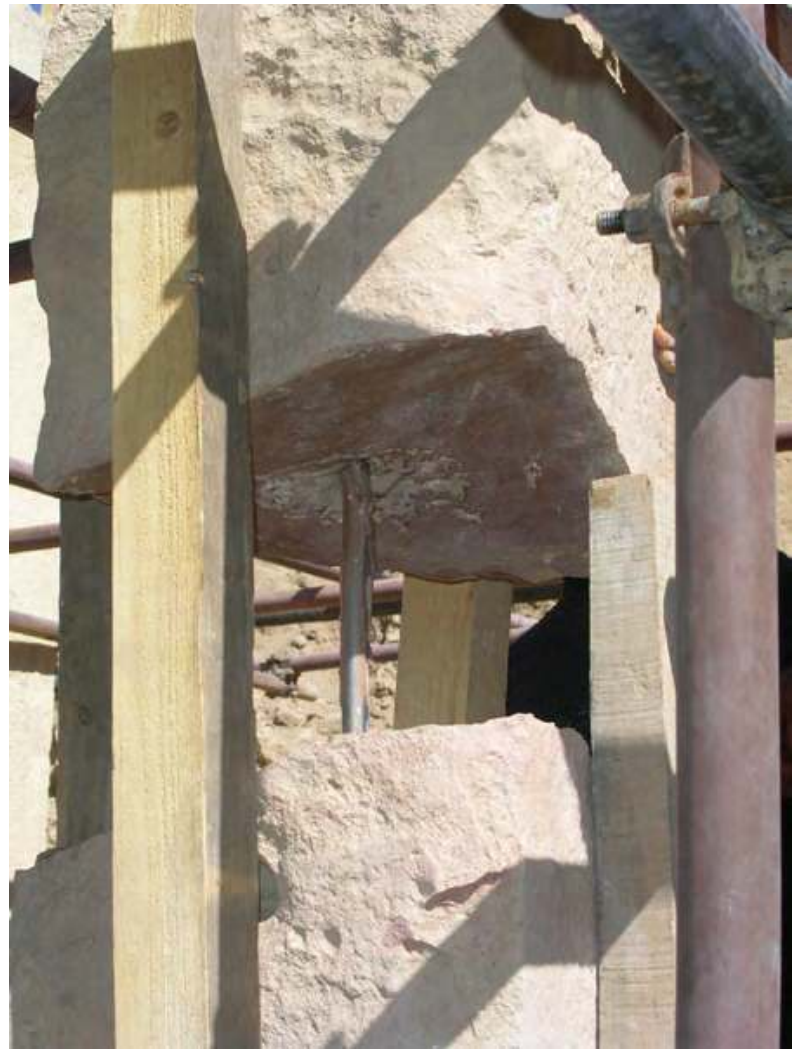

Figure 13. Assemblaggio delle varie sezioni del pilastro P7. (A. Paladino 2003 CMAIRY)

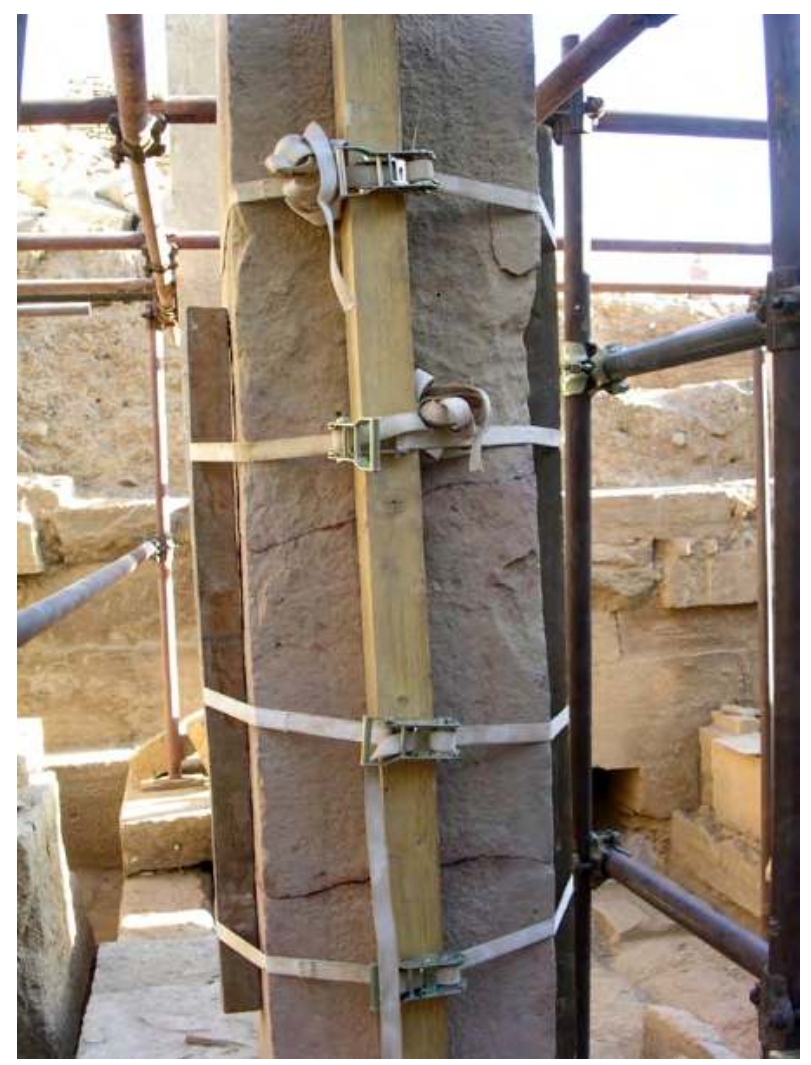

Figure 14. Le tre parti assemblate del P7 sono assicurate ai tubi metallici con cinghie di sicurezza, in posizione verticale. (A. Paladino 2003 @MAIRY) 


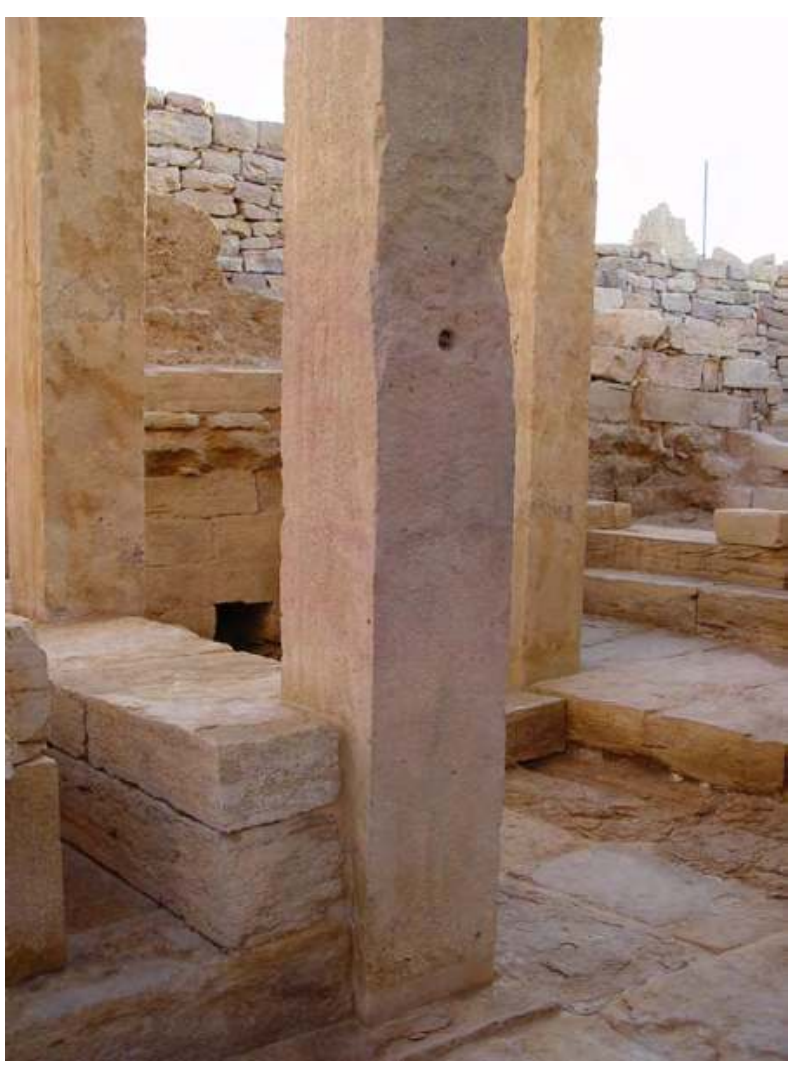

Figure 15. Risultato finale del restauro del pilastro P7. (S.B. Scigliano 2003 OMAIRY)

Consolidata la parte inferiore, si poteva procedere alla realizzazione dei fori per l'assemblaggio delle due parti distaccate del P11. È stato praticato un foro nella sezione di frattura della parte superiore, del diametro di $25 \mathrm{~mm}$ e profondo $30 \mathrm{~cm}$ perfettamente al centro e parallelo ai quattro lati, con l'ausilio di livelle 'a bolla' (come per il P7). Subito dopo, nella sezione di frattura della parte inferiore, è stato praticato un foro centrale 'a dima', del diametro di $25 \mathrm{~mm}$ e passante per tutta la sua altezza. Una barra in acciaio inox, lunga $1 \mathrm{~m}$, doveva essere introdotta all'interno delle due parti distaccate del P11 e attraversare completamente la base d'appoggio artificiale (alta $12 \mathrm{~cm}$ ). Completata la predisposizione dei fori, si è reso possibile effettuare la prova di assemblaggio provvisoria delle due parti del pilastro in orizzontale, per verificare se con l'inserimento della barra in acciaio le due parti coincidevano al millimetro. Con l'ausilio della gru, è stato possibile accostare in orizzontale le due parti staccate del P11, consentendoci di inserire la barra in acciaio all'interno dei fori che sono risultati perfettamente coincidenti, nonostante fossero di diametro appena più grande rispetto al perno (fig. 19).

Come per il pilastro P7, anche il P11 doveva essere rialzato per correggere la quota verticale. Dovevamo quindi predisporre la base d'appoggio per la ricollocazione e riadesione definitiva delle due parti del pilastro fratturato. La lastra pavimentale dove poggiava il pilastro era compromessa da gravi fratture, che avrebbero messo a rischio la stabilità stessa del P11 distacco. I vari frammenti di una porzione della lastra d'appoggio originale, sono stati smontati, puliti, consolidati, al fine di ottenere un unico frammento da riaderire e riassemblare. In seguito, abbiamo predisposto ed inserito, in orizzontale, tra le sezioni di contatto della lastra fratturata, due barre in acciaio inox, del diametro di $10 \mathrm{~mm}$ e lunghe $30 \mathrm{~cm}$, fatte aderire con resina epossidica caricata con quarzite ventilata (fig. 20). Inoltre, tutta la lastra pavimentale d'appoggio è stata consolidata e rinforzata, attraverso il riempimento delle connessure con le lastre confinanti e le lastre sottostanti, mediante, resina epossidica ad alto potere adesivo, caricata con quarzite ventilata e schegge di pietra, per aumentarne la resistenza meccanica. Risanata e messa in sicurezza la lastra pavimentale (fig. 21), è stato possibile realizzare la nuova base d'appoggio artificiale, per correggere la quota verticale del pilastro (fig. 22). Come per il P7, anche per il P11 abbiamo installato una nuova base d'appoggio artificiale, alta $12 \mathrm{~cm}$, in resina epossidica ad alto potere adesivo, caricata con quarzite ventilata, rinforzata all'interno con scaglie e blocchetti in pietra per aumentarne la resistenza meccanica (fig. 23). Al centro della nuova base d'appoggio è stato praticato un foro verticale profondo $25 \mathrm{~cm}$ con diametro di $25 \mathrm{~mm}$, all'interno del quale è stata inserita una barra in acciaio passante attraverso le due parti fratturate del pilastro. La barra, dunque, è stata inserita nella base artificiale fino alla lastra pavimentale, attraversando tutta la parte inferiore $(50 \mathrm{~cm}$ circa), ed entrando per $25 \mathrm{~cm}$ nella parte superiore del P11.

Per evitare errori e ottenere una perfetta risistemazione verticale del pilastro, le due parti del P11 sono state assemblate e fissate definitivamente, una sopra l'altra, in un'unica fase.

Nel foro e sulla superficie della sezione della nuova base d'appoggio è stata applicata malta idraulica (una parte di conglomerato LEDAN C30 e due di polvere di pietra fina), nella quale abbiamo inserito la barra in acciaio inox, lunga $1 \mathrm{~m}$ e ricollocato la parte inferiore del P11. Le due parti distaccate del P11, con all'interno il perno in acciaio inox, sono state fatte aderire definitivamente con resina epossidica, caricata con quarzite. Con travetti di legno e cinghie auto-bloccanti, abbiamo fissato le due parti riassemblate e riaderite, in perfetta posizione di congiunzione verticale, ai ponteggi in tubi metallici, precedentemente predisposti (figg. 24-25).

Il P5 era interessato da una frattura con distacco totale a poco più della metà della sua altezza. La frattura seguiva un andamento irregolare, per metà in orizzontale e poi 


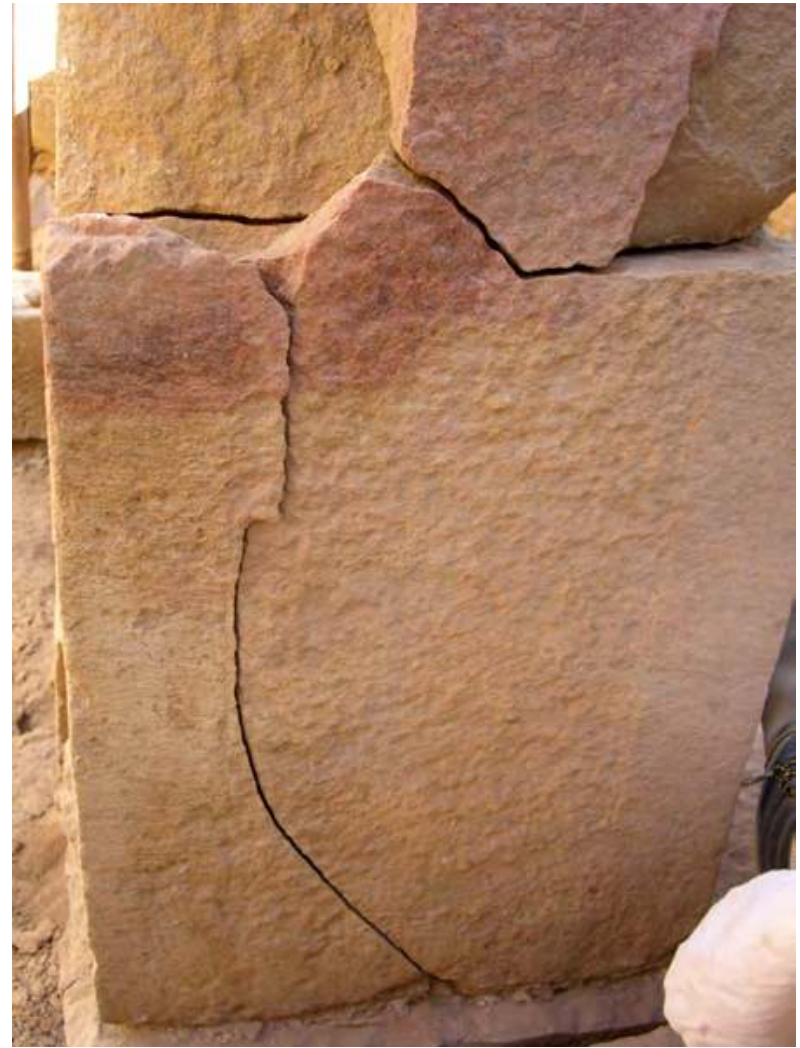

Figure 16. Frattura orizzontale con distacco totale, a circa 50 $\mathrm{cm}$ dalla base, del pilastro P11.

(A. Paladino 2003 OMAIRY)

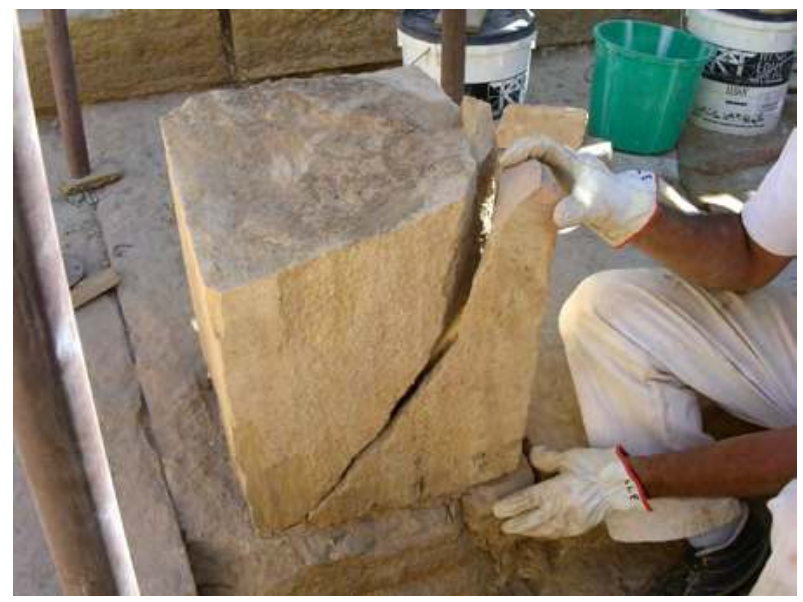

Figure 17. Frattura trasversale con distacco dello spigolo dell'angolo ovest della parte inferiore del pilastro P11. (A. Paladino 2003 @MAIRY)

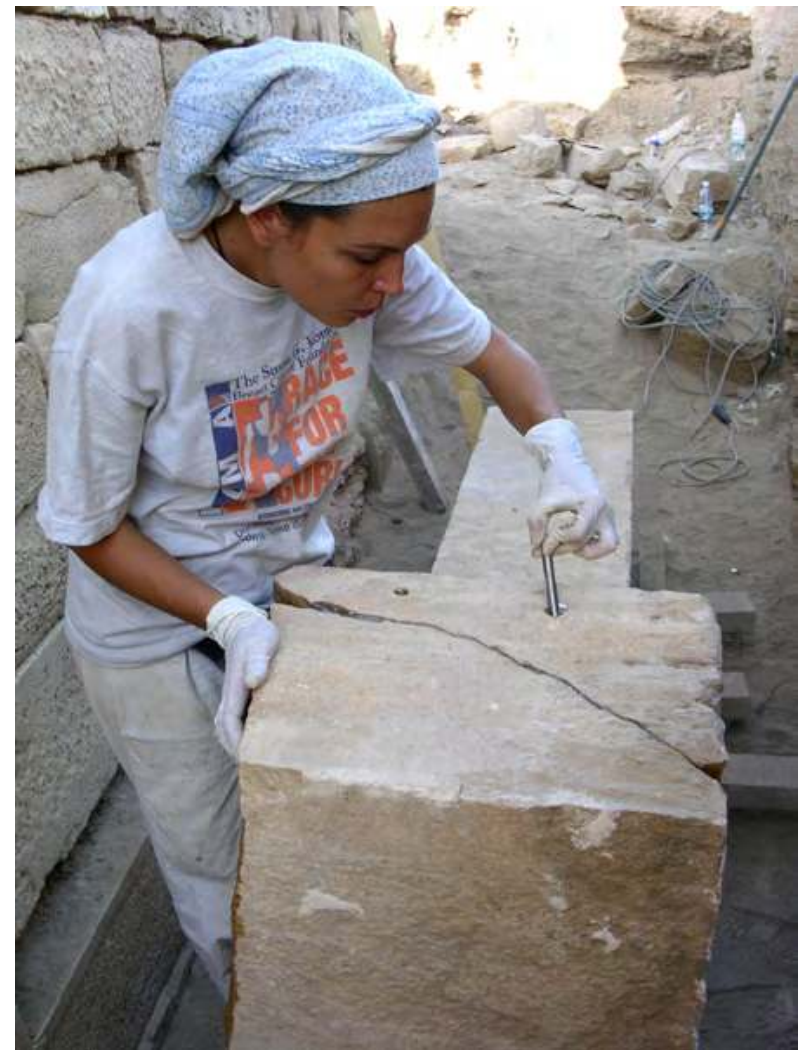

Figure 18. Nel pilastro P11 sono state inserite due barre in acciaio inox, dall'esterno verso l'interno, in fori appositamente praticati. (S.B. Scigliano 2003 CMAIRY)

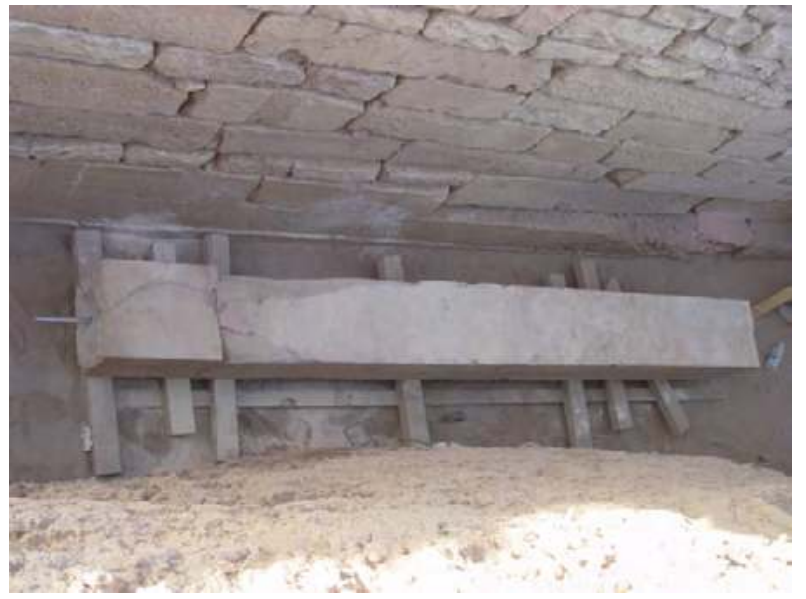

Figure 19. Il pilastro P11 disposto orizzontalmente e assemblato al di fuori del tempio.

(A. Paladino 2003 @MAIRY) 


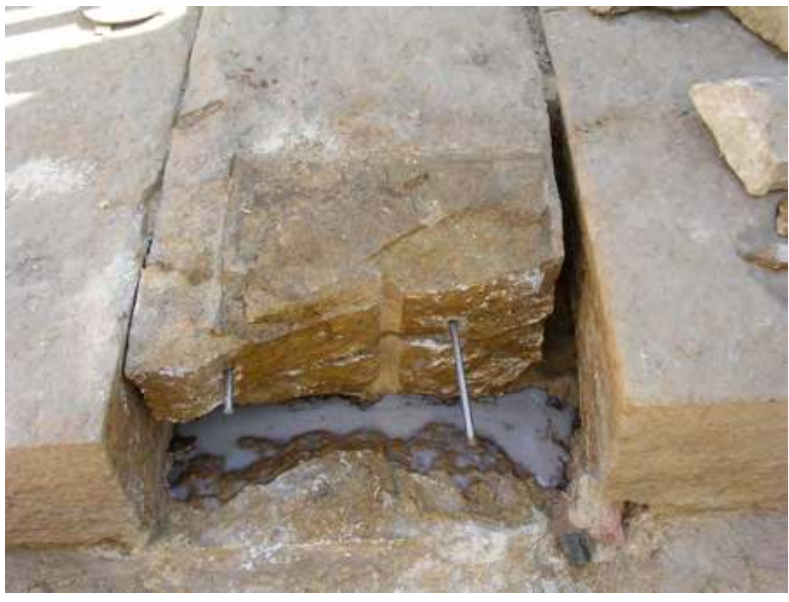

Figure 20. Tra le sezioni di contatto della base di appoggio fratturata del pilastro P11 sono state inserite, in orizzontale, due barre in acciaio inox.

(A. Paladino 2003 OMAIRY)

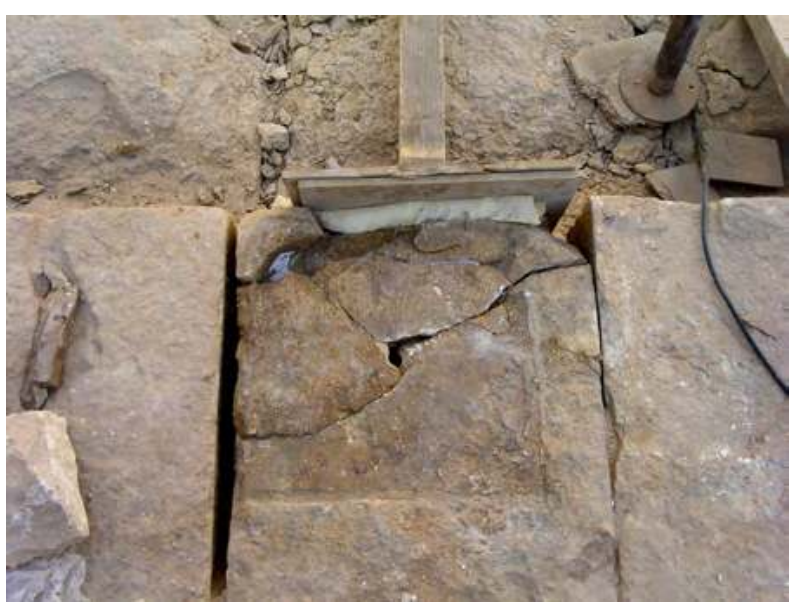

Figure 21. Consolidamento dei frammenti della base di appoggio del pilastro P11. (S.B. Scigliano 2003 OMAIRY)

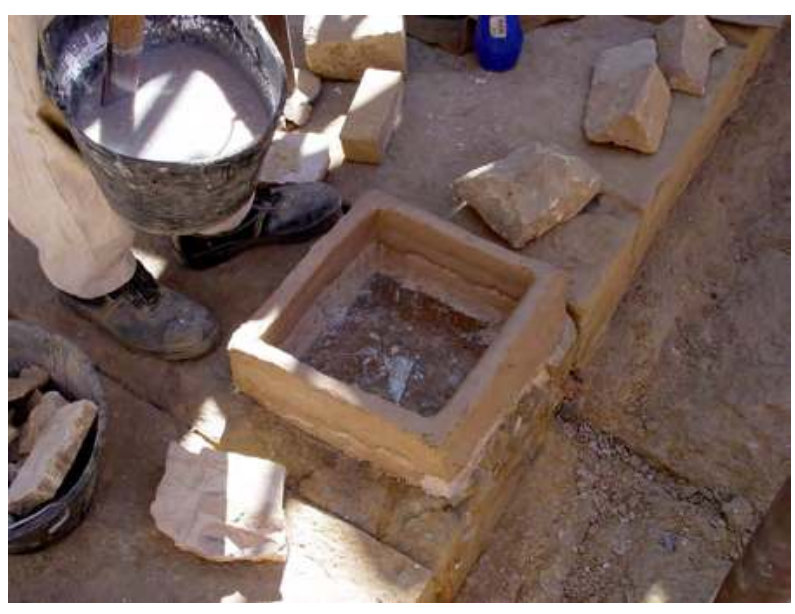

Figure 22. Sull'originaria base del P11 è stata costruita una base d'appoggio artificiale, alta $12 \mathrm{~cm}$, per correggere la quota verticale del pilastro stesso.

(A. Paladino 2003 OMAIRY)

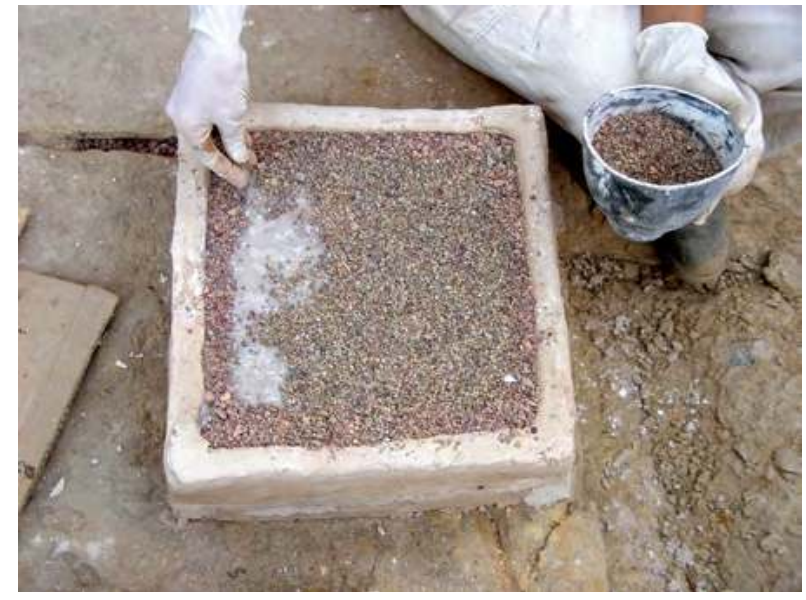

Figure 23. La base d'appoggio artificiale è riempita di resina epossidica ad alto potere adesivo, caricata con quarzite ventilata e rinforzata con scaglie e blocchetti in pietra per aumentarne la resistenza meccanica.

(S.B. Scigliano 2003 OMAIRY)

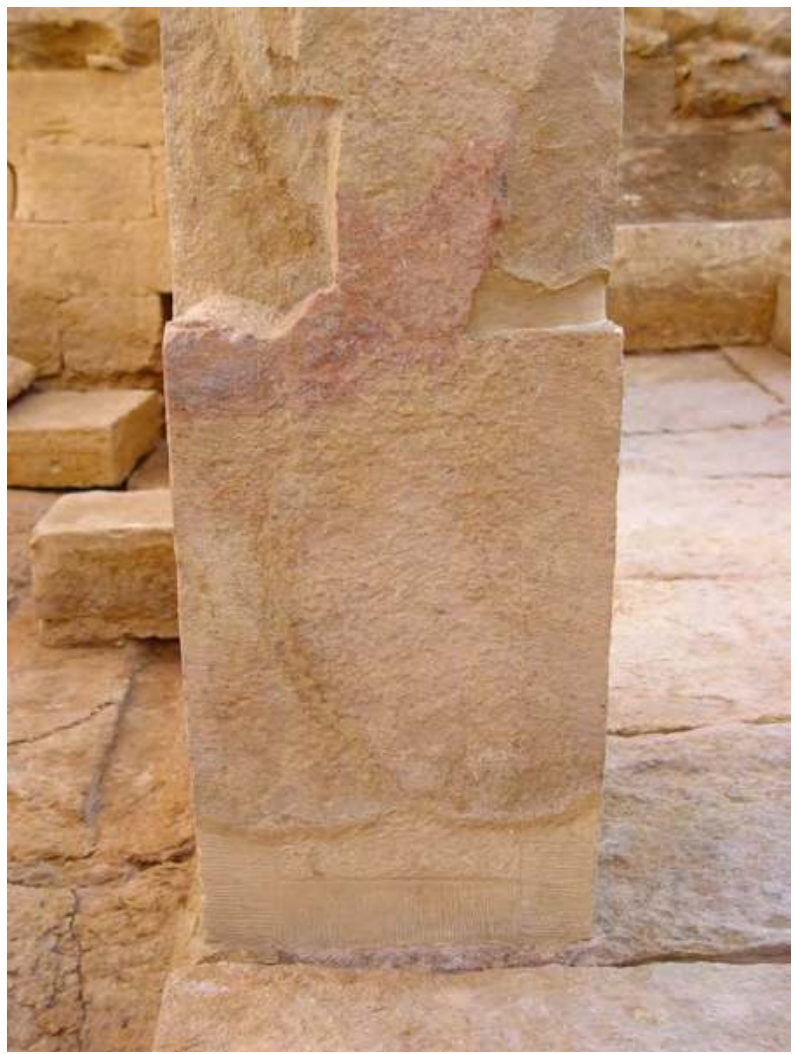

Figure 24. Il pilastro P11 a fine restauro.

(S.B. Scigliano 2003 OMAIRY) 


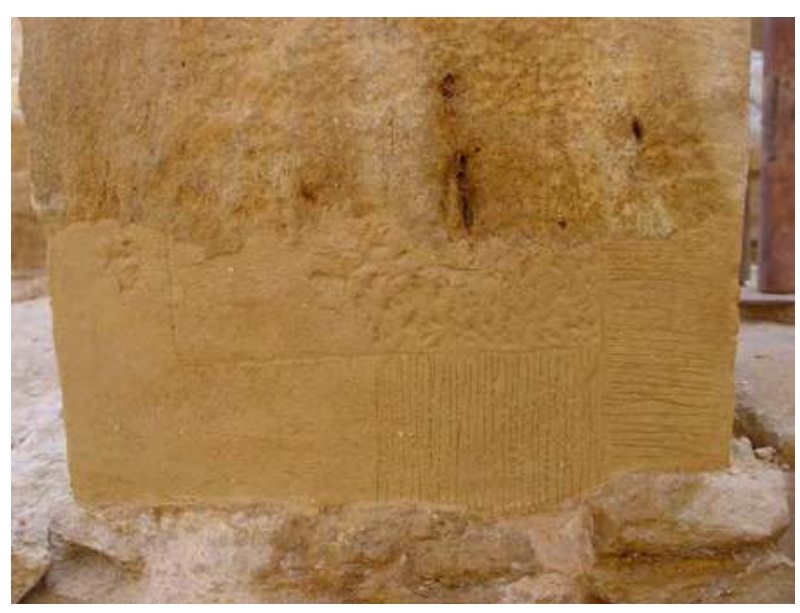

Figure 25. Dettaglio della base artificiale del pilastro P11 a fine restauro. (S.B. Scigliano 2003 OMAIRY)

obliqua verso il basso. Purtroppo, la conformazione complessa della frattura poneva delle preoccupanti problematiche statiche. La parte superiore del pilastro si trovava dislocata di quasi $1 \mathrm{~cm}$ in prossimità della frattura.

Come gli altri pilastri fratturati, anche il P5 è stato rimosso dalla sede originale, in due parti separate, per poter effettuare le operazioni di risanamento strutturale. Le due parti, dopo essere state imbracate, sono state rimosse con l'ausilio della gru e ricollocate provvisoriamente fuori dal tempio in orizzontale (fig. 26).

Nelle due sezioni di contatto della frattura abbiamo effettuato un trattamento protettivo e propedeutico (con Paraloid al $5 \%$ e al $10 \%$ in diluente nitro). In seguito, è stato praticato un foro centrale nelle sezioni di contatto della frattura delle due parti del P5, parallelo ai quattro lati, del diametro di $25 \mathrm{~mm}$ e profondo $34 \mathrm{~cm}$ (fig. 27). Il foro doveva essere perfettamente coincidente e allineato 'a dima'.

Realizzata la foratura per il perno, bisognava riassemblare provvisoriamente le due parti del P5, per verificare se i fori fossero perfettamente coincidenti, inserendo all'interno di essi la barra in acciaio inox, lunga $60 \mathrm{~cm}$ e del diametro di $20 \mathrm{~mm}$. L'esito positivo della verifica era indispensabile per la ricollocazione definitiva delle due parti del P5 nella sede originale. Nel frattempo sono stati predisposti sia la base d'appoggio sia i muretti del sedile a contatto con la parte bassa del pilastro. Dal nostro progetto finale, in relazione ai risultati delle rilevazioni con la Stazione Totale, la quota verticale del P5 doveva essere leggermente abbassata. Non potendo intervenire direttamente sul pilastro, si è pensato di assottigliare di $3 \mathrm{~cm}$ la lastra di pietra sulla quale poggiava il $\mathrm{P} 5$, in prossimità dell'impronta originale. Con un frullino elettrico con disco a lama diamantata al vidiam, è stato possibile effettuare una quadrettatura di $\mathrm{cm} 4$ x 4, profonda $3 / 4 \mathrm{~cm}$, consentendo la rimozione dei cubetti di pietra mediante l'utilizzo di scalpelli (cfr. fig. 33), e attuare così una impronta leggermente più bassa. Sull'impronta assottigliata è stata versata della resina epossidica ad alto potere adesivo, caricata con quarzite ventilata, autolivellante, in modo da ottenere la quota della base perfettamente 'in bolla' orizzontale, al fine di riporre il pilastro in asse verticale ottimale e leggermente più in basso (fig. 28). Il P5 prima della rimozione si trovava in una posizione verticale particolarmente scorretta di oltre $5^{\circ}$, verso $\mathrm{NE}$, e, oltre al pilastro, anche le strutture murarie a contatto della parte bassa seguivano lo stesso andamento inclinato. Per ricollocare e riposizionare il P5 in perfetta posizione verticale, era assolutamente necessario modificare un lato verticale del sedile di muratura, a contatto con il lato sud-ovest del P5. Abbiamo dovuto assottigliare di $4 \mathrm{~cm}$ circa i blocchi di pietra del sedile, sul lato verticale a contatto del P5 (non a vista), per consentire la risistemazione del pilastro in asse verticale perfetto.

Predisposta la sede originale, si è potuto ricollocare e riallettare definitivamente la parte inferiore del P5 (fig. 29) con malta idraulica ad alto potere adesivo (una parte di conglomerato LEDAN C30 e due parti di polvere di pietra fina), ancorata in perfetta posizione verticale alle strutture metalliche di sicurezza, precedentemente predisposte, e fissata ad esse con cinghie auto-bloccanti.

Successivamente, le connessure tra la parte inferiore del pilastro e i tre lati del muretto attiguo sono state riempite con malta idraulica (legante MTX con polvere di pietra finissima) avente caratteristiche tixotropiche, in modo da garantire un sicuro ancoraggio della parte inferiore del P5, prima di riposizionare la parte superiore. Quando la presa delle malte era completata, un paio di giorni dopo si è potuto riassemblare definitivamente anche la parte superiore sopra quella inferiore del P5.

Nelle sezioni di contatto della frattura e nei due fori è stata applicata la resina epossidica caricata con quarzite ventilata, inserendo contemporaneamente la barra in acciaio inox, del diametro di $20 \mathrm{~mm}$ e lunga $60 \mathrm{~cm}$. Con l'ausilio della gru, è stata posta la parte superiore fino al contatto preciso, aiutati da travetti di legno, precedentemente predisposti come guida nella parte inferiore. Verificata la posizione verticale perfetta con l'ausilio di livelle con sistema 'a bolla', abbiamo fissato le due parti del pilastro riassemblate, alle strutture metalliche presenti intorno al P5 (fig. 30).

L'andamento della frattura del P5, come spiegato in precedenza, seguiva una direzione irregolare, per 
metà orizzontale e per metà obliqua verso il basso; di conseguenza l'appoggio della parte superiore non era, per così dire, 'naturale' sulla sezione della parte inferiore. Pertanto, per ottenere maggiori garanzie, abbiamo deciso di inserire due piccole barre in acciaio inox, di sicurezza, dall'esterno verso l'interno ('a tradimento'), in prossimità della frattura inclinata dal lato NE. Sono stati effettuati due fori del diametro di

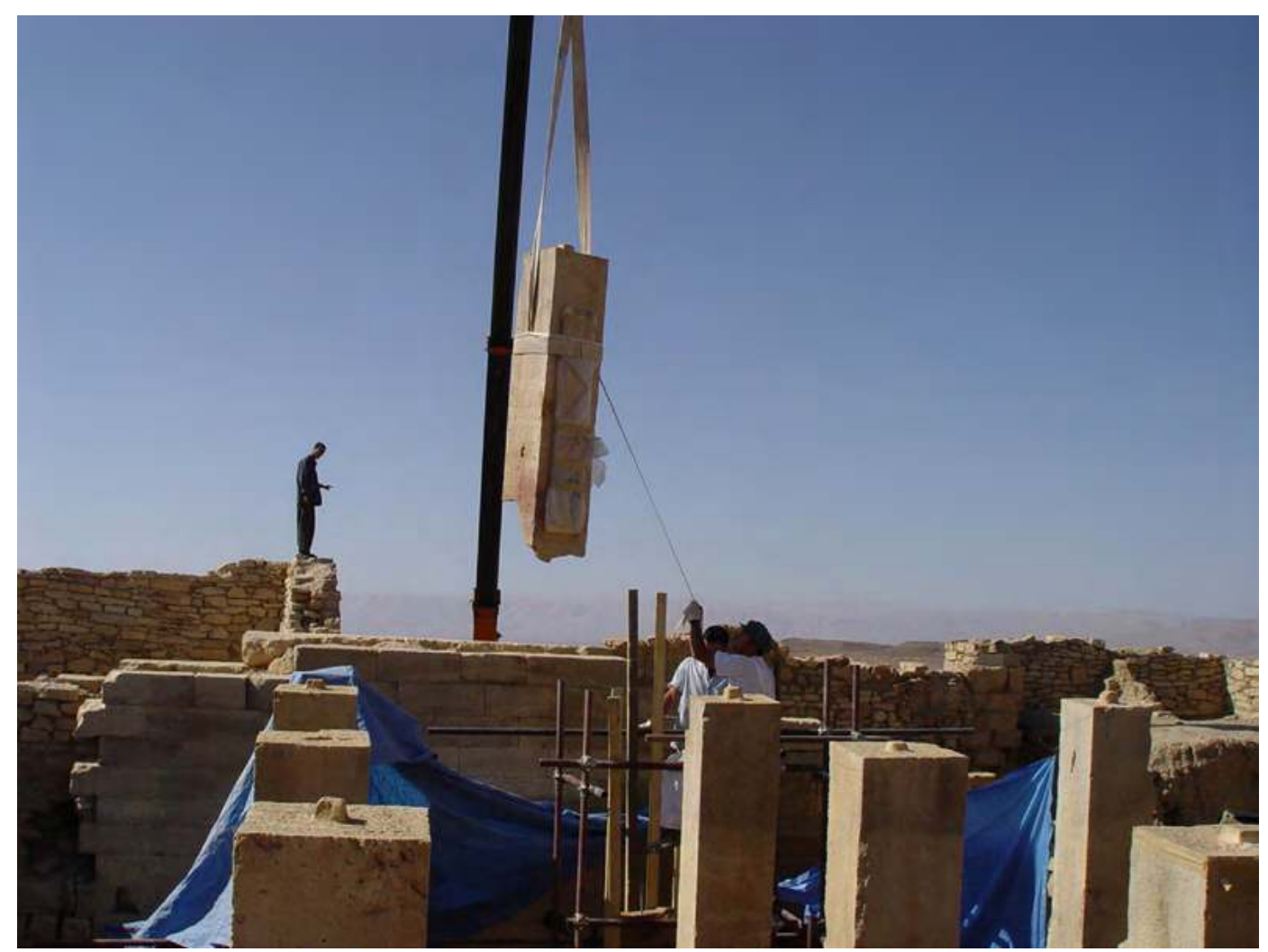

Figure 26. Rimozione del pilastro P5 con l'ausilio della gru, e collocato fuori dal tempio per il restauro. (A. Paladino 2003 @MAIRY)

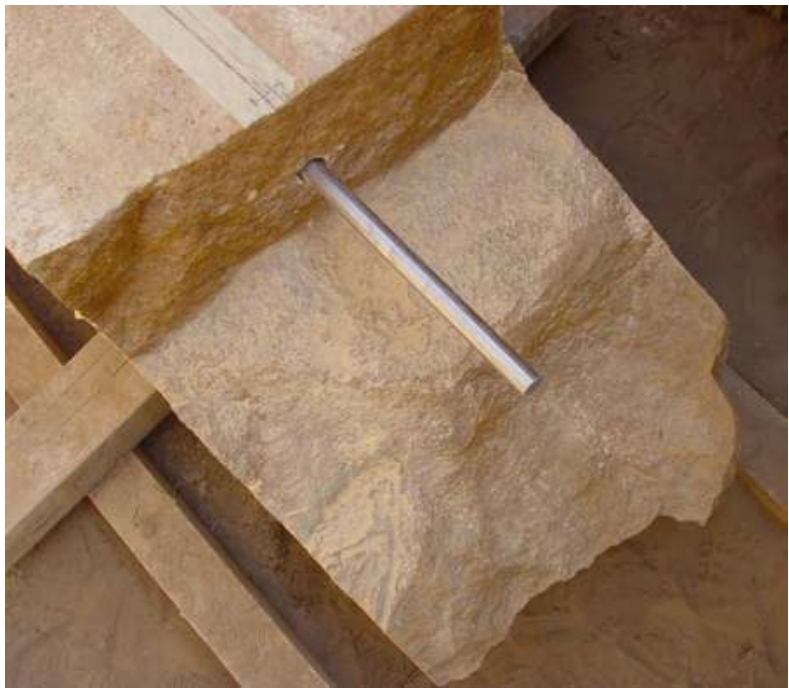

Figure 27. Nelle sezioni di contatto della frattura delle due parti del pilatro P5 è stato praticato un foro per l'inserimento della barra di acciaio inox. (A. Paladino 2003 (CMAIRY)

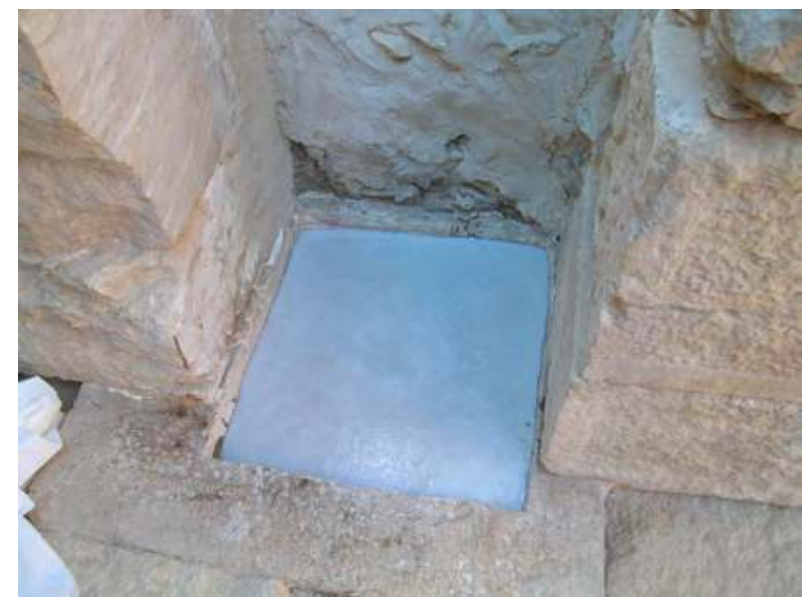

Figure 28. La base d'appoggio originaria, sulla quale si impostava il pilastro P5, è stata abbassata di $3-4 \mathrm{~cm}$; vi è stata versata resina epossidica ad alto potere adesivo, caricata con quarzite ventilata e autolivellante.

(A. Paladino 2003 CMAIRY) 


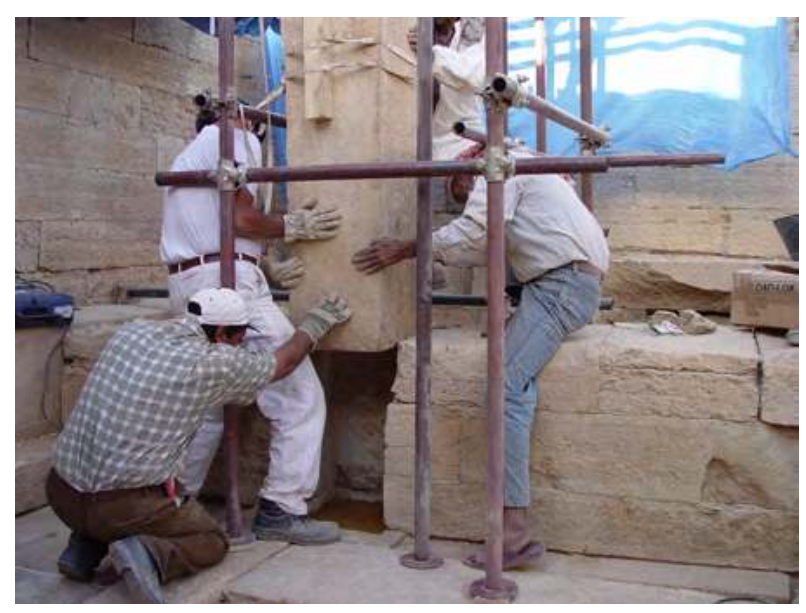

Figure 29. Ricollocamento definitivo della parte inferiore del P5 nel sedile in muratura. (A. Paladino 2003 CMAIRY).

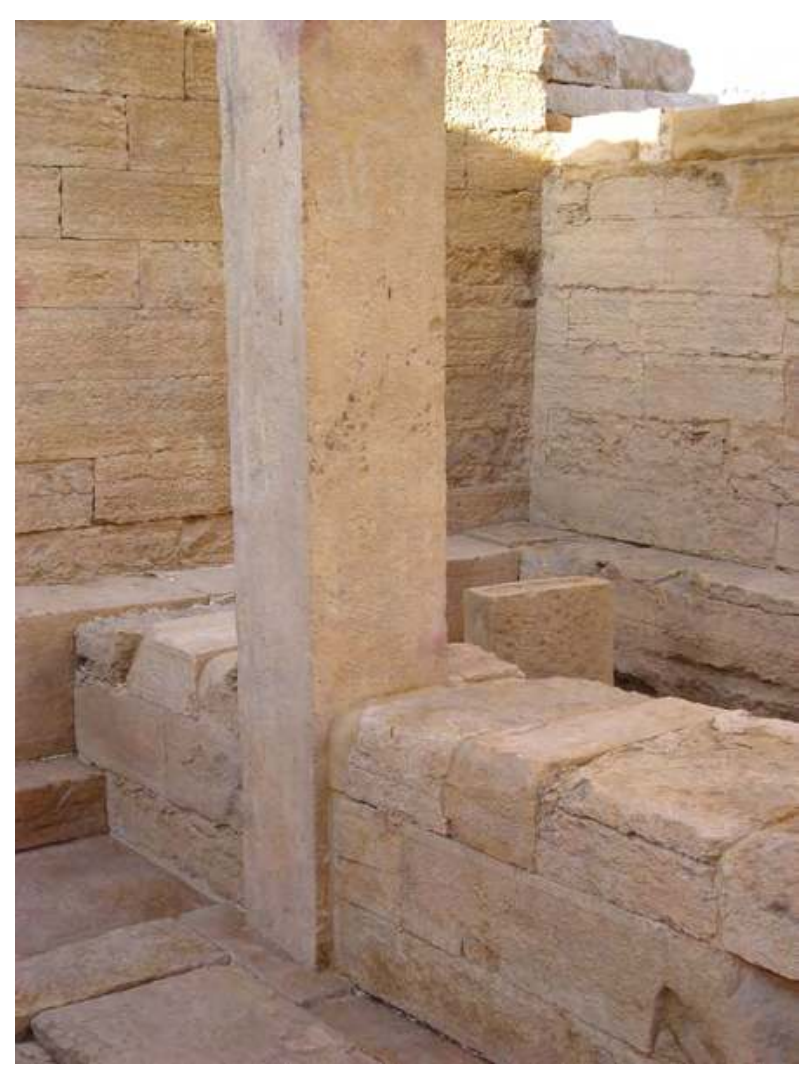

Figure 30. Il pilastro $\mathrm{P} 5$ nella posizione originaria a fine restauro. (S.B. Scigliano 2003 OMAIRY)

$22 \mathrm{~mm}$ e profondi $40 \mathrm{~cm}$, inclinati di $40^{\circ}$ verso il basso e trasversali rispetto alla frattura, all'interno dei quali sono state inserite le due barre in acciaio inox del diametro di $15 \mathrm{~mm}$ e lunghe $36 \mathrm{~cm}$, fatte aderire con la resina epossidica ad alto potere adesivo, caricata con quarzite.
Il P1 era interessato da una frattura orizzontale con distacco, a due terzi circa della sua altezza (fig. 31). Si caratterizzava per essere l'unico pilastro inserito tra due muri, tra la parete M1 sul lato SO e M2 sul lato NE (v. fig. 6). La parte superiore della parete M1, alta circa m 2,30, coincideva con la frattura orizzontale creatasi sul pilastro, mentre la parete M2 a NE era più alta di $1 \mathrm{~m}$ circa. Sia il P1 che le due pareti si presentavano inclinate di circa $5^{\circ}$ nella stessa direzione a NE. Il pilastro, dunque, era serratissimo tra le due pareti inclinate.

Per risanare la frattura, modificare la quota in altezza, ma soprattutto per correggere l'inclinazione dell'asse verticale, dovevamo, anche in questo caso, rimuovere il pilastro. Il fatto che il P1 fosse inserito in M1 ha rappresentato una serie di difficoltà non indifferenti; era necessario, infatti, estrarre ('sfilare') il P1 dalla costruzione originaria minea.

Fu scartata immediatamente l'ipotesi di smontare il muro M1 per poi ricomporlo, dal momento che i diversi blocchi di pietra presentavano accentuati fenomeni di esfoliazione e di disgregazione. I blocchi di pietra si presentavano legati tra di loro da un leggero strato di malta bianca e da terra compattata. Credo che se solo avessimo tentato di rimuovere quel muro, avremmo provocato danni irreparabili, sia per la perdita di materiale originale, sia per una questione estetica e deontologica. Pertanto, la soluzione meno invasiva ci parve quella di 'sfilare' il P1 senza smontare il muro M1, pur intervenendo tra le connessure di contatto tra pilastro e muro. Dovevamo, cioè, creare uno spazio sufficiente in prossimità degli interstizi, che ci permettesse di inserire le cinghie intorno al pilastro da sollevare in seguito con il carro-gru. Una volta rimosse le due sezioni del pilastro, bisognava però regolarizzare la sezione verticale della parete M1 in prossimità del lato SO del P1, che avrebbe impedito di ricollocare in perfetto asse verticale il pilastro. Infine, dovevamo reintegrare lo spazio rimasto vuoto della sezione verticale del muro M2 a contatto con il lato NE del P1.

Conl'ausilio dellagru abbiamo prima rimosso con facilità la parte superiore del P1 e collocata provvisoriamente fuori dal tempio (fig. 32). Il problema principale, tuttavia, consisteva nello sfilare la parte inferiore del P1 che si trovava ben più serrata tra i due muri (larghi circa $35 \mathrm{~cm}$ ). Ci sono voluti alcuni giorni di lavoro per creare uno spazio sufficiente tra il pilastro e i due muri, rimuovendo, dove necessario, qualche blocco di pietra. Successivamente, siamo riusciti ad estrarre anche la parte inferiore del $\mathrm{P} 1$, che è stata collocata anch'essa fuori dal tempio, vicino alla parte superiore.

Per effettuare il risanamento della frattura del pilastro, abbiamo praticato un foro centrale allineato 'a dima', del diametro di $25 \mathrm{~mm}$ e profondo $37 \mathrm{~cm}$, nelle due sezioni di contatto del P1, in modo da poter inserire una barra 
di acciaio inox del diametro di $20 \mathrm{~mm}$ e lunga $70 \mathrm{~cm}$. Nel frattempo abbiamo regolarizzato la sezione inclinata del muro M1. Con l'ausilio di un frullino elettrico grande e uno piccolo con dischi diamantati al vidiam, con scalpelli e altri utensili, siamo riusciti ad assottigliare la sezione verticale del M1 a contatto con il lato SO del P1, tagliando circa $12 \mathrm{~cm}$ nella parte alta, decrescendo in verticale verso il basso fino a 0 alla base del muro. Terminata la faticosa operazione di assottigliamento della parete di M1, ci siamo occupati di predisporre la base d'appoggio del pilastro. Dalle rilevazioni con la Stazione Totale, la quota verticale risultava essere più alta di $30 \mathrm{~cm}$ rispetto al P4. Secondo il nostro progetto, il P1 doveva essere abbassato di almeno $2 \mathrm{~cm}$. Come per il P5 è stata assottigliata la base d'appoggio di 2 $\mathrm{cm}$, mediante frullino elettrico e scalpelli (fig. 33). Successivamente è stata colata la consueta resina epossidica ad alto potere adesivo, caricata con quarzite, autolivellante, sopra alla quale è stata fatta cadere della graniglia di pietra (con granulometria da 2 a $4 \mathrm{~mm}$ ) per realizzare lo strato d'ancoraggio.

Una volta predisposte le sezioni dei muri e la base d'appoggio più bassa perfettamente orizzontale, si è potuto ricollocare e riallettare la parte inferiore del P1 nella sede originale, con una malta idraulica con ottimo potere adesivo (una parte di conglomerato LEDAN C30 e due di polvere di pietra fina). Bloccata ed ancorata ai muretti con malta idraulica, avente caratteristiche tixotropiche (legante MTX con polvere di pietra fina e schegge di pietra), la parte inferiore posizionata con l'asse verticale perfettamente a piombo sarebbe stata in grado di accogliere la parte superiore del pilastro. Il giorno successivo, quando le malte avevano completato la fase di presa, è stato possibile ricollocare la parte superiore. Abbiamo inserito la barra in acciaio inox del diametro di $20 \mathrm{~mm}$ con la stessa resina epossidica ad alto potere adesivo, caricata con quarzite, all'interno dei fori nelle sezioni delle due parti del P1.

Applicata la resina anche sulla superficie delle due sezioni di contatto della frattura, è stato possibile riporre definitivamente la parte superiore sopra la parte inferiore in perfetto asse verticale (fig. 34). Il pilastro a questo punto è stato fissato sia con travetti di legno, sia con cunei tra i due muri, per le successive 24 ore in perfetta posizione verticale (figg. 35-36).

I pilastri $\mathrm{P} 2, \mathrm{P} 3, \mathrm{P} 4, \mathrm{P} 6, \mathrm{P} 8, \mathrm{P} 9, \mathrm{P} 10$ e $\mathrm{P} 12$, pur non avendo gravi fratture con distacco, sono stati rimossi dalla sede originale, per poter correggere sia l'asse verticale che le quote in altezza, in funzione della successiva ricollocazione degli elementi della copertura (fig. 37).

Solo quattro dei pilastri hanno mantenuto invariata la quota verticale: P2, P6, P9 e P10; ciò nonostante, si è dovuto intervenire sulle basi d'appoggio inclinate e correggerle in perfetto piano orizzontale.

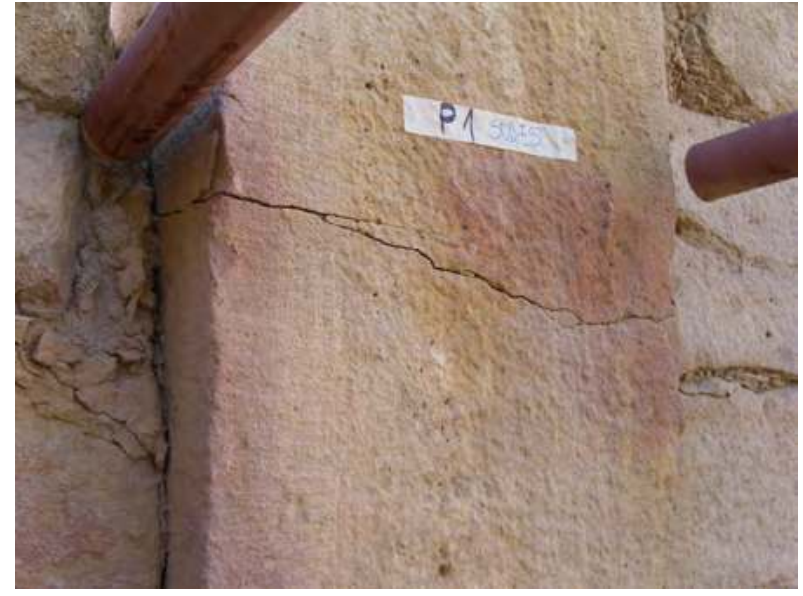

Figure 31. La frattura orizzontale con distacco del pilastro P1. (S.B. Scigliano 2003 CMAIRY)

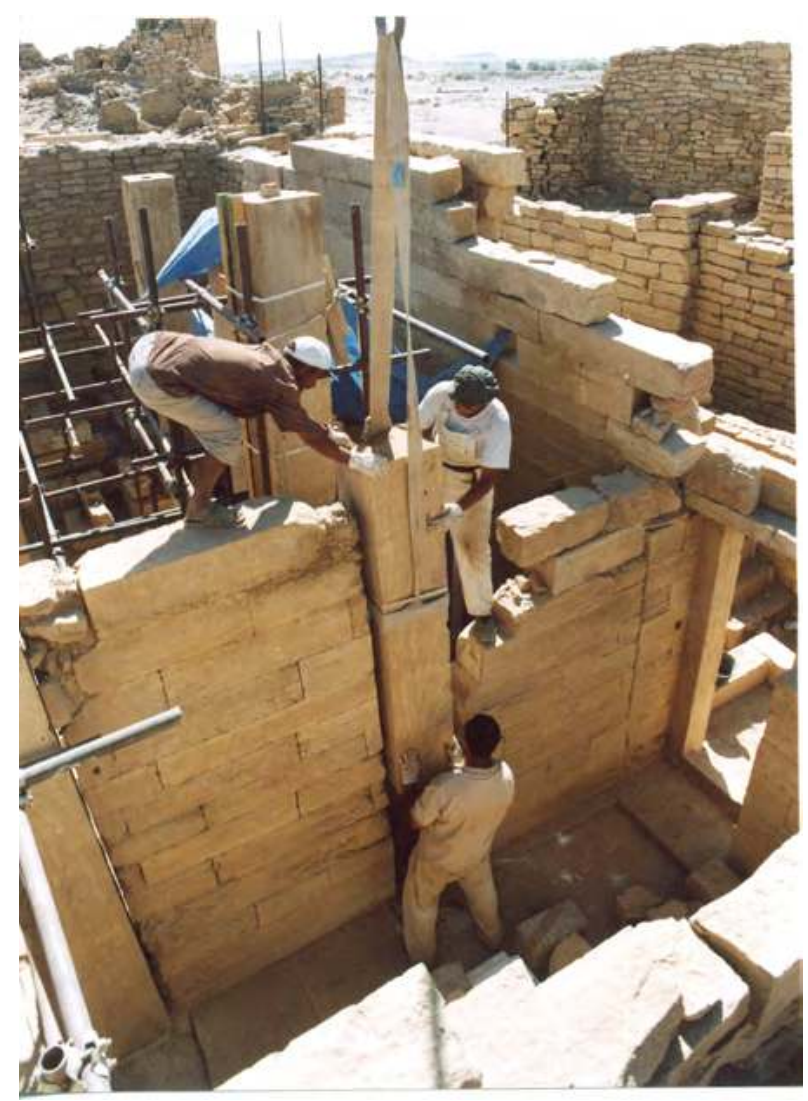

Figure 32. Rimozione della porzione superiore del pilastro P1 'sfilandola' dal M.1 (A. Paladino 2003 OMAIRY) 


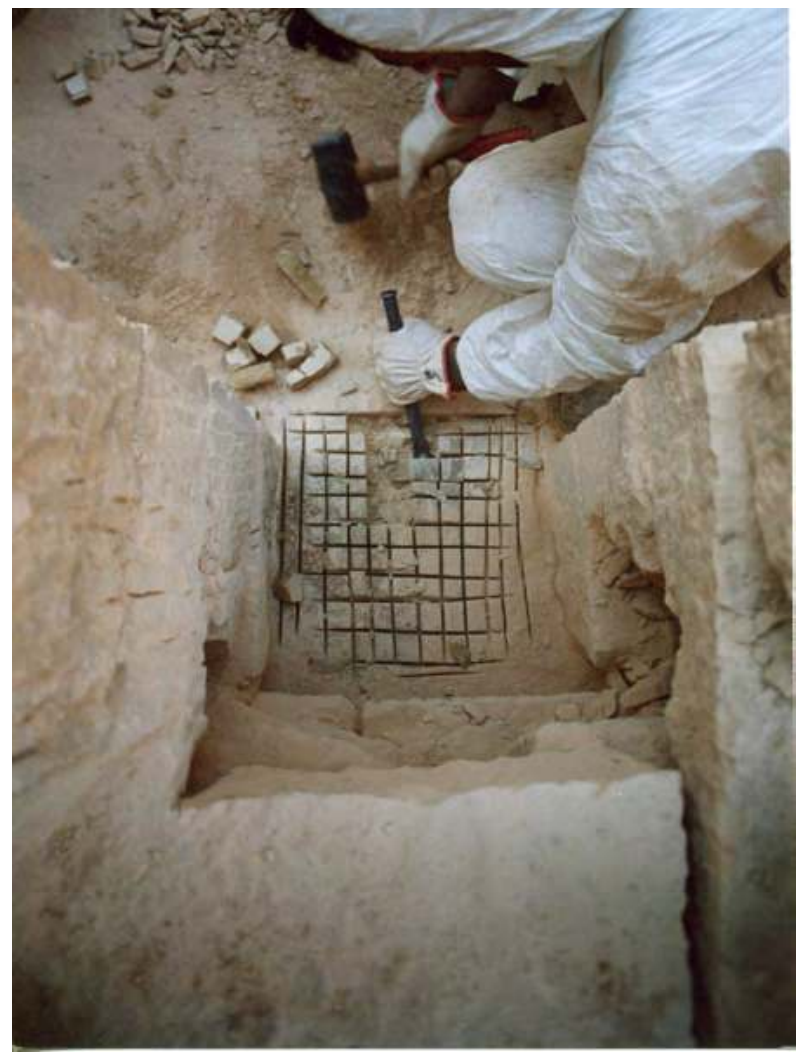

Figure 33. La base su cui appoggiare il pilastro P1 è stata ribassata di $2 \mathrm{~cm}$ mediante quadrettatura e rimozione dei cubetti lapidei con scalpello. (A. Paladino 2003 OMAIRY)

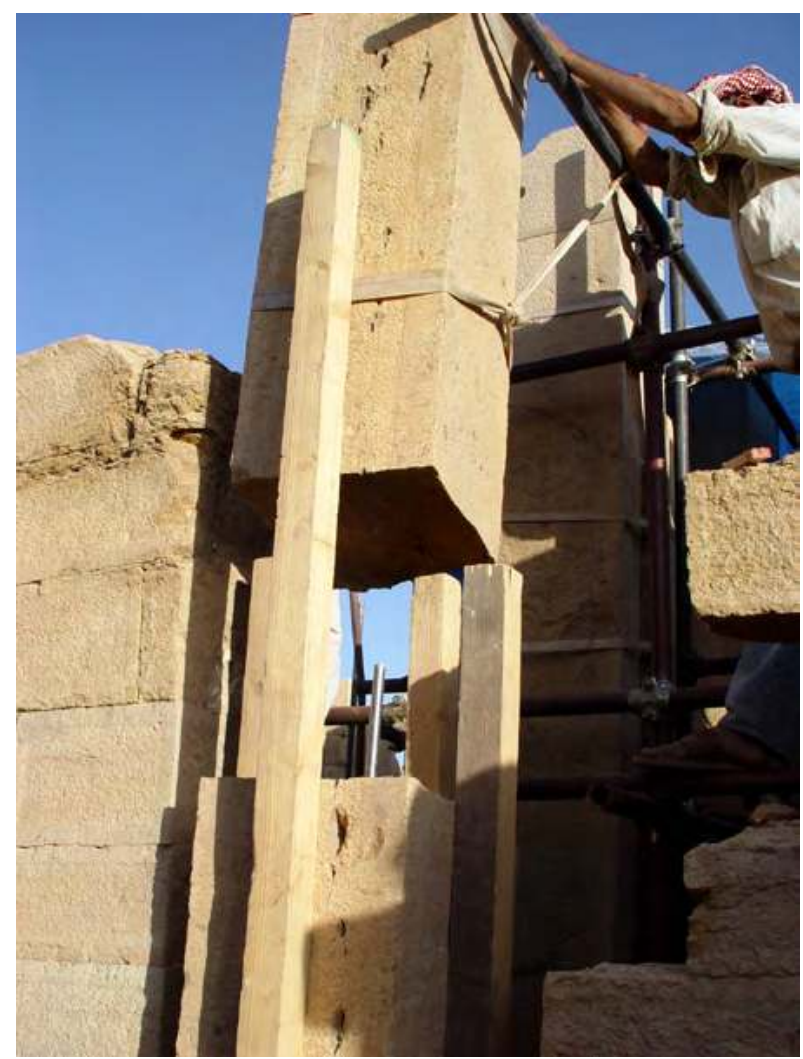

Figure 34. Ricollocamento della parte superiore su quella inferiore del pilastro P1. (A. Paladino 2003 OMAIRY)

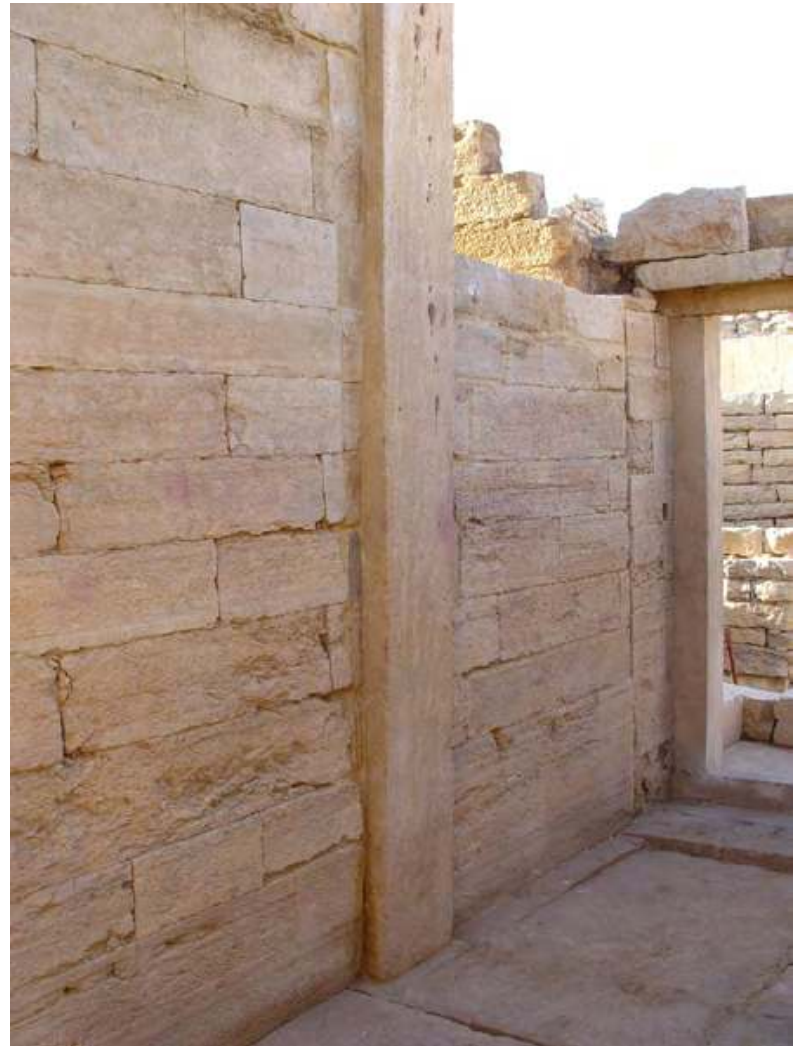

Figure 35. Il pilastro P1 rimesso in situ nel muro M1 dopo il restauro. (A. Paladino 2003 CMAIRY)

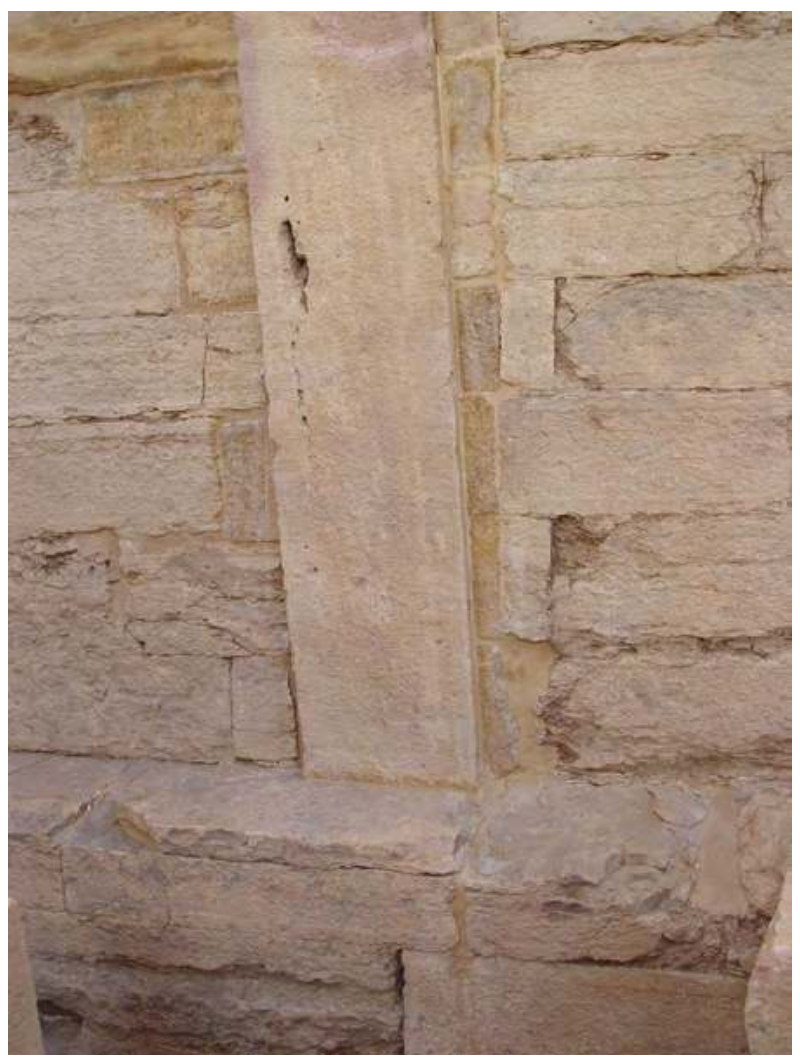

Figure 36. Dettaglio del pilastro P1 dopo il restauro. (S.B. Scigliano 2003 @MAIRY)

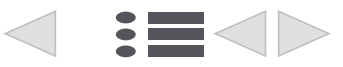


I singoli pilastri, una volta rimossi, sono stati collocati provvisoriamente in verticale, all'interno di una struttura metallica, realizzata in un'area della sala ipostila, con tubi metallici 'Innocenti', dove venivano tenuti in sicurezza con cinghie autobloccanti. La rimozione e la movimentazione dei pilastri rappresentava un momento delicato oltre che rischioso, ma era l'unico sistema per poter intervenire sulla base d'appoggio e modificarne il piano inclinato. Con la stesura di resina epossidica ad alto potere adesivo, caricata con quarzite super ventilata, fluida ed autolivellante, veniva modificato e corretto il piano orizzontale mediante la creazione di una base d'appoggio artificiale. Successivamente, veniva realizzato uno 'strato d'ancoraggio' per mezzo dell'applicazione di un secondo strato sottile di resina epossidica, sulla quale veniva fatta cadere e aderire una graniglia sottile di pietra (da 3 a $5 \mathrm{~mm}$ ). Lo strato d'ancoraggio era necessario ad aumentare l'adesione con la malta idraulica da utilizzare per la successiva ricollocazione del pilastro.

La stessa metodologia è stata applicata per i pilastri P3, $\mathrm{P} 4, \mathrm{P} 8$, e P12, con l'unica differenza che è stata realizzata una base d'appoggio artificiale più alta (fig. 38), con un piano in perfetta posizione orizzontale.

Le basi d'appoggio artificiali (come per P7 e P11), sono state realizzate in resina epossidica ad alto potere adesivo, caricata con quarzite super ventilata, alte a seconda della quota verticale del pilastro da correggere e perfettamente in bolla orizzontale. Per creare una base d'appoggio, era necessario predisporre un cordolo perimetrale, spesso circa $3 / 4 \mathrm{~cm}$, largo quanto la sezione del pilastro, alto delle dimensioni desiderate, prendendo come riferimento il lato più a monte dell'inclinazione, utilizzando una malta idraulica a basso contenuto salino, di consistenza plastica. In seguito, quando la malta aveva completato la fase di presa, si poteva versare la resina epossidica, caricata con la quarzite in un rapporto anche di 1: 1 , all'interno dell'area circoscritta dal cordolo. La resina doveva essere di consistenza fluida per mantenere le caratteristiche autolivellanti, consentendo così di creare un piano perfettamente orizzontale e 'in bolla'. Per ottenere una maggiore resistenza meccanica, durante le varie fasi di colata, all'interno della nuova base, venivano inserite ed inglobate nella resina scaglie di pietra di diverse dimensioni (da 2 fino a $10 \mathrm{~cm}$ di larghezza, di spessore variabile da 5 a $30 \mathrm{~mm}$ ). Sopra l'ultimo strato della nuova base d'appoggio artificiale veniva realizzato lo strato d'ancoraggio.

La base del P3 è stata realizzata con un'altezza di $6 \mathrm{~cm}$ rispetto al lato SO, così come per il P7; di $8 \mathrm{~cm}$ per il P11, di $14 \mathrm{~cm}$ per il P8 e di $16 \mathrm{~cm}$ per il P4.
I pilastri P9, P10, P11 e P12, posti su di un piano rialzato nell'area del 'transetto' antistante le celle del tempio, poggiavano liberi sul piano pavimentale, aderiti soltanto con uno strato sottile di calce bianca, a differenza di tutti gli altri pilastri che erano parzialmente o addirittura completamente inglobati ai muri dei sedili delle tavole offertorie (ad es. P4). Per garantire una maggiore stabilità, i pilastri in questione sono stati ricollocati ed imperniati con una barra in acciaio inox del diametro di $20 \mathrm{~mm}$ e lunga $40 \mathrm{~cm}$, inserita verticalmente all'interno della sezione inferiore dei pilastri e nella lastra d'appoggio pavimentale. Il P12, in particolare, è stato restaurato anche nella porzione inferiore, laterale ed esterna, che mostrava un distaccamento in scaglie (figg. 39-41).

Tutti i dodici pilastri sono stati ricollocati e riallettati alla nuova base d'appoggio artificiale 'a bolla' con una malta idraulica a basso contenuto salino (conglomerato LEDAN C30, e polvere di pietra fina 1:2) e non con resina epossidica, in modo da rispettarne la reversibilità futura.

Tutte le lesioni, le fratture risanate e qualche piccola lacuna sono state stuccate con una malta idraulica con lo scopo di sigillare e proteggere gli elementi in materiale lapideo dall'infiltrazione dell'acqua. Le stuccature sono state realizzate con una malta composta da un legante con caratteristiche idrauliche ed uno con caratteristiche di presa aerea conglomerato LEDAN C30 una parte, grassello di calce una parte, cinque parti di polvere di pietra fina (di colore variabile tra il giallo-ocra ed il rosso-ossido a seconda delle aree d'intervento). La polvere di pietra è stata ottenuta mediante triturazione manuale di frammenti di pietra simile all'originale, reperita in situ, setacciata in diverse granulometrie fine e finissima (figg. 42-43).

\subsection{Stipiti del portale d'ingresso}

Dopo i trattamenti preliminari consueti (v. $\S 1$. Descrizione delle fasi di intervento, A. e B.), i difetti di adesione di piccole porzioni di materiale lapideo, di parti esfoliate e piccole lesioni sono stati consolidati per mezzo di infiltrazioni di resina acrilica in soluzione, a bassa concentrazione (Polycril 205 al 5/10\%), previa bagnatura con acqua e alcol 2: 1, al fine di ottenere un effetto riaggregante delle particelle di materiale superficiale disgregato; a seguire sono state effettuate infiltrazioni con la stessa resina in soluzione, ma con concentrazione fino al 40\% / 50\%. Dove necessitava, veniva effettuata una stuccatura di sigillatura con una malta di consistenza plastica, composta da una parte di conglomerato LEDAN C30 e tre parti di polvere di pietra finissima, simile per colore, ottenuta per triturazione manuale, da materiale lapideo reperito nell'area archeologica. 


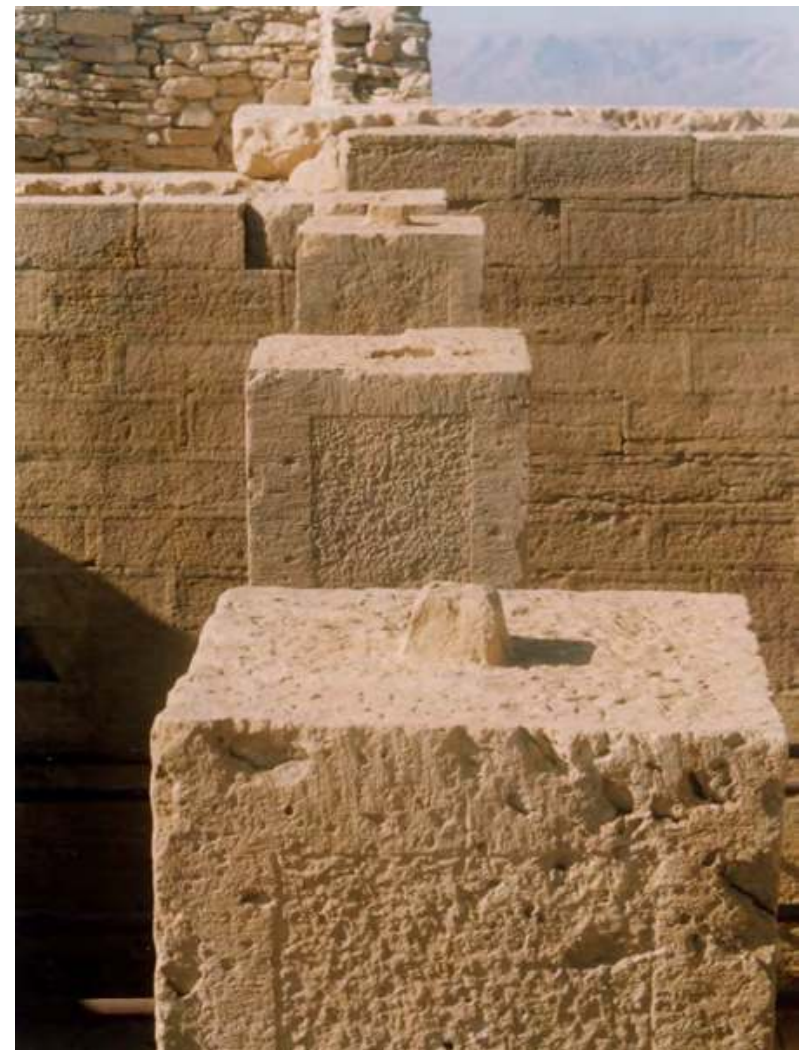

Figure 37. Vista della parte superiore di P12, P11, P10 e P9 da $\mathrm{E}$, in cui è visibile la differenza di quote dei pilastri stessi. (S.B. Scigliano 2003 OMAIRY)

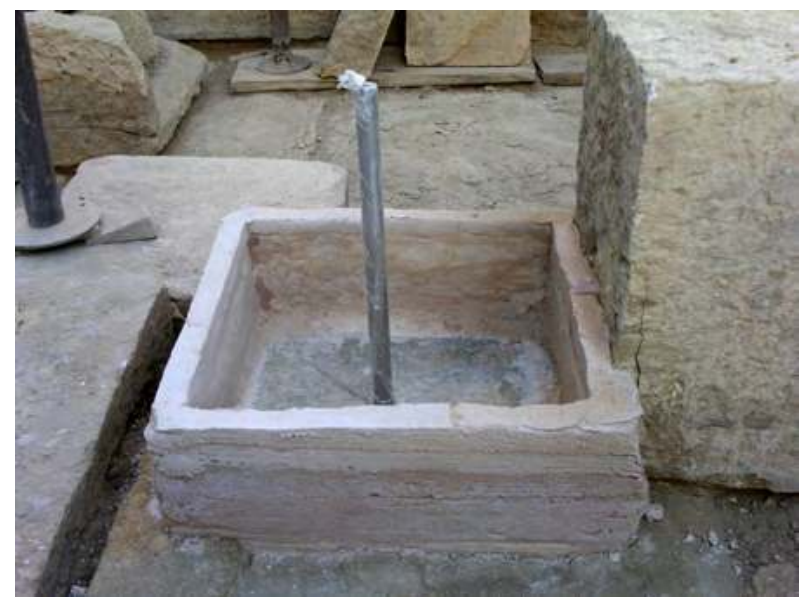

Figure 38. Cordolo perimetrale della base artificiale, realizzato con malta idraulica, per l'alloggiamento del pilastro P12; al centro la barra d'acciaio. (S.B. Scigliano 2003 (OMAIRY)

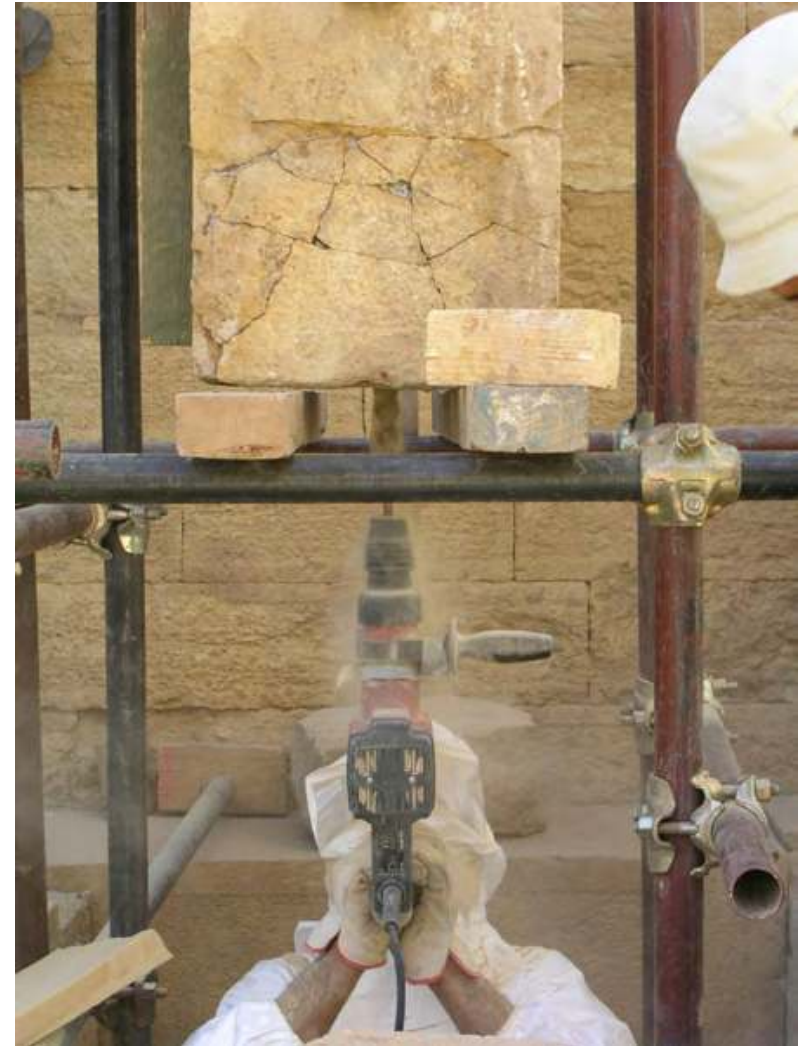

Figure 39. Fase di perforazione al centro della faccia inferiore del pilastro P12, per l'inserimento della barra d'acciaio fissata nella base artificiale del P12 (v. fig. 38).

(A. Paladino 2003 CMAIRY)

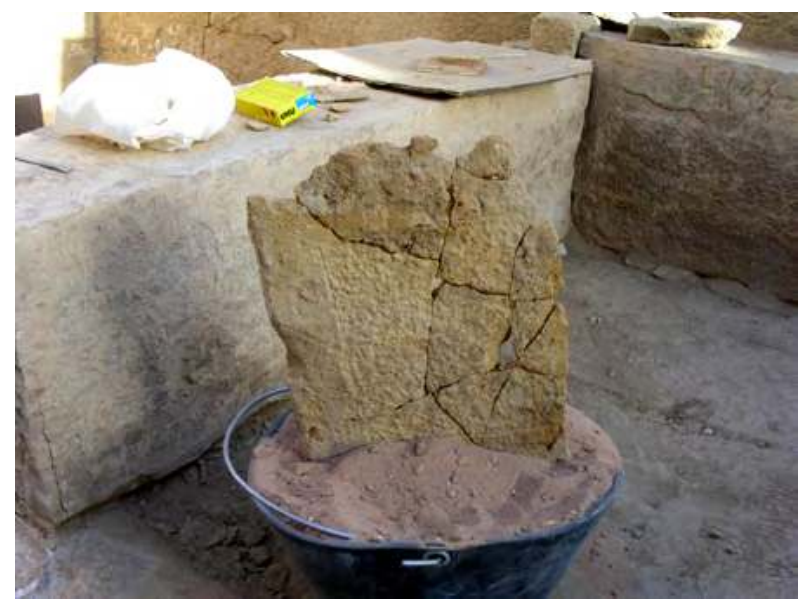

Figure 40. Frammenti ricomposti di una porzione superficiale distaccata del pilastro P12. (A. Paladino 2003 CMAIRY) 


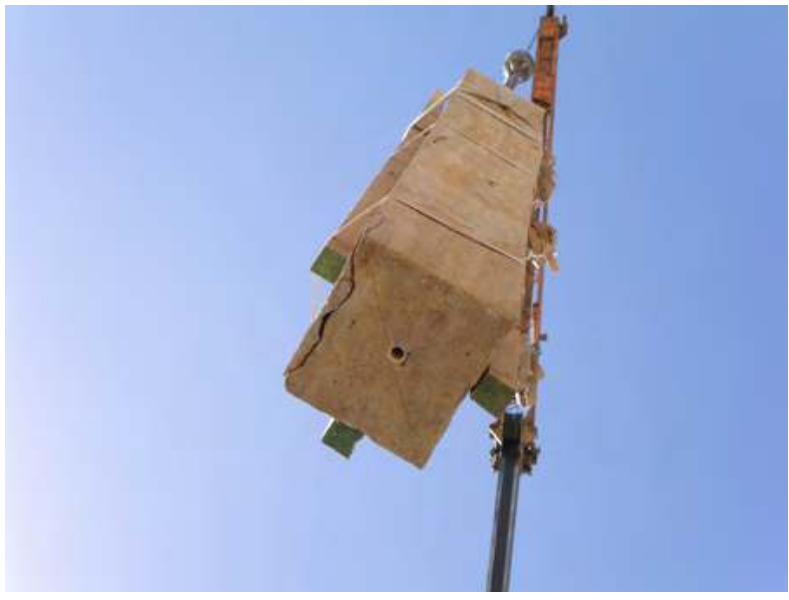

Figure 41. Vista dal basso del pilastro P12 con il foro centrale e la ricomposizione della porzione superficiale restaurata.

(A. Paladino 2003 CMAIRY)

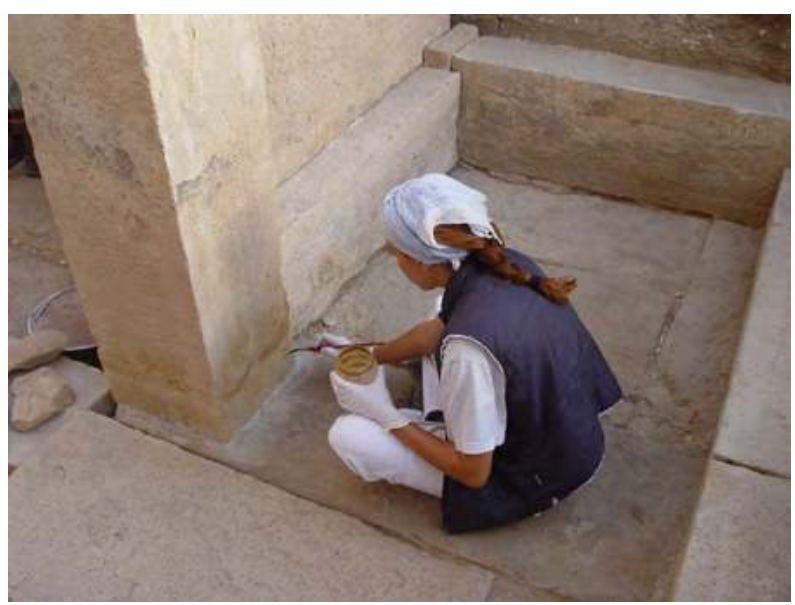

Figure 42. Rifiniture con il colore della pietra (giallo-ocra) del cordolo artificiale. (S.B. Scigliano 2003 OMAIRY)

I distacchi di porzioni di materiale lapideo di maggiore consistenza e le piccole fratture parziali sono state risanate mediante infiltrazioni di malta idraulica fluida, a basso contenuto di sali solubili (conglomerato LEDAN C30), previa bagnatura con acqua e alcol $2: 1$; dove era necessario, fu applicato un puntello per spingere sulla parte distaccata e facilitarne l'adesione, oltre che per correggere l'eventuale divaricazione (fig. 44). In altri casi, dove il distacco presentava l'impronta di contatto ancora perfetta ed il materiale costitutivo si preservava in buono stato, le parti distaccate o in pericolo di caduta sono stati fatti aderire con resina epossidica bicomponente, ad alta resistenza e bassa viscosità (UHU Plus, beecham Italia).

Le parti superiori dei due stipiti erano interessate da fratture multiple, alcune passanti e con dislocazione

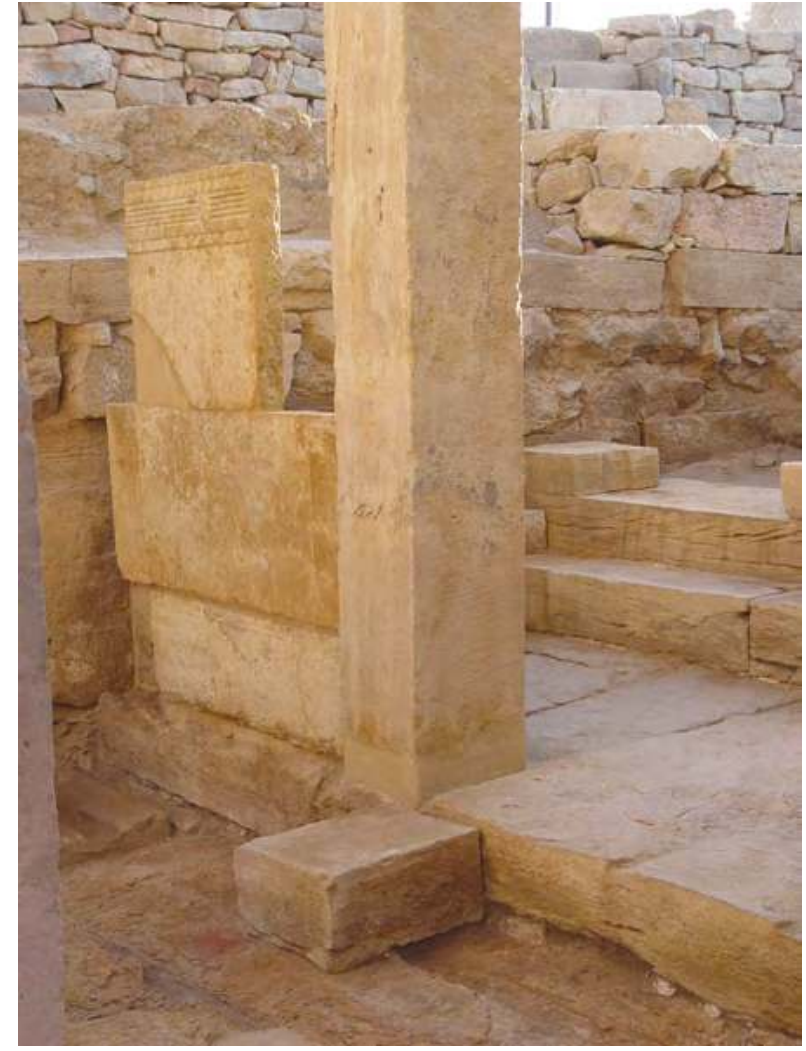

Figure 43. Il pilastro P12 dopo il restauro. (S.B. Scigliano 2003 OMAIRY)

dalla sede originale (fig. 45). I distacchi più preoccupanti interessavano la parte superiore in tutta la larghezza degli stipiti, con fessurazioni da 5 a $10 \mathrm{~cm}$, fino a $1 \mathrm{~m}$ di profondità in verticale, all'interno delle quali il materiale costitutivo versava in uno stato di gravissima disgregazione.

Per risanare e salvaguardare i due stipiti, si è resa necessaria una pulitura in profondità e la eliminazione del materiale disgregato compattato. Completata la pulitura, sono state realizzate stuccature di sigillatura e di contenimento, lungo i bordi delle fessure, tra i due lembi, con malta idraulica a basso contenuto di sali solubili, composta da una parte di conglomerato LEDAN C30 e tre parti di polvere di pietra finissima, simile per colore, ottenuta per triturazione manuale, del materiale lapideo reperito nell'area archeologica. A distanza di qualche giorno, quando la presa della malta di sigillatura era completata, è stato possibile risanare i distacchi con grave entasi infiltrano adesivi riempitivi.

In tutti e due gli stipiti con queste tipologie è stato versato all'interno, dall'alto, un primo strato di 15 $\mathrm{cm}$ circa di conglomerato LEDAN C30 di consistenza fluida, e una parte di polvere di pietra finissima. Successivamente, dopo qualche giorno, all'interno delle fessure è stato versato un secondo strato della resina 
epossidica ad alto potere adesivo caricata con quarzite super ventilata. Il graduale riempimento delle gravi entasi è stato effettuato intervallando i due adesivi fino al completamento (fig. 46). Questa metodologia di intervento è volta a garantire una maggiore resistenza adesiva e meccanica.

Le quattro fratture orizzontali passanti su tre lati che interessavano la parte interna dello stipite di sinistra, sono state risanate per mezzo di inserimento di 8 perni in acciaio inox, fatti aderire con resina epossidica. Sul lato So dello stipite orientale sono stati prima effettuati 8 fori (due per ogni frattura) con trapano a rotazione Hilti, del diametro di $16 \mathrm{~mm}$ e profondi $30 \mathrm{~cm}$, inclinati da $30^{\circ}$ a $45^{\circ}$ verso il basso e trasversali rispetto alle fratture (fig. 47). Successivamente sono state inserite le piccole barre in acciaio inox del diametro di $10 \mathrm{~mm}$ e lunghe $28 \mathrm{~cm}$, dall'esterno verso l'interno ('a tradimento'), in prossimità delle quattro fratture orizzontali, fatti aderire con la resina epossidica ad alto potere adesivo, caricata con quarzite super ventilata.
Tutte le lesioni, le fratture risanate e le aree lacunose sono state stuccate con una malta idraulica, con lo scopo di sigillare e proteggere gli elementi in materiale lapideo dall'infiltrazione dell'acqua (fig. 48). Le stuccature sono state realizzate con una malta composta da una parte di legante con caratteristiche di presa idraulica conglomerato LEDAN C30 e una parte di legante con caratteristiche di presa aerea grassello di calce, cinque parti di polvere di pietra fina (di colore variabile tra il giallo-ocra ed il rosso-ossido a seconda delle aree d'intervento). La polvere di pietra è stata ottenuta mediante triturazione manuale di frammenti di pietra simile all'originale, reperita in situ, setacciata in diverse granulometrie fina e finissima (fig. 49).

Infine, le superfici sono state trattate con il consueto prodotto protettivo idrorepellente (v. § 1. Descrizione delle fasi di intervento, C.).

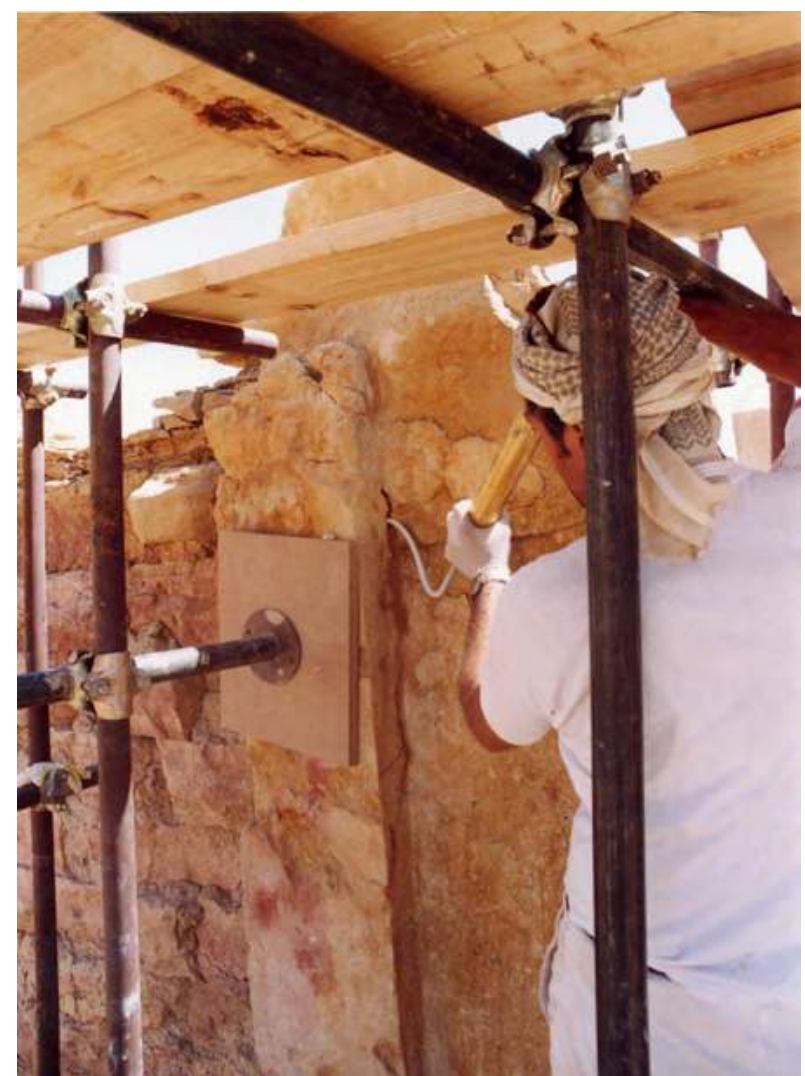

Figure 44. Infiltrazioni di malta idraulica fluida negli spazi distaccati e nelle fratture parziali della parte superiore dello stipite orientale della porta. (A. Paladino 2003 @MAIRY)

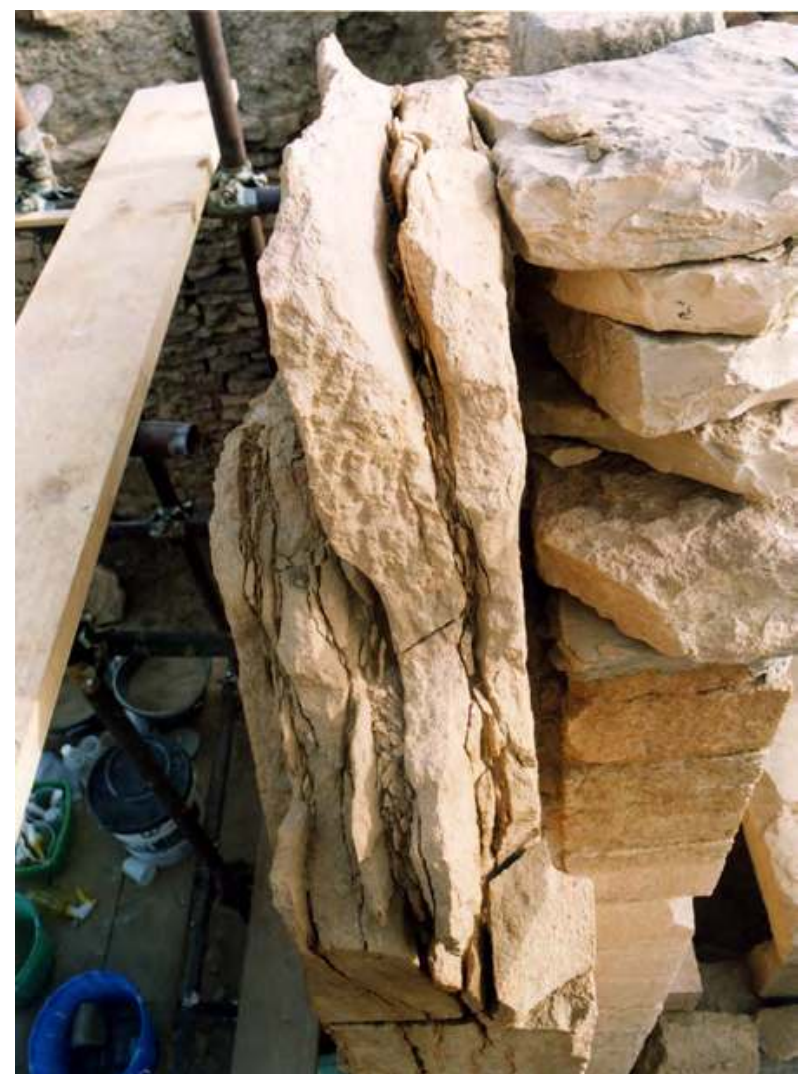

Figure 45. Stato di conservazione con fratture multiple e disgregazione del materiale lapideo della porzione superiore dello stipite orientale della porta del tempio. (S.B. Scigliano 2003 @MAIRY) 


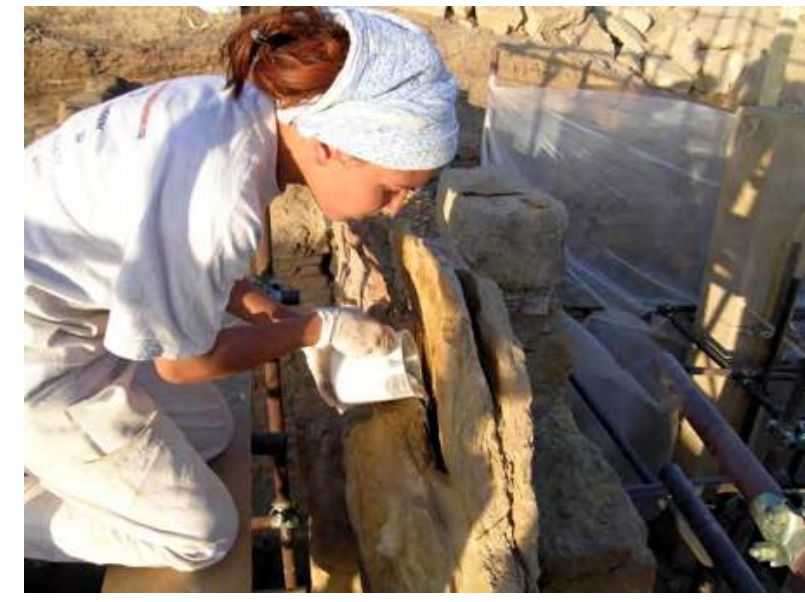

Figure 46. All'interno di entrambi gli stipiti, nelle fessure è stato versato dall'alto uno strato di conglomerato LEDAN C30 di consistenza fluida, e una parte di polvere di pietra

finissima. Dopo qualche giorno, vi è stata versata resina epossidica ad alto potere adesivo caricata con quarzite super ventilata. (S.B. Scigliano 2003 CMAIRY)

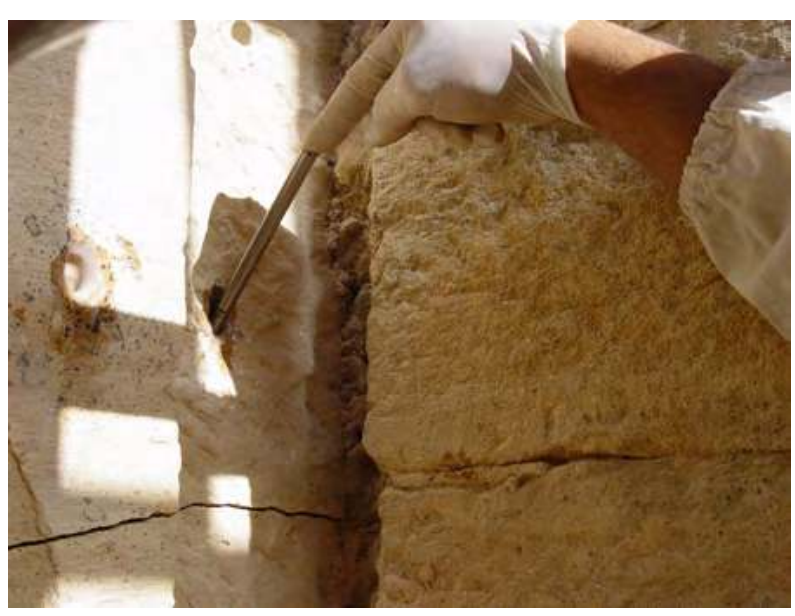

Figure 47. Inserimento di una barra d'acciaio in un foro appositamente praticato in prossimità delle quattro fratture orizzontali della porzione superiore dello stipite orientale della porta del tempio.

(A. Paladino 2003 CMAIRY)

\subsection{La cella centrale}

I due muri della cella centrale, rimasti conservati solo parzialmente, presentavano gravi problemi strutturali e di natura statica. L'inclinazione di $5^{\circ}$ circa delle pareti verso $\mathrm{NE}$ e la perdita di grande quantità dei blocchi murari nella parte superiore avevano reso le due pareti non più in grado di svolgere la funzione di sostegno della copertura. Per poter effettuare la completa risistemazione degli elementi di copertura, rimossi nel 1992, era indispensabile risolvere le precarie condizioni strutturali, legate in parte alla rotazione massificata che aveva coinvolto tutto l'edificio.

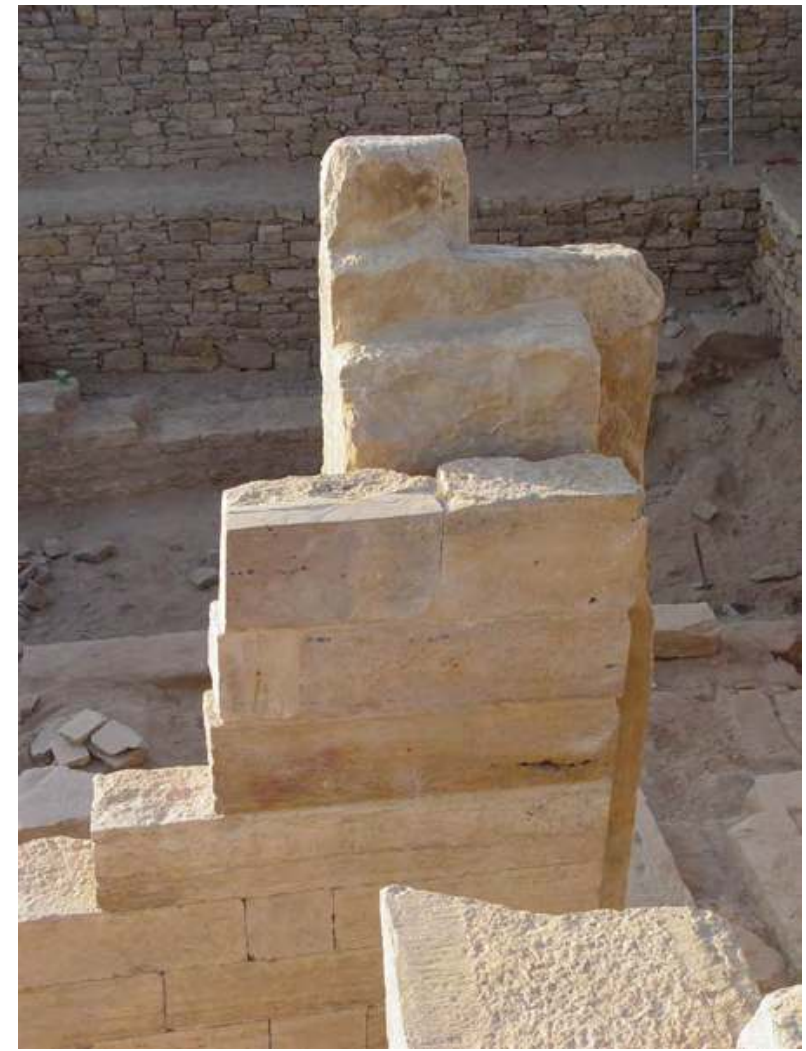

Figure 48. Dettaglio della porzione superiore dello stipite orientale della porta del tempio: sono visibili le stuccature effettuate con malta idraulica con lo scopo di sigillare e proteggere il materiale lapideo da infiltrazioni dell'acqua. (S.B. Scigliano 2003 OMAIRY)

I piccoli distacchi di materiale lapideo sono stati fatti aderire con resina epossidica bicomponente, ad alta resistenza e bassa viscosità (UHU Plus, beecham Italia).

Le fratture parziali sono state risanate mediante infiltrazioni di resina epossidica ad alto potere adesivo. I distacchi di maggiore entità e le fratture totali sono stati ripristinati con la stessa resina epossidica ad alto potere adesivo caricata con quarzite super ventilata.

Dopo accurate analisi e calcoli, è stato deciso coraggiosamente di smontare completamente la parete occidentale della cella centrale (fig. 50), per correggere l'asse verticale e irrobustire la parete, mediante integrazione con blocchi di pietra simili agli originali, aventi finalità statiche. Per la parete orientale, invece, abbiamo deciso di smontare solo la metà superiore dei blocchi di pietra, poiché nel 1992 essa era già stata smontata e rimontata in un primo pronto intervento di restauro dall'architetto Giuseppe Tilia, che era riuscito nell'intento solo parzialmente.

Tutti i blocchi da rimuovere sono stati segnati con una numerazione progressiva, per facilitarne il rimontaggio e per riporre ogni singolo blocco di pietra nella 


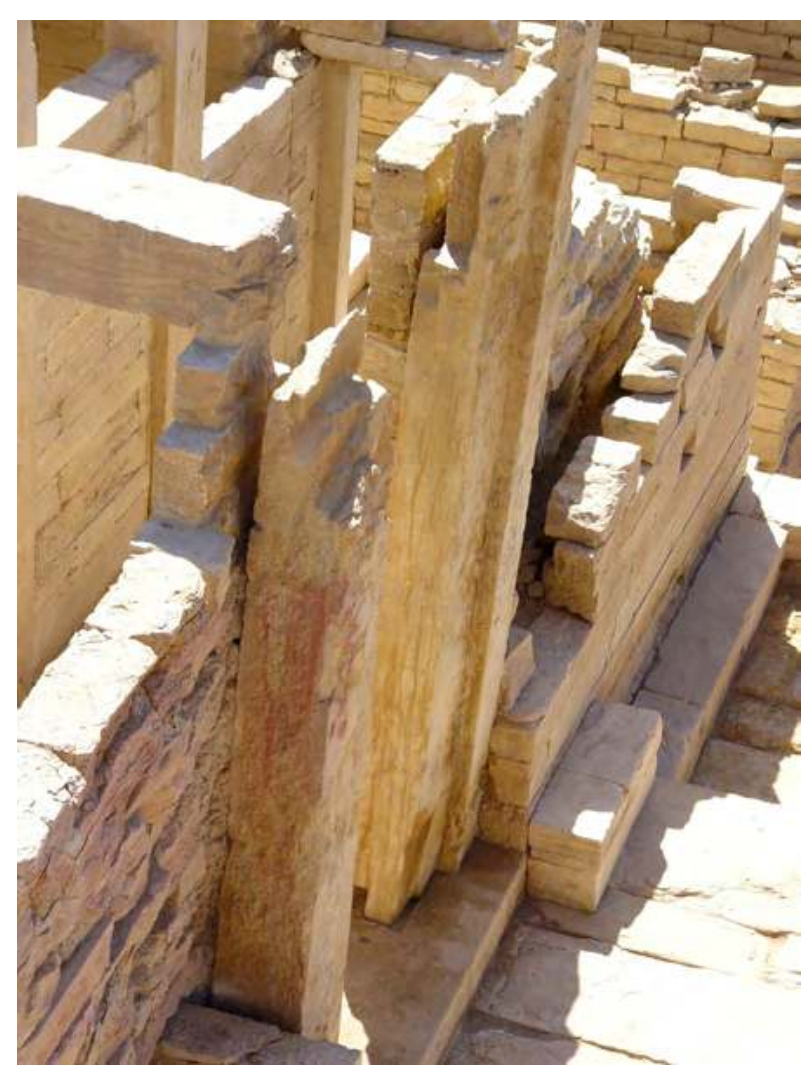

Figure 49. Vista a volo d'uccello (da NE) degli stipiti della porta del tempio dopo il restauro.

(S.B. Scigliano 2003 OMAIRY)

posizione originale, aiutati successivamente anche dalla documentazione fotografica dettagliata, realizzata in precedenza.

Sono stati rimossi prima tutti i blocchi della parete occidentale e collocati a terra, nella stessa posizione in sequenza numerica, ricostruendo in orizzontale l'andamento del muro.

Conclusa la rimozione di tutti i blocchi, abbiamo realizzato una base d'appoggio perfettamente 'in bolla' orizzontale, dell'ampiezza della parete, in modo da correggere i $3 \mathrm{~cm}$ circa che c'erano di dislivello nella larghezza del muro, avente una sezione di circa $40 \mathrm{~cm}$ (fig. 51). La base d'appoggio della parete occidentale è stata realizzata con una malta con caratteristiche idrauliche, a basso contenuto di sali solubili, di consistenza plastica, composta da conglomerato LEDAN C30 una parte, calce idraulica LAFARGE una parte, sabbia gialla fina del wādī cinque parti. Abbiamo steso una quantità sufficiente di malta, da $0,5 \mathrm{~cm}$ a circa $4 \mathrm{~cm}$ e, con l'ausilio di due livelle a bolla d'acqua, abbiamo modificato l'inclinazione del piano pavimentale in un perfetto piano orizzontale.

In seguito, abbiamo riallettato i primi blocchi di pietra, nella sequenza originale, utilizzando una malta idraulica (legante MTX una parte, calce idraulica LAFARGE una parte, sabbia gialla fine del wādī cinque parti) avente caratteristiche tixotropiche.

Come si può notare dalla figura 50, nelle prime file in basso, alcuni blocchi di pietra erano visibilmente sconnessi poiché quasi tutta la metà destra del muro non era originale, ma ricostruita in epoca islamica. Pertanto, dovendo ricostruire un muro solido che non fosse più falso, o, peggio ancora, finto, si è reso necessario reperire blocchi di pietra più simili possibile, sia per lavorazione che per dimensioni, agli originali. Grazie al lavoro di alcuni operai specializzati yemeniti del GOAM, capaci di lavorare la pietra con semplici martelline, è stato effettuato un eccellente lavoro di ricerca all'interno della città, atto al reperimento di blocchi di pietra, che si potessero adattare alla reintegrazione con finalità statiche, dei due muri della cella centrale.

Fila dopo fila, abbiamo ricostruito la parete occidentale, riutilizzando i blocchi di pietra, così come li abbiamo rimossi, integrandoli con blocchi simili a quelli originali (fig. 52). Certamente non abbiamo ricostruito la parete intera, ma sicuramente solida ed in asse verticale perfetto, cercando di renderle un aspetto frammentario ed antico (fig. 53). Affinché gli interventi di restauro e le nostre integrazioni (anastilosi) fossero riconoscibili, abbiamo marcato tutti i conci di reintegrazione, tramite una foratura e stuccatura sottolivello (fig. 54), con una malta di colore rosso-ossido, evidenziando così le zone reintegrate, con un segno indelebile e visibile anche a luce radente (fig. 55).

Della parete orientale, sono state rimosse sei file di blocchi partendo dall'alto (fig. 56). Come per il muro occidentale, sono stati prima numerati i blocchi di pietra in sequenza progressiva, e solo successivamente si è proceduto alla loro rimozione. Anche in questo caso, la parete è stata rinforzata reintegrando la parte superiore con qualche blocco di pietra, dove si è ritenuto fosse più necessario (fig. 57). Complessivamente le due pareti sono state integrate con 55 blocchi di pietra, simili per lavorazione e dimensione, reperite all'interno dell'area archeologica di Barāqish, al fine di risanare i problemi strutturali, di inclinazione e di staticità, soprattutto in relazione alla imminente ricollocazione degli elementi della copertura.

La cornice orizzontale superiore posta sotto l'architrave della porta della cella centrale, era stata rimossa nella campagna di scavo del 1992, in quanto fratturata e divisa in due parti. Inoltre, risultava mancante una considerevole porzione di materiale lapideo, pari a circa un quarto della lunghezza totale, nella parte a ovest.

Per risistemare la parte superiore nella sua sede originale, si è reso necessario un primo intervento 
di riadesione delle due parti originali aventi ancora un'impronta di contatto perfetta, mediante l'inserimento di un perno in acciaio inox. Nelle sezioni di frattura delle due parti staccate abbiamo effettuato un foro del diametro di $25 \mathrm{~mm}$ e profondo $34 \mathrm{~cm}$, centrale e perfettamente 'a dima'. Successivamente è stata inserita una barra in acciaio inox del diametro di $20 \mathrm{~mm}$ e lunga $60 \mathrm{~cm}$, fatta aderire con la resina epossidica ad alto potere adesivo, caricata con quarzite super ventilata. Per favorire un'adesione perfetta, le due parti fratturate sono state posizionate in verticale, tenute ferme ed unite con travetti di legno che avevano una funzione strutturale, legati intorno alla cornice con cinghie auto-bloccanti (fig. 58).

Dopo aver reperito, in prossimità dell'area del tempio, un frammento simile alla parte mancante (verso 0) della cornice, lo abbiamo adattato alle dimensioni della cornice intera, prendendo come riferimento la distanza tra i due muri e i punti d'appoggio nella sede originale (fig. 59). Come per le due parti originali fratturate, abbiamo inserito nelle sezioni della cornice e del frammento d'integrazione un perno in acciaio inox, del diametro di $20 \mathrm{~mm}$ e lungo $60 \mathrm{~cm}$. Le due parti sono state aderite con la resina epossidica ad alto potere adesivo, caricata con quarzite super ventilata.

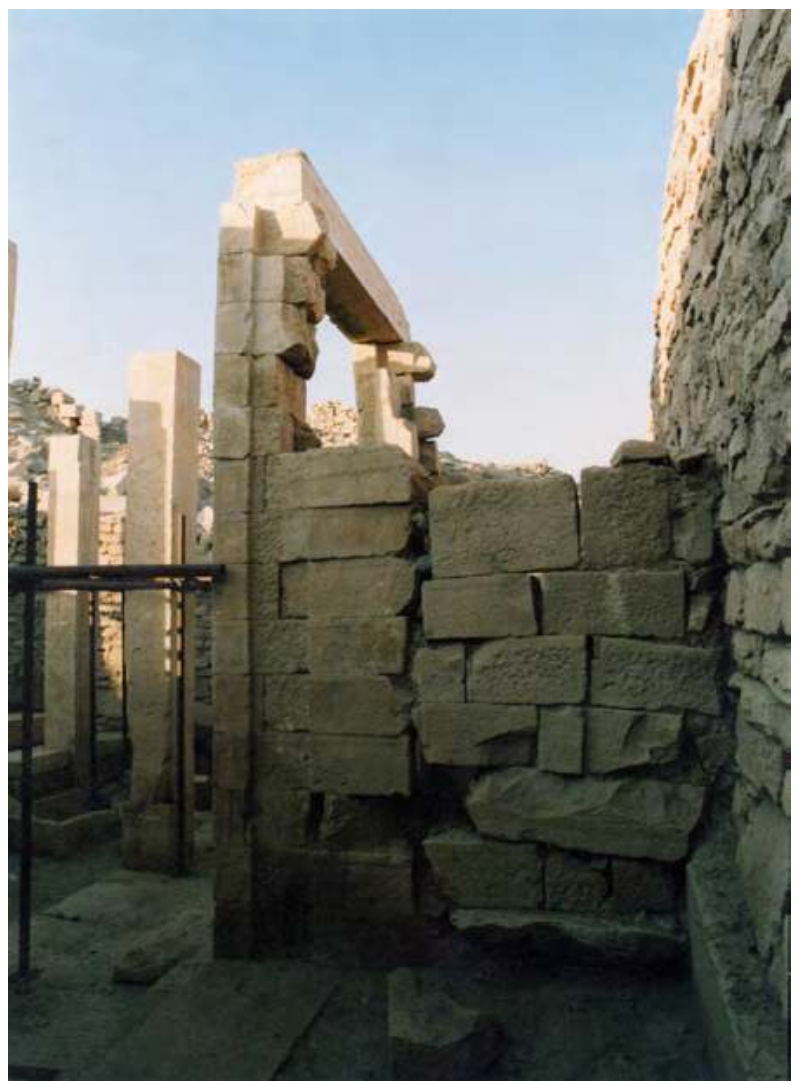

Figure 50. Il muro occidentale della cella centrale del tempio, prima dell'intervento di restauro.

(S.B. Scigliano 2003 OMAIRY)
Dopo aver effettuato il risanamento e la ricostruzione della cornice, si è proceduto alla ricollocazione sopra il montante orientale ancora conservato. La cornice poggiava sopra due blocchi di pietra opportunamente scanalati dai Minei, posti nella penultima fila dei due muri laterali (fig. 60). Per garantire una maggiore sicurezza, abbiamo inserito dall'alto due barre in acciaio inox 'a tradimento' (a destra e sinistra), con inclinazione di $45^{\circ}$, passanti fino ai blocchi di pietra d'appoggio. I due perni non sono stati fissati con alcun tipo di adesivo; inoltre, le due barre in acciaio sono state lasciate sporgenti in alto per $2 \mathrm{~cm}$, rendendo così possibile un eventuale smontaggio della cornice stessa.

Tutte le lesioni, le fratture risanate e qualche piccola lacuna sono state stuccate con malta idraulica, con lo scopo di sigillare e proteggere gli elementi in materiale lapideo dall'infiltrazione dell'acqua. Le stuccature sono state realizzate con una malta composta da una parte di legante con caratteristiche di presa idraulica conglomerato LEDAN C30 e una parte di legante con caratteristiche di presa aerea grassello di calce, cinque parti di polvere di pietra fina (di colore variabile tra il giallo-ocra ed il rosso-ossido a seconda delle aree d'intervento). La polvere di pietra è stata ottenuta mediante triturazione manuale di frammenti di pietra,

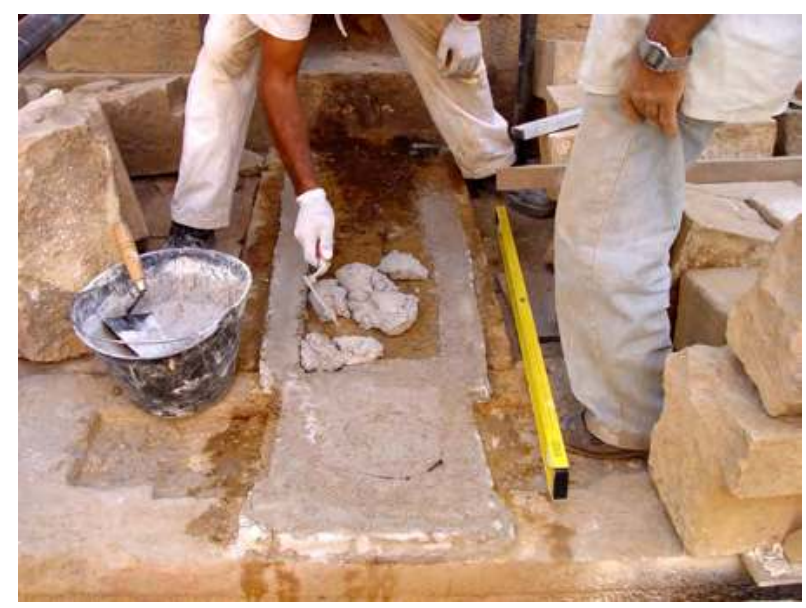

Figure 51. Fase di preparazione della base del muro occidentale, completamente smontato, della cella centrale del tempio.

(A. Paladino 2003 OMAIRY) 


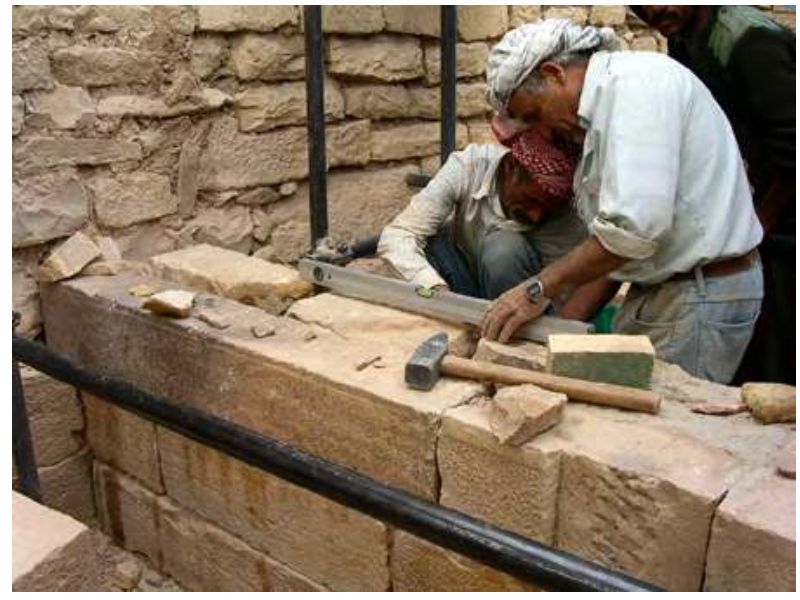

Figure 52. Gli operai specializzati del GOAM ricostruiscono la parete occidentale della cella centrale del tempio. (S.B. Scigliano 2003 CMAIRY)

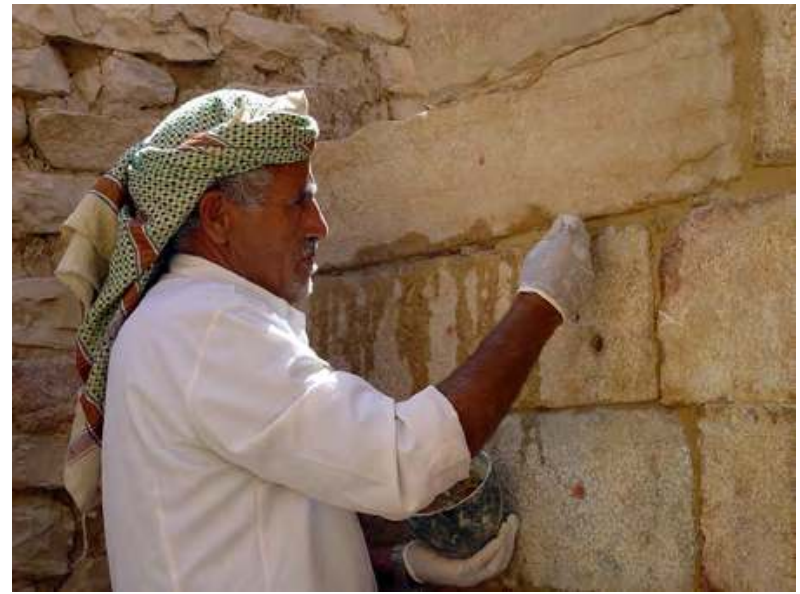

Figure 53. Fase di stuccatura e trattamento del muro occidentale della cella centrale del tempio eseguita da un operaio specializzato del GOAM. (S.B. Scigliano 2003 OMAIRY)

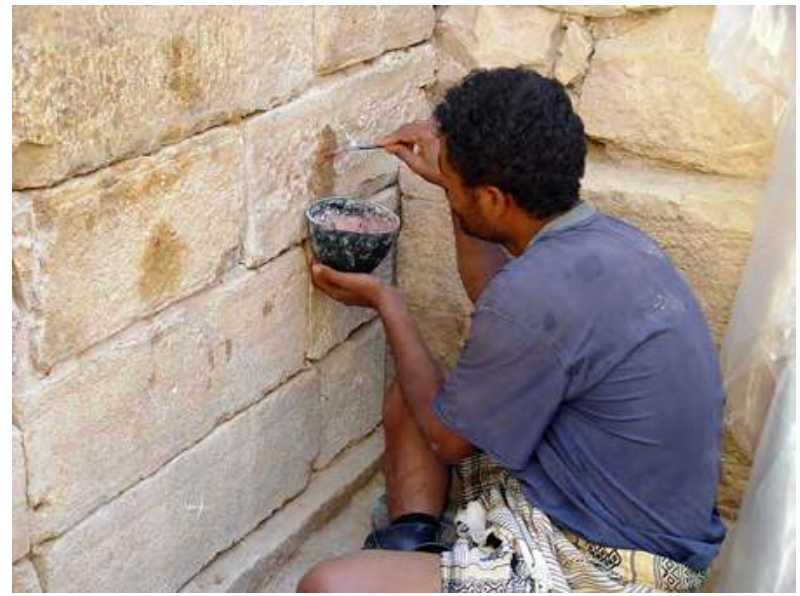

Figure 54. I conci di reintegrazione sono stati marcati con stuccatura in sottosquadro con malta di colore rosso-ossido per renderli riconoscibili.

(S.B. Scigliano 2003 OMAIRY)

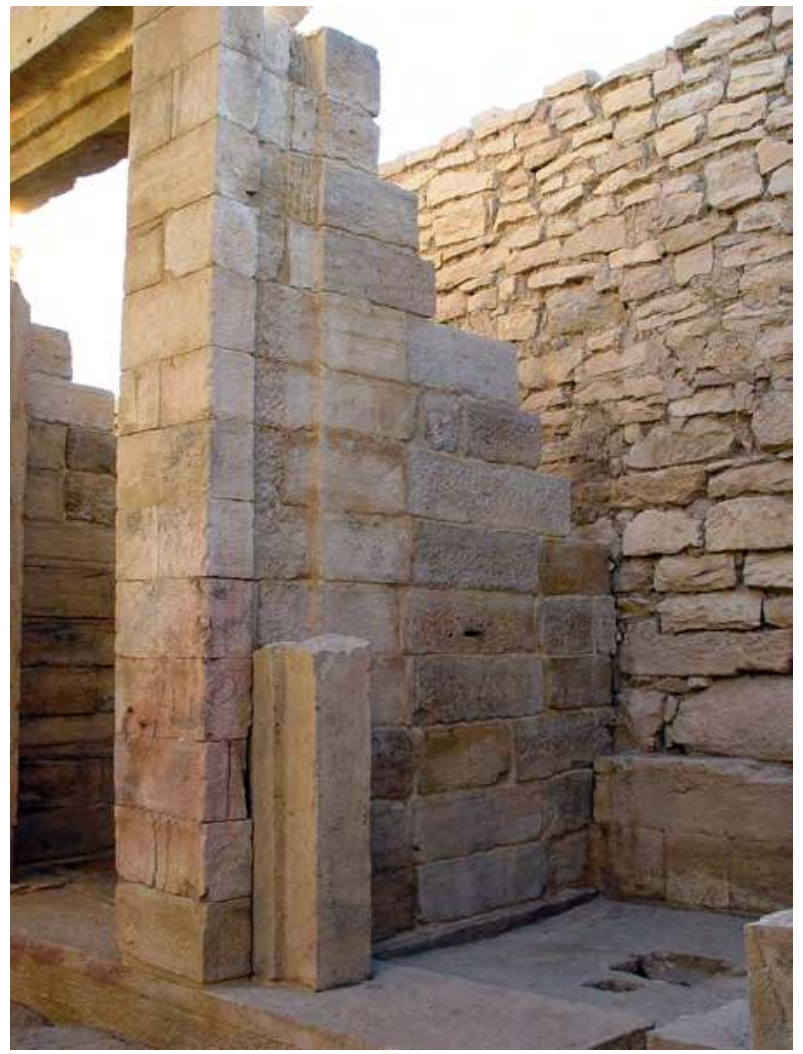

Figure 55. Il muro occidentale della cella centrale del tempio a fine restauro. (S.B. Scigliano 2003 CMAIRY)

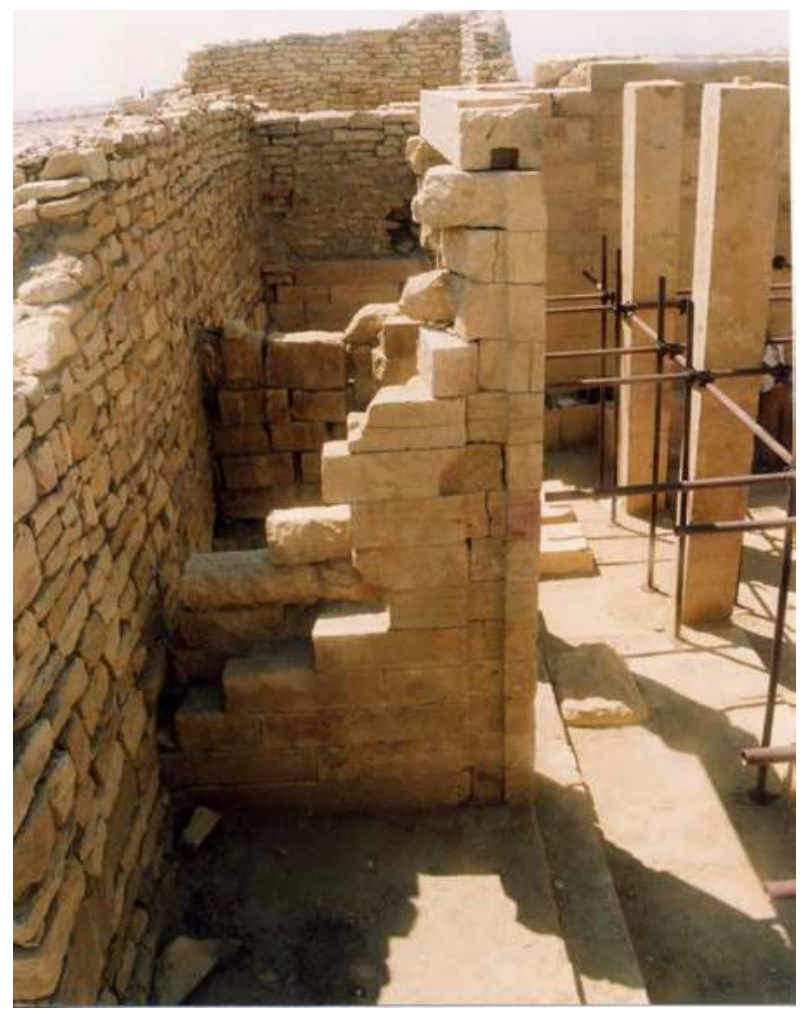

Figure 56. Il muro orientale della cella centrale del tempio, prima dell'intervento di restauro.

(S.B. Scigliano 2003 CMAIRY) 


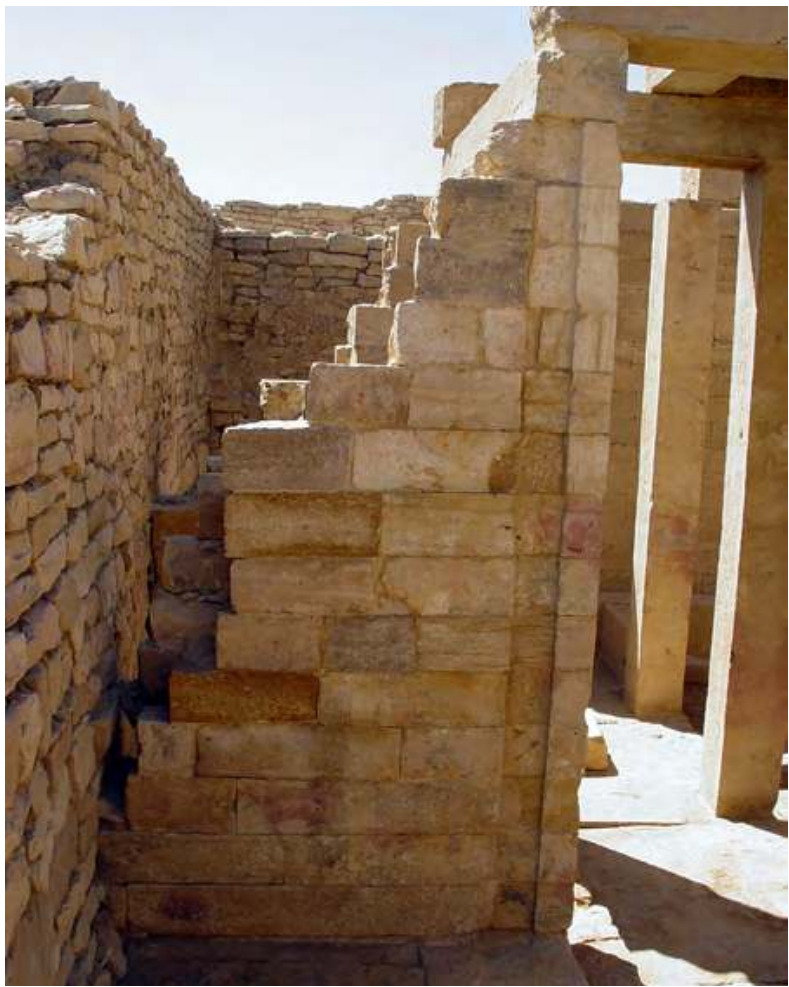

Figure 57. Il muro orientale della cella centrale del tempio, a fine restauro. (S.B. Scigliano 2003 CMAIRY)

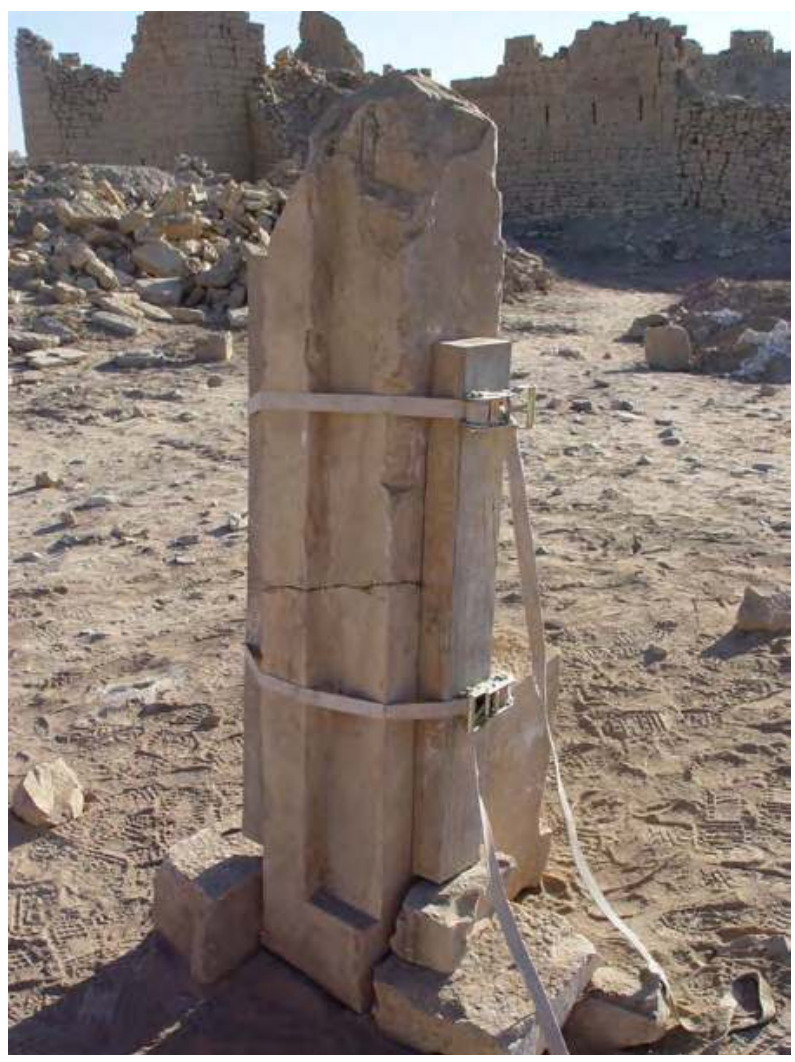

Figure 58. Fase di riadesione dei due frammenti della cornice modanata orizzontale superiore, posta sotto l'architrave della porta della cella centrale del tempio. (S.B. Scigliano 2003 OMAIRY)

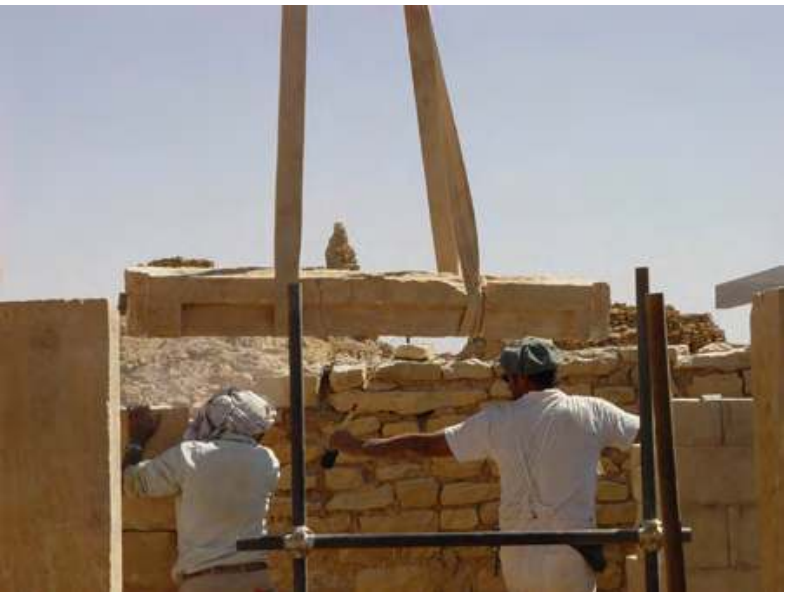

Figure 59. Movimentazione della cornice modanata orizzontale superiore - posta sotto l'architrave della porta della cella centrale del tempio - reintegrata nella parte mancante.

(A. Paladino 2003 OMAIRY).

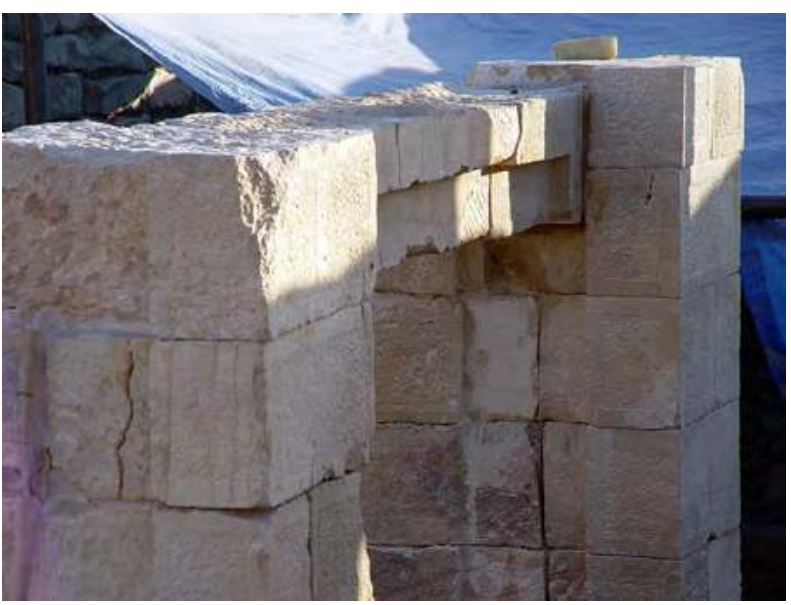

Figure 60. La cornice modanata, ricollocata nella posizione originale, poggiava sopra due blocchi di pietra opportunamente scanalati dagli architetti minei, posti nella penultima fila dei due muri laterali della cella centrale. (S.B. Scigliano 2003 OMAIRY)

simile all'originale, reperita in loco, setacciata in diverse granulometrie fina e finissima.

Tutte le superfici sono state trattate con protettivo idrorepellente.

\subsection{Copertura}

A destra (a O) dell'architrave posto sopra la cella centrale mancava una porzione considerevole di materiale lapideo pari a circa $30 \mathrm{~cm}$, che ha reso opportuno un 
intervento di ricostruzione con finalità statiche, in considerazione del fatto che sopra le due estremità dell'architrave si sarebbero dovute appoggiare due delle travi principali della navata centrale.

Come per la cornice orizzontale superiore della cella, così anche per l'architrave è stato effettuato un intervento d'integrazione per mezzo di un inserto di pietra simile all'originale (figg. 61-62). Dopo aver reperito, nell'area limitrofa del tempio, un frammento simile alla parte mancante della trave, lo abbiamo adattato alle dimensioni dell'architrave intera, prendendo come riferimento la distanza tra i due muri e tra i pilastri della navata centrale. Dopo aver praticato un foro centrale del diametro di $20 \mathrm{~mm}$ e profondo $30 \mathrm{~cm}$ 'a dima', nelle sezioni di contatto abbiamo inserito un perno in acciaio inox del diametro di $15 \mathrm{~mm}$ e lungo $55 \mathrm{~cm}$ facendo aderire le due parti con la resina epossidica ad alto potere adesivo caricata con quarzite super ventilata. Solo in seguito alla ricostruzione dell'architrave si è potuto procedere alla sua ricollocazione e al riallettamento definitivo sopra i due muri della cella, precedentemente ristrutturati e risistemati (fig. 63).

Una delle due travi principali, lunga $\mathrm{m} \mathrm{4,5}$ circa si presentava fratturata e divisa in due parti già ai tempi dello scavo del 1992.

Per poter ricollocare la trave principale nella sua sede originale, sopra i due pilastri e la cella centrale (P6-P10 / muro $O$ della cella), si è resa indispensabile la riadesione delle due parti mediante doppia imperniazione. Ad ognuna delle due parti staccate, abbiamo effettuato due fori paralleli tra loro, del diametro di $30 \mathrm{~mm}$ e profondi $40 \mathrm{~cm}$ centrali e perfettamente allineati 'a dima'. I fori nelle due sezioni delle due parti distaccate sono stati effettuati con la trave in orizzontale, ancora nell'area dove era stata collocata provvisoriamente nel 1992. Per effettuare i quattro fori ci siamo avvalsi di livelle 'a bolla' ad acqua, poste una sul trapano Hilti ed una sulla superficie del lato superiore, in modo da realizzare dei fori paralleli ai quattro lati (fig. 64). La difficoltà maggiore consisteva nel riuscire ad ottenere dei fori allineati al millimetro tra le due parti, oltre che paralleli tra loro, vista anche la loro lunghezza (fig. 65).

Nel nostro caso l'allineamento era perfetto al millimetro, dimostrato dalla prova di riassemblaggio provvisorio effettuato sia in orizzontale (fig. 66) che in verticale (fig. 67). I fori erano più larghi rispetto alla sezione della barra in acciaio di soli $5 \mathrm{~mm}$, il margine necessario di riempimento della resina epossidica. Una delle garanzie in questo tipo di risanamento adesivo e strutturale si otteneva nel riuscire ad effettuare fori precisissimi e con poco margine di gioco per i perni posti all'interno, in considerazione del fatto che sia la trave e di conseguenza i perni saranno sempre in posizione orizzontale e le sollecitazioni di carico, a differenza dei pilastri posizionati in verticale, graveranno notevolmente e costantemente sulla frattura. Un foro molto più grande di diametro rispetto alla barra in acciaio avrebbe potuto, ad esempio, rendere più difficoltoso l'allineamento perfetto tre le due parti risanate, compromettendo il risultato finale. Senza dimenticare che dopo la ricollocazione, sulla trave, in prossimità della frattura, graverà il peso costante di una trave secondaria, di due metope e di quattro lastre di copertura, pari ad un peso complessivo di circa novecento chili (fig. 68).

Dopo la prima fase delicata della foratura e della prova di riassemblaggio, si è proceduto alla adesione definitiva tra le due parti distaccate. Per ottenere una migliore adesione, la trave principale era stata collocata provvisoriamente in verticale, 'a piombo', all'interno di un castello costruito con tubi metallici, lo steso utilizzato per i pilastri.

Abbiamo inserito le due barre in acciaio inox del diametro di $25 \mathrm{~mm}$ e lunghe $75 \mathrm{~cm}$ fatte aderire con la resina epossidica ad alto potere adesivo, caricata con quarzite super ventilata. Durante la fase di adesione le due parti distaccate sono state tenute insieme per mezzo di travetti di legno da $\mathrm{cm} 8 \mathrm{x} 8$ e lunghi $3 \mathrm{~m}$, legati intorno alla frattura con delle cinghie auto-bloccanti.

Gli elementi della copertura che dovevano essere ricollocati comprendevano in ordine:

1 architrave sopra l'ingresso della cella centrale (v. figg. 61-63);

9 travi principali, delle quali 7 lunghe $m 2,20$ c. e 2 lunghe $m 4,45$ c. (v. fig. 68);

13 travi secondarie;

14 metope;

21 lastre di copertura.

La ricollocazione degli elementi della copertura della sala ipostila rappresentava l'obbiettivo principale ed il fine ultimo di tutti gli interventi di restauro effettuati fin dal principio. C'è voluto un lavoro preliminare complesso e articolato, costituito da più fasi consequenziali, dove ogni particolare e ogni piccolo dettaglio è stato vagliato meticolosamente.

Il raggiungimento, dopo mesi di lavoro, della posa in opera della prima trave principale, rappresentava un momento emozionante, la sfida che avevamo intrapreso con tanto coraggio e passione segnava finalmente una svolta decisiva.

La prima fase di lavoro inerente alla ricollocazione degli elementi della copertura consisteva nel riconoscimento di ogni singolo pezzo, in relazione alla propria sede originale. Purtroppo, la numerazione degli elementi 
della copertura effettuata dodici anni prima era andata perduta. Per rimettere esattamente al proprio posto ogni singolo elemento ci siamo affidati alla nutrita documentazione fotografica di scavo, custodita gelosamente dal nostro capo missione Alessandro de Maigret.

Con l'aiuto degli archeologi Rosario Valentini, Alessio Agostini e Danilo Mongiello, siamo riusciti a ricostruire la destinazione di ogni singola trave e degli altri elementi della copertura, ridefinendo una nuova numerazione.

Dopo aver risanato l'unica trave principale fratturata (v. figg. 64-68), sono state svolte delle verifiche alle quote delle sezioni superiori dei pilastri, delle pareti della controfacciata e della cella centrale. Abbiamo apportato qualche modifica sui pilastri P3, P4, P7 e sul muro d'ingresso, alzando le quote da 3 a $6 \mathrm{~cm}$ per correggere il piano orizzontale superiore.

Sono state realizzate basi d'appoggio in resina epossidica ad alto potere adesivo, caricata con quarzite super ventilata, sulle sezioni superiori dei pilastri interessati.

Come spiegato nello stato di conservazione, tra i pilastri a NE e quelli a SO si evidenziava una differenza di quote verticali da 20 a $30 \mathrm{~cm}$. Per pareggiare questa differenza, già descritta negli interventi di restauro dei pilastri, alcuni di essi sono stati abbassati e altri rialzati rispetto al piano d'appoggio, ma ci sarebbe stata comunque una differenza enorme ed incolmabile.

Insieme con la direzione dei lavori si è deciso di mantenere un minimo di dislivello della navata orientale, proponendo un compromesso accettabile. La navata centrale e la navata laterale occidentale dovevano riavere il piano di copertura corretto, mentre tra la navata centrale e la navata orientale abbiamo mantenuto un leggero dislivello di quote, meno di una decina di $\mathrm{cm}$, riscontrabile dalle travi secondarie che collegano le navate in senso latitudinale.

All'inizio si era pensato di graduare l'inclinazione dal pilastro P1 al P4; ma in corso d'opera ci siamo resi conto che non sarebbe stato possibile, poiché l'architrave della cella centrale così come la cornice della porta della cella non avrebbero avuto una corretta ortogonalità rispetto ai montanti verticali.

I primi elementi della copertura ricollocati sono stati le travi principali della navata centrale, seguiti da quelli delle navate laterali. Le difficoltà maggiori della ricollocazione consistevano nella movimentazione (fig. 69), ma soprattutto nella fase delicatissima in cui si dovevano adagiare le travi sopra i pilastri (figg. 70-71), considerando che due delle travi più lunghe sfioravano le due tonnellate. Inoltre, ogni trave prima di essere movimentata per la ricollocazione doveva essere perfettamente orizzontale, verificando il piano con la 'bolla' ad acqua, dopo aver posizionato le cinghie della gru equidistanti tra loro. Un'altra difficoltà tecnica consisteva nell'allineamento longitudinale, come ad esempio nel caso della navata centrale dove si alloggiavano tre travi su un'unica fila (fig. 72).

Per la successiva sovrapposizione delle travi secondarie, le file delle travi dovevano essere perfettamente distanziate e parallele. Tutte le travi sono state prima collocate provvisoriamente sopra i pilastri e solo dopo averle allineate perfettamente, abbiamo effettuato tutte le verifiche di sicurezza. Successivamente, le travi venivano risollevate con la gru di circa $40 \mathrm{~cm}$ in modo da poterle riallettare definitivamente con una malta composta da una parte di legante a basso contenuto salino, con caratteristiche di presa idraulica (conglomerato LEDAN C30) e due parti di polvere di pietra fina.

Completata la ricollocazione delle travi principali, si è proseguito alla ridisposizione delle travi secondarie (fig. 73), così come erano in origine, facendo sempre riferimento alla documentazione fotografica effettuata durante lo smontaggio nel 1992. Gli spazi d'intervallo tra una trave e l'altra sono state calcolati considerando le dimensioni delle metope e delle lastre di copertura perfettamente conservate (fig. 74). Per certi versi, la ricollocazione delle travi secondarie si è dimostrata più semplice, se non altro per il minor peso, nonostante presentasse altre problematiche di allineamento (fig. 75).

A differenza delle travi principali, le travi secondarie non sono state allettate con nessun tipo di malta, poiché non era necessario e di fatto non avevamo riscontrato nessuna traccia di malta originale.

Negli intervallitra le travi secondarie, soprale principali, trovavano alloggio le metope, rettangolari e scolpite a doppia fila di dentelli (fig. 76). Delle quattordici metope, non tutte erano conservate integralmente, ed alcune presentavano porzioni di materiale lapideo mancante.

Tutte le metope sono state riallettate sopra le travi principali e tra le secondarie (fig. 77), con una malta composta da una parte di legante a basso contenuto salino, con caratteristiche di presa idraulica (conglomerato LEDAN C30) e due parti di polvere di pietra fina.

Rimanevano, infine, da ricollocare soltanto le ventuno lastre di copertura sopra le travi secondarie (fig. 78). Alcune di esse erano spezzate in due parti ed è stato possibile ricollocarle solo dopo averle risanate. Dopo aver praticato due fori centrali del diametro di $12 \mathrm{~mm}$ e profondi $25 \mathrm{~cm}$, 'a dima' nelle sezioni di contatto 
abbiamo inserito due perni in acciaio inox del diametro di $10 \mathrm{~mm}$ e lunghi $40 \mathrm{~cm}$, facendo aderire le due parti con la resina epossidica ad alto potere adesivo caricata con quarzite super ventilata (fig. 79).

Con l'ausilio delle foto di scavo del 1992, sono state riposizionate le lastre presenti prima dello smontaggio (fig. 80); e in più, per colmare parte della superficie scoperta, abbiamo avuto la fortuna di trovare nel sito anche una decina di lastre di copertura originali che sono state riutilizzate e ricollocate a formare il soffitto del tempio di Nakrah (fig. 81). Tutte le lesioni, le fratture, le aree lacunose, gli interstizi tra metope e travi e tra lastre di copertura sono state stuccate con una malta idraulica, con lo scopo di sigillare e proteggere gli elementi in materiale lapideo dall'infiltrazione dell'acqua (fig. 82).

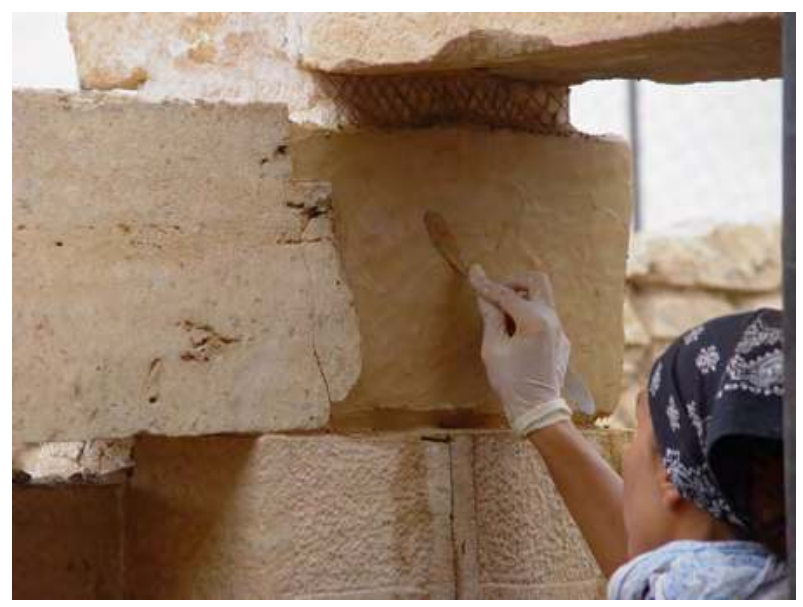

Figure 61. Integrazione lapidea e stuccatura della porzione mancante dell'architrave della porta della cella centrale del tempio. (S.B. Scigliano 2003 OMAIRY)

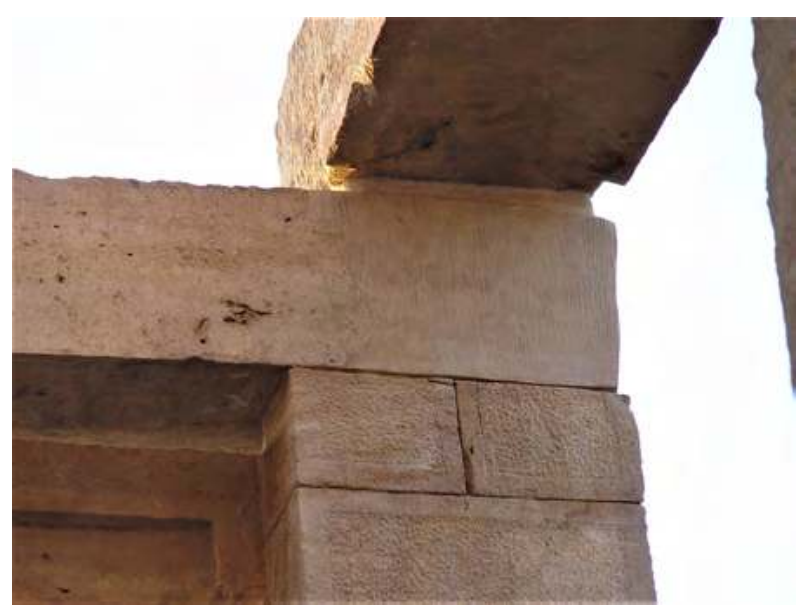

Figure 62. Dettaglio della porzione integrata dell'architrave della porta della cella centrale del tempio dopo il restauro. (S.B. Scigliano 2003 OMAIRY)
Tutte le lastre riposizionate sopra le travi secondarie sono state riallettate con una malta composta da una parte di legante a basso contenuto salino con caratteristiche di presa idraulica e due parti di polvere di pietra fina. Le stuccature sono state realizzate con una malta composta da una parte di legante con caratteristiche di presa idraulica e una parte di legante con caratteristiche di presa aerea grassello di calce, cinque parti di polvere di pietra fina (di colore variabile tra il giallo-ocra ed il rosso-ossido a seconda delle aree d'intervento) (fig. 83). La polvere di pietra è stata ottenuta mediante triturazione manuale di frammenti di pietra, simile all'originale, reperita in situ, setacciata in diverse granulometrie fina e finissima. Infine, tutte le superfici lapidee sono state trattate con il protettivo idrorepellente (fig. 84).

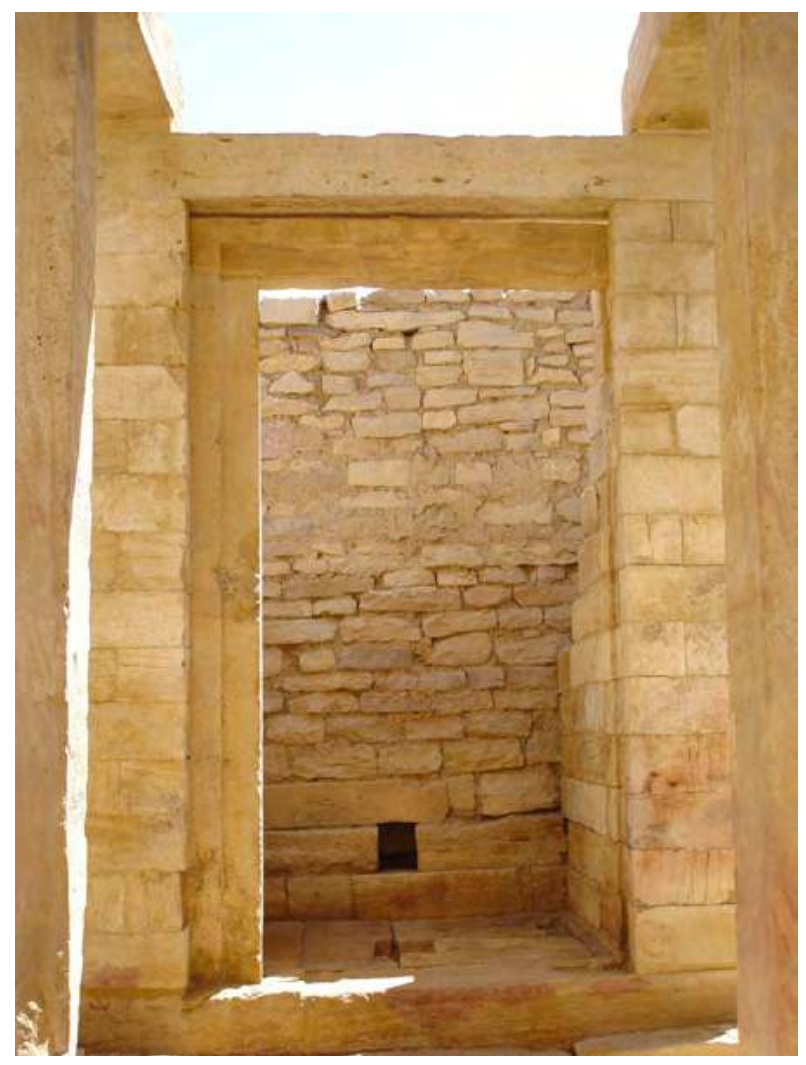

Figure 63. La porta della cella con la cornice e l'architrave in situ dopo il restauro. (S.B. Scigliano 2003 CMAIRY) 


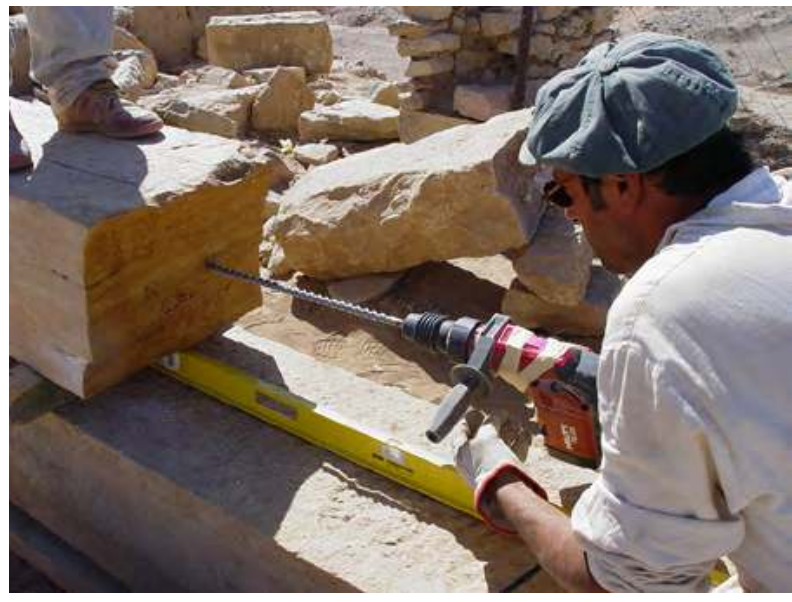

Figure 64. Fase di perforazione per l'inserimento di due barre d'acciaio per la riadesione dei due frammenti della trave principale posta sopra i due pilastri P6 e P10 e sopra il muro O della cella. (A. Paladino 2003 @MAIRY)

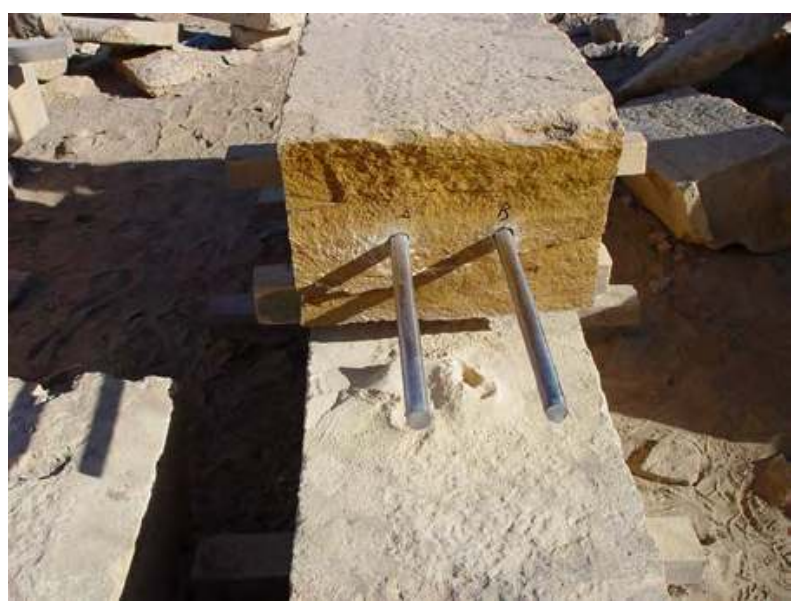

Figure 65. Le barre d'acciaio nei fori praticati nella sezione di uno dei due frammenti della trave principale posta sopra $i$ due pilastri P6 e P10 e sopra il muro O della cella. (A. Paladino 2003 CMAIRY)

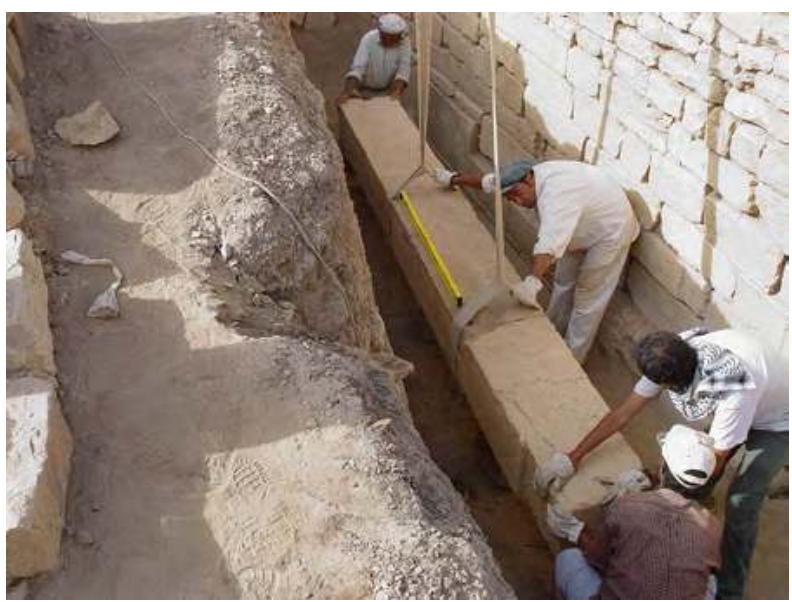

Figure 66. Prova di riassemblaggio, effettuato in orizzontale, della trave principale posta sopra i due pilastri P6 e P10 e sopra il muro O della cella. (A. Paladino 2003 CMAIRY)

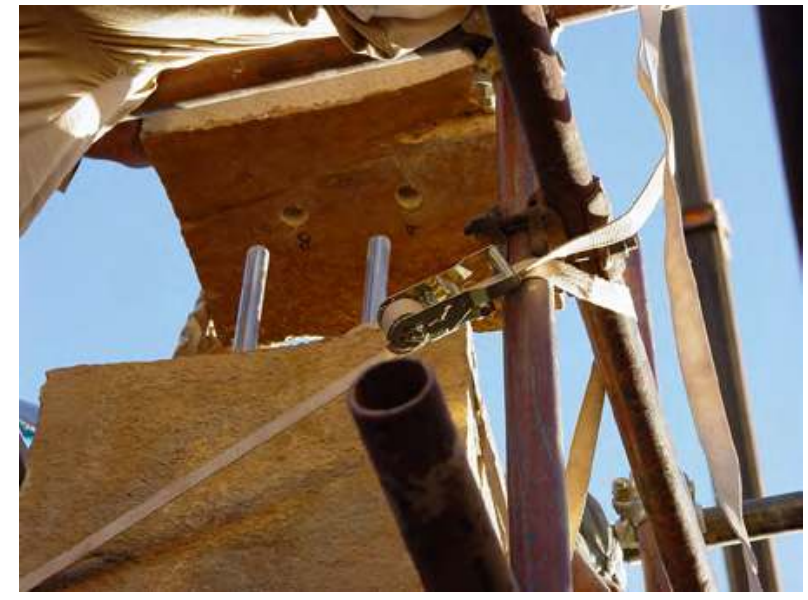

Figure 67. Prova di riassemblaggio, effettuato in verticale, della trave principale posta sopra i due pilastri P6 e P10 e sopra il muro o della cella. (A. Paladino 2003 @MAIRY)

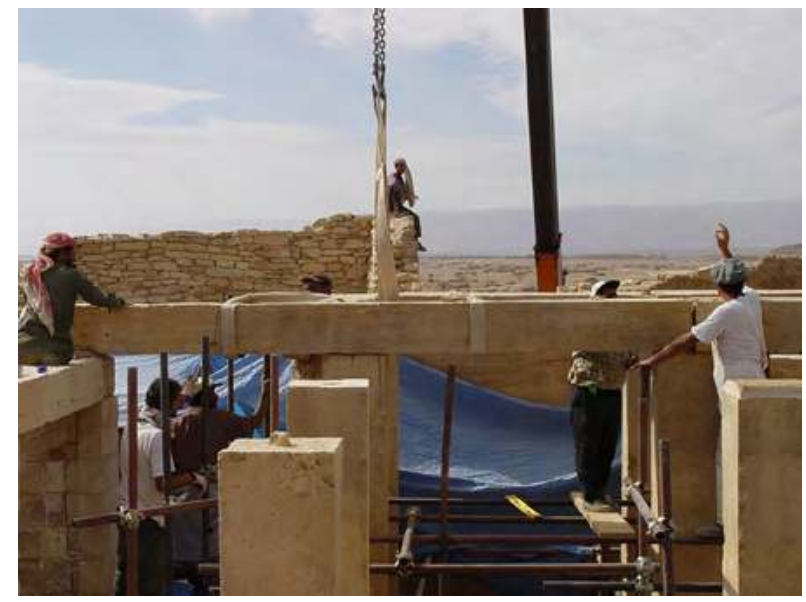

Figure 68. Ricollocazione nella posizione originaria della trave principale posta sopra i due pilastri P6 e P10 e sopra il muro O della cella. (A. Paladino 2003 OMAIRY)

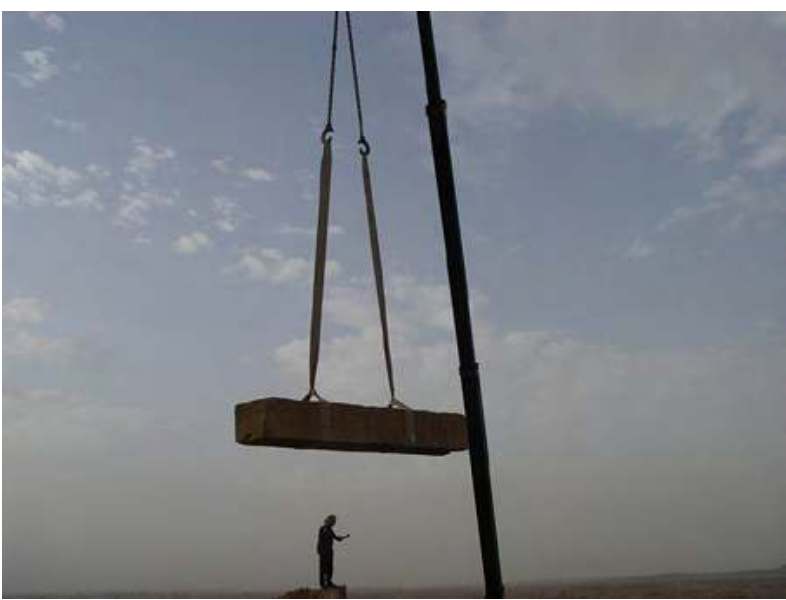

Figure 69. Il personaggio in piedi sulle mura di Barāqish dà indicazioni di movimentazione di una trave al macchinista del carro-gru il quale, trovandosi al di fuori e ai piedi delle mura, non ha alcuna possibilità di vedere quanto accade nell'area interna alla città. (S.B. Scigliano 2003 OMAIRY) 


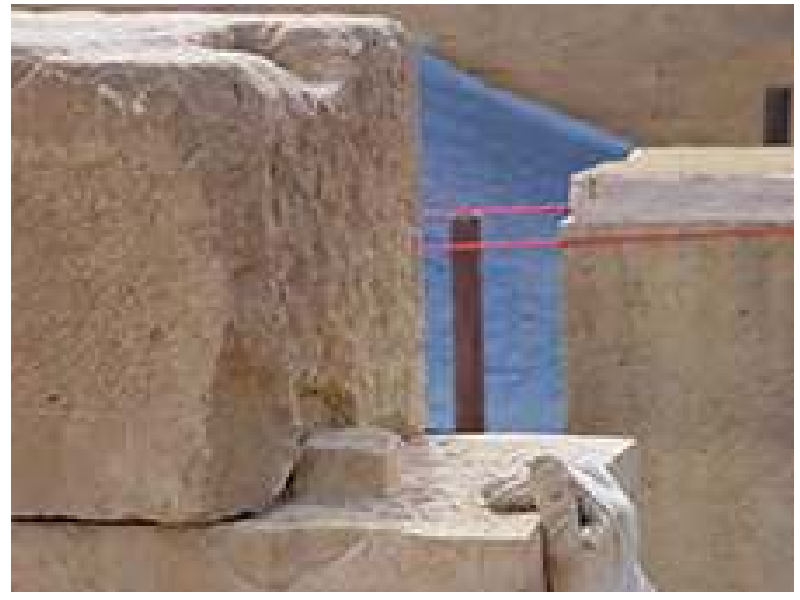

Figure 70. Dettaglio di una trave primaria poggiante su un pilastro con tenone. (A. Paladino 2003 @MAIRY)

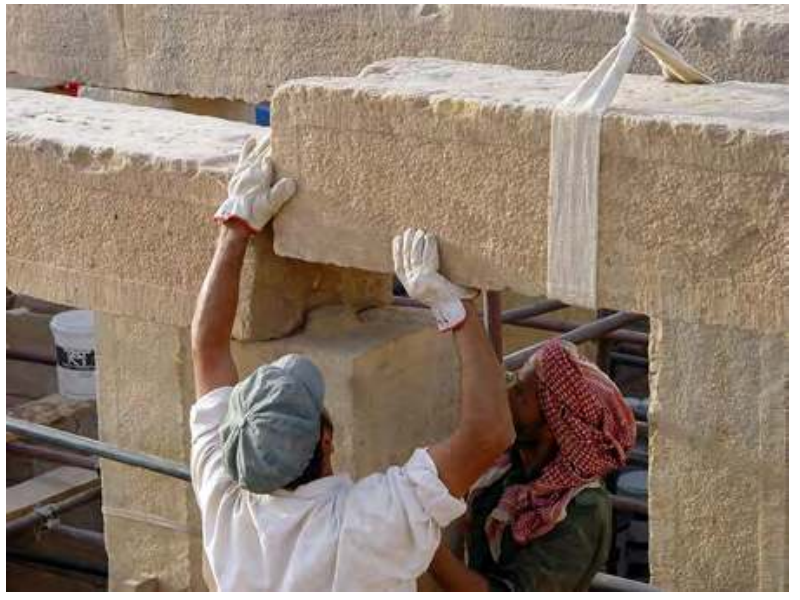

Figure 71. Posizionamento di un'altra trave primaria sul pilatro con tenone. (A. Paladino 2003 CMAIRY)

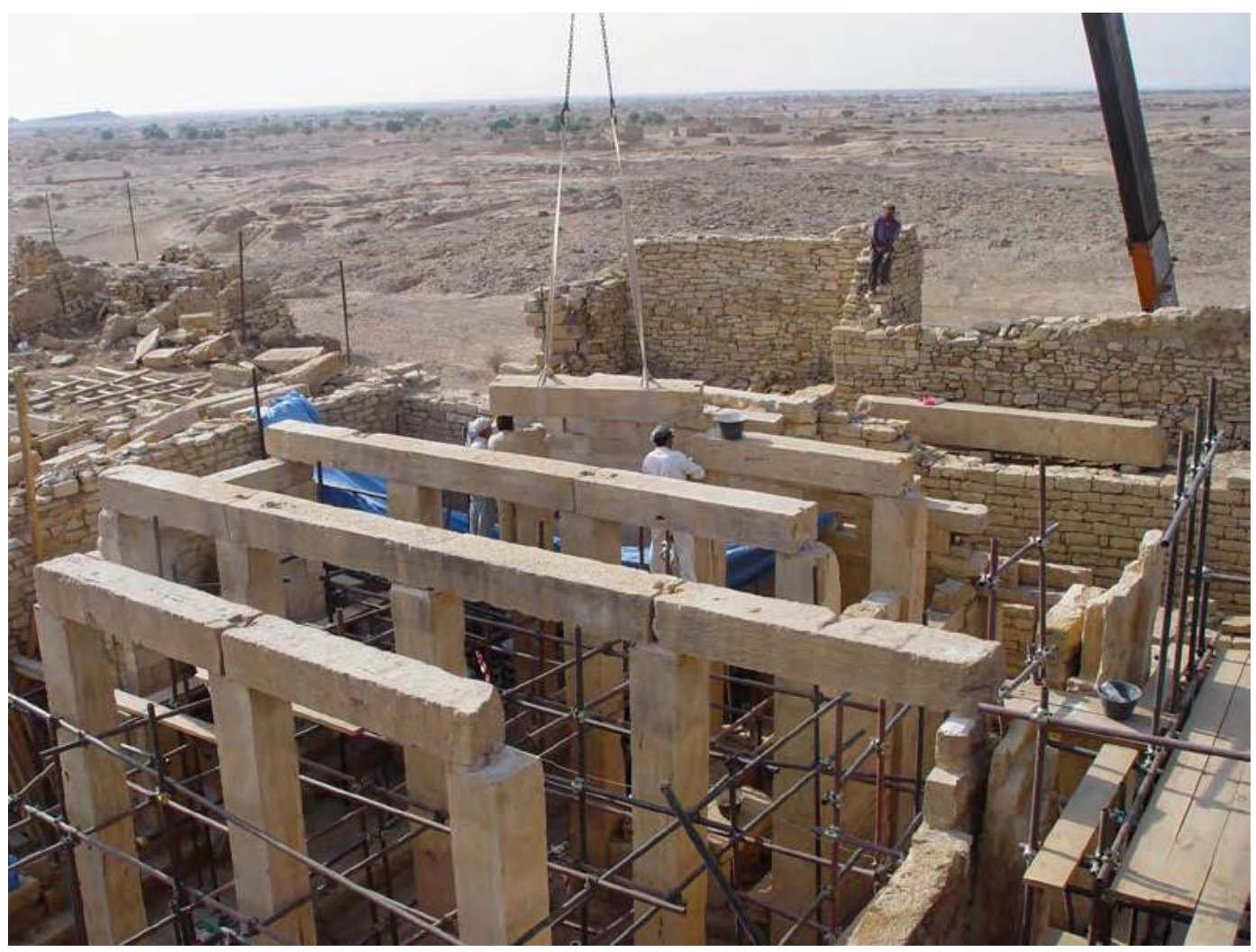

Figure 72. Veduta a volo d'uccello del posizionamento delle travi primarie sui pilatri. Una fila di tre travi si appoggia a partire dallo stipite orientale della porta del tempio, su P3, P7, P11 fino allo stipite orientale della porta della cella centrale (v. fig. 6). (A. Paladino 2003 OMAIRY) 


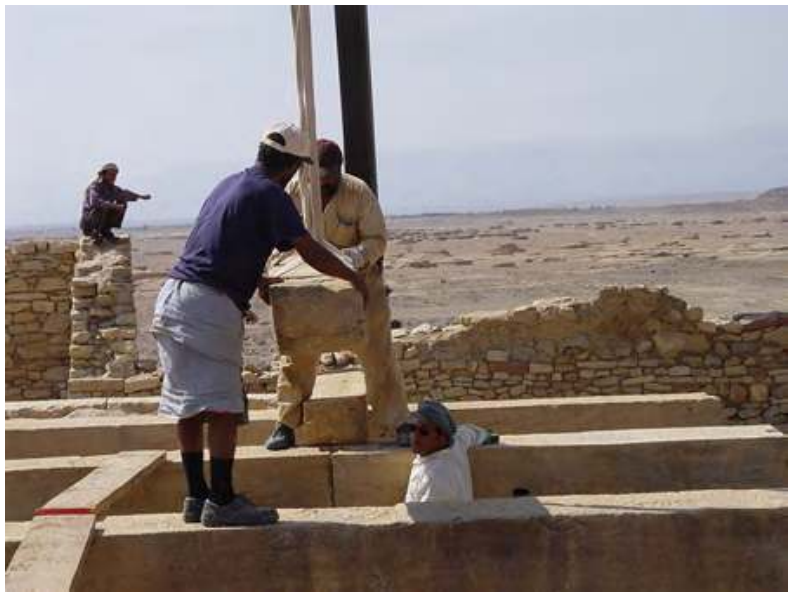

Figure 73. Fase di riposizionamento delle travi secondarie, al di sopra e trasversali alle travi primarie.

(A. Paladino 2003 CMAIRY)

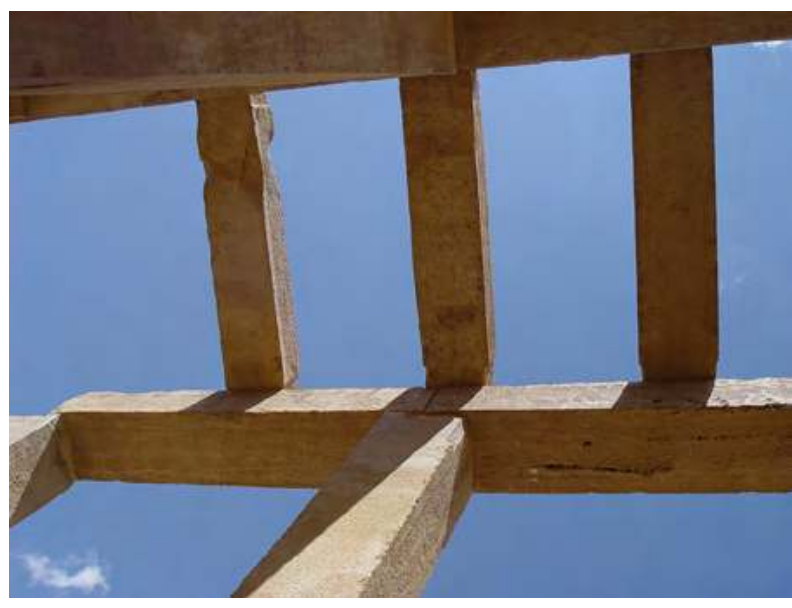

Figure 74. Veduta dal basso, all'interno del tempio, di alcune travi secondarie ricollocate nella loro originaria posizione sopra le travi primarie. (S.B. Scigliano 2003 CMAIRY)

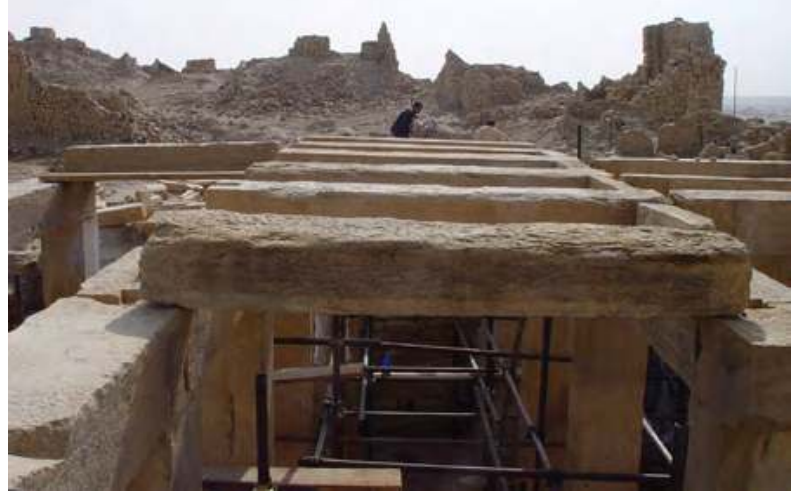

Figure 75. Infilata delle travi secondarie ricollocate sopra le travi primarie in corrispondenza della navata centrale del tempio. (A. Paladino 2003 OMAIRY)

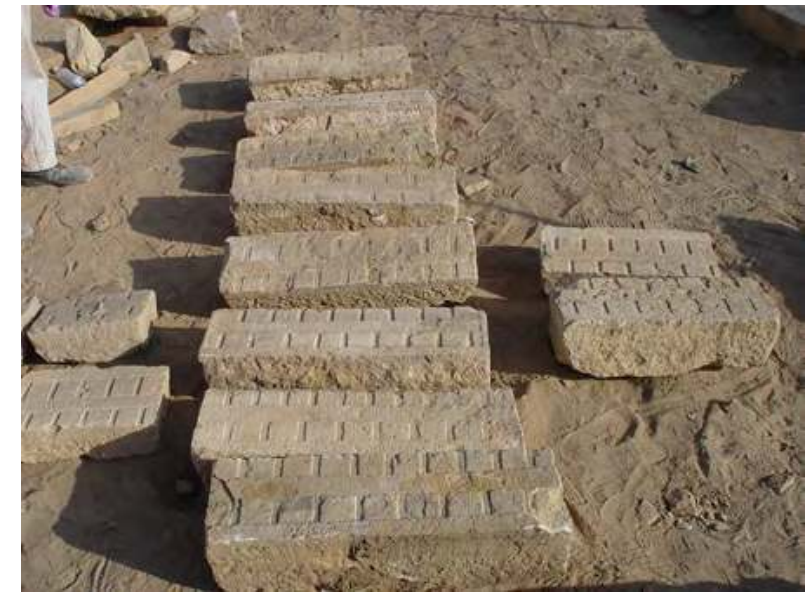

Figure 76. Le metope a doppia fila di dentelli, durante lo smontaggio della copertura del tempio, furono collocate nell'area esterna, a sud del tempio.

(S.B. Scigliano 2003 OMAIRY)

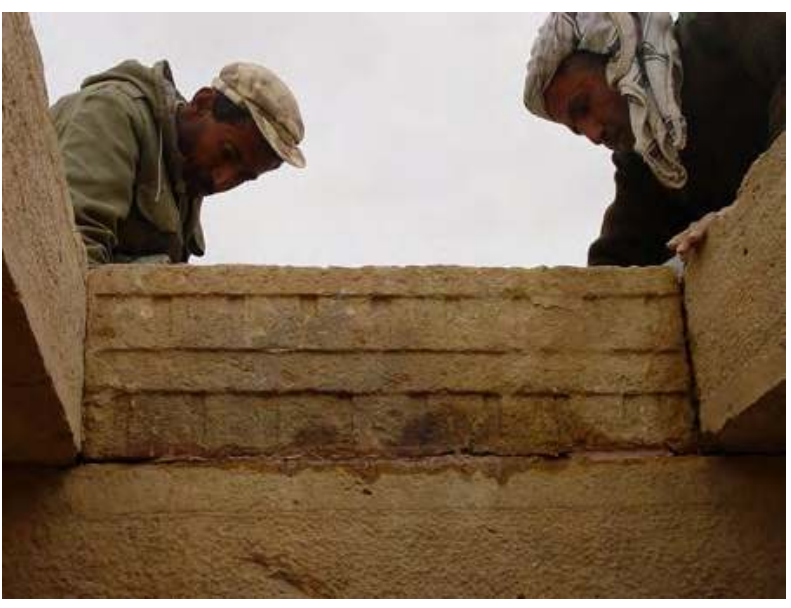

Figure 77. Una metopa ricollocata nella sua posizione originale, sopra una trave principale e nello spazio compreso tra due travi secondarie. (S.B. Scigliano 2003 CMAIRY)

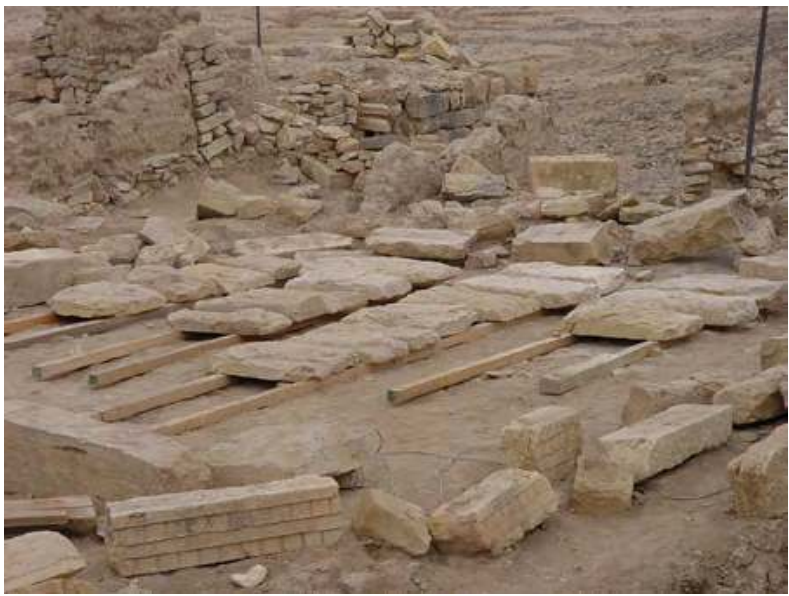

Figure 78. Le 21 lastre rettangolari della copertura del tempio, durante il loro smontaggio, furono collocate nell'area esterna, a sud del tempio.

(S.B. Scigliano 2003 OMAIRY) 


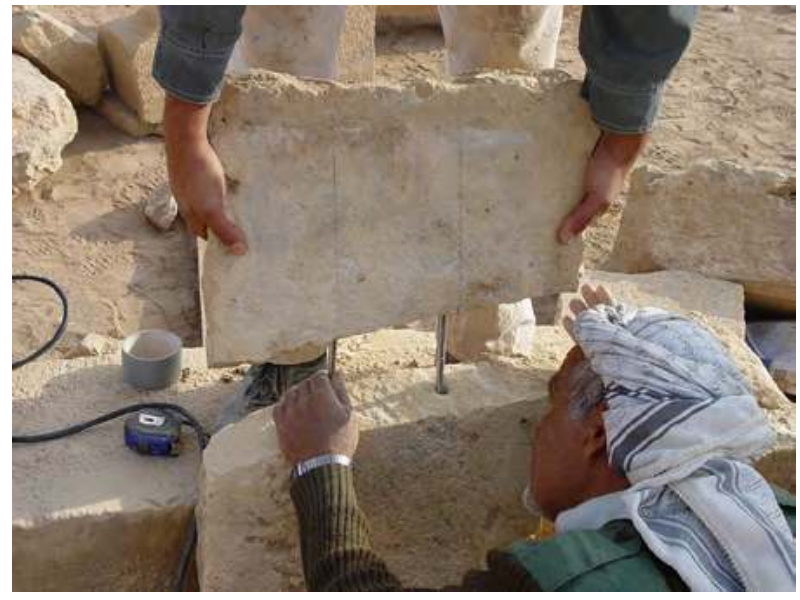

Figure 79. Risanamento di due frammenti di una lastra di copertura, tramite due perni di acciaio (A. Paladino 2003 CMAIRY)

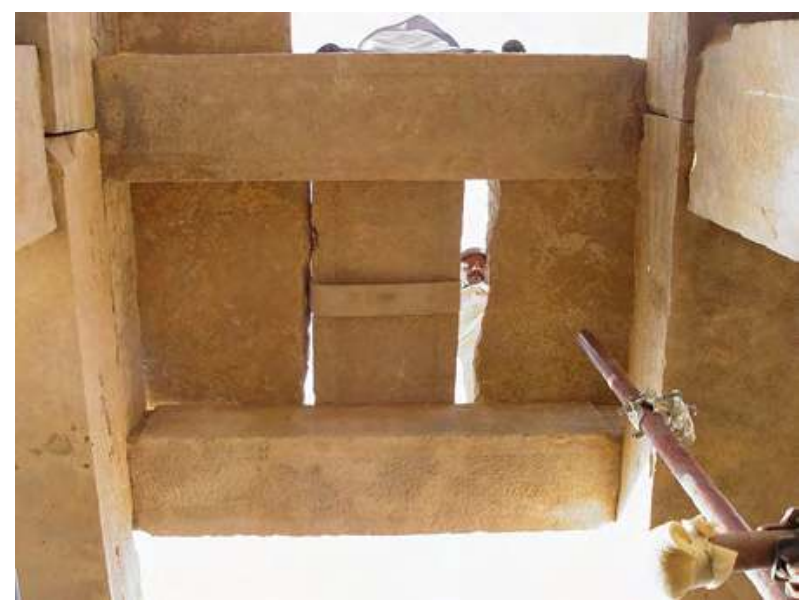

Figure 80. Riposizionamento delle lastre di copertura del tempio nella loro posizione prima dello smontaggio.

(S.B. Scigliano 2003 OMAIRY)

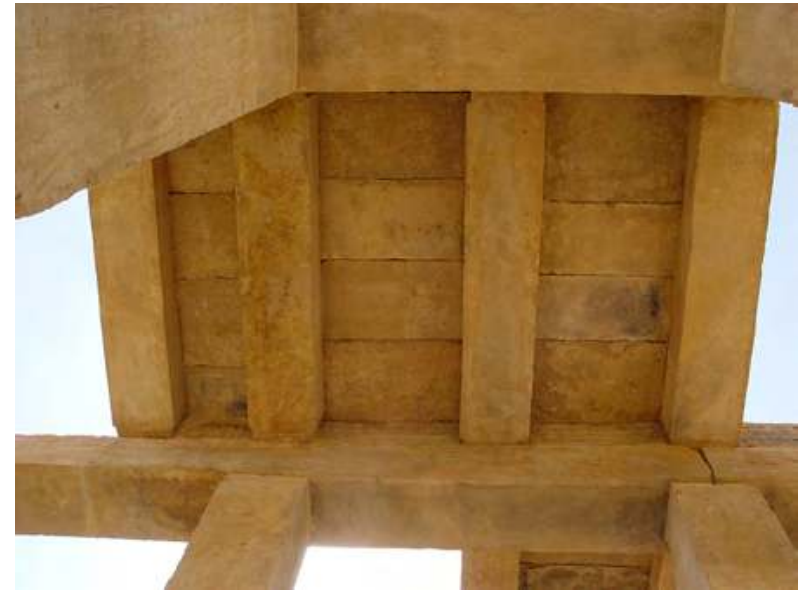

Figure 81. Veduta dal basso, all'interno del tempio, delle lastre di copertura perfettamente combacianti ricollocate nella loro posizione originaria. (S.B. Scigliano 2003 CMAIRY)

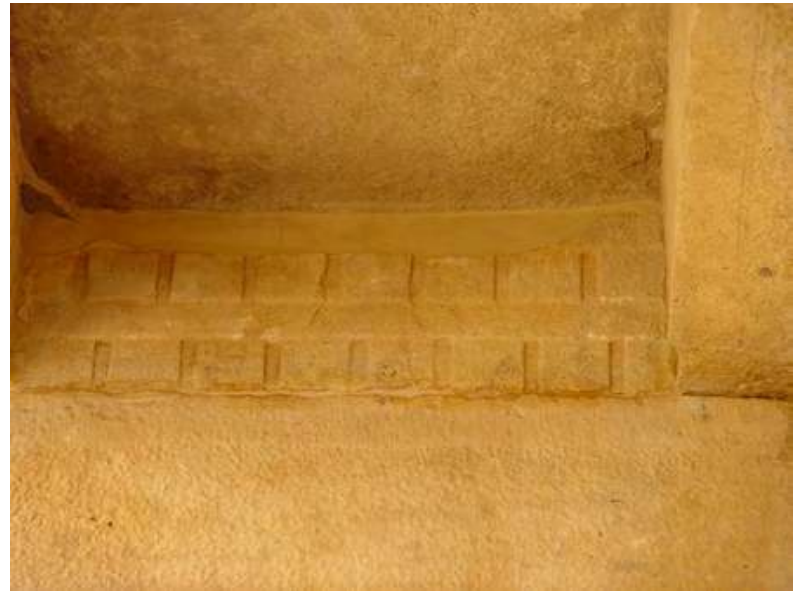

Figure 82. Dettaglio della stuccatura, di colore della pietra giallo-ocra, di una metopa a contatto con una lastra di copertura. (S.B. Scigliano 2003 CMAIRY)

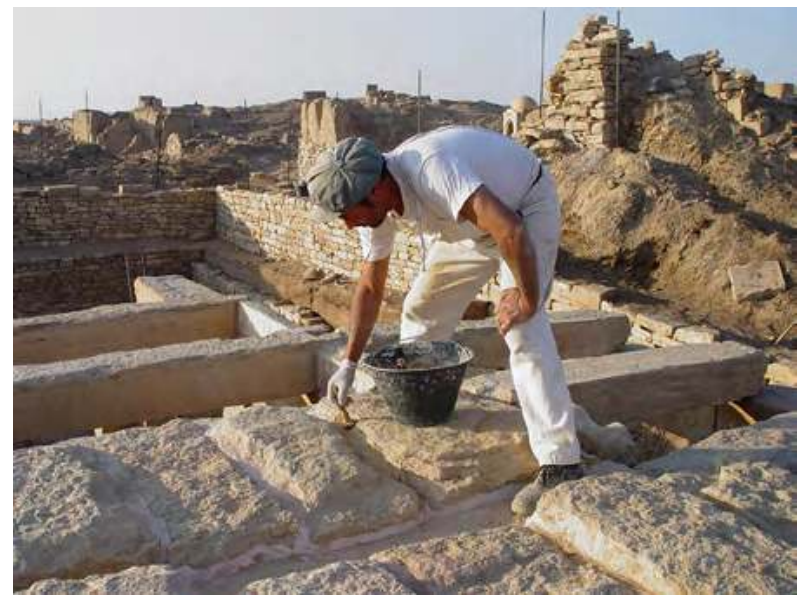

Figure 83. Fase di stuccatura delle lastre di copertura con malta idraulica di colore giallo-ocra. (A. Paladino 2003 (OMAIRY) 


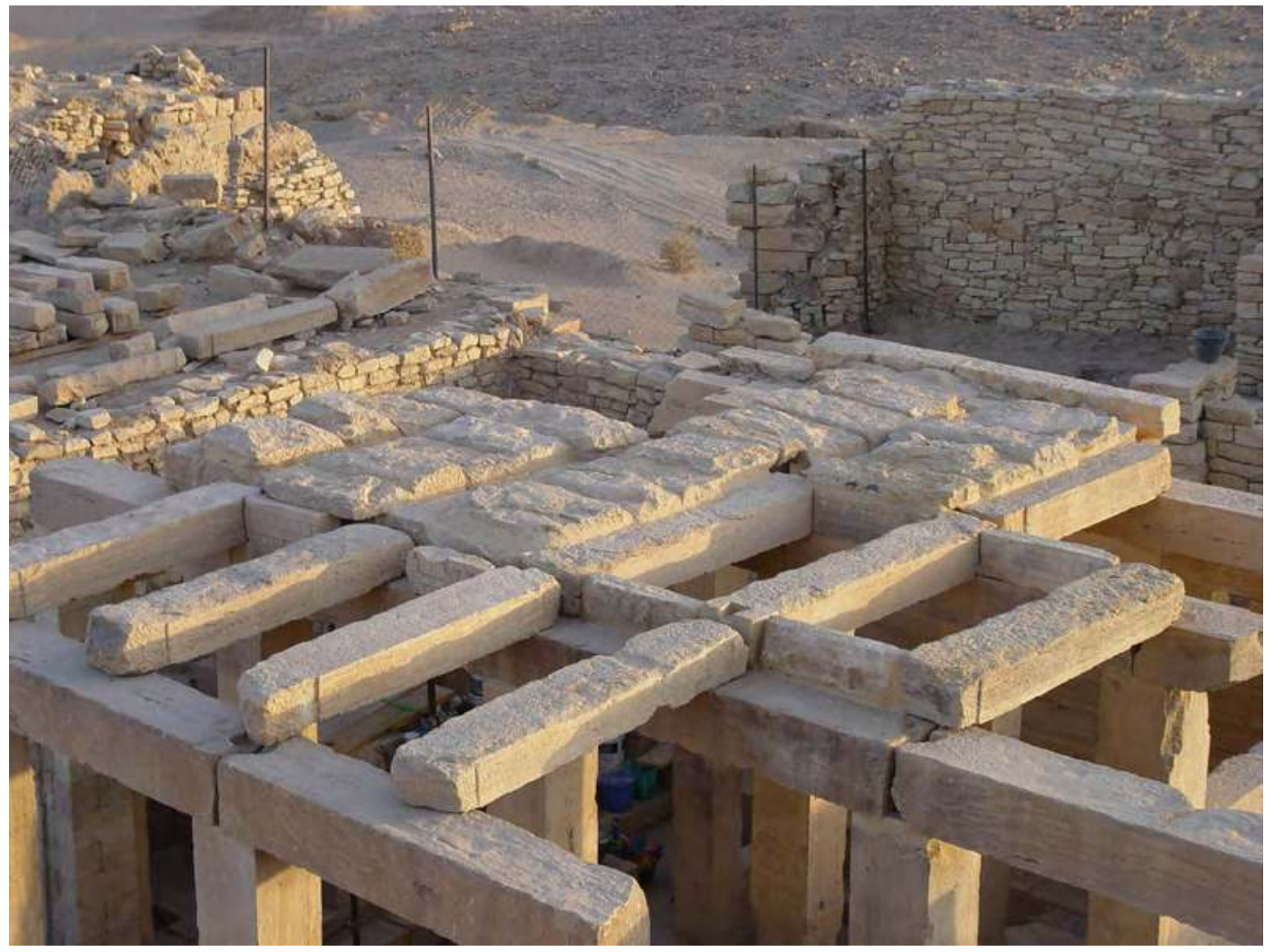

Figure 84. Veduta a volo d'uccello della copertura del tempio a fine restauro. (S.B. Scigliano 2003 @MAIRY)

\subsection{Iscrizioni}

Dopo i consueti e preliminari trattamenti (v. $\S 1$. Descrizione delle fasi di intervento, A.-C.), si è proceduto con la reintegrazione del materiale lapideo iscritto. La lastra con iscrizione più piccola presentava la mancanza di una porzione di materiale lapideo in prossimità dell'angolo inferiore sinistro. Prima di ricollocarla sopra la prima lastra iscritta necessitava di una integrazione strutturale, mediante l'inserimento di un inserto di pietra di simile forma.

Un frammento di pietra, simile per lavorazione, ma di spessore leggermente più sottile, è stato adattato, con l'ausilio di un frullino a lama diamantata, alla forma della sezione della lacuna della lastra originale. In seguito, sono stati praticati due piccoli fori del diametro di $12 \mathrm{~mm}$ e profondi $15 \mathrm{~cm}$, in prossimità delle sezioni di contatto delle due parti da far aderire (fig. 85). Tra la lastra originale e l'inserto di pietra sono state inserite due piccole barre in acciaio inox del diametro di 10 $\mathrm{mm}$ e lunghe $30 \mathrm{~cm}$, aderite con resina epossidica ad alto potere, caricata con quarzite super ventilata. Per favorire un'adesione perfetta, le due parti fratturate sono state posizionate in verticale, tenute ferme ed insieme con travetti di legno che avevano una funzione strutturale, legati intorno alla lastra con cinghie auto bloccanti.
Come accennato prima, l'inserto di pietra era stato scelto di spessore più sottile, in modo da rendere riconoscibile l'intervento di reintegrazione. La superficie dell'inserto è stata successivamente trattata con una stuccatura a sottolivello rispetto alla superficie dell'iscrizione, con una malta di colore simile all'originale (v. fig. 90).

La prima delle due lastre ad essere ricollocata è stata quella più grande, rettangolare, posizionata tra il pilastro P12 ed il muro orientale del tempio, a sinistra, sul piano rialzato antistante le celle (figg. 86, 88). Per garantire una maggiore tenuta in sicurezza, sia per la successiva sovrapposizione della seconda lastra che per eventuali atti vandalici, abbiamo inserito due barre verticali in acciaio inox del diametro di $10 \mathrm{~mm}$ tra la sezione inferiore e il monoblocco di pietra posto sopra la pavimentazione (fig. 87). La lastra è stata allettata sul pavimento con una malta idraulica composta da una parte di legante con caratteristiche di presa idraulica e due parti di pietra fina. La polvere di pietra è stata ottenuta mediante la triturazione manuale di frammenti di pietra simile all'originale, reperita localmente, setacciata in granulometria fina. I perni sono stati aderiti con la stessa malta di allettamento.

Una barra in vetroresina del diametro di $15 \mathrm{~mm}$ è stata inserita tra la parte superiore della lastra ed il pilastro P12, all'interno di un foro 'a tradimento', praticato 
dall'alto verso il basso, inclinato di $45^{\circ}$. La reversibilità del perno in vetroresina è consentita dal fatto che se in futuro si dovesse intervenire per smontare le lastre sarà sufficiente tagliare la barra con una normale lama di un seghetto a ferro, da inserire nello spazio tra la lastra ed il pilastro.

La seconda lastra iscritta è stata collocata sopra la prima con un sistema d'inperneazione analogo alla lastra inferiore (fig. 89). Per poter consentire alla lastra una maggiore stabilità sono stati inseriti due perni verticali tra le due lastre. Sono stati praticati dei fori del diametro di $15 \mathrm{~mm}$ e profondi $30 \mathrm{~cm}$ nella sezione di contatto tre le due lastre, perfettamente paralleli tra loro e con i lati verticali dell' iscrizione. Successivamente, dopo aver verificato l'assemblaggio, e soprattutto che l'asse verticale fosse perfetto, abbiamo inserito le due barre verticali in acciaio inox, del diametro di $10 \mathrm{~mm}$ e lunghi $57 \mathrm{~cm}$; infine, è stata collocata e allettata definitivamente la lastra superiore con malta idraulica, composta da una parte di legante con caratteristiche di presa idraulica e due parti di pietra fina. La polvere di pietra è stata ottenuta mediante triturazione manuale di frammenti di pietra, simile all'originale, reperita in situ, setacciata in granulometria fina. I perni sono stati aderiti con la stessa malta di allettamento.

Gli interstizi delle due lastre e le lacune sono stati stuccati a sottolivello con malta idraulica, avente lo scopo di sigillare e proteggere gli elementi in materiale lapideo dall'infiltrazione dell'acqua. Le stuccature sono state realizzate con malta composta di una parte di legante con caratteristiche di presa idraulica e una parte di legante con caratteristiche di presa aerea grassello di calce, cinque parti di polvere di pietra fina (di colore variabile tra il giallo-ocra ed il rosso-ossido, a

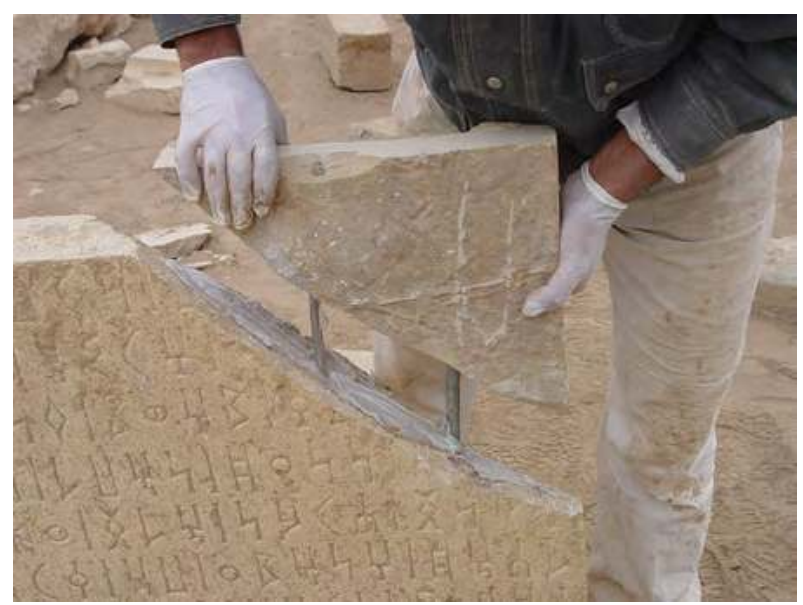

Figure 85. Integrazione del materiale lapideo della lacuna dell'angolo inferiore sinistro di una iscrizione.

(A. Paladino 2003 OMAIRY) seconda delle aree d'intervento), prodotta localmente (fig. 90).

Le superfici, infine, sono state trattate con il consueto prodotto idrorepellente (fig. 91).

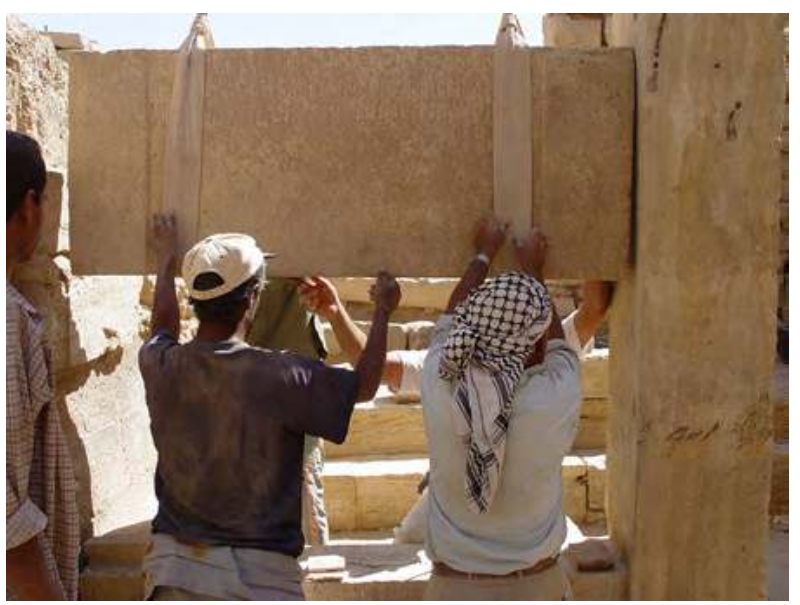

Figure 86. Fase di ricollocamento del blocco iscritto di maggiori dimensioni nella sua posizione originaria, tra il pilastro P12 ed il muro orientale del tempio. (A. Paladino 2003 OMAIRY)

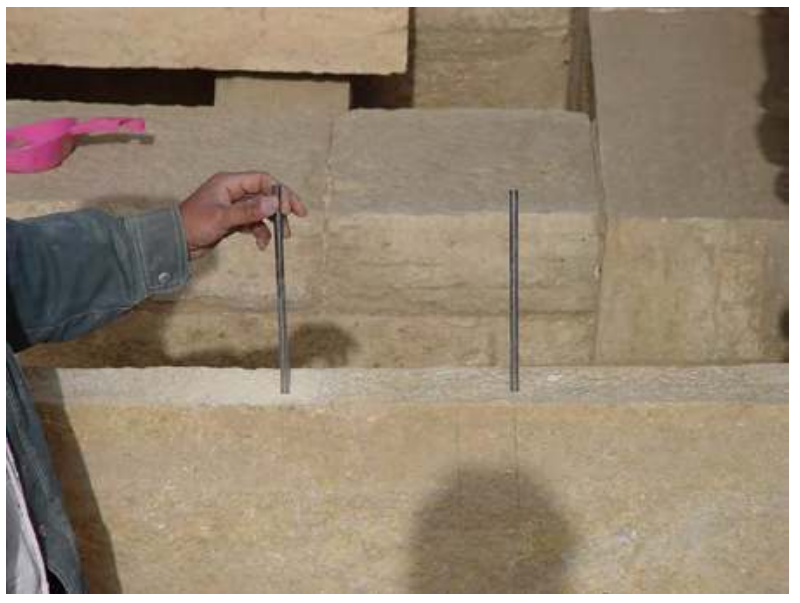

Figure 87. Due barre verticali in acciaio inox sono state inserite tra la sezione inferiore e il monoblocco di pietra posto sopra la pavimentazione. (A. Paladino 2003 @MAIRY) 


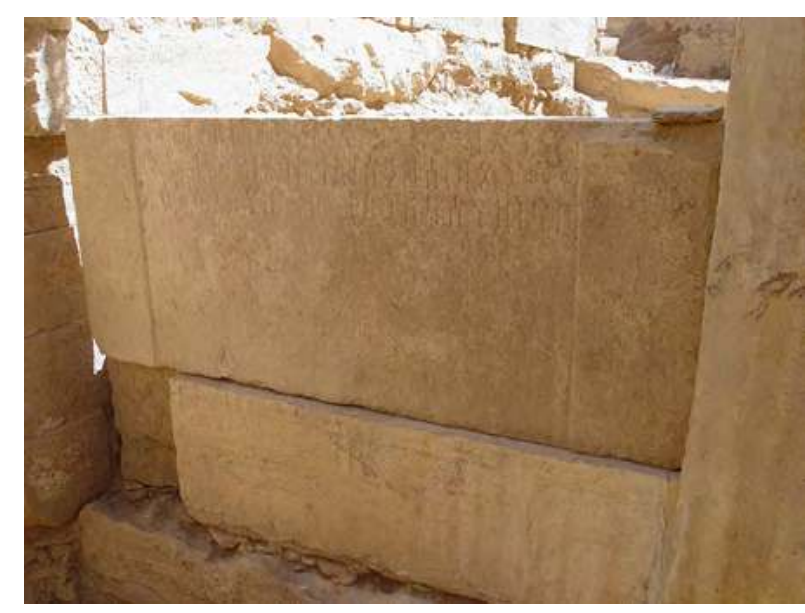

Figure 88. Blocco iscritto di maggiori dimensioni ricollocato nella sua posizione originaria, tra il pilastro P12 ed il muro orientale del tempio. (A. Paladino 2003 @MAIRY)

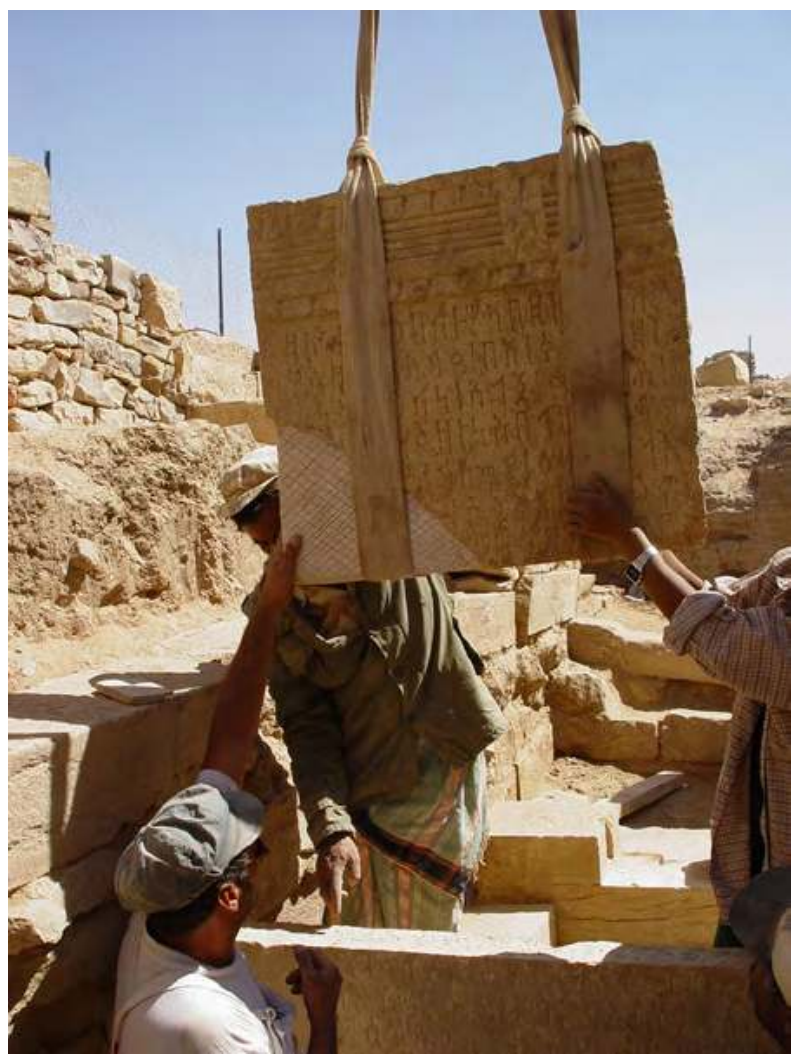

Figure 89. Fase di ricollocamento del blocco iscritto con integrazione lapidea al di sopra del blocco iscritto di maggiori dimensioni. (A. Paladino 2003 CMAIRY)

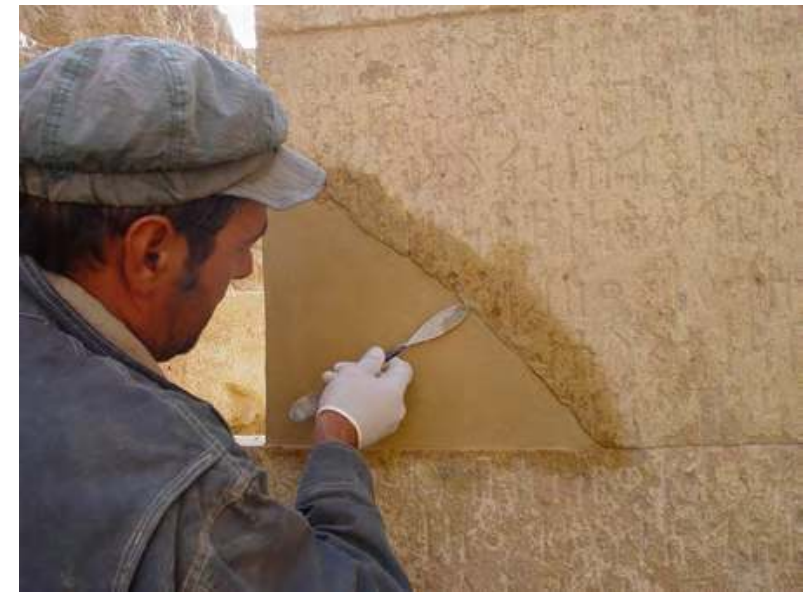

Figure 90. La lacuna del blocco iscritto è stata stuccata a sottolivello con malta idraulica e polvere di pietra gialloocra. (A. Paladino 2003 CMAIRY)

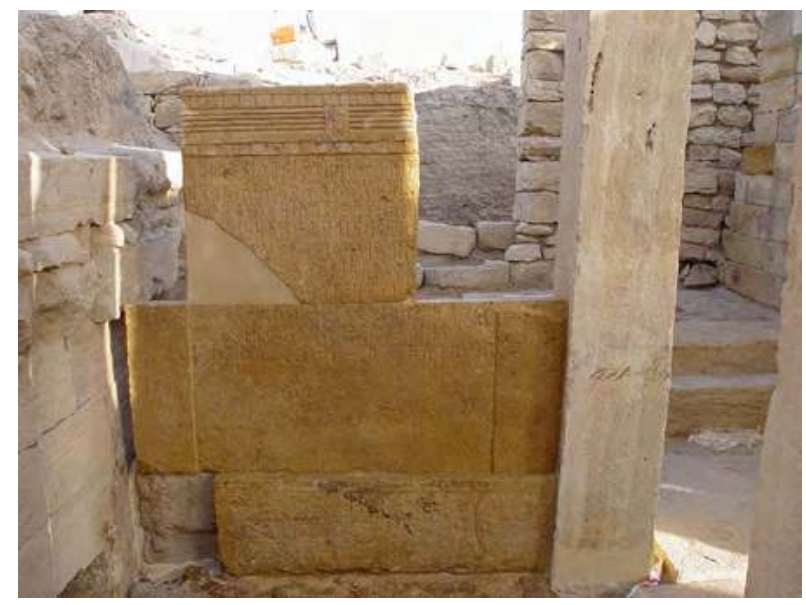

Figure 91. Le due iscrizioni nella loro posizione originaria, tra il pilastro $\mathrm{P} 12$ ed il muro orientale del tempio, a fine restauro. (S.B. Scigliano 2003 CMAIRY) 


\subsection{Pavimentazione}

Dopo i trattamenti consueti mediante irroratore pneumatico a bassa pressione, per il consolidamento coesivo, si è proceduto alla reintegrazione di alcune lastre del pavimento.

La pavimentazione si presentava priva di tre lastre di pietra. Considerata la notevole quantità di materiale lapideo lavorato presente nell'area archeologica di Barāqish, abbiamo ritenuto opportuno integrare le lastre mancanti con altre simili da adattare nelle differenti lacune (fig. 92). Le tre lastre sono state allettate con una malta composta da una parte di legante con caratteristiche di presa idraulica conglomerato LEDAN C30 e una parte di legante con caratteristiche di presa aerea grassello di calce, cinque parti di polvere di pietra fina (di colore variabile tra il giallo-ocra ed il rosso-ossido a seconda delle aree d'intervento). La polvere di pietra è stata ottenuta mediante triturazione manuale di frammenti di pietra, simile all'originale, reperita in situ, setacciata in diverse granulometrie fina e finissima.

Tutti gli interstizi tra le lastre pavimentali sono stati stuccati con malta idraulica, con lo scopo di sigillare e proteggere gli elementi in materiale lapideo dall'infiltrazione dell'acqua (fig. 93). Le stuccature

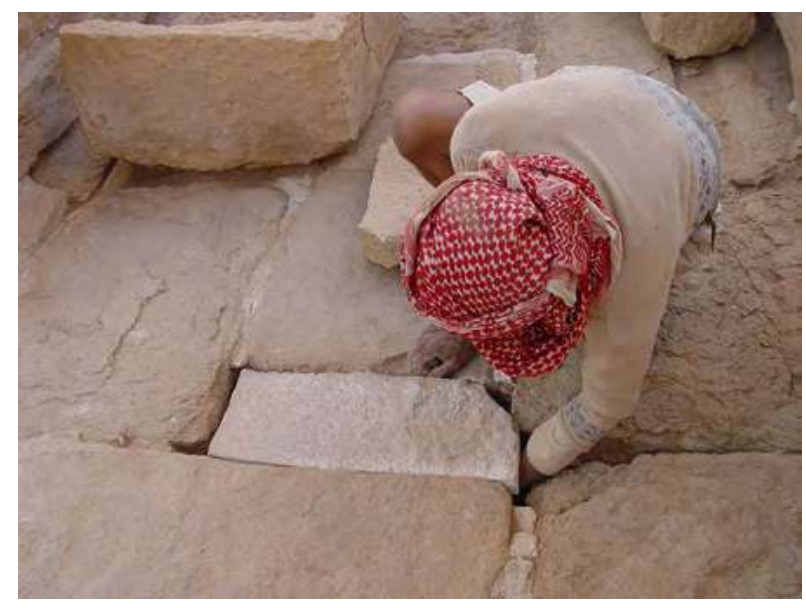

Figure 92. Integrazione di una lastra mancante del pavimento del tempio. (A. Paladino 2003 OMAIRY) sono state realizzate con una malta composta da una parte di legante con caratteristiche di presa idraulica e una parte di legante con caratteristiche di presa aerea, cinque parti di polvere di pietra fina prodotta localmente. Infine, anche il pavimento è stato trattato con protettivo idrorepellente (fig. 94).

\subsection{Stilobate e scalinata}

Come per la pavimentazione all'interno della sala ipostila, dopola pulitura preliminare èstato effettuato un trattamento biocida con Preventol R80. In seguito, dopo una successiva pulitura a secco, è stato assolutamente indispensabile un intervento di consolidamento al fine di sanare e rallentare i gravi fenomeni di decoesione e disgregazione del materiale costitutivo dei blocchi dello stilobate. È stato necessario effettuare una serie di trattamenti ripetuti ed abbondanti (previa prova di una piccola area disgregata) con silicato di etile Rhodorsil RC 70, della Rhộne Poulenc. L'applicazione è stata eseguita su tutta la superficie interessata, per impregnazione, mediante imbibizione per nebulizzazione (fig. 95). Dopo gli interventi di restauro conservativo di consolidamento, al fine di proteggere la superficie lapidea, per altro molto fragile, è stato effettuato un intervento propedeutico con un prodotto idrorepellente, come per gli altri elementi del tempio (fig. 96).

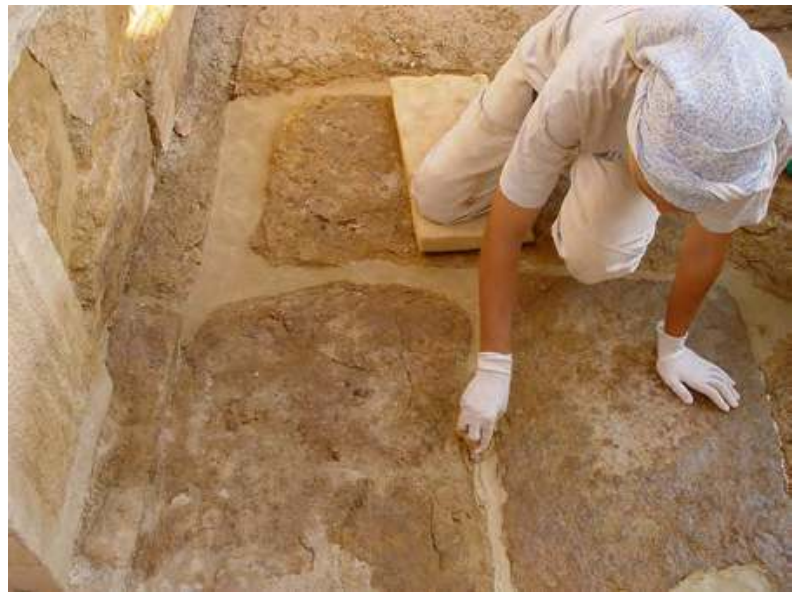

Figure 93. Fase di stuccatura degli spazi tra le lastre che compongono la pavimentazione del tempio. (S.B. Scigliano 2003 CMAIRY) 


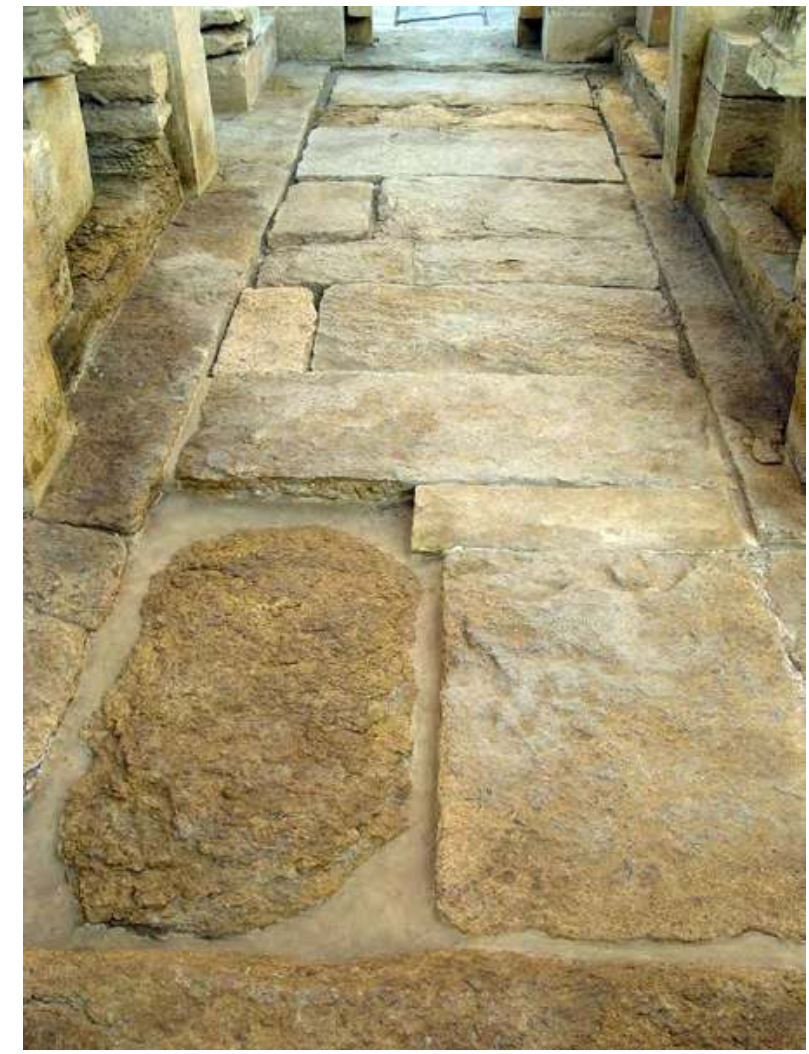

Figure 94. Il pavimento della navata centrale con le integrazioni delle lastre mancanti a fine restauro. (S.B. Scigliano 2003 CMAIRY)

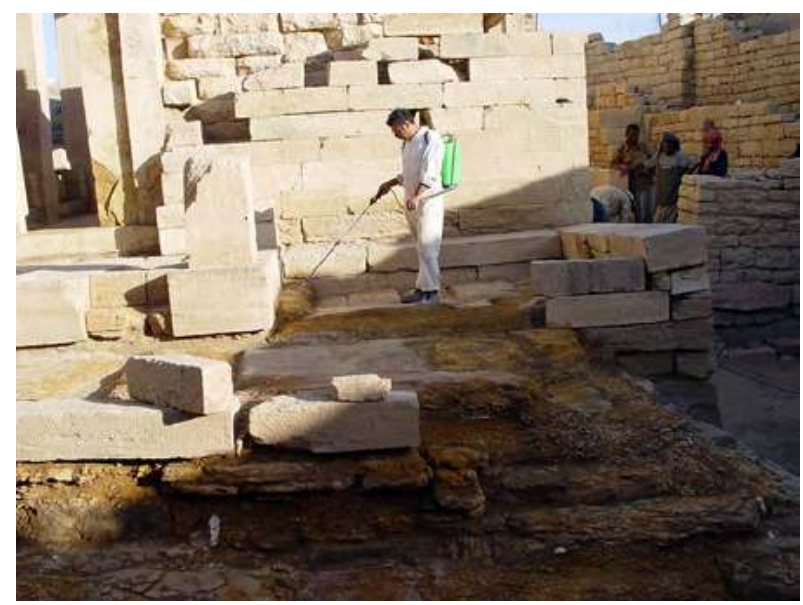

Figure 95. Il restauratore Saverio Bruno Scigliano durante il trattamento conservativo dello stilobate per impregnazione, mediante imbibizione per nebulizzazione. (A. Paladino 2003 CMAIRY)

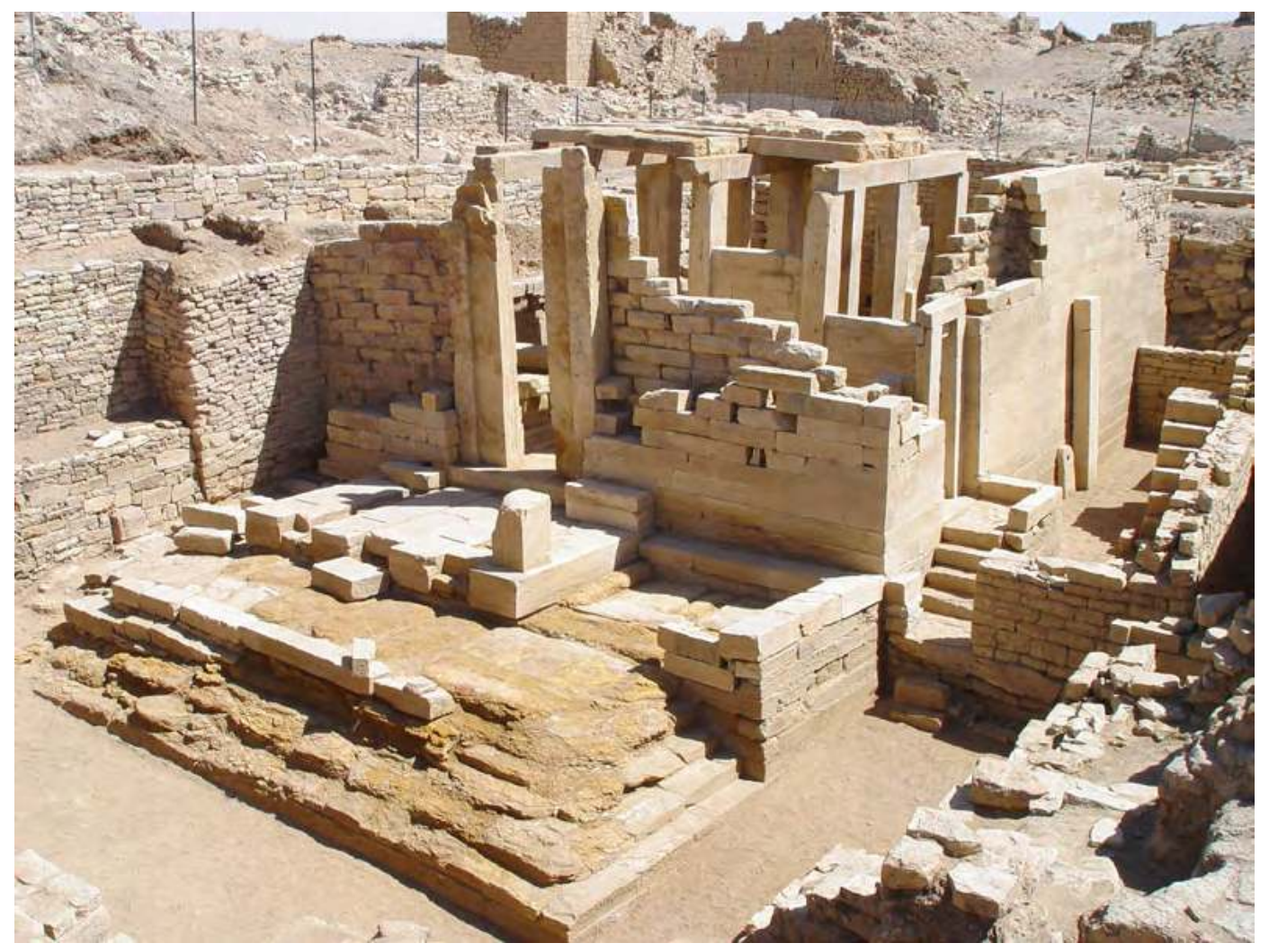

Figure 96. Il tempio di Nakrah alla fine dei lavori di restauro, da NO. (S.B. Scigliano 2003 CMAIRY) 
Appendix A. Consuntivo dei materiali di consumo utilizzati

\begin{tabular}{|l|c|c|c|}
\hline Materiali & Quantità & Consumo & Rimasto \\
\hline Calce Lafarge & $\mathrm{kg} 140$ & $\mathrm{~kg} 140$ & 0 \\
\hline Grassello di calce & $\mathrm{kg} 105$ & $\mathrm{~kg} 100$ & $\mathrm{~kg} 5$ \\
\hline LEDAN MTX & $\mathrm{kg} 105$ & $\mathrm{~kg} 105$ & 0 \\
\hline LEDAN C30 & $\mathrm{kg} 120$ & $\mathrm{~kg} 120$ & $\mathrm{~kg} 125$ \\
\hline Resina Eposs. & $\mathrm{kg} 200$ & $\mathrm{~kg} 75$ & $\mathrm{~kg} 25$ \\
\hline Indurente & $\mathrm{kg} .40$ & $\mathrm{~kg} 15$ & $\mathrm{~kg} 200$ \\
\hline Silicato di etile & $\mathrm{kg} 300$ & $\mathrm{~kg} 100$ & $\mathrm{~kg} 45$ \\
\hline Idrorepellente & $\mathrm{kg} \mathrm{50}$ & $\mathrm{kg} \mathrm{5}$ & 1530 \\
\hline $\begin{array}{l}\text { White spirit (acqua } \\
\text { ragia deaorom.) }\end{array}$ & 1580 & 150 & $\mathrm{~kg} 75$ \\
\hline Quarzite ventilata & $\mathrm{kg} 200$ & $\mathrm{~kg} 125$ & 115 \\
\hline Polycril 205 & 130 & 115 & \\
\hline
\end{tabular}

Barre acciaio Inox

\begin{tabular}{|c|c|c|c|}
\hline$\emptyset 10 \mathrm{~mm}$ & $\mathrm{~m} 12$ & $\mathrm{~m} 9$ & $\mathrm{~m} 3$ \\
\hline Ǿ $15 \mathrm{~mm}$ & $\mathrm{~m} 13$ & m 5 & $\mathrm{~m} 8$ \\
\hline$\emptyset$ Ø $20 \mathrm{~mm}$ & $\mathrm{~m} 13$ & $\mathrm{~m} 12$ & $\mathrm{~m} 1$ \\
\hline$\emptyset$ б $25 \mathrm{~mm}$ & $\mathrm{~m} 6$ & $\mathrm{~m} 2$ & $\mathrm{~m} 4$ \\
\hline
\end{tabular}




\title{
Chapter 14
}

\section{Restauro, movimentazione e messa in sicurezza degli elementi architettonici del tempio di 'Athtar dhu-Qabḍ (Tempio B) \\ a Barāqish}

\author{
Saverio Bruno Scigliano e Alessandra Paladino
}

\section{Introduzione}

Il tempio dedicato al dio 'Athtar dhu-Qabd fu portato completamente alla luce nelle campagne di scavo condotte dal 2004 al 2006 dalla Missione Archeologica Italiana nello Yemen, diretta dal Professore Alessandro de Maigret.

Gli interventi qui di seguito descritti riguardano due fasi distinte: 1 . Movimentazione e messa in sicurezza di pesanti ed ingombranti elementi architettonici trovati in posizione di crollo e che intralciavano il susseguirsi dell'attività archeologica durante la seconda campagna di scavo (2005-2006); 2. Messa in sicurezza del tempio, a seguito della correzione del terzo medio dei cinque pilastri del propileo, oltre ad un intervento di restauro conservativo e propedeutico là dove si era valutato urgente e necessario (novembre 2006).

La prima fase, effettuata tra novembre e dicembre del 2005, fu indispensabile per movimentare e rimuovere dallo scavo parziale numerosi blocchi di pietra, pesanti oltre il quintale. Sono stati portati fuori dalla sala ipostila in fase di scavo molteplici porzioni di pilastri, travi ed altri elementi della copertura del tempio, crollati e rinvenuti anche al di sopra di alcune tavole offertorie. In questo primo cantiere nel tempio di 'Athtar dhu-Qabḍ è stato allestito un adeguato sistema di ponteggi metallici in grado di sorreggere un argano manuale a catena ed il peso di ogni singolo blocco di pietra. In poche settimane è stato così possibile rimuovere dall'area di scavo tutti gli elementi lapidei ingombranti e pesanti. Particolarmente delicata e pericolosa è stata la movimentazione e rimozione di un pilastro spezzato in due parti e caduto nella fase di crollo sopra una delle tavole offertorie. Fu necessario sollevarlo con l'argano manuale a catena predisposto sul piano superiore e, con l'ausilio di funi, fu dislocato a fianco alla parte inferiore dello stesso pilastro. Tutti i blocchi di pietra, legati, venivano tirati su con l'argano posto in superficie sul piano alto del terrapieno.

Tuttiglielementi portatifuoridallasalaipostilavenivano trasportati e dislocati con l'ausilio di rulli metallici in un'area limitrofa, dove sarebbero stati depositati provvisoriamente. Le operazioni di movimentazione e di sgombero di tutte le porzioni di travi e pilastri crollati all'interno del tempio consentirono al Prof. de Maigret ed al team della Missione archeologica di completare lo scavo della sala ipostila del tempio.

La seconda fase di interventi è stata compiuta nel mese di novembre del 2006, quando il tempio era quasi del tutto scavato, tranne l'area di ingresso del propileo.

Come per il tempio di Nakrah (v. Scigliano e Paladino, capitolo 13 in questo volume), anche nel tempio di 'Athtar dhu-Qabd sono stati riscontrati cedimenti del piano dell'edificio, con una evidente inclinazione di tutti gli elementi architettonici, prevalentemente verso N/ NE. Infatti, i lavori di ultimazione degli scavi del tempio erano stati rallentati a causa di cinque dei sei pilastri del propileo rinvenuti ancora eretti nella posizione originale, ma con una ragguardevole inclinazione verso N/NE. Purtroppo i pilastri completi versavano in condizioni molto compromesse, dovute alla pericolosa e grave carenza di natura statica, determinata dal grado di inclinazione del terzo medio oltre il limite di stabilità. Infatti, solo gli strati di terra intorno a tre lati dei pilastri (fig. 1), alti sei metri, prudentemente preservata durante gli scavi, consentiva di mantenerne ancora una posizione eretta verticale.

Dunque, l'esigenza della missione archeologica era di ultimare gli scavi, ma solo dopo aver messo in totale sicurezza i cinque pilastri del propileo. Pertanto, il vero obbiettivo era quello di risolvere il problema principale, raddrizzando e mettendo in sicurezza tutti i pilastri instabili e compromessi staticamente, in modo da consentire agli archeologi la rimozione degli strati di terra rimasta, ossia circa quattro metri di quota, intorno ai pilastri del propileo e dell'area antistante l'ingresso.

Infine, nel novembre del 2006 avevamo effettuato un primo lavoro di rilevazione dello stato di conservazione dei singoli pilastri della sala ipostila, delle tavole offertorie e degli stipiti del portale d'ingresso, in 
previsione di un restauro simile a quello effettuato nel tempio di Nakrah.

Purtroppo gli esiti dei bombardamenti e della distruzione dei due templi di Barāqish, avvenuti nel 2015 da parte della coalizione a guida saudita, hanno di fatto vanificato tutti gli sforzi effettuati per il recupero di edifici così antichi ed importanti per lo Yemen e per tutta l'umanità.

In questo nostro contributo, riporteremo, comunque, il lavoro preliminare da noi effettuato nel tempio di 'Athtar dhu-Qabd.

\section{Stato di conservazione}

Il tempio di 'Athtar dhu-Qabd era semisepolto, coperto da terra e sabbia accumulatasi nel corso dei secoli. $\mathrm{Ci}$ vollero tre lunghe campagne di scavo per rimuovere le centinaia di $\mathrm{m}^{3}$ di materiale terroso che lo ricopriva, per poter restituire ai posteri un'altra importante testimonianza dell'architettura minea. Il tempio di 'Athtar dhu-Qabd era situato a fianco e con lo stesso orientamento dell'adiacente tempio di Nakrah.

Già nella prima campagna di scavo, grazie ad una laboriosa attività da parte di tutta l'equipe della missione archeologica italiana, dopo solo pochi mesi si potevano raccogliere i primi e concreti risultati sull'entità e la grandiosità di un secondo tempio, a pochi passi dal primo portato alla luce precedentemente.

Nel gennaio del 2005, il Prof. de Maigret mi chiese di pianificare e mettere a punto una metodologia d'intervento per la movimentazione, rimozione e messa in sicurezza di grossi e pesanti blocchi di elementi architettonici in pietra che avrebbero ostacolato le fasi di scavo nella campagna del 2005-2006.

Nel febbraio del 2005, grazie ad una piacevole coincidenza, avemmo la fortuna di passare per Barāqish, di ritorno da un sopralluogo al Tempio Awwām a Mārib, per un progetto di restauro richiestoci dalla Missione archeologica americana (American Foundation for the Study of Man). Approfittammo quella circostanza per fare una visita di osservazione del tempio di 'Athtar dhu-Qabd. Nonostante la sala ipostila non fosse stata riportata completamente alla luce, si intravedevano le tavole offertorie, gli imponenti monoliti del propileo e gli stipiti del portale ancora in piedi (fig. 2). Questo tempio, anche se in quel momento era ancora in parte da scavare, riponeva agli occhi dei fortunati spettatori la possibilità di ricostruire nella propria immaginazione l'antico tempio in tutta la sua interezza.

Era di primaria importanza, durante il sopralluogo, annotare e prendere visione della quantità e dell'entità dei blocchi lapidei da movimentare, rimuovere e portare fuori dalla base del tempio che si trovava ad una quota inferiore rispetto al piano di calpestio esterno. Occorreva elencare l'attrezzatura essenziale da reperire in Yemen ed il personale specializzato per portare fuori dal tempio tutti gli elementi architettonici della copertura in pietra, crollati e sparsi nell'area di scavo (fig. 3).

Così, tra la fine di novembre e dicembre del 2005 sono state realizzate strutture di ponteggio con tubi metallici (tipo 'Innocenti'), con l'ausilio di argani a catene adeguate a movimentare e rimuovere dallo scavo numerosi blocchi, pesanti fino a $500 \mathrm{~kg}$. Sono stati portati fuori dalla sala ipostila molteplici porzioni di pilastri, travi principali e secondarie, metope e lastre di copertura del tempio (fig. 4), crollati e rinvenuti tra l'altro su alcune tavole offertorie parzialmente compromesse (fig. 5).

Come si può notare dalle immagini, si intravedono i tubi metallici installati durante la fase di scavo per mantenere in sicurezza i pilastri ancora in piedi, ma non del tutto integri, e soprattutto non perfettamente in asse verticale. Infatti, i pilastri sopravvissuti in posizione eretta erano meno della metà; probabilmente le cause del crollo della copertura potevano essere riconducibili a qualche evento tellurico o eventuali cedimenti del sottosuolo, dovuti ad assestamenti e alla presenza di altre strutture più antiche.

Solo dopo la campagna di scavi del 2005-2006 il tempio era stato quasi completamente riportato alla luce, tranne che per l'antistante area del propileo. Infatti, il Prof. de Maigret aveva dovuto interrompere gli scavi proprio in prossimità dell'ingresso del tempio, dove cinque dei sei pilastri rinvenuti si presentavano ancora in posizione verticale anche se in realtà erano sorretti grazie alla terra di accumulo che sarebbe stata rimossa in seguito alla messa in sicurezza degli stessi (v. fig. 1). Di conseguenza, non sarebbe stato possibile asportare la terra in prossimità dei grandi monoliti del propileo se non dopo aver corretto la posizione verticale dei pilastri, predisponendo un sostegno definitivo.

I pilastri delle navate occidentali erano stati salvaguardati e mantenuti in posizione verticale durante le fasi di scavo con tubi metallici, in quanto presentavano fratture multiple parziali anche su tre lati e con un grado di inclinazione tale da comprometterne la stabilità stessa (fig. 6). Gli stipiti del portale, grazie alla loro mole, con una sezione di $65 \mathrm{~cm}$ e oltre $5 \mathrm{~m}$ di altezza, erano fortunatamente ancora in grado di auto-sorreggersi senza l'ausilio di strutture artificiali di sostegno. Nell'insieme, il tempio dopo l'ultima campagna di scavi del 2006, nonostante la mancanza della copertura e la presenza di molti pilastri frammentari, mostrava tutta la concretezza, il gusto e 
l'equilibrio delle forme di un'opera grandiosa prodotta dalle abili maestranze sudarabiche.

Nel tempio di 'Athtar dhu-Qabḍ si evidenziavano diversi livelli e tipologie di conservazione, differenziati per aree. La prima chiara considerazione era la mancanza degli elementi di copertura del tetto, non rinvenuti nella posizione originale durante gli scavi, riconducibile a crolli antichi.

All'interno della sala ipostila, solo un terzo dei pilastri era stato rinvenuto ancora in posizione eretta nella ubicazione originale, tra l'altro anche con gravi problemi di staticità e fratture varie. Quattro dei dodici pilastri ancora in piedi erano localizzati nelle navate sud-occidentali della sala; mentre nelle restanti aree, i pilastri rinvenuti risultavano incompleti (fig. 7). Gran parte dei pilastri, dunque, sono stati rinvenuti in situ solo con la parte inferiore, preservati probabilmente perché incastrati nelle panche adiacenti alle tavole offertorie.

Il pilastro più basso tra quelli peggio conservati ed incompleti risultava essere il P7 (h $80 \mathrm{~cm})$, un lacerto; il pilastro più alto era il P5 (h c. 2,45 m). Gli altri pilastri (P8 P9, P10, P11) risultavano avere un'altezza media di 130/167 cm. Come per il tempio di Nakrah, anche per il tempio di 'Athtar dhu-Qabḍ le cause ipotizzate della distruzione di gran parte dei pilastri della sala ipostila sarebbero riconducibili probabilmente ad un evento sismico di grande entità, o ad un cedimento del terreno in direzione $\mathrm{N} / \mathrm{NE}$, oppure ad entrambi i fenomeni, accaduti contemporaneamente. Questi hanno, inoltre, determinato il crollo di tutti gli elementi della copertura del tempio.

Dai rilievi topografici e dalle indagini archeologiche, era emersa una similitudine di orientamento dei punti di cedimento del piano pavimentale e della struttura del tempio verso N/NE. Non era certo una coincidenza che i pilastri della sala ipostila, che avevano resistito maggiormente, fossero raggruppati nell'area sudoccidentale, rispetto a quelli fratturati, spezzati ed incompleti dell'area nord-orientale. La dinamica del crollo era avvenuta in direzione N/NE, per cui le grosse e pesanti travi primarie e secondarie della copertura, cadendo in quella traiettoria, andarono a colpire maggiormente i pilastri posizionati verso N/NE.

In base sia all'inclinazione riscontrata dei pilastri, sia alla condizione complessiva dell'edificio, sia allo stato di fatto e di conservazione dei singoli elementi architettonici ancora in piedi, l'ipotesi più plausibile dello stato di conservazione sembrerebbe proprio quella di un importante crollo che ha compromesso prevalentemente tutta l'area e gli elementi della navata orientale del tempio. Infatti tutte e quattro le tavole offertorie presentavano fratture totali multiple, sebbene la sezione frontale con la decorazione a stambecchi recumbenti e le iscrizioni fossero ancora ben conservate (fig. 8).

Gli stipiti del portale del tempio erano anch'essi ben conservati, in piedi e nella posizione originale (fig. 9). La parete perimetrale meridionale risultava quella relativamente più preservata, raggiungendo un'altezza di c. $2 \mathrm{~m}$, mentre delle altre pareti erano rimaste poche file alla base, al livello della soglia d'ingresso.

A differenza del tempio di Nakrah, nel tempio di 'Athtar dhu-Qabd si erano preservati quattro dei sei pilastri del propileo, più un quinto pilastro spezzato a metà, ancora nella sua posizione originale (fig. 10). I pilastri del propileo, benché in buone condizioni di conservazione strutturale, a parte qualche frattura parziale, erano compromessi da una gravosa problematica di statica. Tutti e cinque i pilastri risultavano con una inclinazione del baricentro verticale oltre la soglia di equilibrio statico (fig. 11), con un errore del terzo medio differente per ogni singolo pilastro.

I pilastri del propileo poggiano ciascuno su una singola grande base di pietra dello stilobate, e tutte, probabilmente a causa di cedimenti del piano sottostante, evidenziavano una quota orizzontale di appoggio compromessa ed errata: in sintesi non erano più 'a piombo'. Di conseguenza, i pilastri che poggiavano sopra le basi non perfettamente in quota orizzontale riportavano l'errore nell'asse verticale.

Nei paragrafi successivi saranno descritti più dettagliatamente $i$ fenomeni di degrado che interessavano i singoli elementi architettonici del tempio.

\subsection{Pilastri}

I pilastri del tempio di 'Athtar dhu-Qabd, come per il tempio di Nakrah, sono stati realizzati in singoli monoblocchi di pietra di origine calcarea. Molto ben squadrati e rifiniti a picchiettatura (simile ad un effetto di bocciardatura) su tutti e quattro i lati verticali, contornati da una cornice liscia di c. $5 \mathrm{~cm}$.

I pilastri si differenziano da quelli dal tempio di Nakrah per un particolare tecnico importante: le sezioni inferiori di ogni singolo pilastro sono risultate tutte di dimensioni più piccole rispetto alle rispettive sezioni superiori, cioè sono rastremati verso il basso. Questo aspetto conferisce ai monoliti una forma più affusolata in basso, e probabilmente un effetto ottico compresso anziché di slancio. Tale modalità di lavorazione è stata riscontrata sia nei pilastri rinvenuti nel propileo, che nei quattro pilastri conservati nella sala ipostila del tempio. 


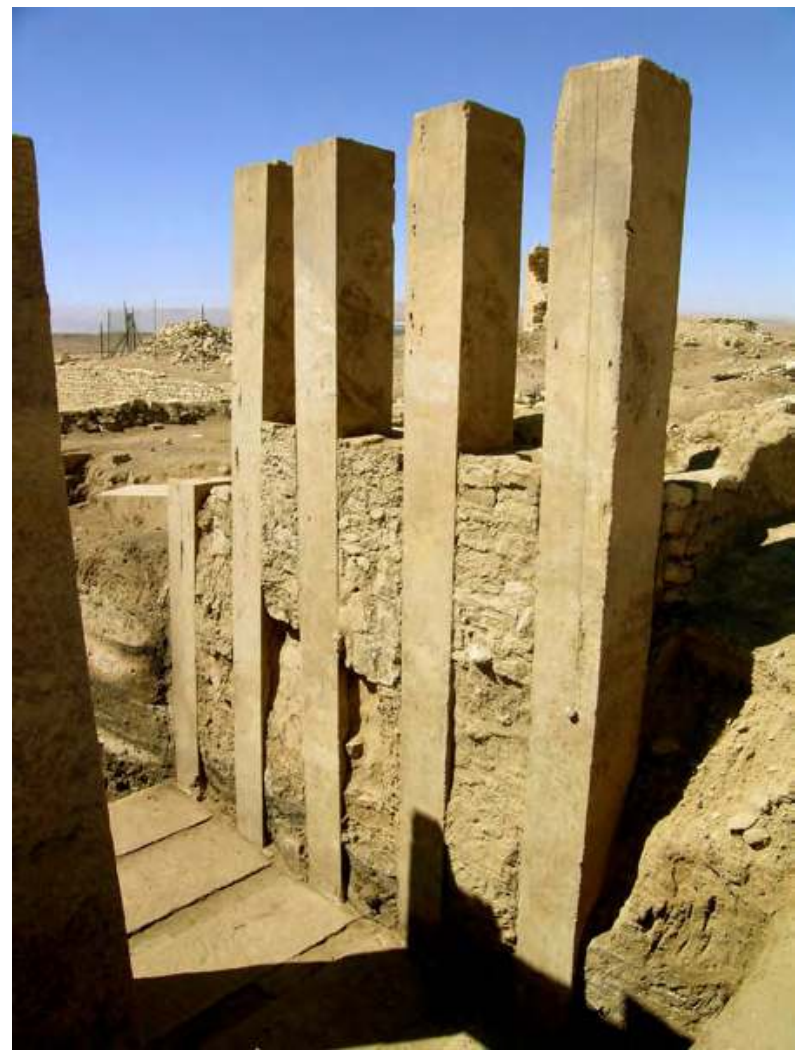

Figure 1. I pilastri del propileo del tempio di 'Athtar dhuQabd mantenuti su tre lati dagli strati di accumulo e dalle strutture di epoca islamica. (S.B. Scigliano 2006 OMAIRY)

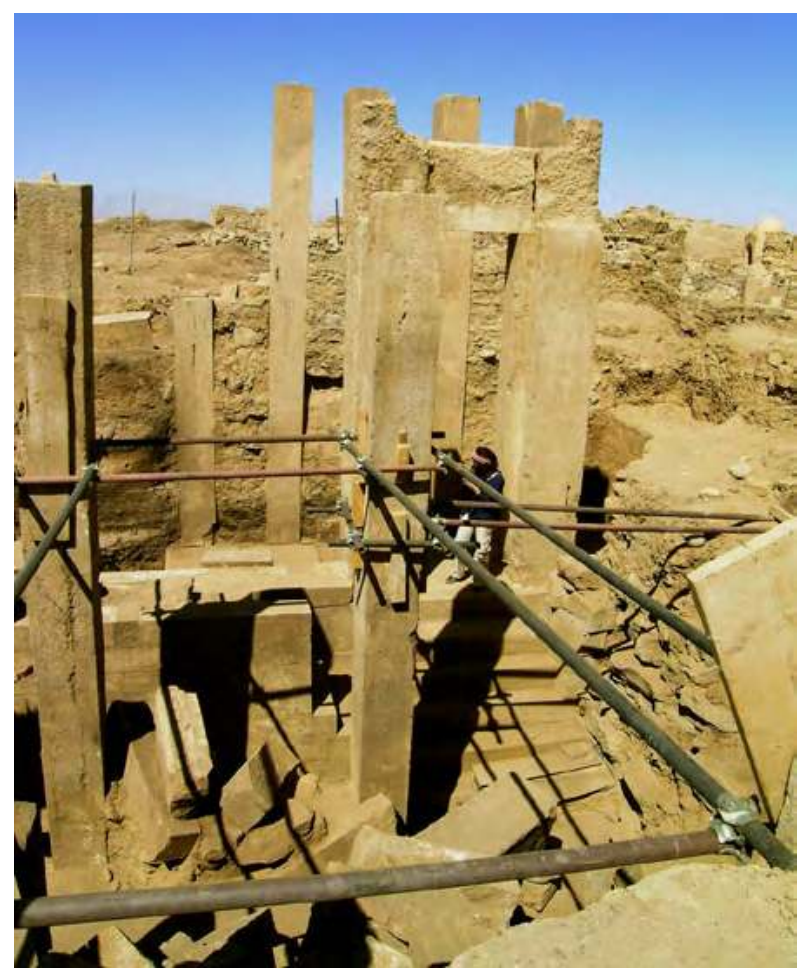

Figure 2. La sala ipostila del tempio di 'Athtar dhu-Qabḍ in primo piano; in secondo piano il portale, e sullo sfondo gli imponenti monoliti del propileo. (S.B. Scigliano 2006 @MAIRY)

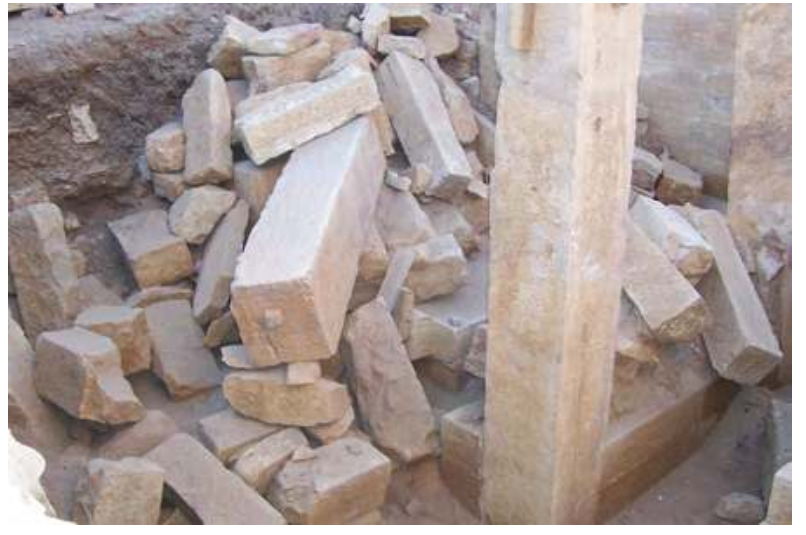

Figure 3. La sala ipostila del tempio di 'Athtar dhu-Qabḍ con il materiale lapideo di crollo (da N). (S.B. Scigliano 2006 @MAIRY)

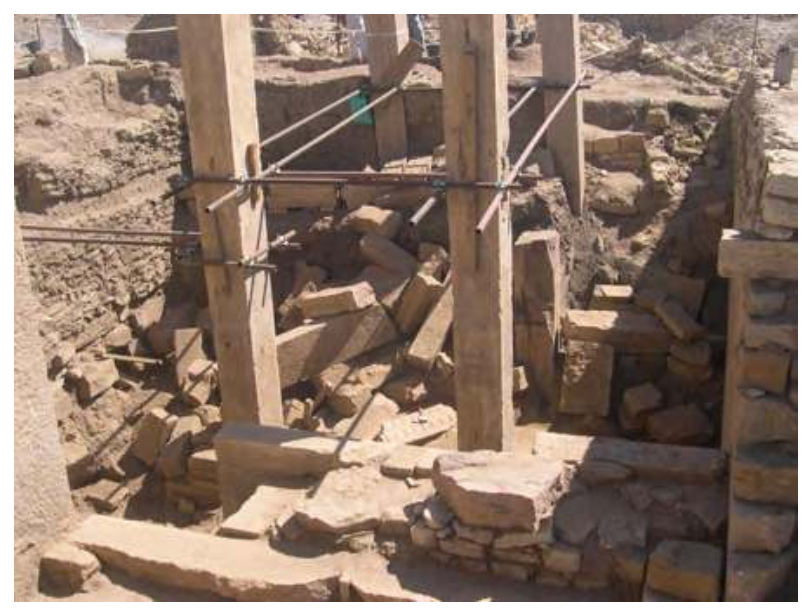

Figure 4. La sala ipostila occupata dal materiale lapideo di crollo. (S.B. Scigliano 2006 CMAIRY)

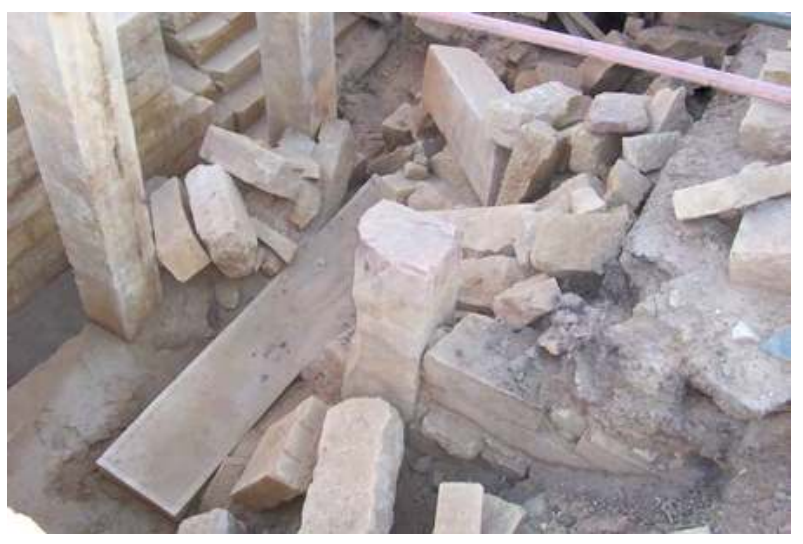

Figure 5. La tavola offertoria Ta in L103 liberata parzialmente dall'accumulo dei materiali di crollo (da SO). (S.B. Scigliano 2006 CMAIRY) 


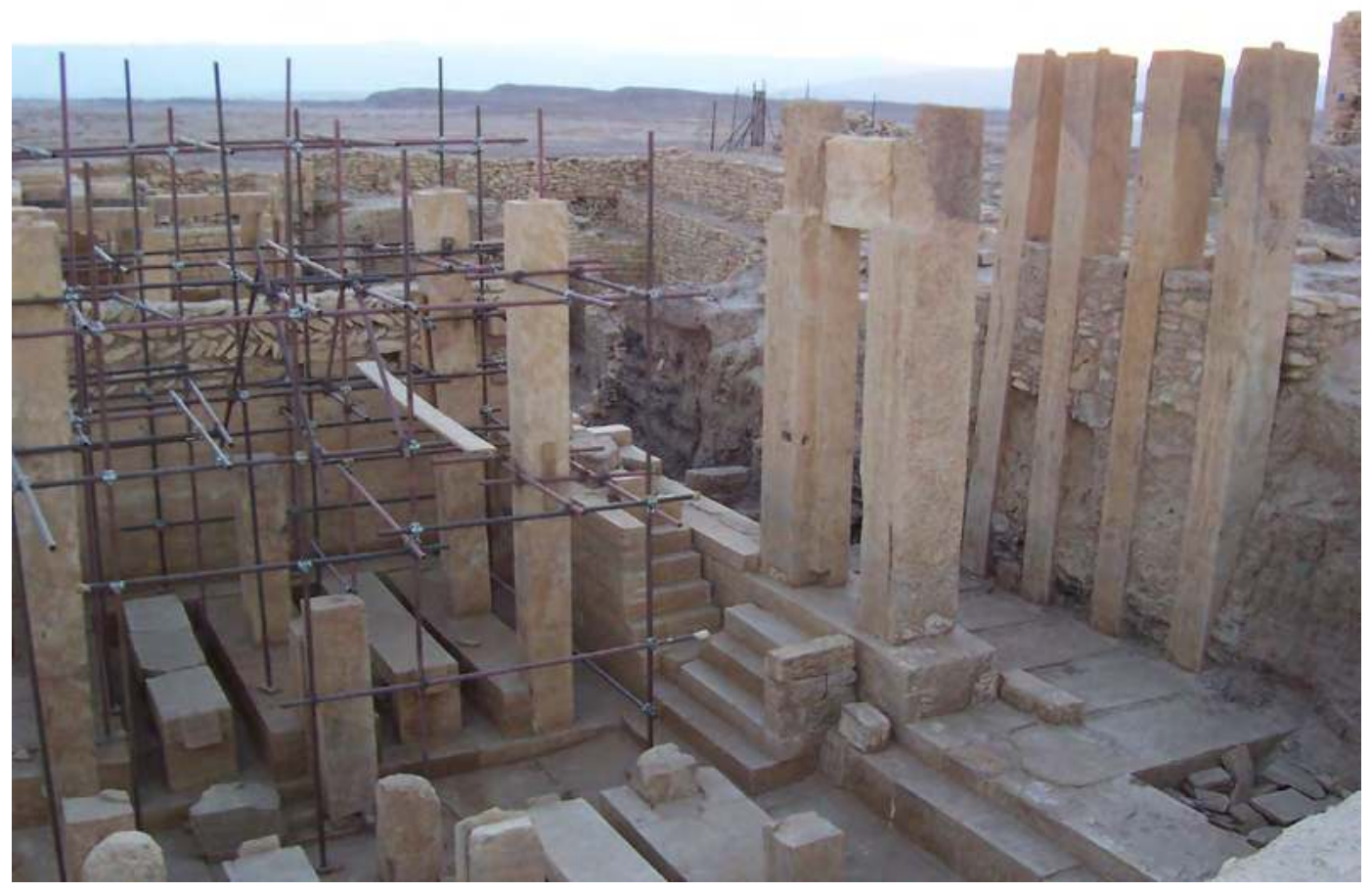

Figure 6. I pilastri occidentali, alcuni dei quali fratturati e inclinati, sono mantenuti in posizione verticale da tubi metallici (S.B. Scigliano 2006 CMAIRY)

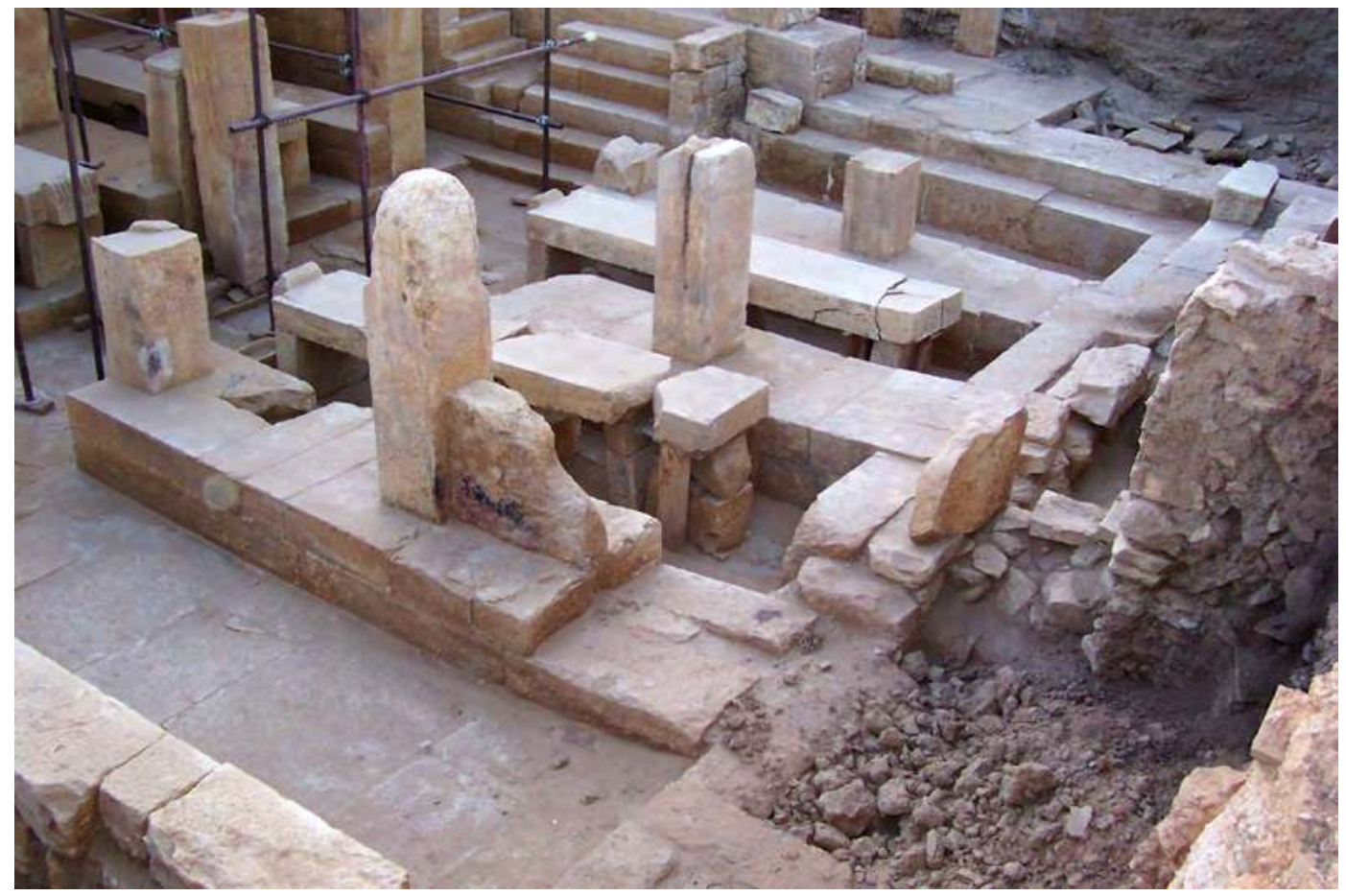

Figure 7. Di tutti i pilastri orientali è conservata solo la porzione inferiore incastrata nelle panche ai lati delle tavole offertorie. (S.B. Scigliano 2006 CMAIRY) 


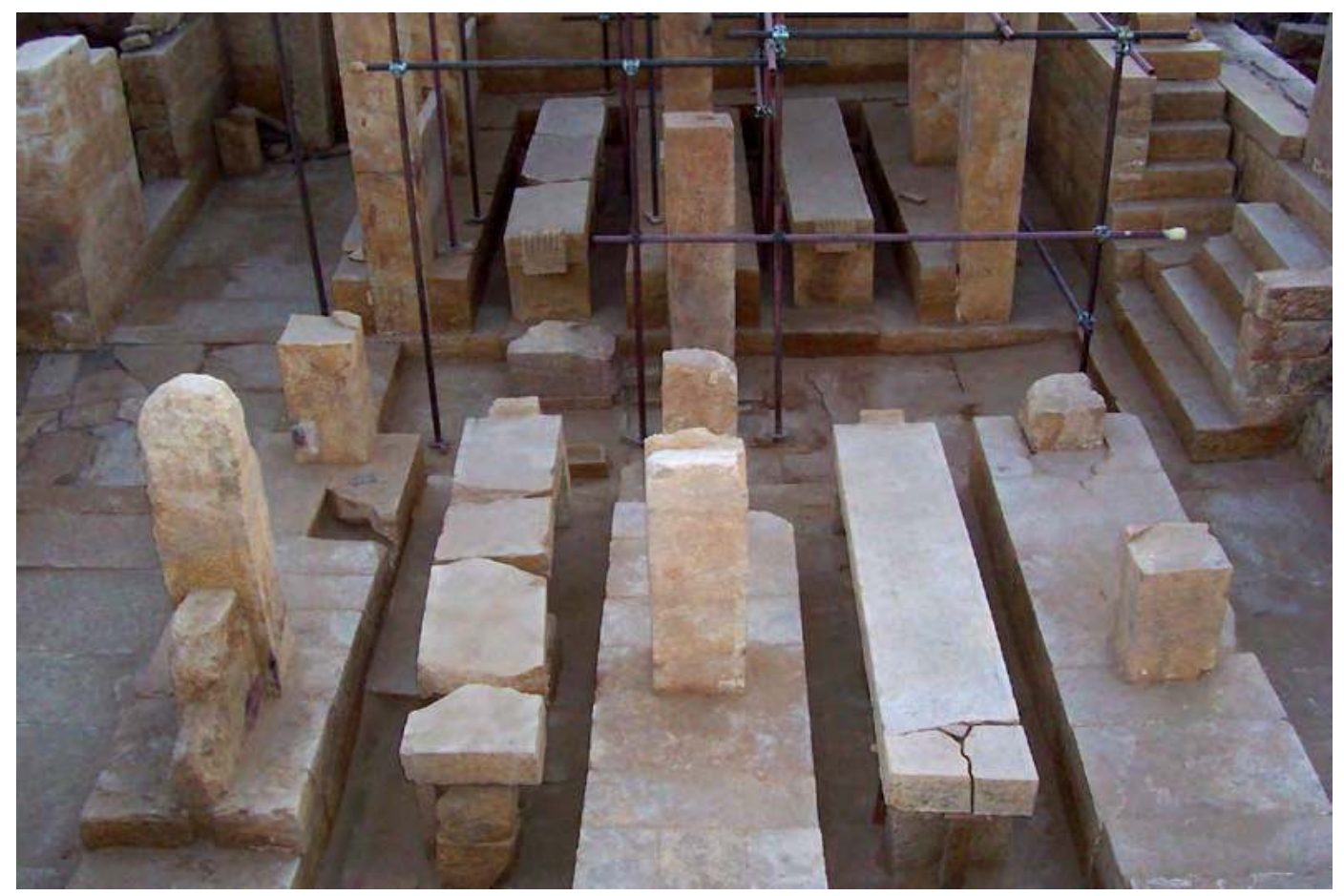

Figure 8. In primo piano le tavole offertorie del settore orientale del tempio, Tc a sinistra e Tb a destra, con fratture multiple; in secondo piano le tavole Td a sinistra e Ta a destra (da E). (S.B. Scigliano 2006 @MAIRY)

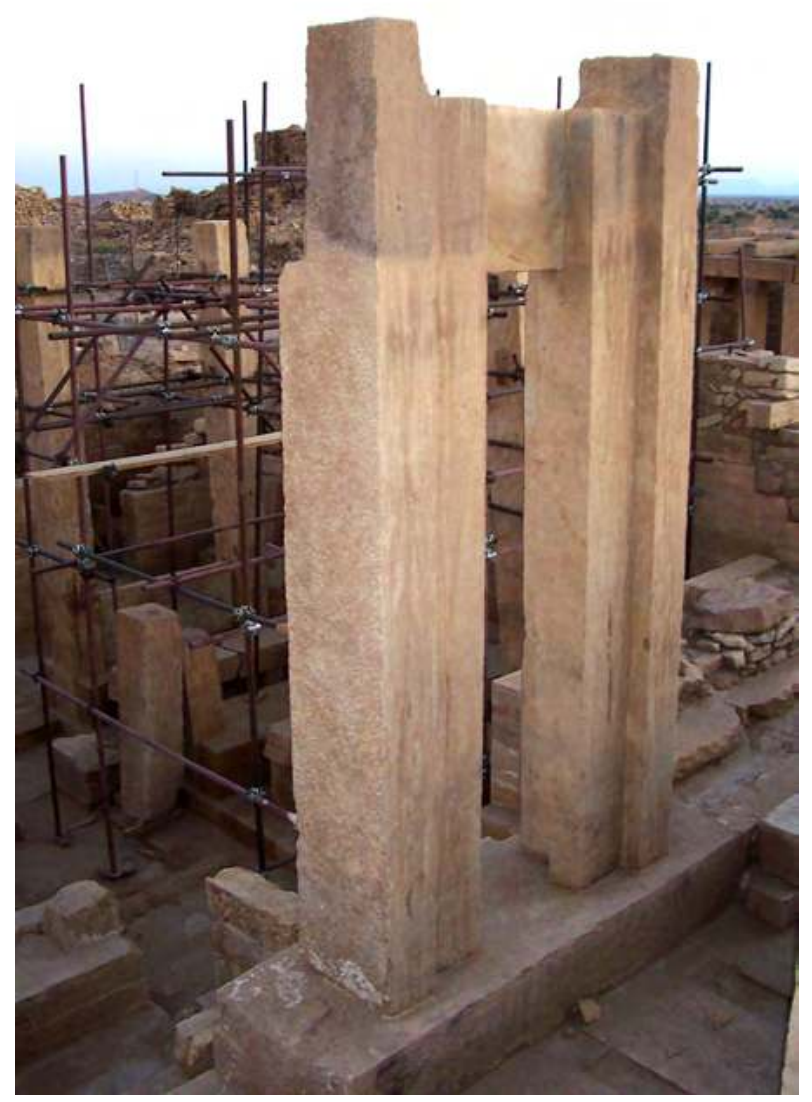

Figure 9. Il portale del tempio in piedi e nella posizione originale (da N). (S.B. Scigliano 2006 CMAIRY) 


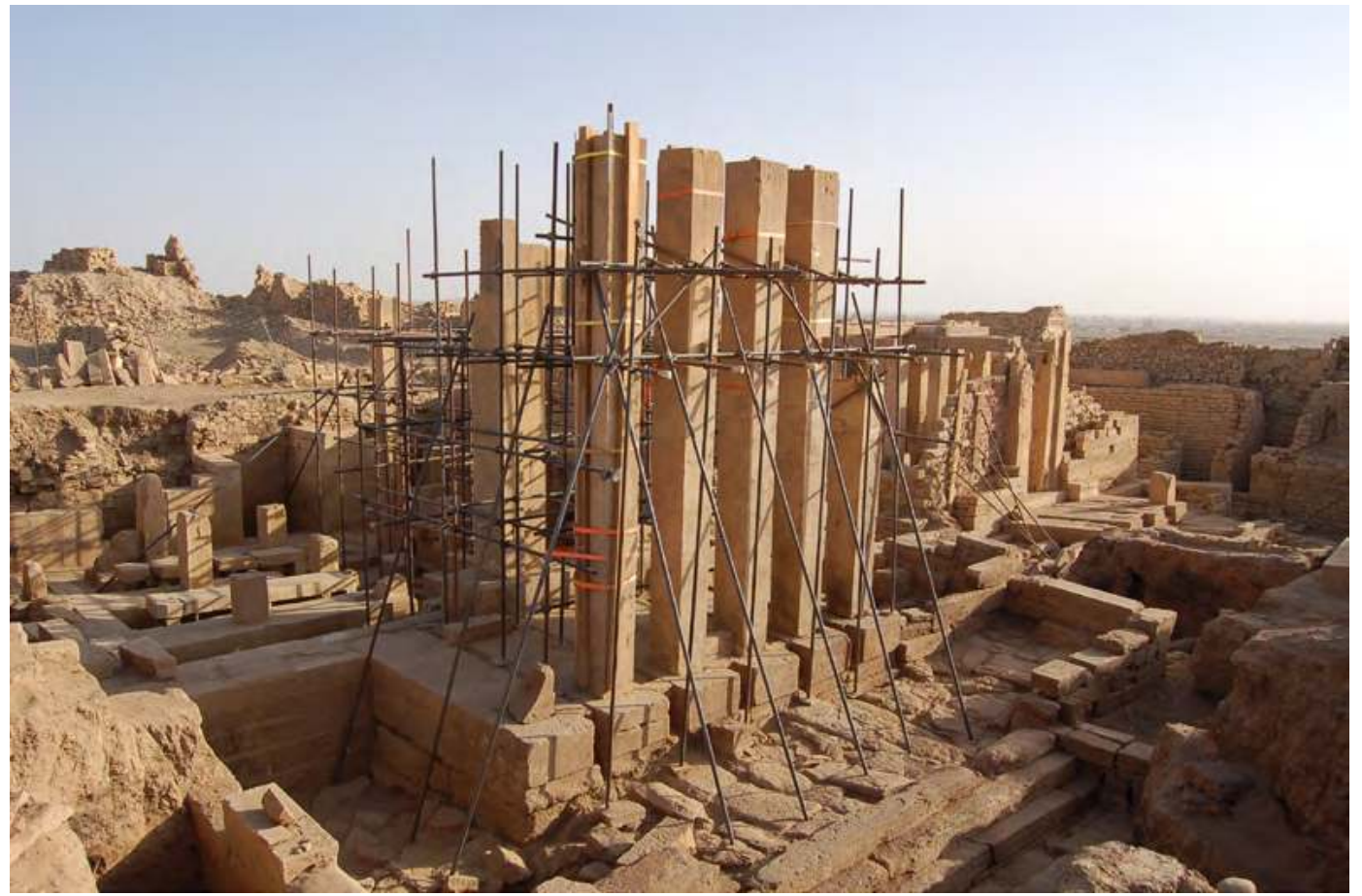

Figure 10. I pilatri del propileo del tempio di 'Athtar dhu-Qabḍ in situ (da N). (S.B. Scigliano 2006 @MAIRY)

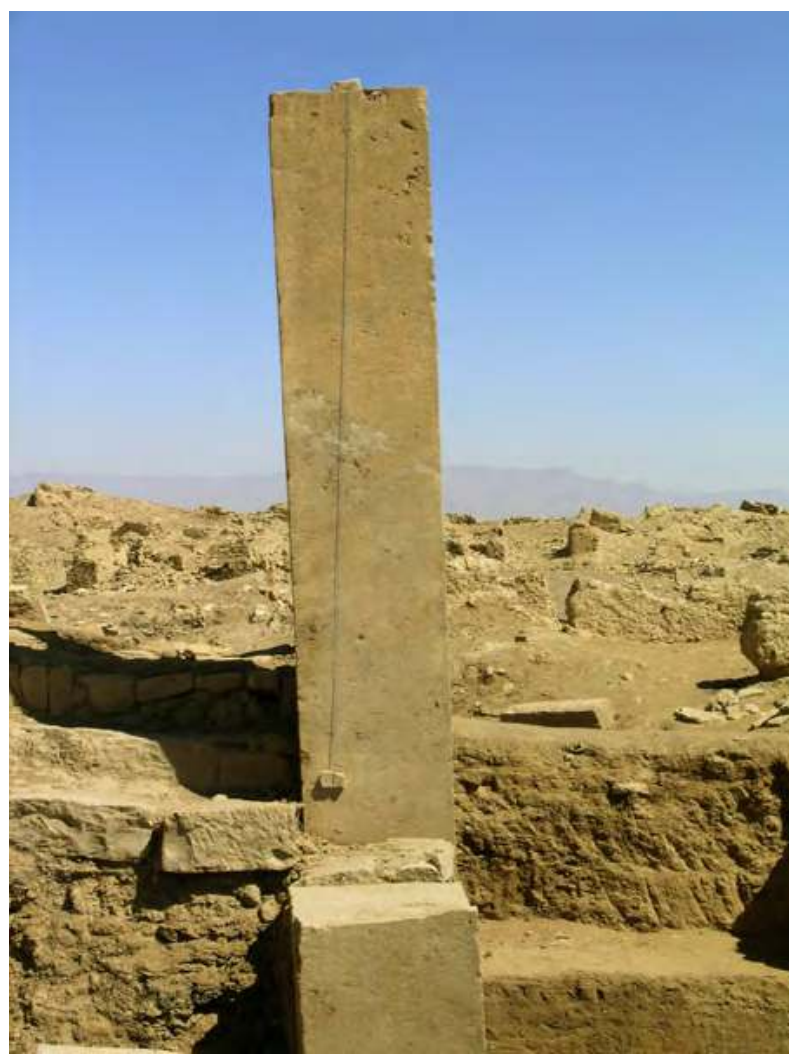

Figure 11. La pendenza dei pilastri del propileo ha provocato una inclinazione del baricentro verticale oltre la soglia di equilibrio statico. (S.B. Scigliano 2006 CMAIRY)
Le caratteristiche del materiale costitutivo di origine calcarea sono le stesse del tempio di Nakrah, a conferma che sia stata utilizzata la medesima cava di pietra, probabilmente non molto lontana dalla città di Barāqish.

Complessivamente le condizioni generali di conservazione dei pilastri risultavano differenziate, sia per i pilastri del propileo che della sala ipostila. Alcuni pilastri sono stati rinvenuti completi ed integri, altri con qualche frattura parziale, altri ancora con fratture totali. Il $60 \%$ dei pilastri della sala ipostila risultava incompleto. Gli unici quattro pilastri completi sono stati rinvenuti nel settore SO (fig. 12), in ragione delle dinamiche di crollo della copertura in direzione N/NE, come per il tempio di Nakrah.

Per quanto riguarda i pilastri dei propilei, quattro su sei di quelli ancora interi risultavano integri. Naturalmente parliamo di pilastri nella posizione verticale 'scorretta', in quanto inclinati verso N/NE. Alcune delle parti mancanti sono state rinvenute o si troverebbero classificate in posizione erratica nell'area di scavo.

Tutti i pilastri rinvenuti in posizione eretta si presentavano conl'asse verticale in posizione 'scorretta'. La conferma della grave inclinazione dei singoli pilastri, oltre che visibile a occhio nudo, è stata convalidata dai rilievi con la Stazione Totale e AutoCad, effettuati dal topografo M. Mascellani con l'aiuto dell'archeologo 
R. Loreto. I dati riscontrati hanno evidenziato la maggiore gravità in relazione alla stabilità soprattutto per i singoli pilastri del propileo, che denotavano una eccessiva alterazione del terzo medio, con conseguente insufficienza di auto-sostegno in modalità verticale.

\subsection{A. Pilastri del propileo}

I pilastri si presentavano privi della copertura originale che si raccordava con l'ingresso interno della sala ipostila del tempio. L'altezza massima dei monoblocchi è di m 6,15 (fig. 13); le sezioni dei monoblocchi lapidei si caratterizzano per una strana differenza tra la sezione inferiore e quella superiore: $48 / 49 \times 56 / 57 \mathrm{~cm}$ per la sezione inferiore e 50/53 x 58/59 cm per la sezione superiore (fig. 14). In sostanza la sezione superiore risulta leggermente più grande di quella inferiore, anche se di pochi centimetri. Certo, anziché essere affusolati e slanciati verso l'alto, come verrebbe più facile pensare, i pilastri, al contrario, sarebbero apparsi leggermente compressi, oltre al fatto che da un punto vista statico sarebbe più saldo ed in equilibrio un pilastro con la sezione inferiore più grande di quella superiore, e non il contrario. Si potrebbe anche ipotizzare che per qualche fenomeno a noi sconosciuto la parte bassa dei pilastri si sia consumata e ridotta in maniera graduale? Oppure era semplicemente una scelta voluta?

Come già detto in precedenza, solo uno dei sei pilastri è mancante, probabilmente crollato in passato $\mathrm{e}$ riutilizzato, oppure ancora sotto terra nelle aree adiacenti. Il pilastro F (v. fig. 13) si presentava mancante della parte superiore; la parte rimasta in piedi in

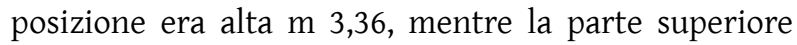
mancante rinvenuta nei pressi era alta m 2,79 a completare la totalità del singolo pilastro. Le condizioni di degrado tra i vari pilastri rinvenuti ancora nella posizione originale risultavano essere di poco differenti da un pilastro all'altro.

Da un punto di vista strutturale, a parte qualche minima lesione o piccola frattura parziale, nel complesso i monoliti rinvenuti negli scavi risultavano in un buono stato di conservazione. Il materiale costitutivo della pietra calcarea, anche se leggermente porosa, si presentava poco pulverulenta in superficie e con qualche lieve fenomeno di alveolizzazione in prossimità di inclusi di materiale scuro, probabilmente più ricco di ferro e manganese; comunque parliamo di piccole porzioni o sottili stratificazioni di particelle meno compatte.

Dopo la campagna di scavo del 2005-2006, i cinque pilastri del propileo parzialmente scavati si potevano intravedere in tutta la loro interezza solo dal lato interno, in quanto gli altri tre lati erano ancora in parte circondati da terra, volutamente conservata dagli archeologi per mantenerli in sicurezza, dati i gravi problemi di statica. Come si può osservare nella fig. 1, dall'interno del lato est i pilastri del propileo erano sorretti solo dalla terra lasciata nell'area antistante l'ingresso del tempio e tra i pilastri. La considerevole inclinazione dei grandi pilastri prevalentemente verso N/NE, visibile anche ad occhio nudo nella fig. 15, a confronto con gli stipiti della porta d'ingresso interna ancora perfettamente in asse verticale, mostra senza ombra di dubbio la gravità e pericolosità in cui versavano i quattro monoliti. Nelle immagini si intuisce palesemente che i pilastri non potevano stare in piedi da soli. La posizione decentrata del baricentro d'ogni singolo pilastro (fig. 16) aveva determinato la perdita di equilibrio verticale, compromettendo in modo serio la staticità e l'integrità degli elementi architettonici principali del tempio.

Grazie alle indagini di rilevazioni (fig. 17) effettuate con la Stazione Totale e in grado di riportare tutte le informazioni dettagliate, restituite graficamente con l'ausilio di AutoCad, effettuate da M. Mascellani e R. Loreto, è stato possibile verificare il reale stato

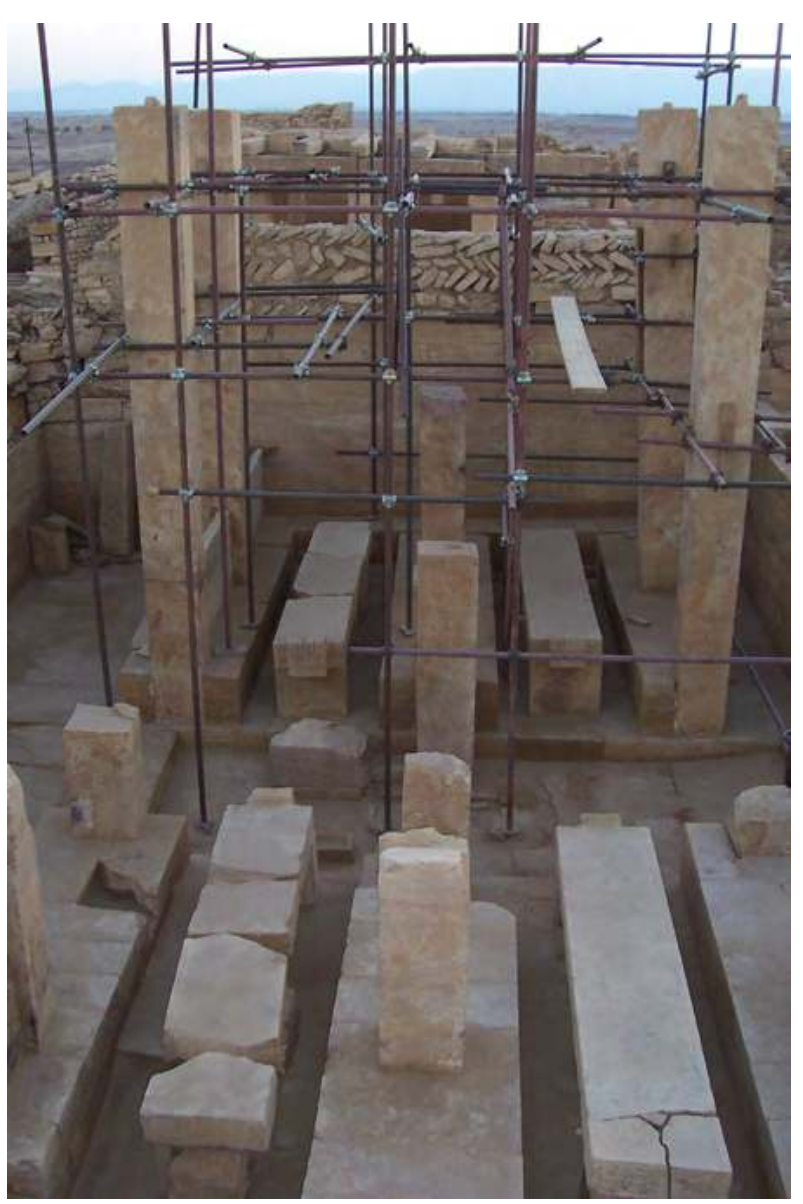

Figure 12. Gli unici quattro pilastri completi sono P1e P4 (a sinistra), P2 e P3 (a destra) nel settore O della sala ipostila. (S.B. Scigliano 2006 @MAIRY) 


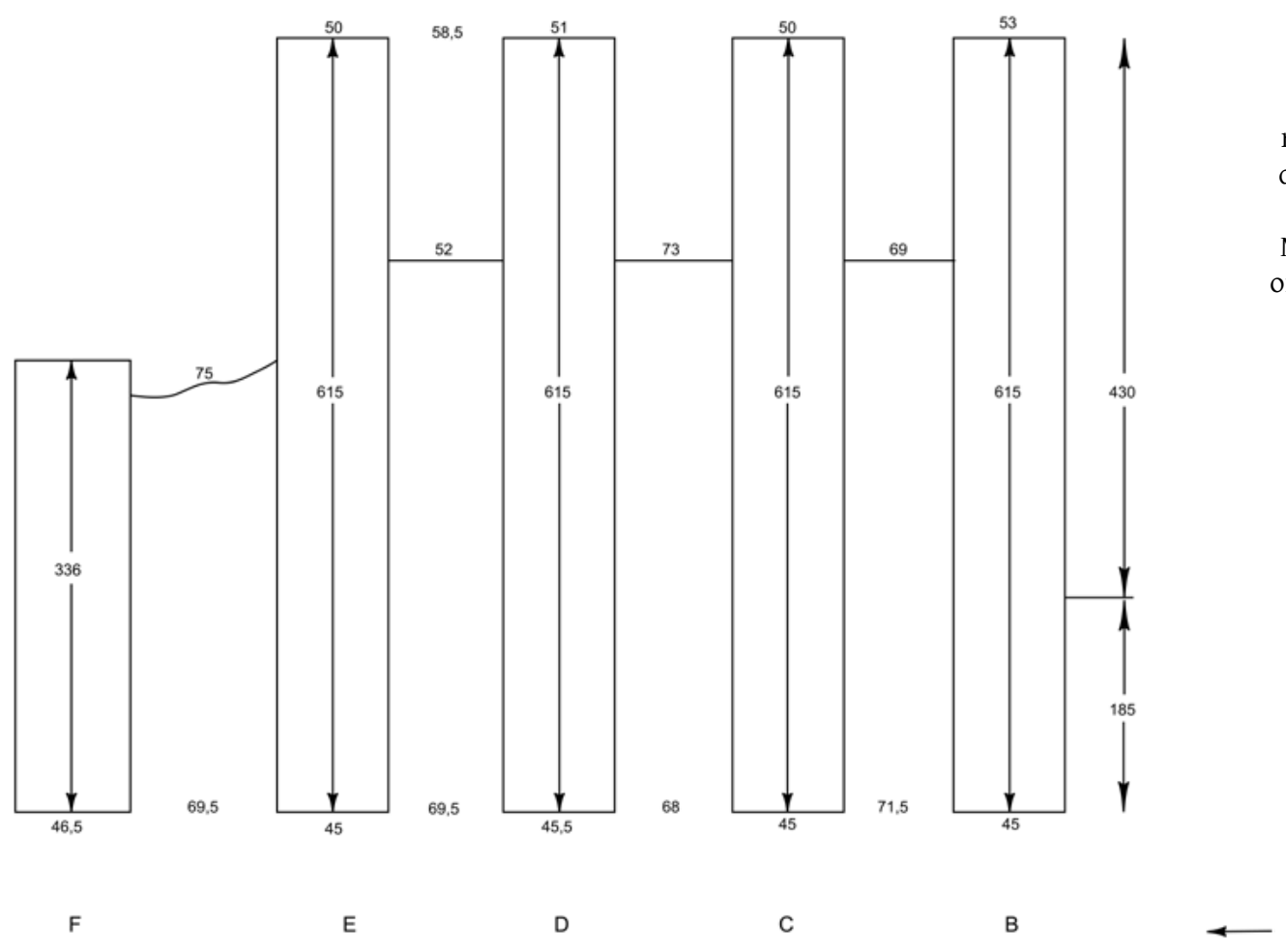

Figure 13. Rilievo metrico del prospetto $S$ dei pilastri del propileo. (Rielaborazione di L. Munduteguy da schizzo originale di S.B. Scigliano 2006, 2019 (CMAIRY)
Figure 14. Rilievo metrico del prospetto $\mathrm{N}$ dei pilastri del propileo, delle sezioni superiori e delle sezioni intermedie in prossimità del piano di terra ancora da scavare. (Rielaborazione di L. Munduteguy da schizzo originale di S.B. Scigliano 2006, 2019 (CMAIRY)
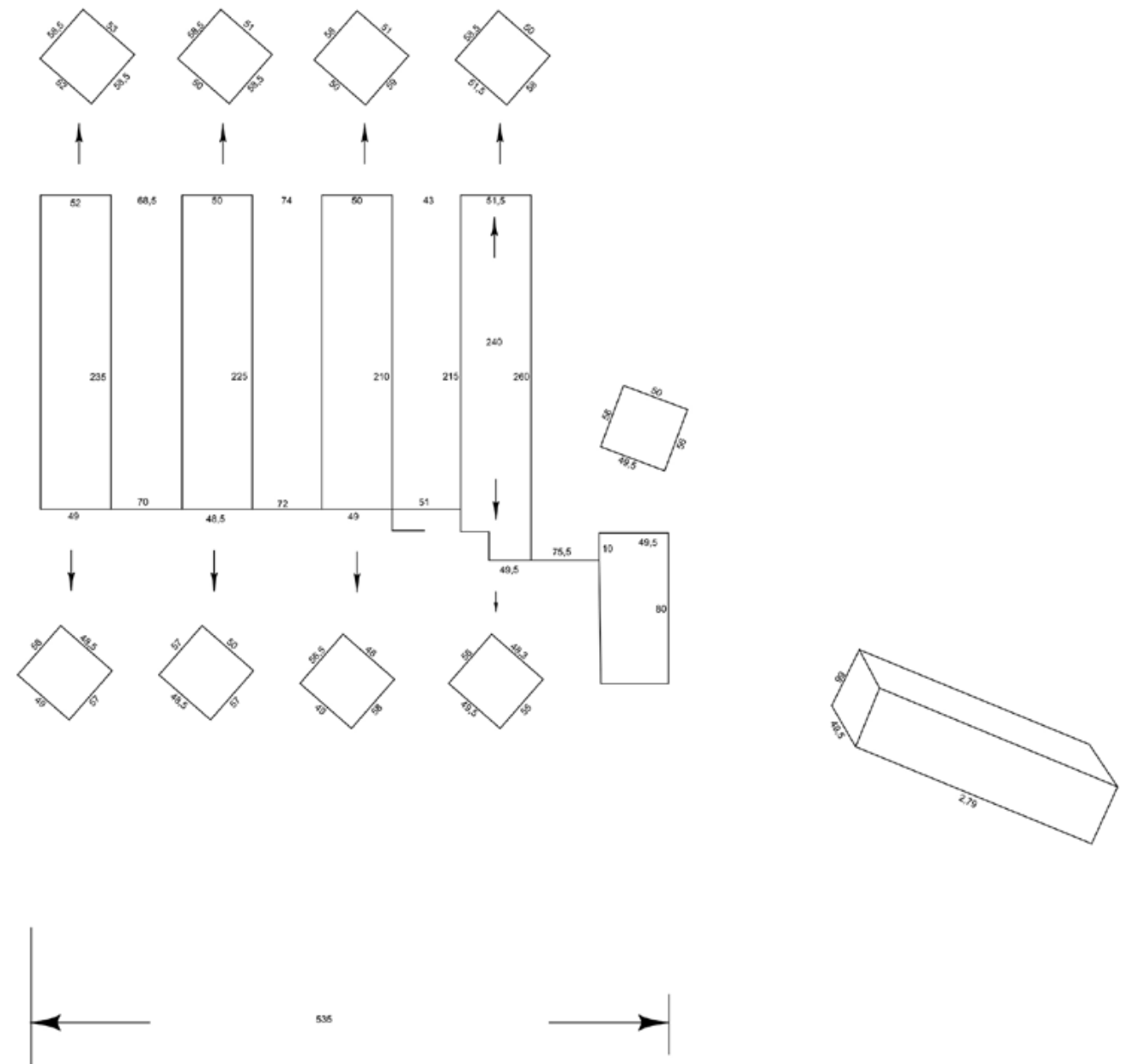


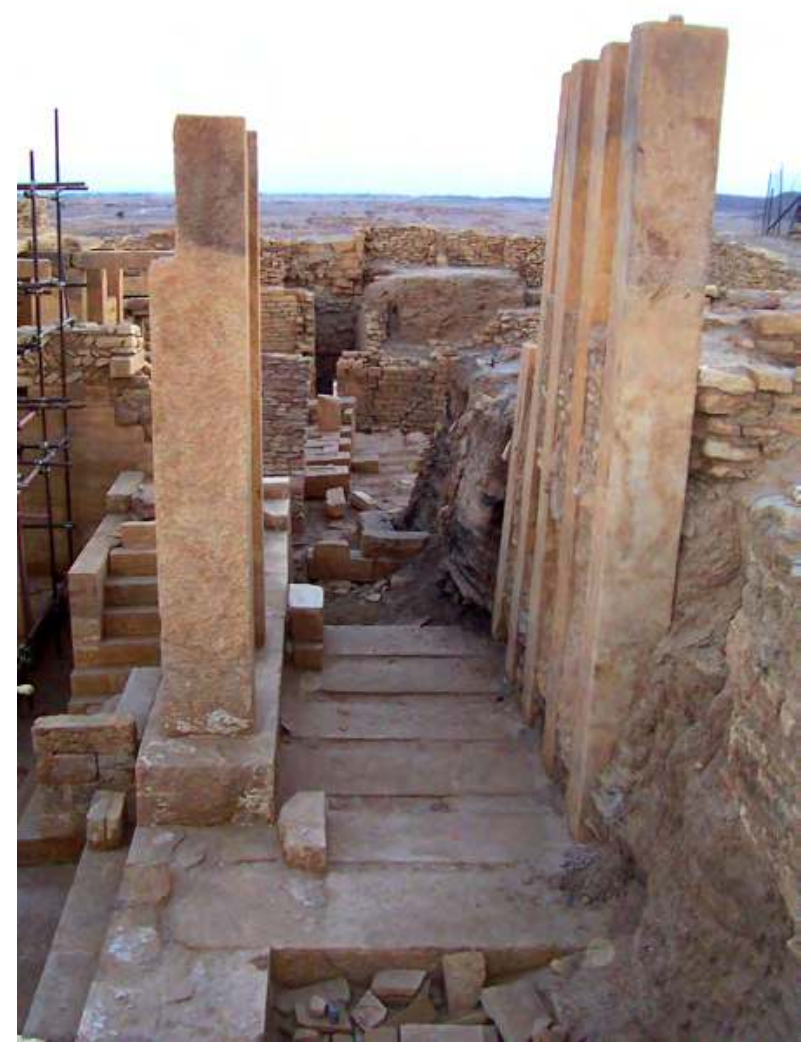

Figure 15. Evidente inclinazione dei pilatri del propileo verso $\mathrm{NE}$ a confronto con il portale del tempio in asse verticale.

(S.B. Scigliano 2006 CMAIRY)

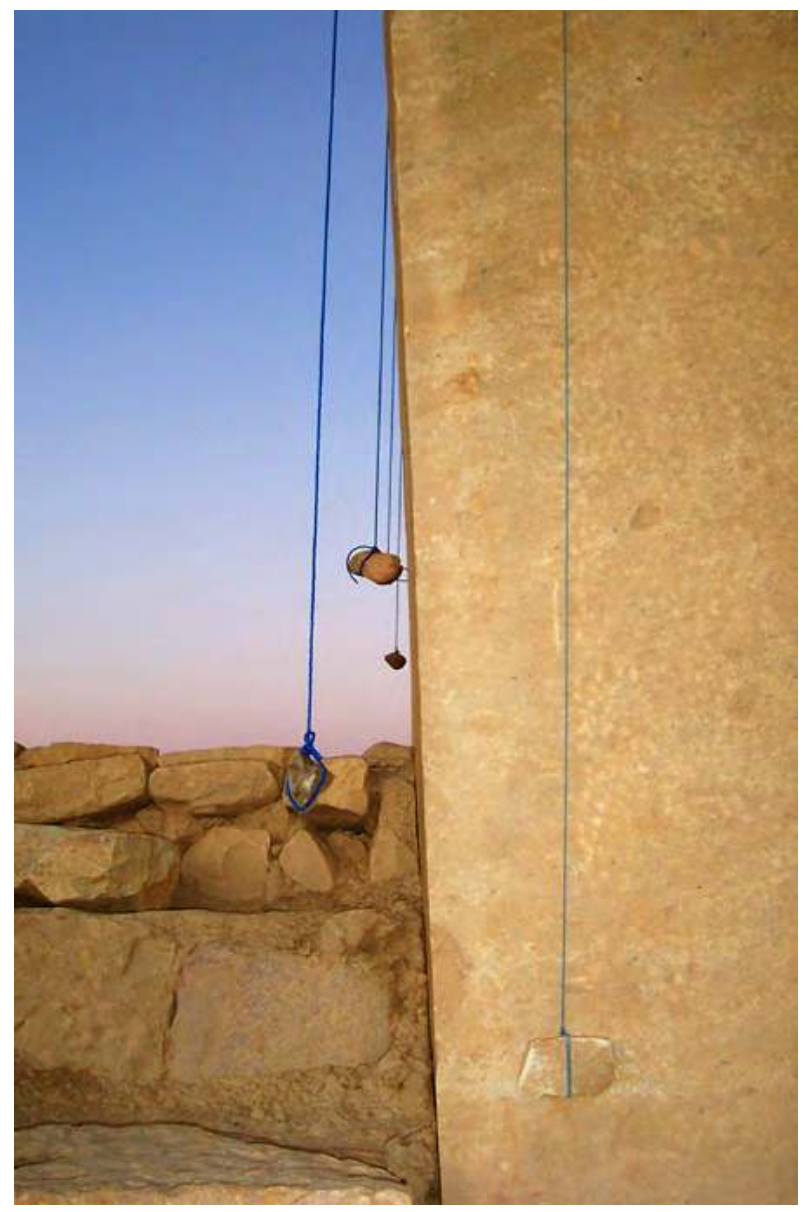

Figure 16. I 'fili a piombo' mostrano la posizione decentrata del baricentro di ogni singolo pilastro.

(S.B. Scigliano 2006 OMAIRY)
Pf
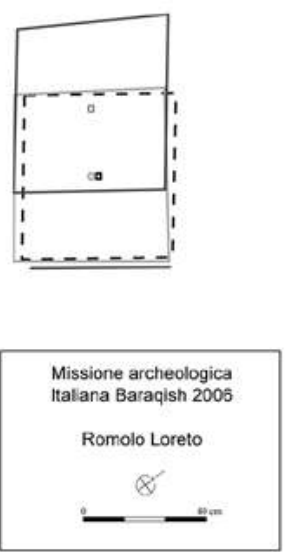

$\mathrm{Pe}$

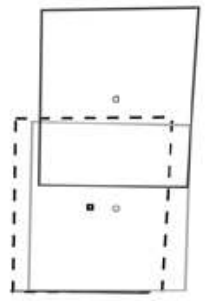

$\mathrm{Pd}$

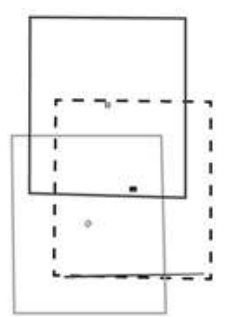

Pc

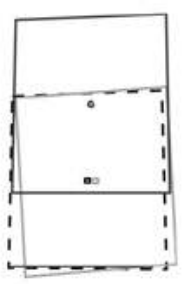

$\mathrm{Pb}$

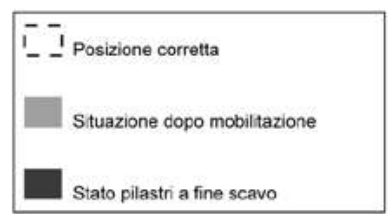

Figure 17. Nel disegno sono mostrate le tre posizioni dei pilastri: a fine scavo con il reale stato dell'asse verticale errato, dopo la loro correzione e, infine, la posizione originale. (Rielaborazione di L. Munduteguy da originale di L. Loreto e M. Mascellani 2006, 2019 OMAIRY) 
dell'asse verticale errato per capire come intervenire, correggere e mettere in totale sicurezza i cinque pilastri del propileo.

\subsection{B. Pilastri della sala ipostila}

Per quanto riguarda i dodici pilastri della sala ipostila, ci siamo attenuti alla numerazione attribuita dagli archeologi in fase di scavo (i numeri venivano dati progressivamente man mano che le strutture venivano messe in luce), per non creare confusione, nonostante non avesse un ordine progressivo (v. Agostini, capitolo 3 in questo volume, fig. 3 ).

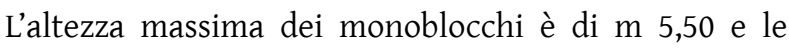
sezioni dei monoblocchi lapidei variano da $38 / 40 \mathrm{x}$ $43 / 46 \mathrm{~cm}$.

La posizione decentrata del baricentro d'ogni singolo pilastro ha determinato danni molto gravi, compromettendo in modo serio la staticità e l'integrità degli elementi architettonici principali del tempio. Tendenzialmente su tutti i pilastri è stato riscontrato un errore dell'asse verticale del $7 \%$ circa e forse anche di più. Ragione per cui i pilastri completi sono stati protetti all'interno di strutture metalliche.

Il pilastro P1 è alto $\mathrm{m} 5,50$, ha una sezione di c. 40 x 46,5 $\mathrm{cm}$ a metà altezza, ma tende ad ingrandirsi in alto e ad affusolarsi in basso di c. $3 \mathrm{~cm}$ (fig. 18). Rimane visibile da terra solo a N, il lato verso il corridoio, in quanto è inglobato per tre lati in una banchina alta $45 \mathrm{~cm}$. Sul lato NE (ossia verso il corridoio centrale) dello stesso pilastro, è visibile un'iscrizione, scolpita appena sopra la frattura totale (Y.05.B.B./14; v. Agostini, capitolo 4, fig. 16). È stato rilevato che il pilastro è particolarmente inclinato verso $\mathrm{N}$. Si presenta intero, ma con una gravissima frattura totale a $\mathrm{m} \mathrm{1,38}$ dalla base, con una evidente dislocazione di c. $2 \mathrm{~cm}$ da $\mathrm{S}$ verso $\mathrm{N}$, con mancanza di materiale costitutivo originale (fig. 19). La parte superiore del pilastro che poggia sulla frattura totale è mantenuta in posizione solo grazie al sostegno dei ponteggi. Presenta varie tipologie di alveolizzazione verticale, larghe e profonde più o meno su tutti i lati. Inoltre sono state riscontrate alterazioni cromatiche probabilmente provocate da surriscaldamento da fuochi. Sono state documentate tracce di malta originale di allettamento al di sotto della sezione inferiore del pilastro.

Il P2 è intero, alto 5,50 $\mathrm{m}$, la sezione inferiore misura $38 \times 43 / 45 \mathrm{~cm}$, mentre quella superiore $41 \times 47 \mathrm{~cm}$. È inglobato per due lati in una banchina alta $45 \mathrm{~cm}$, tranne il lato verso il corridoio NE e NO. È presente una frattura totale orizzontale obliqua a c. 1,10 m da terra, collegata con altre micro fratture verticali. Il pilastro è leggermente inclinato verso $\mathrm{E}$. Presenta varie tipologie di alveolizzazione verticale, larghe e profonde più o meno su tutti i lati. Inoltre, sono state rilevate delle alterazioni cromatiche probabilmente provocate da surriscaldamento da fuochi. Come per il pilastro precedente, erano visibili tracce di malta originale di allettamento, sotto la sezione inferiore del pilastro e sui lati della panca in muratura.

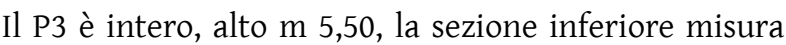
$38 \times 43 \mathrm{~cm}$ mentre quella superiore $45 \times 50 \mathrm{~cm}$. ̀̀ inglobato per tre lati in una banchina alta $46 \mathrm{~cm}$, tranne il lato verso NO. Il pilastro è leggermente inclinato verso NE. È presente una frattura totale orizzontale a m 3,65 da terra, ed una seconda frattura parziale orizzontale obliqua su tre lati a $\mathrm{m} 1 \mathrm{da}$ terra, con piccole perdite di materiale costitutivo in prossimità della frattura. Presenta varie tipologie di alveolizzazione verticale più o meno su tutti i lati. Sono state rilevate alterazioni cromatiche probabilmente provocate da surriscaldamento da fuochi. Vi sono tracce di malta originale di allettamento sotto la sezione inferiore del pilastro e sui lati della panca in muratura.

Il P4 è intero, alto $\mathrm{m} 5,50$; la sezione inferiore misura $\mathrm{cm}$ $38 \mathrm{x} 45,5$, e quella superiore $\mathrm{cm} 41 \mathrm{x} 47$. Esso è inglobato per tutti i quattro lati in una banchina alta $46 \mathrm{~cm}$. Il pilastro è leggermente inclinato verso N. È presente una frattura totale orizzontale a $66 \mathrm{~cm}$ da terra, con leggera dislocazione e piccole perdite di materiale costitutivo in prossimità della frattura. Mostrava varie tipologie di alveolizzazione verticali più o meno su tutti i lati. Sono state rilevate alterazioni cromatiche probabilmente provocate dal fuoco. Vi sono tracce di malta originale di allettamento sotto la sezione inferiore del pilastro e sui lati della panca in muratura.

Il P5 risulta incompleto: la parte in situ è alta c. 2,50 m, la sezione inferiore misura $40 \times 43 / 46 \mathrm{~cm}$, è inglobato per tutti i quattro lati in una banchina alta $46 \mathrm{~cm}$. Il pilastro è leggermente inclinato verso N. Si è riscontrata una frattura parziale orizzontale su due lati a $\mathrm{m} 1,55$ da terra. Risulta mancante una notevole porzione di uno spigolo verso ovest, di $70 / 80 \mathrm{~cm}$. Presenta varie tipologie di alveolizzazione verticale più o meno su tutti i lati, in particolare una profonda e larga sul lato NO. Sono state rilevate alterazioni cromatiche probabilmente provocate da combustione.

Il P6èincompleto espezzato in più parti; la parteinferiore nella posizione originale è alta $\mathrm{m} 1,45$, inclinata verso $\mathrm{N}$, mentre la parte superiore, alta $m 1,90$, è stata rinvenuta e movimentata durante gli scavi, poiché durante i crolli antichi era caduta sopra una tavola offertoria (v. fig. 5); in seguito è stata appoggiata di fianco alla parte inferiore in situ (fig. 20). Un altro frammento di $78 \mathrm{~cm}$ è stato recuperato durante la fine degli scavi. La sezione inferiore misura $37 \times 41 \mathrm{~cm}$, la sezione superiore $38 \mathrm{x}$ $43 \mathrm{~cm}$. Rimane visibile da terra solo a NE in quanto il pilastro P6 è inglobato per tre lati in una banchina alta 
$45 \mathrm{~cm}$, tranne il lato verso il corridoio. Presenta varie tipologie di alveolizzazione verticale, larghe e profonde più o meno su tutti i lati. Inoltre sono state rilevate alterazioni cromatiche probabilmente provocate dal fuoco. Sono state documentate tracce di malta originale di allettamento sotto la sezione inferiore del pilastro.

Il P7 è incompleto, è il più piccolo frammento alto 80 $\mathrm{cm}$, inclinato verso N. La sezione misura circa $36 \times 43 / 46$ $\mathrm{cm}$. È inglobato per tre lati in una banchina alta $45 \mathrm{~cm}$, tranne il lato verso il corridoio a SO (v. fig. 8).

Il P8 è incompleto, è alto $\mathrm{m} 1,10$, inclinato verso $\mathrm{N}$ (fig. 21). La sezione misura $38 \times 46 \mathrm{~cm}$. In origine era inglobato per tre lati in una banchina alta $45 \mathrm{~cm}$, tranne il lato verso il corridoio So; attualmente si presenta libero in quanto parte della muratura della panca è andata perduta. Mostra evidenti e considerevoli mancanze di materiale originale, porzioni degli spigoli dei lati S, E, e O. Presenti fenomeni di alveolizzazione.

Il P9, è incompleto, è alto circa $\mathrm{m} 1,30$, inclinato verso $\mathrm{N}$ (v. fig. 21). La sezione misura circa $39 \times 45 \mathrm{~cm}$, inglobato per tre lati in una banchina alta $45 \mathrm{~cm}$, tranne il lato verso il corridoio SO. Presenta piccole mancanze di materiale originale, parte dello spigolo del lato ovest in alto. Presenti fenomeni di alterazione cromatica.

Il P10 è incompleto, alto $\mathrm{m} 1,10$, inclinato verso $\mathrm{N}$ (v. fig. 21). La sezione misura $38,5 \times 43 \mathrm{~cm}$. Inglobato su tutti e quattro i lati in una banchina alta $45 \mathrm{~cm}$ circa.

Il P11 è incompleto, è alto $\mathrm{m} 1,75$, inclinato verso $\mathrm{N}$ (v. fig. 21). La sezione misura $39 \mathrm{x} 45 \mathrm{~cm}$. Inglobato su tutti e quattro i lati in una banchina alta $45 \mathrm{~cm}$.

Il P12 è incompleto, è alto $m$ 2,10, inclinato verso N. La sezione misura circa $38 \times 43 \mathrm{~cm}$. Inglobato su tutti e quattro i lati in una banchina alta $45 \mathrm{~cm}$ (v. fig. 21).

\subsection{Stipiti del portale d'ingresso}

I due stipiti monumentali d'ingresso del tempio erano nel complesso in buono stato di conservazione, considerando che sono ancora in piedi e sopravvissuti al crollo di tutti gli elementi della copertura (v. fig. 9). I due montanti verticali o stipiti sono alti quasi $5 \mathrm{~m}$, larghi $\mathrm{cm} 65 \times 40$.

Il passaggio tra i due stipiti è ampio $85 \mathrm{~cm}$. La lastra superiore della cornice della porta misura $85 \times 120 \mathrm{~cm}$. Il materiale costitutivo si presentava pulverulento in alcune aree, con lievi fenomeni di decoesione. Sono state riscontrate esfoliazioni con distacco, piccole perdite di materiale originale sulla lastra della cornice. Erano presenti lievi fenomeni di alveolizzazione.

\subsection{Tavole offertorie}

Le quattro tavole offertorie della sala ipostila sono scolpite nella pietra calcarea e presentano la stessa qualità e tecnica di lavorazione di quelle presenti nel vicino tempio di Nakrah; hanno simili iscrizioni scolpite al di sotto degli stambecchi che delimitano il lato corto della tavola stessa, verso il corridoio centrale. Le tavole offertorie erano interessate da significativi urti provocati dal crollo degli elementi della copertura (v. figg. 3-5). Per questo, tutti e quattro i manufatti hanno subìto gravi danni strutturali (con due o tre fratture; v. fig. 8), tranne le decorazioni costituite dalle bellissime serie di stambecchi accucciati (figg. 22-25). ${ }^{1}$

Le lastre monolitiche che costituiscono le tavole offertorie sono spesse $26 \mathrm{~cm}$, larghe $60 \mathrm{~cm}$ e lunghe ben $3 \mathrm{~m}$. Esse poggiano su tre grandi blocchi di pietra, alti ciascuno $50 \mathrm{~cm}$, larghi $60 \mathrm{~cm}$ e spessi $20 \mathrm{~cm}$.

La tavola Ta presentava una sola frattura passante, con perdita di materiale originale in prossimità dell'angolo $\mathrm{N}$. Le decorazioni scolpite risultavano ben conservate.

La tavola $\underline{\mathrm{Tb}}$ presentava due complesse fratture passanti verso $\mathrm{S}$ dal lato opposto delle decorazioni, con perdita di materiale originale in prossimità delle fratture. Sulla parte superiore delle teste di stambecchi è stato rilevato un fenomeno di deterioramento avanzato di decoesione e disgregazione.

Sulla tavola Tc erano presenti tre gravi fratture passanti, con perdita di materiale originale in prossimità delle fratture, con piccolissime mancanze nelle teste di stambecchi. La superficie era leggermente pulverulenta.

La tavola $\mathrm{Td}$ presentava due gravi fratture passanti, con perdita di materiale originale in prossimità delle fratture. Erano presenti piccolissime mancanze da urto nelle parti decorate delle teste di stambecchi. La superficie era leggermente pulverulenta.

\section{Interventi di restauro}

\subsection{Pilastri del propileo}

La prima fase logistica di questo piccolo ma importante cantiere di restauro è stata possibile grazie al prezioso supporto di M. Mascellani che ci ha aiutato a reperire nella capitale Șan'ầ) tutti i materiali e le attrezzature necessarie per organizzare il cantiere di restauro a Barāqish. Ricordo che la maggiore difficoltà è stata trovare i ponteggi metallici, costituiti da tubi di ferro e giunti snodabili a vite e dado (del tipo 'Innocenti'), indispensabili per poter intervenire alla correzione

\footnotetext{
1 Per la disposizione delle tavole offertorie $\mathrm{Ta}, \mathrm{Tb}$, Tc e Td nella sala ipostila del tempio v. Agostini, capitolo 3 in questo volume, fig. 3.
} 


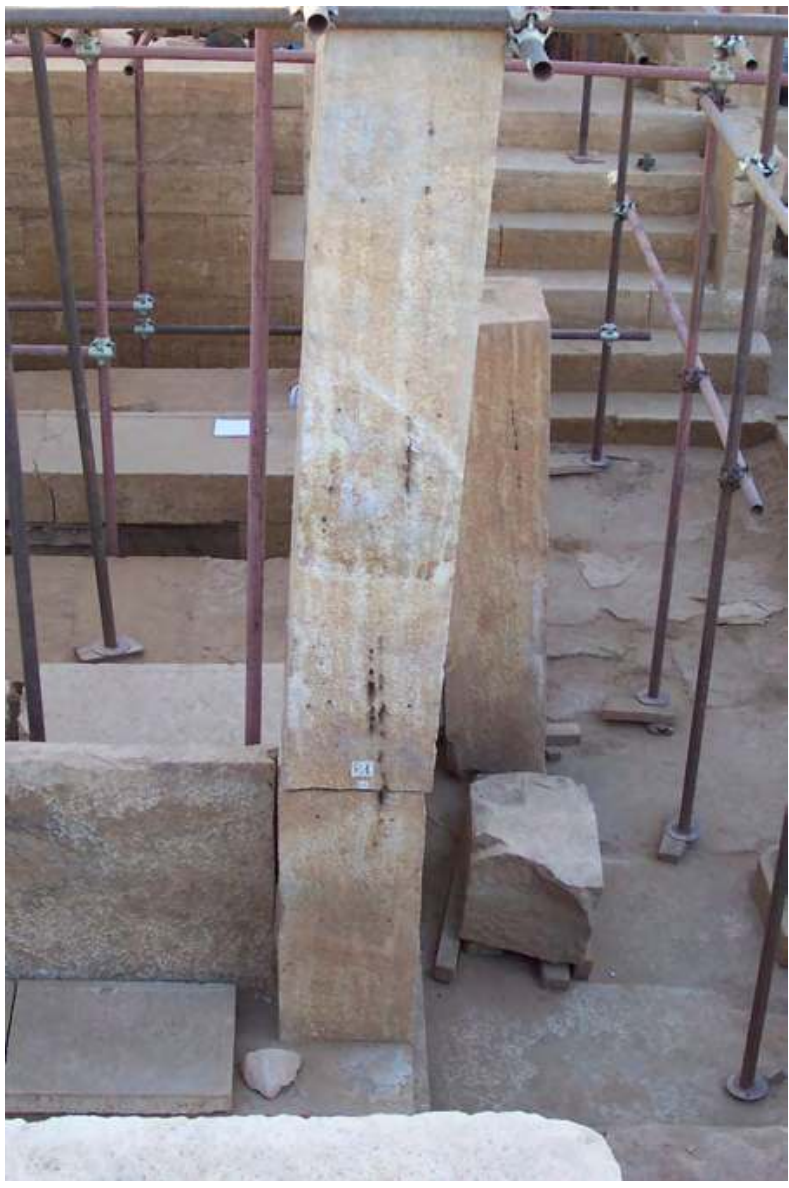

Figure 18. Il pilastro P1, inglobato per tre lati nella banchina, è completo ma spezzato e inclinato verso $\mathrm{N}$.

(S.B. Scigliano 2006 CMAIRY)

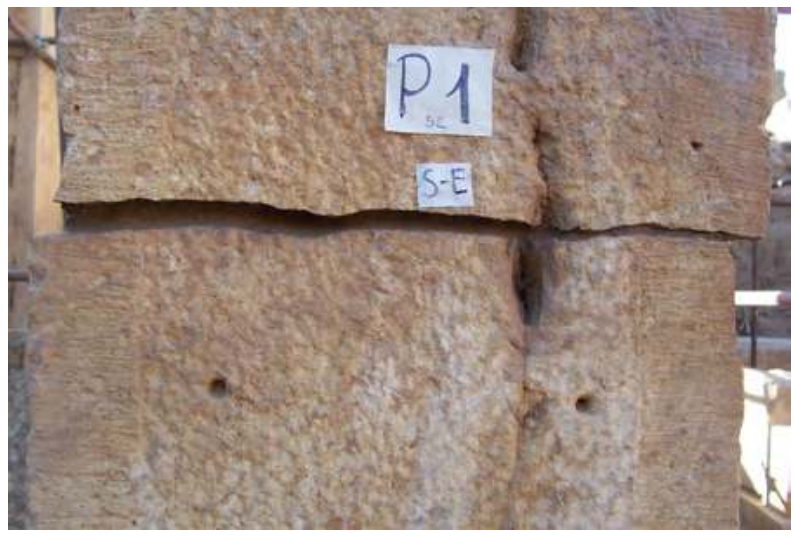

Figure 19. Dettaglio della frattura totale del pilastro P1 con evidente dislocazione di c. $2 \mathrm{~cm}$.

(S.B. Scigliano 2006 CMAIRY)

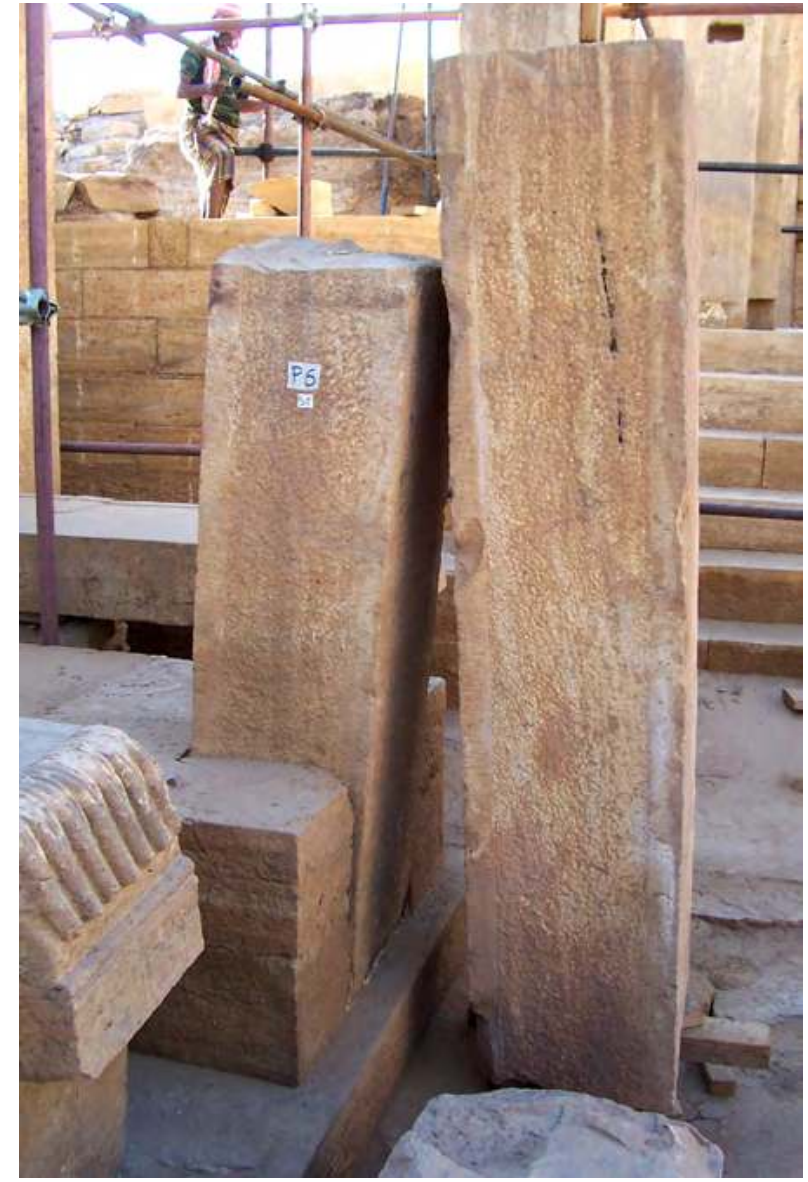

Figure 20. Il pilastro P6, inglobato per tre lati nella banchina, è incompleto e spezzato. La parte inferiore è inclinata verso N; la parte superiore, rinvenuta dislocata, vi è stata appoggiata contro. (S.B. Scigliano 2006 @MAIRY)

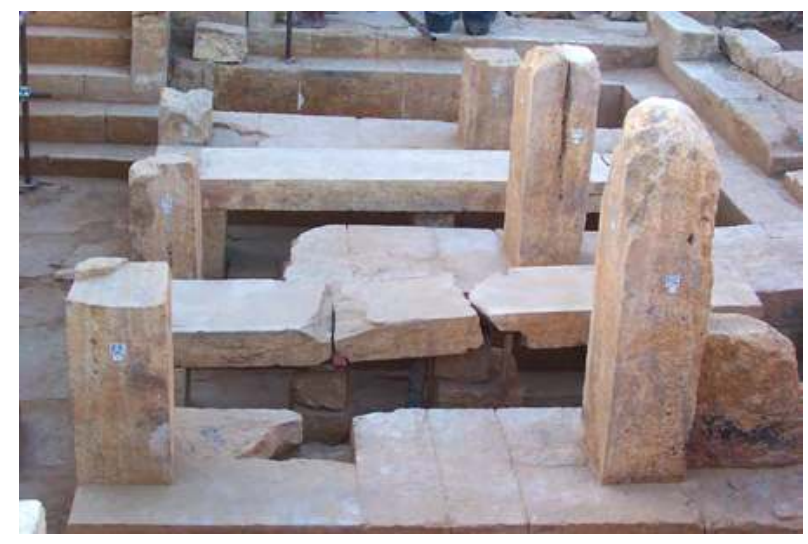

Figure 21. I pilastri orientali della sala ipostila: il P8 si trova sul lato del corridoio tra il P9 (in primo piano) e il P7 (sullo sfondo). (S.B. Scigliano 2006 CMAIRY) 


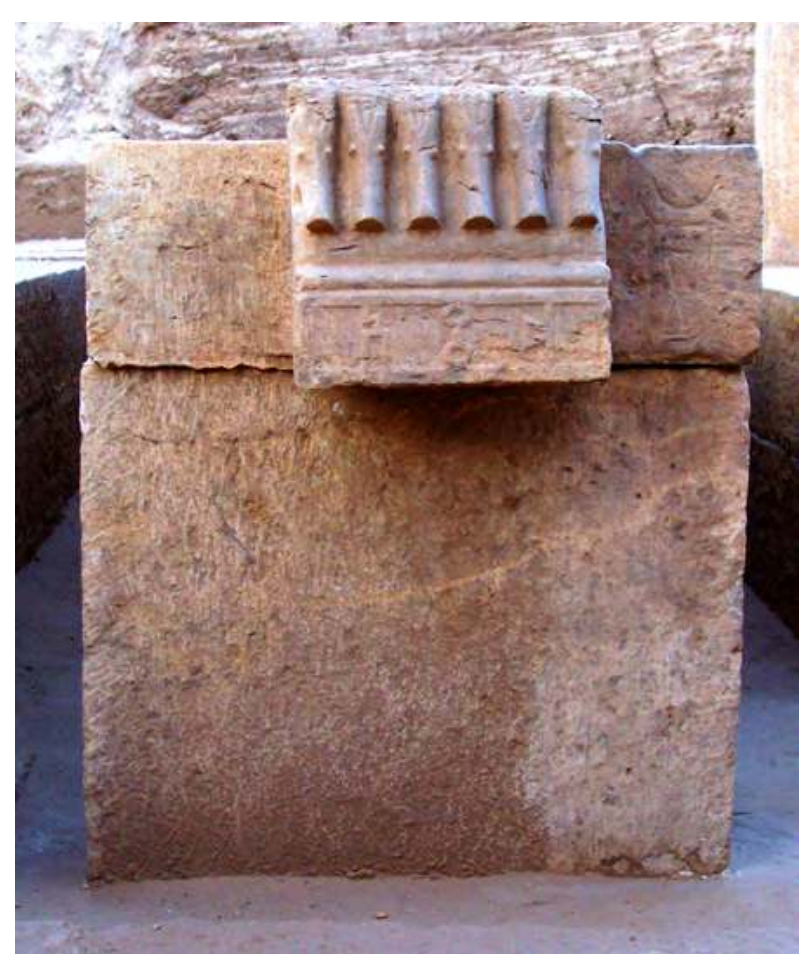

Figure 22. Vista frontale della tavola offertoria Tb situata in L116 della sala ipostila. (S.B. Scigliano 2006 CMAIRY)

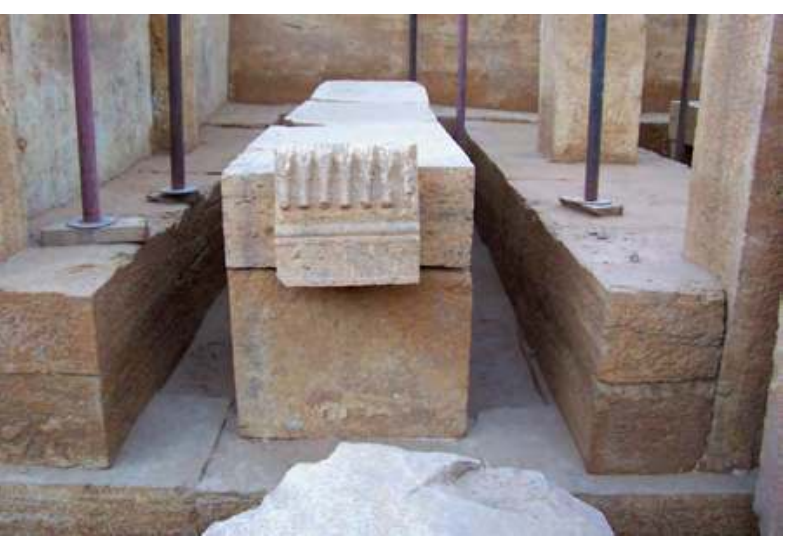

Figure 23. Vista frontale della tavola offertoria Td situata in L114 della sala ipostila. (S.B. Scigliano 2006 CMAIRY)

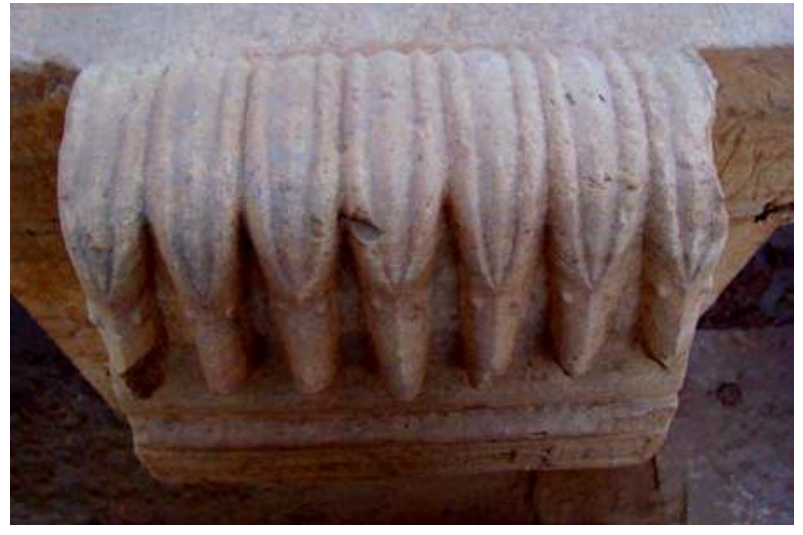

Figure 24. Vista superiore della teoria degli stambecchi accucciati della tavola offertoria Ta situata in L103, dettaglio. (S.B. Scigliano 2006 @MAIRY)

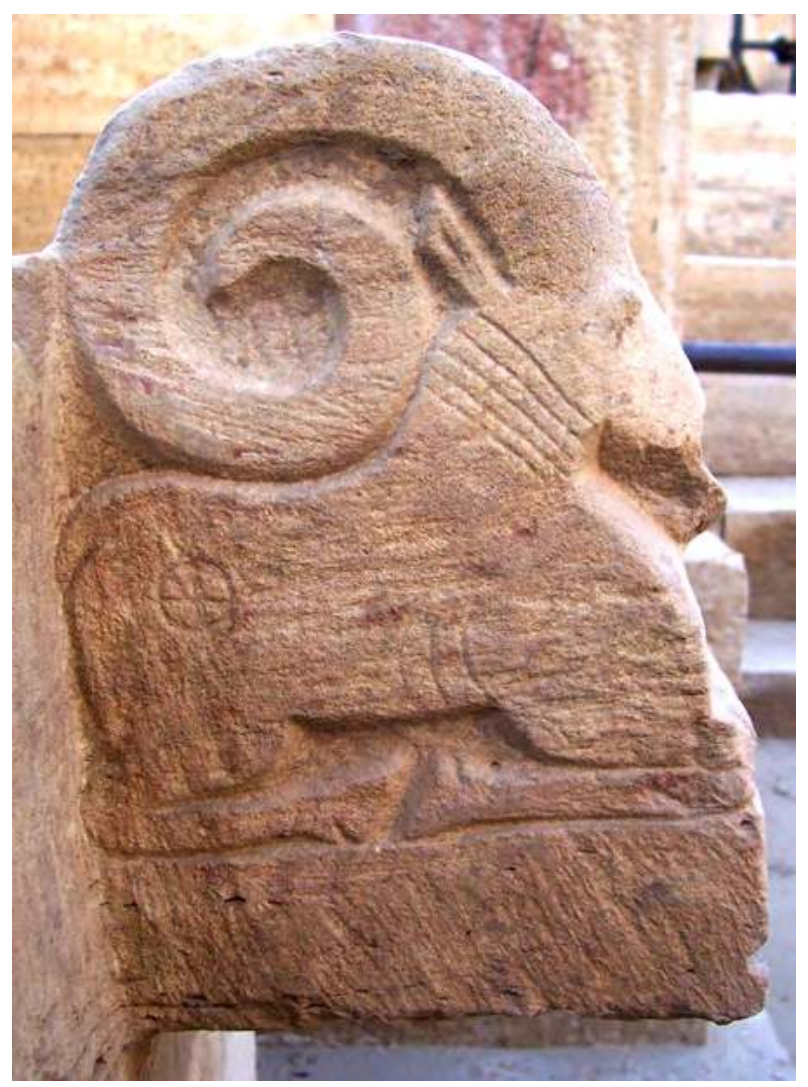

Figure 25. Vista laterale della teoria degli stambecchi accucciati della tavola offertoria Ta situata in L103, dettaglio. (S.B. Scigliano 2006 @MAIRY) 
dell'inclinazione e messa in sicurezza dei pilastri del propileo del tempio.

Per poter risolvere le problematiche di sicurezza di questi pilastri, è stato opportuno realizzare un ponteggio alto $6 \mathrm{~m}$, largo $6 \mathrm{~m}$ e profondo altri $6 \mathrm{~m}$, installato a contrasto con la sezione verticale di terra tra gli intervalli dei pilastri. Abbiamo dovuto installare una struttura di tubi metallici che fosse stabile e adeguata ad ancorare provvisoriamente i 5 pilastri in tutta sicurezza.

La struttura metallica è stata realizzata intorno ai pilastri fino a coprire il portale, ovviamente dall'interno del tempio scavato (fig. 26). Abbiamo posizionato tutti i tubi metallici orizzontali a contrasto con gli spazi di terra intervallati tra i pilastri stessi, predisponendo larghe tavole di legno in prossimità del contatto a pressione, grazie alle basi filettate metalliche poste ai margini del singolo tubo.

Inoltre, il nuovo ponteggio posto all'interno dei pilastri del propileo è stato legato alla precedente struttura di sicurezza presente in prossimità dei pilastri delle navate occidentale della sala ipostila, per aumentare la stabilità di tutti gli elementi verticali.

Il ponteggio metallico predisposto in questa fase aveva due funzioni importanti: la prima, fondamentale, poter attuare la correzione dell'inclinazione scorretta dei singoli pilastri, instabili e privi di equilibrio verticale; la seconda era di preservare i pilastri in sicurezza durante e dopo le movimentazioni, mediante un fissaggio provvisorio alla ampia struttura metallica, prima e dopo le piccole correzioni dell'asse verticale, consentendo agli archeologi di continuare gli scavi e rimuovere gli strati di terra rimasta nell'area antistante il tempio.

Ovviamente non avremmo potuto risolvere il problema definitivamente, in quanto le cause erano altrove, come spiegato nei paragrafi precedenti, cioè dovute alle basi di appoggio dello stilobate che avevano subito un'alterazione del piano orizzontale, con conseguente precarietà riportata nei pilastri. Tutto quello che abbiamo potuto compiere, condizionati o, se vogliamo, facilitati dalla presenza su tre lati dei pilastri di circa quattro metri di terra ancora da rimuovere, è stato di movimentare e raddrizzare quanto più possibile $i$ pilastri nella direzione opposta alla loro inclinazione, cioè da $\mathrm{N} / \mathrm{NE}$ verso $\mathrm{S}$ riportandoli ad un grado di maggiore sicurezza.

Dopo aver predisposto, installato e fissato a contrasto il ponteggio intorno a tutti i pilastri del propileo, sono state completate le verifiche di misurazioni. Nel frattempo, con alcuni archeologi ed alcuni operai, è stata praticata la rimozione di almeno $10 \mathrm{~cm}$ di terra a contatto con due lati di ogni singolo pilastro, il lato
O ed il lato E; mentre il lato SE, ossia il lato interno del tempio era libero. Fare spazio e liberare i due lati $\mathrm{O} e$ E di ciascuno dei cinque pilastri è stata una laboriosa operazione, effettuata con lunghe e sottili sciabole di metallo, con l'intento di creare più spazio di manovra possibile ai lati dei pilastri per le fasi successive di correzione.

Dopo aver liberato quanto più possibile i due lati dei pilastri dalla terra, abbiamo predisposto sul primo pilastro da muovere in direzione $\mathrm{S}$ una specie di antenna sopra la sezione superiore, perfettamente al centro, in modo che durante le fasi di movimento il topografo e l'archeologo, con l'aiuto della Stazione Totale di rilevamento, ci avrebbero seguito e segnalato in diretta su quale sarebbe stata la posizione migliore che avremmo potuto ottenere in fase di spostamento (fig. 27).

Tutte le movimentazioni atte a raddrizzare i pilastri inclinati sono state effettuate con l'ausilio di spesse e larghe cinghie di tela, resistenti fino a 5 tonnellate, con tenditore a cricchetto dentato autobloccante, per tirare e fissare i pilastri al ponteggio dal lato $\mathrm{S}$, mentre dal lato opposto $(\mathrm{N})$ veniva utilizzata una binda idraulica (un martinetto, crick da camion) da 5 tonnellate per spingere il pilastro (fig. 28).

Dopo aver liberato e fatto spazio intorno ai pilastri con la binda posizionata sul lato $\mathrm{N}$, ogni singolo pilastro veniva leggermente spinto verso l'interno del tempio, in modo da far passare intorno al monolite almeno tre o quattro cinghie a cricchetto, posizionando la fibbia del tenditore sul lato E. Le cinghie venivano fatte passare ovviamente anche attraverso la struttura metallica predisposta nella parte superiore ad anello intorno ai pilastri (v. fig. 27). Il ponteggio, quando era sottoposto a trazione dalle cinghie, facendo opposizione contro la sezione della terra tra i pilastri, oltre a resistere senza problemi, facilitava il compito nello spostare i pilastri. La spinta maggiore veniva ad essere effettuata dal martinetto idraulico; nel contempo venivano inseriti cunei di legno nello spazio di terra che si veniva a creare nel lato $\mathrm{N}$, man mano che il singolo pilastro veniva spostato e raddrizzato. Si trattava anche di $10 / 18 \mathrm{~cm}$ di differenza di margine da correggere, con all'interno legni spessi circa 8 x 4 cm e 5 x 5 cm (fig. 29).

Sui lati E dei pilastri e dove è stato possibile, prima di applicare le cinghie a cricchetto, sono stati inseriti travetti di legno da $8 \times 8 \mathrm{~cm}$, sia per proteggere i pilastri dall'azione della fibbia a cricchetto, sia per rinforzo strutturale e di unità nella fase di raddrizzamento.

Il tiraggio del tensore delle cinghie veniva effettuato in maniera graduale, tendendo le quattro cinghie predisposte soprattutto nella parte superiore, a circa 1 $m$ di distanza tra loro. Si effettuavano tanti scatti man 
mano che la binda idraulica da dietro spingeva in avanti (fig. 30). Nel contempo, venivano seguite le istruzioni di verifica effettuate con la Stazione Totale in diretta.

Le spesse cinghie a cricchetto, oltre a consentire di legare i pilastri alla struttura metallica in una posizione ottimale e in sicurezza, avrebbero permesso agli archeologi e agli operai di modificare e migliorare il grado d'inclinazione dei pilastri nel modo più appropriato a scavo completato. Inoltre, si sarebbero potute rimuovere le cinghie inutili e applicare degli 'speroni' con altri tubi metallici per irrobustire il ponteggio in prossimità della scalinata d'ingresso (figg. 31-32).

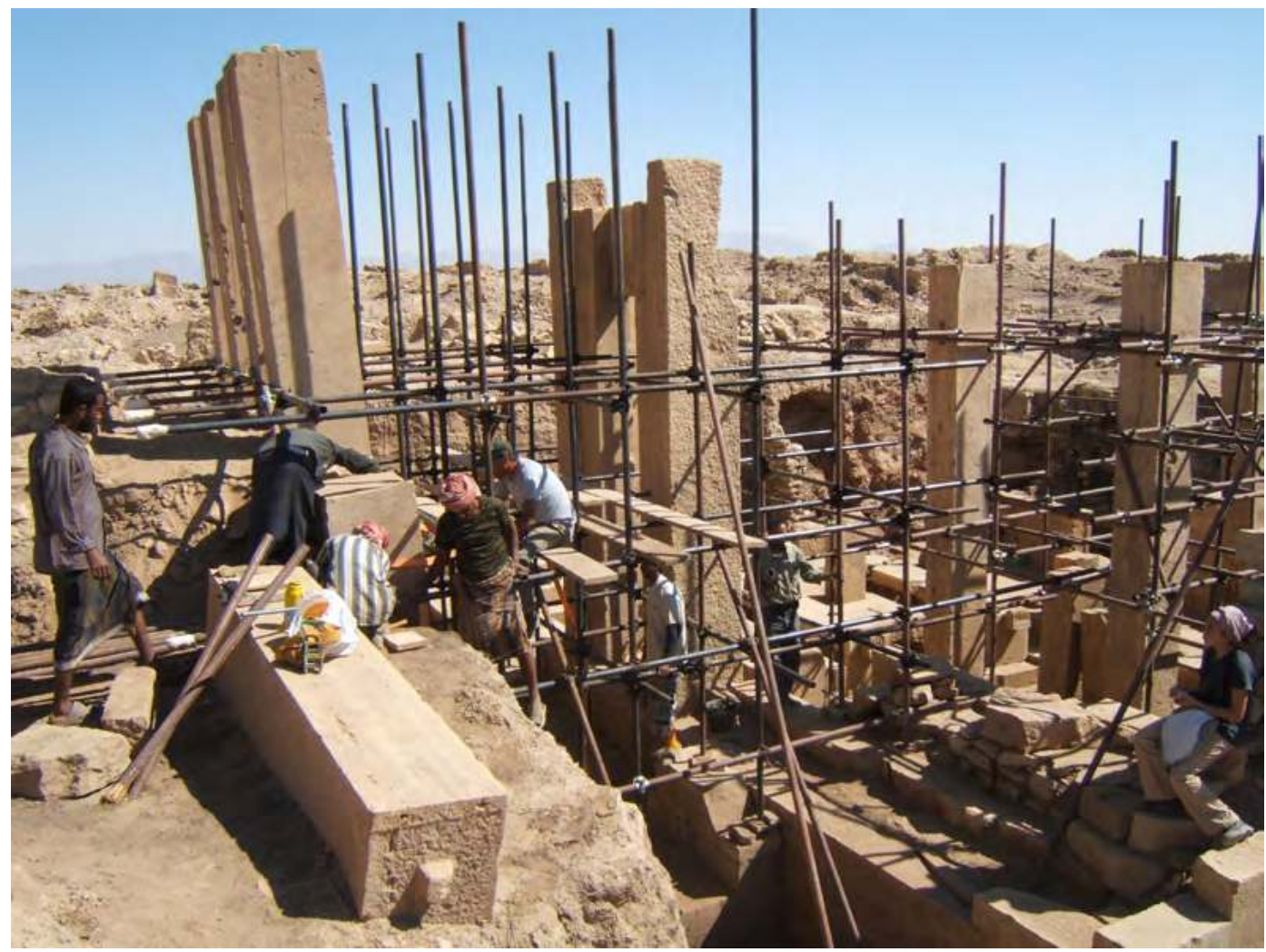

Figure 26. I pilastri del propileo sono legati alla struttura metallica che ingloba sia il portale del tempio sia i pilastri occidentali della sala ipostila. (A. de Maigret 2006 OMAIRY)

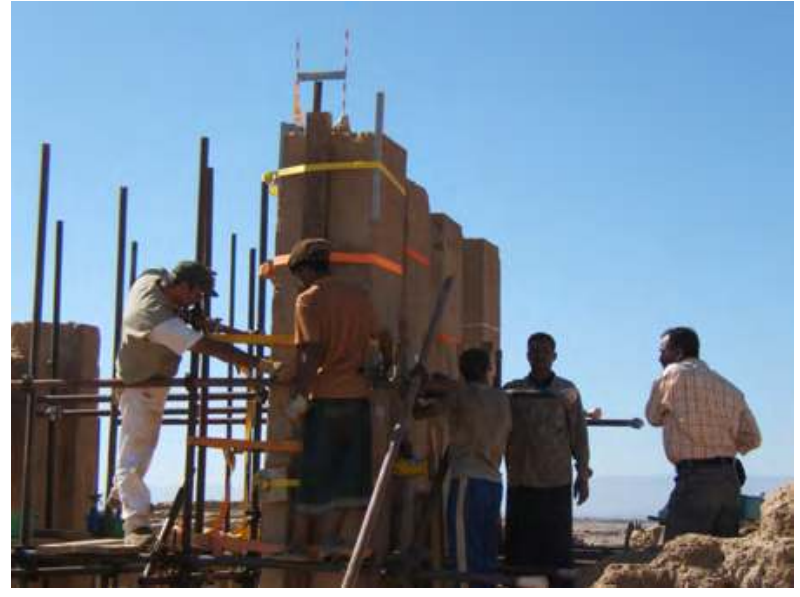

Figure 27. L'antenna posta al di sopra del pilastro viene captata dalla Stazione Totale di rilevamento per segnalare in diretta il posizionamento corretto del pilastro stesso nella fase di movimento. (A. Paladino 2006 CMAIRY)

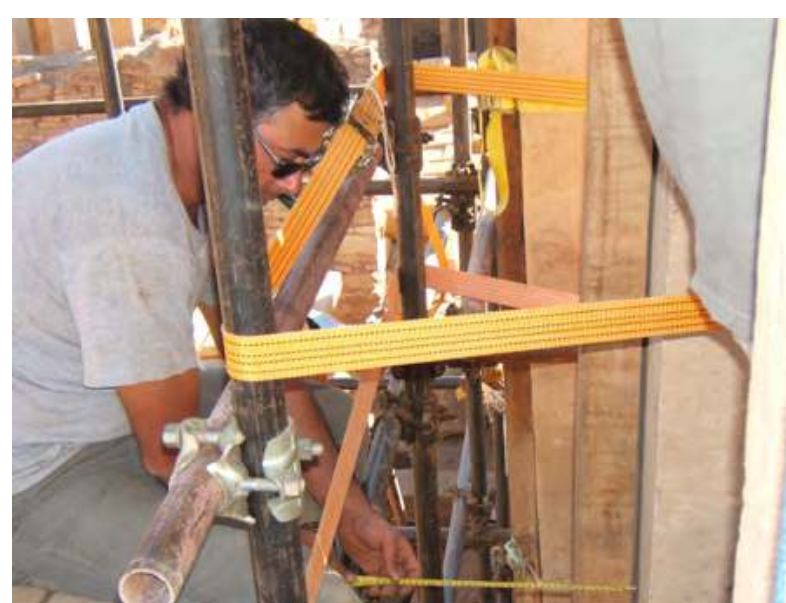

Figure 28. Spesse e larghe cinghie di tela, con tenditore a cricchetto dentato autobloccante, sono utilizzate per tirare e fissare i pilastri del propileo al ponteggio dal lato S. (A. Paladino 2006 CMAIRY) 


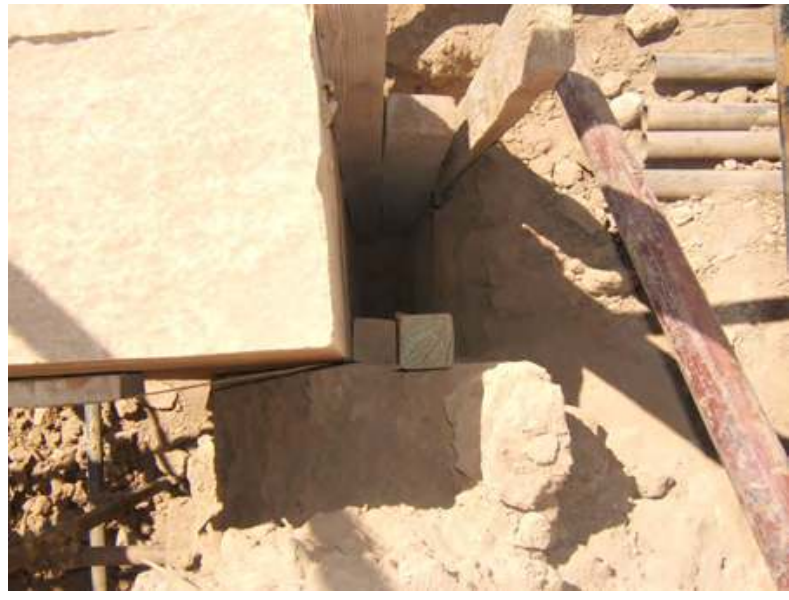

Figure 29. Durante la fase di spostamento per raddrizzare i pilastri del propileo, vengono inseriti cunei di legno nello spazio che si viene a creare nel lato $\mathrm{N}$, tra il pilastro stesso e la sezione di terra. (S.B. Scigliano 2006 CMAIRY)

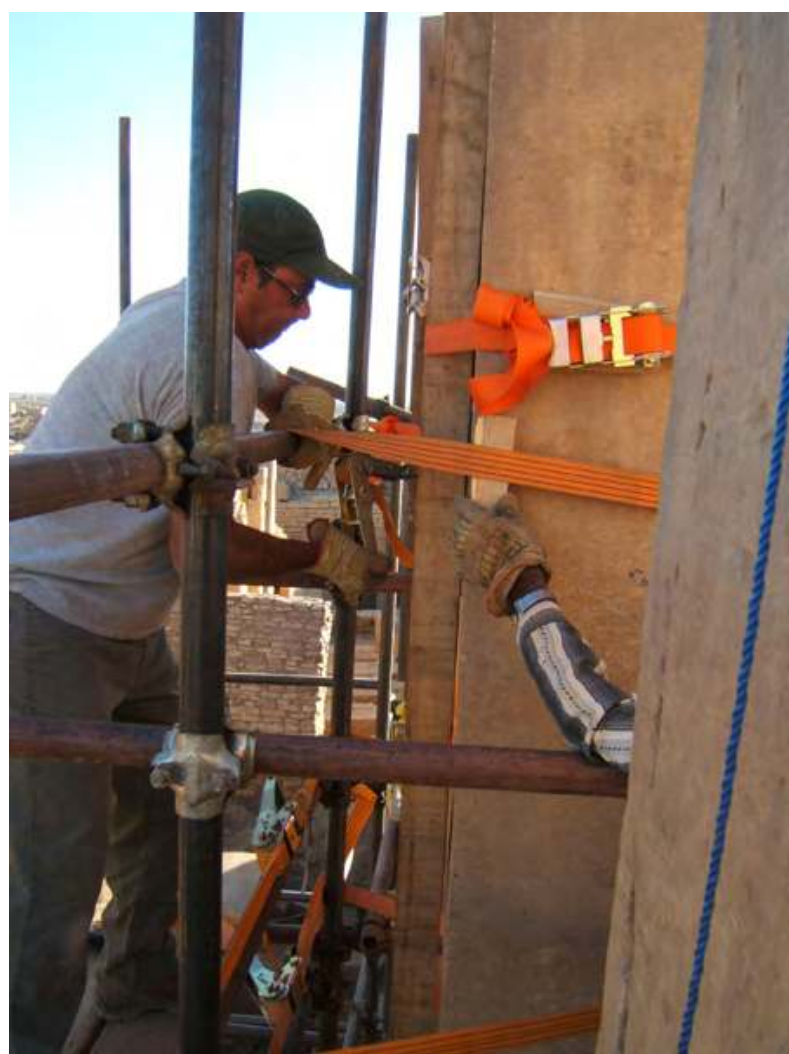

Figure 30. Il restauratore Saverio Scigliano mentre tira manualmente il tensore di una delle cinghie per raddrizzare uno dei pilastri del propileo. (A. Paladino 2006 CMAIRY)

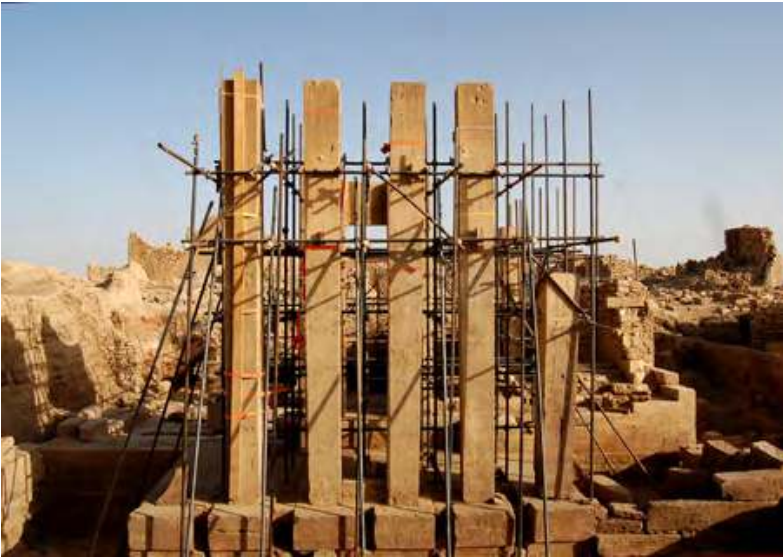

Figure 31. Vista frontale del propileo del tempio di 'Athtar dhu-Qabd: i pilastri sono assicurati all'impalcatura di tubi metallici attraverso spesse cinghie a cricchetto.

(S.B. Scigliano 2006 OMAIRY)

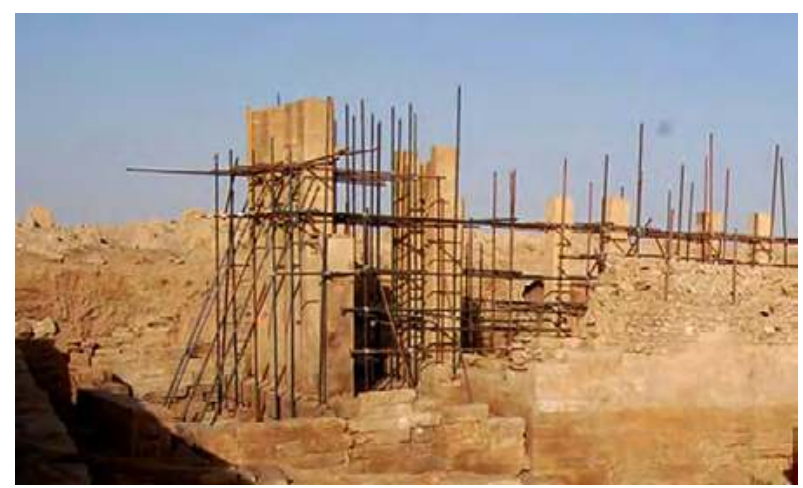

Figure 32. Vista laterale (da NO) del tempio di 'Athtar dhuQabḍ a fine lavori: tutte le strutture sono legate tra loro e assicurate ad una salda impalcatura di tubi metallici.

(S.B. Scigliano 2006 CMAIRY)

\subsection{Stipiti del portale d'ingresso, tavole offertorie e iscrizioni}

Su alcune aree degli stipiti del portale, delle tavole offertorie e delle iscrizioni in pietra si sono resi indispensabili interventi urgenti di carattere conservativo e propedeutico, soprattutto per preservare non solo dalle infiltrazioni corrosive delle annuali piogge, ma anche dall'azione erosiva delle tempeste di vento e sabbia. Infatti, dove sono stati riscontrati fenomeni di esfoliazione della pietra con lievi distacchi e decoesione, sono stati effettuati interventi mirati. Sono state eseguite infiltrazioni per iniezione con resina micro acrilica e malta idraulica fluida Ledan Ta1, in prossimità dei distacchi (figg. 33-34).

In seguito, sono state effettuate stuccature e micro stuccature di sigillatura con malta sottilissima, 


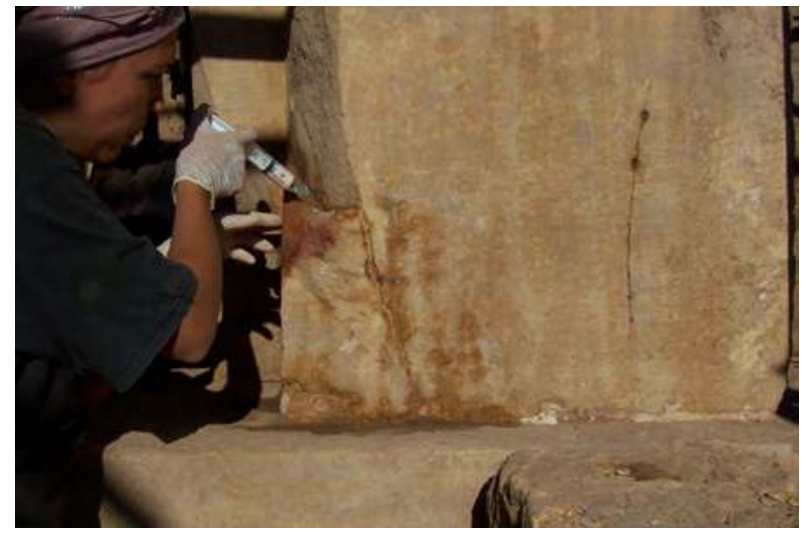

Figure 33. All'interno dei distacchi della pietra la restauratrice Alessandra Paladino inietta resina micro acrilica e malta idraulica fluida per preservare i manufatti da infiltrazioni corrosive. (di S.B. Scigliano 2006 OMAIRY)

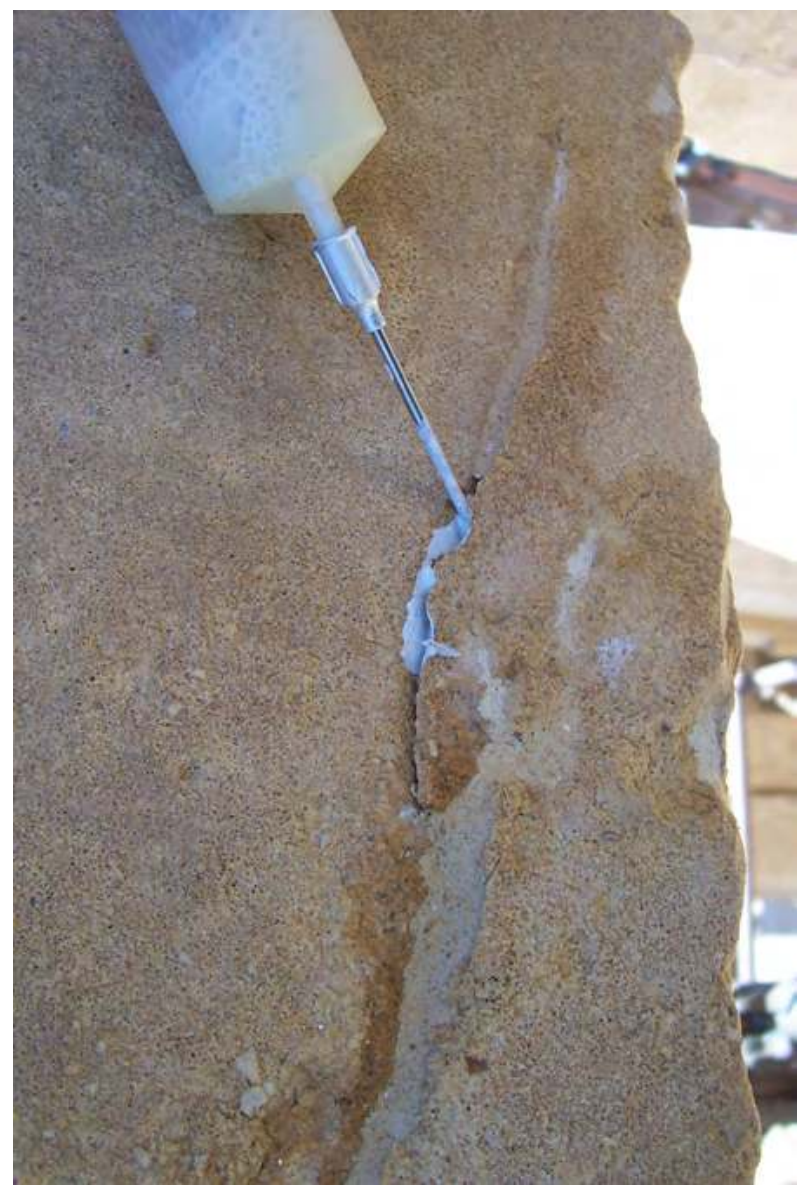

Figure 34. Dettaglio dell'intervento di infiltrazione per iniezione di resina micro acrilica e malta idraulica fluida, per preservare i manufatti da infiltrazioni corrosive dovute ad agenti atmosferici. (S.B. Scigliano 2006 CMAIRY) costituita da polvere di pietra finissima ricavata da frammenti di pietra simile all'originale, reperite nei pressi del sito, tritata e mescolata in un rapporto 1: 3 con Conglomerato C30 e grassello di calce invecchiata (figg. 35-36).

Nelle aree particolarmente decoese, sono stati effettuati interventi di pre-consolidamento coesivo con consolidante a base di silicato di etile (soluzione di silicati organici) Rhodorsil RC 70, della Rhône Poulenc. L'applicazione è stata effettuata per impregnazione (fig. 37), mediante imbibizione a pennello dove abbiamo ritenuto urgente e necessario (figg. 38-39).

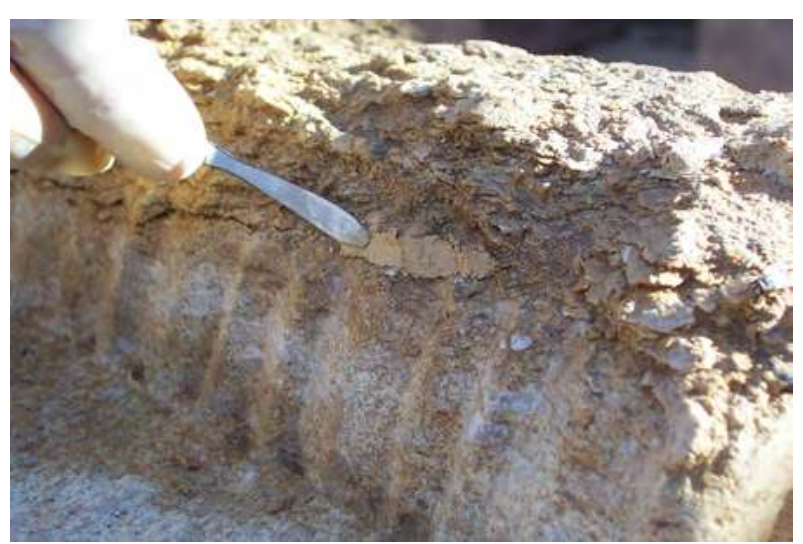

Figure 35. Fase di stuccatura per sigillare le parti esfoliate della pietra, in particolare la parte superiore della teoria di stambecchi della tavola offertoria Tb (in L116). (S.B. Scigliano 2006 CMAIRY)

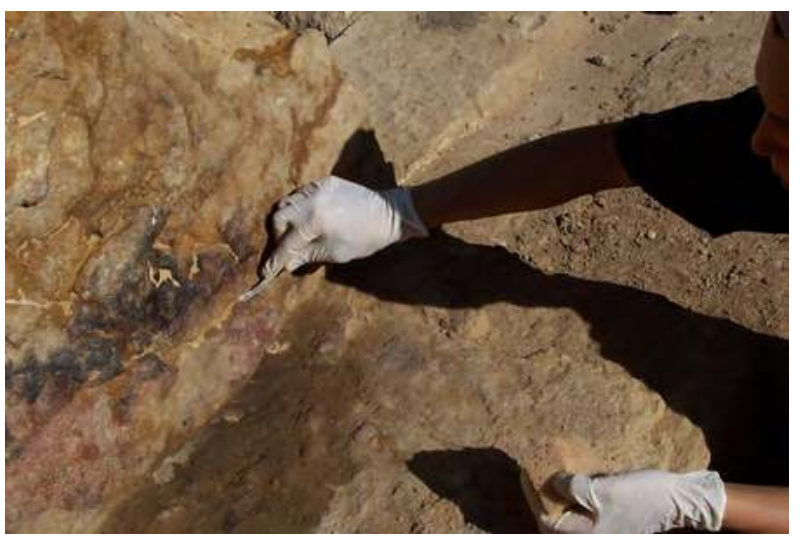

Figure 36. I lievi distacchi della pietra sono stati sigillati con micro stuccature eseguite con malta finissima per proteggere i manufatti da infiltrazioni corrosive dovute ad agenti atmosferici. (S.B. Scigliano 2006 @MAIRY) 


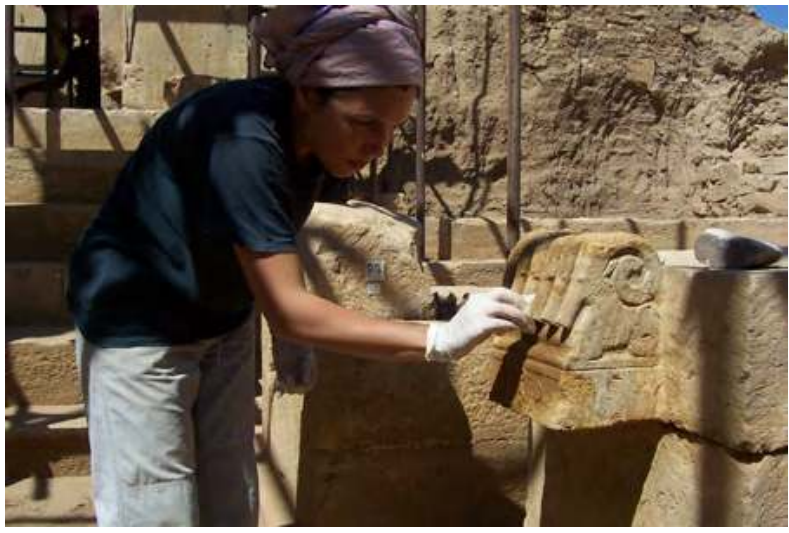

Figure 37. Intervento di pre-consolidamento coesivo con consolidante applicato per impregnazione, in particolare sulla tavola offertoria Tb in L116.

(S.B. Scigliano 2006 @MAIRY)

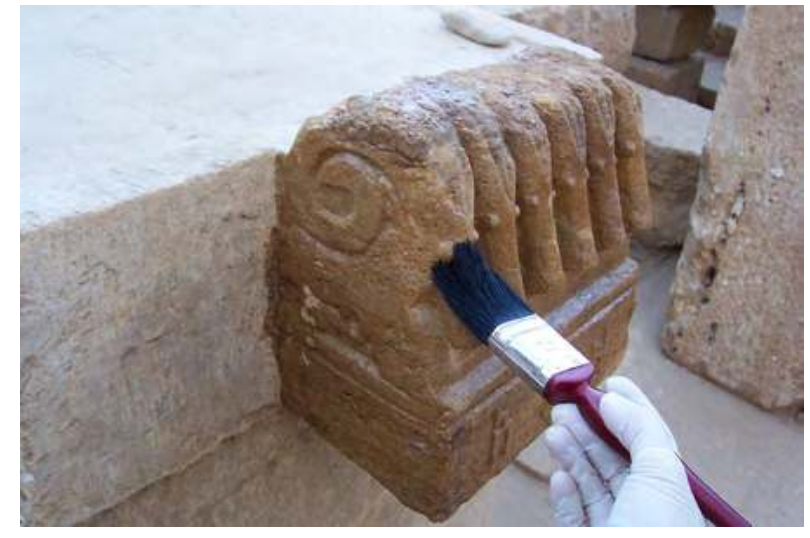

Figure 38. Intervento di pre-consolidamento coesivo con consolidante applicato mediante imbibizione a pennello, in particolare sulla tavola offertoria Tb situata in L116.

(S.B. Scigliano 2006 OMAIRY)

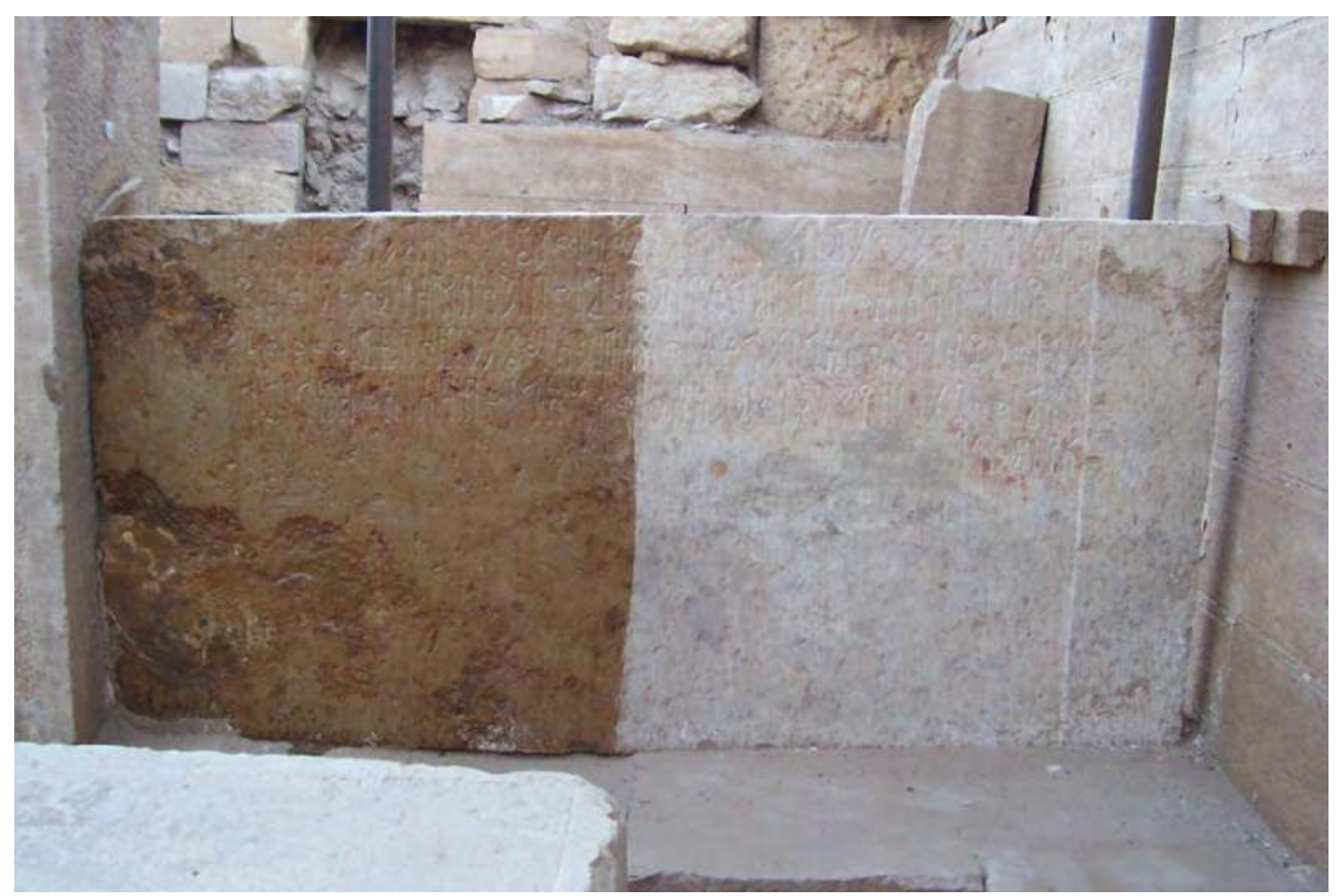

Figure 39. Intervento di pre-consolidamento coesivo con consolidante applicato sul blocco iscritto Y.05.B.B./12 (M121, tra P4 e il muro perimetrale O del tempio). (S.B. Scigliano 2006 OMAIRY) 


\title{
Barāqish/Yathill: Corings and Radiocarbon
}

\section{Chapter 15 \\ Exploratory Coring at Barāqish, 1987 and 1990}

\author{
Francesco G. Fedele
}

\section{Introduction: two coring campaigns at Barāqish}

Having completed a first ground survey of Barāqish in 1986, A. de Maigret began to ponder those aspects of the walled town that had a bearing on excavation, first of all what lay below ground. Although without actual prospects of digging at the site, but in the event of that possibility, he particularly wanted to assess the thickness and composition of the deposits, thereby gaining an insight into their archaeological potential and their possible constraints on excavation. ${ }^{1}$

To that end, in the summer of 1987 de Maigret managed to take to Barāqish a team of geophysicists and drilling specialists from the Lerici Foundation for Archaeological Prospecting, assisted by the Italian archaeological mission's V. Francaviglia. ${ }^{2}$ Basically, this was the same team who had worked the year before at Waraqah, a flat burial site near Damār. ${ }^{3}$ However, at Waraqah only geophysical prospections were eventually performed, while it could be expected that drilling would make a much more substantial contribution at a 'deep' urban site such as Barāqish. For perspective, one should remember that the mid-1980s were a booming period for instrument-assisted archaeological prospection, including archaeological coring. ${ }^{4}$ Italy, with the Lerici

\footnotetext{
1 The same attitude and approach were shared several years later by the German archaeologists preparing to investigate the Sabaean capital, Mārib: 'The survey work included [the] coring of archaeological sediments to obtain previews of occupation deposits and datable samples. [. . .] This work forms the basis for targeted archaeological research, and has already provided important facts about the history of the city without putting spade to ground' (Eichmann and Hitgen 2003, 55).

2 For context and narrative see Antonini and Fedele, Chapter 1, section 3.2 (this volume). Apart from some unavoidable repetitions, the focus in the present chapter will be on technical aspects and results.

3 Cucarzi 1986. See also A. de Maigret, 'Himyarite culture', in de Maigret et al. 1986, 376, 377, fig. 4. At the time de Maigret remarked (p. 377) that the electromagnetic and magnetometric survey was '[a] method used for the first time in the Arabian Peninsula by the "Lerici" technicians': in fact, it probably was a first time for Yemen by any operator.

4 Stein 1986.
}

Foundation established at the Milan Polytechnic during the previous decade, was at the forefront of the process.

This coring operation took place from 26 August to 3 September $1987,{ }^{5}$ and de Maigret was able to visit and examine the works on 31 August. He would subsequently devote a fair amount of time and attention to the findings of this campaign. Apart from the apparent lack of photographs, this operation was fairly well documented. Its observations and results are presented in section 2 .

A second coring operation took place in January 1990 during the first excavation season at Barāqish. This time the operation was closely integrated with the excavations of Temple A, which thanks to the inscriptions was now tentatively identified as the town sanctuary of god Nakrah. This campaign has been described in the opening chapter of this volume with an eye to its historical and organizational contexts. ${ }^{6}$ In 1990 only two drillings were made, directed by $\mathrm{F}$. Brancaleoni with overall geological supervision by $\mathrm{V}$. Francaviglia. ${ }^{7}$ Their results, laboriously gleaned from unaccountably scant documentation, are presented in section 3 .

\footnotetext{
5 The participants were Mauro Cucarzi and Franco Brancaleoni (Lerici Foundation, Milan and Rome) and Vincenzo Francaviglia and Dario Monna ('Istituto per le Tecnologie applicate ai Beni culturali', National Research Council/CNR, Montelibretti, Rome), accompanied by V. Labianca, M. Mascellani, and three inspector-archaeologists from GOAM. Cucarzi, the team leader, was a geophysicist; Brancaleoni was a sediments expert and the chief drilling technician; Francaviglia, a geologist, had been MAIRAY's obsidian-sourcing specialist since 1984. Brancaleoni, Francaviglia and Monna stayed the full period.

6 Chapter 1, section 3.3.

7 Brancaleoni and Francaviglia were aided by a large number of local workers and one or two GOAM's inspector-archaeologists (see for details Chapter 1 , footnote 109). In addition, several members of the Barāqish team helped to label the core samples and record the depth data, including B. Marcolongo (in connection with core D90-1) and S. Antonini and student M. Ricci (core D90-2). The colour slides documenting the operation were taken by A. de Maigret (Sabina Antonini, personal communication, July 2018).
} 
Although overshadowed by the impressive results of monumental archaeology, these corings initially generated great intellectual and emotional impact. As mentioned in Chapter 1, it was decided that the drillings of 1990 should reach as deep as possible below the presumed base levels of Temple A. This was done probing at first outside the back wall of the temple, then alongside its main southwest wall, below the earthen floor of the 'sacristy'. On the very first day of the operation a sensation was caused by finding Sabaean ceramic evidence deep down within buried deposits never sampled before. In 1987 no pottery that could be identified as Sabaean had been retrieved from the cores, in spite of having been seen on the eroded surfaces outside the walled town (see Chapter 2, this volume). A. de Maigret's irrepressible exclamation from his personal diary of 19 January, 'Barāqish is ancient indeed', thus becomes understandable. ${ }^{8}$ Probably such exciting findings continued until the end of both cores, from as far deep as 6-7 $\mathrm{m}$ below the temple, yet without any hint of virgin soil or bedrock at the bottom. ${ }^{9}$

However, the burst of interest soon subsided. Furthermore, whatever the reason, no technical records of the 1990 coring campaign were filed with the MAIRAY/MAIRY archives. The fact is, in two short campaigns the subsurface glimpsing of the town's deposits had been carried out, with sufficient scientific return for the effort: now the future of the investigations at ancient Yathill was entrusted to the spade. Already in 1990, the memory of the first coring campaign had become impressionistic and blurred, ${ }^{10}$ those cores probably looking like relics from an embryonic phase of research: the overarching notion to be retained and retold was that Barāqish had great depth and antiquity. The attribution of the individual drilling campaigns to mistaken field seasons, cursorily made years later, ${ }^{11}$ was a lapse of memory from obsolescence of interest. ${ }^{12}$ Only recently has the significance of the

\footnotetext{
8 'Barāqish è antichissima': see reference in section 3.1, below.

9 In 1987, it must be remembered, the standard idea was that in the southern half of Barāqish the bedrock was rising nearer to the surface (see Chapter 1, section 3.2, footnote 83 and Fig. 18). There is no indication that after the deep drillings of 1990 this idea was put to rest, or even discussed. The question of the geological substratum simply disappeared from discourse, at least until 2006 (cf. Robin and de Maigret 2009, 63; 70, §5). Only Francaviglia later recalled the coring carried out in 1990 - 'down to the level of the surrounding plain' - briefly to argue that Barāqish was a tell (Francaviglia 2002, 119, 121; cf. section 3.2, below). A similar change of impression was echoed in passing by de Maigret (1991a, 15; 1991b, 164). For details and discussion see Fedele, Chapter 26 in Volume 2.

10 de Maigret 1991b, the attribution to ' 1986 ' on p. 164 being contradicted by note 1 on p. 165, where 'an Italian Mission's drillings survey on the site in August 1987' is correctly indicated; and de Maigret 1991a, 15 ('1986'). These texts were from a conference and a paper both given in 1990 .

11 de Maigret 2009a, 315 (Italian edition 1996); 2010a, 68; Robin and de Maigret 2009, 60. The 1990 drilling campaign was attributed to 1992.

12 That de Maigret himself was aware of this is revealed by his
}

cores been resurrected for the purpose of investigating the geometry and evolution of the tell, as reported in Chapter 26 (Volume 2). This is the context in which the Italian mission's pioneering coring programme is reevaluated here.

\section{August-September 1987}

The course of activities was reported by V. Francaviglia as follows: ${ }^{13}$

'The aims of our geoarchaeological survey were the evaluation of the mean thickness of the detrital layer inside the citadel [i.e. Barāqish] and the detection of huge buried monumental structures. With these aims in mind two methods were used: [i] mechanical drilling with continuous coring; [ii] geophysical prospections, both geoelectric and magnetic.

Eight drillings have been performed by using a 10-cm-diameter probe and reaching a depth of 5.40 $\mathrm{m}$ (see the case of drilling No. 5). These drillings allowed us to ascertain the presence of ceramic and limestone structures at the deepest levels together with several fire levels.

The geoelectric survey proved unsuccessful because of the extreme dryness of the surficial layers paving the citadel. The use of sophisticated measuring techniques, such as the use of salt water to wet the electrodes, [proved] worthless, being timeconsuming and leading to scarce improvements. A magnetic profile carried out along the "square" main axis did not detect any buried body with a substantially different magnetic susceptibility.'

Looking forward to a future campaign, Francaviglia concluded his report with two suggestions: that 'the drilling network should be [made] denser'; and that, in order to 'detect buried monumental structures' in 'extra dry soils' such as those of Barāqish, 'a georadar device [was] highly recommended'. ${ }^{14}$ At Barāqish this was not to be. A ground-penetrating radar survey was successfully carried out at Mārib's Mahram Bilqīs in $1999 .{ }^{15}$

Since the geophysical activities were completely unsuccessful, and no information was archived with MAIRAY, only the coring results will be dealt with in these pages. This accords entirely with the publication

uncertainty about the date of the second drilling campaign in his Italian manuscript for 'A Sabaean stratigraphy' (de Maigret 2010a; copy of manuscript in my possession, received on 6 March 2008).

13 Francaviglia 1987, 20. The text was slightly edited for language, and the notes and comments in square brackets are mine.

14 Francaviglia 1987, 20, signed and dated Șan( $\bar{a}) 7$ September 1987. Georadar was the commonly used nickname for the groundpenetrating radar technology.

15 By the American Foundation for the Study of Man: Moorman et al. 2001, 2002. 
plans at the time, as is revealed by a figure intended for a first article about the survey (see source B2 in the next section). The joint paper would have focused on core stratigraphy, charcoal levels, and radiocarbon dating alone.

In 1987 nine drillings were made (D1-D9), but one had aborted (D4), and this unusable core was excluded from further consideration. The failure was apparently due to the dryness and hardness of the surface deposits, perhaps to be expected at the peak of summer in the Jawf lowlands. "Cucarzi tells me of severe technical problems due to the extreme dryness of the terrain', noted de Maigret, ${ }^{16}$ who also has a few words about it in his descriptive pages in Corings, 2-4, translated below; and as we have seen, the problem was twice mentioned by Francaviglia in his report. (For 'Corings' and similar references see list at the end of chapter, 'Archival and personal documents'.)

Rather surprisingly, no coring was attempted within the so-called 'square', the broad, flat depression in the middle of the town. Here again, a presence of hardened, dry mud in the immediate subsurface might have been the reason. Five of the corings were made on the periphery of this central depression (D2D6), two of them in proximity of the Islamic sacred precinct comprising a mosque and a tower (D2 and D3). Two more drillings were made in the space between Temples B and C (D8 and D9), and one, eccentrically, on the southwestern 'rim' of the settlement, about $20 \mathrm{~m}$ from bastion T51 (drilling D7).

It is important to note that one of the drillings (D1) was not made within the town, but outside the curtain wall, close to the Italian party's camp to the south of the mound. The precise location presumably was at the edge of the plain or at the contact with the talus footslope. Being associated with the first drilling, this location was probably chosen for testing the equipment and organizing the required procedures. Whether comparative purposes were also intended is unknown, as the sources are silent.

\subsection{Sources}

The available information on the 1987 coring campaign includes three kinds of sources:

(A) the location of the drillings (Fig. 1);

(B) sedimentary profiles for eight cores, ${ }^{17}$ comprising

\footnotetext{
16 de Maigret, personal diary, 29 August 1987.

17 Sedimentary profiles, or columns, not sedimentary logs in the technical sense; the available information is insufficient to draw proper sedimentary logs.
}

B1. a pencilled, painstakingly coloured original on graph paper at the scale of 1:20, attached as a folding sheet to page 13 of Corings;

B2. a redrawn, synoptic version of B1 intended for publication, here reproduced as Fig. 2;

B3. a coloured version of B2, with the colours closely imitating those of B1, which survives as a slide; and (C) selective descriptions of the cores and their archaeological contents (see next section).

The primary source for the location of the drillings (source A) is a ballpoint-pen drawing by de Maigret on page 4 of Corings, here reproduced in Fig. 1a. The nine points were marked in red onto a photocopy of a simplified plan of Barāqish. Since this plan was not derived from the Italian general plan made in 1986 but, surprisingly, from a pre-existing aerial photograph found in a German or French publication, ${ }^{18}$ in Fig. 1b de Maigret's plot has been empirically best-fitted to the 1986 town plan..$^{19}$ In order to locate each drilling point more precisely I have taken into account its elevation (sources B and C). Lacking detailed topographic records as well as photographs, ${ }^{20}$ at the moment Fig. $1 \mathrm{~b}$ provides the best approximation we can get to the location of the corings. ${ }^{21}$

Concerning source $\mathrm{B}$, all these variants of a single original drawing ${ }^{22}$ contain the radiocarbon dates and show as their heading the same title and authorship: 'Exploration drillings at Barāqish (Y.A.R., 1987): stratigraphy \& ${ }^{14} \mathrm{C}$ dating of fire levels', by C. Azzi, F. Brancaleoni, A. de Maigret, and V. Francaviglia. ${ }^{23}$ The corresponding manuscript, of which this figure would ostensibly have been the centrepiece, was probably never written. Drawing B1 was probably made during the drilling campaign or immediately afterwards. The vertical strips of graph paper representing each

\footnotetext{
18 On this aerial photograph see Chapter 1 , footnotes 54 and 79.

19 Chapter 1, Fig. 3.

20 In spite of repeated searches, photographs from the 1987 operation have not been found in the archives of the Italian Archaeological Mission (Sabina Antonini, personal communication, July 2018). This absence is presently inexplicable, considered that MAIRAY staff photographer A. Solazzi accompanied de Maigret to Barāqish on 31 August (see Chapter 1, footnote 93).

21 Confirmation of the numbering and location of the drillings can be found in de Maigret's axonometric reconstruction of Barāqish, reproduced as Fig. 18 in Chapter 1.

22 The author of this drawing is unrecorded. On the basis of B1, both the language and style of drawing (for instance, the use of a vertical bar to the right of each core profile to indicate the presence of pottery sherds) strongly suggest that the author is Brancaleoni (cf. his diagrams in Linington 1987, together with Linington's remark on p. 293).

23 Carlo M. Azzi was a radiocarbon specialist, formerly in Florence and from about 1988 with the CNR at Montelibretti, Rome; in this latter position he was a colleague of several MAIRAY members (V. Francaviglia, M. Mascellani, A.M. Palmieri). He held a joint affiliation with the radiocarbon-dating team at the Department of Physics of University of Rome 'La Sapienza' (G. Calderoni et al., letter dated 27 January 1989 in the MAIRY 'C14' archive, cf. Chapter 16, this volume).
} 


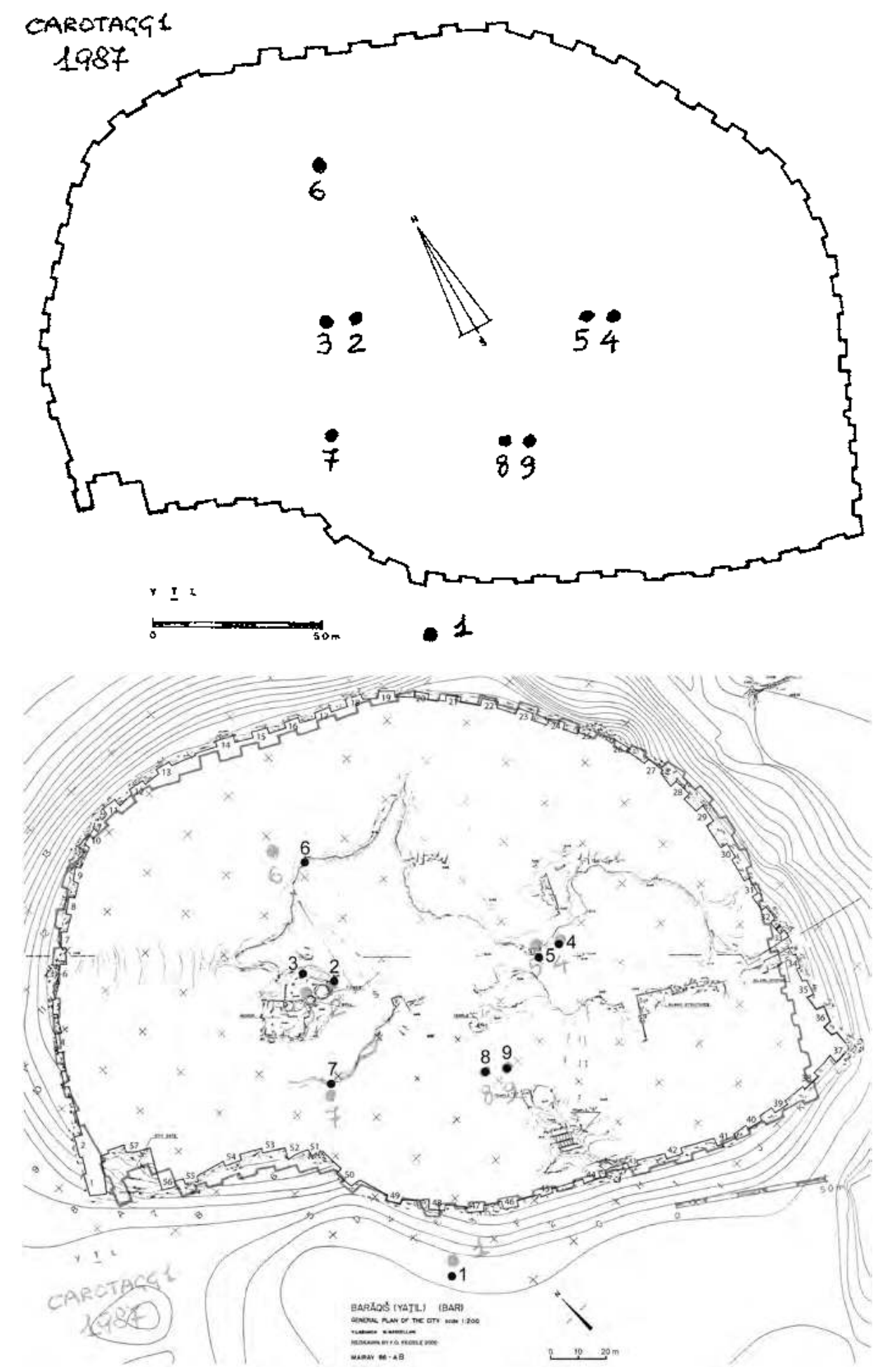

Figure 1. Barāqish, 1987 coring campaign: (a) location of the nine drillings according to A. de Maigret's notebook, Yemen 1987 - Barāqish corings; and (b) plotted onto the 1986 general plan of the town. (F.G. Fedele, based on mission's documents (c) MAIRY) 
core were cut out, then rejoined according to the elevation of the top of core (see section 2.2 below). The radiometric dates must have been added when the University of Rome radiocarbon laboratory announced the determinations, sometime in 1988 (see footnote 33 below; and Chapter 16, this volume). Several pencilled notes indicate that B1 served as a draft for the formal drawing, B2, made after the radiocarbon report. A stratigraphic correlation of the cores is not attempted here because it would be too speculative to be of any interest.

From the bilingual (Italian and English) version of the legend on drawing B1 the following clarifications can be pointed out:

- 'mud' is clayey silt (Italian limo argilloso);

- 'sand with charcoal' is sand with charcoal traces or flecks;

- 'yellow limestone' refers to a compact variety of limestone;

- 'reddish soil' means reddened sediments (Italian terreno arrossato);

- 'intense fire' refers to a charcoal concentration from heavy burning or conflagration (Italian incendio; see comments at the end of section 2.2, below);

- 'fire' means 'the same as above, but less pronounced'.

\subsection{The cores}

In the case of Barāqish, all the cores were sediment cores. Such a core is the hard or solid central part of a sedimentary accumulation retained within the drill bit and/or barrel of a core drill (a hollow steel tube). The coring procedure employed in 1987 was described by Francaviglia (above) as 'continuous coring'. However, due to the dry, unconsolidated nature of the sediments and the presence of cultural and non-cultural rock bodies, it is unlikely that a continuous core in the strict sense of the term could be obtained. Like in 1990 , each core was probably extracted in segments or 'increments', i.e., as cuttings progressively obtained from the bottom of the borehole. ${ }^{24}$

In 1990, as the photographs show, the corer contents obtained by Brancaleoni were extruded onto segments of large-diameter plastic tubes longitudinally sawn in half (see section 3 below), and the same procedure might have been used in 1987. Clearly, a fundamental problem encountered at Barāqish in both campaigns was the difficulty of extruding the sediment from inside the coring tube. Extracting a continuous core of more

\footnotetext{
24 Stein 1986,505
}

than half a metre in length would have been virtually impossible. ${ }^{25}$

The following descriptions of the nine cores were assembled from Corings (source C, above). The 'descriptive field notes' for each core were taken from the first three text pages of Corings (p. 2-4), where they were cursorily written with a red ballpoint pen in table format, a column of the table corresponding to each core. ${ }^{26}$ The descriptions of 'samples' - the word 'sample' refers to contents of archaeological interest were taken from the eight following pages of the same notebook (p. 5-12), which were evidently written at a later time in Șan $(\bar{a}){ }^{27}$

All these hand-written texts are here translated and adapted from the Italian. The pottery entries, written in de Maigret's stenography for ceramic description, were decoded and edited. The following abbreviations will be used: fr, frs = fragment, fragments; $\varnothing=$ diameter. Editorial integrations or corrections are given in square brackets. The elevation of the opening of the drill hole ${ }^{28}$ will be called the 'top' of the core. All top-ofcore elevations are above datum (i.e., the 1986 datum employed for the Italian town plan of Barāqish ${ }^{29}$ ), except for drilling D1, started at $5.09 \mathrm{~m}$ below datum.

\section{Core D1 | 29 August 1987}

Top at $509 \mathrm{~cm}$ below datum.

Descriptive field notes $\mid 0$ to $-250 \mathrm{~cm}$ : sandy sediments.

- $-250 \mathrm{~cm}$. Sample 1: body sherd of chaff-tempered, medium fired, reddish clay, with red slip on the inside, Minaean.

\section{Core D2 | 29 August 1987}

Top at $287 \mathrm{~cm}$.

Descriptive field notes | 0 to $-140 \mathrm{~cm}$, melted mudbrick (?); -140 to $-170 \mathrm{~cm}$, gravelly sand; -170 to $-200 \mathrm{~cm}$, stones and pottery; -200 to $-240 \mathrm{~cm}$, dark earth; -240 to $-280 \mathrm{~cm}$, limestone and 'building' debris; -280 to -310 $\mathrm{cm}$, stone block.

- $200 \mathrm{~cm}$. Sample 1: two body sherds, one similar to Core D1, sample 1 (apparently Minaean), and the other one apparently Islamic.

\footnotetext{
25 Stein 1986, 516-517.

26 Although minuscule, they are recognizably in de Maigret's hand. 'Descriptive field notes' is my designation.

27 Again in de Maigret's hand. A shelved box labelled '1987 - CORINGS' SAMPLES' can be seen in a photograph on page 34 of YICAR Papers 2 (de Maigret 2005a).

28 Stein 1986.

29 The datum line is marked in Figs 4-5, Chapter 1. Cf. footnote 54, below.
} 


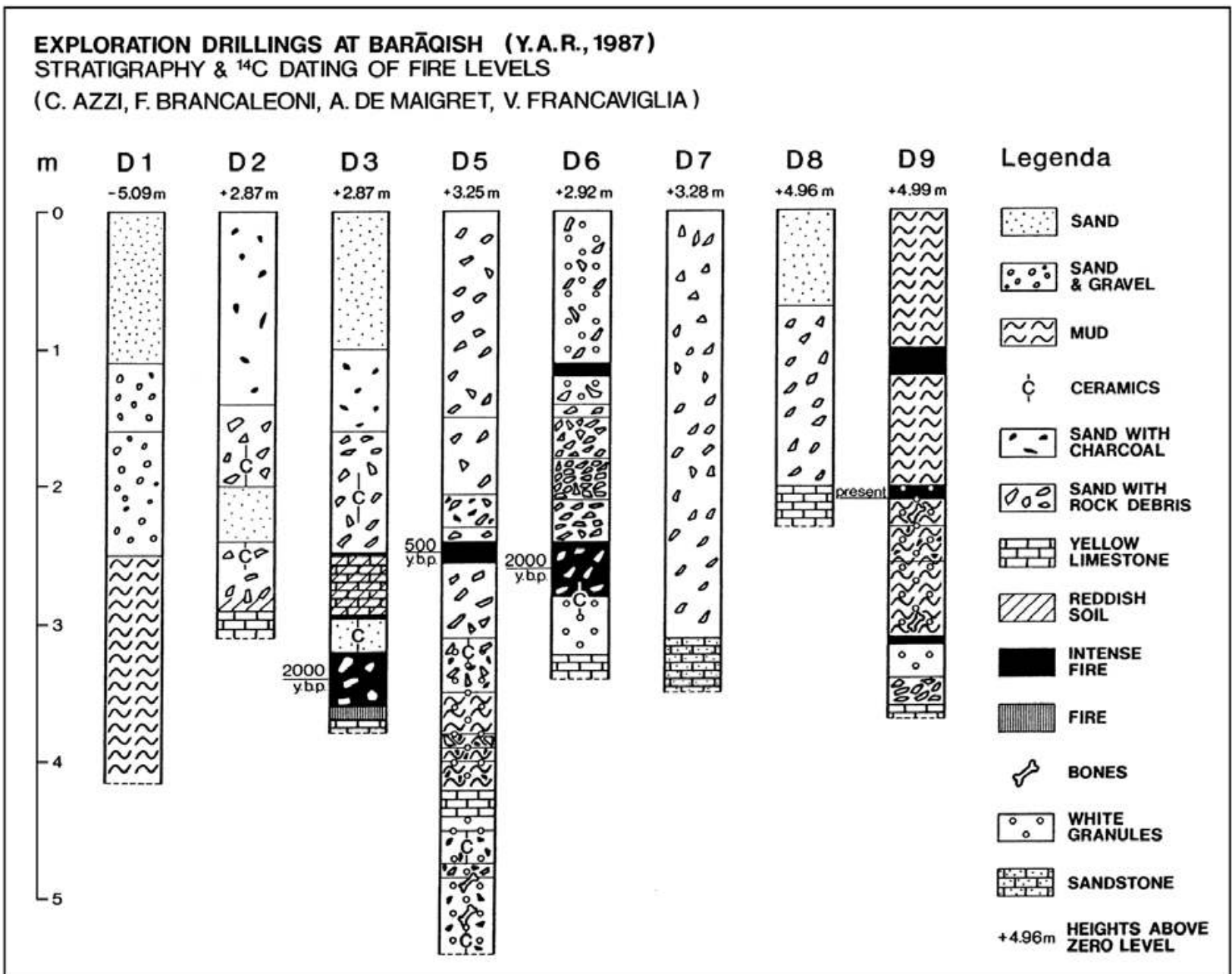

Figure 2. Barāqish 1987: sedimentary profiles of the eight usable cores (D1-D3 and D5-D9). A contemporary drawing intended for publication. (Optimized and partially redrawn by F.G. Fedele @ MAIRY)

- 240/-260 cm. Sample 2: whitish calcarenite stones, $\varnothing 2-3 \mathrm{~cm}$; one reddish porous stone, $\varnothing 3$ $\mathrm{cm}$.

- 290/-310 cm. Sample 3: fr of fire-reddened sandstone block.

Core D3 | 30 August 1987

Top at $287 \mathrm{~cm}$.

Descriptive field notes | -225 to $-250 \mathrm{~cm}$, charcoal traces; -250 to $-295 \mathrm{~cm}$, 'red limestone'; -295 to $-320 \mathrm{~cm}$, charcoal and pottery; -340 to $-360 \mathrm{~cm}$, charcoal layer; -370 to $-377 \mathrm{~cm}$, block of yellow limestone/sandstone.

- 190/-225 cm. Sample 1: four small pottery sherds, Islamic.

- 270/-275 cm. Sample 2: 8-cm-long core (broken in two parts) from a possible stone object made of lumachelle limestone, its flat base perhaps artificially smoothed; completely fire-reddened.

- $310 \mathrm{~cm}$. Sample 3: body sherd of plain, soft, chaff-tempered, pale yellow to pale green ware, Minaean.
- 320/-340 cm. Sample 4: (a) fr of a cuboid incense burner in fire-reddened sandstone; two faces show 'nail' decoration and vertical fluting, respectively; (b) ashy, silty earth.

- 340/-360 cm. Sample 5: ashy, blackish earth.

- 372/-377 cm. Sample 6: 10-cm-long core of yellowish sandstone (broken in two parts), cf. alBayḍāa masonry; no evidence of reddening from fire.

Core D4 | no date: 30 or 31 August 1987

Top at $325 \mathrm{~cm}$.

Descriptive field notes | 0 to $-50 \mathrm{~cm}$ : dry, hard sand and silt.

The drilling was arrested at $-50 \mathrm{~cm}$; no samples.

\section{Core D5 | 31 August 1987}

Top at $325 \mathrm{~cm}$.

Descriptive field notes | -205 to $-230 \mathrm{~cm}$, charcoal traces; -240 to $-255 \mathrm{~cm}$, black layer (destruction); -255 to $-280 \mathrm{~cm}$, some pottery frs; -310 to $-325 \mathrm{~cm}$, pottery; 
-325 to $-350 \mathrm{~cm}$, charcoal and pottery; -380 to $-390 \mathrm{~cm}$, charcoal; -400 to $-420 \mathrm{~cm}$, charcoal and pottery; -420 to $-450 \mathrm{~cm}$, silty loam with [white] granules; -450 to $-475 \mathrm{~cm}$, pottery; -475 to $-485 \mathrm{~cm}$, charcoal, bone; -505 to $-520 \mathrm{~cm}$, bone, charcoal; -520 to $-540 \mathrm{~cm}$, pottery. Arrested at $-550 \mathrm{~cm}$.

- 240/-255 cm. Sample 1: fine, dark brown earth, some charcoal.

- $315 \mathrm{~cm}$. Sample 2: vessel rim sherd of chafftempered, medium fired, reddish-clay ware, with red slip on both the outside and inside, and the inside polished (Fig. 3a).

- $330 \mathrm{~cm}$. Sample 3: (a) body sherd from a large vessel of plain, chaff-tempered, medium fired, hazel-reddish ware; (b) three frs of a soft, porous stone, beige-purple in colour; (c) two frs of firereddened oolithic sandstonesic [limestone].

- $370 \mathrm{~cm}$. Sample 4: small pebbles of plaster-like material; a fr of unfired clay.

- $410 \mathrm{~cm}$. Sample 5: body sherd from a large vessel of plain, medium-fired, beige-greenish ware, showing an incised South Arabian letter (lāmed?) (Fig. 3b).

- $430 \mathrm{~cm}$. Sample 6: 9-cm-long core of whitish sandstone (broken in two parts), from a natural stone of the same thickness.

- 450/-475 cm. Sample 7: base sherd from a large vessel of poorly fired, beige-greyish, chafftempered, red-slipped ware.

- 475/-485 cm. Sample 8: an 'ochre'-stained bone; two limestone frs.

- 505/-520 cm. Sample 9: dark-coloured (burnt?) bone fr.

\section{Core D6 | 31 August-1 September 1987}

Top at $292 \mathrm{~cm}$.

Descriptive field notes $\mid-110$ to $-120 \mathrm{~cm}$, 'burnt' level; -180 to $-210 \mathrm{~cm}$, dense rock frs; -225 to $-255 \mathrm{~cm}$, black layer (destruction); -255 to $-275 \mathrm{~cm}$, heavy fire, pottery; $-280 \mathrm{~cm}$, pottery; -325 to $-340 \mathrm{~cm}$, [limestone] block.

- $240 \mathrm{~cm}$. Sample 1: fine, dark brown earth (burnt wood?).

- $275 \mathrm{~cm}$. Sample 2: (a) two sherds of plain, poorly fired, beige-reddish, chaff-tempered ware, Minaean; (b) burnt, thick bone fr (animal).

- $280 \mathrm{~cm}$. Sample 3: (a) black, charcoal-rich earth; (b) two sherds, one dark red, the other one beige-yellowish and better fired.

- $290 \mathrm{~cm}$. Sample 4: three frs (same vessel) of well fired, chaff-tempered, beige-grey ware, Minaean.

Core D7 | no date: 1 or 2 September 1987

Top at $328 \mathrm{~cm}$.

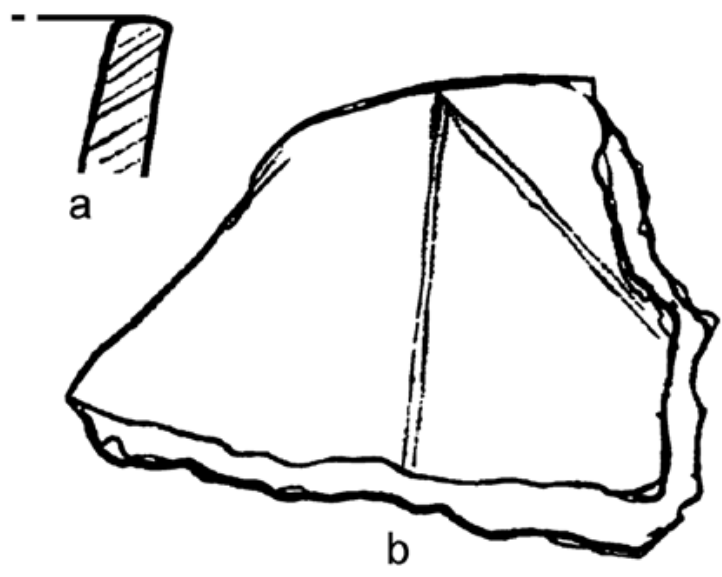

Figure 3. Sketch of two pottery finds from core D5, 1987 (A. de Maigret, Yemen 1987- Barāqish corings notebook, page 9 (C) MAIRY).

Descriptive field notes | -315 to $-350 \mathrm{~cm}$, block of yellow/white sandstone.

- $350 \mathrm{~cm}$. Sample 1: 6-cm-long core of white coarse sandstone; drilling interrupted before boring the stone.

Core D8 | no date: 1 or 2 (3?) September 1987

Top at $496 \mathrm{~cm}$.

Descriptive field notes | First metre below surface: less dry compared to core D9 [and elsewhere]. -200 to -230 $\mathrm{cm}$, block of yellow limestone. Arrested at $-230 \mathrm{~cm}$; no samples.

Core D9 | no date: 2 (3?) September 1987

Top at $499 \mathrm{~cm}$.

Descriptive field notes | First metre below surface: dry. $-100 \mathrm{~cm}$, charcoal; -165 to $-195 \mathrm{~cm}$, presence of charcoal, peaking at -195 [to -205$] \mathrm{cm} ;-220 \mathrm{~cm}$, bone/tooth; -230 $\mathrm{cm}$, pottery; $-255 \mathrm{~cm}$, charcoal level; -280 to $-310 \mathrm{~cm}$, bone; -310 to $-315 \mathrm{~cm}$, black charcoal layer; $-360 \mathrm{~cm}$, block of yellow/white rock.

- 195/-205 cm. Sample 1: brown-blackish, charcoal-rich earth.

- $215 \mathrm{~cm}$. Sample 2: $25-\mathrm{cm}$-long core of whiteyellowish limestone (broken in four parts).

- $220 \mathrm{~cm}$. Sample 3: frs of a tooth (donkey or cattle).

- $230 \mathrm{~cm}$. Sample 4: body sherd of a small vessel of untempered, light pink clay, plain inside and smoothed or burnished outside.

- 240/-255 cm. Sample 5: dark brown earth, some charcoal (less abundant than in sample 1).

- $360 \mathrm{~cm}$. Sample 6: 3-cm-long core of whitish calcarenite. 
The cores obtained in 1987 offered a glimpse of the sedimentary nature and cultural contents of the town deposits at Barāqish. A 4-metre-deep borehole outside the southern wall provided a preliminary idea of the potential of the plain, which only the extramural excavations in Area $\mathrm{C}$ nineteen years later would extend and enrich (Sounding $\mathrm{F}$ in the northwest plain). ${ }^{30}$ However, no intimation of a Sabaean occupation - no clearly identifiable Sabaean pottery - came out of the cores.

As observed in the opening chapter of this book,$^{31} \mathrm{de}$ Maigret paid greatest attention to the finding of ash and charcoal levels, which appeared to suggest occupation and/or destruction and promised chronometric data. ${ }^{32}$ Obtaining the first usable charcoal samples for radiocarbon dating was indeed a significant novelty for Barāqish and the whole Jawf. ${ }^{33}$ Another result that greatly interested de Maigret concerned the 'hollow' in the middle of Barāqish. This depression, he argued, was apparently linked to a thinner cover of Islamic remains, which meant that the Minaean levels would have been reached more easily when excavations could be started. ${ }^{34}$

A comment on 'fire levels' is apposite here. There was in the 1980s, and not only on the part of de Maigret, an uncritical propensity to equate any charcoal layer, however thin, with a 'fire', a conflagration (in Italian un incendio; see end of section 2.1). ${ }^{35}$ Even then, such an attitude disregarded that many different kinds of charcoal bodies and charcoal-containing sediments

30 See Chapter 17, section 17, in Volume 2.

31 Section 3.2 and Appendix A, Document A3.

32 'Brancaleoni in his corings has discovered a burnt level and Minaean sherds 2-3 $\mathrm{m}$ beneath the central square, indicating the existence of structures in this hollow part of the site' (A. de Maigret, personal diary 31 August 1987; reproduced as Document A3 in Appendix A, Chapter 1). The mention of drillings in the "central square' of Barāqish only makes sense as an approximation: it does not match their actual locations (see section 2.1, above).

33 The four charcoal samples selected for dating must have been entrusted to V. Francaviglia on 9 September 1987, when he left Șan' ${ }^{\prime}{ }^{\prime}$ for Rome together with his closest colleagues (Cucarzi, Brancaleoni, and Monna). In that period de Maigret twice gladly accepted Francaviglia's role as an intermediary with the Rome radiocarbon unit. The other instance was in mid-March 1988, when de Maigret handed over the equally invaluable set of samples from Yalā (de Maigret and Robin 1989, 286, note 43; and unpublished documents in the MAIRY 'C14' archive, cf. Chapter 16). It is unknown when the dating results from the corings were announced, but as the measurements were performed before Yalā's - according to the laboratory numbers - a date in early or middle 1988 is likely (see Chapter 16). The results for Yalā were reported by the laboratory in January 1989.

34 'Therefore the concave shape of Barāqish must be attributed to the Islamic dwellings along the walls. This will make excavation in the middle of town easier' (A. de Maigret, personal diary 31 August 1987; reproduced as Document A3 in Appendix A, Chapter 1).

35 In fact, this tendency was probably much more popular among the drilling team (Brancaleoni and the geologists). A. de Maigret might have been ready to make it his own on the basis of some current historical notions (see the following footnote). existed, and that they implied different taphonomic histories and interpretations. Furthermore, the samples taken from the cores lacked context entirely. It was farfetched to infer town-wide conflagrations from this type of evidence, resulting in the probably misjudged contention that Barāqish had once been 'destroyed' in the second century BC. ${ }^{36}$ In December 1987 the same attitude was in evidence at Yalā, in the interpretation of the levels beneath the house that was excavated (House A). ${ }^{37}$ Only the final demise of this house as a result of fire could be substantiated, on the basis of multiple lines of evidence and against the background of the town as a whole.

\section{January 1990}

A painstaking search in the archives of the Italian Archaeological Mission has failed to produce technical reports on the coring campaign of January $1990 . .^{38}$ Neither drilling logs nor core descriptions are known. However, only de Maigret's own records and photographs are present in the archives for the field season in question, which suggests that specific notes on the drillings might have remained in the possession of other members of the Italian mission. Almost all of the available record is photographic. It consists of colour slides, whose sequence and to some extent subject have been retrieved through laborious reidentification in 2018. Several of them are published here, supplemented by a plan and a profile from the excavation records of Temple $\mathrm{A}$, where at least one of the corings is plotted.

A. de Maigret's personal documents represent the only additional source of information, however scanty. For the needs of the present chapter, all the passages of interest from the excavation notebook (Excavs 1990-1992) and his personal diary were collected and reproduced as Document A4 in Appendix A, Chapter 1. The technical details are embedded in the narrative and not always lend themselves to unequivocal reading. A translation of the useful excerpts will be given below.

As a consequence of this paucity of information, no more than an account of the drilling locations and sequence, and a basic description of the core geometry, can be given here, accompanied by a few informative photographs. It is unfortunate that such a demanding and productive operation left so little available record. The scientific loss is minimal, however, because the stratigraphic information provided by the cores was

\footnotetext{
36 See de Maigret and Robin 1993, 431 (de Maigret), 459 (Robin, 'l'effondrement du royaume minéen, vers 120 avant l'ère chrétienne, à partir de divers indices', a notion derived from Hermann von Wissmann [cf. p. 475]); de Maigret 2009a, 315 (Italian edition 1996); 1997a, 138.

37 de Maigret and Robin 1989, 284, 286.

38 Sabina Antonini, personal communications, June-July 2018.
} 
thoroughly replaced - and indeed greatly augmented - by the sounding carried out nearby in 2006. ${ }^{39}$

\subsection{The 1990 campaign, based on excerpts from A. de Maigret's notebook and personal diary}

On 18 January de Maigret noted that in locus Lbe, on the outside of Temple A's eastern corner, alongside its SE wall (Figs 4,5a), the excavation had now reached 'below the foundation level of the temple, although its large foundation blocks [were] continuing': this, he added, was the right point in which to make a first coring the next day, 'in order to understand what archaeological levels lay underneath'. ${ }^{40}$ On Friday 19, evidently chosen because it was a quiet day, ${ }^{41}$ the first coring was started 'at 7 o'clock under a leaden sky' with the help of just four workers. Here this will be called drilling D901. A few hours later the corer had already unearthed '[several] sherds, apparently Sabaean, almost $5 \mathrm{~m}$ beneath the base of the Minaean temple'. Those were the first Sabaean ceramics to be retrieved from the depths of Barāqish. Hence the realization: 'Barāqish is ancient indeed, and the drilling is not finished yet. ${ }^{42}$

As the coring continued, extension rods were added (at Barāqish they were in fact tubes). On 20 January the borehole in Lbe reached a depth of $6.6 \mathrm{~m}$, 'with sherds at the bottom'. ${ }^{43}$ At this point, no more extensions being available, 'it was decided to lower the surface of the sounding [in Lbe] so as to allow the corer to go down deeper'. This expedient digging brought to light five rows of stone masonry below the adjacent 'sill', Mbh (Fig. 4). The masonry rows initially looked like the temple's foundations, but were in fact the continuation of its perimeter wall. 'Having sealed the opening of the drill hole with a piece of tube, the corer [went] down another $70 \mathrm{~cm}$ approximately.' The manifest hope was to reach 'virgin soil or bedrock', and thus obtain a complete profile of the buried deposits, but de Maigret in his diary, at the end of the day, expressed doubts about the chances of fulfilling this goal.

However, the technical impasse inherent in the finite length of the corer did not prevent Saturday, 20 January

\footnotetext{
39 de Maigret 2010a. See Chapter 1, section 4.5.

40 Excavs 1990-1992, p. 52. A contradiction in the passage suggests that by 'the foundation level of the temple' de Maigret probably meant the recently exposed temple's floor across the wall (i.e., locus Lbc across 'sill' Mbh). In 1990 the foundations of the temple had not yet been identified, nor perhaps even exposed (cf. Excavs 1990-1992, p. 58, 20 January 1990).

41 A public holiday, with no excavation crew around.

42 de Maigret's personal diary, 19 January 1990; cf. footnote 8, above, and Chapter 1, section 3.3.

43 Excavs 1990-1992, p. 57. This depth was recorded as $6.5 \mathrm{~m}$ in de Maigret's personal diary. For the uncertainties and problems associated with such snippets of depth information see section 3.2, below. The complete passages for Saturday, 20 January 1990, can be read in Document A4 in Appendix A, Chapter 1.
}

1990, from becoming a significant day. The findings made entirely clear that Barāqish had 'stratigraphy', as de Maigret remarked - had thickness and depth. 'Brancaleoni's drilling has put before me a different picture of Barāqish: it is an important town also from the stratigraphic point of view. All in all, we are floating with our temple in superficial levels. ${ }^{34}$ The paramount revelation from 1990 was that Barāqish not only had been Sabaean, but, in pottery terms, appeared to have been Sabaean for a long time indeed. This point was to be emphasized time and again in publications and lectures..$^{45}$

The resulting picture was confirmed on Sunday, 21 January, the last day in which a mention of the coring appears: 'We go down in Lbe and continue drilling to c. $7.5 \mathrm{~m}$; maybe we will reach virgin soil. ${ }^{46}$ How the team managed to drill deeper is not told; however, the substratum was not attained.

On the same day, while the regular excavations of the temple were approaching their end, most activity was focussing on the so-called 'sacristy', i.e. the temple annex constituted of loci L6 and L3 (Figs 4,5b). The floor was entirely exposed in L3, where it was simply formed of compacted earth. ${ }^{47}$ On Monday, 22 January, the workforce was reduced, as it was to be the penultimate full day of the excavations. 'In locus L3 the remaining fill was removed, bringing to light the stone on which the plinth of the [very tall] stela ${ }^{48}$ is standing. At this level, six jutting-out block joints can be counted in M1 [the southwest wall of the temple]. However, I am not sure that we reached the original floor. We finish the section between L3 and L6. It shows at its top the beginning of the Minaean levels and at its base the outline of a whitish flooring, which is where we [now] stop in L3. ${ }^{49}$

Here de Maigret concludes his notes for 22 January announcing that 'a planned coring' (i.e., a second coring) would be made there, in locus L3. Finally, he records the elevations at the end of the day as usual,

\footnotetext{
44 Personal diary, 20 January 1990.

45 de Maigret 1991a, 15; 1991b, 164 ('Two core drillings carried out on the exterior in the vicinity of the temple have shown that the Minaean level rests on some earlier archaeological layers, more than $7.5 \mathrm{~m}$ thick; several pottery fragments from these drillings clearly show that almost all these preceding levels can be ascribed to the Sabaean period'); 1997a, 138; 1998a, 217; 2000b, 167; 2004a, 4-5 (stating that archaic Sabaean pottery 'came to light at least 8 metres beneath the Minaean levels' - not perhaps an exaggeration, considering the depth estimates presented in section 3.2, below); 2009a, 313 (Italian edition 1996); 2010a, 76 (listing, in addition, all the known occurrences of Sabaean pottery at Barāqish); de Maigret and Robin 1993, 430-431.

46 Excavs 1990-1992, p. 60.

47 Excavs 1990-1992, p. 59.

48 Stone Y.90.B.A 3: not a stela, but a reused slab (possibly a bench) placed vertically.

49 Excavs 1990-1992, p. 61.
} 


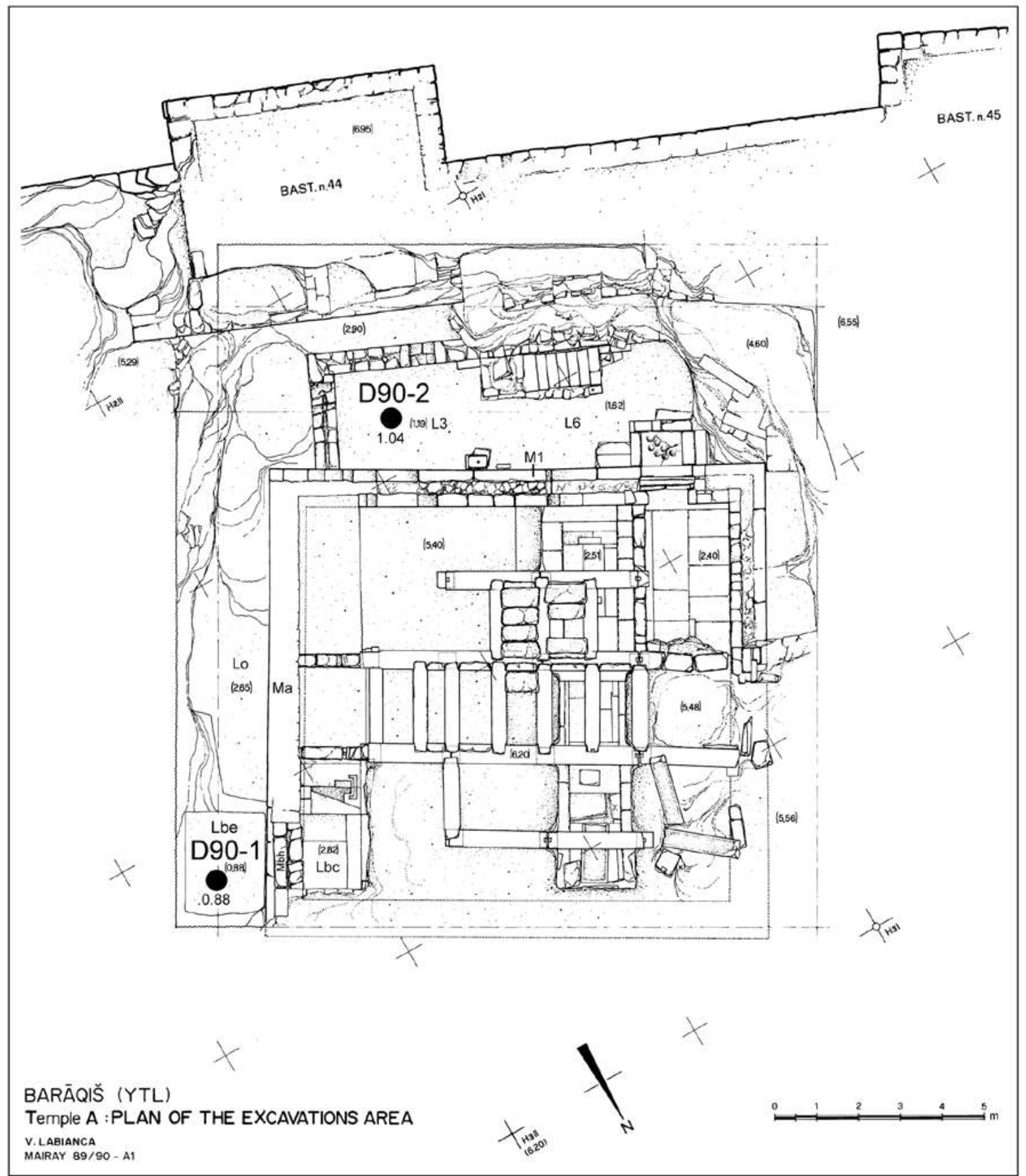

Figure 4. Barāqish, January 1990: location of the two drillings, plotted onto a plan of Temple A at the end of the excavation season (V. Labianca 1990 ( ) MAIRY, with additions by F.G. Fedele). The precise locations of the drillings were derived from excavation plan \#11 by Labianca, dated 20-22 January 1990 (MAIRY Archives), where the nearest surface elevation for core D90-2 in locus L3 is given as $104 \mathrm{~cm}$ above datum.

locus by locus and feature by feature: the surface elevation in L3 was $1.04 \mathrm{~m} . .^{50}$ As it corresponded to the end of the excavations in the locus, this elevation was final.

50 'Se faremo - come da programma - un carotaggio in questo punto, si vedrà se esistono [...] pavimenti più antichi.' 'Quote: L3: 1,04.' (Excavs 19901992, p. 62).
This coring in the 'sacristy' will be called here coring D90-2. No written information about it is known. The available photographs inform that it was certainly in progress on Tuesday, 23 January, the last full day of the excavations, and had probably been started that very day as established. ${ }^{51}$ Both considering the length of the

51 In agreement with Excavs 1990-1992, p. 62. The date of the operation 


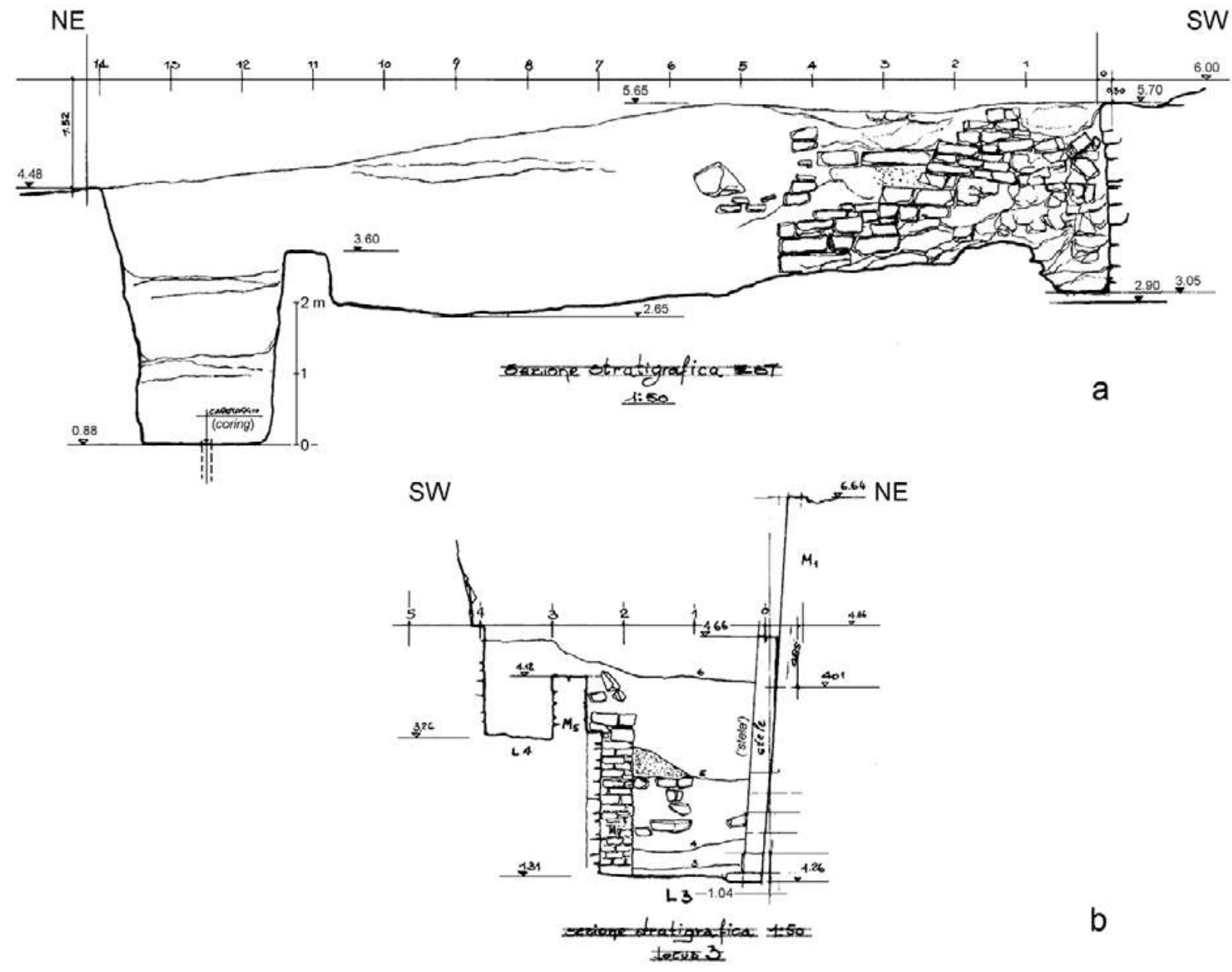

Figure 5. Barāqish, January 1990: stratigraphic profiles at the end of the excavation season, of interest for the two drillings. (a) SE profile of Temple A excavation; (b) a SW-NE profile across locus L3 of the 'sacristy'.

(V. Labianca 1990 @ MAIRY, with integrations by F.G. Fedele)

core, and by analogy to coring D90-1, this operation presumably continued on 24 January, if not on the 25th, but the excavation notebook is silent. On p. 64, the last page of Excavs 1990-1992 as excavation journal, de Maigret limits himself to recording that on 24 and 25 January the mission was occupied in 'cleaning and photographing', that is, in closing the excavation season.

\subsection{The cores}

The photographs (Fig. 8) show two cores of about the same length, $6.5 \pm 0.2 \mathrm{~m}$. However, there is no

is revealed by the photographs, which show the small boundary stone Y.90.B.A 18 already in a standing position during the drilling, as well as a large number of mission's members attending, free from excavation duties and neatly dressed (Fig. 7). Key to dating the photographs is the boundary stone, which was found on 23 January and raised again standing. This perforated and inscribed stone, a borne in French (de Maigret and Robin 1993, 471, photograph 17), was lying on the ground in L6 near the foot of standing slab Y.90.B.A 3 (mentioned above in footnote 48) and was returned to its supposed original position immediately after discovery (Excavs 1990-1992, p. 63). guarantee that core D90-1 is complete, as its last label is illegible. One is tempted to equate the 6.5-metre figure with the maximum length of the corer and its extensions, which unfortunately is unknown, although $6 \mathrm{~m}$, or any length between 6 and $6.5 \mathrm{~m}$, might be a reasonable guess. ${ }^{52}$ In principle, obviously, a core could not exceed the maximum length of the corer. As we have seen, de Maigret and his drilling team strived to attain maximum core length in the case of core D901 , which in fact was extended in length incrementally through consecutive lowerings of the initial surface (with implications that will be examined below). It is

52 According to a possible reading of de Maigret's notes, the maximum reach of the corer would have been 6.5 or $6.6 \mathrm{~m}$ (de Maigret, Excavs 1990-1992 and personal diary, 20 January 1990; see section 3.1 and footnote 43). In fact, this reading can be questioned on the basis that de Maigret is speaking of depths, not necessarily of length of corer or core. It is important not to confuse length of corean objective, if approximate, value - and depth attained: it was this latter quantity that occupied de Maigret's mind and featured in his notes (see below). Whether the value of about $6.7 \mathrm{~m}$ for core D90-2 (Fig. 8) equals the maximum length of the corer is uncertain, because we do not have the details of the drilling proceedings. 


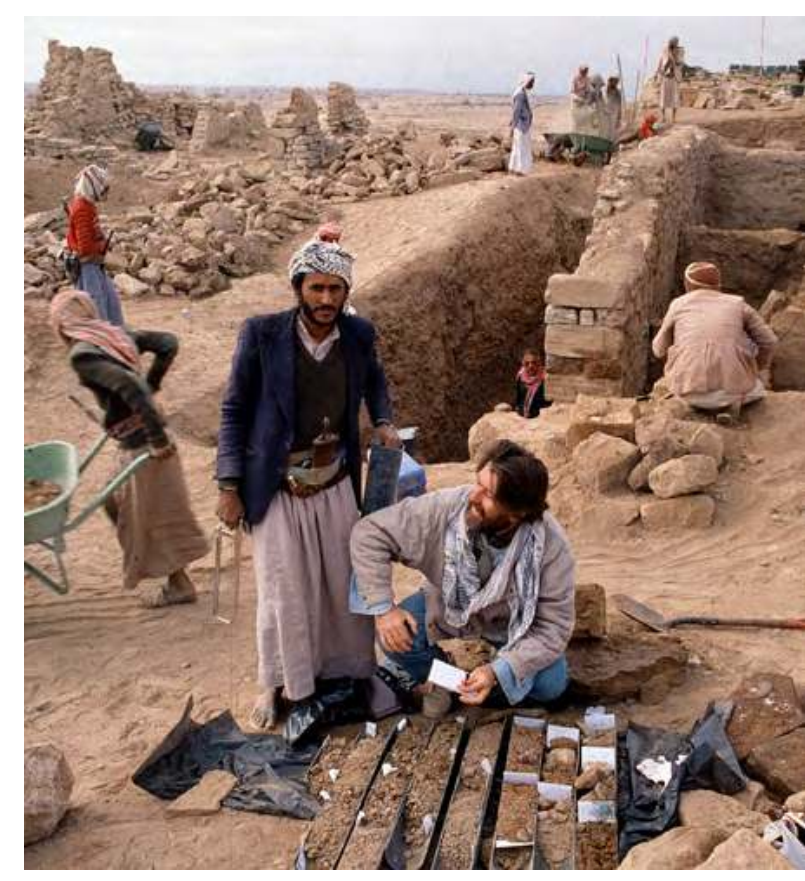

Figure 6. Barāqish, 20 January 1990, drilling operation in Lbe. A workman, in charge of sawing the tubes, stands by B. Marcolongo who, crouched on the ground, is ordering and labelling the samples of core D90-1 onto the half-tubes. In progress in the background is the first phase of the drilling.

(A. de Maigret $\odot$ MAIRY)

conceivable that the maximum reach of the corer and its extensions was exploited again with core D90-2. The existing photographs must be read as a technical source with these notions, questions, and caveats in mind.

The photographs also show that in 1990 the corer contents were extruded onto segments of largediameter plastic tubes longitudinally sawn in half (Figs $6,8)$. This procedure might already have been used in $1987 . .^{53}$ In order to provide a realistic stratigraphic perception of the best photographed, apparently complete core, a sedimentary column from drilling D902 is reconstructed in Fig. 9. In the following account, top-of-core or simply 'top' refers to the elevation of the opening of the drill hole, as already done above in section 2. Concerning elevations, the 1990 datum was once again the datum employed for the town plan of Barāqish back in 1986. ${ }^{54}$

Core D90-1 | 19-21 or 22 January 1990

Drilled in locus Lbe (Figs 4, 5a). Photographs of the drilling: Chapter 1, Fig. 38; the overall scene, and a

53 See section 2.2, above.

54 See footnote 29. Lacking - apparently - explicit statements by de Maigret, the interannual conservation of the Barāqish datum was inferred from a comparison of elevations between the 1986 town plan and the excavation records for Temple A. related operation, also in Fig. 6 here. Photograph of the core: Fig. 8 (the core may not be complete).

The coring was developed in two or three phases incrementally: as I prefer to err on the side of clarity I will retain three phases. In the first phase, starting from an unrecorded level already below the 'base' (the floor?) of the temple, ${ }^{55}$ a core equivalent to the full length of the corer and its extensions was extracted (Fig. 38, Chapter 1, and Fig. 6 here). A second phase resulted from lowering the initial surface by $70 \mathrm{~cm}$ approximately and re-inserting the corer into the preexisting drill hole, having protected the opening of the drill hole with a piece of tube. The corer was again employed full-length. This might be the stage recorded in the photograph of the core (Fig. 8). The third and last coring phase took place after a further, unrecorded lowering of the drilling surface, which brought down the top of core to $0.88 \mathrm{~m}$ above datum (Figs 4, 5a). This second lowering would have amounted to no more than $30 \mathrm{~cm}$ and might have been quick and informal. Inferring two consecutive lowerings of the surface accounts for about a metre of additional depth, from about $6.5 \mathrm{~m}$ (20 January) to about $7.5 \mathrm{~m}$ (21 January). Due note must be taken of the constricted size and shape of the trench in Lbe (Fig. 5a).

The above analysis and reconstruction have consequences for the determination of the length and elevation of the core (its 'geometry'). Unfortunately, the top-of-core elevations corresponding to the first two drilling phases are nowhere stated.

- Using the profile in Fig. 5a as a reference, one can speculate that the top in the first phase would have been at about $1.9 \mathrm{~m}$ above datum (from adding about $1 \mathrm{~m}$ to $0.88 \mathrm{~m}$ ). This estimate matches what can be seen in Fig. 38, Chapter 1; $1.9 \mathrm{~m}$ above datum was about $75 \mathrm{~cm}$ below the level of the trench alongside the SE wall of the temple (2.65 $\mathrm{m}$ above datum). For perspective, one can recall that the nearest floor inside the temple was at about $2.8 \mathrm{~m}$ above datum (Lbc; see below).

- By subtracting '70 cm approximately', an estimate for the top in the second phase would be about $1.2 \mathrm{~m}$ above datum. As already noted, the top in the last phase of coring was recorded as $0.88 \mathrm{~m}$ above datum.

- Length of core: > $6 \mathrm{~m}$; perhaps 6.3-6.4 m minimum, extrapolating from the last legible label in the photograph (the last but one label on the core), which reads $6{ }^{* *} \mathrm{~m}\left(6.10 \mathrm{~m}\right.$ ?). ${ }^{56}$

\footnotetext{
55 See footnote 40.

56 The average core-segment length at the same depth in core D90-2 is c. $25 \mathrm{~cm}$; but extrapolating on this basis, by analogy, is obviously hazardous.
} 


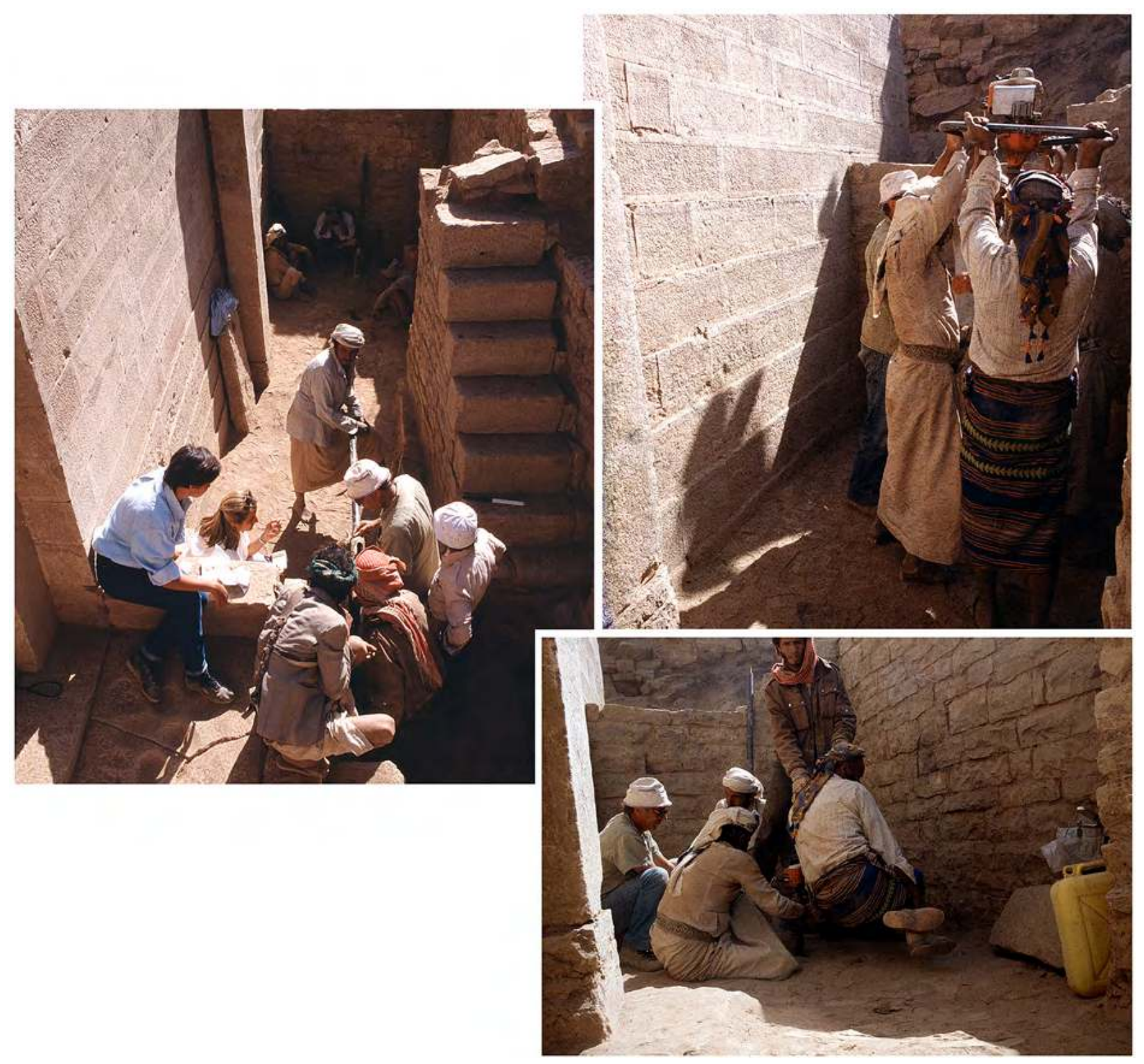

Figure 7. Barāqish, 23 or 24 January 1990: views of the drilling operation in the 'sacristy', locus L3. (A. de Maigret @ MAIRY)

- Maximum depth reached (on the basis of the above reconstruction and considering the uncertainties): a full corer length below $0.88 \mathrm{~m}$, i.e., a conjectural $5.1 \mathrm{~m}$ (maximum $5.6 \mathrm{~m}$ ?) below datum. This would be equivalent to $7.9 \mathrm{~m} \mathrm{(8.4}$ $\mathrm{m}$ ?) below the nearest floor of the temple (Lbc).

A comment will clarify this last statement and put it in context. It appears that A. de Maigret, taking note of the progress of the drillings, continued to count in terms of depth 'below the base of the temple' (diary, 19 January), as that obviously was what interested him. However, what 'base of the temple' meant is nowhere stated unequivocally. Since the foundations of the temple could not be precisely identified in 1990 (see footnote 40), the expression might intuitively refer to the floor or floors of the temple, to the extent that they had been exposed. The elevation of the temple's floor at the end of the 1990 excavations was about 2.4-2.5 $\mathrm{m}$ in the western quadrant of the hypostyle hall, and about $2.8 \mathrm{~m}$ in the cella at its eastern corner, Lbc (see for example Fig. 4).

- Cultural contents: a passage in de Maigret's diary, cited above (section 3.1), mentions 'apparently Sabaean sherds almost $5 \mathrm{~m}$ beneath the base of the Minaean temple'.

Core D90-2 | 23-probably 24 (25?) January 1990

Drilled in locus L3, in the southeastern third of the socalled 'sacristy' (Figs 4, 5b). Photographs of the drilling: 

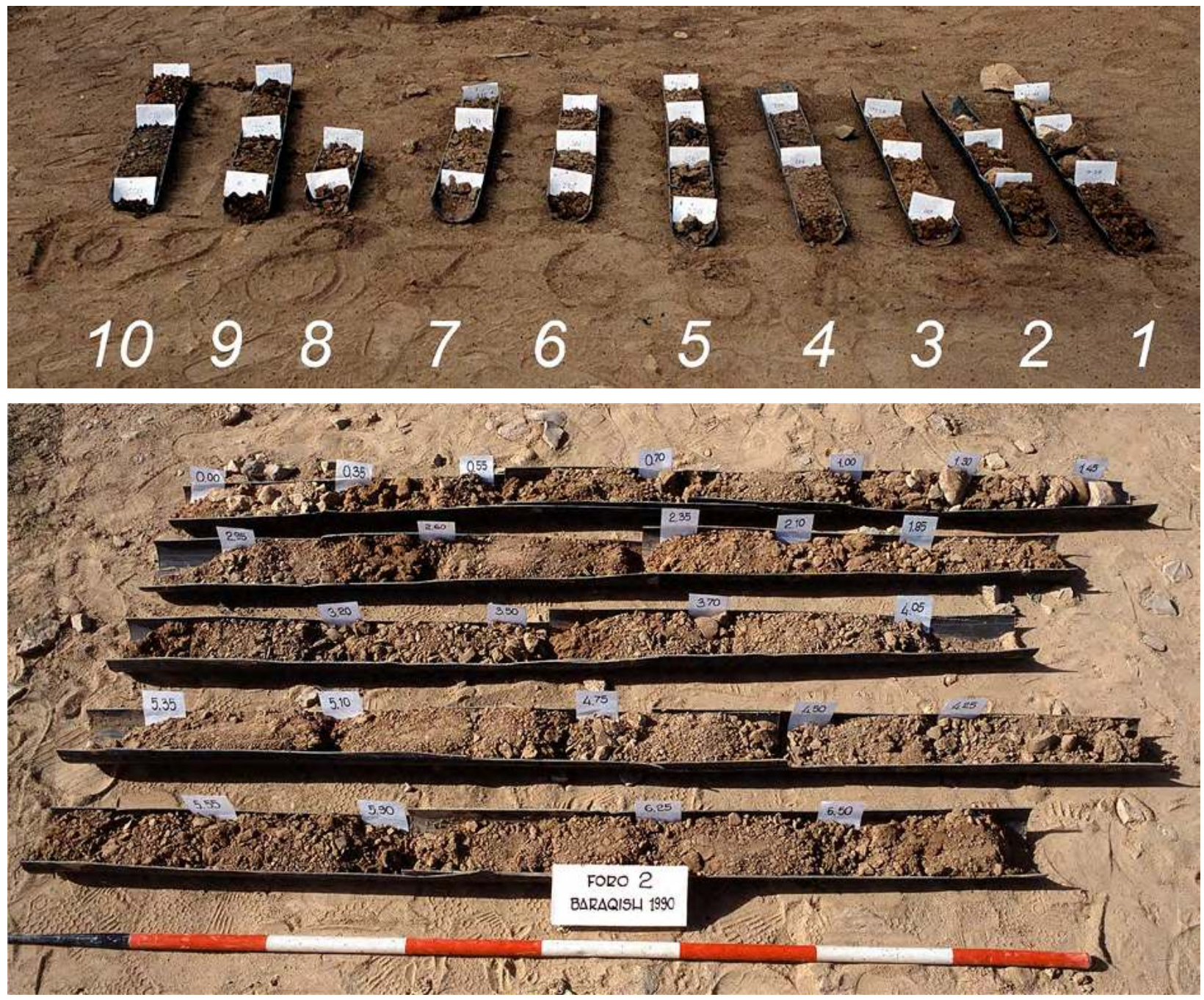

Figure 8. Barāqish, January 1990: field photographs of the core segments comprising core D90-1 (above) and core D90-2 (below). Core D90-1 may not be complete. (A. de Maigret () MAIRY, optimized and arranged by F.G. Fedele)

Fig. 7. No written details of the drilling are known. Photographs of the core: Figs 8, 9.

- Top: $1.04 \mathrm{~m}$ above datum. This elevation was only $16 \mathrm{~cm}$ above the top of coring D90-1 in its last phase.

- Length of core: approximately $6.7 \mathrm{~m}$, extrapolating from the last labelled level of the core in the photograph ('6.50') and the last increment $(25 \mathrm{~cm})$.

- Depth reached: 5.6-5.7 $\mathrm{m}$ below datum. This would be equivalent to $8.0-8.2 \mathrm{~m}$ below the nearest floors of the temple in the western quadrant of the building $(2.4-2.5 \mathrm{~m})$.

From the corings of 1990, which in his vague recollection had reached 'down to the level of the surrounding plain',
Francaviglia will later infer that Barāqish appeared to be a tell, ${ }^{57}$ i.e., not a settlement atop a rocky outcrop..$^{58}$

One final observation concerning the corings of January 1990 is in order: surprisingly, neither the presence of charcoal nor ${ }^{14} \mathrm{C}$ dates were ever mentioned, in stark contrast to the findings and observations made in 1987. This point is discussed in greater detail in Chapter 16, section 2 . The visual inspection of the available photographs (Figs 8-9) is insufficient to detect or exclude the presence of charcoal in the cores. Due to their poorer quality, the photographs of core D90-1 are virtually useless in this respect, while in the goodquality image of core D90-2 no black units can be seen. The nearest approximation is a couple of dark brown units, neither of which visually qualifies as a charcoal layer.

\footnotetext{
57 Francaviglia 2002, 121 (citation) and 119, respectively.

58 See footnote 9 above, with further references.
} 


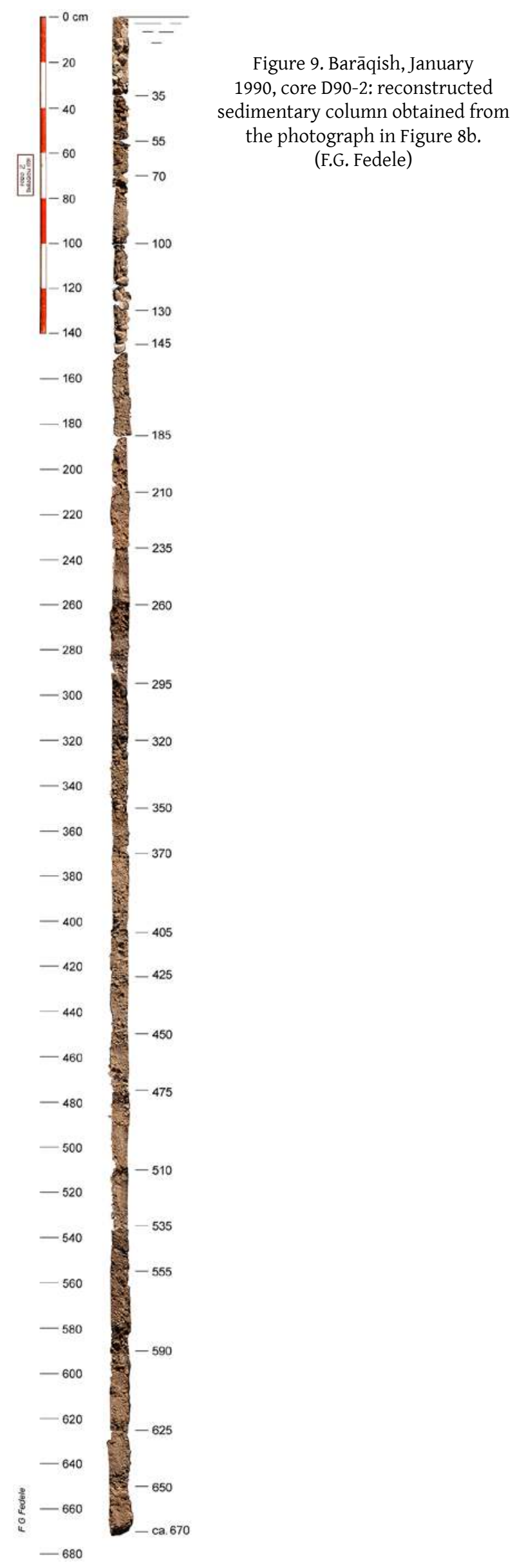

References to MAIRAY/MAIRY archival and personal documents

Corings: A. de Maigret, Yemen 1987- Barāqish corings ['Yemen 1987 - Carotaggi Barāqish'] notebook

Excavs 1990-1992: A. de Maigret, Barāqish 1990 and 1992 excavations, a notebook headed 'Barāqish 1990 scavi', but comprising the excavation journals of both campaigns as two distinct, consecutive sections A. de Maigret, personal diary, 1987

A. de Maigret, personal diary, 1990 


\title{
Chapter 16
}

\section{Radiocarbon Determinations 1987-2006: Corings, Temples A and B, Area D. A Survey and Reappraisal}

\author{
Francesco G. Fedele
}

The aim of this chapter is to make available all the radiocarbon determinations concerning Barāqish/ Yathill, together with their calibration to calendar years. Excluded are the determinations concerning Area C, which can be found in Chapter 18, section 1, in Volume 2. The need for a comprehensive datelist for Barāqish was determined by a number of factors. Chief among them, the dates were scattered in different publications, most often as mere discursive mentions in the treatment of stratigraphic or historical problems. Therefore they appeared on an ad hoc basis and not with reference to formal dating reports, complete with the required technical details. ${ }^{1}$ Some dates were never published, and among those that were, quite a few presented numerical and/or interpretive inconsistencies, contingent on the vicissitudes of research or publication. Finally, the sheer passing of time called for an up-to-date calibration.

This datelist and the relevant conventions are presented in Table 1, where the samples are ordered according to field season or group of seasons. The same ordering will be followed in the text of this chapter to provide basic information about the samples' trajectory, from field context (Figs 1-2) to laboratory report, as well as occasional comments on the significance of their dating. Additionally, two combined dates from pooled measurements are given in Table 2. The calibration plots of the above datasets are presented in Figs 3-5.

All the radiocarbon determinations retrievable from both publications and unpublished documents have been assembled for this chapter. The measurements and their context information were then checked on the main archival source, represented by a bundle of folders in A. de Maigret's papers entitled 'C14' (henceforth

\footnotetext{
1 Previously, in response to the same need, only Edens and Wilkinson (1998, table VIII on p. 91) had attempted a formal compilation of radiometric dates from Barāqish, reflecting the goals of their comprehensive review of pre- and protohistoric archaeological research in Yemen. However, the available dates at the time were solely those from the 1990-1992 excavations of Temple A; moreover, unfortunately, the entries compiled by Edens and Wilkinson derived from de Maigret and Robin 1993 - are incomplete and contain mistakes (see section 2 below).
}

MAIRY 'C14'). ${ }^{2}$ The folders contain the entire dating record of the Italian Archaeological Mission, except for a few cases from the 1980s in which the transmission of samples and the payment for dating were not directly managed by the chief of mission (for example, the samples from the 1987 coring campaign). The documents largely consist of the original laboratory reports, related correspondence, and accounting records, in addition to de Maigret's own processing and interpretation of dates, these latter often carried out with the assistance of more experienced colleagues. ${ }^{3}$ The information concerning 2005-2006 was additionally cross-checked with my own notes and records.

Concerning Barāqish, in particular, all the ${ }^{14} \mathrm{C}$ values in Table 1, column 4, were derived from the original laboratory reports, except for the determinations concerning 1987 (for which see text). This long-needed formalization has not only resulted in corrections, but also in several unexpected findings of some consequence. As Barāqish provides to this day a unique radiometric dataset for the whole Jawf, after more than thirty years since the inception of field testings, ${ }^{4}$ I also thought it justified to provide background information on the organizational aspects of the radiocarbon measurements here presented and on their significance for research on ancient Yemen.

\section{The 1987 coring campaign}

Four samples for radiocarbon dating were extracted from ash and charcoal units observed in four cores

\footnotetext{
2 Heartfelt thanks are due to Sabina Antonini for putting this invaluable archive at my disposal in 2015. I am also grateful for her thoughtful comments on a first draft of this chapter.

3 B. Marcolongo, M. Tosi and myself, in the 1980s to 1992 (cf. Fedele 1990b), and myself in 2005-2008 (see below, section 3). Some documents in the MAIRY 'C14' folders have now acquired historical value, particularly in connection with the work carried out during the 1980s on the Plateau and at Yalā/al-Durayb, but they do not concern us here.

4 The only other radiocarbon determinations obtained for archaeological purposes in the Jawf seem to be those from the temple of 'Athtar dhu-Rișāf ('Ațtar d dū-Rișāf) in al-Sawdā', comprising four samples measured by Beta Analytic in three phases in 1989-1990 (Breton 1992c, 445-449, 450; see also Breton 1998, 68).
} 
(drillings 3, 5, 6 and 9). Their topographic provenance and stratigraphic position were described in Chapter 15, section 2, text and Figs 1-2, where the relevant details can be found. Some comments on the stratigraphic association of the sample from core D6 are presented below. It was possible to establish that the samples were entrusted to V. Francaviglia when he left Șan' $\bar{a}$ ) for Rome on 9 September 1987, having accepted his offer to act as an intermediary with the Rome radiocarbon unit, ${ }^{5}$ and it seems likely that the subsequent processing of the samples was personally supervised by radiocarbon specialist Carlo Azzi. ${ }^{6}$ The University of Rome Radiometric dating laboratory ('Laboratorio Radiodatazioni del Dipartimento di Fisica dell'Università di Roma "La Sapienza"') was a branch of the National Research Council's (CNR) Centre for Applied Geochemistry, with staff from the university's Department of Earth Sciences and Department of Physics.

When the dating results were announced is unknown, since no original communication is preserved in the MAIRY 'C14' archive, but from the laboratory numbers a date in early or middle 1988 is likely. ${ }^{7}$ The only available source about the measurements is a hand-written leaflet inserted in de Maigret's Corings notebook after page $12,{ }^{8}$ and this information is reproduced in Table 1.

The composition of the samples was the following (the samples are listed in the same order as in Table 1):

- core D9 | 'brown-blackish, charcoal-rich earth';

- core D5 | 'fine, dark brown earth, some charcoal' ('black layer', attributed to a town-wide 'destruction');

\footnotetext{
5 See Chapter 15, note 33, this volume.

6 See Chapter 15, note 23. C.M. Azzi was expected to be the lead author of a paper based on the 1987 coring campaign, which was never completed (Chapter 15); together with members of the Italian Archaeological Mission he co-authored de Maigret et al. 1989.

7 See Chapter 15, note 33. Unfortunately, an interruption of reporting in Radiocarbon affected the Rome measurements related to several MAIRAY operations in highland Yemen (e.g., de Maigret and Robin 1989; de Maigret et al. 1989). The Rome laboratory ceased publishing their dates in the journal with datelist XVII, which appeared in volume 33, issue no. 1 (1991) and contained runs from 1976 to 1980, the last laboratory number being R-1523. When a new laboratory was created in 1990, under the responsibility of G. Calderoni at the Department of Earth Sciences, a new series of reports in Radiocarbon was inaugurated with samples submitted in 1989 or later (Radiocarbon 34,1, 1992); the runs were identified with a new numbering and 'Rome' as a code. To my knowledge, no comprehensive datelists for the period between 1980 and 1989 were ever published. (A request for information about the samples from Barāqish 1987, sent to the Department of Physics of University of Rome 'La Sapienza' in 2018, has remained unanswered.) We can infer a reporting date within 1988 from a comparison with the results for Yalā, whose samples were submitted on 15 March 1988 and reported on 27 January 1989 under laboratory numbers from R-1945a to R-1949a (MAIRY 'C14', folders 'Yalā'; de Maigret and Robin 1989, 286; '13.1.1989' in the article refers to an advance communication by telephone).

8 See Chapter 15, section 2.1.
}

- core D6 | 'black, charcoal-rich earth' (from a depth of $-280 \mathrm{~cm}$ according to the leaflet), associated with a layer or layers again attributed to 'destruction';'

- core D3|'ashy, blackish earth' ('charcoal layer' in the field notes).

The chronological interpretation suggested by these dates should be reconsidered in the light of their updated calibration. Furthermore, as pointed out in a previous chapter, ${ }^{10}$ also the cultural-historical interpretations advanced in the 1980s and 1990s from the intuitive equation of ash and charcoal sediments with 'fire levels', or conflagrations, need to be reappraised. What can presently be done is carefully avoiding any inferences of town-wide fires and consequent town destructions, since events of this magnitude require infinitely better evidence to be substantiated. Obviously, only future excavations in the residential quarters of Minaean Yathill will be able to place the findings from the 1987 campaign in perspective.

\section{The 1990 and 1992 excavation campaigns}

The radiocarbon dates from 1990-1992 are all related to Area A (Fig. 1). The original ${ }^{14} \mathrm{C}$ determinations were never published, ${ }^{11}$ and the whole set including the repeated measurements and pooled dates is presented for the first time here (Tables 1-2). Detailed context information for the 1990-1992 samples, listed in the same order as in Table 1 and topographically located in Fig. 1, is presented below. ${ }^{12}$

- Y.90.B/18 | Islamic occupation at roof level of Temple A, ashy charcoal from a tannūr (an oven) in the penultimate occupation level of room Lg-Lh (delimited by walls Mn and Mo), roughly above the $\mathrm{W}$ corner of the temple's hypostyle hall, collected on 7 January 1990 (Excavs 19901992, p. 19-21). Phase Islamic C sensu 1991 (?).

- Y.90.B/34 | Dark ashy sediment from beneath an Islamic flooring in Ln, corresponding to locus L2 of the temple's hypostyle hall, collected on 11

\footnotetext{
9 A depth of -240 to $-280 \mathrm{~cm}$ for the 'intense fire' layer is shown in the drawing of the core profile (Chapter 15, Fig. 2), whereas the descriptive field notes (Chapter 15 , section 2.2) record a 'heavy fire' layer at $-275 /-255 \mathrm{~cm}$ followed by a 'black layer' - attributed to 'destruction' - between -255 and $-225 \mathrm{~cm}$. This registration or description discrepancy invites caution about the stratigraphic provenance and/or compositional integrity of the sample.

10 Chapter 15 , section 2.2 .

11 The list in table VIII of Edens and Wilkinson (1998), although commendable (see footnote 1 above), should be discounted because of its derivative nature.

12 Sources: MAIRY 'C14', folders 'BAR. 1990' and 'BAR. 1992'; Excavs 1990-1992 (cf. Chapter 1, document A4 in Appendix A, and Chapter 15, this volume). Secondary sources: de Maigret 1991b, 164; 1993, 21; de Maigret and Robin 1993, 455.
} 
Table 1. Barāqish 1987-2006: list of radiocarbon age determinations, all operations except Area C. Within each field season and operation, the samples are ordered according to increasing ${ }^{14} \mathrm{C}$ age. The source material of samples is wood or shrub charcoal, unless indicated otherwise. Fractionation data are not available.

Dating laboratories: Beta, Beta Analytic (Miami); DSH, CIRCE Laboratory (Caserta, Italy; the laboratory code was later changed into DSA); R, University of Rome Radiometric dating laboratory (Rome). Calibrated ages and associated probability $(p)$ in column 5 were calculated with the Calib 7.1.0 program (M. Stuiver, P.J. Reimer and

R.W. Reimer 2018, CALIB 7.1 at http://calib.org, accessed 10 September 2018) based on the IntCal13 data set (Reimer et al. 2013). All calendar ages are reported at the 2-sigma (2s) or $95.4 \%$ confidence interval, rounded off to the nearest decade for ${ }^{14} \mathrm{C}$ ages with $s \geq 50$ years; $b p=$ radiocarbon years before present (1950).

\begin{tabular}{|c|c|c|c|c|}
\hline 1 & 2 & 3 & 4 & 5 \\
\hline Sample & $\begin{array}{l}\begin{array}{l}\text { Position and/or } \\
\text { stratigraphy }\end{array} \\
\end{array}$ & $\begin{array}{l}\text { Laboratory } \\
\text { number }\end{array}$ & ${ }^{14} \mathrm{C}$ age $\pm s$ bp & $\begin{array}{l}\text { Calendar ages } \mathrm{BC} / \mathrm{AD} \text { at } 2 s \text {, and relative } \\
\text { probability } p^{\mathrm{b}}\end{array}$ \\
\hline \multicolumn{5}{|l|}{ 1987: drillings } \\
\hline \#4: Core D9 & $-195 /-205 \mathrm{~cm}$ & R-1927 & $0 /-45$ (present) & * invalid age for calibration \\
\hline \#2: Core D5 & $-240 /-250 \mathrm{~cm}$ & R-1925 & $500 \pm 50$ & * AD 1310-1360 (p.18), 1390-1480 (p.82) \\
\hline \#3: Core D6 & $-280 \mathrm{~cm}$ & R-1926 & $2000 \pm 50$ & * $120 \mathrm{BC}-\mathrm{AD} 90(p .95)$ \\
\hline \#1: Core D3 & $-340 /-360 \mathrm{~cm}$ & R-1924 & $2000 \pm 55$ & * 120 BC-AD 90 (p.92) \\
\hline \multicolumn{5}{|c|}{ 1990: Area A/Temple A } \\
\hline \#4: Y.90.B/18 & Lg-Lh, Islamic & Beta-39951 & $790 \pm 50$ & AD $1150-1290(p 1)$ \\
\hline \#3: Y.90.B/34 & Ln (L2), Islamic & Beta-39950 & $870 \pm 60$ & AD $1040-1260(p 1)$ \\
\hline \#1: Y.90.B/82 & $\begin{array}{l}\text { ‘sacristy’, L6, } \\
\text { Minaean A }\end{array}$ & Beta-39948 & $2040 \pm 50$ & 180 BC-AD $60(p 1)$ \\
\hline \#2: Y.90.B/62 & $\begin{array}{l}\text { ‘sacristy’, L3, } \\
\text { Minaean A }\end{array}$ & Beta-39949 & $2380 \pm 70$ & $770-360$ BC (p.99) \\
\hline Y.90.B/82 + repeat ${ }^{\mathrm{c}}$ & see above & Beta - & $1920 \pm 50^{\mathrm{d}}$ & * 1 BC-AD $220(p .96)$ \\
\hline Y.90.B/62+ repeat ${ }^{c}$ & see above & Beta - & $2460 \pm 50^{\mathrm{d}}$ & * $760-410 \mathrm{BC}(p 1)$ \\
\hline Y.90.B/82 bis ${ }^{\mathrm{e}}$ & see above & Beta-42966 & $1940 \pm 50$ & 50 BC-AD 180 (p.98) \\
\hline Y.90.B/62 bis ${ }^{\mathrm{e}}$ & see above & Beta-42965 & $2130 \pm 60$ & $360-40$ BC (p.99) \\
\hline \multicolumn{5}{|l|}{ 1992: Temple A } \\
\hline \#2: Y.92.B/138 & $\begin{array}{l}\text { L4, lower deposits, } \\
\text { Minaean B }\end{array}$ & Beta-59187 & $2380 \pm 50$ & $750-680(p .13), 590-380$ BC (p.82) \\
\hline$\# 1:$ Y.92.B/135 & L31, Minaean C & Beta-59186 & $2530 \pm 50$ & $800-510$ BC (p.99) \\
\hline \multicolumn{5}{|l|}{$2005-2006$} \\
\hline \multicolumn{5}{|l|}{ Temple B } \\
\hline Bar.05.B/2a & $\begin{array}{l}\text { hypostyle hall, floor } \\
\text { L110 }\end{array}$ & DSH-375 & $2438 \pm 27$ & $750-683(p .24), 591-408$ BC (p.68) \\
\hline \multicolumn{5}{|l|}{ Area A, Sounding S1 } \\
\hline \#2: B.06.S1/8 & Stratum C & DSH-235 & $2515 \pm 46$ & $798-488$ BC (p1) \\
\hline \#1: B.06.S1/5 & Stratum B & DSH-232 & $2551 \pm 38$ & $\begin{array}{l}\text { 805-730 (p.49), 692-659 (p.12), 651-543 BC } \\
(p .39)\end{array}$ \\
\hline \#3: B.06.S1/13 & Stratum D & DSH-233 & $2707 \pm 26$ & $903-810$ BC (p1) \\
\hline \#4: B.06.S1/15 & Stratum E & DSH-289 & $2814 \pm 19$ & $1011-913$ BC (p1) \\
\hline \#5: B.06.S1/17 & Stratum H & not measured & - & - \\
\hline \#6: B.06.S1/23 i & Stratum K & DSH-290 & $2902+68$ & $1280-910$ BC (p1) \\
\hline \#7: B.06.S1/23 ii & Stratum M & DSH-291 & $2986 \pm 23$ & $1277-1127 \mathrm{BC}(p 1)$ \\
\hline \multicolumn{5}{|l|}{ Area D } \\
\hline \#2: B.06.D/8 & $\begin{array}{l}\text { Layer } 1, \text { base of fill } \\
\text { above tombs }\end{array}$ & DSH-303 & $1903 \pm 103$ & 120 BC-AD 350 (p.98) \\
\hline \#3: B.06.D/4 & $\begin{array}{l}\text { Layer 3: burial } \\
\text { activity }\end{array}$ & DSH-293 & $1923 \pm 42$ & 2 BC-AD 178 (p.94) \\
\hline
\end{tabular}




\begin{tabular}{|l|l|l|l|l|}
\hline $\mathbf{1}$ & $\mathbf{2}$ & $\mathbf{3}$ & $\mathbf{4}$ & $\mathbf{5}$ \\
\hline Sample & $\begin{array}{l}\text { Position and/or } \\
\text { stratigraphy }\end{array}$ & $\begin{array}{l}\text { Laboratory } \\
\text { number }\end{array}$ & ${ }^{14} \mathrm{C}$ age $\pm s$ bp & $\begin{array}{l}\text { Calendar ages BC/AD at 2s, and relative } \\
\text { probability } \boldsymbol{p}^{\mathrm{b}}\end{array}$ \\
\hline$\# 1:$ B.06.D $/ 2$ & Layer 1 & DSH-376 & $2463 \pm 22$ & $761-677(p .37), 674-477 \mathrm{BC}(p .61)$ \\
\hline \#4: B.05.D/14+18 & $\begin{array}{l}\text { Layer 4: below tombs } \\
\text { (Sabaean) }\end{array}$ & DSH-288 & $2771 \pm 31$ & $998-839 \mathrm{BC}(p 1)$ \\
\hline
\end{tabular}

a Simplified. See text and Figs 1-2 for details.

b $\quad p=$ associated relative probability within 95.46\%: relative maximum in bold; $p 1=100 \% ; p<0.10 \%$ omitted. The asterisk indicates the radiocarbon ages that are being calibrated for the first time here.

c Repeated measurement of samples Y.90.B/82 and Y.90.B/62, on Beta Analytic's initiative (see text).

d N B: these values do not represent the repeated measurements of samples Y.90.B/82 and Y.90.B/62, respectively, but the averaging of the first and second runs for those samples (see text). The italics draw attention to this anomaly.

e New fractions of samples Y.90.B/82 and Y.90.B/62 submitted by A. de Maigret/IsMEO (see text).

Table 2. Barāqish 1990, Temple A: combined dates from mean pooled measurements of 'charcoal 62' and 'charcoal 82' (see Table 1 for samples and details). The lower section of the table lists the available ages for 'charcoal 62'.

The combined ${ }^{14} \mathrm{C}$ age was calculated from the determinations in Table 1 with the R_Combine function in the OxCal 4.3.2 program, updated 14 August 2018, which includes the chi-squared test of significance for the pooling of samples (C2017 C. Bronk Ramsey; at http://C14.arch.ox.ac.uk/, accessed 10 September 2018). This age was then calibrated with the Calib 7.1.0 program (M. Stuiver, P.J. Reimer and R.W. Reimer 2018, CALIB 7.1 at http://calib. org, accessed 10 September 2018) based on the IntCal13 data set (Reimer et al. 2013). All other conventions as in

Table 1.

\begin{tabular}{|c|c|c|c|c|}
\hline Samples & $\begin{array}{l}\text { Laboratory } \\
\text { numbers }\end{array}$ & ${ }^{14} \mathrm{C}$ age $\pm \mathrm{s} b \mathrm{p}$ & $\begin{array}{l}\text { Calendar ages } \mathrm{BC} / \mathrm{AD} \text { at } 2 \mathrm{~s} \text {, and } \\
\text { relative probability } \mathrm{p}\end{array}$ & test of significance $\left(\chi^{2}\right)$ \\
\hline $\begin{array}{l}\text { 'Charcoal 82': } \\
\text { Y.90.B/82; } \\
\text { Y.90.B/82 bis }\end{array}$ & $\begin{array}{l}\text { Beta-39948 + } \\
\text { Beta-42966 }\end{array}$ & $1990 \pm 36^{\mathrm{a}}$ & 58 BC-AD 83 (p.98) & $\begin{array}{l}\mathrm{df}=1 ; \mathrm{T}=2.0(<3.84 \text { at } 5 \%) ; \\
\text { accept pooling }\end{array}$ \\
\hline $\begin{array}{l}\text { 'Charcoal 62': } \\
\text { Y.90.B/62; } \\
\text { Y.90.B/62 bis }\end{array}$ & $\begin{array}{l}\text { Beta-39949 + } \\
\text { Beta-42965 }\end{array}$ & $\begin{array}{l}{[2239 \pm 46]} \\
\text { invalid }^{b}\end{array}$ & $\begin{array}{l}{[394-201 \text { BC (p1)] }} \\
\text { invalid }^{b}\end{array}$ & $\begin{array}{l}\mathrm{df}=1 ; \mathrm{T}=7.4(>3.84 \text { at } 5 \%) \\
\chi^{2} \text { fails: reject pooling }\end{array}$ \\
\hline \multicolumn{5}{|c|}{ Summary of valid ages to be retained for 'charcoal 62' } \\
\hline Y.90.B/62 & Beta-39949 & $2380 \pm 70$ & $770-360 \mathrm{BC}(p .99)$ & \\
\hline Y.90.B/62 + repeat & Beta - & $2460 \pm 50$ & $760-410 \mathrm{BC}(\mathrm{p} 1)$ & \\
\hline Y.90.B/62 bis & Beta-42965 & $2130 \pm 60$ & $360-40$ BC (p.99) & \\
\hline
\end{tabular}

a To be compared with $1920 \pm 50$ in Table 1, derived from the averaging of two runs for sample Y.90.B/82 and equally valid.

b The two original determinations represent different, incompatible ages at 0.05 confidence level. Also distinct is the combined value of $2460 \pm 50$ in Table 1, obtained from the averaging of two runs for sample Y.90.B/62.

January 1990 (Excavs 1990-1992, p. 33-34). Phase Islamic C sensu $1991 .^{13}$
- Y.90.B/82 |Charred wood collected on 22 January 1990 from area L6 in the so-called 'sacristy',

\footnotetext{
13 The attribution of both this and the previous sample to an Islamic phase labelled C ('Stratum C') was made by de Maigret in a handwritten page probably dating from the winter of 1990-1991 (in MAIRY 'C14', folder 'BAR. 1990'), and thus probably referring to his initial periodization (de Maigret 1991a, 7-8; 1991b, 160-161). The Islamic stratum or phase ' $C$ ' was later reclassified as 'Islamic D' (de Maigret 1993, 4-5, 22; de Maigret and Robin 1993, 434). Here I prefer to stick to the former designation, and distinguish it with 'sensu 1991', waiting for the stratigraphic attribution of the two samples to be reassessed.
}

A close reading of Excavs 1990-1992 would indeed suggest that sample Y.90.B/18 might come from a later level than Y.90.B/34, regardless of its dating - a typical instance of 'what dates what?'. Judging from a jotting in the above cited document, it is not impossible that in his attribution to Islamic $C$ de Maigret was influenced by the general agreement between the two calibrated ages and the historical date of imām al-Manșūr billāh 'Abdallāh ibn Hamza, who ruled from Barāqish in 1187-1217 CE. A coin of this ruler had been found near the temple's entrance. 
NW part, in front of the lateral entrance to the temple's hypostyle hall, at the level and in proximity of the plaster face of a statue (Excavs 1990-1992, p. 61-62). Phase Minaean A.

- Y.90.B/62|Charred wood collected on 18 January 1990 from the collapsed upper floor of the socalled 'sacristy', in its southeastern part (or area L3), lying upon the earthen floor near wall M5 and $-1 /-1.10 \mathrm{~m}$ beneath the top of this wall (Excavs 1990-1992, p. 49-51); this level contained the 'millefiori' or mosaic glass bead showing a human face. ${ }^{14}$ Phase Minaean A.

- Y.92.B/138 | Courtyard D, "charcoal from levelling in L4', ${ }^{15}$ i.e., during the removal of deeper deposits in the northwestern part of L4; the sampling was made on 29 August 1992 near the corner of walls M19 and M5 (Excavs 1990-1992, p. 238-239), at a level of about $60 \mathrm{~cm}$ above that of sample $135 .{ }^{16}$ Phase Minaean B.

- Y.92.B/135 | Courtyard D, charcoal collected on 27 August 1992 from plaster floor L31, ${ }^{17}$ a small room associated with wall M38 beneath the corner of walls M18 and M15 (Minaean A) ${ }^{18}$ (Excavs 1990-1992, p. 235-237). Phase Minaean C. This was the lowermost level reached during the 1990-1992 excavations at Temple A.

Four charcoal samples from the initial excavations of Temple A were submitted to Beta Analytic, Inc., on 21 September $1990,{ }^{19}$ and the laboratory reported the results on 25 October. Following the second excavation campaign, two more charcoal samples were sent to Beta on 15 December 1992, whose results were announced by the laboratory on 8 January $1993 .{ }^{20}$

\footnotetext{
14 de Maigret 1991a, 14-15, fig. 10; Antonini 1999, 64, fig. 19 (with references). According to Antonini, this chronologically diagnostic find should be attributed to the 1st century BCE-1st century CE interval. Many more interesting finds of a cultic nature were retrieved from this level, including a gold pendant, as de Maigret noted in his hand-written list of charcoal samples.

15 'Pareggiamento piano in L4', from the bag label in MAIRY 'C14', folder 'BAR. 1992'; similarly in Excavs 1990-1992, p. 238.

16 de Maigret 1993, 21.

17 L31 was described as 'a fine, plastered floor occupying the entire small compartment, thin but hard and characterized by an orange colour' (Excavs 1990-1992, p. 236, translated). In 2003-2004, inadvertently, 'L31' was re-assigned to a room adjacent to bastion T45, as shown by a pencilled addition to a drawing eleven years earlier on page 229 of Excavs 1990-1992 (see, e.g., de Maigret 2010a, fig. 66).

18 'Charcoal from L10 at the corner of walls M18 and M15, earlier level' (bag label in MAIRY 'C14', folder 'BAR. 1992', translated and adapted).

19 In fact, the submission should have been made three months earlier, as indicated by a formal letter of A. de Maigret on IsMEO letterhead dated 5 June 1990, intended to accompany the shipment of samples (MAIRY 'C14', folder 'BAR. 1990'). The submission of these samples might have been delayed until September by administrative problems.

20 MAIRY 'C14', folder 'BAR. 1992'.
}

A total of six charcoal samples were thus selected for radiocarbon dating from the excavations carried out in 1990 and 1992 at Temple A. In fact, the available determinations amount to ten, because two of the samples from 1990 (samples Y.90.B/62 and Y.90.B/82 from the temple's 'sacristy') were subjected to twicerepeated measurements. This resulted from de Maigret's concern that these samples - or age determinations - might have been inverted (communication to Beta Analytic of 1 February 1991). ${ }^{21}$ Beta Analytic remeasured these samples on their own initiative, taking advantage of the remaining amount of material, and reported and commented on the results on 15 February 1991. ${ }^{22}$ On 21 February de Maigret, while acknowledging these results, repeated his request that his two new samples 'from the same excavation units' be measured as well. ${ }^{23}$ These two additional samples will be referred to here as Y.90.B/62 bis and Y.90.B/82 bis. The dates were promptly reported by Beta on 6 March $1991 .{ }^{24}$

These replicated measurements of charcoal from the same sample or from equivalent context lend themselves to pooling (weighted dates), hence to combined age determinations that entail a beneficial reduction in standard deviation (i.e., in statistical uncertainty). If, for the sake of clarity, we call the material in question 'charcoal 62' and 'charcoal 82', we can attempt combined age determinations for both charcoal 62 and charcoal 82, pooling the respective samples from the same 'unit' (Y.90.B/62 and 62 bis; and Y.90.B/82 and 82 bis). The outcome of this exercise is revealing (Table 2). Whereas for charcoal 82 the $\chi^{2}$ test of significance would confirm that the two original

21 A. de Maigret, hand-written note on the Beta submission data sheet accompanying two new samples (see note 23 below). He writes: 'The analyses results on charcoal samples Beta-39948 and Beta-39949, you sent us last 25 october sic, do not correspond to our expectations. According to our archaeological stratigraphy the value $2040 \pm 50 \mathrm{BP}$ should be assigned to Beta-39949, instead of Beta-39948, and vice versa. I'm submitting now two new charcoal samples from the same excavation units (Y.90.B.62 and Y.90.B.82), in order to check the first results'.

22 'We have gone back over all aspects of sample handling and dating procedures, but found no errors. We are confident the radiocarbon contents are correct for the samples as received. In the cross checking procedures, however, we did note that there was sufficient sample weight remaining that they could be reanalyzed [. . . and] we decided to reanalyze both of these samples on a Priority basis. The second set of results closely duplicated the first set of analyses, verifying the apparent anomaly in sequence. Averaging together the first and second runs provides ages of $1920 \pm 50$ for Beta-39948 and $2460 \pm 50$ for Beta-39949' (letter signed by Beta Co-director Jerry J. Stipp, 15 February 1991). This letter is the only source we have for the values from the re-run.

23 'We have to check now if we made some mistakes in handling the charcoal samples here at the IsMEO. So, I think we need additional analyses anyway (unfortunately for us!)' (faxed letter on IsMEO/ MAIRAY letterhead, 21 February 1991). By samples 'from the same excavation units', in February 1991, de Maigret almost certainly meant new fractions of the same samples, being very unlikely that charcoal samples besides those intended for dating could have been exported to Italy.

${ }^{24}$ MAIRY 'C14', folder 'BAR. 1990'. 
samples contained charcoal of statistically identical age (58 BC-AD 83), in the case of charcoal 62 the test failed: two different, incompatible ages were obtained from different fractions of the same sample (or from samples of the same excavation unit; but see note 23). This in turn would suggest that the same sample contained charcoal of heterogeneous origin. ${ }^{25}$

The results in Table 2 only partially match the combined ages already reported by Beta Analytic from the averaging of the first and second runs of the initial samples (Table 1), which to all effects represented a first attempt at pooling the ${ }^{14} \mathrm{C}$ ages from the 'sacristy'. Details about this averaging were not given, ${ }^{26}$ but one can surmise that both charcoal 82 and charcoal 62 passed the $\chi^{2}$ test after the re-runs. From these two exercises in age combination - Beta Analytic in 1991 and ours in these pages - we thus possess three equally acceptable dates for charcoal 62 (Table 2, lower section $^{27}$ and two dates for charcoal 82 (Tables 1-2). Scholars wishing to re-examine the chronology of the temple of Nakrah, and Area A in general, are advised to use the statistically valid, combined ages instead of the individual determinations. In order to aid this reappraisal, a radiometrically 'objective' chronology for the Minaean phases from Area A is outlined in Table 3. Also included in the table is the Islamic period, because the two dates related to this time span (Beta-39950 and Beta-39951) do not appear to have been previously discussed or considered in print.

The only aim of Table 3 is to present in a neutral way the strengths and deficiencies of the available record, so as researchers can improve it when fieldwork in the Jawf can be resumed. The table reveals that the radiometric dataset alone cannot resolve in sufficient detail the dating of the architectural and occupational phases of the Minaean in Area A, and of course in the cultic area of Yathill as a whole. Furthermore, as the dataset combines the disadvantages of old dates tied to a large standard deviation with the problem of the samples' undefined taphonomy, a Bayesian modelling of the dates might be of dubious value. ${ }^{28}$ At the moment, and in broad agreement with de Maigret's conclusions, ${ }^{29} \mathrm{a}$

\footnotetext{
25 This is a common problem in fine-grained deposits in the arid zone subjected to repeated activity and/or redeposition; and charcoal of different origin but similar age is often visually indistinguishable. At Barāqish the problem became evident, and was explicitly addressed, in the extramural excavations at Area C in 2005-2006 (see Fedele, Chapter 18, section 1, in Volume 2).

26 The only information being the passage reproduced in note 22 , above.

27 'Acceptable' means that the dates are valid in a radiometric sense, although, unfortunately, the dates for charcoal 62 carry a very large statistical error that greatly diminishes their 'historical' value (Table 3).

28 Attempts at Bayesian modelling are beyond the scope of the present chapter.

29 Cf. de Maigret 2010a, table 5, last column on the right.
}

chronology for the phasing of Area A and the temple of Nakrah must essentially be based on non-radiometric information in order to be pieced together. As processed in Table 3, the radiocarbon dates can only confirm and concur.

While Table 3 is no more than a statement of chronometric facts, there are additional, cogent justifications today for presenting and clarifying the category of information represented by ${ }^{14} \mathrm{C}$ dates. Firstly, the data from the original laboratory reports need to be made known, as is common usage (Table 1 here), so as to enable readers to separate objective data from subjective utilization. Secondly, the dating for Area A can only benefit from taking into account the calibrated values, obligatorily employing the 2-sigma confidence interval and encompassing all the available dates. This rule does not know exceptions. Indeed it is important to follow the calibrated dates wherever they lead, and learn from what they attempt to 'tell' $\mathrm{us}^{30}-$ if only to evaluate them critically afterwards. Finally, and unfortunately, a tiny error that inadvertently crept into the mention of the dates for Temple A back in 1993 was perpetuated. ${ }^{31}$ Since it is known that de Maigret, after the volume on the excavations at Tamna ${ }^{3},{ }^{32}$ would have dealt with the publication of Barāqish, he presumably would also have reconsidered the old datings of Area A. It is unfortunate that we cannot have his considered opinion.

Neither charcoal samples nor ${ }^{14} \mathrm{C}$ dates were ever mentioned in connection with the corings of January

\footnotetext{
30 Through pooling measurements, for instance (Table 2 here), and of course Bayesian modelling, where applicable.

31 A. de Maigret in the case of Area A always only mentioned the uncalibrated values at 1 sigma and expressed in $B C / A D$ terms, first in de Maigret 1993, 21, and immediately afterwards in de Maigret and Robin 1993, 455, where one of the dates was mistakenly cited (' $10 \pm$ 50 avant l'ère chrétienne' instead of $10 \pm 50 \mathrm{AD}$ for Beta-42966, 1940 $\pm 50 \mathrm{bp}$ ). This unfortunate oversight was incorporated into all the subsequent listings, including Edens and Wilkinson 1998, table VIII, and de Maigret 2010a, table 5 on p. 94. (This latter table, in its fourth column, does not list calibrated dates, as claimed, but uncalibrated 1-sigma values, and this stands in contrast to table 3 on p. 88, concerning the sounding made in 2006, where the equivalent column correctly reports calibrated values. In this latter case, the calibrations supplied by the laboratory were explicitly acknowledged even in the text of the article.) Both the publications and the personal documents preserved in the MAIRY 'C14' folders suggest that de Maigret, in 19911993, chose to use the uncalibrated 1-sigma dates thinking that they fitted the field information better, in the light of some of the finds. (Still a widespread practice at the time; cf. Shennan's remark [1988, 107-108]: 'The trouble is that time intervals of \pm 2 standard deviations are generally so wide that, consciously or unconsciously, archaeologists prefer to overlook them and go for spurious precision'.) In this perspective, three dates were not thought to be useful for the Minaean (Beta-39949 and the Beta repeats and averages). As he did not have reason to modify it, de Maigret maintained his interpretation of dating in each subsequent publication on Temple A. Previously he had exercised admirable attention to chronometry at Yalā/al-Durayb, in that case readily adopting calibration (de Maigret and Robin 1989, 286-288).

32 de Maigret and Robin 2016.
} 
Table 3. Barāqish: radiocarbon dates currently available for Area A and the temple of Nakrah (from Tables 1 and 2). The notes in columns 3 and 4 provide comments on the validity or significance of the radiocarbon ages for dating the corresponding phases.

\begin{tabular}{|c|c|c|c|}
\hline 1 & 2 & 3 & 4 \\
\hline Phases & Selected archaeological features & 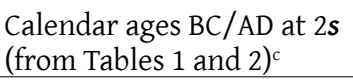 & $\begin{array}{l}\text { Resulting ages for the } \\
\text { phase or part of phase }\end{array}$ \\
\hline Minaean $C^{a}$ & $\begin{array}{l}\text { temple's hypostyle hall and propylon; courtyard } \\
\text { D between temple and curtain wall }\end{array}$ & {$[800]-510 \mathrm{BC}$} & c. $600-510 \mathrm{BC}^{\mathrm{d}}$ \\
\hline Minaean Ba & $\begin{array}{l}\text { monumental staircase M30; house } \mathrm{A} / 1 \text { in front } \\
\text { of temple's entrance }\end{array}$ & {$[750-680], 590-380 \mathrm{BC}$} & $590-380 \mathrm{BC}^{\mathrm{e}}$ \\
\hline \multirow[t]{5}{*}{ Minaean $\mathrm{A}^{\mathrm{a}}$} & temple's annex to the SW ('sacristy') & {$[770-360 \mathrm{BC}]^{\mathrm{f}}$} & c. $300 \mathrm{BC}-\mathrm{AD} 220^{\mathrm{g}}$ \\
\hline & & {$[760-410 \mathrm{BC}]^{\mathrm{f}}$} & \\
\hline & & {$[360]-40 \mathrm{BC}^{\mathrm{f}}$} & \\
\hline & & $58 \mathrm{BC}-\mathrm{AD} 83$ & \\
\hline & & $1 \mathrm{BC}-\mathrm{AD} 220$ & \\
\hline \multirow[t]{2}{*}{$\begin{array}{l}\text { Islamic C } \\
\text { sensu } 1991^{\text {b }}\end{array}$} & $\begin{array}{l}\text { reuse of temple's ruins; stone and mudbrick } \\
\text { houses overlying the ruins }\end{array}$ & AD $1150-1290$ & AD $1150-1260^{\mathrm{h}}$ \\
\hline & & AD $1040-1260$ & \\
\hline
\end{tabular}

a A. de Maigret's (2004a, 20-23;2010a, 93-94) Minaean A to Minaean C'levels'.Previously published in de Maigret 1993, 17-22, and reiterated in de Maigret and Robin 1993, 448-458, figs 4-6. As the Minaean A would radiometrically extend to the 2nd or early 3rd century $\mathrm{AD}$, a more appropriate 'historical' designation for this phase might be Minaean-Amirite or perhaps Minaean-Arab.

b de Maigret 1991a, 8; 1991b, 160-161. For the attribution of both dates to Islamic stratum C (sensu 1991) see text, note 13 , with discussion of potential problems.

${ }^{c}$ Ages of dubious value are in square brackets.

${ }^{d}$ This age must be post-Sabaean, i.e., post-' $805-543$ BC' (DSH-232, 2s total range) and/or post-'798-488 BC' (DSH235). Cf. c. 600-400 BC from Temple B (DSH-375; see Table 1).

${ }^{e}$ From non-radiometric information a 5th-4th-century age appears more likely.

${ }^{f}$ These ages, due to their very large 2 -sigma ranges (410 [!], 350, and 320 years, respectively), are totally or partially unusable for the purpose of column 4.

${ }^{g}$ From non-radiometric information a beginning in the 3rd century appears more likely.

h Overlap of the two ranges in column 3.

1990. To some extent this is surprising, particularly if compared to the findings of 1987 and to the degree of attention accorded to that first series of cores. It is impossible to know whether the explanation should be sought in the absence of charcoal or in a different reason. As already mentioned, the visual inspection of the photographs is insufficient to detect, or to exclude, the presence of charcoal in the cores from $1990 .^{33}$ Certainly, no black units are apparent in the photograph of core D90-2, which is of much better quality than the available images for core D90-1; the nearest approximation is a couple of dark brown units, neither of which can visually qualify as a charcoal layer. On the other hand, the sounding carried out in 2006 at a distance of a mere 16 metres from drilling D90-2 produced quite a few levels of charcoal and corresponding radiocarbon measurements (Sounding $\mathrm{A} / \mathrm{S1}$, see next section).

33 Chapter 15, end of section 3.2 and Fig. 8.

\section{The 2005-2006 excavation campaigns}

In January 2006, soon after the end of the 2005 campaign, de Maigret and I discussed a dating program for Barāqish that would cover the needs brought about by the new field operations. I suggested that the samples be entrusted on a collaborative research basis to the AMS radiocarbon laboratory of Naples University 'Federico II'. ${ }^{34}$ In mid-February a selection of eight charcoal samples from the 2005 campaign, derived from all the operations (Temple B, Area C, and Area D), was submitted to the laboratory. The samples were still awaiting analysis when in the autumn of 2006 we learnt that the Department of Physics at Naples was planning to discontinue the use of the accelerator in

\footnotetext{
34 I had had a research association with this laboratory since the early 1990s, when it had just been formed at the Department of Physics by Filippo Terrasi. Terrasi having later moved to the Second University of Naples at Caserta, the laboratory was now kept operating - at a reduced regime - by one of his former collaborators, Luigi Campajola.
} 
connection with ${ }^{14} \mathrm{C}$. Coincidentally, in the same year, a new and state-of-the art radiocarbon facility had become operational at Caserta, designed and directed by F. Terrasi, who in September 2006 gave me the news and enthusiastically asked me to consider collaborative projects. The Caserta AMS facility, called CIRCE, ${ }^{35}$ was equipped with both a dedicated accelerator for the measurement of carbon isotopes and a specialist laboratory for the preparation of samples.

In consideration of these developments, in early December de Maigret forwarded to CIRCE three samples from his ongoing sounding at Temple A, as a trial, ${ }^{36}$ receiving the dating report on 30 January $2007 . .^{37}$ In the meantime, immediately after the field season of 2006 we reoriented our plans. On behalf of the mission I arranged a partly commercial, partly cost-sharing dating program with Terrasi, and on 18 January a batch of ten charcoal samples from Barāqish was entrusted to CIRCE. This batch included material from both the 2005 and 2006 seasons. The dating results were communicated on 18 April 2007.38 At the same time, the samples with the Naples University laboratory were eventually retrieved (mid-February). Due to limits in university funding and other administrative constraints, two more samples were submitted to CIRCE only later that year, 2007 (Bar.05.B/2a, the single sample from Temple B, and B.06.D/ 2 from the Minaean cemetery). A final batch of seven samples, exclusively comprising material from the extramural excavations in Area C, was submitted to CIRCE on 3 October 2008 in the context of preparing Area $C$ for publication. The results were speedily communicated by the laboratory on 9 December. ${ }^{39}$

\footnotetext{
35 Center for Isotopic Research on Cultural and Environmental Heritage, jointly supported by a regional consortium (Innova) and by the Second University of Naples, Department of Environmental sciences, Caserta. The university has since been renamed Università degli Studi della Campania 'Luigi Vanvitelli'.

36 On my suggestion. Between October and November F. Terrasi and I had already started collaborating on subjects unrelated to Yemen, thus renewing our research partnership of years before, and I had informed de Maigret about CIRCE. A. de Maigret forwarded his samples from Sounding A/S1 during his trip to Italy of 24 November- 9 December 2006, made necessary by university commitments (cf. de Maigret 2010a, 68, footnote 4).

37 On 1 February I sent to de Maigret a cultural-stratigraphic interpretation of the three determinations, complete with probability diagrams.

38 On 15 May I made a first evaluation of these age determinations - again with diagrams - for the benefit of de Maigret and Sabina Antonini, since this information was relevant for both the sounding at Temple A and the cemetery in Area D, in addition to my own excavations at Area $C$. The radiocarbon dates for Area D would be further evaluated with Antonini in January 2008.

39 The publication on Area C (Fedele 2010) was prepared between October 2008 and June 2009 (cf. Chapters 17-19 in Volume 2, and specifically on the datings Chapter 18 , section 1 ). After immediately discussing the results in Naples on 10 December 2008, A. de Maigret asked me permission to cite the datings in his forthcoming lecture at the Académie des Inscriptions et Belles-lettres the following January (with C. Robin; cf. Robin and de Maigret 2009, 67-72).
}

The samples from the 2005-2006 campaigns of our concern in this chapter are related to three different operations: the excavations of Temple B (Area B) and in Area D (Minaean cemetery; Fig. 2), and the deep sounding in front of Temple A (Sounding A/S1; Fig. 1). Detailed context and laboratory information for these samples, complementing the simplified data in Table 1 and listed in the same order, is presented below. ${ }^{40}$

- Bar.05.B/2a | This sample from Temple B was never mentioned in print. ${ }^{41}$ The submission form gives its material, origin, and provenance as charcoal, collected on 29 December 2005, ${ }^{42}$ from '[the] floor of L110, against [wall] M118, at the corner with M122' ${ }^{43}$

- B.06.S1/8 | Stratum C, charcoal from a 'fire' feature in the centre of sounding A/S1, associated with a concave surface (locus L996) and two parallel walls (one made of dry stone and the other of mud bricks).

- B.06.S1/5 | Stratum B, charcoal fragments from a cultural activity level near the base of stratum.

- B.06.S1/13 | Stratum D, charcoal from a 'fire' feature (a hearth?) associated with a beatenearth layer in the NW corner of sounding.

- B.06.S1/15 | Stratum E, charcoal from 'a thick level of ashes' (L998), probably sampled in the NW quadrant of sounding.

- B.06.S1/17 | Stratum H. Not measured, because during pretreatment this sample turned out to be inorganic ('dark grey-brown earth', i.e. disintegrated wood dust, devoid of organic carbon). ${ }^{44}$

- B.06.S1/23 i | Stratum K, charcoal in a dark greyhazel matrix from the NE corner of sounding. ${ }^{45}$

\footnotetext{
40 Sources: MAIRY 'C14', folder '2006', where the original labels of several samples are preserved; and S. Antonini, personal document (in litteris 8 September 2018). Secondary sources: de Maigret 2010a, 88 , table 3 . The provenance and characterization of the samples from Sounding A/S1 were derived from the layer descriptions in de Maigret 2010a, 70-76 and figs 9-72, 77-78, 85 [= 84], 91, 92. The single determination for Temple B and the determinations for Area D were never published. These latter were only mentioned in interpretive passages without formal citation (Antonini and Agostini 2010a, 14, 29, 43-44).

41 '[Charcoal] samples collected during the excavation [of Temple B for $]{ }^{14} \mathrm{C}$ dating' were mentioned by Agostini $(2011,54)$, but the dating performed on this sample had remained unknown (cf. Agostini 2015, 10; and Chapter 3, this volume).

42 Submission form to the Naples University 'Federico II' accelerator laboratory, signed by de Maigret. The accompanying list of all submitted samples mentions 'wood', 'collected on 19.12.2005', but I consider the former a more reliable source.

43 For the sampling location of this charcoal and an evaluation of its historical significance see Agostini, Chapter 3, this volume (sections 2.4 and 2.5 , respectively).

44 The material came from inside the sheath of a big vertical stake (stake 'a'): de Maigret 2010a, 72.

45 Results from two identically labelled samples, here differentiated as ' 23 i' and ' 23 ii', were reported by the laboratory. Alerted in writing (my e-mail of 15 May 2007, mentioned in footnote 38), de Maigret was somehow able to trace the samples to two different strata.
} 
- B.06.S1/23 ii | Stratum M, cm-sized charcoal fragments from hardened, fire-reddened sediments 'against the $\mathrm{S}$ section [of sounding] and near a partly hewn block of limestone', a possible hearth. ${ }^{46}$

- B.06.D/8 | Layer 1, charcoal and bone fragments from the "level at the base of the Minaean fill, above the sandy layer that covers the tombs, $-1.20 \mathrm{~m}$ below ground surface', collected on 27 December 2006.

- B.06.D/4 | Layer 3, 'level of the Minaean funerary structures and stelae, $-1.50 \mathrm{~m}$ below ground surface', collected on 25 December 2006; expected age '3rd century BC-1st century AD'. The tombs have been interpreted as cenotaphs, not body burials.

- B.06.D/2 | Layer 1, '-50 cm from surface (testing)', collected on 21 December 2006.

- B.05.D/14+18 | Layer 4, a charcoal sample composed of separate subsamples ('D/14' and 'D/18') retrieved from a 'test below mudbrick wall M3 of level 3 (Minaean funerary structures and stelae), $-2.80 \mathrm{~m}$ below the ground surface', in association with Sabaean pottery; ${ }^{47}$ expected age 'first half of the 1st millennium $B C$ '. While the individual samples were from the first excavation season at the cemetery, the date on the label, '24.12.2006', probably refers to the constitution of the combined sample.

The date that was possible to obtain in connection with Temple B (Bar.05.B/2a) presents all the limits of a single measurement from an otherwise chronologically unknown locus or sector, and the reader is strongly advised not to forget it. On the other hand, this dating is interesting insofar as it begins to align Temple $B$ and its area with the chronometric information already available for Area A. A provisional suggestion in this respect is advanced in Table 3, note ' $d$ '. In the sample submission form, A. de Maigret had indicated as expected age ' 4 th- 1 st century $B C$ ' $[B C E]$, evidently thinking that the sample could date the portion of architecture being exposed in 2005. However, this radiocarbon result obtained at the end of 2007 or in early 2008 was temporarily set aside, and one can wonder why. A. de Maigret did not have time to deal with it, we can surmise, as in that period he was totally focused on preparing for publication the results of Sounding $\mathrm{A} / \mathrm{S} 1,{ }^{48}$ and in the following months he was occupied with the organization of the Rencontres Sabéennes to be held in Rome..$^{49}$ Presumably he was also

\footnotetext{
46 de Maigret 2010a, 70.

47 Sabaean pottery: Antonini and Agostini 2010a, 28-29.

48 The Italian manuscript for 'A Sabaean stratigraphy' (de Maigret 2010a) was completed in February or early March 2008 (cf. Fedele, Chapter 15, footnote 12).

49 XII Rencontres Sabéennes, held at IsIAO on 11-13 June 2008.
}

waiting - or hoping - for additional datable material with the continuation of the excavations at Barāqish.

Obviously, the great interest of the radiocarbon dates from Sounding A/S1 for the earlier history of Barāqish and the whole Jawf was worth being emphasized..$^{50}$ Promptly compiled for publication (cf. footnote 48), an interpretation of the $\mathrm{A} / \mathrm{S} 1$ dates and ceramic stratigraphy would feature in a forthcoming issue of the journal Arabia, just now reaching the planning stage in connection with the meetings in Rome. ${ }^{51}$ Among the dates from the sounding, the age of 1277-1127 BCE provided by determination DSH-291 for the lowermost inspected layer at Yathill (Stratum M) was the oldest date not only for this site, but also for the presumably urban settlement in the Jawf. It retains this significance to this day.

Conversely, the radiometric results from Area D did not appear to convey much meaning for the understanding of the Minaean cemetery. Upon reading the determination for B.06.D/2, de Maigret pencilled on the laboratory report: "Why is this [date] older than the necropolis covered by this layer?'.52 'Samples of charcoal collected from Level 3 have given results that coincide with those for Level 1', noted Antonini in the publication, ${ }^{53}$ hence her suggestion that sample B.06.D/2 contained reworked charcoal from the plundering of tombs.

In fact, these datings are of great potential interest for the overall history of 'Hill D' - both physical and cultural - in the context of the western belt of 'greater' Yathill, Minaean cemetery included. ${ }^{54}$ In particular, the charcoal ages from both Layer 4, culturally defined by Sabaean material in situ (sample B.05.D/14+18), and Layer 1, containing multiply redeposited Minaean and perhaps Sabaean sediments (B.06.D/2), already contribute rare glimpses of the long and rich utilization which seems to have characterized this part of the Barāqish area, ${ }^{55}$ and which until now has remained underappreciated.

\footnotetext{
50 de Maigret 2010a, 88, 93-94; Robin and de Maigret 2009, 63-67. In this latter publication, the significance of these dates was evaluated together with the chronology resulting from Area C (Fedele 2010, tables 2-3), while C.J. Robin employed both radiometric sets in his wide-ranging reappraisal of the political history of the Jawf-Najrān region.

51 See Chapter 1, section 4.1 and footnote 121, this volume.

52 In Italian in the original.

53 Antonini and Agostini 2010a, 43-44. The Area D 'levels' will be designated here as 'layers'.

54 See Fedele, Chapter 26 in Volume 2.

55 Fedele 2014, 2019; and cf. Chapter 19, section 3, in Volume 2.
} 


\section{References to MAIRAY/MAIRY archival and personal} documents

Corings: A. de Maigret, Yemen 1987- Barāqish corings ['Yemen 1987 - Carotaggi Barāqish'] notebook

Excavs 1990-1992: A. de Maigret, Barāqish 1990 and 1992 excavations, a notebook headed 'Barāqish 1990 scavi', but comprising the excavation journals of both campaigns as two distinct, consecutive sections

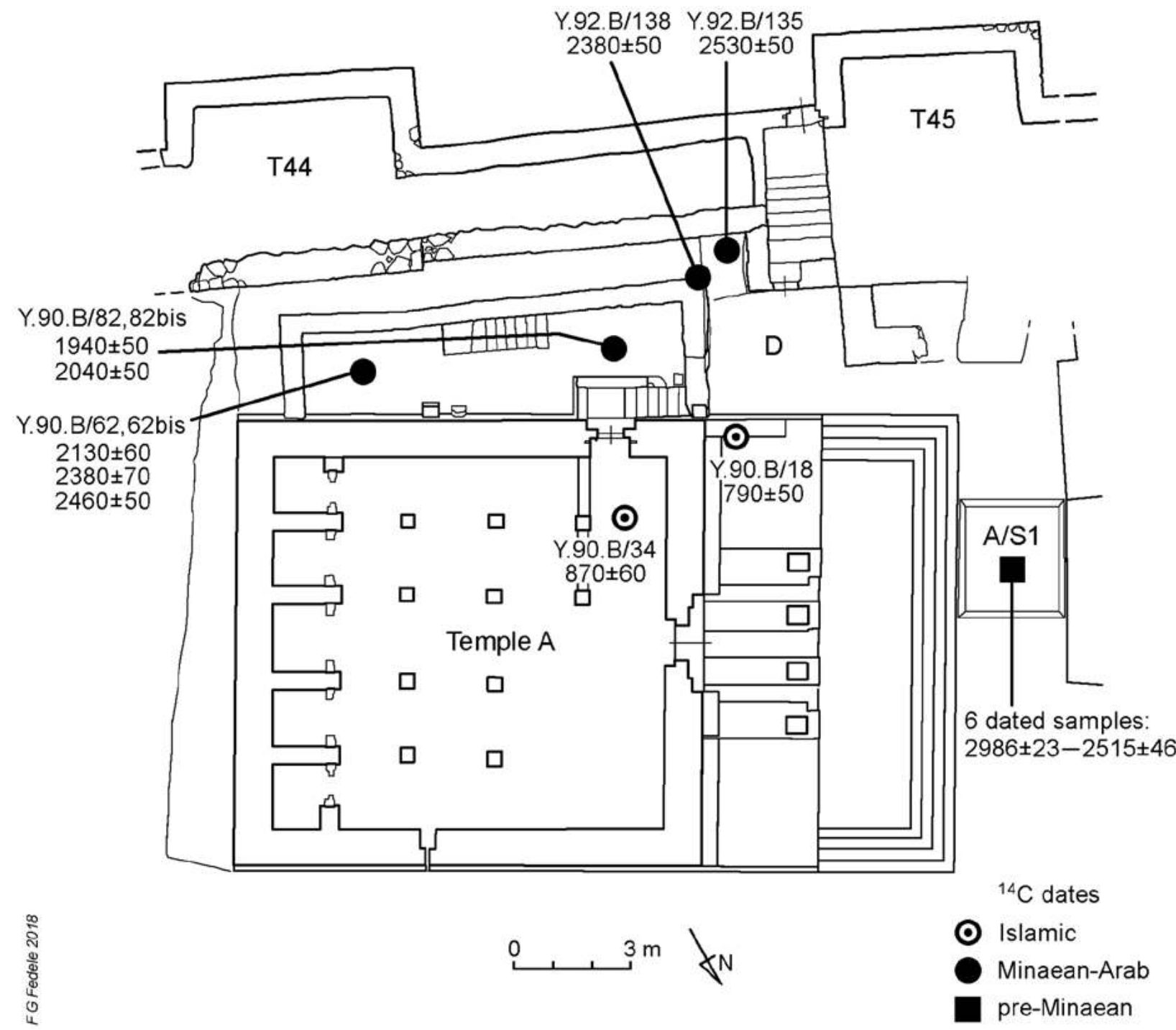

Figure 1. Barāqish, 1990-2006: sampling locations for radiocarbon dating from Area A. Topographic plan by F.G. Fedele after de Maigret 1993, fig. 2 (@ MAIRY), with additions from the 2004-2006 seasons. 


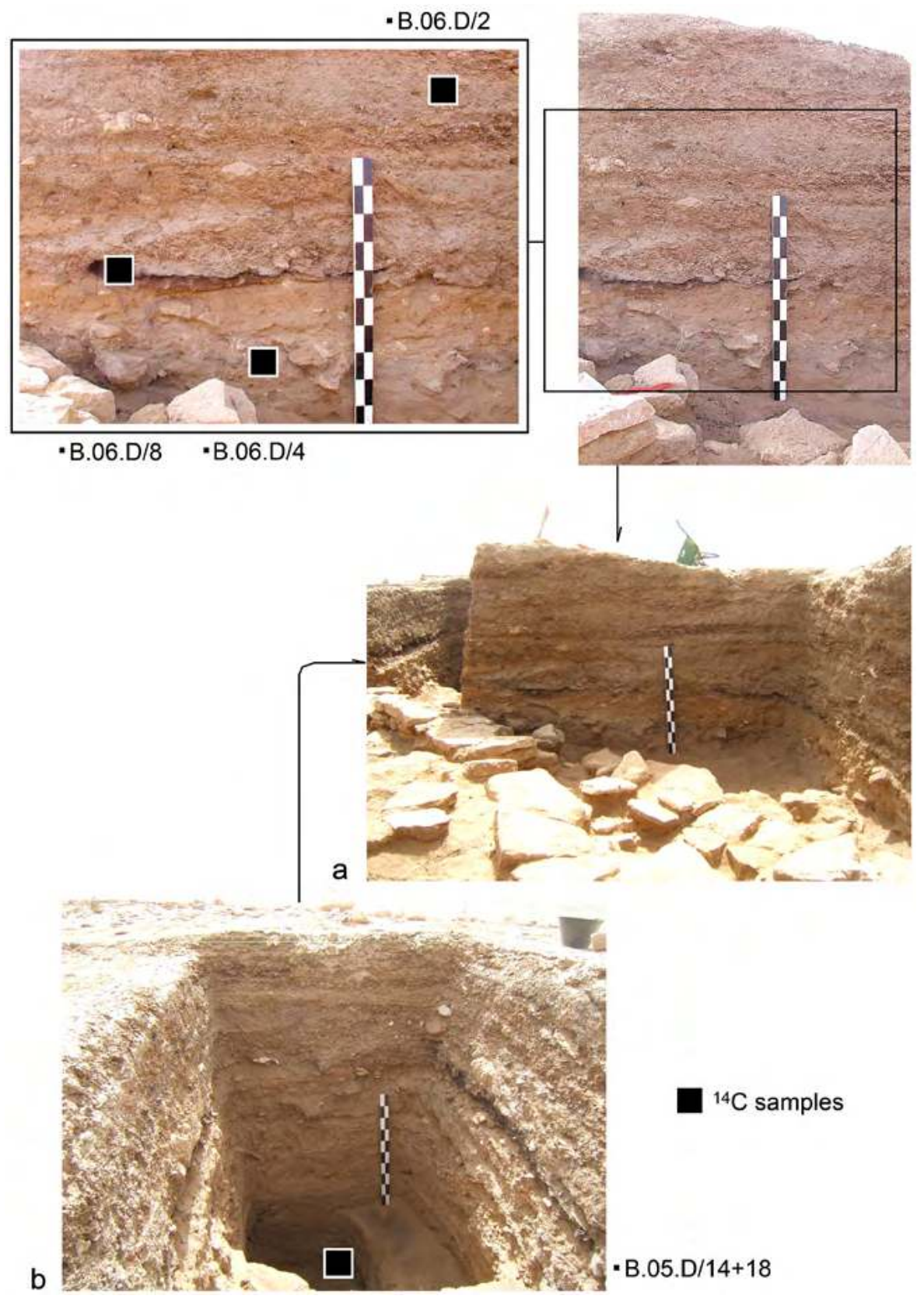

Figure 2. Barāqish, 1990-2006: stratigraphic provenance of samples for radiocarbon dating from Area D, marked onto photographs of the southern section of excavation (a) and nearby sounding (b). Photographs taken on 27 December 2006 (courtesy S. Antonini @ MAIRY).

Figure 3. Barāqish: calibration plot of radiocarbon-dated samples from the 1987 coring campaign.

Original data from Table 1. (F.G. Fedele)

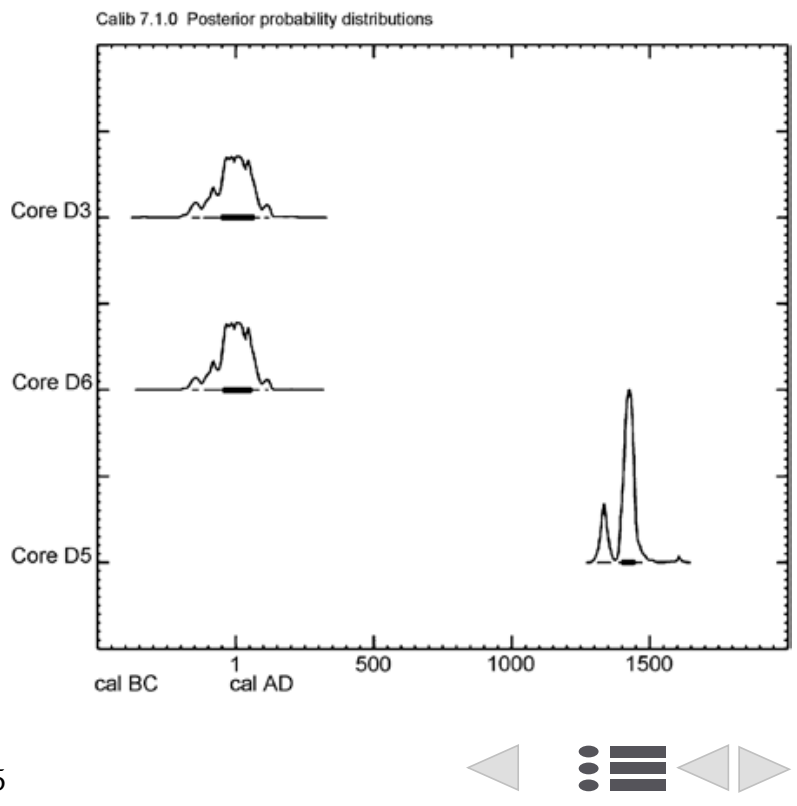


Calib 7.1.0 Posterior probability distributions
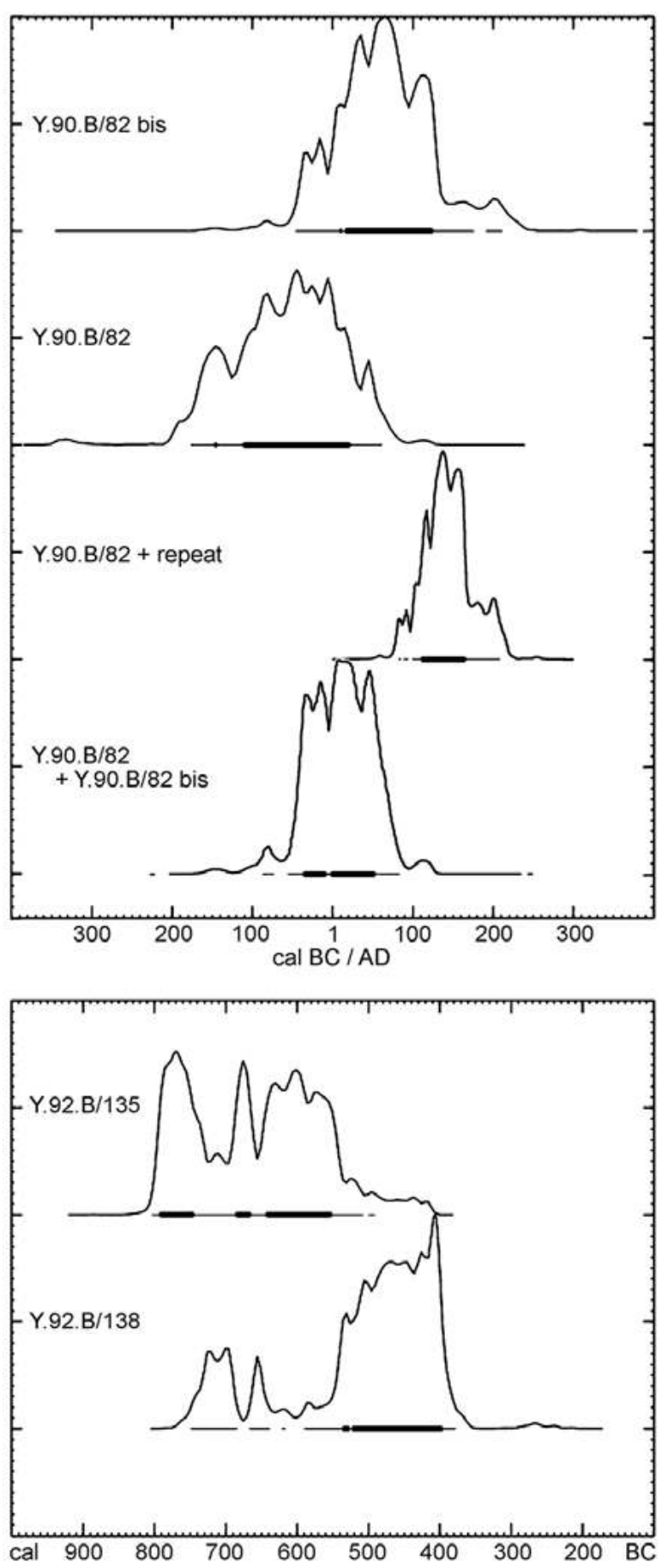
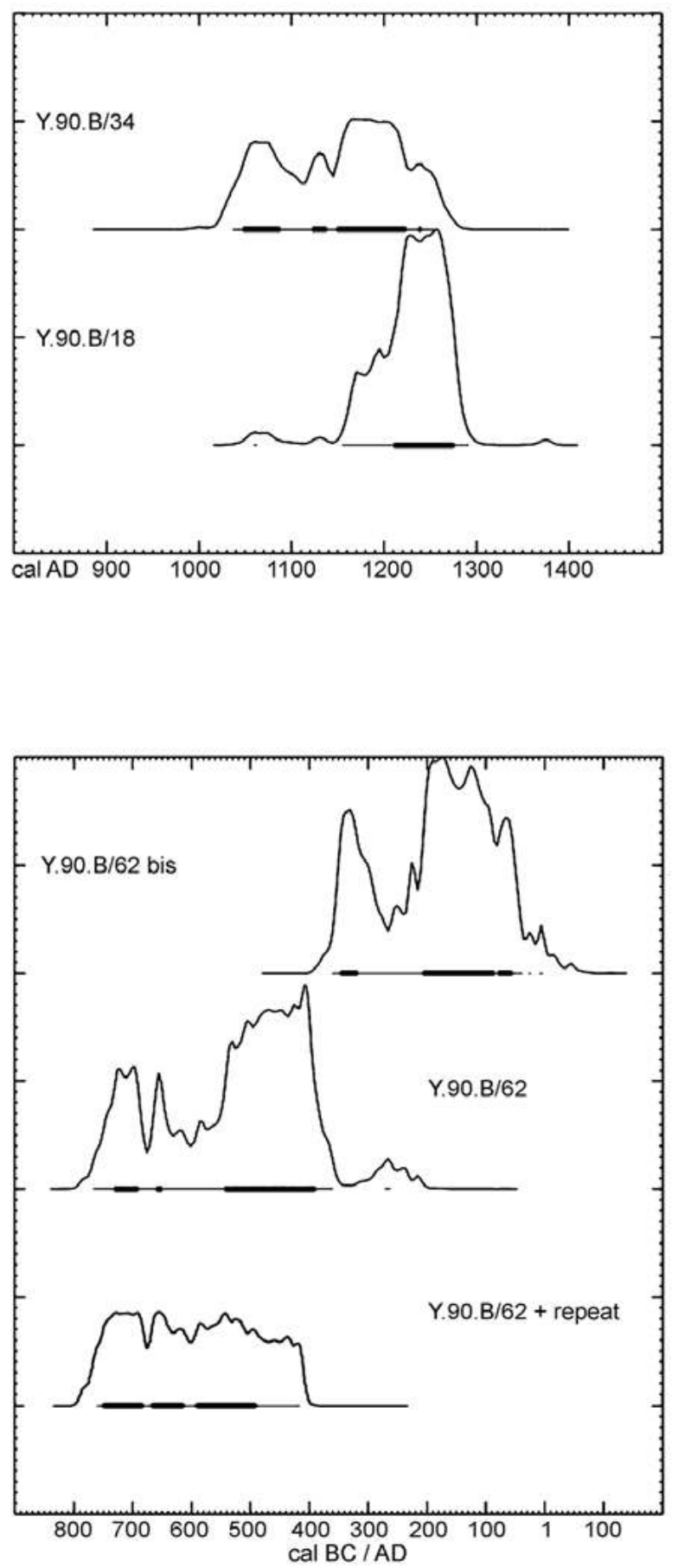

Figure 4. Barāqish: calibration plot of radiocarbon-dated samples from the 1990 and 1992 excavation campaigns in Area A (Temple of Nakrah), including both individual and combined datasets. Original data from Tables 1 and 2. (F.G. Fedele) 


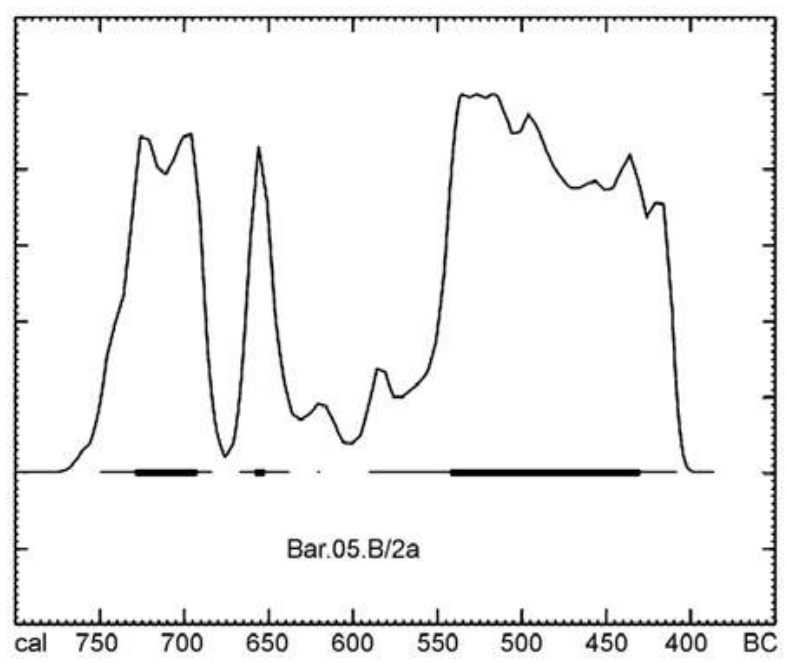

Calib 7.1.0 Posterior probability distributions

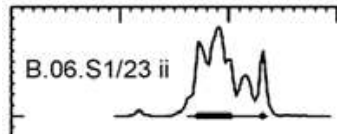

B.06.S1/23i
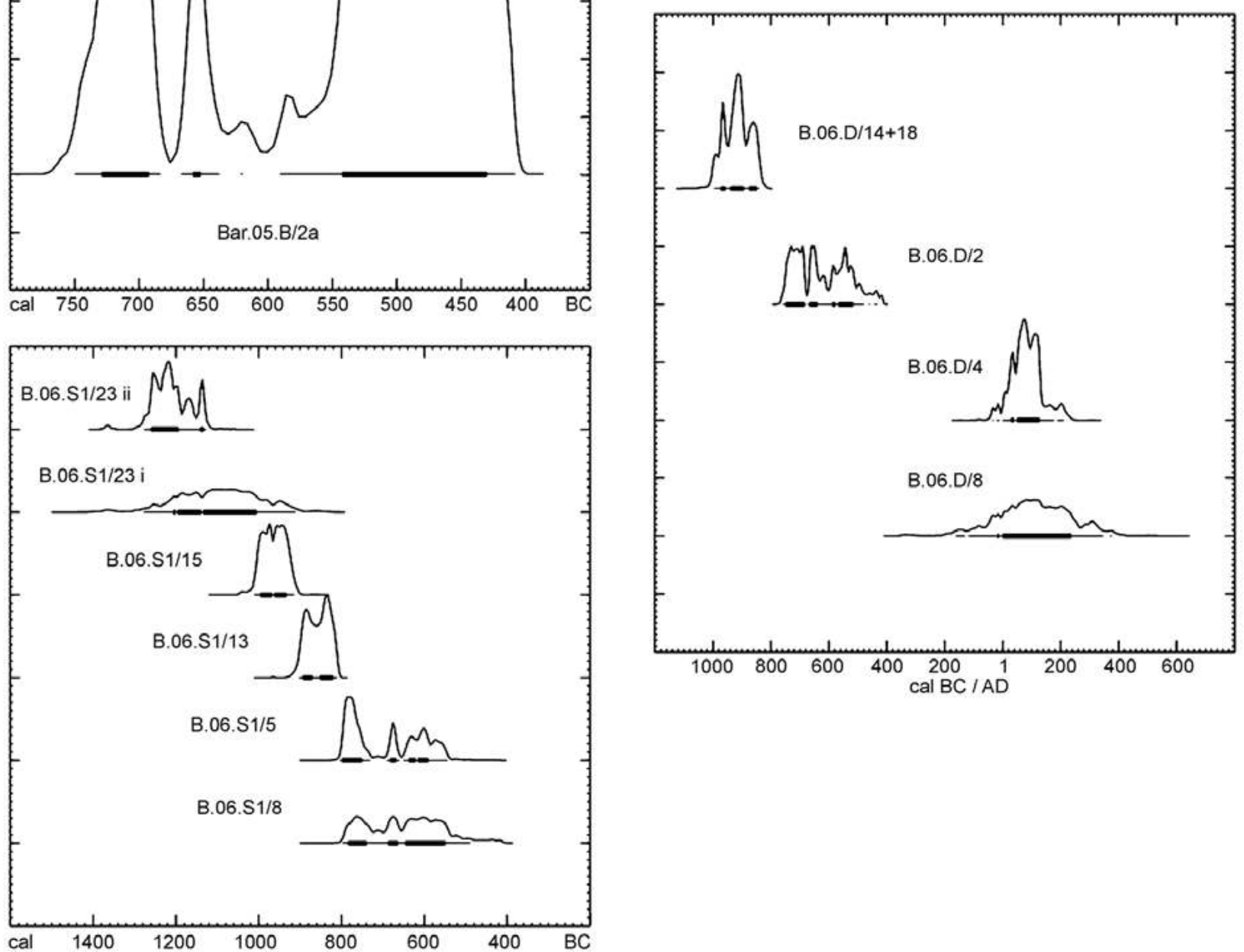

Figure 5. Barāqish: calibration plot of radiocarbon-dated samples from the 2005-2006 excavation campaigns: Temple of 'Athtar dhu-Qabd, Sounding A/S1, and Area D (Minaean cemetery). Original data from Table 1. (F.G. Fedele) 


\section{Bibliography for Volume 1}

In this book the references of the individual chapters were brought together in a unified bibliography. In order to facilitate consultation, however, the bibliographic entries pertaining to the chapters in each volume have been separated. Only the references related to the chapters in the present volume are listed below.

Arabic names with prefixed definite article (al-) are listed according to the first letter of the name following the article.

Adam, J.-P.

1982 L'architecture militaire grecque. Paris: Éditions Picard.

Agostini, A.

2004 Saggio comparativo di alcuni termini architettonici dei templi sudarabici, Arabia. Revue de sabéologie 2, 43-59.

2010 Building materials in South Arabian inscriptions: observations on some problems concerning the study of architectural lexicography, Proceedings of the Seminar for Arabian Studies 40, 85-97.

2011 Two new inscriptions from the recently excavated temple of 'Athtar dhū-Qabḍ in Barāqish (Ancient Minaean Yathill). In memoriam Alessandro de Maigret, Arabian Archaeology and Epigraphy 22 (1), 48-58.

2012 New perspectives on Minaean expiatory texts, Proceedings of the Seminar for Arabian Studies 42, 1-12.

2014 Peccato e trasgressione nei testi di espiazione sudarabici, in A. Bausi, A. Gori and G. Lusini (eds), Linguistic, Oriental and Ethiopian studies in memory of Paolo Marrassini, 3-21. Wiesbaden: Harrassowitz Verlag.

2015 The excavation of the temple of 'Athtar dhuQabḍ in Barāqish. Stratigraphic data and historical reconstruction, Proceedings of the Seminar for Arabian Studies 45, 1-14.

2018a The Jawf Valley as a crossroad: some observations about the tribe of Amir in South Arabia, ARAM 30, 355-368.

2018b Il rito di espiazione sudarabico antico: uno sguardo ai nuovi dati da Barāqish (Yemen), in M. Betrò, S. De Martino, G. Miniaci and F. Pinnock (eds), Egitto e Vicino Oriente antichi: tra passato e futuro. Studi e ricerche sull'Egitto e il Vicino Oriente in Italia. I convegno nazionale, Pisa, 5-6 giugno 2017, 85-95. Pisa: Pisa University Press.

2020a Seasonal offerings among the Minaeans: The case of ancient Yathil, Arabian Archaeology and Epigraphy, https://doi.org/10.1111/aae.12155. [Published online 16 April 2020.] 2020b Clues for Minaean history. A chronological reassessment in light of new epigraphic and archaeological data from Barāqish (5th and 4th centuries BC), Vicino Oriente 24, 167-183.

'Alī 'Aqīl, 'A. and S. Antonini

2007 Repertorio Iconografico Sudarabico, 3. I bronzi sudarabici di periodo pre-islamico. Rome: Istituto Italiano per l'Africa e l'Oriente. Paris: Académie des Inscriptions et Belles-Lettres.

Andrefsky, W., Jr

2005 Lithics. Macroscopic approaches to analysis, 2nd edition. Cambridge: Cambridge University Press.

Antonini, S.

1988 Nuovi incensieri iscritti yemeniti, Oriens Antiquus 27 (1-2), 133-141.

1996 Segni facciali su alcune statue femminili sudarabiche, Annali dell'Istituto Universitario Orientale di Napoli 56 (4), 458-461.

1999 Statuettes from the excavations of the temple of Nakrah (Temple A) at Barāqish (Republic of Yemen), Arabian Archaeology and Epigraphy 10 (1), 58-68.

2004 I motivi figurativi delle banāt ' $\bar{A} \mathrm{~d}$ nei templi sudarabici (Repertorio iconografico sudarabico 2). Paris: Académie des inscriptions et belles-lettres. Rome: Istituto italiano per l'Africa e l'Oriente. [Distribution: Diffusion de Boccard, Paris; Herder, Rome.]

2005 Alcune stele inedite dal Jawf (Yemen), in A.S. Sedov and I.M. Smiljanskaja (eds), Arabia Vitalis. Studies in honour of Vitalij Naumkin in occasion of his 60th anniversary, 308-313. Moscow: Institut Vostokovedenija RAM.

2009 Alessandro de Maigret, in A.M. Sholan et al. 2009, xix-xxiii; bibliography, xxiv-xxxiv. [Originally published Naples and Șan $(\bar{a}), 2005$.]

2010 The archaeological materials, in S. Antonini and A. Agostini (eds) 2010a, 15-41.

2013 New sculptures of the 'Lady of ad-Dālic' style, Raydān. Journal of Ancient Yemeni Antiquities and Epigraphy 8, 9-24.

2016 La necropoli di Hayd bin 'Aqīl, in A. de Maigret and C.J. Robin (eds) 2016, 341-427.

Antonini de Maigret, S.

2012 South Arabian Art. Art History in Pre-Islamic Yemen (Orient \& Méditerranée 10). Paris: Éditions de Boccard.

Antonini, S. and A. Agostini

2010a A Minaean necropolis at Barāqish (Jawf, Republic of Yemen). Preliminary report of the 2005-2006 archaeological campaigns. With an appendix by Paola Pagano (Reports and Memoirs n. s. 9). Rome: Istituto Italiano per l'Africa e l'Oriente. 
2010b Excavations of the Italian Archaeological Mission in Yemen: A Minaean Necropolis at Barāqish (Wadi Jawf) and the Qatabanian Necropolis of Hayd bin 'Aqīl (Wadi Bayhān), in Ll. Weeks (ed.), Death and burial in Arabia and beyond. Multidisciplinary perspectives (BAR International Series 2107; Society for Arabian Studies Monographs 10), 215-224. Oxford: Archaeopress.

2013 Two new bronze statues from Yemen, in F. Briquel-Chatonnet, C. Fauveaud and I. Gajda (eds), Entre Carthage et l'Arabie heureuse. Mélanges offerts à François Bron (Orient \& Méditerranée 12), 3-14. Paris: Éditions de Boccard.

Antonini, S. and V. Buffa

2016 The pottery from the houses on the Market Square of Tamna', in A. de Maigret and C.J. Robin (eds) 2016, 443-597.

Arbach, M.

1993 Le madhābien: Lexique, Onomastique et Grammaire d'une langue de l'Arabie méridionale préislamique. PhD dissertation, Université de Provence Aix Marseille I, Aix en Provence.

1994 Inscriptions sudarabiques, Raydān. Journal of Ancient Yemeni Antiquities and Epigraphy 6, 5-16.

Arbach, M. and R. Audouin

$2007 \operatorname{San}^{(} \hat{a}{ }^{\prime}$ National Museum. Collection of epigraphic and archaeological artifacts from al-Jawf sites - Part II (UNESCO Social Fund for Development, Republic of Yemen). San' $\bar{a}$ ': National Museum.

Arbach, M. and C. Darles

2019 Architecture et épigraphie des temples des citésEtats de la région du Jawf dans les Basses-Terres du Yémen, in G. Hatke and R. Ruzicka (eds), Ancient South Arabia through History: Kingdoms, Tribes, and Traders, 234-317. Newcastle upon Tyne: Cambridge Scholars Publishing.

Arbach, M. and J. Schiettecatte

2006 Catalogue des pièces archéologiques \& épigraphiques du Jawf au Musée national de San' $\hat{a}^{\prime}$ (UNESCO Social Fund for Development, Republic of Yemen). Șan'āa: National Museum; and Centre français d'archéologie et de sciences sociales.

Arbach, M., J. Schiettecatte and I. al-Hādī

2008 Arbach, M., Jérémie Schiettecatte, I. Al-Hādī, San' $\left(\bar{a}^{\prime}\right.$ National Museum - Part III. Collection of funerary stelae from the Jawf valley (UNESCO Social Fund for Development, Republic of Yemen). San( $\bar{a}$ ': National Museum.

Arbach, M., A. Avanzini, A. Bātāyic and C.J. Robin

2001 Matériaux pour le corpus des inscriptions qatabānites (II), Raydān. Journal of Ancient Yemeni Antiquities and Epigraphy 7, 43-101.

Audouin, R.

1994 Les autels à encens de l'Arabie antique, Saba. Art, Littérature, histoire de l'Arabie Méridionale 1 (Parfums d'Arabie), 33-34.
Aurenche, O.

1977 Dictionnaire illustré multilingue de l'architecture du Proche-Orient ancien (Collection de la Maison de l'Orient méditerranéen, 3. Série archéologique 2. Institut Français d'Archéologie de Beyrouth (Liban), Publication Hors-série). Lyon: Maison de l'Orient).

1981 La maison orientale: l'architecture du Proche Orient ancien des origines au milieu du quatrième millénaire (3 tomes) (Institut Français d'Archéologie de Beyrouth, Beyrouth-Damas-Amman, Bibliothèque Archéologique et Historique, T. CIX). Paris: P. Geuthner.

Avanzini A., M. 'Abd al-Q. Bāfaqīh, A. Bāțāyic and C.J. Robin

1994 Materiali per il Corpus Qatabanico, Raydān. Journal of Ancient Yemeni Antiquities and Epigraphy 6, 17-36.

Barca, D., G. Lucarini and F.G. Fedele

2012 The provenance of obsidian artefacts from the Wādī ath-Thayyilah 3 Neolithic site (eastern Yemen Plateau) by LA-ICP-MS, Archaeometry 54 (4), 603622.

Beaucamp, J. and C.J. Robin

1981 Le christianisme dans la péninsule Arabique d'après l'épigraphie et l'archéologie, Hommage à $M$. Paul Lemerle (Travaux et Mémoires [de l'UMR 8167 Orient \& Méditerranée] 8) 45-61. Paris: Éditions de Boccard.

Beeston, A.F.L.

1962 A Descriptive Grammar of Epigraphic South Arabian. London: Luzac \& C.

Beeston, A.F.L., M.A. Ghul, W.W. Müller and J. Ryckmans 1982 Sabaic dictionary - Dictionnaire Sabéen. Louvain: Peeters.

Berenson, A.

2015 Twelve days. A John Wells novel. New York: G.P. Putnam's Sons (Penguin Group).

Bessac, J.-C.

1998a Techniques de construction, de gravure et d'ornementation en pierre dans le Jawf, in J.-F. Breton (ed.) 1998, 173-230.

1998b Le travail de la pierre à Shabwa, in J.-F. Breton (ed.) 1998, 231-283.

2009 La construction en pierre à Shabwa: du palais à l'étude comparative, in J-F. Breton (ed.) 2009, 33-71. Bianchi, E.

2003 Un finto rabbino, una subdola guida, un diario che riappare. Viaggio in Yemen di Joseph Halévy. Milan: Guerini e Associati.

2008 Note di viaggio in Yemen alla ricerca degli ultimi ebrei, in M. Bergaglio (ed.), Popolazioni che cambiano. Studi di geografia della popolazione, 139-157. Milan: Franco Angeli.

Blakely, J.A., J.A. Sauer, M.R. Toplyn [and contributors] 1985 (L.J. Tiede, volume ed.) The Wadi al-Jubah Archaeological Project. 2: Site reconnaissance in North Yemen, 1983. Washington (DC): The American Foundation for the Study of Man. 
Bowen, R.LeB., Jr, F.P. Albright [and contributors]

1958 Archaeological discoveries in South Arabia (Publications of the American Foundation for the Study of Man 2). Baltimore (MD): The Johns Hopkins Press.

Bowersock, G.W.

1983 Roman Arabia. Cambridge (MA), London: Harvard University Press. [Paperback ed. 1994.]

Bradley, R.

1982 The destruction of wealth in later prehistory, Man $17,108-122$.

2005 Ritual and domestic life in prehistoric Europe. London: Routledge.

2017 A geography of offerings. Deposits of valuables in the landscapes of ancient Europe. Oxford, Philadelphia: Oxbow Books.

Breton, J.-F.

1979 Le temple de Syn d-Ḥlșm à Bâ-quțfah (République démocratique et populaire de Yémen), Raydān. Journal of Ancient Yemeni Antiquities and Epigraphy 2, 185-202, pls I-IX.

1992c Le sanctuaire de 'Athtar dhū-Riṣaf d'as-Sawdā' (République du Yémen), Académie des Inscriptions et Belles-Lettres, Comptes rendus des séances de l'année 1992 136 (2), 429-453.

1994 Les fortifications d'Arabie méridionale $d u 7^{e}$ au $1^{\text {er }}$ siècle avant notre ère (Archäologische Berichte aus dem Yemen 8). Mainz am Rhein: Verlag Philipp von Zabern.

1997 L'architecture domestique en Arabie méridionale, du VIIe s. av. au IVe s. ap. PhD dissertation, Université de Paris 1 - Panthéon-Sorbonne.

1998 Les temples de Ma'īn et du Jawf (Yémen): état de la question, Syria. Revue d'Art oriental et d'Archéologie 75, 61-80.

1999 Arabia Felix from the time of the Queen of Sheba. Eighth century B.C. to first century A.D. Notre Dame (IN): University of Notre Dame Press. [French edition 1988, Paris, Hachette Littératures.]

Breton, J.-F. (ed.)

1992a Fouilles de Shabwa II. Rapports préliminaires (Institut Français d'Archéologie du Proche-Orient [IFAPO], Publications hors série 19). Paris: Librairie orientaliste Paul Geuthner. [Reissue as a volume from Syria. Revue d'Art oriental et d'Archéologie 68 (1991).]

1998 Fouilles de Shabwa III. Architecture et techniques de construction (Bibliothèque archéologique et historique 154). Beyrouth: Institut français d'archéologie du Proche-Orient.

2009 Fouilles de Shabwa IV. Shabwa et son contexte architectural et artistique du Ier siècle avant J.-C. au IVe siècle après J.-C. (Centre français d'archéologie et de sciences sociales de Sanaa - Institut Français du Proche-Orient, Damas-Beyrouth-Amman). Șan ( $\bar{a})$ : Print Art.
2011 Le sanctuaire de 'Athtar dhū-Risāf d'as-Sawdä' (Arabia Antica - Archaeological and Philological Series 7). Rome: 'L'Erma' di Bretschneider.

Breton, J.-F. and A. Bațayā' [Ahmed Bāțāyic]

1992 Les autels de Shabwa, in J.-F. Breton (ed.) 1992a, 365-378.

Breton, J.-F. and J.-C. Bessac

2002 Observations sur les remparts de Ma'in et de Kamna, Vestnik drevnej istorii, 147-155.

Breton, J.-F. and C.J. Robin

1987 La muraille de Naqab al-Hağar (Yémen sud), Syria. Revue d'Art oriental et d'Archéologie 64 (1-2), 1-20.

Breton, J.-F., C.J. Robin and R. Audouin

1981 Nord-Yémen, la prospection épigraphique et archéologique: un patrimoine menacé, Archéologia 160, 36-41, 43. [November 1981]

Buffa, V.

2007 Ma layba et l'Âge du Bronze du Yémen (Archäologische Berichte aus dem Yemen 12). Wiesbaden: Reichert Verlag.

Burke, J.G.

1991 Cosmic debris. Meteorites in history. Berkeley: University of California Press.

Calvet, Y. and M. Pic

1997 Les découvreurs de la péninsule Arabique, in Y. Calvet et al. 1997, 77-83.

Calvet, Y. and C. Robin with F. Briquel-Chatonnet and M. Pic

1997 Arabie heureuse, Arabie déserte. Les antiquités arabiques du Musée du Louvre (Notes et documents des musées de France). Paris: Éditions de la Réunion des musées nationaux.

Caquot A. and A.J. Drewes

1955 Les monuments recueillis à Maqallé (Tigré), Annales d'Éthiopie 1 (1), 17-42.

Caton-Thompson, $\mathrm{G}$.

1938 Geology and Archaeology of the Hadhramaut, South-west Arabia. Preliminary Notes on the Lord Wakefield Expedition, Nature 142 (3586), 139-142.

1944 The tombs and moon temple of Hureidha (Hadhramaut) (Reports of the Research Committee of the Society of Antiquaries of London 13). Oxford: University Press.

Caton-Thompson, G. and E.W. Gardner

1939 Climate, irrigation, and early man in the Hadhramaut, The Geographical Journal 93, 18-38. [January 1939]

Caubet, A., I. Gajda and F. Demange

2003 Deux autels de bronze provenant de l'Arabie méridionale, suivi d'un appendice de Mme Françoise Demange sur la technique de fabrication (note d'information), Comptes rendus des séances de l'Académie des Inscriptions et Belles-Lettres 147 (3), 1219-1242.

Charloux, G. and C.J. Robin

2016 De Saba' à Sanaa. La recherche archéologique française au Yémen jusqu'en 2012, in G. Charloux and J. Schiettecatte (eds) 2016, 22-35. 
Charloux, G. and J. Schiettecatte (eds)

2016 Yémen. Terre d'archéologie. Șan'(̄a): Centre français d'Archéologie et de Sciences sociales de Sanaa. Paris: Librairie orientaliste Paul Geuthner.

Chevalier, N.

2012 Early excavations (pre-1914), in D.T. Potts (ed.), A companion to the archaeology of the ancient Near East 1, 48-69. Chichester: Wiley-Blackwell.

Clarke, D.L.

1968 Analytical archaeology. London: Methuen \& Co.

Cleuziou, S.

1986 Rapport de mission en République Arabe du Yémen. Région de Marib, wadi al-Jawf (octobre 1986). Unpublished report. Paris.

Cleuziou S., M.-L. Inizan and B. Marcolongo

1992 Le peuplement pré- et protohistorique du système fluviatile fossile du Jawf-Hadramawt au Yémen (d'après l'interprétation d'images satellite, de photographies aériennes et de prospections), Paléorient 18 (2), 5-29.

Cleuziou, S., M. Tosi and J. Zarins (eds)

2002 Essays on the late prehistory of the Arabian peninsula. Proceedings of the First international conference on the Conservation and exploitation of the archaeological heritage of the Arabian Peninsula held in the Palazzo Brancaccio, Rome, by IsMEO on 28th-30th May 1991. Rome: Istituto Italiano per l'Africa e l'Oriente.

Conolly, J.

2003 Tools and debitage of obsidian and flint, in R. Matthews (ed.) 2003a, 363-375.

Costa, P.M.

1972a Il Museo Archeologico Nazionale dello Yemen, Levante 18 (1971) (4), 5-35.

1972b Archaeology in the Yemen, Proceedings of the Seminar for Arabian Studies 2 [1970-1971], 21-24.

1977 A Latin-Greek inscription from the Jawf of the Yemen, Proceedings of the Seminar for Arabian Studies 7, 69-72.

1978 The pre-Islamic antiquities at the Yemen National Museum (Studia Archaeologica 19). Rome: 'L'Erma' di Bretschneider.

1986 Further comments on the bilingual inscription from Baraqish, Proceedings of the Seminar for Arabian Studies 16, 33-36.

1991 South Arabian jar sealings, Proceedings of the Seminar for Arabian Studies 21, 41-48.

2000 La nascita del Museo Archeologico dello Yemen a San'â [sic], in Yemen 2000, 33-37.

Costantini, L.

1986 Paleobotanical research, in de Maigret et al. 1986, 465.

Costantini, L. and L. Costantini Biasini

1986 Laboratory of Bioarchaeology. Palaeoethnobotanical investigations in the Middle East and Arabian Peninsula, 1986, East and West 36 (4), 354365.
CSAI

2019 Corpus of South Arabian inscriptions, in DASI. $<$ http://dasi.cnr.it/index.php?id= 42\&prjId= 1\&corI $\mathrm{d}=0$ \& colId=0\&navId=0>, accessed 1 December 2019 . [CSAI is a project of DASI.]

Cucarzi, M.

1986 Geophysical prospection in the necropolis of Waraqah, in de Maigret et al. 1986, 465-470.

Darles, C.

1998 Etude typologique de l'architecture civile intramuros, in J.-F. Breton (ed.) 1998, 3-25.

2001 Les temples et leurs dieux, Dossiers d'Archéologie 263, 44-47. [May 2001]

2003 Les fortifications de Shabwa, capitale du royaume de Hadramawt, Proceedings of the Seminar for Arabian Studies 33, 215-217.

2008 Derniers résultats, nouvelles datations et nouvelles données sur les fortifications de Shabwa (Hadramawt), Proceedings of the Seminar for Arabian Studies 38,141-152.

2009a Hypothèses de restitution du dispositif d'entrée du Palais royal de Šabwa, in A.M. Sholan et al. 2009, 151-171.

2009b Les monolithes dans l'architecture monumentale de l'Arabie du Sud antique, Proceedings of the Seminar for Arabian Studies 39, 95-109.

2010 L'emploi du bois dans l'architecture du Yémen antique, Proceedings of the Seminar for Arabian Studies 40, 149-160.

2011 Les fortifications de Khor-Rori (Sumhuram), Proceedings of the Seminar for Arabian Studies 41, 61-68.

2012 L'usage du bois, sa standardisation et sa réutilisation dans la construction au cœur du désert de l'Arabie antique, in A. Sousa Melo and M. do Carmo Ribeiro (eds) História da construção os materiais, 35-58. (Centro de Investigação Transdisciplinar 'Cultura, Espaço e Memória' - Laboratoire de Médiévistique Occidentale de Paris, Université de Paris 1 et CNRS). Braga: Sersilito-Empresa Gráfica, Lda.

2014 Typologie des sanctuaires de l'Arabie du Sud antique: tentative pour une nouvelle classification, Proceedings of the Seminar for Arabian Studies 44, 121138.

2017 Quarante-cinq ans d'archéologie au Yémen, l'émergence d'une mémoire, Le Jardin des Antiques 60, 36-44. [January 2017]

2018 Mud brick architecture in Hadramawt-Yemen under the Qu'aiti and Kathiri Sultanates, in S. Pradines (ed.), Earthen architecture in Muslim cultures. Historical and anthropological perspectives, 146-166 (Arts and Archaeology of the Islamic World 10). Leiden, Boston: Brill.

DASI

2019 Digital archive for the study of pre-Islamic Arabian inscriptions, A. Avanzini (project dir.). Pisa: Università degli studi di Pisa, and Scuola Normale Superiore. 
Rome: Consiglio Nazionale delle Ricerche. <http:// dasi.cnr.it/>, accessed 1 December 2019.

Daum, W. (ed.)

1988 Yemen. 3000 years of art and civilisation in Arabia Felix. Innsbruck: Pinguin-Verlag. Frankfurt am Main: Umschau-Verlag. [Original edition 1987 (German).] de Biberstein-Kazimirski, A.

1960 Dictionnaire arabe-francais: contenant toutes les racines de la langue arabe. Vols I-II. Paris: Editions G.P. Maisonneuve. [1860]

de Contenson, $\mathrm{H}$.

1962 Les monuments d'art sudarabe découverts sur le site de Haoulti (Éthiopie) en 1959, Syria. Revue d'Art oriental et d'Archéologie 39 (1), 64-87.

de Maigret, A.

1986 Sabaean-Minaean culture. A: Archaeological studies, in A. de Maigret et al. 1986, 384-394.

1988 Archaeological survey on the Wādī Yalā antiquities, in A. de Maigret (ed.) 1988, 1-20.

1990b La città dell'incenso, Archeo - Attualità del passato 6 (67), 28-37. [September 1990]

1991a Gli scavi della Missione Archeologica nella città minea di Barāqish. Con una nota di G. Gnoli (Conferenze IsMEO 3). Rome: Istituto per il Medio ed Estremo Oriente. [Contains Gnoli 1991, q.v.]

1991b The excavations of the temple of Nakrah at Barāqish (Yemen), Proceedings of the Seminar for Arabian Studies 21, 159-172.

1993 La seconda campagna di scavi della Missione Archeologica Italiana a Barāqish (Yemen 1992). Con una nota di G. Gnoli (Conferenze IsMEO 6). Rome: Istituto per il Medio ed Estremo Oriente. [Contains Gnoli 1993a, q.v.]

1996 Arabia Felix. Un viaggio nell'archeologia dello Yemen. Milan: Rusconi Libri.

1997a Yathill, in Yémen 1997, 138-139.

1998a Der Tempel von Baraqish, in Jemen 1998, 217-218.

1998b Yathil: la città e il deserto. Scavi italiani nel Vicino Oriente, Archeologia Viva 17 (67), 54-59. [JanuaryFebruary 1998.]

2000a Le attività della Missione Archeologica Italiana nello Yemen, in Yemen 2000, 31-32.

2000b Il tempio di Nakrah a Barâqish/Yathill, in Yemen 2000, 167-168.

2000c Svelando la regina di Saba, in P. Gribaudo (ed.), La regina di Saba. Arte e leggenda dallo Yemen. Torino, Palazzo Bricherasio, 26 settembre 2000-7 gennaio 2001, 26-41. Milan: Electa.

2003 La ceramica sabea. Specificità e sviluppi da uno studio delle forme, Arabia. Revue de sabéologie 1, 8996, 217-244 (plates 12-39).

2004a Barāqish, Minaean Yathill. Excavation and restoration of the temple of Nakrah (YICAR Papers 1). Șan'ā [sic]: Yemeni-Italian Centre for Archaeological Research.

$2004 \mathrm{~b}$ New stratigraphical data for the ancient chronology of Tamna', in A. Sedov (ed.), Scripta Yemenica. South Arabian studies in honour of Prof. Mikhail Borisovich Piotrovskij, 242-256. Moscow. 2005a The Italian Archaeological Mission. An appraisal of 25 years research (1980-2004) (YICAR Papers 2). Șan ‘̄ā [sic]: Yemeni-Italian Centre for Archaeological Research.

2005b Restoration work on the Temple of Nakrah at Barāqish (and related excavations), in Sāleh 'Alī Bāsurrah (ed.), Șan' $\bar{a}$. History and cultural heritage. Proceedings of the Fifth International Conference on Yemeni Civilization. Vol. 1, 33-41. Șan'ā': University of Sanaa; Al-Metha.

2006 Excavations of the Italian Archaeological Mission in the second temple at Barāqish (2004-2005), in C.J. Robin and M.`A.al-R. Jāzim (eds), 2006, 81-92. [Reprinted in de Maigret 2012, article XIV.]

2009a Arabia Felix. Anexploration of the archaeological history of Yemen. Reprinted with a foreword by Professor T.J. Wilkinson. London: Stacey International. [First published 1999, reprinted 2002.]

$2009 \mathrm{~b}$ The excavations of the Italian Archaeological Mission at Barâqish (Republic of Yemen), Newsletter Archeologia (CISA) 0, 50-90. Also available online: <http://www.unior.it/userfiles/workarea_231/file/ Articoli/De\%20Maigret\%2050-90.pdf>, accessed 1 December 2019.

2010a A Sabaean stratigraphy from Barāqish, Arabia. Revue de sabéologie 4 [2007-2010], 67-95, 205-240 (figs 66-127). [Reprinted in de Maigret 2012, article XVI.]

2010b Il grande tempio di Yéha (Etiopia) ed i templi minei di Barāqish (Yemen), in F. Mazzei and P. Carioti (eds), Oriente, Occidente e dintorni... Scritti in onore di Adolfo Tamburello. Vol. 2, 773-781. Naples: Università degli studi di Napoli 'L'Orientale', Dipartimento di Studi asiatici. Rome: Istituto Italiano per l'Africa e l'Oriente.

2012 Saba', Ma'în et Qatabân. Contributions à l'archéologie et à l'histoire de l'Arabie ancienne. Choix d'articles scientifiques préparés par $\mathrm{S}$. Antonini de Maigret and C.J. Robin (Orient \& Méditerranée 8). Paris: Éditions de Boccard.

2016 Il tempio di Athirat. Rapporto finale degli scavi 1999-2000, in A. de Maigret and C.J. Robin (eds) 2016, 109-257.

de Maigret, A. (ed.)

1988a The Sabaean archaeological complex in the Wādi Yalā (eastern Hawlān aț-Tìyāl, Yemen Arab Republic). A preliminary report (Reports and memoirs 21). Rome: IsMEO / Istituto Italiano per il Medio ed Estremo Oriente. [In English and Arabic.]

1990a The Bronze Age culture of Hawlān at-Tiyāl and AlHadā (Republic of Yemen). A first general report (Reports and Memoirs 24). Rome: IsMEO/Istituto Italiano per il Medio ed Estremo Oriente.

de Maigret, A. and C. Robin

1989 Les fouilles italiennes de Yalâ (Yémen du Nord): nouvelles données sur la chronologie de l'Arabie du Sud préislamique, Académie des Inscriptions et BellesLettres, Comptes rendus des séances de l'année 1989133 
(2), 255-291. [Reprinted in de Maigret 2012, article VI.]

1993 Le temple de Nakrah à Yathill (aujourd'hui Barāqish), Yémen, résultats des deux premières campagnes de fouilles de la Mission italienne, Académie des Inscriptions et Belles-Lettres, Comptes rendus des séances de l'année 1993137 (2), 427-496. [Reprinted in de Maigret 2012, article XIII.]

2006 Tamna', antica capitale di Qatabān / Tamna', capitale antique de Qatabān. (YICAR Papers 3). Șan '̄ā: YemeniItalian Centre for Archaeological Research.

de Maigret, A. and C.J. Robin (eds)

2016 Gli scavi italo-francesi di Tamna' (Repubblica dello Yemen). Rapporto finale (Orient \& Méditerranée 20). Paris: Éditions de Boccard.

de Maigret, A., G.M. Bulgarelli, L. Costantini, P. Cuneo, F.G. Fedele, V. Francaviglia, U. Scerrato, M. Tosi and G. Ventrone

1985 Archaeological activities in the Yemen Arab Republic, 1985, East and West n.s. 35 (4), 337-395.

de Maigret, A., G.M. Bulgarelli, L. Costantini, M. Cucarzi, P. Cuneo, F. Di Mario, F.G. Fedele, V. Francaviglia, G. Gnoli, B. Marcolongo, A.M. Palmieri, G. Pettinato, U. Scerrato, M. Tosi and G. Ventrone

1986 Archaeological activities in the Yemen Arab Republic, 1986, East and West 36 (4), 376-470.

de Maigret A., F.G. Fedele, V. Francaviglia, G. Gnoli, G. Pettinato, M. Tosi, U. Scerrato [et al.]

1987 Cooperation activities of the Italian Archaeological Mission in the Yemen Arab Republic. 1987 Report [of] activities. MAIRAY/IsMEO, unpublished report submitted to the General Organization for Antiquities and Museums, Șan' $\bar{a})$, Republic of Yemen.

de Maigret, A., C. Azzi, B. Marcolongo and A.M. Palmieri 1989 Recent pedogenesis and neotectonics affecting archaeological sites in North Yemen, Paléorient 15 (1), 239-243.

del Olmo Lete, G. and J. Sanmartin [and contributors]

2003 A dictionary of the Ugaritic language in the alphabetic tradition. (Handbuch der Orientalistik. Der Nahe und Mittlere Osten 67, Vols 1-2). Leiden: E.J. Brill.

Denzer-Feydy, J.

2009 Le décor sculpté en pierre, in J.-F. Breton (ed.) 2009, 131-164.

Dietz, R.S. and J. McHone

1974 Kaaba Stone: not a meteorite, probably an agate, Meteoritics 9 (2), 173-179.

Doe, D.B.

1983 Monuments of South Arabia (Arabia past and present 12). Santa Maria la Bruna (Naples): The Falcon Press. Cambridge, New York: The Oleander Press.

Durrani, N.

2005 The Tihamah coastal plain of south-west Arabia in its regional context c.6000 BC-AD 600 (Society for Arabian Studies Monographs 4; BAR International Series 1456). Oxford: Archaeopress.
Duveyrier, H. ('Rapporteur')

1873 Rapport sur le concours au prix annuel pour la découverte la plus importante en géographie [etc.], Bulletin de la Société de Géographie [Paris] 6e série, 6, 31-51.

Drewes, A.J. and J. Ryckmans

2016 Les inscriptions sudarabes sur bois dans la collection de l'Oosters Institut conservée dans la bibliothèque universitaire de Leiden. Texte révisé et adapté par Peter Stein. Edité par Peter Stein et Harry Stroomer. Wiesbaden: Harrassowitz.

Edens, C. and T.J. Wilkinson

1998 Southwest Arabia during the Holocene: recent archaeological developments, Journal of World Prehistory 12 (1), 55-119.

Eichmann, R. and H. Hitgen

2003 Marib, Hauptstadt des Sabäischen Reiches / Marib, capital of the Sabaean kingdom, in I. Gerlach (ed.) 2003a, 52-61.

Fakhry, A. [Ahmad Fakhrī]

1948 Les antiquités du Yémen. Un voyage à Șirwâh, Mârib et el-Ǧôf, Le Muséon 61 (3-4), 215-226.

Fakhry, A. [Ahmad Fakhrī] and G. Ryckmans

1951-1952 An archaeological journey to Yemen (March-May 1947), 3 vols. Part I [text] (1952); Part II, Epigraphical texts, by G. Ryckmans (1952) [in French]; Part III, Plates (1951). Cairo: Service des Antiquités de l'Égypte/Mașlaḥat al-Āthār, Government Press.

Fedele, F.G.

1990b Radiocarbon dates, in A. de Maigret (ed.) 1990a, 205-212. [The bibliography, mistakenly omitted from the printed volume, is available at http:// www.researchgate.net/profile/F_Fedele.]

1990c Fossil volcanism and archaeology: the North Yemen Highlands, in C. Albore Livadie and F. Widemann (eds), Volcanology and archaeology / Volcanologie et archéologie. Proceedings of the European Workshops of Ravello, November 19-27, 1987 and March 30-31, 1989 (PACT 25), 11-23. Strasbourg: Conseil de l'Europe/Council of Europe.

2010 Barāqish, over-wall excavations 2005-2006: stratigraphy, environment and economy of the Sabaean-Islamic sequence, Arabia. Revue de sabéologie 4 [2007-2010], 97-161, 241-257 (figs 128-145).

2011a The wall and talus at Barāqish, ancient Yathill (alJawf, Yemen): a Minaean stratigraphy, Proceedings of the Seminar for Arabian Studies 41, 101-120.

$2011 \mathrm{~b}$ In memoriam. Alessandro de Maigret, Proceedings of the Seminar for Arabian Studies 41, xi-xiii.

2014 Camels, donkeys and caravan trade: an emerging context from Barāqish, ancient Yathill (Wādī alJawf, Yemen), Anthropozoologica 49 (2), 177-194.

2017 New data on domestic and wild camels (Camelus dromedarius and Camelus sp.) in Sabaean and Minaean Yemen, in M. Mashkour and M. Beech (eds), Archaeozoology of the Near East 9. In honour of Hans-Peter Uerpmann and François Poplin, 286-311. Oxford, Philadelphia: Oxbow Books. 
2019 First millennium BC archaeofaunas from Yemen: Italian studies at Yalā and Barāqish, in M. Baldi, R. Dan, M. Delle Donne, G. Lucarini and G. Mutri (eds), Archaeology of food. New data from international missions in Africa and Asia. Proceedings of the 1st Workshop on the Archaeology of Food - Rome, 26 May 2016 (ISMEO, Serie Orientale Roma n.s. 17), 187-211. Rome: Scienze e Lettere.

in press Rethinking the Highland Bronze Age of Yemen, in C. Darles, L. Khalidi, M. Arbach and M. BarretAudouin (eds), Arabie du Sud et Corne de l'Afrique: échanges et relations de l'Age du Bronze à l'Islam. Actes des 21es Rencontres Sabéennes tenues à Toulouse en juin 2017 en hommage à Rémy Audouin (Sites et Cités d'Afrique series). Toulouse: Presse Universitaire $d u$ Midi.

Fedele, F.G. and D. Zaccara

2009 Wādì al-Tayyila 3: a mid-Holocene site on the Yemen Plateau and its lithic collection, in A.M. Sholan et al. (eds) 2009, 213-245.

Finster, B.

1986 Die Stadtmauer von Mārib, in Archäologische Berichte aus dem Yemen 3, 73-95. Mainz am Rhein: Philipp von Zabern.

Fogelin, L. and M.B. Schiffer

2015 Rites of passage and other rituals in the life histories of objects, Cambridge Archaeological Journal 25 (4), 815-827.

Fontana, M.V.

2016 A brief note on the Yemenite Chahār Ṭāq Mausoleums. The case of Barāqish, Vicino Oriente 20, 49-56.

Fontaine, H. and M. Arbach

2006 Yémen. Cités d'écritures. Manosque: Editions Le Bec en l'air.

Forte, M.

1967 Sull'origine di alcuni tipi di altarini sud-arabici, Annali dell'Istituto Orientale di Napoli 17, 97-120.

Francaviglia, V.

1987 Geoarchaeological survey at Barāqish, Y.A.R., in de Maigret et al. 1987, 19-20 [unpublished report dated 7 September 1987].

1990 Obsidian sources in ancient Yemen, in A. de Maigret (ed.) 1990a, 129-136.

2002 Some remarks on the irrigation systems of Ancient Yemen, in S. Cleuziou et al. (eds) 2002, 111-144.

Frenez, D.

2019 In memoriam. Paolo M. Costa (1932-2019), Proceedings of the Seminar for Arabian Studies 49, viiviii.

Gajda, I.

2012 Liens entre symboles et divinités dans les inscriptions sudarabiques, in I. Sachet (ed.) [En collaboration avec Christian Julien Robin], Dieux et déesses d'Arabie. Images et représentations, 447-459. Actes de la table ronde tenue au Collège de France (Paris) le 1er et 2 octobre 2007. Paris: Éditions de Boccard.
Garbini, G.

1974 Iscrizioni sudarabiche. I: Iscrizioni minee (Pubblicazioni del Seminario di Semitistica, Istituto Orientale di Napoli, Ricerche 10). Naples: Istituto Universitario Orientale.

2000 Il contributo italiano alle ricerche sudarabiche, in Yemen 2000, 27-30.

Gentelle, P.

2003 Traces d'eau. Un géographe chez les archéologues. Paris: Éditions Belin.

Gerlach, I.

2002 Der Friedhof des Awām-Tempels in Marib, Bericht des Ausgrabungen von 1997 bis 2001, in Archäologische Berichte aus dem Yemen 9, 41-92. Mainz am Rhein: Philipp von Zabern.

2003b 25 Jahre archäologische Forschungen im Jemen: die Station und Aussenstelle Sanaa - Geschichte und Aufgaben / 25 years archaeological research in Yemen: the Station and Branch Sanaa - History and tasks, in I. Gerlach (ed.) 2003a, 24-37.

2012 Yeha: an Ethio-Sabaean site in the highlands of Tigray (Ethiopia). in A.V. Sedov (ed.), New research in archaeology and epigraphy of South Arabian and its neighbors. Proceedings of the Rencontres Sabéenne 15th held in Moscow, May 25th-27th, 2011, 214-238. Moscow.

Gerlach, I. (ed.)

2003a 25 Jahre Ausgrabungen und Forschungen im Jemen 1978-2003 / 25 years excavations and research in Yemen 1978-2003 (Hefte zur Kulturgeschichte des Jemen 1). Șan' $\bar{a}$ ', Berlin: Deutsches Archäologisches Institut, Orient-Abteilung, Aussenstelle Sanaa.

al-Ghabban, A.I., B. André-Salvini, F. Demange, C. Juvin. and M. Cotty. (eds)

2010 Routes d'Arabie. Archéologie et histoire du Royaume d'Arabie Saoudite. Paris: Louvre éditions; and Somogy éditions d'art. [Exhibition catalogue: Paris, Musée du Louvre, 14 July-27 September 2010.]

Ginouvès, R. and R. Martin

1985 Dictionnaire méthodique de l'architecture grecque et romaine. 1. Matériaux, techniques de construction, techniques et forme du décor (Collection de l'École française de Rome 84). (Athens École Française d'Athènes et Rome, École Française de Rome). Rome. Giumlia-Mair, A., E.J. Keall, A.N. Shugar and S. Stock

2002 Investigation of a copper-based hoard from the megalithic site of al-Midamman, Yemen: an interdisciplinary approach, Journal of Archaeological Science 29, 195-209.

Glanzman, W.D. and A.O. Ghaleb [and contributors]

1987a (L.J. Tiede and S.J. Fleming, volume eds) The Wadi al-Jubah Archaeological Project, 3. Site reconnaissance in the Yemen Arab Republic, 1984: the stratigraphic probe at Hajar ar-Rayhani. Washington (DC): American Foundation for the Study of Man.

Glaser, E.

1913 (ed.D.H. von Müller and N. Rhodokanakis) Reisenach Mārib; nebst 4 kartographischen und topographischen 
Beilagen und 3 Skizzen der Dammbauten bei Marib. Vienna: Verlag Alfred Hölder.

Glassé, C.

2001 New encyclopedia of Islam. A revised edition of the Concise encyclopedia of Islam. Walnut Creek (CA), New York: AltaMira Press (a division of Rowman \& Littlefield Publishers).

Gnoli, G.

1986a South Arabian notes 1, East and West 36 (1-3), 267-269.

1986b Sabaean-Minaean culture. B(b): Philological research. South-Arabian cultures and Persian sources, in A. de Maigret et al. 1986, 395-396.

1988 Research activities in Arabia: a foreword to the first scientific contribution by the Italian Archaeological Mission of IsMEO in the Yemen Arab Republic, in A. de Maigret (ed.) 1988a, ix-xiii.

1991 Le iscrizioni venute alla luce nella campagna 19891990, in de Maigret 1991a, 17-19.

1993a Sulle nuove iscrizioni di Baraqish, in de Maigret 1993, 23-33.

1993b Shaqab al-Manașșa (Inventaire des inscriptions sudarabiques 2). Paris: Académie des inscriptions et belles-lettres. Rome: Istituto italiano per il Medio ed Estremo Oriente. [Distribution: Diffusion de Boccard, Paris; Herder, Rome.]

1996a Una nuova iscrizione minea di Barāqish sulla confessione dei peccati, in E. Acquaro (ed.), Alle soglie della classicità. Il Mediterraneo tra tradizione e innovazione. Studi in onore di Sabatino Moscati, 11451159. Pisa, Rome: Istituti editoriali e poligrafici internazionali.

1996b Il sincronismo mineo-persiano, in C.J. Robin and I. Gajda (eds) 1996, 23-34.

2009 Ancora sui 'Medi' in RES 3022, in A.M. Sholan et al. (eds) 2009, 295-300. [Originally published Naples and $\operatorname{Ṣn}^{(} \bar{a}^{\prime}, 2005$.]

Gnoli, G. and C.J. Robin

1992 Nouveaux documents sabéens de Barāqish, in Yemen. Studi archeologici, storici e filologici sull'Arabia meridionale, 1, 93-98. Rome: Istituto Italiano per il Medio ed Estremo Oriente.

Goitein, Sh.D.

1938 An Arabic-Hebrew book on a tour in Yemen in 1870, in F.I. Baer, F.S. Bodenheimer, J.N. Epstein, M. Fekete, A. Fodor, I.J. Kligler and L.A. Mayer (eds), Sefer Magnes / Magnes anniversary book. Contributions by members of the academic staff of the Hebrew University, 89-96. Jerusalem: The Hebrew University Press. [Hebrew with English summaries.]

Goitein, Sh.D. (trans. and ed.)

1941 Travels in Yemen. An account of Joseph Halévy's journey to Najrān in the year 1870 written in San'ani Arabic by his guide Hayyim Habshush, with a detailed summary in English and a glossary of vernacular words. Jerusalem: The Hebrew University Press.

Golvin, J.-C. and J.-C. Goyon

1987 Les bâtisseurs de Karnak. Paris: Presses du CNRS.
Gosden, C. and Y. Marshall

1999 The cultural biography of objects, World Archaeology 31 (2), 169-178.

Grady, M.M.

2000 Catalogue of meteorites. With special reference to those represented in the collection of the Natural History Museum, London, 5th edition (revised and enlarged). London: Cambridge University Press.

Grjaznevič, P.A.

1994 Južnaja Aravija. Pamjiatniki drevnej istorii i kultury. 2. Materialy ekspedicii P.A. Grjaznevičia 1970-1971 gg. Vyp. 1. Istoriko-arkheologičeskie pamjatniki drevnego i srednevekovogo Jemena. Saint Petersburg: Peterburgskoe Vostokovedenie. [In Russian.]

Grohmann, P.A.

1914 Göttersymbole und Symboltiere auf Südarabischen Denkmälern (Denkschriften der Kaiserlichen Akademie der Wissenschaften in Wien. Philosophisch-historische Klasse 58/1). Vienna (In Kommission bei Alfred Hölder).

1963 Arabien. Kulturgeschichte des Alten Orients, Handbuch der Altertumswissenschaft. München: C.H. Beck.

Grolier, M.J., R. Brinkmann, J.A. Blakely [and contributors]

1996 (W.C. Overstreet and J.A. Blakely, volume eds) The Wadi al-Jubah Archaeological Project, 5. Environmental research in support of archaeological investigations in the Yemen Arab Republic, 1982-1987. Washington (DC): American Foundation for the Study of Man.

Guest-Papamanoli, A.

1978 L'emploi de la brique crue dans le domaine égéen à l'époque néolithique et à l'Age du Bronze, Bulletin de Correspondance Hellénique, 102 (1), 3-24.

Gushchina [Guščina], E.

2015 Les inscriptions sudarabiques recueillies dans le Corpus de P. A. Grjaznevič (1929-1997). Doctoral dissertation, Università di Pisa. <http://core.ac.uk/download/ pdf/79619042.pdf>, accessed 16 May 2018.

Habshūsh, Hayyim

1939 (trans. Sh.D. Goitein) Massěêôt hibshūsh - sippûrô šel ribbî hayyîm ben yihyê hibshūsh al masaotav im yôsēf ha-lēvî be-tēmān ha-mizrahit ve-al haye ha-yěhûdim veha-arvim sham. Tel Aviv: A.Y. Stybel. [Translated and annotated, with foreword.]

1976 (trans. and ed. G. Moscati Steindler) Hayyim Habšuš: Immagine dello Yemen (Studi di Semitistica e del Vicino Oriente antico, Ricerche 11). Naples: Istituto Universitario Orientale.

1983 (trans. Sh.D. Goitein) Ru'yā al-Yaman. Massě $e^{\prime} \hat{t}$ hibshūsh - sippûrô šel ribbî hayyîm ben yihyyê hibshūsh (Ben-Zvi Institute for the Study of Jewish Communities in the East publications). Jerusalem: Magnes Press, The Hebrew University. [Translated and edited, with an introduction.]

1992 (translit. and introd. S. Naïm Sanbar) Ru'yat alyaman, in S. Naïm Sanbar 1992,9-137. [Transliterated, with an introduction, by Sāmiyah Na'īm Șanbar.] 
1995 (trans. and introd. S. Naïm-Sanbar) Yémen. Récit traduit de l'arabe yéménite et présenté par Samia Naïm-Sanbar (Terres d'aventure). Arles: Actes Sud. [Translated, with an introduction, by Sāmiyah $\mathrm{Na}$ 'ìm Șanbar.]

1998 (trans. and introd. S. Naïm-Sanbar) Yémen, 2nd edition (Terres d'aventure). Arles: Actes Sud. [Translated, with an introduction, by Sāmiyah $\mathrm{Na}^{\top} \mathrm{i} m$ Șanbar.]

2018 A vision of Yemen by Hayyim Habshūsh translated from the original Hebrew and Judeo-Arabic, in A. Verskin 2018a, 61-212, 230-248.

Halévy, J.

1872a Rapport sur une mission archéologique dans le Yémen, Journal Asiatique 6e série 19, 5-98, 129-266, 489-547. [Published in the January, FebruaryMarch, and June issues.]

1872b Rapport sur une mission archéologique dans le Yémen (Extrait $N^{\circ} 2$ de l'année 1872 du Journal Asiatique). Paris: Imprimerie Nationale. [Re-edition as a volume with partially modified page numbering.]

1873 Voyage au Nedjran, Bulletin de la Société de Géographie [Paris] 6e série 6, 5-31, 249-273, 581-606. [Published in the July, September, and December issues; with folding map, 'Itinéraire d'un voyage dans le Yémen, 1869-1870'.]

1873-1874 Études Sabéennes. Examen critique et philologique des inscriptions sabéennes connues jusq'à ce jour, Journal Asiatique 7ème série, 1 [1873], 434-521; 2 [1873], 305-365, 388-393; 4 [1874], 497585.

1875 Études Sabéennes. Examen critique et philologique des inscriptions sabéennes connues jusq'à ce jour (Extrait du Journal asiatique [Mai-Juin, Octobre 1873 et Décembre 1874]). Paris: Imprimerie Nationale. [Reedition as a volume with new page numbering.]

1877 Voyage au Nedjran, Bulletin de la Société de Géographie [Paris] 6e série 13, 466-479. [Published in the May issue.]

1992 (trans. M. Arbach) Taqrīr hawla ba‘tah atariyyah ilā 'l-yaman, in S. Naïm Sanbar 1992, 139-195. [Arabic translation of Halévy 1872a, 5-98.]

Hassell, J.

1997 Alabaster beehive-shaped vessels from the Arabian Peninsula: interpretations from a comparative study of characteristics, contexts and associated finds, Arabian Archaeology and Epigraphy 8, 245-281.

Hitgen, $\mathrm{H}$.

2002 Magnesiumhydroxicarbonat. Ein wiederentdeckter Werkstoff in der altsüdarabischen Kunst, in Archäologische Berichte aus dem Yemen 9, 165-180. Mainz am Rhein: Philipp von Zabern.

2013 Aspects of Mediterranean influence on the material culture of South Arabia during the early Himyarite period (1st Century BC - 3rd Century AD) on example of Ğabal al-'Awd', Zeitschrift für OrientArchäologie 6, 278-298.
Hoftijzer, J. and K. Jongeling

1995 Dictionary of the North-West Semitic inscriptions. With appendices by R.C. Steiner, A. Mosak Moshavi and B. Porten. (Handbuch der Orientalistik. 21). Voll. I-II. Leiden: Brill.

Hoskins, J.

1998 Biographical objects. How things tell the stories of people's lives. Abingdon (Oxon), New York: Routledge. Huzayyin, S. A.

1937 Egyptian University Scientific Expedition to South-west Arabia, Nature 140 (3542), 513-514.

Im Land Saba

1999 Im Land der Königin von Saba. Kunstschätze aus dem antiken Jemen. Germering, Munich: I.P. Verlagsgesellschaft International Publishing. [Exhibition catalogue: Staatlichen Museum für Völkerkunde München, 7 July 1999-9 January 2000. W. Daum, W.W. Müller, N. Nebes and W. Raunig, eds.] Inizan, M.-L. and Francaviglia, V.M.

2002 Les périples de l'obsidienne à travers la mer Rouge, Journal des Africanistes 72, 11-19.

Jamme, A.

1953 Les expéditions archéologiques américaines en Arabie du Sud (1950-1953) (Avec une brève étude sur l'estampage en latex), Oriente Moderno 33 (3), 133-157.

Japp, S., I. Gerlach, H. Hitgen and M. Schnelle

2011 Yeha and Hawelti: cultural contacts between Saba' and D'mt. New research by the German Archaeological Institute in Ethiopia, Proceedings of the Seminar for Arabian Studies 41, 145-160. Jemen

1998 Jemen. Kunst und Archäologie im Land der Königin von Saba. Milan: Skira. [Exhibition catalogue: Eine Ausstellung des Kunsthistorischen Museums Wien in Zusammenarbeit mit der Generalinstitution für Altertümer, Museen und Handschriften, Ministerium für Kultur und Tourismus der Republik Jemen. Vienna, Künstlerhaus, 9. November 1998-21 February 1999. W. Seipel, ed.]

Jung, M.

1988 The religious monuments of ancient Southern Arabia. A preliminary typological classification, Annali dell'Istituto Universitario Orientale di Napoli 48 (3), 177-218.

2012 Breve catalogo di troni e frammenti di mobili in pietra dell'Arabia del Sud e dell'Etiopia antica e paleocristiana, in S. Antonini de Maigret, P. D'Amore and M. Jung (eds), Il trono della Regina di Saba. Cultura e diplomazia tra Italia e Yemen. La collezione sudarabica del Museo Nazionale d'Arte Orientale, 291-303. Rome: Artemide.

Kahn, A.R.

1938 On the meteoritic origin of the Black Stone of the Ka'bah, Popular Astronomy 46, 403-407. 
Keall, E.J.

1998 Encountering megaliths on the Tihāmah coastal plain of Yemen, Proceedings of the Seminar for Arabian Studies 28, 139-147. [Published 1999.]

2004 Possible connections in antiquity between the Red Sea coast of Yemen and the Horn of Africa, in P. Lunde and A. Porter (eds), Trade and travel in the Red Sea region. Proceedings of the Red Sea Project I, British Museum, October 2002 (Society for Arabian Studies Monographs 2; BAR International Series 1269), 4355. Oxford: Archaeopress.

2005 Placing al-Midamman in time. The work of the Canadian Archaeological Mission on the Tihama coast, from the Neolithic to the Bronze Age, in Archäologische Berichte aus dem Yemen 10, 87-100. Mainz am Rhein: Verlag Philipp von Zabern.

Khalidi, L.

2005 The prehistoric and early historic settlement patterns on the Tihāmah coastal plain (Yemen): preliminary findings of the Tihāmah Coastal Survey 2003, Proceedings of the Seminar for Arabian Studies 35, 115-127.

2009a Megalithic landscapes: the development of the late prehistoric cultural landscape along the Tihāma coastal plain (Republic of Yemen), in A.M. Sholan et al. (eds) 2009, 359-375. [Originally published Naples and $\left.\operatorname{San}^{(} \bar{a}\right), 2005$.]

2009 b Holocene obsidian exchange in the Red Sea region, in M.D. Petraglia and J.I. Rose (eds), The evolution of human populations in Arabia: paleoenvironments, prehistory and genetics (Vertebrate Paleobiology and Paleoanthropology Series), 279-291. Dordrecht: Springer-Verlag.

Khalidi, L., K. Lewis and B. Gratuze

2012 New perspectives on regional and interregional obsidian circulation in prehistoric and early historic Arabia, Proceedings of the Seminar for Arabian Studies 42, 143-164.

Khalidi, L., C. Oppenheimer, B. Gratuze, S. Boucetta, A. Sanabani and A. al-Mosabi

2010 Obsidian sources in highland Yemen and their relevance to archaeological research in the Red Sea region, Journal of Archaeological Science 37, 2332-2345.

Kitchen, K.A.

1994 Documentation for Ancient Arabia. Part I. Chronological framework and historical sources. Liverpool: Liverpool University Press.

Klein-Franke, A.

1988 The Jews of Yemen, in W. Daum (ed.) 1988, 265-299.

Köhler, L.H. and W. Baumgartner

1994-2000 The Hebrew and Aramaic Lexicon of the Old Testament. Leiden: Brill.

Lane, E.W.

1863-1893 An Arabic-English Lexicon, eight parts. London: Williams-Norgate. [reprinted 1968, Beirut: Libraire du Liban].

Lawrence, A.W.

1979 Greek aims in fortification. Oxford: Clarendon Press.
Leclant, J.

1959 Haoulti-Melazo (1955-1956), Annales d'Ethiopie $3,43-82$.

Lewis, K., L. Khalidi, W. Isenberger and A. Sanabani

2010 Mapping Masna'at Māryah: using GIS to reconstruct the development of a multi-period site in the highlands of Yemen, Proceedings of the Seminar for Arabian Studies 40, 213-226.

Lemaire, A.

1996 Histoire du Proche-Orient et chronologie sudarabique avant Alexandre, in C.J. Robin and I. Gajda (eds) 1996, 35-48.

2010 Chronologie sabéenne et minéenne et histoire du Proce-Orient, Orientalia 79 (3), 379-389.

Leriche P. and O. Callot

1986 Observations sur les remparts de brique crue d'Ä̈ Khanoum, in P. Leriche and H. Tréziny (eds) 1986, 289-298.

Leriche, P. and H. Treziny (eds)

1986 La fortification dans l'histoire du monde grec. Actes du colloque international: La fortification et sa place dans l'histoire politique, culturelle et sociale du monde grec, Valbonne, décembre 1982. Paris: Éd. du C.N.R.S.

Linington, R.E.

1987 Archaeological prospecting in the ancient lagoon, in A.M. McCann, J. Bourgeois, E.K. Gazda, J.P. Oleson and E.L. Will, The Roman port and fishery of Cosa. A center of ancient trade, 285-296. Princeton (NJ): Princeton University Press.

Loreto, R.

2011 L'architettura domestica e i palazzi reali di epoca sud arabica [sic] nello Yemen pre-islamico (VII sec. a.C.-VIsec. d.C.) (Università degli studi di Napoli 'L'Orientale', Dissertationes 7). Naples: Università degli studi di Napoli 'L'Orientale'.

2016 Il grande tempio (TT1) o palazzo reale, in A. de Maigret and C.J. Robin (eds) 2016, 297-323.

Loreto, R. and R. Valentini

2012 Il santuario rupestre del dio Nakrah presso Darb aș-Ṣabī (Barāqišs, antica Yațill), Newsletter di Archeologia (CISA) 3, 265-311. Also available online: <http://www.unior.it/userfiles/workarea_231/file/ NewsletterArcheologia\%20numero\%203/5_\%20 Loreto-Valentini\%202012.pdf>, accessed 15 May 2018.

MacLellan, J.

2019 Preclassic Maya caches in residential contexts: variation and transformation in deposition practices at Ceibal, Antiquity 93 (371), 1249-1265.

Maraqten, $\mathrm{M}$.

1994 Typen altsüdarabischer Altäre, in N. Nebes (ed.), Arabia Felix. Beiträge zur Sprache und Kultur des vorislamischen Arabiens. Festschrift Walter Müller zum 60. Geburstag, 160-177. Wiesbaden: Harrassowitz.

2014 Altsüdarabische Texte auf Holzstäbchen. Epigraphische und kulturhistorische Untersuchungen. Beirut: Erlog verlag Würzburg in Kommission. 
Marcolongo, B.

1994 Le périmètre irrigué, grenier de l'antique Yathill, et les déplacements du wâdî Majzir, Saba. Art littérature - histoire - Arabie Méridionale 1 (Parfums d'Arabie), 60-62. [Contained in Robin and de Maigret 1994, q.v.]

1996 Modelli di utilizzo delle risorse idriche nello Yemen interno dall'età del Bronzo al periodo sudarabico, in C.J. Robin and I. Gajda (eds) 1996, 179-187.

1997 Les systèmes irrigués de Barāqish, in Yémen 1997, 78.

2000 L'oasi di Barâqish, in Yemen 2000, 137-139.

Marcolongo, B. and A.M. Palmieri

1986 Palaeoenvironmental conditions in the areas of Wādī at-Tayyilah and Barāqiš: preliminary report, in A. de Maigret et al. 1986, 461-464.

Marek, C.

1993 Die Expedition des Aelius Gallus nach Arabien im Jahre 25 v. Chr., Chiron. Mitteilungen der Kommission für Alte Geschichte und Epigraphik des Deutschen Archäologischen Instituts 23, 121-156.

1994 Der römische Inschriftenstein von Barāqiš, in N. Nebes (ed.) 1994, 178-190.

Margueron, J.-C.

1982 Recherches sur les palais mésopotamiens de l'âge du bronze (Institut Français d'Archéologie du Proche Orient, Beyrouth - Damas - Amman, Bibliothèque Archéologique et Historique 107). Paris: P. Geuthner. 1985 Notes d'archéologie et d'architecture orientales, no 4. Propos sur le sillon destructeur (étude de cas), Syria. Revue d'Art oriental et d'Archéologie 62 (12), 2-20.

Martin, R.

1965 Manuel d'architecture grecque 1: Matériaux et Techniques. Paris: Picard.

Matthews, R.

2003c A chiefdom on the northern plains. Early thirdmillennium investigations: the Ninevite 5 period, in R. Matthews (ed.) 2003a, 97-191.

Matthews, R. (ed.)

2003a Excavations at Tell Brak. 4: Exploring an Upper Mesopotamian regional centre, 1994-1996 (McDonald Institute Monographs). London: British School of Archaeology in Iraq. Cambridge: McDonald Institute for Archaeological Research.

Meskell, L.

2004 Object worlds in ancient Egypt. Material biographies past and present (Materializing culture 6). Oxford: Berg Publishers.

Miller, R.

1984 Flaked stone industries of Arabia and the Gulf from late Iron Age to Early Islamic times, in R. Boucharlat and J.-F. Salles (eds), Arabie orientale, Mésopotamie et Iran méridional de l'Age du Fer au début de la période islamique. Réunion de travail, Lyon, 1982, Maison de l'Orient (Mémoire 37 / Histoire du Golfe), 145-150. Paris: Éditions Recherche sur les civilisations.
Moorman, B.J., W.D. Glanzman, J.-M. Maillol and A.L. Lyttle

2001 Imaging beneath the surface at Mahram Bilqīs, Proceedings of the Seminar for Arabian Studies 31, 179187.

Moorman, B.J., J.-M. Maillol , J.L. Williams, F.S. Walter and W.D. Glanzman

2002 Imaging the past: archaeological radar stratigraphic analysis at Mahram Bilqis, in S. Koppenjan and H. Lee (eds), Proceedings of SPIE - The International Society for Optical Engineering. Vol. 4758: Ninth international conference on ground penetrating radar (GPR2002), 6 pages. Bellingham (WA): SPIE. DOI: $10.1117 / 12.462200$.

Müller, W.W.

1980 Review of 'Hayyim Habšuš: Immagine dello Yemen', ed. G. Moscati Steindler (Istituto Orientale di Napoli, Ricerche XI), Napoli, 1976, Orientalistische Literaturzeitung 75 (4), col. 353-355.

1982 Bemerkungen $\mathrm{zu}$ einigen von der YemenExpedition 1977 des Deutschen Archäologischen Instituts aufgenommenen Inschriften aus dem Raum Mārib und Barāqiš, in Archäologische Berichte aus dem Yemen 1, 129-134. Mainz am Rhein: Verlag Philipp von Zabern.

Multhoff, A.

2019 Merchant and marauder - The adventures of a Sabaean clansman, Arabian Archaeology and Epigraphy, 30 (2), 239-262.

Naïm Sanbar, S. [Sāmiyah Na`īm Șanbar] (translit. and ed.)

1992 Ru'yat al-yaman bayna habshūsh wa-halīī. Șan'ā’: Markaz al-buhūt wa-'l-dirāsāt al-yamanī. [Transliterated and edited, with an introduction. In Arabic.]

Nāmī, Kh.Y. [Khalīl Yahyyā]

1954 Nuqūš hirbat Barāqiš 'alā dạ' majmū'at Muhammad Tawfīq, Majallat kulliyat al-'Ādāb 16, $1-21$.

1955 Nuqūš hirbat Barāqiš 'alā daw' majmū'at Muhammad Tawfīq, Majallat kulliyat al-'Ādāb 17, $1-22$.

1956 Nuqūš hirbat Barāqiš 'alā ḍaw' majmū'at Muhammad Tawfīq, Majallat kulliyat al-'Ā'āb 18, 1-36.

1957 Nuqūš hirbat Barāqiš 'alā daw' majmū'at Muhammad Tawfīq, Majallat kulliyat al-'ĀĀa 19, 93-124.

Naumann, R.

1971 Architektur Kleinasiens von ihren Anfängen bis zum Ende der hethitischen Zeit. Tübingen: E. Wasmuth (1st Edition 1955).

Nebes, N. (ed.)

1994 Arabia Felix. Beiträge zur Sprache und Kultur des vorislamischen Arabien. Festschrift Walter W. Müller zum 60. Geburtstag. Wiesbaden: Harrassowitz Verlag. [Edited by N. Nebes with collaboration by R. Richter, I. Kottsieper, M. Maraqten.] 
Nini, Y.

1991 The Jews of the Yemen, 1800-1914. New York: Harwood Academic.

O'Neill, D.

2014 First Millenium BC South Arabian terracotta figurines from the Marib oasis and Sirwah, Yemen, Zeitschrift für Orient-Archäologie 7, 324-366.

Orlandos, A.

1966 Les matériaux de construction et la technique architecturale des anciens Grecs (Ecole Française d'Athènes 16, 2 vols). Paris: Éditions de Boccard.

Overstreet, W.C. and M.J. Grolier

1988a Reconnaissance geology of the al-Jubah quadrangle, Y.A.R., in W.C. Overstreet et al. 1988a, 155-288.

1988b Review, in W.C. Overstreet et al. 1988a, 431-475.

1996 Summary of environmental background for the human occupation of the al-Jadidah basin in Wadi al-Jubah, Yemen Arab Republic, in M.J. Grolier et al. 1996, 337-429.

Overstreet, W.C., M.J. Grolier and M.R. Toplyn [and contributors]

1988a (D.M. Kinney and A.L. Dilonardo, volume eds) The Wadi al-Jubah Archaeological Project, 4. Geological and archaeological reconnaissance in the Yemen Arab Republic, 1985. Washington (DC): American Foundation for the Study of Man.

Overstreet, W.C., D.E. Detra, T. Botinelly, M.J. Grolier, D.B. Stoeser and D.L. Schmidt

1988b Mineral resources of the al-Jubah quadrangle, Yemen Arab Republic, in W.C. Overstreet et al. 1988a, 359-417.

Pagano, $\mathrm{P}$.

2010 Funerary stelae and other objects from the Barāqish area (MAIRY collection), in S. Antonini and A. Agostini (eds) 2010a, 75-83.

Parzinger, $\mathrm{H}$.

2003 Vorwort/Foreword, in I. Gerlach (ed.) 2003a, 16-19. Philby, H.St J.B.

1938 The land of Sheba. Parts 1-2, The Geographical Journal 92 (1), 1-21; (2), 107-132.

1943 Halévy in the Yaman, The Geographical Journal 102 (3), 116-124.

Phillips, C. and St J. Simpson

2007 A biographical sketch of Britain's first Sabaeologist - Colonel W.F. Prideaux, CSI, Proceedings of the Seminar for Arabian Studies 37, 201-218.

Phillipson, D.W.

1977 The later prehistory of Eastern and Southern Africa. London: Heinemann Educational Books. New York: Homes \& Meier

2005 African archaeology, 3rd edition. Cambridge: Cambridge University Press. [1st ed. 1985.]

Pirenne, J.

1956 Paléographie des inscriptions sud-arabes: contribution à la chronologie et à l'histoire de l'Arabie du sud antique. Tome 1: Des origines jusqu'à l'époque himyarite. Brussel: Paleis der Academien.
1961 Le royaume sud-arabe de Qatabân et sa datation, d'après l'Archéologie et les sources classiques jusqu'au Périple de la mer Erythrée (Bibliothèque du Muséon 48). Louvain: Université de Louvain, Institut orientaliste, Publications universitaires.

Queen of Sheba

2002 Queen of Sheba. Treasures from ancient Yemen. London: The British Museum Press. [Exhibition catalogue: St J. Simpson, ed.]

Rahimi, D.

1985 Lithic evidence, in J.A. Blakely et al. 1985, p. 129132.

1987 Lithics, in W.D. Glanzman and A.O. Ghaleb 1987a, 139-143.

1996 Obsidian and flint artifacts from the Wadi al-Jubah area, Yemen Arab Republic, discovered during reconnaissance in 1987, in M.J. Grolier et al. 1996, 303-305.

Rathjens C.

1955 Sabaeica, Bericht über die archäologischen Ergebnisse seiner zweiten, dritten und vierten Reise nach Südarabien (Mitteilungen aus dem Museum für Völkerkunde in Hamburg 24). II. Teil, Die unlokalisierten Funde. Hamburg.

Reimer, P.J., E. Bard, A. Bayliss, J.W. Beck, P.G. Blackwell, C. Bronk Ramsey, C.E. Buck, H. Cheng, R.L. Edwards, M. Friedrich, P.M. Grootes, T.P. Guilderson, H. Haflidason, I. Hajdas, C. Hatté, T.J. Heaton, D.L. Hoffmann, A.G. Hogg, K.A. Hughen, K.F. Kaiser, B. Kromer, S.W. Manning, M. Niu, R.W. Reimer, D.A. Richards, E.M. Scott, J.R. Southon, R.A. Staff, C.S.M. Turney and J. van der Plicht

2013 IntCal13 and Marine13 radiocarbon age calibration curves 0-50,000 years cal BP, Radiocarbon 55 (4), 1869-1887. [With online supplementary material, figures S1-S25.]

Robin, C.J.

1976 Résultats épigraphiques et archéologiques de deux brefs séjours en République Arabe du Yémen, Semitica 26, 167-188.

1979a Mission archéologique et épigraphique française au Yémen du Nord en automne 1978, Académie des Inscriptions et Belles-Lettres, Comptes rendus des séances de l'année 1979, 123 (2), 174-202.

1979b À propos des inscriptions in situ de Barāqish, l'antique Ytll (Nord-Yémen), Proceedings of the Seminar for Arabian Studies 9, 102-112.

1979c Les études sudarabiques en langue française: août 1978 - décembre 1979, Raydān. Journal of Ancient Yemeni Antiquities and Epigraphy 2, 167-171.

1981a Sur la piste de l'encens, à la recherche des établissements antiques au Nord-Yémen, Archéologia 160 (November), 44-53.

1981b Les études sudarabiques en langue française: 1981 [with a contribution by J.-F. Breton], Raydān. Journal of Ancient Yemeni Antiquities and Epigraphy 4, 149-158. 
1984 La cité et l'organisation sociale à Maīn: l'exemple de YTL (aujourd'hui Barāqish), in A.M. 'Abdallāh, S. al-Sakkar and R. Mortel (eds), 'A.R.T. al-Ansāāī (general ed.), Studies in the history of Arabia. 2: PreIslamic Arabia, 157-162. Riyad: King Saud University Press. [Arabic summary on p. 163-164, uncorrected.] 1987 Trois inscriptions sabéennes découvertes près de Barāqish (République Arabe du Yémen), Proceedings of the Seminar for Arabian Studies 17, 165-177.

1992 Inabba', Haram, al-Kāfir, Kamna et al-Harāshif(Inventaire des inscriptions sudarabiques 1). Paris: Académie des inscriptions et belles-lettres. Rome: Istituto italiano per il Medio ed Estremo Oriente. [Distribution: Diffusion de Boccard, Paris; Herder, Rome.]

1995 Des villes dans le Jawf du Yémen?, Semitica 4344 (La ville d'après les sources épigraphiques et littéraires ouest-sémitiques de 1200 avant J.-C. à l'Hégire), 141-161.

1998 La fin du royaume de Ma'īn, in R. Gyselen, F. Aubaile-Sallenave et al. (eds), Parfums d'Orient (Res Orientales 11), 177-188. Bures-sur-Yvette: Groupe pour l'Étude de la Civilisation du Moyen-Orient. Leuven: Peeters.

2000 La fortuna di Maîn, in Yemen 2000, 118-119.

2002 Vers une meilleure connaissance de l'histoire politique et religiouse de Kaminahū (Jawf du Yémen), in J.F. Healey and V. Porter (eds.), Studies on Arabia in Honour of Professor G. Rex Smith, 191-213. Oxford: Oxford University Press.

2016a Préface, in G. Charloux and J. Schiettecatte (eds) 2016, 4-5.

2016c Die Kalender der Araber vor dem Islam, in A. Neuwirth and N.K. Schmid (eds), Denkraum Spätantike. Reflexionen von Antiken im Umfeld des Koran, 299-386. Wiesbaden: Harrassowitz.

2017 Les évolutions du calendrier dans le royaume de Himyar: quelques hypothèses, in K. Dmitriev and I. Toral-Niehoff (eds), Religious Culture in Late Antique Arabia. Selected Studies on the Late Antique Religious Mind (Islamic History and Thought 6), 281-373. Piscataway (NJ): Gorgias.

Robin, C.J. and A. de Maigret

1994 Yathill, appelée aujourd'hui Barâqish, Saba. Art - littérature - histoire - Arabie Méridionale 1 (Parfums d'Arabie), 46-60, 62-69. [Contains Marcolongo 1994, q.v.]

1998 Le Grand Temple de Yéha (Tigray, Éthiopie), après la première campagne de fouilles de la Mission française (1998), Académie des Inscriptions et BellesLettres, Comptes rendus des séances de l'année 1998142 (3), 737-798.

2009 Le royaume sudarabique de Ma'în: nouvelles données grâce aux fouilles italiennes de Barâqish (l'antique Yathill). With a 'Note complémentaire sur la guerre entre la Chaldée et l'Ionie' by S. Anthonioz, Académie des Inscriptions et Belles-Lettres, Comptes rendus des séances de l'année 2009153 (1), 57-96. [Reprinted in de Maigret 2012, article XV.]
Robin, C.J. and I Gajda (eds)

1996 Arabia antiqua. Early origins of South Arabian states. Proceedings of the First international conference on the Conservation and exploitation of the archaeological heritage of the Arabian Peninsula held in the Palazzo Brancaccio, Rome, by IsMEO on 28th-30th May 1991 (Serie Orientale Roma 70, I). Rome: Istituto per il Medio ed Estremo Oriente.

Robin, C.J. and M.'A.al-R. Jāzim (eds)

2006 Le pèlerin des forteresses du savoir. Hommage au qādì Ismā'īl b. 'Alì al-Akwa'à l'occasion de son $85^{\circ}$ anniversaire. Șan (âa): Centre français d'Archéologie et de Sciences sociales de Sanaa.

Robin, C.J. and J. Ryckmans

1988 Le sanctuaire minéen de Nkrh à Darb aș-Ṣabī (environs de Barāqish). Rapport préliminaire (seconde partie). Étude des inscriptions, Raydān. Journal of Ancient Yemeni Antiquities and Epigraphy 5, 91-159.

Robin, C., J.-F. Breton and R. Audouin

1979 Prospection archéologique et épigraphique de la Mission archéologique française au Yémen du Nord (octobre-décembre 1978), Syria. Revue d'Art oriental et d'Archéologie 56 (3-4), 417-427.

Robin, C., J.-F. Breton and J. Ryckmans

1981 Le sanctuaire minéen de Nkrh à Darb aș-Șabī (environs de Barāqish). Rapport préliminaire (première partie), Raydān. Journal of Ancient Yemeni Antiquities and Epigraphy 4, 249-261.

Ryckmans, G.

1952 An archaeological journey to Yemen (March-May 1947), Part II: Epigraphical texts [in French]. See Fakhrī and Ryckmans 1951-1952.

Ryckmans, J.

1981 Villes fortifiées du Yémen antique, Bulletin de la classe des lettres et des sciences morales et politiques de l'Académie Royale de Belgique 67 (5), 253-266.

Sachet, I. and C.J. Robin (eds)

2012 Dieux et déesses d'Arabie, images et représentation. Actes de la table ronde tenue au Collège de France (Paris) les 1ers et 2 octobre 2007 (Orient \& Méditerranée 7). Paris: Éditions de Boccard.

Scerrato, U., G. Ventrone and P. Cuneo

1985 Islamic studies, in A. de Maigret et al. 1985, 375395.

Schiettecatte, J.

2006a Villes et urbanisation de l'Arabie du Sud à l'époque préislamique. Formation, fonctions et territorialités urbaines dans la dynamique de peuplement régionale. Thèse de doctorat, Université Paris 1 - PanthéonSorbonne. <http://tel.archives-ouvertes.fr/tel00120900/document>, accessed 9 May 2018.

2006b L'évolution de l'armature urbaine en Arabie du Sud: la vallée du Jawf du VIIIe siècle av. au VIe siècle apr. J.-C., M@ppemonde 84 (4), 1-17. Also available online: <http://mappemonde-archive.mgm.fr/ num12/articles/art06404.html>, accessed 20 May 2018. 
2006c Une collection de statuettes de prisonniers au musée national de San'ā', Arabian Archaeology and Epigraphy 17, 177-189.

2011 D’Aden à Zafar. Villes d'Arabie du Sud préislamique (Orient \& Méditerranée / Archéologie 6). Paris: Éditions de Boccard.

Schiettecatte, J. (ed.)

2019a Barāqish, in DASI. <http://dasi.cnr.it/index. php?id=dasi_prj_sit\&prjId $=1 \&$ corId $=0 \&$ colId $=0 \&$ navI $d=143714431 \&$ recId=243>, accessed 1 December 2019.

2019b Darb aș-Ṣabī, in DASI. <http://dasi.cnr.it/index. php?id=dasi_prj_sit\&prjId $=1 \&$ corId $=0 \&$ colId $=0 \&$ na vId $=143714431 \&$ recId=130>, accessed 1 December 2019.

2019c Shaqab al-Manașșa, in DASI. <http://dasi.cnr. it $/$ index.php?id=dasi_prj_sit\&prjId $=1 \& \operatorname{cor} I d=$ $0 \&$ colId $=0 \&$ navId $=143714431 \&$ recId $=206>$, accessed 1 December 2019.

Schiffer, M.B.

1996 Formation processes of the archaeological record. Salt Lake City: University of Utah Press. [Originally published 1987, Albuquerque: University of New Mexico Press.]

Schmidt, J.

1982a Vorwort des Herausgebers, in Archäologische Berichte aus dem Yemen 1, 1-3. Mainz am Rhein: Verlag Philipp von Zabern.

1982b Bericht über die Yemen-Expediton 1977 des Deutschen Archäologischen Instituts, in Archäologische Berichte aus dem Yemen 1, 123-128. Mainz am Rhein: Verlag Philipp von Zabern.

1982c Zur altsüdarabischen Tempelarchitektur, in Archäologische Berichte aus dem Yemen 1, 161-169. Mainz am Rhein: Verlag Philipp von Zabern.

1988 Ancient South Arabian sacred buildings, in W. Daum (ed.) 1988, 78-98.

1997 Tempel und Heiligtümer in Südarabien. Zu den materiellen und formalen Strukturen der Sakralbaukunst, Nürnberger Blätter zur Archäologie 14, 11-41.

2007 Das Heiligtum des Almaqah in Șirwāḥ. Vorläufiger Bericht über die ersten beiden Grabungskampagnen 1992-93 mit einem Beitrag von Paul Hofmann und einem Fundinventar', in Archäologische Berichte aus dem Yemen 11, 203-240. Mainz am Rhein: Verlag Philipp von Zabern.

Schnelle, M.

2007 Bauhistorische Untersuchungen zur sabäischen Stadtmauer von Sirwāh (Jemen), Architectura. Zeitschrift für Geschichte der Baukunst 37, 43-56.

2015 Ethio-Sabaean libation altars - First considerations for a reconstruction of form and function, in $\mathrm{M}$. Arbach and J. Schiettecatte (eds), Pre-Islamic South Arabia and its neighbours: new developments of research proceedings of the 17th Rencontres Sabeennes held in Paris, 6-8 June 2013, 143-151 (British Foundation for the Study of Arabia, BAR International Series 2740). Oxford: Archaeopress.
Sedov, A.V.

2005 Temples of ancient Hadramawt (Arabia Antica 3). Pisa: Edizioni Plus - Pisa University Press.

Seigne, J.

1982 Les structures I, J et $\mathrm{K}$ de Mashgha, in J.-F. Breton (ed.) 1982, Le Wâdî Hadramawt. Prospections 1978-1979, 22-33 (Centre Culturel et de Recherches Archéologiques de Aden). Beyrouth.

1992 Le château royal de Shabwa. Architecture, techniques de construction et restitutions, in J.-F. Breton (ed.) 1992, 111-165.

al-Sheiba, 'A.Ḧ. ['Abd Allāh Ḥasan aš-Šahīd]

1987 Die Ortsnamen in den altsüdarabischen Inschriften (mit dem Versuch ihrer Identifizierung und Lokalisierung). (Inaugural-Dissertation der Philipps-Universität Marburg/Lahn, 1982), in Archäologische Berichte aus dem Yemen 4, 1-62. Mainz am Rhein: Verlag Philipp von Zabern.

Shennan, S.

1988 Quantifying archaeology. Edinburgh: Edinburgh University Press.

Sholan, A.M. ['Amīda Shu'lān], S. Antonini and M. Arbach (eds)

2009 Sabaean studies. Archaeological, epigraphical and historical studies in honour of Yūsuf M. 'Abdallāh, Alessandro de Maigret and Christian J. Robin on the occasion of their sixtieth birthdays (Orient \& Méditerranée 4). Paris: De Boccard. [Originally published Naples and Șan' $(\bar{a}), 2005$.

Sima, A.

2000 Tiere, Pflanzen, Steine und Metalle in den altsüdarabischen Inschriften. Eine lexikalische und realienkundliche Untersuchungen (Akademie der Wissenschaften und der Literatur (Mainz), Veröffentlichungen der Orientalischen Kommission 46). Wiesbaden: Harrassowitz Verlag.

Simon, $R$.

2002 Aelius Gallus' campaign and the Arab trade in the Augustan age, Acta Orientalia Academiae Scientiarum Hungaricae 55 (4), 309-318.

Speidel, M.A.

2015 'Almaqah in Rom? Zu den Beziehungen zwischen dem kaiserzeitlichen Imperium Romanum und Südarabien im Spiegel der dokumentarischen Überlieferung, Zeitschrift für Papyrologie und Epigraphik 194, 241-258.

Spencer, A.J.

1979 Brick architecture in ancient Egypt. Warminster: Aris \& Phillips.

Stein, J.K.

1986 Coring archaeological sites, American Antiquity 51 (3), 505-527.

Tawfïq, M.

1951 Ātār Ma'in fi Ğawf al-Yaman [Les monuments de Ma'in dans le Jawf (Yémen)] (Publications de l'Institut français d'archéologie orientale du Caire, Études sud-arabiques 1). Cairo: Imprimerie de l'Institut 
français d'archéologie orientale / 'al-Machad 'al'Ilmī 'al-Faransī li-l-Āțār 'al-Sharqìyah. [In Arabic with French summary.]

Tobi, Y.

1999 The Jews of Yemen. Leiden: E.J. Brill.

2005 An unknown study by Joseph Halévy on his journey to Yemen, Proceedings of the Seminar for Arabian Studies 35, 287-292.

Tuchscherer, $\mathrm{M}$.

2016 Le Centre français d'archéologie \& de sciences sociales de Sanaa, in G. Charloux and J. Schiettecatte (eds) 2016, 36-37.

Tufnell, O. [and contributors]

1953 Lachish III (Tell ed Duweir). The Iron Age. 1-2 (The Wellcome Archaeological Research Expedition to the Near East Publications 3). London: Geoffrey Cumberlege; and Oxford University Press. [With contributions by M.A. Murray and D. Diringer.]

Van Beek, G.W.

1958 Marginally drafted, pecked masonry, in R.LeB. Bowen and F.P. Albright 1958, 287-299.

Verskin, A.

2010 Ḥabshūsh family; and Habshūsh, Ḥayyim [two entries], in N. Stillman (ed.), Encyclopedia of the Jews in the Islamic world, 192-193, 193-194. Leiden: E.J. Brill.

2018a A vision of Yemen. The travels of a European orientalist and his native guide. A translation of Hayyim Habshush's travelogue. Stanford (CA): Stanford University Press.

2018b Hayyim Habshūsh and the European explorers, in A. Verskin 2018a, 3-38, 215-225.

$2018 \mathrm{c}$ The people and politics of Yemen, in A. Verskin 2018a, 39-56, 225-229.

Villeneuve F., C. Phillips and W. Facey,

2002 Une inscription latine de l'archipel Farasān (sud de la mer Rouge) et son contexte archéologique et historique, Arabia. Revue de sabéologie 2, 143-192, 229-232.

Vogt, B.

2002 Death and funerary practices, in Queen of Sheba 2002, 180-185.

Vogt, B., W. Herberg and N. Röring

2000 „Arsh Bilqis“ - Der Tempel des Almaqah von Bar'an in Marib. Șan'ā’): Deutsches Archäologisches Institut, Außenstelle.

von Müller, D.H.

1896a Athlula, in Paulys Realencyclopädie der classischen Altertumswissenschaft. 2 (2), col. 2065. Stuttgart: J.B. Metzler'sche Verlagsbuchhandlung.

1896b Athrula, in Paulys Realencyclopädie der classischen Altertumswissenschaft. 2 (2), col. 2071-2072. Stuttgart: J.B. Metzler'sche Verlagsbuchhandlung.

von Wissmann, $\mathrm{H}$.

1962 Al-Barīra in Ǧirdān im Vergleich mit anderen Stadtfestungen Alt-Süd Arabiens, Le Muséon 75 (1-2), 177-209.
1964 Zur Geschichte und Landeskunde von Alt-Südarabien (Sammlung Eduard Glaser 3; Österreichische Akademie der Wissenschaften, Philosophischhistorische Klasse, Sitzungsberichte 246). Vienna: Hermann Böhlaus Nachf[olger].

1976 Die Geschichte des Sabäerreichs und der Feldzug des Ælius Gallus, in H. Temporini (ed.), Aufstieg und Niedergang der römischen Welt. Geschichte und Kultur Roms im Spiegel der neueren Forschung. 2: Principat, 9, Part 1, 308-544. Berlin, New York: de Gruyter.

Weeks, Ll., E. Keall, V. Pashley, J. Evans and S. Stock

2009 Lead isotope analyses of Bronze Age copper-base artefacts from al-Midamman, Yemen: towards the identification of an indigenous metal production and exchange system in the southern Red Sea region, Archaeometry 51 (4), 576-597.

Wensinck A.J. and J. Jomier

$1978 \mathrm{Ka}{ }^{\mathrm{c} b a}$, in P.J. Bearman, T. Bianquis, C.E. Bosworth, E. van Donzel and W.P. Heinrichs (eds), Encyclopaedia of Islam, 2nd edition, vol. 4, 317-322. Leiden: E.J. Brill. [12 volumes, 1960-2005.]

Wikipedia

2018 Black Stone. <http://en.wikipedia.org/wiki/ Black_Stone>, accessed 15 October 2018.

Winter, F.E.

1971 Greek Fortifications. Toronto: University of Toronto Press.

1986 A summary of recent work on Greek fortifications, in P. Leriche and H. Tréziny (eds) 1986, 23-30.

Wolf, P. and U. Nowotnick

2010 The Almaqah temple of Meqaber Ga'ewa near Wuqro (Tigray, Ethiopia), Proceedings of the Seminar for Arabian Studies 40, 367-380.

Yadin, $\mathrm{Y}$.

1958 Hazor. Excavation of a biblical city. An archaeological exhibition arranged by the Anglo-Israel Exploration Society at the British Museum by Courtesy of the Trustees (May-June 1958). London: British Museum Press.

Yasseen, G.T., M.M. el-Gamili and A.M. Shalan

1996 Unpublished terracotta figurines in the museum of the archaeology department, Sana'a university, Yemen, Arabian archaeology and epigraphy 7, 287-303.

Yemen

2000 Yemen. Nel paese della regina di Saba. Milan: Skira.

[Exhibition catalogue: Rome, Palazzo Ruspoli, Fondazione Memmo, 6 April-30 June 2000.]

Yémen

1997 Yémen, au pays de la reine de Saba'. Exposition présentée à l'Institut du monde arabe du 25 octobre 1997 au 28 février 1998. Paris: Flammarion. [Exhibition catalogue: C.J. Robin and B. Vogt, scientific coordinators.]

Zimmerman, P.C.

2008 The Middle Hadramūt Archaeological Survey: settlement patterns in South Arabia. PhD dissertation, University of Pennsylvania. <http:// www.lugal.com/mhas/>, accessed 18 May 2018. 


\title{
Barāqish/Yathill (Yemen) 1986-2007
}

\author{
Volume 2:
}

Extramural excavations in Area C and overview studies

Scavi fuori mura (Area C) e studi di sintesi

\author{
Edited by / A cura di
}

Sabina Antonini and Francesco G. Fedele

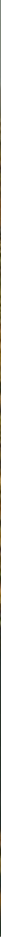





\section{Barāqish/Yathill (Yemen) 1986-2007}

Edited by / A cura di

Sabina Antonini and Francesco G. Fedele

Contributions by / Contributi di

Alessio Agostini, Sabina Antonini, Mounir Arbach, Vittoria Buffa, Christian Darles, Francesco G. Fedele, Solène Marion de Procé, Alessandra Paladino, Jérémie Schiettecatte, Saverio Bruno Scigliano, Rosario Valentini

\section{Volume 2: \\ Extramural excavations in Area $\mathrm{C}$ and overview studies}

\section{Scavi fuori mura (Area C) e studi di sintesi}

Arabic translation of abstracts by / Riassunti in arabo di Khālid al-'Ansī 


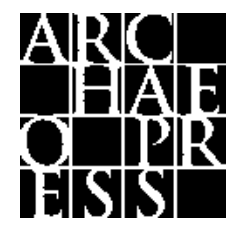

ARCHAEOPRESS PUBLISHING LTD

Summertown Pavilion

18-24 Middle Way

Summertown

Oxford OX2 7LG

www.archaeopress.com

ISBN 978-1-78969-470-3

ISBN 978-1-78969-471-0 (e-Pdf)

(C) Archaeopress and the individual authors 2021

Cover: View of Barāqish from the west-northwest (R. Valentini 2003 C MAIRY)

This book is available in print and as a free download from www.archaeopress.com

CC $9 @ \begin{aligned} & \text { This work is licensed under a Creative Commons } \\ & \text { Attribution-NonCommercial-NoDerivatives } 4.0 \text { International License }\end{aligned}$ BY NC ND 


\section{Contents}

\section{Extramural Excavations in Area C}

Chapter 17

Excavations in Area C. Setting, Stratigraphy, and Geoarchaeology

Francesco G. Fedele

Chapter 18

Excavations in Area C. Chronology and the Historical Sequence

Francesco G. Fedele

Chapter 19

Excavations in Area C. Economy, Trade, and the Environment

Francesco G. Fedele

Chapter 20

The Area C Collection Catalogue and Related Works

Francesco G. Fedele

Chapter 21

Area C. The Objects

Francesco G. Fedele and Sabina Antonini

Chapter 22

Area C. The Minaean Pottery

Vittoria Buffa

Chapter 23

Area C. The Sabaean Pottery: a Survey

Francesco G. Fedele

Chapter 24

Area C. Il materiale epigrafico

Alessio Agostini

\section{Ceramic Typology, Territory, and a Historical Outline of the Jawf}

Chapter 25

The Typological Classification of the Minaean Pottery from the Temple of 'Athtar dhu-Qabd and the Extramural Excavations in Area C

Vittoria Buffa

Chapter 26

A Glimpse of 'Greater Yathill': Sabaean Settlement and Tell Evolution

Francesco G. Fedele

Chapter 27

Les inscriptions de Barāqish : apport à la connaissance de l'antique cité de Yathill et du royaume de Ma'īn.

Jérémie Schiettecatte avec la collaboration de Mounir Arbach

Chapter 28

Risultati di una prospezione archeologica nel sito di Darb al-Ṣabī

Rosario Valentini

Abstracts of Chapters

Bibliography for Volume 2 


\section{MISSIONE ARCHEOLOGICA ITALIANA NELLA REPUBBLICA DELLO YEMEN}

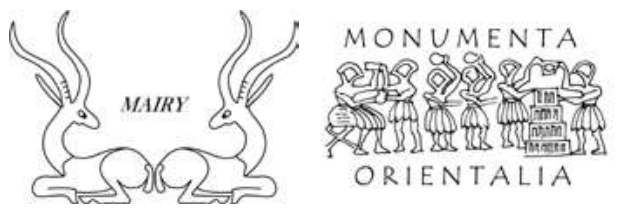

Unless indicated otherwise, the illustrations are from the archives of the Italian Archaeological Mission to Yemen (@ MAIRY).

The research for, and production of, the manuscript for this volume were made possible through a generous grant from The Shelby White and Leon Levy Program for Archaeological Publications (2017-2020). 


\title{
Extramural Excavations in Area C
}

\author{
Chapter 17 \\ Excavations in Area C.
Setting, Stratigraphy, and Geoarchaeology
}

\author{
Francesco G. Fedele
}

\section{Introduction, topography, and the excavations}

\subsection{Introduction: excavations in Area C}

The extramural excavations designated as Area $C$ were devised and carried out by the author during two intense field seasons in 2005 and 2006. ${ }^{1}$ The aim of the operation was to obtain a comprehensive stratigraphy from Barāqish as a tell - an artificially created mound and its immediate setting. For this purpose it was decided to exploit the eroded northwestern talus, below and away from the Minaean wall, where the tell stratification appeared to be locally exposed in rainwater gullies. A concurrent aim was to retrieve for the first time in the Yemeni Jawf - a stratified series of associated plant and animal samples. In this chapter the excavations, stratigraphy, and archaeological sequence will be presented in detail, preceded by a synopsis of their contribution towards understanding the settlement's development through time.

This chapter should be viewed as the first of three units constituting the final report on the extramural excavations in Area $C$. It is concerned with the topography and stratigraphy of the excavations, not only per se but also from the viewpoint of theory and principles. The second unit is Chapter 18, dealing first with chronology, both historical and derived from radiocarbon determinations, and subsequently discussing selected aspects of the cultural sequence. Finally, in Chapter 19, the results of bioarchaeological studies of the faunal and plant samples are summarized, in the context of evaluating the evidence from Area $C$ for economy, trade, and environmental interrelationships. A catalogue of the significant finds, including the items bearing inscriptions, is separately presented in Chapters 20-24, followed by a typological discussion of the Minaean pottery corpus (Chapter 25).

\footnotetext{
1 For the origins, context, and development of this project within MAIRY see Chapter 1 , section 4 , in Volume 1.
}

Further preliminary information about this chapter is in order. Compared to a previous publication, which retains reference value for its comprehensiveness, ${ }^{2}$ the treatment in this chapter aims to be up-to-date and definitive, while varying in the degree of detail with which the different parts of the stratigraphic record are described. Maximum space will be accorded to information that had previously remained largely or totally unpublished, such as subsidiary sections, planimetric records, and significant extracts from excavation control documents. The chief novelty in the present chapter is a fine-grained presentation of the stratigraphy of Sounding A at Minaean bastion T7, based on a detailed analysis of all field records. This treatment of Sounding A supersedes in some important respects and in a number of details what was presented in 2010. On the other hand, subjects that were already exhaustively treated in 2010 will often be presented succinctly, although enriched with newer information whenever available. ${ }^{3}$

Accordingly, the format of this chapter attempts a combination of geoarchaeological history for the whole tell and its talus, in chronological order and repeating the stratum-by-stratum presentation in Arabia 4, with a topographic investigation of the main sectors, particularly focusing on Sounding A. To a certain degree, this sounding needs to be singled out as it provides a reference for the entire sequence of Area $\mathrm{C}$ regarding the Minaean and Islamic periods. In addition, throughout the chapter, a number of problematic aspects of the sedimentary basis will be reviewed, together with methodological issues underpinning the reconstruction and interpretation of tell's stratigraphy. The dual purpose of these more theoretical passages is to provide guidelines for working with the data from

\footnotetext{
2 Fedele 2010; in conjunction with Fedele 2011a on the Minean part of the sequence.

3 To aid the reader, the differences from the 2010 report will be specified where appropriate.
} 


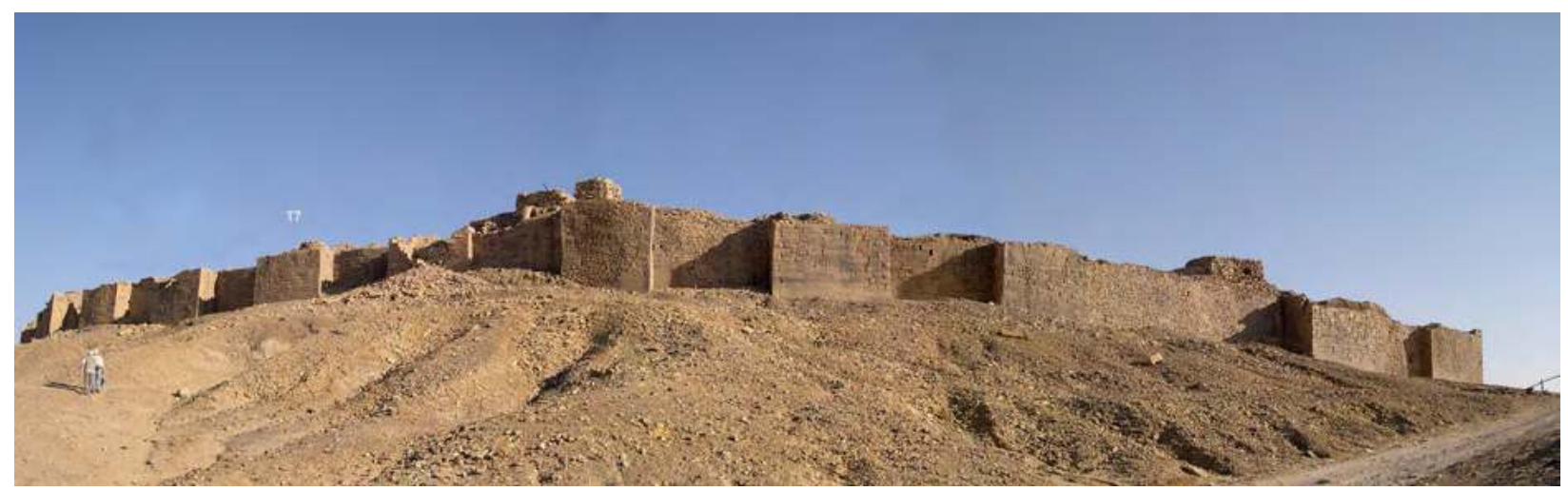

Figure 1. Barāqish, northwestern curtain wall, December 2005. Bastion T7 marked.

(P. Morlupi @ MAIRY, optimized by F.G. Fedele 2020)

Area C and - ideally - to offer a contribution to tell geoarchaeology.

The figures in this chapter cannot all follow the order of citation. Therefore they were arranged according to an ideal logical sequence by combining thematic, stratigraphic, and spatial criteria. The sequence is as follows: view of tell and a scheme of tell and talus; excavation topography; total and reference stratigraphy (photographs, sections, and stratification diagram); a preview of tell and talus evolution; details of stratigraphy, Sectors B to E and Strata R to $\mathrm{K}$ (photographs and drawings of sections and plans); Stratum M; Sounding A in general and the Minaean wall, followed by a stratigraphic overview; Strata J to A in Sounding A (sections and plans); units and features within Gully B; and Sounding F. The six tables accompanying this chapter can be found at the end of chapter.

While the present chapter is intended as self-sufficient and final, it is expected that excavation control documents, supplementary working papers, and other original archival material are made available through an internet site in the future (see Endnote).

\subsection{Excavation topography}

The excavations were carried out outside the Minaean wall in the northwestern sector of Barāqish/Yathill (Fig. 1; cf. Chapter 1, Fig. 42, in Volume 1). Here the Barāqish mound reaches about $15 \mathrm{~m}$ above the present plain level, its imposing talus featuring prominently in the landscape. Mound as a neutral term is used on purpose to avoid any specification of what is talus the debris slope ringing the Minaean walled city - and what is tell, or primary settlement buildup. ${ }^{4}$ Arguably,

\footnotetext{
4 'Mound' will be used as the most general word for the landform (cf., e.g., Matthews 2003a), while 'tell', although broadly interchangeable in this case, will mostly connote its essentially
}

most of the mound would consist of the ancient tell, but it falls on archaeological excavation to establish precisely the relative extensions of the tell and talus, as explained below. Tell, talus, and plain constitute the three geomorphological domains of our concern (Fig. 2); they will be examined in greater detail in section 2.1. The relationships with the alluvial floodplain a few hundred metres to the west are virtually unknown. ${ }^{5}$

Erosional and depositional forces had shaped the mound over the past two millennia, incising rills and furrows of various sizes into some parts of the mound's circumference. ${ }^{6}$ Particularly deep gashes were produced by rainwater in the northwestern talus of Barāqish: Gullies A-D, or the 'western gullies' (Figs 3-4; cf. Chapter 19, Fig. 21, this volume). These gullies show up on aerial photographs and have been known for a while. ${ }^{7}$ The intense erosion hinted at the existence of deeply buried deposits in this sector. Furthermore, erosion evidently permitted an easier archaeological access to these deposits, a situation which had already been exploited for profitable explorative sampling in 1986. ${ }^{8}$ Following an inspection of the Barāqish perimeter and its surface indicators on 5 December 2005, the choice of location precisely fell on this radial sector. Not only it promised an easier stratigraphic window for

cultural origin.

5 Also mentioned in section 2 below, with further cross-references.

6 A frequent phenomenon with Western Asian tells: cf. Matthews 2003a, 3.

7 They notably show on the fine photograph used by von Wissmann (1976, pl. II between pages 488-489) and the French scholars (e.g., Robin 1979b, fig. 1 on p. 109; Breton 1994, pl. 15). Breton (1994, 203) credited the photograph to the Swiss Technical Cooperation. Cf. Chapter 1 in Volume 1, footnote 79. A detail of the photograph is included in Fig. 4. One of the best views of Gullies A-D from the northwest can be found in DASI 2019 ( Schiettecatte 2019a): our Fig. 3 is an earlier photograph (1986).

8 See Chapter 2 in Volume 1 (surface collection site 'BARi') and Chapter 19, section 4.1, this volume (archaeobotanical sampling). The comparison of photographs taken in 1986 and in 2005 reveals a significant stability of the talus and its western gullies over two decades. 


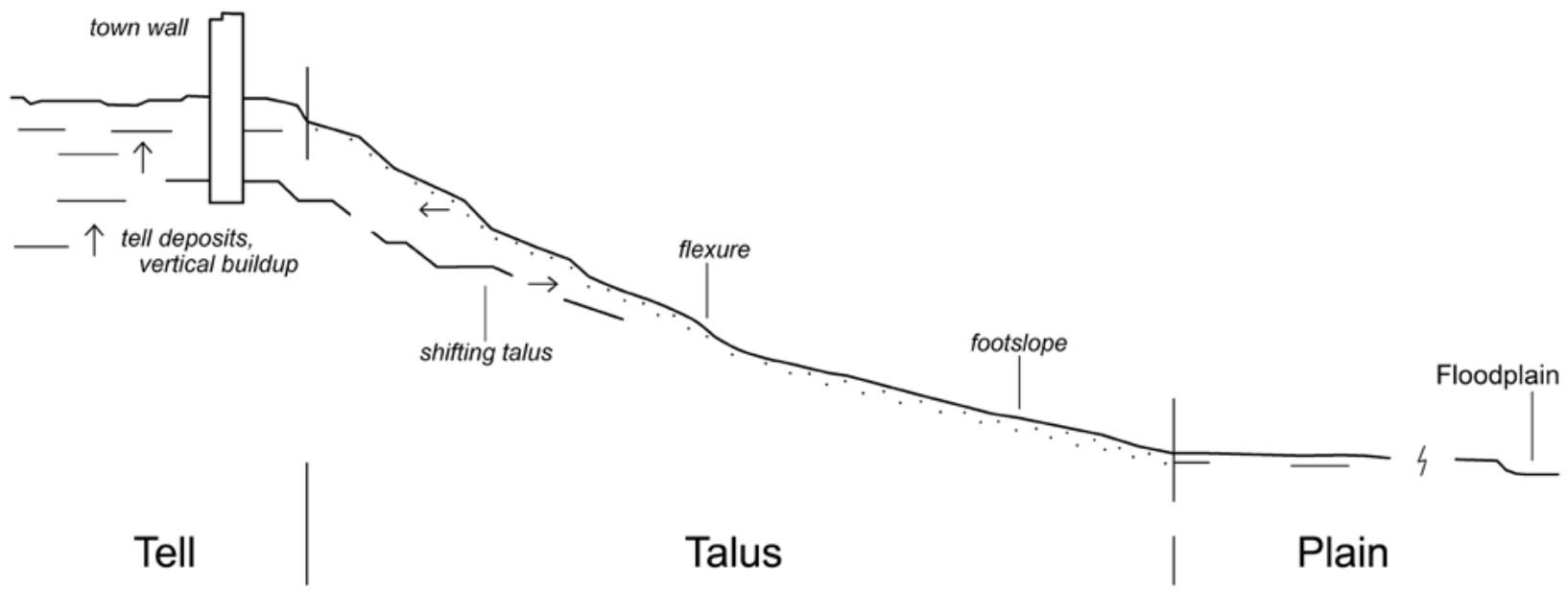

Figure 2. 'Tell', 'talus', and 'plain': a schematic geomorphological profile and associated nomenclature of depositional domains for Barāqish, with particular reference to Area C. (F.G. Fedele 2019)

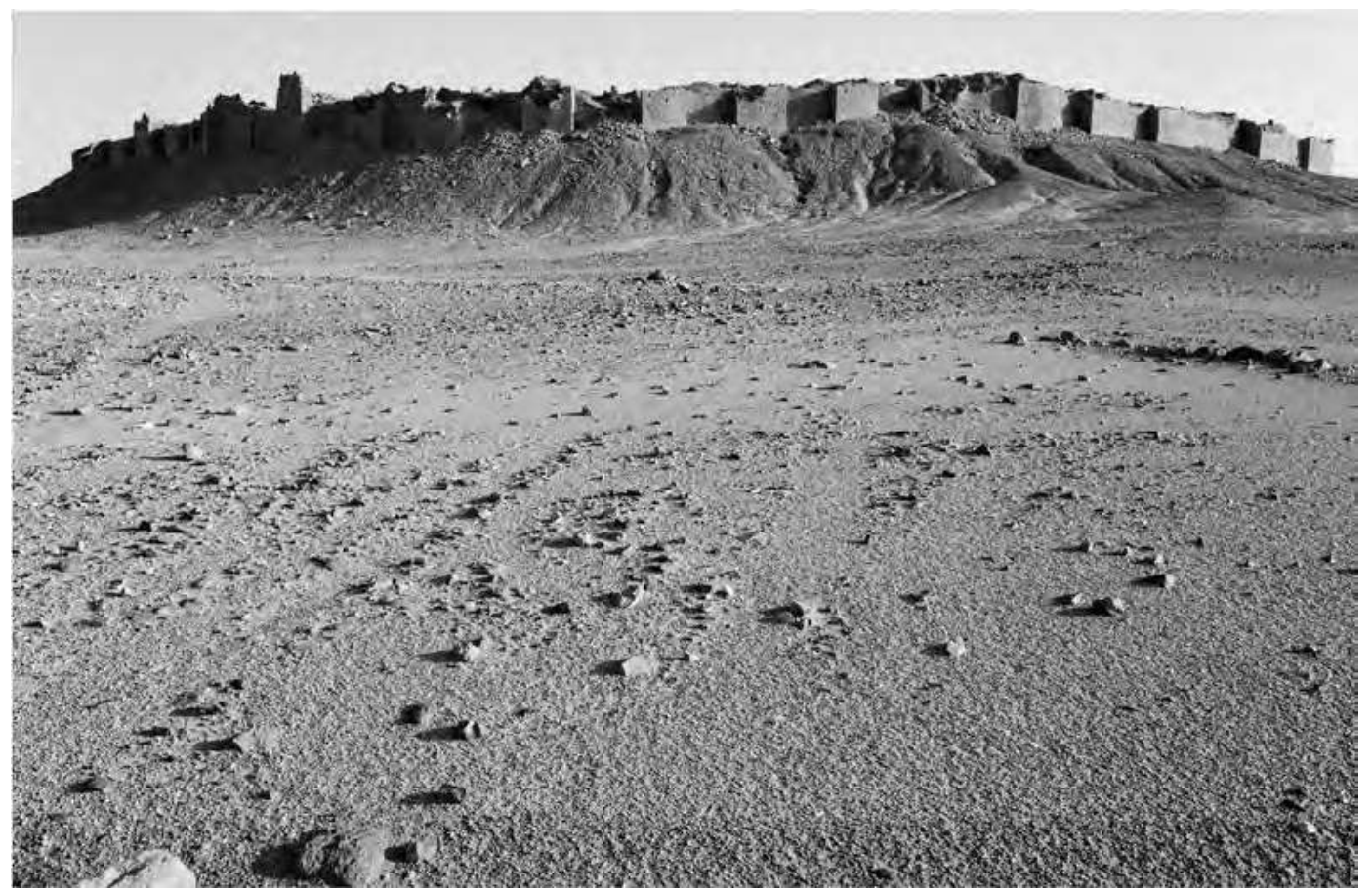

Figure 3. Barāqish: the northwestern talus and its gullies, 1986.

(A. Solazzi $@$ MAIRY, courtesy S. Antonini 2020, adapted)

uncovering the maximum settlement sequence outside the curtain wall, being high enough on the surrounding plain and so scarred by erosion, but it was also relatively close to camp and under direct military protection. ${ }^{9}$

\footnotetext{
9 A regularly staffed machine-gun was positioned atop bastion $\mathrm{T} 6$. Considerations of security were paramount at Barāqish. It was on security grounds that A. de Maigret counselled against the other possible site I had selected, located outside the curtain wall in the northeastern sector (both sites being presumably of equal interest). [Cf. Fig. 9 in Chapter 26, this volume; 'Area 37' in southeastern Barāqish had not yet been discovered in 2005.] For related reasons to avoid interference with the patrol duties of the Barāqish garrison - my excavation trench could not start from the wall as planned (see
}

Both the choice of place and excavation strategy were designed to explore the nature of human occupation at the presumed interface between the settlement and the surrounding plain, well away from the only known area within the city (the temple district).

In particular, Gully B was chosen for the excavation. This was the deepest incision, situated below the wall recess between bastions $\mathrm{T} 5$ and T6. Ideally, the aim of the project was to section as deeply as possible 

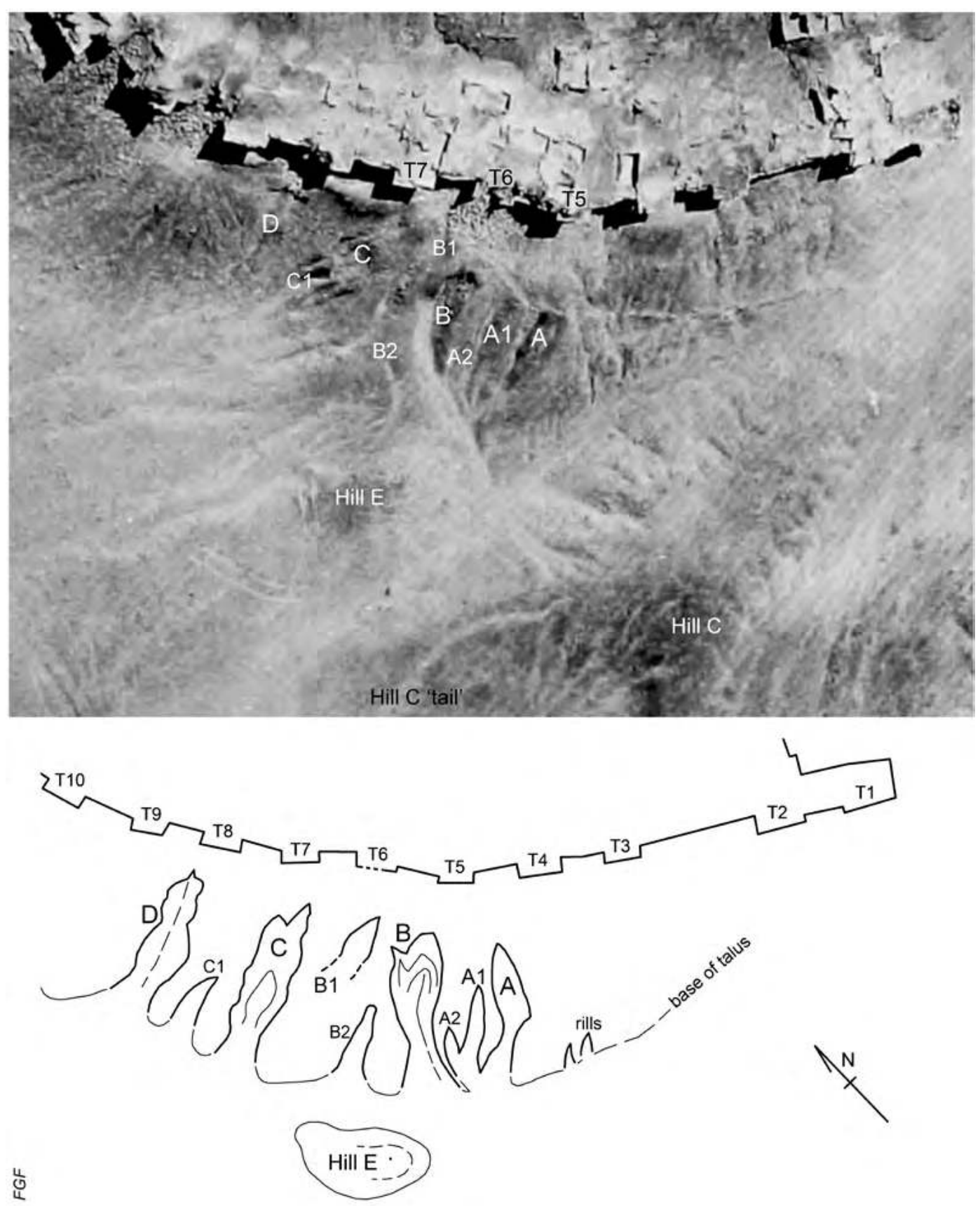

Figure 4. Barāqish: the northwestern erosion gullies, plan and aerial photograph. (F.G. Fedele 2019; photograph from Breton 1994, pl. 15, optimized)

the margin and flank of the Barāqish mound from top to bottom, starting with the gash of Gully B. This extramural excavation area northwest of the Minaean wall was called Area C (see Plan of archaeological operations at Barāqish 1986-2007 in Volume 1, p. xi). The overall plan of the excavations is shown in Fig. ${ }^{10}$

\footnotetext{
10 Fig. 5 was derived from the general plan made in 2007 (Chapter 1, Fig. 45, in Volume 1). The planimetric relationships between the contour-line plan of Area $\mathrm{C}$ and the Minaean wall were corrected on the basis of my own independent ground checks (cf. measurements in Fig. 6).
}

The excavation work was developed over a total of five weeks during two field seasons in 2005 and 2006. The excavation strategy is described in section 1.3 below, together with some notes about work organization and its demanding conditions and schedule.

Basically, a continuous stratigraphic section was obtained by digging a radial, stepped trench down and away from the wall. This initial trench, planned as central, was located so as to cut the steep southern bank of Gully B, where a discontinuous string of 


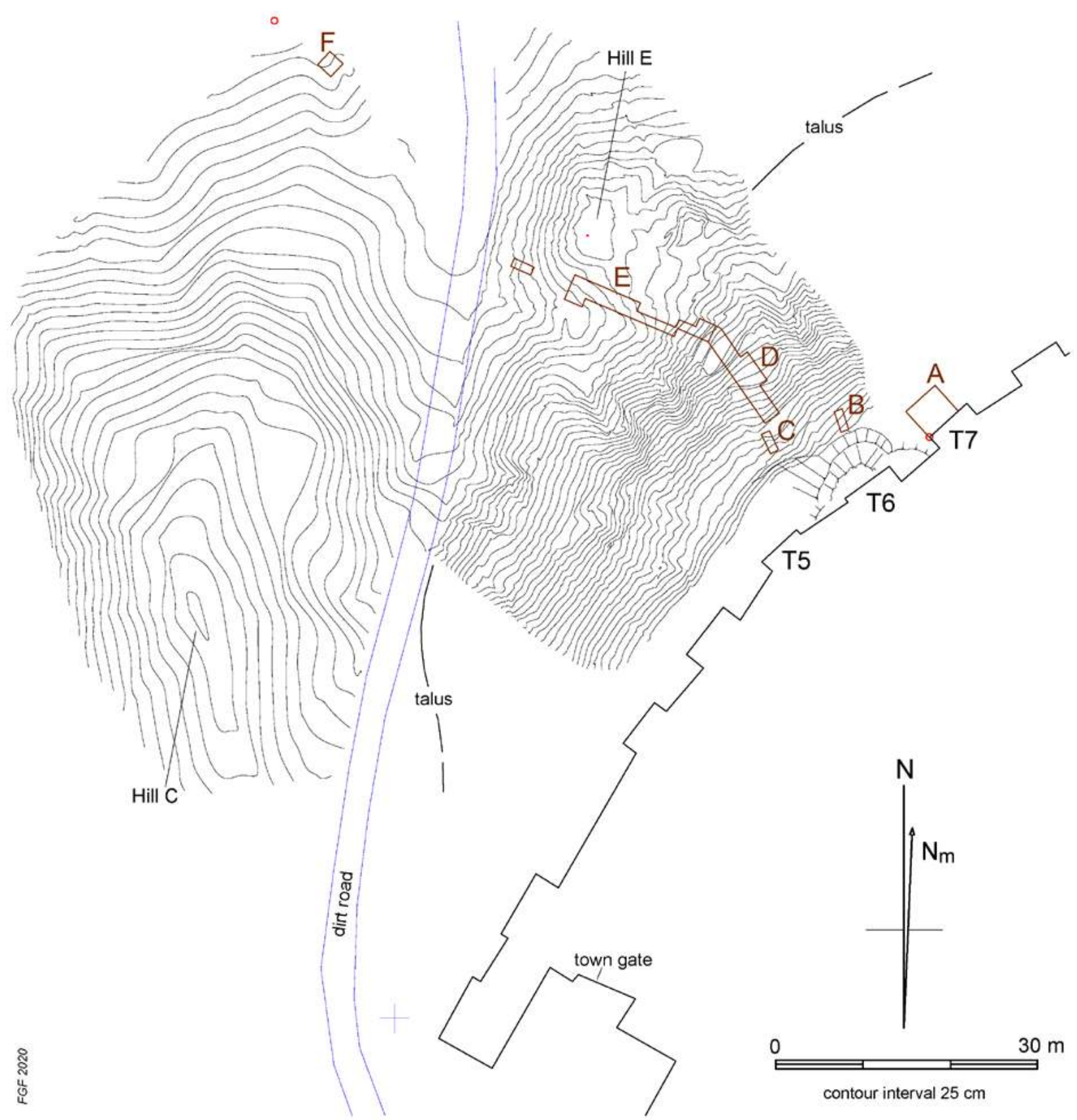

Figure 5. Barāqish Area C, plan of archaeological operations. Contour lines emphasize the talus and Hill C; T, Minaean bastions. Base map is an enlarged detail of the GPS plan reproduced in Chapter 1 in Volume 1, Fig. 45, in which the position of the contour-line area relative to the town wall was revised on the basis of author's ground-checked data. (F.G. Fedele 2020)

archaeological exposures characterized by conspicuous potsherds and animal bones could be seen (cf. Chapter 1, Fig. 42b, in Volume 1). This trench became Sector D in the excavations' plan, based on the sketch shown in Fig. 6. Dated 6 December 2005, this planning sketch contains a drawing of the slope below bastions T5 and T6 before the excavations, together with measurements taken on the ground. ${ }^{11}$

11 A selection of the original ground measurements along the slope of the talus are shown in colour in Fig. 6. For their planimetric
In the original plan, Sector D would be linked upwards, at an angle, to a line of test pits - or even possibly a trench - in order to reach the nearest point of the Minaean wall in recess R5/6. Eventually, however, in consultation with A. de Maigret, this planned upper segment was shifted to the north towards bastion T7

restitution (Figs 7-8) the horizontal value was calculated considering the inclination angle of each corresponding slope segment. Reference elevations linked to the temple-area datum were taken by total station on 9 December 2005 (R. Loreto, with check and supplementary survey in December 2006). 


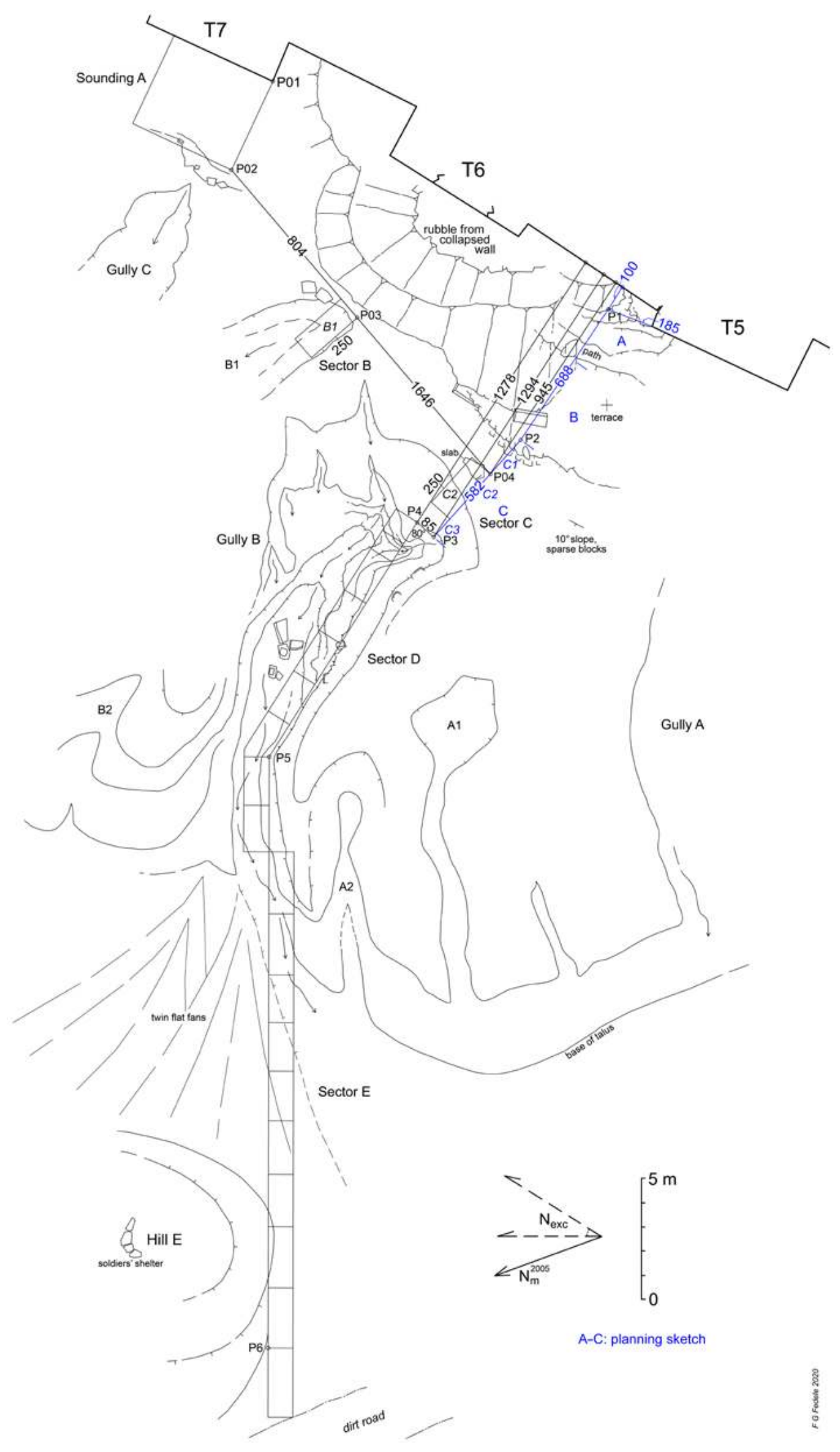

Figure 6. Area C planning sketch, December 2005, with added topography and planimetry from 2006. All measurements in $\mathrm{cm}$. Shown in colour are sectors and profile position as planned, associated with ground-slope measurements; sectors as excavated and their horizontal measurements are in black. (F.G. Fedele 2020) 
in order to avoid interference with the daily routine of the patrolling soldiers..$^{12}$ The shift implied that the probe to investigate the foundations of the Minaean wall would be carried out at bastion T7, this deep pit being named Sounding A. In 2006 the sounding reached a depth of about $8 \mathrm{~m}$ and brought to light the base and foundations of the Minaean wall: at the moment, this is the only complete exposure of a relatively tall portion of the curtain wall. The depth of the wall made it imperative to open a wider excavation instead of a trench. This sounding was $4 \times 4.5 \mathrm{~m}$ in area at the top and was furnished with a staircase in its northern part in order to take away the dirt from the pit.

Two short trenches were then made in the segment between Sector D and Sounding A, a gap that had become much larger as a consequence of the shift of excavation to bastion T7. These were Sectors B and C, this latter coinciding with sector ' $C$ ' as initially planned (Fig. 6). Approximately parallel to the axis of Sector D, trenches B and C served the dual purpose of testing the upper talus and allowing correlation between Sector D and Sounding A. Downwards, again at an angle, Sector D was linked to a trench deeply cutting into the lower talus along the minimum distance to the Barāqish dirt road (Sector E). This latter trench marginally expanded beyond the foot of the slope into the adjoining plain, narrowly skirting so-called 'Hill E' (see below). Finally, in 2006, an individual test pit was sunk in the open plain across the road, about $30 \mathrm{~m}$ northwest of the far end of excavated Sector E. This test, Sounding F, was made into a slight local depression at the foot of the 'tail' of Hill $C$, in the present-day flats surrounding northwestern Barāqish (see below), a part of the plain informally called 'Plain F'. Sounding F measured $2 \times 2 \mathrm{~m}$ at the top.

Thus, overall, Area $C$ came to include a long segmented trench associated with two terminal soundings, which together constitute operation $\mathrm{C} / \mathrm{S} 1$ in the Barāqish programme ('C' from Area C, 'S' for both sounding and section). As the label $\mathrm{C} / \mathrm{S} 1$ was intended to differentiate from future operations in the same area, which did not take place, only the expression 'Area C' will be regularly used in this book.

The Area $\mathrm{C}$ operation was subdivided into the six main planimetric units already mentioned: i.e., east to west, Sounding A, Sectors B to E, and Sounding F. The endpoints of excavated Area $C$ are P01, fixed to Minaean bastion T7, and P07 in the plain, about eight metres beyond Sounding F. Point P01 also coincides with the elevation datum for Area C (see below). Each excavated sector, including Sounding A, was further divided for spatial control into square or rectangular parts that

12 Furthermore T6, as a decayed bastion, provided to soldiers and archaeologists alike a convenient footpath between the exterior and interior of Barāqish through Area C. will be called 'quadrangles', abbreviated 'qu.' where useful or appropriate; 'qu.' is both singular and plural. Each quadrangle is labelled with a capital letter and a number, and these code labels are written in italics to avoid confusion with other letter-based designations (e.g. D3; cf. Figs 7-8). ${ }^{13} \mathrm{~A}$ slash (/) will be used in spatial notations to indicate a boundary, either planimetric (e.g. qu. D7/E1) or stratigraphic (e.g. GZ3/GZ2). An endash (-) means 'from... to...' (e.g. quadrangles D5-D7, units GW-GK1).

Some quadrangle designations employed in 2005-2006 with future fieldwork in mind, and used in previous publications, will now be avoided as unnecessary. These concern Sectors B and C and Sounding F (formerly 'Sector F'), in which the quadrangles B1, C2, and F1 of the planning sketch, respectively, were the only parts that could in fact be excavated. Therefore the tests in Sectors B and C will be simply referred to as B and C; similarly, there is no need to refer to the excavated part of Sounding F as F1. In upper Sector E, a quadrangle labelled EN1 was opened at a distance of a few metres from the main trench, but unfortunately this excavation was brief and negligible (see sections 6.3 and 16.4). In lower Sector E, quadrangles E9-E10 were excluded from excavation so as to avoid the margin of problematic Hill E, impossible to explore under the circumstances (see below). Finally, in Sounding A, 'rectangle A1-A12' will be used as a shorthand expression to encompass a standard part of the excavated surface (see section 9 below).

In spite of their mutual distance, Sounding A can be articulated with linkup Sectors B and C; ${ }^{14}$ Sector C, in turn, gives a virtually continuous stratigraphic profile with Sectors $\mathrm{D}$ and $\mathrm{E}$. This means that excavation sectors A to $\mathrm{E}$ provide a fundamentally continuous cutting through the Barāqish mound between the MinaeanIslamic wall and the dirt road, $52 \mathrm{~m}$ long and $14 \mathrm{~m}$ deep. The total depth amounts to $17 \mathrm{~m}$ if one includes Sounding F across the road. Sounding F is located at a linear distance of $78 \mathrm{~m}$ from the nearest point of the curtain wall. The description and study of the unified and comprehensive stratigraphic profile thus obtained will form the subject of this chapter: the corresponding 'Reference section' constitutes a fundamental tool in the stratigraphic analysis and discussion of Area C (Fig. 13; see section 3.2 below).

The cardinal orientation of trenches between Sounding A and Sector E varies around southeast to northwest,

\footnotetext{
13 Wherever useful, an excavation quadrangle can be subdivided into 'quadrants' in analogy to the quarters of a circle, designated according to orientation.

14 This articulation was made by considering the relative positions of $\mathrm{A}, \mathrm{B}$ and $\mathrm{C}$ on the contour lines and their distances from the nearest point on the wall. The mutual distances indicated in Fig. 13 are estimates.
} 


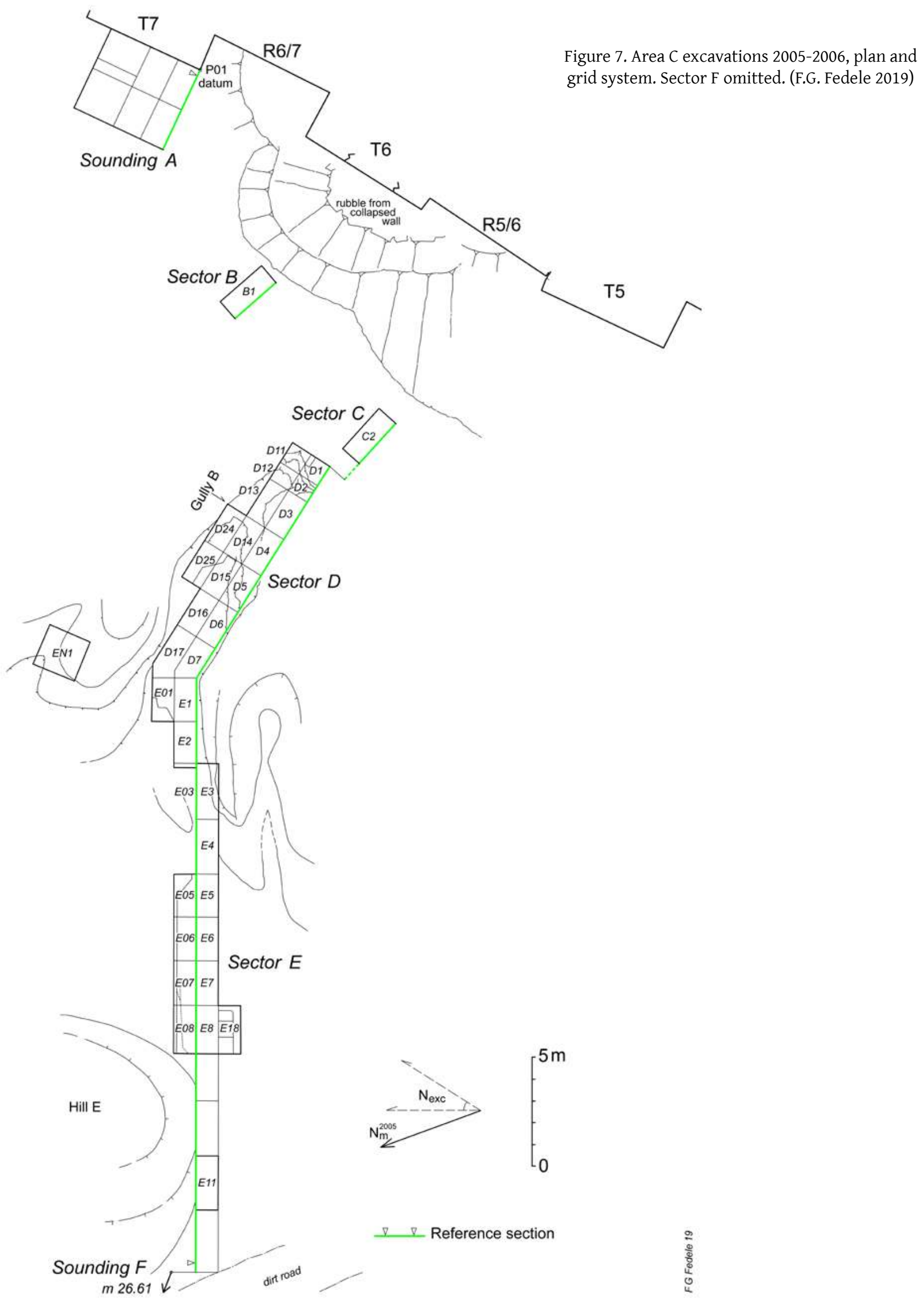


with each segment having its own orientation because of practical choices dictated by local morphology and research strategy. However, to avoid unnecessary multiplication of directional terms when dealing with different parts of the excavations, the excavation north (or grid north) is always set at right angles to the plane of the Reference section. This means that 'north' - indicated in figures by adding 'excav' or 'grid' as a subscript where appropriate - is at right angles to the main axis of each individual trench in sectors $B$ to $E$, and parallel to the Minaean wall in Sounding A. For the equivalence between cardinal and grid orientations, as well as for the magnetic north as of 2005, the reader is referred to Fig. 7.

The Area $C$ excavation datum is placed at the southwestern corner of wall bastion T7, at the level of the interstice between courses 1 and XIII (point P01; see section 3.2 below). The courses of the Minaean-Islamic wall are numbered top to bottom, with Roman numerals indicating the portion above ground - in 2005 - and Arabic numerals the buried part, from datum down. No less than 26 courses of Minaean masonry are still extant; the remaining nine, I-IX, are part of the Islamic restoration (see section 10.2). Where convenient, the Minaean-Islamic wall will be indicated as 'MW', and its bastion T7 as 'MW.T7' (simplified as 'MW.7' in the Total stratigraphic lattice, Fig. 24).

To a large extent Sounding A, on one hand, and the trenches comprising Sectors B to $\mathrm{E}$ on the other, are complementary. Whereas the evidence from the trenches basically records the Sabaean period, Sounding A provides a yardstick for the Minaean and post-Minaean stratigraphy. Thus the two series of records effectively complement each other.

In consideration of their close proximity to excavated Area C, two additional elements of the local topography need be mentioned, Hill E and Hill C. ${ }^{15}$ So-called Hill E is a small, isolated knob near the base of the presentday talus north of lower Sector E, its foot marginally adjoining quadrangles E9-E10 of the excavation grid (Figs 7, 11). ${ }^{16}$ There is little doubt that Hill E hides a structure or structures, their age and nature unknown. Problems with the instability of sandy sections in lower Sector E, and severe time constraints, unfortunately prevented from excavating quadrangles E9-E10 and thus made it impossible to clarify the nature of this knob (see section 16.4, 'Stratum B', for details).

15 Working designations by the author, 2005-2006. Chapter 26, this volume, provides an overview of these and other landform designations intended to frame Barāqish/Yathill in its physical setting.

16 Quadrangle E11 was located downslope from E8, across the southern foot margin of Hill E. An additional view of this 'hill' from above is in Chapter 1, Fig. 42a (bottom right), in Volume 1.
Hill $\mathrm{C}$ is a large ellipsoid landform about $110 \mathrm{~m}$ long, located at some distance from the western end of Barāqish, beyond the present-day dirt road (Figs 9, 11; cf. Chapter 26, Fig. 11C, this volume). Its northern 'tail' slopes down onto Plain F, mentioned above, where Sounding F was situated. Surface data suggesting that the 'tail' of this low relief may have been occupied by some sort of Sabaean satellite settlement will be reviewed in Chapter 26, this volume. The hill as a whole was subsequently involved in Minaean trading activity.

\subsection{Excavation strategy and the archaeological collection}

Excavation strategy was based on standard practice for dry or 'normal' archaeological deposits, with adoption of the author's distinction between 'elementary sediment units' (ESUs, given a code-name) and 'cuts', or numbered dissection units (taglio, plural tagli in Italian). Cuts were correlated with elementary sediment units and conducted as flexibly as working tactics demanded; the same flexibility of approach would dictate the limits of 'elementary' in the case of sediment units. ${ }^{17} \mathrm{~A}$ total of 161 cuts were made in Area C. Their spatial distribution is visually defined in a series of stratigraphic drawings and planimetric sketches with cut limits outlined in colour, of which only the portion for Sounding A and limited to vertical distribution - is published here (Fig. 25). ${ }^{18}$ On the stratigraphic distribution of cuts in Sounding A see also Table 3.

In this system, cuts are digging or dissection units of a deposit of archaeological interest, that is, units of removal employed in disassembling a deposit or site. Each cut receives a cardinal number. ${ }^{19}$ The disassembling of the deposits, hence the subdivision into cuts, was conducted according to sedimentary limits or other lithostratigraphic indicators whenever these appeared to be immediately recognizable in the course of digging. In this case, a cut directly corresponds to a lithostratigraphic unit. But quite often the disassembling of the deposits had to be adjusted to the ambiguities of sediments or the sustained pace of digging, hence cuts had to be modulated ('defined') as circumstances demanded. A cut, in this case, would cut through more than one lithostratigraphic unit, or, conversely, through only part of a unit.

\footnotetext{
17 For an outline of method see Fedele 1976, 1984, and 1995 (all with references). The ESUs are defined in section 3.1 below; usually they will be referred to in abbreviated form as 'sediment units' or simply 'units'.

18 The full set of vertical and horizontal definitions of cuts, as well as their complete list in table format, are expected to be made available online (see Endnote).

19 In practice, a predetermined batch of cut numbers was assigned to each grid portion in advance: e.g., numbers 50-59 for quadrangle $E 7$, or numbers 180-200 for Sounding A in 2006. It must be noted that cut numbers incorporating a capital letter (e.g. 49D) are fully equivalent to designations with numbers alone, the letters merely allowing an extension of the numbering allotment.
} 


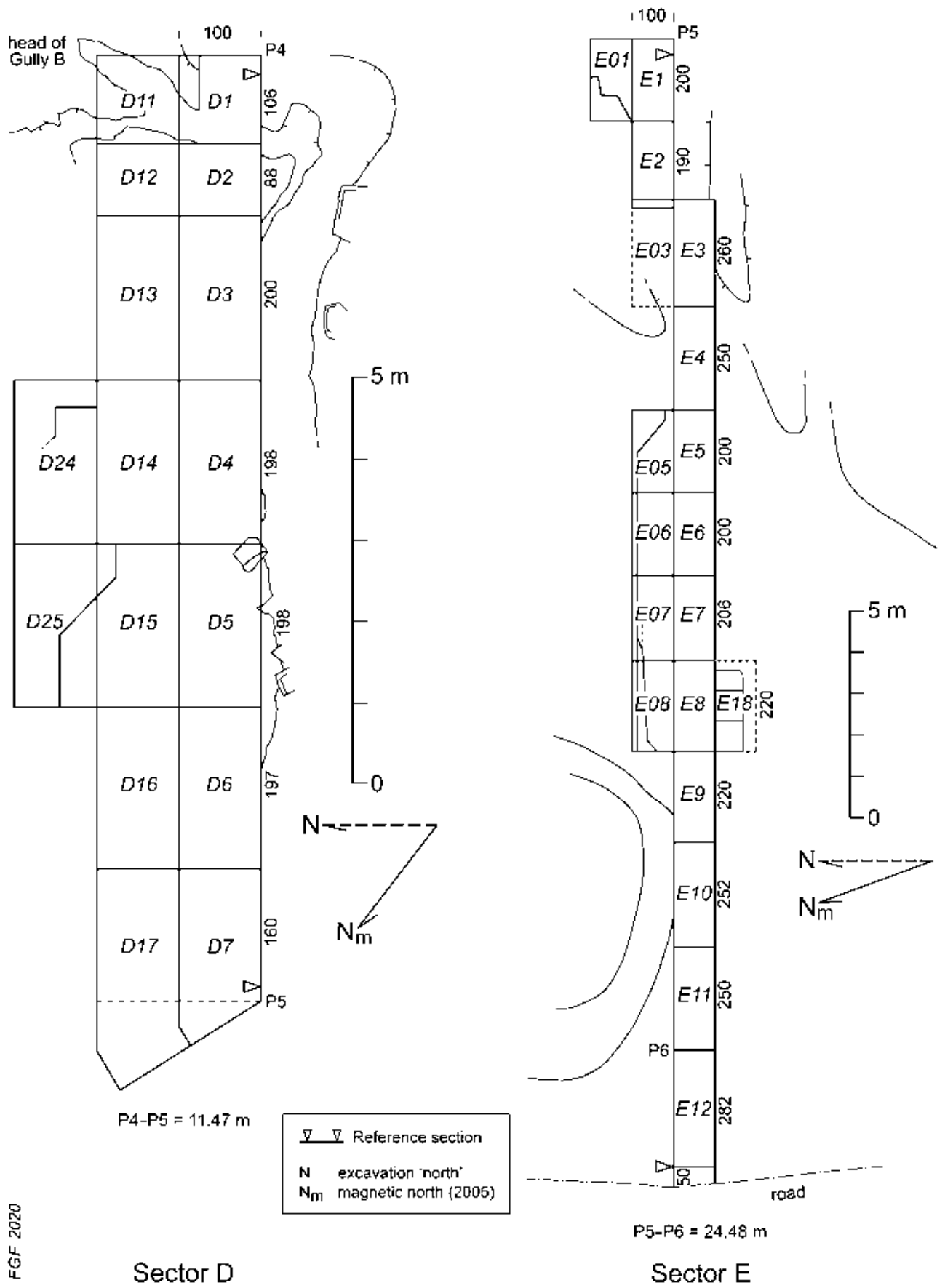

Figure 8. Sectors D and E, detailed plans. Grid measurements in cm. (F.G. Fedele 2020)

It descends from the definition of cut that any single layer of substantial extension or thickness, or both, would be excavated by subdividing it into a number of cuts. The most common example in Area $\mathrm{C}$ was a layer extending in plan over more than a quadrangle of the grid (or an equivalent portion), and/or thicker than it was deemed acceptable for a single cut in terms of spatial control. The above means that at Barāqish Area $C$ the cuts - and the cut numbers - were sometimes equivalent to de Maigret's levées, while at other times they were rather similar to zanābil (singular zanbil, 'bucket' or 'bucketful' in Arabic). ${ }^{20}$ Cuts provide the all-important link to the spatial and stratigraphic data. Concurrently, cut numbers provide the basis for collection register numbers, where 'collection' refers to the whole amount of finds and samples from the

20 de Maigret 2010a, 70. In both conception and terminology the 'levée' system was derived from M. Dunand's classical example at Byblos in the 1920s-1930s. The numbering by zanbil is the same procedure as the 'basket numbers' employed in the Wādī al-Jūbah Project, in which they represented 'the basic unit of recovery for all loci' (Glanzman 1994, 495 [Appendix 1]). 
excavation of a site or part of site - in our case Area C (cf. Chapter 21, section 1). In this latter sense, cut numbers act like zanbil numbers in the usual MAIRY system, employed at Barāqish for the excavations in Areas A, $\mathrm{B}, \mathrm{D}$, and R44/45. Colloquially, the term 'collection' is sometimes used to indicate only a category or group of finds (e.g. 'the pottery collection' or 'the Stratum $\mathrm{H}$ plaster-sealing collection').

Since the chief aim of the project was stratigraphic and concerned with providing diachronic sampling of cultural and palaeoecological evidence, the excavations were essentially conducted with a vertical strategy. The horizontal exposure within the soundings and trenches was severely restricted - Area $C$ was not a wide-area excavation. ${ }^{21}$ However, particularly in Sounding A, the levels and surfaces down to the Minaean accessory works for the curtain wall (Earthwork F10-F12) were excavated and mapped horizontally as well as recorded in profile. In addition, many Later Sabaean archaeosurfaces were recorded in Sectors D and lower E. Useful insights were thus obtained into the spatial arrangement of features and residues; the chief examples will be illustrated in the relevant stratigraphic sections of this chapter.

The excavation recording was conducted by the author as analytically as such a large-scale undertaking permitted, and was supplemented by about 1020 photographs of sections, plans, and terrain or excavation morphology. ${ }^{22}$ Several section profiles were drawn to scale from photographs on the basis of field sketches, descriptions, and measurements. ${ }^{23}$ Due to working conditions, measurements were taken - and spatial control kept - on a sector by sector basis. Only in December 2007 it became possible to anchor the extramural excavations to a precise topography of the entire walled town, and on the occasion the adjoining northwestern sector of Barāqish was specifically surveyed in contour-line detail ('morphological' survey; Fig. 5).

${ }^{21}$ Cf. the case at Hajar ar-Rayhāni: Glanzman 1987e.

22 Two archaeologists from the General Organization of Antiquities briefly took part in the excavations in 2005 ('Isa al-Sha'ibāni and 'Abd al-Bașit Nu'mān) and I had an Italian student assistant in 2006 (Francesco Di Grazia). My other co-workers in 2005-2006 were members of the Yemeni Army stationed nearby, with the occasional participation of personnel from the Barāqish garrison in 2006. Among the former I owe a particular debt to the kind and dedicated assistance of 'Alī 'Abduh 'Abdallah (cf. Chapter 1, section 4.5, in Volume 1). In the field, during both seasons, the collaboration of Patrizio Morlupi as photographer was invaluable.

23 As I was alone in recording field data, there was hardly any time for drawing more than a few scaled profiles while in the field. The elaboration of topography and stratigraphy from the field notes and photographs, and the preparation of stratigraphic analysis and sequencing for publication, took a total of eight months between October 2008 and May 2009, resulting in the Arabia 4 publication (Fedele 2010), while the revision and refinements presented in this book took an additional six months in 2018-2019.
Several categories of material archaeological products resulted from Area C. Basically, they can be classified under the rubrics of 'finds', 'features', and 'samples'. Finds are discrete, movable, and generally smaller items, represented by objects and non-artefactual elements, while features consist of fixed and generally larger bodies or forms. More precisely, features include constructed, man-made entities, indeed often called 'structures' in ordinary language, as well as clearly defined configurations (i.e. bounded, delimited forms). These latter may be entirely cultural, entirely noncultural ('natural'), or a combination of both.

Thosefeaturesthatwere totallyor essentially constituted of sediments were excavated or disassembled with the same criteria applied to any other deposit (i.e., by cuts etc.), and recorded accordingly. In some cases, in fact, distinguishing between sediment-based features and sediment units is a matter of mere convention. The features recognized in Area $\mathrm{C}$, numbered and prefixed by the letter $\mathrm{F}^{24}$ are listed and described in a control document to be made available online (see Endnote). As a category of archaeological 'elements', features ideally belong among the units defined in section 3.1 below, where they will simply receive a mention.

Some additional information on features is apposite here, however. Alongside quite simple features, several complex ones were discovered. The components or parts of a complex feature are indicated with subscripts, e.g. F9 for the vertical eastern limit of mudbrick feature F9. Particularly complex features made up of numerous components, each potentially or effectively constituting a feature in its own turn, can be termed 'mega-features'. The main example is Earthwork F10-F12 attached to the Minaean wall (Sounding A, see section 10.3 below). The formally identified features from Area $C$ amount to 47 , components included (but excluding features or components with dual designation as sediment units).

The two archaeological stone walls from Area C are rather exceptional features, which in consideration of their nature deserve to be exceptionally named: 'Wall F4' the original, complete Sabaean wall indicated by extant features $\mathrm{F} 4_{0}+\mathrm{F} 4_{1}$; and 'MW' the Minaean town wall, with its bastion T7 indicated as 'MW.T7' (cf. section 1.2 above). As a sub-category of features we can additionally list three small individual groupings of cultural or mainly cultural items, provisionally called 'clusters'. They are clearly configurations, hence their ascription to features; details are given in section 3.1 below.

Concerning finds, two recovery procedures were adopted. During excavation, a number of artefacts,

\footnotetext{
${ }^{24}$ Not to be confused with features 'F' are F01 and F02, sediment units of Sounding F.
} 
faunal remains, and other elements $\geq 3 \mathrm{~cm}$ in maximum dimension were point-provenanced (so-called 'individual' finds) and correspondingly plotted onto spatial records. ${ }^{25}$ The individual numbers assigned to finds in the course of excavation (see below) provide precise provenance, normally within a designated level or layer or sediment unit, and within about $\pm 5 \mathrm{~cm}$ in plan. ${ }^{26}$ Cultural objects or other elements smaller than about $3 \mathrm{~cm}$, as well as a large number of elements irrespective of size, were bulk-provenanced with the sediments and recovered through dry screening on site. In other words, they were registered as contents of a cut ('general' finds).

All the excavated deposits were hand-sifted on site. Artefacts, ecofacts (bones, charcoal, plant matter) and manuports (non-modified stones brought in by people) were expertly retrieved, and sediment and rock samples were taken. Fortunately, bone preservation at Barāqish is generally good and this material did not require special treatment on site or afterwards, unlike what often happens in other parts of Yemen, especially on the Plateau. ${ }^{27}$ There is no need to emphasize how the dryness of the area and its predominant sediments, coupled with the microenvironments inside the Barāqish mound, created conditions for the optimal survival of all kinds of organic material. ${ }^{28}$ These are indeed the conditions which also allow easy archaeological retrieval by dry sifting, with good to excellent output results.

Furthermore, fourteen samples from selected cuts were taken for wet screening off-site, that is, simple water screening or a combination of water screening and froth flotation. Both kinds of processing were only carried out during the first season, 2005; the cuts and samples involved are listed in Chapter 20, this volume. For water screening a 2-mm mesh was employed. As to froth flotation, its apparatus and products are also briefly illustrated in Chapter 20. While aimed at the recovery of minuscule contents, flotation and water screening also allowed a detailed, semi-quantitative appreciation of sediments. Selected observations and finds from wet processing will be recalled or utilized in these pages as well as in the following chapters on Area $\mathrm{C}$, where appropriate.

'Finds' and 'samples' constitute the archaeological collection. Table 1 of Chapter 20 offers an overview of

\footnotetext{
25 Individual finds and samples were regularly plotted in situ and collected with individual register numbers (e.g., no. 151.1) in the case of contexts or archaeosurfaces particularly rich in artefactual or ecofactual remains.

26 Within $\pm 1 \mathrm{~cm}$ when intra-quadrangle measurements with a folding metre were taken.

27 See for instance Fedele 1990a; 2008, 164.

28 See Chapter 21, section 2.1, 'Artefacts made from organic materials' (this volume).
}

the astounding repertoire of finds and samples that can be obtained from a site such as the Barāqish mound and its periphery. Each find or close group of finds, and most samples, receive a 'register number' formed by the cut number followed by a dot and an individual identifier, e.g. 215.1 or 15.04. Such 'individual' numbers are those assigned in the field, as explained above, or new numbers from post-excavation or laboratory processing. Register numbers with a slash instead of a dot (e.g. 200/58) originate from the listings compiled in the analysis of particularly large series of finds, normally archaeofauna and pottery. For further details about the numbering of finds from Area $\mathrm{C}$ the reader is referred to Chapter 21 , section 1 , this volume.

Ceramics, an always abundant and important part of cultural finds, were essentially examined during the two field seasons as a functional and taphonomic indicator: functionally, for inferring activity associated with layers and loci, and in terms of taphonomy as a clue to trampling or redeposition. In this latter perspective a wear-grade analysis of potsherds was performed (described in Chapter 20, this volume), which returned illuminating results particularly for the Sabaean period and for the lower half of Sounding A. In the postexcavation phase, the Minaean pottery could be drawn and described typologically (2007), while only a general survey of the Sabaean pottery was possible (20062007). The studies of these two pottery collections are included in the present volume as Chapters 22 and 23, respectively, where additional details on stratigraphic interrelationships are given.

\section{The tell and talus in general: sediments and processes}

\subsection{Tell, talus, and plain}

As mentioned in section 1.2, three parts can be distinguished in the profile of the Yathill/Barāqish mound, corresponding to different depositional domains: the tell, talus, and plain (Fig. 2). These subdivisions not only have morphological significance, but constantly and effectively conditioned the formation and deposition of sediments. Although glimpsed from drillings, ${ }^{29}$ a Sabaean tell at Barāqish had remained an undefined, non-mappable entity until the excavations of 2005-2006 in extramural Area $C$ and in front of Temple A. ${ }^{30}$ The information is completely insufficient for mapping the buried tell within the walled Minaean perimeter, but in Area $C$ a rough idea of the extent and shape of the Sabaean tell can be reasonably gleaned from excavation, and its general evolution described (cf. Fig. 27). Numerous details that

\footnotetext{
29 See Chapter 15 in Volume 1.

30 This latter was A. de Maigret's sounding in 2006: de Maigret 2010a.
} 
can help reconstruct this palaeo-tell will be expounded in the stratigraphic sections of this chapter (sections 5-8 and 10.1).

To summarize the basic data in advance, this was a broad, low tell during the Earlier Sabaean phase, ${ }^{31}$ extending $32 \mathrm{~m}$ away from the line of the subsequent Minaean wall along the radius of bastion T6. At the end of the Sabaean period it had developed into a flat or domed tell, a little smaller in area but now rising to 10$11 \mathrm{~m}$ above the immediate plain to the west. Elsewhere the tell might have been taller, but inferences from present-day topography are hard to make. The tell continued to grow vertically during the Minaean period, gradually burying the lower parts of the great wall that the Minaeans themselves had built. About $4 \mathrm{~m}$ of sediments accumulated along the base of the curtain at bastion T7, some of these sedimentary bodies being created or induced by the existence of the wall itself: for example, from rock exfoliation, carbonate enrichment, and micro-taluses, at the base of the wall, and as aeolian micro-dunes a little away and parallel. Occasionally, deposits were subject to erosion, but accumulation generally prevailed, resulting in intermittent sediment build-up and talus growth. A more detailed summary of the physical history of the Yathill/Barāqish tell will be given in section 4 .

A growing tell often acquires a talus - a sloping margin made of debris. It was so at Yathill, where the work in Area $\mathrm{C}$ also showed how, around the top of the Sabaean tell, the enclosing wall built by the Minaeans and its subsequent Islamic reuse initiated entirely new phases of talus formation. The physical history of a talus is much more complicated than simple tell growth, however, being subject to an array of processes dependent on the varying interactions of tell-edge geometry, sediments, environment, and people. In particular, the talus profile shifted and evolved over time as a result of the accumulation-erosion balance and considerable human activity. It is important to note at the outset that a talus, almost by definition, is a timetransgressive body. In other words, a talus can be formed of time-transgressive lithostratigraphic units and/ or surfaces: the depositional system forming its units, and the landform as a whole, migrate topographically with time. ${ }^{32}$ This essentially horizontal migration or shift, associated with the incremental growth of the talus, occurred east to west in the case of Area C (cf. 'shifting talus' and 'flexure' in Fig. 2; a flexure is the most inclined, sigmoid portion of a slope).

31 This political-historical periodization is explained in section 3.3 below.

32 Cf. Schoch 1989, 115, following an observation of Dunbar and Rodgers 1957, 271. The original concept referred to the theory of stratigraphic correlation, its adaptation to a talus is mine.
The term 'plain', throughout Chapters 17-19 in this volume, will refer to the dry flats immediately surrounding Barāqish: that is, the closely adjacent plain, not to be confused with the true floodplain which can be recognized in all directions a short distance away. In Area C, according to the sedimentary data from excavations and geomorphological inferences, the Sabaean floodplain might lie many metres below the bottom of Sounding F. ${ }^{33}$ Neither culturally sterile soil nor bedrock have yet been found at Barāqish beneath the tell itself. However, minuscule rocky outcrops have become known. The reader will find a thorough discussion of this issue in Chapter 26, section 2, this volume.

\subsection{Sediments and processes: general}

In the Jawf the environment was always semiarid to arid, and at Barāqish its effects variously interacted with artificially supported oasis conditions, at least at the time of Sabaean Yathill. As a consequence, a tell-andtalus system cannot be disassembled and understood ('excavated') without adopting a geoarchaeological approach. The Area C project had such an approach as its basis. ${ }^{34}$ At Barāqish it was particularly aimed at a reconstruction of the physical context that formed the background for the combined action of environment and people, thus establishing a link with the methods of palaeoecology and archaeology, respectively. ${ }^{35}$ Sediments, processes, and people form the core of geoarchaeology as a discipline. ${ }^{36}$

The variety of sediments and sedimentary processes at Barāqish, however common to most arid-zone

\footnotetext{
33 See Chapter 19, section 5, and Chapter 26, end of section 2.2, this volume. The eventual detection of a river-channel bank in Plain $\mathrm{F}$, or nearby, would be a major contribution to the understanding of the early settlement in the locality.

34 Fedele 2010: 100-110.

35 Essential, classic reference works promoting this approach are those of Karl W. Butzer (1976; 1982, particularly 67-122 [chapters 5-7]; with copious references). An encyclopedic if less focused reference is now provided by Gilbert 2017, from which several individual contributions will be cited below. See also Stein 2001, and several other contributions in Stein and Farrand 2001 (on the primacy of sediments); Rapp and Hill 2006, 25-102; Pietsch et al. 2013. Selected studies of tell geoarchaeology are no less indispensable, e.g. Davidson 1976; Rosen 1986. An admirable, general review of tell geoarchaeology has been recently attempted by Wendy Matthews (2017, with references); a parallel review of site formation processes is Mandel et al. 2017 (postdepositional processes on pages 804-807). On the properties of arid and semiarid environments of our interest, including sediments, soils, and geomorphology, see Butzer 1976, 78 120, 376-403; Thomas 1989a, a reference work of continuing relevance (with a chapter by the distinguished editor himself, Thomas 1989b), recently updated (Thomas 2011, 85-267, 427-453); and Parsons and Abrahams 2009, 69-151, 265-300, 517-653. See also, e.g., Kirkby and Kirkby 1976; Goudie 2013, 1-245; and specifically on aspects of sedimentology and geomorphology in arid Yemen, Brunner 1983; Grolier 1988; Overstreet and Grolier 1996, 1988a; Coque-Delhuille and Gentelle 1998; Pietsch et al. 2010.

36 Cf. Fedele 2010, 101, subsection title.
} 
mounds in Western Asia, not only requires particular attention but may pose nomenclature problems. Five main sedimentary processes, linked to different sediments, operated and interacted on the tell and talus throughout the Sabaean and Minaean periods (arrows indicate products):

1. making and decay of mudbrick structures $\rightarrow$ upon decay, release of mixed, nonlocal contents; occasional vertical buildup, sometimes massive;

2. habitation and/or activity residue, both human and nonhuman $\rightarrow$ primary onsite layering and mainly vertical buildup;

3. slumping or sliding of residue, or of whole 'chunks' of deposit $\rightarrow$ local accumulation on middle slope or near the base of tell (various forms); ${ }^{37}$

4. erosion and colluvium from the tell and talus (various incidence and amounts) $\rightarrow$ slopewise transport and redeposition;

5. windblown introduction of silts and sands $\rightarrow$ aeolian deposits.

Processes nos 3 and 4 closely depend on mobilization by rainwater, facilitated in process no. 3 by rain-lubricated silty surfaces. Monsoonal rainstorms are obviously the main factor, but also rainsplash and rainwash erosion is often significant. Process no. 5, aeolian accumulation, is favoured by environmental aridity but depends more on silt and sand supply than wind, hence on suitable land conditions (e.g. abandoned fields). ${ }^{38}$

The making and decay of mudbrick, process no. 1, deserves to be singled out as it is a man-made or maninduced sedimentary process. It involved the artificial creation, accumulation, and eventual disaggregation and redeposition of otherwise natural sediments, sometimes on a massive scale. Examples will be particularly mentioned in sections 7 (Sabaean), 11 (Minaean), and 13-14 (Earlier Islamic). It needs be emphasized that in a geoarchaeological perspective not only the decay of mud bricks or mudbrick material in general, but also their manufacture and installation are merely an aspect of sedimentation, in complete analogy to the case of smaller-sized artefacts (see below).

A related, important consideration is that the clay used to make sun-dried mud bricks at Yathill/Barāqish as elsewhere in ancient Yemen - usually contained varying amounts of rubbish and debris, including potsherds, alluvial pebbles, bits of bone, even flint,

\footnotetext{
37 For displaced, structured chunks of deposit the term 'xenosome' has been proposed (Fedele 2010, 117). The best example is LE $\omega$, an element of a sediment group (LE) which records rain-mobilized debris slides in upper Sector E, quadrangles E1-E2.

38 This process will be particularly examined in connection with Sand YS, see section 6.6 below.
}

and occasionally charcoal and ash. Those were chance inclusions already present in the clay, to which chopped straw or chaff was sometimes intentionally added as a binder. This practice of manufacture transforms our process no. 1 into an entangled and very complicated archaeological and lithostratigraphic process indeed, on both practical and theoretical levels. ${ }^{39}$

Also process no. 2 is largely or totally man-dependent. Moreover, it represents a particularly comprehensive class of processes in terms of both agencies and expressions. Over many centuries the occupants of Yathill not only brought in mineral material, like wādī muds or cobbles, but also plant foods, vegetable fuel, fibers, meat and bone, and organic and inorganic liquids. At times, faeces and urine from animals were added abundantly. Most of such materials would give origin to substances that create or affect sediments, particularly when treated or burnt, generating charcoal, ash, acids, proteins, and lipids. ${ }^{40}$ The biogenic and anthropogenic substances introduced by people and their animals, and the 'cultural' sediments thus made or modified, clearly played a role of primary importance in Area C, where they particularly characterize the Later Sabaean occupation surfaces ${ }^{41}$ and the Minaean upper talus. The extreme, idiosyncratic manifestations in this latter, represented by dung, manure, and plant-organic units, will be illustrated in section 2.3 below. Diagenesis zone $\mathrm{Z} 1$ is an additional, possible example of sediment alteration induced by fluid organic waste (see section 4.1).

The introduction and discard of artefacts is a parallel, important aspect of process no. 2. For the geoarchaeologist artefacts are indeed just sediments,

\footnotetext{
39 In Michael Schiffer's $(1996,111)$ formulation, potsherds and other refuse included in clay used for wall construction constitute 'reclaimed and displaced refuse', and an example is given in fig. 5.4, showing 'Reclaimed sherds in a mudbrick wall [in] Cyprus'. 'Reclaimed' is from reclamation, meaning for Schiffer the transformation of artefacts from archaeological context back into systemic context i.e. living, functioning context (p. 99). Examples from Barāqish Area $C$, concerning pottery inclusions, will be mentioned in section 7.6 apropos of Mass GR1 (feature F9).

40 See, e.g., Butzer 1982, 77-84, with references; and cf. Brinkmann 1996. On the interest and geochemical complexity of sediments affected by organic substances of cultural origin see Heron 2001; and as examples of integrated archaeological-chemical studies of such sediments, from disparate field contexts, Simpson et al. 1999; Bull et al. 1999; Evershed et al. 2001; Shahack-Gross et al. 2008. A fast-burgeoning literature exists on the subject (cf. Spengler 2019, a recent, critical review with copious references). On the detection of ungulate dung in sediments see section 2.3 below.

41 Thoroughly pertinent to these Later Sabaean occupation levels in Sector D is an observation by S. Colledge (2003, 297, adapted): 'The high number of grains and chaff in [flotation] samples could perhaps be an indication of the ubiquity of animal food or dung in the deposits. The digested fodder, in the form of dung cakes, may have been used as fuel for domestic fires. It has been observed that grains and chaff can pass through the guts of animals relatively unaffected by the chemical or mechanical processes of digestion'. Cf. Chapter 19, section 2.1, 'On the uses of ungulate dung, ancient and archaeological' (this volume).
} 
and the deposition of artefacts, whatever their size, represents an additional form of cultural sedimentation. A related aspect and process, the redeposition of artefacts, will be examined at the end of section 2.3.

During the existence of active settlement most of the above processes interacted in varying degree. Particularly processes nos 2-4 co-occurred over the tell margin and talus and sometimes intersected or alternated in complicated ways, resulting in an array of morphological and stratigraphic expressions. There are multiple instances of erosion and redeposition along the evolving profile of the talus, and of accumulation, redeposition and interdigitation near its shifting, expanding base. Discriminating among these processes may be difficult and constitutes one of the chief problems in dealing with a talus. The main depositional trends for the tell and talus, and some general characteristics of sedimentation, will be summarized in section 4 and described case by case in the subsequent stratigraphic sections of this chapter.

\subsection{Particular contexts}

The plain always represented an entirely different geomorphic-depositional district. Most sediments of Sounding F can be traced through processes nos 3-4 to the 'tail' of nearby Hill C (see end of section 1.2, above). Different depositional patterns were active on Hill $C$ and down its sides, and they probably contributed to the composition of pottery associations - or rather aggregates - found in Sounding $F$ and perhaps in nearby Locus P07.42 In the course of time, as suggested by its stratification, the site of Sounding $F$ was also increasingly subjected to aeolian deflation (wind erosion). A specification of the sedimentary agencies operating on the northwestern plain, including Plain F, as well as the cultural activities habitually performed in the area during the successive periods, will require further fieldwork and study.

Particular processes occurred, and sediments were produced, on the upper talus and near the Minaean wall. In this broad sector of Area $C$ the accumulation of deposits was the result of five interacting agencies: ${ }^{43}$

1. human temporary occupation and/or activity residue; and

\footnotetext{
42 A locus eight-ten metres to the northwest of Sounding F: see Chapter 26, section 3.1, this volume. The stratigraphy of Sounding F is treated in the present chapter in section 17.

43 Fedele 2011a, 107. It is important to stress from the outset that nothing in the Minaean deposits outside the curtain wall - at least at bastion $\mathrm{T} 7$ - has the character of dumping from the wall itself (see section 11.4 below). Even during the Islamic period, a practice of rubbish disposal from above the wall may have never existed (see section 13.1 below). This remark should liquidate once and for all the popular cliche that the entire Minaean-Islamic talus is made of dumps from the town wall.
}

2. nonhuman activity residue, mostly fodder and dung; both 1 and 2 mainly producing primary onsite layering and vertical accumulation;

3. aeolian silts and sands, producing accumulation in various forms;

4. the decay of the wall from (4a) thermal or mechanical flaking or breaking, producing rubble lenses, or from (4b) calcium carbonate dissolution and redeposition, producing induration of loose sediments and/or crusts and crystals.

Processes and products 1 and 2 are best considered together, given their often close behavioural interrelationships. Products $4 \mathrm{a}$ and $4 \mathrm{~b}$ represent the weathering of the Minaean wall, with the occasional contribution of human wear or damage ${ }^{44}$ and were mostly deposited near the base of the wall itself.

Of special interest for the Minaean stratification are the biogenic substances introduced by people and their animals in this part of Area C (entries nos 1-2, equivalent to general process no. 2 described above, section 2.2). Intermittently, as already mentioned, faeces and urine from large animals stationing or working on the talus were deposited, generating true dung lenses and what may be called 'manure' units (unità a stallatico in Italian): animal waste mixed with fodder or litter detritus, brown to blackish in colour. Similar sediments, but probably less charged with actual animal waste and without evident excreta, have been termed 'plant-organic' units (cf. Fig. 26).

This distinction is based on the composition and ratio of actual excreta to plant fraction, together with sedimentary texture and structure. A finer classification of such sediment bodies, although attempted in the field ${ }^{45}$ is better suspended until dedicated sampling and chemical determinations can be made. ${ }^{46}$ Such

\footnotetext{
44 On this latter process and its effects see section 10.4 below, 'The wall: physical-chemical behaviour and damage'.

45 From macroscopic observation combined with the results of flotation (Chapter 20, this volume). Cf. Fedele 2010, 102 (slightly amended): 'Among non-minerogenic sediments of special interest, several kinds of "vegetal" sediments with different origins were distinguished: "plant detritus" units, made of dry plant scraps; "plant-organic silts", a mixture of minute vegetable bits and other organic matter in a loamy matrix; and "manure" units, lumpy or laminated animal waste (dung especially) mixed with litter detritus and typically brown to blackish in colour.'

46 The recognition and cultural interpretation of animal dung in sediments is a particular, highly promising field in bio- and geoarchaeology: e.g., Rosen et al. 2005; Bull and Evershed 2012; other contributions in Jones 2012; Wallace and Charles 2013; Canti and Huisman 2015; Broderick and Wallace 2016, 38-39; Matthews 2017, 961; Miller 2020. This type of investigation was initiated long ago by such studies as Miller and Smart (1984) on the burning of dung as fuel, or Charles (1998) on the recognition of dung-derived plant material. A recent discussion of physico-chemical methods of studying or detecting excrements from ungulates in sediments is Spengler 2019, with references. Cf. Chapter 19, section 2.1, 'On the uses of ungulate
} 
analyses, and a search for faecal spherulites, ${ }^{47}$ could not be arranged or carried out at the time of fieldwork, unfortunately, but the nature and origin of such lenses and layers cannot be doubted. Where preservation of excrement lenses and manure units is good, camel and donkey coprolites constitute the large majority of the recognizable components (e.g. Fig. 10 in Chapter 19, this volume) ${ }^{48}$ Several manure units appear as packs of brown, stratified excrement lenses almost devoid of minerogenic matrix (e.g. BR3, BR2k; cf. Fig. 30).

Concerning the talus, a significant process to be addressed is redeposition, involving sediments and their contents. During the the First Intermediate phase and the Minaean period, and to some extent afterwards (for periodization see section 3.3 below), redeposition down the sloping surfaces of the talus became a common occurrence, particularly when and where older sediments had been reworked and thus mobilized by human activity (e.g., by digging for the foundations of the Minaean curtain wall; see sections 9 and 10 below). Until the later phases of the Sabaean period redeposition had generally been more modest, due to the weaker slope of the Sabaean tell at the time. Dealing with redeposition is important for elucidating the actual stratigraphic position of objects and other finds, particularly when their context of retrieval is unclear (cf. Chapter 21, introduction to section 2.1, this volume).

Unsurprisingly, potsherds are a case in point. Even today, Sabaean potsherds are ubiquitous on the Barāqish talus, to the point of often characterizing the local archaeological landscape. The abundance of Sabaean ceramic discard left an indelible sedimentary imprint. Sabaean pottery was found profusely throughout the extramural area, both as primary occupation residue and as repeatedly reworked debris. For centuries, Sabaean fragments continued to litter the surface of the talus through a weak but persistent process of erosion, downslope transport, redeposition, and trampling, a suite of processes that upon and beyond the talus continues to this day.

\footnotetext{
dung, ancient and archaeological' (this volume).

47 'One of the more reliable means of identifying a dung signature in sediments is through the study of spherulites, fibrous crystalline aggregates of calcium carbonate from the guts of ungulates' (Spengler 2019, 219). A specific review of 'coprogenic facies' sediments as recognized from spherulites can be found in Boschian 2017. Recent examples of these studies include Shahack-Gross 2011; Lancelotti and Madella 2012; Henry et al. 2017. It is uncertain whether some of the 'white specks' observed in the lower talus of Area C (see section 4.1) are in fact spherulites.

48 Fedele 2011a, 111; 2014, 190. 'Macroscopic observation of coprolite morphology as well as laminated dung and straw leaves no doubt that both manure and plant-organic layers on the talus are almost exclusively associated with donkeys and dromedaries, with some informal stabling possible' (Fedele 2011a, 111, footnote 3). Cf. Chapter 19 , section 3.1 , this volume.
}

For a long time, Sabaean elements circulated freely upon the Minaean ground surfaces as well as subsurface, where they can generally be distinguished for their pronounced abrasion and wear, in addition to typology. In the excavations, on the contrary, Minaean pottery was almost exclusively found in two locations of Area C: along the curtain wall (Sounding A) and at the opposite end of the excavations in Sounding F. Only relatively little Minaean pottery came to light from Sectors B and C, and extremely little - all redeposited - from the whole of Sectors D and E. One can therefore say that Minaean pottery is not rare, but concentrated. This topographic segregation of the Minaean material reflects entirely different patterns of activity, individual behaviour, and discard. ${ }^{49}$

\section{Stratigraphy}

\subsection{Stratigraphic approach and nomenclature}

Several hundred sediment bodies of various ranks were field recorded from Area C. They are listed in a control document to be made available online (see Endnote). Sediment units and subunits alone amount to 524. The excavation tactics and stratigraphic nomenclature had to cope with such a complexity. In fact, excavation procedures, geoarchaeological criteria, and stratigraphic analysis go hand in hand. In establishing a total stratigraphic profile, expressed in a Reference section, the main task was to achieve coherence and allow sequencing, through data reduction, while at the same time preserving the exceptional wealth of detail retrieved from the field. Splitting and lumping, the two competing stances concerning deposits, ${ }^{50}$ were both adopted by turns. When ranking and classifying sediment bodies in arid-zone archaeological contexts a certain degree of flexibility helps.

In stratigraphic classification, lithostratigraphy has to have precedence on all other stratigraphies. Lithostratigraphy - the description and ordering of the lithological ('geological') components or layers ${ }^{51}$ - is only the first of several types of stratigraphy, to be conceived of as parallel columns. ${ }^{52}$ And in the case

\footnotetext{
49 Fedele 2010, 102. Cf. Chapter 19, section 3.1, this volume.

50 Stein 2001, 5.

51 'Layer' will be used in this chapter as an informal, general word for any kind or rank of stratified sediment, or other stratified or stratiform entity.

52 Other types of stratigraphy of chief interest at Barāqish, as everywhere, are chronostratigraphy, as different from numerical chronology, and ethnostratigraphy or cultural stratigraphy (see section 3.3 below). The concept of multiple stratigraphies lies at the foundations of geological and archaeological stratigraphies alike, as mentioned in Chaper 18, section 2.2, this volume: a standard practice too often ignored in archaeology. See, e.g., Butzer 1982, 67-71; Gasche and Tunca 1983; Fedele 1995; Farrand 2000. An excellent recent treatment of archaeological stratigraphy (with previous literature) is Stein and Holliday 2017.
} 
of Barāqish Area C lithostratigraphy essentially means sediment stratigraphy, the term 'sediment' being used comprehensively. Sediments will sometimes include bodies that formed part of structures, mud structures particularly. The following lithostratigraphic - i.e. sediment-based - classification categories were employed, ranked from the elementary to the most inclusive: 'elementary units', 'suites', and 'groups'.53

a1. Elementary sediment unit (ESU), ${ }^{54}$ often simply 'unit', ${ }^{55}$ mentioned above at the beginning of section 1.3: a conveniently small or the smallest body of sediment that the excavator deems fit to recognize, equivalent to the geological concept of 'bed' or somewhat lower in rank; i.e., units are the smallest homogeneous or essentially homogeneous bodies which make up a sedimentary deposit. Units are principally designated by acronyms or abbreviated descriptions in the form of letters, with or without numbers and supplemented by the occasional 'prime' symbol ('). ${ }^{56}$ Numbers in these code-names do not necessarily have sequential value, so that, for instance, SI3 does not imply any positional relationship with SI1.

In the spirit of footnote 50 , above, lesser sediment bodies within units were distinguished and named wherever convenient and possible, both during fieldwork and in post-excavation analysis: for instance, small lenses or inclusions (such as $\lambda \alpha 1$ ), or semi-conventional partitions (such as $\mathrm{SGL}_{1}$ and $\mathrm{SGL}_{2}$ ), and occasionally also facies (mildly differentiated parts in appearance or composition). These 'subunits' defined by minimal size and spatial extent represent - strictly speaking - the truly elementary components for the purpose of lithostratigraphic description.

a2. Sediment suite: a continuous sequence of relatively similar sediment units, resulting from broadly similar sedimentation processes in the same physical context. By extension, considering lateral - not vertical - continuity, suites can also include close, ribbon-like concatenations of genetically and/or

53 Fedele 2010, 103-104, modified. In principle, if not in terminology or detail, also these categories and their attendant classification follow archaeological (Gasche and Tunca 1983) and geoarchaeological schemes (Stein 1987; Fedele 1995), inspired by normal geological practice (e.g., Schoch 1989; Murphy and Salvador 1999), contra E. Harris, an author inclined to misrepresentation of other people's work and ideas (Brown and Harris 1993). Classic dictionaries such as AGI 1984 and Bates and Jackson 1987 provide useful terminology.

54 Fedele 1976. The adjective 'elemental' in the original designation ('elemental sediment units') is no longer considered appropriate.

55 When unqualified, 'unit' in sedimentary descriptions is shorthand for elementary sediment unit. Repetition of 'sediment' as the common adjectival prefix to units, suites, and groups will usually be avoided.

56 I prefer names to numbers for mnemonic reasons, because strings of letters hinting at sedimentary and/or positional attributes - and thus forming names with meaning - are better memorized than numbers. This practice is in opposition to a preference for sheer numbers, as notably popularized by Harris (1989). compositionally related sediment units ('planar' suites). ${ }^{57}$ The best example is suite E1 $1 \varepsilon 8$, a sheet made of several adjacent loamy-sandy units in lower Sector E, which shows in section as a narrow and irregular band several metres long. Alternatively,

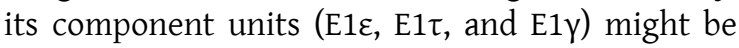
ranked as facies differentiations of a single unit, but, in order not to stretch the definition of unit beyond reasonable limits, I prefer to reserve 'facies' to less contrasted lateral subdivisions of an ESU (see above). Sediment suites are listed in Table 1.

a3. Sediment group: a convenient vertical block of sediment units, be such units grouped into suites or not, often corresponding to an identifiable sedimentary cycle. ${ }^{58}$ Thus, besides its value in a taxonomy of sediments, the group possesses an additional topographic dimension: it refers to a specific, relatively small location in a stratified deposit. The group is both a higher-rank lithostratigraphic category to the sediment suite and sediment unit, and a convenient classifying category to highlight a localized succession of layers - a vertical succession of sediments in a particular location, usually bounded by significant discontinuities. Briefly, it is a localized package of layers useful to be kept in evidence..$^{59}$ Sediment groups are listed in Table 2.

As a higher category of classification, sediment suites have been introduced so as to avoid dealing with a plethora of sediment units too small for practical discourse. Grouping several consecutive or adjacent sediment units into a suite requires that such units display a certain affinity of sedimentary dynamics (a degree of 'continuity', to repeat this term), ideally coupled with broadly similar lithology and structure. Similarly, although reflecting a different concept, sediment groups have been introduced as a matter of convenience whenever there was a practical need to refer to larger complexes of sequential sediment bodies. Strictly speaking, a group, as a convenient column of layers to deal with, is not a proper category of lithostratigraphic classification.

Integral to the identification and description of sediment units is the recognition of discontinuities, or 'surfaces', a semi-lithological category. In fact, the definition of units itself depends on the appreciation of

\footnotetext{
57 The definition of suite has been expanded this way during the preparation of this chapter in 2018-2019.

58 In the context of tell geoarchaeology, I use 'group' in an entirely different sense from the same term in geological stratigraphic classification.

59 As a category of classification, the sediment group - together with the lithocomplex (see section 3.3 below) - was a helpful step in identifying building blocks for the stratigraphic sequencing across Area C. This was in fact its original purpose.
} 
discontinuities, however slight these may be. Surfaces are indicated with numbers prefixed by the letter ' $\mathrm{S}$ '. Some were recognized in the field, others during subsequent studies, for a total of 31. They are listed and described in a control document to be made available online (see Endnote). Marked, sharp discontinuities are very rare in Area $C$ and only a few are angular, no matter how they were formed. Important stratigraphic boundaries may thus be inevident or even invisible, making the isolation of depositional interruptions or gaps difficult. ${ }^{60}$ That is particularly the case in what can be termed sand-on-sand and silt-on-silt contacts. The recognition of local deflation is no less problematic. Furthermore, in Area $\mathrm{C}$ the sediments are pretty monotonous throughout, silt and sand being ubiquitous and pervasive: a not uncommon constant in the more open micro-environments of the Șayhad and the Jawf.

Nevertheless, quite a number of discontinuities, hence surfaces, were recognized, some entirely geological in origin and some partly cultural. Their variety includes (i) particularly distinct lithostratigraphic limits, either recorded in excavation or derived from the interpretation of photographs; (ii) particularly sharp limits determined by erosion (erosion surfaces); (iii) lithostratigraphic limits named as 'surfaces' because they were considered of special stratigraphic significance; (iv) 'archaeosurfaces' connected with activity or occupation on the spot or nearby, often indicated by the resting surfaces of groups of artefacts or other finds; and maybe more.

Sediment units and suites, features, and surfaces, all serve as stratigraphic units. They remain different categories of geoarchaeological entities, however, characterized by different ontological and 'behavioural' properties, and therefore they should not be lumped into a single stratigraphic numbering system as asserted by some authors. ${ }^{61}$

Three supplementary categories of varied stratigraphic status and/or potential stratigraphic significance were employed in spatial and stratigraphic description and analysis. One is semi-lithological (b1), the other two can be ordered under the rubric of archaeological units or 'elements' (b2 and b3). The entries classified in these supplementary categories are listed in a document that is expected to be made available online (see Endnote).

b1. 'Diagenesis/weathering zone': a postdepositional band of modification of primary sediments, essentially

\footnotetext{
60 The same observation was made by Glanzman (1987e, 207) in Wādī al-Jūbah: 'The isolation of depositional hiatuses [is] a difficult task in view of the silty nature of most of the deposits'. Sedimentary interruptions and gaps are often loosely referred to as hiatuses (lato sensu). In spite of superficial impressions, very few at Barāqish Area $\mathrm{C}$ seem to correspond to long time intervals.

61 Notably Harris 1989.
}

produced by biogeochemical agencies like enrichment by calcium carbonate or infiltration by fluid waste substances (animal excreta in particular; see section 2 above). Clearly, diagenesis is here defined in a broader sense than generally used: it encompasses any physical and/or chemical changes in sediments after deposition. Thus understood, in fact, diagenesis is coterminous with weathering. Diagenesis or weathering zones are indicated with code numbers prefixed by the letter ' $Z$ '. Three were identified, Z1-Z3 $3^{62}$ (see descriptions of each in section 4.1 below); they will be commonly cited with a specification such as 'diagenesis zone Z2' or 'Diagenesis Z1'.

As a biogeochemical product, like a weathering profile, a diagenesis zone is akin to soil horizons, hence the subject of a different category of geological stratigraphy, not employed at Barāqish. However, we can include among the diagenesis/ weathering zones at Barāqish the pedogenetic or soil-formation zones indicated by traces of soil horizons. The only actual occurrence is the 'Yathill Palaeosol', this designation being a naming exception (see description in section 5.2 below). Although poorly developed, each diagenesis or weathering zone would mark a stasis (a moment or interval of temporary geomorphic stability) in the tell-talus profile.

b2. 'Cultural horizon' or simply 'horizon': a planar spread of discontinuous cultural elements, more or less closely associated with a certain sediment matrix. Horizons are thus, essentially, horizontal or near-horizontal distributions of cultural materials with overall lateral continuity. Not to be confused with a soil horizon (pedological horizon). Prefixed by the letter ' $\mathrm{H}$ ', only three horizons were named: east to west, Horizons H78, H11, and H11Q. Considering their characteristic of lateral or horizontal concatenation, a horizon is somewhat equivalent to a suite of the lateral or 'planar' variety (see above), but is not defined by sediments only - or by sediments at all..$^{63}$

b3. 'Locus' (plural 'loci'): a spatially delimited portion of an archaeological deposit defined by particular characteristics; a spatial-stratigraphic unit of mere convenience. More precisely, the designation as locus is meant to identify a position, both within a certain layer and topographically: a small bound-

\footnotetext{
62 Diagenesis zones should reasonably be named only when their presence is conspicuous. For an introduction to postdepositional processes and postdepositional alterations the reader is referred to - respectively - Mandel et al. 2017, 804-807, and Matthews 2017, 966-967.

63 Cf. Fedele 2010, 103, where, however, the relationship between horizon and lithological unit had not been adequately resolved (see the horizons belonging to Stratum $\mathrm{M}$ ).
} 
ed area characterized by archaeological properties of particular interest, evidence, or singularity (often an unusual concentration of cultural remains). Prefixed by 'Lo' and designated after the main cut number, only five loci were named, four along the Reference section (Loci 33, 44, 151, and 200) and one a little off section in the plain (Locus P07). An entirely different definition of locus was employed in Yemen by researchers of the Wādĩ al-Jūbah Project, following Near Eastern usage. ${ }^{64}$

Two additional categories of archaeological elements were employed: 'features' and 'stones'. They are listed and described in a control document to be made available online (see Endnote).

c1. 'Features'. They were already defined in section 1.3 , above; here is some specific information about 'clusters'. Three were formally named: Clusters 82.2, 83.1, and 121.1. Clusters are clearly configurations, but not enough well-defined or well-structured to be classified as 'features' and therefore be prefixed 'F'. Nor are they horizons, i.e., true concentration of finds, due to their very restricted lateral spread. In fact, clusters such as those I have so designated belong in a liminal zone at the intersection of Feature, Locus, and Horizon; they represent depositionaltopographical microunits.

c2. 'Stones': in fact, clasts in the broadest sense, ${ }^{65}$ a category inclusive of both rock fragments and artificial elements of lithoid affinity, such as mud bricks (e.g. P50 and P51 in Sector C), mud blocks, or small mud masses. ${ }^{66}$ Identified and numbered independently of their size, shape, and cultural or non-cultural origin, as well as on the basis of research interest or convenience. Stones/clasts are prefixed by the letter 'P'; a total of 51 were listed, counting 'collective' numbers for stone groups as unity.

To conclude, the following main changes of a general nature were made concerning stratigraphic nomenclature, compared to the report in Arabia 4:67 (i) clarifications concerning the unit-subunit hierarchy; (ii) a reorganization and redefinition of suites and groups; and (iii) renaming of sediment units, suites, and groups for simplification or consistency.

\footnotetext{
64 Glanzman and Ghaleb 1987b, 11-12. This field methodology had been introduced by Blakely and Toombs (1980) at Tell el-Hesi; cf. Bennett and Blakely 1989, 13; Seger 1996b, 246.

65 In geology, clast indicates any individual rock fragment.

66 In principle, also terracotta blocks or masses would be classified in this category, but none was found.

67 Fedele 2010.
}

\subsection{Total stratigraphic profile: the Reference section}

As mentioned in section 1.2, a total stratigraphic profile for Area $C$ from curtain wall to plain was obtained by combining the multiple excavation sectors and their partial exposures. This profile coincides with the Reference section, that is, the maximum east-west section as defined in Fig. 13 (cf. photographs in Figs 14-15). ${ }^{68}$ 'East' and 'west' in the Reference section must be understood as excavation east and west, i.e., a unified, conventional orientation, as explained in section 1.2 above. Consecutive portions of the Reference section are shown in greater detail in Figs 17-23, with superimposed culture-historical subdivisions or Strata (see section 3.3 below).

All the other sections will be referred to as 'subsidiary' sections. In fact, many provided important information for clarifying the Reference section itself, or proved useful in interpretation and sequencing, such as - for instance - the key south section of quadrangles E3E5, which affords a stratigraphic window into some of the lowermost layers of the talus (Figs $41 \mathrm{~B}, 46$ ). A large number of subsidiary sections was recorded in drawings, photographs, or both.

Segment by segment, both the south and north excavation sections were chosen to serve as reference section, but in a way that they complemented each other. In particular, the south section was used for Sounding A, Sectors B to D, and Sounding F. In Sector $E$, the south section was used for quadrangles $E 1$ and E2, while for quadrangles E3 to E11 the choice shifted to the north section, which was regarded as generally more informative. Therefore in drawing the Reference section for quadrangles E3-E11 the actual excavation section was inverted horizontally, i.e. reflected eastwest.

In quadrangle $E 3$ this shift had to do with the crossing of Gully B and an associated change in talus morphology and preservation. Here, additionally, we have a good example of the importance of subsidiary sections. The south section of quadrangle $E 3$, where the excavation intersected the mouth of Gully B, was indeed most informative not just because of its greater thickness, but especially for the greater number of sediment units it displayed and their better expression. Therefore the south section represented for E3 the pilot section for understanding its north section, chosen as reference. The south and north sections of this quadrangle were linked - in a chain - via the E3 east section

\footnotetext{
68 For all practical purposes, section and profile will be considered interchangeable terms. The Reference section amounts to a standard profile and provides a summary of the stratigraphic structure of the deposits in question.
} 
supplemented by the ' $20 \mathrm{~cm}$ ' east section of adjacent quadrangle E03 (Figs 42-43, 46). ${ }^{69}$

The standard reference section of quadrangle E6 could not be drawn because two thirds of the section suddenly collapsed before formal recording. ${ }^{70}$ It had to be substituted with a parallel, subvertical section recorded $40-20 \mathrm{~cm}$ within the adjacent quadrangle, E06. This 'recut' section, cleaned and studied in detail in 2006, is indicated in the Reference section as E6(E06), which explains the vertical separation lines and the slight discrepancy with both E5 and E7 in Figs 13 and 21 (see also Fig. 47). ${ }^{71}$ Photographic information from the original north section of quadrangle $E 6$ was taken into account in drawing the published section and linking it to the contiguous quadrangles; only minor discordances remained (cf. section 16.3 below).

All elevations in Area $C$ are measured with respect to a datum plane (Area $\mathrm{C}$ datum), identified by point P01, a looped stake firmy fixed into a joint of the Minaean masonry on the south corner of bastion T7. Its elevation is $+5.43 \mathrm{~m}$ above the datum for Temple A and the temple area, ${ }^{72}$ and it corresponds to the top of Sounding A and the excavations in Area C. The opposite end of the Reference section is stake P07 in the plain, so-called Plain F, at an elevation of $-14.84 \mathrm{~m}$ below the Area C datum. (Plain $\mathrm{F}$ was introduced in section 1.2 above; further information is given in section 17 on Sounding F.) The ground elevation in Sounding F varies between -14.3 and $-14.4 \mathrm{~m}$ below the Area $\mathrm{C}$ datum. The top of Hill $\mathrm{E}$ is -10.24 below the Area $C$ datum.

\subsection{From lithostratigraphy to cultural stratigraphy. Stratification diagram and Strata}

The total sequencing of the extramural profile involved correlation, guided by the same principles and methods of geological correlation, ${ }^{73}$ and, as a last step, a shift in emphasis to cultural stratigraphy, or

\footnotetext{
69 A 20-cm-thick slice on the eastern side of qu. E03 was excavated in detail for the purpose of inspecting directly and over a wider area the south-north stratigraphic correlation across qu. E3, as well as in the E2-E3 segment. The 'retracted' east section thus recorded will be designated the E03 'east-20-cm' section (Figs 42, 46).

70 But, luckily, after photography - the daily shots. The collapse occurred on 15 December 2005 and was due to the fragility inherent in cutting sandy deposits vertically. It also involved smaller parts of the adjacent quadrangles, but qu. E5, E7, and E8 had already been recorded. At ground surface the scar left by the collapsed deposit formed a segment with a chord of $5.8 \mathrm{~m}$ and a height of $0.9 \mathrm{~m}$, while its natural fission surface presented a $75^{\circ}-80^{\circ}$ dip in section, top-down. Approximately, the lowermost $50 \mathrm{~cm}$ of the original north section in qu. E6-E8 - - were not affected by the collapse.

71 Fedele 2010, 108, footnote 47.

72 The figure of ' $11.45 \mathrm{~m}$ ' above the datum for Temple B, stated in Fedele 2010, fig. 132, is incorrect. It resulted from a misunderstanding with R. Loreto concerning the local datum for Temple B in 2005. Cf. Chapter 26, section 2.1, this volume.

73 Schoch 1989, 111-124, an excellent discussion of theory.
}

'ethnostratigraphy'. ${ }^{74}$ These two crucial steps can be summarized as follows.

Step 1. The entities a1-a3 defined in the previous section (sediment units, suites, groups) and particular stratigraphic 'events' (such as a wall construction or a period of sedimentary stasis) were arranged into 'lithocomplexes' (author's term), higher-rank packages of layers identified from persistence of deposition and/or lithological correlation over a short distance. More precisely, these are packages that short-range lithological correlation shows to be relatable; in other cases their definition is contingent on pairs of relatively developed sedimentary discontinuities (see an example in Table 5). ${ }^{75}$ Lithocomplexes are the building blocks on which the stratigraphic ordering of all the excavated components is then attempted (sequencing on the basis of lithological correlation). The need for this intermediate step represented by the lithocomplex was determined by the limits of the excavated exposures in Area $\mathrm{C}$ as well as the complexity and extension of stratigraphic structures, resulting in no less than eight disjunct, parallel sequences. ${ }^{76}$

From the articulation and ordering of the above lithocomplexes and sequences, and taking into account subsidiary sections, a total stratigraphic lattice or 'Stratification diagram' was obtained (Fig. 24). ${ }^{77}$ It summarizes in diagram form the lithostratigraphy of Area C. It is worth noting that any stratigraphic diagram is a lattice and not a matrix, as wrongly popularized. ${ }^{78}$

Step 2. Subsequent to sediment stratigraphy, correlation, and total ordering, the extramural stratigraphy was framed in terms of 'Strata', that is, as a series of chronological-cultural blocks (ethnostratigraphy; cf. section 12.1, below, for a useful clarification). Strata will be designated with capital letters from the top down, in reversed historical order, as listed and defined in Table

\footnotetext{
74 Gasche and Tunca 1983; Fedele 1995, 86-87, fig. 5. Most recently, Stein and Holliday 2017, 35-36 (with references).

75 A lithocomplex differs from a group precisely in that shortdistance correlation and/or pairs of discontinuities (usually 'surfaces') are involved in its definition.

76 Disjunct sequences A, B, C, D, E1-E3, E4-E8, E11, F (E1-E3 and E4-E8 only partially overlapping). Of these, $\mathrm{A}, \mathrm{D}$, and subsequently $\mathrm{D}+\mathrm{E1}-\mathrm{E} 3$ from lithocorrelation across Wall F4, were the longest conformably stratified sequences and served as a basis for all further ordering a pilot succession (Fedele 2010, 104). The full list of lithocomplexes, with procedural justifications, is filed with the working papers of the Area C project in care of the author (cf. Endnote).

77 Previously unpublished (but cf. Fedele 2010, tab. 2, column Lithostratigraphy). The diagram is partly styled after Carver 1995. Following Martin Carver (p. 291), the reader is reminded that the most important function of these diagrams [i.e. the stratification diagram or sequence diagram] is the presentation of uncertainty in the stratigraphic sequence'.

78 By E. Harris (whose disagreement with M. Carver is on record Brown and Harris 1993, 16-19).
} 
$4 .{ }^{79}$ In Figs $17-23$ they are identified by colour outlines superimposed on detailed, consecutive segments of the Reference section.

Ideally, Strata should be sequential and not-overlapping, but in fact some lithocomplexes from Sector $\mathrm{E}$ and Sounding F could not meet that requirement, due to a lack of both lithological continuity with the other sequences and diagnostic contents. As a solution, they were grouped into three non-correlatable sequences or 'floating' blocks, which, although impossible to correlate one-to-one with Strata of the pilot sequence, ${ }^{80}$ could be inserted approximately: hence their alphabetical designation (Strata M, G, and D) and historical placement (e.g. Sabaean 3-4 Indeterminate, see below).

These 'floating' Strata are related to the Strata of the continuous sequence as follows:

- Stratum M approximately spans Strata L and $\mathrm{N}$, or spans a shorter interval around the N/L timeline;

- Stratum G approximately spans Strata F and H;

- Stratum D approximately spans Strata C and E.

Finally, Strata were correlated with political-historical subdivisions (phases, periods) on the usual basis of archaeological contents, temporal position, and comparative considerations (Table 4). ${ }^{81}$ It is important to note that the periodization in the table has exclusive validity within extramural Area C. Only the periods in the first column on the left (Sabaean, Minaean, and Islamic) are broadly parallel to those described from the intramural temple area. ${ }^{82}$ The historical significance of some particular Strata and the extramural sequence in general will be developed in Chapter 18, section 3, this volume.

The cultural-historical columns on the left of Table 4 include several fairly obvious designations, but also two phases called 'Intermediate'. This latter label reflects archaeological usage in other parts of the world,

\footnotetext{
79 Stratum, plural Strata, will be written with a capital S to avoid confusion with stratum as a general term (cf. Glanzman and Ghaleb $1987 \mathrm{~b}, 12)$ and to emphasize the particular utilization of the word in a cultural-stratigraphic sense. Strata are named top to bottom following the MAIRY style (cf. de Maigret 2010a). In this chapter, wherever appropriate for clarity or to stress significance, all the stratigraphic designations including strata will be written in bold: e.g., 'colluvial lenses LE in contrast to lenses L3BC'; 'suite CM (Stratum P), units XE4 and LZ5 (Stratum 0)'.

80 The continuous (i.e. non-overlapping), orderly flowing succession constructed from upper Sector E to Sounding A (see footnote 76 above).

81 This association was initially framed in terms of broad politicalhistorical sweeps, or 'periods' (Sabaean etc.), and subsequently fine-tuned to take into account the subdivisions suggested by each individual Stratum.

82 de Maigret 1991b, 2004, 2010a; de Maigret and Robin 1993.
}

whenever a seemingly undefined, multifaceted, or 'transitional' period inserts itself between periods that are better defined in cultural and especially political terms. A notable case of this terminology is ancient Egypt. For Barāqish, 'Intermediate' was devised in 2010 as a neutral labelling in connection with Stratum $\mathrm{K} .{ }^{83}$ Subsequently, A. Agostini chose the same term to designate the immediate post-Minaean phase, possibly characterized by the presence of the Amir tribe during the 1st-2nd centuries $\mathrm{CE}^{84}$ Our independent choices evidently reflected a shared attitude in classifying the successive stages of Yathill/Barāqish. From the perspective of Area $\mathrm{C}$, the combined lithostratigraphic and cultural record requires being modelled in terms of two 'Intermediate' phases: speaking of a 'Second Intermediate' will avoid confusion with the terminology derived from the temple area. ${ }^{85}$

A final comment is in order. Under the heading of cultural stratigraphy, each individual category of artefacts, each historical or 'ethnic' entity, should ideally lead to a different stratigraphy, and these parallel stratigraphies are not necessarily overlapping. In particular, ceramic phases need not precisely coincide with political-historical phases (cf. Chapter 18, sections 2.2 and 3.2, this volume). Furthermore, each artefactual or historical stratigraphy may coincide only in part - or not at all - with lithostratigraphy. This independence of parallel stratigraphies should always be borne in mind.

\section{Long-distance correlations}

The sequencing on the basis of lithological correlation necessitated some correlations that, at the scale of Area C, we can call long-distance. They were difficult. Most cases will be discussed individually and with the relevant details in the stratigraphic sections of this chapter (sections 5 to 17). Here is a synopsis of these cases and their main problems.

- Sector D and Sounding A were linked via Sectors C and B. Sector C correlates easily with quadrangle $D 1$, as it was excavated so as almost to join this end of Sector D directly, but linking $C$ with $B$, and B with Sounding A, was problematic. In view of its singularity throughout Area $C$ (not just the talus), an idiosyncratic red-pink sand was used to correlate upper Sector D ('pink' sand

\footnotetext{
83 Fedele 2011a, 108, fig. 6. 'Intermediate' replaced the previously employed ‘End-Sabaean' (Fedele 2010).

84 Agostini 2015, 9-10; and Chapter 3, this volume (Fase intermedia in Italian). Cf. Chapter 18, section 3.2, 'On the earliest Minaean'.

85 A scheme including 'First' and 'Second Intermediate' is in a contribution to a memorial volume for A. de Maigret, written in winter 2014-2015 at the invitation of Università di Napoli L'Orientale, as yet unpublished and reportedly discontinued (cf. Chapter 1 in Volume 1, footnote 57 ).
} 


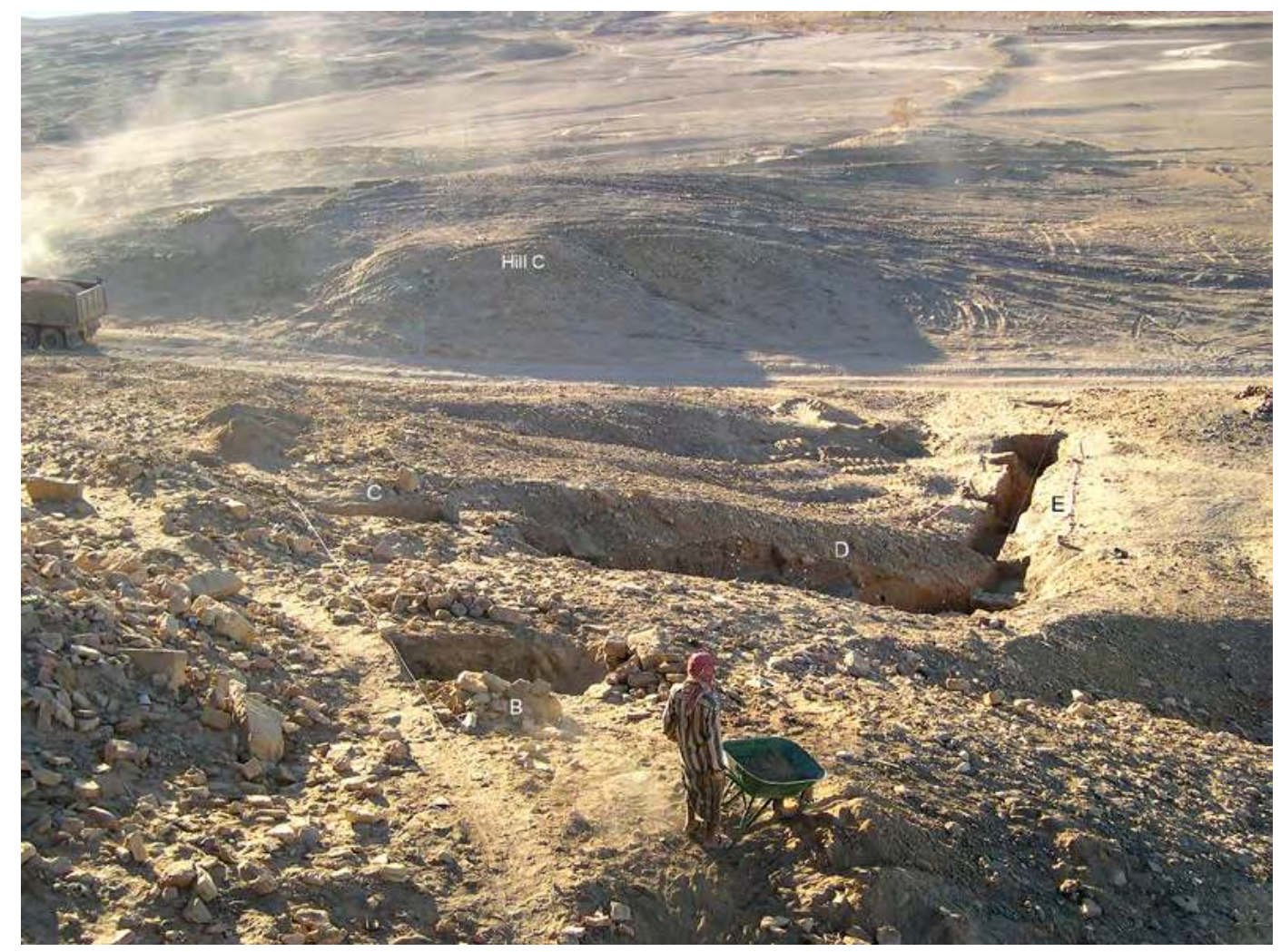

Figure 9. Area C excavations, Sectors B to E from Minaean bastion T7, December 2005.

(P. Morlupi @ MAIRY, optimized by F.G. Fedele 2020)

SA $\pi$ ) with Sector C (cf. unit L13) and Sounding A ('red' sand SR, a component unit of Stratum H).

- Concurrently, a correlation involving Sounding $A$ and Sectors B and C can be proposed by taking into account a particular stone material - limestone slab-like blocks - which appears to have circulated at the surface of the talus during the last phase of the Minaean (see section 15.1 for details, and a mention in section 11.3). However, this attempt only rests on an interesting methodological hypothesis. Whether the platy blocks in Pa, quadrangle D1, were from the same source and part of the same process is doubtful (see section 15.2). As far as Strata I and $\mathrm{H}$ are concerned, the correlation proposed for quadrangle $D 1$ is debatable, at least in detail, and cannot presently be resolved. The recent radiocarbon dating of sample \#2.1 from this quadrangle, unfortunately, was of no help (Chapter 18, section 1, this volume).

- Linking Locus 200 with the Sabaean in Sector D: this correlation is explained in section 7.3 below.

- Quite long-distance correlations were implied in linking lower Sector E (beyond the flexure) with the sequence from the upper talus. The middle sands in lower Sector E were correlated with the upper talus through the presence of organic contents in suite E1ع8, almost unmistakably pointing to an origin from the Islamic deposits at bastions T6 and T7 (possibly Islamic 3; see sections 4.2 and 16.4, 'Stratum B').

- The correlation of Sounding F raised problems entirely of its own. The scene of Plain $F$ is unconnected with the talus and very different in general: the sedimentary catchment is completely separate, obviously, and also several of the depositional and erosional processes differ from those of the tell and talus. Over a depth of $2.5 \mathrm{~m}$ the sounding offered a neatly stratified sequence containing a thick lower part with Sabaean pottery and well-separated Minaean units above. For the lowermost part of the sequence a first step was a lithological correlation with the nearest part of Sector E (quadrangles E11 and E8), based on sandtype similarity; a general correlation with the Sabaean tell was then attempted on the basis of sedimentary discontinuities and ceramics. Ultimately, it turned out that the surest, though less precise way to correlate long-distance was by means of artefactual content. Lithological and cultural details on Sounding $F$ are given in section 17 at the end of this chapter. 


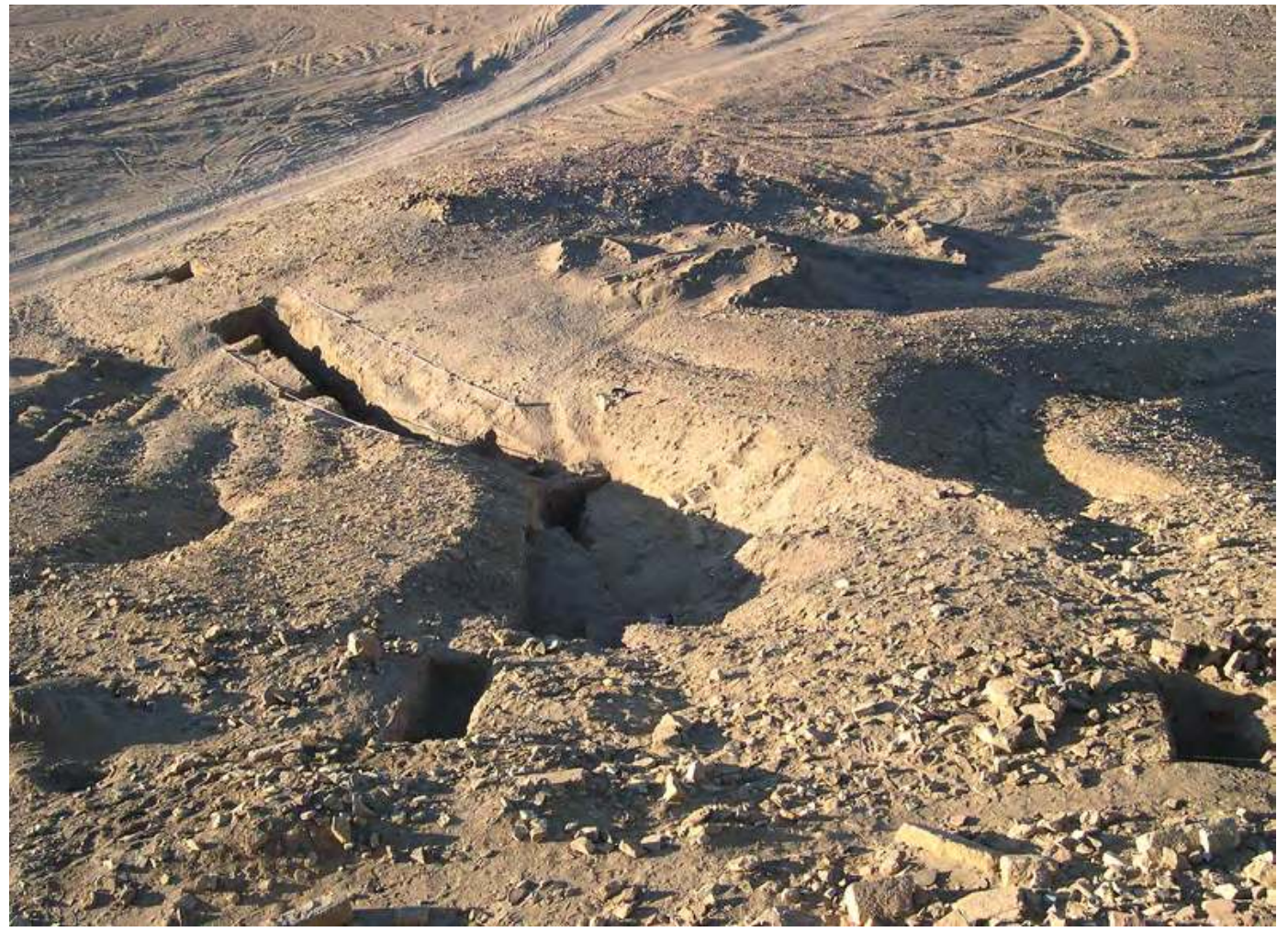

Figure 10. Area C excavations, Sectors B to E from Minaean bastion T5, December 2005.

(P. Morlupi @ MAIRY, optimized by F.G. Fedele 2020)

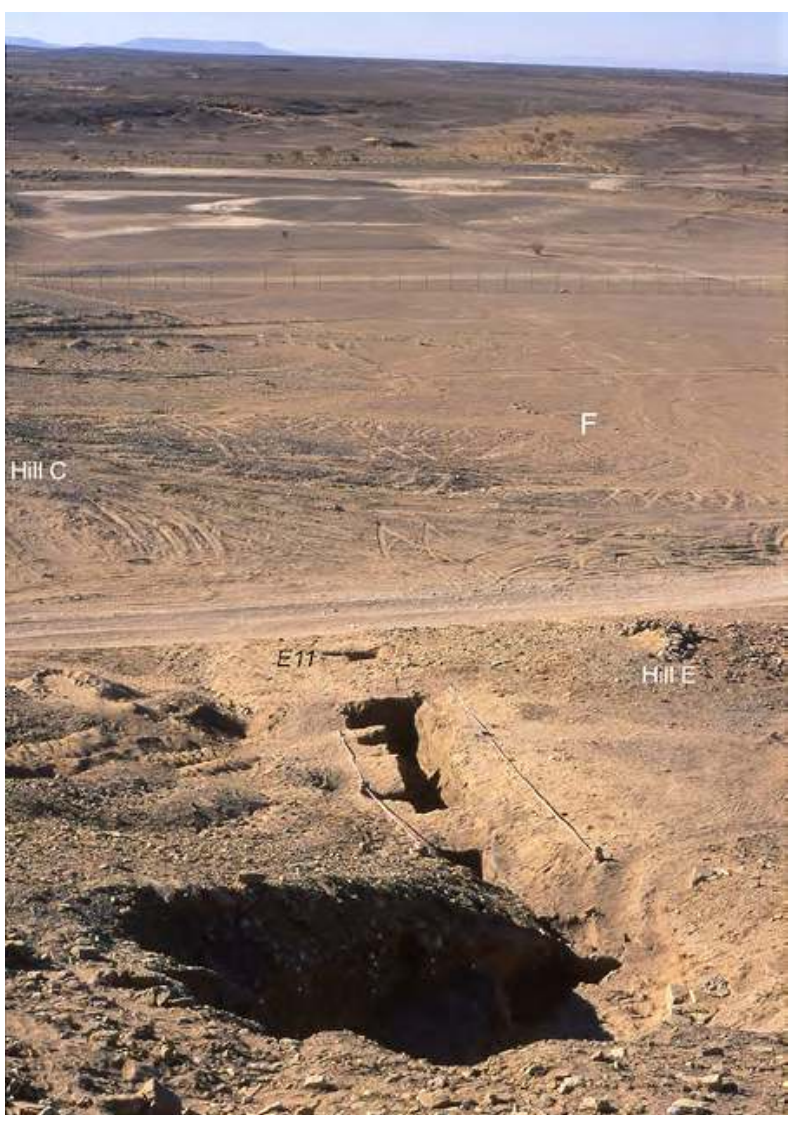

Figure 11. Area $C$ excavations, general view including the plain and floodplain. From Minaean wall recess T5/6, December 2005. (F.G. Fedele)

\section{A preview of tell and talus evolution ${ }^{86}$}

Because of the processes and length of time involved, the physical history of the Barāqish talus is spread over most of the Strata in the sequence. Nowhere is diachroneity more evident than in lower Sector E, where numerous elusive layers constituting a thick sandy cover may each belong to a different Stratum. As a result, the sole description on a Stratum by Stratum basis would disperse information and be barely intelligible. It seems more convenient to take a broader view of the sedimentary and geomorphological evolution of the talus before going into the relevant details in the following sections. Concurrently, an advance synopsis will be given of the physical history of the tell, and the more general phenomena concerning tell and talus will be outlined. ${ }^{87}$ Most of the information is visually summarized in Fig. 27, while Fig. 2 provides useful nomenclature.

\footnotetext{
86 This section updates Fedele 2010, 106-110. This procedure providing a preview of rather complicated stratigraphic matters was perfectly exemplified in the publication of Tell el-Hesi in southern Palestine, volume 3 (Bennett and Blakely 1989, 14-20): 'Because the detailed stratigraphic reconstruction of these strata is so complex, we have provided a brief introductory preview of our stratigraphic conclusions. We trust the reader will find these paragraphs helpful in forming a general overview prior to wrestling with the intricacies of our full analysis' (p. 14, adapted).

87 Except for brief mentions, Sounding $\mathrm{F}$ will be treated in detail in section 17 at the end of this chapter.
} 


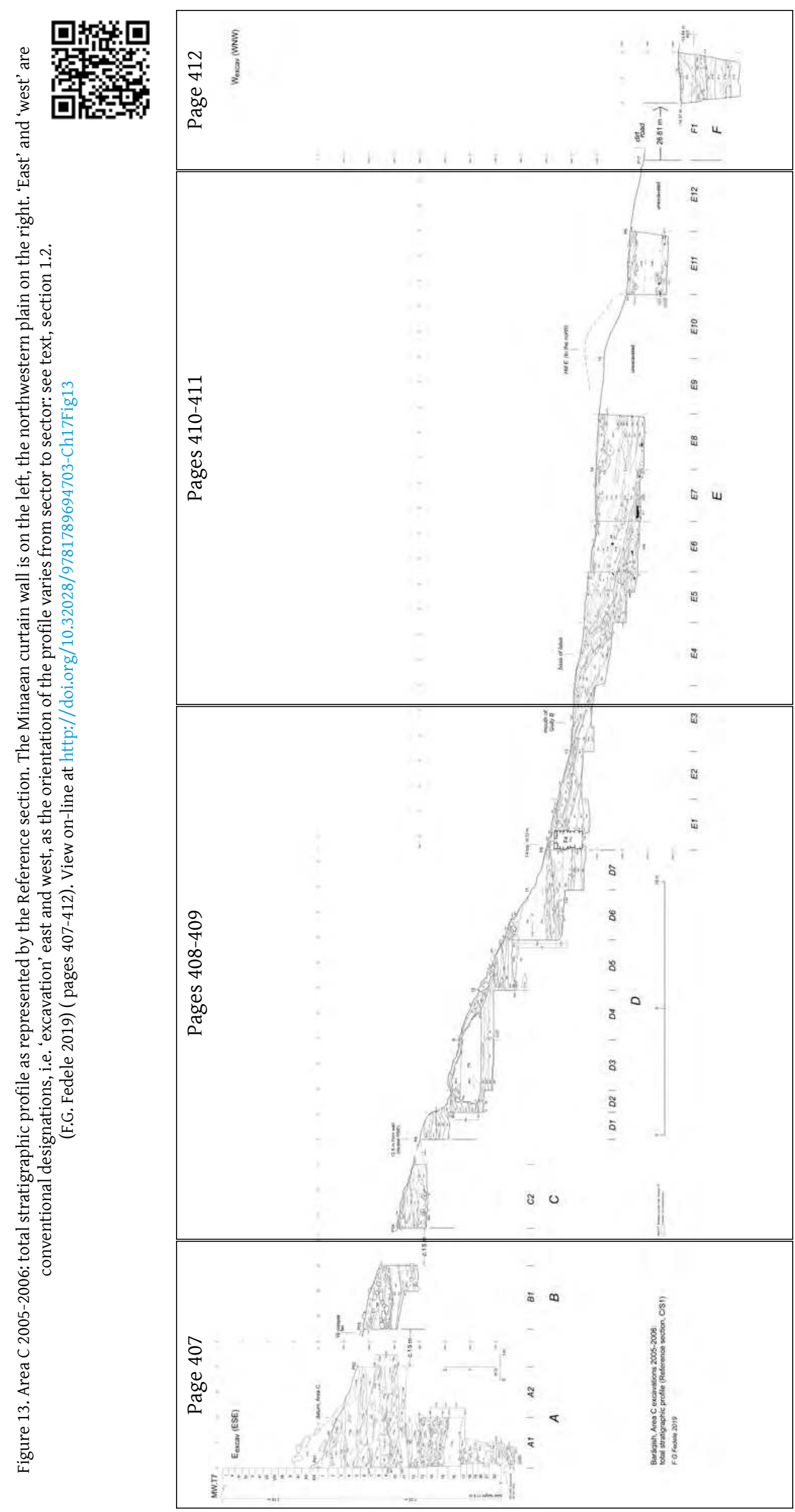




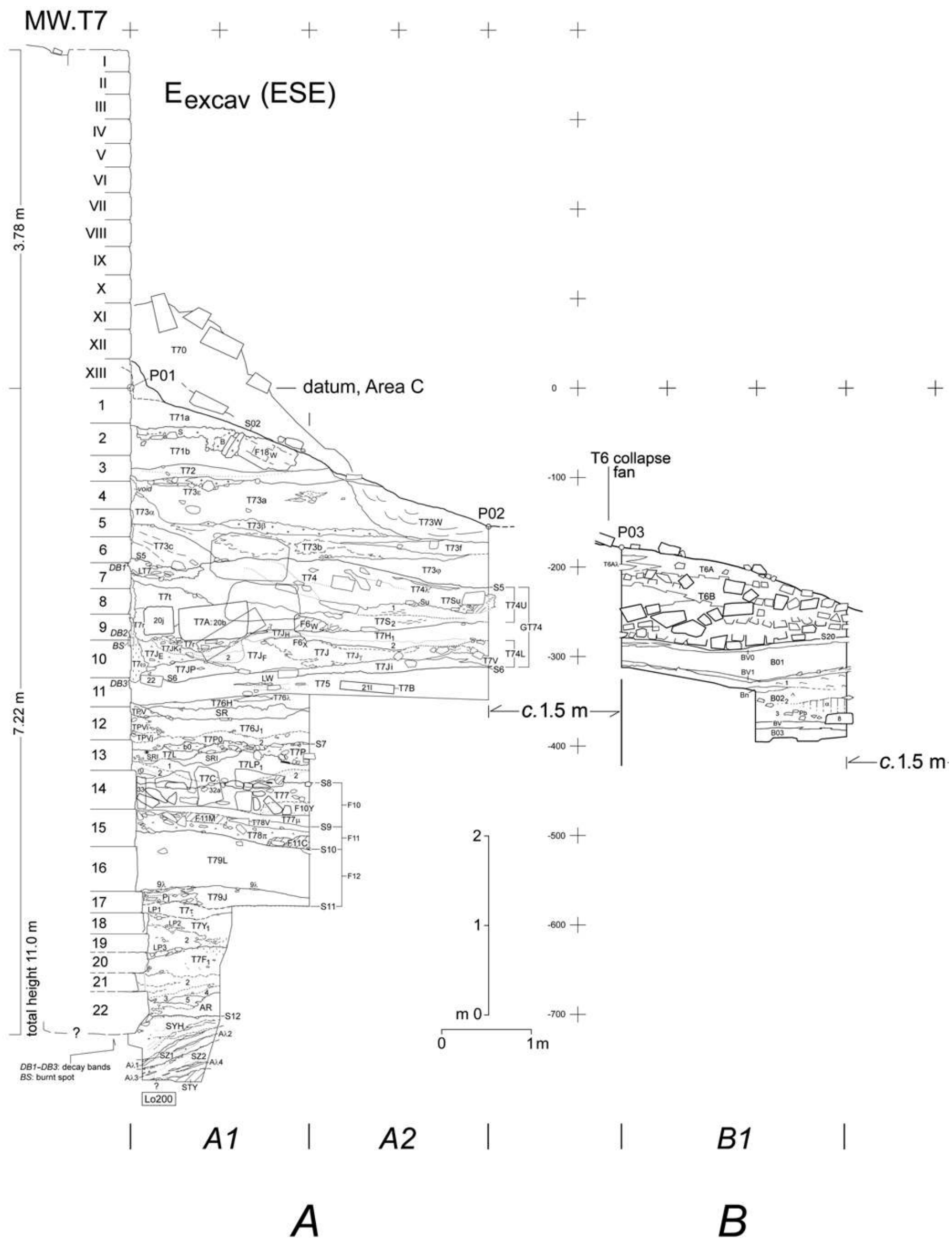

Barāqish, Area C excavations 2005-2006:

total stratigraphic profile (Reference section, C/S1) 


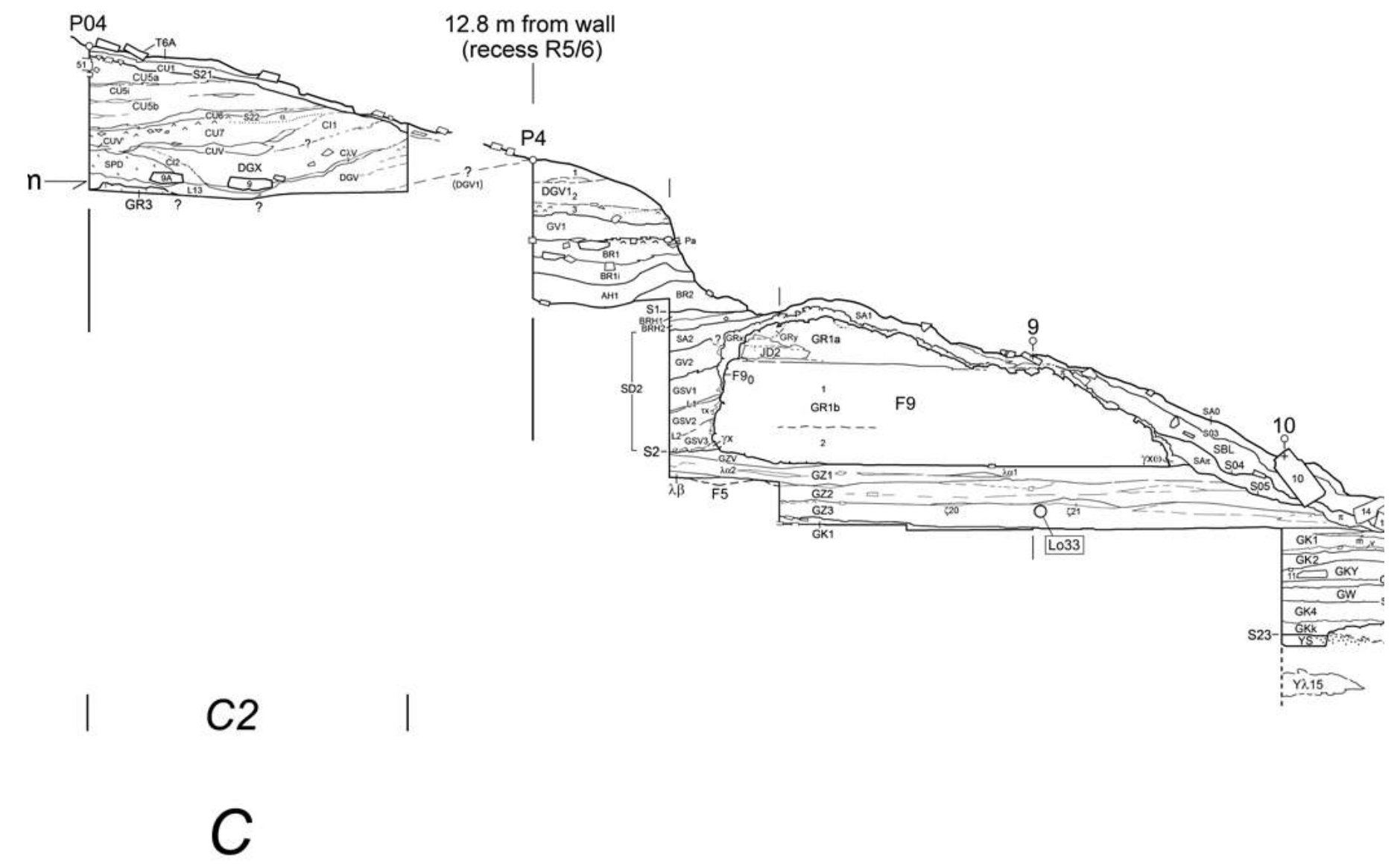

\section{$D 1|D 2| \quad D 3 \quad|\quad D 4 \quad|$}

$D$ 


$+\quad+\quad+\quad+\quad+\quad 0 \quad+$

${ }_{400-+}^{-4} \quad+\quad+\quad+\quad+\quad+$

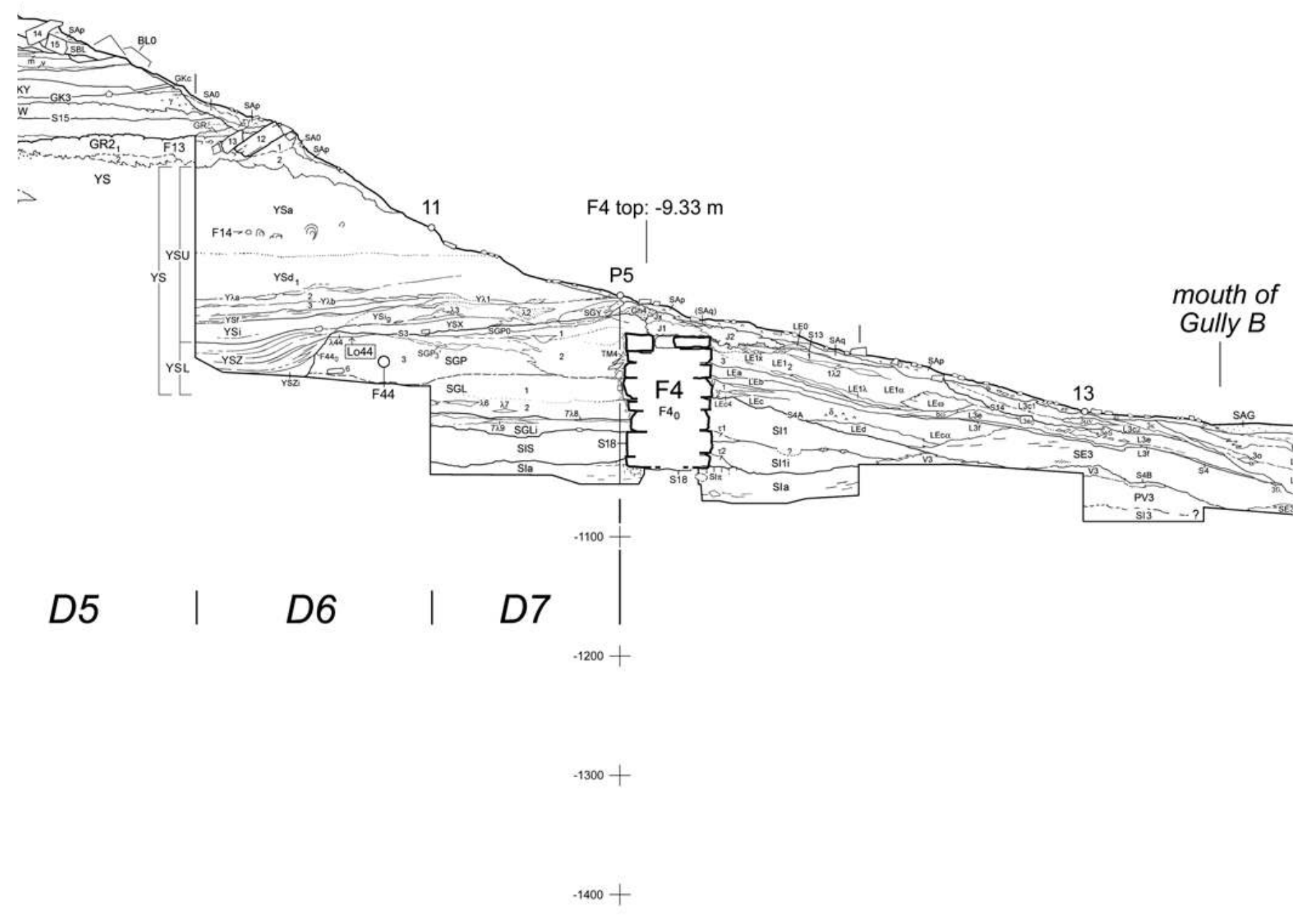




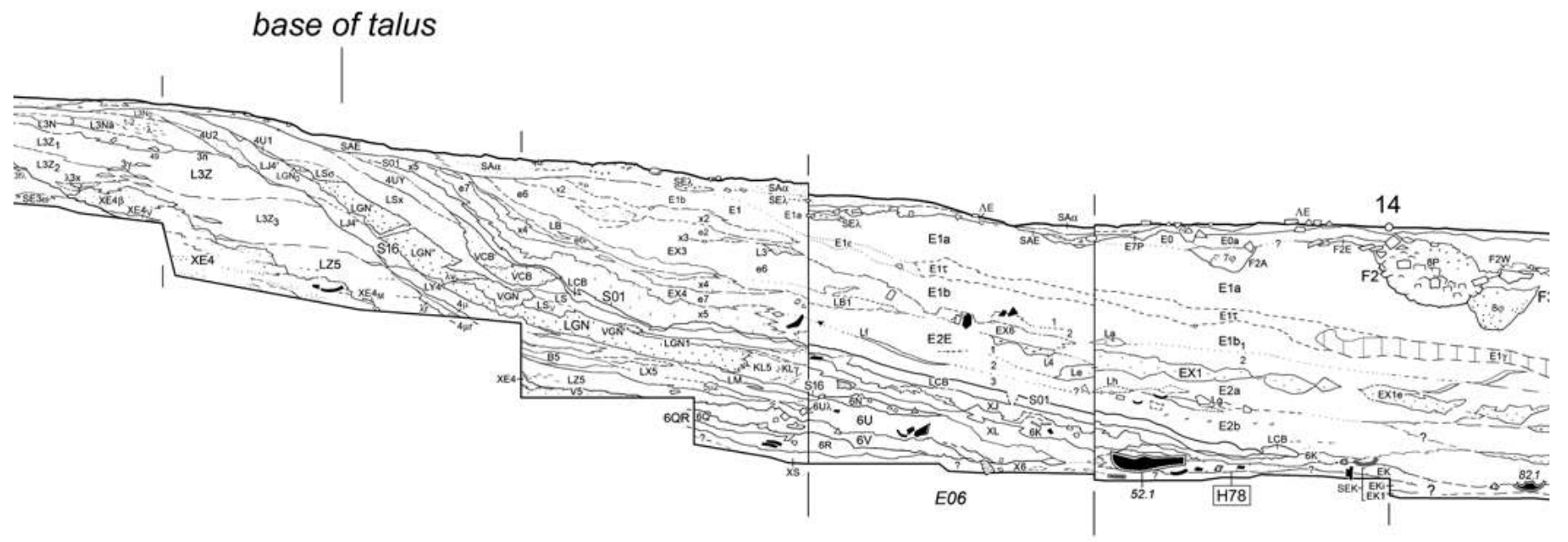

\begin{tabular}{r|l|lll} 
E4 & E5 & & E6 \\
& & $E$
\end{tabular}


$+\quad+\quad+\quad+\quad+\quad+\quad+\quad+\quad+\quad+\quad+$

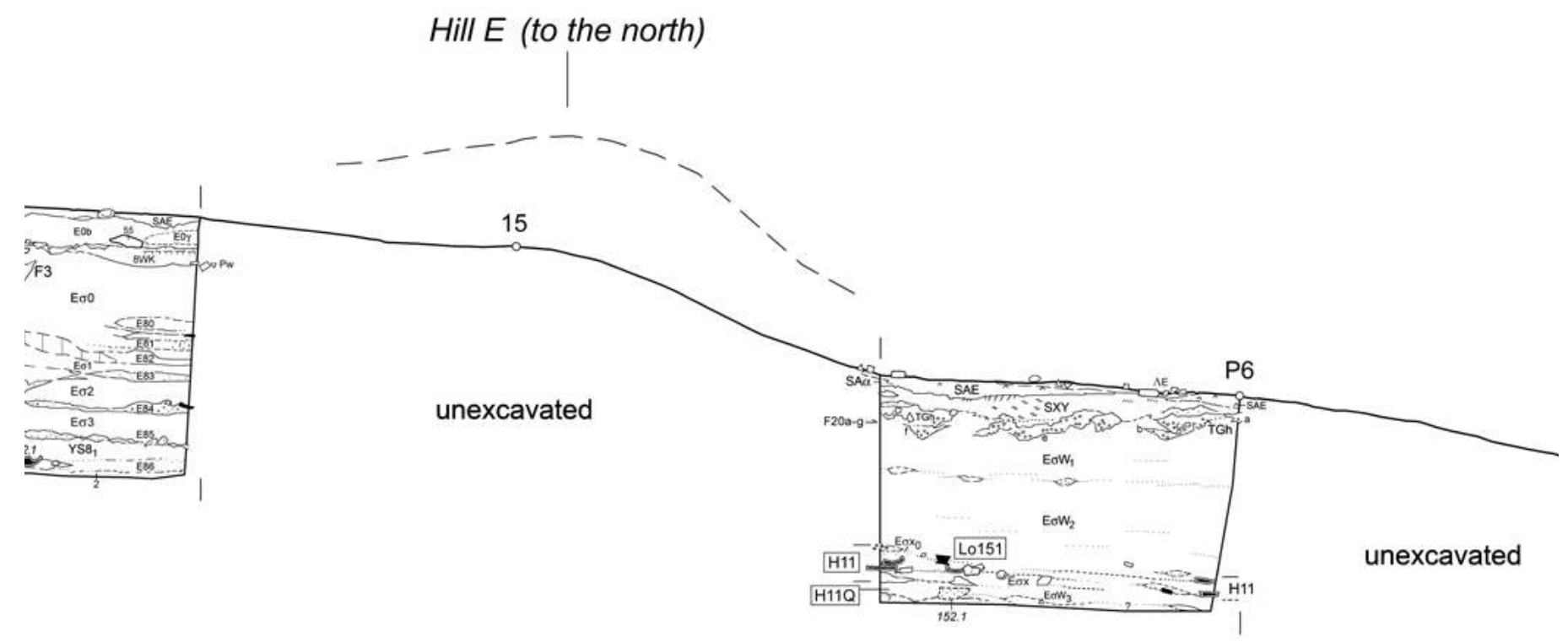

E8

E9

E10

E11

E12 


$$
+\quad-400+
$$

$$
.500+
$$$$
.600+
$$$$
.700+
$$

$-800+$

$900+$

$.1000+$

$-1100+$
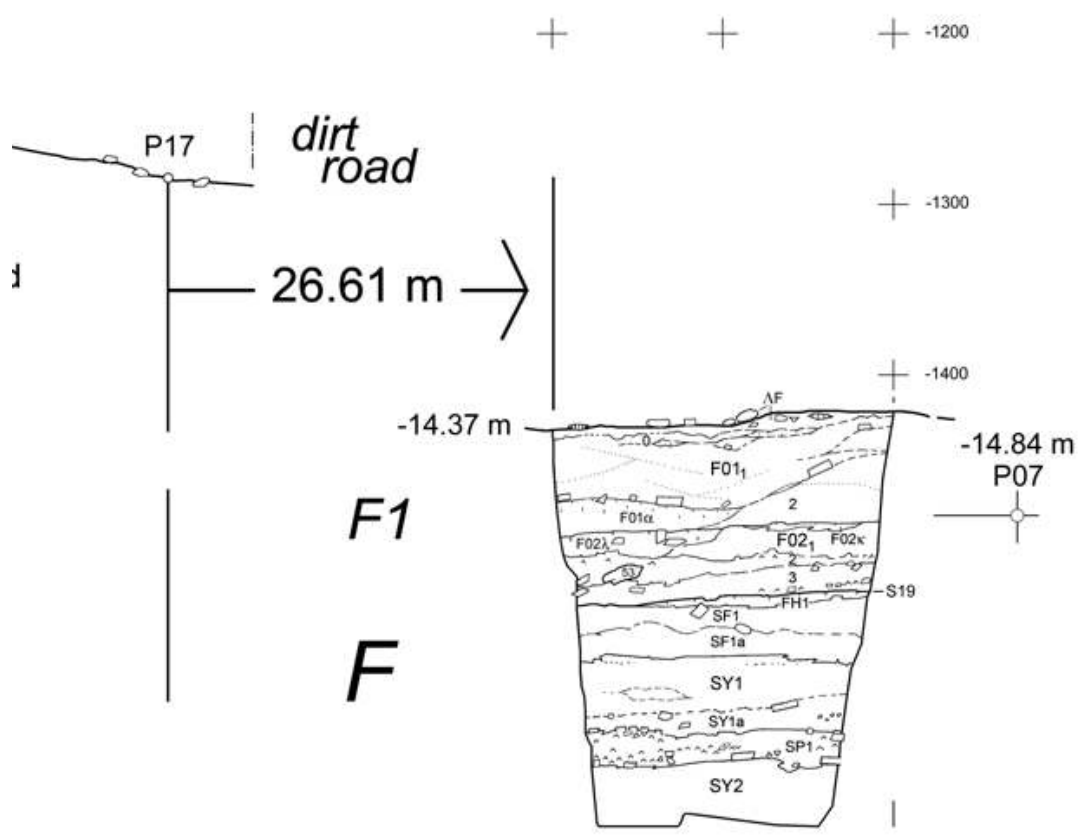


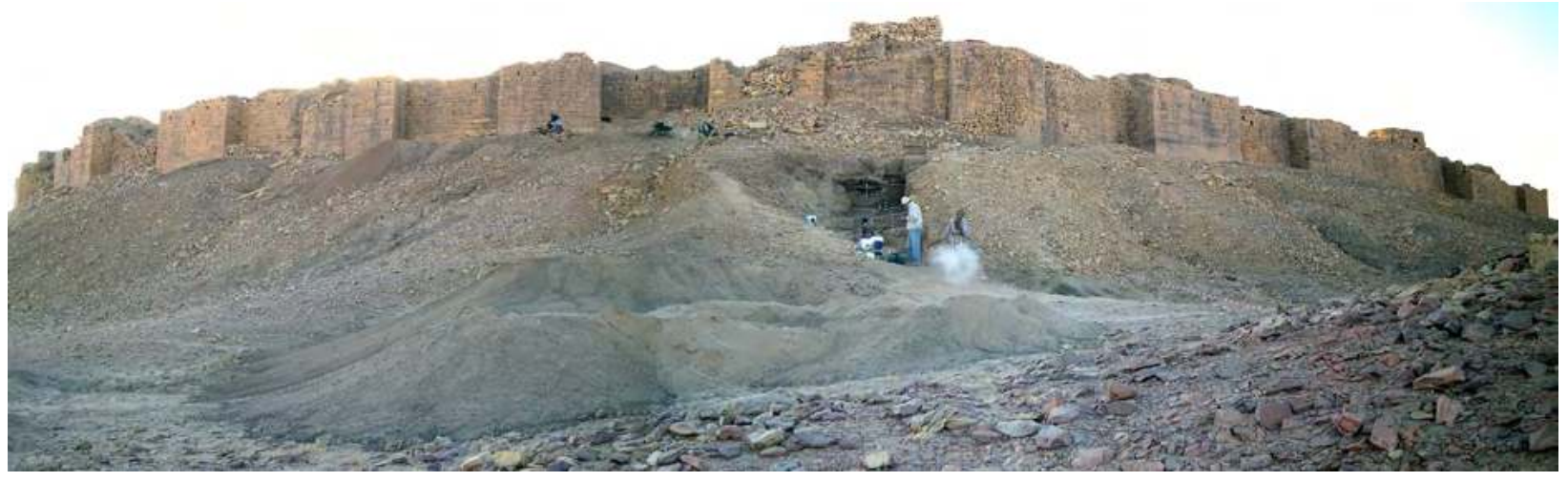

Figure 12. Area C excavations, general view from northwest, December 2005. (P. Morlupi @ MAIRY)

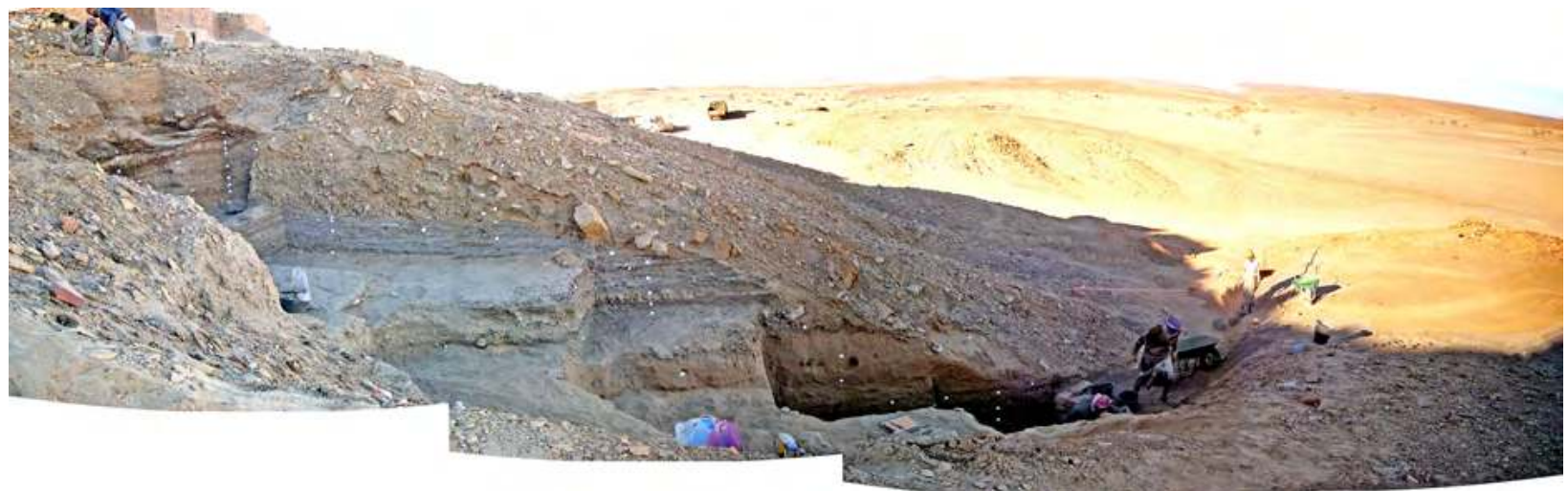

Figure 14. Sector D and the Reference section, facing south, with typically horizontal Later Sabaean surfaces on the left. (P. Morlupi 2005 @ MAIRY, adapted and optimized by F.G. Fedele 2019)

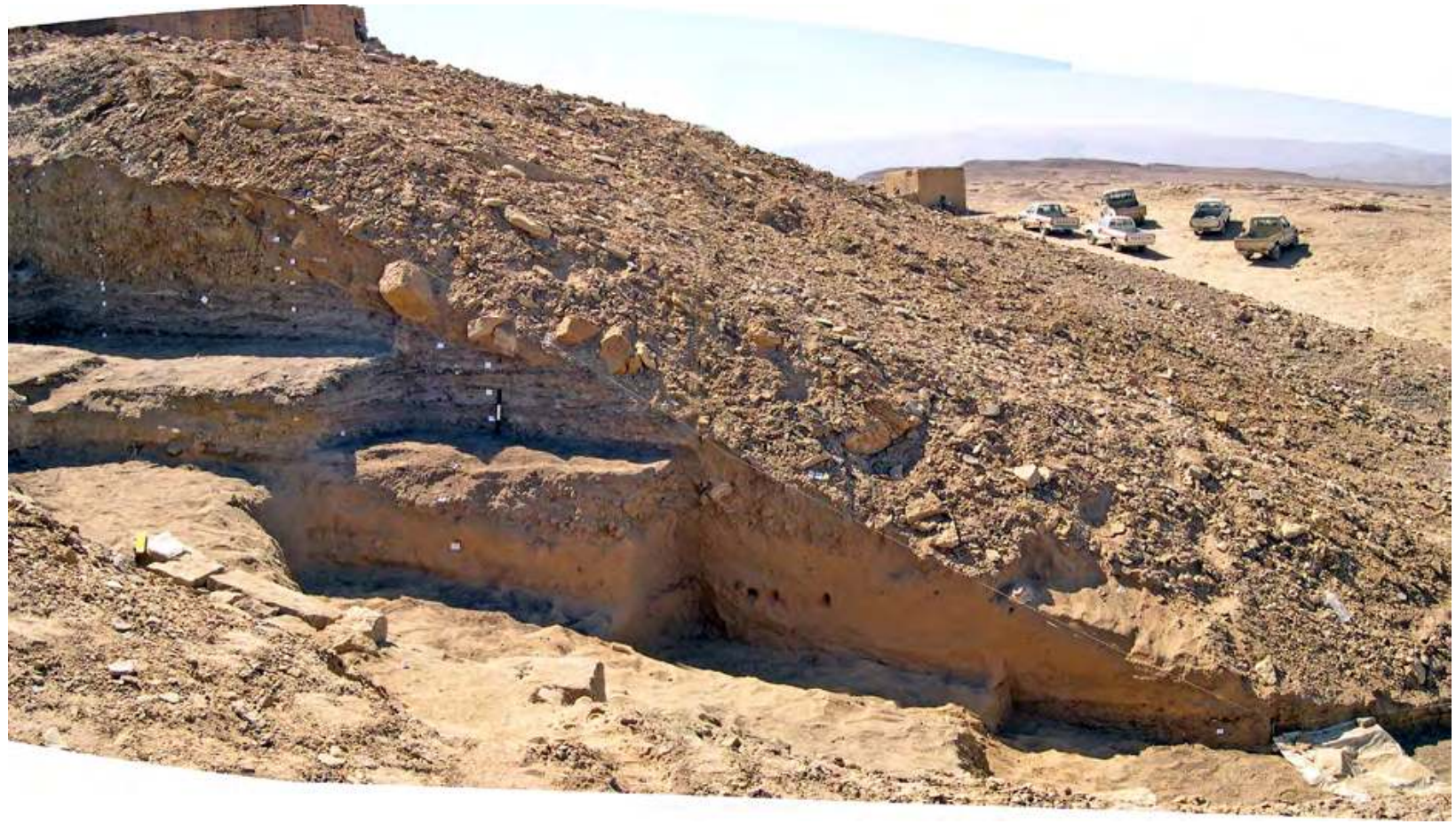

Figure 15. Middle and lower Sector D as seen from across Gully B, facing south. Scale $30 \mathrm{~cm}$.

(P. Morlupi 2005 ( MAIRY, optimized by F.G. Fedele 2019) 


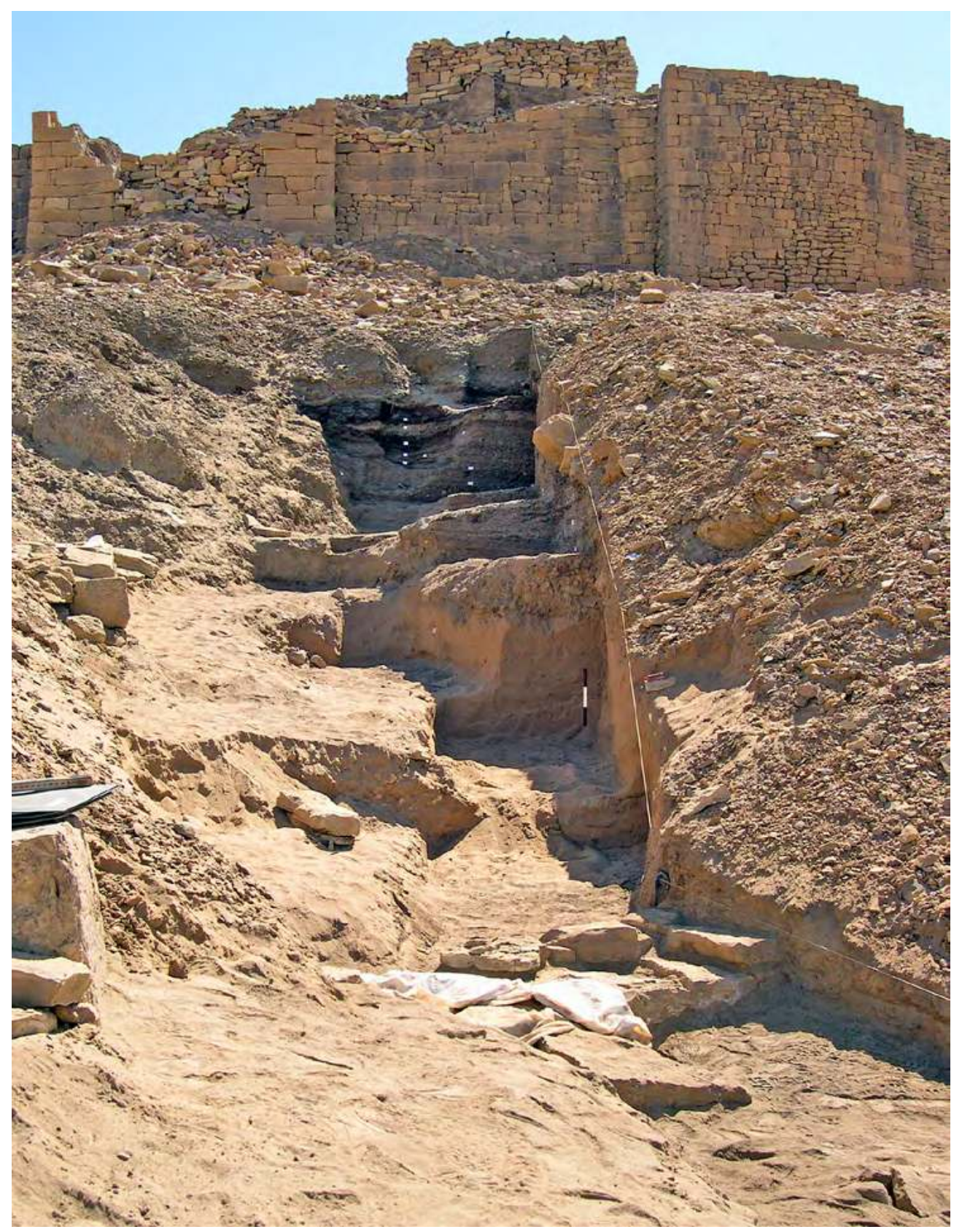

Figure 16. Sector D under excavation: general view from below, with Sabaean Wall F4 being exposed in the foreground and Minaean bastions T5 and T6 in the background. Scale $30 \mathrm{~cm}$. (P. Morlupi 2005 (c) MAIRY, optimized by F.G. Fedele 2019)

\subsection{Evolution during the Sabaean period}

The physical evolution of the Sabaean settlement, as viewed from Area $C$, can be divided into two distinct stages separated by the construction of a stone-andmudbrick wall at the upper end of Sector E, Wall F4, quite possibly a walled enclosure for the settlement. The mound in this part of Yathill was about six metres high (estimated) when the wall was built. The settlement preceding the wall corresponds to the first phase of the Earlier Sabaean, Sabaean 1. The depth of occupational deposits is unknown (see section 2.1, above, and cf. Chapter 26 , this volume).$^{88}$

\footnotetext{
88 A considerable thickness of Sabaean deposits was demonstrated in 2006 by the sounding near Temple A, where levels pre-dating the 10th century BCE were reached (de Maigret 2010a; Robin and de Maigret 2009, 59-76), but, as discussed in Chapter 26, these data are insufficient to gauge the geometry of the early tell in Area C. For an outline and evaluation of the results from Area $C$ see Robin and de Maigret 2009, 67-72 (de Maigret).
} 


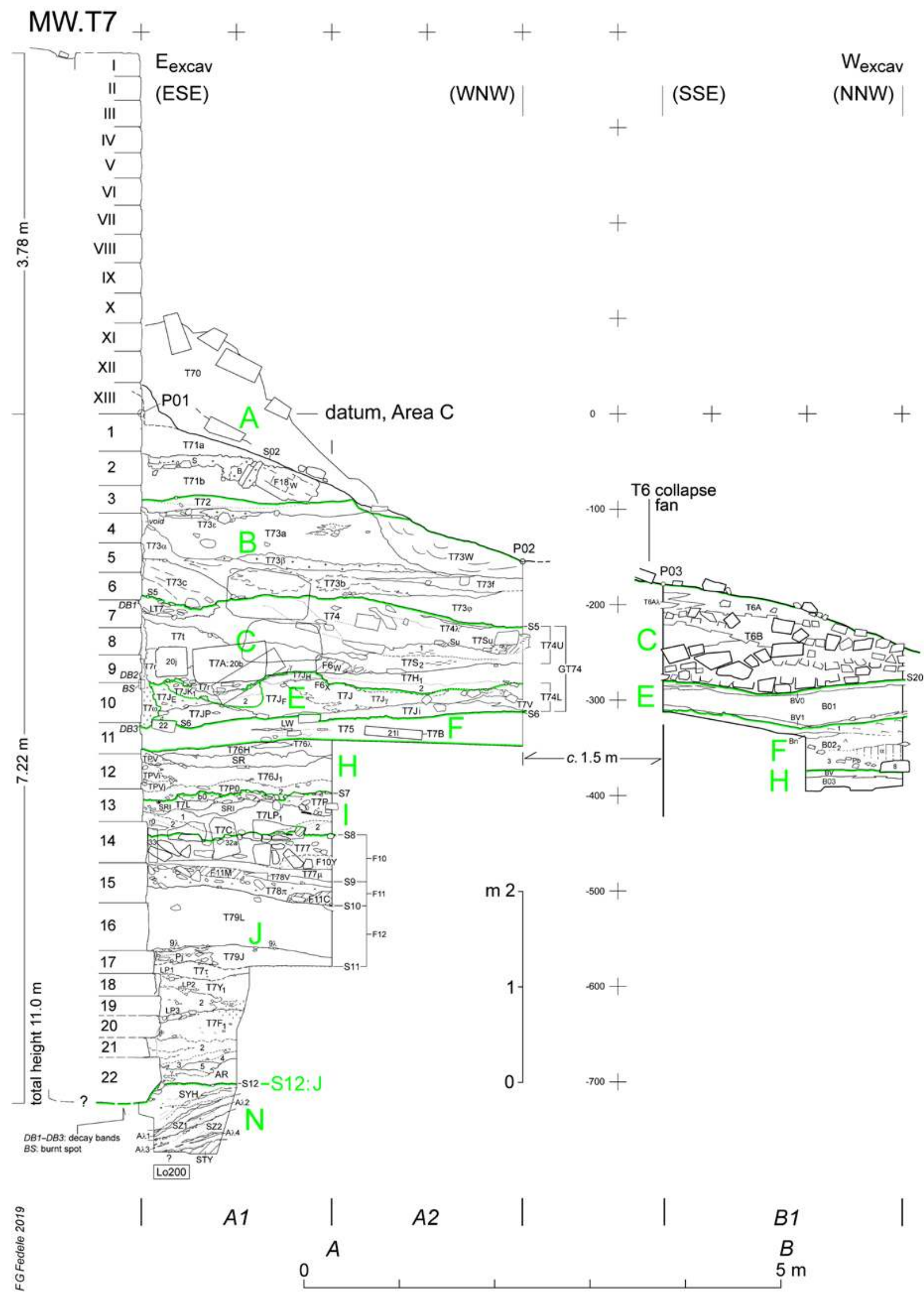

Figure 17. Sounding A and Sector B: enlarged Reference section showing Strata, outlined and designated in colour. This is the first of seven consecutive figures presenting Strata (culture-historical subdivisions) superimposed on detailed segments of the section. (F.G. Fedele 2019) 


$\operatorname{tim}^{+}+\ldots++t_{t \rightarrow m}^{+}$

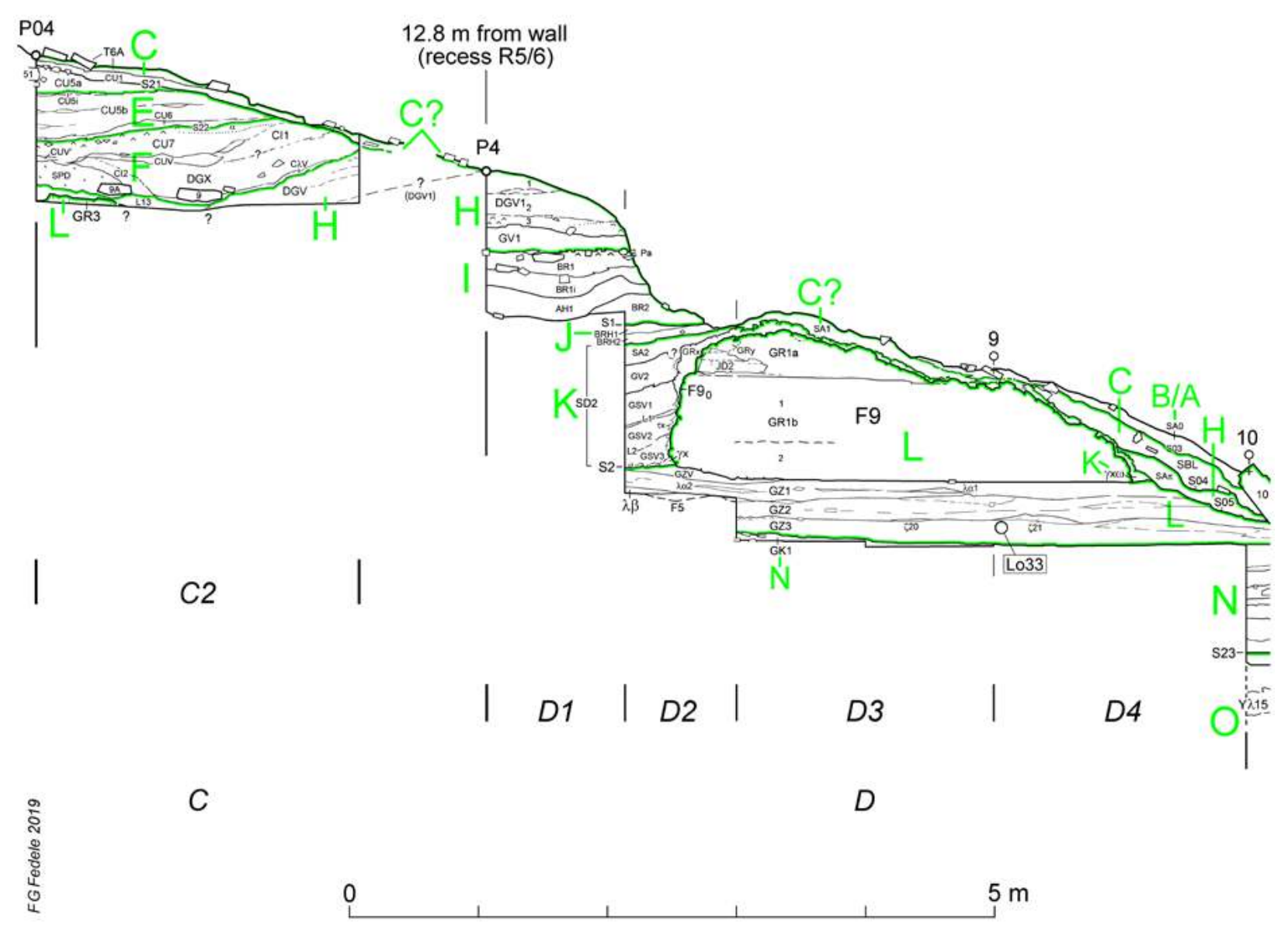

Figure 18. Sector C and upper Sector D: enlarged Reference section showing Strata, outlined and designated in colour. (F.G. Fedele 2019)

The lowermost deposits so far uncovered are those of Strata $\mathrm{T}$ and $\mathrm{S}$ in quadrangles D7-E4. They are part of a Sabaean 1 tell whose edge was formed by unit SE3 $\omega$, this edge in turn indicating that the tell extended $32 \mathrm{~m}$ away from the nearest point of the subsequent Minaean wall (bastion T6; cf. section 2.1 above). A single unit recorded at trench bottom in quadrangle E5, 5S1 (south section), was probably part of the incipient talus descending from this broad, low mound. The establishment of a stone wall on the footslope sealed and at the same time completely changed this situation, locally affecting the evolution of the mound. For some time after the wall's construction the downslope deposition was virtually arrested, apart from the emplacement of a strange bank on the earlier tell (SE3) and some accumulation of aeolian sand lower down (XS, X6). Already by this time a weak organic soil had developed, indirectly suggesting the existence of an oasis. This Yathill Palaeosol tops the sediments of Stratum $\mathrm{T}$ and was locally truncated by the foundation cutting for Wall F4. Faint traces of weathering $(P V 3 \alpha)$ have been observed at the top of unit PV3, Stratum S, while parts of the top of 'bank' SE3 were affected by diagenesis from organic waste (see below). 

$+$
$+$
$+$
$+$
$+$
$+$
$E_{\text {excav }}(\mathrm{SE})$
$\mathrm{W}_{\text {excav }}(\mathrm{NW})$
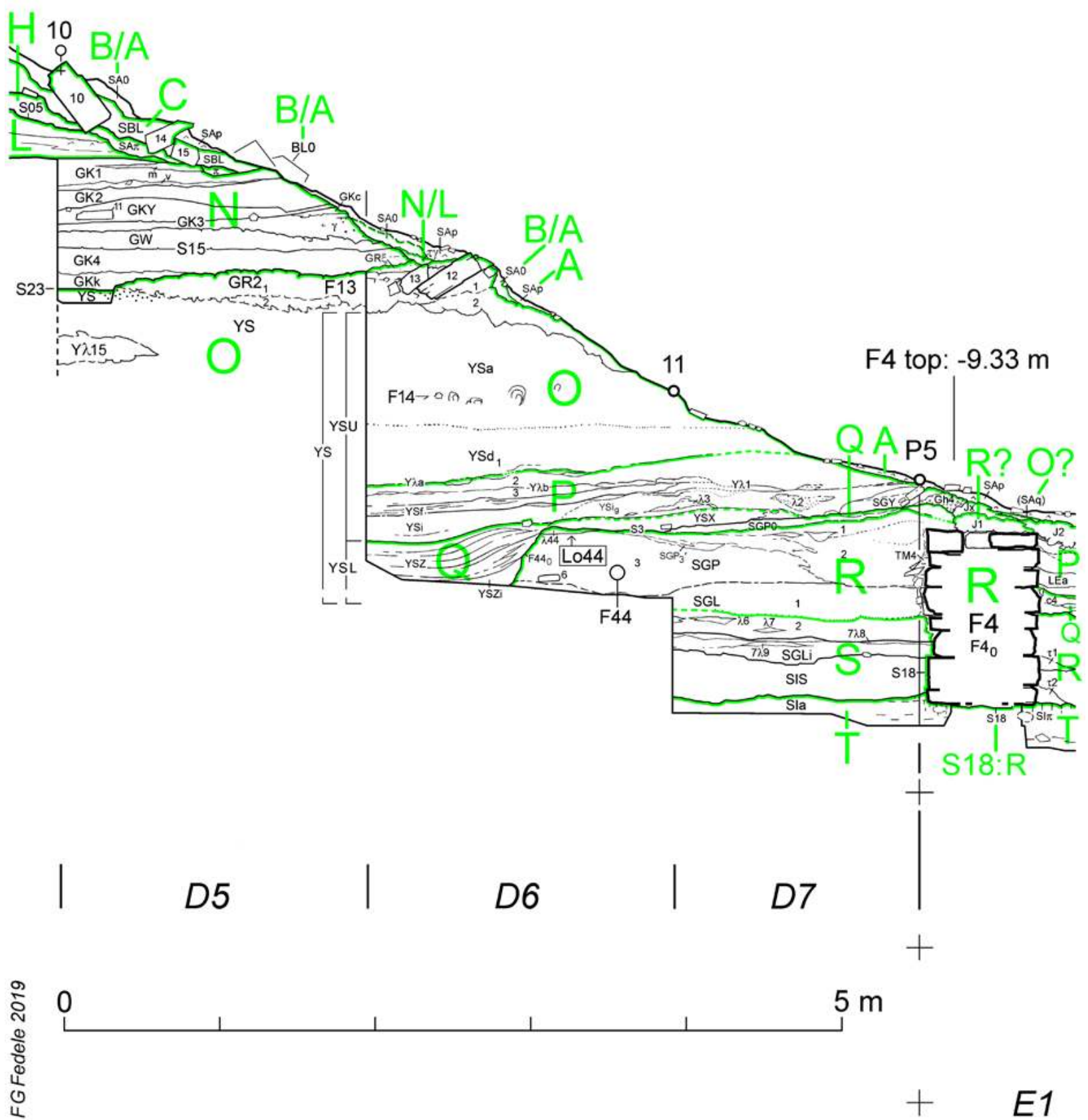

Figure 19. Lower Sector D and Wall F4 in Sector E: enlarged Reference section showing Strata, outlined and designated in colour. (F.G. Fedele 2019) 

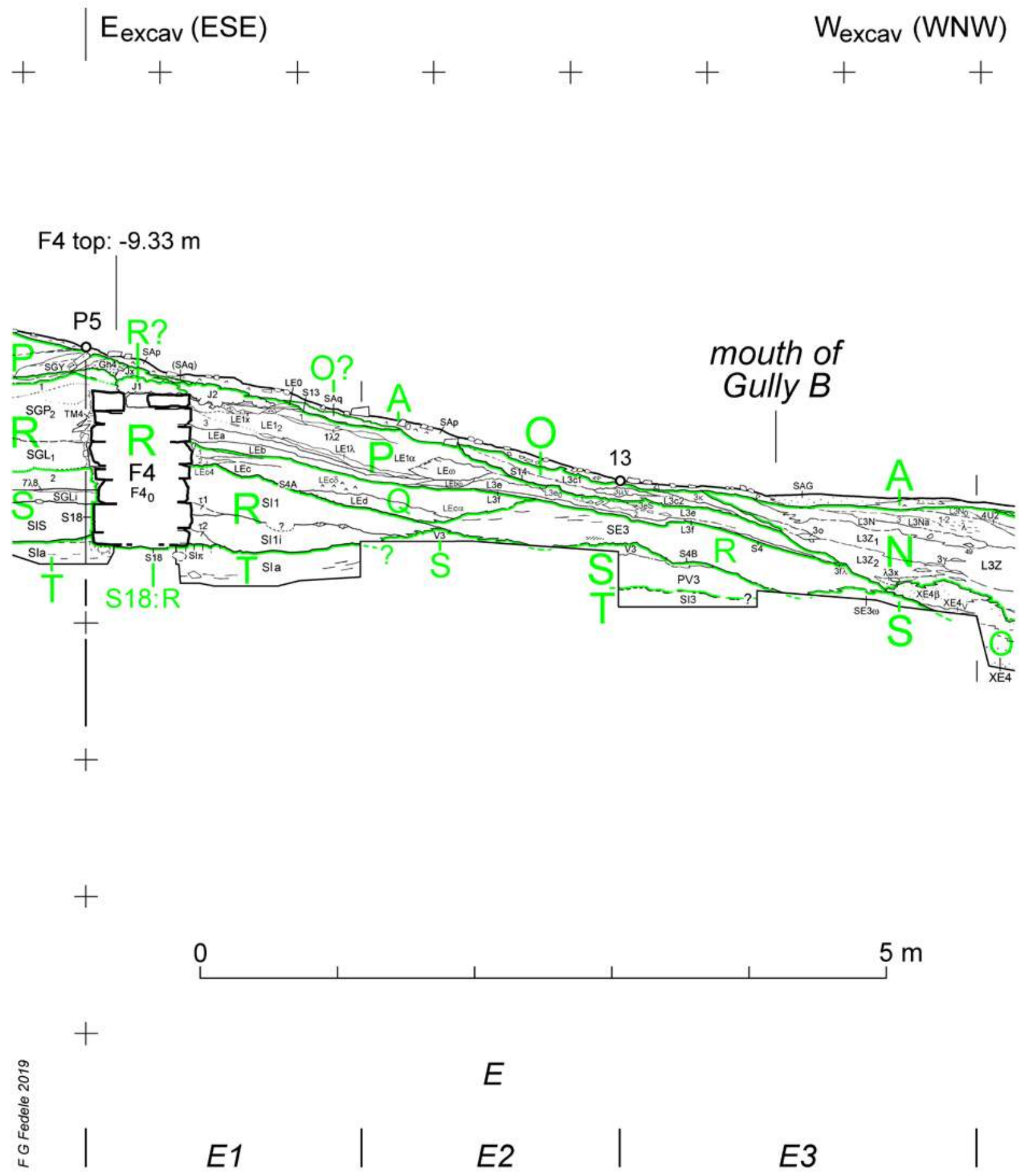

Figure 20. Sector E, quadrangles E1-E3: enlarged Reference section showing Strata, outlined and designated in colour.

(F.G. Fedele 2019)

Subsequently (Sabaean 2), new deposits began to envelope the old core formed by the Earlier Sabaean tell and Wall F4. In the basin between wall and tell ${ }^{89}$ yellow colluvial-aeolian sands began to accumulate (suite YSL of Sand YS, this latter one of the striking

89 A sedimentary basin, suitable for entrapping sand and silt, created by Wall F 4 and bounded to the east by the obstacle of the existing tell. sediment features in Area C). Only occasional deposits were formed lower down upon an essentially stable talus (sandy sediments 6QR and 5SA; sandy mixeddebris suite CM). A little later, as Wall F4 decayed, the windblown sands started to make a dune-like cover on the interior of the wall and the tell's flank (suite YSU of Sand YS), and an apparently simultaneous mantle on the lower talus and plain (yellow-blond sands $\mathrm{YS}_{2}$ 

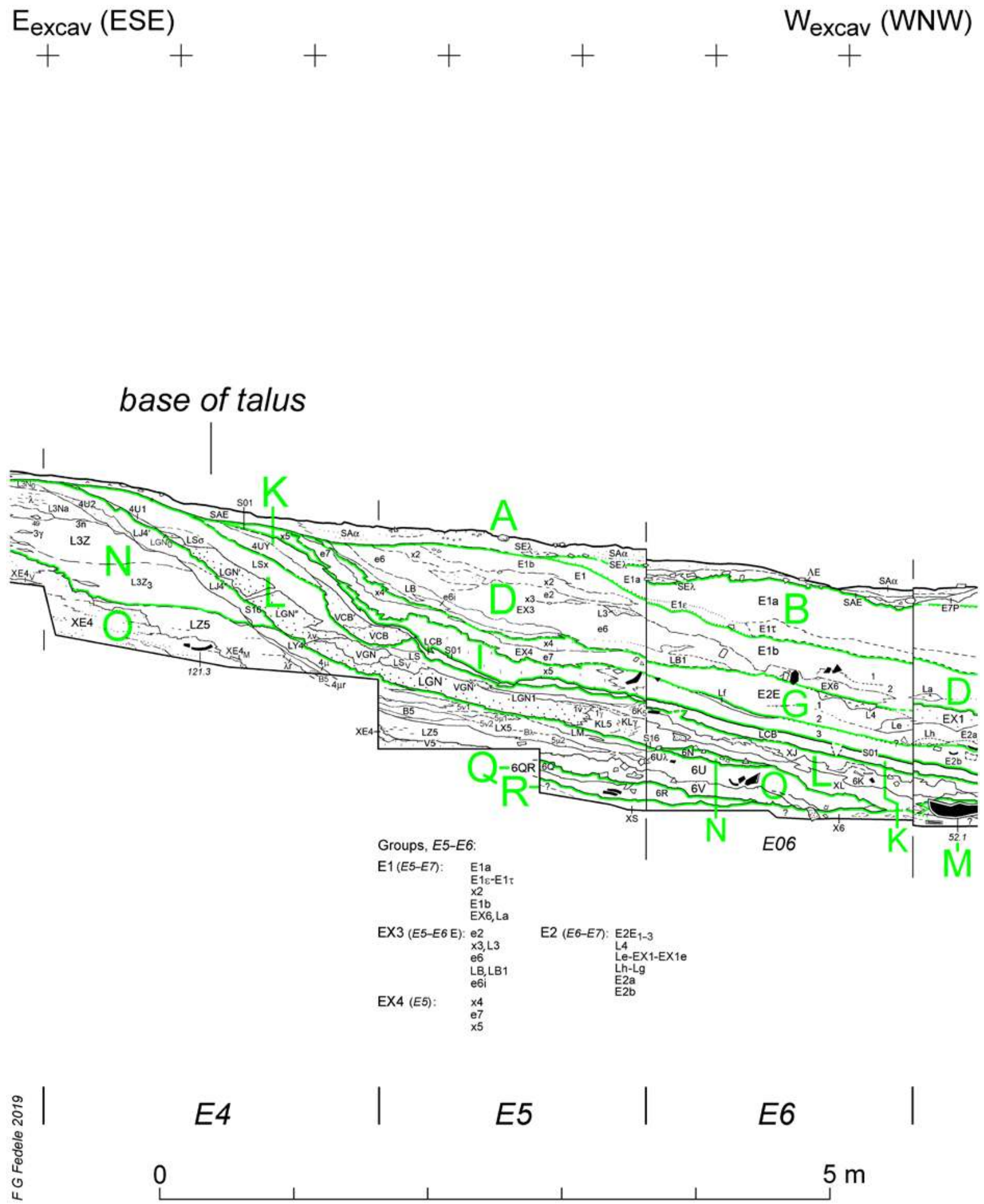

Figure 21. Sector E, quadrangles E4-E6(E06): enlarged Reference section showing Strata, outlined and designated in colour. Also indicated is the composition of several sediment groups. (F.G. Fedele 2019) 


$\mathrm{E}_{\text {excav }(\mathrm{ESE})}$
+

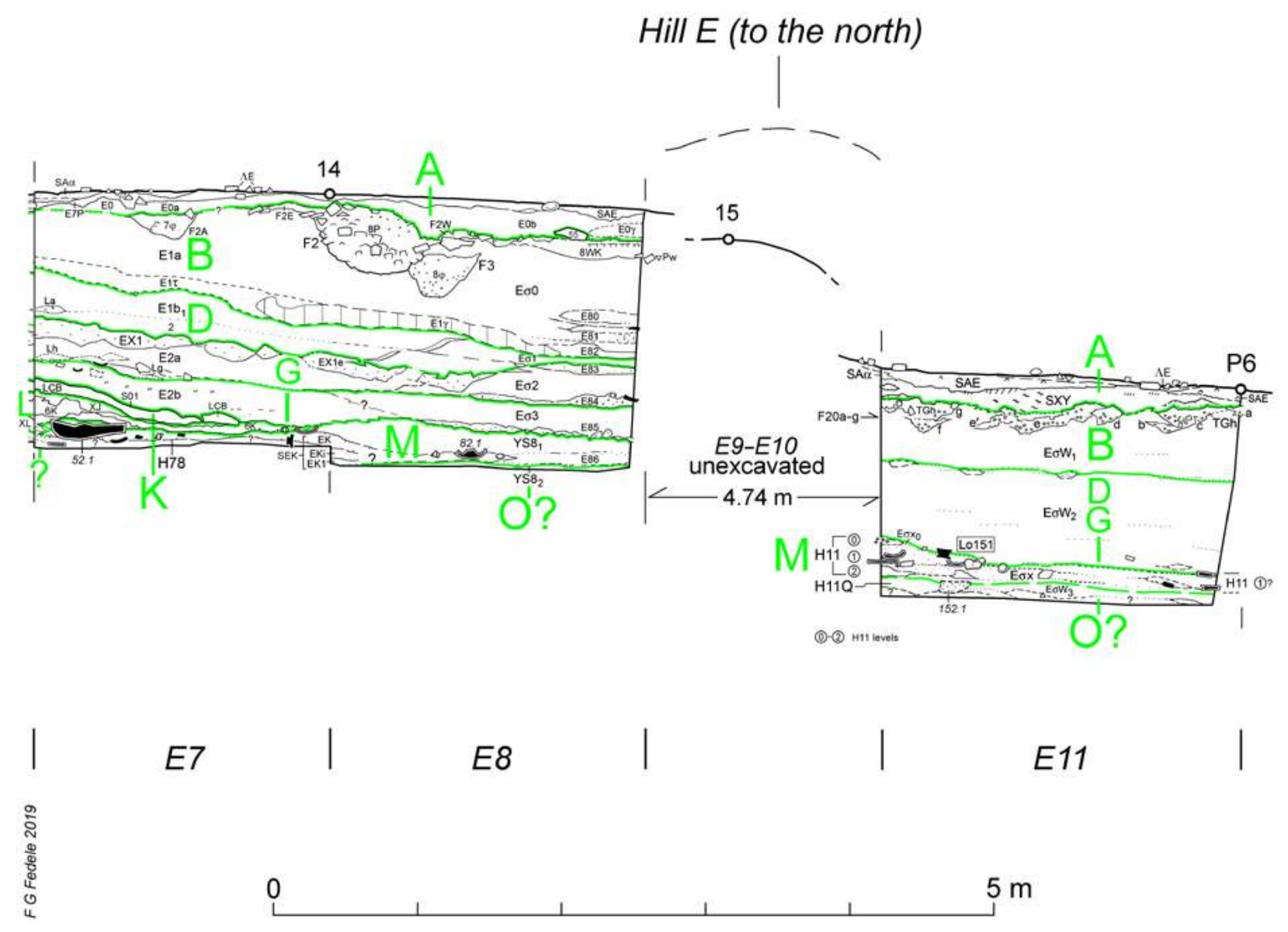

Figure 22. Sector E, quadrangles E7-E8 and E11: enlarged Reference section showing Strata, outlined and designated in colour. (F.G. Fedele 2019)

and $\mathrm{E} \sigma \mathrm{W}_{3}$ ). To explain Sand YS, a seasonal sediment supply from abandoned oasis fields west of Yathill can be invoked, and a correlation with a wādī shift is not impossible.

Slope wash lenses and ephemeral human action, including a hearth and potsherds (LEa), slowly surrounded and eventually buried the stone base of Wall F4, initiating new talus creation (sediment group LE; Strata Q-P). At the end of phase Sabaean 2 a dung-enriched unit in quadrangles E5-E6 (unit 6V of Stratum 0), and possibly earlier dromedary coprolites in quadrangle E2 (unit SE3, Stratum R?), would suggest the occasional stay of pack animals on the talus: if so, they foreshadow a future pattern which will become important during the Minaean. ${ }^{90}$ In quadrangle E11, the deepest excavated layer bears evidence of stays and food preparation ${ }^{91}$ possibly connected with tent camping, hence perhaps camping traders (Horizon H11Q). Coeval or a little later is a potential record of 'foreigners' or 'travellers' from the bottom Sabaean

\footnotetext{
90 See sections 6.2-6.3 and 6.8 below.
}

91 Witness to that a basalt quern. 


\section{$+\quad+\quad+700+$ \\ $E_{\text {excav }}(\mathrm{ESE})$}

$\mathrm{W}_{\text {excav }}(\mathrm{WNW})$

$-800+$

$-900+$

$-1000+$

$-1100+$

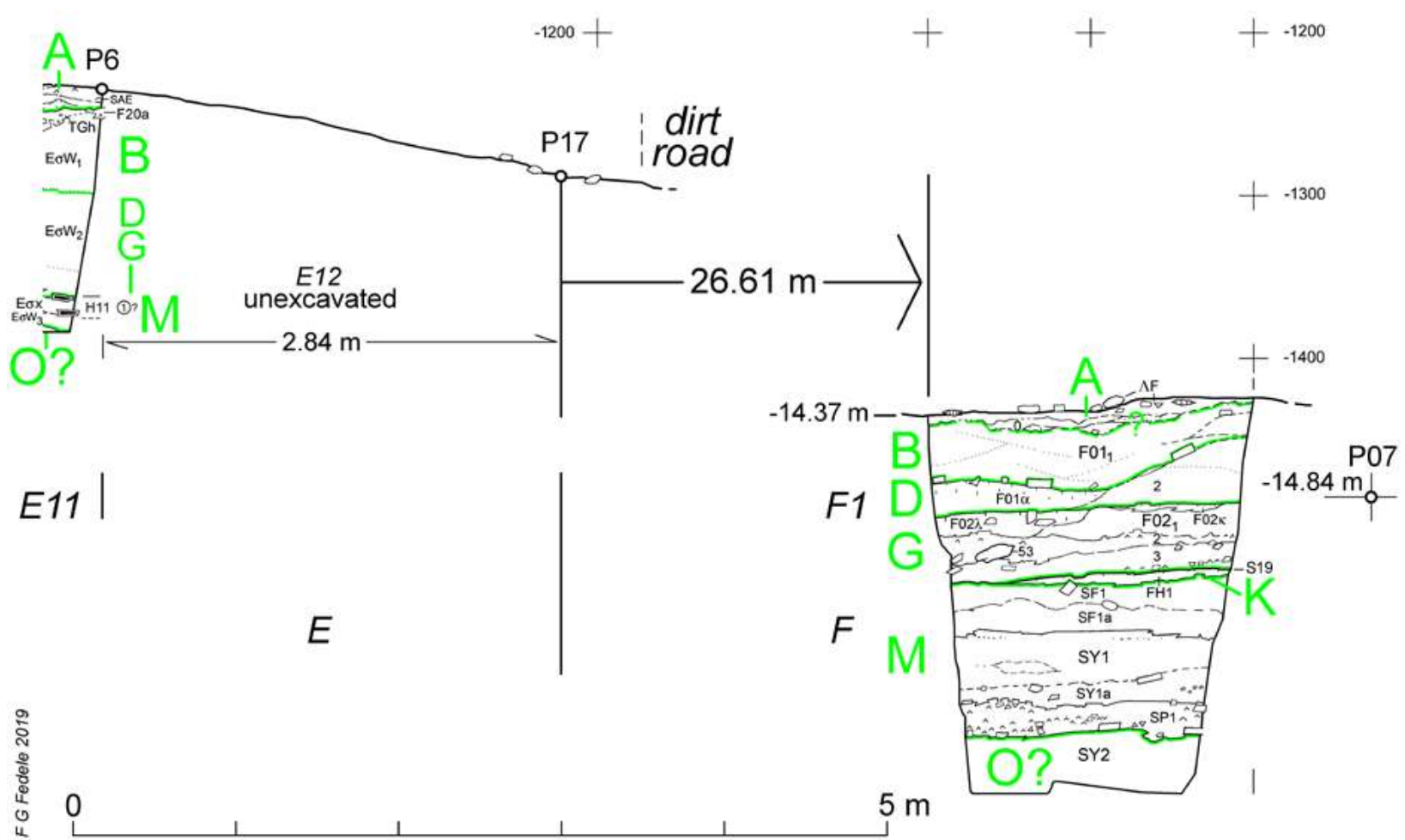

Figure 23. Sounding F: enlarged Reference section showing Strata, outlined and designated in colour. The distance of sounding from Sector E and the hard-earth road is indicated. (F.G. Fedele 2019) 


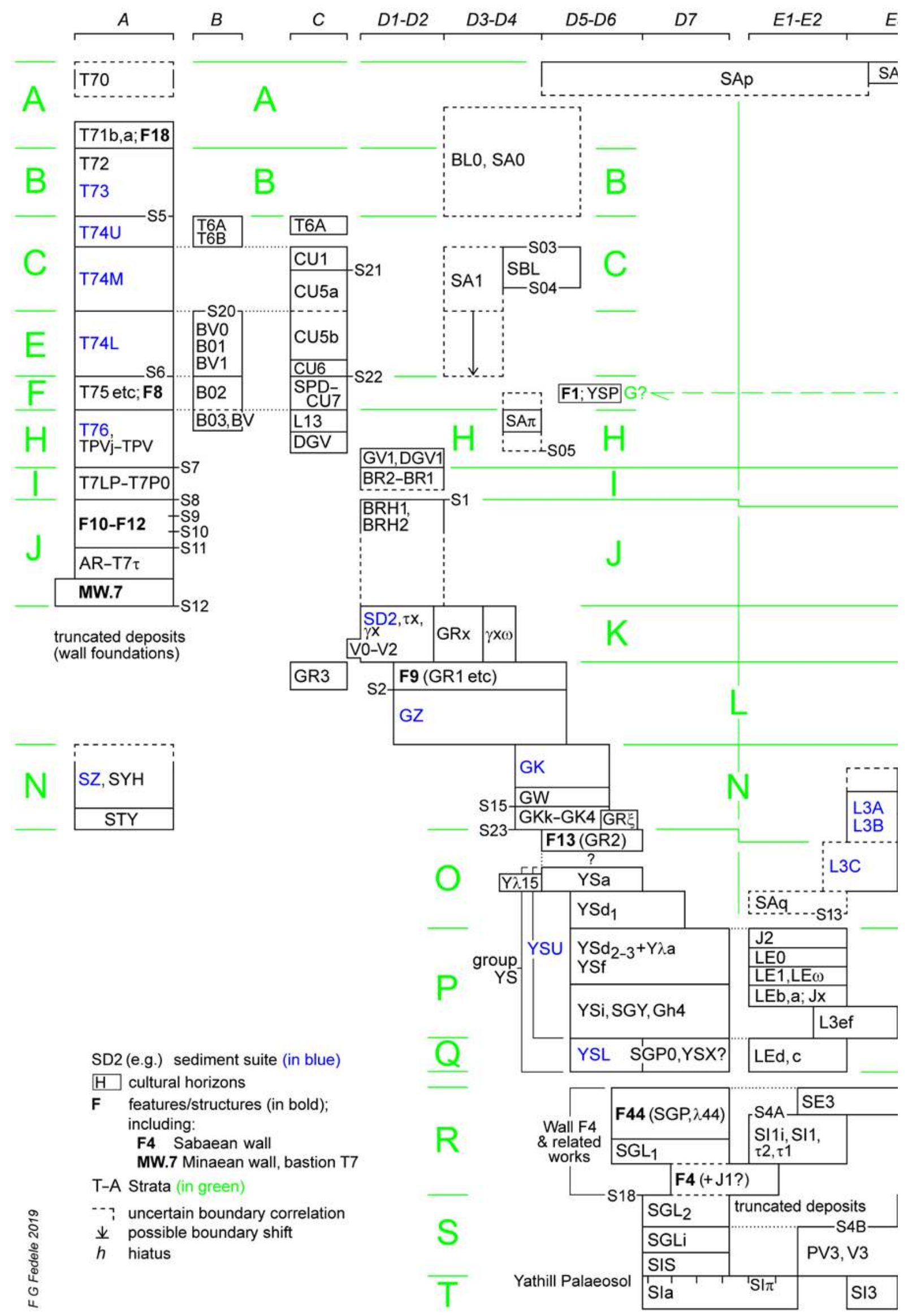




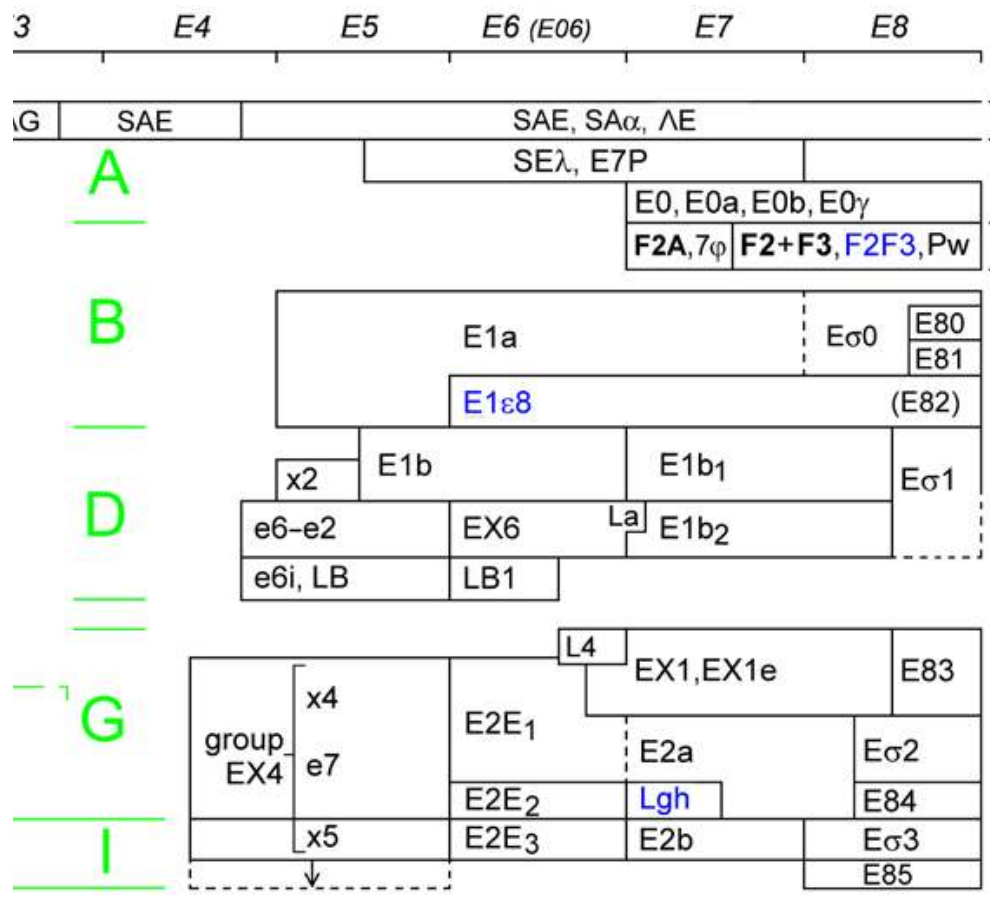

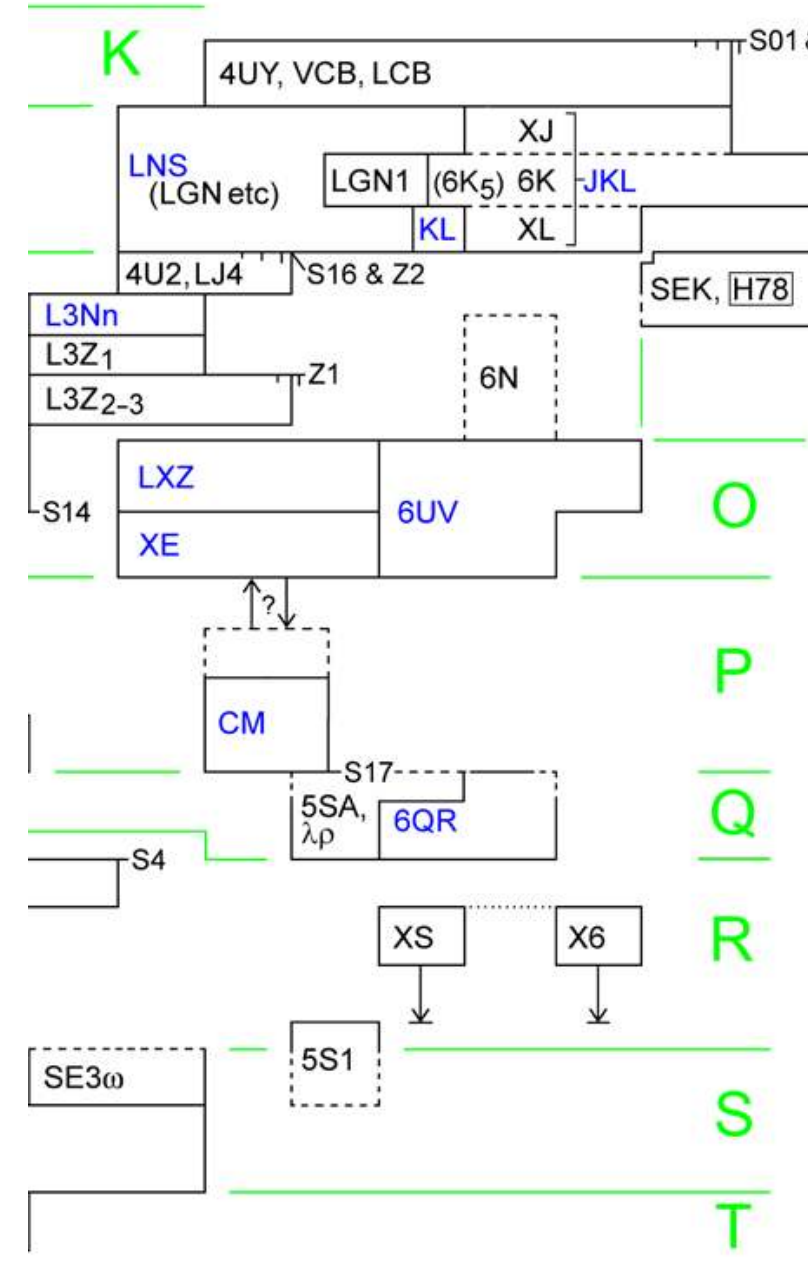

\begin{tabular}{|l|}
\multicolumn{1}{c}{$E 11$} \\
\hline AE etc \\
\hline SXY \\
\hline TGh \\
\hline
\end{tabular}
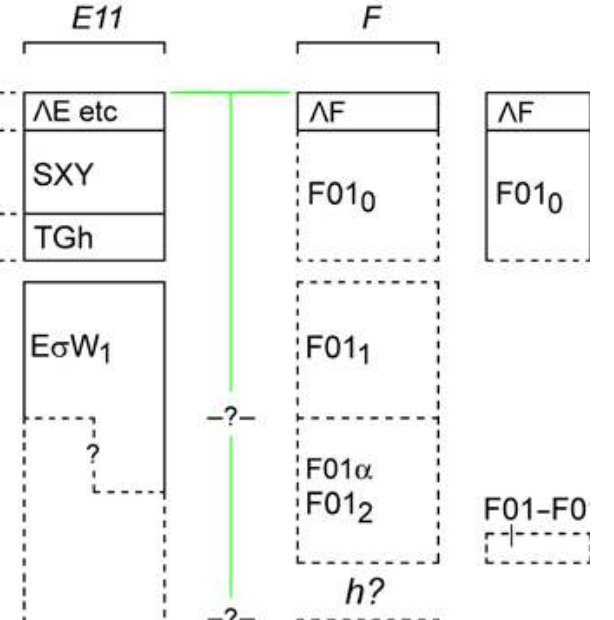

$h$ ?

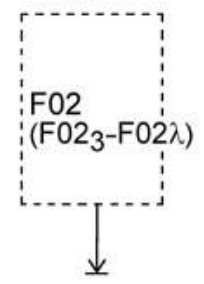

$$
\underset{\text { (possible) }}{h}
$$

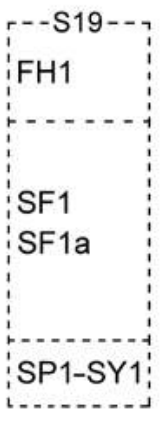

SY2
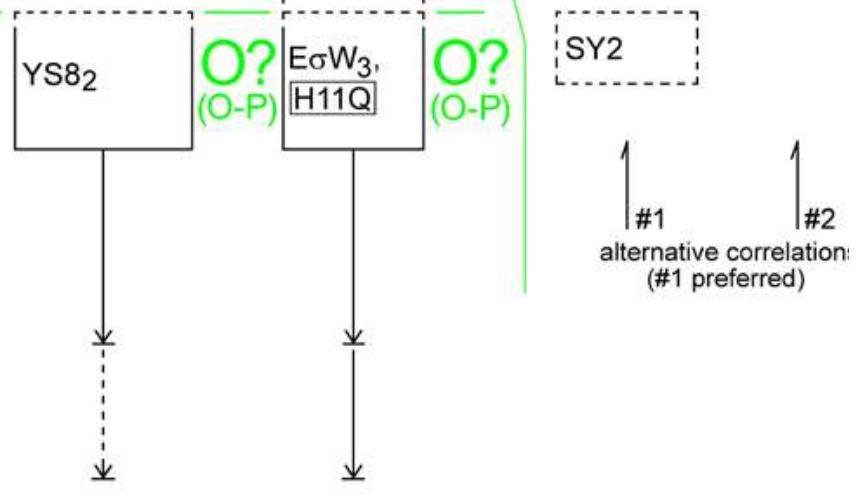

Figure 24. Area C Stratification diagram, or total stratigraphic lattice - a diagram emphasizing sequencing and correlation.

(F.G. Fedele 2015, updated 2019) 


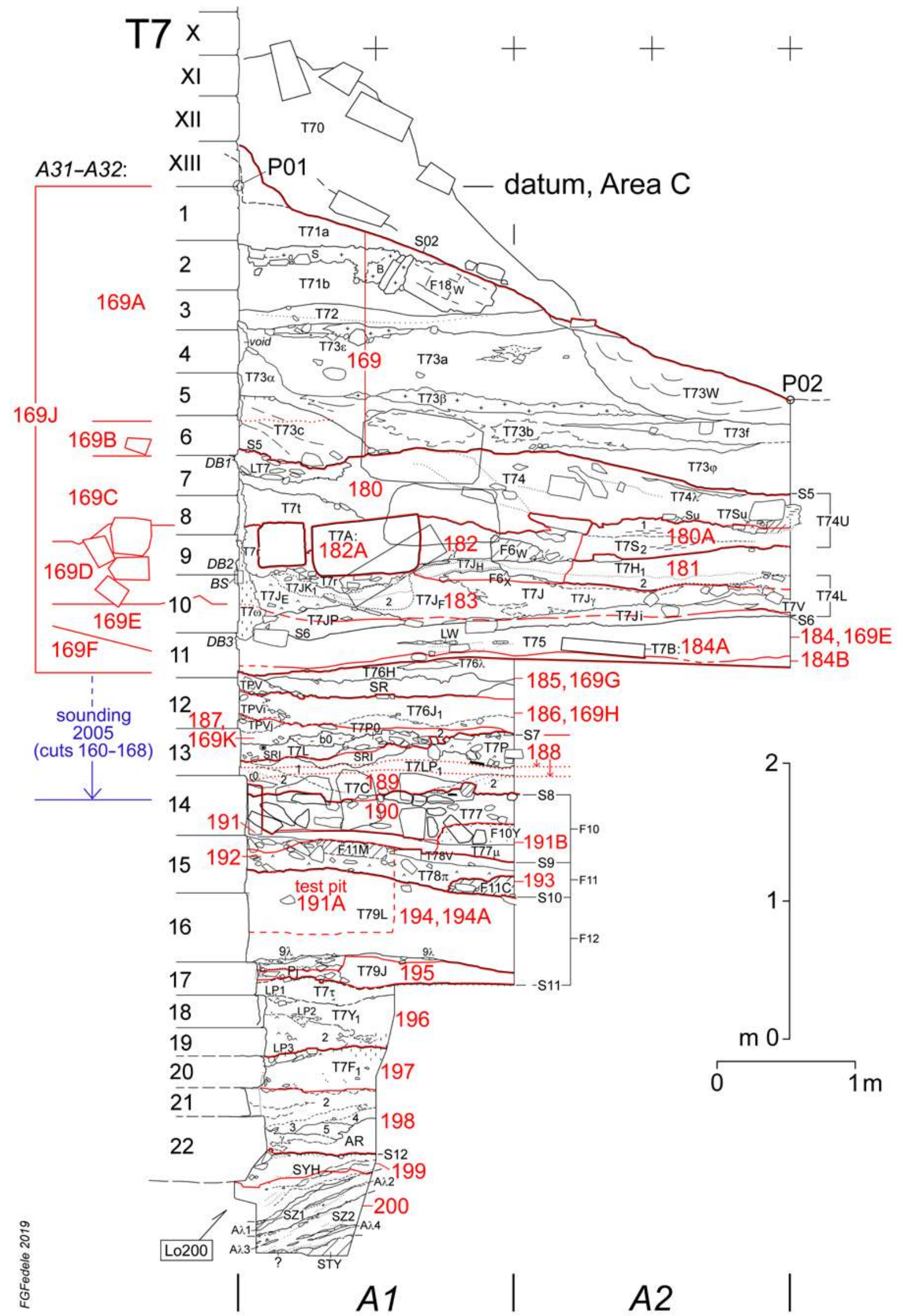

Figure 25. Sounding A: vertical distribution of dissection numbers (cuts), outlined and designated in colour. Cuts of preliminary sounding 2005 are omitted. (F.G. Fedele 2019) 


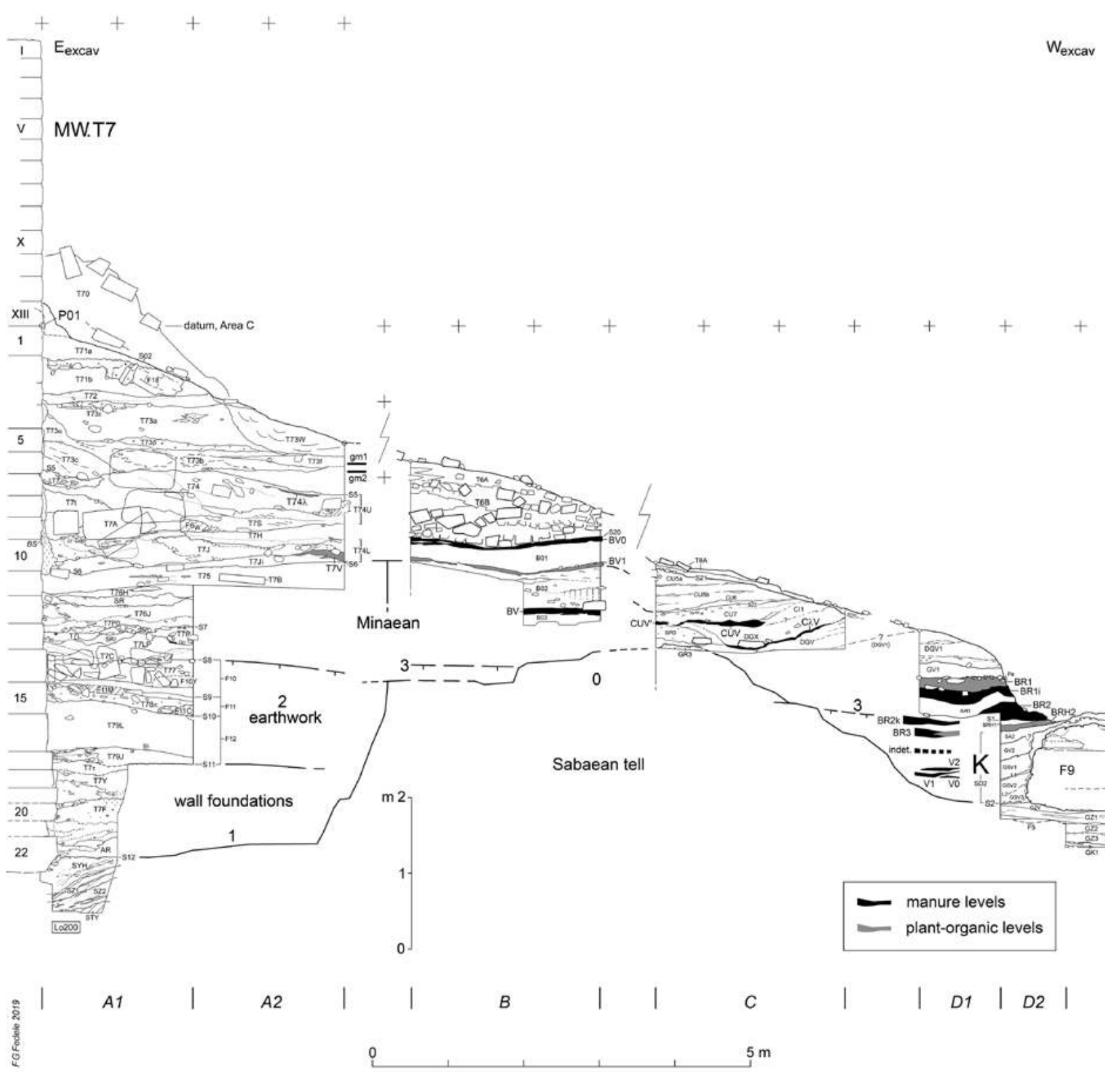

Figure 26. Stratigraphic profile emphasizing the manure and plant-organic units between upper Sector D and Sounding A. A reconstruction of the Sabaean tell and the Minaean wall-related works is also shown. Note that the horizontal relationships of Sectors B and C with Sounding A are purely indicative and that a continuous profile of the Sabaean tell cannot be drawn (cf. Fig. 27). (F.G. Fedele 2019)

levels in the plain (SY2), which, again, would suggest trade or even caravan-trade activity.

During the final part of Sabaean 2, with Wall F4 now reduced to the stone base only ( $\left.\mathrm{F} 4{ }_{0}\right)$, an important process of debris slides and colluviation from the tell commenced which would dominate the talus for some time - and in fact, create talus, setting a new phase in motion. This is revealed by the deposits of Stratum O, including suites L3C (see below), XE, LXZ , 45S, and 6UV. Soon afterwards, active occupation was resumed in the area of our concern, locally atop Sand YS itself. This development marks the beginning of the Later Sabaean and defines Stratum N (Sabaean 3), characterized by the full occupation of Sector D. Residential occupation in this part of the tell can be equated with so-called settlement 'Lobe 5' (see below). Because of the making and remaking of mud structures and the copious domestic refuse, new material was made available for the erosive processes affecting the edge of the tell. The chief twin processes here - the vertical buildup on the mound and its erosion and instability at the margins - coacted throughout the Later Sabaean (Strata N-L), while erosion actively continued afterwards.

Strata $T$ to $R$. The lowermost part reached by excavation in quadrangles E1- E5 consists of apparently primary deposits, that is autochthonous 
(formed locally), suggesting the margin of an occupation. This is the primary Sabaean tell, as well as the substrate to the considerable allochthonous layers (colluvia, slumps or slides) of subsequent Strata Q to L.

Strata $Q$ to $L$. In quadrangle $E 3$ one sees the end of the colluvial lenses having root at Wall $\mathrm{F} 4$, or in any case in quadrangles E1-E2 just down from the wall. These are the polychrome 'banded' lenses, partly ashy, of groups LE (Strata Q-P) and L3BC (Strata O-N). Around the E3/E4 boundary these lenses are replaced by - or interdigitate with - the mass accumulations of the type-sequence in quadrangles E3-E4: from bottom, suite CM (Stratum P), XE4 and LZ5 (Stratum O), L3Z and LY4-LJ4 (Stratum N), and LGN-VGN (Stratum L). These reiterated, intermittent accumulations are sometimes more gravelly ('pebbly'), sometimes more silty. The complete sequence can be observed on the east section of quadrangle E5 (Figs 45-46).

Therefore, during the Sabaean period, we have down-talus a radical change in the depositional pattern, a change affecting sediments as well as directions and mechanism of sedimentation. And this change has both topographical (spatial) and chronological dimensions: the colluvial lenses in E1-E3 partly precede the accumulations (group LE), partly are coeval (group L3BC). These were important facts for talus development.

With the Sabaean 3 the talus effectively began to grow and expand (suites L3B, L3A, L3Nn; stratified accumulation L3Z) and a typical flexure formed between quadrangles $E 3$ and $E 4 .{ }^{92}$ The normal growth of a talus is like a concretion, and it entailes flexure shifts. ${ }^{93}$ A persistent interplay of the three key sedimentary mechanisms - colluviation, episodes of slumping or sliding facilitated by rain-lubricated silty surfaces, and aeolian deposition - operated on and below the flexure and controlled the growth and shape of talus. Lenticular colluvial lenses alternated with non-lenticular sediment bodies, as shown by Sector E.

Seasonal rainwater would have been particularly effective at this stage of mound's evolution. Rainsplash and rainwash erosion over an unspecified period of time generated innumerable thin lenses of slope wash down and away from the edges of occupation, spreading them towards the base of the talus. Intermittently, gravity accumulations would originate from the tell's margin, such as non-colluvial and non-lenticular suite XE, L3Z (already cited), LGN, and VGN-VGN'. The result was a thick complex of both colluvial and gravity-induced units from the Sabaean tell, interfingering with windblown sands and silts. By the First Intermediate the

\footnotetext{
92 For 'flexure' see section 2.1, above.

93 Also mentioned above in section 2.1.
}

flexure of the talus had shifted to E4/E5: the maximum advance recorded in the Reference section, and where the flexure can approximately be perceived today ${ }^{94}$

The whole mass of talus footslope accumulations from surface S4 to surface S01, 2-3 m thick and spreading over quadrangles E2-E7, is Sabaean-First Intermediate in age. Relatively early in this depositional phase massdeposited suite L3C was emplaced. Suite L3C bears some resemblance to LE1 and LE0 of group LE (which reflect the advanced decay of the Sabaean wall), but probably is slightly later (Table 5) and from several indices would correlate with the interface between the Sabaean 2 and 3, i.e., the Earlier and Later Sabaean. ${ }^{95}$

The Sabaean deposits on the talus following L3C - both accumulations and colluvia - could be subdivided into a lower and an upper package, the boundary between them being surface S16. The lower deposits, represented in quadrangles $E 5-E 6$ by group E56.2, are Sabaean 3 and probably related to GKk-GW and suite GK on the tell (Stratum N). The upper deposits, which include group E56.1 in quadrangles E5-E6, are Sabaean 4 to First Intermediate in age and are possibly to be traced to suites GZ and SD2 on the tell (Strata L and K). Lenses containing brown plant detritus would derive from the erosion of GK-type layers, whereas interspersed ashen-whitish lenses would have their origin from ashy deposits such as those starkly represented in suite GZ. Both packages are thus traceable to sheet erosion of the Lobe 5 living areas.

About Strata O-N on the lower talus, middle Sector E. Unit XE4 shows facies variation in a north-south direction, being far richer in fines in the Reference section than in its southern subunit $\mathrm{XE}_{4}$; this latter is also more compact and 'gravelly'. ${ }^{96}$ The emplacement of XE4 was immediately (?) followed by the arrival of fines LZ5, then of occasional lenses of gravel, and then again of a new sheet of fines, L3Z. A particular swarm of small gravel lenses within L3Z (3Y) was emplaced right above the eastern end of XE4 (in qu. E3 west).

Consequently, this complex phase of sedimentation can probably be viewed as a progressive but intermittent buildup of the talus caused by the emplacement of layers of various origin and nature and inclination (also locally sub-horizontal): a buildup during which accumulations or 'banks' of sedimentary masses, and reduction of these masses

\footnotetext{
94 The present-day flexure is much shallower because of the large sand buildup in lower Sector $E$ and the plain after the First Intermediate.

95 Suite L3C is conventionally placed in later Stratum O (Table 4).

96 The south section of qu. E4 shows that unit XE4, as well as suite LNS later, are the end part of thick debris sheets roughly originating southeast of quadrangles E4-E5 (see below in this section; cf. Fig. 46).
} 
by erosion, must have repeatedly alternated. Sediment units such as XE4, LZ5, and L3Z do not have sharp boundaries, given the similarity of sediments and the close succession of depositional microepisodes, but the result is a perceptible cumulative effect on the structure and relationships of the larger sediment bodies they formed. This overall growth of the talus, a conical accretion, entailed a shift of its flexure (see above).

A boundary such as LZ5/L3Z (with lens L41), or 'arrests' such as those suggested by $\lambda \mathrm{v}, \mathrm{LGN}^{\prime} / \mathrm{LGN}$, and $\mathrm{L} 3 \mathrm{~N}-3 \mathrm{n}$, mark episodes of temporary stasis during the growth and expansion of the talus, hence of the flank of the mound.

At least three times, diagenesis by calcium carbonate and clay infiltration, and sometimes by organic waste fluids and/or modest oxidation, punctuated the evolution of the talus, signalling moments of relative stability, or 'stasis' (diagenesis/weathering zones Z1-Z3). The best example is perhaps Diagenesis Z2, associated with surface and stasis S16 and separating Strata N and L. In middle Sector E, surface S16 not only marks a break between the two superposed, welldefined stratigraphic bands mentioned above (groups E56.2 and E56.1), but, in the form of a red band crossing several quadrangles, it effectively provides a snapshot of the talus profile at the time in question. Similarly but less conspicuously, the reddish-brown line of diagenesis Z1 captures a profile of the palaeo-tell at the moment of surface $\mathrm{S} 4$.

Z1. A diagenesis zone affecting lower or bottom $\mathrm{L}_{3} \mathrm{Z}_{2}$ and the top of SE3, in quadrangle E3, and lower or bottom XE4 in quadrangles E3-E4: it therefore overlaps surface S4. Its typical colour is a staining rustbrown (i.e., the sediment so affected stains). This diagenesis appears to combine infiltration of organic waste, as suggested by a limited penetration of Z1 within XE4, and oxidation and reddening from oxides, as one would infer from the similarity of its SE3 segment (a 'brown line' at the top of SE3 in E3 east) to diagenesis zone Z2. On this diagenesis zone see section 7.4, below.

$Z 2$. A diagenesis zone in quadrangles $E 3$ west to $E 5$, marking the bottom of unit LGN and affecting units LJ4, LY4, $4 \mathrm{U} 2,4 \mu \mathrm{r}$, and the top and sloping flank of L3ZLZ5: it therefore closely coincides with surface S16 and contributes to infer a significant stasis ('stasis $\left.\mathrm{S} 16^{\prime}\right) . \mathrm{Z} 2$ is an intense and perhaps multiple (polycyclical) diagenesis/weathering episode consisting in (i) a deep illuviation of clay and perhaps organic fluids, accompanied by infiltrations of calcium carbonate (localized 'white specks', see below); and (ii) a downward accumulation of oxides and consequent generation of a typical red band, particularly evident in quadrangle $E 4$, clearly from oxidization. On this diagenesis zone see section 7.4, below.

Z3. A diagenesis zone in quadrangles $E 4$ west to $E 7$ east but particularly marked in qu. $E 4$, overlapping the long ribbon, $\mathrm{LCB}$, and the top or part of units $\mathrm{VCB}-\mathrm{VCB}$ ', $4 \mathrm{UY}$, and LSx: it thus seems to correspond to surface S01. This is not the only possible interpretation in terms of relationships with lithostratigraphy, but is the most parsimonious. (An alternative would be diagenesis Z3 occurring immediately after the deposition of LSX or LSX+4UY, units composed of fines, with VCB-VCB' and LCB being redeposited Z3 sediments.) Diagenesis Z3 consists of a marked illuviation of light-grey fine silt and clay together with calcium carbonate, which resulted in the most conspicuous density of "white specks' in Area C. A proper weathering zone? ${ }^{97}$ On this diagenesis zone see section 8.4, below.

Prior to zone Z1, an origin from weak weathering can probably be proposed for subunit PV3 $\alpha$, a nuanced ashen 'halo' at the top of PV3 (quadrangle E3), but the field evidence seemed insufficient to list it among the diagenesis zones. PV $3 \alpha$ is interesting as the earliest trace or suggestion of weathering phenomena from Area $\mathrm{C}$.

'White specks' ('tracce bianche' in Italian). Field designation for millimetre-sized white granules or flecks, usually looking like micro-concretions under a hand lens, dotting particular fine-grained sediment units on the talus; most of these units are grey-coloured. White specks show considerable variation in morphology and may also greatly vary in facies and density within the same unit punctuating thickly LCB, for instance. Several forms were identified: ${ }^{98}$ sometimes they are dot-like (cf. micronodules), for instance in silty units such as LCB; in other cases, especially in loose aerated sands or silty sands like E1a and E1b in quadrangle E7, they are filamentous (i.e. mycelia-like), which should indicate illuvial formation. In Sector B, subunit $\mathrm{B}_{2}{ }_{3}$ was punctuated by soft white specks resembling gypsum (section 15.3 below). It is thus clear that white specks can form in a certain range of different sediments acquiring different shapes. In the field, unfortunately, their possible proclivity to colluvial redeposition could not be explored in detail.

Concerning surface and stasis S16, a considerable phase of human activity on the plain and lower talus can probably be dated to this moment. Again possibly connected with tent-camping, this phase is associated

\footnotetext{
97 As mentioned above in section 2.3, footnote 47, after the fieldwork a suspicion arose that some 'white specks' might in fact be animal spherulites.

98 Cf. Overstreet et al. 1988b, 370-371.
} 
with the large-ceramics clusters of Horizons H78 and H11, as well as pottery debris elsewhere (Stratum M). Between quadrangles $E 5$ and $E 6$ a transition from inclined to horizontal sedimentation can be observed: Horizon H78 was probably deposited on a flat bank of older deposits slightly raised above the adjacent ground surface (a méplat colloquially called 'Platform E6-E8'). Significantly, H78 is contiguous to the foot of the talus formed by suites $6 \mathrm{QR}$ and $6 \mathrm{UV}$, looking like the far end of the talus in the Reference section and corresponding to stasis S16. The mutual exclusion between the large ceramics of $\mathrm{H78}$ and these sediment accumulations from the tell makes it entirely reasonable a correlation of Horizons H78 and H11 - hence Stratum M - with stasis $\mathrm{S} 16$, approximately.

The inclinations and orientations of layers can be revealing. The sections of middle Sector E, quadrangles E3-E5, all record inclinations of up to $45^{\circ}$ northwest for the accumulations and colluvial masses, sheets, and lenses between XE4 and LCB, largely formed of mudbrick and domestic debris (cf. Figs 41 and 43-45, photographs; Fig. 46, multiple sections). ${ }^{99}$ This kind of orientation indicates their provenance and origin: it provides strong evidence for the existence of a settled area immediately to the southeast of the trench in middle-upper Sector E, probably an eminence or lobe of the tell. From the nearest bastion upslope (T5) this occupation will be called 'settlement Lobe 5' (Fig. 68). Its original morphology might indeed still be perceived today in the humpback-shaped relief of the talus south of Gully B (Fig. 1, centre-left; Chapter 26, Fig. 10, this volume). The age of Lobe $5-$ or its final age - is necessarily Later Sabaean.

Furthermore, inferred Lobe 5 might link up without interruption to the settlement area revealed by occupation and mudbrick structures in adjacent Sectors D and C, and a little away in Sounding A. In upper Sector D, quadrangles D2-D5, the core of this Later Sabaean occupation consists of suites GK and GZ, terminated by surface S2. Stratification in these suites is strikingly horizontal. The associated archaeosurfaces or 'living floors' are characterized by an abundance of cultural debris and include conspicuous discard areas for domestic refuse (Figs 14-15, 33-36, 59-63). There are authentic hearths, well preserved animal bones, and fragile artefacts (for instance textiles, an ivory comb). Unit GK1 is extraordinarily rich in organic residue and perishable artefacts in organic materials. An additional defining factor, concerning Stratum $L$ from its inception (GZ3), seems to be a marked increase in the frequency of shoddy ceramic productions and plain ware..$^{100}$

\footnotetext{
99 For the upper units (LCB and above), the E4/E5 section (Figs 5, 46) records a $45^{\circ}$ dip north, while a $c .45^{\circ}$ dip west is recorded by the Reference section. The dip is different and varying for the lower units. 100 See Chapter 23, section 3.2, this volume.
}

Mudbrick structures are conspicuously represented by F9 (the corner of a house?), but they also outcrop at the bottom of excavation in Sector $C$ and Sounding A. In fact, we can reckon the existence of no less than five bodies between middle Sector D and Sounding A indicating mudbrick structures in situ or nearby, and as such providing a reasonable suggestion of residential settlement. Bottom to top, they are F13 (GR2), GW (melted mudbrick), F9 (GR1), GR3, and STY in Locus 200 (Figs 64, 68). By this time, the northwestern sector of the tell had grown into a flat or domed relief, at least ten metres high above the plain. The Minaeans probably levelled the mudbrick ruins of Lobe 5 when they built their wall.

\subsection{From the Sabaean-Minaean transition to the present}

In addition to well defined occupational periods, Area $C$ provided clear evidence for two intercalated sediment sequences indicating reduced occupation, which can be termed 'Intermediate' phases. This was explained above in section 3.3. The First Intermediate is synonymous with Stratum $\mathrm{K}$, and the sedimentary core of Stratum K on the upper talus (as the morphology can now be called) is suite SD2. Stratum K coincides with the disappearance of the Sabaean ceramic production. More precisely, it embodies the problematic interface between the last Sabaean layers - in material-culture terms - and the appearance of Minaean indicators in the form of new uses for the talus, new associated sediments, and a different pottery. Lacking any evidence for environmental factors, the preferred interpretation is sociocultural: a shrinking occupancy in this part of the tell, if not of Yathill in general, connected with a period of shifting political control probably accompanied by episodic warfare. ${ }^{101}$

The advent or consolidation of Minaean rule is emphatically marked by the construction of a substantial curtain wall. The Minaeans gave the settlement a completely different style from the Sabaean. In Area C, where the Minaean wall is represented by the segment comprising bastions T5-T7, direct archaeological information was particularly provided by Sounding A, made alongside bastion T7. The base of the Minaean stratigraphy coincides with the cutting of foundations for this town wall. At this stage (Stratum J) the tell margin was stabilized, but soon afterwards its vertical growth started again, particularly because of deposits indirectly induced by the existence of the wall (Strata I, H, and F). For instance, the wall would repeatedly attract human stay and installations and favour aeolian deposition. Limited but not negligible deposits were also generated by the wall itself (section 2.3 above). Sediments about four metre thick accumulated at the

101 See Chapter 18, section 3.2, this volume. 
base of bastion T7 during the Minaean period, burying the lower parts of the wall (cf. section 2.1).

Such important building activity is one of the two lines of evidence highlighting that settlement at Yathill had entered an entirely new phase, after suite SD2 or already during its formation. The second phenomenon consists of plant-organic and manure units, whose repetition on the upper talus not only heralded a relatively new sedimentary regime, but reveal a new behavioural pattern (Figs 26, 30). ${ }^{102}$ Some are extensive and thick excrement lenses in which coprolites and other organic waste testify to the presence of pack animals - donkeys and dromedaries - to the virtual exclusion of other species. There would have been frequent stationing of these animals on the upper talus throughout the Minaean period. Vegetal and dung or dung-enriched sediments were not really without precedent in Area $\mathrm{C}$, but novel were at this moment their frequency and succession, as glimpsed from the restricted sampling surface of the excavations. It is not unconceivable that manure levels in Stratum J resulted from animals employed in the wall's construction. ${ }^{103}$

The sequence of manure and plant-organic units appearing in the Reference section is shown in Fig. 26. Save for unit $6 \mathrm{~V}$ (see section 4.1), these units are inaugurated by V0-V2, exposed at the head of Gully B and belonging to the First Intermediate (Stratum $\mathrm{K}$ ). Lesser units of the same kind are certainly present in Stratum K. They are followed by at least 15 occurrences spanning Strata J to F (Minaean) and E to B (Second Intermediate to Islamic 3). However, the trend is fading after the Minaean period. The last genuine plantorganic unit of a certain consistency is T7V of Stratum $E$, Second Intermediate, reaching up to within a few metres of the Minaean wall. ${ }^{104}$ This is followed by a thin manure layer in Sector B, BV0 (also Stratum E); ${ }^{105}$ by lens T74 $\lambda$, made of plant debris and gravel (later Stratum C, Islamic); and by two very thin manure-looking lenses at the bottom of unit T73b (gm2 and gm1; earlier Stratum B, Islamic 3).

Concurrently, activities related to trading are documented in a strip between the upper talus and the curtain wall during the Minaean and particularly the Later Minaean. The definite impression is that the evidence to this effect, captured at bastion T7 by Sounding A, can be extrapolated to a longer stretch

\footnotetext{
102 Fedele 2011a, 107, 111; 2014, 190. Plant-organic and manure units are defined as both sediments and processes in section 2.3 , above.

103 See Chapter 18, section 3.2, 'On the earliest Minaean', and Chapter 19 , section 3.1 , this volume.

104 T7V was intercepted at the very border of Sounding A. A connection with BV1 in Sector B is not impossible.

105 Sparse vegetal debris and at least two animal coprolites were contained within the fill of feature F6 (unit T7H); they might be related to BVO.
}

of the western wall of Yathill. Several operations connected with trade-jar handling, and perhaps trade goods in general, appear to have been carried out in sheds or simple stone cabins alongside the wall, at least intermittently. That pack animals were kept on the talus a little below is relatively unsurprising. ${ }^{106}$

A related observation is in order: the pronounced acclivity of the present-day talus near the curtain wall and below is due to abandonment and decay, not dumping. And it is an entirely recent morphology, Recent to Present (Stratum A; Table 4). During the Minaean period all the data we have suggest horizontality: that is, the existence and maintenance of a wide horizontal belt along the wall that could occasionally also be used for activities. This belt can be pictured as presumably comprising horizontal surfaces in its upper part and slightly undulating benches lower down, punctuated by sparse manure lenses. And as soon as Minaean life ceased, this upper tract of the talus was partly covered by small dunes and counterscarps (cf. Stratum E), which persisted until the resumption of human presence during the Islamic period.

Besides the belt along the wall, the other part of Area C in which the Minaeans dealt with trade jars and trading in general was the plain, as revealed by both surface evidence and Sounding F. These northwestern flats of Yathill might indeed emerge as the preferred location for caravan trade throughout the florescence of the town. This subject will be developed in Chapter 19, section 3 , this volume.

During the timeframe of Stratum K, the slope of the mound was mantled by the most extensive colluvial sheet in Sector E, unit LCB. LCB appears in sections as a centimetre to decimetre-thick ribbon of steelgrey fines with fluidity structures, often loaded with 'white specks'. Such micronodules ${ }^{107}$ were produced by weathering during a stability interval that immediately followed (Diagenesis Z3). With a sharp upper boundary, surface S01, LCB is a true marker bed. It signalled the end of a long phase of slope-wash deposition presumably connected with at least a minimum of regular monsoonal rainstorms. ${ }^{108} \mathrm{~A}$ leached-hearth level in Sounding F, FH1, topped by surface S9 and followed by a hiatus, may fall within the same timeframe. A period ensued - continuing today - characterized by increasingly sustained aeolian activity, readily recognizable in the thick, stratified sand cover of the talus footslope. A painstaking sequencing of the sand cover has been attempted (Figs 21-22).

\footnotetext{
106 See Chapter 19, section 3.1, this volume.

107 See section 4.1 above.

108 A low frequency of precipitation events does not diminish the effectiveness of rainwater in shaping arid talus landscapes on the human scale (cf. Scoging 1989, 87).
} 
Vast amounts of deposits were eroded away from the middle-lower talus during the Minaean and Second Intermediate intervals, a timespan of about 18 centuries. This is the sediment ultimately redeposited as 'sands' E2-Eø3 to E1b-E $\sigma 1$ over the area corresponding to quadrangles $E 5$ and below, a sequence condensed in quadrangle $\mathrm{E} 11$ as $\mathrm{E} \sigma \mathrm{W}_{2}$ (Strata I, G, and D; Minaean 2 to Earlier Islamic). Apparently uneventful historically, such a mantling in fact constitutes a long and important chapter in the creation of the Barāqish landscape of today.

Aeolian-colluvial interaction proceeded substantially. A chain of fine-gravel pockets (EX1) and several strings of colluvial debris punctuate these sands providing useful - if faint - marker lines within otherwise fairly uniform deposits. A regular alternation of sand sheets and about ten lenses of grit and gravel, with the occasional potsherd (units E86-E80), characterizes E8, the first quadrangle downslope to show a sequence almost completely determined by aeolian deposition and deflation. The long-term balance in favour of deposition resulted in buildup.

Such an incremental, ostensibly continuous buildup of sand and silt becomes more pronounced lower down and away from the talus. The thick sand deposit E $\sigma \mathrm{W}$ in quadrangle E11 is diachronic and shows remarkable facies continuity, but there must have been hiatuses, even if an internal layering is elusive. Only a faint increase in compaction at a depth of $50-60 \mathrm{~cm}$, caused by a fraction of greyish fines, and a cultural horizon lower down (Horizon H11 associated with a minimally differentiated sand sheet, Eox; see section 4.1), suggest subdivisions, hence the partition of $\mathrm{E} \sigma \mathrm{W}$ into three vertical subunits. Moreover, downslope from Hill E the large inclinations characterizing most of Sector $\mathrm{E}$ disappear: in quadrangle $E 11$ the sedimentation planes

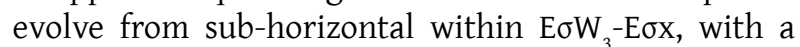
modest dip west, to horizontal within $\mathrm{E} \sigma \mathrm{W}_{2}-\mathrm{E} \sigma \mathrm{W}_{1}$.

On the sand mantle of the lower talus and at the foot of talus (the 'upper sands' in quadrangles E5-E7). The sedimentation in Sector E seems to have resulted from a perpetual interplay between colluvial deposition and aeolian deposition: that is, between the washing of the detritic talus of Barāqish and the contribution of windblown silts from the plain and/or floodplain. In other words, a continuous interplay of 'wet' and 'arid' contributions, coming by definition from opposite directions. The trench in quadrangle $E 5$ shows well the transition from a wet to an arid regime, with many oscillations in between. Hence the differential naming of units, the essentially aeolian ones prefixed by 'E' or ' $\mathrm{e}$ ', and the essentially colluvial ones prefixed by ' $x$ '. The former regularly consist of slightly silty fine sands. The latter consist of a darker (hazel to grey) and often weakly organic sandy matrix containing minute cultural debris, such as pottery bits, charcoal, and small pebbles from melted mudbrick. These cultural contents can sometimes be coarser.

Importantly, this interplay between arid and wet contributions is not an opposition: they alternated continuously, even coacted. So to speak, the opposition was only directional. And their products show only partial, variable, or oscillating contrast, which tends to translate into facies variation (heteropy) on the metric or even sub-metric scale. For example, e6 (quadrangle E5) appears to be the root of EX6 in quadrangle E6 (E06); or, in these same quadrangles, $\mathrm{x} 5$ is transitional to $\mathrm{E}_{2} \mathrm{E}_{3}$. Nevertheless, we are still dealing with different depositional processes.

For the sake of simplicity, I have preferred to classify this mantle of 'sands' in terms of sediment units and groups, avoiding both the suite and the multiplication of subunits or facies. The group seems to be the higher classification category of the right rank for these sands, called during fieldwork the 'upper sands' of E5-E8: a thick band 8 to 10-metre-wide near the foot of the talus. Groups E1, E2, EX3, and EX4 have been created accordingly. In this way these sands are described by means of four ordered sediment groups. ${ }^{109}$ Furthermore, as a rule, I have found it preferable to designate units by quadrangle, given the considerable variability of sediment bodies and facies even on a decimetre scale. Exceptions can be made where the identity of units across the excavation-grid limits is immediately evident. In these quadrangles and layers we also face an intricate plethora of sediment bodies and micro-bodies often with an imbricate structure, which is therefore arbitrary to merge, or impossible to merge and regroup unequivocally.

On cultural materials embedded in the 'upper sands' of quadrangles E5-E7. During Strata I and G (Minaean 2-4) and D (Second Intermediate) large quantities of Sabaean cultural material were eroded and redeposited on the talus in E5-E7. Such material included pottery and was particularly characterized by a high frequency of large or very large fragments (e.g. cuts 51, 70,71, and part of 72). The interesting point in terms of taphonomy is that the large potsherds show strong exfoliation and/ or wind abrasion, but negligible trampling wear. This accords well with an absence of human and animal circulation on the steeper part of the talus

\footnotetext{
109 This classification supersedes what was published in Fedele 2010; 'group E6A' has been abolished. This reordering affects the definition of Strata D and B in quadrangles E5-E6. Details are given in sections 15.2 ('Stratum I'), 15.3 ('Stratum G'), 16.3, and 16.4 below; the composition of these groups is detailed in both Table 2 and Fig. 21.
} 
(the flexure and high-acclivity belt of the middlelower talus) during the Minaean period and - more markedly - the Second Intermediate abandonment of Yathill.

The availability of chrono-cultural indicators is limited. Age estimates for Sector $\mathrm{E}$ are hard to come by, apart from Horizons $\mathrm{H} 78$ and H11, and there is a general lack of Minaean and Islamic dating material from all over the talus. The few reliable indicators, however, safely place the Minaean above marker-surface S01, ${ }^{110}$ and a little Minaean pottery was found in the debris levels intercalating sands E2-Eø3, E1b, and Eø2 in quadrangles E6-E8. An acceptable link to Sector D was provided by the brown plant and manure-looking contents of group EX4, including vegetal-debris units $\mathrm{x} 5$ and $\mathrm{x} 4$ intercalated by sand e7. Being colluvial, not from primary deposition, their origin can only be traced to the idiosyncratic manure layers of Strata K-I, located on the talus from upper Sector D upwards (see above).

Concerning the Islamic period, a correlation link can arguably be found in suite E1ع8, a 'grey band' with diffuse boundaries constituting a minor marker throughout the upper part of the sands. Its loamy-organic character and its relative-stratigraphic placement both suggest indirect connections with the bastion fills from collapses of the Minaean wall, T6 in particular (Islamic 2). Such muddy-loamy fills are quite distinctive. ${ }^{111}$ Considering its long-distance redeposition, possibly involving some time, a tentative correlation with the subsequent time horizon is suggested, i.e., with Islamic $3 .{ }^{112}$ During the Later Sabaean and Earlier Minaean the slope wash reaching the lower talus was coming down from the south-southeast. Later, during the Islamic period, the runoff was probably deflected to the north by the rubble fan from a wall collapse.

Brief mention must finally be made of the fills of Gully B. Surprisingly, Gully B with its precursors has a 2000 or perhaps even 2500-year-long history, materialized as micro-alluvial deposits filling palaeo-channels within the gully. Buried within the fills of the gully, two sediment units were recognized: XF1, filling a furrow (F1), and YSP, of less clear morphology. Both are undatable, but seem to belong to Stratum $G$ or - less likely - Stratum D. Details are given in section 15.3, 'Stratum G'.

\footnotetext{
110 A 'Minaean'-looking sherd from unit 6K (quadrangle E6) is in fact undiagnostic.

111 'Loam' indicates a mixture of sand, silt, and clay with some amount of organic matter.

112 See section 3.3 above, 'Long-distance correlations'.
}

\section{Strata T and S: Earlier Sabaean 1}

\subsection{Introduction and overview}

Starting with this section, the extramural sequence from Area $C$ will be reviewed stratigraphically, that is, in depositional and historical order from Stratum $\mathrm{T}$ to Stratum A (sections 5 to 17). Information on lithostratigraphy and archaeology will be summarized within the discussion of each Stratum, and the main implications for settlement and environmental history will be outlined. Features will be described in detail and the most informative finds will be mentioned. As finds are fully reported in Chapters 19 (animal and plant material) and 21-24 (artefacts), this volume, specific cross-references will only be given for selected finds.

Strata $\mathrm{T}$ and $\mathrm{S}$ are primarily represented by some deposits at the core of the profile, stratigraphically the deepest, located in the middle of the present-day talus. They represent a Sabaean 1 phase within the extramural profile, although not an initial one for Yathill as a whole, since the site had been already occupied for at least four centuries. This core of Earlier Sabaean occupation dates from the end of the 9th century to about 700 BCE; 802-768 BCE should be retained as the best age estimate for Stratum T (Table 4; and Chapter 18, section 1 , this volume). The main reason for distinguishing two strata in these deposits, so far explored over a combined thickness of a little less than $1.5 \mathrm{~m}$, is that the lowermost units SI3 and SIa appear to be only the top of a sedimentary sequence slightly different from what immediately follows, possibly associated with different local conditions. As already mentioned, Strata $\mathrm{T}$ and $\mathrm{S}$ indicate a large Sabaean settlement, much more extended towards the northwest than the future Minaean town.

\subsection{Stratum $T$}

Stratum $\mathrm{T}$ is lithostratigraphically defined by units SIa in quadrangles D7-E1 and SI3 in quadrangle E3. Units SI3 and SIa both consist of ashy, fine-sandy silts which might in fact represent different facies of a single sediment unit. SIa, in particular, is dark grey with a distinctive 'dusty' touch from an organic and/or clay fraction, a characteristic that will persist into unit SIS above (Stratum S) and will reappear as reworked sediment in units SI1i and SI1 (Stratum R). Unit SIa lies almost completely underneath the base of Wall F4 and thus extends on both sides of it, at the junction of Sectors D and E: it is part of the deposits within which this Sabaean stone structure was built (see Stratum R).

As shown by water screening, sediment unit SIa is basically silt, about 95 per cent passing through a 2-mm mesh sieve (see Chapter 20, this volume). In detail, it is almost totally silty to fine-sandy, dark grey, often 
mottled in the field (yellow-beige) and visibly rich in ash, easily producing dust. Dispersed in the sediment matrix are frequent, irregularly shaped, $\mathrm{cm}$-sized silt and fine-sand concretions containing traces of charcoal, cemented by calcium carbonate, grey or whitish in colour. As to SI3, the deepest sediment in quadrangle E3, the small spots of grey, fine-sandy, charcoal-punctuated incrustations which frequently occur on artefacts from this unit suggest fairly long in situ residence.

At the top of SIa some traces of what may be interpreted as a fossil soil-a palaeosol-were observed, particularly in quadrangle E1 partly beneath Wall F4 (subunit SI $\pi$ ). The possibility of a palaeosol rests on some organic matter and clay content (visually determined), coupled with the unusual mottling of the sediment, yellow-beige to brownish on grey; indurated sandy aggregates due to calcium carbonate illuviation also occur. A remnant of a fossil soil horizon was precisely inferred from this coincidence of a band of physico-chemical modification in a former topsoil and its preservation beneath a stone wall. For such a possible pedogenetic body in this particular timeframe, in the Barāqish area, the name 'Yathill Palaeosol' was informally suggested (cf. section 3.1 above, entry 'b1'). ${ }^{113}$ Admittedly, to substantiate this hypothesis, the Yathill Palaeosol will need to be proved pedologically from a much better exposure and the appropriate analyses, but the occurrence of a mildly developed organic soil at the peak of the earlier Yathill florescence is not unreasonable. ${ }^{114}$

If indeed a soil, it could in turn reveal an oasis microclimate. ${ }^{115}$ In other words, the preferred interpretation for this soil is not regional-climatic, but microclimatic and by inference cultural: that is, dependent on the local landscape. Coupled with a sizeable Sabaean settlement, the evidence of extensive hydraulic management of the main wādi ${ }^{116}$ suggests that an oasis was already formed west and southwest of Yathill by the time of Stratum T. Date palm cultivation might have been important. ${ }^{117}$ And at some point lasting for a while - irrigation channels or even a branch of wādī might have skirted the settlement. ${ }^{118}$ As often in Arabia, irrigation and plants would significantly alter the climate on a local scale. As a consequence, a local

113 Fedele 2010, 111. The alternative spelling 'paleosol' is equally used.

114 Our fossil soil might have a coeval equivalent in an anthrosol (an anthropic-cambic palaeosol) from the oasis of Mārib, radiocarbondated to c. 1000-400 BCE (calibrated; Pietsch et al. 2010).

115 Cf. Chapter 26, section 4, this volume.

116 The Wādī Majzir system; see Chapter 19, section 5, this volume (with references).

117 See below, Stratum S, and cf. Chapter 19, section 4.2, this volume.

118 Cf. Chapter 19, section 5, this volume. oasis microclimate would then easily translate into a local soil, however immature. ${ }^{119}$

The loamy-organic fraction typically 'dirty' grey in colour, present in SGP and SE3, can probably be interpreted as inherited, reworked palaeosol material. The same can be said of the powdery, clayey fraction reappearing as reworked sediment in SI1i-SI1. Throughout the extramural sequence such a fraction is exclusively found in these units of Stratum R, in quadrangles D6-D7 and E1-E3.

Finds. Finds from Stratum $\mathrm{T}$ include the contents of cuts 49D and 99A, exclusive to unit SIa. From both excavation and water screening about a hundred numerable finds were obtained. The characteristics of the SIa material suggest cultural debris from a nearby hearth or 'kitchen' area, and a microenvironment with a little calcium carbonate deposition. Domestic waste is abundant. It includes pottery sherds, a chip of white quartzite, copious animal bones, wood and other plant material. Among pottery, a unique potsherd that might be non-Sabaean (Beige Plain, no. 49D.03) and a 7-cmlong fragment in mint condition (no. 49D.02) can be mentioned. Animal bones are typically yellow in colour and totally unworn, all attributable to kitchen or eating residue (some charred or burnt); a neonatal caprine skull, incomplete, can be noted. Vegetal ecofacts include dried and charred seeds of 'ilb (Christ's thorn jujube, Ziziphus spina-christi).

In addition, ash and charcoal, ${ }^{120}$ micro-concretions, many fragments of mud bricks (which are typically grey in the Sabaean period), ${ }^{121}$ two fragments of mud-plaster, and traces of white plaster or gypsum were recovered. A very high frequency of pebbles attributable to melted mudbrick, most of them 'large' (i.e., $4 \mathrm{~cm}$ in average diameter), was recorded.

Also part of the finds from cuts 99 and 112 in quadrangles $E 1$ and E3, respectively, can be attributed to Stratum T. These include a wide repertoire of Sabaean pottery (cf. Chapter 23, Fig. 4, from cut 99). Individual pieces of note are a Red Lustrous large ‘basin' (no. 112.01, Stratum T) and a Black Lustrous globular bowl (no. 112.02, Stratum $\mathrm{T}$ or S).

For a Cerithium fossil from cut 49D which might be related to Wall F4 see section 6.3, 'Accessories and

\footnotetext{
119 I thank Ueli Brunner for comments and clarification on this point (personal communication, Rome, June 2008). For useful information on palaeosols and soils in arid Yemen, albeit on the Plateau, cf. French 2003.

120 Including good cm-sized charcoal for dating: Chapter 18, section 1 , this volume.

121 See sections 6.3 ('Wall F4: foundations and structure') and 10.3 ('Earthwork F10-F12'), below; and Chapter 21, section 2.1 ('Mud bricks'), this volume.
} 
special finds', below. A few dressing flakes and chips attributable to the stones of Wall $\mathrm{F} 4$, including two 5 -cm-long flakes from water screening, probably came from the top of unit SIa and/or surface S18.

\subsection{Stratum $S$}

The lithocomplex represented by SIa-SI3 is followed by units PV3 and V3 in upper Sector E, and units SIS and SGLi in quadrangle D7, the separation having been caused by the subsequent construction of Wall F4. These units were classified under Stratum S. For reasons given below, an overlying deposit in $D 7$ represented by lower unit SGL $\left(\mathrm{SGL}_{2}\right)$ could also be included in this Stratum. Stratigraphic relationships further suggest that SE3 $\omega$ in quadrangles E3-E4, and perhaps 5S1, the deepest unit reached in quadrangle E5 (southern side), may be time-equivalents of $\mathrm{SGL}_{2}$. If so, these three units would constitute a later horizon within Stratum S. In the Reference section, Stratum S is thus lithostratigraphically defined by units SIS, SGLi, and $\mathrm{SGL}_{2}$ in quadrangle D7; PV3 and SE3 $\omega$ in quadrangle $E 3$;and V3 in quadrangles E2-E3.

A correlation was inferred for the lowermost units of E3-E5 on the basis of a reconstruction of the palaeotell profile corresponding to a tell summit comprised of PV3-V3-SE3 $\omega$, constraints being provided by the morphology of the present-day talus and the geometry of the excavation itself. ${ }^{122}$ Stratum $S$ is characterized by fine-textured, horizontal sediments depicting a scene of domestic refuse from habitation on the spot or close by, including plant remains and decayed mudbrick. PV3 contained carinated potsherds, bone, pebbles, and vegetal detritus. Occasionally it had a lighter band at the top, PV3 $\alpha$ : a light-grey halo with a nuanced lower limit, silty-clayey in nature, suggesting weak weathering (see section 4.1, above). PV3 $\alpha$ is not shown in the Reference section as it was mostly observed in the southeast quadrant of E3. Pockets and levels with higher plant content and a darker colour identify unit V3; unit $5 \mathrm{~S} 1$ in $E 5$ might be similar. SE3 $\omega$ is apparently horizontal (cf. SE3, Stratum R).

In lower Sector D, unit SIS is an extremely dusty grey to light-tobacco silt ${ }^{123}$ with fine-sand and clayey-organic fractions, 30 to $40 \mathrm{~cm}$ thick. Flotation confirmed for SIS a silty-clayey texture with a small fraction of sand, also containing hard, $\mathrm{CaCO}_{3}$-cemented coarsesand aggregates, 1-6 $\mathrm{cm}$ in size and grey to brown in colour. SIS was very rich in organic residue and

\footnotetext{
122 This was the basis for stating, in section 4.1 above, that around 700 BCE the edge of the Earlier Sabaean tell was located between quadrangles E3 and E4, that is, no less than $32 \mathrm{~m}$ from the face of the future Minaean wall.

123 Hence 'face powder' (cipria in Italian) as its nickname during fieldwork.
}

artefacts (see below). Horizontal sedimentation was not accompanied by intercalation of lenses, however, a trait that distinguishes SIS from the following unit, SGLi. SGLi is a dark-grey silty sand 15 to $20 \mathrm{~cm}$ thick, topped by a brownish, extensive plant-detritus lens which constitutes a horizontal marker ( $7 \lambda 8)$.

In the overlying unit, SGL, two consecutive, transitional subunits were recognized, in spite of being made of essentially similar sediments. SGL is a 40-cm-thick layer of grey silty sand, varying to sandy silt. The lower part $\left(\mathrm{SGL}_{2}\right)$ is siltier and contains lenticular bodies: two flat pockets of ash or leached hearths, which again suggest horizontal deposition, were captured by the Reference section $\left(\lambda_{7}\right.$ and $\left.\lambda_{6}\right)$. The upper part (SGL $)$ is poorly structured and slightly chaotic; its significance will be discussed in connection with Wall F4 under Stratum R. A persistent affinity of sediments from SGLi up to SGPO and surface $\mathrm{S} 3$ is reflected in diffuse layer boundaries. These relationships have been subsumed under the definition of suite SD67 and group SD (Tables 1-2).

Finds. Exclusive to Stratum S are the contents of cut 49B in quadrangle $D 7$, a large quantity of cultural material (about 200 finds) attributable in large majority to habitation and domestic activity more or less on the spot. This is exemplified by 79 per cent of pottery sherds in a relatively sharp condition. The wear spectrum for cut $49 \mathrm{~B}$, evaluated on washed pottery ( 38 sherds), is 39.5 per cent grade 0 (perfectly angular condition), 39.5 per cent grade 1, 10.5 per cent grade 2, and 10.5 per cent grade 3.

The pottery assemblage (about 70 fragments) comprises unusually numerous ring bases of cooking pots in coarse Beige Plain ware, several Red Lustrous vessels (e.g. bowls and footed bowls), and at least one true Black Lustrous vessel (no. 49B.1.1, from flotation). Further finds include organic artefacts (fragments of baskets and ropes), clay disc/'tripod' fragments (nos 49B.01-02), abundant mudbrick debris (often decimetre-sized), animal bones (127 finds, all unworn, some burnt), a quantity of wood and other plant material (abundant date stones ${ }^{124}$ and jujube nutshells, partly representing food residue), and charcoal. Flotation of a sample from SIS (no. 49B.1) particularly revealed seeds, minute wood branches, and a very large quantitity of pebbles originating from melted mudbrick (poligenetic/polymict, $2.5-3 \mathrm{~cm}$ in average diameter, some fragmented). A small cobble of white limestone, clearly a manuport, lay at the SIS/SGLi interface (marked on the Reference section).

Part of the finds from cuts 49 and 112 in quadrangles $D 7$ and E3, respectively, can be attributed to Stratum S, as well as a small part of cut 102 (quadrangle E2). From cut

\footnotetext{
124 See Chapter 19, section 4.2, this volume.
} 
112 the same repertoire of 'classical' Sabaean pottery as that described for Stratum $\mathrm{T}$ was retrieved. The wear spectrum of potsherds in cut 112 is interesting: 76 per cent in mint condition (wear grade 0), while the rest is 18 per cent grade 1 and 6 per cent grade 2. For cut 102 see under Stratum R, below.

\section{Strata R to O: Earlier Sabaean 2 (including Wall F4)}

\subsection{Overview}

A stone-built wall, feature F4, was uncovered in quadrangle E1 adjacent to the grid boundary with Sector D (Figs 16, 44, 53-55). ${ }^{125}$ It was only a portion of a clearly longer wall that continued on both sides of the trench. As the excavation progressively revealed, F4 was the base (F4) of a more complex structure originally comprising a mud-brick upper component of the wall itself (F4 ${ }_{1}$ ) and a series of associated earth features, these latter apparently to be interpreted as accessories for the wall. The inferred original wall in its entirety will be called Wall F4. It will be examined in section 6.3 below and shown to be a piece of nonresidential architecture, as suggested by a number of unusual characteristics of both the structure and its context. The construction of this wall is the basis for defining Stratum R, while its functioning and subsequent decay form the material correlates for Strata $\mathrm{Q}-\mathrm{O}$.

Wall F4 is in all probability the Sabaean town wall of Yathill, an enclosure previously only known from the important monumental inscription of Sabaean mukarrib Karib’̄il Watār at Șirwāh (RES 3946). The historical context of this attribution will be discussed in Chapter 18, section 3.1, this volume. If this was the case, the transformation into a walled settlement must have brought about changes in the condition of Sabaean Yathill, at least for a limited period. Regardless of this interpretation, however, Wall F4 had important effects on the physical conditions of Area $C$, and this is reflected in the sedimentary evidence. The presence of Wall F4 and its material consequences form the basis for defining a new Sabaean interval, phase Sabaean 2 (Strata Q-O). The functioning and subsequent decay of F4 have been studied in detail. By combining the disparate pieces of evidence, the functional history of the wall was reconstructed in relation to sediments from planning to abandonment, within the resolution afforded by the sediments themselves (Table 5).

With reference to the Wall F4 phases in the table, the periodization of Sabaean 2 is the following:

- Stratum R: wall construction and related works (phases 1-3);

125 Discovered on 15 December 2005. Its excavation was started on 17 December.
- Stratum Q: wall extant, settlement locally rearranged (phase 4);

- Stratum P: wall decaying and largely decayed (phases 5-6), input of aeolian sands;

- Stratum O: mud-brick curtain obliterated (phase 7), sands accumulated; mud-brick structure F13.

\subsection{Stratum $R$ and Wall F4}

Stratum $\mathrm{R}$ is lithostratigraphically defined by surface S18 (the cutting for Wall F4) and Wall F4 itself; upper unit SGL (SGL $)$, Earthwork F44 (SGP, with $\lambda 44$ ), and perhaps unit TM4 in quadrangle D7; and units SI1i, SI1, $\tau 2, \tau 1$, SE3, XS, X6, and 5S1 in Sector E. ${ }^{126}$ Both the artificial features and the sediment units in this list are best described in the next section once the constructional details of Wall F4 have been given (section 6.3, 'Lithostratigraphy of Stratum $\mathrm{R}$ and additional finds'). In fact, all these sediment and earth bodies depend on the wall, either as its accessories or as sedimentary consequences of its existence.

A concomitant reason for describing Stratum $\mathrm{R}$ in function of Wall F4 is the interpretation of this feature as part of the Sabaean town wall. This identification was obtained in steps, ${ }^{127}$ and it best accounts - by far - for the lithostratigraphic and cultural data characterizing a certain horizontal and vertical segment of the deposits of Area C. Paramount to this reading of the evidence is the fact that, archaeologically, F4 is extraordinary in the site and is accompanied in quadrangles D6-E2 by several equally exceptional findings. Three stand out: the form of accumulation SGP, Sand YS, and the symmetrical deposition of sediments. An interrelationship linking these three features is the best explanation. The stratigraphic analysis has revealed how unusual, indeed artificial, the adjoining and encasing sediments were, and how the wall affected sedimentation by producing a 'watershed' effect as a function of its original height. Stone masonry itself must be regarded as special at Yathill, building-quality rocks being a costly commodity requiring transport from some distance: $\mathrm{F} 4_{0}$

\footnotetext{
126 Unit 5S1 can be included in Stratum R entirely or with its upper part only (Fig. 24).

127 Fedele 2010, 113, footnote 62. The wall was encountered during the first digging round in quadrangle $E 1$ and it raised surprise, not least for its singular but chance alignment with the boundary between Sectors D and E (the iron stake for point P5 had been driven within centimetres of the wall's eastern face). But although fleetingly considered, the possibility that F4 might be the curtain wall of Yathill was discounted in view of its presumably insufficient thickness. Subsequently, however, the analysis of the abundant field data led to the wall's anomaly in the overall profile to be reconsidered (cf. Fig. 13). It was A. de Maigret who encouraged me to overcome my hesitation and identify F4 as the Sabaean town wall. In the autumn of 2008, during the preparation of the report for Arabia 4 (Fedele 2010), my own stratigraphic analysis and his cogent opinion converged, and he also provided comparative insights from Yalā (cf. de Maigret 1988b). His support for this idea was finally stated in a wide-ranging conversation we had in Naples on 10 December 2008.
} 
would already be exceptional on this account alone (see next section for its classification as a public rather than private structure). However, the above cannot be taken to imply that F4 was part of a wall effectively enclosing the whole mound. ${ }^{128}$

The position of Stratum $\mathrm{R}$ becomes clearer in the temporal perspective of the Earlier Sabaean phase as a whole. The establishment of a walled enclosure, were it encircling or only partial, locally affected tell evolution. For a while after the wall's construction the downslope deposition along the talus was virtually arrested. Then new deposits began to form both on the talus and between the wall and the edge of the tell, this latter location now constituting an ideal receptacle for colluvial and windblown sands. In spite of erosion and deflation, aeolian sands continued to accumulate ever more freely as the wall decayed (upper Sand YS, or suite YSU; see section 6.6 below), until the ruins of the wall were eventually buried by sands and slope wash. An account of this sequence has been presented in section 4.1.

\subsection{Wall F4}

\section{Foundations and structure}

Wall F4 was built along the margin of the low tell. Not at its foot, in fact, but 3-4 metres higher up, on its sloping edge at the time, while marginally higher was the elevation above the actual plain surrounding the mound. In the excavated area the mound was only about 6 metres high when the wall was erected. ${ }^{129}$ First, a step was cut into the preexisting deposits of Strata $\mathrm{T}-\mathrm{S}$, with a riser of about $60 \mathrm{~cm}$ in quadrangle $D 7$. This cutting is surface S18. An adjacent zone downslope was probably scooped and levelled to make for additional space (quadrangles E1-E2). The stone masonry base of the wall, $\mathrm{F} 4$, was set against the vertical face of the cutting, approximately coinciding with the E1/D7 boundary of the excavation grid. F4 was made of welllayered, level courses of flat stone blocks occasionally bound with interstitial mudmortar or plaster. Within the limits of our trench, spots of plaster could only be seen between the first and second courses (numbering from the top); otherwise $\mathrm{F} 4_{0}$ appeared to be exclusively dry-stone.

The surviving eight courses of masonry seem to be the complete stone base of the wall, at least in quadrangle E1 (Figs 53-56). On the basis of complanarity and finish of masonry an interior and an exterior side can

128 Cf. Chapter 18, end of section 3.1, this volume. A complete circuit is not impossible, and a tantalizing indication might be provided by Area 37 (see Chapter 26, section 3.2, this volume), but the present field evidence is simply insufficient: it is disproportionate to such a claim. 129 Cf. Chapter 18, section 3.1, this volume. be distinguished (the eastern and the western side, respectively), as well as a more irregular profile in the lower half (courses 5-8). All courses are markedly horizontal. The wall was completed with an upper part made of mud bricks or mud blocks (superstructure F4), some of them perhaps slightly and quickly fired. ${ }^{130}$ Abundant sediments from the dissected earlier deposits found their way back into earth features accompanying the wall, both on the inside and the outside of the structure, as will be described below.

The wall was excavated over a linear length of 1.8 $\mathrm{m} .{ }^{131}$ Base $\mathrm{F} 4{ }_{0}$ is $70-75 \mathrm{~cm}$ thick and $105-112 \mathrm{~cm}$ high, which arguably would correspond to two 'feet' and three 'feet', respectively. ${ }^{132}$ The blocks were hewn from a light to whitish grey, cryptocrystalline limestone occasionally veined by thin, yellow, soft calcarenite bands. These interlayers enhance the excellent fissile properties of this rock, which also shows conchoidal fracture (Fig. 56). ${ }^{133}$ The geological provenance of this rock is still undetermined. ${ }^{134}$ Here and there, small flakes and fragments from the dressing of the wall's blocks were reused to fill the fissures of the masonry. Architecturally, base F4 would be classified as Buffa's Type 1, preferentially employed for defensive works and religious buildings: ${ }^{135}$ hence an example of public, nonresidential architecture. For comparison, Yalā's wall is thicker but very similar. ${ }^{136}$

\footnotetext{
130 Judging from unit J1 (see below) and some redeposited decay remnants. On mud bricks and other mud products cf. Overstreet et al. 1988b, 366; on their use in Sabaean walls cf. Glanzman and Ghaleb 1987b. About the walling of Sabaean towns, Breton (2002, 146, citing Bessac 1998) observes that 'the normal method was to have a single horizontal row of stretchers connected by headers to a mudbrick wall'.

131 In 2005 - let alone in 2006 - unfortunately there was no time to explore the continuation of Wall $\mathrm{F} 4$ beyond the narrow confines of our trench. An attempt begun in a quadrangle labelled EN1, 4-5 m north-northeast of quadrangles E1-E01 (Fig. 7; cf. section 1.2 above), lasted less than a day: see sections 6.5 and 16.4 ('Stratum A') below. A few days' work would perhaps have provided sufficient information to record a rough plan of the wall over an adequate length on both sides of our trench, provided that the wall was extant. The further exploration of F4 was foremost in our agenda for 2007.

132 For another suggestion of Sabaean-Minaean metrology see below, section 10.2 ('The Minaean curtain wall'). The foot was perhaps the most universal linear measure of antiquity, as well as the most constant cross-culturally. I wish to acknowledge restorer Alessandro Danesi (Dart, Rome) for pointing me in this direction.

133 It may be interesting to note here that Wall F4 is radically different from the future curtain wall of the Minaean period in two main respects: the choice of rock type and the style of stone working. As to the technological concept reflected in the masonry, the choice of producing flat, slab-like blocks from the chosen limestone was dictated to a large extent by the fissile quality of the raw material, as mentioned, in turn deriving from its inherent laminarity. In addition, the blocks were rough-hewn and finally shaped by hammer percussion: on the interior face of the wall they exhibit conspicuous, even stylish conchoidal scars.

134 Many observations made by Overstreet et al. (1988b, 364-365) on unworked building stone in Sabaean Yemen are pertinent here.

135 Buffa 1996, fig. 1.

136 Buffa 1996, 171; de Maigret 1988b, and personal information (cf. section 6.2 above, footnote 127). On the other hand, the coeval town
} 
Unit J1, a mudbrick mass integral to the stone masonry was preserved on the top of F4 (Fig. 53) and was interpreted as a remnant of the mudbricksuperstructure $(\mathrm{F} 4)_{1}$. However, the wall was not necessarily made in this way over its entire length. The total original height of Wall F4 is unknown, but 3 metres or a little more seems to be a reasonable hypothesis (cf. Fig. 27). ${ }^{137}$ In 2005-2006 it was repeatedly observed that the Sabaean mudbrick can often be distinguished from the Minaean, as the former has a sandier fabric and tends to have a grey or light yellowish-grey colour, whereas the latter is lacking grey hues in favour of a range of dark yellow to brown, and is often siltier. ${ }^{138}$

\section{Accessories and special finds}

Wall F4 was furnished with a large earthwork on its interior and earthen accessories outside. Furthermore, it might have been enhanced with glazed stone elements, judging from a unique find in situ from lower Stratum $P$, a fragment of glazed basalt with mudplaster remnants suggesting insertion in masonry. And what looks like the deposition of a fossil shell might be associated with its construction.

Due to the step-profiled foundations, the earthing up of the wall was only made on the outer face of the masonry. A remblai talus about $2 \mathrm{~m}$ wide in section a sloping bank perhaps intended for stabilizing effects - was piled up against its western face (SI1i-SI1 with top surface S4A). Adjacent to it, between 2 and $5 \mathrm{~m}$ from the wall's face, a large and problematic unit that postdates SI1 was accumulated, unit SE3 (quadrangles E2-E3) (Fig 39). It is a thick, silty sand body with a 'dirty'grey colour, yellowish-brownish shaded at times, rather massive in parts of $E 2$ and markedly horizontal - i.e., with horizontal bedding planes - in E3. ${ }^{139}$ SE3 is rich in Red Lustrous pottery, bone, ash, charcoal, and the occasional hard sandy aggregate. Such contents recall the deposits preceding the wall (cf. SIa), suggesting that SE3 might derive from earth transport and accumulation, synchronous with or closely following wall construction: in this case, in principle, it might be an extramural equivalent of SGP (Earthwork F44, see below). SE3 locally represents the close of Stratum R.

wall of Hajar at-Tamra was thinner than Wall F4: the two portions found in the excavations measured about 58 and $55 \mathrm{~cm}$, respectively. Here is a short description (Blakely 1985, 78): 'Both walls were constructed of both rounded wadi stones and large flat schist slabs consolidated with mudmortar. The stones had not been carefully shaped to fit the wall, but they may have had ends broken off to obtain a relatively flat exterior and interior surface. The centers of the walls were filled with smaller chinking stones and mud in order to create a solid wall.'

137 See below, section 6.7, for the hypothesis that mudbrick mass F13 (quadrangles D5-D6) might be a fragment of the wall.

138 Cf. section 5.2 above, footnote 121 .

139 Horizontal like previous unit SE3 $\omega$, apparently; see section 5.3 above.
A 'brown line' at its top in $E 3$ east is part of weathering zone $\mathrm{Z} 1$ and suggests some geomorphic stability (see section 4.1 above).

On the wall's interior, a layer of more or less horizontal grey silty sands $\left(\mathrm{SGL}_{1}\right)$ may represent aninitiallevelling of the preexisting sediments soon after wall construction. Immediately above, with a diffuse boundary (SGL/SGP) and occupying quadrangles $D 6-D 7$, a vast sediment body of extraordinary shape and structure was formed: accumulation SGP (Figs 57, 66 B). From its morphology and sedimentary structure SGP can best be interpreted as a man-made feature, Earthwork F44: a shallow earthen bank, aimed at steadying and perhaps reinforcing the interior base of the wall. ${ }^{140}$ This earthwork is about 3.6 $m$ wide in section and up to half a metre thick (thicker towards the north); its subvertical eastern side (F44) has a southeast-northwest orientation. Thin voids remained between SGP sediments and the interior face of the stone wall.

F44 might only be an occasional, local device and not necessarily accompany the whole length of Wall F4. As intercepted in excavation, F44 resulted from two consecutive mass accumulations ( $\mathrm{SGP}_{3}-\mathrm{SGP}_{2}$ ), light and porous, an artificial and partly chaotic (unstratified) product of quick remblai en masse. The porosity favoured calcium carbonate infiltration, which left 'tuberculous' crusts on both SGP stones and the blocks of the wall. The earthwork was eventually levelled with an additional fill, SGP. As a sediment, SGP is a stony-silty sand with a small clayey-organic fraction, hazel to 'dirty'-grey in colour, interspersed with ashy pockets particularly in its upper part and containing a lens of silt on the top of $\mathrm{SGP}_{3}\left(\mathrm{SGP}_{3}{ }^{\prime}\right)$. The stones were small to tiny fragments, granules, and abundant pebbles from melted mudbrick. It also contained clusters of plant detritus, bits of charcoal, burnt bone debris, and artefactual waste in minute fragments, all to be understood as reworked earlier deposits from Strata T-S. Fragments of mud bricks and abundant hammering flakes from the dressing of blocks for wall $\mathrm{F}_{0}$ littered the contact with SGL and were present at the bottom of $\mathrm{SGP}_{2-3}$, all over quadrangles D7-D17 (cf. Figs 55 and 66 B). Lumps of plaster, mudmortar, and a wādī cobble were embedded in SGP. ${ }^{141}$ This evidence points to episodes in the making of Wall F4 and to construction residue soon reworked into SGP-F 44 .

In quadrangle $D 6$ one should note the identification of Locus 44 , this being a label for the co-occurrence of a

\footnotetext{
140 Concerning nomenclature, a combined SGP-F44 can be used here: 'SGP as a label for sediments, F44 as an archaeological feature' (Fedele 2010, tab. 1, note 1 ).

141 A decimetre-sized flat stone with a 1-2 mm thick calcium carbonate crust on its top, P6, was lying nearly horizontal at the bottom of SGP (Fig. 38; and shown on the Reference section, qu. D6).
} 
peculiar cluster of archaeological objects and a peculiar morphology (F44). It included $\lambda 44$, a horizontal, grey silty lens on the top of mass SGP, containing a distinct concentration of ash, charcoal, pottery, and animal bone - a weathered hearth, in all probability (Fig. 58). We can reconstruct that a fire was lit upon the edge of Earthwork F44 during or after its completion. Lens $\lambda 44$ might simply be a chance episode, but might equally be suspected of symbolic significance in connection with Wall F4. Locus 44 can be extended to include the whole bottom part of quadrangle D6 and encompass all the peculiarities that are concentrated there, including $\lambda 44$ (the eponymous unit) and suite YSL (see below). The sequence of SGP and $\lambda 44$ was topped by a surface, $\mathrm{S} 3$, recognizable in $D 6$ but becoming vague to the west, as soon as it disappeared under SGP0 (see below). Units SGP, SGP0, and $\lambda 44$, can be grouped as suite SD67 (Table 1).

The relationships of Earthwork F44 with the accumulation of Sand YS were complex (on Sand YS see section 6.6 below). F44 was made of pressed earth only, and its cortical sediments underwent some weathering and mixing (unit SGP0). SGPO shows at its top a little dark staining from a short stasis, probably synchronous with the functioning of the wall. Newer material from sedimentation alongside the wall, then increasing amounts from the incipient deterioration of the wall itself, soon began to be deposited (YSX, a blanket; SGY, a tongue). ${ }^{142}$ Through these two units, SGP-F44 and the lower suite of Sand YS (YSL) are effectively interconnected, sharing part of their sediment matrix and forming a close succession with no evidence of any serious interruption or hiatus. ${ }^{143}$ Furthermore, with its eastern truncation F44, Earthwork F44 heavily conditioned the morphology of sedimentation afterwards. Unit YSZ, filling the depression alongside F44 and belonging to Stratum Q, is hyperlaminated and its laminae depend on F44's profile. Also YSX and partition YSi of unit YSi (this latter dating to Stratum P) reflect the presence and profile of F44.

In addition to the accompanying works above described, some special finds suggest that particular attention may have been lavished on Wall F4. ${ }^{144}$ A Cerithium fossil shell was found in unit SIa in western quadrangle D7 at or below the level of the base of the wall (find no. 49D.01). Immediately after retrieval by workers I had the impression of a provenance from the foundation cutting for the wall, surface S18, just being discovered. The idea of a symbolic deposition by the Sabaean builders,

\footnotetext{
142 In terms of correlation, YSX is in fact Stratum Q, and SGY is Stratum P (Table 5).

143 Cf. section 6.6, 'Sand YS: interpretation', below.

144 The paragraphs on these finds update Fedele 2010, 115-116. All the objects are described in detail in Chapter 21, section 2.1, this volume.
}

although impossible to prove, was unavoidable. The fossil had probably been collected from the outcrops between Barāqish and Darb al-Șabī (see Chapter 21). For the record, an identical fossil Cerithium was found in Minaean Earthwork F10-F12 in 2006 (Sounding A): ${ }^{145}$ this find raises the possibility of a Minaean repetition of the same building-related symbolism, unless it is a reworked element from the Sabaean levels. In this latter case it would provide further intimation of the Sabaeans' taste for environmental curiosities.

Surprisingly for the Sabaean period, a unique glazed stone was found in situ near the bottom of unit YSi, facies $\mathrm{YSi}_{\mathrm{g}}$, in quadrangle D6 west (no. 43A.1, initial Stratum $\mathrm{P}$, cf. section 6.5 below; for retrieval location see Fig. 66 B). It is a small, cubical basalt block with a side of $6 \mathrm{~cm}$, one of its faces covered with a greygreenish vitreous glazing. Its historical significance is assessed in Chapter 18, section 3.1, this volume, where the presumable belonging of 43A.1 in a whole bundle of Assyrian connections is particularly discussed. Importantly, remnants of mudplaster on the nonglazed surface of the block strongly suggest that it was inserted in masonry. One more find which might reveal relationships with the construction of Wall F4 is a centimetre-sized, thin bronze object found alongside the wall's inner face (no. 48A.2a, quadrangle D7 west), either within the fill of Earthwork F44 (SGP $)$ or within an interstitial microunit, TM4 (see below).

\section{Lithostratigraphy of Stratum $R$ and additional finds}

As to the other components of Stratum R, besides Wall F4 and the presumably wall-related findings, two elements from lower Sector D need be noted. One is the unit just mentioned, TM4, a microunit of pale brown earth filling the fissure between SGP and the face of the wall alogside courses 2-3. Its precise chronology is indeterminable, but a correlation with Stratum $R$ seems likely. A second element, bearing superficial resemblance to TM4, is a probably postdepositional modification of sediments in lower SGP and SGL caused by brownish, organic, pluvial-microalluvial inputs from Gully B.

Downslope from the face of Wall F4, marginally overlying artificial talus SI1i-SI1 (see above), we have the important sediment unit already described, SE3. In quadrangle $E 2$, camel coprolites possibly deriving from the SE3 fraction of cut 102 could signify the occasional presence of dromedaries along Wall $\mathrm{F} 4$, an interesting scenario for the Earlier Sabaean (see mention in section 4.1, with details in section 6.8 below).

\footnotetext{
145 No. 192.01, Stratum J; see section 10.3, below, and Chapter 21, section 2.3 , this volume.
} 

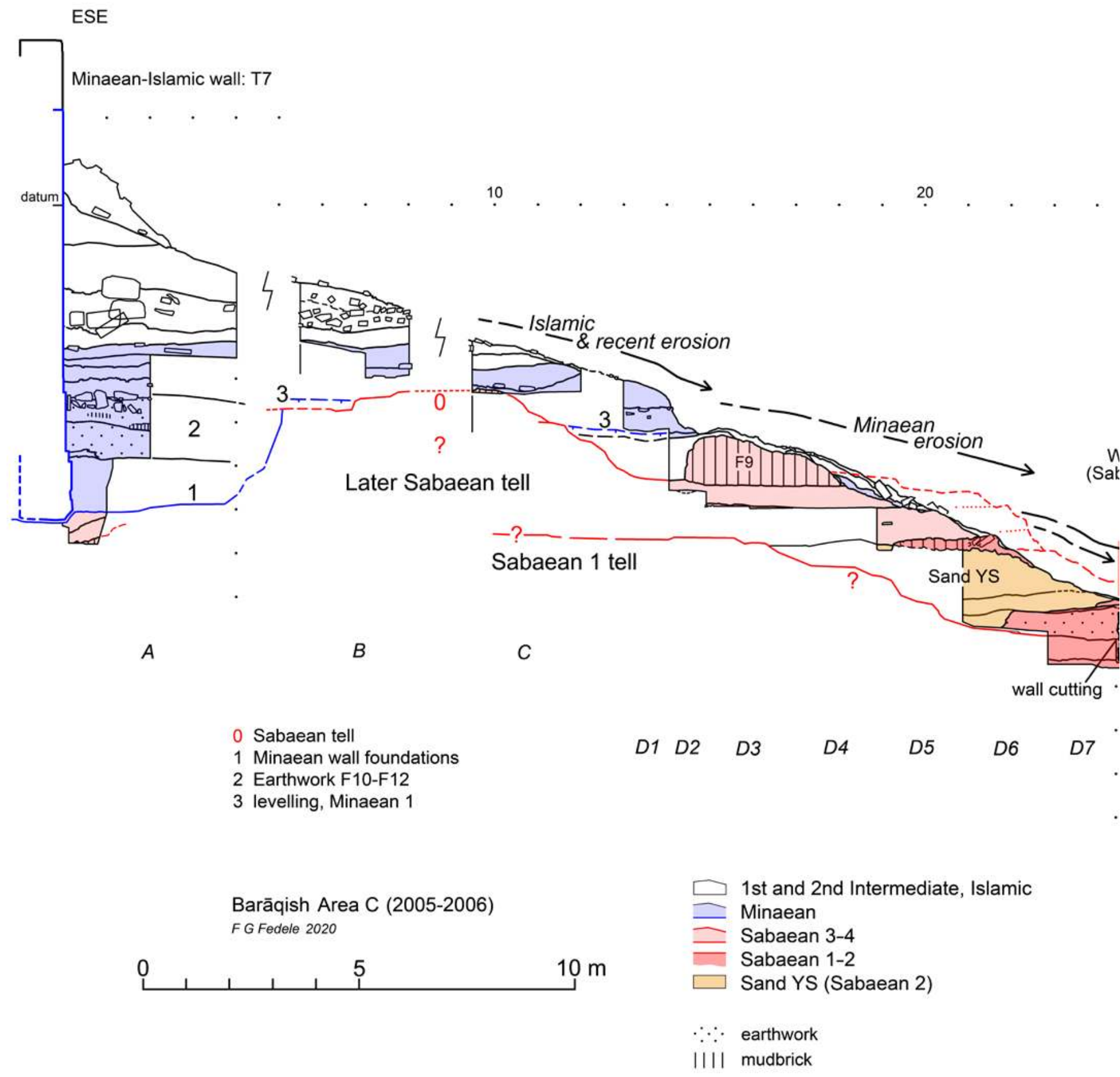

Figure 27. Area C: a partly conjectural reconstruction of the structure and evolution of the Yathill/Barāqish tell, showing the interpolated Sabaean tell profile, the works associated with the construction of the Minaean wall, and phases of tell and talus erosion. Note that the horizontal relationships of Sectors B and C with Sounding A are purely indicative and that a continuous profile of the Sabaean tell cannot be drawn (cf. Fig. 26).

(F.G. Fedele 2009-2015, updated 2020) 
Wall F4
abaean 2)

$+$

$>$ Sabaean 2-4

>

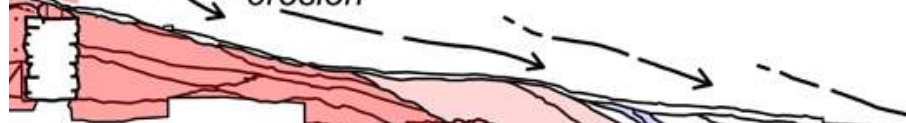

Sabaean 1 tell

tell edge?

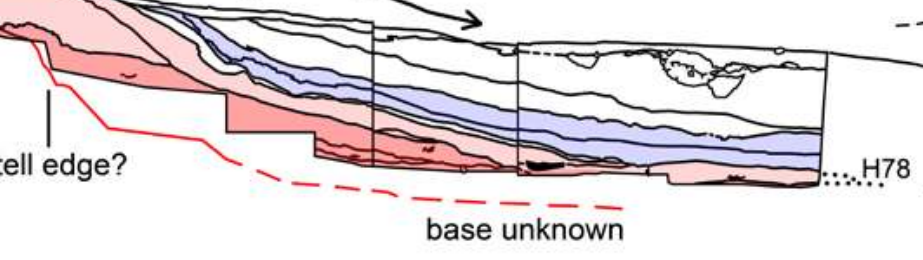

Hill E

- -10

E1

E2

E3

E4

E5

E6

E7

E8

E9

E10

E11 
Further away from the wall, we have in middle Sector E units XS and X6. Just glimpsed at the bottom of the excavation trench in quadrangles E5-E6, XS and $\mathrm{X} 6$ are two sandy units very similar to each other and therefore of conventional separation only: their boundary is vague to indefinite. XS can make sense as a weakly laminated sand in $E 5$ and $E 6$ east, whereas X6 is the coeval sand of quadrangles $E 6$ west and $E 7$ east. An observation of broader interest - relevant in fact for Strata R, Q, O, and M throughout middle Sector E - is the virtually ubiquitous presence of mud-brick debris and chunks, sometimes more than $10-15 \mathrm{~cm}$ in size. This location clearly corresponded for a while to the edge of tell occupation and to its upper talus. An example of large mud-brick fragment appears within sand X6 on the Reference section, but similar chunks were recorded from 6R (Stratum $Q$ ), 6U (Stratum O), and cultural horizon $\mathrm{H} 78$ in quadrangle E7 (Stratum M).

Finds. Concerning objects from Stratum $\mathrm{R}$, an interesting finding is a delicate, thin-walled Black Lustrous bowl whose fragments were displaced by Wall F4's construction. The remains of the vessel were originally within sediments of Stratum $\mathrm{S}$, such as $\mathrm{SGL}_{2}$ (as possibly indicated by potsherd no. 49.01, from either $\mathrm{SGL}_{2}$ or $\mathrm{SGL}_{1}$ ), but due to reworking one sherd ended up over-wall into unit SI1i in quadrangle E1 (no. 99.03). A number of other finds preserved within artificial talus SI1i-SI1 (cut 98) are likely to have belonged originally to Stratum S as well, or even to Stratum T: for example, two fine bowls, one Pale Green (no. 98.02) and the other one Red Lustrous (no. 98.03), and a clay disc (no. 98.01).

From the fill of Earthwork F44 (sediments SGP) a broken quartzite cobble (no. 48A.01), a grinding or rubbing stone (no. 49C.1), and basketry fragments (e.g. no. 48.01) were recovered, while SGP 3 and/or hearth $\lambda 44$ produced some spalls and a possible limestone hammer (spheroid no. 44.1c) from the dressing of the building blocks of wall $\mathrm{F} 4$, together with obsidian flakes (cut 44).

Many finds deriving from Stratum $\mathrm{R}$ were retrieved with cut 102 in quadrangle E2 (as already mentioned in section 5.3, above), including 'classical' Sabaean pottery (e.g. nos 102.06-08) and - probably - a calcite or alabaster flake (no. 102.02), a softstone vessel (no. 102.01), and remains of clay discs (nos 102.03-05). From Stratum R and possibly from the contact of SI1 and SE3 comes a remarkable bowl with 'dragged' wavy line decoration in Pale Green ware, reconstructed from fragments (V97, conjoint 97+101). Down-talus to the west, Stratum R produced a Red Lustrous shallow bowl, probably from SE3 (no. 104.01).

\subsection{Stratum $Q$}

Stratum $Q$ is lithostratigraphically defined by the initial suite of Sand YS (YSL), with which unit YSX is probably to be associated; by unit SGPO on top of Earthwork F44; and, to the west of Wall F4, by units LEd, LEc, 5SA (together with 'red lens' $\lambda \rho$ at the bottom of excavation in quadrangle $E 5$ south), and suite $6 \mathrm{QR}$. In quadrangle $E 5$ south the sequence is topped by surface S17. Stratum $Q$ is chiefly characterized by its correlation with a phase in which Wall F4 was still functional.

With the construction of Wall F4 no occupation apparently continued in the immediate vicinity of the wall itself. Human activity, it appears, ceased in this part of Yathill. Only very occasionally some 'domestic' activity may have occurred nearby. Correlated with the wall's existence is the incipient formation of thin sand deposits on the interior of the walled area (such as YSX), but much more conspicuous are the dark, rhythmic laminae of washed-in organic fines and cultural debris that filled the depressed belt alongside Earthwork F44. These laminae, alternating with equally centimetre-thin sand lenses, constitute units YSZi and YSZ in quadrangle D6 (suite YSL). With its visual quality as a laminated suite, unparalleled in Area C, YSL contributed to the definition of Locus 44 (see section 6.3 above).

This suspension of occupation can best be attributed to a change in settlement organization: habitation was deflected towards other parts of the town, away from either the wall or the entire northwestern part of the tell. Dwellings encroaching upon the wall would perhaps have made this wall insignificant. This area might have been already marginal before the wall was constructed, as sediment units SIa, SI3, and SIS suggest less than intensive occupation. A concurrent hypothesis can be advanced: that something had changed or was changing in the geomorphology of the area. This hypothesis, and the further evolution of Sand YS in relation to the wall, will be examined in the following section on YS and Strata $Q$ to $O$ (section 6.6).

The construction of Wall F4 turned out to be a major destabilizing factor in the local depositional history. Its decay and partial obliteration continued this effect. A 'watershed' model for the sedimentation on the opposite sides of the wall accounts well for the observable evidence, as mentioned above and encapsulated in Table 5. This artificial watershed not only acted while the wall was extant, but continued afterwards: the creation of this otherwise modest wall left an imprint on the sedimentary landscape for a long time.

In Sector E, sandy units 6Q, 6R, and 5SA may correlate with Stratum Q. 6Q and 6R, together, indeed look like a lateral facies of bipartite sand 5SA (5SA ${ }_{1-2}$, which only appears on the south section of quadrangle E5. A small 'red' lens, $\lambda \rho$ (mentioned above), apparently inserts itself stratigraphically between $5 \mathrm{SA}_{2}$ and $5 \mathrm{SA}_{1}$, but is 
otherwise an autonomous unit with respect to 5SA and its appearance in photographs suggests rubefaction from weathering or a hearth. ${ }^{146} 5 \mathrm{SA}$ is topped by a sharp surface, S17, which, in turn, is probably equivalent to surface S4 in quadrangles E3-E4 (cf. discussion of suite $\mathrm{CM}$ in the next section). Sand 6R contained sizable fragments of mud bricks (cf. section 6.3, above) and some large Sabaean potsherds in fairly good condition, suggesting close proximity to the tell.

Finds. Ceramic finds from Stratum $Q$ include a rare Pale Green perforated lid with loop handle, from quadrangle E1 (no. 96.01), as well as - possibly - part of the pottery of cut 101 from quadrangle E2 (e.g. 101.04-08). From this same location two clay disc fragments were retrieved, one $15 \mathrm{~cm}$ in size (nos 101.01-02). This fraction of cut 101 would be attributable to units LEd-LEc. Concerning other finds, a whole dromedary or donkey coprolite (indeterminate) was retrieved from suite YSL with cut 43B.

\subsection{Stratum $P$}

Stratum $\mathrm{P}$ is lithostratigraphically defined by two subsets of sedimentary components. One corresponds to an earlier part of the Stratum and includes units YSi and SGY in Sector D and easternmost E, and units Gh4, Jx, LEb, LEa, suite L3ef, and probably part of suite CM in middle Sector E. The second subset, corresponding to a later part of Stratum P, includes units YSf and $\mathrm{YSd}_{3-2}$ (with marker-lens Y $\lambda \mathrm{a}$ ) in Sector D, and LE1, LE $\omega$, LE1x, LE0, J2, and probably a second part of suite CM in middle Sector E.

Stratum P is based on sediments that relate with a period of deterioration and subsequent decay of Wall F4, phases 5 and 6 in my model (Table 5). Arguably, the wall's deterioration was not uniform in time and the different parts decayed unevenly. There is no evidence of intentional destruction, obviously within the limits of our trench. Part of the wall was still standing when the middle units of Sand YS (upper YSZ, YSi-YSf) were being deposited. At the same time the erosion of the tell had started. With their inclination, the sandy colluvia forming the lower half of Sand YS reveal a provenance from the southwest, where even today a rise in the talus can be perceived. This higher spot would hide some slight eminence in the Sabaean tell and - quite possibly - the continuation of the wall. ${ }^{147}$ The presence of the wall triggered sedimentary as well as small-scale morphological modifications.

\footnotetext{
146 The option of classifying $5 \mathrm{SA}_{2}, \lambda \rho$, and $5 \mathrm{SA}_{1}$ as a suite, just like $6 \mathrm{QR}$, was contemplated, but refused due to insufficient field record.

147 As already emphasized, the plan and height of Wall $\mathrm{F} 4$ beyond the limits of the excavation trench are unknown. An attempt at exploration ended too soon (quadrangle EN1, see in this chapter section 16.4, 'Stratum A', and mentions in sections 1.2 and 6.3, footnote 131, above).
}

The relationships between Wall F4 and Sand YS (see section 6.6 below) cannot be established in detail within the restricted confines of the excavation. The contact between sand and wall at the D7/E1 boundary is marked by a series of intricately connected small units, which involve the top of sediment group SG (SGP0 and SGY, this latter containing mud-brick fragments), a pebbly pocket (Gh4, leaning against wall-related mudbrick mass J1), and 'muddy'-gravelly lenses within the sand ( $Y \lambda 2$, written ' $\lambda 2$ ' on the Reference section for reasons of space). The sand buildup and the life-history of Wall F4 clearly intersected, as reconstructed in Table 5.

Although decayed, Wall F4 acted as a sedimentary watershed up to the top of mudbrick stump J1. West of the wall and downslope, lenticular units of fines were slowly and quietly deposited, first at some distance from the wall (L3f and L3e, tightly forming suite L3ef), then closer (group LE; cf. Tables 1-2). Interestingly, lenses LEd to LEb did not originate at right angles with the wall, but from flowage alongside the wall, with the character of slow mudflows. All the above lenses are strikingly polychrome as a result of their alternating sediments, their colours ranging from dark sienna to pale grey (Figs 39, $54 \mathrm{D}$ ). For instance, LEa is a palegrey to bluish ash lens from a hearth lit near the wall, which contained Red Lustrous potsherds (see below); LE1 is a thick unit of part massive, part lenticular silts of 'banded' appearance with multicoloured subunits, again often grey-ashen to bluish. Group LE built up in perfectly tight contact with the stone blocks of the wall.

Like L3C-L3C1 a little later (suite L3C, Stratum O), LE1 may record debris slides following heavy rains, when tell-edge masses of doughy fines could be mobilized the first such episodes in our sequence. A forerunner to this kind of process was apparently LE $\omega$, an entirely anomalous body within LE1 in quadrangle E2, interpreted as an alien chunk of deposit or 'xenosome' (Fig. 39). ${ }^{148}$ LE $\omega$ would have slid into a different sediment during this latter's formation. Significantly, LE1 contains decay material traceable to Wall F4. Units $\mathrm{J} 1$, as a probable stump of the wall's superstructure, Jx as disaggregated mudbrick, and J2 as a 'flow' of melted mudbrick possibly from the wall, contained some potsherds of Red Lustrous ware and bits of caprine bones.

Lithological and cultural details on Stratum P. At the beginning of Stratum P we can place suite CM ('middle body', corpo mediano in Italian) in quadrangles E4-E5 south, which does not seem to reach the Reference section (Fig. 46). CM is a mixed-debris accumulation shaped like a double ogive and resting on surface S4 (probably equivalent to surface S17, see section

\footnotetext{
148 A new term, inspired from xenolith. In principle, also LE $\omega$ might be related to the wall. See section 2.2 above.
} 
6.4 above). The suite contains units $\mathrm{CM} 1, \mathrm{CM} 2$ with subunits, and CMx. The sequence CM2-CM1 markedly resembles subsequent accumulation XE4 (Stratum O, see Reference section), to the point of suggesting that suites $\mathrm{CM}$ and $\mathrm{XE}$ could be fused together into a single suite. As to units and subunits, CM2 is made of a number of imbricated subunits, including - bottom to top $\mathrm{CM}_{0}$, a band with 'lumps' and vegetal matter; $\mathrm{CM} 2$ as a central, gravelly body; $\mathrm{CM} 2_{2-3}$, apparently sandier subunits; and $\mathrm{CM}_{4}$, the topmost and easternmost subunit. CM1 is apparently coarse and pebbly. CMx is a debris tongue in quadrangle $E 5$ southeast.

At the beginning of Stratum $P$ in quadrangles E2-E3 we have suite L3ef. This is made of a thin, red-brown ribbon below (L3f), and a thicker, ashy ribbon above (L3e), which are indissoluble for a stretch of over $3 \mathrm{~m}$ from E2 west to the middle of $E 3$ - a remarkable concomitance (Figs 39-41, 46). It is this sedimentary combination, together with its position immediately above a nonlenticular body like SE3, that provides one of the best and most visual lithostratigraphic markers in this location. Suite L3ef displays exceptional continuity and regularity. At the same time, the two associated and parallel constituent units - L3f and L3e - maintain a fundamental individuality over their entire extension: a homotaxial relationship, independent of whether at the micro-scale they occasionally seem to merge, or to 'interpenetrate' (unità interlaminanti in Italian, a new term), i.e., to share an indistinct boundary.

L3fis a thingrey lens with sandy-gravelly micro-laminae, which was subsequently reddened by or enriched with brown-red organic (?) fluids due to Diagenesis Z1 (see section 4.1 above). It consists of two or three main laminae, the upper one in the northeast corner of quadrangle $E 3$ being grey, not red. The difference from L3e is that L3f is never ashen in colour or texture, nor ashy in contents. Its average thickness is $\leq 5 \mathrm{~cm}$, but $6 \pm$ $1 \mathrm{~cm}$ in the northeast corner of quadrangle E3. L3f ends in quadrangle $E 3$ with a tiny lens, $3 f \lambda$.

L3e is an ashen-grey to white lens of highly variable thickness which actually contains colluvial ash as well as large scattered charcoal fragments. It appears in section as an ashy ribbon 'sandwiching' distinctly dark microbodies and microlenses of cultural debris. In quadrangle $E 3$ east and south two main bands can be distinguished, $\mathrm{L} 3 \mathrm{e}_{2}$ below and $\mathrm{L}_{3} \mathrm{e}_{1}$ above, this latter with a conspicuous local swarm of dark bodies. $\mathrm{L}^{3} \mathrm{e}_{2}$ contains pebbly laminae sometimes reddened by what might be Diagenesis Z1.

Overlapping with this vertical partition, several subunits were identified over the length of L3e: $3 \delta$, a 'hypermelanocratic' lens; $3 \mathrm{e} \lambda$, a 'ultra-white' lens; $3 \xi$, a tiny red lens at the end of L3e in quadrangle $E 3$ south; and 3eS, the most 'massive' and evident brown inclusion within $\mathrm{L}^{3} \mathrm{e}_{1}$ or at its top in quadrangle E03 (hence appearing on the Reference section). ${ }^{149}$ I also attribute to L3e a lenticular body of beige-orange silt in middle quadrangle $\mathrm{E} 2$, lens $\mathrm{L}^{3} \mathrm{e}_{0}$ (upper L3e, contiguous with lens LEbw to the east).

LEa (above in this section), a leached hearth in quadrangle E1 continuing with a very long colluvial 'tail' into quadrangle $E 2$, is interesting since it reveals a Sabaean-age episode of cooking or even bivouacking right against the face of Wall F4, similar, on a smaller scale, to those that will occur much later against the Minaean wall: see previous section 4.1. LEa is only one of the many Stratum P units starting at, and extending or 'flowing' down-talus from, the face of Wall F4.

In Sector D, sand units YSi and YSf were found to contain tiny charcoal, whereas abundant, coarser charcoal characterized lens $Y \lambda b$, together with bone and pottery bits (cut 43A). This lens, an inclusion of $\mathrm{YSd}_{2-3}$, was made of medium to coarse sand typically 'grating' under the trowel, at least in quadrangles D6D7. A fragment of a crucible with copper slag probably belonging to Stratum $\mathrm{P}$ was recovered from YSiYSd ${ }_{1}$ sands of quadrangle D7 and Gully B (no. 46.02). A dromedary or donkey coprolite similar to the one recorded from Stratum Q (see section 6.4 above) was found in the upper YS sands (YSd to top of YSa, cut 43; Strata P-O). Glazed basalt block no. 43A.1 was examined above in section 6.3 .

In upper Sector E, finds from Stratum P include frequent Red Lustrous pottery from quadrangles E1-E2, e.g. nos 93.1.1 (contained in unit LE1) and 100.01, a shallow bowl, in addition to the potsherds from units LEa, J1, Jx, and J2 mentioned in the main text above. A particularly rich series of finds, some certainly attributable to Stratum $\mathrm{P}$, was produced by the thick exploratory cut in quadrangle E3, cut 110 , which deserves a brief discussion. ${ }^{150}$

Cut 110 involved numerous units from L3e, L3c, L3Z ( $\mathrm{L}_{2}$ ?) to surface (SAp, SAG, SAE), i.e. Strata P-N and A. The specific context of each find is impossible to elucidate. Due to momentary difficulties only two finds from this cut were recorded individually in situ: polychrome glass no. 110.1 (probably intrusive) ${ }^{151}$ and Sabaean torpedo jar sherd no. 110.2 (cf. Figs 51 A, plan, and 52, photograph). This latter find ${ }^{152}$ is of interest

\footnotetext{
$1493 \mathrm{eS}$ is a relatively large clod (a lump or mass of clay or earth), or indeed a clod made of multiple clods, which slided down from the edge of the Sabaean tell. This process will continue in this part of the talus during Stratum $O$, as shown for instance by the case of subunit $3 \mu \nu$ within unit L3c2 (see Reference section).

150 The Collection catalogue entry concerning finds 110 can be seen in Chapter 20, Fig. 1, this volume.

151 No. 110.1 is described in Chapter 21, section 2.5, this volume.

152 Described in Chapter 23, section 3.1, this volume.
} 
here as it was recovered from a context attributable to Stratum $\mathrm{P}$ or $\mathrm{O}$, and having wear grade 1 it belongs in the small fraction of cut 110 objects originating from short-distance transport or even fragmented in situ. The context of this torpedo jar sherd was lower unit L3c, possibly gravel lens $3 \pi$, or a mixture of L3c and L3e. Lower L3c suggests a 'convoluted', fluidal sedimentation (cf. section 6.8 below). Other finds from cut 110 which might well belong to Stratum $\mathrm{P}$ or $\mathrm{O}$ include a clay 'tripod' foot (no. 110.05), ${ }^{153}$ a yellow-calcarenite flake (no. 110.01), a quartzite clast (no. 110.02), and an encrusted, heat-modified (?), fine-sandstone platelet $12 \mathrm{~cm}$ long from kitchen discard or a hearth (no. 110.03; possibly related to a fair amount of charcoal fragments $1-3 \mathrm{~cm}$ in size).

\subsection{Sand YS. Strata Q to $O$ in Sector D}

One of the striking sediment features of the Area $C$ stratigraphic profile is group YS, colloquially Sand YS (Table 2). This a 1.8-metre-thick accumulation of colluvial and aeolian sands that built up in lower and middle Sector D during the Earlier Sabaean phase (Figs 37-38). The base, extent, and geometry of this body are unknown, making its explanation difficult. ${ }^{154}$ Clearly, there was some marked input of windblown sand that generated thick accumulations in particular places, although no other dune-like sand mass of this kind has until now been noticed along the Barāqish perimeter, either above ground or buried.155 Moreover, the Sabaean occupation did not suffer discontinuity on the scale of the settlement: minute cultural residues were occasionally released while YS was being formed, and the continuity in material culture between Strata T-S and $\mathrm{N}-\mathrm{L}$ makes an abandonment appear incongruous. Although remarkable on the local scale of Area C, this accumulation might have been no more than a minor accident in Yathill's history.

Although they are all aeolian in terms of primary material, the sands of YS are colluvial in deposition for the lower two thirds of the group. Only the top third is properly aeolian: that is, the part that accumulated when Wall F4 was decaying or had just decayed, leaving room for unimpeded wind transport.

In particular, following suite YSL (Stratum Q) and the undulating to inclined, coarse sandy colluvia related to initial Stratum P (unit YSi), suite YSU includes slightly inclined, thinly laminated sands starting with marker-

\footnotetext{
153 Described in Chapter 21, section 2.1, this volume.

154 The distribution of Sand YS to the north and east of quadrangles D5-D7 could be recorded from the sides of Gully B; the reconstruction in Fig. 27 takes this information into account.

155 Sand YS came to light thanks to the excavations: previously this thick sand body, although often only covered by a veneer of later sediments, could not be seen anywhere on the surface of the northwestern talus.
}

lens $Y \lambda 1$, an undulating ribbon of coarse sand and cultural debris (Figs 19, 37, $38 \mathrm{C}$ ). $\mathrm{Y} \lambda 1$ is understood as the initial component of serially micro-stratified unit YSf. It is followed in turn by the similarly structured initial levels of YSd, 'hard' aeolian sand with occasional colluvial inclusions ( $\mathrm{YSd}_{3-2}$, Stratum P). 'Hard' means relatively compacted in comparison to the subsequent YSa. The general inclination of sedimentation planes is a few degrees east. YSd ${ }_{2}$ is terminated by coarser band Y $\lambda$ a. Most of thick unit YSd consists of its upper partition YSd : a tight sequence of horizontally layered, distinctively yellow aeolian sands correlated with Stratum 0 . They show a slight inclination reversal towards the top, where they tend to dip west, as also does - in part - the YSd/YSa contact.

Essentially in continuity with YSd, unit YSa is a onemetre-thick layer of pure, well classed, fine to very fine aeolian sand, porous and highly mobile, yellow in colour. ${ }^{156}$ There is virtually no silt. Its origin should apparently be traced to a tract of arid landscape with little circulating silt, if any. As such, YSa seems to be unparalleled in the stratified sequence of Area C. Through time, taken as a whole, sediment group YS unmistakably portrays an evolution from poorly classed sands at the bottom, intercalated with silts and cultural debris, to a well classed aeolian sand at the top. Within sand YSa in quadrangle $D 6$ a horizontal row of old animal burrows was observed, feature F14 (cf. section 6.8 below).

The present classification of Sand YS is innovative compared to that previously published. ${ }^{157}$ The tripartite classification proposed in 2010 is now superseded by a partition into two suites, based on giving preeminence to the criterion of aeolian sedimentation. Ranked as a sediment group, YS comprises a lower suite, YSL, aeolian-colluvial (i.e., made of mostly aeolian sands redeposited as colluvia), and an upper suite, YSU, markedly aeolian in origin. This change is observed at the boundary between units YSZ and YSi. As already mentioned, suite YSU sequentially reflects a depositional trend - progressive but punctuated in the field - from aeolian-colluvial to distinctly aeolian. Another innovation compared to Arabia 4 is unit $Y \lambda 15$.

$Y \lambda 15$ designates a thick, large lenticular inclusion within sand YSa in quadrangles D15-D5, with an unknown extension farther east (Fig. 19). Together with the surrounding sands it is ascribed to Stratum O. Y $\lambda 15$ was observed and marginally excavated within the furrow

\footnotetext{
156 On the colour of sand accumulations (dunes) see Edgell 2006, 289-293, with references. He mentions lighter colours - including 'apricot' - where sands 'have a considerable component of calcareous grains' (p. 292). This might be the case at Barāqish. Unfortunately Stewart Edgell (2006) seems to have been unable to study the Yemeni Jawf in the field - his brief paragraph on p. 106 is literary.

157 Fedele 2010, 118-119.
} 
of Gully B at the eastern limit of the investigated sector (quadrangle D15 southeast; Figs 34, 36). ${ }^{158}$ It has been drawn in the Reference section - though it was not actually captured - for two reasons: (i) its interest as an indication of the internal structure of Sand YS at the core of the Sabaean tell, and (ii) the consideration that it must come in reasonable proximity to the Reference section (less than $1 \mathrm{~m}$ ). ${ }^{159} \mathrm{Y} \lambda 15$ is made of grey sandy fines containing minute charcoal and granules; an organic fraction is possible. ${ }^{160}$ As it obviously extends south and east, to D5 and D14-D4 respectively, it suggests some kind of contact between Sand YS and occupation layers of the Sabaean tell nearby. However, $Y \lambda 15$ cannot provide more than a fleeting glimpse of the unexcavated tell. How deep into the body of the Sabaean tell Sand YS may extend, and what size, shape, and structure it may present, are unknown. ${ }^{161}$

\section{Sand YS: interpretation}

As we have seen, with the erection of Wall $\mathrm{F} 4$ a wide belt on the interior side of the wall must have been freed from habitation, and here Earthwork F44 contributed to produce a modest depression between the wall and the tell. Such an open, depressed belt soon started to act as a trap for aeolian sand blown in from the floodplain as well as a receptacle for colluvia supposedly washed in from the side of the tell. It is worth noting how the intercalating debris lenses of lower Sand YS contain a wealth of washed-in, comminuted cultural debris. A general list would include wood and charcoal chips, ${ }^{162}$ frequent pebbles from melted mudbrick, mud-brick 'crumbs', minute angular stones, and tiny debris from both organic artefacts (including leather) and bone. Meanwhile, sand kept accumulating in the lee of Wall F4. Although the tell was probably low in this part of the settlement, its eroded margin easily created a local obstacle that acted as a sandtrap. Hidden in the unexcavated part of Area $\mathrm{C}$, however, the sandtrap frame is unknown.

The sand input did not start suddenly or massively. In fact, the aeolian deposit (YSa) was the culmination of a trend that had already begun with sandy bodies -

158 There is no genetic relationship between $\mathrm{Y} \lambda 15$ and the other sedimentary bodies excavated and studied within Gully B (F1, with fill XF1, and YSP): on these see section 15.3, 'Stratum G', below.

$159 \mathrm{Y} \lambda 15$ crosses excavation section D15/D5 (Fig. 34 A).

160 Not necessarily related to $Y \lambda 15$, but worth being mentioned here in the context of Sand YS and the fill of Gully B, is the finding of a unique T-shaped ceramic fragment probably to be attributed to Stratum O: object no. 36.01 (Chapter 21, section 2.1, Fig. 23, this volume).

161 The boundaries of the sand body are unknown because the 2005 excavation was insufficient to make YS geometrically comprehensible. Cf. the 'sandtrap frame' mentioned in the subsection on Sand YS interpretation below.

162 With larger, centimetre-sized bits in cut 43, YSd 2 -YSa. primary or reworked - such as SGLi, SGL, SGP, SE3, ${ }^{163}$ and had accompanied the progressive deterioration of Wall F4's superstructure. This trend escalated when the decay of the wall was complete. One of the chief characteristics of Sand YS is its orderly deposition, undisturbed by direct human presence. Not until the beginning of suite GK was human activity resumed in this part of Yathill. At the same time a large supply of sand became available, along with an unprecedented opportunity for sand accumulation in Sector D. The above data help explain the selective buildup of Sand YS: this buildup was the repercussion of a set of locally traumatic, destabilizing artificial factors - the erection of the wall and the suppression of habitation. Sand YS was not a climatic, but a cultural-geomorphic product: it is very doubtful that it reflects regional or broader climatic events, for instance an aridity pulse.

Everything indicates that during the sedimentation of Sand YS - whether this was lengthier or shorter it is impossible to say ${ }^{164}$ - there was no habitation or human circulation in northwest Yathill. A strange and suggestive coincidence is apparent between the erection of Wall F4 and conspicuous, undisturbed sand sedimentation, as if the erection of the wall had abolished human activity nearby: as if, hypothetically, it had deflected it - shifted it to other parts of the town. Thus, considered together, Wall F4 and Sand YS suggest a relocation of part of settlement away from this wall, or from the town wall in general, if that was indeed the status of Wall F4. And ultimately, only a temporary relocation.

To explore this issue further, the variables usually controlling aeolian input must be considered. Sand accumulation implies aeolian activity but not aridity per se: in fact it depends more on sand availability than wind. In conjunction with a minimum of strong unidirectional winds, a seasonal supply of suitable sediments is the most important factor. ${ }^{165}$ The fact

163 The distinction between SGP and YS is made conspicuous by the change in sediments, but otherwise it is much less dramatic than it seems. The boundary or junction between the two is somewhat diffuse, on the order of $2-5 \mathrm{~cm}$, and there is no physical evidence of stasis or hiatus (cf. section 6.3, 'Accessories and special finds', above). SGP, like SGL, already contains abundant sand. Furthermore, unit YSX (cf. sections 6.4-6.5 above) is in many ways a continuation of processes already perceptible in SGP0, particularly 'mud' illuviation and/or the emplacement of 'muddy' (silty-clayey?) sheet material.

164 As an impression, no substantial length of time is implied by the deposition of Sand YS (cf. Table 4, chronology column): in this case, a marked difference in sediments would not be matched by an equal difference in cultural as well as climatic history (Fedele 2010,119).

165 Availability of sand, local conditions favouring an orderly and undisturbed deposition, and wind regime, are the well-known, universal prerequisites for sand accumulation as well as its main controlling factors. See, e.g., Thomas 1989b, 317-324; Coque-Delhuille and Gentelle 1998; Edgell 2006, 270 (and more generally 263-296, two chapters devoted to the sedimentology and mechanisms of accumulation of aeolian sands in Arabia); Parsons and Abrahams 2009, chapters 17-20, particularly Nickling and McKenna Neuman 
that YS initially developed as a product of colluvial transport suggests just basic aeolian activity coupled with interannual variability of rainfall. By the time the wall was erected a good supply of sand and silt was available, and that in turn implies source areas within a reasonable radius from Yathill. The lower half of Sand YS has a light brown, loamy organic fraction, as if the aeolian agency responsible for it was bringing in organic silts from agricultural soils of the old oasis west and southwest of Yathill. This fraction diminishes in YSd $_{1}$ and disappears in YSa, as if the source was no longer available. To become a likely source of windblown sediment, the fields must have been at least partially abandoned. ${ }^{166}$

Three disparate lines of evidence thus appear to emerge: an encircling or partial enclosure wall for the town; a shift in occupation, if not some wider settlement reorganization; and an abandonment of older cultivation. The three might be linked in a causal relationship. Beyond this, interpretation is problematic.

If the inference about abandoned fields is correct, one might propose that around the time of Strata $\mathrm{R}$ to $\mathrm{O}$ a larger-scale landscape change had occurred, however gradually, in the form of the definitive shift of the main wādi from the west to the east of Yathill. ${ }^{167}$ This watercourse might have been either Wādī Majzir or its left tributary, Wādī al-Shaqab. ${ }^{168}$ For this wādī system a general shift eastwards has long been recognized, ${ }^{169}$ although the details are unknown and the chronology of the events is indeterminate. The shift would have originated from a river capture triggered by tectonic impulse. Such a process may have developed in steps and have taken some time to complete, due to the fact that several channels were involved. Furthermore,

2009; all with references. It has been understood that surfaces cannot supply an unlimited amount of sediment to wind transport: most natural eroding surfaces tend to be 'supply limited'. In other words, in general, the initial limiting factor in the process is supply - i.e., availability of sand and/or silt (Nickling and McKenna Neuman 2009, 517).

166 Arguably, abandoned oasis gardens can be one of the most important dust sources, like abandoned farmland in general (e.g. Middleton 1989, 274). Concerning yellow sand YSa-YSd, the contribution of a nearer quarry or 'blowout' area cannot be excluded: see section 17 (Sounding F) and cf. section 6.8, below. In the context of the present discussion it might be appropriate to recall the case of Hajar Yahirr, ancient Awsān, in lower Wādī Marhhah, as studied by Brunner (1997b). He observes how 'during the second and early first millennium $\mathrm{BC}$, when there was irrigation, the sand does not seem to have been a problem because of the vegetation that surrounded the channels and fields': 'the sand [only] became a dominant problem after the lethal defeat of the kingdom of Awsān and the complete destruction of its capital [...] at the beginning of the seventh century $B C$ '; 'without irrigation the vegetation disappeared very fast [and] the present arid conditions were fully established by this time' (p. 82-83).

167 See Fedele 2010, 119, for details. My proposition remains entirely speculative, however, for the important reasons indicated below.

168 Or alternative hydronyms. Cf. Chapter 1, section 5, in Volume 1.

169 B. Marcolongo's investigations: see Chapter 19, section 5, this volume, with summary and references. it needs not be seen as dramatic, because semidesert wādì channels with a shallow, braided pattern can undergo displacements and captures easily. But once completed, the process dramatically affected the local setting by provoking the deactivation of part of the old oasis, hence a need to recreate or expand the Yathill Oasis elsewhere. A test of this scenario would require territorial information that does not exist at the moment. The subject is taken up in Chapter 19, section 5 , this volume.

Was Sand YS a general phenomenon involving the whole of Yathill or even its territory? Or was it no more than a local process confined to excavated Area C? Obviously, only further excavations over a wider area could provide data to answer this question. Furthermore, from the above evidence it appears that this issue cannot be dealt with in isolation, since the emplacement of Sand YS somehow involved the presence and subsequent decay of Wall F4. In fact, only a larger-scale excavation of the northwestern talus of Barāqish, exposing the continuation of Wall F4 and including part of the Lobe 5 occupation (section 7.6 below), would be likely also to sort out the identity and origin of Sand YS.

\subsection{Feature F13}

A large mud-and-stone plate or slab, unit GR2 or 'Mass GR2', sits atop Sand YS in quadrangles D5-D6 of Sector D (Figs 19, 34-37). It is a derived mudbrick feature hence its parallel codename, feature $\mathrm{F} 13^{170}$ - still embedding a chunk of associated bricks and plastered stones. Two superposed subunits of different texture suggest layering, with the bottom one (GR2 $2_{2}$ looking rather like coarse melted mudbrick. Unit or component GR2 contains a block of strangely sandy mudbrick (P12) and a limestone block covered in plaster (P13), both surrounded by smaller stones. ${ }^{171}$

The affiliation with a Stratum is not straightforward, because GR2-F13 presents an obvious sediment contrast with both the sand below and the occupation layers above (units GKk-GW and suite GK). However, GR2-F13 will be considered integral to the top of Sand YS rather than part of the subsequent stratification, on the grounds that its base interfingers intimately with the sand and no weathering or hiatus is apparent, whereas its upper contact - part with GKk, part with GK4 - suggests a sharper discordance. Accordingly, F13 will be ascribed to Stratum O, of which it represents the final part in Sector D.

\footnotetext{
170 This naming was in analogy to F9 for unit GR1 ('Mass GR1') in upper Sector D: see section 7.6 below.

171 Block P12 resembles mud-brick block JD2 contained within structure F9 (Stratum L): see section 7.6 below.
} 
More precisely, the contact with YS is sub-horizontal and distinctly jagged, which gives the precise impression that at least GR2 2 shaped itself onto the eroded sand surface (YSa) and even slipped a little down the talus slope. Conversely, in the area to the side of F13 the boundary between YS and GKk is sharp and linear (surface S23), as observed in quadrangle D5 east. As to the upper boundary of GR2-F13, GKk lies on it unconformably and gives the impression that when local occupation was actively resumed F13 had already been there for a while: small loose-mudbrick pockets, unit GR , seem to indicate some weathering of the mass (Fig. 19).

F13 therefore looks like a mass of slumped and partly melted mudbrick tapering to the east. It may have originated from old ruins on a nearby part of the tell, located outside the excavated area. Or, just in theory, it might be a fragment of Wall F4 itself or a wall-related structure, slid over the large sand body. This intriguing hypothesis, however, clashes with our ignorance of the plan and condition of Wall F4 beyond the excavation. Still another possibility is a platform, made to level and stabilize the surface of the sand mass and enable a reoccupation of the site. In other words, F13 would be a cap of stone-reinforced (?) mud-plaster at the top of YS to protect from erosion the sandy bank underneath. ${ }^{172}$ In this case F13 would be shifted to Stratum N. However, to my knowledge, Sabaean platforms of this kind are not on record.

As the repeated citation of feature F9 suggests, F13 represents the first mud or mudbrick feature that we encounter in the present stratigraphic review (except for the superstructure of Wall F4): it represents a stratigraphic novelty in the sequence of Area C. As a 'mud' body, F13 would be followed in the excavated area by GW (melted mudbrick) and F9 (GR1) in upper Sector D; by GR3 in Sector C; and by STY in Locus 200 (see end of section 4.1, above).

Finds. GR2-F13 was found to contain two date stones (cut 42, quadrangle D6); see mention in Chapter 19, section 4.2 , this volume.

\subsection{Stratum $O$ in Sector $E$}

Stratum $\mathrm{O}$ is lithostratigraphically defined in Sector $\mathrm{E}$ by sediment suites L3C, XE, LXZ, 45S, and 6UV. However, its constitution and composition in Sector E need to be understood in connection with the sedimentary processes and stratigraphic relationships described for Sector D.

172 Cf. the interpretation advanced for the lower part of feature F9, GR1b (see section 7.6 below).
We have seen in section 6.6 that Stratum 0 is defined in Sector D by the climax of sand accumulation, almost exclusively aeolian ( $\mathrm{YSd}_{1}-\mathrm{YSa}$ ). Sands $\mathrm{YS}_{2}$ and $\mathrm{E} \sigma \mathrm{W}_{3}$ in Sector E, $17-25 \mathrm{~m}$ away, and sand SY2 in the plain, $55 \mathrm{~m}$ away, may be part of this sand input. At the same time, they might have been part of the source or 'blowout' area from which yellow sand for the YS accumulation in Sector D was drawn (cf. end of section 6.6, above). They may all be instances of the same phase of sand transport and deposition, involving what can be termed 'YS-YS8type sands', peculiarly yellow or blond in colour. ${ }^{173}$ This emerges from the best correlation option at the moment, which, however, is unavoidably vague: $\mathrm{YS}_{2}$ and $\mathrm{E} \sigma \mathrm{W}_{3}$ might span Strata $\mathrm{P}-\mathrm{O}$ and the affiliation of SY2 with Stratum $\mathrm{O}$ is tentative.

Parallel to aeolian processes, Stratum 0 provides significant evidence of tell-edge instability and erosion. This is the specific landscape of Sector E at this time. Suite XE, up to $60 \mathrm{~cm}$ thick, was the first large accumulation of coarse debris in the known record of the talus (quadrangles E3-E5), only preceded by moundlike accumulation CM (suite $\mathrm{CM}$ ) described in section 6.5, above (Stratum P) (Fig. 46). ${ }^{174}$ The units of suite XE resulted from mass transport involving decayed domestic remains and mudbrick debris located on an abandoned, steep or stepped margin of the tell just to the south of quadrangles E3-E5. Some large potsherds were retrieved from unit XE4 (see below).

Multiple masses, emplaced in several moments, eventually coalesced into a larger sedimentary body. Initially, the accumulation entrained large lumps of plant and other organic detritus, typically dark brown in colour (units V5 and V5S), which lower down spread along the footslope as a continuous layer (unit 6V). Some friction with preexisting unit SE3 $\omega$ occurred during transport (base of loamy-gravelly mass EX4). Subsequently, a steady buildup of nearly horizontal, gravity-induced deposits generated LZ5, composed of 'muddy'-grey fines with white-specked levels. Some colluvial units followed, completing suite LXZ. Several of them are more or less sigmoid in shape (B5, 4 $\mu$ r, LY4), reproducing the flexure of the talus.

Lithostratigraphic details on suite XE. XE4, with XE4$\mathrm{XE} 4_{\mathrm{S}}$ in the south section of quadrangles $E 4-E 5$, is a fine-medium sediment: a fine-sand and silt unit containing cultural debris and stones, these latter certainly in the form of small pebbles and granules. In other words, it may basically be melted mudbrick. As mentioned above, XE4 can be understood as a gravity accumulation originating from house and

\footnotetext{
173 On sand colour see section 6.6, footnote 156, above.

174 The base of suite XE disappears below trench on the Reference section but, along with suite $\mathrm{CM}$, it could be fully recorded from the south section of quadrangles E3-E5 (Figs $41 \mathrm{~B}, 46$ ).
} 


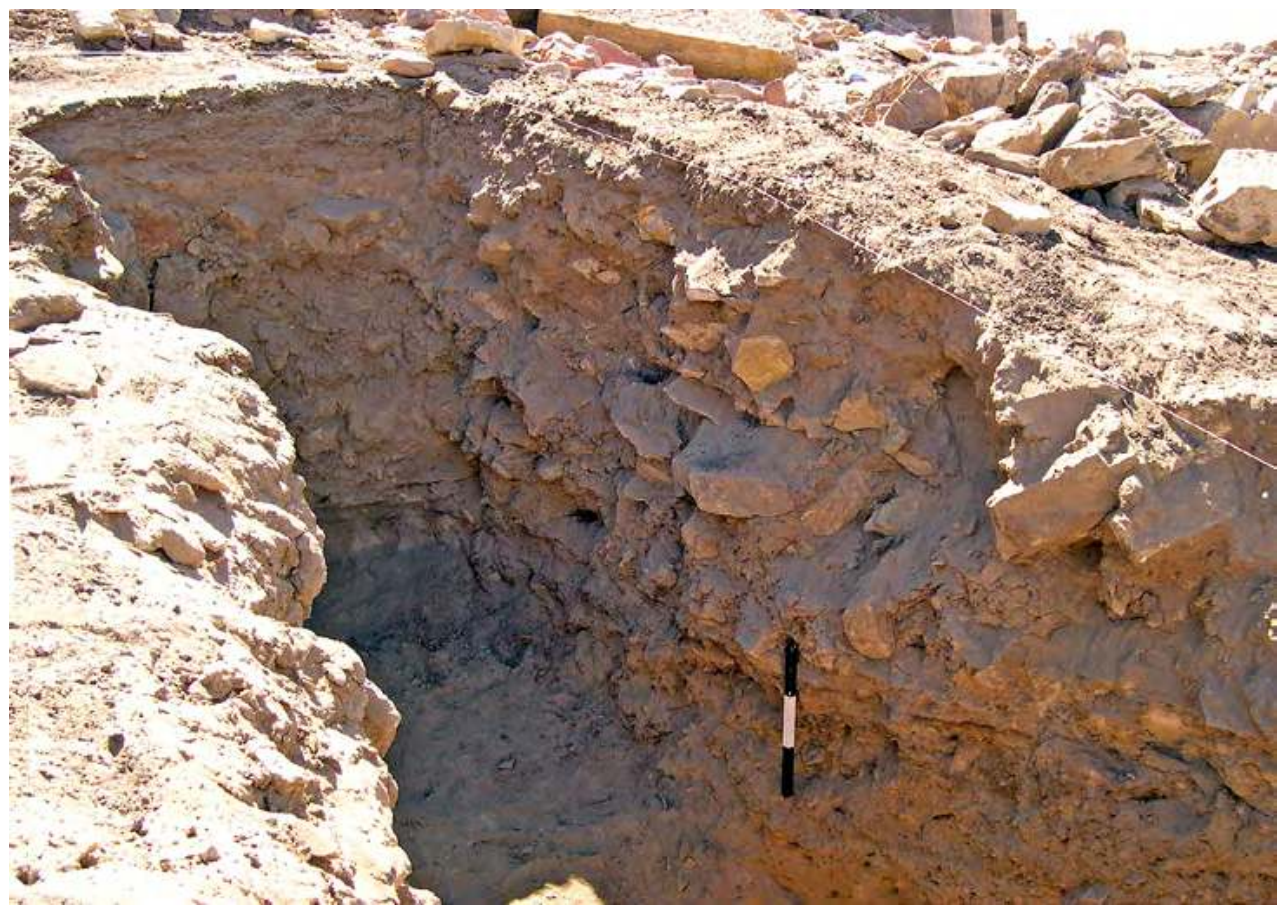

Figure 28. Sector B, facing southeast. Scale $30 \mathrm{~cm}$. (P. Morlupi 2005 @ MAIRY, optimized by F.G. Fedele 2020)

habitation debris on a margin of the old tell. What we observe here is a number of units emplaced in a number of inputs and moments, but at the same time 'enchained' as a large body produced by a unitary process. XE4 is part of the repeated, alternating slides from the edge of tell, sometimes more pebbly, sometimes siltier. A likely explanation is that XE4 was produced by the collapse of blocks of deposit from a near or very close margin of the tell, possibly determined by pluvial undercutting: a slipped-down margin which preserved something of its primary horizontal structure.

In quadrangle E5, XE4 come from the south. It is virtually horizontal in $E 5$ south, not inclined west like the subsequent units. The same horizontality is evident at the very top of XE4 in E5 east. This horizontality could suggest the existence of a local shelf towards the base of the Sabaean tell, located outside the excavation directly to the south of E4-E5 (or E3-E5). Nothing horizontal in terms of total sedimentary bodies can be observed on the Reference section: the trench of Sector $\mathrm{E}$ is at least partly located along the hinge line between two morphologies - and two depositional domains - of the tell. In quadrangle E5 south the usual dip west actually only starts after unit $4 \mu \mathrm{r}$ (a red-and-brown colluvial unit sandwiched between LZ5 and LY4) and becomes accentuated with LGN (Stratum L; see section 7.7 below).

In addition to XE4, suite XE - as now defined - is inclusive of units V5 (Reference section) and V5S (south section). As such, it is similar, parallel, and locally consecutive to suite $\mathrm{CM}$. This is not without interest, as suggested above: suite CM (Stratum P) and suite XE (Stratum O) appear to be two nearly identical consecutive accumulations, to the point that they might even be merged into a single suite; but without feedback from the field this is not feasible.

XE4 and LZ5-L3Z share a blurred limit; this, however, does not mean that they cease to be two recognizable, distinct sediment entities. It only means that, due to an overlapping of processes, the two bodies are not precisely mappable. This notion of mappable vs unmappable has nothing to do with the validity of a sedimentary, hence lithostratigraphic, distinction.

In quadrangles E4-E5 a slightly organic, silty-clayey sheet of a uniform grey colour mantled the slope of the growing talus (unit LY4), starting a depositional trend that was later to continue with LJ4 (Stratum N). Such a repetitiveness characterized the talus throughout the Sabaean 2-3 interval. Laterally, the units of suite LXZ largely interfinger with suite 6UV in quadrangles $E 5-E 6$, formed of two sandy units both remarkably rich in plant detritus (6V and $6 \mathrm{U})$. In their sloping western portion, corresponding to quadrangles E6-E06, these two 'vegetal' units are essentially continuous. An important surface, $\mathrm{S} 16$, which marks the close of Stratum $\mathrm{O}$ in quadrangles E4-E6 and the close of Stratum $\mathrm{N}$ in quadrangles E3-E4, will be examined in section 7.4 below (Stratum N). 


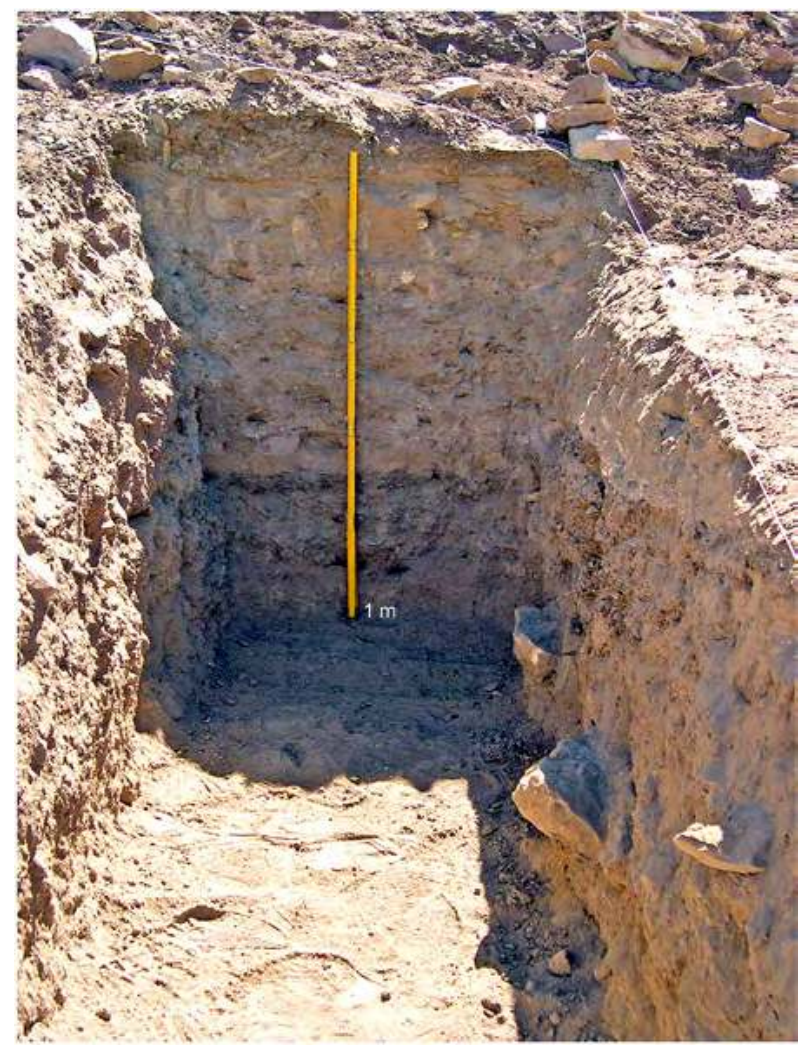

Figure 29. Sector $C$, facing east. (P. Morlupi 2005 C MAIRY, optimized by F.G. Fedele 2020)
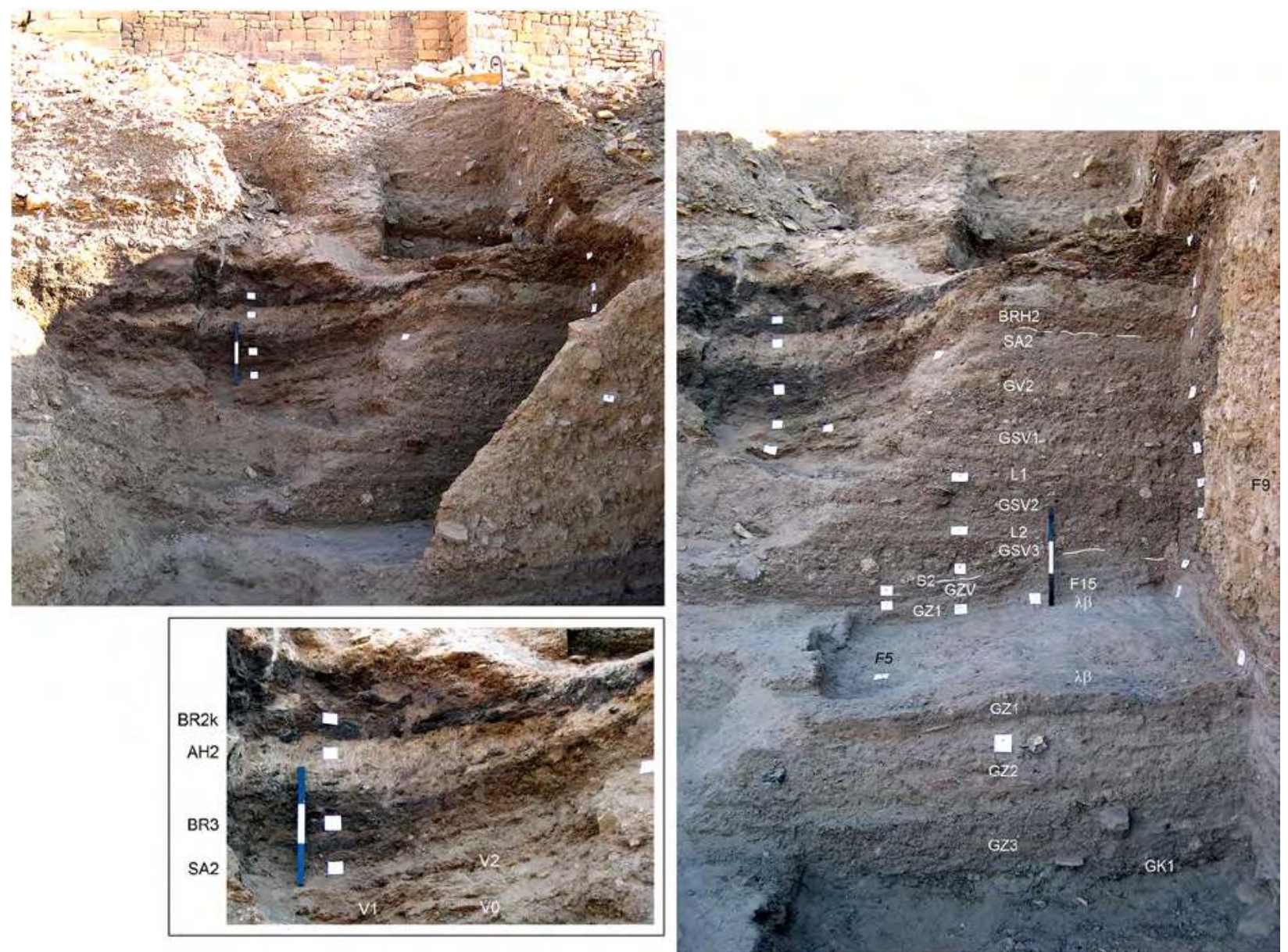

Figure 30. Upper Sector D and head of Gully B, facing east. Sediment units and features in quadrangles D1-D11 and D2-D12 are individually marked. Scale $30 \mathrm{~cm}$. (F.G. Fedele 2020, based on photographs by P. Morlupi 2005 @ MAIRY) 


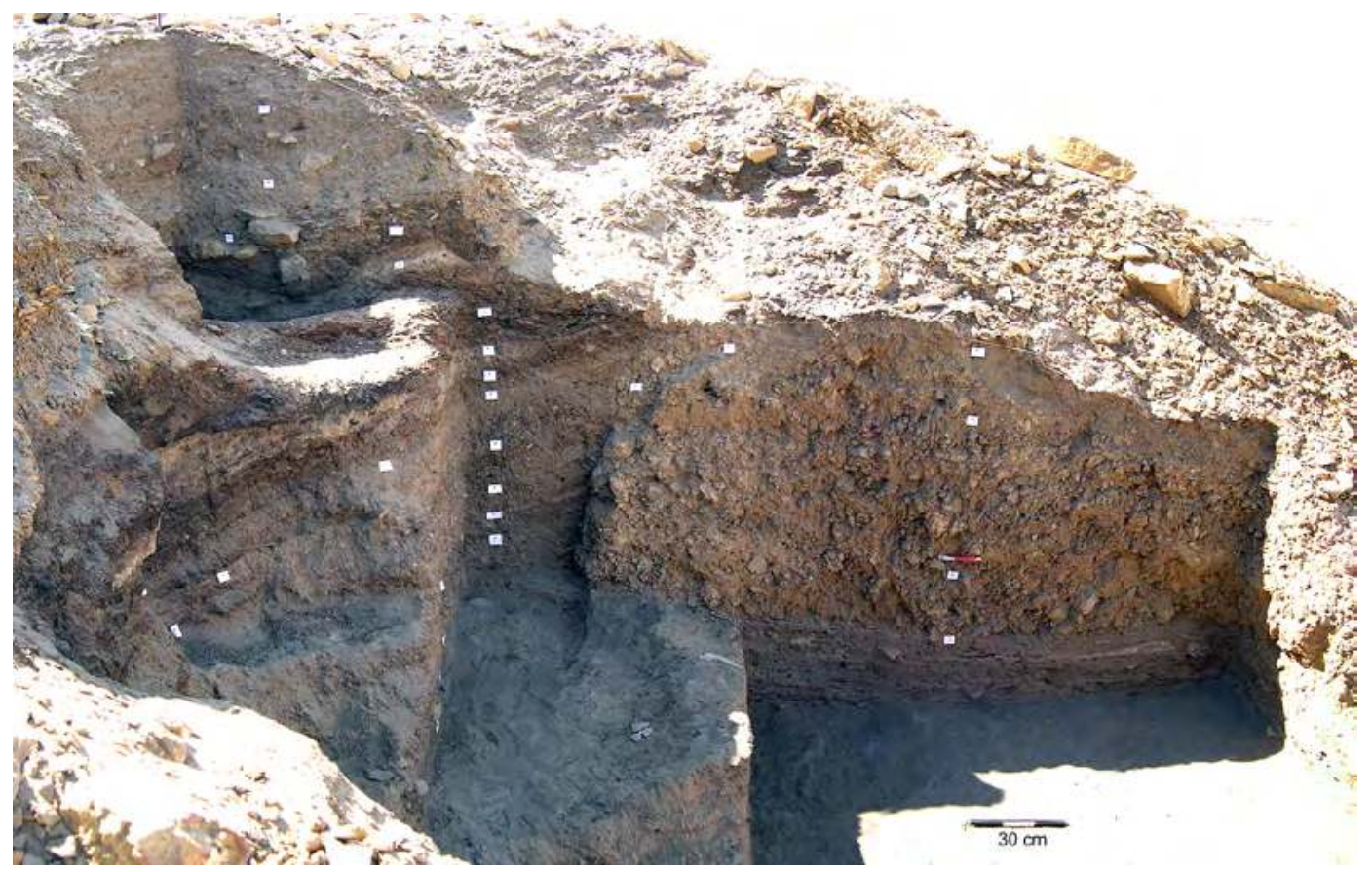

Figure 31. Sector D, quadrangles D1-D3 and D11-D12 from the northern edge of Gully B, facing south. In D2 the surface of the Sabaean layers is exposed. (P. Morlupi 2005 @ MAIRY, optimized by F.G. Fedele 2020)
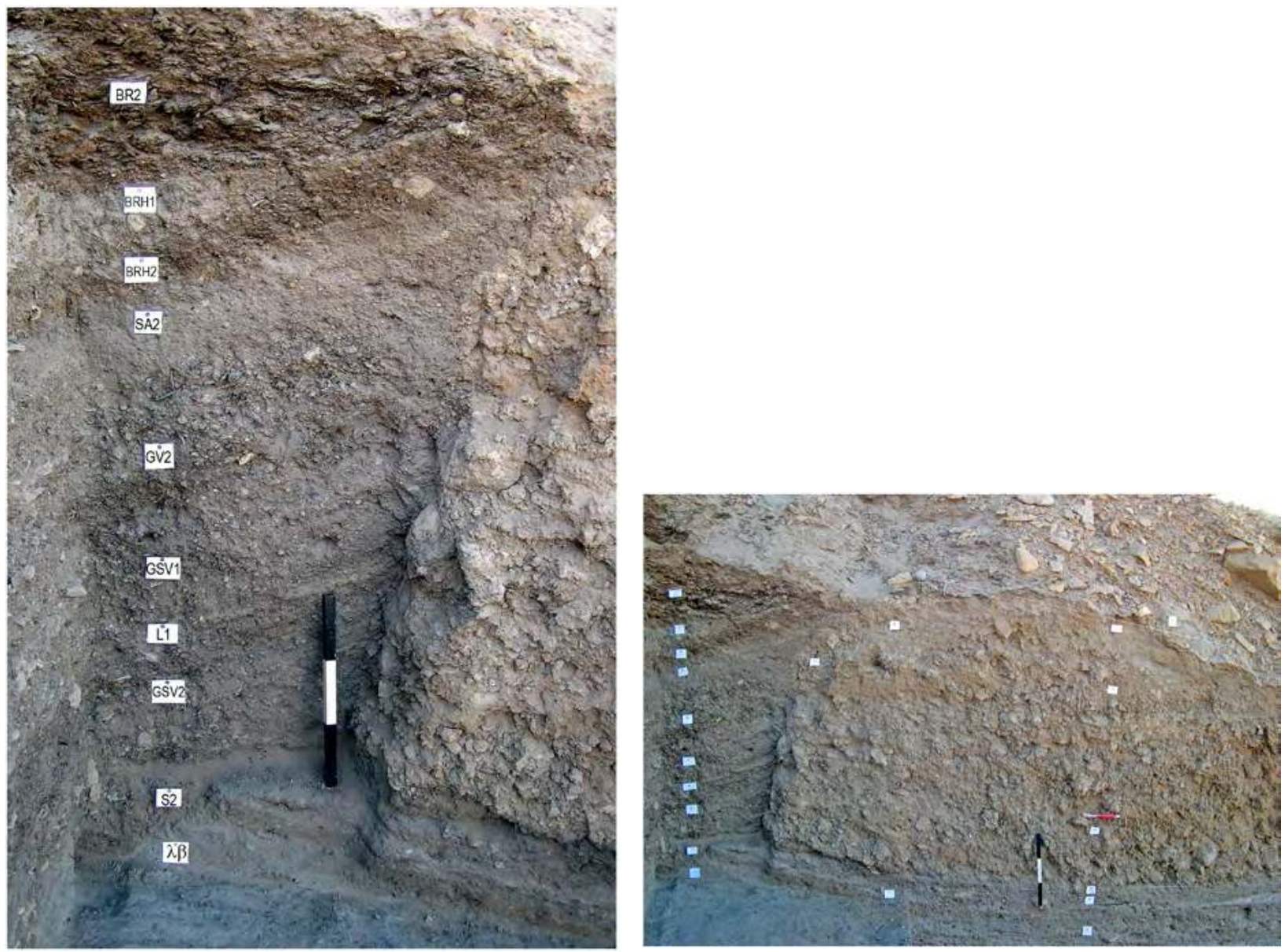

Figure 32. Sector D, quadrangles D2-D3, Reference section. Prominent in the photograph on the right is Mass GR1, i.e. feature F9. Scale $30 \mathrm{~cm}$. (P. Morlupi 2005 @ MAIRY, optimized by F.G. Fedele 2020) 

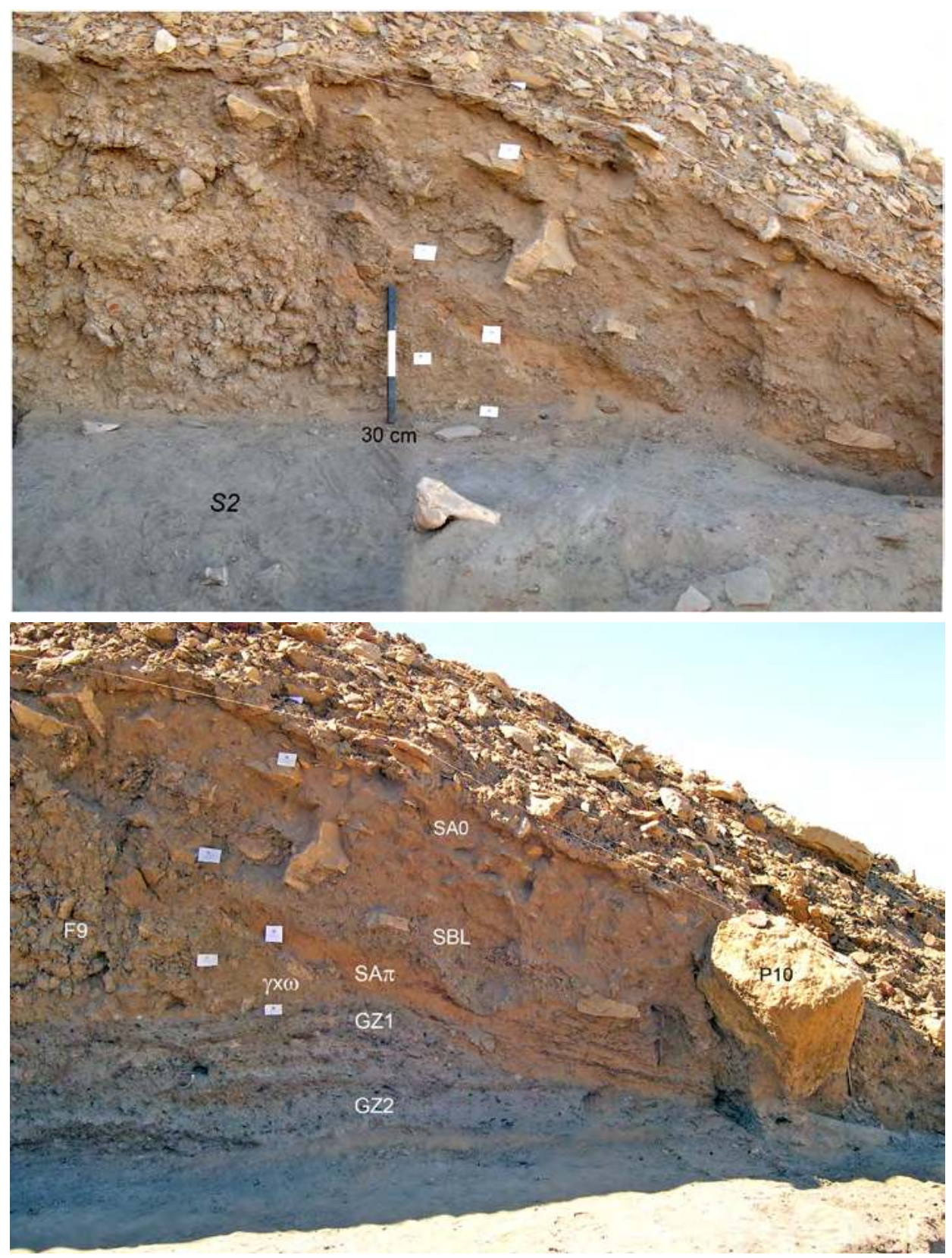

Figure 33. Sector D, quadrangle D4 and Reference section. The exposed surface in the top photograph corresponds with Figs 60 C-D. (P. Morlupi 2005 ( MAIRY, adapted and optimized by F.G. Fedele 2020)

Suite 6UV, and particularly unit 6V, deserve some comments. It is indeed with unit $6 \mathrm{~V}$ that a dung-enriched unit makes its first, isolated appearance in the sequence of Area $C$, at the end of phase Sabaean 2, in quadrangles E5-E6. ${ }^{175}$ This thick lens might well be colluvial, but its derivation is presumably from one or more 'manure' layers not far away (cf. section 7.7 below, Stratum L). Its interest lies in the fact that it not only foreshadows

175 See a brief mention in section 4.1, above. During the excavation, initially, unit $6 \mathrm{~V}$ was recorded as 'a stallatico lens' and intuitively attributed to the Minaean or even the Islamic period. the manure units of the post-Sabaean period on the upper talus, but even appears to anticipate the Minaean positional-behavioural pattern of stationing pack animals on the talus a short distance below a town wall. (Here this supposed town wall would have been Wall F4.) Furthermore, is there any relationship with - or analogy to - the dromedary coprolites of cut 102 in quadrangle E2? If they came from unit SE3 they would be Stratum R (also Sabaean 2) and could suggest the occasional stay of dromedaries along Wall F4 - a notable case for the Sabaean (cf. section 6.3, 'Lithostratigraphy of Stratum R'). The upper unit of 

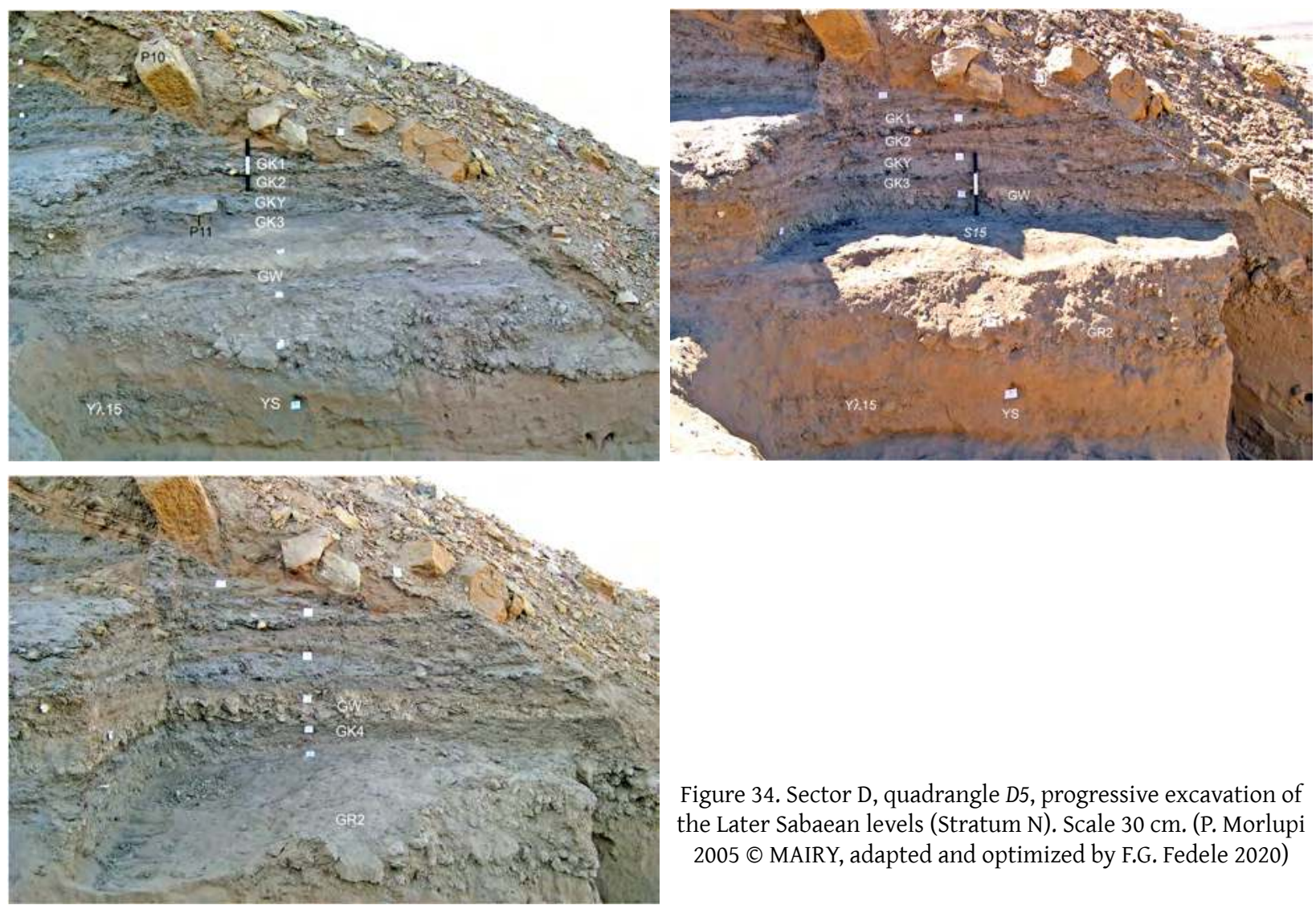

Figure 34. Sector D, quadrangle D5, progressive excavation of the Later Sabaean levels (Stratum N). Scale $30 \mathrm{~cm}$. (P. Morlupi 2005 ( ) MAIRY, adapted and optimized by F.G. Fedele 2020)

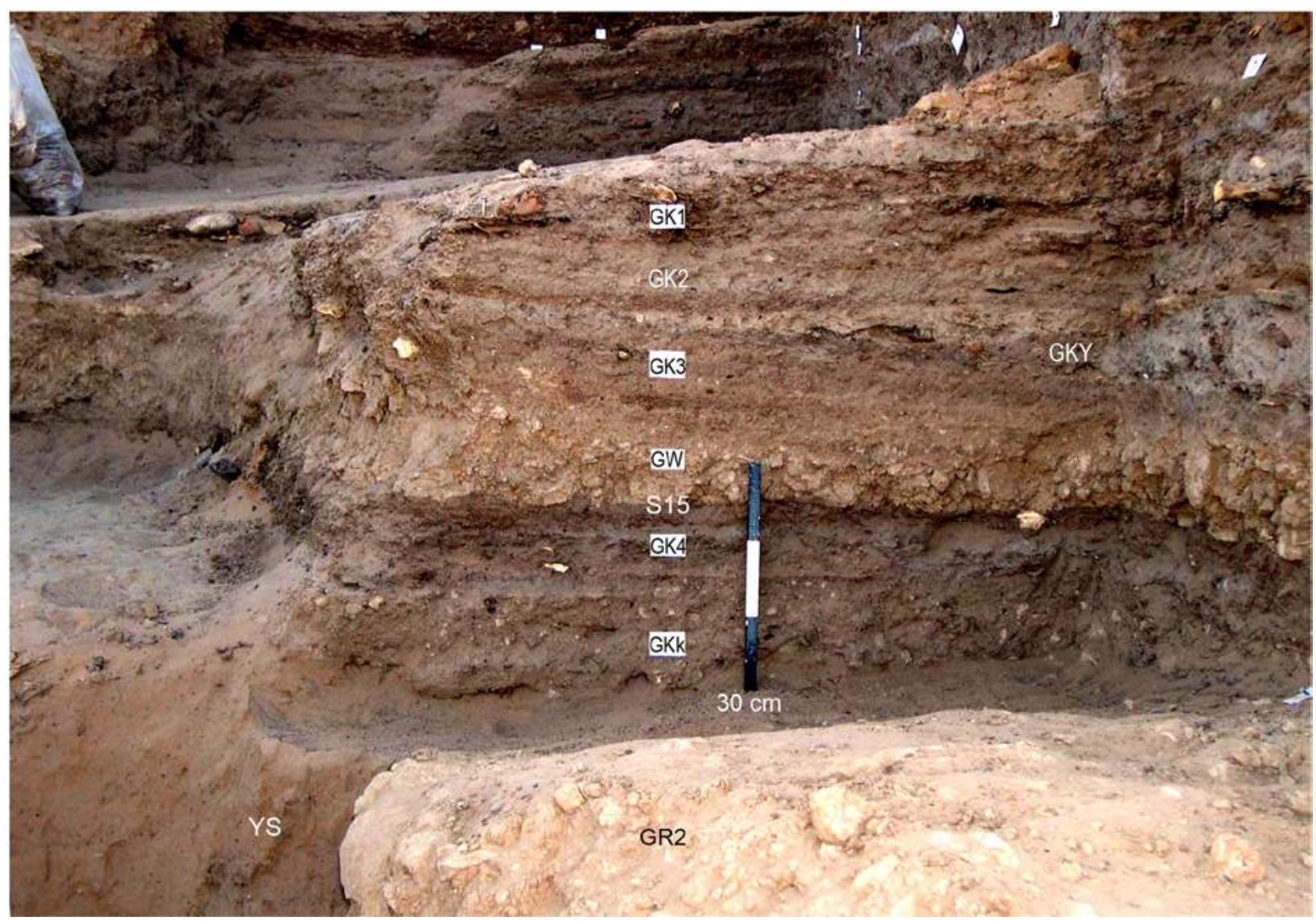

Figure 35. Sector D, quadrangle D5, east section. (P. Morlupi 2005 @ MAIRY, adapted and optimized by F.G. Fedele 2020) 

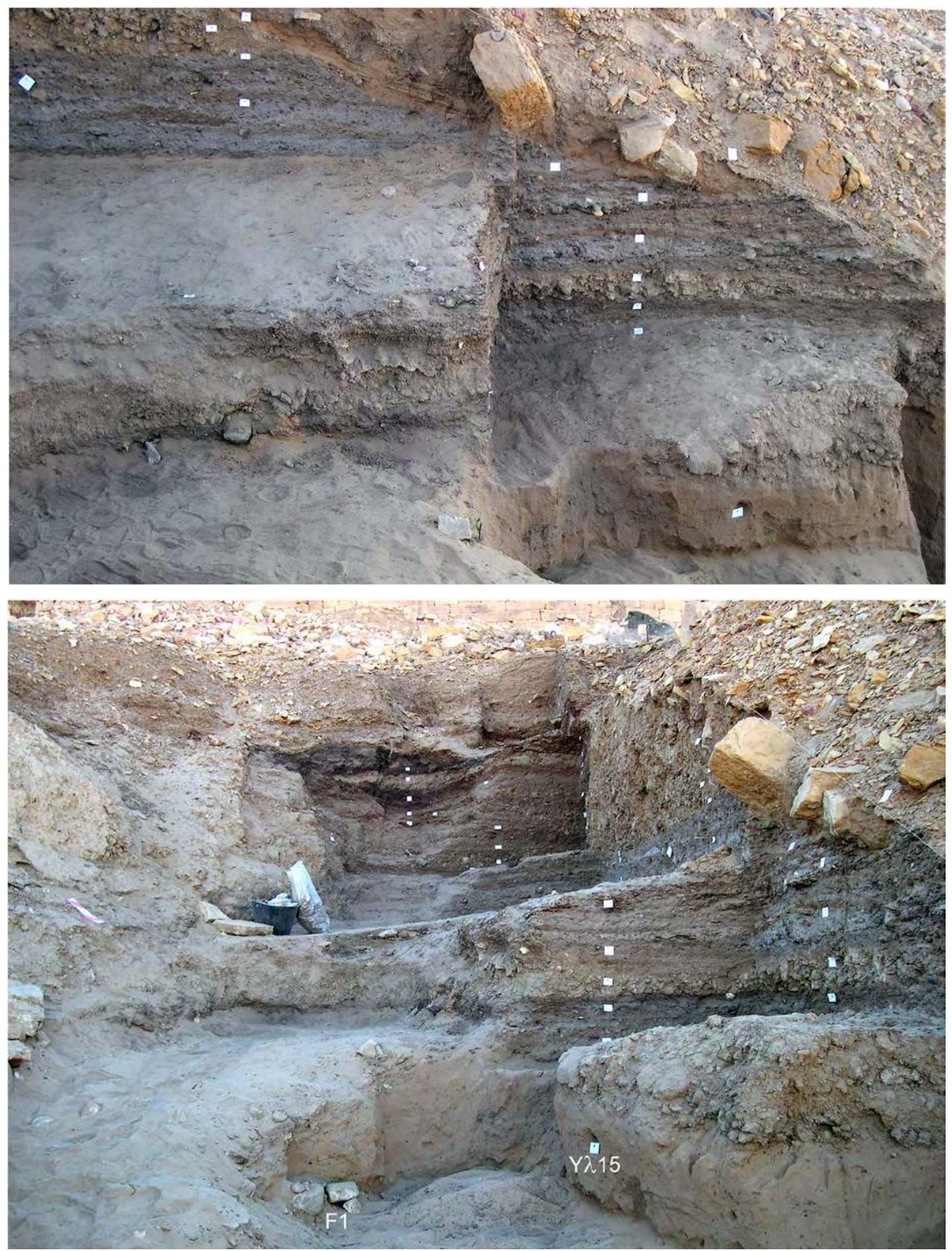

Figure 36. Gully B and middle Sector D under excavation, facing south (above) and east (below). (P. Morlupi 2005 @ MAIRY, adapted and optimized by F.G. Fedele 2020) 

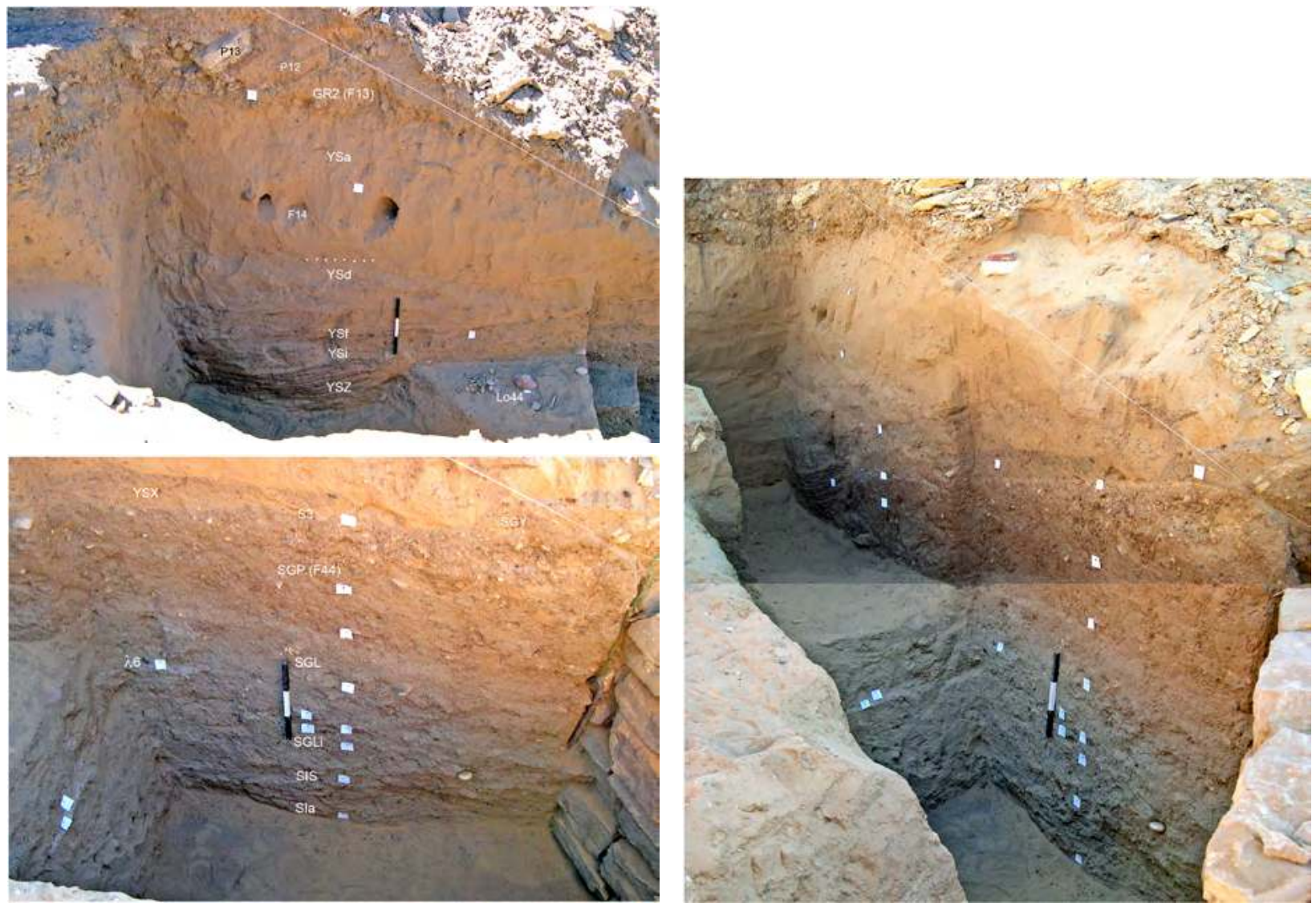

Figure 37. Sector D, quadrangles D6-D7, Reference section. Scale $30 \mathrm{~cm}$. (P. Morlupi 2005 @ MAIRY, adapted and optimized by F.G. Fedele 2020)

suite $6 \mathrm{UV}, 6 \mathrm{U}$, was one of those which contained large pieces of redeposited mudbrick. ${ }^{176}$

In upper Sector E, multicoloured units L3c, L3c2, and L3c1 appear to record a close sequence of debris slumps induced by heavy rains (cf. LE1, Stratum P). This 'stream' of redeposited occupational debris, suite L3C, was put in place by some sort of mass transport following or indeed producing - an erosional surface, S14. The concave upper half of this surface would provide a telltale sign of a 'gouging-out' process at its origin.

A few details concerning suite L3C are appropriate. ${ }^{177} \mathrm{The}$ entire plethora of bodies and micro-bodies appearing on the Reference section and now included in this suite are reduced to two sediment units only, corresponding to two consecutive 'ribbons' largely continuous with each other: L3c2 and L3c1. Each contains several subunits, mostly inclusions (Figs $41 \mathrm{~A}, 42,46$ ). L3c2 contains $3 \mu$ and $3 v$, two bands of brown inclusions which towards the northwest and on the Reference section merge into subunit $3 \mu v$; and subunit $3 \pi$, a greyish gravelly

176 See again section 6.3, 'Lithostratigraphy of Stratum R'.

177 This paragraph, together with Fig. 20, replaces Fedele 2010, 120 and fig. 134, respectively. lens. $\mathrm{L} 3 \mathrm{c} 1$ contains subunits $3 \lambda$ (brown, organic) and $3 \kappa$ ('hyper-brown'), which might in fact be facies of the same subunit. An undivided unit L3c appears instead towards the southeast (quadrangles E2-E3). This revision has revealed the internal complexity of L3c1L3C2-L3c. Details aside, L3C2 and L3C1 are two bundles of laminated-imbricated or lenticular micro-units, colluvial or from sliding, highly variable even on a submetric scale and subject to occasional fusions. As twin ribbons - or sheets - they resemble units L3f and L3e, and in the same way as L3f and L3e they are susceptible to be grouped into a suite. The predominant unit of suite L3C on the Reference section - the one better expressed - is L3C2.

Lower L3c suggests a 'convoluted', fluidal sedimentation (cf. section 6.5 above, Stratum P). Traces of one or several ancient disturbances were also detected. A fossil hollow suggesting activity from burrowing animals and a concomitant patch of mixed sediments were noted within L3C in the south section of quadrangle E3 (both marked in Figs $41 \mathrm{~A}$ and 46). In fact, this section would show along the L3c/L3bi contact a whole level of krotovinas, i.e., infilled tunnels left behind by fossorial animals (Fig. 41). These local disturbances have to do with the context of cut 110, in general, as discussed 

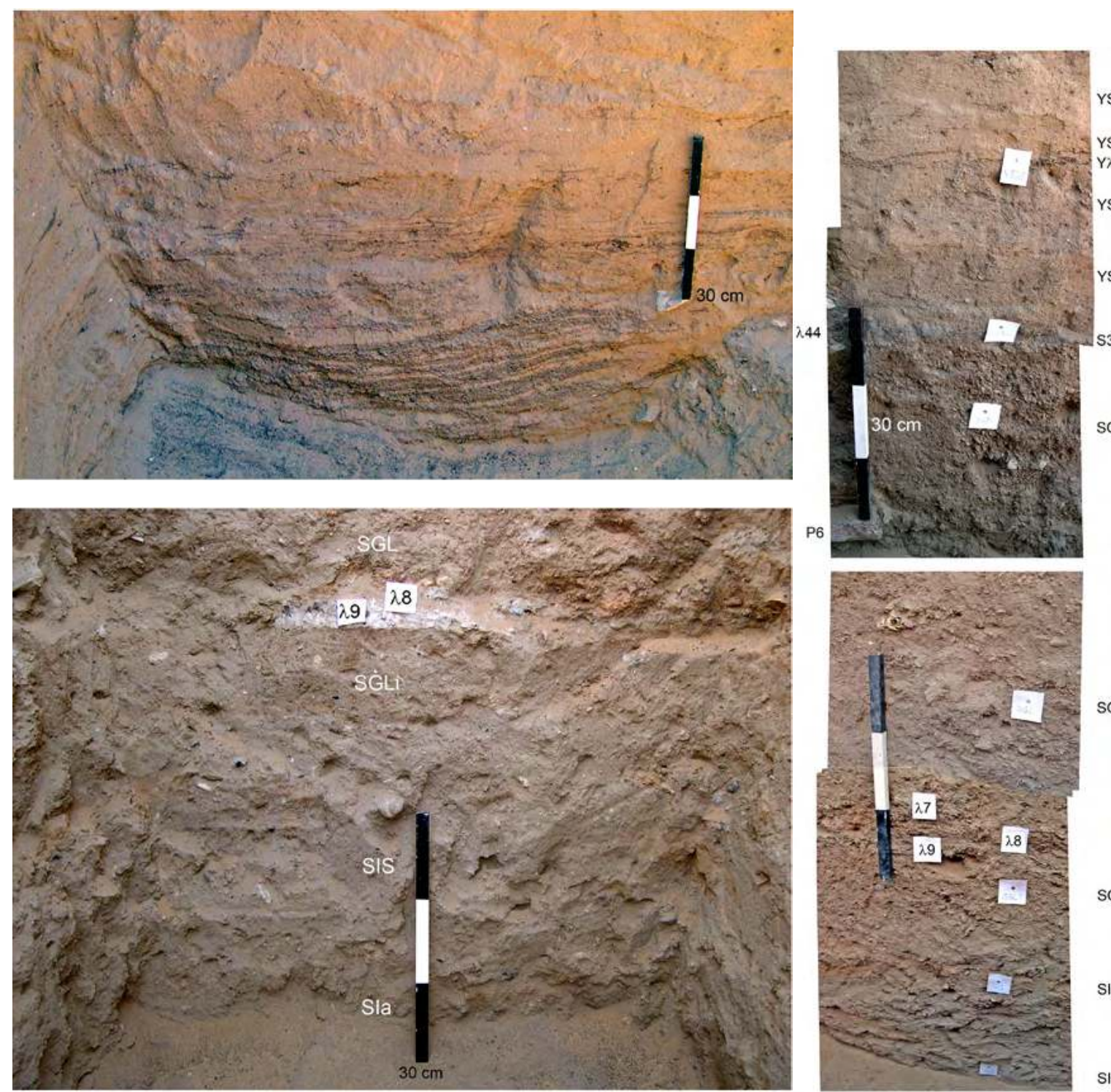

D6 (west)

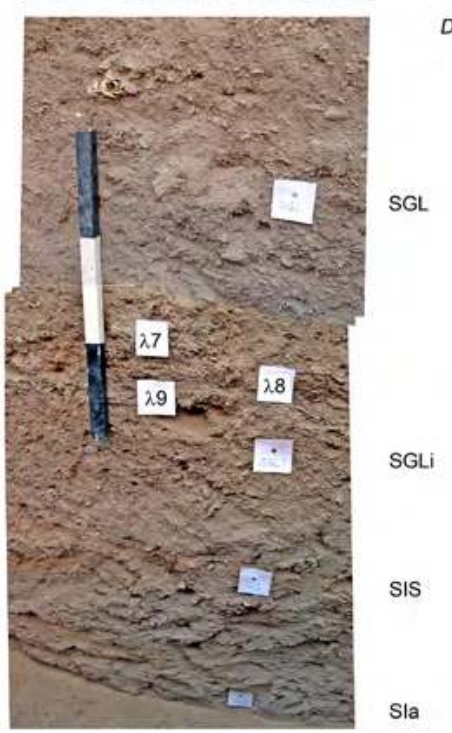

Figure 38. Sector D, quadrangles D6-D7, lithostratigraphic details. Upper left: YSZi to YSd, D6, Reference section. Lower left: SIa to SGL, D7, east section. On the right: stratigraphic column, SIa to YSd. Scale $30 \mathrm{~cm}$. (F.G. Fedele 2020, based on photographs by P. Morlupi 2005 ( ) MAIRY)

above in section 6.5 (Stratum P), as well as with object no.110.1 in particular. ${ }^{178}$ The only other instance of old animal burrows in the talus - and indeed in Area C was observed in lower Sector D, quadrangle D6: feature F14 within sand YSa (see section 6.6 above).

Finds. Finds from Stratum $O$ in Sector $E$ include a large potsherd within XE4, recorded in situ and appearing on the Reference section (no. 121.3, horizontal, not described); and fragments of clay discs in situ in quadrangles E5-E6, recut section (nos 87.5c, 87.6.1). Possibly attributable to Stratum $O$ are a softstone vessel (no. 121.01) and a clay 'tripod' (no. 121.02) from E4; a

178 See Chapter 21, section 2.5, and Chapter 23, section 3.1 (footnote 39), this volume.
Red Lustrous storage jar found in situ in E3 near the 'triangular' contact of SE3, XE4, and L3Z (no. 111.1, if indeed from unit XE4); and several finds of cut 110 (see under Stratum $P$, section 6.5 above).

\subsection{Uncertain Stratum $O(O-P)$. Horizon $H 11 Q$}

Several units of Sector E and Sounding $\mathrm{F}$ are only ambiguously correlatable with Stratum 0 . Such units include, east to west, small pockets of 'ancient' subsurface sand in quadrangles E1-E2 (SAq), a gravelly unit at trench's bottom in E5 south (5G, tentative attribution), yellow sand $\mathrm{YS}_{2}$ in quadrangle $E 8$, beige sand $\mathrm{E} \sigma \mathrm{W}_{3}$ and cultural horizon $\mathrm{H} 11 \mathrm{Q}$ in quadrangle E11, and beige-'blond' sand SY2 in Sounding F (Table 4; cf. Figs 22-24). For units $\mathrm{YS}_{2}$ and $\mathrm{E} \sigma \mathrm{W}_{3}$, as well as 


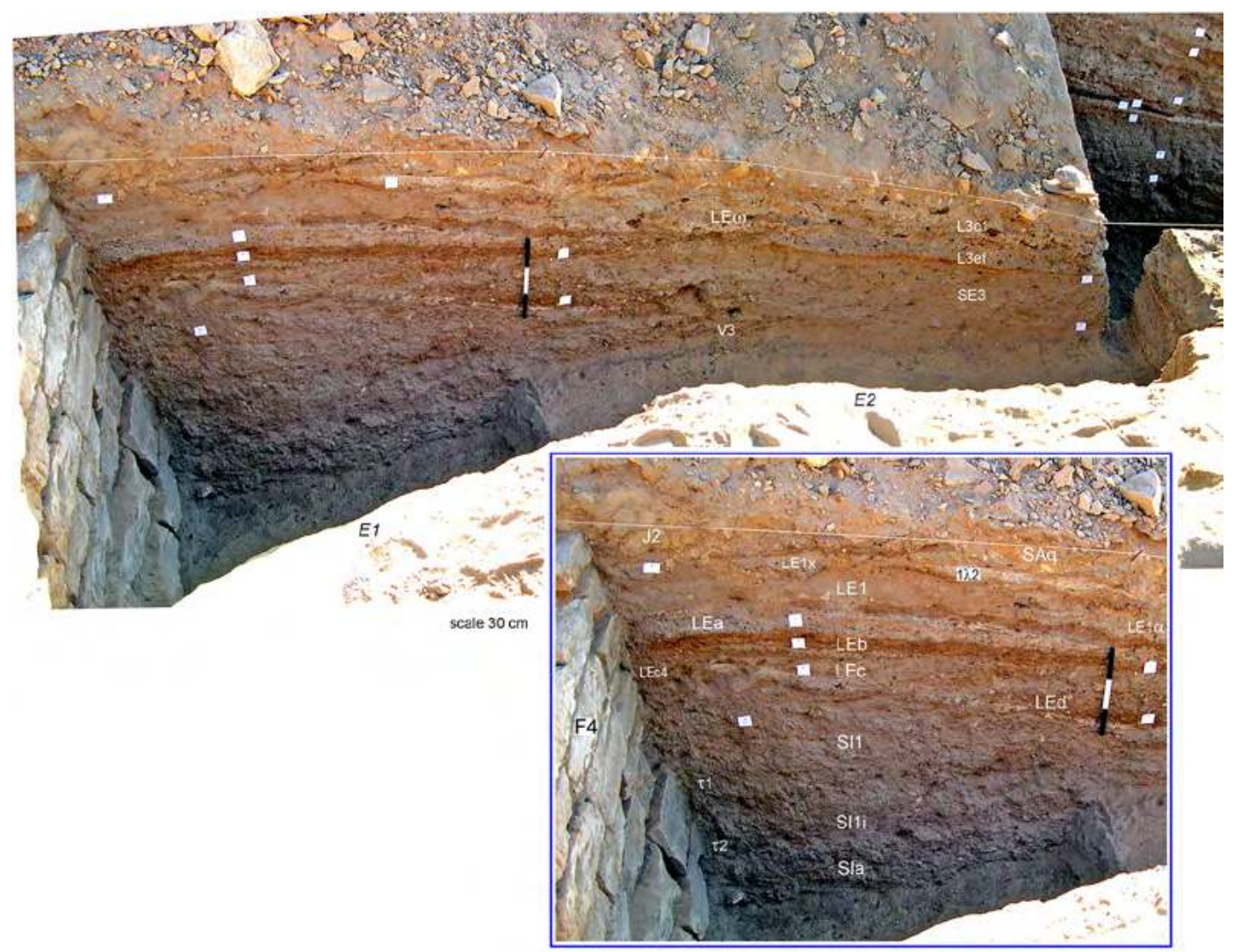

Figure 39. Sector E, quadrangles E1-E2, Reference section. (P. Morlupi 2005 @ MAIRY, adapted and optimized by F.G. Fedele 2020)
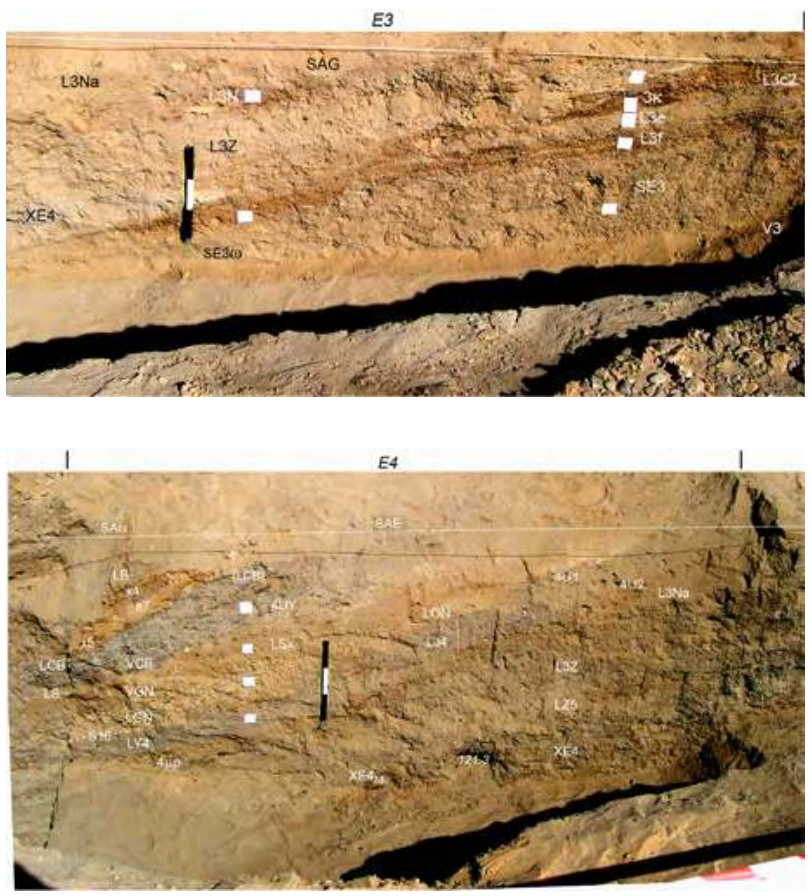

Figure 40. Sector E, quadrangles E3-E5, Reference section. E5 is shown after (above right) and before (below right) the collapse of its western part. Scale $30 \mathrm{~cm}$. (P. Morlupi 2005 ( MAIRY, adapted and optimized by F.G. Fedele 2020)
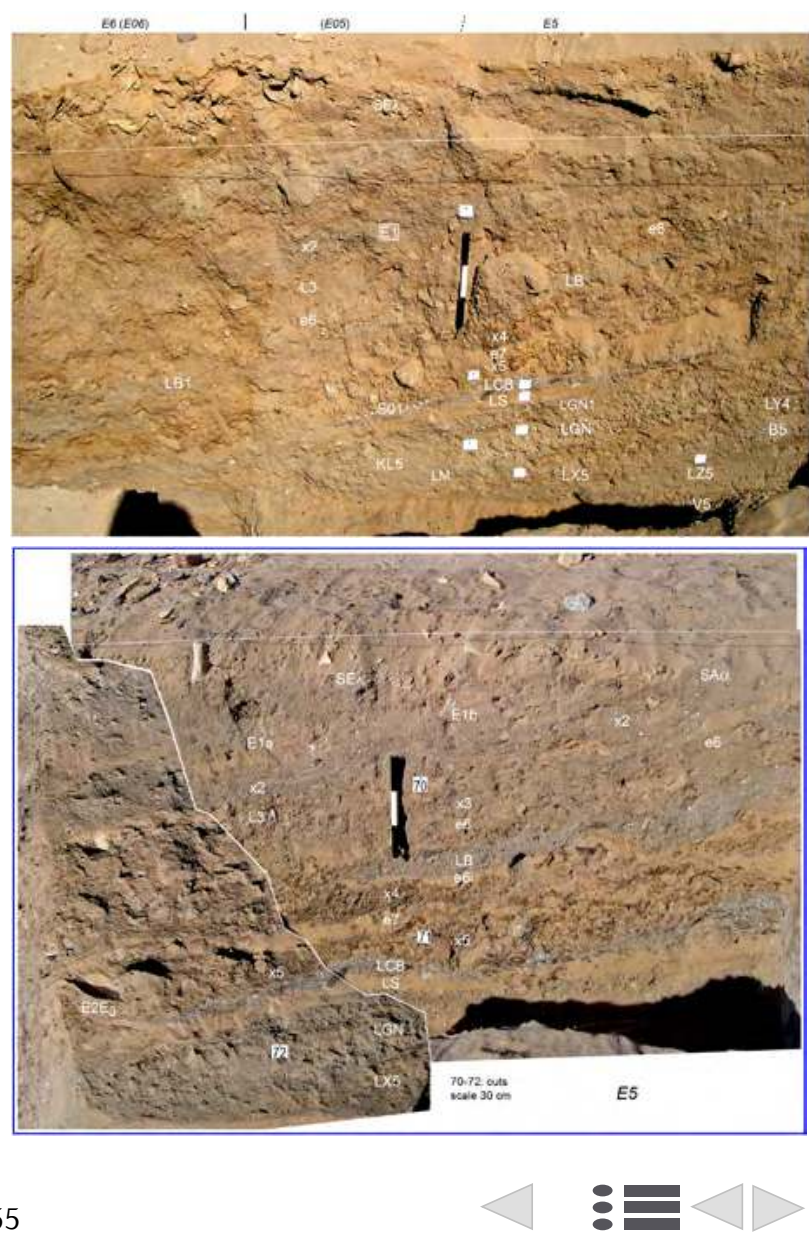

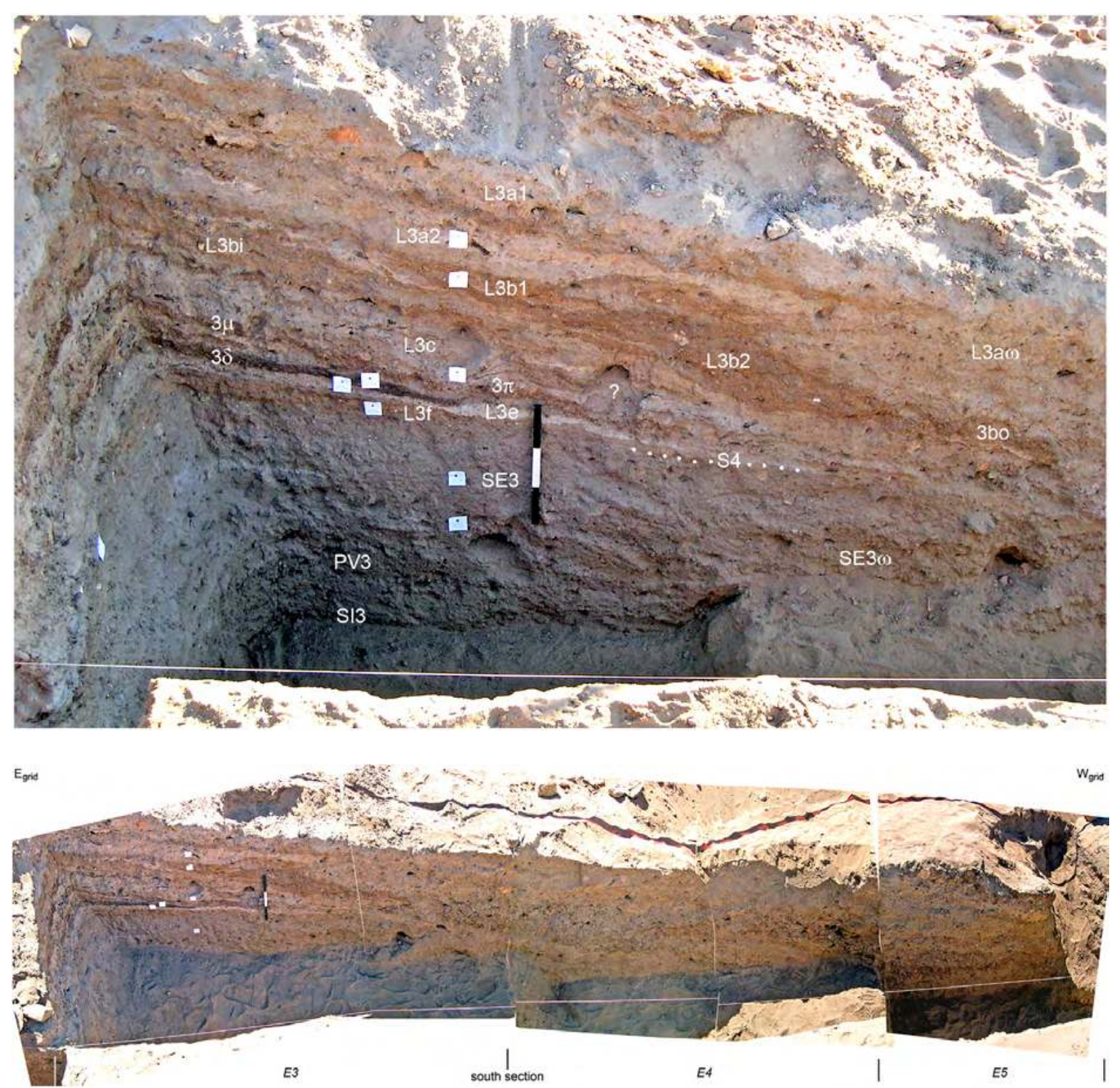

Figure 41. Sector E, quadrangles E3-E5, 'long' south section; cf. Fig. 46. (F.G. Fedele 2019, from photographs by P. Morlupi 2005 @ MAIRY)

Horizon H11Q, the alternative would be a correlation with Stratum P. There is little doubt that the terminal footslope of the talus was mantled by sands $\mathrm{YS}_{2}-\mathrm{E} \sigma \mathrm{W}_{3}$ during the same timespan when similar sands were building up a dune-like cover in lower Sector D (Sand YS).

Particularly troubling in terms of correlation was Horizon H11Q, given its apparent similarity and continuity with a locally superposed horizon, H11, this latter classified within a Stratum M (see section 7.8 below). However, since in quadrangle E11 one is confronted with a general impression of continuity throughout the blanketing sands, attention must be paid to the tiny differences or discontinuities in sediment texture or bedding.

This was the basis for distinguishing as Eøx the levels specifically containing cultural horizon H11, as well as for perceiving a very weak transition to a sand layer underneath, ${\mathrm{E} \sigma \mathrm{W}_{3}}_{3} . \mathrm{E} \sigma \mathrm{W}_{3}$ is a beige, moderately compacted medium sand below E $\sigma \mathrm{W}_{2}$ and cultural horizon H11, with the weakly bounded interposition or interdigitation of sand Eøx. It indeed resembles in texture the sand immediately above E $\sigma x$ (i.e. $\mathrm{E} \sigma \mathrm{W}_{2}$ ), whereas its colour suggests vague affinities with $\mathrm{YS}_{2}$ in quadrangle E8, and ultimately - perhaps - with Sand YS (see section 6.6 above). Horizon H11Q is embedded 


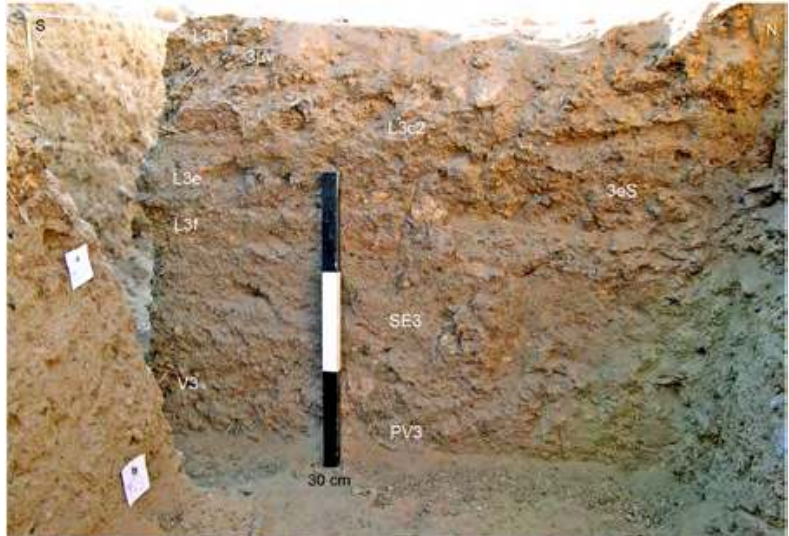

Figure 42. Sector E, quadrangle E03, the 'east-20-cm' section. (P. Morlupi 2005 @ MAIRY, adapted and optimized by F.G. Fedele 2020)

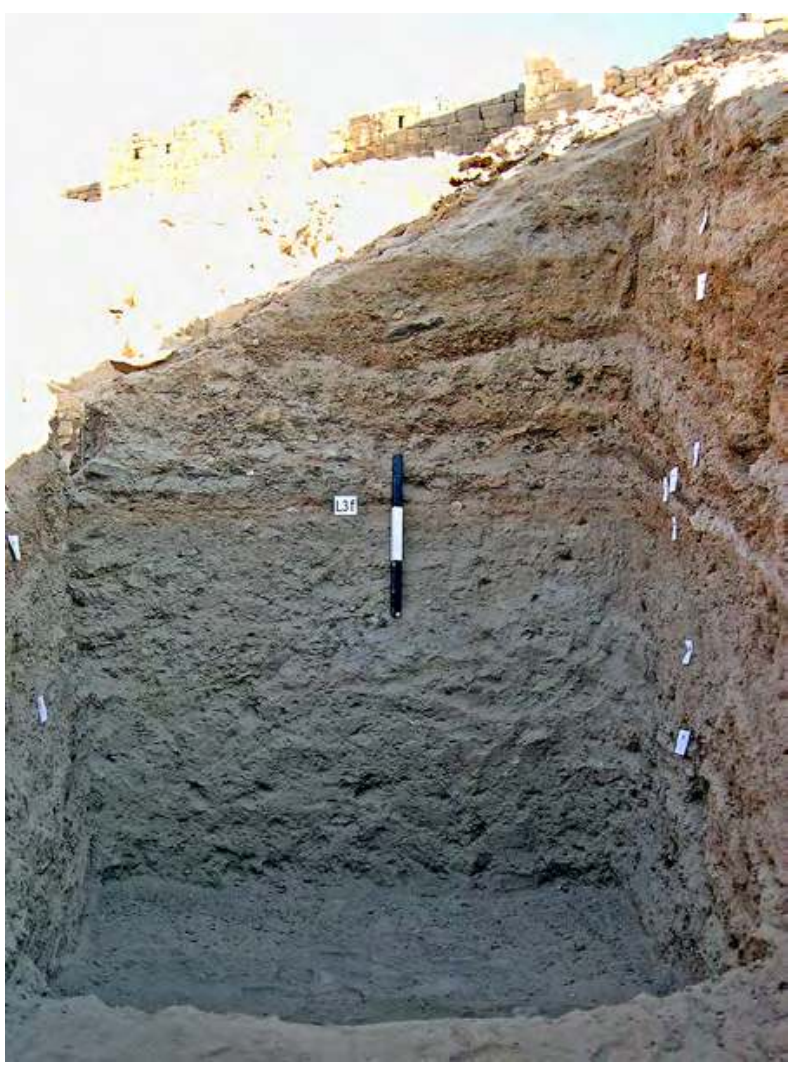

Figure 43. Sector E, quadrangle E3, east section. Scale $30 \mathrm{~cm}$. (P. Morlupi 2005 @ MAIRY, optimized by F.G. Fedele 2019)

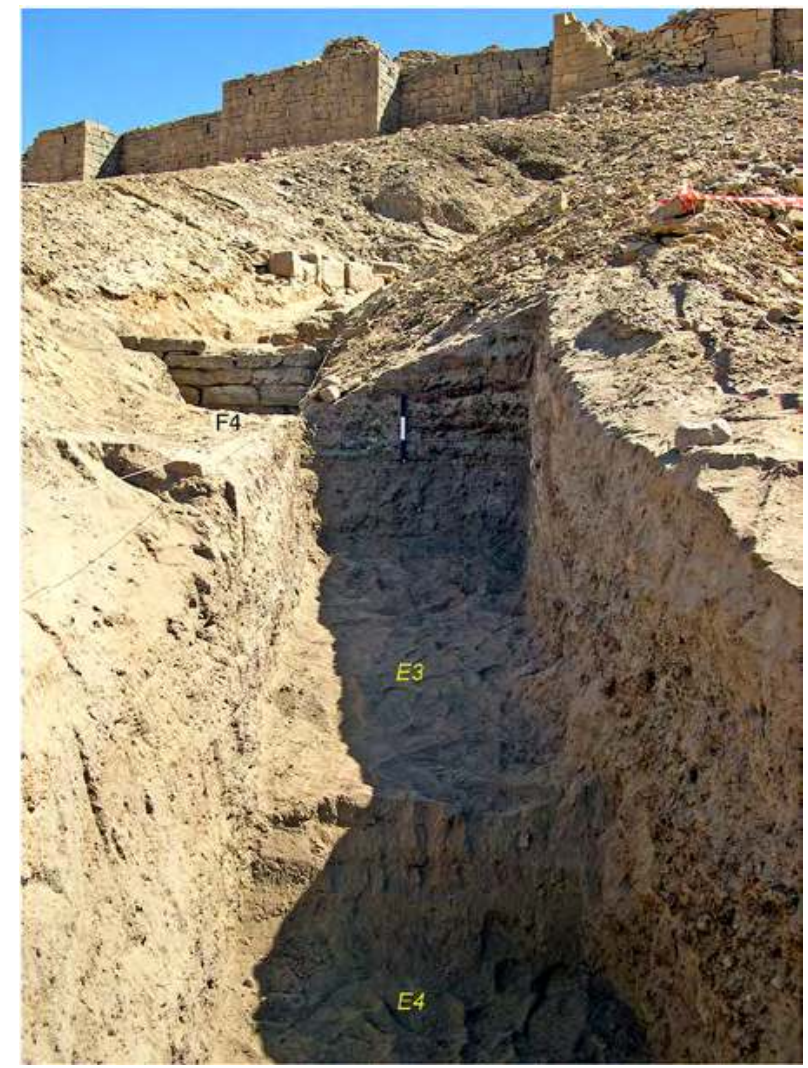

Figure 44. Sector E, quadrangles E3-E4 under excavation, facing east. The $30-\mathrm{cm}$ scale is placed on the east section of E3 (cf. Fig. 43); Sabaean Wall F4 stands out in the middle distance, with Gully B in the background. (P. Morlupi 2005 (c) MAIRY, adapted by F.G. Fedele 2020)

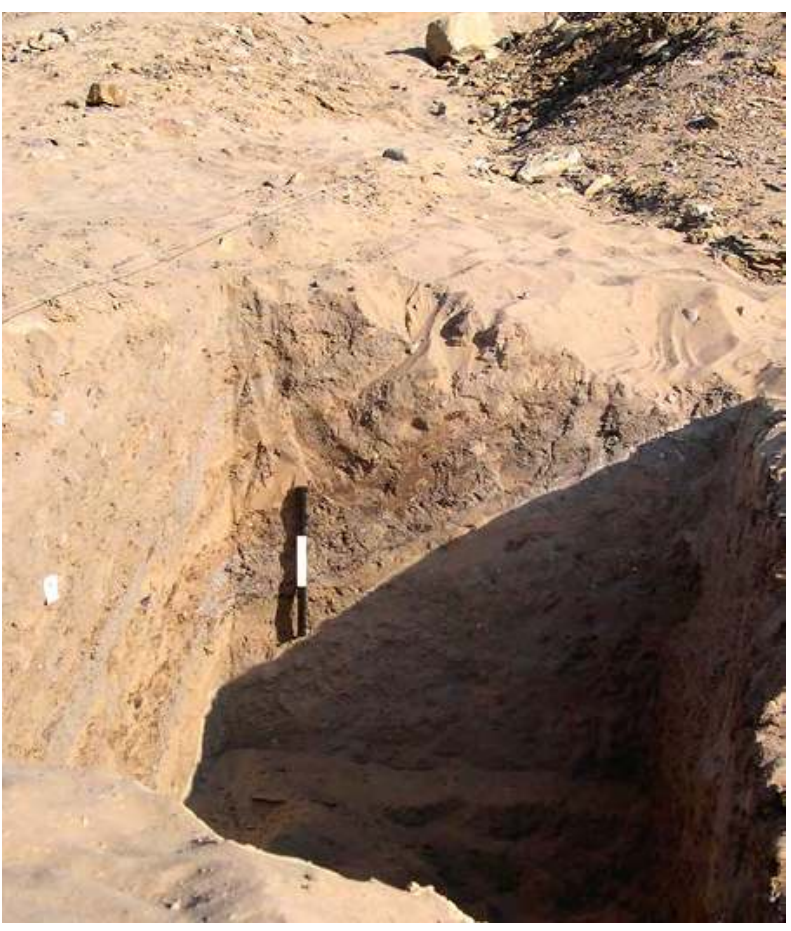

Figure 45. Sector E, quadrangle E5, east section, showing north-dipping sedimentation surfaces. Scale $30 \mathrm{~cm}$.

(P. Morlupi 2005 @ MAIRY, optimized by F.G. Fedele 2020) 


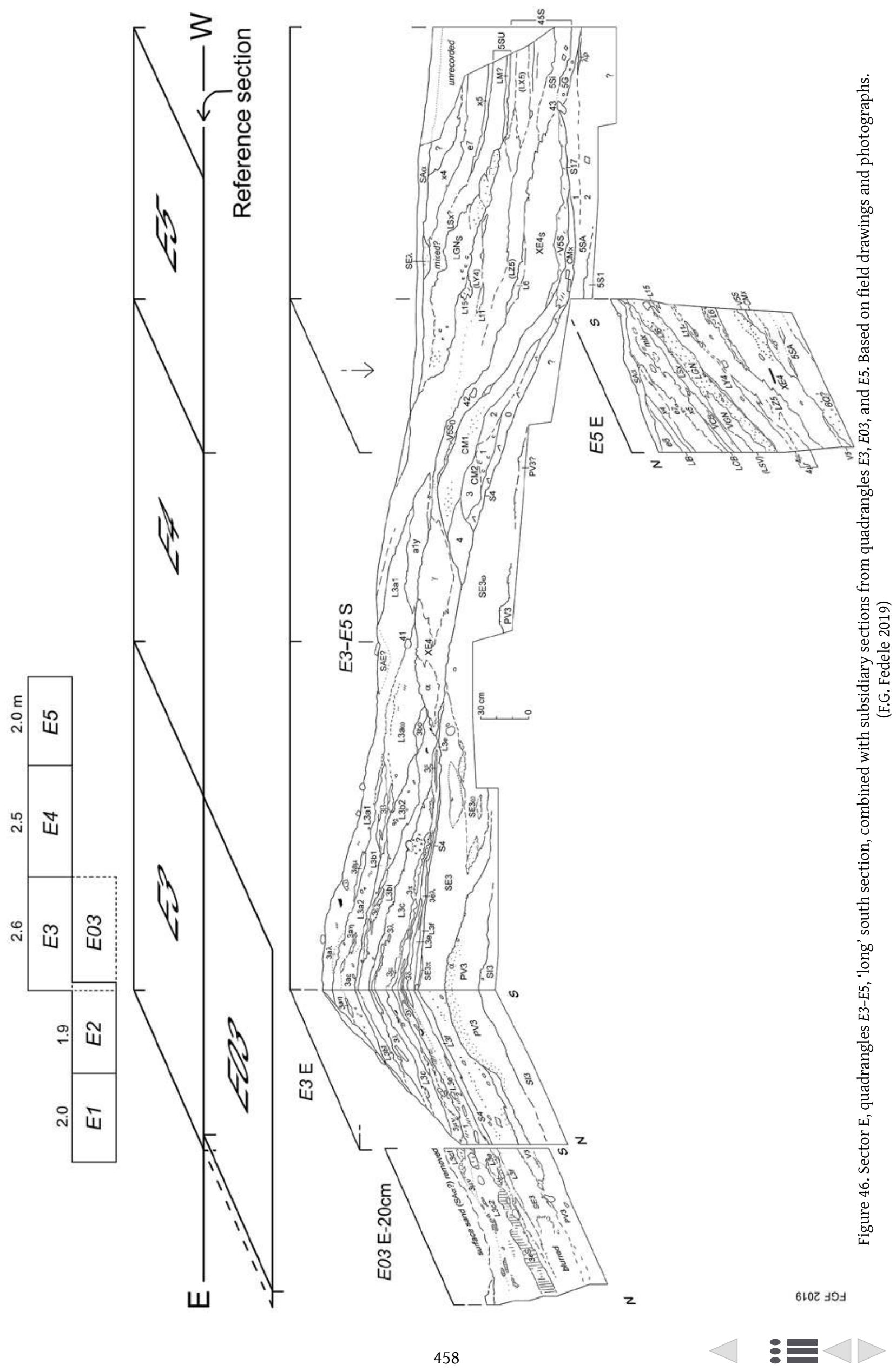



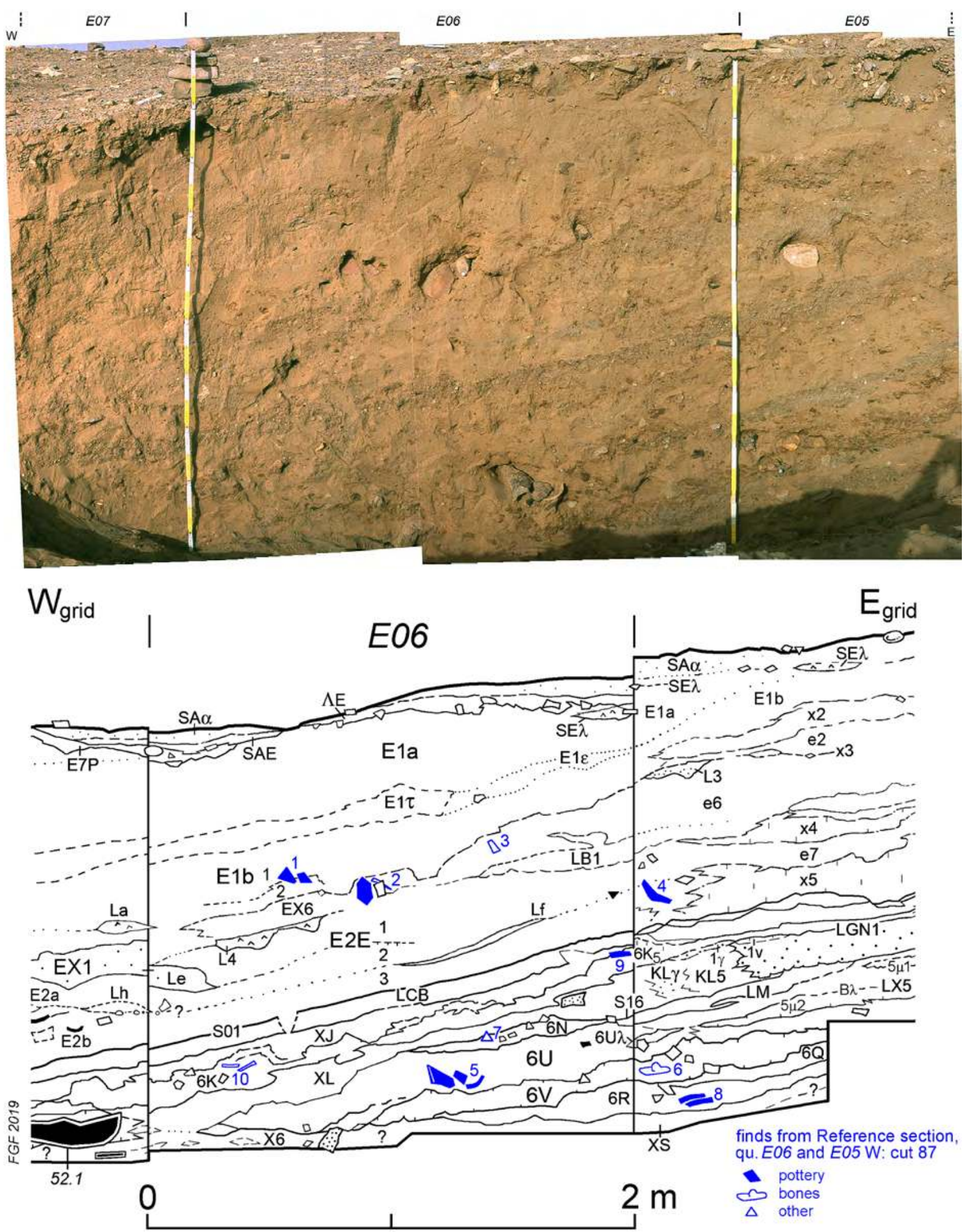

Figure 47. Sector E, Reference section for quadrangle $E 6$ obtained from quadrangle E06 in December 2006, including portions of contiguous E05 and E07 (above); and location of individual finds from the section (below). (F.G. Fedele 2006 and 2019 ). 


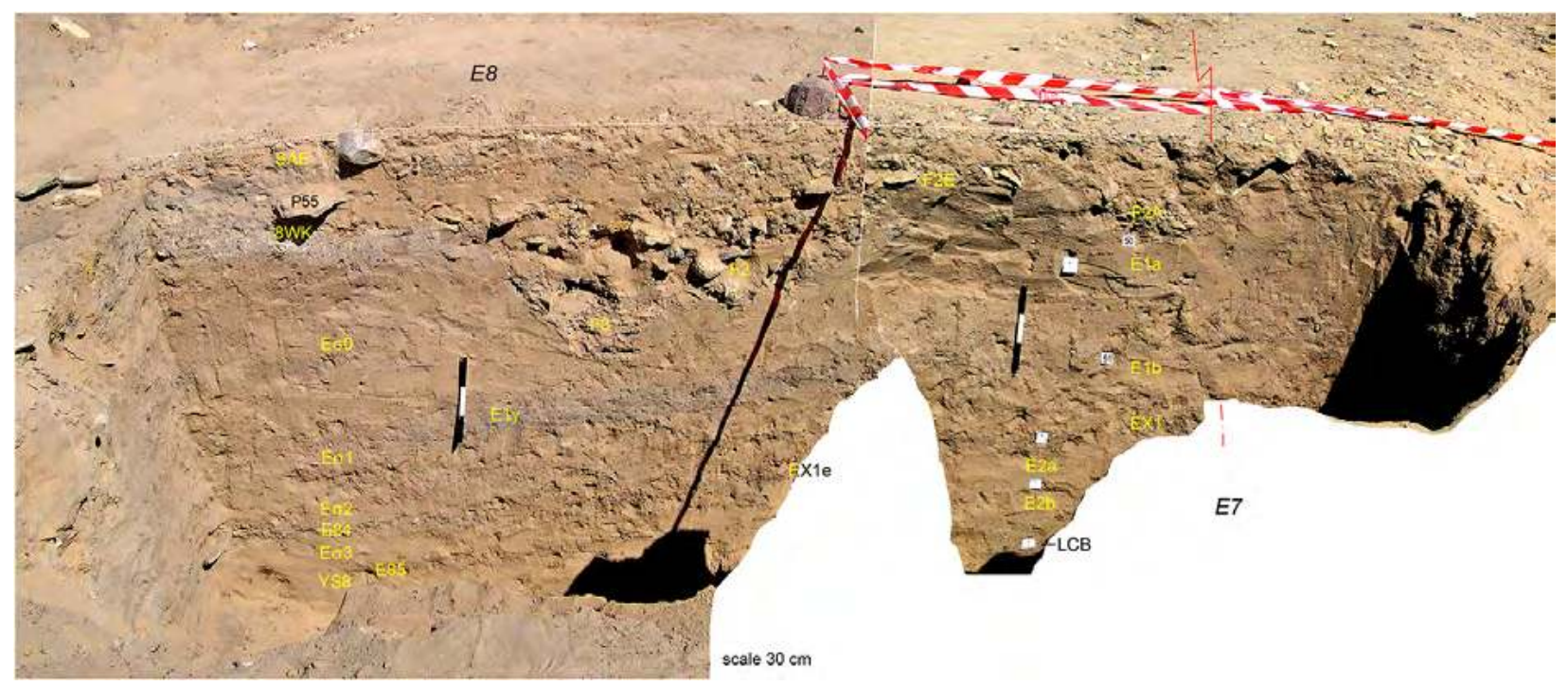

Figure 48. Sector E, quadrangles E7-E8, Reference section. (P. Morlupi 2005 @ MAIRY, assembled and optimized by F.G. Fedele $2008,2020)$

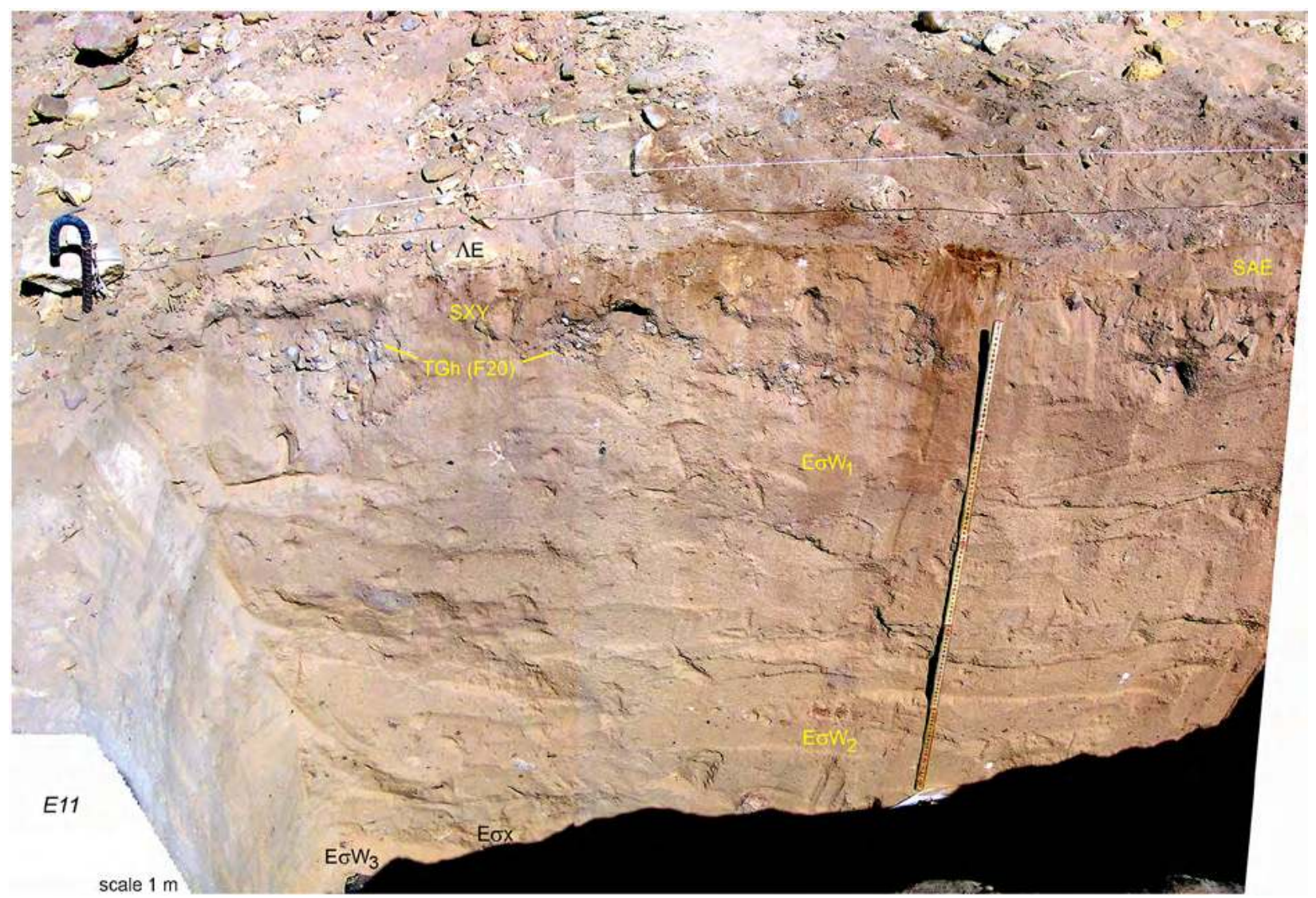

Figure 49. Sector E, quadrangle E11, Reference section. (P. Morlupi 2005 ○ MAIRY, adapted and optimized by F.G. Fedele 2008, 2020) 


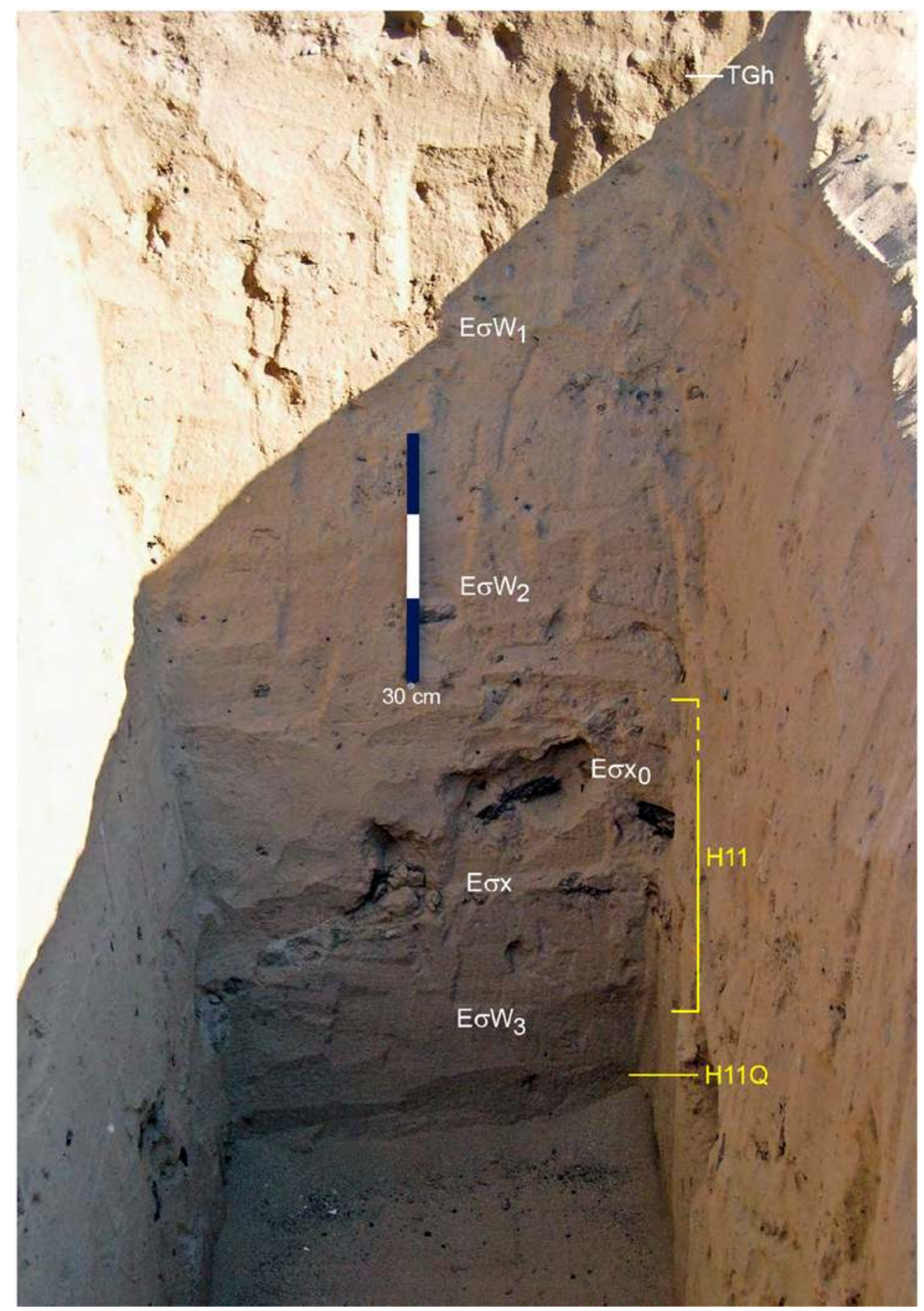

Figure 50. Sector E, quadrangle E11, east section. Cf. Fig. 72. (P. Morlupi 2005 @ MAIRY, adapted and optimized by F.G. Fedele 2020)

in sand $\mathrm{E} \sigma \mathrm{W}_{3}$. Therefore, in principle, a lithological and chronological separation of Horizon H11Q from Horizon H11 can be proposed, together with a cautious correlation of $\mathrm{H} 11 \mathrm{Q}$ with an earlier stratum than M: that is, Stratum O (cf. sand YS8 and most of Sand YS), or even Stratum P. Whether at the bottom of the trench in quadrangle E11 we can indeed glimpse the top of a new sediment unit, as perceived in excavation, is impossible to tell.

\section{Cultural horizon H11Q}

Horizon H11Q (Q from 'quern') was revealed almost at the bottom of E11 by an apparently isolated quern embedded in sand $\mathrm{E} \sigma \mathrm{W}_{3}$, find no. 152.1 (Figs 71-72, $51 \mathrm{D}$; description in Chapter 21, section 2.1, Fig. 12, this volume). However, the horizon also produced seven Sabaean pottery sherds (cut 152) showing a rare association of exfoliation and minimal wear (grade 1). 

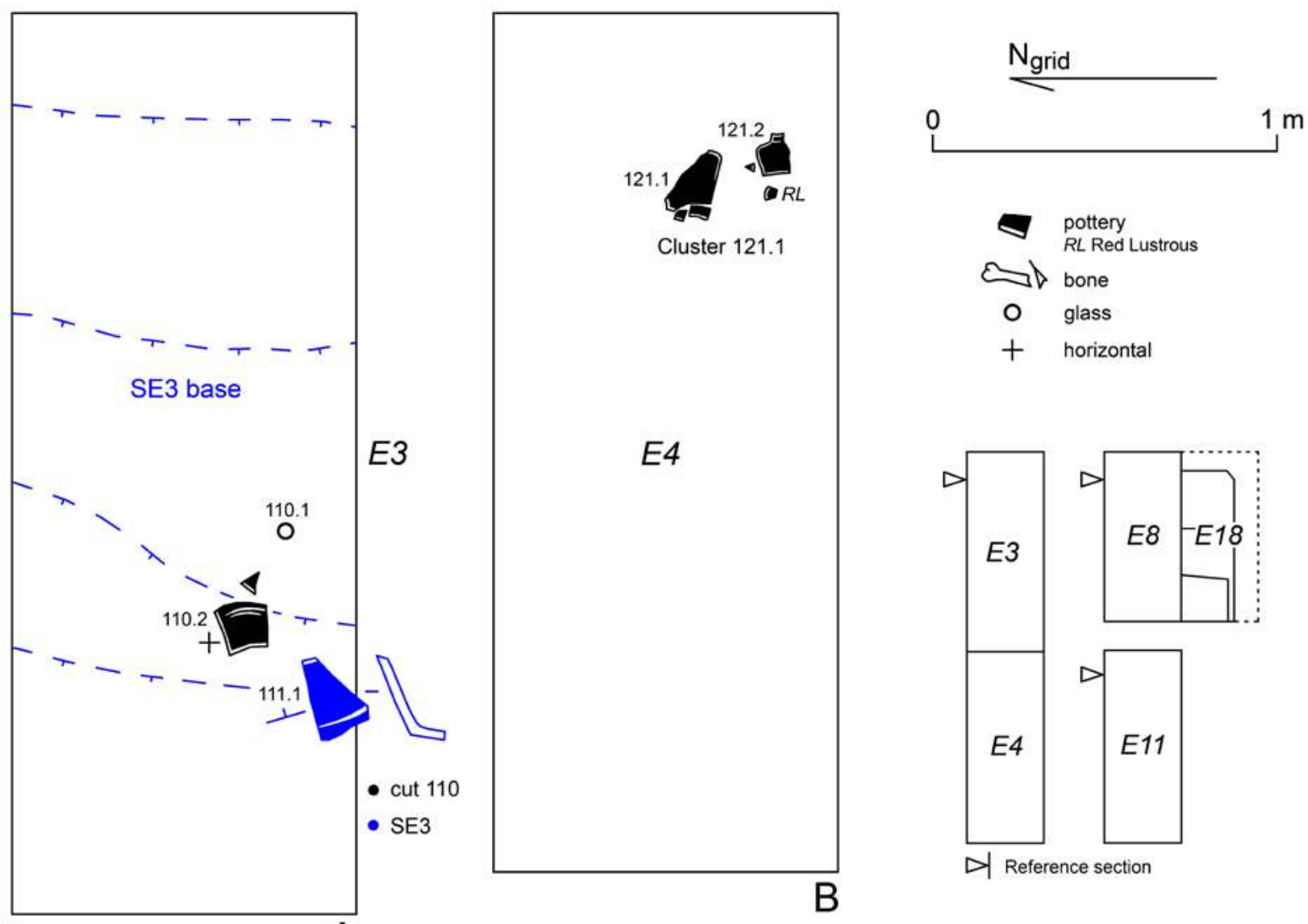

A
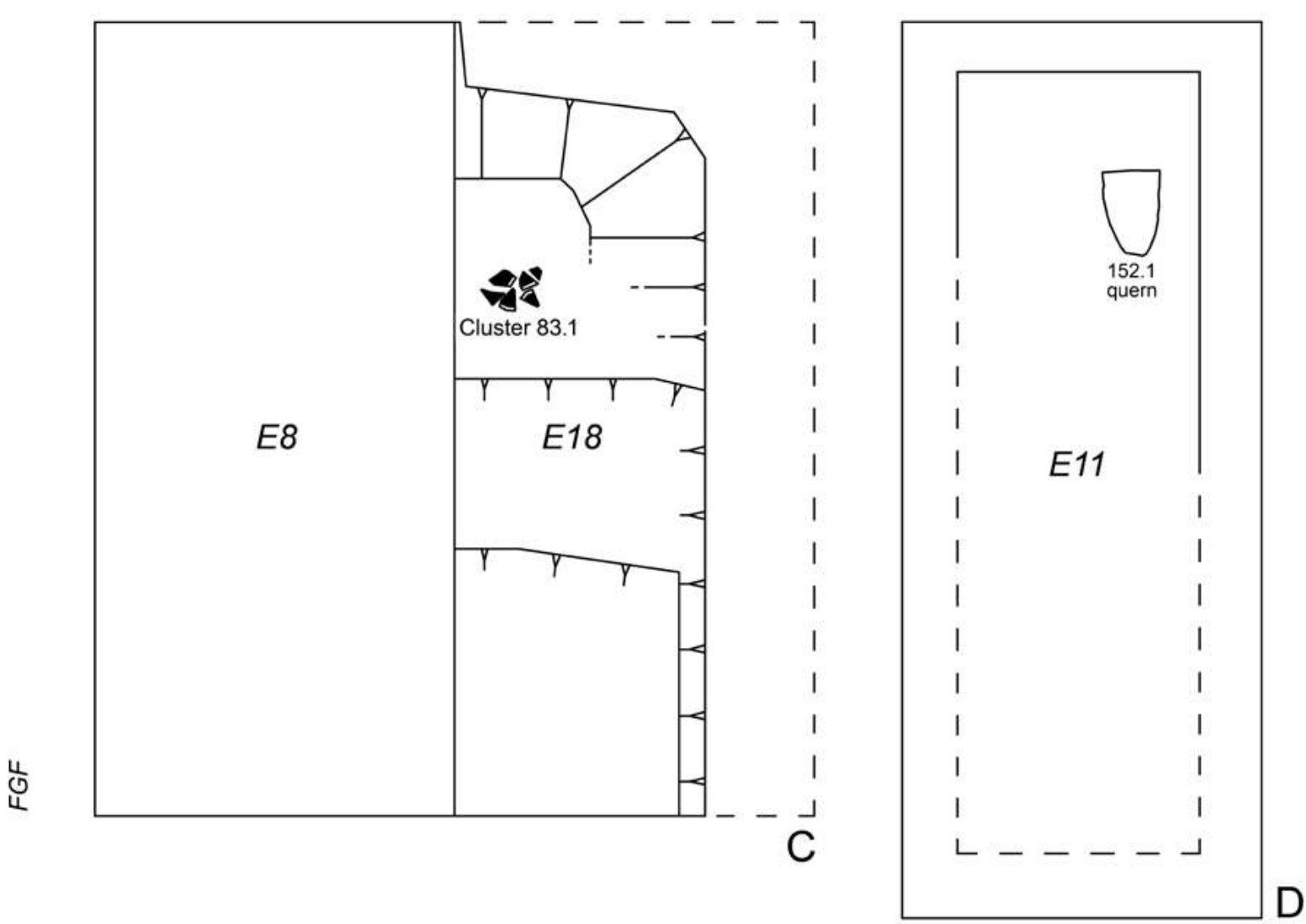

Figure 51. Sector E, plans and composite plans. A: cuts 110 and 111, quadrangle E3. B: Cluster 121.1 (unit L3Z), quadrangle E4. C: Cluster 83.1, quadrangle E18. D: Horizon H11Q, quadrangle E11. (F.G. Fedele 2005 and 2020) 


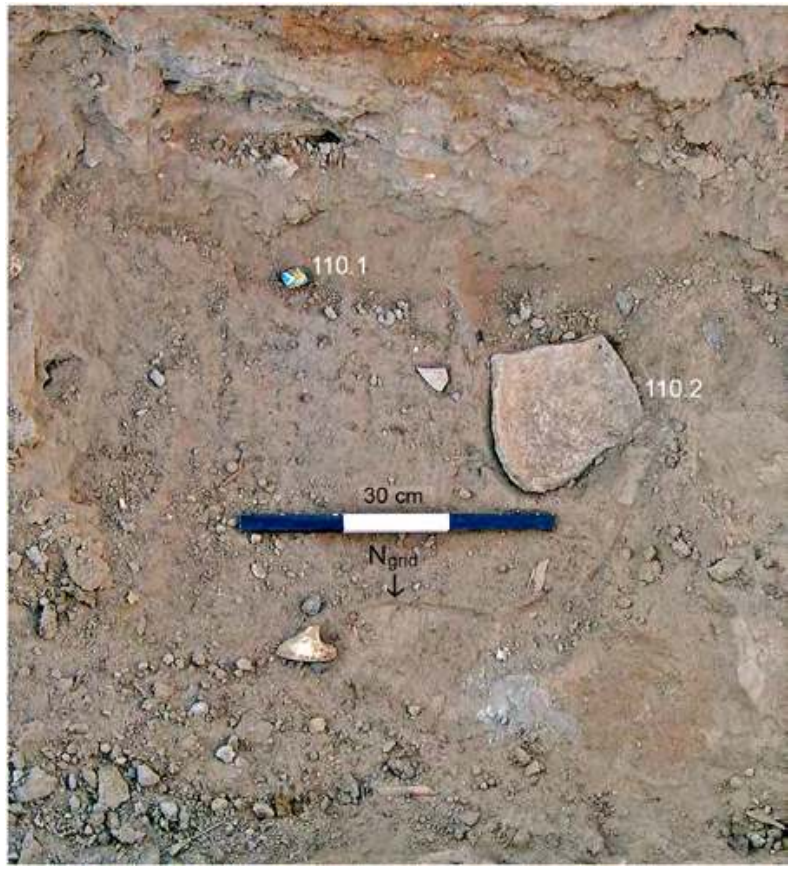

Figure 52. Sector E, quadrangle E3, finds no. 110 in situ. (P. Morlupi 2005 @ MAIRY, optimized by F.G. Fedele 2020)

This condition suggests that the cultural material was buried by sand rather quickly. The potsherds were retrieved from the west section of quadrangle E11 just below those belonging to level 1 (?) of Horizon H11 (Fig. 22).

Already in the field, the hypothesis was entertained that a heavy object such as a quern, enveloped in sands that might have loosened during the rains, could have migrated downwards from an original position within Horizon H11. This remains a theoretical possibility. However, the co-occurrence of ceramics at the very same level as the quern, and the apparent integrity of the $\mathrm{E} \sigma \mathrm{W}_{3}-\mathrm{E} \sigma \mathrm{x}$ sediment sequence (within the limits of both excavation and observation), rather tend to support the interpretation that $\mathrm{H} 11 \mathrm{Q}$ and $\mathrm{H} 11$ are different horizons. The time elapsed between the two cannot obviously be guessed from the sediments alone; considering the relative isolation of test pit E11, only excavation of a wider area would clarify this issue. The same applies to Horizon H78, to be discussed together with Horizon H11 under Stratum M, below.

For Stratum O (?) in the plain, i.e. Sounding F, see section 17 below.

\section{Strata $\mathbf{N}$ to L: Later Sabaean}

\subsection{Overview}

Strata $\mathrm{N}$ and $\mathrm{L}$ mark the active reoccupation of the extramural sector includedinAreaC, probablyassociated with mudbrick buildings. The excavation sampled the settlement in middle-upper Sector D, but there is some evidence that mudbrick structures occupied a wider area embracing Sectors C and B and Sounding A, though perhaps sparsely. Probably continuous with this slightly higher area was settlement Lobe 5 as previously defined (section 4.1) and further illustrated below. This advent of a 'Later Sabaean' occupation shows no major cultural difference from the Earlier Sabaean. In accordance with the lithostratigraphic distinction of suites $\mathrm{GK}$ and GZ two subphases can be proposed, Sabaean 3 and 4 .

These are no more than conventional subdivisions, however. The available information from Strata $\mathrm{T}$ to L suggests complete continuity within an evolving Sabaean tradition, of which the continuing adherence to an established manner of pottery making was a chief component. ${ }^{179}$ From style and technology of pottery production as well as lithostratigraphy, Strata $\mathrm{N}$ and $\mathrm{L}$ belong in this tradition and must be regarded as the latest phase in the Sabaean occupation of Yathill. A rise in the frequency of Beige Plain ware and 'shoddy' Red Lustrous productions from the beginning of suite GZ onwards (the 'epi-Sabaean' ceramic aspect), ${ }^{180}$ on one hand contributes to characterize Stratum L, on the other hand represents no more than a fluctuation in a long-lived tradition. Intuitively, a minimum of one generation should be allowed for the accumulation of suites GK and GZ. The top levels, unit GZV and surface S2, are the last to contain well-documented, freshly made Sabaean pottery. ${ }^{181}$

GK and GZ are conformably and clearly stratified in Sector D (Figs 18-19, 34-36), and their depositional style is entirely concordant. Only minor environmentally produced markers, such as higher calcium carbonate levels, and a difference in organocultural residues GK contains much more and better preserved vegetal debris - justify a separation. Sedimentation is more markedly horizontal than in the Earlier Sabaean deposits. Domestic materials, mostly represented by organic occupational debris, are abundant and often clustered and patterned. Sometimes they suggest in situ discard, if not actual habitation on the spot of excavated Sector D; in any case, there must have been habitation nearby. The dumping of kitchen refuse is documented (e.g. Locus 33).

While Strata $\mathrm{N}$ and $\mathrm{L}$ were defined on the basis of the neatly stratified continuum of Sector D, with the addition of a deposit from the bottom of Sounding A at the Minaean wall (Locus 200), Stratum M was established

\footnotetext{
179 See Chapter 23, section 3.2, this volume.

180 Such as observed with unit GZ3 in quadrangle D5 (cut 37): see Chapter 23, section 3.2, this volume, and cf. end of section 4.1, above.

181 The relevant data are discussed in section 8, below, and in Chapter 23 , section 3.3 , this volume.
} 
so as to regroup several sequences from the foot of the Sabaean tell and the plain whose correlation with Sector D is inferential and general (parallel sequences or 'floating' blocks; see section 3.3 above). Stratum M may span the whole interval of Strata $\mathrm{N}$ and L taken together, i.e., the two stratigraphic sets may overlap completely. Therefore a temporal ordering between $\mathrm{N}$ and $\mathrm{L}$ was preferred, and the floating Stratum was assigned the label ' $M$ '. Stratum $M$ will be described at the end of this section after Strata $\mathrm{N}$ and $\mathrm{L} .{ }^{182}$

\subsection{Stratum N. The Later Sabaean tell in general}

Stratum $\mathrm{N}$ is lithostratigraphically defined - east to west - by suite SZ and units STY and SYH in Sounding A; units GR $\xi$, GKk, GK4, GW, suite GK, and surface S15 in Sector D; suites L3B, L3A, L3Nn, units L3Z, 4U2, LJ4, diagenesis zone $\mathrm{Z1}$, and surface $\mathrm{S} 16$ with diagenesis zone Z2, in Sector E. Also unit $6 \mathrm{~N}$ in quadrangles E6-E06 is probably to be included.

Unit GKk is a grey-brown sand with concretionary micronodules, very rich in cultural residue. GK4 is a dark, organic-rich, laminated sand-silt with ash lenses from occupation. GW is a distinct, grey-whitish layer with a crustiform blandly-humped top and a sharply defined base (S15). It is probably to be interpreted as a stratiform mass of melted, porous mudbrick material infiltrated by descensus of calcium carbonate: ${ }^{183}$ a virtually certain indication of mudbrick structures nearby. ${ }^{184} \mathrm{GW}$ contained four sherds of a plain vessel (wear grade 1) and some animal bones. Part of the adhering matrix on bones - a brownish-hazel, very fine sand to silt that tended to form small crumb aggregates - suggests the presence of an organic fraction in the mud bricks, either coming from a coeval anthrosol or inherited from still circulating Yathill Palaeosol silts. The bottom of GW, surface S15, would itself indicate cementation by percolating solutions at the base of layer. It represents one of the most evident discontinuities in upper Area C.

Stratiform, richly organic units GK3 to GK1 form suite GK, about half a metre thick. They display a distinctive occupation layering composed of organic debris, plant litter in particular, which tends to form a dense felt in an ashy silt matrix. This remarkable succession of nearly horizontal, slightly undulating layers with medium-sharp boundaries, intercalated by occasional

\footnotetext{
182 In connection with Stratum M an important surface, S16, needs be mentioned, as in quadrangles E7-E8 the sediments and cultural episodes marking Stratum M might correlate with this surface and geomorphic stasis. See section 7.8 below.

183 I.e., a mildly developed pedogenic calcrete, due to $\mathrm{CaCO}_{3}$ introduced from above; see (e.g.) Watson 1989.

184 Size and other details apart, GW can be compared to Mass GR1 (F9) in D2-D4, also from the viewpoint of the relationship with its resting surface, S15. See a mention in section 4.1 , above.
}

levels of calcium carbonate enrichment, afforded optimum preservation of organic elements. Such concretionary processes due to calcium carbonate deposition, which had appeared with Stratum $\mathrm{R}$ and had developed intermittently up to GK2, with limited episodes afterwards, would suggest a steady regime of seasonal rains and enhanced evaporation for about a century.

The material from GK3-GK1 points to actual 'living floors ${ }^{185}$ located close by, littered with meal residues, broken kitchenware, discarded everyday objects, mudbrick lumps, and a quantity of organic occupational debris, all exceptionally well preserved. Animal bones in anatomical articulation and many fragile artefacts in excellent condition - including textiles and an ivory comb - were recovered (see below), all resting horizontally or horizontally stratified (Figs 59-62). ${ }^{186}$ Several of these archaeosurfaces were recorded in plan (Figs 63, 66 A; and unpublished). Unit GKY, ogive-shaped in section, tends to stand out as a pack of grey-ashen silt laminae and lenses from occupation in situ and in close proximity, rich in ash and charcoal. It contains a leached hearth, and indeed it might have been a hearth in its entirety - or a stratification of hearths. Embedded in GKY, near the southeast corner of quadrangle D5, a flat limestone block was found, P11, bearing on its top a thick ashy crust of burnt residues (Fig. 34 A, 66 A).

A selection of significant finds from Stratum N, Sector D, listed stratigraphically bottom to top.

- From GK4 (cut 39, quadrangles D5-D15): deep bowls in both Red Lustrous (nos 39.03-04) and Beige Plain ware (no. 39.02); a Grey-black cooking pot (no. 39.06); a ball of fibre thread (?) (no. 39.01); and very numerous date stones (quadrangle D5).

- From GK3-GK1 (suite GK, cut 38, quadrangle D5): Red Lustrous ware, including a grip fragment of a lid (no. 38.07); fragments of clay discs and a whole 'tripod' foot (nos 38.04-06); and an exceptional quantity of cordage, textiles, leather (e.g. nos 38.01-03, cloth, rope, hide and fur; Fig. 39 in Chapter 21, this volume), in addition to wood and twig fragments, wooden sticks, and the usual seeds and dried fruits. Indeed, the excellent preservation of artefacts made of organic materials in this sediment suite, alongside the abundance of animal and plant ecofacts that could be glimpsed from the limited exposure, had been one of the reasons

\footnotetext{
185 Effectively inhabited occupation surfaces, French sols d'habitat. A more general term is 'archaeosurface' (e.g., surface S2, see section 7.5 below).

186 Cf. end of section 4.1, above.
} 
for selecting Gully B for excavation in 2005 (see section 1.2 , above, and cf. 7.5 below). ${ }^{187}$

- GK1 (quadrangle D5) was extremely rich in plant remains (10 per cent of sediment after flotation) and in cultural material, inorganic as well as organic. Very abundant cilb nutshells (Ziziphus spina-christi), charcoal, partly burnt animal bones, mudbrick-derived pebbles, cemented clods, fragments of softstone vessels, and Red Lustrous potsherds in mint condition were retrieved. Among the organic artefacts attributable to GK1 an ivory comb (no. 38.1; Fig. 38 in Chapter 21, this volume) deserves special mention.

- The top levels of GK1 in quadrangle D3 produced a unique vessel with interior handle (?) in Red Lustrous ware (no. 16.2) and a Wavy Rim bowl (vessel V16).

\subsection{Locus 200, Sounding A: the truncated Sabaean deposits beneath the Minaean wall}

In terms of both topography and stratigraphy, Locus 200 designates the primary Sabaean occupation discovered underneath the Minaean wall outside bastion T7 (Figs $17,67,86,88)$. Its deposits have been correlated as a whole with Stratum N. Although this correlation was accepted as the most reasonable on present evidence, it might need revision when future excavations could expose a wider surface of the tell in Area C. This correlation will be discussed below. Apart from Locus 200 , the archaeology and sequence of Sounding A will be treated in sections 9 to 13 .

These Sabaean tell deposits were brought to light and are only known from a restricted stratigraphic window in quadrangles A1-A11 east and A31, where they were examined on a thickness of $70-80 \mathrm{~cm} .{ }^{188}$ They represent a primary occupation characterized by hearthrelated, organic anthrosols with true ash lenses, large broken pottery in situ, and a quantity of animal bone from manifest butchering (i.e. kitchen refuse). More precisely, the Locus 200 deposits contain abundant and unusually fresh, basically untrampled ceramic material (about 30-40 per cent unworn, 50 per cent battered), including instances of sizable, still joining pottery fragments (like Red Lustrous basin 199.01; see below).

\footnotetext{
187 On the remarkable preservation of organic artefacts and biological ecofacts in these sediments see section 1.3, above; and Chapters 19 (section 4) and 21 (section 2.1, 'Artefacts made from organic materials') in this volume.

188 The exploration of the Sabaean deposits of Locus 200 was carried out over a relatively small area comprising quadrangles A1-A11 east and most of A31, for cut 199 (upper half of unit SYH), and A31 southeast in addition to A1-A11 east for cut 200 (middle SYH to bottom of sounding): see section 9, below, for details. Cf. Fig. 88.
}

Not only pottery, but most of the artefactual and ecofactual material from Locus 200 is particularly fresh-looking compared with the other Later Sabaean deposits. This means that there were actual dumps of domestic refuse, and that the burial of cultural residue was rather frequent. Such conditions suggest that Locus 200 is much closer to, or well within, an active residential area of Yathill, whereas, by comparison, the Sabaean layers in upper Sector D look vaguely peripheral. This is one of the reasons for suggesting that Locus 200 might be actually located in the neighbourhood of houses. In all respects it provides a peephole on the core Sabaean settlement, albeit on its margin (cf. Chapter 23, section 3.2 , this volume).

Distinctly organic anthrosol material forms part of the sediment matrix of both suite SZ and unit SYH. These dark-grey silts and very fine sands contain fine domestic debris, ash, charcoal, and frequent postdepositional calcium carbonate often in the form of micronodules and 'dolls' (up to $8 \mathrm{~mm}$ in size). A certain amount of gypsum or plaster crusts is common. Marked inclination, between $20^{\circ}-35^{\circ}$ east, and rhythmic zonation define suite SZ, composed of units SZ2 and SZ1 with a multitude of lenticular subunits. These appear in sections as varicoloured bands with varying thickness and junctions. The dominant alternation is between true ash lenses and purely minerogenic lenses, siltysandy-clayey, sometimes light blue to grey in colour. Unit SZ2 is sandier towards the bottom.

Unit SYH is an ashy silt partly fixed by calcitic and clay illuviation, generally darkish grey in colour. It is now soft, for instance beneath the blocks of the Minaean wall, now cemented; and it is particularly rich in fragments of soft calcium carbonate concretions and roasted, reddish-brown bones. Its upper part shows alternating red and ashen silty-clayey micro-lenses, sticky and indurated at times, topped by a mottled 'gypsum-and-ash' level with yellow 'mud' patches. A likely interpretation is that the top of SYH possibly included, or was close to, a leached hearth. It was truncated by Minaean surface S12. The lowermost unit in the locus, STY, is entirely different: it is pure silt, bright-yellow and 'muddy'. It was identified as melted mudbrick, which is of considerable interest because it might represent the top of some decayed feature or building, not unlike GR3 in Sector C or F9 in Sector D (see both in section 7.6, below).

To an unspecified extent, the deposits of Locus 200 were truncated by the foundation cutting for the Minaean wall. This means that the Sabaean tell was higher originally and Locus 200 cannot represent its summit. Layers belonging to Stratum L may well have existed at the top of the tell in the area of future Minaean bastion T7. Abundant Sabaean materials from 
the destroyed Sabaean layers on the tell's summit were reworked into the Minaean fills of the foundation trench and Earthwork F10-F12, as specified below. The fact itself that most of the layers of Locus 200 are strongly inclined suggests that the deposits nearby were originally higher. ${ }^{189}$ Concerning this last point, the accentuated dip of units SZ2-SYH is in all probability a local fact only, of the order of metres, possibly linked to a local high spot to the west which could have been a ruined building (cf. unit STY).

Why, in linking Locus 200 with the Sabaean lithocomplexes in Sector D, a correlation with Stratum $\mathrm{N}$ instead of $\mathrm{L}$ was preferred? Beyond a broad similarity to the Later Sabaean levels in upper Sector D, the Sabean deposits of Locus 200 are not identical to those of suites GK or GZ: unsurprisingly, they have their own sedimentary characteristics. For example, they are not fine, laminated, and pale like the sediments of GZ, but gravelly, dark, and faintly mottled. They show a style of occupation and discard that evokes suite GK more than suite GZ, although they do not contain as much plant detritus as GK. Therefore the correlation in question was approached (i) from a geometric standpoint, in an overall attempt to model the Later Sabaean tell, ${ }^{190}$ and (ii) on the basis of artefactual contents. The first approach was more productive (cf. Fig. 27). It was also instructive to take into account personal observations about the uppermost sediments of de Maigret's sounding at Temple A. ${ }^{191}$ From the geometric point of view, we need not forget that Locus 200 does not correspond to the top of the Sabaean deposits, destroyed by the Minaean wall, but to layers that at least for this reason should best be equated with the next-to-the-last Sabaean Stratum (Stratum N). ${ }^{192}$

The virtual identity in age of radiocarbon-dated samples \#200 and \#13 might suggest for Locus 200 a correlation with Stratum L (Chapter 18, section 1, this volume). However, the combination of inferred tell geometry and apparent affinity of cultural contents appears to be more consistent with the proposed correlation with Stratum N. A correlation with suite SD2, i.e. Stratum K, was examined but easily refuted. ${ }^{193}$

\footnotetext{
189 A geometric implication concerning the Minaean wall will be examined in section 10.1, 'The Later Sabaean tell at the time of the Minaean walling', below.

190 See section 10.1 below, as in the previous footnote.

191 Personal notes 17 December 2006; the sounding was inspected at the invitation of A. de Maigret. See de Maigret 2010a.

192 For what it's worth, the upper limit of Locus 200 (surface S12) reaches the top of suite GK if one extends it horizontally.

193 In spite of their depositional resemblances, a correlation of Locus 200 with suite SD2 (Stratum K, First Intermediate; see section 8 below) appears untenable on grounds of tell geometry. The problem of the shape and structure of the Later Sabaean tell is impossible to work out precisely on available evidence.
}

A selection of significant finds from Locus 200, listed stratigraphically bottom to top, with detailed taphonomic information.

- Cut 200. SZ2-SZ1 and lower SYH (no finds from STY). Copious pottery was retrieved, including Red Lustrous, pattern-burnished vessels (nos 200.03-05); a Beige Plain storage jar (no. 200.06); two 'eggshell' Beige Plain vessels (nos 200.08-09); and two Wavy Rim bowls of variant A (vessels V200.01 and V200.02). A fragmented cowrie was also found (no. 200/58).

With a predominant edge wear grade of $2 / 3$ or 2 the ceramic material is marginally more angular - 'fresher' - than that of cut 199 . The condition of surfaces is a mixture. In particular, 60-70 per cent of Red Lustrous ware is highly fragmented, with sizes varying from centimetre to medium (i.e. c. $5 \mathrm{~cm}$ ), and the same range of values is also true for the Beige Plain. Therefore, intense trampling? As a whole, the material in cut 200 is modestly encrusted, and the crusts are mostly 'punctuations' of chalky white calcite, dustystaining and soft.

- Cut 199. Middle-upper SYH. These sediments preserved the base of a large, thin-walled basin in Red Lustrous ware, minutely fragmented in situ and also noteworthy for its impeccable redcoralline appearance (no. 199.01; Chapter 23, section 3.2 and Fig. 19, this volume). A patternburnished Red Lustrous vessel (no. 199.02) and a Red-slipped 'kitchen' bowl with a concave base (no. 199.05) can also be mentioned. From an ashen-red silty-clayey lens in middle-upper SYH an obsidian core (no. 199.03) and a fragment of a softstone vessel (no. 199.04) were retrieved.

A fraction of the ceramic material shows battered surfaces (c. 50 per cent), alongside 30 or 40 per cent of much fresher fragments. Edge wear, as computed from lustrous wares only, is distributed as follows: grade 0, nine sherds; grade 1, 27 sherds; grade 2, 25 sherds; grade 3, 23 sherds; grade 4, 10 sherds; grade c. 5, 4 sherds. As a whole, the cut 199 material seems to have originated from a primary house context, with a mixture of non-transport and limited transport or trampling; not, anyway, from a 'living floor' in Locus 200 itself. Occasionally, but more often than in cut 200, the material is encrusted with chalky white calcite often mixed with ashen siltclay, bearing tiny pisolitic 'dolls'. A Red Lustrous wall fragment was covered with a thick siltash-charcoal lump from a hearth or anthrosol, grey-hazel in colour. Also Red Lustrous basin no. 199.01 was extensively covered on the exterior with a grey-beige, firm $\mathrm{CaCO}_{3}$ crust, up to 4 $\mathrm{mm}$ thick, bearing concretionary pisoliths and 
subsequently covered with an entirely different generation of soft, chalky white micro-spots (cf. Chapter 23, section 3.2, this volume).

- Clearly reworked Sabaean pottery sherds embedded in units of Stratum J (e.g. nos 194.03.103.3 and 198.01; Chapter 23, sections 3.2-3.3, this volume), are either attributable to Stratum $\mathrm{N}$ - probably the underlying deposits of Locus 200, as the most parsimonious supposition or to a destroyed Stratum L. The same can be said of a number of other finds from Sounding A. Several possible or probable Sabaean objects were reworked into Minaean layers forming Earthwork F10-F12 (cuts 194, 194A, 192), and many more such elements occur in the backfill of the Minaean foundations between surfaces S12 and S11, largely made of reworked Sabaean sediments, including finds from cuts 198 to 196. ${ }^{194}$

As probable Sabaean objects reworked into Minaean deposits we can list here the following finds, all from quadrangles A1-A11 east and A31: a Pale Green 'eggshell' bowl (no. 198.01); a necked jar apparently in Pale Green ware (no. 194.03.3); several cooking pots of Sabaean typology (nos 194.03.1-03.2); four obsidian flakes and microflakes (nos 192.02-04, 194A.02); four fragments of softstone vessels, one from a pan (nos 197.01-02, 194.02, 194A.03); an incomplete bone or ivory ring (no. 194A.01); a rubefied pebble (no. 198.03); three rubefied sandstone plates (nos 196.02-03, 194.01); and an operculum of a small gastropod (?) (no. 198.04).

A fossil Cerithium shell from Earthwork F10-F12 (no. 192.01) might be a reworked Sabaean element as well, but the possibility that it is in fact Minaean cannot be ruled out. It will be listed in section 10.3 below.

\subsection{Stratum N: the talus (Sector E)}

Only the upper half of Sector E allows an acceptably precise correlation with the tell. The processes set in motion during the timespan of Stratum $\mathrm{O}$ - tell-edge erosion, gravity-emplaced deposits - continued apace, although with interruptions. The most conspicuous deposit was L3Z in quadrangles E3-E4, a 50 to $70-\mathrm{cm}-$ thick buildup of nearly horizontal silts and sands, almost continuous with the preceding LZ5 and trailing domestic debris (Fig. 40). L3Z expanded the talus flexure considerably. A light diagenesis, Z1, appears in sediments of initial Stratum $\mathrm{N}$ in quadrangle E3: a thin, diffuse reddish-brownish band affecting lower $\mathrm{L}_{3} \mathrm{Z}_{2}$, L3f, the contact with $\mathrm{SE} 3$, and marginally penetrating into upper XE4. It looks like faint oxidation, but

194 See list in Chapter 21, section 2.1 ('Unfired or poorly fired clay artefacts'), this volume. the weathering - if any - is hardly climatic; some characteristics rather suggest infiltration and/or modification by exogenous chemicals substances (see section 4.1 above). Animal excreta leached as fluids from occupation layers GK are a possible explanation and suggest a correlation as well.

Following L3Z several colluvia were deposited (L3b to L3N $\mathrm{N}_{0}$ ) and finally capped by a mantle of 'muddy'-grey, clayey silt, LJ4 (LJ4'-LJ4"). Unit LJ4 simply repeated the pattern of previous LY4 (Stratum 0). This repetitiveness characterized the talus throughout the Sabaean 2-3 interval. A small unit rich in cultural debris, $6 \mathrm{~N}$, might represent primary in situ activity on the footslope, in quadrangles E6-E06 or nearby (Fig. 47). From 6N a crucible with copper slag was retrieved (see below).

The close of Stratum $\mathrm{N}$ is taken to coincide in Sector E with surface S16, mentioned above (section 7.1), a litho- and chronostratigraphic boundary of a certain extension and significance that was accompanied by weathering. Surface S16 can be followed over a length of 6-7 metres between quadrangles E4 east and E6E06 west and is indeed made rather conspicuous by diagenesis zone Z2 (see section 4.1 above). A moment of geomorphic stability of the talus, or stasis, is clearly associated with it. One may wonder if the continuous human occupancy of Sector D might have contributed to this momentary stability of the talus, geomorphic stasis S16. At least part of the culturally important units subsumed under Stratum M, below, can be attributed to this timeframe. S16, it should be noted, is defined as the closing surface of the sediment belt composed (east to west) of $\mathrm{LJ}^{\prime}, \mathrm{LJ} 4^{\prime \prime}, \mathrm{LY} 4, \mathrm{LX} 5, \mathrm{LM}, 6 \mathrm{~N}$, and $6 \mathrm{U}$, not as the base of LGN. It terminates Stratum $\mathrm{N}$ in quadrangles E3-E4 and a portion of E6-E06 (in these latter ending the deposition of group E56.2), and terminates Stratum $O$ over most of quadrangles $E 4-E 6$.

Finds. Significant finds were recovered from Stratum N in Sector E, particularly from quadrangles E4 and E6-E06. A near-planar ${ }^{195}$ pottery cluster was found in quadrangle E4 southeast, so-called Cluster 121.1. This cluster was located between $35-60 \mathrm{~cm}$ from the southeast corner and between $10-50 \mathrm{~cm}$ from the southern edge of $E 4,-50$ to $-70 \mathrm{~cm}$ below surface (top of cut 121), i.e. within unit L3Z and probably around the boundary between $\mathrm{L}_{3} \mathrm{Z}_{3}$ and $\mathrm{L}_{3} \mathrm{Z}_{1-2}$. In addition to a large wall fragment (no. 121.1, undescribed) and several smaller potsherds, the cluster contained a tall barrelshaped jar in Red Lustrous ware - an orcio - on whose neck-shoulder flexure a calcitic crust had preserved a fragment of a woven mat (see Chapters 21, section 2.1, and 23 , section 3.2 , this volume). ${ }^{196}$

\footnotetext{
195 'Planar': more/less parallel to the layers.

196 Erroneously listed under Stratum O in Fedele 2010, 120.
} 
Copious pottery was retrieved from unclear contexts of the same quadrangle (E4) spanning Strata O to L, including a unique flaring-neck rim with metope decoration, in an unusual combination of Red Lustrous and Beige Plain wares (no. 121.04), and a Red Lustrous medium-large bowl, possibly a crater (no. 121.05).

In quadrangle E6, a cut equally spanning several units between Strata $O$ and L produced fine Red Lustrous ceramics, including a pot with pattern-burnished decoration (no. 61.01) and a handled cup (no. 61.05), and a Beige Plain bowl unusually ornamented with a carpet of light ovoid impressions (61.02).

From the recut Reference section in quadrangle E06 south, in situ within unit $6 \mathrm{~N}$, a unique fragment of a crucible with a 1-cm-thick copper slag was extracted in 2006 (no. 87.7). This find concurs to reveal traces of smelting activity taking place during the Sabaean period at the foot of the northwestern talus and down in the plain. This group of findings is described in Chapter 21, section 2.1 ('Bronze/copper'), this volume. They include another fragment of copper-encrusted crucible from a mixed context in quadrangle D7/Gully B (no.46.02), and two tiny items from Sounding F, a copper globule (215.2) and a copper-encrusted 'glassy' fragment (214.02), for which information is given in section 17 , below.

\subsection{Stratum L: the tell (Sector D)}

Stratum L is lithostratigraphically defined by unit GR3 in Sector C and suite GZ in Sector D, this latter including mud structure F9. This structure (unit GR1 and other components) will be described and discussed in the next section. The attribution of micro-unit $\tau \gamma$ is uncertain (Stratum N or L). ${ }^{197}$ For the contribution of ceramic developments to the characterization of Stratum L see the 'Overview' (section 7.1 above).

The extramural sequence exclusively contains Sabaean pottery up to surface S2, a distinct archaeosurface in upper Sector D. ${ }^{198}$ Stratum L corresponds to the layers coeval with these latest Sabaean material productions. In fact, Sabaean pottery was also found above S2, but, as discussed below (section 8, Stratum $\mathrm{K}$ ), there is no guarantee that it was freshly-made at the time of deposition. Suite GZ designates a 50-cm-thick succession of horizontal, laminated, ashen-grey organocultural silts extremely rich in artefacts and ecofacts. Several archaeosurfaces were recorded, of which S2 was only

\footnotetext{
$197 \tau$ Ty identifies a debris pocket or microtalus on erosional surface S03 in quadrangle D6 east; it is decay material of GK3, facies GK3 $\gamma$.

198 'Archaeosurface' indicates here a surface without obligatory habitation on the spot, in contrast to a 'living floor' (cf. 7.2, footnote 185 , above). Other surfaces or levels within suite GZ might be 'living floors' (see below).
}

the latest, very well preserved where it had been sealed by structure F9.

Sedimentation during the buildup of the bottom unit, GZ3, appears to have been modest and/or intermittent, leading to prolonged exposure of materials on the ground. GZ3 has coarser sediments than the following units, GZ2-GZ1. During its sedimentation or shortly afterwards, ascensus of salt solutions combined with greater evaporation produced calcium carbonate micronodules (cf. section 17, footnote 412, below).

All units in suite GZ - GZ2 to GZV - are more or less ashy, and GZV is richer in plant detritus. In quadrangles D2-D12 a shallow pit came to light at the base of GZ1 and lens $\lambda \beta$, containing a leached hearth (F5) (Figs 18, 3031). A remnant of layered, calcified ashy-silty hearth material protruding from the top of GZ2 was observed in quadrangle D2 southeast, where it was surrounded by GZ1-GZV sediments. This feature was labelled F15 (Fig. 30). Several indurated ${ }^{199}$ lumps or bumps of ashy sediments similar to F15 were noticed within GZ2-GZ1 in quadrangles D3-D4. Thus it seems that some surfaces within suite GZ actually saw 'living' activity on this spot.

Highly informative was an indurated sediment plate from unit GZ2, quadrangle D4, studied by means of disaggregation by water (sample no. 31.1). The material turned out to be an occupation anthrosol originally composed of an ashy silt and subsequently enriched by heterometric fines entraining cultural debris (vegetal matter and charcoal), then thinly hardened by illuvial calcium carbonate.

An exceptional concentration of bones was found in the middle of the layers defining Stratum L: the 'locus of bones' or Locus 33 (Lo33 in Fig. 18). Together with suite GK, the glimpsing of this concentration of animal bones, partly eroded away by rainwater, had been among the factors for selecting Gully B for excavation in 2005 (see sections 1.2 and 7.2, above). This dense, well-bounded cluster of animal bones at the junction of quadrangles D3, D4, D13, and D14 was identified as a dump made at the GZ3/GZ2 interface and vertically spanning the whole of GZ3 (plans in Figs 63, 66; a detail of finds in Fig. 61). Considering that many of the skeletal pieces were in anatomical articulation - indicating that they were embedded in meat discarded when still fresh - a shallow discard pit from butchery nearby is an equally tenable interpretation. ${ }^{200}$

Finds. In addition to the usual domestic waste and copious animal bone throughout, Stratum L in Sector

\footnotetext{
199 'Indurated': sediment hardened through cementation.

200 See mention in Chapter 19, section 2.1, this volume.
} 
D yielded the following individually interesting finds, listed stratigraphically bottom to top.

- From GZ3,including partofLocus33(quadrangles D3-D5 and D14): remains of many Red Lustrous vessels, including a deep bowl (no. 37.02), a globular necked pot (no. 37.03), a globular jar (no. 15.08); equally numerous Beige Plain vessels, e.g. V33-37, a cooking pot (?) decorated with bands of wavy-line incisions (reconstructed from several fragments); remains of softstone vessels (nos 15.01-03); a rubbing stone (no. 15.04) and a flaked cobble (no. 32.01); several fragments of clay discs/'tripods', one $10 \mathrm{~cm}$ long (nos 15.0507, 32.03); a ball of woven hair (no. 32.02); and a small bunch of plant fibres (no. 33.01). Although not equalling suite GK in frequency (Stratum $\mathrm{N}$ ), the artefacts made of organic materials were an important component of suite $\mathrm{GZ}$ as well.

- From GZ2-GZ1 (quadrangles D3-D4): again numerous Red Lustrous vessels, for instance a shallow bowl (no. 31.09) and a small, low cylindrical jar (no. 31.08); a Beige Plain thinwalled bowl (no. 31.010); a Wavy Rim bowl, vessel V14.9; a small Pale Green vessel apparently represented by at least two fragments (nos 31.06-07); a fragment of a delicate glass object (no. 14.4, qu. D3, probably from unit GZ2); ${ }^{201}$ an obsidian microflake (no. 14.02); a softstone vessel (no. 14.01); five fragments of clay discs/'tripods' (nos 31.02-05 and 14.03); and a braid of plant fibres (no. 31.01).

- From GZ1 (quadrangle D2, including hearth F5): three fragments of clay discs, one with basketry impressions (nos 26.01-03). The apparent frequency of clay-disc remains from the restricted excavation surface of cut 26 , attributable to a Later Sabaean domestic context from the tell, should be noted (cf. Chapter 21, section 2.1, this volume).

- From archaeosurface S2 and the top $10 \mathrm{~cm}$ of unit GZ1 (quadrangles D2-D3): a large number of Red Lustrous vessels, some with exfoliating 'thin shoddy slip', including two carinated bowls (nos 13.01 and 13.03), a shallow bowl (nos 14.11-13), a deep bowl (no.13.02), a ring-footed cup inscribed on its base (no. 14.10), a small, stout cooking pot in Black-grey ware (no. 14.14), a Wavy Rim bowl (vessel V14-24, from several fragments), and a small, delicate Pale Green bowl (no. 13.1.1, from flotation).

- Several objects of rather special quality were found within loose sediments of quadrangles

201 Exotic objects may have been circulating in the settlement during the period of Stratum L: in addition to this glass fragment, a 'Minaean'looking potsherd was recovered from GZ1-GZV in quadrangle D2 (see section 8.2 below).
D13-D14 within Gully B, eroded in all probability from stratified deposits of adjacent suite GZ: no. $5.1 \mathrm{~b}$, an elegant calcarenite container decorated with an ibex protome, to be ascribed to the cuboid-burner production; no. 5.1a, part of a flat, painted cuboid burner; ${ }^{202}$ no. 8.01 , a quern in vesicular basalt; no. 8.02, an uncertain 'stone or weight' in coarse sandstone (not described). A clay 'tripod' foot was also recovered (no. 8.03).

\subsection{Settlement 'Lobe 5', including structure F9}

A portion of the developed Sabaean settlement on the northwestern edge of the tell was marginally captured - as well as indirectly revealed - by the excavations in Area C. It was designated settlement Lobe 5, from the Minaean wall bastion nearest to the point of identification (Fig. 68). Its definition can be found in this chapter at the end of the 'Preview' (section 4.1 above). The present subsection is intended to supplement the evidential basis for Lobe 5 providing additional details, and to discuss aspects of its interpretation. Lobe 5 is further treated in this volume from the viewpoint of the 'Greater Yathill' model (Chapter 26, section 3.2) and is mentioned in Chapter 18, section 3.1.

Briefly, indirect evidence for the existence of a protrusion or 'lobe' of the Later Sabaean settlement, seemingly associated with a small eminence of the tell (a local mass of higher ground), was inferred from the inclination and orientation of colluvial layers in excavated quadrangles lower down (E4-E5; Figs 4546); ${ }^{203}$ and some of its surviving morphology in the talus can still be perceived. By extension, with the support of excavation data from Sector $C$ and Sounding A that allow a tentative but admissible interpolation (together with upper Sector D, this section), Lobe 5 was taken to be a convenient designation for the entire northwestern sector of the Later Sabaean settlement on the tell of Yathill. This reconstruction was equally suggested by the morphological continuity apparent in this part of the mound today. Lobe 5 can thus designate the whole, relatively protruding northwestern sector of the final Sabaean settlement of Yathill, up to the excavation area conventionally called Locus 200 (section 7.3 above) (Fig. 68). A visual idea of settlement Lobe 5 is provided by Figs 14-16 (see also Chapter 26, Fig. 10, this volume). ${ }^{204}$

\footnotetext{
202 See detailed descriptions of both burners in Chapter 21, section 2.1 , this volume.

203 North-dipping sedimentation surfaces, associated with cultural debris indicating a settled high spot to the southeast, were particularly observed on the easternmost sections of quadrangle E5 (see section 4.1 above).

204 The main sampling point for plant macroremains by L. Costantini in 1986 can be traced to Lobe 5 as well, as argued in Chapter 19, section 4.1, this volume.
} 
Suite GZ is terminated in quadrangles D2-D4 by mud feature F9, initially recognized as the largest sediment body in the whole Reference section (GR1, mud-mass or 'Mass GR1'). ${ }^{205}$ Two parts can be distinguished: a massive-mud lower part (GR1b), and an upper part (GR1a) still preserving traces of coursing and a remnant of mud-brick masonry (JD2). More than textural differences, it is differences in structure, porosity, and compaction that separate the build of GR1a from that of GR1b. Mass GR1 was covered by a discontinuous sheath of weathered or melted mudbrick (GRX). Prior to this sheath, a small pocket of grey, disaggregated-GR1 'sand' had formed on the eroded top of mud-mass F9 in quadrangle D2 (GRy) (Figs 18, 31-32, 59, 60 A).

The small exposure precludes a complete understanding of F9. However, the excavation clearly exposed a nearly vertical surface in quadrangle D2, F9 ${ }_{0}$, orientated northnorthwest to south-southeast, which suggested that the trench had caught part of a mudbrick structure with a surviving vertical wall. With two adjacent walls, in fact, forming a corner in the northwest quadrant of D2 and both badly eroded. With its sheer mass, the wall orientated east-northeast to west-southwest, crossing axially rectangle D3-D4-D13-D14 (see plan in Fig. 64), appears to have controlled and stemmed the erosion by Gully B and its precursors. F9 might be an ordinary building, that is a house, in which the actual mud-brick dwelling would be GR1a-JD2, while the lower part (GR1b) might be a supporting or stabilizing structure - a sort of platform or embankment - made on the side of an incipient gully ${ }^{206}$ or along an unstable edge of the tell (an 'edge-bed'). ${ }^{207}$ The mudbrick material constituting F9 exclusively contained Sabaean artefacts, particularly potsherds, and some complete bones; a full list is given below.

Details on F9. F9 is the name given to the feature inferred from sediment unit (mud-mass) GR1 and its right-angled plan, a code name originally given to its subvertical eastern limit, or 'wall', now component F9. That F9 is part of a building is nothing more than a reasonable hypothesis. Its other components are:

- GR1b, the massive or 'chaotic' lower part of GR1 (outlined above), made of hardened to cemented beige silt, spontaneously breaking into large clods of $\mathrm{CaCO}_{3}$-indurated fines, $10-15 \mathrm{~cm}$ in

\footnotetext{
205 'Mud-mass' is a neologism, based on the geological terms 'mudstone' (e.g. AGI 1984, 336) and 'mudflow' (AGI 1984, 335; Butzer 1976 , 94). Cf. also 'mudbrick', obviously, in the sense of type of material, written without a hyphen except where it refers precisely to bricks (mud bricks; 'a mud-brick structure'). Mud-mass will serve to explain the particular type of feature with which we are dealing.

206 For evidence of an incipient gully in this position see sections 8 (Stratum K) and 14.3 (Stratum G) below.

207 'Edge-bed' is a neologism, again proposed in order to account for the particular feature concerned.
}

size (see water processing and flotation details below); subdivided into two largely conventional partitions (GR1b and $G R 1 b_{2}$ ) according to a faintly recognizable joint at $-80 \pm 5 \mathrm{~cm}$ below local datum D2/D3; ${ }^{208}$ at its bottom, calcium carbonate released by GR1b has moderately cemented surface S2, in close contact with the mud-mass; the top surface of GR1b is a sufficiently well delineated, continuous, horizontal break in the mud-mass;

- GR1a, the upper part of GR1 (outlined above), its mud-brick structure still vaguely perceptible; as a sediment, it consists of hardened sandy silts, grey-beige in colour, which through disaggregation by water produce relatively finer aggregates than those of GR1b, within a matrix that seems more sandy; GR1a contains JD2;

- JD2, a large mud-brick block in the easternmost part of GR1a (quadrangle D2), apparently a mud-brick wall fragment surrounded by melted mudbrick; it resembles block P12 of mud-mass F13 in quadrangle D6 (see section 6.7 above);

- F9 $\lambda$, a lens of darkish-grey silt with ash and tiny charcoal at $-60 /-65 \mathrm{~cm}$ below local datum D2/D3, in quadrangle $D 2$ west; a very minor discontinuity within GR1b (mid-GR1b); it contained clay tabular element 23.01 (see below).

Disaggregation by water and detergent of a bucket of sediment from upper GR1b (sample 12.3, screened through a $0.5 \mathrm{~mm}$ mesh) ${ }^{209}$ has revealed 99 per cent matrix $<0.5 \mathrm{~mm}$, composed of clayey silt to silty clay or even plastic clay. Extremely persistent $\mathrm{CaCO}_{3}-$ cemented aggregates, $>5 \mathrm{~cm}$ in size, only break under sustained and intense trowel pressure, and even so, during reasonable processing time, they can merely be reduced to 1-0.4 cm crumbs. Wet colour is dark grey with a shade of yellowish, beige, or hazel. Standard water screening of the remaining 1 per cent of sample, coupled with froth flotation, has revealed a red-rock pebble ( $1 \mathrm{~cm}$ in diameter), a few angular clasts under $1 \mathrm{~cm}$ (one a microflake of yellow calcarenite), tiny charcoal bits, sporadic chips of wood, jujube nutshells (Ziziphus spina-christi, Sabaean 'ilb), and some terrestrial micro-gastropods, apparently belonging to three species (turriculate and discoid). ${ }^{210}$

Numerous cultural inclusions were found inside GR1-F9 (cuts 11, 12, 23, and part of 30; composite plan in Fig. 64), all covered in resistant beige or grey clay and silt (cf. section 2.2 above, process no. 1):

\footnotetext{
208 Local datum here is the ground surface at point (nail) D2/D3 on the Reference section.

209 See Chapter 20, this volume.

210 See Chapter 19, section 2.1 ('Micro-gastropods and seashells'), this volume.
} 
- four large potsherds, up to about $10 \mathrm{~cm}$ in size (nos 12.1, 12.2, Beige Plain ware, and thick-walled vessel 12.4, showing wear grade 1-4), the largest and perhaps most interesting being no. 23.02, a rim fragment of a Red Lustrous storage jar from mid-GR1b (Chapter 23, Fig. 25, this volume);

- seven minute 'epi-Sabaean' pottery fragments, particularly from cut 23 (two 'red', one indeterminate; wear grades 1,2, and 4) and cut 30 (four, very worn, insignificant);

- a softstone fragment from quadrangle D4 (no. 30.01 ), attributed to F9 because covered in resistant yellowish clay like the pottery from cut 30 above (Chapter 21, section 2.1, this volume);

- sporadic bones, characteristically tobaccostained (i.e., deriving from old and/or organic sediments), ${ }^{211}$ including a complete Bos taurus calcaneum (no. 11.2), a charred bone associated with charcoal (no. 11.1), and several fragments of teeth (cut 11);

- a domestic-caprine coprolite (brown; cut 11);

- numerous terrestrial micro-gastropods, frequent in GR1a-GR1b and rare in GR1b (cf. flotation finds above, sample 12.3); evidently collected with the clay for making the mud bricks and mud-mass, hence non-cultural;

- some charcoal (cuts 11 and 23); and

- a melon seed.

When sediment unit GR1 was emplaced, that is, when F9 was built, all the above finds were manifestly embedded inside the mass; they must be attributed to Stratum L or earlier.

In a separate class, as they themselves are pieces of mudbrick material, one can finally list an unfired-clay tabular element from lens $F 9 \lambda$, mid-GR1 ${ }_{1}$ (no. 23.01; see Chapter 21, section 2.1, this volume), and a few small mudbrick 'clods' (cut 23).

\section{GR3 (Sector C)}

A massive silt unit, closely resembling GR1, was barely glimpsed at the very bottom of the test pit in Sector C: unit GR3. ${ }^{212}$ This sediment tends to break into smaller aggregates, but is otherwise similar to GR1 in texture, hardness, and colour (light grey-beige), and can easily be interpreted as mudbrick. Presumably GR3 is only the tip of another mud-mass feature, which can thus provide a linkup in the middle of a poorly known part of the talus. Taken together, as argued in sections 4.1 and 6.7 above, F9 in upper Sector D, GR3 in Sector C,

\footnotetext{
211 And thus radically different in exterior appearance from the bones contained - for instance - in Minaean units GV1-DGV1 (quadrangle D1).

212 Save for this small unit, attributed to Stratum L, the stratigraphy of Sector $\mathrm{C}$ will be treated in section 15.3 below.
}

STY in Sounding A, and earlier features or layers such as F13 and GW in quadrangles D5-D6, suggest that the Later Sabaean occupation in this area included quite a number of mudbrick and mud-mass structures. These can provisionally be interpreted as extant or decayed buildings, and some at least might be houses. The overall impression is that a substantial settlement existed in this part of the tell, i.e. Lobe 5.

\subsection{Stratum L: the talus (Sector E)}

Stratum L is lithostratigraphically defined on the talus, Sector E, by suites LNS, KL, JKL, and 5SU (Figs 21, 40 B-D). Following surface and stasis S16, gravityassisted, partly colluvial sedimentation started again on the talus flexure (suite LNS). More precisely, a combined sedimentation is apparent, comprising slope accumulations, such as unit LGN, and blown-in sands and silts, such as units LSx and LS - LSx more aeolian, LS more colluvial. These sediments interfinger so closely that the two alternating processes, the gravitative and the aeolian, must indeed have occurred together.

LGN sedimented in small, 'cascading', superposed footslope masses of silty-pebbly mudbrick material, generating what looks like a pile of micro-taluses; moreover, it has a distinctive nodular appearance, resulting from disaggregated mudbrick and other detrital inclusions. It is not colluvium, but the result of reiterated slumping or sliding. And it forms a thick, extensive blanket of a distinctive greyish colour, punctuated here and there by 'white specks', which tends to stand out in the Reference section as an inclined, vaguely sigmoid body 3-3.5 metre long. In the southern part of the quadrangles involved, E4-E5, LGN is represented by facies $\mathrm{LGN}_{\mathrm{s}}$ : it recognizably differs from the parent unit for its morphology (Figs 46, 47).

Downslope, LGN dilutes into a number of sandier bodies: KL5 and KLY (suite KL), XL, suite JKL in general. Sands and silts JKL are punctuated by lenses or 'waves' of cultural debris from the erosion and downslope washing of primary occupation deposits higher up. As indicated in Table 1, suites KL and LNS are limited down-talus to quadrangle E5, whereas suite JKL was defined in quadrangle E6(E06): however, KL and LNS, on one side, and JKL on the other are essentially transitional between each other. Suite 5SU comprises a short sequence of poorly known units recorded on the south section of Sector E, which could only be examined post-excavation from photographs.

Plant-detritus masses VGN and VGN', also members of suite LNS, represent a new example in the episodic arrival and/or deposition of such kind of material down on the Sabaean lower talus. Previously we had observed the appearance of this material and process during Stratum 0 , with unit $6 \mathrm{~V}$, which, however, was distinctly 
richer in actual excreta and had probably originated from true manure layers not far away (see section 6.8 above). Here we have instead the inauguration of colluvial plant-detritus deposits: evidently, a dismantling of occupation layers characterized by dense vegetal residue - with or without a dung component - is being set in motion at this time and intermittently reiterated; and its provenance is from south. In this same location (quadrangles E4-E5) the process will shortly continue with units $\mathrm{VCB}$ and $\mathrm{VCB}^{\prime}$ of Stratum K.

Redeposition of Sabaean material down the talus during the Minaean. A large number of Later Sabaean objects and fragments, brought to light during the digging for the foundation of the Minaean wall, continued to 'float' and be redeposited down the talus for a long time: certainly throughout the Minaean period, and less frequently afterwards. This process was clearly documented by the Sabaean pottery sherds found in quadrangles $D 1$ and $D 2$, cuts $1-4$ and 20 , mostly showing wear grade 3 to 5 . Among the intrinsically undatable artefacts, this might be the case with clay 'tripod' fragment 2.03 and clay disc fragment 2.01, this latter in an overall good condition but with edge wear 3 (see Chapter 21, section 2.3 , this volume, with particular reference to footnote 167 and Fig. 60). In this light, also the radiocarbondated charcoal, sample \#2.1, should retrospectively be considered redeposited Sabaean material (see Chapter 18 , section 1 , this volume). This subject is again briefly discussed in Chapter 21, section 2.1, introduction to 'Unfired or poorly fired clay artefacts' (this volume). On redeposition in general see section 2.3 above (end of section).

\subsection{Stratum $M$}

In the footslope belt of the talus (lower Sector E) the units correlatable to Strata $\mathrm{L}$ and $\mathrm{N}$ are subsumed under Stratum M. More precisely, Stratum M comprises sediments from the lower half of Sector E attributable to occupation or activity episodes along the foot of the Sabaean tell, and more than one metre of sediments from Sounding $F$ in the plain. In lower Sector E, at the bottom of quadrangles E7-E8 and E11, two planar concentrations of large ceramic pieces in unusually good condition, lying on rather elusive horizontal levels and basically embedded in sands, were found (Figs 22, 68). These relative concentrations of cultural material constitute Horizons H78 and H11, respectively, the former with the character of a swarm of objects, and the latter essentially constituting a cluster. Stratum $M$ is thus defined in Sector E by sediment suite SEK, sediment units E86, YS8, and EбX, and Horizons H78 and H11; and in the plain (Sounding F) by sediment units SP1, SY1a, SY1, SF1a, SF1. Stratum M in the plain will be treated in section 17 below (Sounding F).
Horizon H78 was made conspicuous in quadrangle E7 by a large portion of a Red Lustrous storage jar or dolium, about $60 \mathrm{~cm}$ tall (no. 52.1; Fig. 69), resting horizontally on a level of ash and charcoal patches (EK, EKi, EK1) and sand lenses constituting suite SEK. Many other cultural elements associated with this matrix with the ashy lenses particularly - lay nearby. About a dozen elements formed a singular cluster in $E$, mostly composed of broken limestone cobbles and a vesicular volcanic stone with traces of bifacial percussion (socalled Cluster 82.2, see below) (Fig. 70). A marine shell from a large cowrie species was found, to be interpreted as a personal ornament. The most interesting finds are described in Chapter 21, section 2.1, this volume.

In addition to the dolium, remains of numerous other vessels were found. Red Lustrous ware included a large shallow bowl with repair holes, fragments of bowls of different types, and a large cylindrical jar. Black Lustrous ware was represented by a delicate small bowl. Beige Plain ware included a narrow-necked globular jar (no. 82.1a), ostensibly the centrepiece in Cluster 82.2 (see below), a cooking pot decorated with a wavy-line motif, fragments of ribbon-decorated vessels, and a stout plate or 'tray'. Descriptions and figures are given in Chapter 23, section 3.3 ('Stratum M'), this volume. Fragments of torpedo jars were also present, as well as brown, poorly-fired clay discs/'tripods'. A detailed discussion of this latter, problematic class of finds can be found in Chapter 21, section 2.1, this volume.

In quadrangle E11, the concentration called Horizon H11 contained fairly large pieces of pottery accompanied by charcoal debris and a notable wild camel bone (Fig. 71; and Chapter 19, Fig. 16, this volume). This horizon appeared to be formed of lenses and pockets on closely spaced levels, resulting from episodic depositions over a certain period of time. Two, possibly three levels could be discerned, numbered top to bottom 0,1 , and 2 (see below). The middle level (level 1) contained the particularly dense cluster of finds that prompted the designation of Locus 151 (Lo151) for these deposits in the eastern half of quadrangle E11, presumably continuing in quadrangle E10. The cultural elements were embedded in sand, but no well-bounded sediment body could be identified, save a tenuous difference in the sand itself, a little more compact than $\mathrm{E} \sigma \mathrm{W}_{2}$ above. This sediment matrix was named Eøx.

Red Lustrous ware included fragments of a large storage jar (possibly similar to no. 52.1 from Horizon H78), shallow angular-walled bowls, and carinated footed bowls (one repaired with plaster). Beige Plain ware was copious and included a cooking pot with a thick carbonaceous crust on the exterior, represented by a sharp-edged fragment suggesting use and breakage on the spot. Fragments of a torpedo jar and two clay 
'tripods' were also found. Both the composition and condition of material would exclude 'normal' kitchen refuse. The pottery was somewhat unusual in the same way as that of Horizon H78. Furthermore, as mentioned, the animal bones included a partial humerus from a wild camel, outstanding not only as a faunal taxon but also for the general appearance of the bone itself (see Chapter 19, section 2.2, this volume).

This context is rather enigmatic, due to the restricted excavation surface. From a general standpoint, however, the archaeological association in both H11 and H78 (shallow bowls, clay discs/'tripods', cooking pots, evidence of burning, unusual or exotic items), combined with what looks like a patchy distribution of activity clusters, suggests a scenario of bivouacs or tents on the plain. This issue is discussed in Chapter 19, section 3 , this volume.

According to a plausible correlation, the 'large ceramics' horizons in lower Sector E, together with several layers from the lower half of Sounding F (units SP1 through SF1; see section 17 below), can be attributed to the Later Sabaean: they appear to overlap with the tell and talus units comprising both Stratum $\mathrm{N}$ and Stratum L. H78 was correlated on the basis of its geometric relationships with the talus footslope formed by colluvial suite 6UV. It certainly precedes suites LNS-JKL (Stratum N) and its placement during stasis S16 seems plausible. Horizon H11 can be linked to Horizon H78 on the basis of general resemblance as well as homotaxy, ${ }^{213}$ and the pottery does not contradict this interpretation. The placement of H78 and $\mathrm{H} 11$ in relation to stasis S16 is the preferred option, but other correlations could be contemplated. Their position might in fact have to be shifted downwards as early as unit LM (suite LXZ, later Stratum 0 ), which would affiliate them with the Sabaean 2. For the correlation of Sounding F see section 17 below.

Concerning the origin and taphonomy of H78, materials from occupation episodes in the immediate vicinity would have sedimented upon a local méplat, a shallow horizontal bank of older deposits ('Platform E6-E8'), where they were preserved in privileged conditions (cf. section 4.1 above). Tracts of level ground might have been common on the flats all along the foot of the mound. Minimal transport, lack of trampling, and protection by rapid sand burial appear to have been responsible for the good preservation of these clusters of large ceramic pieces and bones. The sands involved were different facies of the same aeolian material: YS8, as matrix of SEK, in quadrangles E7-E8 , and E $\sigma \mathrm{x}$, variant of ${\mathrm{E} \sigma \mathrm{W}_{3}}_{3}$, in quadrangle E11. Such conditions persisted for a long time, since in quadrangle E11 at least two

213 I.e., the two cultural horizons occupy the same relative position in the sediment sequence. consecutive levels were preserved, Horizons H11Q and H11. We are dealing in all these contexts with exfoliated, salt-corroded, but sharp-edged in situ material.

\section{Horizon H78: further details}

Cultural horizon $\mathrm{H78}$ is contained within sediment suite SEK and largely within unit EK (Fig. 70). ${ }^{214}$ Suite SEK is formed of pink-beige-ashen sand intermingled with ash, charcoal, and cultural debris, as shown by both field observation and water screening (sample no. 52.5). Its base is unknown, but it thins out in quadrangle $E 8$ west, where it is 'enveloped' in sand YS8 - a persistent aeolian deposition. ${ }^{215}$

The finds from quadrangle $E 7$, mostly recorded in situ (cut 52), include the notable vessels in Red Lustrous ware mentioned above: dolium no. 52.1, shallow bowl with repair holes no. 52.2, footed bowls nos 52.6 and 52.10c, and barrel-shaped jar 52.3. Pottery also includes a Red Lustrous deep vessel with vertical wall (no. 52.7), a large Beige Plain cooking pot with wavy-line decoration (no. 52.10h, mentioned above), and - possibly - a torpedo jar rim (no. 52.10a). Among the non-ceramic finds, part of a mud brick (no. 52.11) and two unfired-clay objects (a disc fragment and a 'tripod' foot, nos 52.01-02), can be noted.

In general, the ceramic assemblage of cut 52 (39 fragments in total) is made of large $(c .8-15 \mathrm{~cm})$, exfoliated and/or salt-corroded potsherds, with wear grade 2-3 or 2-4 (rare 1) and very frequent manganese dendrites. Typologically it reflects almost the entire Sabaean repertoire, with plain wares slightly predominant. Eight animal bones, charcoal fragments up to $6 \mathrm{~cm}$ long, and three angular stones from the northeast quadrant (a black limestone polyhedron and two split cobbles, nos $52.4 \mathrm{f}-4 \mathrm{~h}$, partly beneath the dolium) were also recovered.

An integral part of Horizon $\mathrm{H78}$ in the middle of quadrangle E8 was Cluster 82.2 (Fig. 70). This was a small individual grouping of mostly broken, partly rubefied stones (seven clasts, nos 82.2a-2g), together with a large fragment of a narrow-necked jar (no. 82.1a, see above), a smaller potsherd (no. 82.1b), and several unfired-clay disc fragments (nos $82.2 \mathrm{~h}-2 \mathrm{i}$, and possibly nos $82.02-$ 03, plus smaller debris). The stones surrounded the jar in a seemingly primary, functional fashion. Cluster 82.2 could represent the deflated remnants of a hearth

\footnotetext{
214 The present lithostratigraphy of Horizon H78 and its context supersedes Fedele 2010, 124-125.

215 The partition of YS8 into two levels depends on the local interposition of both SEK (with Horizon H78) and lens E86, not on significant lithological variation. Whether lens - or level - E86 is a continuation of SEK-H78 could not be investigated (see section 15.2, 'Stratum I', and cf. Table 1, footnote).
} 
not only intended for cooking, but also for protracted thermal release. ${ }^{216}$

Unrelated to this cluster, two other significant finds attributable to Stratum $\mathrm{M}$ were retrieved from quadrangle E8 (cut 82, SEK-YS8-E86 fraction): a stout plate or 'tray' in Red Lustrous ware (no. 82.3) and part of a cowrie shell (no. 82.01), both mentioned above. The ceramic material from cut 82 (46 fragments in total) is identical in appearance to that from cut 52. some animal bone and a probable coprolite were also recovered, and a sample of charcoal was collected.

\section{Horizon H11: further details}

Horizon H11 is embedded in sand and particularly associated with sand unit Eox; its lateral extension is unknown. ${ }^{217}$ This cultural horizon first came to light (during cut 151) in conjunction with the transition between two minimally, but appreciably differentiated sands: $\mathrm{E} \sigma \mathrm{W}_{2}$, just a little compacted, and $\mathrm{E} \sigma \mathrm{W}_{3}$, moderately compacted. Trowel digging subsequently suggested - and the photographs later confirmed that a sand unit similar to $\mathrm{E} \sigma \mathrm{W}_{3}$, but again minimally different at least in bedding, could be recognized as the proper sediment matrix of the cultural horizon (Eøx). E $\sigma \mathrm{x}_{0}$ designates a charcoal-rich subunit at the top of E $\sigma \mathrm{x}$ in the easternmost part of the quadrangle.

The following two or three levels of artefacts and ecofacts can be distinguished in Horizon H11 (top to bottom; see Fig. 22):

- level 0 , contained within sediment Eox: an arched cluster of conspicuous charred wood fragments signalling the top of the horizon;

- level 1: the main material-culture level, a concentration defining Locus 151 (see above) but probably extending to the western end of quadrangle E11 (large potsherds recovered with cut 152);

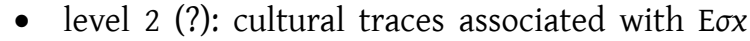
lenses at the bottom of this unit, apparently indicating a separate level.

The finds from quadrangle E11 (cuts 151-152), many recorded in situ (cut 151), include the prominent Camelus humerus, no. 151.1, pertaining to a wild dromedary; large pieces of Red Lustrous pottery, represented by a basin (no. 151.3), a storage jar resembling dolium 52.1 from Horizon H78 (rim fragment no. 152.01 from

216 See discussion, with complementary information, in Chapter 21, this volume, sections 2.1 , 'Remarks on Cluster 82.2' (in 'Other utilized natural stones') and 2.3, introduction to 'Other utilized natural stones' (Minaean group). For an insightful treatment of burnt-rock features the reader is referred to Thoms 2017.

217 The present lithostratigraphy of Horizon H11 and its context supersedes Fedele 2010, 124-125.
E11 west, probably level 1), and at least six footed, carinated bowls, one plaster-repaired (nos 151.5-6, 151.9, 151.13.1-13.4); two Red-slipped vessels (a handled mug, no. 151.13.5, and and a small cup, no. 151.13.6); numerous fragments of Beige Plain ware, including the pot with thick cooking incrustation - and wear grade $0-$ mentioned above (no. 151.7); a complete mouth of a torpedo jar (no. 151.4); and several, notable fragments of clay discs/'tripods' (nos 151.8.1 and 151.10-12). Ecofacts include many more animal bones (one recorded in situ, no. 151.15) and a 6.6-cm-long ovoid cobble of nodular limestone (no. 151.16). A sample of charcoal up to $2 \mathrm{~cm}$ in size was collected.

In general, the ceramic assemblage of cut 151 (33 fragments in total) is made of medium to large fragments (many over $10 \mathrm{~cm}$ in size), which all display surface abrasion and edge damage from trampling rather than sediment transport. A no-transport taphonomic picture is also suggested by the pottery recovered with cut 152 from the western end of quadrangle E11, which comprises dm-sized subangular fragments only subsequently affected by corrosion and exfoliation (seven finds). In addition to no. 152.01, above, a Red Lustrous footed bowl and two sherds from a single torpedo-jar deserve mention.

Horizon $\mathrm{H} 11 \mathrm{Q}$, tentatively attributed to Stratum O, was described above in section 6.9.

\section{Stratum K: the Sabaean-Minaean interface, or First Intermediate}

\subsection{Overview}

Above surface S2, in quadrangles D2-D12 and at the head of Gully B, the units from GSV3 to SA2 can be grouped as suite SD2 (Table 1). They form the sedimentary basis for Stratum $\mathrm{K}$, here termed historically the First Intermediate interval (Table 4). ${ }^{218}$ This conventional designation exclusively reflects the material data on the basis of three considerations:

1. there is no evidence of diagnostic Minaean artefacts throughout SD2, or indeed from the whole upper part of Sector D; only Sabaean pottery occurs, though often battered, hence reworked;

2. there is a general sedimentary continuity from suite $\mathrm{GZ}$ across surface S2, this latter a modest lithological boundary, save where the base of mud-mass F9 determined a sharp discontinuity (see section 7.6 above);

3. no indicator of cultural or environmental turnover is apparent, although at the same

218 On this designation see section 3.3 above. 

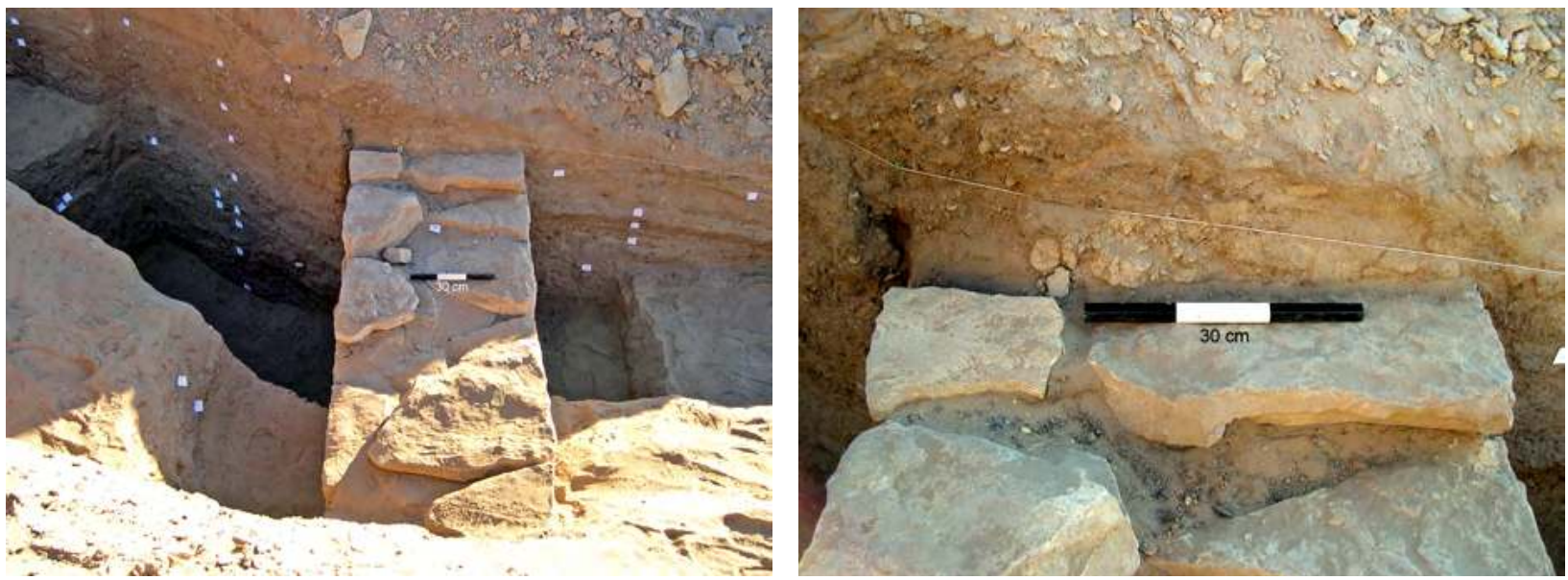

Figure 53. Sabaean Wall F4 in context: from north, with Reference section. The view on the right shows mudbrick residue J1. (P. Morlupi 2005 @ MAIRY, adapted and optimized by F.G. Fedele 2020)

time it is obvious that the intensive occupation reflected in Strata $\mathrm{N}$ and $\mathrm{L}$ and characterized by Later Sabaean pottery had come to an end in the excavation area, or had shifted away in general.

These observations make it probable that Stratum $\mathrm{K}$ represents the interface between the Sabaean and Minaean periods, whatever the pattern of this transition and its reasons. Stratum K might in fact span - politically - the advent of the Minaean occupation. The archaeological problem is twofold: how long did the Sabaean tradition of pottery making persist? and might SD2 include initial Minaean activity? ${ }^{219}$

\subsection{Suite SD2}

Suite SD2 is one metre thick and unusually formed of parallel sandy-gravelly units consistently inclined southeast; the predominant colour is grey (Figs 31-32). The sediments are characterized by striking regularity and an almost rhythmic formation pattern, suggesting quiet but sustained deposition in a micro-environment devoid of any disturbance, human or otherwise. A short-distance colluvium is a likely explanation. The buildup resulted from a steady supply of pebbly sands and cultural debris from the northwest of quadrangle D2. Washed-in sediments - from the recent Lobe 5 occupation or from abandonment levels - gradually filled up the upslope space against the vertical 'wall' of Mass GR1 (F9). They are rich in plant detritus, but unfortunately do not contain fresh, diagnostic pottery, save for a few potsherds which will be discussed below. From contents other than potsherds it is hard to distinguish erosionally reworked from fresh material. This is the case, for example, of an ochred stone tile, no. 22.0, an almost unique occurrence (see

219 Fedele 2010, 128; 2011a, 108. The present treatment is a reappraisal. below). Evidently, a morphological high-spot existed, or was being formed, northwest or west-northwest of quadrangle $\mathrm{D} 2$, not far from the side of $\mathrm{F} 9$, adjacent to the location of the present-day gully.

Perhaps the most significant novelty in SD2 - and Stratum $\mathrm{K}-$ is the appearance of manure layers (Fig. 26). ${ }^{220}$ The first, V0-V2, are brown sandy-organic lenses replete with dung and plant debris, 5-10 cm thick (Figs $26,30)$. Apart from a modest, though revealing, Sabaean precursor (6V), they are the first conspicuous excretarich sediments to appear in the extramural sequence. ${ }^{221}$ V0-V2 occupy a stratigraphic position correlatable to lower GSV1 at the headcut of Gully B, in quadrangle D12. ${ }^{222}$ Together with a smaller subsequent unit, merely glimpsed from the irregular pluvial exposure, they qualify as forerunners of the sedimentary motif which from this time on will become important in the uppertalus deposits, particularly during the Earlier Minaean (Strata J-I); hence their interest.

The product of a distinctive behaviour - the circulation of animals of burden on the talus - the manure lenses of suite SD2 are no more than episodes, but they might also be the first telltale sign of the Minaean presence. A behavioural contrast is apparent with the Later Sabaean pattern, which in this part of the tell was based on habitation (settlement Lobe 5). Since abundant plant

\footnotetext{
220 The 'manure' and 'plant-organic' units are defined as both material and process in section 2.3 above.

221 Unit $6 \mathrm{~V}$ was mentioned in this role in sections 2.3 and 4.2 , above, and is described in section 6.8 (Stratum 0). Two Sabaean plant-organic units, less rich in excreta and colluvial in origin, were described in section 7.7 (Stratum L).

222 Therefore not appearing on the Reference section. Several details of suite SD2 were studied on the irregular headwater sections of Gully B (Figs 6, 8, 30-31; cf. also Chapter 19, Fig. 18, this volume). For reasons of time the sequence of Stratum $\mathrm{K}$ was explored on a relatively restricted surface corresponding to quadrangles $D 2$ and $D 12$ at the head of Gully B.
} 

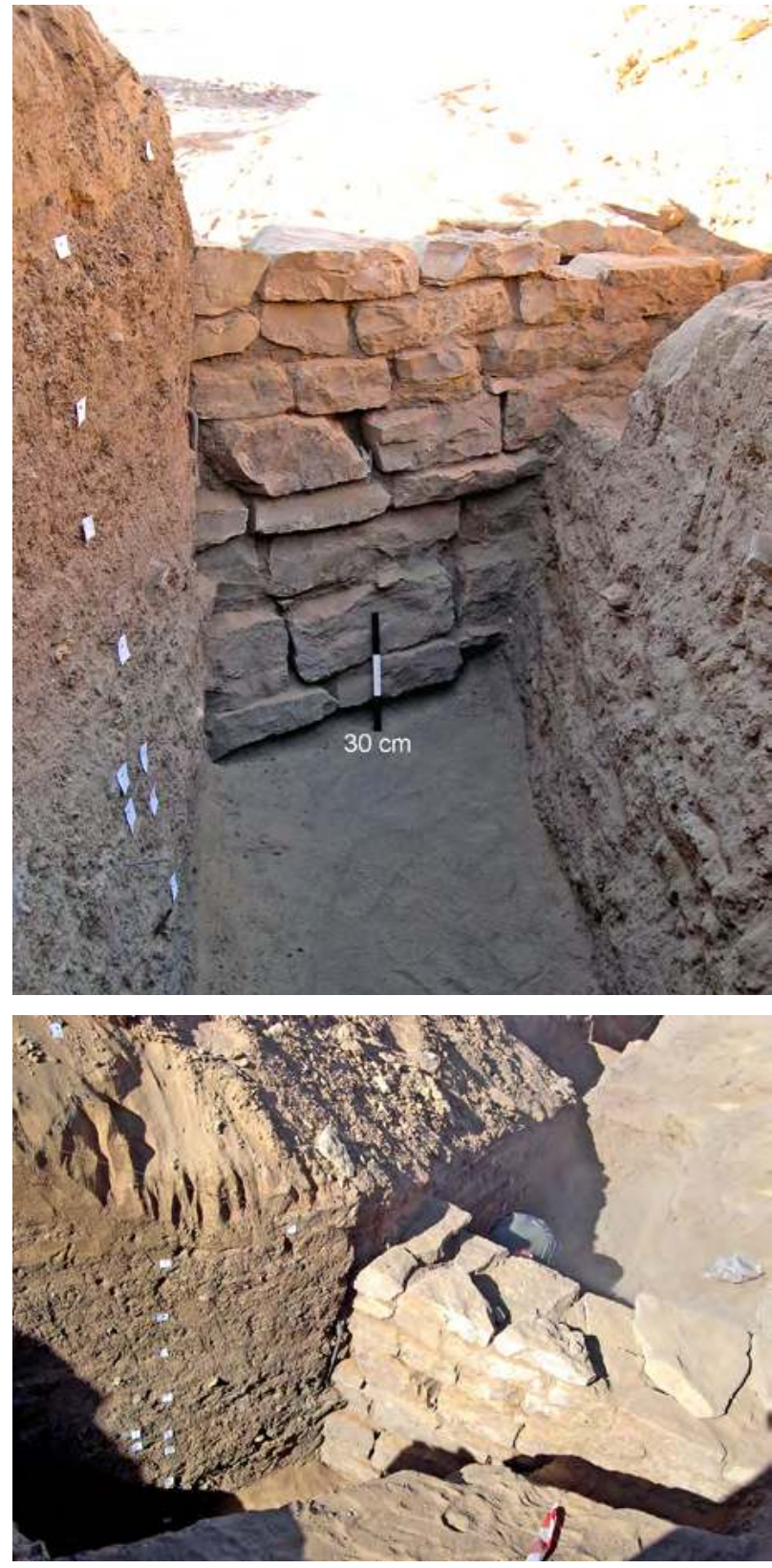

Figure 54. Sabaean Wall F4: above left, eastern face; above right, western face and sediment unit SIa underneath; below left, under excavation, facing southwest; below right, detail of masonry and deposits in quadrangle E1. (P. Morlupi 2005

(c) MAIRY, adapted and optimized by F.G. Fedele 2020)
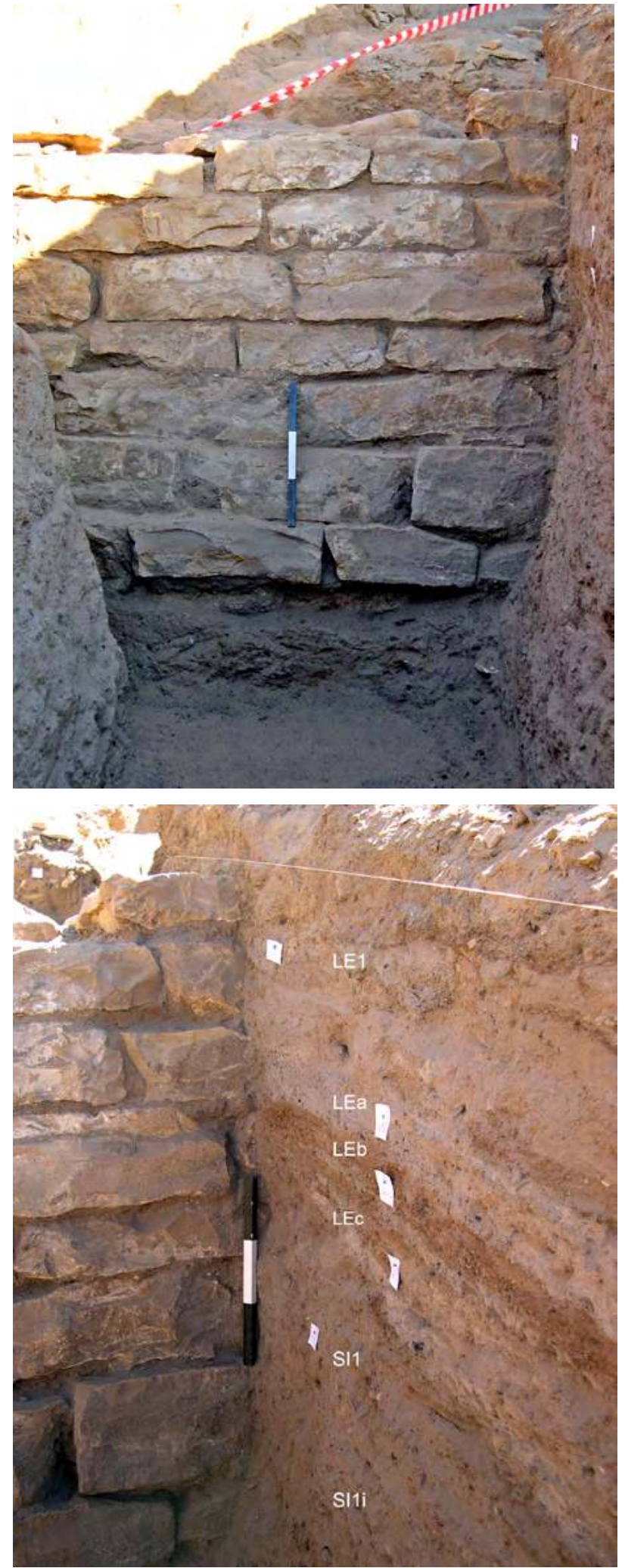


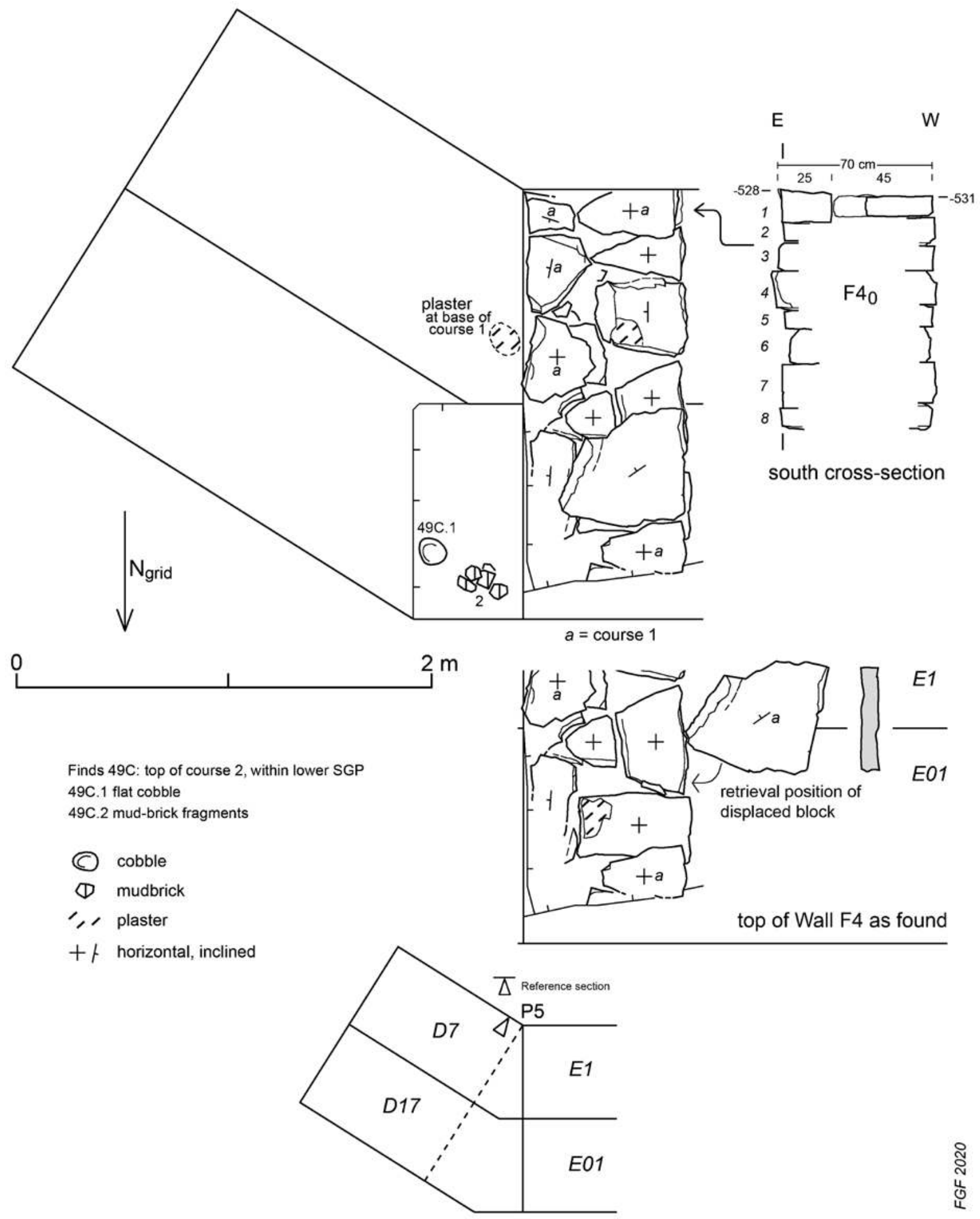

Figure 55. Sabaean Wall F4, plan and section (stone base F4). Plan also shows wall-related context in quadrangles D7-D17. (F.G. Fedele 2009 and 2020) 

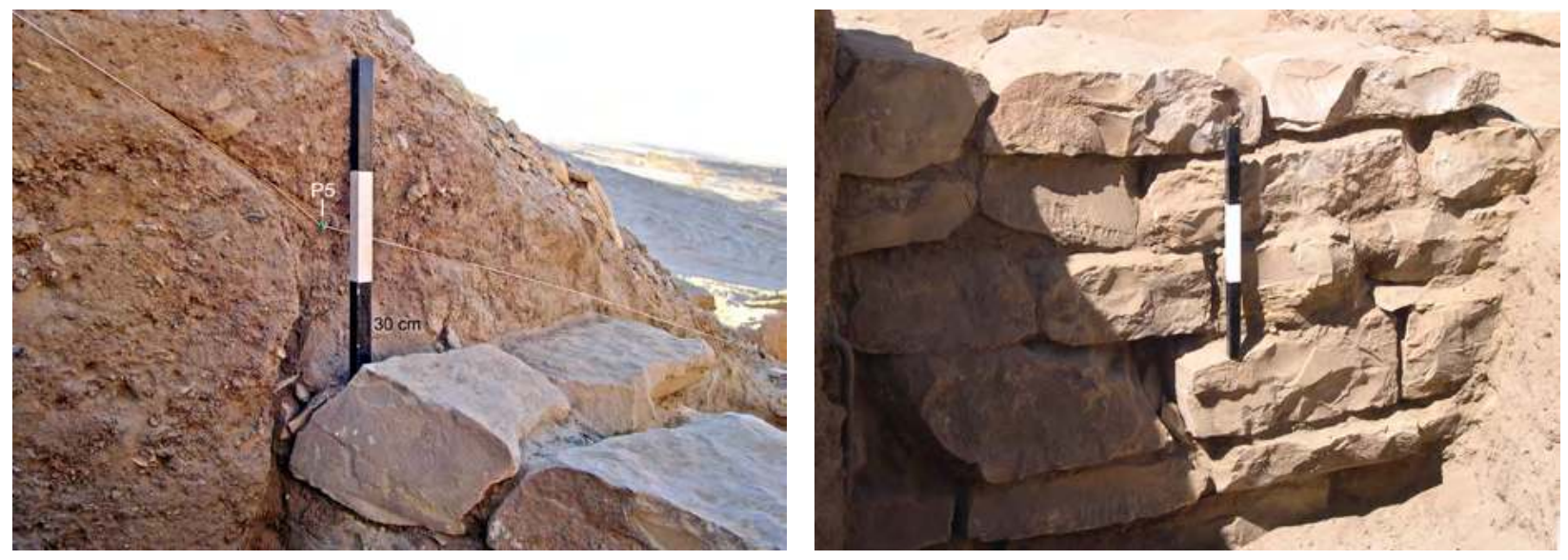

Figure 56. Sabaean Wall F4: details of masonry emphasizing the morphology and workmanship of the individual blocks. Scale $30 \mathrm{~cm}$. (P. Morlupi 2005 @ MAIRY, adapted and optimized by F.G. Fedele 2020)

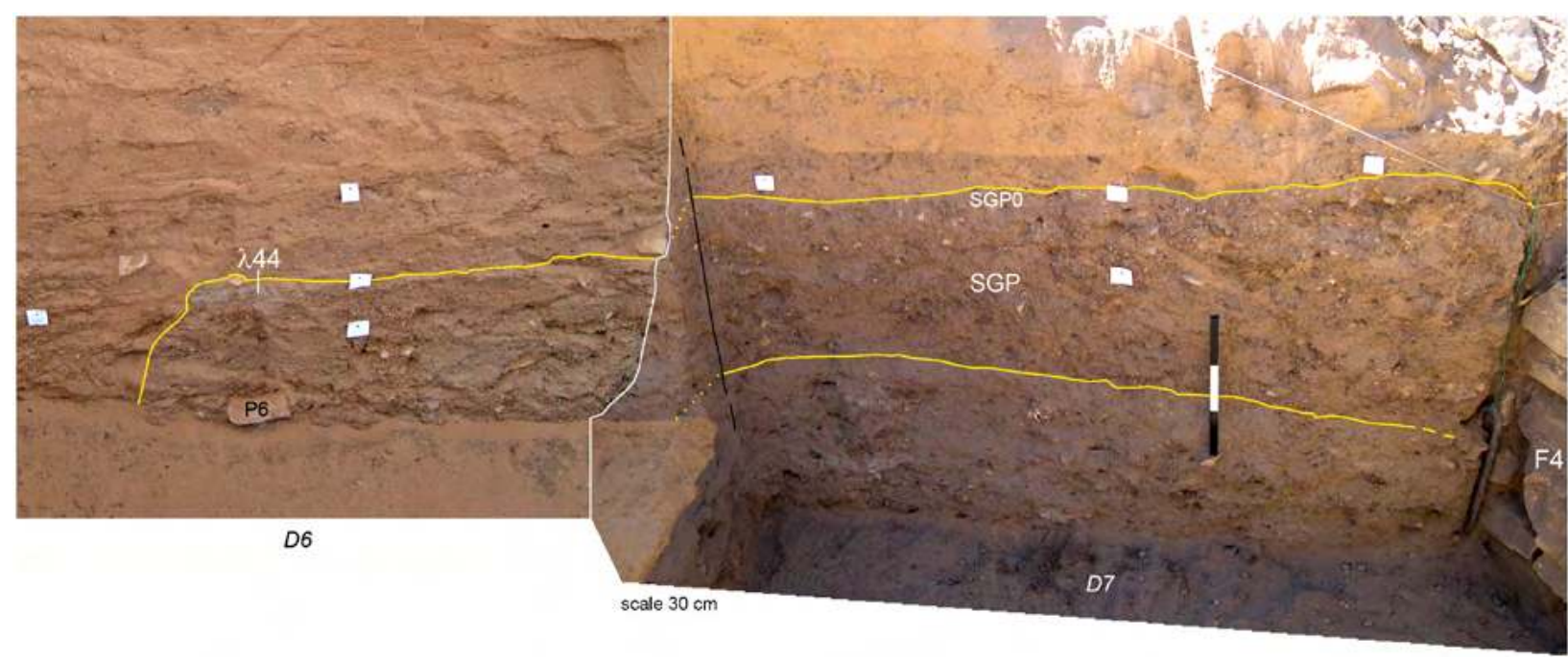

Figure 57. Earthwork F44 (outlined in colour). See also Figs 37-38. (F.G. Fedele 2020, from photographs by P. Morlupi 2005 (c) MAIRY)

detritus is present in GV2, there might be grounds to suggest that this unit and the upper half of suite SD2 represent in fact the earliest Minaean period. This historical reading is argued more fully in Chapter 18, section 3.2 ('On the earliest Minaean'), this volume; it must remain hypothetical, however, until these layers are excavated extensively and dating artefacts are recovered.

Between quadrangles D3-D1 and Sector C, comprehensively, a succession can be observed of (i) horizontal stratiform occupation layers up to surface S2; (ii) inclined sandy units rich in plant detritus up to surface S1 (suite SD2 and units BRH2-BRH1);223 and (iii) horizontal-undulating, often hyperorganic units above,

223 The strong angular unconformity of SD2 relative to suite GZ only becomes manifest with unit GSV2. containing manure beds. In this perspective, suite SD2 looks both anomalous and transitional. Several sedimentary constants across surface S2 would suggest no great change, in fact continuity, although habitation deposits disappear and sandy-pebbly sediments commence. These facts may not exactly indicate a persistence of depositional environment, but point nevertheless to continuously evolving conditions after the cessation of active Sabaean presence.

The cleaning and visual examination of the exposures at the head of Gully B would suggest that precursors of the present-day gully began to form during the sedimentation of suite SD2. There are erosion furrows within SD2 referable to a paleo-Gully B: one was formed post-GSV1 and ante-SA2 and looks like an actual precursor of the current gully. A period of shifting, shallow gullies in this upper part of the talus can 


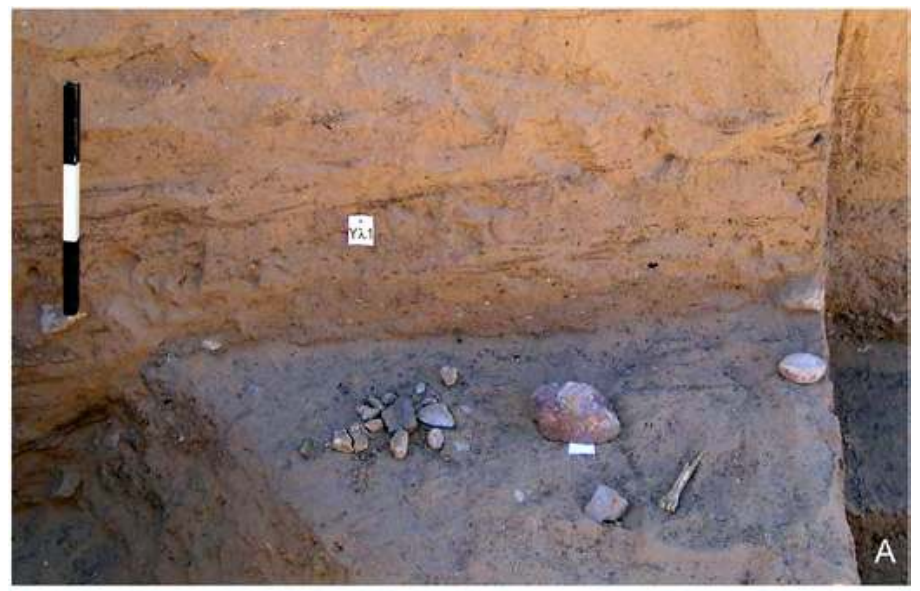

Figure 58. Locus 44, quadrangle D6: unit $\lambda 44$ under excavation, facing south. Scale 30 cm. (P. Morlupi 2005 @ MAIRY, adapted and optimized by F.G. Fedele 2020)
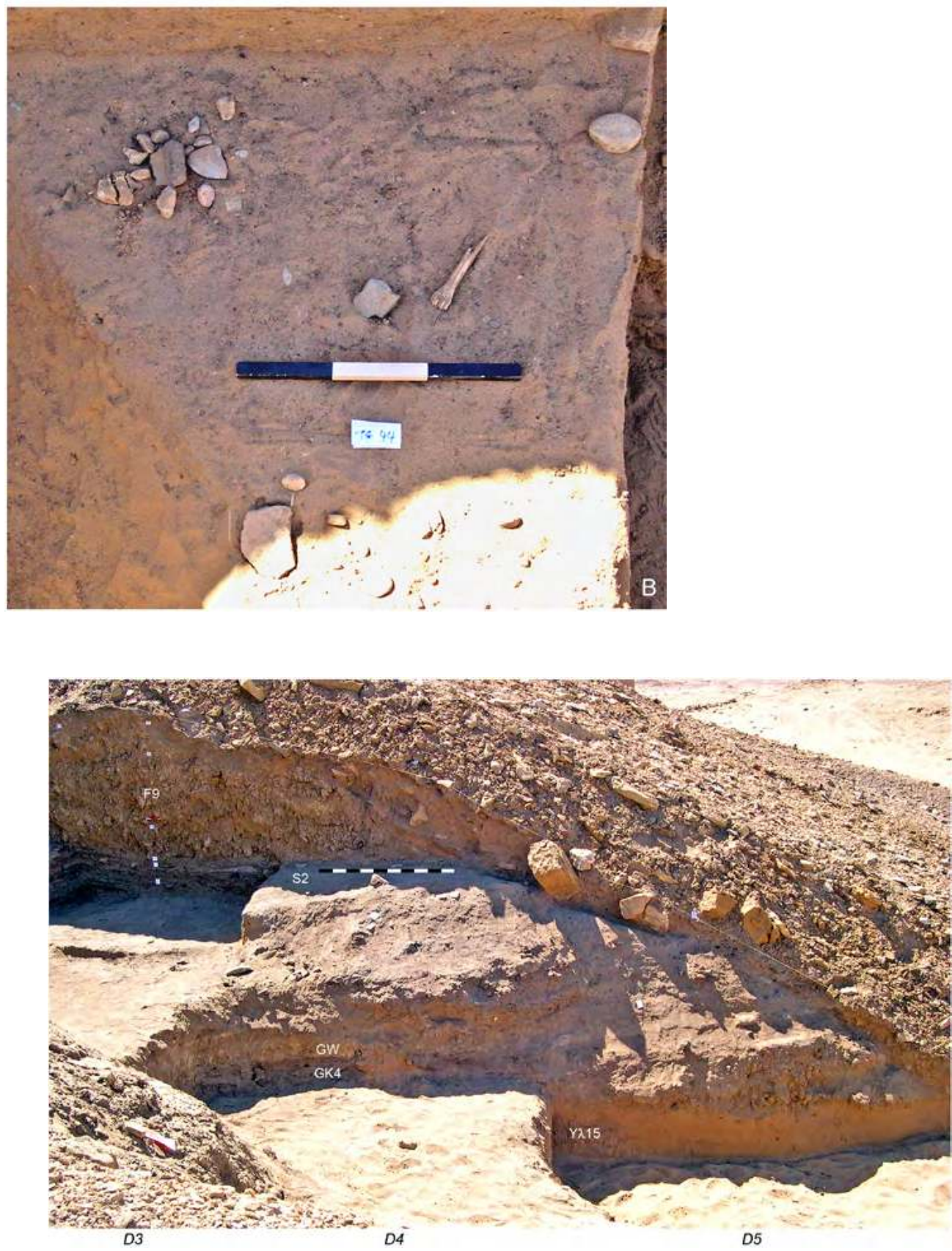

Figure 59. The Later Sabaean layers under excavation in middle Sector D, facing south. Scale 1 m. View corresponds with plan in Fig. 66 A; quadrangle D4 shows surface S2 with bones in situ (cf. Figs 33 A, 60 C-D). (P. Morlupi 2005 @ MAIRY, adapted and optimized by F.G. Fedele 2020) 

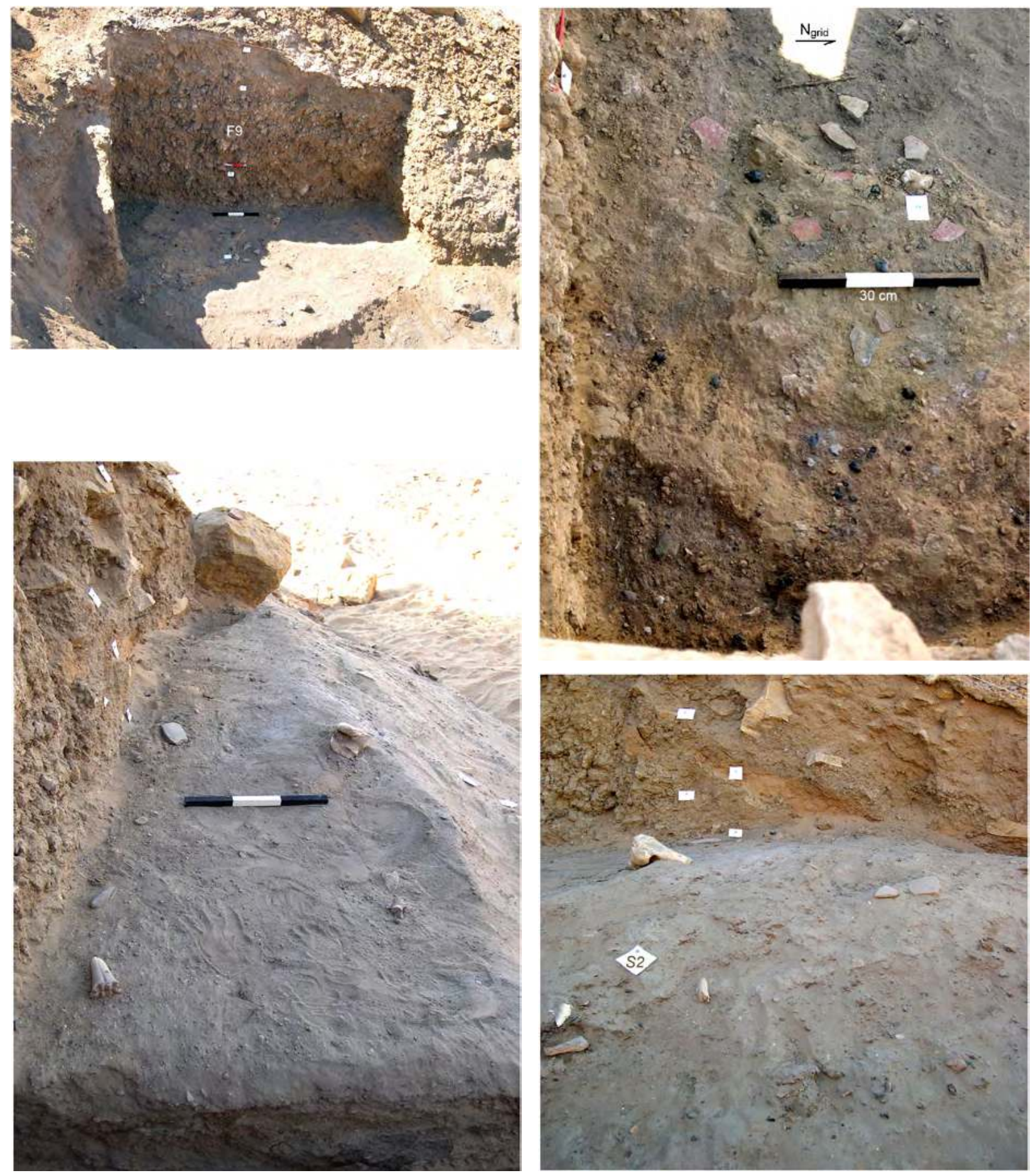

Figure 60. Sector D, surface S2 and in situ finds: quadrangle D3, facing south (above left) and vertical detail (above right); quadrangle D4, facing west (below left) and south (below right), cf. Fig. 33 A. Scale $30 \mathrm{~cm}$. (P. Morlupi 2005 @ MAIRY, adapted and optimized by F.G. Fedele 2020) 

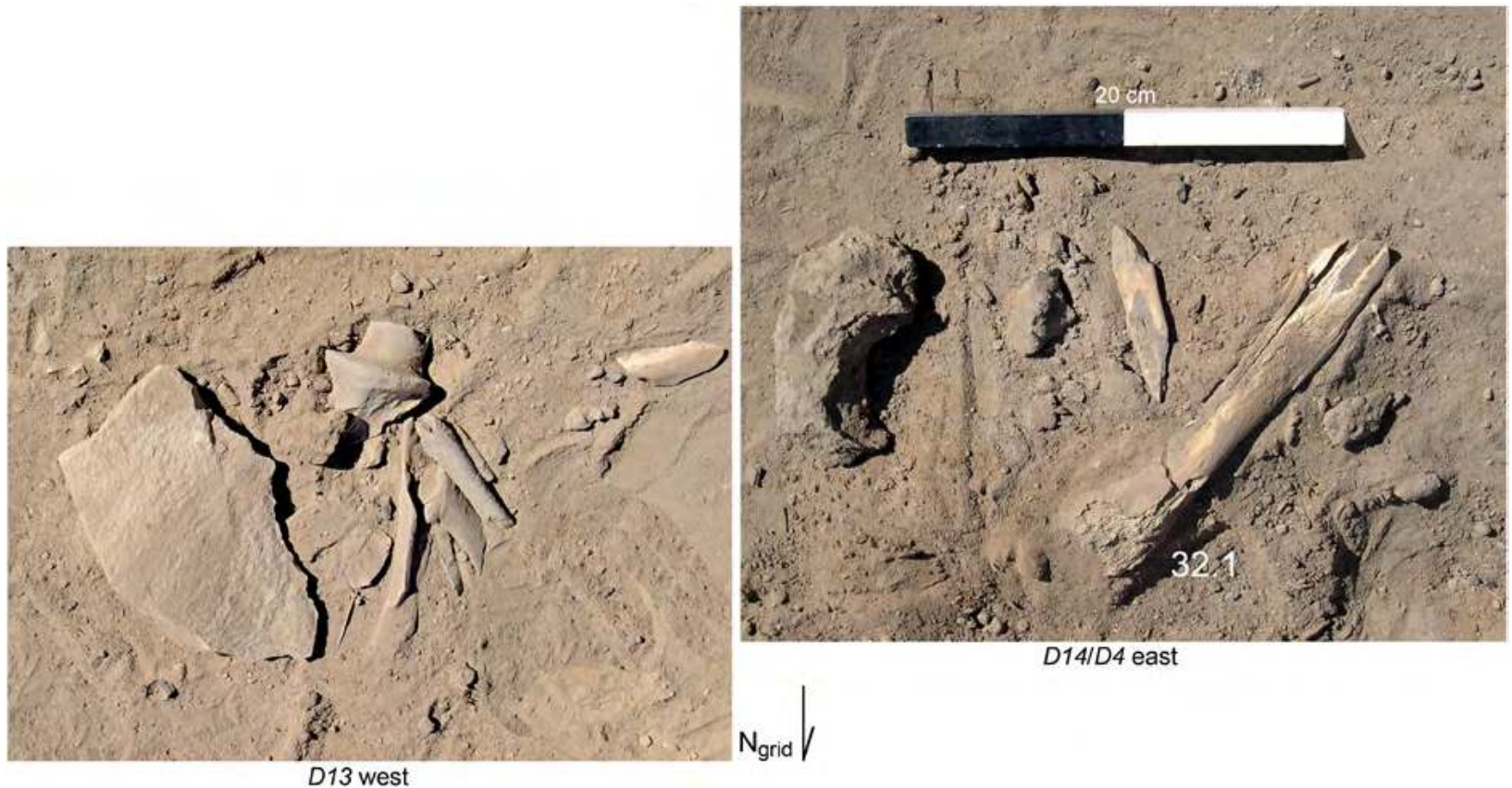

Figure 61. Sector D, animal bones and a limestone 'cleaver' in Locus 33, top of unit GZ3, quadrangles D4/D14 (right; cf. Fig. 66 A) and D13 west (left). (P. Morlupi 2005 @ MAIRY, adapted and optimized by F.G. Fedele 2020)
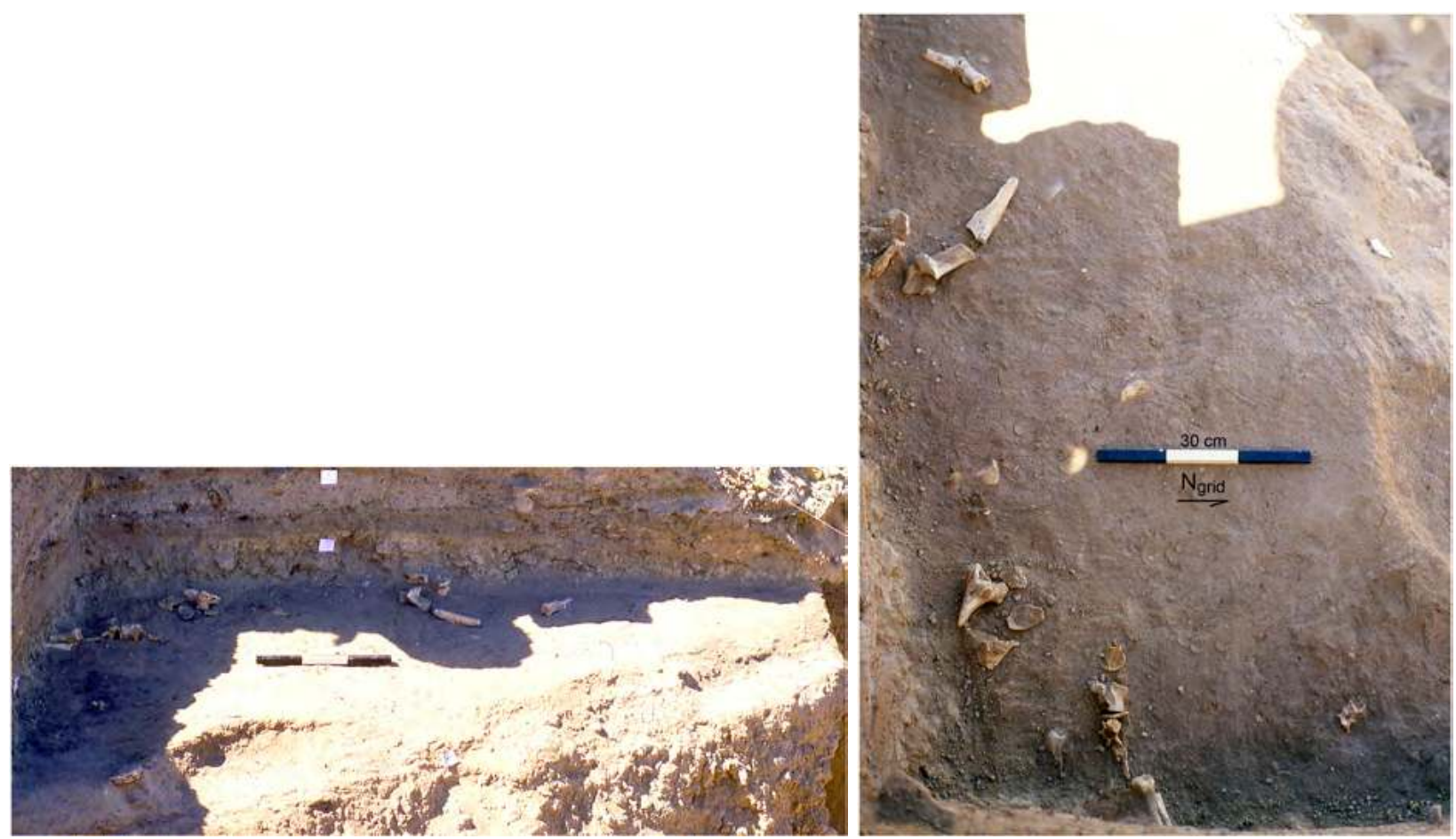

Figure 62. Sector D, animal bones in quadrangle D5, top of unit GK4. (F.G. Fedele 2005, optimized) 

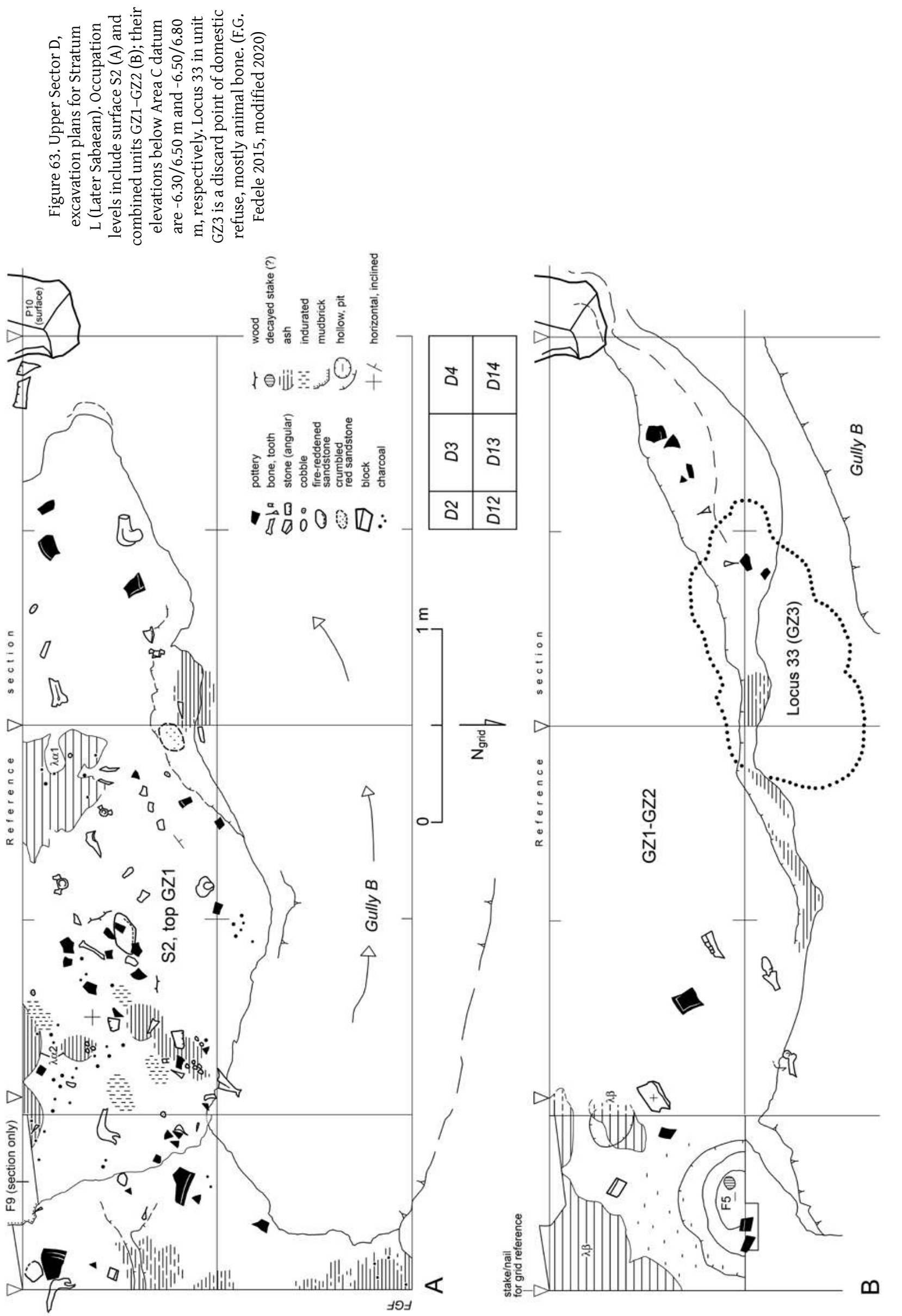


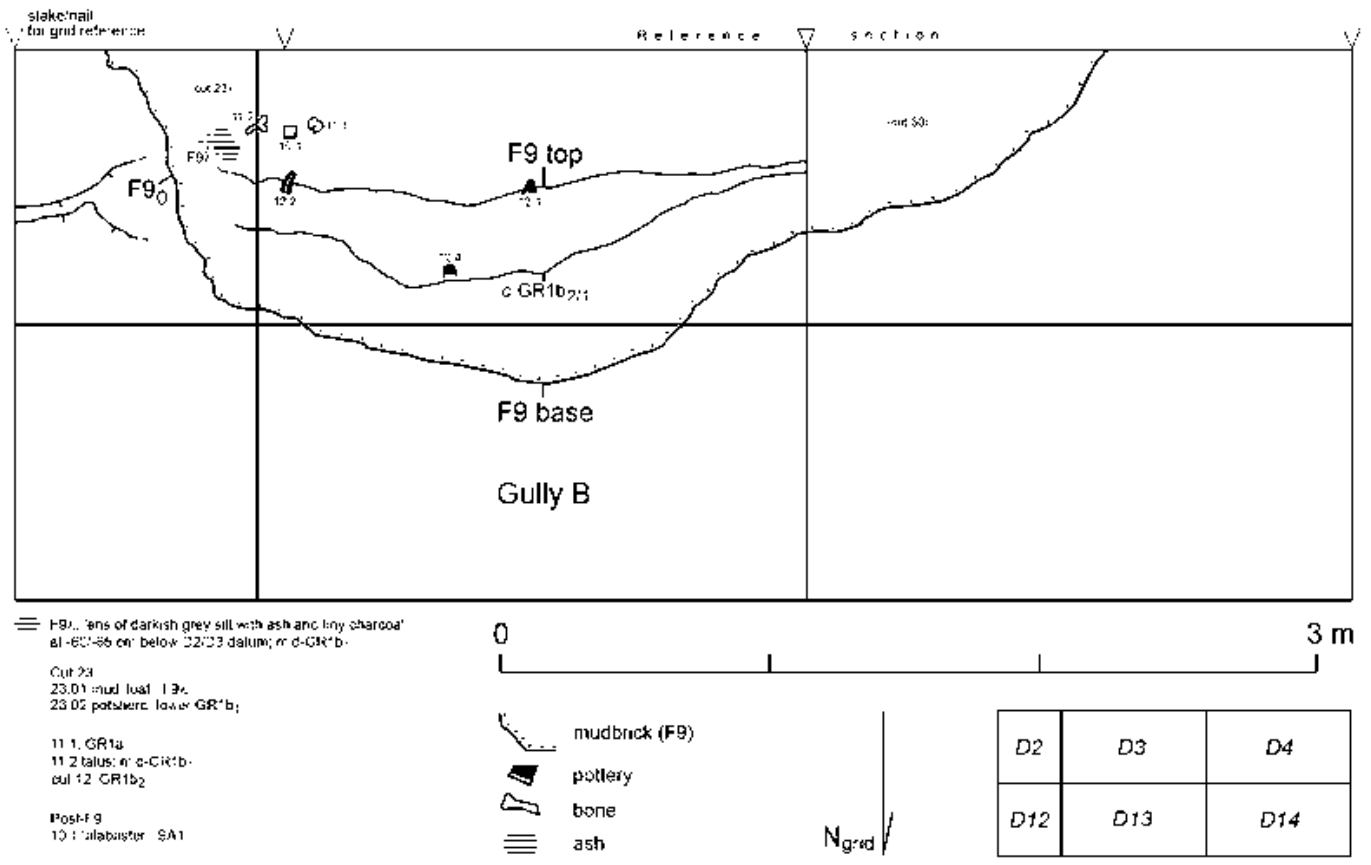

Figure 64. Upper Sector D, feature F9, composite plan. A find from sand SA1 is also included. (F.G. Fedele 2020)

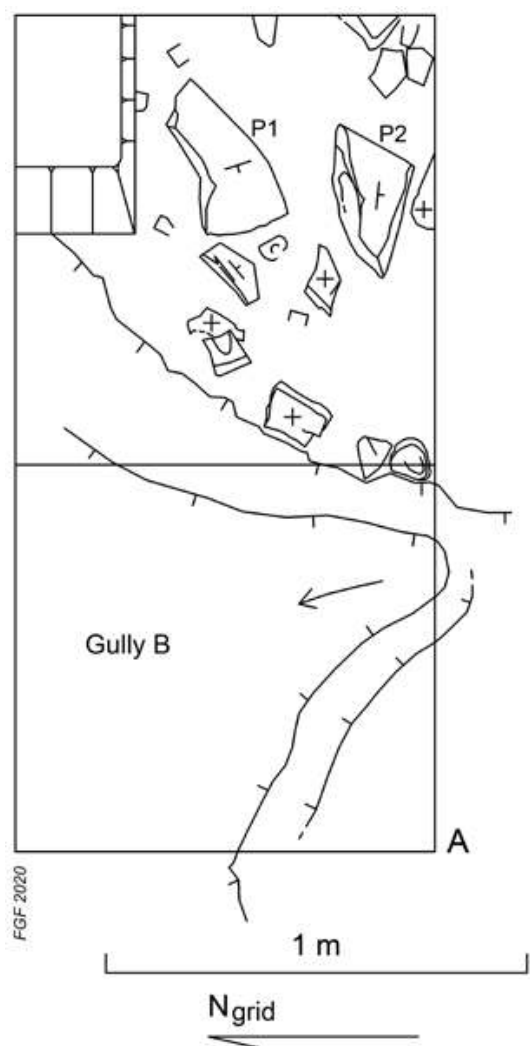

\begin{tabular}{|l|l|}
\hline$D 11$ & $D 1$ \\
\hline$D 12$ & $D 2$ \\
\hline
\end{tabular}

$+\downarrow$ horizontal, inclined
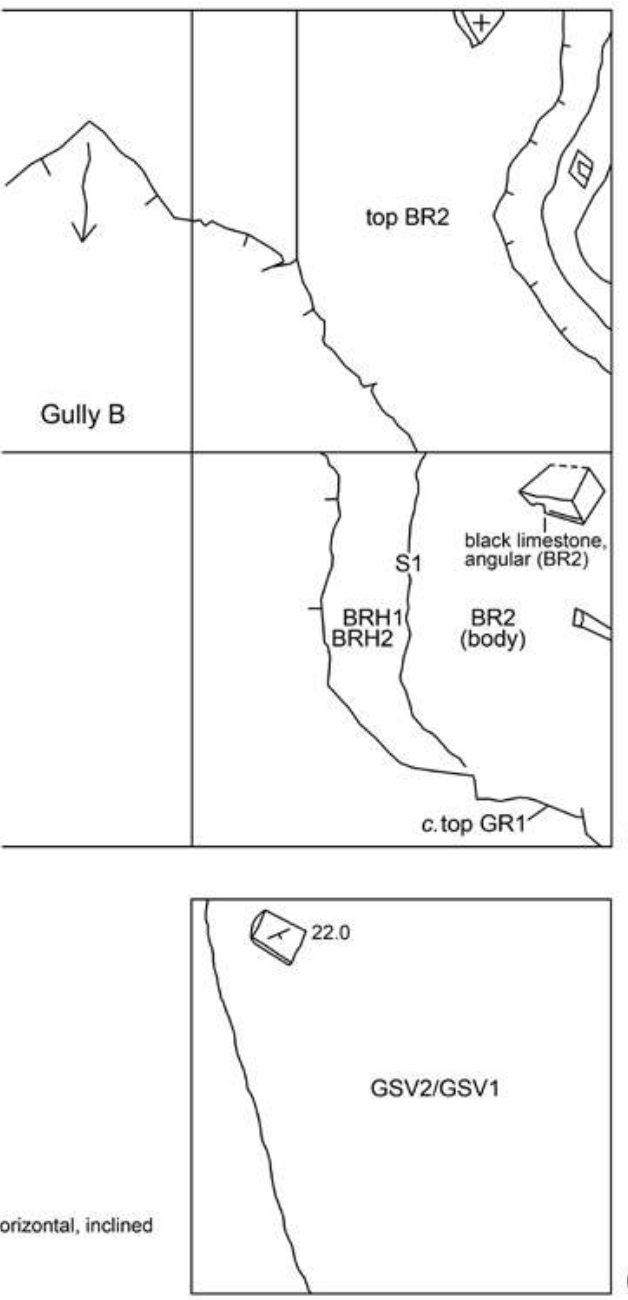

Figure 65. Upper Sector D, plans and composite plans for Strata I and K. A: top of layer BR1-Pa. B: unit BR2. C: find no. 22.0, quadrangle $D 2$, Stratum K.

(F.G. Fedele 2005 and 2020) 


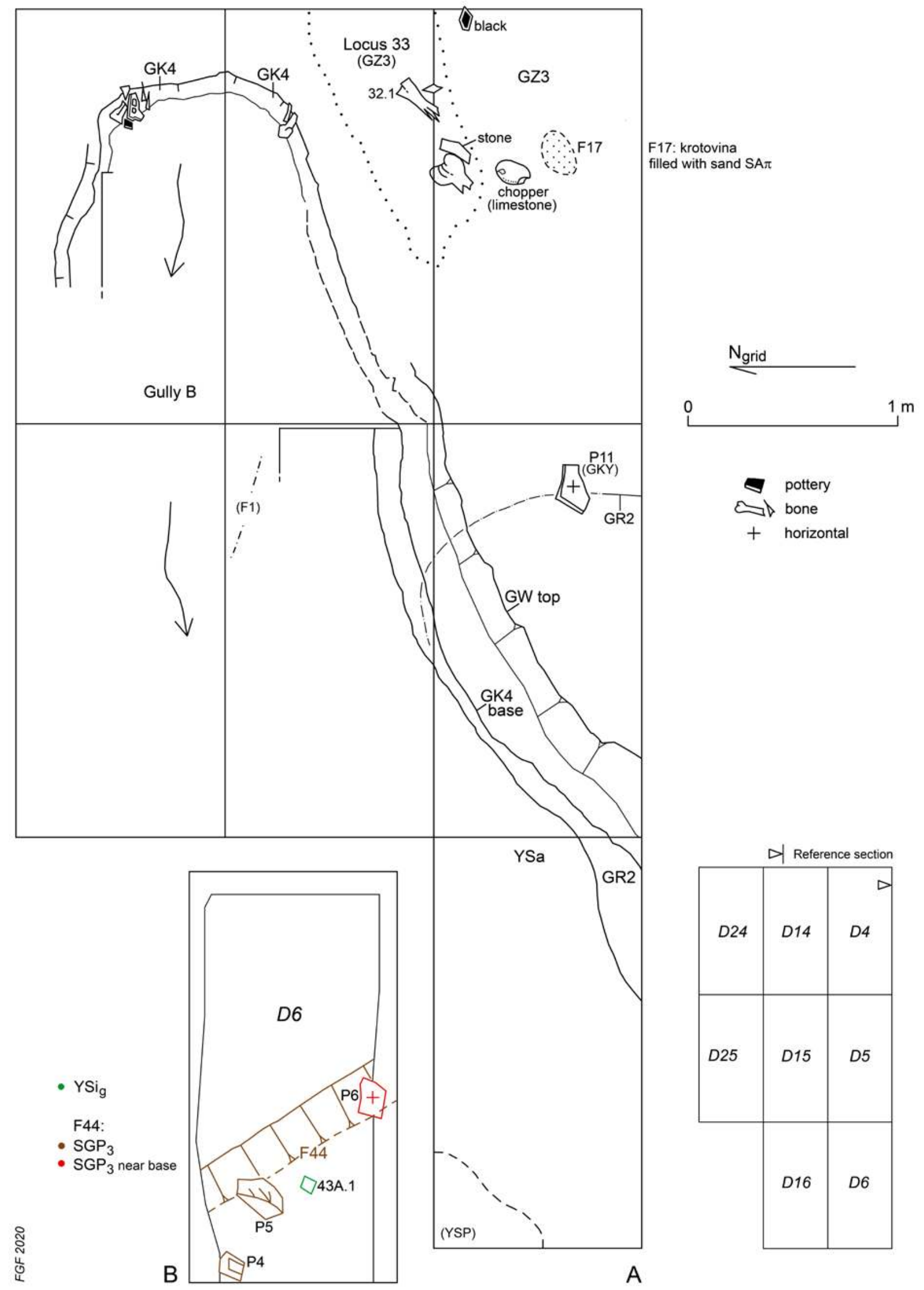

Figure 66. Middle and lower Sector D, composite plans. A: units GR2 to GKY, and part of Locus 33 (unit GZ3). B: quadrangle D6, showing earthwork F44 and findspot 43A.1 in unit YSi. (F.G. Fedele 2005 and 2020) 


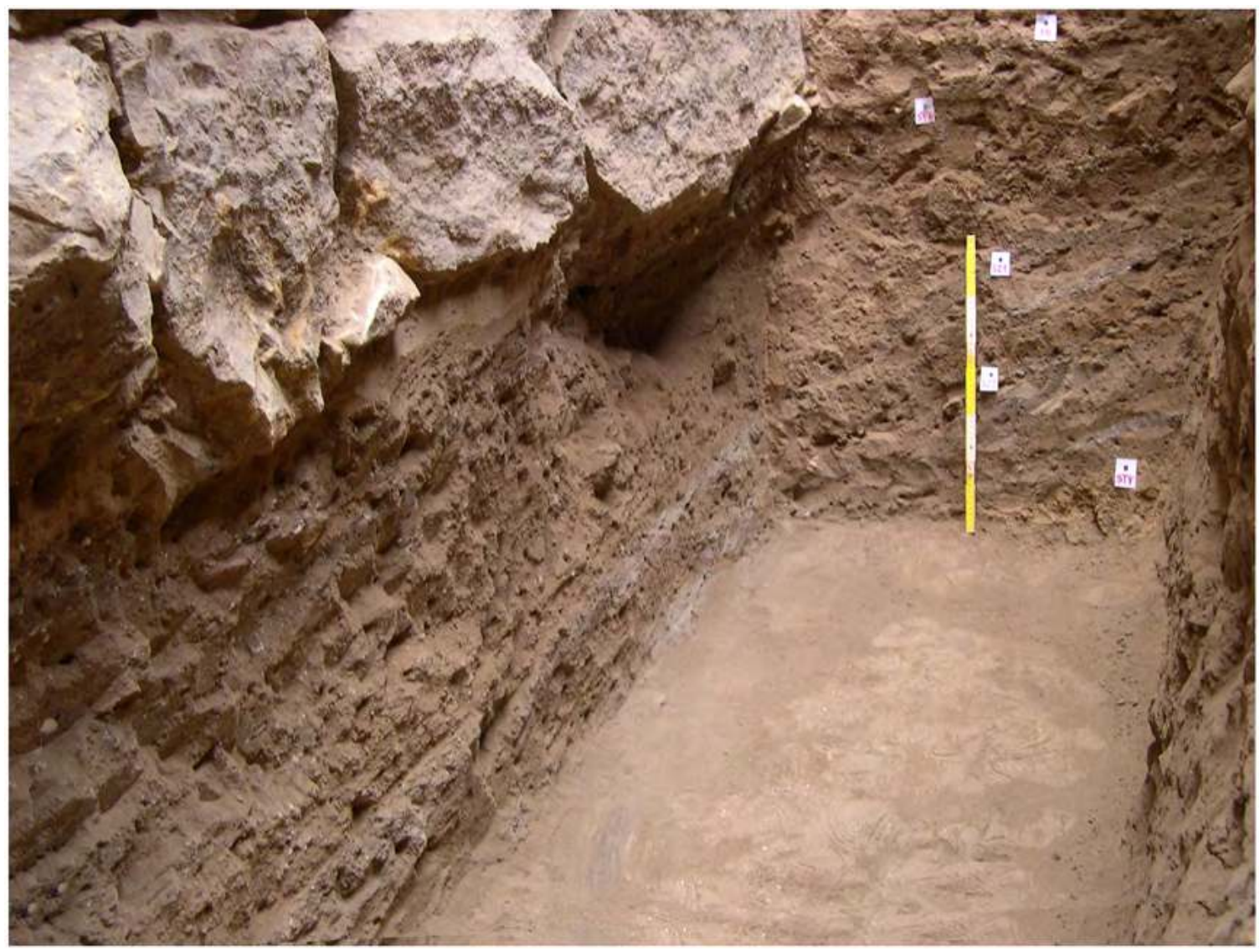

Figure 67. Sounding A: the Sabaean deposits beneath the Minaean wall, Locus 200, facing southeast.

(P. Morlupi 2006 @ MAIRY, optimized by F.G. Fedele 2019)

possibly be envisaged, with human occupation locally suspended. Some pluvial erosion had probably already started towards the end of the Sabaean occupation (cf. section 7.6 above), but an unprecedented level of rill erosion appears to have been set in motion on this part of the tell during the buildup of suite SD2 and immediately afterwards. One or more intervals jointly marked by erosion and human inactivity - not necessarily site abandonment - would be implied.

Some pottery finds from SD2 suggest primary deposition by people who ephemerally still used the place, although the intense occupation of Stratum $L$ had faded away. Sabaean-tradition pottery may have continued to be produced until the end of suite SD2, if two unworn pieces from GV2-SA2 - a Red Lustrous carinated bowl and a plain ware vessel - can be relied on. A 95 per cent of sherds from these units is Red Lustrous ware, and about a half are only little worn. They may have been eroded from primary Sabaean layers close by, and this is perhaps the explanation to be retained (see below), but a production coeval with Stratum $\mathrm{K}$ cannot be ruled out. No evidence of Minaean pottery came from the same units. However, a single 'Minaean'-looking potsherd came from GZ1-GZV in quadrangle D2. The occasional appearance of non-Sabaean vessels at the extreme end of the Sabaean material-culture sequence, or during a putative post-Sabaean inactivity phase, would not be surprising. Furthermore, political affiliation and material-culture production, especially pottery, might not coincide at this particular historical moment or in this particular place. This last point is argued more fully in Chapter 18 , section 2 , this volume.

It should be borne in mind that the correlation of quadrangles D1-D2 with the sequence of Sounding A is tentative, particularly concerning Strata J and $\mathrm{I}^{224}$ but also the placement of the boundary between Strata $\mathrm{K}$ and J might vary considerably.

Finds. Finds from Stratum K, suite SD2, include an ochred stone tile, no. 22.0, found in situ around the GSV2/GSV1 contact, i.e. earlier Stratum K (Fig. 65 C): if indeed a tile - previously it was thought to be an unusual handstone - it is a unique find for the pre-Minaean period, as discussed in detail in Chapter 21, section 2.2, this volume. ${ }^{225}$ Other notable finds from GSV3-GSV1 include cloth and basketry fragments (e.g. nos 22.01-02); a foot

\footnotetext{
224 See section 3.3 above, 'Long-distance correlations', and cf. Chapter 18, section 3.2 ('On the earliest Minaean'), this volume.

225 See also Chapter 18 , section 3.2 , this volume.
} 


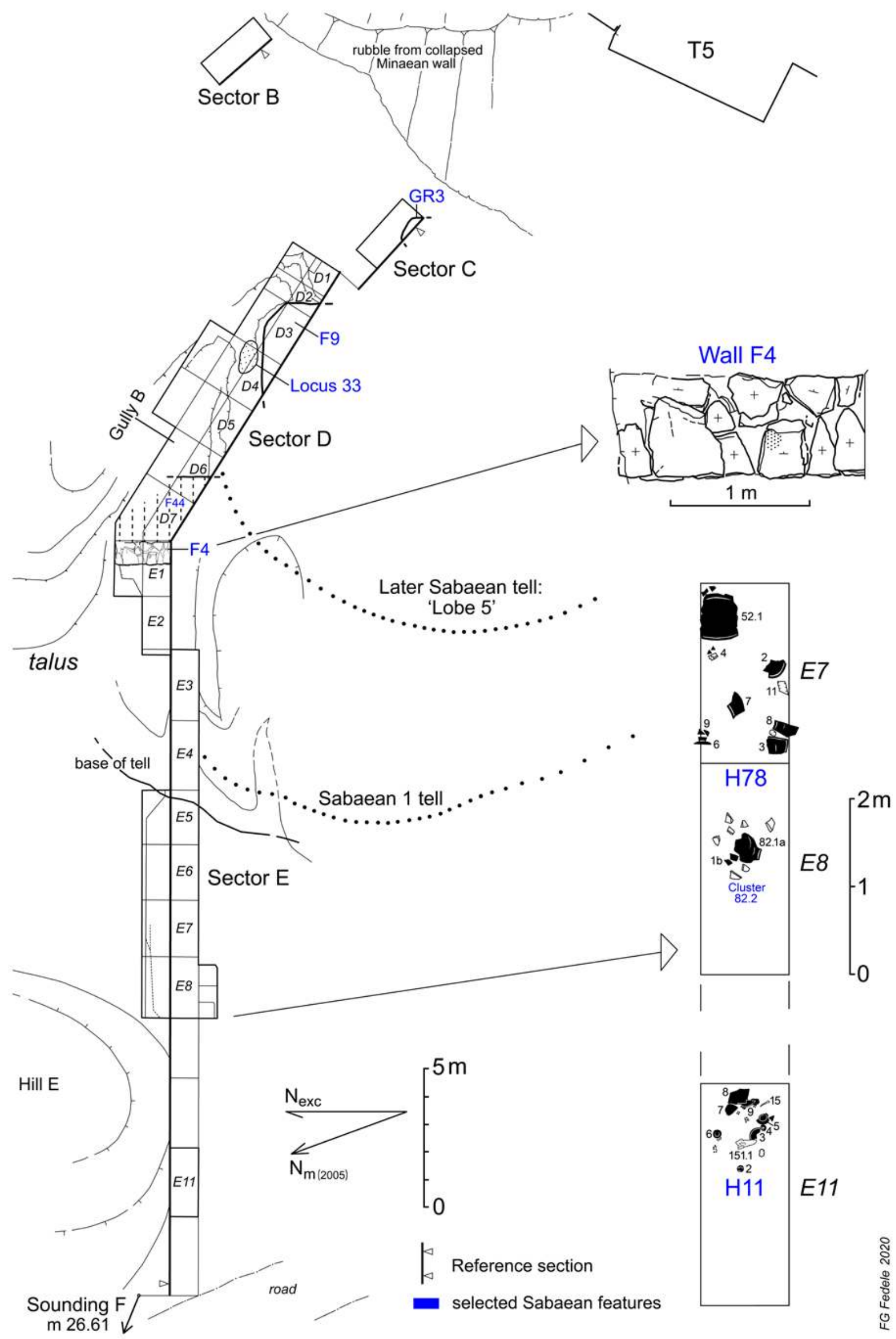

Figure 68. A synopsis of main Sabaean features in Sectors C, D, and E. (F.G. Fedele 2015, updated 2020) 


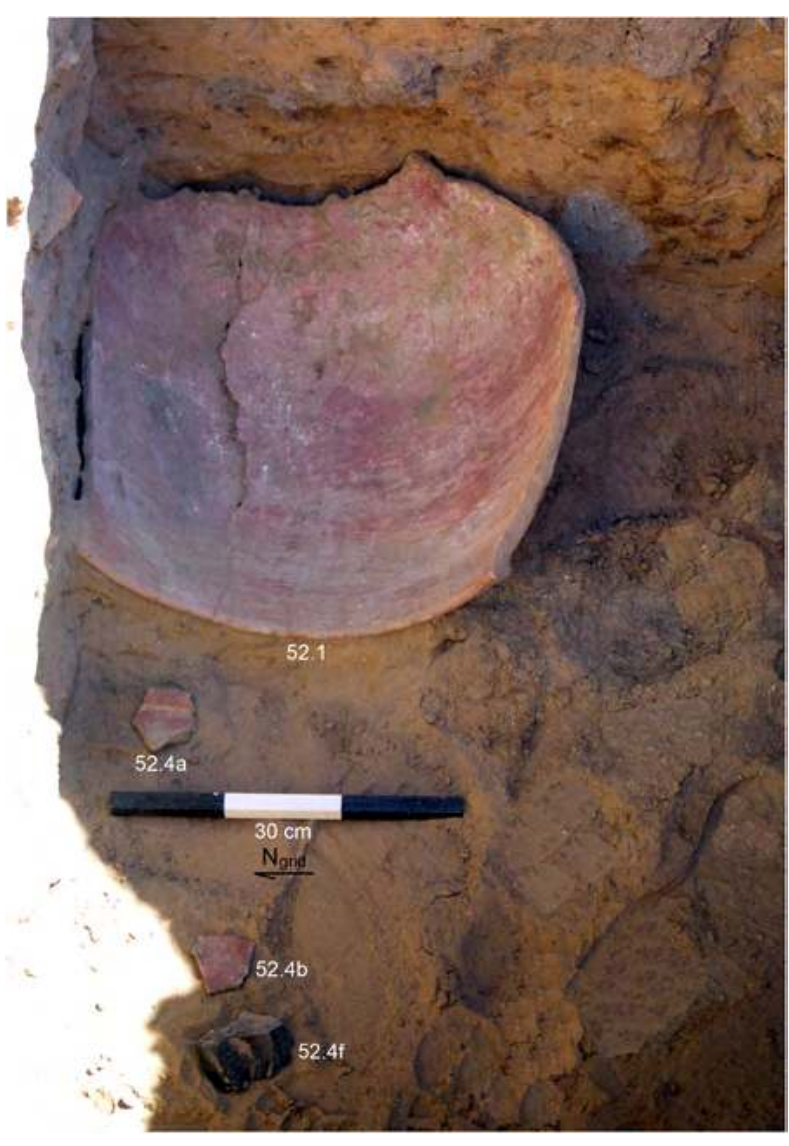

Figure 69. Sector E, cultural horizon H78, quadrangle E7: overhead view with finds in situ. (P. Morlupi 2005 @ MAIRY, adapted and optimized by F.G. Fedele 2020)

of a clay 'tripod', possibly a reworked Sabaean item (no. 22.03); a Wavy Rim bowl (vessel V22.3); and an 'eggshell' bowl in Pale Green ware (no. 22.2). Whether these last two finds could prove the actual circulation of these ceramic types after the Later Sabaean is impossible to determine: in keeping with the other sherds in cut 22, most of which have wear grade 2-3, their slight wear would rather suggest redeposition from Sabaean layers close by (see Chapter 23, section 3.3).

Two unparalleled objects - a pair of sling bullets, 6.1 and 6.2 - came to light from a deposit of quadrangle D12/Gully B firmly attributable to the GSV3-GV2 sequence, which also contained an unusual sandstone chopper (no. 6.01). The functional implications and the potential historical interest of the sling bullets are mentioned in section 8.3, below, and examined and discussed in Chapter 18, section 3.2 ('On the First Intermediate'), this volume. From units GSV1-SA2 (the top of suite SD2) or BRH2 a decimetre-sized cloth fragment was retrieved (no. 21.04), as well as a chipped quartzite tool (no. 21.01).

An exceedingly high number of date stones were collected with cut 21 from units GV2-SA2, but, in fact, the whole upper half of suite SD2 was observed to contain an unusual quantity of date stones. This frequency continues with the subsequent units of quadrangles D1-D2 attributed to the Earlier Minaean, BRH2 to BR2 (cut 20).

\subsection{Interpretation of suite SD2 226}

As the above section suggests, the implications of the sedimentary and artefactual data concerning Stratum $\mathrm{K}$ are largely conjectural. All evidence indicates that Stratum $\mathrm{K}$ is no longer Sabaean in its 'typical' expression, i.e., it is no longer associated with active Sabaean occupation in the excavated area, nor does it yield secure Sabaean pottery in primary deposition. At the same time, Stratum $\mathrm{K}$ cannot be identified as Minaean, lacking diagnostic in situ elements. If, however, the emphasis is placed on sedimentary manifestations rather than artefactual content, there is a distinct possibility that Stratum $\mathrm{K}$ actually represents the transition to the Minaean control. This interpretation takes into account the first hints of a major lithostratigraphic and behavioural novelty, the appearance of manure levels examined above.

How much continuity or discontinuity should be read in surface S2, and what time duration in the production and deposition of suite SD2? Clearly, something changed in human occupation: SD2 must partly have originated from the erosion of the last Sabaean 'living floors' and some duration must be implied. Beyond that, however, a nuanced view seems preferable and the impression of discontinuity must be tempered. For example, an appreciation of the time involved is not yet possible. Structure F9, already not intact when SD2 began to form, clearly underwent further decay during the accumulation of SD2, given that decay products released from $\mathrm{F} 9$ - mudbrick clods ( $\mathrm{yx}$ ) and crumbly and melted mudbrick (GRx) - interfinger with the units of this suite. ${ }^{227}$ But several sedimentary processes suggested by SD2 need not have implied any significant length of time.

For what is worth, the pooling of two radiocarbon samples from suite SD2 gave for earlier Stratum $\mathrm{K}$ a higher-probability date centred on 598 BCE (from 653542 BCE with 62 per cent probability, by combining samples \#22.1 and \#22.1.a). Thus an age range of "early 6th century-550 BCE' for Stratum K could be proposed on this basis (see Chapter 18, section 1 and Tables 2-3, this volume). As explained in Chapter 18, while the pooling helped to reduce the drawback of the individual samples' large standard deviations, the shape of the

\footnotetext{
${ }^{226}$ Cf. Fedele 2010, 130; 2011a, 108-111; both revised.

227 An identical micro-unit of decay material from $\mathrm{F} 9, \gamma \mathrm{x} \omega$, parallel to $\gamma \mathrm{x}$ as well as similar to GRx, can be seen at the foot of F9 to the west, in middle quadrangle $D 4$ (Figs 18,33). It is earlier than Stratum $\mathrm{H}$.
} 


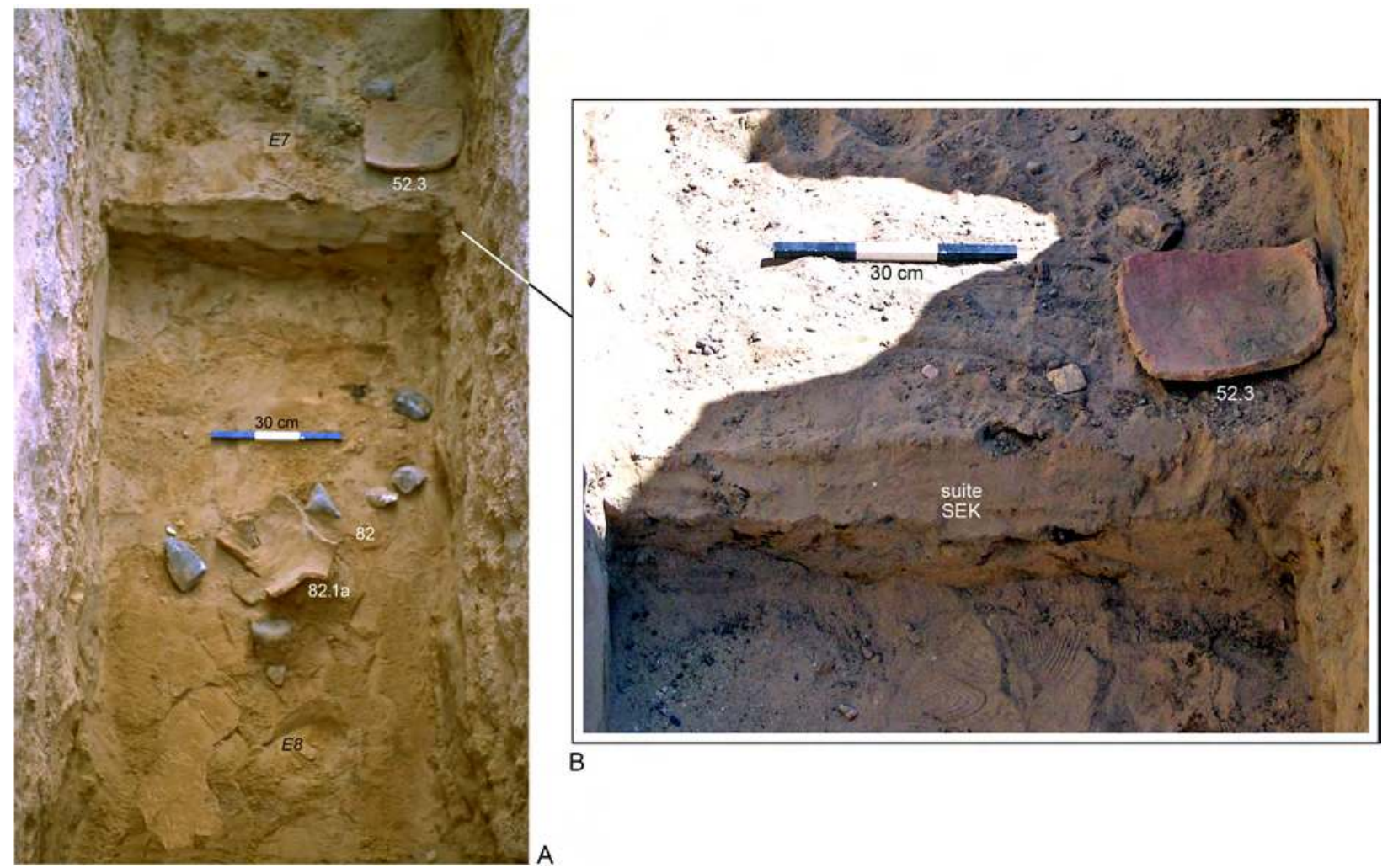

Figure 70. Sector E, cultural horizon H78, quadrangles E7-E8: A, Cluster 82.2; B, detail of E7 west and sediment suite SEK. (A, F.G. Fedele 2005; B, P. Morlupi 2005 @ MAIRY; adapted and optimized by F.G. Fedele 2020)

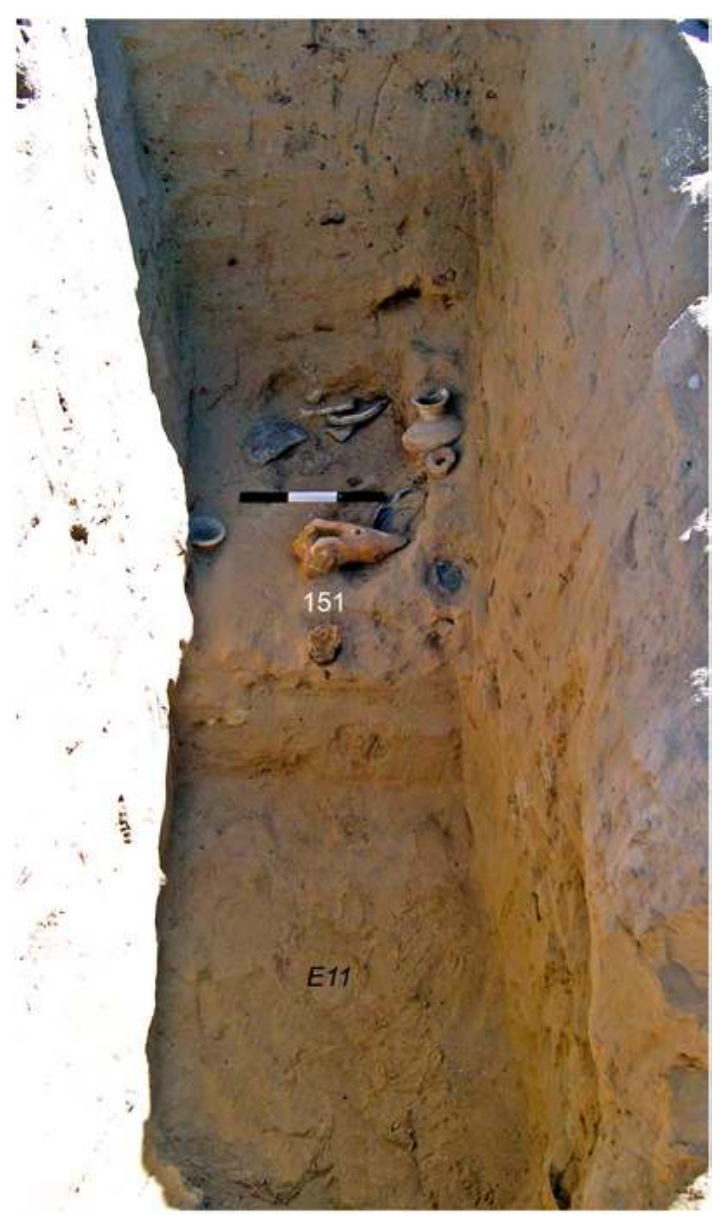

Figure 71. Sector E, cultural horizon H11 in quadrangle E11, facing east.

Finds no. 151 in situ, scale $30 \mathrm{~cm}$. (P. Morlupi 2005 @ MAIRY, optimized by F.G. Fedele 2020) 


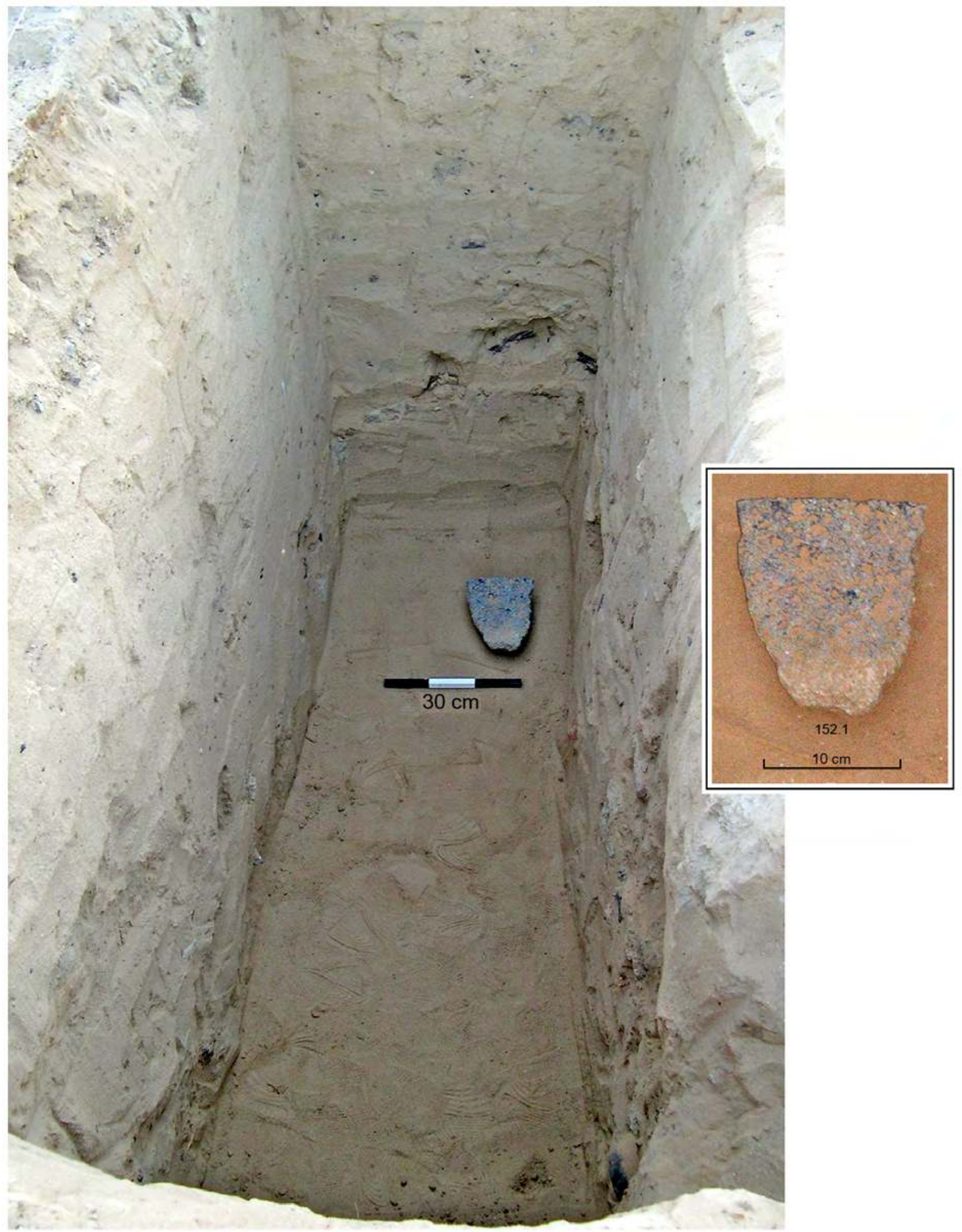

Figure 72. Sector E, cultural horizon H11Q in quadrangle E11, facing east (cf. Fig. 50). Inset: quern no. 152.1. (P. Morlupi 2005 (c) MAIRY, adapted and optimized by F.G. Fedele 2020) 
calibration curve itself imposes limits on age estimate accuracy in this time range.

Was there a break or a crisis rather than a transition? No indicator of environmental turnover is apparent. Equally lacking is any evidence for widespread abandonment, if we consider, for a comparison, that surface S2 and suite SD2 show a very different sedimentary picture from the Second Intermediate interval to be examined below - true settlement desertion in this latter case (Stratum E). Rather, it is conceivable that the Sabaean cultural and population presence became reduced in force or integrity: that it slackened off, so to speak, or rather fluctuated, at a juncture of political instability and power tensions. It is in this context that sling bullets nos 6.1 and 6.2 (cf. section 8.2) can play an interesting historical role. Concurrently, a reduction of occupation intensity or 'pressure' might be involved, its scale to be determined: only this part of Area C, or the entire Yathill? And once again, some reorganization of settlement might have contributed: ${ }^{228}$ a shift of occupation away from this part of the tell, or a shrinking occupancy in general.

In fact, a settlement reorganization could be considered the best explanation (the most parsimonious), whereas a short reduction or interruption of settlement looks like a lesser hypothesis. Such a reorganization would tie in nicely with the restructuring of the town plan, brought about by the Minaeans following a new idea of political expression. In fact, suite SD2 cannot disclose the whole story: it necessarily only records some aspects or moments of the Sabaean-Minaean political shift. The available field evidence is insufficient to resolve the problem of this transition in detail. This discussion will be taken up in Chapter 18, section 3.2 ('On the earliest Minaean'), this volume.

\subsection{Stratum K: the lower talus}

A few sediment units from the lower talus and plain can probably be attributed to Stratum K: 4 UY, VCB, LCB, and surface S01 with diagenesis zone Z3, in Sector E (Figs 21-22, 40, 47-48); and FH1 with surface S19 in Sounding $\mathrm{F}$, which will be treated in section 17 . These correlations are based on relative stratigraphic position and the fact that the deposits in both Sector $\mathrm{E}$ and Sounding $\mathrm{F}$ are topped by an evident discontinuity implying a hiatus (S01 and S19, respectively).

LCB and some allied units (4UY, VCB, and their subunits) clearly record sheet-wash flows originating from hearths and plant-detritus clusters on the middle talus nearby. Unit LCB and surface S01 form an indissoluble whole. LCB is an extraordinary, extensive, light blue-

228 With or without a final modification of the Yathill Oasis: cf. section 6.6, 'Sand YS: interpretation', above. grey, 'white-specked' sandy-silt sheet originating in middle quadrangle $E 4$ and blanketing the middle talus, only to thin down through quadrangles E6 and E7: about 8.5 linear metres east to west on the Reference section (Figs 40 C-D, 47). It seems to have roots, precisely, just upslope of $E 4$ parallel to the inclination of the palaeotalus (Fig. 40 B). Directly or indirectly, LCB clearly originated from the prolonged washout of a hearth or hearths located there or nearby. By indirectly I mean that the washing and runoff may have affected not a primary hearth, in situ, but already redeposited hearth material. At its root LCB contains ash and charcoal, mixed with traces of mudbrick, and is hardened or mildly compacted: this means that it is relatively intact hearth sediment subsequently fixed and occasionally indurated by calcium carbonate infiltration (Diagenesis $\mathrm{Z} 3$, see below). This relative hardness is not recorded anywhere else over the extent of LCB.

Surface S01 is its top, the distinct and equally extensive surface which formed after LCB had blanketed the flexure and the lower talus. This surface is important in the evolution of the talus, considering that nothing less than the sedimentary history of Yathill changes with it. S01 separates 'silts' below from 'sands' above, that is, it constitutes the relatively distinct boundary between two sedimentary cycles: the older, essentially colluvial and silty, linked to the washout or erosion of the talus, and the younger essentially aeolian and sandy (and continuing into the present). This epitomizes the contrast and interplay between aeolian and colluvial processes, which characterized the middle and lower talus for a long time (cf. previous sections, repeatedly). Jointly, LCB and surface S01 constitute the close of a long sedimentary stage, as is particularly evidenced by quadrangle E5. Surface S01 becomes almost invisible in the western or middle part of quadrangle $E 7$, but it is still there.

As to Diagenesis Z3, it appears precisely to correspond to surface S01 (see section 4.1 above). And judging from visual inspection, it seems a proper weathering zone, as the diagenesis consists of a marked illuviation of fine silt and clay together with calcium carbonate solutions, which resulted in the most conspicuous density of 'white specks' in Area C.

Unit VCB with its upper partition VCB' (Stratum $\mathrm{K}$ ) is a couple of small plant-detritus masses closely associated processually with the previously described VGN and $\mathrm{VGN}^{\prime}$, ascribed to Stratum L (see section 7.7 above). They too derive from the repeated dismantling of some plant- and/or manure-rich occupation deposit existing to the south.

Finds. Two notable Red Lustrous pottery finds were retrieved in situ from the 'root' of LCB immediately 
below sand SAE, in quadrangle E4: a shallow bowl (no. 120.1) and a narrow-necked jar (no. 120.2), this latter typologically identical with no. 82.1a from cultural horizon H78. Both belong to Stratum K, but are probably reworked elements from Later Sabaean units belonging to Stratum L (see Chapter 23, section 3.4, this volume).

\section{Sounding A in general: organization, results, and particular remarks}

An exploratory test pit alongside Minaean bastion T7 was dug in 2005, supervised by GOAM inspectors 'Isa al-Sha'ibānī and - for part of the time - 'Abd al-Bașit Nu'mān. A much wider, formal excavation was planned for 2006 and duly carried out in that season to its completion. This work, Sounding A, provided a vertical sequence from the Later Sabaean to the present, in addition to revealing the entire Minaean-Islamic wall at bastion T7, hence its importance in the archaeological landscape of Area C. While the Later Sabaean deposits have been treated in section 7.3, due to their proposed correlation with Stratum $\mathrm{N}$, the whole sequence of Strata J to A is the subject of sections 10-14, after the present section serving as introduction and overview.

The priority given to a continuous, comprehensive presentation of most of Sounding A is due to the fact that its sequence constitutes the reference for the Minaean to Islamic periods in Area C, whereas the talus and the plain only supply imprecisely correlatable deposits, as discussed in sections 15 to 17 below. Only a fragmented summary of this sequence was available from the previous, preliminary publications. ${ }^{229}$

As mentioned in the introduction to this chapter (section 1.1), the stratigraphy of Sounding A in this volume supersedes the provisional account presented in Arabia 4, ${ }^{230}$ which in several parts was based on insufficient analysis of the difficult - if copious excavation records. That applies to both description and interpretation and is reflected in an entirely new drawing of the stratigraphy (Figs 13, 17, 25, 78). The parts most affected by changes are sediment group GT74 in the middle-upper segment of the sounding (particularly suites T74L and T74M) and the megafeature now renamed F10-F12 in the lower third (the Minaean earthwork flanking the wall). Detailed subsidiary profiles of both stratigraphic segments are shown in Figs 79 and 107. The present information is a result of the complete reanalysis of the records from both excavation seasons, the detailed observations made in 2006 incorporating - where useful - the preliminary ones of 2005.

\footnotetext{
${ }^{229}$ Fedele 2010, 2011a.

${ }^{230}$ Fedele 2010, 122 (Locus 200, Sabaean), 131-140 (Minaean to Islamic).
}

The final,complete plan of Sounding A is showninFig. 73. As shorthand for the spatial divisions routinely covered by the excavation the two expressions, 'rectangle A1A12' (or, occasionally, 'area A1-A12') and 'area A1-A31' will be used: the former to indicate quadrangles $A 1, A 2$, $A 11$, and $A 12$ when intended as a whole, and the latter to indicate the combined surface composed of rectangle A1-A12 and the middle and eastern part of quadrangle A31 (the precise limit is shown as a dashed line in Fig. 73). From the top of unit T76 downwards, the sounding area was reduced to a north-south strip formed by quadrangles $A 1$ and $A 11$ and part of $A 31$ (this latter as above): this area will be called 'strip A1-A31'.

On matters of excavation strategy and recording the reader is referred to section 1.3, above. For the purpose of sequential ordering the archaeological finds were grouped according to dissection units (cuts) as shown in Table 3; the same groups form the basis for the stratigraphic analysis of pottery employed in Chapter 22 , this volume. The correspondence to historical phases, as indicated in the table, is more than sufficient for most historical or comparative evaluations.

A significant feature of the sedimentary succession of Sounding A is represented by the block horizons, that is, the repeated occurrence of levels containing stones of about half a metre in diameter, or more. In Area C this phenomenon is peculiar to Sounding A, revealing an evident correlation with the Minaean activity that involved the movement of large-sized rock material directly or indirectly related to the town wall. Indeed, in Area C no stone blocks occur on the talus of Yathill before the Minaean construction works at the wall. However, the details of this activity and the specific explanation of every block horizon in the sequence will escape us until additional, wider extramural excavations are conducted.

Eight block horizons were identified, one of them indicated by a single outsize stone block, and four horizons can be seen or perceived on the Reference section. From the bottom, we encounter an isolated block in unit $\mathrm{T}_{1} \mathrm{~F}_{1}$ (P54, see section 10.1, 'Stratum J', below); blocks T7C of Earthwork F10-F12 (see section 10.3); two blocks at different levels in unit T76J (P25P24, see section 11.2); blocks and slabs T7B related to feature F8 (see section 11.3); blocks T7A, which deserve particular comments below; some minor blocks in upper T74 and lower T73b (see sections 14.1 and 14.2, respectively); and recent blocks $\mathrm{T} 70$ in the adjoining wall recess, $\mathrm{T} 6 / 7$.

The main block horizon is represented by unit T7A, a substantial accumulation of collapse rubble from bastion T7 itself (see section 12.3 below). In the drawing of the Reference section for Sounding A, not only the blocks of T7A exclusively intercepted by the section 
were drawn, but also - selectively - those contained in a 50-cm-deep band on the excavated side of the section, in order to convey a more realistic impression of this collapse-rubble feature. This partial 'projection' (i.e., not a section, strictly speaking) explains the superposition of block profiles in the drawing. A similar convention was adopted for the subsidiary north section shown in Fig. 107.

Some tactical aspects of the work at Sounding A deserve mention.

i. For the purpose of both stability and information, blocks P20b and P20j of accumulation T7A intercepted by the Reference section - had to be left in place on a ledge or supporting buttress tapering towards the bottom (e.g. Figs 85, 104, $109 \mathrm{~A})$. It must be understood that the portion of stratigraphy below those blocks, over a height of about a metre, is in fact off-section. In fact, below this level, the whole Reference section slightly recedes northwards as the sounding progressively deepens. This was dictated by the need to avoid a gravity collapse of this stoneburdened section.

ii. A low wall, located near the edge of the talus drop in front of wall recess $\mathrm{R} 7 / 8$, was constructed as a storage device for the many stone blocks from Sounding A, including T7A, T7B, and T7C.

iii. By mid-campaign, in 2006, a flight of steps had become indispensable in order to allow both access and earth removal. Therefore the deposits on the northern side of the sounding, mostly in quadrangle $\mathrm{A} 32$ north, were dug so as to form a stair leading to and from the archaeological pit proper.

iv. The exploration of the Sabaean deposits at the bottom of the sounding (Locus 200) had to be carried out over a smaller surface than strip A1-A31 (as defined above). Cut 199, related to the upper half of unit $\mathrm{SYH}$, was still made in quadrangles A1-A11 east and most of A31, like cuts 196-198. Cut 200 below, instead, due to severe time constraints, was made over a restricted rectangle of $1 \times 2.20 \mathrm{~m}$ only, covering A31 southeast in addition to A1-A11 east. This was the last cut in Sounding A.

A major problem during the preparation of this chapter - as mentioned - was the analysis and understanding of group GT74, i.e., the sequence formed by suites $\mathrm{T} 74 \mathrm{~L}, \mathrm{~T} 74 \mathrm{M}, \mathrm{T} 74 \mathrm{U}$, and associated individual sediment units (Fig. 78). It soon became clear that the Reference section (the southern section of rectangle A1-A12) is uninformative about this sediment group, and, taken alone, cannot explain its stratigraphic structure and complexities. In particular, the Reference section apparently only captured the margin of rubble accumulation T7A, a major component in the stratified deposits at bastion T7 (see above). Moreover, in the previously published version only the two blocks of T7A materially left in the section were drawn, which failed to do justice to the actual, denser fabric of this rubble heap.

Chance also dictated that several significant stratigraphic elements did not appear on the Reference section (e.g. sediment unit T7N) or were not sufficiently clear (e.g. structure F6). This section captured only a part of the repertoire of sediment units and relationships in Sounding A, a variety that the subsidiary sections reveal to be rich, variegated, and bearer of vital stratigraphic information. Key to understanding the stratigraphic sequence of group GT74 is in fact the northern section of rectangle A1-A12, i.e., the A11-A12/A31-A32 section shown in Fig. 107. ${ }^{231}$

Nor did the Reference section capture the larger blocks of unit T7C (feature F10) and mud-brick casing F11M within feature F11, both essential components of Earthwork F10-F12. Therefore a horizontal projection of several blocks and other significant features from quadrangle A1, not actually represented on the Reference section, had to be included for a more realistic impression of the profile. For optimal information (see Fig. 79), the profile itself had to be extended to show the whole sequence from surface S12 to suite T76 (included). With the same aim, an analytical restitution of the blocks, structures, and sediment boundaries throughout the whole breadth of quadrangle $A 1$ and part of A11 is presented as an 'elevation profile' in Fig. 101 , supplemented by a schematized stratigraphy in Fig. 102 A. See details in section 10.3 below.

Several voids along the Minaean wall are explicitly indicated in the reference profile of the deposits of Sounding A. They are located in the upper half of the Reference section and correspond - significantly to the post-Minaean deposits, starting with the base of sediment group GT74. The main void extends from the top of wall's course 11 to mid-course 7 , and from its base up to the level of course 9 it is partially filled by T7 $\omega$, a 'vertical' deposit (Figs 107, $109 \mathrm{~A}$ ). T7 $\omega$ is made of a 'dust' of grey fines containing stones, and is thus completely different from the adjacent, partly 'close' deposits of the sequential sedimentation. It might have been initiated by voids associated with collapse rubble T7A, and it is possibly time-transgressive; see further mention under later Stratum C, section 14.1,

231 By the way Fig. 107, showing the south, west, and north sections for the sequence comprising T75 and group GT74, represents the entire band of sections for this segment of Sounding A, since the fourth side of the area in question - its eastern side - is the Minaean wall. 
below. More voids, generally open (with no sediments in them), were encountered in excavation at the level of courses 6-5 - where the adjacent 'close' deposit is T73 - and courses $4-3$.

A conclusive remark on Sounding A. Before regular excavation in 2006, it was expected to encounter deposits almost exclusively characterized by noncultural, 'environmental' sediments. Contrary to expectations, however, the sounding revealed a most intense recurrence of human activity alongside the wall. Retrospectively, this was one of the major surprises afforded by our work in Area C. 'Active' cultural deposits not only marked the Minaean period, but continued during at least an initial part of the Islamic reoccupation of the town. It was only during the later Islamic period that 'passive' deposition became predominant, by passive meaning a sedimentary input unaffected by purposeful human agency - or not affected by human agency at all (noncultural).

\section{Strata J and I in Sounding A: Earlier Minaean and wall construction}

\subsection{Overview and Stratum J}

Following the close of suite SD2 and concomitant Stratum K (section 8 above), settlement entered an entirely new phase, indicated by two separate sets of evidence: substantial building activity in stone, and a recurrence of manure layers on the upper talus. The former, as far as Area C is concerned, is a strikingly conspicuous occurrence, only preceded by the smallerscale analogue of Sabaean Wall F4. Such novel processes can be observed over - or indirectly derived from the whole area from upper Sector D to Sounding A. In Sounding A this new phase is associated with the first Minaean ceramics and the still extant Minaean wall: Yathill's famous, imposing curtain wall characterized by bastions and recesses. Of our direct concern here will be wall's bastion T7, against whose exterior face the sounding was made.

As mentioned in the previous section, this sounding has brought to light a condensed but detailed Minaean sequence from which sedimentary data, a lithostratigraphy, stone structures, abundant artefacts and ecofacts, and radiocarbon readings have been obtained. The first part of this sequence, classified as Stratum J, is defined by the construction of the wall and an associated earthwork (Earthwork F10-F12), with their inherent discontinuities. A subsequent part Strata I, $\mathrm{H}$, and F - comprises occupation deposits in the broad sense of the term. They are not connected with ordinary habitation, however, but with occasional stops or specialized activities, such as running workshops related to trade.
Strata J and I are here designated historically the Earlier Minaean phase, susceptible of being subdivided into a Minaean 1 (Stratum J) and a Minaean 2 (Stratum I) (Table 4). Current knowledge of the Minaean 1 is very limited. Little pottery can be attributed to this subphase, and what we have corresponds to chance fragments from within the main fill of the earthwork, and to a slightly larger sample from its stone-supported topmost casing (component F10). Secondly, the construction of the Minaean wall is not known in its architectural and chronological details, not even for bastion T7. To obtain that information, more extensive excavation on both sides of bastion $\mathrm{T} 7$ will be required.

\section{The Later Sabaean tell at the time of the Minaean walling}

As already mentioned in section 8.2 above, with crossreferences, ${ }^{232}$ the correlation of quadrangles D1-D2 of Sector D with the sequence of Sounding A is somewhat tentative, as far as Strata J and I are concerned. This relative uncertainty, however, does not affect the substance of the following reconstruction of the events concerning the tell of Yathill, Area C, at the time of the Minaean walling.

Rather surprisingly, the Minaean curtain wall was built on top of the Sabaean deposits, at least in the area of bastion T7. These deposits are presently known archaeologically from Locus 200 (section 7.3 above). The Minaeans, apparently, chose to build the wall where the mound of Yathill was highest. At bastion T7 this aiming for the local summit is suggested by the original morphology that can be inferred from Locus 200. The remains of Later Sabaean dwellings in Sectors $\mathrm{B}$ to upper D, some already decaying (see section 7.6 above), were perhaps flattened where necessary and underwent burying (cf. units BRH2-BRH1 and GR3). Surface S1 in quadrangle D2 might correspond to this levelling. Such debris was thus sealed within a new layer of talus, and this operation would accord well with a Minaean reorganization of the whole upper margin of the mound. The foundations for the curtain wall were cut into the topmost Sabaean layers (surface S12).

A conjectural reconstruction of the Sabaean tell and the main events associated with the earlier Minaean activities, as based on current evidence, is shown in Figs 26 (detail) and 27 (broader context). The profile of the tell and the hypothetical top of the Later Sabaean occupation, marked as surface ' 0 ', are indicated, and phases of erosion of the tell's edge are suggested. The presumed height and shape of the Sabaean tell were inferred from Locus 200 and quadrangles C-D1-D2 through limited extrapolation. The assumption was

\footnotetext{
232 Repeated here for convenience: section 3.3 above, 'Long-distance correlations'; and Chapter 18, section 3.2 ('On the earliest Minaean'), this volume.
} 
made that the Minaeans would have cut the pre-existing deposits in the location of Sounding A to a depth at least equivalent to the foundation courses planned for the wall (rough-hewn courses 22 to 17), that is, 1.4-1.5 $\mathrm{m}$. In fact it is difficult that less than $1.8 \mathrm{~m}$, equal to six 'feet', ${ }^{233}$ were excavated to found such a wall (cf. surface ' 1 ' in Figs 26 and 27).

On the other hand, in all probability, the Sabaean deposit was not of uniform thickness. Perhaps quite the opposite: unit STY in Locus 200 suggests that there must have been 'highs' due to ruined buildings as well as depressions. If my correlation is correct, that meant the suppression of the Sabaean layers corresponding to Stratum L. Furthermore, a width of 3-4 $\mathrm{m}$ for the western half of the Minaean foundation trench - the part corresponding to the exterior of the wall - was assumed. If these assumptions are combined with the probability of unit GR3 (Sector C) being the top of a mudbrick structure, a reasonable profile for the final Sabaean tell can be proposed. This is the reconstructed profile shown in Figs 26 and 27. Note, however, that this profile is purely indicative, since the horizontal relationships of Sectors B and C with Sounding A are only an approximation.

\section{Stratum J}

Stratum $\mathrm{J}$ is lithostratigraphically defined by the following sediments, elements, and features, distributed between Sounding A and upper Sector D: surface S12, the foundation cutting for the Minaean wall; the Minaean wall itself (MW); group TBF; Earthwork F10-F12, with surfaces S11 and S8.0 (S8 as eroded); units BRH2 and BRH1; and surface S1 (Figs 17 and 78). Stratum J is completely identified with the works for the Minaean curtain wall. The wall itself will be described below, together with the series of structures forming Earthwork F10-F12 (sections 10.2-10.3). Here we focus on the sedimentary aspects of the units below the earthwork.

More precisely, the stratification representing Stratum $\mathrm{J}$ along bastion T7 can be subdivided into two equal parts. The lower half is formed by the backfill of the foundation trench for the wall, between surfaces S12 and S11. This backfill, largely or entirely artificial and essentially composed of reworked Sabaean deposits, is here classified as sediment group TBF. The upper half of the stratification is formed by the earthwork flanking the bastion, F10-F12, bounded by surfaces S11 and S8. The two parts have almost the same thickness, about 1.3 metres each. Thus Stratum J can be neatly described

\footnotetext{
233 For this suggestion about Old South Arabian metrology cf. section 6.3 ('Wall F4'), above, and the next section ('The Minaean curtain wall: bastion $\left.\mathrm{T}^{\prime}\right)$.
}

as constituted by group TBF below and Earthwork F10-F12 above.

Group TBF (Table 2) is formed of a series of massive backfill loads - units AR, T7F, LAR, T7Y, and T7 $\tau$, with numerous subunits - intercalated with stone lenses LP3, LP2, and LP1 (Figs 17 and 79). 'Red clay' AR was recorded as lithologically identical to following unit LAR (see below), but apparently more extensive. AR is characterized by secondary cementation at its bottom, along the north-south axis of rectangle A1-A11, and AR $\gamma$ is a 'shapeless' gravelly facies of it.

Unit T7F is a 'chaotic' mass up to $70 \mathrm{~cm}$ thick, clearly representing repeated loads of backfill material (subunits $\mathrm{T}_{5-1}$ ). Partition T7F includes small patches and spots of 'red clay' identical to LAR and AR. An enigmatic, large crescent-shaped stone block was found isolated within lower $\mathrm{T}_{7}$ in the excavation corner of strip A1-A31234 (stone P54, cut 197). It was 50 $\mathrm{cm}$ long and lay with a northeast dip. It was understood as a Minaean stone intended for the wall, brought there for the construction of the lower courses (20 to 17?) and left unused. P54 represents the first indication of a 'block horizon' at bastion T7, counting from bottom (see section 9 above).

'Red clay lens' LAR is a showy tongue of clayey silt, dark yellow to orange to red in colour, manifestly emplaced and/or subsequently deformed while it was in the mud state. It is decimetre-thick and was only encountered in the western part of rectangle A1-A11, at the level of course 20 of the Minaean wall (Fig. 79). It can be reconstructed that LAR inserts itself within $\mathrm{T7F}_{1}$, perhaps contributing to mark the weak contact between partitions $\mathrm{T}_{2} / \mathrm{T}_{2}$. Unfortunately the field information on the orientation of LAR is contradictory (a slight dip in which direction?). A zone around contact T7F/T7Y along the axis of rectangle A1-A11 (and westwards outside trench) was affected by secondary induration, apparently with a contribution of illuvial clay.

Unit T7Y is a second 'chaotic', unsorted, heterogeneous backfill body of the Minaean foundation trench. Its partitions (T7Y and T7Y) represent two episodes of mass backfilling and share a diffuse, 'shapeless' boundary. T7Y contains stone lens LP2. Unit T7 $\tau$ is an essentially horizontal layer of yellowish, compacted loam (i.e., an unsorted earth), red-clayey in places, containing plaster and small, partly roasted gravels. It tends to split in decimetre-sized clods. Importantly, T7 $\tau$ breaks with the pattern and structure of the previous units and tops - or 'seals' - the foundation backfill in A1-A11. Surface S11 was locally compacted as well: for its possible interpretation see section 10.3 below.

234 'Strip A1-A31' was defined in section 9 above. 


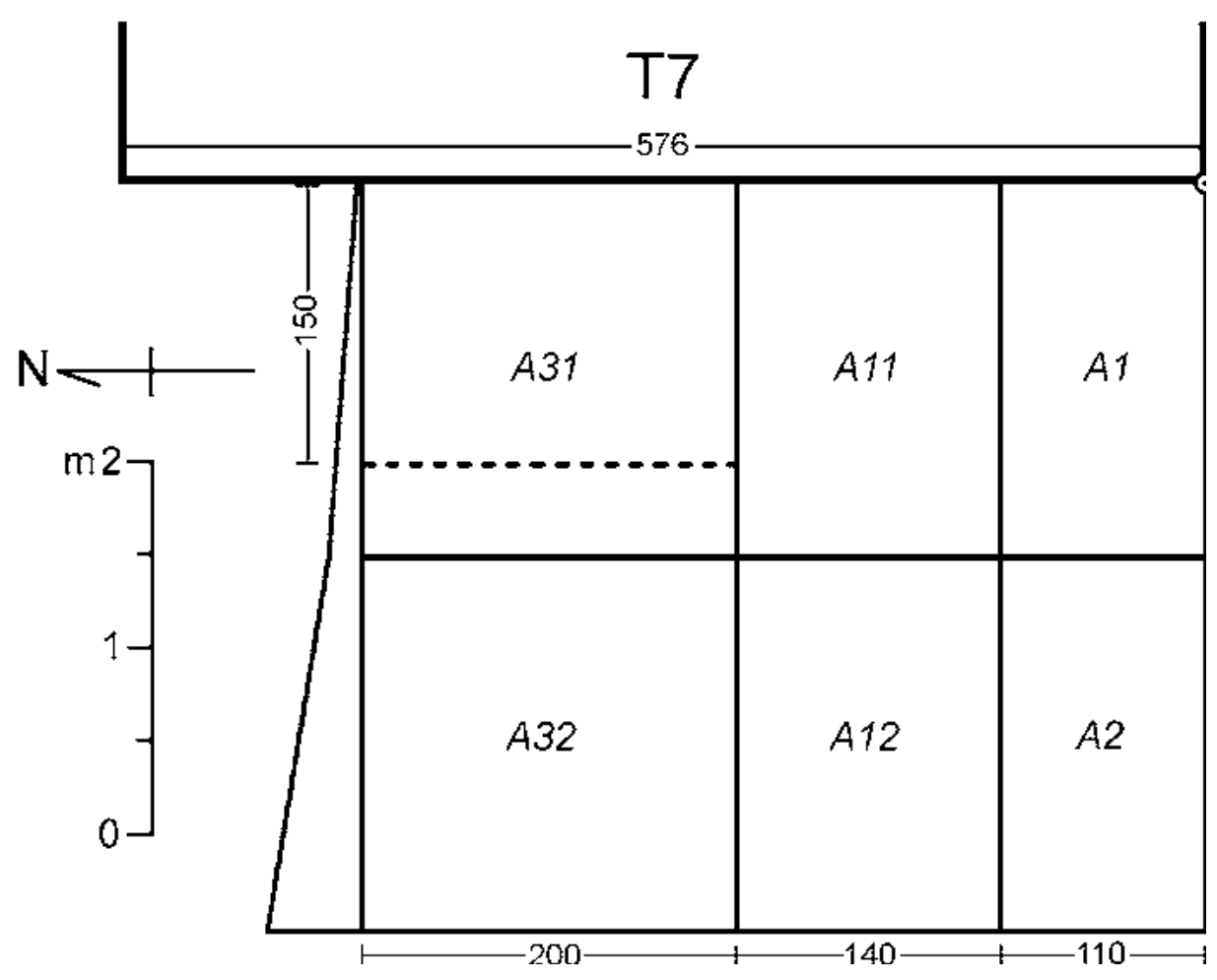

Figure 73. Detailed plan of Sounding A. Measurements in centimetres. (F.G. Fedele 2019)

As the above description suggests, there is nothing horizontal or linear within units T7F and T7Y. They are just massive and 'chaotic'. The backfilling of the Minaean trench produced a mosaic of sediment masses with vague, curvilinear limits ('amoeboid'), differring from each other in terms of coarser vs finer textures: basketfuls? donkey or camel loads? A general dip east, i.e. towards the wall, could barely be perceived with the sediments of $\mathrm{T}_{5-2}$. Indeed, a distinct dip east characterizes the T7F/T7Y boundary and is equally emphasized by the profile of stone lens LP3, this latter precisely corresponding to the top of wall's course 20 .

Repeatedly in Stratum J, the masonry courses in the Minaean wall and the adjacent sediments display a remarkable correspondence. From the bottom up, this is the case of sediment boundaries $\mathrm{T}_{2} / \mathrm{T}_{2} / \mathrm{F}_{1}, \mathrm{~T} 7 \mathrm{~F} / \mathrm{T} 7 \mathrm{Y}$, $\mathrm{T} 7 \mathrm{Y} / \mathrm{T} 7 \tau$, and of stony lenses LP3 and LP1 (and to some extent LP2 as well), whose position precisely matches the top of each course from 21 to 18 (see Figs 78-79 and $102 \mathrm{~A}$ for details). Such a correspondence, as well as the almost rhythmic vertical patterning of sediment units in Stratum J, suggest that the construction of the wall and the backfilling of its foundation trench went in step. A new layer of backfill would have been added at the completion of each new course of masonry (cf. Table 6).

Indeed, such procedure appears to have continued with the construction of earthwork F10-F12, since the first partition in this mega-feature (T79J/T79L in sedimentary terms, including stony lenses $9 \lambda$ ) also perfectly corresponds to the masonry joint between courses 17 and 16. And higher up, within Earthwork F10-F12, surface S9 shows impeccable coincidence with the joint between courses 15 and 14 .

The area investigated at bastion $\mathrm{T} 7$, hence the sediments and cultural materials encountered in Sounding A, were heavily affected by the construction and presence of the Minaean wall in multiple ways. Besides the wall itself and its flanking earthwork, a further, remarkable characteristic of Stratum J was the massive amount of reworked Sabaean deposits and finds. Examples of clearly reworked Sabaean potsherds embedded in units of Stratum J have been listed above in section 7.3 ('A selection of significant finds from Locus 200'). They can either be attributed to Stratum $\mathrm{N}$ deposits surrounding Locus 200, or to destroyed layers belonging to Stratum $\mathrm{L}$, which, as previously suggested, may well have existed in the area of future Minaean bastion T7. Further evidence for the reworking and redeposition of Sabaean material into units of Stratum J is provided by animal bones, thanks to the surface colour of the Sabaean bones of Locus 200 - an idiosyncratic yellow-orange. Such bones were particularly abundant within units T7F $_{1}$ (backfill) and T79J (component F12 of Earthwork F10-F12).

Concerning Minaean artefacts (Sounding A), all the diagnostic pottery and the non-ceramic material from Stratum J that can be attributed to the Minaean with 


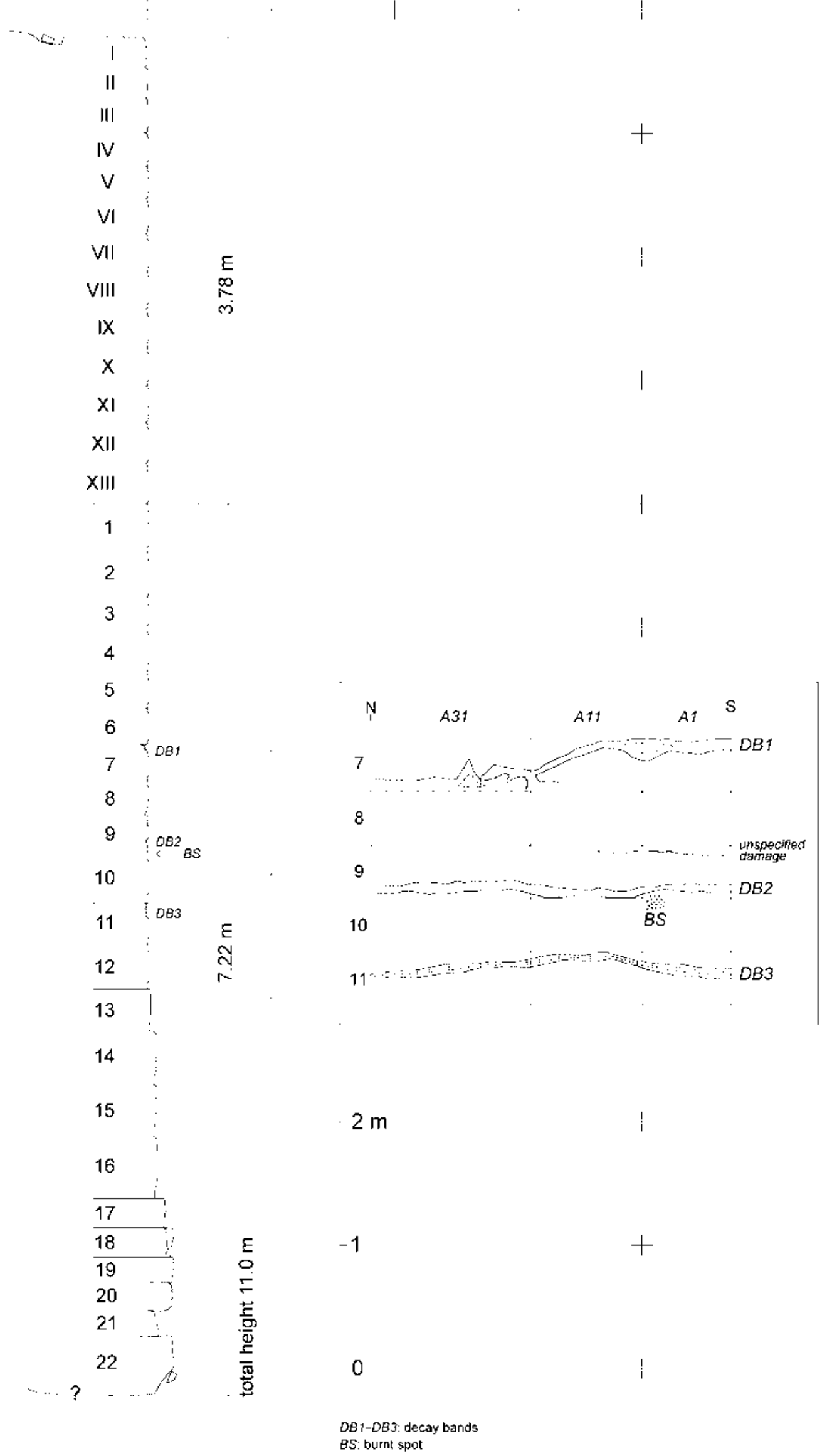

Figure 74. Minaean-Islamic wall: scale profile of bastion T7, south corner. Inset: damage on bastion's west face as revealed by excavation. (F.G. Fedele 2019) 


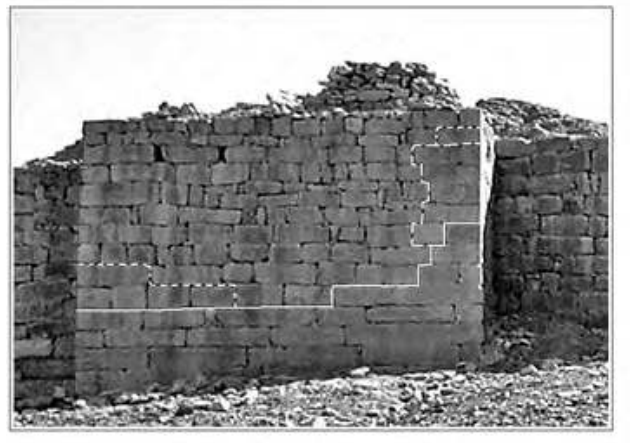

Minaean masonry above ground: certain and possible

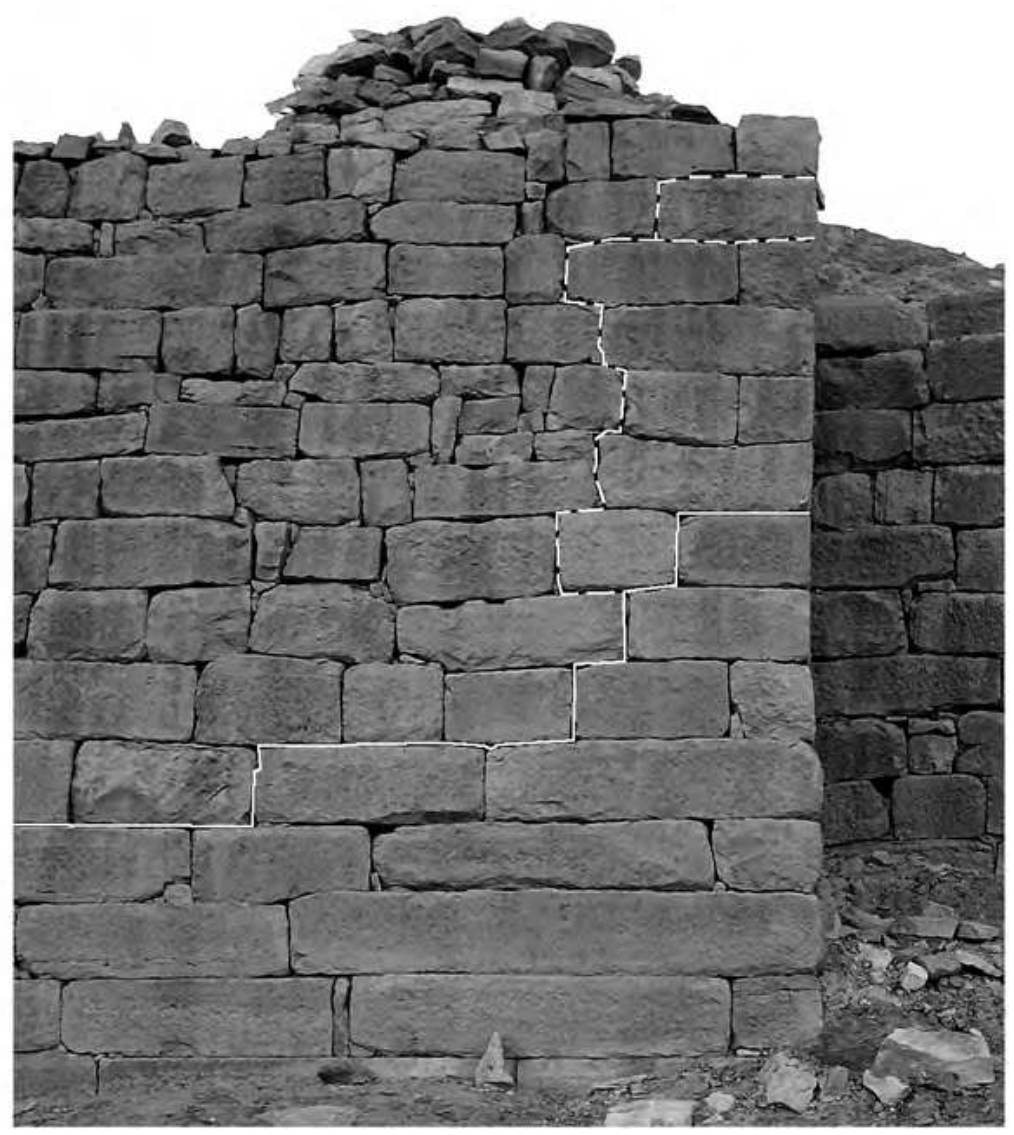

Figure 75. Minaean-Islamic wall: front views of bastion T7, suggesting the outline of the Minaean masonry above ground. (F.G. Fedele from photographs by P. Morlupi 2005 (C) MAIRY)

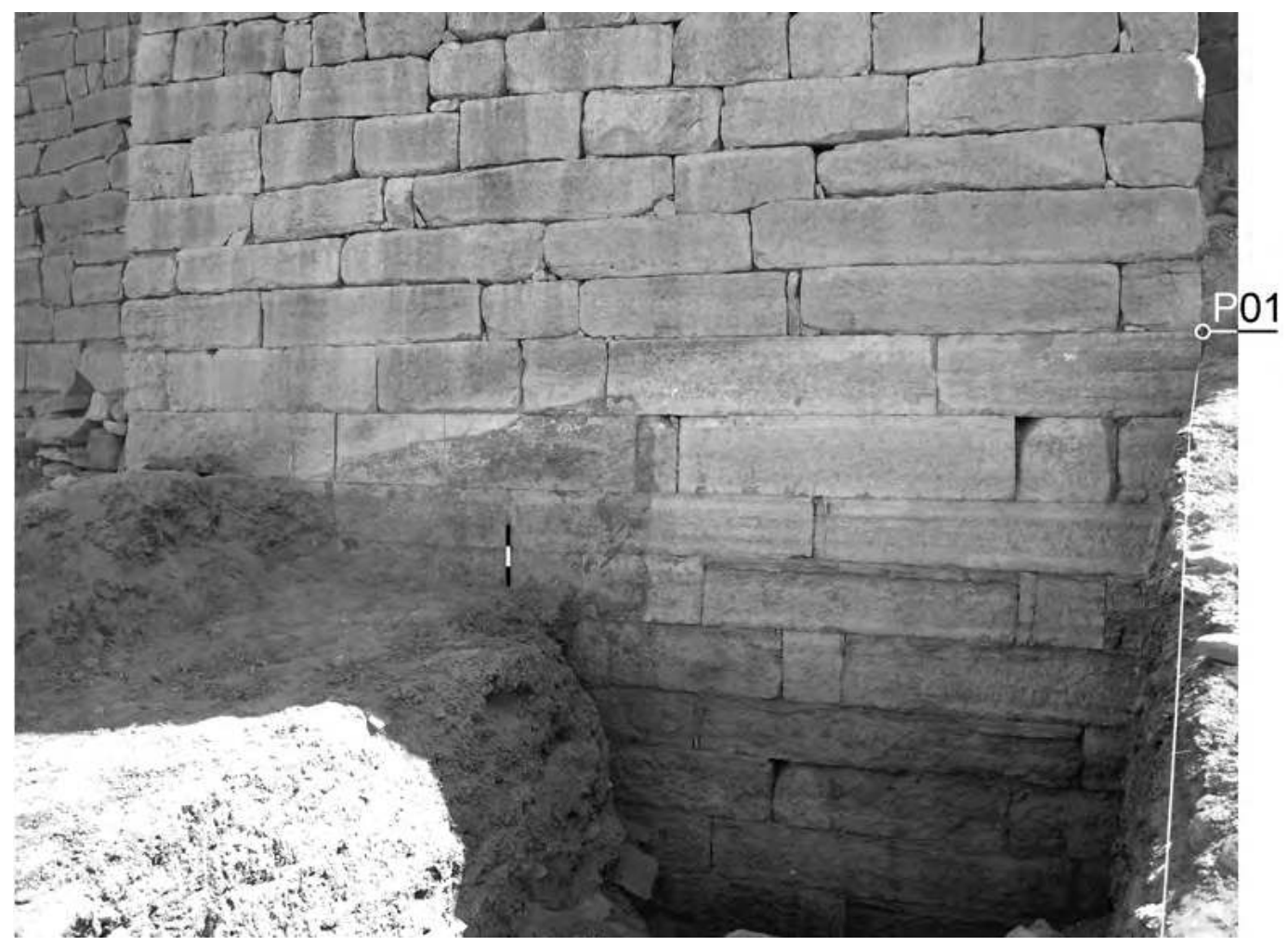

Figure 76. Minaean-Islamic wall: front view of bastion T7 during the widening of Sounding A, December 2006. Area C datum (P01) marked on right. (P. Morlupi @ MAIRY, adapted and optimized by F.G. Fedele 2019) 

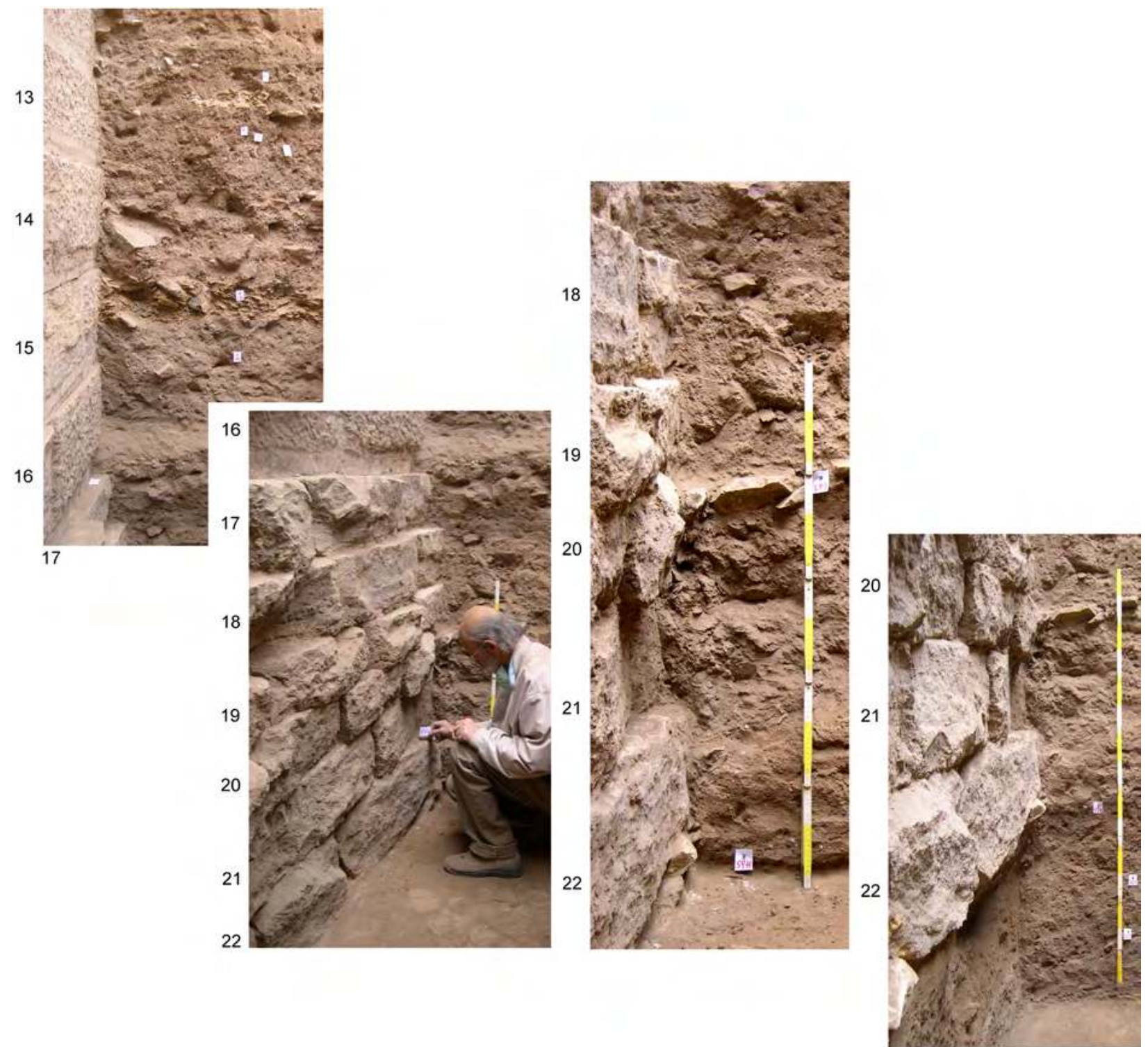

Figure 77. Profile views of bastion T7 from Sounding A during excavation in December 2006, showing courses 22 to 13. (P. Morlupi @ MAIRY, adapted and optimized by F.G. Fedele 2019)

a certain degree of probability came from Earthwork F10-F12. Accordingly, they are listed at the end of section 10.3 below.

\subsection{The Minaean curtain wall: bastion T7}

The top of the Sabaean deposits represented the ground surface when the Minaean construction of the enclosure began, unless a veneer of initial Minaean deposits had already been formed. Overall, the Minaean works included a phase ' 1 ' (Figs 26-27), the digging of a foundation trench, and a series of phases of actual construction, accompanied by the backfilling of the trench and the making of a flanking structure, Earthwork F10-F12 (number '2' in Figs 2627). If protracted, the erection of masonry might have intercalated with the construction of the earthwork. The products of these building phases comprise Stratum J, equated with a Minaean 1 phase in historical chronology. The stratigraphic sequence of bastion T7 and its associated deposits is reconstructed in Table 6.

At ground level bastion T7 had a front width of 5.76 m, as measured in 2006 (Fig. 73). Masonry comprises accurately squared blocks laid in finely jointed horizontal courses, or ashlar. Above ground at its south corner, T7 presented 13 courses of masonry, numbered top to bottom as I-XIII and reaching a height of 3.78 $\mathrm{m}$. Buried underneath, 22 courses of ashlar masonry were revealed by the excavations, here numbered top to bottom as 1-22 and measuring $7.22 \mathrm{~m}$ in height. The total height of the surviving wall at T7 is thus of 11.0 


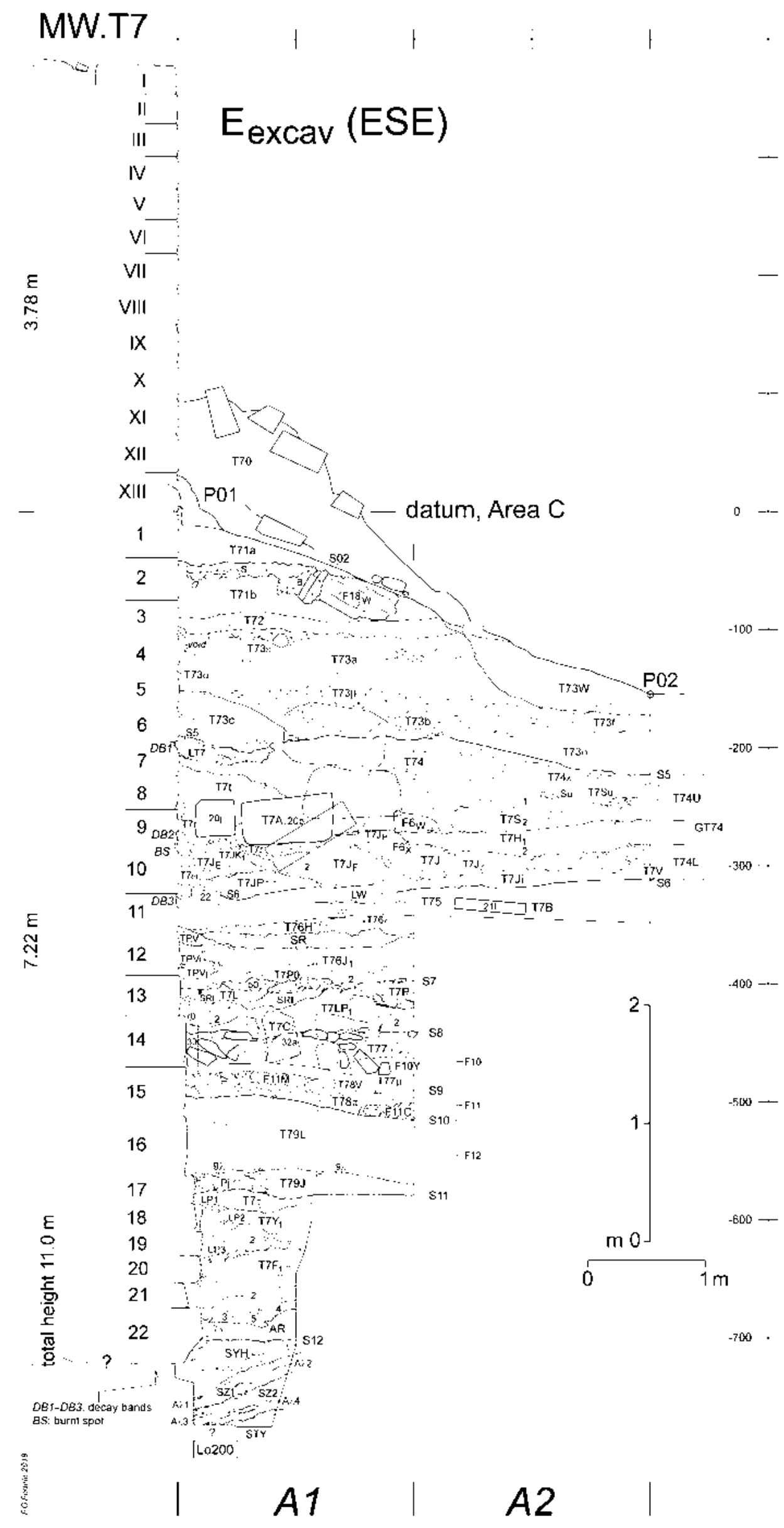

Figure 78. Sounding A: Reference section showing the entire Minaean wall, bastion T7. (F.G. Fedele 2019) 


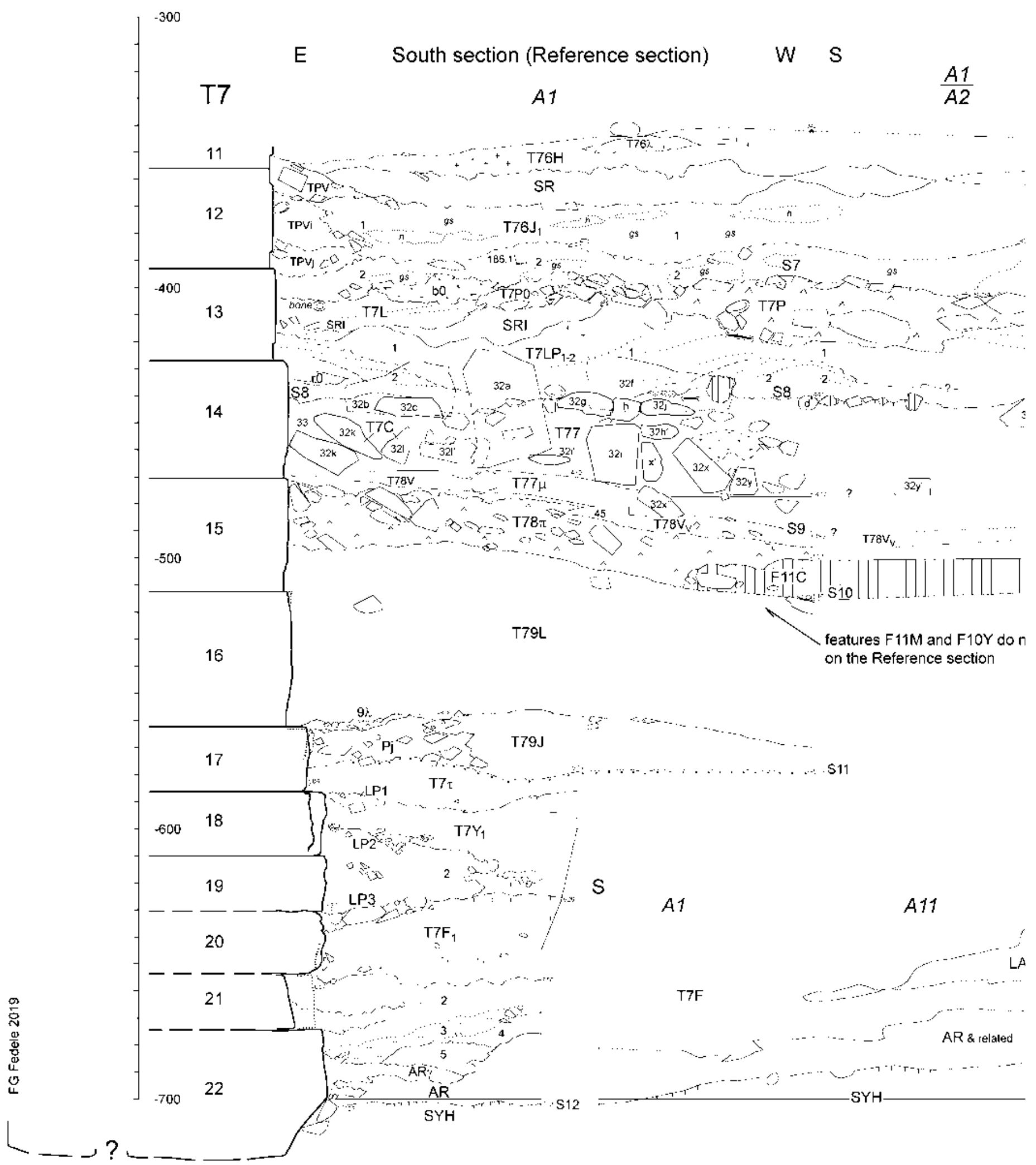

Figure 79. Sounding A: complete south section and subsidiary west sections from surface S12 to the top of suite T76, including Earthwork F10-F12 (Strata J to H). (F.G. Fedele 2019) 


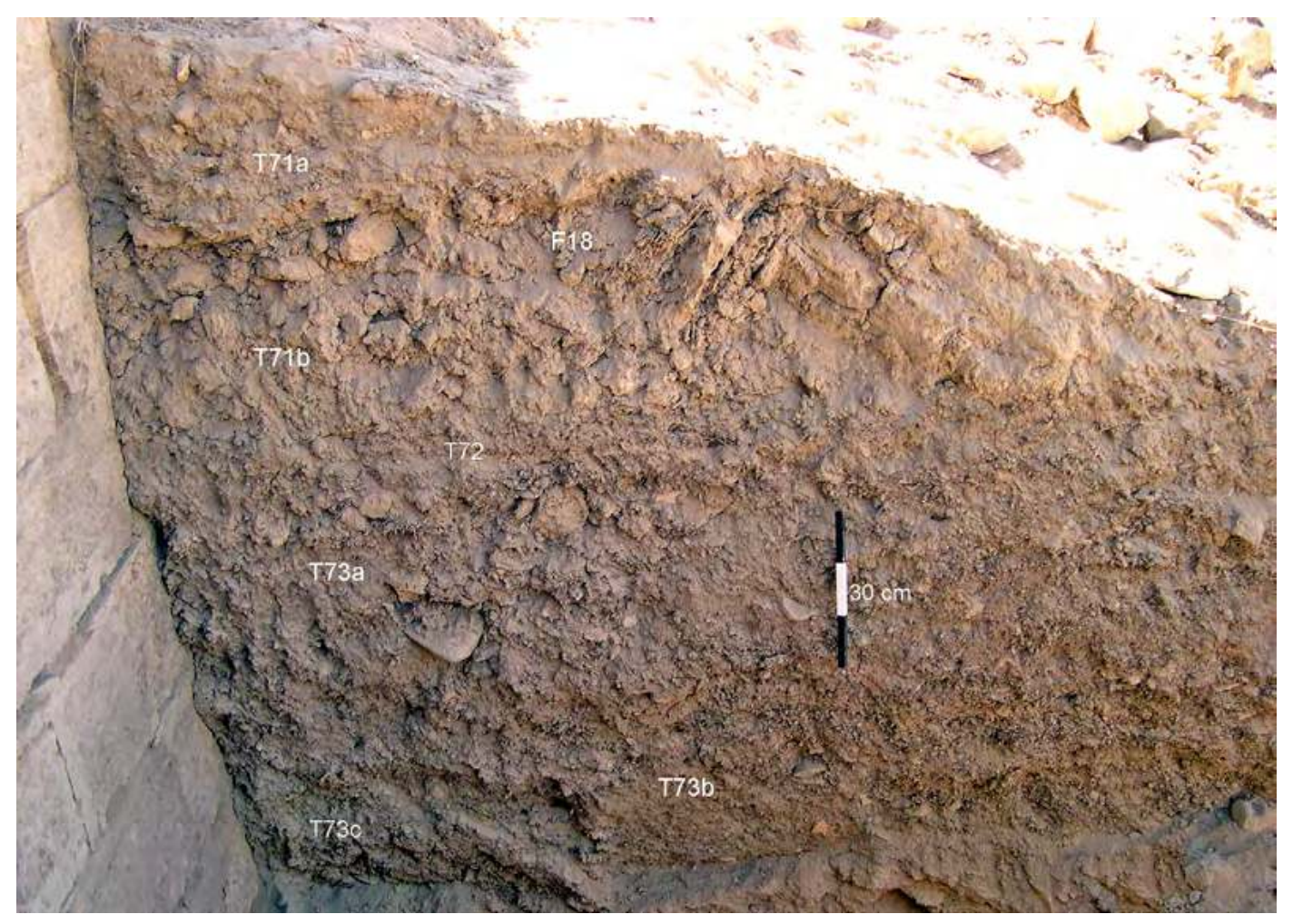

Figure 80. Sounding A, Reference section: the Islamic sequence down to surface S5. (P. Morlupi 2005 @ MAIRY, optimized by F.G. Fedele 2020)

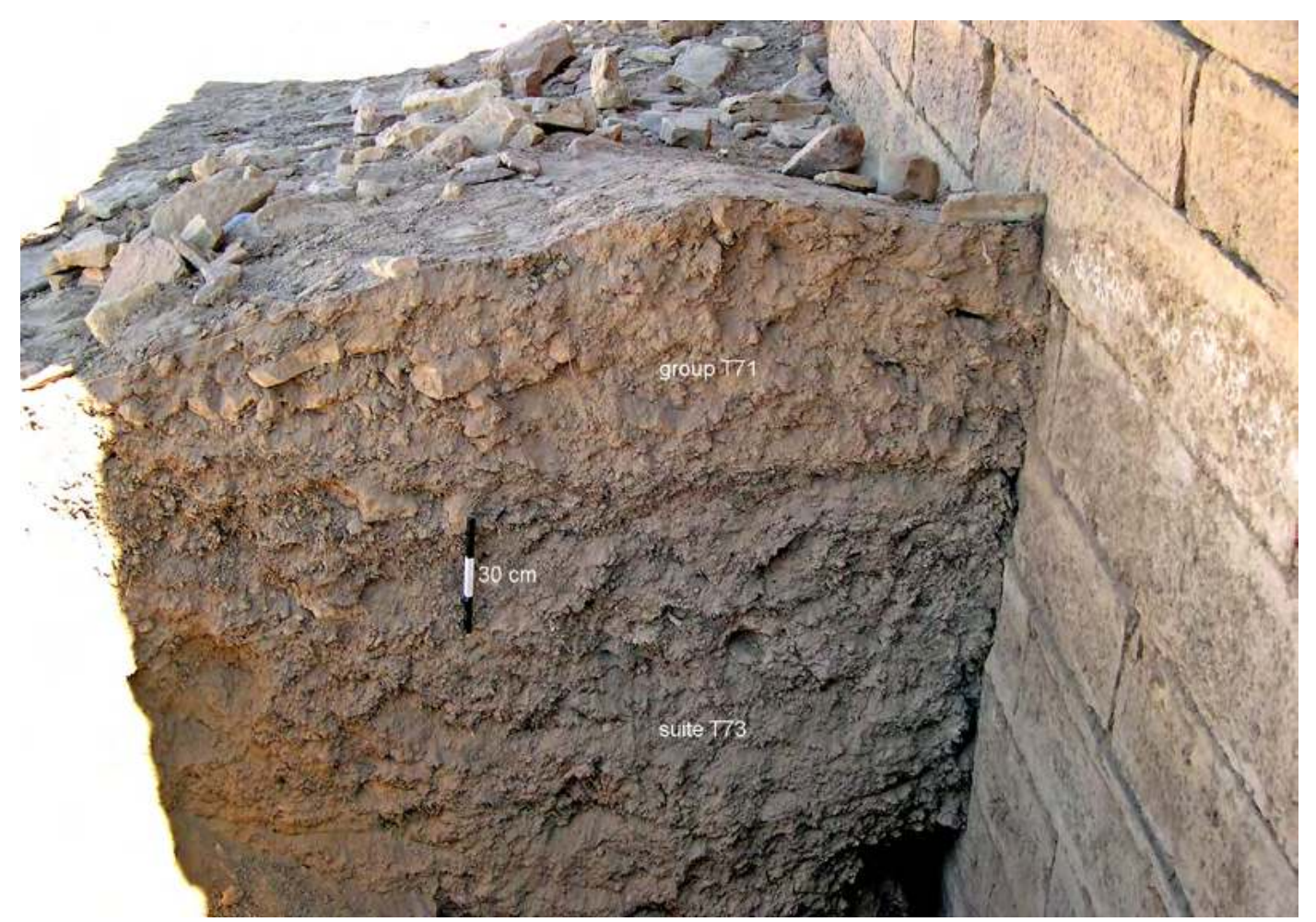

Figure 81. Sounding A, quadrangle A11 north section: the Islamic sequence down to surface S5. (P. Morlupi 2005 @ MAIRY, optimized by F.G. Fedele 2020) 


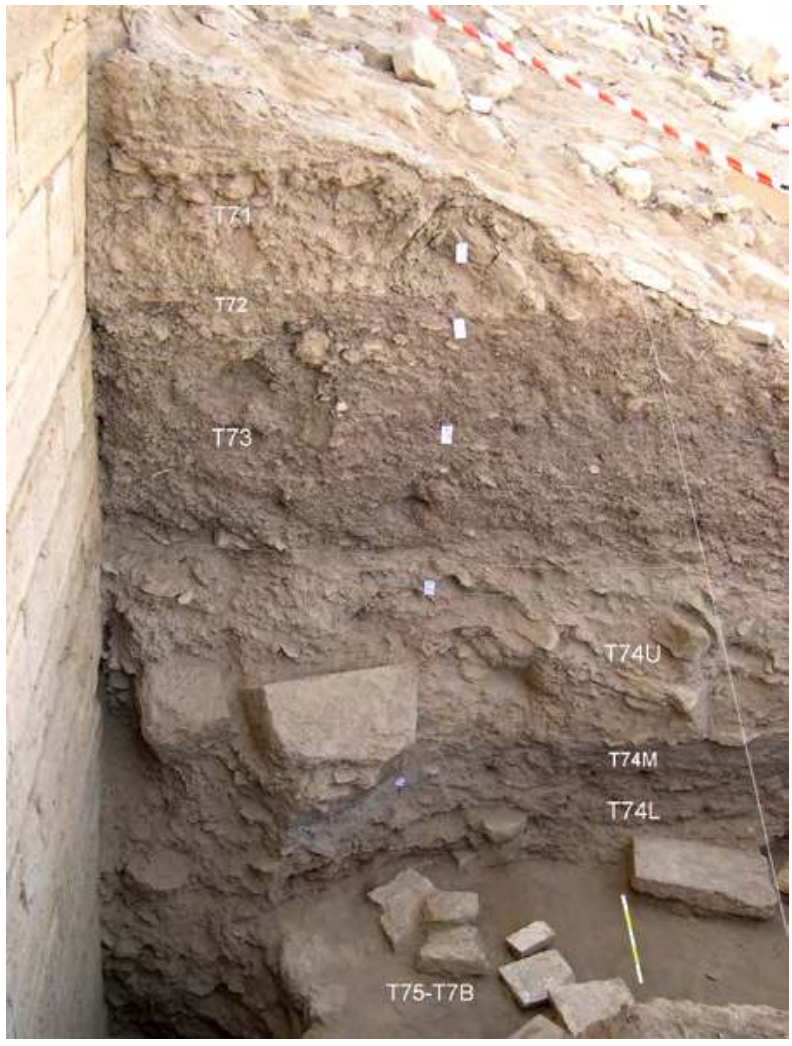

Figure 82. Sounding A, Reference section: the Islamic and final Minaean sequence down to layer T75-T7B. (P. Morlupi 2006 @ MAIRY, adapted and optimized by F.G. Fedele 2020)

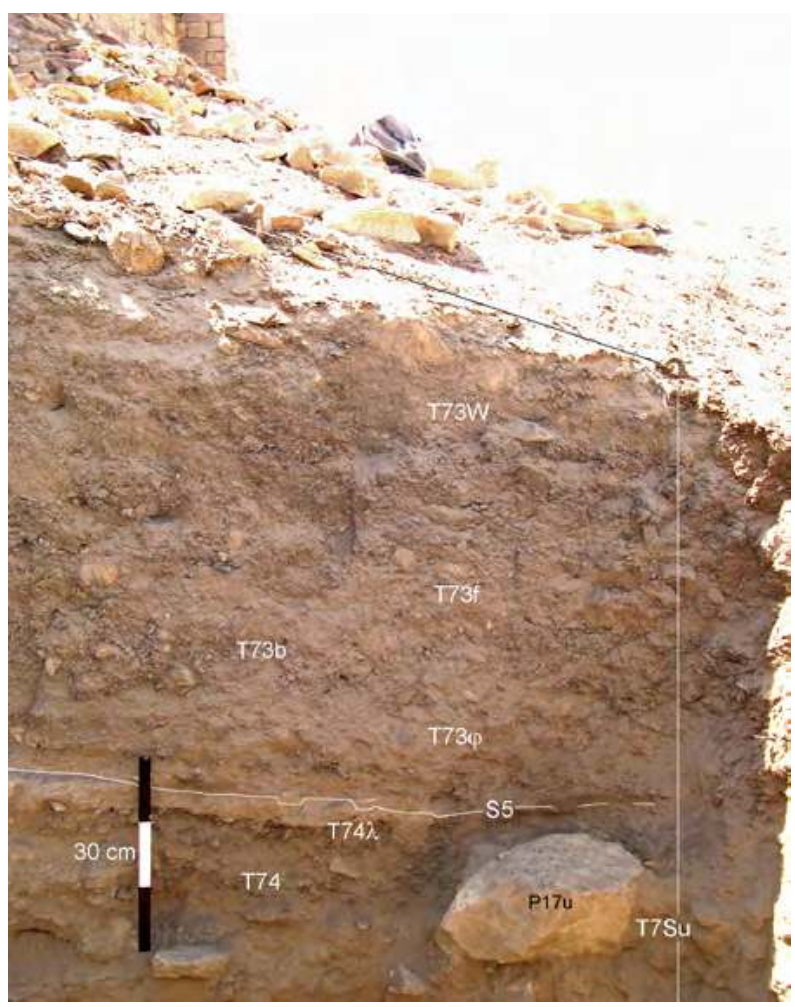

Figure 83. Sounding A, Reference section, quadrangle A2 west: the Islamic sequence down to units T74-T7Su. (P. Morlupi 2006 C MAIRY, adapted and optimized by F.G. Fedele 2020)

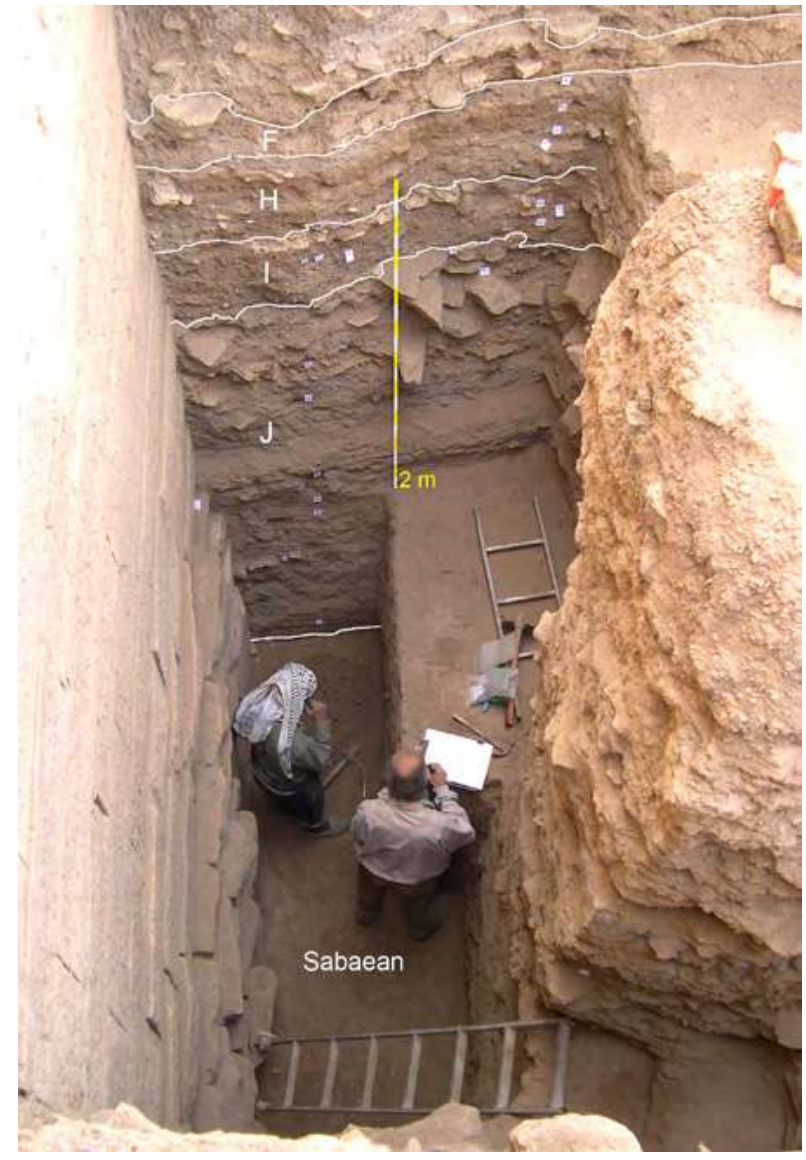

Figure 84. Sounding A, overhead view of the total Minaean sequence: Strata J-F as recorded on the Reference section.

(P. Morlupi 2006 C MAIRY, adapted and optimized by F.G. Fedele 2020)

m. At least 26 courses of Minaean masonry are still extant, amounting to about three fourths of the bastion (courses 1-22 below ground and courses X-XIII above). Details are shown in Fig. 74; this scale profile replaces all previous drawings of bastion T7. Several views of masonry are presented in Figs 75-77. Within its limits, Sounding A thus not only confirmed the size and magnificence of the Minaean curtain, but offered a first opportunity to glimpse the western wall full-height.

Set within a trench defined by surface S12, the foundations for the wall were made of solid stonework, starting with course 22. This base of rough-hewn boulders terminates with course $17-$ six courses in all - and understandably is wider across than the wall above it (on the exterior side at least). Course 17 has a batter ${ }^{235}$ of no less than $10-15 \mathrm{~cm}$ relative to course 16 , and its interstices revealed mudplaster binding.

235 Batter, a thickening of the wall base (Italian risega, plural riseghe), here refers to the progressive jutting out of the ashlar blocks towards the base of the wall. This trend continues irregularly below the regular ashlar courses, down to the very base of the foundations (course 22). 


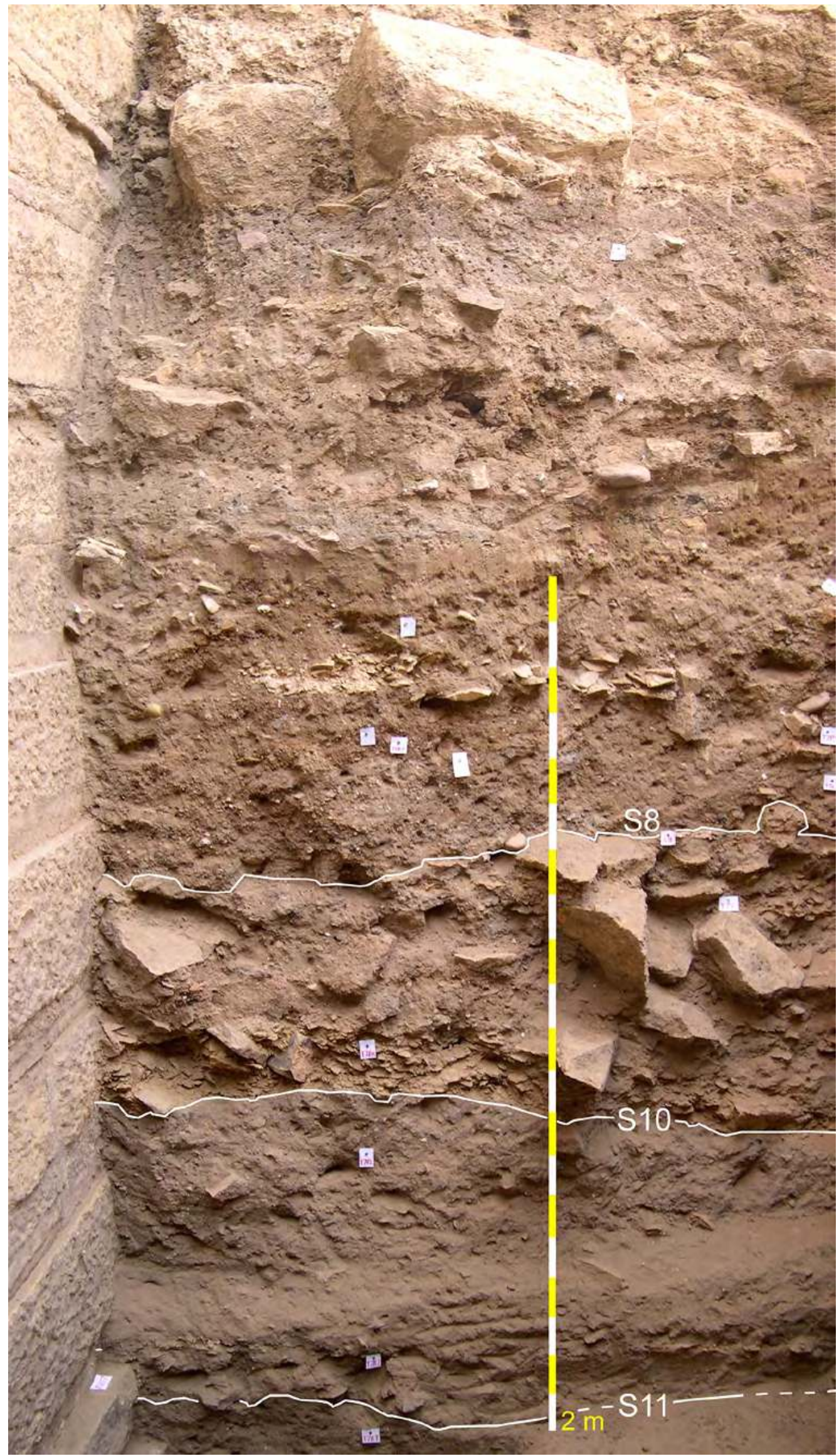

Figure 85. Sounding A, Reference section: group GT74 to surface S11, including Earthwork F10-F12. (P. Morlupi 2006 @ MAIRY, adapted and optimized by F.G. Fedele 2020) 


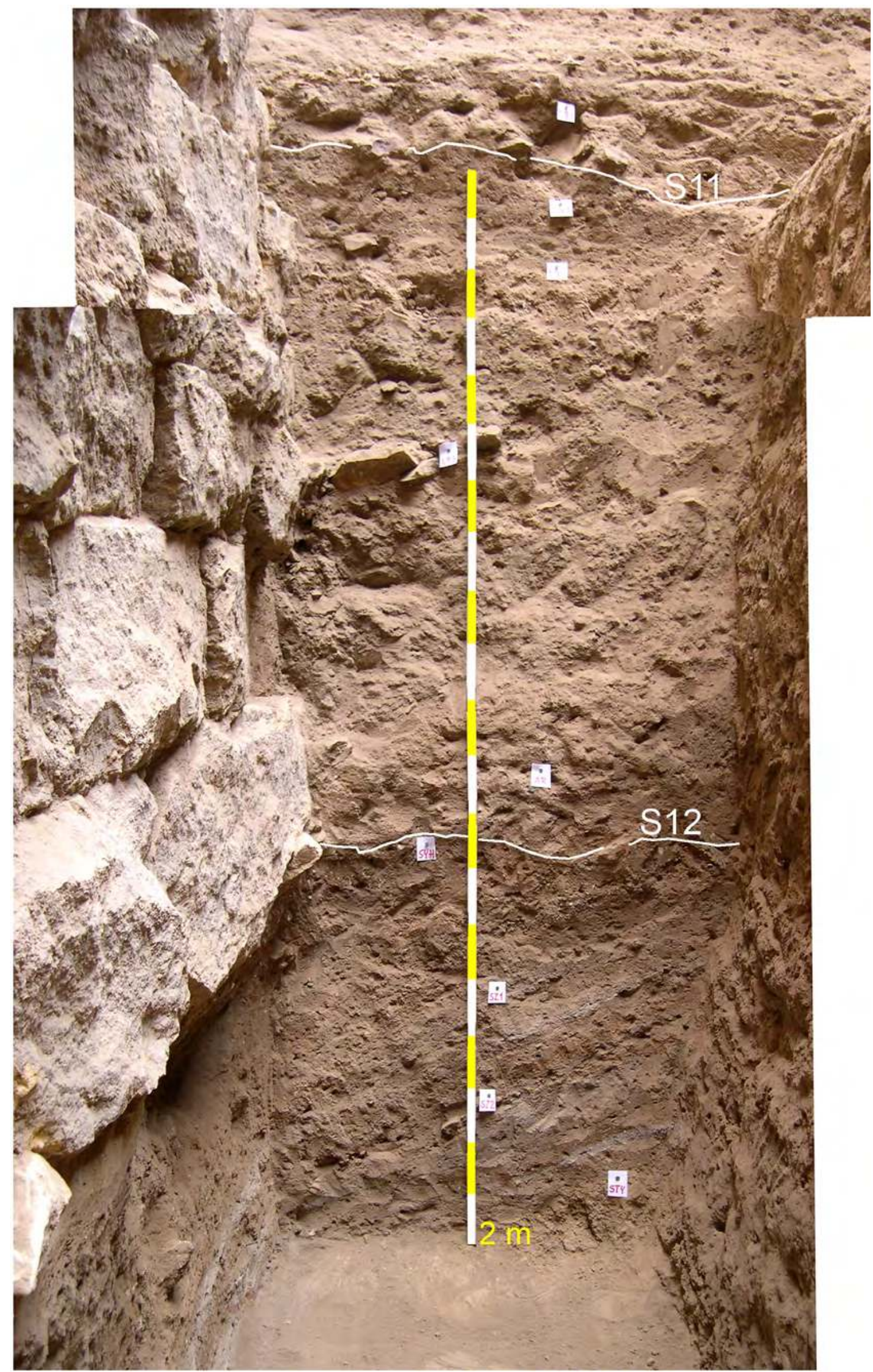

Figure 86. Sounding A, Reference section: surface S11 (base of Earthwork F10-F12) to bottom, Sabaean Locus 200. (P. Morlupi 2006 @ MAIRY, adapted and optimized by F.G. Fedele 2020) 

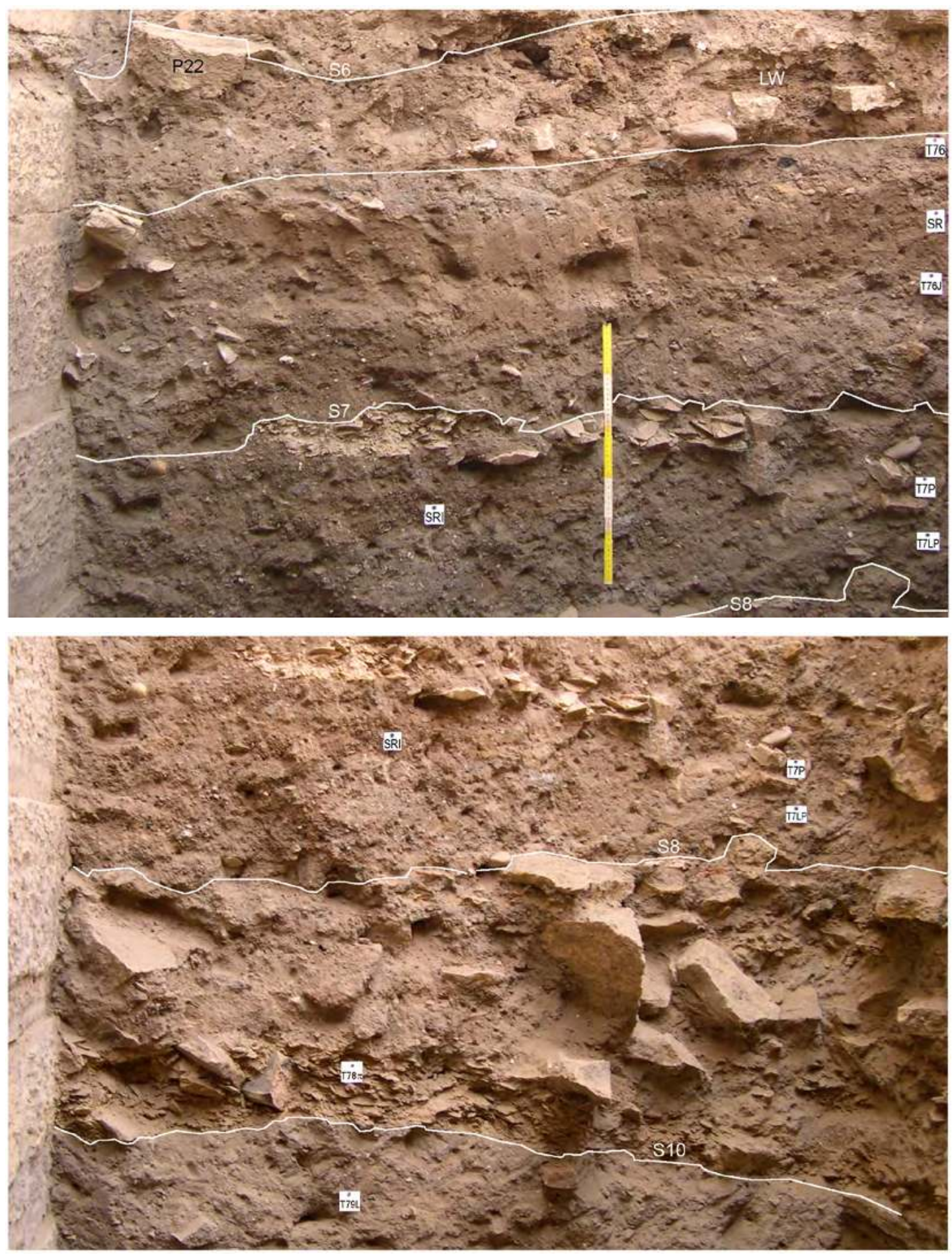

Figure 87. Sounding A, Reference section details: sequence S6 to S8 (above) and sequence S7 to S10 (below), both from quadrangle A1. (P. Morlupi 2006 @ MAIRY, adapted and optimized by F.G. Fedele 2020) 


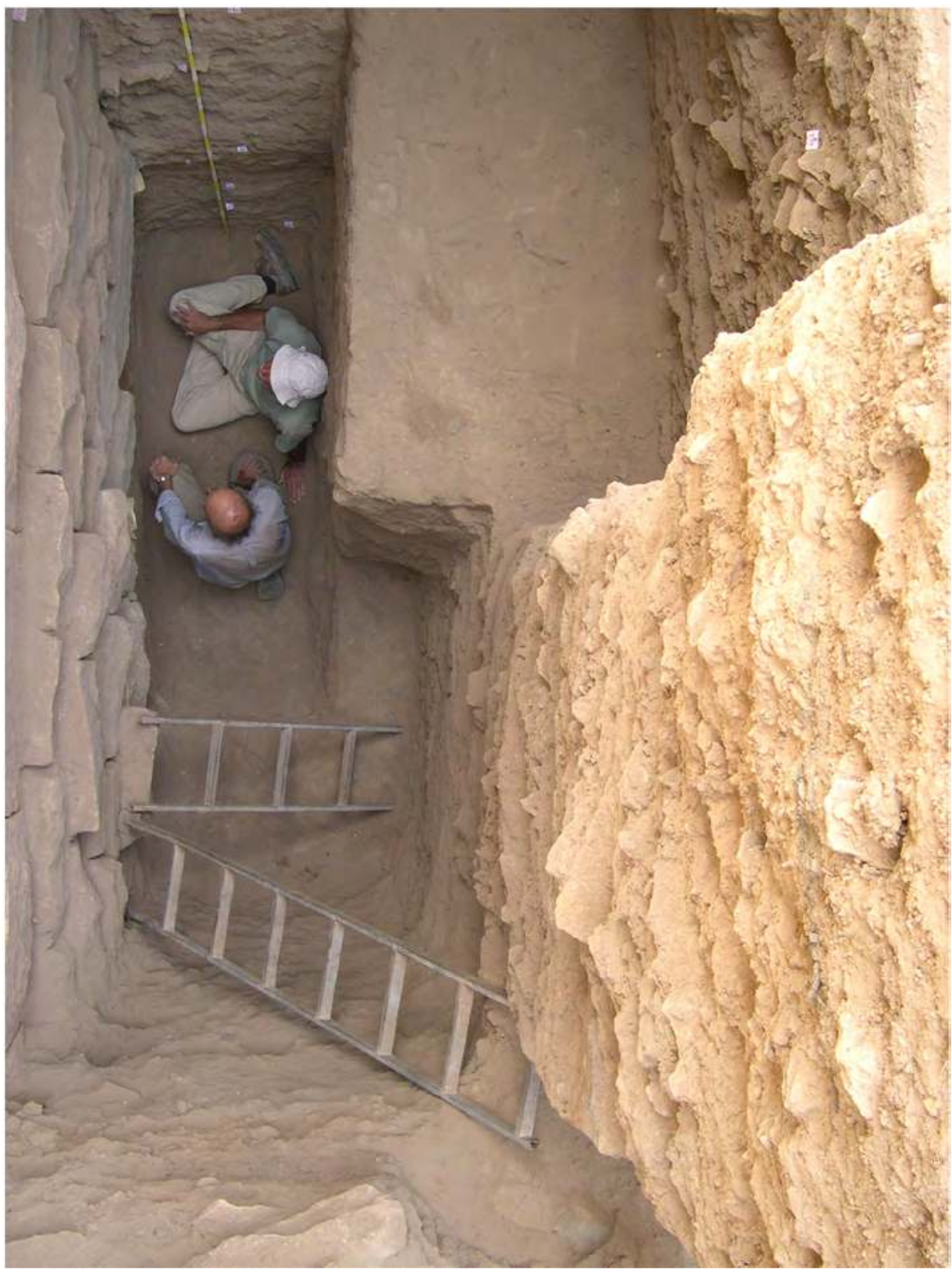

Figure 88. A. de Maigret and the author discussing the Sabaean deposits and the base of the Minaean wall at the bottom of Sounding A, 26 December 2006. (P. Morlupi @ MAIRY, optimized by F.G. Fedele 2019)

It seems clear that courses 22-17 were earthen on as soon as works permitted (cf. section 10.1, 'Stratum J', above). The two overlying courses, 16-15, together about 1-metre-thick, were destined to be buried as well, although they were more regular and hammer-dressed less summarily. In fact, course 16 is the first from bottom to show the typical motif of centrally pecked, marginally drafted decoration (see below). Overall, the foundations represented by courses 22-15 measure 2.4$2.5 \mathrm{~m}$ in height, probably equivalent to 8 'feet' in the mind of the builders. ${ }^{236}$

236 On the equivalence to ancient feet see footnote 233 in the
The chosen rock for the wall is a yellow calcarenite from outcrops located in the area west of Barāqish, sometimes called 'oolitic limestone', ${ }^{237}$ a designation which might be inappropriate. Concerning the ornamentation of the stone blocks, the wall is characterized by 'well finished ashlar with pecked and chiselled margins', as described by B. Doe: it shows 'the finely cut stone work, marginally chiselled with pecked panels to each

previous section (10.1, 'The Later Sabaean tell').

237 Breton 1994, 23-31; Bessac 1998a, 174-176; Agostini 2010a, particularly p. 88 ('a more compact and solid sort of limestone' compared to the lumachelle limestone often used for monolithic pillars). See also Wright 1987. 

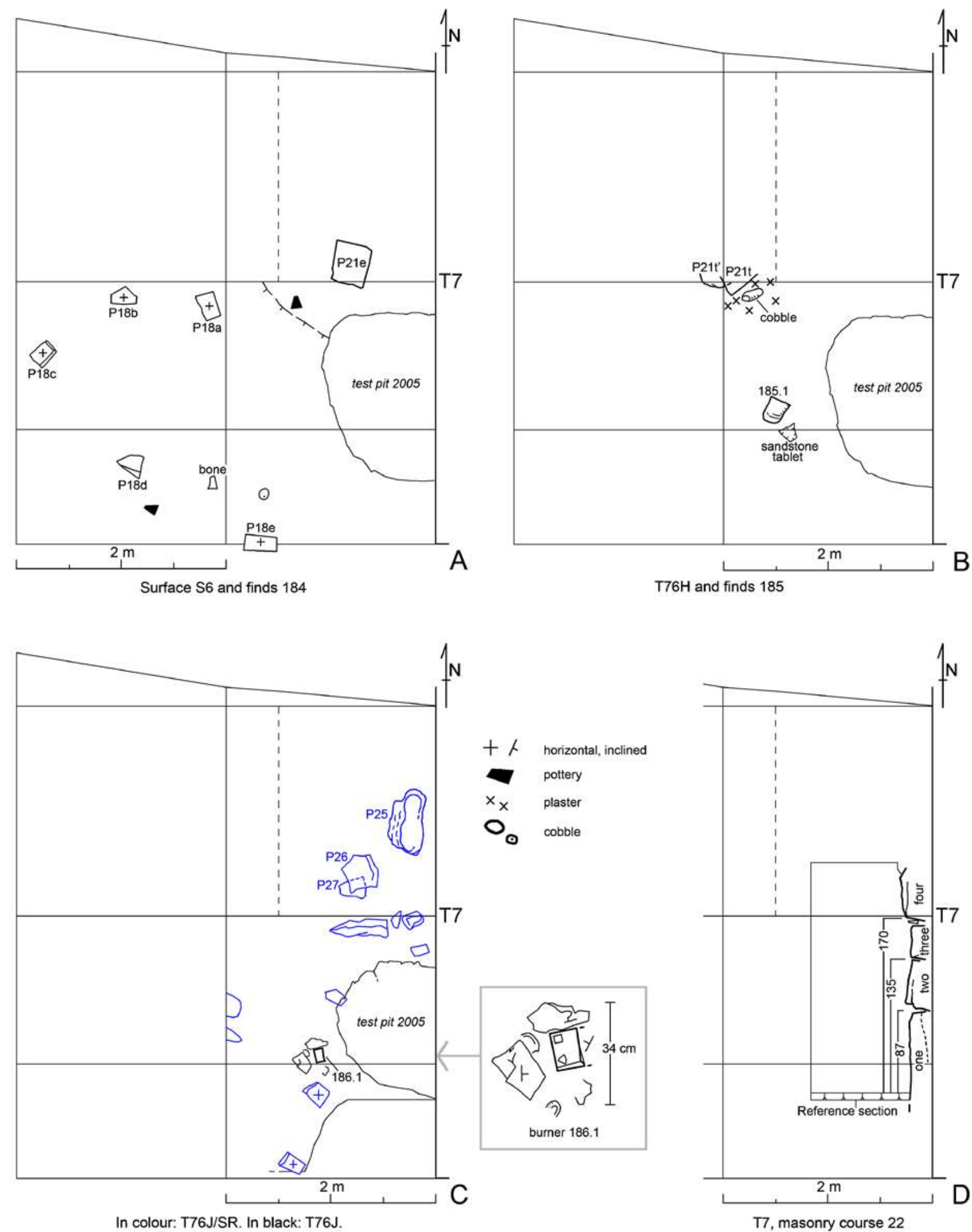

Figure 89. Sounding A, plans and composite plans. A: surface S6 and finds 184. B: top of unit T76H and finds 185. C: composite plan of contact T76J/SR (in colour) and unit T76J, this latter showing cuboid burner 186.1 in situ. D: course 22 of Minaean bastion T7, measurements in centimetres. (F.G. Fedele 2006 and 2020) 
stone, ${ }^{238}$ which regularly embellished the walling of old South Arabian towns and public monuments. This kind of ornamentation was first described by Gus Van Beek in 1958, a pioneering study with comparative discussion. ${ }^{239}$

Based on the known structure of the Minaean wall of Yathill in general, it can be surmised that bastion T7 was constructed as ashlar with infill. In particular, this technique consisted of building two stone faces and infilling the space between them - the core with either mudbrick or a mixture of mudbrick and rubble. ${ }^{240}$ At nearby bastion T6, thanks to the fall of the outer facing of the stone masonry, remnants of a fill essentially made of mudbrick material can be observed. This information will be useful when examining bastion T7's collapse (the event as well as the product, rubble T7A) and some loose sediments possibly connected with it (see sections 12.3, 13, and 14.1, below).

\section{Some details on the lowermost courses of bastion T7.}

- Course 22. Made with big, thick, protruding blocks, crudely worked although orderly laid. Four blocks were unearthed and observed over a length of $2.2 \mathrm{~m}$, '22-one' to '22-four' in plan (Fig. $89 \mathrm{D})$. The lower part of block 22-one is aslant, i.e., it escapes obliquely eastwards. Although irregular, the base of the blocks forming course 22 appears to be fairly horizontal.

- Course 21. A block in quadrangle A31 shows a batter of no less than $15 \mathrm{~cm}$.

- Course 20. Made with rough-hewn blocks of various sizes in plan.

- Course 19. Relatively thin overall, made with thin rough-hewn blocks of various sizes in plan; joint $20 / 19$ is the last relatively irregular joint from bottom, i.e. non-isodomic (non-horizontal).

- Course 18. Relatively thin.

- Course 17. Even a little thinner than course 18, c. $23 \mathrm{~cm}$. Made with irregular blocks. The lateral joints of masonry were mortared with mudplaster, which might have been used also elsewhere in the wall, although only dubious traces were observed. The batter is roughhewn and abraded, and measures $c .10 \mathrm{~cm}$ in quadrangle $A 1$ and as much as $13-15 \mathrm{~cm}$ in A11. The face of blocks is summarily worked as well.

- Course 16. Very thick, $47-49 \mathrm{~cm}$, and somewhat irregular particularly towards the base. Its batter is variable (up to $5-6 \mathrm{~cm}$ ) and relatively

\footnotetext{
238 Doe 1983, 128 and plate 17b, respectively.

239 Van Beek 1958. For more recent studies, particularly concerning the Jawf, see Breton 1994, 39-41, 112, pl. 5 (Barāqish); Bessac 1998a.

240 On the use of mud bricks and mudbrick material at Barāqish in general see Chapter 12 in Volume 1 (Darles).
}

worn. Courses 16 and 15 are the last from bottom to be made of relatively rough-hewn blocks.

At some point, a partial fall of bastion T7 occurred, and it might have been spontaneous. A partly conjectural outline of the surviving Minaean masonry above ground is suggested in Fig. 75. The restoration of the outer walling with reused masonry must be attributed to the Islamic period (see sections 12-13 below). To some extent, our architectural reading of intact Minaean masonry in bastion T7 fits with a recurring pattern of Minaean bastions' collapse at Barāqish, to be seen - for instance - on bastions T6 and T5 nearby (e.g. Figs 1, 16). At bastion T7 as elsewhere, it can be surmised that the fall was initiated by a bulge in the outer facing's middle part, a swelling due to pressure from the melting of the infill. Eventually this was followed by a V-shaped breakage and collapse of the wall. V-shaped ruptures typically affecting the middle part of outer wallings and tendentially sparing the corners do recur all along the Minaean wall; good examples in the southern arc of Yathill are bastions T54-T56. This reconstruction will be further discussed in the context of collapse rubble T7A (see section 12.3 below).

\subsection{Earthwork F10-F12 and the Minaean wall foundations}

An artefact about 1.6 metres thick was constructed along the exterior of the Minaean wall between courses 17 and 14. This will be called Earthwork F10-F12, this code name itself suggesting complexity (Fig. 78). F10-F12 is a 'mega-feature' as defined in section 1.3 above, consisting of relatively complex features (F12, F11, and F10, bottom to top) and subordinate components (such as T77 $\mu$ ). ${ }^{241}$ Structural, inter-feature contacts separate the three features (surfaces S10 and S9). The earthwork rests on surface S11, whose compaction and horizontal orientation have indubitable relationships with the earthwork's construction, and is topped by surface S8, the eroded survivor of original surface S8.0 (see below). In order to make F10-F12 understandable it will be appropriate to say in advance that it can be interpreted as a wall-side or wall-flanking structure, overall shaped like a bench with a small horizontal part and an outwardly inclined top.

Earthwork F10-F12 can be described in terms of a construction style based on the vertical reiteration of massive fillings and stratiform casings, or pavings (Fig. 102 A). Construction was started with two massive fillings, essentially made of mixed fines and constituting the entire lower half of the earthwork (feature F12, c. 0.8 $\mathrm{m}$ thick). This initial core was followed by feature F11, essentially a fill of angular rubble sandwiched between

\footnotetext{
241 As we are dealing with an earthwork, its components can normally be equated with sediment units, hence the dual designation - as feature and as sediment unit - for some of them.
} 
two mud-brick casings, and feature F10, a layer of block ballast over a solid bed of mixed gravel and plaster. Immediately below and above the F11/F10 contact (surface S9) there are two thin levels of loose, unusually coloured materials of uncertain origin. Together, F11 and F10 constitute the upper half of the earthwork. This is a simplified description, and details about all the components will now be given starting with those of feature F12.

F12 consists of a stony unit against the wall, $\mathrm{Pj}$ (or feature F12P), and two consecutive fillings of massive fines, T79J and T79L (Figs 85, 98, 99). Massive, or structureless, refers to a lack of internal structure, ${ }^{242}$ and this degree of uniformity is particularly pronounced in T79L. F12P is a formless layer, originally open-work, of medium to decimetre-sized angular stones, irregular and often platy $(\mathrm{Pj})$, disorderly accumulated along the foot of the wall in strip A1-A31. As a feature, $\mathrm{Pj}$ is earlier than T79J and adjacent to it, but as a sediment, having been infiltrated by the fines of T79J, Pj should rather be classified as a subunit contained within T79J. T79J is a bed of massive clayey silts, beige and occasionally light grey in colour, with sparse stones and a quantity of relatively angular Sabaean pottery and bones; Minaean potsherds are negligible. It is in fact rubbish brought in from other parts of the site to provide levelling fill for the construction of the earthwork. At the top it includes a discontinuous horizon of gravelly lenses, $9 \lambda$, particularly at the foot of the wall, thinly separated from Pj-F12P.

The second filling, T79L, is one of the thickest sediment units encountered in Area C: up to $0.6 \mathrm{~m}$ thick in quadrangle A1. Although massive, it is at the same time unusually light or 'soft'. It is made of perfectly grey silts or a silty loam with rare stones, sometimes in clusters, and is replete with reworked Sabaean potsherds and other household refuse. Minaean potsherds are angular but still rather modest in size and quantity. The stones in T79L are grey, completely different for instance from those of unit T78 $\pi$ (feature F11, see below). The top of T79L is a pisé, a hard-packed or compacted earth surface; it forms a slight hump within a metre from the wall, at least on the Reference section, but slopes down westwards in the rest of the excavated strip and presumably beyond. This top coincides with S10, a sharp, perfectly delineated surface. Both the attributes as a sediment body and its cultural contents make it clear that T79L is a mass accumulation of Sabaean and Minaean material.

Feature F11 is made, in stratigraphic order, of components F11C, T78 $\pi$, F11M, and T78V. Component F11C, or sediment unit T78C, is a mud-brick casing only

242 E.g., AGI 1984, 307, no. 1; Stow 2005, 61. preserved as a truncated bank in A1-A11 west, with limited continuation in A31 (Fig. 97). It is made of mud bricks or mudbrick material mixed with fine rubble, this latter yellow in colour (identical with rubble $\mathrm{T} 78 \pi$ ), and it clearly served as casing or paving for mass T79L. Partial casing only, perhaps, if the missing $1.5 \mathrm{~m}$ alongside the wall were intentional and not the result of disaggregation and weathering (see below). Truncated F11C is surrounded and overlain by rubble $T 78 \pi$, and together they rest upon surface S10 described above.

$\mathrm{T} 78 \pi$ is a layer of angular rubble in a matrix of mildly compacted, perfectly grey silt. The rubble is made of small rough-hewn blocks and a quantity of flakes and spalls from the same limestone as that used for the Minaean wall, often $10-20 \mathrm{~cm}$ in size; and there are cobbles, a separate artificial inclusion. The clasts of $T 78 \pi$ are generally yellow in surface colour, a trait inherited from an unknown primary deposit. Large, worn-out Sabaean potsherds also form a significant part of the coarser fraction, while Minaean potsherds are rare. A large parallelepiped block, P44, was ostensibly put in place together with T78 $\pi$. P44 was set on edge against the Minaean wall (course 15) in northeastern quadrangle A11, with its base resting within the topmost level of unit T79L (Figs 101, 102 A; plan in Fig. 92). P44 is a rough-hewn block similar to those of the Minaean wall, but much smaller, and its intended function within F11 is unclear. It was enveloped by $T 78 \pi$.

F11M and sediment unit T78V need to be examined together (plan in Fig. 92). Feature F11M is a second mudbrick casing, single-layered and made in fact of flat, squat bricks that rather look like tiles. Whether originally it formed a continuous casing is uncertain, however. It appeared in excavation as a largely fragmented and imperfectly preserved feature, apart from an area in quadrangle A11, where it precisely reached the top of block P44 and surrounded its west side. In fact, in its final condition, F11M was only encountered in the middle part of strip A1-A31, and nowhere was it observed along the curtain wall. Taken together, these observations rather suggest that F11M was merely an addition of new tiles to patch up local damage. Possibly such patches were inserted in a genuine casing of mud bricks that had very badly decayed, to the point of having become unrecognizable - an original 'F11M', so to speak. An incomplete but well preserved mud brick was still lying in contact with feature F11M to which it clearly belonged, although displaced (no. 191.2, see 'Finds from F10-F12', below). ${ }^{243}$

243 Reworked fragments of mud bricks, all brown or light brown in
colour, were found within T77 (feature F10 of the earthwork)
and in lower and bottom T7 $\mathrm{LP}_{2}$, at the contact with T77 (cut 189),
presumably all deriving from disaggregated parts of feature F11M
nearby. Whereas the Sabaean mudbricks were typically greyish,
as mentioned elsewhere (e.g. section 6.3, 'Wall F4: foundations and
structure', above), the Minaean mudbricks observed in Area C tend 
Unit T78V is a thin level $(5-15 \mathrm{~cm})$ of compacted silt, grey to dark grey in colour, apart from an area in the southwest quadrant of A1 characterized by a strange pale-green facies (hence ' $\mathrm{V}$ ', from Italian verde, verdino). ${ }^{244}$ It virtually occupied the entire strip A1-A31. The relationships of T78V with mud bricks F11M could not be observed as fully as desired, and the Reference section informs only partially (F11M does not appear on this section). T78V thinly covered, surrounded, and infiltrated the remnants of $\mathrm{F} 11 \mathrm{M}$, which suggests that it was layered immediately (?) after the mud bricks. Whatever its material, was it perhaps a finishing to the top of F11?

Preservation inequalities aside, it is thus apparent that the initial earthwork core represented by F12 was furnished with two successive outer casings of mud bricks, F11C and F11M: thicker and more resistant the former, single-layered and possibly poorer the latter, and both very imperfectly preserved at the foot of the curtain wall. ${ }^{245}$ A distinct linear contact, surface S9, delimited the F11M-T78V-T78 component and the middle feature of the earthwork (F11).

The third and topmost feature of the earthwork, F10, appears at the same time continuous with the previous components and different, the chief novelty being the use of stone blocks. F10 is the 'shell' with which the earthwork was finally capped, perhaps at a slightly later time (see below). It was a structure to complete or adjust the existing earthwork: added after or without a time lag, if it was a completion, and with a time lag if it was adjustment or restoration (see below). In stratigraphic order, F10 consists of a thin bed of loose fines (T77 $\mu$ ), a third and final solid casing (F10Y), and a thick layer of ballast containing and sealed by stone blocks (T77-T7C) - a sandwich-like sequence again.

The first unit, $\mathrm{T} 77 \mu$, resembles the underlying $\mathrm{T} 78 \mathrm{~V}$ in thinness (10-15 cm) and extent (strip A1-A31), but is a strikingly coloured red-brown sediment to be interpreted in all probability as decomposed wood, mixed with melted-mudbrick silt. An organic fraction is evident. It contains sparse plaster lumps and Minaean potsherds: in fact, it is the first unit from bottom with coeval Minaean pottery predominant. Component F10Y ('Y' from gypsum) is a solid 'plaster-and-gravel' mixture up to about $20 \mathrm{~cm}$ thick, only preserved in the western third of quadrangle A11 and truncated or eroded in

to have a dark-yellow or yellowish colour, sometimes approaching brown (Chapter 21, section 2.1, 'Mud bricks', this volume). The Islamic mud bricks recovered from Sounding A were yellowish-beige.

244 This colour is unexplained. During the excavation one had the impression that $\mathrm{T} 78 \mathrm{~V}$ was at least partly composed of an unusual substance or substances.

${ }^{245}$ On this phenomenon of recurrent damage near the wall, as well as its combination with a repetitive pattern in the earthwork's construction, see below. the direction of the wall (Figs 92, 95 D). This condition recalls the surviving portion of F11C (see above), and it is not impossible that F10Y was destroyed near the wall's base by the introduction of blocks T7C. In A11 west F10Y contained at least two old Sabaean potsherds. In quadrangle $A 31$ west it seems to be represented as a thin lens or level, SaY, containing plaster or gypsum (Fig. 79).

The topmost component of Earthwork F10-F12 is best designated as 'layer T77-T7C' (Fig. 101). This paired code name reflects the dual nature of the layer, ${ }^{246}$ which in part consists of stone blocks and smaller rubble, T7C, and in part of a finer, loamy component, T77 (Figs 9091). Overall, T77-T7C can be interpreted as stone ballast. The term ballast ${ }^{247}$ is sufficiently elastic to be employed here with latitude, specifically to indicate a block-bed saturated with earth, without specification of internal structure. T77-T7C can be understood as a layer of blocks and fines, extremely unsorted and heterogeneous by definition, applied in the form of a more or less ordered or regularized casing or finish to the earthwork. The field data did not allow to determine unequivocally whether the non-block fraction (T77) was put in place together with the blocks, that is, like authentic ballast, but it seems likely. That T77-T7C is a product of mass accumulation is suggested by the pisolitic calcium carbonate crusts on stones T7C, particularly in the upper part of the layer, which must have formed within a network of open interstices (Fig. 96). ${ }^{248}$

More specifically, T77 consists of a loamy mass or masses, relatively rich in organic matter from anthrosols, containing all sorts of solid debris: large and small ceramic scrap, both Sabaean (including a torpedo-jar mouth, no. 190.2) and Minaean; fine angular rubble; charcoal and charred bones; pebbles, cobbles; and fragments of brown-hazel mud bricks and other building waste. Two mud-brick pieces $10-15 \mathrm{~cm}$ in size were associated with surface S8, one appearing on the Reference section and the other one in A11 (no. 190.1; Figs 95 B, 101). In the southwest quadrant of A1 this non-block matrix included a concentration or 'swarm' of light-coloured limestone flakes (Fig. 79). As to T7C, its configuration can best be appreciated from the illustrations (Figs 93-95). Its larger blocks and a number of lesser stones share the collective code name

\footnotetext{
246 Cf. 'T75-T7B' in Stratum F (section 11.3 below).

247 Current definitions in geological context include, e.g., 'broken stone, gravel, sand, etc., used for keeping railroad ties in place' (AGI 1984, 38); 'roadbed, gravel or coarse stone used to form the bed of a track or road'. The Italian term massicciata would fit the Yathill case particularly well.

248 This concretionary phase would be linked to surface S8, see below. Pisolitic - from pisolite, a rounded accretionary or concretionary body resembling a pea, $1-10 \mathrm{~mm}$ in diameter - is sometimes spelled pisolithic (from pisolith, same meaning; e.g., Monkhouse 1974, 268; AGI 1984, 382).
} 
P32. ${ }^{249}$ Importantly, there is evidence that originally T7C was not as disorderly as it was found at the time of excavation, ${ }^{250}$ but was more similar to a pavement, although generally not made of slabs.

Two outstanding stone slabs, however, are associated with T77-T7C: P33 and P33a, a pair of 30-cm-tall slabs set upright side by side against the Minaean wall, course 14 (Figs 90, 91, 93, 95 C). Definitely, they are not part of the ballast, and they must have been put in place before - perhaps immediately before - the accumulation of ballast. It seems indisputable that they represent an artifice connected with the wall. Their function might have simply been to prevent damage to the wall, but an ideology-laden, symbolic gesture could be contemplated..$^{251}$

Block ballast T77-T7C was added to the earthwork in a final step, possibly in order to produce a stable, level belt along the base of the wall. This is a first explanation only. In fact, corresponding with F10 and the top of the earthwork, the Minaeans may once again have levelled a wider stretch of the upper talus (cf. number ' 3 ' in Figs 26-27), this time in order to stabilize the mound and keep away rainstorm erosion; ${ }^{252}$ they perhaps intended to enable circulation as well. ${ }^{253}$ The details and reasons involved cannot be determined from Sounding A alone, nor can it be specified how long after the initial core of the earthwork - i.e., features F12 and F11 - the addition represented by F10 was made. It might have been decided and implemented at a slightly later time, but still within Stratum J. This connects with the issue of pauses during the construction of F10-F12, see below ('Some conclusive remarks').

A note on the drawings of Earthwork F10-F12. Figs 78-79 present a new stratigraphic drawing of the earthwork, different from that of previous

249 'Collective' code names for stones have been introduced to simplify the designation of the important, dense stone accumulations recurring in Sounding A - principally, bottom to top, T7C, T7B, and T7A. These designations follow a number-letter style, e.g. P32a, P32b, P32t'.

250 Partly due to unexplained disturbances during the interruption between the 2005 and 2006 field seasons: see next footnote.

251 Surprisingly, stone P33a disappeared from the excavated test pit between late December 2005 and December 2006, and block P32b and several smaller stones in quadrangle $A 1$ southeast were displaced. It is hard to believe that P33a was purposely robbed. Its resemblance to a funerary stela might perhaps provide a clue, but its contiguous and equally standing twin, stone P33, was left intact.

252 Protection from erosion was one of the main reasons for constructing glacis around town walls in Syria and Mesopotamia: cf. subsection 'A comparison between Earthwork F10-F12 and the earthwork at recess R44/45', below.

253 Cf. Fedele 2010, 133 (surface S8, topping the earthwork, as 'the first Minaean treading surface'); 2011a, 114 (S8 as a possible walkway). The notion that S8, or rather S8.0 as defined below, marks the first regular walking surface at bastion $\mathrm{T} 7$ can be retained: cf. section 10.5 below (Stratum I). publications. ${ }^{254}$ The relevant changes and their reason have been stated at the end of section 9 , above. For a more realistic impression this part of the profile was drawn combining the elements on the Reference section with significant elements offsection in quadrangles A1 (major blocks, dashed; cobbles) and A11 (feature F10Y, also dashed). The basis for the new drawing is the 'elevation profile' (profilo altimetrico in Italian; my neologism), a subsidiary drawing made to help understand the particular geometry and composition of a stratigraphic body or feature, here features F10 and F11. The elevation profile is a horizontal projection onto a vertical plane, not a section. More precisely, the elevation profile shown in Fig. 101 is an analytical restitution of the blocks, structures, and sediment boundaries throughout the whole breadth of $A 1$ and part of A11. The relevant section for the same stratigraphic segment is presented in Fig. 79, and this section was amalgamated with the other segments of Sounding A in order to obtain the total profile (Fig. 78). As it will again be the case with group GT74 (see section 12 below), also feature F11 (T77-T7C) demanded that several large blocks from quadrangle $A 1$ were included for a more realistic impression of the stratigraphic profile. A schematic profile of the whole earthwork is shown in Fig. $102 \mathrm{~A}$.

Elevation profiles as an interpretive aid will again be employed for the analysis of blocks T7B (feature F8, Stratum F, see section 11.3 below) and T7A (collapse rubble, Stratum E, see section 12.3).

The final surface topping mega-feature F10-F12 is S8. Or rather, this is the surface observed in excavation. In fact S8, as recorded and drawn (Fig. 79, 101), is an eroded surface resulting from, but not precisely reproducing, what must have been the original top surface of T77T7C (feature F10). This original surface, 'S8.0', is presumably to be reconstructed as broadly coinciding with the top of blocks T7C (Fig. 102 A) ${ }^{255}$ Moreover, S8.0 appears perfectly to correspond to the top of masonry course 14 in the wall, a fit which would reflect a precise architectural plan involving wall and earthwork. The weathering and erosion of surface S8.0 down to surface S8 - a net loss of 5 to $20 \mathrm{~cm}$ - might have taken an appreciable amount of time, at bastion T7 apparently characterized by nondeposition.

More precisely, we can perhaps envisage this interval as characterized by the interstitial erosion of block ballast T77-T7C, the interstices between the stones being filled with loose earth T77, and by the consequent dismemberment of the paving, made of blocks. The

\footnotetext{
254 Fedele 2010, 2011a.

255 To put it simply: 'S8' lato sensu is in fact two surfaces, S8 as recorded (Fig. 79) and S8.0 as reconstructed (Fig. 102 A, a schema).
} 
large blocks P32a, P32b, P32f were certainly not so placed originally, protruding at random. The erosion and general truncation of T77-T7C seem to have been somewhat localized, and particularly widespread and strong at the foot of the wall (see below, 'Some conclusive remarks'). In addition, current surface S8 was to some extent consolidated by calcium carbonate deposition, also responsible for the pisolitic concretions on stones in the upper part of layer T77T7C. ${ }^{256}$ I would therefore infer a relatively important temporal hiatus after the completion of the wall and earthwork, in correspondence with surface S8. This hiatus contributes to the definition of, and separation between, Strata J and I, or Minaean 1 and Minaean 2, respectively (see section 10.5 below).

\section{Some conclusive remarks. Finds from F10-F12}

In conclusion, in Earthwork F10-F12 we have a structure created through the repetition of a leitmotif: the reiteration of covering loose sediment fills with solid protective envelopes, made of mud bricks or a cemented mixture of debris. These successive envelopes, or casings, mostly underwent weathering or were damaged at the foot or in proximity of the wall (see below), but originally they had been conceived and constructed as a continuous, thick, solid bench closely bordering the wall. And the earthwork, perhaps at a slightly later moment, was completed at the top with a substantial and durable paving of blocks associated with a layer of ballast. Together, Earthwork F10-F12 and the backfill of the foundation trench - or sediment group TBF - constitute the accessory works for the Minaean town wall at bastion T7. From the base of the foundation trench (S12) to the top of blocks T7C as currently preserved, these accessory works measure a total height of $2.8 \mathrm{~m}$.

Describing feature F11 we have seen how mud-brick components F11C and F11M have been found in a ruinous state in the zone bordering the wall. And the phenomenon is repeated in F10 with component F10Y, and later on with surface S8.0, reduced by erosion to current S8 (see above). This is an additional repetitive pattern concerning Earthwork F10-F12. It would appear that it is due to the impact of selective wear, corrosion, and/or erosion in a belt along the foot of the wall. However, whether this means that there were significant pauses in the making of the earthwork, and that two or three times its capping structures underwent true revampings rather than mere additions, is uncertain. Uncertainty about such details does not mean that, overall, the making of F10-F12 must have been a stepwise process.

256 See description of this layer, above, and on pisolites footnote 248 .
Obviously, the setting and details of the construction of wall and earthwork cannot be understood from Sounding A alone. Information is completely lacking on the thickness of the wall and the width of the foundation trench on its interior side (if any). ${ }^{257}$ Particularly troubling is the very limited knowledge of the flanking earthwork itself, due to the constricted excavation area deep down in Sounding A. It appears, however, that this earthwork was at the same time unitary in its conception and complex and perhaps lengthy in its construction. A sequencing of stages is suggested in Table 6.

Overall, the building of Wall T7 and its flanking earthwork was not a single event, but entailed a protracted series of episodes and minor breaks (three? - T7F/T7Y, T7Y/T7 , and surface S11). As noted above (section 10.1, 'Stratum J'), an area around contact T7F/T7Y was affected by secondary induration, and surface S11 is locally compacted. Might T7F/T7Y and S11 represent working surfaces from which the construction of the wall was conducted, including use of scaffolding, in addition to all the necessary activities of a 'heavy' kind that building entails? Only the excavation of a wider area will clarify such issues.

Finds from F10-F12. As mentioned above (section 10.1, 'Stratum J'), all the Stratum J material reasonably attributable to the Minaean period was retrieved from Earthwork F10-F12. Reworked and abraded Sabaean potsherds are still predominant in unit $\mathrm{T} 78 \pi$ of feature F11, but the picture changes with units T77 $\mu$ and T77: very little Sabaean potsherds are present and that little is extremely worn, whereas the Minaean material is well-preserved. Below is a selection of the most significant Minaean (or presumed Minaean) finds, listed stratigraphically bottom to top.

- Presumed Minaean, but impossible to exclude that they are reworked Sabaean items: a small bronze element from the bottom of feature F12 (no. 195.01); and a fossil Cerithium retaining sediment matrix similar to T79L (no. 192.01), found in situ at the base of T78 $\pi$ or on the T79L/ $\mathrm{T} 78 \pi$ contact in quadrangle A31. Might this fossil shell hint to some kind of construction-related symbolism?258

- From feature F11: a cobble from upper T78 $\pi$, in situ, allegedly a 'kohl grinder' (no. 191.3); and an incomplete mud brick in situ, part of F11M (no. 191.2; see Chapter 21, section 2.3, Fig. 61, this volume).

\footnotetext{
257 One should bear in mind that the wall's foundation trench might have been asymmetrical.

258 See section 6.3 ('Accessories and special finds') above, discussing the other Cerithium fossil from Area C. In that case too it had been found in close proximity of a wall, Wall F4.
} 
- From feature F11 (T78 $\pi)$ or feature F10 (T77 $\mu)$, strip A1-A31: the head fragment of a bull (no. 191.01), the earlier of two terracotta figurines found in the early and middle Minaean levels of Sounding A; ${ }^{259}$ a unique ceramic disc made from a potsherd (no. 191.02); an iron object 6.4-cmlong, perhaps a nail (no. 191.05); and a fragment of gypsum or plaster likely associated with building activity (no. 191.03).

- From feature F10: two large fragments of Minaean jars retrieved in situ, one in A11 south, probably from T77 $\mu$ (no. 191.1 = Buffa 191,1), and the other one - a base fragment reconstructed from a piece resting vertically against the wall within fill T77, in quadrangle A11, and additional sherds elsewhere (no. 190.3 = Buffa 190,3; see photograph in Fig. 95 C); a large mud-brick chunk in situ from surface S8 in A11 northwest (no. 190.1); and an ochred limestone piece from T77 (no. 190.01), identified as a tile by comparison with an ochred limestone tile found in 2005 at the top of T77-T7C or within T7LP (no. 168.01).

\section{A comparison between Earthwork F10-F12 and the earthwork at recess $R 44 / 45$}

In the field in 2006, A. de Maigret and I readily agreed that what I was finding at bastion T7 was the same structure he had recently found in the recess between bastions T44 and T45 in the southern sector of Barāqish, and called in Italian a 'contrafforte'; ${ }^{260}$ or they were just slightly different expressions of an identical architectural feature. In 2005, in anticipation of what might come to light at bastion T7, I had indeed repeatedly inspected the extant sections of the excavation at recess $\mathrm{R} 44 / 45$, which, incidentally, de Maigret had asked me to record. Unfortunately, no time was available then, or in the following two seasons, to clean and study the sections as planned.

What is in question after the present restudy is the identity of the deposits and features encountered at bastion T7 (Earthwork F10-F12) with those constituting

\footnotetext{
259 The only figurines from Area C; see Chapter 21, section 2.3, this volume.

260 A. de Maigret's 2003-2005 excavations in recess R44/45 and along bastion T45: de Maigret 2004a, 7, fig. 5; 2005b, 36. An excavation report is included in Volume 1 of this book as Chapter 8 (Antonini), with epigraphy in Chapter 9 (Agostini), and the reader is referred to both for the relevant information. Contrafforte was translated into English as 'counterfort' (de Maigret 2004a, 6), which, however, is alien to standard architectural English (e.g. Watkin 2011, Hislop 2013, Pevsner 2016; it exists in engineering with a different meaning), as it was pointed out to me during the publication of Fedele 2011a - hence the quotation marks and a hyphen to qualify the unorthodox use of the term ('counter-fort': Fedele 2011a, 106, 114). A. de Maigret's support for my interpretation of the layers in question from Sounding A as an earthwork, and the equation of my findings with his contrafforte at R44/45, was recorded in Fedele 2010, 132, footnote 121.
}

the structure at R44/45 and bastion T45, or 'earthwork L50'. ${ }^{261}$ Structure L50 has been interpreted as a 'squat counterfort in mud-bricks outside the circuit of walls', which, 'designed to strengthen the walls, also ensured their remarkable preservation'. ${ }^{262}$ Its core was made of a varied 'earthy' fill also containing limestone flakes, furnished with an outer envelope of mud bricks (or mudbrick material) and a low retaining wall (M50), both imperfectly preserved. ${ }^{263}$ Towards the end of the excavations the mud-brick layer was re-described as terre pisée, compacted earth, ${ }^{264}$ perhaps in view of its dismembered or melted condition (cf. F11M in Earthwork F10-F12?). It also became clear that earthwork L50 was not restricted to the wall recess but continued in front of the bastions.

A comparison between Earthwork F10-F12 and earthwork L50 is shown schematically in Fig. 102, with a scale profile of L50 in Fig. 102 B (my restitution).

Two main differences distinguish L50 from Earthwork F10-F12: it is not as complicated and layered as F10-F12, and it lacks the final paving represented by block ballast T77-T7C. Apparently L50 did not undergo additions or refurbishments as was instead the case with Earthwork F10-F12. On the other hand, the two structures follow the same architectural template: a bulky, massive fill cased by harder material, mud bricks specifically. If anything like wall M50 existed at bastion T7 - a revetment within the earthwork ${ }^{265}$ - it would lie outside the excavated surface of Sounding A. The likely conclusion is that Earthwork F10-F12 and L50 are the same kind of structure. At face value, the comparative measurements in Fig. 102 B suggest that F10-F12 might extend for as much as $5 \mathrm{~m}$ from the face of bastion T7: this is the reconstruction proposed in Fig. 27.

If the earthwork against bastion T7 is indeed the same as the complete earthwork found at T44-T45 in the southern sector of Yathill, then such a structure might effectively have encircled the town, over a total length of about $770 \mathrm{~m}$. This was de Maigret's

\footnotetext{
261 This designation is based on data in Antonini, Chapter 8 in Volume 1 (after de Maigret's own fieldnotes, see below).

262 de Maigret 2004a, 6, with a frontal photograph in fig. 5.

263 'L50' was originally the code name for this mud-brick layer joining the top of dry-stone wall M50 (A. de Maigret, Barāqish 2003 Excavations notebook [red cover], page 7; cf. ammattonato, 'brickwork', page 13). A 'casing made of mud bricks' was specifically mentioned to me by de Maigret in 2006 while discussing my findings at T7 (FGF personal records). Cf. Fedele 2011a, 106, 114: 'The Minaeans had made a mud-brick-cased "counter-fort" to retain and strengthen the wall', 'a reinforcement bank or "counter-fort"'.

264 A. de Maigret, Barāqish - 2004-2005 Excavations notebook (green cover), pages 29, 32. I am deeply grateful to Sabina Antonini for having put de Maigret's notebooks at my disposal.

265 Revetment is used here to indicate 'a wall used to shore up a bank of earth' (Hislop 2013, 248).
} 
favourite assumption anyway. ${ }^{266}$ But in fact, whether this structure runs along the whole perimeter of the Minaean wall is not only unknown, but presently unfathomable. The structure might only accompany selected parts of the curtain wall and/or change in size and character according to sections.

No exact parallel to Yathill's earthwork is presently known in Yemen. And thinking of wall-side, 'strengthening' architecture associated with town walls in the most general terms, only two instances could be adduced: Tamna' e Hajar am-Dhaybiyya. ${ }^{267}$ At Tamna', the ancient capital of Qatabān, ${ }^{268}$ a 'glacis' made of roughly hewn stones and with an inclination of 45 degrees flanked the so-called South Gate on its eastern side. ${ }^{269}$ Marginally more interesting is perhaps the 'glacis' reported from Hajar am-Dhaybiyya in Wādi Dura', governorate of Shabwa, datable to the 1st century BCE or the turn of our era. ${ }^{270}$ It was described as "consist[ing] of parallel rows of granite blocks, firmly set into an earth foundation, and fixed with smaller stones', 'a 4-6 metre-wide belt of wādī stones which may encircle the entire tell, but this is not certain'. ${ }^{271}$

If we look outside Yemen, we realize that parallels to the general architectural idea embodied in the Minaean earthwork at Yathill can be found in Syria-Palestine and Mesopotamia since the Bronze Age, and particularly the Middle Bronze Age. ${ }^{272}$ 'One characteristic element of the larger Middle Bronze Age sites [in the northern Levant, e.g. Ebla] is their massive fortifications, consisting of a rampart, ${ }^{273}$ a glacis (slope running down from a fortification wall), and often a moat'. ${ }^{274}$ The glacis of this period were intended to protect the base of the walls from both undermining in war attacks and

\footnotetext{
266 de Maigret 2004a, 6; and personal communication 2006.

267 Cf. Breton 2002, 146 (walls flanked by a 'glacis' for the purpose of fortification). I wish to thank J.-F. Breton for correspondence on this subject in July 2017.

268 de Maigret and Robin 2016.

269 Excavated by the American Foundation for the Study of Man in 1951 under the supervision of G.E. Burcaw. The only published sources are a few early mentions (Jamme 1953, 139; Phillips 1955, 188) and a summary excavation plan (Breton 2001, 25, Fig. 5, after Burcaw, 1951, and Breton himself, 1982, as redrawn by C. Darles; recently reproduced in Loreto 2011, fig. 1 on p. 16). This glacis can be glimpsed at the far right of the 1982 photograph in Breton 1994, pl. 24a. The South Gate was in fact the southwest gateway of the city. I wish to thank Sabina Antonini and Alessio Agostini for exchanging information and views on the South Gate of Tamna' in February 2018.

270 Breton et al. 1998.

271 Breton et al. 1998, 93, 92. Concerning its discovery, the authors of this paper note that 'similar constructions are rare in South Arabia, the only immediately apparent parallel being that on the east side of the southwest Gate at Tamna' (Breton et al. 1998, 93).

272 Burke 2008, with references. Among its reviews see Ilan 2012. Burke 2008, 175-176, contains a list of the common features of the MBA Levantine fortresses.

273 Meaning here a curtain wall.

274 Genz 2012, 622. A still useful synopsis with drawings is Ilan 1998.
}

erosion, observes M. Sauvage, and mud bricks were extensively used in various forms as a choice material for their casing or finish. ${ }^{275}$ At Terqa, in Syria, the glacis defending the curtain wall was made with large stone blocks. In fact, this 'Levantine' model of defensive architecture conquered a large area of western Asia, including Anatolia and Elam, ${ }^{276}$ and, significantly, even reached Nubia. ${ }^{277}$

However, the above concept and its driving principles were apparently implemented in Yemen - or parts of Yemen - on a much smaller scale and with original adaptations (as always in southern Arabia). Whether it was from inspiration and emulation or independent thinking, is impossible to tell. In Yemen the purpose of defense against war attacks or war machines (such as rams) was not paramount, apparently. And, clearly, ancient Yemen had nothing to learn from the outside about how to use unbaked earth and mudbrick.

\subsection{The Minaean wall: physical-chemical behaviour and damage}

Some physical and sedimentary phenomena specifically concerning the Minaean wall at bastion T7 deserve attention. Several sedimentary processes have already been mentioned in some of the previous sections, including for example those outlined in section 10.3 above ('Some conclusive remarks'). Dissolved calcium carbonate extracted from the calcarenite rocks of the wall may have significantly contributed to the formation of calcitic crusts, concretions, or cemented patches within certain units or layers (see section 2.3, with additional details in section 11.3 below). Such products helped create a well-defined and well-sealed stratigraphy both geologically and culturally, largely coinciding with the Minaean period. Thermoclastic weathering of the wall's rocks appears to have directly produced a number of fine-rubble lenses or microtaluses at the base of the wall.

Concurrently, and more effectively, the formation of salt crystals must be held responsible for several notch lines in the wall. Three such 'decay bands' were observed on the exterior face of bastion T7. Top to bottom, they were labelled DB1-DB3 (Fig. 74, inset). The correspondence to the courses of masonry is the following: DB1, the widest and most pronounced ribbon, winding across course 7 from base to top; DB2, lower

\footnotetext{
275 Sauvage 2001, 338. For Mesopotamia he cites the example of Ur during the Ur III period.

${ }^{276}$ For instance at Susa, in Achaemenid times, 'the Apadana Mound, Ville Royale, and Acropole, were surrounded by a plastered mudbrick glacis (artificial earthen slope) with salients (projections)' (Henkelman 2012, 952-953). This example is roughly coeval with Yathill's.

277 Walls and glacis ('angled bases') in Middle Kingdom's fortresses: Romer 2016, 444-445, 594-595.
} 
course 9, linear, medium lesions (but see below for a different perspective brought about by the discovery of a 'burnt spot', BS); DB3, the best delineated and most marked notch line, middle-to-upper course 11.

Although not exclusively produced by salt, these bands help define discrete moments of sedimentary slowdown at bastion T7, during which the wall, not subject to progressive silting up, quietly underwent decay. The ability of salt to cause rock and stone breakdown is well known. ${ }^{278}$ Salt not only moves up from the ground water to evaporate at the surface, causing rock to flake off, ${ }^{279}$ but salts from windblown dust may directly affect the wall's surface, even with low levels of moisture. Crystal growth, salt hydration, and/or thermal expansion of salt can produce substantial pressures. The only case of definite linkage between wall-base rubble and wall damage is rubble 'pocket' LT7, which contains products of the immediately adjacent decay band, DB1. LT7 was recorded on the Reference section, where it is positioned at the upper contact of unit T74 (top of sediment group GT74, Stratum C). ${ }^{280}$

DB3, located in contact with the upper levels of unit T75 (Stratum F, Minaean 4), is an interesting case probably combining physical-chemical damage with mechanical wear. This decay band is a likely indication of ground stability and sustained wear along the wall's base at the beginning of Stratum $\mathrm{F}$, hence a marker of wall-side human 'activity' in a general sense. And T75 does effectively provide clues about this heightened activity, since it contains in its lower half the remains of a structure that - judging from its contents - might have functioned as a jar sealing or unsealing workshop (structure F8; see section 11.3 below). ${ }^{281}$

An entirely different kind of damage is BS, a 'burnt spot' spanning the joint between courses 9 and 10 on the side of quadrangle $A 1$ (Figs 74, inset; 118). BS is a patch of reddened rock on the wall, $20-30 \mathrm{~cm}$ across, and although observed in excavation it was only noticed during the restudy of records and photographs in 2018. The rubefaction was certainly the result of direct contact with fire. Furthermore, the rubble underneath block P20j of collapse T7A, i.e. unit T7r, included at least one fire-rubefied limestone fragment. Was there a conflagration, eventually affecting the interstitial filling of collapse rubble T7A? Was such fire a component - even a crucial component - of unit T7JK and its infiltration of collapse rubble T7A, near the base of the

\footnotetext{
278 On salt weathering see, e.g., Goudie 1989, 18-21. In Schiffer's terms (1996, 155-156, with further references) bastion T7's decay bands are a case of 'salt erosion', a process also affecting bricks ( $\mathrm{p}$. 159, fig. 7.5).

279 E.g. Butzer 1982, 131.

280 Cf. Fedele 2010, 133, but LT7 has been redrawn.

281 Cf. Fedele 2011a, 115; decay band DB3 is marked on fig. 3.
}

wall at the time? A relationship of BS with fire-related (?) unit T7JK has been hypothesized (see discussion of T7JK in section 12.4 below). However, there is a distinct possibility that the fire indicated by BS reflects events which occurred to the south of bastion T7, outside the excavated area, thereby making an understanding of BS impossible.

BS is positionally associated with decay band DB2, in the lower part of masonry course 9, and both rock features are contiguous to collapse rubble T7A and the subsequent deposits that infiltrated the rubble (these collapse blocks and sediments will be examined in sections 12.3-12.4 below). But the precise correlation between DB2 and the deposit is problematic. And unfortunately, there is no precise overlap between DB2 and BS, therefore the relationship between these two features cannot be determined either.

A further complication comes from the upper part of masonry course 9, and specifically from the stone block bordering quadrangle A1 (Fig. 118 A; marked as 'unspecified damage' in Fig. 74, inset). Also this part of course 9 is strongly deteriorated, but at the peckeddrafted contact of block's ornamentation, and not deteriorated in the same way as the decay bands. Is this also a sign of fire? A fire involving collapse rubble T7A after its fall? Maybe quite a while after its fall but when the rubble was still open and pervious? It is impossible to determine.

\subsection{Stratum I}

Surface S8, or originally surface S8.0, topping Earthwork F10-F12, represents the ground surface upon which 'ordinary' sedimentation began: the first Minaean treading surface, so to speak (cf. section 10.3 above, footnote 253). Only after S8, in other words, did a detrital deposit begin to form, without anything artificial or 'built': that is, a proper deposit, no longer a structure. Stratum I, equated with a Minaean 2 phase, corresponds to its beginning.

If we take the long view for a moment and glance at the whole Minaean sequence from here on (cf. Fig. 84), some processes become readily apparent. During the Minaean occupation the tell grew vertically once more. Upon the wall-side earthwork, a 1.3-metrethick series of horizontal, perfectly stratified deposits accumulated at the base of bastion T7, starting with sediment unit T7LP. These layers are generally very rich in pottery fragments, animal bone, and sometimes charcoal, but contain much less plant debris than the Sabaean deposits, in spite of equally good potential for preservation. Percolation of rainwater enriched in calcium carbonate from the wall continued, producing frequent druses of interstitial calcite crystals on stones 
and bones, within the often porous sediments. Similar sedimentation, and slow vertical buildup, might have taken place over a wider belt along the wall, kept level by the Minaeans on purpose. ${ }^{282}$

Stratum I, in particular, is about half a metre thick and includes greyish stony fines (T7LP, T7L), intercalated with thin lenses of organic silt near the wall; a small lens (ro) and a larger unit (SRI) of sandy silt, unprecedented for their reddish colour; and lenses of rubble (T7P, T7P0, b0) (Figs 85,87$)$. Rubble T7P continues west outside the sounding and might be part of a decayed dry-stone structure. More sediment variants or subunits were recorded on the western and northern sections of the sounding (Fig. 79). Stratum I is lithostratigraphically also defined by the upper boundary of this sequence, surface S7.

With Stratum I a new depositional motif appears: the 'red sand' phenomenon, which will accompany the buildup of the upper talus throughout Strata I to F. This was a sedimentary novelty for the whole of Area C; and often the 'sand' was in fact a sand-silt. The beginning is represented by $\mathrm{r} 0$, a scatter of small wallside lenses alongside the top of masonry course 14 in the wall, just above current surface S8, in quadrangle A1. Unit $\mathrm{rO}^{283}$ was recorded in the field as resembling SRI, encountered previously in the sounding, but more organic. It represented the first 'red sand' occurrence stratigraphically: the last recorded occurrence is T75 $\rho$, an isolated pocket or lens of fine 'red' sand at midlayer within unit T75 (Stratum F). On the 'red sand' phenomenon see further considerations in section 11.2 below.

If we consider Strata I and $\mathrm{H}$ together, a depositional leitmotif was encountered between surface S8 and the top of suite T76, characterizing the base of the wall: a concentration of rubble and cultural debris with larger fragments often leaning against the wall - associated with accumulations of aeolian silt. This latter was often greyish from organic content. Although common along the foot of walls everywhere, due to a combination of mechanical and sedimentary processes, both components of this diachronic pattern were further emphasized outside bastion T7 by topography and human agency. As a consequence, every major sediment unit adjoining the wall between surface S8 and T76H - i.e., bottom to top, T7LP, T7L, and T76 displays a wall-foot facies thus characterized. ${ }^{284}$ The

\footnotetext{
282 See section 10.3 above, in the description of Earthwork F10-F12: the Minaeans might have levelled a stretch of the upper talus in order to keep away erosion and enable circulation.

283 Lenses r0 have been classified as a sediment unit although included in T7LP, in analogy to many other micro-deposits encountered at the base of the wall in Sounding A (see below in this section).

284 Interestingly, the wall-foot part of unit T76J contained a bird-of-
}

contact of each such facies with the rest of the unit is too gradational to be drawn, but, as a reasonable approximation, TPVi and TPVj were indicated in the drawing of the Reference section (Figs 17, 78). The last occurrence of this motif is TPV, only different in that its talus-like shape, in profile, and its more pronounced penetration into the adjoining deposits, in plan (cf. Fig. $89 \mathrm{C}$, sketch at the T76J/SR contact), were mappable.

Finds. Among the finds from Stratum I (Sounding A) the following objects can be noted:

- two fragments of softstone vessel(s) from T7LP, mostly T7LP 2 (nos 189.01-02), and a third one from immediately above, T7LP -SRI-T7P (no. 188.02); a small plain burner (no. 189.1, in situ in A1, T7LP [probably T7LP ]); and foot fragments of a clay 'tripod' (no. 188.04, T7LP -SRI-T7P), the only clay disc/'tripod' find from a reliable Minaean-age context (see Chapter 21, section 2.3 , this volume);

- a fist-sized cobble was resting on surface S8, embedded in T7LP, near block P32g of feature F10 (Earthwork F10-F12) in quadrangle A1 south (drawn on the Reference section, Fig. 79).

Cuts spanning later Stratum I and earlier Stratum H (187 and 169K; Fig. 25) produced the second of the two terracotta figurines found in Area C, no. 187.01, a fragmentary dromedary (see Chapter 21 , section 2.3, this volume), in addition to a fragment of a softstone vessel from A1-A11 (no. 187.2), a centimetre-sized copper spherule (no. 169K.02, a finished object?), and frequent cobbles about 7-13 cm in size (not described).

\section{Strata $\mathrm{H}$ and $\mathrm{F}$ in Sounding $\mathrm{A}$ : Later Minaean}

\subsection{Overview}

The Later Minaean levels brought to light in Sounding A show particular characteristics dependent - it seems - on a single unifying theme, trading activity; or rather, trading-related behaviour and episodes. The Later Minaean sequence (Minaean 3-4) as defined from the extramural area is presently attributed to an interval between the 2nd or 1st century BCE and the early or middle 1st century $\mathrm{CE}$, on the basis of a single radiocarbon reading (sample \#185: $93 \mathrm{BCE}-32 \mathrm{CE}$ ) 285 and estimated sedimentation rates. In this section Strata $\mathrm{H}$ and $F$ are presented. The evidence should be sufficient to suggest how the Minaean archaeological remains and sediments contrast with the Sabaean ones, and to what extent they complement the evidence recovered from the temple area in the town.

\footnotetext{
prey pellet (cut $169 \mathrm{H}$ ): see section 11.2 below.
}

285 See Chapter 18 , section 1 , this volume. 
Stratum G, as a conventional construct limited to stratigraphic sequences from the talus and plain, will be examined in section 15.3 after the sections concerned with Sounding A.

\subsection{Stratum $H$}

Surface 57 (see section 10.5 above) may marka significant though undefinable hiatus; its possible correlation with a ceramic shift is examined in Chapter 25, this volume (Buffa), and briefly discussed below (section 11.4). This surface is irregular, and distinctly identifiable only where stony units T7P0 and T7P form a nearly continuous upper boundary. When sedimentation resumed, suite T76 was gradually formed, and this suite is the basis for Stratum H. Bottom to top, in addition to rubble lenses at the base of the wall (TPVj,TPVi, and TPV), the sediments defining Stratum $\mathrm{H}$ include ashenbeige silts (T76J), a new intercalation of 'red sand' (SR, actually grey-pink in colour), and a layer of ashy-sandy fines, mostly silt (T76H, with brown organic lens T76 $\lambda$ ).

Stones are rare. However, a large isolated block was found just below TPV in upper unit T76J (T76 ${ }_{1}$ and contact $\mathrm{T} 76 \mathrm{~J}_{2} / \mathrm{T} \mathrm{J}_{1}$ ), block P25. This was a rounded, elongated limestone block $68 \times 40 \times 27 \mathrm{~cm}$ in size, fissile and weathered, lying horizontally near the base of the wall in quadrangle A31 (Fig. 89 C). Slightly above in the sequence, always in the northern half of strip A1-A31, three outsize stones marked the upper part or top of T76J: pointed, prismatic block P24, $50 \mathrm{~cm}$ long, and horizontal slabs P26-P27. Block P25 and these lesser clasts represent a further block horizon in Sounding A, the third from bottom in the series given above (see section 9). It is not impossible that they could indicate the appearance of wall-side shelters or cabins such as that which will be encountered in Stratum F (see next section).

Suite T76 represents well the 'quieter' sedimentary regime at bastion $\mathrm{T} 7$, and some of its sediments are of great interest. In chemical terms and at least indirectly, the origin of SR and some smaller 'red sand' lenses within suite T76 and the following unit, T75, might have to do with the calcarenites of the Minaean wall. ${ }^{286}$ An equally unusual 'pink sand' from upper Sector D, SA , would allow lithocorrelation with the 'red sands' so far only known from Sounding A, SR in particular. ${ }^{287}$ SA $\pi$ was deposited in quadrangles D3-D5 upon a conspicuous erosional surface marking a significant hiatus, surface S05 (see section 15.3, 'Stratum H', below). The correlation of Sectors B and upper D with

\footnotetext{
286 On the appearance of 'red sand' units in Sounding A and Area C see section 10.5 above; on their further occurrence in T75 see section 11.3 below.

287 This was mentioned in section 3.3, 'Long-distance correlations', above.
}

Stratum $\mathrm{H}$ as defined in Sounding A will be examined in sections 15.1 and 15.3 below.

During the timespan of Stratum $\mathrm{H}$ it becomes very clear that Minaean activities took place near the foot of bastion T7 and, presumably, elsewhere in a characteristically flat belt at the base of the wall. Most activities were concerned with trade, like the handling of sealed trade jars; they possibly also involved the practical organization of the packing and dispatching of caravans. Wādi limestone cobbles for the manufacture of jar stoppers, both flaked and unused, were found in units T76H and T75 (this latter, Stratum F) along with numerous fragments of stamped jar sealings, or cretulae (see Chapter 21, section 2.3, and Chapter 24 , this volume). ${ }^{288}$ Several finds attributable to this behavioural system - or 'activity' package - are listed below.

In conjunction with some data from the underlying levels, it thus appears that during the Minaean occupation the area flanking the northwestern wall was used in connection with work on trade goods, while, occasionally, pack animals were kept nearby (cf. manure units of Strata I, H, and F). It can further be inferred that during the Later Minaean such operations took place in outwall installations (see next section). Nothing is known about the spatial organization of trade at Yathill, however; and in fact, these data from Area $\mathrm{C}$ provide the first material evidence of Minaean trade at the town. Whether extramural posts such as those outside bastion T7 only represented a minor and peripheral reflection of the entrepôt activities being carried out inside the town, or were instead primary locations, is impossible to say. In consideration of the relatively small size of Yathill (about 4 hectares) ${ }^{289}$ the latter might be closer to the truth: at least at the peak of traffic, the handling of goods and jars regularly would take place extramurally.

The limited but significant evidence for trading activity from Strata $\mathrm{H}$ and $\mathrm{F}$, together with the subject of trade at Yathill as a whole, will be specifically addressed in Chapter 19, sections 3.1 and 3.2, this volume.

Finds. Among the finds from Stratum $\mathrm{H}$ (Sounding A) the following objects can be noted:

- an inscribed cuboid burner, no. 186.1, 290 found in situ in quadrangle A11 on a level corresponding to $\mathrm{T}_{76} \mathrm{~J}_{2}$ (earlier Stratum $\mathrm{H}$; its resting surface at

\footnotetext{
288 More flakes and fragments from the chipping of limestone cobbles or blocks came from Stratum F in Sector B, unit B02 (see section 15.3, 'Stratum F', below).

289 A medium-size town in Brunner's (1997a) classification.

290 See detailed description in Chapter 21, section 2.3 and Fig. 47, this volume.
} 
a depth of $-392 \mathrm{~cm}$ and only $8 \mathrm{~cm}$ above surface $\mathrm{S} 7$, near the top of unit T7P0, is indicated in Fig. 79); the object was flanked by two decimetresized angular stones (Fig. 89 C);

- two small fragments of ostrich eggshell(s), no. 186.01 from T76J (thus certainly Stratum $\mathrm{H}$ ) and no. 169K.01 from a cut in quadrangle A31 spanning levels of later Stratum I and earlier Stratum $\mathrm{H}$ (but possibly from T76J);

- two fragments of softstone vessels from T76J (nos 186.03-04);

- from later Stratum H, units SR-T76H and TPV, a transverse half quern in situ (no. 185.1, SR/T76H contact or $\mathrm{T} 76 \mathrm{H}$ bottom); ${ }^{291}$ and a number of large pottery fragments (cuts 185 in quadrangles A1-A11 and 169G in A31), including a 'Bayhāān' Wavy Rim bowl from two fragments (nos 185.34, or vessel V185; Buffa no. 185,3).

A bird-of-prey pellet - a unique finding - was retrieved from T76 $\mathrm{J}_{1}$ or micro-talus TPVi in quadrangle A31 southeast (cut $169 \mathrm{H}$ ); as usual, it was replete with small bones and hair. Turriculate terrestrial microgastropods were observed within unit SR, quadrangle A11 (cut 185).

In a class of its own we can place the behavioural package of trade indicators: essentially, stone jar stoppers, in all stages of manufacture, and remnants of plaster jar sealings. Two fragments of plaster sealings were recovered from earlier Stratum H, unit T76J: nos 186.02 from quadrangles A1-A11 and 169H.02 from A31. But the large majority of the evidence came from later Stratum $\mathrm{H}$.

Frequent limestone cobbles about 10 to $20 \mathrm{~cm}$ in diameter, mostly broken or chipped but including some intact ones, were a dominant feature of units SR and T76H - and micro-talus TPV - in quadrangles A1-A11 (cut 185). No photographic record is available, but one fine example - a cobble of grey cryptocrystalline limestone c. $18 \mathrm{~cm}$ long from $\mathrm{T} 76 \mathrm{H}$ in quadrangle $A 11$ - was recorded in the excavation plan of the cut (Fig. 89 B). ${ }^{292}$ Similar limestone cobbles, accompanied by traces of chipping waste, continue to occur in Sounding A during the next Minaean phase, Stratum F (e.g. no. 169F.1; see next section). On the use of such cobbles for making stone jar stoppers see entry no. 220.3 in Chapter 21, section 2.5 ('Chipped stone: heavy duty'), this volume.

Also the plaster jar sealings forming the collection from Sounding A were mostly found in units SR-T76H and

291 A typical saddle quern. On transverse half querns see Chapter 21, section 2.1, introduction to 'Querns and other grinding tools', this volume.

292 See no. 185 in Chapter 21, section 2.3 ('Chipped stone: heavy duty'), this volume.
TPV: three were retrieved from quadrangles A1-A11 (nos 185.02, 185.05, and 185.010) e many more from quadrangle A31 (nos 169G.04-011); conjoint no. 169G185 combined fragments from both locations.

\subsection{Stratum F, including structure F8}

Stratum $\mathrm{F}$ was established from sediment layers only observed in Sounding A and Sectors B and C. On the middle and lower talus, the broad equivalent to Strata $\mathrm{F}$ and $\mathrm{H}$ together is Stratum $\mathrm{G}$. In Sounding A, Stratum $\mathrm{F}$ is lithostratigraphically defined by units T75 (with inclusion LW), T75B, and T7B, this latter associated with feature F8. A fundamental continuity can be perceived between Stratum $\mathrm{F}$ and previous Stratum $\mathrm{H}$ in both lithostratigraphy and material culture, which contributes to the definition of a Later Minaean phase in Area C.

More precisely, Stratum F corresponds to a horizontal layer of hard, beige-greyish sandy silts, T75, which often looks like melted mudbrick. It is a fairly homogeneous, slow-sedimentation unit about $40 \mathrm{~cm}$ thick. It was the last layer from the top to be excavated over the whole area of Sounding A (area A1-A31, see section 9 above). T75 contains a level of stones, often slabs (T7B), which can be recognized as remnants of a decayed and possibly robbed stone structure, F8. T7B as large clasts, and T75 as matrix, together form an integrated sediment body best designated as 'layer T75-T7B', to adopt the paired-name formula already employed for a component of Earthwork F10-F12. ${ }^{293}$ T75 also contains wooden remains and at least one discontinuous level of partly decomposed wood, LW, neatly captured by the Reference section. In quadrangle A11, a lens or pocket of fine red sand at mid-layer within T75 (i.e., at the general level of slabs T7B) represents the last occurrence of 'red sand' in Sounding A and Area C. ${ }^{294}$

Key to describing and interpreting T75-T7B is feature F8, whose remains were excavated and mapped horizontally (Figs 103-104). This complex feature was initially inferred from blocks and lesser stones T7B, including a line of blocks in quadrangles $A 31$ and A11 north, two of which - superposed - suggested a wall $\left(\mathrm{F} 8_{\mathrm{w}}\right.$, made of blocks P21r, s, u, v). ${ }^{295}$ Apart from the supposed wall, T7B was a planar spread of relatively thin stone blocks and genuine slabs, collectively numbered

\footnotetext{
293 'T77-T7C' of feature F10: see section 10.3 above.

294 On previous 'red sand' units see sections 10.5 (Stratum I) and 11.2 (Stratum $\mathrm{H}$ ), above.

295 'F8' originally designated this 'wall', before being extended to identify the supposed, larger structure containing it. Also blocks P21e and P21e', fallen on sediments of topmost T75 still during the deposition of this unit (and before the onset of T7N, Stratum E), may have belonged to 'wall' $F 8_{\mathrm{w}}$.
} 
P21, ${ }^{296}$ associated with vague traces of earthen features (from mud walls?) and immersed in silts T75.

Subsequently, it became rather clear that at least part of blocks P21a-P21z and part (or most) of silts T75 could be parsimoniously understood as constituting a decayed single structure, made of stones and mud bricks. Several plaster-covered stones (e.g. P21d, P21d') looked like remnants of a hardened ashy-chalky floor. Also wooden and/or wickerwork elements could be attributed to this structure, judging from decomposed wood LW in quadrangle A1 (Fig. 106) and scattered pieces of well preserved wood elsewhere in A1-A12. ${ }^{297}$ An additional component of $\mathrm{F} 8$ was $\mathrm{F} 8_{\mathrm{Y}}$, an ash-andplaster compacted patch observed around the base of stone 'wall' $F 8_{\mathrm{w}}$ (particularly blocks P21u and P21v) in quadrangle $A 31$. Located at the top of unit T75B (see below), this evidently was a beaten-earth surface, or floor.

Overall, as shown by the elevation profile in Fig. 105, the distribution of blocks T7B is near-horizontal, with a relative 'high' in quadrangle $A 31$ (cf. 'wall' $F 8_{\mathrm{W}}$ ) and a slight inclination southwest or south in A31-A11; this orientation also seems to apply to layer T75-T7B as a whole. As a block horizon, one can easily note its difference in orientation and structure from both T7C (Earthwork F10-F12, above) and T7A (Stratum E, below).

What is F8? A reasonable reconstruction is a dry-stone and mud-brick shelter or shed with wooden parts and/ or furniture: a small cabin in which people both worked and lived, since cooking refuse was recovered (see below). As an instance of wall-side construction, it was perhaps only one in a series of accessory extramural structures made near or against the curtain wall. As to its function, both its contents - whole and chipped limestone cobbles, see below - and the overall continuity from Stratum $\mathrm{H}$, as discussed above in section 11.2, suggest as an obvious keynote a connection with trade jars, or jar exchange in general - a trade-related post. To go a step forward, one can think of a specialized structure either functioning as a workshop ${ }^{298}$ for opening and/ or sealing jars, or as a warehouse, a place for storing merchandise before moving it to the next destination. The probable connection of F8 with decay band DB3 on the wall was examined above (section 10.4).

\footnotetext{
296 Several other stones, differently numbered, share the same stratigraphy as stones P21 and may well belong to F8: P22, P23, and P28-P30. The latter three are very large blocks encountered in quadrangles A31-A32 north during a swift extension of Sounding A (Fig. 104).

297 Stakes? poles? The horizontal brown lens intercepted by the Reference section in quadrangle A1 south, sampled as no. 184.1 and individually examined (Fig. 106), suggested a small stake or beam or joist - about $10 \mathrm{~cm}$ in diameter, partially decomposed in situ.

298 An appropriate word in Italian would be bottega; in French, perhaps atélier.
}

A unit made of dense, small stone blocks in quadrangles A31 and marginally A11, with a silt matrix similar to T75, was called T75B. It is a thick lens or talus overlying suite T76 and lateral to T75, contiguous with masonry courses 10-11 of the curtain wall (Figs 104-105, 107). It contains plaster residues, and its internal structure shows two superposed levels grading into each other. In excavation it was interpreted as interspace filling between structure F8 and the curtain wall, but a detailed investigation could not be carried out.

Indirectly, the above observations have a bearing on the definition of surface S6 as the top of unit T75. Its relative clarity suggests either an arrest in sedimentation or an erosion phase before the onset of new deposition, T7Ji in the southern part and $\mathrm{T} 7 \mathrm{~N}$ in the northern part of the sounding. The possibility of a hiatus being hidden behind surface S6 is admissible. However, although sharp and linear, S6 may not qualify as a marker of a considerable sedimentary and temporal gap (see more on this subject in sections 12.1-12.2 below). The meaning of surface S6 will have to be studied over a much larger exposure to be fully understood.

Blocks T7B, due to their peculiarity of being predominantly slabs and often large slabs, have been attributed a role in lithological correlation over the upper talus. This utilization for medium-range correlation has been mentioned in section 3.3 above ('Long-distance correlations') and will be illustrated in detail in section 15.1 below.

Finds. Concerning the finds from Stratum F (Sounding A), numerous fist-sized limestone cobbles of alluvial origin - whole, split, or chipped - were recovered from T75 in quadrangles A1-A12 with cut 184 . This represented a continuation of the pattern and contents already observed in units T76H-SR immediately below (Stratum H). And during Stratum F too, grey cryptocrystalline limestone was often preferred as a rock, certainly because of its excellent conchoidal fracturing. A fragment from a calcarenite cobble was noted (no. 184.02). Some limestone cobbles were also found in unit T75B, such as a spherical specimen in situ in the northeast quadrant of $A 31$ (no. 169F.1). ${ }^{299}$

T75 produced a fragment of a glass armlet (no. 184.01), as well as isolated evidence of circulation and use of exotic rocks, indicated by a sharp fragment of red sandstone or granite and a piece of basalt (cut 184). These latter are part of a series of minuscule findings from layer T75-T7B which, taken together, seem to point rather clearly to the occurrence of foreign materials and quite possibly to the presence of foreigners. Such are, for instance, two seashell pieces, one of them a

\footnotetext{
299 See Chapter 21, section 2.3 ('Other utilized natural stones'), this volume.
} 


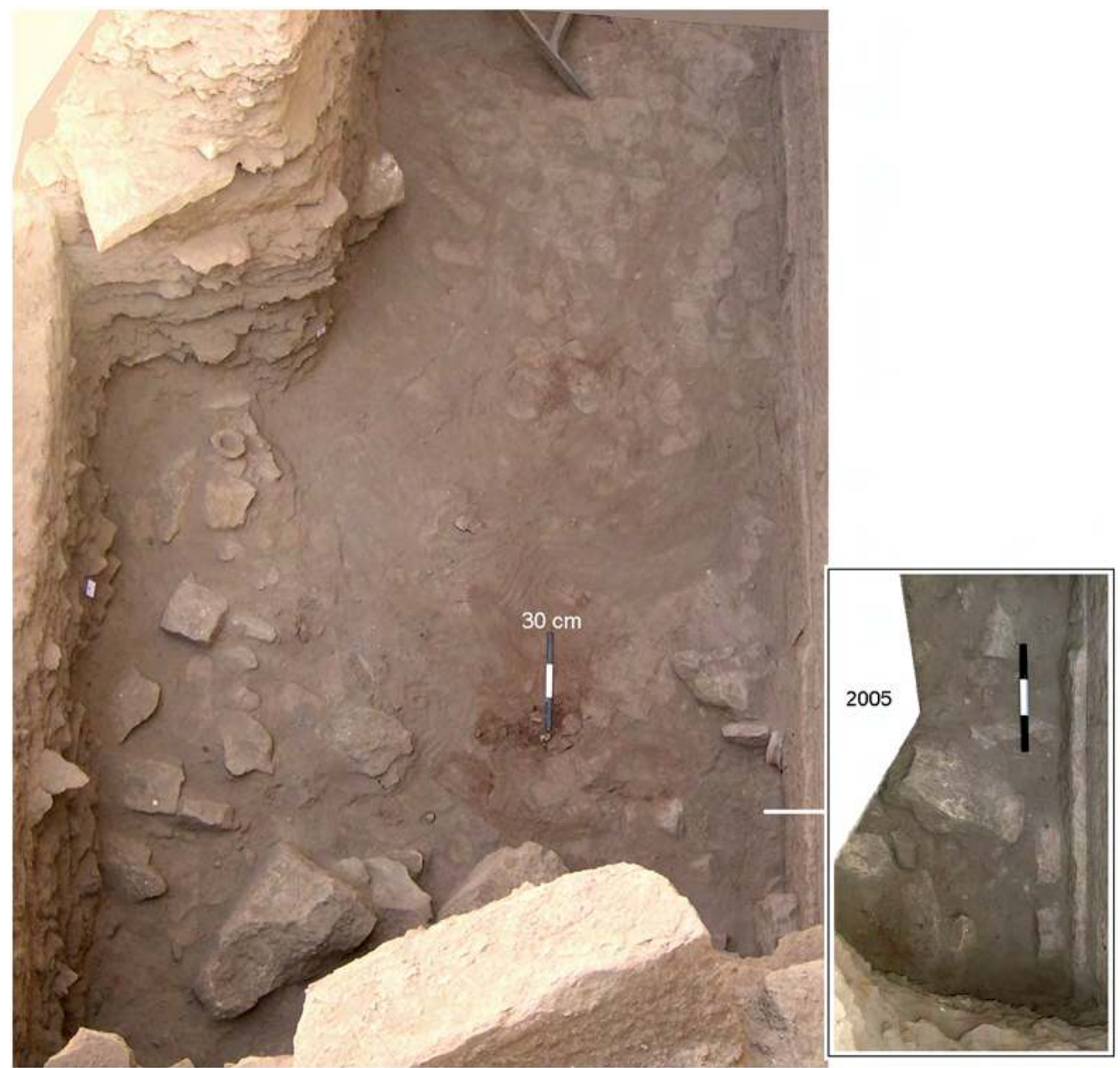

Figure 90. Sounding A, Earthwork F10-F12: overhead view of layer T77-T7C under excavation. Inset, surface S8 in A1-A11 east as reached in 2005. (P. Morlupi 2005, 2006 () MAIRY, optimized by F.G. Fedele 2019)

bivalve that very likely represents food residue, not an ornament (fragment no. 184.3, Anadara cf ehrenbergi). ${ }^{300}$ Additional finds include pottery debris and a quantity of wall-plaster fragments, again probably connected with F8. The partly decomposed wood element no. 184.1 (subunit LW, middle T75) was mentioned in the main text above; many more fragments were present.

From layer T75-T7B a complete, well preserved dromedary coprolite was retrieved (no. 184.2; see Chapter 19, section 2.1, Fig. 10, this volume). This layer also produced a large amount of bone refuse from meals, 123 fragments in total, associated with 'shed' F8 (some items were plotted in plan during the excavation). Besides zooarchaeology, examined in Chapter 19 (section 2), this bone material is interesting for taphonomy. It is heavily encrusted with grey

300 Both seashell finds are described and discussed in detail in Chapter 21, section 2.3, this volume. calcitic veils characterized by tubercles and pisoliths, which frequently also include clusters and carpets of geodes (aggregates of calcite crystals up to $0.5 \mathrm{~cm}$ in length). Like elsewhere in the upper Minaean layers, such incrustations and concretions suggest a copious circulation of calcium carbonate in the deposits, presumably due to the dissolution and leaching of the limestone blocks of the Minaean wall (see sections 2.3 and 10.4 above).

\subsection{The Later Minaean from Sounding A: a summary and some conclusive remarks}

We have seen that the Later Minaean layers at bastion T7 show characteristics dependent on a unifying theme: trade-related activity. By the time of Stratum H, the activities commonly taking place outside the wall and on the upper talus were particularly concerned with the handling of trade jars. As everywhere in Yemen, jars were typically sealed with chipped stone 


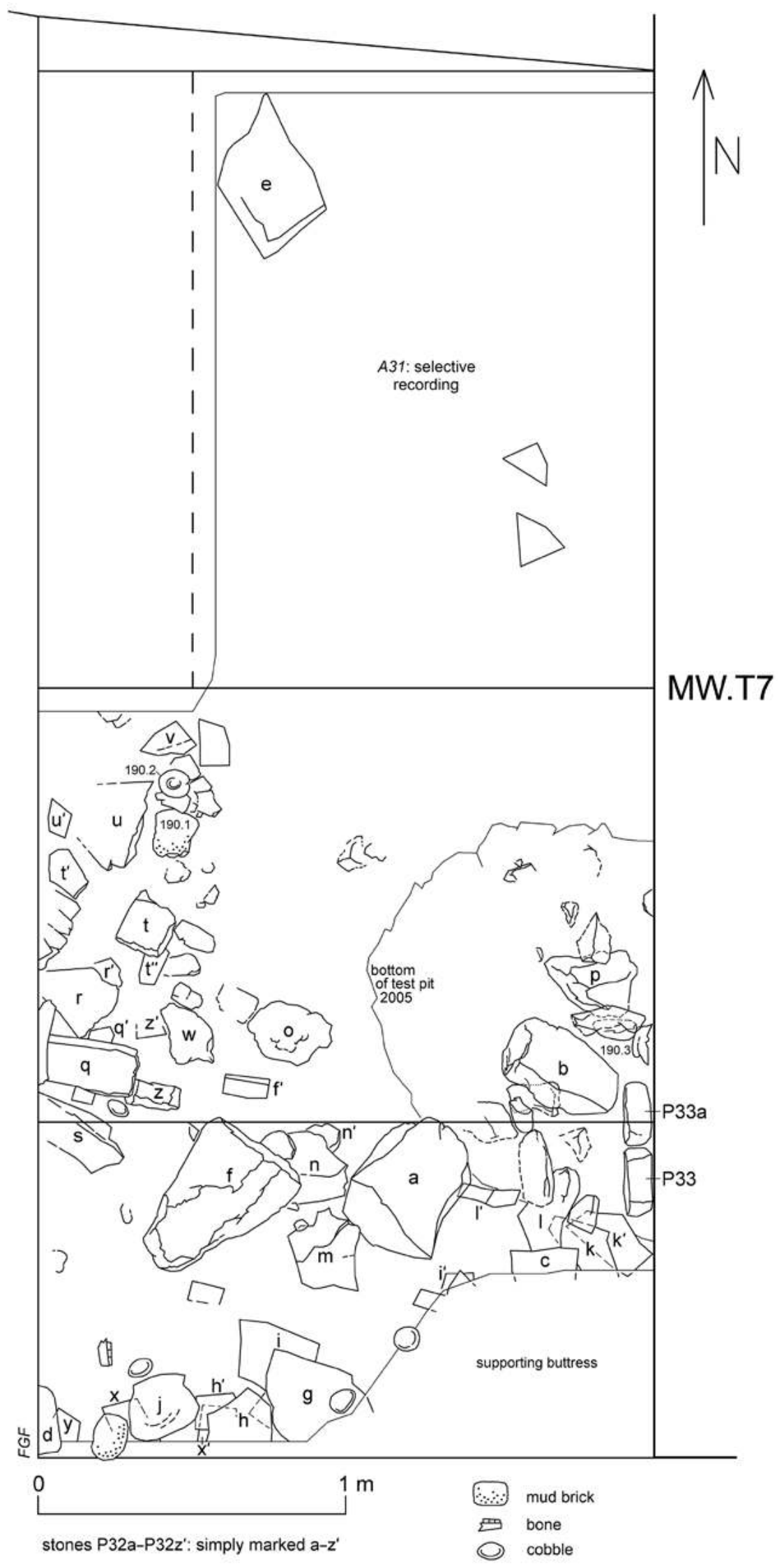

Figure 91. Sounding A, Earthwork F10-F12: surface S8 and layer T77-T7C, composite plan. (F.G. Fedele 2019) 


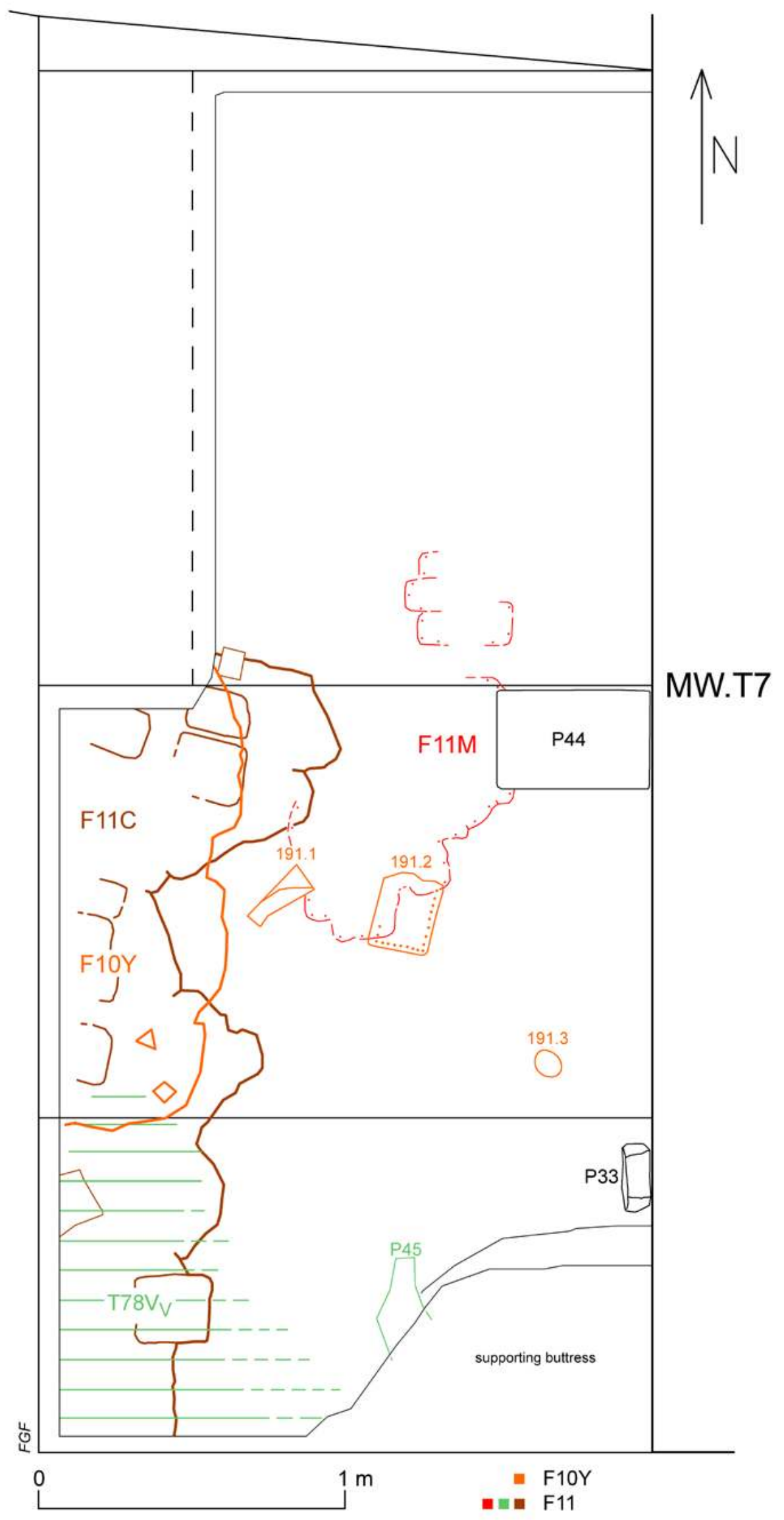

Figure 92. Sounding A, Earthwork F10-F12: features F10Y and F11, composite plan. (F.G. Fedele 2020) 


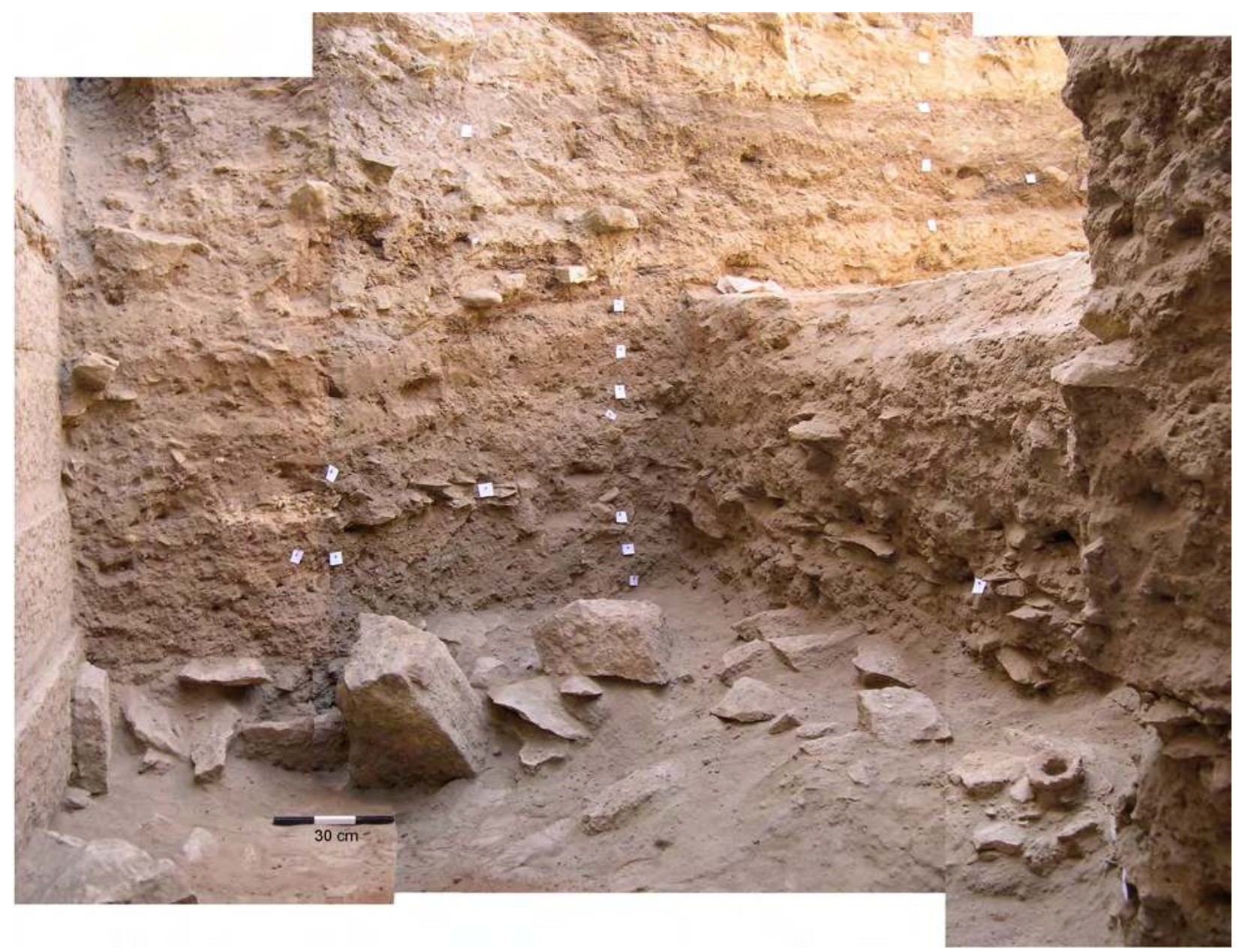

Figure 93. Sounding A, Earthwork F10-F12: layer T77-T7C under excavation in quadrangles A1-A11, with surface S8 still just exposed in A11 west. The south and west sections of sounding are also extensively shown. (P. Morlupi 2006 ( MAIRY, assembled and optimized by F.G. Fedele 2019)

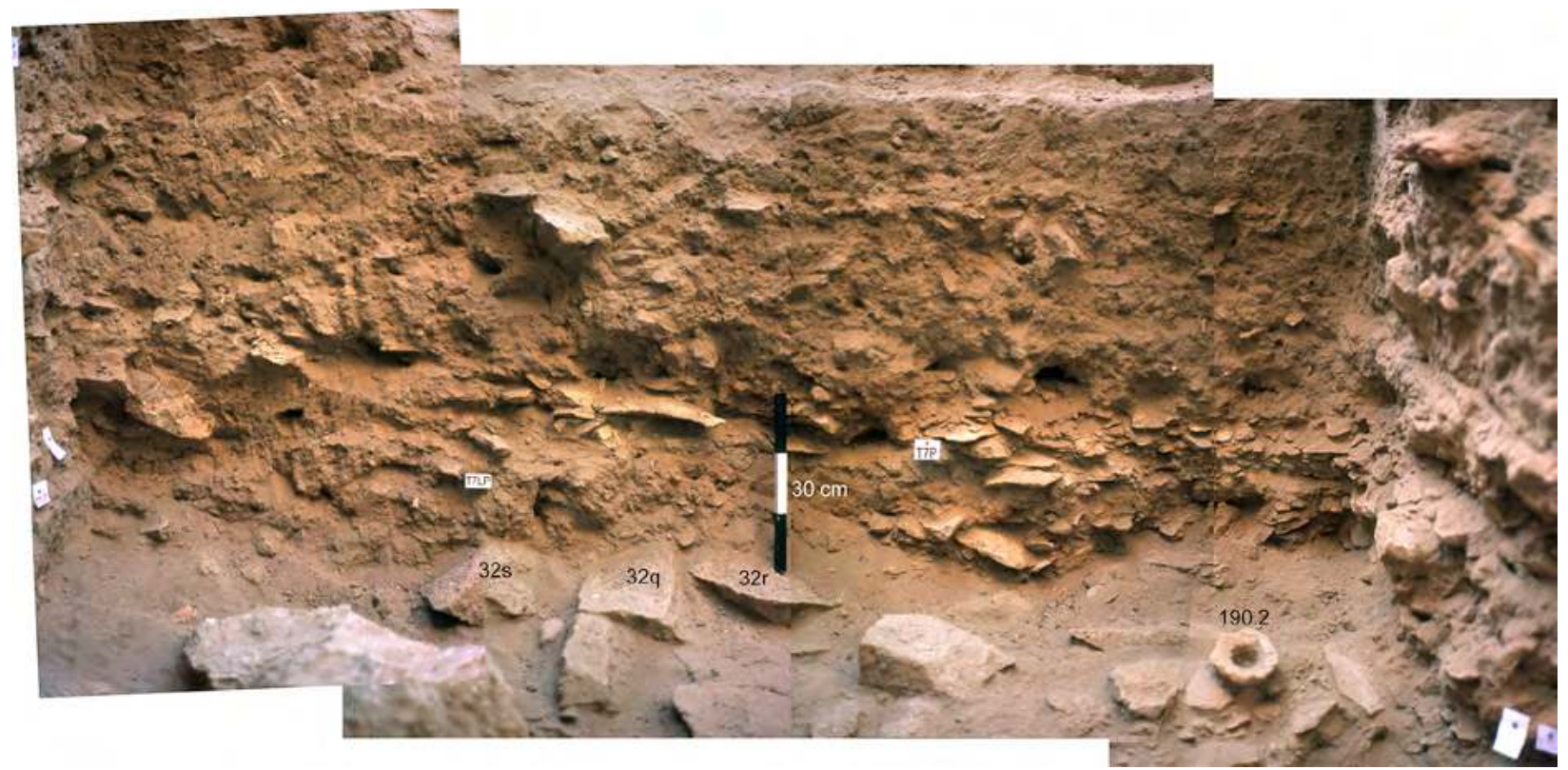

Figure 94. Sounding A, Earthwork F10-F12: top of F10 (surface S8) in quadrangles A1-A11, facing west. The west section in the photograph records the Minaean 2-3 sequence, S8 to suite T76. (F.G. Fedele 2019, from photographs

by P. Morlupi 2006 (C MAIRY) 

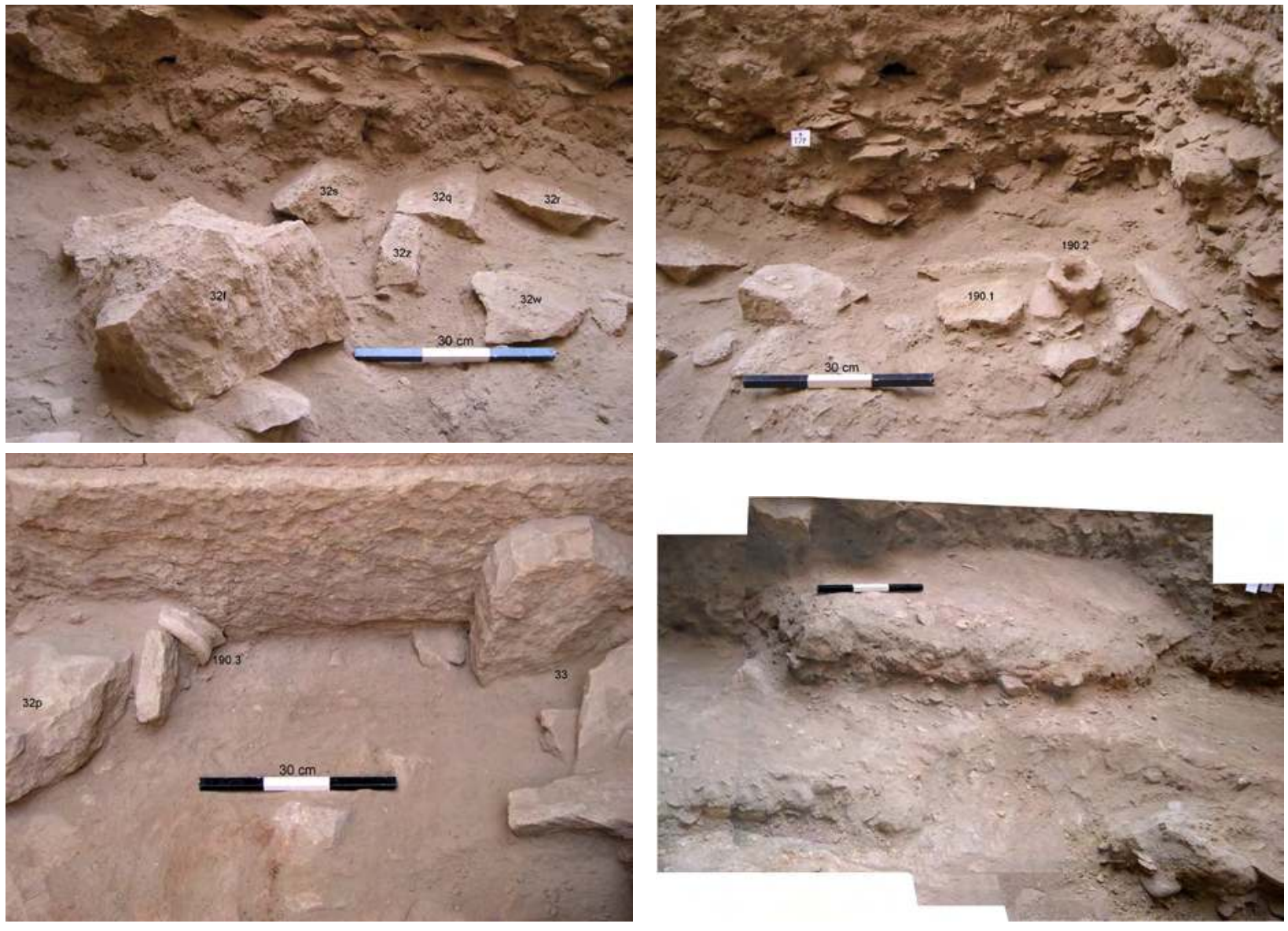

Figure 95. Sounding A, Earthwork F10-F12 under excavation, details. Above: blocks T7C and objects 190.1-2 in A1-A11 west. Below left: stone slab P33 and Minaean potsherd 190.3 in A1-A11 east. Below right: F10Y. Scale $30 \mathrm{~cm}$. (P. Morlupi 2006 @ MAIRY, adapted and optimized by F.G. Fedele 2019)

discs and plaster. Alluvial limestone cobbles for making jar stoppers, both worked and unused, and fragments of stamped sealing plaster bearing 'Minaean' personal names were found. These two types of activity manufacturing lithic stoppers and opening jars, with the attendant breaking of stamped sealings - are well documented during Stratum $\mathrm{H}$.

Subsequent Stratum F - fairly continuous with Stratum $\mathrm{H}$ and equated with the last phase of the Minaean period - even produced the remnants of a wall-flanking shed which might have functioned as a trade-related workshop or warehouse. It was constructed of stone and mud bricks and had a chalky floor and wooden components. People both worked and lived in it and discarded cooking refuse. An associated band of damage along the wall's base is a likely indication of ground stability and sustained wear, hence human activity in a general sense. With Stratum F, chronologically, we have reached the turn of our era. ${ }^{301}$

301 Fedele 2011a, 114-115.

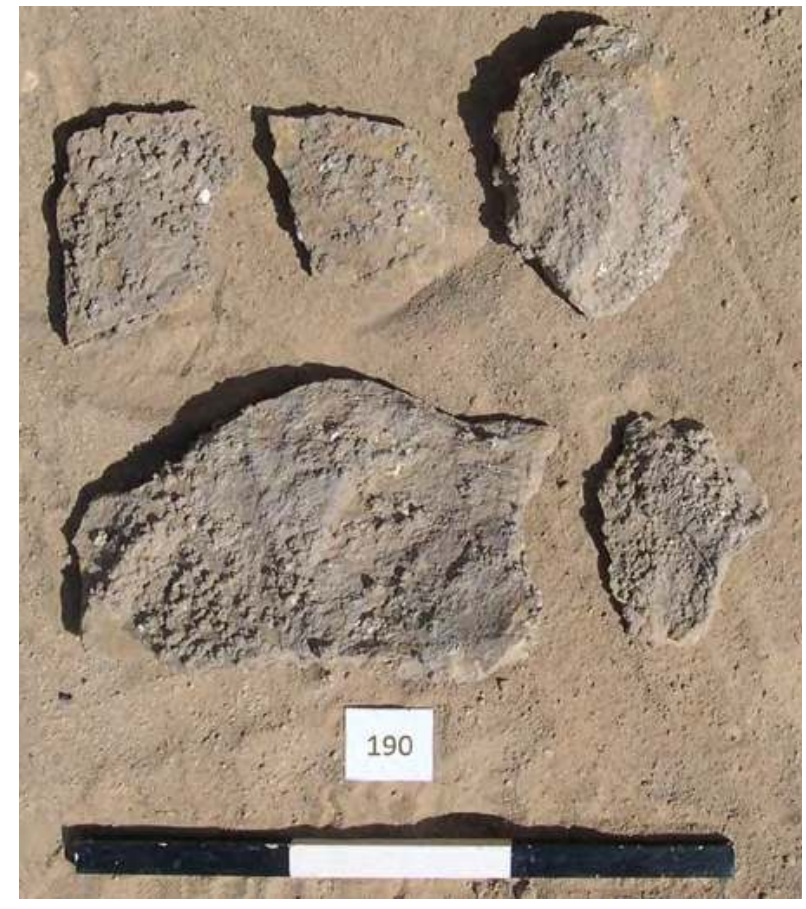

Figure 96. Sounding A, layer T77-T7C: stones with pisolitic calcium carbonate crusts. Scale $30 \mathrm{~cm}$. (P. Morlupi 2006 (c) MAIRY, optimized by F.G. Fedele 2020) 


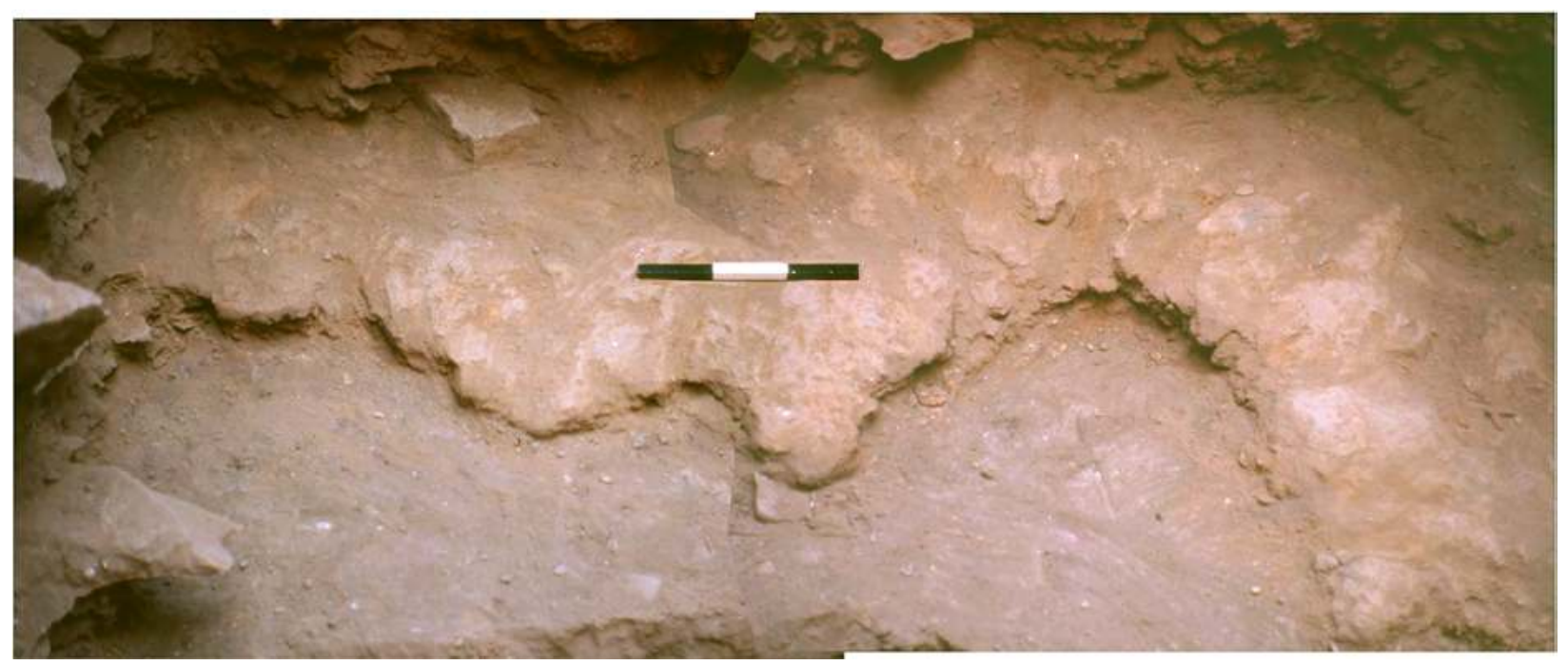

Figure 97. Sounding A, Earthwork F10-F12: F11C. Scale 30 cm. (F.G. Fedele 2006 and 2019)

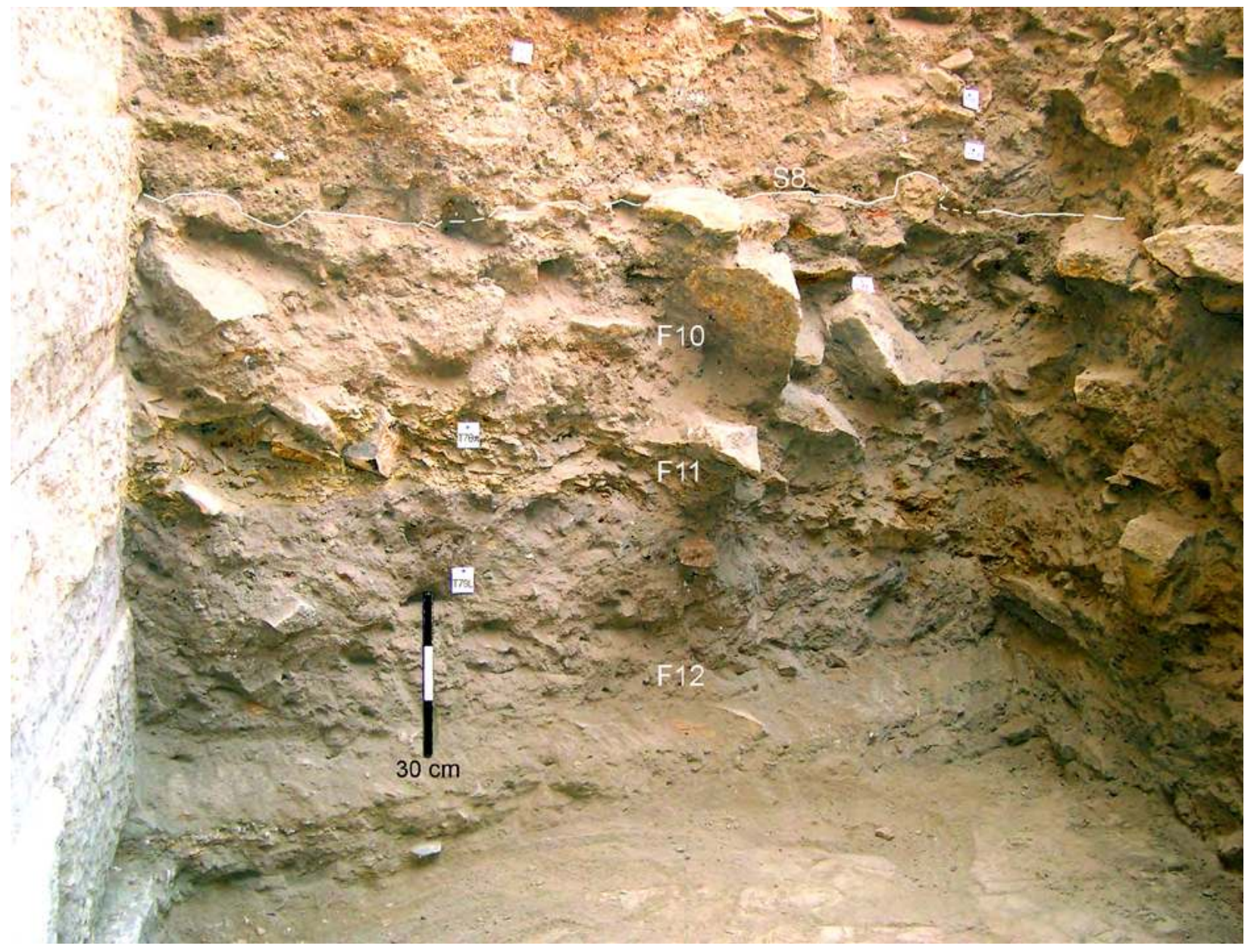

Figure 98. Sounding A, Earthwork F10-F12, Reference section. Unit T79J of component F12 under excavation. (P. Morlupi 2006 (c) MAIRY, optimized by F.G. Fedele 2020) 


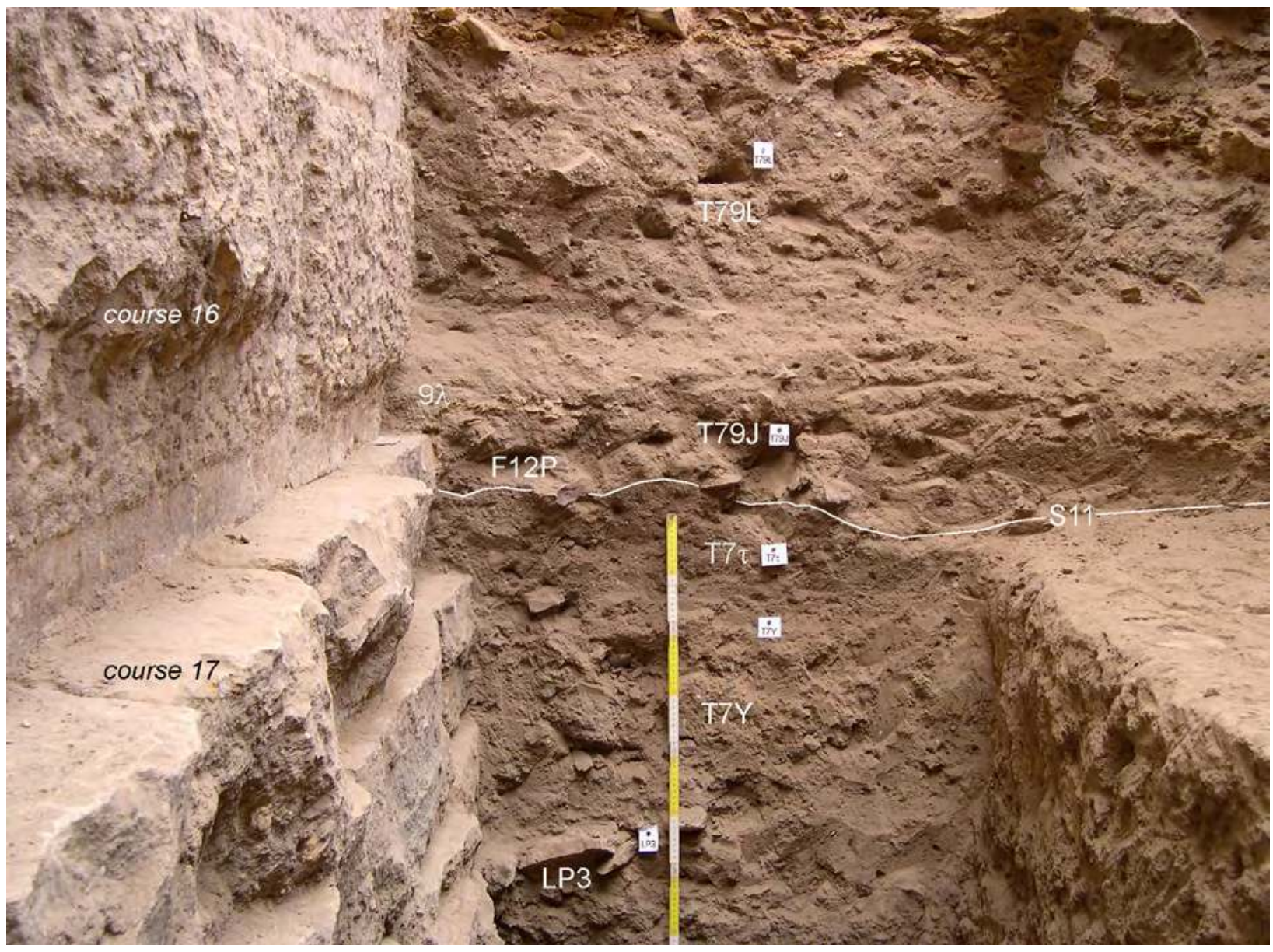

Figure 99. Earthwork F10-F12, Reference section: F12 and units below (T7 $\tau$, T7Y, LP3); Minaean wall's courses 16-20 on left. (P. Morlupi 2006 @ MAIRY, optimized by F.G. Fedele 2020)

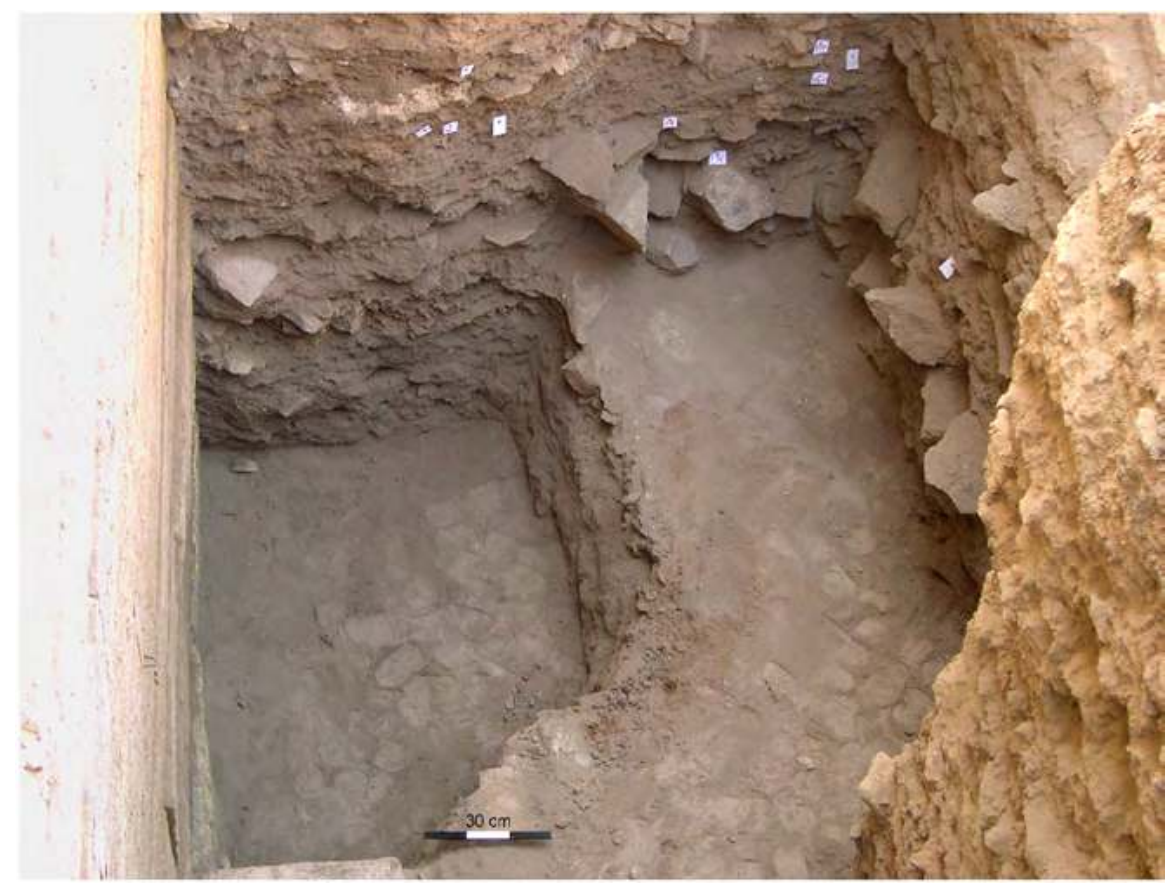

Figure 100. Sounding A, Earthwork F10-F12: test pit 191A under excavation, to explore component F12. For vertical position of cut 191A cf. Fig. 25. (P. Morlupi 2006 C MAIRY, optimized by F.G. Fedele 2020) 


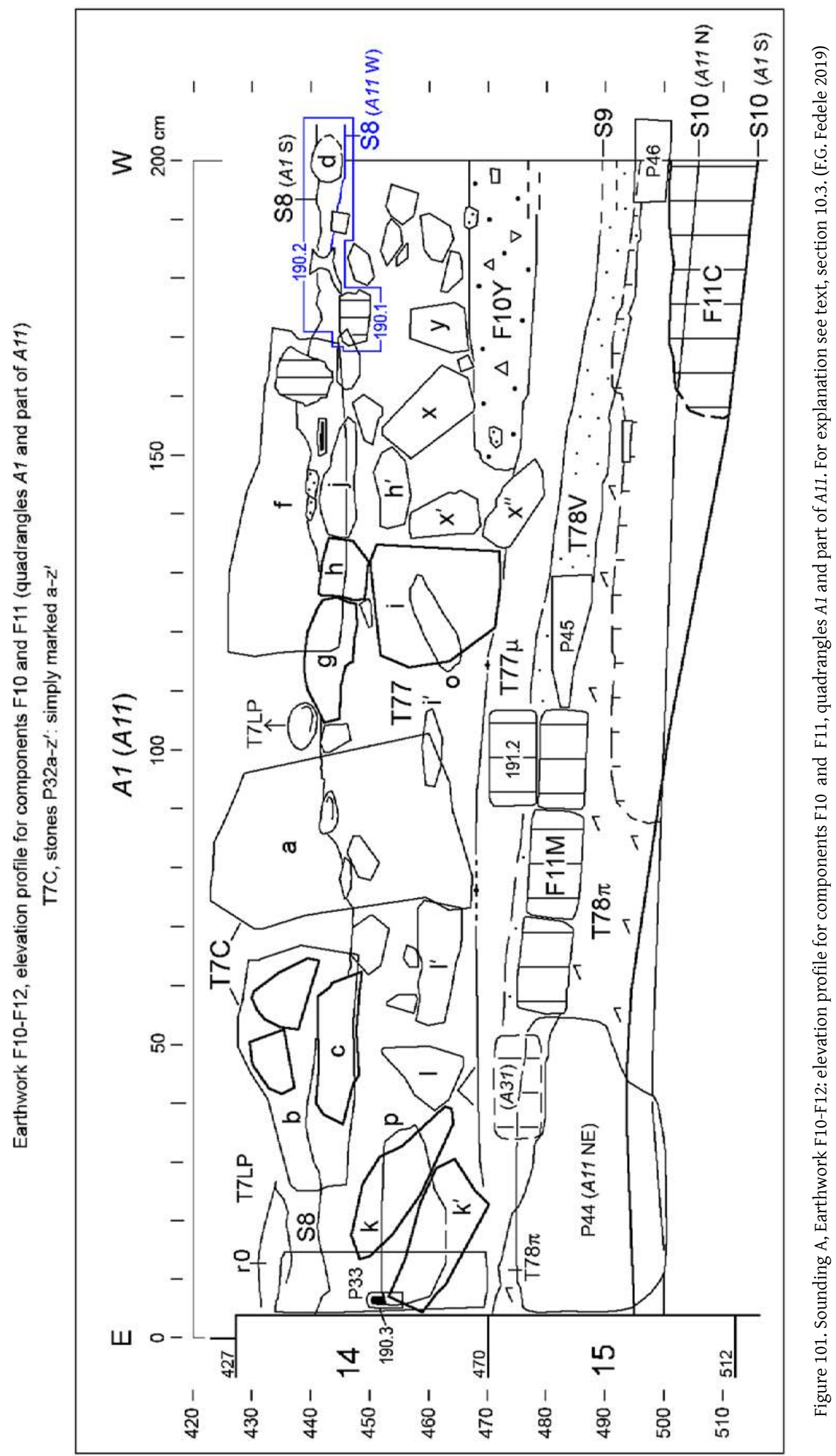



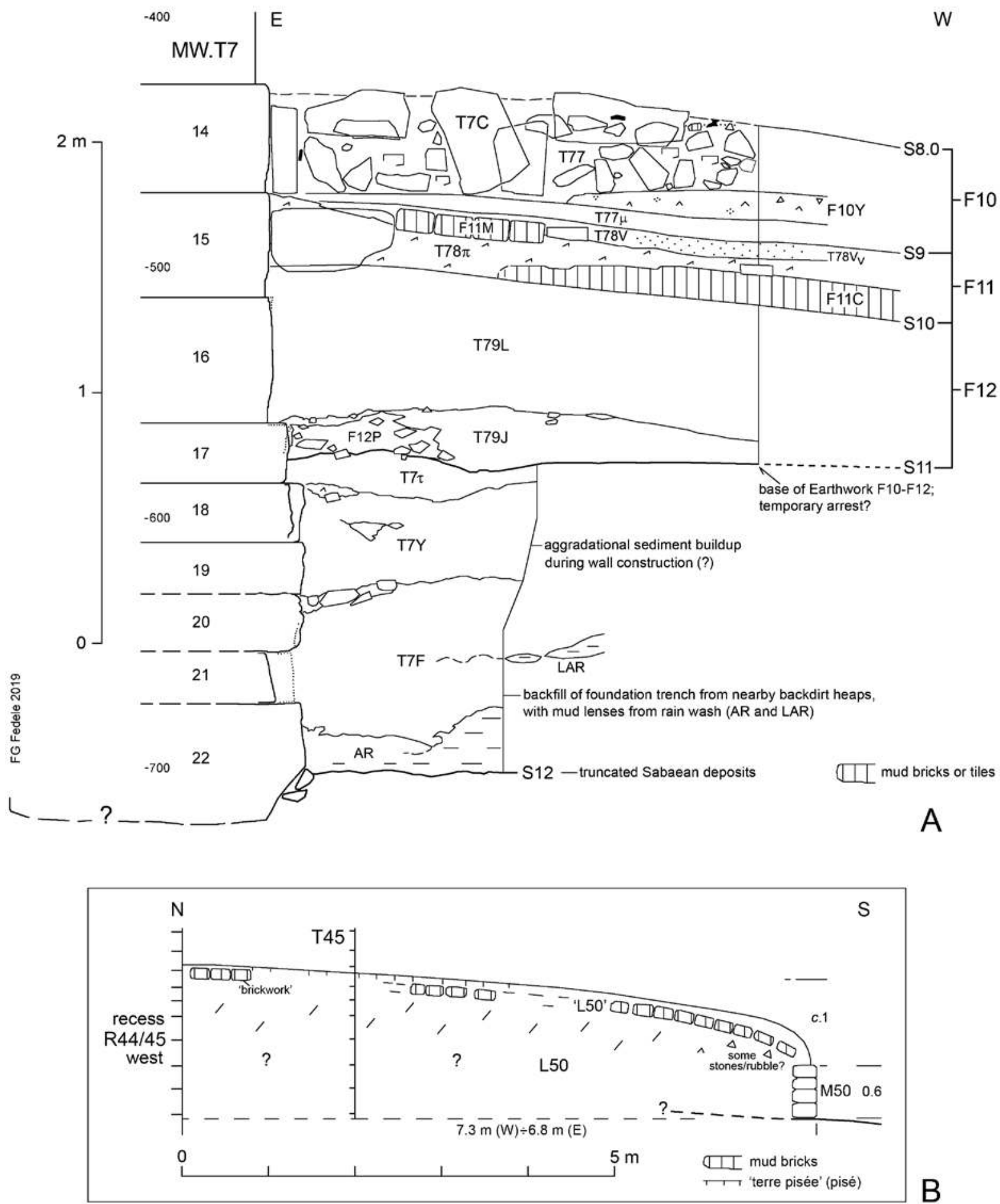

Figure 102. Minaean works at bastion T7 and a comparison between Earthwork F10-F12 and the earthwork at recess R44/45. A: simplified stratigraphy of wall's foundation backfill and interpretive profile of Earthwork F10-F12 (for explanation see text, section 10.3). B: schematic profile of earthwork L50 at R44/45. (F.G. Fedele 2019; data for R44/45 from Antonini, Chapter 8 in Volume 1, and A. de Maigret's notebooks for 2003-2005) 
The above does not mean that in the area of Sounding A human activity was continuous, however. Episodes, moments, or phases of human presence alternated with intervals of undisturbed environmental sedimentation, to some extent controlled or affected by the existence of the Minaean wall as a barrier or as a sediment trap. Nor can one imply that the sedimentary buildup itself was without interruptions and temporal gaps. A look at pottery and the ceramic sequence can be illuminating.

It seems significant that new pottery types make their appearance with Stratum $\mathrm{H}$, that is, with the transition to a later part of the Minaean period as independently derived from lithostratigraphy: surface S7 is correlated with a minor ceramic shift. According to Buffa (Chapter 25 , section 3.2 , this volume), 'it is interesting to note that this transition marks a new phase in the pottery sequence as well', a fact not only suggested by typology but also by the 'different pastes' now employed in manufacture. Among the new types is an example of classical 'Bayhān' Wavy Rim bowl. ${ }^{302}$

The possible hiatus hidden behind surface S7 (see section 11.2 above), and its apparent corroboration from the pottery study, raises the important issue of temporal gaps in the sequence. To warn that the temporal-stratigraphic integrity of the extramural sequence from Sounding A cannot be taken for granted merely reflects a general phenomenon. Strict continuity of sedimentation tends to be rare, and even in the best preserved deposits and on the ostensibly best sections it is probably unrecognizable. ${ }^{303}$ Surface $\mathrm{S} 7$ is a case in point because, if there are lithological breaks, there can be gaps.

After all, a simple chronological consideration is sufficient to suggest it: if five or six centuries are represented in Strata J to F (c. mid-6th century BCE to early or middle 1st century CE; Table 4), there ought to be temporal gaps in the sediments. A chronology based on the assumption of complete continuity such as suggested in Table 4 is almost certainly misleading. Its only justification is that it represents an explicit approximation, together with the fact that the hiatuses cannot be quantified on available evidence. The origin itself of the Minaean deposits at bastion T7 from a presumable mixture of specialized activities and undefinable local discard - not from regular habitation - is conducive to gaps in deposition. This preliminary

\footnotetext{
302 A preliminary statement of this conclusion is in Fedele 2010, 137: 'When arranged in their stratigraphic order the pottery types from the Minaean sequence in Sounding A fall into two ceramic phases that succeed one another around this point' (i.e., surface S7). On 'Bayhān' Wavy Rim bowls as an international type - a ceramic horizon marker - see Chapter 23, section 3.3, this volume.

303 See for instance Schoch 1989, 76 (partly quoting N.D. Newell).
}

discussion underscores the need for further data on extramural litho- and chronostratigraphy. ${ }^{304}$

Two further points.

The marked acclivity of the present-day talus, particularly near the curtain wall, is an entirely recent morphology. Along the wall, this condition directly resulted from recent and present abandonment and decay, and it is still being produced by these processes. One only needs to glance at the complete profile in Fig. 27 to realize that such a degree of acclivity did not exist in pre-Islamic times. During the Minaean period, an extended belt along the wall seems to have been kept more or less horizontal, level and usable. Lower down on the talus, near-horizontality gave way to undulating surfaces where - occasionally - animals could move or rest. As soon as human activity stopped at the end of the Minaean florescence, small dune-like deposits began to form, parallel but slightly detached from the wall (Stratum E, see next section). These may have persisted until human activity was resumed (Islamic 1).

A second point concerns the cliché of Islamic 'dumps' from the walls of Barāqish, intuitively applied as an even more diehard assumption to Minaean Yathill. ${ }^{305}$ To adapt a passage from Dan Potts, the image of presentday Barāqish, with its curtain wall dotted to the brim with ruins of more or less recent Islamic houses, has distorted some scholars' views of the more distant past. ${ }^{306}$ To picture Minaean Yathill according to such an image is anachronistic, because at the time the curtain wall had to be kept free of obstructions and negotiable so that it could fulfil its functions of delimitation and surveillance, ${ }^{307}$ and the Minaean houses were located far below the ridge of the wall. This can be seen even in the temple area, where Temple A and two or three houses in front of it reached within short distance of the interior side of the wall. ${ }^{308}$ The Minaeans and those who occupied Yathill until the 1st or 2nd century CE never dumped a crumb from the walls.

\section{Stratum E in Sounding A: Second Intermediate}

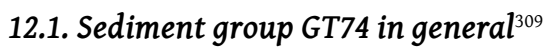

Clearly evidenced by Sounding A, sediment group GT74 provides the lithostratigraphic basis for defining Strata $\mathrm{E}$ and $\mathrm{C}$, which in cultural terms separate the latest

\footnotetext{
304 Cf. Fedele 2010, 137.

305 See a preliminary statement of this objection in section 2.3, footnote 43 .

306 Cf. Potts 1998, 200.

307 Cf. A. de Maigret's 1986 sketch shown as Fig. 22, Chapter 1 in Volume 1.

308 Cf. de Maigret 1991a; 1993; 2004a; 2010a, figs 66-67.

309 This section completely supersedes Fedele 2010, 138-139.
} 
fully 'Minaean' record from the completion of the Earlier Islamic phase. Stratum D from the lower talus and the plain (quadrangles E5-E11 and Sounding F) can be equated with both Strata and will be examined in section 16.3 below.

As a whole, group GT74 embodies a rich and complicated history: the fading of Minaean rule and presence; the ensuing, millennium-long occupational hiatus; and the following period of Islamic reoccupation of Barāqish, as the ancient town was now called - a reoccupation accompanied by selective reconstruction. What will particularly interest us here is the reconstruction of the town curtain wall, followed in turn by one or more of the military incidents recorded for the 13 th century. ${ }^{310}$ This general correlation between extramural sedimentary history and historical occurrences cannot be doubted, although the details may be extremely difficult to come by.

As to definition, Stratum E corresponds in Sounding A to the series of sediments above surface S6 up to the top of sediment suite T74L (Fig. 17). In turn, Stratum $\mathrm{C}$ is defined by the onset of the Islamic occupation, which implies that Islamic diagnostic material makes its earliest appearance. Here more than anywhere else in this chapter it is important to remember that Strata are ethnostratigraphic subdivisions, that is, culturalstratigraphic subdivisions based on lithology as well as cultural-diagnostic content. ${ }^{311}$ The detailed, total stratigraphic profile in Fig. 107 provides a reference for the description of group GT74. The profile is comprehensive, as it shows the south, west, and north sections of Sounding A, the fourth side being the Minaean wall (cf. section 9).

In reconfiguring group GT74, a particularly interesting but problematic issue was 'collapse T7A', a wall-failure event that affected bastion T7. It will be exhaustively examined in section 12.3 below. Another particular issue was represented by the problems associated with the T74L/T74M interface. Full analysis of the records has now shown that in Sounding A, in lithostratigraphic terms, this boundary is an unconformity involving a lacuna. Adopting a conventional, shorthand designation the latter will be called the ' $\mathrm{T} 74 \mathrm{~L} / \mathrm{M}$ lacuna'. The lacuna will be examined in detail below (section 12.4, 'Suite T74M and F6'), while its cultural-stratigraphic and historical contexts will be considered in Chapter 18, this volume (section 3.4).

\footnotetext{
310 See sections 12.4 and 13.1 below, and Chapter 18 , section 3.5 , this volume.

311 See section 3.3 above, and cf. Chapter 18, section 2.2, this volume.
}

\subsection{Suite T74L: Stratum E (Second Intermediate) ${ }^{312}$}

Between the Minaean and Islamic periods the town called Yathill experienced its longest interruption as active settlement, according to both material remains and literary sources: a span of about a millennium emblematically marked by the loss itself of its ancient name. Archaeology immediately confirmed a gap of this order, both in the temple area ${ }^{313}$ and in extramural Area C. In this latter, the clearest sedimentary reflection of this long interval is suite T74L from Sounding A, accompanied by some particular units which will deserve detailed description below (notably T7A). At first glance, these sediments follow surface S6, which seals the last diagnostic Minaean level and shows reworked Minaean debris (cf. section 11.3 above). A lack of artefacts in primary deposition is part of the evidence suggesting the abandonment of the site; a period of reduced, non-cultural sedimentation ensued. ${ }^{314}$ That makes for a somewhat inevident interval, although significant on a sheer chronological basis. This is Stratum E.

Like Stratum F, also Stratum E was established from sediment layers only observed at the Minaean wall and towards the top of the tell. In Sector E and Sounding $\mathrm{F}$, by comparison, the whole interval until the Islamic reoccupation could be documented by a certain thickness of sediments, although with intermittent stops and an equal void of artefacts (Stratum D pro parte, to be examined below). Stratum E in Sectors B and $\mathrm{C}$ will be treated in section 16.1.

In Sounding A, Stratum E is lithostratigraphically defined by suite T74L, units T7A and T7r, and possibly unit T7t (Figs 17, 107). Suite T74L is made up of units T7Ji (fines), T7JP (stony fines), T7V (plant detritus), T7J and T7J' (gravelly fines), and T7N (gravelly-stony fines), some of them with subunits (Tables 1 and 4). Unit T7A, a large heap of collapse rubble from the Minaean bastion, is extraordinary. These sediments compose a complicated mosaic. Here is a detailed description.

Suite T74L, and unit T7J particularly, with its dunelike morphology and numerous facies, ${ }^{315}$ accord well with the interpretation that they represent large part of the non-occupation period of Yathill/Barāqish. A period during which there was sedimentation as well

\footnotetext{
312 Stratum E was called 'Post-Minaean Interval' in Fedele 2010 (p. 138).

313 E.g., de Maigret 1991a, 1993, 2004a; de Maigret and Robin 1993 (with analysis of epigraphic and literary sources by C.J. Robin on p. 490-493).

314 The abandonment of Yathill, and of sites and areas in pre- or proto-Islamic times in Yemen more generally, is examined in Chapter 18 , section 3.4 , this volume.

315 T7J is much more complex lithologically than most units in group GT74, at least in terms of facies variation.
} 
as erosion: contrary to a previous simplification, ${ }^{316}$ this interval neither was a sedimentary hiatus nor an entirely uneventful period. In fact, at least for some centuries in the earlier part of this timespan Area C was occasionally visited (see section 16.1 for evidence from Sectors B and C). Part of the outer wall of bastion T7 broke and fell during this interval (T7A; section 12.3 below).

The most distinctive characteristic of unit T7J, in addition to its overall shape and richness in internal variation (as just mentioned), is to be gravelly, but with a 'gravelly-pocket' structure. Not true gravel, in fact, but fine rubble and angular grains, whose origin is problematic: from century-long aeolian winnowing of rainwash deposits? Colour is dark beige to hazel, albeit with shades of yellow, instead of grey, this latter being distinctive of $\mathrm{T} 7 \mathrm{H}$ above (earlier Stratum C). In the wallside zone, i.e. quadrangles $A 1-A 11$ and $A 31$, the crucial problem in identifying and defining T7J is to distinguish the primary sediment from the subsequently modified sediment: modifications caused by percolations and perhaps other inputs into the interstices within rubble T7A, from the west and probably the south. Interstitial inputs from the south would have contributed to a wallside facies identified in quadrangles A11-A31, called $\mathrm{T}_{\mathrm{E}}$, but the issue cannot be resolved on available evidence. $^{317}$

The upper boundary of T7J, and of suite T74L as a whole, is exceptionally wavy: it is in fact the only one of its kind observed in Sounding A. Was it scooped by erosion, or possibly by deflation? And there is a complication: at the foot of the Minaean wall particular facies can once again be observed (cf. Strata I-H). The units of suite T74L here, as well as unit T7JK of suite T74M later on, display markedly blurred lithological contacts.

T7Ji, T7J, and T7JP can be conceived of as three 'positional' units within suite T74L. In rectangle A1-A12 they are arranged from west to east in this order. T7Ji and T7J are vertically separated by the interposition of plant-detritus unit T7V (see below). T7Ji is the lower, essentially finer unit, and T7J the upper and partly coarser one. The third 'positional' unit, T7JP ('P' from Italian pietre, stones), is a sediment similar to T7J but marginally richer in stones or rubble, restricted to a belt along the wall. It seems to be earlier than T7J and has something 'archaic' about it; but apart from that, its stratigraphic relationships with both T7J and T7Ji could not be determined precisely. ${ }^{318}$ Sand-silts T7Ji and stony

\footnotetext{
316 Fedele 2010, 138; 2011a, 115-116.

317 See related discussion in section 12.4 below (unit T7JK, part of suite $\mathrm{T} 74 \mathrm{M}$ ). Also subunit/facies $\mathrm{T}_{\mathrm{H}}$ will be treated in section 12.4 together with unit T7JK.

318 T7JP is to some extent a reinterpretation of 'T74n' (Fedele 2010), now abolished.
}

fines T7JP will again be mentioned in connection with the 'Yathill-Barāqish Interval', below.

T7J' is in all probability a 'disjoint' partition of T7J, facies T7JY (see Reference section), identified in quadrangle A12; labelling with a prime (') is intended to suggest this interpretation. T7J' and T7J could well join and form a continuous unit in the middle of rectangle A1-A12. The stratigraphic relationship observed on the west section of this rectangle (Fig. 107) shows that T7J' can be the bottom level of T7J and, if so, represent a vertical subunit. T7Jy is a 'pebbly' facies of unit T7J (cf. footnote 321 below).

T7V is a distinct plant-detritus unit (part-'plantorganic', part-'manure') that inserts itself between T7Ji and T7J. Chronologically, it is the last considerable such layer in the extramural sequence, at least in proximity of the Minaean wall. The increasing thickness of T7V in the western part of rectangle A1-A12 suggests that Sounding A only captured its very margin, and the unit extends widely westwards over the talus: as mentioned in section 4.2 above, a connection with BV1 in Sector B is possible.

Last plant-organic/manure levels. T7V is the last genuine plant-organic unit of a certain consistency, but not the absolute last. It may be convenient to summarize here the sequence of the most recent plant-organic and/or manure units of Area C, already outlined in section 4.2 above (see Fig. 26). Independently of their possible or probable connection, T7V on the margin of Sounding A and BV1 in Sector B do suggest the occurrence of extensive plant-organic/manure levels over the upper talus during the earlier part of the Second Intermediate. BV1 was intercepted by the test pit as a thin, regular, 'blanketing' plant-organic layer. After an interval, it was followed in Sector B by an identical layer in terms of distribution and size, but composed of proper manure, BVo (also Stratum E; see section 16.1). Sparse plant debris and at least two animal coprolites, which might be related to BV0, were found in the fill of feature F 6 in Sounding A (unit T7H). And it is this sounding to record the last plant-organic or manure occurrences after T7V: lens $\mathrm{T} 74 \lambda$, made of plant debris and gravel (later Stratum C, Islamic), and 'green mat' lenses gm2 and gm1 at the bottom of unit T73b (earlier Stratum B, Islamic 3). These latter two are very thin lenses of what looks like compacted manure; they follow each other in A11-A12 and A31-A32 at the level of masonry course 7. On T74 $\lambda$ and gm1-gm2 see sections 13.113.2 below.

T7N is an unstratified blanket of beige sandy silts, 0.3 to $0.6 \mathrm{~m}$ thick in quadrangles A11-A12 north and A31, 
characterized by a coarser fraction of sparse small blocks and occasional larger stones; the small blocks are of the same yellow calcarenite as the Minaean wall. Its top and the contact with overlying $T 74 \sigma$ (see section 13.1 below) were punctuated by frequent hammering waste from the Minaean blocks. T7N was found to contain roasted gravel, partly burnt bone debris, rare potsherds (including worn Islamic ones, probably intrusive), and other minute cultural debris. Its siltysandy matrix was occasionally hardened (cf. facies $\mathrm{T7N}_{\mathrm{E}}$, details below).

$\mathrm{T}_{\mathrm{E}}$ is a wall-side facies of $\mathrm{T} 7 \mathrm{~N}$, simultaneously constituting a partition relatable to the upper part of the unit. Its extent and correlation were identified after excavation. $T 7 \mathrm{~N}_{\mathrm{E}}$ can be characterized as gravel in a matrix of fines, and it represents one of those wallside variants which complicate matters in suite T74L, as mentioned above. Its boundary is very blurred, indeed unmappable, due to the excavation conditions as well as the constraints imposed by block accumulation T7A, which means that its relationship with the core of $\mathrm{T} 7 \mathrm{~N}$ at some distance from the wall is unclear. One cannot exclude that $\mathrm{T} 7 \mathrm{~N}_{\mathrm{E}}$ is in fact infill material from bastion T7 emplaced at the time of collapse. ${ }^{319}$ At its western end $\mathrm{T}_{\mathrm{E}} \mathrm{N}_{\mathrm{E}}$ shows a 'white patch' of localized calcium carbonate concretions. Furthermore, a light concretionary zone affecting both $\mathrm{T}_{\mathrm{N}}$ and $\mathrm{T} 7 \mathrm{~N}$ was observed about half a metre from the wall and westwards: this would suggest a long reduction or arrest of sedimentation, post- $77 \mathrm{~N}_{\mathrm{E}}$.

Also the stratigraphic relationship of T7N with T7J is indeterminate, since it could not be adequately examined in the field. On the west section of rectangle A1-A12 the contact between the two units looks transitional or interfingering; and in fact, in sedimentary terms, the two bodies resemble each other remarkably (hypothesis of continuity between T7N and T7J). ${ }^{320}$ The two north-south 'ribbon' profiles across rectangle A1-A12 (Fig. 111) unfortunately do not allow to ascertain whether T7N and T7J are interfingering. ${ }^{321}$ An alternative would be T7N overlapping T7J.

As mentioned at the end of section 11.4, above, when human activity stopped at Yathill small dune-like deposits began to form, parallel but slightly detached from the wall, this being an inclusive reference to

\footnotetext{
319 Unit or facies T74 $\sigma$ (later Stratum C) could be similar material but derived from erosion of the fill, clearly post-collapse (see section 13.1 below). The Minaean walling of Yathill, it should be remembered, consisted of building two stone faces and to infill the space between them with mudbrick and rubble: see section 10.2 above.

320 T7J and T7N were identified and recorded separately in excavation and their possible continuity (i.e. identity) could not be field-checked.

321 T7J is particularly 'pebbly' in the middle and southern parts of rectangle A1-A12: facies T7JY (cf. Reference section).
}

units T7N and T7J together. These micro-landforms essentially persisted until the return of human presence and cultural activity in the Islamic period.

Finds . Finds from Stratum $E$ (Sounding A) might include no. 07, a complete stone tile used for covering floors or walls, half-barrel in shape. Reportedly it was retrieved from among the stones of T7A, but a provenance from later interstitial sediments of suite T74M cannot be ruled out, in which case its deposition would be Earlier Stratum C (section 12.4 below). Its relationships with the Minaean wall, if any, are unknown. Nor can be determined if this tile is Minaean. A. de Maigret, in a discussion on site, expressed the opinion that the tile might derive from some post-Minaean house atop the curtain wall which had collapsed with bastion T7. See Chapter 21, section 2.4, this volume.

\section{The Yathill-Barāqish occupational interval}

Most of Stratum E, and perhaps the majority of the upper-talus deposits forming its material basis (Table 4), clearly correspond to a non-residential period in the history of Yathill; in fact, the only such period that we presently know. Surface S6 and decay band DB3 on the Minaean wall, as we have seen, together suggest a geomorphic stasis, or at least the onset of a markedly quieter period in terms of both human activity and sedimentary aggradation. At some later moment, coinciding with a point difficult to define in the sediments outside bastion T7, all cultural evidence stopped, and Yathill began to be derelict for a very long time. Scanty but informative cultural traces from the upper talus below, in Sectors B and particularly C (see section 16.1), would suggest for this point of arrested human presence in Area $\mathrm{C}$ an indicative date around $200 \mathrm{CE}^{322}$

From the name change of the place, emblematically, the occupational hiatus between c. 200 and 1200 CE will be called here the Yathill-Barāqish (Y-B) Interval. ${ }^{323}$ The adjective, occupational, underscores that it must not be mistaken for a sedimentary hiatus, that is, a mere sediment gap - a lack of sediments from nondeposition. This was noted in Table 4, note 5 . In previous reports it was not sufficiently emphasized that a period of human desertion does not at all imply a lack of sediments: an

\footnotetext{
322 This average date was principally inspired by the evidence from the town temples presented in Agostini 2011 and 2015, and discussed in greater detail in this book (Chapters 3-4 in Volume 1). See also the text-based episodes recalled in de Maigret and Robin 1993, 490-491 (C. Robin).

323 Between 2009 and 2019 other expressions to refer to this hiatus have been contemplated, for instance 'anthropic (cultural) stasis', 'non-cultural period', and 'non-residential phase', but eventually they did not seem as effective as Y-B Interval, nor as neutral. However, a non-cultural period - a period of human absence - remains an important concept on a theoretical level, susceptible of considerable elaboration.
} 
occupational hiatus must not be equated automatically with a sedimentary hiatus. ${ }^{324}$ In fact, such an equation would be extraordinary at Barāqish, particularly in Area $C$, where the extramural environment should have remained as active as usual.

Outside bastion T7, as elsewhere in Area C, during the Y-B Interval sediments indeed continued to accumulate or be shifted, merely unaffected by human agency. The sheer existence of the sediments constituting suite T74L is proof of that. During human absence sedimentation continued, as presumably did erosion. Obviously, in places, the sedimentation-erosion balance may have momentarily resulted in depositional stasis, determining a local hiatus. With its dune-like morphology and its many facies - it was observed above - unit T7J appears to be a suitable material correlate for large part of the long abandonment interval. In sedimentary terms, this interval probably begins with the blanket of sand-silts T7Ji and with the stabilized ('ancient'-looking) accumulation of rubble and fines T7JP near the foot of the wall.

Identifying details in the Y-B Interval is difficult, however, because the interval's signature in terms of material correlates in sediments can be negligible or inevident. Furthermore, lacking episodes of cultural burning and survival of charred organics, time control can be impossible, at least by common chronometric means. This is why we cannot precisely date the partial collapse of bastion T7, which stratigraphically took place at some point of this interval.

About the upper boundary of suite $\mathrm{T} 74 \mathrm{~L}$ - the interface T74L/T74M (an unconformity) - and the associated temporal limit of Stratum E see section 13.2 below.

\subsection{The bastion's collapse: rubble $T 7 A^{325}$}

At an indeterminate moment of the Y-B Interval, part of Minaean bastion T7 collapsed (Figs 107, 111, 114; cf. Fig. 75). 'Collapse T7A', a shorthand from the ESU name of its rubble, will be used as an abbreviated expression to indicate this event. Impressionistic, ambiguous lithostratigraphic clues would suggest that the event occurred rather late in the Y-B Interval, perhaps shortly before the Islamic reoccupation. T7A identifies the resulting collapse rubble, a sediment unit, whose stones were collectively named P20. ${ }^{326}$ It was not possible precisely to separate primary rubble from subsequently reduced and/or dislocated stones (see discussion of structure F6 in section 13.2, below).

\footnotetext{
324 Cf. footnote 316 , above in this subsection.

325 This section completely supersedes the brief and discordant treatment in Fedele 2010, 139-140.

326 P20a-z, P20aa-al, and P20 $\alpha-\beta$, including $\mathrm{f}^{\prime}, \mathrm{g}^{\prime}, \mathrm{h}^{\prime}, \mathrm{m}^{\prime}, \mathrm{n}^{\prime}, \mathrm{o}^{\prime}, \mathrm{q}^{\prime}, \mathrm{q}^{\prime \prime}$, $\mathrm{q}^{\prime \prime \prime}, \mathrm{v}^{\prime}$, and $\mathrm{ag}^{\prime}$; letters $\mathrm{w}, \mathrm{y}$, and ae were not used.
}

It needs to be said at the outset that the exploitation and some shifting of the stones during the Islamic reoccupation have somewhat obfuscated several details of the collapse. A comprehensive plan of T7A is shown in Fig. 112. The reader is advised that only two of the ten large blocks found in 2005 were recorded in situ (P20 $\alpha$ and P20 $\beta$; Fig. 113), and therefore the others need to be crammed into the area shown in the figure as 'test pit 2005' (eastern half of quadrangles A1-A11).

The fall of masonry occurred during the deposition of sediment units T7N and T7J. A more precise correlation appears to be with the topmost part of these units, i.e., towards the end - or at the very end - of the sedimentation of both. The collapse might, indeed, have ended their sedimentation. In other words, it is possible that by dramatically altering the local topography such an event both contributed to stop the sedimentation of T7N and T7J along the wall, and to set in motion a new pattern of local sedimentation along bastion T7, characterized by interstitial infilling.

Painstaking reanalysis of the field records (descriptions, sketches, and sequential photographs) has shown that the emplacement of blocks T7A was integral to sediment unit T7N in the northern part of the sounding (quadrangles A11-A12 and A31-A32) and to unit T7J in quadrangles A1-A2. What integral means in this context is difficult to define. Stratigraphically, anyway, collapse rubble T7A correlates with unit T7J in the southern part of Sounding A and with unit T7N - possibly with the top of subunit $\mathrm{T} 7 \mathrm{~N}_{\mathrm{E}}$ - in its northern part. Whereas in the southern part of the sounding blocks T7A may have collapsed onto T7J (an eroded or still aggrading T7J?), in the northeastern part they collapsed onto an evident rise of the terrain $\left(\mathrm{T}_{\mathrm{N}} \mathrm{E}\right)$. In quadrangles A31-A32, in general, the blocks even appear to form a single sedimentary body with middle-upper T7N and T7N $\mathrm{E}_{\mathrm{E}}$, with the proviso, however, that $\mathrm{T} 7 \mathrm{~N}_{\mathrm{E}}$ can just be culturally disturbed middle-upper T7N material. ${ }^{327}$

The blocks right at the base of T7A are particularly interesting insofar as they offer a glimpse of microscale local topography at the time of collapse (see below). At the same time they help understand the primary structure of accumulation T7A (see Figs 115116). There are two heaps, or 'highs', rather than a fan: a major one in quadrangle $A 1$, represented by a cluster of complete masonry collapsed as a pack (pack F7), and a minor one in quadrangle A31. These two block packs or 'cores' are located about 4 metres apart at the far ends of the excavated area, in A1 south and A31 north. T7A consists of superposed and juxtaposed blocks forming up to four levels in pack F7 (see below), and it is in correspondence with F7 that the accumulation reaches

327 Cf. section 13.3 below. 
its maximum thickness, about 1.5 metres. Properly speaking, T7A is not stratified, since the blocks only piled-up and did not form layers.

Classified in the field as a feature, pack F7 is undoubtedly a part of the wall that fell en bloc. It comprises six whole parallelepiped blocks of the curtain. One of these is inscribed (P20d = Y.06.B.C/1), and, surprisingly, the genre of inscription could raise doubts about the architectural integrity of bastion T7 at the time of collapse: that is, T7 might already have been partially remade or restored at least once (see subsection 'Some observations on individual blocks', below). On the other hand, the excavation did not reveal any traces of previous deteriorations, collapses, or remakes of the wall, strongly suggesting that collapse T7A was the first damage to the curtain at bastion T7. This apparent discrepancy cannot presently be resolved.

Parallelepiped blocks P20ag, P20ag', and P20ai in the northern third of quadrangle $A 31$ probably represent a second pack of wall masonry that fell en bloc, in this case from near the northern corner of the bastion. Interestingly, the collapse group in A31 centre-north consisting of P20ad-P20ai included two blocks showing the marginally drafted, pecked ornamentation which characterizes the primary masonry of the Minaean wall. ${ }^{328}$

Modelling T7A. Figs 115 and 116 provide two analyticalinterpretive drawings of collapse rubble T7A. The plan in Fig. 115 attempts a schematic isopach map of the accumulation, an isopach being a line - on a map - drawn through points of equal thickness of a designated unit (here unit T7A). The map in the figure is non-quantitative and only intended for orientation. The second drawing (Fig. 116) shows elevation profiles of blocks and smaller stones T7A, based on recorded or inferred elevations. ${ }^{329}$ These profiles provide the best quantification of the accumulation's thickness. Through their bases, the bottom blocks of T7A identify the resting surface of the collapse rubble: this is an isochronous surface, ${ }^{330}$ once it is understood (or assumed) that the collapse was instantaneous - a single event and an instant event (see below). Therefore this surface provides a tool for stratigraphic correlation on the scale of Sounding A.

\footnotetext{
328 Unfortunately, due to an oversight, these blocks were not identified in excavation.

329 Cf. the elevation profiles drawn for block units T7C and T7B in sections 10.3 and 11.3 above, respectively. Paragraph 'A note on the drawings of Earthwork F10-F12' in section 10.3 provides information on such profiles.

330 'A time plane within a body of sediment'; e.g. AGI 1984, 264.
}

In quadrangle $A 1$, rubble T7A seems to have settled in a furrow formed by microtalus $T 7 \mathrm{~J}_{\mathrm{E}}$ at the base of the wall and $\mathrm{T} 7 \mathrm{~J}_{\mathrm{F}}$, a dune-like accumulation of fines. Further north, in A31, the rubble fell onto a similarly undulating micro-landscape consisting of $\mathrm{T} \mathrm{N}_{\mathrm{E}}$. Blocks P20z, P20u, P20ab, and P20v in A31 are clearly positioned along a talus-like profile: they fell on a 'high' formed by $\mathrm{T}^{\mathrm{N}} \mathrm{N}_{\mathrm{E}}$ against the wall and by a furrow parallel to the wall a fairly wavy ground surface, as suggested in section 12.2 above (the top of $\mathrm{T} 7 \mathrm{~N}$ ). The local topography at the time of collapse seems to have been very irregular. And in addition to being irregular originally, it was later disturbed by human activities connected with the reuse of the blocaille: not only stone quarrying and/or moving, but also possibly the rebuilding of the wall by means of scaffolding.

Concerning the collapse itself, why and how did it occur? First of all, judging from the geometry of T7A, it appears to have happened at once - to have been an instant event. Three scenarios, in effect reducible to two, can be proposed. The critical distinction to be made about the cause and context of the collapse is between endogenous failure and hostile destruction. All data considered, I would opt for the former. During the excavation I thought of demolition, but my impression after restudying the record rather points to a 'natural' breakage of the curtain wall. However, an alternative to a simple, endogenous fall can be entertained (the third scenario): had the outer wall weakened, and could the collapse have been facilitated? Easily the wall might have become dangerously swollen, as it used to happen everywhere in the curtain wall and particularly the bastions, due to pressure from their aging infill. The outer face of T7 might have become unsafe of its own and failing. Therefore it is possible, in principle, that at the beginning of the Islamic reoccupation this wall was purposely demolished where it was liable to fall, with the aim of restoration and reconstruction. The context of the collapse would remain the same: it was not aggressive destruction (military, for conquest), but the opposite - a constructive and indeed reconstructive action.

On this subject, two rather elusive sediment units seem to be instructive. Both were essentially studied on the Reference section. One is T7r, a unit of small rubble and fines surrounding some blocks of lower T7A within a metre from the wall (Fig. 109 A). It appears that the bastion's curtain fell 'together with T7r': but did T7r immediately precede the collapse, or did it instead follow it? In the former case, could T7r be interpreted as a sign of incipient rupture of the bastion's curtain? This explanation would imply the presence of rubble within the bastion's fill. Alternatively, T7r might be interstitial post-collapse rubble, in this case possibly connected with sedimentary inputs from the south 
(cf. T7JK, see section 12.4 below). This latter seems to be the preferable interpretation. Being located in the middle of accumulation T7A in toto, not at its base, it is unlikely that T7r is an autonomous unit preceding the T7A collapse. Note that rubble T7r, closely adhering to blocks T7A, ${ }^{331}$ remained relatively impervious to T7JK and the percolations of suite T74M (earlier Stratum C).

The second unit in question is T7t, which forms a wall-side talus in $\mathrm{A1}$ and is clearly later than collapse T7A, though just a little later, apparently (Fig. 109 A). It consists of dull-grey, probably organic fines, and its interpretation as fallen infill from the bastion is virtually unproblematic: it perfectly qualifies as bastion's fill material directly involved in the wall's collapse, and/or eroded away and redeposited shortly after the collapse. Its uniformity suggests that its deposition would have spread over a fairly short period of time.

The agency of the collapse is intertwined to some extent with the chronological issue. As already mentioned, the impression from sediments and lithostratigraphy is that the collapse occurred rather late in the Second Intermediate period. For example, the rubble accumulation was still predominantly exposed at the time of the Islamic reoccupation of what was now called Barāqish, and large part of its interstices were still open. But how long rubble T7A remained openwork is impossible to determine. The discussion of radiocarbon-dated samples \#183 and \#181 in Chapter 18 , section 1.2 (this volume) can provide useful elements for an understanding of the chronological issue.

In terms of lithostratigraphy, both the collapse as an event, and collapse rubble T7A as a sediment unit, are best not assigned to any suite. ${ }^{332}$ But apart from classification, their placement either is the end of suite T74L or the contact between suites T74L and T74M. From a sedimentary viewpoint and according to both geometry and depositional evidence, they predate suite T74M. Culturally and chronologically, T7A can thus be said to predate Stratum $C$ and can conventionally be ordered within Stratum E. Also units T7r and T7t, variously connected with collapse rubble T7A (see above), are best non aligned with any suite.

Understandably, the sedimentation and structure of the deposits at bastion T7 were strongly deviated from the normal because of the T7A accumulation: by its presence, much more than by the collapse and emplacement perse.Here 'normal' means aggradational,

\footnotetext{
331 T7r was only recorded in close connection with blocks P20b and P20j preserved as integral to the Reference section (beneath P20b, and probably between P20b and P20j as well as between P20j and the wall), and apparently it is a little cemented with these two blocks.

332 They are part of a sediment group, GT74, based on the definition of 'group'.
}

'horizontal' sedimentation. In an instantaneous collapse, we have seen, the blocks fall on a surface that is by definition isochronous. This surface provides the stratigraphic position and denotes the chronology of the collapse. While the surface is just an instant in the sedimentary history of a layer, the sedimentation can continue after the collapse until it ultimately envelops and bury the blocks. But initially it is more likely that the collapse per se and/or the presence of the accumulation will determine an alteration or arrest of sedimentation, so that the resting surface of the fallen blocks will remain the top boundary of the layer in question. Subsequently, due to the shape and structure of the accumulation, the sedimentation on the site will be abnormal, or so will at least be its sedimentary products. In the particular case of T7A, post-collapse sediments crept into the interstices and did so in a complicated way, made even more complicated by the morphology and internal structure (porosity, hence permeability) of the accumulation.

The subsequent manipulation and exploitation of rubble T7A will be examined in section 13.3 below, apart from a brief mention in section 13.1. A particular find ambiguously associated with rubble T7A, stone tile no. 07 , was examined in section 12.2 above.

\section{Some observations on individual blocks}

Epigraphic block P20d, bearing inscription Y.06.B.C/1. According to Agostini, both the genre of inscription (a legal text) and the small handwriting would make this block unsuitable for being exposed on a curtain wall. ${ }^{333}$ The inscription is incomplete, implying that it originally continued on a contiguous block or blocks, not found with T7A or remained unseen (see below). Moreover, the inscribed surface of the block is in poor condition. At the same time, block P20d is a certain element of bastion T7, since it was part of a section of masonry collapsed en bloc from the bastion (F7) and was also lying right at the base of T7A (Figs $114 \mathrm{C}$, 117; cf. elevation profile in Fig. 116). On all accounts, P20d was still in its structural, primary location. How can we explain, therefore, that such a text was there, and that the rest of the inscription was not found? The explanation can only be one of the following four.

1. The contiguous block or blocks were not seen. Part of the blocks adjacent to F7 - hence to P20d - were excavated expeditiously in 2005. Except blocks P20 $\alpha$ and P20 $\beta$ the portion of T7A encountered in 2005 could not be recorded; it was only noted that ten blocks were removed

333 A. Agostini, in litteris, 28 February 2019. The text is published in Chapter 24, this volume. Alessio Agostini's questions and comments about the context of the inscription, in February 2019, which helped clarify my own thinking on block P20d, are gratefully acknowledged. 
(see above). And in 2006 quite a number of large blocks of T7A, uncleaned, were evacuated unseen. In the circumstances, it was only possible to have the blocks kept in temporary storage outside the $\mathrm{T} 7 / 8$ wall recess for future inspection (which unfortunately could never be made).

2. The contiguous block or blocks were taken away during the Islamic reworking of rubble T7A: an indeterminate number of blocks were quarried on the site or reused and relocated (see above, with cross-references).

3. The contiguous block or blocks lie outside the excavation. In theory it cannot be excluded that part of F7, including other segments of the text, lie in the deposits immediately to the south of Sounding A and the near corner of the bastion. Block P20b, an element of F7 still inserted in the Reference section, and whose faces could not all be inspected, would support this possibility.

4. Bloc P20d, although placed in the wall, was not accompanied by the rest of the inscription: it was a single, reemployed fragment. If so, this would lead to the inescapable conclusion outlined above, that, at the time of collapse T7A, bastion T7 had already been partially remade or restored at least once. However, as mentioned, excavation evidence is lacking.

Block P20e. A parallelepiped element of F7 whose end face to the west was carved to form a step for joining. A similar example, not belonging to primary T7A and possibly unrelated to T7A at all, came to light in earlier Stratum B, bottom of unit T73, quadrangle A31 (incomplete parallelepiped P16b; see section 13.2 below).

\section{Earlier Stratum $C$ in Sounding A: Islamic $1^{334}$}

\subsection{The Islamic period at bastion T7: an overview}

The last settlement period of Yathill/Barāqish is Islamic and rather well known historically. ${ }^{335}$ Given its local complexity, a brief overview of this period as represented by the deposits at bastion T7 is appropriate. Three main phases can be distinguished on lithostratigraphic grounds, dependent on three distinct extramural accumulations (Islamic 1-3; Table 4). Immediately following sediment suite T74L, a first Islamic phase is indicated by pottery, as well as by substantial activity outside the partially ruined bastion and in close contact with collapse rubble T7A. The pottery, not yet studied in detail, was examined in the field with the assistance of A. de Maigret. Also in this

\footnotetext{
334 'Earlier' Stratum C in this section should probably be understood as initial Stratum C.

335 See references in section 12.2 above, footnote 313.
}

phase the pre-Islamic wall was subjected to important rebuilding.

Thick deposits were formed alongside and outside the wall, possibly - at some later point in the sequence with incipient contributions from the decay of houses or other structures erected atop the wall. The buildup produced an undulating or duneform mantle up to surface S5 (end of sediment group GT74, Stratum C), and an increasingly inclined talus afterwards (Strata $\mathrm{B}$ and A). Discontinuity S5 was taken as the separation between Strata C and B, respectively equated with an Earlier and a Later Islamic phase. Stratum D, partially overlapping with Stratum C in the lower part of Area C, will be described in section 16.3 below. A useful radiocarbon date was obtained from sample \#181, suite T74M: 1264-1310 CE with 77 per cent probability, i.e., compatible with the Earlier Islamic (see Chapter 18, section 1.2 and Table 3, this volume). In Chapter 18, section 3.5 and Table 4 (this volume), a hypothesis of Islamic correlation and chronostratigraphy based on the sequence of Sounding A is presented.

From the following pages, up to and including section 14.2 , an unsuspected history of the Islamic period at the foot of the Barāqish curtain wall will emerge. It will be shown how this period saw interesting activities at bastion T7, a far cry from sporadic and/or banal human presence or the supposed dumping of rubbish from the top of the wall. ${ }^{336}$ In the present revision of Sounding A, I will identify activity practices not previously examined in detail or sufficiently noted. At least at bastion T7 and in its immediate environs, these data reveal an unexpected frequency of Islamic activity at the foot of the town wall and in specific connection with the accumulation of collapsed wall masonry (cf. section 13.3). Alongside the wall there was stone quarrying, curtain wall reconstruction, and sheltering for people and possibly animals. At least once there was also fire. This is an entirely different picture from that of simple waste disposal and rubbish heaps. There was no dumping before the Later Islamic (units T73 $\alpha$ ? T73W? - cf. section 14.2), and perhaps no dumping ever, if the only demonstrable instance of sediment inputs from atop or over the wall in the long history of Barāqish is layer T71a-T71b, probably generated by natural decay.

\subsection{Suite T74M and $F 6$}

In Sounding $A$, the earlier part of Stratum $C$ is lithostratigraphically defined by the T74L/M lacuna (defined below) and suite T74M, this latter closely connected with feature F6. Suite T74M is made up of ashy-silty units T7H and T7JK, together with postdepositional modifications originating in $\mathrm{T} 7 \mathrm{H}$

336 Cf. sections 2.3 (footnote 43 ) and 11.4, above. 
and related to feature F6. This set of elements makes for a complicated sedimentary and lithostratigraphic picture, which could only be fully discerned during the preparation of this book in 2018-2019.

As mentioned in section 12.1 above, the T74L/T74M interface involves what we have termed the 'T74L/M lacuna'. This stratigraphic entity is best explained and defined if reference is made to Sector $B$, see sections 14.1 and 15.1-15.2 below. The starting point is that a distinct surface like S20 in Sector B is missing - or rather, it seems to be missing - in Sounding A.

In Sector B surface S20 marks the top of the pre-Islamic layers, hence the close of Stratum E defined as the block of the last pre-Islamic layers. This block is represented in Sounding A by the sediments post-surface S6 up to the top of suite T74L. According to the optimal, 'horizontal' correlation between Sector B and Sounding A, the equivalent of surface S20 in Sounding A can only be the top of suite T74L (Fig. 17). Now, this top is an unconformity, ${ }^{337}$ represented by an exceptionally rough lithostratigraphic boundary, even scooped in places, anything but linear and univocal. ${ }^{338} \mathrm{~A}$ useful illustration is given by the total profile of group GT74 (Fig. 107). A boundary of such irregular delineation is unique throughout the excavated upper talus, including Sounding A.

In fact, it is not that in Sounding A surface S20 - or an equivalent unconformity - did not exist, but, simply, that the surface was eventually disturbed and ultimately abolished. Rather than simply eroded, the equivalent surface was disordered or 'ruffled' culturally ruffled. This cultural disturbance can be attributed to a number of interrelated actions, almost inevitably centred on blocks T7A and the Minaean wall, and forming a particular and unprecedented system: (i) quarrying and re-processing of blocks on the site itself; (ii) handling of blocks for lifting or transport away; (iii) deployment of scaffolding for wall restoration; and (iv) trampling by men and presumably animals (donkeys and dromedaries) in connection with one or more of the above activities. ${ }^{339}$ It seemed obvious to relate this scenario to the beginning of the Islamic reoccupation, if it is true that the restoration of the Minaean wall was immediately undertaken by imām al-Manșūr bin Hamza and - allegedly - rapidly accomplished, in about a

\footnotetext{
337 Unconformity: a surface of erosion or nondeposition that separates beds. It is a lithostratigraphic (boundary) term.

338 See sections 12.2 and 12.3 above. In quadrangles A1-A2 the top of T74L is also blurred by a subsequent percolation, T7J $_{\mathrm{H}}$, as described below.

339 For details see section 12.2, particularly the descriptions of unit T7N and subunit $\mathrm{T}_{7} \mathrm{~N}_{\mathrm{E}}$.
}

decade around $1200 \mathrm{CE} \cdot{ }^{340}$ Additional details about this scenario will be given in the next pages (section 13.3).

This state of affairs implies that the T74L/T74M interface corresponds to a period of time and incorporates human activity, and that it should be ascribed not to Stratum E but to Stratum C, this latter being the ethnostratigraphic subdivision defined by the start of the Islamic occupation of Barāqish. A technical stratigraphic term by which such an interface can best be designated is 'lacuna', in the sense of nondeposited or suppressed lithostratigraphic record at an unconformity. ${ }^{341}$ This is the stratigraphic entity termed in shorthand the T74L/M lacuna.

Key to understanding suite $\mathrm{T} 74 \mathrm{M}$, and to a certain extent group GT74 in general, is feature F6 (Figs 107, $108,112)^{342} \mathrm{~F} 6$ is indicated by the traces of a mudbrick wall $\left(\mathrm{F} 6_{\mathrm{w}}\right)$, by the use or reuse of blocks T7A (especially the so-called 'front' of the blocaille to the west), and by the introduction of small blocks partly obtained from the reduction of T7A. In addition, an area right west of the front of T7A in quadrangles A2-A12 was hollowed out and a shallow depression exceeding the limits of Sounding A was created: $\mathrm{F} 6_{\mathrm{x}}$, identified by cutting of terrain and some stone removal. The incision of the top of unit T7J by F $6_{x}$ can be seen on the Reference section, which $\mathrm{F}_{\mathrm{x}}$ approximately intercepts perpendicularly (Figs 107, 112). West of this point there is horizontal sedimentation ( $\mathrm{T} 7 \mathrm{H}$, see below), while to the east no sedimentary boundary can be seen, but only a chromatic differentiation. ${ }^{343}$

Mudbrick wall $\mathrm{F} 6_{\mathrm{w}}$ partially protected hollow $\mathrm{F} 6_{\mathrm{x}}$ by integrating - it appears - the larger frontal blocks of T7A, including P20h, P20g, and P20a (Fig. 111). In any case there was alteration of the front of T7A down to the base of the blocks, if not a little below. Little of wall $\mathrm{F}_{\mathrm{w}}$ survived after the uselife of $\mathrm{F} 6$. Whatever plan or shape structure $\mathrm{F} 6$ had as a whole, wall $\mathrm{F} 6_{\mathrm{w}}$ seems to have been simply made by filling the interstices between the frontal blocks of T7A with mud blocks or lumps and by inserting here and there smaller clasts (for instance P20g' and P20h') and sporadic cobbles (there were some large cobbles with a rough surface between P20h and

\footnotetext{
340 For further archaeological and historical discussion see Chapter 18, section 3.5, this volume. Main data after deMaigret and Robin 1993, 491 (C. Robin).

341 E.g., AGI 1984, 275, main definition (adapted). Partly overlapping with lacuna is 'hiatus', a near-synonym, which in the present context I will prefer to define as a chronostratigraphic term: the time value of strata missing at a physical break or unconformity in a stratigraphic sequence (cf. AGI 1984, 231).

342 F6 was largely overlooked in Fedele 2010. On the contrary, the presence of this artefact emerges from the excavation data as crucial for understanding the stratigraphy connected with blocks T7A and the immediately following units.

343 A chromatic variation between a deposit of fines above (T7S) and a similar deposit below ('pebbly' T7J $\gamma$, affected by percolation T7J $\mathrm{H}_{\mathrm{H}}$ ).
} 
P20m'). Overall, apart from the incorporation of blocks $\mathrm{T} 7 \mathrm{~A}$, wall $\mathrm{F} 6_{\mathrm{w}}$ must have originally formed a continuous mud mass, light yellow-beige in colour. The laminated silty unit T7S of suite T74U (later Stratum C) possibly represents decay material from the mudbrick part of $\mathrm{F} 6$ (Fig. 109 B).

Probably all the outside blocks and lesser clasts of T7A in quadrangles A2-A12 were affected in various forms and degrees by the making of structure F6. Here the dislocation of T7A continued also later, due to the decay of F6, if by 'dislocation' we mean both the construction and the abandonment of $\mathrm{F} 6$, this latter probably implying immediate decay. The superposition of two resulting levels of stones T7A - the primary blocks and the lesser, dislocated clasts - was particularly clear in the 'inlet' between blocks P20h and P20g. While F6 was decaying, several larger and smaller blocks of T7A employed in the structure fell on and were incorporated into more recent sediments (e.g. blocks P20p and P20al; Figs 107, 110). ${ }^{344}$

What was F6 in terms of shape, size, and function? It is impossible to say. Prima facie it would represent a second instance of wall-side construction after F8, the Later Minaean 'building' associated with layer T75-T7B (see section 11.3 above); but in fact, on present evidence, labelling F6 a building would be far-fetched. ${ }^{345}$ Could F6 have been an animal pen? - see below.

Unit $\mathrm{T} 7 \mathrm{H}$ is a unique stratification of thin, vaguely horizontal fine-sand lenses of darkish to dark ashenbeige colour, brownish at times, characterized by a quantity of minute charcoal and evident ash (Figs 108, $109 \mathrm{~B})$. They contain minute cultural residue of many other kinds as well, including potsherds, mudbrick fragments, some glass, sparse vegetal debris, two dozen animal bones, and at least two animal coprolites. ${ }^{346}$ Here and there induration and concretions occur. T7H is up to $c .30 \mathrm{~cm}$ thick in quadrangle $A 2$, where it can be vertically partitioned into a medium-dark upper band with diffuse lighter, even whitish, lenses $\left(\mathrm{T} \mathrm{H}_{1}\right)$ and a darker lower band $\left(\mathrm{T}_{7} \mathrm{H}_{2}\right)$.

T7H occupies the western half of rectangle A1-A12 (quadrangles A2-A12 and a fringe of A1-A11) and is

344 In the field, a distinction between primary T7A blocks in situ (i.e., still positioned as fallen at the time of collapse T7A) and reused and/ or introduced blocks and smaller stones associated with F6 (e.g., P20g, $\mathrm{g}^{\prime}, \mathrm{o}, \mathrm{h}, \mathrm{h}^{\prime}, 1, \mathrm{~m}, \mathrm{~m}^{\prime}, \mathrm{p}, \mathrm{q}$; and $\left.\mathrm{P} 20 \mathrm{q}^{\prime}-\mathrm{q}^{\prime \prime \prime}\right)$ was attempted, but it turned out not to be straightforward - it could not be established stone by stone. Stones P20q and P20 ' $-\mathrm{q}^{\prime \prime \prime}$ must have fallen en bloc.

345 A third possible instance of 'ephemeral' construction near the wall was ambiguously detected in upper unit T74, as mentioned in section 13.1 below (later Stratum C).

346 Plant detritus and the coprolites were mentioned in sections 4.2 and 12.2 above, together with their possible connection with unit BV0 in Sector B. Whether the coprolites were actually retrieved from the hollow of F6 was not recorded. definitely associated with the depression of feature F6 $\left(\mathrm{F} 6_{\mathrm{x}}\right)$, of which it represents the filling. Part of it must be primary deposition within $\mathrm{F}_{\mathrm{x}}$, its occupation layer so to speak, but the overall impression in excavation pointed to a colluvial origin from some washed-out 'living floor' located just outside and slightly above the depression in A2-A12. Combined, the composition and thickness of T7H make this sediment body unparalleled in Area C. In Sounding A it is the first unit from bottom to contain fresh-looking Islamic pottery fragments, as well as other unworn, diagnostic Islamic artefacts (see end of section).

Whatever its origin, T7H as a proper sediment is delimited or 'contained' by wall $\mathrm{F} \mathrm{w}_{\mathrm{w}}$. Outside this wall, in the direction of the Minaean bastion to the east, only a propagation of very fine T7H matrix can be seen. This is not a proper sediment body. In fact it has the character of a postdepositional percolation into T7J, hence its designation as $\mathrm{T} 7 \mathrm{~J}_{\mathrm{H}}$, suggesting a facies of $\mathrm{T} 7 \mathrm{~J}$ due to a sort of diagenesis. A percolation is the process whereby liquids (including fluid mud) pass through fine interstices, i.e. filter: ${ }^{347}$ filtering in this case through a porous sediment such as T7J. Also the bottom contact of T7H with T7J and T7N is diffuse or transitional, precisely suggesting infiltration of the uppermost sediments of both these units by substance from $\mathrm{T} 7 \mathrm{H} .{ }^{348}$

Evidently, some particular chemical-physical property of T7H and/or a particular condition of the place and moment generated a special propensity to percolation and infiltration of the underlying and contiguous sediments. One hypothesis that comes to mind is that T7H contains a significant dose of fluid excreta from animals used in the repairs to the Minaean wall and in the exploitation of rubble 'quarries' such as T7A (cf. the conjectural interpretation of $\mathrm{F} 6$ as an animal pen, above).

A broadly similar and roughly coeval but separate process - or event? - was responsible for unit T7JK, interpreted as a fluid mixture of mobilized T7J fines (the matrix of $\mathrm{T}^{\mathrm{F}} \mathrm{F}$ ) and ash-and-charcoal or 'burnt' material from an unknown source outside the excavated area. The mixture would have reached and

\footnotetext{
347 E.g. AGI 1984, 374.

$348 \mathrm{T7J}_{\mathrm{H}}$ is an outstanding example of 'fluid fines', i.e. a fluid contribution to, or enrichment of, the topmost level of a pre-existing sediment body: in this case T7J and T7N, in the southern and the northern parts of Sounding A, respectively. The process we see here is no more than a percolation, not actually transporting sediment, apart from negligible amounts of silt or clay, but instead only altering the appearance or facies of the pre-existing sediments. In a sense, it is just another form of diagenesis, with physical, not chemical changes. A parallel conceptualization for T7J $_{\mathrm{H}}$ is 'liquid illuvium': the deposition in a pre-existing layer of sediment of colloids, soluble salts, and small mineral particles which have been leached out of an adjacent or overlying original layer (AGI 1984, 249). Illuviation normally implies somewhat humid conditions, which at Barāqish might have meant at the time high (higher?) seasonal rainfall.
} 
filled all the remaining interstitial voids of rubble T7A. It can reasonably be suspected that T7JK had its origin from the south, hence from somewhere near the southern corner of bastion $\mathrm{T} 7$ and in recess $\mathrm{T} 6 / 7$. T7JK is prominent on the Reference section as a 'zoned', banded body beneath blocks P20b and P20j of T7A, post$\mathrm{T}_{\mathrm{F}}$ and $\mathrm{T}_{\mathrm{E}}$ (Figs 107, $109 \mathrm{~A}$ ). Crucial to describing T7JK is indeed 'infiltration', here the flow of a paste-like sediment - a wet mixture of fines and water - into the voids of T7A. ${ }^{349}$ We can probably picture this process as mud-slumping and/or mud propagation into the surviving openings between and around the bases of the lowermost blocks in T7A. ${ }^{350}$ It is important to note that compared to $\mathrm{T} 7 \mathrm{~J}_{\mathrm{H}}$ - a mere 'halo' from percolation -T7JK is a distinct sedimentary body and can thus be classified as a proper sediment unit.

T7JK can be subdivided into two superposed bands: a lower one whitish and containing ash $\left(\mathrm{T}_{\mathrm{JJK}}\right)$ and an upper one characterized by an abnormal concentration of large charcoal particles (T7JK $)_{1}$. Therefore T7JK must have resulted from a process initially involving ashy and afterwards charcoal-rich fluids. Clearly, T7JK is an entity containing a fire-generated component. It is thus very interesting that the maximum charcoal density observed in its upper subunit shows remarkable spatial coincidence with the 'burnt spot' BS on the Minaean wall (see section 10.4 above). Is there any connection? Or more precisely, a connection between T7JK and the event that produced the 'burnt spot'? A relationship is indeed likely, and its potential historical meaning will be briefly examined in Chapter 18, section 3.5.

Unfortunately, T7JK is presently unmappable. Furthermore, on available evidence, it is impossible to determine the stratigraphic relationship between T7JK and T7H. This is an instance of what was observed in section 9 above, that in some cases Sounding A only captured a very marginal view of sediments and processes that must be much better represented to the south or west of the excavation. T7H, T7JK, and their relative stratigraphy will require excavation beyond the limits of Sounding A to be fully understood.

Finds. Among the finds from unit $\mathrm{T} 7 \mathrm{H}$, one stands out (see Chapter 18, Appendix): no. 182.01, a fragment of a 'star'-shaped steatite lamp with a rectangular basin and a zigzag brim, retrieved from quadrangle $A 12$ centrenorth. In addition, a glass armlet can be mentioned. Stone tile no. 07, a particular find that might be connected with earlier Stratum $C$ rather than with rubble T7A (Stratum E), was examined in section 12.2 above.

349 Cf. AGI 1984, 253, 'Infiltration'.

350 Unfortunately, due to its great geometric complexity, the intrarubble sedimentation within T7A could not be recorded in detail during the excavation.

\subsection{Islamic exploitation of rubble $T 7 A$}

Repeatedly in the above pages mention was made of activity somehow connected with the exploitation of collapse rubble T7A, either aimed at wall repairs or for other purposes. Feature F6 itself was a prime example. To judge from Area C, bastion T7, the new occupants of the ancient and long abandoned walled town seem to have thrown themselves with alacrity into exploiting the piles of blocaille flanking the exterior of the curtain wall, and indeed into reusing the blocks in the most varied and effective ways. With the resumption of occupation there was an understandable need to patch or rebuild the walls (Islamic 1).

Except pack F7, probably, and a small number of other large blocks at the bottom, T7A is not an intact accumulation, but an instance of exploited collapse rubble. It was exploited for reuse, and the most common kind of reuse - the principal way of recycling or quarrying - appears to have been through reworking on the spot, i.e., through 'reduction' for obtaining smaller building material. The larger blocks, partly already fragmented, were reduced in size and apparently often reshaped. Particularly quadrangle A31 has provided evidence for this kind of exploitation, in the form of abundant angular waste from the breaking and hammering of the Minaean limestone masonry, including proper flakes. ${ }^{351}$

Concurrently, the topmost blocks in A31, as well as many blocks in rectangle A1-A12, both larger and smaller, also display manifest flaking and facetting. For instance, several blocks forming the cluster in quadrangle A31 south can be recognized as reduction remnants, not primary T7A rubble, from their characteristic flaking scars and/or cuboid shapes. This is also the case of clasts with typically chipped or nibbled faces from other parts of T7A. These observations appear to pinpoint the origin of the small and rather irregular blocks of the Islamic masonry in the curtain wall, which is strikingly different from the Minaean.

Judging from the amount and distribution of remaining blocks, quarrying probably also included robbing, i.e., hauling intact blocks away as fallen. Presumably, only smaller stones from the ancient wall were of the right size to haul away for house construction. Robbing, like reworking stones on the spot, certainly served the dual purpose of supplying material for both civic and private building in the town.

A variant of the kind of exploitation represented by robbing might have been the lifting of blocks for

351 As mentioned in section 12.2 above, abundant calcarenite debris from the reworking of Minaean fallen blocks was contained in the disturbed levels immediately below and above the $\mathrm{T} 7 \mathrm{~N}_{\mathrm{E}} / \mathrm{T} 74 \sigma$ contact. 
immediate repositioning into the curtain itself at bastion T7: an operation, however, that could not be demonstrated. An unknown number of intact or nearintact parallelepiped blocks may either have been raised locally for the restoration of bastion T7, or carried away for reuse elsewhere. Deployment of scaffolding for wall restoration or rebuilding was mentioned at the beginning of 'Suite T74M and F6' in this section.

The exploitation of rubble T7A revealed by the excavations in Area $C$ is interesting, and can find analogues elsewhere in Yemen. Overall, however, the evidence for systematic stone reduction or quarrying found in Islamic suite T74M was limited, due to the restricted surface of Sounding A. The disturbances to the ground surface and part of the subsurface sediments presumably caused by such activities have been mentioned in sections 12.2 and 12.3 above.

\section{Later Stratum $C$ to Stratum A in Sounding A: Islamic to present}

\subsection{Later Stratum C (Islamic 2)}

The later part of Stratum C is lithostratigraphically defined in Sounding A by suite T74U, unit LT7, and surface S5. Also unit T7 $\omega$, the dusty fines partly filling a fissure between the wall and the ordinary deposits (see end of section 9, above), might tentatively be attributed to later Stratum C. In turn, suite T74U includes units T7S, T7Su, T74 with subunit T74 $\lambda$, and T74 $\sigma$ (provisionally considered an autonomous unit).

As an overall impression, if one looks at the south and north sections of the deposits in rectangle A1-A12 (Figs 80-82), T7S and T74 are light-coloured, even pale (cf. the last Minaean layer, T75), whereas T73 is dark-coloured, probably because it is rich or richer in organic matter. Furthermore, T74 appears to be appreciably continuous with upper T7S in terms of matrix and depositional pattern.

Unit T7S, vertically partitioned into $\mathrm{T} \mathrm{S}_{1-2}$, is a layer of very fine sand and silt, light beige-yellow or 'blond' in colour. Most of it reveals a lenticular or laminated micro-structure of alternating pure sand and silty sand. Clearly a fraction of sediment had its origin in decayed mudbrick, but an aeolian contribution is also apparent. Some parts of T7S were cemented by calcium carbonate and are very hard to cut. Distinctly laminated is the lower subunit, $\mathrm{T} 7 \mathrm{~S}_{2}$, about $20 \mathrm{~cm}$ thick. It largely consists of melted mudbrick and - on the Reference section is neatly bounded eastwards by block P20b of collapse rubble T7A. It distinctly looks like melted mudbrick also on the north section of A1-A12, particularly in A12 and west of block P20p (Figs 79, 109-110). The provenance of this mudbrick matter would have to be traced to the decay of feature F6 (whatever F6 was), but a dual origin from F6 and the continuing erosion or redeposition of fill from ruptured bastion T7 is equally admissible. ${ }^{352}$ $\mathrm{T} \mathrm{S}_{2}$ surrounded and eventually buried the remains of $\mathrm{F} 6$ 's wall $\left(\mathrm{F} 6_{\mathrm{w}}\right)$.

Also part of the upper subunit, $\mathrm{THS}_{1}$, is melted mudbrick in all probability; the rest must be aeolian. The overall continuity of $\mathrm{T}^{7} \mathrm{~S}_{1}$ with overlying $\mathrm{T74}$, at least in terms of sediment matrix, has been noted above and will be further considered once T74 has been described (below). The occasional blocks in T7S, often small, can be interpreted as reworked elements from T7A and/or decayed F6 (e.g. P20o', P20n').

T7Su was identified from a lump of mudbrick containing block P17u and smaller stones, continuous with T7S in the southwest quadrant of quadrangle A2 (Fig. 109 B). An identical, lesser lump also associated with a small stone lies on the same surface - the top of T7S - a little to the east (see Reference section). T7Su may have originated from the decaying core and outer wall of bastion T7 during the Earlier Islamic reconstruction of the curtain. This small mass of old building material was left protruding from the top of layer T7S until it was surrounded and buried by the sand-silt sheets of layer T74.

T74 is a layer of greatly varying thickness (up to 0.6 $\mathrm{m}$ ), consisting of undulating, light-beige sand and silt sheets with clusters of angular stones and generally small blocks. Block P20n towards its bottom, however, is an angular slab $45 \mathrm{~cm}$ long. Some of the clasts in the upper part of the layer might derive from a flimsy stone and mud-brick structure (see below). T74 also contains mudbrick fragments and sparse charcoal. Its upper levels and top show lenses of laminated fine sand, in which loose and cemented millimetre-thick laminae distinctly alternate, the latter hardened by calcium carbonate's ascensus. Westwards, T74 increasingly tends to aeolian silt, beige and extremely powdery.

There are indications, such as laminae and pebble lines, that $\mathrm{T} 74$ accumulated in a dune-like fashion in relative proximity to the Minaean wall (1-2 metres from it; cf. both sections of rectangle A1-A12, south and north), ${ }^{353}$ and more horizontally away from the wall towards the edge of the talus. The dune-like ridge and the horizontal part were separated along the west side of A11-A31 by a relatively deep furrow, parallel to the wall, which appears to have lasted for quite a while (Fig. 79): hence

\footnotetext{
352 The collapse of the exterior curtain of T7 necessarily exposed to erosion the infill at the core of the bastion (cf. unit T7t described above, section 12.3). How complete the Islamic repairs to bastion T7 might have been at the onset of unit T7S is impossible to determine.

353 Unless T74 was a talus-like structure - cf. T74 - - constantly eroded alongside the wall. On the Reference section the same indicators do indeed suggest sedimentation surfaces consistently dipping west, as if originally being rooted talus-like at the wall.
} 
a palaeotopography characterized by undulations and a general 'wavyness', not very different from that reconstructed for the close of Stratum E (cf. sections 12.2-12.3 above).

A further characteristic of T74 as a whole is its difficultto-define internal variation. Thick and polymorphic, T74 would be the result of multiple cultural and environmental agencies of Islamic 2 age impossible to appreciate in their details. This is why I have refrained from naming subunits within T74. ${ }^{354}$ Overall, taking into account the continuity noted above, there is the distinct possibility that T7S and T74 represent by and large two consecutive phases of decayed-mudbrick sedimentation, although T74 is clearly more varied in both composition and structure. The possible origins of mudbrick have been examined above in this section.

The only subunit of T74 formally named is inclusion T74 $\lambda$. This is a thin but conspicuous gravelly lens, probably containing plant detritus, located near the top of T74 in quadrangle A2 and captured by the Reference section. As mentioned in a previous synopsis of the last plant-organic/manure occurrences in Area C (section 12.2 above), the vegetal content would make T74 $\lambda$ an instance of the attenuated, fading continuation of such sediments during the Islamic period, only followed by lenses gm2 and gm1 within unit T73. Lens gm2, being located near the bottom of T73, would in fact closely follow T74 $\lambda$ stratigraphically, this latter occurring about 4.5 metres to the south (cf. Fig. 79).

Against parts of the Minaean wall the formation of T74 was accompanied - or closely preceded? - by T74 $\sigma$, a sediment body similar to 'standard' T74, which according to the two options can either be classified as a wall-side facies of T74 or an autonomous unit. This latter classification is provisionally preferred. T74 $\sigma$ is a fine sand of beige-greyish colour, a little organic, unusually rich - compared to 'standard' T74 - in 'ilb nutshells (Christ's thorn jujube), other plant debris, and sparse charcoal. One can wonder if these contents are primary, or instead were inherited from the fill of damaged bastion T7. ${ }^{355}$ Importantly, T74 $\sigma$ is the sediment that surrounded and eventually buried the upper blocks of rubble T7A in quadrangle A31.

Unit LT7 is a lens of rubble made up of flakes from the Minaean wall, which interfingers with upper T74 at the wall's base in quadrangle A1. As it was originally open-work, and the rock is the same calcarenite as the

\footnotetext{
354 It should be noted in passing that 'T74ع' in Fedele 2010 was an optical illusion generated by some photographs; it does not exist.

355 In the field, T74 $\sigma$ could only be examined cursorily. In terms of sediment material it could be similar to $\mathrm{T} 7 \mathrm{~N}_{\mathrm{E}}$ and might have been enriched by eroded bastion's fill some time after the collapse (as suggested in section 12.2 above).
}

wall, LT7 might represent a further or the latest phase of the curtain's decay before full restoration, or might instead be related to the repair works. It is a pocket, not a talus, well separated from overlying T73 by surface S5; and it cannot be classified within suite T74U because its agency is unrelated to the 'ordinary' sedimentation defining the suite.

As mentioned above, scant surviving evidence for the existence of a flimsy and/or ephemeral structure, unnamed, was found in upper T74. This 'hut' made of stones and mud bricks would be the third instance of dwelling or working structure in the proximity of bastion T7, after F8 and F6. It was in fact not only indicated by small scattered blocks and fragments of mud material (upper T74 contains a large quantity of mud-brick fragments throughout area A1-A31, sometimes exceeding $10 \mathrm{~cm}$ in size), ${ }^{356}$ but also by sporadic fist-sized alluvial cobbles. In the field in 2006 such a structure was thought intuitively to resemble the small makeshift shelters made against bastions and recesses T7-T9 by the present-day soldiers patrolling Barāqish.

Suite T74U is topped by surface S5. This surface is one of the most distinct, emphatic sedimentary contacts of entire Area C. It shows widespread calcium-carbonate induration by ascensus, attributable to sedimentary stasis and therefore implying a temporal hiatus. It is therefore no coincidence that S5 also probably correlates with the deterioration of the Minaean wall marked by decay band DB1. A significant caesura within the Islamic sequence should be inferred. The subsequent sediment suite, T73, would correspond to the beginning of a new sedimentary phase during the Islamic period (see next section).

Finally, it cannot be excluded that the area of Sounding A was very marginally reached by the collapse of bastion T6, correlated with later Stratum C (see section 16.2 below). How far did the collapse fan from T6 reach? Is part of the larger rubble in unit T74 rather to be explained as material from the T6 collapse? During both seasons the field impression was that T74 indeed incorporated debris from T6, for example blocks $\mathrm{P} 17 \mathrm{a}-\mathrm{P} 17 \mathrm{c}$ shown on the Reference section. That T74 is essentially parallel to, and coeval with, units T6B and T6A in Sector B leaves no doubt. But apart from these observations and perceptions the matter could not be explored further.

No notable find was retrieved from later Stratum $C$ in Sounding A. As mentioned in Chapter 18, Appendix, an obsidian flake from suite T74U (no. 169C.01) is supposedly pre-Islamic.

\footnotetext{
356 Such as, for example, mud-brick fragment P17v, intercepted by the north section of quadrangle A12 (Fig. 79).
} 


\subsection{Strata B and A (Later Islamic to present)}

Stratum B identifies a clastic talus extremely rich in organic domestic rubbish, 1-1.3 m thick, formed against bastion T7 during the Islamic 3 or Later Islamic phase. This accumulation was repeatedly and heavily eroded, a process still continuing today. Stratum B is lithostratigraphically defined in Sounding A by suite T73 and units T73W and T72. Suite T73 consists of gravelly loams with plant debris: units T73a (with

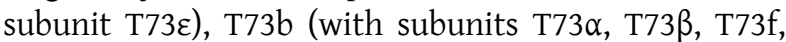
and hypothetically gm 2 and gm1), T73c, and $\mathrm{T} 73 \varphi$. Unit T73W needs to be kept separate from the suite.

As indicated at the end of the previous section, suite T73 would correspond to the beginning of a new sedimentary phase during the Islamic period, following surface S5 and a temporal hiatus of indeterminate length. Compared to the immediately underlying layers this suite is dark-coloured, probably because it is distinctly rich in organic matter. ${ }^{357}$ It forms a thick horizontal deposit of greyish to grey-hazel, or even pale brownish, loamy sediments, containing fine gravels as well as plant matter and rare cultural debris (Figs 8083).

Suite T73 has been completely restudied and redrawn (Fig. 78), ${ }^{358}$ therefore an overview emphasizing the main changes is appropriate. The principal change concerns the mass or masses of fine sediments that occupy the western half or third of the excavated area and can be seen on the Reference section in quadrangle A2. On the whole we can retain $\mathrm{T} 73 \varphi$, though redrawn, which is not lenticular but is an accumulation, thickening to the west and clearly continuing down-talus. It is the first unit above surface S5, bottom to top. $\mathrm{T} 73 \varphi$ appears to underly T73b, in spite of a vaguely defined boundary to the east, and it seems to continue the depositional trend centred on fines already seen with T74. Similar to $\mathrm{T} 73 \varphi$ as a body of fines developing westwards, and also similar to $\mathrm{T} 73 \varphi$ in overall outline, is unit T73f, only imperfectly recognized in the previous version (' $f$ ' again evoking 'fines', like ' $\varphi$ '). T73f is horizontal with a lenticular root to the east - no more than a thin, distinct, pale lamina right above a gravelly patch in $\mathrm{T} 73 \mathrm{~b}$ - and progressively thickening to the west. At the western limit of Sounding A there is an apparent anastomosis of $\mathrm{T} 73 \varphi$ and T73f, an example of 'fines-onfines'.

Fines - i.e., fine sand, silt, and clay - are widespread in suite T73. The fines in T73b and T73a consist of non-lenticular, generally rounded bodies with elusive shapes and boundaries. Particularly T73b shows up

\footnotetext{
357 As observed at the beginning of section 13.1, above.

358 superseding Fedele 2010, 140, fig. 132.
}

as a mosaic of 'gravel muds' with ambiguous limits (pockets rather than lenses) within a predominantly loamy matrix containing abundant organic detritus. A 'vegetal ribbon', T73 $\beta$, can be understood as a final subunit of T73b. Relatively differentiated from T73a, it effectively separates T73b from T73a in spite of its ambiguous contact with this latter.

At the same time, although continuing the deposition of fines characterizing T74, units $\mathrm{T} 73 \varphi$ and T73f appear to represent a decreasing of this trend during the buildup of the Islamic talus. Parallel to it is a growing trend of coarser deposition, increasingly and distinctly organic in content as well (plant material). In terms of depositional pattern, a quieter and essentially horizontal buildup (T73b) was followed by an essentially massive, semi-chaotic, and possibly dumplike sediment buildup with T73a.

Details and clarifications on suite T73. Some additional lithological and lithostratigraphic information on the units in suite T73 may be useful. Bottom to top, T73c is a thick wall-flanking talus of darkgrey stony loams showing inclined sedimentation lines, probably eroded and stabilized before the accumulation of T73b. T73b, as mentioned, is an essentially horizontal mosaic of loam pockets rich in artefactual debris and plant matter, this latter often conspicuous, with gravelly accumulations particularly in its middle part. Subunit T73 $\alpha$ is another wall-flanking talus, overlying $\mathrm{T} 73 \mathrm{C}$ but clearly interfingering with T73b. T73 $\beta$ is an elongated, sub-horizontal lens or level of plant detritus, uneven in thickness and with poorly defined contacts.

Two very thin 'plant-detritus' levels or lenses of compacted manure within lower T73, 'green mats' gm2 and gm1, can tentatively be attributed to T73b (cf. T73ß?). They were clearly observed on the northern section of rectangle A1-A12 and extended particularly in quadrangles A31-A32 (Figs 79, 110). Lens gm2 is located right at the bottom of T73, while gm1 lies a little above to the west, completely within quadrangle A32. They represent the very last occurrences of manure units near the MinaeanIslamic wall in the extramural sequence (Fig. 26):359 apparently, the final episodes of animal presence at the foot of the wall before the ground surface lost its horizontality.

T73a is very similar to T73b in terms of lithology and cultural contents, but is slightly more 'chaotic'. Wall-edge subunit T73E (quadrangle A1) appears on the Reference section as a pair of lenses made of plant matter and a felt of straw. It had previously been misinterpreted as part of T72. At the same

\footnotetext{
359 The last plant-organic/manure occurrences were listed in section 12.2 above.
} 
time, distinguishing T73e cannot hide the fact that suite T73 is basically continuous with T72, the last essentially horizontal unit topwards.

T73W is a large, insufficiently understood subsurface unit at the very edge of excavation, deeply cutting into suite T73 with a concave contact and manifestly extending down-talus. It was interpreted as the result of mass emplacement into an erosional or slumping hollow (from dumping?) truncating T73a and upper T73b.

A particular finding needs to be mentioned in connection with the bottom levels of suite T73, and presumably unit T73b. Towards the base of the suite, or actually at its base and therefore on surface S5, a 'second level' of blocks was recognized. Second level, from the excavation's jargon, is an allusion to a pair of large blocks evidently derived or obtained from the Minaean wall, blocks P16a and P16b, and therefore somehow evoking collapse rubble T7A (intended as the first and main 'level' of Minaean blocaille). Both blocks were recovered from quadrangle A31 during the exploration and excavation of T7A. In particular, P16a is a complete parallelepiped worked in the marginally drafted, pecked style typical of Minaean masonry, and $\mathrm{P} 16 \mathrm{~b}$ is an elongated, incomplete parallelepiped carved at one end to form a mortise-like depression for joining. ${ }^{360}$ The reason for these 'abandoned' blocks their behavioural context - escapes us.

Unit T72 (final Stratum B) consists of superposed, thin levels of fines containing organic debris. It shows on the Reference section as marginally lighter in colour than suite T73. Its sedimentation was fairly horizontal. Its poorly defined bottom contact with T73 has been mentioned above; the upper contact with $\mathrm{T} 71 \mathrm{~b}$ is much clearer.

Stratum A is lithostratigraphically defined in Sounding A by two superposed sets of sediments: earlier Stratum A ('Recent') by units T71b and T71a, intercalated by a massive mega-inclusion, feature F18; and later Stratum A ('Present') by a single unit, T70. The sequence T71bT71a forms sediment group T71.

Overall, the sediments of group T71 consist of hazelgrey organic loam partly containing chunky mudbrick material, and are distinctly lighter in colour than the sediments below (Fig. 80). They represent foot-ofwall deposits, of which inclusion F18 is part and can contribute to identify their origin: we are dealing with a shallow talus against the wall, made of occasionally fallen material from above (notably F18) and possibly also including occasional rubbish. F18 is a large chunk of construction material which in all probability fell en

360 P16b was mentioned in section 12.3, 'Some observations on individual blocks', above. bloc from a decaying building on the brim of the Islamic town wall. Three parts were recognized, one indeed looking like a still structured chunk from a wall $\left(\mathrm{F} 18_{\mathrm{w}}\right)$, and a second one composed of straw and mudbrick $\left(\mathrm{F} 18_{\mathrm{B}}\right)$. The third part, $\mathrm{F} 18_{\mathrm{s}}$, was a layer made of stones and straw which occupied horizontally a good portion of quadrangle $A 1$ south.

The component units of T71 - T71b below and T71a above - are quite different from each other, and the insertion between them of F18, seemingly continuous with $\mathrm{T} 71 \mathrm{~b}$ while separated rather more sharply from T71a, suggests that a certain time interval elapsed between the two units. T71b is massive and coarser than T71a, and is apparently full of mudbrick fragments and clods; T71a is finer and sub-horizontal.

Unit T70 corresponds to the latest, recent collapse rubble in recess $\mathrm{R} 6 / 7$, mostly deriving from the decay of bastion $\mathrm{T} 6$ and only reaching with its very edge the southeast corner of Sounding A. Although not intercepted by the Reference section, an outline of this collapse fan has been represented in the stratigraphic profile of Sounding A for completeness.

Finds. From Strata B and A (Sounding A) the following significant finds were recovered, in stratigraphic order bottom to top: ${ }^{361}$

- a chopper made from a white limestone cobble, $10-15 \mathrm{~cm}$ in diameter, isolated and in mint condition, found in situ in quadrangle $A 1$ at the foot of the Minaean-Islamic wall (no. 162.1, surface S5 or unit LT7, i.e. later Stratum C or earlier Stratum B, Islamic 2/3); also described with additional details in Chapter 18, Appendix, this volume) (Fig. 113);

- a vesicular trachyte quern (no. 169J.01, A32 north, suite T73, i.e. Stratum B);

- half of an elongated cobble used as a grinding stone for a saddle quern (no. 161.01, T73a-T73e, i.e. later Stratum B; not described in Chapter 18);

- a cowrie cutout pendant from a necklace (no. 169A.3, mass removal in quadrangles A31-A32, Strata B-A, i.e. Islamic 3 or Recent); ${ }^{362}$

- a terracotta mouthpiece of a pipe or water pipe (no. 169A.4, same provenance and context as no. 169A.3);

- and a complete fruit of doum palm, probably from the Tihāma (no. 169A.8, provenance and context as for previous nos 169A).

\footnotetext{
361 See descriptions in Chapter 18, Appendix.

362 Also mentioned in the introduction to 'Marine shells' in Chapter 21 , section 2.1 , this volume.
} 


\section{Strata J to F (Minaean period) on the tell's edge and the talus}

\subsection{Sectors $B$ and $C$ : the tests in general $^{363}$}

The short test trenches designated as Sectors B and C (Figs 28-29) were made as linkup excavations between the two main operations in Area C, namely Sectors D-E and Sounding A (cf. section 1.2 above). ${ }^{364}$ In Sector B, the excavation appears to have sampled deposits comparable enough to those of an upper part of Sounding A: a broad similarity of sediment units, in a similar sequence, thus facilitates correlation between the two sectors. In Sector C, due to severe time constraints, the test trench had to be excavated in a single cut (cut 170), whose aim was to obtain a stratigraphic section of sufficient depth to link up with Sector D. A finer record of the archaeological contents was kept visually through apposite field notes (cf. mention in section 1.2).

Sector $C$ is positioned much to the south and lower down compared to Sector B and Sounding A (Figs 9-10). Unsurprisingly, it appears to have sampled a sedimentary environment somewhat discordant from that of Sector B and Sounding A, in terms of both lithology and topography; this makes its correlation with Sector B and Sounding A rather difficult. In particular, such a correlation cannot be linear nor 'horizontal'. On the other hand, Sector C correlates well with quadrangle D1, almost joining this end of Sector D directly.

Linking Sector D and Sounding A with each other and with Sectors $C$ and B is crucial for an understanding of the upper talus during the Minaean and Islamic periods, if only preliminary. It is therefore appropriate to provide here a series of technical details on this multiple correlation, to complement what has already been summarized at the end of section 3.3 above ('Longdistance correlations').

First of all, one can note a uniformity of sedimentary buildup between Sector B and Sounding A, whereas Sector C is completely different, a stratigraphic window onto a different 'landscape': between Sector C and Sector B conditions seem to change considerably. Furthermore, Sounding A indicated the existence of a horizontal sedimentation belt around the wall during the Minaean (cf. section 11.4 above). It was thus possible

\footnotetext{
363 This section should be read in conjunction with 'Sounding A in general' (section 9, above). Unit GR3 in Sector C (bottom) was treated at the end of section 7.6 , above.

364 As mentioned in section 1.2, the field code names of quadrangle 'B1' and quadrangle 'C2' for the excavated parts of Sectors B and $C$, respectively, will be avoided as unnecessary. In both cases, the rectangular test trenches were the only portions of the planned sectors that could be excavated (cf. Figs 6-7).
}

to correlate Sector B with Sounding A 'horizontally' on the basis of (i) the equation of $\mathrm{S} 20$ with the T74L/M lacuna (see section 13.2 above); (ii) the equivalence between the 'plant-detritus' units T7V in Sounding A and BV1 in Sector B; and (iii) the assimilation of blocks in unit T74 (P17a-P17c) to rubble from the collapse of bastion T6 (T6B-T6A in Sector B) (Figs 17-18). The proposed correlation ${ }^{365}$ is only one of several possible options. It was preferred on grounds of sediment affinities and geometric parsimony.

Linking Sounding A to Sectors B and C, or even to quadrangle $D 1$ of sector $\mathrm{D}$, required a different methodology: the correlation was based on the observation that a particular stone material circulated at soil surface over the talus at a certain moment of time. More precisely, a case of plausible correlation could be made between the blocks of T7B (collective number P21) and similar stone slabs which occupy comparable stratigraphic positions in Sectors B and C: on the Reference section they are $\mathrm{P} 8, \mathrm{P} 9$, and $\mathrm{P} 9 \mathrm{~A} .{ }^{366}$ In other words, Sectors B and C were correlated with Sounding A through the presence of sufficiently characteristic slablike blocks in one particular layer of all three sectors, at least those of $B$ and $C$ originating with high probability as displaced T7B blocks from Sounding A. This is a schema of the correlation.

\begin{tabular}{|l|l|l|}
\hline Sounding A & Sector B & Sector C \\
\hline T7B (blocks P21) & $\mathrm{Pb}$ (block P8) & SPD (blocks P9, P9A) \\
\hline
\end{tabular}

As mentioned above (section 11.3), most of blocks T7B embedded in sediment unit T75 in Sounding A are peculiarly slab-like. This is why a number of similarly flat or platy blocks found as exclusive block component in Sectors B and C were tentatively correlated by tracing their origin to T7B as their source. That is, they were correlated as part of a coeval or slightly timetransgressive scatter over the upper talus. From this point of view, it does not matter that such blocks are cultural and that in Sounding A they were part of a decayed structure: what matters is that such peculiar blocks would have continued to be available on the talus - to move around or down the talus during a definite lapse of time. Hence their assumed value in correlation. ${ }^{367}$

\footnotetext{
365 See already Fedele 2010, 135.

366 In Sector C, stony, hardened sand SPD and stone slabs P9 and P9A provide an example of what I would term 'fractionation' of a sediment unit: in this case, the fact that scattered blocks from a single sedimentary event involving a stony flow ended up a little away from the bulk of the unit. For details on SPD and blocks P9 and P9A see section 15.3, 'Stratum F', below.

367 For a moment it was thought that two platy blocks of unit $\mathrm{Pa}$ in quadrangle D1 (P1 and P2) could also be from the same source and part of the same process, but this is in fact doubtful. For a brief discussion of both this supposition and the correlation of quadrangle D1 in general see section 15.2, below.
} 
Except unit GR3 (cf. footnote 363 above), the sequences of Sectors B and C were considered part Minaean, part Islamic, on the basis of a combination of sharp boundaries (S22 and S20), sediment affinity, and artefactual content. The lower sequence in Sector B is made of a thick manure level (BV) and clayey-mottled fines (B02 $\alpha)$. In Sector $C$, dark manure or plant-organic levels (C入V, CUV) are intercalated with porous, sandysilty, plant-detritus units (DGV, DGX, CU7 etc.), which continue a sedimentary trend first apparent in GV1DGV1 in upper Sector D. Via quadrangle D1, Sectors D and $C$ join together to give a continuous sequence. Surface S22 correlates well with an expected discontinuity and possible gap at the end of the Minaean period. Details will be given in section 15.3 below.

During the revision of stratigraphy for this book it was felt useful to order all the units of Sector B from the bottom to surface S20 in a sediment group, GB1 (Table 2). GB1 thus includes units B03, B02, and B01, fines with stony levels, and units BV, BV1, and BV0, plantdetritus or manure units. This is one of the groups that are defined by sediment units only, not suites. The classification at the rank of group depends on the fact that the units differ from each other in sedimentary origin.

\subsection{Strata J-I. The Earlier Minaean on the talus (Sectors $D-E)$}

\section{Stratum J}

Stratum J on the talus is lithostratigraphically defined by units BRH2 and BRH1, and by surface S1 (Sector D). It is a short sequence, a thin stratification of sediments, only recognized in quadrangle $D 2$ and - unexcavated - in the exposures of upper Gully B (Figs 18, 30-31). Only visible at the head of gully is unit BR3, a $17-\mathrm{cm}-$ thick part manure, part plant-organic level made of a number of tightly stratified lenses, dark brown in colour (Fig. 30); it seems to correlate with BRH2, and if not, these two units are essentially coeval (Fig. 26). ${ }^{368} \mathrm{BRH} 2$ is plant-organic in a matrix of almost pure sand, with an indeterminate excreta component, brown in colour. BRH1 ('H' from ashy) is a grey silt varying to sandy silt, with ash lenses and the occasional brown hue.

The bottom contact of BRH2 with suite SD2 is rather diffuse, due to matrix similarity. Surface S1, topping the sequence attributed to Stratum J, is a minor discontinuity (but see a remark about unit BR2 in the subsection below).

368 For a list and synopsis of the manure/plant-organic units see section 4.2 above.

\section{Stratum I}

Stratum I on the talus is lithostratigraphically defined by two widely separated sets of units in terms of topography: in upper Sector D (quadrangles D1-D2), by units BR2, BR2k (head of Gully B), AH1, BR1i, BR1, and $\mathrm{Pa}$; and on the lower talus, between quadrangles $E 4$ and

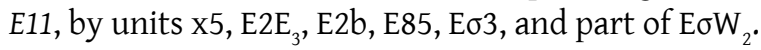

As repeatedly mentioned, ${ }^{369}$ the new sedimentary regime heralded on the upper talus by the manure and plant-organic levels of Strata $\mathrm{K}$ and $\mathrm{J}$ fully continued at the time of Stratum I. During this phase (Minaean 2), there is evidence from D1-D2 and upper Gully B that donkeys and dromedaries at least occasionally circulated or rested on the upper talus. One can wonder whether such dense and thick manure deposits as BR2, BR2k, and BR1i could indicate the existence of makeshift animal enclosures, according to the usual interpretation of similar layers. Where its dense lenses of litter and excreta are particularly compressed, BR2 distinctly marks the beginning of a new sedimentary routine in this part of Area C: a fact underlined by the recognition of surface $\mathrm{S} 1$, however feeble.

BR2 essentially repeats BRH2 (Stratum J), but it is more manifestly manure. It is richer in organic content and strikingly brown in colour. A possible facies of lower BR2 is BR2k, though provisionally classified as an autonomous, interfingering unit. This is another of the thick dark lenses of manure cropping out from the headcut of Gully B (Figs 30-32, 65 B), and the peculiarity that made it conspicuous once freshly exposed and cleaned was its coffee-brown hue, hence its code name. ${ }^{370}$ It is very likely that BR2k, as well as BR2, both extend considerably inside the talus beyond the limits of Gully B and excavated Sector D.

Unit AH1 ('AH' for ash) is an ashy, light-grey sand-silt with charcoal bits, containing not only a considerable fraction of organic residues but also individual dromedary coprolites. Full of identifiable dromedary coprolites is also BR1i, a felt-like manure layer rich in loose, angular stones, and with sandy lenses of cultural refuse. Its clasts include medium to decimetre-sized flakes. Above it in overall continuity, but containing slightly less animal dung, is unit BR1, a light-brown plant-organic sand rich in angular stones, plant detritus, and organic artefacts (for instance leather). In the field it was interpreted as a mildly developed anthrosol, and it is capped by stone level $\mathrm{Pa}$, now reclassified as an autonomous sediment unit. ${ }^{371}$

\footnotetext{
369 Sections 4.2 and 8.2 above; Chapter 18, section 3.2, 'On the earliest Minaean'; Chapter 19, section 3.1.

370 From 'coffee', with mutation of 'c' into ' $k$ '.

371 Contra Fedele 2010, Pa can be ranked as an autonomous ESU because it is a relatively distinct level from both BR1 and GV1,
} 
$\mathrm{Pa}$ (final Stratum I) is a level of medium and small blocks identified in quadrangle $D 1$, where, like all the layers of Strata I-H below and above, it was truncated by heavy sheet and rill erosion and barely survived on the left side of Gully B. It is of particular interest that most of the clasts in $\mathrm{Pa}$ are fragments and flakes of limestone representing two different rock types: a proper oolithic limestone - it seems - and a yellow calcarenite identical with the masonry of the Minaean curtain wall (cf. section 10.2 above). Large flakes from this latter rock, redeposited not only as Pa but also into unit BR1, were instrumental in suggesting a correlation with Stratum I as defined in Sounding A. ${ }^{372}$ In addition, $\mathrm{Pa}$ contained two sizable platy blocks of beige microcrystalline limestone, $\mathrm{P} 1$ and P2, and a cobble. For a plan of stones Pa see Fig. $65 \mathrm{~A}$; the platy block shown on the Reference section is $\mathrm{P} 2$.

P1 and P2, ostensibly representing building material, elicited for a while (2008-2009) the supposition that they could be assimilated with the slab-like blocks in Sectors B and C (P8, P9, and P9A) and ultimately with slabs T7B of Stratum $F$ in Sounding A, as listed and discussed in section 15.1 above. However, given the continuity-by-contiguity established between Sector C and quadrangle D1 of Sector D (involving units DGV and DGV1, respectively), P1 and P2 can only be earlier than P9 and P9A of Sector C, therefore earlier than Stratum F, as well as earlier than DGV1-DGV, tentatively attributed to Stratum $\mathrm{H}$ (Fig. 18). Therefore a linkage of stones $\mathrm{Pa}$ with T7B is more than dubious.

On a more general level, as far as Strata I and H are concerned, the correlation proposed for quadrangle $D 1$ is provisional and cannot presently be resolved in every detail. The new ${ }^{14} \mathrm{C}$ date from this quadrangle (sample \#2.1) would indeed suggest a different correlation with Sounding A. However, as discussed in Chapter 18 , section 1 (this volume), the charcoal sample was unreliable and this single radiocarbon measurement is better considered insufficient for a revision of correlation (cf. section 3.3, 'Long-distance correlations', above).

\footnotetext{
although perhaps only constituting the last episode in a trend of downslope stone inputs throughout the BR1i-BR1 sequence (see below). Stones $\mathrm{Pa}-$ it was noticed in excavation - seem to rest on several levels: they form a loose package within BR1. Some sedimentary details, as well as the presence of two larger blocks, P1 and P2, suggest a moderate distinction from BR1 and a more marked separation with respect to GV1.

372 Fedele 2011a, 114. As mentioned in the previous footnote, Pa seems to represent the last and clearest episode in a process started with BR1i and characterizing BR1i-BR1: the downslope redeposition of stones and chipping waste during this interval, reaching as far down talus as at least quadrangle D1. It appears very likely that such clasts, at least in part, are construction waste from the Minaean curtain wall. Assuming that they had circulated a while over the upper talus before reaching Sector D, it was thought preferable to correlate the containing units BR1i-Pa with Stratum I rather than J, that is, with the first stratum after the construction of the wall (this latter being Stratum J by definition).
}

On the lower talus, tell erosion increased during the Earlier Minaean and even entered into a new phase with the Minaean 2. A particularly effective process on the middle and lower talus in Sector E was aeolian-colluvial interaction. For a synopsis of the process and related colluvia the reader is referred to the section on tell and talus evolution, above, ${ }^{373}$ where the criteria employed in the present re-classification are also explained (cf. Fig. 21, which includes in table form the composition of sediment groups). Some details concerning the difficulties in correlation and dating are given in sections 15.3 ('Stratum G') and 16.3 below. ${ }^{374}$

A conspicuous, extensive aeolian-colluvial body within sediment group EX4, unit $\mathrm{x} 5$, can be attributed to Stratum I (Figs $40 \mathrm{~B}-\mathrm{D}, 47$ ). It is light brown to grey in colour and contains reworked plant detritus and potsherds, perhaps also involving erosion of old manure deposits. Significantly, it blankets quadrangles E4-E5 and continues laterally in E6-E8 as 'sands' $\mathrm{E}_{2} \mathrm{E}_{3}$, $\mathrm{E} 2 \mathrm{~b}$, and Eø3, thus locally constituting the basal layer of the aeolian-colluvial regime or 'cycle' still in action today. Units $\mathrm{E}_{2} \mathrm{E}_{3}, \mathrm{E} 2 \mathrm{~b}$, and $\mathrm{E} \sigma 3$ are fairly uniform, colluvially redistributed aeolian sands and silty sands, 20-40 cm thick, with the occasional inclusion of cultural debris and pebble lines (Figs 47-48). Lines of fine debris, predominantly organic, particularly punctuate aeolian-colluvial sand E2b in quadrangles E7-E8, which tends to be slightly more silty, loose, and yellow than the contiguous, transitional unit upslope $\left(\mathrm{E}_{2} \mathrm{E}_{3}\right)$. Down and west, 'sands' E2b and Eø3 share an uncertain and problematic boundary in quadrangle E8 (Fig. 48).

In quadrangle $E 8$, unit E85 is the first from bottom in a series of recurrent debris levels or lenses which generate a special lithostratigraphic pattern in the western part of the quadrangle (Fig. 48), and clearly continue into the adjacent, unexcavated fringe of the plain. ${ }^{375}$ These recurrent, horizontal units are the result of the repeated deposition of essentially fine debris at the foot of the talus, in the precise area where topography changed to horizontal and the colluvial flows lost energy. If one looks at the Reference section (Figs 13, 21), the visible ends of E85 to E80 actually appear to outline a westward shift of the talus - a slow 'progradation' of the talus into the 'sea' of the plain. ${ }^{376}$ Further information on

\footnotetext{
373 Section 4.2 and particularly subsection 'On the sand mantle of the lower talus and at the foot of talus'.

374 Cf. also section 3.3, 'Long-distance correlations', above.

375 Alternatively, E85 might be considered the second such unit after E86 (Fig. 22), but this latter could only be examined very imperfectly at the bottom of the excavation. Both its inclusion within "yellow sand' YS8 and its possible connection with suite SEK and Horizon H78 (cf. section 7.8, 'Horizon H78: further details', above) suggest in fact that E86 is something different from the subsequent series of levels or lenses in the same location, E85 to E80.

376 In its proper sense, progradation is an advance of land into the sea determined by alluvial sediment deposition.
} 

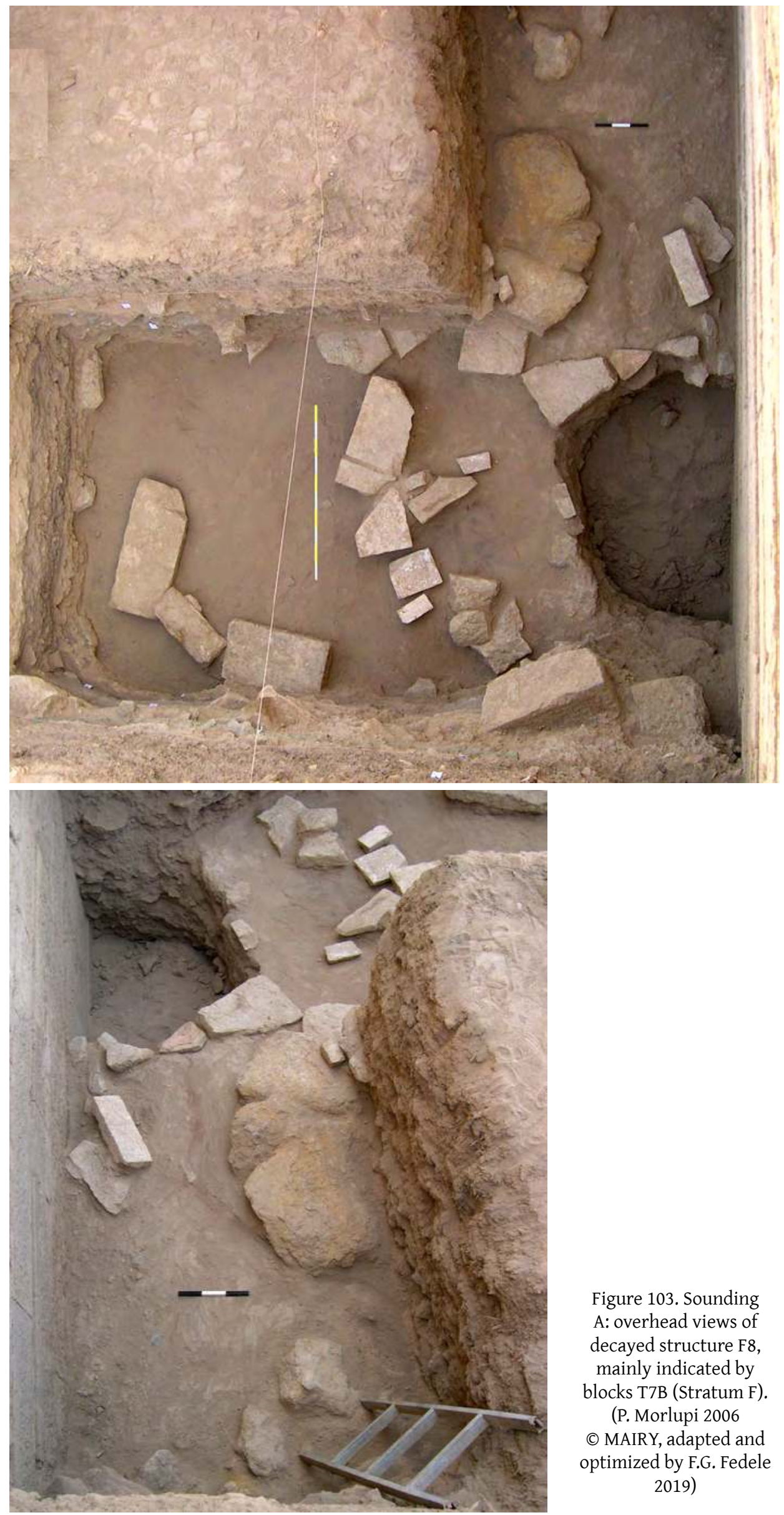

Figure 103. Sounding A: overhead views of decayed structure F8, mainly indicated by blocks T7B (Stratum F).

(P. Morlupi 2006

C MAIRY, adapted and optimized by F.G. Fedele 2019) 


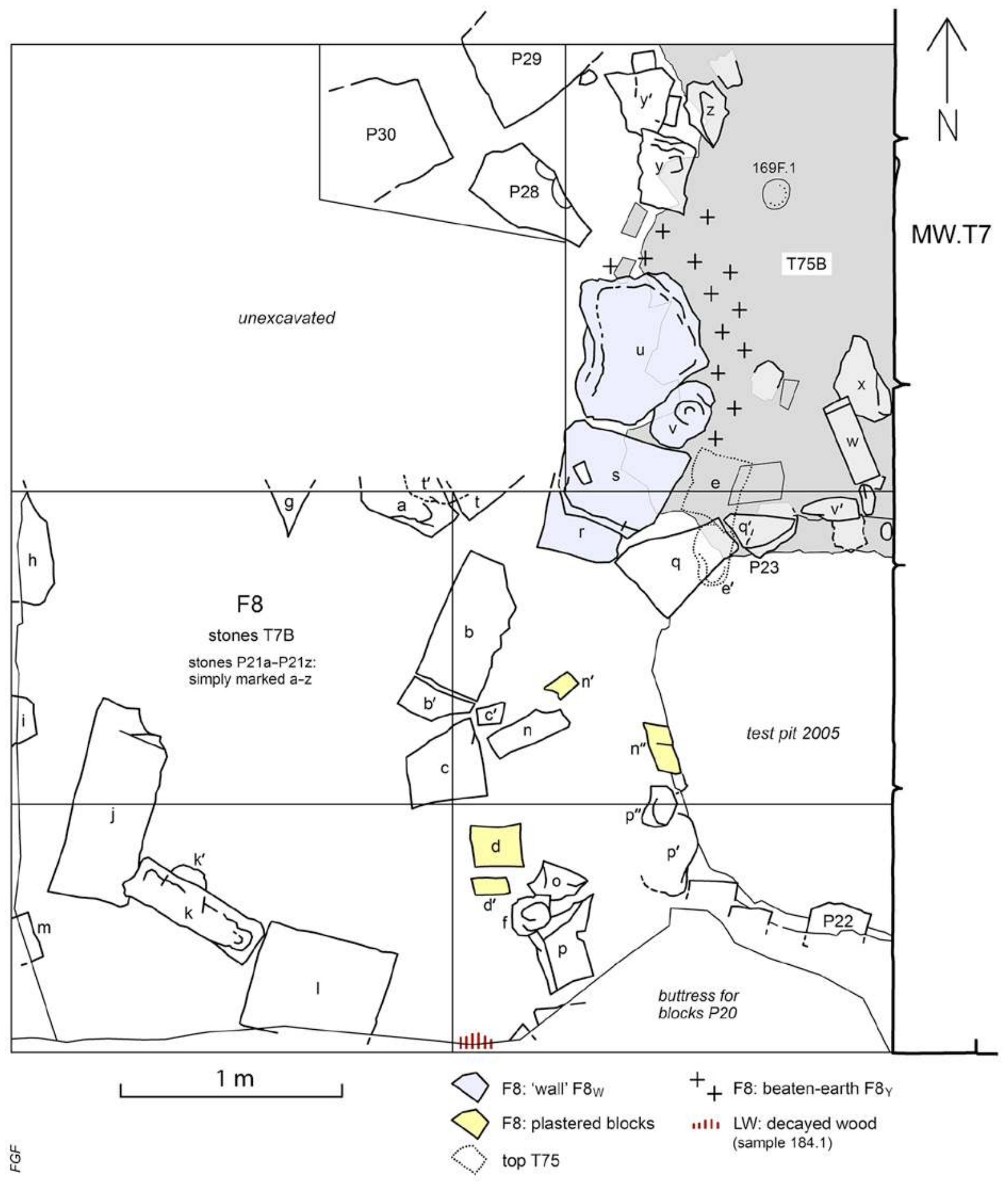

Figure 104. Sounding A: stone blocks T7B and decayed structure F8, plan. Associated unit T75B shown in grey. (F.G. Fedele 2020) 

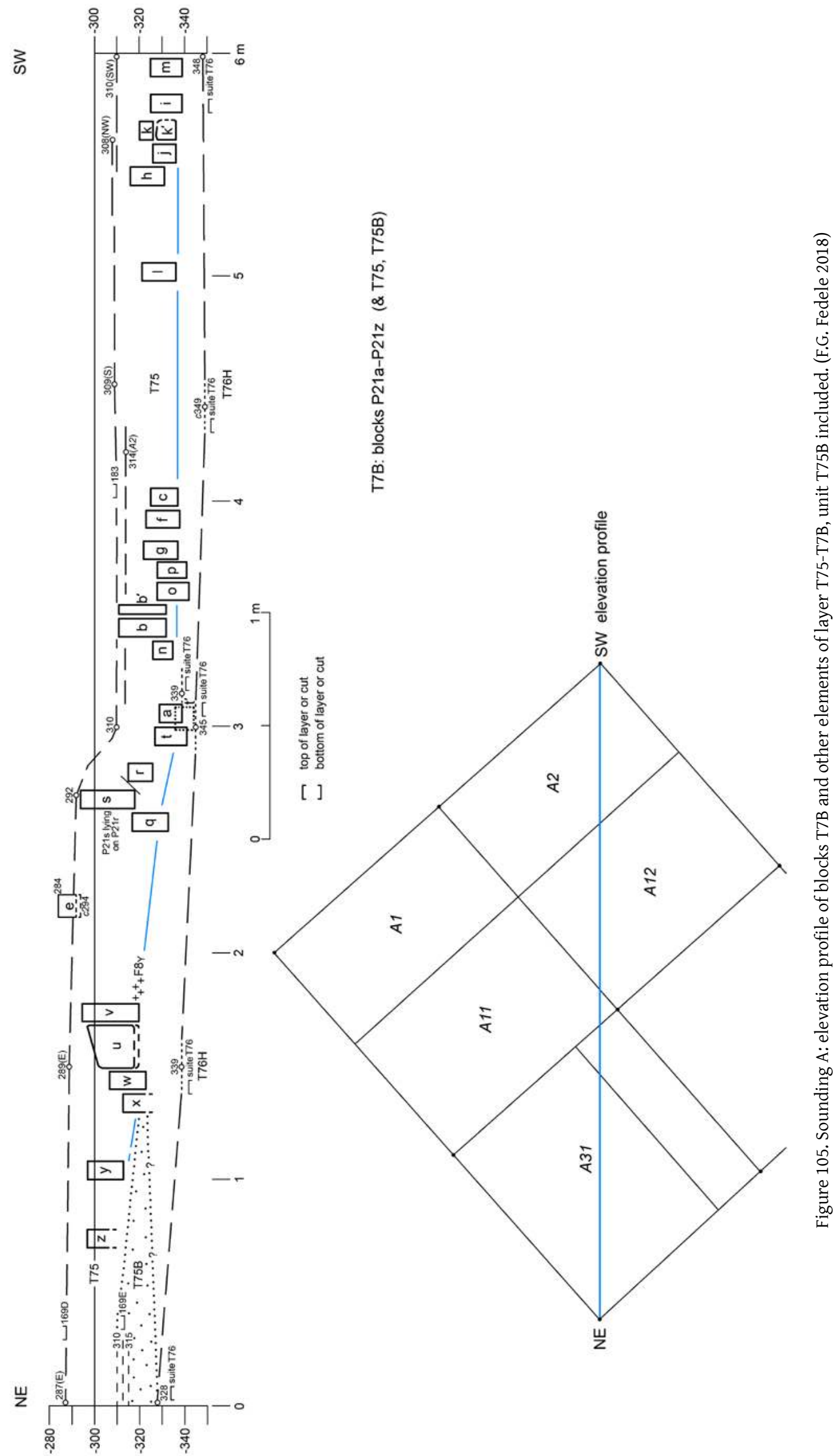

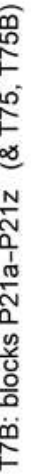

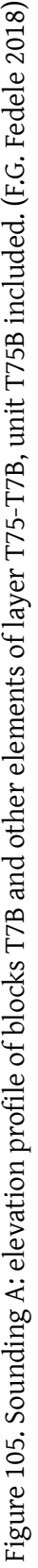

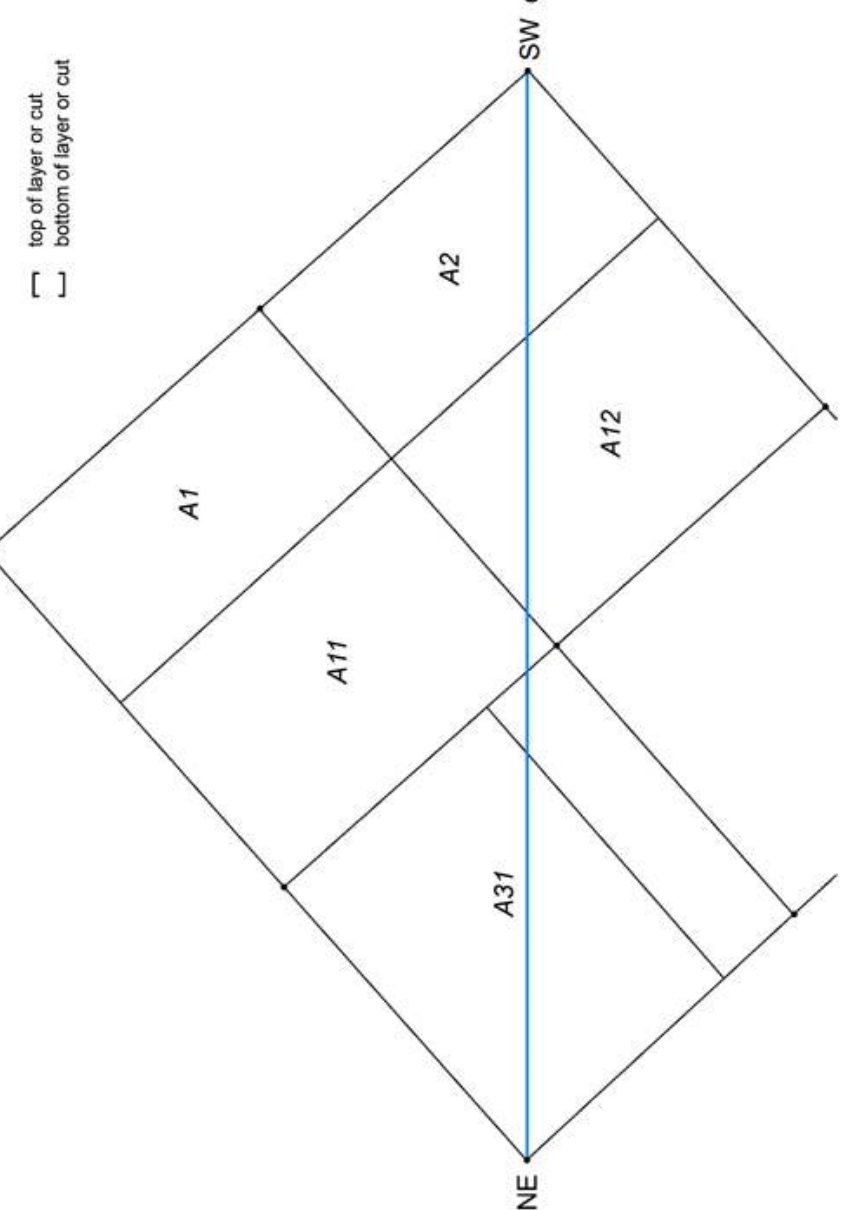




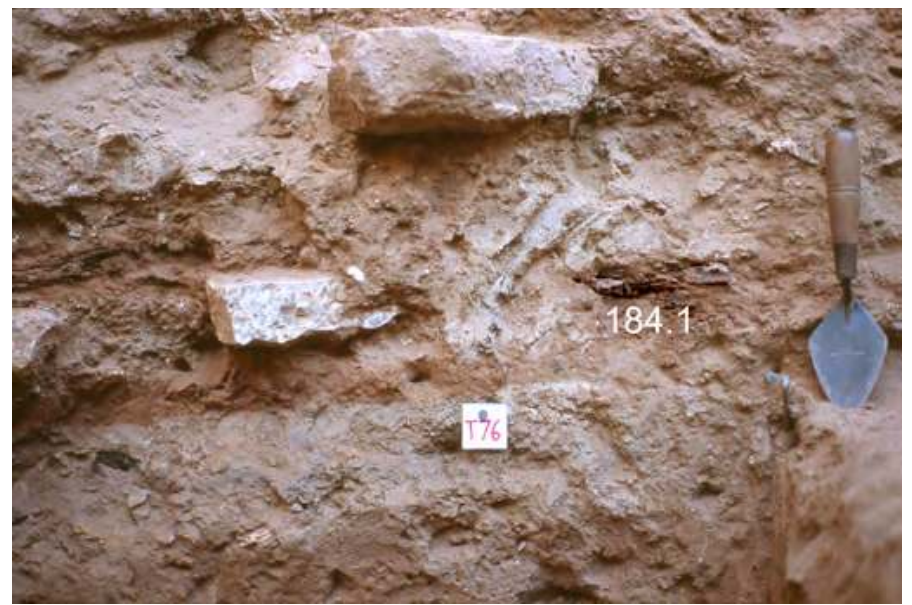

Figure 106. Sounding A, Reference section: wood remains LW (sample no. 184.1) within unit T75 in quadrangle $A 1$ west. (F.G. Fedele 2006)
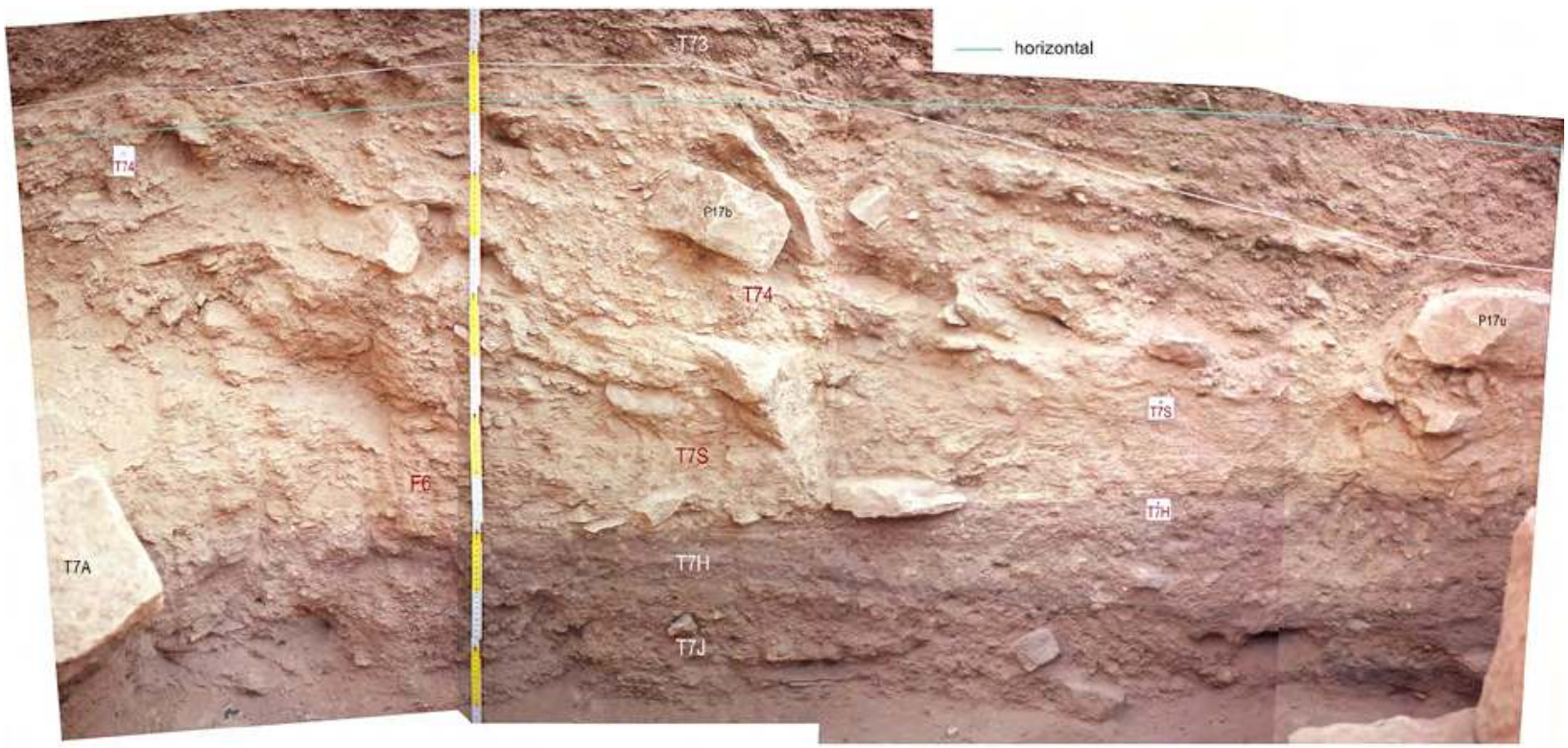

Figure 108. Sounding A, sediment group GT74, Reference section. (F.G. Fedele 2006 and 2019)
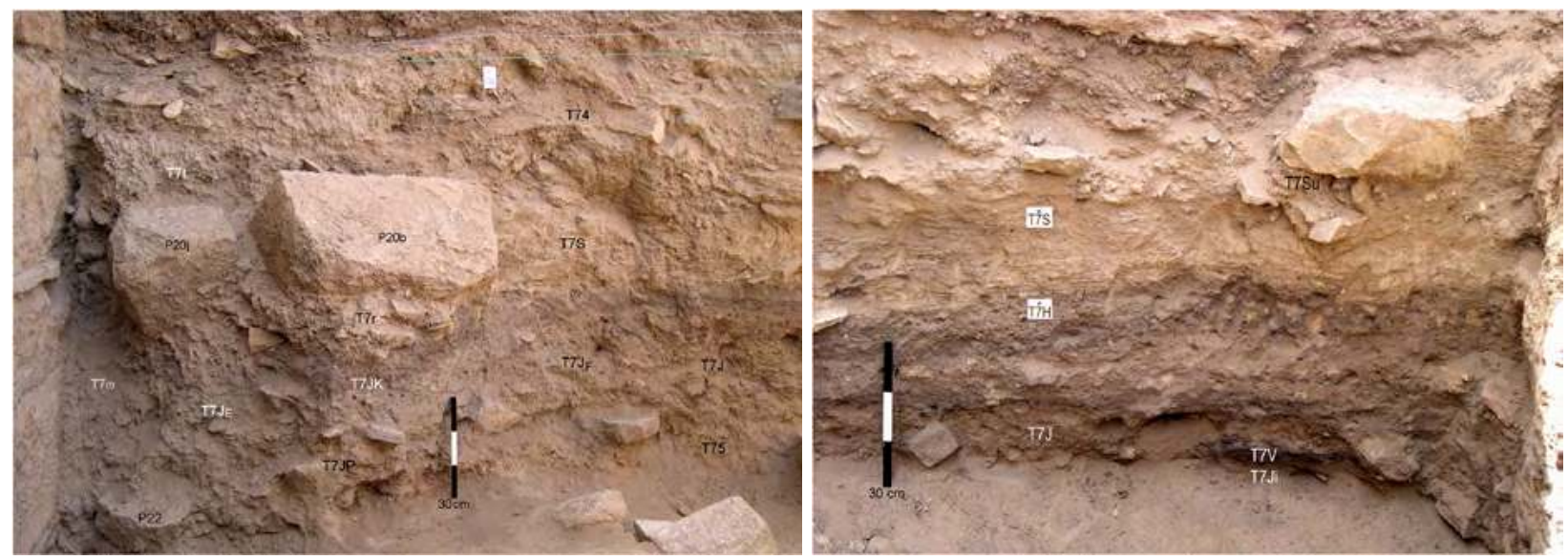

Figure 109. Sounding A, sediment group GT74, details of Reference section: on the left, quadrangle A1, T7JP to T74; on the right, quadrangle A2 west, T7J to T74-T7Su. (P. Morlupi 2006 @ MAIRY, adapted and optimized by F.G. Fedele 2020) 


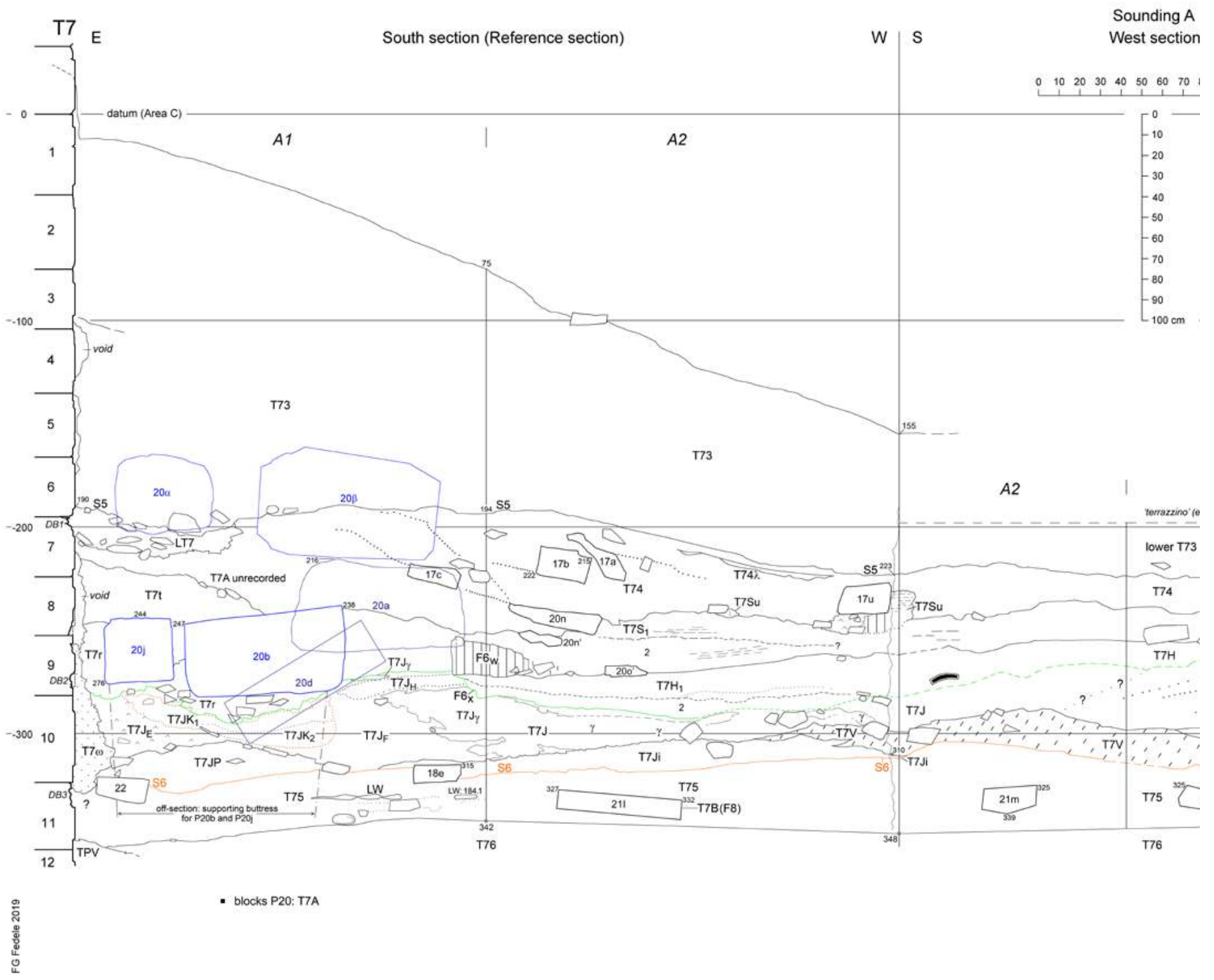

Figure 107. Sounding A, rectangle A1-A12: complete section for layer T75-T7B and sediment group GT74 (Strata F, E, and C). Colour is only used to highlight sediment boundaries and clarify overlaps. (F.G. Fedele 2019) 


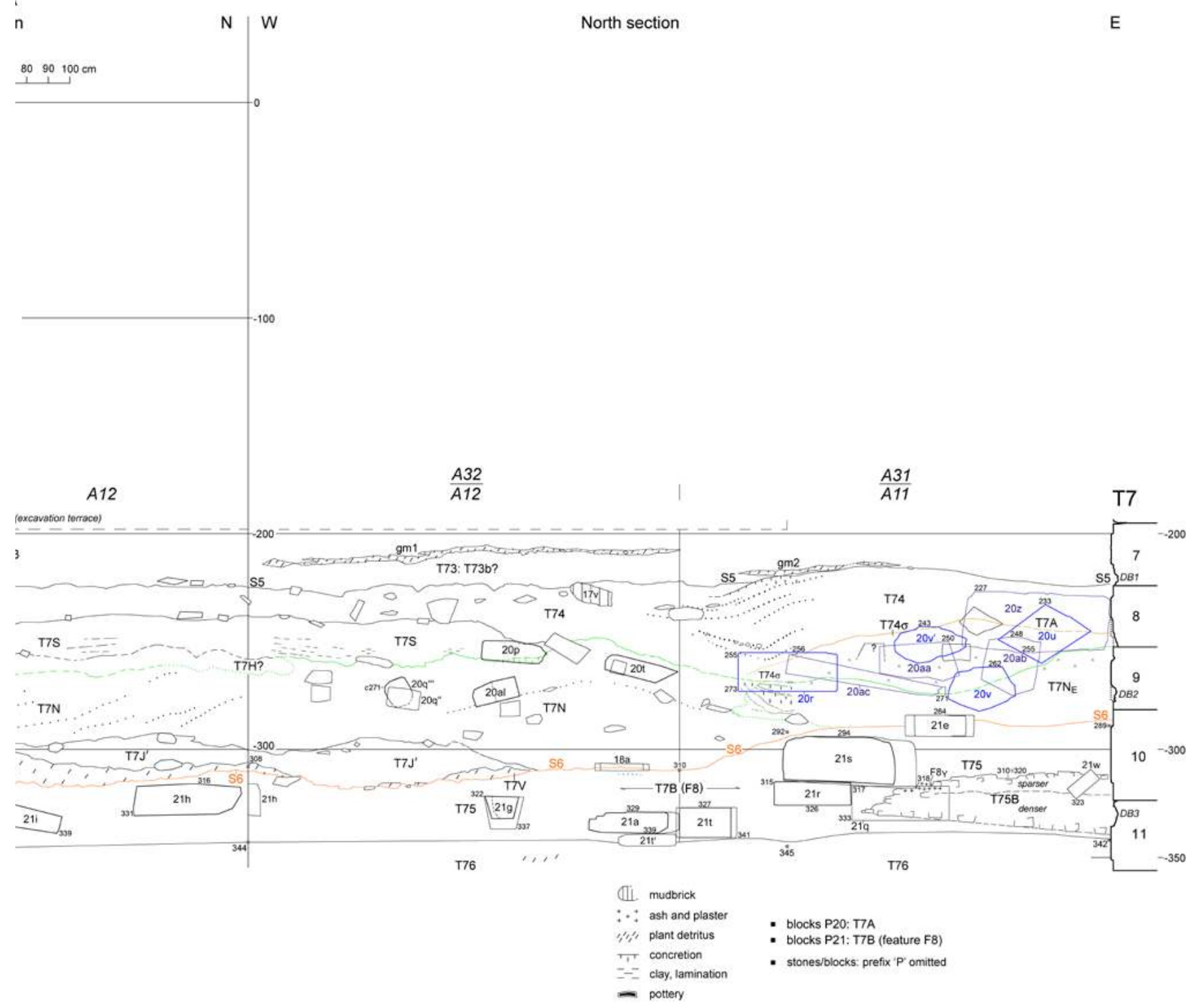




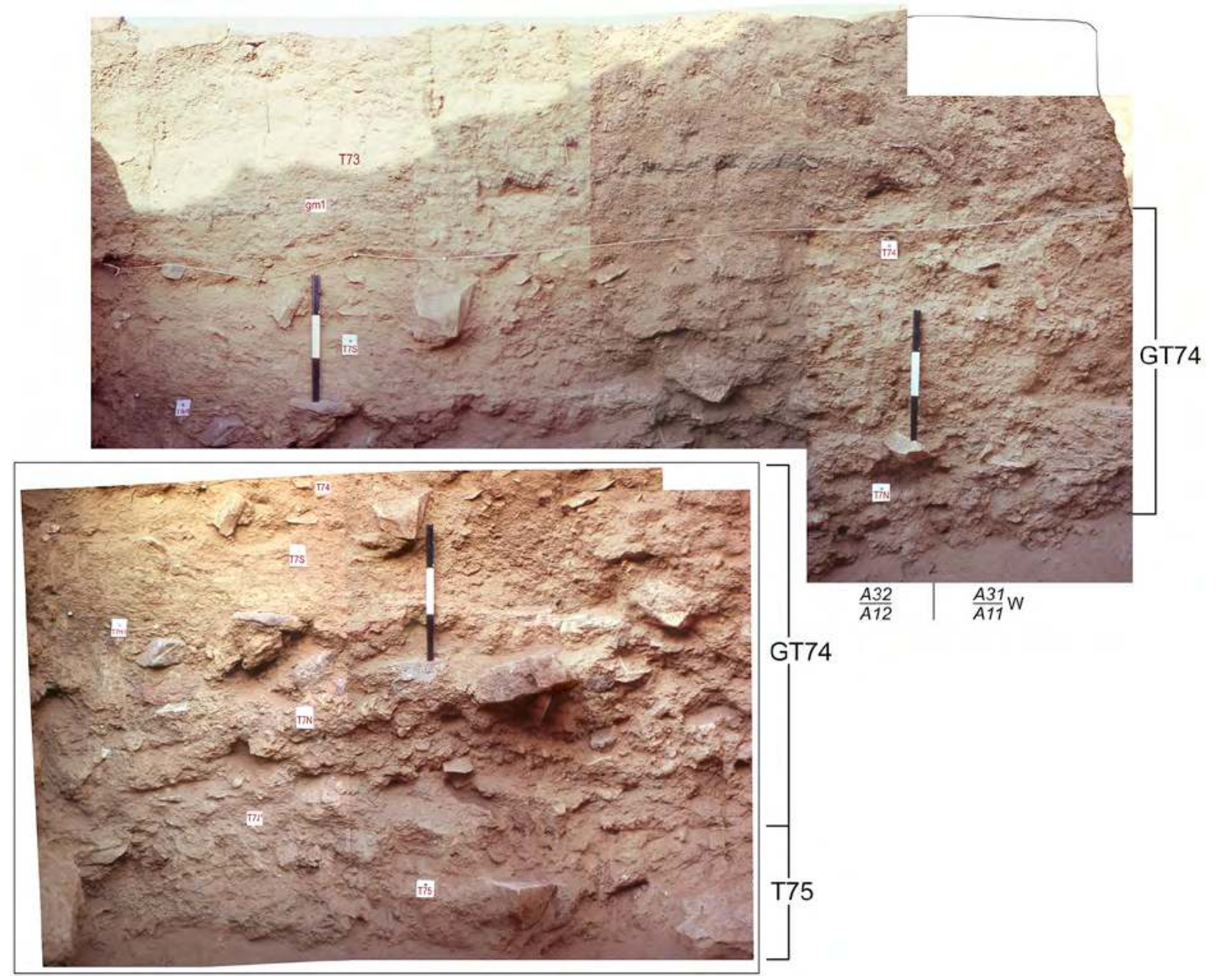

Figure 110. Sounding A, sediment group GT74 and layer T75-T7B, main north section. Upper part above, complete sequence in quadrangle A12 below. (F.G. Fedele 2006 and 2020)

units E85-E80 is given in sections 15.3 ('Stratum G'), 16.3 , and 16.4 below.

At the lower end of excavated Sector E, also a part of aeolian sand $\mathrm{E} \sigma \mathrm{W}_{2}$ is probably to correlate with Stratum I. This should be the lowermost part of this deposit, which is $0.6-0.7 \mathrm{~m}$ thick and according to my current interpretation would span Strata I, G, and D (Minaean 2 to indeterminate Earlier Islamic). Overall, aeolian sands E $\sigma W$ form a diachronic but notably uniform sand cover at least $1.4 \mathrm{~m}$ thick, in which partition $\mathrm{E} \sigma \mathrm{W}_{2}$ can only be distinguished for a greater fraction of greyish fines and a slight increase in compaction with respect to $\mathrm{E} \sigma \mathrm{W}_{1}$ above, at a depth of 50-60 cm (Figs 22, 49-50). This contact is faintly marked by a line of elusive lenses. In turn, the bottom contact of $\mathrm{E} \sigma \mathrm{W}_{2}$ is both determined and affected by cultural horizon H11 and culturally modified sand E $\sigma \mathrm{x}$, as described in section 7.8, 'Horizon H11: further details', above. ${ }^{377}$

\footnotetext{
377 Sand $\mathrm{E} \sigma \mathrm{W}_{3}$, corresponding to a further partition, was examined
}

Finds. From Strata J-I in the talus sector, mostly units BRH2-BR2, a fragment of a softstone vessel was retrieved (no. 20.01). These same sediments, and probably BR2 in particular (Stratum I), revealed great quantity of date stones (cut 20). From sediments exclusively pertaining to Stratum I an incomplete leather shoe (no. 3.01, possibly BR1) and a fragment of a thin clay disc (no. 4.01, upper BR2 or AH1) were recovered; this latter object, however, might well be part of an aggregate of redeposited Sabaean debris (see Chapter 21, section 2.3, this volume).

\subsection{Strata H-F. The Later Minaean on the talus (Sectors $B-E)$}

N B. Stratum G will be treated after Strata $\mathrm{H}$ and F, as it temporally encompasses both. 


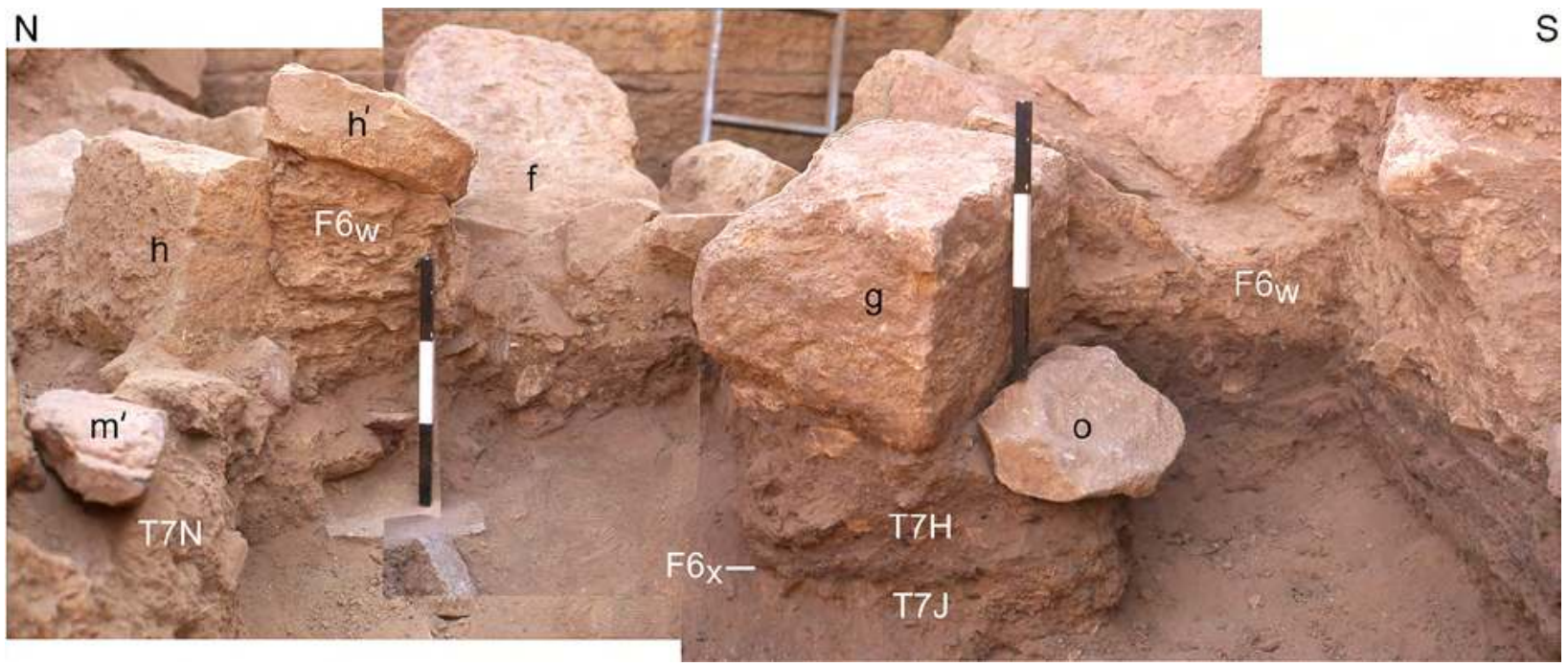

$\mathrm{N}$

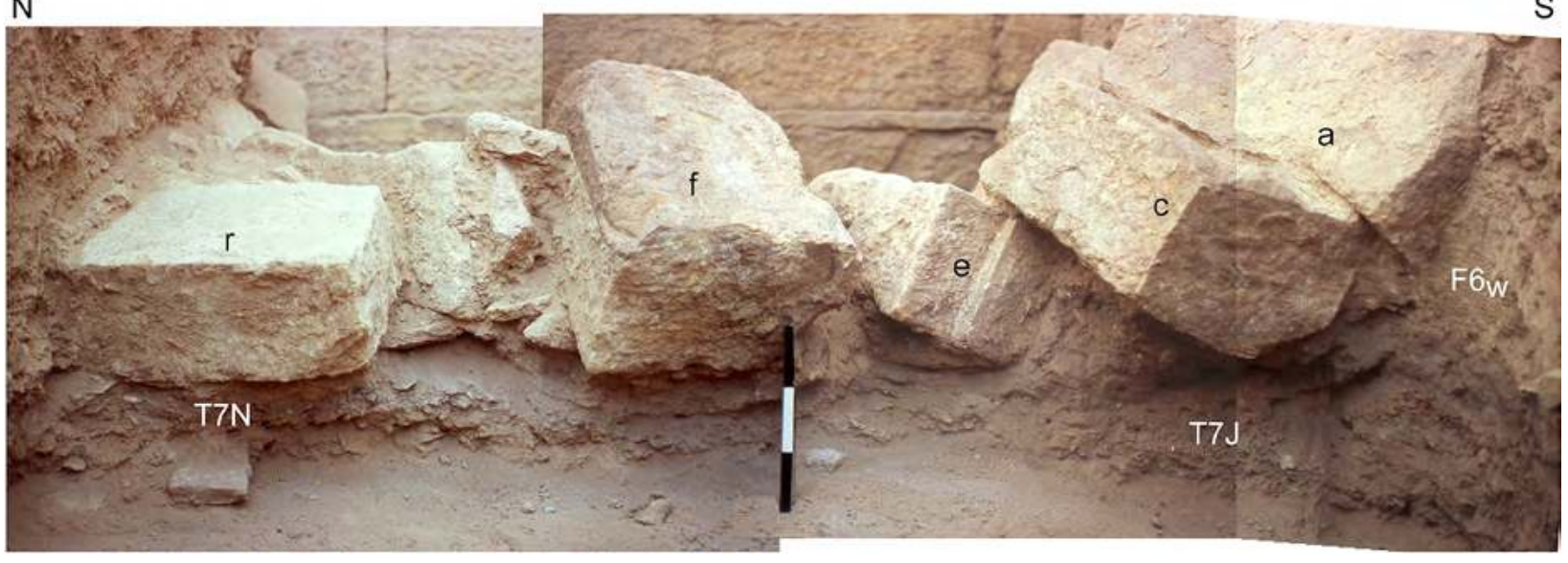

Figure 111. Sounding A, rectangle A1-A12: two north-south profiles across the base of rubble T7A and feature F6, profile 1 above and profile 2 below. For position see Fig. 112. Scale $30 \mathrm{~cm}$. (F.G. Fedele 2006, adapted and optimized 2019)

\section{Stratum $H$}

Stratum $\mathrm{H}$ on the talus is lithostratigraphically defined by units B03 and BV in Sector B; L13 and DGV in Sector $C$; and GV1, DGV1, and SA $\pi$ in upper Sector D (Figs 17$18,28-29){ }^{378} \mathrm{~A}$ brief synopsis of the sediment sequences from Sectors B and C - mentioning units BV and DGV - has been given above at the end of section 15.1. There the reader can also find a justification for the ordering of the units of Sector B, from the bottom to surface S20, in sediment group GB1.

According to the adopted correlation, the earliest unit of Stratum H surviving in Sector D is GV1, consisting of grey 'powdery' silt rich in plant detritus and other minute organic debris. This is followed in quadrangle D1 by DGV1, a dark-coloured, greyish aeolian silt containing plant matter and a little manure, in addition to aggregates of mostly redeposited artefactual debris.

378 Unit GR3, encountered at the bottom of Sector C and correlated with Stratum L, was examined at the end of section 7.6, above.
These units are shown, unmarked, in Figs 30-31. DGV1 can be subdivided into three vertical subunits, of which the bottom one, DGV1 $1_{3}$, is stony-gravelly and is separated from $\mathrm{DGV}_{2}$ by a 'weak' stone line of angular clasts; the top partition, $\mathrm{DGV} 1_{1}$, is partly lenticular. DGV1, with DGV1 1 , appears to be directly overlain by unit DGV of Sector C. DGV appears to consist of layered sediments dipping upslope, again rich in plant litter and perhaps a little manure, that is, very similar to DGV1.

In the eastern part of Sector C, contiguous to DGV at the bottom of trench, unit L13 was uncovered, consisting of silty-clayey fine sand ('L' for Italian limo, fines) with small sporadic stones. One can wonder whether L13 is melted or levelled mudbrick from GR3 and/or related, preexisting Sabaean features nearby. Its stratigraphic relationship with respect to DGV could not be determined.

The lowermost sediment reached in Sector B, unit B03, is an apparently horizontal layer of stony-gravelly silt 


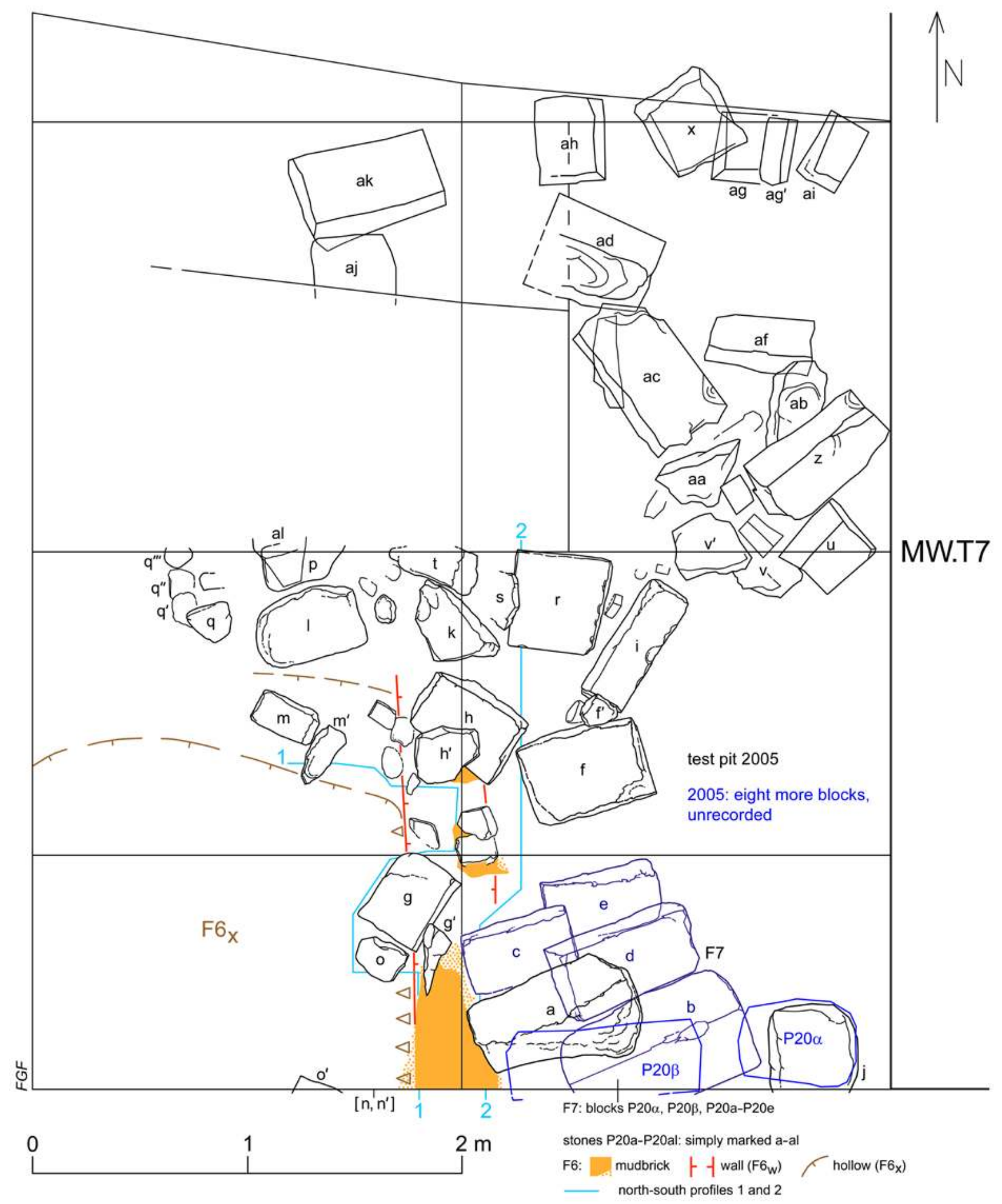

Figure 112. Sounding A: collapse rubble T7A and remnants of structure F6, plan. The layout of the two north-south profiles in Fig. 111 is also shown. (F.G. Fedele 2019) 


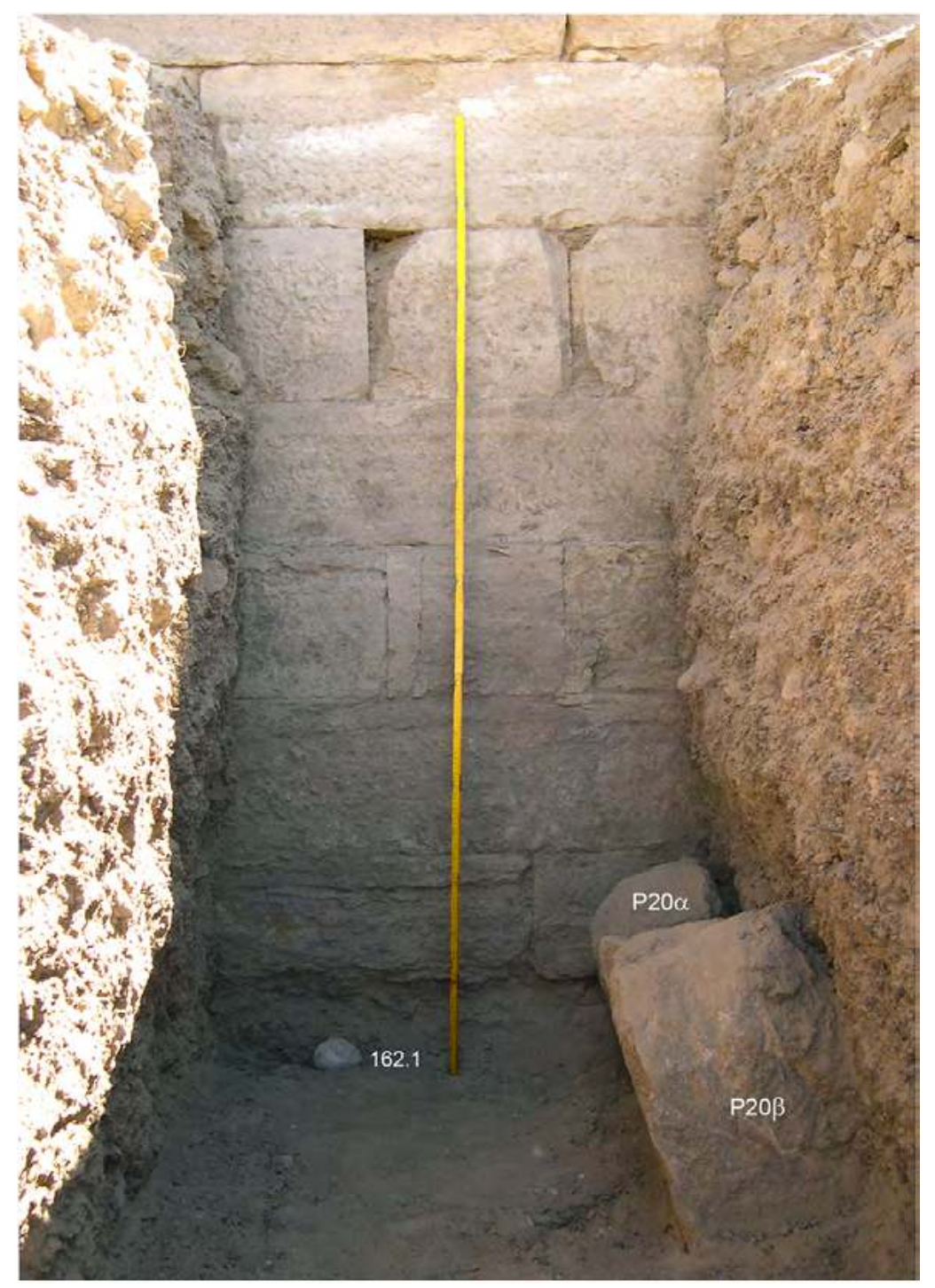

Figure 113. Sounding A: blocks P20 $\alpha$ and P20 $\beta$ of rubble T7A as unearthed in 2005; and chopper 162.1 in situ. (P. Morlupi 2005 C MAIRY, optimized by

F.G. Fedele 2020)

and fine sand. ${ }^{379}$ Unit BV ('V' for 'vegetal') is a horizontal manure level with a silt matrix, varying in thickness from $8-10 \mathrm{~cm}$ in its western part to about $18 \mathrm{~cm}$ at its eastern end. It was repeatedly mentioned in previous sections of this chapter dealing with the manure/plantorganic sequence of the upper talus.

In Sector D, one can attribute to Stratum $\mathrm{H}$ 'pink sand' SA $\pi$ (' $\pi$ ' for pink; its hue in fact a pink-grey). This particular, unmistakable unit was introduced in section 11.2 above, where it was mentioned how it is believed to allow long-distance lithocorrelation with the red sands' otherwise only known from Sounding A, SR in particular (cf. section 3.3, 'Long-distance correlations',

379 Overall, B03 is similar to B01, higher up in the sequence (Stratum above). SA $\pi$ was deposited in quadrangles D3-D5 upon a conspicuous erosional surface marking a significant hiatus, surface S05 (Fig. 33). SA $\pi$ is the first unit above eroded sequence GK-GZ-GR1, as well as below blocky slope slide SBL (Stratum C, see below). In quadrangle D3, in fact, SA $\pi$ is only preserved in small scattered hollows pockmarking the decayed top of Mass GR1 (feature F9). An isolated pit about a decimetre in diameter, filled with a 'red' sand that can be identified with SA nearby, was recorded a few centimetres from the eroded bank of Gully B, in the northwest quadrant of D3, straddling Sabaean layers lower GZ1 and upper GZ2. This pit was certainly made by a small fossorial mammal.

Finds. From unit GV1, quadrangle D1, a unique cylindrical-conical fragment of a fired clay object with a wooden stick at its core was recovered (no. 2.02); it 

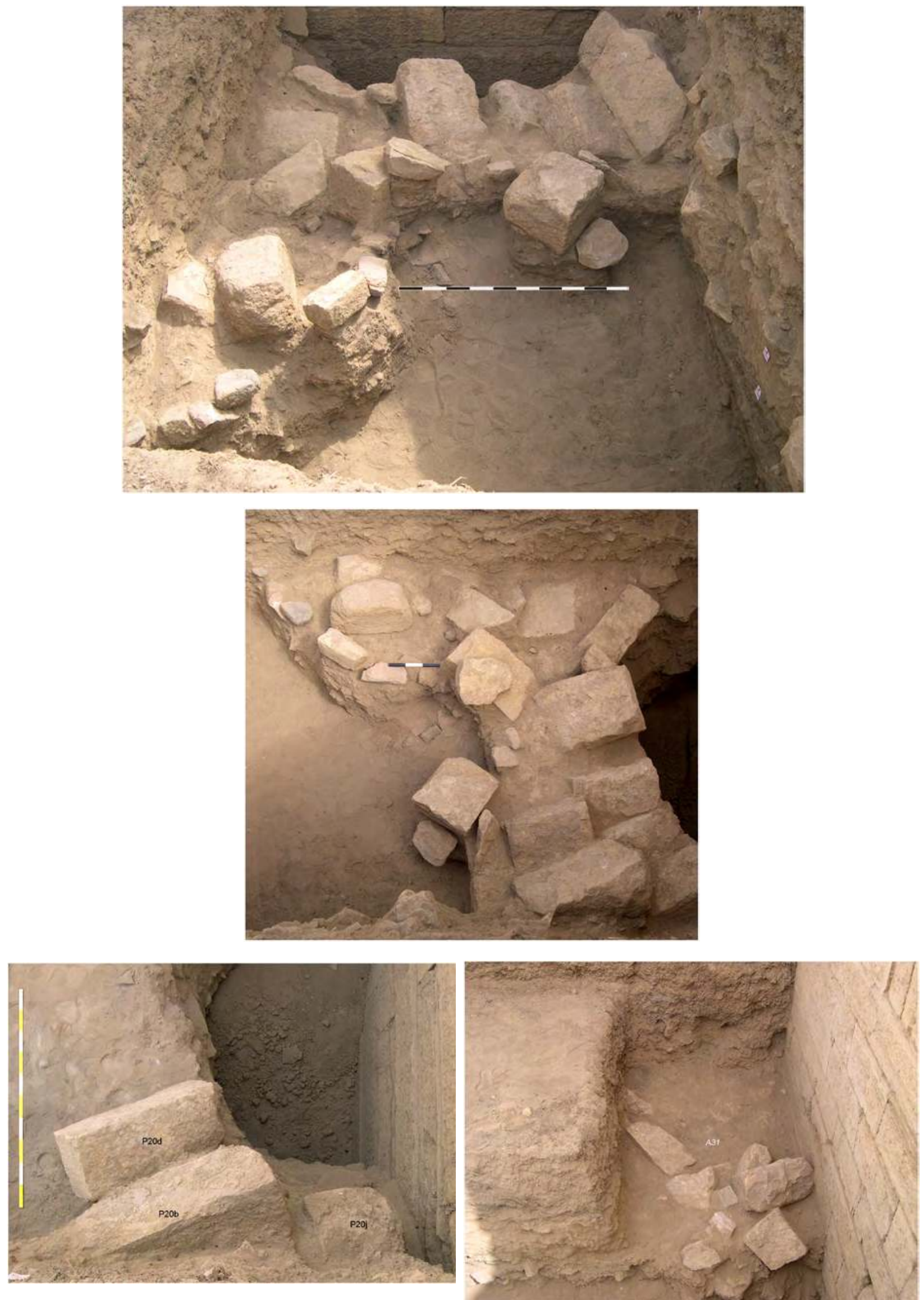

Figure 114. Sounding A, area A1-A31, collapse rubble T7A (blocks P20): rectangle A1-A12 facing east (top) and overhead views (middle and below left); quadrangle A31 facing north (below right). (P. Morlupi 2006 ○ MAIRY, adapted and optimized by F.G. Fedele 2020) 

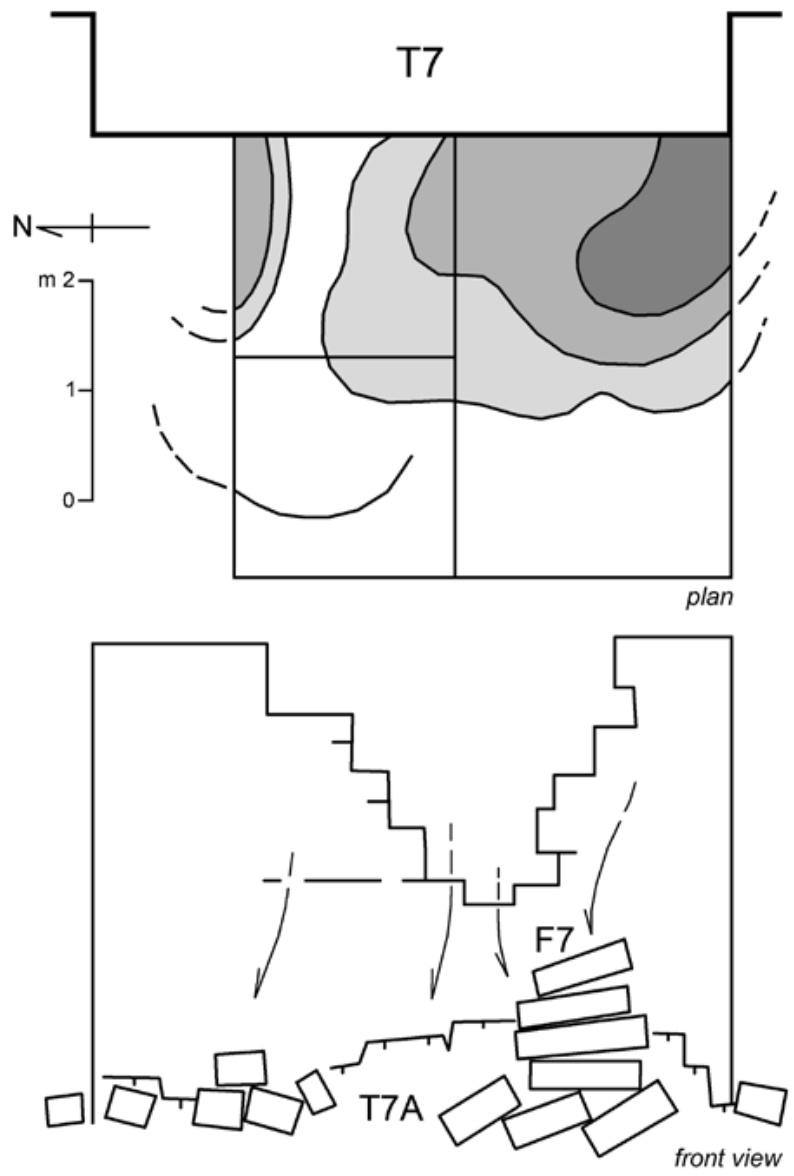

Figure 115. Sounding A, collapse rubble T7A: non-quantitative isopach map of the accumulation (above) and schematic reconstruction of collapse (below, for orientation only). (F.G. Fedele 2018)

was considered stratitaxic, i.e. Minaean. The same unit also produced an unusually large fragment of a clay disc (no. 2.01) and a foot of a clay 'tripod' (no. 2.03), which considering their wear (grade 3) possibly represent reworked Sabaean items. About all these finds see Chapter 21, section 2.3 (including footnote 167 about no. 2.01).

\section{Stratum F}

Stratum $\mathrm{F}$ is exclusively represented on the talus in Sectors B and C - rather the tell's edge than the talus proper. It is lithostratigraphically defined by a single unit in Sector B, unit B02 (a component of sediment group GB1). In Sector C, bottom to top, Stratum F is defined by the sequence of units SPD, C $\lambda \mathrm{V}, \mathrm{CI} 2$, DGX, CUV-CUV', CI1, and CU7, this latter topped by surface S22. This sequence shows on the Reference section as a structurally complicated arrangement of numerous small units and subunits (Fig. 18); it was briefly summarized at the end of section 15.1 above.

B02 designates a layered sequence of fines containing stone levels. It is rather heterogeneous in terms of sediments, and therefore not really elementary as a sediment unit should be, but for the time being this classification is sufficient and can be retained. Three main vertical partitions and several other subunits were identified, principally from the study of sections. $\mathrm{BO}_{3}$ is a loam essentially composed of silt and fine sand, and punctuated by 'white specks'. ${ }^{380} \mathrm{~Pb}$ identifies a swarm or swarms of angular stones within B02, apparently including $\mathrm{P} 8$, a slab-like block resting on the top of $\mathrm{BV} \mathrm{.}^{381}$ B02 $\alpha$ identifies in turn a clayey-mottled facies of upper B02, unusually characterized by a light blue or 'azure' background; its boundaries are diffuse. This subunit becomes thicker eastwards, and tends to be more grey and porous in its lower part and increasingly calcitic towards the top; on the west section of the trench it contained a large flat stone resembling $\mathrm{P} 8 . \mathrm{BO}_{2}$ is a darkish sandy loam (organic?), containing stones. $\mathrm{Bn}$ is a lens of hazel-coloured fine sand, intercalated between $\mathrm{BO}_{2}$ and $\mathrm{B} 02_{1}$.

$\mathrm{B}_{1}$, the top partition of B02, is a sand level containing limestone flakes from a rock unlike that of the Minaean wall and other sporadic angular stones of cultural origin, together with sparse 'domestic' residue. These flakes and fragments from limestone cobbles or blocks probably point to the same stone-chipping activity recorded in Stratum F at bastion T7 (see sections 11.311.4 above).

In Sector C, unit SPD is a hardened tongue or talus - or lens? - made of stony fine sand. The stones are small and sporadic (the unit's lower and eastern parts are virtually stoneless) and the matrix tends to break into hard peds $0.5-1 \mathrm{~cm}$ in size. SPD envelops at its base P9A, a slab-like block resting in part on the top of L13. In all probability the emplacement of P9A was synchronous with that of a similar block a little to the west, P9, resting on C C V : an example of 'fractionation' of a sediment unit. ${ }^{382} \mathrm{C} \lambda \mathrm{V}$ is a thin, extensive plant-detritus unit covering DGV-L13. It apperas on the Reference section as a dark, wavy line markedly dipping east. DGX is a $25-\mathrm{cm}$-thick layer of unsorted fines (mostly sand) replicating the orientation of $\mathrm{C} \lambda \mathrm{V}$; it contains sparse fine gravels. Perhaps a mere variant of DGX is CI2 ('I' for indeterminate), as understood in the field, but reclassified here as an autonomous unit.

CUV is a thick, irregular, manure-and-charcoal lens or ribbon of lenses, dark in colour and markedly undulating and discontinuous. A detached lens in the eastern part of sector, labelled $\mathrm{CUV}^{\prime}$, might well be part of it. CUV' entirely consists of dark grey, straw-like plant

\footnotetext{
380 of a soft variety in this case, dubiously interpreted in the field as gypsum. On white specks see section 4.1 above.

381 On the possible origin and role of P8 see section 15.1 above.

382 On the possible origin and role of P9 and P9A see section 15.1 above; 'fractionation' was defined in footnote 366.
} 
นо!ฺวәร әวนәرәуәу

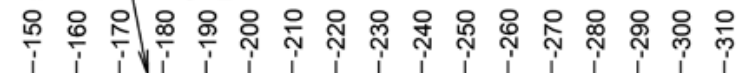

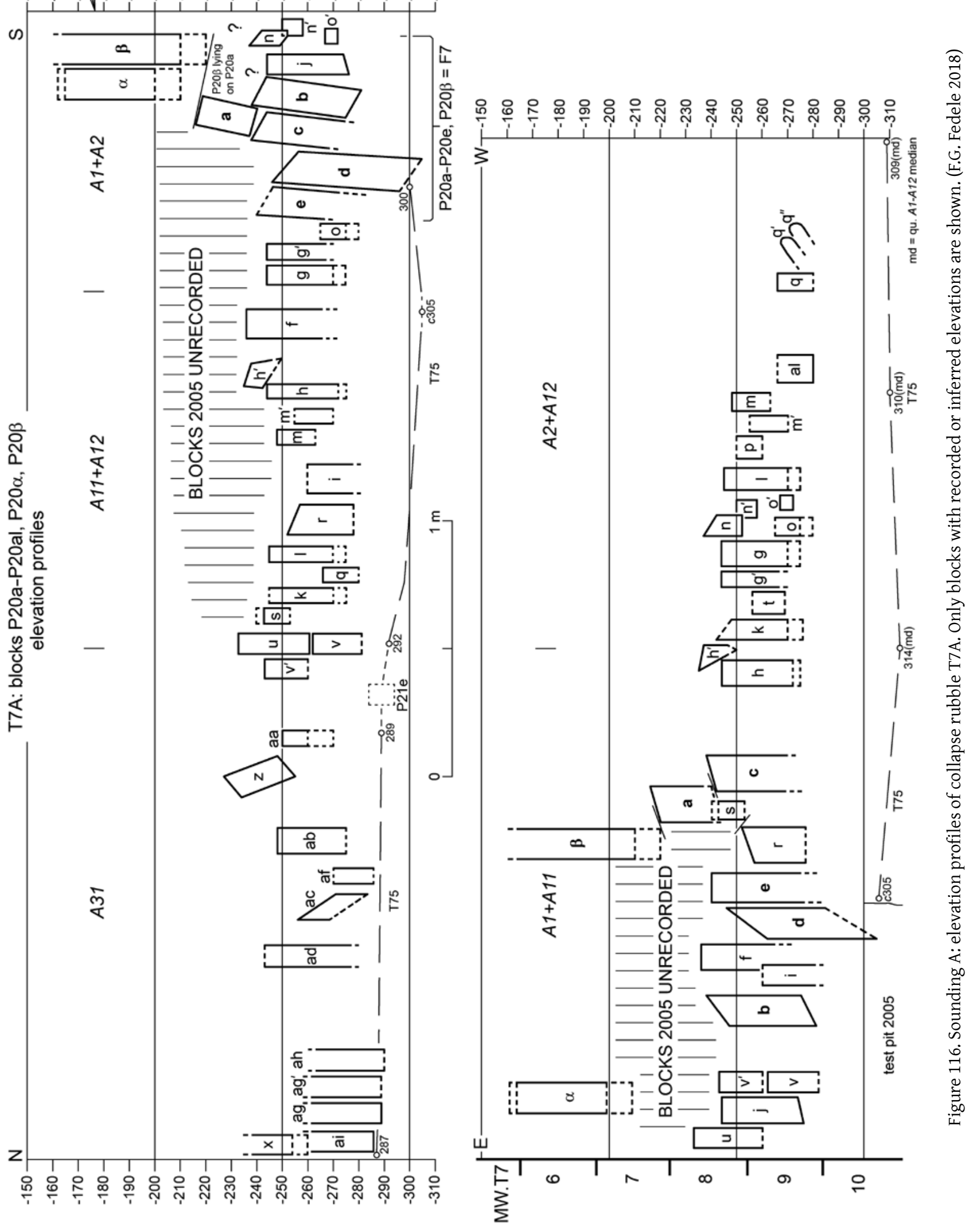



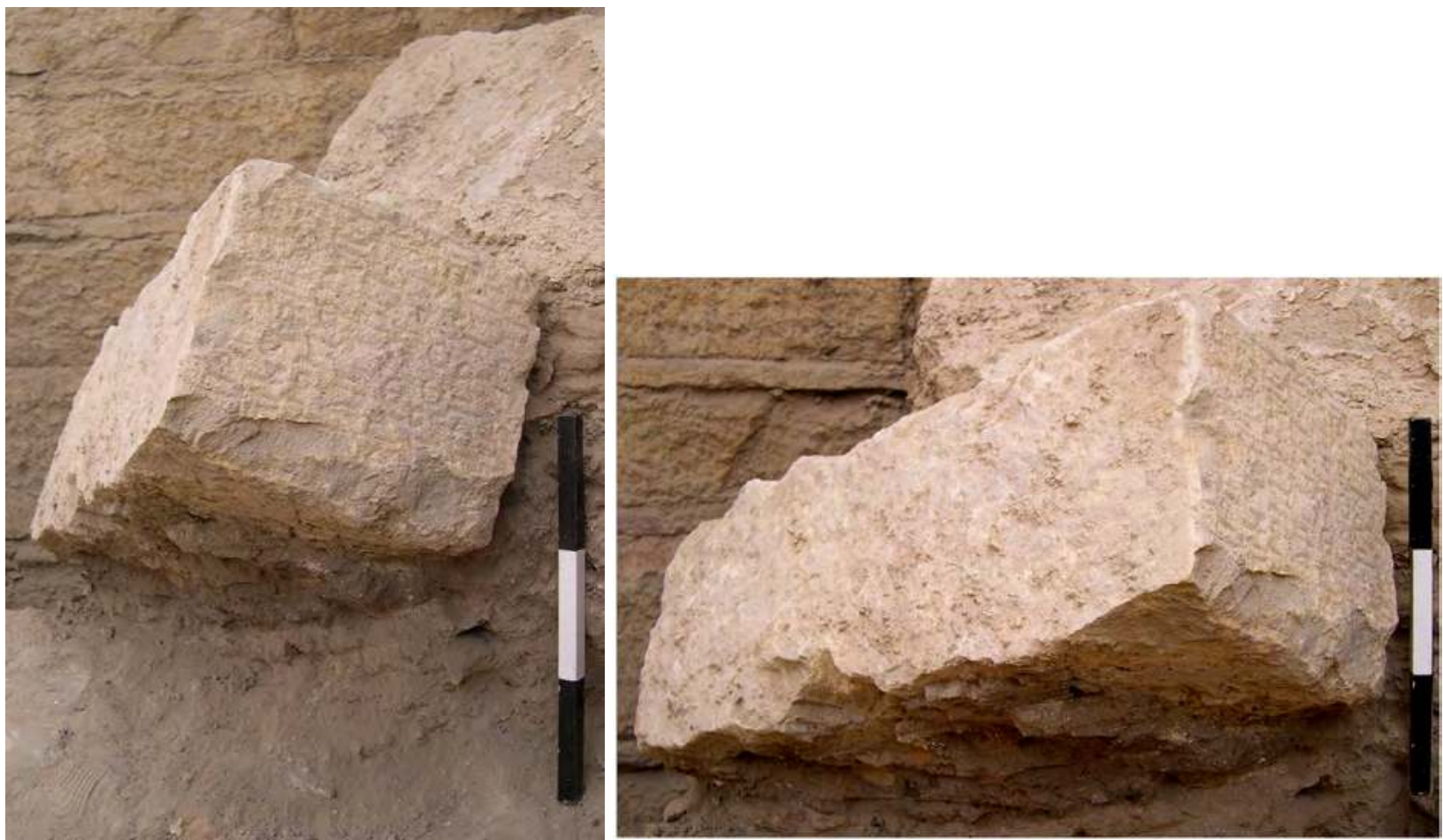

Figure 117. Sounding A, collapse rubble T7A, epigraphic block P20d. (P. Morlupi 2006 @ MAIRY, optimized by F.G. Fedele 2019)

detritus. Unit CI1 ('I' always for indeterminate) is very fine sand. CU7 is another fairly thick layer of unsorted loamy-gravelly sand, with medium sand predominant, containing in its upper part scattered stones, eastwards, and a veneer of 'pure' beige silt to the west. This latter, CU7 $\alpha$, has a transitional contact with main CU7 and is similar to CI1 a little below in the sequence, but darker. The sequence of Sector $C$ attributed to Stratum $F$ is finally topped by a distinct surface, S22.

\section{Stratum G (including a 'window' view from Sector D)}

As explained in section 3.3, Stratum $\mathrm{G}$ is a conventional construct based on parallel, 'floating' sequences restricted to the lower talus and the plain, from quadrangle E4 downwards and westwards, with the exception of a stratigraphic 'window' in Sector D. On the middle and lower talus, Stratum $G$ is broadly equivalent to Strata $\mathrm{F}$ and $\mathrm{H}$ together, and it is for this reason that it is examined here after Strata $\mathrm{H}$ and $\mathrm{F}^{383} \mathrm{In}$ Sector $\mathrm{E}$ it is lithostratigraphically defined by a large number of sediment units: e7, $\mathrm{x} 4, \mathrm{E}_{2} \mathrm{E}_{1-2}$, L4, suite Lgh, E2a, Le, EX1, EX1e, E84, E $\sigma 2, E 83$, and part of $\mathrm{E} \sigma \mathrm{W}_{2}$. An additional unit correlated with Stratum G, F02 from Sounding F, will be described in section 17 below.

383 The same reasons were evoked for Stratum $\mathrm{M}$ in section 7.1 on the Later Sabaean (above), which was similarly treated after Strata $\mathrm{N}$ and $\mathrm{L}$.
Throughout the Later Minaean the erosion of the talus and tell progressed, contributing to sedimentary buildup in middle and lower Sector E. Although uncorrelatable in detail, several sand sheets of middle and lower Sector E speak for the continuing interplay of slope erosion, aeolian deflation, and windblown sediments during the interval of Stratum G. Modelling in terms of sediment groups E1, E2, EX3, and EX4, describes the lithostratigraphy of these 'upper sands' in a belt at least 8-metre-wide along the present-day base of the tell, encompassing not only Stratum $\mathrm{G}$ but also I, D, and B (Figs 21-22). ${ }^{384}$

Such an incremental buildup of sand and silt during the Strata I-D timespan is increasingly pronounced lower down and away from the talus. In quadrangle E11 it materializes as $\mathrm{E} \sigma \mathrm{W}_{2}$, a condensed, diachronic body showing remarkable facies continuity, ${ }^{385}$ as already described in section 15.2 above ('Stratum I'). In this same quadrangle, the sub-horizontal sedimentation planes very slightly inclined west as revealed by minimal tip-

\footnotetext{
384 See 'On the sand mantle of the lower talus and at the foot of talus' in section 4.2, above, and a parallel mention in section 15.2, "Stratum I'. Paragraph 'On cultural materials embedded in the "upper sands"' in section 4.2 summarizes evidence for an absence of human and animal circulation on the steeper part of the talus - the flexure and high-acclivity belt of the middle-lower talus, quadrangles E5-E7 during the Minaean 2 and throughout the Later Minaean.

385 However, there must have been interruptions and gaps, as mentioned in the preview of tell and talus evolution (section 4.2 above). Indicators of internal layering in sands $\mathrm{E} \sigma \mathrm{W}_{2-1}$ are elusive.
} 

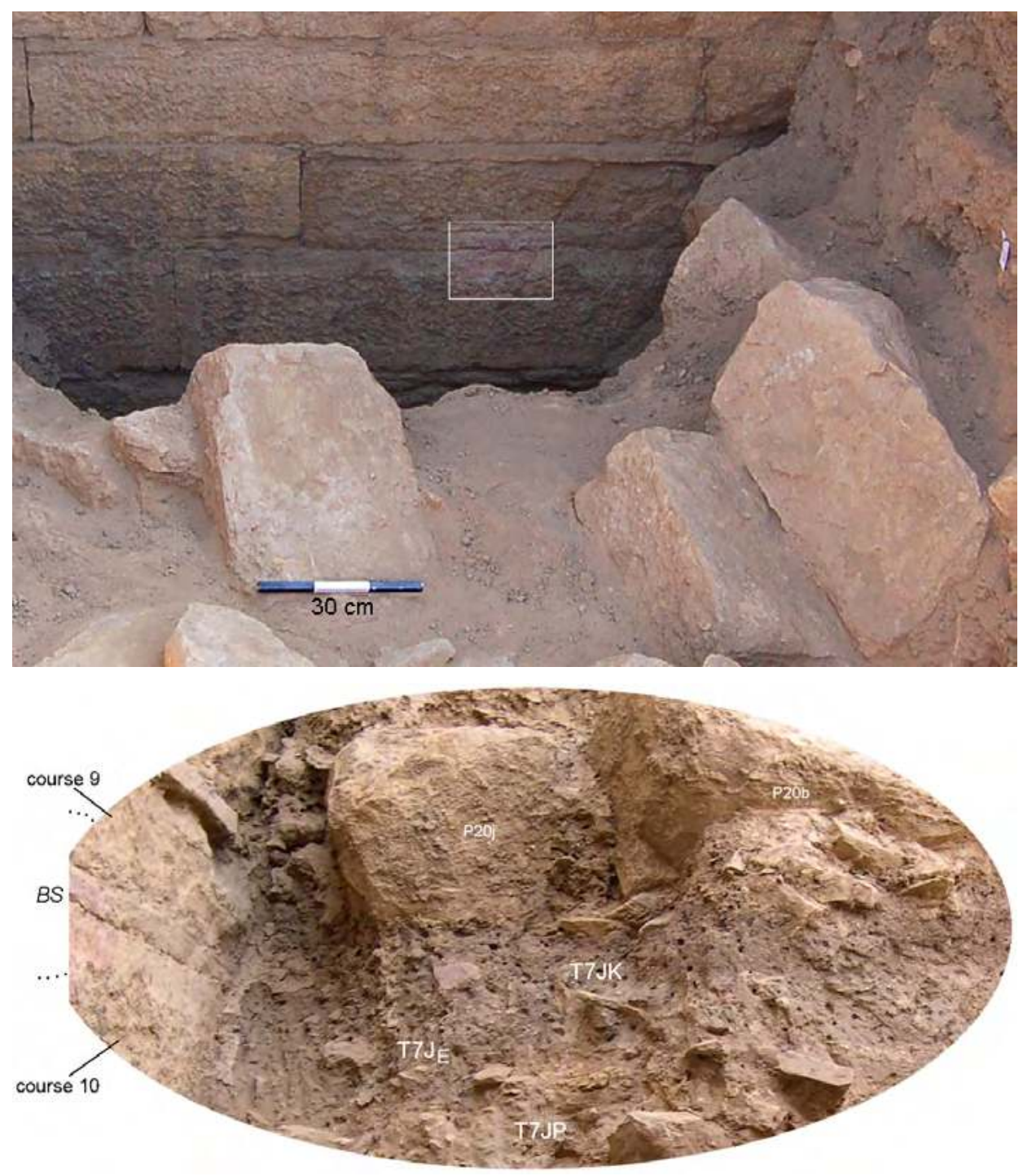

Figure 118. Sounding A: the 'burnt spot' (BS) on the Minaean wall. (P. Morlupi 2006 @ MAIRY, adapted and optimized by F.G. Fedele 2019)

lines - change to virtually horizontal planes during the deposition of $\mathrm{E} \sigma \mathrm{W}_{2}$ and across the contact with $\mathrm{E} \sigma \mathrm{W}_{1}$.

Unit e7 is a 10 to $20-\mathrm{cm}$-thick sheet of silty sand, greybeige in colour, sporadically containing artefactual debris (Figs 40, 47). This unit is noteworthy as it represents the basal layer and the effective beginning of the aeolian regime still in operation today, at least on the middle talus (quadrangle E5). It transitions downslope into the thick upper part of sand-silt E2E, which in the western half of quadrangles E6-E06 clearly divides into two superposed layers, $\mathrm{E}_{2} \mathrm{E}_{2}$ and $\mathrm{E} 2 \mathrm{E}_{1}$. As a whole, ${\mathrm{E} 2 \mathrm{E}_{1-2}}$ consists of colluvially redistributed aeolian sands and silty sands (cf. E2 $\mathrm{E}_{3}$ described above, Stratum I), but compared to both $\mathrm{E}_{2} \mathrm{E}_{3}$ and e7 it is characterized by a much greater deal of inclusions containing cultural debris and gravels. These inclusions are represented by suite Lgh and L4.
Lgh, a 'planar' suite distributed between quadrangles E06 west and $E 7$, is a string or lenticular bundle of colluvial debris: an undulating series of sandy, coarse-debris lenses intercalated between E2b and E2a. Lenses Lh and $\mathrm{Lg}$ are the only two certain, discernible units in a series of similarly ill-defined microunits. Lh contains smaller stones, $\mathrm{Lg}$ is associated with a scatter of medium stones and seems to contain more potsherds. Unit L4 survives as a series of fine-rubble pockets within uppermost E2E, its top contact with overlying EX6 (Stratum D) showing characteristics of a sharply eroded surface.

Very interesting is unit $\mathrm{x} 4$, spanning the talus flexure in quadrangles E4-E5: it is one of the two vegetal-debris units of group EX4, intercalated by sand e7. The other and earlier one is $\times 5$, described under Stratum I. Also $x 4$ consists of aeolian-colluvial, detritus-rich sand and silt, brownish to grey in colour, containing the occasional 
tiny potsherd. Being colluvial, not from primary deposition, these 'brown' units blanketing the middle talus provide an acceptable link to Sector D: their origin can only be traced to the idiosyncratic manure layers of Strata K to I, located on the talus from upper Sector D upwards.

Sand E2E $\mathrm{E}_{2}$ correlates downslope with E2a, an aeoliancolluvial sand similar to E2b described under Stratum I. In turn, further west, E2a shades into, or share an uncertain contact with, sand Eø2, intercalated between E84 and EX1e-E83 in quadrangle E8 (Figs 47-48).

Unit EX1, overlying E2a and 'rooted' in upper E2E, is a rather conspicuous body of relatively coarser sediment spreading for about 3 metres between quadrangles E6E06 west and E8 east (Figs 47-48). It is a discontinuous, darkish lens of aeolian-colluvial sand rich in organic 'earths' and minute cultural debris, including meltedmudbrick pebbles. In section EX1 looks like a chain of fine-gravel pockets - and a ribbon with constrictions, due to its variable thickness and interruptions. At its eastern and western ends, respectively, subunit Le is a coarse-sand pocket or lens, exclusively identified from the recut section (E06), ${ }^{386}$ and EX1e is a multiple, detached partition which the Reference section only captures imperfectly.

As described under Stratum I in section 15.2, above, a regular alternation of sand sheets and half a dozen lenses of grit and gravel, with the occasional potsherd (units E85-E80), characterizes western quadrangle E8 (Fig. 48). Lenses E84 and E83, attributed to Stratum G, are merely part of this sequence. The reader is referred to section 15.2, 'Stratum I', for a description of sand $\mathrm{E} \sigma \mathrm{W}_{2}$ as well.

From Stratum I or $\mathrm{G}$ in quadrangle E8 (sediments Eб3Eб2, E84, EX1e) a fragment of a softstone vessel was retrieved (no. 81.01).

The stratigraphic 'window' referred to in the title of this subsection is represented by two microalluvial units unearthed within Gully B, in middle-lower Sector $D$, which can reasonably be attributed to Stratum $G$. The technical term window is justified by the fact that Strata G to B, insofar as they are represented by hidden layers inside the talus, are only known from the limited excavation of the fills of Gully B.

The two microalluvial deposits, filling palaeo-channels within the gully, were studied on the occasion of a tactical emptying of the gully for the purposes of excavation in Sector D (cf. Fig. 36 B). ${ }^{387}$ This revealed

\footnotetext{
386 In spite of proximity, Le has nothing to do with suite Lgh.

387 In the present context 'microalluvial' refers to deposits essentially pluvial in origin. On the archaeological exploration of Gully B see
}

that furrows somehow precursors of the present-day gully had existed for a long time, only oscillating a little around the same axis or radius. Buried within the sediments of the gully, a distinct morphology, furrow F1, and two sufficiently definable sediment units, XF1 and YSP, were recognized (Figs 119-121). Both are undatable, in fact, but a plausible interpretation of the evidence suggests Stratum $G$ as the most convenient correlation. A less likely alternative, considering the geometry of their position within the talus, is their attribution to the subsequent 'floating' sequence, Stratum D (cf. section 4.2 above).

XF1 is a pluvial watercourse accumulation consisting of a mixture of unsorted rubble and cobbles and worn-out Sabaean and Minaean pottery fragments, in a yellow-sand matrix clearly derived from Sand YS. It is closely associated with a palaeo-channel of the gully, environmental feature F1, of which evidently it is the fill (Figs 36 B, 120; 119, plan). Stratigraphically it postdates GKk in quadrangle D5, i.e., it is coeval with, or later than, Stratum N.

At least a depositional analogy is admissible between F1, with its fill, and unit YSP, a sediment body unearthed within the same gully - or even the same paleo-gully - just downstream of F1 (Fig. 119). Located between quadrangles D6-D16 and D7-D17, YSP is more problematic. This buried body consists of chaotic debris and yellow sand ('YS' in its code name evoking Sand YS), but its morphology is not as clear as in the case of F1: within the limits of the excavation it occupied an erosional depression cut into sand YSd whose cross-section did not look furrow-like (Figs 119, 121). The generally small rubble and pottery fragments of YSP, being unsorted and angular, rather suggest slide material from the near bank of the palaeo-gully, quite possibly redeposited through short water transport. YSP contained Red Lustrous pottery fragment no. 49A.1, a 7.5-cm-long rim piece with raised loop handle, also notable for its relatively sharp condition (wear grade 1 ; see Chapter 23, section 3.4, this volume).

\section{Strata $\mathrm{E}$ to $\mathrm{A}$ on the tell's edge and the talus: Second Intermediate, Islamic, and recent periods}

N B. Stratum D will be treated after Strata E and C, as it temporally encompasses both.

\subsection{Stratum $E$}

Like Stratum F (section 15.3 above), also Stratum E is exclusively represented on the talus in Sectors B and C - rather the tell's edge than the talus proper. Here Stratum E is lithostratigraphically defined in Sector $\mathrm{B}$ by units BV1, B01, and BV0, topped by surface S20;

section 6.6, including footnote 158 . 
and in Sector C by units CU6, CU5b, and CU5i. Units BV1, B01, and BV0 are component of sediment group GB1, defined at the end of section 15.1, above, together with a brief summary of the sediment sequences from Sectors B and C.

During the revision of stratigraphy for this book it was felt useful to order in a sediment group units CU5b to CU5a of Sector C. Named CU5, this is one of the groups that are defined by sediment units alone (Table 2). CU5b and CU5i can tentatively be correlated with Stratum $\mathrm{E}$ and will be described below, whereas CU5a will be examined in the next section under Stratum $C$.

In Sector B, hazel-coloured BV1 is a plant-organic unit, followed after an interval by a similar, but typically brown layer composed of proper manure, BV0 (cf. section 12.2 above); this latter is thicker and internally stratified towards the east (Figs 17, 26). These two units are separated by B01, a 25 to $30-\mathrm{cm}$-thick bed of fine-gravelly, fine-sandy silt with minute charcoal, ${ }^{388}$ completely concordant with both BV1 and BV0 in terms of sedimentation planes and morphology. From the Reference section it appears that these three units were all deposited on the tell's edge within a shallow, north-south trending depression, i.e., roughly parallel to the Minaean wall. This sequence is topped by a marked discontinuity, probably indicating erosion and involving a temporal hiatus (surface S20). ${ }^{389}$

Similarly in Sector C, unit CU6 is - or contains - a leached hearth, F22, recognizable from the association of particular sediments and a half-quern (see below). The quern appeared to be resting on S22, a fairly sharp surface, described under Stratum $F$ in section 15.3. ${ }^{390}$ CU6 is a conspicuous, undulating, whitish lens characterized by ash and copious charcoal, this latter in large part comminuted. It varies in thickness and is uniclinal, with dip east, as it closely follows the counterscarp orientation of the underlying units belonging to Stratum F. This orientation will be changing to nearly horizontal with the subsequent onset of sediments CU5b.

While the BV1-BV0 sequence in Sector B suggests ephemeral stops by people and animals, CU6 thus provides minuscule but direct evidence for an episode of 'domestic' activity on the slopes of what might have been by now a deserted mound - save perhaps squatters. This phase, as viewed from Area C, will be thoroughly discussed in Chapter 18, this volume (section 3.4, "From "Yathill” to "Barāqish").

\footnotetext{
388 As a sediment, B01 is similar to B03 deeper down (Stratum H).

389 Surface S20 would 'clearly reflect a significant temporal hiatus' (Fedele 2010, 140).

390 S22 would correlate rather easily with a gap of the order of a few decades or generations: cf. Chapter 18 , section 3.4 , this volume.
}

A layer up to $35 \mathrm{~cm}$ thick, CUb must correspond to a prolonged period of sand and gravel deposition and complete human inactivity outside the walled town; a state of non-occupation inside the town might well be implied. It is both characterized by reiterated, diffuse lenses or pockets of gravel and angular rubble, and by a relatively chaotic structure of the sandy or unsorted matrix in between. CU5i is a veneer of fine sand or silt apparently enriched by illuvial carbonates, beige in colour. Units CU6 and CU5b, possibly also including CU5i, have been tentatively correlated with the Second Intermediate interval on the basis of sedimentary affinity and relative stratigraphic position with respect to Sector B and Sounding A.

Finds. Two notable finds were recovered from Stratum E in Sectors B and C. One, from the test trench of Sector B, is a pointed, partly burnt wooden stake (no. 176.1), found vertically driven into manure BV0 and sandy silt B01 from a ground surface which probably corresponded to pre-erosion S20 (later Stratum E). This unparalleled find is described as an object in Chapter 21, section 2.4, this volume, and is mentioned and illustrated in Chapter 18, section 3.4, Fig. 5. The second find is the half-quern mentioned in the main text above, no. 170.1, found in situ in Sector C within unit CU6 (hearth F22). It is a $19-\mathrm{cm}$-long saddle quern obtained from a large cobble of vesicular basalt. It too is described in Chapter 21 , section 2.4 , this volume. ${ }^{391}$

\subsection{Stratum C}

Stratum C on the tell's edge and the talus is lithostratigraphically defined by two successive sets of sediment units and associated elements. To an earlier part of Stratum C we can attribute in Sector C units CU5a and CU1, and surface S21; in upper Sector D units SBL (quadrangles D4-D5) and possibly SA1 (quadrangle D3). Two rubble accumulations of Sector $B$, one marginally reaching Sector $C$, can be attributed to a later part of Stratum C: T6B and T6A (Figs 17-19, 24).

Unit CU5a was attributed to Stratum C (Islamic 1) on the basis of some large Islamic mud bricks and related debris. Two incomplete mud bricks, P50 and P51, were intercepted by the east section of the test trench, and the profile of P51, in the southeast quadrant of the trench, was drawn on the Reference section (Figs 18, 29). Apart from mudbrick content, CU5a is a nearly horizontal sand layer characterized by calcium carbonate concentrations and showing a level of stones and cultural fragments (much pottery) at the top. Its horizontality contrasts with the present-day inclination of the slope surface in the area of Sector C. CU1, a thin subsurface unit, consists of gravelly sand containing

\footnotetext{
391 For what it's worth, this half-quern is identical to Sabaean find no. 152.1 (Chapter 21, Fig. $12 \mathrm{~A}$ ) as well as to Minaean examples.
} 
abundant organic debris of cultural origin. Units CU5a and CU1 are separated by a distinct erosional surface, S21, defined as the bottom boundary of CU1.

On the present-day surface in Sector $\mathrm{C}$ is unit T6A, the downslope edge of the collapse cone from bastion T6 (see below). Here in 2005 the bottom of T6A was composed of hazel-grey colluvial earth infiltrating the collapse rubble, a sediment partly originating from decayed mudbrick.

Further downslope, two block horizons from subsequent wall collapses that 'streamed' down the talus coming to rest in Sector D were recognized, SBL and BLO. SBL, attributable to Stratum $C$ and the major one, is part of a discontinuous sandy-stony fan of Earlier Islamic age, according to some potsherds it contained. Both rubble streams must derive from the T5-T6 segment of the Minaean or Minaean-Islamic wall, but it is not yet clear with which wall collapse or collapses SBL and BLO are correlated. SBL would link up temporally with an earlier part of Stratum C. The second rubble generation, BLO, will be described in section 16.4 below (Stratum B or A).

SBL designates a major mass slide of sand and blocks down the talus, recorded in D4-D5 and including - along the Reference section - blocks P10, P14, and P15. Block $\mathrm{P} 10$ is a $45-\mathrm{cm}$-long calcarenite parallelepiped at the eastern side of quadrangle D5, inclined $45^{\circ}$ west (Figs 33-34, 36; 63, plan). All blocks are angular elements from the Islamic restoration of the town wall. Block stream SBL also involved plant detritus and potsherds (among these latter, a large rim fragment of a Minaean jar). It was deposited on erosion surface S04.

Unit SA1 is loose, pure sand, dull-grey to yellowish-grey in colour, exclusively observed above Mass GR1 (F9) and decayed mudbrick GRx in D3, where it marginally underlies subrecent-recent sand SA0 (Stratum B or A; see section 16.4 below). This superposition is the only reason for tentatively attributing SA1 to an earlier date, hence perhaps Stratum C.

In Sector B, the upper half of the sequence is occupied by blocks, rubble and masses of mudbrick from a substantial wall collapse, to be identified with the first major collapse from bastion T6 (units T6B, T6A, T6A $\lambda$; a single layer in spite of the different sediment bodies involved) (cf. Fig. 28). The T6 debris fan can partly be seen above ground near the Minaean-Islamic wall (Fig. 16; see plan in Fig. 6). According to the materials, the collapse of T6 involved Islamic dwellings attached to the ancient wall and must thus have occurred relatively late during the Islamic period (Islamic 2). Some stones from T6B-T6A seem to have reached Sounding A, where they occur towards the top of suite $\mathrm{T} 74 \mathrm{U}$, an acceptable clue to correlation (see section 14.1 above), while the lower end of rubble T6A reached Sector $C$ (as also mentioned above). Apart from minor decay, no further wall collapse is documented in the portion of Minaean wall corresponding to recess R6/7. The base of collapse accumulation T6B-T6A is surface $\mathrm{S} 20$, described in the previous section.

More precisely, T6B must be part of the rubble heap from an initial phase of the bastion's collapse, comprising blocks, smaller stones, and fines. From field and photographic evidence a single collapse event, followed by redeposition down the talus in two or more phases, can probably be inferred. Several potential subunits visible within T6B and outlined on the Reference section (including small masses of fines) cannot be formally identified because of insufficient field definition. T6A is a sheet of fines and sparse stones, the fines mostly formed of melted mudbrick ${ }^{392}$ and the stones comprising small blocks and finer rubble. It represents the edge of the last collapse fan from bastion T6. Included within T6A and continuing out of trench to the east is a swarm of lenticular bodies, T6A $\lambda$, made of laminated units; one of these small lenses contained bones. The possibility that collapse debris from bastion T6 marginally reached the area of Sounding A was examined at the end of section 14.1, above.

Finds. From Stratum $\mathrm{C}$ on the talus several notable finds were recovered (for description see Chapter 18, Appendix, this volume). Rubble T6B-T6A in Sector $B$ included two large fragments of rotatory querns, made from a fine-grained, pale green to grey tuff (one fragment kept, no. 175.1; the other one is no. 175.01). In all probability they were part of the blocks of unit T6B. From the same context a square-angled mud-mortar fragment from two masonry joints was retrieved, about $15 \mathrm{~cm}$ long (no. 175.04; pictured in Chapter 18, Fig. 6). It contributed to the opinion that Islamic buildings had been involved in the rupture of bastion T6. Among finds of less certain stratigraphy from Sector $C$ which might be dated to Stratum C, two can be noted: a fragment of a polychrome glass armlet (no. 170.02) and a large fragment of a softstone cooking pot, or burm (no. 170.01).

Sand SA1 from quadrangle D3 produced a bored globular bone bead, probably Islamic on typological grounds (no. 10.01). The artefactual aggregate of cut 10, however, also contained several abraded Sabaean potsherds and two rim fragments from one or two small calcite/aragonite plates, Minaean or Sabaean in origin (cf. finds nos 10.1a-1b and footnote 216 in Chapter 21, section 2.5 , this volume).

\footnotetext{
392 This colluvial matrix is locally laminated, which suggests that it was washed in as mud.
} 


\subsection{Stratum D (lower talus only)}

Stratum D, restricted to a lower part of the talus from quadrangle E4 downwards and westwards, is lithostratigraphically defined by group EX3 and

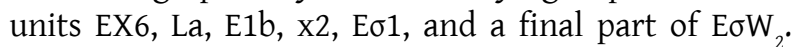
In Sounding $\mathrm{F}$, according to the preferred correlation option, it is defined by subunits $\mathrm{F}_{0} 1_{2}$ and $\mathrm{F} 01 \alpha$ of unit F01 (see section 17 below).

As previously explained, Stratum D is a conventional construct established on the basis of a 'floating' sequence from the middle-lower talus and presumably Sounding F. It accounts for some lithocomplexes of general Second Intermediate and/or Earlier Islamic age from Sector $\mathrm{E}$ and the plain. As it is broadly equivalent to Strata $C$ and $E$ together, the above observations on Strata E (section 16.1 above) and C (section 16.2) are potentially relevant to Stratum D as well.

A continuing, sustained erosion of talus and tell can be documented during Stratum D. Aeolian activity was important and perhaps increasing, with predominant accumulation in middle-lower Sector E and - possibly - stronger deflation on the plain. The thickest and most conspicuous aeolian-colluvial accumulation of Stratum D can be observed on the talus flexure in quadrangle E5, where it corresponds to sediment group EX3 (units e6i to e2) and part of group E1 (units EX6 and La to X2-E1b). In middle $E 5$ these sediments are up to about $70 \mathrm{~cm}$ thick and complicated in the extreme by a number of sinuous and often extensive colluvial inclusions (Figs 21, 40). Several of these levels thin down westwards as colluvial punctuations within the essentially windblown sands (E1b, Eø1). EX3 continues the sedimentary trend of EX4 (Stratum G, see section 15.3 above).

Units e6i, e6, and e2 are consecutive sheets of part primary, part redeposited aeolian sand. All reveal tracts of convoluted bedding. The thickest unit is e6, a grey-beige silty sand blanketing a 3-metre-wide belt between quadrangles E4 west and middle E6-E06. LB and LB1 form - in section - a distinctive 'white ribbon' of hearth-derived ashy fines, apparently discontinuous and showing unusual tongue protrusions. Particularly ashen-white in colour and partly better defined is LB, while LB1 has very vague boundaries and an elusive 'root' to the east. The field records do not make clear if part of the white in these sediments was in fact caused by white specks, as seems possible.

Lenses $\mathrm{x} 3$ and L3 both consist of darkish, aeoliancolluvial coarse sand transporting minute stones and cultural debris, this latter slightly larger in L3. The two lenses were only identified on the Reference section and might actually form one single unit elsewhere around quadrangle E5. It is not impossible that L3 is the upslope 'root' of unit EX6 in E6-E06, in which case sediment groups EX3 and E1 would conveniently merge into a single, more comprehensive group. That groups EX3 and E1 are essentially continuous with each other is clear.

Also group E1 comprises a sequence of aeolian sands containing important aeolian-colluvial units of mixed sand and debris (EX6, La, X2), straddling the limit between Strata D and B (Figs 40,47). Unit EX6 is a thick lenticular body with aeolian-sand matrix containing a cluster of large cultural debris, mainly potsherds (quadrangles E6-E06). EX6 seems to interfinger with the lower partition of $\mathrm{E} 1 \mathrm{~b}, \mathrm{E} 1 \mathrm{~b}_{2}$, but some details of sand-on-sand stratification at the boundary between quadrangles E6(E06) and E7 could not be clarified. ${ }^{393}$ The interposition of fine-gravel lens La allows unit E1b to be subdivided into $\mathrm{E} 1 \mathrm{~b}_{2}$ and $\mathrm{E} 1 \mathrm{~b}_{1}$. As a whole, $\mathrm{E} 1 \mathrm{~b}$ consists of pale yellow, aeolian fine sand and silt containing pottery fragments, and extends continuously from quadrangle $E 5$ to $E 8$ increasing in thickness down-talus. Aeolian-colluvial lens $\mathrm{x} 2$ is rich in plant detritus.

Evidence for a probably complete absence of human and animal circulation on the steeper part of the talus during the Second Intermediate period was summarized in section 4.2, paragraph 'On cultural materials embedded in the "upper sands"'. The area in question is the flexure and high-acclivity belt of the middle-lower talus in quadrangles E5-E7.

Down in quadrangle E8, sand E $\sigma 1$ follows EX1e (Stratum $G)$ and inserts itself between sequential debris levels E83 (also Stratum G) and E82 (Stratum B) (Fig. 48). The eastern boundary of E $\sigma 1$ is uncertain and problematic, as is its vertical partition into two, apparently parallelling that of E1b.

\subsection{Strata B and A}

\section{Stratum B}

The description of Stratum B is better started mid-talus with Sector D. In this location two sediment units were recorded that can be attributed to either Stratum B or Stratum A: sand SA0 and block 'stream' BL0 (Figs 1819, 24). SA0 designates the blanket of mixed, sparsely stony, debris-enriched subsurface or surfacing sands of quadrangles D4-D6 (Fig. 33 B). It was deposited above erosion surface S03 (quadrangles D4-D5). In quadrangle D6 it underlies stony sand SAp, which is why it could rather be attributed to Stratum B than A, or, better still, be classified as Stratum B but time-transgressive into Stratum A. Sand SA0 might be one and the same with

393 This was because the collapsed north section of E6-E7 had to be studied from photographs and the re-cutting and recording of E06 in 2006 left some discrepancies unresolved. Cf. section 3.2 above. 
BL0, a second slide or 'generation' of stone blocks down the upper talus after SBL, and much similar to it (see section 16.2 above). BL0 lies off the excavation trench to the south, and only a few large blocks approach the Reference section, near quadrangle D5 (cf. Figs 34, 36 A; general views in Figs 14-16).

Far off on the lower talus and beyond, east to west from quadrangle $E 3$ to quadrangle E11, Stratum B is lithostratigraphically defined by unit E1a; suite E1ع8; units $\mathrm{E} \sigma 0$ and $\mathrm{E} 82$ to $\mathrm{E} 80$; suite F2F3 and features F2 and F3; feature F2A with its fill $7 \varphi$; unit Pw; subunit $\mathrm{E} \sigma \mathrm{W}_{1}$ of sand $\mathrm{E} \sigma \mathrm{W}$; and unit TGh, contained within features F20a-F20g. In Sounding F, according to the preferred correlation option, Stratum B is defined by subunit F01 of unit F01 (see section 17 below).

Together, excluding stony bodies and ground features, all these sediments constitute a further, considerable package of sands and silts whose thickness increases gradually downslope to reach $0.7-0.8 \mathrm{~m}$ near Hill $\mathrm{E}$, while it thins to half a metre west of the hill (quadrangle E11) (Figs 22, 47-50). Alternating aeolian deflation and accumulation apparently kept increasing during this phase. The upper part of this lithocomplex was truncated in quadrangles E7-E8 and possibly as far as quadrangle E11 by a unique group or spread of sediments and features, including suite F2F3 and pits (or furrows?) F2, F3, F2A, and F20. As they belong to a later part of Stratum B, these latter sediments and features will be examined at the end of this subsection.

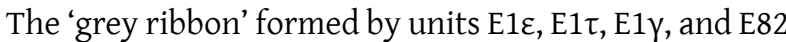
('planar' suite E1ع8), gently sloping across quadrangles $E 6$ to $E 8$ and pertaining to earlier Stratum $B,{ }^{394}$ has been attributed particular importance in the lithocorrelation of the lower talus and footslope with layers of the upper talus, and therefore in the sequencing of Area C. For its particular loamy texture and organic contents, as well as stratigraphic position, this colluvial suite can almost exclusively be linked to Islamic 'earth' deposits such as those resulting from wall collapses like T6B-T6A (Islamic 2). ${ }^{395}$ More precisely, E1ع8 consists of grey-brown organic sediments containing white concretionary micronodules (white specks, or infiltration of diagenetic $\mathrm{CaCO}_{3}$ ?), and as a whole reveals a distinctly linear and regular contact with underlying E1b. It thus marks a relatively new sedimentary episode in Area C. Its unit E1Y is a thick and conspicuously grey mega-lens with both ends rather blurred, whose unmistakable body suddenly stops in the western third

\footnotetext{
394 'Grey ribbon' was the field nickname for this extensive lens. It seems appropriate to include in the suite lens E82 as its westernmost component, in consideration of its close geometric continuity with

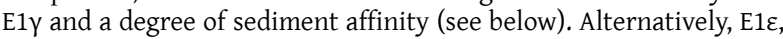
E1 $\tau$, and E1 $\gamma$ might be ranked as facies differentiations of a single unit (cf. Table 1, footnote).

395 Cf. section 3.3, 'Long-distance correlations', above.
}

of quadrangle E8; its continuation westwards, as lens E82, is itself diffuse.

Suite F2F3 is closely associated with two major intersecting pits in quadrangles E7-E8, pits F2 and F3 (Fig. 48). In terms of sediment units, the suite includes the infills of pit F2 (8P) and pit F3 $(8 \varphi)$, two subhorizontal stony-sandy 'tongues' contiguous to pit F2 (F2E and F2W), ${ }^{396}$ and an ash-and-charcoal hearth or 'floor' (8WK). While pit F3 has a loamy-stony infill, and is stratigraphically earlier - just a little earlier? - than pit F2, this latter has a much coarser stone infill, and being elongated in a south-north direction looks more like a trench than a pit (the foundation trench for a wall?). Unit $7 \varphi$, i.e., the infill of pit F2A in quadrangle $E 7$, and unit TGh in quadrangle E11, although vaguely similar to and broadly coeval with F3 and/or F2, cannot safely be related to these latter pits and cannot therefore be included in suite F2F3;397 the same applies to stones $\mathrm{Pw}$ in the west section of quadrangle E8 (cf. Table 1, footnote).

Unearthed in quadrangle E11, at the southern foot of Hill E, TGh designates a discontinuous sediment unit exclusively represented as infills of small 'pits' or pockets (F20a-F20g, including F20e'), ${ }^{398}$ incised into the top of sand $\mathrm{E} \sigma \mathrm{W}\left(\mathrm{E} \sigma \mathrm{W}_{1}\right)$ (Figs 49-50). The code name, TGh, is from tasche a ghiaia, Italian for gravel pockets, with gravel represented by minute pebbles in this case. The fines forming the sediment matrix gave the impression of containing organic matter. Unfortunately the excavation conditions at the opening of quadrangle E11 did not allow to observe if these pits or pockets mainly V-shaped in cross-section and intersecting - were in fact parallel troughs or furrows, as seems likely; in this case they would be roughly orientated south-north, as we noted for pit F2 in E8. It was only possible to infer from the quadrangle's sections that F20a-F20g were deeper and clearer in the northern part of E11, thinning and partly disappearing southwards (rather like pluvial furrows?). At any rate, F20a-F20g apparently occupied an extensive area, exceeding the limits of quadrangle E11. A correlation of TGh and F20a-F20g with features F3, F2, and even F2A in E7-E8 is tempting, but impossible to determine directly.

Suite F2F3, as well as pit F2A and features F20a-F20g (TGh), postdate the essentially aeolian sands defining Stratum B, mentioned above: E1a, E $\sigma 0$, and E $\sigma \mathrm{W}_{1}$. This

\footnotetext{
396 Code names F2E and F2W have dual meaning, i.e., as both feature and sediment unit. Although both F2E and F2W show topographic and lithological connections with F2 and its fill, their code names do not necessarily imply any functional or temporal relationship with F2.

397 Contra the hypothetical inclusion of TGh suggested in Fedele 2010, table 1.

398 Features F20a to F20g must be numbered individually because at the moment a unitary feature (ideally to be named ' $F 20$ ') is indeterminable.
} 
means that the horizon of sediments and features fundamentally represented by F2F3 and TGh is not earlier than phase Islamic 3. It possibly dates back to the very end of the Islamic period at Barāqish. Since all these sediments and features are exclusively located near Hill $\mathrm{E}$ and seem to disappear away from it to the south, during the excavation the hypothesis emerged that they might be related to structures hidden inside this enigmatic hill. Such a relationship appeared particularly convincing for F20a-F20g (TGh). However, a connection is undemonstrated. The unknown structures of Hill E might equally well have deeper foundations than the level of F2F3, or the level of features F20a-F20g, and different hypotheses can be proposed. ${ }^{399}$

What is Hill E? The riddle of this hill deserves some more comments. ${ }^{400}$ In light of its position and morphology (Figs 5, 10-11, 12 on far right), it is very unlikely that this isolated hillock protruding from the talus footslope immediately north of grid quadrangles E8-E11 is a geological feature - a landform. The most plausible explanation is that it conceals a ruin. If so, however, this ruin is not only unknown but presently impossible to date. As just mentioned, subsurface features in the nearest excavated quadrangles, E8 and E11, have been conjecturally linked to the hill, but such a connection is hypothetical. Furhermore, if a link exists, it might involve no more than the latest phases of whatever structure is concealed inside the hill: a much later reuse of the supposed ruin, for instance, not the earlier features or the primitive structure.

Among the conjectures, a relationship of Hill E with the Roman military expedition led by Gaius Aelius Gallus in 25 or 24 BCE was contemplated. This event occurred around the Minaean 3 to Minaean 4 transition as identified from Area C (cf. Chapter 18, Fig. 4, this volume). It is sufficiently well known that Yathill was taken peacefully and briefly occupied with a garrison. However, we have seen that both F20a-F20g and the features associated with suite F2F3 have no connection whatsoever with Gallus' time, therefore the Gallus hypothesis is presently untenable. This subject is further discussed in Chapter 18, section 3.3, this volume. ${ }^{401}$ In terms of military hypotheses, a relationship of Hill $\mathrm{E}$ with the Islamic military events of the 13th century CE (Chapter 18, section 3.5, this volume) might perhaps offer a marginally more admissible explanation.

\footnotetext{
399 Several, entirely speculative hypotheses were mentioned in Fedele 2010, 141, footnote 150.

400 On this issue and Hill $\mathrm{E}$ in general see already section 1.2 above.

401 The provisional refusal of the Gallus hypothesis does not mean that Area C, as an extramural space, cannot provide evidence for the Roman incursion: in fact, quite the reverse (cf. Chapter 18, section 3.3, cited passage).
}

Concerning the lower talus, it is appropriate to mention Cluster 83.1 in quadrangle E18, the extension of quadrangle E8 to the south (Fig. $51 \mathrm{C}$ ). The cluster was found about $50 \mathrm{~cm}$ below surface, a depth roughly corresponding to the bottom of pit F2. It was an isolated aggregate of reworked Sabaean potsherds embedded in the sands of middle unit $E \sigma 0$ (i.e. Stratum B), which also contained a decimetre-sized limestone element. The pottery, including eponymous find no. 83.1, ${ }^{402}$ must have been obtained from some Sabaean context in Area $\mathrm{C}$ or elsewhere, and by association also the broken limestone slab (no. 83.1.1) was thought to have the same origin. ${ }^{403}$ Per se, this latter object is a manuport, except perhaps for its broken status, and its original introduction into the site might well be pre-Islamic and indeed Sabaean; it qualifies at any rate as a reused preIslamic element. Alternatively, Cluster 83.1 might point to an undetected or undetectable pit similar to F3 in quadrangle E8. More generally, can the cluster be related to pits F2 and F3 that are just one metre away? And can it be due to reworking of Sabaean layers determined by the unknown feature hidden inside Hill E?

\section{Stratum A}

Stratum A corresponds to recent to present deposits, including surface sediments, of which a wide repertoire was noted and mapped in the extramural area: rubble and rubbish from decayed parts of the MinaeanIslamic wall, occasional slope debris and deflation lags, rich pluvial infills within the thalwegs of gullies, and sand and silt veneers from present-day aridity. On the talus Stratum A is lithostratigraphically defined by two consecutive sets of units (Table 4). A first set, conventionally attributed to earlier Stratum A, includes SE $\lambda$ (subunit of SAE) and units E7P, E0, and SXY, all restricted to quadrangles $E 7-E 8$ and E11; and subunit F01 $1_{0}$ in Sounding F. A second set, conventionally attributed to later Stratum A, includes units SAp, SAG, $\mathrm{SAE}, \mathrm{SA \alpha}, \Lambda \mathrm{E}$, and unit $\Lambda \mathrm{F}$ in Sounding F. Sounding $\mathrm{F}$ will be examined in the next section.

Subunit SE $\lambda$ identifies a level of grit and gravel lenses towards the bottom of sands SAE, exclusively recognized in quadrangles E5 and eastern E6-E06 (Figs 46-49). Lower down, essentially in quadrangles E7-E8, E7P identifies an irregular, undulating subsurface level of unsorted rubble originating below SAE in quadrangle E06 west, and therefore parallel - or even identical - to SE $\lambda$. Sand EO is a subsurface aeolian sediment largely consisting of three lateral facies (at least on the Reference section): east to west, E0a, sealing the opening of pit F2A as well as stones F2E and barely

\footnotetext{
402 A decorated globular pot in Red Lustrous ware. See Chapter 23, section 3.4, Fig. 46, this volume.

403 No. 83.1.1 is a broken part of a thin limestone slab retaining its geological shape. See Chapter 21, section 2.5, Fig. 78, this volume.
} 

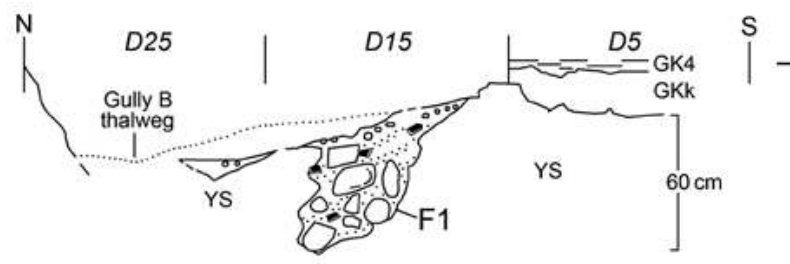

D5-D25 east section
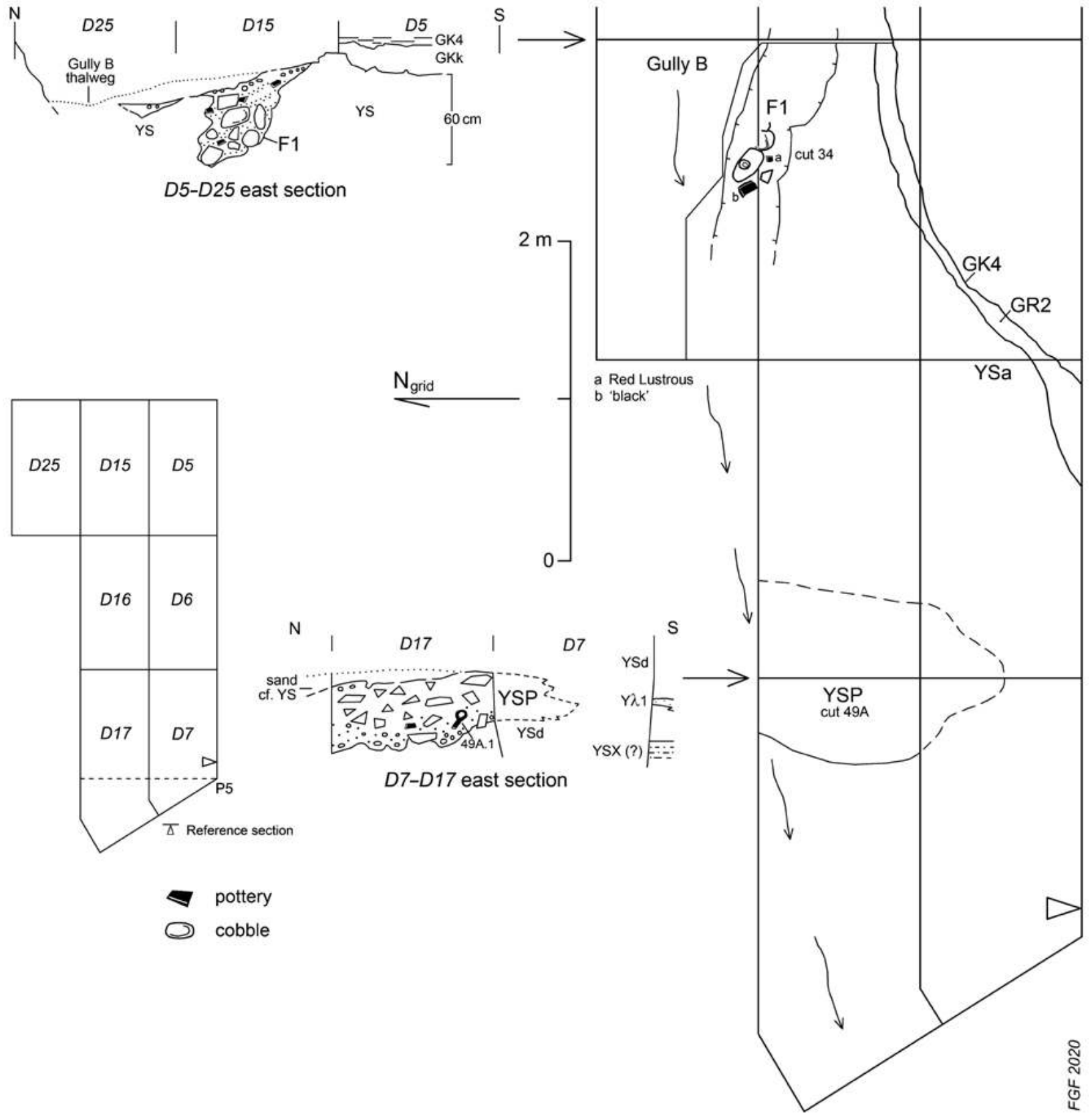

Figure 119. Features and units within Gully B as intercepted in middle and lower Sector D, composite plan and sections.

(F.G. Fedele 2005 and 2020)

distinguishable from underlying sand E1a; thick sand sheet E0b, directly covering F2 and F2W; and 'gritty' EOY, continuing in quadrangle E9. At its bottom EOb contains and envelops a large flat cobble, P55, resting on the contact with 8WK (Fig. 48).

In quadrangle E11, it is unclear whether 'mixed sandand-gypsum' layer SXY should be associated with gravel features F20a-F20g (TGh); despite appearances, their continuity seems rather weak (Fig. 49). During the excavation, SXY indeed gave the impression of being a 'floor', from which the further impression that there might be a relationship with the underlying pockets or furrows. ${ }^{404}$ However, neither the Reference section nor the study of photographs provided firm support, and this latter in fact suggested that F20a-F20g (TGh) and SXY are rather to be correlated with different Strata. Once again, only excavation of a wider area encompassing at least part of Hill $\mathrm{E}$ would resolve

404 Not unlike 'floor' 8 WK relative to F2 and F3 in quadrangle E8, perhaps? 

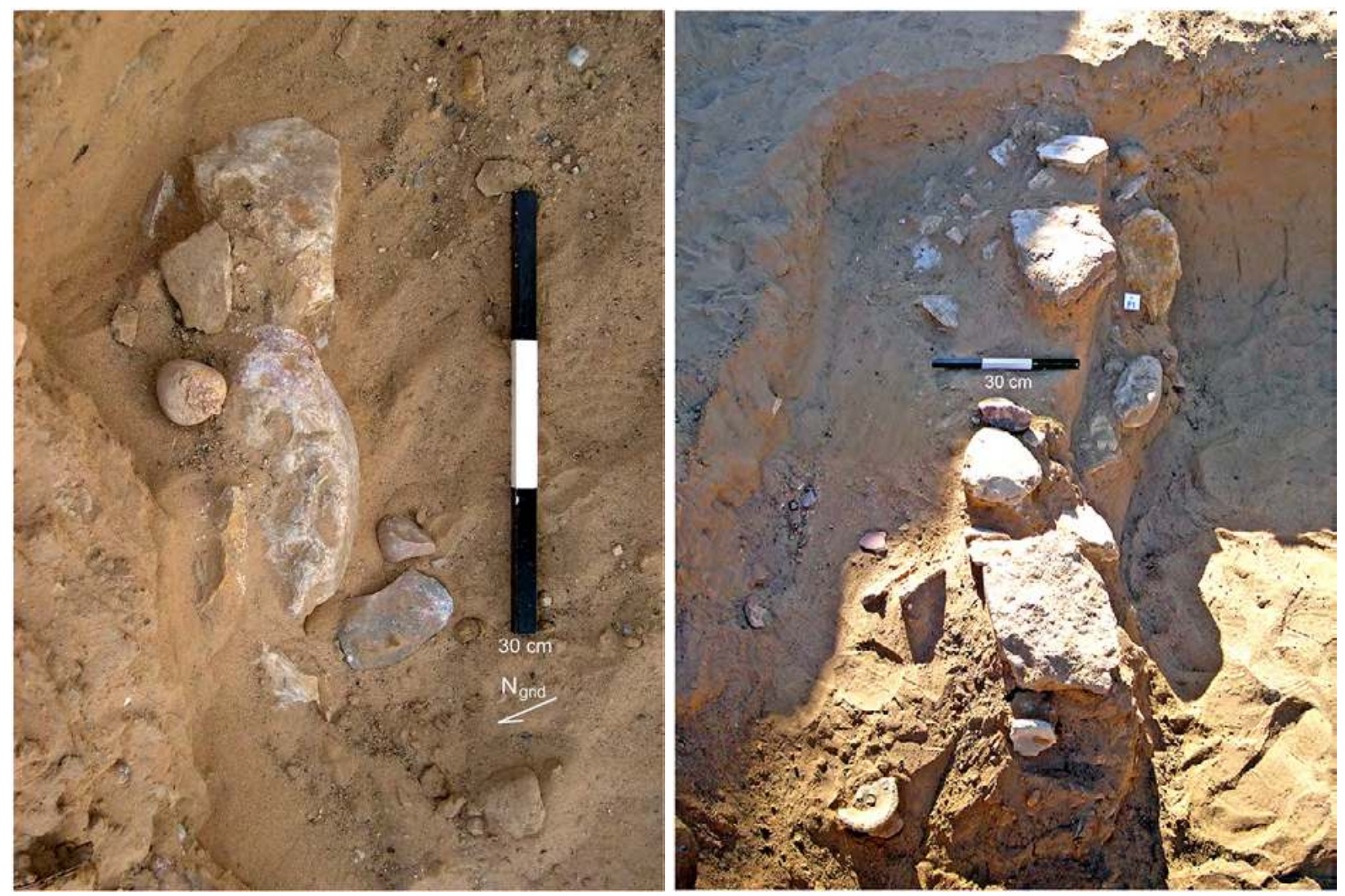

Figure 120. Sector D, feature F1 within Gully B. (P. Morlupi 2005 @ MAIRY, adapted and optimized by F.G. Fedele 2020)

the issue. ${ }^{405}$ SXY is thicker in northern E11 and thins southwards (cf. F20a-F20g). Its sandy-silty matrix looks a 'turbid' dark grey (organic?), and the unit as a whole reveals a lenticular-stratified internal structure with a thick plaster or gypsum level inside and a rust-brown lens at the top (decayed litter? manure?).

As to later Stratum A, SAG ('sand of the gully') identifies the unsorted, microalluvial sand which accumulates at the mouth of Gully B where its rainwater flows out of the steeper talus, intersecting the Reference section in quadrangle E3. Its thickness varies considerably. SAE is the widespread sand-and-rubble cover of the talus footslope and plain's fringe in Sector E, immediately below the present-day lag $(\Lambda \mathrm{E})$. SA $\alpha$ is the pure, loose, windblown surface sand of Sector $E$ and the contiguous plain, principally observed in quadrangles E4-E7 and E11. Stony sand SAp - the present-day lag from the middle and lower talus, quadrangles D5 to E3 - was examined in this section under Stratum B, above. The recent and present surface lag characterizing Sector $E$ and Plain $F$ was labelled, in the respective areas, $\Lambda \mathrm{E}$ and $\Lambda \mathrm{F}$.

Finally, a mention ought to be made here of quadrangle EN1, a brief excavation proposed and conducted by GOAM's archaeologist 'Isa al-Sha'ibānī on the last day of

405 A connection with Hill E was also hypothesized for SXY. the 2005 season. ${ }^{406}$ The test pit measured $2 \times 2 \mathrm{~m}$ and its location and plan are shown in Fig. 7: 3.5-5.3 $\mathrm{m}$ northnortheast of quadrangles E1-E01 and $1.11 \mathrm{~m}$ in elevation above the top of F4 (Wall F4), southeast corner. ${ }^{407}$ The intention was to uncover the continuation of Wall F4 (cf. section 6.3 above), but the excavation lasted less than a day because of the overwhelming commitments at bastion T7, Sounding A, and had to be discontinued at a maximum depth of about half a metre. The excavated part was a totally uniform colluvial and/ or microalluvial cover of silty sediments, dark-grey in colour, containing a mixture of redeposited potsherds of all ages, presumably to be attributed to Strata B and A.

\section{Sounding F: Strata O (?) to A in the plain}

As mentioned above at the end of section 3.3 (cf. also section 2.3), Sounding F is better treated separately because the correlation of its layers with the stratigraphy of Sectors A-E is largely tentative: the geoarchaeological scene of Sounding F is unconnected

406 EN1 was already mentioned in sections 1.2, 6.3 (footnote 131), and 6.5 (footnote 147). The quadrangle was considered part of Sector E, and ' $N$ ' in the code name stands for north.

407 The location exploited a small, shallow gully about $4.5 \mathrm{~m}$ to the north of quadrangles E1-E01 and 0.5-0.8 $\mathrm{m}$ in elevation above point P5, marking the boundary between Sectors E and D. 

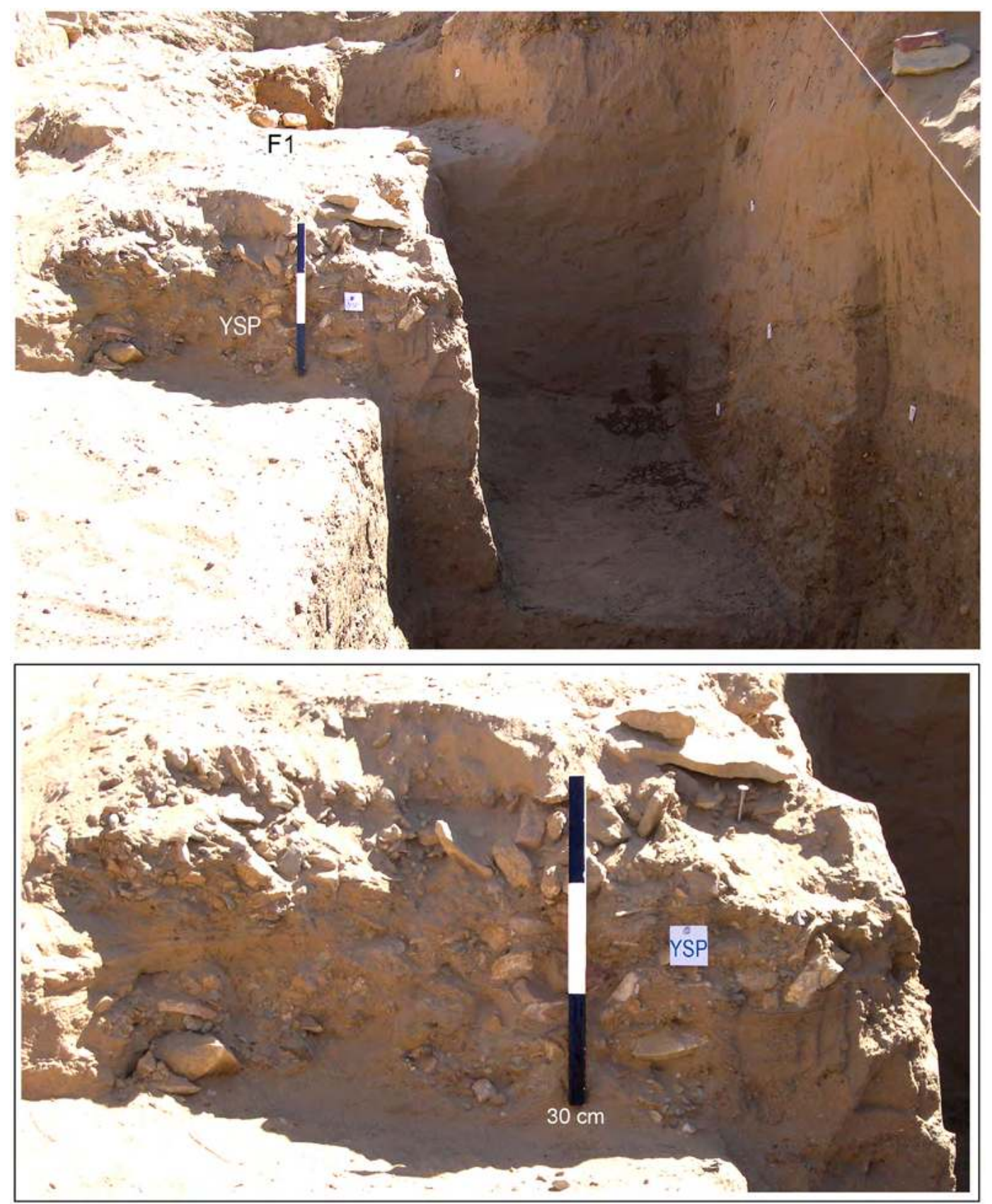

Figure 121. Sector D, unit YSP within Gully B. (P. Morlupi 2005 @ MAIRY, adapted and optimized by F.G. Fedele 2020)

with the Barāqish talus and very different. ${ }^{408}$ The fact itself that the sounding displays a neatly stratified and essentially simple sedimentary sequence, almost cyclic in appearance (cf. Fig. 23), tends to set it apart from the lithostratigraphic pattern of the nearest part of the Barāqish mound, lower Sector E.

Sounding F was made, on purpose, near the base of Hill C, adjacent to the hill's 'tail' on which a Sabaean

408 In Fedele 2010 the record from Sounding $\mathrm{F}$ was presented instead Stratum by Stratum, like all other sectors of Area C, except for a preliminary synopsis on p. 110. occupation site had just been found (2006) (Figs 5, 11, 122). ${ }^{409}$ The style and rhythm of deposition and erosion on Hill $\mathrm{C}$ and its outskirts are completely unknown. However, in Plain F just off the tail of Hill $\mathrm{C}^{410}$ two chief depositional constants are apparent: first, this location was more effectively exposed to cycles of aeolian sand accumulation and deflation (wind erosion) than the tell

409 See Chapter 26, section 3.1 and Fig. 12, this volume.

410 Plain $\mathrm{F}$ as defined in section 1.2 above, and more precisely in Chapter 26, section 3.1, this volume: the relatively depressed area surrounding Sounding F in the western plain, within a radius of 10-20 $\mathrm{m}$ from Area C grid's stake P07. 


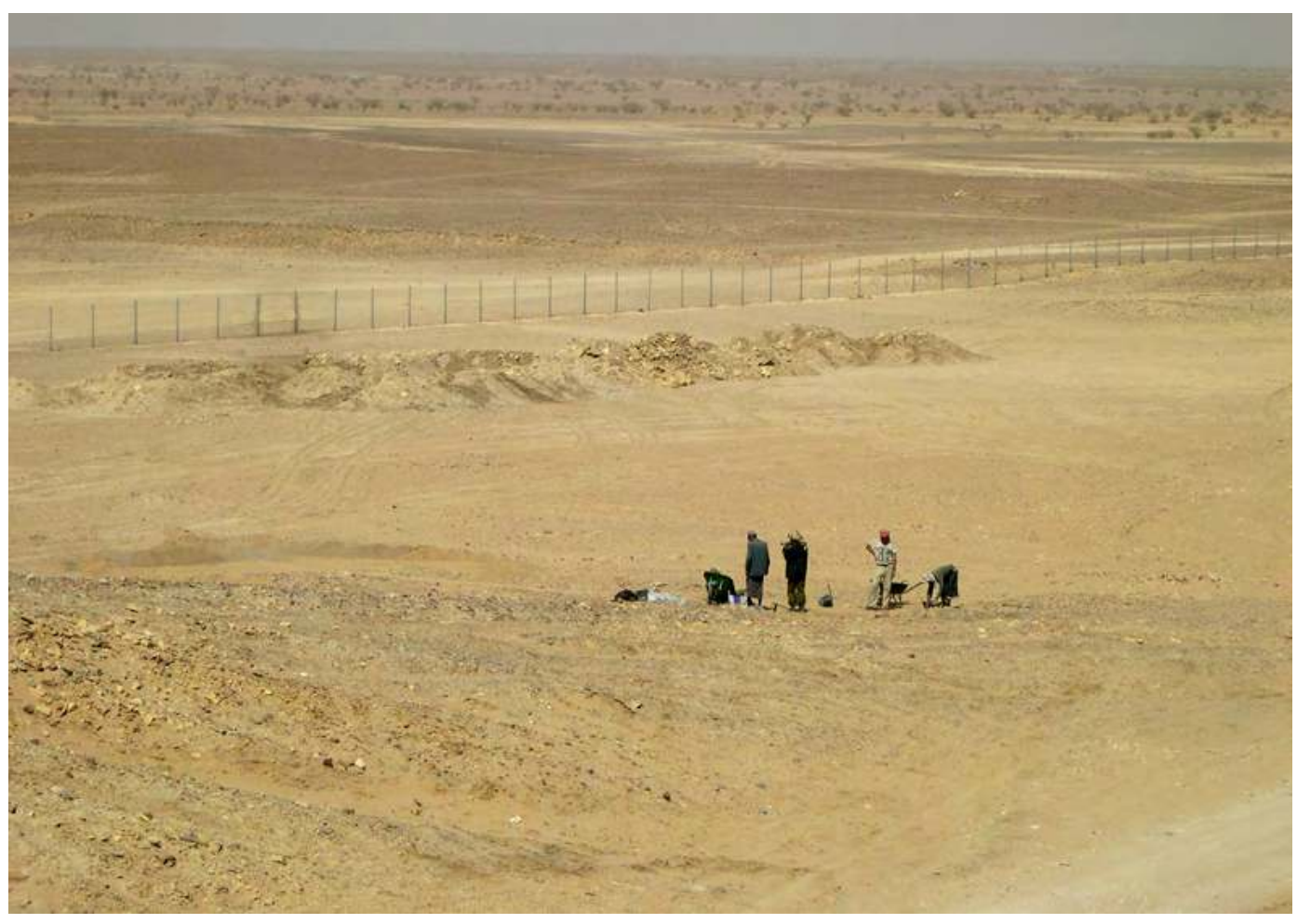

Figure 122. Sounding F, panoramic view facing northwest. (P. Morlupi 2006 C MAIRY, optimized by F.G. Fedele 2019)

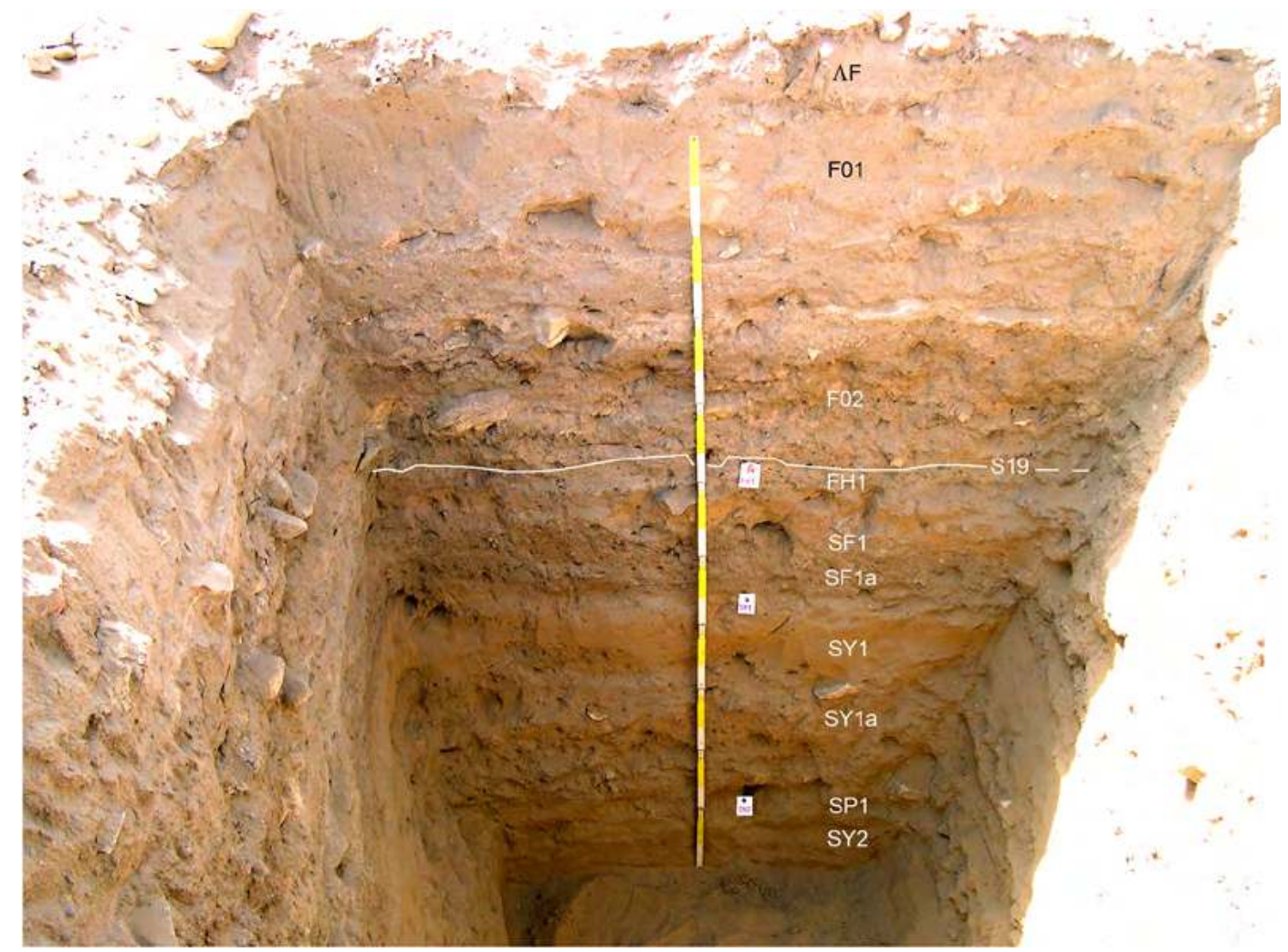

Figure 123. Sounding F, Reference section. (P. Morlupi 2006 @ MAIRY, adapted and optimized by F.G. Fedele 2019) 


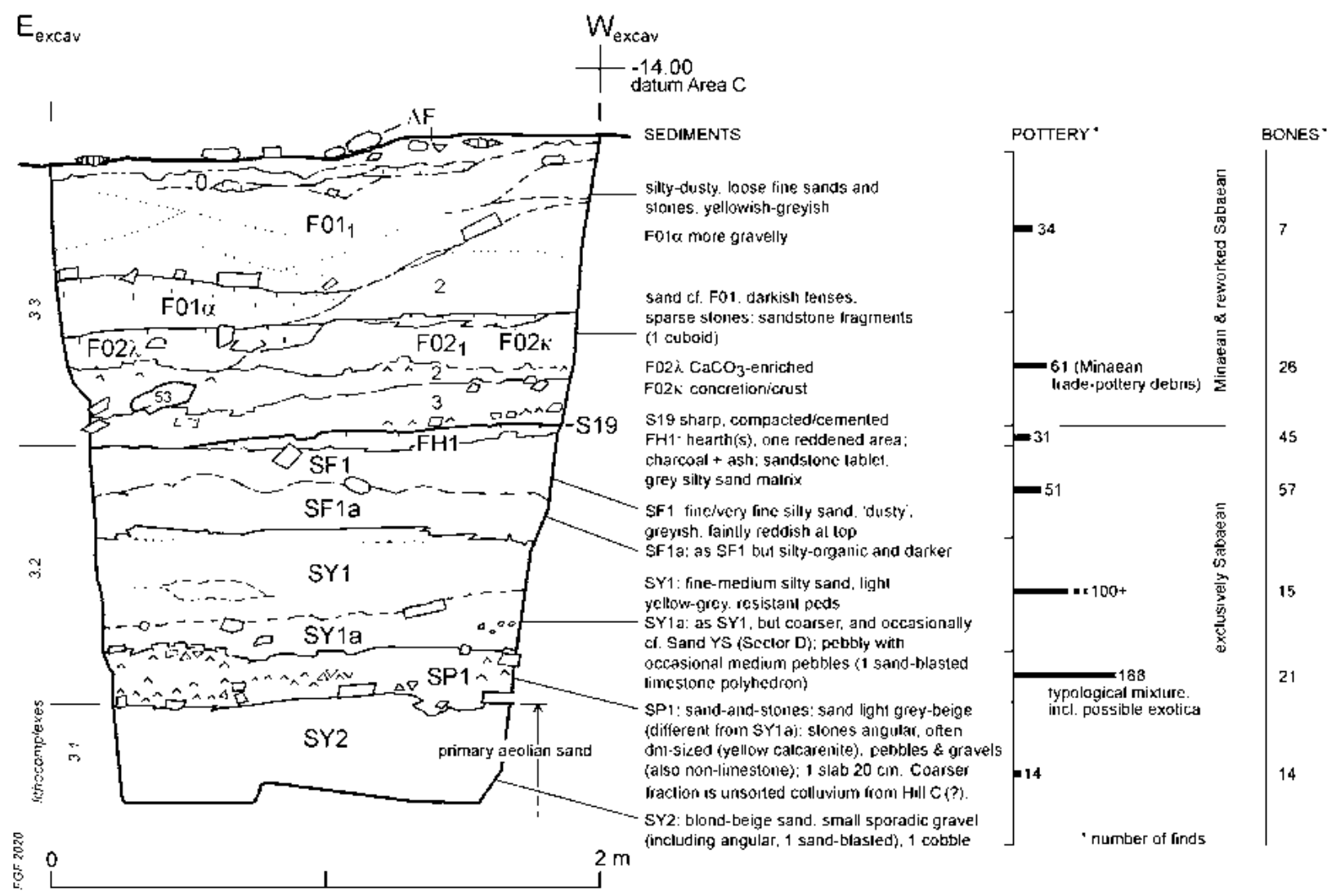

Figure 124. Sounding F: sedimentary information on the sequence and quantitative details on finds. (F.G. Fedele 2009, updated 2020)

and talus of Barāqish; and second, contributions in the form of both fine- and coarse-grained colluvia from the nearby hillslope of Hill C's tail can be recognized. Unit SP1 of Sounding F (below) is an example of stony sediments whose coarser fraction is of likely provenance from Hill C.

All sediments in Sounding F contain sand. However, there is no sand accumulation in the manner of quadrangle E11 $\left(\mathrm{E} \sigma \mathrm{W}_{3-1}\right)$ or Sand YS in Sector D. Plain $\mathrm{F}$ appears always to have been characterized - predominantly - by deflation rather than wind deposition. Concurrently, the sedimentary sequence in Sounding $\mathrm{F}$ is punctuated by repeated interruptions, in what seems - as mentioned - a vaguely cyclic reiteration of sedimentary contributions with regularly varying textures, now finer, now coarser.

Over a depth of 2.5 metres, Sounding F provides a well-stratified succession that can be subdivided into a 1.3-metre-thick lower part, with exclusively Sabaean pottery, and an upper part with predominantly Minaean material (Figs 23, 123). A sharp break, surface S19, associated with the compacted top of a heavily trampled level with traces of a severely deflated hearth (FH1), represents the separation between the two. Apart from sparse elements on the present ground surface, represented by gravel lag $\Lambda \mathrm{F}$, no Islamic material was observed in the deposits. Bottom to top, the Sabaean sequence shows a 'blond sand' layer, unit SY2; a fairly distinct discontinuity (SY2/SP1); an intermediate layer made of sand and angular stones (SP1) followed by two sandy layers (SY1a and SY1); and a sandy-silty layer very rich in well-preserved Later Sabaean pottery (SF1a and SF1) (Fig. 124, with complementary details to this text). From FH1-S19 upwards all layers and their contents reveal sustained aeolian activity with evident sand-blasting.

More precisely, the lowermost unit attained (SY2) is primary aeolian sand, only containing sporadic fine gravel and the occasional sand-blasted clast. SP1 is mostly colluvial, apart from a $20-\mathrm{cm}$-long slab. The stones in this unit are yellow calcarenite, often decimetre-sized and sharp, with a component of limestone and non-limestone gravels and pebbles. SY1a and SY1 are grey-yellowish silty sands, SY1a coarser and sparsely stony, resembling in colour Sand YS, while SY1 is loamy - apparently - and breaks easily into resistant peds. In terms of structure, both SP1 and SY1a-SY1 testify to the persistence of a sandy-gravelly micro-landscape with lag gravels due to deflation, not dissimilar from tracts of the flats west and north of Barāqish today. Trampling was common. SF1a and SF1 
are greyish, 'dusty' silts and sands, SF1a silty-organic and darker and SF1 faintly reddish towards the top. The buildup of layers SP1 to SF1 must have taken a relatively lengthy period of time and seems to reflect certain environmental and cultural-behavioural constants.

Immediately above this sequence, FH1 directly reveals cooking activity on the site of the sounding, during just one of presumably numerous episodes of 'light' occupation. By this term I intend to suggest occupation associated with temporary, movable structures (supposedly tents) and a complete absence of residential architecture. ${ }^{411}$ The data from the Sabaean part of Sounding F complement rather nicely the evidence from the lower talus and may add perspective, further suggesting that camping parties - traders? - were possibly involved. This subject is examined in detail in Chapter 19 , section 3 , this volume.

Concerning the post-Sabaean periods, the hearth and grey-sand unit FH1 still contained extremely worn Sabaean material, whereas F02 was culturally characterized by Minaean pottery debris. F02, a sparsely stony sand layer of a yellowish-greyish colour, can be subdivided into several darkish horizontal lenses, with boundaries often vaguely marked by stone-lines and/or calcitic levels. Three vertical partitions can be distinguished $\left(\mathrm{FO}_{3}{ }_{3}-\mathrm{FO}_{1}\right)$, in addition to calcified or calcitic units F02 $\lambda$ and F02 $\kappa$ which mark the upper contact of F02. F02 $\lambda$ is a $\mathrm{CaCO}_{3}$-enriched, mildly calcified subunit, while F02 $\kappa$ is a true calcitic crust; both are neatly delineated on the Reference section. This reveals that pronounced calcium carbonate deposition repeatedly developed in the plain. ${ }^{412}$

Unit F02 provides evidence of a rich Minaean layer mostly made of trade jars and jar-related remains: it not only yielded sand-blasted potsherds of heavy jars, mostly in situ and heavily corroded from salts, but also flakes from lithic jar stoppers (details below). Stone stoppers for jars are known as a frequent find in Plain $\mathrm{F}$ and on Hill $\mathrm{C}$, and several specimens were found on or near the surface in Sounding $F$ (details below). Fragments of cuboid burners made of white limestone, probably broken lamps left by camping parties, might also be common (witness an example from $\mathrm{F}_{2} 2_{3}$ ).

F01, a thick topmost unit in Sounding F, is similar to F02 save for the imbricated structure of its sandy matrix.

\footnotetext{
411 No mudbrick material was found in Sounding F, a striking difference from the tell and talus domains.

412 The most usual process involving salts in Plain $\mathrm{F}$ and at Barāqish in general (but also manifest in parts of the talus, as evoked elsewhere in this chapter) would be induration by ascensus, whereby strong mineralized solutions drawn to the surface by capillarity evaporate to form a cement which can bind the clasts and debris into a more or less continuous sheet (as succinctly put by Monkhouse 1974, 291; cf. p. 104).
}

The main body of F01 includes silty sand F01, 'whitespecked' coarse-sand accumulations $\mathrm{F} 01 \alpha$, and the distinctive cross-bedded sands and silts of subunit F01. For their correlation to Strata see below. F01 exclusively gave severely worn and corroded pre-Islamic material, probably Minaean, all residual or reworked (including jar plaster, lithic stoppers, and a quern fragment; details below). Evidently, Minaean activity had ended.

Subsurface lenses of fine rubble and salt-corroded bone (F01) may represent the earlier part of Stratum A; the later and present-day part is represented by surface lag $\Lambda \mathrm{F}$. It should finally be recorded that in the most depressed area of Plain $\mathrm{F}$ the present-day surface shows patches of stony fines rich in Sabaean debris, mixed with Minaean material, as if buried Sabaean layers were sporadically emerging. ${ }^{413}$

The correlation of Sounding F with the Barāqish mound (cf. section 3.3 above, 'Long-distance correlations') was established on the basis of ceramic contents, sand-type similarity (SY2 closely resembling the sands of type 'YSYS8' of the talus, see Strata O-P and M), ${ }^{414}$ and the two main sedimentary discontinuities: surface S19 and the one perceived at the SY2/SP1 interface. The presence of Pale Green ware in SP1-SY1 appears to support the attribution of these units to the Later Sabaean. Above marker-surface S19, the layer coeval with the Minaean activity in material-culture terms is F02, subsumed under Stratum $G$ and composed of several subunits. Layer F01 only contains heavily weathered Minaean residue, which makes a detailed correlation almost impossible. Two alternative correlation options can be proposed (Fig. 24):

i. one according to a continuity model, i.e. $\mathrm{F}_{2} 1_{2}+$ $\mathrm{F} 01 \alpha=$ Stratum D $\rightarrow$ then F01 $1=$ Stratum B (Later Islamic) $\rightarrow$ and finally F01 $+\Lambda \mathrm{F}=$ Recent and present;

ii. the other one based on a long-hiatus model, i.e. F01 $1-2+F 01 \alpha=$ initial Stratum D (Second Intermediate) $\rightarrow$ followed by long Islamic hiatus $\rightarrow$ then $\mathrm{F} 01_{0}+\Lambda \mathrm{F}=$ Later Islamic to present.

The former option is presently preferred (\#1 in Fig. 24).

A selection of significant finds from Sounding $F$, listed stratigraphically bottom to top, with quantitative details and

taphonomic information (see synopsis in Fig. 124).

- Stratum O (?). SY2. Pottery: 14 centimetre-sized fragments $(2-6 \mathrm{~cm})$, mostly corroded or battered (only three fragments angular), resulting

\footnotetext{
413 See Chapter 26, section 3.1, this volume.

414 One could even put forward the hypothesis that SY2 and similar sands of the plain were a proximal source for aeolian Sand YS in Sector D: cf. section 6.6, 'Sand YS: interpretation', above.
} 
from long and frequent trampling rather than transport. Five Red Lustrous fragments, two from torpedo jars, and seven from plain wares, including a Grey-black cooking pot (?), wellsmoothed and firm. Non-ceramic finds: a natural cobble used as a grinding stone (no. 216.01) and a rounded cuboid cobble (no. 216.02); 14 animal bones.

- Earlier Stratum M. SP1. This relatively thin unit produced the largest quantity of pottery from Sounding F, 188 fragments in total: comminuted and heavily battered (wear grade $3-5$ or even 4-5) save the torpedo jars. Like the stony sediments, these ceramics are largely to be interpreted as colluvial or reworked material, of likely provenance from Hill C (see above), subsequently subjected to local trampling. 81 fragments are Red Lustrous with 'epi-Sabaean' characteristics - thin flaking slip, 'hazy' colour (orange, red, brown), and soft or friable body -, except for a detached handle of different manufacture (no. 215.1, with a smaller fragment) which might be exotic. The other fragments reveal a remarkable typological mixture: Beige Plain (97), 'soft' Pale Green (5), Black Lustrous (2), torpedo jars (2), and a heavy dolium (indeterminate grey ware). Non-ceramic finds: a bored stone pendant (no. 215.1), a copper slag globule (no. 215.2), ${ }^{415}$ two sandstone tablets, and 21 animal bones.

- Stratum M. SY1a-SY1. Pottery: more than a hundred fragments (88 counted), all worn and extremely comminuted (65 per cent centimetresized), suggesting the same taphonomy as for SP1. 79 fragments are Red Lustrous with 'epiSabaean' features (see SP1), of which ten have interior polish only. The other fragments reflect the same mixture as that represented in SP1: plain wares (numerous small to medium vessels and one dolium); Black Lustrous (3, all bifacially burnished, one with wear grade 1); 'soft' Pale Green (3); torpedo jars (3). Non-ceramic finds: an obsidian core (no. 214.01), a softstone vessel fragment (no. 214.03), a piece of copper slag from SY1 (214.02), some charcoal, and 15 animal bones.

- Later Stratum M. SF1a-SF1. These sands contained numerous (51), sometimes large (22 per cent $10-15 \mathrm{~cm}$ in size), medium worn (predominant wear grade 3 or even 2/3) Sabaean potsherds, some reworked and some in situ; no evidence of trampling was apparent. Red Lustrous, including dark brown variants (24 fragments, one with 'shoddy' slip); Beige Plain (22, including thin-walled plate no. 213.05 and

415 Another tiny bit of copper slag was retrieved from unit SY1, see below. For a list of the traces of Sabaean smelting activity at Yathill see section 7.4 above (Stratum N). a cooking pot); torpedo jars (3); Red-slipped (1). Non-ceramic finds: a rubefied sandstone plate (no. 213.01), connected with fire and/or cooking. The animal bones (57 pieces) included the rare dog, represented by an incomplete left tibia from a small adult individual (no. 213/8). ${ }^{416}$

- Stratum K. FH1 and surface S19. Wind-blasted and wind-worn Sabaean pottery, 95 per cent worn to very worn, with 100 per cent of surfaces battered and some also salt-corroded. Red Lustrous 17 fragments, plain wares 14. Nonceramic fraction: 45 animal bones, mostly corroded, and a sandstone tablet.

- Stratum G. F02. Pottery: 61 fragments, 89 per cent attributable to Minaean trade-pottery debris. They are large-sized $(10-18 \mathrm{~cm})$ and show intense aeolian abrasion (sand-blasting), combined with salt corrosion; most are primary or even in situ. Seven potsherds, worn and encrusted in calcium carbonate, are residual or reworked Sabaean (two Red Lustrous and five Beige Plain). Non-ceramic finds: a fragment of a plain cuboid burner (no. 211.1) and a worked talus from a large goat, probably an ibex (no. 211.01), both from near the bottom of $\mathrm{F}_{2} 2_{3}$; and chipping waste from the manufacture of lithic jar stoppers.

- Strata D or B-A. F01 $2-0$, F01 $\alpha, \Lambda$ F. Pottery: 34 fragments, all Minaean, except six Sabaean (Red Lustrous and Beige Plain, some little worn). The Minaean material is similar to that of F02 and again shows intense aeolian abrasion; it includes several dolia with massive, 4-cm-thick walls. Non-ceramic finds: a fragment of a quern (no. 210.01); fragments of a cowrie (no. 210.05, a personal ornament) and of a fossil bivalve (no. 210.04); two plaster fragments, one clearly a jar sealing (nos 210.02-03); some charcoal; and 7 animal bones, light and crumbly. Four stone jar stoppers were collected from lag $\Lambda \mathrm{F}$ (Stratum A) within a 2-m radius from the sounding (nos 210.1a-d; presumably reworked Minaean). Two more jar stoppers and a split and chipped cobble from the manufacture of stoppers were collected for reference on the surface of Hill C (nos 220.1-3).

Being separated from the next unit above by a fairly distinct discontinuity, sand SY2 looks like the top of an Earlier Sabaean sequence lying buried beneath the $-2.5 \mathrm{~m}$ bottom of Sounding F. The sounding suggests that Sabaean Stratum $\mathrm{T}$ as recognized in Sectors D-E - let alone the initial Sabaean levels and/or virgin

416 This Canis familiaris specimen (cf. Chapter 19, section 2.1, Fig. 4) is light and whitish: it stands out from the rest of the bones of cut 213, which are distinctly yellow-reddish and often roasted as well as better preserved. 
soil - lies several metres below the bottom of our test pit. Considering that by the time of Stratum T Yathill had already existed for several centuries, this in turn implies that the settlement may have been established close to the level of the floodplain, perhaps on a low bank or terrace along the 'Western wādì' (see Chapter 26 , section 3.3, this volume). Together with the 4-metre deep coring made in 1987 off bastion T48 (core D1, see Chapter 15 in Volume 1), Sounding F represents the only source of below-ground information we have for the flats and plains surrounding Barāqish. This means that the plains are virtually unknown.

\section{Endnote}

In order not to exceed reasonable print space limits, the excavation control documents will not be published in these pages. Instead, it is planned to make them available in the future as supplementary online material from a personal web page (F.G. Fedele) or an institutional website (possibly MAIRY). These documents include: a. the list and basic description of sediment units;

b. the list and basic description of surfaces, diagenesis/weathering zones, features, stones (clasts lato sensu), horizons, and loci;

c. the list and spatial distribution of dissection numbers ('cuts') in table format;

d. the visual representation of 'cuts' on the Reference profile (cf. Fig. 25 for Sounding A) and on planimetric sketches, to accompany list/ table ' $c$ '; and

e. the Area C comprehensive collection catalogue (see Chapter 20, this volume).

Supplementary working papers and other original archival material are expected to be made available as well (cf. section 3.3, footnote 76, above). 
Table 1. Area C excavations 2005-2006: list and definition of sediment suites, arranged topographically down-talus from Sounding A to Sector E (see location in the right-hand column).

\begin{tabular}{|c|c|c|}
\hline $\begin{array}{l}\text { Sediment } \\
\text { suite }\end{array}$ & Component units and short description & $\begin{array}{l}\text { Documented } \\
\text { location }\end{array}$ \\
\hline T73 & T73 $\varphi$, T73c, T73b, T73a, gravelly loams with plant debris; ${ }^{1}$ with subunits & Sounding A \\
\hline T74U & T7Su, T7S, silts and mudbrick; T74, T74, , stony fines; with subunits & Sounding A \\
\hline T74M & T7H, T7JK, ashy-silty; and postdepositional modifications from T7H related to feature F6 & Sounding A \\
\hline T74L & $\begin{array}{l}\text { T7Ji, fines; T7JP, stony fines; T7V, plant-detritus; T7J, T7J', gravelly fines; T7N, gravelly-stony } \\
\text { fines; with subunits }\end{array}$ & Sounding A \\
\hline T76 & T76J, T76H, ashy-sandy silts; $6 \mathrm{~J} \pi$, stony level; SR, 'red sand'; with subunits & Sounding A \\
\hline SZ & SZ2, SZ1, 'banded' units; all with subunits & Sounding A \\
\hline SD2 & GSV3, GSV2, GSV1, GV2, silty sands; L1, L2, silt levels; $\gamma \mathrm{x}, \tau \mathrm{x}$, decayed mudbrick; SA2, 'old' sand & D2-D12 \\
\hline GZ & GZ3, GZ2, GZ1, GZV, stratiform, laminated units and lenses rich in cultural debris; with subunits & D2-D4 \\
\hline GK & $\begin{array}{l}\text { GK3, GKc, GKY, GK2, GK1, stratiform, richly organic levels and lenses replete with cultural } \\
\text { debris; with subunits }\end{array}$ & D3-D5 \\
\hline YSU & YSi, YSf, YSd, YSa, aeolian sands; all with subunits & D6-D7 \\
\hline YSL & YSZi, YSZ, aeolian-colluvial sands and debris, with subunits; probably also YSX & D6-D7 \\
\hline SD67 & SGP, $\mathrm{SGP}_{3}{ }^{\prime}$, artificial mass accumulation; ${ }^{2} \mathrm{SGP} 0$, veneer of fines; $\lambda 44$, leached hearth & D6 W-D7 \\
\hline L3ef & L3f, thin organic level; L3e, ashy sheet; ${ }^{3}$ with subunits & E2-E3, also S \\
\hline $\mathrm{L} 3 \mathrm{C}$ & L3c, L3c2, L3c1, multicoloured, fine-debris slides; with subunits & $E 2-E 3$, also S \\
\hline L3B & L3bi, L3b, multicoloured lenses; with subunits & E3 S \\
\hline L3A & L3a1, L3a2, 3 $\beta$, L3aw, colluvial lenses and masses; with subunits & $E 2 \mathrm{~W}-E 4 \mathrm{~S}$ \\
\hline L3Nn & L3N, L3Na, L3N ${ }_{0}$, colluvial lenses; with subunits ${ }^{4}$ & E3-E4 E \\
\hline $\mathrm{XE}$ & V5, XE4, V5S, mixed debris and plant-detritus units; with subunits & E3-E5, also S \\
\hline $\mathrm{CM}$ & CM1, CM2, CMx, mixed-debris accumulation; with subunits & E4-E5 S \\
\hline LNS $^{5}$ & $\begin{array}{l}\text { LGN, ‘pebbly’; VGN, VGN', plant-detritus masses; LGN1, thin long lens; LSx, LS, silty sands; with } \\
\text { subunits }\end{array}$ & $\begin{array}{l}\text { E4-E5, partly } \\
\text { also S }\end{array}$ \\
\hline LXZ $^{6}$ & 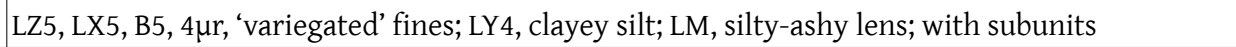 & E4-E5 \\
\hline $5 \mathrm{SU}$ & undefined units ${ }^{7}$ between $\mathrm{LGN}_{\mathrm{S}}$ and $\mathrm{x} 5$, including cf. $\mathrm{LM}^{8}$ and cf. LSx-LS (see Fig. 46) & E4-E5 S \\
\hline $45 \mathrm{~S}$ & $\begin{array}{l}\text { 5Si and less defined units and subunits above, }{ }^{7} \text { between XE4 }{ }_{s} \text {-a1y-L3a1 and } \text { LGN }_{s} \text {, including } \\
\text { cf. LZ5, cf. } 4 \mu \text { r, cf. LX5, and cf. LY4 (see Fig. } 46 \text { ) }\end{array}$ & E4-E5 S \\
\hline $\mathrm{KL}^{5}$ & $\mathrm{KL} 5, \mathrm{KL} \gamma$, sands and debris & E5 W \\
\hline $6 \mathrm{UV}^{6}$ & 6V, 6U, sandy plant-detritus units (some manure); with subunits & $E 5 \mathrm{~W}-E 6^{9}$ \\
\hline $6 Q R$ & $6 \mathrm{R}$, sand and debris; $6 \mathrm{Q}$, sand; suite probably equivalent to $5 \mathrm{SA}_{1-2}$ in qu. E5 S & $E 5 \mathrm{~W}-E 6^{9}$ \\
\hline $\mathrm{JKL}^{5}$ & $\mathrm{XL}, \mathrm{XJ}$, silty sands; $6 \mathrm{~K}$, sand and plant-detritus unit; with subunits & $E 6^{9}-E 7 \mathrm{E}$ \\
\hline E1ع8 & 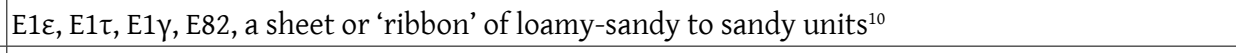 & $E 6^{9}-E 8$ \\
\hline Lgh & Lh, Lg, and lesser, associated microunits & E7 E \\
\hline SEK & EK1, EKi, EK, ${ }^{11}$ sand-and-charcoal cultural layer (cf. horizon H78); with subunits & E7-E8 \\
\hline F2F3 & $8 \mathrm{P}, \mathrm{F} 2 \mathrm{E}, \mathrm{F} 2 \mathrm{~W}$, stony-sandy units; $8 \varphi$, loamy-stony fill; $8 \mathrm{WK}$, a hearth or 'floor' ${ }^{12}$ & E7-E8 \\
\hline $\begin{array}{l}{ }^{1} \text { Unit T73W } \\
{ }^{2} \text { Sediments } \\
{ }^{3} \text { In quadrar } \\
{ }^{4} \text { Including } \\
{ }^{5} \text { Suites KL } \\
\text { and LNS, on } \\
{ }^{6} \text { Suite LXZ } \\
{ }^{7} \text { Indefinabl } \\
{ }^{8} \text { Both the i }\end{array}$ & $\begin{array}{l}\text { lot included. } \\
\text { onstituting the main body of Earthwork F44. } \\
\text { le E3, east section, L3f and L3e tend intermittently to be fused. } \\
\text { icrounit 3n (a small lens) as a disjointed subunit of L3N. } \\
d \text { LNS are limited down-talus to quadrangle E5, whereas suite JKL was defined in quadrangle E6 } E C \\
\text { ne side, and JKL, are essentially transitional between each other. } \\
\text { limited down-talus to quadrangle E5: however, LXZ and suite } 6 \mathrm{UV} \text { are essentially transitional bet } \\
\text { from photographs and not field-checked. } \\
\text { ntification of this unit with Reference section's LM and its inclusion in suite } 5 \mathrm{SU} \text { are tentative. } \\
\text { nits mostly recorded in quadrangle E06, due to section collapse (see text). }\end{array}$ & 06): however, KL \\
\hline
\end{tabular}


${ }^{11}$ Possibly also including unit E86 (not field-checked). More minuscule units, identified through photographs, are classified as subunits of EK.

${ }^{12}$ Units $7 \varphi$ (pit F2A; quadrangle E7) and TGh (quadrangle E11), although similar and perhaps coeval, cannot be safely related to pits F2 and/or F3 and cannot thus be included in this suite (contra the hypothetical inclusion of TGh suggested in Fedele 2010, table 1); the same applies to stones Pw (quadrangle E8, west section).

Table 2. Area C excavations 2005-2006: list and definition of sediment groups, arranged topographically downtalus from Sounding A to Sector E (see location in the right-hand column).

\begin{tabular}{|c|c|c|}
\hline $\begin{array}{l}\text { Sediment } \\
\text { group }\end{array}$ & Component suites and units & $\begin{array}{l}\text { Documented } \\
\text { location }\end{array}$ \\
\hline T71 & units $^{1}$ T71b, T71a, foot-of-wall deposits (with inclusion F18) & Sounding A \\
\hline GT74 & suites T74L, T74M, T74U; and units T7A (collapse rubble), T7r, T7t, LT7, T7 $\omega$ & Sounding A \\
\hline TBF & $\begin{array}{l}\text { units }{ }^{1} \text { AR, T7F, LAR, T7Y, T7 } \tau \text {, massive backfill loads for the Minaean wall foundations, with } \\
\text { subunits; LP3, LP2, LP1, stone lenses }\end{array}$ & Sounding $A$ \\
\hline GB1 & units $^{1}$ B03, B02, B01, fines with stony levels; BV, BV1, BV0, plant-detritus or 'manure' units & $B$ \\
\hline CU5 & units $^{1}$ CU5b, CU5i, CU5a, sands with stony, carbonate, and mudbrick levels & C \\
\hline $\mathrm{YS}^{2}$ & suites YSL, YSU; and unit YSX & D15-D25, D6-D7 \\
\hline SG & suite SD67; and units SGLi, SGL, SGY, with subunits & D6-D7 \\
\hline LE & $\begin{array}{l}\text { units }{ }^{1} \text { LEd, LEc, LEb, LEa, all lenticular; LE1, LE0 lenses or slides of fines; 'xenosome' LE } \omega \text {; with } \\
\text { subunits }\end{array}$ & $E 1-E 2$ \\
\hline L3BC & suites L3C, L3B & E2-E3 \\
\hline E56.1 & suites JKL, KL, LNS & $E 5-E 6^{5}$ \\
\hline E56.2 & suites $6 \mathrm{UV}, \mathrm{LXZ}$; and units $\mathrm{V} 5,{ }^{4} 6 \mathrm{~N}$ & $E 5-E 6^{5}$ \\
\hline E1 & part of suite E1E8 (quadrangles E5-E7 only); and units EX6, La, E1b, x2, E1a & E5-E7 \\
\hline E2 & suite Lgh; and units E2b, E2a, Le, EX1, EX1e, L4, E2E, with subunits ${ }^{3}$ & $E 6^{5}-E 7$ \\
\hline EX3 & units $^{1}$ e6i, LB, LB1, e6, x3, L3, e2, aeolian-colluvial sands & $E 5-E 6^{5} \mathrm{E}$ \\
\hline EX4 & units $^{1} \times 5, e 7, x 4$, aeolian-colluvial sands and debris & E5, also S \\
\hline
\end{tabular}

${ }^{1}$ Groups T71, TBF, GB1, CU5, LE, EX3, and EX4 contain only units, no suites.

${ }^{2}$ Also, colloquially, 'Sand YS' (Sabbie YS in Italian).

${ }^{3}$ Including EX1e and Le as subunits of EX1.

${ }^{4}$ Unit V5 (quadrangle E5) was equally classified within suite XE.

${ }^{5}$ Sediment units mostly recorded in quadrangle E06, due to section collapse (see text). 
Table 3. Area C, Sounding A: stratigraphic-historical groups employed in the study of archaeological finds, based on the stratigraphic distribution of dissection units ('cuts').

\begin{tabular}{|c|c|c|c|}
\hline $\begin{array}{l}\text { Phase } \\
\text { (Barāqish Area C) }\end{array}$ & Stratum & $\begin{array}{l}\text { Stratigraphic-historical groups } \\
\text { based on dissection units ('cuts') }\end{array}$ & Notes \\
\hline Recent and present & A & \multirow{2}{*}{$\bullet 160-164 ; 169,169 \mathrm{~A}, 169 \mathrm{~B}$} & \\
\hline Islamic 3 & B & & 169B: Islamic 3 \\
\hline Islamic 2 & \multirow{2}{*}{$\mathrm{C}$} & - $180,169 \mathrm{C}$ & \\
\hline Islamic 1 & & - $180 \mathrm{~A}, 181,182 ; 169 \mathrm{D}$ in part & \\
\hline Second Intermediate & E & - $183 ; 169 \mathrm{D}$ in part & occasional/ephemeral occupation episodes \\
\hline \multirow{2}{*}{ Minaean 4} & \multirow{2}{*}{$\mathrm{F}$} & - $184,169 \mathrm{E}$ & \\
\hline & & - $184 \mathrm{~B}, 169 \mathrm{~F}$ & \\
\hline \multirow{2}{*}{ Minaean 3} & \multirow{2}{*}{$\mathrm{H}$} & - $185,169 \mathrm{G}$ & \\
\hline & & - $186,169 \mathrm{H}$ & \\
\hline Minaean $2 / 3$ & $\mathrm{I}, \mathrm{H}$ & - $187,169 \mathrm{~K}$ & $\begin{array}{l}\text { cuts } 187 \text { and } 169 \mathrm{~K} \text { may contain finds from both later } \\
\text { Stratum I and earlier Stratum H }\end{array}$ \\
\hline \multirow{2}{*}{ Minaean 2} & \multirow{2}{*}{ I } & • 188 & \\
\hline & & - 189 & \\
\hline \multirow{5}{*}{ Minaean 1} & \multirow{5}{*}{$\mathrm{J}$} & - 190 & \multirow{2}{*}{$\begin{array}{l}\text { material within Earthwork F10-F12: partly reworked } \\
\text { and mostly Minaean? }\end{array}$} \\
\hline & & - $191,191 \mathrm{~B}$ & \\
\hline & & - 191A, 192, 193, 194, 194A, 195 & $\begin{array}{l}\text { reworked material within Earthwork F10-F12, } \\
\text { apparently a mixture of Sabaean and Minaean } \\
\text { deposits (pottery mostly Sabaean in cuts } 194 \text { to 195) }\end{array}$ \\
\hline & & • 196 & \multirow{2}{*}{$\begin{array}{l}\text { back fill of the foundation trench for the Minaean } \\
\text { wall (initial Minaean 1), largely or totally deriving } \\
\text { from the local Sabaean deposits }\end{array}$} \\
\hline & & - 197,198 & \\
\hline Later Sabaean & $\mathrm{N}$ & • 199,200 & \\
\hline
\end{tabular}


Table 4. Area C excavations 2005-2006: sequencing into Strata and a synthesis of stratigraphy. The Strata marked with an asterisk are only documented in middle and lower Sector E or in Sounding F. Lithological units not represented in the Reference section are also listed. Chronology refers to lithostratigraphy, not necessarily to political history, and is based on evidence from Area C alone (see Chapter 18, this volume, for detailed information).

\begin{tabular}{|c|c|c|c|c|c|}
\hline \multicolumn{3}{|c|}{$\begin{array}{l}\text { Cultural-historical stratigraphy } \\
\text { (periods and phases) }^{1}\end{array}$} & Strata & \begin{tabular}{|c|} 
Lithostratigraphy: \\
selected lithological components (units, ${ }^{2}$ \\
suites, groups, surfaces, diagenesis zones) and \\
features $^{3}$
\end{tabular} & $\begin{array}{l}\text { Tentative } \\
\text { chronology }\end{array}$ \\
\hline \multirow{8}{*}{$\begin{array}{l}\text { Post- } \\
\text { Minaean } \\
\text { and } \\
\text { Islamic }\end{array}$} & & Present & \multirow{3}{*}{ A } & \begin{tabular}{l|l} 
Later A & T70; SAp, SAG, SAE, SA $\alpha ; \Lambda \mathrm{E} ; \Lambda \mathrm{F}$ \\
\end{tabular} & \multirow{3}{*}{ 19C AD-present } \\
\hline & & \multirow{2}{*}{ Recent } & & Earlier A | T71b, F18, T71a; SE $\lambda$, E7P, E0, SXY; F01 & \\
\hline & & & & A or B $\mid \mathrm{SA} 0, \mathrm{BLO}$ & \\
\hline & Later Islamic & Islamic 3 & B & 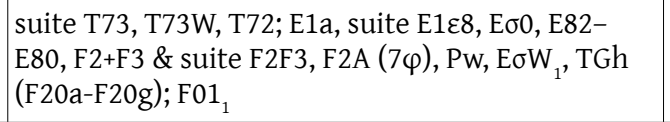 & c. AD $1400-1800$ \\
\hline & Earlier & Islamic 2 & \multirow{2}{*}{ C } & $\begin{array}{l}\text { Later C | suite T74U, LT7, ?T7 } \omega \text {, surface S5; T6B, } \\
\text { T6A }\end{array}$ & \multirow[b]{2}{*}{ c. AD $1190-1400^{5}$} \\
\hline & Islamic & Islamic 1 & & $\begin{array}{l}\text { Earlier C | T74L/M lacuna, suite T74M \& F6; CU5a, } \\
\text { surface S21, CU1; SBL, ?SA1 }\end{array}$ & \\
\hline & & $\begin{array}{l}\text { 2nd Intermediate } \\
\text { and Earlier } \\
\text { Islamic indt }\end{array}$ & $\mathrm{D}^{*}$ & $\begin{array}{l}\text { group EX3, EX6, La, E1b, x2; E } \sigma 1, \mathrm{E} \sigma \mathrm{W}_{2} \text { (pt); prob. } \\
\mathrm{F} 01_{2}, \mathrm{~F} 01 \alpha\end{array}$ & $1 C$ AD-c. 1400 \\
\hline & $\begin{array}{l}\text { Second } \\
\text { Intermediate }\end{array}$ & & E & $\begin{array}{l}\text { suite T74L, T7A, T7r, ?T7t; BV1, B01, BV0, surface } \\
\text { S20; CU6 (F22), CU5b, CU5i }\end{array}$ & $1 C \mathrm{AD}-\mathrm{c} .1190^{6}$ \\
\hline \multirow{6}{*}{ Minaean } & \multirow{4}{*}{$\begin{array}{l}\text { Later } \\
\text { Minaean }\end{array}$} & Minaean 4 & $\mathrm{~F}$ & $\begin{array}{l}\text { T75, T7B \& F8, T75B; B02; SPD, C C V, CI2, DGX, } \\
\text { CUV-CUV', CI1, CU7, surface S22 }\end{array}$ & $\begin{array}{l}\text { end } 1 C B C \text {-early/ } \\
\text { mid-1C AD }\end{array}$ \\
\hline & & \multirow{2}{*}{$\begin{array}{l}\text { Minaean 3-4 } \\
\text { uncorrelatable }\end{array}$} & \multirow[t]{2}{*}{$\mathrm{G}^{*}$} & 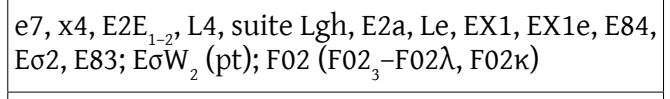 & \multirow[t]{2}{*}{$2 C \mathrm{BC}$-early $1 \mathrm{CAD}$} \\
\hline & & & & G? $\mid \mathrm{F} 1 ; \mathrm{YSP}$ & \\
\hline & & Minaean 3 & $\mathrm{H}$ & $\begin{array}{l}\text { suite T76, TPVj, TPVi, TPV; B03, BV; L13, DGV; } \\
\text { GV1, DGV1, SA } \pi\end{array}$ & $2 C-1 C B C$ \\
\hline & \multirow{2}{*}{$\begin{array}{l}\text { Earlier } \\
\text { Minaean }\end{array}$} & Minaean 2 & I & 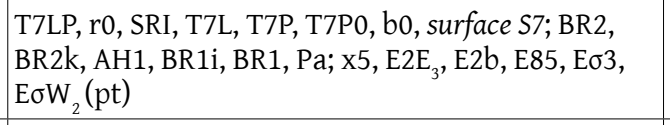 & $4 C-2 C B C$ \\
\hline & & $\begin{array}{l}\text { Minaean } 1 \text { and } \\
\text { wall construction }\end{array}$ & $\mathrm{J}$ & $\begin{array}{l}\text { cutting S12, MW bastion T7; group TBF, surface } \\
\text { S11, Earthwork F10-F12, surface S8.0 (S8 as eroded); } \\
\text { BRH2, BRH1, BR3, surface S1 }\end{array}$ & c. $550-5 \mathrm{C} \mathrm{BC}$ \\
\hline & $\begin{array}{l}\text { First } \\
\text { Intermediate }\end{array}$ & & K & $\begin{array}{l}\text { suite SD2, V0-V2, } \tau \mathrm{x}, \mathrm{GRx}, \mathrm{GRy}, \gamma \mathrm{x}, \gamma \mathrm{x} \omega ; \text {; } \mathrm{UY}, \mathrm{VCB} \\
\mathrm{LCB} \text {, surface S01 \& Z3; FH1, surface S19 }\end{array}$ & early $6 C-550 \mathrm{BC}$ \\
\hline \multirow{9}{*}{ Sabaean } & \multirow{4}{*}{ Later Sabaean } & \multirow[t]{2}{*}{ Sabaean 4} & \multirow[t]{2}{*}{$\mathrm{L}$} & $\begin{array}{l}\text { GR3; suite GZ, F9 (GR1 \& components); suite LNS, } \\
\text { suite KL, suite JKL, suite 5SU }\end{array}$ & \multirow{4}{*}{$7 C$-early $6 C \mathrm{BC}$} \\
\hline & & & & $\mathbf{L}$ or $\mathbf{N} \mid \tau \gamma$ & \\
\hline & & Sabaean 3-4 indt & $\mathrm{M}^{*}$ & $\begin{array}{l}\text { suite SEK, H78, E86, YS8 }{ }_{1} \text {, E } \sigma x, H 11 ; \text { SP1, SY1a, SY1, } \\
\text { SF1a, SF1 }\end{array}$ & \\
\hline & & Sabaean 3 & $\mathrm{~N}$ & $\begin{array}{l}\text { STY, suite SZ, SYH; GR }, \text { GKk, GK4, surface S15, GW, } \\
\text { suite GK; suite L3B, suite L3A, L3Z, suite L3Nn, Z1, } \\
\text { 4U2, LJ4, surface S16 \& Z2, prob. 6N }\end{array}$ & \\
\hline & \multirow{5}{*}{$\begin{array}{l}\text { Earlier } \\
\text { Sabaean }\end{array}$} & \multirow{2}{*}{$\begin{array}{l}\text { Sabaean 2: } \\
\text { Upper Sand YS }\end{array}$} & \multirow{2}{*}{0} & $\begin{array}{l}\text { F13 (GR2); YSd, YSa, Y } 115 \text {; suite L3C, suite XE, } \\
\text { suite LXZ, suite 45S, suite 6UV }\end{array}$ & \multirow{5}{*}{ c. $680-7 \mathrm{C} \mathrm{BC}$} \\
\hline & & & & O? (O-P) | SAq, ?5G, YS8 ${ }_{2}, \mathrm{E} \sigma W_{3}, \mathrm{H} 11 \mathrm{Q} ; \mathrm{SY} 2$ & \\
\hline & & \multirow{2}{*}{$\begin{array}{l}\text { Sabaean 2: } \\
\text { Wall F4 decaying }\end{array}$} & \multirow{2}{*}{$\mathrm{P}$} & $\begin{array}{l}\text { Later P | YSf, YSd } \\
\text { LE0, J2, prob. suite CM (pt) }\end{array}$ & \\
\hline & & & & $\begin{array}{l}\text { Earlier P | YSi, SGY; Gh4, Jx, LEb, LEa, suite L3ef, } \\
\text { prob. suite CM (pt) }\end{array}$ & \\
\hline & & $\begin{array}{l}\text { Sabaean 2: } \\
\text { Wall F4 functional }\end{array}$ & Q & $\begin{array}{l}\text { suite YSL, prob. YSX, SGP0; LEd, LEc, suite 6QR, } \\
5 \mathrm{SA} \text {, surface } S 17, \lambda \rho\end{array}$ & \\
\hline
\end{tabular}




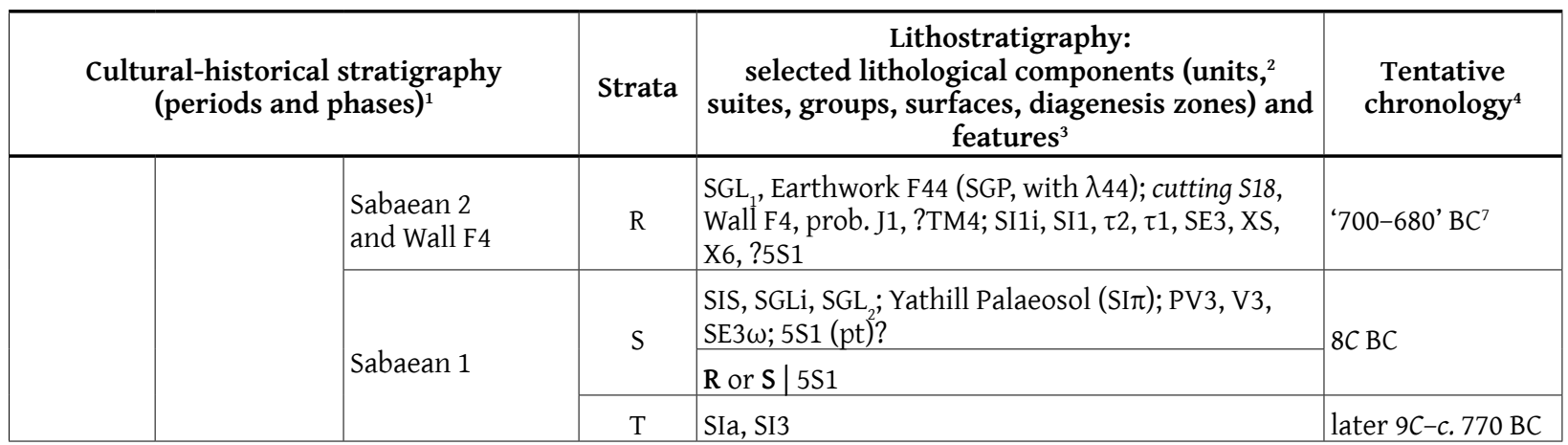

${ }^{1}$ These periods and phases have primary or exclusive validity within extramural Area C.

${ }^{2}$ Subunits are occasionally included for specific attribution to Strata.

${ }^{3}$ Features include, top to bottom, F18, F2+F3, F2A, F20a-F20g, F6, F22, F8, F1, MW, F10-F12, F9, F13, F44, F4. Cultural horizons prefixed by ' $\mathrm{H}$ ' (e.g. H11). Surfaces and diagenetic zones in italics (e.g. surface S1; cutting S12; Z2). Abbreviations: indt = indeterminate; $\mathrm{MW}=$ Minaean curtain wall; $\mathrm{pt}$ = in part; prob. = probably.

${ }^{4} \mathrm{BC}$ (or $\mathrm{BCE}$, Before the current era) and $\mathrm{AD}$ (or $\mathrm{CE}$, current era). This chronology is derived from Table 3 , column 4 , in Chapter 18 (this volume). Abbreviations: $8 C=$ Eighth century (and so on); $c$. $=$ circa.

${ }^{5}$ Possibly including interruption of occupation during part of the 14th century: see Table 4 in Chapter 18 , this volume.

${ }^{6}$ Includes the Yathill-Barāqish Interval, an occupational hiatus c. AD 200-1200; this hiatus was not depositional.

${ }^{7}$ Wall F4 constructed c. 700-690 BC (ante-689 BC, following Potts 2003, 198): see Table 3, footnote 5, in Chapter 18 (this volume).

Table 5. Area C excavations 2005-2006: sequencing of the Sabaean 2 interval and associated Wall F4. Time flows from bottom to top.

\begin{tabular}{|c|c|c|c|c|c|c|c|}
\hline \multicolumn{2}{|c|}{$\begin{array}{l}\text { Wall F4 ‘biography’ } \\
\text { (inferred phases) }\end{array}$} & \multirow{2}{*}{ Stratum } & \multicolumn{5}{|c|}{ Lithostratigraphy } \\
\hline & $\begin{array}{c}\text { material } \\
\text { correlates }\end{array}$ & & Lithocomplex & qu. D6-D7 & $\begin{array}{c}\text { wall } \\
\text { break }\end{array}$ & $\mathrm{qu}$ & E1-E2 \\
\hline \multirow{4}{*}{$\begin{array}{l}7 \text { Mud-brick } \\
\text { curtain obliterated }\end{array}$} & \multirow{4}{*}{$\begin{array}{l}\text { stone base only } \\
\left(\mathrm{F} 4_{0}\right)\end{array}$} & \multirow{4}{*}{0} & \multirow{4}{*}{1.5 .3} & feature F13 & & \multirow{2}{*}{ ? } & \multirow{2}{*}{$\begin{array}{l}\text { L3c } \\
\text { base }=\text { S14 }\end{array}$} \\
\hline & & & & YSa & & & \\
\hline & & & & \multirow[b]{2}{*}{$\mathrm{YSd}_{1}$} & $?$ & SAq & \\
\hline & & & & & & $\begin{array}{l}\text { erosion } \\
\text { surface S13 }\end{array}$ & \\
\hline \multirow{3}{*}{6 Decayed curtain } & \multirow{3}{*}{$\begin{array}{l}\text { curtain reduced } \\
\text { to mud-brick } \\
\text { stumps, e.g. J1 }\end{array}$} & \multirow{7}{*}{$\mathrm{P}$} & \multirow{3}{*}{1.5 .2} & \multirow{3}{*}{$\begin{array}{l}Y_{S d_{2-3}, Y \lambda a,}, Y \lambda b \\
Y S f-Y \lambda 1\end{array}$} & & $\mathrm{~J} 2$ & \multirow{7}{*}{$\begin{array}{l}\text { detailed } \\
\text { stratigraphic } \\
\text { correlation } \\
\text { difficult }\end{array}$} \\
\hline & & & & & & LE0 & \\
\hline & & & & & & LE1. LE $\omega$ & \\
\hline \multirow{4}{*}{5 Decaying wall } & \multirow{4}{*}{$\begin{array}{l}\text { curtain F } 4{ }_{1} \text { partly } \\
\text { extant }\end{array}$} & & \multirow{4}{*}{1.5 .1} & \multirow{2}{*}{ YSi } & & LEa & \\
\hline & & & & & & LEb & \\
\hline & & & & SGY & & 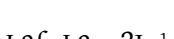 & \\
\hline & & & & Gh4 & & L3I -L3e. ?]X & \\
\hline 4 Wall extant & $\begin{array}{l}\text { wall fully extant: } \\
\mathrm{F} 4_{0}+\mathrm{F} 4_{1}\end{array}$ & Q & 1.4 & $\begin{array}{l}\text { YSX (?). } \\
\text { YSZ, SGP0. } \\
\text { YSZi }\end{array}$ & & $\begin{array}{l}\text { LEc. } \\
\text { LEd }\end{array}$ & \\
\hline \multirow{4}{*}{3 Accessory works } & \multirow{4}{*}{$\begin{array}{l}\text { remblai, } \\
\text { Earthwork F44 }\end{array}$} & \multirow{6}{*}{$\mathrm{R}$} & \multirow{2}{*}{1.3 .1} & \multirow{2}{*}{ F44: SGP } & \multirow{2}{*}{$?$} & surface S4 & \\
\hline & & & & & & SE3 & \\
\hline & & & \multirow{2}{*}{ 1.3.0 } & F44: SGP ${ }_{2-3}+\lambda 44$ & & \multirow{2}{*}{$\begin{array}{l}\text { top }=\mathrm{S} 4 \mathrm{~A} \\
\mathrm{SI} 1 ; \mathrm{SI} 1 \mathrm{i}\end{array}$} & \\
\hline & & & & $\mathrm{SGL}_{1}$ & & & \\
\hline $\begin{array}{l}2 \text { Wall } \\
\text { construction }\end{array}$ & $\begin{array}{l}\text { Wall F4: } \\
\mathrm{F} 4_{0} \rightarrow \mathrm{F} 4_{1}\end{array}$ & & 1.2 .2 & \multicolumn{3}{|c|}{ Wall F4: F4 $4_{0}+F 4_{1}$} & \\
\hline $\begin{array}{l}1 \text { Cutting for wall's } \\
\text { insertion }\end{array}$ & surface S18 & & 1.2 .1 & \multicolumn{3}{|c|}{ S18 } & \\
\hline \multicolumn{2}{|c|}{ Pre-existing deposits } & $\mathrm{T}-\mathrm{S}$ & $1.0-1.1$ & up to $\mathrm{SGL}_{2}(?)^{3}$ & \multicolumn{2}{|c|}{ up to SIa, SI $\pi$} & \\
\hline
\end{tabular}

${ }^{1} \mathrm{Jx}$ is earlier than, or coeval with, Gh4.

${ }^{2}$ Wall F4 is composed of a stone base (F4) and a mud-brick curtain (F4 ), this latter essentially inferred from sediment unit J1.

${ }^{3}$ Preferred option. Alternatives are the SGLi/SGL ${ }_{2}$ boundary or the SGL/SGP boundary. 
Table 6. Area C excavations 2005-2006: sequencing of the Minaean 1 interval and associated curtain wall, bastion T7. Time flows from bottom to top.

\begin{tabular}{|c|c|c|c|}
\hline \multicolumn{2}{|l|}{ Minaean Wall, bastion T7: phases } & \multirow[t]{2}{*}{$\begin{array}{l}\text { Lithostratigraphy } \\
\text { of associated deposits }\end{array}$} & \multirow[t]{2}{*}{$\begin{array}{l}\text { Cultural } \\
\text { phases }\end{array}$} \\
\hline & sedimentary correlates \& features & & \\
\hline & start of ordinary sedimentation & & Minaean 2 \\
\hline & & surface S8 & \multirow{19}{*}{$\begin{array}{l}\text { Earlier } \\
\text { Minaean: } \\
\text { Minaean } 1 \\
\text { (Stratum J) }\end{array}$} \\
\hline \multirow{3}{*}{$\begin{array}{l}8 \text { Earthwork F10-F12, stage } 4 \text { : } \\
\text { completion of the accessory works } \\
\text { at the base of wall }\end{array}$} & F10, new stone-bed and ballast & T77 \& stones T7C & \\
\hline & \multirow{2}{*}{ F10, 'horizontal' casing } & F10Y & \\
\hline & & $\mathrm{T} 77 \mu$ & \\
\hline \multirow{2}{*}{$\begin{array}{l}7 \text { Wall construction } 3: \\
\text { completed to top? }\end{array}$} & wall's bastion T7 finished? & & \\
\hline & & surface S9 & \\
\hline 6 Earthwork F10-F12, stage 3 & F11, incl. mud bricks F11M & $\mathrm{T} 78 \pi, \mathrm{T} 78 \mathrm{~V}, \mathrm{~F} 11 \mathrm{M}$ & \\
\hline \multirow[t]{2}{*}{5 Earthwork F10-F12, stage 2} & F11, mud-brick casing F11C & $=\mathrm{T} 78 \mathrm{C}$ & \\
\hline & & surface S10 & \\
\hline \multirow{2}{*}{4 Earthwork F10-F12, stage 1} & \multirow{2}{*}{ 'core' fills: F12 } & fill $2=\mathrm{T} 79 \mathrm{~L}$ & \\
\hline & & fill $1=$ T79J, stones F12P & \\
\hline $\begin{array}{l}3 \text { Wall construction } 2 \text { : } \\
\text { courses } 16 \text { and above. } \\
\text { Probably continuing during phases } \\
\text { 4-6 }\end{array}$ & & & \\
\hline \multirow{6}{*}{$\begin{array}{l}2 \text { Wall construction } 1 \text { : } \\
\text { courses } 22-17\end{array}$} & break: temporary arrest? & surface S11 & \\
\hline & \multirow{3}{*}{$\begin{array}{l}\text { backfill of the foundation trench, stage } 2 \text {; } \\
\text { or aggradation during wall's } \\
\text { construction }\end{array}$} & $\mathrm{T} 7 \tau$ & \\
\hline & & 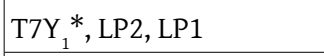 & \\
\hline & & $\mathrm{T}_{2} \mathrm{Y}_{2}$ & \\
\hline & \multirow{2}{*}{$\begin{array}{l}\text { backfill of the foundation trench, stage } 1 \\
\text { (largely or totally Sabaean deposits) }\end{array}$} & $\mathrm{T} \mathrm{F}_{1-5}, \mathrm{LP} 3, \mathrm{LAR}$ & \\
\hline & & AR, LP3 & \\
\hline \multirow[t]{2}{*}{1 Cutting for wall's foundations } & $\begin{array}{l}\text { foundation trench, defined by surface } \\
\text { S12 }\end{array}$ & S12 (W limit unknown) & \\
\hline & pre-existing deposits, Locus 200 & & Later Sabaean \\
\hline
\end{tabular}

* and cementation of sediment matrix of lower T7Y and upper T7F by calcium carbonate and related salt solutions 


\title{
Chapter 18 \\ Excavations in Area C. Chronology and the Historical Sequence
}

\author{
Francesco G. Fedele
}

\section{Radiocarbon chronology}

\subsection{Sampling and dating}

A very large number of charcoal samples for both anthracology and radiocarbon dating were collected during the excavations. Radiocarbon determinations were started immediately after the 2005 season, with five samples as a first trial, but this batch incurred in the deactivation of the University of Naples laboratory mentioned in Volume 1, Chapter 16. A new plan was thus devised to begin a comprehensive dating programme after the second and final excavation season. Unanticipated difficulties, however, emerged in December 2006. In the first place, the fieldwork did not leave enough time to perform the ideal, well pondered selection of samples from the large collection. Indeed some of the choices eventually turned out not to be optimal, as they were based on the provisional knowledge of stratigraphy from Area $C$ then available. More serious was a second problem: unexpected restrictions were raised by the GOAM representatives regarding the number of charcoal samples that would be allowed to export for study. ${ }^{1}$

This meant that a very restricted selection had to be made for Area $\mathrm{C}$, compared to the extensive sampling performed. ${ }^{2}$ For instance, no samples from middle and lower Sector E and from Sounding F could be included, in order to assist in the correlation of these distant sectors with the stratigraphic core for Area C, represented by Sector D and Sounding A. One of the consequences is that no independent means for the placement of such 'floating' entities as horizons H78 or H11 is available as a control of lithostratigraphic correlation per se.

Nineteen charcoal samples in total were submitted for measurement in three batches: to CIRCE (Caserta,

\footnotetext{
1 In 2007, due to the absence of A. de Maigret (see Chapter 1 in Volume 1), no radiocarbon-sample allowance could be negotiated with GOAM.

2 The remaining fraction of charcoal samples for radiocarbon was kept in storage at Barāqish, curated and bagged with the plant collection (December 2007). Whether it reached San' $(\vec{a})$ is presently unknown (cf. Chapter 21, this volume, footnote 4).
}

Italy) in January 2007 and October 2008, four and seven samples respectively; ${ }^{3}$ and eight samples to Beta Analytic (Miami, USA) in September 2018. ${ }^{4}$ This last run was especially aimed at improving the chronological resolution, if possible, with the needs of the present publication in mind. The respective laboratory reports were issued by CIRCE on 18 April 2007 and 9 December $2008,{ }^{5}$ and by Beta on 17 October 2018.

The results of radiocarbon chronometry are presented in Tables 1-3. Table 1 lists the individual determinations and Table 2 the pooled dates. Replicated measurements of charcoal from the same sample or from equivalent context lend themselves to pooling (weighted dates), hence to combined age determinations that entail a beneficial reduction in statistical uncertainty. Table 3 outlines a tentative chronology for Area $C$, on the basis of radiocarbon dates supplemented by non-radiometric information. The spatial and stratigraphic distribution of the calibrated dates is shown in Fig. 1. In Figs 2 and 3 calibration plots are presented for the individual measurements and the pooled dates, respectively.

\subsection{A critical assessment of the dated samples}

The 19 samples submitted for radiocarbon dating will be prefixed in this chapter by the hash sign (\#). A detailed description of each sample is provided below, together with a critical assessment of the sample's value for establishing a chronometry of the sedimentary

\footnotetext{
3 Charcoal samples \#13, 99A, 183, 200 (submitted on 18 January 2007); and \#22.1,38.2, 49D, 102,181, 185, 191 (submitted on 3 October 2008). Through an agreement by the author with the CIRCE accelerator centre, directed by F. Terrasi, the costs of radiocarbon measurements at CIRCE were met by the University of Naples L'Orientale concurrently with the dating laboratory (see Chapter 16, section 3, in Volume 1).

4 Charcoal samples \#2.1, 13.1, 14, 22.1.a, 43, 43B, 102.a, 191.a (submitted on 21 September 2018). These measurements were paid for by the author.

5 I wish to record that A. de Maigret not only granted financial support for the datings at CIRCE, but followed with keen interest my chronological and stratigraphic interpretation of the results, which we thoroughly discussed in Naples on 10 December 2008. As already recalled in Chapter 16, section 3 (in Volume 1), he was equally keen to cite the datings during a lecture at the Académie des Inscriptions et Belles-lettres in Paris in January 2009 (with C. Robin; see Robin and de Maigret 2009, 67-72).
} 


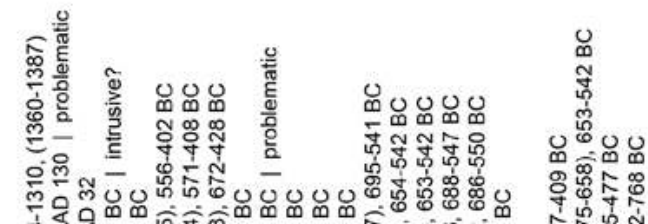

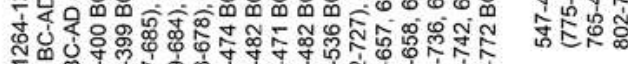

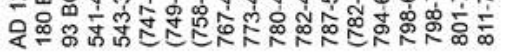

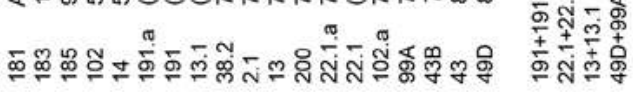
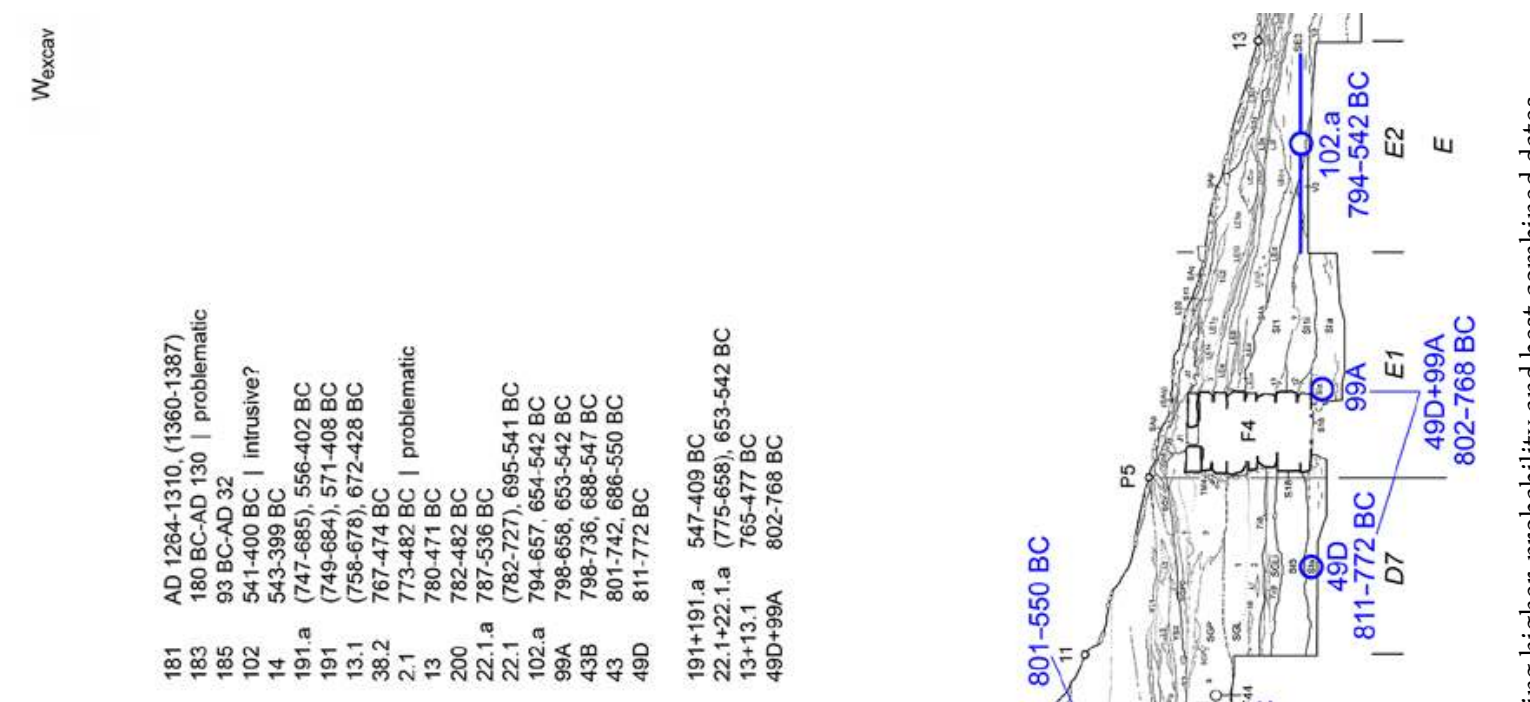
entities involved. The samples are arranged combining topographic provenance (from Sector E to Sounding A) and calendar age (from the oldest to the most recent). For immediacy of reference the strata designations will be written in bold (e.g. Stratum H). Whatever their individual merits, the Area $C$ samples are presented in such a degree of detail because, until new research can be carried out at Barāqish or elsewhere in the Jawf, this is the best we could do in radiometric terms to illuminate the ancient vicissitudes of the region.

\section{Abbreviations and conventions}

cm-sized: centimetre-sized $(c .1-4 \mathrm{~cm})$

fr., frs: fragment, fragments

qu.: quadrangle of excavation grid (e.g. qu. D5)

Dates in the text of this chapter will be expressed as 'BCE' or ' $\mathrm{CE}$ '. The abbreviations 'BC' and 'AD' are used in the tables.

\#102, \#102.a. Qu. E2. Units V3, SI1i-SI1, SE3, but predominantly SE3 and SI1. Strata S-R. ${ }^{6} \mid$ This sample consisted of a dozen frs of good quality, large (1-5 $\mathrm{cm}$ ), relatively massive wood, ostensibly of the same appearance and possibly derived from a branch of about $12 \mathrm{~cm}$ in diameter. Although vitiated by a rather loose association with stratigraphy, this charcoal was therefore considered helpful in dating the Earlier Sabaean. However, a problem emerged concerning the homogeneity of the sample. Two charcoal frs, separately measured in 2008 and 2018, produced mutually exclusive ages, thus revealing that the sample was in fact heterogeneous. While the fragment measured in 2018 (\#102.a) produced a date compatible with Stratum S or R and an attribution to the Earlier Sabaean (2-sigma total range $=794-542 \mathrm{BCE}$ ), fragment \#102 measured in 2008 indicated a younger date (post-541 BCE), ${ }^{7}$ irreconcilable with the Sabaean. This second fragment could well be intrusive. ${ }^{8}$ In Fig. 1 only the age produced by charcoal \#102.a is plotted. A pooled calendar date from samples \#102.a and \#43B is presented in Table 2.

\#99A. ${ }^{9}$ Qu. E1 east. Unit SIa, including SIr. Stratum T. I This sample was obtained from flotation of the sediment and soil exclusively preserved beneath Wall F4. ${ }^{10}$ It consisted of three charcoal frs of $2-3 \mathrm{~cm}$ and several smaller frs, as well as several cilb nutshells. These latter were spared from dating and preserved

\footnotetext{
6 Cf. alabaster flake no. 102.02 (chapter 21, section 2.1, this volume).

7 Re-calibrated according to the IntCal 13 curve and omitting the low-probability 'tail' of the 2-sigma range $(726-695 \mathrm{BCE}, p=0.023)$.

8 Traces of fossorial animals were observed at similar depth in qu. E3, as mentioned in the study of find no. 110.1 (Chapter 21, section 2.5, this volume) and reported in Chapter 17 , section 6.8 , this volume.

9 '99A.1' in Fedele 2010, table 3.

10 The flotation was executed on the last day of the 2005 field season.
}

for archaeobotany. Associated elements also showing traces of burning included bone splinters and hearthstained cobbles. Together with \#49D, sample \#99A was collected specifically for dating Stratum T.

\#49D. Qu. D7 west. Unit SIa, below the level of the base of Wall F4. | This sample was obtained from water screening of the whole sediment of cut 49D. It consisted of about a dozen good-quality wood frs $1-3.5 \mathrm{~cm}$ in size, as well as several charred 'ilb nutshells. These latter were spared from dating and preserved for archaeobotany. Associated elements also showing traces of burning included charcoal-stained pebbles. Particularly in qu. D7, the deposit formed of unit SIa ${ }^{11}$ was interpreted as the residue-rich periphery of a hearth area, only subjected to mild pedogenesis: hence a good sampling context for the dating of Stratum $\mathrm{T}$.

\#43B. Qu. D6. Units YSZ and YSX. Stratum Q. This sample consisted of five centimetre-sized wood frs of uniform carbonization, deriving from two or three different branches of one or two shrub/tree species: a branch of 'knotty' wood, possibly 'ilb, represented by a whole section $9-10 \mathrm{~mm}$ in diameter; and four frs of smooth, regular wood from bigger branches, one of which unusually hard. This last was sent for dating together with two smooth-wood specimens. For additional information on the sedimentary context of \#43B see sample \#43, below.

\#43. Qu. D6. Units YSd ${ }_{1-2}$ to YSa top, i.e. most of suite YSU. Strata $\mathrm{P}(\text { ? })^{12}$ and $\mathrm{O}$. | This sample consisted of three $\mathrm{cm}$-sized and five smaller wood frs, with one fragment looking different from the others in wood type. Five wood fragments of the same kind and characterized by manifest rings - one $1.7-\mathrm{cm}$-long and well carbonized, and four $0.8-1.0-\mathrm{cm}$-long ones from small branches - were submitted for dating. Both samples \#43B and \#43 were obtained from debris lenses within Sand YS, probably representing colluvia from the nearby edge of the Earlier Sabaean tell. Their statistically identical radiocarbon ages strongly suggest a uniform source for the charcoal throughout the timespan of Sand YS, Strata $Q$ to $0 .{ }^{13}$ In turn, the probability of a common origin suggests that a pooling of samples \#43B and $\# 43$, producing an age of 798-587 BCE with a $96 \%$ probability (or 798-748 BCE with $p$ reduced to $68 \%$ ), can

\footnotetext{
11 SIa: a powdery, ashy, dark-grey silt ('grey powder') with sparse charcoal and pebbles, topped by remnants $(\mathrm{SI} \pi)$ of the Yathill Palaeosol, beneath the base of Wall F4 in qu. D7-E1. Cf. Chapter 17, section 5.2 , this volume.

12 The records for cut 43, firstly taken during the cut and subsequently during the drawing of the relevant section, present a discrepancy that cannot be resolved.

13 This supposed source possibly also originated the charcoal fraction dated as sample \#102.a: as already mentioned, a statistical check of \#102.a and \#43B through pooling is given in Table 2.
} 
be considered a good date for the second part of the Earlier Sabaean (Strata Q-0).

\#38.2. Qu. D5. Suite GK, i.e. units GK3-GK1. Stratum N. | This sample, from flotation and presumably from GK1, contained a relatively large selection of $2-3-\mathrm{cm}$-sized charcoal frs from occupation layers that also produced charred wood pieces about $10 \mathrm{~cm}$ long. The context, suite GK, included burnt and charred bones, in addition to all sorts of well preserved organic artefacts (among them an ivory comb, no. 38.1). Unfortunately, no large charcoal wood was allowed to be taken out of Yemen for radiocarbon. Sample \#38.2 gave for Stratum $\mathbf{N}$ an age bracketed by 767-474 BCE. Through pooling with sample $\# 200$, on the assumption of a correct correlation of Locus 200 with Stratum $\mathbf{N}$, the age range could be reduced to two centuries and a half: 768-511 BCE. All combinations of datings attempted from Strata $\mathbf{N}$ and $\mathbf{L}$ in order to obtain better dates for the Later Sabaean are presented in Table 2 and Fig. 3.

\#14. Qu. D3 + D13. Units GZ2 and lower GZ1. Stratum L. | The small sample from cut 14 allowed out of Yemen consisted of three $\mathrm{cm}$-sized charcoal frs of the smooth wood type with evident rings, of which one fr. 3.4-cmlong was submitted for dating. The context was represented by the core of suite GZ, a richly laminated silty-ashy series from nearby habitation, containing abundant cooking residue. The age obtained was unexpectedly younger than that for the top of suite GZ (samples \#13 and \#13.1). The statistically admissible pooling with \#13 and \#13.1 marginally corrected this minor case of stratigraphic inversion (Table 2).

\#13, \#13.1. Provenance for both: qu. D3 + D13 south. Surface S2 and top $10 \mathrm{~cm}$ of unit GZ1. Final Stratum L. | Samples \#13.1 (from flotation) and \#13 (from dry sediment) consisted of a great abundance of charred wood of both the smooth and 'knotty' types, the former with evident rings, the later possibly from 'ilb. All the useful frs were $1-3.5 \mathrm{~cm}$ in size. They derived from the ash-and-charcoal lenses and leached hearths observed in the upper $10-15 \mathrm{~cm}$ of laminated unit GZ1, including surface S2, and precisely recorded in situ. Again, only a small fraction could be taken to Italy. Both samples appeared to provide the best material for dating the end of Stratum L. However, because of the plateau in the ${ }^{14} \mathrm{C}$ curve, also their pooled age unfortunately only produced a timespan of some three centuries, 765-477 BCE (Table 2).

\#22.1, \#22.1.a. Qu. D2. Units GSV3-GSV1, L1, L2. Earlier Stratum K. | This sample consisted of two 5-cm-plus frs and one $\mathrm{cm}$-sized fr. of brittle but well carbonized wood, all probably derived from a single branch of $12-15 \mathrm{~cm}$ in diameter. A fr. 2.5-cm-long, obtained from the same piece that had been measured at CIRCE (\#22.1), was submitted to Beta (\#22.1.a) with the aim of reducing the statistical error. The new measurement did not offer increased precision, but validated the previous one with perfect statistical concordance, and the pooling of \#22.1.a and \#22.1 produced for Earlier Stratum $\mathrm{K} \mathrm{a}$ marginally improved age of 693-542 BCE, with 79\% probability (Table 2).

\#200. Qu. A1-A11 east and A31 southeast. Units SZ2lower SYH. ${ }^{14}$ Stratum $\mathbf{N}$. | Charcoal \#200 came from suite SZ and the lower half of unit SYH. The entire sample allowed out of Yemen, three small fragments, was used for measurement in 2007. The recalibration with the IntCal13 curve produced an optimal probability value, although less precise than with IntCal04 (Fedele 2010, table 3). A virtual identity in age between sample $\# 200$ and sample $\# 13$ can be observed, both radiocarbon and calendar. This might suggest for Locus 200 a correlation with Stratum $\mathrm{L}$, rather than $\mathbf{N}$, and the pooling of samples \#200 and \#13 obviously generates a statistically good date. However, as explained in Chapter 17 (this volume), the inferred geometry of the Later Sabaean tell, together with the apparent affinity of cultural contents and particularly sediments, are more consistent with the proposed correlation with Stratum $\mathbf{N}$. The fact that age pooling from samples $\# 200$ and \#38.2, this latter being Stratum $\mathbf{N}$ by definition, gives a marginally narrower age range than pooling \#200 with \#13 (768-511 BCE instead of 774-509 BCE), could be taken as supporting the correlation of Locus 200 with Stratum $\mathbf{N}$.

\#2.1. Qu. D1. Unit 'GV1 bottom'. Stratum H. Also Pa (Stratum I)? - see discussion below. | This sample gave a calendar age, 773-482 BCE, completely incompatible with the age previously obtained for Stratum $\mathrm{H}$ from sample \#185 (see below). Charcoal \#2.1 was retrieved from flotation of a nearly full bucket of sediment from the bottom of unit GV1 in qu. D1, at the beginning of the excavations at Area C. ${ }^{15}$ Retrospectively, however, it cannot be excluded that \#2.1 sampled sediment matrix of Pa-top BR1 (Stratum I). Several cm-sized frs of well carbonized wood ostensibly of the same appearance, possibly derived from two branches less than $5-8 \mathrm{~cm}$ in diameter, were selected for radiocarbon. Unfortunately, at the time of submission it had not been realized that cut 2 evidently contained a fraction of reworked, earlier elements (Sabaean sherds, and perhapsclay disc/'tripod' fragments nos 2.01 and 2.03). ${ }^{16}$ Furthermore, stony unit $\mathrm{Pa}$ might itself have resulted from mobilization of a mixture of Minaean wall construction debris and reworked Sabaean sediments. In this light, it would not surprise if also the radiocarbon-dated charcoal were

\footnotetext{
14 No charcoal was observed in Locus 200's bottom unit STY.

15 See flotation photographs in Chapter 20, this volume.

16 See Chapter 21, section 2.3 (particularly footnote 167), this volume.
} 
redeposited Sabaean material. For these reasons uncertainty of association and supposed redeposition - sample \#2.1 cannot contribute to the dating of the Later Minaean, nor can it alone cast doubt on the correlation of GV1 with Stratum H. ${ }^{17}$

\#191, \#191.a. Qu. A1-A31. Unit/feature T77 $\mu$ (F10). Later (?) Stratum J. | Samples \#191 and \#191.a are precisely associated with $\mathrm{T} 77 \mu$, a component of feature F10 in Earthwork F10-F12. The two charcoal samples can be considered equivalent. For a second measurement in 2018, aimed at reducing the statistical error, a section 2-cm-long from a small branch about $3 \mathrm{~cm}$ in diameter was selected (sample \#191.a). The higher-probability interval of the samples' pooled age, about 140 years (547-409 BCE), provides an improved, acceptable dating for Minaean phase 1.

\#185. Qu. A1-A11. Units SR, T76H, TPV, but very probably from unit $\mathrm{T} 76 \mathrm{H}$, no charcoal having been reported from SR or TPV. Stratum H. | The dated sample consisted of three $\mathrm{cm}$-sized charcoal frs from unit $\mathrm{T} 76 \mathrm{H}$, which exhibited several ash-and-charcoal lenses representing leached hearths. The age obtained, $93 \mathrm{BCE}-32 \mathrm{CE}$, is entirely acceptable for Stratum $\mathrm{H}$ and Minaean phase 3.

\#183. Qu. A1-A11. Suite T74L (Stratum E) and unit T7JK (Earlier Stratum C). | The re-classification and partial reinterpretation - for this book - of the sediment units composing group GT74 has resulted in the complete indeterminacy of stratigraphic association for sample \#183. The fragment or fragments that were measured cannot precisely be assigned to any of the units excavated with cut 183. While an association with suite T74L (Stratum E) appears to be likely, there is a possibility that the dated material came from charcoal-rich unit T7JK, attributed to earlier Stratum C (provided that the T7JK charcoal was coeval with the sediment matrix, which is not guaranteed). But stratigraphic revisions aside, sample \#183 turned out to be intrinsically flawed, since it exhibited the larger (by far) statistical uncertainty among the dated samples, $\pm 65{ }^{14} \mathrm{C}$ years - an outcome that probably indicated heterogeneity in composition. This in turn resulted in a very large statistical uncertainty in calendar age, no less than 310 years at 2 sigma, i.e. $15 \%$ of the median age (Table 1). Such an age not just overlaps, but envelops, the age of sample \#185 from a layer below (Fig. 2).

The above drawbacks suggest that sample \#183 has no historical value. It is perhaps more constructive, however, to take the measured age as a maximum age (a terminus post quem). In fact, the 'tail' of the calendar age range of sample \#183 which is younger than the age

17 A check on the dating of Stratum H from qu. D1 (unit DGV1) could be obtained in the future from measuring sample \#1, available in the batch exported from Yemen. of sample \#185 (i.e. 33-130 CE) might be taken to suggest that some old charcoal from the first few centuries $\mathrm{CE}$ contributed to the ${ }^{14} \mathrm{C}$ age of \#183. On the other hand, there is no point in running a Bayesian treatment of these radiocarbon ages when one sample is so imperfect, and both samples were measured only once. Since only one cm-sized fr. of sample \#183 survives, ${ }^{18}$ no further dating is presently warranted.

\#181. Qu. A2-A12 + A11 west. Unit T7H (F6). Earlier Stratum C. | The dated sample consisted of two cmsized frs from charcoal-rich unit $\mathrm{T} 7 \mathrm{H}$, probably collected in qu. A2 along the 'front' of collapse rubble T7A. As discussed in Chapter 17, this volume, unit T7H is closely associated with feature $\mathrm{F}^{19}$ and exclusively produced Islamic pottery. The age obtained, 1264-1310 CE with 77\% probability, is compatible with the Earlier Islamic. Being a single date, however, the assumption that it particularly dates Islamic phase 1 is provisional (cf. Table 3).

Two general problems in dating Area C - or Barāqish in general - require some comments: heterogeneous charcoal and the 'Sabaean-Minaean' plateau in the calibration curve. Samples containing charcoal of heterogeneous origin represent a common problem in fine-grained deposits subjected to repeated activity and/or redeposition, particularly in arid environments where material of different ages tends to be equally well preserved. Minute charcoal of disparate origin is often visually indistinguishable..$^{20}$ At Barāqish the problem was explicitly addressed in the extramural excavations of Area C, a complex of deposits mostly characterized by the above conditions and lacking large charred-wood pieces. But apart from constant attention to depositional context, it was not always possible to evaluate the taphonomic integrity of the charcoal taken for radiometric use.

As to the calibration curve, it is well known that the shape of the curve between about 800/750 and 400 calendar years BCE is affected by a plateau, i.e., the curve levels out. This hinders an accurate calibration of radiocarbon dates in that interval, and even samples which have low statistical error, such as ours, provide wide-ranging calendar ages that often are of modest archaeological value. ${ }^{21}$ Because of this plateau in the curve, radiocarbon

\footnotetext{
18 Outside Yemen.

19 The evidence suggesting that provisional 'F6' was a former structure was precisely recognized during cut 181.

20 Cf. Chapter 16 in Volume 1, note 25.

21 Cf., e.g., Durrani 2005, 75, footnote 2; and Magee 1996, 249, fig. 8 , who comments: 'The most that can be stated [in such cases] is that the ${ }^{14} \mathrm{C}$ samples passively support the chronology suggested by [material culture parallels]'. In a Eurocentric perspective, this flat segment of the calibration curve affecting the ${ }^{14} \mathrm{C}$ values scattered around 2500 bp was called the 'Hallstatt plateau' (see, e.g., Chugunov et al. 2004, 172-173; Zaitseva et al. 2004, 278-279). The plateau is obviously global,
} 

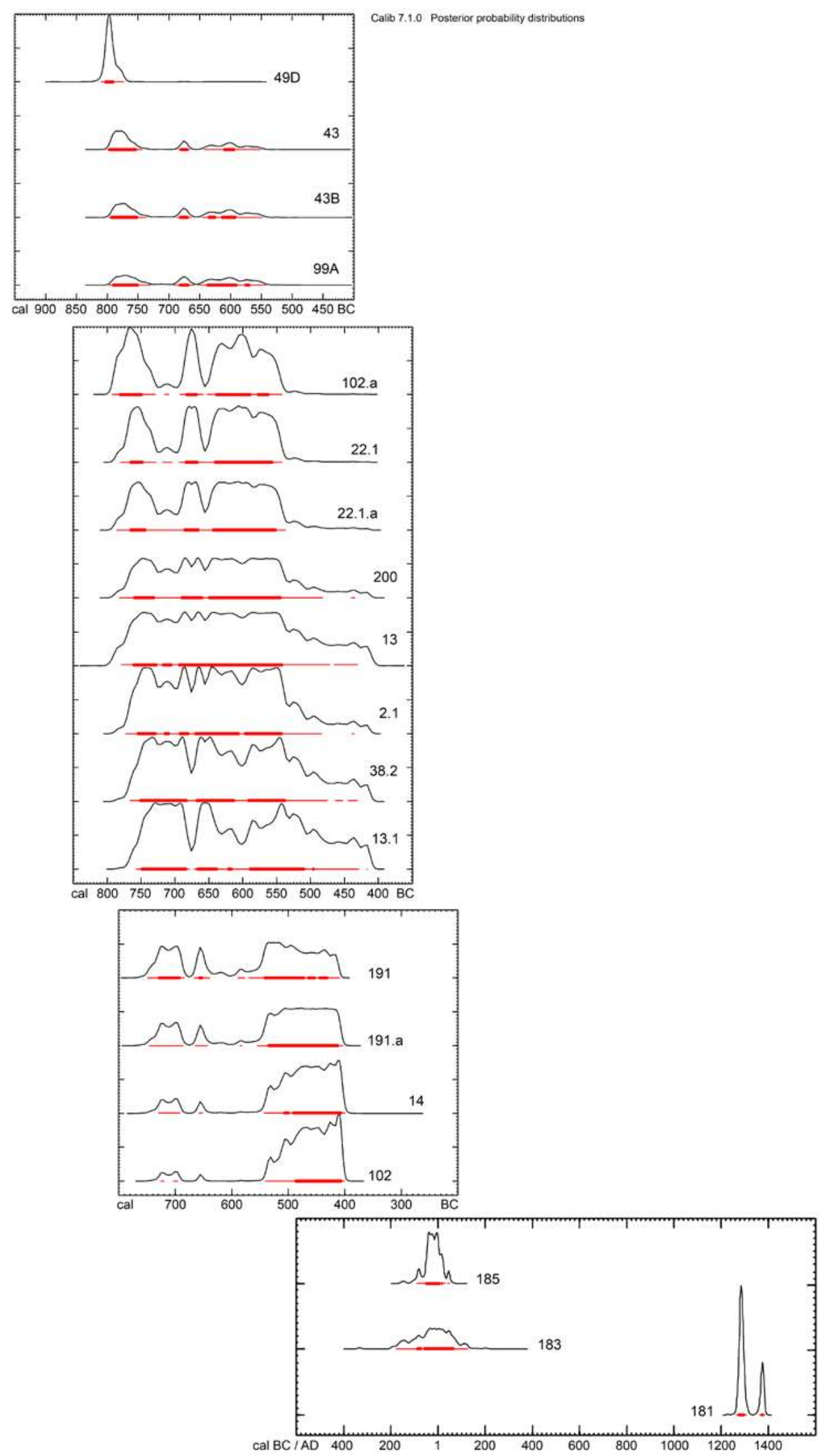

Figure 2. Area $\mathrm{C}$ radiocarbon dates: calibration plot of individual measurements. Original data and additional information from Table 1. (F.G. Fedele 2019) 


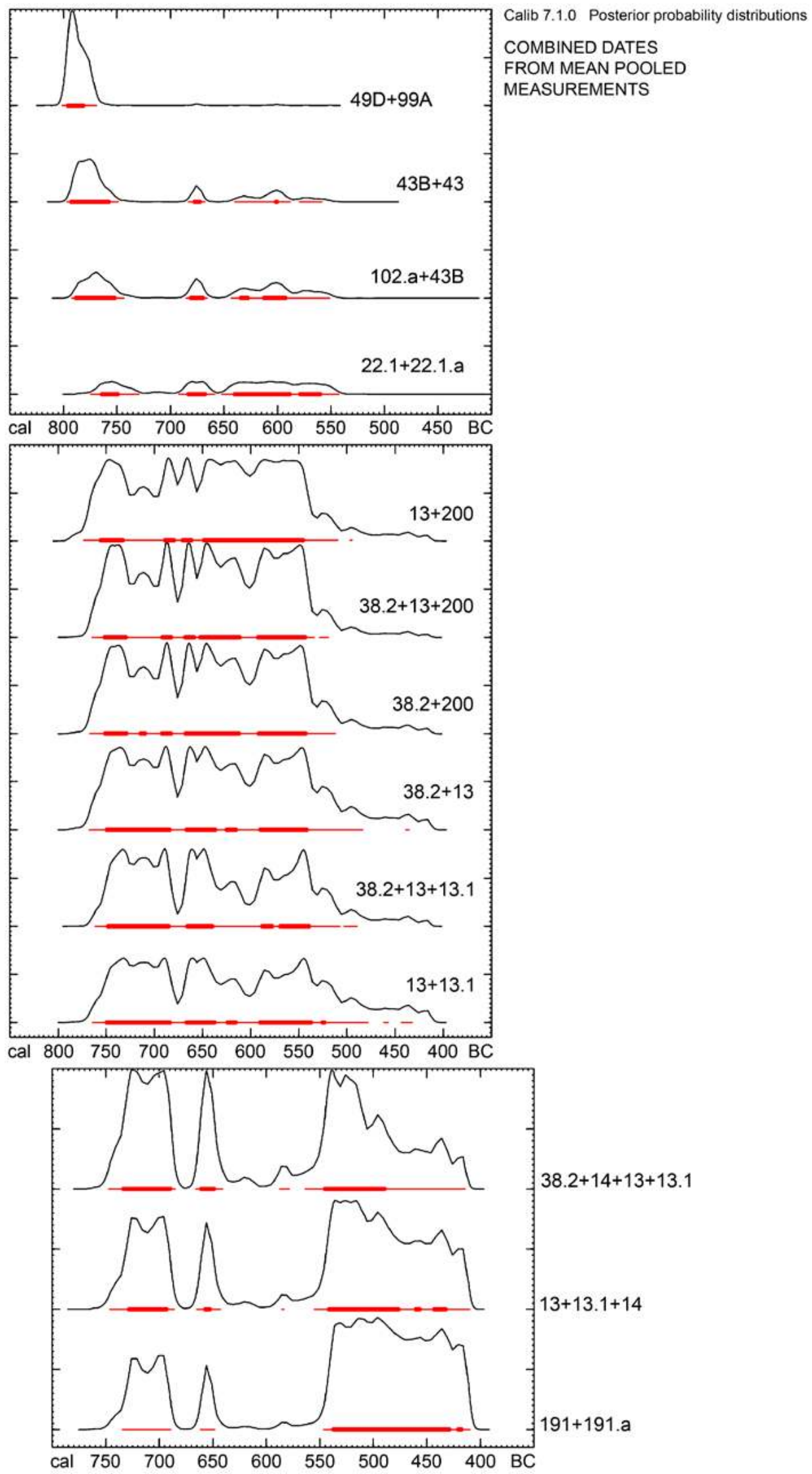

Figure 3. Area $\mathrm{C}$ radiocarbon dates: calibration plot of combined dates from mean pooled measurements. Original data and additional information from Table 2.

(F.G. Fedele 2019) 
Table 1. List of radiocarbon age determinations for Area C, excavations 2005-2006. The samples are ordered according to increasing ${ }^{14} \mathrm{C}$ age. The source material is wood charcoal in all samples, derived from branches or small tree trunks not bigger than about $12 \mathrm{~cm}$ in diameter. The available fractionation data are given in column 4. Dating laboratories: Beta, Beta Analytic (Miami, USA); DSH, CIRCE Laboratory (Caserta, Italy; the laboratory code was later changed into DSA). The $\delta{ }^{13} \mathrm{C}$ values were measured separately in an isotope ratio mass spectrometer at Beta. Calibrated ages and associated probability $(p)$ in column 6 were calculated with the Calib 7.1.0 program (M. Stuiver, P. J. Reimer, R. W. Reimer 2019, CALIB 7.1 [WWW program] at http://calib.org, accessed 6 August 2019) based on the IntCal13 data set (Reimer et al. 2013). All calendar ages are reported at the 2-sigma (2s) or $95.4 \%$ confidence interval, rounded off to the nearest decade for ${ }^{14} \mathrm{C}$ ages with $s \geq 50$ years.

\begin{tabular}{|c|c|c|c|c|c|}
\hline 1 & 2 & 3 & 4 & 5 & 6 \\
\hline Sample & $\begin{array}{l}\text { Quadrangle and } \\
\text { stratigraphy }^{\mathrm{a}}\end{array}$ & $\begin{array}{l}\text { Laboratory } \\
\text { number }\end{array}$ & $\delta^{13} \mathrm{C}$ & ${ }^{14} \mathrm{C}$ age $\pm s b p^{b}$ & $\begin{array}{l}\text { Calendar ages } \mathrm{BC} / \mathrm{AD} \text { at } 2 s \text {, and relative } \\
\text { probability } p^{c}\end{array}$ \\
\hline 181 & \begin{tabular}{|l|l|} 
A2-A12 & T7H (F6) \\
\end{tabular} & DSH864 & & $695 \pm 30$ & AD $1264-1310(p .77), 1360-1387$ (p.23) \\
\hline 183 & A1-A11 $\mid$ suite T74L \& T7JK & DSH297 & & $2008 \pm 65$ & $180 \mathrm{BC}-\mathrm{AD} 130(p 1)$ \\
\hline 185 & A1-A11 $\mathrm{T} 76 \mathrm{H}$ & DSH860 & & $2023 \pm 25$ & $93 \mathrm{BC}-\mathrm{AD} 32(p .96)$ \\
\hline 102 & \begin{tabular}{l|l} 
E2 & V3, SI1i-SI1, SE3
\end{tabular} & DSH861 & & $2397 \pm 25$ & $541-400 \mathrm{BC}(p .98)$ \\
\hline 14 & \begin{tabular}{l|l} 
D3-D13 & GZ2, lower GZ1 \\
\end{tabular} & Beta505411 & $-24.3 \%$ o & $2400 \pm 30$ & 543-399 BC (p.91) \\
\hline 191.a & A1-A31 $\mid \mathrm{T} 77 \mu(\mathrm{F} 10)$ & Beta505416 & $-22.3 \%$ & $2420 \pm 30$ & 747-685 (p.16), 556-402 (p.79) ВC \\
\hline 191 & $»$ & DSH862 & & $2439 \pm 25$ & 749-684 (p.25), 571-408 (p.65) BC \\
\hline 13.1 & \begin{tabular}{l|l} 
D3 & GZ1 top \& surface S2
\end{tabular} & Beta505410 & $-24.2 \%$ & $2460 \pm 30$ & 758-678 (p.31), 672-428 (p.69) ВC \\
\hline 38.2 & \begin{tabular}{l|l} 
D5 & suite GK (GK1?)
\end{tabular} & DSH866 & & $2469 \pm 31$ & 767-474 BC (p.96) \\
\hline 2.1 & D1 GV1 bottom; $\mathrm{Pa}$ ? & Beta505409 & $-23.8 \%$ o & $2480 \pm 30$ & 773-482 BC (p.996) \\
\hline 13 & D3-D13 S $\mid$ GZ1 top \& surface S2 & DSH306 & & $2483 \pm 47$ & 780-471 BC (p.95) \\
\hline 200 & $\begin{array}{l}\text { A1-A11 E, A31 SE | suite SZ \& } \\
\text { lower SYH }\end{array}$ & DSH298 & & $2486 \pm 34$ & 782-482 BC (p.995) \\
\hline 22.1.a & \begin{tabular}{l|l} 
D2 & GSV3-GSV1, L2, L1
\end{tabular} & Beta505412 & $-24.3 \%$ o & $2500 \pm 30$ & 787-536 BC (p1) \\
\hline 22.1 & $»$ & DSH865 & & $2503 \pm 25$ & 782-727 (p.22), 695-541 (p.75) ВC \\
\hline 102.a & E2|V3, SI1i-SI1, SE3 & Beta505415 & $-26.3 \%$ & $2520 \pm 30$ & $\begin{array}{l}\text { 794-728 (p.31), 694-657 (p.16), 654-542 } \\
\text { (p.53) BC }\end{array}$ \\
\hline $99 \mathrm{~A}$ & $\begin{array}{l}\text { E1 E | SIa beneath Wall F4, } \\
\text { including SI } \pi\end{array}$ & DSH295 & & $2532 \pm 33$ & $\begin{array}{l}798-729 \text { (p.38), 693-658 (p.15), 653-542 } \\
\text { (p.48) BC }\end{array}$ \\
\hline $43 \mathrm{~B}$ & D6 | YSZ, YSX & Beta505414 & $-24.5 \%$ & $2540 \pm 30$ & $\begin{array}{l}798-736(p .47), 688-663(p .13), 647-547 \\
(p .41) \text { BC }\end{array}$ \\
\hline 43 & D6 $\mid \mathrm{YSd}_{1-2}$ to YSa top & Beta505413 & $-23.9 \%$ & $2550 \pm 30$ & $\begin{array}{l}\text { 801-742 (p.58), 686-665 (p.10), 644-550 } \\
\text { (p.32) BC }\end{array}$ \\
\hline 49D & D7 $\mid$ SIa & DSH863 & & $2600 \pm 25$ & $811-772$ BC $(p 1)$ \\
\hline
\end{tabular}

Notes indicated by letters to avoid confusion with other numbers.

${ }^{\text {a }}$ Simplified. See text for details.

${ }^{\mathrm{b}} \mathrm{bp}=$ radiocarbon years before present $(1950)$; re-read by Aitken $(1990,93)$ as 'before physics', 'AD 1950 being the year in which radiocarbon dates began to be published'.

${ }^{c} p=$ associated relative probability within $95.46 \%$ : relative maximum in bold; $p 1=100 \% ; p<0.10 \%$ omitted. 
Table 2. Area C excavations 2005-2006: combined dates from mean pooled measurements (see Table 1 for samples and details).

The combined ${ }^{14} \mathrm{C}$ age was calculated from the original determinations in Table 1 with the R_Combine function in the OxCal 4.3 program (Web interface build no. 118), last updated 25 April 2019 and accessed 6 August 2019, which includes the chi-squared test of significance for the pooling of samples (@2019 C. Bronk Ramsey, and see Bronk Ramsey 2009; http://c14.arch.ox.ac.uk/ oxcal). This age was then calibrated with the Calib 7.1.0 program (M. Stuiver, P. J. Reimer, R. W. Reimer 2019, CALIB 7.1 [WWW program] at http://calib.org, accessed 6 August 2019) based on the IntCal13 data set (Reimer et al. 2013). All other conventions as in Table 1.

\begin{tabular}{|c|c|c|c|c|}
\hline Samples & $\begin{array}{l}\text { Stratigraphic } \\
\text { objective }\end{array}$ & $\begin{array}{l}\text { pooled }{ }^{14} \mathrm{C} \text { age } \\
\pm \mathrm{s} \text { bp }\end{array}$ & $\begin{array}{l}\text { test of significance }\left(\chi^{2}\right) \\
\text { for pooling }\end{array}$ & $\begin{array}{l}\text { Calendar ages } \mathrm{BC} / \mathrm{AD} \text { at } 2 \mathrm{~s}, \text { and } \\
\text { relative probability } p^{\mathrm{a}}\end{array}$ \\
\hline \multicolumn{5}{|c|}{ Dating the Earlier Sabaean } \\
\hline $49 \mathrm{D}+99 \mathrm{~A}$ & Stratum $\mathbf{T}$ & $2575 \pm 20$ & $\begin{array}{l}\mathrm{df}=1 ; \mathrm{T}=2.7(<3.84 \text { at } 5 \%) ; \\
\text { accept pooling }\end{array}$ & 802-768 BC $(p 1)$ \\
\hline 102. $a+43 B$ & Strata $\mathbf{S}$ to $\mathbf{Q}$ & $2530 \pm 22$ & $\begin{array}{l}\mathrm{df}=1 ; \mathrm{T}=0.2(<3.84 \text { at } 5 \%) \\
\text { accept pooling }\end{array}$ & $\begin{array}{l}793-743(p .43), 686-665(p .14), 644-550 \\
(p .43) \text { BC }\end{array}$ \\
\hline $43 B+43$ & Strata $\mathbf{Q}$ to $\mathrm{O}$ & $2545 \pm 22$ & $\begin{array}{l}\mathrm{df}=1 ; \mathrm{T}=0.1(<3.84 \text { at } 5 \%) \\
\text { accept pooling }\end{array}$ & 798-748 (p.68), 641-587 (p.18) ВC \\
\hline \multicolumn{5}{|c|}{ Dating the Later Sabaean } \\
\hline $38.2+14+13+13.1$ & Strata N-L & $2448 \pm 17$ & $\begin{array}{l}\mathrm{df}=3 ; \mathrm{T}=3.7(<7.82 \text { at } 5 \%) ; \\
\text { accept pooling }\end{array}$ & $\begin{array}{l}749-684(p .34), 667-640(p .11), 565-413 \\
(p .53) \mathrm{BC}\end{array}$ \\
\hline $38.2+13+13.1$ & Strata N-L & $2468 \pm 20$ & $\begin{array}{l}\mathrm{df}=2 ; \mathrm{T}=0.2(<5.99 \text { at } 5 \%) ; \\
\text { accept pooling }\end{array}$ & 763-507 BC (p.98) \\
\hline $38.2+13$ & Strata N-L & $2473 \pm 26$ & $\begin{array}{l}\mathrm{df}=1 ; \mathrm{T}=0.1(<3.84 \text { at } 5 \%) \\
\text { accept pooling }\end{array}$ & $768-482$ BC (p1) \\
\hline $38.2+200$ & Stratum $\mathbf{N}$ & $2477 \pm 23$ & $\begin{array}{l}\mathrm{df}=1 ; \mathrm{T}=0.1(<3.84 \text { at } 5 \%) \\
\text { accept pooling }\end{array}$ & 768-511 BC (p1) \\
\hline $38.2+13+200$ & Strata N-L & $2478 \pm 21$ & $\begin{array}{l}\mathrm{df}=2 ; \mathrm{T}=0.2(<5.99 \text { at } 5 \%) \\
\text { accept pooling }\end{array}$ & $766-533$ BC $(p .98)^{b}$ \\
\hline $13+200$ & Strata N-L & $2485 \pm 28$ & $\begin{array}{l}\mathrm{df}=1 ; \mathrm{T}=0.0(<3.84 \text { at } 5 \%) \\
\text { accept pooling }\end{array}$ & $774-509$ BC (p1) \\
\hline \multicolumn{5}{|c|}{ Dating the end of the Sabaean } \\
\hline $13+13.1+14$ & Later Stratum L & $2439 \pm 20$ & $\begin{array}{l}\mathrm{df}=2 ; \mathrm{T}=3.1(<5.99 \text { at } 5 \%) ; \\
\text { accept pooling }\end{array}$ & $747-685$ (p.25), 556-409 (p.68) BC \\
\hline $13+13.1$ & End of Stratum $\mathbf{L}$ & $2467 \pm 26$ & $\begin{array}{l}\mathrm{df}=1 ; \mathrm{T}=0.2(<3.84 \text { at } 5 \%) \\
\text { accept pooling }\end{array}$ & 765-477 BC (p.98) \\
\hline \multicolumn{5}{|c|}{ Dating the First Intermediate } \\
\hline $22.1+22.1 . a$ & Earlier Stratum $\mathbf{K}$ & $2502 \pm 20$ & $\begin{array}{l}\mathrm{df}=1 ; \mathrm{T}=0.0(<3.84 \text { at } 5 \%) \\
\text { accept pooling }\end{array}$ & $\begin{array}{l}775-729(p .21), 693-658(p .17), 653-542 \\
(p .62) \mathrm{BC}^{\mathrm{c}}\end{array}$ \\
\hline \multicolumn{5}{|c|}{ Dating the Minaean 1 and wall construction } \\
\hline $191+191 . a$ & $\begin{array}{l}\text { End (?) of Stratum } \\
\mathrm{J}\end{array}$ & $2431 \pm 20$ & $\begin{array}{l}\mathrm{df}=1 ; \mathrm{T}=0.2(<3.84 \text { at } 5 \%) \\
\text { accept pooling }\end{array}$ & 736-688 (p.17), 547-409 (p.79) ВС \\
\hline
\end{tabular}

Notes indicated by letters to avoid confusion with other numbers.

${ }^{a} p=$ associated relative probability within $95.46 \%$ : relative maximum in bold; $p 1=100 \% ; p<0.10 \%$ omitted.

${ }^{b}$ Calibration with OxCal 4.3 would produce the following: 766-517 BC ( $\left.p 1\right)$.

${ }^{c}$ Calibration with OxCal 4.3 would produce the following, omitting $p<0.10 \%$ : 776-728 (p.21), 694-542 (p.79) BC. 
Table 3. Barāqish: a tentative chronology for Area $\mathrm{C}$ based on radiocarbon dates, supplemented by nonradiometric information. Because of a plateau in the calibration curve, radiocarbon is unable to provide accurate calendar dates for Strata Q to K (see text). In all columns, ages of dubious value are in square brackets.

\begin{tabular}{|c|c|c|c|c|}
\hline 1 & 2 & 3 & 4 & 5 \\
\hline Strata & $\begin{array}{l}\text { Calendar ages } \mathrm{BC} / \mathrm{AD} \text { at } \\
\text { 2s (from Tables } 1 \text { and } 2 \text { ) }\end{array}$ & $\begin{array}{l}\text { Resulting or accepted } \\
\text { age range for the } \\
\text { interval in column } 2^{1}\end{array}$ & $\begin{array}{l}\text { Proposed age range } \\
\text { for the Stratum or } \\
\text { Strata }^{2}\end{array}$ & Notes and comments \\
\hline A & & & 19C AD-present & \\
\hline B & & & c. AD $1400-1800$ & \\
\hline C & AD 1264-1387 & AD 1260-1310 & c. AD $1190-1400$ & column 2: Earlier Stratum C \\
\hline D & & & $1 C \mathrm{AD}-c .1400$ & \\
\hline $\mathrm{E}$ & ? AD 33-130 and later & ? AD 30-[...] & $1 C$ AD-c. 1190 & $\begin{array}{l}\text { column 2: a terminus post quem for } \\
\text { Stratum E? }\end{array}$ \\
\hline $\mathbf{F}$ & & & $\begin{array}{l}\text { end } 1 C B C \text {-early/ } \\
\text { mid- } 1 C A D\end{array}$ & \\
\hline G & & & $2 C \mathrm{BC}$-early $1 C \mathrm{AD}$ & \\
\hline $\mathrm{H}$ & $93 \mathrm{BC}-\mathrm{AD} 32$ & $90 \mathrm{BC}-\mathrm{AD} 30$ & $2 C-1 C B C$ & Minaean 3 \\
\hline I & & & $4 C-2 C B C$ & \\
\hline $\mathrm{J}$ & {$[736]-409 \mathrm{BC}$} & $550-410 \mathrm{BC}$ & c. $550-5 C \mathrm{BC}$ & column 2: later (?) Minaean 1 \\
\hline K & $\begin{array}{l}\text { Earlier Stratum K: } \\
\text { [775]-542 BC }\end{array}$ & [690] 650-540/later BC & early $6 C-550 \mathrm{BC}$ & \\
\hline $\mathrm{L}$ & $\begin{array}{l}\text { Later Stratum L: } \\
\text { 765-477 BC (i) } \\
747-[409] \text { BC (ii) }\end{array}$ & {$[\ldots]^{3}-c .480 \mathrm{BC}$} & \multirow{3}{*}{$7 C$-early $6 C \mathrm{BC}$} & $\begin{array}{l}\text { (i) end of Stratum L; } \\
\text { (ii) later Stratum L }\end{array}$ \\
\hline $\mathrm{N}$ & $\begin{array}{l}767-474 \text { BC (i) } \\
768-511 \text { BC (ii) }\end{array}$ & $770-510 \mathrm{BC}$ & & $\begin{array}{l}\text { (i) single-sample, \#38.2; } \\
\text { (ii) pooled \#38.2+\#200 }\end{array}$ \\
\hline $\mathrm{N}-\mathrm{L}$ & $\begin{array}{l}749-[413] \mathrm{BC} \\
763-507 \mathrm{BC} \\
{[766-533] \mathrm{BC}^{4}} \\
768-482 \mathrm{BC} \\
{[774-509] \mathrm{BC}^{4}}\end{array}$ & $770-480 \mathrm{BC}$ & & $\begin{array}{l}\text { column 3: maximum range from pooled } \\
\text { ages (excluding dubious values) }\end{array}$ \\
\hline$Q-0$ & $798-587 \mathrm{BC}$ & {$[800]-590 \mathrm{BC}$} & \multirow{5}{*}{ c. $680-7 C \mathrm{BC}$} & $798-748 \mathrm{BC}, \mathrm{p}=68 \%$ \\
\hline 0 & & & & \\
\hline $\mathbf{P}$ & & & & \\
\hline $\mathrm{P}-\mathrm{O}$ & $801-550 \mathrm{BC}$ & {$[800]-550 \mathrm{BC}$} & & single-sample, \#43 \\
\hline Q & $798-547 \mathrm{BC}$ & {$[800]-550 \mathrm{BC}$} & & single-sample, \#43B \\
\hline $\mathbf{R}$ & & & ‘700-680’ BC & $\begin{array}{l}\text { column 4: based on identification of F4 } \\
\text { with the Sabaean walling of Yathill }\end{array}$ \\
\hline$S-Q$ & $793-550 \mathrm{BC}$ & $790-[550] \mathrm{BC}$ & & \\
\hline $\mathrm{S}-\mathrm{R}$ & $794-542 \mathrm{BC}$ & $790-[540] \mathrm{BC}$ & & single-sample, \#102.a \\
\hline$S$ & & & $8 \mathrm{C} \mathrm{BC}$ & \multirow{2}{*}{ Sabaean ante-Wall F4 } \\
\hline $\mathrm{T}$ & $802-768 \mathrm{BC}$ & before $800-770 \mathrm{BC}$ & before $800-c .770 \mathrm{BC}$ & \\
\hline
\end{tabular}

${ }^{1}$ All ages rounded to the decade.

${ }^{2}$ Based in part on non-radiometric information or inferences (Strata B-C after Table 4). All ages approximate. Abbreviations: $8 C=$ Eighth century (and so on); $c$. = circa.

${ }^{3}$ Earlier Stratum L undated.

${ }^{4}$ Dubious values because pooling involved isolated Locus 200 (sample \#200).

${ }^{5}$ For this walling the date c. 700-690 BC can be proposed (ante-689 BC following Potts 2003, 198); see section 3.1. 
is unable to provide accurate calendar dates for Strata $\mathrm{Q}$ to $\mathrm{K}$ of Area $\mathrm{C}$. The wider consequence, in the case of Yathill, is that a considerable loss of temporal resolution affects the Later Sabaean and the centuries involved in the Sabaean-Minaean transition. ${ }^{22}$ While an objective portrayal of this situation, Table 3 provides an attempt to minimize its negative effects. A clearer picture of the Sabaean-Minaean transition at Yathill will only be obtained from the excavation of residential areas coupled with a dedicated sampling and dating programme of the highest accuracy. ${ }^{23}$

As a whole, according to Table 3, the periodization dates from Area $\mathrm{C}$ are distributed as follows: the Earlier Sabaean from the later 9th century to perhaps the middle 7th century BCE; the Later Sabaean - here defined solely on the basis of material culture (ceramics) - between the middle 7th century and perhaps the initial 6th century BCE (very approximate dates); a Sabaean-Minaean divide in the first half of the 6th century; and a Minaean beginning, in terms of material culture and architecture (curtain wall's bastion T7), around $550 \mathrm{BCE} .{ }^{24}$ Needless to say, Area $\mathrm{C}$ as excavated in 2005-2006 only provides a local and partial view of the global, evolving reality of Yathill in historical terms.

\section{The stratigraphic-historical sequence from Area $C$ and its regional context}

\subsection{Area $C$ and the temple area}

In this subsection the stratigraphic-historical sequence from Area $\mathrm{C}$ will be discussed, as particularly examined from the perspective of a correlation with the excavated intramural area. This latter will be briefly called the 'temple area'. ${ }^{25}$ A synthesis of the Area $C$ sequence the stratified succession of events and phases brought to light in the area - is provided by Table 4 and Fig. 24 of Chapter 17, this volume, which will jointly serve as our reference. The reader will refer to Chapter

and van Geel et al. (1998) have shown that it follows a period with increased atmospheric concentration of ${ }^{14} \mathrm{C}$ caused by solar activity changes. These changes had concomitant climatic effects and locally resulted in environmental and ecological impact.

22 Fedele 2011a, 106-107.

${ }^{23}$ In addition to the purely epigraphic reconstruction (cf. Chapter 27 , this volume).

24 In other words, in spite of the plateau in the calibration curve, radiocarbon was helpful in indicating that the transition to the Minaean period dates from no later than the mid-6th century BCE, depending on the aspect considered (building activity, inferences from sediments, material culture, political control). The subject will be taken up at the end of section 3.2 below.

25 It comprises Areas A and B of the Italian mission's operations, so designated from the conventional labelling of the two temples (cf. de Maigret 2009b; and see overall plan of operations on page xi, Volume 1). Area A includes the excavated sector of Temple A and the deep sounding carried out in front of the temple in 2006 (see Chapter 1 in Volume 1). Areas A and B are part of the intramural temple precinct of Yathill.
17 for a detailed description and discussion of the lithostratigraphic evidence forming the basis for the sequence. Establishing a correlation between Area C and the temple area is a further step to extract historical meaning from the rich archaeological information of both areas. The correlation is presented in Fig. 4. For the time being, this correlation can only be provisional.

It needs be stressed at the outset that the Sabaean, Minaean, Islamic, and Intermediate phases identified in Area $\mathrm{C}$ have primary or even exclusive validity within this extramural area, on the basis and within the limits of the exploration carried out in 2005-2006. In particular, no general periodization of the Sabaean settlement is implied by the 'Sabaean 1-4' of Area $C$, however significant these phases are at the local, intrasite level. ${ }^{26}$

Judging from the ceramic composition, ${ }^{27}$ one can suggest that the extramural sequence represented by Strata $\mathrm{T}$ to $\mathrm{O}$ is to be correlated with de Maigret's Strata $D$ to $A$ as recognized from his sounding at Temple A. ${ }^{28}$ The town's deposits underlying Stratum D from the sounding would all predate the Sabaean layers so far uncovered in the extramural area. The end of the Sabaean 1 phase from Area C (i.e. Strata T-S) appears to be broadly coeval with Strata C-B from the sounding at Temple A. The Later Sabaean (Sabaean 3-4) certainly existed in the temple area, as indicated by reworked potsherds, but intact layers were not encountered in the excavations probably because of the Minaean truncation of the topmost deposits (Fig. 4). The same can perhaps also be said of the First Intermediate of the extramural sequence, defined by Stratum K. More probably, however, extramural Stratum $\mathrm{K}$ could be materially unrepresented in the temple area, or in the 'core' residential area of Yathill in general.

Tosome extent, these concordances as well as differences already contribute to a realistic understanding of the Sabaean history of Yathill.

Some observations on the Sabaean ceramics from Area $\mathrm{C}$ appear to be relevant to more detailed comparisons with the temple area, as pointed out in Chapter 23, this volume. Examples are provided by some potsherds from Stratum C of the town's sounding: a few pieces of 'light yellowish ware' which can probably be equated with the 'earlier' Pale Green ware recognized in Area C; and a straight vertical wall with an incised wavy-band decoration which would parallel the Wavy Rim bowls

\footnotetext{
26 Fedele 2010, 141-142 (updated).

27 Fedele, Chapter 23, this volume.

28 de Maigret 2010a. On the 'geometric' relationships between Sounding A of Area C and the intramural sounding at Temple A, particularly concerning elevations, see Chapter 26 , this volume.
} 
(variant B) from the extramural area, belonging to the Later Sabaean. ${ }^{29}$

Concerning the post-Sabaean period, it must be realized that the Area $\mathrm{C}$ excavations and those in the temple area represented separate archaeological operations located in two distant and entirely unrelated parts of the site. The minimum linear distance between Sounding A in Area C and Temple B is $165 \mathrm{~m}$, and the equivalent distance to Temple A is $185 \mathrm{~m}$. Not only are we dealing with very different physical settings, but the sedimentary and lithostratigraphic data from Area C, on one hand, and the temple area on the other must be each appraised on its own merits. Nothing being known from the substantial area in between, any correlation is presently tentative.

This means, in particular, that the extramural area always represented a different environmental 'catchment' from the walled basin constituted by the town: a separate depositional basin in which the sediments and processes that were common inside the town - the interior catchment of the mound, so to speak - left only a vague, rare, and selective imprint. It was so during the Minaean period and to a greater extent during the Islamic reoccupation of the site (see section 3.5 below). Only future fieldwork will elucidate the details. For the Minaean, correlations can presently only be attempted on the basis of pottery (see Buffa, Chapters 22 and 25, this volume). For the Islamic period, an exhaustive attempt at correlation will be presented in section 3.5 below.

\subsection{Parallel stratigraphies, regional correlations}

Figure 4 provides additional information of interest. The correlation between Area $\mathrm{C}$ and the area of Temple $\mathrm{A}$, in the middle columns of the figure, is accompanied on the left by two separate stratigraphies: a ceramic stratigraphy (or 'ceramostratigraphy') and a sketch of political history of Yathill and the Jawf, this latter mostly derived from epigraphic sources. ${ }^{30}$ These two

\footnotetext{
29 See Chapter 23, section 3.3, this volume (where details are given).

30 Political history of the Jawf after Robin and de Maigret (2009), and Arbach and Rossi (2012). End of the Minaean according to Robin (1998; with revised dating after Robin 2016b, 79, note 202; 72, table 4); cf. Arbach 2009. In the 'Barāqish Area A' column, the term Amirite refers to a cultic utilization of Temple A by the Amir tribe, arguably in the context of a limited occupation of the town during the 1st-2nd centuries CE: see Agostini, Chapter 4 in Volume 1, sections 3 and 5 (with references and table, as well as cautionary remarks). For about two centuries the Amīr's homeland had comprised the northern Jawf and the town of Haram (see, e.g., Robin 1992, 9-126; Prioletta 2012, 309-310, note 4). For the term 'Intermediate' see Chapter 17, section 3.3, this volume. Also in the Barāqish column, '25/24 Aelius Gallus' means that the Roman army led by this prefect stationed at Yathill in 25 or 24 BCE (see below, section 3.3). [Figure 4 and this subsection, 2.2, were completed in August 2019. The reader will find newer information in Chapter 27, this volume, submitted by the authors in February 2020.-Eds]
}

stratigraphies intend to stress the need for multiple, parallel stratigraphies: a standard stratigraphers' practice too often ignored or misunderstood in archaeology. ${ }^{31}$ A column devoted to ceramics is only one among possible material-culture stratigraphies, and it is obviously justified by the relevance of pottery in pre-Islamic South Arabian archaeology. Importantly, the parallel stratigraphic columns are complementary but at the same time distinct. At Yathill, for example, a Sabaean pottery period may not necessarily be exactly the same as a Sabaean phase, in a political, epigraphic, or even economic sense, and one must be careful in making the appropriate distinctions.

In the right half of Fig. 4 this regional stratigraphy for the Jawf (or 'periodization', according to a parallel terminology) has been developed into a comparative stratigraphy of selected Yemeni sites spanning the Iron Age to Islamic periods. These sites from the lowlands and the desert fringe were chosen as particularly interesting for a comparative stratigraphy of ceramic production and types. ${ }^{32}$ By outlining a broad spectrum of parallel stratigraphies, Fig. 4 implicitly points out existing problems in correlation and chronology, while at the same time showcasing the great potential inherent in a comparative approach.

The sources for the right half of Fig. 4 were cited and extensively discussed in a previous publication. ${ }^{33} \mathrm{As}$ far as the Șayhad Iron Age is concerned, both the pottery sequences and their intersite correlation, on one side, and their radiometric chronology on the other, still represent work in progress. What the figure provides is no more than an interim correlation-chronological chart and must be understood as a synthesis of partially controversial information. ${ }^{34}$ Hajar al-Rayhānī's stratigraphy, for example, is complicated by the fact that the two successive reports on the site use different phasing schemes, one based on 'strata' ${ }^{35}$ and the second on 'occupational phases'. ${ }^{36}$ The stratigraphy presented in Fig. 4 takes into account both reports. Several radiocarbon determinations for Hajar al-Rayhānī

\footnotetext{
31 On this practice, borrowed with adaptations from geology, see the now classical example by Farrand (2000), while Gasche and Tunca (1983) and Fedele (1995) have advocated an 'ethnostratigraphy' encompassing material-culture stratigraphies. Ceramic stratigraphy is one component of the latter. Cf. Chapter 17 , section 3, this volume, and the excellent overview of archaeological stratigraphy by Stein and Holliday (2017); on geological stratigraphy a number of textbooks and guides are available.

32 Cf. de Maigret 2003, 2010a; Robin and de Maigret 2009, 63-67 (de Maigret).

33 Fedele 2017, 289, 294-295, 297. Chief sources include Van Beek 1969, 355-365; Glanzman and Ghaleb 1987b; Glanzman 1994; de Maigret 2010a, 89-93, table 4.

34 Fedele 2017, 289.

35 Glanzman and Ghaleb 1987b.

36 Glanzman 1994, chapter 2, particularly 47-97.
} 


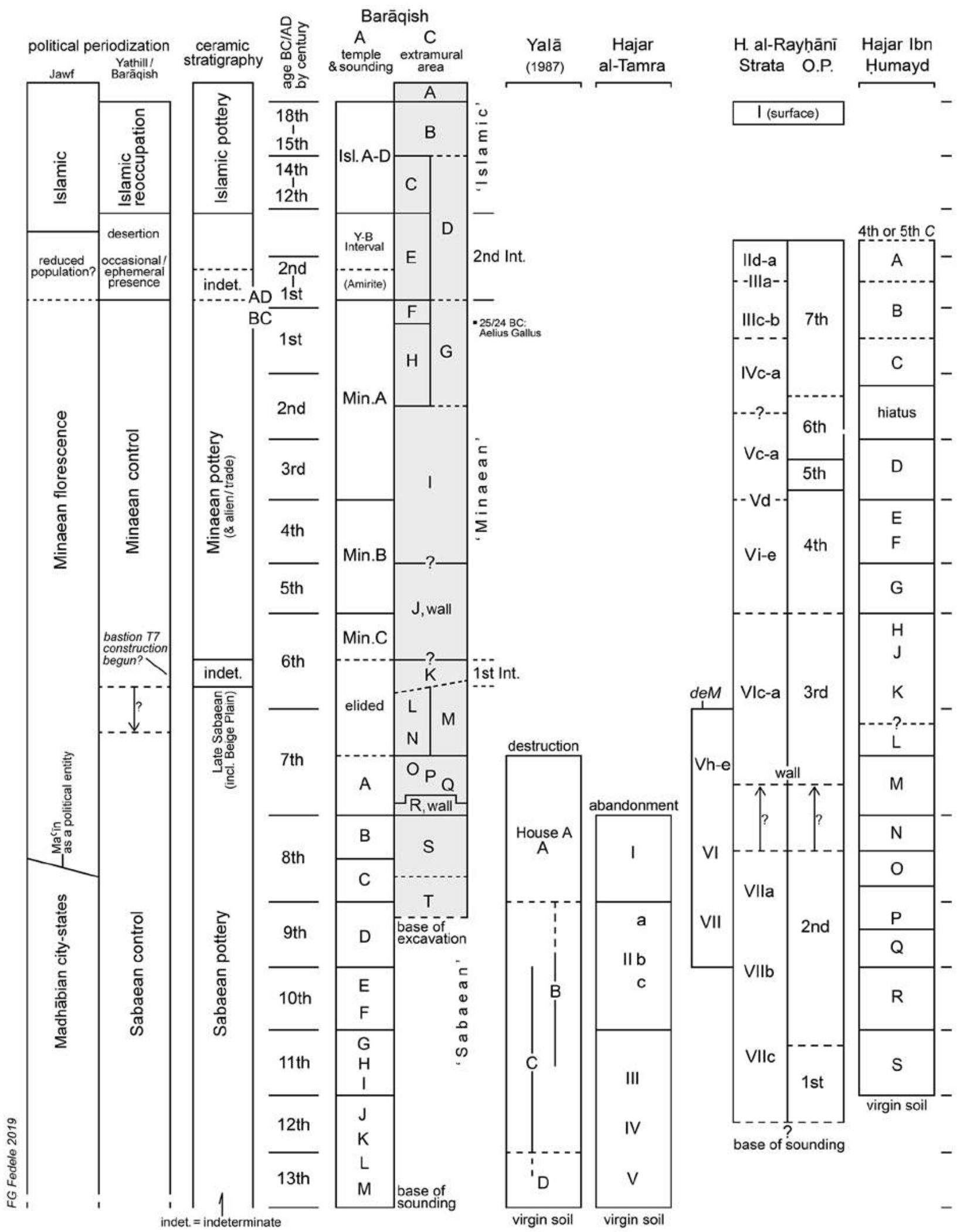

Figure 4. Approximate stratigraphic correlation of Area C (in light grey) with the temple area, and comparison with other sequences from Yemen (F.G. Fedele, 2019). Figure's core after Fedele 2011a, fig. 5, and 2017, fig. 20.2, revised and updated; Area A after de Maigret 1993 and 2010a. Abbreviations in the Hajar al-Rayhānī column: O.P. = Occupational phases, after Glanzman 1994; deM = de Maigret's (2010a) correlation. See text for further information and sources. 
are inconsistent because of their large standard deviations..$^{37}$

Intersite correlations based on pottery parallels raise questions as well. A. de Maigret would equate Hajar alRayhạni’s Strata VII-Ve with the 9th-7th centuries BCE, a much shorter interval than Glanzman's. ${ }^{38}$ This will affect the chronology and duration of the 3rd and 4th Occupational Phases, or Strata VI and lower V. In Fig. 4, a compromise has been attempted between the demands of stratigraphic inference and pottery correlation, on one side, and radiometric dating, but inconsistencies remain and cannot presently be resolved. In placing the end of Hajar al-Tamra's sequence at 700 BCE, de Maigret himself explicitly admits the considerable change in interpretation inherent in such a revision. ${ }^{39}$ Concerning Hajar ibn Humayd ${ }^{40}$ it is perhaps good to remember that its stratigraphy was basically established through the seriation of pottery rather than well-defined physical layers. ${ }^{41}$ The relevant column in our figure takes into account Glanzman's revision, ${ }^{42}$ which, however, little modified the earlier part of the sequence. There is sufficiently good agreement with the pottery correlation with Hajar ibn Humayd established by de Maigret. ${ }^{43}$

\section{Particular historical issues}

In this section a series of selected historical issues either raised by notable findings from Area $C$, or implicit in the correlations of Fig. 4 , will be addressed. The lithostratigraphic and contextual evidence that forms the basis for the discussion will once again be found in Chapter 17, this volume.

\subsection{Sabaean settlement archaeology at Yathill}

\section{The origins of Yathill: an oasis and agricultural centre? ${ }^{44}$}

Based on re-calibration of the pooled radiocarbon determinations from samples \#49D and \#99A to within no more than a generation, 802-768 BCE, with optimal statistical likelihood (Table 2), a date of 'before 800c. $770 \mathrm{BC}$ ' was determined for Stratum $\mathrm{T}$ (Table 3).

\footnotetext{
37 A handy list of the datings for both al-Rayhānī and Hajar al-Tamra, together with a useful commentary, can be found in Edens and Wilkinson 1998, 94-95, table VIII.

38 de Maigret 2010a, 91.

39 de Maigret 2010a, 90-91.

40 Van Beek 1969.

41 Blakely and Glanzman 1996, 3-4.

42 Glanzman 1994, 538-547, tables 2.6-2.8; see also Van Beek 1997.

43 de Maigret 2010a, 89-94.

44 The present subsection is based on reflections matured during the fieldwork sojourns of 2005-2007. My views were finally shaped by personal observations made during a team visit to the alluvial plain south of Barāqish, and to its framing hills to the southwest, made on 30 November 2007.
}

A settlement-archaeological investigation into the origins of Yathill would be a rewarding and fascinating subject for future research. At the moment, except for the basic information that the locale was already settled in the 13th century BCE (sounding at Temple A) and had developed into a low tell by the end of the 9th century (Area C), nothing is known. Nor is any evidence available from elsewhere in the Jawf, lacking excavations of settlements. The change or changes that led from the Bronze Age villages of the 3rd and 2nd millennia $\mathrm{BCE}^{45}$ to the 'Iron Age' towns of the early 1 st millennium ${ }^{46}$ is still completely obscure in both its pattern and details.

Nevertheless, geographically as well as ecologically, we can conceive of this region as being of great potential interest for an undestanding of urban and non-urban settlement processes in interior southern Arabia. Predictably, from locational considerations, ${ }^{47}$ choosing to settle in such a location as Yathill might have been dictated originally by a combination of agricultural potential and connectivity advantage. Agriculture, and more precisely the topographic and hydrological potential for the establishment of an oasis, was in all probability the pre-eminent consideration. Furthermore, the land south and southwest of Yathill could support both cultivation and grazing. The locational advantage related to regional communication - tribal exchanges, routes, transit, local trade - presumably came second, and acquired importance subsequently. ${ }^{48}$

Gertrude Caton Thompson, an advocate of 'severely practical archaeology' and a scholar enthusiastic about 'the archaeology of the everyday life of humble people', ${ }^{49}$ could not be more scathing about placing too much emphasis upon South Arabia's trade in luxury products: where settlement is concerned, what always mattered in ancient Yemen was first of all agriculture..$^{50}$ In my

\footnotetext{
45 Recognized by members of the French Mission to Yemen (19841990) in the northern valleys of the Jawf, particularly Wādī Hirāb and Wādī Sadbā: Cleuziou et al. 1992; Buffa 2007, 8, 224-227 ('Les Basses Terres'), figs 53-54; mentioned in de Maigret 2009a, 160. See also Fedele in press.

46 Schiettecatte $2006 \mathrm{~b}$.

47 For the meaning of 'locational' in this context cf. Fedele 2013.

48 Cf. for instance Sharon Steadman's (2005, 289-290, 298-299) discussion of the rational and cognitive choices for 'place', inspired by the case of Çadır Höyük in central Turkey; see also Steadman 2000. In principle, I would explain the beginnings and permanence of Yathill, starting with the choice of settlement place, along the lines of Steadman's functional model predicated on three practical, ecological factors: land quality, natural resources, and access to goods. Read for this latter, in the case of Yathill, access to exchange routes. The case of Shabwa in the western Hadramawt was not perhaps dissimilar (cf. synthesis in Breton 1992b).

49 Caton Thompson 1944, quotations from p. 154 and xii, respectively. 50 Caton Thompson's synopsis of Chapter II $(1944,9)$ is worth being quoted in full (emphasis mine): 'The essential semi-civilization of ancient south-west Arabia sprang, not from her export trade in luxury
} 
opinion it makes sense to apply a similar viewpoint to Yathill's origins. The fundamental raison d'être at the beginning of this settlement was the opportunity for cultivation on a large scale, once again harnessing the flood waters of a reliable wādi where it discharged into the plain. The supposed coincidence with a useful node in the economic and social geography of the later 2nd millennium was an added bonus, which became increasingly effective in the course of time.

However, these are mere predictions and the entire subject remains speculative. It will be briefly taken up at the beginning of Chapter 19, on economy, and again in Chapter 26, this volume, where aspects of the subsequent development of Sabaean Yathill are presented and settlement archaeology at Barāqish is further discussed. Among the scant data on the developed Sabaean settlement is so-called Lobe 5, on the northwestern edge of the tell, a portion of settlement located in Area $\mathrm{C}$ and indirectly revealed and marginally captured by the excavations..$^{51}$ Importantly, it was the Sabaean occupation - not the Minaean that generated a tell in the place called Yathill. The settlement grew into a substantial mound during the approximately seven centuries of the Sabaean period. This was the legacy that the Minaeans simply only exploited, by enclosing the flat-topped mound with a wall, but otherwise adding very little to the form and consistency of the mound itself.

\section{On some issues raised by Wall F4: the Sabaeans and Assyria}

In Area C, the tell was only about $6 \mathrm{~m}$ high when Wall F4 was built. ${ }^{52}$ As illustrated in Chapter 17, this locally remarkable feature has been tentatively identified with the historically recorded walling of Yathill by Sabaean mukarrib Karib’īl Watār, known from Șirwāh's annalistic text RES 3946 (line 1). ${ }^{53}$ What 'walling' might have meant in this case is perhaps impossible to ascertain, unless Wall F4 is indeed an actual portion of it. Certainly, for a number of considerations, we cannot afford to be misled

products, the importance of which (for a limited and late period only in any case) has been unwisely exaggerated in popular estimation, but in the unspectacular development of an effective method of irrigation and dry farming which made large areas habitable on a higher standard than that of bedouins dependent, like animals, on rock pools and springs.' In the same vein, a much more recent study of Iron Age settlement patterns in interior Oman c. 1300-300 BCE (Condoluci et al. 2014, 116) concluded that 'The presence of viable agricultural soils would have been a major determining factor in the location of settlement from the Bronze Age to recent times.'

51 Lobe 5 was treated in Chapter 17, section 7.6, this volume; see also Chapter 26, section 3.2.

52 Wall F4 (Stratum R) was treated in Chapter 17, sections 6.2-6.3, this volume. Its role in a settlement-archaeology perspective will be considered in Chapter 26, section 3, this volume.

53 On Karib'il Watār - Karib'il the Great in C. Robin's appellation - see, e.g., Robin 1996b, col. 1089-1126; Nebes 1997. On the inscription at Șirwāḥ, RES 3945-3946 (= Glaser 1000) see Rhodokanakis 1927, 1996; CSAI 2019, 'Epigraphs', entries RES 3945 and 3946; the secondary literature is vast. See also footnote 73 , below. by an intuitive analogy with the massive Minaean stone wall of centuries later.

Integral to the dating of Karib'il's walling of Yathill is the chronology of this ruler himself. This in turn is based on the now commonly accepted identification of Karib'îl the Great with 'Karibilu king of Saba' who, during the reign of Sennacherib of Assyria (705/704$681 \mathrm{BCE})$, made a gift of precious beads and spices for the foundation of the temple of the New Year festival (bit akiti) at Ashur. ${ }^{54}$ We can follow Potts in dating this gesture of long-range diplomacy to before $689 \mathrm{BCE}:{ }^{55}$ and concurrently, a date of $c$. 700-690 BCE for the walling of Yathill can be proposed (Table 3; also Chapter 17, Table 4 , this volume). ${ }^{56}$ The radiocarbon determinations bracketing Stratum $\mathrm{R}$ and the construction of Wall F4 are clearly compatible with a date in the 700-680 BCE range (see section 1 above).

A unique find appears to lend support to a connection of Wall F4 with Karib'il the Great - and this via Assyria, or Mesopotamia generally. This find is no. 43A.1, a fist-sized, cubical basalt block covered with a vitreous glazing on one of its faces. As remarked in its description (Chapter 21, section 2.1 and Fig. 35, this volume), this is not only a unique element from Yathill but an unparalleled find for the Sabaean region and period. ${ }^{57}$ This small stone block could in fact hint at a whole world of Mesopotamian connections which, though long recognized, are still in need of a deeper understanding.

Glazing technology was not new at the time in the region between Iran-Elam and Egypt. ${ }^{58}$ By 700 BCE glazing already had a particularly long and rich tradition in Mesopotamia, expressed in applying monochrome or polychrome glazes to clay vessels, statuary, and bricks. The earliest examples of such glazed terracotta manufactures date from the middle

\footnotetext{
54 E.g., Robin and de Maigret 2009, 76-77 (Robin); and more recently Robin 2016b, 55: 'His reign, notably marked by eight military campaigns, seems to have been quite long. Always hypothetically, we place it around 700-670 before the Christian era' (my translation); with references.

55 D. Potts $(2003,198)$ has convincingly argued a date ante- $689 \mathrm{BCE}$ from cross-referencing Karib'īl Watār's annals at Șirwāh with Sennacherib's bit akiti inscription, from the shrine's foundation deposit, recording the Sabaean ruler's gift (nāmurtu in Assyrian).

56 The consensus of opinion is for dating the 'conquest' and walling of Yathill to after $700 \mathrm{BCE}$, and some specialists would favour an earlier rather than later dating, i.e., soon after 700 BCE (Nebes 1997, 95; Potts 2003, 198); whence my dating for Stratum R here.

57 Fedele 2010, 116, fig. 144/A. The present treatment is an updating.

58 Oppenheim et al. 1970; Moorey 1994, 159-171, 181, 188, 312-322; Bienkowski and Millard 2000, 43, 61, 281; Henderson 2001. On Elam see, e.g., Bridey 2018, particularly 188, fig. 208 (Susa, 800-600 BCE); with references. On northwestern Iran, ancient Mannaea, Hassanzadeh and Curtis 2018, 171, fig. 189 (Qalaichi and Tappeh Rabat, 800-700 BCE). On Egypt, Nicholson with Peltenburg 2000, particularly 182-185 (including use in architecture).
} 
of the 2nd millennium BCE. ${ }^{59}$ In the Neo-Assyrian period, after about $1100 \mathrm{BCE}$, glazed pots and jars were commonly produced, and by at least the 8th century glazed pottery - now often polychrome - was current in Babylonia. ${ }^{60}$ In architecture, the Neo-Assyrian court patronized a vigorous industry producing glazed architectural terracotta, which by at least the early 9th century BCE specialized in polychrome glazed bricks to produce friezes comparable to those achieved in sculptured reliefs and murals. ${ }^{61}$

Perhaps of particular interest, in light of the direct diplomatic relationship involving Karib'il the Great, are the glazed-brick friezes from the reign of Sennacherib and the personal attention that the king paid to them. In his inscriptions Sennacherib refers to his palace 'without a rival' at Nineveh as embellished with glazed bricks 'the colour of obsidian and blue'; he also provides what may be the first textual reference to glazed bricks, speaking of a temple..$^{62}$ At Nimrud, a series of decorated glazed bricks or tiles show Assyrian soldiers in 7thcentury uniforms campaigning in Egypt, portrayed in a distinctive technique thus described by Sir Austen $\mathrm{H}$. Layard, the excavator: 'The colours have faded [...]. The outlines are white, and the ground a pale blue and olive green. The only other colour used is a dull yellow. ${ }^{63}$ This mention of olive green inevitably brings to mind the grey-greenish glazing on Yathill's no. 43A.1. The presence of cracks in the glaze of our find, which suggests use of a soda-lime technology, fits a dating in the 8th-7th centuries BCE very well. ${ }^{64}$

Glazed flat bricks as public decoration attained popularity also at Babylon, ${ }^{65}$ where, shortly after 600 BCE, a famous variant with moulded reliefs made a monumental and startling appearance in Nebuchadnezzar II's so-called Processional way. ${ }^{66}$

\footnotetext{
59 Moorey 1994, 159-162, 164-165.

60 Moorey 1994, 160-162, 181; also, e.g., Zimmerle 2014b, 346 (postKassite glazed jars, c. 1100-700 BCE).

61 Nunn 1988, 165-184; Moorey 1994, 181, 188, 312-322, with references. See also, e.g., van Lemmen 2013, 16-20; Reade 2018. The oldest dated Neo-Assyrian glazed brick scene is an orthostat from the reign of Tukulti-Ninurta II, c. 890-884 BCE (Moorey 1994, 315). Probably the best-known Neo-Assyrian glazed-brick friezes are those set up at Khorsabad by Sargon II, c. 721-705 BCE (Moorey 1994, 316; Reade 1995). A coeval example is known at Tell Halaf, in northern Syria, a region where earlier examples also exist, purely Assyrian in style, notably at Carchemish.

62 Moorey 1994, 317, with further references.

63 Layard 1853, 166, as cited in Moorey 1994, 317. See now, particularly, Nadali 2006; and for context and details Russell 1991.

64 E.g., Freestone 1991. Roger Moorey's compendium on the techniques in glazed brickwork is still valuable (Moorey 1994, 319322).

65 E.g., Nunn 1988, 185-190; Moorey 1994, 317-319.

66 Nunn 1988, 189; Moorey 1994, 318; Marzahn 2008, 48-50; van Lemmen 2013, 19-20. Famously, the Processional way at Babylon passed through the 15-metre-high Ishtar Gate, whose modern reconstruction from the original finds is in the Vorderasiatisches
}

Mentioning Babylon here has a reason: the technology of glazing might as well have come to Yemen from Babylonia, considering that by the 9th-8th centuries BCE South Arabians were involved in the movement of goods in the cities of southern Mesopotamia, and there must have been Sabaean residents at international centres like Babylon and Ur. ${ }^{67}$ During the middle centuries of the first millennium BCE, as Potts cogently remarks, at least a dozen ethnically different peoples, from Scythians to Indians and Egyptians, and we should include Sabaeans, 'made Babylonia a thoroughly multicultural society'. ${ }^{68}$ Material evidence strengthens this connection between Babylonia and Saba', including such revealing finds as a bilingual burnt brick from 8th or 7th-century Ur, bearing a two-line inscription in Sabaean, ${ }^{69}$ or South Arabian seals from Babylon. ${ }^{70}$

Overall, however, around the date of our chief interest -700 BCE - the web of exterior relationships of Saba' appears to have predominantly involved Assyria. Exchanges between Saba' and Assyria are demonstrated before Karib'il the Great in the later 8th century ${ }^{71}$ and must have remained current for a while afterwards, during at least part of the 7th century BCE. We can even suspect that Yathill, a frontier town, played a forefront role in that interaction. Since the diffusion of new technologies and commodities operated as a twoway process,${ }^{72}$ this particular exchange would probably have seen Saba' and Yemen contribute valuable goods, and Assyria contribute technological know-how and statecraft customs: not only glazing, for instance, but also the practice of king's annalistic inscriptions. The monumental res gestae inscription of Karib'īl Watār at Șirwāh, previously cited, appears to be a direct emulation of the Assyrian royal annals, particularly Sennacherib's, so 'Assyrian' is its flavour. ${ }^{73}$

\section{Museum in Berlin.}

67 Eph`al 1974; Retsö 2003, 147-210; Hausleiter 2012, 822; Zimmerle 2014a, 335-363; Hausleiter and Eichmann 2018, 9; Bagg 2018, 253255. Cf. Chapter 21, section 2.1, this volume (introduction to 'Stone burners and containers'). One can agree with Zimmerle (2014b, 346) that 'there must have been many Arabians connected with the incense trade, who visited or resided in commercial cities such as Nippur, Babylon, and Ur'.

68 Potts 2007, 136. He continues: 'The diversity of exotic materials attested at sites such as Uruk and Babylon in the first millennium suggests that Babylonia was like a great harbour in a vast sea of resources, a harbour in which a multitude of peoples, goods and ideas mixed on a daily basis. Babylonia was, by this time, truly a land open to [vast] cross-cultural possibilities' (insertion in square brackets mine).

69 Ur, find no. U.7815: Woolley 1962, 31, 114 (catalogue), pl. 36.

70 cf. Zimmerle 2014b, 346, footnote 16.

71 In the time of Yita'amar Watār of Saba' and Sargon II of Assyria. See now Nebes 2007, 2016.

72 Cf. Zimmerle 2014b, 346.

73 Bagg 2018, 260. See already Frahm 1997, 145-146; 2001, 86; Potts 2003, 198; Lanfranchi 2004, 248; Nebes 2007. Potts (2003, 199-201) also provides an insightful discussion of why and how Karib'il the Great interacted with his faraway Assyrian counterpart, with an eye to the caravan trade routes closer to home. On Assyrian inspirations in 
Viewed against the above background, Yathill's glazed block takes the definite aspect of being a further and unexpected element in Sabaean-Assyrian connections and Assyrian inspirations - in every sense a tessera from a mosaic. If the Mesopotamian use of glazed bricks or tiles in wall decoration is anything to go by, ${ }^{74}$ one is entitled to suggest that find 43A.1 is to be associated with Wall F4 - as just one more unusual element among many ${ }^{75}$ This is the explanation preferred here. Remnants of mudplaster on a face of the block would indeed confirm that originally it was inserted in masonry, as a decorative tessera or plaque, or affixed to some background anyway; if so, the Sabaean wall might be a good candidate. In fact, it is the only candidate we can presently suggest.

Additional support for this suggestion might come from the observation that glazed bricks and tiles were used especially to decorate exterior spaces, such as courtyards, and architectural elements such as archways, gates, and external doors, probably because they were more resistant to the elements. ${ }^{76}$ Particularly intriguing here is the association with gates, such as at Khorsabad, where glazed bricks were employed in the superstructure of the principal gateways. ${ }^{77}$ Furthermore, alongside a production of figurative, 'narrative' glazed bricks there were non-figured bricks and tiles, mere architectural decoration in colour: ${ }^{78}$ and find 43A.1, by itself, does not seem to have been part of anything figurative-narrative. Could one ever say of Wall F4, as of certain Assyrian exterior walls, '[its] glazed decoration sparkled in the sunlight'? ?9 And in this case, could the glazed decoration found in the context of Wall F4 have been associated with a gateway nearby?

Before being unique for its glazing, find no. $43 \mathrm{~A} .1$ is special and exotic as a stone. Basalt, as well as trachyte, are completely foreign to Barāqish. Basalt had to come from distances of at least 20-25 kilometres westsouthwest or between 33-45 kilometres west-northwest, unless it could be found a little nearer as cobbles in the alluvial deposits of the upper Jawf. More probably,

\footnotetext{
Sabaean visual arts around 700 BCE see, e.g., Gerlach 2003c.

74 Noting, though, that architectural glazed stone was not current in the Mesopotamian region. And conversely: as find 43A.1 is unique, it is presently unknown whether the Sabaeans also glazed clay features in the Mesopotamian tradition, architectural features in particular (see on this tradition, e.g., Moorey 1994, 159-162, 315-322). The glazing of clay objects was equally common in Egypt (Nicholson with Peltenburg 2000).

75 See 'Accessories and special finds' in Chapter 17, section 6.3, this volume.

76 Nadali 2006, 109. Cf. examples in Reade 1979, 19; 1987, 32; 1995, 233-234 ('the weather-proof glazed bricks are normally recorded on exterior facades')

77 E.g. Reade 1995, 227.

78 E.g. Reade 1995, figs 11, 13-14.

79 Quotation from Reade 1995, 236.
}

basalt was brought to Barāqish from the extensive Mārib Lava Fields, 60-70 kilometres to the southeast, where the rock is plentiful, with much smaller occurrences at a minimum distance of 45 kilometres to the south-southeast. The nearest trachyte source is located 40 kilometres to the southwest near Naqil alFardah Pass, on the Plateau. ${ }^{80}$ The use of basalt, a rare stone, in conjunction with the occurrence of glazing, suggests a meaningful association.

To conclude, Wall F4 is one of the most interesting extramural findings on several counts. In a region where building-quality rocks were a precious commodity, F4 stands out for its stone masonry, although restricted to a low base (associated with mudbrick walling on top), and for a style resembling Sabaean walls and public buildings elsewhere. Its construction took an unusual amount of care and was accompanied by acts of probable symbolic significance, such as the deposition of a fossil shell in its foundations. The finished wall might have been enhanced with exceptional glazed stone elements, affixed to its masonry. Furthermore, Wall F4 was furnished with a large earthwork on the inside (F44) and - apparently - earthen accessories at its base on the outside.

Despite this, one cannot determine beyond doubt that F4 is the Sabaean town wall, previously only known from Karib'il the Great's res gestae. At present, Wall F4 is the sole candidate, and an acceptable candidate at that ${ }^{81}$ Even if F4 is the Sabaean wall, no one presently knows whether architecturally it is representative of the entire structure or circuit, or is only a local and particular expression of it. In fact, whether it encircled the whole settlement is equally unknown.

If we take the historical identification of Wall F4 as plausible, it follows that the Sabaean wall of Yathill was rather modest. Clearly it was built to delimit and define, not to defend: it was an 'urban political landmark in the oasis', to borrow Breton's expression. ${ }^{82}$ Certainly it had an intended, powerful role in political symbolism - the walling of a settlement as 'a hallmark of the Sabaean state $^{83}$ - and we can imagine that it fulfilled a social role as well, fostering a sense of community. Only future

\footnotetext{
80 Kruck et al. 1996: Quaternary basalts 'Qb' and Tertiary trachyte 'Tsp' in Sheets 2 (Al-Hazm) and 5 (San' $(\bar{a})$ by Kruck and Schäffer, published 1991. See also Overstreet et al. 1988b, 391-392.

81 This attribution was strongly supported by A. de Maigret, as mentioned in Chapter 17, section 6.3, this volume (see Robin and de Maigret 2009, 68, fig. 12), and has been accepted by C. Robin (Robin and de Maigret 2009, 78). More recently, the significance and historical interpretation of find no. 43A.1 have been prominently cited in Loreto 2019, 136. Wall F4 is also mentioned, and accepted as the possible Sabaean town wall, in Chapter 27, this volume.

82 Breton 2002,146.

83 Breton 1994, 167-169 ('L'art des sièges'); 2002, 145, 'The city wall appears to be a hallmark of the Sabaean state from the 7th century BC' (the whole section titled 'City walls', p. 145-146, is of great interest).
} 
excavations can test this line of argument. At the basic level, in order to be fully understood, a longer portion of Wall F4 needs to be excavated, mapped, and studied. This is a top priority as soon as researchers can return to Barāqish.

\subsection{First Intermediate and Minaean 1}

Several finds from Stratum K, equated with a First Intermediate period, point to an interval of suspended occupation in Area $C$, hence perhaps no longer Sabaean, and seem to be characterized by shadowy hints of non-Sabaean material culture, although not yet clearly Minaean ${ }^{84}$ An example is ochred stone tile no. 22.0, a unique find for the pre-Minaean period, if its typological interpretation is correct. ${ }^{85}$ Potsherds are less reliable, due to possible redeposition, but even so, finds such as no. 22.2 (Later Pale Green ware) and 22.3 (Wavy Rim bowls, variant C) suggest that a ceramic variation possibly occurred between Strata $\mathrm{L}$ and $\mathrm{K} .{ }^{86}$ However, the most revealing find attributable to Stratum $\mathrm{K}$, and an extraordinary finding from Yathill in general, is the pair of clay sling bullets already mentioned in the previous chapter (nos 6.1 and 6.2). ${ }^{87}$ The discussion that follows will focus on them, as they bear potential significance for the understanding of the First Intermediate.

\section{On the First Intermediate}

Nos 6.1 and 6.2 are two elongated sling bullets made of fired clay. The writer is unaware of similar finds from Yemen, at least of equivalent age. Comparisons suggest that the GSV3-GV2 specimens belong in a typological family of biconical or torpedo-shaped sling bolts ${ }^{88}$ very widely distributed in space and time - between Nubia and Turkmenistan, and from the 7th millennium BCE to the Sasanian period. Reasonable parallels can be found, for example, at prehistoric sites in northern Syria (Tall Sabi Abyad) and Iran (Tall-i Bakun), and during the Achaemenid to Sasanian periods at Merv, in Turkmenistan. ${ }^{89}$ Almost identical specimens are

\footnotetext{
84 Chapter 17, section 8.2, this volume.

85 Previously thought to be an unusual handstone; see Chapter 21, section 2.2 , this volume.

86 See Chapter 23, section 3.3, this volume.

87 Chapter 17, sections 8.2-8.3, with details on context and as an introduction to the present appraisal. The objects are described and illustrated in Chapter 21, section 2.2 (Fig. 44), this volume. See already Fedele 2011a, 108-109, fig. 10/a; the present treatment is an updating.

88 Stout (1977), in the context of his experiments on the ballistic properties of sling bullets, lists the following shapes and weights: biconical, average weight 35 grams; elongated biconical, 57 grams; point-ended ellipsoid, 28 grams; and flat-ended ellipsoid, 43 grams. Cf. Korfmann 1972.

89 For Tall Sabi Abyad, Late Neolithic, see Akkermans 1993, 50, 63-64, 81,233: thousands of biconical sling missiles of unbaked clay stored in small, round pits sunk into floors - 'by far the most common object made of clay' (p. 81); see also Akkermans and Schwartz 2003, 128, 132.
}

known from Buhen (Nubia, Middle Kingdom). ${ }^{90}$ In Mesopotamia, generally biconical sling missiles made from clay and variously described as fired or unfired are attested as early as the 'Ubaid period (5th millennium $\mathrm{BCE})^{91}$ and are common during the 4 th millennium (e.g. at Tell Brak) and afterwards. ${ }^{92}$ An accumulation of sling bullets featured near the main gate of an Isin-Larsa fortified settlement at Khafaje (old Babylonian period, c. 2000-1800 BCE). ${ }^{93}$ It is clear from these brief notes that sling bullets appear in contexts that suggest both ordinary use, in activities such as hunting or playing, and a military function. ${ }^{94}$ They were used in war, but not exclusively.

As to our finds, the Mesopotamian-Iranian area is perhaps the most likely source from which similar sling bullets were adopted in Yemen. Excellent overviews of the use of slings in the ancient Near East were compiled by M. Korfmann, ${ }^{95}$ while F. Beeston provides useful background information on combat in ancient Yemen. ${ }^{96}$ But something more specific can perhaps be said about the historical and regional context of our finds.

Considering the interchange between Saba' and Assyria discussed above (section 3.1), it is interesting to note how the sling played a prominent military role in Assyria. The Assyrian war machine, which rested essentially on the infantry, was massively made up of archers and slingers, and the slingers became more numerous from the 8th century onwards. ${ }^{97}$ Significantly, in the Stratum $\mathrm{K}$ time bracket 'a great host of slingers' is mentioned as part of an Arab chieftain's army c. 550 BCE. ${ }^{98}$ Five centuries later, in 25 or $24 \mathrm{BCE}$, but suggesting the existence of an already long tradition in the Yemeni Jawf, slingers are mentioned in Strabo's passage reporting the battle of Aelius Gallus' army at a stream which can be identified with Wādī Khārid or Wādī Madhāb: 'Here

On Achaemenid slingers see, e.g., Head 1992, Sekunda and Chew 1992. I thank St J. Simpson (British Museum) for drawing my attention to Merv and Iran (personal communication, August 2010).

90 British Museum EA65751, 65752, 65754 (personal observation, 2009).

91 Roaf 1989, 131-4, fig. 18 (a house of the 'Ubaid period at Tell Madhur contained over 4000 sling bullets, perhaps originally stored on the roof); Moorey 1994, 165-166; for Upper Mesopotamia, Wilkinson et al. 1996, fig. 14/1-4.

92 Matthews 2003b, 28, figs 3.5, 3.17/4; Felli 2003, 60, 73, fig. 4.26/9; Steele et al. 2003, 198, fig. 6.61/12; all with further references. On the interpretation of use and function see, e.g., Tsuneki and Miyake 1998, 111.

93 Hill et al. 1990, 219, plates 52, 57b; cf. Moorey 1994, 165.

94 'The sling was, as it remains, the poor man's natural weapon, as effective in combat as in hunting in skilled hands' (Moorey 1994, 166).

95 Korfmann 1972; Arsebük and Korfmann 1976.

96 Beeston 1976.

97 E.g., Lafont et al. 2001, 77, 78. See also, e.g., Saggs 1963; Reade 1972; Postgate 2000, 106-107.

98 Xenophon Cyropaedia, as cited in Retsö 2003, 185. 
the barbarians ${ }^{[99}$ attacked the Romans, and lost about ten thousand men; the Romans lost only two men. For the barbarians were entirely inexperienced in war, and used their weapons unskilfully, which were bows, spears, swords, and slings; but the greater part of them wielded a double-edged axe. ${ }^{100}$ The sling featured in the South Arabian and particularly himyarite weaponry of the 6th century $\mathrm{CE},{ }^{101}$ and has been recognized in rock engravings of various ages (mostly loosely defined) in southern Saudi Arabia. ${ }^{102}$

Sling bullets 6.1 and 6.2 could well be interpreted in terms of everyday, individual activity, unrelated to warfare, as mentioned above. Hunting, for instance. But hunting is negligible throughout Yathill's history (see Chapter 19, section 1.2, this volume). As to context of origin, these finds could well have been part of a cache or store of sling bullets in one of the houses of Lobe 5 (cf. footnote 91). This is a possibility. However, the coincidence of a unique finding with a unique suite of sediments strongly suggests a less ordinary or nonordinary origin.

As an extramural occurrence in more than one specimen, it does not seem unreasonable to link the sling bullets from Area $C$ to a warfare episode or episodes. At the time, such projectiles were commonly used in war. An event of this kind would have concerned the western margin of Yathill's tell after the local cessation of settlement, as indicated by stratigraphy. A more specific and admissible origin for these finds is a siege, and this raises an intriguing possibility. One may wonder whether Stratum $\mathrm{K}$ partly records the siege of Yathill by a Sabaean ruler of the decades around $600 \mathrm{BCE}$ as reported by Sabaean inscription RES 3943, lines 3-4. ${ }^{103}$ Besides the siege, the whole area saw episodes of turmoil. As the mukarrib's scribe relates, 'the two plains of [Ya]thill, Dyt and $S^{2} \mathrm{~mm}$, were ravaged and the buildings of the two plains were burnt and destroyed'. ${ }^{104}$ In the light of the excavation data

\section{The Jawfites.}

100 Strabo 164.24 (1930). The translation quoted, however, is from the classical edition by H.C. Hamilton and W. Falconer (1857, reprinted 1903): <http://www.perseus.tufts.edu/hopper/ text?doc=Perseus:text:1999.01.0239>, accessed 31 December 2019. For a recent English edition see Roller 2014. Cf. Pirenne 1961, 95; Robin 1997a, 47.

101 Robin 2019a, 170.

102 According to C. Robin, the weapons appearing in rock engravings at the Murayghān Wells in Saudi Arabia, $240 \mathrm{~km}$ north of Najrān, are slings: see Robin 2019a, 170, figs 19-23 (Mission franco-sa'ū ${ }^{`}$ dienne de Najrān) and 24 (taken from Khan 2012).

103 Fedele 2010, 130; 2011a, 108-109.

104 'Et il assiégea Yathill, dévasta les deux plaines de [Ya]thill, Dyt et $S^{2} \mathrm{~mm}$, et incendia et détruisit les édifices des deux [plai]nes de Yathill', trans. C. Robin (Robin and de Maigret 2009, 79, note 39). Dyt and $S^{2} m m$ can be identified with two parts of the oasis of Yathill. RES 3943, a text from Mārib, relates about the 'war' ( $d r)$ waged by a mukarrib (name lost) against Qatabān, Ma'īn, Nagrān, and Muha'mir. It is the first known Sabaean inscription mentioning Ma'inn. On palaeographic grounds it and related interpretations discussed in Chapter 17 (suspension of settlement in Area C, traces of changing or alien material culture, etc.), the layers of suite SD2 which define Stratum $\mathrm{K}$ might indeed be compatible with events of that kind. And, of course, a date around $600 \mathrm{BCE}$ would be alluring.

\section{On the earliest Minaean as recorded in Area C (Minaean 1)}

As seen in Chapter 17, section 10.1, this volume, the Minaean 1 corresponds to Stratum J. Integral to our definition of Stratum $\mathrm{J}$ is the construction of bastion T7 of the curtain wall of Yathill. Within its limits, ${ }^{105}$ radiocarbon can support a completion of the Minaean wall and its accessories at bastion T7 during the later 6th or the 5th centuries BCE, approximately (Table 3; cf. Chapter 17, Table 5, this volume). ${ }^{106}$ This age is one and the same with the above statement that 'a Minaean beginning' in terms of material culture and architecture (bastion T7) can be placed 'around 550 BCE' (end of section 1.2, above). And this age is somewhat earlier than the commonly admitted chronology for the Minaean walling of Yathill, which, to this day, is obligatory to deduce from the inscriptions originally embedded in parts of the masonry. ${ }^{107}$ Bastion T7, and by inference a wall segment on either side of it, would possibly rank among the earliest parts of the Minaean curtain wall to be built.

How long might this segment be? The nearest part of the wall for which epigraphy provides chronological clues is recess R2/3, where an in situ inscription of major historical importance is located (RES $3022=$ M 247). With reference to a 'Minaean-Persian' synchronism in this text, at least part of the recess would have been built shortly after $343 \mathrm{BCE}$ - or in fact much earlier, around $500 \mathrm{BCE} \cdot{ }^{108}$ Typically, in any case, and whatever

would date from 'the last quarter of the VII or the beginning of the VI century BC' (Arbach and Rossi 2012, 324; see now Arbach 2019, 33 , 'around the beginning of the 6th century $\mathrm{BC}$ '). For Arbach, RES 3943 would have been written after the formation of the kingdom of $\mathrm{Ma}^{\text {'in }}$ through the 'tribal confederation of $\mathrm{Ma}^{\text {'in }}$ and Yathill'. (Hence a Sabaean attempt to snatch back Yathill from the Minaean control?) See also Robin 1996, col. 1124-1125; de Maigret and Robin 1993, 490; de Maigret 2009a, 210. [The present subsection was last revised in December 2019. The reader will find a more recent, detailed discussion of RES 3943 in Chapter 27, this volume.-Eds]

105 See discussion at the end of section 1.2, above.

106 At the time of the first report on the Area $\mathrm{C}$ excavations (Fedele $2010,134)$, de Maigret opted for a 5th-century date (Robin and de Maigret 2009, 71, 72; and personal communications 2008-2009).

107 de Maigret and Robin 1993, fig. 1; Robin and de Maigret 1994, fig. 5. See in this volume the updating presented in Chapter 27.

108 According to a hypothetical identification of the Persian military event alluded to in the inscription. On this synchronism see, e.g., Robin 1979b; 1991c, 59, 62, fig. 16; de Maigret and Robin 1993, 490 (Robin); Lemaire 1996; Gnoli 1996b, 2009; see also Robin and de Maigret 2009, 71, note 22 (de Maigret). Acceptance is not unanimous, however (Agostini 2011, 54-55), and an alternative option would point to an earlier historical date in the last quarter of the 6th century BCE (Lemaire 1996, 44-47). For an independent updating on this subject see Agostini, Chapter 4, section 1.5, in Volume 1, and Schiettecatte 
the historical dating in question, it cannot be excluded that the date in the inscription refers to a completion of the part of wall concerned, not to its initial or entire construction. A general point to be made is that epigraphy alone can hardly tell the complete story of a town wall.

Except for the immediate context outside the Minaean wall at bastion T7, current knowledge of the Minaean 1 phase is very limited. A relatively small amount of pottery can be attributed to this phase, and what there is corresponds to chance fragments from within Earthwork F10-F12 ${ }^{109}$ and the foundation fills for the wall (cf. Chapter 17, Table 3, and Buffa, Chapter 22, both this volume). Secondly, the construction of the wall is not known in its architectural and chronological details, including the length of time involved. Once again, only sufficiently extensive excavations on both sides of the Minaean wall can provide information to answer such questions.

As a last problem, we need to try and review the relationship between Strata $\mathrm{K}$ and J, or, in purely historical terms, the First Intermediate and Minaean 1 phases. To do this, it is essential to bear in mind once again that, at the moment, both those strata and phases exclusively reflect the stratigraphic record from Barāqish Area C. The problem basically revolves on the question: are these two phases, historically, really distinct? ${ }^{110}$

Also terminology can be critical here. The phase corresponding to Stratum $\mathrm{K}$ was successively labelled 'End-Sabaean' ${ }^{111}$ and 'Sabaean-Minaean Intermediate'. ${ }^{112}$ This latter designation, 'Intermediate', was devised in $2010^{113}$ in reference to what ever more clearly appeared to be an interruption of settlement in Area C. Although perhaps effective as a concept, End-Sabaean was discounted because applying a cultural-political label to such a phase did not seem justified. Indeed, a politically neutral designation was considered essential for conveying in a manner as objective as possible the most significant characteristics of the archaeological evidence. 'Intermediate', it became clear in $2015,{ }^{114}$

and Arbach, Chapter 27, sections 6.1-6.2 and Table 6, this volume.

109 Earthwork F10-F12 and its comparison with Earthwork 'L10' at Minaean wall recess R44/45 are illustrated and discussed in Chapter 17 , section 10.3 , this volume.

110 The present discussion is a follow-up from Chapter 17 , end of section 8.3 , this volume.

111 Fedele 2010, 128-131.

112 Fedele 2011a, 108, fig. 6.

113 Independently of Agostini, who had the same name in mind for the phase succeeding the Minaean-Amirite period (Agostini 2015). Not simply as a term, but conceptually, my own 'Intermediate' was influenced by the stadial terminology employed in Egypt as well as the Andes (in this latter region by Edward P. Lanning in 1967). Cf. Chapter 17, section 3.3, this volume.

114 Fedele, 'Barāqish stratigraphy and Sabaean Yathill', a contribution would designate equally well the two intervals of shrinking, reduced, or suspended occupation in Area C, i.e., those corresponding to Strata $\mathrm{K}$ and $\mathrm{E}$ (Chapter 17, section 3.3 and Table 4, this volume).

Whether the First Intermediate, having been defined from Area C, is represented elsewhere at Yathill in one form or another is unknown at the moment. In Chapter 17 it was argued that a town-wide abandonment of settlement may well be a subjective impression. Furthermore, the time span implied, materially translated into the sediments of Stratum K, cannot be determined from sediments alone, and, once again, the impression that it was rather short is subjective if not illusory.

Only two major facts are evident enough. First, Stratum K marks a suspension of settlement in Area C. Most clearly in Lobe 5 of the Sabaean tell, a centurylong, uninterrupted history of occupation ended with the close of Stratum L, thus signalling a major change in the organization of at least part of Yathill. And second, during Stratum K fundamentally new kinds of sediments made their appearance in the deposits on the flank of the tell: the 'manure' layers, inaugurated by units V0 to V2 exposed at the head of Gully B. ${ }^{115}$ Whole coprolites were found in almost all manure layers, and some of these sediments are true excrement lenses almost free of minerogenic matrix. Manure units are of great interest from the behavioural point of view, as they reveal the frequent presence of dromedaries and donkeys in this part of Area C, now in fact best described as the upper talus of the Sabaean mound (cf. Chapter 19, Fig. 18, this volume). This too was a new chapter in the physical and cultural history of Yathill as a tell.

In light of these two changes, a partially different interpretation jointly concerning Strata $\mathrm{K}$ and $\mathrm{J}-$ the First Intermediate and Minaean 1 - can be advanced: in fact, it is a complementary interpretation to the one previously discussed. It is entirely possible that the novelties of Stratum $\mathrm{K}$ not only mark the transition to the Minaean political rule in a general sense, as suggested above, but denounce the actual onset of Minaean activity in Area C. And activity of a remarkably novel kind, in fact: the construction of a major town wall. Indeed, the archaeological data from suite SD2 and V0-V2, as well as those from the subsequent sediments attributed to Stratum J in quadrangles D1-D2, ${ }^{116}$ would very well fit a reorganization of this part of the tell in

\footnotetext{
written in winter 2014-2015 and as yet unpublished (cf. Chapter 1 in Volume 1, footnote 57 , and Chapter 17 , section 3.3 , this volume).

115 See Chapter 17, section 4.2 and Fig. 26, this volume.

116 It should be remembered that the correlation of quadrangles D1D2 with the sequence of Sounding A is tentative: Chapter 17, section 3.3 ('Long-distance correlations'), this volume.
} 
conjunction with the beginning of curtain walling. One can envisage a scenario in which the old and decaying Sabaean dwellings were levelled, pack animals were engaged over the tell's flank and talus for the transport and traction of building material, and sediments were actively mobilized.

The manure lenses and levels of Strata $\mathrm{K}$ and $\mathrm{J}$ - in quadrangles D1-D2 and (unexcavated) in the area around upper Gully B - are demonstrably connected with dromedaries and donkeys (see Chapter 19, this volume), and it is not inconceivable that such levels in Stratum J resulted from animals employed in the construction of the Minaean wall. Animal stalls or enclosures may have existed, as dung concentrations are often indicative of enclosed animals. Certainly, the presence of beasts of burden on the talus represents a significant novelty in Yathill's extramural sequence (see Chapter 17, this volume). The starting observation, of course, is simply the movement and/or stationing of dromedaries and donkeys, while the specific reasons for their presence and use can only be a matter of speculation. The hypothesis is that at least one of the reasons - at that particular moment and upon the more or less flattened upper talus - was the mobilization of loads for the erection of the wall. The fact that the manure layers of Stratum J are foreshadowed by units V0-V2 of Stratum $\mathrm{K}$ might be a telltale sign of initial Minaean control. ${ }^{117}$

Only further excavations in northwest Barāqish, including on the inside of the Minaean wall, will test this hypothesis, thereby throwing light on what is meant here provisionally by the separate labels of 'First Intermediate' and 'Minaean 1'. The limited testexcavation on the upper talus that could be carried out in 2005-2006 was insufficient for a detailed description let alone an understanding - of the First IntermediateMinaean 1 sequence in such a complicated and critical belt of the tell.

\subsection{Minaean 4, including the Roman military incursion}

As seen from Area C, the 'Minaean' period at Yathill began no later than $c$. 550 BCE (see data above) and lasted until an undefined moment of the 1st century CE ('early/mid-1st century'). Its last phase, Minaean 4, corresponds to Stratum $\mathrm{F}$, the beginning of which can tentatively be dated to the end of the 1st century $\mathrm{BCE}$ (Table 3; and Chapter 17, Table 4, this volume). ${ }^{118}$ It is in this phase that the famous Roman military expedition to Saba' of 25 or $24 \mathrm{BCE}$, ordered by emperor Augustus and led by the praefectus of Egypt, Gaius Aelius Gallus, took place (Fig. 4). ${ }^{119}$

\footnotetext{
117 Fedele 2011a, 111.

118 Cf. Fedele 2011a, 107. The present section is a revised treatment.

119 A selection of the copious literature on this military incursion in Arabia felix and its historical context would include Pirenne 1961,
}

Unfortunately, the Italian work at Barāqish could not contribute information of direct interest about the Roman incursion. This event concerns us here because Yathill was reached by Gallus on his advance towards Mārib and - reportedly - was briefly occupied with a garrison. ${ }^{120}$ Indirectly, however, the two extramural excavations of 2005-2006 $6^{121}$ were informative, considering that for the first time they outlined a tangible framework for the military episode, thus ideally paving the way for desirable future research.

The cemetery in Area D, tested by S. Antonini, ${ }^{122}$ has provided a potential context for the provenance of YM 605 , the extraordinary bilingual stone acquired in the early 1970 s by the recently created National Museum in $\left.\operatorname{San}^{(} \bar{a}\right){ }^{123}$ This tiny slab fragment bears part of a two-section, two-line engraved inscription in Latin and Greek. ${ }^{124}$ However, apart from other uncertainties,

93-124 ('L'expédition d'Aelius Gallus en Arabie heureuse'); Jameson 1968; von Wissmann 1976; Bowersock 1983; Sidebotham 1986a, 1986b; Buschmann 1991; Marek 1993, 1994; Potts 1994; Cuvigny 1997; Robin 1997a, 45-47; Luther 1999; Simon 2002; Wiegels 2015, 36-45 ('Der Arabienfeldzug des praefectus Aegypti Aelius Gallus'); and Arbach and Schiettecatte 2017 (with a list of the classical sources on p. 677). See also Chapter 27, this volume. Concerning the main sources, Strabo's $\Gamma \varepsilon \omega \gamma \rho \alpha \varphi$ เ $\alpha$ can be read in the excellent edition of Roller (2014), while a recent edition of Book 16 is Biffi 2002, and Alison Cooley (2009) has provided the 'definitive' edition of Res Gestae Divi Augusti. Arbach and Schiettecatte (2017) have most recently recognized epigraphic 'echoes' of the Roman incursion in two South Arabian texts, which might suggest that the event had more far-reaching consequences - both economic and political - than hitherto believed. For further developments on this subject see now Robin $2019 \mathrm{~b}$.

120 Yathill, spelled Athrula ('A $\theta \rho \circ u \lambda \alpha$ ), was taken ' $\alpha$ kovıนí, without a fight, says our earliest source and Aelius Gallus' friend, Strabo (16, 4.24; cf. footnote 100, above). He alone also tells us, in the same passage, that Gallus stationed troops at Yathill, where he obtained food provisions consisting of wheat and dates. Bowersock, citing Ahmed Fakhrī's eyewitness account (Fakhry and Ryckmans 19511952), comments that Barāqish was ideally suited for a garrison due to its situation and defenses (Bowersock 1983, 152). Interestingly, Pliny omitted Yathill from his extensive list of towns 'destroyed' by Gallus (Naturalis historia, book 6, 32.17), and this is probably an indication that Yathill was the only place that had been subdued without any

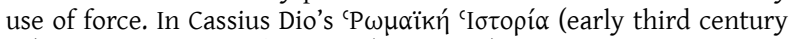
$C E)$, Yathill was spelled Athlula ('A $A \lambda$ ou $\lambda \alpha$ ), with an inversion of the liquid consonant not unusual in spoken Greek. It cannot be excluded, however, that Strabo's 'A $\theta \rho \circ u \lambda \alpha$, or both 'A $\theta \rho o u \lambda \alpha$ and 'A $A \lambda$ ou $\lambda \alpha$, are corruptions, as unusual toponyms are subject to corruption at all stages of their transmission (Roller 2015, 111).

121 Area C and Area D: see Chapter 1, sections 4.4 and 4.5, in Volume 1 ; and plan of Barāqish operations on page xi of the same volume.

122 Antonini and Agostini 2010a, 2010b.

123 See Chapter 1 , section 2, note 39, in Volume 1.

124 Limestone, $15.5 \times 16.5 \times 7 \mathrm{~cm}$. Photographs include Yémen 1997, 69, 231; Jemen 1998, 87 (no. 18); Queen of Sheba 2002, 202 (no. 286); Yemen 2000, 76 (an enlarged image). The principal studies on this find, subsequent to its first edition by P. Costa (1977), include Bowersock 1983, 148-153 (appendix I, 'The new inscription from Barāqish'); 1984; Marek 1994. About its hypothetical connection with the presence of Aelius Gallus' army at Yathill in 25 or 24 BC see, e.g., Beaucamp and Robin 1981,61; Bowersock 1983, cited above; Sidebotham 1986a, 597598; Marek 1993; Robin 1997a, 44; Jemen 1998, 86; Speidel 2015; Arbach and Schiettecatte 2017. Other authors, first and foremost Costa (1977, 1986; see below), would favour a later date, thus excluding any connection with Aelius Gallus. For instance, Shahid (1984, 72-73) argued for a 4th century CE context, while on both historical and epigraphic grounds Villeneuve et al. (2004, 152-153, note 44) would 
the ascription of YM 605 to a funerary context is wholly conjectural, although widely accepted, ${ }^{125}$ and an association with the Area D cemetery - which has been interpreted as comprising only cenotaphs - is presently beyond demonstration. ${ }^{126}$ Other Minaeanage cemeteries which seem to exist at Barāqish are still archaeologically unknown. ${ }^{127}$

In Area $\mathrm{C}$, as reported in this volume, the excavations have provided direct contact with sediments and contexts clearly spanning the time of Aelius Gallus' expedition. The valuable aspect is that we are dealing here with a material record from outside the town wall, that is, so to speak, from an area that the Roman army might have actually trodden. Obviously enough, no Roman imprint was detected, but the excavation has at least generated formal questions about extramural evidence of potential relevance. In particular, the land strip along the base of the talus may preserve actual traces of the stay by the Roman army, however short: ${ }^{128}$ and such hypothetical evidence could be concealed not only in quadrangles E8-E12 of Area C, as tested in 2005-2006, ${ }^{129}$ but throughout the plain adjacent to northwestern Yathill.

rather date the inscription to the second century $\mathrm{CE}$.

125 Accepted somewhat acritically, perhaps, following Bowersock's (1983, 148-153) forceful advocacy of a funerary interpretation. As outlined in Queen of Sheba 2002, 202 (St J. Simpson and A. Porter), 'It is uncertain whether it is a funerary stela or whether it could represent a dedicatory inscription by a merchant who had the rank of eques and for wich a date as late as the fourth century AD has been suggested (Costa 1977, 1986)'. Costa thought it to be dedicatory - 'but he offers no argument for this presumption' (Bowersock 1983, 149, referencing Costa 1977). In fact, Costa articulated his view carefully enough to warrant attention: 'I still favour the humbler explanation that a Roman trader called Publius Cornelius, during a visit to the Jawf, left a dedication in the temple of a local deity' (Costa 1986, 34). There is presently no way to resolve this debate.

126 This possible association was suggested by C. Robin before the Italian excavation in Area D: 'Probablement dans la nécropole qui se trouve au sud-ouest de la ville, à l'extérieur de l'enceinte, une courte inscription en grec et en latin a été trouvée, au nom d'un certain Publius Cornelius Eques' (Robin 1997a, 44). Presumably revealed by pillaging, the existence of this cemetery had been known since before 1981 .

127 Cf. de Maigret 2010c, 8; Fedele 2011b, xii; and Chapter 1, section 4.1 , in Volume 1 . Not directly related to the present issue, but not to be forgotten, is the fact that two graveyards, one Arab and the other Jewish, existed 'close to the ruin' of Barāqish at the time of Habshūsh (Habshūsh 2018 [ed. Verskin], 144-145). As the description of the Jewish graveyard includes the citation of 'Aramaic inscriptions in Hebrew script', with added details of very personal content, there can be little doubt that these cemeteries and their association with Barāqish were real. Where are these graveyards now? Nobody - to my knowledge - ever mentioned them afterwards.

128 Probably no more than three-four weeks in August-September, 25 or $24 \mathrm{BCE}$. The year is debated. Although persuasively argued by Shelagh Jameson (1968, 76-78; cf. Sidebotham 1986a, 590, note 1), the date of 26-25 BCE for the expedition has not been unanimously accepted (e.g. Marek 1993, Nappo 2010). The indication '25/24 Aelius Gallus' in Fig. 4, this chapter, means that Aelius Gallus stationed at Yathill in 25 or $24 \mathrm{BCE}$, and more precisely for a short period during the spring or summer of 25 or $24 \mathrm{BCE}$.

129 Only quadrangles E8 and E11 could be tested (Chapter 17, section 1.2 , this volume); the surroundings, including enigmatic Hill E, could only be recorded by surface inspection. The possibility that Hill E conceals military works somehow connected with the Roman army
As to the end of the Minaean kingdom at Yathill, its dating depends on epigraphy and coins. It has conclusively been understood that two Minaean kings still ruled in the first quarter of the 1st century CE, and at least one still had the impulse and economic power to build or repair a part of the town wall of Yathill (recess R40/41). The information is provided by a Minaean subject living in Qatabān, who having taken part in the construction or restoration of this wall recess invokes, on the occasion, a king of Qatabān now independently dated from coinage to about 1-25 CE. ${ }^{130}$ The text in question is inscription RES 2999, a rare in situ occurrence, precisely located in recess R40/41 of the curtain wall of Yathill. ${ }^{131}$

In my opinion, a town that in 25 or 24 BCE 'opened its gates to the Romans ${ }^{132}$ and was still able to supply wheat and dates to the ten-thousand-strong RomanNabataean army of Aelius Gallus (Strabo 16 4.24), 133 and that a couple of generations later still had a ruler intent on completing or augmenting the curtain wall, could not be in decadence. At the time of Gallus, at least the Yathill oasis had to be adequately functional and productive, regardless of any incipient fluctuations the caravan trade could already reveal. And around 25 CE the proudly walled town still had to be inhabited regularly, although it might not have been as thriving as in its heyday. The rapid decline started later, perhaps not before the middle of the 1st century $\mathrm{CE}$, and might have had the characteristics of a system collapse (see next section). The often repeated statement about the 'decline' of Yathill at the turn of our era, or indeed already by the time of Gallus' incursion, appears more and more to be a commonplace to be dismissed.

\subsection{End of Yathill and Second Intermediate}

\section{From 'Yathill' to 'Barāqish': the end of the Minaean town and polity}

At an indeterminate date in the 1st or 2nd century CE Yathill must have been completely abandoned. ${ }^{134}$

can be contemplated, but is entirely theoretical (see Chapter 17 , section 16.4, 'Stratum B').

130 On this re-dating based on coinage see Robin 2016b, 77-79, and particularly on Barāqish footnote 202. The Qatabānian king in question is Shahr Yagill Yuhargib.

131 See Chapter 1 in Volume 1, Appendix B (de Maigret's no. 123). RES 2999 is on two blocks. Its chronological importance had long been suggested by Robin (1998): 'un article qui fait date', says Arbach in his own reappraisal $(2009,27-28)$. An account of the evidence concerning Yathill in the 1st century CE, including this text, can be found in Chapter 27, this volume, whose Fig. 1 supersedes fig. 1 of de Maigret and Robin 1993.

132 Cf. von Wissmann 1968, 10 ('Yațil öffnet den Römern die Tore').

133 Cf. Fedele 2011a, 116.

134 E.g., Robin 1998; 2010a, 84 (Yathill abandoned at the turn of our era or shortly afterwards); Schiettecatte 2006b; 2010a, 48; 2010b; Fedele 2011a, 115. 
Between the Minaean and Islamic occupation phases the town experienced its longest interruption in settlement history, according to both material remains and literary sources: a span of about eleven centuries, underscored by the loss of the original name itself. ${ }^{135}$ In 1990-1992, excavation immediately confirmed a gap of this order. ${ }^{136}$ From an archaeological viewpoint, however, the end of Yathill was perceived differently in Area $\mathrm{C}$ and within the town, in the temple area, although some concordant aspects can be recognized. ${ }^{137}$

Near the temple of Nakrah, a deposit of sterile sand more than one metre thick afforded evidence that the place had been deserted. ${ }^{138}$ Again from the temple record, Agostini has painstakingly explored the evidence for a presence of the Amir tribe, indicated at least by cultic activity and very difficult to define in terms of both continuity (an Amirite 'phase'?) and political impact. ${ }^{139}$ Similarly, it is almost impossible to distinguish Amirite characteristics in material-culture productions. ${ }^{140}$ From a ceramic perspective, Minaean-looking pottery appears to have remained in common use until active occupation at Yathill expired. Might a tall terracotta container or support from Temple B, uniquely prismatic in morphological conception (no. B.05.B/58+74), constitute a non-Minaean ethnic marker? ${ }^{141}$ What is relatively certain is that during the middle or later 1st century CE the Minaean polity rapidly waned. Only a large-scale excavation of residential parts of the town, with their attendant stratigraphy and datable associations, might cast light on the matter.

In Area C, great care was devoted to identifying the material correlates - depositional, sedimentary, artefactual - of both the decrease in occupation and subsequent residential discontinuity (Stratum E). As we have seen in Chapter 17, this volume, Stratum E records ephemeral visits for perhaps a couple of centuries, on the outskirts of a deserted settlement undergoing sand

\footnotetext{
135 For the earliest documented appearance of the new name, Barāqish, see section 3.5 below.

136 de Maigret 1991a, 1991b; de Maigret and Robin 1993 (compendium of epigraphic and literary sources by C.J. Robin on p. 490-493).

137 Area C: Fedele 2010, 110, 138-139 ('Post-Minaean Interval'); 2011a, 115-116. Temple area and concordances: Agostini 2015.

138 de Maigret 1991a, 15; cf. 1993, 8-9.

139 Agostini 2015, 2018a; and Chapters 3-4 in Volume 1. See also Chapter 27, this volume.

140 Evidence for a precise characterization of 'Amirite' material culture has not yet been forthcoming; the subject cannot be dwelt upon here. It may be interesting to remember that the first, pioneering archaeological-historical examination of the ancient tribes of Amir and Muha'mir, with particular reference to their main centre, Najrān/Ukhdūd, was by H.St J. Philby (1952, 254-273, and illustrations)

141 Described among the pottery from Temple B in Chapters 7 (Volume 1) and 25 (this volume; both by Buffa); for its context see Agostini, Chapter 3 in Volume 1. The writer personally examined this object, and together with Vittoria Buffa guided its reconstruction, in December 2007.
}

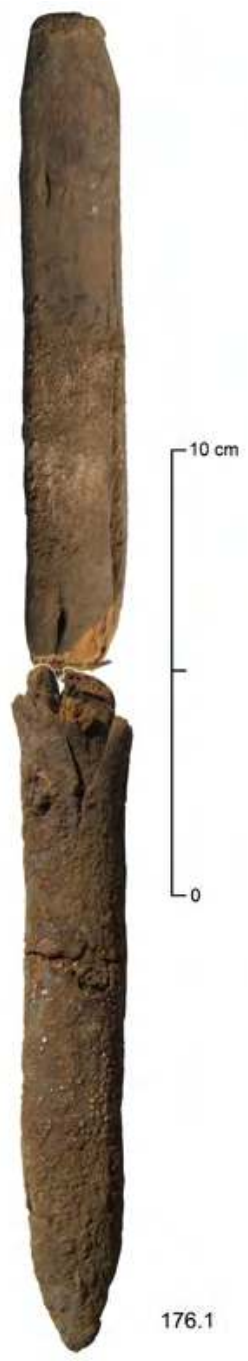

Figure 5. Wooden stake (no. 176.1), Second Intermediate period. (G. Di Rosa and S. Iavarone 2007 (c) MAIRY, rearranged and optimized by F.G. Fedele 2020)

accumulation. Excavations encountered a 'manure' level in Sector B, and a hearth yielding a quern in Sector C. In greater detail: the only layer that can be safely attributed to the interval in question is suite T74L in Sounding A, on the basis of both sediments and radiocarbon. T74L contains reworked Minaean debris and follows surface $\mathrm{S} 6$ that seals the last diagnostic Minaean level. A lack of artefacts in primary deposition is part of the evidence suggesting highly reduced anthropogenic pressure. ${ }^{142}$

Stratum E was only recognized at the Minaean wall and towards the top of the tell. In Sector B, the Second Intermediate interval - Stratum $\mathrm{E}$ - probably starts with a plant-detritus unit (BV1) and ends with a typically brown 'manure' layer (BV0), separated by a thick unit of fine-sandy, gravelly silt with minute charcoal (B01). This sequence suggests repeated though ephemeral stops by people and animals, and is topped by a marked discontinuity, erosion and hiatus (surface S20). Probably in connection with the original, pre-

142 Cf. Fedele 2010, 138; 2011a, 115. 
erosion ground surface corresponding to $\mathrm{S} 20$, a wooden stick was found vertically planted into 'manure' BV0, find no. 176.1 (Fig. 5): it might be related to keeping animals tied. ${ }^{143}$

Similarly, in Sector C, units CU6 and CU5b can tentatively be referred to Stratum $\mathrm{E}$ on the basis of sedimentary affinity and relative stratigraphic position. A sharp boundary, surface S22, separates these two units from the Minaean sequence below, and correlates well with a gap of the order of a few decades or generations. ${ }^{144} \mathrm{CU} 6$, an extended, ashy level to be identified as a hearth, yielded a basalt quern of archaic typology (i.e., SabaeanMinaean). ${ }^{145}$ The unit suggests an episode of 'domestic' activity right on the talus, as if from an occasional stop on the outskirts of an abandoned settlement, at the onset of what was going to be a prolonged period of sand-and-gravel deposition (CU5b). That the second Intermediate interval might have seen sporadic human presence is not surprising. ${ }^{146}$ Layer CU5b seems to correspond to a condition of absolute inactivity outside the Minaean wall; whether it also implies non-residence inside the town is impossible to tell.

Elsewhere in Area C, and precisely in Sector E and the plain (Sounding F), the whole interval until the Islamic reoccupation is documented by part of the consistent sediments of Stratum D. Although with intermittent hiatuses and a void of artefacts in primary deposition, these colluvial-cum-aeolian sediments reach a thickness of about one metre at the base of the talus in quadrangle E5.

An approximate date spanning the 1st and 2nd centuries $\mathrm{CE}$ seems reasonable for the phase of fading human pressure documented in Area C, correlated with an earlier part of Stratum E. What essentially amounts to a very long hiatus would have ensued, using 'hiatus' in a strictly residential sense, by far the longest interval in the history of Yathill-Barāqish - c. 200-1200 CE. Here this occupational hiatus has been labelled the YathillBarāqish (Y-B) Interval. ${ }^{147}$ However, an occupational hiatus must not automatically be equated with a sedimentary-depositional hiatus (cf. Chapter 17, Table 5, note 5). What I mean by hiatus in the present context is a timespan marked by reduced, totally non-cultural sedimentation routinely intercalated by episodes of greater or lesser erosion.

\footnotetext{
143 See description of find no. 176.1 in Chapter 21, section 2.4, this volume.

144 Fedele 2011a, 115.

145 Quern no. 170.1: see Chapter 21, section 2.4 (Fig. 12 A), this volume.

146 Cf. the record of an episode from c. 260 CE (C. Robin in de Maigret and Robin 1993, 491; see also Chapter 27, this volume).

147 Chapter 17 , section 12.2 , this volume.
}

At an indeterminate moment of the Y-B Interval, part of Minaean bastion T7 collapsed (collapse rubble T7A). Charcoal for dating the event is currently unavailable, in the sense that no suitable charcoal for determining the T7A age bracket through radiocarbon could be taken to Italy; therefore the collapse cannot be dated independently of stratigraphy. Formally, radiocarbon can only situate the event after the minimum age of unit $\mathrm{T} 76 \mathrm{H}$ (sample \#185), i.e. post-32 CE, and probably after the minimum age of sample \#183, i.e. post-130 CE, and before the maximum age of T7H (sample \#181), i.e. ante-1264 CE. Lithostratigraphic and impressionistic clues, both ambiguous, would suggest that the event occurred rather late in the Y-B Interval, perhaps even shortly before the Islamic reoccupation of the ancient town. ${ }^{148}$

\section{Yathill deserted: on the circumstances and causes}

In the collapse of the Yathill socio-cultural system a web of interacting economic and environmental factors was probably implied. Foremost among the former, possibly, were the changes in the international aromatics trade. It is possible that the Nabataeans, who by the turn of our era were replacing the Minaeans in the management of the trans-Arabian trade, ${ }^{149}$ had little interest in Yathill: caravans still followed the traditional routes, but the staging-post system might have been changing. Concurrently, it is well known that from the 1st century CE the overland 'incense route' began to lose importance due to competition with the Red Sea maritime route. In parallel with these economic and political changes, environmental circumstances may also have been involved in the decline and abandonment of Yathill. All these issues need to be reviewed, however briefly.

First of all, the collapse of Yathill was not unique among the caravan towns of the Sayhad, the desert fringe of Yemen. The phenomenon was in fact fairly general, and on the subject an abundant, if often cursory literature has been produced. Looking at the period leading up to the Persian conquest of Yemen around $570 \mathrm{CE}$, almost all authors have listed as factors a drop in demand for the frankincense of South Arabia, a dramatic decline in the caravan trade, the ensuing impoverishment of cultivation through neglect of irrigation systems, and the growing influence of the nomadic or 'bedouin'

148 Cf. Chapter 17, section 12.3, this volume. Reportedly, collapse rubble T7A contained a half-barrel stone tile, find no. 07, for which, however, a provenance from interstitial sediments of suite T74M (earlier Stratum C) could be contemplated. A. de Maigret, in a discussion on site, expressed the opinion that the tile might have derived from some Minaean or post-Minaean building - constructed atop the curtain wall - which had collapsed with bastion T7. See description of this find in Chapter 21, section 2.4, this volume.

149 Robin 2010a, 84-85. Cf. Fedele 2011a, 116. For a most recent hypothesis about the involvement of the Nabataeans see Robin $2019 \mathrm{~b}$. 
component throughout Arabia. ${ }^{150}$ Speaking of the Jawf, M. Arbach observed long ago that when South Arabia lost the monopoly of the incense trade and its control, beginning in the 1st century CE, 'the shift to exchanges carried out mainly by sea, the penetration in the Jawf of Arab tribes from the north of the Peninsula - replacing the Minaeans in trade - and the rise of the tribes of the Highlands, gradually contributed to the decline and to the disintegration of the caravan kingdoms', including Ma'īn. ${ }^{151}$

The decline and disappearance of the kingdom of Qatabān, as reconstructed by C. Robin, may offer the most pertinent analogue to Yathill and the Jawf, in spite of a slightly later chronology.

The reasons for the disappearance of Qatabān [between 160 and $205 \mathrm{CE}]^{152}$ were undoubtedly multiple. Bruno Marcolongo and Daniele Morandi Bonacossi observed that the wādì Bayḥān was affected around this time by tectonic movements which destroyed the old irrigation networks.[153] They therefore insist on a natural cause. But we can also notice that the end of Qatabān is part of a process of abandoning the oases of the interior piedmont of Yemen, which itself had other causes: these are primarily the lower and more irregular precipitations, a reduced strategic significance of these regions following the decline of the long distance caravan trade, and a growing insecurity brought about by the Arabs of the steppe and the desert. Even the vast city of Marib, the capital of Saba', is now only a shadow of what it used to be. South Arabia is now dominated by the highland communities and polities [les communes des HautesTerres]. ${ }^{154}$

As evoked by the last quotation, the possible contribution of environmental circumstances ${ }^{155}$ needs to be taken into account; and in the case of climatic

\footnotetext{
150 E.g., Müller 1988, 53; summarized in de Maigret 2009a, 252.

151 Arbach 2009, 28-29. He adds (my translation): 'The main political centres, which had been turned towards the desert throughout the 1st millennium BC, gradually lose their importance in favour of the towns of the Highlands and the coast, now turned towards the sea. With the disappearance of the kingdom of $\mathrm{Ma}^{\mathrm{C}} \mathrm{i}$ ' a page in the history of the caravan trade in South Arabia is turned.'

152 Robin 2016b, 67 (my translation): 'The epigraphic record provides two complementary chronological indications. The last dated mention of Qatabān as an independent kingdom, with a king at its head, dates from 160. An inscription of Yarim Ayman, undated, could be one or two decades later. The first evidence that the kingdom of Qatabān was wiped off the map and that its territory was annexed by its neighbours appears from around 205. The end of Qatabān is therefore to be placed between 160 and 205 [CE], without possibility of being more precise.'

153 Marcolongo and Morandi Bonacossi 1997.

154 Robin 2016b, 67 (my translation).

155 Circumstances rather than 'causes', this latter rarely being the right word in human ecology.
}

conditions, not so much climate as a physical factor per se, but as a force acting and affecting people through landscape modification. The human-ecological interconnections among the disparate factors listed above, however, still await elucidation, as lamented in 1997 by geographer Pierre Gentelle. ${ }^{156}$ Taking Mārib as an example, he particularly observed a marked, out-ofcontrol silting up of the irrigated fields at the beginning of the current era, exacerbated by the increase in soil salinization which had begun during the second half of the 1st millennium BCE.Climatic aridity per se, clearly in evidence after about $400 \mathrm{CE}$, was not perhaps as crucial to the cultural landscape as was the unpredictability of streams, together with erosion and the opening of vegetation, this latter having now become markedly xerophile. ${ }^{157}$

The problems raised by the abandonment of sites and areas in Yemen in pre- or proto-Islamic times have occupied scholars since at least the 1930 s. ${ }^{158}$ As recalled by Maurice Grolier for Wādī al-Jūbah, 'the causes, time, and extent of abandonment of agricultural plots there and elsewhere [...] are open to debate, but compelling archaeological, literary, and legendary evidence from nearby regions in southern Arabia suggests that a strong pulse of aridity in the sixth century AD is the main natural culprit (Huzayyin 1935)'.159 Between approximately 550 and $950 \mathrm{CE}$ this arid pulse would have been responsible for the collapse of agriculture and pastoralism in the Jawf and the abandonment of Mārib as a capital. ${ }^{160}$ The same interval is among the predominantly arid periods that Fairbridge identified on a purely palaeoclimatic basis as early as $1976,{ }^{161}$ and that more recently were confirmed by studies of regional geomorphology ${ }^{162}$ and of the Arabian sand seas. ${ }^{163}$ of course, although we are dealing with processes at a supraregional scale, we should not automatically apply them to the Yemeni Jawf in their entirety or details, as they were identified from areas more or less distant and different from the Jawf. ${ }^{164}$

\footnotetext{
156 Gentelle 1997.

157 Gentelle 1997, adapted. On both salinization and stream erosion, see below.

158 Cf. Fedele 2010, 138-139.

159 Grolier 1988, 353.

160 Huzayyin 1935, as quoted in Grolier 1988, 350.

161 Fairbridge 1976, 533, table 1.

162 E.g. Overstreet and Grolier 1996, a landmark synthesis on Wādī al-Jūbah.

163 E.g. Radies et al. 2004.

164 It is worth recalling that an isolated (?), though probably acute aridity episode appears to have affected the Jawf already towards the end of the 1st century BCE, as inferred from a passage in inscription Haram 10. [Robin 1992, 74-76; cf. 1991d.] 'Un phénomène climatique est évoqué dans l'inscription Haram 10, qui daterait de la fin du $I^{\text {er }}$ siècle [BCE]: la divinité amïrite dhū l-Samāwì refuse aux deux clans principaux de Haram (Amir et 'Athtar) la "mise en eaux de leur réseau d'irrigation au printemps et à l'automne, à cause d'une eau en faible quantité à l'extrême" (Schiettecatte 2011, 67; cf. 69). Haram and its irrigated area were still
} 
During the last two decades, quantitative palaeoclimatic research in South and Southeast Arabia based on cave speleothems, ${ }^{165}$ as well as on dune systems and former lakes, has greatly improved the available information. ${ }^{166}$ From these data it is apparent that starting with the first centuries of our era inland Yemen was affected by repeated, increasing aridity pulses. Furthermore, a landmark study of streams and alluviation in Yemen's Hadramaut has shown that 'the post-South Arabian period correspond[ed] to a continuous period of regressive erosion, associated with deep gullying into the upper anthrosols and the Mid-Holocene silts'. ${ }^{167}$ Such an obliteration of anthrosols as well as the overall hydrological response, both independent of aridity per se, must have brought about a major negative impact on cultivation.

The Minaean oases and centres would have found themselves in the middle of such processes. In the case of Yathill, one should consider whether an oasis collapse - hydrological first of all - may have led to the eventual abandonment of the once prosperous site with or without concomitant factors. Following its final shift to the east of Yathill, ${ }^{168}$ the main wādi may have become less susceptible to control, and eventually useless for traditional sayl irrigation. Channels of shallow semidesert streams change rather easily, particularly where tectonic activity is important, as in the Jawf. ${ }^{169}$ Floodplain topography, irrigation, and microclimate are interconnected. In a scenario of difficult hydraulics and decreasing human investment, one related factor might additionally have become relevant, salinization, which in the case of ancient irrigated landscapes may steadily destroy the agricultural productivity of the land. ${ }^{170}$

These distinct possibilities concerning the oasis field system should be investigated when a return to Barāqish is permitted. Until then, whether the end of occupation resulted from a single factor, or else was multivariate and systemic, is impossible to tell. ${ }^{171}$ In contrast to what may have happened in interior Yemen

\footnotetext{
functioning at this moment; 'however, the site will not survive long' (Schiettecatte 2011, 69; see also 2006b, 2010b). Cf. Robin 1992, 60.

165 Laminated stalactites and stalagmites.

166 See Lüning and Varenholt 2019 for a major synthesis, although mostly devoted to earlier periods. See also Parker and Goudie 2008 (and subsequent works). Details of interest for the later Holocene of Yemen can be found in Lézine et al. 2007, 2014; Fleitmann et al. 2007, particularly p. 180; 2011; Fleitmann and Matter 2009; Van Rampelbergh et al. 2013.

167 Berger et al. 2012, 153.

168 Unfortunately, this diversion or capture is undated (cf. Chapter 19 , section 5 , this volume).

169 On the subject of wādī shifts at Barāqish/Yathill see Chapter 19, section 5 , this volume (with references).

170 Cf. Chapter 19, section 5, this volume.

171 Fedele 2011a, 116.
}

elsewhere, Yathill succumbed rapidly, in my opinion:172 its demise is probably to be pictured as a collapse rather than decay or 'decline' - a system collapse. This view is grounded in a perception that the Minaean state was a fairly simple and fragile adaptive system. Therefore, in a way, the end of Yathill was predictable. The system in question - Yathill's fortunes - rested on the two pillars of cultivation and caravan trade (in order of appearance), and lately had probably come to rely more and more on the latter. Independent of each other, we can surmise that there was a more or less simultaneous deterioration of both: the agricultural output failing because of silting up, soon exacerbated by diminishing communal efforts to keep the irrigated plains functioning, ${ }^{173}$ and caravan traffic undergoing a really sudden collapse originating not from Yemen but from the 'world' system at large. In the case of Yathill, the arrest in trade and traffic might have tipped the balance first, but it took the coincidence of the two processes for precipitating the collapse of the settlement and its final abandonment. ${ }^{174}$

Those outlined here are no more than considerations and speculations. They, however, raise a human ecological problem worth being studied in depth, and, as far as northern interior Yemen is concerned, Barāqish may prove to be a very suitable site to do it. ${ }^{175}$

\subsection{The Islamic phase: 'Barāqish'}

In this section, the correlation between Area $C$ and the temple area will be discussed in detail, as it is instrumental for attempting an interpretation of the Islamic archaeological record from Area C. Archaeologically, establishing connections between the extramural and the temple areas revolves on identifying in the former some material correlate of activities or events that occurred in the latter, or at least in the town - an unlikely perspective.

It cannot obviously be expected, for instance, that the deposits outside a nondescript bastion such as T7 can speak of the arrival and residence of an imām, unless an unambiguous sign of the authority of that particular imām did translate into material consequences (cutting stone blocks for the restoration of masonry, for instance). This example concerning masonry is realistic, insofar as the restoration of the Minaean wall is thought to have been one of the chief initiatives immediately undertaken at the Islamic reoccupation of Yathill, now called Barāqish

\footnotetext{
172 Contrary to gradualistic views (for instance, Arbach 2009, cited above).

173 Aridification per se was hardly a factor, since the seasonal sayl is not linearly correlated to climatic dryness.

174 For a readable account of how states as adaptive systems can collapse see Ferguson 2011, 295-300, 322-324.

175 Fedele 2010, 139.
} 
(c. $1190 \mathrm{CE}$ ?). ${ }^{176}$ C. Robin even states that the curtain wall was soon 'restored in its entirety', as Barāqish was mentioned as a 'city' (madina) already in 1204. ${ }^{177}$

Marginally more feasible, perhaps, would be recognizing extramurally the consequences of agencies that presumably affected the town in part or as a whole. ${ }^{178}$ From this standpoint, one notes with interest that during 65 years in the 13th century, from 1208 to 1274, Barāqish as a fortified town - a stronghold was subjected to no less than three military events. ${ }^{179}$ By presumably implying activity at the curtain wall, it is not unreasonable to expect that this kind of events entailed some effects on the deposits immediately outside the curtain itself. Such a 'dynamic' period may have had cumulative sedimentary repercussions, compared to the immediately preceding and succeeding periods. One is thus tempted to attribute to the 13th century the lithostratigraphic sequence at bastion T7 which follows the T74L/M lacuna (expressed in the highly irregular upper surface of suite T74L), and which includes suites T74M and perhaps T74U. The following interruption represented by surface $\mathrm{S} 5$, and the 'quieter' sedimentary regime afterwards (suite T73 etc.), would reflect in this case the period from the 14th century onwards.

If T7JK, with or without the 'burnt spot' BS on the wall, is effectively connected with violent fire in the proximity of bastion $\mathrm{T} 7$, then a relationship with one of the military events which affected Barāqish in the 13th century is not impossible. Considering the specific actions involved, a possible connection - or even the most likely one in this case - could be with the Ayyūbid capture of Barāqish in 1208/1209 CE. ${ }^{180}$ Admittedly, any attribution of this sort will remain highly speculative at the moment.

\footnotetext{
176 Barāqish, the Arabic place name for the town, is apparently first mentioned in Abū Muhammad al-Hamdānī's Kitāb al-iklil, in the first half of the 10th century CE: in Book 8 the site is listed among the Yemeni 'castles' (which include ruins), as opposed to towns. Cf. (e.g.) Tobi 2005, 288, 289; and on al-Hamdānī's 'castles', de Maigret 2009a, 32. For additional information see Chapter 27, section 3.1, this volume.

177 de Maigret and Robin 1993, 491 ('enceinte entièrement restaurée'). Details for this statement are not given, and the amount and duration of work required by the restorations is in fact unknown; see footnote 187 below.

178 This approach was provisionally attempted in Fedele 2010, 142, based on assuming 'a positive correlation between sedimentary "activity" at Wall's T7, in terms of cultural discard, and sustained "activity" in the city as suggested by excavation and textual data", albeit with the caveat that extramural Area C and the town's interior represented entirely separate depositional environments (see section 2.1 , above). The treatment presented here is a revision.

179 According to C. Robin in de Maigret and Robin 1993, 491-493.

180 A dramatic but entirely ephemeral episode, after which imām alManșūr (see below; †1217) and his successors kept Barāqish until 1263/1264 CE.
}

In 1990-1992 de Maigret thought he could recognize an event of 'heavy fire and destruction' in the Temple A area, terminating the first Islamic occupation of Barāqish by imām al-Manșūr bi-(A)llāh 'Abd Allāh bin Hamza and his successors (de Maigret's phase Islamic D). ${ }^{181}$ No date was stated, apart from a vague 'end of the 13 th century', but $1273 / 1274$ CE was implied, ${ }^{182}$ this being the final Rasūlid capture of Barāqish and the end of this town's political and economic significance. ${ }^{183}$ A. de Maigret further maintained that after the event Barāqish was probably abandoned for about a century, ${ }^{184}$ a hypothesis apparently only based on the lack of recognizable 14th century pottery from Area A (see footnote 185). However, the subsequent excavations at Temple B and in the area between B and A led de Maigret to modify his opinion: the fire appeared to have only been a local accident restricted to Temple $\mathrm{A}$, and the hypothesis of a town-wide destruction was no longer mantained. ${ }^{185}$ This put to rest any idea of linking data from Sounding A directly to events from the temple area. ${ }^{186}$ On the other hand, the 14th-century abandonment hypothesis continued to appear tenable.

In this light, $\mathrm{F} 6$ and sediment unit $\mathrm{T} 7 \mathrm{H}$ would rather point - in principle - to some episode during essentially peaceful times and possibly reconstructive activities, such as those that can be attributed to imām al-Manșūr's occupation and eventual residence between 1190/1196 and c. $1210^{187}$ (punctuated by the military event of 1208/1209 mentioned above); times and activities that may have continued under al-Manșūr's successors for about half a century afterwards. However, the radiometric age of charcoal from $\mathrm{T} 7 \mathrm{H}$ points to a

181 de Maigret 1993, 4-5, 8; de Maigret and Robin 1993, 434, 440 ('les traces d'une destruction violente'; 'un incendie violent, qui détruisit la ville et mit fin au premier et plus ancien niveau d'occupation, correspondant à l'installation de l'imām zaydite al- Manșūr', p. 434).

182 A. de Maigret himself did not attempt a detailed comparison of his Islamic excavation data (de Maigret and Robin 1993, 432-434, 458) with the political and military history summarized in the same study by Robin (p. 478, 491-493).

183 C. Robin in de Maigret and Robin 1993, 493: 'C'est la dernière mention de Barāqish comme place-forte dans les chroniques médiévales et modernes; la ville n'est pas abandonnée, mais elle cesse de jouer un rôle militaire, politique ou économique.'

184 'Il est probable que Barāqish fut alors abandonnée pendant un siècle environ (le xive), avant d'être réoccupée (niveau islamique C)' (de Maigret and Robin 1993, 434, 458; cf. de Maigret 1993, 5; the abandonment is proposed as virtually certain on p. 22).

185 Personal communication of 4 April 2009, upon request of his comments on my preliminary correlation between Area $\mathrm{C}$ and the temple area (a working draft for Fedele 2010, 141-142).

186 Initially, in 2006, it seemed to me tempting to correlate such units as T7H and T7JK (present labels) with the fire at Temple A.

187 An occupation of Barāqish from about 1190 can be inferred from the birth at Barāqish of al-Manșūr's son Muhammad in 1196. The imām himself resided in Barāqish at least from 1199 (1197?) to 1201. A phase of intensive wall reconstruction and other building activity from c. 1195 to $c .1210$ is conceivable on the basis that imām al-Mansūr might well have lost interest in spending energy and resources on Barāqish after his foundation of a new citadel at Zafār (completed $c$. $1210 \mathrm{CE})$. 
Table 4. Area C excavations 2005-2006: a hypothesis of Islamic correlation and chronostratigraphy based on the sequence of Sounding A. All dates are $\mathrm{AD}(\mathrm{CE}) ; \mathrm{C}=$ century; $c_{\text {. }}=$ circa.

\begin{tabular}{|c|c|c|c|c|c|}
\hline \multicolumn{2}{|c|}{$\begin{array}{l}\text { Strata and historical } \\
\text { phases from Area C }\end{array}$} & \multirow{2}{*}{\multicolumn{2}{|c|}{$\begin{array}{l}\text { Lithostratigraphy (Sounding A) and inferred } \\
\text { characterization }\end{array}$}} & \multirow{2}{*}{$\begin{array}{l}\text { Dates from textual } \\
\text { records }{ }^{1} \text { and } \\
\text { radiocarbon }\end{array}$} & \multirow{2}{*}{$\begin{array}{l}\text { Tentative } \\
\text { chronology }\end{array}$} \\
\hline Strata & Phases & & & & \\
\hline A, earlier & Recent & T71a, T71b; F18 & $\begin{array}{l}\text { decay material from above } \\
\text { wall }\end{array}$ & & c. $19 \mathrm{C}$ \\
\hline \multirow{2}{*}{ B } & \multirow{2}{*}{ Islamic 3} & T72 & \multirow{2}{*}{ horizontal sedimentation } & & \multirow{2}{*}{ c. $1400-1800$} \\
\hline & & suite T73, T73W & & & \\
\hline \multirow{6}{*}{ C } & \multirow{3}{*}{ Islamic 2} & surface S5 & $\begin{array}{l}\text { interruption of occupation } \\
\text { \& short sedimentary hiatus }\end{array}$ & & to c. 1400 \\
\hline & & T74, T74。 (suite T74U), LT7 & $\begin{array}{l}\text { including collapse(s) from } \\
\text { bastion } \mathrm{T}^{3}\end{array}$ & & \multirow[t]{2}{*}{ c. $1280-1350$} \\
\hline & & T7S, T7Su (suite T74U) & & & \\
\hline & \multirow{4}{*}{ Islamic 1} & $\begin{array}{l}\mathrm{T}^{4} \mathrm{H}^{4}(\text { suite } \mathrm{T} 74 \mathrm{M}) \\
\& \text { structure F6 }\end{array}$ & $\begin{array}{l}\text { postdepositional } \\
\text { modifications from } \mathrm{T} 7 \mathrm{H}\end{array}$ & $\begin{array}{l}1264-1310(\mathrm{~T} 7 \mathrm{H}){ }^{5} \\
1273 / 1274 \text { Rasūlid } \\
\text { conquest }\end{array}$ & \multirow{4}{*}{ c. $1190-1280$} \\
\hline & & \multicolumn{2}{|l|}{ indeterminate lacuna? } & & \\
\hline & & ? T7JK ${ }^{4}$ (suite T74M) & $\begin{array}{l}\text { an episode; also 'burnt } \\
\text { spot' BS? }\end{array}$ & $(? 1208 / 1209)$ & \\
\hline C, initial & & T74L/M lacuna & $\begin{array}{l}\text { quarrying/reworking the } \\
\text { T7A blocks }\end{array}$ & ‘1196’-[...] & \\
\hline E & $\begin{array}{l}\text { Second } \\
\text { Intermediate }\end{array}$ & $\begin{array}{l}\text { suite T74L; } \\
\text { T7A (collapse from bastion T7) } \\
\text { \& T7r, T7t }\end{array}$ & $\begin{array}{l}\text { includes long occupational } \\
\text { hiatus }\end{array}$ & & to $c .1190$ \\
\hline
\end{tabular}

${ }^{1}$ After C. Robin (de Maigret and Robin 1993, 491-493).

${ }^{2}$ All dates approximate and rounded to the decade.

${ }^{3}$ Units T6B-T6A in Sector B: reaching only marginally the area of Sounding A, cf. unit T74?

${ }^{4}$ The stratigraphic position of T7JK relative to T7H is unknown.

${ }^{5}$ Radiocarbon date, $p=77 \%$.

later date, starting with $1264 \mathrm{CE}$ (Table 1), albeit with the usual caveat that 'one date is no date'. ${ }^{188}$ If we take this isotopic reading at its face value (1264-1310 CE), and if the 'peaceful' correlation is correct, F6 and T7H could probably be related to an episode or episodes of extramural occupation or other activity of Rasūlid age, i.e., falling in the period after the Rasūlid conquest of 1273/1274. Town wall reconstruction again?

The above information, considerations, and uncertainties, form the basis for the correlation proposed in Table 4. Chronostratigraphy, hence a tentative calendar chronology, are particularly based on

- the ${ }^{14} \mathrm{C}$ dating of T7H, sample \#181, i.e. post-1264 CE;

- interpreting surface S5 as a significant discontinuity;

- relating suite T74M and at least part of suite T74U to the 'dynamic' 13th century; and

- accepting - reluctantly - the supposed abandonment during the 14 th century.

188 As Martin Aitken reminds us (1990, 95).
As to this last point, once again an occupational hiatus must not automatically be equated with a depositional hiatus, and this applies not only to Barāqish. ${ }^{189}$

Occupation at Barāqish in the Islamic period appears to have ended around 1800 fide J. Halévy, who in 1872 recorded that a Jewish community still lived there about a century before his visit to the Jawf in the spring and summer of $1870 .{ }^{190}$ The source of this information was a dated written contract which he had seen at al-Ghayl. Also his companion, H. Habshūsh, retained notion that his ancestors must have lived at Barāqish. ${ }^{191}$

It is on this basis that the Later Islamic of Area C, or Islamic 3 (corresponding to Stratum B), is here terminated at approximately $1800 \mathrm{CE}$.

\footnotetext{
189 Cf. section 3.4, 'From "Yathill” to "Barāqish"', above.

190 Halévy 1872a, 43.

191 See Chapter 1, section 1, in Volume 1.
} 


\section{Appendix. \\ A note on the Islamic collection from Area C}

Since the finds of Islamic age from Area $C$ could not be studied in detail (see in this volume Chapter 21, section 1 , footnote 7 ), a brief note on this interesting collection is given here. The collection amounts to about 250 finds, excluding animal bones, charcoal, and other ecofacts. Ten finds stand out, described below in approximate chronological order. ${ }^{192}$

182.01. Fr. of 'star'-shaped soapstone lamp with a rectangular basin and a zigzag brim; steatite. ${ }^{193} \mathrm{Qu}$. A12 centre-north; unit T7H. Earlier Stratum C, Islamic 1.

10.01. Small, bored, globular bone bead. Qu. D3; unit SA1. Earlier Stratum C, Islamic 1 (?). Age indeterminable, Sabaean to Islamic, but probably Islamic on typological grounds. Cf. finds nos $10.1 \mathrm{a}-1 \mathrm{~b}$ and footnote 216 in Chapter 21, section 2.5, this volume.

175.1. Rotatory quern, large fr.; fine tuffaceous rock, grey to light green in colour. Sector B. Units T6B-T6A, most likely one of the stones of T6B. Later Stratum C, Islamic 2.

175.01. Rotatory quern, incomplete; rock similar to no. 175.1. Provenance and context as for no. 175.1.

175.04 (Fig. 6). Square-angled mud-mortar fr. from two masonry joints; $c .15 \mathrm{~cm}$. Provenance and context as for previous nos 175 . This piece is the most unusual fragment from a large aggregate of mudbrick and related building materials contained within T6B-T6A, attributable to decayed Islamic buildings.

162.1 (see Fig. 113 in Chapter 17, this volume). Large chopper, white limestone; $\varnothing 10-15 \mathrm{~cm}$. Qu. A1, in situ at the foot of wall's bastion T7 and contiguous with the top of course 7 (c. $200 \mathrm{~cm}$ below datum). Interface between group GT74 and suite T73, i.e., surface S5 or unit LT7. Later Stratum C or earlier Stratum B, Islamic 2/3. An isolated, chipped cobble with sharp-edged fracture, already mentioned in Chapter 17, end of section 14.2, 'Finds'.

169J.01. Quern; vesicular trachyte. Qu. A32 north; suite T73; Stratum B, Islamic 3.

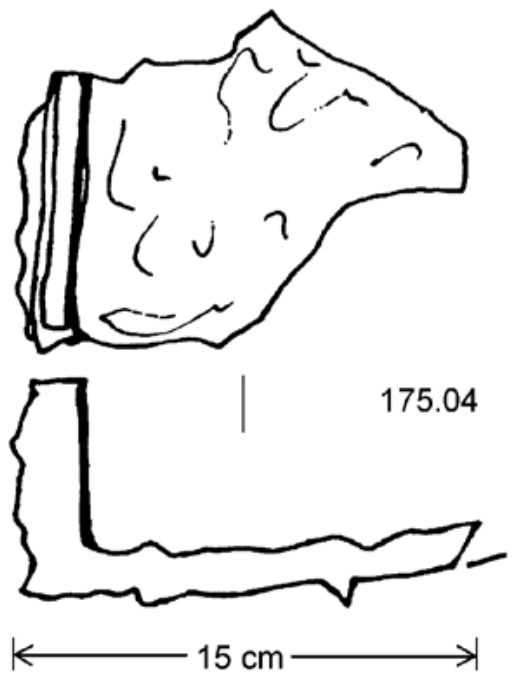

Figure 6. Islamic object no. 175.04, mud-mortar fragment. (F.G. Fedele 2005)

169A.3. Cowrie cutout pendant from a necklace. Qu. A31-A32, mass removal. Strata B-A, Islamic 3 or Recent. See introduction to 'Marine shells' in Chapter 21, section 2.1, this volume.

169A.4. Terracotta mouthpiece of a pipe; or from a water pipe (hookah), according to my Yemeni excavators. Provenance and context as for no. 169A.3.

169A.8. Doum palm fruit, complete; probably from the Tihāma. Provenance and context as for previous nos 169A.

Other finds of interest include: fragments from a large number of softstone cooking pots (burm/burmah in Arabic); ${ }^{194}$ pottery sherds, including plain, painted, and glazed wares; many fragments of glass or vitreouspaste bracelets or armlets; fragments of glass bottles and drinking glasses; fragments of textiles, leather artefacts, basketry; and wooden sticks. An obsidian flake from suite T74U (no. 169C.01) was interpreted as a pre-Islamic object. ${ }^{195}$

\footnotetext{
192 The descriptions are styled after the catalogues in Chapters 21 and 23 , this volume.

193 Cf. Muchawsky-Schnapper 2018, 240, fig. 3; Simpson 2018, 183, fig. 5.
}

\footnotetext{
194 E.g. Glanzman 2018, 131; cf. Chapter 21, section 2.1, footnote 92 (Fedele).

195 See Chapter 21, section 2.5, this volume.
} 


\title{
Chapter 19
}

\section{Excavations in Area C. Economy, Trade, and the Environment}

\author{
Francesco G. Fedele
}

\section{Introduction: Sabaean and Minaean economy and ecology}

Barāqish (Figs 1-2), located at $16^{\circ} 01^{\prime} 07^{\prime \prime}$ north, $44^{\circ} 48^{\prime} 16^{\prime \prime}$ east (Fig. 3), ${ }^{1}$ and at an elevation of about $1120 \mathrm{~m}$ above sea level, ${ }^{2}$ is supposed to have had caravan trade as its sole - or main - raison d'être. Certainly a role in caravan trade was of great importance during the middle and late 1st millennium BCE, but one should not assume, on this basis, that trade had been the chief factor for the origin of the settlement, sometime during the previous millennium. During the 2nd millennium BCE factors such as the availability and relatively easy control of the seasonal flood (sayl), and the extent of potential agricultural area, had most probably been more fundamental than anything connected with exchange or interregional contact. ${ }^{3}$ Certainly farming retained its importance throughout the 1st millennium BCE. The archaeological collections of animal and plant remains, or 'bioarchaeological' evidence, are instrumental for an understanding of farming, hence of economy in general, and can also cast light on aspects of trade.

In 2005-2006, as expected, the excavations in Area C produced a wealth of bone and vegetal material from a wide range of sediment contexts. Since the project had been designed to shed light on settlement history and its evolving ecological framework, environmental data and activity indicators were sought. As previously mentioned, one particular purpose was to retrieve animal and plant remains from controlled stratigraphic units, a first-time for the Yemeni Jawf. ${ }^{4}$ These goals were met with considerable success: abundant remains were collected, and contexts of use and discard were obtained. ${ }^{5}$

The bone collection thus formed could be studied in large part at the Barāqish camp in 2005 and 2007, some

\footnotetext{
1 See also Map of southern and central Arabia in Volume 1, p. x.

$21122 \mathrm{~m}$ a.s.l. for the plain immediately to the south of the mound, as determined by GPS in 2007 (Chapter 26, this volume).

3 See Chapter 18, section 3.1 ('The origins of Yathill'), this volume.

4 Chapter 17 , section 1.1, this volume; cf. Chapter 1 , section 4.4, in Volume 1.

5 Fedele 2010, 142-144; 2019, 190, 199.
}

of it exhaustively (the Minaean-period subset from Sounding A, see next section). ${ }^{6}$ The information from the analysis of animal bones was coordinated with artefacts, sediments, and stratigraphy in order to get as detailed a picture as possible of the history of Yathill and its area, as recorded extramurally. ${ }^{7}$ Conversely, the majority of the plant remains could only be examined briefly, preliminary to a specialist study planned for a future season. The samples obtained from water screening or flotation could not be studied at all. ${ }^{8}$

The available results of faunal studies are presented in section 2, with a particular view to Sabaean and Minaean animal management, economy, and ecology, as well as their changes through time. The supposed connections of some particular faunal findings with the presence of 'non-residents' at Yathill, and/or with trading activity in general, are examined in section 3, followed by a discussion of 'campsite' archaeology inspired by Yathill. The results of plant studies, due to their preliminary nature, will simply be summarized (section 4). When reading the present report, it will be good always to keep in mind that the archaeofaunal and archaeobotanical samples of Yathill/Barāqish derive from a long-lived town and fluvial oasis in a semi-desert, which notably also flourished as a caravan station in a dynamic commercial network.

\section{Animal remains: zooarchaeology9}

\subsection{The record}

The stratified archaeofaunas from Area $C$ number about 6610 skeletal specimens in total, including small

\footnotetext{
6 The archaeofaunal collection was not exported to Italy because a laboratory sufficient for most of research needs had been set up on site, furnished with a small reference collection (begun by the writer at Șan'â') in the 1980s); cf. Chapter 1, section 4.6, in Volume 1. Moreover, it was expected that further study seasons could be arranged after 2007.

7 Fedele 2010, 142.

8 The faunal and macrobotanical finds (i.e., the specimens visible to the naked eye), as well as the flotation samples, were stored in the antiquities warehouse at Barāqish when the archaeological mission left in December 2007. Unfortunately it was not possible to establish what part - if any - had reached safety in Șan' $\bar{a}^{\prime}$ in September 2013, upon the transfer mentioned in Chapter 1 in Volume 1 (section 4.1, footnote 122).

9 This section is based on Fedele 2010, 142-144; 2014, 182-185; and
} 


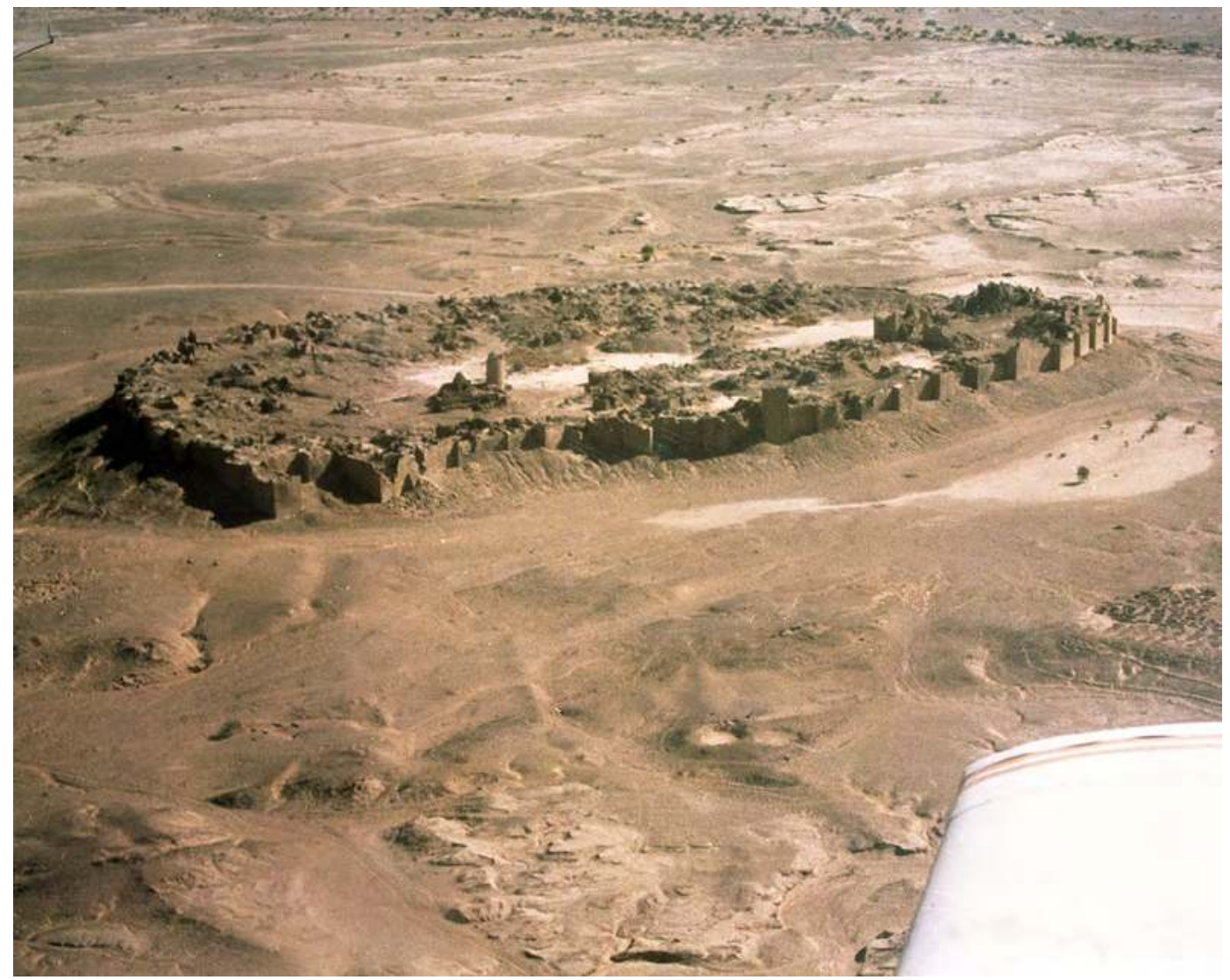

Figure 1. Aerial view of Barāqish from the southwest, December 1975 (see Chapter 1 in Volume 1, section 2, footnote 44). From A. deMaigret/MAIRY archives, courtesy of Deutsches Archäologisches Institut, Orient-Abteilung, c. 1986.

rodents, but excluding flots (flotation material), ${ }^{10}$ microgastropods, and coprolites. The finds are divided as follows by topographic provenance:

- 2473 specimens from Sounding A, Sabaean and Minaean;

- c. 45 specimens from Sectors B-C;

- c. 3910 specimens from Sectors D-E;

- 185 specimens from Sounding $\mathrm{F}$.

In addition, lenses and layers of animal coprolites characterize the First Intermediate and Minaean deposits on the upper talus, as detailed in Chapter 17 (sections 2.2, 4.2) and discussed in a behavioural and historical perspective below (section 3 ).

It must be clarified at the outset that the Sabaean and Minaean archaeofaunas retrieved from Area $C$ are essentially associated with two different archaeological contexts, which can be described as complementary, or interfingering. The Sabaean material from the tell's

2019, 199-207 (written in 2015-2016); with important corrections and additions.

10 On flotation samples see Chapter 20, this volume. edge can be characterized as kitchen or house refuse from 'ordinary' habitation, often roasted or burnt, with occasional butchering discard. The richest assemblages belong to the Later Sabaean occupation, including for instance Locus 33, a dump - or discard pit? - from butchery nearby (quadrangles D3-D4, Stratum L). ${ }^{11}$ The Minaean material can be characterized instead as meal refuse from contexts suggesting specialized groups or activities (trading installations, for instance); some refuse associated with local cooking shows cutmarks. Such Minaean contexts are located on both the upper talus and down in the plain, and subsequent trampling of the bone debris is common. A 'campsite' type of context can similarly be inferred for some of the Sabaean record from the talus footslope and the plain. Details will be given and discussed in section 3, below.

A two-part overview of species composition is presented in Figs 4 and 5. The first part (Fig. 4) is a species list for the whole pre-Islamic archaeofaunal collection from Area C, accompanied by a qualitative indication of relative frequencies. An attempt at quantification is given in the second part, exclusively based on the

11 Chapter 17 , section 7.5 , this volume. 


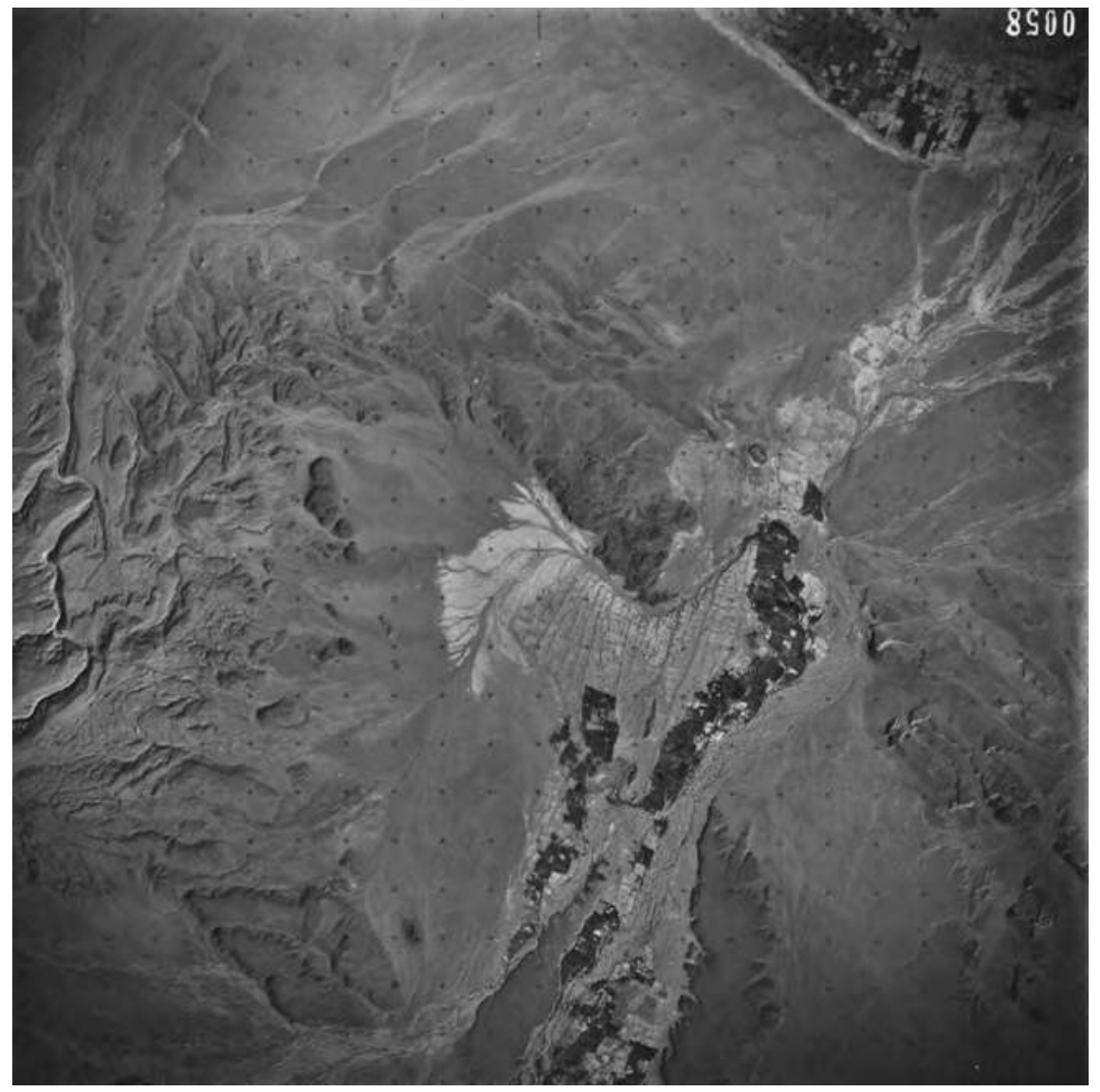

Figure 2. Barāqish and its immediate region: the wādi system and the irrigated area. Barāqish is the halfmoon feature slightly northeast of centre. RAF aerial photograph of 24 January 1973 (optimized by F.G. Fedele, 2019). Source: Bodleian Library, University of Oxford, and EAMENA Project, University of Oxford (courtesy of Michael Fradley); the document contains public sector information licensed under the Open Government Licence v3.0 (<http://www.nationalarchives. gov.uk/doc/open-governmentlicence/version/3/>, accessed 3 October 2019).

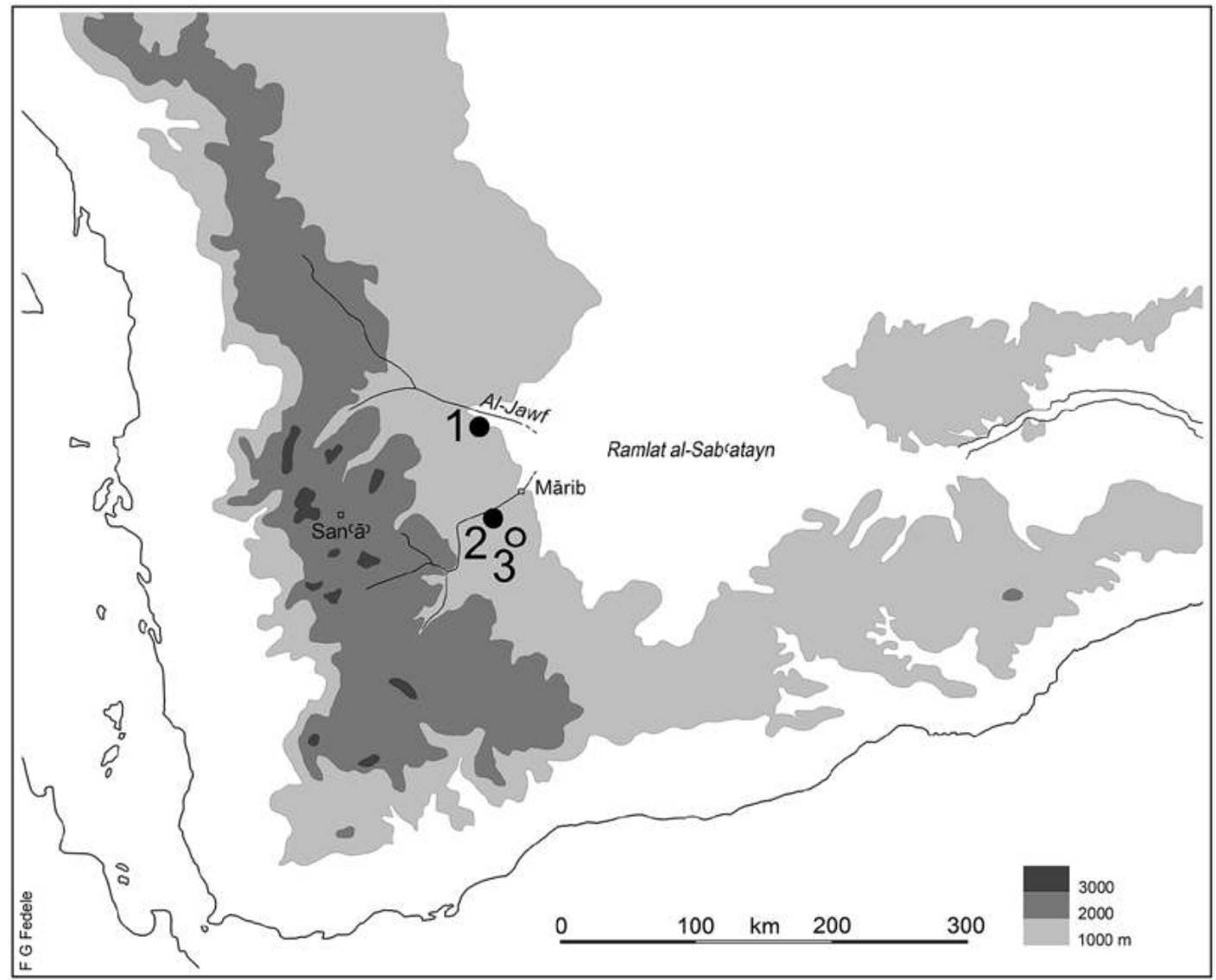

Figure 3. Locations of the archaeofaunal sites mentioned in this chapter: 1 Barāqish, 2 Yalā/al-Durayb, 3 Hajar al-Rayhānī and Hajar al-Tamra (Wādī al-Jūbah). (F.G. Fedele 2016) 


\begin{tabular}{|c|c|c|c|}
\hline & $\begin{array}{l}\text { Earlier Sabaean } \\
\text { kitchen/house refuse fre } \\
\text { often roasted or burnt }\end{array}$ & $\begin{array}{l}\text { Later Sabaean } \\
\text { \& Stratum K } \\
\text { 'ordinary' habitation, } \\
\text { Locus 33: a discard pit } \\
\text { from butchery nearby? }\end{array}$ & \begin{tabular}{l}
\multicolumn{1}{c}{ Minaean } \\
meal refuse, some cooking \\
(cutmarks, trampling); \\
contexts suggest specialized \\
activities'specialist groups
\end{tabular} \\
\hline $\begin{array}{l}\text { DOMESTIC SPECIES } \\
\text { Caprines indet. } \\
\quad \text { Ovis aries } \\
\text { Capra hircus } \\
\text { Bos taurus } \\
\text { Camelus dromedarius } \\
\text { Equus asinus } \\
\text { Equid hybrid(s) } \\
\text { Canis familiaris, small }\end{array}$ & $\mathbf{\square}+$ coprolites & $\begin{array}{l}\square \\
\square+\text { coprolites } \\
\mathbf{1}\end{array}$ & $\begin{array}{l}\text { incl.hornless sheep } \\
\text { + coprolites } \\
\text { + coprolites } \\
1(? 4) \text { ass } \times \text { ?hemione } \\
\square+\text { ? }\end{array}$ \\
\hline $\begin{array}{l}\text { WILD SPECIES } \\
\text { Camelus sp., wild dromedary } \\
\text { Gazella } \text { sp. } \\
\text { Capra ibex } \\
\text { Small carnivore, ?wild } \\
\text { Large rodent (Hystrix?) } \\
\text { Small rodents, spp. } \\
\text { Struthio camelus syriacus } \\
\text { Long-legged bird, ?Struthio } \\
\text { Micro-gastropods, spp. }\end{array}$ & $\begin{array}{l}? 1=\text { talus } 211.01 \\
1 \\
1 \mathrm{G} \\
1 \\
\square\end{array}$ & $\begin{array}{l}1 \text { (from qu. EII) } \\
? 1\end{array}$ & $\begin{array}{l}\text { ?1 (from Minaean 1) } \\
\square \\
1(? 3) \\
1 \mathrm{G} \\
\square+2 \mathrm{E} \\
+ \text { frequent G }\end{array}$ \\
\hline $\begin{array}{l}\text { MARINE SHELLS } \\
\text { Cypraeids, cowries* } \\
\text { Arcids, Anadara } \text { sp. }\end{array}$ & & [2 frs] & $\begin{array}{l}{[1 \mathrm{fr}]} \\
1 \mathrm{fr}\end{array}$ \\
\hline
\end{tabular}

length of bar proportional to the relative frequency of specimens

\begin{tabular}{|c|c|c|}
\hline $\mathrm{fr}, \mathrm{frs}=$ fragment $/ \mathrm{s}$ & $\square=$ traces & 1 etc. $=$ actual number of specimens \\
\hline $\mathrm{E}=$ eggshell fragment & $\mathrm{G}=$ gnawed bone & \\
\hline
\end{tabular}

* All personal ornaments (see Chapter 21).

Figure 4. Area C: archaeofaunal species list for the Sabaean and Minaean phases; the frequencies are approximate. From Fedele 2019, corrected and updated.

material from Sounding A (Fig. 5). The separation in two parts is necessary because, as the Barāqish mission came to an unfortunate halt, only the fauna from Sounding A could be studied completely and in reasonable detail. Frequencies in Figs 3-4 are based on bone count, not weight. ${ }^{12}$

The overview shows that domestic animals are overwhelming. During both the Sabaean and Minaean phases, the occupants and travellers who left or discarded bone refuse on the tell and talus in Area $C$ relied heavily on sheep and goat, the domestic caprines, ${ }^{13}$ with taurine cattle (Bos taurus) subordinate.

12 Weights would have been preferable, as convincingly shown by H.-P. Uerpmann (e.g. Uerpmann and Uerpmann 2017), but a scale for measurements of sufficient precision was not available at Barāqish.

13 Caprines is the correct colloquial designation for sheep and goat as a group (zoological tribe Caprini), hence 'domestic caprines' for the domesticated varieties. This latter is also a convenient label to indicate two species which, to a certain extent, is difficult to
The relatively high frequency of cattle during the Later Sabaean points to a local oasis environment, sufficiently rich in pasture and probably still sparsely wooded, although the broader setting of Yathill was already a semi-desert, according to sediments. ${ }^{14}$ Particularly large Bos taurus males were retrieved from Stratum $M$. The donkey and the domesticated dromedary were present, and, indeed, they necessarily occupied a much more significant niche than the one suggested by their osteological frequencies. ${ }^{15}$ They were occasionally butchered and eaten along with cattle and caprines, and both will be examined in greater detail below (section 2.2). The dog is documented from the Later Sabaean onwards (tibia no. 213/8 from Sounding F, see

\footnotetext{
differentiate osteologically on fragmentary material.

14 Fedele 2017, 298.

15 It is usual that non-meat animals are considerably underrepresented in terms of bones (see section 2.2 below).
} 


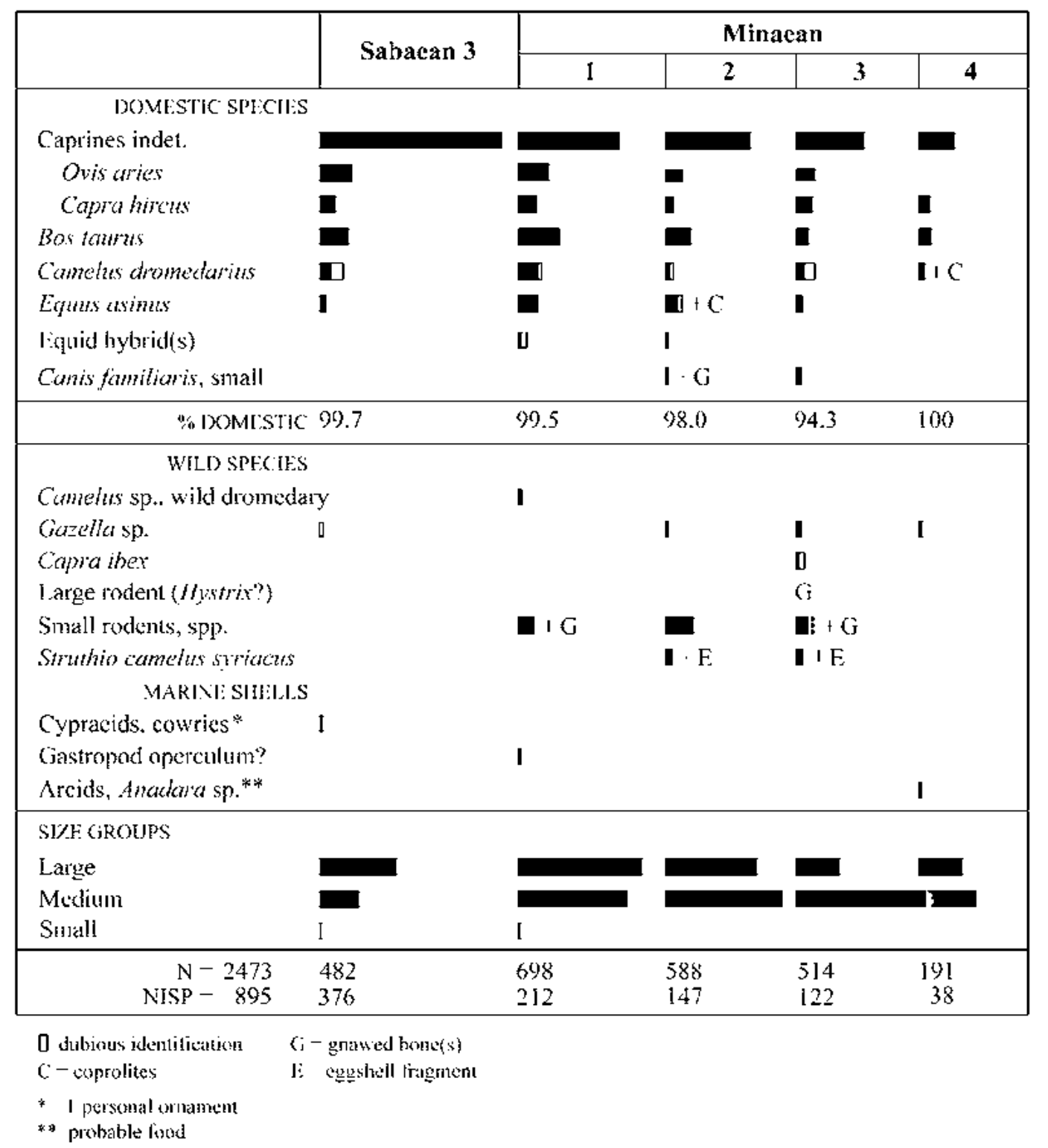

Figure 5. Area C: quantitative archaeofaunal analysis for the Later Sabaean and Minaean levels from Sounding A. From Fedele 2014, corrected and updated.

Chapter 17, section 15, this volume) and, apparently, it was sometimes eaten.

A sample of the actual bone finds is illustrated in Figs 6-9, a selection of dromedary coprolites in Fig. 10. Among these latter, coprolite no. 184.2 deserves special mention: spheroid-ovoid in shape and measuring about $3 \mathrm{~cm}$ in maximum diameter, it was retrieved from layer T75-T7B in Sounding A, rectangle A1-A12, i.e., from the context of structure F8 (cf. Table 1). A little calcification due to the layer's microenvironment might have contributed to its perfect preservation (see Chapter 17, section 11.3 , this volume).

From Area $\mathrm{C}$ we thus have evidence of a mature, stable animal husbandry traditionally based on caprines and cattle, alongside a significant use of the dromedary and the donkey. Complete continuity from the Sabaean to Minaean is apparent in the faunal record or the economic data in general, with no great shifts over time. According to bone counts, also Minaean Yathill concentrated heavily on husbandry, raising sheep, goats, and cattle alongside donkeys and dromedaries. In other words, we have a picture of essential stability in people-animal relationships through time at Yathill and possibly in the Jawf.

Overall, this picture from early historic Yathill closely matches the equivalent, non-specialized archaeofaunas from the Sabaean homeland, as best represented at 
the moment by the Wādī al-Jūbah sites ${ }^{16}$ and Yalā/ al-Durayb (Fig. 3). Also at Yalā, for instance, ${ }^{17}$ the range of animal species was very limited and the dominance of the domestic animals was overwhelming. The domestic species were represented by sheep, goat, and subordinate cattle, dromedary, donkey, and the occasional dog, with the domestic caprines being by far the most common (a staggering 86 per cent of refuse).

Additional similarity between Yathill and the other Sabaean centres along the desert fringe comes from the fact that evidence for the hunting or capture of wild animals is very scanty. In terms of material remains, game species are virtually nonexistent at Yathill, where only the occasional gazelle and no more than four ibex bones (three of them dubious) can be noted. Also a long-legged bird documented by a single bone from the Earlier Sabaean is almost certainly a wild species. At Yalā/al-Durayb the wild species are the gazelle, ibex, and hare, all recorded in almost negligible percentages. Based on epigraphic data from the territory of Yalā, some ibex bones might be connected with the practice of ritual or ceremonial hunting..$^{18}$ No evidence was found of pig or wild boar, and this absence extends to Iron Age Yemen as a whole. It might as well depend on the environment being too dry for raising pigs, ${ }^{19}$ as on pork avoidance as a food taboo. This latter explanation is considered more probable.

Against this background, however, a few individual finds belonging to wild species do stand out at Yathill: several ostrich bones in the Minaean levels (Fig. 11), ${ }^{20}$ and isolated skeletal elements of wild dromedary during the Later Sabaean and possibly the Minaean phases. ${ }^{21}$ Lacking a formal zoological name for the wild dromedary, the designation 'Camelus sp.' will be employed. While Yathill does not add much to what was observed at Yalā and elsewhere from the alimentary viewpoint, the site's most distinctive contribution revolves on the donkey and the dromedary. Section

\footnotetext{
16 Hajar al-Tamrah: Toplyn 1985. Hajar al-Rayhānī: Hesse 1996a, 1996 b (two complementary reports). For an overview see Fedele 2017, 294-297.

17 Fedele 2009; 2019, 191-199. The animal remains from Yalā's House A (c. 850-650 BCE) exclusively represent food refuse, resulting from both kitchen and 'table' contexts. This archaeofauna constitutes an archaeological assemblage, i.e., a group of elements produced and deposited together during a relatively short period of time.

18 Fedele 2009, 149-150; 2019, 197, 198, fig. 3/C. As hunting emerges from bone studies as scarcely relevant in the economy of Iron Age Yemen, a marked contrast is apparent between the prominence of hunting in 'art' - in symbolic, depictive, and epigraphic contexts -- and its prima facie marginality in actual bone samples (Fedele 2019, 198-199, with references). For wild fauna in 'art' see Antonini de Maigret 2012, 32-60, and for a wide-ranging review of hunting in epigraphic sources Maraqten 2015 (including ibex on p. 214-215).

19 An immature pig or wild boar is documented from a Highland Bronze Age site on the Yemen Plateau: Fedele 1990a; in press, table C2.

20 Fedele 2011a, 111-112, fig. 10/f.

21 Fedele 2017, 302-303.
}

2.2 will be devoted to these two species particularly, through a joint investigation of their occurrence and significance in the case of Yathill: at a trading station on the Arabian frankincense route pack animals had to be important.

\section{Additional data on wild species: ibex and gazelle}

Capra ibex. An artificially abraded right talus from a Minaean 3-4 layer in Sounding F, no. 211.01, ${ }^{22}$ can be attributed in all probability to an ibex. Alternatively, but much less likely, it belongs to a very large domestic caprine. Its lateral surface was flattened by intentional rubbing: a piece for playing dice? Morphological measurements: ${ }^{23} \mathrm{GLm}=30.5$; $\mathrm{Dl}$ (abraded bone) $=16.6$; original $\mathrm{Dl}($ reconstructed $)=18.5 ; \mathrm{Dm} c .16 .5$.

Apart from no. 211.01, the only ibex considered relatively certain is no. $185 / 2$, a distal fragment of a left humerus from Sounding A, later Stratum $\mathrm{H}$ (quadrangles A1-A11, suite T76, TPV) (Fig. 7). Morphological measurements: $\mathrm{BT}=33.7 ; \mathrm{HT}=19.9 ; \mathrm{HTC}=14.4 ; \mathrm{Bd}=$ $35.1 ; \mathrm{Dd}=27.1$. For comparison, a distal left humerus of an adult domestic goat from the same cut, slightly gnawed by rodents (Capra hircus no. 185/3), provides the following measurements: $\mathrm{BT}=c .27$; $\mathrm{HT}=15.6$; $\mathrm{HTC}=11.8 ; \mathrm{Bd}=c .28 ; \mathrm{Dd}=23.4$.

Probably from Nashshān, in the Jawf, is a small limestone statuette of an ibex on a pedestal in the South Arabian collection of the British Museum. Although stylized, the animal is unusually well represented. The palaeography of the Minaic inscription on the pedestal, LuBM 2, would date the object to the 6th-4th centuries BCE. ${ }^{24}$

Gazella sp. A safe identification as gazelle is a right first phalanx from a Minaean 2 level in Sounding A, no. 189/85 (quadrangles A1-A11, lower T7LP, Stratum I) (Fig. 7). It was weakly reddened by roasting in hot embers. Morphological measurements: $\mathrm{GL}=38.6 ; \mathrm{Bp}=$ 7.9; $\mathrm{Dp}=12.0 ; \mathrm{SD}=6.0 ; \mathrm{Bd}=7.7$. For comparison, a first phalanx of an adult sheep from the same cut (Ovis aries no. 189/47), provides the following measurements: GL $=36.2 ; \mathrm{Bp}=12.4 ; \mathrm{Dp}=14.9 ; \mathrm{SD}=9.8 ; \mathrm{Bd}=11.3$.

Other gazelle finds, illustrated in Fig. 7, are nos 169G/11 and 169G/12 from a Minaean 3 level in Sounding A (quadrangle A31, suite T76, TPV; later Stratum H): no. $169 \mathrm{G} / 11$ is a cranial fragment preserving the base of the horncore, and no. 169G/12 is a blunted horncore which

\footnotetext{
22 Described as an artefact in Chapter 21, section 2.3, Fig. 69.

23 All morphological measurements in the text of this chapter are those defined by A. von den Driesch (1976), unless otherwise indicated, and are in millimetres (cf. Tables 1-2). c. = circa, best approximation. 24 Frantsouzoff 2006. The inscription is of great interest for the ideology of the cilb-tree, see section 4.2 below.
} 


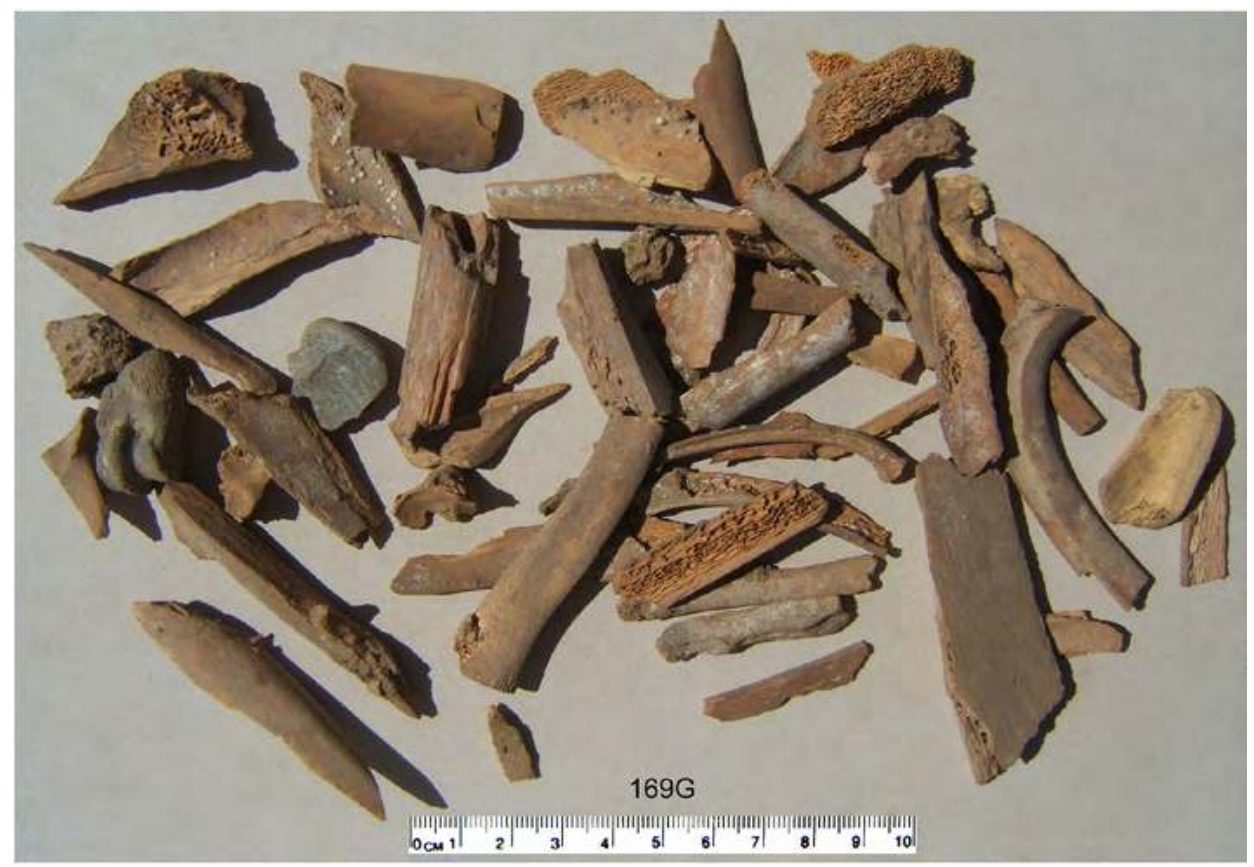

Figure 6. An example of archaeofaunal finds from Area C: cut $169 \mathrm{G}$ in Sounding A, later Stratum H, Minaean 3. (G. Di Rosa and S. Iavarone 2007

(c) MAIRY, optimized by F.G. Fedele 2020)
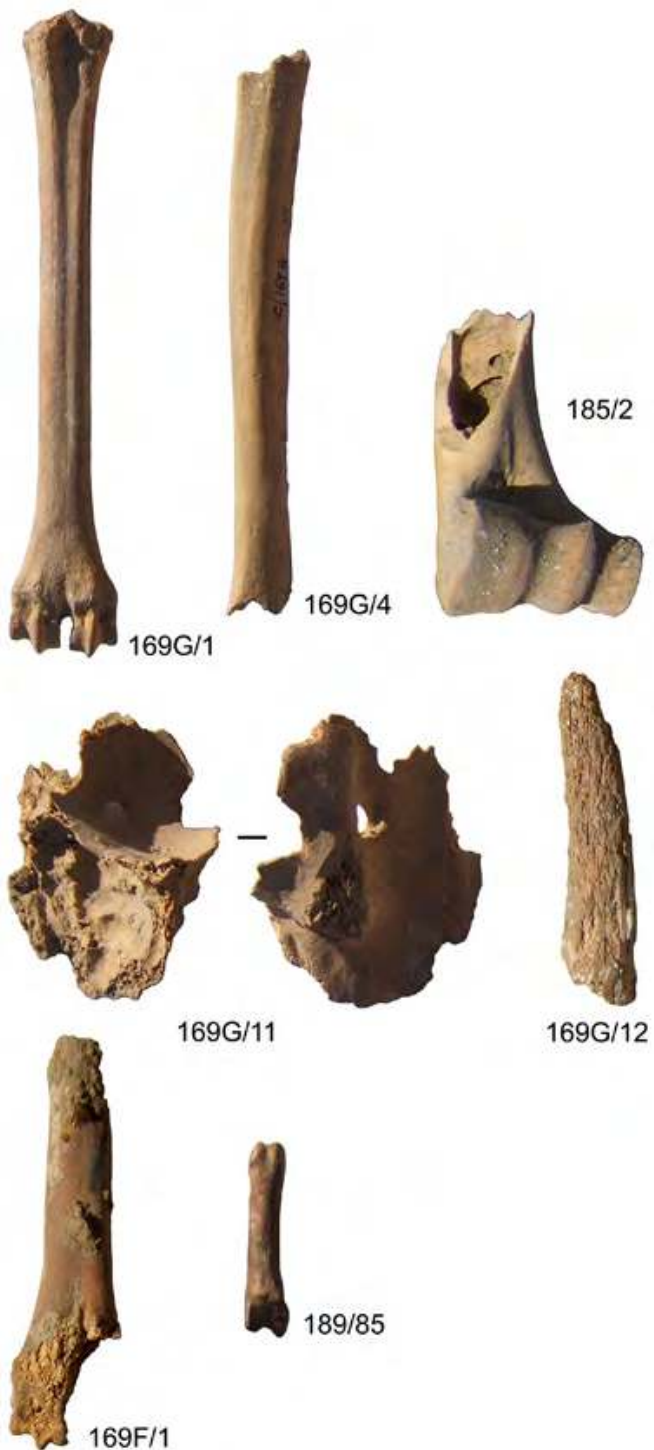
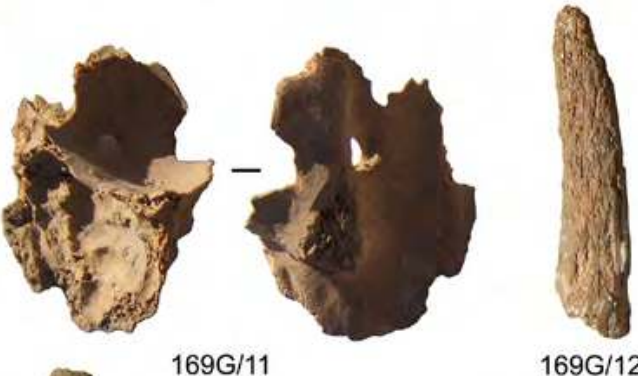

finds from Area C: reg. nos $169 \mathrm{G} / 1$ Ovis aries right metatarsal; 169G/4 Canis familiaris right tibia; 185/2 Capra ibex left humerus; 189/85 Gazella first phalanx; 169G/11-12 Gazella cranial bone and horncore; 169F/1 Gazella metacarpal; 49B/1 large bird (Struthio?) tibiotarsus.

(G. Di Rosa and S. Iavarone 2007 @ MAIRY, arranged and optimized by F.G. Fedele 2020)

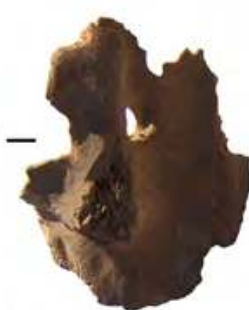

$169 \mathrm{G} / 11$

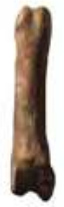

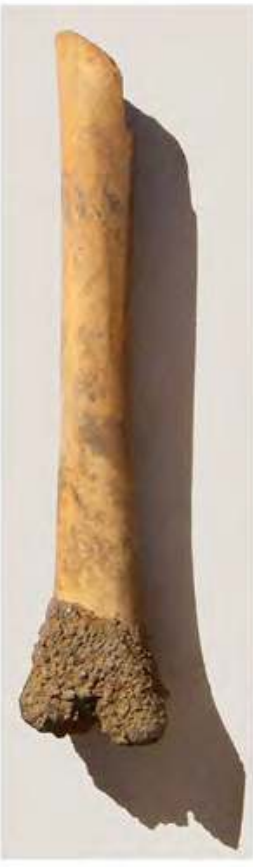

$49 B / 1$ 

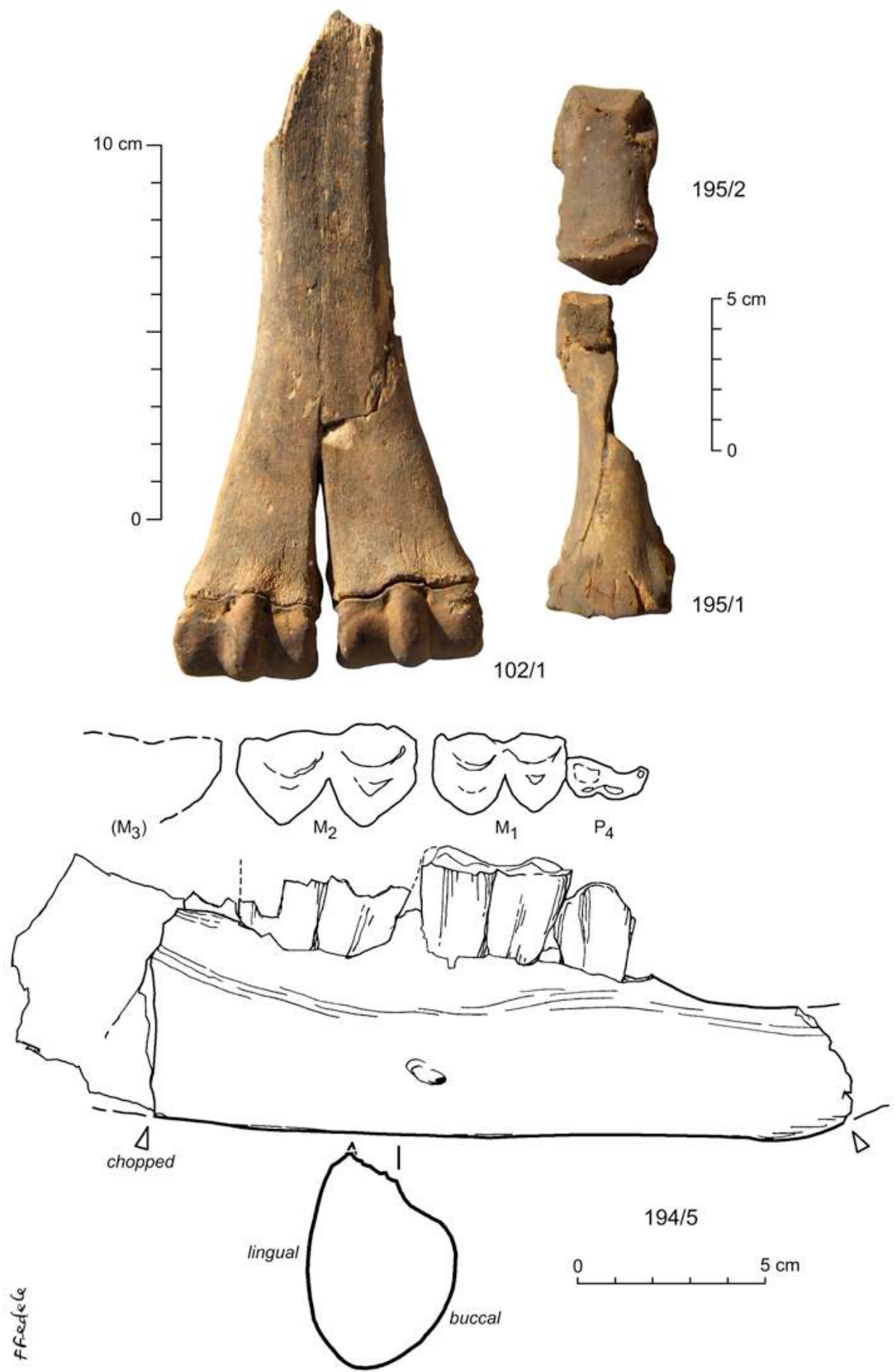

Figure 8. A selection of Camelus dromedarius skeletal finds from Area C: reg. nos 102/1, metacarpal; 195/1-2, phalanges; 194/5, mandible. (F.G. Fedele 2007, optimized and arranged 2010) 


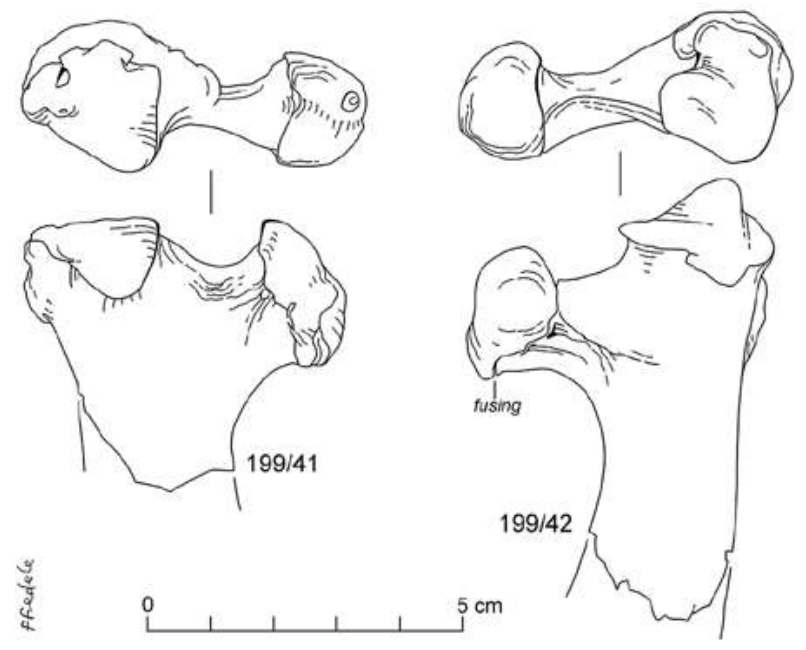

Figure 9. Camelus dromedarius: skeletal finds from Area C. Reg. nos 199/41-42, ribs. (F.G. Fedele 2007, inked 2020)

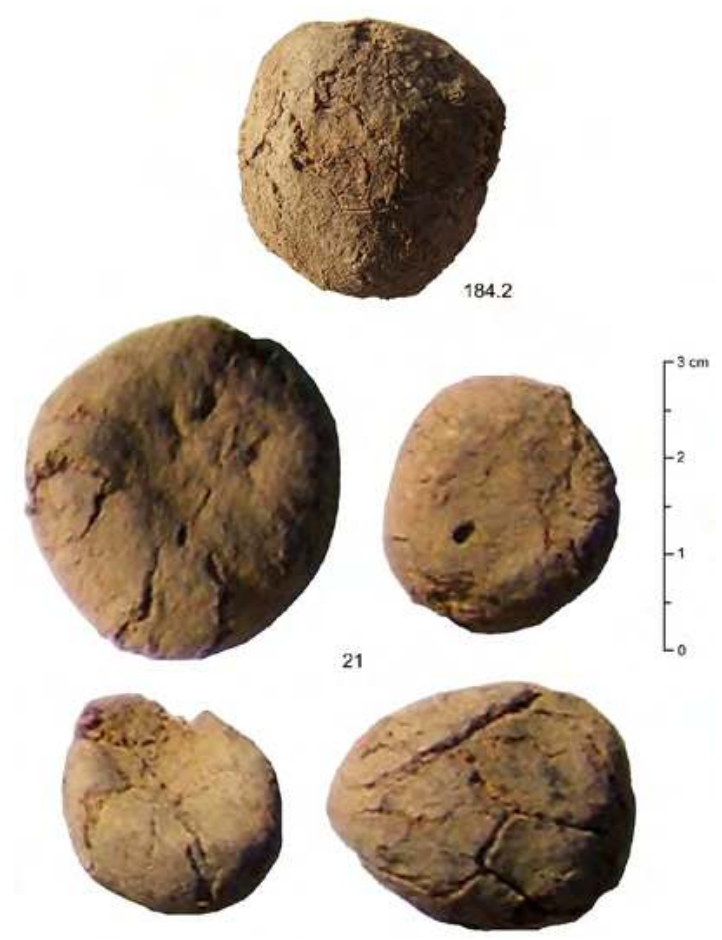

Figure 10. Camelus dromedarius: coprolites. Reg. nos 21 from qu. D2, later Stratum K, and 184.2 from Sounding A, Stratum F. (F.G. Fedele 2007)

might well belong to the same individual. ${ }^{25}$ The most recent gazelle in the Area $C$ collection was identified from a distally damaged metacarpal (half trochlea missing) from a robust male individual, no. 169F/1 (Fig. 7), found in unit T75B, quadrangle A31, Stratum F (Minaean 4). The length of this distal third of the bone is

25 Cf. the Gazella horncores from Yalā/al-Durayb (Fedele 2009) and site HAR2 in the Ramlat al-Sab'atayn (Fedele, 'Animal remains', in Di Mario et al. 1989, 141-145, fig 17, pl. III).
$8.0 \mathrm{~cm}$, and the bone shows a much slender morphology than, for instance, a domestic caprine metacarpal from cut 169G. For comparison, an equivalent Gazella sp. metacarpal fragment in my reference collection (see footnote 6 above) measures $7.0 \mathrm{~cm}$. Find no. 169F/1 is characterized by a faintly red-brown colour, almost typical of lightly roasting wild game meat. A gazelle here fits well with the other exotica of the Minaean 4 consumed as occasional food at wall bastion T7 (e.g. ostrich meat and large ark clams from the seashore, see below).

\section{Ostrich skeletal remains}

Struthio camelus syriacus (Arabian ostrich). ${ }^{26}$ The occurrence of ostrich bones was among the most surprising finds from the Minaean levels (Fig. 11). ${ }^{27}$ They were retrieved from Strata I and $\mathrm{H}$, including the same context as the jar sealings (see section 3.1 below): no. $\mathbf{1 8 9 . 3}$ from lower T7LP, Stratum I, Earlier Minaean; no. 188.1a-1b from units T7LP-SRI-T7P, also Stratum I; and nos 169G.02-03 from suite T76 and TPV in quadrangle A31, later Stratum H, Minaean 3. These bones are extremely pneumatized and very hard, even lithoid. This latter quality was enhanced by roasting, as was their colour, ranging from grey to chocolate brown. The largest piece, 169G.02, is a decimetre-sized conjoint of three fragments (total fragment length $9.8 \mathrm{~cm}$ ). A few more unidentified fragments from sediment units of Stratum I might be present.

All identified bone ${ }^{28}$ appear to derive from roasted meat of the pelvic region. The pelvis is the most voluminous bone of the ostrich, and as in all birds the pelvic region is the body part that provides the largest mass of edible meat. As a consequence, chopped pelvic bones could frequently be preserved and roasted with the meat. Fragment no. 169G.02 is probably part of the acetabular ilio-ischiatic rim, and more precisely of the tuberosity of the iliac margin, while the likely provenance of no. 189.3 (maximum length $4.6 \mathrm{~cm}$ ) is the middle part of the lumbosacral.

The partial co-occurrence of ostrich bone remains and trade-jar sealings (Stratum H) suggested that ostrich meat was at some point a traded import, for instance from central Arabia. ${ }^{29}$ The odd importation of joints

\footnotetext{
26 See, e.g., Carruthers 1922; Prater 1923; Meinertzhagen 1954, 573575; Cramp 1977, 37-41.

27 Fedele 2010, 144.

28 The ostrich finds from Area $C$ were provisionally identified at Barāqish in 2007. They were subsequently studied at the Natural History Museum at Tring in February 2008, with the assistance of Joanne Cooper, chief curator of birds. Her support and kindness, extending to the provision of literature, is acknowledged with gratitude.

29 A number of biotopes in central Arabia probably supported substantial ostrich populations: the insightful description by Alison
} 

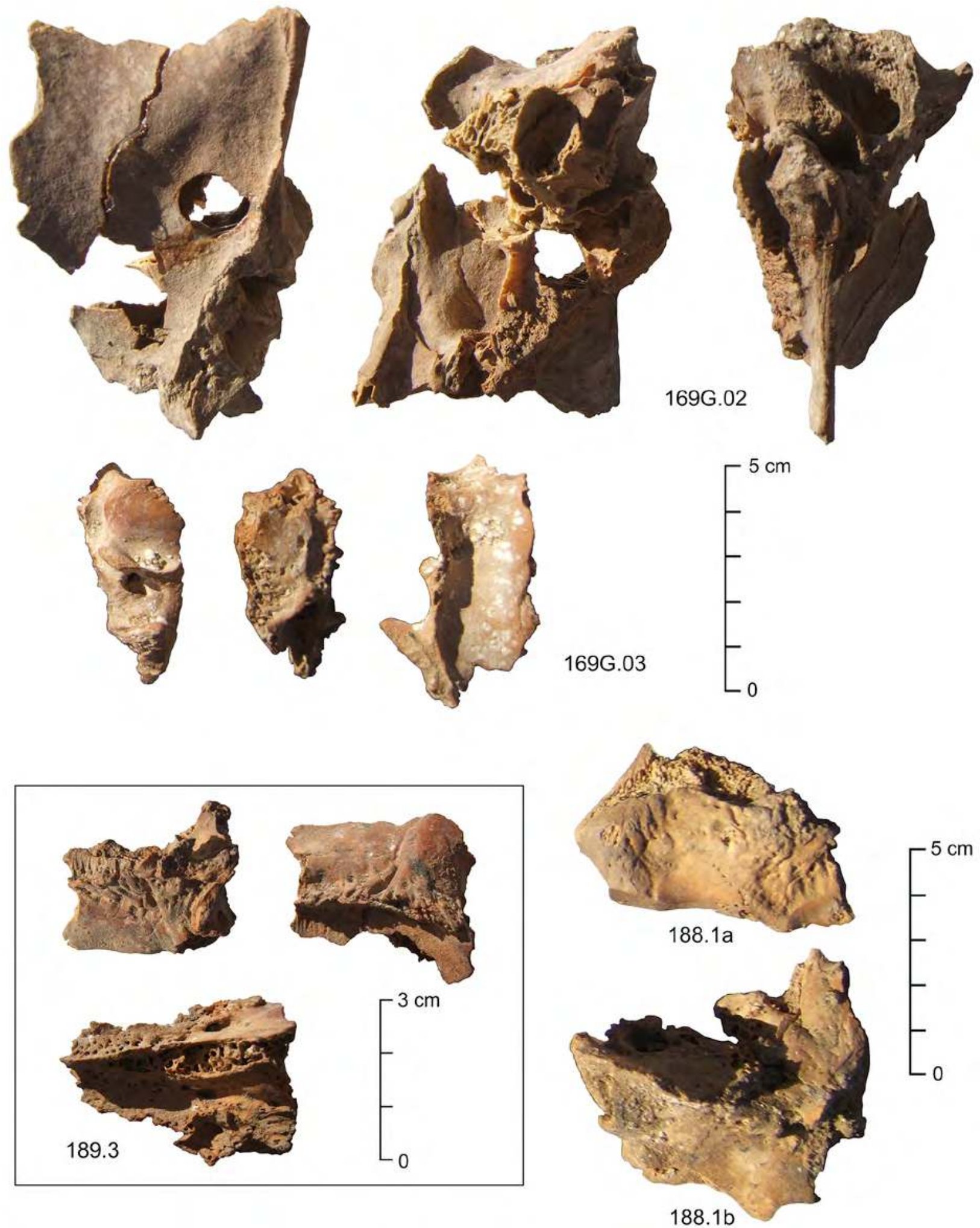

Figure 11. Struthio camelus syriacus: ostrich bones from Sounding A. Reg. nos 188.1 and 189.3, Minaean 2; 169G.02-03, Minaean 3. (F.G. Fedele, assisted by G. Di Rosa and S. Iavarone, 2007) 
of ostrich might have featured amid the traded goods. However, local capture and cooking is an equally reasonable explanation, particularly in the case of Stratum I (in which no particular indicators of trading were recognized), as is the possibility of occasional hunting episodes in the course of travel (see section 2.2 below). ${ }^{30}$ The occurrence of ostrich meat and eggshell is plotted in Table 5 as a potential indicator of 'foreigners/travellers'. A further possibility should be contemplated, however untestable: ritual hunting, as also the ostrich - like the ibex - was the subject of this kind of activity in ancient Yemen. ${ }^{31}$

The ostrich finding here described has some importance due to its extreme rarity, possibly being the first osteological identification of ostrich bones from an archaeological context in southern Arabia $^{32}$ - or in the entire Arabian Peninsula. ${ }^{33}$ Although the occasional bone has turned out at sites in the Levant (e.g. Syria, Israel), this rarity of skeletal ostrich finds extends outside the Arabian Peninsula. For instance, it was explicitly mentioned in reference to Egypt ${ }^{34}$ and the Horn of Africa. ${ }^{35}$ While ostrich eggshell is a fairly common archaeological find throughout the AfricanArabian area inhabited by the species, including Yemen, ${ }^{36}$ and although ostrich imagery features

Betts $(2008,37)$, although concerning the North Arabian steppe, is apposite here.

30 Group or individual travelling. For a topographic reconstruction and discussion of the main route travelled by caravan traders between Yathill and central Arabia see de Maigret 1997b; on the Arabian scale, Potts 1988.

31 Werner Daum, in discussion at the 20th Rencontres Sabéennes, Perugia, June 2016.

32 Fedele 2010, 144; 2011a, 111-112, footnote 4. A pneumatized bone fragment from House A at Yalā/al-Durayb was only tentatively identified as Struthio camelus (Fedele 2009, 145; 2019, 196). Five 'ostrich' items, with no specification whether bones or eggshell fragments, were reported from Hajar al-Rayhānī (Fig. 3): Hesse 1996b, table 8.05; on p. 267-268 this author mentions that 'small mammal, bird, and reptile specimens will be reported separately' (cf. Hesse 1996a, 108), but no such publication appeared.

33 'Not one ostrich (Struthio camelus syriacus) bone has ever been recorded in an archaeological excavation anywhere in the Arabian peninsula': Potts 2001, 182. According to Dan Potts, who relies on an extensive bibliography, the absence of ostrich bones in the archaeological record suggested that they were not hunted for meat, in spite of representational, eggshell, and ethnohistoric evidence showing that the ostrich was widely distributed in Arabia. More recently, similar information and remarks were offered by Tebes (2014, 182-183). Hodos et al. (2020), also quoting Tebes, observe that 'ostrich bones [...] are rarely found in excavated archaeological contexts, suggesting that the animals were not a significant source of food' (p. 383).

34 E.g., von den Driesch 2001, 353, fig. 6 (Egyptian Red Sea, New Kingdom); Riemer et al. 2009 (Egypt's Eastern Desert); LesurGebremariam 2010 (oasis of Kharga, Late Neolithic, one bone out of 3064 identified specimens).

35 Lesur 2007, 63: 'Les restes provenant de cet animal [the ostrich] sont tous des fragments de coquille d'oeuf et aucun ossement n'a été trouvé (Annexe 1.3).'

36 E.g., Crassard 2008, 33, mentioning the survey along the Yemen LNG Pipeline route Mārib-Balhaf (by R. Crassard and H. Hitgen, 2004/2005). prominently in Sabaean art, nothing is known about the distribution of ostrich populations in southern Arabia during the 1st millennium BCE, where precise information is required. ${ }^{37}$ Also the geography and timing of ostrich survival in the Arabian Peninsula are only sketchily known. ${ }^{38}$

As usual, the pictorial evidence must be treated with caution, if only because its dating is often vague and/ or the relationships to local ostrich populations are left totally undefined..$^{39}$ Recent research in this field, however, promises to improve the quality of the record. ${ }^{40}$

One more bone find from Area $\mathrm{C}$ which might be Struthio camelus was recovered from Stratum S, Earlier Sabaean (quadrangle D7, units SIS-SGLi). The bone, no. 49B/1, is a juvenile tibiotarsus with a porcelain look belonging to a long-legged bird (Fig. 7). With a length of $14.2 \mathrm{~cm}$ this fragment exceeds in size any expected farmyard fowl, considering the Sabaean period in question, and therefore it points almost unequivocally to a wild species.

I hope this short section on the ostrich will help alert other researchers to the possibility of ostrich bones being present in their archaeofaunal assemblages.

\section{Micro-gastropods and seashells}

Small terrestrial gastropods. Land snails, mostly represented by tiny species, were extensively retrieved from several excavation contexts of Area C. A specialist study was not possible, but at least five species were visually recognized: three centimetre-sized turriculate species, ${ }^{41}$ particularly well represented in Stratum L (Later Sabaean, see flotation of sample 12.3 in Chapter 17 , section 7.6 , this volume); a larger turriculate species, with shell height of c. $2 \mathrm{~cm}$; and one discoid species.

\footnotetext{
37 For instance, the actual presence of the ostrich in the Yemeni Tihāma, throughout the recent prehistory and allegedly into the early historical period, is no more than inferential, being based on the abundance of surface eggshell debris and on the recovery of eggshell tools at rare sites (e.g., M. Tosi in de Maigret et al. 1986, 405-406, fig. 32; Khalidi 2005; cf. Durrani 2005).

38 There is a vast if episodical literature on this subject; here is a sample. Sauer et al. 1996, 12, footnote 1: 'Of [the] quarry known to be sought by early hunters in Yemen, including [the] ostrich, only a few gazelle remained by 1954, when Serjeant $(1976,2)$ traveled in the Bayhan-Marib region.' The ostrich was still hunted in Saudi Arabia during the 1930s (Field 1952, 1958; cf. Potts 2001; Crassard 2008, 33). It was considered extinct in Arabia and Syria by 1941 (Meinertzhagen 1954, 574), but an individual was reported from Jordan in 1966 (Cramp 1977, 38). Across the Red Sea, in the Eastern Desert of Egypt, ostriches have been seen as late as 1982 (Goodman et al. 1984).

39 E.g., from a vast literature, Rothenberg and Glass 1983, fig. 1; Rothenberg 2003; Bednarik and Khan 2005.

40 E.g., Bednarik 2017; Maria Guagnin, Max Planck Institute for the Science of Human History (Jena), personal communication 2019.

${ }^{41}$ Shape terms after Claassen 1998, fig. 5.
} 
Turriculate species were also found in Minaean units of Sounding A, for example 'red sand' SR (Stratum H).

Seashells. The findings of marine shells will be exhaustively described and discussed in Chapter 21, this volume, including their zooological identification and a photograph (Fig. 40). It seemed more logical to deal with all shells in that chapter in consideration of their unrelatedness to local economy. In the present chapter these finds are simply mentioned as items of the faunal record, noting their origin as seafood where relevant, as well as shells which having travelled overland from a sea coast can provide insights into distant movement or exchange (see section 3 and Tables 3-5).

As to molluscs as seafood, we can only mention the probably alimentary nature - rather than artefactual ${ }^{42}$ - of find no.184.3, an arcid (Chapter 21, Fig. 40 D, this volume). Considering the context of the find, Sounding A at bastion T7, the most likely explanation for the presence of this large ark clam at Yathill is its meat its use as food. Together with the roasted ostrich bones described above, and wild dromedary humerus no. 151.1, this arcid shell is one of a small group of skeletal and exoskeletal elements indicating that exotic animal food was occasionally consumed (cf. Tables 3-5). As indicators of unusual food, presumably alien to the ordinary practice of Yathill's residents, these finds are interesting as such but unrelated to local economy.

People-molluscs relationships in ancient Yemen represent - apparently - a story still to be written. A mention is made in the introduction to 'Marine shells' in Chapter 21, section 2.1, this volume: 'Building up a broader picture of the cultural use of seashells throughout Yemen's ancient history remains a distant goal.' Even the relationships with seashells in the recent past and the present seem to have been comparatively neglected. An interesting step in that direction, probably unknown outside malacological or conchological circles, was represented by the Dutch 'Tibia I' expedition of $1993 ;{ }^{43}$ the attempt, however, had to be confined to the present-day Tihāma.

\section{On the uses of ungulate dung, ancient and archaeological}

At Sabaean and Minaean Yathill ungulate dung must have been used extensively, judging from human ecological analogy and taking into account a very wide area of Western Asia and North and East Africa, as well as a good stretch of time - the last several millennia. In the context of this chapter there is only space for a few remarks and suggestions, bearing in mind that in 20052007 neither fieldwork conditions nor time allowed

\footnotetext{
42 I.e., a non-dietary, aesthetic role.

43 Dekker and de Ceuninck 1994, 137-139, Annex 3, significantly titled 'Man and molluscs'.
}

to investigate the subject specifically, or to carry out targeted sampling.

Yathill's residents and visitors were certainly adept at the use of animal dung as fuel. From the researcher's viewpoint, this practice of intentional burning is a well known mechanism for the incorporation of charred seeds into the archaeological record, and the literature on the subject has been steadily growing. ${ }^{44}$ Camel dung burns particularly well; and, aside from burning, no less than T.E. Lawrence "wrote evocatively about camel shit in the desert'. ${ }^{45}$ Sue Colledge, among others, has carried out studies which are very pertinent to our case from Yathill, and particularly to the Later Sabaean occupation represented by suite GK, Stratum N: 'The digested fodder, in the form of dung cakes, may have been used as fuel for domestic fires, thus explaining the admixtures of grains of one taxon with chaff of another in the charred assemblages. ${ }^{46}$ Dung is also one of the best fuel materials for firing pottery. ${ }^{47}$

An aspect of great interest at Barāqish is the archaeological use of dung - and excreta in general - for the detection of animals at ancient sites and in stratified deposits. In our case this means donkeys and dromedaries particularly (cf. section 2.2 below). The detection of donkeys, more perhaps than dromedaries, is often a difficult task. However, because equids are not ruminants, larger fragments of vegetation make donkey dung readily distinguishable from that of cattle, sheep and goat, ${ }^{48}$ and this criterion is helpful when physical preservation is good. In the future, a more sophisticated assessment of the presence and eventual penning of donkeys and dromedaries outside the Minaean town wall could be obtained by dedicated field sampling, coupled with analytical techniques for the recognition of dung or dung-enriched deposits (cf. section 3.1 below). These latter methods have been undergoing sustained development. ${ }^{49}$

\footnotetext{
44 The seminal paper was Miller and Smart 1984. Naomi Miller (1999, 20-21) also used measures of seeds and charcoal in order to infer the use of different fuels, including dung (cf. Colledge 2003, 398). A brief but insightful review of camel dung as fuel is McCorriston and Johnson 1998, 182, with references. On animal dung and archaeology in general see Miller's (2020) database, and on the recognition and interpretation of dung-derived plant material Charles 1998.

45 Irwin 2010, 56, who further remarks that camel dung is also high in ammonia and therefore good as fertilizer'.

${ }^{46}$ Colledge 2003, 396-398; quotation from p. 397. Cf. Chapter 17, section 2.2, this volume.

47 Spengler 2019, 218; cf. Chapter 23, this volume.

48 Marshall and Weissbrod 2009, 75, with references.

49 E.g., Heron 2001; Rosen et al. 2005; Shahack-Gross et al. 2008; Canti and Huisman 2015, with references; Henry et al. 2017 (a fine study of faecal spherulites, although from a different context); Boschian 2017 (spherulites, 'coprogenic facies' in general); Matthews 2017, 961 (animal dung), 966-967 (organogenic alterations of sediments). Cf. Chapter 17 , section 2.3 , this volume. Plans to develop biochemical and thin-section examination of coprolites to determine source of diet, based on samples from Barāqish Area C (Fedele 2011a, 111, footnote
} 


\subsection{Donkeys and dromedaries ${ }^{50}$}

In Southwest Arabia during the 1st millennium BCE donkeys and dromedaries were the only pack animals commonly employed, although their usefulness extended to other tasks and economic sectors, at least occasionally. They were multi-purpose animals, as the dromedary still is in rural Yemen today. ${ }^{51}$ In addition, following historical analogy, one can surmise that the two species might have fulfilled broadly complementary roles in parcel transport: the camel as a long-range specialist, while the donkey was particularly efficient on a local to regional scale. However, these latter aspects should be tested archaeologically at a number of sites in order to define their temporal and/ or regional oscillations.

A joint examination of camels and donkeys is thus justified in the perspective of a functional study of their combined role as beasts of burden. This role was at the same time economic and technological. If considered in isolation, each single species is insufficient for the purpose of a functional, 'behavioural' investigation of this particular role and the techno-economic system it determined. A further reason of interest lies with the unique importance of such a component in an Arabian context, and, more specifically, within an oasis community preeminently associated with an evolving trade network..$^{52}$ For this subject and period Yathill represents a most favourable research locale and already offers an incipient, closely combined archaeological and archaeofaunal record.

At Barāqish Area $\mathrm{C}$, the first significant aspect concerning the dromedary and the donkey - or the equids in general - is their temporal distribution. In the stratigraphic record one can observe an increase of both species with the Later Sabaean, and a relatively sharper increase in numbers with the advent of the Minaean control (Minaean 1; Fig. 5). No donkey remains were retrieved from Earlier Sabaean levels, although there might be traces of equid coprolites in a layer of that age (cultural horizon H78, quadrangle E8). When the donkey becomes apparent in the Later Sabaean, all its bones derive from mature or old animals. The fact that donkeys were killed at the end of their working life provides indirect confirmation of their chief use for work, and particularly pack transport (cf. Table 4, bottom). In this regard, it is important to caution that an animal kept for nonfood purposes, especially one not frequently consumed, such as the donkey, the

\footnotetext{
3), unfortunately could not be implemented.

50 This subject was previously treated in Fedele 2014. The present account is a revision.

51 E.g. Fedele 2009, 145; 2010, 143.

52 Fedele 2014, 178.
}

dog, and to some extent the dromedary, may leave comparatively fewer remains. ${ }^{53}$

Concerning the dromedary, both skeletal morphology and size indices show that the domesticated species was already present in some of the lowermost levels of Area $C$, during the 8 th century BCE (or at the turn of the 7th century: Stratum S or R). ${ }^{54}$ Its domesticated status is of particular interest in the light of this relatively high chronology: Yathill's is one of the earliest occurrences of domestic camels in Yemen. ${ }^{55}$ Table 1 presents a nearlycomplete selection of the Camelus skeletal finds from Area C, together with their available morphological measurements; a well-preserved coprolite is also listed (no. 184.2, see Fig. 10). In order to interpret the logarithmic size indices for the measurable Yathill finds the diagram generated by the Uerpmanns from their Southeast Arabian database ${ }^{56}$ was employed; the details have been discussed elsewhere. ${ }^{57}$

Equally interesting is the evidence that after the timespan of Strata S-R dromedaries were present throughout the sequence from Area C. Furthermore, on morphological grounds most of the bones manifestly belong to domesticated animals. A terracotta figurine of a dromedary was found in Sounding A, apparently associated with surface S7 (Minaean 2/3). ${ }^{88}$ This wellstratified, multi-context record from Yathill and the Yemeni Jawf is obviously interesting vis-à-vis the much-debated subject of dromedary domestication in the Arabian Peninsula. Here, however, there is neither reason nor possibility to dwell on the matter: the position and contribution of Yathill have been presented in detail elsewhere. ${ }^{59}$

53 See, e.g., Marshall 2007; Marshall and Weissbrod 2009, 75. Cf. Fedele 2014, 185; 2017, 301, with references; and footnote 15, above. In archaeofaunal collections, the donkey is 'a valuable, but largely archaeologically invisible, domestic species', says Diane Gifford-Gonzales speaking of African archaeological sites (italics mine): 'Donkey remains are seldom retrieved from pastoralists' archaeological bone deposits, as they are not food animals nor are they disposed of as if they were' (Gifford-Gonzales 2009, 13).

54 Metacarpal no. 102/1 from qu. E2 (Fig. 8). Find no. 112/1 from qu. E3, slightly earlier in date (Stratum T or S), must be deleted from the previously published list (Fedele 2017, table 20.6) as its identification as Camelus was incorrect.

55 Fedele 2017, 300, fig. 20.8, table 20.6. Broadly coeval is the earliest appearance of the domesticated dromedary at Yalā/al-Durayb: Fedele 2009, 141-143; 2017, 289-294, fig. 20.2.

56 Uerpmann and Uerpmann 2002, fig. 3; cf. Beech et al. 2009, fig. 9.

57 Fedele 2017, fig. 20.5. The assistance and encouragement of Marjan Mashkour (MNHN, Paris) at an initial stage of my research on 'early' camels from Yemen is gratefully acknowledged (cf. Fedele 2010, 143, footnote 154).

58 Find no. 187.01: see Chapter 21, section 2.3 and Fig. 57, this volume.

59 Fedele 2017, particularly 298-306 and 311 ('Update April 2016'), both sections with references. Much to be regretted is the fact that the faunal samples obtained from the crucially important 13th-8th century BCE levels of the sounding at Temple A (de Maigret 2010a) remain unknown. I spotted dromedary bones in the samples, but as a planned return to the site for further study proved impossible after 2007, they could not be examined at all. Cf. Fedele 2019, 190. 
More difficult to establish is the particular economic basis underscoring the occurrence of dromedaries during each period. At Yathill it seems reasonable to suggest that the dromedary had already acquired its multiplicity of roles $^{60}$ by the time of Stratum $\mathrm{T}$. There is no need to remember how the chief quality of the dromedary is to be a major provider of milk, and before any adaptation to serve as a transport animal this must have been very important, particularly among semi-desert farmers and pastoralists. At Yathill the dromedary was also butchered and consumed. However, at least during the Later Sabaean and the Minaean, when the archaeological indications of trade become more evident, most of the dromedary bones from Area $\mathrm{C}$ might derive from transport animals only occasionally utilized as a source of meat, or so dispatched subsequently. ${ }^{61}$ This latter pattern would be analogous to the treatment of donkeys (see above).

In section 2.1 mention was made of wild Camelus. The case for wild dromedaries can be argued on the basis of a distal humerus from the outskirts of the Later Sabaean settlement, bordering the plain (find no. 151.1 from Locus 151, quadrangle E11), ${ }^{62}$ and less confidently for a phalanx from a Minaean 1 level of Sounding A (no. 190/45). ${ }^{63}$ Humerus no. 151.1 is a prominent component in the cluster of objects of Locus 151 (cf. Fig.16). This well-preserved bone belongs to an animal of dromedary morphology, very different in surface appearance and size from all other camel material from the extramural area. Its logarithmic size index $(+0.045)$ leaves no doubt that this large and robust bone belonged to a wild camel. ${ }^{64}$ The bone was chopped by heavy percussion and partially roasted, resulting in a reddish hue on its anterodistal part; the orange pigmentation on the rest of the bone is also relatively unusual. Locus 151 contained two more fragments of Camelus long bones, also reddened and slightly burnt (Table 2). As we have seen elsewhere in this volume (Chapters 18, 21, 23), Locus 151 can be dated within the 7th century BCE; its significance in terms of archaeological context will be discussed in sections 3.1 and 3.3, below.

Although limited, these Camelus sp. finds are interesting because they indicate that wild dromedary herds still

Concerning the dromedary in Assyrian and North Syrian textual and pictorial sources, a valuable article to be added to my previous references (Fedele 2017) is Herles 2008.

60 On the multiple, useful roles of camels in human society see, e.g., Gauthier-Pilters and Dagg 1981; Wilson 1984, particularly chapters 3 ('Types and breeds') and 10 ('Productivity'); Irwin 2010; in Arabian cultures, Eisenstein 2010.

61 Fedele 2017, 301-302.

62 Fedele 2014; 2017, 303, figs 20.7, 20.9 (Locus 151), table 20.6. Locus 151 is a component of cultural horizon H11 (Stratum M); cf. Chapter

21, section 2.1, footnote 119 .

63 Fedele 2017, 302, fig. 20.5, table 20.6.

64 Fedele 2017, fig. 20.5.

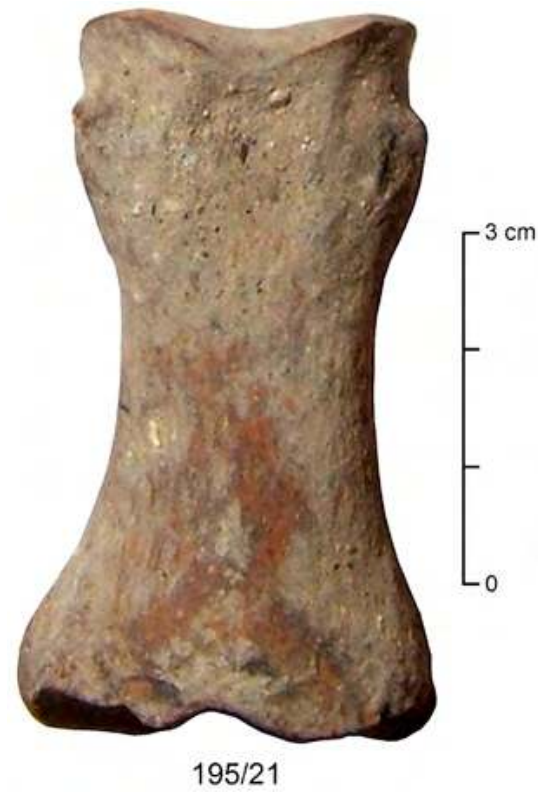

Figure 12. Equid hybrid: first phalanx no. 195/21. (F.G. Fedele 2007)

existed in Yemen during the 7th and perhaps as late as the mid-1st millennium BCE, when the domestication of the species had been under way for a long time and was being perfected. ${ }^{65}$ Wild dromedaries may have survived much longer, if rock depictions in southern and central Arabia can be trusted to portray wild camel and to span the whole 1st millennium BCE, as claimed. ${ }^{66}$ The wild population inferred from humerus 151.1 might be located in the wider area of Yathill and suggest episodical hunting by local residents. An alternative scenario would be a chance encounter with a wild herd in the course of travel or caravan traffic, in which case meaty joints would have been brought in from greater distance. The same probably applies to the roasted or scorched ostrich remains from Minaean phases 2 and 3, found in Sounding A (see section 2.1 above). ${ }^{67}$

Also the recognition of presumed equid hybrids in the archaeofauna was based on a combination of morphological and metrical observations, as well as on considerations of context. A search for equid hybrids, or 'mules' in a general sense, was justified by two considerations: their presence had been suspected at Yalā, ${ }^{68}$ and, more generally, by the mid-1st millennium $\mathrm{BCE}$ the great usefulness of mules in the context of transport and trade had been widely recognized across Western Asia. ${ }^{69}$

\footnotetext{
65 Cf. the data from the U.A.E.: Uerpmann and Uerpmann 2002, 257.

66 E.g., Khan 1998; for a necessary re-dating see Bednarik and Khan 2005, and Bednarik 2017, with references. Cf. Fedele 2017, 303.

67 Fedele 2010, 144

68 'One or two bones suggest the theoretical possibility of an equid hybrid, i.e. a mule in a general sense' (Fedele 2009, 143).

69 Among the vast literature see, most recently, Goulder 2018, 63-66,
} 


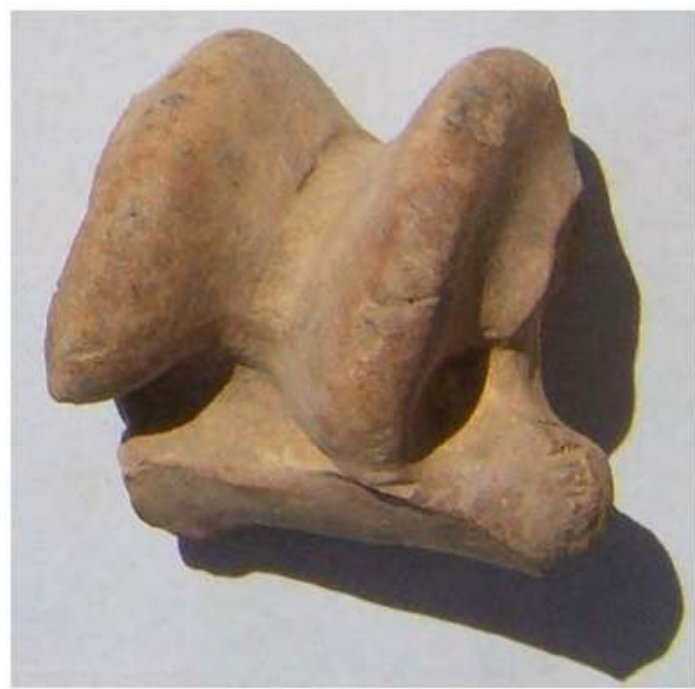

$195 / 20$

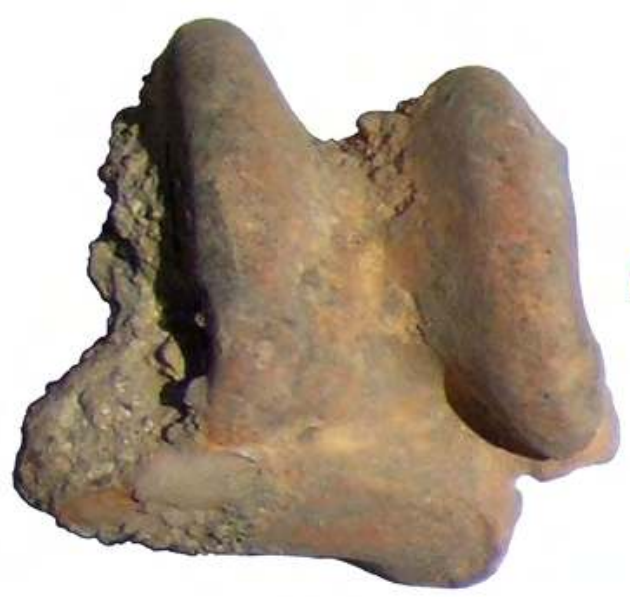

$190 / 53$

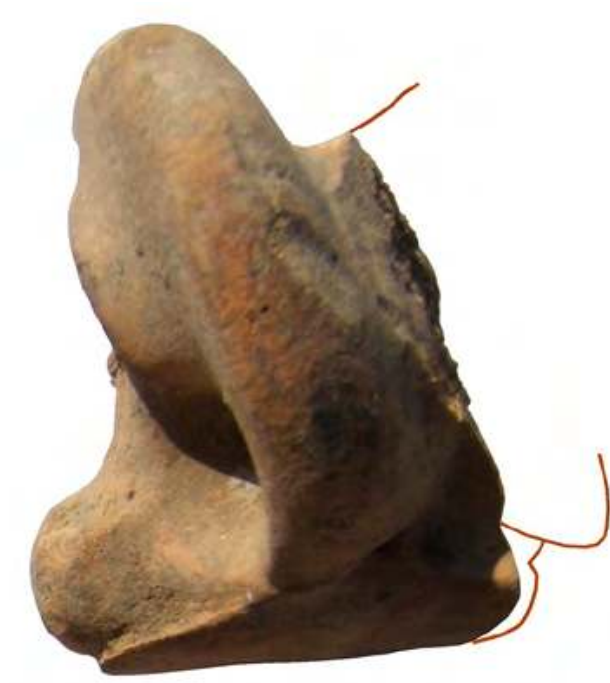

$194 \mathrm{~A} / 5$

\section{Equus hybrid}

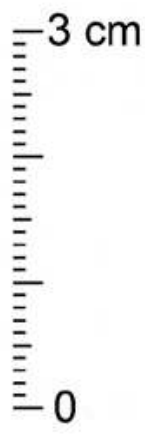

Figure 13. Equus asinus and equid hybrids: taluses from Sounding A. Reg. nos 195/20 (Earthwork F10-F12, Minaean 1), 194A/5, and 190/53. (F.G. Fedele 2007)

At Yathill both the Sabaean and Minaean donkeys were characteristically small, as elsewhere in Yemen. However, in spite of the very limited evidence, equid hybrids were indeed present at Yathill during the Minaean period. At least one talus is from a mule (no. 194A/5), while a first 'asinine' phalanx appears to fall within the hemione distribution (no. 195/21), as do two second phalanges, although perhaps less clearly (nos 188/1 and 199/44) (Figs 12-14). ${ }^{70} \mathrm{~A}$ left upper premolar or molar, no. 195/15, shows a mix of ass and 'hemione' traits as well (Fig. 15; described with metrical data in Table 2). Since no caballine trait is detectable, all these presumed hybrids would derive - surprisingly -

\footnotetext{
577-579, with references.
}

70 Cf. Fedele 2014, fig. 4 (in the topmost and middle diagrams of this figure 'Equus hominious' is a layout-editor's error for Equus hemionus; see the original structure of the diagrams in Uerpmann 1991). The two second phalanges, nos 188/1 and 199/44, fall at the borderline of the hemione and 'recent donkey' scatterplots. from crosses with hemiones. Hemiones (onagers) were probably still present on the nearby borders of the Ramlat as-Sabcatayn desert of Yemen; ${ }^{71}$ and, at any rate, no horse remains were found at Yathill. The problem of equid hybrids at Yathill, and indeed elsewhere on Yemen's trade routes, can only be addressed through targeted research and larger collections.

\section{Some specialist details on equids, and further information.}

The morphological measurements of the taluses and phalanges plotted in Fig. 14, attributed in part to

71 Site HAR2: Fedele 2014, 185, based on an unpublished revision of data from Fedele in Di Mario et al. 1989, 141-145 (Equus sp. in fig. 18 and pl. IV). Personally communicated, this revision was quoted by Edens and Wilkinson $(1998,69)$. Unfortunately, surface site HAR2 is confusingly dated: if indeed associated with the lithics, the hemione bones would be earlier than the 1st millennium BCE. 

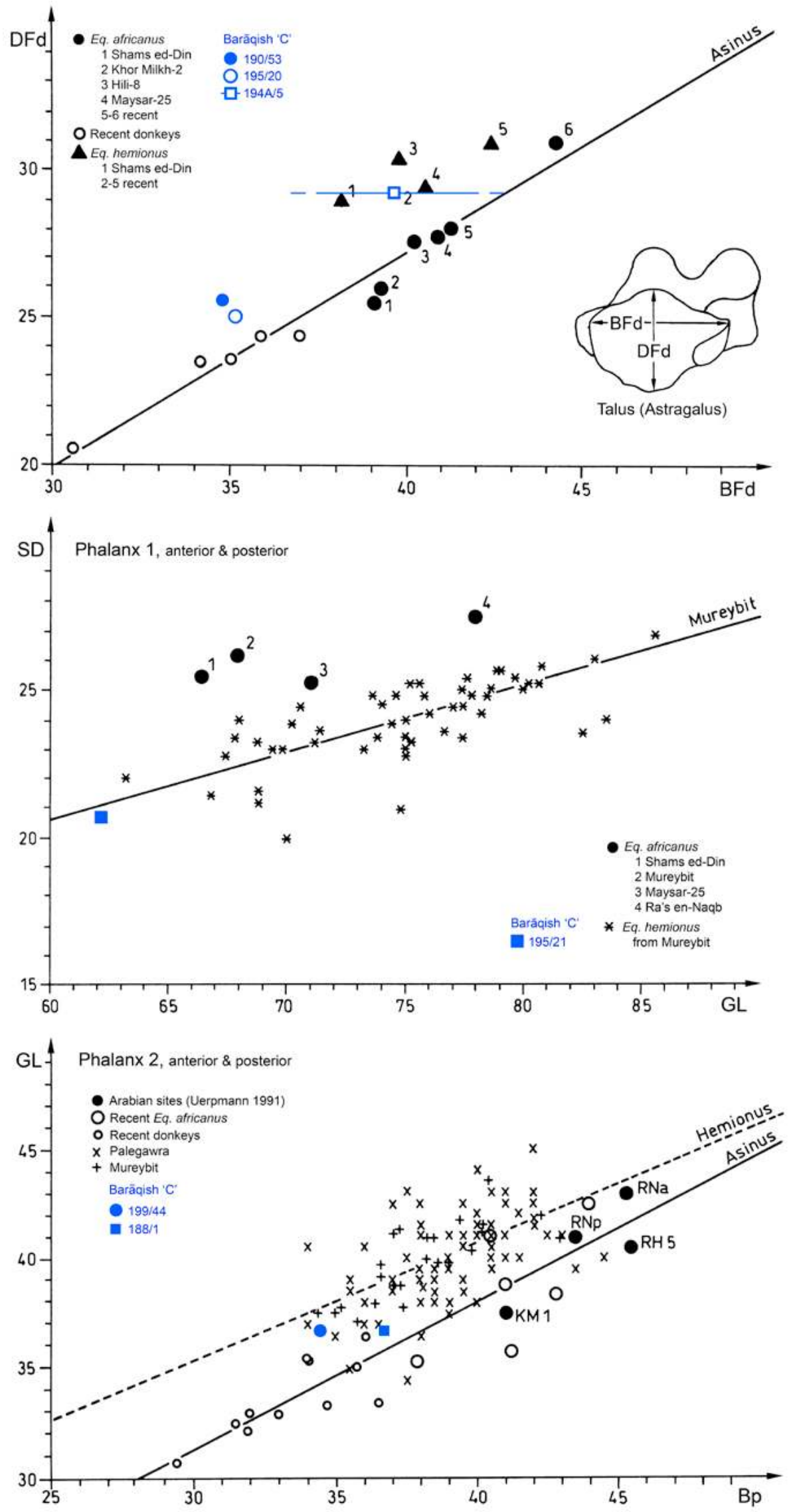

Figure 14. Area C, Sounding A: bivariate plots for equid bones, including the talus and the first and second phalanges. Reference plots from Uerpmann 1991. (F.G. Fedele 2010) 


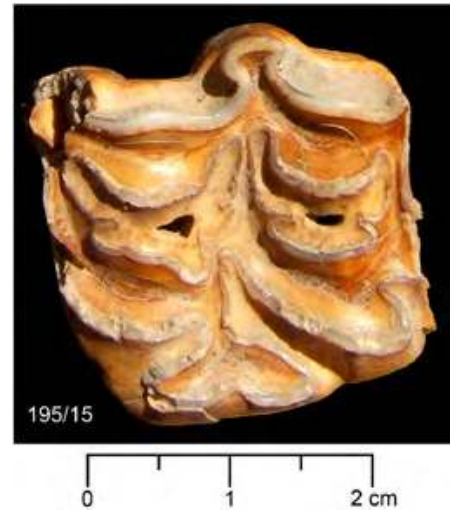

Figure 15. Equus asinus or equid hybrid: premolar or molar no. 195/15. (F.G. Fedele 2007)

ass/donkey $\times$ hemione hybrids, are the following, in millimetres:

- right talus $195 / 20 \mid \mathrm{GB}=46.5 ; \mathrm{BFd}=35.2 ; \mathrm{Dfd}=$ 25; $\mathrm{LmT}=40.2 ; \mathrm{BTr}=36.9 ; \mathrm{GH}=43.1$;

- left talus 194A/5 (distal articulation broken)| $\mathrm{Dfd}=29.2 ; \mathrm{LmT}=48.8 ; \mathrm{GH}=48.9$;

- left talus $190 / 53 \mid \mathrm{GB}=46.4 ; \mathrm{BFd}=34.8 ; \mathrm{Dfd}=$ 25.5; $\mathrm{LmT}=43.3 ; \mathrm{BTr}=35.9 ; \mathrm{GH}=43.7$;

- first phalanx 195/21 $\mathrm{GL}=62.2 ; \mathrm{Bp}=35.2 ; \mathrm{BFp}$ $=32.5 ; \mathrm{Bd}=29.2 ; \mathrm{BFd}=28.2 ; \mathrm{Dp}=24.1 ; \mathrm{SD}=20.7$;

- second phalanx 199/44 $\mid \mathrm{GLcal}=36.7 ; \mathrm{Bp}=34.4$; $\mathrm{BFp}=31.2 ; \mathrm{Dp}=23.6 ; \mathrm{Bd}=31.0 ; \mathrm{SD}=28.8 ;$

- second phalanx 188/1 $\mid \mathrm{GLcal}=36.7 ; \mathrm{Bp}=36.7$; $\mathrm{BFp}=35.1 ; \mathrm{Dp}=24.6 ; \mathrm{Bd}=31.7 ; \mathrm{SD}=29.6$.

In Table 2 the morphological description is given of two equid finds, both teeth. No. 03, an upper molar from a small donkey, Equus (Asinus) asinus, is interesting because of its provenance from Stratum K. It had recently been eroded from the rough section in upper Gully B, quadrangle D12, and could be attributed to the earliest 'manure' units, V0-V1, which probably correlate with lower GSV1 (suite SD2). No. 195/15, the above mentioned upper premolar or molar identified as probably belonging to an equid hybrid (Fig. 15), was retrieved from unit T79J of Earthwork F10-F12 in Sounding A, Stratum J (Minaean 1). It might be a reworked Later Sabaean element.

A still excellent characterization of the donkey as a working companion was offered by Roger Moorey: ${ }^{72}$ "Before the camel the ass was the pack-animal par excellence, even if rarely shown in art and not yet common among the osteological evidence from excavated settlements. [...] Carrying a full load the ass goes about 2.5 m.p.h. for 6 hours daily (15 miles a day).

\footnotetext{
72 Moorey 1994, 12-13.
}

The mule goes at 3 to 4 m.p.h., covering about 20 to 25 miles a day loaded.' Loads in the recent past were about $50 \mathrm{~kg}$ maximum for an ass, in two packs, and about 75 $\mathrm{kg}$ for a mule. But, contrary to camels, donkeys and mules need water. 'Peoples using the ass moved around the water sources and did not venture into the desert. Asses could only be used on desert tracks during exceptionally rainy winters and then only on a few of them. ${ }^{73}$ Recently, the archaeology of the donkey has been ably reviewed by Peter Mitchell ${ }^{74}$ while working donkeys - and working animals in general - have been subjected to an innovative study by Jill Goulder from the perspective of modern development studies. ${ }^{75}$

The archaeological contexts in which dromedaries and donkeys occur at Yathill will be reviewed in the following section. As always with archaeofaunas, an examination of archaeological context is essential for approaching a functional study of animals' roles through time and in connection with people.

\section{Sabaean and Minaean trade}

\subsection{An overview}

Trade is an important secular aspect of the Minaean society about which the excavations in Area $C$ have produced direct and indirect information: and the direct, tangible part of the information is a first for the Yemeni Jawf. In fact, there is evidence for such an activity during both the Sabaean and the Minaean periods: in the Sabaean, from the plain bordering a still shallow tell and possibly the footslope, and during the Minaean from both the open plain and a belt close to the town wall. The evidence for sustained trade developed during the Later Minaean, as will be detailed below.

In the extramural sector captured by Area C, trade activity was perhaps intermittent, or not strictly continuous, but nevertheless it appears to have represented a constant through time. On available evidence, it was a defining functional signature for the plain and the talus to the virtual exclusion of any other kind of systematic activity. As fully functioning parts of Yathill, the plain and the talus appear to have been devoted specifically and traditionally to trading, and/or to temporary stands and sojourns by people and animals probably often associated with trading. ${ }^{76}$ In this discourse the material remains of beasts of burden acquire major significance.

\footnotetext{
73 Moorey 1994, 13.

74 Mitchell 2018. The evidence from Barāqish, and our work (Fedele 2014), are mentioned on p. 107.

75 Goulder 2018 (evidence from Barāqish mentioned on p. 112-113, 266, 474, with references); 2019.

76 Fedele 2010, 148.
} 
Most of the archaeofaunal finds presented in section 2 can be fully understood only considering their contexts. ${ }^{77}$ In summary, and focusing on dromedaries, the study of archaeological context appears to link at least some of the Sabaean-age dromedaries to campsites or tent sites possibly formed by non-residents. ${ }^{78}$ This might be particularly true for the Later Sabaean. This pattern greatly developed during the Minaean period, with trade-jar handling posts outside the walled town and frequent stationing of dromedaries and donkeys on the upper talus. Such data directly support the role of Yathill in the overland caravan trade and reveal that the northwestern extramural area was functionally important in this respect. But apart from trade proper, or 'exchange', what interests us here is any evidence for activity involving non-residents and/or exotica.

We can start with Locus 151, dated to the Later Sabaean and mentioned above in section 2.2. The composition and condition of its material do not suggest 'ordinary' kitchen refuse, nor intensive occupation in general. As a clustered feature, Locus 151 rather suggests a 'tent site' outside the settlement, arguably only one in a series of such features stratified on the former plain along the footslope of the talus (Fig. 16). The materialculture association of this locus - cooking pots, clay discs/'tripods', pans, torpedo jars - combined with a patchy distribution of activity clusters including burning (Fig. 17), suggests a scenario of bivouacs or tents on the plain. Such traces point to repeated episodes of activity in the open, possibly associated with light-shelter constructions. Some unusual or exotic items may further suggest that foreign parties were possibly involved (caravan merchants? occasional travellers?). Also torpedo jars, as a particular type of jar associated with sealed beverage transport, ${ }^{79}$ appear to fit a non-resident campsite scenario, as does the extraordinary wild camel bone already described (no. 151.1).

Here the excavated context may thus provide first-hand material evidence for trade as early as the 7th century BCE: camels as both pack animals and game, handling of trade jars, presumably exotic items, camping in tents. ${ }^{80}$ With further data in the future, trade might emerge - unsurprisingly - as a crucial factor in Yathill's flourishing from perhaps the 8th or even the 9th century BCE. ${ }^{81}$ Of course, the Sabaean occupation

\footnotetext{
77 Fedele 2014, 185; 2019, 205-207.

78 See below for details. 'Non-residents' is perhaps the most neutral and effective designation for the human agents involved.

79 See Chapter 23, section 2, this volume. Torpedo jars have recently been demoted from their presumed role of specialized, long-range trade containers. Cf. Fedele 2014, 186.

80 The previous passages in this paragraph refer to the discussion and tables in section 3.3, below ('Towards a campsite archaeology').

81 Cf. the discussion in Chapter 18, section 3.1, 'The origins of Yathill' (this volume).
}

at Yathill needs to be much more widely investigated before sound judgments can be made on the subject, and a knowledge of demography of the pack-animal herds involved will also be important.

During the Minaean occupation, this kind of archaeological pattern developed further, with the Area $C$ data pointing to a broad specialization in the material repertoire. The finds from the Minaean sequence in the extramural area can indeed be reduced to a very narrow range of categories. A vast proportion is represented by an increased number of activity indicators for 'tent-camping' and/or 'foreigners' and/ or trade..$^{82}$ Trade can now be written without quotation marks because there is positive evidence for it, and hints of this development already appeared during the First Intermediate (Stratum K). Furthermore, within the obvious excavation limits, the indisputable evidence pertaining to trade is spatially concentrated, as it essentially derives from two locations: the plain, and the area flanking the town wall (cf. Table 5). This spatial patterning itself adds to the evidence for extramural specialization during the Minaean period. ${ }^{83}$ This dual specialization, typological and topographical, deserves to be examined in greater detail.

In the open plain, the restricted but significant stratigraphic window allowed by Sounding F revealed Minaean levels replete with both trading-jar remains and flakes from lithic jar stoppers. Whole stoppers are also frequent. In both Sounding $\mathrm{F}$ and lower Sector E, fragments of cuboid burners of very basic types, probably to be explained as broken lamps left by camping parties ${ }^{84}$ seem to be common only in this areas. The material inventory from Sounding $F$ is so unusual and specific that, on this basis alone, the adjoining flats to the northwest of the tell appear to be the principal area in which the Minaeans dealt with trading and trade jars, presumably in connection with both caravan tent camps and the daily unloading and loading of animals.

Also a low outlying relief, Hill C (cf. Fig. 19), clearly played a role in connection with trade jars - or trade in general. The northern half of Hill C, and especially its 'tail', are scattered with discoid jar stoppers, mostly made from light-grey pelagic limestone, and the whole hill shows copious traces of raw material - whole wādī pebbles - at various stages of chipping (cf. finds 220.13 in Chapter 21, section 2.5, this volume). Remarkable

\footnotetext{
82 See section 3.3, below, and Tables 3-5.

83 Fedele 2011a, 114-115.

84 Although recognized as incense burners in general, simple and undecorated limestone containers from similar contexts were probably multipurpose burners or lamps: see Chapter 21, section 2.1 ('Stone burners and containers'), this volume. Already suggested in Fedele 2010, 148
} 

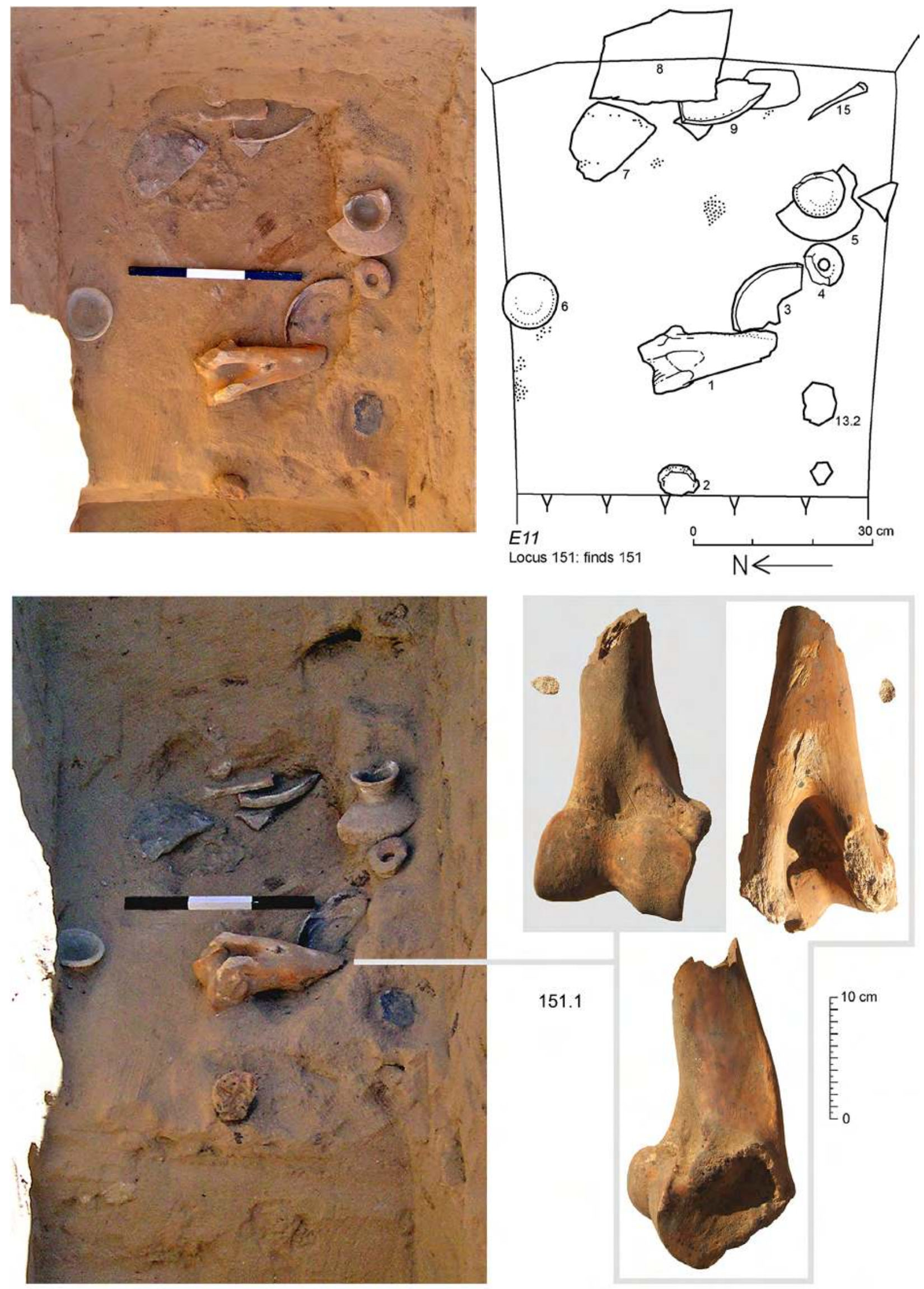

Figure 16. Area C, Locus 151: wild dromedary humerus no. 151.1 and its context in quadrangle E11, horizon H11. (Excavation context, P. Morlupi 2005 @ MAIRY; bone, F.G. Fedele 2007, rearranged 2010) 


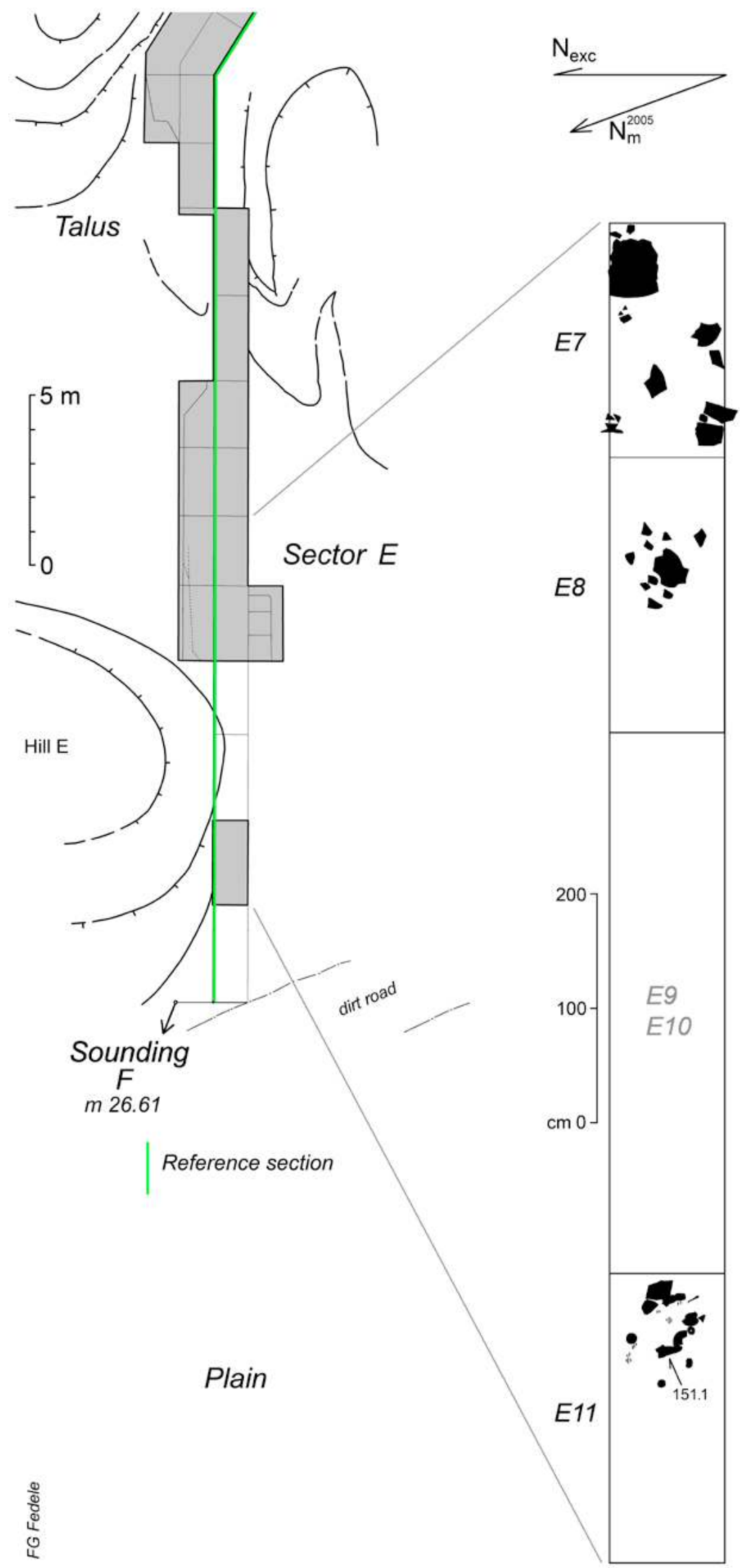

Figure 17. Area C: spatial clustering in the main Later Sabaean cultural level, lower Sector E, as an indication of 'campsite' occurrences. (F.G. Fedele 2010, revised 2020) 


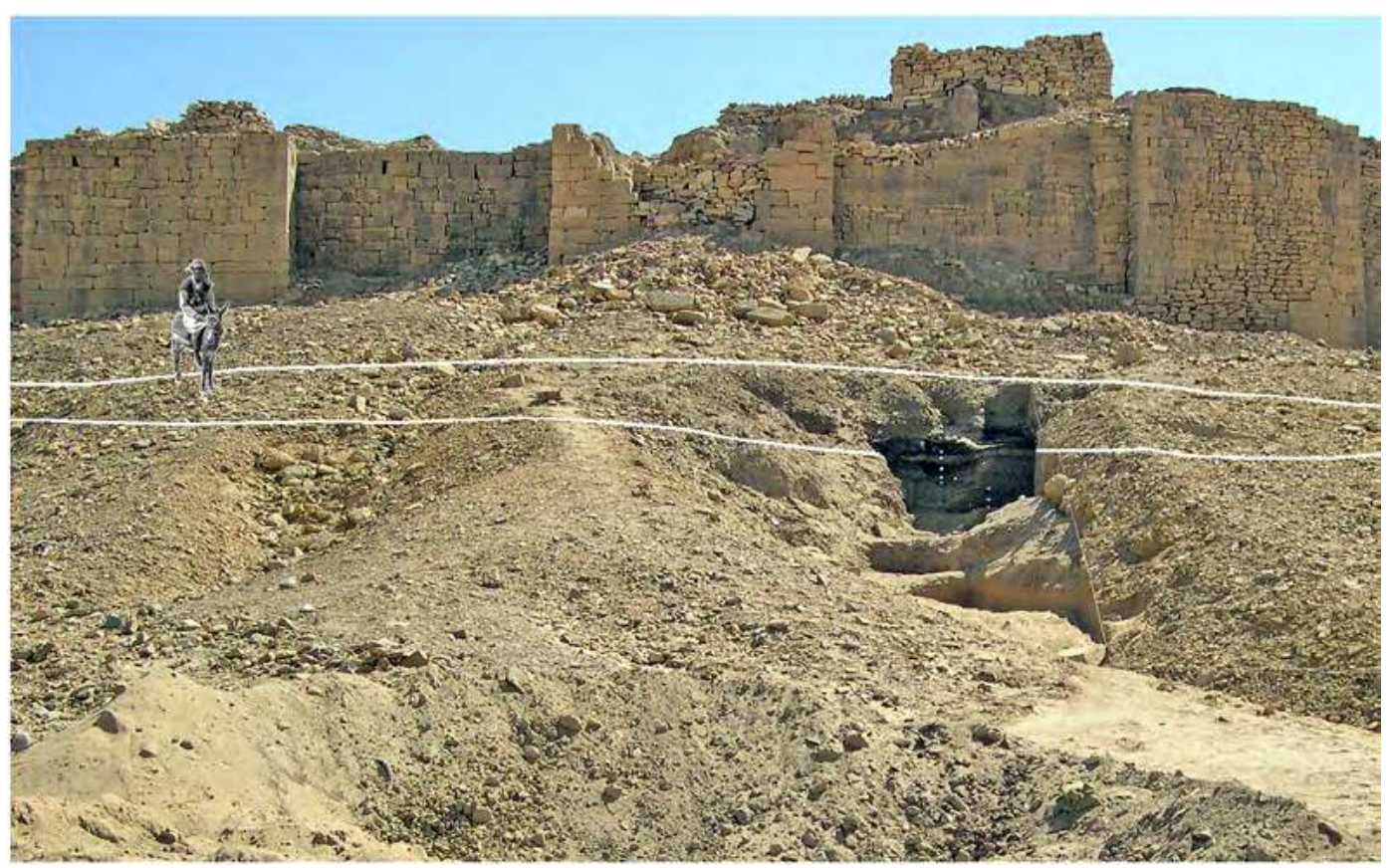

Figure 18. Barāqish Area C: the area of the upper talus which was subjected to repeated stationing of donkeys and dromedaries during the Minaean occupation. Minaean wall's bastions T5-T7 in the background. Some of the earliest 'manure' layers, belonging to the First Intermediate period, can be seen in the section on the right (upper Gully B, Sector D).

(F.G. Fedele 2010; main photograph P. Morlupi 2005 @ MAIRY)

evidence for trade-related activity is thus apparent on the hump of Hill $\mathrm{C}$, where a whole suite of subsidiary workshops might even have existed, and the surface finds point to a date in the full or later Minaean period..$^{85}$

Additional clues to the role of the extramural areas to the west of Yathill come from Hill D, a hillock to the west-southwest of Hill C (cf. Fig. 19). ${ }^{86}$ Here the presence of plaster jar sealings, clay stoppers for trade jars, and even a bronze seal fragment, although recovered from reworked aggregates,$^{87}$ might provide further evidence for caravan-trade activity on the hill itself or nearby, at a distance of a mere $100-120 \mathrm{~m}$ from the locations of Minaean activity in Area C. Besides, it needs be emphasized in this context that the excavation of the cemetery on Hill D - probably made of cenotaphs ${ }^{88}-$ has directly demonstrated the presence of foreigners at Minaean Yathill. Considering the 'rather lowly social status' inferred from the burials as well as the personal names of the deceased, ${ }^{89}$ it was thought that the Area

\footnotetext{
85 On Hill C as a site of Sabaean activity see Chapter 26, this volume; part of this earlier activity might already have been connected with trading. Chapter 26 also mentions the hypothesis that Hill C is a small tell, a possibility that extends in principle to Hill D (below).

86 Also Hill D has revealed previous Sabaean evidence: see Chapter 26 , this volume.

87 Antonini 2010a, 2010b.

88 Area D excavations: Antonini 2010a.

89 Study of the onomastics by A. Agostini (2010b); see particularly p. 67-70, 'Conclusion'.
}

D cemetery was 'possibly to be associated with the caravaneers themselves'..$^{90}$

The second area in which Minaean trading activity can be observed archaeologically is the strip between the upper talus and the curtain wall at bastion T7, a short distance from the city's gate. Significant evidence is provided by the recognition of trade-jar handling posts outside the walled town during the Later Minaean, along and near the wall itself. Evidently, the existence of a tall, sheltering wall created new opportunities for functional wall-side locations. Direct evidence for trade includes jar sealing, or rather unsealing, as demonstrated by stamped plaster fragments associated with lithic residue from the manufacture of jar stoppers (flaked limestone discs). ${ }^{91}$ During the Minaean 4 such material is particularly associated with a decayed stoneand-mudbrick structure interpreted as a jar-sealing workshop, structure F8, in which people worked, lived, and ate. ${ }^{92} \mathrm{~F} 8$ was perhaps only one of several such sheds located against the wall. One could surmise that several operations connected with trade goods took place in installations outside the walls, plausibly including the packing and dispatching of caravans, while pack animals were often kept on the talus a little below..$^{93}$

\footnotetext{
90 Antonini 2010b, 45; see also Agostini 2018b, 91.

91 See Chapter 21, section 2.3, this volume.

92 See Chapter 17, section 11.3, this volume.

93 Fedele 2014, 191.
} 


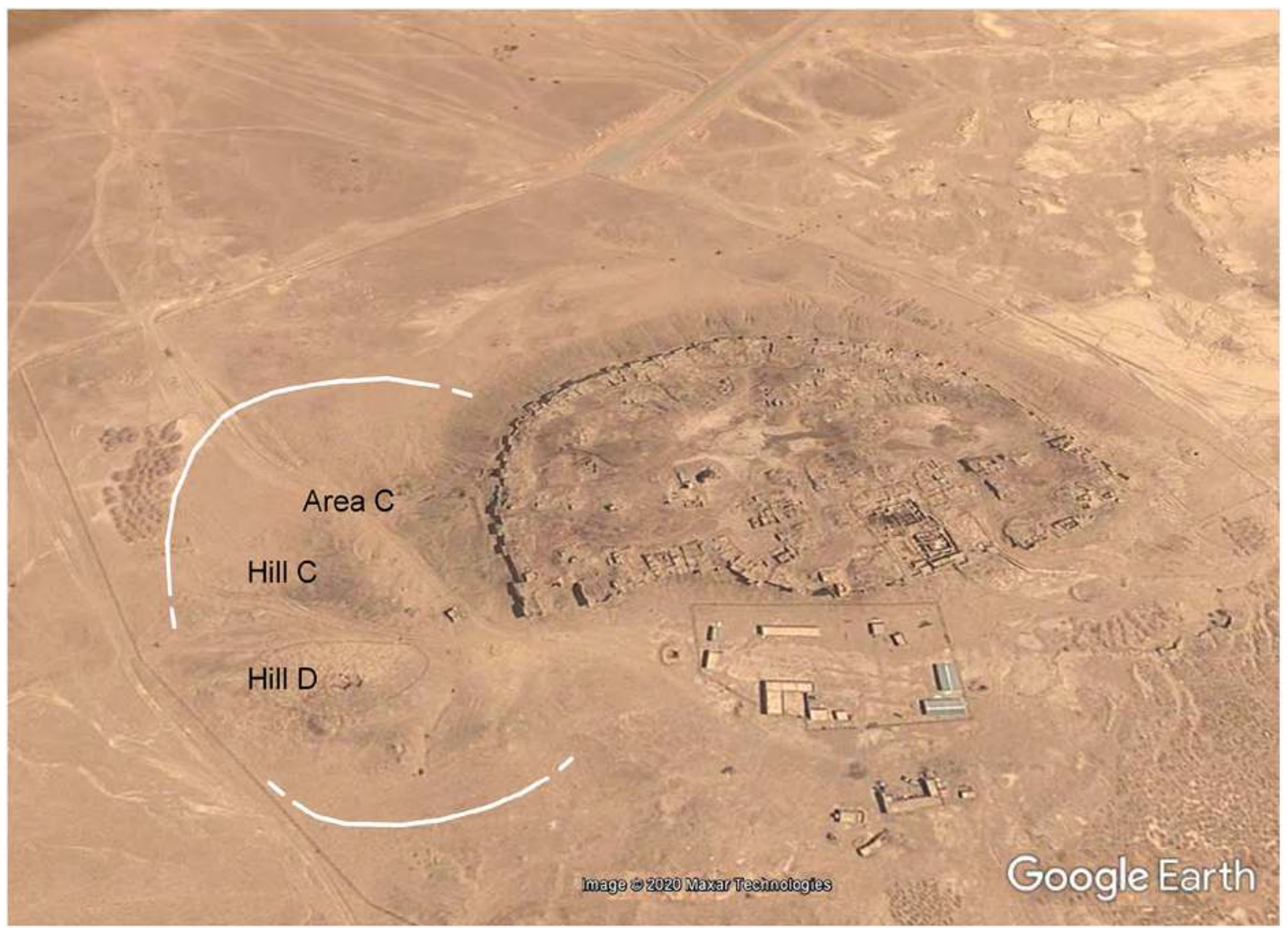

Figure 19. The plain immediately to the west of Barāqish as an area in which the Sabaeans and Minaeans dealt with trade. (Google Earth image, 4 September 2011; adapted by F.G. Fedele 2020)

This last detail is based on a concurrent piece of evidence, tentatively recognized in the dark-brown 'manure' layers that recur in the upper part of the Area $C$ deposits. They precisely correspond to the Minaean strata, although beginning with units of the First Intermediate period (Stratum $\mathrm{K}$ ), and their principal location is the Minaean-age upper talus. In these layers, both 'manure' (i.e., basically dung) and 'plant-organic' units were distinguished on the basis of the composition and ratio of actual excreta to plant fraction, as well as sedimentary texture and structure. The reader is referred for details to previous chapters in this book. ${ }^{94}$ Unfortunately, chemical analyses and a search for faecal spherulites (indicating ruminants) could not be made, but the nature and origin of such lenses and layers is rather self-evident. ${ }^{95}$ As already mentioned in Chapter 17 , section 2.3 , in the dung or manure units coprolites of dromedaries and donkeys constitute the large majority of the recognizable components (cf. Fig. 10).

94 Chapter 17, sections 2.2, 2.3, and 4.2; Chapter 18, section 3.2.

95 Fedele 2011a, 111, footnote 3; 2014, 190. See also section 2.1 above, 'On the uses of ungulate dung, ancient and archaeological'.
As a sedimentary pattern, such a sequence of dung and dung-enriched layers is unprecedented in the physical and cultural history of the extramural area. The interpretation is inescapable: throughout the Minaean period there must have been frequent stationing of dromedaries and donkeys on the upper talus. Ad hoc excavations (the test pits in Sectors B and C, this latter linkable down-talus to quadrangle D1) have shown that the stationing would particularly occur on level strips below the curtain wall, in a belt 7-20 m from the wall's face. Indeed, the area concerned can still be perceived in the present-day morphology (Fig. 18). ${ }^{96}$ At times, enclosures for dromedaries and/or donkeys may have existed, as dung concentrations are likely to indicate enclosed animals.

This repetition of manure and plant-organic layers reflects what I would call a tradition of practice, ${ }^{97}$ which is entirely post-Later Sabaean. One thing is the first

\footnotetext{
96 For a previous, black-and-white version of Fig. 18 see Fedele 2014, fig. 6.

97 A socially ingrained, persistent behavioural disposition to a certain way of using space; hence, to some extent, a 'habitus' in the sense of Bourdieu (1977).
} 
appearance of such layers in suite SD2 (corresponding to Stratum K, First Intermediate) and in the units of Stratum $\mathrm{J}$ in quadrangles D1-D2, interpreted hypothetically as connected with the construction works for the Minaean wall. ${ }^{98}$ Another thing is the continuation of these layers during the subsequent growth of the talus - i.e., Strata I, H, and F, culturally Minaean - and occasionally even afterwards (Second Intermediate period). In this latter case we are clearly in the presence of habitual episodes of donkeys and dromedaries stationing on what was now the outsidewall upper talus. The possibility that this practice was related to the activities and installations connected with bivouacking and trade-jar handling along the town wall ${ }^{99}$ remains a likely hypothesis. What is evident, is that the wide band adjacent to the Minaean wall on the upper flank of the tell came to constitute an activity area and an entirely different sedimentary environment from the previous, equivalent margin of the Later Sabaean tell.

Although Yathill's association with overland caravan trade had long been deduced from geographic position and textual sources, mainly classical, the record from Area $C$ now supports this pivotal role of the town with direct and explicit archaeological evidence. The emphasis is on material culture, that is, on tangible evidence related to a defining aspect of Minaean society. The field information suggests that the plain and talus were not inert appendages, but in fact specialized, fully functional parts of Minaean Yathill. ${ }^{100}$ Equally relevant, and not limited to Yathill alone, is the question of trade in the Sabaean period. Area C provides the important if preliminary indication that at least part of the functional patterns detected for the Minaean period were already in operation during the preceding Sabaean rule. ${ }^{101}$ Obviously, what we presently have is no more than glimpses from minuscule extramural contexts - the little that could be tangibly captured by the excavations in Area C.

Perhaps of broader interest is a methodological conclusion. This brief account should have indicated the usefulness of studying together dromedaries and donkeys as a pack-animal 'system' (the approach introduced in section 2.2, above). Furthermore, this kind of study necessarily gains significance from combining zooarchaeology with an investigation of archaeological context. If such a combined study was particularly justified at Yathill from this town's location on a famous early-historic caravan route, arguably its

\footnotetext{
98 See in this volume Chapter 18 , section 3.2 , 'On the earliest Minaean'.

99 As proposed in Fedele 2011a and 2014.

100 Fedele 2011a, 115.

101 Fedele 2010, 147-148, 'Evidence of Sabaean and Minaean trade'.
}

potential transcends this particular case: the approach lends itself to much wider applicability.

\subsection{Yathill in the trade system: further comments}

We know nothing of Yathill's actual functioning in the trade system - nothing in detail. Admittedly, almost nil is known about the 'trade system' and/or 'trade chain' in ancient Yemen. ${ }^{102}$ How was it organized operationally, spatially, temporally? What were the practical, behavioural characteristics involved, at the scale of the small group or even the individual? And how do the Sabaean and the Minaean periods compare as far as trade organization is concerned? Obviously, Barāqish/ Yathill would be a choice site to investigate this subject, and this is indeed what we uniquely glimpsed from the Area C excavations in 2005-2006 - a very modest, but promising start. ${ }^{103}$ This is also the rationale behind this brief section.

Particularly on the role of jar sealing, a few suggestions towards the goal of achieving a wider perspective can be advanced from a trade-system approach. Those found at Yathill - not only at Area C - are sealings for containers that were clearly jars, not for instance packages or baskets. On the reverse of the sealings are marks suggesting that the plaster pieces had been affixed to vessels. And most of our finds display an inscription as part of the stamp-seal impression. ${ }^{104} \mathrm{Jar}$ sealing must both be analyzed in conjunction with, and decoupled from, jar unsealing, i.e. opening a jar to transfer or decant its contents, to distribute its contents into other containers.

Arguably, broken sealings are related to incoming jars and goods. What we see for instance from Stratum $\mathrm{H}$ at bastion T7 is the opening of incoming jars, whereas the making of stone stoppers arguably has to do with the opposite 'line' of operations: the sealing of outbound jars (and outgoing goods). This latter might have been the business of workshop F8, mentioned above. One further aspect of analysis: we normally cannot be sure 'whether a seal was in use at the site itself or at another site exporting commodities'; ${ }^{105}$ at least, this kind of study does not seem to have yet been attempted in Yemen. On the other hand, foreign stone stoppers can

\footnotetext{
102 Reference is made here to an application of trade-system or trade-chain theory, as employed by contemporary economists and some historians.

103 'Trade at Barāqish would deserve full investigation in the future using the widest range of data. More and better information can indeed be expected, and the task will require direct archaeological records from both the outside and the inside of the town. For this task Barāqish may be perfectly suited' (Fedele 2010, 148).

104 See, in this volume, Chapter 21, section 2.3, 'Plaster jar sealings'; and for stratigraphic details Chapter 17, section 11.2.

105 Cf. McDonald 2003, 213.
} 
be recognized in some cases from their being made of rocks geologically alien to the site of recovery. ${ }^{106}$

Trade jars, or other narrow-necked vases, could perfectly well be stopped and sealed with non-lithic and non-plaster devices and substances. At Yathill we have no evidence for the practice of plaster jar sealing in the Sabaean period, not at least from reliable contexts. ${ }^{107}$ Until examples are found, this must be regarded in the Jawf as a Minaean novelty. Might this practice - sealing and stamping jars with plaster - have been borrowed by the Minaeans from their Syrian and/or Mesopotamian counterparts?

At the scale of the site, always in a trade-system perspective, it needs be emphasized that apart from our scrutiny along radius $\mathrm{E}-\mathrm{F}$ of Area $\mathrm{C}$ little is known of the remainder of the circuit of Yathill. However, as we have seen above, Sounding F is adjacent to Hill C, an undulation - or a tell? - that was evidently the scene of intense and prolonged activity in connection with trade jars (section 3.1). The plains to the west of Yathill - nothing is known of the narrow stretch of plain to the south - might indeed emerge as the preferred location for Yathill's caravan trade, and especially the stands or sojourns of people and animals. The relative proximity to the town's gate might have been important. A resting place for caravan animals might have existed within the walls, as at Mārib: at the peak of traffic, however, caravan space had to be found extramurally, the town itself being too small to provide rest for hundreds or thousands of dromedaries - the average caravan. In such a case a separation of 'caravan space' from 'city space' was probably standard. ${ }^{108}$ Analogies from premodern historical sources may help flesh out the composition of ancient trans-Arabian caravans and their behaviour in relation to staging-post cities. ${ }^{109}$

The surroundings of Yathill have not been sufficiently explored to determine whether there existed a caravanserai. ${ }^{110}$ With reference to the spatial and landuse notion of 'Greater Yathill' as advanced in Chapter 26 , this volume, it is not perhaps far-fetched to propose that the western quadrants of the area served as a de facto caravanserai, "where the caravans might rest

\footnotetext{
106 On the presence of exotic stone stoppers, as inferred from alien rocks, see (e.g.) Antonini 2016c, 453 (cf. Buffa 2016a, 330, footnote 15). 107 It cannot be entirely ruled out that the three plaster jar-sealing fragments described in Chapter 21 , section 2.5 , this volume, are in fact Sabaean.

108 Fedele 2011a, 115; 2014, 191.

109 E.g. Jazem and Leclercq-Neveu 2001.

110 A notable compound of this type is known from Qaryat al- $\mathrm{Fa}^{3} \mathrm{w}$ in Saudi Arabia (al-Ansari 1982; 2010, 314-315; Demange 2010a, 135; $2010 \mathrm{~b}$ ), and a small caravanserai of undefined antiquity was reported from al-Lisān between Barāqish and Mārib (Robin 1979a). Cf. Fedele 2011a, 115, footnote 7 .
}

before undertaking the next stage of their journeys'. ${ }^{111}$ Topographically, the plains of Yathill immediately surrounding the mound to the southwest, west, and northwest would have been the best suited to that purpose (Fig. 19), and the archaeological evidence from Area $\mathrm{C}$ - however limited and provisional - appears to tell a compatible story.

\subsection{Towards a campsite archaeology}

This part of section 3 particularly deals with a theory of archaeological evidence for 'caravan' activity, adapted to the case of Barāqish/Yathill (Table 3). Certain kinds of evidence from the extramural area might be used as indicators for camping parties - 'tent sites', the presence of 'foreigners' - and/or trading activity. ${ }^{112}$ The archaeological, material indicators to this effect are summarized in Tables 4 and 5, for the Sabaean and the Minaean periods respectively. This subsection is intended as a contribution towards 'campsite' archaeology, an underdeveloped research field of great promise in Yemen. ${ }^{113}$

In sections 3.1-3.2 a review of the excavation findings, including archaeofaunal remains, has shown that the sampled contexts at the base of the Sabaean talus and in the adjacent plain seem to suggest the occurrence of campsites or tent sites, possibly partly formed by non-residents. Fragments of a non-resident campsite scenario were recognized in cultural horizon H78, in Locus 151, and from the stratified Sabaean deposits of Sounding F. In broad continuity, it appears, also the evidence from the Minaean period strongly suggests that the northwestern plain of Yathill was among the preferred areas for caravan tent camps and the daily unloading and loading of animals.

This kind of inference sounds rather daring at the present stage of research, given the very limited evidence that it was possible to obtain from one restricted sampling around Yathill's perimeter. At the moment one can only glimpse a pattern to which the direct, walking experience of the Barāqish setting and surface observations at some distance west of the tell seem to add credibility. With this caveat in mind, how can we enhance our possibility of detecting patterns and contexts capable of shedding light on any remnant of transient campsites? It is widely known that the available literature on the material correlates of nomadism - or 'transience' more generally - is fairly scanty. Caravan activity should be understood in fact, archaeologically, as a kind of nomadism; this is a fundamental standpoint in the present discourse.

\footnotetext{
111 Van Beek 1969, 368.

112 Fedele 2011a, 115.

113 For a previous version see Fedele 2014, 185-191.
} 
As noted by Marjan Mashkour and Kamyar Abdi two decades ago, ${ }^{114}$ 'archaeologists are just beginning to develop techniques for identifying sites representing early forms of pastoral activities, especially those with higher mobility. [...] Ephemeral occupations, shallow deposits, and poor surface evidence cannot be dismissed as reasons why mobile pastoralist sites have been neglected in regional surveys.' But whereas mobile pastoralist sites have now been examined with a relatively focused approach, sites generated by other kinds of 'migrants' - including pack-transport sites and even 'caravan' sites - have generally eluded specific consideration. This touches particularly upon the material, non-textual evidence for caravan trade, a research subject still sadly neglected in mainstream South Arabian archaeology. Artefactual correlates and off-site traces await investigation in Yemen and over most of Arabia. ${ }^{115}$

In Table 3 the elements of a theory of archaeological evidence for caravan activity are tentatively outlined, as an attempt towards a more general theory of the material correlates of 'transience'. The table lists five separate 'activity modes' and a number of archaeological and zooarchaeological 'indicators', admittedly inspired from the case of archaeological Barāqish and ancient Yathill. The information in the table was compiled from a critical reading of literature, while informal ethnoarchaeological observations personally made in Iraq (1980-1981) and Yemen (19842007) were also useful. For such data and the relevant interpretive framework particular reference should be made to the literature here given in footnote. ${ }^{116}$ This complex subject is being developed for publication elsewhere.

With the above framework in mind, two separate lists of activity indicators potentially bearing on caravan trade have been compiled for the Sabaean and the Minaean levels. Table 4 is a summary of the indicators for 'tent-camping' and/or 'foreigners/travellers' from the Sabaean sequence, mostly dating from the Later Sabaean. Following the entries in the figure, one can recognize: (i) indications of regular stays of dromedaries

\footnotetext{
114 Mashkour and Abdi 2002, 211 (my emphasis).

115 Cf. Glanzman 2004b.

116 In alphabetical order: Akkermans 1993, 181, 256-265; Biagetti 2014, particularly 99-142 (chapter 6, 'The abandoned campsites in the Tadrart Acacus'); Bradley 1992; Chang and Koster 1986; Cribb 1991, 2004; David and Kramer 2001, 239-242, 255-270; Frendo 1996; Gilbert 1975; Hauser 2006b; Hole 1978, 1979, 1980, 2009; Jesse 2006; Köpp 2013; Mashkour and Abdi 2002; McDonald 1998, 126; Mortensen 1972; Pachur 1991; Rosen 1992, 1993, 2003, 2011 (numerous passages); Rosen and Saidel 2010; Saidel 2009; Sweet 1965; Yekutieli 2009; Zarins 1989, 135-144. Important contributions to the subject can be found in seminal edited volumes such as Gamble and Boismier (1991), BarYosef and Khazanov (1992), and Barnard and Wendrich (2008). The Finnish team investigating Jebel Bishri in central Syria has recently published a report which could also serve as a model for future work in the Yemeni Jawf (Lönnqvist et al. 2011).
}

and perhaps donkeys; (ii) the occurrence of clustered cultural residue, suggestive of 'light' cooking and meals in the open, already mentioned above; and (iii) a possibility that 'foreigners' were often involved, to judge from some rather exotic items, such as the wild dromedary humerus of Locus 151 and its cluster of artefacts. Were these non-residents not just 'foreigners' or 'travellers', but traders? The peculiar clustering of cultural debris and burnt patches can be particularly observed in the Later Sabaean occupation levels (Fig. 17), by which time dromedaries and donkeys had become more significant in the archaeofaunal record.

In Table 5 a list of activity indicators for 'tent-camping' and/ or 'foreigners' and/or trade is presented for the Minaean. The principle is once again to identify the kinds of archaeological evidence that can provide at least an indirect clue to recognizing cases of camping parties - tent sites, ephemeral stops, the presence of non-residents - and/or markers of trading behaviour. As suggested in the table, also the occurrence of broken and abandoned cuboid lamps of very basic types, for tent lighting, probably belongs among such indicators.

Can clusters of burnt stones from the outskirts of the Later Sabaean tell and the plain, attributed to Stratum M, indicate makeshift hearths? campfire arrangements? - and therefore be part of the often elusive evidence for travellers/traders? Admittedly, the evidence is minimal, but suggestive, even evocative: a 'roasted' stone tablet from Sounding F (213.01) ${ }^{117}$ and, possibly, the stones forming Cluster 82.2 in quadrangle E8 of lower Sector E. ${ }^{118}$ As noted in Chapter 21, here we are dealing with a phenomenon that appears to include the so-called 'roasted' lithics and the 'thermal stones' (or their fragments), these latter possibly represented by Cluster 82.2; and the phenomenon also recurs in the Minaean. Roasted lithics and possible thermal stones - or 'Cluster 82.2'-type features in general might be variable expressions of a single behaviouralfunctional complex related to the use of fire, be they formal hearths or more occasional contrivances (e.g. campfires). ${ }^{119}$

In this context, we may look once again at the wild dromedary humerus 151.1 (Fig. 16). I have argued (section 3.1 above) that Locus 151 in quadrangle E11 could easily fit in a patchy distribution of activity clusters in the open, resulting from a customary practice of tent sites or bivouacs on the plain, up to the

\footnotetext{
117 Its occurrence in the plain would suggest an origin from a cooking arrangement or a campfire: Chapter 21, section 2.1 ('Other utilized natural stones'), this volume.

118 See 'Remarks on Cluster 82.2' in 'Other utilized natural stones', in Chapter 21, section 2.1, this volume.

119 See Chapter 21, introduction to 'Other utilized natural stones' in section 2.3 (Minaean group).
} 
footslope of the tell. A final suggestion can now be put forward about the bone and the locus, if only because the bone in question is not only conspicuous but - on the basis of setting and context - could provide a clue to the material cluster in which it features. Can this cluster represent the remnants of a feasting by a small-group of non-residents, chopping and consuming cuts from a wild dromedary on a particular occasion? The basis for this hypothesis is ethnoarchaeological analogy. Here is Willeke Wendrich speaking of a nomadic group from the Egypt-Sudan border:120 'The remains of the feast, stacks of bones (the skins are taken) and concentrations of charcoal, will leave a material trace. One episode of rainfall and the subsequent flash flood will probably be sufficient to wash away most of the evidence of a feast.' Whence a feature like Locus 151.

Some cultural finds from Area $\mathrm{C}$ can raise the issue of ethnicity (cf. passages in Chapters 21-23, this volume). Ethnicity is almost always one of the most elusive subjects when the status of foreigner must be deduced from equally elusive or dubious exotica, as it is in our case. A useful standpoint is that at a caravan station such as Yathill the presence of foreigners should not only be expected, but regarded as a constant. ${ }^{121}$ Foreign cultural elements might offer relatively better archaeological visibility in extramural contexts, like those of Area C. For example, makeshift clay equipment such as our unfired discs/'tripods' is well suited to include artefacts brought in - or made on the spot - by nonSabaean and non-Minaean traders or visitors. ${ }^{122}$ Alien cuboid burners can occur. ${ }^{123}$ Equally to be expected is the occurrence of exotic earthenware, foreign to local production or even alien to the regional culture: this possibility has been evoked, for instance, for finds 215.01 and 120.3 described in Chapter 23. ${ }^{124}$

Finally, also certain bone and shell finds might present interest as potential indicators of foreigners, travellers, or traders. Cowries for adornment, a bivalve possibly used as food, a marine gastropod operculum (?), and a worked talus probably from an ibex, have been mentioned in section 2.1 above, with references to their descriptions in Chapter 21. Rather conspicuous from this point of view seems to be the consumption

\footnotetext{
120 Wendrich 2008, 530-531. The feasting referred to is a karama, an occasional meeting among the Ababda nomads of the southern Eastern Desert, functioning as an important occasion to renew social integration. The preferred location to hold karamas is a wādi floor, 'where there is sand suitable for baking bread and stones for roasting the meat'; the meal consists of 'sand-baked meat and bread', and 'several sheep or even camels are slaughtered and consumed' (italics mine).

121 Cf. Agostini 2018b, 91, as cited in Chapter 21, section 2.1, footnote 118.

122 See Chapter 21, section 2.1, 'Unfired or poorly fired clay artefacts: discs and/or "tripods"'.

123 See Chapter 21, section 2.1, introduction to 'Stone burners and containers'.

124 Cf. Chapter 23, section 3.3, 'Pale Green ware'.
}

of ostrich meat, also examined in section 2.1. And can the two ostrich eggshell fragments found in the same Minaean layers at bastion T7 have to do with 'travellers' as well? ${ }^{125}$ All these possibilities have been noted in Tables 3-5.

\section{Plant samples: archaeobotany}

\subsection{Exploratory sampling $1986^{126}$}

This section on plant samples will be no more than a reminder of the extraordinary potential that Barāqish/ Yathill holds for increasing the knowledge of plantpeople relationships in ancient Southern Arabia. Barāqish has been known for an unusual wealth of ancient plant remains since 1986, when A. de Maigret and his co-workers first inspected the town and its talus outside the curtain wall. ${ }^{127}$ In particular, IsMEO's Lorenzo Costantini was able to examine and sample the rainwater gullies dissecting the part of talus where an excavation trench was later placed in 2005 (AreaC, Sector D). ${ }^{128}$ In his first report he merely mentions 'samples of earth taken along the calanques [i.e. the gullies] outside the western sector of the city wall', and remarks the 'excellent state of preservation of the plant remains'. ${ }^{129}$ Much more detailed is the second report, accompanied by six photographs of plant macroremains, in which it is stated that the archaeobotanical research at Barāqish 'was concerned with the study of 400 pottery fragments from the Minean [ic] period and 9 archaeological soil samples taken from middens outside bastion no. 6 [i.e. T6]'. ${ }^{130}$ The 'archaeological soil samples', writes Costantini,

were collected [during] a brief visit of 2 days (7-8 December) from an area in which a concentration of biological remains had previously been noted. The deposit, immediately under bastion no. 6, belongs to the city levels. Interest has been concentrated on the levels belonging to the Minean [sic] period. The excavation of a limited area was also prompted by the presence of pottery fragments typical of this occupation phase. ${ }^{131}$

\footnotetext{
125 Nos $169 \mathrm{~K} .01$ and 186.01 from Strata I-H: see Chapter 21, section 2.3 , footnote 181 .

126 This subject was previously treated in Fedele 2010, 144-145. The present account is an updating.

127 de Maigret 1986, 384-388. See Antonini and Fedele, Chapter 1 in Volume 1, section 3.2.

128 Costantini 1986; Costantini and Costantini Biasini 1986, 362-363, figures $9-14$. On the rainwater gullies of the northwestern talus and Area C see Chapter 17, section 1.2, this volume.

129 Costantini 1986. No examination of pottery for plant impressions is mentioned in this report.

130 Costantini and Costantini Biasini 1986, 362.

131 Costantini and Costantini Biasini 1986,362. The attribution of the samples to the Minaean in 1986 was strongly biased by the opinion that all or most of the visible pre-Islamic occupation at Barāqish was Minaean, including the deposits exposed in gullies. The designation
} 
Costantini's samples for macroremains were taken from the northwestern talus exposures: but where from, precisely? From the above information, mentioning spots outside or below bastion T6, it was held that the location must have been Gully B, the very same place where the excavations would have been conducted in 2005 (Sector D). To some extent, it was also accepted that the samples could have been taken from Minaean levels. ${ }^{132}$ However, as the later excavations revealed, extremely little exposure of Minaean deposits was available naturally along the gully: in fact, there were some exposed Minaean units only in irregular niches at the upper end of the gully, adjacent to quadrangle $D 1$ of the later excavations. Thus it became necessary to find out whether costantini had additional information, ideally in the form of photographs of his actual sampling.

This research was a success. More than thirty years after the fact, it became possible to establish the precise location of the sampling carried out in 1986. This was accomplished in 2017 thanks to a comparison between the photographs in Costantini's possession (Fig. 20) with the detailed records of the 2005-2006 excavations in Area C. ${ }^{133}$ There is no question about the macroremains having been retrieved from sediments of middle-upper Gully A, the main erosion gully about 10 metres to the south-southwest of Gully B (Fig. 21). ${ }^{134}$ In turn, this knowledge has allowed a stratigraphic attribution of this plant material to the Later Sabaean. According to field observations of 2005 and Costantini's photographs, however, some intrusion of eroded later material is possible or even likely.

Gully A descends from a point near the southern side of bastion T5 (not T6), and more precisely between this bastion and recess R4/5 of the Minaean wall. The sampled sediments, as shown in both the photographs

as 'Minaean' thus needs to be treated with caution. Although recognized, the existence of a Sabaean-pottery phase remained of no import in archaeobotanical sampling. This is implicitly confirmed by V. Buffa's report of 2017 on part of the ceramic fragments used in the seach for plant impressions, which include both Minaean and Sabaean potsherds (see below).

132 Fedele 2011a, 111, footnote 3: 'As to plant material, it is possible to surmise that Costantini's samples were probably taken from Minaean levels, then already exposed in gullies.'

133 The collaboration of Lorenzo Costantini, extended with typical efficiency and generosity, is gratefully acknowledged. We regret that it was not possible for him to contribute directly to this book. Unfortunately, throughout 2017-2019, the closure of IsIAO and then of the bioarchaeology laboratory at the Museum of Oriental Art in Rome, followed by the transfer of collections and equipment and further combined with other personal commitments, made it impossible for Costantini to re-examine his samples and records, and write up his contribution as expected.

134 Mentioned in Chapter 1, section 3.2, this volume. A short amateur movie of the sampling, supplied by Sabina Antonini in 2016, confirms the results from the photographs. Significantly, the sampling location was chosen in collaboration with A. de Maigret, who personally followed part of the sampling and sieving. and the movie (see footnote 134), clearly have a silty matrix rich in ashy and organic contents, grey to dark grey in colour, and typically producing big clouds of dust when disturbed. The particular sample documented in the photographs was apparently obtained by scratching several sediment levels from a small area of a darkgrey outcrop. A spatial and stratigraphic extrapolation from the excavated Sector D strongly suggests that this outcrop belongs to Stratum $\mathrm{N}$ of the local Later Sabaean sequence (Sabaean 3), as does the eroded north side of middle Gully A in general. Both locations, Costantini's sampling point and the Stratum $N$ layers excavated in Sector D, can actually be seen together and appreciated positionally in panoramic excavation photographs of $2005 .{ }^{135}$ It follows that at least the majority of the plant macroremains was obtained in 1986 from Lobe 5, the protruding Later Sabaean settlement sector eventually gashed by Gullies A and B. ${ }^{136}$

The 1986 archaeobotanical sample comprises a mixture of carbonized and non-carbonized, dried plant remains. ${ }^{137}$ The material includes quantities of straw and seeds of Gramineae (Triticum cf. dicoccum, Tr. aestivum s.l., Hordeum vulgare, $H$. vulgare var. nudum, Avena sp., Echinochloa cf. colonum, Setaria sp., Gramineae indet.), non-carbonized fruit kernels and whole fruits of Phoenix dactylifera and Ziziphus cf. spina-christi, ${ }^{138}$ seeds of Cucurbitaceae (Citrullus colocynthis and Citrullus sp.), ${ }^{139}$ and charcoal and semi-carbonized wood fragments of Acacia sp. and Tamarix sp. Also recovered were grape seeds of Vitis vinifera, but they might be Islamic rather than Minaean. ${ }^{140}$ The abundance of Ziziphus stones suggests a 'particular attention and care' for this plant, 'so that it may be considered a cultivated species', ${ }^{141}$ an interpretation that seems to be supported today by both epigraphy and the excavations (see section 4.2

\footnotetext{
135 E.g., Chapter 17, Figs $9-10$ and 12, and Chapter 26, Fig. 10, both in this volume.

136 On Lobe 5 see in this volume Chapter 17, sections 4.1 and 7.6, and Chapter 26, section 3.2; with figures. As noted in Chapter 17, section 1.2 , the concordance between the photographs taken in 1986 and in 2005-2006 indicates considerable stability of the talus and its gullies in this part of Barāqish.

137 The identified taxa are listed in both Costantini and Costantini Biasini 1986, 362, and Costantini 1986, with minor differences. See a summary in Fedele 2010, 144. For a handbook of the Yemen flora see Wood 1997, whose nomenclature is followed here (apart from 'Zizyphus', changed into Ziziphus; see next footnote).

138 The correct botanical name is Ziziphus with an $i$. The generic name with the spelling 'Zizyphus' - a variant that appeared in 1882 - has not been approved: see a deliberation in Taxon 49 (2000), 806, and again more recently in the same journal (e.g., Taxon 55 [2006], 1049-1050).

139 Apparently corresponding to Cucumis sp. in Costantini 1986; I will retain as final determination Citrullus sp. from Costantini and Costantini Biasini 1986, 362, fig. 14.

140 Costantini and Costantini Biasini $(1986,362)$ caution that the presence of grapevine might in fact represent contamination, since only five pips were found in the samples and there is a 'conspicuous presence of grape pips in the inspected Islamic levels'.

141 Costantini and Costantini Biasini 1986, 362.
} 

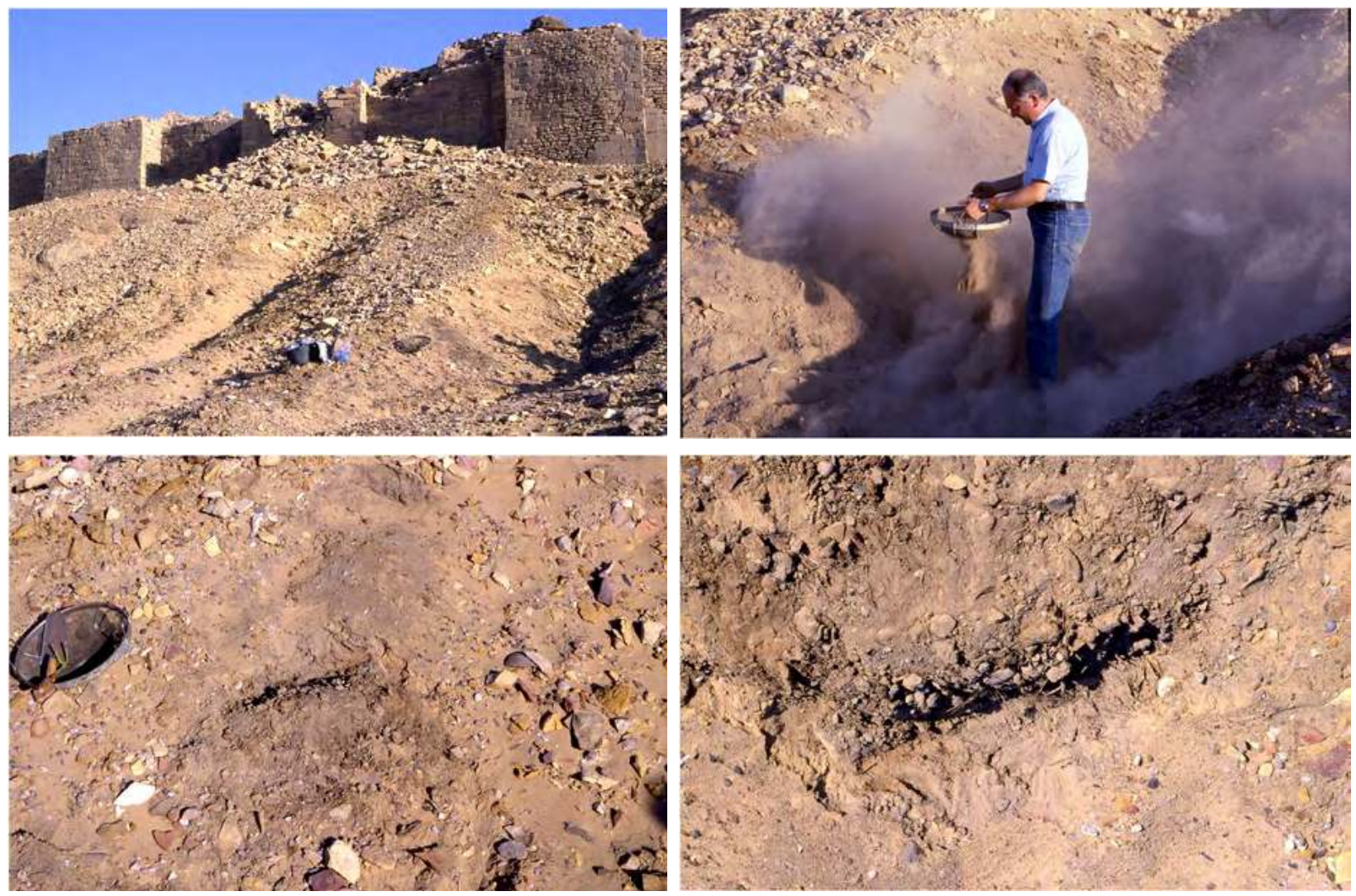

Figure 20. L. Costantini's archaeobotanical sampling for macroremains in December 1986 (photographs courtesy L. Costantini, optimized by F.G. Fedele 2017).

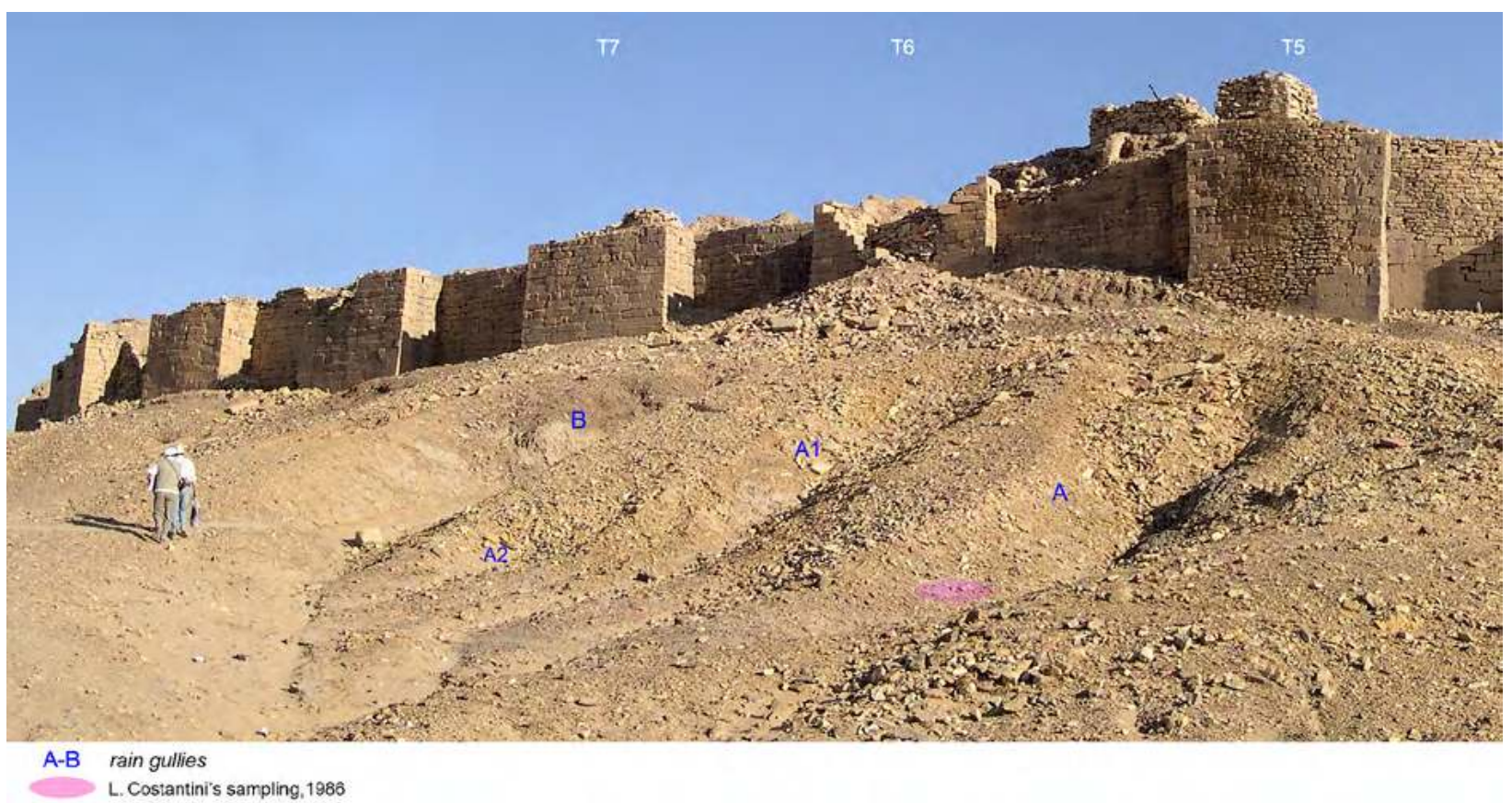

Figure 21. Re-identified location of L. Costantini's archaeobotanical sampling in December 1986.

(F.G. Fedele 2017; photograph P. Morlupi 2005 @ MAIRY) 
below). Costantini and Costantini Biasini conclude: 'The landscape that one can deduce from this preliminary analysis is one of a well-developed and fertile area with an economy based on irrigation cultivation with banks of vegetation on the margins of the savannah. ${ }^{142}$

The finds from Barāqish were briefly mentioned by A. Sima: 'Zizyphus, showing features of cultivation, has been found in the Minaean settlement layers of Barāqiš. ${ }^{143}$ To my knowledge, Costantini's sample from Barāqish was discussed in detail only by D. de Moulins and colleagues. ${ }^{144}$ After remarking at the outset that the material came 'from unspecified contexts', they offer a selective list of the wide range of species obtained from dry-sieving of the charred and dried remains. 'There is certainly no evidence for sorghum', they care to observe, ${ }^{145}$ although Barāqish in this respect is not alone among the sites of the desert fringe. These authors also list Hordeum vulgare, and possibly Rumex $\mathrm{sp}$. and Astragalus sp., from impressions in pottery (see below), while voicing diffidence towards identifications from imprints in pottery or mud bricks.

Indeed L. Costantini, in addition to the field sampling for macroremains mentioned above, also examined pottery. This information has mostly remained unpublished. ${ }^{146}$ The potsherds collected for examination in 1986 'consisted of surface finds from inside and outside the [Minaean] wall and from two neighbouring areas, BARii and BARiii'. ${ }^{147}$ The grass impressions observed were clearly Gramineae shredded as chaff. The authors report "numerous seed imprints and silica remains of glumes belonging to Echinochloa', and ' 10 Hordeum vulgare seed imprints, 8 of which on fragments from BARii'. Two incomplete impressions 'may belong to Rumex and Astragalus'. ${ }^{48}$ A recent note, personally communicated, informs that a majority of potsherds bearing impressions were Minaean, particularly among those from findspot 'BARii', but a number of Sabaean specimens were also included. ${ }^{149}$

142 Costantini and Costantini Biasini 1986, 362-363.

143 Sima 2000, 187, who lumped together the two reports in East and West 1986 and misspelled the authors' surnames (cf. his bibliography on p. 351): 'In den minäischen Siedlungsschichten von Barāqiš wurde Zizyphus nachgewiesen, der Züge von Kultivierung aufweist (Constantini) Constantini Biasini 1986, 362b) [' $b$ ' is the page column].'

144 de Moulins et al. 2003, 218 and table 1.

145 de Moulins et al. 2003, 224; see section 4.2 below.

146 L. Costantini, personal information 2016. As mentioned above, a contribution inclusive of the pottery data could not be completed for this book.

147 Costantini and Costantini Biasini 1986, 362; a total of 400 potsherds were examined (see above). On areas or sites BARii and BARiii see Antonini, Chapter 2 in Volume 1.

148 Costantini and Costantini Biasini 1986, 362.

149 About two dozen potsherds with plant imprints, most of them from 'BARii' and a few from a collection made in 1987, have been typologically identified by V. Buffa in 2017 on the occasion of the present research (list kindly copied to me by L. Costantini, in litteris,

\subsection{Plant samples from the excavations}

In 2005-2006 a preliminary but rich and well-stratified collection of plant-material samples was put together, largely obtained by froth flotation and 2-mm-mesh water sieving. ${ }^{150}$ In addition, fruits, seeds, numerous centimetre- to decimetre-sized wood fragments, and coprolites, were directly recovered from excavation. Their preservation is excellent (Fig. 22-23). ${ }^{151}$ Although the collection could not be studied, it seems on preliminary inspection that the same continuity from the Sabaean to the Minaean period observed in the fauna obtains for plants. Throughout the sequence the nutshells and branches of 'ilb, or sidr/șidr, the Christ's thorn jujube (Ziziphus spina-christi), are extremely common - and its thorny branches are particularly dangerous for the excavator. Interestingly, the cilbtree is mentioned among the cultivations of the Yathill Oasis in a Sabaean inscription from al-Darb, or alDarb al-Ashrāf, near Barāqish: '... and the Yśq'l include grapevines and Ziziphus trees and their entire yield' (Y.90.DA 1, lines 10-11, translation Sima). ${ }^{152}$

Christ's thorn jujube is followed in frequency by noncarbonized fruit kernels of the date palm (Phoenix dactylifera), melon seeds (Citrullus, Arabic hanzil), ${ }^{153}$ and some small legumes. Date stones were very frequent in units GV2-SA2 and BRH2 to BR2 of upper Sector D (quadrangles D1-D2), dating from the First Intermediate and the earliest Minaean period, but were already abundant in the Earlier Sabaean (units SIS and SGLi); some were embedded within mud-mass F13, Stratum O (quadrangles D5-D6). ${ }^{154}$ The inference is made that palm groves were an important part of the Yathill Oasis, alongside managed plantations of Christ's thorn jujube. Melon seeds were frequent within aeolian Sand YS, particularly suite YSU, and units GZ2-GZ1. Cereals do not seem equally abundant, although wheat species are frequent. Sorghum, a subject of heated debate in South Arabian archaeobotany, ${ }^{155}$ has yet to be observed.

\footnotetext{
31 July 2017).

150 See Chapter 20, this volume. The current location of the plant collections from Area $\mathrm{C}$ is unknown (cf. footnote 6 in section 1, above).

151 Fedele 2010, 144-145.

152 Gnoli and Robin 1992; Sima 2000, 186, no. 10 (where the stela is attributed to the 8 th century BCE), 377,402 ; see Chapter 1 , section 3.3 , footnote 108. On the 'ilb-tree in Old South Arabian epigraphic records in general see Sima 2000, 184-188, and on the Sabaean name of the tree p. 187, particularly: ' $L B$, whence 'ilb in Yemeni Arabic (cf. Wood 1997, 413, Arabic (ilb/'alb). In Yemeni Arabic the tree is also referred to as dōm or nabaq, particularly meaning its fruit. In the Qur'anic tradition this tree used to be called șidr or sidr, often rendered in current English as ‘sidder' (e.g. Gale et al. 2000).

153 Two melon seeds were found inside mudbrick mass GR1 of feature F9 (cut 11, qu. D3), from both excavation and flotation.

154 Cf. Chapter 17, sections 5.2 and 6.7, this volume.

155 See (e.g.) de Moulins et al. 2003; Fedele in press. A lively and informative discussion between C. Phillips, D. de Moulins, and L. Costantini concerning sorghum took place at the XII Rencontres Sabéennes in Rome, 2008.
} 


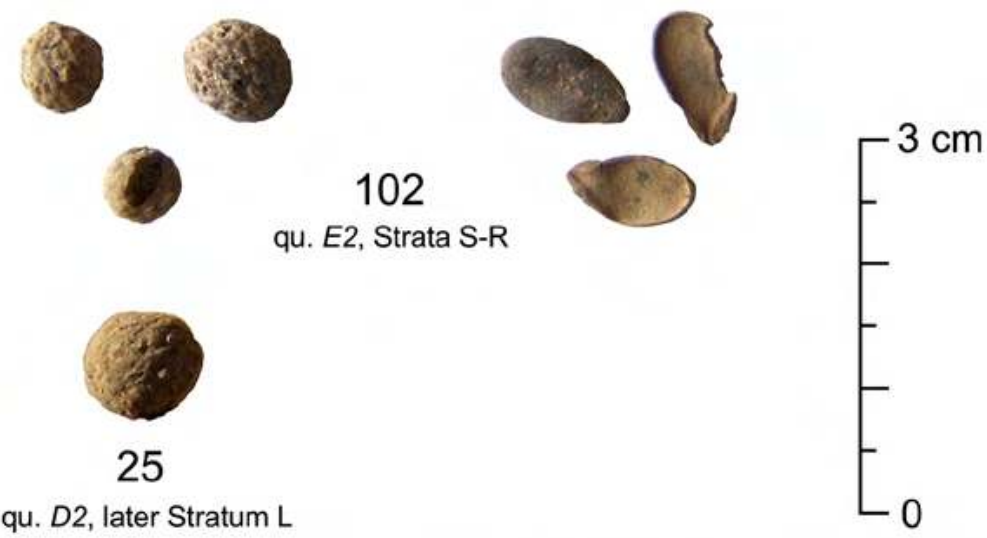

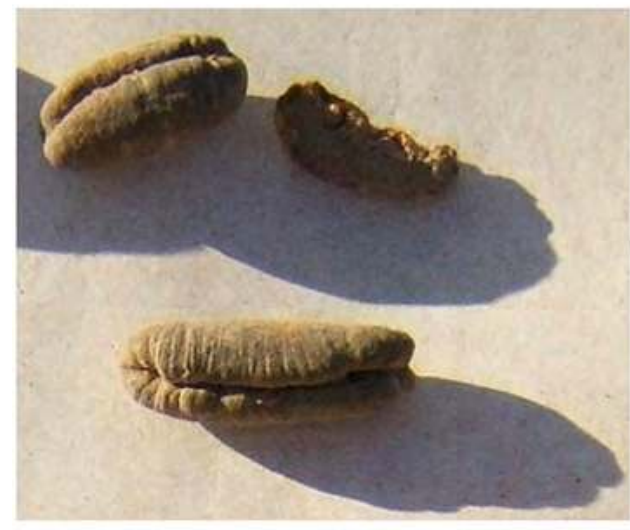

39 qu. D5, earlier Stratum N

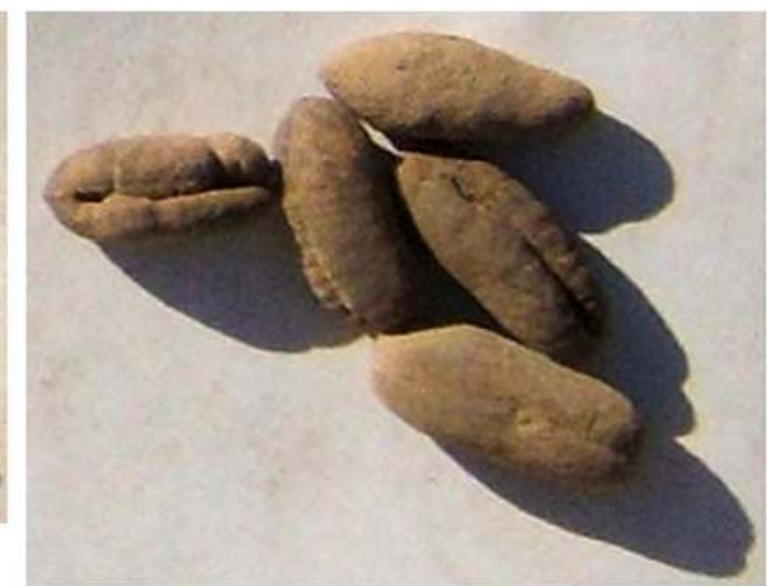

21 qu. $D 2$, Stratum $\mathrm{K}$

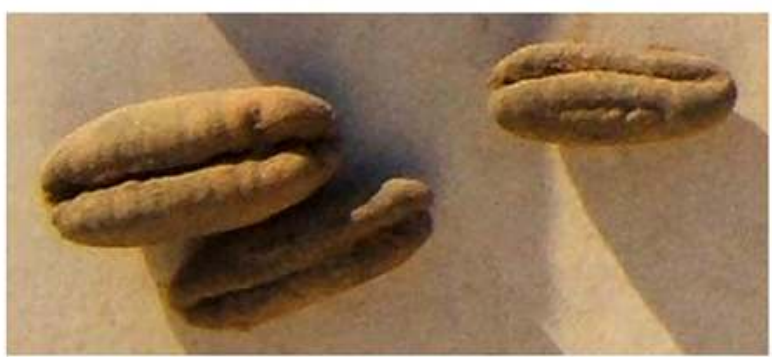

3 qu. D1, Stratum I

Figure 22. A selection of archaeobotanical finds from Area C: reg. nos 102, 'ilb nutshells and cf. water melon; 25, 'ilb nutshell; 39, 21, 3, date stones. (G. Di Rosa and S. Iavarone 2007 @ MAIRY, arranged and optimized by F.G. Fedele 2020)

Ziziphus spina-christi and the fruit trees in the Jawf deserve a few more comments in the present context. Christ's thorn jujube, a shrub or tree, ${ }^{156}$ is well known for its fruit, a fleshy, spherical, small cherry-sized drupe, its single seed encased in a corrugated nutshell. ${ }^{157}$ Such small woody shells were retrieved extensively from both the Sabaean and Minaean layers in Area C. Wrote Freya Stark in The southern gates of Arabia, in her inimitable

156 Zohary 1972, 307-308; Wood 1997, 191-192.

157 Wood 1997, 191: 'Fruit a dark red-brown spherical $(1 \mathrm{~cm})$ drupe of sweetish taste.' style: '... and 'ilb trees here and there, brooding on their shadows like a hen on eggs. ${ }^{158}$

The extraordinary multitude of uses for cilb and its products has been described and investigated extensively, in the first place from the point of view of economic importance. ${ }^{159}$ 'This is the most useful of all

158 Stark 1936, 148 [cited from the American edition; 'ilb is her spelling].

159 See, e.g., Kohler 1995; Schönig 1998; Saied et al. 2008. In Egypt, the tree has been appreciated for its shade, fruit, and timber since Predynastic times (Murray 2000, 627). 

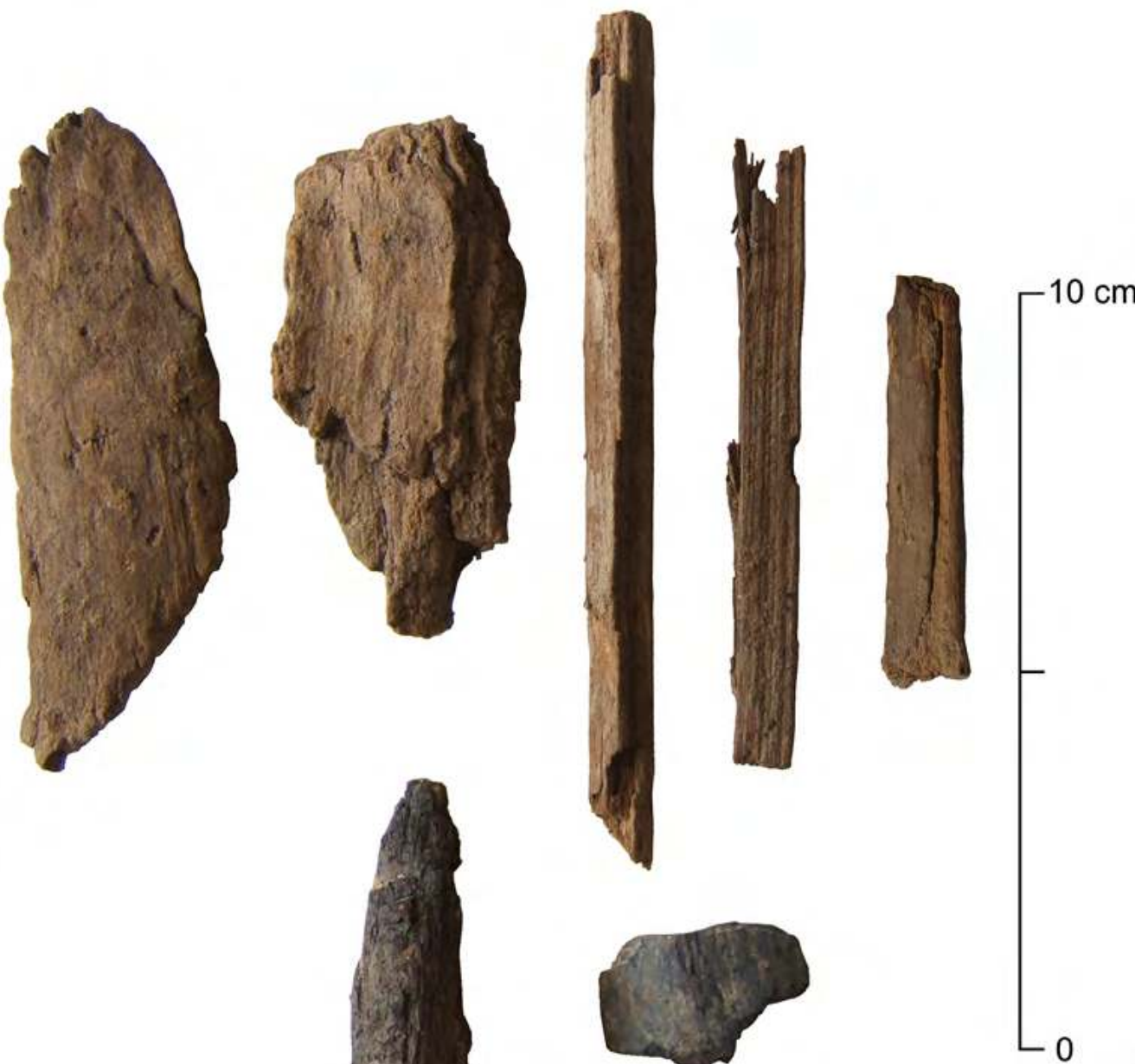

102
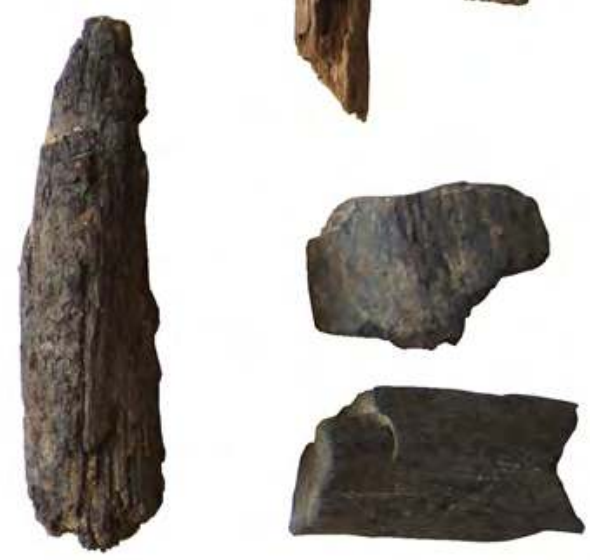

Figure 23. An example of wood fragments from Area C: cut 102, quadrangle E2, Strata S-R, Earlier Sabaean. (G. Di Rosa and S. Iavarone 2007 @ MAIRY, arranged and optimized by F.G. Fedele 2020)

trees in the traditional Yemeni economy', says Wood. ${ }^{160}$ Virtually all parts of the plant were used in the past and to some extent they still are in rural areas. Like elsewhere in the arid tropics, also in interior Yemen the cilb-trees provide browsing forage for livestock and firewood, and serve as a windbreak and as an erosion control. ${ }^{161}$ In Yemen and Eritrea the flowers are an important source of honey. Attention has also often been paid to the tree's equally deep ideological associations. ${ }^{162}$ In the Arab world this is the only tree species considered 'holy' by Muslims in addition to its status as a 'sacred'

\footnotetext{
160 Wood 1997, 191-192, quotation from p. 191.

161 FAO 1988, 538-539; cf. Murray 2000, 627.

162 E.g. Dafni et al. 2005. 'Christ's thorn is still prized by bedouin and other desert peoples for the spiritual qualities associated with the tree; [it] held a religious significance for the ancient Egyptians as well' (Murray 2000, 627, with references).
}

tree, a unique condition which is echoed in the Levant and other parts of the Near East. ${ }^{163}$ More to the point, S. Frantsouzoff ${ }^{164}$ has presented inscriptional evidence indicating that 'the 'ilb-tree should be understood as an abode of the goddess Athirat or as her incarnation', and the source of this finding is the limestone figurine of an ibex - probably coming from the Jawf - mentioned in section 2.1 above ('Additional data on wild species: ibex and gazelle').

Ingrid Hehmeyer has outlined the important role of cilb in oases and gardens in her recent history of water engineering and management in Yemen. ${ }^{165}$ She emphasizes how in the ancient oasis of Mārib the Christ's

\footnotetext{
163 Dafni et al. 2005.

164 Frantsouzoff 2006, 71-72 (probably 6th-4th centuries BCE).

165 Hehmeyer 2018, 44-45, with references; fig. 25.
} 
thorn jujube did not grow randomly, but was cultivated under irrigation: as indicated above, this certainly applies to the former oasis of Yathill as well. In many ways, the cilb and the date palm complemented each other in uses and roles, jointly forming an ecological and economic subsystem of utmost importance. ${ }^{166}$

Of particular interest is the fact that three of the ten epigraphic records mentioning cilb-trees come from the Jawf. ${ }^{167}$ An accurate and intense passage from Hayyim Habshūsh bears testimony to the continuing significance of the cilb-tree in this region during the recent centuries, although with sad overtones: 'In the Jawf, may God have mercy on them, $\left.{ }^{168}\right]$ we did not see any fruit trees other than the qurūd, a kind of lote tree that is found in abundance ${ }^{169}$ - where the qurūd is to be identified as the Christ's thorn jujube. ${ }^{170}$ In the oasis of Khabb, explains Habshūsh, the inhabitants also produce grapes and dates, although relatively 'insubstantial' compared to those of Najrān. Moreover,

in and around Khabb they gather date pits [date stones], soak them in water, and then crush them in a mortar until they break into pieces. They feed this to their flocks, which like it and become very fat. I had already been amazed at the abundance of fat on the sheep that was slaughtered for us, and they said that it was on account of these dates. ${ }^{171}$

These observations not only cast light on the fruit trees in the Jawf and the neighbouring regions to the north, but most probably echo century-old conditions and traditions.

\section{Issues in environmental history: the oasis and floodplain at Yathill}

The brief notes in this final section will be concerned with only one of the main issues in environmental history which are relevant to an understanding of Barāqish: what one could term the oasis-floodplain interaction problem, and, more particularly, how the Yathill oasis would have been conditioned by the shifting wādi system. ${ }^{172}$ Some aspects of the postMinaean environmental history, for instance the role

\footnotetext{
166 Hehmeyer and Schmidt 1991, 59, 67-74; Hehmeyer 2018, 43.

167 Sima 2000, 184-186.

168 Habshūsh compares the miserable living conditions in the Jawf with those of the inhabitants of the oasis of Khabb (north-northeast of the Jawf) and of the communities living in the "blessed Wādi Najrān'.

169 Habshūsh 2018, 155.

170 Verskin 2018, 242, note 3 (adapted); cf. Piamenta 1997, 392.

171 Habshūsh 2018, 155.

172 This subject was previously treated in Fedele 2010, 146-147 (see also p. 118-119). The present notes are a revision.
}

of climatic aridity, have been examined in Chapter 18, section 3.4 ('Yathill deserted'), this volume.

Taking the Area $\mathrm{C}$ sequence as a whole, one can detect in the landscape a general trend from well-irrigated and/or mildly wet to dryer and then to frankly dry conditions, associated with the highly monsoonal semi-desert of the Minaean and Islamic periods. The earliest units contain traces of clay and humus not found later in the sequence. The 'Yathill' fossil soil preserved beneath Wall $\mathrm{F}^{173}$ would point to an oasis microclimate from an adjoining irrigated floodplain - with date palm cultivation - rather than to wetter climate in general. Expanses of ancient irrigated fields to the west and south of Barāqish have been known for a long time, as they show from the air and form typical yardangs on the ground (Fig. 2). ${ }^{174}$ Still lacking, however, are a formal cartography and an idea of their chronology and phasing. The detailed stratigraphic work done at Barāqish both allows and demands to be coordinated with a comparable survey of the Yathill Oasis field system during the Sabaean and Minaean periods. Excavations outside of the walled city, of which our experiment of 2005-2006 in Area C was intended to be a mere beginning, seem particularly well-suited to establish linkage between the stratigraphies of the tell and the oasis.

In this context, the nature of the floodplains in the vicinity of Barāqish, and first of all to the west of the town and tell, should be investigated. This might help identify the earliest settlement, unless deep, vertical digging inside the town becomes feasible sooner. But it would more particularly help define the geomorphological setting of Sabaean and Minaean Yathill in connection with the floodplain and its wādī channels and/or irrigation canals. ${ }^{175}$ In B. Marcolongo's earliest report the essential observations were outlined as follows: ${ }^{176}$

Baraqiš is built roughly at the confluence of Wādī Mağzir in the wider valley of the Ğawf. [...] Many traces of palaeo-river beds of the Wādì Mağzir are to be found in the plain behind [Barāqish], which

\footnotetext{
173 Chapter 17, section 5.2, this volume.

174 See (e.g.) Robin 1987; Marcolongo and Palmieri 1986, 463; Francaviglia 2002. The use of geomorphological term yardang is mine. 175 The pioneering geomorphological work by Bruno Marcolongo (Marcolongo 1994, 1996, 1997, 2000; Marcolongo and Palmieri 1986) had to be by its very nature preliminary, in the circumstances, as well as incompatible in scale with the smaller-scale problems we are addressing here. On this subject the reader is referred to the previously unpublished drawings by Marcolongo presented as Figs 23-24 in Chapter 1, in Volume 1 of this book. On the open problems concerning the floodplains in the vicinity of Barāqish see also Chapter 26 , this volume. A separate examination of the Barāqish/Yathill irrigation system has been presented by V. Francaviglia (2002, 119127 , followed by comparisons and recommendations on p. 127-142).

176 Marcolongo and Palmieri 1986, 462-463.
} 
extends towards the present village of Ad-Darb. A whole series of principal and secondary irrigation canals derive from this, making up the ancient Minaean irrigation network. In particular, the most developed and continuous course extends to the west of Baraqiš, delimited also by marked fluvial terraces downstream from Al-Ḥusn. Many hydraulic works accompanying this course have been discovered about $500 \mathrm{~m}$., ${ }^{\text {sic] }}$ from the city. Amongst these is an imposing parapet made of large square blocks of limestone [...]. The parapet acted as a container for the run-off waters during flood time. At the time of the Minaean occupation the flow of the palaeo-Wādì Mağzir probably already tended to move towards the east, under the effect of a probable subsidence of the Ğawf valley bed, $\left.{ }^{177}\right]$ thus depriving the western fields of their irrigation supply. [...]

To the east of the first palaeo-river bed another two ancient alternative beds of the Mağzir can be distinguished, underlining the progressive northeast shift of the wādi even in historical times. [... In the aerial photos] the canal systems seem to belong to two successive chronological phases, marked by a change of direction. In particular, the one running NW-SE, more discontinuous and broken up, seems at some time to have been abandoned precisely because of a supply problem brought about by changes in hydraulic levels, while the system developed roughly N-S is more continuous and active. $\left.{ }^{[178}\right]$ Nowadays there are far fewer cultivated fields and these are to be found near the presentday villages.

At Barāqish Area $\mathrm{C}$, the sediments and palaeosol from Strata $T-R$ might suggest that the Sabaean irrigation system was for some time actually near to the settlement; some active channel - or a canal might have run not far from the area of our Sounding $\mathrm{F}$, as is perhaps also suggested by satellite photographs.

\footnotetext{
177 A repeated 'renewal of the relief following neotectonic movements of the faulted syncline of the Ğawf' (Marcolongo and Palmieri 1986, 463).

178 On the supply problem Francaviglia $(2002,135)$ relates: 'The inevitable steady rise in the level of the irrigated area created increasing difficulties for the water supply, and eventually meant abandoning the cultivated fields to erosion (mainly aeolian)'; 'as the irrigable fields diminished in number the city itself must have declined.'
}

Testing this hypothesis in the future through small-scale geomorphology and direct excavation would produce insights into the crucial relationships between the early settlement and its irrigation system. ${ }^{179}$

Floodplain, irrigation and microclimate are interconnected. Furthermore, channel bed morphology of semi-desert streams is particular: because of their subdued bed topography, channels of shallow braided streams may shift rather easily, ${ }^{180}$ particularly where tectonic activity is influent, as in Yemen along the contact between the Plateau and the interior lowlands. ${ }^{181}$ This kind of argument is part of the hypothesis that a final shift of the main wādi from west to east of Yathill might have broadly coincided with the c. 700 BCE reorganization and walling of Yathill itself. ${ }^{182}$

Unfortunately, this wādi diversion or capture is undated, but, whatever its chronology, following its final shift eastwards the main wādī (if not the whole wādī network) may have become less amenable to control. ${ }^{183}$

One further factor, salinization, might be relevant for the later pre-Islamic history of the area. Salinization of ancient irrigated landscapes is well-known, particularly in Iraq, ${ }^{184}$ but only occasionally has been addressed in Yemen and could not be studied at Barāqish at all. The process of salinization is often self-amplifying and may become widespread, gradually destroying the agricultural value of the land within and around the irrigation networks. One may ask whether the above processes - changing wādī and floodplain geometry, and supposed salinization - might have led to the eventual abandonment of the initial oasis at Yathill, with or without concomitant socio-cultural factors. ${ }^{185}$ A detailed reconstruction of environmental history at Barāqish will require consideration of such hypotheses. A great deal of further fieldwork at different scales is obviously needed. ${ }^{186}$

\footnotetext{
179 Only high-resolution geomorphology, as applied for instance at Mārib (Brunner's 1983 ground-breaking work), could shed light on the precise plan, functioning, and chronology of the hydraulic system at Yathill.

180 Cf. Reid and Frostick 1989. And Francaviglia 2002, 121: “'Yathill] rose in a plain interrupted by modest rises in ground level where the widian ran along uncertain, variable beds', these latter a result of the very small differences in waterbed elevations. Wādī Majzir retains the character of a braided stream to this day (Fedele 2010,119).

181 As well as along the upper Jawf depression generally (see above).

182 A hypothesis put forward in the discussion of Strata $\mathrm{P}-\mathrm{O}$ and Sand YS in Fedele 2010, 118-119, and re-examined in Chapter 17, section 6.6 , this volume.

183 Cf. Chapter 18, section 3.4 ('Yathill deserted'), this volume.

184 A classical study on the effects of salinization is semi-arid environments is Jacobsen and Adams 1958.

185 See already Chapter 18, section 3.4 ('Yathill deserted'), this volume.

186 For ground-breaking work along these lines in semi-desert Yemen see Grolier 1988 and Overstreet and Grolier 1996, with references.
} 
Table 1. Barāqish Area C: a selection of Camelus bone finds. Measurements in $\mathrm{mm}$, with estimates in parentheses, as defined in von den Driesch (1976) and in the list of non-standard measurements. LSI is the averaged logarithmic size index. From Fedele 2017, table 20.6, corrected and augmented.

\begin{tabular}{|c|c|c|c|c|c|c|c|c|c|}
\hline \multicolumn{10}{|c|}{ Barāqish: Camelus dromedarius and Camelus sp. } \\
\hline \multicolumn{10}{|c|}{ Sabaean 3. Stratum N, 7th century } \\
\hline \multirow[t]{2}{*}{ Find no. } & \multirow[t]{2}{*}{ Grid and layer } & \multirow[t]{2}{*}{ Skeletal element } & \multicolumn{6}{|c|}{ Measurements } & \multirow[t]{2}{*}{ LSI } \\
\hline & & & GLV & & & & & & \\
\hline $199 / 41$ & A1-A31 east: $\mathrm{SYH}$ & rib fr & 52.2 & & & & & & \\
\hline $199 / 42$ & A1-A31 east: $\mathrm{SYH}$ & rib fr, head fusg & 51.5 & & & & & & \\
\hline \multicolumn{10}{|c|}{ Sabaean 3-4. Stratum M, 7th/6th century } \\
\hline & & & $\mathrm{Bd}$ & BT & SD & HT & HTC & $\mathrm{Dd}$ & \\
\hline 151.1 & E11: H11, Locus 151 & humerus ${ }^{\mathrm{s}} \mathrm{di}$ & 101.6 & 89.3 & $(53)$ & 68.3 & 46.0 & $(87)$ & +0.045 \\
\hline \multicolumn{10}{|c|}{ Minaean 1, fill of Earthwork F10-F12. Stratum J, 6th (7th) century ${ }^{1}$} \\
\hline & & & GL & SD & Bp & BFp & Dp & $B d$ & \\
\hline $195 / 1$ & A1-A31: T79J, Pj & phalanx $1_{3}$ an $^{\mathrm{s}}$ & 102.3 & $(19.5)$ & 39.8 & - & - & - & -0.015 \\
\hline $195 / 2$ & A1-A31: T79J, Pj & phalanx $2_{3} a^{\mathrm{s}}$ & 62.8 & 26.9 & 32.6 & 30.2 & 24.4 & 34.5 & -0.045 \\
\hline \multirow[t]{2}{*}{$190 / 45$} & A1-A31: T77 & phalanx 1 an, px & - & - & 44.1 & - & 38.0 & - & +0.034 \\
\hline & & & $\mathrm{Bp}$ & $\mathrm{Dp}$ & & & & & \\
\hline \multirow[t]{2}{*}{$190 / 46$} & A1-A31: T77 & metatarsal ${ }^{\mathrm{D}} \mathrm{px}$ & 59.0 & 44.3 & & & & & -0.015 \\
\hline & & & $\mathrm{P}_{4}:$ Lo & $\mathrm{P}_{4}: \mathrm{Bo}$ & $\mathrm{M}_{1}:$ Lo & $\mathrm{M}_{1}:$ Bo & $\mathrm{M}_{2}: \mathrm{La}$ & $\mathrm{M}_{2}: \mathrm{Ba}$ & \\
\hline \multirow{2}{*}{$195 / 3-4$} & A1-A31: T79J, Pj & mandible ${ }^{\mathrm{s}} \mathrm{fr}+\mathrm{rM}$ & - & - & - & - & 40.1 & 19.3 & \\
\hline & & & & & & & & $\mathrm{H}_{\mathrm{P} / \mathrm{M}}$ & \\
\hline $194 / 5$ & A1-A11: T79L & mandible ${ }^{\mathrm{D}}+\mathrm{P}_{4}-\mathrm{M}_{2}$ & 22.5 & 9.8 & 39 & $(19.5)$ & 42.2 & $(48)$ & \\
\hline \multicolumn{10}{|c|}{ Finds nos. 194/5, 195/1-2, and 199/41-42 are illustrated in Figs 8-9. } \\
\hline \multicolumn{3}{|c|}{ Additional finds } & \multicolumn{7}{|c|}{ Chronology $(\mathrm{BCE})^{2}$ and remarks } \\
\hline $102 / 1$ & E2: predom. SE3, SI1 & metacarpals $\mathrm{J} /$ fusg & \multicolumn{7}{|c|}{ Sabaean 1-2. Strata S-R, c. 770-680. Fig. 8. Bd = 84.} \\
\hline $47 / 1$ & D7: SGP $-\mathrm{SGPO}-\mathrm{YSX}$ & humerus di J & \multicolumn{7}{|c|}{ Sabaean 2. Stratum R or Q, 7th C. Resected, cutmarks. } \\
\hline $39 / 1$ & D5: GK4 & phalanx 2 & \multicolumn{7}{|c|}{ Sabaean 3. Stratum N, 7th C. Pathological (arthrosic?). } \\
\hline $200 / 42$ & A1-A31 east: SZ2-SYH & rib fr & \multicolumn{7}{|c|}{ Sabaean 3. Stratum N, 7th C. Roasted. } \\
\hline $199 / 43$ & A1-A31 east: SYH & rib fr & \multicolumn{7}{|c|}{ Sabaean 3. Stratum N. } \\
\hline $151 / 01$ & E11: horizon H11 & ulnas fr & \multicolumn{7}{|c|}{ Sabaean 3-4. Stratum M, 7th/6th C. Roasted, reddened. } \\
\hline $151 / 02$ & E11: horizon H11 & humerus $^{\mathrm{D}}$ px fusg & \multicolumn{7}{|c|}{ Sabaean 3-4. Stratum M, 7th/6th C. Roasted, reddened. } \\
\hline $33 / 1$ & D14: GZ3 & humerus px fr & \multicolumn{7}{|c|}{ Sabaean 4. Stratum L, 7th/6th C. } \\
\hline $33 / 2$ & D14: GZ3 & femur di fr & \multicolumn{7}{|c|}{ Sabaean 4. Stratum L, 7th/6th C. } \\
\hline $198 / 4$ & A1-A31: AR-T7F $2-5$ & humerus di fr & \multicolumn{7}{|c|}{ Minaean 1 , foundation trench. Stratum J. ${ }^{1}$} \\
\hline $198 / 5$ & A1-A31: $\mathrm{AR}-\mathrm{T} \mathrm{F}_{2-5}$ & epistropheus fr & Minae & 1 , foun & tion trer & h. Strat & $\mathrm{m} \mathrm{J} .^{1}$ & & \\
\hline $198 / 7$ & A1-A31: $\mathrm{AR}-\mathrm{T}_{7} \mathrm{~F}_{2-5}$ & phalanx $1 \mathrm{~J} \mathrm{fr}$ & Minae & 1 , foun & tion trer & h. Strat & $\mathrm{m} \mathrm{J} \cdot{ }^{1}$ & & \\
\hline $197 / 1$ & A1-A31: AR-T7F ${ }_{1}$ & metapodial di fr & Minae & 1 , foun & tion trer & h. Strat & $\mathrm{m} \mathrm{J} .^{1}$ & & \\
\hline $195 / 5$ & A1-A31: T79J, Pj & rib fr, just fused & Minae & 1, Earth & rork F10- & 12. Stra & $\mathrm{Im} \mathrm{J.}{ }^{1}$ & & \\
\hline $195 / 6$ & A1-A31: T79J, Pj & thoracic vertebra fr & Minae & 1, Earth & ork F10- & 12. Stra & Im J. ${ }^{1}$ & & \\
\hline $194 \mathrm{~A} / 6$ & A31: T79L & lower canine fr & Minae & 1, Earth & rork F10- & 12. Stra & $\mathrm{Im} \mathrm{J.} .^{1}$ & & \\
\hline
\end{tabular}




\begin{tabular}{|c|c|c|c|}
\hline $191 / 6$ & A1-A31: T77 $\mu$ & mandible ramus fr & Minaean 1, Earthwork F10-F12. Stratum J. ${ }^{1}$ Small, burnt. \\
\hline $191 / 7$ & A1-A31: T77 $\mu$ & radius $^{\mathrm{s}} \mathrm{px}$ fr & Minaean 1, Earthwork F10-F12. Stratum J. ${ }^{1}$ \\
\hline $189 / 74-76$ & A1-A31: lower T7LP & pubis $^{s}$ frs, fusg & Minaean 2. Stratum I. \\
\hline $188 / 4$ & A1-A31: T7LP-SRI-T7P & humerus di fr & Minaean 2. Stratum I. Roasted. \\
\hline $188 / 5$ & A1-A31: T7LP-SRI-T7P & metacarpal di fr & Minaean 2. Stratum I. Chopped, metal-tool cutmarks. \\
\hline $169 \mathrm{H} / 1$ & A31: T7P0-T76J, TPVi & phalanx 2 & Minaean 3. Stratum H. Corroded. \\
\hline $185 / 16$ & A1-A31: SR-T76H, TPV & talus fr & Minaean 3. Stratum H. Carbonized 'black'. \\
\hline $185 / 17$ & A1-A31: SR-T76H, TPV & phalanx 2 di fr & Minaean 3. Stratum H. \\
\hline $185 / 18$ & A1-A31: SR-T76H, TPV & mandible fr $+\mathrm{rM}$ & Minaean 3. Stratum H. \\
\hline $211 / 1$ & $F: \mathrm{F}_{1-3}-\mathrm{F} 02 \lambda, \mathrm{F} 02 \mathrm{~K}$ & humerus di fr & Minaean 3-4. Stratum G. Sandblasted. \\
\hline $184 \mathrm{~B} / 2$ & A1 south: lower T75 & cervical vertebra & Minaean 4. Stratum F. Dorsocaudal fr. \\
\hline $183 / 1$ & $\begin{array}{l}\text { A1-A31: suite T74L, } \\
\text { part }\end{array}$ & mandible + P-M & Second Intermediate. Stratum E. Weathered $+\mathrm{CaCO}_{3}$ crust. \\
\hline 184.2 & A south: T75-T7B & whole coprolite & Minaean 4. Stratum F. Fig. 10. $\varnothing=27-31$. \\
\hline
\end{tabular}

${ }^{1}$ Most bones from the foundation trench of the Minaean wall, and some from the fill of Earthwork F10-F12, are reworked Sabaean material (probably Sabaean 3).

${ }^{2} 7$ th $\mathrm{C}=7$ th century BCE (and so on).

Abbreviations and osteology codes, in alphabetical order:

an = anterior; ${ }^{\mathrm{D}} / \mathrm{s}=$ right/left; $\mathrm{di}$ = distal; fr/frs = fragment/s; fusg = fusing; $\mathrm{J}$ = juvenile; predom. = predominantly; $\mathrm{px}=$ proximal; $\mathrm{rM}=$ root of molar tooth; ${ }_{3}=$ third or axial toe (phalanges)

Non-standard bone measurements:

- mandible $\mid \mathrm{H}_{\mathrm{P} / \mathrm{M}}=$ height of mandibular body at the P/M contact, lingual side (cf. von den Driesch no. 15b for Bos);

- mandibular cheekteeth $\mid \mathrm{Ba}, \mathrm{Bo}=$ alveolar, occlusal breadth; $\mathrm{La}, \mathrm{Lo}=$ alveolar, occlusal length;

- humerus, distal | Dd = greatest depth of the distal end, by analogy to Dd of tibia; HT = maximum height of trochlea, medial side (Payne); HTC = height of trochlea at main constriction (Davis);

- rib | GLV = greatest length of the dorsal (vertebral) end, head to tubercle. 
Table 2. Barāqish Area C: morphological description and measurements of equid teeth nos 03 (quadrangle D12, Stratum K) and 195/15 (Sounding A, Stratum J, but possibly Sabaean). Measurements in mm.

No. 03: $\mathrm{M}^{35}$

\begin{tabular}{|c|c|c|c|c|c|c|c|c|c|c|}
\hline age & $\begin{array}{l}\text { wear } \\
\text { stage }^{1}\end{array}$ & \multicolumn{2}{|c|}{ caballine fold } & \multicolumn{3}{|c|}{ protocone } & \multicolumn{2}{|c|}{ interstylar walls } & styles & size \\
\hline adult+ & $\begin{array}{l}\text { 4, 'full } \\
\text { wear' }\end{array}$ & & & \multicolumn{3}{|c|}{$\begin{array}{l}\text { long (elongated di); slightly } \\
\text { S-shaped (lg wall slightly } \\
\text { concave) }\end{array}$} & & $\begin{array}{l}\text { mesostyle pointed, } \\
\text { small; } \\
\text { parastyle pointed, } \\
\text { protruding }\end{array}$ & small \\
\hline \multicolumn{11}{|c|}{$\begin{array}{l}\text { additional notes: } \\
\text { - prefossette merging into the lg sulcus, hence caballine fold inexistent; } \\
\text { - postfossette with elongated di-lg extroflexion (no hypoglyph); } \\
\text { - occlusal surface very oblique to axis of tooth crown (cf. Payne 1991, 167) }\end{array}$} \\
\hline $\mathrm{OL}$ & Lo & $\mathrm{Be}$ & lo & B & LP & PC index ${ }^{3}$ & $\mathrm{Hbu}$ & Hlg & $\mathrm{Ht}$ & \\
\hline 22.0 & 21.8 & 18.7 & 19.4 & 20.9 & 11.4 & 51.8 & 54.8 & 55 & 65.7 & \\
\hline
\end{tabular}

No. $195 / 15: \mathrm{P}^{3} \div \mathrm{M}^{1 \mathrm{~S}}$

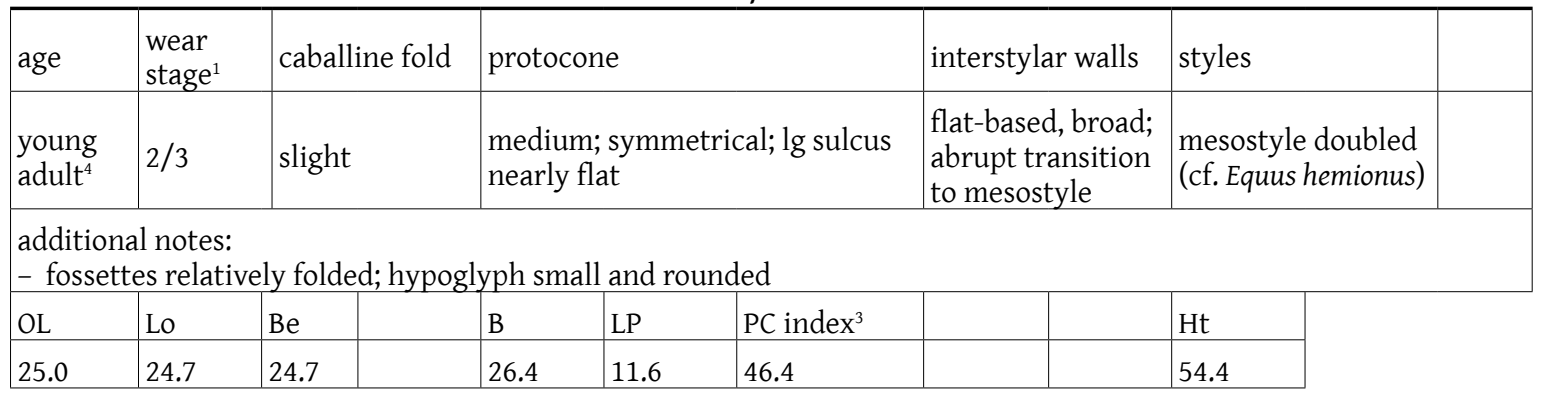

${ }^{1}$ After Payne 1991.

${ }^{2}$ However, measurements were taken.

${ }^{3}$ Protocone index $=100 \times$ LP/OL (Payne 1991).

${ }^{4} 5 \div 8$ years.

Abbreviations:

$\mathrm{bu}=$ buccal; di = distal, distally; $\lg =$ lingual

Definition of measurements:

- B: after von den Driesch 1976, fig. 6b

- Be: bu-lg length excluding external cement

- Lo, lo, Ht: after Eisenmann 1980, 81

- LP: length of protocone including enamel

- OL: maximum occlusal length including external cement

- Hbu, Hlg: after Levine 1982, 228-229, fig. 2 (Hbu adapted from F. Prat 1966, p. 11/F) 
Table 3. Towards a theory of archaeological evidence for 'caravan' activity, particularly adapted to the case of Barāqish/Yathill: a preliminary list. As detailed in the right-hand part of the table, five behavioural entities with their attendant attributes (1-5) can be distinguished, and their archaeological indicators should be sought. From Fedele 2014, table 3, modified.

Behavioural entities or 'activity modes' (1-5)

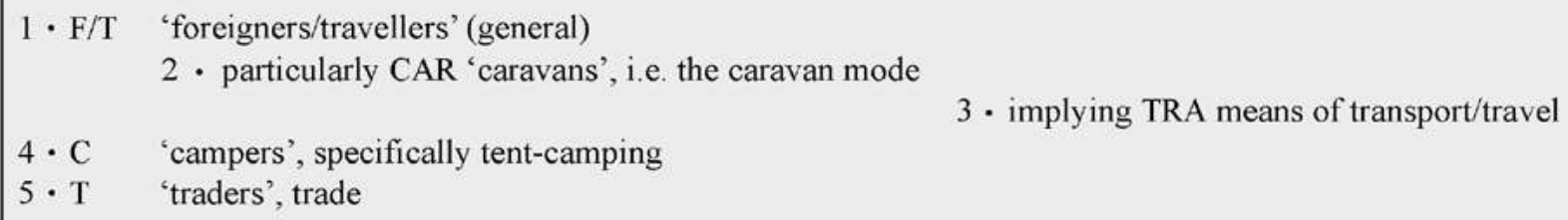

A tentative list of archaeological (material) indicators, with an emphasis on the case of Barāqish/Yathill

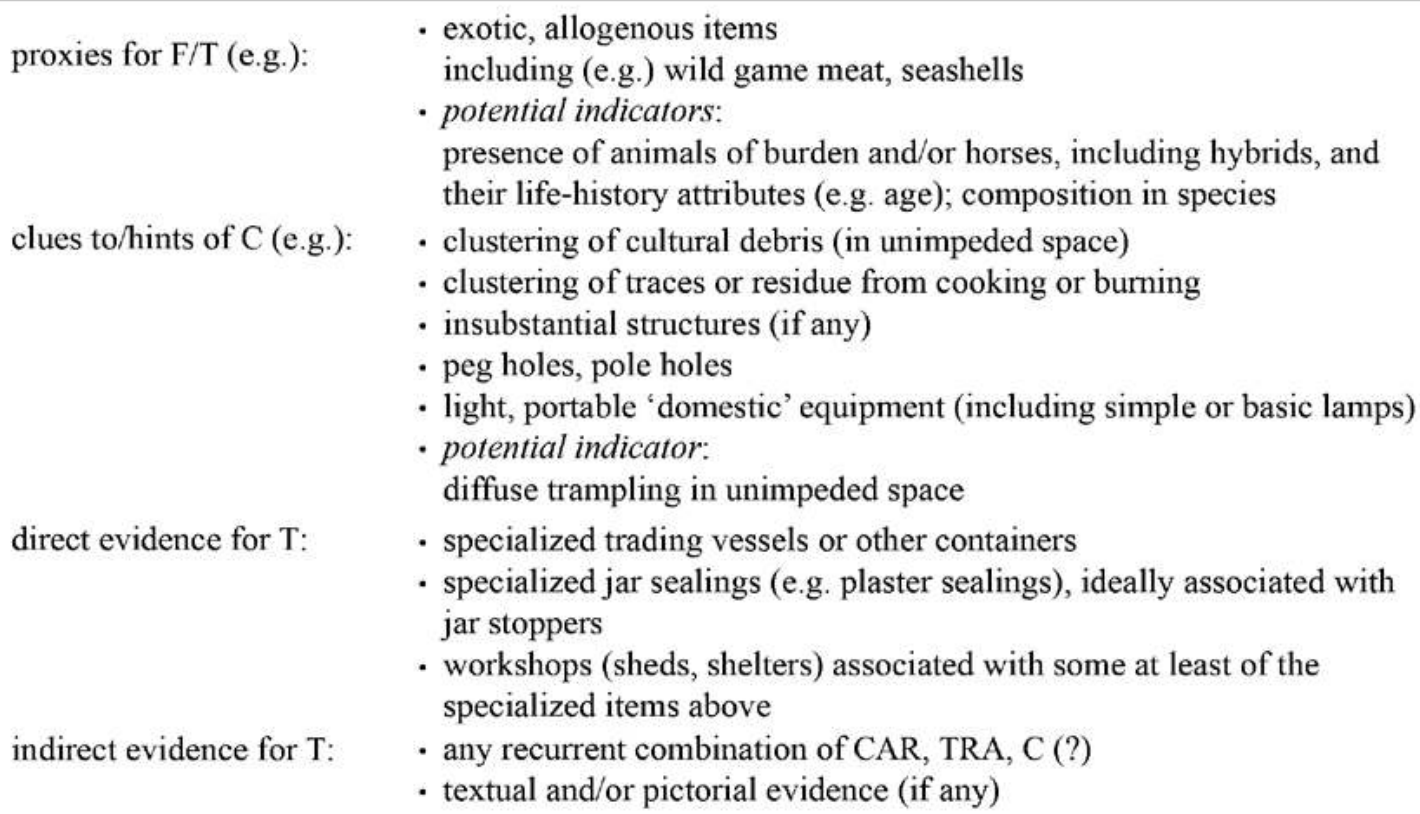


Table 4. Barāqish Area C: actual or potential indicators for 'tent-camping' (C) and/or 'foreigners/travellers' (F/T) in the Sabaean strata, and particularly the Later Sabaean. From Fedele 2014, table 4, modified.

\section{Sabaean}

- All evidence comes from the base of talus and plain;

- mostly dating from the Later Sabaean

- a 'manure' layer at the foot of the Sabaean-2 tell, and coprolites both in quadrangle E8 and near Sabaean Wall F4 in quadrangle $E 2$

- indicating regular stay of Camelus dromedarius and perhaps Equus asinus (no bones of this latter)

- a clustering of cultural debris (1) as well as traces on the ground (2):

(1) what cultural debris?

- cooking pots and related items employed in cooking (clay discs/'tripods' etc.), several of them indicating cooking on the spot (i.e. in situ debris);

- burnt and broken limestone cobbles, 'roasted' sandstone tablets/plaquettes, etc.;

- unusually large charcoal fragments, ash concentrations;

- a frying pan with mending holes;

- a broken quern;

- animal bones all from cooking and meals, and from caprines and cattle exclusively (i.e., no donkey, no domestic dromedary!), except for a highly unusual bone from a wild dromedary (no. 151.1, see below)

(2) burnt patches in particular (Sounding F)

- and associated ash pockets and burnt stones, see above

- the above, all likely indicators of 'tent-camping' or campsites (hence 'foreigners/travellers'?)

- recurrent trampling (in the plain) - pointing to habitual circulation by animals and/or people

- indication of encounters with wild dromedary herds (bone 151.1, Locus 151); and

- introduction of an obsidian core (from Sounding F);

- a perforated pendant of unusual shape (from Sounding F);

- a fragment of a cowrie

- all potential indicators of 'foreigners/travellers' 
Table 5. Barāqish Area C: actual or potential indicators for 'tent-camping' (C) and/or 'foreigners/travellers' $(\mathrm{F} / \mathrm{T})$ and/or trade (T) in the Minaean strata. From Fedele 2014, table 5, modified.

Minaean

\begin{tabular}{|c|c|c|c|}
\hline \multicolumn{4}{|c|}{ The evidence comes from two main areas: } \\
\hline \multicolumn{2}{|c|}{$1 \diamond$ the area flanking the Minaean wall } & \multicolumn{2}{|c|}{$2 \diamond$ the plain and the talus footslope } \\
\hline $\begin{array}{l}\text { a belt along the wall } \\
\text { (Sounding A) }\end{array}$ & $\checkmark$ the upper talus & $\checkmark$ the base of talus & $\begin{array}{l}\text { the open plain } \\
\text { (Sounding F) }\end{array}$ \\
\hline$\Downarrow$ & $\Downarrow$ & $\Downarrow$ & $\Downarrow$ \\
\hline $\begin{array}{l}\text { - structure F8, quite probably a } \\
\text { workshop for handling trade jars } \\
\text { (sealing/unsealing; Minaean 4) } \\
\text { containing: } \\
\text { - both flaked \& unused limestone } \\
\text { cobbles for making jar stoppers; } \\
\text { - stamped plaster sealings, } \\
\text { broken (Minaean 3) }\end{array}$ & $\begin{array}{l}\text { - repeated, thick 'manure' } \\
\text { layers from dromedaries and } \\
\text { donkeys, containing coprolites, } \\
\text { urine chemicals, lenses of fodder } \\
\text { etc. - suggesting that animals } \\
\text { were frequently stationed on } \\
\text { the upper talus (occasionally } \\
\text { enclosed?); } \\
\text { - an intercalated level of } \\
\text { limestone spalls from the making } \\
\text { of jar stoppers }\end{array}$ & $\begin{array}{l}\text { - traces of plaster } \\
\text { sealings (from qu. E8 } \\
\text { etc.); } \\
\text { - a limestone burner, } \\
\text { i.e. a lamp (from qu. E8); } \\
\text { - fragments of trade } \\
\text { jars; } \\
\text { - an isolated quern (a } \\
\text { 'Minaean' type?) }\end{array}$ & $\begin{array}{l}\text { - concentrations of trade } \\
\text { jars, jar stoppers, fragments } \\
\text { of plaster sealings; and in } \\
\text { addition: } \\
\text { - a limestone burner, i.e. a } \\
\text { lamp; } \\
\text { - a cowrie (probably from a } \\
\text { necklace); } \\
\text { - a fossil shell }\end{array}$ \\
\hline $\begin{array}{l}\text { - the above providing the only } \\
\text { direct evidence of trade at Yathill } \\
\text { for the moment (Later Minaean) }\end{array}$ & & $\begin{array}{l}\text { - the above suggesting } \\
\text { tent-camping and } \\
\text { indicating involvement } \\
\text { in trade }\end{array}$ & $\begin{array}{l}\text { - the above suggesting } \\
\text { tent-camping, 'foreigners/ } \\
\text { travellers', and indicating } \\
\text { involvement in trade }\end{array}$ \\
\hline $\begin{array}{l}\text { In addition: } \\
\text { - remnants of large trade jars; } \\
\text { - roasted ostrich meat (Minaean } \\
\text { 2-3), ? F/T; } \\
\text { - ostrich eggshell containers } \\
\text { (Minaean 2-3), ? F/T; } \\
\text { - a marine ark clam, possibly food } \\
\text { (Minaean 4), ? F/T } \\
\text { - ? wild camel meat }{ }^{1}\end{array}$ & & & \\
\hline
\end{tabular}

- Concerning the animals of burden, one can observe during the Minaean:

- an unprecedented frequency of Equus asinus, almost exclusively represented by adult or aged individuals;

- and almost certainly the appearance of mules;

- all indicators of systematic use of donkeys in work and/or pack transport;

and plausible indicators of at least local transport (hence probably short-distance trade?)

${ }^{1}$ No. 190/45 (see Table 1), unless it is a reworked Sabaean element. 


\title{
Chapter 20 \\ The Area $\mathrm{C}$ \\ Collection Catalogue and Related Works
}

\author{
Francesco G. Fedele
}

The archaeological collection from Area $\mathrm{C}^{1}$ was formed according to the procedures outlined in Chapter 17, section 1.3. The laboratory processing of the collection from both excavation seasons was organized and carried out in 2006 and 2007. In 2006 a cleaning and basic cataloguing of the finds from the previous season was made, as well as a summary study of stratigraphic variation as reflected in the artefacts. In 2007 a study of the collection from Sounding A was carried out and numerous refinements were introduced to the catalogue for Area $\mathrm{C}$ as a whole, in conjunction with a fuller photographic coverage. The results in terms of inventory will be called 'comprehensive collection catalogue'.

Comprehensive catalogue means full cataloguing. The finds and samples were inventoried and coded according to the classification shown in Table 1. Finds are here defined as discrete elements of archaeological significance. It will be noted that in this system no hierarchical or value-laden distinction is made among finds, given that every find can contribute information. Importantly, Table 1 is exclusively based on the variety of finds and samples that were recovered from Area C. More than a simple tool for inventory-making, the table thus aims to define the spectrum of materials of archaeological interest contained in these extramural deposits, which, thanks to good preservation, is very broad indeed. A sample page from the Area C comprehensive collection catalogue is shown in Fig. 1. ${ }^{2}$

It would be heartening if the entries in Table 1 served as a guide to the potential contents of other tell sites in arid Yemen, when archaeological fieldwork is resumed. To phrase it differently, ${ }^{3}$ it is hoped that archaeologists working on urban historical sites in Yemen (or indeed elsewhere in Arabia) will be provoked to adopt methods of recording and cataloguing that are more faithful to the nature and potential of tell sites than those now in common use.

\footnotetext{
1 'Collection' refers to the whole amount of finds and samples from the excavation of a site or part of site, in this case Area C (Chapter 17, section 1.3 , this volume).

2 The full catalogue is expected to be made available online in the future from a personal or institutional website (cf. Endnote in Chapter 17, this volume).

3 Cf. Schiffer 1996, xviii.
}

At the same time such a comprehensive, laborious cataloguing is intended to match the field objective of total recovery. The recovery of all and every piece of archaeological significance, within the limits of practical possibility, is a frequent goal in excavations of prehistoric sites, or of sites of palaeoecological importance, all over the world. Precisely because our project shared palaeoecological objectives, total recovery was adopted as a defining strategy at Barāqish Area $C$, where a historical archaeological site simulates in all respects a prehistoric site. In retrospect, ours can be regarded as one of the few total recovery endeavours in Yemen. ${ }^{4}$

In evaluating the collection from Area C, already during the first field season, one of the urgent needs was that of distinguishing between materials due to primary deposition (i.e., produced by use and discard on the spot) and materials that had been subjected to reworking and redeposition. Reworking or intrusions were expected, since erosion and downslope transport over the talus, on one hand, and cutting and backfilling for the construction of walls on the other, all had entailed reworking of older materials. A quantitative edge-wear analysis of pottery fragments aimed at screening redeposition was thus devised, and was carried out for most layers and contexts. Use was made of the original table here shown as Table $2 .^{5}$ Edge wear was graded according to six stages through a combination of intensity and distribution; the edge estimates were further supplemented by a qualitative evaluation of surface wear. ${ }^{6}$ The resulting statistics proved very helpful.?

\footnotetext{
4 A strong plea for the practice of 'total recovery' in the context of Yemen has now been voiced by William Glanzman (2018, 125 and footnote 2), on the basis of the two fieldwork projects carried out by the American Foundation for the Study of Man in Wādī al-Jūbah (1982-1987) and more recently at Mārib.

${ }_{5}^{5}$ Mentioned and outlined in Fedele 2010, 100, footnote 17.

6 Although only indirectly relevant to our practical needs, the landmark studies on ceramic abrasive degradation by James Skibo, Michael Schiffer, and colleagues were taken into account (particularly Skibo and Schiffer 1987; Skibo et al. 1997). It needs be noted that these authors call 'wear' the artefact modifications resulting from human use, as distinct from the breakdown by noncultural processes, or 'deterioration' (Skibo and Schiffer 1987, 83).

7 A study and quantification of pottery sherd abrasion was rather novel in 2005, and not only for Yemen. As aptly remarked by John C. Chapman, writing in 2006 in the context of European prehistoric
} 
Barāqish - Area C 2005-2006

Catalogue of finds and samples, with notes for chrono-cultural diagnosis

CUT/TG nOS. $\quad 110.111 .112 .120$

fo. 7

\begin{tabular}{|c|c|c|c|c|c|c|}
\hline $\begin{array}{c}\text { CUT/TG } \\
\text { no. }\end{array}$ & Category & $\begin{array}{l}\text { Number } \\
\text { of items }\end{array}$ & $\begin{array}{l}\text { Indiv. } \\
\text { nos. }\end{array}$ & Description, notes & \begin{tabular}{|c|} 
Culturel \\
Chronology
\end{tabular} & $\begin{array}{c}\text { Edge wear } \\
\text { stage }\end{array}$ \\
\hline \multirow[t]{12}{*}{110} & $\mathrm{AE}$ & $\ldots$ & & & & \\
\hline & $\mathrm{AL}$ & 2 & $.01,02$ & 01 flake. 02 quartzite & & \\
\hline & $\mathrm{AT}$ & 47 & & 18 rims & $\mathrm{SAB}$ & $\underline{0}: 4 ; \underline{1}: 10$ \\
\hline & & & & & & $\underline{2}: 4 ; \underline{3}: 2$ \\
\hline & & & .2 & fr amphora, wall, wavy-line decor. & $\$ A B$ & 1 \\
\hline & $\mathrm{AU}$ & I & .05 & 'tripod' foot, accurate (Sindies p10) & & \\
\hline & AV & 1 & .1 & polychrome glass element (Excovo5 055$)$ & ?MIN & \\
\hline & $\mathrm{AY}$ & 1 & 94 & plaster fr & & \\
\hline & FM & 80 & & & & \\
\hline & $\mathbf{P}$ & 1 & .03 & burnt platy stone, $\mathrm{dm}$ & & \\
\hline & $\mathrm{C}$ & $x$ & & & & \\
\hline & GT & ב- & & & & \\
\hline \multirow[t]{5}{*}{111} & AT & 11 & .1 & \begin{tabular}{|l|l}
3 rims & .1 large fr $\mathrm{SAB}$ jar
\end{tabular} & SAB 6+ & $0: 4 ; 1: 3 ;$ \\
\hline & & & & & & $2: 1 ; \underline{3}: 2$ \\
\hline & FM & 20 & & & & \\
\hline & GS & $\ldots$ & & incl. I burnt sandstone & & \\
\hline & $\mathrm{GT}$ & 10 & & small & & \\
\hline \multirow[t]{9}{*}{112} & $\mathrm{AE}$ & 13 & & incl. $7 \mathrm{md}$-sized frs & & \\
\hline & AL & 3 & & flakes $4: 7 \mathrm{~cm}$ & & $0: 3$ \\
\hline & $\mathrm{AT}$ & 21 & & & $\mathrm{SAB}$ & $\underline{0}: 13 ; 1: 3 ;$ \\
\hline & & & & & & $2: 1$ \\
\hline & $\mathrm{FC}$ & 1 & & $\varnothing 3 \mathrm{~cm}$ from Camelus & & \\
\hline & FM & 31 & & all angular, some large & & \\
\hline & $\mathrm{B} / \mathrm{C}$ & 20 & & I 'itb. I datestone. large frs wood/charcoal & & \\
\hline & GS & $x$ & & & & \\
\hline & $\mathrm{x}$ & I & & ?AT?G & & \\
\hline \multirow[t]{7}{*}{120} & $\mathrm{AT}$ & 38 & $.1,2$ & 12 rims & & fairly worn \\
\hline & $\mathrm{AT} / \mathrm{AU}$ & 1 & .3 & small ?unfired cup, extraordinary & ? nonsAB & \\
\hline & $\mathrm{AU}$ & I & .01 & disc, 4 frs & & \\
\hline & $\overline{F M}$ & $\sqrt{x}$ & & & & \\
\hline & MIX & $1: 7$ & & abundant $\mathrm{B} / \mathrm{C}$; sediment & & \\
\hline & & & & & & \\
\hline & & & & & & \\
\hline
\end{tabular}

Individual numbers assigned post-excavation (laboratory) / Numen individuall assegnali in laboratorio prefix 0 [e.g. 120.01]

Analyst: F G Fedele : F Di Grazia, assistant

Date(s): $7 ; 12 ; 19-25.12 .06$

Figure 1. Comprehensive collection catalogue, Area C: a page sample. (F.G. Fedele, 2019, adapted from the hand-written version 2007) 

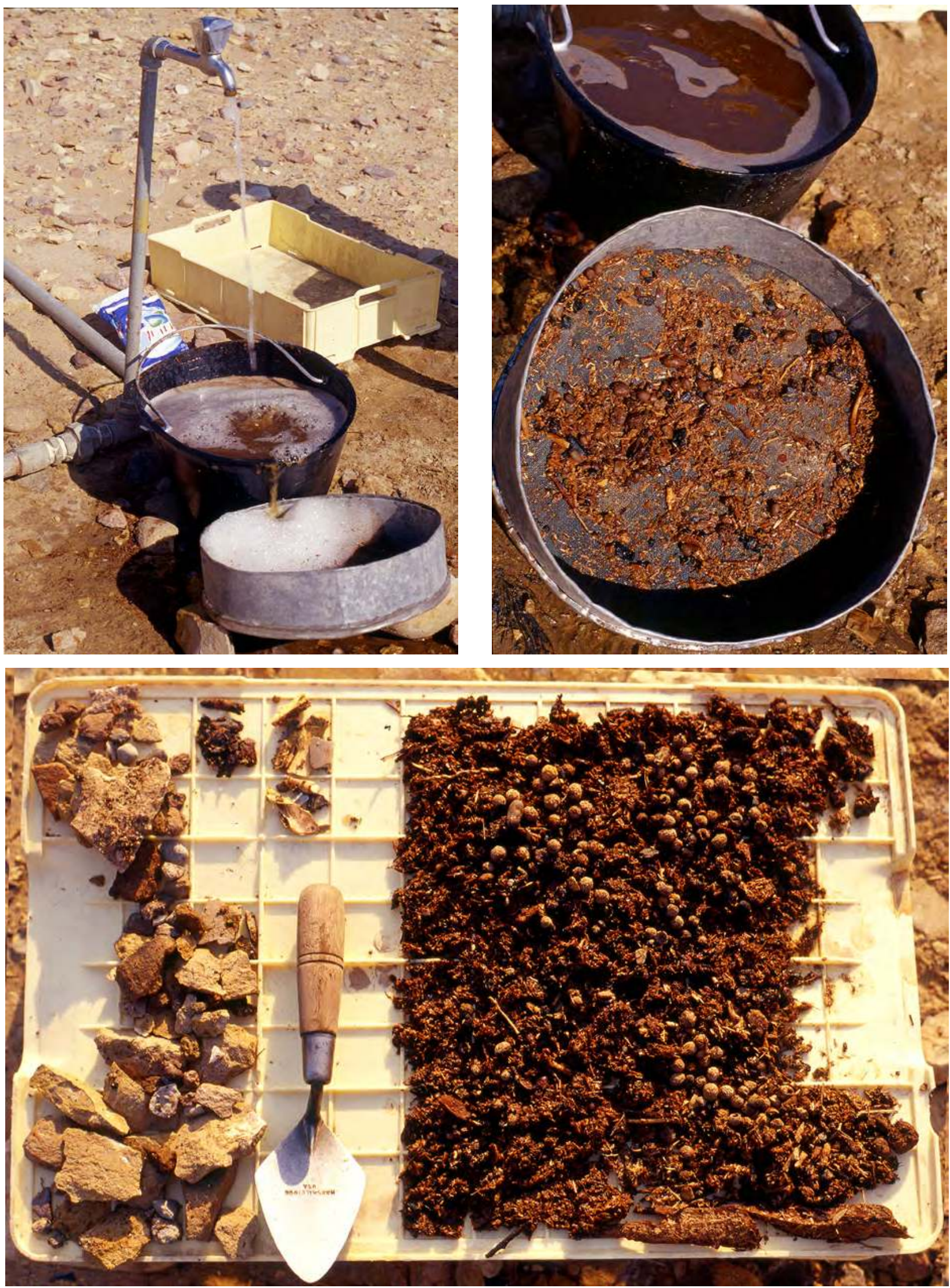

Figure 2. Flotation device (above) and flotation products (below). The sample being processed is no. 2.1 from quadrangle D1, bottom of sediment unit GV1. (F.G. Fedele, Barāqish camp, 7 December 2005) 


\section{Water screening and flotation}

During the first fieldwork season, in 2005, sample buckets from selected sediment units were waterscreened at the Barāqish camp. Those units which in the field could not be examined in sufficient detail, because of speedy digging, were particularly selected for such a treatment. In each case the sediment was screened through a 2-mm mesh, save for sample 12.3 (sediment GR1b from structure F9), which was screened at 0.5 $\mathrm{mm}$ after disaggregation by water and detergent. In addition to wet sieving, a simple froth flotation device was prepared for the fullest recovery of the minuscule and/or organic contents (Fig. 2). ${ }^{8}$ This also allowed a detailed, semi-quantitative appreciation of sediments. For producing froth a commercial detergent was used.

Quite obviously, the whole process was time consuming. The flotation and screening of a three-fourths-full bucket of moderately clayey sediment, followed by hand picking of the residue retained by the sieve, took three hours on average (e.g., sample 2.1, see below). The processing took much longer with sediments rich in clay and organic matter, such as those from the Later Sabaean occupations in quadrangles D4 and D5 (samples 31.1 and 38.2).

The excavation cuts that provided samples for water screening or flotation are listed in one of the excavation control documents for Area C mentioned in Chapter 17, Endnote, this volume (the list and spatial distribution of 'cuts'). Flotation was carried out on nine samples, taken from cuts 2 (sample 2.1), 3 (sample 3.1), 12 (sample 12.3, mentioned above), 13 (sample 13.1), 14 (sample 14.3), 31 (sample 31.1), 38 (sample 38.2), 48A (sample 48A.1), and 49B (sample 49B.1). Five more samples were only water-screened: these derived from cuts 40 (sample 40.1), 49D, 52 (sample 52.5), 93 (sample 93.1), and 99A (sample 99A.1). The overall results of wet processing were incorporated in the descriptions of sediments and cultural contents throughout Chapters 17 to 19, where appropriate. ${ }^{9}$ archaeology, it represented 'an alternative methodology': 'intensive studies of each sherd for size, weight, abrasion and other traces of the sherd's life-history [had] been taken seriously in studies of pottery and/or lithics' only during the past few years (Chapman and Gaydarska 2007, 100; and pages 100-105 more generally).

8 The flotation system was set up on 7 December and kept operating until the 23rd. All water processing was carried out by the author.

\footnotetext{
9 Unexpectedly, because of insufficient drying, two bags containing flotation products developed putrefaction while still in the Barāqish warehouse and had to be destroyed (samples 13.1 and 38.2; A. de Maigret, personal communication 10 January 2006). They survive as recorded information, which was duly used.
} 
Table 1. Area C catalogue of finds and samples: coding for category, English/Italian (F.G. Fedele, version 4, 2007). This table is strictly based on the variety of finds and samples from Area C.

\begin{tabular}{|l|l|}
\hline A $\bullet$ artefacts: cultural items sensu stricto / manufatti: elementi culturali s. s. \\
\hline AE & building material: mud bricks and related / materiale edilizio: terra cruda \\
\hline AL & $\begin{array}{l}\text { lithics: chipped or broken stone / pietra scheggiata, inclusi litici rotti o spezzati } \\
\text { - AL1 lighter artefacts / litici scheggiati leggeri } \\
\text { - AL2 heavy-duty products / litici scheggiati pesanti }\end{array}$ \\
\hline AM & metal, including slag / metallo, incluse scorie \\
\hline AP & $\begin{array}{l}\text { other lithics: including stone vessels, polished or sculpted stone / altri litici: levigati, incisi, scolpiti, torniti, inclusi vasi di } \\
\text { pietra }\end{array}$ \\
\hline AO & artefacts made from organic materials / manufatti di materia organica \\
\hline AT & $\begin{array}{l}\text { pottery and fired clay (terracotta) in general / terracotta, non soltanto vascolare I } \\
\text { and other fashioned and fired mineral material / include altri materiali minerali modellati e cotti }\end{array}$ \\
\hline ATf & fired clay figurines / figurine di terracotta \\
\hline AU & artefacts made of unfired clay (non AE) / manufatti di terra cruda (non AE) \\
\hline AV & glass, vitreous material / vetro, pasta vitrea \\
\hline AY & plaster sealings, cretulae [Y from 'gypsum'] / gesso a sigillamento di giara (cretula, bulla) \\
\hline A/Pp & mineral pigment, modified or unmodified / pigmento minerale, sia pure non o poco modificato \\
\hline
\end{tabular}

B • plant material: 'archaeobotanical' items / resti vegetali o 'archeobotanici'

B/C unburnt and burnt/carbonized plant material, mixed / misto fresco e carbonizzato, specialmente legno

BO plant and other organic material, mixed* / resti vegetali e altri organici, commisti [* see also FLO, below]

C • charcoal, carbonized material / 'carboni' e carbonizzati

$14 \mathrm{C}$ charcoal for radiocarbon dating / carbone prelevato espressamente per misura ${ }^{14} \mathrm{C}$

\begin{tabular}{|l|l|}
\hline F • faunal finds: 'archaeofaunal' items / resti animali o 'archeofaunistici' \\
\hline Fb & $\begin{array}{l}\text { pellets (from birds of prey) or similar aggregates of small bones etc. / borre (perlopiù di rapaci) o aggregati di residui } \\
\text { scheletrici affini }\end{array}$ \\
\hline FC & coprolites / coproliti \\
\hline FI & invertebrates (except molluscs) / invertebrati (tranne molluschi) \\
\hline FM & macrovertebrates / macromammiferi e altri grandi vertebrati \\
\hline Fm & microvertebrates / microvertebrati \\
\hline Fmo & molluscs (shells) / molluschi (conchiglie) \\
\hline FO & eggs / uova eloro frammenti \\
\hline
\end{tabular}

\begin{tabular}{|l|l|}
\hline \multicolumn{2}{|l|}{ Samples and non-artefactual, non-ecofactual elements / campioni ed elementi diversi da A-F } \\
\hline FLO & mixed, small-sized flotation material / materiale misto minuto da flottazione \\
\hline G & $\begin{array}{l}\text { geological sample or element / campioni o elementi geologici } \\
\text { - GS selected sediment material or element / campione selettivo o parziale, singolo elemento } \\
\text { - GT total sediment sample / campione totale del sedimento }\end{array}$ \\
\hline MIX & mixed, minute material with sediment (unscreened) / minutame misto in sedimento (non discriminato) \\
\hline P & $\begin{array}{l}\text { manuports / 'manuport', elementi ambientali introdotti/portati [a] } \\
\text { | includes crystals, fossils / include cristalli, fossili }\end{array}$ \\
\hline $\mathbf{X}$ & indeterminable finds / indeterminabili \\
\hline
\end{tabular}

a In archaeology and anthropology a manuport is an environmental ('natural') object which has been moved from its original context by human agency, but otherwise remains unmodified (http://en.wikipedia.org/wiki/Manuport, page last edited on 13.3.2019). The term was introduced by archaeologist Mary D. Leakey in 1971. 
DESCRIPTION FORMAT: sequence, conventions, and abbreviations / Sequenza di descrizione, convenzioni, abbreviazioni

$$
\mathrm{A} \rightarrow \mathrm{F} \rightarrow \mathrm{P} \rightarrow \mathrm{B} \rightarrow \mathrm{C} \rightarrow \mathrm{G} \rightarrow \mathrm{X}, \text { FLO }
$$

/ intermediate / intermedio, indicatore di ambiguità

? uncertain identification / incertezza di identificazione

+ composite group / gruppo composito [e.g. AL+AP]

Quantity:

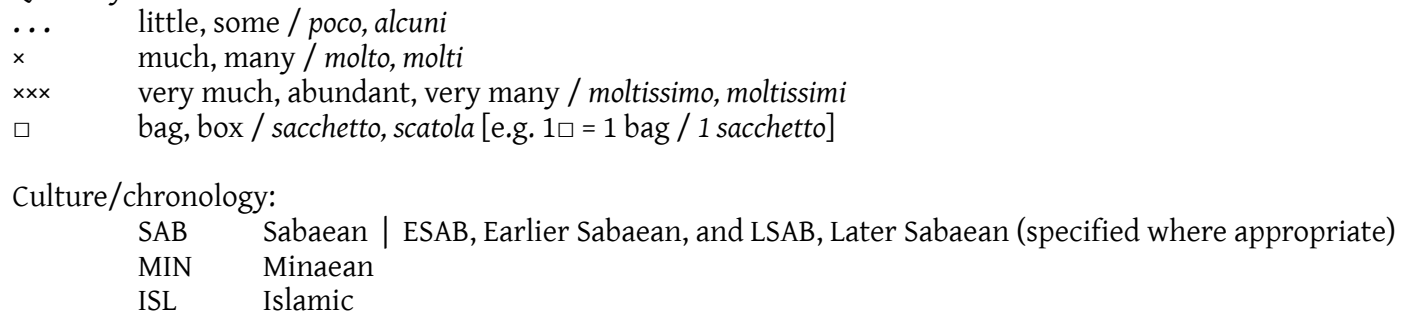

Table 2. Area C: coding for edge wear grade, particularly of pottery fragments; English/Italian (F.G. Fedele, version 2006).

Edge wear grades, according to intensity and distribution / gradi di usura, in base a intensità e distribuzione:

0 mint/sharp / interamente e palesemente acuto

1 fairly sharp: some edge abraded, or all edges a little abraded / qualche spigolo un poco abraso, o spigoli tutti poco abrasi (a)

2 moderately abraded: abrasion c. $50 \%$ in intensity and/or distribution / abrasione c. 50\% in entità e/o distribuzione

3 medium abraded: all edges more or less abraded / mediamente abraso nella totalità degli spigoli (b)

4 very abraded: major abrasion of all or most edges / molta abrasione nella totalità o nella maggior parte del pezzo (b)

5 completely abraded and worn out ('rounded') / completamente abraso e sfericizzato (c)

a By 'edge' a border with its immediately adjacent surface is intended. / Con 'spigolo' si intende un bordo con tratto di superficie adiacente.

${ }^{\mathrm{b}}$ In addition to edges, abrasion of surfaces should be recorded, if any. / Oltre all'abrasione degli spigoli è bene rilevare anche quella (eventuale) delle superfici.

${ }^{c}$ For this grade also surfaces must show at least some abrasion. / Per l'attribuzione a questo grado occorre che mostrino dell'abrasione anche le superfici.

Style of notation / Stile della notazione:

wear grade:number of fragments / grado di usura:numero di pezzi

e.g. / per es. 0:15; 1:28; 3:7 [= mint, 15 fragments; and so on / acuto, 15 frr; e così via ] 


\section{Chapter 21}

\section{Area C. The Objects}

\section{Francesco G. Fedele and Sabina Antonini}

\section{Introduction ${ }^{1}$}

This chapter presents a selection of about 245 artefacts from the excavations at Barāqish Area C, listed according to 227 numbered entries. The term artefact is here employed in its broadest sense. ${ }^{2}$ In addition to the so-called 'objects', as inventoried by the Italian archaeological mission for GOAM, ${ }^{3}$ the catalogue aims to report a large number of finds that are often considered humble or uninteresting, and which, on the contrary, can explain or clarify many behavioural and cultural aspects of the site (even if only indirectly). These finds thus contribute to a more realistic picture of the archaeological record obtained from the best stratified extramural deposits. ${ }^{4}$ The greater part of the chapter is formed by the catalogue constituting section 2 .

Excluded from this chapter are pottery (treated in Chapters 22 and 23, this volume) and the single epigraphic block (Chapter 24). Also excluded are the

\footnotetext{
${ }^{1}$ This chapter was structured and written by the first author, who also compiled the catalogue entries and researched and prepared all the unsigned texts, including the often extensive introductions to material categories. Among these latter, some may contain elements of personal opinion or interpretation. The context information for each find was compiled from data presented in Chapter 17, this volume, with added details from the primary field records (FGF). Antonini contributed the catalogue entries or part of entries signed $\mathrm{SA}$, generally related to finds that she had already inventoried as 'objects' for GOAM in 2005-2006.

2 I.e., not only artefacts proper, but also utilized manuports, or manuport-artefacts, particularly querns and rubbing stones (see Chapter 20, this volume). Also included are artificially modified, or presumably modified, bone and shell elements, particularly seashells that might have been employed as personal ornaments. At least in principle, such shell and bone finds constitute at the same time 'artefacts' and 'fauna' and thus possess multiple significance. Also treated here is seashell no. 184.3 from a Minaean layer, possibly an alimentary element rather than an artefact. As an integrated description of these finds is clearly in order, full zooarchaeological analysis is included in this chapter. Details on this matter are given under 'Marine shells' in the Sabaean group, below.

3 As is usual in Near Eastern as well as Yemen's archaeology, 'objects' are intended as a selective category of notable artefactual finds: cf. Tamna' (de Maigret and Robin 2016, 205-257) and Chapter 5 in Volume 1 (Antonini).

4 The finds in this catalogue were stored in the antiquities warehouse at Barāqish when the archaeological mission left the site, in December 2007. In September 2013, upon the transfer mentioned in Chapter 1, section 4.1, in Volume 1 (footnote 122), unanticipated constraints made it impossible to check what collections from Area C - if any had reached the National Museum in Șan' $\bar{a}$. . Therefore the present location and condition of the finds here described are unknown.
}

minute fragments of mud bricks and related material, while it was felt important to describe a sample of larger and better preserved Sabaean and Minaean mud-brick remains and a clay 'loaf' from structure F9 (no. 23.01). Ecofacts, i.e. charcoal and non-artefactual plant and animal finds, are excluded from treatment in this chapter by definition. Charcoal samples were listed and discussed in Chapter 18, section 1, and the plant and animal collections were treated in Chapter 19, except for seashells and a worked animal bone which are catalogued here in section 2 (see footnote 2 for justification).

The entries in the catalogue are arranged in a culturestratigraphic order according to the following chronological and cultural groups, constituting sections 2.1 to 2.5 (henceforth simply 'groups'): Sabaean; First Intermediate (Stratum K); Minaean; Second Intermediate; and Uncertain chronology, comprising finds of indeterminable archaeological age (mostly unstratified finds). ${ }^{5}$ The finds within each group are subsequently arranged into typological categories based on material and/or manufacture ('material categories' for short), starting with stone artefacts and manuports, and continuing with clay, plaster, metal, glass, organic materials, ostrich eggshell, and seashells. The ordering of material categories is uniform across all groups, whereas their headings may slightly vary according to the specifics of each group.

As far as possible, the Later Sabaean finds will be listed after those datable to the Earlier Sabaean, as well as after the stratigraphically unspecified Sabaean finds. Items that are believed to be Sabaean objects redeposited into Minaean layers, due to reworking of sediments, will be treated on a case by case basis, and generally listed within the Sabaean group. The Minaean group in this chapter is to be understood as 'Minaean' in the broad sense, since it is apparently impossible to distinguish the Minaean proper from the Amirite phase in artefactual terms. ${ }^{6}$ Chronologically excluded

\footnotetext{
5 The number of entries in these groups is as follows: Sabaean, 104; Minean and First and Second Intermediate, 88; and Uncertain chronology 35.

6 See Agostini, Chapters 3 and 4, and Buffa, Chapter 7 in Volume 1; Buffa, Chapter 25, this volume; and a mention in Fedele, Chapter 18, section 3.4 , also in this volume.
} 
from this chapter is the Islamic collection from Area $\mathrm{C}$, apart from a single problematic glass element in the Uncertain chronology group (no. 110.1).?

Each catalogue entry is introduced by the 'register number'. As explained in Chapter 17, section 1.3, this volume, this is an inventory number which combines the 'cut' number from the excavation with the 'individual' number identifying the find, this latter assigned in the field or in the laboratory. The cut is the first element in the register number, e.g. ' 5 ' in find no. 5.1a, or ' $43 \mathrm{~A}$ ' in find no. 43A.1. ${ }^{8}$ The cut number provides the all-important link to the spatial and stratigraphic data concerning the find. Where applicable, the register number is followed by the 'object' inventory number for GOAM (e.g. B.05.C.O/1, where the 'O' stands for 'object') and by the reference to its illustration (figure number) in this chapter or elsewhere in the book.

The provenance of each find is indicated for Sounding $A$ and Sectors $D$ and $E$ with the code of the quadrangle, in italics as usual (e.g. A1-A11, D4), but with a simple B, C, or $F$, exceptionally in italics, for the test pits in Sectors $B$ and $C$ and for Sounding F, respectively. Concerning stratigraphic information, sediment layers and Strata are ordered from the oldest to the most recent, with the strata designations written in bold throughout the catalogue for ease of reference (e.g., 'V3, SI1i-SI1, SE3'; 'Strata S-R').

\section{Catalogue}

\section{ABBREVIATIONS AND SYMBOLS}

approx.: approximate, approximately

c.: circa, about

$\mathrm{cm}$-sized: centimetre-sized $(c .1-4 \mathrm{~cm})$

$\mathrm{dm}$-sized: decimetre-sized (c. 8-12 cm)

fr., frs: fragment, fragments

max. : maximum, maximal

qu. [where needed]: quadrangle of excavation grid (e.g. qu. D5)

$\varnothing$ : diameter

\footnotetext{
7 The Islamic-age finds from Area C could not be studied in detail, and they are not treated in this book. However, a brief note on this relatively small collection can be found as an appendix to Chapter 18 , this volume (Fedele).

8 Register numbers with a slash after the cut number, instead of a dot, originate from the working lists compiled in archaeofaunal analysis. The only instance in this chapter is no. 200/58, a seashell fragment in the Sabaean group. Researchers who might work on the Area $\mathrm{C}$ collection in the future are advised that, for inventory and object-marking purposes agreed with A. de Maigret in 2006, the Area $C$ register numbers were integrated into the MAIRY inventory system by being prefixed 'B.05.C/' or 'B.06.C/', according to excavation year. Such prefixed numbers are employed by V. Buffa in her pottery study (Chapters 22 and 25, this volume). However, the prefixes are irrelevant for working on Area C. Therefore they will be avoided both in the present chapter and in Chapter 23.
}

\subsection{Sabaean (Strata $T$ to $L$ )}

Due to various processes, at particular times, materials from the Sabaean-age tell were subjected to redeposition along the talus, by either geological agencies or human reworking of older sediments, or both. As a consequence, the cataloguing of a number of Sabaean-age finds poses problems. In general, we have preferred to list such presumably or probably Sabaeanage finds in the stratigraphic group corresponding to the location of actual retrieval, accompanied by a note mentioning their hypothetical Sabaean affiliation. This issue is specifically addressed in the introduction to the 'Unfired or poorly fired clay artefacts' category below, where examples of the decisions taken are illustrated in detail.

\section{Chipped stone: obsidian, limestone}

Some obsidian artefacts were collected as petrographic samples during the first Italian surveys at Barāqish in 1986. This scanty, unreferenced surface material was examined for obsidian sourcing by Francaviglia, with no definite results. ${ }^{9}$ The excavations of 2005-2006 produced the first finds from controlled contexts and amenable to archaeological examination. In particular, Area $\mathrm{C}$ has generated a total of 12 obsidian lithics, all small and some microlithic. In addition to the six Sabaean finds (this section), four were recovered from Minaean layers (but they too are probably Sabaean in origin) and two were found in Uncertain chronology contexts. No obsidian was found in the Islamic layers. With such low numbers it is impossible to be certain, but the collapse of obsidian frequency after the Sabaean period recorded in Area C might be historically real. For additional discussion of obsidian from Yathill see Chapter 6 in Volume 1 (Fedele).

44.01, 44.02 (Fig. 1). Two small obsidian flakes. $2.1 \times 2.4$ $\mathrm{cm}$ (44.01) and $1.6 \times 0.8 \mathrm{~cm}$ (44.02). | D6 west, including Locus 44. Units SGP, mostly SGP (SGP being the fill of Earthwork F44), and $\lambda 44$. Stratum $R$.

199.03. Obsidian core. | A1-A11 east + A31, Locus 200, in situ. Within the ashen-and-red silty-clayey lens of middle-upper SYH, c. $15 \mathrm{~cm}$ below top of unit. Stratum N. | Details unavailable.

214.01. Obsidian core. | F. Lower (?) unit SY1. Stratum M. | Details unavailable.

Mentioned in Fedele 2010, 125.

72.02 (Fig. 1). Obsidian microflake or microlith. Length $1.45 \mathrm{~cm}$. | E5. Units V5, XE4 (marginally); suites LXZ and

\footnotetext{
9 Francaviglia 1990, 1996; Barca et al. 2012, 618 (Fedele).
} 
LNS; units LCB, x5: but most probably from below unit LCB. Strata $\mathrm{O}$ to I, including K: probably $\mathrm{O}$ or $\mathrm{L}$. | The pointed edge seems to exhibit intentional retouch, in which case this flake would be a microtool (microlith).

72.03 (Fig. 2). Bipolar chipped pebble. Rare greygreenish veined (or laminated?) limestone. $6.5 \times 2.9 \times$ $1.5-2 \mathrm{~cm}$. E5. Units V5, XE4 (marginally); suites LXZ and LNS; units LCB, $\mathrm{x} 5$ : but most probably from below unit LCB. Strata $\mathrm{O}$ to I, including K: probably $\mathrm{O}$ or L. | One end of this elongated pebble tool is manifestly écaillé, the opposite one is truncated or snapped.

14.02 (Fig. 1). Obsidian microflake. Max. length $0.9 \mathrm{~cm}$. | D3. Units GZ2-GZ1. Stratum L. | This thin chip in mint condition is an acceptable indicator of local obsidian working in the occupation area of upper Sector D.

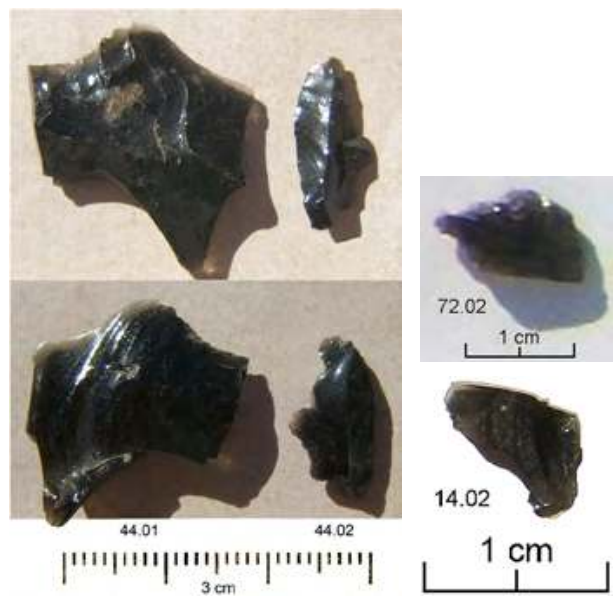

Figure 1. Obsidian, Sabaean, reg. nos 14.02, 44.01-02, and 72.02. (G. Di Rosa and S. Iavarone 2007 ( ) MAIRY, arranged and optimized by F.G. Fedele 2019)

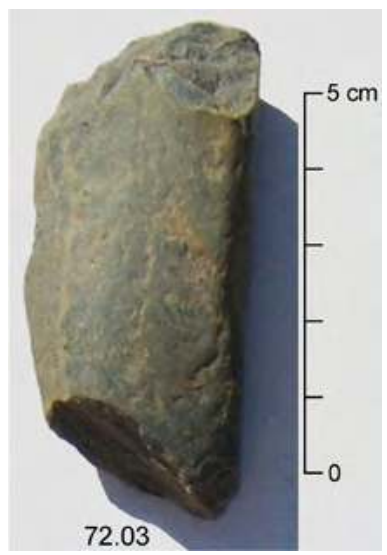

Figure 2. Chipped limestone, Sabaean, reg. no. 72.03. (G. Di Rosa and S. Iavarone 2007 (C) MAIRY, adapted and optimized by F.G. Fedele 2019)

\section{Chipped stone: calcite or alabaster}

102.02 (Fig. 3). Broad flake. Either calcite (calcareous sinter) or alabastrine gypsum (alabaster). $5.4 \times 3.7 \mathrm{~cm}$. | E2. Units V3, SI1i-SI1, SE3, but predominantly SE3 or SI1. Strata S-R. | This piece of working waste was struck from a showily banded, multicoloured rock that could not be precisely determined. ${ }^{10}$ The find provides a unique indication that variegated rock types of the calcite-alabaster kind were worked at Yathill already during the Earlier Sabaean period. If alabastrine gypsum, it would represent the only true alabaster find from extramural contexts. Understandably, the object during whose manufacture this flake was struck cannot be determined. If it was a container, a large inventory of objects and types is offered for consideration. ${ }^{11}$

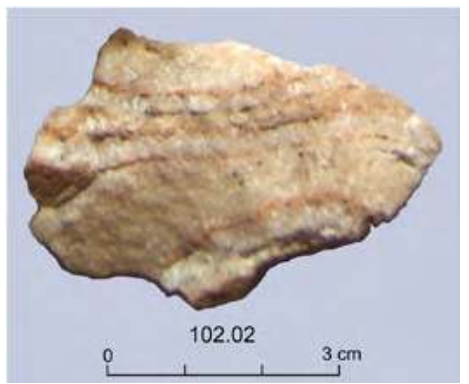

Figure 3. Chipped calcite or alabaster, Sabaean, reg. no. 102.02. (G. Di Rosa and S. Iavarone 2007

(C) MAIRY, adapted and optimized by F.G. Fedele 2019)

Chipped stone: heavy duty

44.1a, 44.1b (Fig. 4). Two large spalls. Yellowish-grey cryptocrystalline limestone cf. Wall F4. $11.5 \times 18.2 \mathrm{~cm}$ and $6.2 \times 9 \mathrm{~cm}$, respectively. $\mid$ D6 west, including Locus 44. Units SGP (mostly SGP ${ }_{3}$ ), i.e. the fill of Earthwork F44, and $\lambda 44$. Stratum R. | Broad spalls from the dressing of the building blocks of Wall F4, both rock type and hewing style being those of F4. Mass SGP, and particularly subunit $\mathrm{SGP}_{3}$, contained a huge quantity of $\mathrm{cm}$-sized to $\mathrm{dm}$-sized flakes and fragments clearly associated with the construction of Wall F4, and subsequently reworked - chaotically - into Earthwork F44. The spalls here described are part of a reference sample of this coarse hammering debris.

\footnotetext{
10 For the identification as banded calcite (calcareous sinter or 'calcsinter') see the introduction to 'Calcite or aragonite vessels' in the Uncertain chronology group (section 2.5). The alternative identification as alabastrine gypsum, i.e. alabaster, relies on the documented occurrence of fine, crystalline, sugary-textured varieties closely reminiscent of our find (e.g. Stow 2005, 209). In common parlance such varieties are often improperly called 'onyx marble' (including Mexican onyx, see AGI 1984, 354; onyx in mineralogy is a form of silica, i.e. quartz, not gypsum).

11 See, e.g., Phillips and Simpson 2018b, fig. 31; 2018c.
} 
44.1c (Fig. 4). Spheroid, possibly a hammer. Dark grey limestone, different from the rock type of nos 44.1a and 44.1b. Max. $\varnothing 10.7 \mathrm{~cm}$.|D6: provenance and stratigraphy as for nos $44.1 \mathrm{a}-1 \mathrm{~b}$. Stratum R. | This presumed hammer is an additional find from the context and earthwork described for nos 44.1a and 44.1b. The rock it is fashioned with seems to have different mechanical properties from the limestone employed in Wall F4.

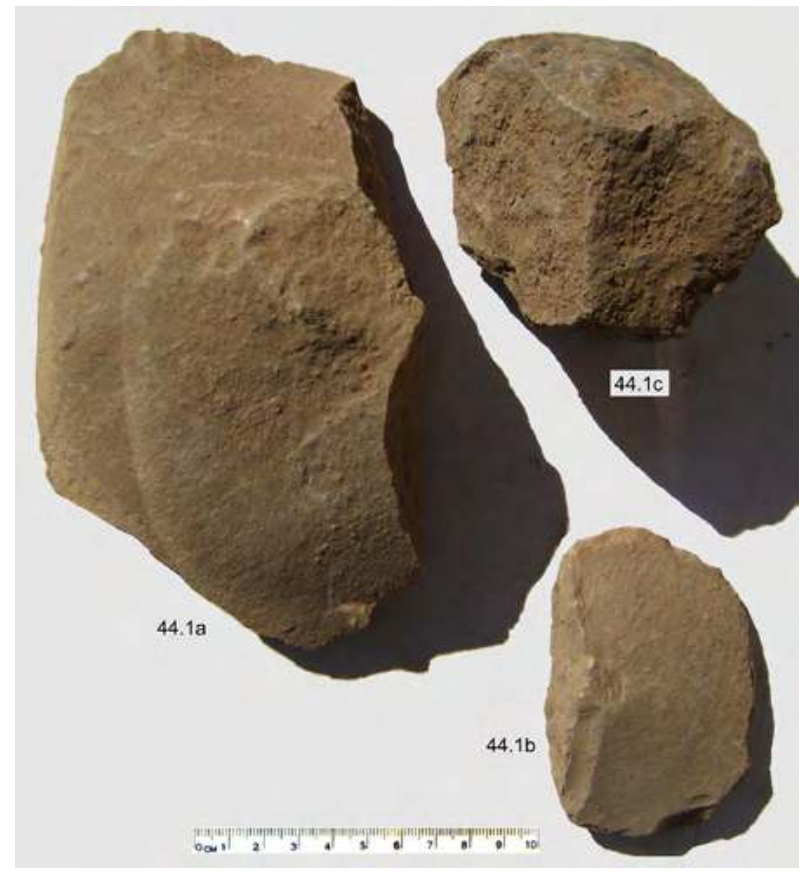

Figure 4. Chipped stone (heavy duty), Sabaean, reg. nos 44.1a-1c. (G. Di Rosa and S. Iavarone 2007 @ MAIRY, arranged and optimized by F.G. Fedele 2019)

32.01 (Fig. 5). Chopper. Quartzite, visually a very-finegrained quartz sandstone cemented by silica. $12.8 \times 7.8$ $\times 4 \mathrm{~cm}$. | D4. Unit GZ3. Earlier Stratum L. | A bipolarly and bifacially flaked cobble, with a largely intact cortex preserving an orange-reddish pigmentation from iron oxides. The context was related to domestic activity nearby and specifically included hearth and/or kitchen refuse and fire-damaged stones, occasionally cemented by calcium carbonate.

\section{Stone burners and containers}

Five or six objects attributable to burners, Arabian cuboid burners in particular, were retrieved from Area C: nos 5.1a and possibly 5.1b in the Sabaean group (this section); nos 189.1, 186.1, and 211.1 in the Minaean group (section 2.3); and no. 80.1 in the Uncertain chronology group (section 2.5). The identity of an additional find also listed in section 2.5, a fragmentary foot (no. 06), is uncertain, as this piece can either belong to a burner or a saucer. In the case of find $5.1 \mathrm{~b}$ the uncertainty

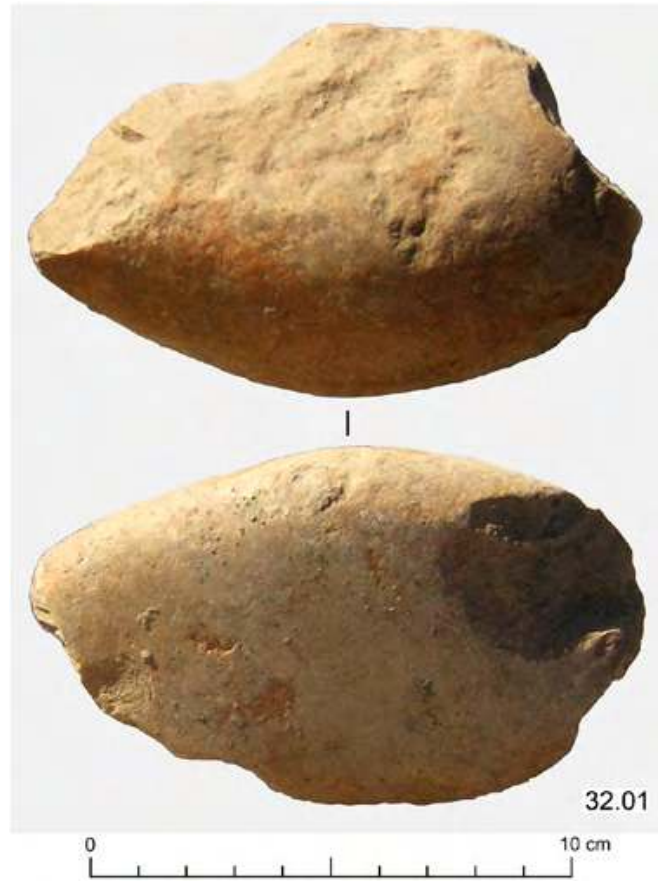

Figure 5. Chopper, Sabaean, reg. no. 32.01. (G. Di Rosa and S. Iavarone 2007 (C) MAIRY, arranged and optimized by F.G. Fedele 2019)

depends on this object being a cuboid or a different kind of burner, or a compartmented container (see catalogue).

This material category comprises a certain class of artefacts often referred to as 'incense burners'. ${ }^{12}$ However, for reasons outlined below that involve individual variation and unresolved points of classification and function, this designation will be avoided in this chapter. As a consensus designation for the class, the simple term 'burner' will be used instead, meaning a portable device characterized by a demonstrable or inferred association with combustion. ${ }^{13}$ An equally neutral, strictly morphological term, 'cuboid burner', will designate the particular family of artefacts that constitutes the vast majority of burners, characterized by the cubical or prismatic shape of the basin at the top of the object. Implicit in this morphology is a square or rectangular aperture of the

\footnotetext{
12 Another common label in English until the 1980s was incense stands'. Equally subjective designations in other European languages are Altäre and Räucherkästchen in German (including kleine kuboid Räucherkästchen, e.g. Sima 2000, 265), autels à encens, brûle-encens, or brûle-parfums in French, and incensieri or the less frequently used bruciaprofumi in Italian. Terms such as autels in French or Altäre and Miniaturaltäre in German, even when meant as merely conventional, press upon the reader the arbitrary idea of a cultic or even exclusively cultic destination, which is certainly inappropriate.

13 A nonexclusive association. Moreover, combustion can take different operational and material forms (see below).
} 
basin. ${ }^{14}$ The reason why we need a neutral descriptor for these common and important objects is to refrain from preconceptions and keep the door open to critical examination of each individual find. A shift of focus on their context of retrieval, ${ }^{15}$ and wherever possible on rigorous determinations of function and use (still very rare), would be a first step forward in understanding cuboid burners. A recent study by W. G. Zimmerle ${ }^{16}$ will provide a convenient background for a brief reappraisal.

The first point to consider is the pattern of variation within this family. Three forms of stone cuboid burners ${ }^{17}$ were produced in southern Arabia, and to some extent replicated elsewhere: ${ }^{18}$ single-footed, ${ }^{19}$ the foot usually being tall and pyramidal; four-footed, with one foot or leg at each corner; and footless or flat-based ('flat' for short). ${ }^{20}$ Only the latter two forms are represented among the finds from Area C. Beyond that, a virtually endless range of individual variation is recorded within each form. Being too individual, the specimens defy grouping: the Arabian cuboid burners do not seem easily amenable to objective typologies. ${ }^{21}$ The possession of inscriptions, decoration, or even 'art' quality ${ }^{22}$ does not carry per se any typological value, irrespective of the importance it may have from other cultural viewpoints. This fundamental 'individualism' might indeed constitute a defining component of the cuboid burner as a conceptual and sociological entity. ${ }^{23}$ 14 Here again, one is dealing with an overwhelming but nonexclusive
attribute (see below).
15 Often paid scant or uncritical attention in Yemen. For a
commendable exception see Hassell 2002 .
16 Zimmerle 2014a; 2014b (a summary and selected topics from his
dissertation).
17 The attribute of being made of stone must be specified, if one
looks beyond Yemen, as there is a broad, long-known opposition
between stone and clay productions according to geographical areas.
Stone burners characterized southwestern and western Arabia, in
connection with a presumably overland distribution, whereas in
southeastern and eastern Arabia, as well as northwards along the
Mesopotamian-Euphrates axis, clay burners were predominant (e.g.,
Ziegler 1942; Pritchard 1972; Zarins et al. 1983, 36, pl. 29; Tiede 1987,
150; Zimmerle 2014a, 101-150, with further literature; 2014b). Aside
from general functional considerations, clay burners will not concern
us here.

18 Cf. Zimmerle 2014a, 152-320, with literature, to which the extensive review by Frevel and Pyschny (2014, 116-134, 156-204) must now be added.

19 Hassell's (2002) 'piriform-based'.

20 Bowen's (1958) 'squat', as the form is not only flat but often also shallow.

21 For attempts at typological classifications see, e.g., Breton and Bațayā' 1992, 365-367; Zimmerle 2014a, 175-180, 221-307; and cf. Marion de Procé, Chapter 11, section 8.2, in Volume 1. Hassell (2002, 157) made a point of noting that 'This is not a typological study'. Perhaps needless to say, types are not styles. Regional or local styles do exist in Yemen, but they await to be studied.

22 As with most other objects, categorizations based upon our own aesthetic responses must be resisted, if only because we are dealing with ancient traditions that did not abstract 'art' works - indeed any kind of works or objects - 'from a matrix of cultural function' (Winter 2002, 7, 11 [quote]).

23 Fedele, 'Burners, lamps, and the trading-caravan context' (in
The classification of cuboid burners as a family of artefacts is based on a clearly recurrent morphological concept, and therefore seems to be sufficiently robust. However, rare or 'fringe' variants occur. An example might be no. $5.1 \mathrm{~b}$ in this catalogue, as discussed below (this section). Another instance is represented by occasional specimens with a circular basin and a cylindrical foot, ${ }^{24}$ but otherwise identical to single-footed, cuboid burners in overall morphology, manufacture, and quality - thus justifying the idea that they are mere variants in a 'mainstream' cuboid production. More problematic is accommodating the flat circular burners which, locally, seem to become common at the turn of our era. ${ }^{25}$

Concomitant issues arise vis-à-vis two relatively comparable families of artefacts, encompassing circular objects of small size that appear to be broadly contiguous to cuboid burners in morphological concept, except for the rounded top: tripod-footed bowls and tripod-footed offering saucers. ${ }^{26}$ Small three-footed bowls made from several workable rock types form a 'very distinctive class' of artefacts, often with feet or legs imitating the digits of lions' paws; ${ }^{27}$ rare four-footed examples seem to occur. Quite similar in form and size are the widespread tripod-footed offering saucers ${ }^{28}$ a family of small stands variously understood and termed by each excavator from each different site..$^{29}$ Here again, fourfooted examples are documented. Saucers usually lack traces of burning, but there are exceptions. ${ }^{30}$ Likewise,

preparation). The cuboid burner would represent a 'symbolic-cumfunctional artifact', as for instance it was said of the Mesopotamian cylinder seal (Charvát 2005, 283): an object individually symbolic of the person and his/her identity, or of the house or household.

24 E.g. at Tamnac, where they are known from well-documented temple and elite contexts: the temple of Athirat (de Maigret 2016, 229-231; fig. 164/4, 7) and building TT1 (Loreto 2016, 317, fig. 36/8, a small clay specimen). TT1 has been tentatively recognized as a royal palace (Loreto 2016, 313-314, and cautiously de Maigret 2016, 10, 14); on its debated identification see Breton et al. 1997, 61-72.

25 Khawr Rūrī/Sumhuram: Lombardi et al. 2008, 319-320 and plates $2 / 3,5-7 ; 38-39$. Whether they should be ordered in a separate class is problematic, since, except for their round shape, they replicate the pattern and manufacture of flat cuboid burners. Furthermore, marginally transitional examples are known (square with rounded corners). A full examination is outside the scope of the present discussion, but see the section about burners as lamps, below.

26 Nomenclature and classification follow Phillips and Simpson (2018c), with the understanding, however, that in both families occasional four-footed specimens also occur.

27 Phillips and Simpson 2018c, 172-173. The specimens in the British Museum have a diameter of 6-7 cm.

28 Phillips and Simpson 2018c,173-175, with previous literature.

29 E.g. Tamna': Cleveland 1965, 115-117, pl. 90; de Maigret 2016, 234235, fig. 167, 'stands' con struttura analoga agli incensieri (stands emulating incense burners in form). Shabwa: Breton and Batayāc 1992, 376-377, fig. 5/36, 38-39 (autels à offrande). Sumhuram, where they were classified as a variety of 'incense burners': Lombardi et al. 2008, 319-320, plates 3, 38, 39 (cf. Phillips and Simpson 2018c, 174). Diameters range from a few centimetres to $15 \mathrm{~cm}$.

30 Notably a four-footed specimen from the city temple at Sumhuram, used as a burner in connection with some kind of pine resin: Ribechini and Colombini 2008. As noted by Phillips and Simpson 
traces of burning can be lacking on actual burners, for a number of reasons, and cuboid burners are no exception. ${ }^{31}$

This leads to the important topics of function and context of use. The main reason for avoiding terms such as incense burner or altar, in referring to burners, is that their range of functions and association with organic materials were definitely much broader. These were not restricted to cult, ${ }^{32}$ and most likely included the utilization of such burners as lamps (see below). As to context, cuboid burners have been recovered from four kinds of settings in Yemen: $:^{33}$ funerary, votive, cultic or liturgical, ${ }^{34}$ and domestic. Barāqish Area $\mathrm{C}$ has revealed a further type of context (see below). The domestic context is still very imperfectly known in Yemen, due to a relative lack of archaeological interest for residential areas and non-monumental sites, ${ }^{35}$ but it is illustrated by findings from Syria-Palestine and Mesopotamia, these latter particularly well documented. ${ }^{36}$ In fact, the native setting in which the cuboid burner evolved was probably the home, ${ }^{37}$ though not necessarily in terms of a domestic 'cult': $3^{8}$ the deposition of burners in tombs,

(2018c, 173), the presence vs absence of burning cannot thus be taken as a conclusive feature for identifying function; it serves even less for classification or typological purposes.

31 For example, Phillips and Simpson (2018c, 173) suggest that cuboid burners 'were probably originally fitted with removable sheetmetal inserts which do not survive'. Presumably, the ways in which the ancient Arabian burners functioned were manifold. In addition, combustion can take multiple forms and entails many resulting traces, almost never described in the literature, let alone scrutinized.

32 Mervyn Fowler cautioned long ago that "to use the term "incense" indiscriminately, with its cultic overtones, conceals the variety of use to which various spices and the like were put' (Fowler 1984, 186; 1985, 25).

33 Cf. Marion de Procé, Chapter 11, section 8.2, in Volume 1.

34 Votive, i.e. given or done by a person, and liturgical, i.e. employed in cult services, represent two entirely distinct manifestations of what is often loosely called 'religious' context ('temple context' would be a better designation to encompass both). A rigorous identification of votive vs liturgical objects among temple findings is badly needed. Hassell alone $(2002,186)$ has hinted at a distinction between 'personal dedications by worshippers' and 'actual temple furniture'.

35 A rare example of burners in a domestic context is provided by a house near the 'South gate' at Tamna' (Building B; W. Phillips 1955, 159), as re-evaluated and clarified by Hassell $(2002,176,179)$.

36 Zimmerle 2014a, 215-363, with extensive literature. Indeed, Räucherkästchen were first identified by Robert Koldewey at Babylon in 1901. At multiethnic centres like Babylon or Ur, these burners might often have been connected with South Arabian residents (Retsö 2003, 147-210; Hausleiter 2012, 822; Zimmerle 2014a, 335-363; 2014b, 346; Hausleiter and Eichmann 2018, 9; Bagg 2018, 253-255); cf. Chapter 18, section 3.1 ('On some issues raised by Wall F4: the Sabaeans and Assyria'), this volume. For Palestine see Frevel and Pyschny $(2014,141-143)$.

37 Shea 1980, summaring his MA report (cf. Zimmerle 2014a, 23-26); 1983; 1987, 162; Maraqten 1994, 170. Potential evidence is provided by the findings from Ra's al-Jinz site RJ-2, c. 2250-2200 BCE, which plausibly represent items of household equipment (Cleuziou and Tosi 1997; 2000, 53-54; Zimmerle 2014a, 152-167; 2014b, 341-342, fig. 4).

38 In Yemen, the association of cuboid burners with a Hauskult (e.g. Sima 2000, 265, wrongly citing Maraqten 1994) is an assumption still to be substantiated. A domestic routine does not constitute a cult. More generally, 'problems arise when excavators presume that and their votive offering and/or liturgical employment in temples, look like subsequent developments. ${ }^{39}$

The variety of contexts is interwoven with a multiplicity of functions - or, more precisely, of purposes. There can be no doubt that one general function served by cuboid burners was fumigation through burning. That is at least true for those specimens inscribed with names of gum resins. Clearly, a multitude of substances were burnt, obtained not only from plants ${ }^{40}$ but also from animals. ${ }^{41}$ The burning of mixtures may in fact have been the rule..$^{42}$ And according to data from ethnology, ethnohistory, a few texts, and the shape of the objects themselves, the common process of fumigation served a disparate range of uses and purposes - the fumigation functions were 'multifaceted'. ${ }^{43}$ Three interrelated effects were mainly sought: ${ }^{44}$ (i) purification and cleansing, both hygienic and spiritual, 'in tandem with prayers'; 4 (ii) protection, i.e. the apotropaic function of warding off evil; and (iii) fulfilling hospitality. ${ }^{46}$ Thus it is equally clear that fumigation and fragrance, while

because an artefact appears to belong to a particular class of sacred object, a cultic interpretation of the artefact in question is assured at every findspot' (Fowler 1985, 25).

39 As Phillips and Simpson (2018c, 179) remark, the 'placement of stone vessels and offering saucers as grave offerings [...] reflected secondary use rather than primary intent'; 'it would be wrong to extrapolate from the funerary evidence about the relative popularity of different forms of material'. An example: a rural house at al-'Oqm, in the irrigated zone near Shabwa (excavations by R. Audouin as reported in Breton 1992a), contained an offering saucer (Breton and Bațayāc 1992, 376, fig. 5/39).

40 See - from a vast literature - Robin 1994; Müller 1997; Sima 2000, 265-287; Serpico 2000; Zimmerle 2014a, 76-99. 'Less-prized alternatives to incense' (Creasman and Yamamoto 2019, 357; see Serpico 2000) were certainly of common use.

41 E.g. seashell opercula (Bosch et al. 1995, 113; corroborating the testimony of Sir Samuel W. Baker, 1863, cited in Zimmerle 2014b, 340).

42 Perhaps the strings of names written on individual burners, often four names over the four sides of the object, were a recipe for such concoctions (Fedele, in preparation, see footnote 23). Several ingredients were intended for particular effects, including the shape and behaviour of the smoke column, which, in ancient Yemen as elsewhere in western Asia, might have embodied a rich individual and collective symbolism. In the preparation of resins, spices, or perfumes to form compounds prior to burning, mortars might have been used (Hassell 2002, 189, as inferred from the repeated cooccurrence of cuboid burners and mortars at Sumhuram, Hayd ibn 'Aqīl, and Hajar ibn Humayd).

43 Zimmerle 2014a, xi (with R.L. Zettler).

44 What follows is my personal synthesis and reformulation from disparate sources, including several of the references in Zimmerle $2014 \mathrm{a}$ and 2014b. Main additions include the detailed discussion by Frevel and Pyschny (2014, 143-164, 'Function and purpose'). Useful elements were derived from details in Hassell's study (2002, e.g. 179, 184), as well as Maraqten's (1994) lexicography of old South Arabian names for altars or supposed altars (where the Räucherkästchen are briefly treated as a category of their own, p. 170-171).

45 Zimmerle 2014b, 343.

46 'In Bedouin cultures, an incense burner is placed in the centre of the tent for hospitality, and all life centres on it' (Zimmerle 2014b, 348; citing Dickson 1951, 76-77, and Rosen and Saidel 2010, 67, table 2); 'some form of welcoming' in connection with caravan life, involving burners, was evoked by Hassell $(2002,179)$. This scenario may be particularly pertinent to our finds from Barāqish Area $C$, see below (footnotes 56 and 57). 
also playing an ideology-laden role in mortuary and temple practices, first of all had to meet the people's physical, spiritual, and social needs in everyday life in mundane contexts, so to speak. ${ }^{47}$ General wellbeing was the overarching aim: the fragrance from burning was essential to generate a good atmosphere and represented an existential necessity. ${ }^{48} \mathrm{As}$ a consequence, narrowly focusing on a single function or purpose does not seem appropriate to understanding burners. ${ }^{49}$

Besides the practices destined for the above functions, and intersecting with them in different ways, incense and other suitable substances were used as inhalants or for cosmetic purposes. ${ }^{50}$ But of greater interest here is the distinct possibility of a non-fumigation line in burners' utilization, tied to a second general process: ${ }^{51}$ probably a separate function of cuboid burners was that of lamps. This idea was tersely advanced by Gus Van Beek $^{52}$ and has since found wide support, ${ }^{53}$ although strangely neglected by Sabaeologists. Provision of light would have alternated with fumigation, as suggested by Van Beek, or would have been specific to some burners. Contrary to custom, it should not automatically be assumed that all uninscribed and undecorated cuboid examples were exclusively gum-resin burners. At the same time, plain, poorer-looking burners can just as well have been used as oil lamps exclusively: good examples are finds nos 80.1, 189.1, and 211.1 from Area C. ${ }^{54}$ The above does not mean that - at least locally -

47 This wording must be qualified. Through fumigation, the Arabian cuboid burner would provide an exemplary instance where the cognitive boundary between the mundane (ordinary, secular, profane) and the sacred (religious, symbolic, often mislabelled 'ritual') gets blurred or fades away. Or rather, in the societies of our concern this dichotomy did not in fact exist (Fedele, in preparation, see footnote 23). The information collected in Zimmerle 2014a is instructive to this effect.

48 Creasman and Yamamoto 2019, 356. Cf. Harvey 2003, 82-83 (a 'vital pleasure' for both people and gods); Frevel and Pyschny 2014, 154.

49 This is also the conclusion of Frevel and Pyschny (2014, 154-156).

50 E.g. Zayadine 1995; 'The archaeology of scents and fragrances' features among Zimmerle's (2014a) chapter headings. In a posthumous paper, already W.F. Albright (1974) had proposed to interpret cuboid burners as cosmetic devices for the beautification of women - a controversial suggestion (cf. Shea 1987, 162, note 3).

51 I.e., a utilization line still based on burning, but not on the process of fumigation. This terminology based on 'utilization lines' is introduced here (from Fedele, in preparation, see footnote 23).

52 Van Beek 1969, 100: 'Another curious omission in the South Arabian repertory of [pottery] forms is the lamp. Thus far, no single pot which might have served as a lamp has been identified at Hureidha, Hajar bin Humeid, or any other site in this region. The only objects with traces of burning that might have been used for this purpose are those objects which are commonly referred to as incense burners [...]. Perhaps these functioned both as lamps and incense burners depending on the needs of the moment in the South Arabian household.'

53 E.g. Shea 1983; 1987; Tiede 1987, 150-151; Hassell 2002, 189, 192 (with qualifications); Jasmin 2005, 56; Fedele 2010, 136; 2011a, 115. In the context of Predynastic Egypt and Nubia, see now Creasman and Yamamoto 2019, 348.

54 Another strong possibility as a lamp - only an example among very many - is a squat square burner in 'granit' from TT1 at Tamnac the need for lighting was not met by a different sort of lamps, exclusively or concurrently. ${ }^{55}$

The foregoing discussion is important for placing in perspective not only the few finds from Area C at Barāqish, but those that can be expected from extramural areas at other sites, particularly caravan stations. This is because, as mentioned above, some of the well stratified and well documented finds from Area $\mathrm{C}$ do not belong in the usual contexts described for cuboid burners (votive, cultic/liturgical, and mortuary). In this field the contribution of Area $\mathrm{C}$ is twofold. First, the two burners from the Later Sabaean residential tell (nos 5.1a and 5.1b) can be confidently related to a domestic context, as explained in Chapters 18 and 26 , this volume. And second, a new type of context is tangibly introduced, which is 'extramural', to use a neutral term, but can be characterized more explicitly as a 'trading-caravan' context ${ }^{56}$ (finds nos 211.1, 80.1, $186.1,189.1$, and possibly 06). Details in support of this claim have been presented elsewhere ${ }^{57}$ and the subject was taken up in Chapter 19, section 3, this volume. In particular, within the confines of limited sampling, the archaeological record from the talus footslope and the plain can be construed as evidence for a recurring caravan-campsite scenario, to which the remains of cuboid burners with their relative frequency are believed to contribute.

Cuboid burners were found at Barāqish in other operations as well. 21 finds in total are known, almost all fragmentary or incomplete. Seven specimens were obtained from Temple A (Marion de Procé, Chapter 11 in Volume 1, with references), five from Temple B (Antonini, Chapter 5), three from the Minaean cemetery at Area D. ${ }^{58}$ The exploratory survey of 1986

\section{(Loreto 2016, 317, fig. 36/8).}

55 At the turn of our era, large bivalve shells (scallops) were manifestly used as oil lamps at coastal Sumhuram (Wilkens 2005, fig. 9 ; Lombardi et al. 2008, 397-398, plates 34/1,60/1-4). Chemical analysis of combusted residue from a specimen has revealed the presence of fatty substances and cholesterol of animal origin, mixed with pine resin. One can wonder whether the single scallop from Tomb A5 at Hurayda, although lacking residues as well as earlier in date (Caton Thompson 1944, 77, pl. XLI/4; Jackson 1944, 104), did not fulfil the same function. At Yathill itself, judging from their concentrations, fragmentary ring-foot bases of ceramic bowls might have been used as oil lamps in connection with funerary equipment at both Area D and collection 'sites' BARii and BARiii (Antonini, Chapter 2 in Volume 1 , footnote 60 , figs 24,28 ).

56 This context is not the same as the one perceptively suggested by Jonathan Hassell from groups of burners found in an entirely different setting - on the inside of city gateways at Tamna' and Sumhuram. At each of those sites, five elaborate cuboid burners would have played a role in 'some form of welcoming process' in relation to 'the incoming caravan traffic', the burners being located at Tamna' near the front of Building C, a special-purpose costruction (Hassell 2002, 179-180 [quote], 188), and at Sumhuram in association with the main gateway (Hassell 2002, 165, 167, 188).

57 Fedele 2014, particularly tables 3-5. Cf. also footnote 46, above.

58 Antonini 2010b, 23, 25, plates 36-37. All retrieved from the layer corresponding to the Minaean tombs ('Level 3'), and all uninscribed. 
(Antonini, Chapter 2) had already produced two finds from the talus outside Minaean wall's bastions T1-T5 ${ }^{59}$ and one find from Hill D, ${ }^{60}$ while three occasional finds of unknown context were obtained from local residents during the campaigns of 2005-2006. ${ }^{61}$ However, the burners from Area $C$ find only general parallels in the other collections from Barāqish. This once again underscores the extremely high individuality that characterized the production of Arabian cuboid burners.

5.1a = B.05.C.O/1 (Fig. 6). Incomplete, flat cuboid burner, broken along the middle. White fine-grained limestone, ${ }^{62}$ smoothed and painted. $10.7 \times 6.8 \times 5.7$ $\mathrm{cm}$; basin, wall thickness $1.5-1.7 \mathrm{~cm}$, depth $3.3 \mathrm{~cm}$. | D13 east within Gully B, $20-30 \mathrm{~cm}$ from the subvertical erosion at head of gully. Found within loose, recently reworked sediments (greyish sandy silts and occasional stones) deriving from adjacent stratified deposits of sediment suite GZ. Stratum L. | A square or rectangular container of rather poor workmanship, with walls of variable shape and uneven height, a flat base, and a crudely carved, slightly concave basin. Although plain and uninscribed, ${ }^{63}$ all its surfaces appear to have been covered with a red paint or slip, patches of which survive in places inside the basin, while on the outside a uniform thick paint, mostly turned reddish-grey from sedimentary contamination, is extensively preserved. ${ }^{64}$ There are traces of burnt residues on the bottom and sides of the basin. Parts of the outer surfaces and especially the rim are scarred by deep battering marks.

Remarks on red colouring. A distinctive red or reddish paint frequently appears on cuboid burners from Yemen. It also appears to be geographically ubiquitous. It was first noticed by G. Caton Thompson at Hurayda in the Hadramawt (five finds, all 'reddened', 'stained

\footnotetext{
59 Site 'BARi'. One find is a fragment, the other one is the nearly complete specimen Y.86.BARi/13, first published in Antonini 1988, 133-135, fig. 1, and dated from palaeography to the 4th-3rd centuries BCE. This latter find is listed in Sima $(2000,268)$, where the four aromatics named on the sides of the burner are discussed in detail ( $p$. 269-276); see also Müller 1997.

60 Site 'BARii', a little to the south of the Area D cemetery, a fragment.

61 Pagano 2010, 80-81, plates 49-51. About the single word inscribed on two of these burners ( $h \underline{d} d k$ ) see Agostini 2010b, 65, 66 .

62 As a provisional reckoning would suggest, white or pale limestone was the rock predominantly chosen for making cuboid burners in Yemen. It was the most common rock type used for burners at Barāqish Area C (nos 189.1, 186.1, 211.1, and 80.1).

63 See the above introduction to 'Stone burners and containers' for the alternative interpretation of plain, 'ordinary' burners as lamps.

64 This thick paint or coating might have been intended as an overlay for an unsatisfactory rock, in the present case a lesser-quality and wear-prone limestone. If so, burner 5.1a would evoke the technique of plastering a coarser-stone object mentioned by Van Beek $(1969,80$, 272-273) from Hajar ibn Humayd and other Qatabānian sites (Wādī Bayhān). See Hassell 2002, 187, and further details in 'Remarks on red colouring', appended to this same entry.
}

with haematite'), ${ }^{65}$ and concurrently reported from unprovenanced museum finds. ${ }^{66}$ Besides Area $C$ and other Barāqish locations (this book), ${ }^{67}$ numerous examples are known for instance from Mārib ${ }^{68}$ and the main sites in Wādī Bayhān: Hajar ibn Humayd, ${ }^{69}$ Tamnac, ${ }^{70}$ and the Hayd ibn 'Aqil cemetery. ${ }^{71}$ Notes Hassell in his detailed study of the cuboid burners from the three latter sites, a total of 30 finds: ${ }^{72}$ 'Red colouring had been applied to at least nine of the 24 smaller cuboid altars prior to the application of any incised decoration. [This] colouring had sometimes been applied on top of a white slip. $\left[{ }^{73}\right]$ At least three stone altars appeared to be covered by a white slip and two by a hard [lime] plaster.' Occasionally, a red colour can appear on other small objects as well, e.g. on a tripod-footed bowl or saucer from Sumhuram. ${ }^{74}$ Two cases from Tamnac - the choice of red quartzite for carving a burner, ${ }^{75}$ and the further, artificial reddening of a limestone which was merely light red originally ${ }^{76}$ - provide additional evidence that red was given aesthetic or ideological significance in the making of cuboid burners and comparable objects. A specific investigation of this phenomenon might be rewarding. There is some widespread symbolism involved, but its nature is elusive. In the light of its ubiquity, an ethnic factor should be excluded.

$5.1 \mathrm{~b}=$ B.05.C.O/2 (Fig. 7). Incomplete, multiple container furnished with an ibex protome and showing evidence of burning. Yellow-white, medium-grained, slightly heterometric calcarenite. Max. preserved length $9.1 \mathrm{~cm}$, width $7.0 \mathrm{~cm}$, height $3.6 \mathrm{~cm}$; rim thickness 0.8-1.1 cm; ibex head max. length $2.5 \mathrm{~cm}$, width $1.5-$ $2.3 \mathrm{~cm}$. D13: provenance and stratigraphy as for no. 5.1a. Stratum L. | A container made of two or more rectangular compartments and outwardly decorated between two compartments - with the head of an ibex in high relief. This protome is transversely crossed by a cylindrical through hole. of the ibex only the eyes,

65 Caton Thompson 1944, 50, 153. While citing haematite, Hassell $(2002,170,178,187)$ cautiously prefers to speak of 'a red substance'.

66 Bowen 1958, 149 ('One of the burners at Harvard and both of the burners at Pennsylvania show traces of artificial reddening on the sides and top edges'), 151 (catalogue description).

67 Temple B (Antonini, Chapter 5 in Volume 1) and an indeterminate location (MAIRY.05/11; Pagano 2010, 81, pl. 50; Marion de Procé, Chapter 11, section 5.1, in Volume 1).

68 E.g. Albright F.P. 1958, 274 (object no. 119).

69 Van Beek 1969, 273.

70 Hassell 2002, 170, 174, 175, 177, 178.

71 Cleveland 1965, 118-120; Hassell 2002, 183.

72 Hassell 2002, 187, adapted (emphases mine - FGF).

73 This sequence or stratigraphy was standard: from earliest to latest, (1) white slip or coating $\rightarrow$ (2) red colouring $\rightarrow$ (3) decoration (usually incision). [FGF]

74 Hassell 2002, 161, fig. 4.

75 Hassell 2002, 175, 178. From one of the houses near the 'South gate'. The rock, an uncommon choice, was either a proper quartzite or a quartzarenite [FGF].

76 Hassell 2002, 175, figs 22-23 (a rectangular flat burner). 


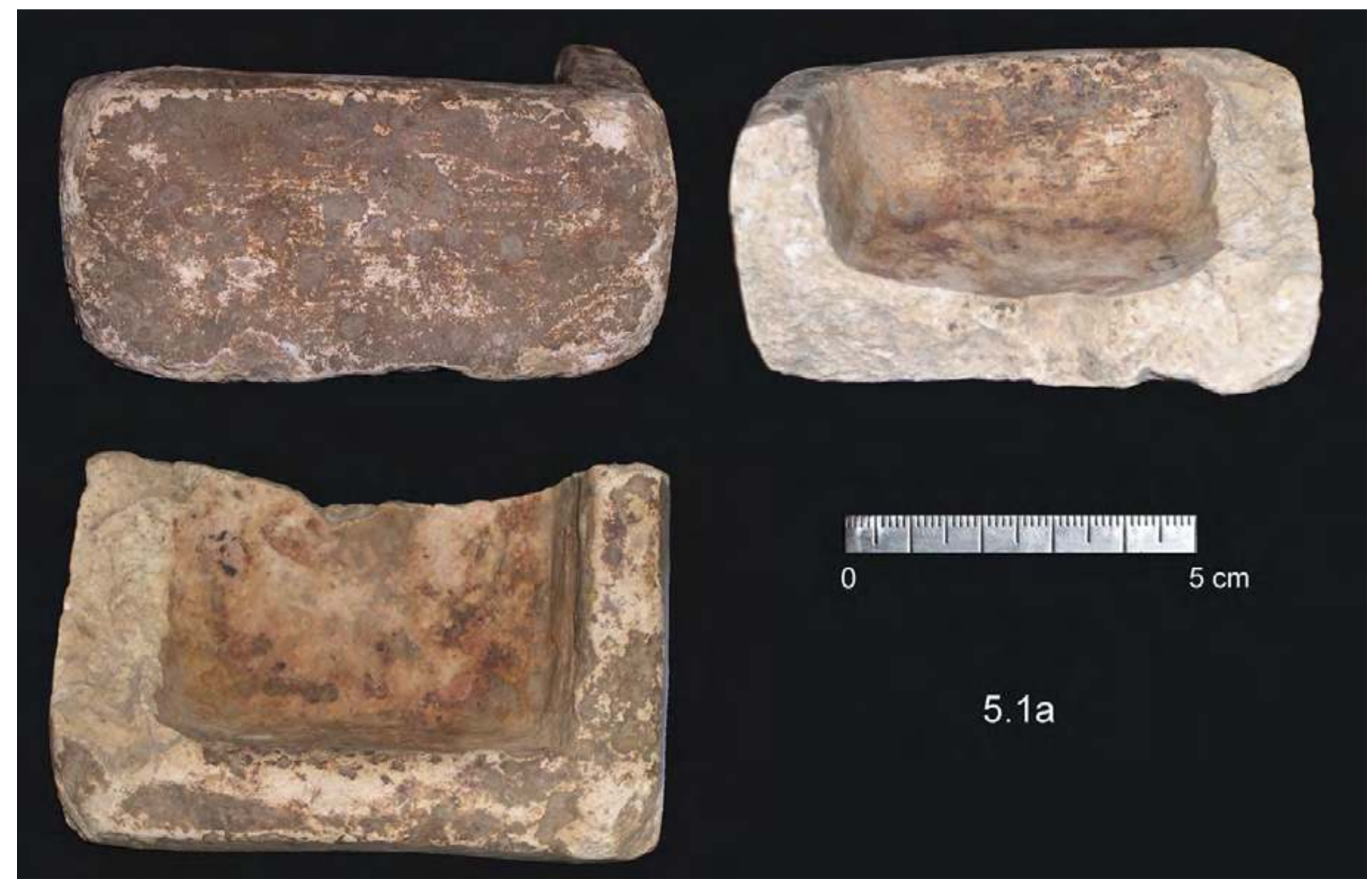

Figure 6. Stone burners and containers, Sabaean, reg. no. 5.1a. (P. Morlupi 2005 @ MAIRY, optimized by F.G. Fedele 2019).

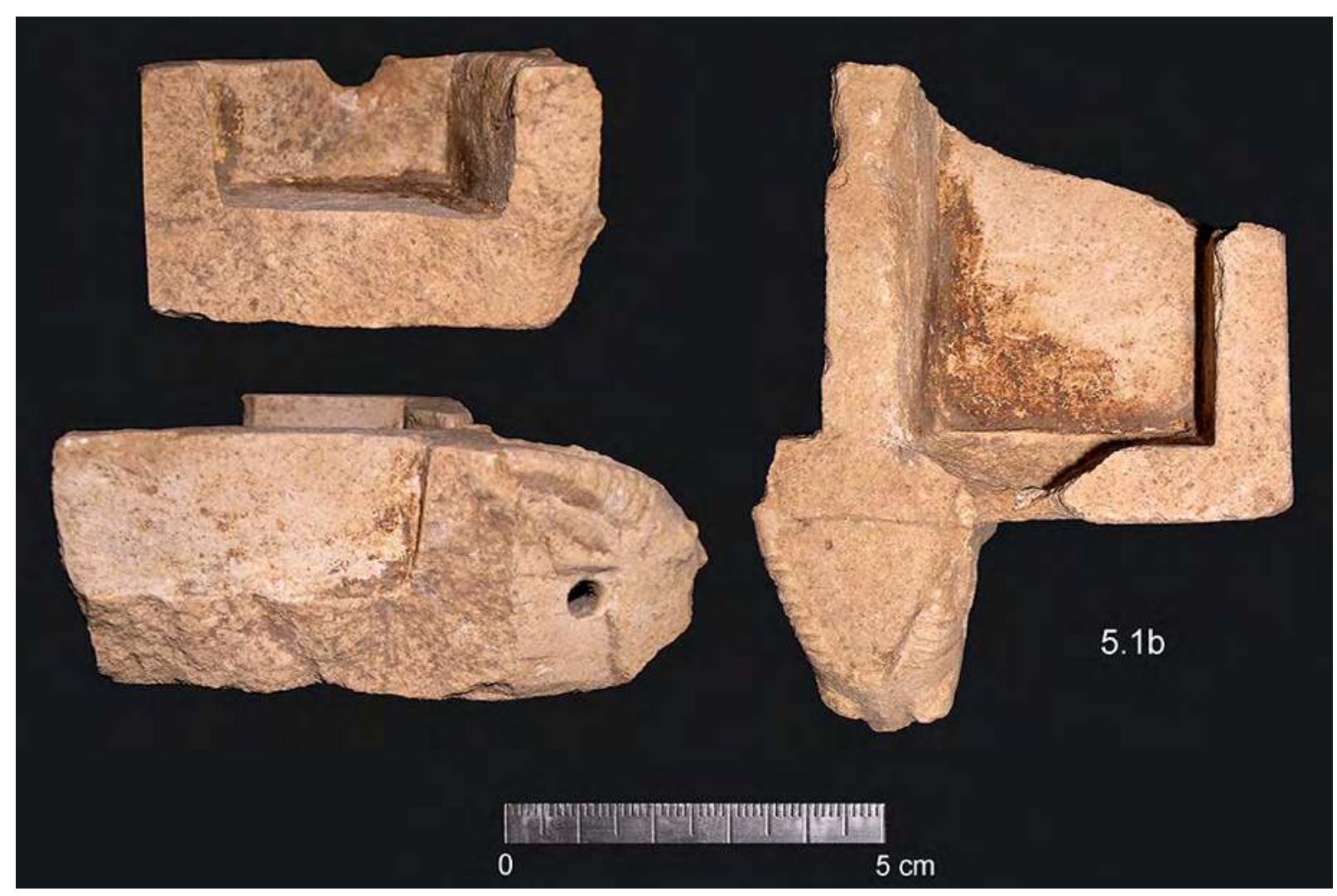

Figure 7. Stone burners and containers, Sabaean, reg. no. 5.1b. (P. Morlupi 2005 @ MAIRY, optimized by F.G. Fedele 2019). 
the ears in low relief, and part of the horns with their growth rings are preserved. A parallel in terms of ibex decoration is provided by a terracotta container or burner from a Sabaean temple in Wādī Quțūța (Mārib area) dating from the 8th-7th centuries BCE. ${ }^{77}$ Some burnt-looking residue survives as a reddish-brown stain in a corner on the bottom of the extant receptacle. ${ }^{78}$ Stone of choice and meticulous craftmanship.

Publication: Fedele 2010, 123 (mention), fig. 144/E.

$[\mathrm{SA}, \mathrm{FGF}]$

\section{Softstone vessels}

The term softstone (also 'soft stone') is perhaps the most frequently used in Arabian archaeology as shorthand for any kind of more or less massive, easily workable rock for making containers and vessels. It is 'an ambiguous yet convenient term used by archaeologists to encompass stones of Mohs hardness 3 or less', 'specifically used to describe objects carved of gypsum, limestone, calcite [travertine], alabaster or the family of greyish or greenish stones characterised as steatite, chlorite or talc'. ${ }^{79}$ In this chapter softstone will be restricted to the last family mentioned (cf. Pliny's lapis ollare, 'the stone for carving pots'), and it is employed with the proviso that any number of minute varieties may be subsumed. Softstone in this sense is a member of the larger group of ophiolithic rocks.

Since the 1970s the initiators of softstone studies already stressed the point that this umbrella term 'actually designates two main varieties of stones: chloritite, which is basically composed of the chlorite mineral, and steatite, which is made of talc' ${ }^{80}$ Also rocks containing both chlorite and talc occur, for instance in

\footnotetext{
77 Krautwurst 2007, 97, fig. 23/1a-b, pl. 9/10 (cat. no. A 421). [SA]

78 Unfortunately such residue was not described in detail nor sampled, but its presence and appearance do not necessarily imply that the object was strictly a burner, or a burner at all, since dark stainings can have many origins (from cosmetics, for instance). From a typological viewpoint this container, being composed of square or rectangular basins, could well belong in the cuboidburner production, of which it retains the square module as a core concept, but a different classification would be equally admissible (a 'compartmented' vessel, see Phillips and Simpson 2018c, 171-172; cf. Lombardi et al. 2008, 327-328, pl. 5/3, from Khawr Rūrī/Sumhuram). [FGF]

79 Phillips and Simpson 2018b, 2. Cf. Glanzman, 1987b, 131 ('steatite' as a collective term, see below, 'though in fact [the vessels] may well be made of a number of other minerals').

80 David 2002, 333 - italics mine (FGF). David adds that, if one wishes to be petrographically correct, "the term "chloritite" is the right one, since chlorite designates the mineral itself, which is never found chemically pure in ophiolitic context' (David 2002, 334). Similarly Glanzman $(2018,124)$ : the minerals talc and chlorite are major constituents of the metamorphic rocks in question, these being in turn the frequent 'result of lowgrade alteration of parent rock formations'.
}

Yemen, ${ }^{81}$ but - as Hélène David remarks - relatively few softstone vessels 'contain steatite, and when they do, the rate of chlorite is always higher (vessels of pure steatite are extremely rare) ${ }^{\prime}{ }^{82}$ When precise analyses are lacking, it is thus more correct to speak of chloritite rather than steatite vessels. In their quest for a collective term, however, researchers working in Arabia have long differed in their preferences, or have simply avoided the petrographic issue.

In Yemen, archaeologists have often called all the workable talc-chlorite-based rocks steatite. ${ }^{83}$ Other researchers prefer to speak of 'chlorite', ${ }^{84}$ to be rectified as chloritite as indicated above. Chloritites occur widely in the highlands of Yemen and western Arabia, as well as Oman, and, understandably, rocks formed of homogeneous chloritite were preferred, including both darker (dark grey-green) and lighter (pale grey) varieties. ${ }^{85}$ In Yemen, during the 1st millennium BC, the rock types employed for softstone vessels not only included chloritite, but specific varieties of chlorite-rich steatite, for instance a talc-actinolite-chlorite schist. ${ }^{86}$ Softstone as one of the mineral resources of Yemen was examined in a landmark review by W.C. Overstreet and colleagues, ${ }^{87}$ but an updated appraisal focusing on the distribution of outcrops as well as lithology would be welcome. While additional petrography is needed, a recent study of steatite-tempered pottery production in ancient Yemen has provided a significant start. ${ }^{88}$

In terms of lithology, also the softstone collection from Area $\mathrm{C}$ can be reduced to the two rock types generally recognized in South Arabia: chloritite, 'dark ordinary softstone' in provisional field parlance, comprising the large majority of the finds (78 per cent) and specifically identified in one instance as a chlorite-micaschist (Sabaean find no. 102.01, this section); and steatite, only reliably determined from four fragments, including a rare 'pale steatite' (Minaean find no. 197.01). Within each rock type a moderate assortment of varieties was observed, including the darker and lighter varieties

\footnotetext{
81 Such as so-called soapstone, 'which is now exploited in the Yemen mountains' (David 2002, 333-334). Phillips and Simpson (2018b, 2) mention soapstone as a popular name for the talc-steatite-chlorite family (see also Glanzman 2018, 124, and for a more precise statement Porter 2018, 164).

82 David 2002, 333-334; though speaking of Omani Bronze Age vessels, her remarks can be generalized to later periods and most of South Arabia.

83 For instance, and consistently, Glanzman (1987b; 2018), and in a Saudi Arabian context Zarins (1978). Steatite as a general term was also preferred by de Maigret (2016, 235-238; in Italian the written form is the same as in English, steatite).

84 E.g. Simpson 2018 (following Kohl et al. 1979).

85 E.g. Phillips and Simpson 2018b, 6-9, 51-52; 2018c, 177-178.

86 Porter 2018, 164. This is one of the varieties popularly known as 'soapstone', see footnote 81 above.

87 Overstreet et al. 1988b, 392-406.

88 Porter 2018.
} 
of chloritite noted above. A formal petrographic examination of the softstone vessels produced by the operations at Barāqish remains to be done.

Like in pre-Islamic Yemen generally, also at Yathill carved softstone containers were mostly used for the processing of foodstuffs. ${ }^{89}$ Equally shared with most ancient sites in Arabia and elsewhere is the general condition of the archaeological evidence. As Simpson observes, 'this material represents discarded refuse and is therefore typically fragmented, although it often shows signs of previous repair and recycling; and repairs were usually made with iron rivets inserted through paired holes, or with iron staples, traces of which often remain..$^{90}$ Frequently, at multi-period sites, softstone sherds were also 'subject to repeated redeposition and thus residuality', ${ }^{91}$ and Barāqish Area $\mathrm{C}$ is a case in point.

In particular, the softstone kitchenware from Area C predominantly comprises fragments of cooking pots, burm/burmah in Arabic, ${ }^{92}$ which sometimes still preserve carbonized residues of foodstuffs on the inside (13 per cent of the finds) and shows darkening from burning outside (26 per cent). Studies of traditional softstone manufacture in Yemen offer information of archaeological interest for understanding ancient cooking-pot production. ${ }^{93}$ No pre-Islamic softstone find from Area $C$ shows evidence of lathe-turning, except perhaps the Minaean 'pale steatite' container no. $197.01 .^{94}$

In addition to the finds below, also two softstone fragments listed in the Minaean group might be reworked Sabaean material (nos 197.01 and 197.02 from Sounding A).

102.01 (Fig. 8). Rim fr. of softstone vessel. Chloritite lato sensu. $8.0 \times 3.8 \mathrm{~cm}$, rim thickness $0.5 \mathrm{~cm}$, max. thickness $0.8 \mathrm{~cm}$. E2. Units V3, SI1i-SI1, SE3, but predominantly SE3 or SI1. Strata S-R. | The rock was specifically

\footnotetext{
89 Cf. Glanzman 2018, 131-132, 134-135.

90 Simpson 2018, 180.

91 Simpson 2018, 180

92 'The modern Yemeni kitchenware equivalent of the ancient Steatite Cooking Bowl is the burma or burmah (Posey 1994, 39), vocalized as bourm in French (Badre 1992, 247), and rendered as birmeh elsewhere (Caton Thompson 1944, 177-179). Generically, the burmah refers to the cooking pot (Posey 1994, 40, 55-56), but also seems to refer specifically to the stone from which some are made (Glanzman 2018, 131; main references only, adapted - FGF). Cf. Chapter 18, Appendix (Fedele).

93 E.g. Muchawsky-Schnapper 2018; Weir 2018.

94 If correct, this identification of manufacture with a wheelmounted lathe might suggest a dating in the 3rd century BC or later (see find no. 85.01 in the Uncertain chronology group, "Calcite or aragonite vessels'). As Phillips and Simpson (2018b, 51) observe, the introduction of the wheel-mounted lathe transformed the softstone industry by increasing speed of production, but does not appear to have led to an increase in output.
}

described as a dark chlorite-micaschist (magnifyingglass examination at Barāqish, 2006). It is manifestly crystalline and overall silvery in shine and colour.

121.01 (Fig. 8). Fr. of softstone cooking pot. Steatite. $11.5 \times 6.9 \mathrm{~cm}$, thickness varying $0.9-1.3 \mathrm{~cm}$. $\mid E 4$. Units XE4, LZ5, L3Z, $4 \mu r-V C B$ : unclear context. Strata $\mathrm{O}$ to $\mathrm{L}$ (to $\mathrm{K}$ ?). | Considering its estimated hardness and overall aspect, the dull, dark grey, fine-grained rock appears to be largely made of talc, hence its classification as steatite. The inside is well smoothed and preserved, whereas the outside is pockmarked with deep scars from uselife damage rather than manufacture (or from a combination of both). The fragment derives from the bottom part of the vessel.

199.04 (Fig. 8). Fr. of softstone vessel. Chloritite. 5.6 $\times 4.6 \mathrm{~cm}$, thickness $0.8 \mathrm{~cm}$. | A1-A11 east + A31, Locus 200. Middle-upper unit SYH. Stratum N. | Grey-silvery chlorite-based rock. A battered sherd.

214.03 (Fig. 8). Fr. of softstone vessel. Chloritite. $8.5 \times$ $7.1 \mathrm{~cm}$, thickness $c .1 .5 \mathrm{~cm}$. $\mid$ F. Units SY1a-SY1, probably SY1a. Stratum M. | Pale green, coarse-grained rock possibly containing both chlorite and talc. A rounded fragment from a thick-walled vessel.

15.01, 15.03 (Fig. 9). Two frs of softstone vessels. Chloritite. $15.5 \times 6.3 \mathrm{~cm}$, rim thickness $0.7 \mathrm{~cm}$, max. thickness $1.1 \mathrm{~cm}$; and $8 \times 4.5 \mathrm{~cm}$, thickness $c .1 \mathrm{~cm}$, respectively. |D3. Unit GZ3. Earlier Stratum L. | No. 15.01 is a large rim fragment from a capacious, well smoothed vessel with a ledge handle $1.5 \mathrm{~cm}$ below the rim. Four repair holes, still partly filled with rusty remnants of iron wire, can be seen along a fracture $4-5 \mathrm{~cm}$ below the rim and handle. The rim preserves thin crusts of carbonized matter and is generally blackened. Traces of burning on the outside. No. 15.03 is a fairly rounded wall sherd, showing traces of burning on the outside and a light hazel-reddish pigmentation inside.

15.02 (Fig. 9). Fr. of softstone vessel. Steatite. $12 \times 9$ $\mathrm{cm}$, average thickness $c .1 \mathrm{~cm}$. D3. Unit GZ3. Earlier Stratum $\mathrm{L}$.| The stone resembles the variety of find no. 121.01, above. Inside of the vessel (a cooking pot?) well fashioned and smoothed, outside surface battered or intentionally rough.

14.01 (Fig. 10). Fr. of softstone vessel. Steatite. $6.2 \times$ $4.0 \mathrm{~cm}$, average thickness $1.1 \mathrm{~cm}$. | D3. Units GZ2-GZ1. Stratum L. | Dull, dark grey talc-based rock similar to finds nos 121.01 and 14.01, above. Although it has not been cleaned (in order to preserve a sample of Later Sabaean 'living floor' sediments) the fragment suggests poor craftmanship.

30.01. Rim fr. of a softstone cooking vessel. Chloritite; $\mathrm{cm}$-sized. | D4. Mass GR1 and units $\gamma \mathrm{x} \omega$, SA $\pi$-SA0; but 

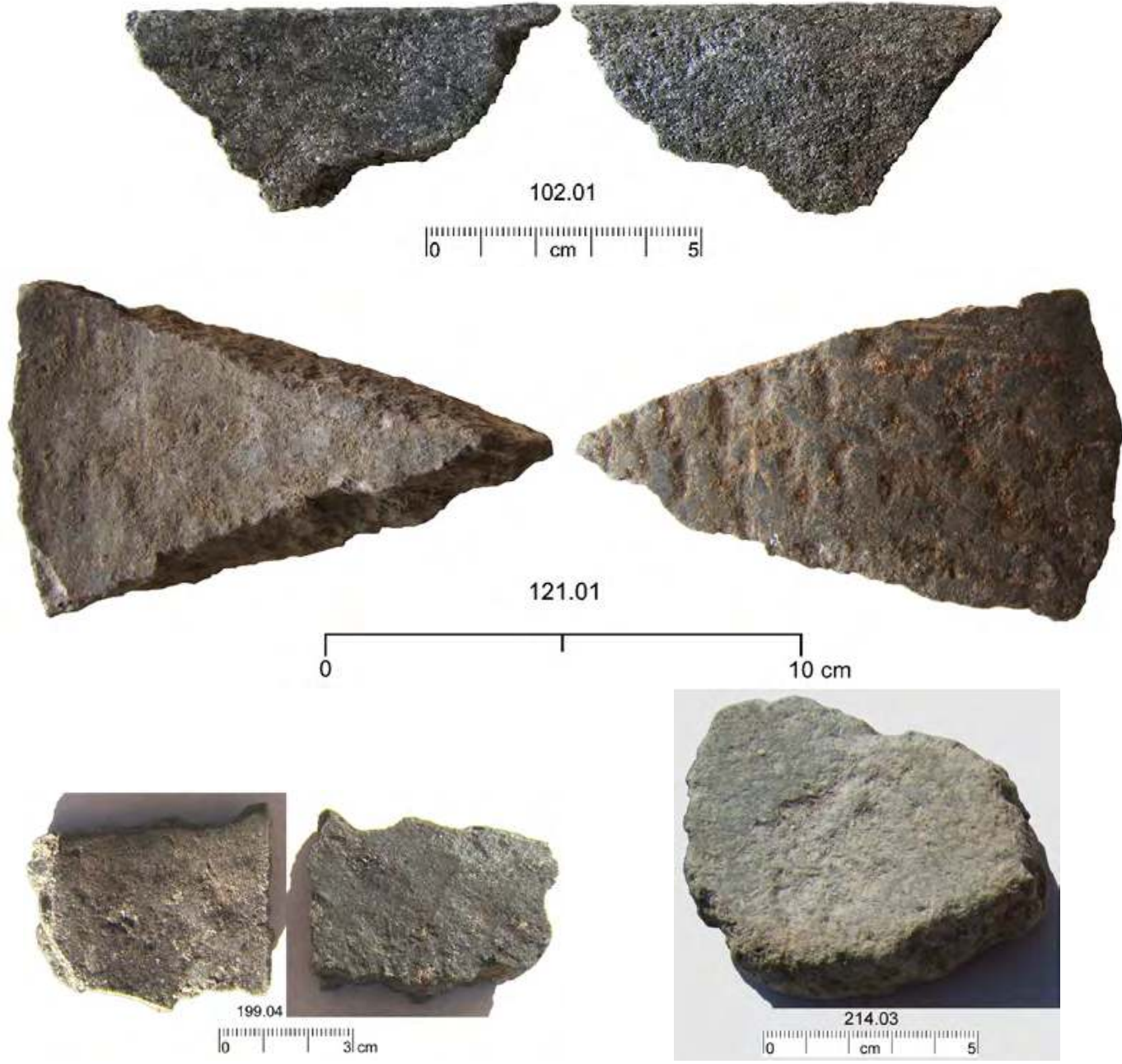

Figure 8. Softstone vessels, Sabaean, reg. nos 102.01, 121.01, 199.04, and 214.03. (G. Di Rosa and S. Iavarone 2007 (c) MAIRY, arranged and optimized by F.G. Fedele 2019)

probably from GR1 or $\gamma \times \omega$, since at the moment of recovery the find bore traces of yellow silty-clayey matrix cf. GR1 (see Chapter 17, section 7.6, this volume). Strata L or K, but probably a reworked Later Sabaean element from F9. I The fragment has a through hole below the rim and is encrusted with kitchen/cooking residues.

\section{Querns and other grinding tools}

Five querns, all incomplete, were recovered from Area C. Three of them were produced by transverse breakage: nos 152.1 in the Sabaean group (this section), 185.1 (Minaean), and 170.1 (Second intermediate). They are all elongated querns of 'saddle' shape (saddle querns), broken halfway transversely instead of lengthwise. For the purpose of reference they will be designated here as 'transverse half-querns'. This is to distinguish them from incomplete querns or quern fragments resulting from different kinds of breakage, such as, from Area C, no. 80.2 (Uncertain chronology group), which can be described as an incomplete quern affected by random damage, and Sabaean find no. 8.01 (below), which is a rare quern broken in half lengthwise.

Admittedly, broken querns occur at many types of site, but transverse half-querns represent a somewhat special category whose presence and frequency seem to be worth some attention. As also the single quern find from Area D at Yathill is a transverse half-quern, ${ }^{95}$ one is tempted to envisage a 'strange' frequency of them in extramural Areas C and D, which, if it were indeed the case, would call for an explanation. In principle, a certain frequency of transverse half-querns can simply be explained in terms of residual effect, i.e., abandoned or discarded random fragments of utilized querns. But a marginally higher frequency of this material could

95 Antonini 2010b, 23, 24, pl. 35/c ('oval grindstone' of 'pink granite' from Level 1, Late Minaean). Granite, properly speaking, is not an optimal choice for a quern. While the identification as granite is compatible with the photograph in the publication, which shows a compact, medium-textured rock, on the other hand a grinding stone from the same context, also said to be 'granite' (Antonini 2010b, pl. 36/a), suspiciously looks like a slightly vesicular extrusive rock, therefore not granite at all. 

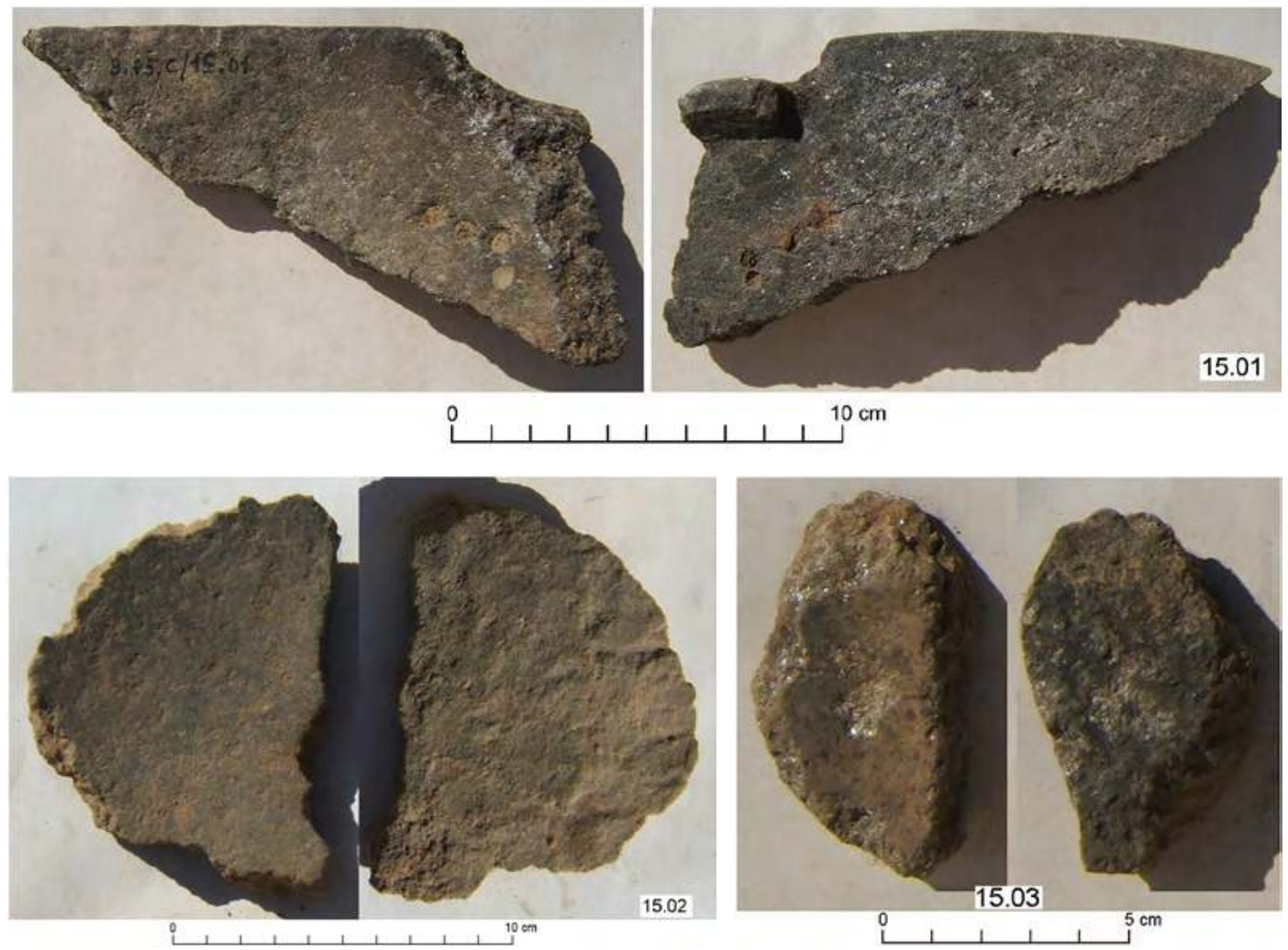

Figure 9. Softstone vessels, Sabaean, reg. no. 15.01-03. (G. Di Rosa and S. Iavarone 2007 @ MAIRY, arranged and optimized by F.G. Fedele 2019)

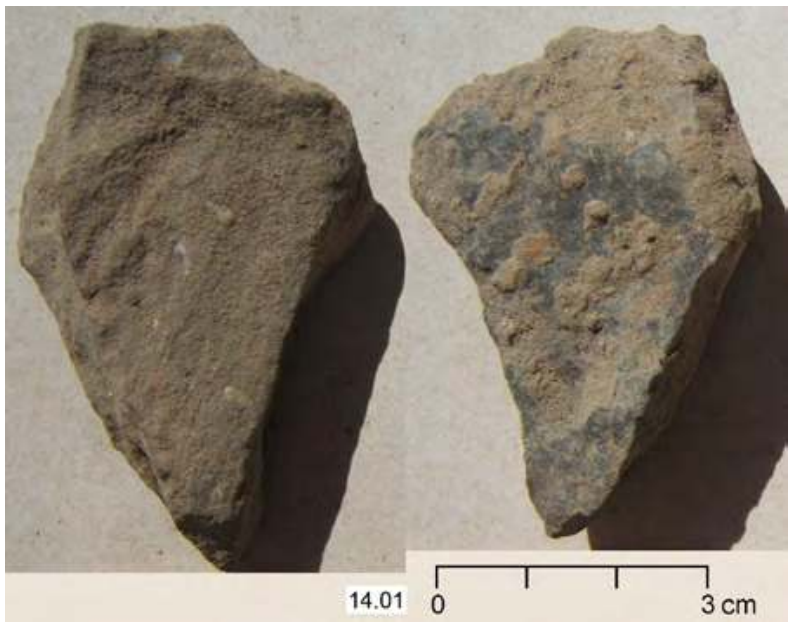

Figure 10. Softstone vessel, Sabaean, reg. no. 14.01. (G. Di Rosa and S. Iavarone 2007 ( ) MAIRY, arranged and optimized by F.G. Fedele 2019)

otherwise reflect a purposeful choice of half-querns, either by reuse of naturally broken pieces (hypothesis 1) or through pieces intentionally produced by breaking a suitable cobble in half (hypothesis 2). This latter behaviour would not be surprising, considering that half cobble - if used well - could be just as functional as a whole one, and would have represented an excellent way to economize rare rock.

49C.1 (Fig. 11). Cobble used as a grinding/rubbing stone. White-yellowish coarse calcarenite. $\varnothing 13.5 \times 13.4$ $\times$ c. $8.5 \mathrm{~cm}$. $\mid$ D17 west, in situ: see plan in Chapter 17, Fig. 55, this volume. Unit cf. SGP (SGP ${ }_{2}$, middle or lower, at level approx. corresponding to the top of Wall F4's masonry course 2 (counting from the top); location and stratigraphy as for no. 49C.2, see 'Mud bricks and cf. mud bricks' in this section (below). Stratum R. | The cobble can be described as either sub-spherical or planoconvex in shape, with a naturally flattened area. This latter was the utilized part of the object, and some use wear as well as traces of orange-reddish pigmentation can be observed on it. What substance may have imparted this 'ferrous' pigmentation (different from ochre, for instance) is difficult to guess.

152.1 (Fig. 12). Incomplete saddle quern: transverse half-quern. Vesicular basalt. $19 \times 15 \times 8.5 \mathrm{~cm}$. $\mid$ E11 east, in situ. Unit $\mathrm{E} \sigma \mathrm{W}_{3}$ (whose yellow medium sand deeply permeated the vesicles of the stone), cultural horizon H11Q. Stratum O? | This quern, preserved as a half, is of the same morphology and rock type as no. 170.1 from Sector C (Second Intermediate group, below). For its context see Chapter 17, section 6.9 and Figs 55 and 72, 


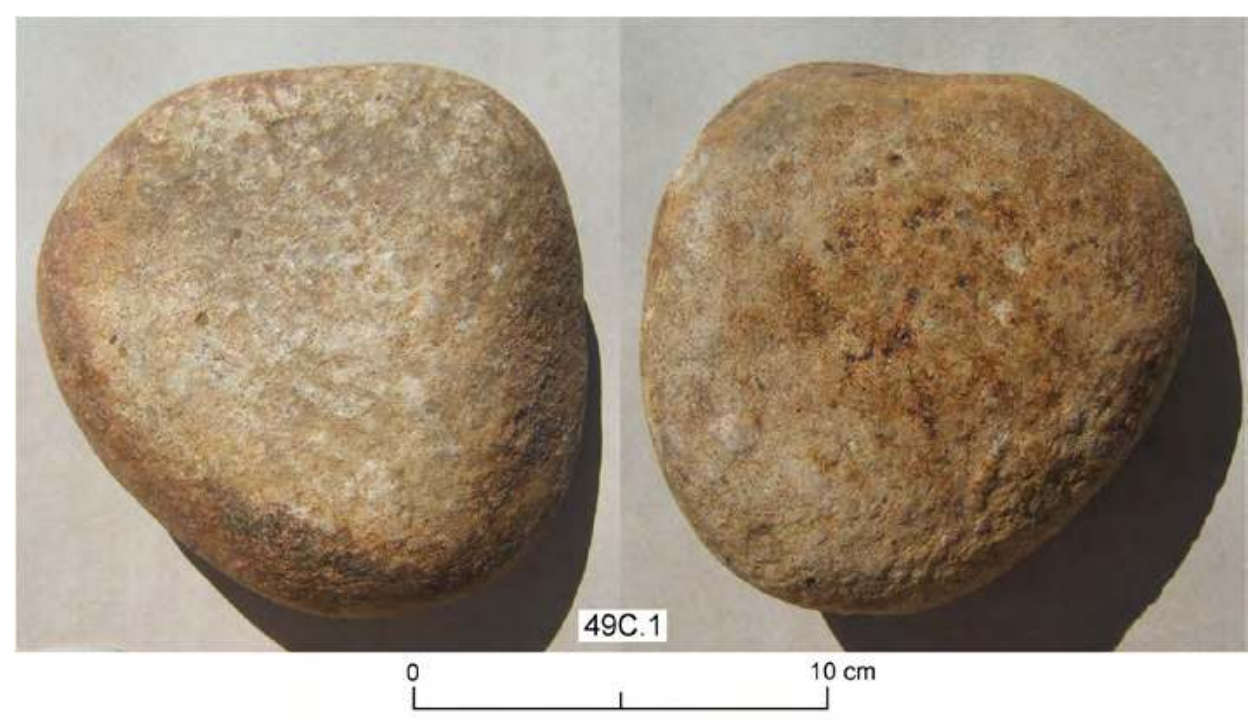

Figure 11. Grinding tool, Sabaean, reg. no. 49C.1. (G. Di Rosa and S. Iavarone 2007 C MAIRY, arranged and optimized by F.G. Fedele 2019)

this volume. As to the breakage pattern and its possible implications see the introduction to 'Querns and other grinding tools', above.

Mentioned in Fedele 2010, 119-120, and pictured in fig. 145/B (excavation photograph).

216.01 (Fig. 13). Grinding stone, incomplete. Dark grey limestone. $\varnothing 6.3 \times 5.8 \times c .3 \mathrm{~cm} \mathrm{|F}$. Unit SY2. Stratum O? | Natural cobble, showing two or three systems of evident striations from grinding on its flat surface.

15.04 (Fig. 14). Rubbing stone. Whitish fine-grained calcarenite. $\varnothing 6.1 \times 5.5 \mathrm{~cm}$. |D3. Unit GZ3. Earlier Stratum L. Natural cobble. Further details unavailable.

8.01 (Fig. 15). Incomplete quern, broken in half lengthwise. Vesicular basalt. $16.7 \times 7.6 \times 4.5 \mathrm{~cm}$. $\mid$ D14, within Gully B. Reworked within loose sediments probably eroded from stratified deposits of adjacent suite GZ. Stratum L. | A flat and remarkably thin specimen, broken nearly in half longitudinally. See the introduction to 'Querns and other grinding tools', above.

Other utilized natural stones (stone manuports, including fossils)

Some finds in this category could equally well be classed as 'Chipped stone: heavy duty', above.

49D.01 (Fig. 16). Fossil mollusc: internal mould of a gastropod shell, Cerithium sp. Brownish-greyish lithified silt. Length $5.7 \mathrm{~cm}, \max . \varnothing 2.4 \mathrm{~cm}$. $\mid D 7+E 120 \mathrm{~cm}$ east. Upper unit SIa, at or below the level of the base of Wall
F4 and apparently from the foundation cutting for the wall. Stratum T. | A sub-cylindrical, lithified internal mould from a turritelloid gastropod. Internal mould means that the original shell has been replaced by a hardened sandstone-siltstone fill. These fossils are now found as resistant remnants littering the semi-desert floor at well-known Lowermost Cretaceous outcrops to the west-northwest of Barāqish, between this town and Darb al-Ṣabi ${ }^{96}$ where the shell moulds have been released from their host rock or sandy matrix by a probable combination of rainsplash and wind erosion. Such fossils were presumably well-known to the Sabaean and non-Sabaean residents of Yathill just as they are today (the fossils are sometimes offered to tourists). Also specimen 49D.01 had probably been collected at one of those sites. This extraordinary find associated with Wall F4 is probably to be interpreted as a symbolic deposition by the Sabaean builders (cf. Chapter 17, section 6.3, 'Accessories and special finds', this volume). Another Cerithium sp. fossil, either a Minaean or reworked Sabaean element, was found within Minaean Earthwork F10-F12 in Sounding A (no. 192.01 in the Minaean group, below)

Publication: Fedele 2010, 115, fig. 144/B.

48A.01 (Fig. 17). Broken quartzite cobble. Max. length $8.3 \mathrm{~cm}$. D7 west alongside Wall F4. Units SGP 2 or TM4. Stratum R. | Further details unavailable.

96 These outcrops are very rich in such turritelloid gastropods. On the age of Cerithium (Amran Limestone, Upper basin facies) see Kruck et al. 1996, 41. For Darb al-Ṣabī see Chapter 1 in Volume 1, section 5; and Chapter 28, this volume. 

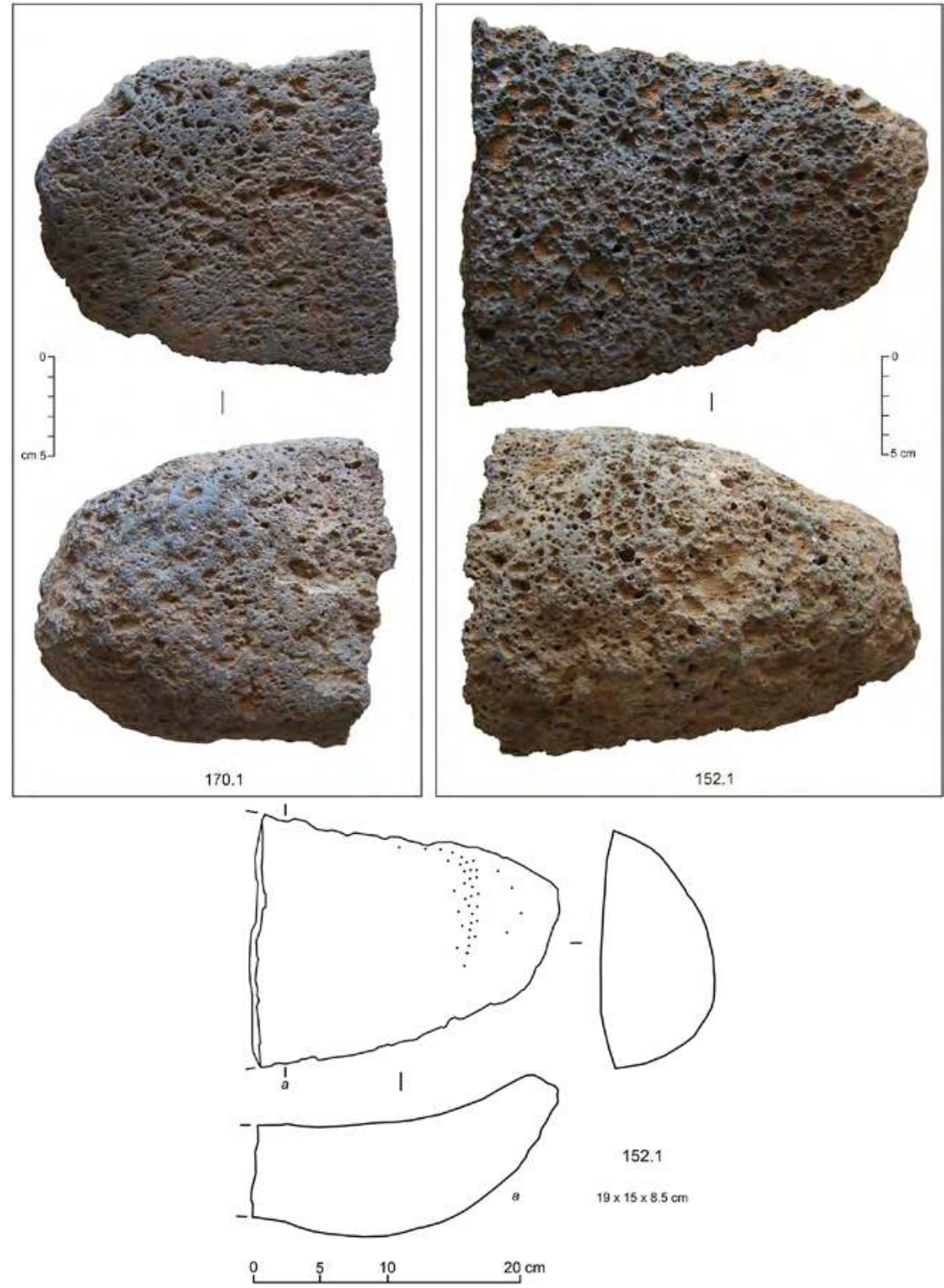

Figure 12. Querns: Sabaean, reg. no. 152.1, and Second Intermediate, reg. no. 170.1.

(P. Morlupi 2006 @ MAIRY, arranged and optimized by F. G. Fedele; drawing F.G. Fedele 2006)

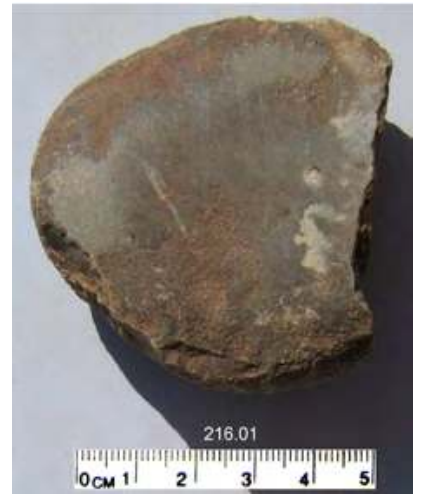

Figure 13. Grinding tool, Sabaean, reg. no. 216.01. (G. Di Rosa and S. Iavarone 2007 (C) MAIRY, optimized by F.G. Fedele 2019)

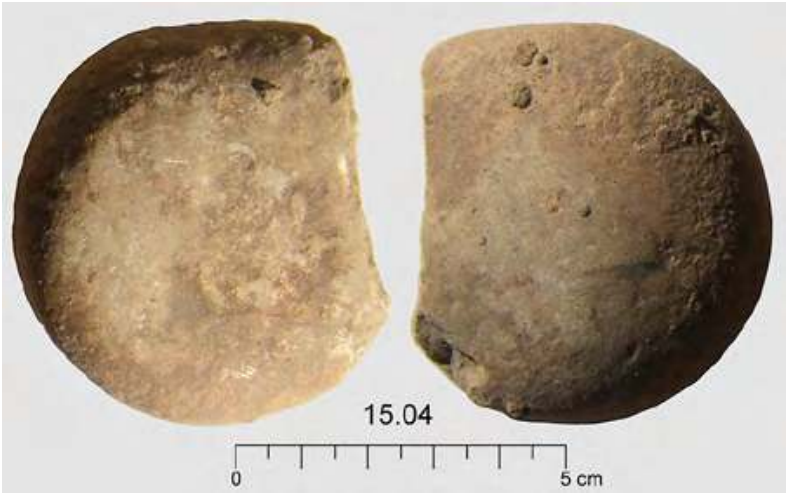

Figure 14. Rubbing tool, Sabaean, reg. no. 15.04. (G. Di Rosa and S. Iavarone 2007 @ MAIRY, arranged and optimized by F.G. Fedele 2019) 


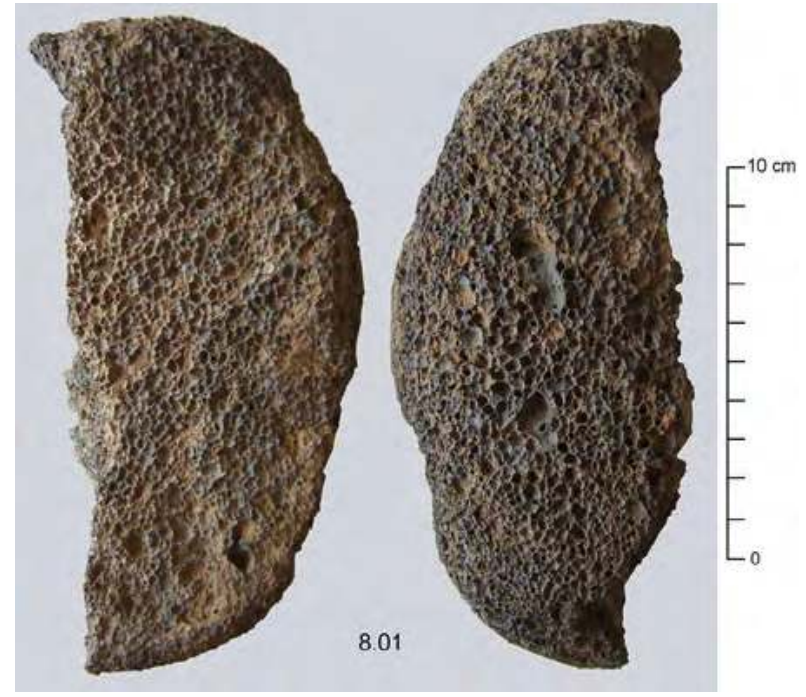

Figure 15. Quern, Sabaean, reg. no. 8.01. (G. Di Rosa and S. Iavarone 2007 @ MAIRY, arranged and optimized by F.G. Fedele 2019)

216.02 (Fig. 18). Cuboid cobble. Calcarenite. $5.4 \times 4.9 \times$ c. $5 \mathrm{~cm}$. |F. Unit SY2. Stratum 0? |Facetted and rounded.

82.2a, 82.2b, 82.2c (Fig. 19). Three broken cobbles constituting part of Cluster 82.2; the remaining elements are described below. Various rocks and sizes, max. length range 10.2-13.8 cm. $\mid$ E8 centre, in situ. Suite SEK, cultural horizon H78. Stratum M. | Stone no. $82.2 \mathrm{a}$ is a dm-sized spall (max. length $13.8 \mathrm{~cm}$ ) from an elongated cobble of a dark grey, compact volcanic rock subjected to bifacial percussion. The faint reddening on the main fission surface can either be cultural or geological. $82.2 \mathrm{~b}(7.4 \times 10.2 \mathrm{~cm})$ is a cobble of dark grey, compact volcanic rock split in half along the maximum diameter. $82.2 \mathrm{c}(7.7 \times 10.3 \mathrm{~cm})$ is a pyramidal - or trihedral - fragment from a summarily smashed, grey, fine-grained limestone cobble.

82.2d (Fig. 20). A virtually complete cobble, part of Cluster 82.2; the other stone components of the cluster are described both above and below. Vesicular basalt. Max. $\varnothing 7.2 \times 9.6 \mathrm{~cm}$.|Provenance and stratigraphy as for nos $82.2 \mathrm{a}-2 \mathrm{c}$. | The cobble does not reveal any obvious sign of cultural modification.

82.2e, 82.2f, 82.2g (Fig. 20). Three broken cobbles constituting part of Cluster 82.2; the remaining elements are described above. Various rocks and sizes, max. length $\varnothing \varnothing$ range $7-9.5 \mathrm{~cm}$. Provenance and stratigraphy as for nos $82.2 \mathrm{a}-2 \mathrm{~d}$. $\mid 82.2 \mathrm{e}(8.1 \times 8.1 \mathrm{~cm})$ is the larger part of a smashed, dark grey, mediumcoarse calcarenite cobble. $82.2 \mathrm{f}$ is a small fragment (max. length $7.0 \mathrm{~cm}$ ) of a grey, compact, fine-grained limestone cobble. $82.2 \mathrm{~g}(8.6 \times 5.8 \times 3.5 \mathrm{~cm})$ is a spall from a large calcarenite cobble resembling no. $82.2 \mathrm{e}$ in rock

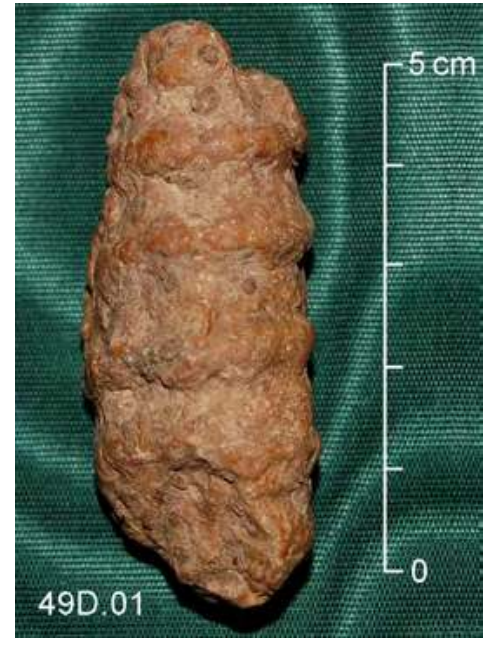

Figure 16. Fossil mollusc, Sabaean, reg. no. 49D.01. (P. Morlupi and F.G. Fedele 2006 ( $)$ MAIRY)

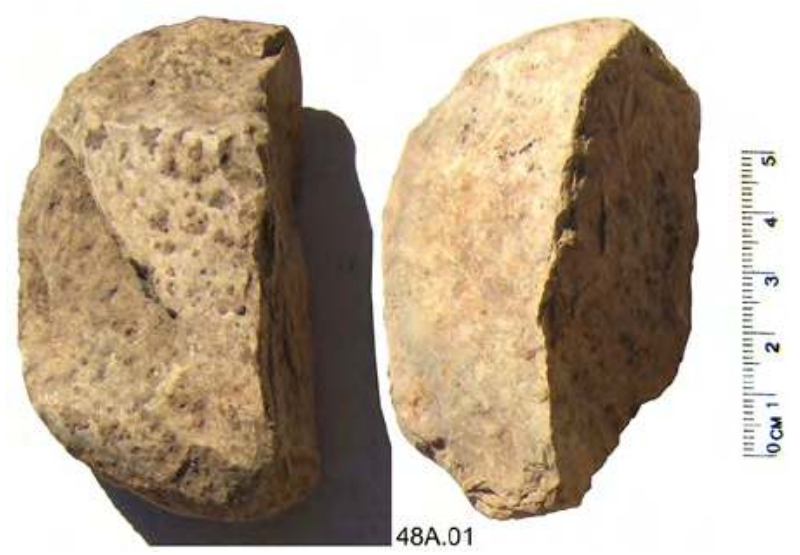

Figure 17. Utilized natural stone, Sabaean, reg. no. 48A.01. (G. Di Rosa and S. Iavarone 2007 @ MAIRY, arranged and optimized by F.G. Fedele 2019)

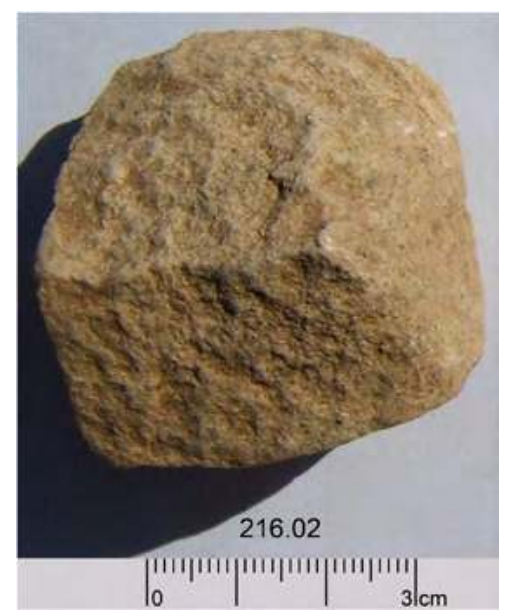

Figure 18. Utilized natural stone, Sabaean, reg. no. 216.02. (G. Di Rosa and S. Iavarone 2007 ( ) MAIRY, optimized by F.G. Fedele 2019) 

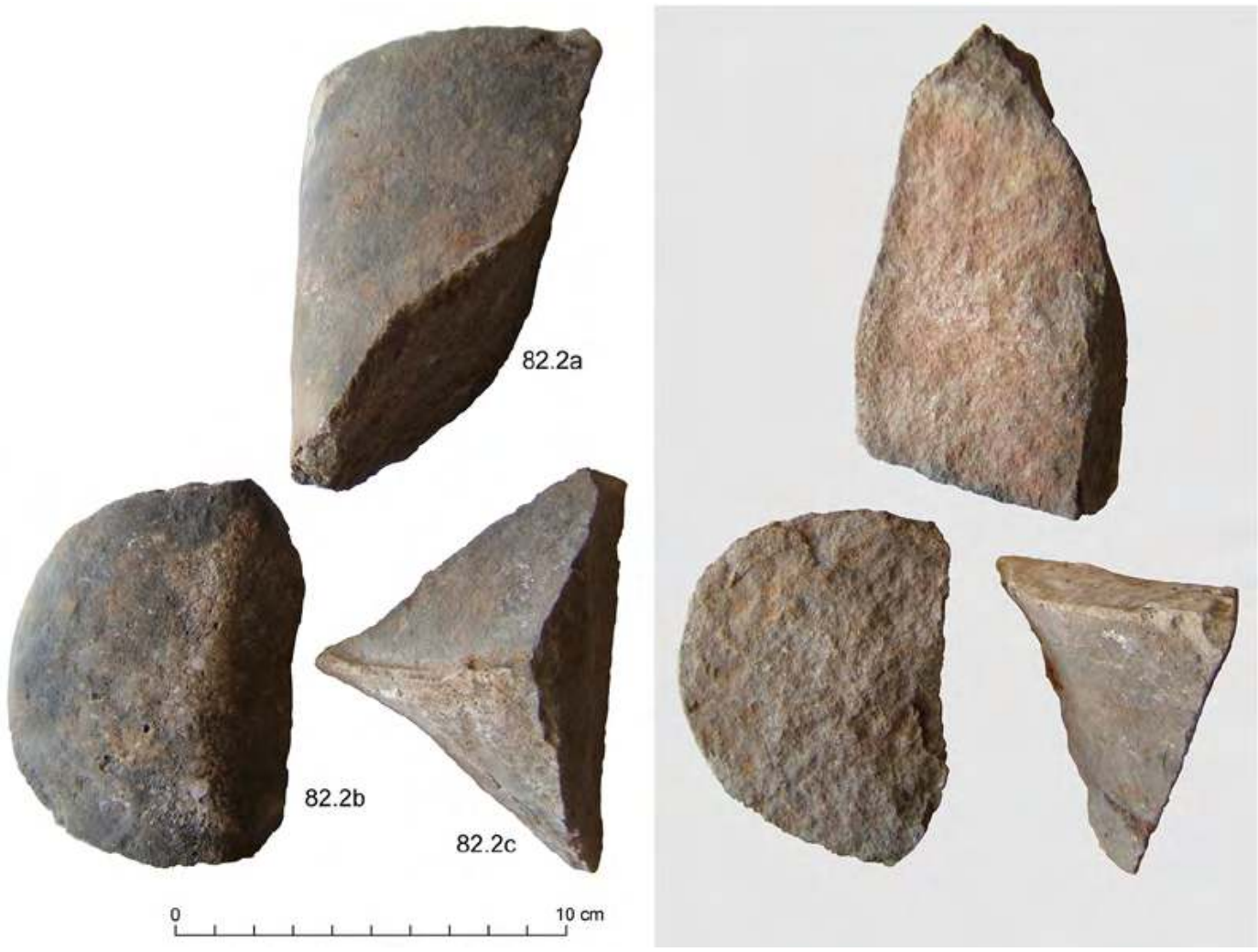

Figure 19. Utilized natural stones, Sabaean, Cluster 82.2. (G. Di Rosa and S. Iavarone 2007 (c) MAIRY, arranged and optimized by F.G. Fedele 2019)

type. This spall also shows slight traces of rubefaction from roasting.

Remarks on Cluster 82.2. ${ }^{97}$ Cluster 82.2 was interpreted in the field as composed at least in part of fragments of 'thermal stones', i.e. stones for storing and slowly releasing heat after having been heated by fire. Another possible example is find no. 51.02 in the Uncertain chronology group, below. This interpretation was borne out by the rubefaction traces from burning on some stone fragments (e.g. nos $82.2 \mathrm{~g}, 82.2 \mathrm{a}$ ), as well as their lithology and size. At the same time, the breakage pattern of other stones in the cluster suggested some different kind of action: a summary smashing of cobbles, apparently aimed at the speedy fashioning of a hearth. In fact, a makeshift hearth could satisfactorily explain both the percussion-generated clasts and the thermalstone effect, if this latter was indeed sought by the makers and users. Notably, Cluster 82.2 also contained unfired-clay disc fragments (nos $82.2 \mathrm{~h}-2 \mathrm{i}$, and perhaps also nos 82.02-03, see below), in addition to the Sabaean necked jar no. 82.1a (described in Chapter 23). In conclusion, Cluster 82.2 seems to represent the deflated remnants of a hearth made and used within cultural

97 Cluster 82.2 was described as part of cultural horizon $\mathrm{H78}$ in Chapter 17 , section 7.8 , this volume. The present remarks are intended as complementary.
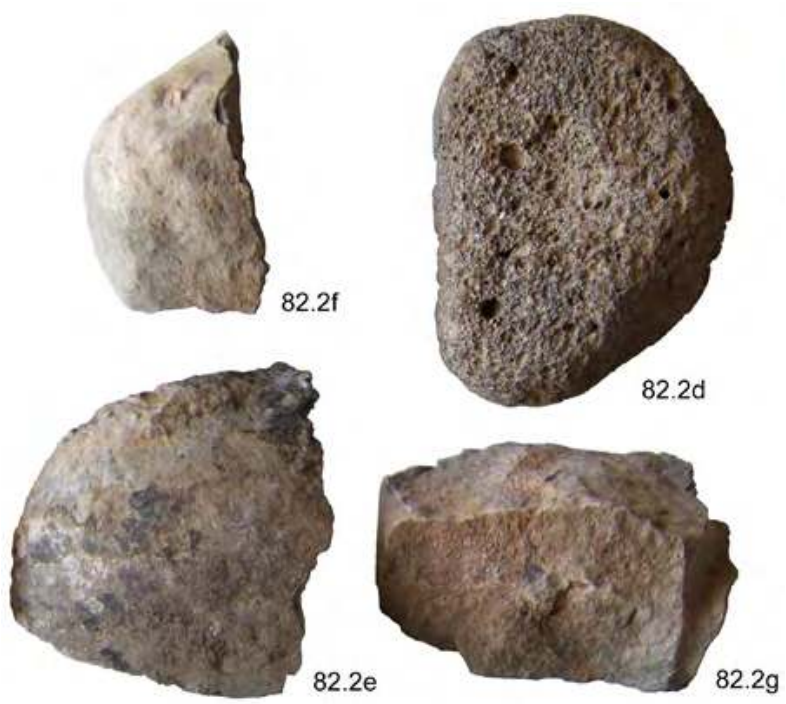

0 $10 \mathrm{~cm}$

Figure 20. Utilized natural stones, Sabaean, Cluster 82.2. (G. Di Rosa and S. Iavarone 2007 @ MAIRY, arranged and optimized by F.G. Fedele 2019) 


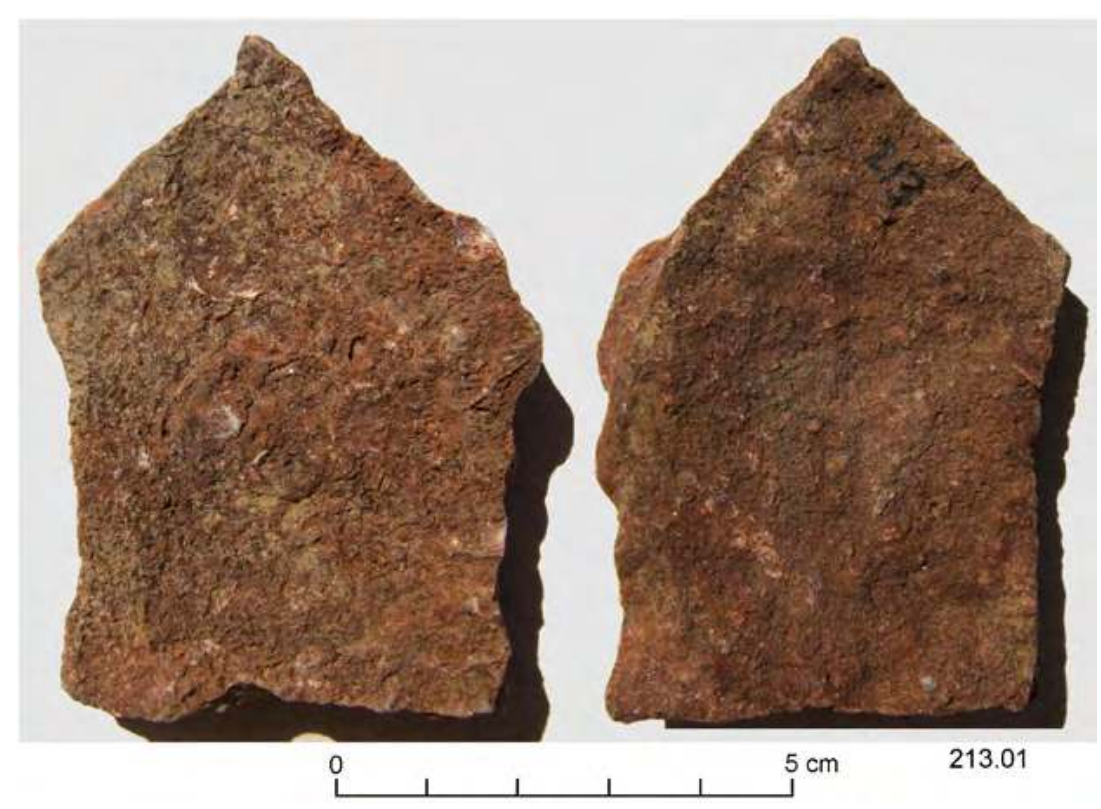

Figure 21. Utilized natural stone (rubefied plate), Sabaean, reg. no. 213.01.

(G. Di Rosa and S. Iavarone 2007 C MAIRY, arranged and optimized by F.G. Fedele 2019)

horizon H78, possibly intended for protracted thermal release. Its characteristics might suggest a cooking or heating contrivance rather than a campfire. ${ }^{98}$

213.01 (Fig. 21). Rubefied sandstone plate. $7.6 \times 5.6 \times$ 0.7-1 cm. | F. Units SF1a-SF1. Stratum M. | The coarse, fossiliferous sandstone of this thin 'roasted' plate is identical to the rock of find no. 194.01 from Sounding A (Fig. 53; see Minaean group, below). Its occurrence in the plain (Sounding F) would suggest a behavioural origin from a cooking arrangement or a campfire.

\section{Stone personal ornaments (?)}

215.1 (Fig. 22). Triangular, bored stone platelet. Grey to pale greenish, fine-grained calcarenite. Width 3.6 $\mathrm{cm}$, height $3.1 \mathrm{~cm}$, average thickness $0.8 \mathrm{~cm}$; hole $\varnothing$ 6.7-7.1 mm. | F. Unit SP1. Stratum M. | This element was interpreted by the excavators as a pendant, or a centrepiece for a necklace ${ }^{99}$ Alternatively, SA suggests a smoothing or polishing tool.

Mentioned in Fedele 2010, 125.

[FGF, SA]

98 The behavioural-functional issues raised by a feature such as Cluster 82.2 should be appraised in conjunction with the so-called 'roasted' stones, for instance Sabaean specimen no. 213.01, described immediately below. The subject is further discussed in the introduction to 'Other utilized natural stones', Minaean group (section 2.3). On burnt-rock features in general, from a geoarchaeological perspective, see Thoms 2017.

99 A row of small triangular pendants is shown on the neck of the limestone statue of the so-called Lady of al-Dalī' dated to the first century BCE (Queen of Sheba 2002, 119, no. 130). [FGF]

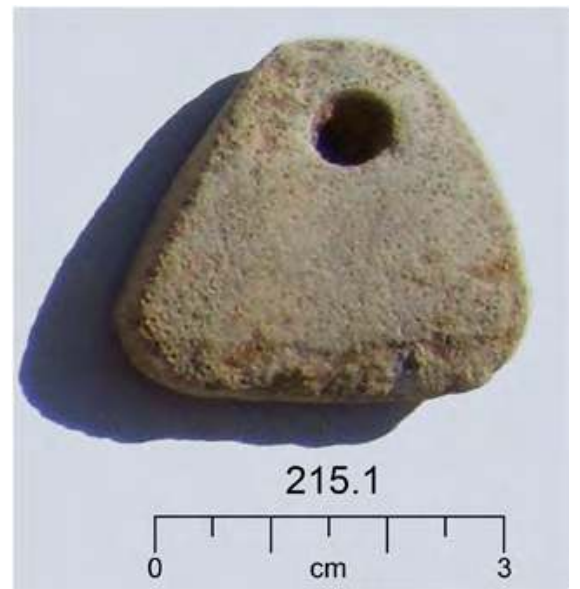

Figure 22. Stone personal ornament (?), Sabaean, reg. no. 215.1. (G. Di Rosa and S. Iavarone 2007 (C) MAIRY, adapted and optimized by F.G. Fedele 2019)
Non-pottery ceramics

36.01 (Fig. 23). T-shaped ceramic fr. Fired clay, pinkbuff in colour. Max. length $8.5 \mathrm{~cm}$. D15 east, within Gully B. From apparently intact Sand YS, thus probably Stratum 0. | A well-fashioned, well-fired, flat fragment from some kind of 'grid', and a unique terracotta find from Yathill. ${ }^{100}$ When found, the object was encrusted

100 In December 2006 A. de Maigret (personal communication at Barāqish) did not know anything similar and was thus unable to suggest an identification. 


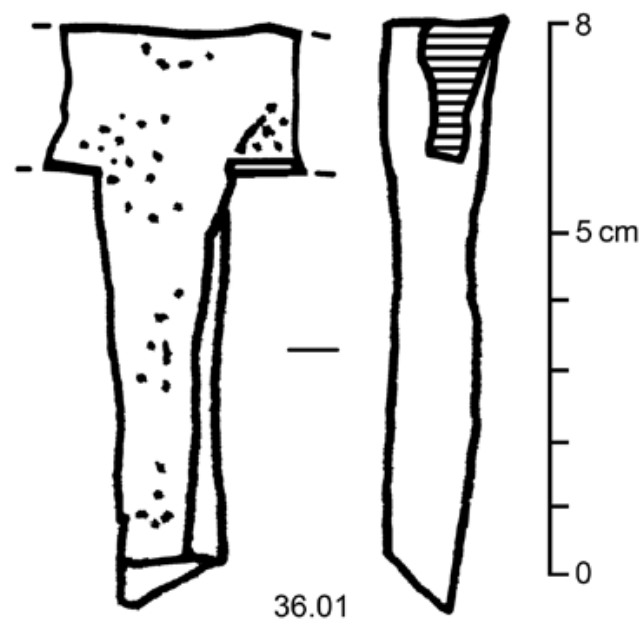

Figure 23. Non-pottery ceramics, Sabaean, reg. no. 36.01 . (F.G. Fedele 2006)

in remnants of hard, white calcite or gypsum, as if it had been originally inserted in plastered masonry. Two interpretations can be proposed, both speculative. The first hypothesis is a fragment of a clay grill used in cooking. This idea is indirectly inspired by an actual finding from Yemen: a heat 'diffuser' for cooking food reported from House A at Yalā/al-Durayb, room L2. ${ }^{101}$ Though it cannot constitute an effective parallel for no. 36.01 at Yathill, as it is in micaschist, perforated, and smaller $(6.1 \times 4.4 \times 0.8 \mathrm{~cm})$, Yalā's finding suggests that devices of this kind did exist in Sabaean Yemen. The second interpretation is entirely conjectural: a fragment of a window frame.

\section{Unfired or poorly fired clay artefacts: discs and/or 'tripods'}

Fragments of unfired or poorly fired ${ }^{102}$ clay 'discs' and clay footed objects, typically made in a dark brown, 'gritty'-clayey paste, were found abundantly in several locations at Barāqish Area C. These objects were discovered thanks to careful digging with the trowel, but also because, presumed to be friable in water, they were simply brushed dry. Their retrieval contexts repeatedly suggested a particular relationship to cooking. This was rather obvious from quadrangles D2 (ground-hollow hearth F5, cut 26); D3-D4 ('kitchen' residues and refuse, e.g. cuts 15 and 31); E7-E8 (debris from 'campsite' cooking, cultural horizon H78, cuts 52 and 82); and E11

101 Loreto 2011, 276, 282; functional information on House A in de Maigret and Robin 1989, Loreto 2009. See mentions of this 'hotplate' in Fedele 2009, 145 (information based on de Maigret's excavation records, kindly supplied in 2008) and 2019, 197.

102 'Poorly fired' is here used in precisely the same sense as described by Ochsenschlager $(1974,163)$ : 'Very lightly baked [objects], apparently by exposure to fire during the course of their use in ancient times.' (For Ochsenschlager's case study see below, this introduction.) Examples of poorly fired finds are nos 49B.01-02 and 151.10 (Sabaean group) and 22.03 (First Intermediate). (horizon H11, cut 151, a 'campsite' context similar to H78). Furthermore, the provisional field evidence from the 2005 season suggested a distinct association with the Sabaean occupation (see discussion below).

Published information on comparable or similar artefacts is apparently lacking, except a mention from Barāqish itself. ${ }^{103}$ This latter, in retrospect, can be understood to be the basis - or one of the bases - for the interpretation shared by A. de Maigret with the author during the field season of 2006, when he cautiously suggested that the finds in question might belong to clay 'tripods' (treppiedi in Italian), adding that their form and use were totally unclear. ${ }^{104}$ Unfortunately, it was not possible to further this investigation either in the field or otherwise, and, as a consequence, the present attempt to understand this puzzling class of artefacts is no more than tentative. ${ }^{105}$ Likewise, for different reasons, the search for parallels to our findings outside Yemen could not be fully developed in time for this book. ${ }^{106}$

What emerges from all reliable contexts of Area $C$ is a close association between disc fragments and foot fragments. In some cases this association is strongly suggestive of derivation from a single artefact, either simple or composite (for example in cultural horizon H78, see nos 52 and 82). Although small, and as such

103 A. de Maigret's sounding at Temple A, Stratum C, zanbil 6: '1 cylindrical foot in unbaked clay (from a tripod?)'; de Maigret 2010a, 83, not pictured. Interestingly, this same layer also produced 'traces of a fire' (de Maigret 2010a, 74), presumably a hearth. Charcoal from the layer was radiocarbon-dated to 798-488 cal BC, 2-sigma (de Maigret 2010a, 88, table 3; age corrected according to Table 1 in Fedele, Chapter 16 in Volume 1).

104 A. de Maigret probably had finds from Tamna' in mind (see next footnote). On a separate viewing of disc fragments from Area C, and particularly noting no. 26.01, S. Antonini cited similar clay finds from Tamna' to advance the interpretation that the discs might have been used to cover the top of cooking pots when on fire. Both these pieces of oral information were given, on my request, at sessions to examine and discuss my finds from Area C, held during the field season of 2006 ('Laboratory notes and records, 2006-2007', FGF personal archive). I was grateful for those exchanges, and I thank S. Antonini for sharing again her recollections about the unfired discs from Tamna' and Barāqish more recently (June 2019). [FGF]

105 In retrospect, thanks to the publication of the Tamna ${ }^{c}$ volume (de Maigret and Robin 2016), it appears that in thinking of 'tripods' de Maigret might have been influenced by the miniature, dm-sized tripod-footed bowls and offering saucers in alabaster and limestone found at Tamna' (discussed in the introduction to 'Stone burners and containers', above); also a minuscule offering table and a normal-sized tripod-footed mortar, both in stone, might have been conceptually appealing (de Maigret 2016, 234-235, fig. 167; 240, fig. $172 / 4 ; 239$, fig. 171/2; 242, fig. 174/3). However, equating the basic clay artefacts represented by foot fragments at Barāqish with such refined stone objects from a cultic context (the temple of Athirat) would only be admissible in terms of morphological templates what I would term a 'tripod concept'. The following descriptions and considerations in this section, though informed by the oral expertise mentioned in footnote 104, only reflect my personal observations and views. Regrettably, I failed to explore in greater detail the issue of the supposed clay 'tripods' with A. de Maigret afterwards. [FGF]

106 One interesting result of these investigations is reported below. 
insufficient, find no. 151.10 from cultural horizon H11 would suggest that the disc and the feet were integral parts of the same object. They would just be parts of a 'simple' artefact, as opposed to a 'composite' artefact made of separate, regularly paired components. On the other hand find no. 49B.01, a whole object in the shape of a knob (if it is indeed a foot belonging to this class of artefacts and not something else), would indicate that feet and discs were fashioned as separate objects - at least occasionally and/or by some users.

From the finds of Area $C$ alone it is impossible to determine whether discs and feet constituted a single object, or were instead combined ad hoc as a composite artefact. According to the first interpretation, the object would have looked like a low, footed stand, whereas in the latter case the complete set would have to be pictured either as a flat disc placed on separate feet or legs (cf. 49B.01), or laid on some kind of frame formed by the feet. In functional terms, however, the difference between the two reconstructions is modest, and for the time being de Maigret's term 'tripod' could be used as shorthand to indicate the artefact in question whatever its nature or appearance. In the present catalogue, in order to emphasize the recurrent association of disc and foot fragments, it seems preferable to describe the two sets of finds in a single list. ${ }^{107}$

Most interesting for the above interpretations appear to be certain archaeological finds from 3rd-millennium BCE southern Mesopotamia, complemented by remarkable ethnoarchaeological evidence from the same region. The finds in question are fragmentary, sun-dried clay objects found at Tell al-Hiba, recognized as parts of portable hearths used primarily for cooking and baking. ${ }^{108}$ However, there is much more to this evidence. The impression of variety in the excavated record is both confirmed and clarified by the presentday evidence from the area, where the traditionally manufactured 'mud' objects include tripod-footed hearths, heavy disks, and shallow flat-bottomed dishes, employed for cooking and related domestic purposes, in addition to a range of other equipment and goods. ${ }^{109}$

The manqala (plural manaqil), a portable hearth constituted of a shallow round plate often with three attached legs (i.e. a tripod), but sometimes without legs of any kind, ${ }^{110}$ would provide a particularly good

107 The reader is warned that for many disc and/or 'tripod' finds no descriptive details are available, as their cleaning and identification could only be completed at the end of the 2007 season and no time was left to proceed with detailed cataloguing.

108 Ochsenschlager 1974.

109 Ochsenschlager 1974, 165-169, 173 (ten types of dried-mud containers and discs were identified).

110 Ochsenschlager 1974, 166, pictured. 'The manqala can be used outside in any convenient place for cooking, heating water or keeping tea and coffee warm, and it can be moved from place to place to take analogue for the single-object interpretation of the 'tripods' from Area C. Similarly a tabag (plural atbag), a heavy disc primarily used for cooking and baking, and held and made hot over the fire by three wedge-shaped supports or legs, ${ }^{111}$ would make a perfect analogue for interpreting our finds as a composite object - a 'tripoddisc'. Furthermore, discs 'of the same size and shape as the tabag are used as covers for dried-mud storage jars', as well as to protect the opening of an oven, or 'to knead straw with dung and flatten the mixture into dung patties': we are clearly dealing here with an exemplary multifunctional tool. ${ }^{112}$ Incidentally, use as a cover or lid for jars would very well fit our find no. 26.01 (cf. footnote 104). Another suggestion that could be drawn from this Iraqi evidence is that our tripod 'feet' could instead - in some instances - be 'fingers', i.e. fragments of interior upward supports belonging to rimmed dishes placed on the ground. ${ }^{113}$

The complex of potential parallels provided by the Tell al-Hiba project might gain strength from being jointly based in archaeological examples and observation of recent traditional craft, moreover from an area which in the hot season is not much dissimilar from arid interior Yemen. ${ }^{114}$ However, this is just one suggestive comparison. To echo P.R.S. Moorey's complaint about archaeological inattention to sun-dried clay artefacts in ancient Mesopotamia, ${ }^{115}$ little about unfired clay objects is known for ancient Yemen as well, and this in spite of clay and mud having always been important in the lifeways of Yemen and southern Arabia more generally.

advantage of strong winds or the heat of the sun. During the winter, [it] is used inside both for cooking and as a portable brazier.'

111 Ochsenschlager 1974, 166-167, pictured. 'One side [of the tabag] is wet-smoothed and slightly concave, [and] used for cooking; the other, which is sometimes used for other purposes, is flat.' The normal procedure is heating the clay disc over a hot fire of dung patties, then lay the disc on the ground with its hot surface up, and place the food to be cooked (or bread to be baked) on top of it. 'Two disks and a set of three dried-mud supports can be used to construct an even more effective oven.' The general shape of supports or legs might be replicated at Barāqish, cf. find no. 110.05 (below).

112 Ochsenschlager 1974, 167; a large container covered with a mud disc is pictured on p. 172. He concludes from his ethnoarchaeological observations (p. 167): 'Such variety of use indicates the danger of assigning function to ancient artefacts on the basis of limited evidence' - a warning that fully applies to our case from Barāqish.

113 Cf. the Iraqi mogad (Ochsenschlager 1974, 15, photograph; 169).

114 It is worth noting that the manaqil were also employed (and sometimes made) by the desert Bedouin groups from Saudi Arabia who seasonally settled in the Tell al-Hiba area (Ochsenschlager 1974, 164, 165, 167).

115 Moorey 1994, 163, section on 'Working with clay: aspects of the wider repertory': 'Since they are only recovered in the most careful of recent excavations, and then in fragments, little is known of the sun-dried clay objects used in ancient Iraq.' Even when recovered by experienced researchers in well-conducted projects, unbaked objects are often 'mystifying' and can elude comparisons (e.g., small clay discs of c. 1800 BCE from Tell Brak, see McDonald and Jackson 2003, 294, fig. 7.32/2). Moorey again (1994, 163): 'This is clearly an age-old craft, particularly in the south of Mesopotamia, providing a whole range of household equipment not to be overlooked in assessments of daily equipment in antiquity.' 
To return to the Area $\mathrm{C}$ materials, all the 'tripod' finds from reliable contexts (i.e., from non-slope, noncolluvial deposition) are demonstrably Sabaean, except no. 188.04, which was found in Minaean Stratum I in Sounding A. Therefore, at the moment, it seems parsimonious to assume that several 'tripod' finds from First Intermediate, Minaean, or Islamic contexts on the talus represent redeposited Sabaean artefacts, their redeposition originating from the reworking or erosion of older tell or talus deposits (see the discussion of find no. 2.01 in the Minaean group). Such an assumption is indeed likely with many worn fragments retrieved from Minaean layers on the upper and middle talus, ${ }^{116}$ or found within lower talus colluvia of ages ranging from Minaean to Islamic (see Chapter 17, sections 15-16, this volume). Accordingly, the solution was contemplated to list all the finds except 188.04 in the Sabaean group, with the important caveat that their attribution to the Sabaean was hypothetical. In this chapter, however, for the sake of objectivity, these finds will instead be listed either in the Uncertain chronology group, or, in three particular cases, in the First Intermediate and the Minaean groups. ${ }^{117}$ Specific information is given at the end of this introduction.

In fact, it is unlikely that unfired clay 'tripods' of one kind or another were not used after the Sabaean period, or outside the Sabaean cultural area. If find no. 188.04, per se, can be taken as a good indicator of their continuing use in the Minaean period, find no. 22.03 might just as well indicate use during the First Intermediate period.

The chronological range of utilization is not the only problem, however: concerning 'tripods', the important issue of ethnicity should also be raised. There is no need to emphasize - although it seems to be easily forgotten - that at a caravan station such as Yathill the presence of foreigners should not only be expected, but regarded as a constant. ${ }^{118}$ Furthermore, I would predict that foreign cultural elements might display relatively better archaeological visibility in extramural contexts, like those attributed to 'trading' or 'camping' in Area C. Makeshift clay equipment such as our unfired 'tripods' is perfectly suited to include examples of foreign artefacts, brought in (or made on the spot) by non-

116 The Sabaean material dug up during the construction of the Minaean wall continued to 'float' down the talus for a long time, and certainly throughout the Minaean period. This process is particularly well documented by the Sabaean pottery sherds found in quadrangles $D 1$ and D2, cuts 1-4 and 20, mostly showing wear grade 3 to 5 .

117 As already stated, find no. 188.04 is listed below as Minaean.

118 A rare instance of explicit attention for this fact is Agostini 2018b, 91: 'La presenza di forestieri doveva essere tutt'altro che un caso eccezionale a Yathil ${ }^{\text {sic, }}$, come in tutta la regione circostante, [...] - una situazione che è sembrata ulteriormente corroborata dall'analisi del materiale onomastico proveniente dalla vicina necropoli' (see English translation in Chapter 19 , section 3, this volume). The study of the onomastics referred to is Agostini 2010b: see particularly pages 67-70, 'Conclusion'.

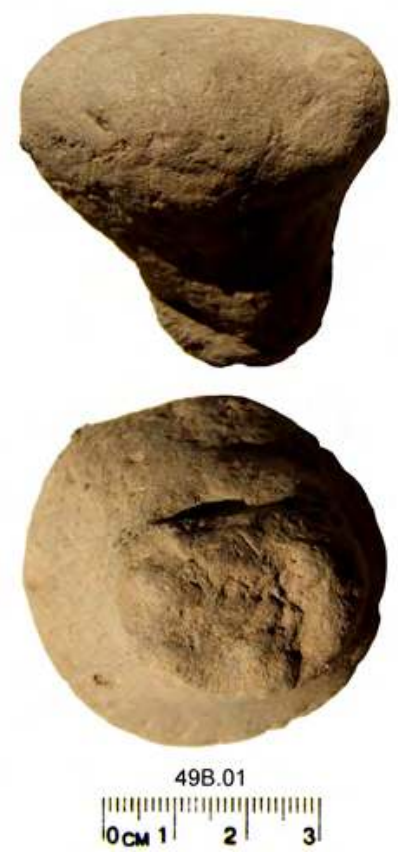

Figure 24. Unfired clay 'tripod' foot (?), Sabaean, reg. no. 49B.01. (G. Di Rosa and S. Iavarone 2007 @ MAIRY, arranged and optimized by F.G. Fedele 2019)

Sabaean and non-Minaean traders or visitors. Locus 151 and related horizon $\mathrm{H} 11$ in lower Sector E are a case in point. ${ }^{119}$ The variation observed among discs and 'tripods' apparently embodies much that is individual. At the same time it might reflect a cultural or 'ethnic' factor alongside the chronological dimension, the former perhaps more influential than the latter.

Concerning the issue of redeposition, a fair number of redeposited clay 'tripod' fragments were recovered from colluvial contexts of Sector E which lacked stratigraphic definition, or whose excavation did not allow a more precise stratigraphic determination. Accordingly, they are listed in the Uncertain chronology group, although most of such fragments are in all probability Sabaean. These finds include, in broad stratigraphic order from earlier to later, nos $120.01,51.04,87.3$, and 70.1 .

Three finds from post-Sabaean layers in upper Sector $D$ were equally interpreted in the field as probably reworked Sabaean items, or at least Sabaean-age items, but the possibility that they are in fact coeval with the layers - i.e. "stratitaxic"120 - cannot now be ruled out. This is of particular interest in the light of the ethnicity issue mentioned above. The items in question are nos 22.03 (Stratum K), listed in the First Intermediate

\footnotetext{
119 Fedele 2014; 2017, 303, figs 20.7, 20.9 (Locus 151); and Chapter 19, sections 2.2 and 3.1 , this volume.

120 A term proposed to indicate that an object or other element is not redeposited, but functionally coeval with the layer in which it was found (Fedele 1973, 157, note 5).
} 


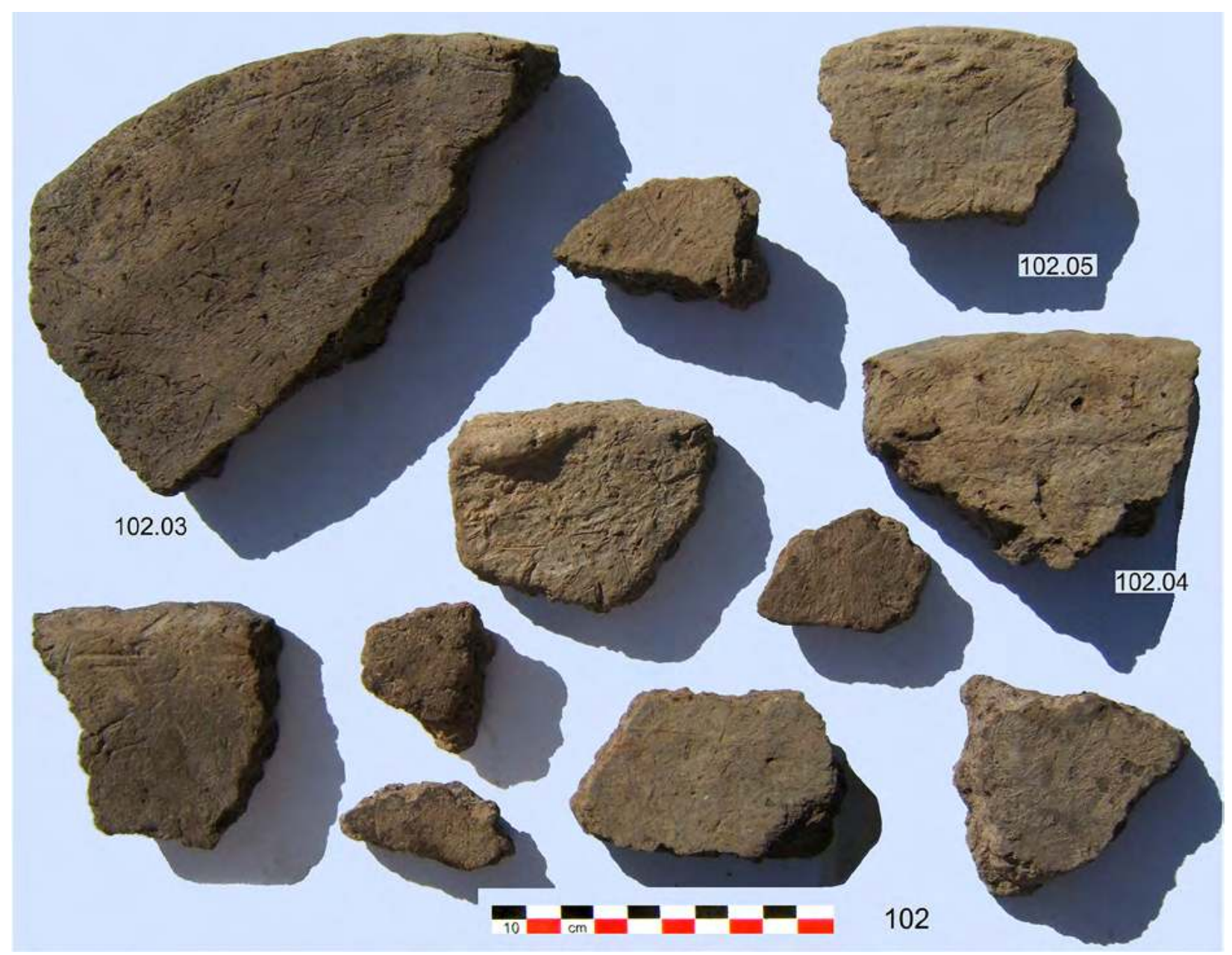

Figure 25. Unfired clay discs, Sabaean, reg. nos 102.03-05; also shown in the figure are the unnumbered clay disc fragments in cut 102. (G. Di Rosa and S. Iavarone 2007 ( ) MAIRY, arranged and optimized by F.G. Fedele 2019)

group; and 4.01 (Stratum I) and 2.01 (Stratum H), listed in the Minaean group.

An entirely distinct aggregate of probably reworked, redeposited Sabaean elements is represented among the material retrieved from the lower third of Sounding A. There, an undefinable number of Sabaean elements from previous deposits were reworked into Minaean layers forming Earthwork F10-F12: e.g., finds nos 194.01-02, 194A.01-03, and 192.02-04 (obsidian). Many more such elements clearly occur in the backfill of the Minaean foundation trench between surfaces S12 and S11, largely made of reworked Sabaean sediments, including all the catalogued finds from cuts 198 to 196: i.e., 198.03-04, 197.01-02, and 196.02-03. These finds are listed and described in the Minaean group, below, and explicitly indicated as 'possibly reworked Sabaean'.

49B.01 (Fig. 24). Clay 'knob', supposedly from a 'tripod'. Unfired clay (?). $\varnothing 5.0 \mathrm{~cm}$, max. length $c .7 \mathrm{~cm}$. D7. Units SIS-SGLi. Stratum S. | Tempered, moderately coarse paste with a smoothed surface. Interpreted in 2006 as
- possibly - an unusual foot of a 'tripod'. According to visual impression, the paste might be lightly baked, possibly by exposure to fire during the uselife of the object $^{121}$ (this object was neither washed nor tested for hardness).

49B.02. Fr. of a clay disc. Unfired clay (?) visually identical to no. 49B.01, above. | D7. Units SIS-SGLi. Stratum S.

102.03, 102.04, 102.05 (Fig. 25). Three rim frs from one or more clay discs. Length of no. $102.03 \mathrm{c.} 12 \mathrm{~cm}$. | E2. Units V3, SI1i-SI1, SE3, but predominantly SE3 or SI1. Strata S-R.| The other clay disc fragments from cut 102 are also shown in the photograph, unnumbered.

98.01. Frs from at least one clay disc. Coarse to very coarse blackish paste. | E1 western half. Units SI1i-SI1. Stratum R.

121 Cf. Ochsenschlager 1974, 163 (as in footnote 102, above). 


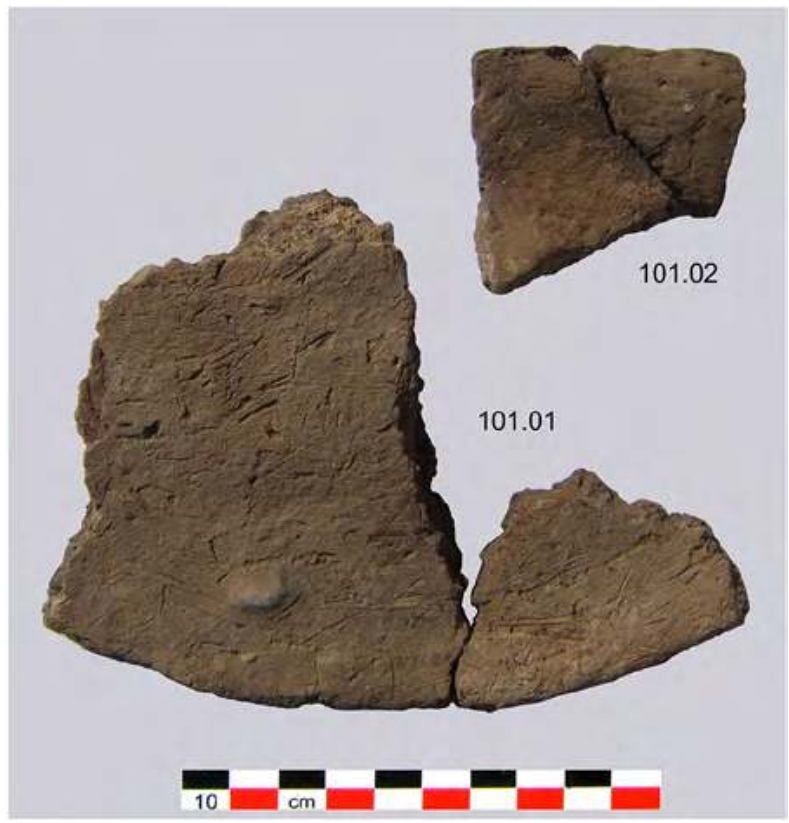

Figure 26. Unfired clay disc, Sabaean, reg. nos 101.01-02. (G. Di Rosa and S. Iavarone 2007 @ MAIRY, arranged and optimized by F.G. Fedele 2019)

101.01, 101.02 (Fig. 26). Two frs of a clay disc (both conjoints). Coarse/very coarse blackish paste tempered with chaff. Length of frs $c .15 \mathrm{~cm}$ and $c .4 \mathrm{~cm}$, respectively. | E2. Units SE3, LEd-L3e. Strata $\mathbf{R}$ to $\mathbf{P}$. | The rim is accurately fashioned and the surface rather well smoothed.

110.05. Fr. of a clay 'tripod'. |E3. Units L3e-L3c2, L3Z (?),

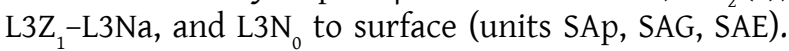
Strata P to N. | An incomplete, carefully formed foot in the shape of a truncated cone. A reworked element. The precise provenance could not be determined and the context is impossible to elucidate. However, in view of the potential fragility of the object, its origin from one of the colluvial units of the thick cut cannot be doubted. ${ }^{122}$ The shape of this foot recalls the wedgeshaped supports or legs connected with the utilization of tabag discs in the case reported by Ochsenschlager (see the above introduction, at footnote 111).

87.6.1. Multiple frs of clay discs and/or 'tripods'. Dark brown paste. | E5/E05 recut section, in situ. Unit 6V. Stratum 0. | For the retrieval context see Chapter 17, section 6.8 and Fig. 47, this volume.

87.5c. Fr. or frs of discs and/or 'tripods'. Unspecified and undescribed, but paste similar to n. 87.6.1. | E6/

122 For additional stratigraphic information see Chapter 17 , sections 6.5 and 6.8 , this volume. Only two finds from cut 110 were recorded individually in situ: polychrome glass no. 110.1 (this chapter, section 2.5) and Sabaean torpedo jar sherd no. 110.2 (see Chapter 23, section 3.1 , this volume).

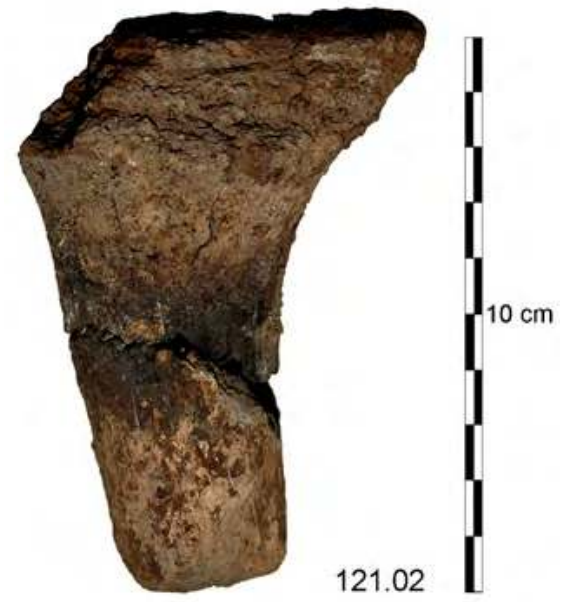

Figure 27. Unfired clay disc/'tripod', Sabaean, reg. no. 121.02. (G. Di Rosa and S. Iavarone 2007 @ MAIRY, adapted and optimized by F.G. Fedele 2019)

E06 recut section, in situ. Unit 6U. Stratum 0. | For the retrieval context see Chapter 17, section 6.8 and Fig. 47, this volume.

121.02 (Fig. 27). A clay 'tripod' foot (conjoint). Firm paste. Max. length of fr. $10.5 \mathrm{~cm}$. E4. Units XE4, LZ5, $\mathrm{L} 3 Z_{3}, 4 \mu \mathrm{r}-\mathrm{VCB}$ : unclear context. Strata $\mathrm{O}$ to $\mathrm{L}$ (to $\mathrm{K}$ ?). I A complete, well fashioned, elongated conical foot or leg preserving a small part of the associated 'table', this latter supposedly being the disc. For a similarly fashioned and equally informative example, though with a different type of foot, cf. no. 151.10, below.

72.04. A clay 'tripod' foot, complete.| E5. Units V5, XE4, LZ5-x5: colluvia, undefined context. Strata O, L, K, or I, indeterminable.

38.04. A clay 'tripod' foot, complete. Coarse brownish paste. | D5. Units GK3-GK1. Later Stratum N.

38.05, 38.06. Two rim frs from a clay disc (or two). $\mid D 5$. Units GK3-GK1. Later Stratum N.

52.01. A clay 'tripod' foot. | E7. Cultural horizon H78. Stratum M. | Considering the identical paste, aspect, and location of retrieval, this element and the disc fragment no. 52.02 (below) look like parts of the same object.

52.02. Fr. of a clay disc (a conjoint of 2 frs). | E7. Cultural horizon H78. Stratum M. | A disc with a fairly well formed, raised rim. Possibly the same object as the 'tripod' foot no. 52.01 (above).

82.2h, 82.2i (Fig. 28). Two frs probably from a single clay disc, part of Cluster 82.2. Chaff tempered, dark brown paste. Max. length 7.8 and $5.7 \mathrm{~cm}$, respectively. 


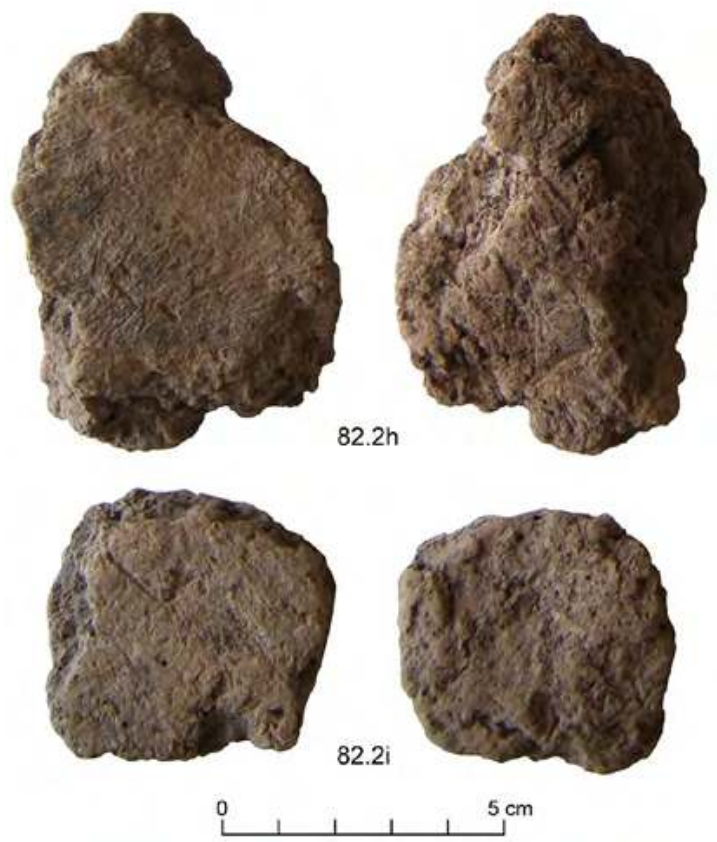

Figure 28. Unfired clay discs, Sabaean, reg. nos 82.2h-2i. (G. Di Rosa and S. Iavarone 2007 C MAIRY, arranged and optimized by F.G. Fedele 2019)

| E8 centre, in situ. Suite SEK, cultural horizon H78. Stratum M. | For other components of Cluster 82.2 see 'Other utilized natural stones', above (Figs 19-20). Considering the context, this disc and the 'tripod' foot fragments nos 82.02-03 (below) might be parts of the same object, scattered over quadrangle $E 8$ and perhaps just outside it. Several unnumbered fragments were also recovered (below).

82.02, 82.03. Two clay 'tripod(s)' feet. Paste similar to nos $82.2 \mathrm{~h}-2 \mathrm{i}$, above. | E8. Suite SEK, and units YS8-E86 and lower Eø3+E85, but probably from cultural horizon H78. Stratum M. | Several probable foot fragments (unnumbered) were also recovered, all possibly originating from the same object as disc or discs nos 82.2h-2i, above.

82 (unnumbered). Clay disc frs. | E8. Stratigraphy as for nos 82.02-03. Stratum M. | See clay disc/'tripod' finds nos 82.2h-2i and 82.02-03 above.

151.8.1 (Fig. 29). Large fr. of clay disc and/or 'tripod'. Greyish-beige, sandy-'gritty' paste. Max. length 8.7 $\mathrm{cm}$, thickness c. $4.5 \mathrm{~cm}$ (irregular). | E11 Locus 151, in situ. Unit Eox, cultural horizon H11. Stratum M. | The fragment is attributed to a disc and/or 'tripod' in spite of the unusually light colour and arenitic texture of the paste. On the context of finds nos 151.8.1 to 151.12, Locus 151, cf. footnote 119, above.
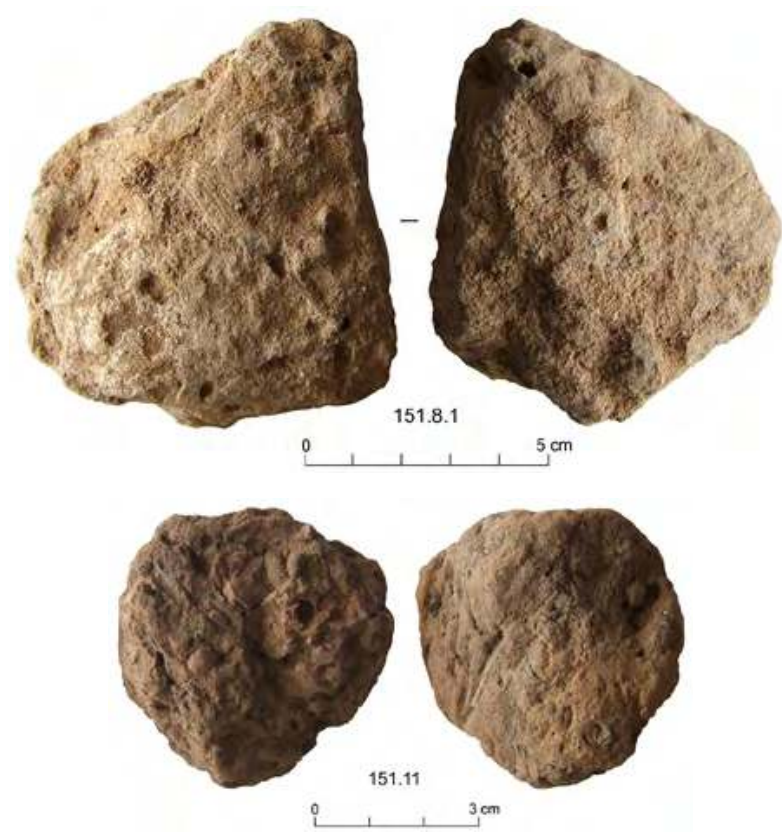

Figure 29. Unfired clay discs, Sabaean, reg. nos 151.8.1 and 151.11. (G. Di Rosa and S. Iavarone 2007 @ MAIRY, arranged and optimized by F.G. Fedele 2019)

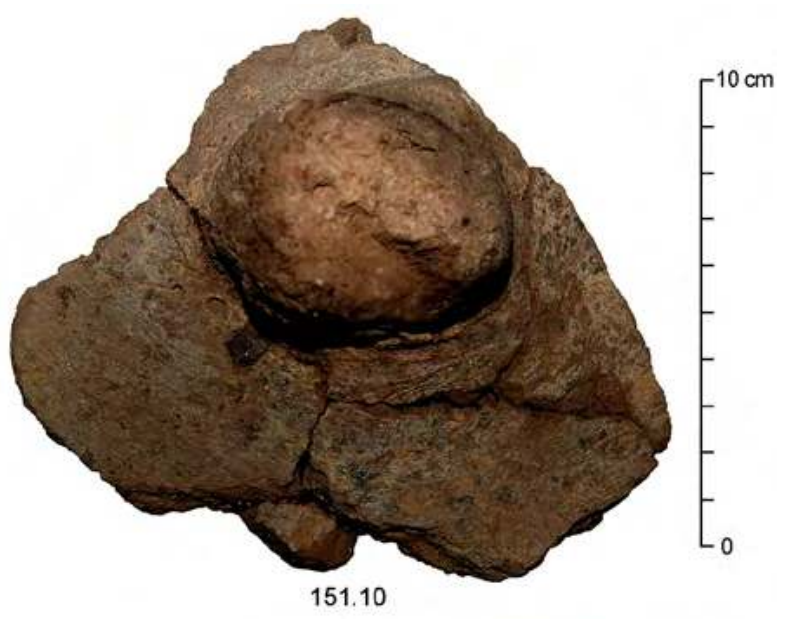

Figure 30. Unfired clay disc/'tripod', Sabaean, reg. no. 151.10. (G. Di Rosa and S. Iavarone 2007 @ MAIRY, adapted and optimized by F. G. Fedele)

151.10 (Fig. 30). Fr. of a clay 'tripod' (conjoint of several frs). Medium, brittle, dark brown paste. Max. length $14.4 \mathrm{~cm}$. E11 Locus 151. Unit Eøx, cultural horizon H11. Stratum M. | Both this fragment and no. 121.02, above, are unusually informative insofar as they combine a complete foot and part of the associated 'table' as a single object (the table supposedly being the disc). The paste was locally hardened by exposure to fire in the course of use (cf. footnote 121). 

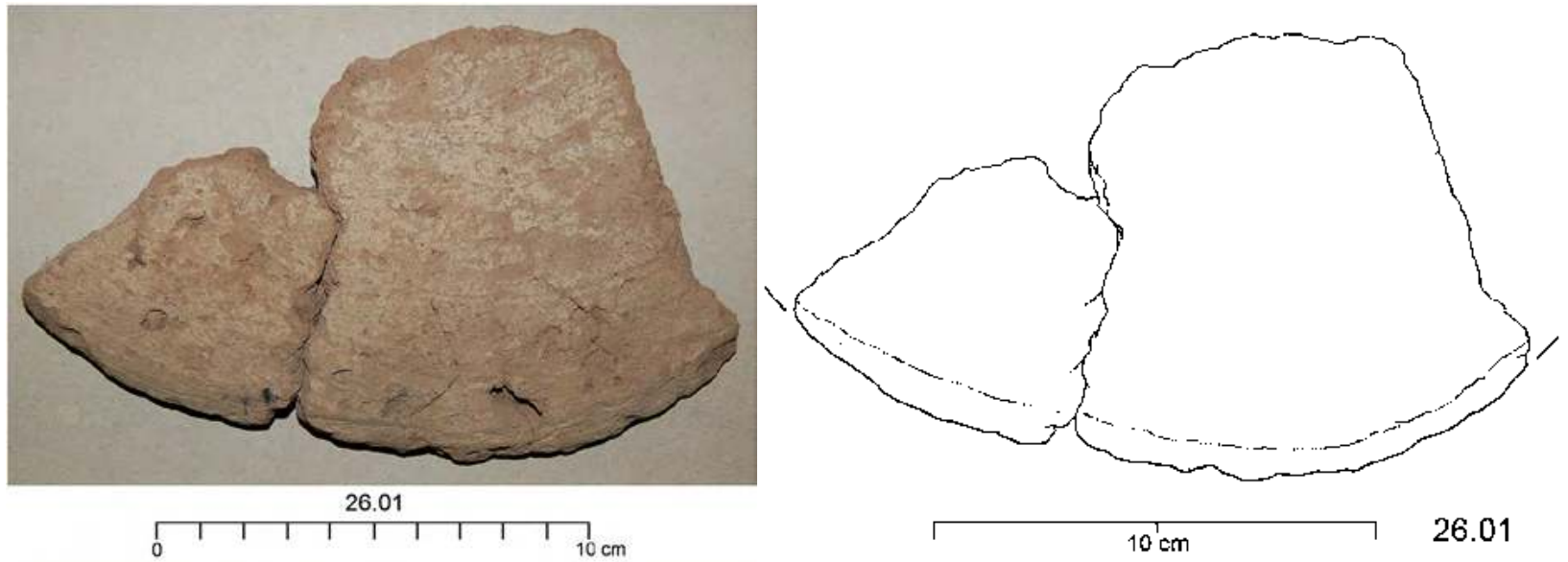

Figure 31. Large, unfired clay disc, Sabaean, reg. no. 26.01. (P. Morlupi 2006 @ MAIRY, adapted and optimized by F.G. Fedele 2019; drawing FGF, 2006)

151.11 (Fig. 29). Small fr. of a clay disc. Clayey-sandy, chaff tempered, dark grey-hazel paste with scattered, large angular grits. Max. $\varnothing 5.3 \mathrm{~cm}$.| E11: provenance and stratigraphy as for no. 151.10. Stratum $\mathbf{M}$.

151.12. Clay disc and/or 'tripod' frs. | E11: provenance and stratigraphy as for nos 151.10-11. Stratum M. | Details unavailable.

15.05 (and unnumbered frs). Fr. of a clay disc (a conjoint of $3 \mathrm{frs}$ ). Coarse, dark brown paste. Max. length $c .10 \mathrm{~cm}$. | D3. Unit GZ3, incl. part of Locus 33. Earlier Stratum L. | A fairly large, completely flat, non-rim fragment looking like the base of a jar (but unfired). Encrusted with calcium carbonate like most contents of the same unit.

15.06, 15.07. Two feet frs from a clay 'tripod' (or two). | D3. Unit GZ3, including part of Locus 33. Earlier Stratum L. | Details unavailable.

32.03. A foot of a clay 'tripod'. Coarse, dark brown paste. | D4. Unit GZ3, incl. part of Locus 33. Stratum L.

14.03. A foot of a clay 'tripod'; and a smaller fr., unnumbered. Coarse, dark brown paste. |D3. Units GZ2GZ1. Stratum L.

$31.02,31.03,31.04,31.05$. Four frs of clay disc, or discs. | D4. Units GZ2-GZ1. Stratum L.

26.01 (Fig. 31). Fr. of a large clay disc (conjoint of 2 frs). $\varnothing c .50 \mathrm{~cm}$. | D2. Unit GZ1, incl. hollow F5 (a hearth?). Later Stratum $\mathbf{L}$. | This piece derives from a very large disc, about $0.5 \mathrm{~m}$ in diameter. It is noteworthy for its carefully crafted, bevelled edge, which renders the disc slightly inequifacial. Some traces visible on the surface of greater diameter suggest that this disc had been

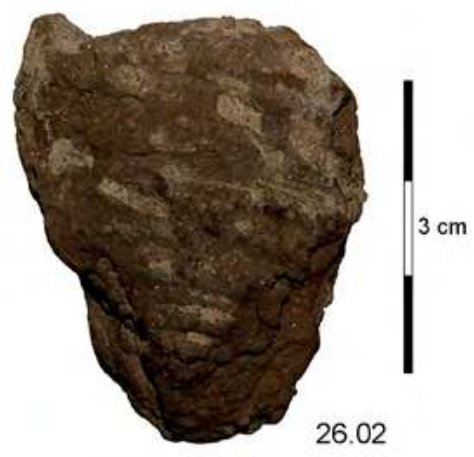

Figure 32. Unfired clay 'tripod' with basketry impressions, Sabaean, reg. no. 26.02. (P. Morlupi 2006 (C) MAIRY, adapted and optimized by F.G. Fedele 2019)

fashioned in a basket or on a mat (cf. find no. 26.02); this surface might be conventionally called the 'base' of the disc. The opposite surface (the smaller or 'top' one) is completely covered with a pisolitic calcium carbonate crust from long subsurface residence accompanied by evaporation. The size, overall conformation, and basketry or mat impressions that define this object, find very good parallels in the tabag discs described by Ochsenschlager (see the above introduction, at footnote 111).

26.02 (Fig. 32). Small fr. of a clay disc showing basketry impressions (conjoint of 2 frs). | D2: provenance and stratigraphy as for no. 26.01. Later Stratum L. | Apparently from a different disc from no. 26.01. There is also an additional, smaller fragment. The basketwork or mat imprint on the 'base' of 26.02 is evident from the photograph.

26.03. Small fr. of a clay disc. | D2: provenance and stratigraphy as for no. 26.01. Later Stratum L. | The 

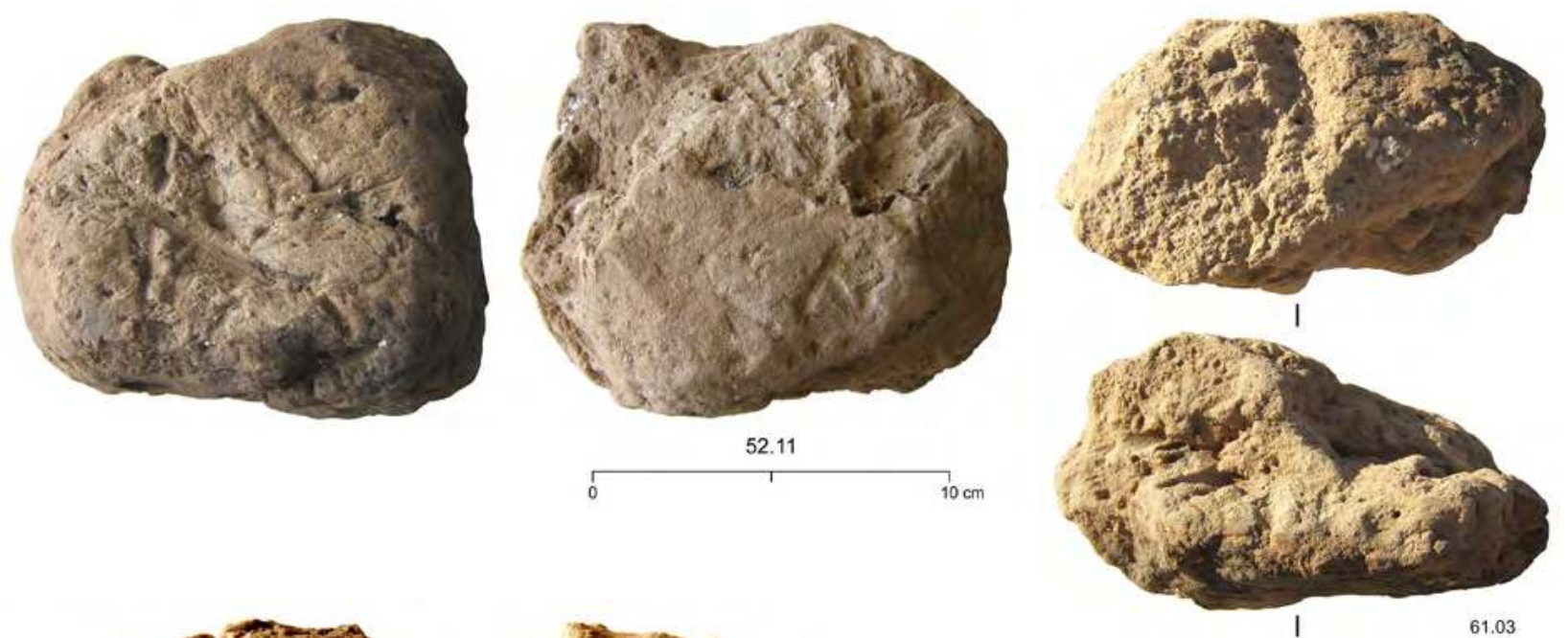
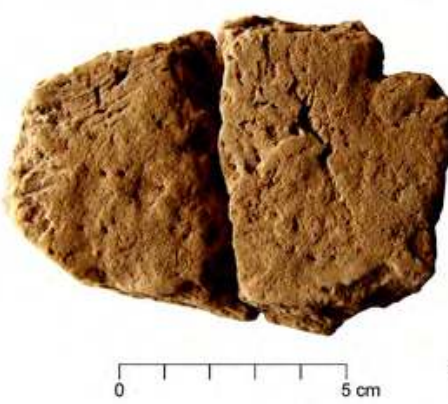

23.01

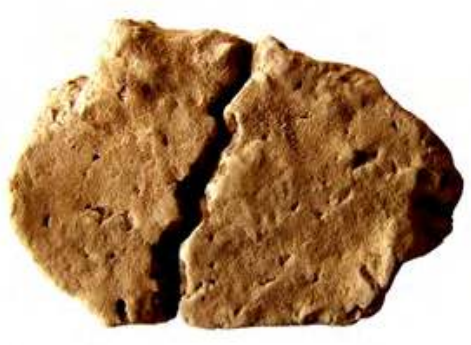

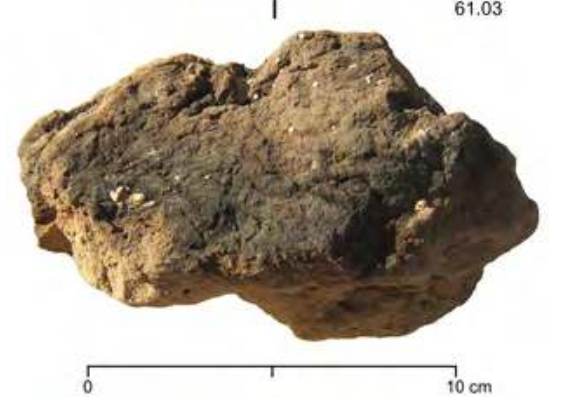

Figure 33. Mud bricks and cf. mud bricks, Sabaean, reg. nos 52.11, 61.03, and 23.01. (G. Di Rosa and S. Iavarone 2007 ( MAIRY, adapted and optimized by F.G. Fedele)

apparent frequency of clay-disc remains from the restricted excavation surface of cut 26 , attributable to a domestic context in the Later Sabaean tell, should be noted.

8.03. Foot of a clay 'tripod'. | D14, within Gully B. Reworked within loose sediments probably deriving from stratified deposits of suite GZ. Stratum L. | The immediate context of the find included several sherds of extremely worn Sabaean pottery and a fragment of Islamic glazed ware.

\section{Mud bricks and cf. mud bricks}

Sabaean mud bricks at Yathill, so far only recorded from Area $\mathrm{C}$, are typically grey or beige in colour, in contrast to the Minaean ones which are usually in the yellow range (dark yellow to brown; see section 2.3 below, this same material category, and cf. footnotes 168-169). The fabric or 'body' characteristics are generally similar. As no complete Sabaean mud brick was found, their size or size variation cannot be determined. It may be worth mentioning that perhaps the best available example of Sabaean mudbrick material, still in primary context, is unit J1 preserved above $\mathrm{F} 4$, the stone base of Wall F4 in quadrangle $E 1$ east (cf. Chapter 17, section 6.3 and Fig. $53 \mathrm{~B}$, this volume).
99A.1 Frs of mudbricks; cm-sized.|E1 east, from beneath the base of Wall F4. Unit SIa, including palaeosol SI $\pi$. Stratum T. | Grey.

49C.2 Frs of mud bricks; cm- to dm-sized. | D17 northwest quadrant, in situ: see plan in Chapter 17, Fig. 55 , this volume. Unit cf. SGP ( $\mathrm{SGP}_{2}$ ), middle or lower, at level approx. corresponding to the top of Wall F4's masonry course $2 .{ }^{123}$ Stratum R. | Grey to pale yellow, cf. mud-brick unit J1 associated with Wall F4 (cited above).

52.11 (Fig. 33). Fr. of mud brick. Approx. $14 \times 11.5 \mathrm{~cm}$, thickness 6-7 cm.| E7 south edge, $90 \mathrm{~cm}$ from southwest corner, in situ (see Chapter 17, Fig. 68, this volume). Horizon H78. Stratum M. | Grey-hazel in colour. Clearly a reworked fragment, but part of one of the principal faces of the original parallelepiped is well preserved.

61.03 (Fig. 33). Fr. of mud brick, semibaked on part of the surface. Approx. $13 \times 8 \mathrm{~cm}$, minimum thickness $7 \mathrm{~cm}$. E6. Units $6 \mathrm{U}$ up through $\mathrm{E}_{2} \mathrm{E}_{3}$. Strata O, L, K, I, but a provenance from Stratum $\mathrm{L}$ is suggested, as mudbrick frs are notably present in units belonging to this Stratum (for instance in upper XL, quadrangle E06 east, Reference section; see Figs 21 and 47 in Chapter 17, this

123 Location and stratigraphy as for no. 49C.1, see 'Querns and other grinding stones' in this section (above). 
volume). | Beige-greyish in colour. An irregular lump from evident redeposition. A flat face, sufficiently well preserved, is superficially scorched from contact with fire as well as blackish from limited carbonization. The above estimate of the brick's thickness is based on the assumption that this surface is one of the principal faces of the parallelepiped.

23.01 (Fig. 33). Unfired clay 'loaf', beige in colour. 10 $\times 7.1 \mathrm{~cm}$, thickness $2-2.5 \mathrm{~cm}$. $\mid$ D2 west. From inside F9 ('Mass GR1'), lying near-horizontally within lens F9 $\lambda$ in mid-GR $1 b_{1}$. Stratum L. | This mudbrick-type element was retrieved as a separable artefact from the mass of structure F9, with which it was otherwise integrated: one can assume it is coeval with structure F9. As to context, GR1b is the relatively 'massive' component of mud-mass GR1 (forming feature F9), and $G R 1 b_{1}$ is its upper subdivision. $F 9 \lambda$ was recorded in the disassembling of $\mathrm{F} 9$ as 'a lens of darkish grey silt with ash and tiny charcoal' at $-60 /-65 \mathrm{~cm}$ below the quadrangle D2/D3 datum. For details see Chapter 17, section 7.6 and Fig. 64 , this volume.

\section{Bronze/copper}

Copper or cupric slag traces of Sabaean age (globules, crusts, prills) were repeatedly found in Area C, distributed between lower Sector D and Sounding F, and in two cases they were associated with fragments of crucibles. The record is not impressive, but sufficient at least to suggest some sort of diffuse, small-scale smelting activity during the Sabaean period, apparently located at the western edge of the settlement and down in the plain. Similar, coeval occurrences near the margin of a Sabaean tell were noted at Ḥajar al-Rayḥ̄āi (ancient Mardac) in Wādī al-Jūbah. ${ }^{124}$

48A.2a (Fig. 34). Fr. of a thin, cuprous metal object, probably bronze. Max. $\varnothing 1.2 \mathrm{~cm}$. | D7 west alongside Wall F4. Unit SGP (SGP ${ }_{2}$ ) or TM4. Stratum R. | Further details unavailable.

46.02. Fr. of crucible with copper slag (conjoint of 2 frs). Pottery and metal. Max. length $c .5 \mathrm{~cm}$. $\mid D 7$ north and Gully B. Units YSX, SGY, YSi-YSd. Strata P-O, probably P. | A copper-encrusted crucible base. The parallel with find no. 87.7 (below) contributes to suggest a derivation from the sand component of the sediment mixture, i.e. Sand YS.

Mentioned in Fedele 2010, 123, note 93: 'A copperencrusted crucible base from quadr. D7 $\mathrm{N}$ was part of a

124 Glanzman 1987c, and for location and context Glanzman and Ghaleb 1987b. Cf. Edens and Wilkinson 1998, 97: 'Concentration[s] of slags, prills, and possible crucible or oven-lining fragments indicative of copper or tin bronze working occur in Rayhani Stratum VII deposits.' On copper slag in Yemen see also Overstreet et al. 1988b, 411-413.

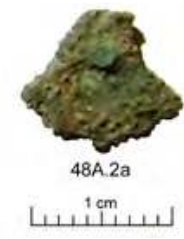

Figure 34. Bronze/copper, Sabaean, reg. no. 48A.2a. (G. Di Rosa, S. Iavarone 2007 @ MAIRY, adapted and optimized by F.G. Fedele)

mix of YSi-YSd sands and Gully B rubble, an unreliable context'.

87.7. Fr. of a crucible with copper slag. Pottery and metal, cm-sized. | E6/E06 recut section, in situ. Unit $6 \mathrm{~N}$. Stratum N. | A fragment of a crucible with a green, 1-cm-thick copper slag crust (cf. find no. 46.02 from a less clear stratigraphic context, above). Redeposited in colluvium, but possibly from a location of primary activity nearby. For the retrieval context see Chapter 17, section 7.4 and Fig. 47, this volume.

Mentioned in Fedele 2010, 122-123.

215.2. Copper slag globule. Approx. $\varnothing 0.7 \mathrm{~cm}$. $\mid$ F. Unit SP1. Stratum M. | Green in colour. For a similar find, but larger (a spherule), see no. 169K.02 in the Minaean group below.

Mentioned in Fedele 2010, 123, note 93; 125.

214.02. Copper-encrusted glassy (?) fr., cm-sized. |F. Units SY1a-SY1. Stratum M. | The uncertainty about this vitreous-looking material appears to repeat what was experienced by the excavators of Hajar al-Rayhānī, where, in fact, that identification eventually called for a revision: "The subsequent recovery of more glassy fragments, this time with copper prills protruding [...]', led to the material being 'considered slag, originally associated with copper/bronze production'. ${ }^{125}$ At Barāqish the lack of additional finds made a better archaeometallurgical definition impossible. About these copper-slag traces revealed by Sounding F and attributable to Stratum M (nos 215.2 and 214.02) see Chapter 17, section 17, this volume; a list of the traces of Sabaean smelting activity at Yathill can be found in Chapter 17, section 7.4.

Mentioned in Fedele 2010, 116, 125.

Glass and glazed elements

43A.1 (Fig. 35). Glazed stone block. Dark grey basalt and vitreous paste. $6 \times 6 \times 6 \mathrm{~cm}$. $\mid D 6$, centre of the west half

125 Glanzman 1987c, 145 


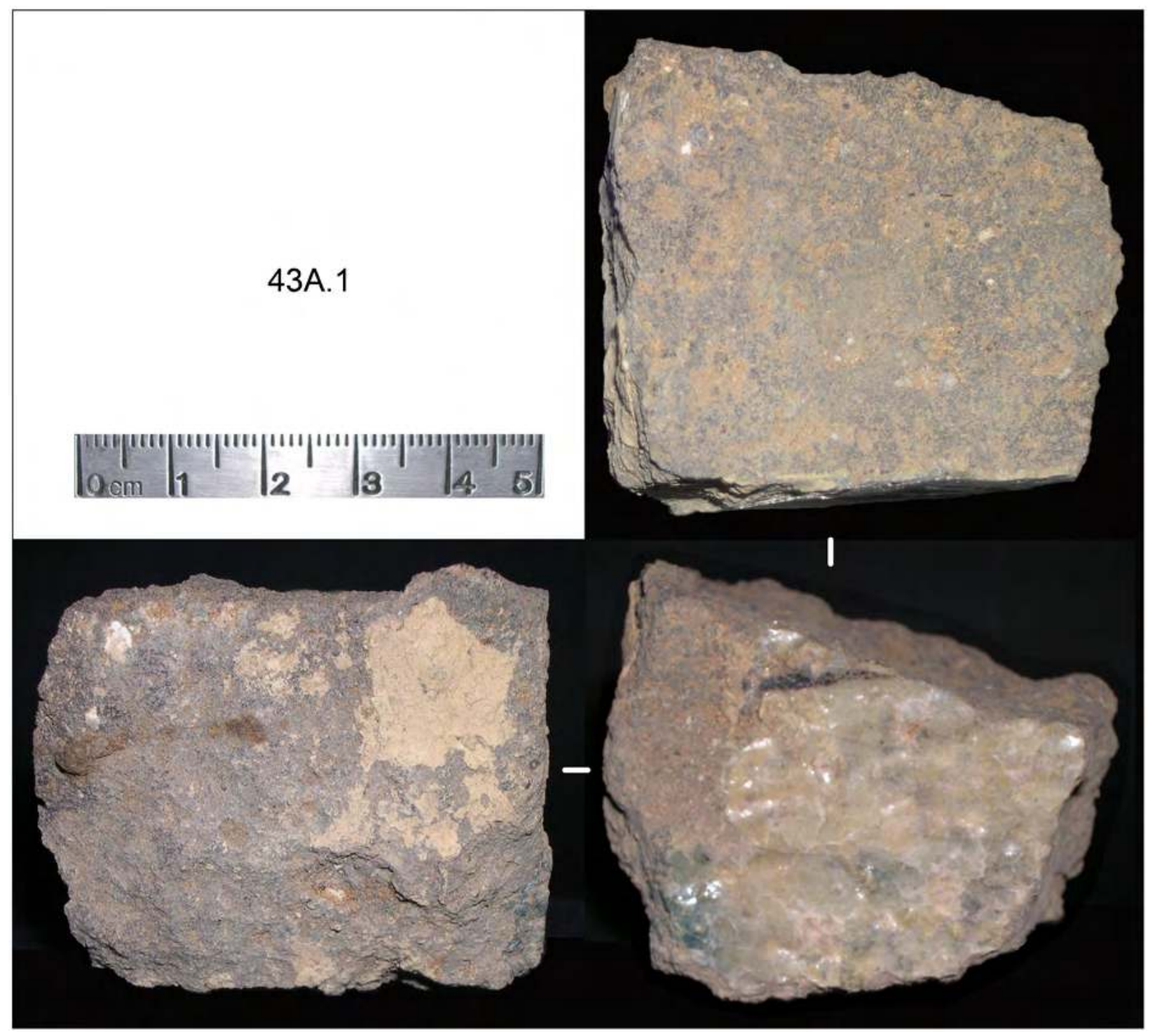

Figure 35. Glazed basalt block, Sabaean, reg. no. 43A.1. (P. Morlupi and F.G. Fedele 2005 @ MAIRY, optimized by F.G. Fedele)

of quadrangle, in situ. Found at the bottom of cut 43A, near the bottom of unit YSi (facies YSi ). Earlier Stratum P. A small cubical element, one of its faces covered with a grey-greenish vitreous glazing showing latent, line-thin, reticulate cracks. Basalt is an exotic rock for Baraqish and its area, and must have been obtained from locations at least $20-25 \mathrm{~km}$ away. As a clast, this cube would appear to have been intentionally obtained by splitting and chipping. Remnants of mud plaster on one of its faces suggest that originally it might have been inserted in masonry. This element is not only a unique find from Area C (and Barāqish/Yathill), but, apparently, also a novelty for the Sabaean region and period. Its excavation context and stratigraphy are illustrated in Chapter 17, this volume (section 6.3, 'Accessories and special finds'; and Fig. 66 B), while its social and historical implications are discussed in
Chapter 18, section 3.1, including the value accruing to the stone from the geological provenance of basalt.

Publication: Fedele 2010, 116 (mention), fig. 144/A.

14.4 (Fig. 36). Fr. of a glass artefact. Max. length of fr. $3.7 \mathrm{~cm}$. | D3. Suite GZ, probably from unit GZ2. Stratum L. A tiny handle? There was no taphonomic indication of its being intrusive.

Mentioned in Fedele 2010, 123: 'Exotic objects were probably circulating during the period of Stratum L: a glass paste fragment (a tiny handle ?) was retrieved from an intact GZ1-GZ2 context in quadr. D3.'

For a partially vitreous (?) element from Stratum M see no. 214.02 in the 'Bronze/copper' category, above. 

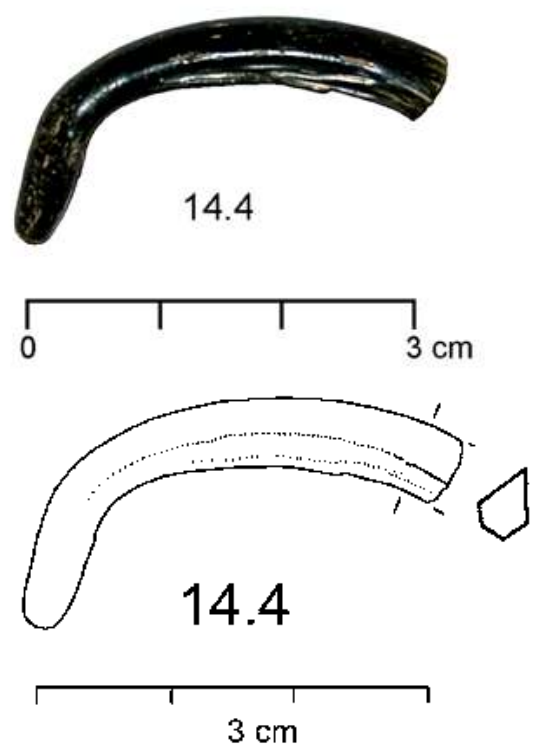

Figure 36. Glass element, Sabaean, reg. no. 14.4. (P. Morlupi 2006 ○ MAIRY, adapted and optimized by F.G. Fedele 2019; drawing F.G. Fedele 2006).

\section{Artefacts made from organic materials}

Due to a combination of dryness and the predominance of fine-grained sediments inducing anaerobic or anoxic conditions, the tell and talus deposits at Barāqish Area $C$ provide an almost ideal microenvironment for the exceptional preservation of artefacts made of organic materials. This is particularly true of the Sabaean tell and, buried within it, of such organo-silty-clayey layers as those of the Later Sabaean in upper and middle Sector D (Strata L and N). ${ }^{126}$

The following list of objects is highly selective. Many more minute fragments of organic artefacts were found in the Sabaean deposits and often retrieved in situ. Although extensive photographic coverage was made in 2007 , time restrictions prevented from studying them individually. ${ }^{127}$

48.01 (Fig. 37). Fr. of a basket. Plant fibres. Max. length of fr. $5.9 \mathrm{~cm}$. | D7. Unit $\mathrm{SGP}_{2-3}$, i.e. the fill of Earthwork F44. Stratum R. | The surviving, well plaited circular portion $(\varnothing c .3 \mathrm{~cm})$ suggests that the fragment belongs to the bottom of a conical container.

\footnotetext{
126 See Chapter 17, this volume (sections 1.3, 7.2, and 7.5). While only Area $C$ is presently known, such sediments and conditions - hence preservation - can be expected across the Sabaean and Minaean deposits throughout the western flanks of Barāqish, if not the whole circuit of the tell. An exceptional preservation of artefacts made of organic materials is also recorded from the cemetery on Hill D (Area D), where cloth, leather, basketry, ropes, threads, and wood including parts of wooden bowls - were recovered (Antonini 2010b, 27-28, plates 39/d, 40, 41; all from Level 1, 'Late Minaean').

127 See mentions in Fedele 2010, e.g. 112, 121-122. The photographic record is expected to be made available online.
}

121.2 (see Fig. 16 in Chapter 23, this volume). Fr. of woven mat preserved on pottery. Organic, mineralized; $\mathrm{cm}$-sized. | E4, $15 \mathrm{~cm}$ from south edge and $35-50 \mathrm{~cm}$ from southeast corner, within Cluster 121.1 (a nearplanar pottery cluster in quadrangle $E 4$ southeast), in situ. Top of cut $121,-50$ to -70 below ground surface, i.e. within unit $\mathrm{L} 3 \mathrm{Z}$ and probably around boundary

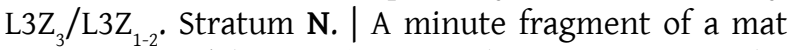
was preserved by a calcium carbonate crust on the neck and shoulder of Sabaean barrel-shaped jar 121.2, described in Chapter 23, section 3.2. The crust and mat were inadvertently destroyed during cleaning before a photograph could be taken (December 2006). A similar case of preservation by concretion was noted on a Sabaean pottery sherd from cut 32 (quadrangle D4, unit GZ3, earlier Stratum L), where it involved a tiny fragment of textile.

Mentioned in Fedele 2010, 120.

39.01. A small ball of plant fibre thread (?). $\mid D 5+D 15$ south. Unit GK4. Earlier Stratum N. | The material was tentatively identified in the field as leather, but laboratory examination later suggested a rather unusual leather-looking plant fibre (a strip from a palm leaf?).

Mentioned in Fedele 2010, 122.

$38.1=$ B.05.C.O/5 (Fig. 38). Decorated comb. Ivory. $5 \times 6 \times 3 \mathrm{~cm}$, width of each tooth $1.5 \mathrm{~mm}$. | D5, in situ. Suite GK, probably from unit GK1. Later Stratum N. | This ivory comb was found among minute plant and bone debris in an ashy-silty level within GK2-GK1, and when unearthed it was encrusted in dark grey silt cf. GK1; the most tenacious crusts have been preserved. The comb has an intact square handle and seventeen (or eighteen?) variously fragmented teeth arranged at regular intervals. Both faces of the handle are decorated with an incised frame containing a series of incised circles with a central hole: six circles decorate the lateral sides of the handle as well as its outer border, seven circles the side along the series of teeth. The row on the outer border is formed of three circles on either side of a pair of through holes.

Publications: Fedele 2010, 122, fig. 144/C; Antonini 2015, 91, fig. k.

[SA, FGF]

38.01 (Fig. 39). Frs of cloth. Max. length 5.2-6.5 cm. | D5, in situ. Units GK3-GK1. Later Stratum N.

38.02 (Fig. 39). Fr. of a rope made of plant fibres. Length $11.5 \mathrm{~cm}, \varnothing 1.0-1.4 \mathrm{~cm}$. | D5, in situ. Units GK3-GK1. Later Stratum N. | Very thin fibres (no more than $1 \mathrm{~mm}$ in diameter), tightly plaited. 

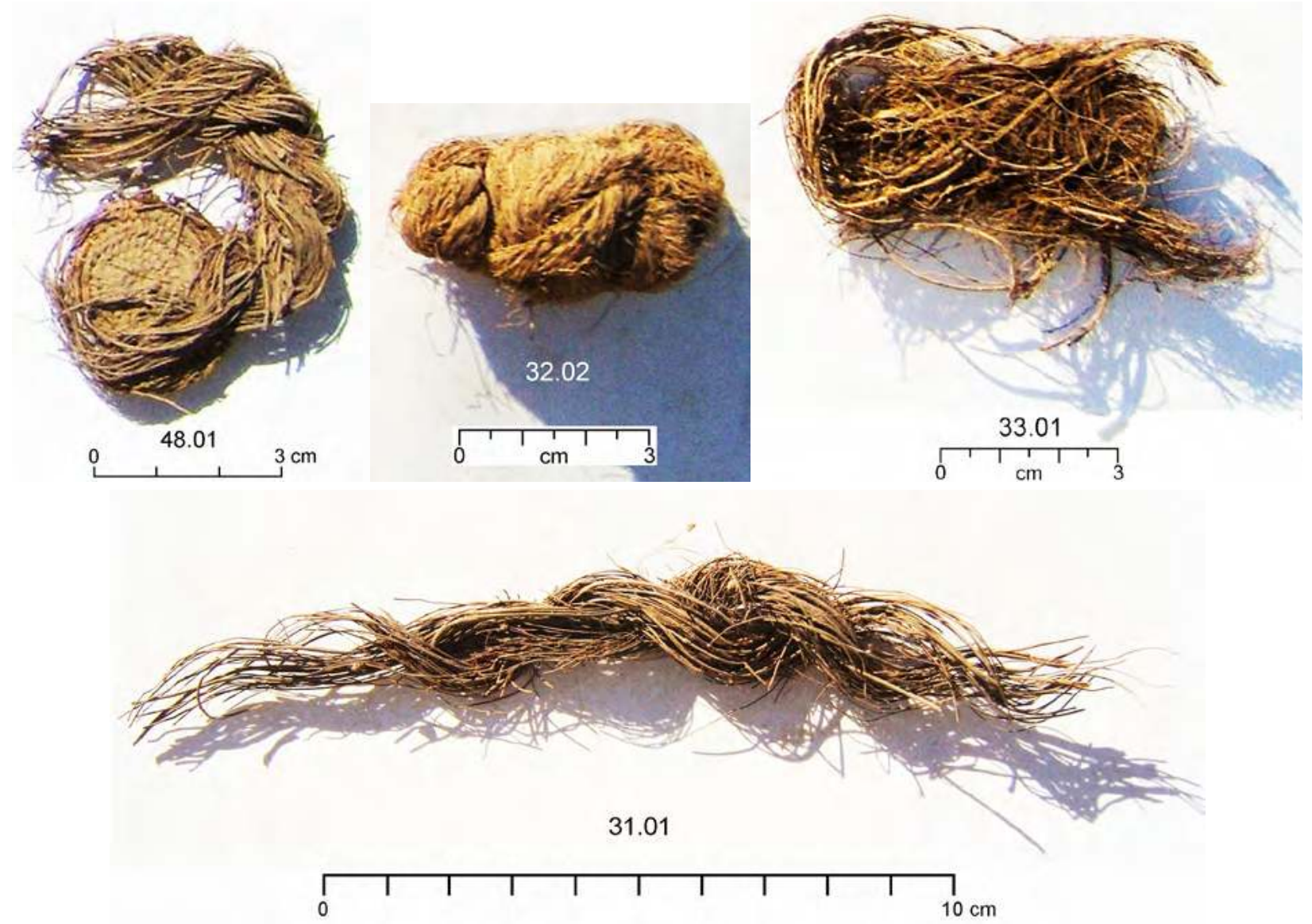

Figure 37. Artefacts made from organic materials, Sabaean, reg. nos 31.01, 32.02, 33.01, and 48.01. (G. Di Rosa and S. Iavarone 2007 (C) MAIRY, arranged and optimized by F.G. Fedele 2019)

38.03 (Fig. 39). Frs of hide and fur. Max. length 4-4.6 $\mathrm{cm}$. | D5, in situ. Units GK3-GK1. Later Stratum N.

32.02 (Fig. 37). Small ball of woven hair. Length $5.3 \mathrm{~cm}$. | D4. Unit GZ3. Earlier Stratum L. | Elongated and tightly woven.

33.01 (Fig. 37). Small bunch of plant fibres. $8.6 \times 3.9 \mathrm{~cm}$. | D14. Unit GZ3. Earlier Stratum L. | Rather coarse fibres, loosely woven.

31.01 (Fig. 37). Braid of plant fibres. Max. length c. 16.5 $\mathrm{cm}$. D4. Units GZ2-GZ1. Stratum L. | Very thin fibres, no more than $1 \mathrm{~mm}$ in diameter. A neatly plaited fragment.

\section{Marine shells}

Five mollusc shells were retrieved from the pre-Islamic layers at Area $\mathrm{C},{ }^{128}$ none of them individually complete. All belong to tropical marine species (seashells), whose

128 One more find was recovered from the Islamic levels: a cutout cowrie pendant, no. 169A.3 (see Chapter 18, Appendix ['A note on the Islamic collection from Area $\left.C^{\prime}\right]$, this volume). provenance is most parsimoniously to be sought in the Arabian Sea to the east and south, or the Red Sea to the west. And all were initially understood as shells transformed into personal ornaments, dubiously only excluding the single bivalve in the collection, find no. 184.3, suspected to be food refuse. In fact, both the interpretation of these shells as cultural elements, on one hand, and their zoological identification on the other, raise interesting problems which need scrutiny and deserve to be discussed in detail.

There is no need to stress how any object made of animal hard tissue has dual significance as both fauna and artefact, and shells are no exception: they are at the same time animal species and items of material culture. In a more inclusive perspective, in fact, shell or other animal-tissue finds can possess a triple meaning, whenever such material contains - or is supposed to contain - culturally transferred or manipulated elements (i.e. manuports or ecofacts, respectively). For this volume it was thought to be simpler and more logical to describe all the shell finds together and give priority to their status as artefacts or manuports, actual or possible. They are examined in this chapter 


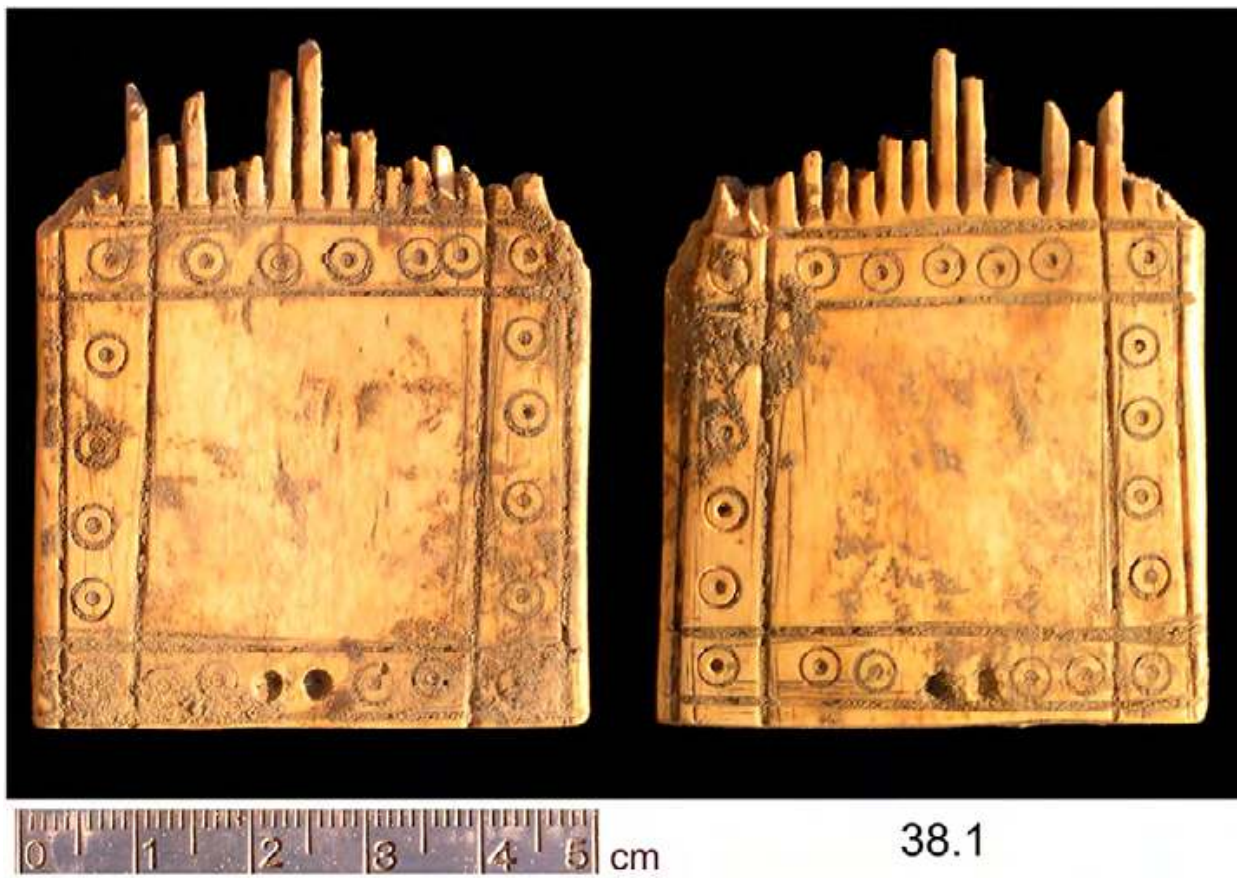

Figure 38. Ivory comb, Sabaean, reg. no. 38.1. (P. Morlupi and F.G. Fedele 2005 @ MAIRY)

accordingly. Independently of cultural interpretation, also their zoological determination is presented in full in the present chapter rather than in Chapter 19. ${ }^{129}$

The finds in question are nos 200/58 and 82.01 in the Sabaean group (this section), nos 198.04 and 184.3 in the Minaean group (section 2.3), and 210.05 in the Uncertain chronology group (section 2.5) (Fig. 40). The Sabaean and Uncertain chronology shell finds reasonably fit the category of body decoration. However, their fragmentary condition does not allow to observe traces of manufacture or use wear. In particular, there is no indication that these cowries were modified to be strung as necklaces, although this is likely. Not a body ornament at all is no. 198.04, an intriguing shell 'pebble', while the other find in the Minaean group (no. 184.3) more likely was seafood rather than personal adornment, as already mentioned.

However, the alternative between ornament and food refuse does not in the least exhaust the potential function played by seashells at an ancient site. This subject has been examined innumerable times, most recently in archaeomalacology volumes, conference proceedings, and general textbooks. ${ }^{130}$ While an extended discussion

\footnotetext{
129 In Chapter 19, this volume, these finds are simply mentioned as items of the faunal record (section 1, 'Animal remains', noting their origin as seafood where relevant), as well as shells which having travelled overland from the coast can provide insights into distant movement or exchange (section 3, 'Trade').

130 E.g., Claassen 1998, 196-219; Bar-Yosef Mayer 2005; Bar-Yosef Mayer and Kolska Horwitz 2015; Szabó et al. 2016; Ridout-Sharpe 2017. Particularly on the human interaction with cowries see Kovács 2008
}

is outside the scope of this chapter, I will limit myself to a remark about cowries: it is often forgotten that cowries widely also served in games and in fortune telling. ${ }^{131}$ As to the latter, cowrie-shell divination has been recorded in East Africa ${ }^{132}$ and, more importantly, is still practised in present-day Yemen. ${ }^{133}$ This might bear on the interpretation of some finds from Area C. More precisely, one can wonder whether the presence at Yathill of such a shell element as no. 198.04 had to do with divination, ${ }^{134}$ whatever its zoological identity and geographic provenance (both problematic).

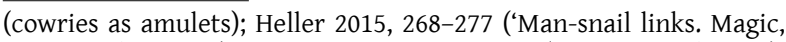
status and money'); Lorenz 2017a, chapter 1 ('Cowries and man'); Ridout-Sharpe 2017, 301-303 (a synopsis of ideological aspects); Yang 2019, 229-234 (aesthetics and ideology); and for an earlier, influential treatment Moorey 1994, 129, 131-133.

131 The pioneering work was Jackson 1916, reissued 'with new plates and additional information' in Jackson 1917, 123-194; it is still useful today. See Claassen 1998, 210-211.

132 Jackson 1917, e.g. 145, 158-161, 170; for full indexing see p. 212, 'Cowries used for divination'.

133 Regourd 2013 (English version of a paper originally published in Annali dell'Università degli Studi di Napoli 'L'Orientale'), focusing on Șan' $(\bar{a}$ ', but this practice is also found elsewhere in the country, particularly at Mārib, Radā' , in the Tihāma, and probably in Hadramawt (Regourd and Julliard 2003). The fundamentals of cowrie-shell divination are shared world-wide: the cowrie, as collected from a beach, has a flattened side with a longitudinal slit, and a smooth, rounded side; when tossed on a flat surface, the shell has only two stable positions, with the slit side facing either up (this outcome being often called 'open' and portending good) or down ('closed', a bad omen). Most diviners use modified cowries whose rounded part (dorsum) has been ground away, creating a second, artificial opening; the two stable positions, however, remain the same (Wikipedia 2019a, adapted).

134 Cf. Regourd 2013, 186, 187, fig. 1: in the 'vocabulary' of cowrieshell divination in Yemen, pieces of seashells as opposed to whole shells signify concerns, sorrows, or woes. 


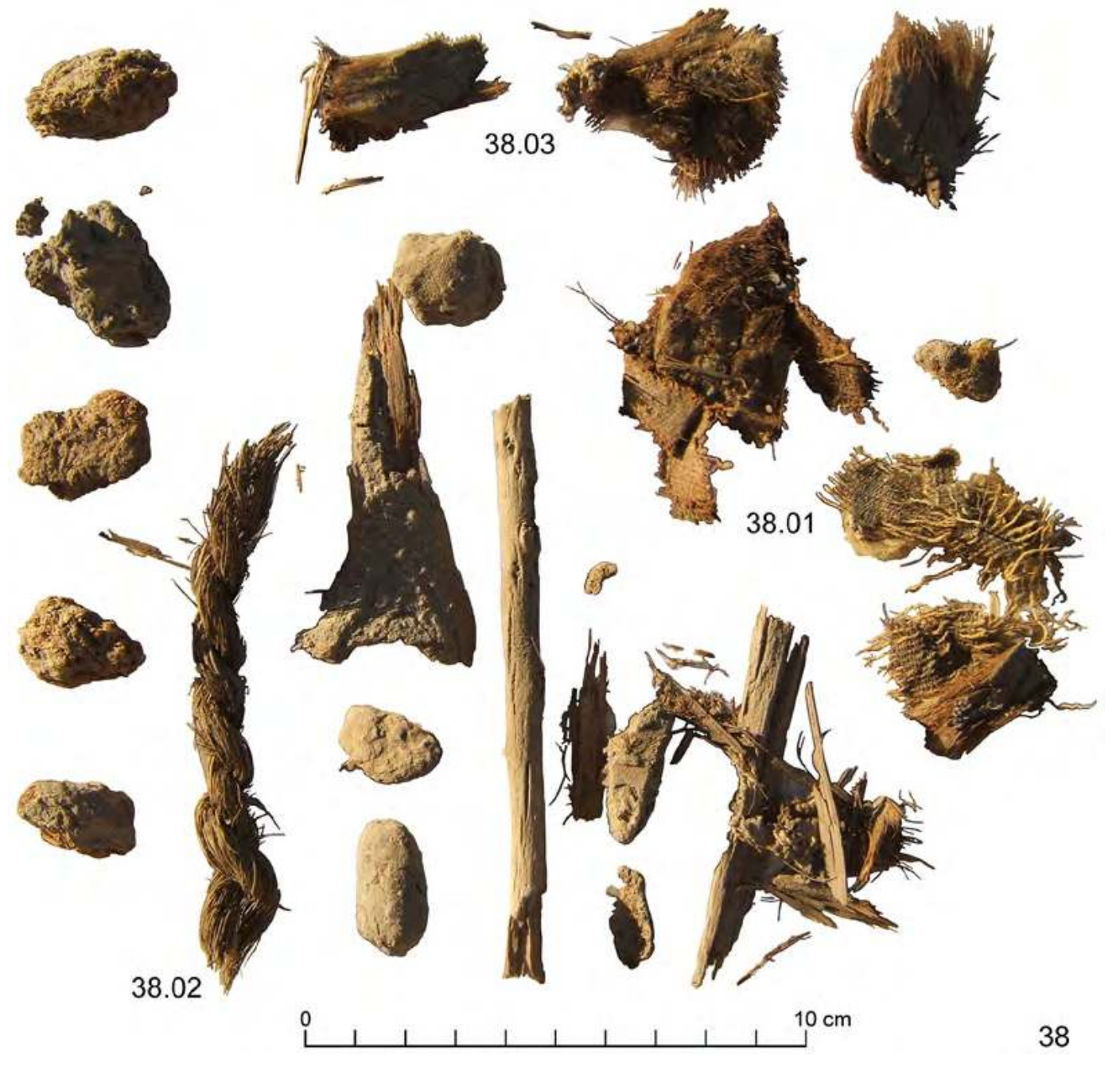

Figure 39. Artefacts made from organic materials, Sabaean, reg. nos 38.01-03. (G. Di Rosa and S. Iavarone 2007 @ MAIRY, arranged and optimized by F.G. Fedele 2019)

As far as Yemen is concerned, identifying marine molluscs correctly from archaeofaunal shells is both important and challenging. Important, because species identification represents a crucial step in sourcing the shell finds to regions of origin and thus pinpoint transfer routes or even processes. And challenging because one encounters difficulties both at the basic zoological or conchological level and in attempting comparisons. While the former are of a general nature, ${ }^{135}$ the difficulties in comparisons depend on circumstances more specific to Yemen. Here, one ought to be very suspicious of uncredited determinations to the species level, particularly when unsupported by well referenced, regional malacological collections.

135 For instance, working on finds from eastern Oman, Martin (2005, 167) encountered 'several problems of identification' partly because suitable reference material is difficult to come by, but also because geographic distributions of species have changed. Students of Yemen can fully share such remarks, particularly when dealing with sites in the interior where shell finds do not allow any inherently preferential linking to one sea coast or another.
In addition, comparisons with acritically published material are made more problematic than in other zoological and zooarchaeological subfields by the constantly changing nomenclature of molluscs. ${ }^{136}$ It follows that building up a broader picture of the cultural use of seashells throughout Yemen's ancient history remains a distant goal (cf. Chapter 19, section 1 , this volume).

Concerning the shells from Area C, a precise zoological determination was not feasible at the Barāqish camp and was subsequently shelved. A deferred examination was carried out during the preparation of this volume on the basis of the available photographs and limited field notes. Obviously, identifying fragmentary archaeofaunal shells without the possibility of re-

136 Cf. Dekker and de Ceuninck 1994, 98; Zuschin and Oliver 2003, 60 ('over 50 nomenclatural or identification changes [in the Red Sea bivalve fauna during just a decade] illustrate how fluid the taxonomy remains'); Christie et al. 2019, 481. 
inspecting and handling the actual specimens presents limits. It proved a clarifying exercise nevertheless, certainly for the purpose of extracting all possible information from the scanty material from Area $C^{137}$ and full details will be given for each find. Specialized reference collections were consulted via their websites, ${ }^{138}$ while the online database MolluscaBase was used for the correct denomination of species. ${ }^{139}$

As to intrasite comparisons, the only other operation at Barāqish that has produced marine shells is the Minaean cenotaph cemetery (Area D). ${ }^{140}$ However, in addition to the present impossibility of accessing the material, the seashells from Area C and Area D cannot easily be compared for two reasons. First, as already remarked, the finds from Area C are highly fragmentary; and second, the zoological determinations of the specimens from the cemetery are unreferenced. ${ }^{141}$ Comparative observations will therefore be limited to Area $C$ nos 184.3 and 210.05.

It is important to note that in addition to shells from living species Area $\mathrm{C}$ has produced three fossil molluscs: nos 49D.01 (Earlier Sabaean), 192.01 (possibly reworked Sabaean), and 210.04 (Uncertain chronology). From a number of viewpoints, including material, obtention, provenance, and cultural manipulation, these finds obviously represent a completely different class of archaeological objects from those represented by living species. They are illustrated in this catalogue under the rubric 'Stone manuports'.

The two following seashell fragments in the Sabaean group seem to represent personal ornaments, although traces of manufacture were not observed.

200/58 ${ }^{142}$ (Fig. 40). Shell fr. from a medium-sized (?) cowrie species, not determined. Length of fr. $2.3 \mathrm{~cm}$. | A1-A11 east + A31, Locus 200. Units STY (?), SZ2-SZ1, and lower SYH. Stratum N. | A fairly fresh-edged shell fragment preserving its lustre. It was identified in

137 For sending specialist publications I wish to thank Annalisa Christie, Felix Lorenz, Graham Oliver, Michael Stachowitsch, Suzanne Williams, and Martin Zuschin (who generously provided a copy of Zuschin and Oliver 2003). [FGF]

138 For instance, the important collection at the Natuurhistorisch Museum Rotterdam: http://www.marinespecies.org/nmr/.

139 MolluscaBase 2019, conveniently accessed via WoRMS (2019). For additional information the WMSDB database (Galli 2019) was also consulted. Non-biologists and 'traditional' archaeologists in particular are reminded that taxonomic names are not language formalities, but capsule statements integrating the evolving knowledge of a species' characteristics and affiliation, therefore only the current names must be used.

140 Antonini and Agostini 2010a; on the finds in question see Antonini 2010b, 25-26, plates 37-38.

141 The identifications of the shells from Area D were made in the field and intended as provisional [SA, personal communication 8 November 2019].

142 For register numbers with a slash see section 1 above, footnote 8 .
2007 as a posterior-dorsal part of a cypraeid possibly reaching $4-5 \mathrm{~cm}$ in total height, its dorsum still faintly spotted and its posterior labral ${ }^{143}$ teeth relatively reduced. A species identification without re-examining the actual find does not seem feasible. A possibility is a specimen of Naria turdus at the upper end of its size range. ${ }^{144}$

82.01 (Fig. 40). Apertural rim fr. of a shell from a large cowrie species, cf. Lyncina camelopardalis. Length of fr. $3.5 \mathrm{~cm}$, total shell height (estimated) $c .5 .5-6 \mathrm{~cm}$. | E8. Suite SEK, and units YS8-E86 and lower Eø3+E85. Stratum M (SEK, YS8-E86) or Stratum I (Eø3+E85); more probably M. | A shiny, freshly broken fragment, representing the anterior two thirds of the labral part of a large cowrie; additional fragments were not present within quadrangle E8. From the top photograph of this find in Fig. 40 (an endo-apertural view of the labral lip) several attributes of potential diagnostic interest can be gleaned: cream-coloured teeth and ventral surface; developed and relatively spaced teeth; ${ }^{145}$ an outwardly expanded and slightly bulging anterior end of lip; and but as a mere impression - an anteriorly wide aperture. The tentative identification as Lyncina camelopardalis (Perry, 1811) ${ }^{146}$ is based on size, colour, and distribution (Red Sea, Gulf of Aden, Somalia). On grounds of similar morphological pattern, the only alternative would be the circum-Arabian subspecies of Erronea caurica, E. c. quinquefasciata, ${ }^{147}$ unless we contemplate a northerly presence of stray populations of E. c. elongata, whose documented distribution is East African. ${ }^{148}$ However, the labral teeth of 82.01 do not seem to be as massive or 'coarse' as in either subspecies of Erronea caurica. ${ }^{149}$

Mentioned in Fedele 2010, 125.

143 Or labial in a parallel terminology, from labium instead of labrum (e.g. Christie et al. 2019, 482, fig. 1).

144 Cf. Coulombel 1994, 45 (Djibouti); Lorenz and Hubert 2000, 191, pl. 94/3, 6; Lorenz 2018, plates 39-40. Regrettably, it was not observed whether the fragment had an umbilicate spire and lacked a sulcus (the photograph would suggest so), nor were the brownish spots recorded in detail. About Naria turdus and its common circum-Arabian subspecies, N. t. winckworthi, see also find no. 210.05 in the Uncertain chronology group.

145 A hint of pale orange tinge in the tooth interstices, such as conveyed by the photograph, was not recorded during the laboratory examination.

146 MolluscaBase 2019, AphiaID 216863; Lorenz and Hubert 2000, 72, pl. 21; Lorenz 2018, pl. 146.

147 Represented in this case by a large specimen from the Red Sea? Cf. comments on find no. 210.05 in the Uncertain chronology group (with references).

148 Lorenz and Hubert 2000, 138, pl. 52; Lorenz 2018, pl. 281.

149 For exceptions - i.e., seemingly good photographic matches for fragment 82.01 - see for instance Bosch and Bosch 1989, 46 ('Cypraea caurica', Oman, 3-6.5 cm). 

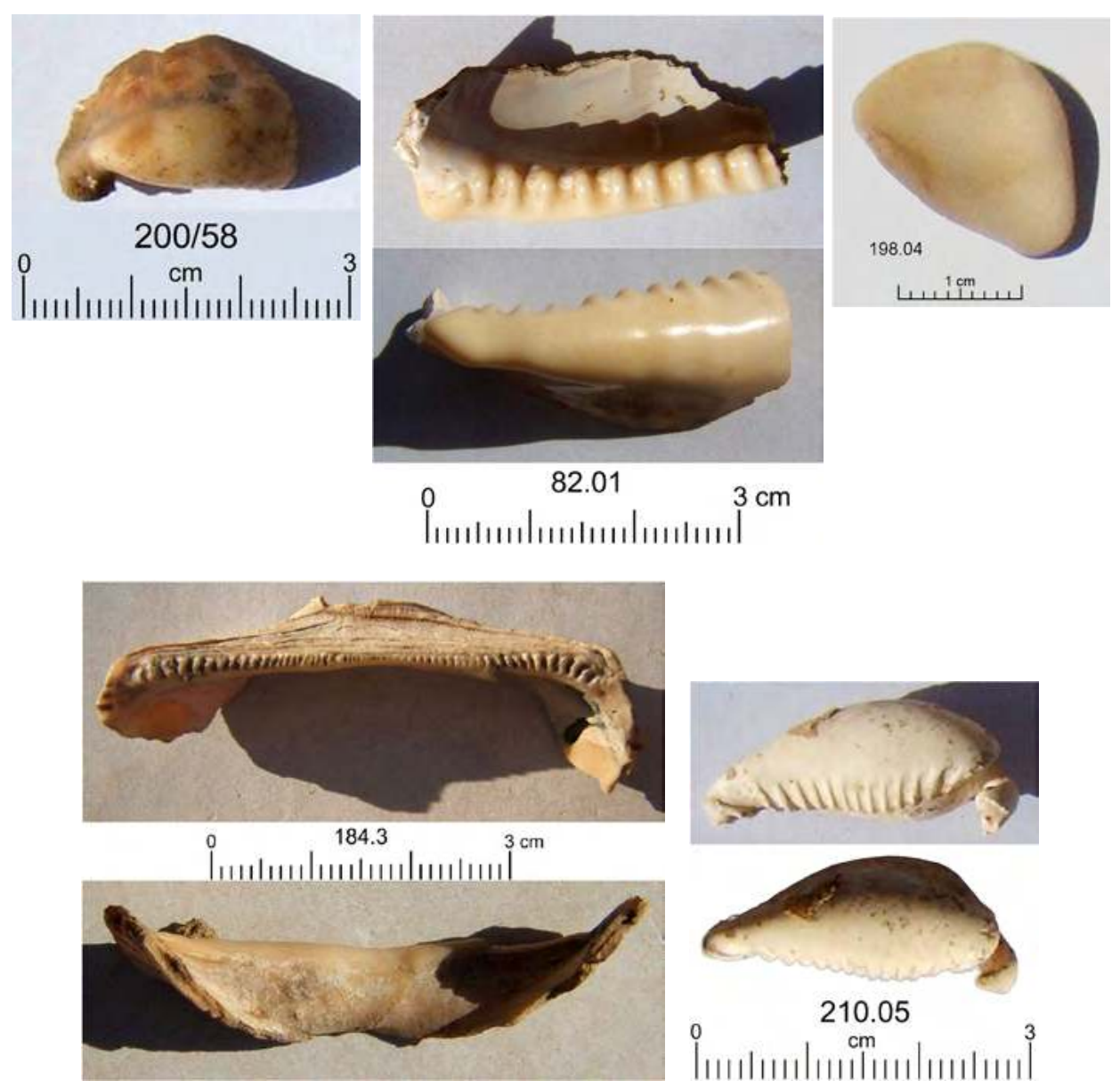

Figure 40. Marine shells: Sabaean, reg. nos 82.01, 200/58; Minaean, reg. nos 184.3, 198.04; and Uncertain Chronology, reg. no. 210.05. (G. Di Rosa and S. Iavarone 2007 (c) MAIRY, arranged and optimized by F.G. Fedele 2019)

\subsection{First Intermediate (Stratum $K$ )}

\section{Chipped stone: quartzite}

21.01 (Fig. 41). Chipped stone flake. White, semihyaline quartzite. $3.8 \times 2.8 \times 0.7 \mathrm{~cm}$. | D2 east. Units GSV1 (top) to SA2; small part of BRH2. Later Stratum K. | Slightly worn flake with S-shaped longitudinal section and clearly defined ventral and dorsal surfaces. ${ }^{150}$ The striking platform, associated bulb of force, and point of impact are indicated in the drawing. Unifacial edge damage, as is visible from the ventral side, looks more like use wear than primary retouch. This quartzite tool represents a unique find from Area C. A likely interpretation is a prehistoric object collected as a curious stone, and perhaps briefly reused.

\section{Chipped stone: heavy duty}

6.01 (Fig. 42). Chopper. Grey-hazel, fine, moderately sorted sandstone. $\varnothing 12.7 \times 11.9 \mathrm{~cm}$, max. thickness 3.8

\footnotetext{
150 Lithic terminology follows Andrefsky 2005.
}

cm. | D12. Cf. cuts 21 (lower) and 22, i.e. units GSV3GV2. Stratum K. | A relatively flat, circular, planoconvex cobble unifacially flaked on about 25 per cent of its circumference. ${ }^{151}$ The flaked edge is linear, as a chord of circle, and straight when viewed edge-on. The flaking is in fact marginally bifacial, scaled on one side and looking dulled on the opposite side. Flakes were removed - or went off - from the convex face of the cobble leaving deep, invasive, imbricate scars, while on the corresponding plane surface a shorter series of marginal, steep chips (écailles) were produced. The resulting damage looks like battering from utilization - a crushed edge from impact damage - rather than primary retouch. However, a combination of both intentional fashioning and use-wear is more probable. This well-chosen cobble might have been prepared and rather heavily used for general chopping or butchering.

\footnotetext{
151 For terminology see Shea 2013, e.g. 36, 50, 99 (table 4.3, Bordes' type no. 59), and Andrefsky 2005.
} 


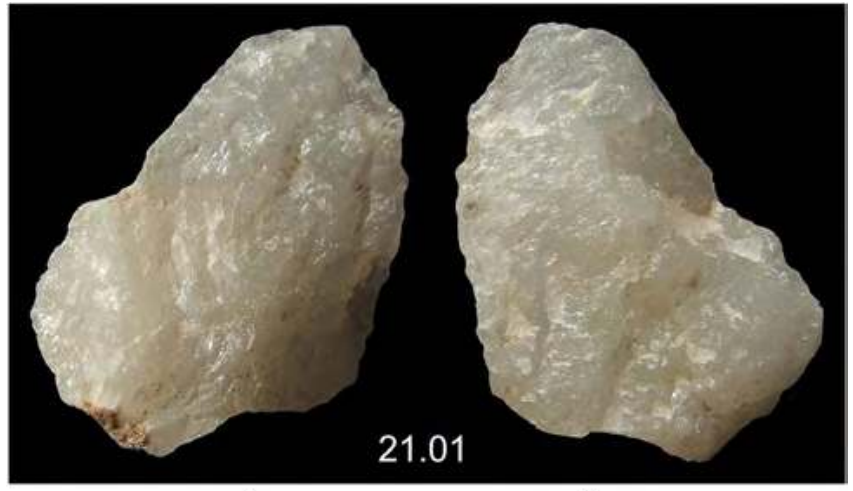
$3 \mathrm{~cm}$

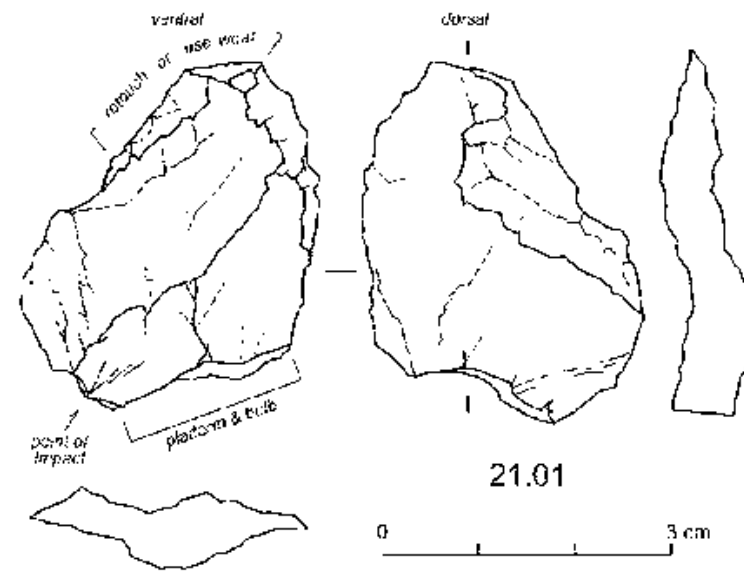

Figure 41. Chipped quartzite, First Intermediate, reg. no. 21.01. (P. Morlupi and F.G. Fedele 2006 C) MAIRY; drawing F.G. Fedele 2007)
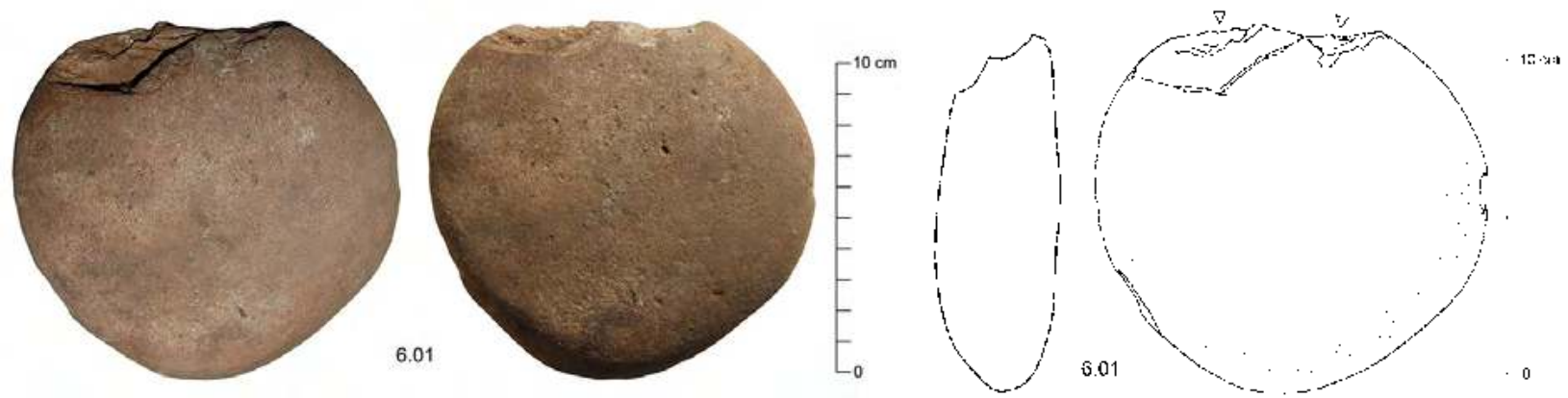

Figure 42. Chopper, First Intermediate, reg. no. 6.01. (P. Morlupi 2006; G. Di Rosa and S. Iavarone 2007 C MAIRY; drawing F.G. Fedele 2006)

Softstone vessels

Softstone fragments nos 121.01, listed in the Sabaean group (above), and 20.01 (see Minaean group) might have originated from Stratum $\mathrm{K}$.

Stone tiles (?)

22.0 (Fig. 43). Ochred tile (?). Beige-greyish fine sandstone or calcarenite. Approx. $11.5 \times 10.5 \times 5 \mathrm{~cm}$. | D2 northeast, in situ; lying a little inclined west, i.e., counter to the general dip of the units in suite SD2, and with its flat surface facing up (see Chapter 17, Fig. 65 C, this volume). Around the limit between units GSV2 and GSV1. Earlier Stratum K. | This object was documented and interpreted as a handstone, obtained from an especially chosen cobble with a natural D-shaped cross-section and an almost square rubbing surface. The overall form can be described as half-barrel. The edges are rounded and battered, apparently from a combination of use wear and redeposition, while the convex surface is not only damaged but geologically very irregular. Conversely, the rubbing surface is perfectly flat and well preserved, and is covered by faint stains of red pigment all over, as if the object had been used to grind ochre.

In 2019, however, the possibility of an alternative interpretation for this stone has emerged. During the final restudy of the Minaean collection an analogy in some attributes was noted between no. 22.0 and the Minaean ochred tiles, particularly no. 168.01 (Fig. 54). Especially striking in 22.0 is the characteristic of a flat, red-coloured face opposite to a rough, unmodified 'back'. Also the red hue and the chosen rock types seem to be very similar. Perhaps more significantly, a strong similarity in shape and size to a unique stone tile from Sounding A has further become apparent. This is stone tile no. 07, described in the Second Intermediate group below and shown for comparison in Fig. 43 here. In the light of these multiple analogies to nos 168.01, 190.01, and 07 , find no. 22.0 is here tentatively interpreted as a possible tile instead of a grinding or rubbing stone as previously thought. Without a comparative reexamination of the actual objects involved, one has to leave the question to this stage. 

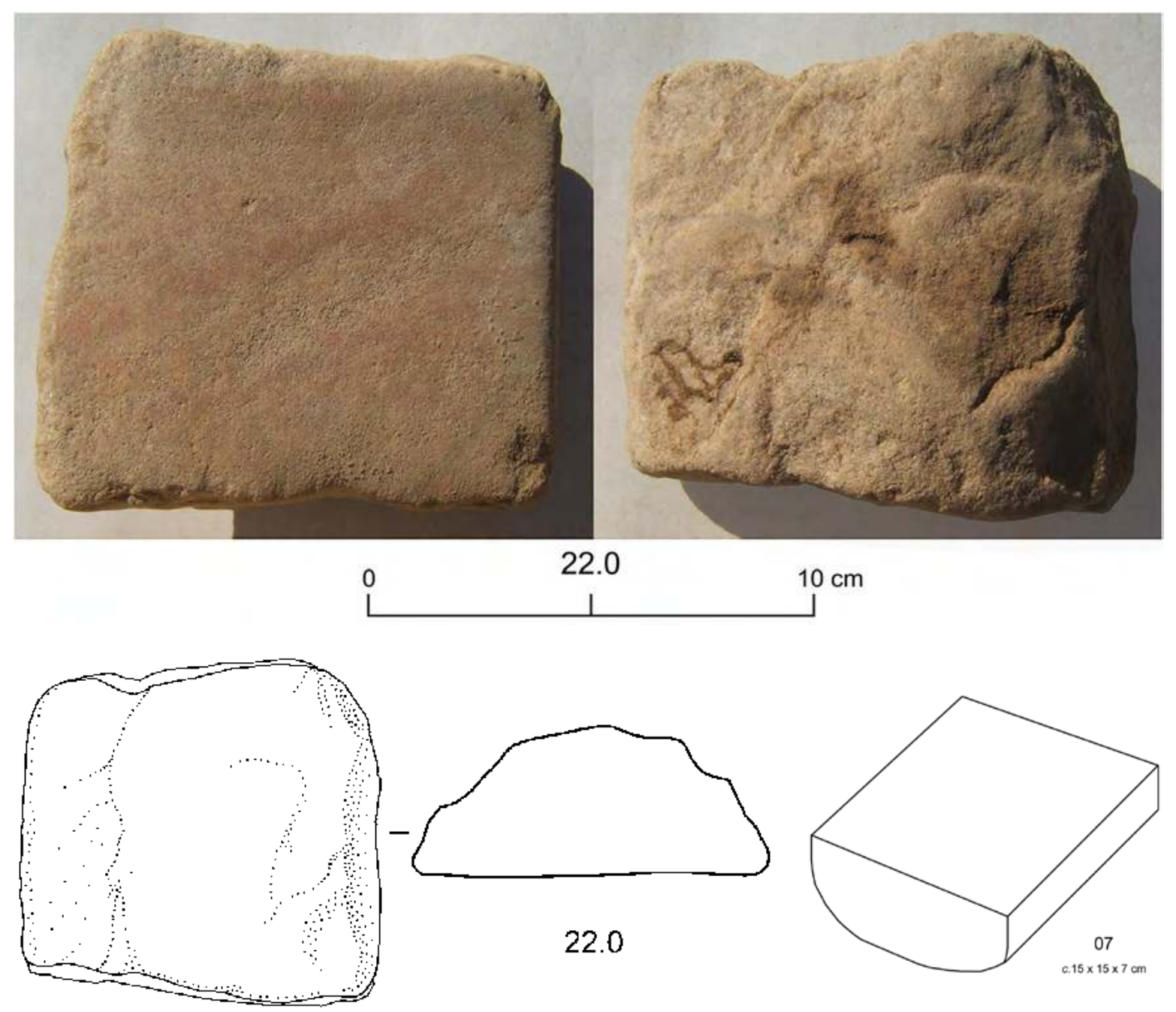

Figure 43. Stone tiles and cf. stone tiles: First Intermediate, reg. no. 22.0; Second Intermediate, reg. no. 07.

(No. 22.0: G. Di Rosa and S. Iavarone 2007 @ MAIRY, adapted and optimized by F.G. Fedele; drawing F.G. Fedele 2006. No. 07: F.G. Fedele 2005)

Mentioned in Fedele 2010, 129 ('a grinding/rubbing stone with an ochre-stained working surface - an almost unique occurrence').

\section{Clay sling bullets}

6.1, 6.2 (Fig. 44). Two clay sling bullets. Fired clay. Length $8.7 \mathrm{~cm}, \varnothing 4.0 \mathrm{~cm}$ (no. 6.1); length $8.1 \mathrm{~cm}$ (one tip missing), $\varnothing 4.1 \mathrm{~cm}$ (no. 6.2). | D12. From sediments cf. cuts 21 (lower) and 22, i.e. units GSV3-GV2. Stratum K. | These two elongated, torpedo-shaped projectiles about 9-cm-long, made of untempered clay, can be recognized as sling bullets. ${ }^{152}$ Critical information on their retrieval context is provided in Chapter 17, sections 8.2-8.3, this volume, while their possible significance for Yathill in

152 Also slingshots, sling bolts, or sling missiles. In 2010 Mark Beech (Abu Dhabi) half-jokingly pointed out to me the striking morphological similarity of the sling bullets from Area $\mathrm{C}$ with the Lebanese meatballs called kebbe. [FGF]

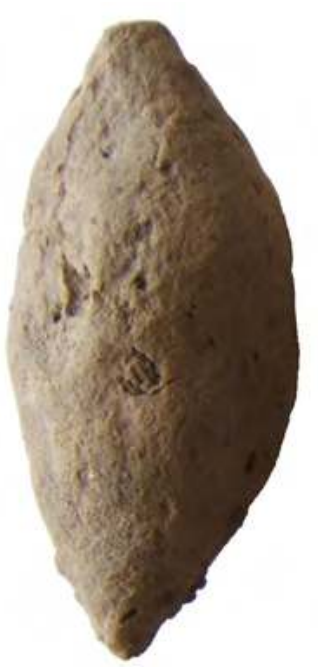

6.1

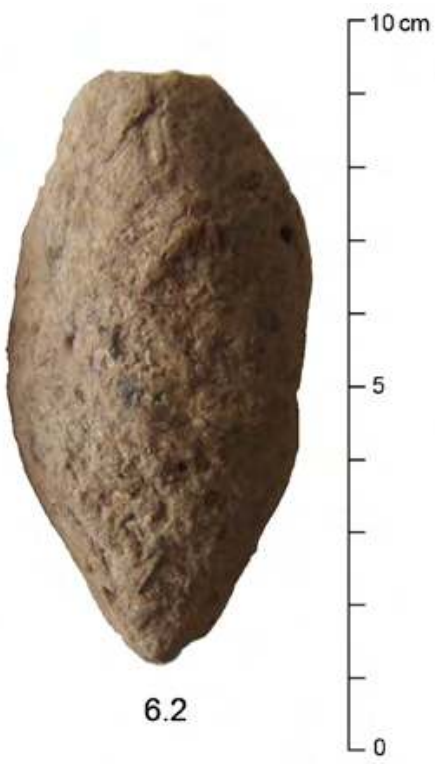

Figure 44. Clay sling bullets, First Intermediate, reg. nos 6.1-2. (G. Di Rosa and S. Iavarone 2007 @ MAIRY, arranged and optimized by F.G. Fedele 2019) 

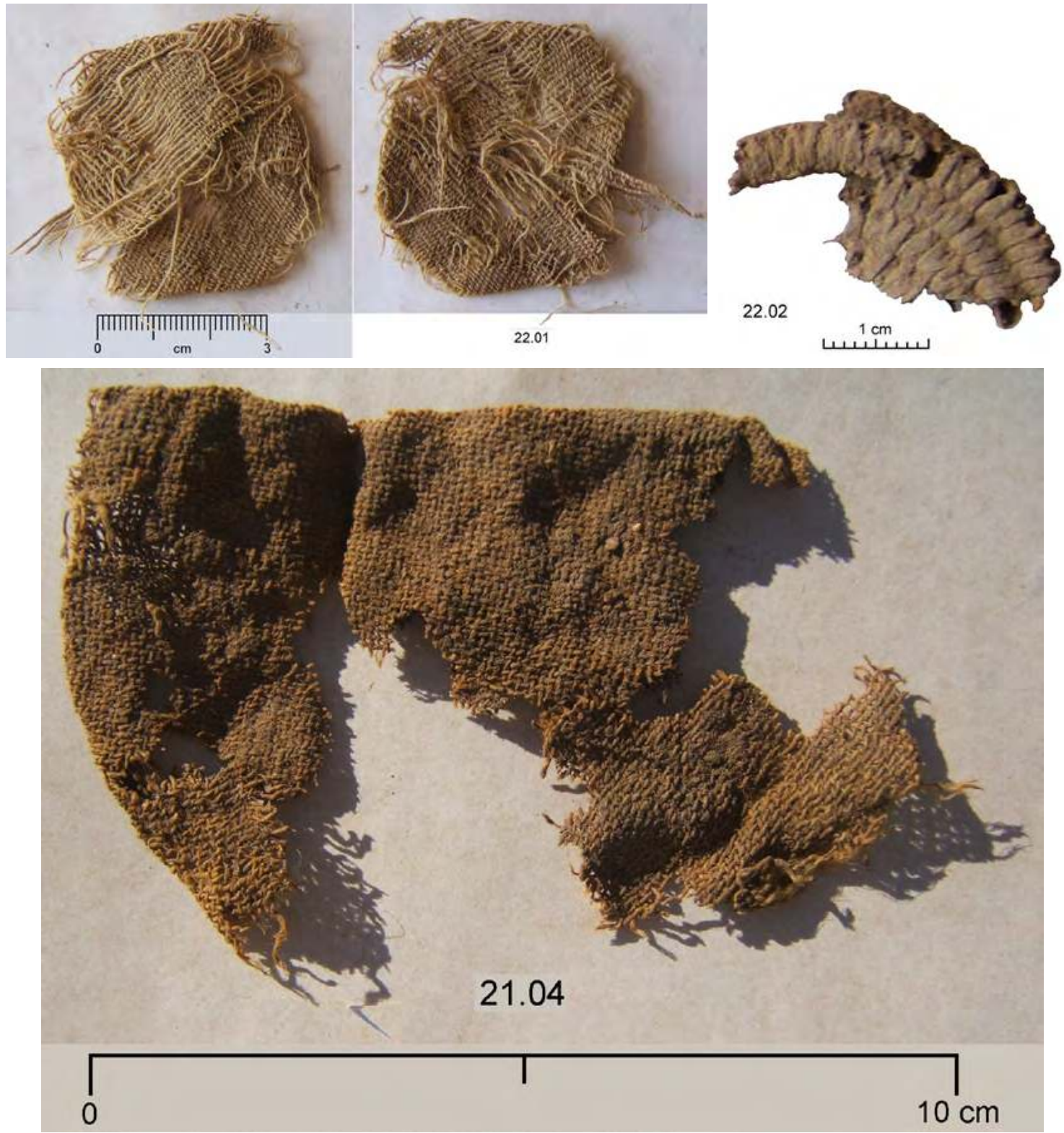

Figure 45. Artefacts made from organic materials, First Intermediate, reg. nos 21.04 and 22.01-02. (G. Di Rosa and S. Iavarone 2007 (c) MAIRY, arranged and optimized by F.G. Fedele 2019)

historical terms, together with likely foreign parallels, are discussed in Chapter 18, section 3.2.

Publication: Fedele 2011, 108-109, fig. 10/a. Mentioned in Fedele 2010, 130.

Unfired or poorly fired clay artefacts: discs and/or 'tripods'

22.03. Foot of a clay 'tripod'. Coarse, brown-blackish paste, lightly baked or 'roasted'. | D2 east. Units GSV3GSV1. Stratum $\mathrm{K}$ - but might be a redeposited Sabaean element. | Further details unavailable. For Sabaean examples of light baking due to exposure to fire during the use of the object see finds nos 49B.01-02 and 151.10.
Artefacts made from organic materials

The following list is selective. Many more minute fragments of organic artefacts were found in the First Intermediate deposits, but time constraints prevented from studying them individually. ${ }^{153} \mathrm{Cf}$. Sabaean group, above.

22.01 (Fig. 45). Square fr. of cloth. $4.6 \times 4.3 \mathrm{~cm}$. $\mid$ D2 east. Units GSV3-GSV1. Stratum K. | The colour is a natural light beige. The individual threads are $0.5-0.8 \mathrm{~mm}$ in average diameter.

153 See mentions in Fedele 2010, e.g. 112, 121-122. 
22.02 (Fig. 45). Fr. of a basket. Plant fibres. Max. length $3.4 \mathrm{~cm}$. | D2 east. Units GSV3-GSV1. Stratum K. | A fragment in the shape of a segment, possibly from the bottom of a circular container.

21.04 (Fig. 45). Edge fr. of cloth. $10 \times 6.6 \mathrm{~cm}$. | D2 east. Top of unit GSV1 to SA2, and small part of unit BRH2. Later Stratum K. | From a fine cloth, possibly a garment, now brown in colour. The preserved edge is straight, 8.3 $\mathrm{cm}$ long, and the individual threads are $0.3-0.6 \mathrm{~mm}$ in average diameter.

\subsection{Minaean (Strata J-F)}

Finds from Minaean layers believed to be Sabaean items redeposited from reworking of sediments will be explicitly indicated. Redeposited Minaean items (or supposedly Minaean) found in Islamic layers include no. 06 , catalogued in the Uncertain chronology group.

\section{Inscribed masonry block}

182A.P20d = Y.06.B.C/1. Inscribed stone block P20d. Oolithic limestone. $77 \times 23 \times 24 \mathrm{~cm}$. $\mid$ A1 centre. Part of the T7A collapse rubble from the Minaean wall, component F7, bottom level of the rubble heap. Stratum E (the collapse). | Like the other stone blocks in component F7 (a structured cluster of the T7A collapse material), this parallelepiped block ${ }^{154}$ was an integral element of the Minaean masonry of bastion T7: see Chapter 17, section 12.3 ('Some observations on individual blocks') and Fig. 117 (excavation photographs), this volume. When excavated, the block was lying with an estimated dip of $31^{\circ}$ east. For its inscription and related comments see Chapter 24 (Agostini).

Mentioned in Fedele 2010, 137, note 136.

Chipped stone: obsidian

194A.02. Obsidian flake. Length c. $3 \mathrm{~cm}$. | A31 centreeast. Found at bottom of cut 194A 'within beige silt of unit T79J', i.e. in units T79J-9 $\lambda$ (component F12 of Earthwork F10-F12). Stratum J. | Possibly a reworked Sabaean element, though in perfectly mint condition.

192.02, 192.03, 192.04. Three obsidian microflakes. Length c. $0.8 \mathrm{~cm}$ (192.02), c. $1 \mathrm{~cm}$ (the other two). |A11 centre, in situ, $50 \mathrm{~cm}$ to the southwest of block P44. ${ }^{155}$ Bottom of unit T78 $\pi$ or surface S10 (component F11 of Earthwork F10-F12). Stratum J - but, possibly, reworked Sabaean elements. | The two identical microflakes 192.03-04 were found close to each other.

\footnotetext{
154 Parallelepiped: a solid the six faces of which are all parallelograms. The faces of most blocks employed in the Minaean wall are rectangles.

155 On block P44 see Chapter 17, section 10.3, this volume.
}

Mentioned in Fedele 2010, 133.

Chipped stone: heavy duty

185 (no individual numbers). Cobbles and chipped cobbles. Mostly limestone. Various sizes, but generally dm-sized. | A1-A11, in situ. Units SR-T76H, TPV. Later Stratum H. | Details unavailable. An elongated cobble of grey cryptocrystalline limestone from quadrangle A11 north, almost $20 \mathrm{~cm}$ long and chipped at one end, is recorded in the excavation plan of unit $\mathrm{T} 76 \mathrm{H}$ (Chapter 17, section 11.2 and Fig. 89 B, this volume). In all probability, at least some of this material is related to the making of jar stoppers: see 'Chipped stone: heavy duty' in section 2.5 , below.

184.02 (Fig. 46). Fr. or flake. Yellow-grey calcarenite. $2.7 \times 1.7 \times$ c. $1 \mathrm{~cm}$. | A1-A12. Unit T75. Stratum F. | An angular clast detached by percussion from a larger stone, possibly a cobble.

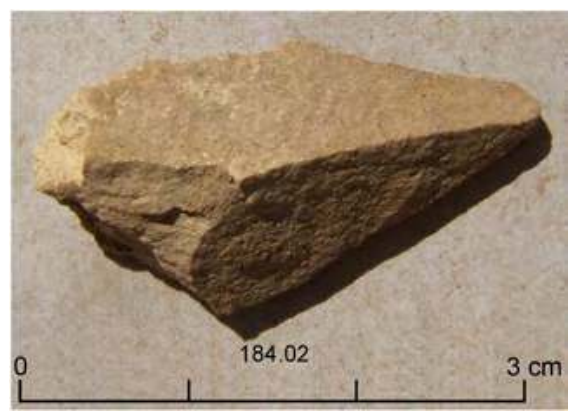

Figure 46. Chipped stone (heavy duty), Minaean, reg. no. 184.02. (G. Di Rosa and S. Iavarone 2007 @ MAIRY, optimized by F.G. Fedele 2019)

184 (no individual numbers). Cobbles and chipped cobbles. Grey cryptocrystalline limestone and other, less frequent limestone varieties. Various sizes, but generally dm-sized. |A1-A12. Unit T75. Stratum F.| The sample includes wādī cobbles and a dm-sized spherical segment from the controlled splitting of a large or very large cobble. In all probability this material is related to the making of jar stoppers: see 'Chipped stone: heavy duty' in section 2.5 , below.

\section{Stone burners}

189.1. Fr. of a small plain burner or lamp. White limestone. |A1 south, in situ near block P32f (T7C) at the level of its top surface; see Chapter 17, section 10.5, this volume. Unit T7LP, probably T7LP ${ }_{1}$. Earlier Stratum I. | For the alternative interpretation of such basic, plain burners as lamps see the introduction to 'Stone burners and containers' (section 2.1); about the choice of rock type see no. 5.1 a, footnote 62 . 

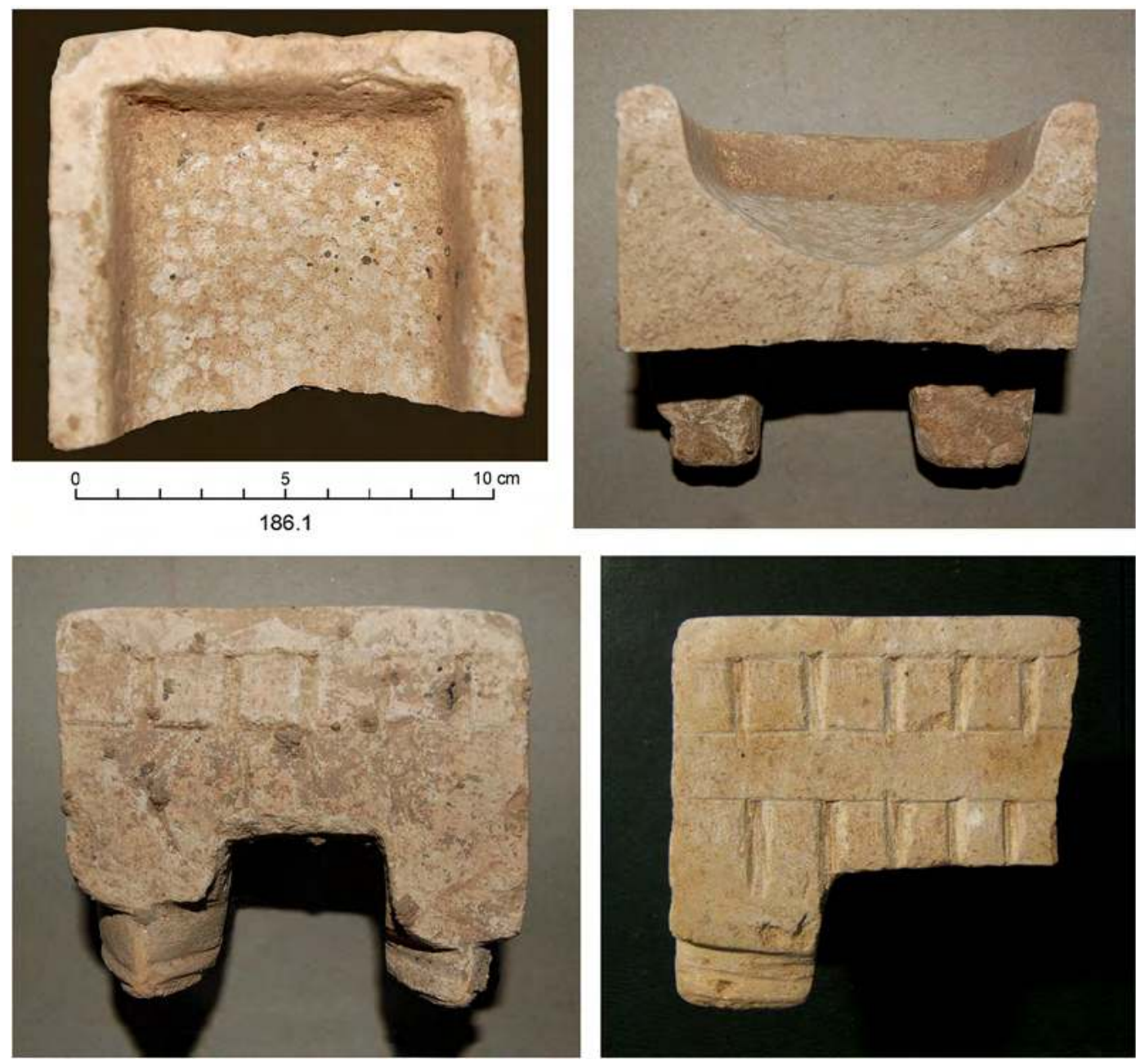

Figure 47. Stone burner, Minaean, reg. no. 186.1. Additional photograph in Chapter 24, Fig. 2, this volume. (P. Morlupi 2006 @ MAIRY, arranged and optimized by F.G. Fedele 2019)

186.1 = B.06.C.O/16 (Fig. 47). Part of a cuboid burner for aromatics, inscribed. White to pale beige, fine-grained limestone (about the choice of rock type see no. 5.1a, footnote 62 ). $9.4 \times 10.7 \times 9.1 \mathrm{~cm}$, feet height $3.8-4.2 \mathrm{~cm}$, basin wall thickness $c .1 \mathrm{~cm}$. | A11 southern half, centre, in situ: found upside down and tilted to the east within a cluster of decimetre-sized, angular stones at a depth of $-381 \mathrm{~cm}$ (top), $-392 \mathrm{~cm}$ (base); see details in Chapter 17, section 11.2 and Figs $89 \mathrm{C}$ (plan) and 79 (stratigraphy), this volume. Upper unit T76J . Earlier Stratum H. | Fourfooted burner formed by a cubical body with a foot at each corner. Two feet (or legs) are preserved, subtriangular in cross section and apparently carved in the shape of a bull's hoof. Due to breakage along the middle, only half burner survives. The thickness of the basin wall is fairly even and the rim is flat. The basin is well smoothed inside and preserves faint traces of red colour. ${ }^{156}$ Two sides are decorated with two rows of dentils 1 to $1.5 \mathrm{~cm}$ wide, alternating with two smooth

156 On artificial reddening see no. 5.1a and 'Remarks on red colouring' (Sabaean group). bands. ${ }^{157}$ The third side is decorated by a smooth band that runs along the upper edge, and a parallel row of six dentils below. Three letters were engraved on what serves as the front of the object (see Agostini, Chapter 24, Fig. 2, this volume). ${ }^{158}$

Publications: Fedele 2010, 137, fig. 144/F; 2011a, 113, fig. 10/c2.

\section{$[\mathrm{SA}, \mathrm{FGF}]$}

211.1. Fr. of a plain burner or lamp. White limestone. $\mid F$, northwest quadrant. From near bottom of unit F02 (F02 ${ }_{3}$ ). Stratum G. | Rather crudely carved. For the

\footnotetext{
157 There is no resemblance, however, between this find and a dentildecorated burner from Area D (Antonini 2010b, pl. 37/a). [FGF]

158 The inscription confronts the reader with an unusual term or name, rbq, for which Agostini (Chapter 24) can only cite an occurrence from Baynūn (siglum Byn 248, Baynun Museum, a flat cuboid burner; photograph in CSAI 2019, http://dasi.cnr.it/index.php?id=dasi_prj_ obj\&prjId $=1 \&$ corId $=0 \&$ colId $=0 \&$ navId $=45459465 \&$ recId $=482$ ). $R b q$ is not included in Sima (2000, chapter 3, 265-287). [FGF]
} 

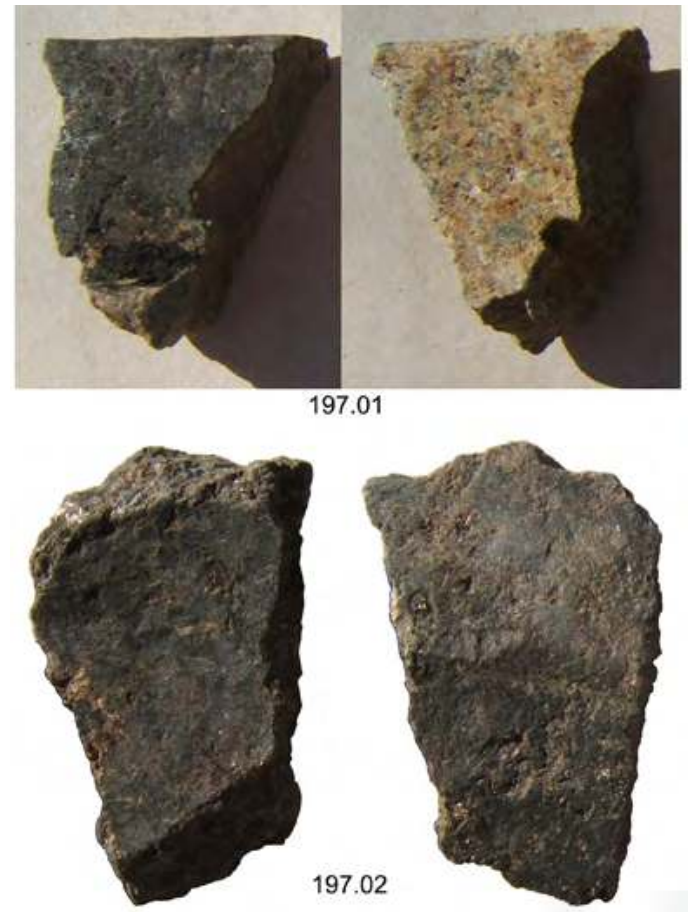

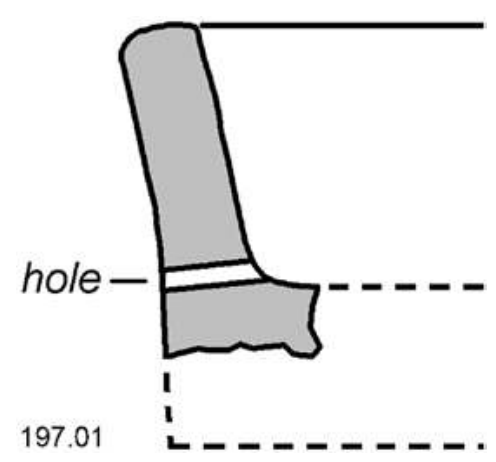

Figure 48. Softstone vessels, reworked Sabaean (?), reg. nos 197.01-02; the drawing shows section of pan 197.01. (G. Di Rosa, S. Iavarone, and F.G. Fedele 2007 (c MAIRY; drawing F.G. Fedele 2007)

alternative interpretation of such basic, plain burners as lamps see the introduction to 'Stone burners and containers' (section 2.1); about the choice of rock type see no. $5.1 \mathrm{a}$, footnote 62 .

Mentioned in Fedele 2010, 136.

Softstone vessels

197.01 (Fig. 48). Fr. of a shallow circular container (a pan or a brazier). Light green-grey steatite, mildly porous. ${ }^{159}$ Max. length of fr. $3.5 \mathrm{~cm}$, arc $3 \mathrm{~cm}$, estimated height of vessel 4.5-5 cm. | A1-A11 east + A31. Units T7F, LP3. Stratum J - but, possibly, a reworked Sabaean element. | Edge fragment from a pan-like vessel with a through hole near the bottom of the basin, probably a repair hole. Wall nearly vertical, rim flattened, base flaked off. The inside of the container, besides being completely blackened, is encrusted with thick carbonaceous or charred residues along the junction between the wall and the bottom, suggesting that the object might be a container for burning - a brazier - rather than a kitchen pan.

197.02 (Fig. 48). Fr. of a softstone vessel. Chloritite. Max. length of fr. $4.7 \mathrm{~cm}$. | Provenance and stratigraphy

159 Determined in the field as 'pale steatite' (see the introduction to 'Softstone vessels' in section 2.1, above).

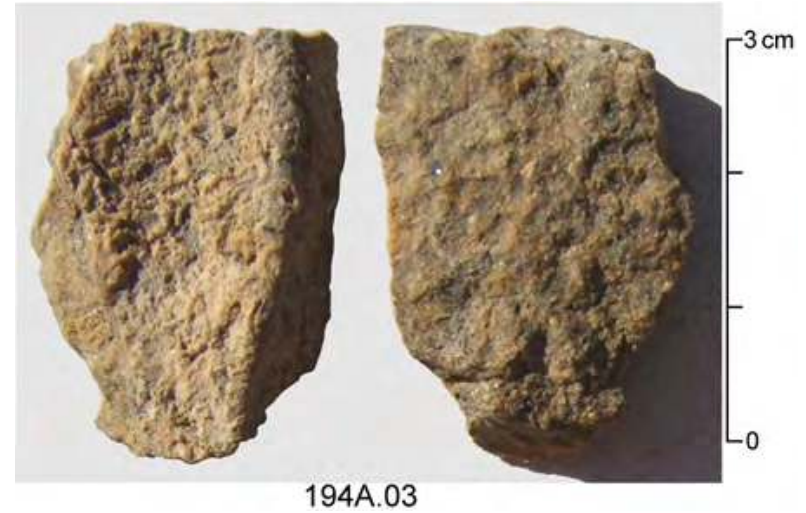

Figure 49. Softstone vessel, reworked Sabaean (?), reg. no. 194A.03. (G. Di Rosa and S. Iavarone 2007 C MAIRY, arranged and optimized by F.G. Fedele 2019)

as for no. 197.01. Stratum J - but, possibly, a reworked Sabaean element. | From a thin-walled, globular vessel.

194.02. Fr. of a softstone vessel. Chloritite. |A1-A11. Units Pj (part) and T79L (Component F12 of Earthwork F10-F12). Stratum J - but, possibly, a reworked Sabaean element. | Details unavailable.

194A.03 (Fig. 49). Fr of a softstone vessel. Chloritite (?). $3.5 \times 2.3 \mathrm{~cm}$, thickness $0.8-0.9 \mathrm{~cm}$. A31. Units Pj (part), T79L (Component F12 of Earthwork F10-F12). Stratum $\mathrm{J}-$ but, possibly, a reworked Sabaean element. | The 


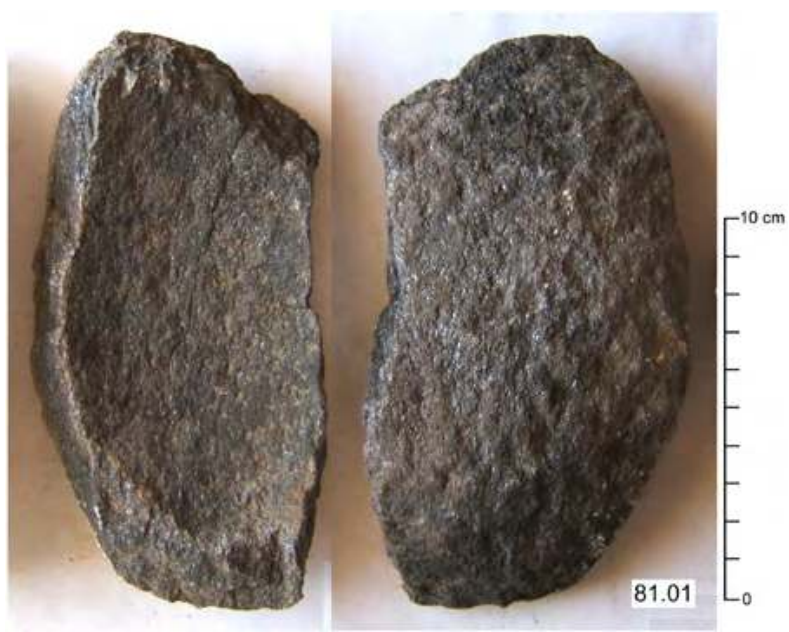

Figure 50. Softstone cooking pot, Minaean, reg. no. 81.01. (G. Di Rosa and S. Iavarone 2007 @ MAIRY, arranged and optimized by F.G. Fedele 2019)

stone is a light green to grey-yellowish variety of a coarse crystalline rock, only provisionally identified in the field as belonging to chloritites. The abrasion and smallness of the fragment, together with the presence of resistant calcium carbonate crusts, prevent from certain determination.

20.01. Fr. of a softstone vessel. Chloritite. | D2. Mostly units BRH2-BR2; also unit SA2? Strata J-I; also K? | Details unavailable.

81.01 (Fig. 50). Fr. of a softstone cooking pot. Chloritite.

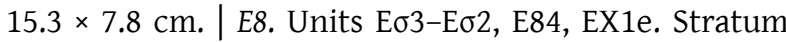
I or Stratum G. | The curvature of the wall indicates a fragment from near the bottom of the pot. Minaean 2 to Minaean 4 material, cf. plaster jar sealings 81X.1-2.

189.01, 189.02. Frs of softstone vessel(s). Chloritite. | A1-A31. Units T7LP (mostly T7LP 2 ), r0. Earlier Stratum I. | Details unavailable.

188.02. Fr. of a softstone vessel. Chloritite. | A1-A31. Units T7LP ${ }_{1}$, SRI, and T7P. Stratum I. | Details unavailable and poor quality photograph.

187.2. Fr. of a softstone vessel. Chloritite.|A1-A11. Units T7L-T7P0, b0, T76J, and TPVj. Strata I-H (later I, earlier $\mathrm{H})$. | Details unavailable.

186.03, 186.04. Two frs of softstone vessels. Chloritite. A1-A11. Units T76J (mostly T76J) and TPVi. Stratum H.| Details unavailable and poor quality photograph.

Querns and other grinding tools

191.3. Cobble used as a grinding/rubbing stone, "kohl grinder'. Approx. $\varnothing 8 \mathrm{~cm}$. | A11 southeast, in situ; see

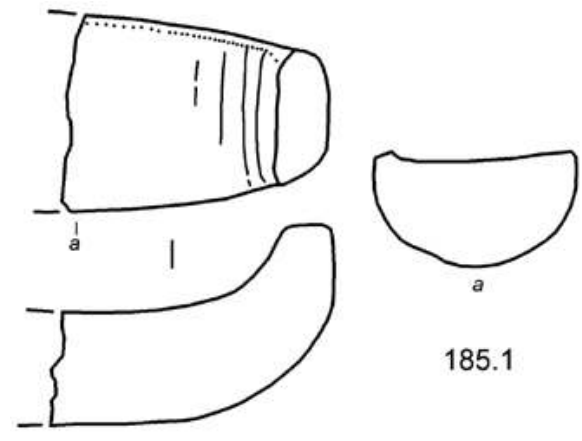

Figure 51. Quern, Minaean, reg. no. 185.1. (F.G. Fedele 2006)

Chapter 17, section 10.3 and Fig. 92 (plan), this volume. Unit T78 , upper part (Component F11 of Earthwork F10-F12), from among the gravels of the unit. Stratum J. | A flattish cobble, instantly recognized by the Yemeni excavators as a grinding tool for kohl ( $k u h l / k o h l) ;$ and if so, a unique find from Area $\mathrm{C}$. However, such a precise functional identification might not be strictly correct. The available information on this object is based on field description and memory: due to a misidentification this find escaped examination and photography during the study sessions in 2007.

185.1 (Fig. 51). Incomplete saddle quern: transverse half-quern. Basalt (?). Size unrecorded. | A11 south, in situ; see Chapter 17, section 11.2 and Fig. 89 B (plan), this volume. Unit T76H bottom or SR/T76H boundary (c. $10 \mathrm{~cm}$ below top of unit and cut). Later Stratum $\mathrm{H}$. | A typical saddle quern. For the breakage pattern see the introduction to 'Querns and other grinding tools' in section 2.1 , above.

Mentioned in Fedele 2010, 137.

Other utilized natural stones (stone manuports, including fossils)

Finds nos 196.02, 196.03, 194.01, as well as (possibly) 198.03 - 'roasted' lithics in field parlance - represent a sample of heat- or fire-modified rock material that was retrieved from several locations of Area C. All four lithics listed here come from Sounding A. While a general association with fire is clear, the details may suggest taphonomic and behavioural differences from context to context. As described below, typically such 'roasted' stones are angular-tabular sandstone clasts, although other clast morphologies may occasionally be involved. From this viewpoint, these platey sandstone elements are entirely different from other rubefied or burnt stone fragments, cobbles, or split cobbles. They particularly need to be distinguished from the 'thermal stones' (or their fragments), which would be represented at Barāqish Area C by such findings as Cluster 82.2. For a clearer understanding of these 
occurrences, as suggested above, ${ }^{160}$ future research at the site should jointly appraise roasted lithics and possible thermal stones (or features of the Cluster 82.2 type in general) as variable expressions of a single behavioural-functional complex related to the use of fire, be they formal hearths or more occasional contrivances (e.g. campfires).

198.03 (Fig. 52). Rubefied pebble. Medium-coarse sandstone. $3.6 \times 2.8 \times 1.5 \mathrm{~cm}$. | A1-A11 east + A31. Units AR-T7F . Stratum J - but, possibly, a reworked Sabaean element. | An irregularly cubical, subrounded, coarse sandstone clast bearing a dendrite on one of its surfaces (see photograph). ${ }^{161}$ Its variable rubefaction might be geological but is more likely cultural.

196.02, 196.03 (Fig. 53). Two rubefied sandstone tablets. $4.7 \times 2.2 \times 1.5 \mathrm{~cm}(196.02)$ and $3.5 \times 2.7 \times c .1$ cm (196.03). | A1-A11 E + A31. Units T7Y-T7 $\tau$, LP2, LP1. Stratum J - but, possibly, reworked Sabaean elements. | Angular tabular clasts. Two examples in a series of sandstone fragments and flakes reddened by fire, which also included no. 194.01 (below) and several others not listed here. They were presumably all redeposited with the backfill of the Minaean wall foundation. The angular material of this kind from Sounding A, Stratum J, is cmsized to dm-sized and fairly uniform in appearance, a probable indication of origin from a single source.

194.01 (Fig. 53). Rubefied sandstone plate. $6.4 \times 3.9 \times 1.3$ cm. | A1-A11. Units Pj (part), 9 $\lambda$, and T79L (component F12 of Earthwork F10-F12). Stratum J - but, possibly, a reworked Sabaean element. I Angular tabular clast, thermally split (?). Both the specimen and the unmistakable rock, a coarse fossiliferous sandstone, are identical to find no. 213.01 recovered from the opposite end of Area C, Sounding F in the plain (Fig. 21; see Sabaean group, above). At face value, this degree of lithological and behavioural identity might confirm that also 194.01 is Sabaean.

192.01. Fossil mollusc: internal mould of a gastropod shell, Cerithium sp. Lithified silt. Length $c .4 \mathrm{~cm}$. |A31 northeast, in situ. Bottom of unit T78 $\pi$ or surface $\mathrm{S} 10$ (component F11 of Earthwork F10-F12), but retaining matrix cf. T79L (component F12 of the earthwork). Stratum J - but, possibly, a reworked Sabaean element. | A Sabaean date for this manuport is suggested by the inferred provenance from fill T79L. If, in principle, the existence of an analogy between this finding and

160 See 'Remarks on Cluster 82.2' in 'Other utilized natural stones', Sabaean group, above.

161 A dendrite is a plant-like pseudofossil formed by the precipitation of manganese dioxide crystals, commonly occurring on bedding planes. Apparently, the dendrite on no. 198.03 is pre-rubefaction, hence of geological origin. For another example of dendrite see no. 83.1.1 in the Uncertain chronology group.

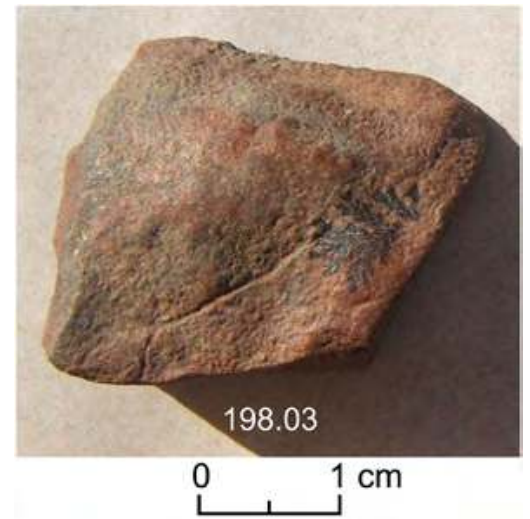

Figure 52. Utilized natural stone (rubefied pebble), Minaean or reworked Sabaean, reg. no. 198.03. (G. Di Rosa, S. Iavarone, and F.G. Fedele 2007 (C MAIRY)

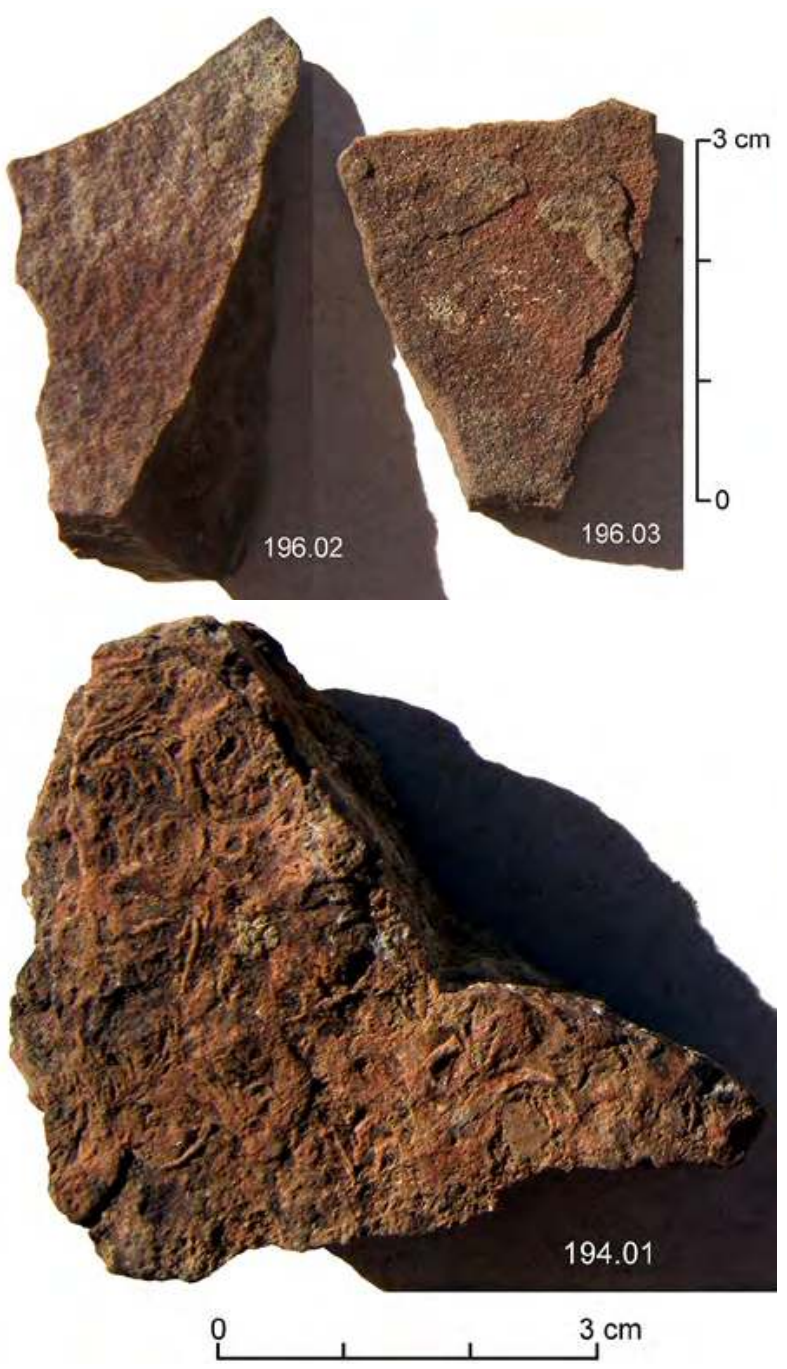

Figure 53. Utilized natural stones (rubefied tablets), Minaean or reworked Sabaean, reg. nos 194.01 and 196.02-03. (G. Di Rosa and S. Iavarone 2007 (C) MAIRY, arranged and optimized by F.G. Fedele 2019) 


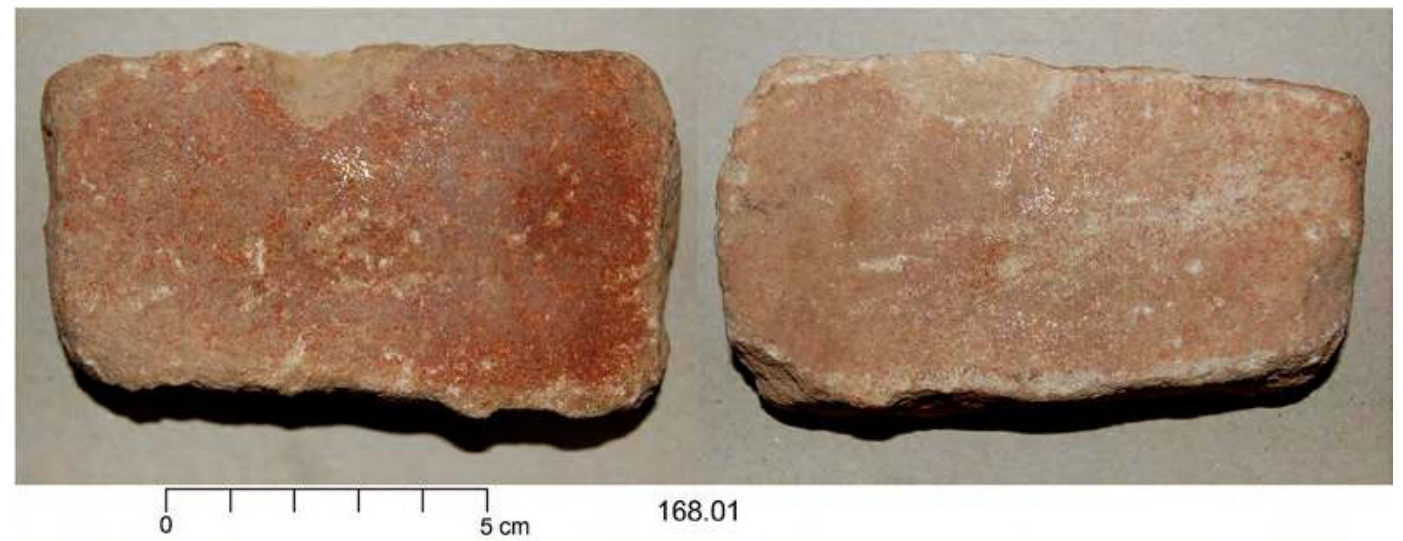

Figure 54. Ochred limestone tile, Minaean, reg. no. 168.01. (P. Morlupi 2006; G. Di Rosa and S. Iavarone 2007 (C) MAIRY, arranged and optimized by F.G. Fedele 2019)

the Cerithium fossil placed at the base of Wall $F 4^{162}$ were accepted, one could again think of a symbolic deposition connected with the foundation of a wall, in this case the Minaean curtain wall. However, this is entirely speculative (see Chapter 17, section 6.3, this volume).

Mentioned in Fedele 2010, 115, and cf. p. 132.

169F.1. Nearly spherical cobble. Grey cryptocrystalline limestone. Max. $\varnothing$ c. $10 \mathrm{~cm}$. |A31 northeast, in situ; see Chapter 17, section 11.3 and Fig. 104, this volume. Unit T75B. Stratum F. | This limestone cobble is probably to be interpreted as raw material for manufacturing jar stoppers: see 'Chipped stone: heavy duty' in section 2.5, below.

Stone tiles

190.01. Ochred tile (?). Pale red, fine-grained calcarenite; dm-sized. | A1-A11. Units T77-T7C (component F10 of Earthwork F10-F12). Final Stratum J. |A tile cf. no. 168.01 below, encrusted with ashy residues from a hearth. The rock was already light red in its natural colour.

168.01 (Fig. 54). Ochred tile. Yellow fine-grained calcarenite. $10.5 \times 6 \times 2.2 \mathrm{~cm}$. $\mid$ A1. Units T7LP and top of T77, approx. (2005 excavation season). Final Stratum J and Stratum I. | A squat parallelepiped. The tile was probably coloured with red ochre all over, but conspicuous traces only survive on one of the main faces and the two long sides. Cf. no. 190.01, above, from a clearer stratigraphic context. For hypothetically comparable objects cf. finds nos 22.0 (First Intermediate) and 07 (Second Intermediate).

162 Find no. 49D.01 in the Sabaean group, above (Fig. 16).

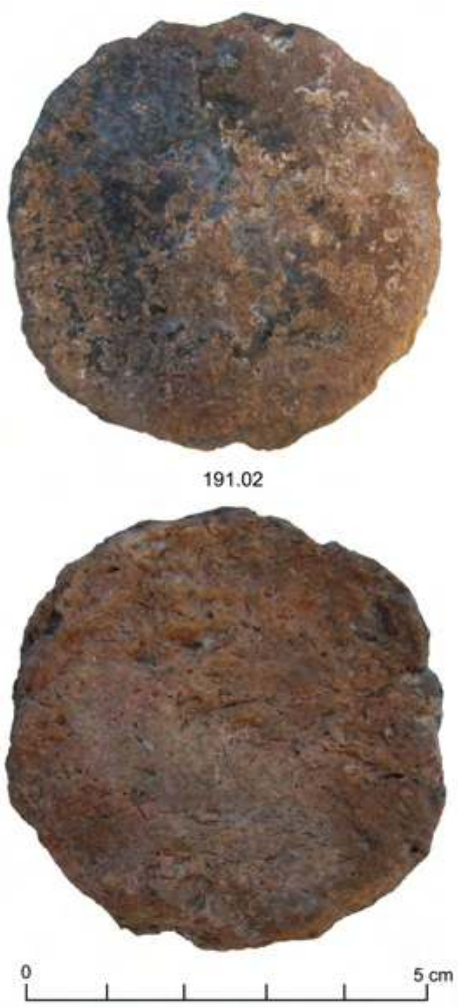

Figure 55. Ceramic object, Minaean, reg. no. 191.02. (P. Morlupi 2006 C MAIRY, arranged and optimized by F.G. Fedele 2019)

\section{Clay figurines and other clay finds; ceramic objects}

Two fired clay figurines were found in Area C, both associated with the early and middle Minaean levels of Sounding A. The other finds in the present category are two unparalleled items from Sounding A and upper Sector D.

191.02 (Fig. 55). Circular ceramic object. Fired clay. Max. $\varnothing 5.5 \mathrm{~cm} . \mid$ A1-A31. Unit T77 $\mu$ (component F10 


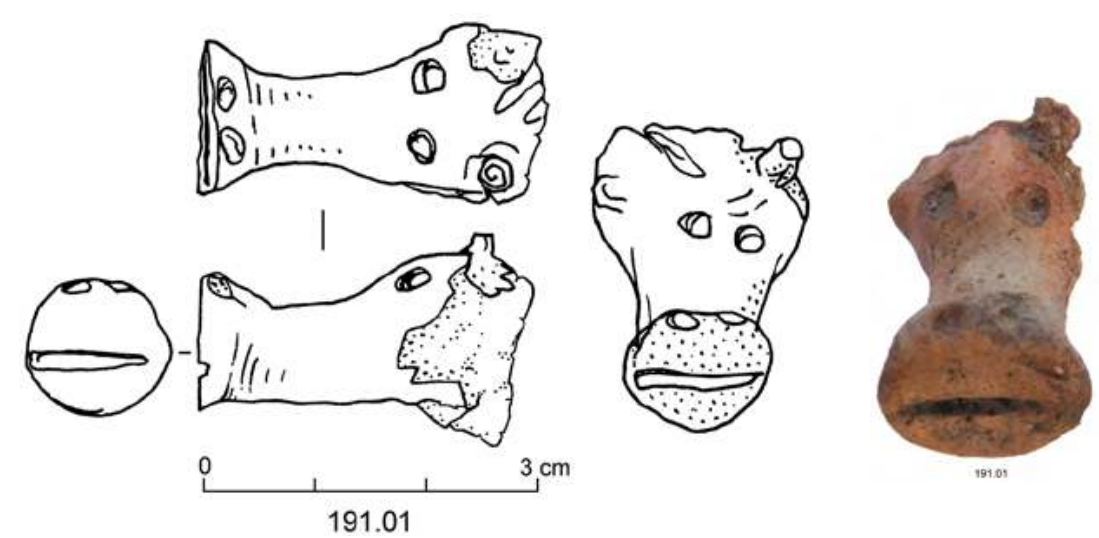

Figure 56. Terracotta figurine (bull), Minaean, reg. no. 191.01. (G. Di Rosa and S. Iavarone 2007 @ MAIRY; working sketch F.G. Fedele, December 2007)

of Earthwork F10-F12) and parts of F11M and T78 $\pi$ (component F11). Stratum J, but in light of its ceramic attributes the object could be Sabaean. | A nearly flat disc cut out from a body sherd belonging to a large, thick-walled vessel. The light-brownish, hard but porous, organic-tempered ware is rather undiagnostic, but possibly Sabaean, although knobs (such as the one preserved on this specimen, see below) very rarely occur in Sabaean pottery. This disc shows a crudely rounded, continuous edge, whose remaining angularities were mostly smoothed. A shallow conical knob from the outer surface of the vessel was intentionally spared in cutting. As this face of the disc is extensively covered by a postdepositional, sandy-silty, calcium carbonate crust, originating from an air-pervious sedimentary environment, the object was probably embedded in T78 $\pi$. This object can be a discoid stopper for a smallmouthed vessel, in which case torpedo jars are a prime or the only typological candidate. Sabaean torpedo jars from Area $\mathrm{C}$ have an average mouth-opening diameter of $3 \mathrm{~cm}$ (e.g., $3.1 \mathrm{~cm}$, jar no. 151.4; $3.0 \pm 2 \mathrm{~cm}$, jar no. 70). ${ }^{163}$ An alternative would be a rubbing or polishing tool, for instance a smoother or polisher for pottery.

191.01 (Fig. 56). Fragmentary figurine of a bull. Fired clay, mottled (reddish and grey). Length of head $3.1 \mathrm{~cm}$. | A1-A31: provenance and stratigraphy as for no. 191.02. Stratum J. | The fragment only preserves the head of the animal, who has a domestic-looking appearance.

Publication: Fedele 2011a, fig. 10/h2.

187.01 (Fig. 57). Fragmentary figurine of a dromedary. Fired clay, reddish-orange in colour. Max. length of fr. $9 \mathrm{~cm}$. | A1-A11. T7L-T7P0, b0, T76J, TPVj, but probably from surface S7. Later Stratum I or earlier Stratum H. | This is a fragmentary representation of a quadruped

163 On Sabaean pottery from Area C, including torpedo jars, see Chapter 23, this volume.
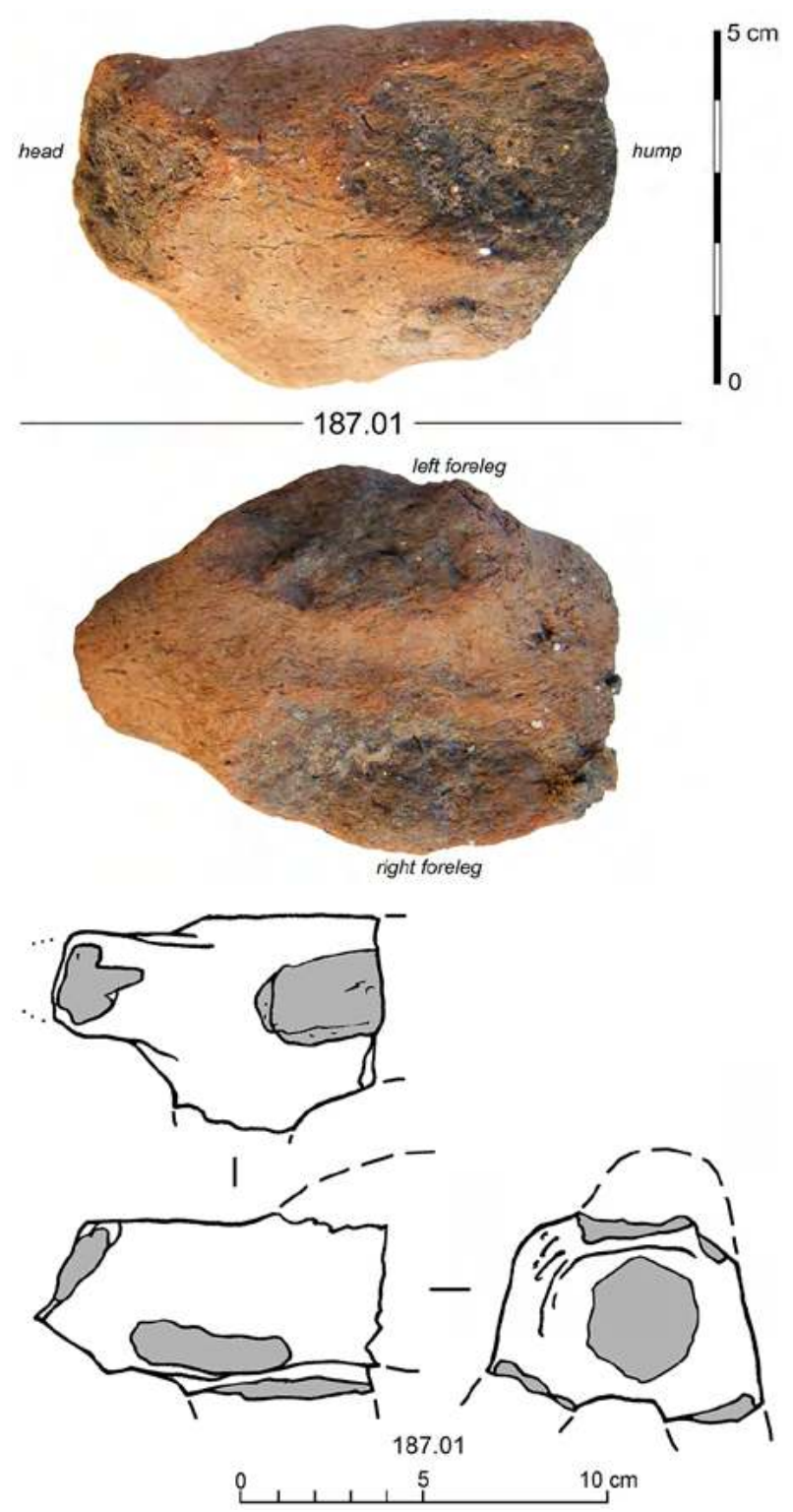

Figure 57. Terracotta figurine (dromedary), Minaean, reg. no. 187.01. (G. Di Rosa and S. Iavarone 2007 C MAIRY, arranged and optimized by F.G. Fedele 2019; working sketch F.G. Fedele, December 2007) 
of which only part of the fore half of the body remains (the neck, withers, and forelegs). In spite of the limited surviving portion the portrayed animal can be identified as a dromedary. Particularly conspicuous is the scar from the missing hump. The animal outline that can be reconstructed from this figurine recalls a bronze dromedary figurine attributed to the 'Bayyin' temple at Haram, in the Jawf, dedicated to the 'Amir tribe's godpatron dū-Samāwi. ${ }^{164}$ The Haram figurine is smaller, 4 $\mathrm{cm}$ long and $1.3 \mathrm{~cm}$ wide across each pair of legs, but size per se is unimportant, considered the difference in material. It was dated from its inscription to c. 200$150 \mathrm{BCE}$, i.e. the period in which the caravaneer tribe of 'Amir began to replace the Minaeans at several towns in the Jawf. ${ }^{165}$ As our figurine and the one from Haram can be roughly coeval (c. $200 \mathrm{BCE}$ ), one can wonder whether also our figurine has an ethnic relationship with the 'Amir, to the point of indicating the presence of Amirite traders at Yathill at the beginning of our Minaean 3.

Publication: Fedele 2011a, fig. 10/h1.

2.02 (Fig. 58). Fr. of a clay artefact with a wooden stick at its core. Max. length $11.0 \mathrm{~cm} ; \varnothing 5.4 \mathrm{~cm}$ (cylinder portion), $7.1 \mathrm{~cm}$ (fragmented body). D1. Unit GV1. Stratum H. | A fragment from an unknown artefact, of which only a cylindrical part is completely preserved. ${ }^{166}$ The wooden stick is broken and burnt precisely at the fracture of the clay body. It is worth noting that this unusual artefact from quadrangle D1 was found in the same assemblage - an aggregate rather than an association? - that contained two clay disc/'tripod' fragments, nos 2.01 and 2.03 (see below).
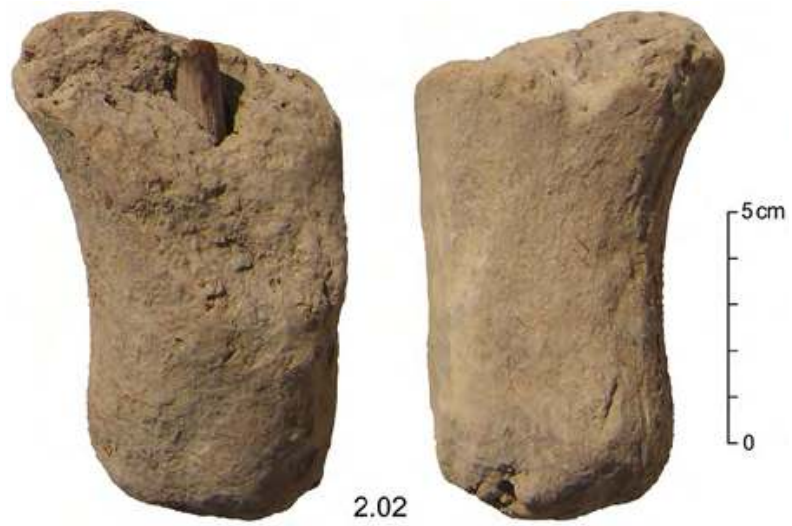

Figure 58. Terracotta object with wooden core, Minaean, reg. no. 2.02. (G. Di Rosa and S. Iavarone 2007 @ MAIRY, arranged and optimized by F.G. Fedele 2019)

164 Kitchen 1999, 152-154, figs 5-7; Ludwig 2015, 35, no. 2. This bronze figurine belongs typologically in Ludwig's $(2015,34)$ group 1 , variant 1.

165 E.g. Robin 1992, 54

166 S. Antonini (personal communication, June 2019) would point out that a wooden stick inside a clay or terracotta element was a common device for joining parts of figurines, for example those from the 'sacristy' annex of Temple A. That, however, does not imply that find no. 2.02 was part of a figurine.

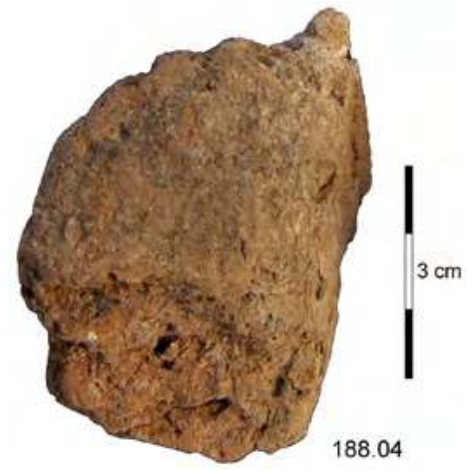

Figure 59. Unfired clay 'tripod', Minaean, reg. no. 188.04. (G. Di Rosa and S. Iavarone 2007 @ MAIRY, adapted and optimized by F.G. Fedele 2019)

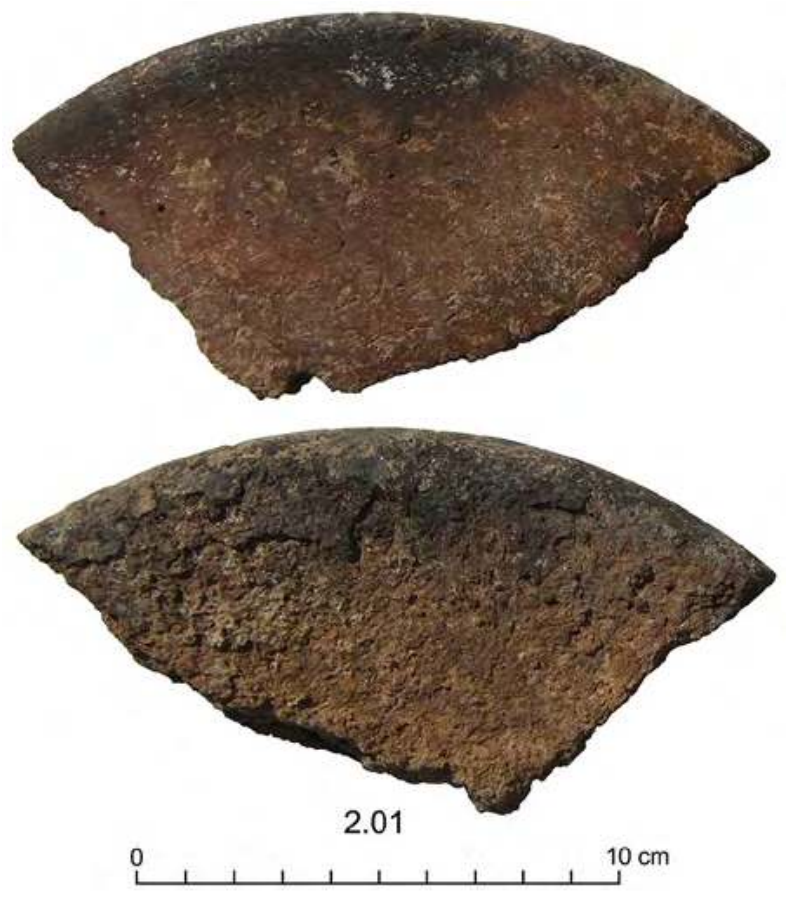

Figure 60. Large, unfired clay disc, Minaean, reg. no. 2.01. (G. Di Rosa and S. Iavarone 2007 C MAIRY, arranged and optimized by F.G. Fedele 2019)

Unfired or poorly fired clay artefacts: discs and/or 'tripods'

Concerning clay discs and 'tripods', only 'tripod' foot fragment or fragments 188.04 can reliably be attributed to the Minaean period. For other possible Minaeanage artefacts in the disc-'tripod' category the reader is referred to the following finds in the "Uncertain chronology' group below: nos 51.04, 70.01, 87.3, and 120.01. About the reworked Sabaean component among the discs and/or 'tripods' see the information given 
in the introduction to this material category in the Sabaean group, above.

4.01. Fr. of a thin clay disc. |D1-D2. Upper unit BR2 and AH1. Stratum I - but, probably, a reworked Sabaean element. | Details unavailable. This find was part of redeposited debris dominated by worn Sabaean sherds (cut 4), hence its likely original age is Sabaean.

188.04 (Fig. 59). Foot fr. (or frs?) of a clay 'tripod'. | A1A31. Units T7LP , SRI, and T7P. Stratum I. | The fragment pictured is cylindrical. The notes from the photography sessions record multiple fragments, but details are unavailable.

2.01 (Fig. 60). Large fr. of a clay disc. Max. length of fr. $15 \mathrm{~cm}$. | D1. Unit GV1. Stratum H. | This find might either be a reworked and redeposited Sabaean element, considering its edge wear (grade 3), or a stratitaxic element. ${ }^{167}$ This latter interpretation depends on some manufacture attributes (more careful shaping, possible slight firing, general good condition in spite of edge wear) that could situate this object outside the standard Sabaean production documented in Area C, and therefore mark it out as non-Sabaean in age (i.e., First Intermediate or Minaean). See also find no. 2.03, below, and for context find 2.02, 'Clay figurines and other clay finds', above.

2.03. Foot of clay 'tripod'. | D1. Unit GV1. Stratum H. | This object is in a fairly good condition despite its unfired paste. Like no. 2.01 above, it could just as well be a stratitaxic Minaean product, or a reworked and redeposited Sabaean element.

\section{Mud bricks}

Context and stratigraphic details for the finds listed below can be found in Chapter 17, section 10.3, this volume. Fragments of brown and light brown mud bricks reworked within units T77 (component F10 of Earthwork F10-F12) and T7LP ${ }_{2}$ can also be mentioned; two decimetre-sized pieces were associated with surface S8. ${ }^{168}$

192 (unnumbered). Frs from at least three mud bricks. Brick thickness $8 \pm 1 \mathrm{~cm}$. | A1-A11. A sample of mud bricks belonging to structure F11M (component F11

167 See mention of disc 2.01 in the introduction to this same material category in section 2.1, above (Sabaean group), and a discussion of its possible redeposition vs stratitaxy in Chapter 17, end of section 7.7, this volume. The issue of heterogeneity for some contents of cut 2 was treated in conjunction with radiocarbon sample \#2.1 in Chapter 18 , section 1.2 , this volume.

168 Comparisons with the Sabaean mud bricks were noted in section 2.1 above, this same material category. For instructive parallels with brick-making in mud and clay in Mesopotamia see Moorey 1991, 302309; in Egypt, Kemp 2000, 79-88, and cf. Ayyad et al. 1991. of Earthwork F10-F12). Stratum J. | The Minaean mud bricks employed in F11M are squat, apparently oblong parallelepipeds, ${ }^{169}$ generally made in a dark, fine-sandy to silty fabric, brown to hazel-yellow in colour. In the present sample the fabric is markedly micro-porous (pore $\varnothing$ less than $1 \mathrm{~mm}$ ) and essentially inorganic. Compare, for differences, with the Sabaean mud bricks described in section 2.1 above ('Mud bricks and cf. mud bricks', Sabaean group).

191.2 (Fig. 61). Mudbrick (incomplete). Size of preserved fr. $26.8 \times 18.2 \times 7-8 \mathrm{~cm}$. | A11 centre, horizontal, in situ; see Chapter 17, section 10.3 and Figs 92 (plan) and 101 (profile of feature), this volume. An element of structure F11M (component F11 of Earthwork F10-F12), detached from the structure's body but still lying in contact with its surface. Stratum J. | This relatively well-preserved mud brick further exemplifies the masonry employed in F11M. Same shape and size as described for finds no. 192, above, but in the case of 191.2 the fabric is partly organic, containing quite a bit of chopped straw as a binder, apparently distributed in patches.

\section{Plaster jar sealings}

A large number of plaster fragments from jar sealings, many of them stamped, were recovered from the later Minaean layers in Sounding A (Figs 62-63). Context details are given in Chapter 17, section 11, this volume. All were recovered by sifting, and as they were completely unexpected their discovery caused a genuine surprise. Upon discovery in 2006 they were immediately called by the workers, in Yemeni Arabic, guș (gypsum). These so-called cretulae or bullae ${ }^{170}$ represent one of the significant contributions not only from this sounding but from Area $\mathrm{C}$ in general.

The inscribed pieces are examined epigraphically by A. Agostini in Chapter 24. Here they are simply described for supplementary information about the object itself, and for reporting their correspondence with the excavation numbering, hence context. In the present chapter we particularly focus on the non-inscribed or non readable finds from Sounding A. Additional finds, which expand the distribution of plaster jar sealings from Area C not only in space but also possibly in time (nos 81X.1-2, Minaean; 72.01 and 210.02-03, Minaean

\footnotetext{
169 Here a solid with six rectangular faces.

170 Bulla, plural bullae, was preferred by de Maigret (1991b; 2016, 255); cretula, pl. cretulae, is perhaps more common. On the jar sealing practices in Yemen see Buffa 2016a, 328-331. As summarized by Antonini $(2016 c, 453)$, 'jars used for transportation [...] were closed with stone or terracotta stoppers and then sealed with liquid plaster and stamped. Fragments of plaster with the impression of seals are frequently found in the excavations'. A sample of lithic jar stoppers and related raw material from Yathill is described in the present catalogue under 'Chipped stone: heavy duty' in the Uncertain chronology group (below).
} 


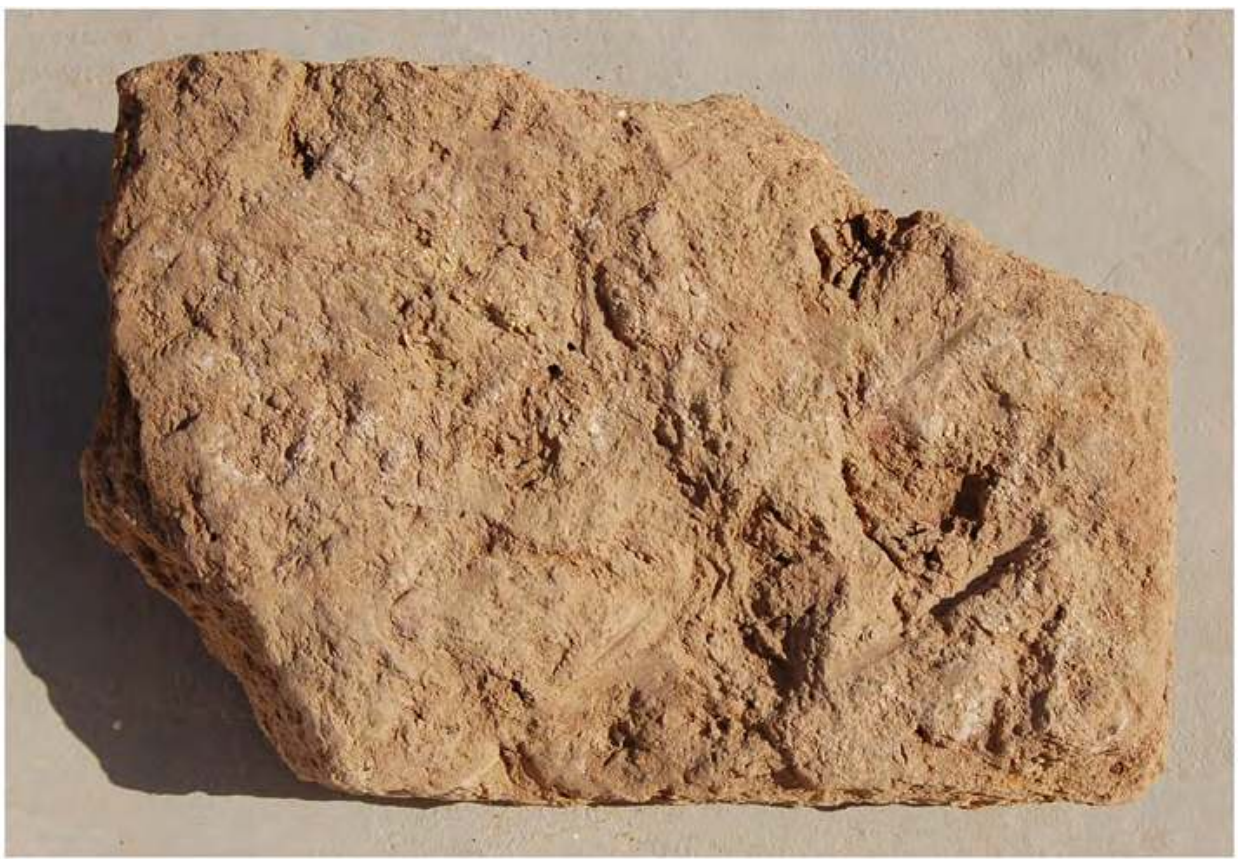

191.2
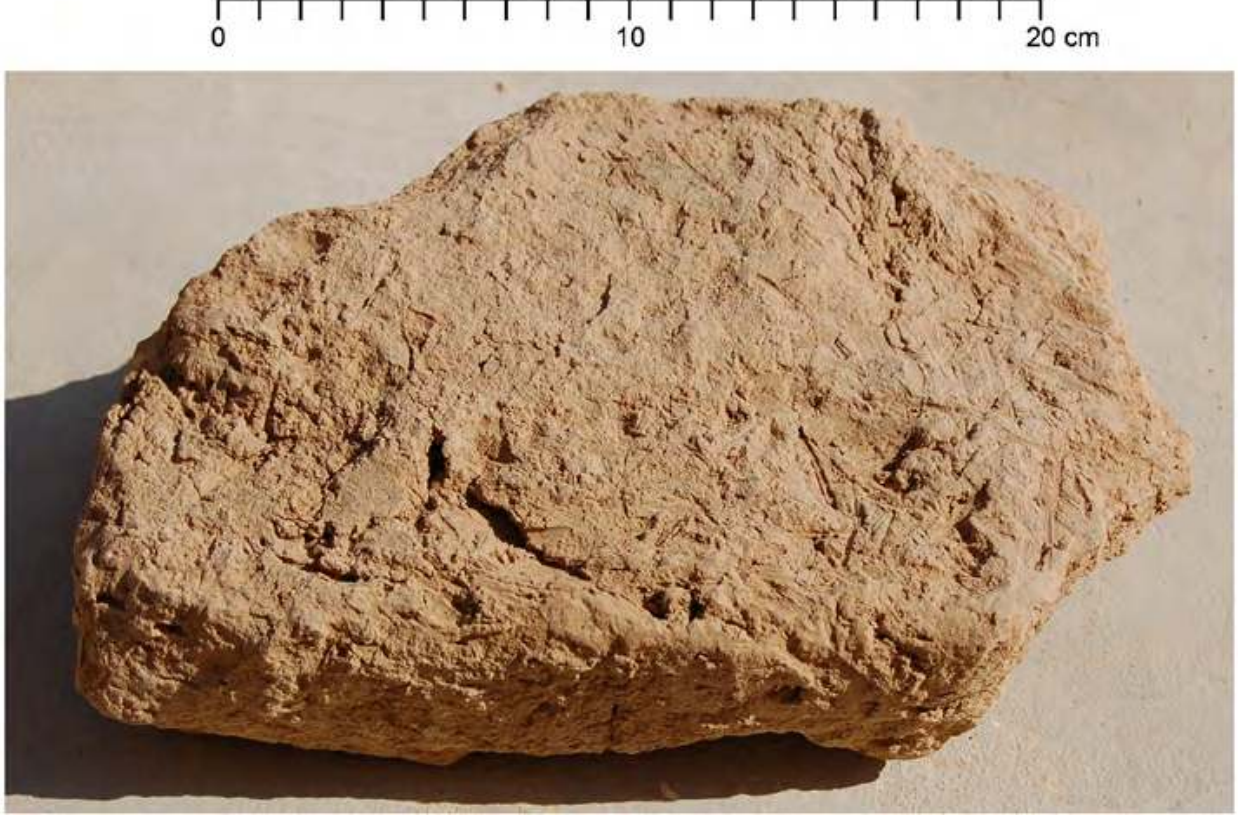

Figure 61. Mud brick, Minaean, reg. no. 191.2. (P. Morlupi 2006 (C MAIRY, arranged and optimized by F.G. Fedele 2019)

or Sabaean), will be described in the appropriate chronological groups below.

The plaster jar sealings recovered in stratigraphic and functional context from Sounding A represent the best such record from Barāqish, ${ }^{171}$ but similar fragments were also found in extramural Area D and in the excavations of Temple A. This latter, a single stamped fragment from the 'sacristy' of the temple, was the only

171 Antonini 2010b, 26. previous find from the tell itself. ${ }^{172}$ Five fragments of plaster sealings were retrieved from the topmost level of the Area D cemetery (Level 1, 'Late Minaean'). ${ }^{173}$ The cemetery also produced an additional find of direct relevance to the practice of sealing trade jars, and a unique find for Barāqish: a fragment of a bronze stamp

\footnotetext{
172 de Maigret 1991b, fig. 7/c ; Costa 1991, 43, fig. 10; mentioned in Antonini 1999, note 7. See also Antonini and Fedele, Chapter 1 in Volume 1, note 103.

173 Antonini 2010b, 26-27, pl. 39/a-b.
} 

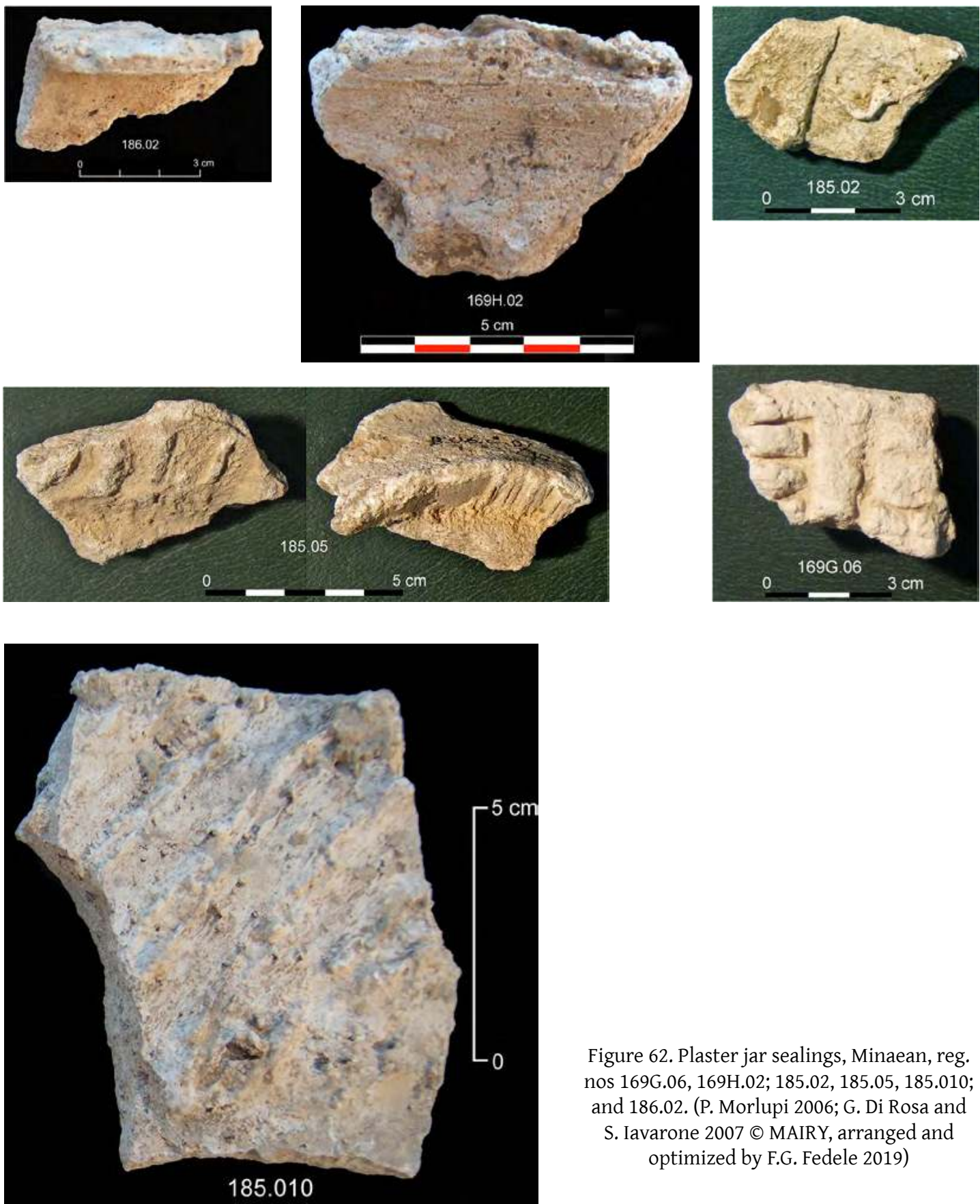

Figure 62. Plaster jar sealings, Minaean, reg. nos 169G.06, 169H.02; 185.02, 185.05, 185.010; and 186.02. (P. Morlupi 2006; G. Di Rosa and S. Iavarone 2007 @ MAIRY, arranged and optimized by F.G. Fedele 2019)

seal à jour, with the owner's name inscribed within a rectangular frame. ${ }^{174}$ Comparisons for plaster jar sealings from outside the Jawf include the recently published material from Tamnac ${ }^{\text {c. }}{ }^{\text {in }}$

The Yemenitradition ofjarsealing(Qatabānian,Sabaean, and Minaean) can be contrasted with the tradition or

\footnotetext{
174 Antonini 2010b, 26, pl. 37/c/e. Also this find came from Level 1 of the site.

175 de Maigret 2016, 255; Antonini 2016a, finds nos 55-57, 99; Antonini 2016b, finds nos 140, 141, 148; Antonini 2016c, 453, pl. VI, fig. 15.
}

traditions of Mesopotamia and the adjoining regions, for instance, where clay - instead of plaster - was employed. Furthermore, in Mesopotamia clay sealings were used to secure a much broader range of containers and even doors. The impressions were commonly made with roll seals, whereas in Yemen stamp seals were the rule. In spite of these differences, a knowledge of the excellent and well studied Mesopotamian evidence is instructive for an archaeological understanding of the Arabian sealing practices and the record from Yemen 
particularly ${ }_{1}^{176}$ in addition to a wider perspective on this multifaceted component of culture. Some suggestions towards the goal of achieving a deeper understanding of the role of jar sealing in Yemen, based on a tradesystem approach, are advanced in Chapter 19 , section 3 , this volume.

186.02 (Fig. 62). Fr. of a plaster jar sealing. Length of fr. $6.5 \mathrm{~cm}$. | A1-A11. Units T76J (mostly T76J) and TPVi. Stratum $\mathrm{H}$.

169H.02 (Fig. 62). Fr. of a plaster jar sealing. Max. length of fr. $7.1 \mathrm{~cm} . \mid$ A31. Units T76J (mostly T76 ${ }_{1}$ ) and TPVi. Stratum H. | Marginal portion of a thick sealing. The photograph shows the negative of the jar's mouth on its reverse.

185.02 = B.06.C.O/6 (Fig. 62). Fr. of a plaster jar sealing. $5 \times 3.5 \times 1 \mathrm{~cm}$. $\mid$ A1-A11, in situ. Units SR-T76H, TPV. Later Stratum $\mathrm{H}$. | Small and damaged fragment bearing on the obverse an unreadable, partial impression. Still visible is the smooth band that usually separates two impressions. The reverse shows the smooth oblique profile left by the impression of the jar's inner lip.

$185.03=$ B.06.C.O/7 (Chapter 24, this volume, Fig. 6). Fr. of a plaster jar sealing. $5 \times 4 \times 2 \mathrm{~cm}$. $\mid$ A1-A11, in situ: provenance and stratigraphy as for no. 185.02. Later Stratum H. | The fragment shows on the obverse two deep and narrow impressions, both incomplete. The reverse shows a flat oblique profile. The stopper must have been rather thick, as suggested by the depth of the impression on the lower face. For the inscription and related comments see Chapter 24 (Agostini).

$[\mathrm{SA}, \mathrm{FGF}]$

$185.04=$ B.06.C.O/8+9 (Chapter 24, this volume, Fig. 7). Fr. of a plaster jar sealing. $10 \times 6 \mathrm{~cm}$. A1-A11, in situ: provenance and stratigraphy as for no. 185.02. Later Stratum $\mathbf{H}$. | The fragment shows on the obverse two incomplete seal impressions inside a frame, separated by a plain band $2 \mathrm{~cm}$ wide. On the reverse, the part that was in contact with the jar's lip has a regular oblique profile, while the part in contact with the stone stopper is irregular. For the inscription and related comments see Chapter 24 (Agostini).

\section{$[\mathrm{SA}]$}

$185.05=$ B.06.C.0/10 (Fig. 62). Fr. of a plaster jar sealing. $6 \times 3.5 \mathrm{~cm}$, central part $1 \mathrm{~cm}$ thick. $\mid$ A1-A11,

176 For the Upper Mesopotamian region see, e.g., Matthews 2003b, 111-113, figs 5.77, 5.80, 5.82; McDonald 2003, 212-217 (on jars, p. 215 and figs 6.69/1-2); with references. in situ: provenance and stratigraphy as for no. 185.02. Later Stratum H. | The fragment bears on the obverse a shallow, abraded, unreadable seal impression. On the reverse, the profile that was in contact with the jar's inner lip is oblique and slightly flared. The stopper was $1.5 \mathrm{~cm}$ thick.

\section{[SA]}

185.06 = B.06.C.O/11 (Chapter 24, this volume, Fig. 8). Fr. of a plaster jar sealing. $9 \times 3.5 \times 2 \mathrm{~cm}$. $\mid$ A1-A11, in situ: provenance and stratigraphy as for no. 185.02. Later Stratum H. | Fragment with two partial seal impressions on the obverse, partly readable. For the inscription and related comments see Chapter 24 (Agostini).

\section{$[\mathrm{SA}]$}

185.07 = B.06.C.O/12 (Chapter 24, this volume, Fig. 9). Fr. of a plaster jar sealing. $5 \times 4.5 \times 1 \mathrm{~cm}$. $\mid$ A1-A11, in situ: provenance and stratigraphy as for no. 185.02. Later Stratum H. | Small fragment with the impression of the symbol of god Nakrah on the obverse. The reverse shows two clear, straight, spaced out impressions that seem to suggest a jar stopper formed of two pieces of stone or pottery. For the inscription and related comments see Chapter 24 (Agostini).

\section{$[\mathrm{SA}]$}

$185.08=$ B.06.C.O/13 (Chapter 24, this volume, Fig. 10). Fr. of a plaster jar sealing. $9.5 \times 7 \times 1 \mathrm{~cm}$. $\mid A 1-A 11$, in situ: provenance and stratigraphy as for no. 185.02. Later Stratum H. | A triangular fragment that retains some of the edge and adjacent central part of the sealing. The edge profile of the reverse is oblique, while the central part is square and rather flat and regular. Only a letter of the sealing on the obverse is visible. ${ }^{177}$ For the inscription and related comments see Chapter 24 (Agostini).

[SA]

$185.09=$ B.06.C.O/15 (Chapter 24, this volume, Fig. 11). Fr. of a plaster jar sealing. $10 \times 6 \times 2 \mathrm{~cm}$. $\mid$ A1-A11, in situ: provenance and stratigraphy as for no. 185.02. Later Stratum H. | On the obverse is a framed seal impression difficult to read. The individual impressions were separated by a band $1 \mathrm{~cm}$ wide. On the reverse, the profile is slightly everted towards the lip of the jar, while the part corresponding to the stone stopper is

\footnotetext{
177 At Barāqish, limestone stoppers of lenticular shape appear to be the most common, with frequency and dispersion of finds suggesting that they were produced locally (cf. finds nos 210.1a-1d and 220.1-2 in the Uncertain chronology group, below), whereas at Tamna', for instance, the stoppers were mostly square in shape, having been obtained from small granite tablets or pottery sherds. In principle, jar sealing no. 185.08 could derive from the reuse - at Barāqish - of a stopper of foreign origin. [FGF]
} 


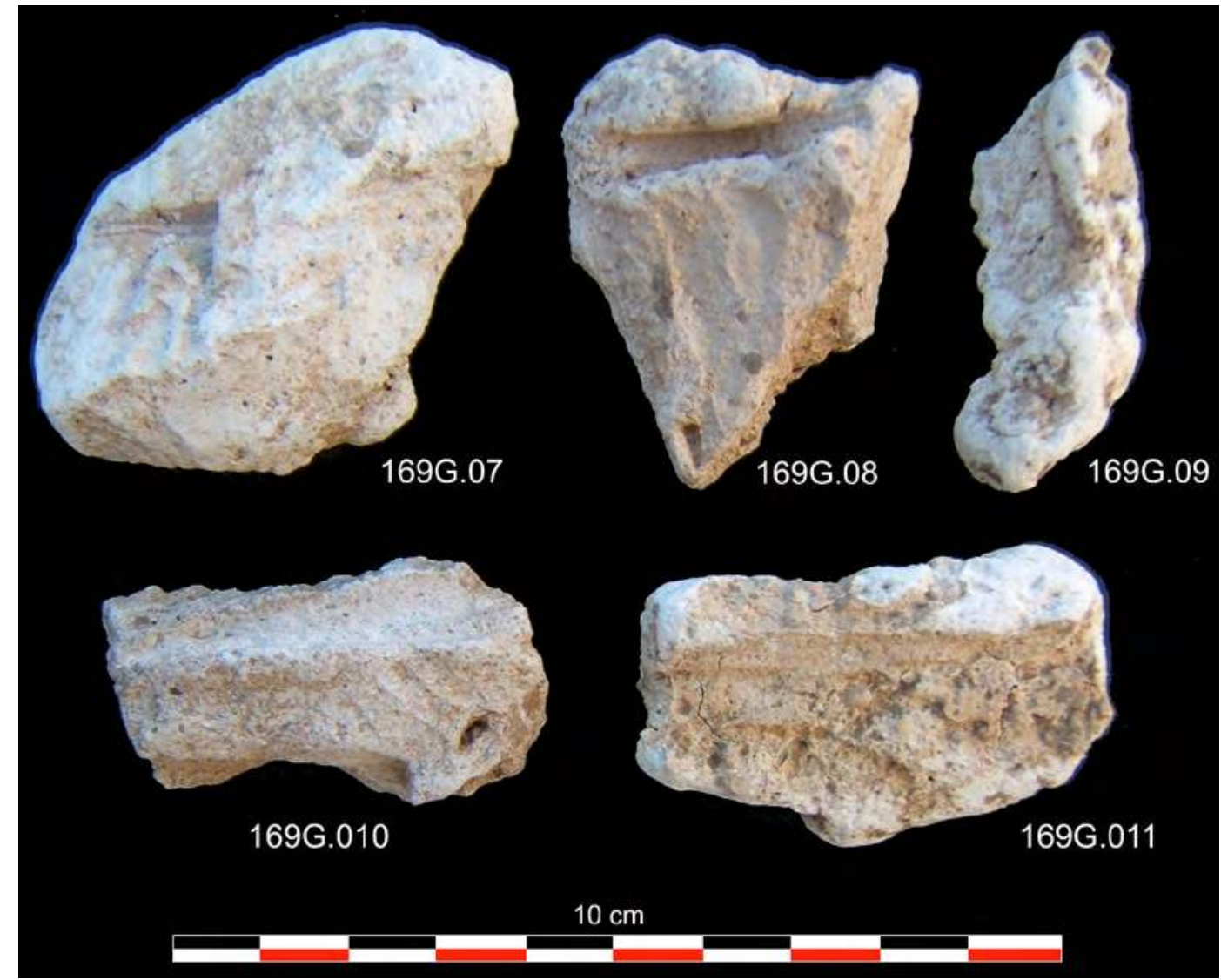

Figure 63. Plaster jar sealings, Minaean, reg. no. 169G.07-011. (G. Di Rosa and S. Iavarone 2007 C MAIRY, arranged and optimized by F.G. Fedele 2019)
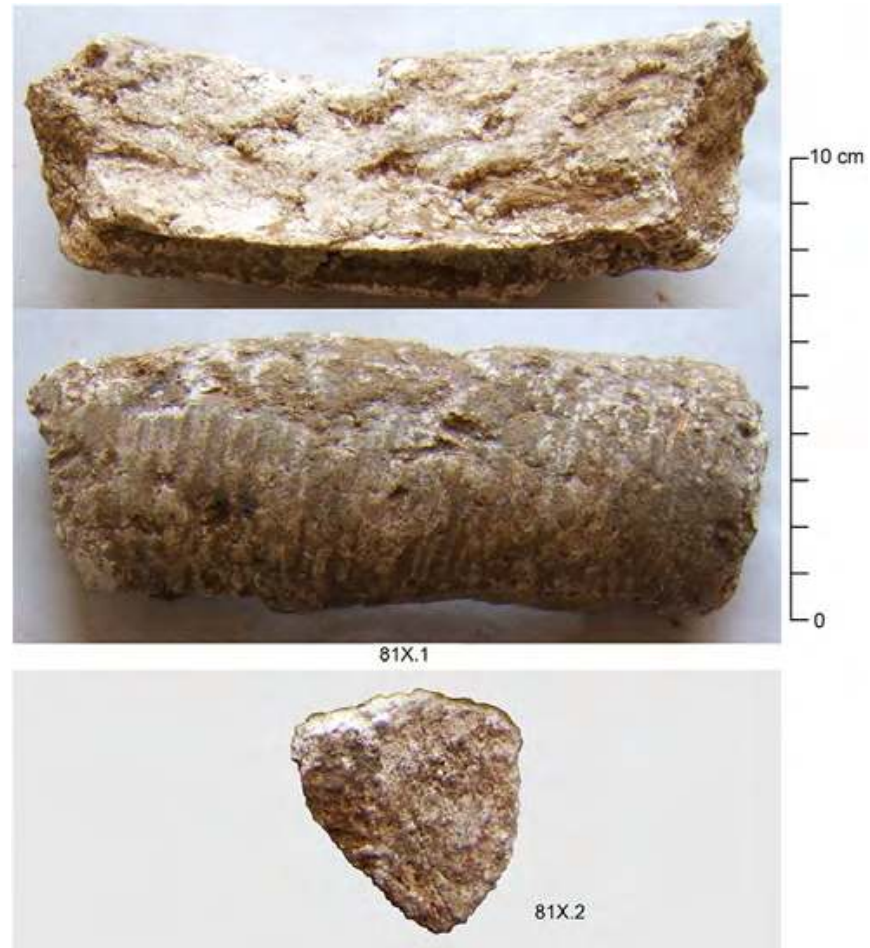

Figure 64. Plaster jar sealings, Minaean, reg. nos 81X.1-2.

(G. Di Rosa and S. Iavarone 2007 @ MAIRY, arranged and optimized by F.G. Fedele 2019)

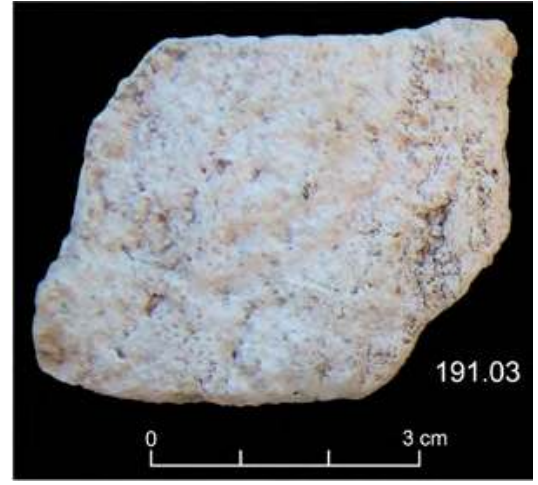

Figure 65. Gypsum/plaster, Minaean, reg. no. 191.03. (G. Di Rosa and S. Iavarone 2007 @ MAIRY, adapted and optimized by F.G. Fedele 2019) 
flat and regular. The presence of a seam indicates that the plaster had been added to a prior paste mixture. For the inscription and related comments see Chapter 24 (Agostini).

[SA, FGF]

185.010 (Fig. 62). Fr. of a plaster jar sealing. $12.2 \times 7.7 \mathrm{~cm}$, average thickness $1.3 \mathrm{~cm}$. | A1-A11, in situ: provenance and stratigraphy as for no. 185.02. Later Stratum H. | A large, strangely flat fragment, with a corrugated surface opposed to a generally even surface. Further details are unavailable.

169G-185 = B.06.C.O/2+3+14 (Chapter 24, this volume, Fig. 3). Almost complete plaster jar sealing. Max. $\varnothing 14$ $\mathrm{cm}$, thickness $0.8-2 \mathrm{~cm}$. | Conjoint of fr. 185.01 from A1-A11 and frs 169G.01 from A31. Units SR-T76H, TPV. Later Stratum H. | This circular cretula sealed a jar whose mouth had an everted rim. The obverse bears three impressions of the same seal (a fourth is missing), showing an inscription enclosed in a rectangular frame $5 \times 3.5 \mathrm{~cm}$. A bronze stamp seal was almost certainly used (cf. introduction, footnote 174). A straight groove, $5 \mathrm{~cm}$ long and $0.5 \mathrm{~cm}$ deep, can be seen close to two of the impressions. The background surface is porous and shows oblique traces from the brushing of the liquid plaster. The lower face reproduces the smooth, everted rim profile of the jar's inner lip, while its uneven central part would have contained - or have been in contact with - the lenticular stopper, generally made of chipped stone. For the inscription and related comments see Chapter 24 (Agostini).

Publications: Fedele 2010, fig. 144/G; Fedele 2011a, fig 10/g.

[SA, FGF]

169G.04 = B.06.C.O/4 (Chapter 24, this volume, Fig. 4). Fr. of a plaster jar sealing. $7.4 \times 4.4 \times 3.5 \mathrm{~cm}$. $\mid$ A31: provenance and stratigraphy as for no. $169 \mathrm{G}-185$. Later Stratum H. | Part of an ovoid cretula originally coating a lenticular stone stopper. For the inscription and related comments see Chapter 24 (Agostini).

169G.05 = B.06.C.O/5 (Chapter 24, this volume, Fig. 5). Fr. of a plaster jar sealing. Max. size of fr. $6 \times 7 \mathrm{~cm}$. $\mid$ A31: provenance and stratigraphy as for no. 169G-185. Later Stratum H. | A near-triangular fragment. Its obverse bears two impressions separated by a $1-\mathrm{cm}$-wide plain band, each impression showing a stamped letter within a frame. The reverse shows the oblique outline of the vessel's rim. For the inscription and related comments see Chapter 24 (Agostini).

$[\mathrm{SA}, \mathrm{FGF}]$
$169 \mathrm{G} .06=$ B.06.C.O/1 (Fig. 62). Fr. of a plaster jar sealing. $4.5 \times 3.5 \times 2.5 \mathrm{~cm}$. | A31: provenance and stratigraphy as for no. 169G-185. Later Stratum H. | A near-rectangular fragment. Its obverse bears parts of two impressions separated by a $1-\mathrm{cm}$-wide band. The reverse profile in contact with the inside surface of the vessel's rim is oblique.

\section{$[\mathrm{SA}, \mathrm{FGF}]$}

169G.07, 169G.08, 169G.09, 169G.010, 169G.011 (Fig. 63). Five frs of plaster jar sealings. Range of max. length of fr. 5.0-6.7 cm. | A31: provenance and stratigraphy as for no. 169G-185. Later Stratum H. | Not bearing impressions.

169F.01. Fr. of a plaster jar sealing. | A31. Probably from the contact between suite T76 and units T75-T75B. Strata H/F interface. | Details unavailable. Collected during the exposure of the base of unit T75B (cf. plan of unit in Chapter 17, Fig. 104, this volume).

81X.1, 81X.2 (Fig. 64). Two frs of jar sealings. Max. length of fr. $16.1 \mathrm{~cm}$ (81X.1) and $5.6 \mathrm{~cm}$ (81X.2). | E8.

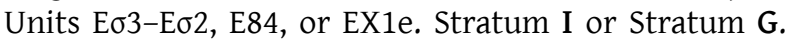
| Minaean 2 to Minaean 4 material, cf. softstone pot no. 81.01 (above). The fragments do not bear seal impressions.

Plaster or gypsum: other artefacts

191.03 (Fig. 65). Fr. of gypsum or plaster. Max. length 6.4 $\mathrm{cm}$. A1-A31. Units T77 $\mu$ (component F10 of Earthwork F10-F12) and parts of F11M, T78 $\pi$ (component F11). Stratum J. | Judging from field context as well as its own attributes (quality of material and shape), this fragment seems different from the jar sealings of the Later Minaean, described above. A relationship with building activity seems more likely, for instance as a residue of 'facing plaster' sensu Glanzman ${ }^{178}$ or of lime plaster combined with gypsum, this latter predominant. ${ }^{179}$

\section{Bronze/copper and iron}

195.01. Small bronze element. | A1-A31, probably from A31. From near bottom of unit T79J, or including part of Pj (component F12 of Earthwork F10-F12). Stratum J. | Details unavailable.

Mentioned in Fedele 2010, 132.

\footnotetext{
178 Glanzman 1987d, 157. Surface use as opposed to mortaring masonry.

179 Cf. the practices in Mesopotamia: Moorey 1994, 329-331. On p. 331 Moorey notes the difficulty of separating gypsum from lime plaster by eye.
} 
191.05 (Fig. 66). An iron object (a nail?). Length $6.4 \mathrm{~cm}$, $\max . \varnothing$ (rust) $1.5 \mathrm{~cm}$. $\mid A 1-A 31$. Unit T77 $\mu$ (component F10 of Earthwork F10-F12) and parts of F11M and T78 $\pi$ (component F11). Stratum J. | A weathered (rusted) rod covered with small, sparse patches of calcium carbonate crust. Found in apparent association with decomposed wood and melted mudbrick.

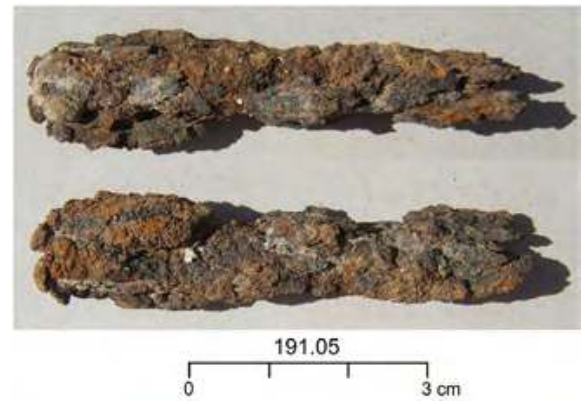

Figure 66. Iron, Minaean, reg. no. 191.05. (G. Di Rosa and S. Iavarone 2007 @ MAIRY, arranged and optimized by F.G. Fedele 2019)

169K.02 (Fig. 67). A copper spherule. $\varnothing 1.95 \times 1.7 \times 1.6$ cm. | A31. Units T7L-T7P0, b0, T76J ${ }_{2}$ TPVj. Strata I-H (later I, earlier $\mathrm{H})$. | An element of rather more regular geometry than the normal slag globule (such as Sabaean find no. 215.2, for instance): a finished object?

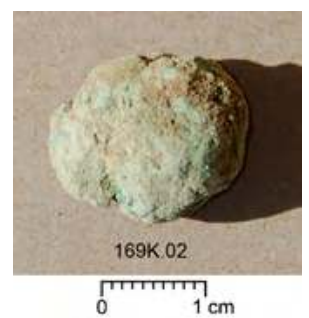

Figure 67. Bronze/copper, Minaean, reg. no. 169K.02. (P. Morlupi 2006 @ MAIRY, adapted and optimized by F.G. Fedele 2019)

Glass

184.01. Fr. of a glass armlet. |A2. Unit T75, immediately above the slabs (T7B) of structure F8. Stratum F. | Details unavailable.

\section{Artefacts made from organic materials}

194A.01. Fr. of a bone or ivory ring. | A31. Units $\mathrm{Pj}$ (part) and T79L (component F12 of Earthwork F10-F12). Stratum J - but, possibly, a reworked Sabaean element. | Details unavailable.

3.01 (Fig. 68). Frs of a leather shoe. Max. length $5.7 \mathrm{~cm}$. | D1-D2 east. Units BR1-BR1i. Stratum I. | Apparently made of multiple strips of leather.

Mentioned in Fedele 2010, 137.

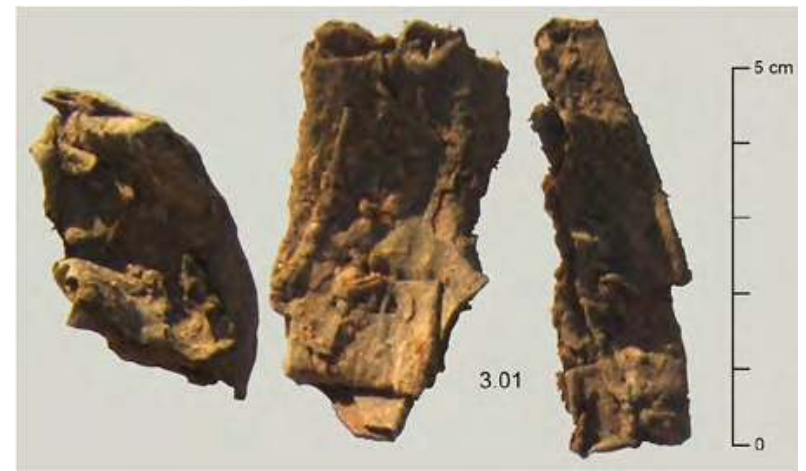

Figure 68. Leather shoe, Minaean, reg. no. 3.01. (G. Di Rosa and S. Iavarone 2007 @ MAIRY, arranged and optimized by F.G. Fedele 2019)
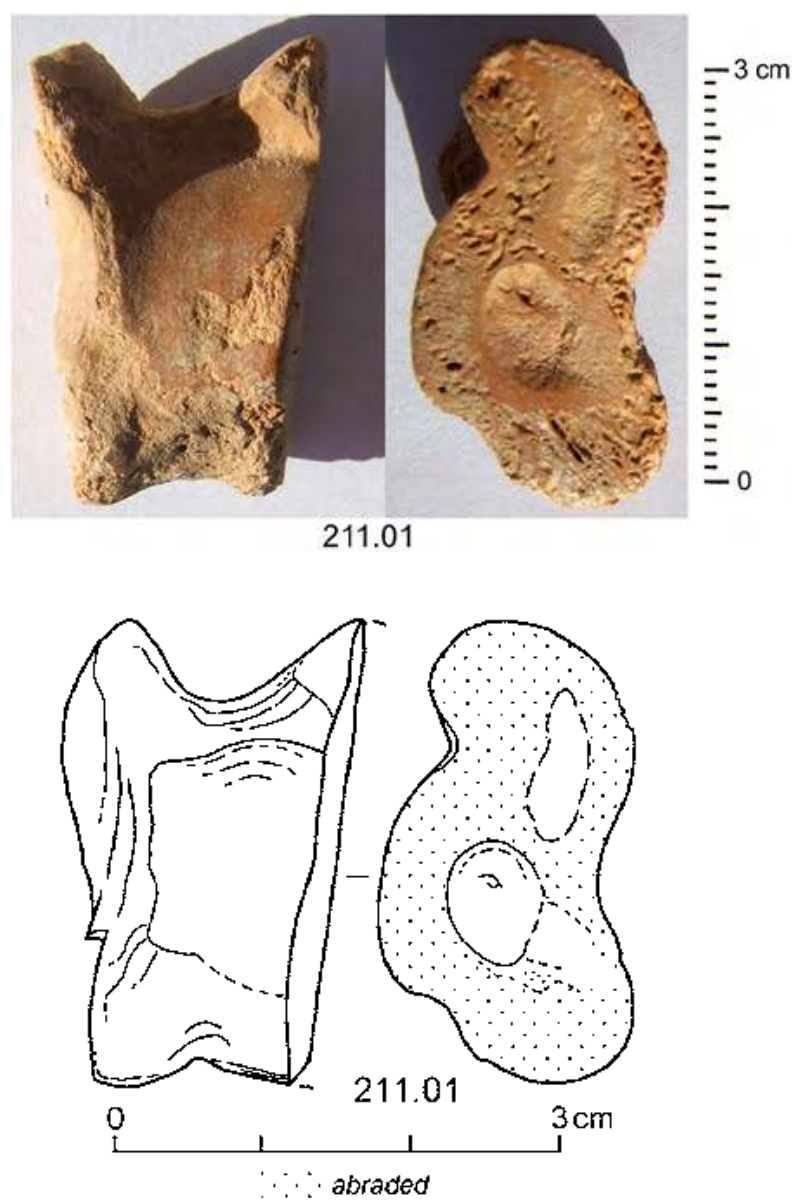

Figure 69. Abraded ibex (?) talus, Minaean, reg. no. 211.01. (G. Di Rosa and S. Iavarone 2007 @ MAIRY, arranged and optimized by F.G. Fedele 2019; drawing F.G. Fedele 2007) 
211.01 (Fig. 69). Abraded ibex (?) talus. Max. length and width (measured as a trapezium) $3.2 \times 2.0 \mathrm{~cm}$, max. thickness $1.65 \mathrm{~cm}$. For morphological measurements and related zoological details see Chapter 19 , section 2.1, this volume. $\mid F$, northwest quadrant. From near bottom of unit F02 ( $\left.\mathrm{FO}_{3}\right)$. Stratum G. | Caprine skeletal element probably from Capra ibex. The lateral surface of the talus was flattened by intentional rubbing and the bone has acquired a trapezoid outline as a consequence. The unabraded parts of the bone surface display a darkorange ('red') pigmentation comparable to that of the wild Camelus humerus from Locus $151,{ }^{180}$ a possible confirmation of wild status for the animal. As an artefact, this talus can be identified as a dice for a game of chance, or as a smoothing or burnishing tool for use in pottery manufacture.

Mentioned as a faunal element in Fedele 2010, 155, table 8; 2014, table 2; 2017, table 20.5 .

\section{Ostrich eggshell}

Ostrich eggshells, usually fragmented, are not uncommon among the grave goods, and not only in ancient Yemen. It is instead unusual to find them in other contexts, such as, particularly, at the Minaean bastions of extramural Area C. Taking into account the recurrence of trade-related activities, as inferred from the deposits in question (of Minaean 2-3 age), one can wonder whether the two small eggshell fragments described below had not to do with the presence of 'travellers'. ${ }^{181}$

169K.01 (Fig. 70). Fr. of ostrich eggshell, Struthio camelus syriacus. $2.3 \times 1.5 \mathrm{~cm}$; thickness fairly uniform, 1.79-1.83 mm. | A31. Units T7L-T7P0, b0, T76J ${ }_{2}$ TPVj. Strata I-H (later I, earlier $\mathbf{H}) . \mid$ Orange and semilustrous on the outside, pale grey-yellow and matt on the inside. For comparison, a thickness of 1.91-1.98 $\mathrm{mm}$ is reported for the African ostrich. ${ }^{182}$

186.01 (Fig. 70). Fr. of ostrich eggshell, Struthio camelus syriacus. $1.95 \times 1.4 \mathrm{~cm}$; thickness fairly uniform, c. 1.81 mm. | A1-A11. Units T76J (mostly T76J ) $_{1}$ and TPVi. Stratum H. | A square fragment, identical to find no. 169K.01 in overall appearance and size.

\footnotetext{
180 In qu. E11: see Chapter 19, sections 2 and 3, this volume.

181 Cf. Chapter 19, sections 2.1 ('Ostrich skeletal remains') and 3.3, this volume.

182 Laufer 1926. This author comments (p. 6): 'The pores are exceedingly fine in ostrich eggs from North Africa and Syria' [hence also Arabia]; 'the egg of the Syrian species is said to be of smaller size and higher polish than the North African one.' For recent information on ostrich eggshells and their attributes see, e.g., Hodos et al. 2020.
}

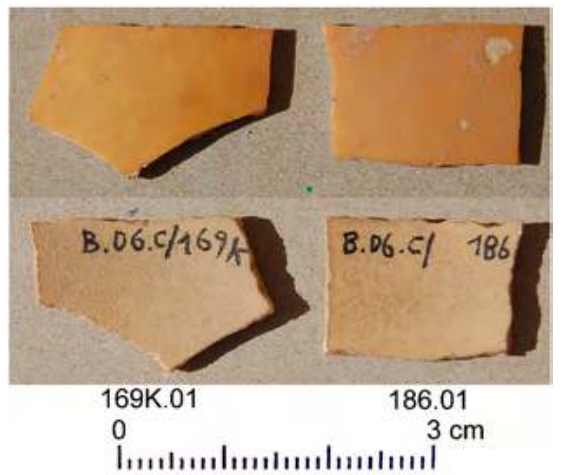

Figure 70. Ostrich eggshells, Minaean, reg. nos 169K.01 and 186.01. (G. Di Rosa and S. Iavarone 2007 (c) MAIRY, arranged and optimized by F.G. Fedele 2019)

\section{Marine shells (probably non-artefactual)}

198.04 (Fig. 40). Probably a calcareous operculum of a small gastropod. $2.1 \times 1.5 \mathrm{~cm}$. | A1-A11 east + A31. Units AR-T7F ${ }_{2}$. Stratum J; possibly a reworked Sabaean element. | This tiny, sub-triangular shell 'pebble' was initially interpreted as a fragment of a thick seashell heavily rounded by wave abrasion, collected from gravels on a beach. However, a reappraisal of the find raises doubts about its being a nondescript fragment and points instead to its resembling a gastropod operculum. If an operculum, its defining attributes for taxonomic determination are necessarily its shape (sub-triangular or semicircular and apparently thin), size (about $2 \mathrm{~cm}$ ), and surface (smooth, dull and plain, as opposed to granulated or ribbed); furthermore, the color is yellow or greyish. Surely the surface aspects can depend to some degree on its being a beached element, and this has to be taken into account. These observations would suggest that no. 198.04 is compatible with opercula of the neritid family, and particularly of Nerita sp. ${ }^{183}$ The face shown in the photograph might just as well be the outer or the inner one; the slight eminence visible on the sub-rectilinear edge could be a remnant of the internal, partly chitinous peg. More laborious attempts at identification may be useless, since information on the opposite surface of the find was not recorded. ${ }^{184}$

183 Dekker 2000, particularly pl. 6; Eichhorst 2016, pl. 5, and individual species. The calcareous operculum characteristic of Neritidae is a semicircular or half-moon shaped disc, smooth on both surfaces, formed of a deposit of calcium carbonate on a chitinous layer, and with the inner face bearing a peg-like projection (Bosch et al. 1995, 43; Dekker 2000, 29). Somewhat outdated but still useful repertoires are Bosch and Bosch 1989, 33-34; Coulombel 1994, 29-31 (for Djibouti); Bosch et al. 1995, 42-44. Possibilities among Nerita are N. quadricolor from the Red Sea, N. longii, and perhaps N. plicata, this latter with an operculum concave outside and thin, but not matching in colour (brown).

184 As an alternative to an operculum, a calcified funnel-locking cartilage of a cuttlefish (Sepioidea) was contemplated, but nothing of the kind was found in the available malacological or zooarchaeological literature. Fish otoliths were reviewed, but discounted. 
As to behavioural and cultural interpretation, why collecting and keeping a natural element which is so anonymous in our eyes? The object does not lend itself to a ready explanation. Some speculative possibilities were suggested in the introduction to 'Marine shells' in section 2.1 (Sabaean group): was this element a pawn used in a game, or a dice or token from a set employed in divination?

184.3 (Fig. 40). Fr. of a bivalve shell from an arcid species, Anadara cf ehrenbergi. Length of fr. $5.5 \mathrm{~cm}$, hinge length $4.6 \mathrm{~cm},{ }^{185}$ estimated shell length $c .6 .5 \mathrm{~cm}$. | A1A12. Unit T75. Stratum F. | Almost complete umbonalcardinal part of a medium-large ark clam shell; the umbo is damaged. The perfectly straight hinge line, the hinge plate in the form of a nearly isosceles triangle (i.e., the beak of the valve in an almost median position, in front of mid-hinge), the ligament with a single chevron (the outer one), and shell size itself, all suggest Anadara. Particular compatibility is apparent with A. ehrenbergi (Dunker, 1868), known from the Red Sea to the Gulf of Aden to Muscat, where it lives as a burrower in sand and mud shallows and is locally common. ${ }^{186}$ The nearest alternative is perhaps A. tuberculosa (G. B. Sowerby I, 1833). ${ }^{187}$ For the record, no. 184.3 represents a different species from shorter-hinged arks such as Anadara broughtonii (Schrenck, 1867), the currently accepted taxon with which Arca inflata Reeve, 1844, has been synonymized. ${ }^{188}$ This we note because a mid-valve fragment identified as 'Arca inflata' was reported from Barāqish Area D. ${ }^{189}$

185 Measurement after Irvy R. Quitmyer, see Claassen 1998, 108, fig.
20.
186 Oliver 1992, 38, pl. 3/5; 1995, 210; also Oliver and Chesney 1994, 186 Oliver 1992,38, pl. $3 / 5 ; 1995,210 ;$ also Oliver and Chesney 1994 ,
$29-30$, pl. $3 / 3-4$, and on the mollusc-habitat relationships the exemplary study by Zuschin and Oliver $(2003,70)$. Morphologically if not in size, the holotype of 'Arca pharaonis' from Suez (MNHN 2019, specimen 2000-3896; reported shell length $8.7 \mathrm{~cm}$ ) provides an excellent match for our find. A. pharaonis P. Fischer, 1871, is an invalid name synonymized with Anadara ehrenbergi (MolluscaBase 2019, AphiaID 537938).

187 According to some specimens only, such as Natuurhistorisch Museum Rotterdam no. 19159 from Hong Kong, shell length $7.3 \mathrm{~cm}$ (MolluscaBase 2019, AphiaID 504313). One shall also take into account that a form considered by some to be a subspecies $-A$. tuberculosa secticostata (Reeve, 1844) - and whose specimens would indeed be compatible with our no. 184.3, was reportedly identified along the coastline of Oman (Bosch and Bosch 1989, 79; reputed as different from A. ehrenbergi, p. 78). But in fact Anadara tuberculosa, as currently accepted, poses problems, since this species has a Pacific distribution and its relationships with A. secticostata - if a valid species and not a subspecies - appear to be controversial (cf. MolluscaBase 2019, AphiaID 504356; Galli 2015, Arcidae, version 7.9.2015). We cannot dwell upon this problem here.

188 See MolluscaBase 2019, AphiaID 504357 (Anadara broughtonii) and 537824 (Arca inflata).

189 Antonini 2010b, 26, pl. 38/c (Level 1 'Late Minaean'). Complete, reliable archaeological specimens of Arca inflata were first described from Hurayda in a now classic study by experienced conchologist Wilfrid Jackson (1944, 104, pl. XLI; from a burial association).
From the cultural viewpoint, it seems very likely that fragment 184.3 is food residue and not an ornament. ${ }^{190}$ This interpretation reflects the fact that most arks are not only edible, but in several parts of the Tropics they are indeed chiefly collected for their meat. An archaeological example of Anadara clams being used as seafood comes from Mersa Gawasis, the Egyptian Middle Kingdom harbour on the Red Sea. ${ }^{191}$ One arcid species 'obviously [collected] for food' has also been reported from the trading port of Khawr Rūrì on the Zufār coast (ancient Sumhuram, 3rd century BCE-5th century CE). ${ }^{192}$ While it is interesting as an indicator of unusual, 'exotic' food, fragment 184.3 is unrelated to local economy (see comments in Chapter 19, section 1, this volume).

\subsection{Second Intermediate (Stratum E and part of Stratum D)}

Querns

170.1 (Fig. 12). Incomplete saddle quern: transverse half-quern. Vesicular basalt. $19 \times 15 \times 8.5 \mathrm{~cm}$. $\mid C$, in situ. From within unit CU6, a leached hearth (F22) probably associated with surface S22. Earlier Stratum E. | This quern, preserved as a half, ${ }^{193}$ is of the same morphology and rock type as no. 152.1 (Later Sabaean): see Sabaean group, above.

\section{Stone tiles}

07 (Fig. 43). Square stone tile. Approx. $15 \times 15 \times 7 \mathrm{~cm}$, drawn and measured on site. |A1-A11 (2005 excavations). Retrieved after discard by workers, reportedly having been found with collapse rubble T7A (cut 165), but a provenance from interstitial sediments of suite T74M (earlier Stratum C) cannot be ruled out. Stratum E (or earlier Stratum C?), but possibly Minaean or reworked Minaean. ${ }^{194}$ A complete stone tile, used for covering floors or walls. ${ }^{195}$ The overall form is a cylindrical segment ('half-barrel'); no artificial pigmentation was recorded. 
Unfired or poorly fired clay artefacts: discs and/or 'tripods'

For possible clay 'tripod' finds dating from the Second Intermediate (Stratum D) see nos 70.01 and 87.3 in the Uncertain chronology group, below.

\section{Artefacts made from organic materials}

176.1 (see Fig. 5 in Chapter 18, this volume). Pointed, slightly burnt wooden stake. Two nearly-joinable frs, minimum total length $30.2 \mathrm{~cm}$. $\mid$ B east, $80 \mathrm{~cm}$ from eastern side of quadrangle and $40 \mathrm{~cm}$ from the Reference section, in situ. Driven vertically into unit BVo from an eroded ground surface probably equivalent to surface S20. Later (?) Stratum E. | This stake or short stick was found snapped in situ - probably by the pressure of stony-blocky sediments T6B - with its pointed part still vertically stuck in the underlying deposits. Its proximal end is flattened as if from battering. ${ }^{196}$

\section{Mentioned in Fedele 2011a, 111; 2014, 191.}

\subsection{Uncertain chronology: unstratified and indetermin- able}

'Unstratified': finds collected from the present-day surface or from mixed recent deposits. 'Indeterminable chronology': a stratified find for which, due to context, no precise or certain attribution to period can be advanced. In each material-typological category the finds will be arranged topographically, Sounding A to Sounding F (i.e. east to west). A few surface finds from Hill C, of comparative interest for Sounding F and the plain, are included.

\section{Stone cultic (?) equipment}

$02=$ B.05.C.O/4. Fr. of an offering table. Biogenic calcarenite. Approx. $10 \times 10 \mathrm{~cm}$, slab thickness $4 \mathrm{~cm}$. | Unstratified, lower Sector E, surface. | This clearly preIslamic slab-like fragment has an incised, slightly raised frame on one of its main faces. Provisional laboratory notes recorded a general resemblance to a find from Temple B (no. B.05.B.0/43); ${ }^{197}$ general parallels are also provided by fragmentary offering tables from the Minaean tombs at Barāqish Area D. ${ }^{198}$

\section{Chipped stone: obsidian, chalcedony}

169C.01. Obsidian flake. Length c. $5 \mathrm{~cm}$. | A31, middle north section, 'behind block P20x' [of T7A]. Top of unit

\footnotetext{
196 For the historical context of find no. 176.1 see, in this volume, Chapter 18, section 3.4 ('From "Yathill" to "Barāqish"'), and for overall stratigraphic context Chapter 17, section 16.1.

197 See Chapter 5 in Volume 1, Fig. 6 (Antonini).

198 Antonini 2010b, 23, 24 (all sandstone); plates 34/e, 35/a-b (from 'Level 3', i.e. the layer of the tombs).
}

T74, 'within beige fine sand'. Stratum C, but probably pre-Islamic. | Typological details unavailable.

01 (Fig. 71). Retouched flake: an awl or borer. Translucent to semi-transparent chalcedony with a waxy lustre, colourless in general appearance but with a faintly differentiated milky-ivory core. Max. width $3.0 \mathrm{~cm}$, axial length $2.1 \mathrm{~cm}$, max. thickness $0.8 \mathrm{~cm} .{ }^{199}$ | Unstratified, collected from the stone-littered talus surface about $2 \mathrm{~m}$ to the north of the angle of trenches $\mathrm{D}$ and $\mathrm{E}$, i.e. north of quadrangle D17, measured parallel to the angle bisector (cf. Chapter 17, Fig. 7, this volume). | A broad, stout flake of pronounced dorsal convexity. Striking platform esquillée and almost reduced to the point of impact, associated with a wide, flat bulb of force. Dorsal surface considerably facetted. The flake was transversely truncated so as to obtain an awl or borer, whose trihedral point was further shaped through steep bilateral retouch, scaly on the right side. Opposite to the truncation, the right-proximal edge of the flake shows mixed, irregular battering. This combination of attributes in the chipped-stone element, in addition to its converging sides, suggest that the element was in all probability hafted as part of a composite tool. The functional axis of the lithic awl or borer makes an angle of $35^{\circ}$ with the percussion axis of the flake. The object is in good condition. It might well be a reworked element - with very limited transport - from the Later Sabaean layers of 'Lobe 5'.

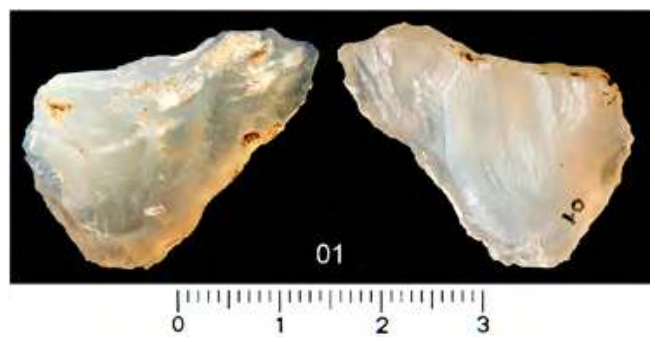

Figure 71. Retouched flake (awl or borer), Uncertain chronology, reg. no. 01. (F.G. Fedele n.d.)

150.01. Small obsidian flake; cm-sized. |E11. Subsurface: recovered by sifting during an initial part of cut 150, hence from units SXY, TGh, or SAE; topmost $\mathrm{E} \sigma \mathrm{W}_{1}$ unlikely. Later Stratum B (unlikely) or Stratum A, but probably pre-Islamic. | Details unavailable.

\section{Chipped stone: heavy duty}

From the functional viewpoint, the objects listed here are closely linked to the plaster jar sealings, described in the category of this title both in the Minaean group (above) and in the present group, below (further five

\footnotetext{
199 Lithic terminology essentially follows Andrefsky 2005. Axial length in find no. 01 is equivalent to Andrefsky's 'maximum flake length' (fig. 5.8/c); 'axial' - not Andrefsky's term - refers to the
} percussion or 'technological' axis bisecting the bulb of force. 
specimens). Several objects are stone stoppers for trade jars, a further item is an example of raw material for the manufacture of stoppers. Similar raw material is represented in all probability by the Minaean findings described in section 2.3 under 'Chipped stone: heavy duty' (nos 185, 184) and 'Other utilized natural stones' (no. 169F.1); cf. find no. 220.3, below.

At Barāqish, limestone stoppers of lenticular shape appear to be the most common, as one can infer from an inspection of surface finds in the plain to the west; the combination of frequency and dispersion of specimens, and rock type, further suggests that they were produced locally. ${ }^{200}$ The rock of choice is a compact, nicely fracturing cryptocrystalline limestone, usually grey in colour, which in all probability can be obtained from wādī beds a short distance away. ${ }^{201}$

210.1a, 210.1b, 210.1c, 210.1d. Four stone jar stoppers. Limestone. Average $\varnothing 10-15 \mathrm{~cm}$. |F. Surface $(\Lambda \mathrm{F})$, collected within a $2 \mathrm{~m}$ radius from the sounding. Stratum A, but reworked Minaean or Sabaean. |Discoid/ lenticular jar stoppers, cf. nos 220.1-2 below.

220.1, 220.2 (Fig. 72). Two jar stoppers. White, faintly pink limestone. Average $\varnothing 12 \mathrm{~cm}$. | Hill C. 'Minaean material from surface' collected on 3 December 2007 as a reference for finds from Sounding $\mathrm{F}$; it might just as well be Sabaean (see Fedele, Chapter 26, this volume). | Good examples of discoid, chipped jar stoppers such as those which occur as surface material in the area of Sounding F, where they are exposed through the deflation or erosion of Later Minaean deposits. Such discoid stone stoppers seem to be common at trading centres across Yemen. ${ }^{202}$

Publication: Fedele 2010, fig. 144/G (left); 2011a, fig. 10/b (right).

220.3 (Fig. 72). Split and chipped cobble. Dark grey cryptocrystalline limestone. Surface of cleavage $15.5 \times$ c. $8 \mathrm{~cm}$, max. height $8.8 \mathrm{~cm}$. | Hill C. 'Minaean material from surface' (it might in fact be Sabaean; see Fedele, Chapter 26, this volume). Provenance and collection date as for nos 220.1-2. | An example of lithic raw material for making jar stoppers. A large number of similar cobbles, all limestone and representing all stages of processing, were recorded from levels of Strata $\mathrm{H}$ and $\mathrm{F}$ in Sounding $\mathrm{A}$, as mentioned in the above introduction to this category (see Chapter 17, sections 11.2-11.4, this volume). Such manuports not only characterize those levels, but contribute to their

\footnotetext{
200 Already briefly stated in section 2.3 above, footnote 177 .

201 This can be surmised from regional geology (cf. Kruck et al. 1996); regrettably, no field survey could be made.

202 E.g. at Tamna' (Buffa 2016a, 328-331, fig. 6; Antonini 2016c, 453, pl. VI, fig. 14).
}

interpretation as extramural locations associated with trade jar handling and possibly sealing (cf. Chapter 19, section 3 , this volume).

Publication: Fedele 2011a, fig. 10/b (left).

Stone burners and offering saucers

80.1 = B.05.C.O/3 (Fig. 73). Incomplete square burner. White to cream-pink limestone. ${ }^{203} 15 \times 17 \times 6.3 \mathrm{~cm}$, average wall thickness c. $2 \mathrm{~cm}$. E8. Units Eб2 to surface. Strata $\mathbf{G}$ to $\mathbf{A}$ indeterminable (Stratum B?), but typologically the object is probably pre-Islamic. Given its battered condition, a provenance from suite F2F3 is possible (cf. no. 80.2). | This piece is summarily made and shows minimal ornamentation. It is a shallow, uninscribed, and mostly plain quadrangular box with a flat rim, a slightly concave bottom, and a flat base. The outer surface of one of the sides is decorated with a coarse zigzag motif. ${ }^{204}$ There is general resemblance between this find and a plain specimen from Area D. ${ }^{205}$

Publication: Fedele 2011a, 115 (indirectly mentioned), fig. 10/c1.

\section{[SA, FGF]}

06 = B.06.C.O/17. Incomplete foot of a burner or offering saucer. Sandstone or calcarenite. Height $13 \mathrm{~cm}$, max. $\varnothing$ $9.5 \mathrm{~cm}$ at the top and $5.5 \mathrm{~cm}$ at the base. $\mid E 8$, west section, c. $20 \mathrm{~cm}$ below surface, retrieved on 26 December 2006 and kept separate from cut 80. From 'recent' yellow sand (EOb?). Stratum A, but the object is typologically pre-Islamic (Minaean?). | An overall cylindrical foot, slightly conical towards the base, where a kind of ring might have framed a bull's hoof (lost). The fragment appears to derive from a single-footed burner, but its origin from a footed offering saucer ${ }^{206}-a$ fairly large one in this case - cannot be excluded. The main fracture corresponds to the contact with the receptacle (if a burner) or the hollowed-out top.

\section{$[\mathrm{FGF}, \mathrm{SA}]$}

\section{Softstone vessels}

169D.01. Fr. of a softstone vessel. Chloritite; $\mathrm{cm}$-sized. | A31. $\mathrm{T} 74 \sigma$, matrix of blocks $\mathrm{T} 7 \mathrm{~A}$; or $\mathrm{T}_{\mathrm{N}} \mathrm{E}$ ? Stratum C (or

\footnotetext{
203 About the choice of rock type see no. 5.1a in the Sabaean group, above (footnote 62).

204 As discussed in the introduction to 'Stone burners and containers' in section 2.1, plain or nearly plain square burners of this kind could alternatively - or even likely - be interpreted as lamps. [FGF]

205 Antonini 2010b, pl. 37/b.

206 Offering saucers sensu Phillips and Simpson (2018c,173-174); cf. autels à offrande (Breton and Bațayā' 1992, 376-377), 'stands emulating incense burners' (de Maigret 2016, 234). See the introduction to 'Stone burners and containers' in section 2.1.
} 


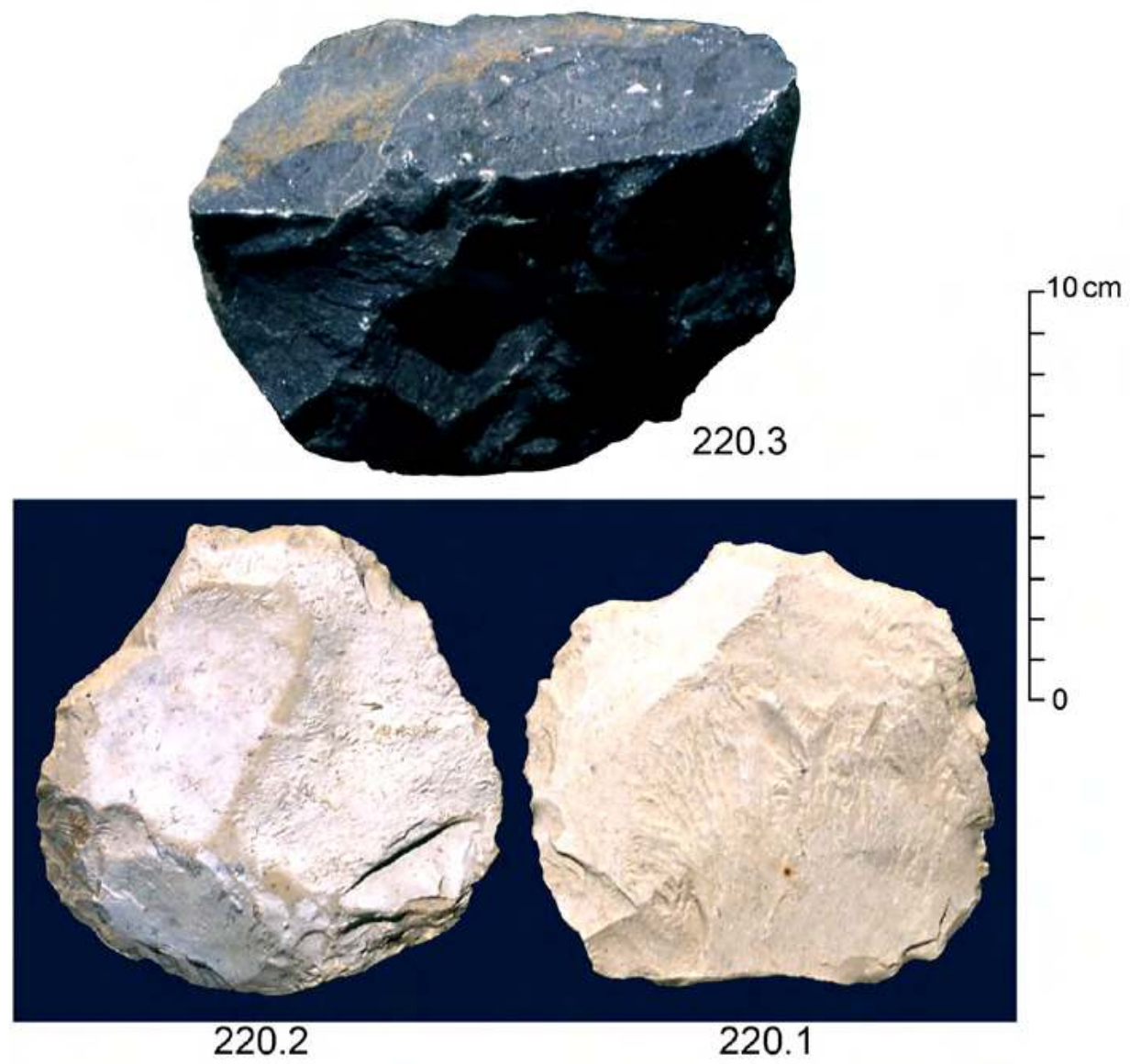

Figure 72. Stone jar stoppers and a split cobble from Hill C, Minaean or Sabaean, reg. nos 220.1-3. (F.G. Fedele 2007)

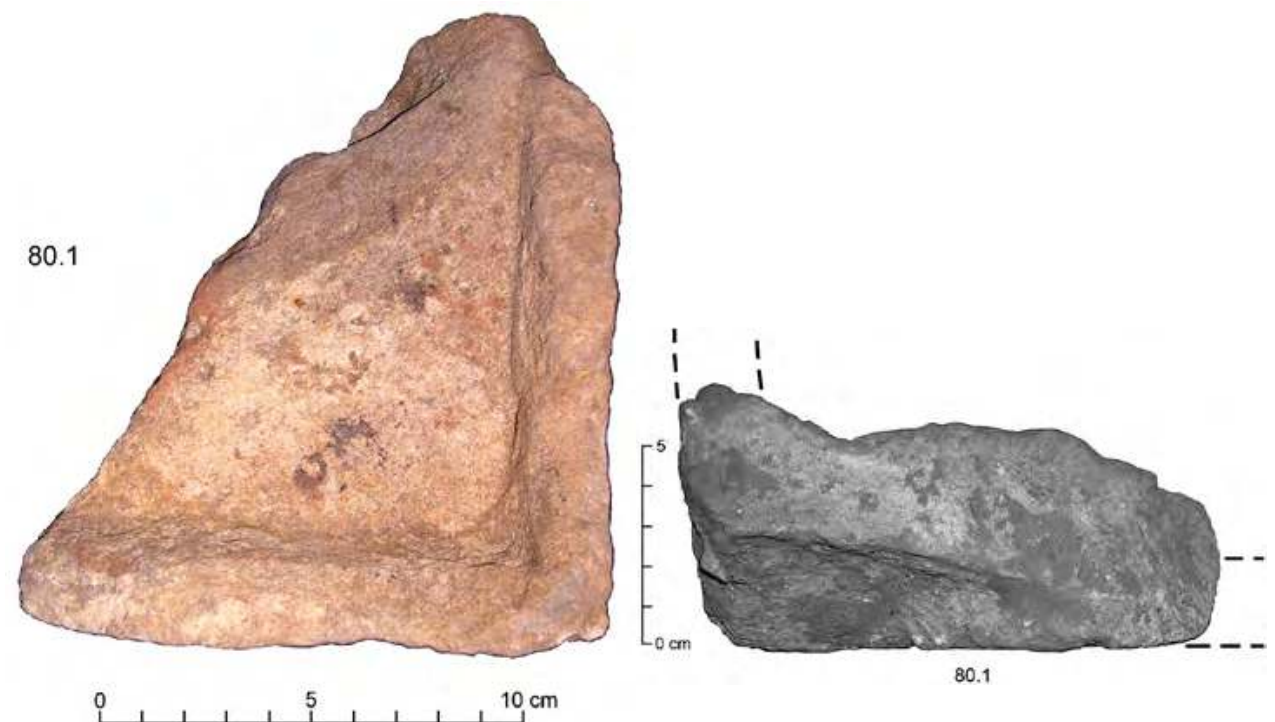

Figure 73. Stone burner, Uncertain chronology, reg. no. 80.1. (P. Morlupi 2005 @ MAIRY; adapted and optimized, with suggested profile, by F. G. Fedele 2010) 


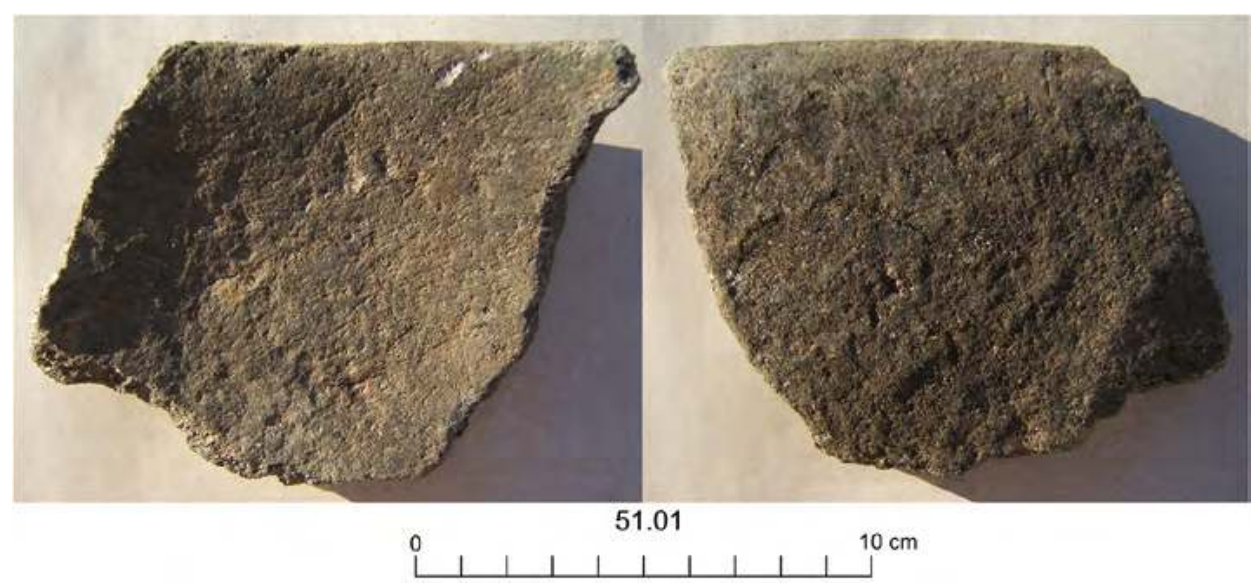

Figure 74. Softstone vessel, Uncertain chronology, reg. no. 51.01. (G. Di Rosa and S. Iavarone 2007 (c) MAIRY, arranged and optimized by F.G. Fedele 2019)

E?), i.e. Second Intermediate (?) or Islamic 2.| Probably from a cooking pot.

51.01 (Fig. 74). Rim and wall fr. of a softstone cooking pot. Chloritite. $13.5 \times 9.8 \mathrm{~cm}$, thickness $0.5-0.8 \mathrm{~cm}$. | E7. Units XL-LCB, E2b-E1 $b_{1}$, and a small part of E1Y; indeterminate colluvial context. Strata $\mathrm{L}$ to earlier $\mathrm{B}$, indeterminable (incl. L, K, I, G, D), but probably from Strata I-G; likely interpretation is redeposited Sabaean debris. | A severely worn fragment from a capacious, thin-walled, fragile pot. The concave surface, darkened along the mouth, is slightly better preserved than the crumbly outer surface, blackened from cooking.

\section{Calcite or aragonite vessels}

The finds below require a qualification of the commonly, if improperly used term 'alabaster' in archaeology. In mineralogy, alabaster is hydrated calcium sulphate, i.e. gypsum: a massive, fine-grained aggregate of gypsum. However, 'alabaster' has long been used by archaeologists as a popular term to refer to the finer, massive, often veined variants of calcite, i.e. calcium carbonate ${ }^{207}$ Calcite is the proper name of the mineral, and aragonite the name of its dimorphous variant. In the Near East the archaeological usage of the term 'alabaster' may have much to do with the importance in antiquity of the so-called 'Egyptian alabaster', which is in fact calcite or aragonite as a mineral, and travertine as a rock. ${ }^{208}$ Egyptian alabaster, or simply 'alabaster', has its origin as calcareous sinter or 'calc-sinter'209 and is known in two principal forms: (i) a translucent, yellowish-orangish calc-sinter, coarse-grained and

\footnotetext{
207 E.g. Potts 2007, 132; Casanova 2018, 70; Phillips and Simpson 2018c, 175-177, 179 .

208 Aston et al. 2000, 21-22, 59-60. Not to be confused with the coarser and porous varieties of travertine, or Roman travertine (e.g. from Tivoli).

209 E.g. AGI 1984, 456.
}

fibrous and displaying either a faint or a marked layering; and (ii) a strikingly banded calc-sinter. ${ }^{210}$ At Barāqish Area C, finds nos 10.1a, 10.1b, and 85.01 belong in the first form, while find no. 102.02 (Sabaean group, above) might belong in the second. ${ }^{211}$

It may be recalled in this context that a major 'alabaster' quarry, associated with pottery and architecture attributed to the Sabaean period, exists not far from Barāqish in the upland area north of Șirwāh, at Manqaz al-Milhāt. ${ }^{212}$ An early survey of the site was conducted by the Italian mission in $1986,{ }^{213}$ de Maigret mentions 'thin veins of alabastrine stone', interstratified within 'thick banks of reddish-yellow Mesozoic limestone', ${ }^{214}$ but the precise petrography is not stated.

10.1a, 10.1b. Two rim frs from a small dish or plate (or two). Calcite or aragonite ('alabaster'), precise variety undescribed. Both frs $\mathrm{cm}$-sized. | D3, in situ, $12 \mathrm{~cm}$ from eastern side of quadrangle and $30 \mathrm{~cm}$ from the Reference section. SA1, above Mass F9 and its decay sheet GRx. ${ }^{215}$ Earlier (?) Stratum C, but redeposited Minaean or Sabaean objects. | One fragment was plotted in situ, the other one was retrieved from nearby sediments. The morphological similarity of the two pieces suggests that they probably derived from a bigger fragment, split more or less on the spot, hence were part of the same vessel. The SA1 sediments in quadrangle D3 contained

\footnotetext{
210 Aston et al. 2000, 60.

211 A small 'alabaster' vessel of a completely different type from both $10.1 \mathrm{a}-1 \mathrm{~b}$ and 85.01 (cylindrical and flat-bottomed, $4 \mathrm{~cm}$ in diameter) was recovered as a probably reworked element from the Area D cemetery (topmost level; Antonini 2010b, 23, 25, pl. 36/c).

212 E.g. Edens and Wilkinson 1998, 97.

213 de Maigret et al. 1986, 390; de Maigret and Antonini 2005, 29-30, figs 2-3.

214 de Maigret and Antonini 2005, 29.

215 Sand SA1 was described in qu. D3 as very loose, 'dirty' grey to yellowish, relatively well classed, and poor in clasts. For the retrieval location of finds 10.1a-1b see Chapter 17, Figs 32 B and 64, this volume.
} 
four abraded Sabaean pottery sherds (wear grade 3-4): this being an aggregate, however, the co-occurrence is insufficient for identifying the vessel or vessels 10.1a$1 \mathrm{~b}$ as Sabaean. ${ }^{216}$

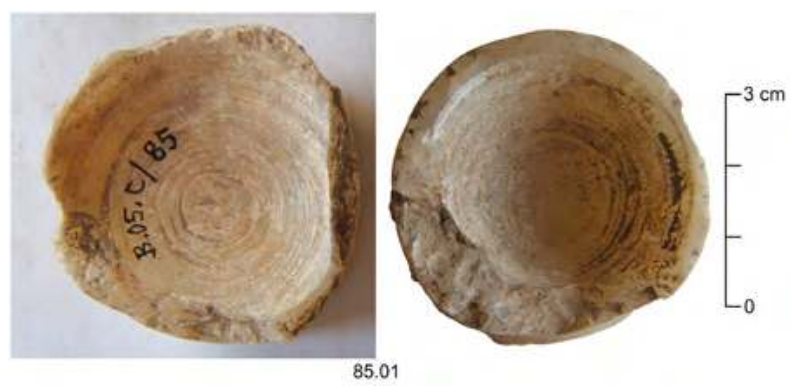

Figure 75. Calcite vessel, Uncertain chronology, reg. no. 85.01. (G. Di Rosa and S. Iavarone 2007 C MAIRY, arranged and optimized by F.G. Fedele 2019)

85.01 (Fig. 75). Flaring, ring base of a vessel. Weakly translucent, white-creamy calcite or aragonite ('alabaster'). $\varnothing 4.7 \mathrm{~cm}$ (exterior foot), height c. $3.5 \mathrm{~cm}$. | E06-E08, removal of collapsed Reference section, all layers. Strata $\mathbf{L}$ to $\mathbf{A}$, indeterminable, but the object is Sabaean or Minaean.| This fragment is the concave, subconical foot of a small bowl or jar, or a footed chalice, made on the lathe. Polished surfaces, but lathe-turning striae (rilling) evident on both the underside and inside of the artefact. This type of manufacture would date the vessel to the Minaean period, unless the object was a long-distance import from outside southern Arabia. ${ }^{217}$ It should also be recalled that valuable calcite or 'alabaster' vessels were often kept for a long time as heirlooms. Both find no. 85.01 and the fragments $10.1 \mathrm{a}-1 \mathrm{~b}$ (above) were unfortunately retrieved from uninformative contexts.

\section{Querns and other grinding tools}

80.2 (Fig. 76). Incomplete, battered quern. Whiteyellowish coarse calcarenite, medium-sorted and with occasional $\mathrm{cm}$-sized calcite grains and crystals (cf. no. 50.1 below). $16 \times 12 \times$ c. $5 \mathrm{~cm}$. $\mid$ E8, -50 to -100 $\mathrm{cm}$ below surface, retrieved after discard by workers: possibly from unit 8P (pit F2) or unit F2W. Stratum B (?), but probably pre-Islamic. | An elliptical quern with

\footnotetext{
216 The aggregate also contained a small globular bone bead (of indeterminable age, Sabaean to Islamic), many $\mathrm{cm}$-sized fragments of limestone and mudbrick, and a Ziziphus nutshell.

217 In Southeast Arabia, a wheel-mounted lathe for making softstone vessels was introduced during the 3rd century BCE, replacing an earlier hand-carving tradition (Phillips and Simpson 2018b, 51; Simpson 2018, 180). It is unclear whether lathes for stone working had appeared earlier outside Arabia, as some unconfirmed data would indicate (cf. Simpson 2018, 180, footnote 3, with references; also, e.g., Eiland 2003, 339-340, suggesting a post-7th century BCE dating for their appearance in the Near East).
}

inequilateral hollow, showing sparse surviving traces of working polish. It was affected by an apparently random type of breakage, which might have terminated its uselife; concurrently or at a later time the stone underwent heavy damage. The highly irregular base is probably geological, however. Both the overall shape and the breakage pattern of this quern are different from those of the saddle querns broken in half, previously described. ${ }^{218}$ If its vague similarity in shape to a Minaean quern is anything to go by (see no. 185.1, above), a Minaean rather than a Sabaean dating could be suggested.

210.01. Fr. of quern. Basalt (?). | F. Units F01 $\alpha-\mathrm{F} 01$ and $\Lambda$ F. Stratum D or B. | Details unavailable.

Other utilized natural stones (stone manuports, including fossils)

51.02. Fr. of burnt red sandstone. Max. length c. $5 \mathrm{~cm}$. | E7. Units XL-LCB, E2b-E1b, and a small part of E1\%; indeterminate colluvial context. Strata $\mathrm{L}$ to earlier $\mathrm{B}$, indeterminable (incl. L, K, I, G, D), but probably from Strata I-G; likely interpretation is redeposited Sabaean debris. | An angular rock fragment probably employed in a hearth and split by fire. No further details are available. About the possibility that this is a thermal stone' see 'Remarks on Cluster 82.2' in 'Other utilized natural stones', Sabaean group (above).

50.1 (Fig. 77). Cobble with opposed cupules. Greywhitish, coarse calcarenite, cf. quern no. 80.2 (above) but slightly better sorted. Approx. $12.5 \times 11.5 \times 5 \mathrm{~cm}$; max. $\varnothing$ of cupules $1.5-2.5 \mathrm{~cm}$. | From a point 'adjacent to quadrangle $E 7^{\prime}$, unstratified: noticed and retrieved while closing the excavation of quadrangle E7. Surface, lag $\Lambda \mathrm{E}$. Stratum A (Islamic? reworked Minaean or Second Intermediate?). | A flat cobble with a slightly planoconvex cross-section and a shallow cupule (or cupmark) in the centre of each face. Both cupules are crudely produced, and the one on the convex surface is no more than a shapeless scar, thus suggesting use wear rather than intentional making. D-shaped in plan, this stone looks like half of a truncated natural cobble, its rectilinear truncation either geological or cultural in origin and now heavily blunted. A grey, silty calcium carbonate crust selectively survives all along the circumference of the stone. As an object, no. 50.1 can have gone through several functions over time, all uncertain. It could be an old quern reused as an anvil, since the cupules seem to be the result of repeated, point-like application of force. Two far less likely (?) explanations are (i) a makeshift mortar for crushing small quantities of some substance, and (ii) a sledgehammer.

\footnotetext{
218 See the introduction to 'Querns and other grinding tools' in section 2.1 , above.
} 


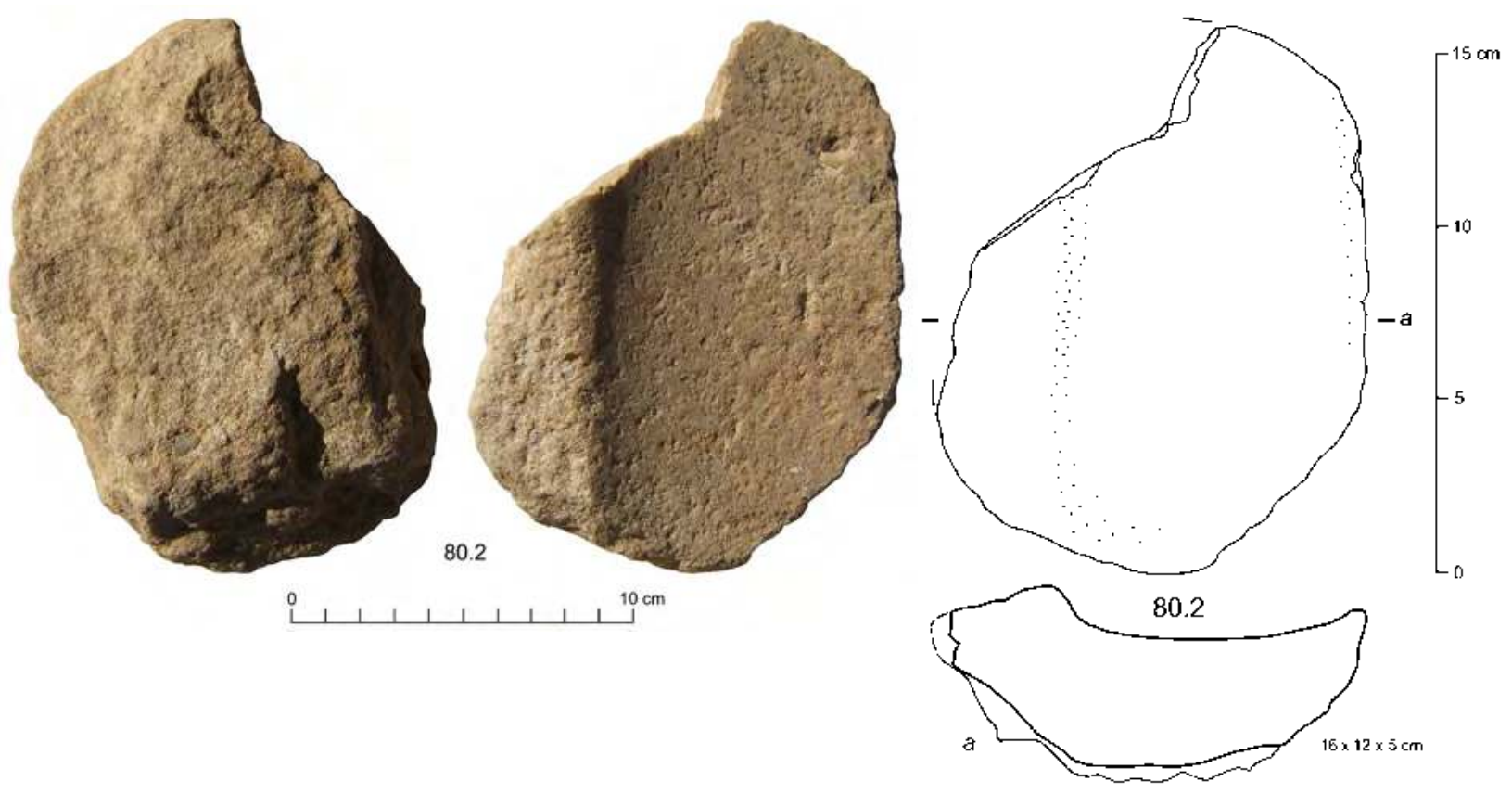

Figure 76. Quern, Uncertain chronology, reg. no. 80.2. (G. Di Rosa and S. Iavarone 2007 @ MAIRY, arranged and optimized by F.G. Fedele 2019; drawing F.G. Fedele 2006)
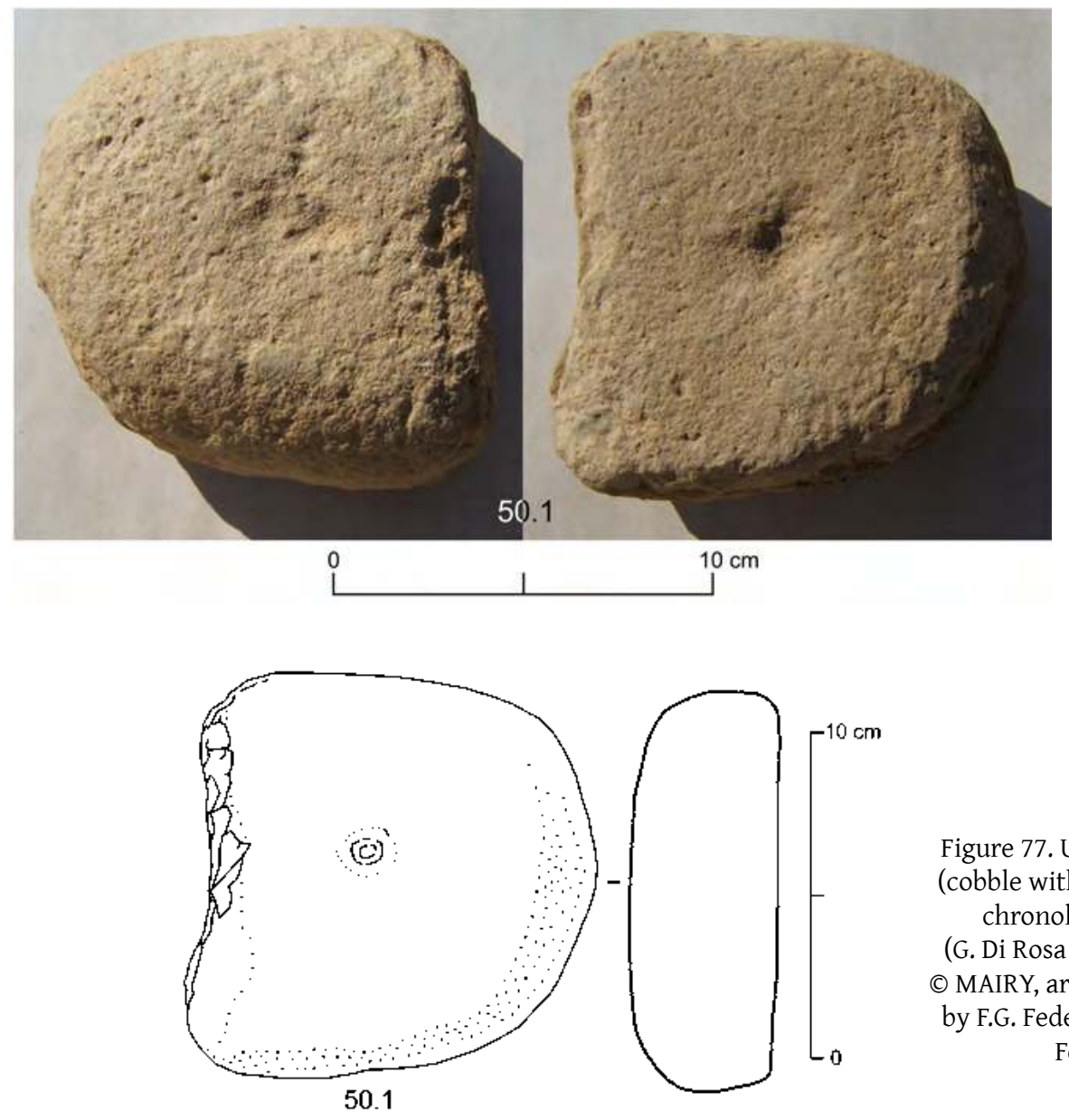

Figure 77. Utilized natural stone (cobble with cupules), Uncertain chronology, reg. no. 50.1.

(G. Di Rosa and S. Iavarone 2007 (c) MAIRY, arranged and optimized by F.G. Fedele 2019; drawing F.G. Fedele 2006) 


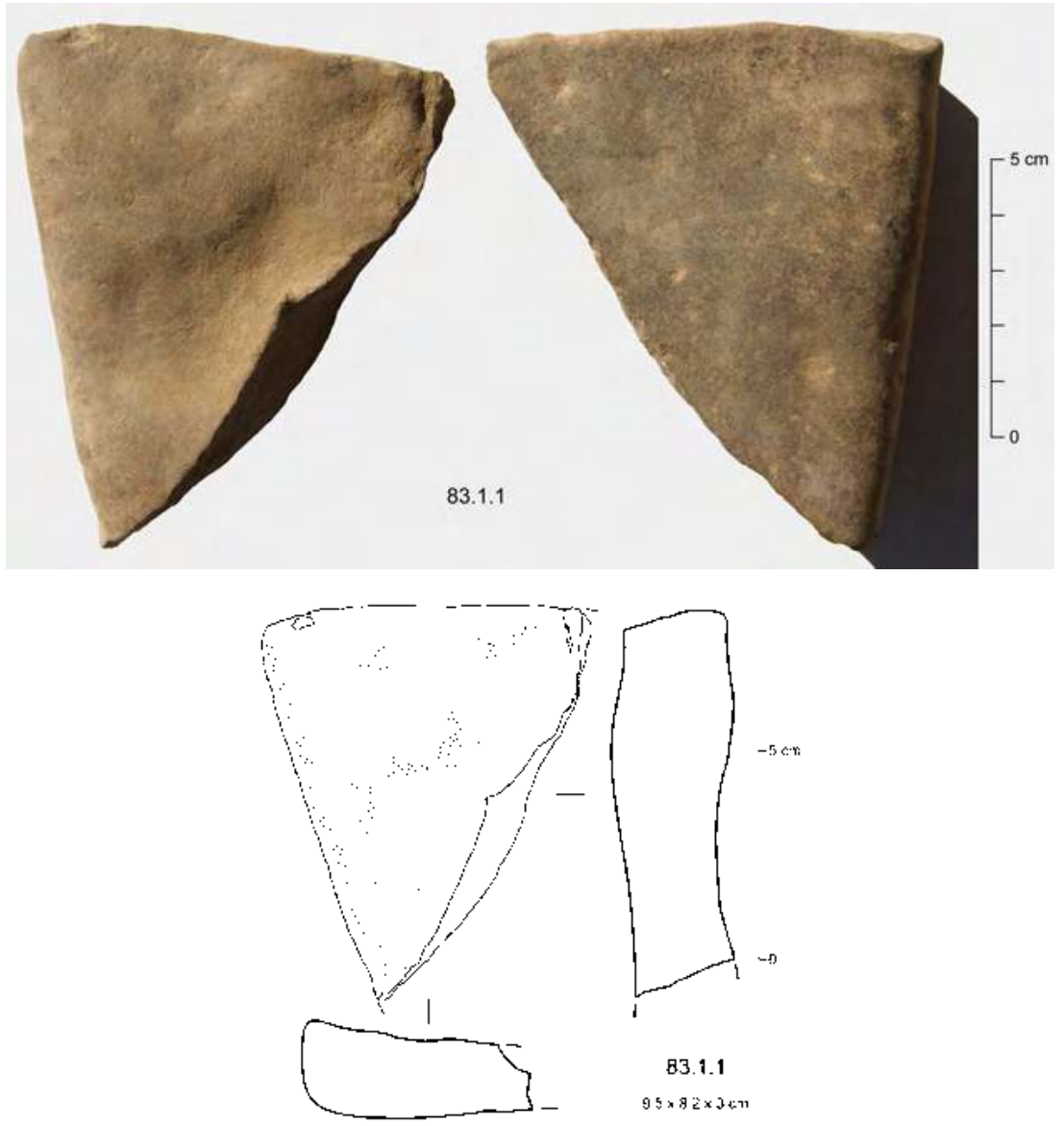

Figure 78. Utilized natural stone (limestone slab), Uncertain chronology, reg. no. 83.1.1. (G. Di Rosa and S. Iavarone 2007 @ MAIRY, arranged and optimized by F.G. Fedele 2019; drawing F.G. Fedele 2006)

83.1.1 (Fig. 78). Fr. of a thin limestone slab retaining its original, geological shape. $9.5 \times 8.2 \times c .3 \mathrm{~cm}$. $\mid$ E18 east. From Cluster 83.1, an isolated cluster of Sabaean pottery frs $c .50 \mathrm{~cm}$ below surface in middle unit E $\sigma 0$, excavated by workers during a non-supervised extension of trench. Stratum B, but possibly a re-employed and/or redeposited pre-Islamic object. | Reportedly, Cluster 83.1 was embedded in sands, and judging from pottery, it was formed with ancient material obtained from a Sabaean context in Area C or elsewhere at the site. Alternatively, the cluster might point to an undetected or undetectable pit similar to F3 in quadrangle E8 (see Chapter 17, section 16.4 ['Stratum B'] and Fig. 51 C, this volume). Per se, stone 83.1.1 is a manuport, except perhaps for its broken status; its introduction into the site might well be Sabaean like the aggregated pottery. A tiny dendrite ${ }^{219}$ can be seen on the undulating face of the slab, near the upper edge in the photograph on the left.

210.04. Fr. of a fossil shell (an undetermined bivalve?); cm-sized. | F. Units F $01 \alpha-F 01$ and $\Lambda$ F. Stratum D or B. | Details unavailable.
Unfired or poorly fired clay artefacts: discs and/or 'tripods'

120.01. Four frs from a single clay disc. $\mid E 4 . \mathrm{L}_{3} \mathrm{Z}_{3}$ to group EX4 (plus small part of EX3), and SAE-SA : undefined context. Strata N, L, K, I, G (and D?), indeterminable. | The object is likely Sabaean.

70.01. A foot of a clay 'tripod'. Dark brown paste. | E5. Unit e7 to surface, undefined context. Strata G-D, B-A, but probably Stratum D. | Redeposited Sabaean or Minaean debris.

87.3. Frs of a foot from a clay 'tripod'. Dark brown paste. | E06 recut section, eastern part, in situ at $-62 \mathrm{~cm}$. Within sand and plant debris lens EX6, probably continuing X3-L3; colluvial context. Stratum D. | For the retrieval context see Chapter 17, section 16.3 and Fig. 47, this volume. Likely interpretation is redeposited Sabaean debris.

51.04. Frs of clay discs/'tripods': multiple frs, unspecified. Dark brown paste. |E7. Units XL-LCB, E2b$\mathrm{E} 1 \mathrm{~b}_{1}$, and a small part of $\mathrm{E} 1 \gamma$; indeterminate colluvial context. Strata L to earlier B, indeterminable (incl. L, K, I, G, D), but probably Strata I-G. | Likely interpretation is redeposited Sabaean debris.

219 On this kind of dendrites see footnote 161, above (no. 198.03, Fig. 52, Minaean group). 


\section{Plaster jar sealings}

72.01. Fr. of plaster (from a jar sealing?); cm-sized.| E5. Units V5, XE4, LZ5-X5. Strata 0 to I, indeterminable. | A Minaean or Sabaean element, most likely a redeposited jar sealing of the Minaean 1-2.

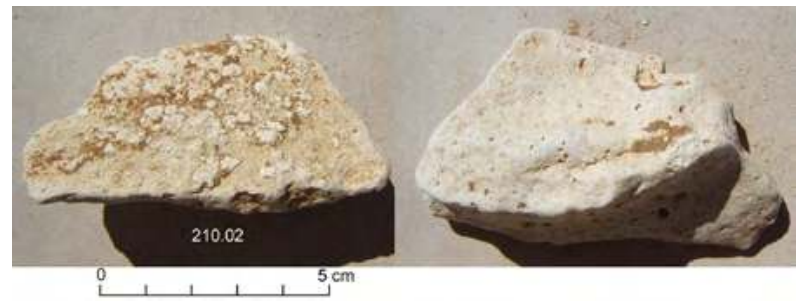

Figure 79. Plaster jar sealing, Uncertain chronology, reg. no. 210.02. (G. Di Rosa and S. Iavarone 2007 @ MAIRY, arranged and optimized by F.G. Fedele 2019)

210.02 (Fig. 79). Fr. of a plaster jar sealing. Length of fr. $8.0 \mathrm{~cm}$. $\mid F$. Units F01 $\alpha-F 01$ and $\Lambda$ F. Stratum D or Stratum B. | A well-rounded fragment, shaped by a combination of corrosion, sand-blast (aeolian erosion), and perhaps trampling in a sub-recent lag-gravel environment. Presumably Minaean.

210.03. Fr. of plaster, probably from a jar sealing; $\mathrm{cm}$ sized. |F: provenance and stratigraphy as for no. 210.02. Stratum D or Stratum B. | No seal impression.

Glass

110.1 (Fig. 80). Fr. of polychrome glass. Max. $\varnothing 2.4$ $\mathrm{cm}$. E3, centre of the south half of quadrangle (see Chapter 17, Figs $51 \mathrm{~A}$ and 52, this volume), in situ at about $-105 \mathrm{~cm}$ below the local datum (E3 SE corner, ground surface). According to excavation records and photographs, this object was collected from greyish, silty-gravelly sediments belonging to lower unit L3c or a mixture of $\mathrm{L} 3 \mathrm{C}$ (including $3 \pi$ ) and L3e, i.e. Stratum $\mathbf{P}$ or O. However, the minuscule object was possibly intrusive: it might have fallen inadvertently from a higher level or have been displaced by an ancient disturbance. Indeed, a fossil hollow suggesting activity from burrowing animals and a concomitant patch of mixed sediments were noted within L3c in the nearby south section of E3 (marked in Figs 41 A and 46, Chapter 17, this volume). ${ }^{220}$ | Smooth, polychrome glass element (a broken bead?) characterized by bands in bright colours.

220 No. 110.1 is a unique find from Area C, but unfortunately, after being diagnosed in the field, it was not subjected to autoptic laboratory examination. These are the reasons for presenting it here in spite of chronological uncertainties. The excavation context of cut 110 is also described in this chapter for clay 'tripod' fragment no. 110.05 (Sabaean group, above) and in this volume for in situ potsherd no. 110.2 (Chapter 23, section 3.1), and is examined in greater stratigraphic detail in Chapter 17, sections 6.5 (general) and 6.8 (animal burrows and possible krotovinas). The Collection catalogue entry for cut 110 can be seen in Chapter 20, Fig. 1, this volume. [FGF]
During fieldwork, in 2005, it was cautiously interpreted as an Alexandrine production (1st century BCE-1st century CE; A. de Maigret, personal communication). A re-examination on the photograph suggests instead that, if a bead, it may be related to the cylindrical glass bead type with dragged trails in feather pattern (the dragging alternating up and down, not in one direction like in the festoon pattern type). According to this attribution the date would be 10th to 14 th centuries CE. ${ }^{221}$ If so, the object's original location would be the topmost layer in quadrangle E3, comprising units SAp, SAG, and SAE (Stratum A).

\section{Mentioned in Fedele 2010, 137.}

[FGF, SA]

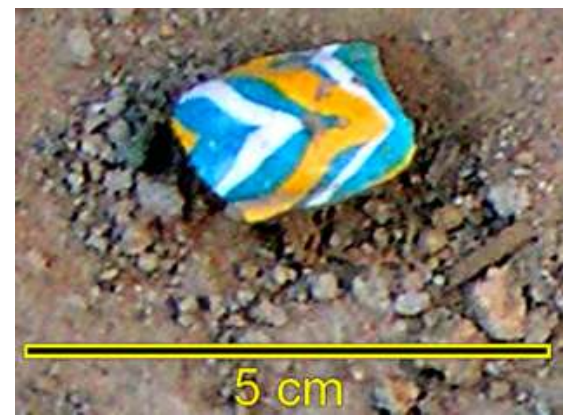

Figure 80. Glass element, Uncertain chronology, reg. no 110.1 (detail from an excavation photograph). (P. Morlupi 2005 (c) MAIRY, adapted and optimized by F.G. Fedele 2009)

\section{Marine shells (personal ornaments)}

210.05 (Fig. 40). Columellar half of a cowrie shell from a relatively small species, cf. Erronea caurica quinquefasciata. Length of fr. $2.8 \mathrm{~cm}$, estimated shell height $2.8-3.0 \mathrm{~cm}$, aperture height $2.6 \mathrm{~cm} .^{222} \mid F$. Units F01 $\alpha-F 01$ and $\Lambda$ F. Stratum D or B. | This broken cowrie $e^{223}$ is a delicate specimen with a dull white surface; a remnant of lustre only survives on the aperture rim. Whether the white colour is due to fading with time and exposure, augmented by decalcification (?), or is essentially native and thus of taxonomic relevance, is impossible to say. The overall shape is distinctly pyriform. Within the limits of the attributes that can be observed in our archaeological find, particularly in ventral view (Fig. 40, top photograph of specimen), two are the morphological details of diagnostic interest:

\footnotetext{
221 Cf. Dubin 1987, 95-97, Synoptic table nos 501-502. The production centres were Egypt, Syria, and the Levant. [SA]

222 Measurement in analogy to Irvy R. Quitmyer's, see Claassen 1998, 108, fig. 21/B.

223 Broken sensu Ridout-Sharpe $(2017,294)$, i.e. 'more than one half present', as different from fragmentary. Just a little more than half shell is present in the case of no. 210.05. For a more refined coding of shell condition see now Christie et al. 2019, 489-490, fig. 8.
} 
long, pronounced, rather spaced columellar teeth, relatively extending over the base; and a columellar lip characterized by weak indentations anteriorly (as opposed to deeper indentations such as often appear in Naria). Together with distribution, the above attributes point to the five-banded cowrie, Erronea caurica quinquefasciata (Röding, 1798), or one of its hybrids. ${ }^{224} \mathrm{E}$. c. quinquefasciata lives in all sorts of habitat between the intertidal zone and $-30 \mathrm{~m}$, and is a common gastropod along the Red Sea and throughout the South Arabian seabord from Muscat to the Gulf of Aden and Somalia. Our specimen would be an individual near the lower end of the subspecies' size range (adult average c. 2.8$4.4 \mathrm{~cm}$ ), thus possibly originating from the Arabian Sea rather than the Red Sea (cf. footnote 224).

However, in the circumstances, an alternative identification cannot be totally excluded.225 Even with a intact shell from a living cowrie, a firm zoological determination would be made difficult by the considerable local variability of the taxa or forms within the 'Erronea caurica complex', a debated subject in gastropod taxonomy. ${ }^{226}$
The dorsum of no. 210.05 is largely missing. Therefore, from a cultural viewpoint, it cannot be determined whether this object resulted from the longitudinal breakage of a shell intentionally 'rubbed down on the back', having been used in a necklace or tied to some kind of support. ${ }^{227}$ No thread wear could be seen within the notches of the anterior and posterior canals. Judging from a review of the literature, the breakage pattern shown by 210.05 would appear to reproduce a standard occurrence in cowries, inherent in their fragility once they are deprived of the dorsum. ${ }^{228}$ In any case, it is good to remember that a virtually identical modification, involving the breaking off of dorsum while the region around the aperture is left intact, is commonly also inflicted to cowries by crabs. ${ }^{229}$

As to the excavation context of the find, in theory it cannot be excluded for such an object a proximate origin from the robbing of tombs on Hill D. ${ }^{230}$ Intuitively, however, both distance and topography would make this scenario unlikely.
224 Lorenz and Hubert 2000, 137, pl. 52/3; Lorenz 2017a, 549; 2017b, 31, pl. $1 ; 2018$, plates $280 / 1-3,7-10 ; 281 / 1-2$. Particular resemblance can be noted with specimens such as Natuurhistorisch Museum Rotterdam no. 33431 from the Red Sea (MolluscaBase 2019, AphiaID 579200), as well as with Erronea hybrids such as the one shown in Lorenz and Hubert 2000, pl. 106/19 (E. errones $\times$ caurica, admittedly from a different part of the geographic range of E. caurica). Larger, heavier forms of E. c. quinquefasciata are common among its Red Sea populations (e.g. Lorenz and Hubert 2000, 137).

225 The nearest alternatives would be Naria lamarckii (J. E. Gray, 1825) and Naria ocellata (L., 1758), this latter a good match for teeth (e.g. Lorenz and Hubert 2000, pl. 89/33); more distantly, Naria turdus (Lamarck, 1810). All these cowries are compatible with no. 210.05 in average size: for N. lamarckii see MolluscaBase 2019 (AphiaID 1079153), Lorenz 2018, plates 42-43; for N. ocellata, MolluscaBase 2019 (AphiaID 1079115), Lorenz 2018, pl. 38; for N. turdus, MolluscaBase 2019 (AphiaID 1079151), Lorenz 2018, plates 39-40. N. lamarckii and N. turdus are common on the Arabian Sea coasts between Somalia and Pakistan, and N. turdus also along the Red Sea, where they live in mud shallows, muddy reefs, and sand pockets; $N$. ocellata prefers a stony or reef habitat and has a wider geographic range (Lorenz and Hubert 2000, 189-191). The current genus name replaces Erosaria, itself a revision of the original placement of both species in genus Cypraea. 'Cypraea turdus' was identified for instance at Hajar al-Tamrah, in Wādī al-Jūbah, by J. Blakely, who considered his three worked cowries from the site as clear evidence of trade items, and also mentioned that in Senegal cowries were 'used in divination to determine the cause of disease' (Blakely 1985, 119, fig. 42). Details of morphology would rule out Naria turdus winckworthi, a subspecies prevalent in eastern Arabia and reportedly identified at Khawr Rūrī/Sumhuram in Zufār (Wilkens 2005).

226 Lorenz 2017b, 30 (variability), 31 (conchological differences between the Red Sea and the Oman-Gulf populations of Erronea caurica quinquefasciata); this article attempts a revision of the whole 'Erronea caurica complex'. On the great variation of E. caurica in size, shape, and colour see already Bosch et al. 1995, 73.
227 Quotation from Jackson $(1944,105)$, who provided ethnographic remarks and archaeological comparisons. Worldwide, the abrasion of dorsum was (and indeed is) the most usual preparation for cypraeid shells intended to be strung as necklaces or attached to a support. Extensive literature exists on this subject (e.g., Ridout-Sharpe 2017, 301-302, fig. 17.3; Christie et al. 2019, 491-497). For other possible utilizations see the introduction to 'Marine shells' in section 2.1 above.

228 E.g. Ridout-Sharpe 2015, fig. 3, bottom right (Tell Abu Hureyra, Syria).

229 This and other kinds of gastropod shell damage due to predation by crabs have been widely documented by Geerat J. Vermeij (e.g. 1993, 94, fig. 5). In a general theory of shell fragmentation such as the one proposed by Zuschin et al. (2003) our cypraeid case would be classified as 'partial destruction from predation' (p. 39-40, fig. 4/B). Recent studies of crab-made breakage simulating human cultural action include Szabó 2005, 126-130, figs 4.23-4.25; see also Çakırlar 2009, 46-47.

230 Several cowries reported as 'Cypraea turdus', some abraded on the back but complete, were retrieved from Levels 1 and 3 of Barāqish Area D (Antonini 2010b, 25-26, plates 37/c/g, 38/a/e, and 38/b-d). 


\title{
Chapter 22
}

\section{Area C. \\ The Minaean Pottery}

\author{
Vittoria Buffa
}

\section{Introduction}

The Minaean pottery from the excavations in Area C was studied at Barāqish in November-December 2007. Due to time limits examination had to be restricted to Sounding A, from which excavation numbers (or 'cuts') 169E-169K and 183-193 were particularly analysed. Cuts from insecure contexts (169J, 191A) were excluded from further study, and cut $184 \mathrm{~A}$ did not contain pottery.

For the purpose of sequential ordering, the pottery from the sounding was grouped as in Table 1 . The rationale for this stratigraphic-'historical' grouping is grounded in the information presented in Chapter 17, this volume (F.G. Fedele), particularly section 1.2, concerning the spatial distribution of cuts, and section 9, on Sounding A in general, with their relevant figures and tables.

The pottery collection from Sounding A examined for the study of the Minaean ceramics numbered 1236 fragments. Rims, bases, handles, and decorated wall sherds were 136 . The pottery assemblage studied here comprises 127 diagnostic fragments. They are catalogued following the stratigraphic sequence illustrated in the table. The description of pastes is illustrated in Chapter 25, section 1, this volume; the attribution to a type refers to the typological classification also proposed in Chapter 25.

\section{Catalogue}

$193(B .06 . C / 193)$

193,1 (Fig. 1/1). Small deep bowl with convex profile, one incised line below the rim. Interior and exterior coated with a burnished red slip (10R 5/6). Fine paste 1 with some black grits and mica. Type III.A.3.

$192($ B.06.C/192)

192,3 (Fig. 1/2). Deep cup on foot with vertical sides, rounded rim. Rim diameter $13 \mathrm{~cm}$. Medium compact paste 2 with some grits and straw temper. Traces of red paint on the exterior. Type II.2.a.

192,2 (Fig. 1/3). Bowl with flaring, curving sides, rounded rim. Compact paste 2 with some grits and straw temper; interior smoothed. Type III.B.3.a.

192,1 (Fig. 1/4). Large deep bowl with vertical upper sides, rounded rim. Rim diameter $22 \mathrm{~cm}$. Compact paste 2 with some grits and straw temper, decoration of a line of red paint on rim; interior smoothed, exterior wet smoothed. Type III.C.3.

Table 1. Barāqish Area C, Sounding A: stratigraphic groups employed in the study of Minaean pottery. (Courtesy F.G. Fedele. See Chapter 17 for details)

\begin{tabular}{|l|l|l|l|}
\hline $\begin{array}{l}\text { Stratigraphic groups } \\
\text { (according to cut numbers) }\end{array}$ & Phase (Area C) & Stratum & Notes \\
\hline$\bullet 183$ & Second Intermediate & E & Occasional occupation (Amirite) \\
\hline$\bullet 184+169 \mathrm{E}$ & Minaean 4 & F & \\
\hline$\bullet 184 \mathrm{~B}+169 \mathrm{~F}$ & Minaean 3 & H & \\
\hline$\bullet 185+169 \mathrm{G}$ & Minaean 2/3 & I, H & Late Stratum I and early Stratum H \\
\hline$\bullet 186+169 \mathrm{H}$ & Minaean 2 & I & \\
\hline$\bullet 187+169 \mathrm{~K}$ & & & Including wall construction and earthwork \\
\hline$\bullet 188$ & & \multirow{2}{*}{$\mathrm{J}$} & \\
\hline$\bullet 189$ & Minaean 1 & & Reworked pottery in structure F10 (part of the earthwork) \\
\hline$\bullet 190$ & & & \\
\hline$\bullet 191+191 \mathrm{~B}$ & & & \\
\hline$\bullet 192,193$ & & &
\end{tabular}


192,4 (Fig. 1/5). Low ring base with flaring convex foot. Rim diameter $18 \mathrm{~cm}$. Compact paste 2 with some grits and straw temper, yellow slip on the exterior. Type VII.B.3.

\section{B (B.06.C/191B)}

191B,6 (Fig. 1/6). Small deep bowl with convex profile, two incised lines below the rim, rounded rim. Interior and exterior coated with reddish brown burnished slip (5YR 5/4). Rim diameter $19 \mathrm{~cm}$. Compact paste 1 with some black grits, mica and little straw temper. Type III.A.3.

191B,5 (Fig. 1/7). Deep cup on foot (?) with slightly flaring upper sides. Rather fine paste 6 with few grits and some straw temper; burnishing on both surfaces. Type II.2.a.

191B,3 (Fig. 1/8). Deep bowl with vertical upper sides. Ledge handle below the rim. Rim diameter $20 \mathrm{~cm}$. Medium compact paste 6 with few grits and some straw temper, decoration of a line of red paint below the rim and on the ledge. Type III.C.3.

191B,2 (Fig. 1/9). Basin with slightly flaring sides, rounded lip. Two incised wavy lines below the rim. Rim diameter $45 \mathrm{~cm}$. Compact paste 6 with few grits and some straw temper; surface wet smoothed. Type IV.1.

191B,4 (Fig. 2/1). Jar with barrel shape body, slightly converging upper sides with rounded profile, beveled rim. Rim diameter $27 \mathrm{~cm}$. Compact paste 2 with a quantity of straw temper and some grits; surfaces smoothed. Type V.A.4.

191B,1 (Fig. 2/2). Dolium with out-turned rim and flattened lip. An incised wavy line at the base of the neck. Rim diameter $44 \mathrm{~cm}$. Compact paste 3 with some black grits, some large red inclusions and straw temper; interior smoothed, exterior wet smoothed. Type VI.6.b. 191B,8 (Fig. 2/4). Flat base with slightly projecting foot. Base diameter $13 \mathrm{~cm}$. Medium compact paste 6 with black and white grits. Type VII.A.2

191B,7 (Fig. 2/3). Low ring base with flaring, convex foot. Base diameter $13 \mathrm{~cm}$. Compact paste 6 with few grits and some straw temper; surfaces smoothed. Type VII.B.3.

191 (B.06.C/191)

191,5 (Fig. 2/5). Deep cup with vertical upper sides. Two incised lines in the interior below the rim. Rim diameter $15 \mathrm{~cm}$. Rather fine paste 2 with few grits and some straw temper; external surface wet smoothed, interior smoothed. Type II.2.a.

191,17 (Fig. 2/6). Deep cup with vertical upper sides. Rim diameter $14.5 \mathrm{~cm}$. Compact paste 6 with few grits and some straw temper; exterior wet smoothed, interior smoothed. Type II.2.a.
191,16 (Fig. 2/7). Deep cup with vertical upper sides. Medium compact paste 5 with a quantity of straw temper and grits; exterior smoothed. Type II.2.a.

191,15 (Fig. 2/8). Deep cup with flaring upper sides and convex profile. Rim diameter $12.5 \mathrm{~cm}$. Rather fine paste 6 with some grits and straw temper; exterior wet smoothed, traces of burnishing on the rim. Type II.2.b. 191,4 (Fig. 2/10). Bowl of small dimensions with straight flaring sides. Wall quite thick. Rim diameter 18 $\mathrm{cm}$. Compact paste 6 with many grits and some straw temper; surfaces wet smoothed. Type III.A.1.c.

191,10 (Fig. 2/11). Bowl of small dimensions with straight flaring sides; one horizontal incised line below the rim. Rim diameter $17 \mathrm{~cm}$. Compact paste 7, with few grits and some straw temper; burnished light grey slip on the exterior (10YR 7/2), interior burnished. Type III.A.2.b.

191,19 (Fig. 2/9). Small deep bowl with convex profile, one incised line below the rim. Fine paste 1 with some black grits and mica. Interior and exterior coated with a burnished red slip (10R 6/4). Type III.A.3.

191,9 (Fig. 2/12). Bowl of medium depth with rounded sides. Compact paste 6 with some grits and straw temper; burnishing on the interior, smoothing on the exterior. Type III.B.3.a.

191,8 (Fig. 2/13). Bowl with vertical upper sides incurving toward the bottom. A line of red paint is applied over the rim. Rim diameter $19 \mathrm{~cm}$. Compact paste 2 with some grits and straw temper; exterior wet smoothed, interior burnished on the upper part. Type III.C.3.

191,14 (Fig. 2/14). Bowl with incurving upper sides with angular profile. Rim diameter $15 \mathrm{~cm}$. Rather fine paste 6 with some grits and straw temper; traces of red paint on the exterior and on the rim. Type III.C.4.

191,7 (Fig. 3/2). Deep bowl with cylindrical profile. Rim diameter $27 \mathrm{~cm}$. Compact paste 6 with some grits and straw temper; interior surface burnished, exterior wet smoothed. Type III.D.1.

191,13 (Fig. 3/1). Deep bowl with cylindrical profile. Rim diameter $21 \mathrm{~cm}$. Medium compact paste 6 with some grits and straw temper; traces of burnishing on the rim, exterior smoothed. Type III.D.1.

191,11 (Fig. 3/3). Jar with converging sides, rounded, globular, squatted body. Rim forming a short collar with rounded lip. Rim diameter $12 \mathrm{~cm}$. Compact paste 6 with many grits and some straw temper; surfaces smoothed. Type V.A.9.

191,12 (Fig. 3/4). Jar with everted rim shaped as a short lid ledge; sloping rounded shoulder. Round knob on the shoulder. Rim diameter $19 \mathrm{~cm}$. Compact paste 2 with some grits and straw temper; exterior smoothed. Type V.B.5.

191,3 (Fig. 3/5). Jar with developed everted rim shaped as a lid ledge. Rim diameter $24 \mathrm{~cm}$. Medium compact paste 6 with some grits and straw temper; exterior wet smoothed. Type V.B.6. 
191,1 (Fig. 3/7). Low ring base with flaring, convex foot. Base diameter $23 \mathrm{~cm}$. Compact paste 6 with some grits and straw temper; exterior wet smoothed. Type VII.B.3. 191,2 (Fig. 3/8). Low ring base with flaring, convex foot. Base diameter $20 \mathrm{~cm}$. Medium compact paste 6 with many grits and some straw temper; exterior wet smoothed. Type VII.B.3.

191,18 (Fig. 3/6). Medium-high ring base with cylindrical foot. Base diameter $15 \mathrm{~cm}$. Compact paste 8 with many grits and some straw temper; surfaces smoothed. Type VII.B.5.a.

191,6 (Fig. 3/9). Fragment of wall decorated with a horizontal ridge with impressions and two parallel wavy lines. Paste 3 with black and white grits, some large red (chamotte) and straw temper; exterior wet smoothed. Type IX.A.2 + IX. B.2.

190 (B.06.C/190)

190,9 (Fig. 4/1). Small cup on foot, slightly flaring sides. Faint traces of red paint on the exterior. Rather fine paste 5 with some grits and straw temper; surfaces smoothed. Rim diameter $7 \mathrm{~cm}$. Type II.1.

190,14 (Fig. 4/3). Deep cup with slightly flaring upper sides. Rim diameter $14 \mathrm{~cm}$. Medium compact paste 2 with some grits and straw temper; exterior smoothed. Type II.2.a.

190,12 (Fig. 4/4). Deep cup with vertical upper sides. Rim diameter $15 \mathrm{~cm}$. Compact paste 2 with some grits and straw temper; exterior wet smoothed, interior smoothed. Type II.2.a.

190,13 (Fig. 4/2). Cup with tronconical profile, straight flaring sides, rounded lip. Rim diameter $13 \mathrm{~cm}$. Compact paste 6 with some grits and straw temper; burnished surfaces. Rim diameter $13 \mathrm{~cm}$. Type II.3.

190,11 (Fig. 4/5). Deep bowl with convex profile and incurving rim. Rim beveled inside. Rim diameter 17.5 $\mathrm{cm}$. Compact paste 5 with some grits and straw temper; exterior wet smoothed, interior smoothed. Type III.C.5. 190,7 (Fig. 4/6). Fragment of a jar, probably troncoovoid, with thickened rim. Coarse paste 1 with few grits and some straw temper. Reddish brown burnished slip on the exterior (5YR 5/4) and red on the interior (2.5YR 5/6). Type V.A.3.b.

190,6 (Fig. 4/7). Ovoid jar with incurving thickened rim. Traces of red paint on both surfaces. Rim diameter 15 $\mathrm{cm}$. Compact paste 2 with some grits and straw temper; surfaces smoothed. Type V.A.6.a.

190,5 (Fig. 4/8). Jar with converging sides, rounded profile; globular, squatted body. Rim forming a short collar with rounded lip. Rim diameter $15 \mathrm{~cm}$. Medium compact paste 6 with a quantity of grits and some straw temper; exterior wet smoothed. Type V.A.9.

190,2 (Fig. 4/9). Fragment of amphora or jug with a high narrow neck and flaring rim. Medium compact paste 6 with some grits and straw temper; surfaces smoothed. Type V.C.2.
190,3 (Fig. 4/10). Low ring base with flaring, convex foot. Base diameter $19 \mathrm{~cm}$. Compact paste 5 with some grits and straw temper; wash on the exterior. Type VII.B.3.

\section{$189($ B.06.C/189)}

189,12 (Fig. 4/11). Small cup on foot with vertical upper sides, rounded lip. A band of red paint is applied on the rim. Rim diameter $9.5 \mathrm{~cm}$. Compact, rather fine paste 2 with some grits and straw temper; surfaces smoothed. Type II.1.

189,15 (Fig. 5/1). Deep cup with vertical upper sides bending toward the base with an angular profile. Rim diameter $15 \mathrm{~cm}$. Medium compact paste 2 with many grits and some straw temper. Interior burnished, exterior roughly smoothed. Type II.2.a.

189,16 (Fig. 4/12). Deep cup with slightly flaring upper sides, convex profile. Rim diameter $15 \mathrm{~cm}$. Rather fine paste 2 with some grits and straw temper; exterior wet smoothed, interior smoothed only at the rim. Type II.2.b.

189,19 (Fig. 5/2). Deep small cup with convex profile. Rim diameter $9.5 \mathrm{~cm}$. Rather fine paste 5 with some grits and straw temper; surfaces smoothed. Type II.2.b. 189,22 (Fig. 4/13). Deep cup with slightly flaring upper sides and a convex profile. Rim diameter 14 $\mathrm{cm}$. Compact paste 5 with some black and white grits; surfaces burnished. Type II.2.b.

189,24 (Fig. 5/4). Bowl of medium depth with flaring, rounded sides. Medium compact paste 2 with many grits and some straw temper; interior burnished, exterior wet smoothed. Type III.B.3.a.

189,25 (Fig. 5/3). Bowl of medium depth with flaring, rounded sides. Medium compact paste 5 with many grits and some straw temper; surfaces smoothed. Type III.B.3.a.

189,11 (Fig. 5/5). Deep tronconical bowl with straight flaring sides and rounded lip; burnished red paint on both surfaces (5YR 7/4). Two horizontal incised lines on the side. Rim diameter $21 \mathrm{~cm}$. Compact paste 6 . Type III.A.2.b.

189,21 (Fig. 5/6). Carinated bowl with convex base; flaring, curved sides. Maximum diameter $21 \mathrm{~cm}$. Medium compact paste 5 with some grits and straw temper; exterior smoothed. Type III.B.6.

189,17 (Fig. 5/8). Bowl of large dimensions with incurving, rounded rim. Rim diameter $23 \mathrm{~cm}$. Medium compact paste 2 with some grits and straw temper; interior burnished, exterior wet smoothed. Type III.C.5. 189,23 (Fig. 5/7). Deep bowl with cylindrical profile; rounded rim. Rim diameter $21.5 \mathrm{~cm}$. Compact paste 2 with some grits and straw temper; interior smoothed, exterior wet smoothed. Type III.D.1.

189,8 (Fig. 5/9). Tronco-ovoid jar with thickened rim. Compact paste 6 with many grits and some straw temper; remains of yellow slip on the exterior, interior smoothed. Type V.A.3.b. 
189,18 (Fig. 5/10). Ovoid jar with incurving, thickened rim forming a short vertical collar. Band of red paint on the interior of the rim. Rim diameter $11.5 \mathrm{~cm}$. Fine paste 2 with some grits and straw temper; exterior smoothed. Type V.A.6.b.

189,26 (Fig. 5/11). Ovoid small jar with converging sides, rim forming a short collar, marked by a shallow groove. Rim diameter $13.5 \mathrm{~cm}$. Coarse paste with large angular black inclusions and some smaller ones. Weak red slip (10R 5/4) on both surfaces. Variant of type V.A.6.

189,13 (Fig. 5/12). Small jar with everted, thickened rim, incurving upper sides, thinned lip. Rim diameter $10 \mathrm{~cm}$. Fine paste 4 with some black grits and mica. Interior coated with burnished light reddish brown slip (2.5YR 6/4), exterior burnished. Type V.B.3.c.

189,4 (Fig. 5/13). Jar with sloping shoulder, developed everted rim shaped as a lid ledge. Band of red paint inside and outside of the rim. Compact paste 6 with some grits and straw temper; surfaces smoothed. Type V.B.6.

189,6 (Fig. 5/15). Dolium with out-turned rim, cylindrical (?) shape. Rim diameter $39 \mathrm{~cm}$. Coarse paste 2 with many grits and some straw temper; surfaces not preserved. Type VI.4.a.

189,5 (Fig. 5/14). Dolium with barrel shape, rim thickened outside. Decoration of an incised wavy line on the shoulder and a band of red paint on top of the rim. Rim diameter $32 \mathrm{~cm}$. Compact paste 6 with some grits and straw temper; exterior wet smoothed, interior smoothed. Type VI.6.b.

189,3 (Fig. 6/1). Disc flat base with slightly projecting foot. Base diameter $33 \mathrm{~cm}$. Compact paste 1 with some grits and straw temper; surfaces coated with a burnished red slip (2.5YR 6/6). Type VII.A.2.

189,7 (Fig. 6/2). Low ring base with convex foot. Base diameter $17 \mathrm{~cm}$. Compact paste 6 with many grits and some straw temper; surfaces smoothed; wheel made. Type VII.B.3.

189,1 (Fig. 6/5). High ring base with flaring straight foot. Four bands of red paint on the foot. Base diameter $13 \mathrm{~cm}$. Fine paste 2 with some grits and straw temper; surfaces smoothed; wheel made. Type VII.B.4

189,2 (Fig. 6/3). High ring base with flaring, straight foot. Base diameter $10 \mathrm{~cm}$. Paste 1 with some grits and straw temper; burnished red slip on both surfaces (10R 5/6); wheel made. Type VII.B.4.

189,9 (Fig. 6/4). High ring base with flaring, straight foot. Base diameter $10.5 \mathrm{~cm}$. Fine paste 9 , with few black grits. Type VII.B.4.

189,14 (Fig. 6/6). Vertical loop handle with triangular section. Compact paste 2 with some grits and straw temper, grey core; surface smoothed. Type VIII.1.a.

188 (B.06.C/188)

188,6 (Fig. 6/7). Deep cup with straight upper sides, vertical rim and rounded lip; angular profile. Rim diameter $8.5 \mathrm{~cm}$. Compact paste 5 with some grits and straw temper; smoothing on both surfaces. Type II.2.a. 188,5 (Fig. 6/8). Deep tronconical bowl with straight, flaring sides; wall quite thick. Rim diameter $15 \mathrm{~cm}$. Medium compact paste 6 with a quantity of straw temper and some black and white grits; irregular burnishing on both surfaces. Type III.A.1.c.

188,10 (Fig. 6/9). Carinated bowl with short, concave, flaring sides; rounded lip; two incised lines below the rim. Rim diameter $15 \mathrm{~cm}$. Medium compact paste 1 with many grits and some straw temper; burnished red slip on both surfaces (7.5R 5/6). Type III.A.4.a.

188,15 (Fig. 6/10). Bowl of medium depth with rounded sides. Band of red paint over the rim. Very compact paste 6 with some grits and straw temper; exterior wet smoothed, interior burnished. Type III.B.3.a.

188,14 (Fig. 6/12). Large tronconical bowl with thickened walls. Compact paste 2 with some grits and straw temper; exterior wet smoothed, interior burnished. Rim diameter $22 \mathrm{~cm}$. Type III.B.4.a.

188,13 (Fig. 6/14). Bowl of large dimensions with vertical upper sides. Band of red paint on rim. Rim diameter $30 \mathrm{~cm}$. Compact paste 2 with many grits and some straw temper; exterior wet smoothed, interior burnished. Type III.C.3.

188,1 (Fig. 6/13). Bowl with incurving rim, flattened lip. Rim diameter $20 \mathrm{~cm}$. Medium compact paste 2 with some grits and straw temper; interior burnished light red slipped (10R 6/6), exterior wet smoothed. Type III.C.4.

188,12 (Fig. 6/11). Basin with convex profile sides, decorated with an incised wavy line on the wall. Compact paste 2 with some grits and straw temper; both surfaces wet smoothed. Type IV.1.

188,16 (Fig. 7/5). Ovoid jar with incurving, thickened rim. Band of red paint over the rim. Rim diameter 22 $\mathrm{cm}$. Compact paste 2; exterior wet smoothed. Type V.A.6.a.

188,3 (Fig. 7/1). Barrel shaped dolium with out-turned rim, flattened lip. Rim diameter $21 \mathrm{~cm}$. Medium compact paste 6 with many grits and some straw temper; exterior wet smoothed, interior with some burnishing. Type VI.4.a.

188,7 (Fig. 7/3). Dolium with out-turned thickened rim, flattened lip. Red paint on top of rim. Rim diameter $36.5 \mathrm{~cm}$. Medium compact paste 2 with many grits and some straw temper, grey core; exterior wet smoothed, interior smoothed. Type VI.4.b.

188,8 (Fig. 7/2). Dolium with out-turned thickened rim, flattened lip. Red paint on top of rim. Rim diameter $18 \mathrm{~cm}$. Rather fine paste 6 with some grits and straw temper; some burnishing on the interior, wet smoothing on the exterior. Type VI.4.b.

188,9 (Fig. 7/4). Ovoid dolium with slightly thickened, out-turned rim. Rim diameter $25 \mathrm{~cm}$. Medium compact paste 6 with many grits and some straw temper; interior smoothed, exterior wet smoothed. Type VI.5. 
188,11 (Fig. 7/6). High stem with flaring sides. Base diameter $5.5 \mathrm{~cm}$. Compact paste 6 with some grits and straw temper; exterior smoothed. Type VII.C.1.

188,17 (Fig. 7/7). Fragment of wall decorated with and applied ridge with impressions. Medium compact paste 6 with a quantity of straw temper and some grits. Pale yellow slip on the exterior (2.5Y 8/3), some burnishing on the interior. Type IX.B.2.

\section{$187($ B.06.C/187)}

187,3 (Fig. 7/8). Deep cup with convex profile, slightly flaring upper sides. Rim diameter $14 \mathrm{~cm}$. Rather fine paste 2 with only some black grits and mica; surfaces burnished. Type II.2.b.

187,2 (Fig. 7/9). Bowl with rounded sides, medium depth; lip beveled on top. Rim diameter $20 \mathrm{~cm}$. Rather fine paste 2 with some grits and straw temper; interior burnished, exterior wet smoothed. Type III.B.3.c.

187,4 (Fig. 8/1). Barrel shaped jar; ledge handle on shoulder. Compact paste 2 with some grits and straw temper; exterior wet smoothed, interior smoothed. Type V.A.4.

187,1 (Fig. 8/2). Ovoid jar with incurving rim. Band of red paint over the rim. Rim diameter $16 \mathrm{~cm}$. Medium compact paste 5 with some grits and straw temper; surfaces smoothed. Type V.A.6.a.

\section{$169 \mathrm{~K}($ B.06.C/169K)}

169K,2 (Fig. 8/3). Deep tronconical bowl with straight, flaring sides. Interior and rim coated with red slip (5YR 6/4). Rim diameter $19 \mathrm{~cm}$. Compact, rather fine paste 2 with only some black grits and some mica; exterior wet smoothed, interior burnished. Type III.A.2.a.

169K,1 (Fig. 8/4). Jar with ovoid body, flaring, wide short neck. Decoration of two incised wavy lines on the body. Rim diameter $15 \mathrm{~cm}$. Compact paste 6 with some grits and straw temper; exterior smoothed. Type V.C.3.

$186($ B.06.C/186)

186,4 (Fig. 8/5). Carinated bowl with thickened carination, short, concave, flaring sides, rounded lip; one incised line below the rim. Rim diameter $13 \mathrm{~cm}$. Medium compact paste 1 with only some black grits and mica; surfaces coated with burnished red slip (7.5R 5/4). Type III.A.4.a.

186,1 (Fig. 8/6). Fragment of a carinated wall with convex foot. Medium compact paste 6 with some grits and straw temper; exterior smoothed. It could be a variant of type III.A.4.c.

186,2 (Fig. 8/7). Large tronconical bowl with flaring sides, rim slightly thickened, flattened lip. Rim diameter $22.5 \mathrm{~cm}$. Rather fine paste 6 with many grits and some straw temper; interior with tight burnishing, exterior wet smoothed. Type III.B.4.b.
186,5 (Fig. 8/8). Bowl with converging upper sides and rounded profile, thinned rim. Rim diameter $13 \mathrm{~cm}$. Medium compact paste 6, with some white grits, some large black, large red and straw temper; interior coated with burnished red slip (10R 5/6), exterior smoothed. Type III.C.4.

186,6 (Fig. 8/9). Basin with flaring, straight sides, thickened and flattened rim. Rim diameter $34 \mathrm{~cm}$. Medium compact paste 6 with some grits and straw temper; surfaces smoothed. Type IV.4.c.

186,3 (Fig. 8/10). Jar with converging sides, barrel shaped body; beveled rim. Rim diameter $19 \mathrm{~cm}$. Compact paste 6 with some grits and straw temper; exterior surface wet smoothed, interior smoothed. Type V.A.4. 186,7 (Fig. 8/11). Dolium with high neck, concave sides; rim slightly out-turned and flattened lip. Rim diameter $37 \mathrm{~cm}$. Coarse paste 6 with few black grits, mica and some straw temper; interior coated with red slip (10R 5/6) and light brown on the exterior (7.5YR 6/4). Type VI.6.a.

\section{$169 \mathrm{H}($ B.06.C/169H)}

169H,3 (Fig. 9/1). Large bowl of medium depth, rounded sides; lip beveled on top. Rim diameter $26 \mathrm{~cm}$. Coarse paste 6 with some white grits, some large black and red inclusions, straw temper. The surfaces are coated with a burnished light brown slip (5YR 6/4). Type III.B.3.c.

169H,1 (Fig. 9/2). Basin with steep, straight sides; rim thickened inside, flat lip. Decoration of a band of three comb incised wavy lines on the wall. Rim diameter $23 \mathrm{~cm}$. Medium compact paste 4 with many grits and some straw temper; interior and top of rim coated with reddish brown slip (2.5YR 5/4), exterior wet smoothed. Type IV.3.

169H,2 (Fig. 9/3). High neck of a jar (?), flaring rim. Rim diameter $18 \mathrm{~cm}$. Compact paste 1 with only some black grits and mica. Surfaces coated with burnished red slip (10R 5/6). Type V.C.4.

185 (B.06.C/185)

185,6 (Fig. 9/4). Deep bowl with convex profile, one incised line below the rim. Rim diameter $21 \mathrm{~cm}$. Surfaces coated with weak red slip (10R 5/4); band of red paint on the rim. Medium compact paste 1 with some grits and straw temper. Type III.A.3.

185,3 (Fig. 9/6). Wavy rim bowl with vertical sides. Fine paste 4 with some black grits and mica; interior coated with very pale brown slip (10YR 7/3), exterior smoothed. Type III.A.5.

185,5 (Fig. 9/5). Deep, tronconical bowl, with thickened rim, straight, flaring sides. Traces of red paint on the rim. Rim diameter $21 \mathrm{~cm}$. Medium compact paste 4 with few grits and some straw temper; traces of slip on the interior, exterior wet smoothed. Type III.B.4.a.

185,9 (Fig. 9/7). Jar with short, vertical neck, rim cut obliquely. Rim diameter $15 \mathrm{~cm}$. Rather porous paste 5 
with a quantity of grits and some straw temper; exterior wet smoothed, interior smoothed. Type V.C.1.a.

185,8 (Fig. 9/8). Disc base with slightly projecting foot. Surfaces coated with red slip. Compact paste 1 with some grits and straw temper. Type VII.A.2.

185,4 (Fig. 9/11). Low ring base with flaring, convex foot, possibly belonging to a wavy rim bowl. Base diameter $10 \mathrm{~cm}$. Rather fine paste 5 with some grits and straw temper; exterior smoothed, internal surface not preserved. Type VII.B.2

185,7 (Fig. 9/9). Low ring base with flaring, convex foot. Compact paste 6 with only some black grits and mica; surfaces smoothed. Type VII.B.3.

185,2 (Fig. 9/10). High ring base with flaring straight foot. Base diameter $12 \mathrm{~cm}$. Fine paste $9(10 \mathrm{R} 5 / 6)$ with some black grits; external smoothed. Type VII.B.4.

185,10 (Fig. 9/12). Vertical loop handle with circular section. Compact paste 6 with some grits and straw temper; surface wet smoothed. Type VIII.1.b.

$169 G(B .06 . C / 169 G)$

169G,5 (Fig. 9/13). Cup with tronconical profile, straight, flaring sides. Rim diameter $16.5 \mathrm{~cm}$. Fine paste 6 with few black grits and mica; surfaces smoothed. Type II.3.

169G,6 (Fig. 9/15). Bowl of small dimensions, with straight, flaring sides. Rim diameter $16.5 \mathrm{~cm}$. Fine paste 2 with only some mica; on both surfaces irregular burnishing. Type III.A.1.a.

169G,13 (Fig. 9/14). Small tronconical bowl with straight, flaring sides. Rim diameter $12 \mathrm{~cm}$. Rather fine paste 6 withy some mica; exterior smoothed, interior burnished. Type III.A.1.a.

169G,12 (Fig. 10/1). Small, deep bowl with convex profile; one incised line below the rim. Rim diameter 13 $\mathrm{cm}$. Compact paste 1 with some grits and straw temper; red slip (10R 5/6) on interior, light reddish brown slip (5YR 6/4) on exterior. Type III.A.3.

169G,4 (Fig. 10/3). Carinated bowl with thickened carination, flaring upper side; one incised line below the rim. Compact paste 1 with only black grits and mica; surfaces coated with burnished red slip (10R 5/6). Type III.A.4.a.

169G,11 (Fig. 10/2). Carinated bowl with thickened carination, rim diameter equal to that of the carination. Rim diameter $16 \mathrm{~cm}$. Rather compact paste 1 with a quantity of straw temper and some grits. Burnished red slip on both surfaces (10R 10/6). Type III.A.4.b.

169G,10 (Fig. 10/4). Shallow bowl with convex profile sides, flaring rim. Rim diameter $19.5 \mathrm{~cm}$. Compact, rather fine paste 5 with some grits and straw temper; surfaces smoothed. Type III.B.1.

169G,9 (Fig. 10/5). Deep tronconical bowl, with straight, flaring sides; rim thickened. Rim diameter 23 $\mathrm{cm}$. Compact paste 5 with some grits and straw temper; surfaces smoothed. Type III.B.4.a.
169G,8 (Fig. 10/6). Large bowl with angular profile; flattened rim. Rim diameter $26 \mathrm{~cm}$. Compact paste 5 with a quantity of grits and some straw temper; exterior wet smoothed. Type III.C.2.

169G,3 (Fig. 10/8). Ovoid jar with strongly converging upper side; decoration of two wavy comb incisions. Rim diameter $21 \mathrm{~cm}$. Compact paste 7 with few grits and a small quantity of straw temper; exterior coated with a pale yellow slip (2.5Y 8/2), interior smoothed. Type V.A.5.

169G,7 (Fig. 10/7). Jar with ovoid body with converging sides; decoration of an incised line below the rim. Rim diameter $16.5 \mathrm{~cm}$. Compact, rather fine paste 6 with some grits and straw temper; irregular burnishing on both surfaces. Type V.A.8.

169G,1 (Fig. 10/ 10). Low ring base with flaring, concave foot. Base diameter $11 \mathrm{~cm}$. Compact paste 6 with some grits and straw temper; exterior wet smoothed, interior smoothed. Type VII.B.3.

169G,2 (Fig. 10/9). Low ring base with flaring foot. Base diameter $22.5 \mathrm{~cm}$. Coarse paste 6 with some white grits, some large black inclusions, some grey and red inclusions, grey core; exterior coated with red slip (2.5YR 5/6). Type VII.B.3

\section{4 (B.06.C/184)}

184,1 (Fig. 10/11). Basin with flaring, straight sides. Compact paste 6 with few grits and straw temper; exterior smoothed, interior coated with a dark red slip (5YR 6/4). Type IV.4.c.

184,2 (Fig. 10/13). Ring base with vertical foot. Base diameter $13 \mathrm{~cm}$. Rather fine paste 6 with some grits and straw temper; exterior smoothed. Type VII.B.5.a.

184,3 (Fig. 10/12). Fragment of wall with applied decoration of two horizontal, parallel ridges. Compact paste 2 with some grits and straw temper, exterior smoothed. Type IX.B.1.

\section{F (B.06.C/169F)}

169F,1 (Fig. 10/15). Low ring base with slightly flaring foot. Base diameter $19 \mathrm{~cm}$. Medium compact paste 8 , with few grits and some straw temper; exterior coated with a very pale brown slip (10YR 8/3), interior smoothed. Type VII.B.3.

169F, 2 (Fig. 10/14). Low ring base with flaring, convex foot. Base diameter $14 \mathrm{~cm}$. Medium compact paste 7 with some grits and straw temper; exterior coated with a burnished very pale brown slip (10YR 8/3). Type VII.B.3.

\section{E (B.06.C/169E)}

169E,2 (Fig. 10/18). Low ring base with flaring foot. Base diameter $9 \mathrm{~cm}$. Compact paste 1 with some black grits and mica; surfaces coated with burnished light red slip (7.5YR 7/4). Type VII.B.2. 
$183($ B.06.C/183)

183,2 (Fig. 10/16). Small cup with vertical, rounded sides. Medium compact paste 1 with only some black grits and mica; burnished red slip on both surfaces (7.5R 5/6). Type II.1.
183,1 (Fig. 10/17). Large shallow bowl with convex profile sides, flaring rim. Rim diameter $22.5 \mathrm{~cm}$. Compact paste 2 with many grits and some straw temper; both surfaces smoothed. Type III.B.1.
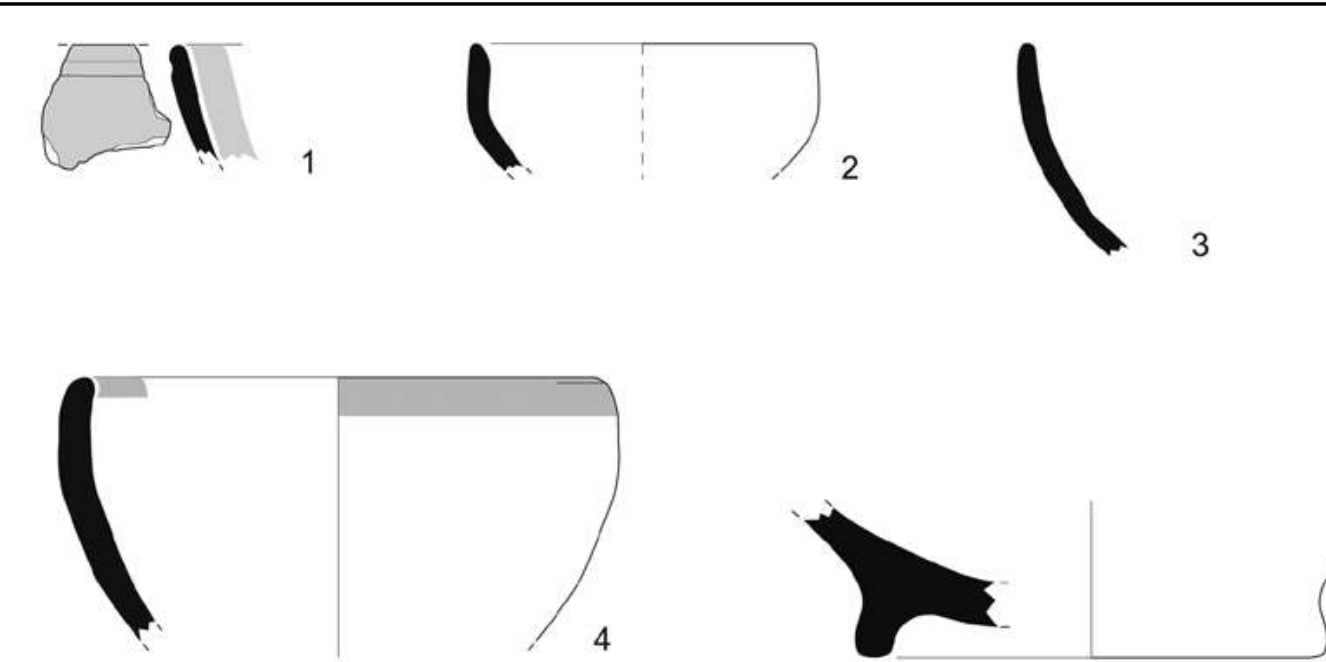

5
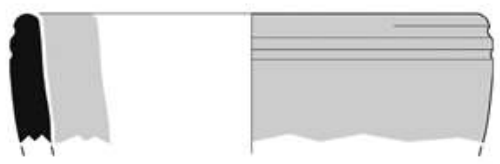

6
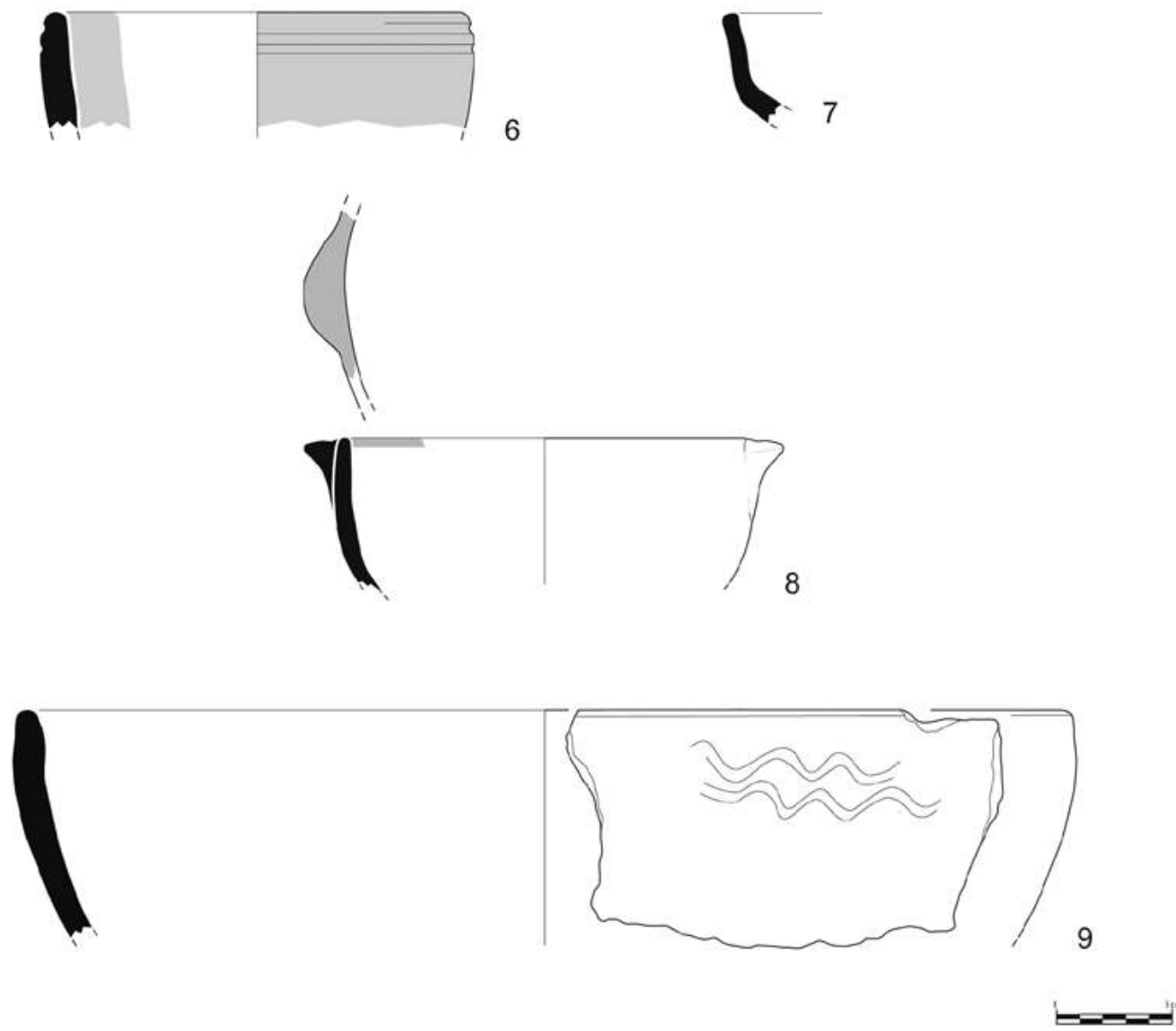

Fig. 1. 1: B.06.C./193,1; 2: B.06.C./192,3; 3: B.06.C./192,2; 4: B.06.C./192,1; 5: B.06.C./192,4; 6: B.06.C./191B,6; 7: B.06.C./191B,5; 8: B.06.C./191B,3; 9: B.06.C./191B,2. (G. Stelo 2006 @MAIRY) 
VitToria Buffa: AReA C. THE MinaEAn POTTERy
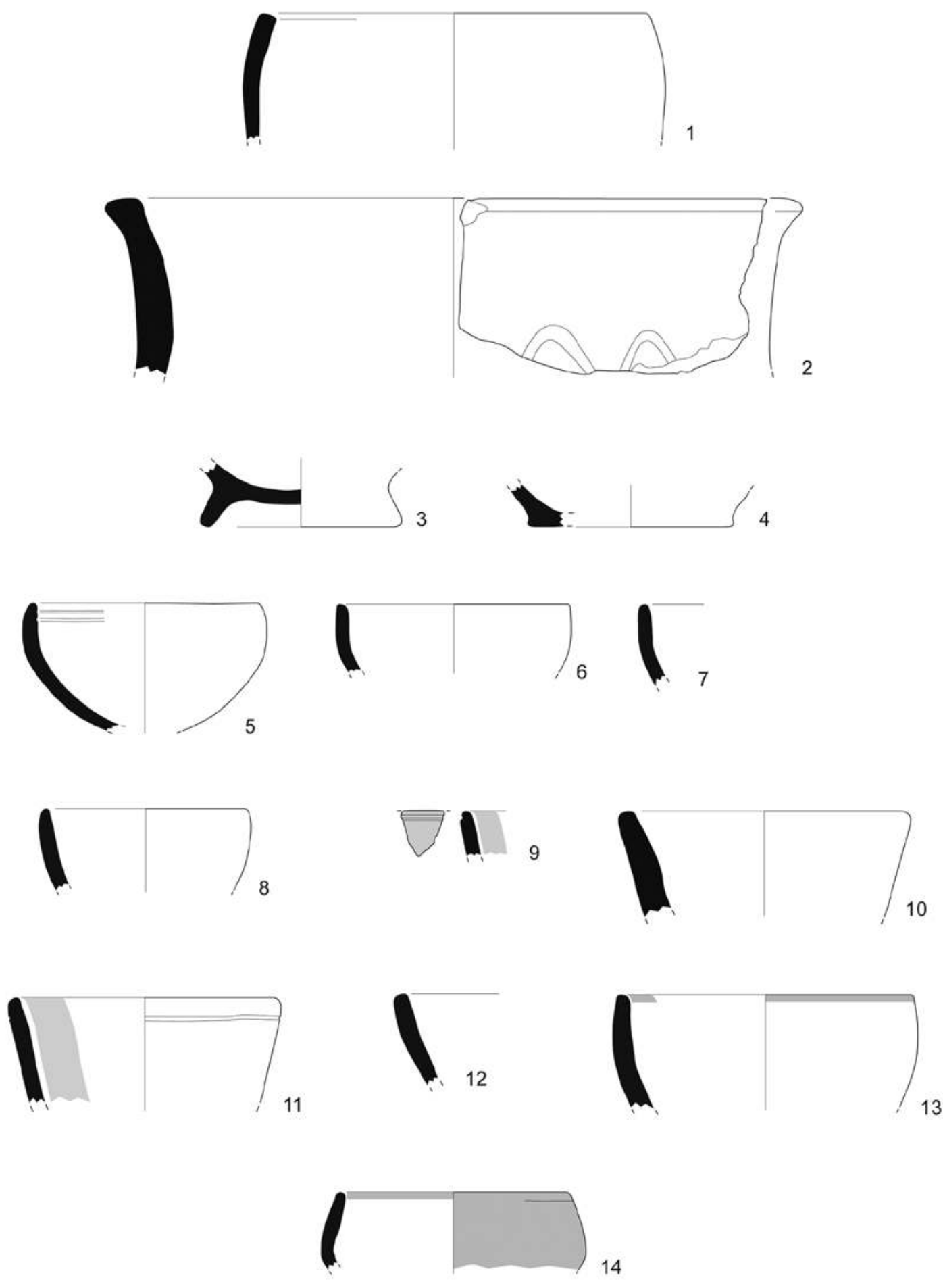

Fig. 2. 1: B.06.C./191B,4; 2: B.06.C./,191B,1; 3: B.06.C./191B,7; 4: B.06.C./191B,8; 5: B.06.C./191,1; 6: B.06.C./191,17; 7: B.06.C./191,16; 8: B.06.C./191,15; 9: B.06.C./191,19; 10: B.06.C./191,4; 11: B.06.C./191,10; 12: B.06.C./191,9; 13: B.06.C./191,8; 14: B.06.C./191,14. (G. Stelo 2006 CMAIRY)

727 


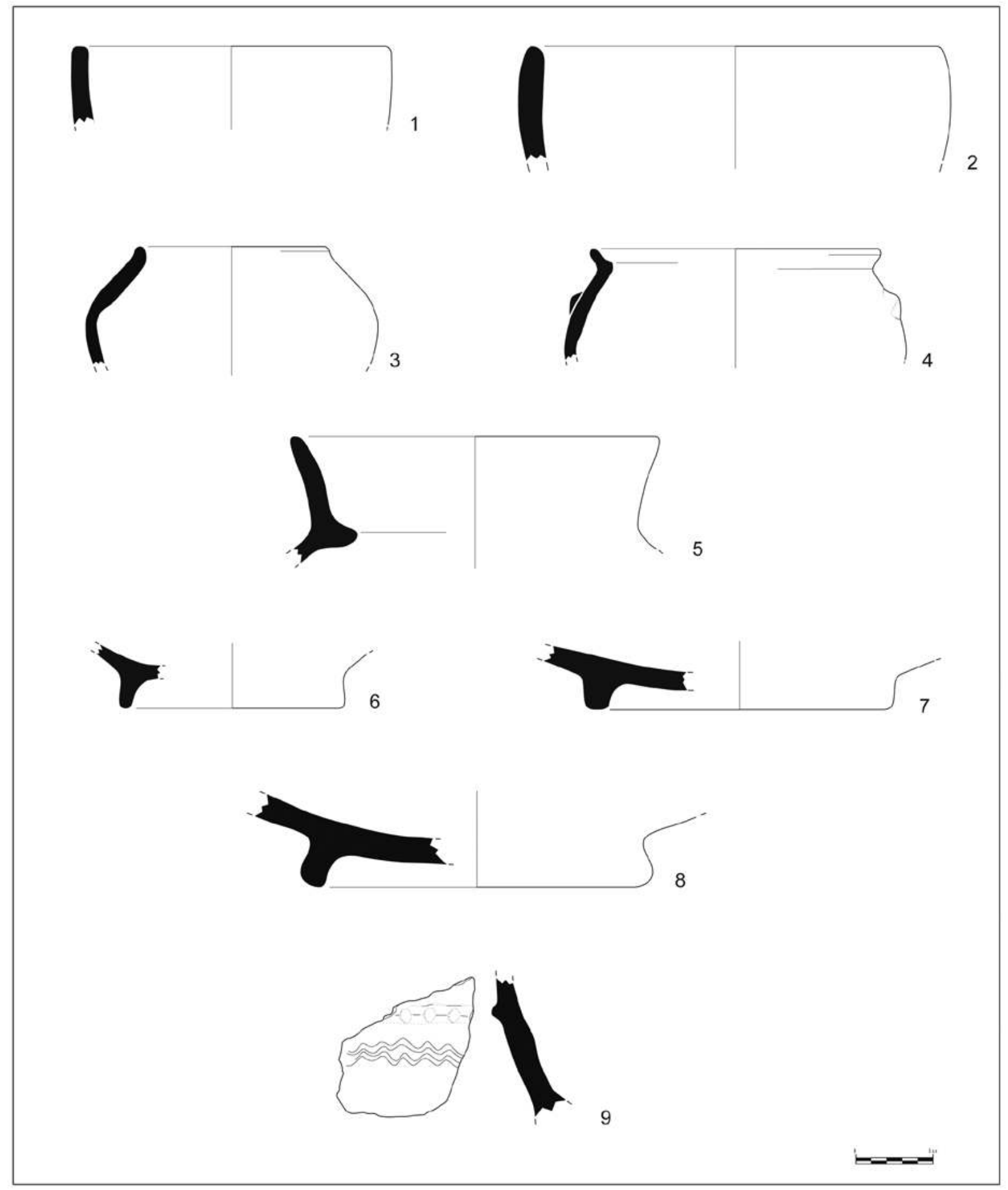

Fig. 3. 1: B.06.C./191,13; 2: B.06.C./191,7; 3: B.06.C./191,11; 4: B.06.C./191,12; 5: B.06.C./191,3; 6: B.06.C./191,18; 7: B.06.C./191,1; 8: B.06.C./191,2; 9: B.06.C./191,6. (G. Stelo 2006 @MAIRY) 


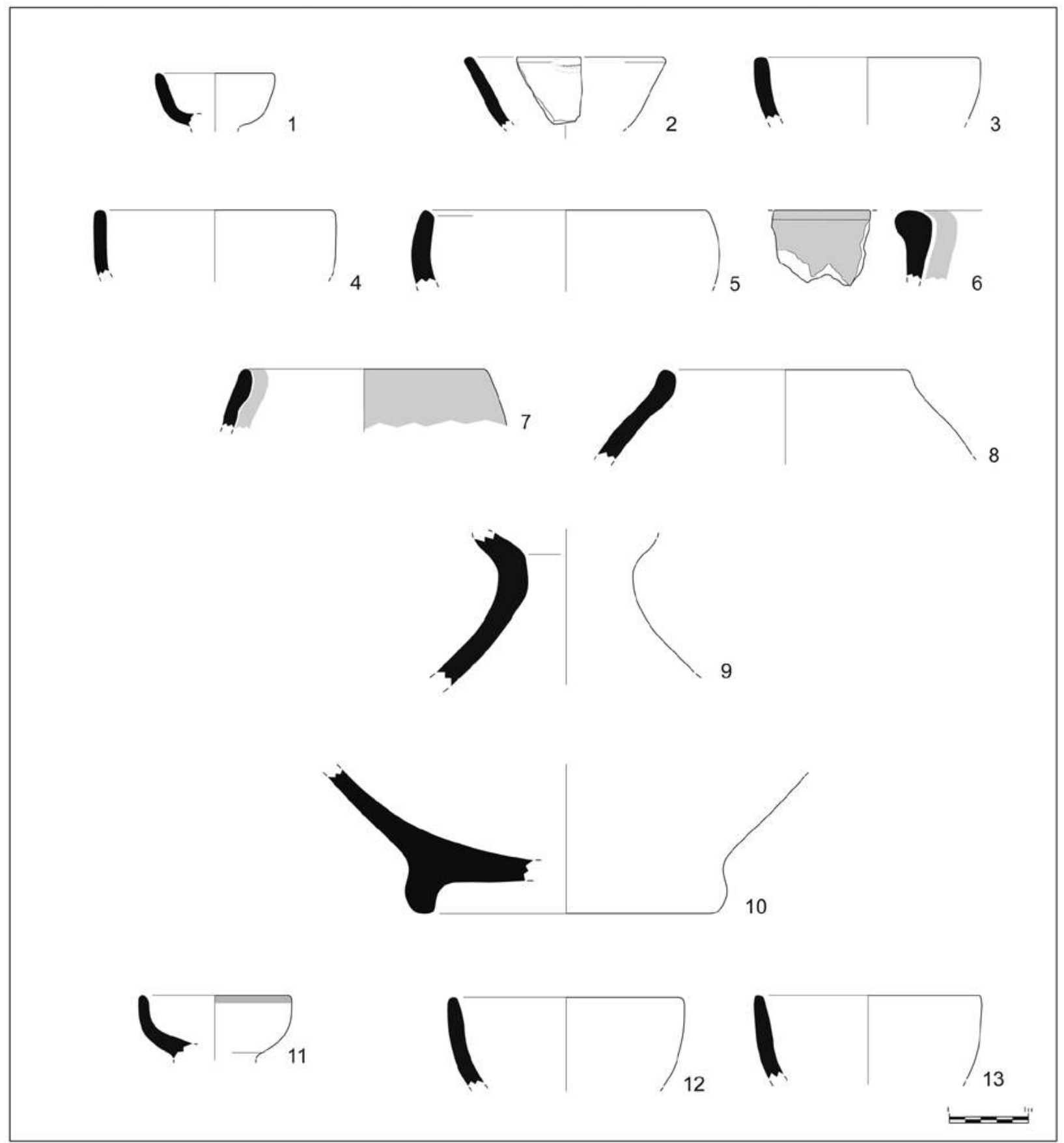

Fig. 4. 1: B.06.C./190,1; 2: B.06.C./190,13; 3: B.06.C./190,14; 4: B.06.C./190,12; 5: B.06.C./190,11; 6: B.06.C./190,7; 7: B.06.C./190,6; 8: B.06.C./190,5; 9: B.06.C./190,2; 10: B.06.C./190,3; 11: B.06.C./189,12; 12: B.06.C./189,16; 13: B.06.C./189,22.

(G. Stelo 2006 @MAIRY) 


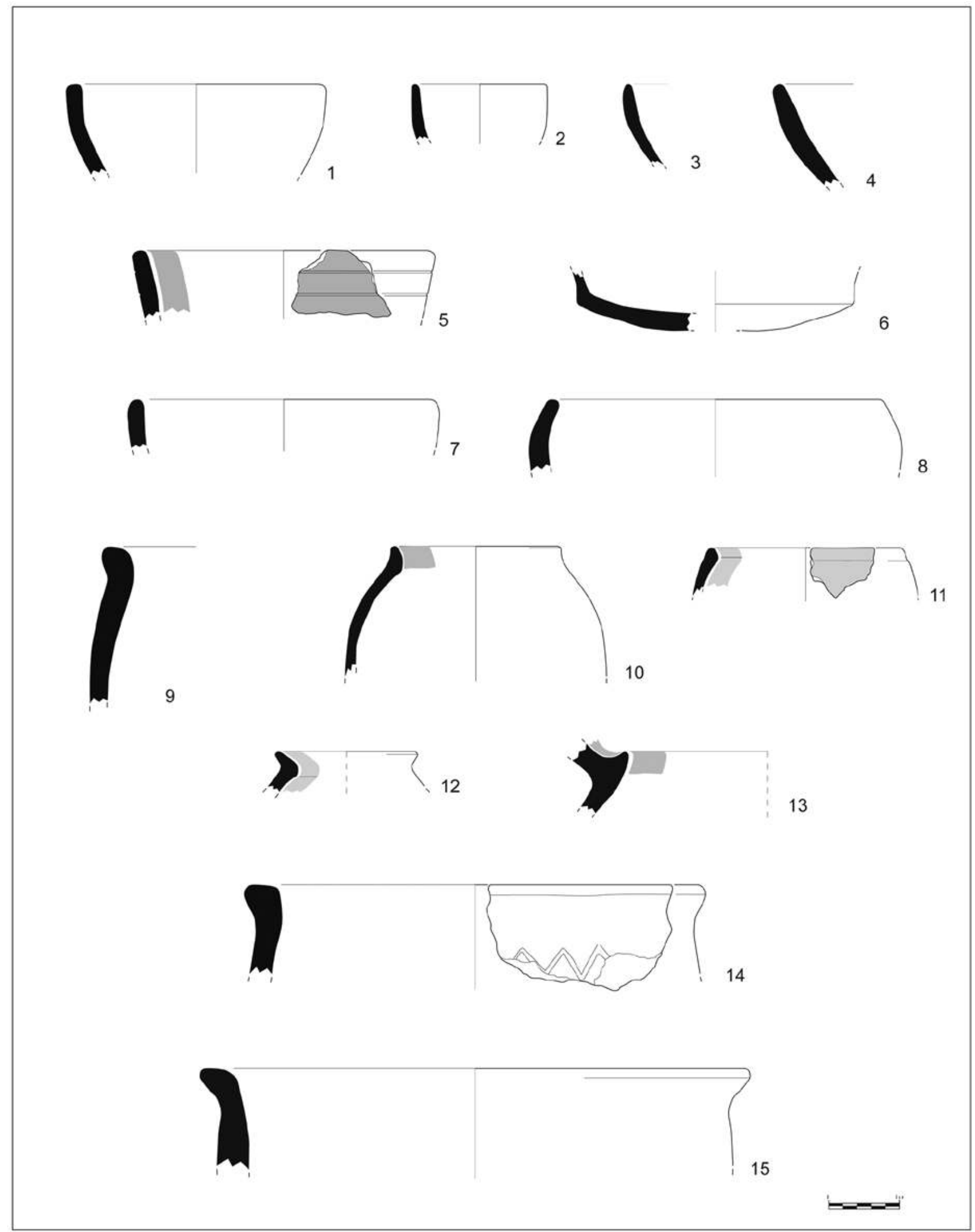

Fig. 5. 1: B.06.C./189,15; 2: B.06.C./189,19; 3: B.06.C./189,25; 4: B.06.C./189,24; 5: B.06.C./189,11; 6: B.06.C./189,21; 7: B.06.C./189,23; 8: B.06.C./189,17; 9: B.06.C./189,8; 10: B.06.C./189,18; 11: B.06.C./189,26; 12: B.06.C./189,13; 13: B.06.C./189,4; 14: B.06.C./189,5; 15: B.06.C./189,6. (G. Stelo 2006 CMAIRY) 


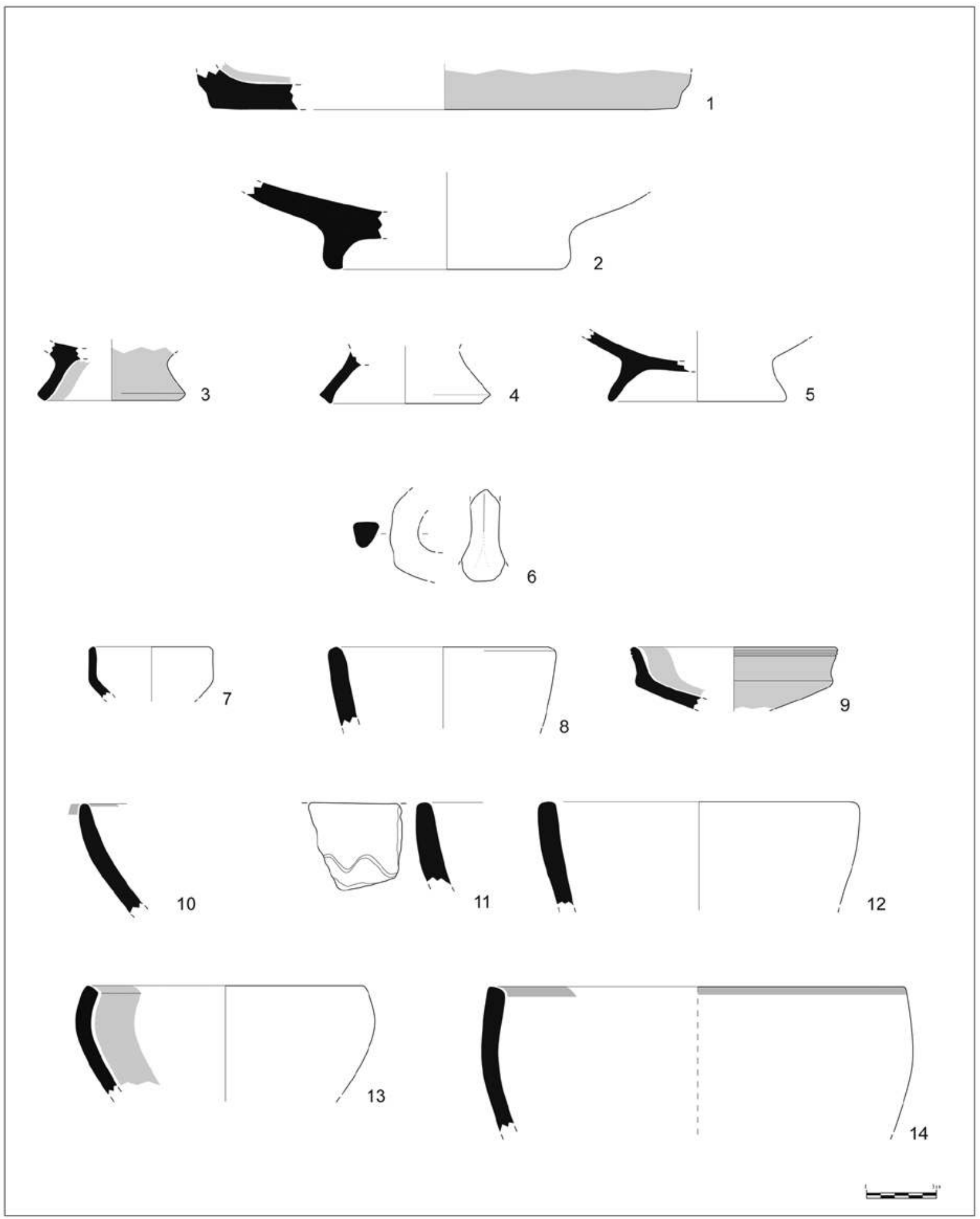

Fig. 6. 1: B.06.C./189,3; 2: B.06.C./189,7; 3: B.06.C./189,2; 4: B.06.C./189,9; 5: B.06.C./189,1; 6: B.06.C./189,14; 7: B.06.C./188,6; 8: B.06.C./188,5; 9: B.06.C./188,10; 10: B.06.C./188,15; 11: B.06.C./188,14; 12: B.06.C./188,1; 13: B.06.C./188,13; 14: B.06.C./188,12. (G. Stelo 2006 CMAIRY) 


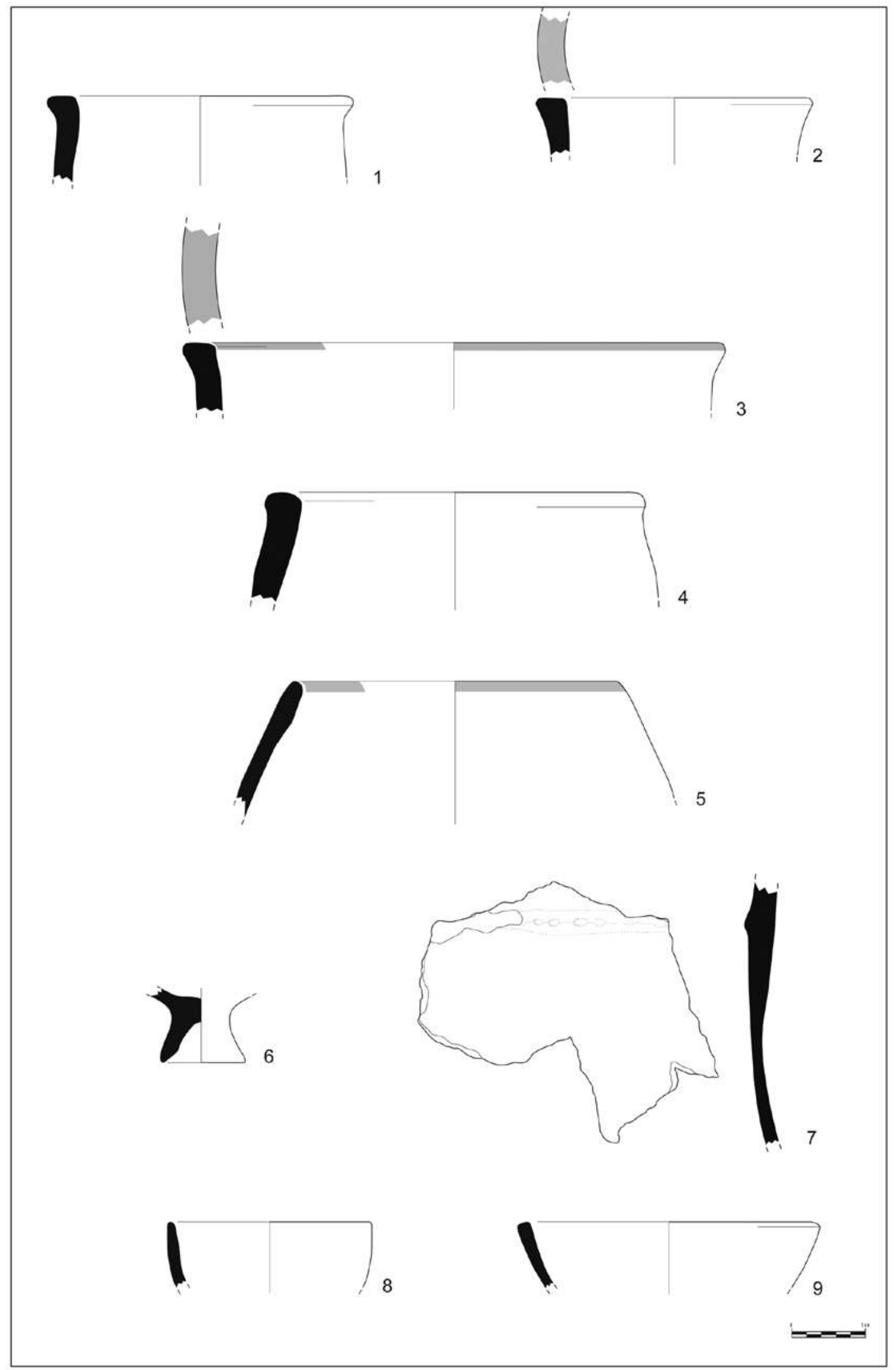

Fig. 7. 1: B.06.C./188,3; 2: B.06.C./188,8; 3: B.06.C./188,7; 4: B.06.C./188,9; 5: B.06.C./188,16; 6: B.06.C./188,11; 7: B.06.C./188,17; 8: B.06.C./187,3; 9: B.06.C./187,2. (G. Stelo 2006 OMAIRY) 


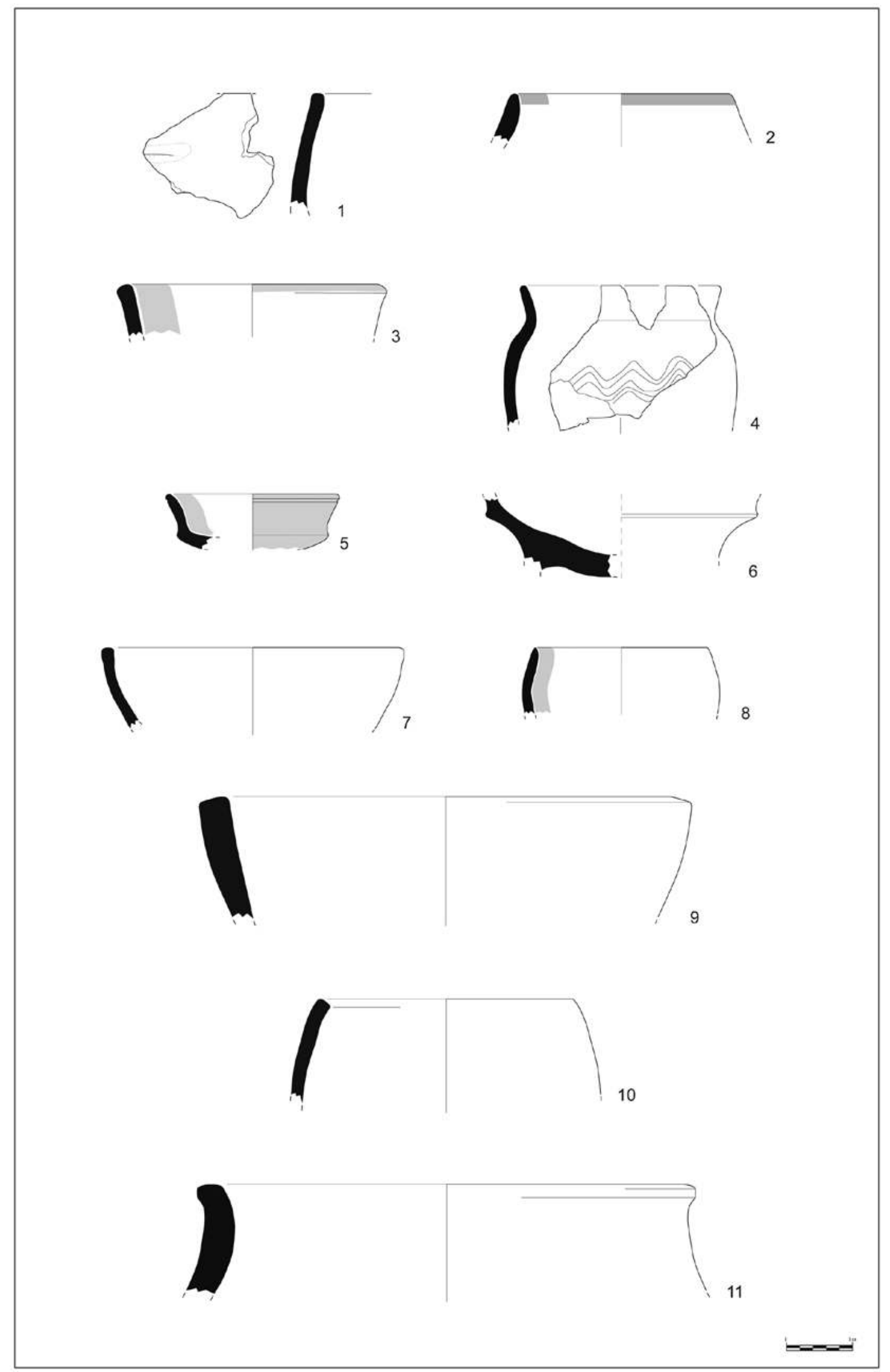

Fig. 8. 1: B.06.C./187,4; 2: B.06.C./187,1; 3: B.06.C./169K,2; 4: B.06.C./169K,1; 5: B.06.C./186,4; 6: B.06.C./186,1; 7: B.06.C./186,2; 8: B.06.C./186,5; 9: B.06.C./186,6; 10: B.06.C./186,3; 11: B.06.C./186,7. (G. Stelo 2006 @MAIRY) 


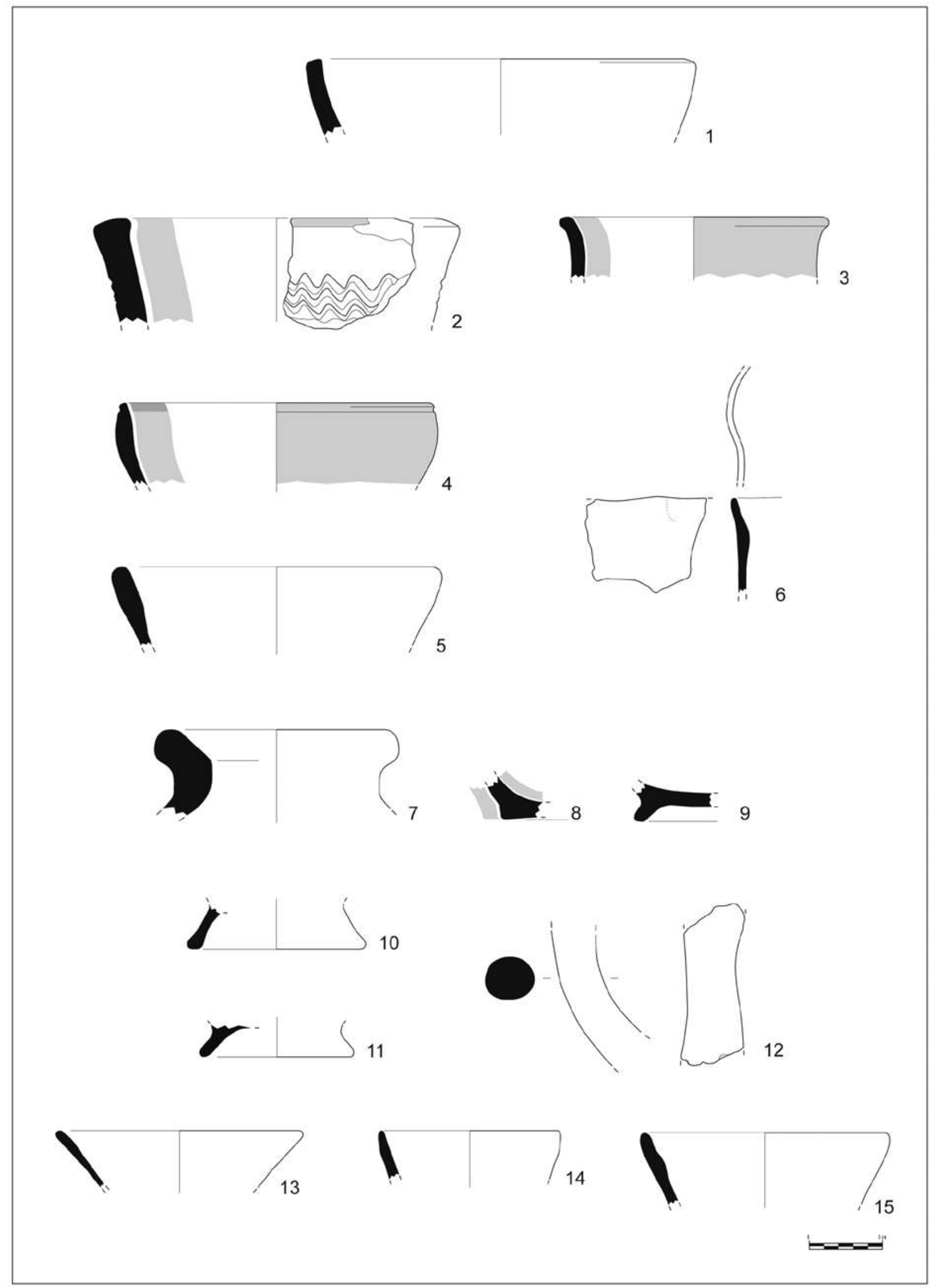

Fig. 9. 1: B.06.C./169H,3; 2: B.06.C./169H,1; 3: B.06.C./169H,2; 4: B.06.C./185,6; 5: B.06.C./185,5; 6: B.06.C./185,3; 7: B.06.C./185,9; 8: B.06.C./185,8; 9: B.06.C./185,7; 10: B.06.C./185,2; 11: B.06.C./185,4; 12: B.06.C./185,10; 13: B.06.C./169G,5; 14: B.06.C./169G,14; 15: B.06.C./169G,6. (G. Stelo 2006 @MAIRY) 


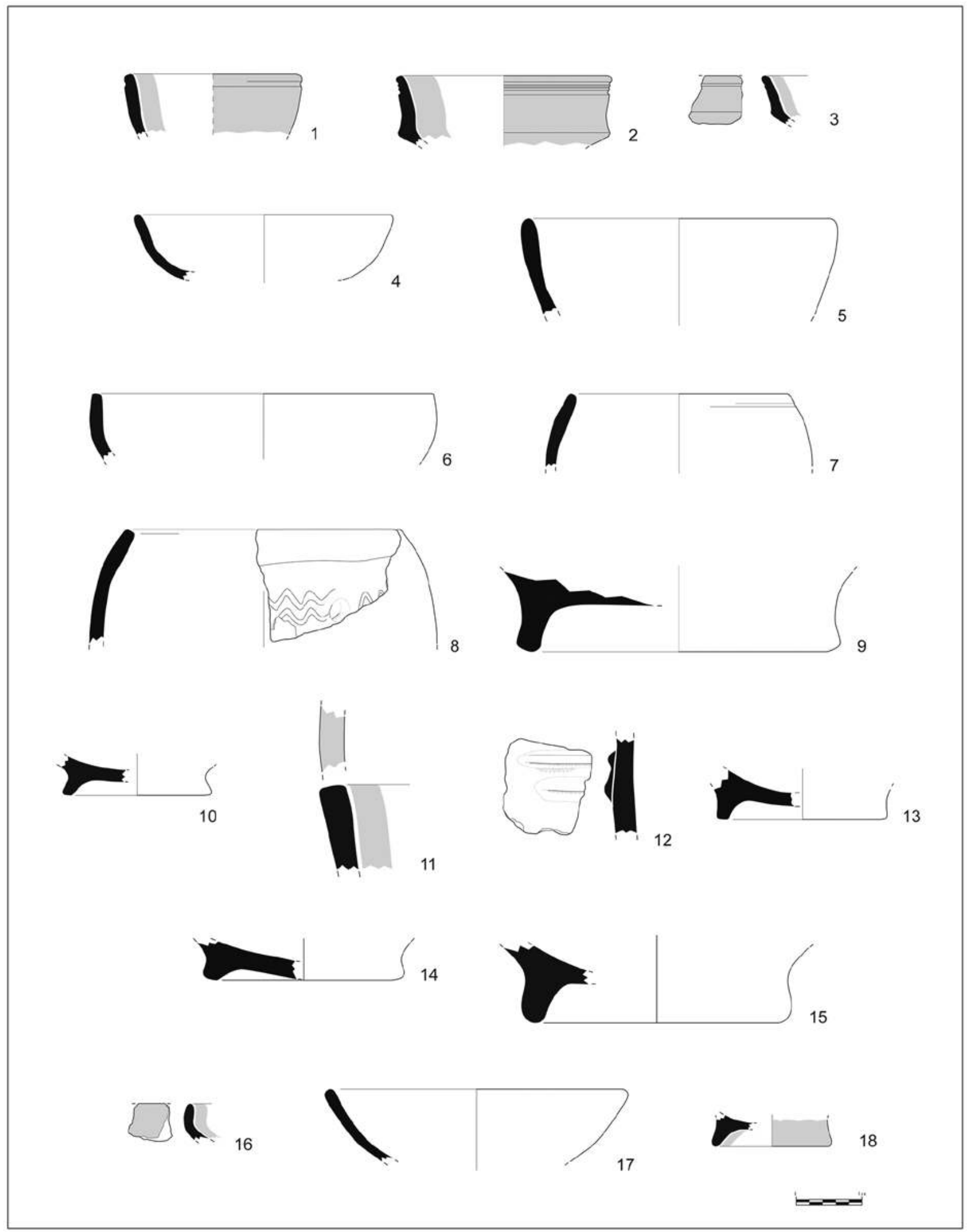

Fig. 10. 1: B.06.C./169G,12; 2: B.06.C./169G,11; 3: B.06.C./169G,4; 4: B.06.C./169G,10; 5: B.06.C./169G,9; 6: B.06.C./169G,8; 7: B.06.C./169G,7; 8: B.06.C./169G,3; 9: B.06.C./169G,2; 10: B.06.C./169G,1; 11: B.06.C./184,1; 12: B.06.C./184,3; 13: B.06.C./184,2; 14: B.06.C./169F,2; 15: B.06.C./169F,1; 16: B.06.C./183,2; 17: B.06.C./183,1; 18: B.06.C./169E,2. (G. Stelo 2006 @MAIRY) 


\title{
Chapter 23
}

\section{Area C. The Sabaean Pottery: a Survey}

\author{
Francesco G. Fedele
}

\section{Introduction}

A study of the Sabaean pottery from the excavations in Area C, parallel to the detailed typological study of the Minaean ceramics carried out in 2007 and similarly accompanied by formal drawings (see Buffa, previous chapter in this volume), was planned for 2008, but that season was not to be. ${ }^{1}$ As such a study still lies in an indeterminate future, the present chapter mainly intends to offer a survey of the pottery collection on the basis of my own observations and sketches. Given the early termination of the field and laboratory work, it does not constitute a formal typology nor can provide a full record of the material. A more formal treatment will be reserved only to some important developments of ceramic production during the so-called Later Sabaean phase. ${ }^{2}$

It needs be stressed that the Sabaean pottery was essentially examined with two aims in mind: as a complement to stratigraphy, and as a functional indicator. ${ }^{3}$ Those were also the aims of the selective photographic record of the Sabaean pottery that was carried out between 2006 and 2007. ${ }^{4}$ Stratigraphically, pottery can be instrumental in assigning cultural affiliation, and so it was at Area C. Observed ceramic changes through time were then used to identify the traits of a local ceramic sequence during the Sabaean period at Yathill - a ceramic 'evolution'. ${ }^{5}$ Integral to that, the ceramic finds were expected to perform a particular function in lithostratigraphy, that of taphonomic indicators: the quantification of

\footnotetext{
1 See Chapter 1 , section 4.1, in Volume 1.

2 The information in this chapter is based on the extensive studies carried out at Barāqish in 2006-2007, subsequently developed for the excavation report in the journal Arabia (Fedele 2010), and further reappraised for the present volume in 2018-2019.

3 Cf. Chapter 17 , section 1.3 , this volume.

4 In December 2006 with staff photographer Patrizio Morlupi, and in December 2007 with graduate students Gennaro Di Rosa and Stefano Iavarone, under my supervision (cf. Chapter 1, sections 4.5 and 4.6 , in Volume 1). I am greatly indebted to them all for their goodhumoured, invaluable contribution.

5 In 2005. A year later this seriation was separately perfected by A. de Maigret through his sounding in front of Temple A, Sounding A/S1 (cf. Chapter 1, section 4.5, this volume; published in de Maigret 2010a, with a synopsis in Robin and de Maigret 2009, 63-67).
}

physical condition of sherds described in Chapter 20 (this volume) was key to distinguishing redeposited from primary material, and thus helped to establish stratigraphic correlation across the expanse of Area C. ${ }^{6}$ From the functional point of view, it is well known how pottery can contribute vital clues to identifying the activity 'signature' of deposits and loci, and Area C was no exception. The above orientations must be kept in mind in reading and using the present survey.

The Sabaean ceramic typology established by A. de Maigret on the basis of the pottery assemblage from Yalā, Phase A, dated to the 8th-7th centuries BCE, is well suited to suggest activity clues. ${ }^{7}$ His typological exercise was indeed strictly conceived along morphological lines, while function was attributed from excavated context. This enabled a primary distinction to be made in table, kitchen, storage, and transport or 'trade' vessels, and secondarily allowed refinements based on intuitive inference. Here I will designate this typology as 'morpho-functional'. It is a prime example of the conventional typological approach, which focuses on vessel shape and assumed function, an approach, however, which ran contrary to the most widely followed ceramic classification for Iron Age Yemen. ${ }^{8}$ In the following description of Sabaean pottery reference will be made to de Maigret's type list, where appropriate, and his types will be identified as 'Type' with a capital T. For a more specific typological characterization of the local ceramic repertoire at Yathill, the above cited Sounding at Barāqish Area A will be taken into account, ${ }^{9}$ bearing in mind, however, that the Area A forms were never intended to represent a formal typology.

\footnotetext{
6 Cf. Fedele 2010, 100.

7 de Maigret 2003. Summarized in Loreto 2009; 2011, 230-233. This type list identifies 41 formal types, illustrated by specimens representing 23 per cent of the pottery finds from House A. The full publication of the pottery collection, with minor typological additions, can be found in Loreto 2011, 242-269. Yalā/al-Durayb is ancient Hafary, $30 \mathrm{~km}$ south of Mārib; on the dating of its House A and Phase A see Fedele 2009, 136-138, and Chapter 18, this volume, Fig. 4.

8 Van Beek 1969, 115-266. A. de Maigret was unable to take into account Glanzman's (1994) dissertation, which greatly refined previous ceramic analyses from Wādī al-Jūbah (principally Glanzman 1987a). For some recent, insightful comments about 'defining shapes' and 'naming types' see Buffa 2016b.

9 de Maigret 2010a, 76-87.
} 
Both the Area A sounding and the Area C collection already show that in several details the ceramics from Yathill possess originalities with respect to the Sabaean homeland, as represented by Yalā, either in terms of further variation in already known type groups or because entirely new types appear. These still modest hints of regional variation are obviously not surprising, nor is the perception - difficult to substantiate at the moment - that ceramic elements foreign to the Sabaean area are present at a trading and border centre such as Yathill.

\section{Sabaean pottery at Yathill: an overview from Area C}

Four basic 'categories' of Sabaean ceramics were recognized and used by de Maigret in his classification for Yathill (Table 1, left half): A, 'red-burnished', i.e., pottery with 'red and/or reddish brown-burnished slip'; B, beige plain, 'beige pottery devoid of surface finish'; $C$, grey/black burnished and not burnished, a rather mixed category whose definition varied stratigraphically (this problem will be discussed below); and D, "heavy pottery with sandy temper', exclusively identified with the socalled torpedo jars. ${ }^{10}$

For de Maigret these four pottery categories 'seem[ed] to reflect four distinct functions, respectively: table ware, food storage vessels, cooking ware and transport vessels. The persistence of precise, immutable vase morphologies in these four categories surely illustrates the perfect functional correspondence between vase types and the needs of the Sabaean community of Yathill. ${ }^{11}$ The work done so far on the collection from Area $C$ requires, however, that the categories now mentioned are to a limited but significant extent integrated and partially modified. The seven technological groups resulting from this reappraisal will be designated with capital initials to indicate formal ware classes: Red Lustrous and Black Lustrous, ${ }^{12}$ Red-slipped, Beige Plain, Pale Green, Grey-black, and Heavy Sandy wares (Table 1, right half).

The Red Lustrous ware is not problematic, having been reported and discussed by a number of authors in connection with widely distributed sites. New to the present proposal, however, is its relationship with the Black Lustrous ware, as discussed below. The colours characterizing the Red Lustrous ware include a very wide range of red to brown hues, the latter suggesting a distinction from the bright reds as already accurately

\footnotetext{
10 de Maigret 2010a, 76-77, 80-82, 85-87.

11 de Maigret 2010a, 85.

12 'Lustrous' was preferred as a conventional label in order to stress the specificity of the Sabaean production as well as to avoid 'burnished', a term already commonly used in a number of other instances and meanings.
}

noted by de Maigret; ${ }^{13}$ this chromatic variety was further multiplied by pattern-burnishing, i.e., the effect on the surface of a vessel produced by rubbing or beating the leather-hard clay in a patterned motif. Criss-cross and parallel-linear strokes are the patterns documented at Area C. Pattern-burnishing 'created an attractive surface in which the alternation of burnished and unburnished areas developed an interplay of the glossy and matte surface'..$^{14}$ Chronologically, on present evidence from Area C, pattern-burnishing is dubiously documented at the end of the Earlier Sabaean (find no. 61.01), but effectively characterizes the Later Sabaean phase (see the introduction to section 3.2).

In both the catalogue and commentary parts of section 3 the distribution of burnishing on the vessel will not always be noted, largely because it could not be recorded during the laboratory time at my disposal in 2006-2007. The available records suggest that all three possible styles were employed: the burnishing of both the interior and exterior surfaces, the restriction of burnishing to the interior surface, and the total or prevalent burnishing of the outside. Even in wellburnished vessels the underside was sometimes left unburnished.

The possibility of unequivocally identifying a Redslipped ware is thin at the moment, as it is based on a small number of rather minute fragments from the Earlier Sabaean (e.g. no. 101.07 in Fig. 9, less clearly no. 99.07 in Fig. 4) and on sparse observations on later finds made during the inventory work. Eventually the creation of this class was determined by the rare but definite existence of totally red-slipped or red-painted vessels which manifestly were not burnished. The class includes occurrences of 'shoddy' productions, such as those that appear to be on the rise towards the end of the Sabaean ceramic phase of Yathill. During this Later Sabaean phase Red Lustrous and Red-slipped wares are apparently transitional, but, once again, the lack of recognizable burnishing on several well preserved, redcoloured finds suggests that a separate ware category is warranted.

Beige Plain ware (uncoated ware) is well represented at Yathill. In his typology based on Yalä's House A assemblage de Maigret did not deal with fabric, and nothing was said of the presence of a plain ware alongside the burnished ware. There was no need to elaborate on an observation which replicated what had

\footnotetext{
13 de Maigret 2010a, 77, note 9; 85. The reddish-brown hues appeared to characterize the oldest strata of his sounding, leading him to think that 'the light, poorly conserved aspect of these dark colourings' suggested the use of a different type of slip, originally red but turned darker over time (p. 85).

14 As described by Van Beek $(1969,96)$ in an early definition of this treatment.
} 
been very well recorded elsewhere, ${ }^{15}$ and from surface collections at Yalā itself. ${ }^{16}$ At Barāqish, however, both the surface collections and the reworked Sabaean sherds from Area A appear to have soon alerted de Maigret to the probable variety and frequency of Sabaean plain wares,$^{17}$ particularly those characterized by a beige body. This notion was distinctly reinforced initially in 2005, through our joint examination and discussion of finds from Area C, supported by my demonstration that 'beige' ceramics of many sorts were integral to in situ Sabaean associations. The notion took shape more definitely with the sounding at Temple A in 2006. Our discussions of both his finds from the sounding and mine from Area C, at Barāqish in December 2006, were instrumental for the understanding of what de Maigret informally called 'beige' pottery, back then, and would later describe as beige plain (category B) in his 2010 paper. The 'beige plain' label is retained here.

Virtually all burnished vessels and a fraction of the Beige Plain ones were made in a fine fabric, obtained from selected clay and with very fine grit or grit-andvegetal inclusions. Fine-bodied, ultrathin products in Beige Plain ware appeared during the Later Sabaean (see section 3.2, 'Locus 200', below). While such coated and uncoated vases made for excellent tableware and efficient and flexible containers, they were not suitable for fire. These are well-known and fairly general properties, not specific to the Sabaean production documented at Yathill. Untempered vessels have repeatedly been shown experimentally to have low or minimal heating effectiveness, a disadvantage that applies to cooking or kitchen use in general. Temper - organic or mineral - may also allow the vessels to maintain adequate cooling effectiveness after long periods of use. ${ }^{18}$

Pale Green ware will be specifically examined in section 3.3 below. This ceramic class could be considered akin to Beige Plain ware, since it represents an uncoated production and is often vegetal-tempered. However, the particular association of fabric, vessel's morphology, and delicate manufacture strongly suggests that also in this case a separate ware class is warranted. ${ }^{19}$

Since both Beige Plain ware (e.g. no. 39.02) and Pale Green ware (e.g. vessel V97, Earlier Sabaean, and no. 194.03.3, Later Sabaean) provide clear examples of organic tempered pottery, the advantages and

\footnotetext{
15 E.g., Van Beek 1969, 93, figs 26-27; Glanzman 1987a.

16 de Maigret 1988b, 14-15, figs 21-26. The meticulous descriptions of fabric in de Maigret 1988b effectively complement the nontechnological typology of de Maigret 2003.

17 An indirect reference can be read at the end of de Maigret 2003 (p. 95).

18 Skibo et al. 1989, 139-140.

19 Fedele 2010, 127.
}

disadvantages of organic tempering of clay thoroughly apply to the Sabaean production and deserve to be kept in mind.$^{20}$ In addition to the information summarized in footnote 20 , it is useful to recall that organic-tempered ceramics are up to 50 per cent more susceptible to abrasion than sand-tempered wares, a characteristic with obvious taphonomic implications. ${ }^{21}$ Lacking thinsection observation and biochemical analyses it is impossible to determine whether the use of chaff in Sabaean pottery at Yathill is also an indication of the use of dung. In light of the context and activities of the town, however, the use of dung as organic temper ${ }^{22}$ at Yathill can be taken as certain, considering the undoubted abundance of animals and particularly of ungulates around. ${ }^{23}$

The recognition and separation of Black Lustrous and Grey-black wares require a more extended discussion. The basis for both was provided by de Maigret's category C, which turned out to be unsatisfactory and possibly provisional. In his report of 2010 category C was initially defined in connection with Strata $M$ and $\mathrm{J}$ and described as a plain, coarse (grit-tempered), grey or grey-black pottery, 'possibly cooking ware'. ${ }^{24}$ But this understanding of category $C$ gradually changed, so to speak stratigraphically, apparently to respond to stratigraphic variation. In Strata $\mathrm{F}$ and $\mathrm{E}$ the relevant finds were ordered in a 'dark-grey and/or blackburnished pottery', ${ }^{25}$ while further up, in the topmost Strata D-B, only a 'black-burnished pottery' was mentioned. ${ }^{26}$

Clearly, starting with Stratum $\mathrm{F}$ and probably as a consequence of the very small sample size, de Maigret amalgamated the occasional black-burnished vessel with his previously defined coarse, grey-black cooking ware. ${ }^{27}$ But in fact, as the Area $\mathrm{C}$ collection indicated when studied between 2006 and 2007, the black-

\footnotetext{
20 Following the lead imparted by K.C. Reid, Skibo et al. (1989) confirmed by experiment that organic-tempered pottery provided two advantages: the pots would be noticeably lighter than pots with mineral tempers, as well as more resistant to breakage by impact, especially if a surface treatment were applied (p. 123, 139-140). Being lightweight and strong, organic-tempered vessels would particularly benefit groups that transported their pots during residential shifts or for work (for example travelling traders, in the case of Yathill). In addition, organic temper was found to provide several advantages during vessel manufacture: dry organic matter, in particular, was found to be most effective for making an excessively wet and plastic clay workable (Skibo et al. 1989, 139-140).

21 Skibo and Schiffer 1987; Skibo et al. 1989, 127-129, 139-140, 142.

22 E.g., from a large literature, London 1981; Skibo et al. 1989; Nelson and Associates 2002, 48-50; Lancelotti and Madella 2012; Spengler 2019, 217-218; for bibliography, Miller 2020.

23 Fedele 2014.

24 de Maigret 2010a, 76-78 (see above).

25 de Maigret 2010a, 80-81.

26 de Maigret 2010a, 82-84.

27 Retrospectively, this is also borne out by some of the discussions de Maigret and I had at the time (December 2006; see above).
} 
burnished vessels that occurred at Yathill were made in an entirely different fabric in order to produce a different range of forms. What matters here is that these vessels were made by a specific and distinct process, unrelated to the making of coarse and heavy cooking ware, and their forms - hence functions were completely different from those of cooking pots as well.

Furthermore, it has become clear that black-burnished vessels did parallel red-burnished vessels, and probably were intended to do so. Both classes were burnished in the same way. Their production was identical in all respects apart from a single technological detail: the deposition of carbon on and immediately below the surface of the vessel in order to turn it black, either in a post-firing, smudging or smoking technique, ${ }^{28}$ or through a suitable slip at the leather-hard stage..$^{29}$ Apart from the black and glossy external appearance due to this technical variation, the production of Black Lustrous ware was identical to that of Red Lustrous ware. Also the vessel forms produced appear to be most similar. This is what one can presently say according to the evidence from Area C. In the future, a technological study of these ceramics will certainly clarify the details.

In my classification of fabric and surface treatment informed by the evidence from Area C, I will therefore retain the essence of de Maigret's category $C$ as derived from the lowermost strata of his sounding, and with a little formalization I will rename it Grey-black ware. The interpretation of this class as cooking ware, essentially, is borne out not only by its common association with globular pots but also by the presence and patterning of food and/or burning residues. ${ }^{30}$ The Grey-black ware will be divorced completely from the black-burnished production, which will form the Black Lustrous ware category (Table 1).

The last of the ceramic classes identified, Heavy Sandy ware, does not require many comments. It simply reproduces de Maigret's category D from Yathill and, morphologically, it corresponds completely to Types

\footnotetext{
28 E.g., Balfet et al. 1989, 126-127; Gibson and Woods 1990, 106, 243245; and similar, more recent literature. An interesting parallel for the technology of Black Lustrous ware is perhaps provided by the Khirbet Kerak Ware in Palestine: 'The black colour of the outer face would have been [produced] in the process of the final firing. After the firing, vessels received a further round of polish' (Iserlis 2009, 189).

29 These are the two usual technological options. Most surface treatments are executed at the leather-hard stage (Gibson and Woods $1990,197)$, including the application of a suspension of clay in water in order to cover the vessel with a coloured slip (p. 243). In Sabaean Yemen the slip was red, red-brown, or black.

30 Unsurprisingly, Barāqish Area C confirms that more coarsely tempered pots are certainly the most appropriate for use in cooking, as they are more resistant to thermal shock and in some cases abrasion; yet, such pots might be less suitable for non-cooking functions (Skibo and Schiffer 1987; Skibo et al. 1989, 123).
}

D1a and D1b of Yalä's typology, for which 'torpedo jar' as a designation will be preferred (among the many put forward). ${ }^{31}$ From Area $\mathrm{C}$ a good record was retrieved of the two standard shapes of this jar: the ovoid, often almost globular type (D1a), and the more slender and tapered type (D1b). The fabric is typically coarse, dense, and very heavy. In addition to their particular shape, torpedo jars are almost always unmistakably characterized by the extremely rough moulding of the interior and a highly varying wall thickness. Specific details are given in the description of find no. 110.2 in section 3.1, below.

Area $\mathrm{C}$ confirmed that torpedo jars are abundantly and exclusively found in Sabaean layers. Contrary to earlier opinion, this distinctive vessel was not necessarily a trading jar. From an organic residue analysis of five jars it was concluded ${ }^{32}$ that torpedo jars were a locally produced container ${ }^{33}$ for the transport, storage, and perhaps preparation of some special beverage, possibly a fermented drink. In this case, according to chemical results, beer rather than wine might be a good candidate, while beeswax almost certainly was the usual jar sealant.

An important outcome of work in Area C, supported by the analysis of its stratified archaeological record, was the demonstration of the evolution of Sabaean ceramics during the final century or two of Sabaean Yathill. As the following section will show, an earlier production often consisting of 'classic' carinated pottery comparable to Yalā A - carinated, lustrous, coral-red bowls and jars - was succeeded by a later production more frequently characterized by modestly or even slovenly burnished vessels, together with a substantial frequency of smoothed, plain ware in association with particular, thin-walled vessels. This transition could be only vaguely glimpsed from the sounding in Area A, which, on the other hand, has provided for the moment a longer sampling of Sabaean ceramic evolution at Yathill.

\section{Catalogue and discussion}

In this part of the chapter a selection of 121 pottery specimens from the excavations at Barāqish Area $C$ is illustrated and briefly discussed, out of a collection numbering about 6000 individual sherds, of which

\footnotetext{
31 In both English and Italian: e.g., Type 4100 Jar 1 or 'amphora' (Van Beek 1969, 92-93, 170, 256, fig. 113); 'torpedo-shaped jar' (Glanzman 1987a, 85-87; 1994, 308-324); Type D1 or 'giara oneraria', i.e. trading jar (de Maigret 2003, 92, plates 32-33); 'torpedo jar' (de Maigret 2010a, following Glanzman). Additional terminology is mentioned in Porter 2004, 263.

32 Porter et al. 2009.

33 For the demonstration that torpedo jars were made locally and could not be involved in the regional or long-range trade as previously supposed see Porter 2004.
} 
about 4760 'Sabaean'. From Area C no complete vessel was retrieved, Sabaean or later, although the vessel's size and its complete profile could be inferred for about 25 per cent of the individual sherds or reconstructed portions. The catalogues are styled after Chapter 21, sections 2.1-2.4, this volume, and will follow the conventions and abbreviations set out there. The presentation is organized in approximate stratigraphic and chronological order, and for ease of reference the strata designations in the catalogue will be written in bold (e.g. Stratum P).

General abbreviations and conventions employed in the catalogue

approx.: approximate, approximately

c.: circa, about

$\mathrm{cm}$-sized: centimetre-sized (c. 1-4 cm)

$\mathrm{dm}$-sized: decimetre-sized (c. 8-12 cm)

fr., frs: fragment, fragments

max.: maximum

The measurements refer to the size of the fragment or fragments, unless otherwise indicated.

\subsection{Earlier Sabaean and Sabaean indeterminate}

The Earlier Sabaean ceramic production revealed by Area $C$ at Barāqish can be easily compared to the pottery assemblage from Yalā in the Sabaean homeland, c. 8th-7th centuries BCE. It already includes all seven ware classes in Table 1. None of these classes appears to be dominant, to judge from a provisional estimate of vessels, ${ }^{34}$ although Red Lustrous and Beige Plain wares might together account for perhaps two thirds of the finds.

49D.03 (Fig. 1). Wall fr. buff on the exterior and coated with a yellow-grey slip on the interior. Beige Plain ware, grit-tempered, body ranging in colour from buff to reddish to grey. $6.4 \times 4.5 \mathrm{~cm}, c .1 \mathrm{~cm}$ thick. $\mid D 7+E 120$ $\mathrm{cm}$ east, from flotation sample. Unit SIa. Stratum T. | A unique pottery sherd from Area C, particularly unusual considering its provenance from the earliest Sabaean layer so far tested extramurally. One is tempted to think of a non-Sabaean production.

112.01 (Fig. 2). Large shallow bowl or 'basin', possibly Type A4. ${ }^{35}$ Red Lustrous ware, coral-red. $11.7 \times 5.9 \mathrm{~cm}$, height c. $3.5 \mathrm{~cm}$. E3. Units SI3-V3, but probably from SI3 (on the basis of incrustations), hence Stratum T. |

\footnotetext{
34 A qualitative calculation of the minimum number of vessels (MNV) represented in the collection was attempted in 2007. On MNV see, e.g., Yekutieli 2009, 229.

35 I use 'basin' - a round open container usually for food - to indicate a large open bowl such as de Maigret's (2003) 'cratere' (Type A4, a tableware form).
}

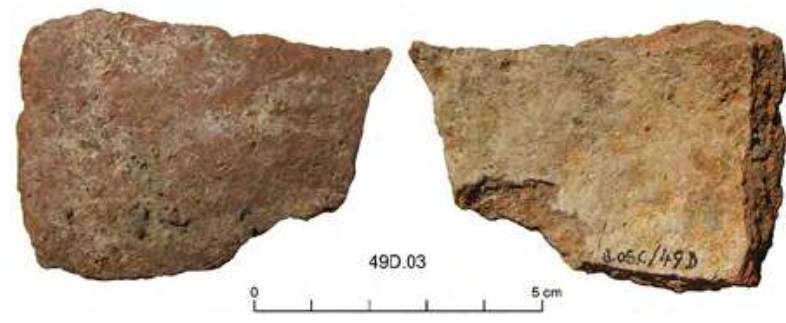

Figure 1. Earlier Sabaean pottery, Stratum T: reg. no. 49D.03. (G. Di Rosa and S. Iavarone 2007 @ MAIRY, arranged and optimized by F.G. Fedele 2020)

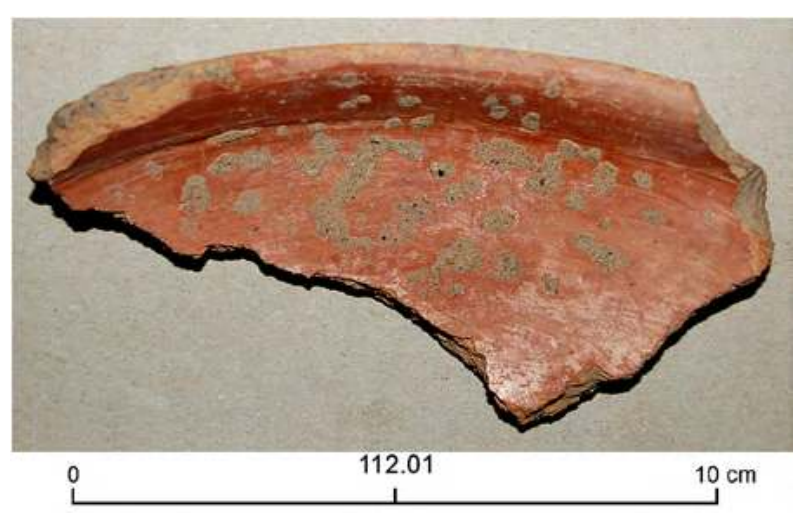

Figure 2. Earlier Sabaean pottery, Stratum T: reg. no. 112.01. (P. Morlupi 2006 @ MAIRY, adapted and optimized by F.G. Fedele 2020)

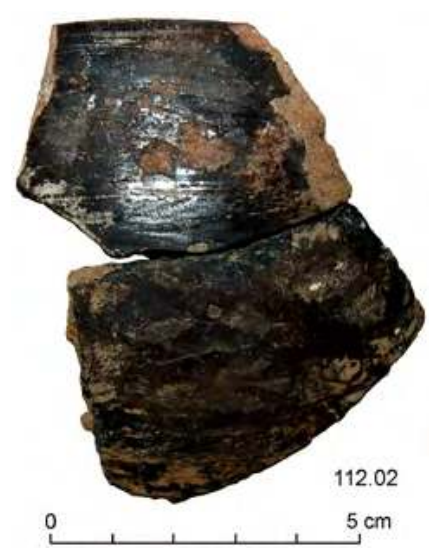

Figure 3. Earlier Sabaean pottery, Strata T-S: reg. no. 112.02. (P. Morlupi 2006 C MAIRY, adapted and optimized by F.G. Fedele 2019)

A sherd in a mint condition (wear grade 0), like 77 per cent of the pottery sherds in cut 112 . The small spots of grey, fine-sandy, charcoal-punctuated incrustations visible on this sherd are particularly common in the deepest sediments of quadrangle E3 (unit SI3), and suggest fairly long in situ residence. 


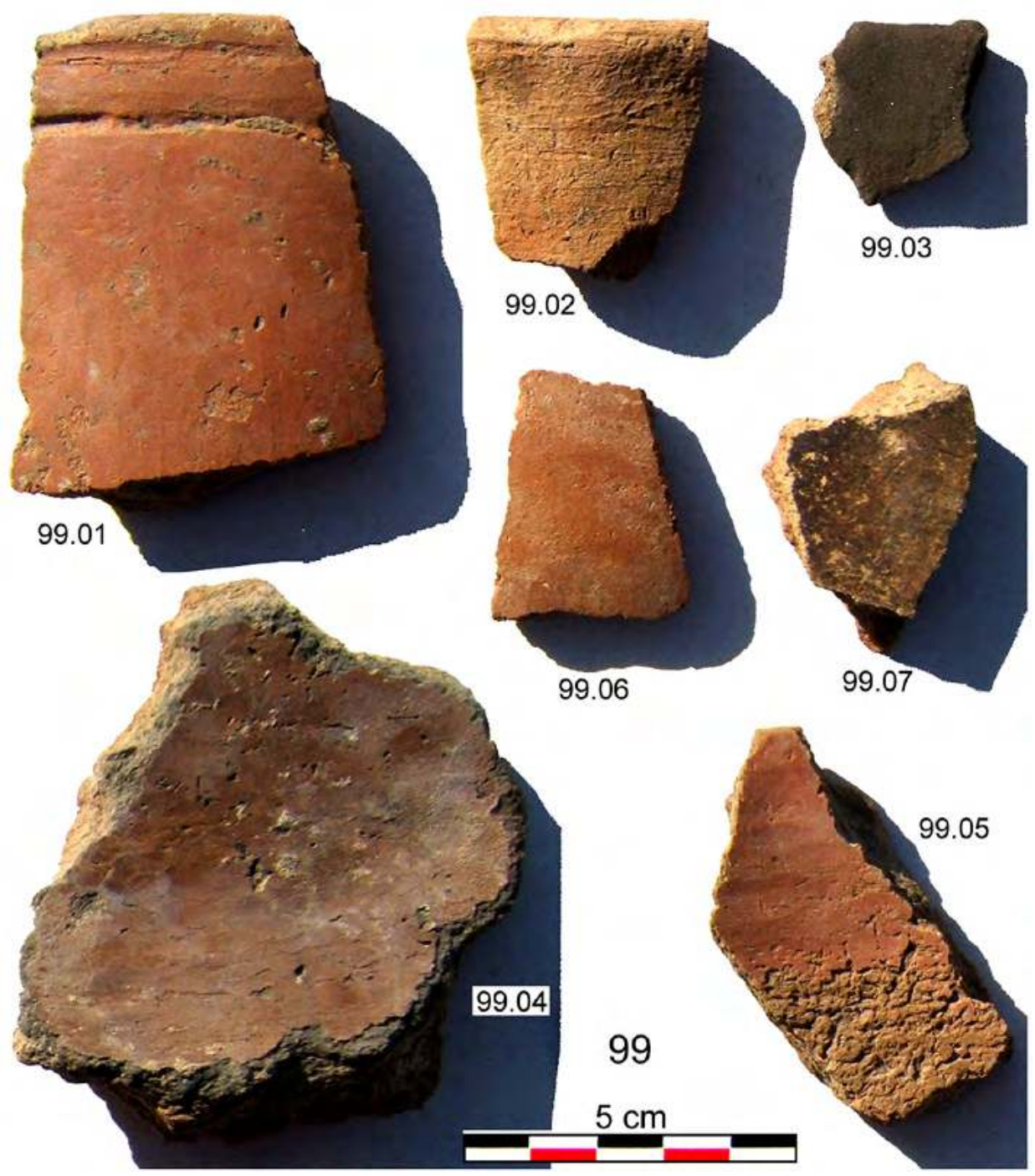

Figure 4. Earlier Sabaean pottery, Stratum T or R: ceramics from cut 99. (G. Di Rosa and S. Iavarone 2007 C MAIRY, arranged and optimized by F.G. Fedele 2019)

112.02 (Fig. 3). Globular bowl (from 2 frs). Black Lustrous ware. $7.8 \times 6.6 \mathrm{~cm}$. $\mid$ E3. Units SI3, PV3, V3. Strata T-S. | Well-burnished and retaining high shine. Occasional near-horizontal striations and facetted effect were produced by polishing with a rounded tool. Wear grade 1.

49B.1.1. Black Lustrous ware, burnished on both the exterior and the interior. Approx. $2 \mathrm{~cm}$. $\mid$ D7, from flotation sample. Unit SIS. Stratum S.

99.01-07 (Fig. 4). The ceramic variety in cut 99, representing most of the repertoire of the Earlier Sabaean. | E1. Upper unit SIa and lower SI1i. Stratum T or R. Nos 99.01-03 are rims. Red Lustrous ware: 99.01 storage jar of Type C3b or C3c, vertical wall, two furrows below rim; 99.05 greyish-red on the interior; 99.06 thin and poorly burnished slip; 99.04 purple-grey to brownish. Black Lustrous ware: 99.03 small thin-walled vessel, body hazel-brown. Red-slipped ware (apparently): 99.07, buff body, matt hazel on surfaces. Beige Plain ware: 99.02 rough exterior surface.

102.06-08 (Fig. 5). A sample of Red Lustrous and Beige Plain wares from cut 102. All rims.|E2. Units V3, SI1iSI1, SE3, but predominantly SE3 or SI1. Strata S-R. | Red Lustrous ware: 102.06 storage jar of Type C3b or C3c, vertical wall, two furrows below rim; 102.07 deep bowl, reddish brown variant. Beige Plain ware: 102.08 rough surface (intentionally roughened 'wiped' ware?).

V97: ${ }^{36}$ conjoint of $97.01+101.03$ (Fig. 6). Bowl with 'dragged' wavy line decoration. Pale Green ware: exterior yellow to light green, interior grey-yellow, yellow on base; fine-sandy and chaff-tempered. No. 97.01: max. width $9.4 \mathrm{~cm}$, height of vessel $8 \mathrm{~cm}$. No.

\footnotetext{
36 ' $\mathrm{V}$ ' is the prefix for an individually identified and numbered vessel.
} 


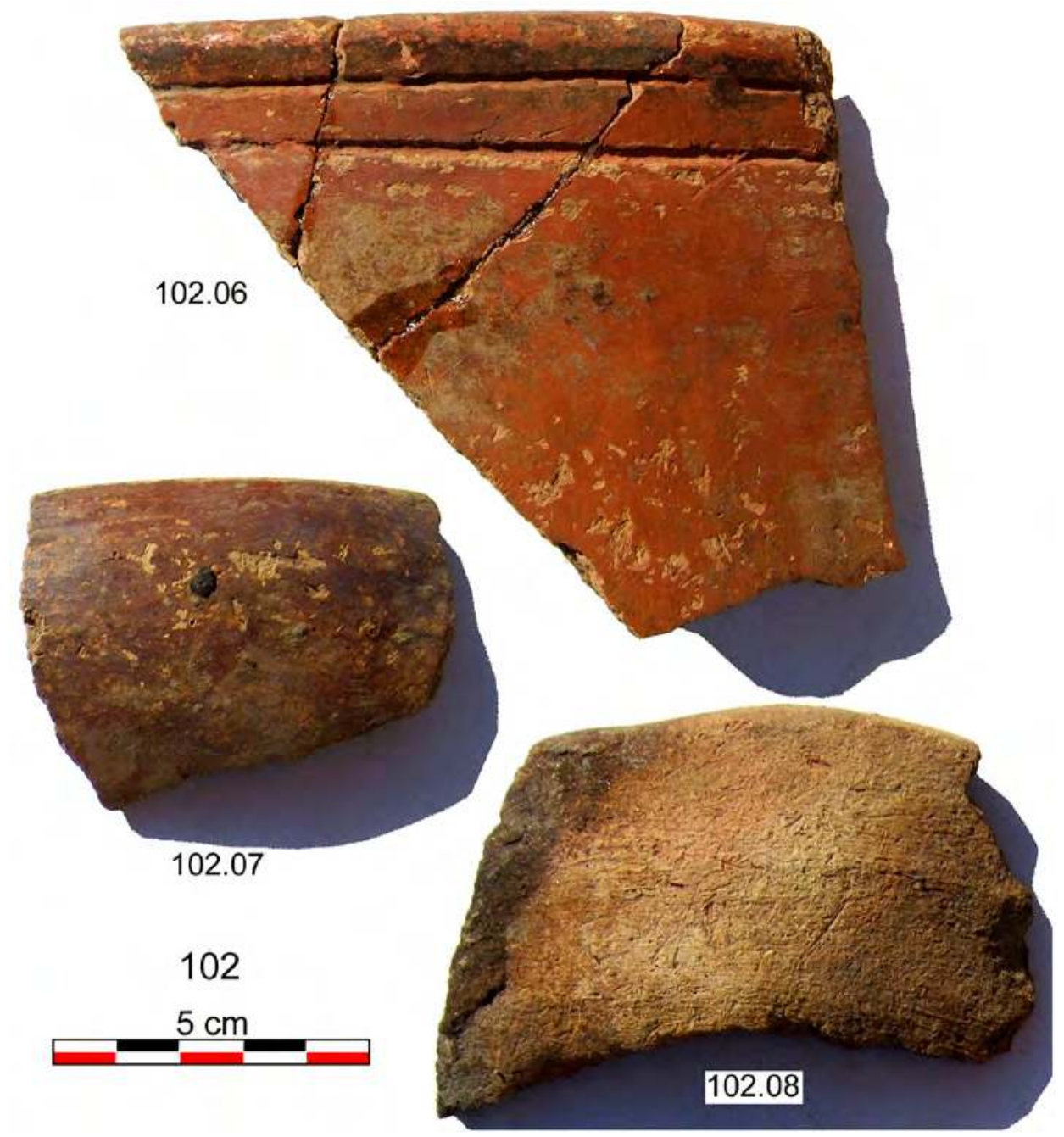

Figure 5. Earlier Sabaean pottery, Strata S-R: ceramics from cut 102. (G. Di Rosa and S. Iavarone 2007 C MAIRY, arranged and optimized by F.G. Fedele 2019)

101.03: $3.7 \times 2.4 \mathrm{~cm} . \mid$ No. 97.01: E1 east, against Wall F4; units SI1i-SI1 and $\tau 2, \tau 1$. No. 101.03: E2; possibly from the contact of units SE3 and SI1 in the eastern third of quadrangle. Stratum R. | Vessel V97 is mainly composed of 97.01 ( 3 frs), but joins with a fourth fragment from cut 101; some unnumbered cm-sized frs from cut 97 are also probably pertinent. On this bowl see also section 3.3 below.

104.01 (Fig. 7). Shallow bowl with attenuated carination. Red Lustrous ware. Fr. max. $12.5 \mathrm{~cm}$. | E03 20 cm east. Units V3 (?), SE3, L3f, and L3e $e_{2}$. Most probably from SE3, i.e. Stratum R.

98.02 (Fig. 8). Wide, shallow carinated bowl, possibly a Type A2 variant. Pale Green ware, light yellow-grey on the exterior and base (base mottled), body beige. $9.2 \mathrm{~cm}$, height c. $3.5 \mathrm{~cm}$. | E1 western half. Units SI1iSI1. Stratum R. | Low wall decorated with horizontal lines; foot narrow (if any). Comments concerning this bowl, centred on some perceived differences from the standard Sabaean production, are given in section 3.3 below.

98.03 (Fig. 7). Deep bowl, medium, possibly Type B2b although no lugs are present on sherd. Red Lustrous ware, coral-red. $8.2 \times 8 \mathrm{~cm}$. $\mid$ E1: provenance and stratigraphy as for no. 98.02. Stratum R.

101.04-08 (Fig. 9). A selection of Earlier Sabaean pottery from cut 101 . The unnumbered frs give a general impression of the contents. | E2. Units SE3, LEd-L3e. Strata R to P. | Nos 101.04-05 and 101.07 are rims. Red Lustrous ware: 101.04 sector of large bowl or basin, Type A4 (?); 101.05 storage jar of Type C3b or C3c, vertical wall, two furrows below rim. Red-slipped ware: 101.07 small deep bowl, one furrow below rim. Beige Plain ware: 101.06 , a 4-cm-long wall fr. carpeted with packed curvilinear grooves, an exceptional decoration. Grey-black ware (apparently): 101.08 cooking-pot fr. 


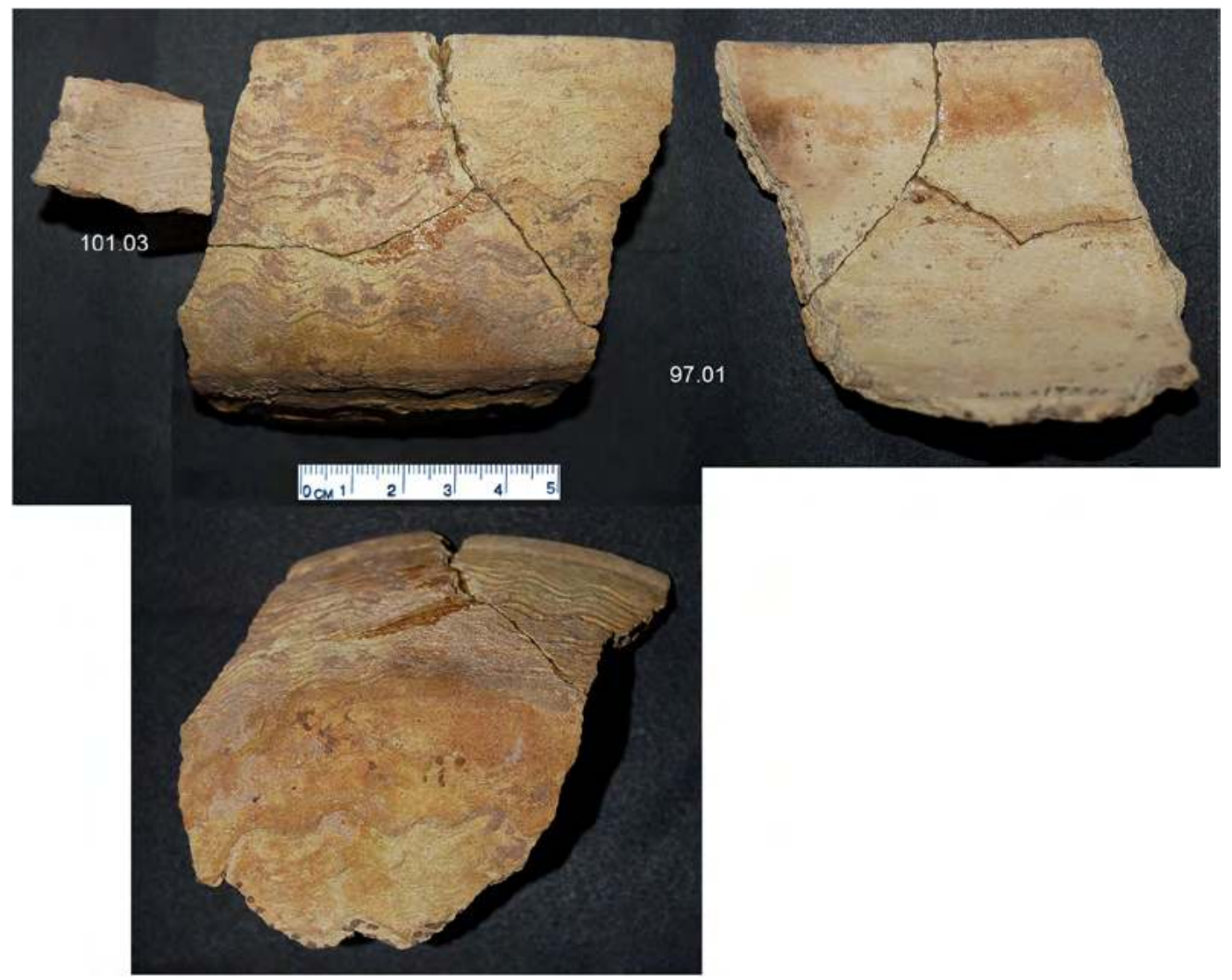

Figure 6. Earlier Sabaean pottery, Stratum R: vessel V97. (P. Morlupi 2006 @ MAIRY, arranged and optimized by F.G. Fedele 2020)
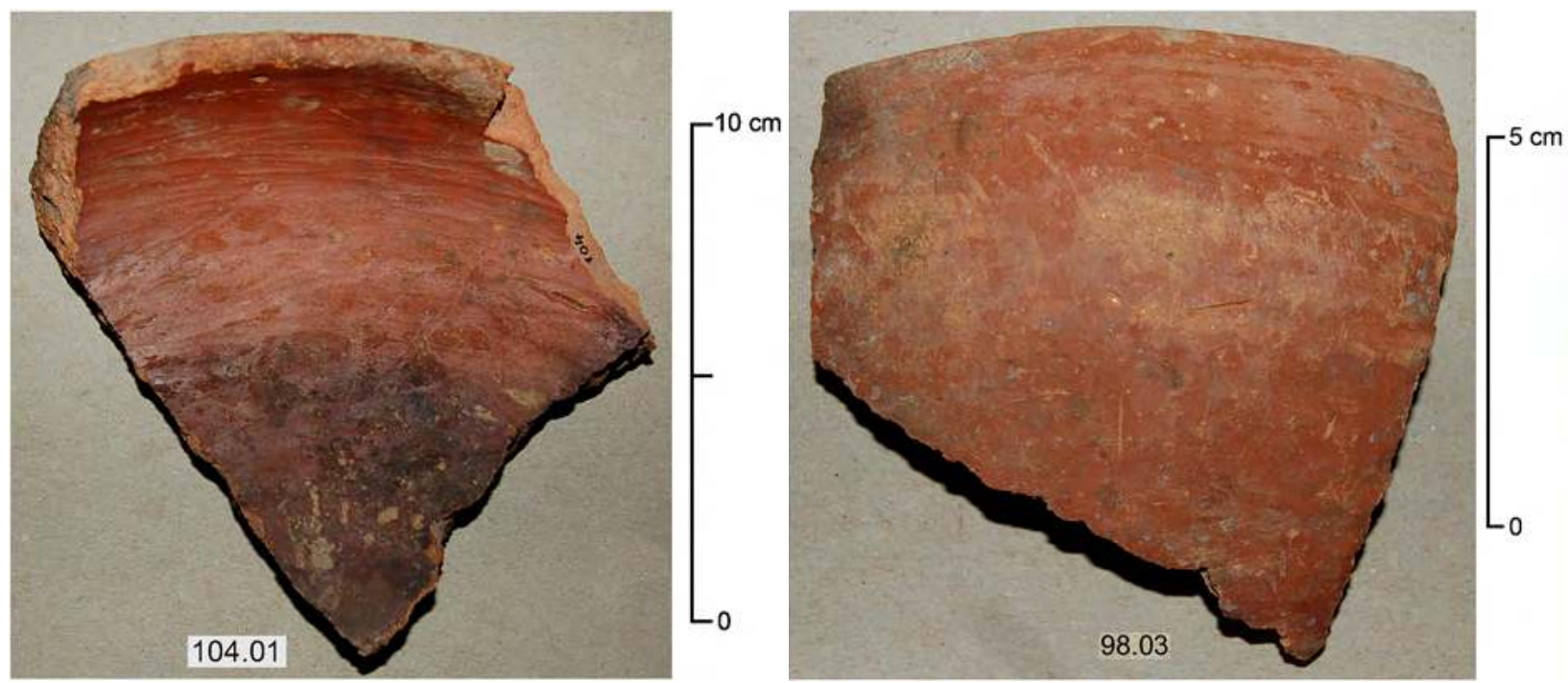

Figure 7. Earlier Sabaean pottery, Stratum R: reg. nos 104.01 and 98.03. (P. Morlupi 2006 @ MAIRY, optimized by F.G. Fedele 2020) 

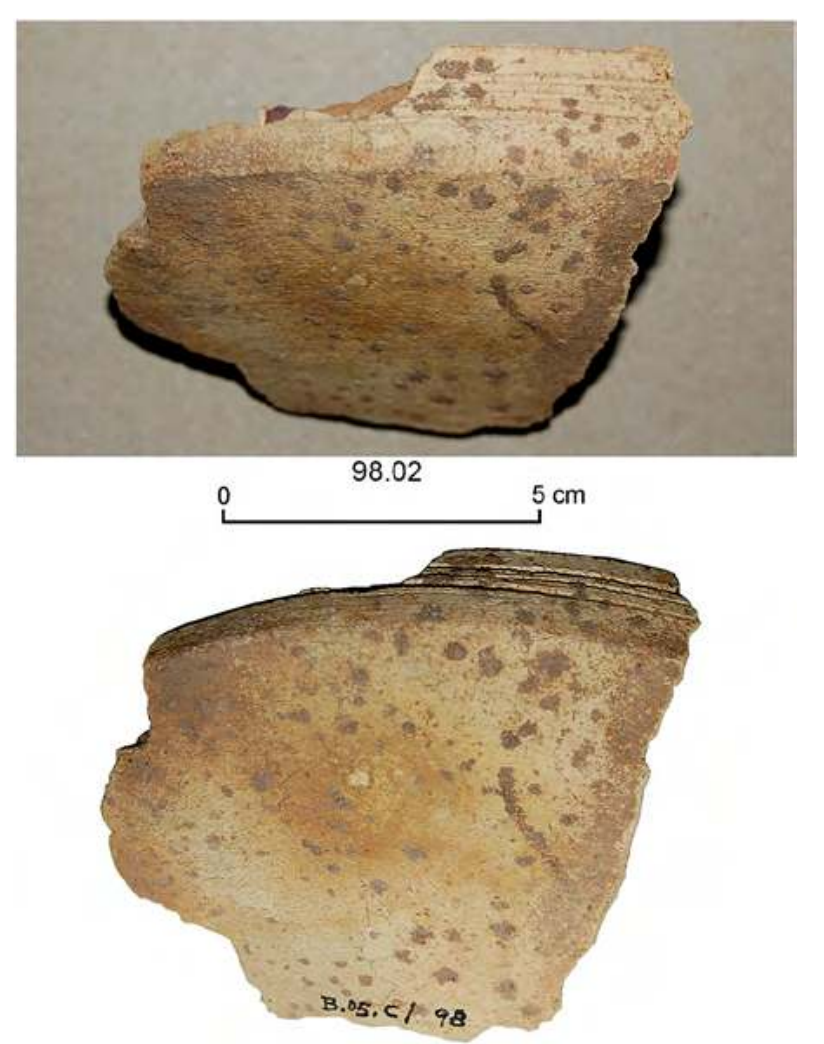

Figure 8. Earlier Sabaean pottery, Stratum R: reg. no. 98.02. (P. Morlupi 2006 @ MAIRY, arranged and optimized by F.G. Fedele 2020)

with thick carbonized matter on the interior, and with different wear on each of its three sides (grades 2, 3/4, and 5).

96.01 (Fig. 10). Perforated lid with loop handle, Type E1e. ${ }^{37}$ Pale Green ware similar to $97.01 .4 .7 \times 4.1 \mathrm{~cm}$. | E1. Units LEd, LEc, and part of LEb; LEc4. Essentially Stratum Q.

111.02. Handle, detached. Light green-beige paste: either Beige Plain ware or Pale Green ware. For the record, the sherds in cut 111 were predominantly Beige Plain. ${ }^{38} \mid$ E3. Units SE3 $\omega$, SE3, L3f, L3e, XE4 $\beta$, and L3Z . Strata later S-R, P-O, and earlier $\mathbf{N}$.

111.1 (Fig. 11). Storage jar of Type C2. Red Lustrous ware, but exterior of base unburnished, reddish-beige like the body. Large wall and base fr., max. height 21.5 $\mathrm{cm}$. E3 west, near south edge, $c .70 \mathrm{~cm}$ from southwest corner, subhorizontal in situ (see Chapter 17, Fig. 51 A, this volume). Unit SE3 bottom; otherwise at the 'triangular' contact of units SE3, XE4, L3Z. Probably

37 For a specific parallel see de Maigret 2003, pl. 36/2 (Yalā Y.87. Y35/1).

38 Confirmed by A. de Maigret in one of the joint examinations in which Beige Plain ware was defined at Barāqish in December 2006.
Stratum R or 0. | Exfoliated in spots, but otherwise very fresh and exhibiting meticulous burnishing. Attribution to Type C2 (de Maigret's otre) depends on both the size of the vessel and its flattened-convex base.

93.1.1. Red Lustrous ware, burnished on both the exterior and the interior, buff-brownish. Approx. $2 \mathrm{~cm}$. |E1, from flotation sample. Units LEb (?), LEa, LE1, LE1X, but sample most or totally from LE1. Stratum P.

100.01 (Fig. 12). Shallow bowl. Red Lustrous ware. Approx. $9 \mathrm{~cm}$, height $5 \mathrm{~cm}$. E2. Units LEa-LE1 $\lambda-L 3 e-$ LE $\omega$ up through L3c1 (and SAp). Strata P-O.

110.2 (Fig. 13). Torpedo jar, cf. Type D1a but larger. Heavy Sandy ware, sand fraction less pronounced than average. Wall fr., approx. $16 \times 15.5 \mathrm{~cm}$, c. $1-1.5 \mathrm{~cm}$ thick. |E3, centre of the south half of quadrangle (see Chapter 17, Fig. $51 \mathrm{~A}$, this volume), in situ at the bottom of cut 110, about $-105 \mathrm{~cm}$ below the local datum (E3 SE corner, ground surface). According to the excavation records and photographs, this object was retrieved from greyish, silty-gravelly sediments belonging to lower unit L3c (particularly gravel lens $3 \pi$ ) or a mixture of L3C and L3e, i.e. Stratum P or $0 .{ }^{39} \mid$ A fairly sharpedged wall fragment (wear grade 1$)^{40}$ of a thick-walled vessel identified by A. de Maigret as belonging in the variation range of Sabaean torpedo jars (personal communication, Barāqish, December 2006). Defining features for this attribution are the deep moulding impressions on the interior - from both fingers and hands - and the wildly variable thickness; otherwise the sherd could equally well be attributed to a Type C3a storage jar. The fragment shows traces of red slip on the exterior and a band of wavy-line decoration. This latter is composed of two tightly superposed sinusoids separated by a horizontal line, summarily executed by dragged impression, and is located immediately above the maximum diameter of the vessel.

\section{Strata T-S}

Red Lustrous bowls and Beige Plain vessels were recovered from the lowermost deposits reached in the excavations, belonging to Stratum $\mathrm{T}^{41} \mathrm{~A}$ Beige Plain fragment from unit SIa (no. 49D.03), shows the unusual combination of a plain exterior surface and a

\footnotetext{
39 Retrieved together with glass element no. 110.1 from the same findspot: see Chapter 21, section 2.5 (Uncertain chronology group), this volume; and field photograph of both finds in Chapter 17, Fig. 52, this volume. In the case of no. 110.2, however, the find was securely in situ in a level and within sediments which were amenable to stratigraphic determination. For discussion of cut and context see Chapter 17, sections 6.5 ('Lithological and cultural details on Stratum P') and 6.8 .

40 The Collection catalogue entry concerning finds 110 , including no. 110.2, can be seen in Chapter 20, Fig. 1, this volume.

41 Cf. cuts 99A, 49D, and parts of 112 and 99.
} 


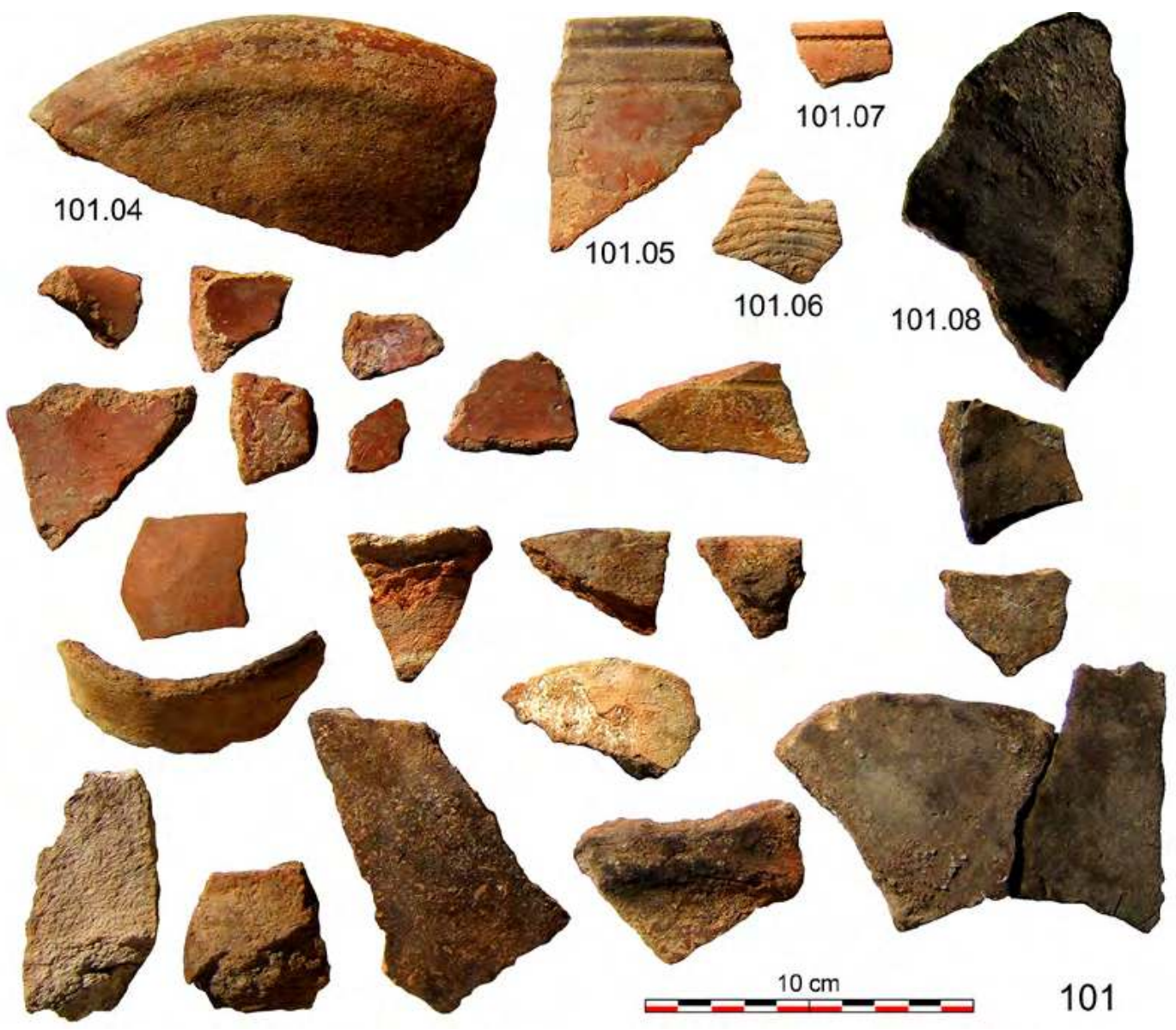

Figure 9. Earlier Sabaean pottery, Strata R-P: ceramics from cut 101. (G. Di Rosa and S. Iavarone 2007 (C) MAIRY, arranged and optimized by F.G. Fedele 2020)

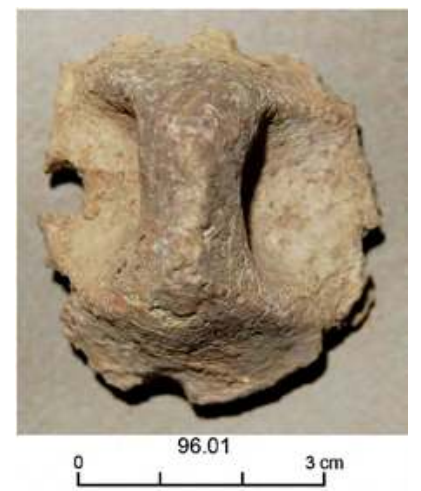

Figure 10. Earlier Sabaean pottery, Stratum Q: handled lid no. 96.01. (P. Morlupi 2006 @ MAIRY, optimized by F.G. Fedele 2020)

yellow-slipped interior: can it be foreign to the Sabaean cultural area? Significantly, most of the pottery sherds from Stratum $\mathrm{T}$ are in a fairly fresh condition, and particularly in upper Sector E they suggest proximity to undisturbed occupation. Fig. 4 offers a glimpse of the ceramic variety represented in the currentlyknown bottom units of Area C, including Red and Black Lustrous ware, Beige Plain ware, and a rare example apparently - of Red-slipped ware.

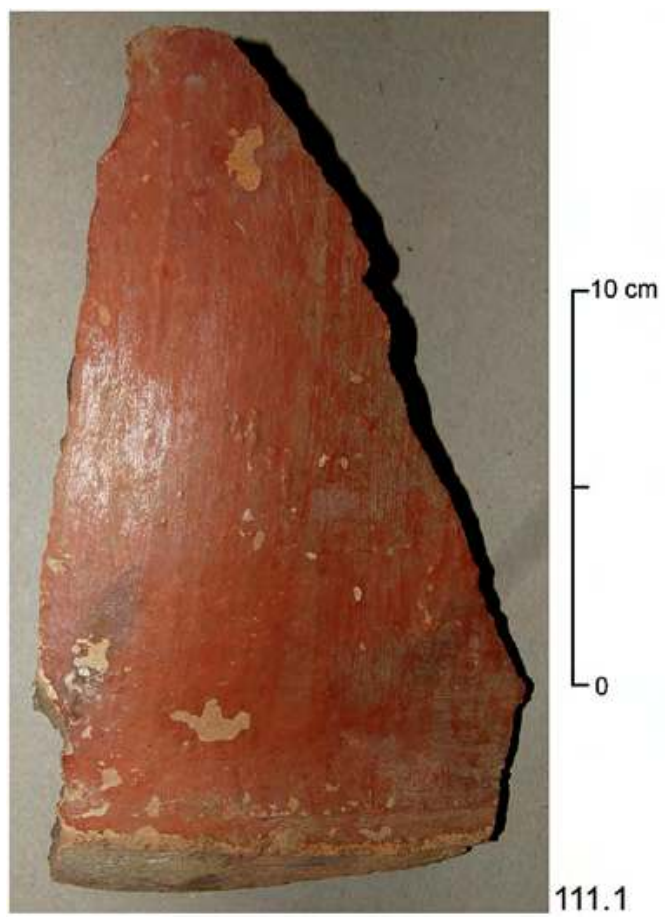

Figure 11. Earlier Sabaean pottery, Stratum R or O: reg. no. 111.1. (P. Morlupi 2006 ( ) MAIRY, optimized by F.G. Fedele 2020) 


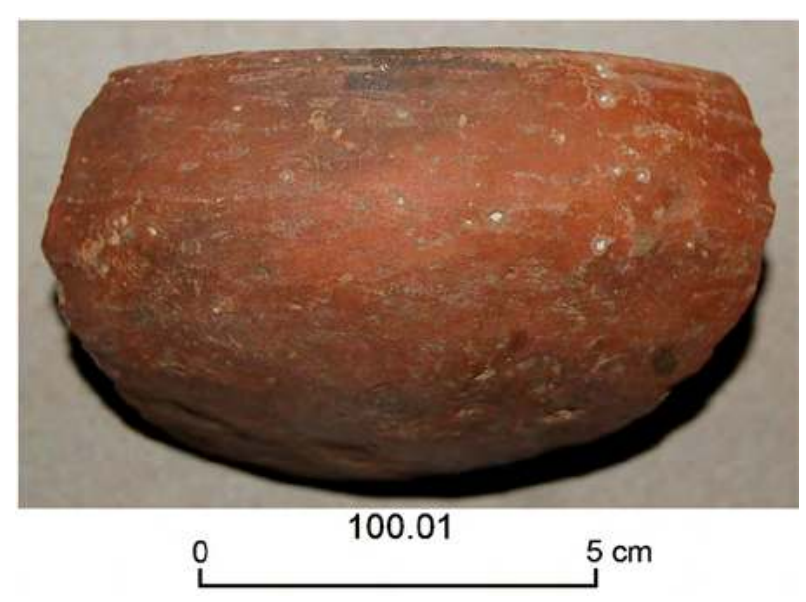

Figure 12. Earlier Sabaean pottery, Strata P-O: reg. no. 100.01. (P. Morlupi 2006 (C) MAIRY, optimized by F.G. Fedele 2020)

No less than three Black Lustrous bowls were recovered from these levels: a globular one from Stratum $\mathrm{T}$ or $\mathrm{S}$, still in possession of its shine (no. 112.02); a small and delicate one from Stratum T or R (no. 99.03); and another small example from unit SIS of Stratum S, carefully burnished on both its surfaces (no. 49B.1.1). Unit SIS contained examples of Grey-black cooking ware.

\section{Stratum R}

Stratum R corresponds to the construction of Sabaean Wall F4 and to the works and disturbances that it entailed. In addition to the broad typological inventory already observed in the previous strata, Stratum $\mathrm{R}^{42}$ produced the earliest examples of Pale Green ware, if the equation of these earlier ceramics with the 'typical' Later Sabaean examples is correct. The notable specimens are vessel V97, reconstructed from fragments in quadrangles E1-E2 (Fig. 6), and carinated bowl 98.02, represented by a decimetre-sized portion that reveals its entire profile (Fig. 8). The selection shown in Fig. 9 can suggest the ceramic variety represented in Strata $\mathrm{R}$ to P. It includes Red Lustrous ware, whose finds from Stratum R are numerous; a small deep bowl in a clear example of Red-slipped ware; and Beige Plain and Greyblack wares.

\section{Strata Q-P}

Good-quality Red Lustrous pottery was found in a number of units belonging to Stratum $\mathrm{P}$ in the area of Wall F4, e.g. LE1 (no. 93.1.1) and LEa-L3c1 (no. 100.01; Fig. 12). In close connection with the wall itself, small Red Lustrous potsherds were contained within J1, a probable stump of the wall's mudbrick upper part, as

42 Cf. cuts $98,97,48,48 \mathrm{~A}, 44$, and parts of 99, 49, 102, and 111. well as in unit Jx (disaggregated mudbrick) and unit J2. An unparalleled perforated lid in Pale Green ware (Fig. 10) was retrieved from Stratum $Q$ in quadrangle E1. Also an applied handle (no. 111.02) from a low-resolution cut in the colluvia of quadrangle E3, encompassing most of the Earlier Sabaean, is probably Pale Green.

\section{Stratum 0}

In Stratum $\mathrm{P}$ or $\mathrm{O}^{43}$ torpedo jars make their first definite appearance. As already mentioned in section 2, they can be identified quite easily by their being made in Heavy Sandy ware. Their relatively late appearance may simply reflect sampling bias, but to some extent it finds a parallel in the sounding at Temple A, where torpedo jars only become common in the upper third of the sequence. ${ }^{44}$ The best example is a large wall fragment of a torpedo jar of the bulbous type, D1a, decorated with a wavy-line motif (no. 110.2; Fig. 13). ${ }^{45}$ It was recovered from a context of Stratum $\mathrm{P}$ or $\mathrm{O}$ in quadrangle E3. Quite a number of severely trampled potsherds from torpedo jars were retrieved from SY2, the lowermost unit attained in Sounding F, tentatively correlated with Stratum 0 . This unit also produced a probable cooking pot in Grey-black ware. In upper Sector $E$ a necked, bottle-shaped jar of unfrequent Type $\mathrm{C} 2$ was recovered from units belonging to Stratum $\mathrm{R}$ or $\mathrm{O}$ (no.111.1; Fig. 11).

\subsection{Later Sabaean: a general characterization and major occurrences}

As illustrated in Chapters 17 and 18, this volume, Strata N to L of Area C can be attributed to a 'Later Sabaean' phase in the occupation of Yathill on the basis of style and technology of pottery production as well as stratigraphy. The available information for the ceramologically defined Later Sabaean suggests complete continuity within an evolving Sabaean tradition in material culture, of which the continuing adherence to an established manner of pottery making was perhaps the essential component. In all wares, forms continued the earlier typology, apart from oscillations in carinated types and the appearance of new variants, and good firing continued as well. Against a background of substantial continuity, however, some particular trends can be perceived and novelties appeared.

Carinated forms in Red Lustrous ware are always in evidence, and the Later Sabaean levels exhibit red and shiny cups and bowls made according to centuries-long

\footnotetext{
${ }^{43}$ Contexts attributable to Stratum $O$ include cut 43, probably cut 216 in Sounding F (unit SY2), and parts of cuts 152, 121, 110, 103, 91, 61 , and 42 .

44 de Maigret 2010a, 87, table 2, column/form 9.

45 On the functional interpretation of torpedo jars see end of section 2, above.
} 

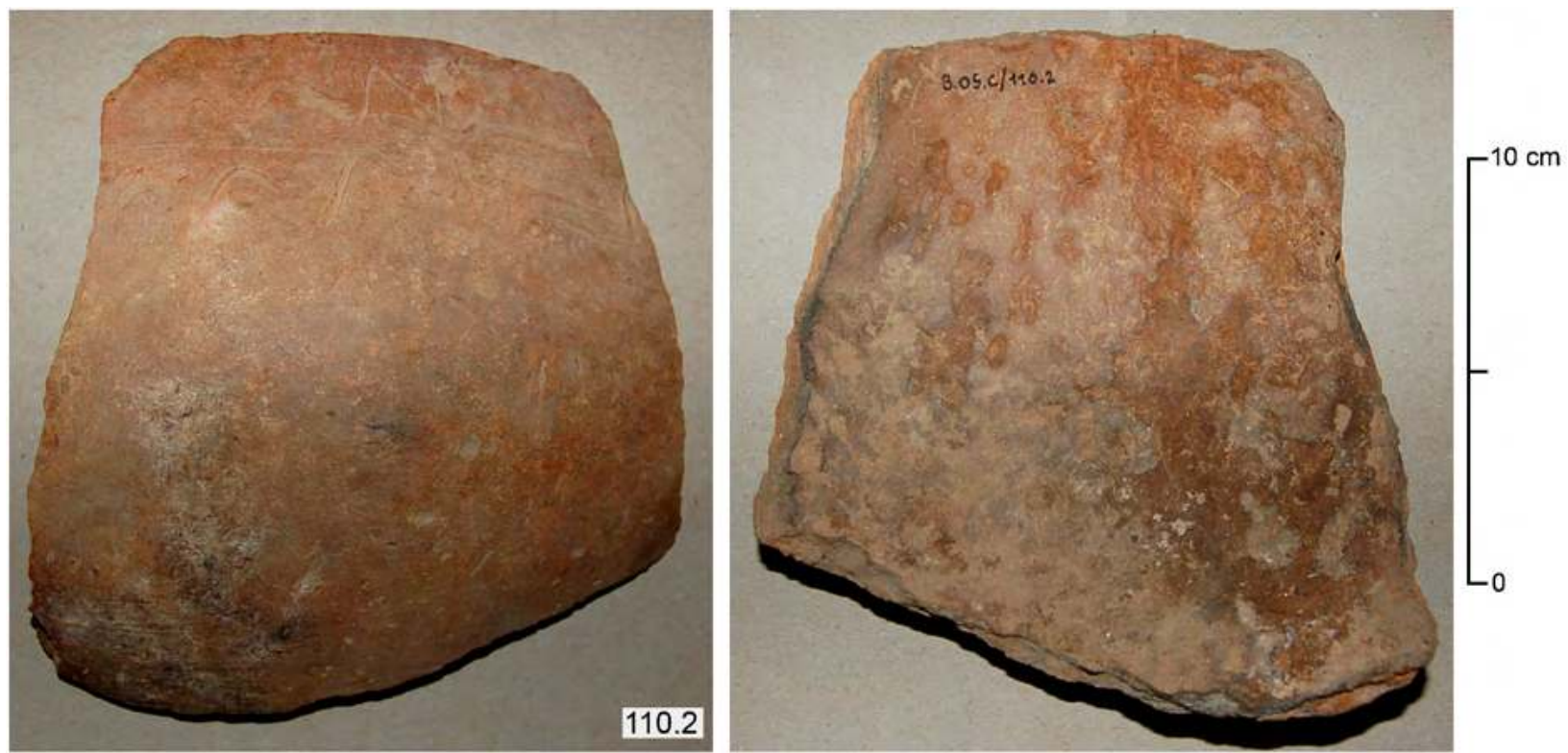

Figure 13. Earlier Sabaean pottery, Strata P-O: reg. no. 110.2. (P. Morlupi 2006 @ MAIRY, arranged and optimized by F.G. Fedele 2020)

tradition, but Beige Plain and other untreated wares are now as common or commoner than the slip-burnished production. The definition of Stratum L was indeed partly based on a perceived explosion of plain wares, which appears to occur concomitantly with the start of suite GZ (unit GZ3, e.g. cut 37 in quadrangle D5). ${ }^{46}$ In suite $\mathrm{GZ}$ more than 50 per cent of the vessels are Beige Plain ware. And they are clearly coeval with the layers, whereas a fraction of the burnished potsherds is worn and residual. Suites GK and GZ saw the expansion of plain pottery with a beige, light red, or buff exterior and fabric, clearly within the Sabaean potting tradition. Plain vessels now increasingly had a wet-smoothed beige surface.

Among the burnished production, the lustrous brightred finish became rarer and was supplanted by less meticulous and durable slips. Vessels with a somewhat 'impoverished' surface appearance now coexisted with a florescence of unrefined but well-made vessels of traditional Sabaean morphology. Like at different times elsewhere, what we are noting here as a feature of Later Sabaean pottery is a 'declining investment in surface treatment'. ${ }^{47}$ Also at Yathill, visual observations show that quality of slipped burnish in the later strata decreases in comparison to that of Strata $\mathrm{T}$ to $\mathrm{O}$. This

46 Cf. Chapter 17 , sections 7.1 and 7.5 , this volume.

47 This observation, which seem very pertinent to our case, is inspired by the evolution of the Khirbet Kerak Ware of Palestine, as studied by Iserlis $(2009,191)$. He remarks that 'under the microscope, the slip layers in later strata are thinner in comparison to the earlier production': on the basis of my own magnifying-glass examination at Barāqish in 2007 this would perfectly apply to part of the Later Sabaean production. marked increase in simpler or expeditiously burnished products was provisionally called 'epi-Sabaean' in the field terminology of 2005-2006. In quotation marks, this term might perhaps be retained specifically to indicate the 'impoverished' aspects of the Later Sabaean ceramics. A pale or orange slip - rather than red - was frequent, and being often applied or burnished slovenly it was prone to exfoliation ('thin shoddy slip', a defining element of the 'epi-Sabaean' aspect).

Regardless of being poor or refined, Red Lustrous ware is widely found throughout Strata N and L both in Sector D and in Locus 200 of Sounding A, i.e., essentially in residential contexts of the tell. As revealed by weargrade analysis, the high incidence of unworn, sharpedged fragments points to primary deposition: these layers were all formed when the most classic Sabaean wares and forms were still in common use. The pottery from Locus 200 is particularly fresh-looking. Locus 200 - in all respects a peephole on the core Sabaean settlement ${ }^{48}$ - has also offered fine examples of pattern-burnished decoration, as represented for instance by potsherds nos 199.02 and 200.03-05 (of which no. 200.05 from a vessel surprisingly used on the fire). Pattern-burnished decoration is considered rare in the Sabaean repertoire, ${ }^{49}$ at Barāqish Area C it is uncertainly documented already in the Earlier Sabaean, as mentioned in section 2 above. Locus 200 also produced two examples of ultrathin, 'eggshell' vessels in Beige Plain ware which are unparalleled in the collection (nos 200.08-09).

\footnotetext{
${ }^{48}$ Cf. Chapter 17, section 7.3, this volume.

49 E.g., Glanzman 1987a, 71.
} 
What can be termed 'eggshell' products are only one of the interesting if relatively minor novelties of the Later Sabaean as revealed by Area C. They represent an extreme in a recognizable trend, given that thin-walled cups and bowls, in general, increase in frequency from Stratum N to Stratum L. Some new or unusual ceramic types also related to light and sometimes ultrathin variants will be described in the next section (Wavy Rim bowls and 'typical' Pale Green ware). To round up this account of the Later Sabaean ceramics, we can finally observe that torpedo jars occur until the end of the Sabaean phase of Yathill - 'Sabaean' again intended only in terms of material culture.

At Yathill, we can conclude, the long-established Sabaean tradition in the making and using of pottery continued until the very end of Stratum L, in terms of both formal repertoire and basic technological knowhow, in spite of what we tend to perceive as a loss of visual quality. One may speculate on the conditions that brought about this last-mentioned development. Factors such as a reduced competition among potters, changed demand, and/or modified provisioning at clay sources, should be considered, ${ }^{50}$ against the general and perhaps more compelling background of changing political control (cf. Chapters 18 and 27, this volume). Future research will be able to elucidate this interesting problem.

\section{Strata N and L (Sectors D-E); and Stratum N, Locus 200 (Sounding A)}

The vessels described as find nos 121.04 to 61.05 derive from stratigraphic intervals spanning Strata $O$ to L, perhaps including Stratum K in the case of cut 121. All the other finds were precisely recovered from Stratum $\mathrm{N}$ (nos 121.2 to 199.05 and 39.02 to 16.2), Stratum L (nos 23.02 to 13.03), or as reworked material attributable to Strata N or L (nos 198.01 to 194.03.3). A selection of Later Sabaean pottery specifically obtained from upper Sector D (mostly from quadrangles D3-D5), and representing Strata $\mathrm{N}$ and L, is illustrated in Figs 22-24 and 26-30.

\subsection{See below, under Stratum $\mathbf{N}$.}

121.04 (Fig. 14). Flaring-neck rim fr. showing metope decoration, in an unusual combination of Red Lustrous and Beige Plain wares, unique for Area C. $11.5 \mathrm{~cm}$, height $8 \mathrm{~cm}$. |E4. Units XE4, LZ5, L3Z, $4 \mu \mathrm{r}-\mathrm{VCB}$ : unclear context. Strata $\mathrm{O}$ to $\mathrm{L}$ (or to $\mathrm{K}$ ?). | This vessel is probably a deep carinated bowl (Type A3c). ${ }^{51}$ Metope decoration is represented on this vessel by alternating red-

\footnotetext{
50 Fedele 2010, 126.

51 de Maigret's (2003) salsiera, literally 'saucepan'; pl. 14/6 (Yalā Y.87.Y.48/3) might provide a pertinent parallel.
}

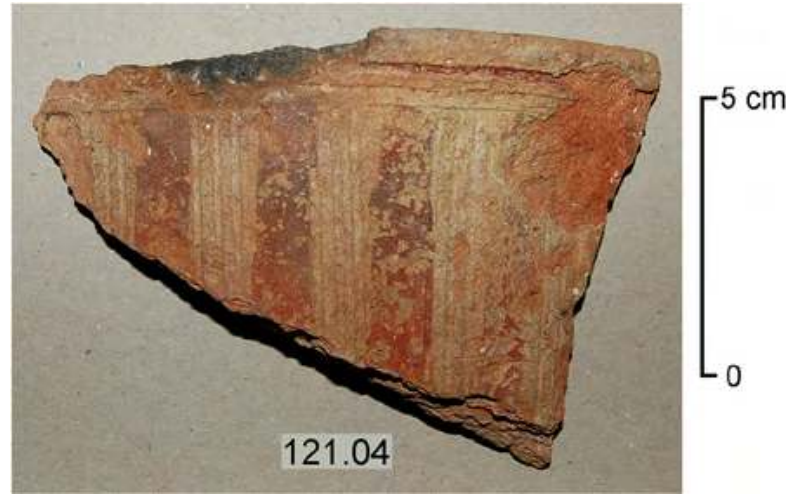

Figure 14. Sabaean pottery, Strata O-L (K?): reg. no. 121.04. (P. Morlupi 2006 @ MAIRY, optimized by F.G. Fedele 2020)

burnished and plain-incised vertical zones. ${ }^{52}$ The latter are beige in colour and engraved with vertical grooves. A frame formed by a plain-beige groove below and a red-coloured groove above separates the metope motif from the lip of the vessel, which is thick, rounded, and plain beige, with its body showing carbonization. The interior surface was not recorded.

121.05 (Fig. 15). Medium-large bowl with rounded wall and one groove below the thickened rim. Red Lustrous: dark red to brown, long horizontal burnish facets. 14 $\mathrm{cm}$, height $7.5 \mathrm{~cm}$. E4: stratigraphy as for no. 121.04 . Strata $\mathrm{O}$ to $\mathrm{L}$ (or to $\mathrm{K}$ ?). | This might be a Type A4 vessel, de Maigret's 'crater'. The burnished slip is exfoliating.

61.01. Pattern-burnished pot or deep bowl, polish in sub-horizontal strokes or striations. ${ }^{53}$ Red Lustrous ware, body and surfaces light brown, polish hazel. 15 $\mathrm{cm}$. E6. Units 6U up through E2 $\mathrm{E}_{3}$. Strata O, L, K, I, but probably from Strata O-L. S Similar in manufacture and burnishing to no. 199.02, below.

61.02 (Fig. 15). Carinated bowl with unusual decoration (orientation of profile approx.). Beige Plain ware, greybeige. Approx. $10 \mathrm{~cm}$. | E6: stratigraphy as for no. 61.01 . Probably from Strata O-L. | A wall fragment of a large, slightly carinated bowl decorated with a carpet of light ovoid impressions; carination blunted. The overall shape suggests a product in the Sabaean tradition.

61.05 (Fig. 15). Handled cup, preserved for nearly a half. Red Lustrous ware. $\varnothing$ c. $14 \mathrm{~cm}$. E6: provenance and stratigraphy as for previous nos 61. Probably from Strata O-L. | Handle broken.

\footnotetext{
52 On metope motifs see, e.g., Gibson and Woods 1990, 203-204: 'panels of decoration which occur in bands or friezes and which are usually separated from each other by vertical lines'.

53 Cf. a 'black-burnished' jar, described as 'burnished with horizontal strokes', in de Maigret 2010a, 82 (fig. 105/6).
} 

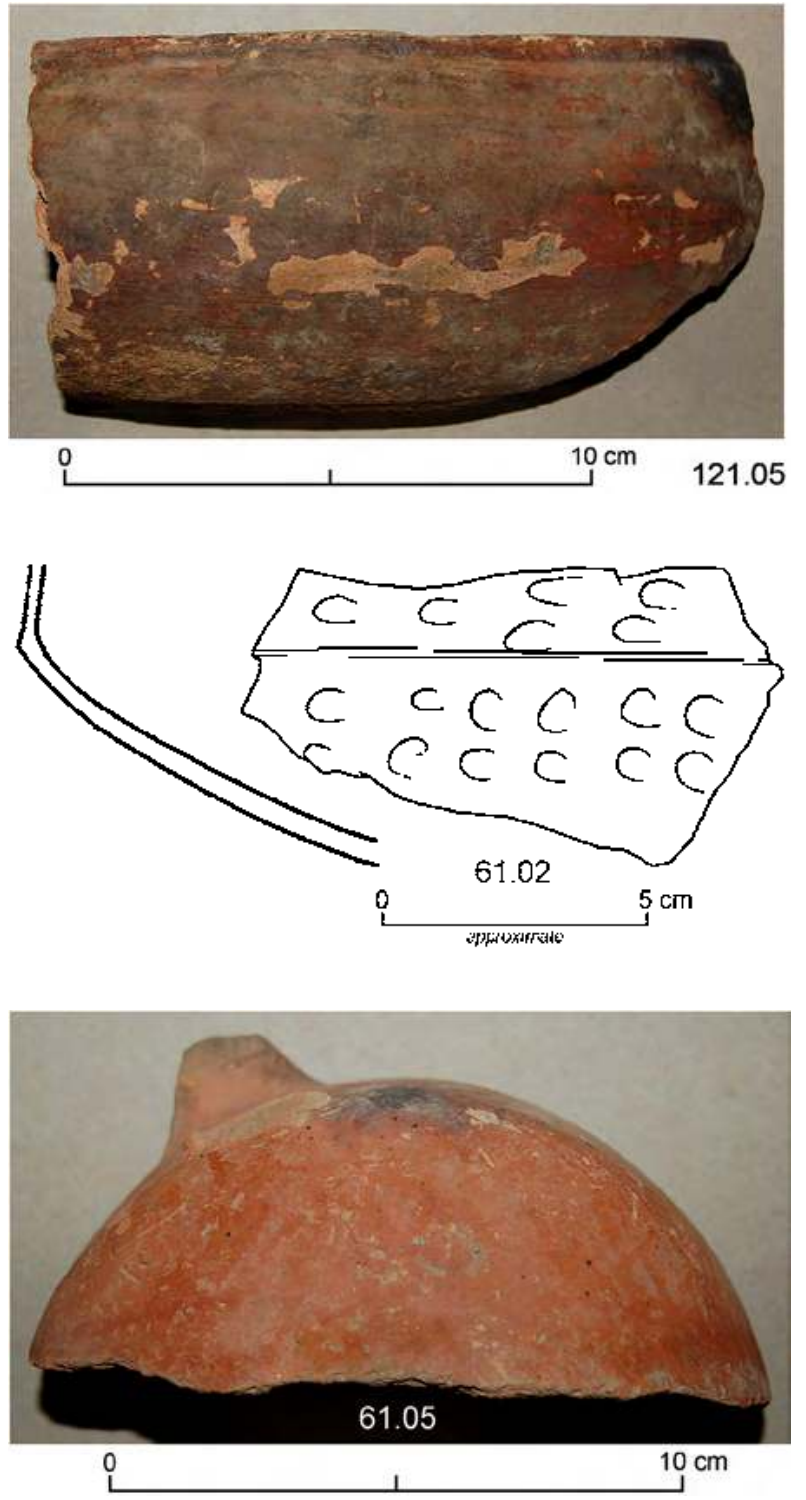

Figure 15. Sabaean pottery, probably Strata O-L: reg. nos 121 and 61. (A, C: P. Morlupi 2006 C MAIRY, optimized by F.G. Fedele 2020; B: F.G. Fedele 2006)

121.2 (Fig. 16). Tall barrel-shaped jar. Red Lustrous ware, brownish-red variant, mottled. Large wall and rim fr., max. height $17 \mathrm{~cm}$. $\mid E 4,15 \mathrm{~cm}$ from south edge and 35-50 cm from southeast corner, within Cluster 121.1, , $^{54}$ in situ. Top of cut $121,-50$ to -70 below ground surface, i.e. within unit L3Z and probably around boundary ${\mathrm{L} 3 Z_{3}}_{3} / \mathrm{L}_{3} \mathrm{Z}_{1-2}$. Stratum N. | The jar is Type C1b or C1c (de Maigret's orcio). On its neck-shoulder flexure a calcium carbonate crust had preserved a piece of woven mat, described in Chapter 21, section 2.1 ('Artefacts made from organic materials'), this volume. ${ }^{55}$ This potsherd

54 A near-planar pottery cluster in the southeast quadrant of quadrangle E4: see Chapter 17, section 7.4 and Fig. 51 B, this volume.

55 Similarly, a tiny fragment of a textile was preserved on a Sabaean pottery sherd from cut 32 (quadrangle D4, unit GZ3, earlier Stratum L). is burnt and carbonized on part of the exterior and severely exfoliated.

V200.01, V200.02. See section 3.3.

200.03-05. ${ }^{56}$ Three frs of pattern-burnished vessels similar to no. 199.02 (below). Red Lustrous ware of sombre colours, slightly gritty fabric, medium fired. | A1-A11 east + A31, Locus 200. Units STY (?), SZ2-SZ1, and lower SYH. Stratum N. | No. 200.03: c. $5 \mathrm{~cm}, 5-6 \mathrm{~mm}$ thick; light brown with criss-cross pattern hazel-grey; interior surface buff, scabrous, finger-marked, hence wall thickness variable. No. 200.04: c. $5 \mathrm{~cm}, 6-8 \mathrm{~mm}$ thick; body grey-beige. No. 200.05: c. $8 \mathrm{~cm}$, varying thickness; brick-orange body and crudely fashioned interior surface; exterior brown, further darkened by cooking or combustion; burnished pattern lighter, made of wide, irregular lines or bands.

200.06 (Fig. 17). Vertical-walled jar, possibly a storage jar or 'dolium' (from 2 frs). Beige Plain ware. Size unrecorded. | A1-A11 east + A31, Locus 200: stratigraphy as for previous numbers of cut 200. Stratum N. | A heavy container, decorated with an irregular band of wide wavy furrows in the upper part of jar, below the thickened, rounded rim.

200.08 (Fig. 18). Large 'eggshell' bowl or pot. Beige Plain ware, ultrathin variant: very fine fabric, well-fired and firm; body and surfaces light ashen grey, perfectly smoothed. $5.9 \times 4.7 \mathrm{~cm}, 3-5 \mathrm{~mm}$ thick. | A1-A11 east + A31, Locus 200: stratigraphy as for previous numbers of cut 200. Stratum N.

200.09 (Fig. 18). Small or medium 'eggshell' vessel. Beige Plain ware in an unusual dark-grey and ultrathin variant: equally unusual micaceous fabric, fine, wellfired and firm, but slightly friable and powdery on the exterior; surfaces grey to dark grey. $3.3 \times 2.7 \mathrm{~cm}$. | A1A11 east + A31, Locus 200: stratigraphy as for previous numbers of cut 200. Stratum N. | In material terms (not necessarily for morphology) the vessel represented by this small sherd is probably unparalleled in the Area C collection.

199.01 (Fig. 19). A relatively thin-walled basin with a slightly convex base. Red Lustrous ware. Horizontal width $33.8 \mathrm{~cm}$, max. height c. $10 \mathrm{~cm}$. | A31, Locus 200, in situ. Middle-upper unit $\mathrm{SYH}$, about $15 \mathrm{~cm}$ below top of unit. Stratum N. | Type A4 or a new type. ${ }^{57}$ This large part of the vessel, fragmented in situ by sediment pressure, was reconstructed from seven dm-sized

Details were not recorded.

56 No images of these finds are presented because the stock photographs available cannot adequately show the burnished patterns.

57 On the term 'basin' see find no. 112.01 in section 3.1, above. 

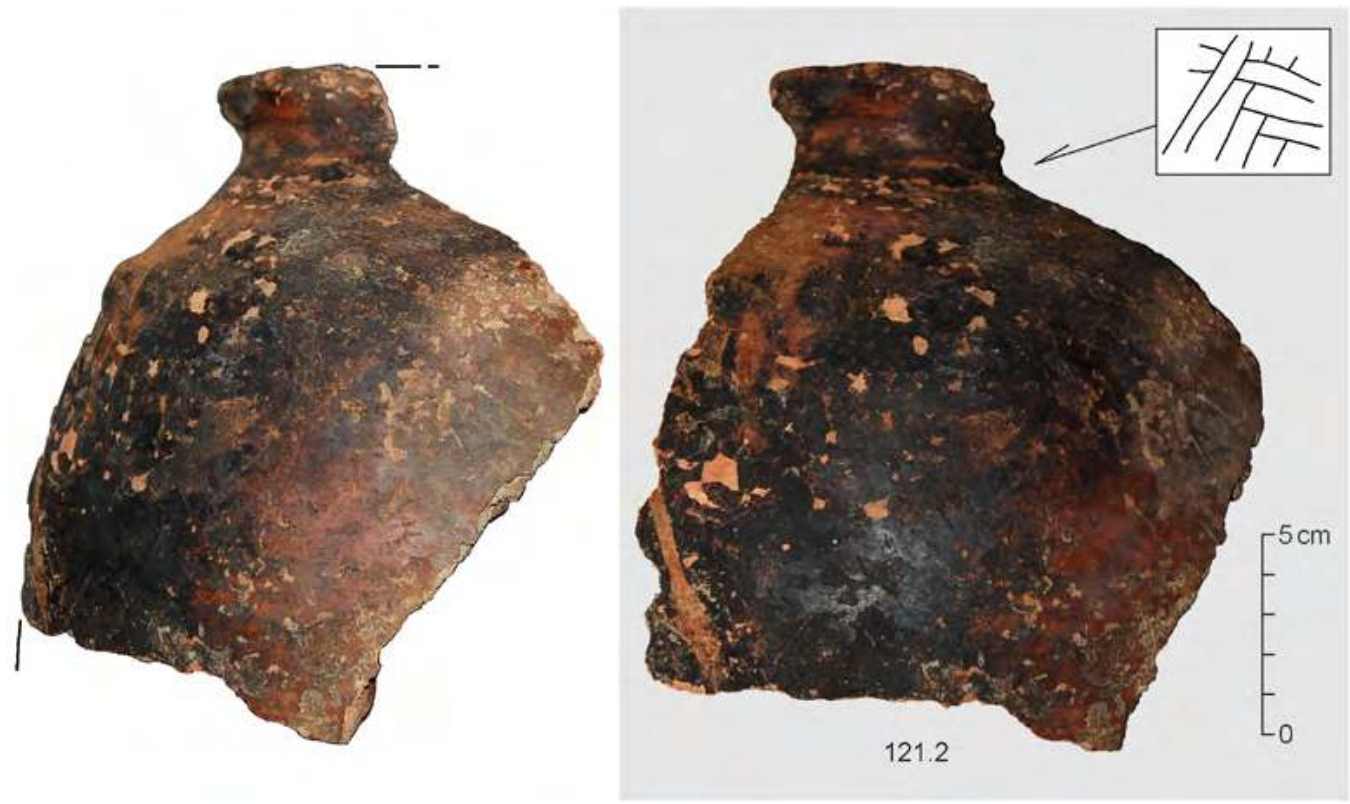

Figure 16. Later Sabaean pottery, Stratum N: jar no. 121.2, with a preserved fragment of woven mat. (P. Morlupi 2006 C MAIRY, drawing and adaptation by F.G. Fedele 2006 and 2019)

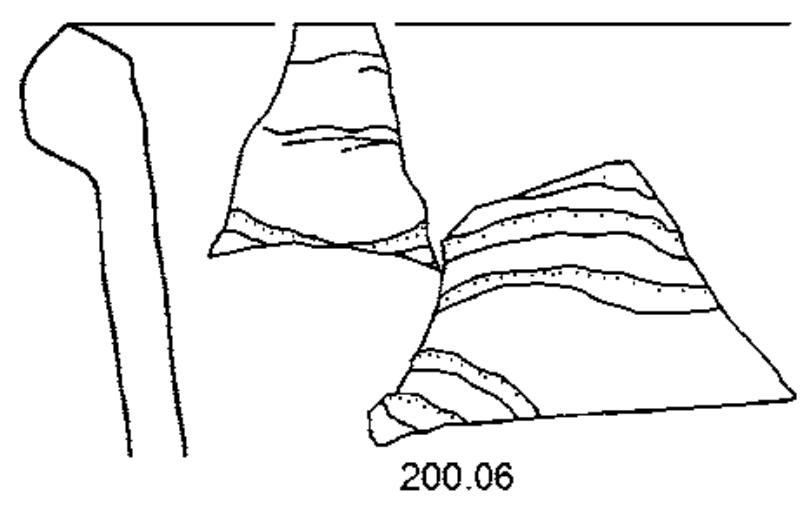

Figure 17. Later Sabaean pottery, Stratum N, Locus 200: reg. no. 200.06. (F.G. Fedele 2007)

sherds found in mutual proximity. ${ }^{58}$ The exterior is coral red and meticulously burnished, the interior rough and scabrous. Body buff to light red on the exterior transitioning to a grey-black zone on the interior. On the exterior the base of the vessel was extensively covered with a grey-beige, firm calcium carbonate crust, up to $4 \mathrm{~mm}$ thick: see Chapter 17, section 7.3 (this volume), for further details.

\footnotetext{
58 A probable fragment from the vessel's base (c. $7 \mathrm{~cm}$, non-joining) was found in cut 200. Judging from the shape and state of the extant portion, more fragments must exist immediately outside the excavated area, including beneath the Minaean wall. Sediment pressure may have been heightened by human agency connected with the Minaean works for the wall. Initially it was thought that this vessel had been smashed (trampled over?) while planted in the ground on this spot.
}

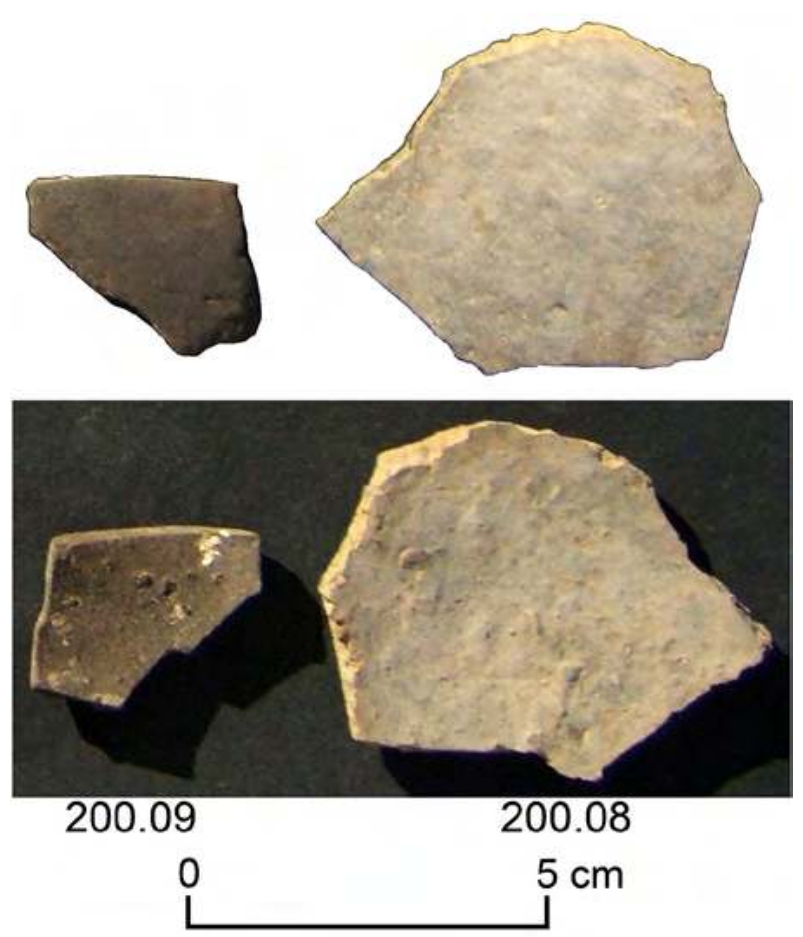

Figure 18. Later Sabaean pottery, Stratum N, Locus 200: reg. no. 200.08-09. (G. Di Rosa and S. Iavarone 2007 () MAIRY, arranged and optimized by F.G. Fedele 2020)

199.02 (Fig. 20; two views). Pattern-burnished vessel. Red Lustrous, reddish to brownish with hazel crisscross pattern; well fired, hard, greyish brick-red body; interior surface brick-red to buff, scabrous and fingermarked, hence variable wall thickness. $4.5 \times 3.4 \mathrm{~cm}, 5-6$ mm thick. | A1-A11 east + A31, Locus 200. Middle-upper 

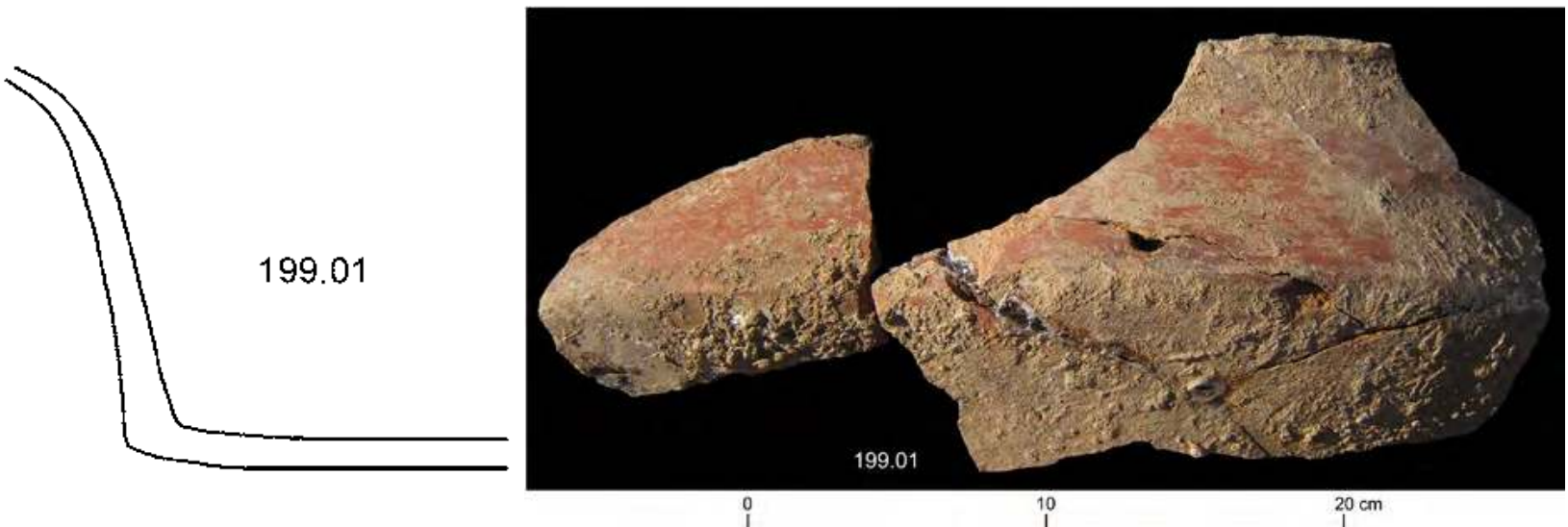

Figure 19. Later Sabaean pottery, Stratum N, Locus 200: basin no. 199.01. (G. Di Rosa and S. Iavarone 2007 @ MAIRY, drawing and adaptation by F.G. Fedele 2007 and 2020)

unit SYH. Stratum N. Similar in manufacture and polish to no. 61.01, above.

199.05 (Fig. 21). Bowl or cup with concave base (cf. no. 51.08): a Type B1c 'kitchen' shallow bowl ${ }^{59}$ Red-slipped ware: exterior well smoothed with evident slip (prone to exfoliation), interior rough, body buff; well fired. Size unrecorded. | A1-A11 east + A31, Locus 200: stratigraphy as for no. 199.02. Stratum $\mathbf{N}$.

\subsection{See section 3.3.}

194.03.1, 194.03.2 (Fig. 21). Two cooking pots attributable to Sabaean forms, cf. Type B3c. ${ }^{60}$ Probably Grey-black ware: fine, firm, dull beige to dark grey on the exterior and blackish on the interior. |A1-A11. Units Pj (part) and T79L (Component F12 of Earthwork F10-F12). Stratum J - but, probably, reworked Later Sabaean elements from underlying Stratum $\mathbf{N}$ or destroyed Stratum L. | A pot with a profile almost identical to no. 194.03.2, but with a thinner lip, was retrieved from the same units in quadrangle $A 31$ (no. 194A.05.1; not illustrated).

\subsubsection{See section 3.3 .}

39.02 (Fig. 22). Subvertical wall fr. probably from a deep bowl of Type A3d. Beige Plain ware, buff throughout; medium fabric, lightly chaff-tempered, firm; wiped exterior surface, mildly vesicular. $5 \times 3.3 \mathrm{~cm}$. $\mid D 5+D 15$ south. Unit GK4. Earlier Stratum N. | One groove below the rim. This appears to be a frequent vessel type at

59 Cf. de Maigret 2003, pl. 21/8.

60 Their morphology is Sabaean. For Barāqish cf. specimens in de Maigret 2010a, fig. 105/6 and pl. 113 right; the first of these is described on p. 82 as a black-burnished 'globular jar with short slightly flaring rim'. Our finds from Area C are unburnished.

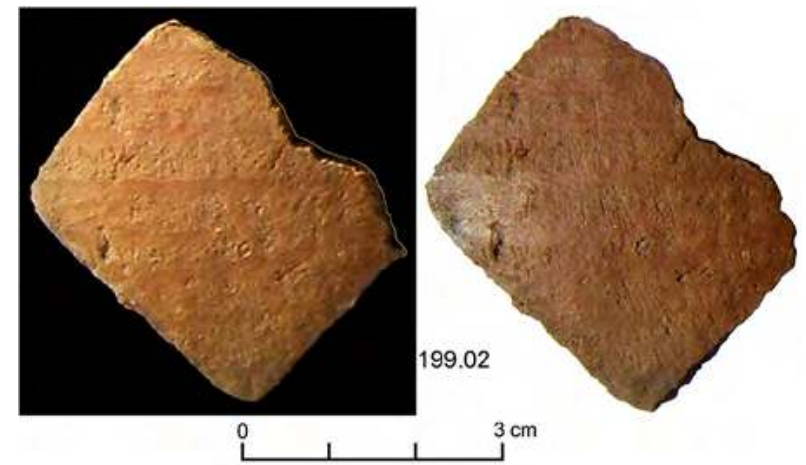

Figure 20. Later Sabaean pottery, Stratum N, Locus 200: reg. no. 199.02. (G. Di Rosa and S. Iavarone 2007 @ MAIRY, arranged and optimized by F.G. Fedele 2020)
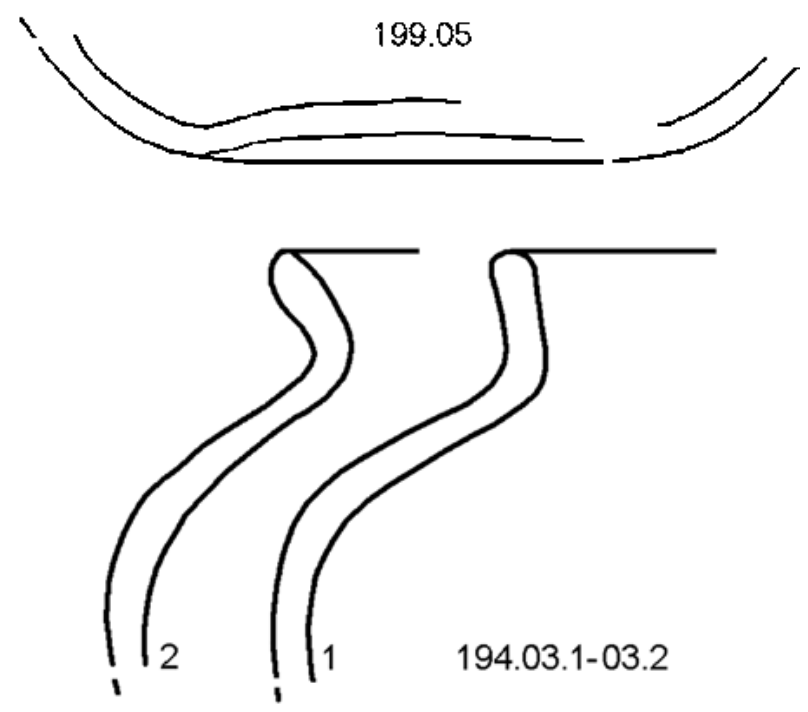

Figure 21. Later Sabaean pottery: above, Stratum N, Locus 200, reg. no. 199.05; below, reworked Sabaean material from Stratum J, reg. no. 194. (F.G. Fedele 2007) 


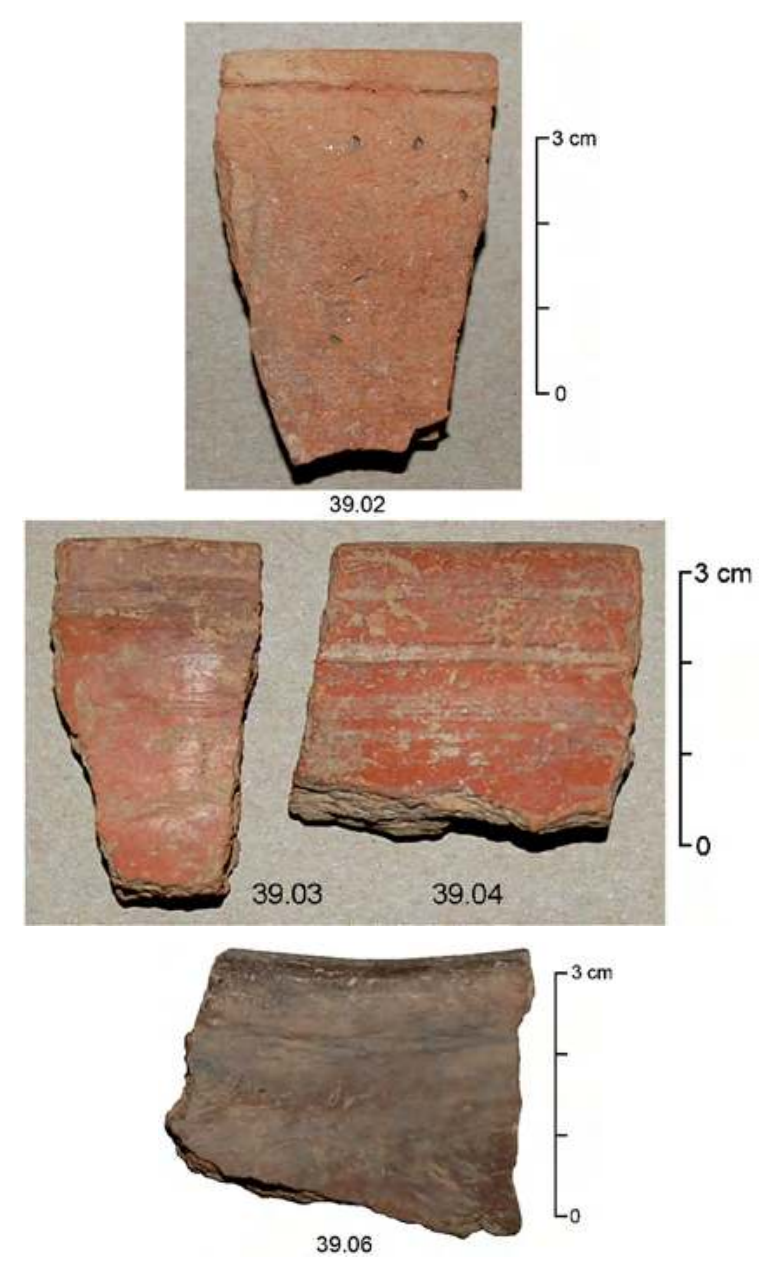

Figure 22. Later Sabaean pottery, Stratum N: reg. no. 39. (P. Morlupi 2006 @ MAIRY, adapted and optimized by F.G. Fedele 2020)

Yathill, perhaps particularly in Area C's Later Sabaean. ${ }^{61}$ Cf. no. 13.02, below, for a later example in Red Lustrous ware.

39.03, 39.04 (Fig. 22). Vertical or subvertical rim frs with two grooves below the rim, possibly from Type A3d deep bowls. Red Lustrous ware. Max. height $4 \mathrm{~cm}$ (no. 39.03) and $3.3 \mathrm{~cm}$ (no. 39.04). | D5 + D15 south: stratigraphy as for no. 39.02. Earlier Stratum N.

\footnotetext{
${ }^{61}$ Cf. de Maigret 2010a, table 2, column/form 4. He observes (p. 86): 'The potsherds which testify to the so-called small jars with straight vertical rim are never able to give us - on account of the fragility of these thin-walled vases - a clear idea of the original form of this vase type. We cannot in fact rule out that, rather than small jars, they might actually have been deep bowls. Always characterised by a deep single groove beneath the rim, they occur from Stratum $\mathrm{G}$ to Stratum $\mathrm{D}[\mathrm{..}]$. We can observe, however, that while the specimens from Strata $G$ and $F$ do indeed resemble deep bowls, those from Strata $E$ and D are undoubtedly jars, recalling the "insalatiere" with thin walls discovered in excavations at Yalā [i.e., Type A3d; de Maigret 2003, 90, pl. 16]. These vases dwindle drastically in numbers in Stratum $C$ and vanish altogether in Stratum B.' Find no. 39.02 has a precise parallel in Stratum E of Area A (de Maigret 2010a, fig. 102/16).
}

39.06 (Fig. 22). Small, neckless globular jar of Type B3a. Grey-black ware, fine, brown-hazel in colour throughout. Max. height $3.6 \mathrm{~cm}$. | D5 + D15 south: stratigraphy as for previous nos 39. Earlier Stratum N. | Rim fragment from an unelaborated, bulbous cooking pot with a very short rim and a beaded lip.

38.07 (Fig. 23). Fr. of lid: a pointed, 'pinched' grip. Red Lustrous ware, bright brown. Max. length $3.2 \mathrm{~cm}$. | D5. Units GK3-GK1. Later Stratum N. | Clearly from an elaborate and possibly medium-sized lid falling in Types E1a-E1d. ${ }^{62}$

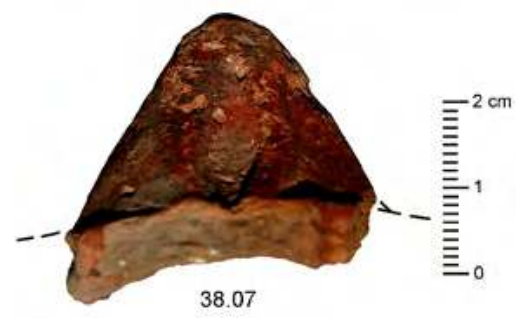

Figure 23. Later Sabaean pottery, Stratum N: lid fragment no. 38.07. (P. Morlupi 2006 C MAIRY, adapted and optimized by F.G. Fedele 2020)

\subsection{See section 3.3.}

16.2 (Fig. 24). Interior handle? A rim fr. apparently with a handle on the inside of the mouth. Red Lustrous ware, dark red body, both surfaces brown. $9 \times 7 \mathrm{~cm}$. | D3. Top levels of unit GK1. Later Stratum N. | The lip is decorated with indentations. Alternatively, this unparalleled find ${ }^{63}$ might be from a Type E1c lid with support rib inside, ${ }^{64}$ in which the rib was substituted by a handle-like protrusion.

23.02 (Fig. 25). Heavy storage jar (dolium), Type C3b or C3c. Red Lustrous ware. $13.6 \times 9.5 \mathrm{~cm}$. | D2 west, in situ at $-65 \mathrm{~cm}$ below the quadrangle D2/D3 datum. ${ }^{65}$ From mid-GR1b inside F9 ('Mass GR1'). Stratum L or earlier. | This sherd is both an exceedingly large inclusion for the mudbrick fabric of feature F9 and a typologically interesting find for the Later Sabaean. Wear grade 2, encrusted with mud.

62 For the record, this lid is completely different from the one collected from these same erosion gullies of western Barāqish in 1986, which is plain and has a flattened and unelaborated grip (Antonini, Chapter 2 in Volume 1, site 'BARi', Type 23).

63 'A type never seen before' (A. de Maigret, personal communication, Barāqish 2006).

64 de Maigret 2003, 94, pl. 34/4 (type 'con listello di appoggio interno').

65 The same level as for no. 23.01, a clay 'loaf': see Chapter 21, section 2.1 , this volume. On this find and other cultural contents of structure F9 see Chapter 17, section 7.6 and Fig. 64, this volume. In the same chapter, Fig. 32 shows photographs of F9 (sectioned) in quadrangle D2 west. 

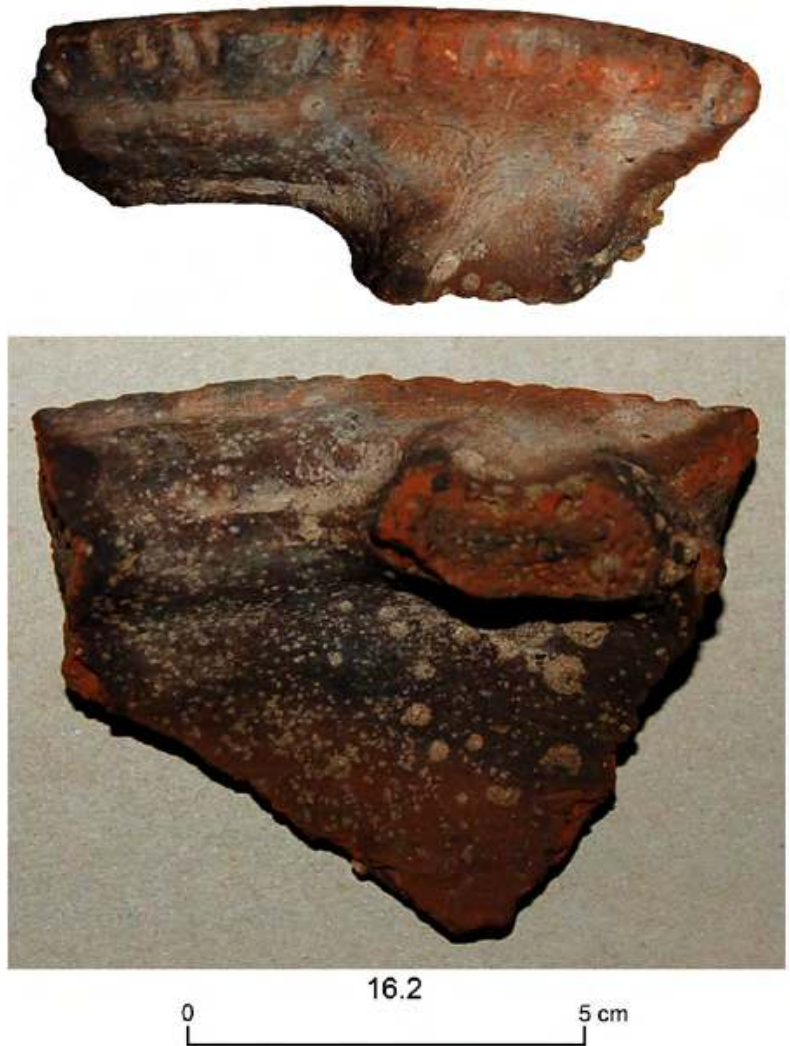

Figure 24. Later Sabaean pottery, Stratum N: reg. no. 16.2. (P. Morlupi 2006 @ MAIRY, arranged and optimized by F.G. Fedele 2020)

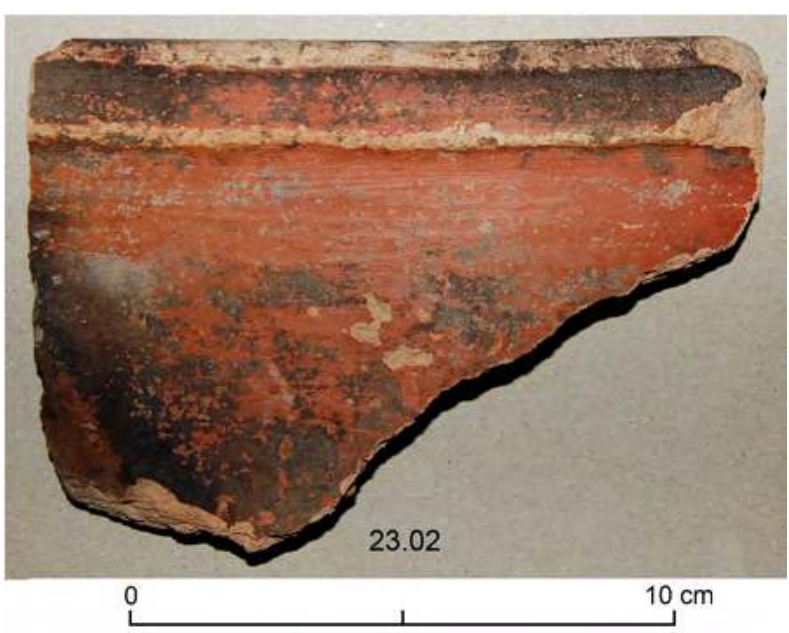

Figure 25. Later Sabaean pottery, Stratum L or earlier, from inside mudbrick mass F9: reg. no. 23.02. (P. Morlupi 2006 (c) MAIRY, optimized by F.G. Fedele 2020)

15.08 (Fig. 26). Medium, thick-walled globular jar cf. Type B3b. Red Lustrous ware, apparently only burnished in the upper half or upper third of the vessel. $12.7 \times 12.1$ $\mathrm{cm}$. D3. Unit GZ3. Earlier Stratum L. | A unique case from Area C: the beige slip in the portion below the maximum diameter of the vessel seems to have been
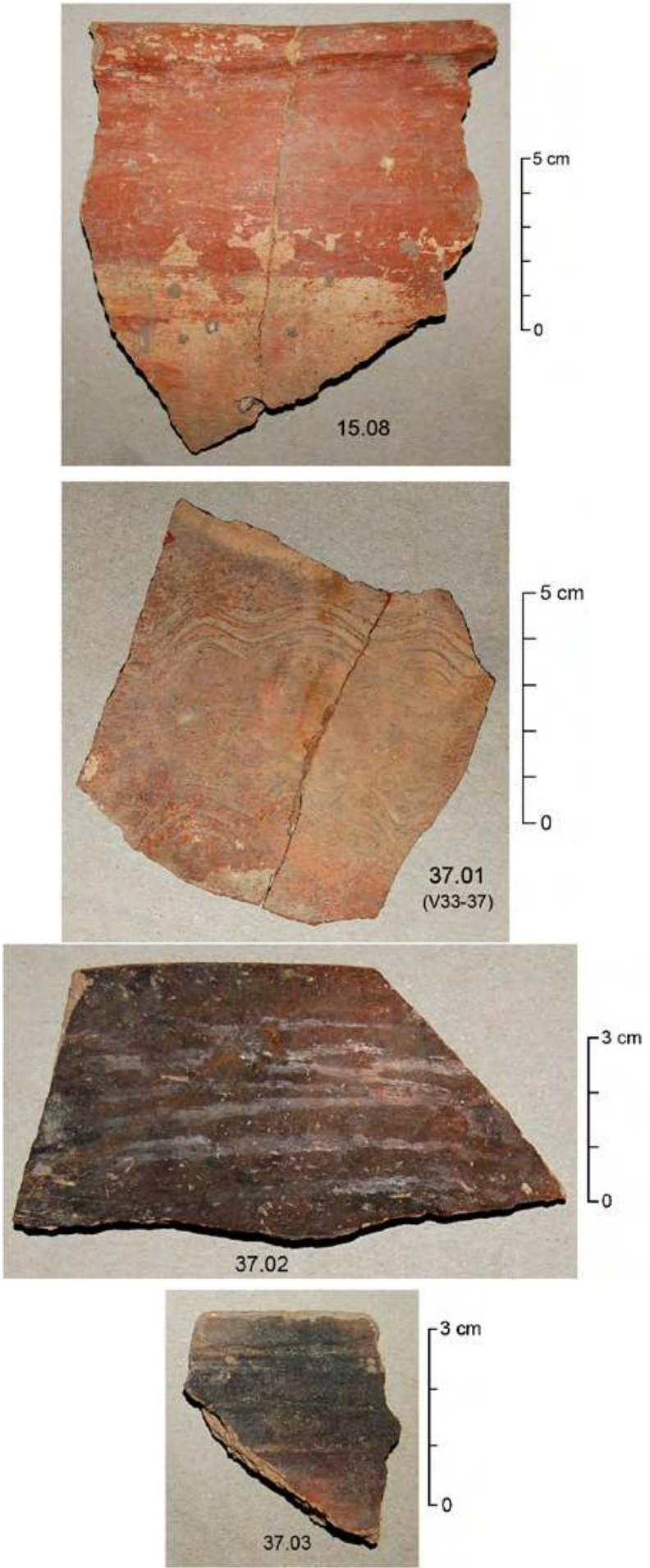

Figure 26. Later Sabaean pottery, Stratum L: reg. nos 15, above, and 37, below; in the middle, part of vessel V33-37. (P. Morlupi 2006 ( ) MAIRY, optimized by F.G. Fedele 2020)

left intentionally non-burnished. Smudges of red slip (or wash?) ${ }^{66}$ covering the plain beige coating contribute to this impression. Thickened rim.

${ }^{66}$ J.P. Thorley's classical definition of slip and wash is followed: a slip
is a coating applied before firing, and a wash an identical coating 
V33-37: conjoint of $33.02+37.01$ (Fig. 26, fr. no. 37.01; no photograph of no. 33.02). Vessel decorated with bands of wavy-line incisions, possibly a medium cooking pot of Type B3b. Beige Plain ware, body varying from beige to buff to brick-red. Reconstructed from a pair of non-joining wall sherds from cuts 33 and 37, each one a conjoint of two frs. No. $37.01: 8.1 \times 8.0 \mathrm{~cm}$. | No. 33.02 from D14, unit GZ3. No. 37.01 from D5, units GZ3 and lower GZ2 (eroded). Stratum L. The higher ridges of the wavy furrows are sometimes abraded. Edge wear is nil or minimal (0 on no. 33.02 and $0 / 1$ on no. 37.01). In both cases the further breakage of the vessel's remains seems to have resulted from ancient trampling on site.

37.02 (Fig. 26). Deep bowl of Type A3d: flaring rim fr. on which marginal traces of polish and some paler striations suggest pattern-burnishing. Red Lustrous ware, dark grey to brown-reddish exterior surface. $10 \times 5.1 \mathrm{~cm}$. | D5. Units GZ3 and lower GZ2 (eroded). Stratum L. | For both this sherd and no. 37.03, below, the combination of a largely matt surface - due to obliterated burnish - and minimal edge wear suggests damage from prolonged cooking or other fire-related use.

37.03 (Fig. 26). Globular necked pot of Type A5a, identical to no. 37.02 in ware, appearance, and surface damage. Red Lustrous ware. $4.1 \times 3.2 \mathrm{~cm}$. | D5: stratigraphy as for no. 37.02. Stratum L. | Multiple furrows on the short neck's exterior. The sherd is a little more edge-worn than no. 37.02.

V14-24. See section 3.3.

\subsection{See section 3.3.}

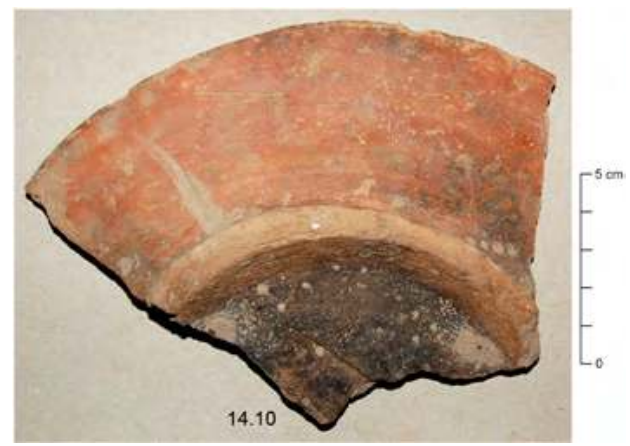

Figure 27. Later Sabaean pottery, Stratum L: reg. no. 14.10. (P. Morlupi 2006 @ MAIRY, optimized by F.G. Fedele 2020)

14.10 (Fig. 27). Ring-footed A1a cup inscribed on its base with an incomplete word in old South Arabian. Red Lustrous ware, but surfaces and foot very worn and polish lost. Max. length $14.4 \mathrm{~cm}$. D3. Units GZ2GZ1. Stratum L. | Such inscriptions typically occur on

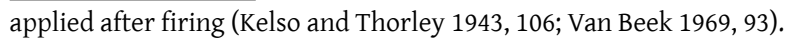

shallow footed bowls of Type A2. ${ }^{67}$ On the photograph, taken in 2006, barely a few thin, illegible scratches can be seen. A second inscribed vessel's base from Area C is described in section 3.4 below (no. 180.0).

14.11-13 (Fig. 28). Shallow bowl with turned-in rim: three rim frs apparently from the same vessel. Red Lustrous ware. Max. heights 6.3 to $7.6 \mathrm{~cm}$. | D3: stratigraphy as for no. 14.10. Stratum L. | The fragments show very week and irregular horizontal ripples in the topmost zone of the wall: this surface treatment turns out to be a decoration, since one ripple is in fact a slightly deeper impression (on frs 14.11-12) and changes into a wavy line on fr. 14.13. These bowls, rather frequent in the Later Sabaean of Area C, are similar to some bowls reported from the sounding at Temple A. ${ }^{68}$

14.14 (Fig. 29). Small, stout cooking pot cf. Type B3a with incised wavy-line decoration. ${ }^{69}$ Black-grey ware, with a distinctly dark grey body and a hazel slip on the exterior. $9.5 \mathrm{~cm}, 1-1.5 \mathrm{~cm}$ thick. | D3: stratigraphy as for nos 14.10-13. Stratum L. | Dark brown traces of burning on the exterior.

\section{$31,06,31.07$. See section 3.3 .}

31.08 (Fig. 28). Small, low cylindrical jar of Type C1a affinity. Red Lustrous ware with purple polish; the abraded polish reveals an orange surface, while body varies from buff to hazel to brownish. Max. height $6.3 \mathrm{~cm}$. | D4. Units GZ2-GZ1. Stratum L. | The upper carination is a thick, obtuse ribbing; the lower one is markedly rounded.

31.09 (Fig. 28). Shallow bowl of Type B1a. Red Lustrous ware, shiny, with 'fire cloud' on the rim (black patch from direct contact with the smoky part of the flame). Height $5.6 \mathrm{~cm}$. D4: stratigraphy as for previous nos 31 . Stratum L.

31.010. Thin-walled shallow bowl cf. Type B1a, small, attenuated carination. Beige Plain ware. Wall and base fr., max. $3.7 \mathrm{~cm}$.|D4: stratigraphy as for previous nos 31 . Stratum L.
67 de Maigret 2003, 90, pl. 13.

68 de Maigret 2010a, table 2, column/form 2. He observes (p. 86): 'From Stratum $G$ we begin to find among the table ware - and in significant numbers with respect to other vases - red-burnished bowls with inverted rim. These shallow bowls, all between 15 and 25 $\mathrm{cm}$ in diameter and very numerous also in the higher levels, may have served as authentic serving dishes.' No equivalence to Yalā's types was stated, although affinity with group B1 was possibly implied. The Area C finds resemble, e.g., the bowl in de Maigret 2010a, fig. 105/16, from his Stratum $C$.

69 A possible parallel, undecorated, is Yalā no. Y.87.Y.64/7 (de Maigret 2003, pl. 23/5). 

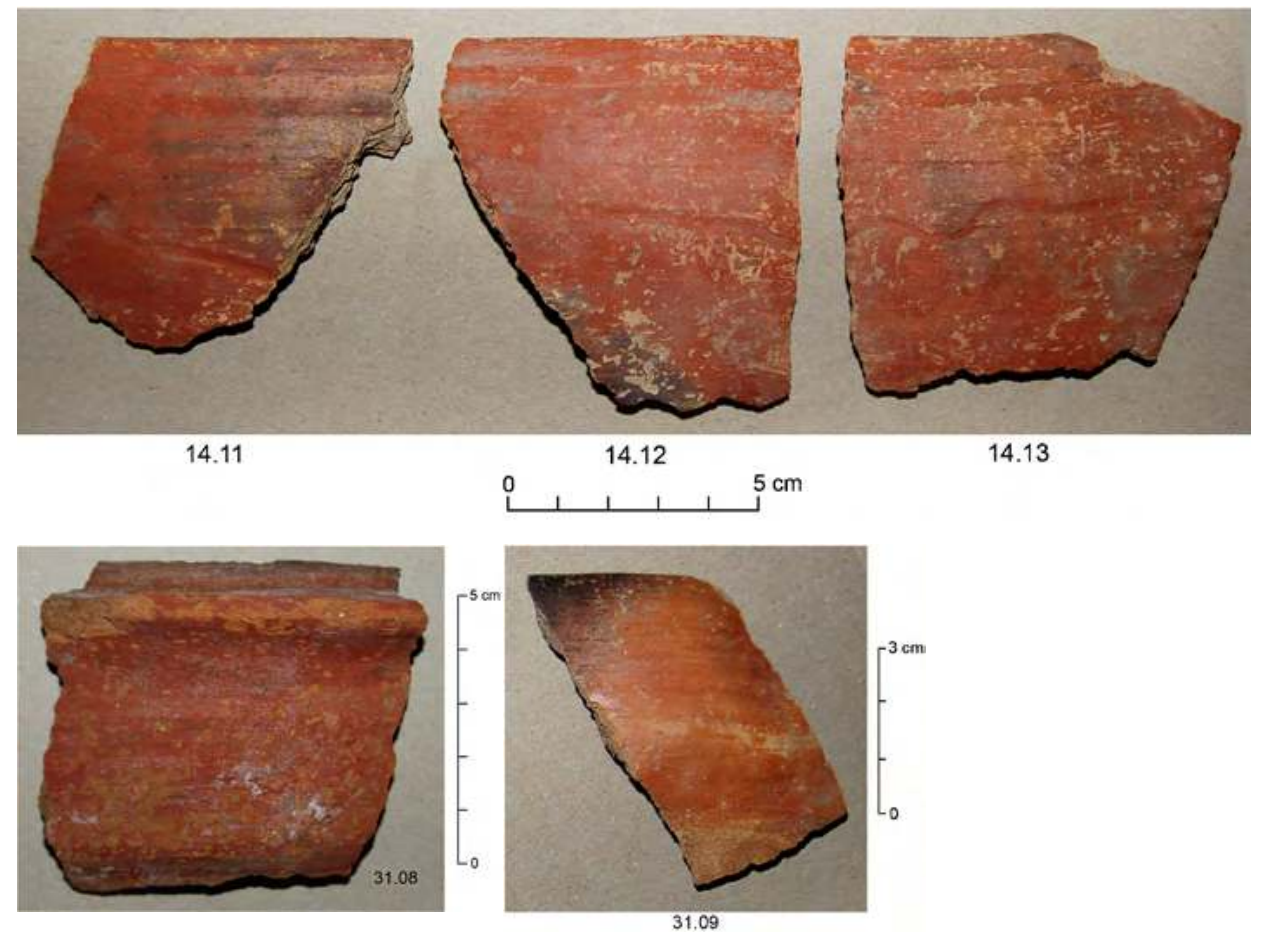

Figure 28. Later Sabaean pottery, Stratum L: reg. nos 14, above, and 31, below. (P. Morlupi 2006 @ MAIRY, optimized by F.G. Fedele 2020)

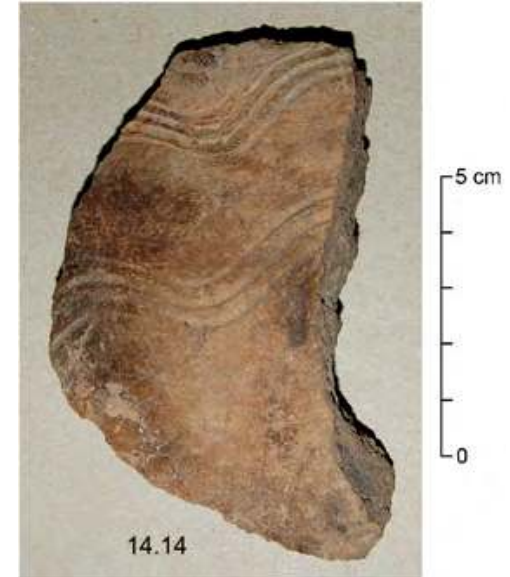

Figure 29. Later Sabaean pottery, Stratum L: reg. no. 14.14. (P. Morlupi 2006 @ MAIRY, optimized by F.G. Fedele 2020)

\subsubsection{See section 3.3}

13.01 (Fig. 30). Type A2 carinated bowl (from 2 rim frs). Red Lustrous ware, red-brown. Max. height $4.5 \mathrm{~cm}$, preserved rim length $10.2 \mathrm{~cm}$. D3. Top $10 \mathrm{~cm}$ of unit GZ1 and surface S2. Later Stratum L. | Two ribs and a groove below the rim.

13.02 (Fig. 30). Subvertical wall fr. probably from a deep bowl of Type A3d. Red Lustrous ware, greyish and mottled, of rather dull appearance. Height $7 \mathrm{~cm}$. D3: stratigraphy as for previous no. 13.01. Later Stratum L. |
Two neatly formed furrows below the rim. Cf. no. 39.02 above, including discussion.

13.03 (Fig. 30). Type A2 carinated bowl. Red Lustrous ware, unburnished on the underside; buff fabric. Max. height c. $7 \mathrm{~cm}$. D3: stratigraphy as for previous nos 13. Later Stratum L. | Thick-walled and rather crudely formed, with two grooves below the rim.

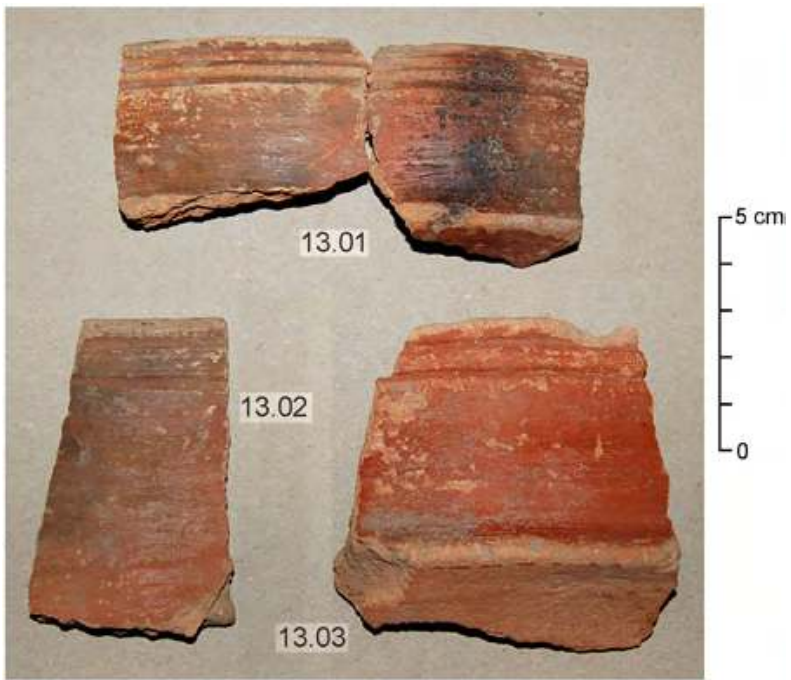

Figure 30. Later Sabaean pottery, Stratum L: reg. nos 13.0103. (P. Morlupi 2006 @ MAIRY, optimized by F.G. Fedele 2020)

The occupational layers representing Stratum $\mathrm{N}$ in Sector D (suites GK and GZ) are replete with cultural debris, including the whole inventory of Sabaean 


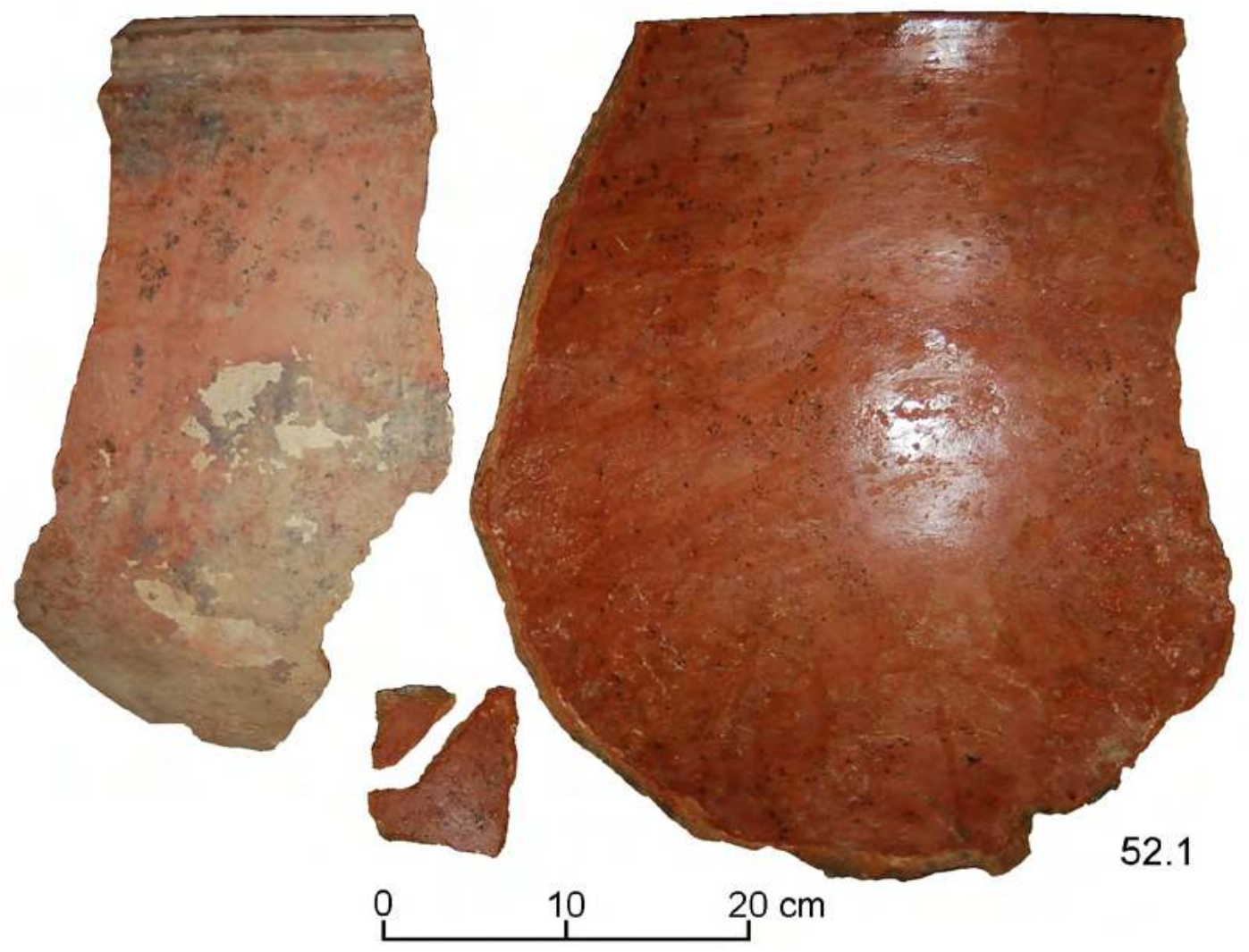

Figure 31. Later Sabaean pottery, Stratum M, cultural horizon H78: large storage jar no. 52.1. (F.G. Fedele and P. Morlupi 2006 (C) MAIRY, arranged and optimized by F.G. Fedele 2019)

pottery. Fragments of burnished vessels in mint condition are often in evidence, for instance Red Lustrous ware in unit GK1. From Stratum L, a Red Lustrous carinated bowl inscribed on its base was retrieved (no. 14.10), one of two such instances from Area C; the other one is no. 180.0, described in section 3.4 and more likely Minaean. Unfortunately, neither could be documented epigraphically.

Of great interest as a sample of Later Sabaean pottery is the assemblage from Locus 200, at the bottom of Sounding A, correlated with Stratum N. The lower levels (cut 200) produced 200 fragments, precisely, reduced to 168 as a result of the numerous joins. Red Lustrous ware is dominant: 119 fragments, mostly red (102), otherwise in dark non-red colours (14), including dark grey, greybrownish, hazel, and tobacco; or pattern-burnished in hazel-grey motifs (3). The shapes include carinated bowls, medium and large pedestalled vases with conical or trumpet feet, and a large heavy jar. Black Lustrous ware is present with a bifacially burnished sherd. Beige Plain ware amounts to 32 fragments, some of them from thin-walled vessels. Two fragments are in fact from ultrathin or 'eggshell' variants (nos 200.08-09; already noted in section 2 and in the introduction to the present section). Pale Green ware is represented by two sherds.
The upper levels of the locus (cut 199) produced 153 fragments. Red Lustrous ware is present with 98 fragments: 89 exhibit all shades of red, though with a prevalence of non-brilliant tones, and the slip and gloss are marginally poorer than in cut 200; eight are non-red fragments, and one is pattern-burnished. Black Lustrous ware is present with two fragments of bifacially burnished vessels. Beige Plain ware is more abundant (50 potsherds), generally well-smoothed and beige-buff in colour, but also including thin scabrous variants ( 11 fragments) and cooking pots and heavy jars with a buff-orange body (two fragments). Pale Green ware is again represented by two sherds. There are at least two heavy-sandy fragments from torpedo jars. As recorded in the above catalogue, 'hearth' SYH - an ashy silt partly fixed by calcitic substance - preserved the base of a large basin minutely fragmented in situ (no. 199.01).

Apart from details, cuts 199 and 200 are concordant in their ceramic record. From the evidence of Locus 200 it is apparent that there is absolute technological and morphological continuity between the burnished and the unburnished productions. The material and functional quality of the plain wares is identical - in general - to the quality of the visually more elegant lustrous wares. It seems clear that the evolution in the 

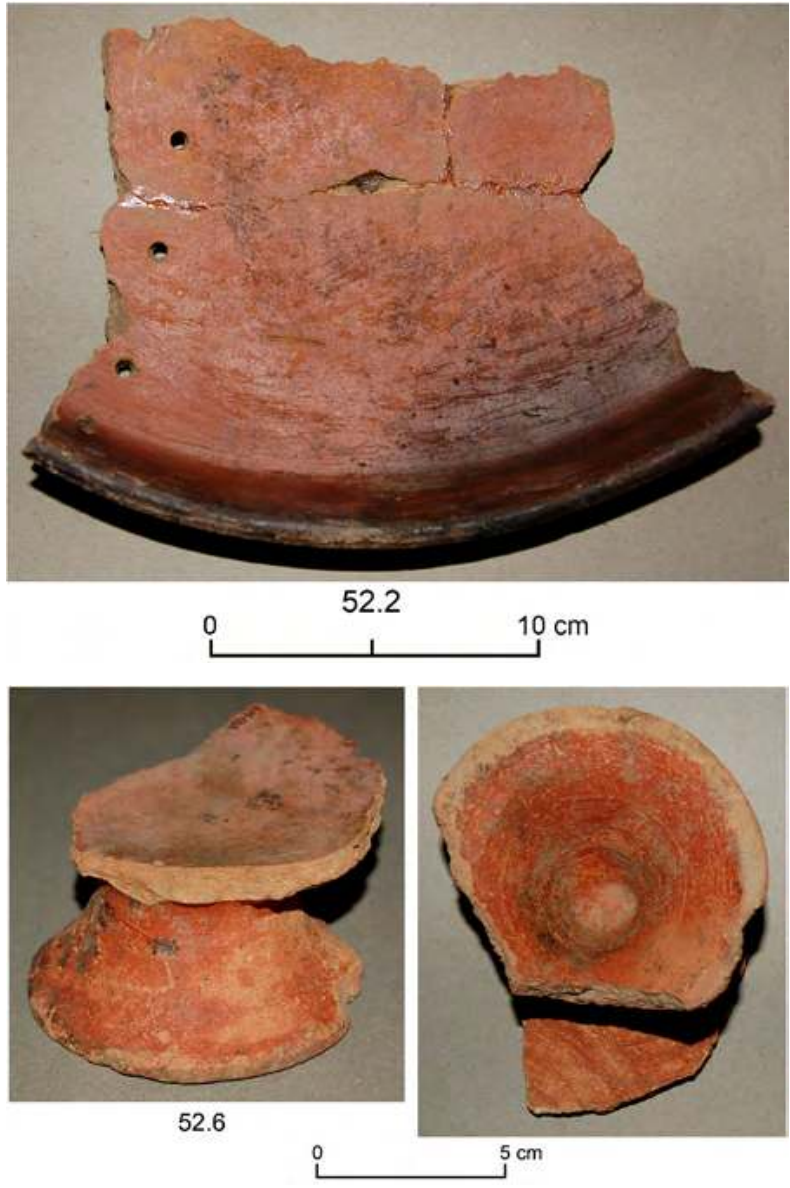

Figure 32. Later Sabaean pottery, Stratum M, cultural horizon H78: reg. nos 52.2 and 52.6. (P. Morlupi 2006 @ MAIRY, optimized by F.G. Fedele 2020)

Later Sabaean phase merely consisted in the expansion of plain and slip-burnished wares both characterized by increasingly expeditious and even shoddy manufacture (the 'epi-Sabaean' aspect, see the introduction to this section).

\section{Stratum M: Horizon H78 (Sector E)}

52.1 (Fig. 31). Large storage jar or 'dolium': an oversize vessel cf. Type C3a. Red Lustrous ware. Larger fr. $48 \times 42$ $\mathrm{cm}$, estimated height of vessel $56-58 \mathrm{~cm}$. $\mid$ E7 northeast corner, in situ. Suite SEK, cultural horizon H78. Stratum $\mathbf{M}$. The coral-red slip on the exterior is exfoliating and the base of the vessel is frayed. It is thus unclear from the extant portion whether the vessel had a ring base. ${ }^{70}$ The larger portion was treated for preservation with a standard acrylic polymer dissolved in acetone (a 25 per cent solution of Paraloid B72); the smaller portion was left intact.

70 Fragments of a similar vessel may be present in cultural horizon H11 (quadrangle E11), see below.
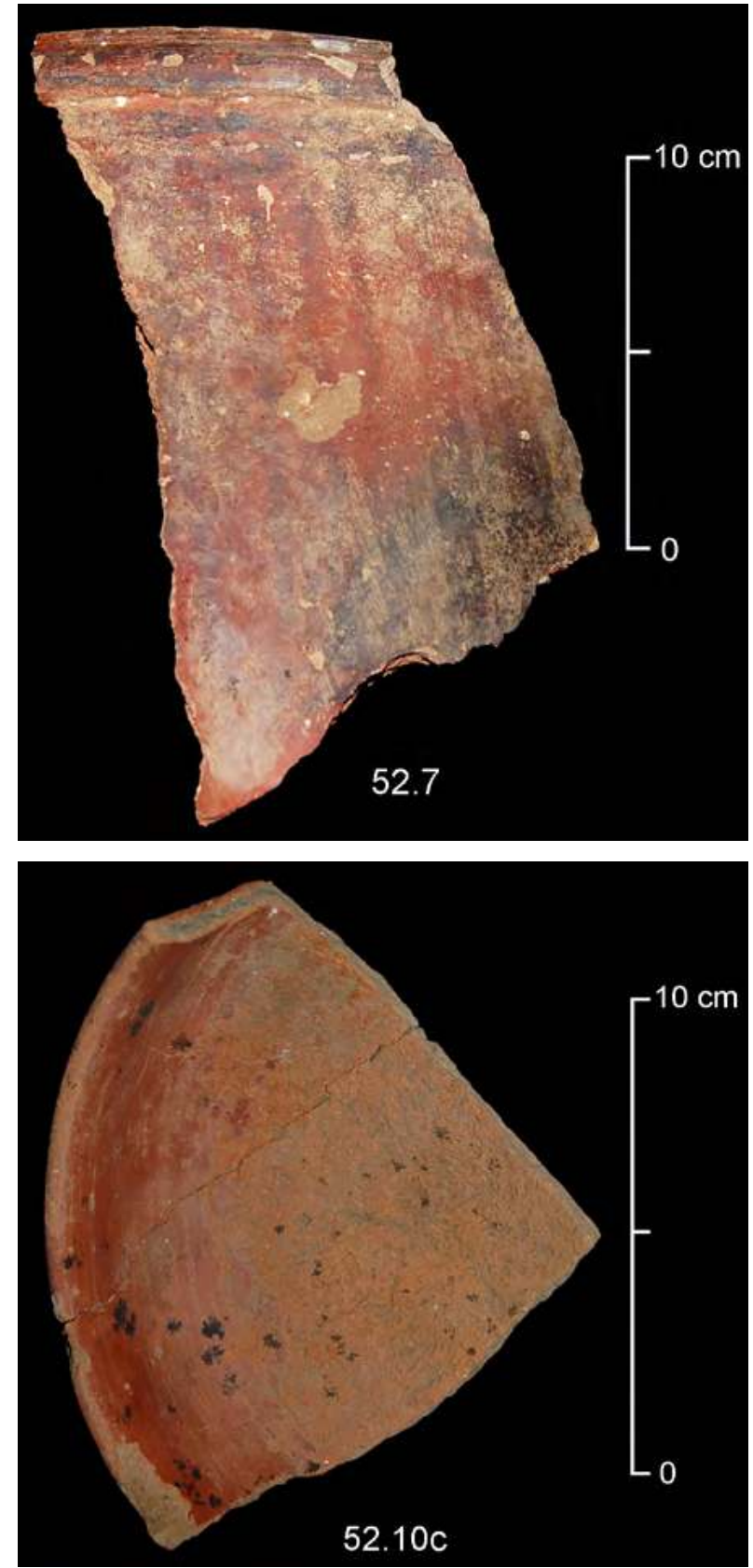

Figure 33. Later Sabaean pottery, Stratum M, cultural horizon H78: reg. nos 52.7 and 52.10c. (P. Morlupi 2006 @ MAIRY, optimized by F.G. Fedele 2020)

52.2 (Fig. 32). Large shallow bowl with repair holes (from 3 frs). Red Lustrous ware. $23.3 \times 16.4 \mathrm{~cm}$, height $c$. $5 \mathrm{~cm}$. | E7 middle southern side, sub-horizontal, in situ. Suite SEK, cultural horizon H78. Stratum M.

52.3. Barrel-shaped jar. Red Lustrous ware, but only burnished on the exterior and with an orange slip on the interior. Large wall fr., $\max .26 \mathrm{~cm}$. $\mid$ E7 southwest corner, horizontal, in situ. Suite SEK, cultural horizon H78. Stratum M. | A vessel belonging in the C1 group, but non-carinated and undecorated, hence apparently 


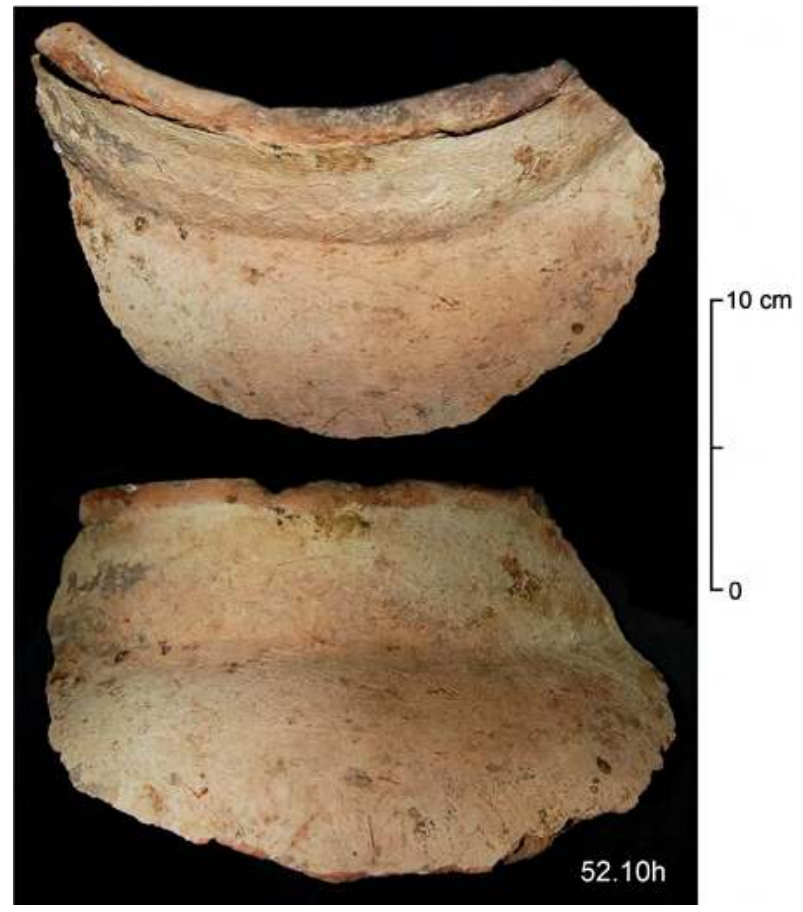

Figure 34. Later Sabaean pottery, Stratum M, cultural horizon H78: reg. no. 52.10h. (P. Morlupi 2006 @ MAIRY, optimized by F.G. Fedele 2020)

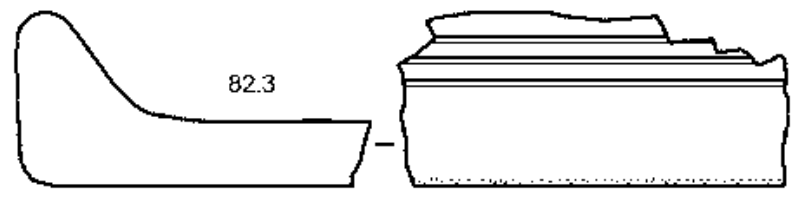

Figure 36. Later Sabaean pottery, Stratum M, cultural horizon H78: plate ('tray') no. 82.3. (F.G. Fedele 2006)

shows postdepositional manganese-oxide dendrites on its surfaces. The same context and quadrangle contained another identical conical foot (no. 52.10g, not illustrated).

52.7 (Fig. 33). Deep vessel with straight vertical wall, Type A3d: wall and rim fr. Red Lustrous ware, greyish pink to purple, mottled or pattern-burnished. Max. height $20.4 \mathrm{~cm}$. | E7, middle of western half, in situ. Suite SEK, cultural horizon H78. Stratum M. | Lip ribbed on the exterior and two wide grooves below the rim, both delimited by ribs as well.

52.10c (Fig. 33). Footed bowl of Type A3d: vertical wall, no foot preserved. Red Lustrous ware. $14.3 \times 11.7 \mathrm{~cm}$, max. height $4.5 \mathrm{~cm}$. $\mid$ E7. Suite SEK, cultural horizon $\mathrm{H78}$.
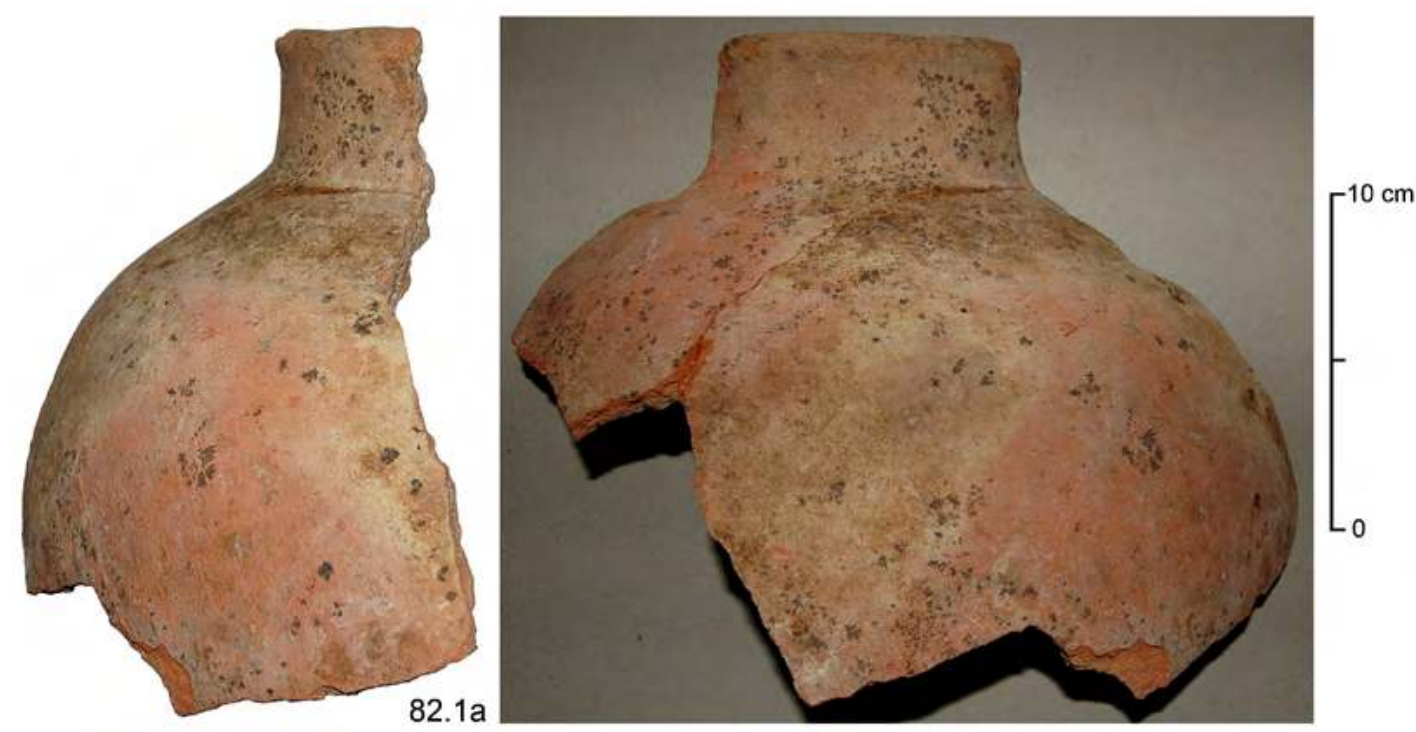

Figure 35. Later Sabaean pottery, Stratum M, cultural horizon H78: reg. no. 82.1a. (F.G. Fedele and P. Morlupi 2006 (C) MAIRY, arranged and optimized by F.G. Fedele 2019)

not represented in the extant typologies (Yalā and the sounding at Temple A).

52.6 (Fig. 32). Footed bowl of Type A3d: foot and base fr. Red Lustrous ware. Foot max. $\varnothing 9 \mathrm{~cm}$, height $5.7 \mathrm{~cm}$. | E7 northern side, $30 \mathrm{~cm}$ from northwest corner, in situ, lying on edge (it is drawn on the Reference section). Suite SEK, cultural horizon H78. Stratum M. | Like other pottery fragments from Horizon H78, also this piece
Stratum M. | Identical to no. 151.13.4, and resembling typologically footed bowl no. 151.5 (see both below).

52.10h (Fig. 34). Large cooking pot with wavy-line decoration: wall and rim fr. Beige Plain ware, the exterior unusually covered with a whitish beige slip or wash, faintly mottled, best preserved on neck; the body is buff, blackened on the interior of the mouth. $22.4 \times$ $14.4 \mathrm{~cm}$. | E7. Suite SEK, cultural horizon H78. Stratum 
M. | A large B3 cooking pot of a type apparently not represented at Yalā. It is similar in overall morphology and decoration to Type B3b, but with a distinct, slightly everted rim as in Type B3c. Thickened lip, and a very superficially incised decoration.

82.1a (Fig. 35). Narrow-necked, globular jar of Type C2. Beige Plain ware, buff on both surfaces. Large fr., height $20 \mathrm{~cm}$. | E8 centre, in situ: apparently the 'centrepiece' of Cluster 82.2. ${ }^{71}$ Suite SEK, cultural horizon H78. Stratum M. | Type C2 is de Maigret's otre, presumed for storage. On the surface numerous manganese-crystal spots and dendrites can be seen (cf. find no. 52.6, above).

82.3 (Fig. 36). A stout plate (de Maigret's 'tray') with a plain, beige-whitish exterior and body and a redburnished slip on the interior. Red Lustrous ware, poorly fired. Size unrecorded, but fr smaller than a dm. E8. Suite SEK, and units YS8-E86 and lower Eб3+E85. Stratum M (SEK, YS8-E86) or Stratum I (Eб3+E85); more probably M. It is impossible to determine whether the exposure of beige-whitish fabric on the exterior was intentional and primary, or else caused by abrasion. See text below for further discussion of this find.

The assemblage constituting cultural horizon H78 (cuts 52 and 82) was visually dominated by a large portion of a Red Lustrous storage jar about $60 \mathrm{~cm}$ tall (no. 52.1); several unusually large fragments of different vessels lay nearby, scattered in quadrangles E7-E8. A small cluster of partly burnt stones in quadrangle $E$, Cluster 82.2, contained in its middle a tall necked jar (no. $82.1 \mathrm{a}){ }^{72} \mathrm{~A}$ total of 85 pottery fragments was recovered from the horizon, comprising a good sample of Sabaean wares in terms of typology and production quality. Burnished and unburnished wares are represented in similar proportions.

Among the Red Lustrous vessels, dolium 52.1 is presently unparalleled at Yathill, unless some potsherds from Horizon H11 belong to a similar vase (see below). Other forms include shallow and footed bowls of different types (some with attenuated carination), a deep vertical-walled vessel, a barrel-shaped jar, necked globular jar no. 82.1a, and a remarkable plate or 'tray' (no. 82.3), to be examined below. Black Lustrous ware is represented by a small and thin-walled bowl or cup of otherwise inferior workmanship ('poorly fired'). ${ }^{73}$

71 Cluster 82.2 was described as part of cultural horizon H78 in Chapter 17, section 7.8 and Fig. 70, this volume. For other finds see Chapter 21, section 2.1, 'Other utilized natural stones', including 'Remarks on Cluster 82.2'.

72 For complementary descriptions of Horizon H78 see the sections on Stratum M in Chapters 17 and 19, this volume; Fig. 68 in Chapter 17 shows the planimetric distribution of finds. Interpretations were discussed in Chapter 19.

73 No. 52.10b, not illustrated. See a mention in connection with unfired cup no. 120.3 in section 3.4, below.
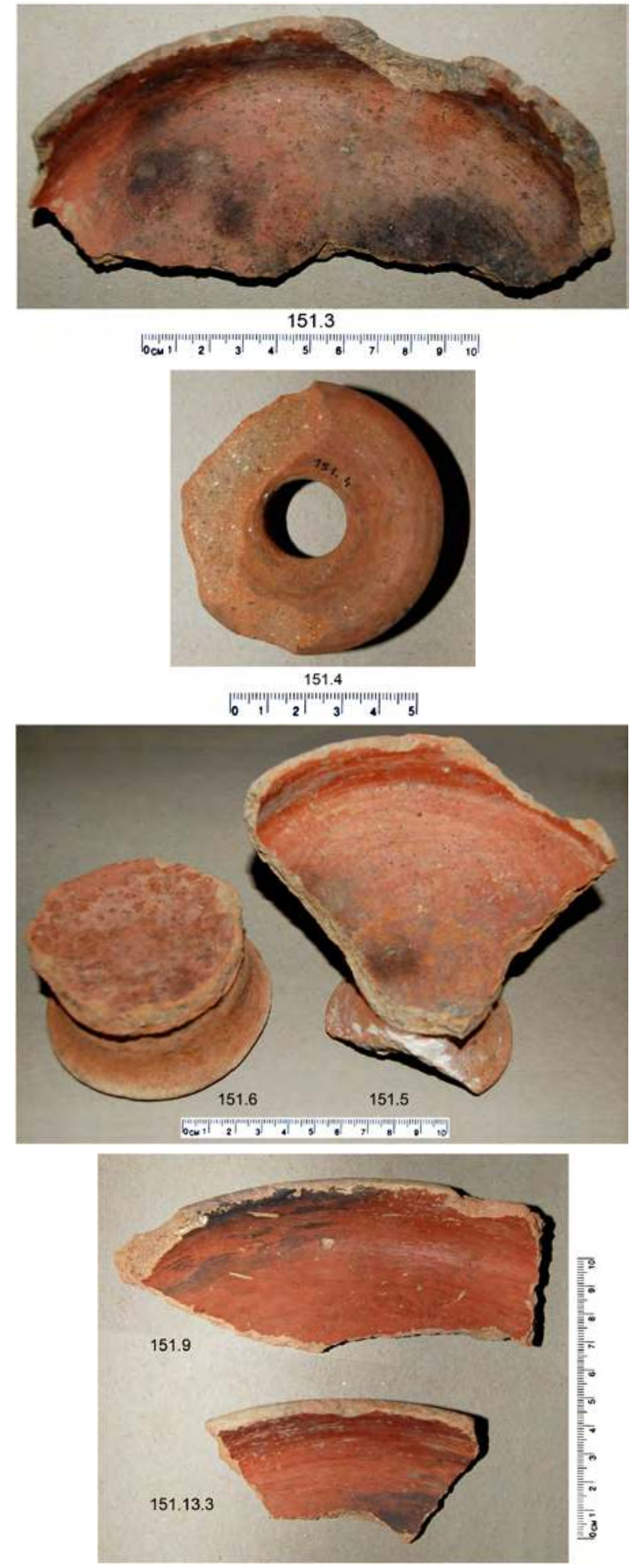

Figure 37. Later Sabaean pottery, Stratum M, cultural horizon H11: reg. nos 151.3-6, 151.9, 151.13.3. (P. Morlupi 2006 (c) MAIRY, optimized by F.G. Fedele 2020) 
Among the Beige Plain vessels a cooking pot with wavy line decoration can be noted, of a form not otherwise documented. Two fragments of torpedojars are present.

Find no. 82.3, a fragment of a stout plate, deserves attention as an example of the objects that de Maigret called 'trays' ${ }^{74}$ Fragments were retrieved in 2006 from the sounding at Temple A. They were subsequently published by de Maigret in 2010, ${ }^{75}$ when they were identified as a rare ceramic type with potential cultic use. ${ }^{76}$ Only at Barāqish this type had come to light with sufficient frequency to attract attention, since no more than a single find was previously known from Yalā/alDurayb (a surface sherd) ${ }^{77}$ and two had been published from Wādī al-Jūbah. ${ }^{78}$ This rarity explains the absence of such a type from the morpho-functional typology based on Yalā. Together with a possible interpretation of the object, also the term 'tray' was introduced on the basis of the finds from the sounding at Temple A, where both the interpretation and name appeared to be justified by some aspects of the associated ceramic collection. ${ }^{79}$

Concerning the use of such plates, the find from Area C as well as those from Yalā and Hajar al-Rayhānī appear to contradict de Maigret's supposition that they might be linked to religious activity. His reconstruction in terms of a supposedly composite set - a tray or platter on the top of a pedestal or stand - deserves consideration, but needs direct evidence from securely defined contexts to be substantiated.

\section{Stratum M: Horizon H11 (Sector E) and Sounding F}

151.3 (Fig. 37). Large wide bowl or 'basin' cf. Type A4. Red Lustrous ware. $17.2 \times 7.8 \mathrm{~cm}$, height c. $4.5 \mathrm{~cm}$. |E11 Locus 151, southeast quadrant, in situ. Unit Eox, cultural horizon H11. Stratum M. | Conspicuous blackened patches from burning appear on the interior, as if the vessel was used on occasion as a brazier.

151.4 (Fig. 37). Torpedo jar: mouth and neck fr. Heavy Sandy ware. Mouth $\varnothing 7.4 \mathrm{~cm}$, hole $\varnothing 2.2 \pm 0.1 \mathrm{~cm}$. $\mid$ E11, in situ: location and stratigraphy as for no. 151.3. Stratum

\footnotetext{
74 This section on find no. 82.3 updates Fedele 2010, 128.

75 de Maigret 2010a, 79 (Stratum F), 80 (Stratum E), 84 (an isolated sherd from Stratum B); figs 100/1-2, 102/12-14, 108/6; table 2, column/form 7. A. de Maigret did not know of my find from Area $\mathrm{C}$ because I only noticed it myself after reading in manuscript de Maigret's (2010a) article; it is unfortunate that we never had the opportunity of discussing this find or indeed this subject together.

76 de Maigret 2010a, 87, fig. 110.

77 de Maigret 1988b, fig. 19/1.

78 Hajar al-Rayhānī: Glanzman's (1987a, 109, fig. 5/12-13) 'platters'.

79 While suggesting 'tray' as his preferred term, de Maigret (2010a) also adopted Glanzman's 'platter', which he almost always cited in quotation marks. Originally, platter is American English for a large flat dish. W. Glanzman later presented some more information on the finds from al-Rayhānī in his Ph.D. dissertation (Glanzman 1994).
}
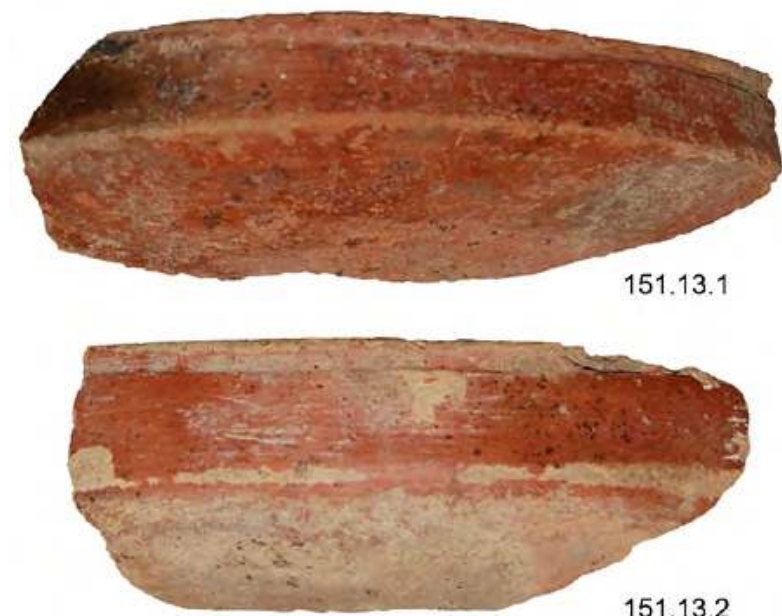

151

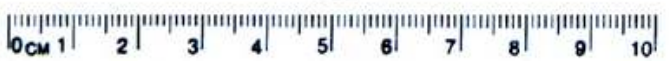

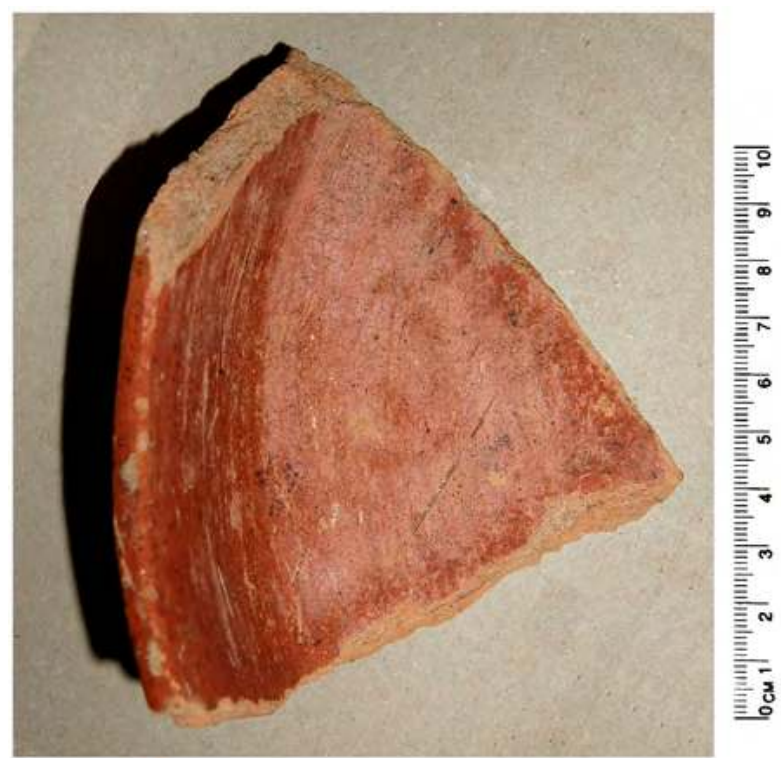

151.13.4

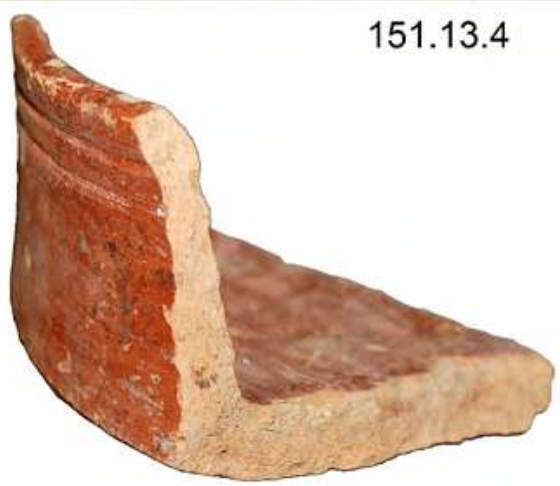

Figure 38. Later Sabaean pottery, Stratum M, cultural horizon H11: reg. nos 151.13.1-2 and 151.13.4. (P. Morlupi 2006 (C) MAIRY, arranged and optimized by F.G. Fedele 2020) 


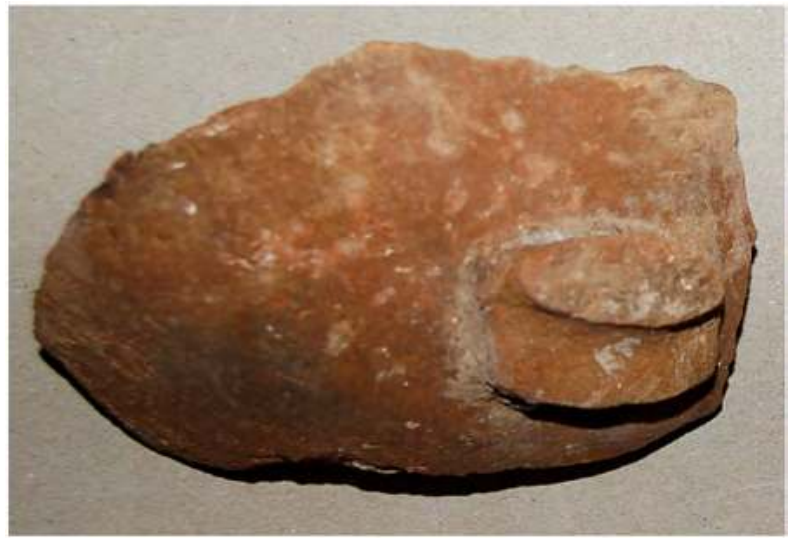

151.13 .5

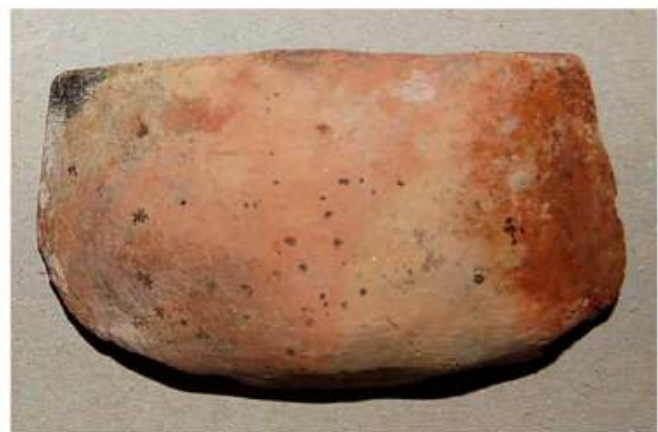

151.13.6

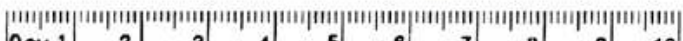

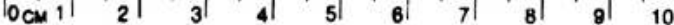

Figure 39. Later Sabaean pottery, Stratum M, cultural horizon H11: reg. nos 151.13.5-6. (P. Morlupi 2006 C MAIRY, optimized by F.G. Fedele 2020)

M. | A smaller fragment found nearby may be from the same or a similar vessel.

151.5 (Fig. 37). Footed bowl. Red Lustrous ware. Container $13 \times 11 \mathrm{~cm}$; foot max. $\varnothing 7 \mathrm{~cm}$, height $3.5 \mathrm{~cm}$; vessel $\varnothing c .15 \mathrm{~cm}$, height $c .15 \mathrm{~cm}$ (both estimated). E11, in situ: location and stratigraphy as for nos 151.34. Stratum M. | The total profile of vessel is preserved, showing a type unparalleled at Yalā: a Z-shaped profile cf. Type A3d, but rounded and with a shorter, vertical upper third. The medium, narrow conical foot shows a lacuna filled with gypsum from an ancient repair. Cf. nos 151.13.4 (below) and 52.10c (above).

151.6 (Fig. 37). Foot fr. of a bowl, type indeterminable. Red Lustrous ware. Foot max. $\varnothing 8.8 \mathrm{~cm}$, height $7 \mathrm{~cm}$. | E11 Locus 151, north side of northeast quadrant, in situ. Unit Eox, cultural horizon H11. Stratum M.

151.9, 151.13.3 (Fig. 37). Carinated bowl or bowls of Type A2: two frs probably from the same vessel. Red Lustrous ware. $15.5 \times 6.3 \mathrm{~cm}$ (no. 151.9); $9.6 \times 5 \mathrm{~cm}$ (no. 151.13.3). E11 Locus 151, near middle of eastern side, in situ (no. 151.9). Unit Eox, cultural horizon H11. Stratum M. | A wide and shallow variant of Type A2.
151.13.1, 151.13.2 (Fig. 38). Carinated bowls of Type A2. Red Lustrous ware. Two large frs: $11.6 \mathrm{~cm}$, wall height $2 \mathrm{~cm}$ (no. 151.13.1); $10.5 \mathrm{~cm}$, wall height $2.3 \mathrm{~cm}$ (no. 151.13.1). E11 Locus 151. Unit Eox, cultural horizon H11. Stratum M. | Wide and shallow variants of Type A2.

151.13.4 (Fig. 38). Footed bowl of Type A3d: vertical wall, no foot preserved. Red Lustrous ware. $11.7 \times 9.8$ $\mathrm{cm}$, height c. $5 \mathrm{~cm}$. | E11: location and stratigraphy as for previous nos 151.13.1-13.3. Stratum M.| Identical to no. 52.10c, and resembling footed bowl no. 151.5 (see both above).

151.13.5 (Fig. 39). Handled cup or mug cf. Type A1a. Red-slipped ware. $10.5 \times 6.5 \mathrm{~cm}$. | E11: location and stratigraphy as for previous nos 151.13.1-13.4. Stratum M. | Wide ribbon handle, broken and missing.

151.13.6 (Fig. 39). Small, summarily fashioned cup: a Type A1b chalice? Red-slipped ware. $8.8 \times 5.2 \mathrm{~cm}$. | E11: location and stratigraphy as for previous nos 151.13.113.5. Stratum $\mathbf{M}$.

215.01 (Fig. 40). Handle, detached. Red Lustrous ware, well formed and firm. Height $4.5 \mathrm{~cm}$. |F. Unit SP1. Earlier Stratum M. | A triangular handle in front view, splayed in its lower part and narrowed and thickened towards the top. It appears to be a rare or unknown type for the Sabaean area, not being documented in Yalā's typology nor in the collection from the sounding at Barāqish
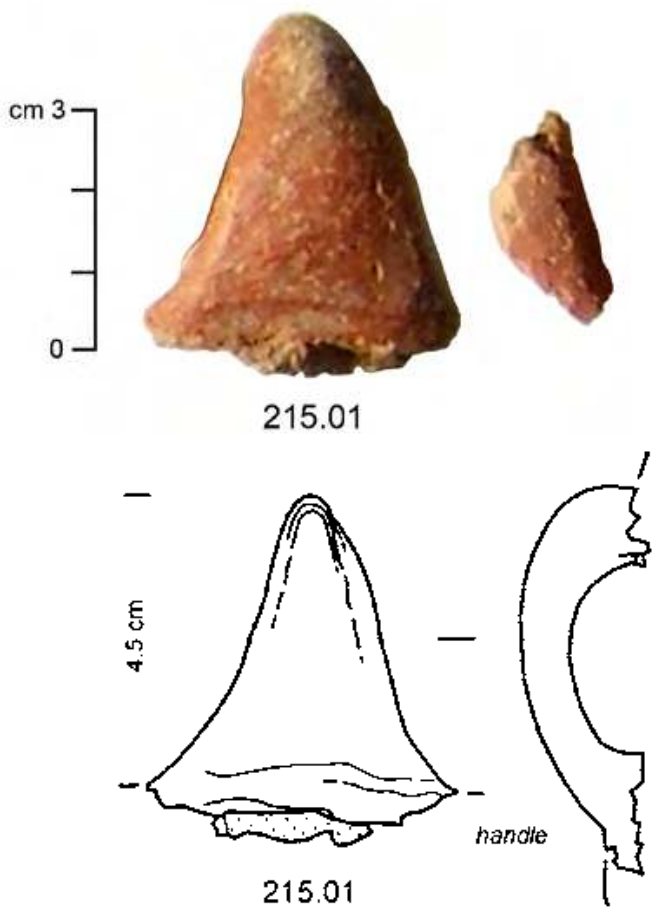

Figure 40. Later Sabaean pottery, Stratum M, Sounding F: handle no. 215.01. (G. Di Rosa and S. Iavarone 2007 (C) MAIRY, drawing and adaptation by F.G. Fedele 2007 and 2020) 


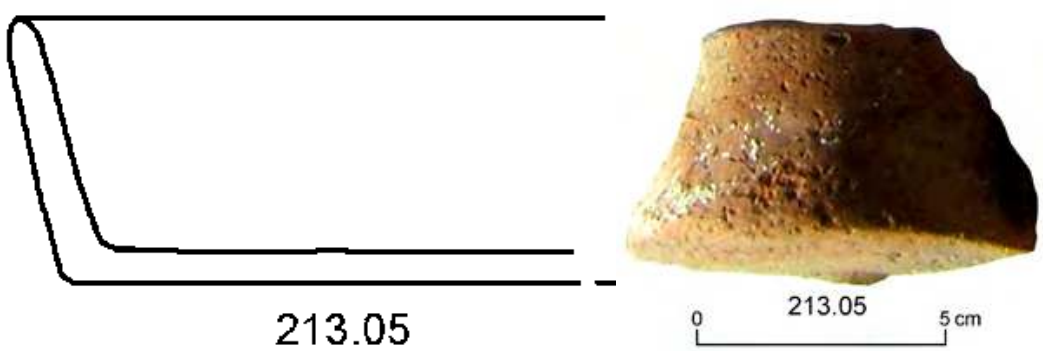

Figure 41. Later Sabaean pottery, Stratum M, Sounding F: reg. no. 213.05.

(G. Di Rosa and S. Iavarone 2007 (C) MAIRY, drawing and adaptation by F.G. Fedele 2007 and 2020)

itself, Area A. Considering its provenance from the plain (Sounding F), this tiny handle could be an indication of a vessel foreign to local production or even alien to the Sabaean culture, associated with caravan movement. A possibly similar handle is represented in cut 215 by a 2.6-cm-long fragment (also pictured).

213.05 (Fig. 41). Thin-walled bowl or plate with subvertical wall. Beige Plain ware, buff semifine body. Length $8.3 \mathrm{~cm}$, rim height $4.2 \mathrm{~cm}$. $\mid F$. Units SF1a-SF1. Stratum M. | Type unclear - indeterminable whether flat-based or footed ${ }^{80}$ - and possibly unparalleled. Carefully fashioned.

The assemblage constituting cultural horizon H11 in quadrangle E11 (probably extending outside the excavated test trench) included large ceramic fragments of different wares, mainly clustered in Locus $151 .{ }^{81} \mathrm{Cut}$ 151 retrieved a total of 33 pottery fragments, mostly abraded from exposure in lag gravel and trampling. Red Lustrous ware includes a basin, a vessel with a vertical wall (probably footed), and different forms of footed bowls, some sharply carinated and one of a type not otherwise documented (no. 151.5, plaster-repaired). There are several carinated shallow bowls, and some potsherds might belong to a large storage jar similar to dolium 52.1 from Horizon H78. Red-slipped ware is represented by a rare chalice (tentative attribution) and by a handled cup.

Uncoated wares seem to be slightly predominant in terms of vessel count. Beige Plain ware is copious. Some examples are blackened from a use or uses associated with fire, and several can tentatively be assigned to a cooking function on the basis of carbonaceous matter adhering to their exterior surface..$^{82}$ Cooking pot no.

\footnotetext{
80 Small flat-based vases, but in Red Lustrous ware, were reported from the two lowermost strata of the sounding at Temple A (de Maigret 2010a, 77, fig. 97/4-5).

81 For complementary descriptions of Horizon H11 see the sections on Stratum M in Chapters 17 and 19, this volume; Fig. 16 in Chapter 19 illustrates the distribution of finds. Interpretations were discussed in Chapter 19.

82 Cf. Glanzman 2018, 129, 134.
}

151.7 (not illustrated) is an example, with its thick crust on the exterior; and through its combination with wear grade $0-$ an indication of minimal postdepositional transport (if any) - this vessel further suggests that cooking would have occurred on the spot. Horizon H11 also produced fragments from perhaps two torpedo jars (no. 151.4 in situ).

Sounding F gave abundant Later Sabaean pottery that included two isolated handles (one possibly foreign to Yemen), some Pale Green ware (see next section), and many fragments of torpedo jars. For further details see Chapter 17, section 17, this volume.

\subsection{On some particular Later Sabaean pottery types ${ }^{83}$}

Observations are presented in this section on the ceramic class of Pale Green ware, previously introduced (section 2), and on the typological group of Wavy Rim bowls (WR bowls). Both manifestations were revealed at Yathill by the Later Sabaean contexts of Area $C$ and at least the second appears to be diagnostic of this phase. Instead, in the case of the Pale Green ware we seem to be dealing with the continuance and further variation of an already existing production. Although technologically belonging to plain wares, WR bowls and the Later Sabaean Pale Green vessels stand out from the rest of the ceramic production, hence their particular interest.

\section{Wavy Rim bowls}

WR bowls represent a rather well-known and functionally peculiar vessel type. ${ }^{84}$ They were first precisely described, with this name, by Gus Van Beek in his study of Hajar ibn Humayd. In his classification they fall into three forms: ${ }^{85}$

\footnotetext{
83 This section updates the treatment of the subject in Fedele 2010, 126-127.

${ }^{84}$ Glanzman 1987a, 76; 1994, 215-229, table 3.17; 2004a; 2005; all with references.

85 Stratigraphic distribution from Van Beek 1969, fig. 23. Chronology as re-appraised by Glanzman (1994, 8-11, 538-547, tables 2.6-2.8); cf. Chapter 18, this volume, Fig. 4.
} 
- Type 1000 (straw, plain) Bowl 11, with two stratigraphic ranges: Strata R-P (10th-8th centuries $\mathrm{BCE}$ ), single find per stratum; and $\mathrm{D}-\mathrm{A}$ (3rd century BCE-early centuries CE); 86

- Type 1001 (straw, incised) Bowl 4, with 'rim pinched like pie crust', represented in Strata L, $\mathrm{K}$, and $\mathrm{G}$ (7th-5th centuries $\mathrm{BCE}$ ), single find per stratum; ${ }^{87}$

- Type 1001 Bowl 5, 'wavy with deep scallops', represented in Strata $D_{-} C_{1}$ (3rd-1st centuries BCE). 88

Van Beek did not attribute to wavy rims typological significance and did not find reason to dwell on the subject. However, with his observation of stratigraphic ranges and his incisive descriptions of the Type 1001 bowls, he correctly foresaw the two main stages of development of wavy rim bowls: a long earlier period, characterized by lighter 'prototypes' (c. 10th?5th centuries $\mathrm{BCE}$ ), and a later period, marked by the international diffusion of the generally heavier ‘Bayhāan' bowls.

In the extramural sequence of Barāqish Area $C$ these bowls appear towards the end of the Later Sabaean occupation, in Stratum L, possibly continuing into the First Intermediate period. Remains of six vessels were identified (Table 2; Figs 44-45), suggesting three variants. Variant A is represented by bowls with a shallow hemispherical basin and an obviously indented rim-and-wall component in rim-plane view (a 'multilobate' opening). The wall is medium-thin with variable fluting on the exterior; the fabric in the known specimens vary from medium to fine and is beige-buff or reddish. Variant B includes distinctly deep bowls with a blandly sinuous rim - a widely spaced wavy-rim pinch - and with thin to very thin wall and evident vertical fluting. They are made in a typical beige-yellow or light yellow ware, hence 'yellow fluted' as a characterization. From a technological point of view this yellow ware closely associated with Wavy Rim bowls B resembles the Pale Green ware.

Variants A and B are patently Sabaean: conjoinable sherds of two variant A vessels were found in Locus 200, and partly conjoinable fragments from three 'yellow fluted' bowls were recovered from units GK1 to GZV. The fragments of bowl V14-24 were probably scattered on the surface corresponding to the GZ1/GZV limit.

A third variant, $\mathrm{C}$, is represented by bowl V22.3 from lower suite SD2 (earlier Stratum K). This vessel is reminiscent of the classical WR bowls from a later

\footnotetext{
86 Van Beek 1969, 117, fig. 33.

87 Van Beek 1969, 123, fig. 42.

88 Van Beek 1969, 123, fig. 43.
}

period, popularly also known as 'Bayhān' bowls, mentioned above. A proper Bayhān bowl, V185, was recovered from a Minaean level further up in the sequence, belonging to Stratum $\mathrm{H}$ (see details in Table 2). ${ }^{89}$ Numerous fragments of Bayhān bowls were also recovered from the Minaean cemetery on Hill D, ${ }^{90}$ where such bowls had been collected as surface finds since $1986,{ }^{91}$ and more fragments came to light in the excavations of Temples A and B. As an international type the Bayhān bowl provides a rather loose, but useful, ceramic horizon marker, c. 3rd-1st centuries BCE. ${ }^{92}$

However, V22.3 cannot probably be classified within the range of Bayhān bowls. At the same time it suggests morphological differences from the more or less coeval variants $A$ and $B$ - no fluting, for instance - and was made in a different, buff fabric with a pale-beige matt slip. Coming from a transitional stratum in Yathill's history, could V22.3 be an exotic item hinting at foreign contact or 'ethnic' change? An early, material intimation of 'Minaean'? Unfortunately, it cannot be guaranteed that vessel V22.3 - based on a single sherd - was effectively manufactured at the time of Stratum K (see comment on finds nos 22.2-3 at the end of catalogue).

A single fragment of a non-Bayhān WR bowl features among the surface finds collected in 1986 from the erosion gullies of western Barāqish, corresponding to extramural Area $C$ and the adjacent sector outside bastions T4-T1. The find has been compared to V200.01 from Area $\mathrm{C} .{ }^{93}$

Concerning the earlier period of WR bowls in Yemen, it is not yet clear to what extent the Later Sabaean bowls from Barāqish Area C can be compared to specific predecessors or 'prototypes' of WR bowls from other regions and timeframes. The evidence from Hajar ibn Humayd, summarized above, shows the appearance of WR bowls during the deposition of Strata R-P of this Qatabanian site, putatively dated to the 10th-8th centuries BCE, i.e., much earlier than the Barāqish finds. A new type of WR bowl, unfortunately only documented by a single find per stratum, would occur in Strata $L-G$, datable to the 7th-5th centuries BCE, the same period of our Area $C$ finds. The meagre evidential basis (in terms of finds) prevents from effective comparisons to be made between our Later Sabaean WR bowls and those of Hajar ibn Humayd L-G. Parallels

\footnotetext{
89 Fedele 2010, 137. See now Buffa, Chapters 22 and 25, this volume, and a mention in Chapter 17, section 11.4 (Fedele).

90 Antonini 2010b, 28-32.

91 Antonini, Chapter 2 in Volume 1, site 'BARii' (Type 5).

92 E.g. Glanzman 2004a, with references; 2005. See also Antonini and Buffa 2016, 459-461, plates 5-8.

93 Antonini, Chapter 2 in Volume 1, site 'BARi' (Type 12).
} 


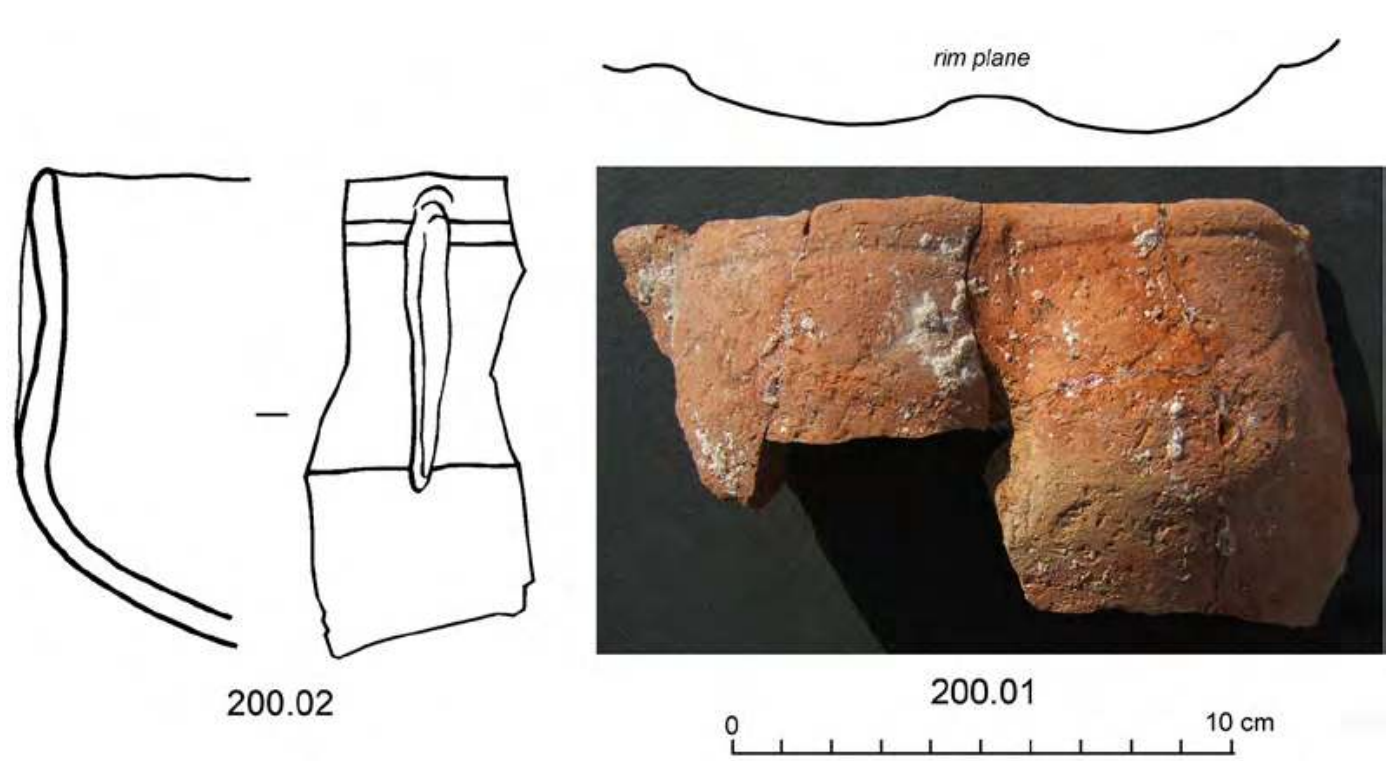

Figure 42. Later Sabaean pottery, Stratum N: Wavy Rim bowls from Locus 200, reg. nos 200.01-02. (G. Di Rosa and S. Iavarone 2007 ( ) MAIRY, drawings and adaptation by F.G. Fedele 2007 and 2020)

can instead be drawn with finds from Hajar al-Rayhān̄ī (Wādī al-Jūbah) as reported in an illuminating review of the WR bowl phenomenon, attempted by Glanzman. ${ }^{94}$ That Barāqish at least participated in the circulation of WR bowls during the 7th-6th-century timeframe is sufficiently clear; future research should bring in the details.

\section{Pale Green ware}

Partly overlapping with WR bowls in terms of both fabric and distribution is Pale Green ware. ${ }^{95}$ Finds are listed in Table 3. This ware is defined by a combination of fabric and form: carefully smoothed, delicate bowls or cups of small size made in dense, fine, pale-green to light-yellow fabrics, soft at times. Some reveal a very thin slip, ${ }^{96}$ yellowish or beige in colour. Pale Green vessels may look like variants of Beige Plain ware, but are always lighter and typically characterized by at least a hint of green hue; and some at least are vegetal-tempered. Only rarely the body tends to buff, but in those cases a light green slip compensates for the standard appearance of this ware (e.g. no. 22.2). Pale Green ware differs from the Minaean greenish fabrics in that these latter are coarser and characteristically 'turbid' in colour, and were generally employed to make thicker-walled vessels.

A certain variation can be observed in both wall thickness and hue. At least two vessels with a millimetre-thin wall

\footnotetext{
94 Glanzman 2004a, 122, 128-131, fig. 1. Cf. Glanzman 1994, 228.

95 Fedele 2010, 127. Although updated, the present definition remains tentative.

96 Or wash? It could not be determined from magnifying-glass inspection.
}

reveal a variant that can be termed 'eggshell'. Only very occasionally were ultrathin vessels also produced in other ware classes. ${ }^{97}$ Although possibly representing related conceptions in a potter's perspective, WR bowls and Pale Green ware seem to be different productions and might reflect a separate evolution with different temporal spans. It is therefore of some interest that pottery largely similar to the Pale Green ware from the Later Sabaean levels was also identified in the Earlier Sabaean. ${ }^{98}$ The apparent occurrence in two stratigraphic and chronological intervals is noted in Table 2, where the provisional designations of Earlier and Later Pale Green wares are introduced.99 The perception at the moment is that we are dealing with consecutive expressions - or developments - of a single potting tradition.

The best examples of Earlier Pale Green ware are bowls V97 and 98.02 from units SI1i-SI1, which form a talus against Wall F4 in uppermost Sector $\mathrm{E}$ and belong to Stratum R (see section 3.1 above). Interestingly, no. 98.02 is a carinated bowl, but not perhaps entirely fitting in the standard typological repertoire of the Sabaean homeland. This can raise suspicions that the bowl originated in a regional sub-tradition (supposedly 'Jawfite'?), or that 'foreigners' were responsible for its introduction. ${ }^{100}$ In this context, it may also be

\footnotetext{
97 Some examples in both Beige Plain and Grey-black wares from Locus 200 have been described in section 3.2 above.

98 Previously only reported without discussion in Fedele 2010, table 5 (p. 153), on the basis of find no. 111.02 (cf. section 3.1 above, 'Strata Q-P').

99 The attribution of sherd no. 194.03.3 to Pale Green ware is tentative, hence the question mark in Table 2.

100 Due to Yathill's role as a caravan post, and the presence of
} 

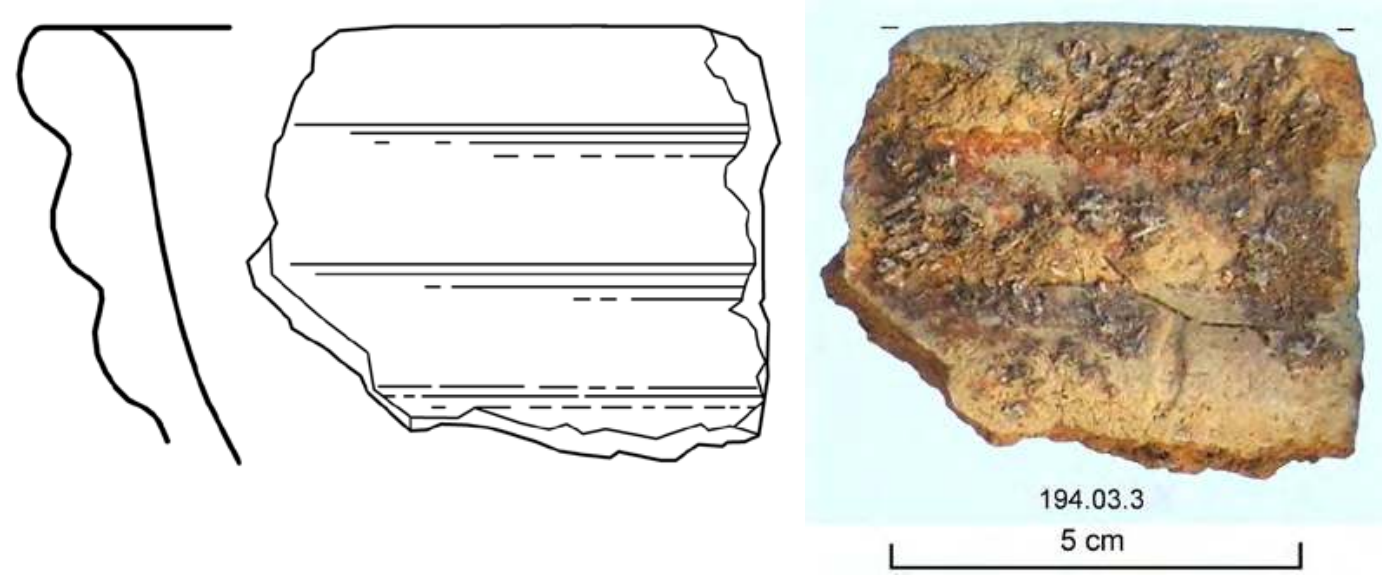

Figure 43. Later Sabaean pottery: reworked Sabaean material from Stratum J, reg. no. 194.03.3. (G. Di Rosa and S. Iavarone 2007 @ MAIRY, drawings and adaptation by F.G. Fedele 2007 and 2020)

interesting to note the seemingly frequent occurrence of Pale Green vessels in the plain, considering that the ware is present with no less than eight fragments from Sounding F (units SP1 to SY1; Table 2, nos 214-215). ${ }^{101}$

Probably to be equated with the Pale Green ware are the few sherds of 'light yellowish ware' from Stratum C of the town's sounding at Temple A. ${ }^{102} \mathrm{~A}$ straight-vertical wall fragment from the same stratum, decorated with a wavy-band motif, ${ }^{103}$ suggests morphological affinity to our WR bowls, variant B. Deep bowls with a relatively thin vertical wall are frequent in de Maigret's Strata $G$ to D (or even C), but all are made in Red Lustrous ware, save for a single instance in Beige Plain ware from Stratum G. ${ }^{104}$ However, all such bowls have a wall very rarely thinner than $1 \mathrm{~cm}$, thus suggesting a marked functional difference from the Pale Green ware production, in which the walls are distinctly thin and sometimes eggshell-thin, as we have seen. The above observations could have a bearing on correlations between the extramural sequence and the temple area (Areas A-B), as examined in Chapter 18, this volume.

Pottery that retrospectively might be identified with the Later Pale Green ware (at least in part) might have been noted by A. de Maigret among the surface finds collected from the erosion gullies of western Barāqish in 1986, when it was tentatively 'classified as later than red burnished pottery'. ${ }^{105}$ This impression

foreigners thus being expected and perhaps perceived archaeologically (Fedele 2014; Chapter 19, section 3.3, this volume), also the occurrence of exotic earthenware is likely. In this chapter this possibility has been evoked, for instance, for finds 215.01 (above) and 120.3 (below).

101 See stratigraphic and context details in Chapter 17, section 17.

102 de Maigret 2010a, 82.

103 de Maigret 2010a, fig. 106/17.

104 de Maigret 2010a, 78, fig. 98/17.

105 A. de Maigret, Barāqish 1990 and 1992 excavations notebook, p. 51 (in re-emerged in 1990 when apparently similar material came to light among reworked Sabaean-Minaean debris during the excavations of Temple A. ${ }^{106}$ This much can be reconstructed from the fact that de Maigret echoed those observations in a book review a few years later, deducting from them - with corroboration from Wādī Bayhān - a ceramic change at the Yemeni scale. ${ }^{107}$ However, it is not clear whether by "light yellow/light green pottery' (see footnote 105) he really intended pottery resembling the Pale Green ware, or rather pottery in the Minaean repertoire. ${ }^{108}$

V200.01, V200.02 (Fig. 42). Rim frs from two Wavy Rim Bowls: see Table 2, and details in text. | A1-A11 east + A31, Locus 200. Units STY (?), SZ2-SZ1, and lower SYH. Stratum N.

198.01 (Fig. 44). 'Eggshell' bowl in Pale Green ware, see Table 3. Body and surface both light green, lip thickened

the context of the excavations of Temple A): "la ceramica mi pare sia quella giallina/verdina, che, già trovata nell's6 negli scarichi 0 della città [i.e. the western talus], classificammo come posteriore a quella rosso lustrata.' (On this notebook see Chapter 1, Appendix A, in Volume 1.) Apparently, these finds of 'light yellow/light green pottery' from the gullies were not drawn, and as a consequence they do not feature among the collection from 'site BARi' illustrated by S. Antonini in Volume 1, Chapter 2.

106 A. de Maigret, Barāqish 1990 and 1992 excavations notebook, pages 50-51.

107 de Maigret 1998c, 570: [Jean-Charles Arramond's] contribution is useful because it confirms what can already be said for the more northern areas (e.g., in the ceramic sequences of Yalā and Barāqish), namely that to an earlier panorama with red-burnished wares, carinated bowls and ovoid jars a more recent one followed, with light yellow-greenish pottery and wavy-rim bowls. The transition between the two repertoires should occur around the 5th century BC' (my translation).

108 When in 2005 and in 2006 de Maigret and I examined together some of my Pale Green finds from the well-stratified deposits of Area $\mathrm{C}$ he appeared puzzled, but thoroughly agreed with my dating to the 'Later Sabaean' based on stratigraphy and associations. Afterwards he endorsed my definition of a Pale Green ware advanced in 2009 (Fedele 2010, 127). 


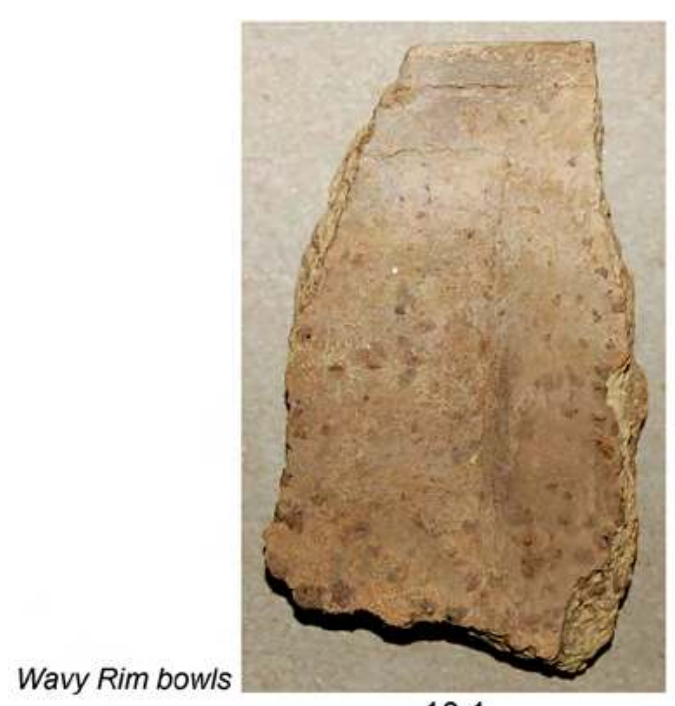

16.1

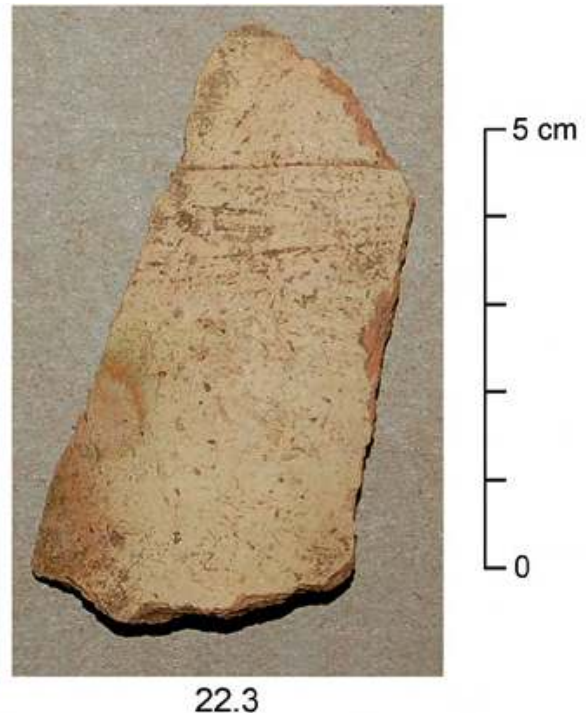

22.3

Pale Green ware
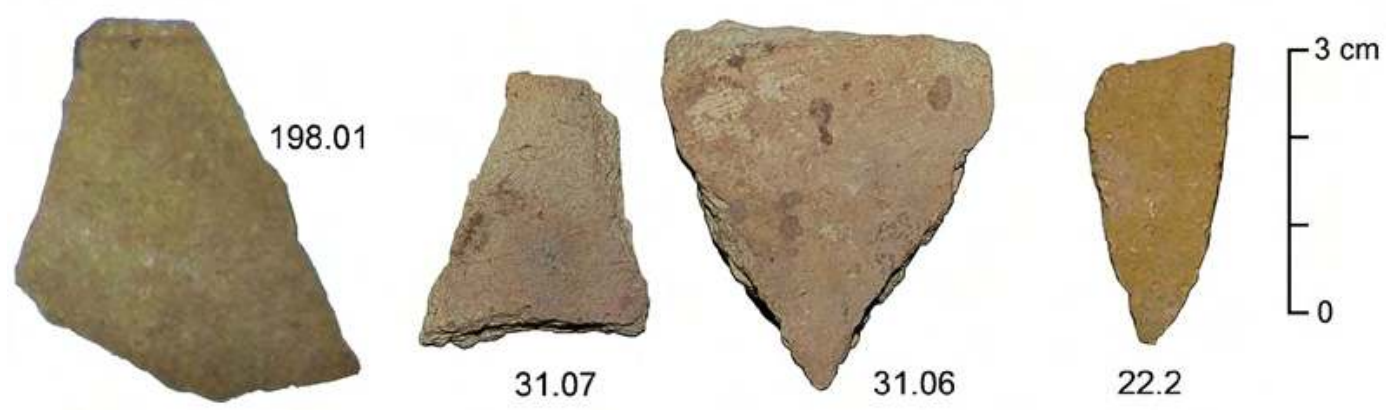

Figure 44. Later Sabaean pottery, Strata N and L: Wavy Rim bowls and Pale Green ware from reg. nos 16, 22, 31, and 198. (P. Morlupi 2006, except no. 198.01, G. Di Rosa and S. Iavarone 2007 @ MAIRY; arranged and optimized by F.G. Fedele)
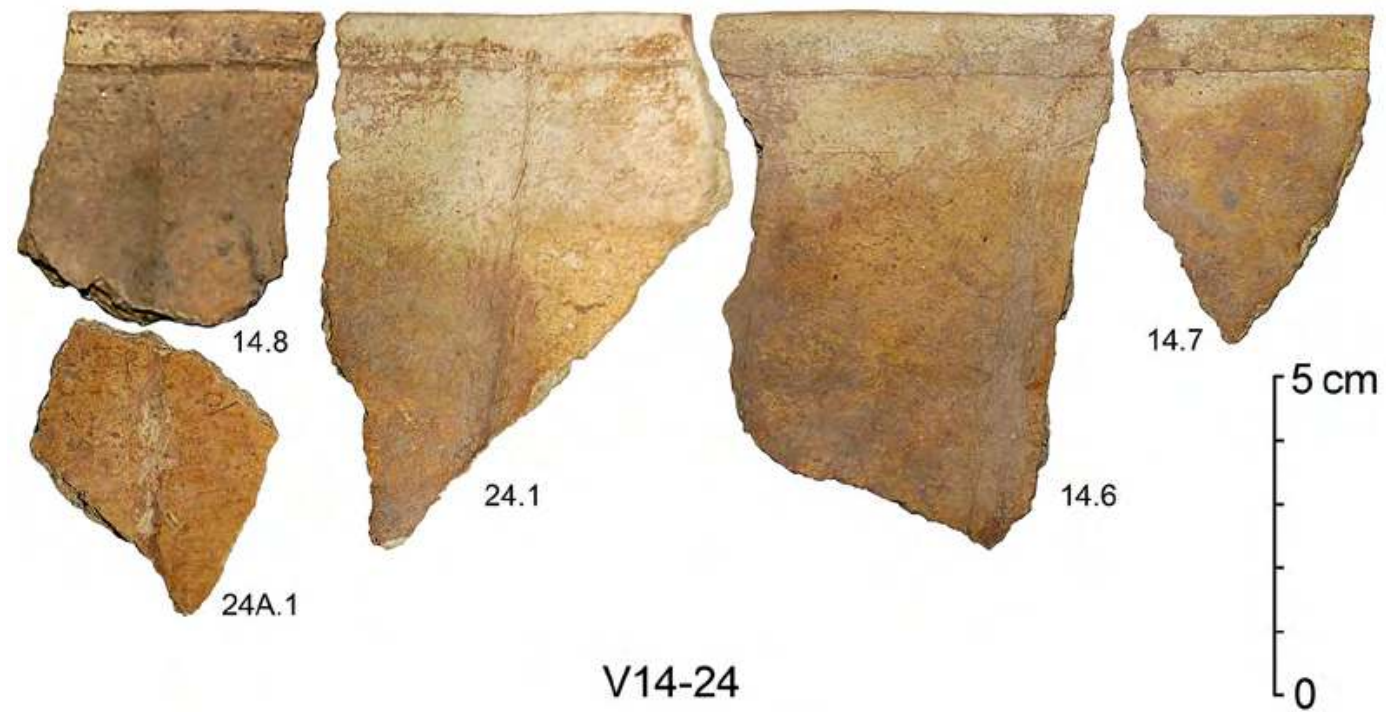

Figure 45. Later Sabaean pottery, Stratum L: reconstructed Wavy Rim bowl V14-24. (P. Morlupi 2006 (C) MAIRY, arranged and optimized by F.G. Fedele 2009) 
on the exterior. Rim fr., height $4.4 \mathrm{~cm}, 3-4 \mathrm{~mm}$ thick.

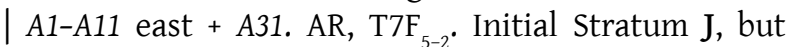
reworked Sabaean material attributable to Stratum $\mathbf{N}$ or destroyed Stratum L. | Preserved lip is only $1.3 \mathrm{~cm}$ long.

194.03.3 (Fig. 43). Rim fr., possibly from a necked jar. Probably Pale Green ware, see Table 3: grit- and chafftempered, porous, body and surfaces both light green; traces of red paint on the exterior. $6.7 \times 5.6 \mathrm{~cm}$. $\mid$ A1-A11. Units Pj (part) and T79L (Component F12 of Earthwork F10-F12). Stratum J - but, probably, reworked Later Sabaean elements from underlying Stratum $\mathbf{N}$ or destroyed Stratum L. | This unusual vessel can either be Later Sabaean or Minaean. ${ }^{109}$ What interests here is its decoration, formed of horizontal ripples on the rim and below, which distinctly evokes the Sabaean Red Lustrous jars reported from the sounding at Temple A, Stratum C: ' 5 jars with narrow neck and slightly flaring rim, thickened and with multiple grooves on exterior. ${ }^{110}$ At Yalā similar rims occur on globular pots of Type A5. ${ }^{111}$

V16 = 16.1 (Fig. 44). Wavy Rim bowl, vessel V16 in Table 2. Coarse beige-yellow body, beige slip, fluted. Height $7.0 \mathrm{~cm}$. D3. Top levels of unit GK1. Later Stratum $\mathbf{N}$.

V14-24 (Fig. 45). Wavy Rim bowl reconstructed from five non-joining frs from cuts 14, 24A, and 24: see Table 2. Yellow, fluted, one incised line below the rim. Heights of individual frs from 4.6 to $8.1 \mathrm{~cm}$; max. length of preserved rim $20.5 \mathrm{~cm}$. | Nos 14.6-8 (3 frs) from D3, units GZ2-GZ1; no. 24.1 from D2 east, unit GZV and surface S2; no. 24A.1 from D2 east, units GZ1 (top) and GZV. Stratum L. | Wear grades 0-1.

V14.9=14.9. Wavy Rim bowl, see Table 2. Yellow, fluted, three incised lines below the rim. Height $4.7 \mathrm{~cm}$. | D3. Units GZ2-GZ1. Stratum L. | Wear grade 0.

31.06, 31.07 (Fig. 44). Pale Green ware: two frs possibly from the same vessel, see Table 3. Medium greygreenish body, remnants of beige slip (or wash?) on the exterior. $4.2 \mathrm{~cm}$ (no. 31.06) and $3.2 \mathrm{~cm}$ (no. 31.07). D4. Units GZ2-GZ1. Stratum L.

13.1.1. Small, delicate bowl in Pale Green ware, see Table 3. Green-yellow. Fr. of the thin, flat base; $\mathrm{cm}$ sized. | D3. Top $10 \mathrm{~cm}$ of unit GZ1 and surface S2; from flotation. Later Stratum L.

22.2 (Fig. 44). 'Eggshell' bowl in Pale Green ware, see Table 3. Buff-beige body, bright yellow-green slip (or

\footnotetext{
109 V. Buffa considered it Minaean on the basis of paste (personal communication December 2007).

110 de Maigret 2010a, 83, fig. 106/9-10.

111 de Maigret 2003, pl. 19.
}

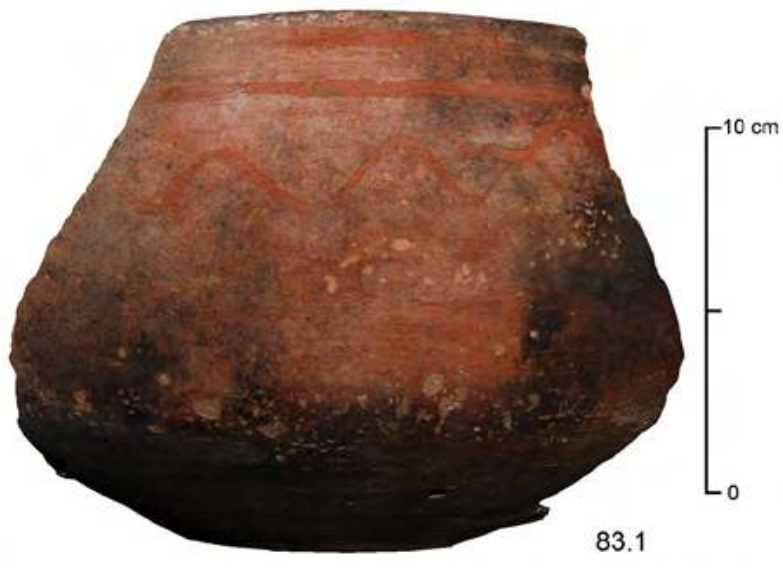

Figure 46. Sabaean pottery: globular pot from Cluster 83.1, within Stratum B. (P. Morlupi 2006 ( ) MAIRY, optimized by F.G. Fedele 2020)

wash?) on the exterior. Wall fr., $3.6 \mathrm{~cm}$. | D2 east. Units GSV3-GSV1. Earlier Stratum K. | Wear grade 1/2.

V22.3 = 22.3 (Fig. 44). Wavy Rim bowl, see Table 2. Very fine buff body, beige slip. Rim fr., $7.1 \mathrm{~cm}$.| D2: provenance and stratigraphy as for no. 22.2. Earlier Stratum K. | Wear grade $1 / 2$. Preserved lip is only $8 \mathrm{~mm}$ long.

Whether the last two finds, nos 22.2-3, are proof of the actual continuance of these kinds of vessels after the Later Sabaean cannot be determined. Their slight wear would rather suggest redeposition from Sabaean layers nearby, in keeping with the other sherds in cut 22 , most of which have wear grade 2-3. See discussions of Stratum K in Chapters 17 and 18, this volume.

\subsection{Some significant finds of uncertain stratigraphy}

The relevant comments on the following finds are presented item by item.

83.1 (Fig. 46). Globular pot cf. Type B3a, decorated; from a large wall fr. (pictured) and a small rim fr. (not pictured and not joined). Red Lustrous ware. Wall fr., max. width $18.7 \mathrm{~cm}$; vessel $c .15 \mathrm{~cm}$ tall. | E18 east. From Cluster 83.1, an isolated cluster of Sabaean pottery fragments embedded in middle unit Eø0. ${ }^{112}$ Stratum B, but obviously obtained from a Sabaean context in Area $\mathrm{C}$ or elsewhere at the site. | Two grooves below the rim and incised wavy-line decoration in the upper third of vessel. Exterior blackened by fire and damaged from reworking. Red colour best preserved inside the incisions (grooves and wavy line).

112 On Cluster 83.1 see Chapter 17, section 16.4 ('Stratum B') and Fig. $51 \mathrm{C}$, and Chapter 21, section 2.5 (find no. 83.1.1), both in this volume. 


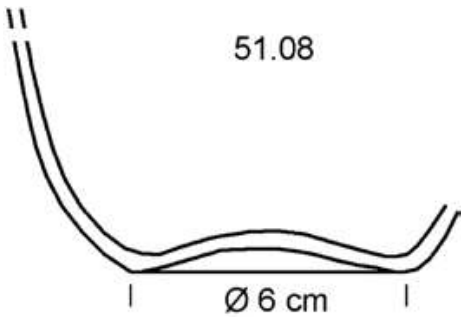

Figure 47. Sabaean pottery, probably from Strata I-G: reworked bowl, reg. no. 51.08. (F.G. Fedele 2007)

51.03. Perforated lid, Type E1e. Details unavailable.

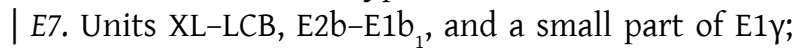
indeterminate colluvial context. Strata $\mathrm{L}$ to earlier B, indeterminable (incl. L, K, I, G, D), but part of redeposited Sabaean debris probably from Strata I-G.

51.08 (Fig. 47). Cup or small bowl of Type B1c with concave base (cf. no. 199.05). Beige Plain ware, buff, thin-walled and firm. Base $\varnothing c .6 \mathrm{~cm}$. $\mid$ E7: provenance and stratigraphy as for no. 51.03. Part of redeposited Sabaean debris probably from Strata I-G. | A 'kitchen' shallow bowl. With this same cut a second example of concave base, but in Red Lustrous ware, was retrieved (no. 51.09).

71.01 (Fig. 48). Wide, shallow bowl or basin with attenuated carination and turned-in rim, cf. Type A4 $4^{113}$ (two non-joining frs, 71.01a-01b). Red Lustrous ware, base unburnished (red slip only). Largest fr. $15.5 \mathrm{~cm}$. | E5. Units x5, e7, x4. Strata I, G, but redeposited Sabaean debris. | Other similar finds from Area $C$ have been described in section 3.2 above (nos 14.11-13).

71.02 (Fig. 48). Carinated bowl cf. Type A2a, ${ }^{114}$ undecorated; ring base missing. Red Lustrous ware, dark red. $10 \mathrm{~cm}$. |E5: stratigraphy as for no. 71.01. Strata I, G, but redeposited Sabaean debris.

70.02 (Fig. 49). Torpedo jar, mouth and neck fr. Heavy Sandy ware. Rim $\varnothing 8 \mathrm{~cm}$, mouth hole $\varnothing 2.7 \mathrm{~cm}$. E5. Units e7, x4, e6i, and up through surface. Strata G, D (and A), but redeposited Sabaean.

60.01 (Fig. 50). Bipartite cup with narrowing upper half and markedly rounded carination ("narrow-top cup'); from three large frs. Red Lustrous ware, both surfaces burnished. $\varnothing 9.5 \mathrm{~cm}$, height of preserved part $6 \mathrm{~cm}$. | E6. E2E -Le up through E1a, and present surface units, but probably from Ex6-E1b. ${ }^{115}$ Stratum

113 Cf. also de Maigret 2010a, table 2, column/form 2.

114 Cf. also de Maigret 2010a, table 2, column/form 3.

115 A suggestion based on the actual distribution pattern of pottery sherds in the colluvial units concerned: see re-cut section E06 in Chapter 17, Fig. 47, this volume.
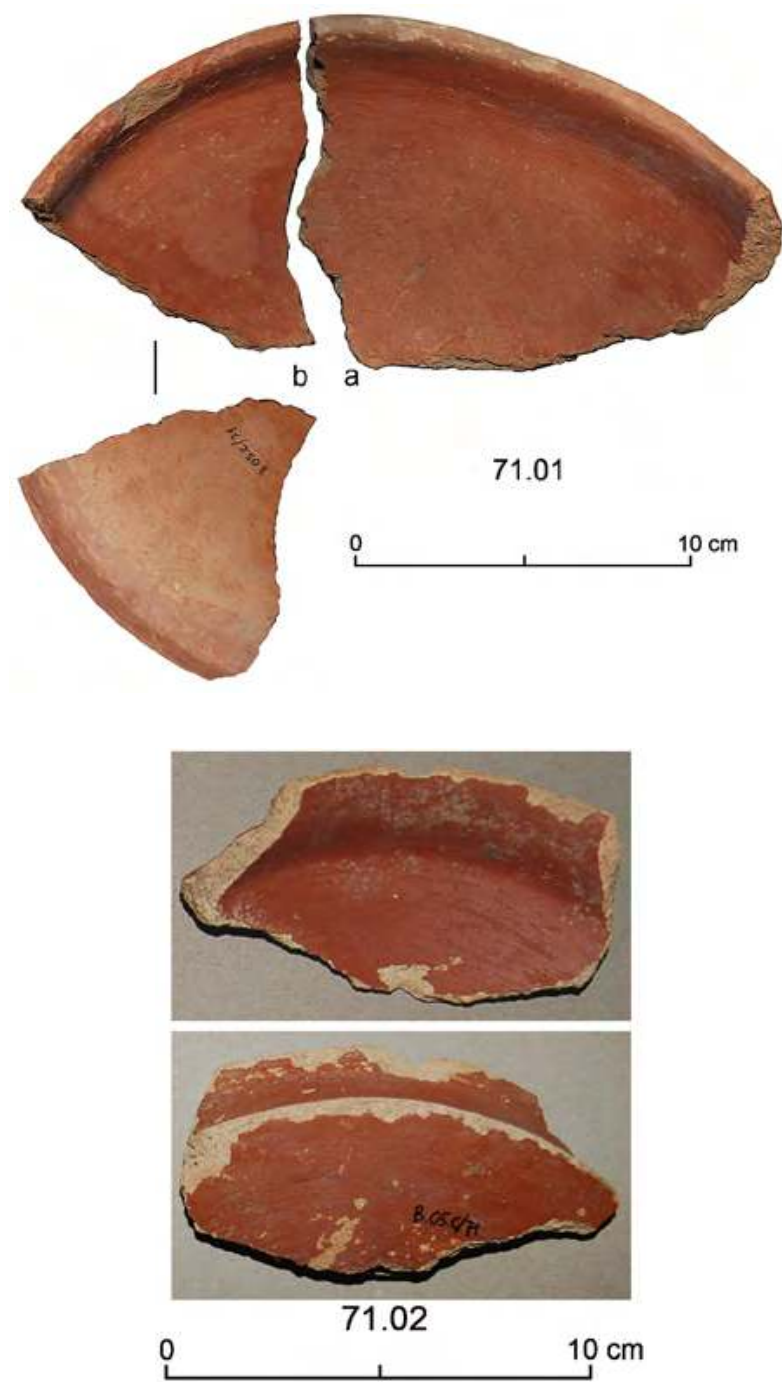

Figure 48. Sabaean pottery from Strata I-G: reworked bowls, reg. nos 71.01-02. (P. Morlupi 2006 @ MAIRY, optimized by F.G. Fedele 2020)

D (less probably Stratum G), but redeposited Sabaean debris. | A closed vessel with the maximum diameter apparently occurring at mid-height (unless the vessel is a chalice). The whole upper half is covered with subdued horizontal fluting (or rippling), and one deep groove is incised immediately below the simple rim. The shape of this vessel is absent from both de Maigret's typologies; ${ }^{116}$ 'narrow-top cup' as a shorthand designation is proposed here.

60.02 (Fig. 51). Wall fr. with complete handle. A windabraded and/or corroded sherd, ware indeterminable; medium fabric, buff to reddish. $10.7 \times 9 \mathrm{~cm}$, height of handle $6.5 \mathrm{~cm}$. |E6: stratigraphy as for no.60.01. Stratum D (less probably Stratum G). | The handle is irregularly

116 de Maigret 2003, 2010a. 


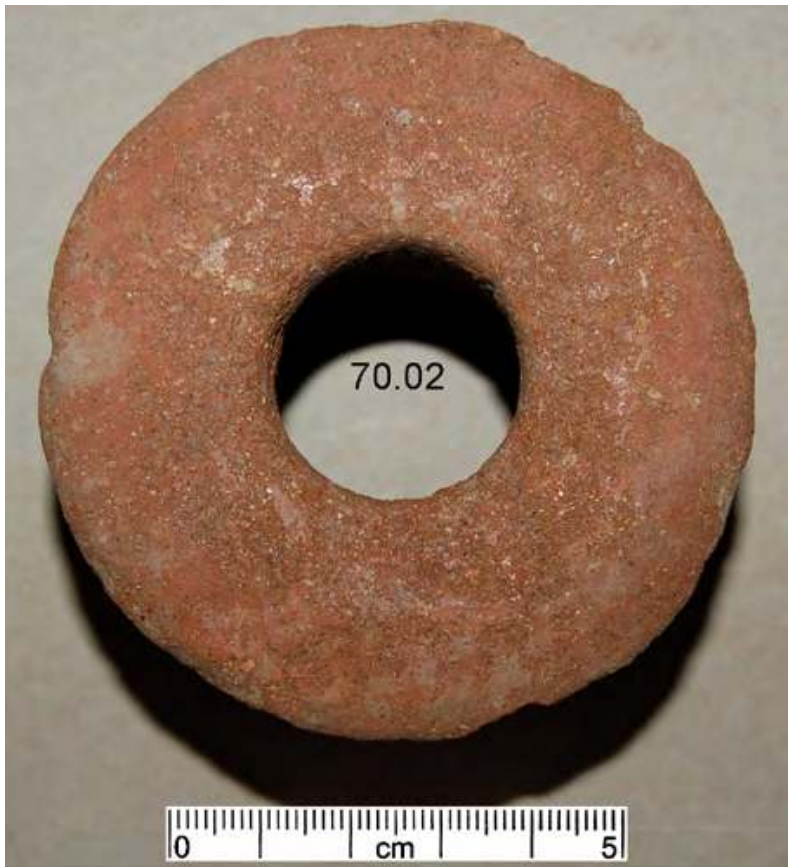

Figure 49. Sabaean pottery from Strata G-D: reworked torpedo jar fragment no. 70.02. (P. Morlupi 2006 C MAIRY, optimized by F.G. Fedele 2020)
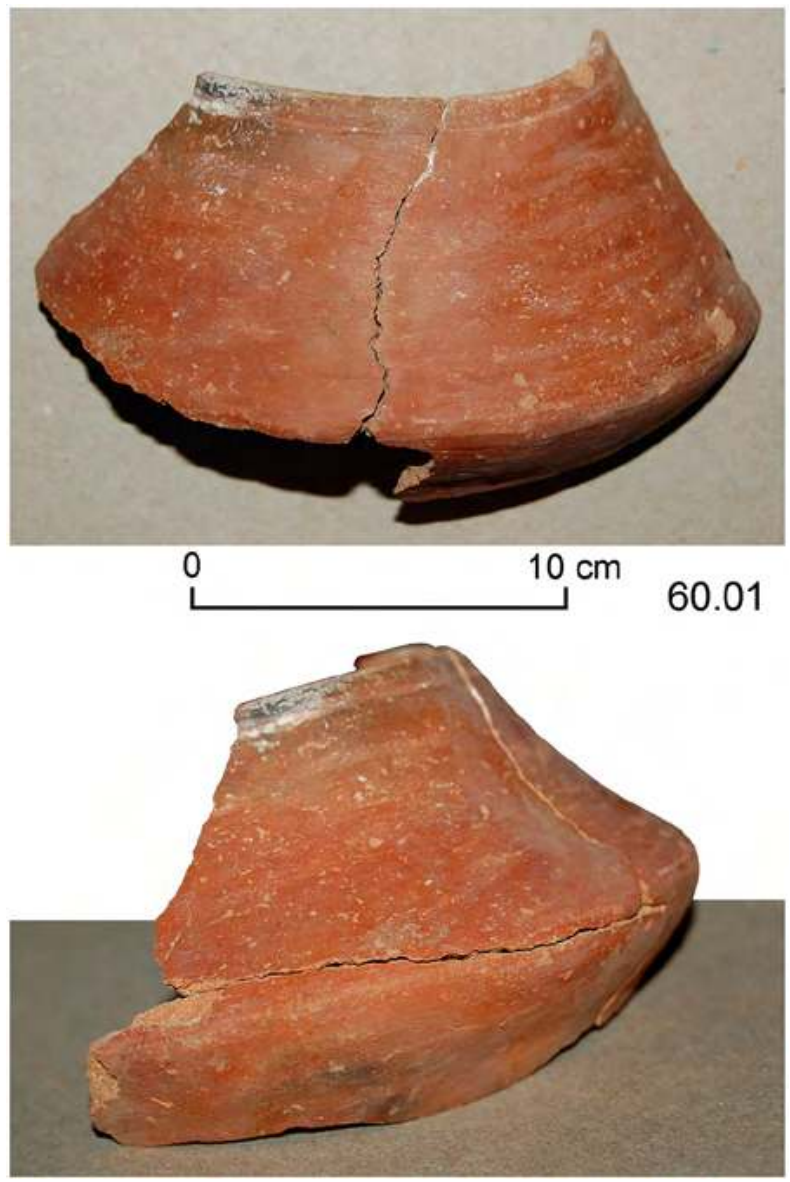

Figure 50. Sabaean pottery, probably from Stratum D: 'narrow-top' cup no. 60.01. (P. Morlupi 2006 @ MAIRY, arranged and optimized by F.G. Fedele 2020)
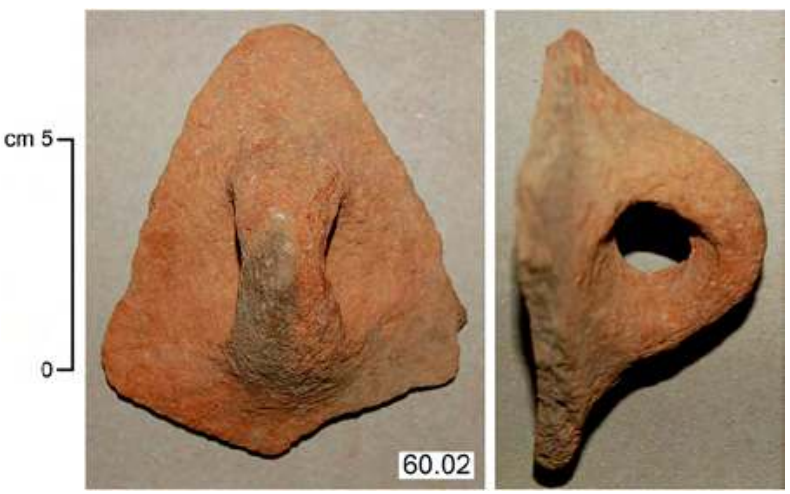

Figure 51. Sabaean pottery, probably from Stratum D: handled wall no. 60.02. (P. Morlupi 2006 @ MAIRY, optimized by F.G. Fedele 2020)

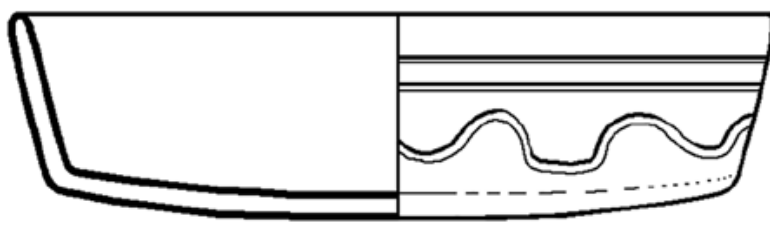

120.1

Figure 52. Sabaean pottery, Stratum K, but probably reworked from Stratum L: reg. no. 120.1. (F.G. Fedele 2006)

cylindrical in section and D-shaped in lateral view (Type E3a small).

120.1 (Fig. 52). Shallow bowl of Type B1a with rounded base and incised wavy-line decoration. Red Lustrous ware, burnished on both surfaces. Size unrecorded. | E4 south edge, middle; in situ. 'Root' of unit LCB immediately below sand SAE. Stratum K, but probably reworked from Later Sabaean units belonging to Stratum L. | Corroded and exfoliated on the exterior, in perfect condition on the interior.

120.2 (Fig. 53). Narrow-necked jar of Type C2, bottom missing. Red Lustrous ware. Size unrecorded. | E4 in situ: provenance and stratigraphy as for no. 120.1. Stratum $\mathrm{K}$, but probably belonging to Later Sabaean units. | Cf. find no. 82.1a from cultural horizon H78 (section 3.2 above).

120.3 (Fig. 54). Miniature cup in unfired clay. Approx. $5 \times 4 \mathrm{~cm}$. For the position of missing rim cf. the dashed line in the drawing. $\mid E 4 . \mathrm{L}_{3} \mathrm{Z}_{3}$ to surface, including L3Z, L3Na, LJ4, 4U2, 4U1, LGN', LS $\sigma, \mathrm{LSx}, \mathrm{VCB}^{\prime}, \mathrm{LCB}$, $\mathrm{x} 5-\mathrm{e}$, and SAE-SA $\alpha$. Strata $\mathbf{N}$ to $\mathrm{G}$ (to $\mathbf{D}$ ?) and Stratum A, indeterminable. I This wall fragment of a crudely shaped vessel appears to stand out from the rest of the Area C ceramic collection, and it represents an exceptional artefact in the repertoire of Yathill. Possible interpretations are a makeshift and possibly 


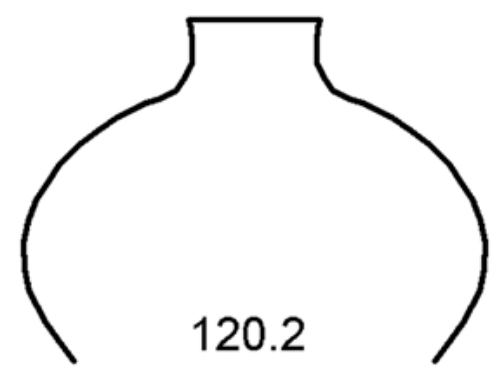

Figure 53. Sabaean pottery, Stratum K, but probably reworked from Stratum L: reg. no. 120.2. (F.G. Fedele 2006)

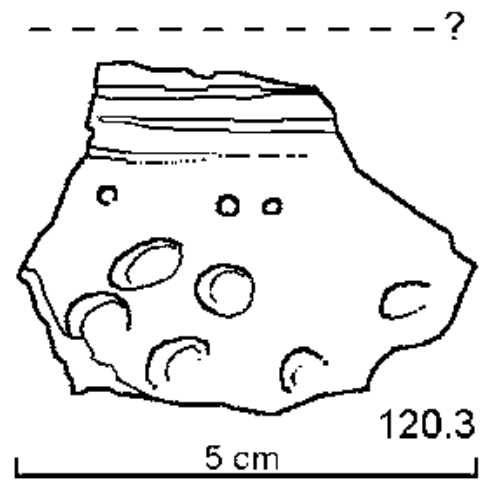

Figure 54. Sabaean pottery, Strata N-G (D?): unfired miniature cup no. 120.3. (F.G. Fedele 2006)
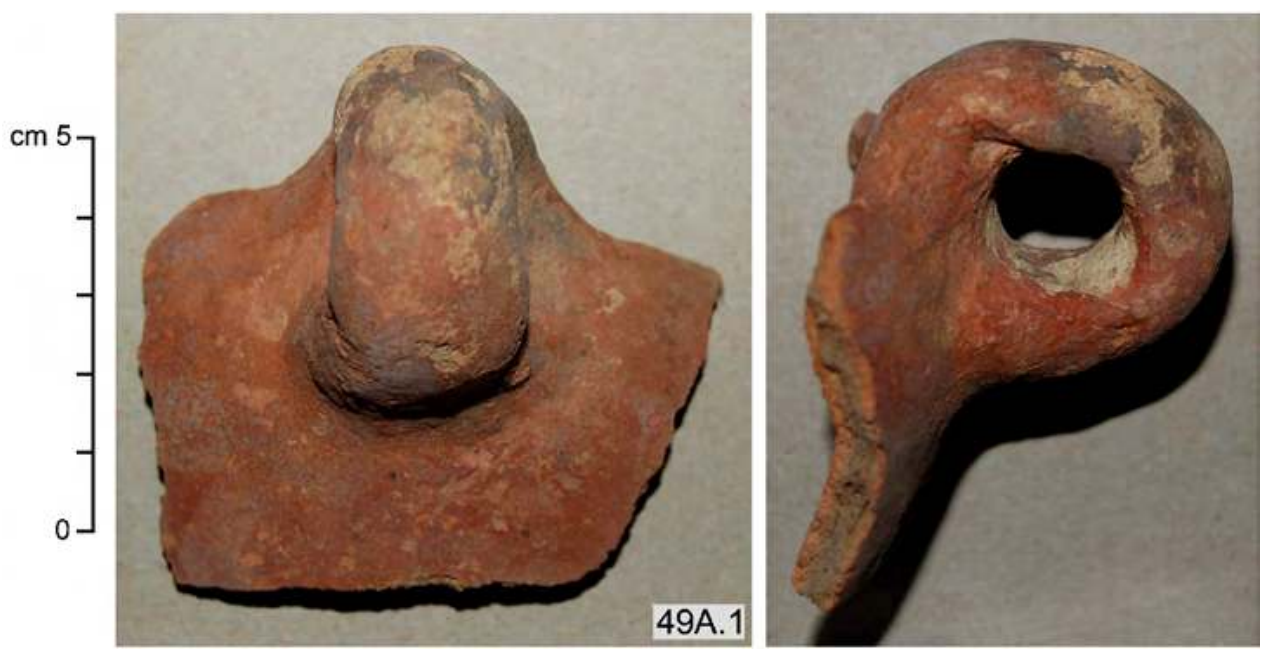

Figure 55. Sabaean pottery from palaeo-gully B, possibly Stratum G: above-mouth loop handle, reg. no. 49A.1. (P. Morlupi 2006 @ MAIRY, optimized by F.G. Fedele 2020)

exotic item, ${ }^{117}$ or a child's product or toy. ${ }^{118}$ As an unfired object, no. 120.3 falls at the most generic level into the category of clay discs and/or 'tripods' discussed in Chapter 21, sections 2.1 and 2.3 , this volume. A relationship with a 'poorly fired' small bowl or cup in Black Lustrous ware from Horizon H78, Stratum $\mathbf{M}$ (no. $52.10 \mathrm{~b}$, evoked in section 3.2 above), is probably only accidental.

49A.1 (Fig. 55). Rim fr. with vertical loop handle extending above the mouth. Red Lustrous ware. 7.5 $\times 7 \mathrm{~cm}$. | D6-D16/D7-D17. Unit YSP, a buried body of

\footnotetext{
117 About the possible or perceived presence of 'foreigners' at Yathill, through presumed foreign artefacts, see section 3.3, 'Pale Green ware', and section 3.2, find no. 215.01, above.

118 On children's toying with sun-dried clay see for instance Ochsenschlager 1974, 164-165, 170 (photograph), 171-172 (Ochsenschlager's is a case study from Iraq, in the context of the investigation referred to in Chapter 21, section 2.1, 'Unfired or poorly fired clay artefacts', this volume); and Moorey 1994, 163: 'Little is known of the sun-dried clay objects used in ancient Iraq. Children, who are often adept at this work, produce [in sun-dried clay] their own toys, models, animals, boats, etc.'
}

chaotic debris in yellow sand within a palaeo-gully of Gully B. Possibly Stratum G. ${ }^{119}$ | A relatively sharp sherd (wear grade 1). This raised handle can be compared with a surface find from these same erosion gullies of western Barāqish, also in Red Lustrous ware, ${ }^{120}$ and with two finds from the sounding at Temple A, one in Red Lustrous ware and the other one in Beige Plain ware. ${ }^{121}$

\section{Non-Sabaean?}

180.0. Jar base fr. inscribed with a word in old South Arabian. ${ }^{122}$ The ceramic ware was tentatively identified

119 See Chapter 17, section 15.3 ['Stratum G (including a "window" view from Sector D)'] and Figs 119 and 121, this volume.

120 Antonini, Chapter 2 in Volume 1, site 'BARi' (Type 25).

121 de Maigret 2010a, 79, 80; figs 100/13, 101/6 (both from sounding's Stratum F).

122 A. Agostini (personal communication, December 2006). Regrettably, as Agostini was not at Barāqish when the Area C ceramic collection was catalogued in 2007, this inscription went unrecorded. Cf. the other inscribed vessel's base from Area C, no. 14.10 (section 3.2 above). 
Table 1. Sabaean ceramic wares at Barāqish/Yathill: an interim classification based on technology attributes (surface treatment and fabric).

\begin{tabular}{|c|c|c|c|}
\hline \multicolumn{2}{|c|}{ A. de Maigret (2010a) } & \multirow{2}{*}{$\begin{array}{l}\text { this chapter } \\
\text { ware classes } \\
\end{array}$} & \multirow[t]{2}{*}{ comments } \\
\hline 'broad categories' & & & \\
\hline \multirow[t]{3}{*}{ burnished wares } & A. red-burnished pottery & 1. Red Lustrous ware & $\begin{array}{l}\text { colours include a very wide range of red } \\
\text { to brown hues, further multiplied by } \\
\text { pattern-burnishing }\end{array}$ \\
\hline & & 2. Black Lustrous ware & $\begin{array}{l}\text { delicate, cf. Red Lustrous (part of de } \\
\text { Maigret's C) }\end{array}$ \\
\hline & & 3. Red-slipped ware & $\begin{array}{l}\text { red slipped and red painted (not } \\
\text { manifestly burnished); this class includes } \\
\text { 'shoddy' productions }\end{array}$ \\
\hline \multirow[t]{4}{*}{ plain wares } & B. beige plain pottery & 4. Beige Plain ware & $\begin{array}{l}\text { produced in a range of fabrics and colours, } \\
\text { including grey, beige, and buff; ultrathin } \\
\text { variants occur }\end{array}$ \\
\hline & & 5. Pale Green ware & delicate \\
\hline & $\begin{array}{l}\text { C. grey-black and/or black- } \\
\text { burnished pottery }\end{array}$ & 6. Grey-black ware & $\begin{array}{l}\text { coarser; 'cooking ware' (part of de } \\
\text { Maigret's C) }\end{array}$ \\
\hline & $\begin{array}{l}\text { D. heavy sandy-tempered } \\
\text { pottery ('torpedo jars') }\end{array}$ & 7. Heavy Sandy ware & $\begin{array}{l}\text { i.e. 'torpedo jars' only; both ovoid and } \\
\text { tapered forms }\end{array}$ \\
\hline
\end{tabular}

Table 2. Barāqish Area C: findings of Wavy Rim bowls. The table is organized in stratigraphic order, bottom to top.

\begin{tabular}{|l|l|l|l|l|}
\hline Find $^{\mathrm{a}}$ & Description $^{\mathrm{b}}$ & \multicolumn{3}{l|}{ Spatial-temporal distribution } \\
\hline & & horizontal & stratigraphic & Stratum \\
\hline & Minaean & & & \\
\hline V185 & 'Bayḥān' Wavy Rim bowl (2 sherds) & A1-A11 & SR-T76H, TPV & H \\
\hline
\end{tabular}

\begin{tabular}{|l|l|l|l|l|}
\hline & Sabaean & & & \\
\hline V22.3 & variant C (1 sherd): buff fabric, beige slip & D2 & GSV3-GSV1 & Earlier K \\
\hline V14-24 & $\begin{array}{l}\text { variant B (5 sherds from cuts 14, 24A, 24): YF, 1 line } \\
\text { below the rim }\end{array}$ & D2-D3 & $\begin{array}{l}\text { GZ1/GZV interface or } \\
\text { GZV }\end{array}$ & Latest L \\
\hline V14.9 & variant B (1 sherd): YF, 3 lines below the rim & D3 & GZ2-GZ1 & Later L \\
\hline V16 & variant B (1 sherd, no. 16.1): YF & D3 & GK1 top & N \\
\hline V200.01 & variant A (5 sherds): reddish fabric & A, Locus 200 & SZ2-SZ1 and lower SYH & N \\
\hline V200.02 & variant A (3 sherds): beige-buff fabric & A, Locus 200 & SZ2-SZ1 and lower SYH & N \\
\hline
\end{tabular}

${ }^{a}$ Identified vessel (V). The number following this prefix derives from the register umbers of the constituent finds.

${ }^{\mathrm{b}} \mathrm{YF}=$ yellow, fluted.

${ }^{c}$ Nos 185.3-4, two conjoinable fragments.

as Minaean. $^{123}$ | A1-A12 at the intersection of the four quadrangles. From a level corresponding to the top of blocks T7A (cf. block P20a), i.e., very likely from middle or lower unit T74, an Earlier Islamic context (Stratum C).

123 Like the other reworked fragments from the Islamic layers, this find was excluded from typological examination (V. Buffa). 
Table 3. Barāqish Area C: findings of Pale Green ware (identified specimens as of January 2020). Their apparent occurrence in two stratigraphic and chronological intervals is recorded.

\begin{tabular}{|c|c|c|c|c|}
\hline \multirow[t]{2}{*}{ Find $^{\mathrm{a}}$} & \multirow[t]{2}{*}{ Description $^{\mathrm{b}}$} & \multicolumn{3}{|c|}{ Spatial and temporal distributions } \\
\hline & & horizontal & stratigraphic & Stratum \\
\hline & Later Pale Green ware & & & \\
\hline 22.2 & 1 fr. buff-beige, yellow-green slip, ${ }^{c}$ EG & D2 & GSV3-GSV1 & Earlier K \\
\hline 31.06-07 & 2 frs (1 vessel?) grey-greenish + slip $^{c}$ & D4 & GZ2-GZ1 & $\mathrm{L}$ \\
\hline 13.1.1 & 1 fr. green/yellow (vessel base) & D3 & top GZ1 and surface S2 & $\mathrm{L}$ \\
\hline 215 & 5 frs green, soft body (1 rim) & $F$ & SP1 & M \\
\hline 214 & 3 frs green, soft body & $F$ & SY1a-SY1 & M \\
\hline 200 & 2 frs pale yellow & $A$, Locus 200 & SZ2-SZ1, lower SYH & $\mathrm{N}$ \\
\hline 199 & 2 frs pale yellow & $A$, Locus 200 & SYH & $\mathrm{N}$ \\
\hline 198.01 & 1 fr. light green, EG & A & $\mathrm{AR}, \mathrm{T} \mathrm{F}_{5-2}$ & $(\mathrm{~J}) \mathrm{N}$ or $\mathrm{L}^{\mathrm{e}}$ \\
\hline ?194.03.3 & 1 fr. light green; painted? ${ }^{d}$ & $A$ & T79L, Pj & (J) $\mathrm{N}$ or $\mathrm{L}^{\mathrm{e}}$ \\
\hline
\end{tabular}

\begin{tabular}{|c|c|c|c|c|}
\hline & Earlier Pale Green ware & & & \\
\hline 111.02 & 1 handle, pale green/beige & E3 & SE3 $\omega$, SE3, L3f-L3e, XE4 $\beta, \mathrm{L}_{2} Z_{2}$ & S to earlier $\mathrm{N}$ \\
\hline 96.01 & 1 fr. perforated lid & E1 & LEd, LEc, LEc4, part of LEb & essentially Q \\
\hline V97 & $\begin{array}{l}\text { conjoint of } 97.01 \text { and 101.03, light } \\
\text { grey-green }^{\text {d }}\end{array}$ & $\begin{array}{l}\text { 97.01: E1; } \\
\text { 101.03: E2 }\end{array}$ & $\begin{array}{l}\text { 97.01: SI1i-SI1, } \tau 2, \tau 1 \\
\text { 101.03: presumably SE3 }\end{array}$ & $\mathrm{R}$ \\
\hline
\end{tabular}

${ }^{a}$ Find number or identified vessel $(\mathrm{V})$.

${ }^{\mathrm{b}}$ fr., frs: fragment, fragments. EG: 'eggshell' variant.

c Or wash?

${ }^{\mathrm{d}}$ See text for details.

${ }^{\mathrm{e}}$ Initial Stratum J, but reworked Later Sabaean material. 


\title{
Chapter 24 \\ Area $C$.
Il materiale epigrafico
}

\author{
Alessio Agostini
}

\section{Introduzione}

Gli scavi condotti nell'Area C hanno riportato in luce una collezione copiosa ed eterogenea di reperti (v. Fedele, capitolo 20, e Fedele e Antonini, capitolo 21 in questo volume), comprendente però ben pochi elementi di interesse epigrafico. Due soli i reperti lapidei: un concio in calcare con iscrizione su una delle facce di testa, proveniente dal crollo della cortina esterna del bastione T7, e un piccolo incensiere frammentario. La maggior parte dei ritrovamenti epigrafici consta di un gruppo di cretule con stampigliata una o più impronte di sigillo. Si presentano in questa sede gli esemplari per i quali sia stato possibile ipotizzare una lettura di almeno uno dei segni; per una descrizione del resto del materiale si rimanda al catalogo già citato (v. Fedele e Antonini, capitolo 21 in questo volume). Queste cretule venivano usate per chiudere giare da trasporto e sono spesso rinvenute in contesti archeologici, ma la loro frequente frammentarietà limita fortemente l'interpretazione del testo e le possibilità di confronti (Costa 1991). I sigilli che venivano utilizzati per realizzare queste stampigliature sono di tipo bronzeo, con lavorazione a giorno, che lasciano impronte profonde con direzione destrorsa; un'altra tipologia sembra invece produrre segni meno profondi con andamento sinistrorso (cfr. ad es. n. 4, n. 5, n. 10). Nel presente lotto si ha un solo caso di impronta completa e si tratta di un nome proprio personale (cfr. B.06.C.O/2+3+14). Vi sono inoltre due interessanti esemplari che presentano anche simboli di natura religiosa: sicura è l'individuazione di quello relativo al dio Almaqah (B.06.C.O/11) e forse uno è quello del dio Nakrah (B.06.C.O/12), questo potrebbe in effetti far pensare che le giare su cui erano stati applicati questi sigilli fossero di prerogativa templare/sacerdotale e, nel caso del sigillo con simbolo di Almaqah, si può pure ipotizzare una provenienza sabea. In effetti, queste sigillature venivano realizzate per contenitori destinati al trasporto, come dimostra il recente rinvenimento a Tamna' e a Khawr Rūrī di frammenti ceramici su cui prima della cottura era stato impresso lo stesso sigillo (Agostini 2016; Avanzini 2015). Questi resti di cretule sono riferibili al Mineo 3 della sequenza dell'Area C e si datano genericamente al II-I secolo a.C. (v. Fedele, capitolo 17 in questo volume). In base al contesto sedimentario e archeologico essi sembrano da ricollegare a operazioni di tipo commerciale occasionalmente svolte in strutture di fortuna al piede delle mura (v. già Fedele 2010, 2011a, 2014).

\section{Catalogo delle iscrizioni}

\section{A. Iscrizioni lapidee}

\section{Y.06.B.C.1 (= blocco P20d) (fig. 1)}

Provenienza: Barāqish, Stratum E, crollo dal bastione T7.

Collocazione: già Barāqish magazzino del Museo

Materiale: calcare oolitico

Dimensioni della faccia iscritta: lungh. $25 \mathrm{~cm}$; largh. 20 $\mathrm{cm}$; lettere $2,7 \mathrm{~cm} c$.

Conservazione: testo incompleto su blocco murario intero.

Descrizione: l'iscrizione si sviluppava certamente su altri blocchi contigui, ma questi non sono stati rinvenuti durante lo scavo (per ulteriori dettagli circa il contesto di ritrovamento, v. Fedele, capitolo 17 in questo volume). La porzione di testo a disposizione non consente di proporre una traduzione, ma gli elementi lessicali che sono stati individuati permettono di attribuire con certezza questo testo a quelli di natura legale, di cui sono noti due altri esemplari frammentari dalle mura cittadine (cfr. M168A e M168B, di cui però non è stato possibile verificare l'effettiva presenza in situ). La grafia minuta e fitta è tipica di questa tipologia testuale in quest'area, come è stato evidenziato anche dai testi legali rinvenuti nel Tempio B. Stile grafico C4? Periodo B.

\section{Testo:}

1. $[. .] r.[\ldots \ldots] d b[\ldots]$

2. (b) $-r s^{2} w n(k) w n[\ldots . .$.

3. $d b t w-l y h[\ldots \ldots . .$.

4. $[.].\left({ }^{\circ}\right) s^{3} l \ln f[. .$.

5. $[\mathrm{b}] \mathrm{ht}(\mathrm{h}) \mathrm{mrs} \mathrm{s}^{\mathrm{w}} \mathrm{w}[\mathrm{...}]$

6. $b-w s^{2} d w-w s(l)[\ldots]$

7. wn $l-d y n w-l[. .$.

8. $(r)[.] w-.l[] h.[\ldots]$ 


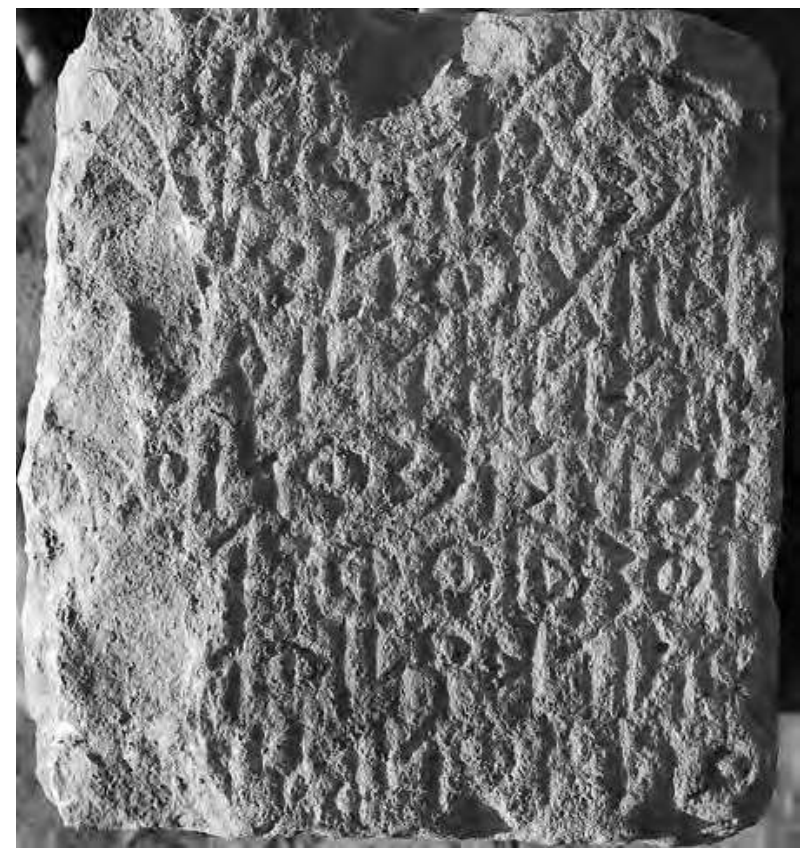

Fig. 1. Iscrizione scolpita su un blocco di calcare (Y.06.B.C.1 = blocco P20d). (F.G. Fedele 2006 CMAIRY)

\section{Note:}

L.2: $\quad r s^{2} w n$ : si tratta di un titolo religioso indicante una particolare categoria sacerdotale, che in area minea sembra essere stata investita anche di un importante ruolo legislativo e giudiziario, come suggerisce la loro menzione in contesti di ambito legale.

L.5: [b]ht: l'integrazione della prima lettera (verosimilmente da collocare alla fine della linea precedente) è adeguato alla tipologia testuale, dato che si tratta di un termine rinvenuto nel complesso testo legale as-Sawdā' 37, oltre ad essere coerente con le due lettere finali superstiti: 'promulgare'.

L.6: $\quad b$-ws ${ }^{2} d$ : questo termine, in analoga costruzione, è rinvenuto nei testi legali minei as-Sawdā' 31, asSawdā’ 38 e in YM 28980, in tutti i casi è preceduto dal termine qrs $^{3}$.

wș(l): questo termine compare in un altro contesto legale mineo (A.20.850), pure in Sabeo è utilizzato in questa tipologia testuale col significato di 'conformarsi a un ordine'.

L.7: l-dyn: la radice DYN indica un'imposizione di tipo legale (es. un'obbligazione, un tributo), qui in costruzione verbale di tipo iussivo (cfr. Ma'īn 1, Ma'īn 7 e Ma'īn 17, per una costruzione simile cfr. Ma'īn 73).

\section{B.06.C.O/16 (fig. 2)}

Provenienza: Unità T76J (Stratum H, Mineo 3). Collocazione: già Barāqish magazzino del Museo Materiale: calcare bianco

Dimensioni: altezza lettere $2,5 \mathrm{~cm}$
Conservazione: frammentaria

Descrizione: nonostante la natura estremamente grossolana dell'iscrizione, ci pare di poter individuare un tratto superiore per il terzo segno a contatto con la decorazione a dentello; questo suggerisce quindi una lettura con $\mathrm{Q}$ e non con $\mathrm{Y}$, come poteva sembrare a prima vista. Scrittura destrorsa.

Testo:

1. $R b q$

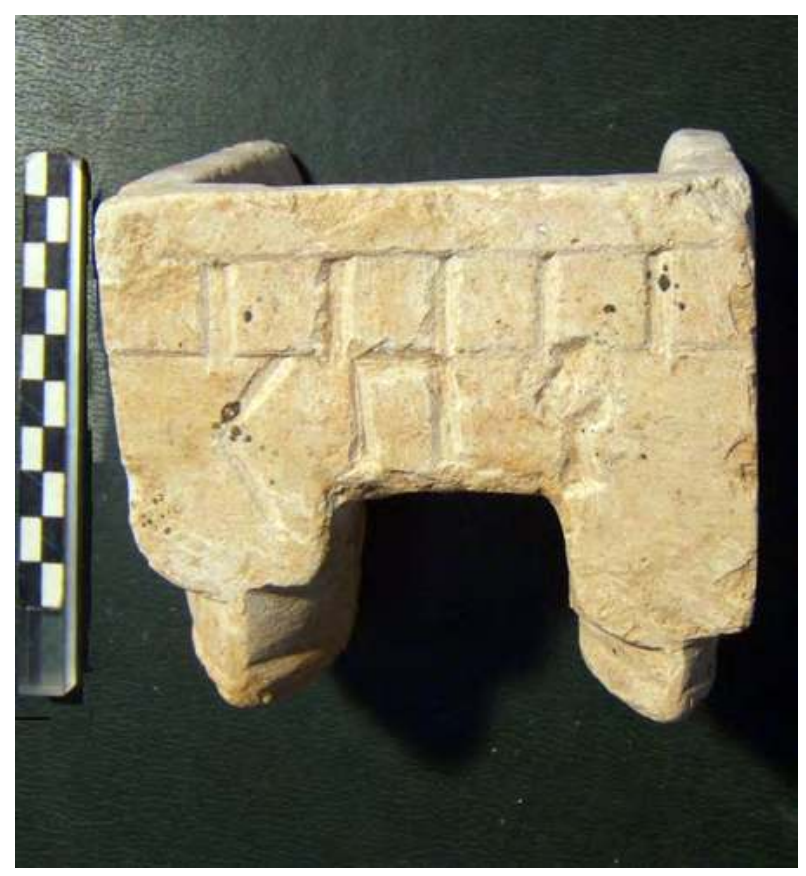

Fig. 2. Incensiere cubico con decorazione a dentelli e iscrizione (B.06.C.O/16). (F.G. Fedele 2006 @MAIRY)

Note:

Il termine $R b q$ presenta confronto con un altro piccolo incensiere dalla regione del Khawlān (BynM 248).

\section{B. Cretule}

\section{B.06.C.O/2+3+14 (fig. 3)}

Provenienza: Unità T76H-SR (Stratum H, Mineo 3). Collocazione: già Barāqish magazzino del Museo Materiale: gesso

Dimensioni: altezza lettere $2,3 \mathrm{~cm}$

Conservazione: frammentaria

Descrizione: la cretula presenta tre impronte dello stesso sigillo. L'impressione è molto profonda e la scrittura è destrorsa. Il nome è suddiviso in due parti all'interno di due rettangoli sovrapposti. 

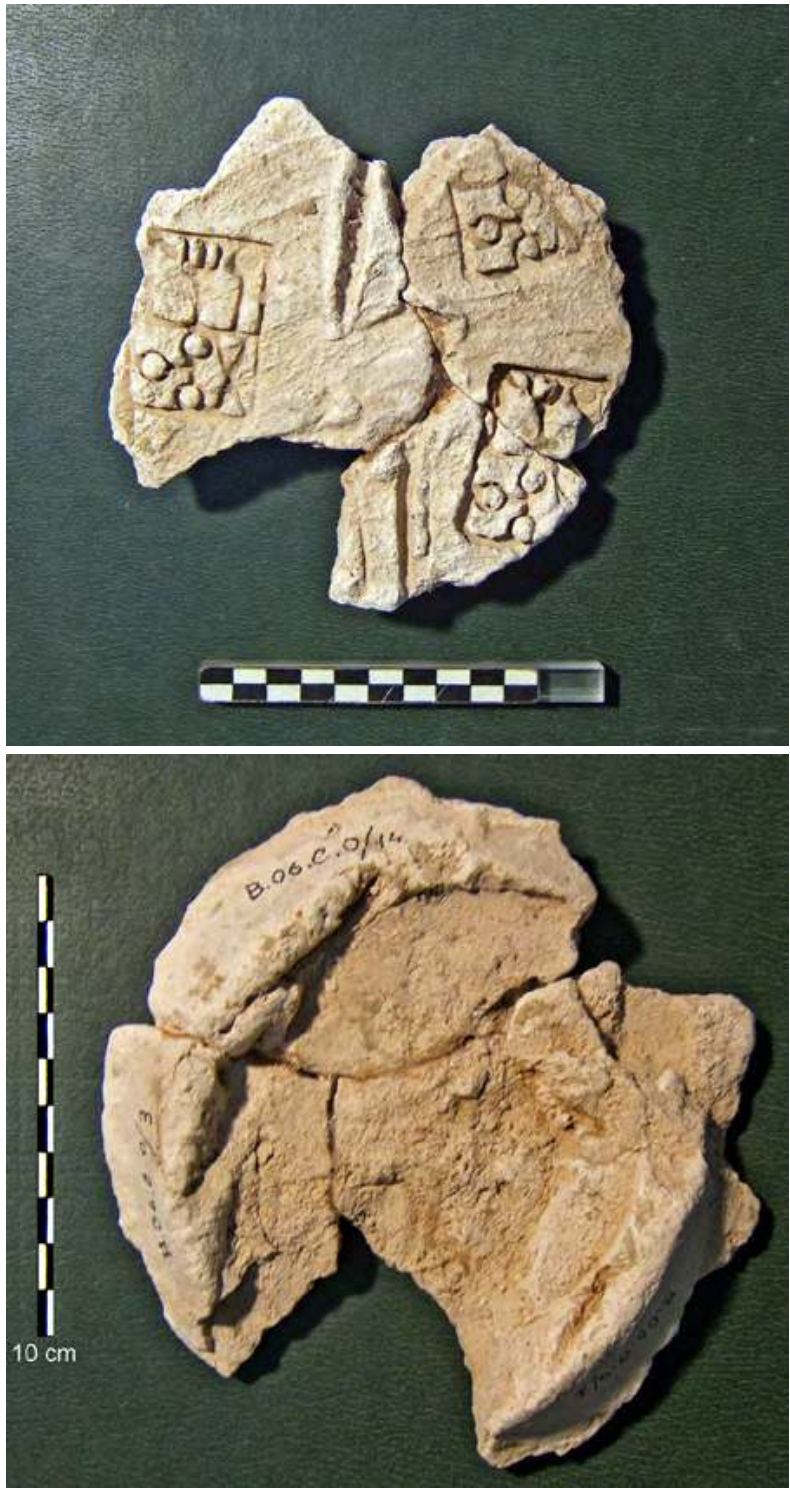

Fig. 3a-3b. Sigillo in gesso con impressione; viste superiore ed inferiore (B.06.C.O/2+3+14). (F.G. Fedele 2006 @MAIRY)

Testo:
1. Lhy-
2. 't $t$

\section{Note:}

Il nome Lahay'athat è molto frequente in tutto il Sudarabico, significa 'splendore di 'Athtar', con abbreviazione della componente teofora. Presente anche in Mineo come nome personale maschile.

\section{B.06.C.0/4 (fig. 4 )}

Provenienza: Unità T76H-SR (Stratum H, Mineo 3). Collocazione: già Barāqish magazzino del Museo Materiale: gesso

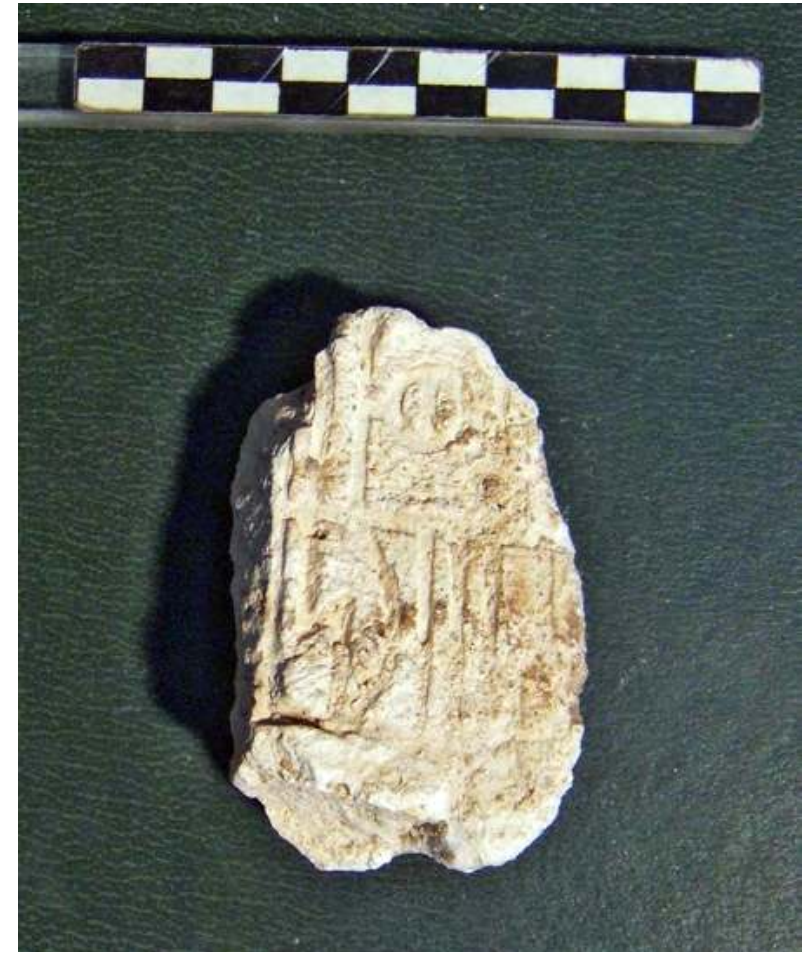

Fig. 4. Sigillo frammentario di giara, in gesso con impressione (B.06.C.O/4). (F.G. Fedele 2006 CMAIRY)

Dimensioni: altezza lettere $3 \mathrm{~cm}$

Conservazione: frammentaria

Testo:

1. [.]w[.]

2. (h)trn

Note:

Il nome Hțrn è noto in Qatabanico come nome familiare (UAM 368). Andamento sinistrorso.

\section{B.06.C.O/5 (fig. 5)}

Provenienza: Unità T76H-SR (Stratum H, Mineo 3). Collocazione: già Barāqish magazzino del Museo Materiale: gesso

Dimensioni: altezza lettere $2,8 \mathrm{~cm}$

Conservazione: frammentaria

\section{Testo:}

1. $[. .].(h)$

2. $[\ldots]$ 


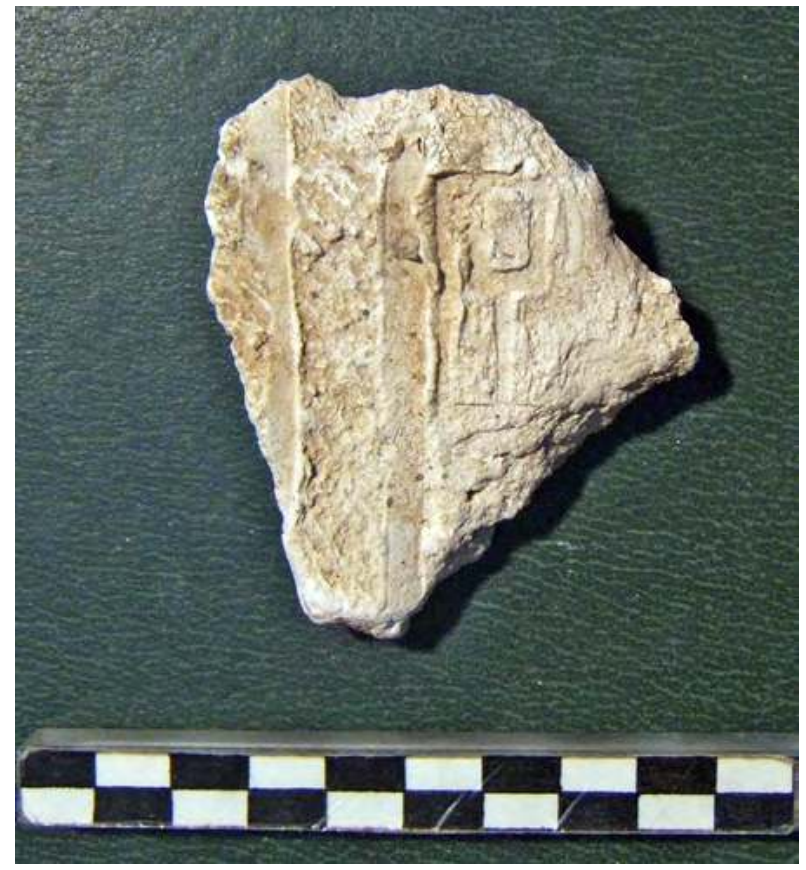

Fig. 5. Frammento di sigillo in gesso con impressione (B.06.C.O/5). (F.G. Fedele 2006 CMAIRY)

\section{Note:}

Possibile anche una lettura dell'unico segno visibile come Y. Meno verosimile l'identificazione di una sibilante.

\section{B.06.C.0/7 (fig. 6)}

Provenienza: Unità T76H-SR (Stratum H, Mineo 3). Collocazione: già Barāqish magazzino del Museo Materiale: gesso

Dimensioni: altezza lettere $1,5 \mathrm{~cm}$

Conservazione: frammentaria

Descrizione: l'impronta è molto parziale e la lettura fortemente ipotetica.

\section{Testo:}

$$
\text { 1. }[.](b m)
$$

\section{B.06.C.0/8+9 (fig. 7)}

Provenienza: Unità T76H-SR (Stratum H, Mineo 3). Collocazione: già Barāqish magazzino del Museo Materiale: gesso

Dimensioni: altezza lettere $3 \mathrm{~cm}$

Conservazione: frammentaria

Descrizione: il pezzo presenta due impressioni, la cui parte superstite è molto limitata.

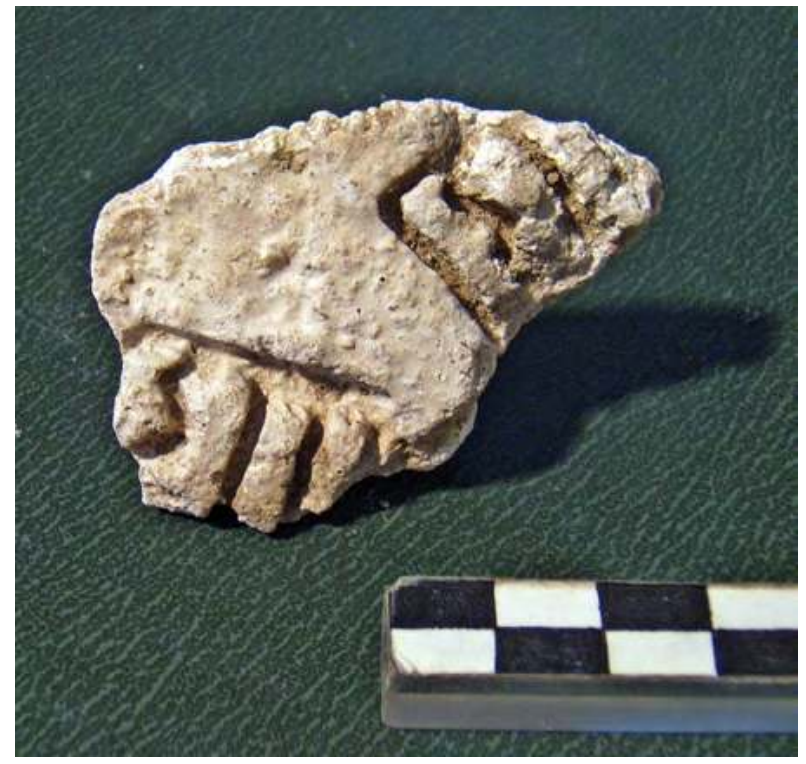

Fig. 6. Frammento di sigillo in gesso con impressione (B.06.C.O/7). (F.G. Fedele 2006 CMAIRY)

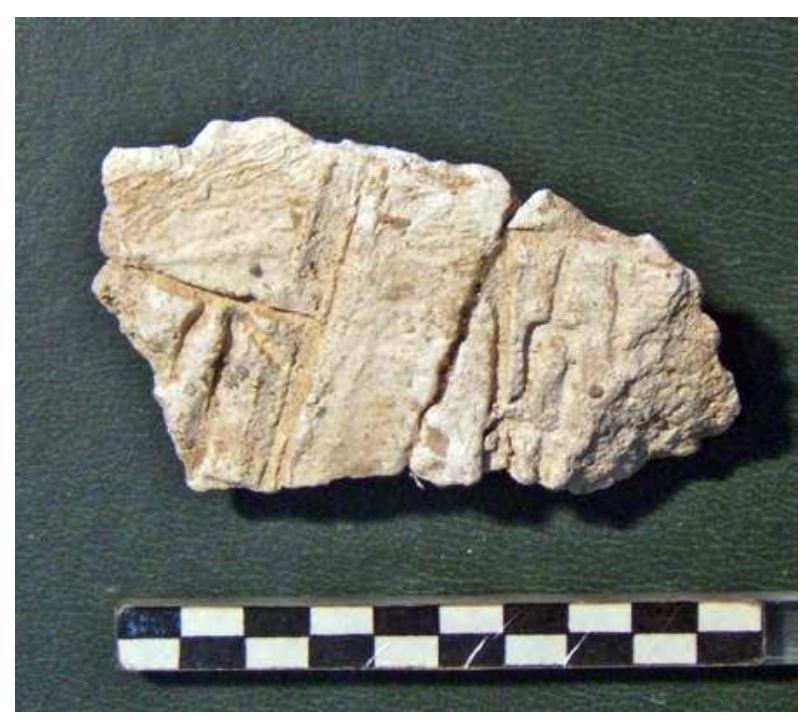

Fig. 7. Frammento di sigillo in gesso con impressione (B.06.C.O/8+9). (F.G. Fedele 2006 CMAIRY)

Testo:

1. $S^{1}[\ldots]$

Note:

Unalettura con una $\mathrm{H}$ finale potrebbe essere ugualmente possibile data l'incertezza sull'orientamento del pezzo; possibile anche come simbolo religioso.

\section{B.06.C.0/11 (fig. 8)}

Provenienza: Unità T76H-SR (Stratum H, Mineo 3). Collocazione: già Barāqish magazzino del Museo 


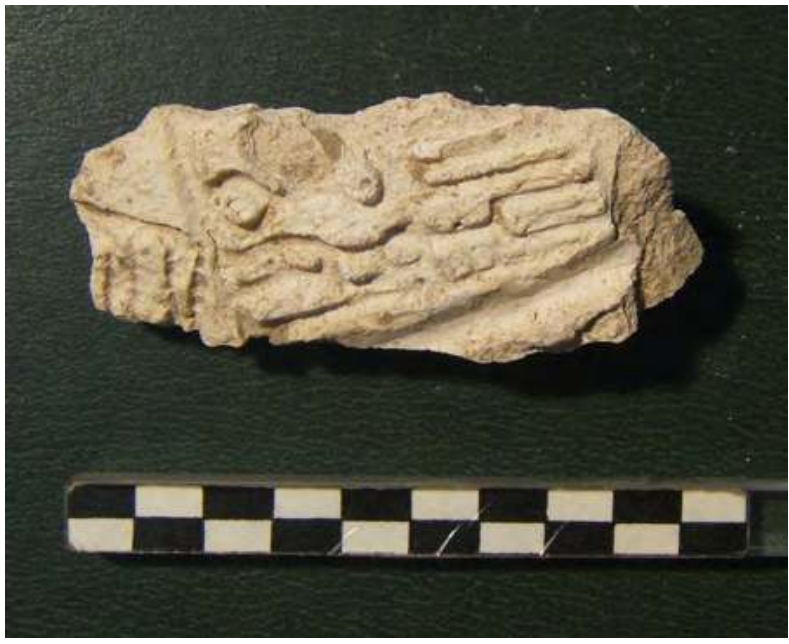

Fig. 8. Frammento di sigillo in gesso con impressione (B.06.C.O/11). (F.G. Fedele 2006 CMAIRY)

Materiale: gesso

Dimensioni: altezza lettere $2,7 \mathrm{~cm}$

Conservazione: frammentaria

Descrizione: la presenza del simbolo del tipo 'mazza' o 'Totschläger' (Grohmann 1914, 17-19; Gajda 2012, 447), che è notoriamente collegato col dio Almaqah, potrebbe suggerire un'origine sabea per il contenitore sigillato da questa cretula. Impressione probabilmente destrorsa.

\section{Testo:}

$$
\begin{aligned}
& \text { 1. Simbolo } t[\ldots] \\
& \text { 2. } S^{1}[\ldots]
\end{aligned}
$$

\section{B.06.C.O/12 (fig. 9)}

Provenienza: Unità T76H-SR (Stratum H, Mineo 3). Collocazione: già Barāqish magazzino del Museo Materiale: gesso

Dimensioni: altezza lettere $2 \mathrm{~cm}$

Conservazione: frammentaria

Descrizione: il primo segno potrebbe rappresentare il simbolo del dio Nakrah del tipo della 'forchetta a due denti' (Grohmann 1914, 55; Gajda 2012, 448), ma dato il contesto estremamente frammentario non si può totalmente escludere che si tratti della lettera $\mathrm{H}$ con una parte superiore disegnata con tratto più circolare. La prima possibilità ci sembra essere preferibile, tenendo anche presente la presenza di un altro simbolo di natura religiosa in questo lotto (B.06.C.O/11). Andamento sinistrorso?

\section{Testo:}

1. Simbolo $\left(s^{1}\right)[\cdot]$

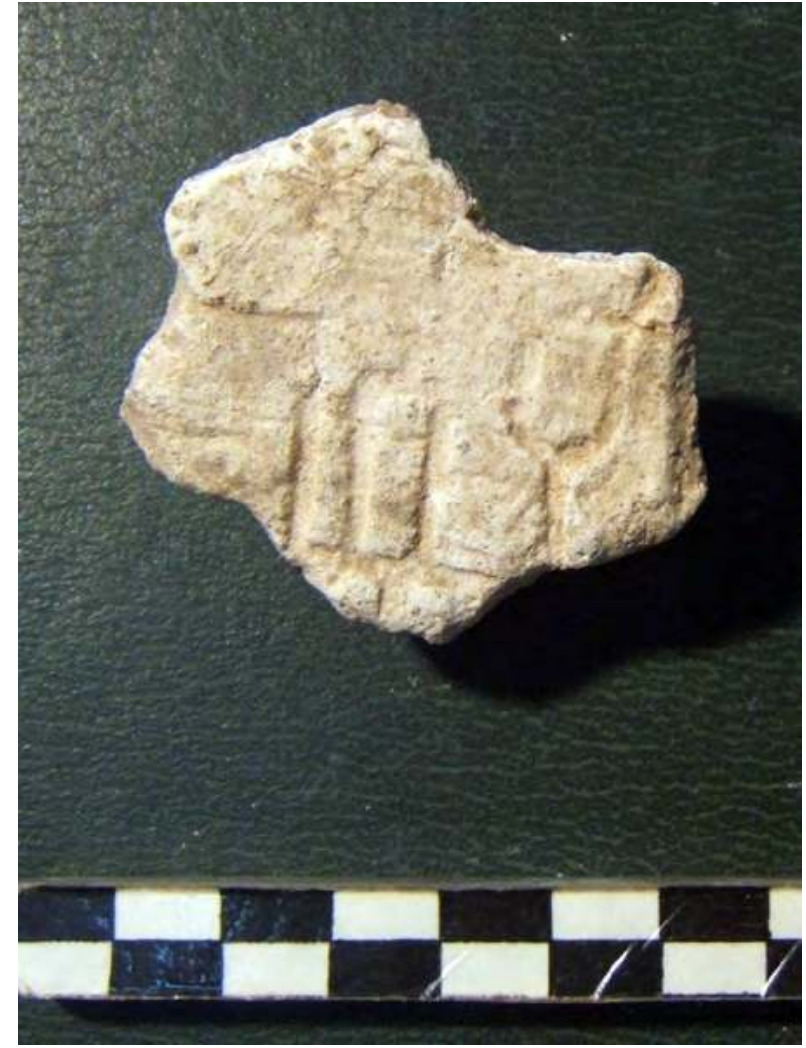

Fig. 9. Frammento di sigillo in gesso con impressione (B.06.C.O/12). (F.G. Fedele 2006 OMAIRY)

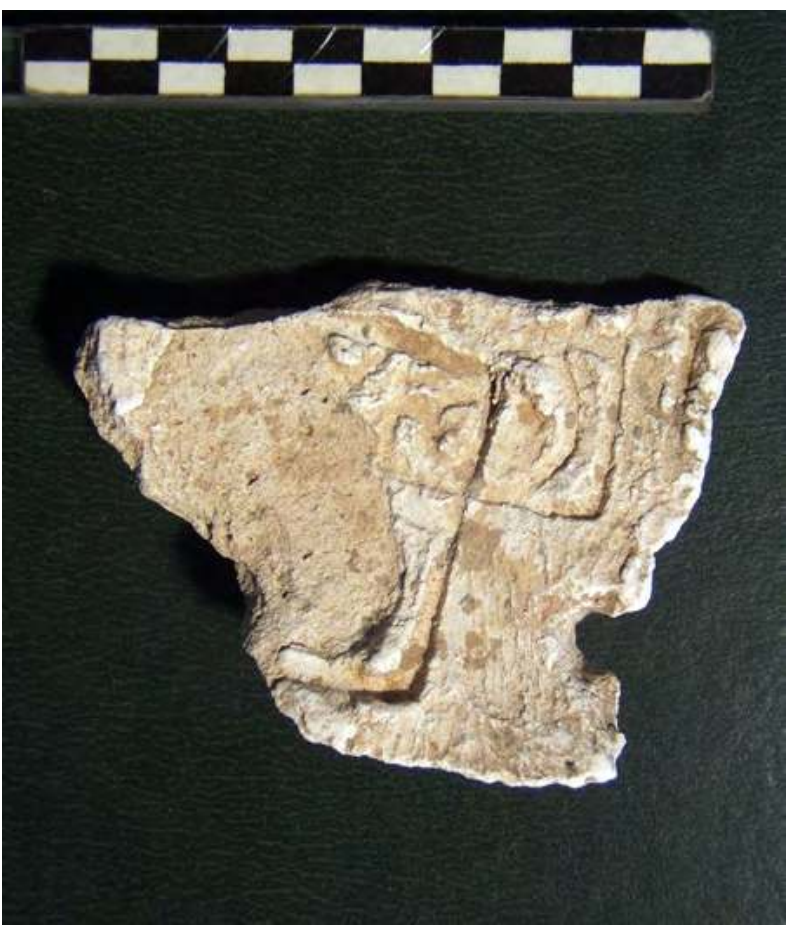

Fig. 10. Frammento di sigillo in gesso con impressione (B.06.C.O/13). (F.G. Fedele 2006 CMAIRY) 


\section{B.06.C.O/13 (fig. 10)}

Provenienza: Unità T76H-SR (Stratum H, Mineo 3). Collocazione: già Barāqish magazzino del Museo Materiale: gesso

Dimensioni: altezza lettere $2 \mathrm{~cm}$

Conservazione: frammentaria

\section{Testo:}
1. $m[\ldots]$
2. $[\ldots]$

\section{Note:}

Andamento probabilmente sinistrorso; possibile doppia impressione disallineata.

\section{B.06.C.0/15 (fig. 11)}

Provenienza: Unità T76H-SR (Stratum H, Mineo 3). Collocazione: già Barāqish magazzino del Museo Materiale: gesso

Dimensioni: altezza lettere $2,7 \mathrm{~cm}$

Conservazione: frammentaria

Descrizione: iscrizione con impressione destrorsa su due linee.

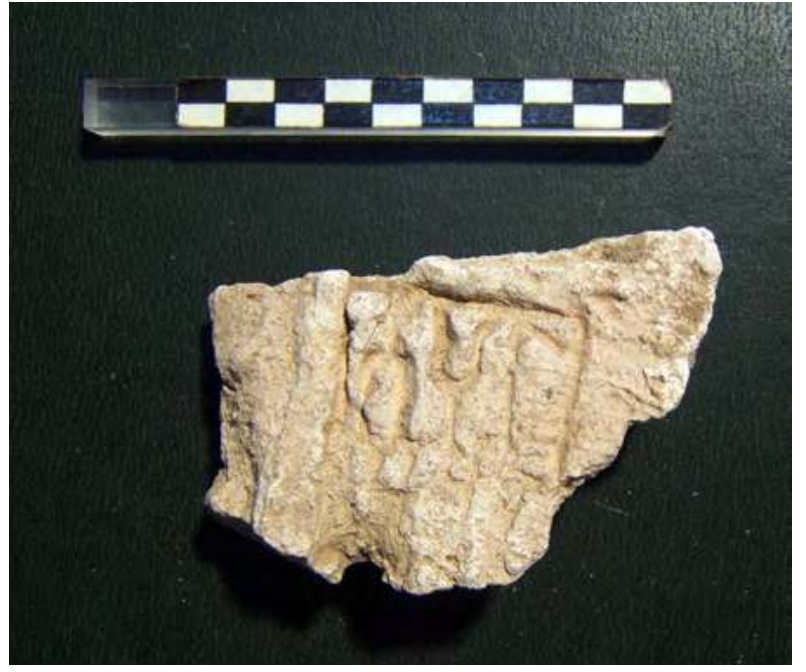

Fig. 11. Frammento di sigillo in gesso con impressione (B.06.C.O/15). (F.G. Fedele 2006 CMAIRY)

Testo:
1. $\left(S^{1}\right) h l$
2. $[\ldots]$

\section{Note:}

La lettura del primo termine non dà confronti in questo contesto. Non si può neanche escludere una lettura ' $h l$, che potrebbe introdurre un nome di tribù, ma una prima 'Alif non è chiaramente osservabile. 


\title{
Ceramic Typology, Territory, and a Historical Outline of the Jawf
}

\author{
Chapter 25

\section{The Typological Classification of the Minaean Pottery from the Temple of 'Athtar dhu-Qabd and the Extramural Excavations in Area $\mathrm{C}$}

\author{
Vittoria Buffa
}

\section{Introduction}

The pottery assemblages from Sounding A in Area C and from the excavations of the Temple of 'Athtar dhuQabd are examined in this chapter. ${ }^{1}$

Overall the great majority of the vessels were hand made. They were often finished with the aid of a tournette or slow wheel; ${ }^{2}$ this accounts for the striations visible on the internal surface - less often on the exterior - of the vessels. In neighbouring sites, the same manufacture technique has been documented in the Jawf in the pottery assemblage of al-Sawdā' and also in Mārib. ${ }^{3}$ Only 3 examples of wheel-made vessels were collected; they belong to high ring bases (types VII.B.3, VII.B.4).

Nine different types of paste have been distinguished on the basis of visual analysis; no physical or chemical analysis have been made. The colour is described with reference to the Munsell charts. ${ }^{4}$

Paste 1. Compact pale brown or pale yellow paste with few black and/or white grits and mica; less common with many grits and straw temper. ${ }^{5}$ Exterior and interior surfaces coated with burnished red slip, dark red (10Y 5/4) or weak red (7.5Y 5/4).

Paste 2. Compact or rather fine paste with few black and white grits, mica and little straw temper, light brown (7.5YR 6/4), or pale brown (10YR 6/3 or 8/3). Exterior

\footnotetext{
1 The author wishes to thank Prof. Francesco Fedele for entrusting her with the study of the Minaean pottery assemblage from the excavation in Area C, Sounding A.

2 Yon 1981, 237.

3 Arramond 2011, 79. Japp 2007, 348.

4 Munsell 1994.

5 The traditional term of 'straw' is used here meaning organic temper.
}

often burnished or wet smoothed. In some vessels a red slip or red paint is applied on the exterior or on the interior. The rim of the vessels is often covered with a band of red paint.

Paste 3. Compact paste with few or many black and white grits, mica and some straw temper. Less common is a paste with more straw. Vessels have a light red external surface (2.5YR 6/6, 6/4, 5YR 5/4) and light red or reddish brown (2.5YR 6/6, 5YR 5/4) interior. Finishing includes in general wet smoothing. Four vessels are made with black, white grits, some larger ones, some large red (chamotte) and straw temper.

Paste 4. Few vessels are made with a compact paste, characterized by a pale brown burnished or pink, light reddish brown slip on the interior surface $(10 \mathrm{R} 7 / 3)$ and a pale yellow or very pale brown $(2.5 \mathrm{Y} 7 / 3,10 \mathrm{YR} 7 / 4)$ exterior surface, usually smoothed; inclusions include few black grits, mica and some straw temper or only some grits and mica.

Paste 5. Fine or compact paste with few black and white grits, mica and some straw temper; in few vessels the presence of a quantity of straw temper can be noted; finishing consists in smoothing, sometime wet smoothing. External and internal surfaces pale brown or pale yellow in colour $(2.5 \mathrm{Y} 7 / 3,2.5 \mathrm{Y} 7 / 4,10 \mathrm{R} 8 / 2)$.

Paste 6. Fine or compact pink or light reddish brown (5YR 6/6, 7/6) paste, with few grits and some straw temper; very rarely a lot of straw temper has been noted; interior is burnished or smoothed. Some types of vessels made with paste 6 have a red paint over the rim or all over the external surface or a dark red slip on the exterior or the interior.

Paste 7. Only 4 vessels are made of a compact or fine light reddish brown (10YR 6/4, 2.5YR 6/4, 7.5YR 6/4) 
paste with black grits and some straw temper; exterior coated with a pale brown or pale yellow burnished slip (10YR $7 / 2,10$ YR $8 / 3,2.5$ Y $8 / 2$ ).

Paste 8. One vessel is made in a compact, fine red (10R 5/6) paste with some white grits, mica and some larger black, grey, red inclusions; exterior and interior polished.

Paste 9. Fine red fabric (10R 5/6 or 6/4) with few black grits and mica; surfaces smoothed.

\section{The typological classification}

Typological classification of the Minaean pottery from Barāqish is based on the same principles put forward in a recent article dealing with the assemblage from Tamnac. ${ }^{6}$ It is a classification based on the shape of the vessels and in some cases also on the size of them. Only in some instances the technical characteristics (see for instance some treatments of the surface) have been judged relevant enough to group in one type fragments that otherwise would have probably fallen in different types. The identification of a type is given by a name and the definition of the shape.

No complete vessels have been recovered from the Temple or from Sounding A. This has been crucial in the process of building the typology. Nevertheless, in some cases parallels with ceramics from the tombs at Barāqish Area $\mathrm{D}^{7}$ have been important in hypothesizing the complete shape of a type.

Although in an urban society such the Barāqish one, shape and function of a vessel must have been closely related, the nature of the sample analysed has made difficult to assign a sure function to many shapes. While for instance in the case of shallow, small cups or bowls, footed or not, the function of containing liquids to be drunk seems clear, larger bowls, with or without foot, more or less deep, can have been used for a collective consumption of food or for preparation of meals.

In the category of closed vessels, the situation is clearer, but the division between the storage and the cooking functions is clear only in some cases. On the surface of closed shape vessels soot was present in very few cases. Probably the small number of types assigned to cooking ware is also in connection with the presence in Barāqish of soft-stone vessels of types known from other sites to have been used for cooking. As can be expected, hole mouth jars that could have been used for cooking were found mainly in Sounding A and not in the Temple.

\footnotetext{
6 Buffa 2016b.

7 Antonini and Agostini 2010a.
}

Summing up, while in a broad sense, the division between table, storage and cooking wares seems correct, in some cases the functions assigned are only hypothetical.

The following categories and types have been identified:
I. Plate
II. Cups on foot
III. Bowls

A. Bowls of small dimensions (on foot?)

B. Bowls of large dimensions with flaring sides

C. Bowls of large dimensions with vertical or incurving upper sides

D. Cylindrical bowls or jars.

\section{Basins}

V. Jars
A. Jars with rim from vertical to incurving
B. Jars with everted rim
C. Necked jar

VI. Dolia

VII. Bases

A. Flat bases
B. Ring bases

VIII. Handles

IX. Decorations
A. Applied
B. Incised
C. Painted

\section{Plate}

1. Large plate. Large plate with short, straight vertical sides. Rounded rim. The outer surface of the bottom is left unfinished or anyway very coarse; this could be explained with the hypothesis given by A. de Maigret that these plates, or 'trays', found in the Sabaean layers from the sounding in front of the temple of Nakrah, had a high foot. Rim diameter from 33 to $62 \mathrm{~cm}$. Medium compact, pale brown or pink paste, inclusions not visible; surfaces smoothed. Interior coated with red slip in one case; in the other sherd the inner surface is blackened by fire. Fedele reports one fragment of a similar 'tray' from Stratum M (7th-early 6th century BC). ${ }^{8}$ (Fig. 4 B). ${ }^{9}$

\section{B.05.B. $/ 57,1 ; 78,2$.}

\section{Cups on foot}

Small containers on foot, apt to individual consumption of liquids. Rim diameter from 7 to $15 \mathrm{~cm}$.

\footnotetext{
8 de Maigret 2010a, 78-79, Fig. 110. Fedele 2010, 128; updated record in Chapter 23, this volume. It shall be noted that the vessels studied by de Maigret and Fedele are dated to the Sabaean period.

9 The illustrations of the types have been organized according to the chronological phases (see below).
} 
1. Small cup on foot. Small, shallow cup on foot or stem; wide mouth, slightly flaring or vertical rounded sides. Rounded rim with diameter from 7 to $9.5 \mathrm{~cm}$. Compact, rather fine paste, pale yellow or pink with few grits and little straw temper; red slip or red paint on exterior.

This type of cup is attested in sanctuary of al-Sawdā' and in the Bar’ān temple in Mārib. ${ }^{10}$ Among the LateMinaean pottery from Level 1 above the tombs a similar cup is made with a light brown clay with plain surfaces..$^{11}$ (Fig. 1 B).

$$
\text { B.06.C./183,2; B.06.C./189,12; B.06.C/190,9. }
$$

2.Deep cup. Wide mouth, vertical or slightly flaring upper sides. Vertical rim and rounded lip. Foot not preserved. Rim diameter from 8.5 to $15 \mathrm{~cm}$. Compact, rather fine, light brown or pink paste, with few or several grits and straw temper; the surfaces are smoothed or burnished.
a. bending toward base with an angular profile (Fig. $1 \mathrm{~B})$.
B.06.C. $/ 188,6$; B.06.C. $/ 189,15 ; \quad$ B.06.C. $/ 190,12$, 14; B.06.C./191,5, 16, 17; B.06.C./,191B,5; B.06.C./192,3.
b. with convex profile (Fig. $1 \mathrm{~B}$ ).
B.06.C./187,3; B.06.C./189,16,19,22; B.06.C./191,15.

3. Cup with tronconical profile. Wide mouth, straight flaring sides. Flaring rim, rounded lip. One piece has a knob on the rim. No foot preserved. Rim diameter 13-16.5 cm. Compact light brown or pink paste, with few grits and some straw temper; both surfaces are burnished. (Fig. 2 B).

In the Jawf region several cups of this type were recovered. ${ }^{12}$ Similar cups are present among the assemblages from the Bar’ān temple in Mārib, Tamnac and also Shabwa. ${ }^{13}$

B.06.C./169G,5; B.06.C./190,13.

4. Red slipped cup with tronconical profile. Straight or slightly convex flaring sides, flaring rim. No foot preserved. Rim diameter from 10 to $14 \mathrm{~cm}$. Compact or fine paste with few grits and in some cases some straw temper. The interior or both surfaces are coated with a burnished red slip. Red slipped cups of the same shapes are present in Bar’ān temple in Mārib. ${ }^{14}$

a. thickened, bevelled rim on interior (Fig. 4 B).

\footnotetext{
10 Arramond 2011, 85, pl. 65,3. Ayoub 2007, 323, Typ 100 pl. 66,1.

11 Antonini 2010b, 38, Fig. 6,2.

12 Arbach and Schiettecatte 2006, 87 (al-Jawf 04.106), pl. 27, Fig. 109; pl. 41.

13 Ayoub 2007, 321, Typ 100 pl. 66,2. Antonini and Buffa 2016, 458, type III.A.1, Fig. 3,3. Breton et al. 2010, 58-59, Fig. 60, 10/01, phase 4.

14 Ayoub 2007, 313, Typ 1c pl. 12,3.
}

B.05.B./54,7,11.

b. thinned rim above a thickening of the wall. In alJawf similar bowls have been recovered (Fig. 4 B). ${ }^{15}$ B.05.B.73,1.

5. Deep cup on low foot/beaker. Slightly flaring, convex profile walls, low foot with concave, flaring sides. Very compact, fine light pale brown paste with some black grits, including mica. The exterior is wet smoothed. Diameter base $5-5.5 \mathrm{~cm}$. (Fig. $4 \mathrm{~B}$ ).

The same type of low foot was found among the material of Level 1 above the necropolis of Barāqish. This type also recalls a beaker found in the Bar’ān temple in Mārib and one from al-Sawdāa ${ }^{16}$

B.05.B./58,10; B.05.B./76,9.

\section{Bowls}

This category includes a wide range of vessels. It has been organized according to the size and to the geometric features, but also according to the size, supposing that it would help to understand the function. The category includes small vessels for table use as well as large ones for other uses such as preparation, storage of food or collective consumption of food.

\section{A. Bowls of small dimensions (footed)}

Containers apt to the individual consumption of liquids and food. Rim diameter $12-21 \mathrm{~cm}$.

1. Small, deep tronconical bowl on low foot. Straight, flaring sides. Compact, fine pale brown or pink paste, with few grits and little straw temper or only mica. The exterior is usually wet smoothed, sometimes burnished. Rim diameter $12-18 \mathrm{~cm}$.

a. on inner surface below the rim the wall shows a thickening (Fig. $3 \mathrm{~B})$. Among the pottery from Level 3 in the necropolis in Barāqish a similar bowl is present; the type is also present among the LateMinaean material from the surface, but with both surfaces red slipped, ${ }^{17}$ and among the pottery from the eastern part of the intra-muros sector in alUkhdūd (Najrān). ${ }^{18}$

B.05.B./58,16; B.06.C./169G,6,13.

\footnotetext{
15 Arbach and Schiettecatte 2006, 87 (al-Jawf 04.107), pl. 27, Fig. 110; pl. 41.

16 Antonini 2010b, 40, Fig. 8,1. Ayoub 2007, 317, pl. 35. Arramond 2011, 84, Fig. 64, 3.

17 Antonini 2010b, 29, Fig. 2,17; 31, Fig. 9,1.

18 al-Zahranī A. et al. 2005, pl. 1.5 B.
} 
b. rim thickened outside (Fig. 4 B). This variety of bowl is present in Tamna'; a similar bowl is also found in Shabwa and in Hajar ibn Humayd. ${ }^{19}$

B.05.B./58,25; B.05.B./76,13.

C. wall quite thick (Fig. 1 B). Again, in the Minaean Level 3 in the necropolis a similar rim is present. ${ }^{20}$ B.06.C./188,5; B.06.C./191,4.

One additional fragment could belong to this type: B.05.B./58,23.

2. Red slipped, small deep tronconical bowl (footed). Straight flaring sides, thickened upper wall or rim, red slip on interior. Rim diameter from 17 to $21 \mathrm{~cm}$. No foot preserved. Compact, rather fine pale brown paste, with some grits.

a. rim slightly thickened outside, in one case bevelled (Fig. $3 \mathrm{~A}$ ). In the necropolis a similar dark red slipped bowl was recovered from Level $3 .{ }^{21}$

B.06.C./169K,2. Uncertain attribution to the type: B.05.B./18,9.

b. decorated with horizontal incised lines. Straight flaring sides, rounded lip; decorated with one or two horizontal incisions below the rim. Red slip or red paint on both surfaces. No foot preserved (Fig. 1 B). B.06.C./189,11 (larger than other pieces); B.06.C./191,10.

3. Red slipped, small deep bowl with convex profile, incised lines below the rim (footed?). Flaring sides with convex profile, rounded lip. Decorated with one or two horizontal grooved below the rim. Rim diameter from 13 to $21 \mathrm{~cm}$. No foot preserved. Compact, rather fine paste 1 , with few grits and some straw temper. The exterior and the interior are coated with red slip. B.06.C./185,6 is also decorated with red paint on rim (Fig. 2 B).

The horizontal parallel incised lines below the rim of bowls is a motif that has a long history from Sabaean times onward. In Barāqish itself it is attested on a red slipped convex profile bowl from Area D, Level 4, dated by S. Antonini to the Sabaean period, but also in de Maigret's sounding at the temple of Nakrah. ${ }^{22}$ In Hajar ibn Humayd the type is attested for a long time from the 9th-8th to the 6th-5th centuries BC, well into the Minaean period. ${ }^{23}$ Also in Tamnac few carinated bowls

\footnotetext{
19 Antonini and Buffa 2016, 459, type III.A.4.b, Fig. 3. Breton et al. 2010, 58-59, Fig. 61, 3/16.

20 Antonini 2010b, 29, Fig. 2,8.

21 Antonini 2010b, 29, Fig. 2,18.

22 Antonini 2010b, 29, Fig. 1,7. de Maigret 2010a, 84, Fig. 108,4 from stratum B; 74, Fig. 105,22; 107,1 from stratum C, dated to the 8 th century $\mathrm{BC}$.

23 Van Beek 1969, 238, type 1511, bowl 3, from strata Q and J.
}

have been recovered from layers dated not earlier than the 4 th century BC. ${ }^{24}$

$$
\begin{aligned}
& \text { B.06.C./169G,12; B.06.C./185,6; } \quad \text { B.06.C./191,19; } \\
& \text { B.06.C./191B,6; } 193,1 .
\end{aligned}
$$

4. Red slipped, carinated bowl on foot. Thickened carination, medium high flaring upper side, bevelled edge. Decorated with one or more horizontal grooves below the rim. Rim diameter 13 to $16 \mathrm{~cm}$. Medium compact pale yellow paste, some pores, with a variable amount of grits and straw temper. Both surfaces are coated with a burnished red slip. Versions $a$ and $b$ of this type are present in the sounding at the temple of Nakrah in layers dated to the 8 th century $\mathrm{BC},{ }^{25}$ showing that this eponymous type of the Sabaean period continued to be produced at least in Barāqish into Minaean times. The same seems to be true in Hajar ibn Humayd where Type 1511 , bowl 1 is attested until the 6th century BC. ${ }^{26}$

a. diameter at the rim larger than that at carination, short, concave, flaring sides, rounded lip; overall a shallow vessel. Red burnished slip on both surfaces or only on inside (Fig. $3 \mathrm{~A}$ ).

B.06.C./169G,4; B.06.C./186,4; $\quad$ B.06.C. $/ 188,10$. Uncertain attribution to the type: B.05.B./73,2.

b. rim diameter equal at that at carination, taller, vertical, concave sides; shallow lower part. Red burnished slip on both surfaces or only on inside (Fig. 3 B).

B.06.C./169G,11.

C. plain surfaces (Fig. 3 B).

B.06.C./186,1.

\section{Wavy rim bowls on foot}

Deep wavy rim bowl. Small dimensions, vertical sides; one sample has a low foot with flaring sides, rounded edge. Compact, fine, pale yellow/brown paste, with some grits and mica. The surface is smoothed (Fig. 3 B).

Wavy rim bowls were found at Barāqish in the Minaean tombs, Level 3, and in Level 1 covering the Minaean tombs and on the surface. ${ }^{27}$ From Area C, Fedele reports the presence of fragments of wavy rim bowls 'towards the end of the Later Sabaean occupation, Stratum L, possibly continuing into the End-Sabaean'. ${ }^{28}$ Unfortunately the fragmentation of the two vessels from the Minaean layers and of the specimens from the area of the necropolis cannot be of help in trying to build a formal development through time, and therefore

\footnotetext{
24 Antonini and Buffa 2016, 463, type III.E.1, Fig. 15, 6-10.

25 de Maigret 2010a, Fig. 105,8; 107,6 from strata C and B respectively.

26 Van Beek 1969, 157, type 1511, bowl 1, Fig. 94

27 Antonini 2010b, 29, Fig. 2,12; 31, Fig. 6, 4-6; 9,3-4.

28 Fedele 2010, 127, Table 5, Fig. 144; updated record in Chapter 23, this volume ('End-Sabaean' renamed First Intermediate).
} 
to build a sound chronological local development of this famous type. To remain in neighbouring areas, this type of bowl was recovered from al-Jawf. ${ }^{29}$ Wavy rim bowls are present also in al-Ukhdūd..$^{30}$

B.05.B./20,6; B.06.C./185,3. B.06.C. 185,4 could be the base of a wavy rim bowl.

\section{B. Bowls of large dimensions with flaring sides}

Here shallow bowls types as well as rather deep ones are included. Rim diameter from 19.5 to $27.5 \mathrm{~cm}$. Several types are probably footed. Containers apt to consume and prepare food. The size of the vessels suggests that the consumption of food could be a collective one.

1. Shallow bowl. Convex profile sides, flaring rim. Rounded lip. Rim diameter from 19.5 to $27 \mathrm{~cm}$. Although no complete pieces are preserved, the vessels most probably had a ring base (see B.05.B/58,1,5). Very compact pale brown paste, with few grits and a variable amount of straw temper. The exterior is sometime wet smoothed (Fig. 3 B). The same bowl, of slightly smaller dimensions, comes from the Minaean tombs at Barāqish and it is found also at Tamna and in the Bar'ān temple at Mārib. ${ }^{31}$

$$
\text { B.05.B./18,7; 20,8; B.06.C./169G,10; 183,1. }
$$

2. Shallow bowl with thickened rim. More or less flaring, slightly curving sides. Rim strongly thickened interiorly, bevelled on top. Rim diameter $2.5-31 \mathrm{~cm}$. The vessel had probably a low foot or ring base (cf B.05.B/58,1). Compact light brown paste, with few grits and straw temper (Fig. 4 B).

In Level 1 above the Minaean tombs a bowl of this shape was recovered. ${ }^{32}$

$$
\text { B.05.B./58,11; 76,8. }
$$

3. Bowl with rounded sides, medium depth. Flaring, slightly curving sides. Rim diameter from 20 to 26 . The vessels could have a ring base or low foot. Compact light reddish brown or reddish yellow or pale yellow paste with some grits of variable dimension and some straw temper. In some fragments the inner surface is burnished.

a. rounded sides becoming vertical at rounded rim (Fig. 1 B).

B.06.C. $/ 188,15 ; 189,24,25 ; 191,9 ; 192,2$.

\footnotetext{
29 Arbach and Schiettecatte 2006, 94 (al-Jawf 04.151), pl. 38; pl. 42.

30 al-Zahranī et al. 2005, pl. 1.8 D. al-Zahranī et al. 2001, pl. 14

31 Antonini 2010b, 29, Fig. 2,10. Antonini and Buffa 2016, 494, type III.B.1, Fig. 4. Ayoub 2007, 312, 327, typ 1, Tafel 10, 1, 2; 12, 1, 2.

32 Antonini 2010b, 30, Fig. 5,9.
}

b. more flaring sides; reddish brown slip on inner surface (Fig. 4 B).

B.05.B./58,19.

c. lip bevelled on top (Fig. $3 \mathrm{~A}$ ).

Similar bowls are present in the Minaean tombs and in the layer above the tombs at Barāqish Area D..$^{33}$

B.06.C./169H,3; 187,2.

4. Deep, large tronconical bowl. Straight sides, from vertical to slightly flaring in the upper part, converging toward the bottom; the upper part of wall is marked by a thickening. The rim is flaring or almost vertical; the lip is rounded or flattened. Rim diameter 21 to $26 \mathrm{~cm}$. No foot preserved. Compact pale brown or pale yellow or reddish brown paste with a variable amount of grits and straw temper. The exterior is wet smoothed.

a. rim thickened (Fig. 3 A).

Among the pottery from Level 1 at Barāqish Area D a similar bowl was recovered. ${ }^{34}$

B.05.B./58, 14+15; 76,4; B.06.C./169G,9; 185,5; 188,14. B.05.B.72,2 is a smaller variant.

b. rim slightly thickened, lip flattened, sides becoming vertical at rim (Fig. 3 B). A similar bowl was found in the assemblage from the Bar'ān temple in Mārib. ${ }^{35}$

B.05.B./51,4; B.06.C./186,2.

5. Large bowl with everted rim. Slightly curved, flaring sides. Everted rim, forming an edge with inner side. Rounded lip. The shape and the size of the vessel suggest the collective consumption of food. Fine red paste with some grits and some larger inclusions of different colours; surfaces polished (Fig. 4 B).

B.05.B./54,12.

6. Carinated bowl with convex base. Flaring upper sides. Medium compact pale yellow paste, with some grits and straw temper. The exterior surface is smoothed (Fig. 2 C).

$$
\text { B.06.C./189,21. }
$$

\section{Bowls with vertical or incurving upper sides}

Among these types some can be considered apt to prepare, but also to cook food.

1. Bowl with strongly thickened upper sides. Vertical upper sides, curving toward the bottom. Slightly incurving rim, lip bevelled outside. The vessel could have a ring

\footnotetext{
33 Antonini 2010b, 29, Fig. 2,13; 31, Fig. 9,2.

34 Antonini 2010b, 31, Fig. 5,3.

35 Ayoub 2007, 318, typ 30, pl. 34,5.
} 
base. Rim diameter $25 \mathrm{~cm}$. Coarse, porous light red paste, with many grits and straw temper (Fig. 4 B).

The type is present in Mārib in the Bar’ān temple. ${ }^{36}$

$$
\text { B.05.B./54,6. }
$$

2. Bowl with angular profile. Vertical upper sides, curving toward the base. Rim straight, lip rounded or flattened. Rim diameter from 21 to $26 \mathrm{~cm}$. The vessels could have a ring base or low foot. Medium compact, light brown paste with many grits and straw temper. The exterior is wet smoothed (Fig. 3 B).

This type finds a parallel in some bowls in Bar'ān temple in Mārib, in Hajar ibn Humayd and in Tamnac ${ }^{\text {. }}{ }^{37}$

$$
\text { B.05.B./58, 17; B.06.C./169G,8. }
$$

3. Deep bowl with red paint on the vertical rim. Vertical upper wall, incurving toward bottom. Lip rounded or bevelled. Red paint on rim. Rim diameter from 19 to $30 \mathrm{~cm}$. One vessel has a ledge handle on rim. Compact reddish brown or pale brown paste with a variable amount of grits and straw temper. Burnishing or wet smoothing on both surfaces (Fig. 3 A). This type, as well as the two next ones, seems apt to prepare and/or consuming solid food. Rather similar bowls come from Tamna' and Hajar ibn Humayd. ${ }^{38}$

$$
\text { B.06.C./188,13; 191,8; 191B,3; 192,1. }
$$

4. Red slipped bowl with incurving rim. Converging upper sides, incurving rim, angular or rounded profile. Walls are thin. Rim rounded, thinned or slightly thickened and bevelled. Rim diameter from 13 to $20 \mathrm{~cm}$. Compact or rather fine reddish brown or pale brown paste with few grits and straw temper. The burnished red slip can be applied to both surfaces or only on the interior. In one case (B.06.C./191,14) the exterior and the rim show traces of red paint (Fig. 2 B).

$$
\text { B.05.B./54,10; B.06.C./186,5; 188,1; } 191,14 \text {. }
$$

5. Deep bowl with incurving rim. Convex profile sides and incurving rim. Rim rounded or bevelled inside. Rim diameter from 18 to $24 \mathrm{~cm}$. Medium compact light brown or reddish paste with few grits and straw temper. Wet smoothing on outer surface (Fig. 1 B). Similar bowls are present in Bar ān temple in Mārib. ${ }^{39}$

\footnotetext{
36 Ayoub 2007, 316, pl. 26,11.

37 Ayoub 2007, 315, pl. 23,8, 10; Van Beek 1969, 116, type 1000, bowl 5, Fig. 31, strata G-A; Antonini and Buffa 2016, 461, type III.B.6.b, Fig. 10,6 .

38 Antonini and Buffa 2016, 462, type III.B.8, Fig. 12. Van Beek 1969, 216, Fig. 73, H333 from stratum C1.

39 Ayoub 2007, 319, typ 50, pl. 43.
}

B.05.B./58,12; B.06.C./189,17; 190,11.

\section{Cylindrical bowls or jars}

The fragmentation of the sherds does not allow the reconstruction of the depth of the specimens, so that we cannot attribute the pieces with certainty to the category of bowls or jars. They seem apt to storage goods.

1. Deep bowl with cylindrical profile. Deep bowls or cylindrical jars, slightly rounding sides, vertical rim. Rim diameter from 19 to $27 \mathrm{~cm}$. Compact reddish brown paste, some pores, with few grits and some straw temper. External surface is wet smoothed (Fig. 1 B).

B.06.C. $/ 189,23 ; 191,7,13$.

\section{Basins}

This class of types has in common the size larger than the size of bowls and in general the thickness of the walls. They can have several uses: store foodstuffs, preparing/cooking food.

1. Basin decorated with incised wavy lines. Slightly flaring, convex profile sides, becoming vertical just below the rim. Rounded lip. Decoration of two incised wavy lines below the rim. Rim diameter $45 \mathrm{~cm}$. Compact pale brown paste with few grits and some straw temper. Wet smoothing on inner surface (Fig. 1 B).

In Hajar ibn Humayd and in Shabwa this decoration is present on bowls of this shape. ${ }^{40}$ Like in other instances, this shape combined with this type of decoration has a long history, being attested already in Sabaean layers at Barāqish and Yalā. ${ }^{41}$

\section{B.06.C./188,12;191B,2.}

2. Basin with thickened rim. Convex profile sides, slightly flaring, becoming vertical at rim. Rim strongly thickened, rounded lip. One horizontal groove below the rim. Rim diameter $30 \mathrm{~cm}$. Medium compact pale brown paste with few grits and some straw temper. Wet smoothing on outer surface (Fig. 4).

A parallel can be found at Hajar ar-Rayhāāīi. ${ }^{42}$

B.05.B./51,3.

\footnotetext{
40 Van Beek 1969, 123, type 1001, bowl 3, Fig. 42. Breton et al. 2010, 198, Fig. 58, top row.

41 de Maigret 2010a, 84, Fig. 109,1. de Maigret 2003, 91, pl. 18, 1, 4.

42 Glanzman 1987a, 119, Fig. 5.17,7, phase Va, dated to the 3rd century BC.
} 
3. Basin with rim protruding inside. Thick, straight, steep sides, slightly flaring. Rim thickened inside, near the flat lip. Below the rim a horizontal band of three comb wavy incisions. Reddish brown slip on interior and on top of rim. Rim diameter $21 \mathrm{~cm}$. Medium compact pale yellow paste with few grits and some straw temper (Fig. $3 \mathrm{~B})$.

This type has a parallel in the assemblage from the Bar’ān temple at Mārib and also at Tamnac ${ }^{c}{ }^{43}$

$$
\text { B.06.C./169H,1. }
$$

4. Basin with thickened rim. Deep tronconical basins with flaring, straight sides. Rim thickened. Rim diameter from 21 to $38 \mathrm{~cm}$. Medium compact or coarse pale yellow or reddish brown paste with many grits and a considerable amount of straw temper. Often wet smoothing on outer surface.

a. rim internally thickened with a continuous profile, rounded lip (Fig. 4 B).

The basin of variant a has parallels among the pottery from the surface of Barāqish Area $\mathrm{D}$, at al-Sawdā', at Hajar ibn Humayd and at Hajar arRayhạānī. ${ }^{44}$

B.05.B./54,1; 72,1.

b. rim strongly thickened inside and outside (Fig. 4 B).

The basin of variant $b$ has parallels among the pottery from the surface of Barāqish Area D, at alSawdā', in the Bar'ān temple at Mārib, at Hajar arRayhānī and at Shabwa. ${ }^{45}$ In Tamna' a bowl has the same shape. ${ }^{46}$

B.05.B./54,5; 58,9; 59,6; 76,5,6.

c. rim thicker that the wall, flattened lip. On one fragment red slip on rim and inner surface (Fig. 4 A).

B.06.C./184,1; 186,6.

\section{Jars}

The principle used in the classification of this category of vessels is the progressive inversion of the sides and rim. This is the only possible criterium because the fragmentation of the samples prevents, in many cases, the reconstruction of the general shape of the vessels. Nevertheless in most cases the inversion of the rim

43 Ayoub 2007, 319, type 52, pl. 45. Antonini and Buffa 2016, 464, type IV.2 Fig. 16.

${ }_{44}$ Antonini 2010b, 31, Fig. 9,5. Arramond 2011, 80, Fig. 63,4. Van Beek 1969, 116, type 1000, bowl 4, Fig. 31, H601, H565, dated to the 3rd century BC. Glanzman 1987a, 119, Fig. 5.17, 6, phase Va, 3rd century $\mathrm{BC}$.

45 Antonini 2010b, 30, Fig. 5,12. Arramond 2011, 85, Fig. 66,1. Ayoub 2007, 319, type 43, pl. 38,12, 13. Glanzman 1987a, 123, Fig. 5.19,4, from phase Va. Breton et al. 2010, 202, Fig. 62, phase 4.

46 Antonini and Buffa 2016, 463, type III.F.1, Fig. 15. and sides seem to correspond to specific shapes. In this group the types represent storage/transport and cooking vessels.

\section{A. Jars with rim from vertical to incurving}

1. Cylindrical jar. Vertical rim, cylindrical profile. Rounded rim. Rim diameter $18.5 \mathrm{~cm}$. Compact light yellow paste with few grits and straw temper. The exterior is wet smoothed (Fig. 5).

The type is present in Tamnac. ${ }^{47}$

B.05.B./54,9.

2. Cylindrical jar with thickened rim. Thickened, slightly converging rim, obliquely cut. Rim diameter $13 \mathrm{~cm}$. Compact pale brown paste with many grits and a quantity of straw temper (Fig. 5).

The type finds a parallel in Hajar ar-Rayhānī and in Shabwa. ${ }^{48}$

B.05.B./54,3.

3. Tronco-ovoid jar with thickened rim. Slightly converging upper sides. Compact or coarse pale brown paste with variable amount of grits and straw temper.

a. Vertical thickened rim forming a short collar with flat lip. Exterior wet smoothed. Rim diameter $21 \mathrm{~cm}$ (Fig. 5).

B.05.B./74,3.

b. rim thickened in the exterior. One specimen has a yellow slip on the exterior, the other a red slip on both surfaces (Fig. $2 \mathrm{~A}$ ).

B.06.C./189,8; 190,7 .

4. Barrel shaped jar. Barrel shaped body, more or less converging sides, with rounded profile. Rim rounded or bevelled. Rim diameter 19-27 cm. Medium compact or compact light reddish brown paste with few grits and straw temper. In one case, B.05.B./56,4, medium compact paste with small and large grits, chamotte and straw temper (Fig. 2 B).

B.06.C./186,3; 187,4; 191B,4; B.05.B./56,4.

5. Ovoid jar with strongly converging upper sides. Ovoid body, convex profile, decoration of two incised wavy comb incisions. Rim diameter $21 \mathrm{~cm}$. Compact light reddish brown paste with few grits and straw temper; exterior coated with a thick pale yellow slip (Fig. 3 B).

\footnotetext{
47 Antonini and Buffa 2016, 465, type VI.A.2, Fig. 20.

48 Glanzman 1987a, 123, Fig. 5.19, 1. Breton et al. 2010, 201, Fig. 61, 03/13.
} 
The type has a parallel in Hajar ibn Humayd in an earlier context. ${ }^{49}$

B.06.C./169G,3.

6. Ovoid jar with red paint on rim. Ovoid body, more or less incurving rim. Rim diameter from $11.5-22 \mathrm{~cm}$. Compact pale brown or reddish brown paste with few grits and straw temper.

a. converging sides, thickened rim. Red paint on rim (Fig. 2 A).

B.06.C./187,1; 188,16; 190,6.

b. convex body, strongly converging upper sides. Rim forming a short vertical collar, thinned lip. Red paint on internal rim. Rim diameter $11.5 \mathrm{~cm}$ (Fig. $2 \mathrm{C})$.

B.06.C./189,18.

Variant: ovoid body, converging sides; weak red slip on exterior. Rim forming a short collar, marked by a shallow groove. Rim diameter $13.5 \mathrm{~cm}$.

B.06.C./189,26.

7. Globular jar with tronconical collar. Globular body, converging sides. Thickened rim forming a tronconical collar, obliquely cut inside. Rim diameter $17 \mathrm{~cm}$. Compact light red paste with few grits and straw temper. Interior wet smoothed (Fig. 5).

The type finds a parallel in Tamnac; two jars from the layer above the Minaean tombs at Barāqish Area D have a similar rim. ${ }^{50}$

$$
\text { B.05.B./76,2. }
$$

8. Jar with ovoid, squatted body. Converging sides, angular profile. Rounded rim. Decorated with an incised line below rim. Rim diameter 16.5-17 cm. Compact pink paste with few grits and straw temper. Irregular burnishing on exterior (Fig. 3 B).

$$
\text { B.05.B./18,14; B.06.C./169G,7. }
$$

9. Jar with globular, squatted body. Converging sides, rounded profile. Rim forming a short collar, rounded lip. The vessels could have a ring base. Rim diameter from 12 to $15 \mathrm{~cm}$. Compact light reddish brown paste with many grits and a quantity of straw temper (Fig. $1 \mathrm{~A})$.

Very similar jars come from Tamnac ${ }^{51}$

$$
\text { B.06.C./190,5; } 191,11 \text {. }
$$

\footnotetext{
49 Van Beek 1969, 124, type 1001, jar 2, Fig. 44, stratum M.

50 Antonini and Buffa 2016, 466, type VI.C.1.b, Fig. 24. Antonini 2010b, 30, Fig. 6, 7,8.

51 Antonini and Buffa 2016, 466, type VI.B.2, Fig. 23, 5.
}

\section{B. Jars with everted rim}

This category of jars can have an ovoid or a globular body. These jars seem apt to store liquids and food products and probably also to transport them. Many fragments of plaster once sealing the stopper of jars were recovered on the site.

1. Ovoid jar with everted rim. Narrow mouth, sloping shoulder, everted rim. Rim diameter from 12 to $23 \mathrm{~cm}$. Compact pale brown or reddish paste with few grits and straw temper or some grits and mica.

a. everted, rounded rim, interior coated with light reddish brown slip (Fig. 5).

A similar jar was found in the Minaean tombs at Barāqish Area D. ${ }^{52}$

B.05.B./18,3; 20,5; 56,1.

b. everted, bevelled rim (Fig. 5).

B.05.B./58,21.

2. Ovoid jar with thickened, everted rim. Narrow mouth, sloping shoulder. Rim strongly thickened, curved, everted rim. The type has a ring base. Rim diameter 15.5 $\mathrm{cm}$. Compact pink paste with grits of different colours and a quantity of straw temper (Fig. 5).

This type of jar is a well known type in South Arabia. ${ }^{53}$ In Minaean territory this type of jar has a parallel among the Late-Minaean pottery from Level 1 at Barāqish Area $D$ and al-Ukhdūd. Also among the pottery assemblage of the Bar'ān temple at Mārib, of Tamna' and of Shabwa. ${ }^{54}$

B.05.B./51,1.

3. Small jar with curving everted rim. Narrow mouth, lip rounded or thinned. Rim diameter 7.5-13 cm. One vessel has Old South Arabian letters incised on the rim. Very compact reddish brown paste with few grits and straw temper; in two cases some chamotte is present.

a. sloping shoulder (Fig. 5).

This type of jar has parallels among the LateMinaean pottery from Level 1 at Barāqish Area D, in Hajar ibn Humayd and in Tamnac ${ }^{55}$

B.05.B./20,4,7; 58,18,20.

b. sharply incurving shoulder and more vertical rim (Fig. 5).

\footnotetext{
52 Antonini 2010b, 29, Fig. 3,11.

53 Buffa 2015.

54 Antonini 2010b, 30, Fig. 7,8. al-Zahranī et al. 2001, pls 13, 14, 15, 25. Ayoub 2007, 321, type 68, pl. 54. Antonini and Buffa 2016, 469, type VI.D.10, Fig. 32. Badre 1992, 303, Fig. 32,259.

55 Antonini 2010b, 31, Fig. 7,1. Van Beek 1969, 118, type 1000, jar 6, Fig. 35, dated from the 3rd century BC to the mid-1st century AD; Antonini and Buffa 2016, 468, type VI.D.5.a, Fig. 29.
} 
Also this variant finds a good parallel among the Late-Minaean pottery from Level 1 at Barāqish Area D, in the Bar'ān temple at Mārib and at Tamnac. ${ }^{56}$

B.05.B./18,5; 54,4;56,2; 76,7.

C. inner rim thickened (Fig. 2 C).

B.06.C. $/ 189,13$.

4. Jar with flaring collar. Rounded, sloping shoulder. Rim forming a slightly flaring collar, diameter $12.5-13.5 \mathrm{~cm}$. Compact pale brown paste with few grits and straw temper. Exterior wet smoothed (Fig. 5).

A parallel for this shape can be found among the pottery from the Late-Minaean Level 1 at Barāqish Area D. ${ }^{57}$

B.05.B./59,5,7.

5. Jar with lid ledge. Sloping rounded shoulder, everted rim shaped as a lid ledge. A rounded knob is placed below the rim. Rim diameter $19 \mathrm{~cm}$. Compact brown paste with few grits and straw temper (Fig. 1 A).

A similar jar can be found in the Bar'ān temple at Mārib.58

B.06.C./191,12.

6. Jar with large lid ledge. Sloping shoulder, developed everted rim shaped as a lid ledge. Rim diameter $24 \mathrm{~cm}$. Compact pink paste with few grits and straw temper. One piece has some red paint applied on the ledge (Fig. $2 \mathrm{~A})$.

B.06.C./189,4; 191,3 .

\section{Necked jars}

The same functions as the jars with everted rim were probably performed with this class of jars.

1. Jar with short vertical neck. Short vertical neck, sloping shoulder. Everted, thickened rim, diameter 9-18 cm. Compact pale yellow paste with grits and a variable amount of straw temper.

a. heavy neck, rim cut obliquely, forming an edge with the internal side (Fig. 3 B).

This variant has a parallel among the pottery from the Late-Minaean Level 1 at Barāqish Area D. ${ }^{59}$

B.06.C. $/ 185,9$.

b. thickened, rounded rim (Fig. 5).

56 Antonini 2010b, 32, Fig. 9,6. Ayoub 2007, 320, type 60, pl. 49,1. Antonini and Buffa 2016, 468, type VI.D.4, Fig. 29.

57 Antonini 2010b, 31, Fig. 7,7.

58 Ayoub 2007, 321, type 64a, pl. 52.

59 Antonini 2010b, 31, Fig. 7,4.
A jar with a similar neck comes from the pottery found in the Minaean tombs at Barāqish Area D..$^{60}$ B.05.B./18,6; 54,2.

2. The fragmentation of this vessel prevents a certain identification of the type. It could be an amphora (therefore with two vertical handles), high narrow, tronconical neck with flaring rim. Medium compact light reddish brown paste with grits and straw temper (Fig. 1 A).

$$
\text { B.06.C./190,2. }
$$

3. Jar with flaring, wide, short neck. Ovoid body, sloping angular shoulder. Decorated with wavy comb incisions. Rim diameter $15 \mathrm{~cm}$. Compact light reddish brown paste with few grits and straw temper (Fig. $3 \mathrm{~A}$ ).

B.06.C./169K,1.

4. Jar with high cylindrical neck with flaring rim. Rim diameter $18 \mathrm{~cm}$. Compact reddish brown paste with few black and white grits. Surfaces coated with red slip (Fig. $3 \mathrm{~B})$.

B.06.C./169H.2.

\section{Dolia}

Dolia are vessels for the storage of foodstuffs. Their wide mouth probably excludes the storage of liquids. They are distinct from jars more for their size and the thickness of the wall than for their shape.

1. Barrel shaped dolium. Vertical rim, thick walls. Rounded rim. Rim diameter $39 \mathrm{~cm}$. Medium compact light brown paste with many grits and straw temper (Fig. 5).

Several similar rims of dolia are present in Shabwa. ${ }^{61}$

B.05.B./51,2.

2. Large barrel shaped dolium. Square transverse section with rounded edges. Slightly flaring rim, flattened lip. Horizontal ridge below the rim. Reddish brown slip on both surfaces. Rim diameter $39 \mathrm{~cm}$. Compact paste with grits and straw temper. The lower part and bottom are missing (Fig. 5). ${ }^{62}$

B.05.B. $/ 58+74,1$.

3. Barrel shaped dolium with horizontal ridge. Two horizontal ribs on the shoulder where the wall is

\footnotetext{
60 Antonini 2010b, 29, Fig. 3,10.

61 Badre 1992, 287, for example Fig. 24, 35, 40.

62 This ceramic piece with a square transverse section could, in fact, not be a dolium.
} 
strongly thickened. Burnished red slip on interior. Compact light red paste with grits and straw temper (Fig. 5).

$$
\text { B.05.B./74,7. }
$$

4. Dolium with out-turned rim. Barrel shape (?), flattened lip. Compact pink or pale brown paste with a variable amount of grits and straw temper. Rim diameter from 18 to $39 \mathrm{~cm}$.

a. plain surface (Fig. 2 C).

This variant finds a parallel in the Barān temple at Mārib. $^{63}$

B.06.C./188,3; 189,6 .

b. red paint on top of rim (Fig. 2 C).

B.06.C. $/ 188,7,8$.

5. Ovoid dolium. Slightly thickened out-turned rim. Rim diameter $25 \mathrm{~cm}$. Medium compact pink paste with many grits and straw temper. Exterior wet smoothed (Fig. 2 C).

$$
\text { B.06.C./188,9. }
$$

6. Dolium with high neck. High neck with concave sides, rim slightly out-turned, flattened lip. Rim diameter from 32 to $44 \mathrm{~cm}$. Compact light brown paste with many grits and straw temper or grits, straw temper and chamotte. Exterior wet smoothed or slipped.

a. high vertical neck with concave sides (Fig. 3 B). This variant has a parallel in the Bar'ān temple at Mārib and in Shabwa. ${ }^{64}$

B.06.C./186,7.

b. high neck with slightly flaring, concave sides, slightly out-turned rim, flattened lip. Decorated with incised wavy line at the base of the neck (Fig. $2 \mathrm{~A})$.

B.06.C./189,5; 191B,1.

\section{Bases}

\section{A. Flat bases}

1. Base with omphalos. B.05.B./74,8.

2. Disc base with slightly projecting foot.

B.06.C./185,8; 189,3; 191B,8.

63 Ayoub 2007, 322, type 80, pl. 61,1-6.

64 Ayoub 2007, 321, type 70, pl. 56, 5, 6. Badre 1992, 301, fig 31,231, 232.

\section{B. Ring bases}

Ring bases with flaring or cylindrical foot.

1. Very low ring base with thick foot. Rounded edges.

B.05.B./58,2.

2. Low ring base with flaring, concave foot. Vessel of small size.

B.05.B./18,1;20,2; 46,1; 51,5; 58,8,10; 59,4; 76,9,10; B.06.C./169E, $2 ; 185,4$.

3. Low ring base with more or less flaring, convex foot. The vessels are from medium to large size.

B.05.B./18,2; 58,1,3,7,5; 59,3; 68,1,2; 74,4; 76,3; 78,1; B.06.C./169F,1,2; 169G,1,2; 185,7; 189,7; 190,3; 191,1,2; 191B,7; 192,4.

4. High ring base with flaring straight foot.

B.06.C./185,2; 189,1,2,9.

5. Ring base with cylindrical foot.

a. medium-high ring base.

B.06.C. $/ 184,2 ; 191,18$; B.05.B./58,6.

b. high ring base; foot incurving at base on the inner surface; thick walls.

B.05.B./18,11;20,3; 58,4;59,1; 76,1,15.

\section{Trumpet foot}

1. High stem with flaring sides.

B.06.C./188,11.

\section{Handles}

Very few vessels have handles.

1. Vertical loop handle.

a. triangular section.

B.06.C./189,14.

b. circular section.

B.06.C./185,10.

C. oval section.

B.05.B./18,8.

\section{Decorations}

\section{A. Incised}

1. One or more horizontal straight lines. 
See types III.A.2.b; III.A.3; III.A.4; IV.2; V.A.8.

2. One or more parallel wavy lines, comb incision.

B.05.B./18,10; 54,8; B.06.C./191,6. See also types IV.1; IV.3; V.A.5; VI.C.3; VI.6.b.

\section{B. Applied}

1. Two superimposed horizontal ridges.

B.06.C. $/ 184,3$.

2. Ridge with impressions.

B.06.C./188,17; 191,6 .

\section{Painted}

1. Line of red paint over the rim.

B.05.B./54,10. B.06.C./ 184,1; 169H,1; 187,1; $188,7,8,13,15,16 ; 189,4,12,18 ; 190,6 ; 191,8 ; 191 \mathrm{~B}, 3$; 192,1 .

\section{Chronology}

In studying the temporal development of ceramic shapes, through a chart of association of pottery types and stratigraphic units, we have followed the stratigraphic sequences established by Francesco Fedele in Area C, Sounding A, ${ }^{65}$ and by Alessio Agostini for the temple of 'Athtar dhu-Qabd. ${ }^{66}$

The chart combines in an association the types along the abscissae and the strata along the ordinates, according to the stratigraphic sequence from the earliest to the most recent, underscoring the development through time of the pottery shapes (Table 1). The result is a series of groups of types either exclusive of a chronological horizon (as determined by the excavators), or common to two or more horizons. The first observation is that a number of pottery types are present only in the layers from Sounding A, while other types are common to both the Sounding and temple layers. Finally, a number of types only occur in the temple. These results are illustrated hereinafter following the subdivision in Earlier Minaean (including Minaean 1 and Minaean 2) and Later Minaean (including Minaean 3 and Minaean 4), proposed by Fedele as the result of the deep sounding

\footnotetext{
65 See the introduction to the catalogue of the Minaean pottery from the sounding, including Table 1 (Buffa, Chapter 22); and for the updated stratigraphic information Fedele, Chapter 17. Since Chapter 17 had not been completed by the time of closing this contribution, reference will again be made - as above - to Fedele 2010.

66 Agostini, Chapter 3, Volume 1, and Agostini 2018a.
}

at bastion $\mathrm{T} 7,{ }^{67}$ because the study of the development of the pottery types has confirmed the distinction in two main stratigraphic phases, each characterized by a set of pottery types.

The results, however, are to be considered to some extent biased by the type of record. As Fedele explained about Sounding A, since "the chief aim of the project was stratigraphic and concerned with providing diachronic sampling of palaecological evidence, the excavations were essentially conducted with a vertical strategy it was not a wide-area excavation' ${ }^{68}$ As to the record from the temple, on the other hand, we expect to have certain categories of vessels linked to ceremonies that were taking place in the temple, rather than the categories more linked to daily life.

\subsection{The Earlier Minaean}

Minaean 1 sub-phase, Stratum J

Stratum J corresponds to cuts 190, 191+191B and 192+193 (Chapter 22, Table 1).

The Minaean occupation is most conspicuously defined by the construction of the city wall on top of the Later Sabaean deposits. As Fedele has observed, a large quantity of essentially Sabaean pottery was recovered from layers related to the back-filling of the foundation trench and to the construction of both the Minaean wall and its flanking earthwork (C./192, C./193). ${ }^{69}$ Only a small number of Minaean pottery sherds were found. More diagnostic fragments were instead recovered from the first layers accumulated after the local completion of the wall (C./191B, C./191, C./190). Only three types of jars can be attributed exclusively to the Minaean 1 sub-phase; they are made with reddish brown or brown paste with grits and straw temper (Fig. 1 A). The wall at bastion T7 appears to have been erected - at least in part - during the 6 th-5th centuries $\mathrm{BC} .^{70}$

\section{Minaean 2 sub-phase, Stratum I}

Stratum I corresponds to cuts 188 and 189 (Chapter 22, Table 1).

At the base of bastion T7 thick deposits attributed to the Minaean 2 sub-phase are instead documented. They have yielded numerous pottery fragments. Many of them represent types also common to sub-phase 1. They mainly belong to the table and storage categories

\footnotetext{
67 Fedele 2010, 150, Table 2; updated and modified in Chapter 17, Table 4.

68 Fedele 2010, 100.

69 Fedele 2010, 134; with substantial updating in Chapter 17; cf. also Chapter 21, under 'Sabaean' and 'Minaean' groups.

70 Fedele, this volume, Chapters 17 (section 10) and 18 (section 1).
} 
(Figures 1 B, 2 A). Cups and bowls are mostly made with a fine reddish brown or pale brown paste with some grits and straw temper, surfaces burnished or wet smoothed (types II.2.a, II.2.b, III.A.1.c, III.B.3.a). In one type of cup a line of red paint is applied on the rim (type II.1). The surfaces of another type of bowl are coated with red paint (type III.A.2.b). Other larger bowls could have been used for storage or for cooking. ${ }^{71}$ They are made with a compact, less refined paste, usually reddish brown or pale brown, with grits and straw inclusions (types III.C.3, III.C.5, III.D.1); in one case a line of red paint is applied on the rim. Storage basins and jars are made with a medium compact light brown or reddish paste with grits and straw temper; surfaces are wet smoothed (types IV.1, V.A.3.b, V.A.6.a, V.B.6, VI.6.b). Jar type V.A.6.a has the rim decorated with a line of red paint. Wavy lines are present on one basin and on the shoulder of one dolium (IV.1).

Six types are exclusive of Stratum I (Fig. 2 C). One fragment of a small jar (V.B.3.c) has a reddish brown burnished slip on the interior, other two have the rim decorated with a line of red paint (V.A.6.b, VI.4.b). Outside the wall, this period appears to be often characterized by the presence and stationing of donkeys and dromedaries on the talus, supposedly connected with trading activities in a general sense. If so, it is possible that the three types of basins (VI.4.a, VI.4.b, VI.5) were connected with storage activities in the immediately extramural area. The Minaean 2 subphase is dated by Fedele to the 4 th-2nd centuries BC.

As already observed, in the assemblage of the Earlier Minaean phase the ubiquitous - but often reworked? red slipped vessels of the Sabaean production become less frequent. The pottery is now characterized mainly by a reddish brown or light brown paste, more or less refined according to the type of vessel, with more or less straw temper and grits; the red slip is often substituted by a red paint on the surface or more often applied only on the rim. But the Sabaean tradition has not completely disappeared: bowl III.A.3, with 5 specimen, with surfaces covered with burnished red slipped, has rather close parallels in the Sabaean layer at Barāqish Area D (Level 4, below the Minaean tombs), as well as among the pottery from stratum $B$ in the probe at the temple of Nakrah. Another type (III.C.4), although certainly not Sabaean in shape, has in three cases the surfaces covered with a burnished red slip, while in another case the exterior has traces of red paint. Also in the Level 3 of the Minaean tombs vessels with burnished red slip or paint have been recorded, as well as vessels covered with a dark brown slip in Level $1 .{ }^{72}$

\footnotetext{
71 It is interesting to note that no vessels tempered with steatite, usually used in cooking ware, have been recorded from Barāqish so far.

72 Antonini 2010b, 29-31.
}

Pottery types of the Earlier Minaean have parallels not only in the assemblage from the tombs of the necropolis of Barāqish, as expected, but also - in line with the dating of the phase - from al-Sawdā', the Bar'ān temple at Mārib, Tamnac', Hajar ibn Humayd and Shabwa.

A limited group of types are documented in the Earlier Minaean as well as in the Later Minaean, sub-phase 3 (Figures 2 B, 3 A). The majority of these types show characteristics more typical of the Earlier Minaean assemblage than of the later one; in four types (III.A.2.a, III.A.3, III.A.4.a, III.C.4) surfaces are covered with a burnished red slip. Other types have parallels at Area D among the assemblage of the Minaean tombs, but also in the level above the necropolis (Level 1).

For the first time two, possibly three types of bowls (III.A.2.a and III.B.4.a, III.4.4.a?) are also present in the layers accumulated above the floors of Temple B, and two others in the deposits marking the abandonment and collapse of the temple (III.C.4, V.A.4); in the case of the fragments in the abandonment deposits it is possible that they are in secondary deposition. Agostini dates his 'Mineo B' phase from the 5th century BC - probably its second half - to the 1st century $\mathrm{BC}$. We can remark that there are only two or three types in common between the temple and Area C. This is probably due to the nature of the two assemblages: on one side, layers formed from extramural activities (Sounding A), on the other side layers related to ceremonial activities in a temple.

\subsection{The Later Minaean}

Fedele observed that in Sounding A 'Surface S7 may mark a significant though undefinable hiatus [...]; when sedimentation resumed Stratum $\mathrm{H}$ accumulated'. ${ }^{73}$ It is interesting to note that this lithostratigraphic transition marks a new phase in the pottery sequence as well: a number of new types, often made with different pastes, appear at this point.

\section{Minaean 3 sub-phase, Stratum $H$}

Stratum H corresponds to cuts $186+169 \mathrm{H}$ and $185+169 \mathrm{G}$ (Chapter 22, Table 1).

Apart from the few types that, as we have remarked, started to be produced in the 2nd sub-phase of the Earlier Minaean, a set of types is exclusive of the stratum H (Fig. 3 B). We can distinguish fine bowls (III.A.1.a, III.A.4.b, III.A.4.c, III.A.5 wavy rim bowls, III.B.1, III.B.4.b, III.C.2) usually made with pale brown or pale yellow fine or compact paste with few grits and straw temper, in

73 Fedele 2010, 135; confirmed and updated in Chapter 17. 
one case with surfaces covered with red slip (III.A.4.b); a storage basin made with compact pale yellow paste with interior and rim covered with reddish brown slip (IV.3); a jar made with reddish brown paste and exterior covered with a pale yellow slip (V.A.5); one jar made with a pink paste (V.A.8); another jar made with a light reddish brown compact paste, surfaces coated with red slip (V.C.4); finally a large dolium to store great quantity of goods, made in light brown paste with many grits and straw (VI.6.a) (Fig. 3 B). Overall, starting with the Minaean 3 sub-phase, a pale brown or pale yellow paste is used more frequently in the manufacture of a variety of shapes.

Fedele has pointed out that in the Later Minaean phase most recorded activities outside the NW wall of Yathill were related to trade, as evidenced, for instance, by numerous plaster fragments from jar sealing. The jar V.C.1.a from stratum $\mathrm{H}$ belong to a well known type associated with transport of goods, with the rim shaped to house a stopper, sealed to the vessel with plaster. ${ }^{74}$

Several sherds belonging to types, mainly bowls, of the Minaean 3 are also present in the accumulations above the floors of Temple B, in line with the established chronology of the two sequences. The Minaean 3 from Area $\mathrm{C}$ has been dated by Fedele to the 2 nd-1st centuries BC. Parallels for these types can be found in the Barāqish Area D necropolis, Level 3 (Minaean tombs), at Tamna', at Mārib's Bar'ān temple, at Hajar ibn Humayd strata G-A, and at Shabwa; some traces (reworked elements?) also from Barāqish Area D, Level 1.

Minaean 4 sub-phase, Stratum F

Stratum F corresponds to cuts $169 \mathrm{~F}$ and $184+169 \mathrm{E}$ (Chapter 22, Table 1).

Unfortunately, the Minaean 4 sub-phase (Stratum F, dated by Fedele to the end of the 1st century BC-early 1st century $\mathrm{AD}$ ) has not yielded any diagnostic pottery fragment. Only one ring base possibly of an ovoid jar has been recorded. Instead several pottery types come from the temple floors and from the aeolian deposits marking the abandonment of the temple.

When first analysing the Minaean pottery assemblage it had seemed possible to suppose, as an explanation, that at Barāqish Area $\mathrm{C}$ area the accumulation might have ended before the end of Minaean Yathill - a possibility that Fedele did not rule out..$^{75}$ Another explanation seemed to lie in the different functions of

74 A carinated red slipped bowl from Stratum H, with parallels among the Sabaean assemblage dated to the 8th century BC from the sounding at Temple A, clearly is a reworked element (Fedele, personal communication).

75 Fedele 2010, 137. the two areas; although not assignable with certainty to ceremonial functions, the majority of vessels from the temple are more in line with a use in a public building than in an extramural area connected with the organization of transport by pack animals. Now, finally, it seems more probable that this group of types from the temple (see below) do not have parallels in Sounding A simply because they represent the late phase of occupation in the temple, contemporaneous to the Minaean 4 sub-phase from Area C, for which we do not have any diagnostic sherds. The majority of parallels for the Minaean 4 as defined from Area C Barāqish necropolis level 1 and surface, Shabwa phase $4-$ are in line with the proposed dating of the pottery types in question.

\section{The Temple of 'Athtar dhu-Qabd}

\section{Mineo C}

Deep soundings have been performed below the floors of the temple; only one of them, B./73, has yielded some pottery. Cup II.4.b is made of compact, fine pale brown or reddish brown paste with few grits and sometime some straw temper; the surfaces are coated with weak red slip, different from the red slip of earlier periods (Fig. 4). Agostini dates the Mineo $C$ phase to prior to the 5th century BC.

\section{Mineo B}

Mineo $\mathrm{B}$ corresponds to the accumulations above the floors of the rooms of the temple. The layers of Mineo B have yielded several fragments. Three types are present only in layers of the accumulations on the temple floors. Jars V.A.3.a and V.A7, and dolium VI.3 are made of compact pale brown paste or light red paste with grits and straw temper (Fig. 5). It has been supposed above that they are contemporaneous with the Minaean 4 sub-phase in Sounding A.

Another group of types is present in the layers above the floors and in the aeolian deposits marking the abandonment of the temple. Basins IV.4.a and IV.4.b, jars V.B.3.b and V.C.1.b are made with a compact pale yellow or pale brown paste with some grits and straw temper; jar V.B.1.a, made of a pale brown paste, has the surfaces coated with a light reddish brown slip (Figures $4 \mathrm{~B}, 5)$. They can be dated to the first centuries AD.

\section{Fase Intermedia - The Amir tribe}

Agostini has identified an occupation of the Amir tribe during the 1st-2nd centuries $\mathrm{AD}$ on the basis of architectural observations and of inscriptions. ${ }^{76}$ His

\footnotetext{
76 Agostini 2018a.
} 
'Fase Intermedia' is interpreted as a reutilization of the temple by the Amirite. The zanābil possibly associated with the Amir presence, B./58, B./59, covered in part the accumulations above the floors of the temple.

B./58 and B./59 have yielded several pottery sherds. Some are typologically associated with types present in the accumulations above the floors of the temple. Cup II.5, bowls III.A.1.b, III.B.2, basin IV.4.b, jar V.B.3.a are made with a compact pale yellow or pale brown paste with some grits and straw temper (Figures 4 B, 5). All of these types find parallels in Level 1 of Barāqish Area D (above the necropolis), or in Shabwa in layers dated to the 1 st to 4 th century $\mathrm{AD}$.

Other four types stand alone and are found only in the Amirite layers. Bowl III.B.3.b, made in reddish brown or pale yellow paste, with grits and some straw, has the surface coated with light reddish brown slip, like 'dolium' VI.2, covered with reddish brown slip on both surfaces. Other vessels are made with pale brown or pale yellow paste. They have parallels at Barāqish Area $\mathrm{D}$ in the Minaean tombs and in Level 1 (Figures 4 B, 5). Also Fedele has identified from Stratum E, cut 183, an occasional occupation that the scholar would date to the 1st-2nd centuries AD (early 'Second Intermediate'). Unfortunately, only one diagnostic fragment of bowl III.B.1 has been recovered from this stratum.
The presence of the Amīr tribe at Barāqish, with their specific ethnicity, proven by architectural observation and inscriptions, seems not to be reflected with specific ceramics in the pottery assemblage.

\section{Abbandono}

A long phase of collapses and abandonment, marked by the accumulation of aeolian deposits, has been documented in all rooms of the temple (B./57, B./51, B./54, B./56, B./46, B./68). Some pottery types are documented only in these layers; it is probable that they belong to the last phase of the life the temple. Plate I.1 is probably to be considered in secondary deposition as it has been recorded in the Sabaean layers. Cup II.4.a is made of compact, fine pale brown or reddish brown paste with few grits and sometime some straw temper, with surfaces coated with weak red slip, different from the red slip of earlier periods; jars V.B.2, V.A.2, V.A.1 and dolium VI.1 are made of a pale yellow or pale brown paste with many grits and straw temper; bowl III.B.5 is made of a fine paste with surfaces coated with a thick burnished red slip (Figures 4 B, 5).

Agostini has dated the abandonment of the area to the 3rd century AD. The general appearance of the vessels and the established parallels are in line with a dating of the types to the first centuries $\mathrm{AD}$. 


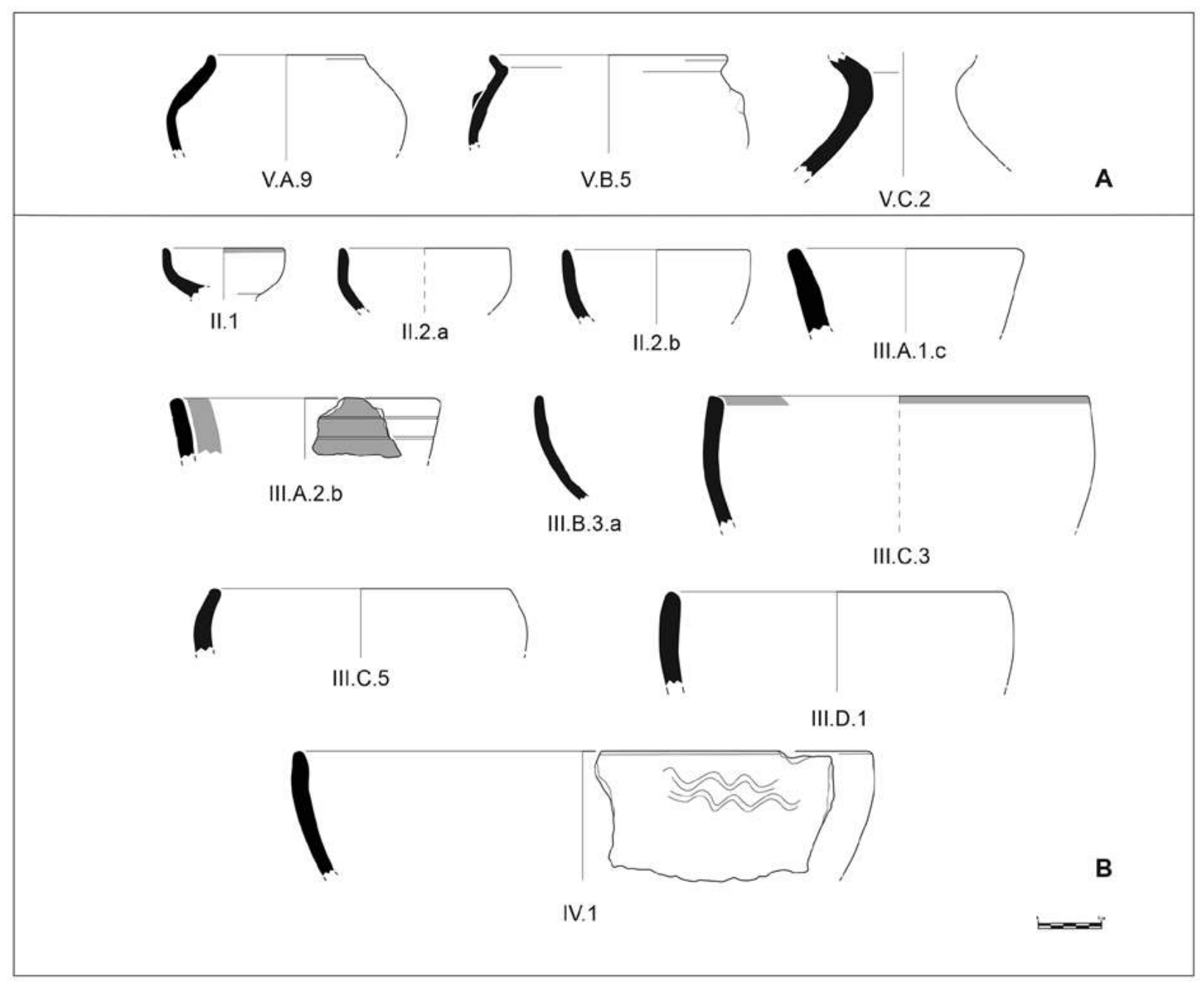

Figure 1 


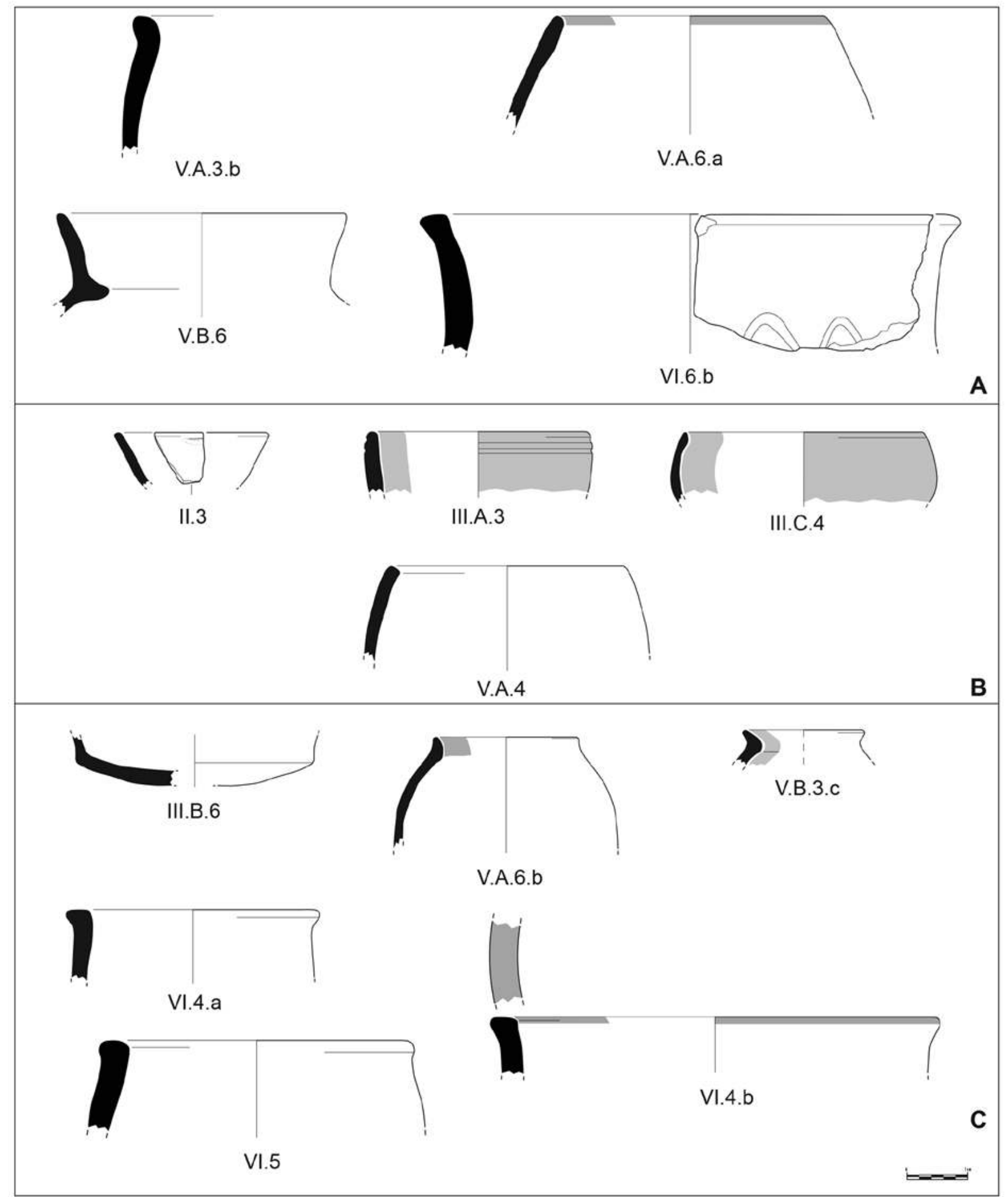

Figure 2 


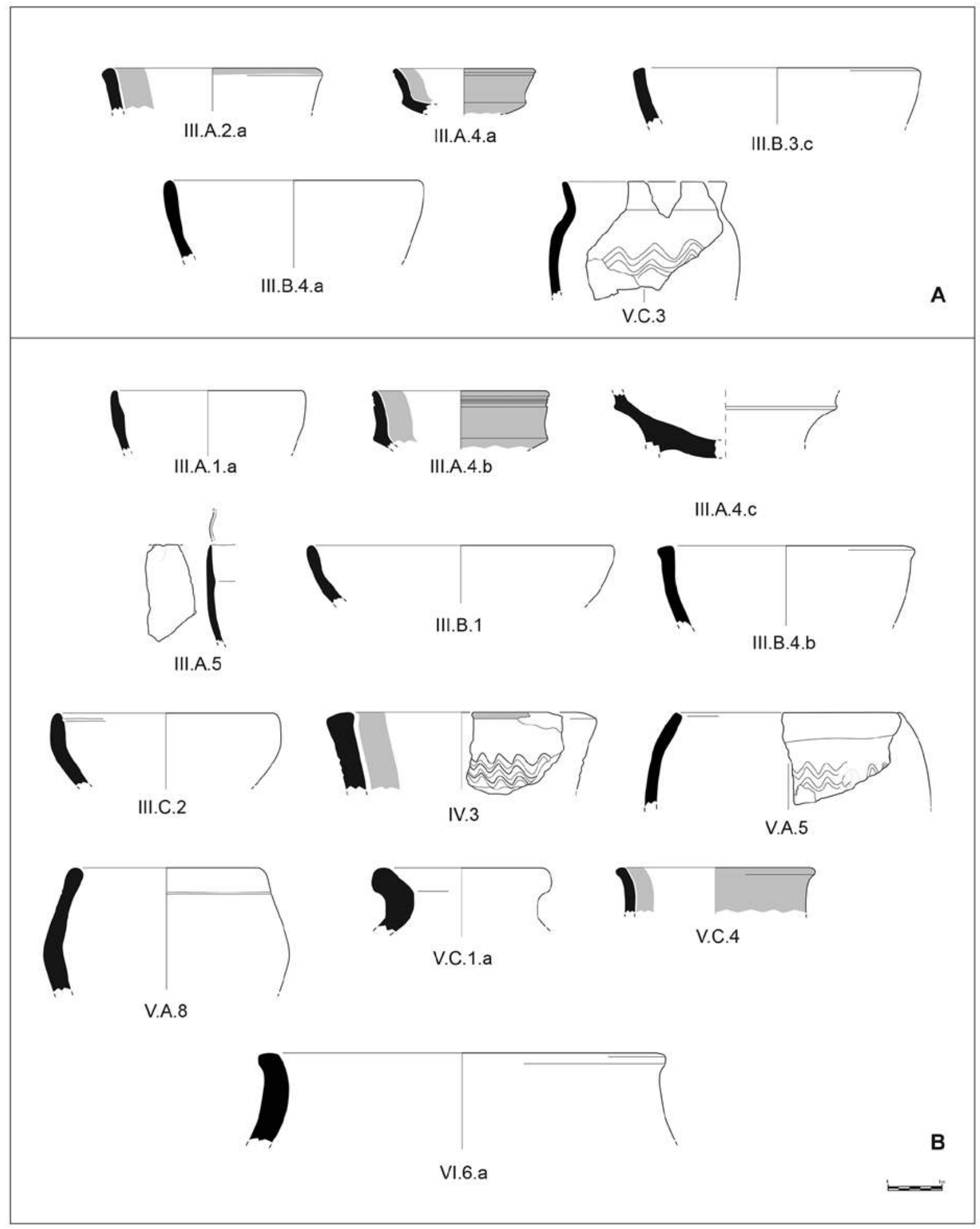

Figure 3 


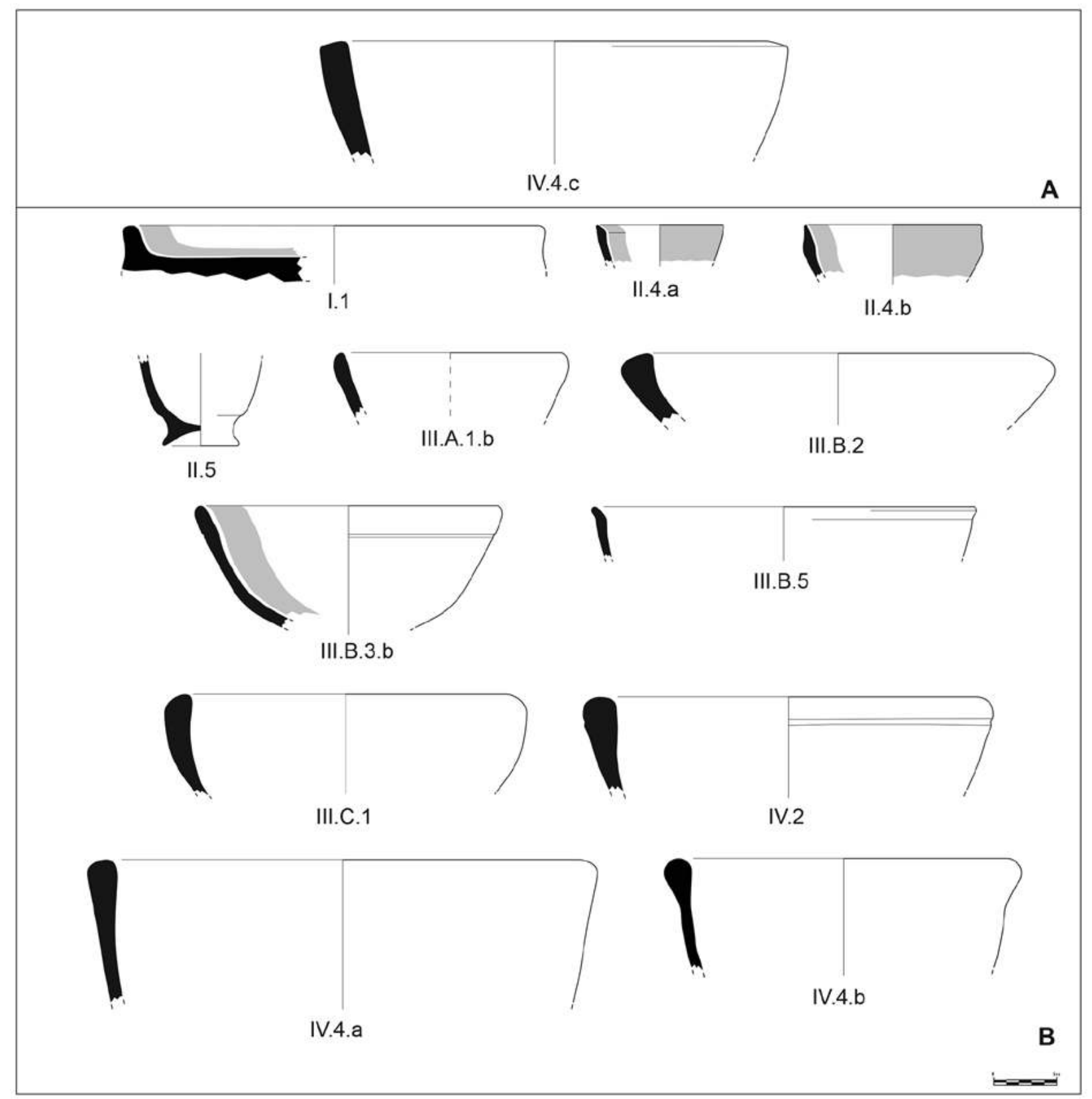

Figure 4 


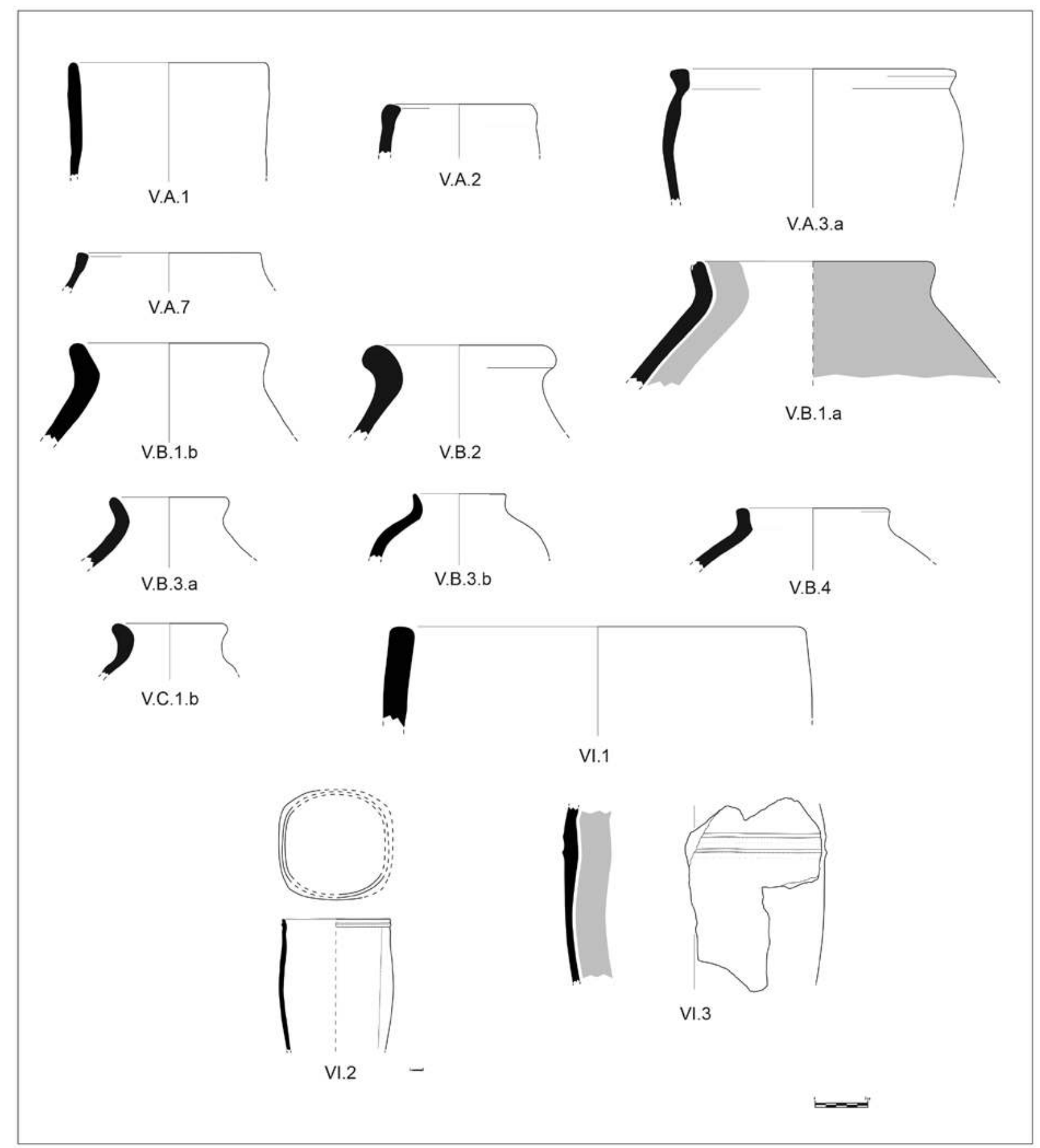

Figure 5 
Table 1. Chart combining in association stratigraphic units and pottery types.

\begin{tabular}{|c|c|c|c|c|c|c|c|c|c|c|c|c|c|c|c|c|c|c|c|c|c|c|c|c|c|}
\hline \multirow[b]{3}{*}{ Type } & \multicolumn{11}{|c|}{ Barāqish C, sounding A } & \multicolumn{14}{|c|}{ Temple of 'Athtar dhu-Qabḍ } \\
\hline & \multicolumn{3}{|c|}{ Min. 1} & \multicolumn{2}{|c|}{ Min. 2} & \multirow{2}{*}{ 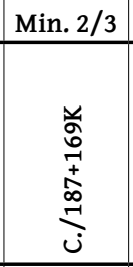 } & \multicolumn{2}{|c|}{ Min. 3} & \multicolumn{2}{|c|}{ Min. 4} & \multirow{2}{*}{ 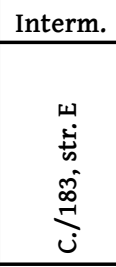 } & \multirow{2}{*}{ 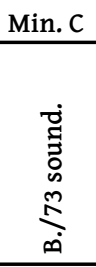 } & \multicolumn{5}{|c|}{ Mineo B } & \multicolumn{2}{|c|}{ Interm. } & & & bban & ndon & & \\
\hline & 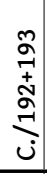 & 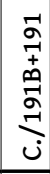 & $\stackrel{\circ}{\stackrel{8}{-}}$ & $\stackrel{\infty}{\stackrel{\infty}{\Im}}$ & $\stackrel{\substack{\infty \\
-}}{-}$ & & 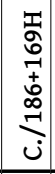 & 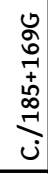 & $\stackrel{\text { 岕 }}{\stackrel{0}{0}}$ & 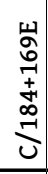 & & & 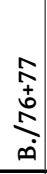 & $\underset{\infty}{\stackrel{N}{*}}$ & 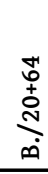 & $\stackrel{\infty}{\stackrel{\infty}{\oplus}}$ & 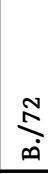 & $\underset{\infty}{\stackrel{\infty}{n}}$ & $\stackrel{\text { ติ }}{\stackrel{\infty}{n}}$ & $\stackrel{\hat{n}}{\stackrel{n}{n}}$ & $\stackrel{i n}{\text { n }}$ & 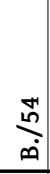 & 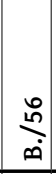 & $\underset{\infty}{\stackrel{+}{+}}$ & $\stackrel{\infty}{\bullet}$ \\
\hline V.A.9 & & 1 & 1 & & & & & & & & & & & & & & & & & & & & & & \\
\hline V.B.5 & & 1 & & & & & & & & & & & & & & & & & & & & & & & \\
\hline V.c.2 & & & 1 & & & & & & & & & & & & & & & & & & & & & & \\
\hline II.1 & & & 1 & 1 & & & & & & & 1 & & & & & & & & & & & & & & \\
\hline II.2.a & 1 & 4 & 2 & 1 & 1 & & & & & & & & & & & & & & & & & & & & \\
\hline II.2.b & & 1 & & 3 & & 1 & & & & & & & & & & & & & & & & & & & \\
\hline III.A.1.c & & 1 & & & 1 & & & & & & & & & & & & & & & & & & & & \\
\hline III.A.2.b & . & 1 & & 1 & & & & & & & & & & & & & & & & & & & & & \\
\hline III.B.3.a & 1 & 1 & & 2 & 1 & & & & & & & & & & & & & & & & & & & & \\
\hline III.C.3 & 1 & 2 & & & 1 & & & & & & & & & & & & & & & & & & & & \\
\hline III.C.5 & & & 1 & 1 & & & & & & & & & & & & & & 1 & & & & & & & \\
\hline III.D.1 & & 2 & & 1 & & & & & & & & & & & & & & & & & & & & & \\
\hline IV.1 & & 1 & & & 1 & & & & & & & & & & & & & & & & & & & & \\
\hline V.A.3.b & & & 1 & 1 & & & & & & & & & & & & & & & & & & & & & \\
\hline V.A.6.a & & . & 1 & & 1 & 1 & & & & & & & & & & & & & & & & & & & \\
\hline V.B.6 & & 1 & & 1 & & & & & & & & & & & & & & & & & & & & & \\
\hline VI.6.b & & 1 & & 1 & & & & & & & & & & & & & & & & & & & & & \\
\hline II.3 & & & 1 & & & & & 1 & & & & & & & & & & & & & & & & & \\
\hline III.A.3 & 1 & 2 & & & & & & 2 & & & & & & & & & & & & & & & & & \\
\hline III.C. 4 & & 1 & & & 1 & & 1 & & & & & & & & & & & & & & & 1 & & & \\
\hline V.A.4 & & 1 & & & & 1 & 1 & & & & & & & & & & & & & & & & 1 & & \\
\hline III.B.6 & & & & 1 & & & & & & & & & & & & & & & & & & & & & \\
\hline V.A.6.b & & & & 1 & & & & & & & & & & & & & & & & & & & & & \\
\hline V.B.3.c & & & & 1 & & & & & & & & & & & & & & & & & & & & & \\
\hline VI.4.a & & & & 1 & 1 & & & & & & & & & & & & & & & & & & & & \\
\hline VI.4.b & & & & & 2 & & & & & & & & & & & & & & & & & & & & \\
\hline VI.5 & & & & & 1 & & & & & & & & & & & & & & & & & & & & \\
\hline III.A.2.a & & & & & & 1 & & & & & & & & & & $?$ & & & & & & & & & \\
\hline III.A.4.a & & & & & 1 & & 1 & 1 & & & & $?$ & & & & & & & & & & & & & \\
\hline III.B.3.c & & & & & & 1 & 1 & & & & & & & & & & & & & & & & & & \\
\hline III.B.4.a & & & & & 1 & & & 2 & & & & & 1 & & & & 1 & 1 & & & & & & & \\
\hline V.C.3 & & & & & & 1 & & & & & & & & & & & & & & & & & & & \\
\hline III.A.1.a & & & & & & & & 2 & & & & & & & & & & 1 & & & & & & & \\
\hline III.A.4.b & & & & & & & & 1 & & & & & & & & & & & & & & & & & \\
\hline III.A.4.c & & & & & & & 1 & & & & & & & & & & & & & & & & & & \\
\hline III.A.5 & & & & & & & & 1 & & & & & & & 1 & & & & & & & & & & \\
\hline III.B.1 & & & & & & & & 1 & & & 1 & & & & 1 & 1 & & & & & & & & & \\
\hline III.B.4.b & & & & & & & 1 & & & & & & & & & & & & & & 1 & & & & \\
\hline III.C. 2 & & & & & & & & 1 & & & & & & & & & & 1 & & & & & & & \\
\hline IV.3 & & & & & & & 1 & & & & & & & & & & & & & & & & & & \\
\hline V.A.5 & & & & & & & & 1 & & & & & & & & & & & & & & & & & \\
\hline V.A.8 & & & & & & & & 1 & & & & & & & & 1 & & & & & & & & & \\
\hline V.C.1.a & & & & & & & & 1 & & & & & & & & & & & & & & & & & \\
\hline V.C. 4 & & & & & & & 1 & & & & & & & & & & & & & & & & & & \\
\hline VI.6.a & & & & & & & 1 & & & & & & & & & & & & & & & & & & \\
\hline
\end{tabular}




\begin{tabular}{|c|c|c|c|c|c|c|c|c|c|c|c|c|c|c|c|c|c|c|c|c|c|c|c|c|c|}
\hline \multirow[b]{3}{*}{ Type } & \multicolumn{11}{|c|}{ Barāqish C, sounding A } & \multicolumn{14}{|c|}{ Temple of 'Athtar dhu-Qabd } \\
\hline & \multicolumn{3}{|c|}{ Min. 1} & \multicolumn{2}{|c|}{ Min. 2} & \multirow{2}{*}{ 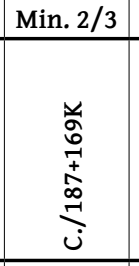 } & \multicolumn{2}{|c|}{ Min. 3} & \multicolumn{2}{|c|}{ Min. 4} & \multirow{2}{*}{ 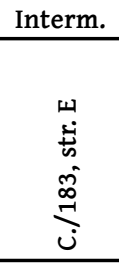 } & \multirow{2}{*}{ 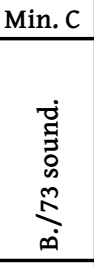 } & \multicolumn{5}{|c|}{ Mineo B } & \multicolumn{2}{|c|}{ Interm. } & \multicolumn{6}{|c|}{ Abbandono } \\
\hline & 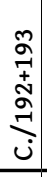 & 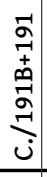 & $\stackrel{\circ}{\stackrel{\circ}{v}}$ & $\stackrel{\infty}{\stackrel{\infty}{\nu}}$ & 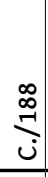 & & $\begin{array}{l}T \\
5 \\
0 \\
-1 \\
+ \\
0 \\
0 \\
-1 \\
ن\end{array}$ & 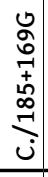 & 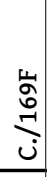 & $\begin{array}{l}\omega \\
0 \\
0 \\
\pm \\
\pm \\
0 \\
0 \\
0\end{array}$ & & & 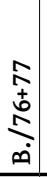 & $\underset{\infty}{\stackrel{N}{*}}$ & 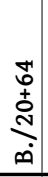 & $\stackrel{\infty}{\stackrel{\infty}{\infty}}$ & $\stackrel{N}{\stackrel{N}{\curvearrowright}}$ & 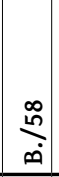 & 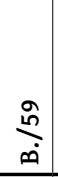 & $\stackrel{\hat{n}}{n}$ & $\stackrel{5 n}{\infty}$ & $\stackrel{n}{\stackrel{n}{n}}$ & 总 & $\underset{\infty}{\stackrel{+}{+}}$ & $\stackrel{\infty}{\stackrel{\infty}{\bullet}}$ \\
\hline IV.4.c & & & & & & & 1 & & & 1 & & & & & & & & & & & & & & & \\
\hline II.4.b & & & & & & & & & & & & 1 & & & & & & & & & & & & & \\
\hline V.A.3.a & & & & & & & & & & & & & & 1 & & & & & & & & & & & \\
\hline V.A.7 & & & & & & & & & & & & & 1 & & & & & & & & & & & & \\
\hline VI.3 & & & & & & & & & & & & & & 1 & & & & & & & & & & & \\
\hline III.A.1.b & & & & & & & & & & & & & 1 & & & & & 1 & & & & & & & \\
\hline II.5 & & & & & & & & & & & & & 1 & & & & & 1 & & & & & & & \\
\hline V.B.3.a & & & & & & & & & & & & & & & 2 & & & 2 & & & & & & & \\
\hline III.B.2 & & & & & & & & & & & & & 1 & & & & & 1 & & & & & & & \\
\hline IV.4.b & & & & & & & & & & & & & 2 & & & & & 1 & 1 & & & 1 & & & \\
\hline IV.4.a & & & & & & & & & & & & & & & & & 1 & & & & & 1 & & & \\
\hline V.B.3.b & & & & & & & & & & & & & 1 & & & 1 & & & & & & 1 & 1 & & \\
\hline V.C.1.b & & & & & & & & & & & & & & & & 1 & & & & & & 1 & & & \\
\hline V.B.1.a & & & & & & & & & & & & & & & 1 & 1 & & & & & & & 1 & & \\
\hline VI.2 & & & & & & & & & & & & & & & & & & 1 & & & & & & & \\
\hline III.B.3.b & & & & & & & & & & & & & & & & & & 1 & & & & & & & \\
\hline V.B.1.b & & & & & & & & & & & & & & & & & & 1 & & & & & & & \\
\hline V.B.4 & & & & & & & & & & & & & & & & & & & 2 & & & & & & \\
\hline $\mathrm{I} .1$ & & & & & & & & & & & & & & & & & & & & 1 & & & & & \\
\hline II.4.a & & & & & & & & & & & & & & & & & & & & & & 2 & & & \\
\hline III.B.5 & & & & & & & & & & & & & & & & & & & & & & 1 & & & \\
\hline VI.1 & & & & & & & & & & & & & & & & & & & & & 1 & & & & \\
\hline V.B.2 & & & & & & & & & & & & & & & & & & & & & 1 & & & & \\
\hline IV. 2 & & & & & & & & & & & & & & & & & & & & & 1 & & & & \\
\hline V.A.1 & & & & & & & & & & & & & & & & & & & & & & 1 & & & \\
\hline III.C.1 & & & & & & & & & & & & & & & & & & & & & & 1 & & & \\
\hline V.A.2 & & & & & & & & & & & & & & & & & & & & & & 1 & & & \\
\hline
\end{tabular}




\title{
Chapter 26 \\ A Glimpse of 'Greater Yathill': Sabaean Settlement and Tell Evolution
}

\author{
Francesco G. Fedele
}

In memory of Karl W. Butzer (1934-2016)

\section{Introduction and synopsis ${ }^{1}$}

During the 2005-2007 campaigns, the writer was able occasionally to devote himself to observations of a larger scale than the single excavation, or even the city itself: micro-territorial observations, so to speak, with the aim of understanding Yathill's development as an urban centre and its articulation with its immediate surroundings. ${ }^{2}$ In 2005, at the beginning of the extramural project in Area C, some of these observations were shared and discussed with A. de Maigret, whose knowledge of the place was obviously unparalleled, and such exchanges occasionally continued in 2006. This chapter has the primary purpose of making this personal record known, however limited and preliminary it may be. The field observations have been integrated with subsequent studies, including a sketch of settlement archaeology for Barāqish and a framework for understanding the physical evolution of Yathill as a tell. My data will also be integrated with the equally limited observations of the same kind previously assembled by the Italian mission, either published elsewhere in this book ${ }^{3}$ or communicated colloquially.

As reported in previous chapters (Chapters 1 in Volume 1 and 17, this volume), between 2005 and 2006 two

\footnotetext{
${ }^{1}$ This chapter is a revised version of a paper presented at the 20èmes Rencontres Sabéennes, held in Perugia, Italy, in June 2016. All the factual observations have been assembled and re-evaluated in full in 2019-2020. I am very grateful to Sabina Antonini, the organizer of the RS conference, for her invitation to give a paper in its sessions and for her suggestion that the paper should be published in this book.

2 All my observations were made strictly within - or from within - the fenced perimeter of the archaeological site, since for both safety and security reasons the Italian mission was not allowed to survey outside this space. Places outside the fenced area were only visited in 2005-2007 on the few occasions of pre-arranged, collective excursions to particular sites, conducted under military escort. Obviously, the impossibility to move freely at some distance from Barāqish severely restricted the range and scale of observations. For the same reason, the entire plan to carry out at some point a 'site catchment' survey around Barāqish, which I had included in my 2005 programme ('Surface observations over a wider area', cf. Chapter 1, section 4.4, in Volume 1), instantly fell apart.

3 Antonini, Chapter 2 in Volume 1.
}

separate operations cast vivid light on Sabaean Yathill. The first was an extramural stratigraphic testing on the northwestern flank of the tell and in the adjacent plain, so-called Area C, accompanied by geoarchaeological and bioarchaeological studies, and the second was a 6-metre-deep sounding outside and beneath Temple $\mathrm{A}$, in 2006, labelled A/S1. Also in the extramural area, a Sabaeanlayer was unearthed during a limited excavation of a Minaean cemetery on 'Hill D', or Area D. Sabaean deposits from these three key locations (marked in Fig. 1) were promptly radiocarbon-dated. ${ }^{4}$ As a result, a local cultural sequence for the Sabaean period was revealed, described by parallel stratigraphies.

A distinct contribution of Area $\mathrm{C}$ was to confirm the existence of a substantial Sabaean settlement underneath the Minaean layers and offer a glimpse of the horizontal extent and vertical growth of the Sabaean tell. ${ }^{5}$ At the present state of research, this settlement reaches back to about $800 \mathrm{BCE}$ in Area C and apparently to the 13th century BCE in the temple area. It was shown that at least in the northwestern quadrant the Sabaean settlement extended further west than the Minaean walled town. In fact, Sabaean Yathill probably exceeded in surface area its Minaean successor in most directions, according to the evidence presented in this chapter. The area of four hectars that the Minaean rulers enclosed with a wall not only constituted a smallish town for the period, ${ }^{6}$ but brought about a reduction in settlement surface, consequent upon an entirely new concept of town space.

Therefore we need to approach the identity of Sabaean Yathill by forgetting the glorious Minaean walls completely (Fig. 2). Indeed, we need to abolish from our sight and judgments everything that does not belong to the Sabaean occupation or conform to an

\footnotetext{
${ }^{4}$ Chapters 16 (Volume 1) and 18 (this volume).

5 Barāqish/Yathill was first mentioned as a 'tell' in de Maigret 1991a, 15, and 1991b, 164 (based on the corings of 1990); repeated in de Maigret 1997a, 138. About tell geoarchaeology in general see W. Matthews 2017.

6 A medium-size city in Brunner's (1997) classification.
} 

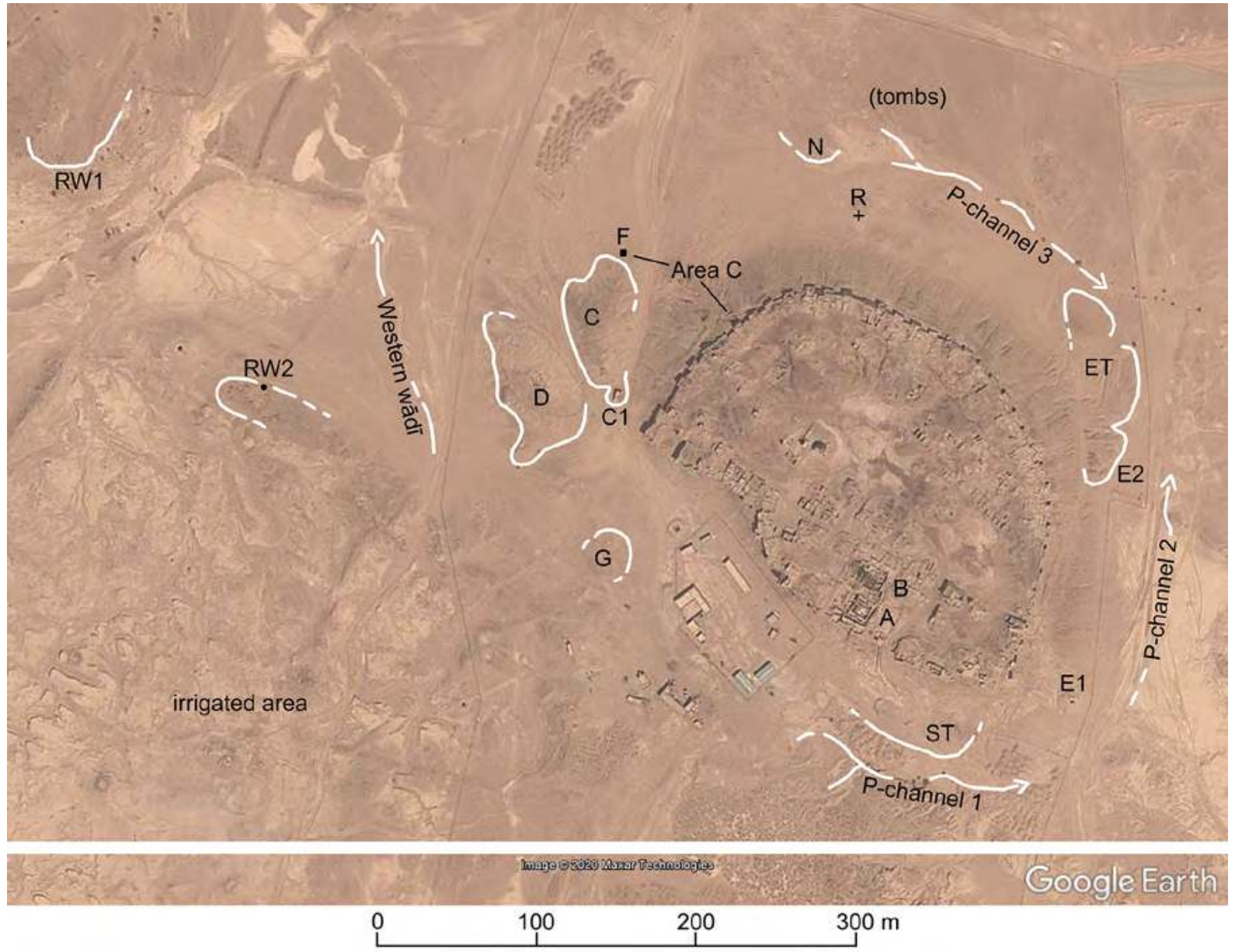

Figure 1. Locations providing data employed in this chapter. See text for details. (Google Earth image, 4 September 2011; adapted by F.G. Fedele 2020)

earlier - and different - conception of settlement. In this context, it is appropriate to point out at the outset that nowhere in Area $\mathrm{C}$ has the bedrock been found, nor even culturally sterile soil. Therefore a physical and conceptual baseline for the settlement's trajectory, so to speak, is still missing.

This chapter is an exercise in settlement archaeology. It has the dual purpose of investigating the nature of the Barāqish mound and describing what is presently known about the development and overall organization of Sabaean Yathill. Towards the first goal (section 2), topographic profiles incorporating data from archaeological 'windows' (corings, soundings, excavations) and local bedrock outcrops will be drawn and evaluated. It will be shown that the mound can probably be reconstructed as an entirely artificial landform, that is, a tell in the usual archaeological sense, whose initial settlement might have been established on a modestly raised rock surface or a long-stabilized wādī terrace or spur. As to settlement configuration (section 3), the data from Area $C$, combined with surface observations, appear to reveal a Sabaean main settlement surrounded by several smaller installations or 'satellite' sites. These latter owe existence to mere locational opportunity or in some cases - perhaps to a specialized function. ${ }^{7}$ It is this configuration that I propose to call 'Greater Yathill'. ${ }^{8}$

The two sets of field data referred to above have remained until now unpublished, apart from very brief mentions. ${ }^{9}$ Schematically they can be called 'vertical' and 'horizontal' data, as they refer to elevation and planimetric information, respectively. Under these simplified rubrics several particular research questions will be addressed in the following pages:

i. what lies at the core of the tell or beneath the tell, and on what kind of substratum did the tell develop?

\footnotetext{
7 Such as farming or exchange-related activity.

8 The concept and term of 'Greater Yathill' were introduced in Fedele 2010,145 . The use of quotation marks in association with the expression Greater Yathill is intended to draw attention to the problematic nature of this label and construct. With that caveat in mind, this designation will henceforth appear without quotation marks.

9 Fedele 2010, 101, footnotes 18-22; 145-146.
} 


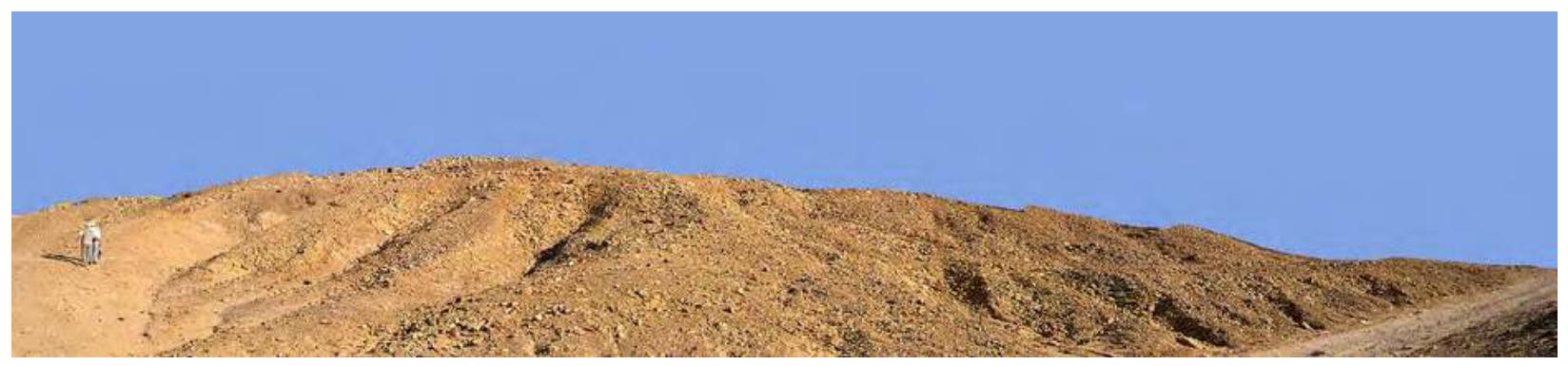

Figure 2. Barāqish/Yathill: the tell without the Minaean wall. (P. Morlupi 2005 @ MAIRY, modified by F.G. Fedele 2016; the original photograph can be seen in Chapter 17, this volume, Fig. 1)

ii. in connection with the previous issue, how was the strictly local landscape before Yathill was established?

iii. how did the tell develop spatially, i.e., horizontally as well as vertically?

iv. how can we reconstruct the extent and form of the Sabaean settlement, and can we already suggest some implications?

\section{Vertical information}

\subsection{The data base}

The simplest and most efficient way to use vertical information to investigate the evolution of Yathill is through topographic profiles. And crucial to meaningful profiles are the deep soundings made into the tell and the position and shape of bedrock ${ }^{10}$ - not only its nature but also its local morphology (Figs 3-5). In addition to the soundings in Areas $\mathrm{C}$ and A already mentioned, the exploratory corings made in the early years need to be considered. ${ }^{11}$ The positions of the corings relevant to the topographic profiles are marked in Fig. 6.

Concerning bedrock, two series of outcrops are of interest for the present investigation. One is strictly local and is represented by a few minuscule, point-like outcrops closely associated with the location of Yathill: $\mathrm{R}_{1}-\mathrm{R}_{5}$ (marked ' $\mathrm{R}$ ' in Fig. 1) and a hypothetical, probable $\mathrm{R}_{0}$ (marked in Fig. $9 \mathrm{~B}$ ). The other series comprises two much larger outcrops located at greater distance to the west and southwest of Yathill, RW1 and RW2 (Fig. 1). Here is a detailed description.

- $\mathbf{R}_{1}-\mathbf{R}_{5}$ (Fig. 3). The 'northern outcrops': five outcrops at ground level to the north of the tell off bastions T12T14, between 40-70 $\mathrm{m}$ from the Minaean wall, each rock unit measuring $\leq 5 \times 5 \mathrm{~m}$ in size. The rock is a tabular sandstone, grey to hazel to light brown in colour (see below). The elevations below the top of Minaean wall recess $\mathrm{R} 12 / 13$, measured by total station in December 2006 (R. Loreto assisted by P. Morlupi), are the following:

\footnotetext{
10 The solid rock underneath the site and its surroundings.

11 Data on the corings from Chapter 15 in Volume 1.
}

$R_{1}=-18.753 m ; R_{2}=-18.789 m ; R_{3}=-19.108 m ; R_{5}=-19.677$ $\mathrm{m}$.

In particular, $\mathrm{R}_{1}-\mathrm{R}_{2}$ is a flat cluster of outcrops occupying a total area of $c .10 \times 15 \mathrm{~m}$, located c. $15 \mathrm{~m}$ from the base of talus perpendicular to wall recess R12/13. The main rock plate protrudes up to $40 \mathrm{~cm}$ from the surrounding plain surface. ${ }^{12} \mathrm{R}_{3}$ is surmounted by two detached blocks. $\mathrm{R}_{4}$ is slightly higher above ground than the other outcrops. Further north-northwest, the bedrock disappears under an elongated undulation, 'Hill N', upon which in 2007 were remnants of makeshift military shelters.

The plain flanking the wide northern arch of the tell is a distinctive near-level erosion surface, the product of long-sustained denudation: a land surface worn down by erosion to a nearly flat or broadly undulating plain. Technically it is a planation surface, ${ }^{13}$ eroded according to a sedimentary or structural joint.

- ? $\mathrm{R}_{0}$ at bastion T37 (Fig. 4). Probably bedrock. A $50 \times$ $50 \mathrm{~cm}$ rock body - a block or an outcrop - immediately at the base of the Minaean wall, and precisely beneath the most protruding basal block of masonry in the northeastern corner of bastion T37 (Fig. 16). Its status as bedrock was inferred (i) from its lithology being slightly different from that of the basal blocks of the wall, and (ii) from the size and style of the overlying wall's base, by analogy to bastion T7 as excavated in Area C. The rock of $R_{0}$ is a compact, thick-bedded, medium-fine sandstone, with relatively fissile beds.

This spot was definitely noted and recorded by myself in December 2007, thanks not only to its denudation by

\footnotetext{
12 This particular outcrop was observed by A. de Maigret on 17 December 2005, the day after a group visit to Darb al-Șabi in which I had expressed to him my emerging ideas about the rocky substratum (if any) beneath Barāqish. We then examined $R_{1}-R_{2}$ together on the same day. The finding of this tiny flat outcrop immediately off the base of the northern talus corroborated my idea of a geomorphological analogy with a certain area at Darb al-șabì (see below, end of section). I was able to inspect and record in greater detail the northern outcrops in 2006-2007.

13 Planation: the denudation and grading of an area or district by any erosive process.
} 
recent erosion, but also because it was now possible to approach it with the prior knowledge of the complete masonry sequence of a Minaean bastion, T7 in Area C. $R_{0}$ had not been previously observed by researchers (J.-F. Breton and V. Francaviglia, this latter in 1987) probably for insufficient erosion at the time..$^{14}$ Of course, it would make sense if the Minaeans founded their big curtain wall on bedrock wherever possible. If $R_{0}$ is actually bedrock, it almost necessarily follows that it must be a relatively isolated and protruding outcrop (a spur or even a minuscule butte), and therefore it might have represented a local landmark. This hypothesis will be developed at the end of this section. Both in light of this hypothesis and in anticipation of fieldwork in 2008, I mapped in relative detail the tell and talus slope below T37, which I propose to designate as Area 37 (see section 3 below).

The sandstone outcropping at Yathill, identical to that of Darb al-Șabì (Fig. 11 A), is part of the Amran [Amrān] Limestone, Upper basin facies, of Kruck and colleagues, 'Jau' in their map. ${ }^{15}$ Among its units, this geological formation includes greyish sandstone and interbedded limestone. In my own notes from visits to Darb alȘabì I described this rock type as mostly fine-medium sandstones in massive beds, with beautiful scaly to conchoidal fracture, interstratified with calcarenite (yellowish calcareous sandstones). ${ }^{16}$

Outcrops $R_{1}-R_{5}$ are a typical example of sandblasted sandstone on a pediment surface. ${ }^{17}$ The plain closely surrounding Barāqish to the north and west is a pediment, an essentially rock-cut pediment surface: ${ }^{18}$ that is, a rock-floored lowland plain resulting from intensive denudation, marginally mantled by thin alluvial veneers and local alluvial fans at the exit of major upland streams. ${ }^{19}$ As Karl Butzer put it in his crisp and concise style, "pediments are commonly interrupted by residual hills near the fretted, upland margins: such residuals may form steep pinnacles

14 Cf. Breton 1994, fig. 6 (here reproduced in Fig. 4, far right); Francaviglia 1987, 19.

15 Kruck et al. 1996, 41; map Sheets 2 (Al-Hazm) and 5 (Șan(ā) by Kruck and Schäffer, published in 1991. The age is PortlandianValendisian, terminal Jurassic. This sandstone was formerly ascribed to a 'Tawilah [Tawilah] Group', part of a 'Medj-Zir Series' (Grolier and Overstreet 1978).

16 I also noted that Darb al-Șabī and its surroundings actually offer a whole repertoire of sandstones: not only the variety mentioned above, but also, for instance, coarse yellow sandstones (apparently fossiliferous) and coarse, poorly sorted red sandstones with evident quartz.

17 Cf. Butzer 1976, 385, fig. 19-5.

18 A pediment also for Kruck et al. 1996. They mapped the territory 2-5 km to the southwest of Barāqish as 'Qp', '[Holocene] pediment deposits, undifferentiated', mantled within a $2-\mathrm{km}$ radius around Barāqish by 'wadis and outwash plain deposits (gravel, sand, silt and loess)', indicated as 'Qw'.

19 Butzer 1976, 376, 383-392. It would once have been called a peneplain. (buttes), flat-topped hills (mesas), $\left.{ }^{20}\right]$ bell-shaped "domes", [21] or simply heaps of blocks and boulders [22] - depending on their size and lithology. ${ }^{23}$

RW1 and RW2, the second series of bedrock outcrops in the vicinity of Yathill, are two low mesaform residuals produced by emerging tabular caprock, each a few metres high and much bigger horizontally than the northern outcrops described above (particularly so RW1). These small mesas ${ }^{24}$ feature as topographic residuals in a semi-desert or savanna-like landscape..$^{25}$

- RW1 (Fig. 5). The larger outcrop. It is located on the left bank of the so-called Western wādi (see end of section 3, below), about $400 \mathrm{~m}$ west-northwest of Minaean bastions T5-T6. Its tabular caprock is almost perfectly horizontal. This small mesa is surrounded by some vegetation, fostered by subsurface aquifers of the floodplain. In both winters, 2005 and 2006, there was a bedouin camp of one or two black tents at the foot of its southern cliff, amidst the acacias.

- RW2 (Fig. $11 \mathrm{~A}$; it can also be glimpsed in the middle of Fig. 42/above photograph, Chapter 1, in Volume 1). The smaller outcrop, marked by perfectly horizontal caprock and apparently lower than RW1. It is located on the left of the Western wādī as part of a long low hill orientated northwest-southeast, edging the ancient irrigated area. ${ }^{26}$ Its eastern end is $220 \mathrm{~m}$ west of wall bastion T1 (the southwestern 'corner' of Minaean Yathill, flanking the town gate), and $150 \mathrm{~m}$ from excavation Area D on Hill D.

In summary, Barāqish/Yathill belongs in a geomorphology and landscape for which the following characterization is perfectly pertinent: '[In structural landscapes in horizontal sedimentaries,] intensive dissection can favor tableland development as stream activity detaches tabular mesas or smaller buttes from the unconsumed uplands, producing an open hill

\footnotetext{
20 On 'mesa' see below.

21 I.e., inselbergs, 'domed hills' (Butzer 1976, 405).

22 Such as 'tors' (Butzer 1976, 405).

23 Butzer 1976, 391.

24 Following Butzer (1976, e.g. 390, 391, fig. 19-11), the most appropriate term for these landforms in the case of Barāqish is mesa (a small mesa), or, more precisely, a mesaform relief. As a general term, 'mesa' designates a tableland, a flat-topped elevation bounded on at least one side by a steep cliff (AGI 1984, 314); a flat-topped eminence (Monkhouse 1974, 225 and figure); an isolated, flat-topped hill or mountain with steep sides, smaller in area than a plateau (Viljoen et al. 2016, 296). Neither 'butte' nor 'inselberg' apply to the Barāqish area, the first term because our outcrops lack prominence, and the second because inselbergs are domed (Butzer 1976, 405-423), whereas our forms are definitely not. Cf. for instance Viljoen et al. 2016, 296 (glossary).

25 E.g., Butzer 1976, 411, 417, figs 20-2 and 20-10.

26 This hill could not be visited and its nature is completely unknown. It could very well host one or more minor Sabaean and/or Minaean sites.
} 

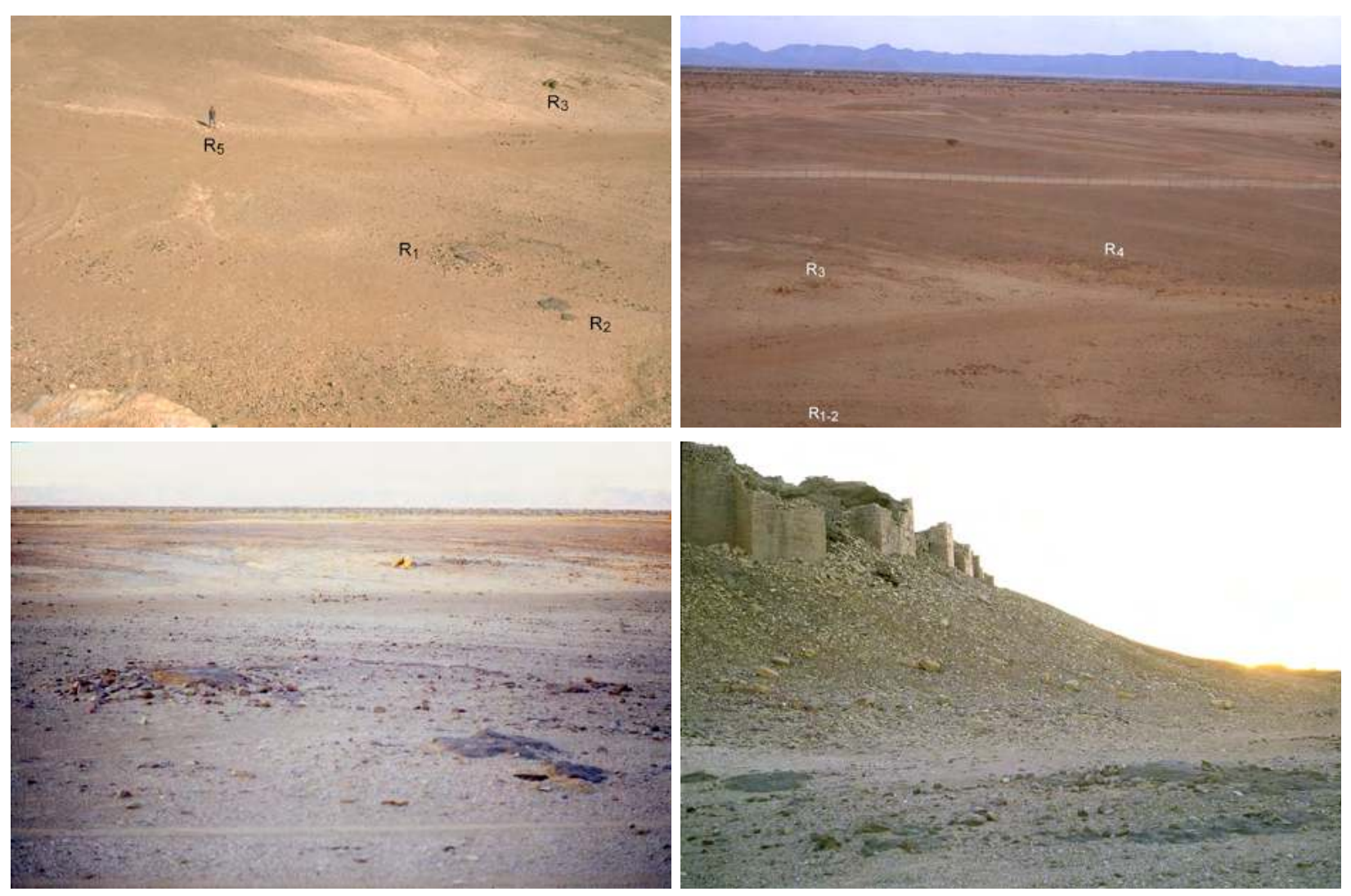

Figure 3. Views of the bedrock outcrops off the northern talus of Barāqish, $R_{1}-R_{5}$. Above, from the Minaean wall; below left, $\mathrm{R}_{1}-\mathrm{R}_{2}$ from the talus; below right, $\mathrm{R}_{1}-\mathrm{R}_{2}$ from ground level, with the northern talus and bastions $\mathrm{T} 10-\mathrm{T} 12$ in the background. (F.G. Fedele 2005 and 2006)

country and, often, plains studded with residual hills. At the same time, resistant caprocks and other differences in lithology favor backwearing processes, generally preserving the tabular arrangement of the landscape. Dendritic drainage patterns are characteristic. ${ }^{27}$

Combining two by two the four segments indicated in the layout (Fig. 6), four topographic profiles have been obtained for the Barāqish mound (Fig. 7). All elevation data are the original measurements employed in the Barāqish general plan of 2007 (Chapter 1, Fig. 45, in Volume 1), based on GPS survey and incorporating the total station records. ${ }^{28}$ The known bedrock outcrops are particularly marked. An elevation of $1122 \mathrm{~m}$ above sea level for the plain immediately to the south of the mound was determined by GPS in 2007, and this 'Base-camp datum' provides altimetry reference in the profiles.

The profiles themselves do not require many comments. As to elevation relationships, the Area $C$ datum (P01) is $+12.38 \mathrm{~m}$ above the Base-camp datum and $+5.43 \mathrm{~m}$ above the datum for Temple A and the temple area ('Temple

\footnotetext{
27 Butzer 1976, 302.

28 GPS survey by M. Mascellani, 2007; total station data by M. Mascellani and R. Loreto, 2003-2006.
}

datum'), ${ }^{29}$ this latter in turn $+6.95 \mathrm{~m}$ above the Basecamp datum. The Area $C$ datum and the corresponding top of Sounding A is $+6.4 \mathrm{~m}$ above the average ground level of the monumental staircase of Temple A, this latter, in turn, reportedly $+5.98 \mathrm{~m}$ above the Base-camp datum.

The top of the Sabaean deposits in extramural Sounding A (i.e. surface S12) roughly coincides in elevation with the top of the truncated Sabaean deposits at Temple A, as revealed by the sounding in front of the temple (A/ $\mathrm{S} 1):+5.4 \mathrm{~m}$ the former, with reference to the Base-camp datum, and $+6.08 \mathrm{~m}$ the latter, indicating a difference of about $70 \mathrm{~cm}$, with the topmost surviving Sabaean terrain in Sounding A being lower in elevation..$^{30}$ The bottom of sounding $\mathrm{A} / \mathrm{S} 1$ was at the average level of the base camp, precisely $30 \mathrm{~cm}$ below the Base-camp datum. ${ }^{31}$ Both this sounding and the corings at Temple

29 The figure of ' $11.45 \mathrm{~m}$ ' above the datum for Temple B, stated in Fedele 2010, fig. 132, is incorrect: see Chapter 17, section 3.2, this volume. As to the Temple datum, its bench mark was located in 20032006 on wall M45 of so-called House A/1 in front of the staircase of Temple A (cf. de Maigret 2010a, fig. 66).

30 Cf. the provisional estimate in Fedele 2010, 142, footnote 151. For the geometry of sounding A/S1 at Temple A see de Maigret 2010a.

31 Also in V. Francaviglia's recollections, the corings carried out in 1990 had reached 'down to the level of the surrounding plain' 

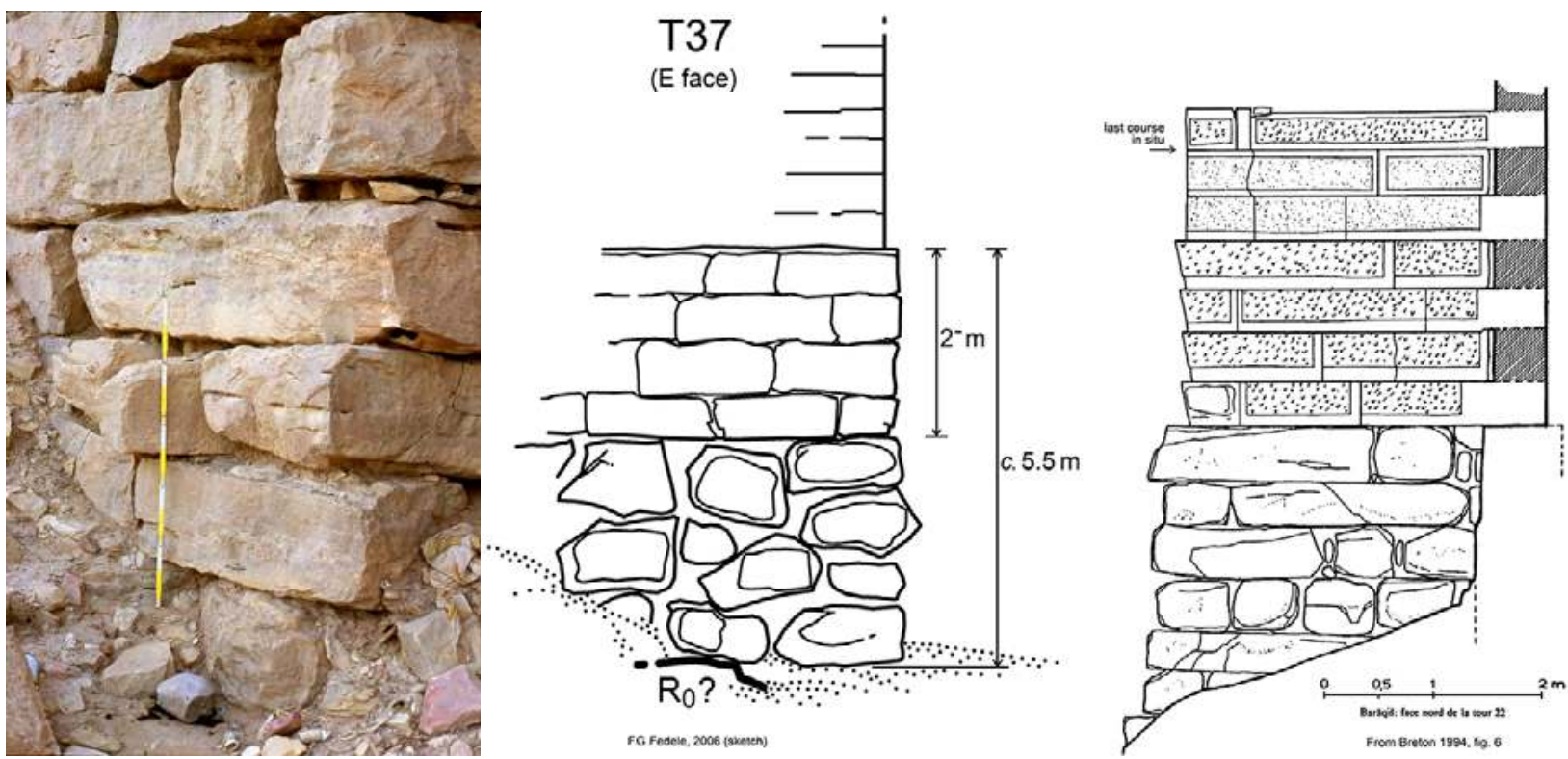

Figure 4. Barāqish/Yathill: foundations of bastion T37 and presumed bedrock underneath, $\mathrm{R}$. Photograph: diagonal view of T37, northeastern corner; folding metre rests on $\mathrm{R}_{0}$. The drawings show the base of the wall at T37, northern face (on the right, from Breton 1994, fig. 6) and eastern face (on the left, author's). (Original records by F.G. Fedele 2006).

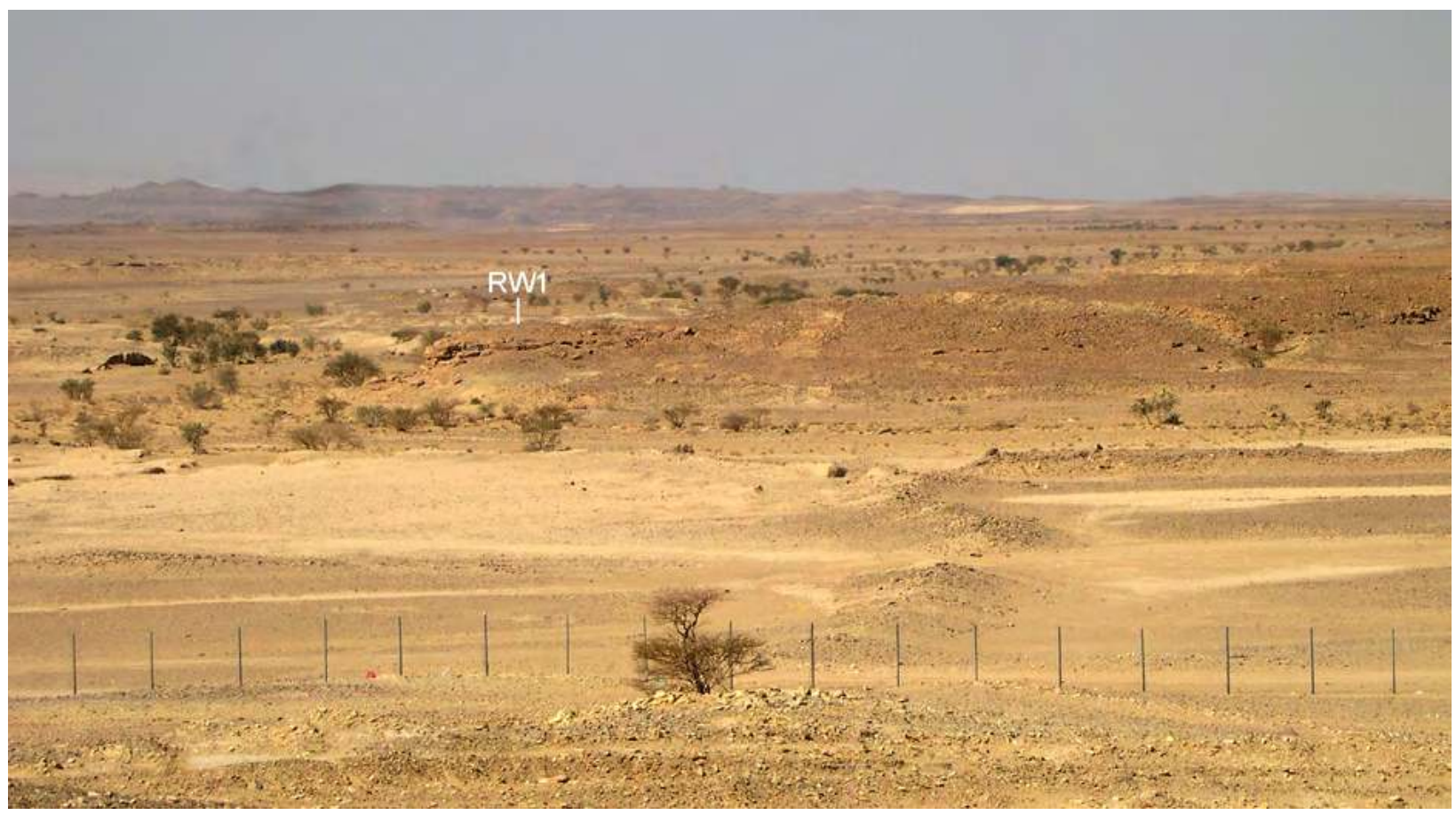

Figure 5. RW1, a mesaform bedrock outcrop at short distance to the west of Barāqish, as seen from Minaean wall bastion T5. (P. Morlupi 2005 ( ) MAIRY, adapted and optimized by F.G. Fedele 2019)

A may have reached down to within a few metres of the substratum.

Unfortunately, the Islamic well in the middle of the town of Barāqish between the minaret and the mosque

(Francaviglia 2002, 121)
(Fig. 9) could not be investigated, therefore its depth is lacking from the profiles. Could this well be Minaean in origin? The sheer existence of a well in this place suggests that there was an aquifer at reachable depth, possibly determined by an impermeable layer, and it cannot be excluded that such a layer is some sort 


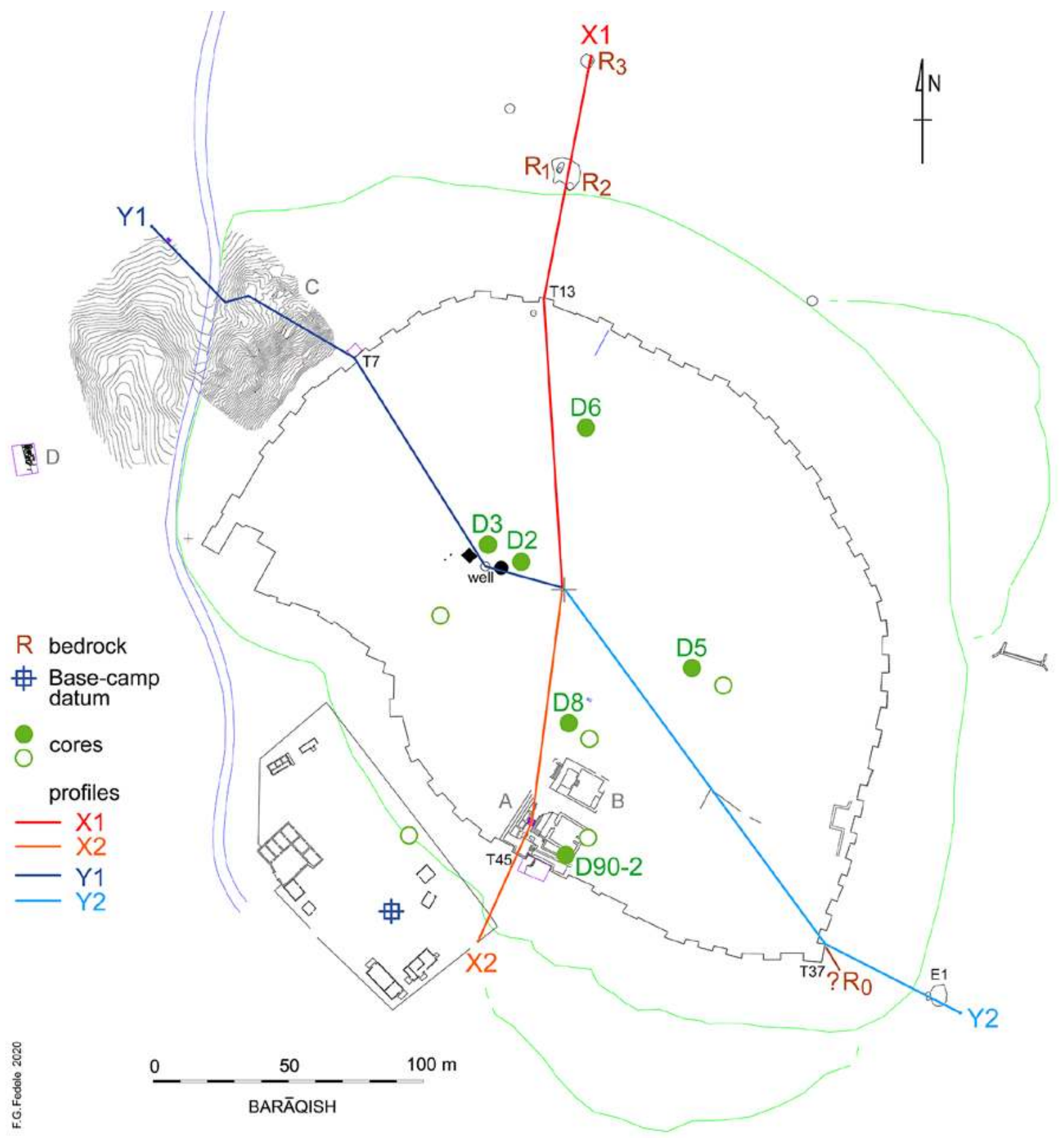

Figure 6. Barāqish/Yathill: layout of the topographic profiles shown in Fig. 7 and position of the relevant cores (1987 and 1990 coring seasons). (F.G. Fedele 2020)

of substratum. In 1990 V. Francaviglia volunteered to go down into the well but was dissuaded..$^{32}$ Nor was it possible to examine or measure well E1, the only known local well in the plain, located below the southeastern corner of the town wall (see section 3, below, and Figs 15-16). However, well E1 is of great interest in the present discussion because it reveals that there cannot be bedrock near the surface. This provides support for thinking that $\mathrm{R}_{0}$ at bastion T37, if it is bedrock, must be a relatively tall and protruding spur.

\footnotetext{
32 S. Antonini, personal communication. An observation of Francaviglia about this well is reported below.
}

\subsection{Interpretation}

What can one conclude about the hypothetical substratum lying beneath Yathill? What is the hidden geological entity forming the base of the settlement? Back in 1986, as no information on the underlayer on which both the town and the Minaean wall rested could actually be gleaned from the surface, B. Marcolongo argued on the basis of air-photograph interpretation that Barāqish occupied a north-dipping sandstone mesa, similar to those present at a distance of several kilometres in the region. ${ }^{33}$ The Barāqish relief was

33 Marcolongo and Palmieri 1986, 462-463: 'Barāqiš is built on an 
marked as such in his geomorphological map and in several publications. ${ }^{34}$ This view was also cited by other authors..$^{35}$ An accompanying idea was that the bedrock was rising nearer to the surface in the southern half of Barāqish. As mentioned in a previous chapter, ${ }^{36}$ there is no indication that this idea was put to rest - or even discussed - despite the deep drillings of 1990. At best, these drillings only initiated a change of impression. ${ }^{37}$ In fact, after that phase of research, the subject of the geological substratum of Barāqish disappeared from discourse. . $^{38}$

A different view was held by geologist V. Francaviglia. He wrote in his report for $1987^{39}$ that

the walled city of Barāqiš was built on a bit of an old fluvial terrace, the remnant of an old hydrogeological equilibrium, today changed. The top of the terrace upon which Barāqiš was built is horizontal, so that its walls show an average horizontal allure. The structure of the terrace in question is made of debris whose thickness is more than $30 \mathrm{~m} .\left[^{40}\right]$ At the $\mathrm{E}$ and $\mathrm{W}$ sides of the Citadel [= Barāqišs some mesas made of tilted Mesozoic limestone outcrop from these terraces.

Francaviglia reported no sighting of bedrock, either from T37 $7^{41}$ or elsewhere: '[No] outcropping of "in situ" limestone [can] be seen along the walled city; the public well of Barāqiš is entirely lined with limestone. ${ }^{42}$ The opinion that Barāqish appeared to be entirely a tell, 'just like Hazm [or] Ma'īn', not a settlement atop a rocky outcrop, was repeated in a later publication. ${ }^{43}$

The present re-examination of the subject, with the previously unavailable contribution of objective

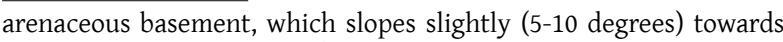
the north-northeast'; cf. Fedele 2010, 101. See mention in Chapter 1, section 3.2 (with footnote 83), in Volume 1.

34 Marcolongo's 'Geomorphological map of [the] Barāqiš area', 1986, unpublished, but presented at a smaller scale in Marcolongo 1994, 1996, 2000.

35 Notably J.-F. Breton. Breton 1994, 12: 'Assez rares sont les villes qui s'installent sur des éminences naturelles: c'est le cas de Șirwāh adossé à une arête granitique, et probablement aussi de Barāqiš et de Šibām (Hadramawt)'; adding in a footnote, "Pour Barāqiš: hypothèse formulée par A. de Maigret dans une communication à Șan' 'ä' en 1989'. Cf. Breton 1999, 77 (French original 1988): 'The city [of Barāqish] is built along a sandstone ridge.'

36 Chapter 15, section 3.2, in Volume 1.

37 Cf. de Maigret 1991a, 15; 1991b, 164.

38 At least until 2006: cf. Robin and de Maigret 2009, 63; 70, §5.

39 Francaviglia 1987 (unpublished), 19.

40 This figure is not qualified and perhaps unsupported. The Barāqish mound rises no more than $20 \mathrm{~m}$ above the surrounding plain. FGF

41 As already mentioned: see footnote 14 .

42 Francaviglia 1987, 19. The well referred to is the Islamic one inside the town, see above. Given the context, Francaviglia seems to be saying that the Islamic well, being lined with limestone (?), prevents one from seeing any bedrock.

43 Francaviglia 2002, 119 (quotation), 121. topographic profiles, would suggest a more nuanced interpretation. Yathill was likely established on a flat patch of surfacing bedrock, and more precisely on a structural surface coinciding with a bedding plane in the regional sandstone, or on a very low natural rise: in this latter case, on a pediment locally constituted by flat mesaform bedrock. An equally possible alternative - in fact a mere variant of the latter option - is that this modest natural rise is not a rock surface, but an alluvial morphology: a long-stabilized wādī terrace or spur (see section 1 above). These alternatives are not incompatible. In fact, a low natural rise formed by flat or low bedrock in combination with adjacent stabilized alluvium is entirely admissible. In spite of their vicinity, outcrops RW1 and RW2 described above are too tall and RW1 is also too extensive - to represent suitable analogues for the rocky substratum of Barāqish.

If positioned on a structural surface - possibly the most linear or 'parsimonious' interpretation - Yathill would be underlain by a ground-level rocky flat with a 2.17 per cent northwest dip. ${ }^{44}$ This figure depends on the nearest exposed bedrock to the north of the tell, $\mathrm{R}_{1-2}$ (elevation of $R_{1}$ below the 2007 Base-camp datum $=-3.70$ $\mathrm{m}$ ), as well as on accepting that $\mathrm{R}_{0}$ is bedrock (elevation above the same datum $=2.90 \mathrm{~m}$ ). The linear distance between the two points is $304 \mathrm{~m}$.

The decision to settle on a natural rise, be it outcropping bedrock or old stable alluvium, 'may simply reflect a desire to avoid wasting valuable arable land, ${ }^{45}$ observed Steadman from her experience of Western Asian tells. ${ }^{46}$ Significantly, however, this consideration applies equally well to settling on a tract of rocky flat land.

The hypothesis that $R_{0}$ is bedrock fits easily in this interpretive framework. As argued above, if we have bedrock immediately beneath Minaean bastion T37 this rock would quite possibly form an isolated, protruding outcrop, a sort of small butte flanked or surrounded by wādi terraces, at least to the south. Not terraces alone, in fact: this rock had to be located on a spur overlooking an active wādì channel to the south and, probably, a relatively major confluence to the east (Figs 1 and 9). Consequently, one would have here a natural feature which constituted a local landmark and was very well located: both suitable factors to attract settlers in search of a place. And to develop this speculation a little further: might such a landmark, combined with its location, have become an organizing element at the origin and during the initial phase of the Sabaean settlement? ${ }^{47}$

\footnotetext{
${ }^{44}$ Cf. my provisional suggestion (Fedele 2010, 101, footnote 22).

45 Not 'arable' but agricultural, in the case of Yathill.

46 Steadman 2005, 299.

47 A rocky outcrop and several wells inside a Sabaean settlement are now known at Șirwāh: Schnelle 2016.
} 

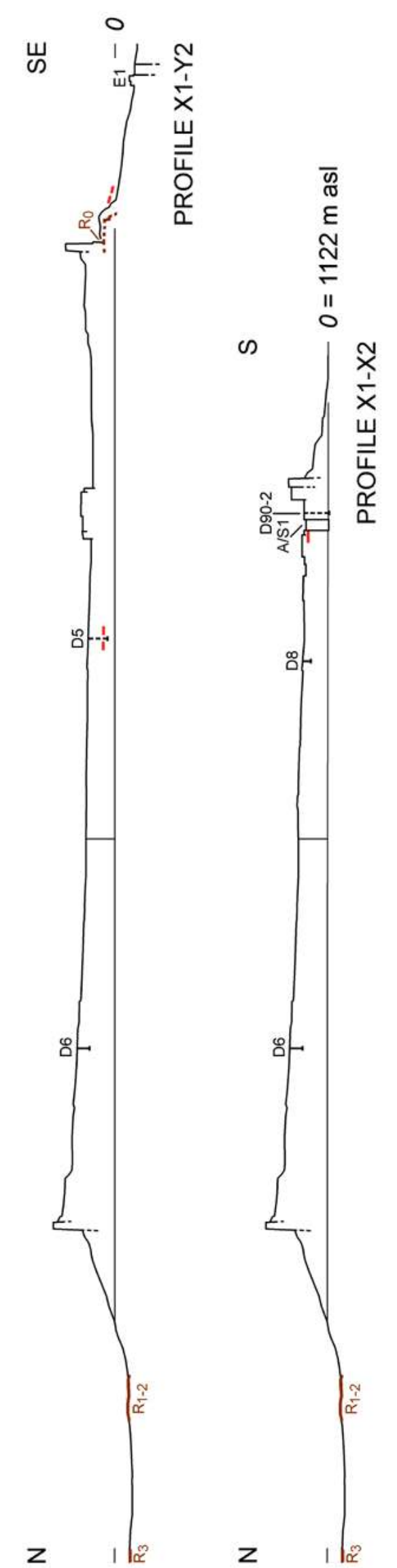

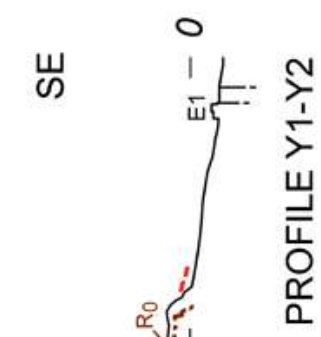

岸

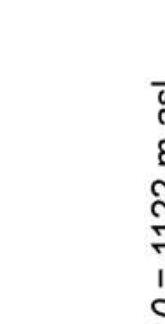

$\omega$

$\gtreqless$

$\gtreqless$

эอрอง 워

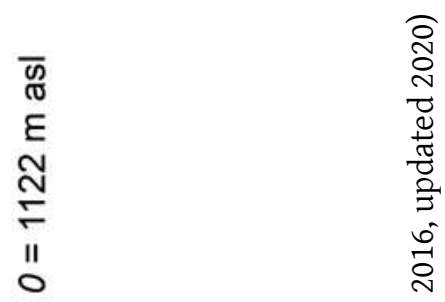

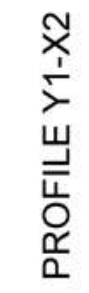

$\frac{0}{\frac{8}{0}}$

ن

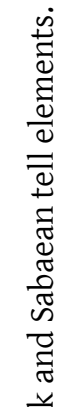

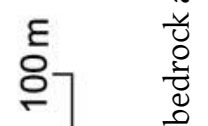

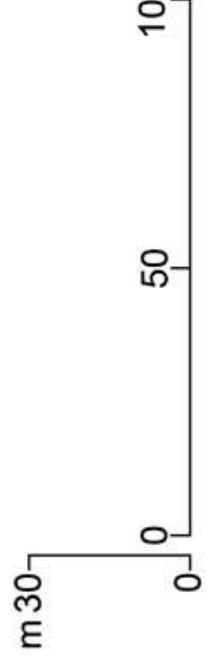

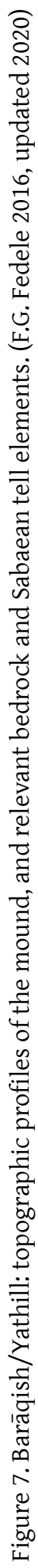

3 


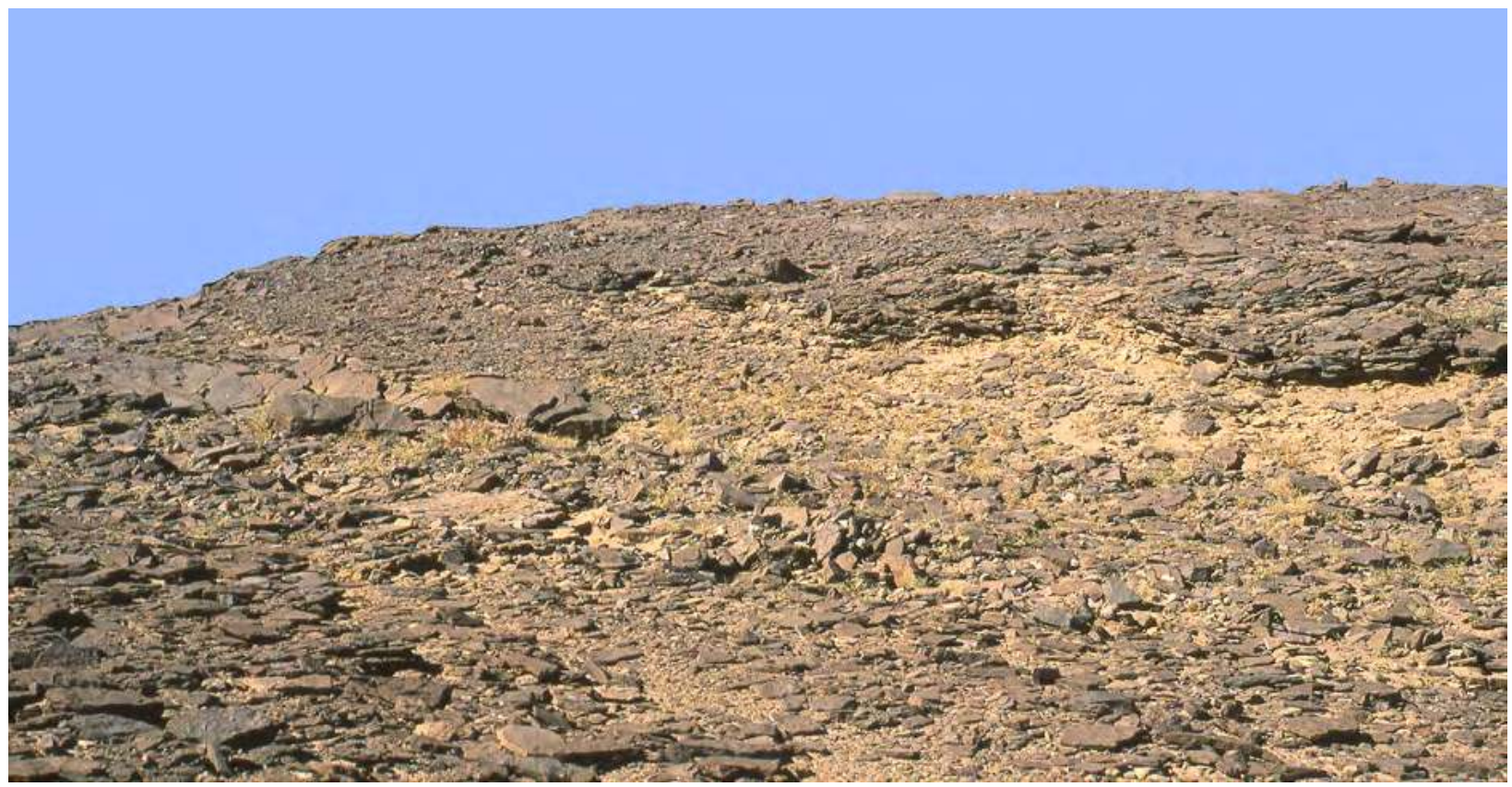

VIEW FACING NORTHEAST

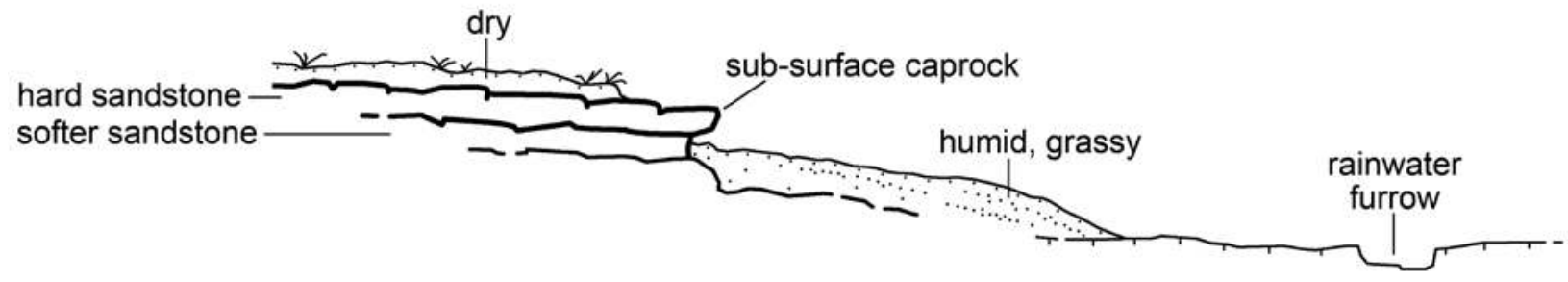

Figure 8. A possible analogue for the substratum of Yathill before the settlement, as observed at Darb al-Șabī; only the rocky surfaces in the middle of the photograph are of interest. Below: interpretive sketch from the author's first visit on 16 December 2005. (F.G. Fedele 2005)

A possible analogue for the pre-Yathill local landscape was observed at Darb al-Șabī, a large and dissected mesa in the same sandstone units about $2 \mathrm{~km}$ west of Barāqish. ${ }^{48}$ Apart from visual resemblances, the bedrock appearing at ground level in the northern outcrops at Yathill could be readily understood on the basis of the much wider geomorphological repertoire just observed at Darb al-Șabī in 2005. Particularly $R_{1}-R_{2}$ can evoke the specific expression of the interplay between lithology and tabular caprock that one sees in some parts of Darb al-Șabi, mostly on the slightly depressed edges of the flat-topped hill. An example is shown in Fig. 8. The analogy only involves the surface of the Darb al-Ṣabi mesa. ${ }^{49}$

48 The mesa takes its name from the cultic complex of Darb al-Sabi: see Chapter 1, section 5, in Volume 1 (with references), and Valentini, Chapter 28, this volume.

49 A first visit to Darb al-Ṣabī, on 16 December 2005, was crucial in starting an understanding of this analogy (the photograph and sketch in Fig. 8 are from that visit). The concept was put to good use already the next day when A. de Maigret told me of having seen possible bedrock just off the northern edge of Barāqish: see footnote 12, above.
The limits inherent in our current knowledge are obvious. Two particularly. First, until targeted fieldwork is carried out the position, shape, and geological nature of any underlayer beneath the mound of Barāqish will remain unseen, hence unresolved in detail. Finding bedrock or its equivalent (alluvium, sterile soil) would clearly be a useful element for both a thorough reconstruction of settlement history and an evaluation of the choices that were at the origin of Yathill..$^{50}$ The second limitation has to do with the tracts of floodplain, since the bedrock in those areas is presumably affected by erosional features.

The relationships of Yathill with the alluvial floodplain a little to the west (coinciding with the 'Western wādì', see end of section 3, below ) are de facto unknown, and this deprives us of a crucial component for understanding the setting and functioning of Yathill. In fact, all the plains surrounding Yathill are still virtually unknown. The only source of below-ground information

50 Fedele 2010, 146. Cf. section 4 below. 
we have about them is Sounding F in Area C, together with the 4-metre-deep coring made in 1987 off bastion T48 (core D1): ${ }^{51}$ both are obviously insignificant at a territorial scale. No hint whatsoever of bedrock or of alluvial deposits is apparent at the northwestern end of our topographic profiles, in so-called 'Plain F' (i.e., the plain around Sounding F; Fig. 9 B). And until now it has been impossible to examine the relationships of Yathill with the alluvial landforms to the east: indeed, with the whole, undoubtedly interesting palaeo-landscape created by Wādī Majzir and its possible precursors ${ }^{52}$ in the lowland area east of the mound.

\section{Horizontal information}

\subsection{Satellite units}

How can we reconstruct the extent and overall configuration of Sabaean Yathill? The planimetric or horizontal information we can rely on derives from the excavations in Areas C and D as well as from surface evidence from around the tell, primarily Sabaean pottery in association with appropriate ancient sediments. Such evidence was recorded over the years thanks to erosion, although, unfortunately, no survey of the Barāqish tell and its surroundings could ever be made into a formal programme $\mathrm{e}^{53}$ (cf. section 1 and Fig. 1 , above). Cumulatively, these observations have produced the results shown in Fig. 9, with photographic details in Figs 10-15. Figure $9 \mathrm{~B}$ provides an implicit, synthetic definition of what I propose to model as Greater Yathill.

The quality or 'value' of the available information was taken into account, leading to a distinction - indicated in the figure - between

- general pottery debris, represented by more or less dense scatters of potsherds; ${ }^{54}$ and

- occupational debris, i.e., diagnostic Sabaean material (including non-ceramic, if any) in conjunction with sedimentary contexts suitable to suggest the existence of actual occupation on the spot.

\footnotetext{
51 See Chapter 15 in Volume 1.

52 Cf. Chapter 19 , section 5 , this volume.

53 As an example of formal surveys of this kind one could cite the project carried out at Salūt in interior Oman, c. 1300-300 BCE (Condoluci et al. 2014, 103): '[These] survey sites were defined based mainly on the presence of surface pottery scatters', with only occasional traces of other kinds of archaeological evidence. All the sites in question 'were found above the level of the floodplain'. From both composition and density it was inferred that 'they were indicative of habitation or some other localized activity' at the site 'and not derived from elsewhere'.

54 Dispersed or occasional potsherds, as well as findspots of uncertain taphonomy, were not taken into account. Occurrences of this sort are almost ubiquitous along the perimeter of Barāqish.
}

Here is a detailed description of the outlying occupations - 'sites' for short - that have been recognized, counterclockwise starting from the western quadrants (Fig. 9 B).

Hill C (Figs 11-12). Hill $\mathrm{C}^{55}$ is a low outlying hillock elongated in south-north direction, about $110 \mathrm{~m}$ long, its axis converging with the Minaean wall from a distance of about $80 \mathrm{~m}$ in the north to a distance of $30 \mathrm{~m}$ in the south (terminal lobe $\mathrm{C} 1$ ). The minimum distance from the wall varies accordingly, from $55 \mathrm{~m}$ to $23 \mathrm{~m}$. A Sabaean deposit in situ, characterized by large pottery fragments, was identified on the northwestern part of the so-called 'tail' of Hill C (i.e., the gently sloping flank of this relief), and was photographically recorded (Fig. 12). It might in fact occupy most of the tail. Sabaean ceramic scatters occur towards the top of the hill. An obsidian fragment found with Minaean trade-related material from the surface of the hill might also be Sabaean. ${ }^{56}$

Whether Hill C is a hill or a tell will be examined below.

Located nearby and potentially connected to Hill C is Locus P07, near Sounding F, in what was called for convenience 'Plain F' (Fig. 9). ${ }^{57}$ Both Sounding F and Locus P07 are just off the tail of Hill C. Locus P07 designates a small area around grid stake P07, this topographic mark being placed $7.37 \mathrm{~m}$ northwest from Sounding F (western side) at an elevation of $45-50 \mathrm{~cm}$ below the ground surface at Sounding F (-14.84 m, Area C datum, compared to $-14.30-14.40 \mathrm{~m}$ in Sounding F). Locus P07 attracted attention for a dense scatter of partly Sabaean potsherds seemingly associated with stone clusters and a matrix of grey sub-recent silts. Surface evidence for in situ occupation was lacking, and there was no time to test the deposit. It was thought that Locus P07 could be an outcrop of the upper Sabaean deposits found in Sounding F, but a derivation from the erosion of the tail of Hill $\mathrm{C}$ is perhaps a more plausible explanation.

On the other hand, patches of stony sands and silts rich in Sabaean debris, almost always mixed with Minaean material, punctuate the surface all over the most depressed area of Plain F, as if rises of buried Sabaean layers could indeed occur. ${ }^{58}$

\footnotetext{
55 See mentions in Chapter 17, section 1.2, and Chapter 19, section 3.1, this volume.

56 On this surface aggregate of Minaean material see Chapter 19 , section 3.1, this volume. A Sabaean obsidian find was retrieved from Sounding F (no. 214.01; see Chapter 21, section 2.1, this volume, and for stratigraphy and context Chapter 17 , section 17 ).

57 'Plain F' is informally defined as the area in the western plain within a radius of 10-20 $\mathrm{m}$ from point (stake) P07.

58 Cf. Chapter 17, section 17, this volume.
} 


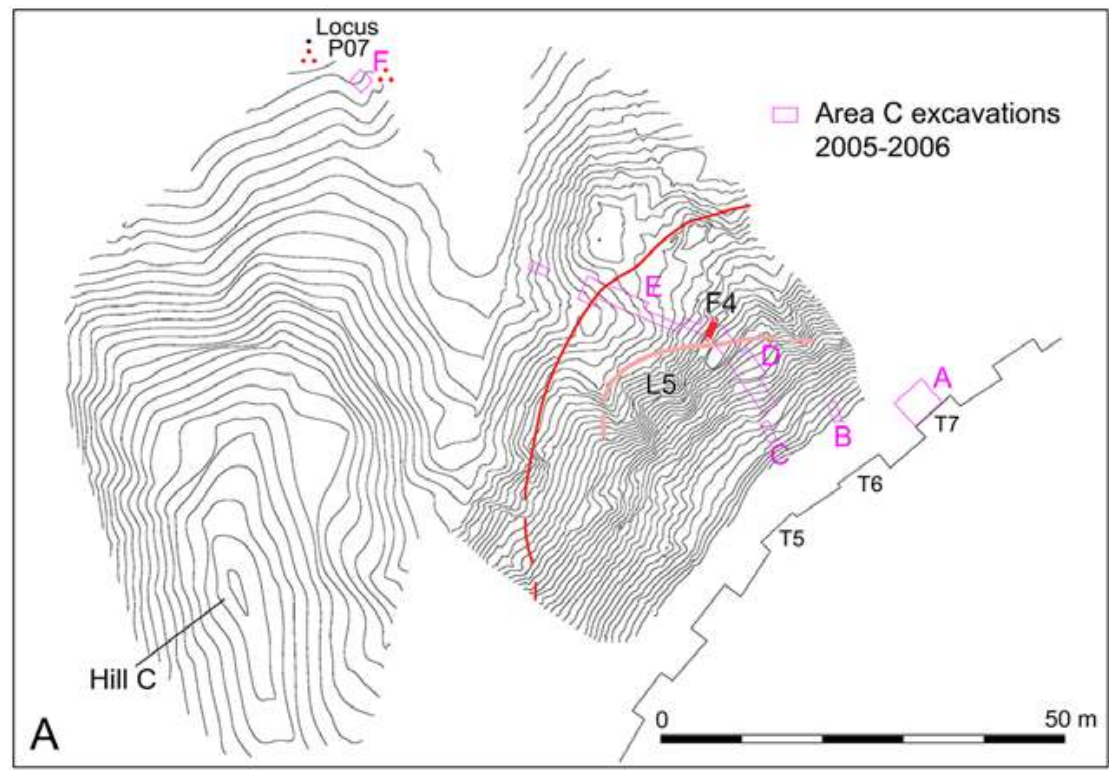

Sabaean tell - hypothetical

F4 Sabaean wall occupation, 'site'

L5 settlement Lobe 5

? Sabaean structures?

$\therefore \quad$ potsherd scatters

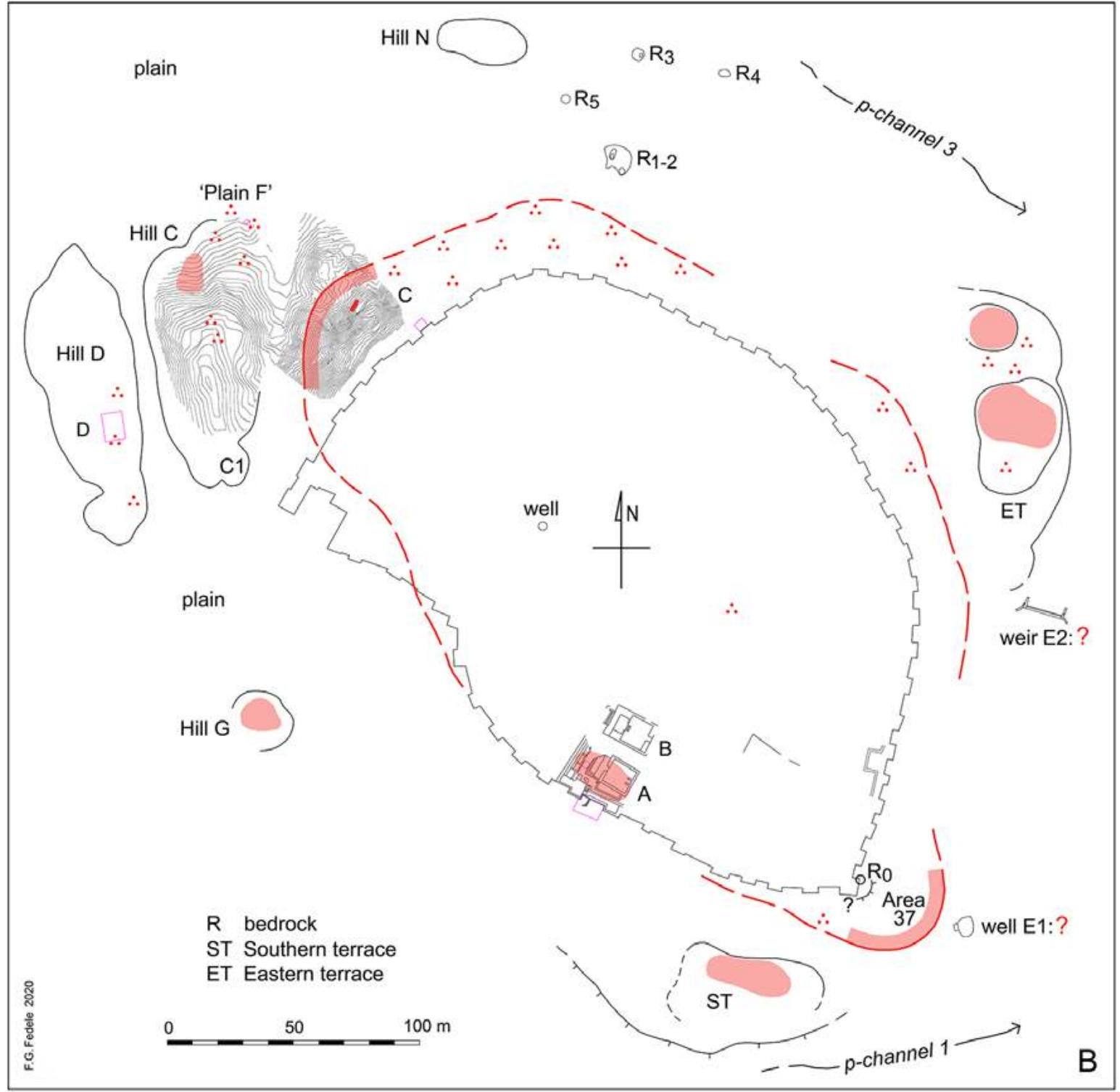

Figure 9. Greater Yathill: suggested extent of the Sabaean occupation, including satellite locations from surface evidence. The Minaean wall and temples merely provide reference. A: observed limits of the Sabaean settlement in Area C, including Wall F4 during the Earlier Sabaean and settlement Lobe 5 during the Later Sabaean. (F.G. Fedele 2016, updated 2020) 


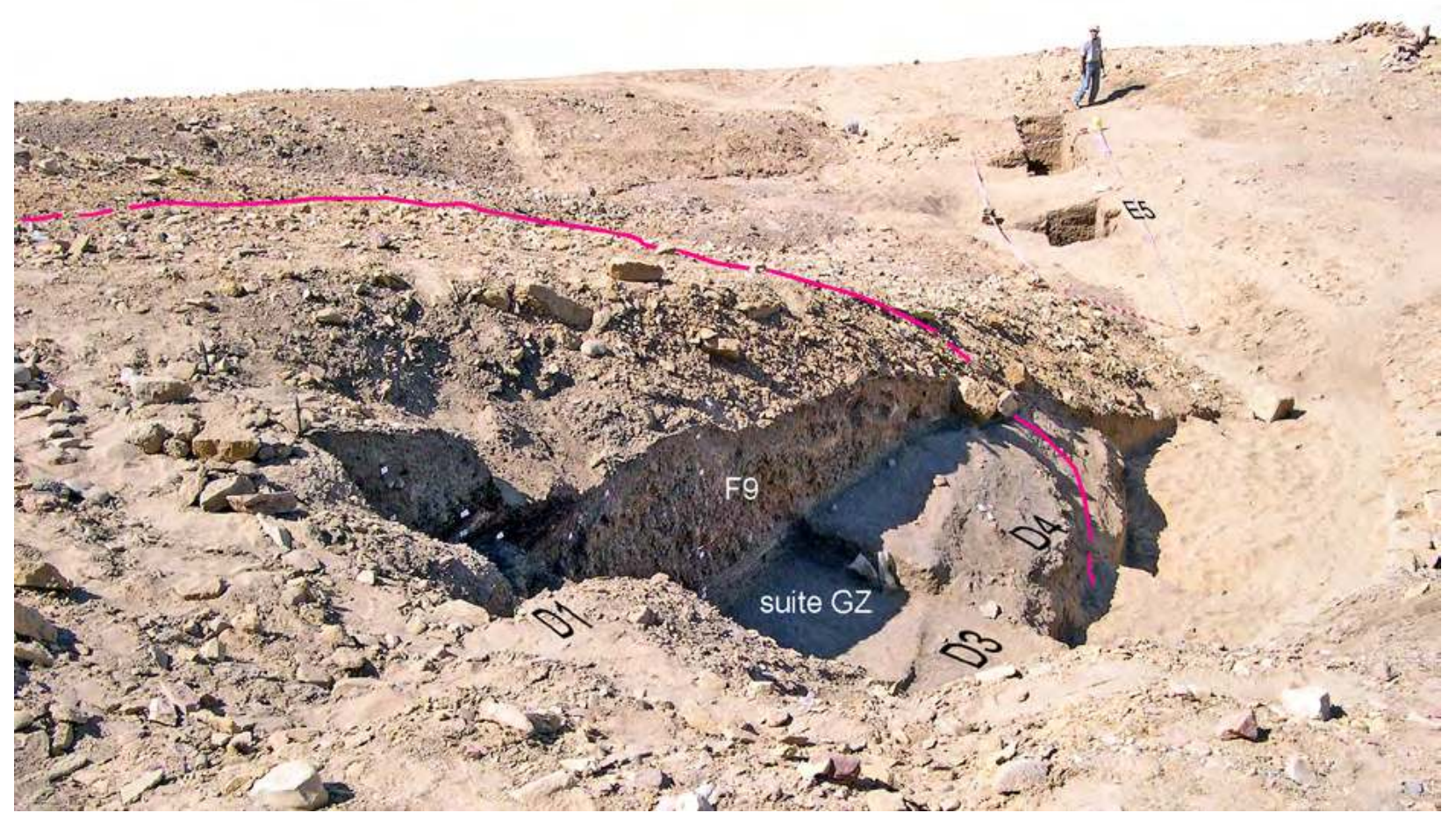

Figure 10. Area C: Later Sabaean surfaces of settlement's Lobe 5 (outlined in colour) under excavation in middle and upper Sector D, from above. (P. Morlupi 2005 @ MAIRY, adapted by F.G. Fedele 2020)

Hill $\mathrm{G}$ (it can be glimpsed in the right-hand third of Fig. 39, Chapter 1, in Volume 1). A small isolated hill (or tell?) located about $90 \mathrm{~m}$ south-southwest of the Minaean gate. Concentrations of Sabaean potsherds, clearly associated with grey or grey-hazel fine-grained sediments and 'darkened' stones, indicate a Sabaean occupation of unknown size on the hill. The sediments were described as similar to those of suite GZ in Sector D of Area C.

ST, 'Southern terrace' (Figs 13, 15). The site is located on the alluvial terrace along the left bank of Palaeochannel 1,59 30-45 $\mathrm{m}$ to the south of the southeastern corner of Barāqish. Scatters and small heaps of cultural material, similar to those of site ET (below) and indicating a Sabaean occupation, form a low, spreadout eminence, not a mound. The site was largely buried by the dumps from the excavations in the temple area.

ET, 'Eastern terrace' (Fig. 14). This large site, or cluster of sites ${ }^{60}$ is located at a distance of $40-80 \mathrm{~m}$ from the northeastern arch of the Minaean wall, in the middle third of a long and wide alluvial terrace apparently constituting a wedge at the confluence of Palaeo-channels 2 and 3. This dissected terrace forms a natural rise completely detached from the Barāqish talus, equivalent in this to Hill $\mathrm{C}$ on the opposite side

\footnotetext{
59 These former watercourses are described below.

60 Observed by A. de Maigret. After a short visit in December 2005 I examined the site and the terrace in December 2007.
}

of the main mound. In turn, the site or sites form a low but evident mound with two or three humps. An extensive and probably thick deposit characterized by a combination of Sabaean pottery and fine-grained sediments distinctly evokes the Later Sabaean suites of Sector D in Area C (suites GK and GZ). ${ }^{61}$ There is little doubt that ET is to be understood as a small tell concealing a significant Sabaean occupation, of great potential for future research.

Sites ST and ET, exclusively characterized by Sabaean pottery, can thus be identified as fully Sabaean, proper occupation sites. Judging from surface evidence, including its horizontal extent, at least ET is quite possibly a residential satellite site to the main Sabaean settlement. Considered together, all the sites described - Hill C, Hill G, ST, and ET - appear to form a regularly spaced crown of satellite occupations at distances of 20 $\mathrm{m}$ (ST) to $90 \mathrm{~m}$ (Hill G) from the base of the main tell at the time; and at least two of them seem eventually to have developed into minor mounds in their turn.

\subsection{Additional data: scatters and the eroded tell}

Two further, different sources of horizontal information must be added to the inferred occupation sites above. The first source is represented by the simple scatters of

61 Carinated, Red Lustrous ceramic types (cf. Chapter 23, this volume) are prominent. These sediments are locally eroded, but otherwise not much disturbed. 
pottery debris, not necessarily or positively indicative of in situ occupation. As a second source of information we have the visible, locally outcropping parts of the Sabaean tell itself.

The Sabaean pottery scatters do not require many comments beyond the fact of their topographic occurrence, plotted in Fig. 9. They have been observed round most of the perimeter of the walled town, but appear to be particularly important along the northern arch of the talus, which suggests that the Sabaean tell exceeded in area the Minaean walled town here as well (see below). The only portion completely devoid of Sabaean ceramic evidence is - or was, when inspected in 2005 - the string of exposures below bastions T30T33 created by the construction of a long ramp for excavation-waste disposal. This dirt road evidently cut through post-Sabaean deposits. ${ }^{62}$

On Hill D (Fig. 11 A), in addition to sparsely occurring on the surface, Sabaean pottery came to light from layer 4 of the Area D cemetery, below the Minaean tombs. A genuine Sabaean site could exist on Hill D in the same way as on the tail of Hill C, but excavation data so far have not allowed to determine its presence or nature. The excavation in Area $\mathrm{D}^{63}$ 'confirmed the presence of an Ancient South Arabian or "Sabaean" stratum [...] dating back to the beginning of the 1st millennium B.C. ${ }^{64}{ }^{6}$ but it was not possible to ascertain whether this presence consists of tombs or a settlement. ${ }^{65}$ Elsewhere in this book I discuss whether the Sabaean traces on Hills C and D, in conjunction with those from Sounding F nearby, could suggest a centuries-long vocation for specialized activity - trade, and apparently caravan trade. ${ }^{66}$

A major problem in this context is the nature of Hills C, D, and G. Are they natural landforms, such as low mesas or emerging inselbergs (if domed), merely covered by a veneer of loose sediments? Or are they essentially man-made tells, that is, smaller replicas of Yathill's main mound? Sadly, this could not be determined and nobody knows. But the possibility that they are artificial mounds or forms is clear, and more probable still is a combination of a natural rise and a man-made component. In fact we know that at least a small portion of Hill D - the cemetery - is made up of a 3-metre- thick blanket of partly cultural deposits, covering whatever hard substratum there

\footnotetext{
62 This road for motor vehicles, constructed when work at Barāqish was resumed in 2003, accessed the interior of the town via the Islamic postern located in wall recess R32/33 (Chapter 1 in Volume 1, Fig. 45).

63 Antonini 2010a.

64 For this dating see Fedele, Chapter 16 in Volume 1.

65 Antonini 2010b, 43.

66 Chapter 19, section 3.1, this volume.
}

may exist. ${ }^{67}$ It is not inconceivable that Hill D, for its location and vaguely tabular form, preserves a remnant of old alluvial terrace as its underlayer or core, while a significant 'tell' component can perhaps be conceived for humpback-shaped Hill C. Hill G looks like the typical tell, but is in fact equivocal as to its nature.

As for the outcropping parts of the Sabean tell itself, the prime example is so-called settlement Lobe 5, revealed by the excavations in Area C (Figs $9 \mathrm{~A}$ and 10). ${ }^{68}$ Towards the end of the Sabaean occupation, an area of mudbrick structures, probably houses, appears to have developed on the northwestern edge of the mound, in a jutting-out and slightly eminent position which the erosion eventually remodelled as a lobe. This tell eminence was located southeast of middle Sector E and south of Sector D, clearly the edge of the Sabaean tell at the moment. It overlooked from short distance what remained of Sabaean Wall F4.

But although defined - stricto sensu - as roughly adjacent to excavated sectors $\mathrm{E}$ and $\mathrm{D}$, Lobe 5 might be an appropriate if provisional designation for the whole portion of Sabaean settlement located in the area comprising upper Sector D and reaching up to future Minaean bastions T5 and T6. Except for two restricted test pits (Sectors B and C) this area still awaits excavation. Stratified 'living floors', extremely rich in domestic refuse, have been excavated in upper Sector D, and traces of mudbrick structures have been recognized up to the area conventionally called Locus 200 in Sounding A, underneath Minaean bastion T7. By this time, the tell had developed into a flat or domed relief, a little retracted but now rising to $10-11 \mathrm{~m}$ above the immediate plain. Elsewhere the tell might have been higher. Accepting this further extension, supported by the perceived morphological and archaeological continuity, Lobe 5 can designate the whole, relatively protruding northwestern sector of the Later Sabaean settlement on the tell of Yathill.

The significance of Lobe 5, as represented by the horizontal exposures in upper Sector D, should not be underestimated. Admittedly, the field evidence does not allow to speak of residential architecture, but at any rate, however minuscule these exposures, here we have at the moment the only known fragment of Sabaean residential space and context not only from Yathill but the whole Jawf. This is worth being noted in the light of what were lamenting C. Edens and T. Wilkinson in 1998, a few years before the excavations at Barāqish Area

\footnotetext{
67 Area D, unpublished photographic records of full sections and the Sabaean layer, kindly made available by S. Antonini in 2018. Cf. Chapter 16, Fig. 2, in Volume 1.

68 On the identification of Lobe 5 see Chapter 17, sections 4.1 and 7.6, this volume, with stratigraphic and horizontal illustration. Brief mention was made in Chapter 18, section 3.1.
} 

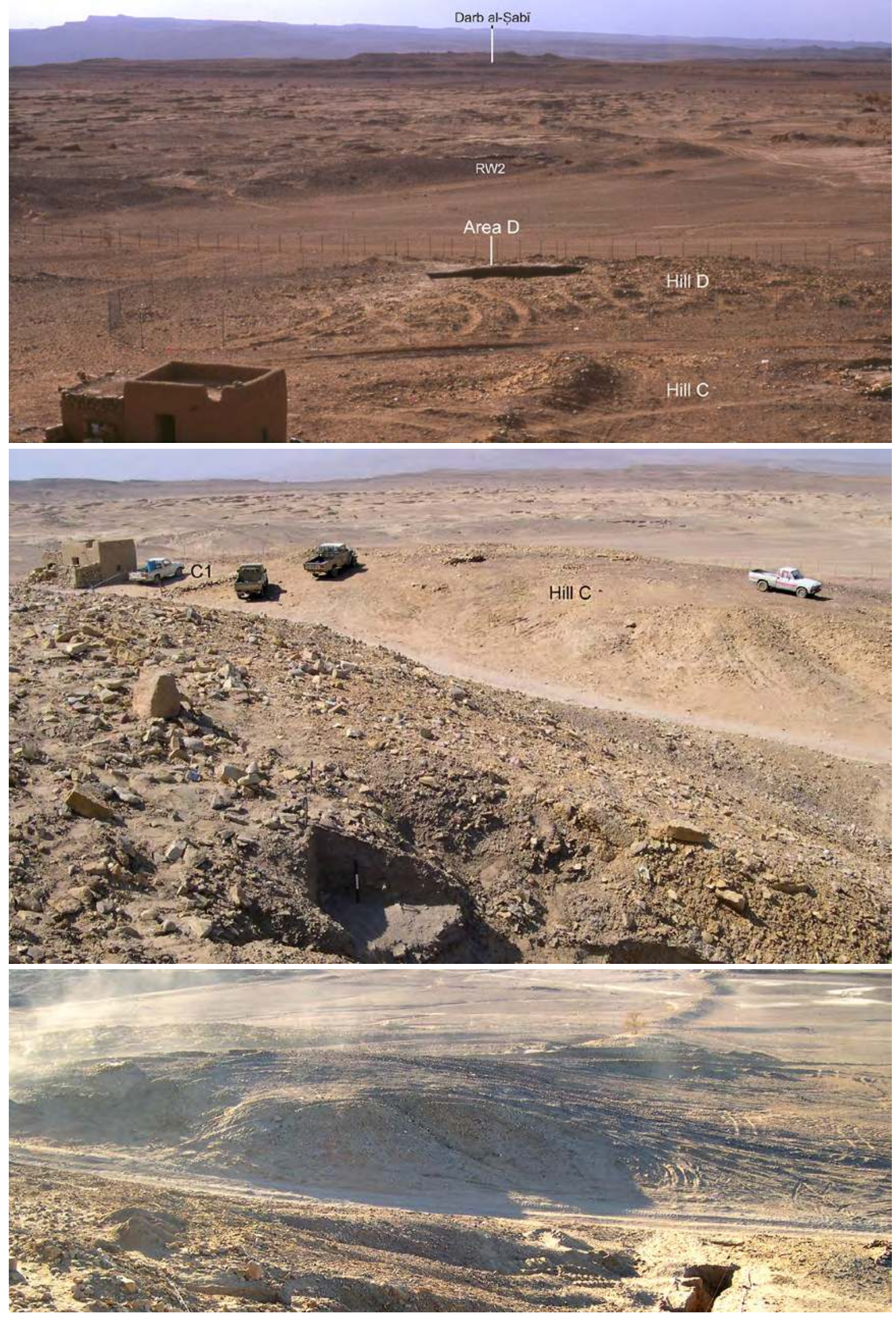

Figure 11. Views of Hills C and D from upper extramural Area C, with Darb al-Șabi mesa and outcrop RW2 in the background of top photograph. Bottom: Hill C, detail from Fig. 9 in Chapter 17, this volume. (Top, F.G. Fedele 2006; other images, P. Morlupi 2005 (C) MAIRY; all adapted and optimized by F.G. Fedele 2020) 


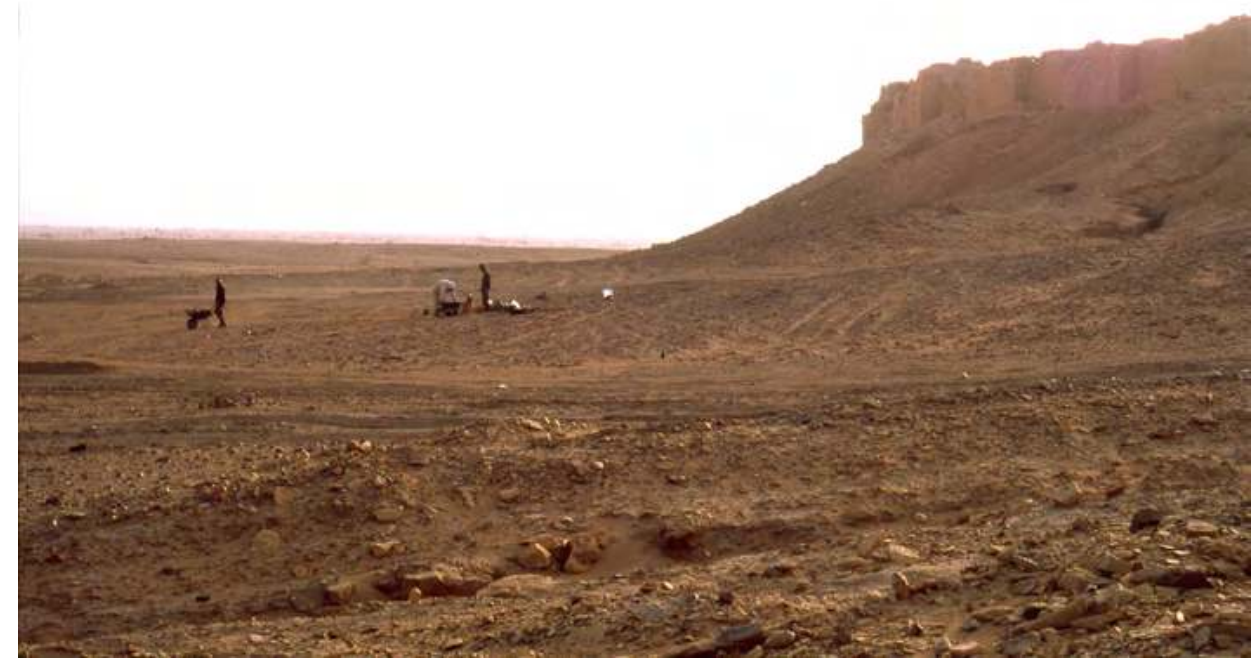

Figura 12. 'Tail' of Hill C with Sabaean site (foreground) and Sounding F in progress in middle distance. Northwestern Barāqish in the background to the right. (F.G. Fedele 2006)

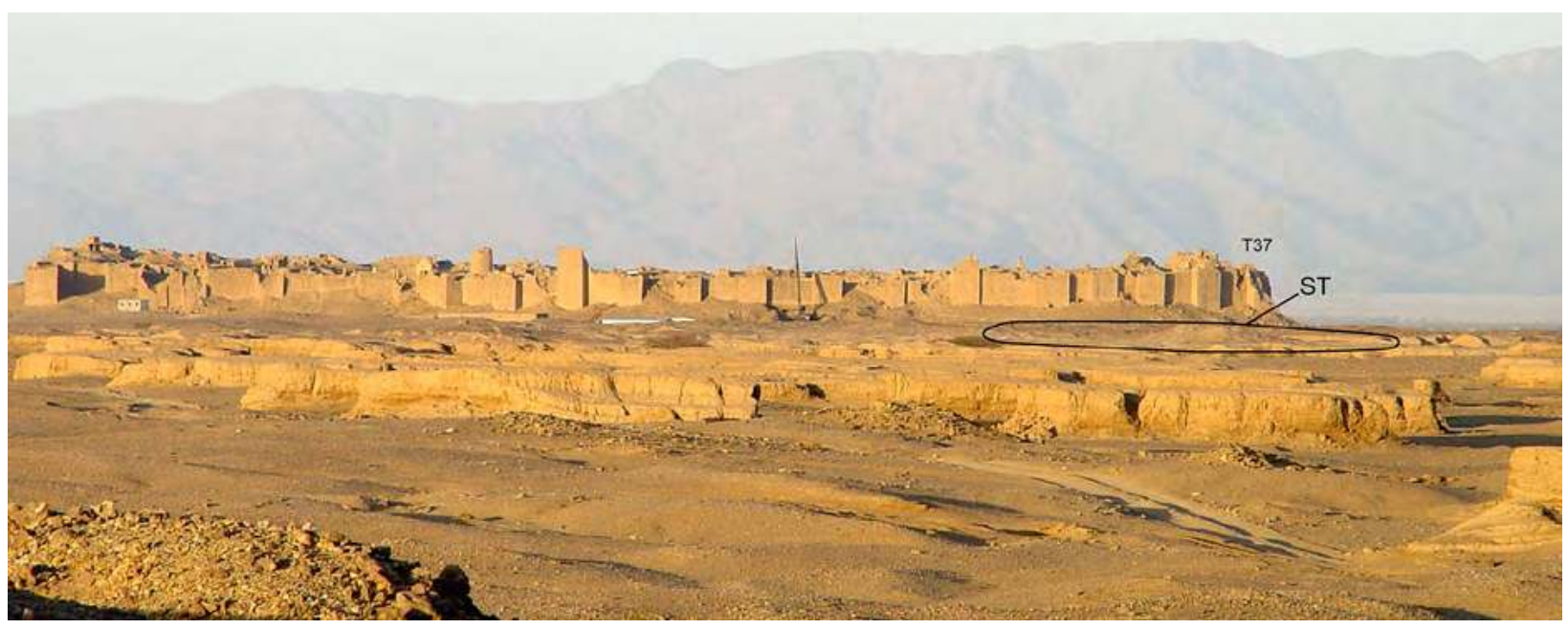

Figure 13. Barāqish from the southwest, with the Southern terrace and Sabaean site ST marked. In middle distance is the floodplain of Palaeo-channel 1. (A. de Maigret 2003 @ MAIRY, adapted by F.G. Fedele 2020)

C, that exposures of residential architecture had been until then too limited to be of any use in a perspective of social or settlement archaeology. ${ }^{69}$

A second portion of the Sabaean tell, equivalent to Lobe 5 though dissimilar in morphology, was discovered in December 2007 at the southeastern 'corner' of Barāqish/Yathill below bastions T37 and T36. This exposure was provisionally called Area 37, and duly mapped for future investigation (Figs 15-16). Area 37

69 'Evidence for differentiation of wealth and status [in the Șayhad Iron Age society] is not readily available because exposures of residential architecture have been too limited to compare house size, elaboration, and contents, and burials have not been reported in useful numbers'; 'archaeological evidence remains rudimentary' (Edens and Wilkinson 1998, 97). encompasses a sector of talus east and southeast of bastion T37, severely dissected by gullies. There are seven main gullies, covering the entire sector of the 'corner'. The two largest and deepest, B and C, descend radially towards the southeast and then partially bend to the south; there is decreasing depth of incision from gully B to gully D. The active erosion observed in 2007 was bringing to light 'old' sediments from grey to beige, unequivocally similar to those of Sector D in Area C, containing abundant Sabaean pottery of 'classic' typology (e.g., carinated forms in coral-red lustrous ware) and animal bones. Concealed within the talus, a segment of an ancient wall could be seen: a continuation of the Sabaean wall in Area C, Wall F4, perhaps? ${ }^{70}$

70 On Wall F4 see Chapter 17, sections 6.2-6.3, and Chapter 18, 


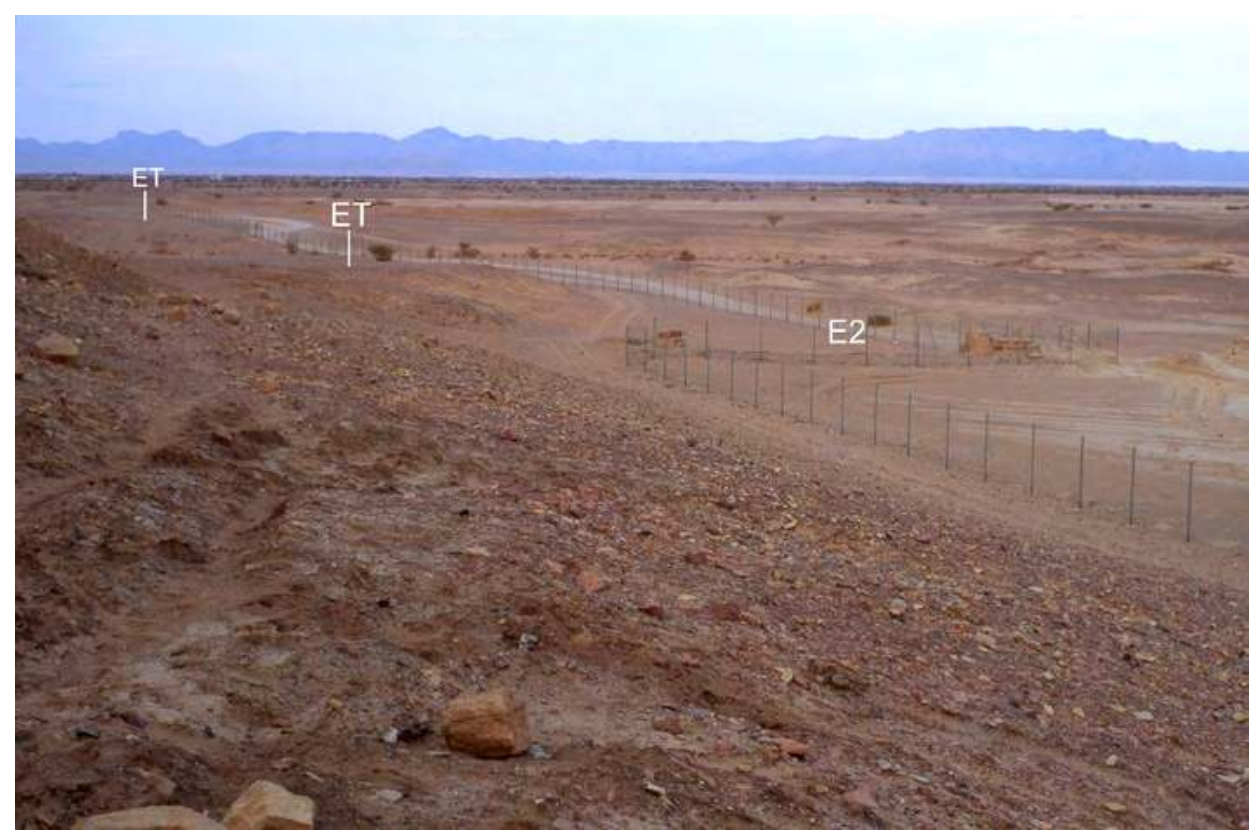

Figure 14. The Eastern terrace with Sabaean site ET and weir E2, facing north, from the talus. (F.G. Fedele 2006)

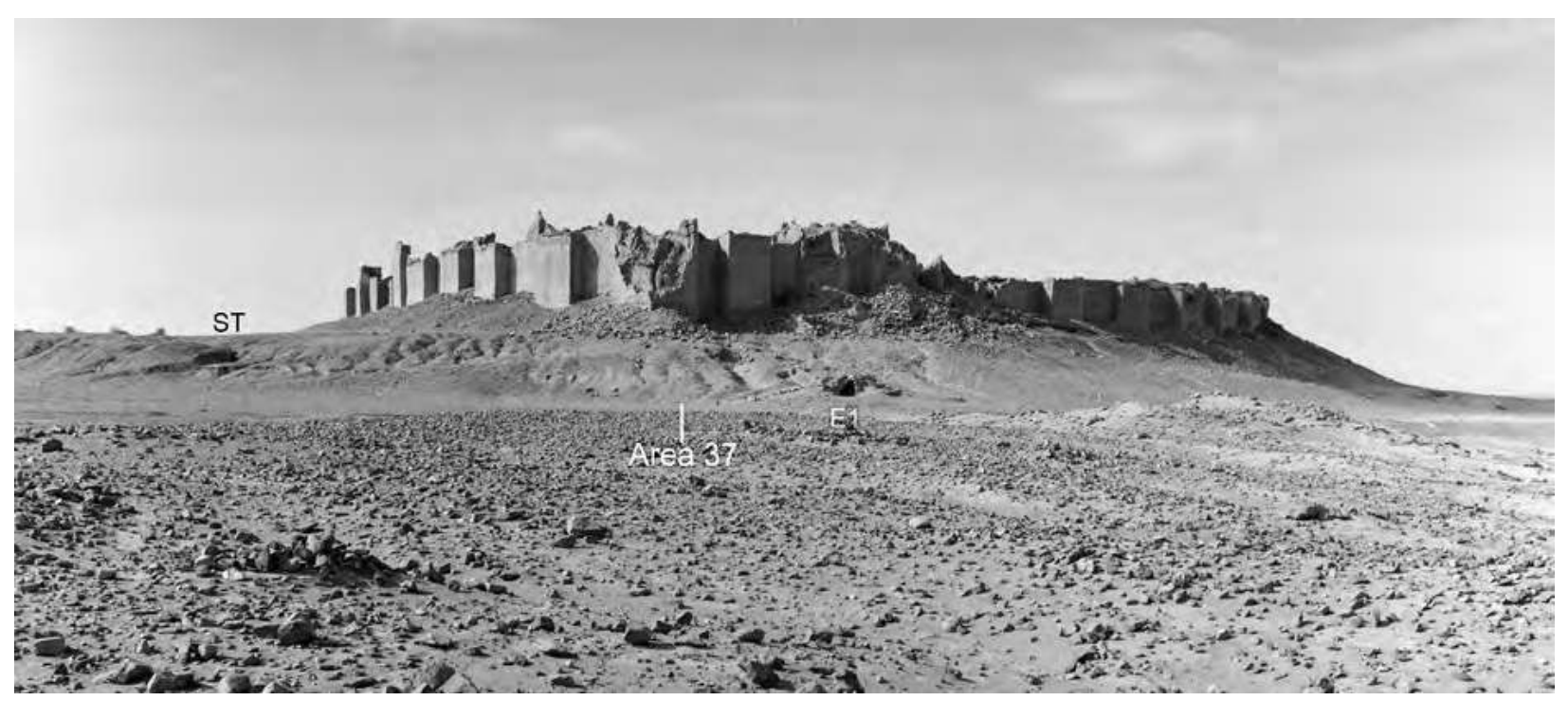

Figure 15. Barāqish/Yathill: Area 37 from the southeast; the Southern terrace on the far left.

(A. Solazzi 1986 @ MAIRY, adapted by F.G. Fedele 2020)

In the future, repeating the successful strategy adopted in Area $C$, it would be of great interest to carry out an excavation in Area 37 that directly connected all the relevant features: the Minaean wall, the base of bastion T37 with presumed bedrock $R_{0}$, the ancient wall emerging from the talus, well E1, and the eastern plain. Needless to say, obtaining a complete profile of $R_{0}$ would be of utmost interest.

section 3.1, both in this volume.
The above data definitely show that Sabaean Yathill exceeded in surface area its Minaean successor at least in two directions, to the northwest and to the southeast. A further hint of areal extent would be provided by Wall F4 (Fig. 9 A), and by its expected continuation when discovered..$^{71}$ section 4 , below. 


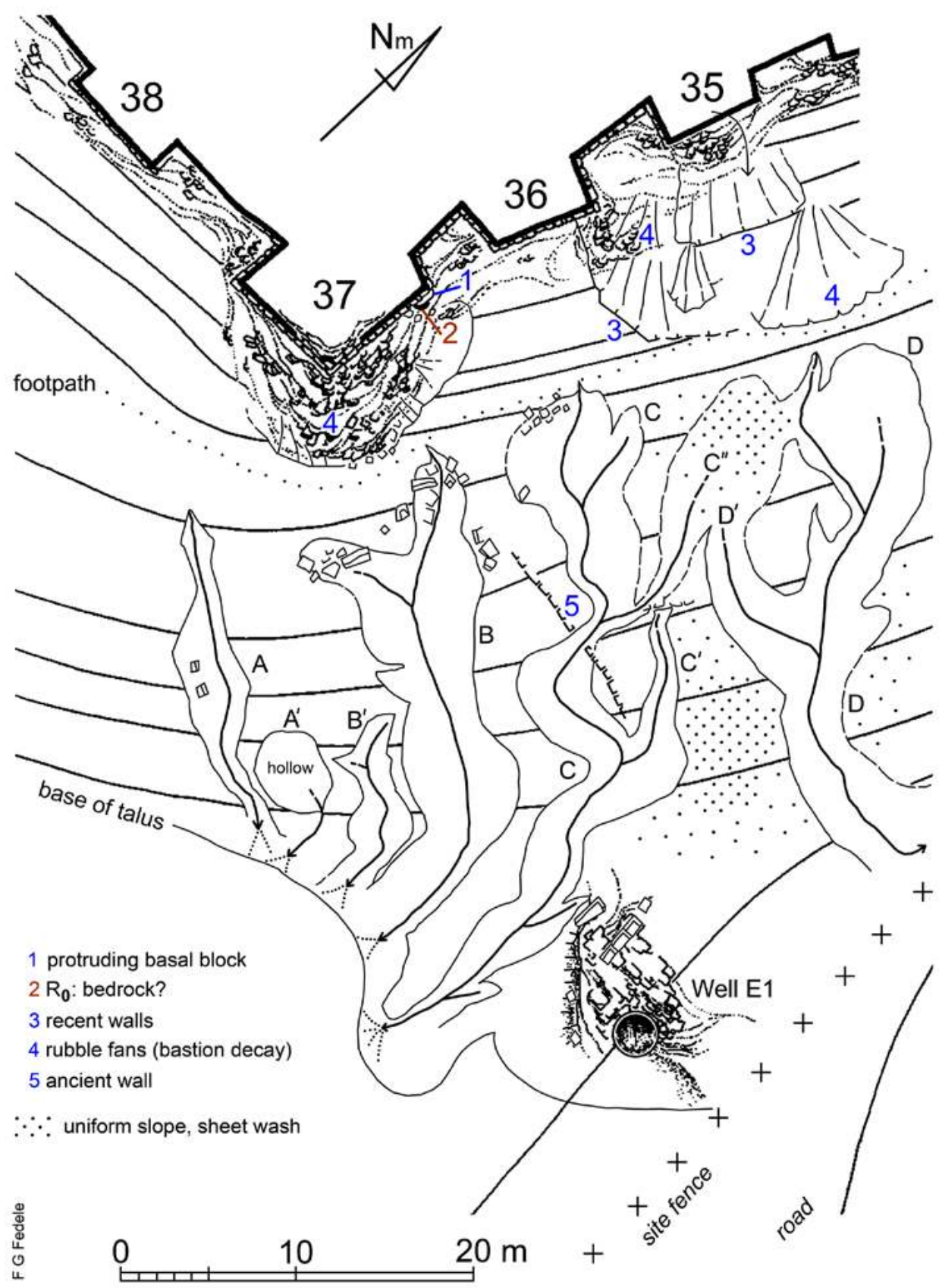

Figure 16. Barāqish/Yathill: a plan of Area 37 as surveyed in December 2007. (F.G. Fedele 2007, inked 2020)

\subsection{Other 'outliers'}

Finally, mention must be made of three outlying sites of completely different nature. The problem common to all three is their age, because there is no evidence for assigning them to the Sabaean period. One is funerary: site 'BARiii' in the northern sector of the Barāqish fenced area (approximate location marked as 'tombs' in Fig. 1). In Chapter 2, in Volume 1 of this book, S. Antonini describes it as located 'in an area of higher ground, 80-100 $\mathrm{m}$ to the north of the [Minaean] wall, in front of bastions $\mathrm{T} 15$ and T18'.72 'Since fragments of human bones were noted alongside scarce preIslamic pottery, the area was interpreted as a cemetery, although neither remains of surfacing structures nor fragments of funerary stelae were in evidence. From this fact, combined with the well-fired red pottery, de Maigret argued that one was dealing with Sabaean tombs. Unfortunately it was impossible to carry out

\footnotetext{
72 Apart from the issues of cultural attribution and dating, this burial site will need to be located more precisely in the future, when not only can archaeological research be resumed but adequate protection of the site be ensured.
} 
excavations. ${ }^{73}$ Except for a few other fragments, the ceramic collection 'was composed exclusively (and curiously) only of ring-foot bases', belonging to bowls, which by analogy with the Minaean cemetery in Area D were interpreted as oil lamps. ${ }^{74}$

The other two sites, E1 and E2, are instances of hydraulic works. Both are located east of the Barāqish mound at a distance of 20-30 $\mathrm{m}$ from the base of talus (Figs 1 and 9). E1 is a well covered with a cyclopean structure, now decayed (cf. Fig. 15, seen from a distance). Because of its potential interest in connection with the depth of bedrock, it was mentioned above in section 2. E2 is a weir (Fig. 14). ${ }^{75}$ It shows an east-west orientation as if the purpose of the structure was to divert the flood water away from the Eastern terrace ${ }^{76}$ which supported Sabaean site ET. None of the two could be investigated and their date is unknown, but in their present form both are probably Minaean. ${ }^{77}$ Concerning the ancient wells of Barāqish/Yathill, neither the Islamic well in the middle of the town could be inspected. ${ }^{78}$

Three dry watercourses flank the mound of Barāqish within minimum distances of 60-120 metres to the south, east, and north. They can be designated, in that order, as Palaeo-channels 1, 2, and 3 (Figs 1 and 9).

- Palaeo-channel 1. A narrow, deep furrow to the south and east of the town. It cuts a sinuous bank several metres high in the Southern terrace on which site ST is located. This fossil channel meanders in a tract of floodplain filled with eroded, thick silty alluvium (Fig. 13). It is the remnant of a larger wādi that approached Yathill from the south and then skirted the incipient mound (?) to flow east.

- Palaeo-channel 2. An elongated, linear depression to the east of the town, outside the fenced archaeological area, on the margin of the much wider floodplain further east (see above, end of section 2). It looks like the continuation of Palaeo-channel 1.

- Palaeo-channel 3. A relatively deep furrow to the north and northeast of the town, within the fenced archaeological area. The Eastern terrace, on which site ET is located, slopes down onto its

\footnotetext{
73 Antonini, Chapter 2; cf. de Maigret 1986, 388. Site 'BARiii' was mentioned in Chapter 1, section 3.2, in Volume 1: 'The operations of 1986 [...] also led to the discovery of important satellite monuments around Barāqish, including probable Sabaean tombs in the northern sector.'

74 Antonini, Chapter 2.

75 Weir: a wall across a channel, controlling or stopping the flow.

76 The watercourse involved is Palaeo-channel 2 (see below).

77 See mentions of both E1 and E2 in Francaviglia 2002, 119-127.

78 See mention in section 2 , above.
}

right bank. This channel might be a fossil branch of a wādi that flowed round Yathill to the north.

Small and shallow, these fossil channels appear to have been completely abandoned by the seasonal water flow for a long time, but a provisional evaluation of the relationships of sediments and morphology with site ST and Area 37 suggests that at least in the case of Palaeo-channel 1 water may still have been running during the Later Sabaean period. With its thick blanket of silty alluvium and 30-50 m wide on average, the waterbed of Palaeo-channel 1 bears testimony to innumerable cycles of alluviation and erosion, with the character of a minor braided rivercourse. Lateral scarps and remnants of bed alluvium several metres high, now deeply scarred by rainwater, are evident over a west to east stretch of about $200 \mathrm{~m}$ south and southeast of Barāqish (Fig. 1).

A fourth watercourse is closely associated with Barāqish. It is an occasionally active channel, apparently, which pending an available name will be called the 'Western wädī'. ${ }^{79}$ It flows in a general northward direction between $120 \mathrm{~m}$ and $350 \mathrm{~m}$ west of the town, widening from less than $40 \mathrm{~m}$ upstream to about $210 \mathrm{~m}$ downstream (Fig. 1). The widening begins at the passage between mesaform outcrop RW2 and Hill D, and largely coincides with a bend around Hills D and $\mathrm{C}$. For a mention of this wādī in the context of the floodplain of Barāqish and Plain F see Chapter 17, end of section 17 , this volume.

\section{The Greater Yathill model: discussion ${ }^{80}$}

On the basis of the data in the previous sections, it is entirely apparent that Yathill had its origins as a substantial Sabaean occupation, which the successors merely inherited. The Sabaean period reveals itself as prominent in Yathill's history. During the Earlier Sabaean phase Yathill was a broad, low tell, extending horizontally at least $35 \mathrm{~m}$ away from the line of the future Minaean bastion T6. The lowermost deposits we have uncovered in this area already show a mound with its incipient talus. This earlier Yathill was not fortified a few Sabaean settlements were, if any. A weak organic soil had developed, ${ }^{81}$ probably connected with an oasis microclimate that could reveal extensive hydraulic management of the main wādī already by that time. ${ }^{82}$ And by the time of the walling by mukarrib Karib'ill

\footnotetext{
79 In the Barāqish area the denomination of topography from oral information has remained vague or contradictory, particularly in the case of hydronyms.

80 This section updates and expands the very preliminary version presented in Fedele 2010, 145-146.

81 The provisionally defined Yathill Palaeosol.

82 Chapter 17 , section 5.2 , this volume.
} 
Watār, shortly after 700 BCE, ${ }^{83}$ Yathill was already a sizeable Sabaean settlement. Its initial characteristics and basal layers are unknown, however, and their recovery is a distant goal..$^{84}$

What can we say about the organization of Sabaean Yathill and its eventual fluctuations through time?

Although fragmentary, the surface observations made around the tell allow a slightly broader glimpse of settlement archaeology for the Sabaean period than was possible on the basis of test trenches and soundings alone. To the extent that we can rely on these observations, there were satellite units in addition to the main mound, and such units were possibly residential in nature. Surface clusters of pottery and ecofacts around Barāqish, contained in sediments of partly cultural origin, tend to suggest for Sabaean Yathill a settlement complex made up of an 'urban' central core and a 'ring' of more or less sparse occupation units. At least at some developed stage, Sabaean Yathill included 'an occupational mound as well as wider scatters of dispersed settlement in the surrounding area'. ${ }^{85}$

This type of organization was perhaps not unlike the Hajar al-Durayb complex at Yalā, a town surrounded by 'farmsteads' in the immediate vicinity ${ }^{86}$ or rather 'homesteads' (see below). At Hajar al-Durayb the raised area, known as the 'upper city', was flanked to the north and west by a 'lower city' of around 20 sparse habitation units. ${ }^{87}$ But this organizational pattern was possibly widespread, as suggested for example by some data from Mārib and the Mārib Oasis, or from Najrān, modern Al-Ukhdūd, in southern Saudi Arabia. In the Mārib Oasis, the 8th-5th centuries witnessed a trend from sparse residence to settlement centralization, connected with the growth of the irrigation system. ${ }^{88}$ At Najrān, 'satellite sites' were distributed at various distances around a 'central walled area' (al-Ukhdūd), and these satellite sites are described as including 'vague scatter[s] of ceramic material', 'low elevations', 'small elevations', and even 'small libn tell[s]'. ${ }^{89} \mathrm{~A}$

83 Chapter 18, section 3.1, this volume.

84 One could say, with A. de Maigret in the case of Yalā/al-Durayb (1988b, 20, italics mine), that in the future it would be important 'to establish whether there was a more ancient and, so to speak, poorer period of habitation prior to this' - i.e., prior to the documented flourishing of the settlement. At Yathill we presently know the mere existence of such a period, not its substance.

85 Lawrence and Wilkinson 2015, 330, speaking of northern Mesopotamia (italics mine).

86 'Farms': de Maigret 1988b.

87 de Maigret 1988b, 10-11; Queen of Sheba 2002, 157 (St J. Simpson and A. Porter).

88 Papers by S. Japp and H. Hitgen read at the 12th Rencontres Sabéennes, held at IsIAO, Rome, 11-13 June 2008; and Eichmann and Hitgen 2003.

89 Zarins et al. 1983, 24, 36 (note 2), pl. 16 (plan); quotations from p. 24. Libn, leben: mud bricks, mud blocks, or mudbrick material in similar pattern is documented in more or less coeval settings outside South Arabia, for instance in Oman, ${ }^{90}$ and at a different date and territorial scale elsewhere in Western Asia. ${ }^{91}$

Unfortunately, we presently have no clues that can help establish the relative chronology of the components of Greater Yathill. Therefore it is entirely possible that Yathill, in fact, originated as a dispersed settlement rather than a nucleated one,${ }^{92}$ that is, a settlement with no 'central' or core unit, hence no main mound, at least at the beginning.

As to the constituting units of the Yathill settlement complex, different organizational-functional models can be proposed: $:^{93}$

- 'nuclei': small groups of buildings; transitional to hamlets;

- 'hamlets': small settlements (on small elevations, be they natural hills or artificial mounds, or the combined result of both);

- 'homesteads': a house and land, a farm and its buildings; ${ }^{94}$

- 'trading posts', trade installations or micro-sites.

Until specific field research is carried out, however, we lack information for choosing among these options. Concerning the last one, some of the observations in these pages can provide contextual information on Yathill as a Sabaean caravan trade post. The material and stratigraphic evidence for caravan trade at Sabaean Yathill has been discussed in Chapter 19, section 3, this volume, and there is no need to repeat that here. I will just note that, at least during the Later Sabaean phase as defined from Area $\mathrm{C}$, there is a modest but relatively explicit record of 'camping' and perhaps 'foreigners' from the bottom Sabaean levels away in the plain ('Plain F', including Sounding F and Locus P07).

By analogy to Najrān/al-Ukhdūd, Yalā/al-Durayb, and a few other examples, ${ }^{95}$ a hypothesis can be put forward here about the walled area of Sabaean Yathill. If it is accepted that Wall F4 is the known portion of the town wall (see section 3.2, above), it is not impossible that

\footnotetext{
general.

90 To paraphrase Condoluci et al. $(2014,111$, on Salūt in interior Oman), one could say that the main mound at Yathill 'was not an isolated site, [but] was at the centre of a more extensive and articulated settlement'. Also at Salūt there was a ring of smaller sites on isolated hillocks, and coeval pottery was present at all of them.

91 E.g., the North Mesopotamian case cited above (Lawrence and Wilkinson 2015).

92 Cf. Steadman 2005, 288.

93 'Organizational-functional models' is provisional terminology.

94 Cf. 'homesteads' in the case of Najrān, as termed by Zarins et al. 1983, 26.

95 Breton 1991; 1999, 88-90; 2002, 145; Breton et al. 1998, 94.
} 
this stone-and-leben wall was discontinuous, and that it only joined together existing buildings. ${ }^{96}$

Throughout the Later Sabaean phase, the settlement still extended horizontally far outside the Minaean walled perimeter in the northwestern and perhaps the northern sectors of the tell. Speculative extrapolation from surface finds and talus morphology suggests that the Sabaean settlement also exceeded the Minaean walled surface to the southeast (Area 37). As glimpsed from Area $C$, the Minaeans probably obliterated most of those outlying mudbrick ruins when they built their wall.

Both the main tell itself and the conceptual and spatial arrangement we call Greater Yathill were terminated by the Minaean nucleation and conspicuous, emphatic walling of the town. What intervened between the Sabaean and the Minaean forms of town was a substantial change in settlement organization, and indeed in settlement ideology - an entirely different urban concept. Not only the spatial and material arrangement of settlement were different, but the idea itself of a 'town' did change. This much can be inferred not only from Yathill, based on the evidence presented here, but also to a certain extent from what is known of Sabaean urbanism elsewhere, however limited the present information.

Unfortunately, we cannot say anything about the layout of the Sabaean settlement, either in the interior of the town (i.e. the main settlement) or in the satellite sites. Initially, the Sabaean settlement may indeed have been large, but it was not necessarily dense, compared to the subsequent developments (see 'The problem of unoccupied space in towns and cities', below). With the Later Sabaean, the settlement in some parts of the town might in theory have become denser, and the extremely little we can infer from Lobe 5 does not contradict this hypothesis.

To interpret settlement history in a case like that of the tell exposures in Area C, a quantitative assessment of accumulation rates would be useful, provided that better time control through radiocarbon dates can be obtained in the future. 'Issues central to settlement pattern analysis, such as abandonment and reoccupation events, population fluctuations, building activities, and activity areas are more easily identified

\footnotetext{
96 At Yalā, the later and higher curtain stone wall 'protect[ed] and extend[ed] an earlier settlement, which was not fortified but only defended by houses forming a ring, built on the southern side of a low natural rise in the valley' (de Maigret 1988b, 13; cf. Queen of Sheba 2002, 157 [St J. Simpson and A. Porter]). At Al-Ukhdūd, Zarins et al. $(1983,26)$ describe the method as 'using curtain walls to join existing buildings whose outer walls constituted part of the defensive perimeter'. A more detailed exposition of this practice is in Breton 1991.
}

when accumulation rates are calculated', as effectively shown by Julie Stein. ${ }^{97}$ Understandably, also the availability of larger exposures would be very helpful for this approach.

\section{The problem of unoccupied space in towns and cities}

According to Eichmann and Hitgen, at Mārib the walled city's interior was not entirely built-up.$^{98}$ This condition might have been rather common in Sabaean towns, as it was elsewhere during the 1st millennium BCE, for example in Mesopotamia and in several or most parts of Arabia. The phenomenon of unoccupied space has been specifically investigated by Heather Baker for the Babylonian cities of the 1st millennium BCE. ${ }^{99}$ She identified three categories of 'unbuilt urban land': (i) unbuilt urban plots in residential areas; (ii) cultivable land within the city, i.e. gardens and orchards; and (iii) public space, including streets. Gardens and orchards presuppose an adequate water supply, which can hardly be imagined for the interior of Yathill - a mound in a semi-desert - except perhaps the oldest Sabaean town.

A potential comparison - with both affinities and differences - is Taymā', excavated since 2004 by a joint Saudi-German project. The oasis and the settled parts of the site are surrounded by a system of walls of altogether $15 \mathrm{~km}$ length, of which large portions can be dated to the early 2 nd millennium BCE. However, the actual settlement was clustered: large parts of the wallenclosed area were unoccupied. Taymā', apparently, always was a mega-site but not a mega-city. ${ }^{100}$

\section{Interim conclusions}

Conclusions can best be phrased as research tasks for the future. From a strictly cultural viewpoint, our knowledge would obviously make progress if each of the satellite sites listed in section 3 were tested sufficiently, together with a good sampling for humanpalaeoecological data. Particular goals relevant to the understanding of the 'main' settlement itself have already been mentioned in the previous pages: exploring the continuation of Wall F 4 or excavating Area 37 are preeminent. In the same perspective, settlement Lobe 5 should be unearthed horizontally over a suitable surface, if only because it is a particularly accessible part of the Sabaean settlement, unencumbered by thick overburden.

\footnotetext{
97 Stein et al. 2003, 297.

98 Eichmann and Hitgen 2003.

99 Baker 2009, with references. See also, e.g., Baker 2012, 918, 920.

100 For topographic information on Taymā' see Hausleiter 2010; Hausleiter and Eichmann 2018.
} 
Concerning the setting of Yathill, two main tasks can be indicated. ${ }^{101}$ As pointed out in section 2, still missing is direct knowledge of the terrain or terrains strictly underlying the settlement. Their determination and inspection would be important, perhaps even revealing from a morphological viewpoint, provided that a suitable exposure could be obtained. Equally important, and within reasonable reach, would be a stratigraphic exploration of the contact belt comprising the presentday plain (for instance Plain F) and the western edge of the Sabaean tell and talus, aimed at resolving the precise nature of the settlement in this part of Area $C$ and - possibly - its beginnings and context.

At Barāqish we not only have 'an extraordinarily wellpreserved Minaean town', as Christian Robin wrote long ago, ${ }^{102}$ but, underneath, an equally sealed and preserved Sabaean town, awaiting full rediscovery. Unfortunately, there was no way to develop this subject further through fieldwork during the early 2000s. What I have presented here, much more than a report of still minuscule observations and provisional hypotheses, is a blueprint for the future - a research agenda for focused work on a remarkably informative site and its area. A. de Maigret was looking forward to doing more testing of the large Sabaean settlement lying beneath Minaean Yathill, while I wished to broaden the investigations of the earliest settlement record extramurally, and had plans to test the Greater Yathill model if at all possible. If the above glimpse of the model is correct, those who will eventually set foot at Barāqish again for archaeological research 'will have enormous work ahead'. ${ }^{103}$
101 Cf. Fedele 2010, 145, 146.

102 '[Une] ville minéenne étonnamment bien conservée’: Robin 1979a, 193.
103 '[...] l'enorme lavoro che ancora ci attende': A. de Maigret, preface to Arabia 4, p. 10 (Naples, October 2009). 


\title{
Chapter 27
}

\section{Les inscriptions de Barāqish : apport à la connaissance de l'antique cité de Yathill et du royaume de $\mathrm{Ma}^{\mathrm{c}} \mathrm{i} n$}

\author{
Jérémie Schiettecatte \\ avec la collaboration de Mounir Arbach
}

\section{Introduction}

Le site de Barāqish et sa zone agricole irriguée ont livré plus de 600 inscriptions sudarabiques. Cela inclue les sanctuaires extra muros de Darb al-Șabī et de Shaqab alManașṣa, les ruines de Ḥuṣn Āl Șāliḥ et du Wādī Malāhāā. Ces inscriptions sont en majorité de langue ma'īnique, une dizaine est en langue saba'ique, une inscription enfin est une bilingue gréco-latine.

À partir de ce corpus et d'études antérieures, ${ }^{1}$ le propos consistera à apporter quelques éclairages sur la toponymie antique de la ville et de ses environs, sur son histoire économique, sociale, administrative et politique, sur ses réalisations architecturales et plus largement sur son inscription dans l'histoire des royaumes sudarabiques.

En outre, le corpus complète notre connaissance de la succession des souverains du royaume de Ma'īn. Une restitution des successions dynastiques est présentée dans le tableau 6 de cette contribution.

Les bornes chronologiques de cette approche sont fixées par les inscriptions elles-mêmes, du $8^{\mathrm{e}}$ siècle avant au $3^{\mathrm{e}}$ siècle de l'ère chrétienne. Pour les périodes antérieures, on se reportera aux contributions de F.G. Fedele dans ce volume (chapitres 17 et 18, en particulier dans ce dernier la Fig. 4). ${ }^{2}$ Concernant l'histoire du site à l'époque islamique et les sources relatives à cette occupation, une présentation synthétique en a été faite par Ch. Robin. ${ }^{3}$

\section{Inventaire épigraphique}

Le corpus épigraphique de Barāqish et de ses environs est exceptionnel par sa quantité et son contenu. Pour les besoins de cette contribution, 611 inscriptions ont été recensées (voir le tableau 3 pour les sigles et table de concordance). Rares sont les sites sudarabiques qui excèdent un tel nombre (Mārib, Raybūn, Hayd ibn 'Aqīl). Parmi ces derniers, seul Mārib rivalise par la variété du contenu (religieux, social, économique, politique, historique).

Nous devons en premier lieu ce recueil aux prospections épigraphiques (voir Antonini et Fedele, vol. 1, chapitre 1), et résumé ci-dessous :

- Joseph Halévy en $1870 ;^{4}$

- Eduard Glaser qui y envoie des émissaires en $1888 ;^{5}$

- Muhammad Tawfiq en 1944-1945;

- Ahmad Fakhry en 1947 ; $^{7}$

- Petr Grjaznevich ;8

- Jürgen Schmidt en 1977. ${ }^{9}$

Des prospections épigraphiques plus systématiques furent entreprises par la Mission Archéologique Française en République Arabe du Yémen (MAFRAY) sous la conduite de Ch. Robin, à partir de $1976,{ }^{10}$ puis la Mission Archéologique Italienne en République du Yémen (MAIRY) sous la conduite de Gh. Gnoli et A. de Maigret à partir de $1986 .{ }^{11}$

\footnotetext{
Halévy 1872a.

5 Glaser 1913, 83, 182.

6 Nāmī 1954-1957; $1955 ; 1956$; 1957.

7 Fakhry and Ryckmans 1951-1952.

8 Bauer et Lundin 1998.

9 Müller 1982.

10 Robin 1979a; 1979b ; 1987 ; Robin et al. 1988.

11 Gnoli et Robin 1992 ; Gnoli 1993a.
} 
Les fouilles sur le site par la mission archéologique italienne à partir de 1989, sous la direction d'A. de Maigret, ont livré des inscriptions supplémentaires trouvées en contexte religieux ${ }^{12}$ et funéraire. ${ }^{13} \mathrm{~S}^{\prime} \mathrm{y}$ ajoutent les inscriptions publiées par A. Agostini (voir chapitres 4 et 9 , volume 1 ; chapitre 24 dans ce volume).

Une part significative des textes relevés n'a pas encore fait l'objet d'une publication. Tous ne nous sont pas connus et cette présentation ne prétend pas à l'exhaustivité. Les paragraphes suivants présentent les grands ensembles du corpus.

\subsection{Barāqish}

\subsubsection{Rempart}

297 inscriptions, le plus souvent fragmentaires, ont été relevées sur le rempart de Barāqish dont 281 par la MAFRAY, numérotées B-M 1 à B-M 280. ${ }^{14}$ La moitié de ces textes était déjà connue par les prospections antérieures et publiée.

Un premier ensemble de textes fut réuni dans le Répertoire d'Épigraphie Sémitique (RÉS 2929-3060, RÉS 3535, RÉS 4224). G. Garbini ${ }^{15}$ les a republiés et complétés de textes additionnels signalés lors des prospections 'Tawfiq' et 'Grjaznevich' : numérotation discontinue comprise entre M 151 et M 467. ${ }^{16}$ Onze fragments ne figurent que dans la publication de la prospection 'Grjaznevich'. ${ }^{17}$ Un texte, Robin-Barāqish 80, est publié à part. ${ }^{18}$

Sept inscriptions trouvées en fouille au pied de la courtine R/44-45 du rempart sont publiées par A. Agostini (chapitre 9, volume 1) : Y.03.B.R44-45.1 à 3 et Y.04.B.T45.1 à 4 .

Au moins 136 textes restent inédits. Une monographie des inscriptions du rempart est en préparation sous la responsabilité de M. Arbach, F. Bron et I. Gajda.

\subsubsection{Temple intra muros de Nakrah}

74 inscriptions provenant des fouilles du temple de Nakrah ont été portées à notre connaissance. Ch. Robin

\footnotetext{
12 de Maigret et Robin 1993 ; Agostini 2011 ; 2015.

13 Agostini 2010b; Antonini et Agostini 2010a.

14 Cela inclut trois numéros bis (B-M 19 bis, 23 bis, 211 bis) et deux associations (B-M $247+255$ et B-M $26+23$ ).

15 Garbini 1974.

16 M 151-158, M 160-161, M 163-174, M 177-201, M 210-220, M 222233, M 236-270, M 272-283, M 347, M 378, M 404-406, M 410-444, M 446, M 448-449, M 466-467.

17 Gr 251, 253, 274, 278, 287, 299, 301, 308, 325-326 (Bauer et Lundin 1998, 90-110)

18 Robin 1979a, 193.
}

mentionne 95 inscriptions en incluant les fragments les plus modestes. ${ }^{19}$ Treize ont été publiées par Ch. Robin, ${ }^{20}$ une par Gh. Gnoli, ${ }^{21}$ une par A. Agostini. ${ }^{22}$ Les autres restent inédites.

Les sigles commencent par la séquence Y.90.B.A..., Y.92.B.A... et Y.03.B.A...

\subsubsection{Temple intra muros de 'Athtar dhu-Qabd}

26 inscriptions provenant des fouilles du temple de 'Athtar dhu-Qabḍ ont été portées à notre connaissance. Leurs sigles commencent par la séquence Y.04.B.B..., Y.05.B.B... ou Y.06.B.B...

Trois ont été publiées par A. Agostini : Y.05.B.B.12 et $13{ }^{23}$ et Y.05.B.B.16. ${ }^{24} 25$ sont publiées par A. Agostini (chapitre 4, vol. 1).

\subsubsection{Barāqish, reste du secteur intra muros}

A l'intérieur des remparts de Barāqish, hormis les deux temples, 50 inscriptions ont été relevées par la MAFRAY. Elles portent le sigle B-Int 1 à 50 . Seules cinq d'entre elles sont connues de prospections antérieures (B-Int 4, 10, 18, 19 et 21) et publiées par G. Garbini : respectivement M 208, M 426, M 204, M 207 et M 206. ${ }^{25}$

On peut ajouter à ce groupe de textes 16 inscriptions relevées par les prospections épigraphiques antérieures à 1976, republiées par G. Garbini, ${ }^{26}$ ainsi que cinq inscriptions de la prospection 'Grjaznevich' : Gr 254, $280,286,300,322 . .^{27}$

La MAIRY a relevé quatorze inscriptions, non publiées, dont le sigle comporte la séquence Y.90.B..., Y.90.B.ext... et Y.92.B... Un brûle-encens inscrit (Y.86.BAR/13) a été publié. $^{28}$

\subsubsection{Barāqish, secteur extra muros $\mathcal{C}$ - sondage}

Onze fragments d'inscriptions proviennent du sondage extra muros réalisé au pied du bastion 7. Ce sont pour neuf d'entre eux des fragments de scellements. Tous sont publiés par A. Agostini (chapitre 24, dans ce

\footnotetext{
19 de Maigret et Robin 1993, 458.

20 de Maigret et Robin 1993.

21 Gnoli 1996b.

22 Agostini 2012.

23 Agostini 2011.

24 Agostini 2015.

25 Garbini 1974.

26 Garbini 1974. Ce sont les inscriptions M 159, 162, 175-176, 203, 205, 209, 221, 234-235, 270, 305, 439, 445, 447, 450.

27 Bauer et Lundin 1998.

28 Antonini 1988.
} 
volume), avec un sigle commençant par la séquence B.06.C.O... auxquels il faut ajouter Y.06.B.C.1.

\subsubsection{Barāqish, secteur extra muros D - nécropole}

45 inscriptions, principalement des stèles funéraires, ainsi que trois brûle-parfums et tables d'offrande ont été exhumés lors de la fouille de la nécropole. Les inscriptions portent les sigles commençant par les séquences B.05.D.O..., B.06.D.O... Par ailleurs, des objets avec les sigles MAIRY.05 et MAIRY.06 proviennent d'une zone indéterminée du territoire Barāqish. ${ }^{29}$ Tous sont publiées dans un ouvrage consacré à la nécropole. ${ }^{30}$

On peut ajouter à cet ensemble une stèle funéraire inscrite, Antonini Stela 2, trouvée dans le temple de Nakrah mais provenant vraisemblablement de la nécropole..$^{31}$

\subsection{Darb al-Șabī}

31 inscriptions ont été relevées dans le sanctuaire extra muros de Darb al-Ṣabī, à l'ouest de Barāqish, lors des prospections de la MAFRAY. Elles portent le sigle MAFRAY-Darb aș-Ṣabī 1 à 32 et ont toutes été publiées. ${ }^{32}$

\subsection{Shaqab al-Manașșa}

19 inscriptions ont été relevées dans le sanctuaire extra muros de Shaqab al-Manașșa, au sud-ouest de Barāqish : une lors de la prospection 'Halévy' (Hal 484), quatorze par la MAFRAY (MAFRAY-ash-Shaqab 1 à 14) et quatre par la MAIRY (Y.86.SHQ/1, Y.90.SHQ/2, Y.92.SHQ/3 et 4). Toutes ont été republiées dans une monographie consacrée au site avec le sigle Shaqab 1 à $19 .{ }^{33}$

\subsection{Périmètre irrigué (al-Darb, Ḥuṣn Āl Șāliḥ, Wādī Malāḥā)}

\subsubsection{Darb al-Ashrāf}

Deux inscriptions ont été retrouvées dans les alluvions, à quelques centaines de mètres au sud du village de Darb al-Ashrāf (ou al-Darb). Elles ont été publiées avec les sigles Y.90.DA/ 1 et $2 .^{34}$

\subsubsection{Wādī Malāhāa}

Trois inscriptions ont été retrouvées par la MAFRAY en bordure du Wādī Malāhāà ou remployées dans le

\footnotetext{
29 Pagano 2010; Agostini 2010b.

30 Antonini et Agostini 2010a.

31 Antonini 2005.

32 Robin et al. 1988. MAFRAY-Darb aș-Ṣabī 14, initialement considérée comme une inscription, s'est avérée être une frise de bouquetins.

33 Gnoli 1993b.

34 Gnoli et Robin 1992.
}

village de Malāhāa, au sud de Barāqish. Elles ont pour sigle MAFRAY-Malāhāa 1 à 3 . Les deux premières ont été publiées ${ }^{35}$ la troisième est inédite.

\subsubsection{Husụn Āl șālị̣}

Cinq inscriptions ont été retrouvées par la MAFRAY aux alentours du village de Ḥuṣn Āl șâliḥ, cinq kilomètres au sud-sud-ouest de Barāqish. Elles ont pour sigle MAFRAY-Husun Âl Șāliḥ 1 à 5. Seules les deux premières, de langue saba'ique, ont été publiées. ${ }^{36}$ Les trois autres, en langue ma'īnique, sont inédites.

\subsection{Les inscriptions de musées pouvant provenir de Barāqish}

Plusieurs musées comportent dans leurs collections des inscriptions dont la provenance probable est $\mathrm{Ma}$ 'in ou Barāqish. Cette provenance est le plus souvent déduite de la langue des inscriptions (toutes sont en ma'īnique) ${ }^{37}$ et du contenu (mention des rois et divinités de Ma'īn). 28 inscriptions sont ici recensées : ${ }^{38}$

- Altes Museum de Berlin : M 337 = RÉS 3403;

- Kunsthistorisches Museum de Vienne : M $342=$ RÉS 3458;

- Musée d'Istanbul:CIH 678;

- Musée de Dhamār : DhM 384-385, 388, 391-393, 399):

- Musée militaire de Șan( $\bar{a}):$ A-20-207;

- Musée national de Șan(āa) : al-Jawf 04.9, 04.10, 04.21-22, 04.28, 04.30-33, 04.44, 04.46, GOAM 314-315, YM 28166, YM 28335, YM 28336, YM 28988.

Il est rare de pouvoir déterminer duquel des sites de Ma'īn ou Barāqish les textes peuvent provenir. Treize proviennent d'un temple de Nakrah or on en trouve un à $\mathrm{Ma}^{\mathrm{c}} \mathrm{i} n$ et deux à Barāqish (intra et extra muros). Concernant les inscriptions des musées yéménites de Șan'ā' et Dhamār, la provenance de Ma'īn apparaît plus probable. Leurs objets proviennent pour la majorité de fouilles clandestines et Ma'īn a été très largement pillée tandis que Barāqish a été relativement épargnée. Un second argument, moins décisif, est que les clans et sous-clans mentionnés par ces inscriptions nous sont plus souvent connus dans les inscriptions de $\mathrm{Ma}^{\text {‘inn que }}$ dans celles de Barāqish :

- Gzyn dans DhM 384 et 388 est attesté dans Ma'īn 80 ;

\footnotetext{
35 Robin $1987 ; 1988$.

36 Robin 1987.

37 Pour le texte YM 28988, le doute est permis. Il pourrait être en saba'ique. Rien ne permet de trancher.

38 Les renvois bibliographiques sont accessibles dans DASI (http:// dasi.cnr.it).
} 
- Hdir dans al-Jawf 04.33 est attesté dans Ma'in 1 et 2 ;

- Yd' dans GOAM 315 est attesté dans Ma'īn 6 (l'auteur de ces deux textes pourrait d'ailleurs être une seule et même personne);

- Seul Mlh dans YM 28336 est absent des textes de Ma'īn et fréquent dans ceux de Barāqish.

Pour le propos de cette contribution, seuls trois textes dont la provenance de Barāqish semble assurée seront retenus :

- M 337 = RÉS 3403 qui évoque un kabir de Yathill, titre uniquement porté sur ce site ;

- YM 28336 dont l'auteur appartient à la fraction de clan Mlh, dont le nom apparaît à plusieurs reprises à Barāqish, jamais à Ma'īn ;

- YM 28988 dont l'auteur porte la nisba 'le Yathillī / de Yathill' (Yțly) d'après le nom antique de Barāqish (voir $§ 3$ ci-dessous).

\section{Toponymie et topographie antique}

\subsection{Barāqish, le nom moderne}

Le toponyme Barāqish n'est pas unique au Yémen. L'index toponymique geonames.org recense trois localités ainsi nommées dans les gouvernorats de 'Amrān, Ibb et pour ce qui nous concerne, de Mārib, en limite méridionale de la vallée du Jawf.

Dans le Jawf, le toponyme Barāqish (Ar. barqash 'multicolore') n'apparaît qu'à la période islamique. ${ }^{39}$ La plus ancienne mention de Barāqish en tant que ville pourrait se trouver dans l'anthologie de la poésie d'alAșma'ī (v. 740-828), dans un poème attribué à 'Amrū b. Ma'add Yakrub. ${ }^{40}$

Plusieurs explications ont été données à l'origine de ce nom. Le proverbe arabe "Barāqish nuit à sa propre famille' ('alā ahlihā tajn̄̄ Barāqish) trouve son origine dans plusieurs légendes qui se réfèrent tantôt à une femme, tantôt à une chienne multicolore, du nom de Barāqish. ${ }^{41}$ L'une de ces légendes nous est rapportée par al-Hamdānī ${ }^{42}$ et serait à l'origine du nom du site. La légende raconte qu'alors qu'ils étaient assiégés, les habitants d'une forteresse se ravitaillaient en eau à une citerne située hors les murs en empruntant un tunnel. La présence du tunnel fut révélée aux assaillants par une chienne nommée Barāqish qui, pour aller boire à la citerne, en émergea en aboyant. Les assaillants

\footnotetext{
39 al-Hamdānī, al-Iklīl 8, 64-66 ; Yāqūt, Mưjam al-buldān 1, 535.

40 al-Așma'ī al-Așma'iyyāt, 172.

41 Heinrichs 1998.

${ }^{42}$ al-Hamdānī al-Iklīl 8, 65.
}

empruntèrent le tunnel et prirent la forteresse. Celle-ci porte depuis le nom de la chienne, Barāqish.

Selon Yāqūt, ${ }^{43}$ ce sont simplement les fleurs multicolores qui parsèment le site qui lui valent ce nom.

\subsection{La ville antique : $\mathrm{Yt} \mathrm{l}$}

Dans l'antiquité, le site de Barāqish était nommé Yathill (Ytl), au moins jusqu'au $3^{e}$ siècle de l'ère chrétienne. Le toponyme est mentionné dans les inscriptions sudarabiques de manière isolée ou dans la locution hgrn Yțl, 'la ville de Yathill' (Ja 643, M 177, M 185, M 202, M 242, etc.). On retrouve également Yathill dans la locution $s^{2 c} b(h) M^{(} n^{(m)} w-(\underline{d}-) Y \underline{t l}$, "la tribu de $M a{ }^{(i} n^{(u m)}$ et de (dhū-)Yathill' (M 29, M 236, M 247, 250, etc.). Cette locution désigne les deux composantes du royaume de Ma'in : la tribu de Ma'īn d'une part, avec ou sans mimation, et la tribu de Yathill (Yțll) / 'celle/celui de Yathill' ( $\underline{d}-Y \underline{t} l)$ d'autre part. La présence fréquente, mais non systématique, de la préposition $\underline{d}$ - devant Yathill incite à voir dans cette tribu l'ensemble des habitants de la ville et de ses environs immédiats.

La nisba yțly, le Yathillī, apparaît à une seule reprise, vers le $7^{\mathrm{e}}$ siècle av. J.-C. (YM 28988 : ' 'b'ns ${ }^{1}$ bn Lhy'tt bn Șbhyd' $Y \underline{t} l y)$, sans que l'on puisse dire si elle est dérivée du nom de la tribu ou de la ville.

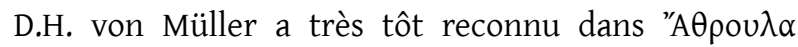
(Strabon, Geogr. 16, 4, 24) et "A $\theta \lambda$ ou $\lambda \alpha$ (Dion Cassius LIII, 29) le nom de Yathill. ${ }^{44}$ Dans les deux sources grecques, il s'agit d'une ville prise sans coup férir par l'armée romaine d'Ælius Gallus (26 av. J.-C.) sur la route qui

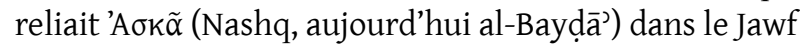
à M $\alpha \rho s i ́ \alpha \beta \alpha$ [Maryab/auj. Ma’rib], capitale sabéenne. Si l'on note une légère distorsion du nom dans sa transcription grecque, le contexte géographique ne laisse que peu de doute sur l'identification.

J. Pirenne faisait par ailleurs remarquer que le grec "A $\theta \rho \circ u \lambda \alpha$ / "A $\theta \lambda$ ou $\lambda \alpha$ rend vraisemblablement la vocalisation du nom: Yathul. ${ }^{45}$ Bien que cette hypothèse soit convaincante, on conservera par commodité la vocalisation Yathill, dont l'usage s'est imposé.

\subsection{L'oasis : Dyt et $\mathrm{S}^{2} \mathrm{~mm}$}

L'oasis antique de Barāqish était divisée en deux parties, dont on a conservé les noms : Dyt te $S^{2} m m$. Elles sont désignées comme les deux plaines irriguées (dhby) de Yathill dans l'inscription sabéenne RÉS 3943 (fin $7^{\mathrm{e}}-$ début $6^{e}$ siècle av. J.-C.). Il fut un temps envisagé qu'il

\footnotetext{
43 Yāqūt, Mứjam al-buldān 1, 535.

44 von Müller 1896a, 1896b; voir également Antonini et Fedele, chapitre 1 , section 1 , vol. 1 .

45 Pirenne 1961, 105-106.
} 
s'agisse là de noms communs pour 'l'aval' et 'l'amont'. ${ }^{46}$ Toutefois, on trouve ces deux noms mentionnés au $7^{\mathrm{e}}$ siècle av. J.-C. dans l'inscription Shaqab 2 comme objets d'une dédicace, à côté du nom des divinités 'Athtar Shariqān et 'Athtar dhu-Yahriq. Il faut en déduire soit que les noms des deux parties constitutives de l'oasis étaient hérités de ceux d'un couple divin, soit que les deux territoires se voyaient conférer une forme de sacralité.

Si l'étude géomorphologique de l'oasis de Barāqish a montré l'existence de deux secteurs distincts, ${ }^{47}$ il ne s'agit vraisemblablement pas des deux oasis connues par l'épigraphie. Ces dernières apparaissent contemporaines tandis que celles distinguées par B. Marcolongo ont été utilisés à deux périodes successives et relèvent d'une adaptation aux changements des conditions hydrographiques. Le secteur plus ancien était localisé à l'ouest et au sud-ouest de Barāqish ; le second n'aurait été mis en eau qu'à la suite d'une modification du tracé des paléo-cours du Wādī Majzir. F. Fedele associe cet événement à l'épaisse accumulation éolienne observée dans le sondage hors-les-murs (Sand YS), épisode daté vers le milieu du $7^{\mathrm{e}}$ siècle av. J.-C. ${ }^{48}$

La résolution chronologique n'est pas suffisamment précise pour dater les inscriptions Shaqab 2 et RÉS 3943 ainsi que l'événement géomorphologique qui entraîne l'abandon d'une zone irriguée au profit d'une seconde. A titre d'hypothèse et en s'accordant avec les dates proposées, on peut envisager la succession des événements comme suit : milieu du $7^{\mathrm{e}}$ siècle av. J.-C., abandon d'une zone irriguée au sud-ouest de Barāqish et redéploiement de l'oasis vers le sud-est; ce nouveau périmètre irrigué se scinderait en deux oasis dont on peut imaginer que chacune disposait de son propre système d'adduction en eau : Dyt et $S^{2} \mathrm{~mm}$. D'après Shaqab 2 ( $7^{\text {e }}$ siècle av. J.-C.), on ne peut exclure que les noms de ces deux oasis soient hérités d'un couple de divinités locales mineures. Les deux oasis sont ravagées dans le courant du $6^{e}$ siècle av. J.-C. (RÉS 3943). ${ }^{49}$

Les textes ont livré quelques toponymes supplémentaires qui se trouvaient dans le secteur irrigué de Barāqish mais ne peuvent être localisés de manière précise :

- $\quad \underline{d}-B^{\prime} r n$ : secteur agricole dans lequel un puits est creusé (Shaqab 16) ;

- $\underline{d}$-Hrș : propriété agricole (qny) de Wqh'l Rym, roi de Ma'in (Shaqab 18) ;

\footnotetext{
46 Robin 1987, 165.

47 Marcolongo et Palmieri 1986, 461-464 ; Marcolongo 1997.

48 Fedele 2010, 118-119 et chapitres 17 (section 6.5) et 19 (section 4), dans ce volume.

49 Voir Fedele, chapitre 18, section 3.2, dans ce volume.
}

- $\underline{d}$-Hzwwt : parcelle irriguée (mdr) (MAFRAY-Malāhāā 1) ;

- $\quad \underline{d}-N^{3} d m$ : secteur agricole (Y.90.DA 1 et 2);

- $d$-Ynzm: secteur agricole (Y.90.DA 2);

- d-Zwr : palmeraie (nhll) (MAFRAY-Ḥuṣn aṣ-Ṣālị 3) ;

- $\underline{d t-R m l n}$ : propriété agricole (qny) de Wqh'l Rym roi de Ma`īn (Shaqab 18).

Certains pourraient tirer leur nom du patronyme ou du lignage de leur propriétaire. Zwr par exemple est un nom de lignage connu par ailleurs (as-Sawdāa 91).

\subsection{Les sanctuaires extra muros : Yhrq et $\mathrm{Ft}^{c} \mathrm{n}$}

Les environs de Barāqish comptent deux sanctuaires extra muros. Le premier, localisé à Shaqab al-Manașșa, environ $2,5 \mathrm{~km}$ en direction du sud-ouest Barāqish, borde la rive gauche du Wādī al-Khawr. Consacré au dieu 'Athtar dhu-Yahriq, Gh. Gnoli voit dans l'épithète Yhrq le nom antique du sanctuaire. ${ }^{50}$ L'élément le plus déterminant est l'inscription Shaqab 8 qui mentionne 'Athtar dieu de Yahriq' (1. 2 : 'ttr 'l Yhrq). L'inscription sabéenne du Jabal Riyām RÉS 4176, bien que géographiquement éloignée, pourrait évoquer ce sanctuaire dans la formule "Athtar et les dieux de Yahriq' (l. 9 : 'ttr w-'l’lt b-Yhrq) (voir également \$ 5.2.5).

Le second sanctuaire extra muros se trouve à Darb alȘabī, moins de deux kilomètres à l'ouest de Barāqish. Il s'agit d'un vaste enclos sacré $(\mathrm{mhrm})$ délimité par neuf bornes et comprenant une quarantaine d'édifices. ${ }^{51}$ Le nom antique de ce périmètre sacré, $F t^{c} n$, nous est connu par l'inscription MAFRAY-Darb aș-Ṣabī $1^{52}$ (voir également \$ 5.2.6).

\subsection{Les villes périphériques : $\mathrm{Mh} f \mathrm{dn}, \mathrm{N}^{`} \mathrm{mn}$, $\mathrm{Rd}^{`}$ et $\mathrm{Y}^{\mathrm{c}} \mathrm{d}$}

L'inscription ma'īnique Shaqab 1, datée du $7^{\mathrm{e}}$ siècle av.J.C., rapporte les offrandes faites par les auteurs du texte dans le temple de Wadd à Qarnā (auj. Ma'īn), Yathill (aujourd'hui Barāqish) et dans les bourgades (hgrn) de Mhfdn, $N^{\prime} m n, R d^{c}$ et $Y^{c} d$. Nous avons vraisemblablement ici les noms de quatre agglomérations du territoire du royaume de $\mathrm{Ma}^{\text {'īn }}$ qu'il faut chercher dans les environs de Ma'īn et Barāqish. Aucun de ces toponymes n'est précisément localisé.

\footnotetext{
Gnoli 1993b, 15-16.

51 Voir R. Valentini, chapitre 28 dans ce volume.

52 Robin et al. 1988, 92.
} 


\section{Histoire de la cité antique de Yathill}

L'histoire de l'antique cité de Yathill a été évoquée à travers plusieurs études. ${ }^{53}$ On en rappellera ici les principaux éléments.

Pour commencer, Yathill est une ville de frontière. Elle se trouve en bordure méridionale de la vallée du Jawf, à la frontière nord du royaume de Saba' et au contact des principautés du Jawf. Au cours du Ir millénaire av. J.-C., la ville se trouve ainsi successivement intégrée dans le royaume de Saba', puis dans le royaume dominant de la vallée du Jawf, Ma'īn, avant d'être peuplée par des membres de la tribu d'Amìr à partir du $2^{\mathrm{e}}$ siècle av. J.-C. Ces changements politiques eurent une incidence sur la vie sociale, culturelle et religieuse de la cité.

\subsection{Une cité sabéenne (jusqu'au $7^{e}$ siècle av.J.-C.)}

Jusqu'au milieu du $7^{e}$ siècle av. J.-C., un faisceau d'éléments montre l'inscription de la ville de Yathill dans le royaume de Saba?.

La langue des inscriptions est le saba'ique (YM 28988, MAFRAY-Ḥuṣn Āl Șāliḥ 1 et 2, MAFRAY-Malāḥā’ 2, Y.90. DA 1 et 2 , Shaqab 15). Toutes proviennent du secteur irrigué et des sanctuaires extra muros. Toutes sont de graphie A (pal.Pi.) $)^{54}$ et datent de la fin $8^{\mathrm{e}}$-début $7^{\mathrm{e}}$ siècles av. J.-C.

Le panthéon, lui aussi sabéen, inclut la triade divine 'Athtar, Almaqah et dhat-Ḥimyam (MAFRAY-Ḥuṣn Āl Șāliḥ 2) ou Almaqah et 'Athtar (MAFRAY-Malāhā̄’ 2).

Le calendrier est sabéen, avec la référence faite aux mois de $\underline{d}-K s^{2} b m$ (Y.90.DA/1) et $\underline{d}-S^{1} h r r(Y .90 . D A / 2)$.

Une inscription est datée par un magistrat (prêtre) éponyme de Saba' : Y.90.DA/2 qui mentionne 'lrm fils de $M l k s^{1} m^{c}$, nom qui apparaît dans la liste des éponymes (Ja 2848y) du Jabal Balaq al-Janūbī, non loin de Mārib. ${ }^{55}$ Y.90.DA/1 mentionne un second magistrat éponyme de Saba', $S^{1} m h k r b$ fils de Yhqm, inconnu par ailleurs.

Enfin, la reconnaissance du mukarrib sabéen comme souverain apparaît dans Shaqab 15 , où un certain ' $\mathcal{S}^{1} d y \underline{t^{c}}$ se définit comme serviteur du souverain sabéen $S^{1} m h{ }^{l} l y$.

Le sondage stratigraphique sous les niveaux du temple de Nakrah dans le secteur intra muros a révélé une

\footnotetext{
53 Robin 1979b; 1984 ; 1987 ; Gnoli et Robin 1992 ; de Maigret et Robin 1993 ; Gnoli 1993b ; Robin et de Maigret 2009 ; de Maigret 2010a ; Fedele 2010 ; Schiettecatte 2011, 51-57.

54 L'abréviation Pal.Pi. désigne les styles paléographiques définis par J. Pirenne (1956). L'abréviation Pal.Av. désigne ceux définis par A. Avanzini (2004).

55 Gnoli et Robin 1992, 97.
}

occupation continue du $13^{e}$ au $7^{e}$ siècle av. J.-C. et a livré, dans les niveaux des trois derniers siècles de cette occupation, un assemblage céramique homogène et caractéristique des productions attestées sur les sites sabéens contemporains, en particulier la céramique carénée rouge à brunissage. ${ }^{56}$

Au cours de cette période sabéenne, trois institutions ou offices apparaissent dans les inscriptions Huṣn 'l Șālih 1 et Y.90.DA/ 2 : le conseil de Yathill $\left(m s^{3} w d Y t l\right)$, le chef de Yathill ( $k b r$ Yțl) et un contrôleur de l'irrigation ( $m d r r)$. Gh. Gnoli et Ch. Robin proposent de voir dans le kabir un représentant du pouvoir sabéen tandis que le conseil réunit les membres influents de la tribu locale, Yathill, ${ }^{57}$ chefs des principaux clans ou lignages. Le kabir est investi d'un pouvoir exécutif. ${ }^{58} \mathrm{Il}$ est également chargé, comme édile, de la gestion du périmètre irrigué et parlà même de l'approvisionnement de la ville de Yathill. La tribu de Yathill bénéficie d'une certaine autonomie, puisque l'invocation aux divinités sabéennes n'est pas systématique et que le droit de légiférer lui incombe au moins partiellement.

L'unique réalisation majeure du pouvoir sabéen à Yathill est la construction d'un premier rempart à l'initiative du mukarrib sabéen Karib'īl Watār fils de Dhamar'alī (RÉS 3946), vers 680 av. J.-C.

\subsection{L'alliance des tribus de Ma'in et Yathill (v. 670-650 av. J.-C.) et les relations ultérieures avec Saba}

L'existence d'un royaume de Ma'īn a longtemps été niée avant le $7^{e}$ siècle av. J.-C., notamment par l'absence de mention du royaume dans les récits des hauts faits des mukarribs sabéens des $8^{\mathrm{e}}-7^{\mathrm{e}}$ siècles av. J.-C. (DAI Șirwāh 2005-50, RÉS 3945 et 3946). La découverte récente d'inscriptions royales minéennes datées de ces périodes anciennes a substantiellement modifié cet état de fait : Ma'īn existait en tant qu'entité politique dès le $8^{e}$ siècle av. J.-C..$^{59}$

Le silence des textes sabéens pourrait donc plutôt s'expliquer par une alliance entre $\mathrm{Ma}^{(} \mathrm{i}$ in et Saba' aux $8^{\mathrm{e}}-7^{\mathrm{e}}$ siècles av. J.-C. Trois éléments vont dans ce sens :

- La mention de la divinité dhat-Himyam dans l'inscription Ma'īn 109, v. le $7^{\mathrm{e}}$ siècle av. J.-C., une

\footnotetext{
56 de Maigret 2010a, 85-87. Voir aussi Antonini, chapitre 2, vol. 1.

57 Le nom de la tribu apparaît distinctement dans plusieurs inscriptions sabéennes des $8 \mathrm{e}-7 \mathrm{e}$ siècles du site et de ses environs : dans l'invocation finale de MAFRAY-Huṣn Āl Șālih 2 ; dans les locutions

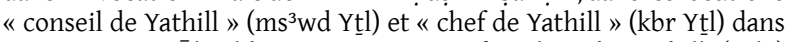
MAFRAY-Huṣn Āl Șālih 1 et Y.90.DA 2 ; et dans la nisba Yathillī (Yțly) dans l'inscription YM 28988.

58 Gnoli et Robin 1992, 97.

59 Robin et al. 2007 ; Schiettecatte 2011, 61-62 ; Arbach 2011 ; Arbach et Rossi 2012 ; Arbach 2018.
} 
divinité dont le culte est principalement attesté en domaine sabéen ;

- La mention de la fraternité entre 'byd $Y f^{2}{ }^{2}$ fils de $N b t^{\prime} l$ roi de $\mathrm{Ma}^{\prime}$ in d'une part et $\left.Y d^{\circ}\right)$ [Drh] mukarrib de Saba' d'autre part, vers le $7^{\mathrm{e}}$ siècle av. J.-C.

- La dédicace du roi de Ma'in Wqh'l fils de 'lyf dans le temple de Wadd dhu-Masma'im (Schm/ Samsara 3) à proximité de Mārib vers le milieu du $7^{\mathrm{e}}$ siècle av. J.-C.

$\mathrm{Au}$ sein de cette alliance vraisemblable entre $\mathrm{Ma}^{\mathrm{i}} \mathrm{in}$ et Saba', on voit la tribu de Yathill quitter la sphère sabéenne pour se rallier à $\mathrm{Ma}^{\mathrm{c} i ̄ n}$ dans le courant du $7^{\mathrm{e}}$ siècle av. J.-C.

Cet événement intervient tôt dans le courant $\mathrm{du} 7^{\mathrm{e}}$ siècle av. J.-C. Le plus ancien document attestant cette bascule est l'inscription Shaqab 6 datée par la graphie de la première moitié du $7^{\mathrm{e}}$ siècle av. J.-C. (Pal.Pi. A4B1). Le texte mentionne un membre du clan $G b^{2} n$, clan dominant de la tribu de $\mathrm{Ma}^{\text {cīn }}$, prêtre $\left(r s^{2} w\right)$ de la divinité tutélaire de la tribu de Yathill, 'Athtar dhu-Yahriq, qui dédie son inscription aux dieux de $\mathrm{Ma}^{\top}$ inn et de Yathill à l'époque de 'lyf' Rym (I) roi de Ma'īn.

Peu de temps après, l'inscription Shaqab 1 , datable du $7^{\mathrm{e}}$ siècle av. J.-C. (Pal.Pi. B2-B3), évoque la réalisation de sacrifices au profit des divinités du royaume de Ma'īn : 'Athtar dhu-Qabd et Wadd. L'inscription commémore des célébrations réalisées conjointement dans l'ensemble du royaume de Ma'īn : au torrent de Wadd ( $\dot{g} y l W d m$ ), dans les villes du royaume : Qarnā, Yathill, Mhfdn, $N^{c} m n, R d^{c}, Y^{c} d$ et dans le sanctuaire Yahriq (Shaqab al-Manașșa).

Cette fédération des tribus de Ma'in et Yathill reste proche du pouvoir sabéen comme le montre la dédicace de Wqh'l fils de 'lyf' roi de $\mathrm{Ma}^{\text {'în }}$ dans le temple sabéen de Wadd dhu-Masma'im, au $7^{\mathrm{e}}$ siècle av. J.-C.

Cette proximité est également suggérée par la culture matérielle. La production céramique présente un répertoire formel et des caractéristiques techniques héritées des productions dites 'sabéennes' antérieures, en dépit d'une perte de qualité..$^{60}$

À compter de cette date et jusqu'au $1^{\text {er }}$ siècle av. J.C., l'insertion de Yathill dans le royaume de $\mathrm{Ma}^{\text {'inn se }}$ manifeste par:

- L'usage de la langue ma`īnique ;

- L'adoption du panthéon de Ma'īn avec la triade 'Athtar dhu-Qabd, Wadd et Nakrah ;

\footnotetext{
60 de Maigret 2010a ; Fedele 2010, 126. Voir aussi Antonini, chapitre 2, vol. 1 .
}

- L'association des 'dieux (des villes) de Qarnā et Yathill' ('Pl't Qrnw w-Ytl) ;

- L'association des 'dieux (des tribus) de Ma'īn et Yathill' ('l'lt M'nm w-Ytl) ;

- La reconnaissance de l'autorité des rois de $\mathrm{Ma}$ 'īn et de l'assemblée de Ma'īn (RÉS $3013:$ mlky M`n $\left.w-m s^{3} w d M^{c} n^{m}\right)$.

- L'insertion de la tribu de Yathill au sein de "la

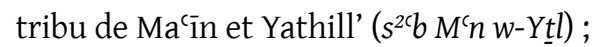

- L'adoption de la structure clanique du royaume de Ma'inn. ${ }^{61}$

Tout au long de cette période, les rapports avec le royaume de Saba' oscillent entre des périodes d'alliance et d'affrontement :

- Alliance $-2^{e}$ moitié du $7^{e}$ siècle av. J.-C. : dédicace d'un roi de $\mathrm{Ma}$ 'īn, Wqh'l fils de 'lyf', dans le temple sabéen de Wadd dhu-Masma'im ;

- Affrontement - fin $7^{\mathrm{e}}$-début $6^{\mathrm{e}}$ siècle av. J.C. : un conflit oppose Saba à une coalition regroupant Muha'mir, Amir et Ma'in et aboutit au siège et à la destruction de la ville de Yathill. L'événement est rapporté dans l'inscription RÉS 3943 vraisemblablement datée du règne de Y $\underline{t}^{\prime} \mathrm{mr}$ Byn fils de $S^{1} m h h^{\prime} l y$ Ynf, mukarrib de Saba', que l'on situe entre la fin du $7^{\mathrm{e}}$ siècle av. J.-C. ${ }^{62}$ et le milieu du $6^{e}$ siècle av. J.-C. ${ }^{63}$

- Affrontement - Fin $5^{\mathrm{e}}$ siècle av. J.-C. : sous le règne de 'byd' $Y t^{c}$, attaque d'une caravane de Ma'īn par la tribu de Saba'c (RÉS 3022) dont l'inscription Demirjian 1 semblerait également se faire l'écho ;64

- Alliance - Fin $5^{e}$-début $4^{e}$ siècle av. J.-C. : le roi Wqh'l Rym fils de 'byd' place la construction d'un réservoir 'sous la protection de 'Athtar Shāriqān, des divinités de $\mathrm{Ma}^{\mathrm{c} i} \mathrm{n}^{\text {um }}$, et des divinités de

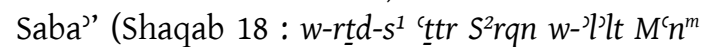
$\left.\left.w-()^{2}\right)^{\prime} l t S^{1} b^{3}\right)$;

- Alliance - Fin $5^{\mathrm{e}}$-début $4^{\mathrm{e}}$ siècle av. J.-C. : un texte contemporain du précédent par la graphie, Shaqab 8, place le temple de 'Athtar dhu-Yahriq sous la protection des divinités de $\mathrm{Ma}^{\text {'inn et }}$ de 'Athtar dhu-Dhibān or cette divinité n'est attestée qu'en domaine sabéen ; 65

- Alliance - Vers le $4^{\mathrm{e}}$ siècle av. J.-C., sous la corégence de $Y t^{\circ} l \mathrm{Rym}$ et de son fils $T b \mathrm{k} k \mathrm{rb}$, des membres du sous-clan Dbr, fraction de Ylqz consacrent leurs travaux aux dieux de Ma'īn et de Yathill ainsi qu'à 'tous les dieux, patrons, rois

\footnotetext{
61 Robin 1984.

62 Avanzini 2016, 133.

63 Robin 2016b, 71.

64 Multhoff 2019.

65 Robin 1996, 64.
} 
et tribus de Saba' (RÉS 2980 bis : kl 'l'lt w-S'2ymhy $\left.w-{ }^{2} m l k w^{-} s^{2 c} b S^{1} b^{3}\right)$.

De cette succession d'événements, il apparait qu'après une période d'alliance entre Ma'īn et Saba au $7^{\mathrm{e}}$ siècle av.J.-C., le rapprochement de la tribu de Yathill à celle de Ma'īn puis la prise progressive de contrôle du commerce caravanier par $\mathrm{Ma}^{\prime} \mathrm{i} n$ a contribué à l'accroissement des tensions entre les deux royaumes, menant à l'assaut de Yathill à la fin $7^{\mathrm{e}}$-début $6^{\mathrm{e}}$ siècle av. J.-C et à l'attaque d'une caravane minéenne vers la fin du $5^{\mathrm{e}}$ siècle av. J.-C. Les relations entre Saba' et Ma'īn s'apaisèrent ensuite avec une période d'alliance manifeste dans le courant du 4 e siècle av. J.-C.

\subsection{Yathill, cité minéenne (mi-7e-1 $1^{\text {er }}$ siècle av. J.-C.)}

\subsubsection{De la cité moribonde à la monumentalisation urbaine}

La cité de Yathill ne semble guère florissante au moment où elle intègre la sphère minéenne, au $7^{\mathrm{e}}$ siècle av. J.C. La fouille du secteur extra muros a révélé un épais ensablement de l'ouest du site, postérieur à l'abandon de ce qui apparaît comme le rempart sabéen (wall F4).

Peu après, l'inscription RÉS 3943 rapporte le siège et le sac de la ville de Yathill et de ses environs :

'Et il assiégea Yathill et dévasta les deux oasis de Yathill, Dyt et $S^{2} \mathrm{~mm}$, et il incendia et détruisit les constructions des deux oasis de Yathill' (RÉS 3943/3-4 : w-s³k Yțl $w$-gbd dhby $[Y] \underline{t} l$ Dyt $w$ - $S^{2} m m$ w-wfț $w-s^{2} \operatorname{tr} m b n(y)\left[\underline{d}^{(4)} h\right](b)$ $y$ Y $\underline{t} l])$. Ce n'est qu'à la suite de ces événements que sont entrepris les premiers travaux de monumentalisations de la ville de Yathill avec l'aménagement du temple de Nakrah et du rempart, entamés au cours du 6 e siècle av. J.-C. (voir $\S 5.5) .66$

\subsubsection{Yathill, organisation sociale}

Avec l'intégration au royaume minéen, les institutions de la période sabéenne cèdent la place à d'autres formes de pouvoir. Les décisions émanent du souverain minéen $\left(m l k M^{c} n\right)$ et du conseil de $\mathrm{Ma}^{\mathrm{c} i}$ in $\left(m s^{3} w d M^{\mathrm{c}} n\right)$, réunissant les notables de la tribu de Ma'īn-et-Yathill (ex.: RÉS 2959, RÉS 3013). L'application de leurs décisions semble être à la charge d'un chef/kabir de Yathill $(k b r$ $Y \underline{t}$ ) choisi au sein du clan dominant $G b^{\prime} n$ (sous-clans de Blh, Yf $f^{\prime} n$ et $\left.R d^{c}\right)^{67}$.

Les habitants de la Yathill minéenne se rattachent alors à la vaste tribu de Ma'īn-et-[dhu-]Yathill $\left(s^{2} b M^{c} n\right.$ $w$-[ $\underline{d}-] Y \underline{t} l)$, qui fédère l'ensemble des clans du royaume

66 Sur la portion du rempart minéen liée au bastion T7, voir Fedele, chapitres $17, \S 10$, et $18, \S 3.2$, dans ce volume.

67 Un kabīr de Yathill est mentionné dans les inscriptions RÉS 2961; RÉS 2939 ; M 419 ; RÉS 3022 ; Y.92.B.A 21+30, Y.03.B.R44-45.3. minéen. Elle se subdivise en clans, eux-mêmes divisés en sous-clans, puis en lignées. Lorsqu'il décline son identité, l'individu mentionne l'un ou l'autre de ces éléments. La parenté ou la lignée est introduite par bn, le sous-clan en général par $\underline{d}$ - ou 'hl et le clan par ' $h l .{ }^{68}$

Les clans et sous-clans attestés à Yathill sont recensés dans le tableau 5. Cette liste permet quelques observations.

Les sous-clans attestés à Barāqish ne le sont presque jamais à Qarnā. ${ }^{69}$ Les rares exceptions concernent des fractions du clan $G b^{\prime} n\left(H f n, R d^{c}, S^{2}{ }^{2} t m\right.$, Zlwmn) qui apparaissent aussi bien à Qarnā qu'à Yathill. De même, rares sont les clans attestés dans les deux villes. Mwqh et Ylqz sont attestés à Qarnā (Ma'in 30 et 15) mais à travers d'autres sous-clans que ceux connus à Yathill. Cette observation va dans le sens de deux populations relativement distinctes, celle réunie dans la tribu de Yathill d'un côté, celle de la tribu de Ma'īn de l'autre.

Parmi les clans s'instaure une hiérarchie au sein de laquelle le clan $G a b$ àn $\left(G b^{\prime} n\right)$ domine clairement. Outre la charge de chef de Yathill ( $k b r$ Y $t$ tl), on retrouve les membres de ce clan au sein de la congrégation (qhlt) de 'Athtar dhu-Yahriq (Y.92.B.A $21+30$ ), parmi les prêtres $\left(r s^{2} w\right)$ de 'Athtar dhu-Yahriq (Shaqab 6), parmi les chefs des caravaniers de Ma'īn (RÉS 3022 : kbr M'n mșrn). Ce sont en très grande majorité les membres de ce même clan qui financent les principales réalisations monumentales dans la ville : le réaménagement du temple de Nakrah, la construction du temple de Wadd, celle de sept courtines et de quinze bastions du rempart et celle de quatre résidences (voir $\S 5.5$ ). Certains de ses membres prennent le titre d'ami du roi (RÉS 2771), d'autres prennent épouse dans les différentes villes et régions partenaires du commerce caravanier transarabique : Dadān, Yathrib, Ghazzat, Sidon, Hagar/ Gerrha, en Égypte et en Ionie (Ma'īn 93 à Ma`īn 98).

Cet ascendant pris par les membres du clan $G b^{2} n$ amène à penser que certains membres de sous-clans de Yathill ayant des offices importants et pour lesquels le clan d'appartenance n'est pas connu pourraient appartenir à $G b^{2} n$. On peut en particulier penser au sous-clan $D f g n$ duquel sont originaires les chefs des caravaniers de Ma'īn (RÉS 3022 : kbr M'n mșrn) et le sous-clan de Ġzr$S^{1} h f n$ au sein duquel on trouve un chef des serviteurs du roi ( $k b r$ 'dm mlk), bâtisseur d'un bastion (RÉS 2976) et un chef des maçons et du transport (kbr grbn w-nqln), bâtisseur du temple Qabḍ ${ }^{\text {um }}$ (Y.05.B.B.13).

\footnotetext{
68 Robin 1984.

69 Sont exclues ici les inscriptions de Qarnā réunies sous l'appellation de 'Liste des hiérodules'. Dans ces dernières, les personnes évoquées ne relèvent pas seulement de la population de Qarnā mais de la totalité du royaume de $\mathrm{Ma}^{\mathrm{C} i ̄ n}$; ces textes recensent les épouses prises par des commerçants minéens dans les villes et régions partenaires.
} 
Tableau 1 : Relation des clans / sous-clans de Yathill (actuelle Barāqish) avec l'étranger : attestations hors du royaume de $\mathrm{Ma}^{\mathrm{i} i n}$ et mariages avec des épouses étrangères (J. Schiettecatte).

\begin{tabular}{|c|c|c|}
\hline $\begin{array}{l}\text { Sous } \\
\text { clan }\end{array}$ & Clan & $\begin{array}{l}\text { Attestation d'un (sous-)clan originaire de Yathill ou lieu d'origine d'une } \\
\text { épouse d'un membre de ces (sous-)clans }\end{array}$ \\
\hline Mlh & $?$ & $\begin{array}{l}\text { Qaryat al-Fāw (Qaryat-Zaydwadd) : Chef (kbr) des Minéens de Qaryat al-Fāw } \\
\text { al-'Ulā (RÉS 3272) }\end{array}$ \\
\hline Mrn & ? & $\begin{array}{l}\text { Qaryat al-Fāw (Riyād 302F8) } \\
\text { al-'Ulā (RÉS 3339, RÉS 3700): Chef (kbr) des Minéens de Dadān }\end{array}$ \\
\hline Rwyn & $?$ & Tamna' (VL 9) : Chef (kbr) des Minéens de Tamna $^{c}$ \\
\hline rqn & $?$ & al-'Ulā (RÉS 3608) : Chef (kbr) des Minéens de Dadān \\
\hline$[\mathrm{Zhrn}]$ & $G b^{\prime} n$ & Épouse prise à Dadān [al-'Ulā] (Ma'īn 93 A/30) \\
\hline Họdln & $G b^{2} n$ & Épouse prise à Ghazzat [Gaza] (Ma'īn 93 B/11) \\
\hline$R d^{c}$ & $G b^{3} n$ & $\begin{array}{l}\text { Épouses prises à : } \\
\text { Ghazzat [Gaza] (Ma'in } 93 \mathrm{~A} / 50) \\
\text { Hagar/Gerrha [al-Hufüf] (Ma'īn } 93 \text { D/36) } \\
\text { Dadān [al-'Ulā] (al-Saîd 2009) }\end{array}$ \\
\hline$S^{2} \underline{t} \underline{t}$ & $G b^{\prime} n$ & Épouse prise à Yathrib [Médine] (Ma'īn 95/10) \\
\hline$Y f^{c} n$ & $G b^{\prime} n$ & $\begin{array}{l}\text { al-'Ulā (Ja 2288, RÉS 3344, RÉS 3346, RÉS 3353) : Chef (kbr) des Minéens de Dadān } \\
\text { Épouse prise à Awsān [wādī Markha] (Ma'īn 93 C/52) }\end{array}$ \\
\hline Zlwmn & $G b^{3} n$ & $\begin{array}{l}\text { Madā’in Șāliḥ (RÉS 3708) } \\
\text { Tamna`(VL 9) } \\
\text { Épouses prises à Ghazzat [Gaza] }\left(\mathrm{Ma}^{\mathrm{i} i ̄ n} 93 \mathrm{C} / 3,19\right)\end{array}$ \\
\hline$\dot{G r b t}$ & Mwqh & 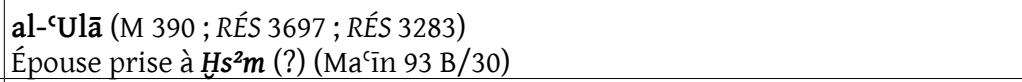 \\
\hline Zyrn & Mwqh & $\begin{array}{l}\text { Madāin Șāliḥ (RÉS 3708) } \\
\text { Fayyūm (RÉS 3427) } \\
\text { Épouses prises en Égypte (Ma'īn 93 C/39-40; Ma`īn 95/13-14) }\end{array}$ \\
\hline$H \underline{d} \underline{d} t$ & Qrn & $\begin{array}{l}\text { Épouses prises à : } \\
\text { Qaryat al-Fāw (Ma'in } 93 \text { B/36-37) } \\
\text { Tmlḥ (?) (Ma'īn 95/17) }\end{array}$ \\
\hline$D b r$ & Ylqz & $\begin{array}{l}\text { Qaryat al-Fāw (Riyad 262F8) } \\
\text { Épouse prise dans le Haḍramawt (Ma'īn } 93 \mathrm{~A} / 60)\end{array}$ \\
\hline \multirow[t]{2}{*}{ Mhdr } & Ylqz & Épouse prise à Mo’ab (Ma'īn 93 D/31) \\
\hline & Ylqz & $\begin{array}{l}\text { Épouses prises à : } \\
\text { Dhakir (Fontaine et Arbach 2006, fig. 26) } \\
\left.\text { Égypte (Ma'īn } 93 \mathrm{~B} / 4 ; \mathrm{Ma}^{\mathrm{C}} \text { īn } 93 \mathrm{C} / 26\right) \\
\text { Ghazzat [Gaza] (Ma'īn } 93 \mathrm{C} / 43) \\
\text { Tmlh (?) (Ma'in } 93 \mathrm{~A} / 19)\end{array}$ \\
\hline Siyl & $7 y^{\prime} l$ & Épouse prise à Samcy (Ma'in 93 B/25) \\
\hline$F^{3} m n$ & 'ly’l(?) & $\begin{array}{l}\text { Madā’in Șāliḥ (RÉS 3708) } \\
\text { al-'Ula (RÉS } 3343 ; R E ́ S 3357 ; R E ́ S \text { 3707) : Chef (kbr) des Minéens de Dadān } \\
\text { Épouse prise à Dadān [al-'Ulā] (Ma'īn 94/1) }\end{array}$ \\
\hline
\end{tabular}

\subsubsection{Yathill, cité caravanière}

La documentation épigraphique minéenne, en particulier celle de Barāqish, reflète l'importance du commerce caravanier transarabique pour l'économie de l'antique Yathill et du royaume de Ma'īn.

Parmi les débouchés commerciaux majeurs des $5^{\mathrm{e}}-4^{\mathrm{e}}$ siècles av. J.-C. figurent les provinces perses du ProcheOrient : l'Égypte, l'Assyrie et la Transeuphratène (Mṣr

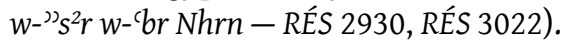

Les membres de la tribu de Yathill s'établissent dans des comptoirs commerciaux fondés dans les principales oasis qui ponctuent le tracé des pistes caravanières (tableau 1).

À Yathill, cinq clans se partagent l'organisation du commerce transarabique : $G b^{\prime} n, M w q h$, Qrn, Ylqz et 'ly'. Le fonctionnement de ce commerce est coordonné par deux offices : les chefs des caravaniers d'une part (kbr M`n mșrn - RÉS 3022, RÉS 3535) qui se chargent du transport des marchandises; les chefs des communautés 
Tableau 2 : Liste des sous-clans de Barāqish et leurs homonymes qatabānites (J. Schiettecatte).

\begin{tabular}{|c|c|c|}
\hline $\begin{array}{l}\text { Sous-clan attesté dans les } \\
\text { inscriptions de Barāqish }\end{array}$ & $\begin{array}{l}\text { Lignage / patronyme attesté dans les } \\
\text { inscriptions qatabānites }\end{array}$ & Inscription qatabānite \\
\hline Dfgn & Dfgn & ATM 694 \\
\hline Ḍmrn & Demrn & BM 141583, CSAI I, 208, 304, 306, 313, 579, 660, 665, 968 \\
\hline $\mathrm{Hbrr}$ & Hbrrm & CSAI I, 144,148 \\
\hline Mlh & Mlhm & CSAI I, 208, 669, 971, MuB 144 \\
\hline Mrn & Mrn & CSAI I, 53, 96, 208 \\
\hline Rwyn & Rwyn & MuB 694, ATM 610 \\
\hline$S^{2} \underline{\underline{t}} \underline{m}$ (fraction de $\left.G b^{2} n\right)$ & $S^{2 c} \underline{\underline{t} m m}$ & CIH 947, CSAI I, 155, 208, 1054, 1069 \\
\hline$Y f^{c} n$ (fraction de $G b^{\prime} n$ ) & $Y f^{\prime} n$ & TC 1996 \\
\hline Mhdr (fraction de Ylqz) & Mhdrm & ATM 866, CSAI I $, 47,208,269,562,563,600,962$ \\
\hline
\end{tabular}

minéennes implantées dans les villes étapes majeures le long du tracé des voies caravanières : Tamnac (VL 9), Qaryat al-Fāw (Qaryat-Zaydwadd) et Dadān, l'actuelle al-'Ulā (Ja 2288, RÉS 3346, RÉS 3608).

Les trois royaumes sudarabiques contemporains de $\mathrm{Ma}^{\text {cin }}$ apparaissent comme des partenaires commerciaux relativement constants au cours de la période du $5^{\mathrm{e}}$ au $2^{\mathrm{e}}$ siècle av. J.-C.

Les liens avec le royaume de Saba' sont visibles dans les évocations des souverains et dieux sabéens aux côtés de ceux de Ma'īn dans les textes Shaqab 8, Shaqab 18 et RÉS 2980 bis (voir § 4.2).

On trouve mention de liens manifestes avec le royaume du Hadramawt :

- La présence à Yathill d'habitants originaires du Hadramawt et de Shabwa sa capitale, et la commémoration d'une construction par (la tribu de) Ma'īn et le Hadramawt (M 416 + $275+$ $275+423)$;

- La commémoration du transport de marchandises du Hadramawt (Y.05.B.B.25) ;

Avec le royaume de Qatabān:

- La présence d'un chef $(k b r)$ des Minéens dans la capitale Tamnac et la réalisation d'une tombe pour les Minéens de Tamna' ${ }^{c}$ Van Lessen $9=$ CSAI I, 72) ;

- La dédicace conjointe de la restauration de l'enceinte de Yathill 'aux jours de leur seigneur Wqh'l $Y \underline{t}^{c}$ et de son fils 'lyf ${ }^{c} Y s^{2} r$ rois de Ma'īn, avec son seigneur $S^{2} h r$ Ygl Yhrgb roi de Qatabān' (RÉS 2999) ;

- La dédicace d'un lion de bronze par une Minéenne dans un sanctuaire qatabānite, aux dieux et aux rois de $\mathrm{Ma}^{\text {īn }}$ et Qatabān. ${ }^{70}$
- On note enfin que neuf des sous-clans minéens attestés à Barāqish ont pour homonyme un lignage ou patronyme (avec parfois l'ajout de mimation) dans la ville de Tamna' et sa nécropole Hayd ibn 'Aqiil (tableau 2). La fréquence du phénomène ne semble pas être le fruit du hasard et on peut postuler dans certains cas une origine minéenne ou le résultat de mariages mixtes.

A Yathill, la richesse qu'ont procurée les recettes commerciales fut déterminante dans la monumentalisation de la ville. Une dîme sur les recettes commerciales était en effet prélevée par les temples. La construction monumentale était une manière de s'acquitter de cette taxe due au temple de 'Athtar dhuQabḍum (RÉS 2975, RÉS 3012, RÉS 3021, RÉS 3022, RÉS 3535).

L'activité architecturale et caravanière atteint un pic aux $5^{\mathrm{e}}-4^{\mathrm{e}}$ siècles av. J.-C. Les siècles suivants sont moins bien renseignés. Il n'est pas improbable que la concurrence des royaumes de Muha'mir puis Amīr dans le Wādī Najrān, de la cité de Qaryat al-Fāw, de celle de Hagar/ Gerrha en Arabie orientale et de Maryamat ${ }^{\text {um }}$ dans le Wādī Harīib se soit accrue, freinant progressivement l'essor du royaume de Ma'īn.

\subsection{Yathill, déclin et abandon ( $1^{\text {er }}-3^{e}$ siècle ap. J.-C.)}

Les derniers investissements monumentaux interviennent à Yathill au $1^{\mathrm{er}}$ siècle av. J.-C. Le rempart est restauré vers -70 (RÉS 2973, règne de $\left.Y t^{\prime} l \underline{S} d q\right)$; il est fait l'acquisition d'une résidence Mhdr (RÉS 3016, durant la corégence de $Y \underline{t}^{(} l \underline{S}$ dq et son fils $\left.W q h^{\prime} l \underline{t}^{t}\right)$.

Les habitants de Yathill n'opposent qu'une faible résistance face à l'expédition romaine menée par Ælius Gallus (-26/-25). Strabon mentionne le passage de l'armée romaine par la ville d' 'A $\theta \rho o u \lambda \alpha$, qui se rend sans coup férir. L'armée romaine s'y réapprovisionne en blé et en dattes (Strabon Géogr., 16, 4, 24). C'est probablement à cette occasion là qu'est gravée la pierre

70 Arbach 2009 
tombale gréco-latine du cavalier Publius Cornelius provenant de Barāqish (YM 605). ${ }^{71}$

A la suite du passage de l'armée romaine, les derniers travaux de réfection connus sur le rempart sont entrepris sous les règnes conjoints de Wqh'l $Y t^{c}$ et 'lyf $Y S^{2} r$ rois de $\mathrm{Ma}^{\text {'inn }}$ et $S^{2} h r$ Y $\mathrm{gl} Y \mathrm{hrgb}$ roi de Qatabān (RÉS 2999) sans que l'on puisse affirmer si ceux-ci sont la conséquence de destructions engendrées par l'armée romaine.

$\mathrm{Au}$ tournant de l'ère chrétienne, les indices d'une occupation du site sont limités et soulignent l'arrivée de nouvelles populations issues des tribus d'Amīr et Saba'.

L'inscription $\mathrm{CIH}$ 609, v. 70 è. chr. (règne de Hlk'mr fils de Krb'l Wtr Yhn'm roi de Saba' et dhu-Raydān), montre qu'en moins d'un siècle, Ma'īn est passé du statut de royaume indépendant à celui de tribu dépendant de Saba?. ${ }^{72}$ Ce texte est un acte juridique concernant la cession de propriétés foncières (palmeraies et terres agricoles) et immobilières dans les villes de Qarnā, Yathill et Shu'ub. Yathill y apparait encore comme une ville peuplée et entourée d'un secteur irrigué ; la tribu de Yathill n'est en revanche pas nommée.

Vers 90 è. chr., le territoire de Yathill est au cœur des affrontements qui opposent l'armée de $Y d^{\circ} l$ roi du Hadramawt à celle de Krb'l Byn roi de Saba' et dhuRaydān (Ja 643). L'armée du Hadramawt y trouve refuge avant d'en être chassée.

Ce même événement semble avoir été à l'origine de l'acte de confession des tribus d'Amìr et 'Athtar au dieu Halfān, sur le site de Haram, qui n'avaient pu s'acquitter de la chasse rituelle de Halfān et avaient dû trouver refuge à Yathill 'durant la guerre de Hadramawt' (Haram 10). Les membres de ces deux tribus mentionnent avoir alors effectué le pèlerinage de dhu-Samāwì à Yathill. Cet événement pourrait trouver un écho à Barāqish dans la présence de l'inscription Y.92.B.A.20 commémorant l'offrande de deux statues à dhu-Samāwì dans le temple de Nakrah (voir § 5.2.2) et d'une dédicace au dieu Halfān (Y.05.B.B.16) dans le temple de 'Athtar dhu-Qabdum (voir $\S 5.2 .3)$.

Ces textes illustrent la réappropriation/réutilisation des temples de Yathill par les tribus d'Amïr et 'Athtar pour le culte de leurs divinités, dhu-Samāwī et Halfān. Il n'est pas possible de préciser si ces tribus ont trouvé

\footnotetext{
71 Une abondante bibliographie est consacrée à cette inscription bilingue. Sur les interprétations et sa datation controversée, voir Arbach et Schiettecatte 2017, 684-685 et références citées. Voir également Antonini et Fedele, chapitre 1 (n. 39), volume 1, et Fedele, chapitre 18 (§ 3.3), dans ce volume.

72 Robin 1998, 184.
}

refuge à Yathill de manière ponctuelle ou si elles s'y sont établies durablement. Ces tribus, originaires de la région de Najrān, étaient déjà présentes dans la ville voisine de Haram dès le $2^{\mathrm{e}}$ siècle av. J.-C. ${ }^{73}$

Dans la seconde moitié du $3^{e}$ siècle è. chr., la ville de Yathill est mentionnée pour la dernière fois dans la documentation épigraphique comme le lieu à proximité duquel un représentant du roi de Saba' à Nashq (actuelle al-Bayḍā'), avait fait une lourde chute de dromadaire. À cette période, Yathill n'est mentionnée ni dans la liste des villes et des tribus fournissant des contingents militaires au roi ni comme lieu d'origine de dédicants dans le temple confédéral de Ma'rib. ${ }^{74}$ Elle ne semble plus occupée que sporadiquement, par des groupes de taille limitée, n'engageant aucun chantier monumental, à l'image de ce qu'ont révélé les fouilles archéologiques. ${ }^{75}$

Malgréleur abandon, les remparts étaient suffisamment bien préservés pour qu'au $10^{\mathrm{e}}$ siècle, al-Hamdānī mentionne le site - désormais nommé Barāqish comme citadelle $(m h f d) .{ }^{76} \mathrm{Il}$ fut réoccupé deux siècles plus tard et de manière quasi-continue jusqu'au $18^{\mathrm{e}}$ siècle. $^{77}$

\section{Les monuments de Barāqish}

Le corpus des inscriptions de Barāqish et des sites environnants nous renseigne inégalement sur l'architecture et l'activité de construction. La très grande majorité des textes date d'une période comprise entre le $5^{\mathrm{e}}$ et le $1^{\text {er }}$ siècle av. J.-C. Très peu d'éléments nous sont connus des premiers et derniers siècles de l'occupation du site. Par ailleurs, les textes apportent des éclairages sur le rempart et les temples. Les constructions hydrauliques et domestiques sont mentionnées de manière plus occasionnelle. C'est là un artifice lié à l'histoire de l'élaboration du corpus épigraphique, qui s'est avant tout constitué à travers l'étude du rempart d'une part et des temples intra et extra muros d'autre part. Le tableau 4 récapitule l'ensemble des constructions connues par les textes.

\footnotetext{
73 Robin 1991.

74 Robin 1987, 165.

75 Fedele 2010, 138 ; Agostini 2015, 11. Voir également Fedele, chapitre 17 ( $\$ 12$ ) et chapitre 18 (§3.4), dans ce volume

76 al-Hamdānī, al-Iklīl 8, 65.

77 Voir au sujet de cette réoccupations les données issues du secteur extra muros du bastion T7 dans Fedele, chapitre 18 (§ 3.5), dans ce volume.
} 


\subsection{Le rempart}

\subsubsection{Les éléments du rempart}

Le rempart actuellement visible se compose de 57 bastions ${ }^{78}$ - également appelés tours ou saillants dans la littérature spécialisée - et de courtines en nombre presque identique.

Ce rempart est une restauration médiévale du rempart antique, dont il reprend le tracé. En élévation, il est rare que le rempart antique soit préservé au-delà de quelques assises. Seul le bastion 48 est intégralement conservé. On entendra par rempart antique le rempart tel qu'il était au moment de l'abandon du site vers les $2^{\mathrm{e}}-3^{\mathrm{e}}$ siècles è. chr., il s'agit donc du rempart bâti à l'époque minéenne (voir $\S 5.1 .2$ ).

Chacun de ces bastions et courtines était baptisé d'un nom propre dont les inscriptions ont parfois gardé le souvenir. Certaines dédicaces de construction sont encore visibles, tantôt dans leur emplacement d'origine, en partie inférieure, tantôt remployées dans les assises supérieures du mur. Associer les noms des bastions et courtines connus par les textes avec une structure architecturale permet de retracer l'histoire de la construction du rempart. Cette entreprise se confronte à une difficulté : lorsque le nom est connu par un texte remployé, il n'est jamais assuré que celui-ci ait été remployé dans la construction d'origine. On peut néanmoins faire l'hypothèse d'une mobilité limitée des inscriptions lors de leur remploi pour deux raisons. Premièrement, lorsqu'une construction est identifiée à la fois par un texte en place et par un texte remployé, ce dernier est soit remployé dans la construction même soit à proximité immédiate. C'est le cas des bastions $L b^{\prime} n$ (I), $L b^{\prime} n$ (II), Nmrn et de la courtine $T s^{2} b m$ (I), dans une moindre mesure de la courtine $\operatorname{Tn}^{\mathrm{C}} \mathrm{m}$ (mentionnée dans un remploi quatre bastions plus loin). Deuxièmement, on observe que les fragments d'une même inscription ne sont jamais remployés loin les uns des autres. Sur treize cas observés, ils sont soit remployés dans un même bastion, ${ }^{79}$ soit dans un bastion et son voisin, ${ }^{80}$

\footnotetext{
78 Nous utilisons ici la numérotation des bastions proposée par la Mission italienne, qui commence dans l'angle ouest du rempart et suit le tracé du rempart dans le sens des aiguilles d'une montre. Cette numérotation est différente de celle qui a été proposée et utilisée par la Mission française, qui débutait dans le même secteur et suivait le rempart dans le sens inverse des aiguilles d'une montre - se reporter notamment à Robin 1979b, fig. 1 et à Breton 1994, fig. 42 qui amende le plan de $\mathrm{Ch}$. Robin par le décalage du bastion numéro 1 et l'ajoute d'un numéro 58.

79 B-M $111=$ M $431+432$ dans le bastion 35; B-M 139= RÉS $2991+2993$ + 2994 dans le bastion 38 ; B-M $253=$ M $405+189$ dans le bastion 52 ; B-M $256=R E ́ S 2972+2970+2971+2971$ bis B +2971 bis A dans le bastion 54

80 B-M $26+23$ dans les bastions 5 et $6 ;$ B-M $44=$ RÉS $3040+3039+3049$ dans les bastions 15 et $16 ; \mathrm{B}-\mathrm{M} 73=R E ́ S 3053+3056+3050$ et RÉS 3051 + 3052a dans les bastions 23 et 24 ; B-M $115=$ M $436+430$ dans les bastions 36 et 37 ; B-M $132=$ M $439+212$ dans les bastions 37 et 38 ;
}

soit au maximum à deux bastions de distance. ${ }^{81}$ C'est là encore la preuve d'une dispersion moindre.

Vingt bastions et quatorze courtines sont nommés par des inscriptions. Une majorité peut être placée avec plus ou moins d'assurance sur le plan (fig. 1).

\subsubsection{1. [.] $r^{3} n$}

Bastion (mhfd) mentionné dans l'inscription de fondation B-M 272 = RÉS 3021. Sa construction (ou reconstruction) est commanditée par des membres du sous-clan $S^{2}{ }^{2} t m$, dont l'inscription Ma'īn 95/10-11 nous apprend qu'il s'agit d'une fraction du clan $G b^{2} n$. Ces travaux interviennent sous le règne de 'lyf $f^{c} Y s^{2} r$ (I) et de son fils $\mathrm{Hfn}{ }^{m} \mathrm{Rym}$, vers les $3^{\mathrm{e}}-2^{\mathrm{e}}$ siècles av. J.-C. ${ }^{82}$ Le bastion [.]r’n est mentionné dans une inscription conservée en place dans le bastion 57, au sein d'une énumération de sept bastions dont trois sont localisés ( $1=$ Rbqn (I) ; 54 $=L b^{2} n$ (I) ; $55=$ Zrbn). On peut faire l'hypothèse que les quatre bastions non localisés se trouvent dans le même secteur, a priori les bastions $n^{\circ} 50$ à 53 , les seuls qui restent non identifiés dans la section comprise entre le bastion $n^{\circ} 43$ à l'est et $n^{\circ} 2$ à l'ouest. On ne peut pas non plus exclure qu'il s'agisse d'un ensemble situé à l'ouest du site (nº 3 à 6 par exemple).

\subsubsection{2. ' brm}

Courtine (?) ([șh]ftn) mentionnée dans l'inscription B-M 108. L'auteur de l'inscription se dit serviteur de Wqh'l. Il s'agit de l'un des cinq rois de Ma'īn portant ce nom. D'après la graphie, le candidat le plus vraisemblable serait Wqh'l Nbt (v. $3^{\mathrm{e}}-2^{\mathrm{e}}$ siècles av. J.-C.) mentionné dans $\mathrm{B}-\mathrm{M} 1$ = RÉS 2975, B-M 136 = RÉS $2996+2995+2988+$ 2992, RÉS 3707 et L $106 .^{83}$ On peut à titre hypothétique localiser la courtine à proximité du lieu de remploi de l'inscription, entre les bastions 33 et 34 .

\subsubsection{3. $\underline{d}-B q r n$}

Bastion (mhfd) mentionné dans l'inscription B-M 241 = RÉS 2965 dans le cadre de l'aménagement de ses parements (tzwrt). Cet aménagement est commandité par des membres du sous-clan $H f d$, fraction du clan $G b^{\prime} n$. Ces travaux interviennent sous le règne de 'bkrb Sdq, vers le $4^{\mathrm{e}}$ siècle av. J.-C. L'inscription est conservée en place, sur le bastion 48. Nous faisons l'hypothèse que le bastion $\underline{d}$-Bqrn, dont elle mentionne la construction,

\footnotetext{
B-M $182=$ RÉS $2929+2941+2945+2946$ dans les bastions et courtines 41 et 42 .

81 B-M $38=R E ́ S 3035+3048$ dans les bastions 14 et 16 ; B-M $136=R E ́ S$ $2996+2995+2988+2992$ dans les bastions et courtines 37, 38 et 39 ; B-M $247+255$ = RÉS $2966+2968$ dans les bastions 50 et 52

82 Concernant l'ordre et la date des règnes, voir le tableau 6.

83 Drewes and Ryckmans 2016, 53, pl. 54-55; cf. tab. 6, 469.
} 
lui correspond. Cette localisation a déjà été reconnue par Ch. Robin et A. Agostini. ${ }^{84}$

\subsubsection{4. - - $H f n$}

Bastion (mhfd) mentionné dans l'inscription de fondation B-M $182=$ RÉS $2929+2941+2945+2946$. Sa (re)construction est commanditée par des membres du sous-clan $H f n$, fraction du clan $G b^{2} n$. Ces travaux interviennent sous le règne de 'byd' $Y \underline{t}^{\prime}$ et de son fils Wqh'l Rym, vers les $5^{\mathrm{e}}-4^{\mathrm{e}}$ siècles av. J.-C. B-M 182 nous apprend que le bastion $\underline{d}-H f n$ est relié au bastion $L b^{\prime} n$ par une courtine. Il existait deux bastions portant le nom $L b^{\prime} n$ : l'un identifié avec le bastion 54 ou 55 et l'autre avec le bastion 44 (voir $L b^{\prime} n$ (I) et $L b^{\prime} n$ (II) au-dessous). B-M 182 est remployée par fragments dans les bastions 41 et 42 et la courtine qui les sépare. La proximité avec $L b^{\prime} n$ (II) (bastion 44) fait supposer que le bastion $\underline{d}-H f n$ était connecté à ce dernier. Il s'agirait donc du bastion 43. Cette localisation diffère de celle proposée par $\mathrm{Ch}$. Robin ${ }^{85}$ et A. Agostini ${ }^{86}$ qui localisent $L b^{3} n$ (II) et $\underline{d}-H f n$ au niveau des bastions 41 et 42 , lieu de leur remploi. L'hypothèse qui nous conduit à privilégier les bastions 43 et 44 est développée sous l'entrée Lbn (II).

Le bastion $\underline{d}-H f$ fn est un des rares exemple de construction portant le nom du sous-clan de ses bâtisseurs.

\subsubsection{5. $\underline{d}-\mathrm{H} s \underline{b} b r$}

Courtine (shff) mentionnée dans l'inscription de fondation B-M 272 = RÉS 3021. Sa (re)construction est commanditée par des membres du sous-clan $S^{2}$ trm, dont l'inscription $\mathrm{Ma}^{\text {'in }}$ 95/10-11 nous apprend qu'il s'agit d'une fraction du clan $G b^{\prime} n$. Ces travaux interviennent sous le règne de 'lyf $f^{c} Y^{2} r$ (I) et de son fils $H f^{m} n^{m}$ Rym, vers les $3^{\mathrm{e}}-2^{\mathrm{e}}$ siècles av. J.-C. Il s'agit de l'une des courtines non localisées que liste RÉS 3021 dans le secteur sudouest de la ville.

\subsubsection{6. $\underline{d}-M l h$}

Bastion (mhfd) mentionné dans l'inscription de fondation B-M $10=$ RÉS 3012. Sa (re)construction est commanditée par des membres du sous-clan $Y f^{f} n$, dont l'inscription $\mathrm{Ma}^{\text {'inn }} 93 \mathrm{C} / 52$ nous apprend qu'il s'agit d'une fraction du clan $G b^{2} n$. Ces travaux interviennent sous le règne de 'byd' $Y t^{c}$ et de son fils $W q h^{\prime} l$ Rym, vers les $5^{\mathrm{e}}-4^{\mathrm{e}}$ siècles av. J.-C. L'inscription B-M 10 est conservée à sa place d'origine, à la base du bastion. L'identification de $\underline{d}$-Mlh avec le bastion 2 est assurée. Cette localisation avait déjà été reconnue par Ch. Robin ${ }^{87}$ et J.-F. Breton. ${ }^{88}$

L'inscription B-M1 = RÉS 2975 mentionne l'aménagement d'un passage maçonné entre le bastion $\underline{d}$-Mlh (bastion 2) et la tour Rbqn (tour 1) lors de l'édification de celle-ci, sous le règne postérieur de 'lyf $f^{\wedge} Y_{s^{2}} r$ et de son fils Wqh'l $N b t ̦\left(3^{\mathrm{e}}-2^{\mathrm{e}}\right.$ siècles av. J.-C.).

Le bastion $\underline{d}$-Mlh porte le nom d'une fraction de clan minéen (YM 28336, Qaryat-Zaydwadd, RÉS 3272). Il ne s'agit pas cette fois du sous-clan des commanditaires, tel qu'on a pu l'observer avec le bastion $\underline{d}-H f n$. Il n'est pas certain dans le cas présent qu'il y ait un lien entre le nom du bastion et celui du clan.

Notons néanmoins que l'on retrouve également le nom Mlh de manière isolée sur plusieurs bastions et courtines de la partie nord du rempart (fig. 1 : bastions $11,13,20,21,23$, courtines 11-12, 15-16, 17-18, 18-19). Là encore, le lien entre ce nom, le rempart et celui du sousclan minéen ne peut pas être clairement établi.

\subsubsection{7. $-\mathrm{d}-N d b n$}

Bastion (mhfd) mentionné dans trois inscriptions qui semblent se rapporter à la même structure. L'inscription de fondation Y.03.B.R44-45.2bis +2 ter +2 évoque la construction de ce bastion et de la courtine $T f^{2}$ sous le règne de 'byd' $Y \underline{t}^{c}$ et de son fils $H y w^{m}$, vers le $5^{\text {e }}$ siècle av. J.-C. Les commanditaires ne sont pas identifiés. Toutefois, l'inscription Y.92.B.A.37 A-B, qui se rapporte aussi à la fondation du bastion $\underline{d}-N d b n$ et de la courtine $T f^{2}$, a pour auteurs des membres du sousclan Ġrbt, dont l'inscription Ma'in 93B/30 nous apprend qu'il s'agit d'une fraction du clan Mwqh. C'est la seule attestation de la construction d'un élément du rempart par un autre clan que celui de $G b^{\prime} n$.

Notons que quelques générations plus tard, sous le règne de 'bkrb Șdq, des parements (tz̧wr) sont maçonnés au niveau de cette tour par le sous-clan $H f d$, fraction de Gb’n (B-M 241 = RÉS 2965).

Les deux courtines qui encadrent le bastion $d-N d b n$ sont connues: $S^{1} l f(' / h n)$ d'une part (B-M $241=R E ́ S$ 2965) ; TfS ${ }^{2}$ d'autre part (Y.92.B.A.37 A-B ; Y.03.B.R44-45.2bis + 2ter $+2)$.

Parmi les trois inscriptions qui mentionnent la construction du bastion $\underline{d}$-Ndbn, l'une (Y.03.B.R44$45.2 \mathrm{bis}+2$ ter +2 ) a été trouvée en fouilles entre les saillants 44-45 et les fouilleurs font l'hypothèse de la proximité de l'inscription avec les structures qu'elle

\footnotetext{
87 Robin 1979b, fig. 2.

88 Breton 1994, 110-111.
}

\footnotetext{
84 Robin 1979b, fig. 3 ; Agostini 2011, fig. 5.

85 Robin 1979b, fig. 4.

86 Agostini 2011, fig. 5.
} 
décrit (bastion $\underline{d}$-Ndbn et courtine $\left.T f_{s}^{2}\right)^{89}$ La tour $\underline{d}-N d b n$ pourrait correspondre au bastion 45 et serait bordée par les courtines $S^{1} l f$ à l'ouest et $T f^{2}$ à l'est (sur le choix de placer $T f s^{2}$ à l'est, se reporter à l'entrée concernée). Une identification de $\underline{d}-\mathrm{Nd} d b$ avec le bastion 44 est moins probable (voir l'entrée $L b^{2} n$ (II), localisée à cet emplacement). La seconde inscription (Y.92.B.A.37 A-B), provient du temple de Nakrah, à l'arrière des bastions 44-45, et conforte l'identification proposée. La troisième inscription (B-M $241=$ RÉS 2965) est conservée in situ sur le bastion 48 (bastion $\underline{d}$-Bqrn). La proximité relative avec le bastion 45 ne contredit pas l'identification de ce dernier.

\subsubsection{8. $d-S^{2} f t n$}

Courtine (shft) mentionnée dans l'inscription B-M $241=$ RÉS 2965 dans le cadre de la réalisation de son parement (tzwr). Cet aménagement est commandité par des membres du sous-clan $H f d$, fraction du clan $G b^{3} n$. Ces travaux interviennent sous le règne de ' $b k r b s \underline{d} d q$, vers le $4^{e}$ siècle av. J.-C. La courtine est mentionnée dans le secteur du saillant 48 sans que sa position précise ne puisse être précisée. Nous faisons l'hypothèse d'une courtine attenante au saillant 48 .

\subsubsection{9. $D d n$}

Courtine (șft) mentionnée dans l'inscription de fondation B-M $56=$ RÉS 3060. Sa (re)construction est commanditée par des membres du sous-clan $Y f^{c} n$, dont l'inscription Ma'in $93 \mathrm{C} / 52$ nous apprend qu'il s'agit d'une fraction du clan $G b^{2} n$. Ces travaux interviennent sous le règne de 'byd' Rym, vers le $4^{e}$ siècle av. J.-C. L'inscription est conservée à son emplacement d'origine et permet d'identifier $D d n$ avec la courtine comprise entre les bastions 18 et 19 . Cette localisation avait déjà été reconnue par Ch. Robin..$^{90}$

Ce bastion tourné dans la direction de la lointaine Dadān (oasis d'al-'Ulā), pourrait tenir son nom de ce partenaire commercial.

\subsubsection{0. $\mathrm{Hrs}^{2}$}

Courtine (shft) mentionnée dans l'inscription B-M $272=$ RÉS 3021. Sa (re)construction est commanditée par des membres du sous-clan $S^{2 c t} t m$, dont l'inscription Ma'in 95/10-11 nous apprend qu'il s'agit d'une fraction du clan $G b^{2} n$. Ces travaux interviennent sous le règne de 'lyf ${ }^{c} \mathrm{YS}^{2} r$ (I) et de son fils $H \mathrm{Hn}^{m}$ Rym, vers les $3^{\mathrm{e}}-2^{\mathrm{e}}$ siècles av.J.-C. Il s'agit de l'une des courtines non localisées que liste RÉS 3021 dans le secteur sud-ouest de la ville.

89 Voir S. Antonini, chapitre 8 et A. Agostini, chapitre 9, volume 1 .

90 Robin 1979b, fig. 5.

\subsubsection{1. $L b^{\prime} n(I)\left(L b^{3} n \underline{d}-{ }^{-} n n\right)$}

Bastion ( $m h f d$ ) dont l'inscription de fondation, B-M 256 $=$ RÉS $2972+2970+2971+2971$ bis, rapporte qu'il fut commandité par des membres du sous-clan Blh, fraction du clan $G b^{\prime} n$, sous le règne de 'byd $Y t^{c}$, vers le $5^{\mathrm{e}}$ siècle av. J.-C. Parmi ces membres se trouve un certain ' $\mathrm{m}^{\prime} n s^{1}$. L'inscription Y.92.B.A.21 + 30, datée du même règne, est rédigée par ${ }^{\top} m s^{1} m^{c} \underline{d}-B l h$, père de ${ }^{\prime} m^{\prime} n s^{1}$, kabïr de Yathill, attesté dans plusieurs inscriptions. Ce second texte évoque la tour $L b^{\prime} n d-{ }^{-} n n$. Nous pourrions avoir ici le nom complet du bastion, dont la construction aurait été entreprise par le père et se serait poursuivie sous la conduite du fils.

Une phase de restauration de plusieurs bastions et courtines entreprise par des membres du sous-clan $S^{2}{ }^{2} t m$, fraction du clan $G b^{2} n$ est entreprise sous le règne postérieur de 'lyf ${ }^{c} \mathrm{Ys}^{2} r$ (I) et de son fils $\mathrm{Hfn}{ }^{m}$ Rym (B-M $272=R E ́ S$ 3021).

D'après RÉS 3022, les bastions $L b^{3} n$ et Zrbn constituent les extrémités de la courtine $T^{c} \mathrm{~m}$, que l'on peut précisément localiser entre les bastions 54 et 55 (voir l'entrée correspondante).

L'inscription de fondation du bastion $L b^{2} n$, B-M 256, étant remployée dans le bastion 54, celui-ci apparaît comme le meilleur des deux candidats. Dans ce cas, le bastion 55 serait Zrbn. Ces localisations avaient déjà été envisagée. ${ }^{91}$ Elles diffèrent des restitutions de J.F. Breton et d'A. Agostini qui identifient $L b^{\prime} n$ avec le bastion 55 et Zrbn avec le $54 .{ }^{92}$

\subsubsection{2. $L b^{3} n$ (II)}

Bastion (mhfd) homonyme mais distinct du précédent dont l'inscription de fondation (B-M $182=$ RÉS 2929 $+2941+2945+2946)$ date de la corégence de 'byd' $Y t^{c}$ et de son fils Wqh'l Rym, vers les $5^{\mathrm{e}}-4^{\mathrm{e}}$ siècles av. J.-C. Ses commanditaires sont membres du sous-clan $\mathrm{Hfn}$, fraction du clan $G b^{2} n$. Un second texte commémore la construction de ce bastion par les membres d'un même clan, sous le même règne (B-M 211 + B-M $204=$ RÉS 2952 +2949 ).

B-M 182 mentionne qu'un bastion $\underline{d}-H f n$ était relié au bastion $L b^{3} n$ par une courtine. Le remploi de ce texte par fragments entre les bastions 41 et 42 amène $\mathrm{Ch}$. Robin et A. Agostini à localiser les bastions $\underline{d}-H f n$ et $L b^{2} n$ aux $n^{\circ} 41-42 .{ }^{93}$

\footnotetext{
91 Robin 1979b, fig. 2.

92 Breton 1994, 110-111; Agostini 2011, fig. 5.

93 Robin 1979b, fig. 4 ; Agostini 2011, fig. 5.
} 
Néanmoins, l'inscription B-M 211 + B-M 204 se trouve remployée entre les bastions 43 et 44 et rapporte que le bastion $L b^{\prime} n$ fait face à la porte de $Y \underline{t}$ l. Le bastion 44 fait face à la poterne qui donne accès au temple de Nakrah. Il apparaît donc comme la meilleure hypothèse pour l'identification de $L b^{\prime} n$ (II).

\subsubsection{3. $M \underline{d} b$}

Courtine (șht) mentionnée dans l'inscription de fondation B-M 238 = RÉS 3535 (fragment de Bauer 5). Sa (re)construction est commanditée par des membres du sous-clan Dfgn, fraction d'un clan qui ne peut être identifié en l'état. Ces travaux interviennent sous le règne de 'byd' $Y \underline{t}^{c}$ et de son fils Wqh'l Rym, vers les $5^{\mathrm{e}}-4^{\mathrm{e}}$ siècles av. J.-C.

L'inscription de fondation est conservée dans son emplacement d'origine, entre les bastions 47 et 48 . Cette localisation a déjà été reconnue par Ch. Robin, J.F. Breton et A. Agostini. ${ }^{94}$

\subsubsection{Nmrn}

Bastion (mhfd) mentionné dans l'inscription de fondation B-M $6=R E ́ S$ 3025. Son commanditaire est un souverain de Ma'inn dont le nom n'est pas préservé. Il s'agit de l'unique intervention directe d'un roi de Ma'īn sur le rempart de Barāqish.

L'inscription de fondation est remployée dans la tour 1 (Rbqn) et ne nous renseigne guère sur la localisation. Une seconde inscription commémore sa construction (B-M 264 = RÉS 3015) et décrit le bastion Nmrn comme attenant à la courtine $T s^{2}[\mathrm{bm}]$, à proximité de la porte de la ville. Si la localisation proposée pour $T s^{2} b m$ est correcte, à savoir la courtine percée par la porte de la ville entre les bastions 56 et 57 (voir sous ' $\mathrm{Ts}^{2} \mathrm{bm}$ '), Nmrn serait le bastion 56. C'est d'une part celui dans lequel l'inscription B-M 264 est remployée, d'autre part le bastion 57 ne peut être retenu car il semble assuré qu'il portait le nom de $Y^{\dagger} n$ (voir l'entrée correspondante).

\subsubsection{Rbqn (I)}

Tour $(m h f d)$ située à l'extrémité sud-ouest du rempart de Barāqish. Elle est reliée au bastion d-Mlh $\left(n^{\circ} 2\right)$ par un passage maçonné. Cette tour est un ajout postérieur au rempart. Sa construction est commémorée par une inscription de fondation, B-M 1 = RÉS 2975, datée de la corégence de 'lyf $\mathrm{Ys}^{2} r$ (I) et [Wqh'l] $N b t$, vers les $3^{\mathrm{e}}-2^{\mathrm{e}}$ siècles av. J.-C. L'inscription, préservée à son emplacement d'origine, nous donne l'emplacement de
Rbqn (tour $\mathrm{n}^{\circ} 1$ ). Cette localisation a déjà été reconnue par Ch. Robin et J.-F. Breton. ${ }^{95}$

Les commanditaires des travaux sont membres du sousclan Zlwmn, fraction du clan Gb’n.

La construction de la tour Rbqn a vraisemblablement débuté dès la corégence qui précède, entre 'lyf $Y s^{2} r$ (I) et son fils Hfn ${ }^{m}$ Rym (tableau 6) car son nom apparaît dans B-M 272 = RÉS 3021, qui liste les tours et bastions édifiés dans le secteur sud-ouest de la ville.

\subsubsection{Rbqn (II)}

Bastion $(m h f d)$ homonyme mais distinct du précédent également mentionné dans l'inscription B-M $272=$ RÉS 3021. Sa (re)construction est commanditée par des membres du sous-clan $S^{2} t \underline{t} m$, fraction du clan $G b^{2} n$ (Maīn 95/10-11). Ces travaux interviennent sous le règne de 'lyf' $\mathrm{Ys}^{2} r$ (I) et de son fils $H f n^{m}$ Rym, vers les $3^{\mathrm{e}}-2^{\mathrm{e}}$ siècles av. J.-C. Le bastion Rbqn (II) est mentionné dans une inscription conservée en place dans le bastion 57, au sein d'une énumération de sept bastions dont trois sont localisés ( $1=$ Rbqn (I) ; $54=L b^{2} n$ (I) ; $55=$ Zrbn). On peut faire l'hypothèse que les quatre bastions non localisés se trouvent dans le même secteur, a priori les bastions $n^{\circ} 50$ à 53 , les seuls qui restent non identifiés dans la section comprise entre le bastion $n^{\circ} 43$ à l'est et $n^{\circ} 2$ à l'ouest. On ne peut pas non plus exclure qu'il s'agisse d'un ensemble situé à l'ouest du site ( $n^{\circ} 3$ à 6 par exemple).

\subsubsection{Rḍwn}

La description de Rbqn (II) s'applique en tout point à Rdwwn. Il s'agit de l'un des bastions non localisés que liste RÉS 3021 dans le secteur sud-ouest de la ville, peutêtre l'un de ceux que nous ne sommes pas parvenus à identifier (bastions n 50 à 53).

\subsubsection{8. $R t^{\mathrm{c}}$}

Courtine (șhft) mentionnée dans l'inscription B-M 266 = RÉS 4224. Cette inscription fragmentaire évoque des travaux commandités à une date indéterminée par le sous-clan $Y f^{c} n$, fraction du clan $G b^{\prime} n$ (d'après Ma'īn 93 $\mathrm{C} / 52$ ). Cette courtine n'est pas localisée. L'inscription B-M 266 est remployée dans la courtine qui sépare les bastions 56 et 57 ; par conséquent, la courtine se trouvait vraisemblablement dans le secteur sud-ouest de la ville. 
5.1.1.19. $S^{1} l f$

Courtine (shfft) mentionnée dans l'inscription B-M 241 = RÉS 2965 lors de la réalisation de son parement (tzwr). Cet aménagement est commandité par des membres du sous-clan $H f d$, fraction du clan $G b^{2} n$, sous le règne de 'bkrb Șdq, vers les $4^{\mathrm{e}}$ siècle av. J.-C. D'après B-M 241, la courtine jouxtait le bastion $\underline{d}-N d b n$, identifié au bastion $n^{\circ} 45$, à l'est ou à l'ouest de ce dernier.

\subsubsection{0. $S^{2} b m t$}

Construction mentionnée dans l'inscription de fondation B-M $10=$ RÉS 3012, dont la construction est commanditée par des membres du sous-clan $Y f^{c} n$, fraction du clan $G b^{2} n$ (d'après $M a^{c}$ īn $93 \mathrm{C} / 52$ ). Ces travaux interviennent sous le règne de 'byd' $Y \underline{t}^{c}$ et de son fils Wqh'l Rym, vers les $5^{\mathrm{e}}-4^{\mathrm{e}}$ siècles av. J.-C. Bien que trouvée dans son emplacement d'origine, RÉS 3012 comporte des lacunes et la nature de la structure $S^{2} b m t$ n'est pas connue. Toutefois, elle est mentionnée conjointement à $T s^{2} b m$, une courtine localisée non loin du lieu de l'inscription B-M 10. $S^{2} b m t$ était vraisemblablement elle aussi une courtine localisée dans le secteur sud-ouest du rempart.

\subsubsection{1. Șdqn}

Bastion (mhfd) mentionné dans l'inscription Y.05.B.B.13, dont la construction est commanditée par des membres du sous-clan Ġz-Sihfn, fraction d'un clan non identifié. Ces travaux interviennent sous le règne de Wqh'l Rym, vers la fin $5^{\mathrm{e}}$-début $4^{\mathrm{e}}$ siècle av.J.-C. L'inscription provient du temple de 'Athtar dhu-Qabd, non du rempart luimême et le bastion ne peut pas être localisé.

\subsubsection{2. $T f^{2}$}

Courtine (shft) dont la construction est commémorée par deux inscriptions, Y.03.B.R44-45.2bis +2 ter +2 et Y.92.B.A.37 A-B. La première est datée du règne de 'byd' $\underline{t}^{\mathrm{c}}$ et de son fils $H y w^{\mathrm{m}}$, vers le $5^{\mathrm{e}}$ siècle av. J.-C. ; la seconde, non datée, a pour auteurs des membres du sous-clan Grbt, dont l'inscription Ma'īn 93B/30 nous apprend qu'il s'agit d'une fraction du clan Mwqh. Les deux textes en font une courtine attenante au bastion $\underline{d}-N d b n$, identifié au bastion $n^{\circ} 45$. Elle se trouvait d'un côté ou de l'autre de ce dernier.

\subsubsection{3. $\operatorname{Tn}^{\mathrm{C}} \mathrm{m}$}

Courtine (shfft) mentionnée dans l'inscription de fondation B-M 257 = RÉS 3022, qu'elle localise entre les bastions Z Zrbn et $L b^{\prime} n$. Sa construction est commanditée par des membres du sous-clan $Y f^{n} n$, fraction du clan $G b^{\prime} n$ (d'après $\mathrm{Ma}^{\mathrm{i} i n} 93 \mathrm{C} / 52$ ), et du sous-clan $\mathrm{Dfgn}$, fraction d'un clan non identifié. Ces travaux interviennent sous le règne de 'byd' $Y \underline{t}^{c}$, vers le $5^{\mathrm{e}}$ siècle av. J.-C.
L'inscription de fondation est conservée dans son emplacement d'origine, dans la courtine entre les bastions 54 et 55 . Cette localisation avait déjà été reconnue par Ch. Robin et A. Agostini. ${ }^{96}$

Cette courtine semble également mentionnée dans l'inscription B-M $248=R E ́ S$ 3010, remployée dans le bastion 50, qui évoque la courtine $\operatorname{Tn}[[m]$ (șhftn $\operatorname{Tn}[$ [.]).

\subsubsection{4. $T s^{2} b m(I)$}

Courtine (shft) mentionnée dans l'inscription de fondation du bastion $\underline{d}-M l h$ (bastion 2), B-M $10=$ RÉS 3012, datée du règne de 'byd' $Y \underline{t}^{c}$ et son fils Wqh'l Rym, vers les $5^{\mathrm{e}}-4^{\mathrm{e}}$ siècles av. J.-C. Cette inscription comporte des lacunes qui ne permettent pas de déterminer la nature de $T s^{2} b m$. Toutefois, deux inscriptions trouvées à proximité, RÉS 3015 (bastion 56, Nmrn) et RÉS 3024 (tour $1, R b q n)$, mentionnent respectivement « sa courtine $T s^{2}[b m]$ » $\left(s h f t-s^{1} T\left(s^{2}\right)[b m]\right)$ et « la [courti]ne $T s^{2} b m$ » ([shff] $\left.t^{n} T s^{2} b m\right)$. L'ouvrage $T s^{2} b m$ est donc certainement une courtine (shft).

A cela s'ajoute B-M 267 = RÉS 3017 bis qui mentionne une structure attenante à la porte sud-ouest de la ville sous le nom de $[. ..] s^{2} b m$ que l'on peut restituer en $[T]$ $s^{2} b m$.

RÉS 3012, 3015, 3017 bis et 3024 ont été trouvées en place ou remployées dans les bastions 1,2 et 56 . La courtine est censée être proche de la porte sud-ouest, qui est localisée entre les bastions $56(\mathrm{Nmrn})$ et $57\left(\mathrm{Yt}^{t} n\right)$. On peut la restituer à cet emplacement, sans toutefois exclure également une localisation entre les bastions 57 et 2 telle qu'envisagée par J.-F. Breton. ${ }^{97}$

Malgré leurs lacunes, RÉS 3012 et RÉS 3017 bis apparaissent comme les inscriptions de fondation de cette courtine. Sa construction serait donc commanditée par le sous-clan $Y f^{n} n$, fraction du clan $G b^{\prime} n$ (d'après Ma'īn $93 \mathrm{C} / 52$ ).

\subsubsection{5. $T s^{2} b m(I I)$}

Courtine (șhft) mentionnée dans deux inscriptions, B-M $41=R E ́ S 3038$ et $\mathrm{B}-\mathrm{M} 43$, respectivement remployées dans le bastion 15 et la courtine 15-16. La date précise des deux inscriptions n'est pas connue (v. $5^{e}-1^{\text {er }}$ siècles av. J.-C.).

Compte tenu de la distance qui les sépare, nous faisons l'hypothèse d'une courtine homonyme mais distincte de $T s^{2} b m$ (I) mentionnée à l'autre extrémité du rempart

\footnotetext{
96 Robin 1979b, fig. 2 ; Agostini 2011, fig. 5.

97 Breton 1994, fig. 26.
} 
(voir $T s^{2} b m(\mathrm{I})$ ). Elle serait à localiser sur le côté nord du rempart, aux environs des bastions 15 et 16 .

\subsubsection{6. $T^{\mathrm{C}} \mathrm{rm}$}

Courtine (șhft) mentionnée dans l'inscription de fondation B-M 147 = RÉS 2999. Sa (re)construction est commanditée par des membres du sous-clan Dmrn, fraction d'un clan non identifié. Ces travaux interviennent sous le règne de $W q h^{\prime} l Y^{c}$ et de son fils 'lyf $f^{c} \mathrm{Ys}^{2} r$ (II), dans le dernier quart du $1^{\text {er }}$ siècle av. J.C. Il s'agirait donc d'une courtine reconstruite à une date tardive de l'occupation du site. L'inscription de fondation est conservée à son emplacement d'origine et permet de localiser la courtine entre les bastions 40-41. Cette localisation a déjà été reconnue par Ch. Robin.98

\subsubsection{7. $Y \dot{g} l$}

Bastion (mhfd) mentionné dans l'inscription B-M $10=$ RÉS 3012, sous le règne de 'byd' Y $Y t^{c}$ et son fils Wqh'l Rym, vers les $5^{\mathrm{e}}-4^{\mathrm{e}}$ siècles av. J.-C. Les lacunes de l'inscription ne permettent pas de savoir si ce bastion a été bâti à Yathill. Il pourrait s'agir du bastion homonyme du rempart de Qarnā mentionné dans B-M 231 (fragment de Bauer 5).

\subsubsection{Yhr}

Bastion (mhfd) mentionné dans l'inscription de fondation B-M 242. L'inscription fragmentaire ne peut pas être précisément datée. Elle est remployée dans le bastion 48 (d-Bqrn). Yhr pourrait être un bastion voisin ( ${ }^{\circ} 49$ ?), ou un nom alternatif, ultérieur, pour le bastion 48.

\subsubsection{9. $Y s^{2} b m$}

Bastion (mhfd) mentionné dans l'inscription de fondation B-M $280=$ RÉS 2976. Sa (re)construction est commanditée par des membres du sous-clan Gzr$S^{1} h f n$, fraction d'un clan non identifié. Ces travaux interviennent vers les $5^{\mathrm{e}}-4^{\mathrm{e}}$ siècles av. J.-C. d'après la graphie du texte (Pal.Pi. E2). L'inscription B-M $259=$ RÉS 2973 le mentionne probablement lors d'une phase de restauration, sous le règne de $Y \underline{t}^{(0)} S \underline{S} d q$, au début du $1^{\mathrm{er}}$ siècle av. J.-C.

Ces deux mentions apparaissent dans deux inscriptions remployées dans le secteur sud-ouest du rempart (courtine 1-57 et bastion 56). D'après la localisation des remplois, J.-F. Breton fait l'hypothèse que $Y^{2} b m$ correspond au bastion $57\left(\mathrm{n}^{\circ} 1\right.$ dans sa propre numérotation). ${ }^{99}$ Pour que cette hypothèse soit

\footnotetext{
98 Robin 1979b, fig. 4.

99 Breton 1994, 111.
}

recevable, il faudrait exclure l'identification du bastion 57 avec $Y \underline{t}^{\dagger} n$ (voir l'entrée correspondante). Il s'agit plus vraisemblablement de l'un des bastions non identifiés du secteur sud-ouest de Barāqish.

\subsubsection{0. $Y \underline{t}^{t} n$}

Bastion (mhfd) mentionné dans l'inscription de fondation B-M $273=$ RÉS 2978. Sa (re)construction est commanditée par des membres du sous-clan $S^{2} t \underline{t} m$, fraction du clan $G b^{\prime} n$ (Ma'in 95/10-11). L'inscription est conservée dans son emplacement d'origine, dans le bastion 57 et permet d'identifier celui-ci à $Y t^{c} n$. Cette localisation a déjà été reconnue par Ch. Robin. ${ }^{100}$

D'après sa position dans la maçonnerie, l'inscription RÉS 2978 serait pour J.-F. Breton postérieure à RÉS $3021,{ }^{101}$ et donc postérieure au règne de ${ }^{~} l y f^{c} Y S^{2} r$ et de son fils $H \mathrm{Hn}^{m}$ Rym, que l'on peut dater entre le $3^{\mathrm{e}}$ et le $2^{\mathrm{e}}$ siècle av. J.-C. (tableau 6).

\subsubsection{Zbyn}

La description de Rbqn (II) s'applique en tout point à Zbyn. Il s'agit de l'un des bastions non localisés que liste RÉS 3021 dans le secteur sud-ouest de la ville, peutêtre l'un de ceux que nous ne sommes pas parvenus à identifier (bastions n ${ }^{\circ} 50$ à 53). J.-F. Breton l'identifie au bastion $n^{\circ} 56$ sans autre fondement que son apparition dans l'énumération des bastions et courtines de RÉS 3021. Le bastion $n^{\circ} 56$ semblait plus vraisemblablement nommé Nmrn (voir l'entrée correspondante).

\subsubsection{Zrbn}

Bastion (mhfd) mentionné dans l'inscription B-M 257 = RÉS 3022 comme l'une des extrémités de la courtine $\mathrm{Tn}^{\mathrm{C}} \mathrm{m}$ (courtine 54-55). Il s'agit donc du bastion 54 ou 55. Nous avons fait l'hypothèse que le bastion 54 était vraisemblablement nommé $L b^{2} n$; il remploie dans sa maçonnerie l'inscription B-M 256 qui mentionne la construction de $L b^{\prime} n$ (voir l'entrée $L b^{\prime} n$ (I)). Zrbn serait donc le bastion 55. Cette localisation a déjà été reconnue par Ch. Robin. ${ }^{102}$ Elle diffère des restitutions de J.-F. Breton et d'A. Agostini qui positionnent $L b^{\prime} n$ au bastion 55 et Zrbn au n ${ }^{\circ} 54 .{ }^{103}$

Le bastion Zrbn existait déjà sous le règne de 'byd' $Y t^{c}$, vers le $5^{\mathrm{e}}$ siècle av. J.-C. (RÉS 3022). Il semble faire l'objet d'une restauration commanditée par des membres du sous-clan $S^{2} \underline{t} \underline{t} m$, fraction du clan $G b^{3} n$ (d'après $\mathrm{Ma}^{\mathrm{i}} \mathrm{i} n$

\footnotetext{
100 Robin 1979b, fig. 2.

101 Breton 1994, 110.

102 Robin 1979b, fig. 2.

103 Breton 1994, 110-111; Agostini 2011, fig. 5.
} 
95/10-11) sous le règne de 'lyf $f^{c} Y s^{2} r$ (I) et de son fils $H f n^{m}$ Rym, vers les $3^{\mathrm{e}}-2^{\mathrm{e}}$ siècles av. J.-C.

\subsubsection{Essai de mise en ordre chronologique}

L'inscription de Șirwāḥ-Khawlān RÉS 3946, datée du début du $7^{\mathrm{e}}$ siècle av. J.C., est la plus ancienne mention épigraphique d'une fortification de Yathill (Barāqish). Ce rempart est l'œuvre du mukarrib sabéen Karib'il Watār fils de Dhamar'alī. Le sondage extra muros réalisé en 2005-2006 au pied du bastion 7 par F. Fedele a montré que le rempart actuellement visible date exclusivement de la période minéenne du site. Il ne peut en aucun cas être identifié avec la première fortification commanditée par le souverain sabéen. ${ }^{104} \mathrm{~F}$. Fedele propose d'identifier le rempart sabéen au mur F4 (stratum R) de ce sondage, à savoir un mur dont le tracé déborde celui de l'enceinte minéenne et d'une altitude inférieure. Les vestiges de ce mur en pierre sont haut de $105 \mathrm{~cm}$ et épais de $75 \mathrm{~cm}$. Il était surmonté d'une superstructure en briques crues. Il s'agit d'une enceinte modeste dont le rôle aurait été de marquer la limite $\mathrm{du}$ site plus que de le défendre. ${ }^{105}$ Cette hypothèse se défend d'autant mieux au regard du nombre élevé de villes et bourgades prétendument fortifiées par Karib'īl Watār fils de Dhamar'alì dans RÉS 3945 et 3946. Il est peu probable que toutes aient bénéficié de solides défenses dans des délais aussi limités. Il s'agit plutôt de la manifestation d'un pouvoir conquérant dont les réalisations architecturales hautement symboliques cherchent à marquer la présence dans le paysage.

Les inscriptions de Barāqish nous renseignent exclusivement sur le rempart minéen, encore visible aujourd'hui. Celui-ci est bâti sur les niveaux de l'occupation d'époque sabéenne, à une date qui est postérieure au début du $7^{\mathrm{e}}$ siècle av. J.-C. Se pose la question du début et du rythme de sa construction. On ne peut y répondre sans se heurter à quelques difficultés.

Premièrement, les constructions connues par les textes ne sont pas toujours aisément localisables.

Deuxièmement, les inscriptions ne mettent en lumière que des instantanés de la construction du rempart, mettant l'accent sur les aménagements à proximité de la porte principale (bastions 1-2 et 54-58), de la poterne et des temples (bastions 43-49). Ce sont les zones de circulation privilégiées, celles qui bénéficient de la plus forte visibilité. Les parties ouest, nord et est demeurent peu documentées.

\footnotetext{
104 Fedele 2010.

105 Fedele 2010, 116. Voir également Fedele, chapitres 17 (§ 6.2) et 18 (§3.1) dans ce volume.
}

Troisièmement, les textes ne font pas toujours la différence entre une construction et une restauration de sorte que nous ne pouvons bien souvent les considérer que comme terminus ante quem.

Quatrièmement, la chronologie des inscriptions se fonde quasi exclusivement sur celle des rois de Ma'in or beaucoup d'incertitudes demeurent. Pour les besoins de cette mise en ordre, on s'appuiera sur une révision de la chronologie royale (tableau 6).

En dépit de ces contraintes, plusieurs périodes d'interventions sont identifiables et peuvent être mises en perspective (voir la fig. 1 qui fait figurer les différentes phases de construction). Si une ébauche en avait été esquissée par J.-F. Breton, ${ }^{106}$ il semble utile d'en reprendre les éléments. Nous nous éloignons en effet de sa reconstruction pour deux raisons principales : d'une part, il supposait l'antériorité du règne de 'lyf $Y s^{2} r$ sur ceux de 'byd' $Y \underline{t}^{\complement}$ et $W q h^{\prime} l$ Rym là où il y aurait postériorité107 ${ }^{1}$ d'autre part, l'identification de plusieurs bastions et courtines diffèrent (voir § 5.1.1).

$\mathrm{Au}$ total, 37 inscriptions se rapportant à l'édification et à la restauration du rempart ont été identifiées (tableau 4). Parmi elles, 24 peuvent être associées à un ou plusieurs rois de $\mathrm{Ma}^{\mathrm{i}} \mathrm{i}$, soit explicitement, soit par recoupement. ${ }^{108}$ La succession des règnes permet la reconstruction suivante :

Étape 1 - Une inscription de $\mathrm{Ma}^{\text {‘inn }}$ (Ma'īn 6), de style paléographique C3 (Pal.Pi.), mentionne la réalisation de trente coudées de maçonnerie dans la muraille de Yathill ( $s^{2} l \underline{t} y$ ' $\left.m h m b-g n^{\prime} Y \underline{t l}\right)$. Aucun souverain n'est mentionné. Seules les inscriptions du règne de Hlkrb $S$ Sdq bn 'byd' présentent ce style C 3 ce qui indiquerait une date vers le $6^{e}$ siècle av. J.-C. Une inscription antérieure, RÉS 2947, datée du $6^{e}$ siècle par la graphie (Pal.Pi.C1), est remployée dans le rempart et mentionne le roi de $\mathrm{Ma}^{\prime}{ }^{\top} i n$ 'lyf' Rym (II). Si le remploi et le contenu fragmentaire du texte ne permettent pas de l'associer à une étape de construction du rempart, on ne peut toutefois pas

\footnotetext{
106 Breton 1994, 109-112.

107 La succession de ces règnes se fonde sur la paléographie des inscriptions. Celles du règne de 'lyf $\mathrm{f}^{c} \mathrm{Ys}^{2} \mathrm{r}$ sont du type D2-D3 défini par J. Pirenne, celles de 'byd' $\mathrm{Yt}^{\mathrm{c}}$ et Wqh'l Rym du style E2 et E3 (plus rarement E1). Toutefois J. Pirenne a elle-même envisagé de décaler son style paléographique D après le E (von Wissmann 1976, 373, no 127), von Wissmann à sa suite et A. Avanzini (Avanzini 1995, 49) s'accordent à considérer le type paléographique $\mathrm{D}$ comme postérieur aux types $\mathrm{E} 2$ et $\mathrm{E} 3$, opinion à laquelle nous nous rangeons.

108 Les recoupements concernent Y.92.B.A.37 A-B et RÉS 2976 : Y.92.B.A.37 A-B daterait du règne de 'byd' $\mathrm{Yt}^{\mathrm{c}}$ et de son fils Hywm par association à Y.03.B.R44-45.2bis + 2ter + 2. Toutes deux se rapportent à l'édification du bastion d-Ndbn et de la courtine Tfs ${ }^{2}$. RÉS 2976 daterait du règne de Wqh'l Rym par association à Y.05.B.B.13. Toutes deux sont du style paléographique E2, se rapportent à des constructions prises en charge par la fraction de clan des Ġzr-S1 hifn et évoquent un certain Rțd'l (bn Wdd'l) d- $\mathbf{G} z r S^{1} h \underline{h}$.
} 


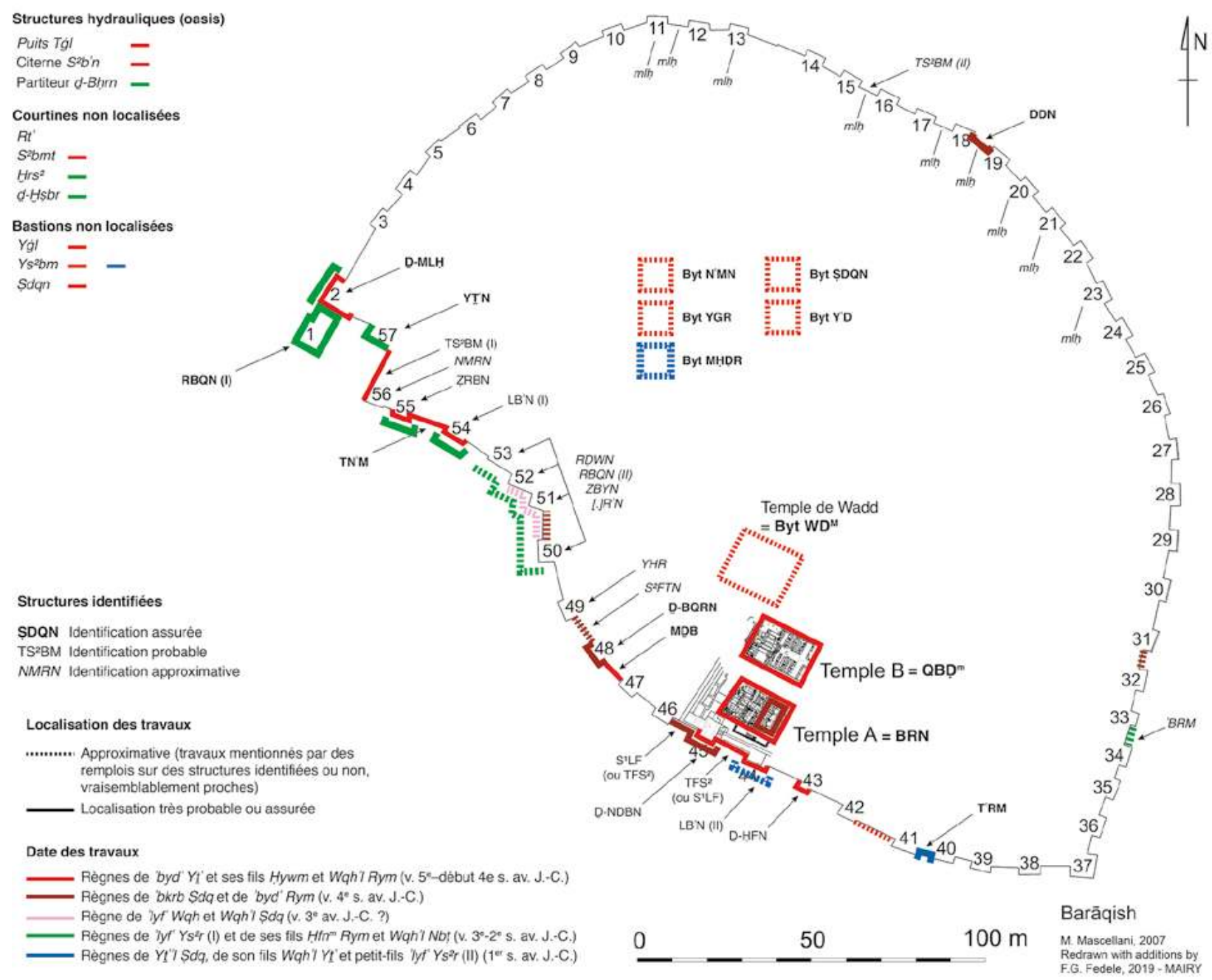

Figure 1. Barāqish : Localisation des monuments attestés par la documentation épigraphique dans l'antique cité de Yathill et périodisation des cinq phases principales de construction (M. Mascellani 2007, F.G. Fedele 2018, infographie J. Schiettecatte).

exclure une mise en chantier de la fortification sous ce règne.

Étape 2-Règnes successifs de 'byd' $Y \underline{t}^{`}$ seul, en corégence avec son fils $H y w^{m}$, en corégence avec son fils Wqh'l Rym et Wqh'l Rym seul (v. $5^{\mathrm{e}}$-début $4^{\mathrm{e}}$ siècles av. J.-C.) : la majorité des interventions datent de cette période, avec 13 inscriptions de styles paléographiques E1, E2 et E3 (Pal.Pi.). ${ }^{109}$ Sont mentionnées les constructions des bastions $\underline{d}-H f n, \underline{d}-M l h, \underline{d}-N d b n, L b^{2} n$ (I) et (II), Șdqn, Y $\dot{g} l$, $Y s^{2} b m$ et $Z r b n$ et des courtines $M \underline{d} b, S^{2} b m t, T f s^{2}, T n^{c} m$ et $\mathrm{Ts}^{2} \mathrm{bm}$ (I). Ils se répartissent dans le secteur de la porte sud-ouest, entre les bastions 54 et 2, et plus au sud, entre les bastions 41 et 45 , le long du temple de Nakrah (fig. 1, en rouge). Cet ensemble donne le sentiment d'un aménagement d'une large partie méridionale du rempart.

109 B-M $10=$ RÉS $3012 ; \mathrm{B}-\mathrm{M} 180=$ RÉS $2942 ; \mathrm{B}-\mathrm{M} 182=$ RÉS $2929+2941$ $+2945+2946 ; \mathrm{B}-\mathrm{M} 211+\mathrm{B}-\mathrm{M} 204=R E ́ S 2952+2949 ; \mathrm{B}-\mathrm{M} 222=R E ́ S$ $3005 ; \mathrm{B}-\mathrm{M} 238=$ RÉS $3535 ; \mathrm{B}-\mathrm{M} 256=$ RÉS $2972+2970+2971+2971$ bis B + 2971 bis A ; B-M $257=$ RÉS 3022 ; B-M 280 = RÉS 2976 ; Y.03.B.R4445.2 bis + 2 ter $+2 ;$ Y.05.B.B.13; Y.92.B.A. $21+30 ;$ Y.92.B.A.37 A-B.
Étape 3 - Règnes de 'bkrb Șdq et de 'byd' Rym fils de Hyw Șdq (v. $4^{\text {e }}$ siècle av. J.-C.) : aucun argument décisif ne permet de savoir lequel précède l'autre. Ils semblent régner peu après deux successeurs de Wqh'l Rym qui sont Hfn S $d q$ et 'lyf' $Y f_{S}^{2}$ (tableau 6). Quatre inscriptions de style paléographique E3 (Pal.Pi.) commémorent la construction d'au moins trois bastions ( $\underline{d}-B q r n$, $\left.\underline{d}-N d b n, \underline{d}-S^{2} f t n\right)$ et deux courtines $\left(S^{1} l f, D d n\right) .{ }^{110}$ Ces constructions semblent s'inscrire dans la continuité de celles entreprises à l'étape précédente en poursuivant l'édification du rempart entre les bastions 45 et 51 , faisant de la sorte la jonction avec le secteur de la porte sud-ouest (fig. 1, en bordeaux).

Des travaux sont également entrepris sur le côté nord du rempart (courtine $D d n$ ) et probablement à l'est (courtine 31-32). Il est probable que l'ensemble du site ait été alors progressivement ceint.

110 B-M 56 = RÉS 3060 ; B-M 103 = Robin-Barāqish 80 ; B-M 241 = RÉS 2965 ; B-M 249. 
Étape 4 - Règnes de 'lyff $Y s^{2} r$ (I) en corégence avec son fils $H f^{m} n^{m}$ Rym puis avec son fils Wqh'l $N b t$ et règne de Wqh'l Nbț seul (v. $3^{\mathrm{e}}-2^{\mathrm{e}}$ siècles av. J.-C.) : trois inscriptions relatent des réaménagements substantiels de l'ensemble du secteur de la porte sud-ouest, ${ }^{111}$ depuis le bastion 2 jusqu'au 54 à l'ouest et probablement au-delà, jusqu'au bastion 50 (fig. 1, en vert). Outre la restauration d'au moins huit bastions et deux courtines (bastions [.]

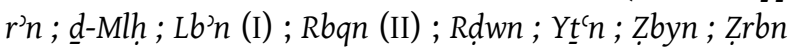
et courtines $\underline{d}-\mathrm{H} s \mathrm{~b} b r$ et $H \mathrm{Hrs}^{2}$ ), la tour Rbqn (I) est bâtie en avant du bastion 2 et reliée à ce dernier par un passage maçonné.

Une inscription supplémentaire, B-M 108, évoque la (re)construction de la courtine 'brm sous le règne de Wqh'l. Au moins cinq rois de Ma'in portent ce nom. ${ }^{112}$ Néanmoins le style paléographique se rapproche le plus de celui des inscriptions du règne de Wqh'l Nbț.

Étape 5 - Règnes de $Y t^{\circ} l \underline{S d q}$ puis de son fils $W q h^{\prime} l$ $Y \underline{t}^{c}$ en corégence avec son fils 'lyf $Y^{c}{ }^{2} r$ (II) (1 $1^{\text {er }}$ siècle av. J.-C.) : de cette époque datent les deux dernières interventions connues par les inscriptions ma'inniques (respectivement B-M 259 = RÉS 2973 et B-M $147=$ RÉS 2999). Il s'agit là d'opérations limitées. L'une d'elle (B-M 147 = RÉS 2999) intervient après le passage de l'expédition romaine menée par Ælius Gallus et s'explique peut-être par des destructions occasionnées par l'armée romaine.

Une étape intervient à une date indéterminée sous le règne de 'lyf' $W q h$ en corégence avec son fils Wqh'l șdq (B-M $247+255$, graphie Pal.Pi. E1). Une courtine est aménagée, probablement dans le secteur des bastions 50-52 (fig. 1, en rose). Ces règnes peuvent être datés du $5^{\mathrm{e}}$ ou du $3^{\mathrm{e}}$ siècle av. J.-C., voire des deux périodes dans le cas de souverains homonymes. ${ }^{113}$ Dans le doute, nous préférons laisser cette intervention en dehors de la séquence chronologique.

En résumé, nous aurions une fortification dont le chantier aurait débuté au cours du $6^{\mathrm{e}}$ siècle, sous l'impulsion de Minéens établis à Qarnā (actuelle $\mathrm{Ma}^{\top}$ in $-\mathrm{Ma}^{\text {'inn }}$ 6). Le chantier prend progressivement de l'ampleur tout au long du $5^{\mathrm{e}}$ siècle pour s'achever, semble-t-il, au $4^{\mathrm{e}}$ siècle. Le pic d'activité correspond aux règnes de 'byd' $Y t^{c}$ et de son fils Wqh'l Rym, et la construction se poursuit sous les règnes de 'bkrb $S d q$, Yt $t^{\text {'l }}$ Rym et 'byd' Rym (déb. $5^{\mathrm{e}}$-fin $4^{\mathrm{e}}$ siècle av. J.-C.).

La restitution en plan (fig. 1) semble indiquer une priorité donnée à l'aménagement des secteurs de la

111 B-M $272=$ RÉS 3021; B-M 1 = RÉS 2975 ; B-M 1 = RÉS 2975.

112 Wqh'l bn 'lyf' (7e siècle av. J.-C.) ; Wqh'l Rym (5e-4e siècle av. J.C.) ; Wqh'l Șdq bn 'lyf' (3e siècle av. J.-C. ?); Wqh'l Nbt (3e-2e siècle av. J.-C.) ; Wqh'l Yț (1er siècle av. J.-C.).

113 Bron 2019, 244. porte et de la poterne, reliés entre eux dans un second temps, avant que ne soit mis en œuvre le reste du chantier, vers le nord. L'élaboration de ces grands traits demande désormais à être confrontée à une étude minutieuse de l'appareil du rempart pour en valider la séquence.

\subsubsection{Pour une datation absolue des débuts du chantier}

Une difficulté réside dans le fait que les premières inscriptions connues évoquant le rempart pourraient être postérieures au début de la mise en chantier du rempart. Barāqish passe sous le contrôle des rois de

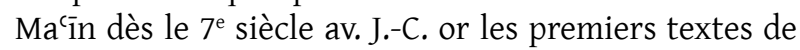
construction ne datent que du $6^{e}$ siècle av. J.-C. Si l'on confronte les données épigraphiques aux datations ${ }^{14} \mathrm{C}$ obtenues dans le sondage extra muros du secteur C (en particulier les datations DSH298 et DSH 862) ${ }^{114}$, on constate que ces dates sont cohérentes avec la reconstruction historique proposée : le chantier s'étale principalement aux $6^{\mathrm{e}}-5^{\mathrm{e}}$ siècles av. J.-C. L'hypothèse d'un chantier du rempart minéen qui débuterait dès le passage de la ville sous l'autorité des rois de $\mathrm{Ma}^{\text {inn }}$, dans le courant du $7^{\mathrm{e}}$ siècle av. J.-C., est d'autant moins probable qu'une phase de transition durable s'intercale entre l'abandon du rempart sabéen et la construction du rempart minéen. Elle a été observée dans le sondage extra muros du secteur C (Stratum K). ${ }^{115}$

Les trois arguments dont on dispose pour dater le début $\mathrm{du}$ chantier dans le courant du $6^{\mathrm{e}}$ siècle sont :

- Les datations ${ }^{14} \mathrm{C}$;

- L'inscription Ma'in 6 (style Pal.Pi. C3, v. $6^{\text {e }}$ siècle av.J.-C.) qui évoque la construction de 30 coudées du rempart de Yathill ;

- La fouille du temple de Nakrah qui a montré que le parement externe de la courtine 44-45 existait déjà durant la phase la plus ancienne du temple (Minéen C), ${ }^{116}$ dont l'occupation est associée à une inscription de style paléographique $\mathrm{C} 2$ (v. $6^{e}$ siècle av. J.-C.) (voir « 4.2.1 - Brn, temple de Nakrah à Barāqish »).

\subsection{Les temples}

Les sources épigraphiques nous renseignent sur la présence de cinq temples; quatre sont identifiés et deux ont été fouillés.

\footnotetext{
114 Voir Fedele, chapitre 18, tables 1-3, dans ce volume.

115 Fedele 2010, 128-131.

116 de Maigret et Robin 1993, 453.
} 


\subsubsection{Brn, temple de Nakraḥ à Barāqish}

Le temple de Nakrah - Temple A dans la nomenclature de la Mission italienne - est localisé à proximité du rempart. La Mission italienne l'a intégralement fouillé et restauré, ${ }^{117}$ avant sa destruction par les bombardements de l'aviation saoudienne en 2015. Sa chronologie, son identification et ses principaux textes ont été l'objet d'une étude détaillée. ${ }^{118}$ L'essentiel est ici synthétisé et quelques éléments sont actualisés.

L'inscription Y.92.B.A. $21+30$ provenant du temple de Nakrah rapporte la construction d'un chancel $\left(s^{3} n f n\right)$ dans le temple Brn par des membres de la fraction Blh du clan $G b^{\prime} n$, sous le règne de 'byd' $Y t^{c}$ (v. $5^{\text {e }}$ siècle av. J.-C.). Ce texte nous donne le nom antique du temple, que $\mathrm{Ch}$. Robin vocalise Barrān. On le retrouve mentionné dans d'autres inscriptions provenant du temple : Y.92.B.A.14 et 15, ainsi probablement que RÉS 2959.

La divinité vénérée était Nakrah ou Nakrah le Patron (Nkrḥ S'ymn) toutefois, d'autres divinités y font l'objet de dédicace : 'Athtar dhu-Qabḍ, Wadd et Nakrah (Y.92.B.A 37 A-B), Shahr et Ma'ān ( $S^{2} h r$ et $M^{c} n$ - Y.03.B.A.1), 'Athtar dhu-Yahriq (Y.92.B.A.10 et 17), 'Athtar Shariqān (Y.92.B.A.46), Kahlān Nabaț'athtar (Khln Nbt'ttr - Y.92.B.A.28). Il se peut que certains documents ne soient pas en place et proviennent de temples de voisins. Néanmoins cela reflète un lieu de culte non exclusif.

La fouille a montré trois phases successives de construction. ${ }^{119}$

Le niveau Minéen C (v. $6^{\mathrm{e}}$ siècle av. J.-C.), le plus ancien, correspond à la construction du temple. On peut faire l'hypothèse que l'inscription Y.92.B.A.15 date de cette période. Remployée dans la terrasse sud du niveau tardif Minéen A, c'est le plus ancien texte connu dans le temple d'après la paléographie. ${ }^{120}$ Il est de style C2 (Pal.Pi.), datable vers le 6 ${ }^{\mathrm{e}}$ siècle av. J.-C. ${ }^{121}$ L'inscription évoque une taxe sur les animaux introduits dans l'avant-cour (șrht) et dans l'édifice (hțb) Barrān. ${ }^{122}$ Sur la base de parallèles architecturaux, A. de Maigret proposait également de dater cette phase des $7^{\mathrm{e}}-6^{\mathrm{e}}$

\footnotetext{
117 de Maigret 1991a ; 1991b ; 1993 ; 2004a, 2005b ; 2009b ; 2010a ; de Maigret et Robin 1993 ; Robin et de Maigret 2009. Voir également Scigliano et Paladino, chapitre 13, vol. 1.

118 de Maigret et Robin 1993.

119 de Maigret et Robin 1993, 448-458.

120 Voir notamment de Maigret et Robin 1993, 474.

121 Ce style paléographique caractérise plusieurs inscriptions du mukarrib de Qatabān Hwf'm Yhn'm fils de $S^{1}$ mhwtr dont le père serait mentionné dans l'une des dernières inscriptions des mukarribs de Saba', RÉS 3943, vers la fin 7e-6e siècle av. J.-C. (Robin 2016c, 84-85).

122 Concernant les termes désignant les différentes parties du temple, on se reportera à de Maigret et Robin 1993, 461-469.
}

siècles av. J.-C. ${ }^{123}$ Une datation radiocarbone confirme cette fourchette chronologique. ${ }^{124}$

Le niveau Minéen B (v. $5^{\mathrm{e}}$ siècle av.J.-C.) se caractérise par l'aménagement d'un avant corps et une réorganisation interne. Des aménagements secondaires y sont réalisés pendant le règne de 'byd' $Y \underline{t}^{c}$ (Y.92.B.A.21 + 30). Outre Y.92.B.A.21 + 30, quatre inscriptions rédigées par $B s^{1}$ fils de $M^{c} s^{1}$ de la fraction $S^{2} t \underline{t m}$ du clan $G b^{2} n$ se rapportent à des aménagements qui sont, d'après la fouille, contemporains de celui du chancel et donc du règne de 'byd' $Y t^{c}\left(v .5^{\mathrm{e}}\right.$ siècle av. J.-C.) : aménagement de banquettes (twtb, Y.90.B.A.7), offrande d'un brûleencens (Y.92.B.A.46), d'une stèle (Y.90.B.A.18), d'un élément architectural $\left(m w s^{3} l t\right.$, Y.92.B.A.32 + 5) ${ }^{125}$

Le niveau Minéen A se caractérise par le réaménagement du parvis et la construction de l'annexe $C$ au sud du temple. Les datations radiocarbones montrent que ce niveau caractérise l'occupation du temple durant toute la seconde moitié du $1^{\mathrm{er}}$ millénaire av. J.-C. ${ }^{126}$ Ces réaménagements pourraient correspondre aux importants travaux évoqués dans l'inscription RÉS 2980 bis, sous la corégence de $\left.Y t^{(}\right)$Rym et de son fils $T b(k r b$, que nous situons cinq générations après 'byd' $Y t^{c}$, vers le $4^{\mathrm{e}}$ siècle av. J.-C. L'occupation se poursuit jusqu'aux $1^{\mathrm{er}}$ siècles av./ap. J.-C. d'après le mobilier exhumé ${ }^{127}$ et les datations radiocarbones.

De manière générale, cette chronologie ne s'éloigne guère de celle proposée par Ch. Robin en 1993, ${ }^{128}$ excepté dans les datations absolues que permettent les analyses ${ }^{14} \mathrm{C}$.

\subsubsection{Byn, temple de dhu-Samāwì à Barāqish (?)}

Sur le site voisin de Haram, l'inscription Haram 10, datée du tournant de l'ère chrétienne, est une confession des membres des tribus arabes de Amīr et 'Athtar alors qu'elles trouvèrent refuge à Yathill pendant une guerre avec le Hadramawt et y effectuèrent un pèlerinage à dhu-Samāwī.

Parallèlement, l'inscription Y.92.B.A.20 découverte dans le temple Brn de Nakrah, et également datée du tournant de l'ère chrétienne, commémore l'offrande de deux statues à dhu-Samāwī dans le temple Byn. Ch.

\footnotetext{
123 de Maigret et Robin 1993, 455.

124 Voir Fedele, chapitre 16, vol. 1. Voir également Robin et de Maigret 2009, 67.

125 Il est d'autant plus probable que $\mathrm{Bs}^{1} 1$ fils de $\mathrm{M}^{\mathrm{c}} \mathrm{s}^{1}$ soit le contemporain du roi 'byd' $\mathrm{Yt}^{\mathrm{c}} \mathrm{si}$ l'on considère que son fils est un contemporain du roi Wqh'l Rym, fils de 'byd' $\mathrm{Yt}^{\mathrm{c}}$ (Y.90.B.ext 2).

126 Voir Fedele, chapitre 16, tableau 1, vol. 1.

127 Antonini 1999, 67.

128 de Maigret et Robin 1993, 471-475.
} 
Robin propose deux interprétations possibles. ${ }^{129}$ Soit le temple Brn de Yathill a été renommé Byn dans les dernières décennies de son occupation et consacré au culte de dhu-Samāwī, dieu d'Amīr. Cette hypothèse implique l'installation pérenne de tribus arabes à Barāqish après l'effondrement du royaume de Ma'īn, à l'instar de ce qui s'observe à Haram. ${ }^{130}$ Soit l'inscription Y.92.B.A.20 provient de la ville de Haram où la présence d'un temple Byn consacré à dhu-Samāwī est par ailleurs attestée. Nous privilégions la première hypothèse compte tenu de la reconversion qui affecte également le temple voisin de $Q b d^{m}$ au tournant de l'ère chrétienne.

\subsection{3. $\mathrm{Qbd}^{\mathrm{m}}$, temple de 'Athtar à Barāqish}

Le temple de 'Athtar dhu-Qabdum - Temple B dans la nomenclature de la Mission italienne - est bâti immédiatement au nord du temple de Nakrah (voir Agostini, chapitre 3, volume 1). Il a été intégralement fouillé131 et restauré par la Mission italienne (voir Scigliano et Paladino, chapitre 14, vol. 1). Le temple portait le nom de Qabdum ce dont témoigne aussi bien l'épithète de la divinité qui y est vénérée que la

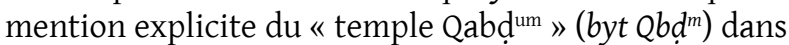
l'inscription Y.05.B.B.13/5, découverte in situ (voir Agostini, chapitres 3 et 4 , volume 1). ${ }^{132}$ L'inscription commémore la construction du temple. Les travaux sont coordonnés par un membre de la fraction de clan Ġzr-Sihfn, chef des maçons et du transport ( $k b r$ grbn w-nqln), sous le règne de Wqh'l Rym, vers la fin du $5^{\mathrm{e}}$-début 4 siècle av. J.-C.

La présence d'une dédicace à Halfān (Y.05.B.B.16) découverte dans ce temple ${ }^{133}$ souligne les changements qui s'opèrent sur le site au tournant de l'ère chrétienne. Halfān, tout comme dhu-Samāwī, sont les divinités vénérées par la tribu arabe d'Amīr, originaire de la région de Najrān. La présence de cette tribu est bien attestée à partir du $2^{\text {e }}$ siècle av. J.-C. dans le Jawf, en particulier dans la ville de Haram. ${ }^{134}$ Or au tournant de l'ère chrétienne, des inscriptions sont dédiées à dhuSamāwī et Halfān dans les deux temples principaux de Yathill. Il est vraisemblable qu'à la suite du passage de l'expédition d'Ælius Gallus, la ville de Yathill ait connu un renouvellement de sa population avec l'introduction d'éléments venus du nord.

\footnotetext{
129 de Maigret et Robin 1993, 475.

130 Robin 1991.

131 de Maigret 2006, 2009b, 2010b ; Agostini 2011, 2015.

132 Agostini 2011, 49-51.

133 Agostini 2015. Voir également Agostini, vol. 1, chapitre 4.

134 Robin 1991.
}

\subsubsection{Byt $\mathrm{Wd}^{\mathrm{m}}$, temple de Wadd à Barāqish}

La construction d'un temple consacré à Wadd ${ }^{u m}$ (byt $\left.W d^{m}\right)$ est commémorée par l'inscription B-M $277=R E ́ S$ 3019. Le commanditaire des travaux est $B s^{1} l$ fils de $M^{\top} S^{1}$ $\underline{d}-S^{2 c} t m$ (clan $G b^{3} n$ ), l'un des bienfaiteurs du temple de Nakrah, connu par plusieurs inscriptions et actif sous le règne de 'byd' $Y t^{c}$ au $5^{\mathrm{e}}$ siècle av. J.-C. Alessio Agostini propose d'en localiser les vestiges immédiatement au nord du temple de 'Athtar dhu-Qabd ${ }^{\text {um }}{ }^{135}$

\subsubsection{Yhrq, temple de 'Athtar à Shaqab al-Manașșa}

Le sanctuaire antique de Shaqab alManașsa est implanté à $2,5 \mathrm{~km}$ au sud-sud-ouest de Barāqish, en bordure $\mathrm{du}$ périmètre irrigué antique, sur un affleurement gréseux, à proximité d'une zone de redistribution des eaux d'irrigation.

Ce sanctuaire, composé de deux grandes salles hypostyles, était consacré au culte de 'Athtar dhuYahriq. ${ }^{136}$ L'épithète de la divinité indique le nom du sanctuaire : Yahriq/Yuhariq (Yhrq). Il apparaît explicitement dans la locution "Athtar dieu de Yhrq" (Shaqab 8 : 'ttr'l Yhrq).

La graphie des inscriptions provenant du sanctuaire indique une activité entre les $8^{\mathrm{e}}$ et $2^{\mathrm{e}}$ siècle av. J.-C. Le portique est remis à neuf sous les règnes de 'bkrb șdq fils de Wqh'l (Shaqab 4) et de son successeur Y tol $^{\circ} \mathrm{Rym}$ (Shaqab 5), vers le $4^{e}$ siècle av. J.-C.

'Athtar dhu-Yahriq est la divinité tutélaire de la tribu de Yathill. Les dédicaces à cette divinité sont uniquement effectuées à Barāqish, dans le temple de Nakrah (Y.92.B.A.10, Y.92.B.A.16, Y.92.B.A.17), où siège la congrégation (qhlt) de 'Athtar dhu-Yahriq (Y.90.B.A.3), et surtout dans le temple Yahriq de Shaqab al-Manașșa (Shaqab 3, 6, 7, 16). La localisation extra muros du sanctuaire de la divinité en facilite l'accès à l'ensemble des membres de la tribu de Yathill. Les sacrifices offerts à la divinité lors de son festival ('hdr) sont fréquemment commémorés sur le rempart de la ville (B-M 12, 44, 182, 211, 267).

\subsubsection{Fț $\mathrm{t} n$, sanctuaire de Nakrah à Darb al-Șabi}

Al-Ṣabī se trouve moins de $2 \mathrm{~km}$ à l'ouest de Barāqish. On y trouve un complexe religieux dédié à Nakrah. ${ }^{137}$ Nous avons vu précédemment que le nom antique de ce périmètre sacré était vraisemblablement $F \underline{t}^{\dagger} n$ (MAFRAYDarb aṣ-Ṣabī 1). ${ }^{138}$

\footnotetext{
135 Agostini 2011, 53-54.

136 Breton et al. 1979, 425-427 ; Gnoli 1993b,

137 Robin et al. 1981. On trouvera une description actualisée du sanctuaire par Valentini, chapitre 28, dans ce volume.

138 Robin et al. $1988: 92$.
} 
Le sanctuaire semble avoir connu une longue période de fréquentation, la graphie des inscriptions couvrant la période des $8^{\mathrm{e}}-2^{\mathrm{e}}$ siècles av. J.-C. L'inscription la plus ancienne d'après sa graphie, MAFRAY-Darb aș-Ṣabī 13, est rédigée en saba’ique vers le $8^{\mathrm{e}}$ siècle av. J.C. Elle mentionne la construction d'un portique. La plupart des inscriptions, de graphie $\mathrm{D}$, datent l'activité principale $\mathrm{du}$ sanctuaire de la période minéenne $\left(3^{\mathrm{e}}-2^{\mathrm{e}}\right.$ siècles av. J.C.). Consacré au culte d'une divinité minéenne et ne présentant pas de texte récent, le sanctuaire semble abandonné tandis que disparaît le royaume de Ma'īn ( $1^{\mathrm{er}}$ siècle av./ap. J.C.).

On peut s'interroger sur les raisons de la présence de deux sanctuaires consacrés à Nakrah faisant l'objet, tous deux, de confessions et d'actes de pénitence. A. Agostini l'explique par la fonction : le sanctuaire de Darb al-Ṣabī est une destination de pèlerinage qui doit permettre d'offrir un refuge, des conditions d'accessibilité et de prophylaxie que n'offre pas le petit temple intra muros de Nakrah. ${ }^{139}$ Il évoque également l'hypothèse de temples réservés à des classes sociales distinctes. Cette hypothèse semble moins convaincante si l'on considère que les deux temples comportent des dédicaces de personnes de même extraction sociale. Ainsi, des membres de la fraction Grbt du clan Mwqh font des offrandes dans les deux temples de Nakrah, à Yathill (Y.92.B.A.37 A-B) et Darb al-Ṣabī (MAFRAY-Darb aș-Ṣabī 3). En revanche, il est possible que le sanctuaire de Darb al-Șabī ait été ouvert à l'ensemble de la population du royaume de Ma'inn là où l'accès du temple intra muros était avant tout restreint aux habitants de Yathill. ${ }^{140}$

Outre la grande accessibilité du sanctuaire du Darb alȘabī, celui-ci nous semble également se distinguer par deux autres traits : d'une part, son antériorité sur le temple intra muros de Nakrah. Il lui semble antérieur d'au moins un siècle; d'autre part il ne présente aucune inscription royale ni même aucune mention de souverain sabéen ou minéen. En ce sens, le sanctuaire apparaît comme l'un des rares lieu d'asile où le pouvoir royal ne se manifeste - voire ne peut se manifester - en aucune manière.

\subsection{Les structures hydrauliques et agricoles}

Les inscriptions commémorent à de rares occasions l'aménagements d'ouvrages hydrauliques et en réglementent l'usage. Ce sont :

- Des vannes ( $\left.m^{\prime} h \underline{d} \underline{d}\right)$ et canaux $\left(m t y^{\prime}\right)$ dont l'inscription MAFRAY-Ḥuṣn Āl Șāliḥ 1 réglemente l'usage vers le $8^{\mathrm{e}}$ siècle av. J.-C.

\footnotetext{
139 Agostini 2012, 6.

140 Voir également sur ce point Valentini, chapitre 28 dans ce volume.
}

- Le puits $\left(b^{2} r\right) T \dot{g} l$ creusé par un membre du clan $G b^{\prime} n$ sous les règnes de 'byd' $Y t^{\prime}$ et Wqh'l Rym (5 siècle av. J.-C. - RÉS $2952+2949)$.

- Le réservoir $\left(m^{\prime} h \underline{d} d n\right) S^{2} b^{c} n$ commandité par le souverain minéen Wqh'l Rym $\left(5^{\mathrm{e}}-4^{\mathrm{e}}\right.$ siècle av. J.C. - Shaqab 18).

- Les répartiteurs ( $m z f)$ de Bhrn réparés sous les règnes de 'lyf $Y s^{2} r$ et de son fils $H w f^{t} t t$ (v. $3^{\mathrm{e}}-2^{\mathrm{e}}$ siècles av. J.-C.). Ces travaux sont menés par des membres des sous-clans Hbrr et $S^{1} y l$, fractions du clan 'ly'.

\subsection{L'habitat}

Les dernières formes de réalisations architecturales commémorées par des inscriptions sont les constructions de cinq résidences. Quatre sont bâties aux $5^{\mathrm{e}}-4^{\mathrm{e}}$ siècles av. J.-C., sous les règnes successifs de 'byd' Yt' et Wqh'l Rym :

- Byt ?, pour des membres du sous-clan Blh, fraction du clan $G b^{2} n$ (Y.03.B.R44-45.3);

- Byt $N^{\top} m n$, pour des membres du clan Gb'n (RÉS $2952+2949)$

- Byt Șdqn, pour des membres du sous-clan $S^{2 c} t m$, fraction du clan Gb’n (YM 26117) ;

- Byt $Y^{c} d$, pour des membres du sous-clan $S^{2 c} t m$, fraction du clan Gb'n (YM 26117).

La cinquième, byt Mḥdr, est bâtie au $1^{\mathrm{er}}$ siècle av. J.-C.

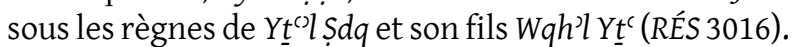

\subsection{L'activité de construction}

\subsubsection{Quand?}

$\mathrm{Au}$ total, 52 inscriptions de construction ont été identifiées au sein du corpus (tableau 4).

Elles ont principalement trait à la construction du rempart (36), dans une moindre mesure aux temples et à leur aménagement (8), à des résidences (5) et à des aménagements hydrauliques (5).

Elles confortent les observations faites à propos du rempart.

La monumentalisation de Barāqish débute vers le $6^{\mathrm{e}}$ siècle av. J.-C. par la mise en chantier du rempart, sous l'impulsion de Minéens établis à Qarnā (Ma'īn 6), et celle du temple de Nakrah. La monumentalisation du site s'intensifie au cours du $5^{\mathrm{e}}$ siècle av. J.-C., sous les règnes de 'byd' Yt' seul, en corégence avec son fils Wqh'l Rym puis sous le règne de ce seul Wqh'l Rym : réaménagement du temple intra muros de Nakrah, construction du temple de 'Athtar dhu-Qabdim, construction du temple de Wadd, construction de la majeure partie du rempart 
(fig. 1) ${ }_{141}^{141}$ construction des résidences $N^{c} m n$, Șdqn et $Y^{\prime} d$, creusement de puits, aménagement de citernes.

Yathill est un chantier permanent qui se poursuit au cours du $4^{e}$ siècle av. J.-C., sous les règnes de 'bkrb Șdq, Yt' ${ }^{\prime}$ l Rym et 'byd' Rym : nouveaux aménagements dans le temple de Nakrah, achèvement du rempart autour de Yathill (en particuliers les courtines $S^{1} l f$ et $D d n$ et les bastions $\underline{d}-B q r n, \underline{d}-N d b n$ et $\left.\underline{d}-S^{2} f t n\right)$, remise à neuf du portique du temple de 'Athtar Yahriq à Shaqab alManaș̣̦a.

Entre le $3^{e}$ et le $2^{e}$ siècles av. J.-C., les interventions se limitent à des travaux de fortifications avec un réaménagement en profondeur du secteur sud-ouest du rempart sous les règnes de 'lyf ${ }^{c} Y s^{2} r$ et de ses fils $H f n m$ Rym et Wqh'l Nbț (courtines 'brm, d-Hsbr et $\mathrm{Hrs}^{2}$; bastions d-Mlh, Lb'n (I), Rbqn (I) et (II), Rdwn, Zbyn et Zrbn) et des travaux hydrauliques dans le secteur irrigué de Malāhāā.

Au début du $1^{\text {er }}$ siècle av. J.-C., les commémorations de réalisations monumentales se font rares. Des réfections commanditées par le souverain lui-même, $Y t^{\circ} l \underline{S} d q$, sont entreprises sur le bastion $Y s^{2} b m$. L'achat de la résidence Mḥdr est évoqué sans qu'il soit possible de préciser s'il s'agit ou non d'une construction neuve.

Enfin, des derniers travaux de réfection sont menés sur le rempart à la suite du passage de l'expédition romaine d'Ælius Gallus, dans le dernier quart du $1^{\text {er }}$ siècle av. J.-C.

En résumé, la monumentalisation de Barāqish intervient à partir du $6^{\mathrm{e}}$ siècle et surtout au cours des $5^{\mathrm{e}}-4^{\mathrm{e}}$ siècles av. J.-C. Au-delà de cette date, ce sont essentiellement des travaux d'entretien et de restauration que l'on commémore.

\subsubsection{Le processus de nomination toponymique}

La plupart des monuments de Barāqish étaient désignés par un nom propre. Les raisons qui président au choix de tel ou tel nom ne peuvent pas être élucidées.

On observe de manière exceptionnelle que certaines structures sont nommées d'après le nom de la fraction de clan qui en finance la construction. C'est le cas du bastion $\underline{d}-H f n$, financé par le sous-clan $H f n$, fraction de $G b^{3} n$. Le bastion $\underline{d}-M l h$ porte lui aussi le nom d'une fraction de clan qui n'est toutefois pas celle de ses bâtisseurs ( $Y f^{c} n$ fraction du clan $G b^{2} n$ ). Ce processus de nomination reste donc occasionnel.

On observe également à de rares occasions des structures portant le nom des villes avec lesquelles les caravaniers de Yathill étaient en contact régulier :

141 Bastions : d-Hfn; d-Mlh ; d-Ndbn; Lb’n (I) ; Lb’n (II) ; Șdqn ; Ys² bm ; Y $\dot{\mathrm{g} l} ; \mathrm{Z}$ rbn. Courtines : Mdd ; $\mathrm{S}^{2} \mathrm{bmt} ; \mathrm{Tn}^{\mathrm{C}} \mathrm{m} ; \mathrm{Tfs}^{2}$. le bastion Zrbn est homonyme de la ville de Zrbn (auj. al-Ukhdūd, région de Najrān) ; la courtine $D d n$ est homonyme de la ville de $D d n$ (auj. al-'Ulā). Ddn étant par ailleurs un nom propre fréquemment attesté en Arabie du Sud, il est là encore difficile d'établir une règle.

\subsubsection{Par qui?}

Il est remarquable que le roi de $\mathrm{Ma}^{\text {cīn n}}$ n'intervienne que rarement en tant que commanditaire, tant dans la capitale Qarnā (Ma'īn 2, 82, 90) qu'à Yathill où seules cinq inscriptions de construction sur 52 ont pour auteur le roi (Shaqab 18, B-M 6, B-M 103, B-M 249, B-M 259). La commande architecturale est avant tout le fait d'une élite locale relevant de cinq clans : ${ }^{142}$

- $\mid y^{\prime} l\left(\right.$ fraction $\left.S^{1} y l\right): 1$ ouvrage hydraulique à Malāhā ;

- Qrn (fraction Hidkt) : 1 ouvrage hydraulique à Darb al-Șabì ;

- Ylqz (fraction Dbr): 1 réalisation (aménagement intérieur du temple de Nakrah à Barāqish);

- Mwqh (fractions Grbt et Zyrn) : 5 ouvrages de types variés (résidence, bastion, courtine, portique de temple, bassin) à Barāqish, Shaqab al-Manașșa et Darb al-Ṣabi ;

- Gb'n (fractions Blh, Hfd, Hfn, $S^{2} t \underline{\underline{t}} m, Y f^{2} n$, Zlwmn): 33 ouvrages parmi lesquels la quasi-totalité des bastions et courtines ainsi que le temple de Wadd et les principaux aménagements intérieurs du temple de Nakrah.

Si les trois premiers clans interviennent de manière anecdotique (ouvrages hydrauliques périphériques, aménagements intérieurs de temple), c'est essentiellement le clan $G b^{\prime} n$ et dans une moindre mesure le clan Mwqh qui œuvrent à la monumentalisation du site. Ces deux clans constituent indéniablement l'élite tribale marchande du royaume.

La suprématie du clan $G b^{\prime} n$ au sein du royaume se manifeste par plusieurs éléments :

- Il est l'un des plus anciens clans du royaume de Ma'īn, attesté dès le $8^{e}$ siècle av. J.-C., et des rois de Ma'in sont issus de ce clan $;^{143}$

- Des membres de ce clan prennent pour épouse des femmes originaires des principales régions

142 Les noms de clans sont rarement mentionnés dans les inscriptions, c'est le plus souvent la fraction de clan (sous-clan) qui apparaît. Les noms des clans sont restitués grâce à la liste des Hiérodules de Ma'īn qui associe fraction de clan et clan. Ajoutons que pour 21 des 52 inscriptions de construction, le clan n'a pu être restitué : 11 sont fragmentaires et l'information est perdue, 10 mentionnent un nom de sous-clan auquel aucun clan ne peut être associé au regard de la documentation actuelle - le détail est présenté dans le tableau 4.

143 Arbach et Rossi 2012. 
partenaires du commerce caravanier : Dadān (al'Ulā), Ghazzat (Gaza), Hagar/Gerrha (al-Hufūf), Yathrib (Médine), Awsān (wādī Markha) (Ma'īn 93, Ma'īn 95, al-Saîd 2009) ;

- L'un d'eux commerce avec l'Égypte (Mșr), l'Assyrie (" $\left.{ }^{2}{ }^{2} r\right)$ et Ghazzat ( $\dot{G} z t$, Gaza) (Ma'īn 7).

- Plusieurs membres occupent des postes honorifiques : chef des serviteurs du temple (?) ( $q d m^{\prime} \mathrm{hl}$ 'mnhtn), chef des Minéens (kbr M`n) dans le comptoir de Dadān en Arabie du Nord (RÉS 3346, Ja 2288).

- On les trouve attestés à Madāin Șālih (RÉS 3708) et al-'Ulā (RÉS 3344, RÉS 3353) dans le Nord de l'Arabie ainsi que dans la capitale qatabānite Tamna' (CSAI I, 72).

- Ce clan finance la construction d'une large partie du rempart de Qarnā (actuelle Ma'īn - Ma'īn 1, Ma'in 7).

- On lui connaît enfin de vastes domaines fonciers autour de Qarnā (Ma'īn 1) et de Yathill, jusqu'aux limites de la ville d'Inabba' (A-20-849). ${ }^{144}$

Le clan Mwqh relève dans une moindre mesure de cette classe dominante minéenne :

- Mention de ses membres dans des inscriptions trouvées en Arabie du Nord, à al-'Ulā (M 390, RÉS 3697, RÉS 3283) et Madāin Șālih (RÉS 3708) ;

- Des membres de ce clan prennent pour épouse des femmes étrangères originaires d'Égypte (Ma'in 93, Ma'in 95) et de Khasham (lieu non identifié, Ma'īn 93).

- Le sarcophage d'un membre de ce clan enfin a été découvert dans l'oasis du Fayyoum en Égypte (RÉS 3427).

En résumé, on observe que Yathill, une fois intégrée au royaume de $\mathrm{Ma}^{\mathrm{c} i n}$ ( $7^{\mathrm{e}}$ siècle av. J.-C.) ne fait pas l'objet d'un investissement monumental immédiatement. Ce n'est qu'au cours du $6^{\mathrm{e}}$ siècle que l'impulsion est donnée par des Minéens établis dans la capitale Qarnā (Ma'īn 6). Les fractions locales des clans dominants Mwqh et $G b^{\prime} n$ prennent alors le relais, sans que l'influence de la volonté royale ne puisse être déterminée. Yathill fait l'objet d'aménagements ambitieux bâtis entre le $6^{\mathrm{e}}$ et le $4^{\mathrm{e}}$ siècle av. J.-C. L'élément déterminant dans cette monumentalisation de la ville est la richesse accumulée par les principaux clans à travers les réseaux commerciaux transarabiques. Une dîme sur les recettes commerciales est prélevée par les temples (Ma'in 7). À Yathill, la construction monumentale est une manière fréquemment employée pour s'acquitter de cette taxe due au temple de 'Athtar dhu-Qabḍm (RÉS 2975, RÉS 3012, RÉS 3021, RÉS 3022, RÉS 3535).

144 Le sous-clan $\underline{\mathrm{d}}$-Zllwmn mentionné dans ce texte est une fraction de Gb’n (Ma'īn $93 \mathrm{C} / 3,19)$.

\section{Revisiter la chronologie royale de $\mathrm{Ma}^{\mathrm{c}} \mathrm{i} n$}

Pour les besoins de cette étude et l'ancrage des événements rapportés par les inscriptions dans un cadre chronologique, une liste de la succession des rois de Ma'īn s'avérait nécessaire. La mention épigraphique des souverains est, avec la paléographie, l'un des rares éléments de chronologie que nous offrent les textes. Plusieurs chronologies ont été élaborées (pour n'en citer que les principales : Winnett 1939; Albright 1953 ; Pirenne 1956 ; Von Wissmann 1976 ; Arbach 1993 ; Kitchen 1994 ; Bron 1998 ; Arbach 2018.

Aucune n'est pleinement satisfaisante dans le sens où les souverains ne sont pas tous connus, les homonymes ne sont pas aisément distinguables et la filiation des souverains n'est pas toujours renseignée. Tout au plus pouvons-nous restituer des groupes de souverains qu'il n'est pas toujours aisé de positionner les uns par rapport aux autres.

Il est ici apparu nécessaire d'entreprendre un nouveau classement pour deux raisons. La première est qu'un corpus plus large de données est désormais disponible; la seconde est que la datation absolue du règne d'un souverain majeur, 'byd' $Y t^{c}$ se précise grâce au croisement des données archéologiques (voir Agostini, chapitre 3, et Fedele, chapitre 16, dand le volume 1) et épigraphiques (voir Agostini, chapitre 4, dans le volume 1).

\section{1 'byd' $\mathrm{Yt}^{\mathrm{c}}$, roi de $M a^{\mathrm{c}}$ in au 5 e siècle av. J.-C.}

L'inscription RÉS 3022 a été rédigée sous le règne de 'byd' $Y^{t}$ roi de $\mathrm{Ma}^{\mathrm{i}} \mathrm{i} n$ et rapporte une révolte de l'Égypte contre les Mèdes $(M \underline{d y})$. Rares sont les événements historiques externes renseignés par les inscriptions sudarabiques et ce texte a été l'une des clés dans l'établissement de la chronologie sudarabique. Une littérature abondante est consacrée à ce synchronisme. ${ }^{145}$

L'événement de RÉS 3022 a fréquemment été associé à l'expédition d'Artaxerxés III Ochos en Égypte en 343 av. J.-C. et le règne de 'byd' $Y t^{c}$ est de ce fait situé au milieu du $4^{\mathrm{e}}$ siècle av. J.-C. Cette date ne semble toutefois pas devoir être retenue. Une date du $5^{\mathrm{e}}$ siècle av. J.-C. est préférable pour plusieurs raisons.

A. Lemaire a déjà présenté plusieurs arguments dans ce sens : $:^{146}$

- Trois satrapies perses sont mentionnées dans RÉS 3022 : l'Égypte (Msr), l'Assyrie ( $\left.{ }^{2} s^{2} r\right)$, la Transeuphratène ('br Nhrn) : la création

\footnotetext{
145 Voir en particulier Lemaire 1996, 44-47 et références citées.

146 Lemaire 1996, 45-47.
} 
d'une satrapie de Transeuphratène, distincte de celle d'Assyrie, date de la réorganisation administrative de la région par Xerxés $\mathrm{I}^{\mathrm{er}}$, vers 482 av. J.-C. Par ailleurs, la Transeuphratène est rattachée à la Cilicie en 345. La mention de la Transeuphratène, si elle est évoquée en tant que satrapie et non comme aire géographique, indique une période comprise entre 482 et 345.

- L'inscription RÉS 3022 évoque une révolte $(\mathrm{mrd})$ des Égyptiens contre les Mèdes et non une guerre (dr). Cela renverrait plutôt à l'un des cinq événements identifiés par A. Lemaire comme des révoltes avérées ou des périodes de rejet de l'autorité perse (463-454; 422; 414-413; 411 ; 405-398 av. J.-C.).

A. Multhoff a également démontré sur la base d'une analyse philologique et historique précise que les événements rapportés par les inscriptions RÉS 3022, Bauer 5, RÉS 3869 et Demirjian 1 étaient liés les uns aux autres de sorte que RÉS 3022 évoque très certainement une révolte égyptienne de la fin du $5^{\mathrm{e}}$ siècle av. J.-C. et que la guerre entre Chaldéens et Ioniens rapportée par Demirjian 1 renverrait à la guerre d'Euagoras (vers 390-380 av. J.-C.), ${ }^{147}$ tel que proposé dans une récente étude. ${ }^{148} \mathrm{~A}$. Multhoff a donc proposé, à la suite d'A. Lemaire, de dater le règne de 'byd' $Y \underline{t}^{\mathrm{c}}$ à la fin du $5^{\mathrm{e}}$ siècle av. J.-C.

Un troisième point semble faire pencher la balance en faveur de cette datation haute : les datations radiocarbones obtenues dans les temples de Barāqish (voir Agostini, chapitre 3, et Fedele, chapitre 16, dans le volume 1).

Un échantillon prélevé au niveau du pavement du temple de 'Athtar, dans un contexte de peu postérieur à la construction de l'édifice, est daté de 750-408 calBCE. ${ }^{149}$ La construction de ce temple intervient au cours du règne de $W q h^{\prime} l$ Rym fils de 'byd' $Y t^{c}$; il est donc peu probable que la construction du temple soit postérieure à 343 av. J.-C., date habituellement proposée pour le règne du père de Wqh'l Rym. Le temple de 'Athtar dhuQabḍm fut vraisemblablement bâti à une date plus haute (fin $5^{\mathrm{e}}$-début $4{ }^{\mathrm{e}}$ siècle av. J.-C.), ce qui s'accorderait mieux avec la datation radiocarbone.
Un second échantillon analysé provient des dépôts inférieurs de la phase B du temple de Nakrah. Ces aménagements furent réalisés sous le règne de 'byd' $Y \underline{t}^{c}$ (voir § 5.2.1). L'échantillon est daté de 750-380 cal$\mathrm{BCE} .{ }^{150}$ Là encore, l'échantillon indiquerait des travaux réalisés avant la date de 380 av. J.-C.

Compte tenu des données philologiques, historiques et des datations radiocarbones, le règne de ' $b y d^{\prime} Y t^{c}$ semble devoir être remonté à la seconde moitié du $5^{\mathrm{e}}$ siècle av. J.-C. L'événement rapporté par RÉS 3022 intervient à une date comprise entre 463 et 405 av. J.-C. Les datations radiocarbones tendent également à faire remonter des réalisations architecturales datées du règne de son fils Wqh'l Rym au $5^{\mathrm{e}}$ siècle av. J.-C. Les échantillons ne sont toutefois pas assez nombreux pour en être assuré. Les données s'accordent au moins pour dater celui-ci de la fin du $5^{\mathrm{e}}$-début $4^{\mathrm{e}}$ siècle av. J.-C.

\subsection{Les rois de $\mathrm{Ma}^{\mathrm{c} i n}$ dans la documentation épigraphique}

Le tableau 6 propose une chronologie royale où la succession des groupes se fonde sur la graphie, en partant du principe que le style paléographique $\mathrm{D}$ de J. Pirenne est postérieur au style E, tel qu'elle l'admettait elle-même. Lorsque les inscriptions propres à certains groupes relèvent de mêmes types paléographiques, leur mise en ordre n'est pas toujours assurée. Dans ce cas, ils sont présentés accolés de la mention 'groupes interchangeables', en laissant la possibilité de leur succession ouverte.

Certains groupes présentant une graphie identique peuvent être calés les uns par rapport aux autres grâce au contexte de découverte de l'inscription ou à des éléments prosopographiques. Cela reste rare.

Les datations absolues se fondent sur les datations radiocarbones obtenues sur le site de Barāqish (la graphie $C$ est contemporaine de constructions datées du $6^{e}$ siècle av. J.-C. ; la graphie E2-E3, celle des règnes de 'byd' $Y \underline{t}^{\mathrm{c}}$ et $W q h^{\prime} l \mathrm{Rym}$, de la seconde moitié du $5^{\mathrm{e}}-$ première moitié du $4^{e}$ siècle av. J.-C.).

147 Multhoff 2019.

148 Sørensen et Geus 2019.

149 Voir Fedele, vol. 1 chapitre 16, échantillon Bar.05.B/2a.

150 Voir Fedele, vol. 1 chapitre 16, échantillon Y.92.B/138. 
Tableau 3. Les inscriptions de Barāqish. Sigles et concordances (intra muros indéterminé) (J. Schiettecatte).

\section{Barāqish intra muros (indéterminé).}

\begin{tabular}{|c|c|c|c|c|c|c|}
\hline Antonini Stela 2 & & & & & & Antonini $2005,308-309$ \\
\hline \multicolumn{7}{|l|}{ B-Int 1} \\
\hline \multicolumn{7}{|l|}{ B-Int 2} \\
\hline \multicolumn{7}{|l|}{ B-Int 3} \\
\hline B-Int 4 & & & M 208 & & RÉS 2985 & Garbini 1974 \\
\hline \multicolumn{7}{|l|}{ B-Int 5} \\
\hline \multicolumn{7}{|l|}{ B-Int 6} \\
\hline \multicolumn{7}{|l|}{ B-Int 7} \\
\hline \multicolumn{7}{|l|}{ B-Int 8} \\
\hline \multicolumn{7}{|l|}{ B-Int 9} \\
\hline \multicolumn{7}{|l|}{ B-Int 11} \\
\hline \multicolumn{7}{|l|}{ B-Int 12} \\
\hline \multicolumn{7}{|l|}{ B-Int 13} \\
\hline \multicolumn{7}{|l|}{ B-Int 14} \\
\hline \multicolumn{7}{|l|}{ B-Int 15} \\
\hline B-Int 16 & & & & & & Garbini 1974 \\
\hline \multicolumn{7}{|l|}{ B-Int 17} \\
\hline B-Int 18 & & & M 204 & & RÉS 2981 & Garbini 1974 \\
\hline B-Int 19 & Gr 327 & Hal 489 & M 207 & Nāmī B 97 & RÉS 2984 & Bauer et Lundin 1998, 123 ; Garbini 1974 \\
\hline \multicolumn{7}{|l|}{ B-Int 20} \\
\hline B-Int 21 & & & M 206 & & RÉS 2983 & Garbini 1974 \\
\hline \multicolumn{7}{|l|}{ B-Int 22} \\
\hline \multicolumn{7}{|l|}{ B-Int 23} \\
\hline \multicolumn{7}{|l|}{ B-Int 24} \\
\hline \multicolumn{7}{|l|}{ B-Int 25} \\
\hline \multicolumn{7}{|l|}{ B-Int 26} \\
\hline \multicolumn{7}{|l|}{ B-Int 27} \\
\hline \multicolumn{7}{|l|}{ B-Int 28} \\
\hline \multicolumn{7}{|l|}{ B-Int 29} \\
\hline B-Int 30 & & & & & & \\
\hline B-Int 31 & & & & & & \\
\hline B-Int 32 & & & & & & \\
\hline B-Int 33 & & & & & & \\
\hline B-Int 34 & & & & & & \\
\hline B-Int 35 & & & & & & \\
\hline B-Int 39 & & & & & & \\
\hline B-Int 40 & & & & & & \\
\hline B-Int 41 & & & & & & \\
\hline B-Int 42 & & & & & & \\
\hline B-Int 45 & & & & & & \\
\hline B-Int 45 bis & & & & & & \\
\hline B-Int 46 & & & & & & \\
\hline B-Int 49 & & & & & & \\
\hline & Gr 322 & & & & & Bauer et Lundin 1998, 121 \\
\hline Y.90.B.1 & & & & & & \\
\hline
\end{tabular}




\begin{tabular}{|l|l|l|l|l|l|l|}
\hline Y.90.B.2 & & & & & & \\
\hline Y.90.B.3 & & & & & & \\
\hline Y.90.B.4 & & & & & & \\
\hline Y.90.B.5 & & & & & & \\
\hline Y.90.B.6 & & & & & & \\
\hline Y.90.B.7 & & & & & & \\
\hline Y.90.B.ext 3 & & & & & & \\
\hline Y.90.B.ext 4 & & & & & & \\
\hline Y.90.B.ext 5 & & & & & & \\
\hline Y.90.B.ext 6 & & & & & & \\
\hline Y.90.B.ext 7 & & & & & & \\
\hline
\end{tabular}

\section{Temple de Nakrah}

\begin{tabular}{|c|c|c|c|c|c|}
\hline & & Hal 485 & M 203 & RÉS 2980 bis & Garbini 1974 ; de Maigret et Robin 1993, 488-489 \\
\hline Y.03.B.A.1 & & & & & Agostini 2012, 6-7 \\
\hline \multicolumn{6}{|l|}{ Y.90.B.A 1} \\
\hline \multicolumn{6}{|l|}{ Y.90.B.A 2} \\
\hline Y.90.B.A 3 & & & & & de Maigret et Robin 1993, 480 \\
\hline \multicolumn{6}{|l|}{ Y.90.B.A 4} \\
\hline \multicolumn{6}{|l|}{ Y.90.B.A 5} \\
\hline \multicolumn{6}{|l|}{ Y.90.B.A 6} \\
\hline Y.90.B.A 7 & & & & & de Maigret et Robin 1993, 480-481 \\
\hline \multicolumn{6}{|l|}{ Y.90.B.A 8} \\
\hline \multicolumn{6}{|l|}{ Y.90.B.A 9} \\
\hline \multicolumn{6}{|c|}{ Y.90.B.A $10(A+B)$} \\
\hline \multicolumn{6}{|l|}{ Y.90.B.A 11} \\
\hline \multicolumn{6}{|l|}{ Y.90.B.A 12} \\
\hline \multicolumn{6}{|l|}{ Y.90.B.A 13} \\
\hline \multicolumn{6}{|c|}{ Y.90.B.A $14(A+B)$} \\
\hline \multicolumn{6}{|l|}{ Y.90.B.A 15} \\
\hline \multicolumn{6}{|c|}{ Y.90.B.A $16(+$ Y.86.B.ext 1) } \\
\hline \multicolumn{6}{|l|}{ Y.90.B.A.17 } \\
\hline Y.90.B.A.18 & & & & & de Maigret et Robin 1993, 482 \\
\hline \multicolumn{6}{|l|}{ Y.90.B.A.19 } \\
\hline \multicolumn{6}{|l|}{ Y.90.B.ext 1} \\
\hline Y.90.B.ext 2 & YM 26117 & & & & de Maigret et Robin 1993, 482-483 \\
\hline \multicolumn{6}{|l|}{ Y.92.B.A.1 } \\
\hline \multicolumn{6}{|l|}{ Y.92.B.A.2 } \\
\hline \multicolumn{6}{|l|}{ Y.92.B.A.3 } \\
\hline \multicolumn{6}{|l|}{ Y.92.B.A.4 } \\
\hline \multicolumn{6}{|l|}{ Y.92.B.A.6 } \\
\hline \multicolumn{6}{|l|}{ Y.92.B.A.7 } \\
\hline \multicolumn{6}{|l|}{ Y.92.B.A.8 } \\
\hline \multicolumn{6}{|l|}{ Y.92.B.A.9 } \\
\hline \multicolumn{6}{|l|}{ Y.92.B.A.10 } \\
\hline \multicolumn{6}{|l|}{ Y.92.B.A.11 } \\
\hline \multicolumn{6}{|l|}{ Y.92.B.A.12 } \\
\hline Y.92.B.A.13 & & & & & \\
\hline Y.92.B.A.14 & & & & & \\
\hline
\end{tabular}




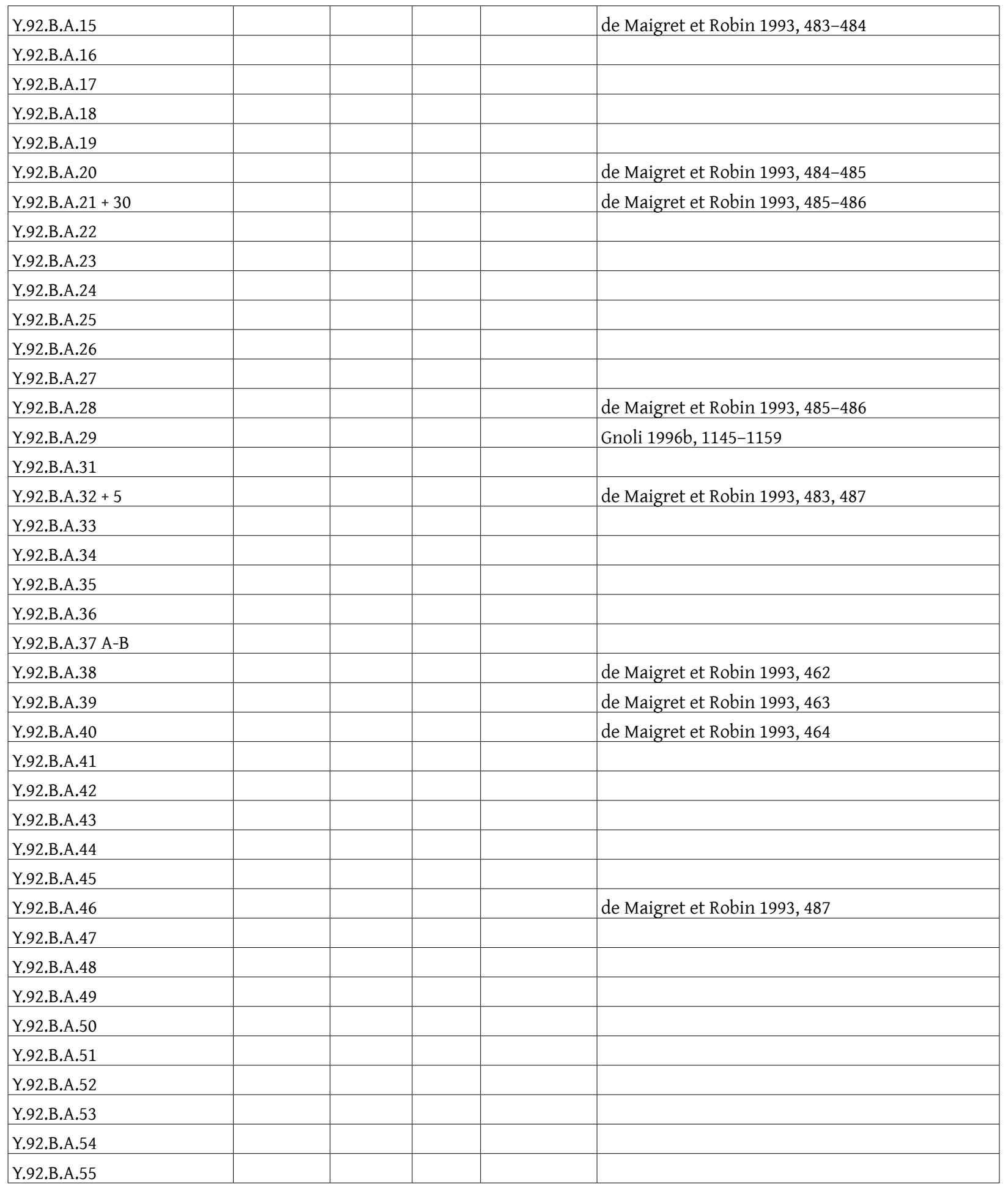

\section{Temple de 'Athtar dhu-Qabd}

\begin{tabular}{|l|l|}
\hline Y.04.B.B.. bis & Agostini, chapitre 4, Volume 1 \\
\hline Y.04.B.B. 10 & Agostini, chapitre 4, Volume 1 \\
\hline Y.04.B.B. 11 & Agostini, chapitre 4, Volume 1 \\
\hline Y.05.B.B. 1 & Agostini, chapitre 4, Volume 1 \\
\hline Y.05.B.B. $3+18$ & Agostini, chapitre 4, Volume 1 \\
\hline Y.05.B.B. 8 & Agostini, chapitre 4, Volume 1 \\
\hline Y.05.B.B. 9 & Agostini, chapitre 4, Volume 1 \\
\hline
\end{tabular}




\begin{tabular}{|l|l|}
\hline Y.05.B.B. 10 & Agostini, chapitre 4, Volume 1 \\
\hline Y.05.B.B. 11 & Agostini, chapitre 4, Volume 1 \\
\hline Y.05.B.B. 12 & Agostini 2011, 51-53. \\
\hline Y.05.B.B.13 & Agostini 2011, 49-51. \\
\hline Y.05.B.B. 14 & Agostini, chapitre 4, Volume 1 \\
\hline Y.05.B.B. 16 & Agostini 2015, 10-11 \\
\hline Y.05.B.B. 17 & Agostini, chapitre 4, Volume 1 \\
\hline Y.05.B.B. 19 & Agostini, chapitre 4, Volume 1 \\
\hline Y.05.B.B. 21 & Agostini, chapitre 4, Volume 1 \\
\hline Y.05.B.B. 23 & Agostini, chapitre 4, Volume 1 \\
\hline Y.05.B.B. 25 & \\
\hline Y.05.B.B. 26 & Agostini, chapitre 4, Volume 1 \\
\hline Y.05.B.B. 27 & Agostini, chapitre 4, Volume 1 \\
\hline Y.06.B.B. 4 & Agostini, chapitre 4, Volume 1 \\
\hline Y.06.B.B.6 & Agostini, chapitre 4, Volume 1 \\
\hline Y.06.B.B.7 & Agostini, chapitre 4, Volume 1 \\
\hline Y.06.B.B. 8 & Agostini, chapitre 4, Volume 1 \\
\hline Y.06.B.B.10 & Agostini, chapitre 4, Volume 1 \\
\hline Y.06.B.B.11 & Agostini, chapitre 4, Volume 1 \\
\hline
\end{tabular}

\section{Rempart}

\begin{tabular}{|c|c|c|c|c|c|c|}
\hline \multicolumn{7}{|l|}{ B-Int 36} \\
\hline \multicolumn{7}{|l|}{ B-Int 37} \\
\hline \multicolumn{7}{|l|}{ B-Int 38} \\
\hline \multicolumn{7}{|l|}{ B-Int 43} \\
\hline \multicolumn{7}{|l|}{ B-Int 44} \\
\hline \multicolumn{7}{|l|}{ B-Int 48} \\
\hline \multicolumn{7}{|l|}{ B-Int 50} \\
\hline B-M 1 & Gr 316 & $\begin{array}{l}\text { Hal } 478+ \\
479\end{array}$ & M 197 & Nāmī B 63 & RÉS 2975 & $\begin{array}{l}\text { Bauer et Lundin 1998, 118-120 ; } \\
\text { Garbini } 1974 \text {; Müller 1982, 132-133 }\end{array}$ \\
\hline \multicolumn{7}{|l|}{ B-M 2} \\
\hline \multicolumn{7}{|l|}{ B-M 3} \\
\hline B-M 4 & Gr 321 & Hal 540 & M 252 & & RÉS 3027 & Bauer et Lundin 1998, 121; Garbini 1974 \\
\hline B-M 5 & Gr 319 & Hal 539 & M 251 & & RÉS 3026 & Bauer et Lundin 1998, 121; Garbini 1974 \\
\hline B-M 6 & Gr 318 & Hal 538 & M 250 & Nāmī B 64 & RÉS 3025 & Bauer et Lundin 1998, 120 ; Garbini 1974 \\
\hline B-M 7 & & & M 249 & & RÉS 3024 & Garbini 1974 \\
\hline \multicolumn{7}{|l|}{ B-M 8} \\
\hline \multicolumn{7}{|l|}{ B-M 9} \\
\hline B-M 10 & & Hal 520 & M 236 & & RÉS 3012 & Robin 1979b, 103 ; Garbini 1974 \\
\hline \multicolumn{7}{|l|}{ B-M 11} \\
\hline B-M 12 & & & M 237 & RÉS 3013 & & Garbini 1974 \\
\hline B-M 13 & & & M 238 & & RÉS 3014 & Garbini 1974 \\
\hline \multicolumn{7}{|l|}{ B-M 14} \\
\hline B-M 15 & & & M 255 & & RÉS 3029 & Garbini 1974 \\
\hline B-M 16 & & & M 256 & & RÉS 3030 & Garbini 1974 \\
\hline \multicolumn{7}{|l|}{ B-M 17} \\
\hline B-M 18 & & & M 258 & & RÉS 3032 & Garbini 1974 \\
\hline \multicolumn{7}{|l|}{ B-M 19} \\
\hline B-M 19 bis & & & M 257 & & RÉS 3031 & Garbini 1974 \\
\hline
\end{tabular}




\begin{tabular}{|c|c|c|c|c|c|c|}
\hline \multicolumn{7}{|l|}{ B-M 20} \\
\hline B-M 21 & & & M 248 & & RÉS 3023 & Garbini 1974 \\
\hline \multicolumn{7}{|l|}{ B-M 22} \\
\hline B-M 23 & & & M 253 & & RÉS 3028 & Garbini 1974 \\
\hline \multicolumn{7}{|l|}{ B-M 23 bis } \\
\hline \multicolumn{7}{|l|}{ B-M 24} \\
\hline B-M 25 & & & M 260 & & RÉS 3034 & Garbini 1974 \\
\hline B-M 26 & & & M 254 & & RÉS 3028 bis & Garbini 1974 \\
\hline \multicolumn{7}{|l|}{ B-M 27} \\
\hline \multicolumn{7}{|l|}{ B-M 28} \\
\hline \multicolumn{7}{|l|}{ B-M 29} \\
\hline \multicolumn{7}{|l|}{ B-M 30} \\
\hline \multicolumn{7}{|l|}{ B-M 31} \\
\hline \multicolumn{7}{|l|}{ B-M 32} \\
\hline B-M 33 & & & M 271 & & RÉS 3045 & Garbini 1974 \\
\hline B-M 34 & & & M 259 & & RÉS 3033 & Garbini 1974 \\
\hline \multicolumn{7}{|l|}{ B-M 35} \\
\hline \multicolumn{7}{|l|}{ B-M 36} \\
\hline \multicolumn{7}{|l|}{ B-M 37} \\
\hline B-M 38 & & & $\begin{array}{l}\text { M 261+ } \\
273\end{array}$ & & $\begin{array}{l}\text { RÉS } 3035+ \\
3048\end{array}$ & Garbini 1974 \\
\hline B-M 39 & & & M 272 & & RÉS 3047 & Garbini 1974 \\
\hline \multicolumn{7}{|l|}{ B-M 40} \\
\hline B-M 41 & & & M 264 & & RÉS 3038 & Garbini 1974 \\
\hline B-M 42 & Gr 277 & Hal 555 & M 267 & & RÉS 3041 & Bauer et Lundin 1998, 102 ; Garbini 1974 \\
\hline B-M 43 & & & M 268 & & RÉS 3042 & Garbini 1974 \\
\hline B-M 44 & & & $\begin{array}{l}\text { M 266+ } \\
265+274\end{array}$ & & $\begin{array}{l}\text { RÉS } 3040+ \\
3039+3049\end{array}$ & Garbini 1974 \\
\hline \multicolumn{7}{|l|}{ B-M 45} \\
\hline B-M 46 & & & M 269 & & RÉS 3043 & Garbini 1974 \\
\hline \multicolumn{7}{|l|}{ B-M 47} \\
\hline \multicolumn{7}{|l|}{ B-M 48} \\
\hline \multicolumn{7}{|l|}{ B-M 49} \\
\hline \multicolumn{7}{|l|}{ B-M 50} \\
\hline \multicolumn{7}{|l|}{ B-M 51} \\
\hline \multicolumn{7}{|l|}{ B-M 52} \\
\hline \multicolumn{7}{|l|}{ B-M 53} \\
\hline B-M 54 & & & & & & \\
\hline B-M 55 & & & M 410 & Nāmī B 74 & & Garbini 1974 \\
\hline $\begin{array}{l}\text { B-M } 56 \text { = Robin- } \\
\text { Barāqish } 1\end{array}$ & & & M 283 & & RÉS 3060 & $\begin{array}{l}\text { Garbini } 1974 \text {; Robin 1979b, 104-105 ; Robin } \\
\text { 1979a, } 195\end{array}$ \\
\hline B-M 57 & & & & & & \\
\hline B-M 58 & & & & & & \\
\hline B-M 59 & & & & & & \\
\hline B-M 60 & & & & & & \\
\hline B-M 61 & & & & & & \\
\hline B-M 62 & & & M 280 & & RÉS 3057 & Garbini 1974 \\
\hline B-M 63 & & & & & & \\
\hline B-M 64 & & & & & & \\
\hline B-M 65 & & & & & & \\
\hline
\end{tabular}


JÉRÉMIE SCHIETTECATTE AVEC LA COLLABORATION DE MOUNIR ARBACH: LES INSCRIPTIONS DE BARĀQISH

\begin{tabular}{|c|c|c|c|c|}
\hline B-M 66 & & & & \\
\hline \multicolumn{5}{|l|}{ B-M 67} \\
\hline B-M 68 & M 415 & Nāmī B 81 & & Garbini 1974 \\
\hline B-M 69 & M 414 & Nāmī B 80 & & Garbini 1974 \\
\hline B-M 70 & M 413 & Nāmī B 79 & & Garbini 1974 \\
\hline B-M 71 & M 412 & Nāmī B 78 & & Garbini 1974 \\
\hline B-M 72 & M 411 & Nāmī B 77 & & Garbini 1974 \\
\hline B-M 73 & $\begin{array}{l}\text { M 4 416 + } \\
275+275\end{array}$ & & $\begin{array}{l}\text { RÉS 3053+ } \\
3056+3050\end{array}$ & Garbini 1974 \\
\hline \multicolumn{5}{|l|}{ B-M 74} \\
\hline B-M 75 & M 278 & & RÉS $3052 \mathrm{~B}$ & Garbini 1974 \\
\hline B-M 76 & $\begin{array}{l}\text { M 276 + } \\
277\end{array}$ & & $\begin{array}{l}\text { RÉS 3051 + } \\
3052 \mathrm{a}\end{array}$ & Garbini 1974 \\
\hline \multicolumn{5}{|l|}{ B-M 77} \\
\hline \multicolumn{5}{|l|}{ B-M 78} \\
\hline \multicolumn{5}{|l|}{ B-M 79} \\
\hline B-M 80 & M 279 & & RÉS 3054 & Garbini 1974 \\
\hline B-M 81 & M 417 & Nāmī B 85 & & Garbini 1974 \\
\hline B-M 82 & M 275 & & RÉS 3050 & Garbini 1974 \\
\hline B-M 83 & M 420 & Nāmī B 91 & & Garbini 1974 \\
\hline B-M 84 & M 421 & Nāmī B 93 & & Garbini 1974 \\
\hline B-M 85 & M 422 & Nāmī B 95 & & Garbini 1974 \\
\hline B-M 86 & M 274A & & RÉS 3055 & Garbini 1974 \\
\hline B-M 87 & M 423 & Nāmī B 96 & & Garbini 1974 \\
\hline \multicolumn{5}{|l|}{ B-M 88} \\
\hline B-M 89 & M 282 & & RÉS 3059 & Garbini 1974 \\
\hline \multicolumn{5}{|l|}{ B-M 90} \\
\hline \multicolumn{5}{|l|}{ B-M 91} \\
\hline B-M 92 & M 424 & Nāmī B 99 & & Garbini 1974 \\
\hline \multicolumn{5}{|l|}{ B-M 93} \\
\hline B-M 94 & M 425 & Nāmī B 100 & & Garbini 1974 \\
\hline \multicolumn{5}{|l|}{ B-M 95} \\
\hline B-M 96 & M 426 & Nāmī B 101 & & Garbini 1974 \\
\hline \multicolumn{5}{|l|}{ B-M 97} \\
\hline \multicolumn{5}{|l|}{ B-M 98} \\
\hline \multicolumn{5}{|l|}{ B-M 99} \\
\hline \multicolumn{5}{|l|}{ B-M 100} \\
\hline \multicolumn{5}{|l|}{ B-M 101} \\
\hline \multicolumn{5}{|l|}{ B-M 102} \\
\hline $\begin{array}{l}\text { B-M } 103 \text { = Robin- } \\
\text { Barāqish } 80\end{array}$ & & & & Robin 1979a, 193-194 \\
\hline \multicolumn{5}{|l|}{ B-M 104} \\
\hline \multicolumn{5}{|l|}{ B-M 105} \\
\hline B-M 106 & M 427 & Nāmī B 102 & & Garbini 1974 \\
\hline \multicolumn{5}{|l|}{ B-M 107} \\
\hline \multicolumn{5}{|l|}{ B-M 108} \\
\hline \multicolumn{5}{|l|}{ B-M 109} \\
\hline B-M 110 & M 428 & Nāmī B 104 & & Garbini 1974 \\
\hline B-M 111 & $\begin{array}{l}\text { M 431 + } \\
432\end{array}$ & $\begin{array}{l}\text { Nāmīi B } 107 \text { + } \\
\text { Nāmī B } 108\end{array}$ & & Garbini 1974 \\
\hline B-M 112 & & & & \\
\hline
\end{tabular}




\begin{tabular}{|c|c|c|c|c|c|c|}
\hline \multicolumn{7}{|l|}{ B-M 113} \\
\hline B-M 114 & & & M 429 & Nāmī B 105 & & Garbini 1974 \\
\hline B-M 115 & & & $\begin{array}{l}\text { M 436+ } \\
430\end{array}$ & $\begin{array}{l}\text { Nāmī B } 112+ \\
\text { Nāmī B } 106\end{array}$ & & Garbini 1974 \\
\hline \multicolumn{7}{|l|}{ B-M 116} \\
\hline \multicolumn{7}{|l|}{ B-M 117} \\
\hline \multicolumn{7}{|l|}{ B-M 118} \\
\hline B-M 119 & & & M 434 & Nāmī B 110 & & Garbini 1974 \\
\hline B-M 120 & & & M 433 & Nāmī B 109 & & Garbini 1974 \\
\hline B-M 121 & & & M 437 & Nāmī B 113 & & Garbini 1974 \\
\hline \multicolumn{7}{|l|}{ B-M 122} \\
\hline \multicolumn{7}{|l|}{ B-M 123} \\
\hline B-M 124 & & & M 435 & Nāmī B 111 & & Garbini 1974 \\
\hline \multicolumn{7}{|l|}{ B-M 125} \\
\hline B-M 126 & & & M 438 & Nāmī B 114 & & Garbini 1974 \\
\hline \multicolumn{7}{|l|}{ B-M 127} \\
\hline \multicolumn{7}{|l|}{ B-M 128} \\
\hline \multicolumn{7}{|l|}{ B-M 129} \\
\hline \multicolumn{7}{|l|}{ B-M 130} \\
\hline \multicolumn{7}{|l|}{ B-M 131} \\
\hline B-M 132 & $\begin{array}{l}\text { Gr } 249+ \\
250\end{array}$ & Hal 494 & $\begin{array}{l}\text { M 439+ } \\
212\end{array}$ & $\begin{array}{l}\text { Nāmī B 116 (+ } \\
\text { RÉS 2989) }\end{array}$ & & Bauer et Lundin 1998, 118 ; Garbini 1974 \\
\hline \multicolumn{7}{|l|}{ B-M 133} \\
\hline B-M 134 & Gr 252 & & M 440 & Nāmī B 118 & & Bauer et Lundin 1998, 118 ; Garbini 1974 \\
\hline B-M 135 & Gr 253 & & & & & Bauer et Lundin 1998,118 \\
\hline B-M 136 & $\begin{array}{l}\text { Gr } 261 \\
+260+ \\
248+ \\
257\end{array}$ & $\begin{array}{l}\text { Hal } 501+ \\
500+493 \\
+497\end{array}$ & $\begin{array}{l}\text { M } 219+ \\
218+211+ \\
215\end{array}$ & & $\begin{array}{l}\text { RÉS } 2996+ \\
2995+2988+ \\
2992\end{array}$ & Bauer et Lundin 1998, 119 ; Garbini 1974 \\
\hline \multicolumn{7}{|l|}{ B-M 137} \\
\hline B-M 138 & Gr 255 & Hal 495 & M 213 & Nāmī B 119 & RÉS 2990 & Bauer et Lundin 1998, 118 ; Garbini 1974 \\
\hline B-M 139 & $\begin{array}{l}\text { Gr } 256+ \\
\text { Gr 259+ } \\
\text { Nāmī B } \\
109+\text { Gr } \\
258\end{array}$ & $\begin{array}{l}\text { Hal } 496+ \\
498+499\end{array}$ & $\begin{array}{l}\text { M } 214+ \\
216+217\end{array}$ & & $\begin{array}{l}\text { RÉS 2991 + } \\
2993+2994\end{array}$ & Bauer et Lundin 1998, 91; Garbini 1974 \\
\hline B-M 141 & Gr 262 & Hal 502 & M 220 & & RÉS 2997 & Bauer et Lundin 1998, 92 ; Garbini 1974 \\
\hline \multicolumn{7}{|l|}{ B-M 142} \\
\hline \multicolumn{7}{|l|}{ B-M 143} \\
\hline \multicolumn{7}{|l|}{ B-M 144} \\
\hline B-M 145 & Gr 264 & & M 441 & Nāmī B 126 & & Bauer et Lundin 1998, 92 ; Garbini 1974 \\
\hline \multicolumn{7}{|l|}{ B-M 146} \\
\hline B-M 147 & Gr 271 & Hal 504 & M 222 & Nāmī B 127 & RÉS 2999 & $\begin{array}{l}\text { Bauer et Lundin 1998, 95-98; } \\
\text { Garbini } 1974\end{array}$ \\
\hline B-M 148 & Gr 270 & Hal 508 & M 225 & Nāmī B 131 & RÉS 3002 & $\begin{array}{l}\text { Bauer et Lundin 1998, 94-95; } \\
\text { Garbini } 1974\end{array}$ \\
\hline B-M 149 & Gr 268 & Hal 507 & M 224 & Nāmī B 129 & RÉS 3001 & Bauer et Lundin 1998, 93; Garbini 1974 \\
\hline B-M 150 & $\begin{array}{l}\text { Gr } 267+ \\
\text { Gr } 266\end{array}$ & $\begin{array}{l}\text { Hal } 506+ \\
505\end{array}$ & M 223 & Nāmī B 128 & RÉS 3000 & Bauer et Lundin 1998, 92 ; Garbini 1974 \\
\hline B-M 151 & Gr 269 & & M 442 & Nāmī B 130 & & $\begin{array}{l}\text { Bauer et Lundin 1998, 93-94; } \\
\text { Garbini } 1974\end{array}$ \\
\hline B-M 152 & & & & & & \\
\hline
\end{tabular}




\begin{tabular}{|c|c|c|c|c|c|c|}
\hline B-M 153 & & & & & & \\
\hline \multicolumn{7}{|l|}{ B-M 154} \\
\hline \multicolumn{7}{|l|}{ B-M 155} \\
\hline B-M 156 & & & M 160 & & RÉS 2938 & Garbini 1974 \\
\hline B-M 157 & & & M 158 & & RÉS 2936 & Garbini 1974 \\
\hline B-M 158 & & & M 157 & & RÉS 2935 & Garbini 1974 \\
\hline B-M 159 & & & M 156 & & RÉS 2934 & Garbini 1974 \\
\hline B-M 160 & & & M 155 & & RÉS 2933 & Garbini 1974 \\
\hline B-M 161 & & & M 154 & & RÉS 2932 & Garbini 1974 \\
\hline B-M 162 & & & M 153 & & RÉS 2931 & Garbini 1974 \\
\hline B-M 163 & & & M 152 & & RÉS 2930 & Garbini 1974 \\
\hline \multicolumn{7}{|l|}{ B-M 164} \\
\hline \multicolumn{7}{|l|}{ B-M 165} \\
\hline \multicolumn{7}{|l|}{ B-M 166} \\
\hline \multicolumn{7}{|l|}{ B-M 167} \\
\hline \multicolumn{7}{|l|}{ B-M 168} \\
\hline \multicolumn{7}{|l|}{ B-M 169} \\
\hline \multicolumn{7}{|l|}{ B-M 171} \\
\hline \multicolumn{7}{|l|}{ B-M 172} \\
\hline \multicolumn{7}{|l|}{ B-M 173} \\
\hline \multicolumn{7}{|l|}{ B-M 174} \\
\hline \multicolumn{7}{|l|}{ B-M 175} \\
\hline B-M 176 & Gr 274 & & & & & Bauer et Lundin 1998, 102 \\
\hline \multicolumn{7}{|l|}{ B-M 177} \\
\hline B-M 178 & Gr 275 & Hal 442 & M 166 & Nāmī B 139 & RÉS 2944 & Bauer et Lundin 1998, 102 ; Garbini 1974 \\
\hline B-M 179 & & Hal 441 & M 165 & & RÉS 2943 & Garbini 1974 \\
\hline B-M 180 & & & M 164 & & RÉS 2942 & Garbini 1974 \\
\hline \multicolumn{7}{|l|}{ B-M 181} \\
\hline B-M 182 & $\begin{array}{l}\text { Gr } 272+ \\
273\end{array}$ & $\begin{array}{l}\text { Hal } 424+ \\
435\end{array}$ & M $151+163$ & & $\begin{array}{l}\text { RÉS } 2929+ \\
2941+2945+ \\
2946\end{array}$ & $\begin{array}{l}\text { Bauer et Lundin } 1998,98 \text {; Garbini } 1974 \text {; } \\
\text { Robin } 1979 b, 104\end{array}$ \\
\hline \multicolumn{7}{|l|}{ B-M 183} \\
\hline \multicolumn{7}{|l|}{ B-M 184} \\
\hline \multicolumn{7}{|l|}{ B-M 185} \\
\hline \multicolumn{7}{|l|}{ B-M 186} \\
\hline B-M 187 & Gr 278 & & & & & Bauer et Lundin 1998, 102 \\
\hline \multicolumn{7}{|l|}{ B-M 188} \\
\hline \multicolumn{7}{|l|}{ B-M 189} \\
\hline B-M 190 & Gr 282 & & M 444 & Nāmī B 143 & & $\begin{array}{l}\text { Bauer et Lundin 1998, 104-105; } \\
\text { Garbini } 1974\end{array}$ \\
\hline B-M 191 & Gr 279 & & M 467 & & & Bauer et Lundin 1998, 102 ; Garbini 1974 \\
\hline \multicolumn{7}{|l|}{ B-M 192} \\
\hline B-M 193 & & & & & & \\
\hline B-M 194 & Gr 284 & Hal 445 & M 167 & Nāmī B 145 & RÉS 2947 & Bauer et Lundin 1998, 107 ; Garbini 1974 \\
\hline B-M 195 & & & & & & \\
\hline B-M 196 & $\begin{array}{l}\text { Gr } 285+ \\
283\end{array}$ & $\begin{array}{l}\text { Hal } 447+ \\
446\end{array}$ & M 168 & Nāmī B 146 & RÉS 2948 & $\begin{array}{l}\text { Bauer et Lundin 1998, 105-107 ; } \\
\text { Garbini } 1974\end{array}$ \\
\hline B-M 197 & & & & & & \\
\hline B-M 198 & & & M 443 & Nāmī B 138 & & Garbini 1974 \\
\hline B-M 199 & Gr 287 & & & & & Bauer et Lundin 1998, 107 \\
\hline B-M 200 & & & & & & \\
\hline
\end{tabular}




\begin{tabular}{|c|c|c|c|c|c|c|}
\hline \multicolumn{7}{|l|}{ B-M 201} \\
\hline B-M 202 & Gr 288 & & M 446 & Nāmī B 147 & & Bauer et Lundin 1998, 107 ; Garbini 1974 \\
\hline B-M 203 & Gr 290 & Hal 449 & M 170 & Nāmī B 149 & RÉS 2950 & Bauer et Lundin 1998, 108 ; Garbini 1974 \\
\hline $\begin{array}{l}{[\mathrm{B}-\mathrm{M} 211+] \mathrm{B}-\mathrm{M}} \\
204\end{array}$ & Gr 289 & Hal 448 & M 169 & Nāmī B 148 & RÉS 2949 & $\begin{array}{l}\text { Bauer et Lundin 1998, 107-108; } \\
\text { Garbini } 1974\end{array}$ \\
\hline \multicolumn{7}{|l|}{ B-M 205} \\
\hline B-M 206 & & & M 173 & & RÉS 2953 & Garbini 1974 \\
\hline B-M 207 & & & M 171 & & RÉS 2951 & Garbini 1974 \\
\hline \multicolumn{7}{|l|}{ B-M 208} \\
\hline \multicolumn{7}{|l|}{ B-M 209} \\
\hline B-M 210 & & & M 174 & & RÉS 2954 & Garbini 1974 \\
\hline $\begin{array}{l}\text { B-M } 211[+ \text { B-M } \\
204]\end{array}$ & & & M 172 & & RÉS 2952 & Garbini 1974 ; Müller 1982, 132 \\
\hline B-M 211 bis & & & M 177 & & RÉS 2957 & \\
\hline B-M 212 & & & M 178 & & RÉS 2958 & Garbini 1974 \\
\hline \multicolumn{7}{|l|}{ B-M 213} \\
\hline \multicolumn{7}{|l|}{ B-M 214} \\
\hline \multicolumn{7}{|l|}{ B-M 215} \\
\hline B-M 216 & Gr 291 & & M 179 & & RÉS 2959 & Bauer et Lundin 1998, 108 ; Garbini 1974 \\
\hline \multicolumn{7}{|l|}{ B-M 217} \\
\hline $\begin{array}{l}\text { B-M 218 = } \\
\text { Y.03.B.R44-45.4 }\end{array}$ & & & M 180 & & RÉS 2960 & $\begin{array}{l}\text { Garbini } 1974 ; \\
\text { Agostini, chapitre 4, Volume } 1\end{array}$ \\
\hline \multicolumn{7}{|l|}{ B-M 219} \\
\hline B-M 220 & & & M 181 & & RÉS 2961 & Garbini 1974 \\
\hline B-M 221 & & & M 226 & & RÉS 3003 & Garbini 1974 \\
\hline B-M 222 & Gr 293 & Hal 512 & M 228 & Nāmī B 26 & RÉS 3005 & Bauer et Lundin 1998, 109 ; Garbini 1974 \\
\hline B-M 223 & Gr 292 & Hal 511 & M 227 & Nāmī B 23 & RÉS 3004 & $\begin{array}{l}\text { Bauer et Lundin 1998, 108-109; } \\
\text { Garbini } 1974\end{array}$ \\
\hline $\begin{array}{l}\text { B-M } 224 \\
\text { [frag. de Bauer } 5 \\
=\text { B-M } 231+224 \\
+238]\end{array}$ & & Hal 462 & M 182 & & RÉS 2962 & $\begin{array}{l}\text { Bauer et Lundin 1998, 110-112; } \\
\text { Garbini } 1974\end{array}$ \\
\hline \multicolumn{7}{|l|}{ B-M 225} \\
\hline B-M 226 & Gr 294 & Hal 513 & M 229 & Nāmī B 28 & RÉS 3006 & Bauer et Lundin 1998, 109 ; Garbini 1974 \\
\hline B-M 227 & Gr 296 & & M 466 & & & $\begin{array}{l}\text { Bauer et Lundin 1998, 109-110; } \\
\text { Garbini } 1974\end{array}$ \\
\hline B-M 228 & Gr 295 & Hal 464 & M 184 & Nāmī B 29 & RÉS 2964 & Bauer et Lundin 1998, 109 ; Garbini 1974 \\
\hline B-M 229 & & & M 183 & & RÉS 2963 & Garbini 1974 \\
\hline \multicolumn{7}{|l|}{ B-M 230} \\
\hline $\begin{array}{l}\text { B-M 231 = Robin- } \\
\text { Barāqish } 50 \\
\text { [frag. de Bauer } 5 \\
=\text { B-M } 231+224 \\
+238]\end{array}$ & Gr 299 & & & & & Bauer et Lundin 1998, 110 \\
\hline B-M 232 & Gr 298 & Hal 515 & M 231 & & RÉS 3008 & Bauer et Lundin 1998, 110 ; Garbini 1974 \\
\hline B-M 233 & Gr 297 & Hal 514 & M 230 & & RÉS 3007 & Bauer et Lundin 1998, 110 ; Garbini 1974 \\
\hline B-M 234 & & & M 161 & & RÉS 2939 & Garbini 1974 \\
\hline \multicolumn{7}{|l|}{ B-M 235} \\
\hline B-M 236 & Gr 301 & & & & & Bauer et Lundin 1998, 110 \\
\hline B-M 237 & & & M 404 & Nāmī B 32 & & Garbini 1974 \\
\hline $\begin{array}{l}\text { B-M } 238 \\
\text { [frag. de Bauer } 5 \\
=\text { B-M } 231+224 \\
+238]\end{array}$ & Gr 303 & & M 347 & Nāmī B 33 & RÉS 3535 & $\begin{array}{l}\text { Bauer et Lundin } 1998,110-112 \text {; } \\
\text { Garbini } 1974 \text {; Robin 1979b, } 104\end{array}$ \\
\hline
\end{tabular}


JÉRÉMIE SCHIETTECATTE AVEC LA COLLABORATION DE MOUNIR ARBACH: LES INSCRIPTIONS DE BARĀQISH

\begin{tabular}{|c|c|c|c|c|c|c|}
\hline B-M 239 & & & M 419 & Nāmī B 87 & & Garbini 1974 \\
\hline B-M 240 & & & M 418 & Nāmī B 86 & & Garbini 1974 \\
\hline B-M 241 & Gr 304 & $\begin{array}{l}\text { Hal } 465+ \\
466\end{array}$ & M 185 & Nāmī B 34 & RÉS 2965 & $\begin{array}{l}\text { Bauer et Lundin 1998, } 113 \text {; Robin 1979b, } \\
104 ; 1979 b, 193 \text {; Garbini } 1974\end{array}$ \\
\hline \multicolumn{7}{|l|}{ B-M 242} \\
\hline B-M 243 & & & M 232 & & RÉS 3009 & Garbini 1974 \\
\hline \multicolumn{7}{|l|}{ B-M 244} \\
\hline \multicolumn{7}{|l|}{ B-M 245} \\
\hline B-M 246 & & & M 187 & & RÉS 2967 & Garbini 1974 \\
\hline B-M $247+255$ & & & $\begin{array}{l}\text { M } 186+ \\
188\end{array}$ & & $\begin{array}{l}\text { RÉS } 2966+ \\
2968\end{array}$ & Bauer et Lundin 1998, 114 ; Garbini 1974 \\
\hline B-M 248 & & & M 233 & & RÉS 3010 & Garbini 1974 \\
\hline \multicolumn{7}{|l|}{ B-M 249} \\
\hline \multicolumn{7}{|l|}{ B-M 250} \\
\hline \multicolumn{7}{|l|}{ B-M 251} \\
\hline \multicolumn{7}{|l|}{ B-M 252} \\
\hline B-M 253 & $\begin{array}{l}\text { Gr } 307+ \\
306\end{array}$ & & $\begin{array}{l}\text { M } 405+ \\
189\end{array}$ & Nāmī B $40+39$ & RÉS 2969 & $\begin{array}{l}\text { Bauer et Lundin 1998, 114-115; } \\
\text { Garbini } 1974\end{array}$ \\
\hline \multicolumn{7}{|l|}{ B-M 254} \\
\hline B-M 256 & $\begin{array}{l}\text { Gr } 309+ \\
\text { Gr } 310+ \\
\text { Gr } 312+ \\
\text { Gr } 311\end{array}$ & $\begin{array}{l}\text { Hal } 471+ \\
472+474 \\
+473\end{array}$ & $\begin{array}{l}\text { M } 194+ \\
190+191+ \\
193+192\end{array}$ & & $\begin{array}{l}\text { RÉS } 2972+ \\
2970+2971+ \\
2971 \text { bis B }+ \\
2971 \text { bis A } \\
\end{array}$ & $\begin{array}{l}\text { Bauer et Lundin 1998, 115, } 116 \text {; } \\
\text { Garbini } 1974 \text {; Robin 1979b, } 104\end{array}$ \\
\hline B-M 257 & Gr 313 & $\begin{array}{l}\text { Hal } 535+ \\
578\end{array}$ & M 247 & Nāmī B 46 & RÉS 3022 & $\begin{array}{l}\text { Bauer et Lundin 1998, 116-117; } \\
\text { Garbini } 1974 \text {; Robin 1979b, } 104\end{array}$ \\
\hline B-M 258 & Gr 314 & Hal 477 & M 196 & Nāmī B 47 & RÉS 2974 & Bauer et Lundin 1998, 117 ; Garbini 1974 \\
\hline B-M 259 & Gr 315 & Hal 476 & M 195 & Nāmī B 45 & RÉS 2973 & $\begin{array}{l}\text { Bauer et Lundin 1998, 117-118; } \\
\text { Garbini } 1974\end{array}$ \\
\hline \multicolumn{7}{|l|}{ B-M 260} \\
\hline B-M 261 & & & M 406 & Nāmī B 44 & & Garbini 1974 \\
\hline B-M 262 & & & M 210 & & RÉS 2987 & Garbini 1974 \\
\hline \multicolumn{7}{|l|}{ B-M 263} \\
\hline B-M 264 & & & M 239 & & RÉS 3015 & Garbini 1974 \\
\hline B-M 265 & & & M 240 & & RÉS 3016 & Garbini 1974 \\
\hline B-M 266 & & & M 378 & & RÉS 4224 & Garbini 1974 \\
\hline B-M 267 & & & M 242 & & RÉS 3017 bis & Garbini 1974 ; Müller 1982, 133 \\
\hline B-M 268 & & & M 241 & & RÉS 3017 & Garbini 1974 ; Müller 1982, 133 \\
\hline B-M 269 & & & M 243 & & RÉS 3018 & Garbini 1974 \\
\hline \multicolumn{7}{|l|}{ B-M 270} \\
\hline \multicolumn{7}{|l|}{ B-M 271} \\
\hline B-M 272 & & & M 246 & & RÉS 3021 & $\begin{array}{l}\text { Garbini } 1974 \text {; Müller 1982, } 134 ; \\
\text { Robin 1979b, } 103\end{array}$ \\
\hline B-M 273 & & & M 200 & & RÉS 2978 & Garbini 1974 ; Robin 1979b, 103 \\
\hline \multicolumn{7}{|l|}{ B-M 274} \\
\hline \multicolumn{7}{|l|}{ B-M 275} \\
\hline B-M 276 & & & M 245 & & RÉS 3020 & Garbini 1974 \\
\hline B-M 277 & & & M 244 & & RÉS 3019 & Garbini 1974 \\
\hline B-M 278 & & & M 199 & & RÉS 2977 & Garbini 1974 \\
\hline B-M 279 & & & M 201 & & RÉS 2979 & Garbini 1974 \\
\hline \multirow[t]{3}{*}{ B-M 280} & Gr 317 & Hal 480 & M 198 & Nāmī B 61 & RÉS 2976 & Bauer et Lundin 1998, 120 ; Garbini 1974 \\
\hline & Gr 251 & & & Nāmī B 117 & & Bauer et Lundin 1998,118 \\
\hline & Gr 281 & & M 445 & Nāmī B 144 & & Bauer et Lundin 1998, 102 ; Garbini 1974 \\
\hline
\end{tabular}




\begin{tabular}{|c|c|c|c|c|c|c|}
\hline & Gr 308 & & & & & Bauer et Lundin 1998,115 \\
\hline & Gr 323 & & M 448 & Nāmī B 155 & & Bauer et Lundin 1998, 121 ; Garbini 1974 \\
\hline & Gr 286 & & & & & Bauer et Lundin 1998,107 \\
\hline & Gr 280 & & & & & Bauer et Lundin 1998, 102 \\
\hline & Gr 326 & & & & & Bauer et Lundin $1998,122-123$ \\
\hline & Gr 325 & & & & & Bauer et Lundin 1998,122 \\
\hline & Gr 300 & & & & & Bauer et Lundin 1998,110 \\
\hline & Gr 265 & Hal 503 & M 221 & & RÉS 2998 & Bauer et Lundin 1998, 92 ; Garbini 1974 \\
\hline & Gr 324 & Hal 575 & $\begin{array}{l}\text { M 281 = } \\
449\end{array}$ & Nāmī B 156 & RÉS 3058 & Bauer et Lundin 1998, 121 ; Garbini 1974 \\
\hline & & & M 439 & Nāmi B 116 & & Garbini 1974 \\
\hline Y.03.B.R44-45.1 & & & & & & Agostini, chapitre 9, Volume 1 \\
\hline $\begin{array}{l}\text { Y.03.B.R44-45.2bis } \\
+2 \text { ter }+2\end{array}$ & & & & & & Agostini, chapitre 9, Volume 1 \\
\hline Y.03.B.R44-45.3 & & & & & & Agostini, chapitre 9, Volume 1 \\
\hline Y.04.B.T45.1 & & & & & & Agostini, chapitre 9, Volume 1 \\
\hline Y.04.B.T45.2 & & & & & & Agostini, chapitre 9, Volume 1 \\
\hline Y.04.B.T45.3 & & & & & & Agostini, chapitre 9, Volume 1 \\
\hline \multirow[t]{4}{*}{ Y.04.B.T45.4 } & & & & & & Agostini, chapitre 9, Volume 1 \\
\hline & & & M 159 & & RÉS 2937 & Garbini 1974 \\
\hline & & & M 262 & & RÉS 3036 & Garbini 1974 \\
\hline & & & M 263 & & RÉS 3037 & Garbini 1974 \\
\hline
\end{tabular}

\section{Extra muros - Area C}

\begin{tabular}{|l|l|}
\hline B.06.C.O $/ 2+3+14$ & Agostini, chapitre 24, dans ce volume \\
\hline B.06.C.O $/ 4$ & Agostini, chapitre 24, dans ce volume \\
\hline B.06.C.O $/ 5$ & Agostini, chapitre 24, dans ce volume \\
\hline B.06.C.O $/ 7$ & Agostini, chapitre 24, dans ce volume \\
\hline B.06.C.O $/ 8+9$ & Agostini, chapitre 24, dans ce volume \\
\hline B.06.C.O $/ 11$ & Agostini, chapitre 24, dans ce volume \\
\hline B.06.C.O $/ 12$ & Agostini, chapitre 24, dans ce volume \\
\hline B.06.C.O $/ 13$ & Agostini, chapitre 24, dans ce volume \\
\hline B.06.C.O/15 & Agostini, chapitre 24, dans ce volume \\
\hline B.06.C.O $/ 16$ & Agostini, chapitre 24, dans ce volume \\
\hline Y.06.B.C.1 & Agostini, chapitre 24, dans ce volume \\
\hline
\end{tabular}

Extra muros - Area D, nécropole

\begin{tabular}{|l|l|}
\hline B.05.D.O./10 & Antonini et Agostini 2010a, 18, 52 \\
\hline B.05.D.O./11 & Antonini et Agostini 2010a, 21, 52-53 \\
\hline B.05.D.O./12 & Antonini et Agostini 2010a, 19, 53 \\
\hline B.05.D.O./13 & Antonini et Agostini 2010a, 53 \\
\hline B.05.D.O./15 & Antonini et Agostini 2010a, 16-17, 53 \\
\hline B.05.D.O./16 & Antonini et Agostini 2010a, 18, 54 \\
\hline B.05.D.O./18 & Antonini et Agostini 2010a, 17, 54-55 \\
\hline B.05.D.O./20 & Antonini et Agostini 2010a, 17, 55 \\
\hline B.05.D.O./21 & Antonini et Agostini 2010a, 55 \\
\hline B.05.D.O./22 & Antonini et Agostini 2010a, 18-19, 55 \\
\hline B.05.D.O./23 & Antonini et Agostini 2010a, 17, 56 \\
\hline B.05.D.O./24 $/ 2010 \mathrm{a}, 20,56$ \\
\hline
\end{tabular}




\begin{tabular}{|c|c|}
\hline B.05.D.0./25 & Antonini et Agostini $2010 \mathrm{a}, 20,56-57$ \\
\hline B.05.D.0./26 & Antonini et Agostini 2010a, 57 \\
\hline B.05.D.o./3 & Antonini et Agostini 2010a, 51 \\
\hline B.05.D.0./33 & Antonini et Agostini 2010a, 19, 58 \\
\hline B.05.D.O./4 & Antonini et Agostini 2010a, 51 \\
\hline B.05.D.0./9 & Antonini et Agostini 2010a, 21, 51 \\
\hline B.06.D.o./13 & Antonini et Agostini 2010a, 17, 58 \\
\hline B.06.D.0./15 & Antonini et Agostini 2010a, 22, 58-59 \\
\hline B.06.D.0./16 & Antonini et Agostini 2010a, 17, 59 \\
\hline B.06.D.0./17 & Antonini et Agostini 2010a, 17, 59 \\
\hline B.06.D.0./18 & Antonini et Agostini 2010a, 22, 59 \\
\hline B.06.D.o./19 & Antonini et Agostini 2010a, 60 \\
\hline B.06.D.O. $/ 20$ & Antonini et Agostini 2010a, 18, 60 \\
\hline B.06.D.O./21 & Antonini et Agostini 2010a, 19, 60-61 \\
\hline B.06.D.0./23 & Antonini et Agostini 2010a, 22, 61 \\
\hline B.06.D.O./24 & Antonini et Agostini 2010a, 21, 61 \\
\hline B.06.D.0./25 & Antonini et Agostini 2010a, 24, 65 \\
\hline B.06.D.0./26 & Antonini et Agostini 2010a, 18, 62 \\
\hline B.06.D.O./27 & Antonini et Agostini 2010a, 18, 62 \\
\hline B.06.D.0./30 & Antonini et Agostini 2010a, 18, 62-63 \\
\hline B.06.D.0./31 & Antonini et Agostini 2010a, 19, 63 \\
\hline
\end{tabular}

\section{Extra muros - Indéterminé}

\begin{tabular}{|l|l|}
\hline Y.86.BARi/13 & $\begin{array}{l}\text { Antonini 1988, 133 (Antonini chapitre 2, } \\
\text { Volume 1) }\end{array}$ \\
\hline MAIRY.05/11 & Antonini et Agostini 2010a, 65, 81 \\
\hline MAIRY.05/12 & Antonini et Agostini 2010a, 66 \\
\hline MAIRY.05/14 & Antonini et Agostini 2010a, 66, 81 \\
\hline MAIRY.05/16 & Antonini et Agostini 2010a, 64, 77 \\
\hline MAIRY.05/17 & Antonini et Agostini 2010a, 64, 77 \\
\hline MAIRY.05/18 & Antonini et Agostini 2010a, 64 \\
\hline MAIRY.05/6 & Antonini et Agostini 2010a, 63-64, 78 \\
\hline MAIRY.05/7 & Antonini et Agostini 2010a, 64, 76 \\
\hline MAIRY.05/9 & Antonini et Agostini 2010a, 64, 77 \\
\hline MAIRY.06/3 & Antonini et Agostini 2010a, 65, 79 \\
\hline MAIRY.06/4 & Antonini et Agostini 2010a, 66, 81 \\
\hline MAIRY.06/5 & Antonini et Agostini 2010a, 65, 78 \\
\hline
\end{tabular}

\section{Indéterminé}

\begin{tabular}{|l|l|l|l|l|}
\hline B 31 & Gr 254 & & & Bauer et Lundin 1998, 90 \\
\hline BM 125142 & & M 305 & RÉS 3326 & Garbini 1974 \\
\hline Fa 126 & & M 209 & RÉS 2986 & Garbini 1974 \\
\hline Nāmī B 147 & M 447 & & Garbini 1974 \\
\hline Nāmī B 158 & M 450 & & Garbini 1974 \\
\hline YM 28336 & & & Arbach et Audouin 2007, 64 \\
\hline YM 28988 & & & & Arbach et Audouin 2007, 67 \\
\hline & & M 162 & RÉS 2940 & Garbini 1974 \\
\hline & & M 175 & RÉS 2955 & Garbini 1974 \\
\hline & & M 176 & RÉS 2956 & Garbini 1974 \\
\hline
\end{tabular}




\begin{tabular}{|l|l|l|l|l|}
\hline & & M 205 & RÉS 2982 & Garbini 1974 \\
\hline & M 234 & RÉS 3011 & Garbini 1974 \\
\hline & M 235 & RÉS 3011 bis & Garbini 1974 \\
\hline & M 270 & RÉS 3044 & Garbini 1974 \\
\hline & M 337 & RÉS 3403 & Garbini 1974 \\
\hline
\end{tabular}

\section{Al-Darb (Darb al-Ashrāf)}

\section{Y.90.DA/1}

Y.90.DA/2

\section{Darb al-Ṣabī - Temple de Nakrạ̣}

MAFRAY-Darb aș-Șabī 1

MAFRAY-Darb aș-Șabī 10

MAFRAY-Darb aș-Ṣabī 11

MAFRAY-Darb aș-Șabī 12

MAFRAY-Darb aș-Ṣabī 13

MAFRAY-Darb aș-Ṣabī 15

MAFRAY-Darb aș-Ṣabī 16

MAFRAY-Darb aș-Ṣabī 17

MAFRAY-Darb aș-Șabī 18

MAFRAY-Darb aș-Șabī 19

MAFRAY-Darb as-Șabī 2

MAFRAY-Darb aș-Ṣabī 20

MAFRAY-Darb aș-Ṣabī 21

MAFRAY-Darb aș-Ṣabī 22

MAFRAY-Darb aș-Șabī 23

MAFRAY-Darb aș-Șabī 24

MAFRAY-Darb aș-Ṣabī 25

MAFRAY-Darb aș-Ṣabī 26

MAFRAY-Darb aș-Ṣabī 27

MAFRAY-Darb aș-Ṣabī 28

MAFRAY-Darb aș-Șabī 29

MAFRAY-Darb aș-Ṣabī 3

MAFRAY-Darb aș-Șabī 30

MAFRAY-Darb aș-Ṣabī 31

MAFRAY-Darb aș-Ṣabī 32

MAFRAY-Darb aș-Ṣabī 4

MAFRAY-Darb aș-Ṣabī 5

MAFRAY-Darb aș-Șabī 6

MAFRAY-Darb aș-Șabī 7

MAFRAY-Darb aș-Ṣabī 8

MAFRAY-Darb aș-Ṣabī 9
Gnoli et Robin 1992, 93-95

Gnoli et Robin 1992, 93-95

\section{Ḥuṣn Āl șāliḥ}

MAFRAY-Huṣn Āl Șālih 1

MAFRAY-Huṣn Āl Șālih 2

MAFRAY-Huṣn Āl Șālih 3

MAFRAY-Huṣn Āl Șālih 4
Robin et al. 1988, 99-109

Robin et al. 1988, 120-121

Robin et al. 1988, 121-122

Robin et al. 1988, 122

Robin et al. 1988, 123-124

Robin et al. 1988, 124-125

Robin et al. 1988, 126-128

Robin et al. 1988, 128-129

Robin et al. 1988, 129-130

Robin et al. 1988, 130

Robin et al. 1988, 109-111

Robin et al. 1988, 131

Robin et al. 1988, 131-132

Robin et al. 1988, 132

Robin et al. 1988, 133

Robin et al. 1988, 133

Robin et al. 1988, 133-134

Robin et al. 1988, 134-136

Robin et al. 1988, 136-137

Robin et al. 1988, 111-112

Robin et al. 1988, 137-138

Robin et al. 1988, 138

Arbach 1994, 5-8

Robin et al. 1988, 113

Robin et al. 1988, 114-115

Robin et al. 1988, 116

Robin et al. 1988, 116-118

Robin et al. 1988, 118-119

Robin et al. 1988, 119-120 
MAFRAY-Hușn Āl șālih 5

\section{Shaqab al-Manașsa - Temple de 'Athtar dhu-Yahriq}

\begin{tabular}{|c|c|c|c|c|c|c|}
\hline Shaqab 1 & & & MAFRAY-ash-Shaqab 3 & & & Gnoli 1993, 69-72 \\
\hline Shaqab 2 & & & MAFRAY-ash-Shaqab 4 & & & Gnoli $1993,72-74$ \\
\hline Shaqab 3 & & & MAFRAY-ash-Shaqab 5 & & & Gnoli 1993, 74-75 \\
\hline Shaqab 4 & & & MAFRAY-ash-Shaqab 1 & & & Gnoli 1993, 75-78 \\
\hline Shaqab 5 & & & MAFRAY-ash-Shaqab 2 & & & Gnoli 1993, 78-80 \\
\hline Shaqab 6 & & & & & Y.90.SHQ/2 & Gnoli 1993, 80-82 \\
\hline Shaqab 7 & & & MAFRAY-ash-Shaqab 7 & & & Gnoli 1993, 83-84 \\
\hline Shaqab 8 & & & & & Y.86.SHQ/1 & Gnoli 1993, 84-86 \\
\hline Shaqab 9 & & & & & Y.92.SHQ/3 & Gnoli 1993, 86-87 \\
\hline Shaqab 10 & & & MAFRAY-ash-Shaqab 8 & & & Gnoli 1993, 87 \\
\hline Shaqab 11 & & & MAFRAY-ash-Shaqab 11 & & & Gnoli 1993, 87 \\
\hline Shaqab 12 & & & MAFRAY-ash-Shaqab 6 & & & Gnoli 1993, 88 \\
\hline Shaqab 13 & & & MAFRAY-ash-Shaqab 9 & & & Gnoli 1993, 88-89 \\
\hline Shaqab 14 & & & MAFRAY-ash-Shaqab 10 & & & Gnoli 1993, 89 \\
\hline Shaqab 15 & & & & & Y.92.SHQ/4 & Gnoli 1993, 91-92 \\
\hline Shaqab 16 & & & MAFRAY-ash-Shaqab 12 & & & Gnoli 1993, 92-95 \\
\hline Shaqab 17 & & & MAFRAY-ash-Shaqab 14 & & & Gnoli 1993, 95 \\
\hline Shaqab 18 & & & MAFRAY-ash-Shaqab 13 & & & $\begin{array}{l}\text { Gnoli 1993, 95-97; } \\
\text { Robin 1988, 102-103 }\end{array}$ \\
\hline Shaqab 19 & Fa 14 & Hal 484 & M 202 & RÉS 2980 & & $\begin{array}{l}\text { Garbini } 1974 \text {; Gnoli } 1993 \text {, } \\
100-112\end{array}$ \\
\hline
\end{tabular}

\section{Wādī Malāḥā’}

\begin{tabular}{|c|c|}
\hline MAFRAY-Malāḥā̄ 2 & Robin $1987,171-172$ \\
\hline MAFRAY-Malāḥā' 1 & Robin $1988,101-102$ \\
\hline MAFRAY-Malāḥā' 3 & \\
\hline
\end{tabular}


Tableau 4. Liste des constructions attestées dans les inscriptions de Barāqish (J. Schiettecatte).

\begin{tabular}{|c|c|c|c|c|c|c|}
\hline \multirow{2}{*}{$\begin{array}{l}\text { Nom de la } \\
\text { structure }\end{array}$} & \multirow[b]{2}{*}{ Nature } & \multicolumn{2}{|c|}{ Commanditaires } & \multirow[b]{2}{*}{ Règne } & \multirow[b]{2}{*}{ Date } & \multirow[b]{2}{*}{ Inscription } \\
\hline & & $\begin{array}{c}\text { Fraction de } \\
\text { clan } \\
\end{array}$ & Clan & & & \\
\hline- & $\begin{array}{l}30 \text { coudées de } \\
\text { muraille }\end{array}$ & $Y d^{c}$ & $?$ & $?$ & $6 e-5 e$ av. & Ma'in 6 \\
\hline$?$ & Courtine (shftn) & $?$ & $?$ & 'lyf' Wqh w-Wqh'l șdq & 3e av. (?) & B-M $247+255$ \\
\hline$?$ & Courtine (shftn) & $\dot{G} z r-S^{1} h f n$ & $?$ & Wqh'l Rym & $5 \mathrm{e}-4 \mathrm{e}$ av. & B-M 222 = RÉS 3005 \\
\hline$?$ & Courtine (shftn) & Royal & Royal & 'bkrb șdq & $5 e-4 e$ av. & B-M 249 \\
\hline$?$ & Maison (byt) & Blh & $G b^{3} n$ & 'byd' $Y \underline{t}^{t^{1}}$ & 5e av. & Y.03.B.R44-45.3 \\
\hline$?$ & Bastion (mhfdn) & $Y f^{c} n ?^{2}$ & $G b^{2} n ?$ & $\begin{array}{l}\text { 'byd' } Y t^{\complement} w-b n-s^{1} W q h^{\prime} l \\
\text { Rym }\end{array}$ & $5 e$ av. & B-M 180 = RÉS 2942 \\
\hline$?$ & Bastion (mhfdn) & Royal & Royal & 'bkrb $s d q$ & $5 \mathrm{e}-4 \mathrm{e}$ av. & B-M 103 \\
\hline$?$ & Bastion $(m h f d n)$ & Mrn & $?$ & $?$ & 2e-1e av. & B-M $218=R E ́ S 2960$ \\
\hline$[\ldots] R^{\jmath} N$ & Bastion (mhfdn) & $S^{2 c} \underline{t} m$ & $G b^{2} n$ & $\begin{array}{l}\text { गlyf } f^{c} Y s^{2} r w-b n-s^{1} H f n m \\
\text { Rym }\end{array}$ & $4 \mathrm{e}-2 \mathrm{e}$ av. & B-M 272 = RÉS 3021 \\
\hline 'BRM & Courtine ([șh]ftn) (?) & $?$ & $?$ & Wqh'l [Nbt? ?] & $4 \mathrm{e}-2 \mathrm{e}$ av. & B-M 108 \\
\hline \multirow{4}{*}{$B R N$} & $\begin{array}{l}\text { Temple (byt) } \\
\text { Aménagement } \\
\text { intérieur }\end{array}$ & Blh & $G b^{2} n$ & 'byd ${ }^{c} Y \underline{t}^{c}$ & $5 e$ av. & Y.92.B.A $21+30$ \\
\hline & - & $c^{1} d n$ & $?$ & 'byd' $Y \underline{t}^{c}$ & $5 e$ av. & B-M 216 = RÉS 2959 \\
\hline & $\begin{array}{l}\text { [Brn n'est pas } \\
\text { nommé] } \\
\text { Table à offrande } \\
\text { (mssrb) } \\
\text { Banquettes (twt b) } \\
\text { Piliers (hwr) }\end{array}$ & $S^{2} \underline{\underline{t} m}$ & $G b^{2} n$ & 'byd' $Y \underline{t}^{\mathrm{c}}(?)$ & $5 e$ av. & Y.90.B.A.7 \\
\hline & $\begin{array}{l}\text { [Brn n'est pas } \\
\text { nommé] } \\
\text { Adyton (gwb) } \\
\text { Naos (mknt) }\end{array}$ & Dbr & Ylqz & Y $\underline{t}^{\circ} l$ Rym w-bn-s ${ }^{1} \mathrm{~Tb} k \mathrm{krb}$ & $5 e-4 e$ av. & RÉS 2980 bis \\
\hline BYT WDM & Temple (byt) & $S^{2} \underline{\underline{t} m}$ & $G b^{\prime} n$ & 'byd' $Y \underline{t}^{c} m l k M^{c} n(?)$ & $5 e$ av. & B-M 277 = RÉS 3019 \\
\hline$\underline{D}-B H R N$ & $\begin{array}{l}\text { Répartiteur (?) } \\
(m z f y)\end{array}$ & $H b r r / S^{1} y l$ & $? / 4 y)$ & 'ly $y f^{c} Y s^{2} r w-b n-s^{1} H w f^{c} t t$ & $4 \mathrm{e}-2 \mathrm{e}$ av. & MAFRAY-Malāḥā' 1 \\
\hline D-BQRN & Bastion (mhfdn) & $H f d$ & $G b^{3} n$ & 'bkrb șdq & $5 e-4 e$ av. & B-M $241=$ RÉS 2965 \\
\hline$\underline{D}-H F N$ & Bastion (mhfdn) & $H f n$ & $G b^{2} n$ & 'byd' $Y \underline{t}^{`} w-W q h^{\prime} l$ Rym & $5 e$ av. & $\begin{array}{l}\text { B-M } 182=\text { RÉS } 2929+ \\
2941+2945+2946\end{array}$ \\
\hline D-HSSBR & Courtine (shftn) & $S^{2} \underline{\underline{t} m}$ & $G b^{\prime} n$ & $\begin{array}{l}\text { 'lyf } f^{\prime} Y s^{2} r w-b n-s^{1} H f n m \\
\text { Rym }\end{array}$ & $4 \mathrm{e}-2 \mathrm{e}$ av. & B-M 272 = RÉS 3021 \\
\hline \multirow{2}{*}{$\underline{D}-M L H$} & \multirow{2}{*}{ Bastion (mhfdn) } & $Y f^{c} n$ & $G b^{\prime} n$ & $\begin{array}{l}\text { 'byd } d^{`} Y t^{`} w-b n-s^{1} W q h^{\prime} l \\
\text { Rym }\end{array}$ & $5 e$ av. & B-M $10=$ RÉS 3012 \\
\hline & & Zllwmn & $G b^{2} n$ & 'lyf $f^{\prime} s^{2} r w-\left(W q h^{\prime} l ?\right) N b t$ & $4 \mathrm{e}-2 \mathrm{e}$ av. & B-M $1=R E ́ S 2975$ \\
\hline \multirow{3}{*}{ D-NDBN } & \multirow{3}{*}{ Bastion (mhfdn) } & $?$ & $?$ & 'byd' $Y t^{c} w-b n-s^{1} H y w m$ & $5 e$ av. & $\begin{array}{l}\text { Y.03.B.R44-45.2bis + } \\
2 \text { ter }+2\end{array}$ \\
\hline & & $\dot{G} r b t$ & Mwqh & $\begin{array}{l}\text { 'byd' } Y \underline{t}^{\mathrm{c}} w-b n-s^{1} \\
\text { Hywm (?) }\end{array}$ & $5 e$ av. & Y.92.B.A 37 A-B \\
\hline & & $H f d$ & $G b^{2} n$ & 'bkrb $s d q$ & $5 e-4 e$ av. & B-M $241=$ RÉS 2965 \\
\hline
\end{tabular}

\footnotetext{
1 En considérant que l'auteur est le même ' $m s^{1} m^{`}$ kabīr de Yathill que dans les inscriptions RÉS 2959, RÉS 3022 et Y.92.B.A 21 + Y.92.B.A 30 toutes trois datées du règne de 'byd' $Y \underline{t}$.

2 Nous faisons l'hypothèse que les auteurs de l'inscription apparaissent aussi dans l'inscription RES 3012.
} 
JÉRÉMIE SCHIETTECATTE AVEC LA COLLABORATION DE MOUNIR ARBACH: LES INSCRIPTIONS DE BARĀQISH

\begin{tabular}{|c|c|c|c|c|c|c|}
\hline$\underline{D}-S^{2} F T N$ & Bastion (mhfdn) & $H f d$ & $G b^{3} n$ & 'bkrb șdq & $5 e-4 e$ av. & B-M 241 = RÉS 2965 \\
\hline$D D N$ & Courtine (șftn) & $Y f^{c} n$ & $G b^{\prime} n$ & $\begin{array}{l}\text { 'byd'Rym bn Hyw Șdq } \\
\text { mlkh } M^{\prime} n\end{array}$ & $5 e-4 e$ av. & B-M 56 = RÉS 3060 \\
\hline HRN & $?$ & $Y f^{c} n$ & $G b^{\prime} n$ & $\begin{array}{l}\text { 'byd' } Y t^{\complement} w-b n-s^{1} W q h^{\prime} l \\
\text { Rym }\end{array}$ & $5 e$ av. & B-M 10 = RÉS 3012 \\
\hline$H R S^{2}$ & Courtine (șftn) & $S^{2} \underline{t} \underline{m}$ & $G b^{\prime} n$ & $\begin{array}{l}\text { 'lyf }{ }^{c} Y s^{2} r w-b n-s^{1} H f n m \\
\text { Rym }\end{array}$ & $4 e-2 e$ av. & B-M $272=R E ́ S 3021$ \\
\hline \multirow{4}{*}{$\begin{array}{l}L B^{\prime} N(I) \\
\left(L B^{\prime} N \underline{D}-{ }^{C} N N\right)\end{array}$} & \multirow{4}{*}{ Bastion (mhfdn) } & \multirow{2}{*}{ Blḥ } & \multirow{2}{*}{$G b^{\prime} n$} & \multirow{2}{*}{ 'byd' $Y \underline{t}^{c}$} & \multirow{2}{*}{$5 e$ av. } & B-M 256 \\
\hline & & & & & & Y.92.B.A $21+30$ \\
\hline & & $Y f^{\prime} n / D f g n$ & $G b^{2} n / ?$ & 'byd' $Y \underline{t^{c}}$ & 5e av. & B-M 257 = RÉS 3022 \\
\hline & & $S^{2} \underline{\underline{t}} \underline{m}$ & $G b^{\prime} n$ & $\begin{array}{l}\text { 'lyf }{ }^{c} Y s^{2} r w-b n-s^{1} H f n m \\
\text { Rym }\end{array}$ & $4 e-2 e$ av. & B-M 272 = RÉS 3021 \\
\hline \multirow{2}{*}{$L B^{\top} N(I I)$} & \multirow{2}{*}{ Bastion (mhfdn) } & $H f n$ & $G b^{2} n$ & 'byd' $Y \underline{t}^{`} w-W q h^{\prime} l$ Rym & $5 e$ av. & $\begin{array}{l}\text { B-M } 182=\text { RÉS } 2929+ \\
2941+2945+2946\end{array}$ \\
\hline & & $?$ & $G b^{3} n$ & 'byd' $Y \underline{t}^{`} w-W q h^{\prime} l$ Rym & $5 e$ av. & $\begin{array}{l}\text { B-M } 211+\text { B-M } 204= \\
\text { RÉS } 2952+2949\end{array}$ \\
\hline$M D B$ & Courtine (șhftn) & Dfgn & $?$ & 'byd' $Y t^{c} w-W q h^{\prime} l$ Rym & $5 e$ av. & B-M $238=$ RÉS 3535 \\
\hline$M H \oplus \underline{D R}$ & Maison (byt) & $?$ & $?$ & $\begin{array}{l}Y \underline{t}^{\curlywedge} l \underline{s} d q w-b n-s^{1} W q h^{\prime} l \\
Y \underline{t}^{c}\end{array}$ & $\begin{array}{l}\text { 1e av. } \\
\text { v. } 60 \text { av. }\end{array}$ & B-M 265 = RÉS 3016 \\
\hline \multirow{2}{*}{ NMRN } & \multirow{2}{*}{ Bastion (mhfdn) } & $?$ & $?$ & $?$ & $5 e-1 e$ av. & B-M $264=$ RÉS 3015 \\
\hline & & Royal & Royal & $?$ & 5e-1e av. & B-M $6=R E ́ S 3025$ \\
\hline$N^{c} M N$ & Maison (byt) & $?$ & $G b^{\prime} n$ & 'byd' $Y \underline{t}^{\mathrm{c}} w-W q h^{\prime} l \mathrm{Rym}$ & $5 e$ av. & $\begin{array}{l}\text { B-M } 211+\text { B-M } 204= \\
\text { RÉS } 2952+2949\end{array}$ \\
\hline QBDQM & Temple (byt) & $\dot{G} z r-S^{1} h f n$ & $?$ & Wqh'l Rym & $5 e-4 e$ av. & Y.05.B.B.13 \\
\hline $\begin{array}{l}\text { RBQN } \\
\text { (I ou II) }\end{array}$ & Bastion (mhfdn) & $?$ & $?$ & $?$ & $5 e-1 e$ av. & Y.92.B.A 16 \\
\hline \multirow[t]{2}{*}{ RBQN (I) } & \multirow[t]{2}{*}{ Bastion (mhfdn) } & $S^{2} \underline{\underline{t}} \underline{m}$ & $G b^{\prime} n$ & $\begin{array}{l}\text { 'lyf } \text { Y }^{2} r w-b n-s^{1} H f n m \\
\text { Rym }\end{array}$ & $4 e-2 e$ av. & B-M 272 = RÉS 3021 \\
\hline & & Ẓlwmn & $G b^{\prime} n$ & 'lyf $Y s^{2} r w\left(W q h^{\prime} l ?\right) N b t$ & $4 \mathrm{e}-2 \mathrm{e}$ av. & B-M $1=R E ́ S 2975$ \\
\hline RBQN (II) & Bastion (mhfdn) & $S^{2} \underline{\underline{t}} \underline{m}$ & $G b^{\prime} n$ & $\begin{array}{l}\text { 'lyf' Ys }{ }^{2} r w-b n-s^{1} H f n m \\
\text { Rym }\end{array}$ & $4 e-2 e$ av. & B-M $272=$ RÉS 3021 \\
\hline$R D W N$ & Bastion (mhfdn) & $S^{2} \underline{\underline{t}} \underline{m}$ & $G b^{\prime} n$ & $\begin{array}{l}\text { 'lyf } \text { Ys }^{2} r w-b n-s^{1} H f n m \\
\text { Rym }\end{array}$ & $4 e-2 e$ av. & B-M 272 = RÉS 3021 \\
\hline$R T^{c}$ & Courtine (shftn) & $Y f^{c} n$ & $G b^{3} n$ & $?$ & $5 e-1 e$ av. & B-M $266=R E ́ S 4224$ \\
\hline$S^{1} L F$ & Courtine (șftn) & $H f d$ & $G b^{3} n$ & 'bkrb șdq & $5 e-4 e$ av. & B-M 241 = RÉS 2965 \\
\hline$S^{1} L F$ & ? (mbny) & $?$ & $?$ & $?$ & $5 e-1 e$ av. & Y.92.B.A 16 \\
\hline$S^{2} B M T$ & Courtine (shftn) (?) & $Y f^{c} n$ & $G b^{\prime} n$ & $\begin{array}{l}\text { 'byd' } Y t^{\complement} w-b n-s^{1} W q h^{\prime} l \\
\text { Rym }\end{array}$ & $5 e$ av. & B-M $10=$ RÉS 3012 \\
\hline$S^{2} B^{C} N$ & $\operatorname{Bassin}\left(m^{\prime} h \underline{d} \underline{d} n\right)$ & Royal & Royal & Wqh'l Rym & $5 e-4 e$ av. & Shaqab 18 \\
\hline ȘDQN & Maison (byt) & $S^{2} \underline{t} \underline{m}$ & $G b^{2} n$ & Wqh'l Rym & $5 e-4 e$ av. & Y.90.B.ext 2 = YM 26117 \\
\hline$S \subseteq Q Q N$ & Bastion (mhfdn) & $\dot{G} z r-S^{I} h f n$ & $?$ & Wqh'l Rym & $5 e-4 e$ av. & Y.05.B.B.13 \\
\hline \multirow{2}{*}{$T_{F S}{ }^{2}$} & \multirow{2}{*}{ Courtine (shftn) } & $?$ & $?$ & 'byd ${ }^{`} Y \underline{t}^{\complement} w-b n-s^{1} H y w m$ & $5 e$ av. & $\begin{array}{l}\text { Y.03.B.R44-45.2bis + } \\
2 \text { ter }+2\end{array}$ \\
\hline & & $\dot{G} r b t$ & Mwqh & $\begin{array}{l}\text { 'byd } d^{`} Y \underline{t}^{\complement} w-b n-s^{1} H y w m \\
(?)\end{array}$ & $5 e$ av. & Y.92.B.A 37 A-B \\
\hline$T \dot{G} L$ & Courtine (șftn) & $\begin{array}{l}\text { bny } d-M^{c} d \\
w-N f \underline{d}(?)\end{array}$ & $?$ & $?$ & $5 e-3 e$ av. & B-M 231 \\
\hline
\end{tabular}




\begin{tabular}{|c|c|c|c|c|c|c|}
\hline$T \dot{G} L$ & Puits $\left(b^{2} r\right)$ & $?$ & $G b^{2} n$ & 'byd' $Y t^{c} w-W q h^{\prime} l$ Rym & $5 e$ av. & $\begin{array}{l}\text { B-M } 211+\text { B-M } 204= \\
\text { RÉS } 2952+2949\end{array}$ \\
\hline \multirow{2}{*}{$T N^{c} M$} & \multirow{2}{*}{ Courtine (shftn) } & $?$ & $?$ & $?$ & 5e-1e av. & B-M $248=R E ́ S 3010$ \\
\hline & & $Y f^{c} n / D f g n$ & $G b^{3} n / ?$ & 'byd' $Y t^{c}$ & $5 \mathrm{e}$ av. & B-M $257=$ RÉS 3022 \\
\hline \multirow{4}{*}{$T S^{2} B M(I)$} & Courtine (shftn) & $?$ & $?$ & $?$ & $5 e-1 e$ av. & $\begin{array}{l}\text { B-M } 264=R E ́ S 3015: \\
T^{2}[B M]\end{array}$ \\
\hline & $?$ & $Y f^{c} n$ & $G b^{2} n$ & $?$ & 5e-1e av. & $\begin{array}{l}\text { B-M } 267=R E ́ S 3017 \text { bis : } \\
{[T] S^{2} B M}\end{array}$ \\
\hline & Courtine $([s \underline{\text { h }}] f t n)$ & $?$ & $?$ & $?$ & 5e-1e av. & B-M $7=R E ́ S 3024$ \\
\hline & $?$ & $Y f^{\prime} n$ & $G b^{2} n$ & $\begin{array}{l}\text { 'byd }{ }^{`} Y t^{\complement} w-b n-s^{1} W q h^{\prime} l \\
\text { Rym }\end{array}$ & $5 e$ av. & B-M $10=R E ́ S 3012$ \\
\hline \multirow{2}{*}{$T S^{2} B M(I I)$} & \multirow{2}{*}{ Courtine (shftn) } & \multirow{2}{*}{$?$} & \multirow{2}{*}{ ? } & \multirow{2}{*}{ ? } & \multirow{2}{*}{$5 e-1 e$ av. } & B-M $41=$ RÉS 3038 \\
\hline & & & & & & B-M 43 \\
\hline$T^{\complement} R M$ & Courtine (shftn) & Ḍmrn & $?$ & 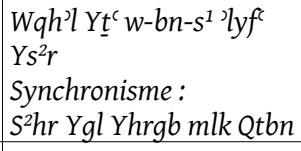 & $\begin{array}{l}\text { 1e av. } \\
\text { v. } 25-1 \text { av. }\end{array}$ & B-M 147 = RÉS 2999 \\
\hline$Y F^{c} N$ & $?$ & $Y f^{c} n$ & $G b^{3} n$ & $\begin{array}{l}\text { 'byd' } Y t^{c} w-b n-s^{1} W q h^{\prime l} \\
\text { Rym }\end{array}$ & $5 e$ av. & B-M $10=R E ́ S 3012$ \\
\hline YǴL (I) & Bastion $(m h(f d) n)$ & $\begin{array}{l}b n y \underline{d}-M^{c} d \\
w-N f \mathfrak{f}(?)\end{array}$ & $?$ & $?$ & $5 e-3 e$ av. & B-M 231 \\
\hline YǴL (II) & Bastion (mhfdn) & $Y f^{c} n$ & $G b^{2} n$ & $\begin{array}{l}\text { 'byd' } Y \underline{t}^{\complement} w-b n-s^{1} W q h ' l \\
\text { Rym }\end{array}$ & $5 e$ av. & B-M $10=$ RÉS 3012 \\
\hline YGR & Maison (byt) & Zyrn & Mwqh & $\begin{array}{l}\text { 'byd' } Y t^{\complement} w-b n-s^{1} W q h^{\prime} l \\
\text { Rym }\end{array}$ & $5 e$ av. & B-M $224=R E ́ S 2962$ \\
\hline YHR & Bastion (mhfdn) & $?$ & $?$ & $?$ & 5e-1e av. & B-M 242 \\
\hline \multirow{2}{*}{$Y S^{2} B M$} & Bastion (mhfdn) & $\dot{G} z r-S^{1} h f n$ & $?$ & Wqh'l Rym (?) & $5 e-4 e$ av. & B-M $280=$ RÉS 2976 \\
\hline & Bastion (mhfdn?) & Royal & Royal & $Y \underline{t}^{\circ} l \underline{s} d q$ & $\begin{array}{l}\text { 1e av. } \\
\text { v. } 70 \text { av. }\end{array}$ & B-M 259 = RÉS 2973 \\
\hline$Y S^{2} H R$ & Building (hthbn) & $?$ & $?$ & $?$ & $8 \mathrm{e}$ av. & MAFRAY-Malāḥā’ 2 \\
\hline$Y \underline{T}^{c} \mathrm{~N}$ & Bastion (mhfdn) & $S^{2 c} \underline{t} m$ & $G b^{3} n$ & $\begin{array}{l}\text { Postérieur à } \\
\text { 'lyf } \mathrm{Ys}^{2} r \text { w-bn-s }{ }^{1} \mathrm{H} f \mathrm{~nm} \\
\text { Rym }\end{array}$ & $3 e-1 e$ av. & B-M 273 = RÉS 2978 \\
\hline$Y^{C} D$ & Maison (byt) & $S^{2 c} \underline{t} m$ & $G b^{2} n$ & Wqh'l Rym & $5 e-4 e$ av. & Y.90.B.ext $2=$ YM 26117 \\
\hline ZBYN & Bastion (mhfdn) & $S^{2} \underline{t} m$ & $G b^{3} n$ & $\begin{array}{l}\text { 'lyf } f^{\prime} Y s^{2} r w-b n-s^{1} H f n m \\
\text { Rym }\end{array}$ & $4 \mathrm{e}-2 \mathrm{e}$ av. & B-M 272 = RÉS 3021 \\
\hline \multirow[b]{2}{*}{ ZRBN } & \multirow[b]{2}{*}{ Bastion (mhfdn) } & $Y f^{c} n / D f g n$ & $G b^{3} n / ?$ & 'byd' $Y \underline{t}^{c}$ & $5 e$ av. & B-M $257=R E ́ S 3022$ \\
\hline & & $S^{2} \underline{t} m$ & $G b^{\prime} n$ & $\begin{array}{l}\text { llyf } f^{\prime} Y s^{2} r w-b n-s^{1} H f n m \\
\text { Rym }\end{array}$ & $4 \mathrm{e}-2 \mathrm{e}$ av. & B-M 272 = RÉS 3021 \\
\hline
\end{tabular}


Tableau 5. Liste des clans et fractions de clan à Barāqish (J. Schiettecatte).

\begin{tabular}{|c|c|c|}
\hline Clans & Sous-clans & Offices de membres des sous-clans \\
\hline \multirow{10}{*}{$G B^{\prime} N$} & Blh & $\begin{array}{l}\text { Chef de Yathill (kbr Ytll) } \\
\text { Congrégation de 'Athtar dhu-Yahriq (qhlt }{ }^{\text {'ttr }} \underline{d} \text {-Yhrq) }\end{array}$ \\
\hline & $F^{3} d$ & \\
\hline & Hḍln & \\
\hline & Hfd & \\
\hline & $H f n$ & \\
\hline & $R d^{c}$ & Chef de Yathill (?) (kbr [Yt $\underline{\underline{t} l(?)])}$ \\
\hline & $S^{2} \underline{t} \underline{m}$ & \\
\hline & $Y f^{f} n$ & 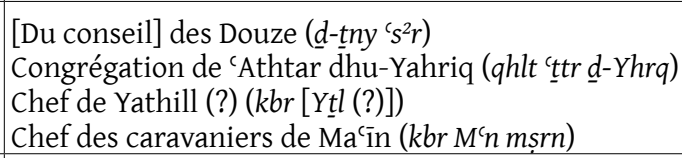 \\
\hline & Zhrn & Prêtre de de 'Athtar dhu-Yahriq $\left(r s^{2} w^{\prime} \underline{t} t r \underline{d}-Y h r q\right)$ \\
\hline & Ẓlwmn & Congrégation de 'Athtar dhu-Yahriq (qhlt $\left.{ }^{c} t \operatorname{tr} \underline{d}-Y h r q\right)$ \\
\hline \multirow{2}{*}{ MWQH } & Grbt & \\
\hline & Zyrn & Congrégation de 'Athtar dhu-Yahriq (qhlt 'ttr $\underline{d}-Y h r q)$ \\
\hline QRN & $H \underline{d} k t$ & \\
\hline \multirow{2}{*}{ YLQZ } & Dbr & Chef de la ville de [?] (kbr hgrn [?]) \\
\hline & Mhạr & \\
\hline \multirow{2}{*}{${ }^{C} L Y^{\prime} L$} & $F^{3} m n$ & \\
\hline & $S^{1} y l$ & \\
\hline$?$ & Dfgn & Chef des caravaniers de Ma`īn ( $\left.k b r M^{c} n m s ̦ r n\right)$ \\
\hline$?$ & Dmrn & \\
\hline$?$ & $D^{f} f$ & \\
\hline$?$ & $\dot{G} z r S^{1} h f n$ & $\begin{array}{l}\text { Chef des maçons et du transport ( } k b r \text { grbn w-nqln) } \\
\left.\text { Chef des serviteurs du roi ( } k b r^{\prime} \mathrm{dm} m \mathrm{mlk}\right)\end{array}$ \\
\hline$?$ & Hbrr & \\
\hline$?$ & $H r n$ & \\
\hline$?$ & Mlh & \\
\hline$?$ & Mrn & \\
\hline$?$ & $M^{2} f y$ & \\
\hline$?$ & Rwyn & \\
\hline$?$ & Siylm & Congrégation de 'Athtar dhu-Yahriq (qhlt $\underline{\text { cttr }} \underline{d}-Y h r q)$ \\
\hline$?$ & $S^{2} g^{2}$ & Sacrificateur (?) de 'Athtar dhu-Qabḍ ( $\left.s^{2} w^{c} \underline{c} \operatorname{tr} \underline{d}-Q b d\right)$ \\
\hline$?$ & $S^{2} y d$ & Prêtre de de 'Athtar dhu-Yahriq $\left(r s^{2} w^{\prime} \underline{t} t r \underline{d}-Y h r q\right)$ \\
\hline$?$ & $\mathrm{~s}^{2} m$ & \\
\hline$?$ & 'qrn & \\
\hline$?$ & rrqn & \\
\hline$?$ & $c^{1} d n$ & \\
\hline$?$ & $y s^{2} n$ & Congrégation de 'Athtar dhu-Yahriq (qhlt 'ttr $\underline{d}$-Yhrq) \\
\hline
\end{tabular}


Tableau 6. La chronologie des rois de Ma'īn revisitée (J. Schiettecatte).

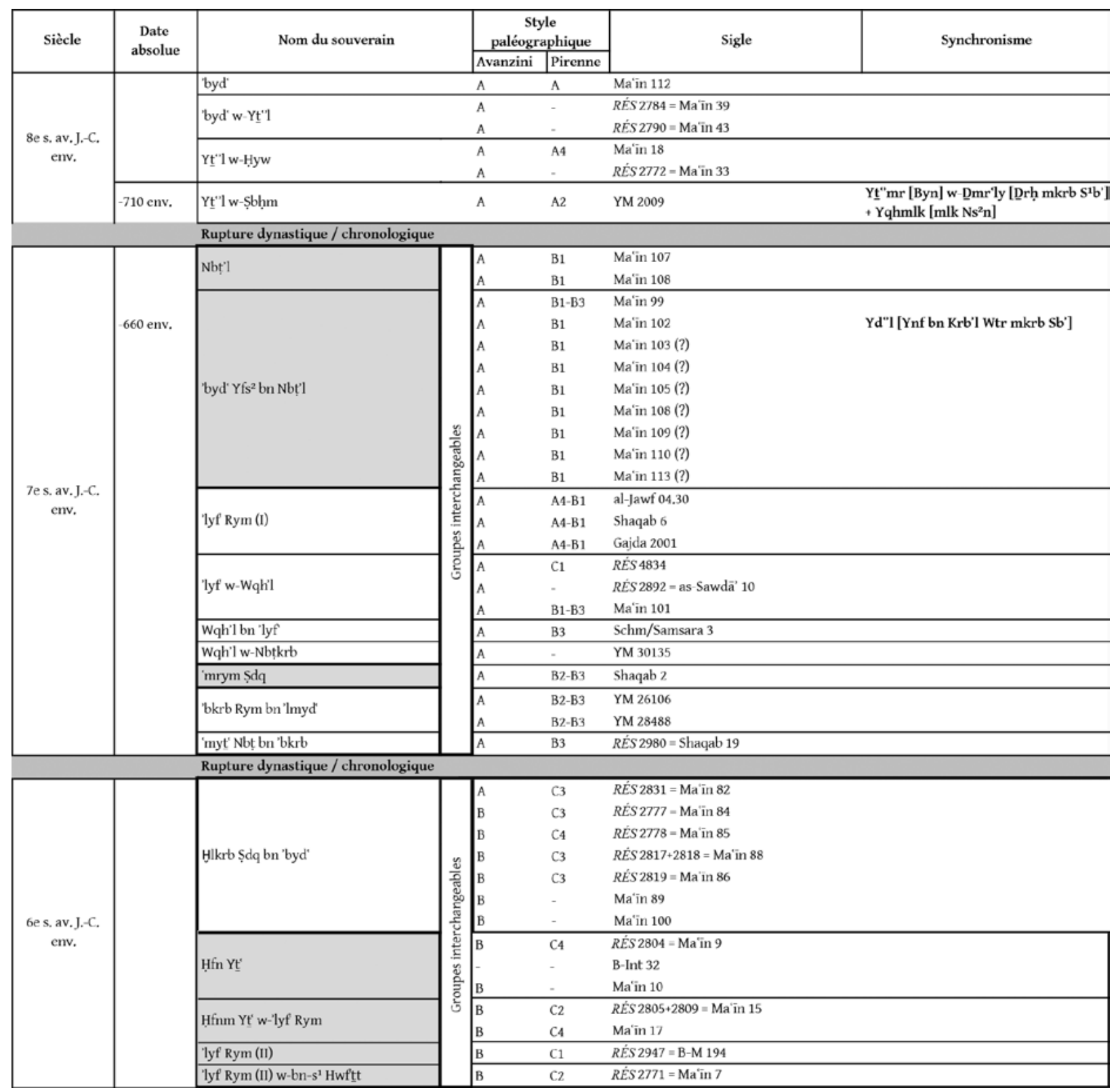


JÉRÉMIE SCHIETTECATTE AVEC LA COLLABORATION DE MOUNIR ARBACH: LES INSCRIPTIONS DE BARĀQISH

\begin{tabular}{|c|c|c|c|c|c|c|c|}
\hline & & \multicolumn{6}{|c|}{ Rupture dynastique / chronologique } \\
\hline \multirow{13}{*}{$\begin{array}{l}\text { Se s. av. J.-C. } \\
\text { env. }\end{array}$} & \multirow{13}{*}{$\begin{array}{l}\text { Après }-463 \\
\text { Avant }-405\end{array}$} & "lyf Y Yt" & & B & - & RÉS 2835 - Ma' in 90 & \multirow{12}{*}{ 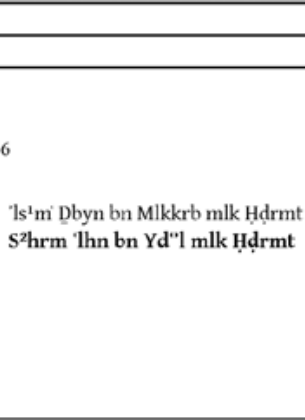 } \\
\hline & & 'lyf ' Yt w' w'byd' & & B & $\mathrm{C} 4$ & RÉS 2789 - Ma' in 13 & \\
\hline & & \multirow{10}{*}{\multicolumn{2}{|c|}{ byd' $Y_{t}^{t}$}} & B & E2 & RÉS 3022 = B-M 257 & \\
\hline & & & & B & - & GOAM 315 & \\
\hline & & & & B & - & $R \dot{E} S 2972+2970+2971+2971$ bis $=$ B-M 256 & \\
\hline & & & & B & E2 & RÉS 2774 - Ma'in 1 & \\
\hline & & & & B & E3 & $R \dot{E} S 2775=$ Ma' in 8 & \\
\hline & & & & B & & RÉS $2050=\mathrm{B}-\mathrm{M} 216$ & \\
\hline & & & & B & - & RÉS 3006 = B-M 226 & \\
\hline & & & & B & E1 & $R E ́ S 3029$ = B-M 15 & \\
\hline & & & & B & - & Y.92.B.A $21+$ Y.92.B.A 30 & \\
\hline & & & & B & - & Y.92.B.A 27 & \\
\hline & & \multicolumn{2}{|l|}{ byd' Yț w-bn-s șywm $^{1}$} & B & E2 & \multicolumn{2}{|l|}{ Y.03.B.R44-45.2bis + 2ter + 2} \\
\hline \multirow{21}{*}{$\begin{array}{c}\text { fin } 5 \text { e s. - début } \\
\text { 4e s. av. J.-C. } \\
\text { env. }\end{array}$} & & \multirow{9}{*}{\multicolumn{2}{|c|}{ 'byd' Yt' w-bn-s' Wqh'l Rym }} & B & - & B-M $122(?)$ & \\
\hline & & & & B & E1 & \multicolumn{2}{|l|}{ RÉS $2929 \cdot 2941+2945 \cdot 2946=\mathrm{B}-\mathrm{M} 182$} \\
\hline & & & & B & & \multicolumn{2}{|l|}{$R \dot{E} S 2942=\mathrm{B}-\mathrm{M} 180$} \\
\hline & & & & B & E2 & \multicolumn{2}{|l|}{ RÉS 2944 = B-M 178} \\
\hline & & & & B & $\mathrm{E} 3$ & \multicolumn{2}{|l|}{$R \dot{E} S 2952$ = B-M 211} \\
\hline & & & & B & E2 & \multicolumn{2}{|l|}{ RÉS 2962 = B-M 224} \\
\hline & & & & B & E3 & \multicolumn{2}{|l|}{$R \dot{E} S 3013=\mathrm{B}-\mathrm{M} 12$} \\
\hline & & & & B & E2 & \multicolumn{2}{|l|}{ RÉS 3535 = B-M 238} \\
\hline & & & & B & - & \multicolumn{2}{|l|}{ RÉS 3012 = B-M 10} \\
\hline & & \multirow{7}{*}{\multicolumn{2}{|c|}{ Wqh'l Rym bn 'byd' }} & B & - & B-M 68 & \\
\hline & & & & B & - & Bron Semitica 55.1 & \\
\hline & & & & B & - & RÉS 3005 = B-M 222 & \\
\hline & & & & B & $\mathrm{E} 3$ & RÉES 3055 = B-M 86 & \\
\hline & & & & B & E2-E3 & Shaqab 18 & \\
\hline & & & & B & E3 & Y.90.B.ext 2 = YM 26117 & \\
\hline & & & & B & E1-E2 & Y.05.B.B.13 & \\
\hline & & \multirow{2}{*}{\multicolumn{2}{|c|}{ Wquh'1 Rym w-bn-s' ws $^{1} \mid$}} & B & E1-E2 & Y.05.B.B.12 & \\
\hline & & & & B & $\mathrm{E} 2$ & Y.06.B.B.6 & \\
\hline & & & & B & E3 & $R \dot{E} S 3051+3052 \mathrm{a}=\mathrm{B}-\mathrm{M} 76$ & \\
\hline & & Wqh'l Rym w-bn-s' Hfn șdq & & B & $\mathrm{E} 3$ & $R E S S 3040+3039+3049=\mathrm{B}-\mathrm{M} 44$ & \\
\hline & & & & B & - & Y.92.B.A 34 & \\
\hline & & & & B & E3 & B-M 69 & \\
\hline & & Ḥfnm Șdq & & B & & $R \dot{E} S 2886$ = as-Sawdā' 30 & \\
\hline & & & & B & E3 & $R \dot{E} S 3050=\mathrm{B}-\mathrm{M} 82$ & \\
\hline $\begin{array}{c}\text { 4e s. av.j.c. } \\
\text { env. }\end{array}$ & & Hụfn Șdq w-'lyf Yfs ${ }^{2}$ & & $\mathrm{~B}$ & $\mathrm{E} 3$ & RÉS 2762 & \\
\hline & & & & B & - & RÉS 2982 & \\
\hline & & lyf Yfs ${ }^{2}$ & & B & & Y.06.B.B.11 & \\
\hline & & & & B & E2 & Y.04.B.T45.1 & \\
\hline & & Rupture dynastique / chron & & & & & \\
\hline & & & & $B$ & E3 & B-M 103 = Robin-Baraqish 80 & \\
\hline & & bkrb Șdq bn Wqh'l & $\dddot{\omega}$ & B & - & RÉS 2965 = B-M 241 & \\
\hline & & & 芯 & B & $\mathrm{E} 3$ & Shaqab 4 & \\
\hline & & Yt"I Rym & हี & B & - & Bron Semitica 56 & \\
\hline $\begin{array}{l}\text { env. } \\
\text { ens. av. }\end{array}$ & & & 这 & $\mathrm{B}$ & $\mathrm{E} 3$ & Shaqab 5 & \\
\hline & & $\mathrm{Yt}^{\circ} \mathrm{I}$ Rym w-bn-s $\mathrm{s}^{1} \mathrm{~Tb}$ krb & $\stackrel{\Xi}{s}$ & $\mathrm{~B}$ & - & $R \dot{E} S 2980$ bis & \\
\hline & & & 芼 & B & E3 & $R \dot{E} S 3060$ - B M 56 & \\
\hline & & byd' Rym bn Hyw Șdq & อั. & B & - & B-M 120 & \\
\hline & & & & B & - & RÉS 2801 = Ma in 55 & \\
\hline
\end{tabular}




\begin{tabular}{|c|c|c|c|c|c|c|}
\hline & & Rupture dynastique / chronol & & & & \\
\hline \multirow{8}{*}{$\begin{array}{c}\text { 4e-3e s. av. J.-C. } \\
\text { (?) } \\
\text { [on ne peut } \\
\text { exclure } \\
\text { totalement le } \\
\text { début du 5e } \\
\text { siècle] }\end{array}$} & & 'lyf Wqh & $\mathrm{B}$ & E2 & $R \dot{E} S 3307$ = as-Sawdä 27 & \\
\hline & & 'lyf Wq̣h w-Wqh'1 șdq & B & - & \multicolumn{2}{|l|}{$\begin{array}{l}\text { RÉS 2966+2968 - B-M } 247+255 \\
R E ́ S 3562\end{array}$} \\
\hline & & Wqh'l șdq bn 'lyf & $\mathrm{B}$ & E1 & \multicolumn{2}{|l|}{ RÉS 2829 = Maīn 2} \\
\hline & & Wqh'l Sdq w-bn-s $s^{1} \mathrm{Hwf} t \mathrm{t}$ & $\mathrm{B}$ & E1 & \multicolumn{2}{|l|}{ B-Int 35} \\
\hline & & Wqh'l șdq w-'bkrb Yt' & B & E1 & \multicolumn{2}{|l|}{ RÉS 3346} \\
\hline & & \multirow{3}{*}{ 'bkrb Yt' bn Wqh'1 } & B & E1 & \multicolumn{2}{|l|}{$R \dot{E} S 3697$} \\
\hline & & & & & \multicolumn{2}{|l|}{ Y.92.B.A 10} \\
\hline & & & $\mathrm{B}$ & E1 & \multicolumn{2}{|l|}{ A-20-850 } \\
\hline \multicolumn{7}{|c|}{ Rupture dynastique / chronologique } \\
\hline \multirow{13}{*}{$\begin{array}{c}\text { 3e-2e s. av. J.-C. } \\
\text { env. }\end{array}$} & & \multirow{5}{*}{ 'lyf $Y s^{2} r(I)$} & B & - & \multicolumn{2}{|l|}{ B-Int 31} \\
\hline & & & B & $\mathrm{D} 2$ & \multicolumn{2}{|l|}{ RÉS 2813 - Ma in 62} \\
\hline & & & B & D2 & \multicolumn{2}{|l|}{$R E S 2869=$ as Sawdä' 20} \\
\hline & & & B & D3 & \multicolumn{2}{|l|}{ RÉS 3341} \\
\hline & & & B & - & \multicolumn{2}{|l|}{ RÉS $3355 \mathrm{~B}$} \\
\hline & & lyff Ys ${ }^{2} r(I) w-b n-s^{1} H w f \underline{t t}$ & B & - & \multicolumn{2}{|l|}{ MAFRAY-Malāḥā 1} \\
\hline & & \multirow{2}{*}{ 'lyf Ys ${ }^{2} r(I) w-b n-s^{1} \stackrel{H f n m}{R y m}$} & B & D2 & \multicolumn{2}{|l|}{$R E ́ S 3021=\mathrm{B}-\mathrm{M} 272$} \\
\hline & & & $\mathrm{B}$ & - & \multicolumn{2}{|l|}{ Y.90.B 2} \\
\hline & & \multirow{2}{*}{ 'lyf Ys ${ }^{2} \mathrm{r}(\mathrm{I}) \mathrm{w}$-Wqhil Nbt } & $\mathrm{B}$ & D3 & \multicolumn{2}{|l|}{$R E ́ S 2975$ = B-M 1} \\
\hline & & & $\mathrm{B}$ & - & $R E ́ S 2996+2995+2988+2992=$ B-M 136 & \\
\hline & & \multirow{3}{*}{ Wqh'l Nbţ } & B & - & \multicolumn{2}{|l|}{$R E ́ S 3707$} \\
\hline & & & B & - & \multirow{2}{*}{\multicolumn{2}{|c|}{$\begin{array}{l}\text { B-M } 108(?) \\
\text { L } 106\end{array}$}} \\
\hline & & & - & RyIIIb & & \\
\hline \multicolumn{7}{|c|}{ Rupture dynastique / chronologique } \\
\hline \multirow{6}{*}{$\begin{array}{l}\text { ler s. av. J.-C. } \\
\text { env. }\end{array}$} & -75 env & \multirow{2}{*}{ Yțt"1 șdq } & B & & \multicolumn{2}{|l|}{$R E \dot{S} 2973=\mathrm{B}-\mathrm{M} 259$} \\
\hline & & & B & & RÉS $2991+2993+2994=$ B-M 139 & \\
\hline & -60 env. & $\mathrm{Yt}^{*} 1 \mathrm{Sdg} \mathrm{w}-\mathrm{bn}-\mathrm{s}^{1} \mathrm{Woh}^{*} 1 \mathrm{Yt}^{*}$ & B & & $R E ́ S 2963=\mathrm{B}-\mathrm{M} 229$ & \\
\hline & -60 env. & 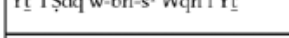 & $\mathrm{B}$ & & RÉS 3016 = B-M 265 & \\
\hline & -50 env. & Wqh'l Yt' & B & & Lion 1 & $\begin{array}{l}\text { S2hr Hll w-bn -hw Hwf m Yhn'm mlkw } \\
\text { Qtbn }\end{array}$ \\
\hline & $-25 /-1$ env. & Wqh'l Yt' w-bn-s' ${ }^{1}$ lyf $Y s^{2} \mathrm{r}$ (II) & $\mathrm{B}$ & & RÉS $2999=\mathrm{B}-\mathrm{M} 147$ & S2hr Ygl Yhrgb mlk Qtbn \\
\hline
\end{tabular}




\title{
Chapter 28
}

\section{Risultati di una prospezione archeologica nel sito di Darb al-Ṣabī}

\author{
Rosario Valentini
}

\section{Introduzione}

Il sito di Darb al-Sabī (fig. 1) si trova $95 \mathrm{~km}$ a NE da Șan' $\bar{a}$ ', 86 km a NO da Mārib, e fa parte delle numerose testimonianze archeologiche, quali templi, opere idrauliche, resti di campi antichi, disseminate nella vasta zona irrigua intorno a Barāqish, l'antica Yathill (fig. 2). Darb al-Șabī, infatti, si trova in una regione dove numerosi corsi d'acqua alimentavano il Wādī Majzīr, il principale tributario del Wādī Jawf, che sfociava nel grande bacino del Ramlat al-Sabcatayn (fig. 3). ${ }^{1}$

I primi studi su Darb al-Ṣabī furono condotti dalla Missione francese, guidata da Christian Robin, che, a più riprese dal 1976 al 1986, vi condusse prospezioni archeologiche ed epigrafiche, realizzando alcuni rilievi planimetrici e catalogando una trentina di iscrizioni. ${ }^{2}$ I risultati dello studio delle iscrizioni sono sintetizzati qui di seguito.

Il sito costituisce un mhrm, ossia un 'perimetro sacro' (iscr. 1-4) consacrato al dio Nakrah, ${ }^{3}$ la sola divinità menzionata (iscr. 1,3,5, 27); il perimetro, contrassegnato da cippi ( $q f$, iscr. 4), delimitava una vasta superficie, il cui accesso era controllato e regolamentato (iscr. 1). L'insediamento, il cui nome potrebbe essere stato $\mathrm{Ft}^{\mathrm{cn}}$ (iscr. 1, 3), comprendeva anche alcune abitazioni (iscr. $2,11)$. Nakrah è una divinità maschile, e tra i riti che si praticavano nel suo santuario principale era quello della confessione espiatoria pubblica (iscr. 5, 16, 26, 27, 30).

Il santuario di Darb al-Șabī sembra essere stato un luogo di asilo, dove avrebbero trovato protezione a determinate condizioni, oppure - a seconda di come viene interpretato il testo - da cui sarebbero stati esclusi i malati terminali e le donne che avessero partorito o abortito (iscr. 1). Al dio Nakrah viene riconosciuto il dono di guarire, ${ }^{4}$ paragonabile alla divinità femminile mesopotamica della medicina Ninkarrak. ${ }^{5}$ Il potere di guarire è attribuito genericamente anche ad altre

\footnotetext{
1 Marcolongo 2000.

2 Robin 1979a; Robin et al. 1981; Robin et al. 1988.

3 Robin 2012, 23-25.

4 Ryckmans 1989, 166.

5 Ryckmans 1963, 463.
}

divinità del pantheon sudarabico, ma per Nakrah si tratta del suo carattere principale. Nell'insieme dei testi minei, Nakrah è, inoltre, l'unica divinità nel pantheon mineo ad essere insignita del titolo di 'patrono' (shym) (iscr. 20/2, 22/2, 27/3, 29/3, ma anche RES 2274/3, 2831/2, 3535/3 da Barāqish).

Nessuno dei testi studiati fa riferimento a sacrifici avvenuti a Darb al-Ṣabī, ma spesso si cita una consultazione oracolare (iscr. 1/2, 9, 5/4, 16/6-7) che si svolgeva in $b-g w b^{n}$, cioè un non meglio identificato luogo del tempio.

Il termine mkhtn (iscr. 1/1, 2/5, 13), in relazione con $m h r m$, indicherebbe il 'territorio-asilo' e il termine srht il 'vestibolo' di una casa o anche un intero edificio ('maison d'hôtes'), dove i visitatori/pellegrini ricevevano accoglienza.

Le iscrizioni ivi rinvenute hanno dunque permesso di stabilire che il luogo ebbe la funzione di un santuario dedicato al dio Nakrah, una divinità maschile con capacità guaritrici, venerata principalmente nella vicina Yathill (di cui era patrono). A Nakrah i fedeli rivolgevano le confessioni dei propri peccati necessarie, probabilmente, alle guarigioni. ${ }^{6}$

Nel dicembre del 2005 la Missione archeologica italiana, che era impegnata negli scavi del Tempio di 'Athtar dhu-Qabḍ a Barāqish, eseguì un primo rilievo topografico del sito, con la prospettiva futura di avviare uno scavo archeologico. Una équipe guidata dallo scrivente, con l'ausilio di R. Loreto (archeologo e rilevatore), G. Stelo (disegnatrice) e 'Abd al-Bāsit $\mathrm{Nu}^{\mathrm{C}}$ mān (ispettore della Organizzazione Generale per le Antichità e i Musei, GOAM), ${ }^{7}$ fu inviata sul sito per due settimane, con il compito di esplorare nuovamente le evidenze archeologiche e di rilevarne le strutture. ${ }^{8}$ Il lavoro di ricognizione ci diede, inoltre, l'opportunità

\footnotetext{
6 Robin et al. 1988, 93.

7 A tale proposito vorrei ricordare con grande affetto l'amico e collega 'Abd al-Bāsiṭ Nu'mān, scomparso nel 2017.

8 Per lo studio del sito ci siamo avvalsi di strumenti di rilievo satellitare (palmare Garmin GPSmap 60CS) per il posizionamento degli edifici individuati, e di Stazione Totale (Pentax R-300) per il rilievo planimetrico delle strutture meglio conservate. I dati ottenuti costituiscono la base delle tavole grafiche presentate in questo mio contributo.
} 
di documentare lo stato di conservazione del sito. Infatti, rispetto agli anni in cui si recarono i Francesi, si notarono molte fosse dovute a scavi illegali.

Presentiamo qui di seguito i risultati di questa preliminare ricognizione.

\section{Il sito}

Percorrendo il paleoalveo del Wādī Majzīr, dopo 2,5 $\mathrm{km}$ ad ovest di Barāqish la monotonia del paesaggio è improvvisamente interrotta da un tavolato di forma irregolare, dove sorge un pianoro, alto in media $14 \mathrm{~m}$, sul quale si estende la maggior parte delle strutture di

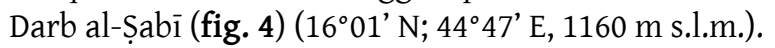

Intorno al pianoro sono ancora visibili nove cippi isolati infissi nel terreno (fig. 5). I cippi sono in calcare, a sezione rettangolare ed hanno un'altezza media di 1,40/1,50 m (fig. 6). Il cippo n. 2 è frammentario e sporge dal terreno soltanto $95 \mathrm{~cm}$; del cippo n. 3 resta solo la base impiantata nel terreno, e, infine il n. 4, alto $1,80 \mathrm{~m}$, giace disteso sul terreno. Quest'ultimo cippo potrebbe testimoniare la lunghezza originale dei monoliti. Tutti i cippi, tranne il n. 2 e il n. 3 per i motivi sopra esposti ed il n. 9, che è in gran parte interrato, hanno un'iscrizione incisa sulla faccia rivolta verso il

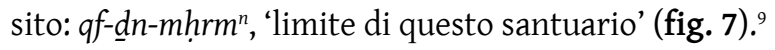

Posti a distanza variabile l'uno dall'altro, questi cippi delimitano un temenos, l'area sacra di circa 16 ettari, nella quale si trovano tutte le strutture individuate (fig. 8).

In alcune zone, sui fianchi del pianoro, affiorano spessi banchi di arenaria con abbondanti scarti antichi di lavorazione. È probabile che questa sia stata una cava da cui fu estratto il materiale per la costruzione di alcune delle strutture di Darb al-Ṣabì.

Tutti gli edifici documentati sono in cattivo stato di conservazione, tanto che, spesso, a malapena è stato possibile disegnarne le piante. I resti visibili consistono principalmente in affilamenti di muri affioranti dal suolo per pochi $\mathrm{cm}$. Le rovine più evidenti sono rappresentate da alcuni gruppi di monoliti che, in diverse aree del sito, emergono dal terreno in posizione verticale (fig. 9).

Questi monoliti ricordano i pilastri dei templi presenti in altri siti della regione (Ma'īn, Barāqish, al-Sawdā’) alBayḍā); ma, rispetto a quelli, questi sono di dimensioni minori e le superfici non sono lavorate con la tipica picchiettatura marginata da cornice liscia. ${ }^{10}$ Talvolta,

\footnotetext{
9 Robin et al. 1988, 113.

10 V. per esempio i pilastri dei templi di Nakrah e 'Athtar dhu-Qabḍ, in Darles, capitolo 10 nel Volume 1, fig. 24.
}

gruppi di monoliti sono collegati da muri, dando forma ad edifici più complessi di altri; ulteriori monoliti isolati sono sparsi sul sito.

Diverse strutture sono state individuate ai piedi del pianoro, come per esempio alcune tombe 'a torretta', ${ }^{11}$ distanti c. $300 \mathrm{~m}$ lungo il crinale occidentale, all'esterno del temenos (fig. 10).

Nelle due settimane di ricognizione, sono state georeferenziate con tecnologia GPS, tutte le strutture affioranti e, con la Stazione Totale, è stato eseguito il rilievo planimetrico di cinque tra gli edifici più completi del sito. Questi includono tre strutture già rilevate dalla Missione francese nel 1980. ${ }^{12}$

Lo stato di conservazione delle strutture di Darb al-Ṣabī ha reso difficile, nella maggior parte dei casi, l'esatta individuazione degli ambienti che compongono gli edifici, e non è stato possibile determinare le dimensioni complete di alcuni degli edifici rilevati, né individuare i passaggi che mettevano in comunicazione i vani tra loro.

\section{Le strutture}

La principale concentrazione di rovine si ha nella zona orientale di Darb al-Șabī, dove gruppi di pilastri monolitici, in posizione verticale e talvolta uniti da architravi, sembrano formare più edifici contigui. Tra questi spicca una grande struttura denominata dalla Missione francese 'Edificio 1'. ${ }^{13}$

Si tratta di una delle strutture più complesse oggi visibili sul sito, le cui misure maggiori si aggirano intorno a $47 \mathrm{~m}$ di lunghezza (asse N-S) e $50 \mathrm{~m}$ di larghezza (asse E-O). Questo edificio, da noi denominato 'Edificio A', è composto da almeno tre grandi ambienti o loci (L1, L2 e L3) (fig. 11). Allo stato attuale di conservazione dei muri (conservati solo per pochi centimetri di altezza) sembra che questi non comunichino tra loro, e non è stato possibile individuare gli accessi né di L1, né di L2. Gli studiosi francesi avevano ipotizzato l'ingresso principale all'edificio attraverso il muro meridionale, escludendo il lato settentrionale poiché il muro M3 di L1 è costruito a filo con il margine del pianoro sul pendio roccioso. ${ }^{14}$ Tuttavia, due pilastri monoliti, posti in posizione isolata c. $3 \mathrm{~m}$ a N dal muro settentrionale (M3) dell'edificio, potrebbero indicare l'avancorpo di un ingresso (fig. 12). La differenza di quota che si ha tra M3 e i pilastri, probabilmente doveva essere colmata da

\footnotetext{
11 Per questa tipologia di tombe cfr. de Maigret 2005c

12 Robin et al. 1981, 252.

13 Robin et al. 1981, 252.

14 Robin et al. 1981, 253.
} 
una rampa di accesso. Non è da escludere infine, che un ingresso all'Edificio A si trovasse sul lato orientale.

\section{Locus L1}

Il locus L1 dell'Edificio A consiste in un ampio ambiente $(20 \times 20 \mathrm{~m})$ di forma trapezoidale, forse una corte. A ridosso del muro occidentale $\mathrm{M} 2$ si trovano diverse strutture, tra cui un vano, L5 $(4 \times 3 \mathrm{~m})$, delimitato dai muri M7 a nord, M8 a est e M9 a sud. All'interno di L5 sporgono 5 pilastri, conservati ad altezze diverse e disposti in modo irregolare, su cui poggiano alcune travi in pietra, di dimensioni modeste, che formano gli architravi.

Nell'angolo SO di L1 due muri delimitano il locus L4 (4 × 2,50 m). Tra questo e L5, su M2 sporgono altri muri (M10, M11, M12), che dovevano delimitare altri ambienti.

\section{Locus L2}

Si tratta di un ampio ambiente di dimensioni leggermente maggiori di L1, ma di forma più regolare. In L2 le strutture si concentrano a ridosso del muro perimetrale orientale M15, dove si aprono i loci L10, L11 e L12. In quest'ultimo è conservato un solo pilastro in posizione più o meno decentrata, verso l'angolo NO.

Altre strutture si aprono lungo il muro meridionale M14: un ambiente centrale L7 $(3,70 \times 3,60 \mathrm{~m})$, preceduto a N da L9 $(3,70 \times 1,80 \mathrm{~m})$ e seguito a S da L19 $(3,70 \times$ $1,50 \mathrm{~m}$ ). Un muro poco spesso (M24) attraversa in senso trasversale L19. Un unico pilastro monolitico è posto al centro di L7. Questi loci, dislocati lungo i muri M14 e M15, delimitano nell'angolo SE una superficie rettangolare, chiamata L13 $(7,50 \times 5,30 \mathrm{~m})$. Un passaggio largo 1,80 $\mathrm{m}$ nell'angolo NO mette in comunicazione L13 con L2.

Nella parte SO di L2 si trova l'ambiente L6, lungo oltre 12 $\mathrm{m}$, delimitato a $\mathrm{N}$ da M17. In L6 si rilevano due pilastri e un muro (M18). All'estremità O di M13 (lungo c. 8,30 m) sono collocati, ad una distanza di $2 \mathrm{~m}$ l'uno dall'altro, due pilastri sormontati da un architrave monolitico.

\section{Locus L3}

Questa parte dell'Edificio A sembra essere la più ampia, dato che attualmente si estende per l'intera lunghezza $\mathrm{N}-\mathrm{S}$ di L1+L2.

Parallelamente a M4, che divide L3 da L1, sei pilastri sono allineati su due file. L'elevazione dei pilastri sul piano di calpestio attuale è di $1,50 \mathrm{~m}$. Altri due pilastri sono posti rispettivamente a 3,70 $\mathrm{m}$ (in direzione $\mathrm{N}$ ) e 5,70 $\mathrm{m}$ (in direzione S) dal gruppo precedente. I pilastri, delimitati ad $\mathrm{E}$ da un muro visibile solo per $8 \mathrm{~m}$ di lunghezza (M25), si dispongono lungo un ambiente rettangolare (L18) parallelo al fianco orientale di L1. Su un primo gruppo di quattro pilastri, distanti l'uno dall'altro $c .2$ $\mathrm{m}$ e perfettamente allineati al centro di L18, poggia una complessa trabeazione composta di due travi $(1,95 \times 45$ $\times 35 \mathrm{~m}$ ) in posizione ortogonale all'allineamento dei pilastri e sormontate da altre due travi $(1,90 \times 35 \mathrm{~m})$, disposte questa volta in modo longitudinale (fig. 13).

Sebbene non si sia conservata la travatura al di sopra dei due pilastri allineati subito a $\mathrm{N}$ con i primi quattro, un fitto crollo di travi è oggi visibile tutto intorno. Tra queste, alcune giacciono ancora sui resti del muro M4; questo proverebbe, così come riscontrato in altri templi ipostili del Wādī Jawf, che anche a Darb al-Șabì il complesso sistema delle travi primarie e secondarie della copertura poggiava anche sui muri perimetrali, oltre che sui pilastri dell'ambiente ipostilo. Non è stato possibile verificare, in particolare, se le travi fossero appoggiate sulla sommità dei muri perimetrali o se fossero inserite nei muri stessi. Un tipo di trabeazione simile si trova nel Tempio di Nakrah a Barāqish (v. Scigliano e Paladino, capitolo 13 nel Volume 1, figg. 72-75).

Poco a S, alcuni scavi illegali hanno messo in luce dei brevi affilamenti di muri disposti ad angolo (M26 e M27), che preludono alla presenza, nell'ambiente in questione, di altri loci minori.

Più a $\mathrm{S}$, si trova un ampio spazio di circa $13 \mathrm{~m}$ (L16), delimitato da M28 e M33. Un passaggio di 2 metri immette in L14 $(8 \times 4 \mathrm{~m})$. Nella metà occidentale sono visibili quattro pilastri che, disposti in quadrato, si elevano dal terreno per $1,30 \mathrm{~m}$. In realtà questo ambiente non è costituito da un unico spazio in quanto, sul lato orientale, quasi nell'angolo $\mathrm{SE}$, un troncone di muro (M32), lungo 2,40 m e allineato con due dei quattro pilastri precedentemente indicati, doveva creare un'ulteriore suddivisione. Ad O di questo ambiente si trova un piccolo locus quadrato (L15) avente i lati di circa $2,40 \mathrm{~m}$.

Il muro M31, di cui non è definito il limite nordoccidentale, si estende per $10 \mathrm{~m}$ in direzione NO-SE. Non si tratta, tuttavia, del limite orientale dell'Edificio $\mathrm{A}$, in quanto M16 prosegue oltre, in direzione $\mathrm{E}$, per altri $8 \mathrm{~m}$ circa delimitando a sua volta un nuovo ambiente (L17).

Dalla testa orientale del muro M16 al limite est del pianoro, lo spazio (poco più di mezzo ettaro) è occupato da un'ampia area di lavorazione dei blocchi, che a sua volta nasconde i resti di una piccola struttura isolata. Infine, sulla punta estrema, alcune pietre disposte in circolo sembrerebbero rivelare i resti di una tomba 'a torretta' (non indicata sui nostri rilievi topografici).

Le rovine visibili nella zona immediatamente ad $\mathrm{O}$ dell'Edificio A, restano di difficile interpretazione. 
Si tratta di pilastri monolitici, talvolta isolati, ma spesso inglobati in strutture in pietra. Il tempo a nostra disposizione ci ha permesso di eseguire il rilievo topografico di una sola delle strutture presenti in quest'area, ma, nel contempo, è stato possibile posizionare in pianta tutti i pilastri monolitici individuati (fig. 12).

Un primo pilastro, visibile a c. $12 \mathrm{~m}$ dall'angolo NO dell'Edificio A, è seguito da un secondo pilastro a 16,50 $\mathrm{m}$ dallo stesso angolo. Una coppia di pilastri, associata ad altrettanti affilamenti che corrono in direzione E-O, sono visibili a circa $15 \mathrm{~m}$ a $O$ dal muro perimetrale dell'Edificio A, e definiscono una struttura da noi denominata 'Edificio B'.

Altri tre monoliti distano circa $45 \mathrm{~m}$ a SO dallo stesso muro e fanno parte di un edificio a pianta rettangolare ('Edificio D'; la pianta non è indicata sulle nostre carte) lungo $30 \mathrm{~m}$ (in direzione $\mathrm{N}-\mathrm{S}$ ) e largo $20 \mathrm{~m}$ (in direzione E-O). Un gruppo di una decina di pilastri, disposti su due file, ed alcuni affilamenti ad essi associati (non indicati sulle nostre carte), sembrerebbero rivelare un'unica grande struttura oblunga, chiamata 'Edificio E'.

Dall'Edificio E, proseguendo per circa $40 \mathrm{~m}$ in direzione $\mathrm{N}-\mathrm{O}$, si ha di fronte un ampio ambiente delimitato da muri appena affioranti dal terreno; qui si ergono dal suolo alcuni pilastri, in mezzo ai quali sono crollate grosse lastre della copertura (le misure medie delle lastre sono $1,75 \times 0,85 \times 0,12 \mathrm{~m}$ ). Questa struttura rettangolare, denominata 'Edificio F' (fig. 14), è orientata NO-SE e le sue dimensioni sono $40 \times 15 \mathrm{~m}$. L'edificio potrebbe avere l'ingresso a NO, dove sembrerebbe collocarsi un avancorpo d'entrata. L'Edificio $\mathrm{F}$ è quindi formato da un ampio spazio, $\mathrm{L} 19(20 \times 15 \mathrm{~m})$, forse una corte, al termine del quale un muro trasversale (M47), conservato per oltre $3 \mathrm{~m}$, divide la struttura in due parti non uguali tra loro. Quella meridionale, di dimensioni minori, ma più articolata, presenta nell'angolo SE un ampio ambiente quadrangolare, L21 (c. $7 \mathrm{~m}$ per lato); qui sono visibili tre pilastri monolitici disposti in modo simmetrico all'angolo delimitato dai muri M39 e M40. Affiancati alla parete M42 di questo ambiente, sono visibili i due piccoli loci contigui, L23 e L24 (c. 2,50 × 1,50 m). Un'ampia area, L20, è disposta intorno a L21. Nella parte O, M48 e M49 formano un angolo leggermente ottuso il cui vertice è a So. Le misure dei muri sono rispettivamente di $4 \mathrm{~m}$ e di $2 \mathrm{~m}$. Un pilastro affianca all'esterno M48, quasi all'altezza del vertice d'angolo. L'angolo NO di L20 è occupato dal locus L22 $(3,5 \times 2 \mathrm{~m})$. All'estremità $\mathrm{N}$ di L19 altri muri possono rivelare un ulteriore sviluppo dell'Edificio E.

All'estremità $\mathrm{N}$ del pianoro sono visibili alcuni grandi blocchi di riutilizzo dalla forma ricurva. Poco oltre, uno scavo illegale ha messo in luce una parete incurvata. I blocchi e la parete potrebbero appartenere ad un edificio, da noi denominato 'Edificio G', il cui limite settentrionale, limitato dall'andamento del ciglio del pendio, assume una forma semicircolare. Un muro, lungo $20 \mathrm{~m}$ e probabilmente appartenente all'Edificio $\mathrm{G}$, è posto $c .14 \mathrm{~m}$ a SE dalla parete ricurva.

La parte restante del pianoro sembra essere stata meno interessata dal piano urbanistico dell'insediamento. Vi è un'ampia area vuota, grande poco meno di un ettaro, che giunge fino al limite occidentale. Tutto intorno a questo spazio si impostano alcune strutture dall'aspetto abbastanza diverso da quelle viste sino ad ora. Si tratta di edifici dalle dimensioni modeste, quasi privi di pilastri (se ne contano uno o due) e che includono una distribuzione degli ambienti molto più fitta e articolata da renderli, allo stato attuale, di difficile lettura.

Un rilievo topografico per una di queste costruzioni è stato predisposto nel corso della nostra ricognizione. Si tratta dell'Edificio C (c. $20 \times 18 \mathrm{~m})$, che sorge a meno di $20 \mathrm{~m}$ dall'angolo SO dell'Edificio A (fig. 15).

La parte NO è costituita da un ambiente pressappoco quadrato, L26, con i lati di 5,50 m. Sul fianco $O$ un corridoio d'ingresso lungo $3,60 \mathrm{~m}$ e ben definito da M61 e M62 distanti meno di $1 \mathrm{~m}$ l'uno dall'altro, occupa quasi per intero la larghezza NE-SO del locus. Oltre il muro M58, che delimita a sud L26, si colloca il locus L28 $(5 \times 3 \mathrm{~m})$. Un pilastro isolato, quasi al centro, e due passaggi negli angoli NO e SE caratterizzano L28. A S, oltre M65, si trova un altro locus rettangolare, L29 (6 × 2,60 m). Al centro del muro meridionale, formato da M68 e M69, un passaggio (largo 1,50 m) immette in un ampio spazio, L30, forse una corte $(9,50 \mathrm{~m} \mathrm{E}-\mathrm{O}$ per $5 \mathrm{~m}$ $\mathrm{N}-\mathrm{S})$. Un affilamento, che da M68 si estende verso S per $1,40 \mathrm{~m}$, potrebbe indicare una suddivisione di questo vasto ambiente a cielo aperto.

La parte orientale dell'Edificio $C$ è poco chiara allo stato attuale. Oltre M59, L31 è un locus rettangolare con il lato lungo di circa $6 \mathrm{~m}$ orientato sull'asse NO-SE. A sud, L32 presenta una forma irregolare e probabilmente può essere diviso in più loci.

A NO il nostro rilievo topografico riguarda alcuni resti di una struttura già identificata, rilevata e denominata 'Edificio 3' dalla Missione francese. ${ }^{15}$ La struttura, da noi denominata per l'occasione 'Edificio H' (fig. 16), è orientata sull'asse NE-SO.

Addossato tra le pendici nord-occidentali del pianoro e un'altura naturale, l'Edificio H si sviluppa sostanzialmente intorno ad un ambiente centrale, L35 $(6,20 \times 2,50 \mathrm{~m})$. Un troncone di muro M86 $(1,50 \mathrm{~m})$ e un pilastro a questo addossato, suddividono l'ambiente,

\footnotetext{
15 Robin et al. 1981, 254.
} 
delimitando a S L36 $(2,50 \times 2 \mathrm{~m})$. Ad O si dispongono due loci contigui, L37 $(4,20 \times 3,40 \mathrm{~m})$ e L38 $(3 \times 2 \mathrm{~m})$.

A nord, due altri ambienti, L39 e L40, cui si accede da un unico passaggio posto nell'angolo So, si dispongono uno dopo l'altro coprendo una superficie complessiva di $4 \times 1,60 \mathrm{~m}$. Subito ad E, un'ampia area, denominata L41 $(6,70 \times 6,20 \mathrm{~m})$ è delimitata da due muri, M82 a N e M81 a E.

A S di L35 un ambiente di forma irregolare $(3,80 \mathrm{~m} \mathrm{~N}-\mathrm{S}$ $\times$ 3,50 m E-O) comprende due loci, L42 e L43 separati da M101. Ancora oltre, a S, M102 delimita L44.

Il dato rilevante di questo edificio è ben documentato dallo studio dei Francesi. Si tratta di un'iscrizione scolpita su un pilastro che, posto tra L35 e L36, a ridosso di M86, si eleva dal terreno per 1,10 m. L'iscrizione suggerisce trattarsi di un'abitazione e non di un tempio, poiché nel testo, oltre alla parola bayt, si leggono altri termini che indicherebbero gli ambienti di una casa; in particolare il termine șrht significherebbe 'vestibolo di accesso' dell'abitazione. ${ }^{16}$

Come già indicato in precedenza, altre strutture sono state individuate alla base del pianoro. Tra queste, una è già stata esaminata e identificata come 'Edificio 2' dalla Missione francese del $1980 .{ }^{17} \mathrm{Di}$ questa struttura, per noi 'Edificio I', resta visibile ben poco (fig. 17). Posta a c. $70 \mathrm{~m}$ di distanza dalla base del pianoro di Darb al-Ṣabī, dall'osservazione della pianta topografica sembrerebbe appartenere alla categoria tipologica degli edifici appena descritti. Tuttavia, l'aspetto interessante che viene fuori dai pochi resti visibili è la presenza, a ridosso di M110, di un pilastro iscritto recante il nome della divinità Nakrah. Il testo inciso sul pilastro (1,35 m $\times 70 \mathrm{~cm}$ ), assegnerebbe così, all'edificio in questione, la funzione di luogo di culto, nonostante, come precisato anche dagli archeologi della Missione francese, non siano stati rinvenuti elementi architettonici che lo confermerebbero. Il corpo centrale dell'edificio sembrerebbe collocato a NO, dove alcuni muri sono conservati per soli $20-30 \mathrm{~cm}$ di altezza. Due pilastri sono visibili in questa zona e indicherebbero l'ingresso. Il resto dell'edificio consiste in un'ampia corte larga 16 m e lunga $11 \mathrm{~m}$ circa (L45).

\section{Ceramica}

La ceramica raccolta sul sito durante la prospezione è attribuibile prevalentemente all'occupazione di epoca minea (fig. 18). Pochi sono i cocci di periodo islamico, e solo alcuni frammenti di pareti, caratterizzati dalla tipica ingubbiatura di colore rosso scuro o violaceo

\footnotetext{
16 Robin et al. 1981, 254.

17 Robin et al. 1981, 254.
}

e lustrata, sono riconducibili ad una produzione di periodo sabeo. Gli altri frammenti di orli e di fondi, per le forme, gli impasti e i trattamenti superficiali, trovano puntuali confronti con la ceramica proveniente dal sito di Barāqish. Si vedano per esempio i confronti, dei nn. 4-5 della fig. 18 con il Tipo 11 in Antonini, capitolo 2, fig. 21, nn. 2-6; fig. 22, 1-2, nel Volume 1; infine il fondo ad anello n. 10 della fig. 18 con i fondi del Tipo 21 in Antonini, capitolo 2, fig. 24, nn. 10-11, nel Volume 1.

\section{Tecniche architettoniche}

Più di una volta è stato ricordato il cattivo stato di conservazione in cui versano le antichità di Darb al-Ṣabī. Tuttavia, dall'osservazione dei pochi muri conservati per una certa altezza, è possibile fare alcune osservazioni sulla tecnica costruttiva. Questa consiste prevalentemente in filari di conci medio-piccoli, irregolari, sbozzati, giustapposti e spesso inzeppati con schegge. Negli Edifici A eE, dove i loci sono perfettamente squadrati, la posa dei conci sembra eseguita in modo più raffinato $\mathrm{e}$, di conseguenza, l'inserimento di zeppe è stata resa meno necessaria. I muri, eseguiti a secco, sono a doppia cortina colmata con un riempimento di terra frammista a schegge di pietra ben compattato.

In alcune fosse di scavi illegali è stato possibile notare alcuni pilastri impostati su murature orizzontali delle strutture, che, procedendo in basso, scompaiono nel terreno. Questa osservazione, già segnalata dalla Missione archeologica francese, ${ }^{18}$ porta ad ipotizzare la presenza di uno zoccolo di basamento (si veda come esempio le case di Tamna') o di edifici a più piani a Darb al-Ṣabī.

Talvolta, infine, nell'alzato dei muri si riscontra una tecnica particolare, costituita da file di grosse pietre rozzamente squadrate, alternate a file di pietre più piccole, piatte, disposte a spina di pesce (fig. 19). Tale metodo costruttivo trova paralleli, ad esempio, in alcune strutture di Yalā al-Durayb. ${ }^{19}$

\section{Funzione delle strutture}

Lo studio dei Francesi, basato principalmente sulle iscrizioni rinvenute, ma anche sulla topografia delle strutture rilevate, ha permesso di ipotizzare la presenza a Darb al-Ṣabī sia di edifici sacri, sia di strutture destinate ad altre funzioni, come per esempio l'ospitare i frequentatori del santuario. ${ }^{20}$

La pratica di disporre edifici diversi da quelli sacri nell'area del temenos non è insolita nel mondo antico.

\footnotetext{
18 Robin et al. 1981, 255.

19 de Maigret 1988, 8-9, 19, figg. 7, 13, tav. 25; Buffa 1996, 168, 170, fig. 3.3.

20 Robin et al. 1981, 259; Robin et al. 1988, 96.
} 
Molti sono i santuari dell'Arabia Meridionale dove è stato possibile individuare la stessa disposizione di edifici. A Riyam presso Șirwāh, per esempio, sono stati rinvenuti più edifici sacri affiancati da altre costruzioni predisposte per l'accoglienza e l'alloggio di pellegrini. ${ }^{21}$

I pochi dati oggi a nostra disposizione sembrano, tuttavia, confermare l'ipotesi che anche a Darb al-Ṣabī, accanto agli edifici sacri (parte degli Edifici A, B, D, E e F), vi siano state strutture destinate a luoghi di accoglienza per i visitatori e fedeli del santuario (Edifici A, C, G, H e I). Queste costruzioni potrebbero essere state destinate a frequentatori occasionali del luogo sacro, per esempio viaggiatori che lungo la via carovaniera, giunti ad una tappa importante del tragitto (Yathill) avrebbero potuto sostare a Darb al-Ṣabī.
Così anche Yathill/Barāqish, come molte altre città prossime al deserto (al-Sawdā') Kamnah, Karibat Hamdān, Ma'īn e Mārib) aveva il suo santuario esterno alle mura. Probabilmente questo era stato pensato per evitare l'accesso indiscriminato alla città, all'interno della quale sorgeva un tempio dedicato a Nakrah, ${ }^{22}$ e proteggere i suoi abitanti, nel caso, dal rischio di epidemie. Una tale scelta avrebbe garantito, del resto, una maggiore e duratura stabilità all'ordine pubblico. Un edificio in particolare (il vasto Edificio A) è stato indicato da C. Robin come șrht (vestibolo di accesso) del territorio-asilo di Darb al-Șabī ${ }^{23}$

Uno scavo nel sito di Darb al-Ṣabī potrebbe restituire nuovi ed importanti dati archeologici da confrontare con quelli già noti provenienti dagli studi epigrafici. I nuovi dati permetterebbero di chiarire meglio le relazioni tra le varie strutture e la loro funzione. 


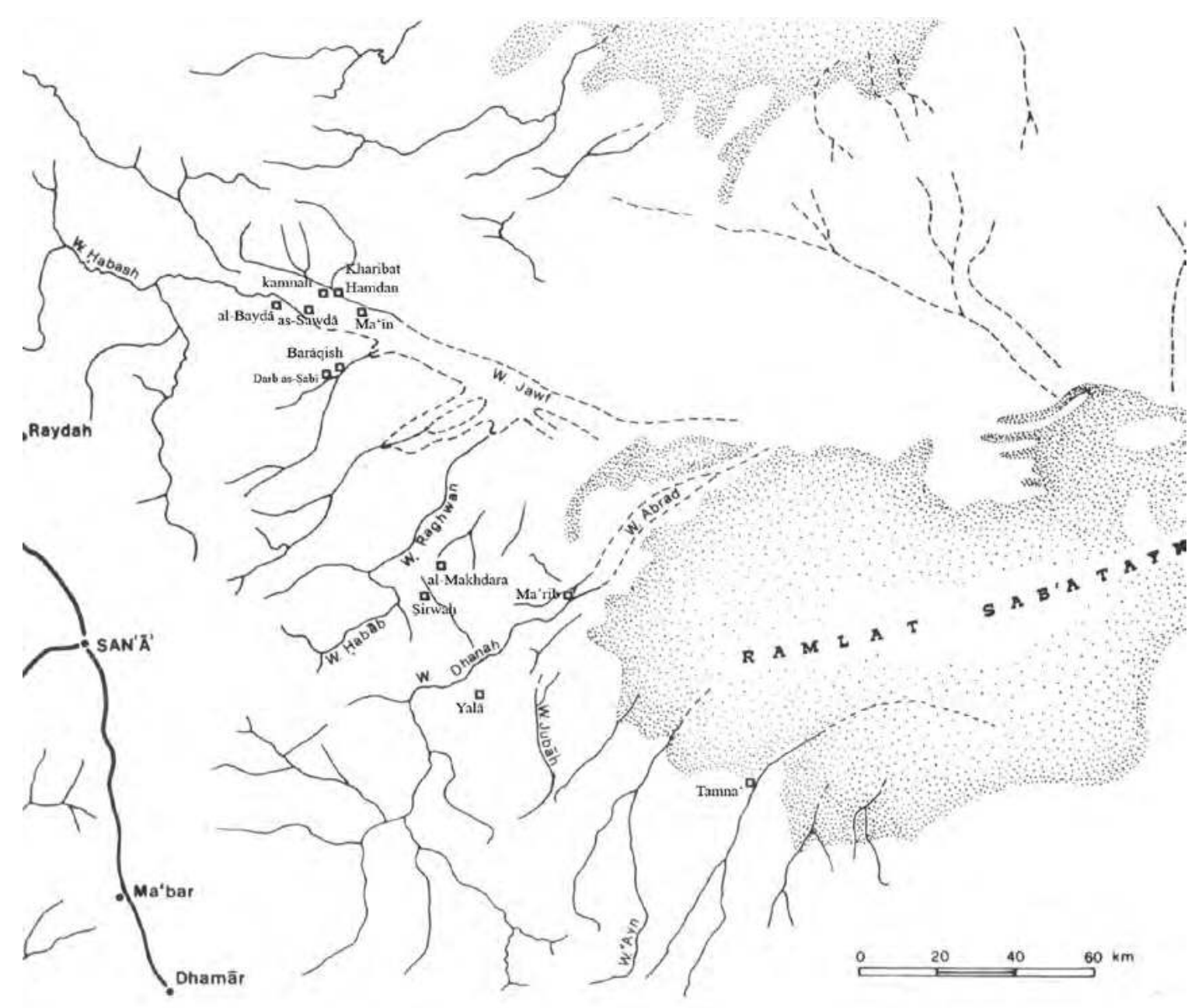

Fig. 1. Distribuzione dei siti antichi nel Wādī Jawf, tra cui Barāqish e Darb al-Ṣabī, a NE della capitale Șancāà (OMAIRY)

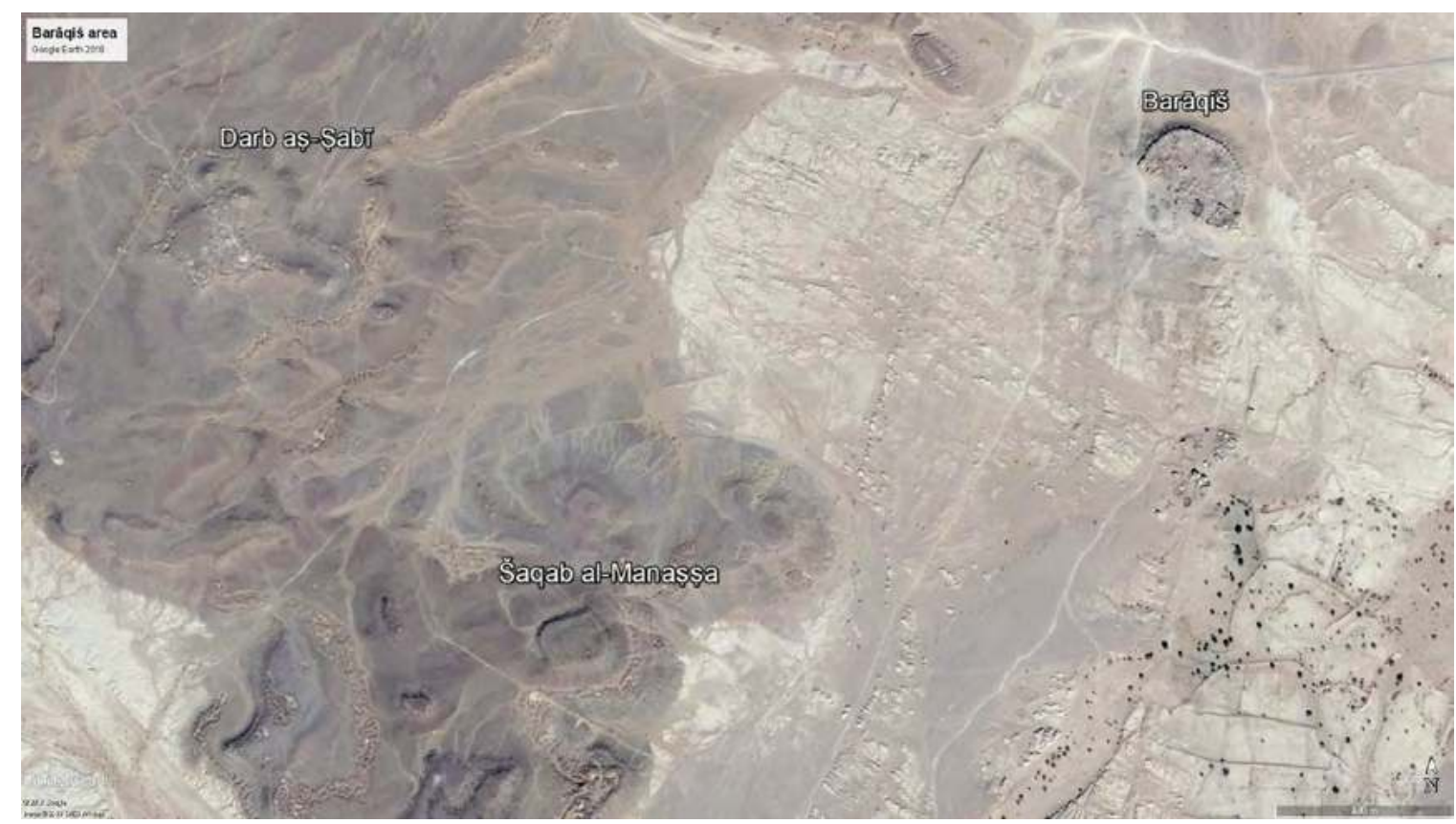

Fig. 2. Foto satellite con la zona irrigua intorno a Barāqish e localizzazione di Darb al-Ṣabī. (Google Earth 2017) 


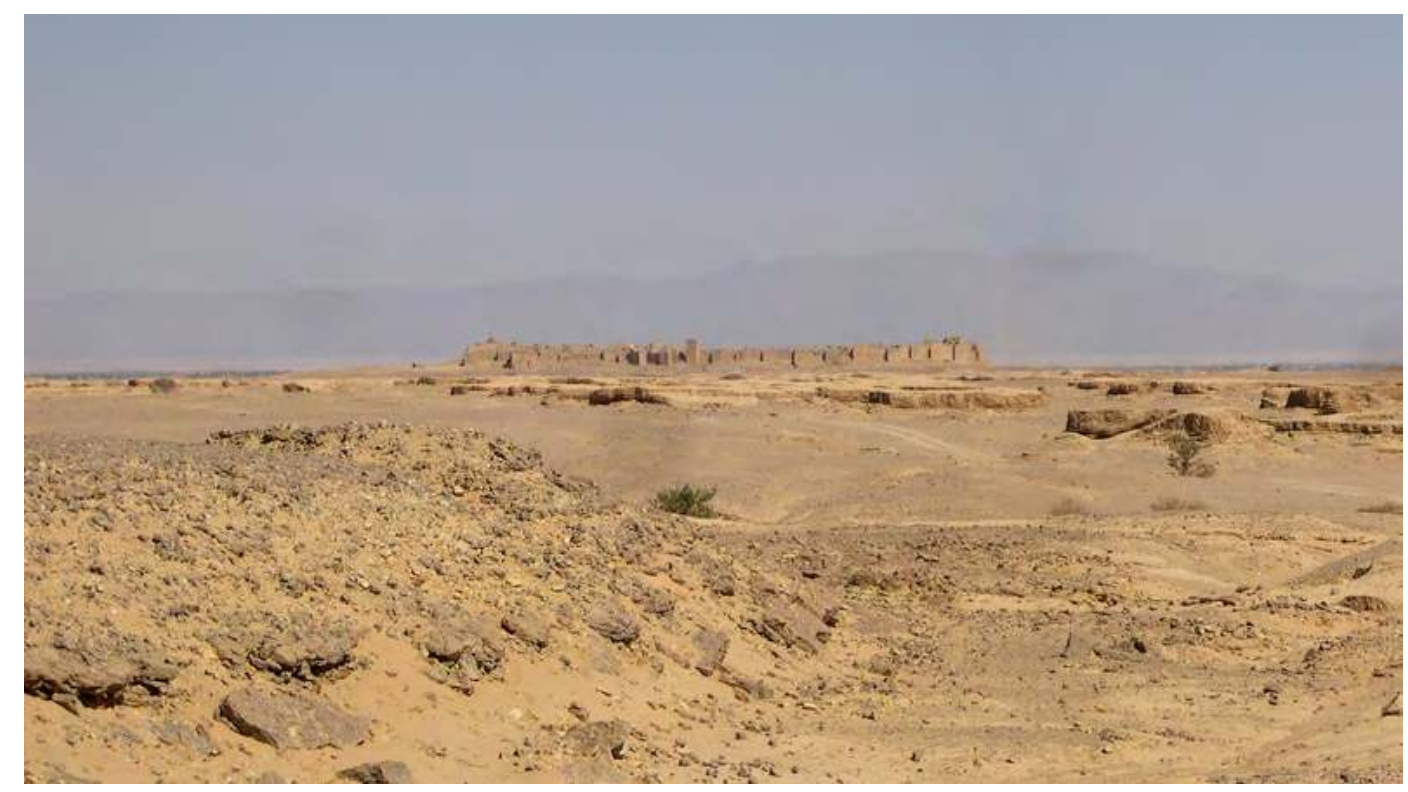

Fig. 3. Il Wādī Majzīr e parte dell'area irrigua con i resti di sedimenti dei campi antichi intorno a Barāqish, da Darb al-Ṣabì. (R. Valentini 2005 @MAIRY)

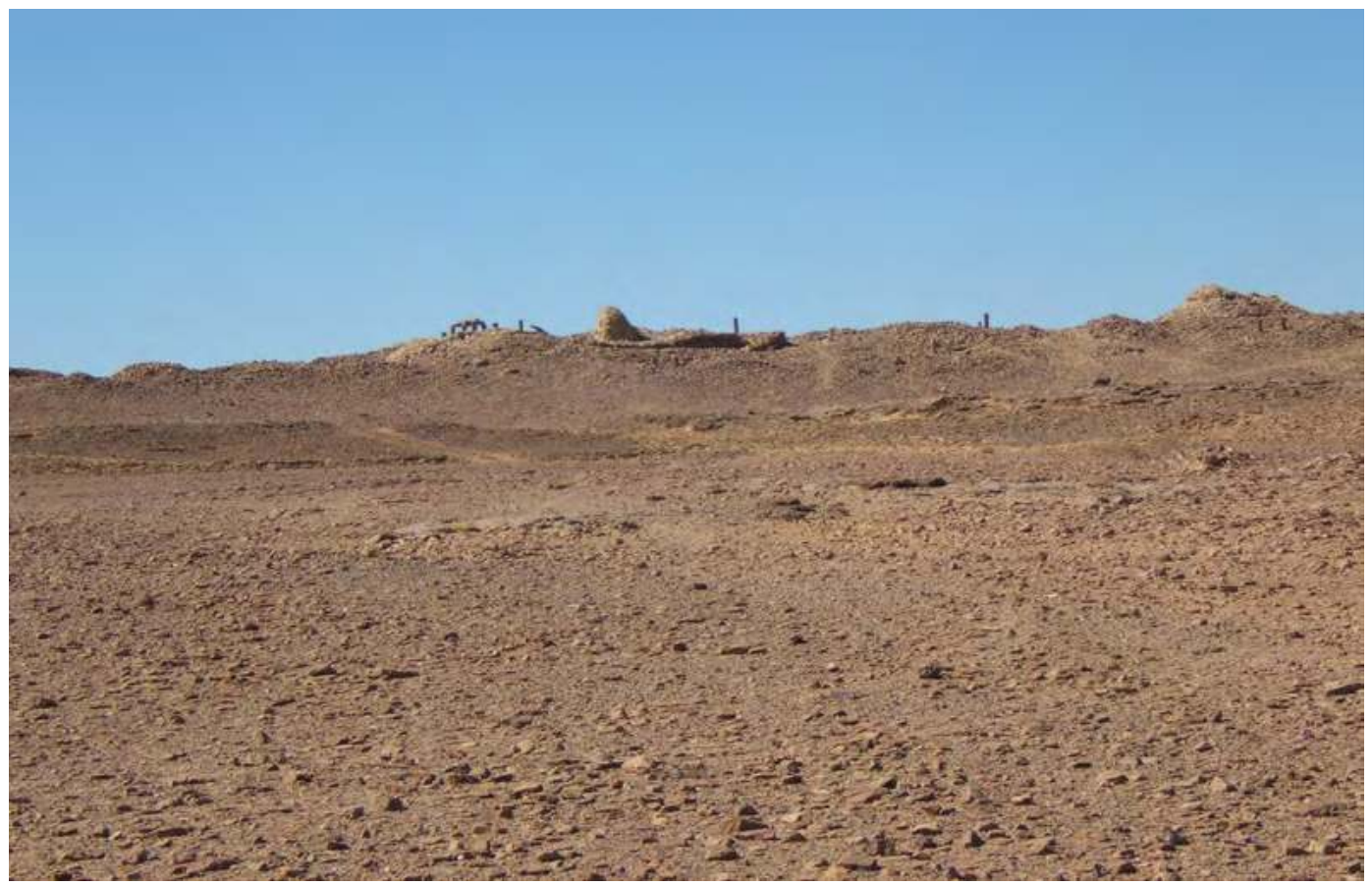

Fig. 4. Veduta di Darb al-Șabī (da N) con alcune strutture affioranti. (R. Valentini 2005 OMAIRY) 


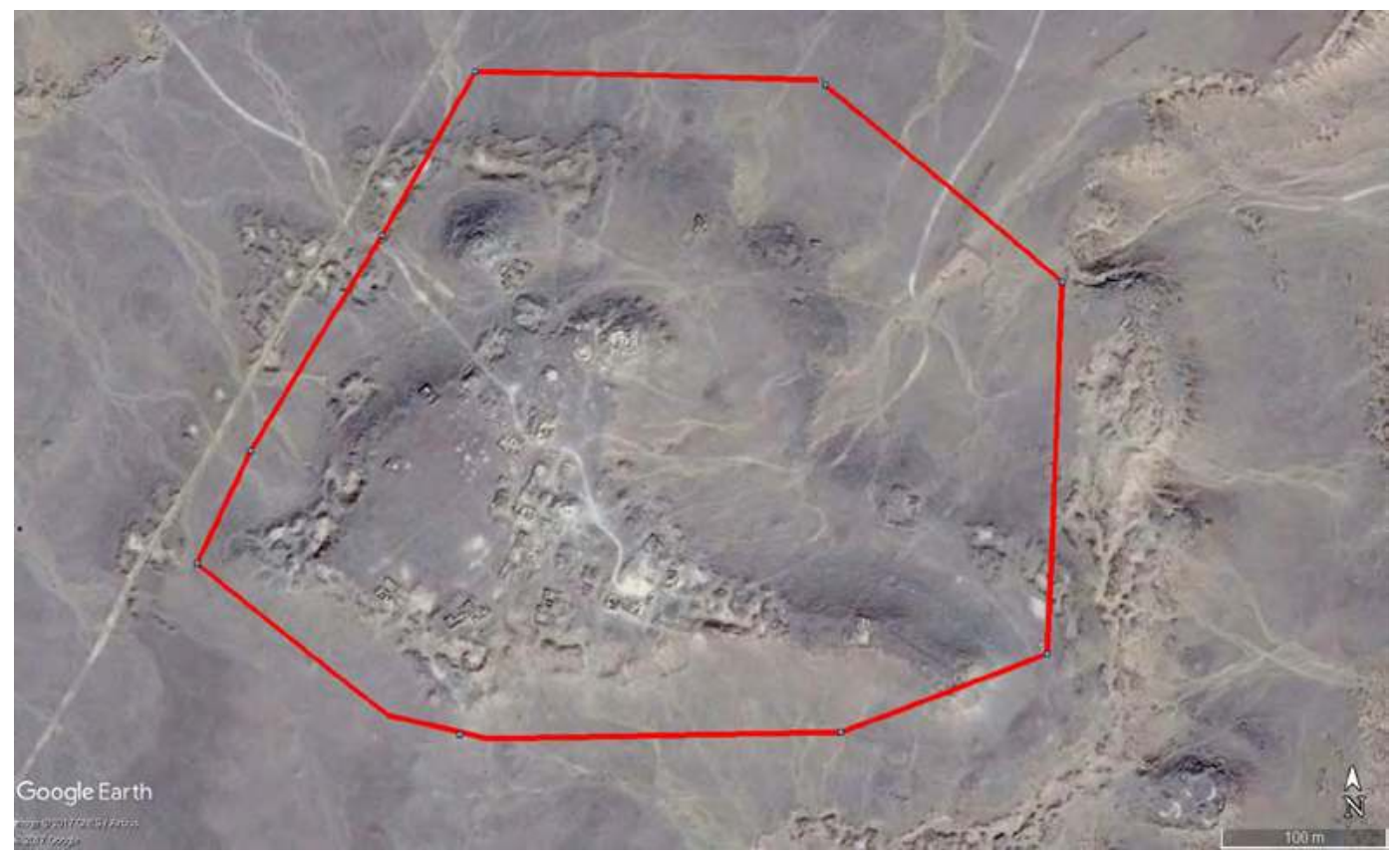

Fig. 5. Il perimetro che congiunge i 9 cippi intorno a Darb al-Ṣabī. (Google Earth 2017)

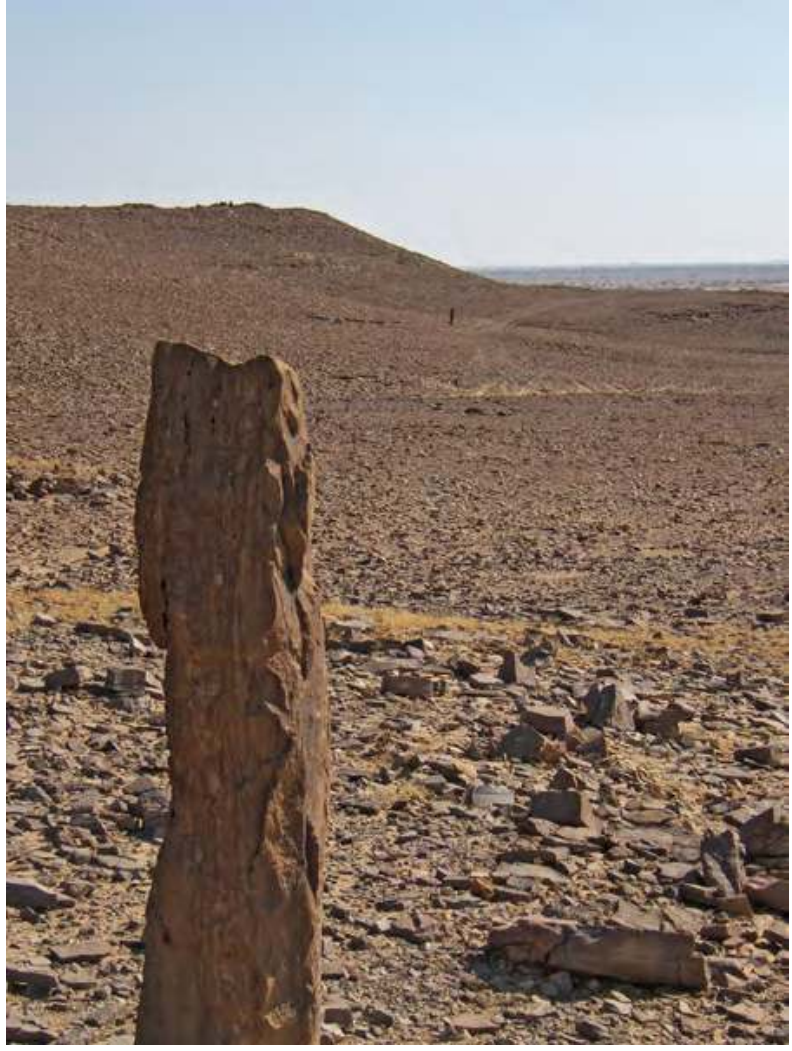

Fig. 6. In primo piano il cippo n. 5, da ovest; in lontananza si vede il cippo n. 4. (R. Valentini 2005 OMAIRY)

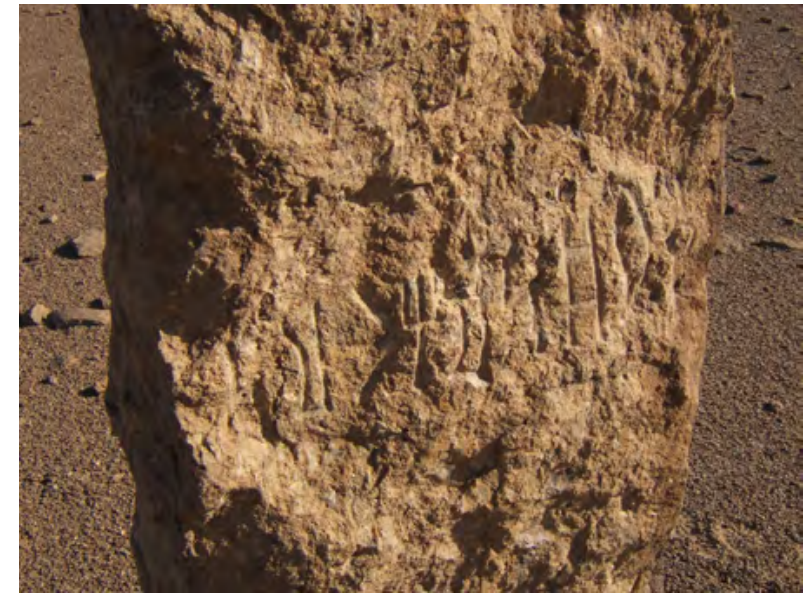

Fig. 7. Dettaglio dell'scrizione scolpita sulla parte alta della faccia meridionale del cippo n. 1. (R. Valentini 2005 OMAIRY) 


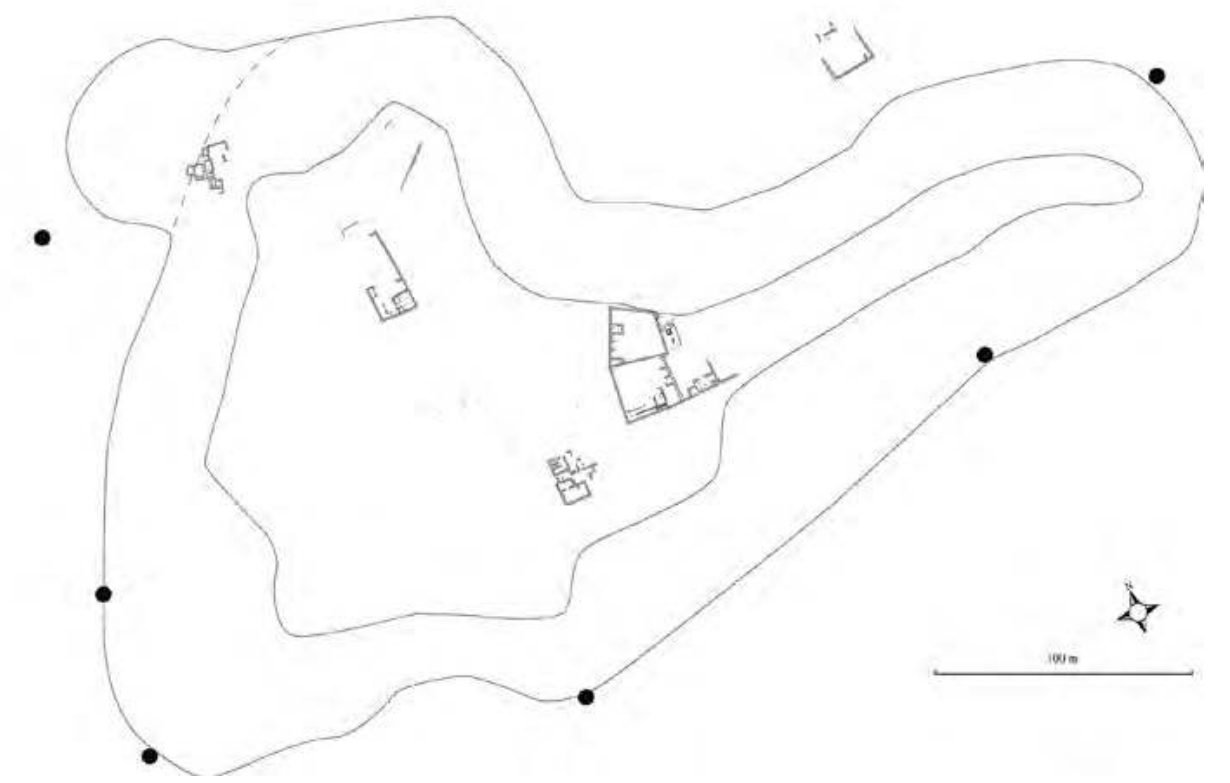

Fig. 8. Posizionamento topografico delle strutture rilevate con i 9 cippi. (R. Valentini 2005 CMAIRY)

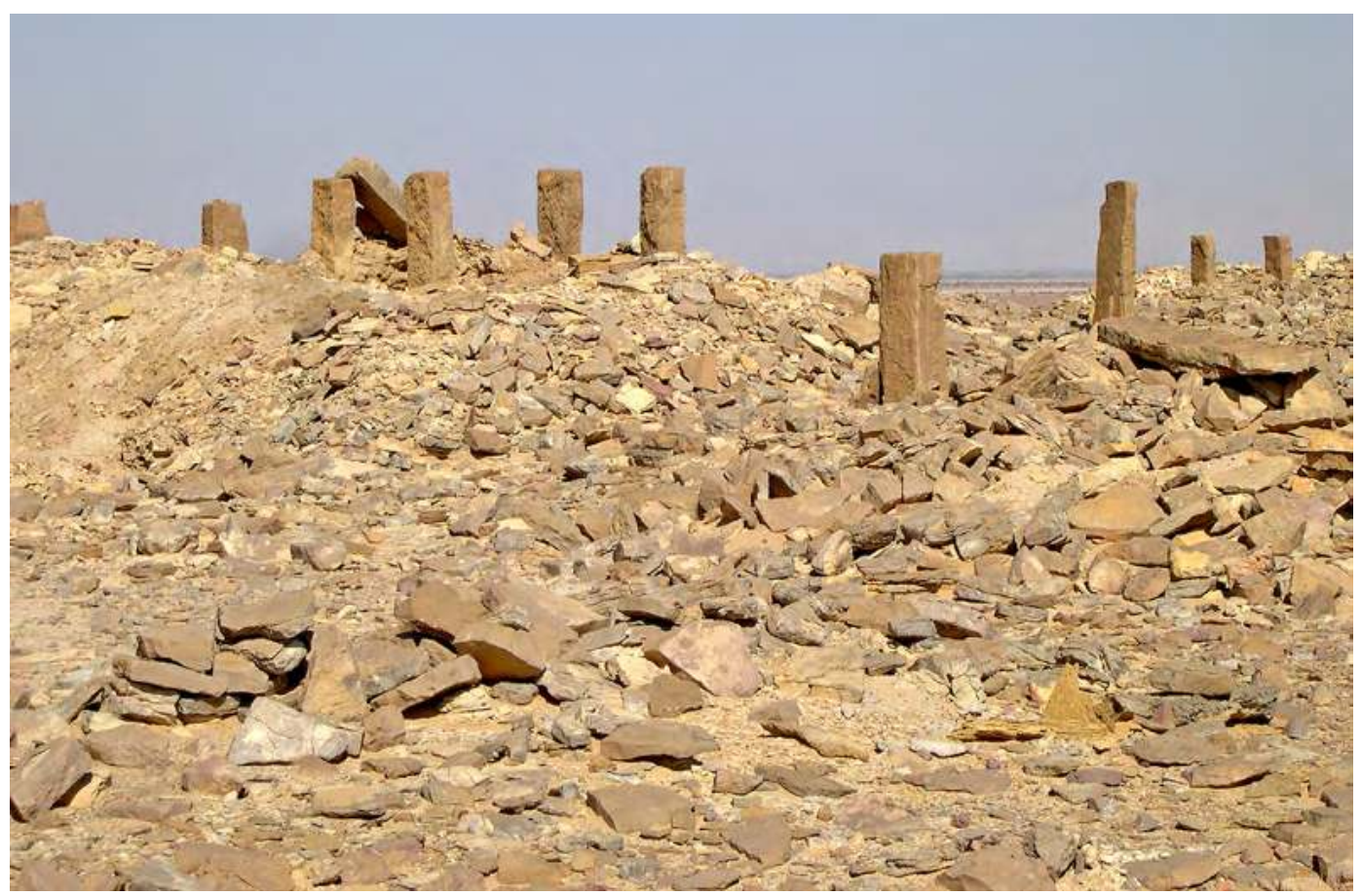

Fig. 9. Alcuni pilastri dell'Edificio E di Darb al-Ṣabī. (R. Valentini 2005 OMAIRY) 

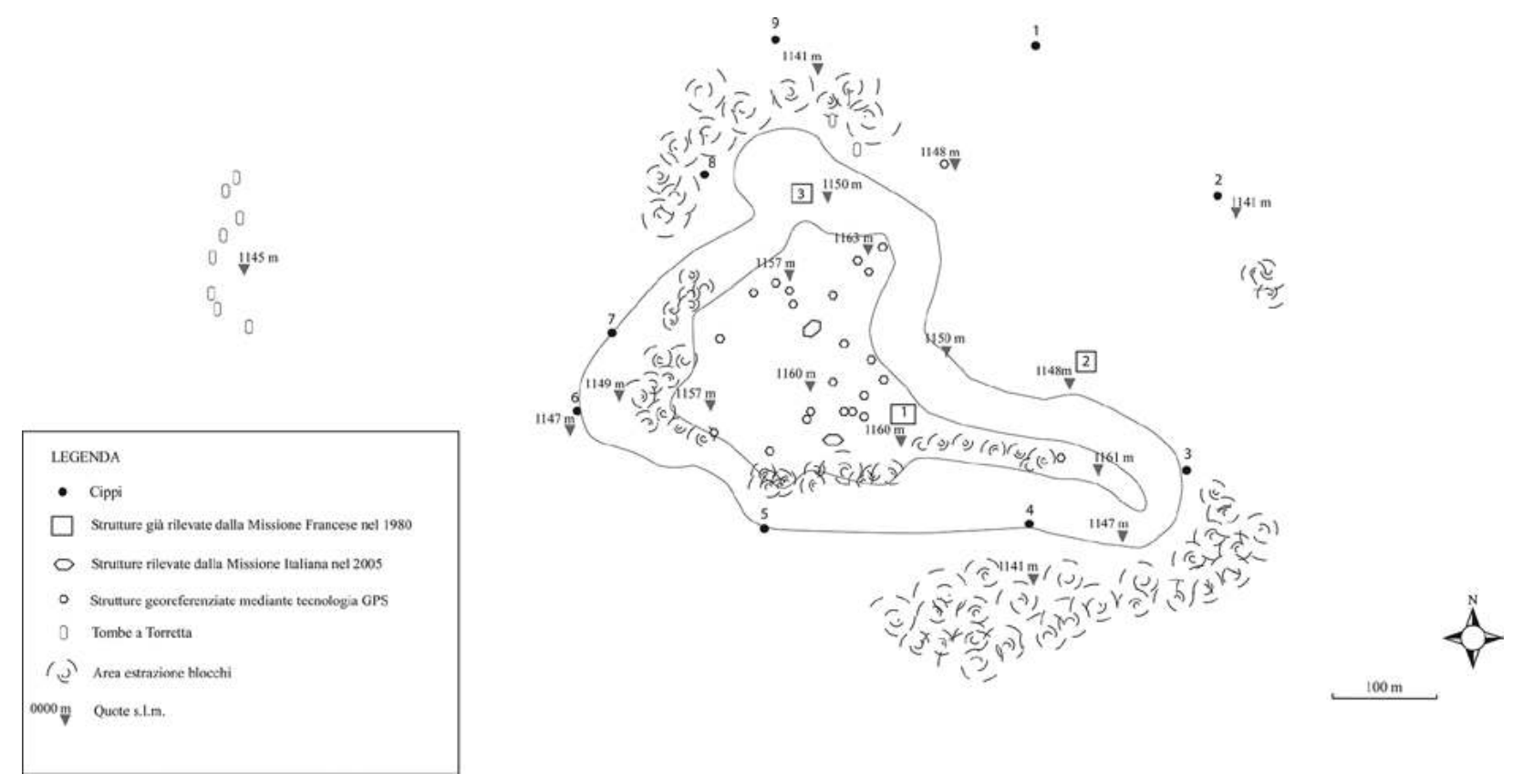

Fig. 10. Posizionamento topografico dei resti archeologici individuati a Darb al-Ṣabī. (R. Valentini 2005 CMAIRY)
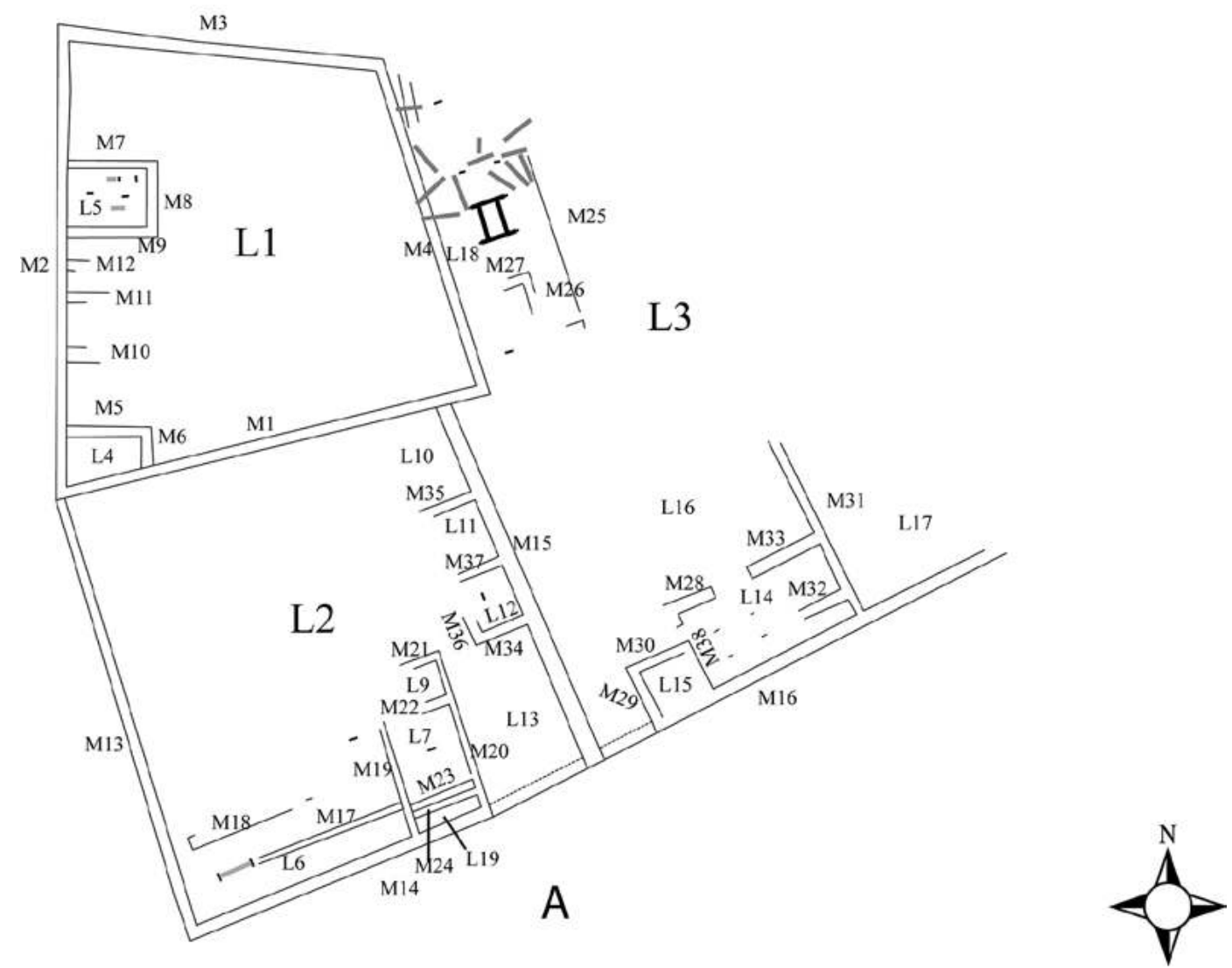

Fig. 11. Planimetria dell'Edificio A di Darb al-Ṣabī. (R. Valentini 2005 @MAIRY) 

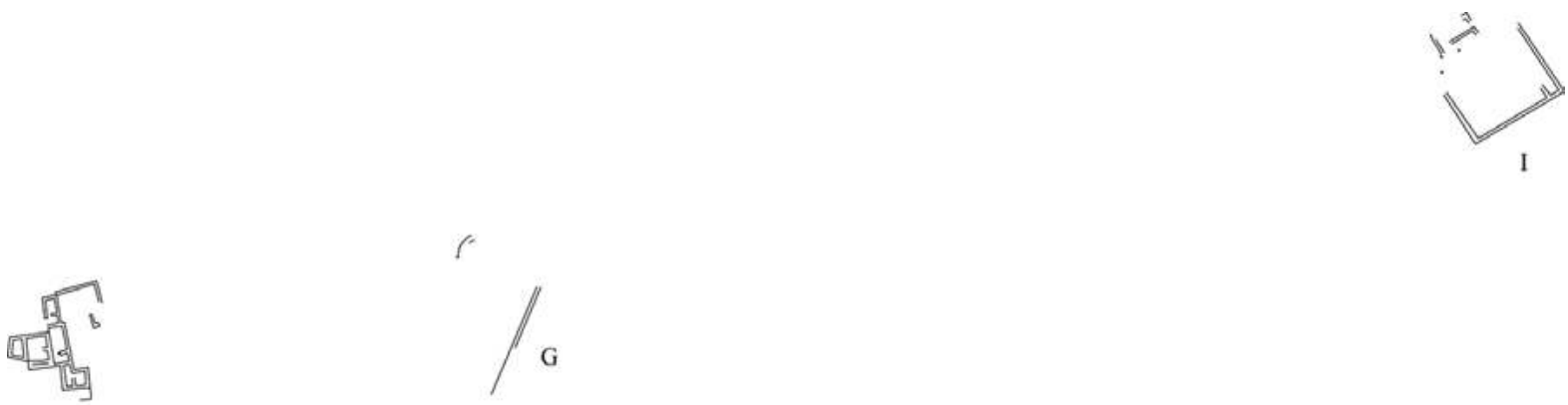

$\Upsilon^{2}$

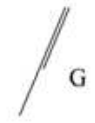

$\mathrm{H}$

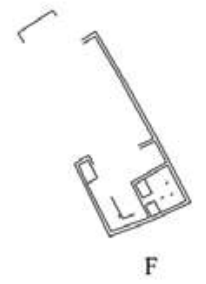

D

B

$\mathrm{E}$
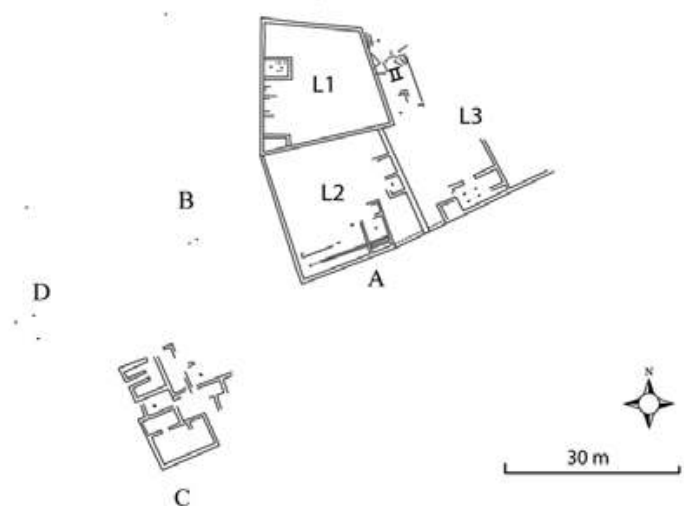

Fig. 12. Insieme planimetrico degli edifici rilevati dalla Missione Archeologica Italiana a Darb al-Ṣabì. (R. Valentini 2005 OMAIRY)

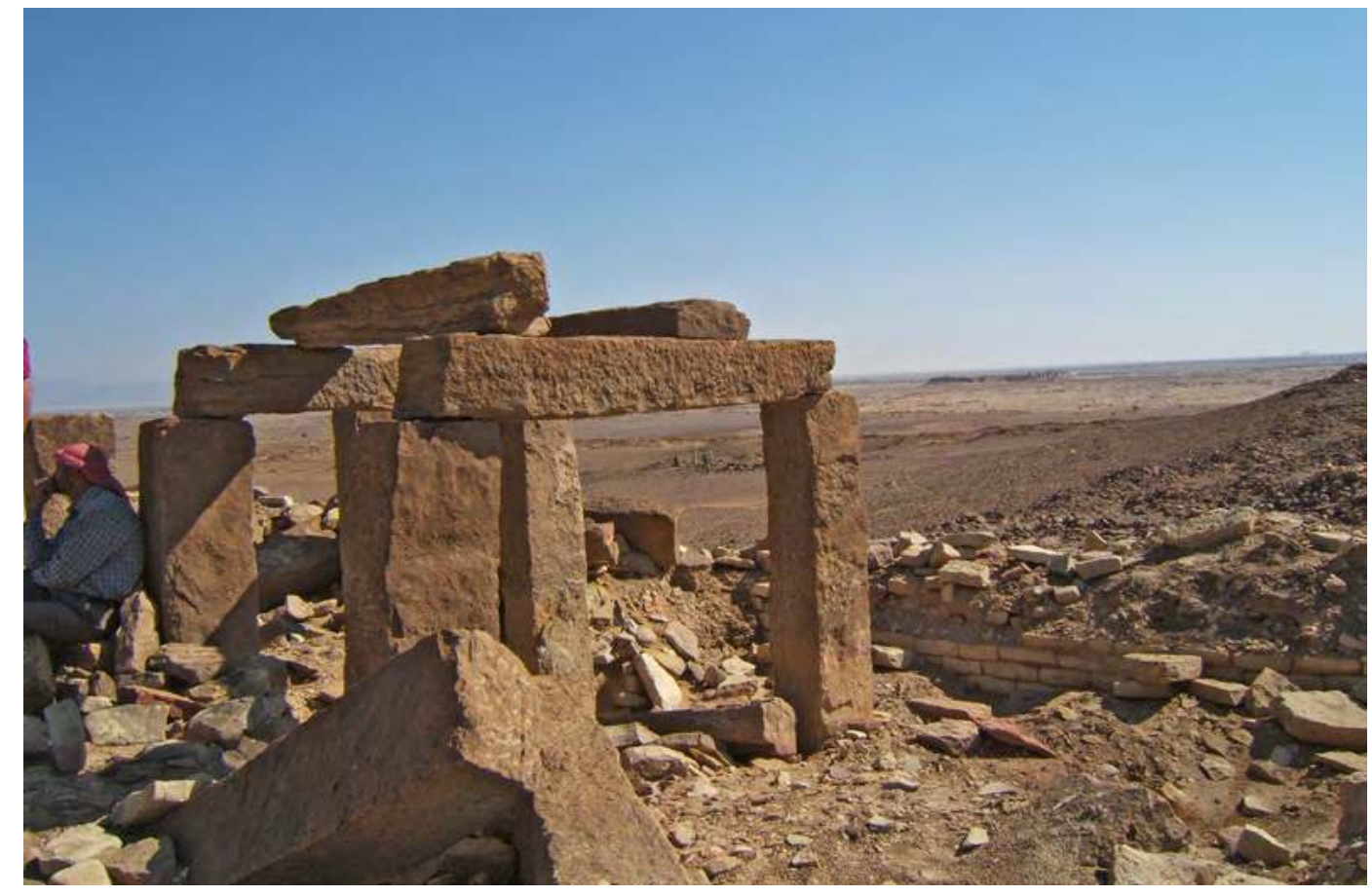

Fig. 13. Darb al-Șabī, pilastri e travi (primarie e secondarie) del locus L3 dell'Edificio A. Sullo sfondo Barāqish. (R. Valentini 2005 CMAIRY) 

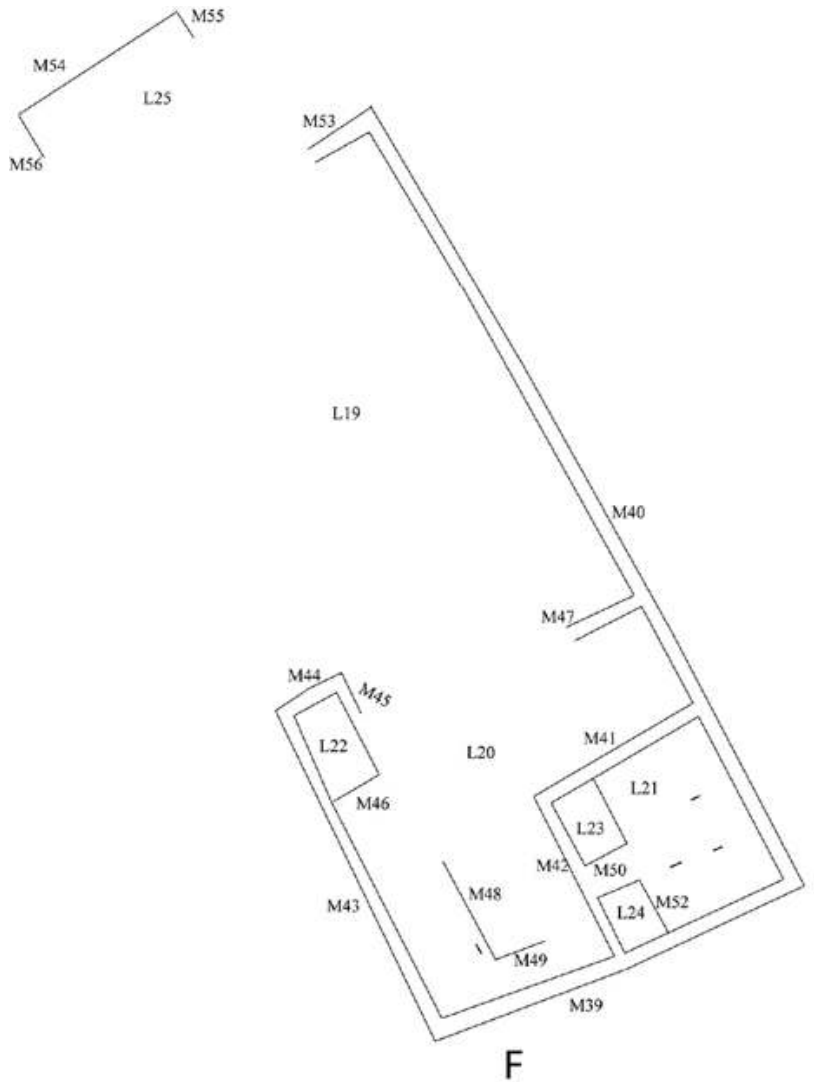

Fig. 14. Darb al-Șabī, pianta dell'Edificio F. (R. Valentini 2005 CMAIRY)

$\mathrm{F}$
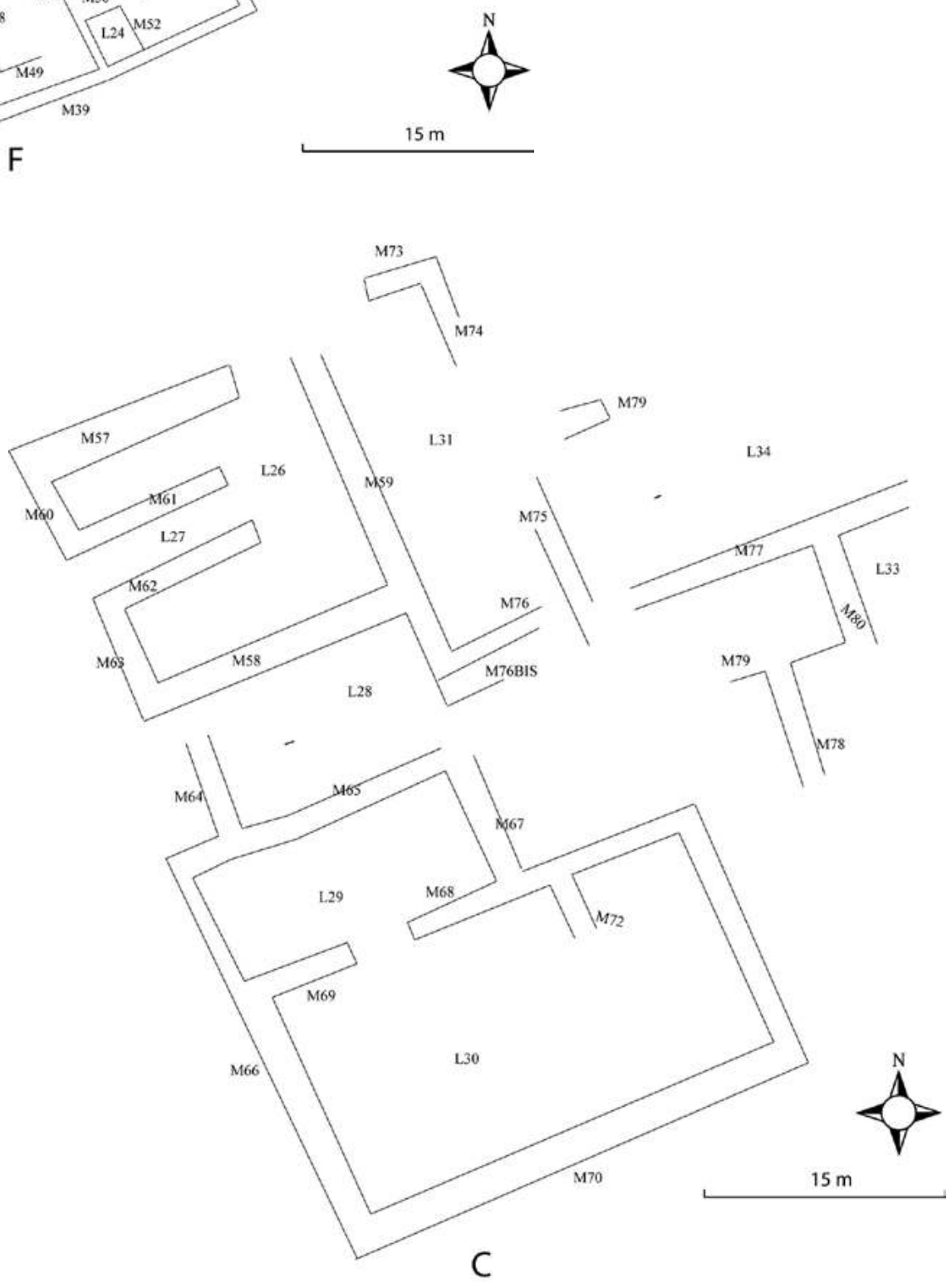

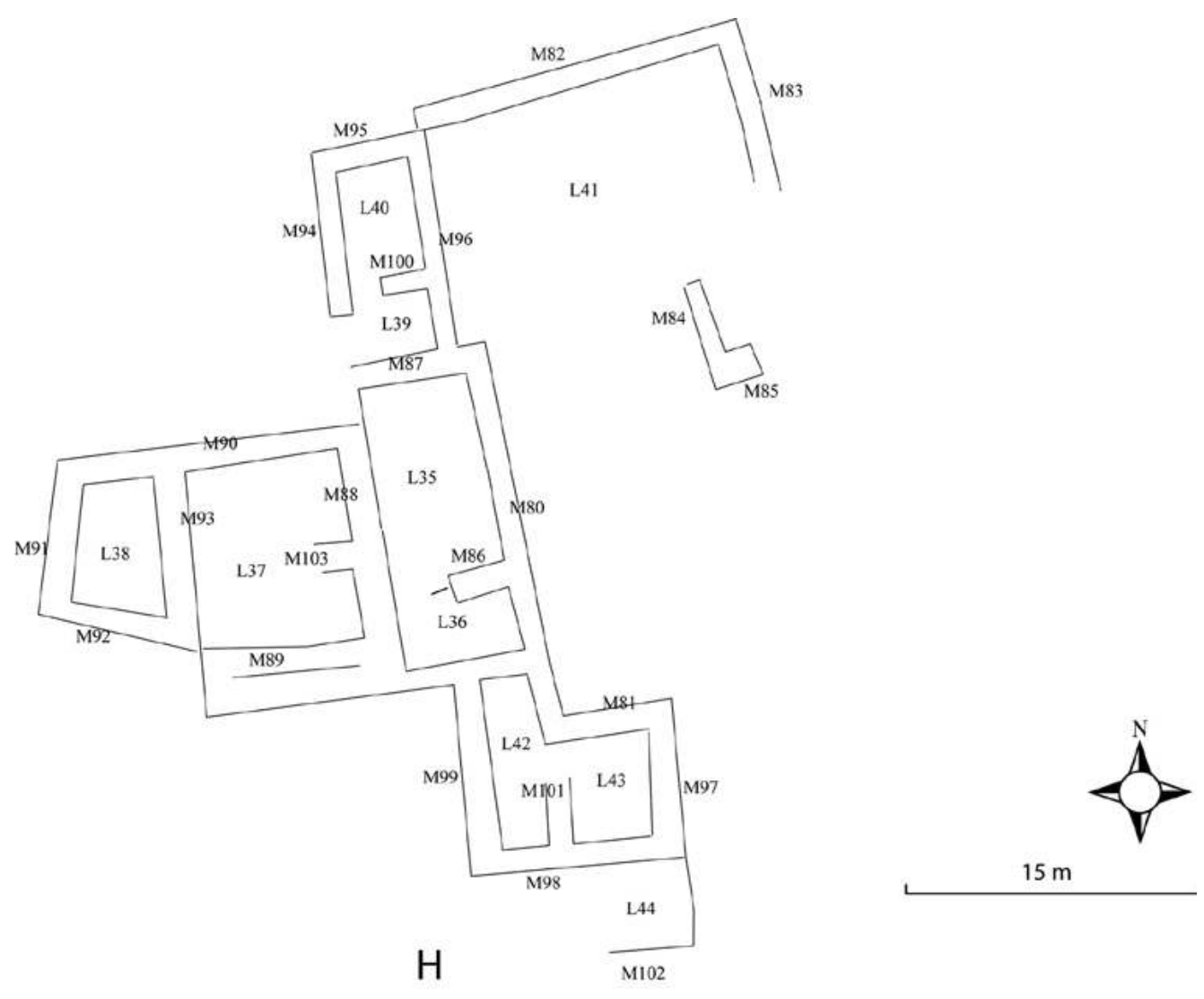

Fig. 16. Darb al-Ṣabī, pianta dell’Edificio H. (R. Valentini 2005 CMAIRY)

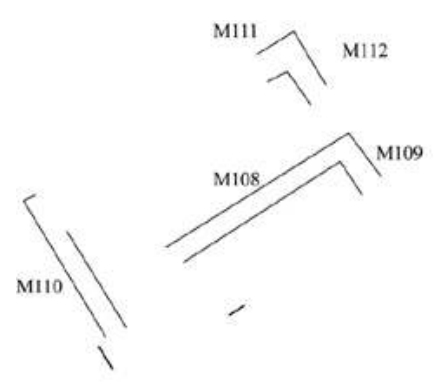

।

L45

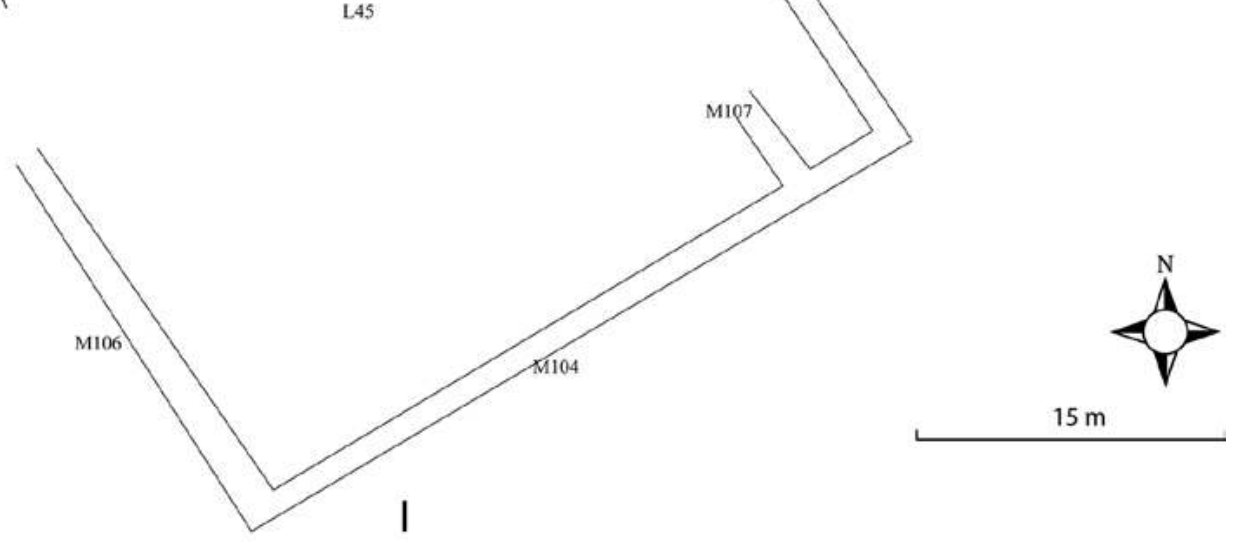

Fig. 17. Darb al-Ṣabī, pianta dell'Edificio I. (R. Valentini 2005 CMAIRY) 


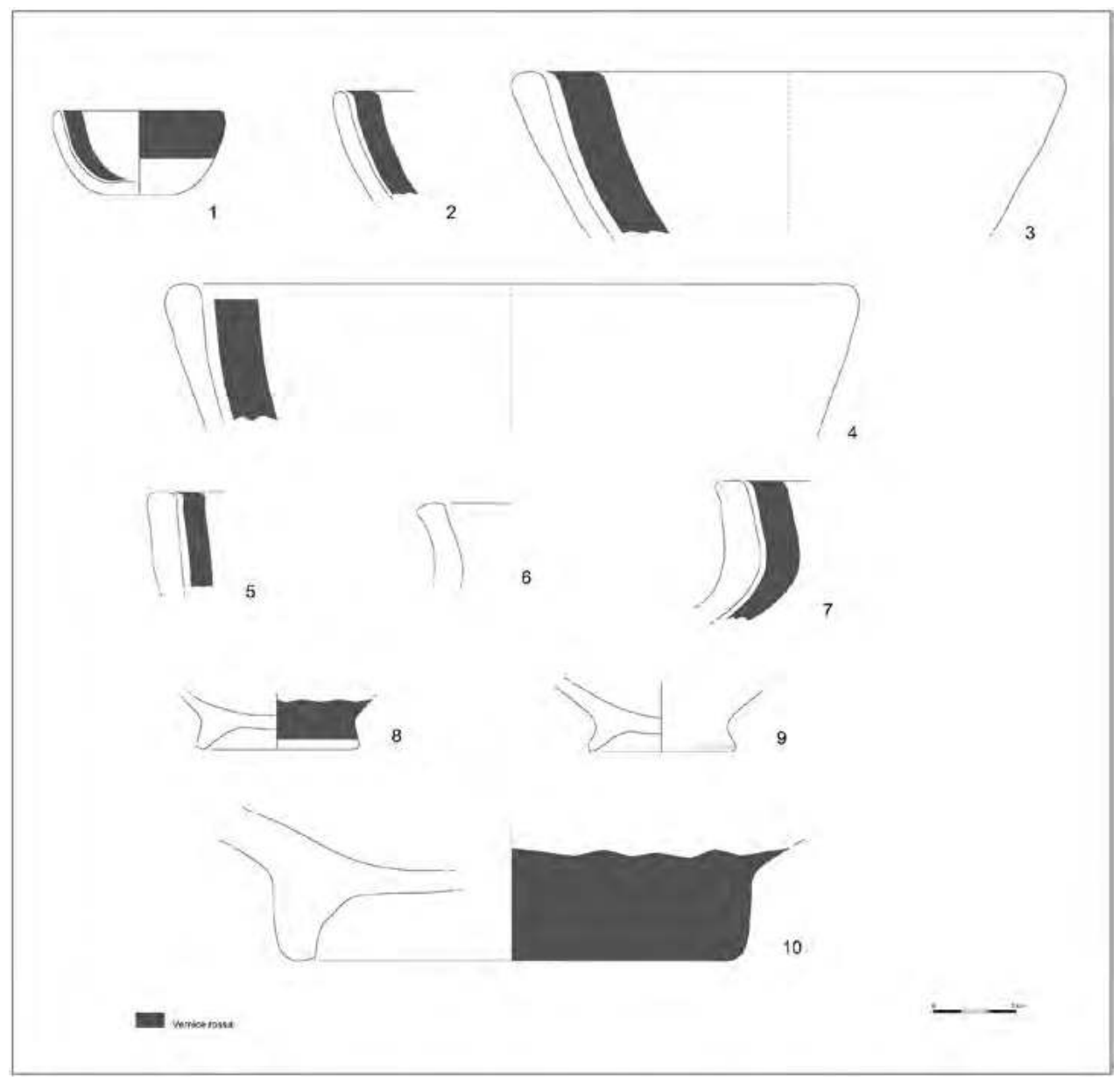

Fig. 18. Ceramica raccolta in superficie durante la prospezione archeologica a Darb al-Șabī. 1: Y.DS.05/1; 2: Y.DS.05/3; 3: Y.DS.05/9; 4: Y.DS.05/8; 5: Y.DS.05/2; 6: Y.DS.05/4; 7 Y.DS.05/5; 8: Y.DS.05/7; 9: Y.DS.05/6; 10: Y.DS.05/10. (G. Stelo 2005 OMAIRY)

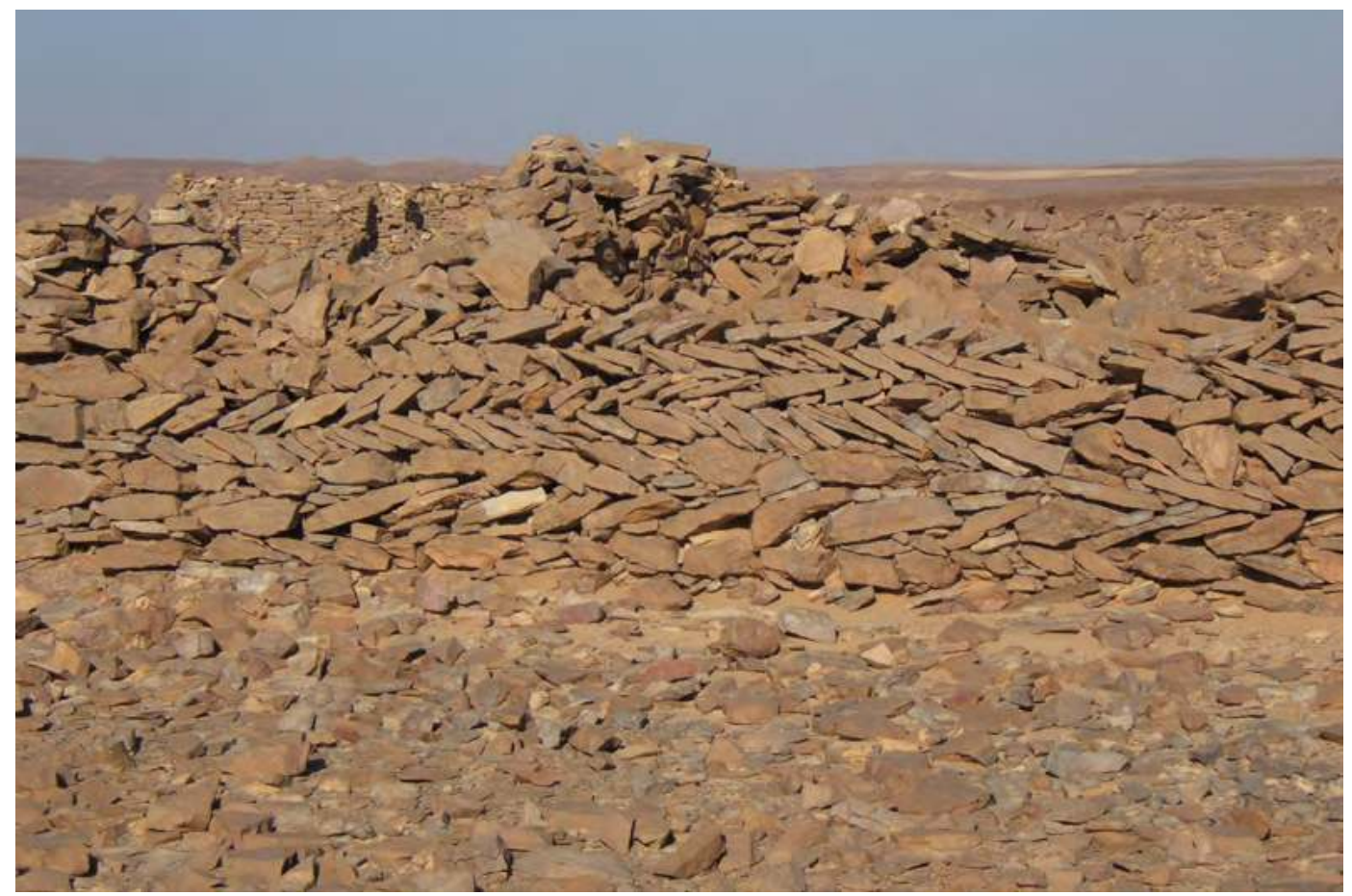

Fig. 19. Tecnica costruttiva muraria a spina di pesce di alcuni muri a Darb al-Ṣabī. (R. Valentini 2005 CMAIRY) 


\section{Abstracts of Chapters}

These synopses by the individual authors have been translated into Arabic by Khālid al-`Ansī. The English version was edited by F.G. Fedele.

\section{Volume 1}

\section{A history of archaeological research at Barāqish and in its area, by Sabina Antonini and Francesco G. Fedele}

The town site of Barāqish, ancient Sabaean and Minaean Yathill (YTLL), was brought to the attention of the wider world outside Yemen in 1872, following an exploratory journey by European semitist J. Halévy and Șan'ā’ni Jew H. Habshūsh in 1870. Further visits and reports only followed much later, by Egyptian scholars M. Tawfìq and A. Fakhrī in 1944-1947, due to the persistent difficulties the area presented to access and stay. Eventually, formal recording was started by a French mission in the late 1970s with a focus on epigraphy. A sustained archaeological initiative to investigate Barāqish comprehensively, and thus contribute to a fuller understanding of the Jawf region, was arranged in 1986. This effort by the Italian Archaeological Mission to Yemen, led by A. de Maigret (1943-2011), developed in two phases until 2007, supported by prompt publication. Between 1989 and 1992 the town temple of the patron god, Nakrah, was excavated, while in 2003-2006 a range of new excavations were undertaken, devoted to the temple of 'Athtar dhu-Qabd, to a deep sounding near the temple of Nakrah, and to two operations outside the Minaean wall (extramural Areas C and D). Substantial restoration work of the excavated monuments was also accomplished. A collections study season followed in 2007. Research in the Jawf proved impossible after that year, this arrest continuing to this day due to war in Yemen. In 2015 the Barāqish archaeological site was damaged by a Saudi Arabian attack and the archaeological camp and museum were razed to the ground. The present book is a final report on the Italian project, bringing together unpublished material and reappraised earlier subjects.

\section{Report on the data collected during the first survey of the Italian Archaeological Mission at Barāqish, 1986, by Sabina Antonini}

In late October 1986 Alessandro de Maigret, director of the Italian Archaeological Mission to Yemen, together with the writer, carried out a first archaeological survey of the site of Barāqish. The numerous pottery finds and other materials collected from four different locations outside the city wall (BARi-BARiv) are published for the first time here. The study of the ceramics led to the identification of two distinct productions in terms of shape and surface treatment. The first was a Sabaean production, datable to the 8th-6th centuries BCE, and the second a Minaean production datable between the 3rd century BCE and the first century CE.

\section{The Temple of 'Athtar dhu-Qabḍ at Barāqish. The excavation, by Alessio Agostini}

This chapter examines the main archaeological phases that have been recognized in the area of the temple of 'Athtar dhu-Qabḍ at Barāqish (Temple B) during the excavations by MAIRY between 2004 and 2006. This imposing Minaean religious structure is characterized by a wide staircase leading to the middle of the front terrace, and by a monumental propylaeum, originally consisting of six monolithic pillars. The temple's main body is a large hypostyle hall, organized inside with four well-preserved offering tables and a large transept, in the middle of whose long side a single cella opens. Among the unprecedented features of this temple are the presence of a staircase leading down into the hypostyle hall's floor, situated at a lower level, and another interior staircase to the right of the entrance, possibly leading to an upper storey. The inscriptions and a radiometric reading date the building to the second half of the 5th century BCE, at the time of Waqah'îl Riyām king of Ma'īn.

Two small soundings were carried out in the central corridor and in the area in front of the cella, both too shallow to reveal possible previous phases of the building. However, an 'Intermediate' phase was detected just above the Minaean floor, attesting to an ephemeral occupation after the fall of the Minaean kingdom. Some epigraphic finds suggest that members of the Amīr tribe, at this time, reused the building to offer dedications to their god Halfān (1st-2nd centuries CE). A long abandonment followed, during which the temple probably suffered a suite of serious collapses. The place was again intensely occupied only during the Islamic period (from about the 11th century CE). Three main phases were recognized: Ancient, Middle, and Recent Islamic, with several sub-phases occasionally 
evident in some areas. The dense Islamic layers testify to the continuous occupation of the site from medieval to recent times. During these last phases the temple suffered further expoliation, but elements of its architecture continued to provide solid support for some of the more durable Islamic constructions.

\section{The Temple of 'Athtar dhu-Qabḍ at Barāqish. The inscriptions, by Alessio Agostini}

Among the considerable number of inscriptions found in the area of the temple of 'Athtar dhu-Qabd, the most relevant for an understanding of the historical and religious functions of this building during the Minaean phase are presented. Some of them were discovered still in place, but the vast majority came from secondary deposition, having been found re-employed in the subsequent Islamic structures. The typology of the texts concerned is varied: construction inscriptions, dedicatory inscriptions, and brief texts written on the cultic equipment of the temple (offering tables, incense burners, stelae). In this chapter a selection from the category of legal documents, particularly abundant in this temple, is especially discussed, as it helps to focus on the cultic function and historical significance of the building. Additional information is derived from a number of the most significant fragmentary texts of indeterminate typology.

\section{The Temple of 'Athtar dhu-Qabḍ at Barāqish. The objects, by Sabina Antonini}

South Arabian objects were found in the temple of 'Athtar dhu-Qabd and in the area between this building and the temple of Nakrah during the field seasons of 2004-2007. Some objects were found in Islamic contexts, others in strata belonging to the pre-Islamic occupation. Objects in the latter group, all of Minaean origin, include gutters or spouts of libation tables, carved in the form of bull's heads, incense burners, alabaster jars, stelae, and fragments of metal tools.

\section{An obsidian cache from Temple B, by Francesco G. Fedele}

An exceptional group of six chipped obsidian pieces from beneath the floor of the cella, one of them about 20 centimetres long, is described and discussed. This cache appears to combine raw material and waste products, arguably associated at some point with liturgical purposes. However, the charged ideological context of this finding - the innermost part of a temple - invites consideration of different scenarios and levels of meaning. A comparative discussion ranging from a possibly similar case at Al-Midamman in the Yemeni Tihàmah (dated to the Bronze Age) to the sacred 'Black stone' within the Ka'ba at Mecca, is offered as an exploratory approach. The lack of closely comparable cases makes the explanation of the finding from Temple B problematic.

7. The Temple of 'Athtar dhu-Qabd. The pottery, by Vittoria Buffa. See Abstracts, Chapter 25.

\section{The extramural excavation R44/45 at Barāqish, by Sabina Antonini with collaboration by Rosario Valentini}

In 1992, and again in 2003-2005, the installation of a crane outside the town wall to enable the excavation and restoration of Temple A made necessary an excavation in wall recess R44/45 (i.e., between bastions T44 and T45). This excavation brought to light a kind of embankment, L50 (called by Alessandro de Maigret contrafforte, i.e., literally, 'counterfort' or 'buttress'), delimited by retaining wall M50. This embankment was preserved for $80-90 \mathrm{~cm}$ of its height and approximately $7 \mathrm{~m}$ of its width. It was made of earth and rubble mixed with limestone flakes and was partly covered with compacted earth and mudbricks. It might have served as a reinforcement for the curtain wall's base, and it was hypothesized that it enclosed the entire perimeter of the city (770 m approximately). In front of small postern gate M39P, situated in recess R44/45, a kind of stone platform was discovered, possibly constructed when the postern's threshold was raised. The R44/45 excavation produced seven inscribed blocks, four of which reused in the Islamic restoration of the wall.

\section{The extramural excavation R44/45 at Barāqish. The inscriptions, by Alessio Agostini}

Seven inscribed blocks pertaining to the façade of the town wall were brought to light in the clearing of the extramural area between bastions T44 and T45 (Chapter 8). Some blocks were found among the collapsed material, while others, re-employed during the early Islamic restoration of the defensive wall masonry, were discovered in the newly exposed part of the wall. This scant, fragmentary material mainly consists of inscriptions concerning construction, the most frequent textual typology among the inscriptions engraved on the town wall. Relevant from a historical point of view is the collation of three fragments of text Y.03.B.R44-45.2, which revealed a previously unknown co-regency between king Abyada' Yatha' and his son Haywum. 


\section{The architecture of the temples of Nakrah and 'Athtar dhu-Qabḍ at Barāqish, by Christian Darles}

The two intramural temples at Barāqish are representative of an architectural type developed by Minaean builders. There appear to be two variants of the same type with similar characteristics, such as the architectural features, spatial organization, the presence of twelve monolithic pillars, the altars and the offering tables. These emblematic temples are examples of a distinct architecture, rich in symbolism, which was exported to Ethiopia (notably at Yeha).

\section{The cult equipment in the temple of Nakrah at Barāqish, by Solène Marion de Procé}

Most of the religious rites of ancient South Arabia remain to us a mystery. The main sources of information about them are the objects that were used during the rituals: altars, offering tables and incense burners destined to be used in a specific ceremony, or figurines and miniatures offered to the deity within the temple. Together they compose a dense corpus of objects, which are presented and discussed in this contribution. The focus of a first part of the chapter are the findings from the temple of Nakrah at Barāqish. In a subsequent part, the different types of altars, offering tables, and incense burners from ancient Yemen are examined, as known from various excavations and publications. This forms the basis for a broader discussion of the cultic paraphernalia of ancient Yemen and a first, tentative assessment of this material in general.

\section{Mudbrick in the fortifications of southern Arabia. The example of Barāqish, by Christian Darles}

The use of mudbrick as a building material is common throughout Yemen. From antiquity, it has served as an element in the construction of vertical structures. In this chapter its use in fortifications is emphasized. Mudbrick played an important role in foundation devices in the form of a balanced structure apt to support further construction, as well as being used for the core of stone-faced walls. At Barāqish, as elsewhere, the city walls were largely built of mudbrick.

\section{Conservation and structural restoration of the architectural elements in the hypostyle hall of the Temple} of Nakrah (Temple A) at Barāqish, by Saverio Bruno Scigliano and Alessandra Paladino

The temple of Nakrah at Barāqish was found tilted towards its northeast corner due to a structural failure of the floor. Most of the damage in the structure and in the architectural elements was produced by a unidirectional movement; this was probably due to earthquakes that in the past would have compromised the statics of the temple. Severe fractures with total detachment were detected in four of the twelve monolithic pillars and in one of the main beams of the roof. In addition, the walls of the central cella and the door jambs of the main entrance showed damage. Between October 2003 and February 2004, structural and conservative restoration works of the whole temple, including its pillars, cella, and floor were carried out. An in situ inscription was restored and the roof was completely reassembled.

14. Restoration, mobilization, and securing of the architectural elements in the Temple of 'Athtar dhu-Qabd (Temple B) at Barāqish, by Saverio Bruno Scigliano and Alessandra Paladino

In the temple of 'Athtar dhu-Qabḍ at Barāqish structural failures were observed, showing an evident tilt of all architectural elements mainly towards the north. The conservation works entailed two distinct phases:

(1) the mobilization and securing of collapsed architectural elements in the temple, so as to allow the carrying out of archaeological activity during the second excavation campaign (November-December 2005); (2) securing the temple with pipe scaffolding, after the correction of five slanting pillars in the propylaeum and preliminary conservation wherever it was found to be urgent and necessary (November 2006).

\section{Exploratory coring at Barāqish, 1987 and 1990, by Francesco G. Fedele}

Eleven mechanical drillings (or 'corings') were carried out during the first stages of the Italian work at Barāqish in order to obtain preliminary information on the deeper deposits at the site. Nine drillings were made in 1987, eight (one aborted) inside the town and one outside the curtain wall, in the adjacent plain to the south. Two additional drillings were performed in January 1990 alongside the temple of Nakrah, with the aim of reaching as deep as possible below the presumed base of this building. These two core samples, 6.5-7 metres long, provided direct 
evidence that there were layers characterized by Sabaean pottery up to at least 6 metres beneath the base of the Minaean temple. In 1987 a geo-electric survey was also attempted, but was unsuccessful.

\section{Radiocarbon determinations 1987-2006: corings, Temples A and B, Area D. A survey and reappraisal, by Francesco G. Fedele}

This chapter provides the first formal publication of all carbon-14 age measurements obtained from Barāqish Area C excluded - between 1987 and 2006. The determinations, 26 in total, were all made on carbonized wood. The provenance and contextual association of the samples are discussed and their chronological significance evaluated. A table (Table 3) highlights both the significance and limitations of these radiocarbon ages for dating the phases of the temple of Nakrah.

\section{Volume 2}

\section{Extramural excavations in Area C. Setting, stratigraphy, and geoarchaeology, by Francesco G. Fedele}

A 52-metre-long stepped trench was dug in the sloping northwestern margin of Barāqish - the 'talus' of the mound, outside the Minaean wall - where the mound reaches 14 metres above the surrounding plain. This operation ('Area C') was carried out according to geology-based archaeological approaches ('geoarchaeology'). It was aimed at investigating the overall history of the tell and settlement, establishing a stratigraphy, and recovering plant, animal, and environmental evidence. At the upper end, a sounding eight-metre-deep brought to light the base of Minaean bastion T7, founded in incoherent Sabaean deposits, while at the opposite end of Area C a sounding was also made in the plain. In this chapter, a detailed illustration of the results and a final assessment of the sedimentary, stratigraphic, and cultural and occupational evidence are presented. These results are visually expressed by a total stratigraphic profile, or 'Reference section', and summarized in a total stratigraphic lattice or 'Stratification diagram'.

Clearly, Barāqish had its origins as a substantial Sabaean occupation, its earliest form still unknown. In the excavated sequence four Sabaean phases were distinguished (Strata T to L). A slightly organic soil developed at the end of the first phase, while the second phase is marked by the construction of stone-and-mudbrick wall $\mathrm{F} 4$, accompanied by an earthwork on the inside. F4 can provisionally be identified with the epigraphically known walling by mukarrib Karib'il Watār c. 700 BCE. The Sabaean occupation continued despite a substantial influx of sands. In fact, the excavation brought to light a small but still unique portion of the Later Sabaean, residential Yathill, characterized by mudbrick structures, hearths, abundant domestic refuse, and well preserved organic materials. Here the Sabaean settlement extended horizontally far outside the perimeter later delimited by the Minaean wall.

After an interruption or alteration (Stratum K, First Intermediate), settlement at Yathill entered an entirely new phase under Minaean control, indicated by substantial levelling and building activities associated with the construction of a stone curtain wall. Alongside the base of the wall, a thick earthwork made of multi-layered fill and mud-brick casing (F10-F12) was constructed, plausibly equivalent to the structure found at wall recess R44/45 (see Chapter 8). Four Minaean phases were distinguished (Strata J to F). During the Later Minaean, activities related to trading repeatedly took place in makeshift shelters near the wall, as evidenced by plaster jar sealings, while throughout the Minaean period the talus below saw occasional stationing by donkeys and dromedaries, sometimes stalled. A subsequent series of sediments provides clear evidence of rapidly decreasing human presence, followed by the longest void of occupation in Yathill's history (Stratum E and partial D, Second Intermediate). Part of bastion T7 collapsed during this period. The last settlement phase at Barāqish, as the place was now called, is Islamic. Three phases were distinguished from Area C (Strata D to B), followed by localized deposits formed in the last two centuries (Stratum A). A significant activity during the Islamic 1 and probably 2 was the quarrying of collapse rubble from $\mathrm{T} 7$ to restore the wall and presumably erect new buildings in town. This chapter includes numerous tables providing summaries of, or supporting material for, the above data.

\section{Extramural excavations in Area C. Chronology and the historical sequence, by Francesco G. Fedele}

The first section in this chapter deals with the dating and chronology of the layers, phases, and periods described in Chapter 17. Nineteen carbon-14 determinations were obtained. Their historical significance is evaluated in the light of their contribution and limits. In a following section, the stratigraphy-based historical sequence from Area C (Strata A-T) is appraised, in conjunction with a figure showing parallel stratigraphies and local and regional correlations (Fig. 4). Particular historical issues are discussed in the third section, including the attribution of Wall 
F4 to Karib'il the Great, the possible evidence for warfare from Stratum K, the record for the Minaean 1 phase and the dating of the wall (bastion T7). Also discussed - as viewed from Area C - are the final Minaean phase, encompassing the Roman military incursion; the abandonment of Yathill and the Second Intermediate period; and the considerable problems involved in correlating the Islamic record from Area $\mathrm{C}$ with the sequence of the intramural temple area.

\section{Extramural excavations in Area C. Economy, trade, and the environment, by Francesco G. Fedele}

In the first part of this chapter the animal and plant evidence from Area C is examined ('bioarchaeology'), with a particular view to Sabaean and Minaean economy, ecology, and their changes through time. Concerning archaeobotany, the knowledge now acquired has allowed to identify the stratigraphic position of the carbonized and non-carbonized plant sample collected in the exploratory campaign of 1986 (Later Sabaean). A further section is devoted to an appraisal of Sabaean and Minaean trade as tangibly captured by the excavations in Area C. This part is also intended as a contribution towards 'campsite' archaeology, an underdeveloped research field of great promise in Yemen. In the last section, some of the main issues in environmental history are briefly examined, such as the Yathill oasis as conditioned by the shifting wādì system and the role of climatic aridity. A great deal of further fieldwork at different scales is obviously needed.

\section{The Area C collection catalogue and related works, by Francesco G. Fedele}

This short section serves as an introduction to Chapter 21, concerned with the archaeological finds from extramural Area $\mathrm{C}$. It outlines the nature and composition of the archaeological collection and provides guidelines for the use of the catalogues in Chapters 21 to 24, encompassing artefacts ('objects'), pottery, and inscriptions.

\section{Area C. The objects, by Francesco G. Fedele and Sabina Antonini}

240 artefacts from the excavations in Area $C$ are described, representing about 10 per cent of the total retrieved. The entries in the catalogue are arranged in a culture-stratigraphic order, according to the following groups: Sabaean; First Intermediate; Minaean; Second Intermediate; and Uncertain chronology, i.e., indeterminable archaeological age or unstratified find. The finds within each chronological and cultural group are subsequently arranged into typological categories partly based on material, in the following order: chipped stone (obsidian, calcite); heavyduty chipped stone; inscribed blocks; stone cultic (?) equipment; stone burners and containers; softstone vessels; calcite or aragonite vessels; querns and other grinding tools; other utilized natural stones (including fossils); stone tiles; stone personal ornaments; non-pottery ceramics; sling bullets; clay figurines and other clay finds; unfired or poorly fired clay artefacts (discs and/or 'tripods'); other unfired clay artefacts, including mud bricks and tiles; plaster jar sealings; other plaster fragments; bronze/copper and iron; glazed elements; glass; artefacts made from organic materials; ostrich eggshell; marine shells.

\section{Area C. The Minaean pottery, by Vittoria Buffa. See Abstracts, Chapter 25.}

\section{Area C. The Sabaean pottery: a survey, by Francesco G. Fedele}

This section offers a preliminary, general view of the Sabaean pottery collection, since full description and formal drawings could not be executed. The aim is to outline and understand the ceramic evolution from the Area $\mathrm{C}$ record as a complement to stratigraphy. In the Earlier Sabaean, pottery assemblages dominated by coral-red, lustrous, carinated cups and bowls are common, as elsewhere in the Sabaean culture area (cf. Yalā 'A'). The Later Sabaean (Strata $\mathrm{N}$ to L) shows the continuing adherence to an established ceramic tradition, but against a background of substantial continuity some particular trends can be perceived. 'Beige Plain' and other untreated wares are now as common or commoner than the slip-burnished production. A fragment of a 'tray', a rare group, is described from Stratum M. An extended section of the chapter is devoted to a study of two plain-ware groups which appear to be of particular interest for the Later Sabaean: 'Wavy Rim' bowls (a precursor of the 'Bayhān' bowl?) and 'Pale Green' ware. The occurrence of apparently exotic earthenware - i.e. foreign to local production - is recorded. All Sabaean levels were relatively rich in 'Heavy Sandy-tempered' ware ('torpedo jars').

\section{Area C. The inscriptions, by Alessio Agostini}

The excavations at Barāqish Area C produced a limited number of inscribed material. One fragmentary inscription on a stone block, from the collapse rubble at T7 (Chapter 17), probably pertains to an inscribed portion of the town 
wall. The majority of the epigraphic data concerns stamped impressions identified on a number of plaster cretulae that served as jar sealings, made with rectangular bronze seals. A reading of these impressions is presented. From the few best-preserved items some personal names were identified.

\section{The typological classification of the Minaean pottery from the Temple of 'Athtar dhu-Qabd and the extramural excavations in Area C, by Vittoria Buffa}

In this book two Minaean pottery assemblages are presented: the ceramics found in the extramural excavations by Francesco Fedele (Chapter 17) and those found in the excavation of the temple of 'Athtar dhu-Qabd, reported by Alessio Agostini (Chapter 3). The two assemblages are separately studied in Chapters 22 and 7, respectively, where the shape, ware, colour, and inclusions of all the diagnostic fragments are described. It must be noted that no complete vessels were recovered, making the reconstruction of the original shape often difficult. In this chapter, the two assemblages are examined together in order to propose a typological classification of the Minaean pottery as documented from Barāqish. The development of the ceramic shapes through time is established and the connections with neighbouring areas in terms of material culture are highlighted.

\section{A glimpse of 'Greater Yathill': Sabaean settlement and tell evolution, by Francesco G. Fedele}

This chapter, an exercise in settlement archaeology, has the dual purpose of investigating the nature of the Barāqish mound and describing what is presently known about the development and overall organization of Sabaean Yathill. Towards the first goal, topographic profiles incorporating data from archaeological 'windows' (corings, soundings, excavations) and local bedrock outcrops were created and evaluated. The mound can probably be reconstructed as an entirely artificial landform, i.e. a tell in the usual archaeological sense, whose initial settlement might have been established on a modestly raised rock surface or a long-stabilized wādī terrace or spur. As to settlement history, the data from Area $C$ as well as surface observations made over the years would reveal a Sabaean main settlement surrounded by several smaller installations or 'satellite' sites, perhaps of a specialized function: a configuration here called 'Greater Yathill'. This spatial arrangement was terminated by the Minaean nucleation and powerful walling of the town.

27. The inscriptions of Barāqish: a contribution to the knowledge of the ancient city of Yathill and the kingdom of $\mathrm{Ma}^{\mathrm{i}} \mathrm{i} n$, by Jérémie Schiettecatte with collaboration by Mounir Arbach

The archaeological area of Barāqish, including the extra muros sanctuaries of Shaqab al-Manașsa and Darb alȘabì, yielded an exceptional amount of pre-Islamic South Arabian inscriptions. Over 600 texts provide us with an insight into the political as well as social and economic history of the ancient kingdoms of Saba' and Ma'in. In this contribution we draw up an inventory of the inscriptions from the site and consider this corpus under the angle of both ancient toponymy and cultural and architectural history. The examination of the textual content, once put in chronological order, allows for the identification of a series of ancient monuments and the date of their construction, thus highlighting the monumental evolution of the site. Concurrently, the comparison of epigraphy with the archaeological data produced by the Italian excavations enables us to propose a new chronological sequence of the kings of $\mathrm{Ma}^{\mathrm{c}} \mathrm{i}$ and to reconsider the date of inscription RÉS 3022 and that of the reign of Abiyadac Yatha' and his son Waqah'īl Riyām.

\section{Results of an archaeological survey of Darb al-Șabī, by Rosario Valentini}

During the field season at Barāqish in December 2005, an archaeological survey was carried out by the writer at the nearby site of Darb al-Sabī, an important sanctuary site associated with the cult of Nakrah. Earlier researches at Darb al-Șabi conducted by the French Mission (see Chapter 1) had produced plans of buildings and recorded about thirty inscriptions. Although the site has increasingly been damaged by illegal digging, it was possible to produce a new topographic survey of all ancient structures within the sacred enclosure forming the site. This enclosure is marked by nine votive stones, each one bearing the engraved inscription $q f-d n-m h r m n$, the climit of this sanctuary'. The most impressive architecture at the site consists of monolithic pillars, beams, and slabs belonging to religious monuments, flanked by rooms for hospitality to visitors and pilgrims. Apart from a few Sabaean and Islamic potsherds, the pottery collected during the survey is mainly Minaean. 
مختصر ات الفصول

تم ترجمة هذه الملحصات إلى اللغة العربية من قبل خالد علي العنسي وتحرير النسخة الإنجليزية من قبل فر انشيسكو ج. فيديليه

المجلد 1

Volume 1

1. تاريخ البحوث الأثرية في بر اقش وفي منطقتها| بقلم: سابينا أنطونيني و فر انشيسكو ج. فيديله

تم لفت انتباه العالم الأوسع خارج اليمن إلى موقع المدينة السبئية و المعينية بر اقش قديما (يثل) في اليمن عام 1872، بعد الرحلة الاستكثافية التي قام بها

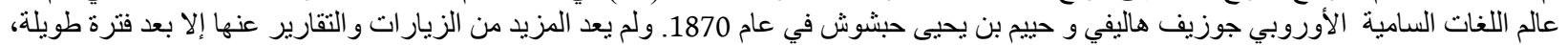

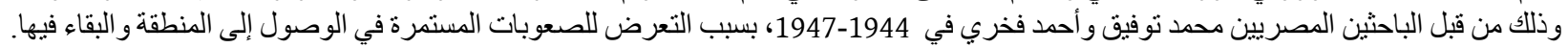

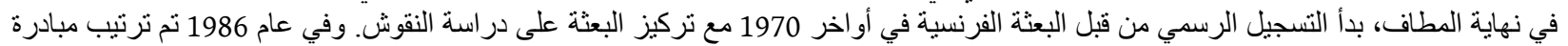

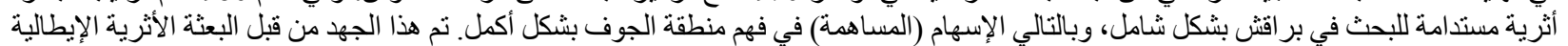

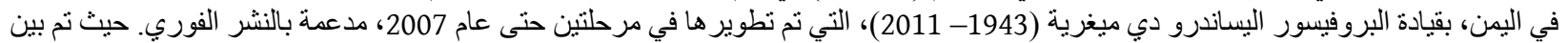

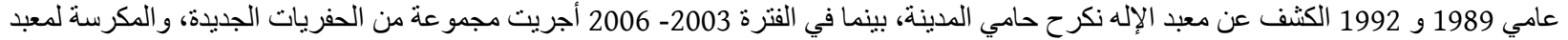

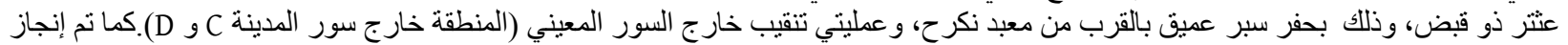

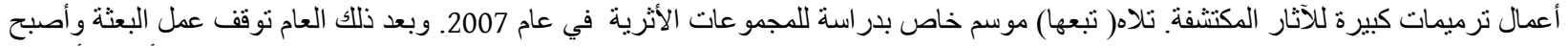

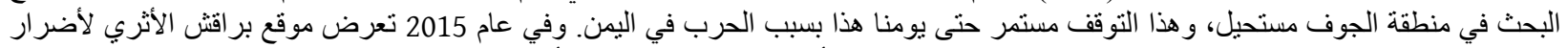

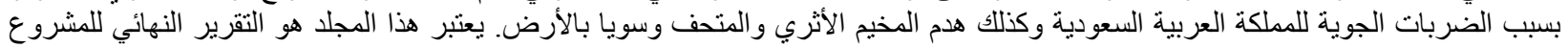

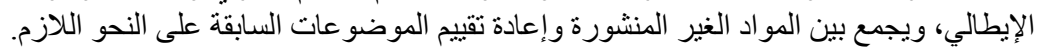

2. تقرير عن البيانات التي تم جمعها خلال أعمال المسح الأثري الأول للبعثة الأثرية الإيطالية في بر اقش عام 1986| بقلم : سابينا انطونيني

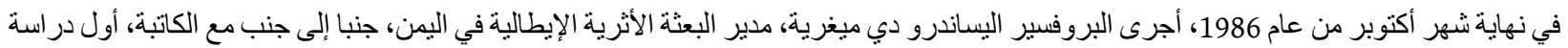

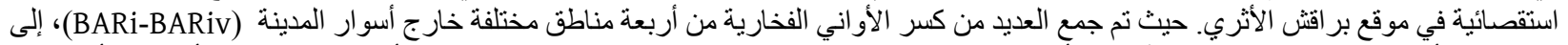

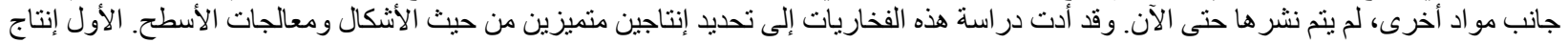

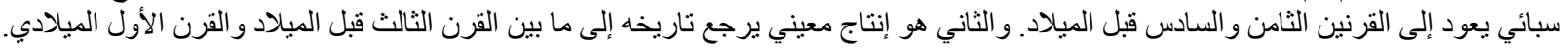

3. معبد عثر ذو قبض في بر اقش: التنقيب| بقلم اليسيو أغوستيني

هذا الفصل يدرس المر احل الأثرية الرئيسية التي تم التعرف عليها في المنطقة التي يشغلها معبد عثتر ذو قبض في بر اقش (المعبد B) و الذي تم الكئ الكثف عند

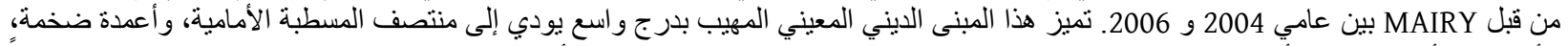

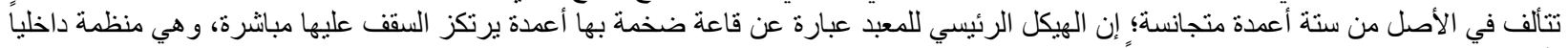

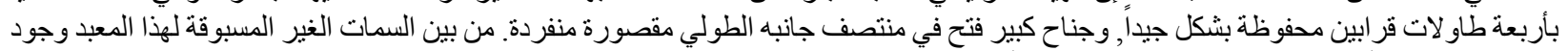

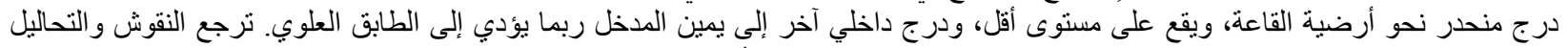

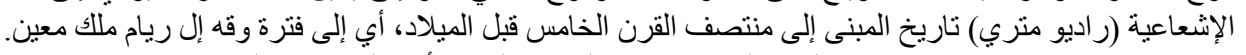

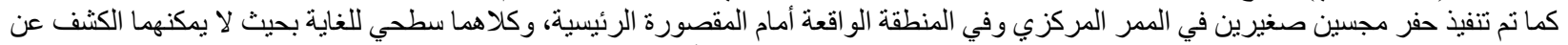

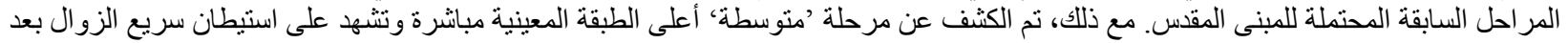

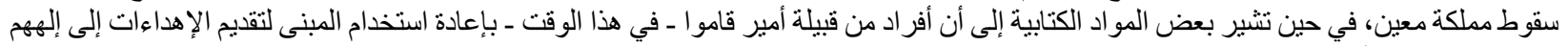

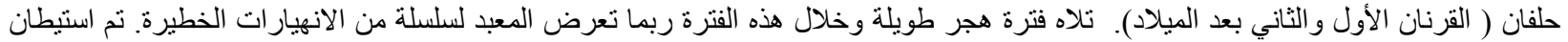

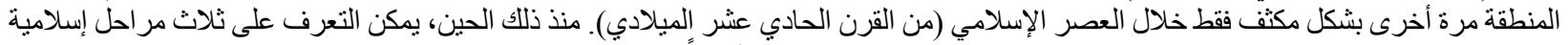

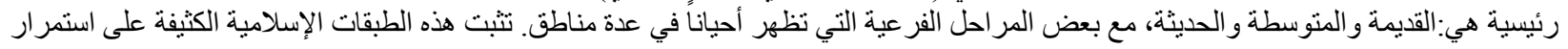

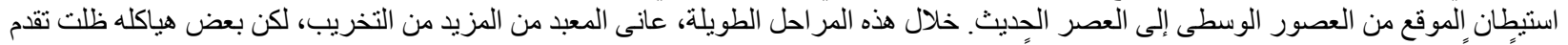
دعماً قوياً لبعض الهوفع دن العياكل الإسلامية التي دامت طويلاً.

4. معبد عثر ذو قبض في بر اقش: نقوش| بقلم: اليسيو أغوستيني

من بين عدد كبير من النقوش التي عثر عليها في منطقة معبد عثثر ذو قبض، يقدم أكثر ها الصلة بفهم الوظيفة التاريخية والدينية لهذا المبنى خلال المرحلة

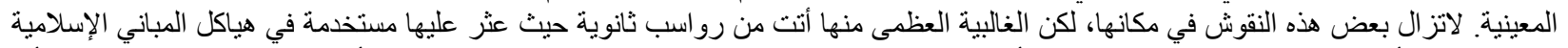

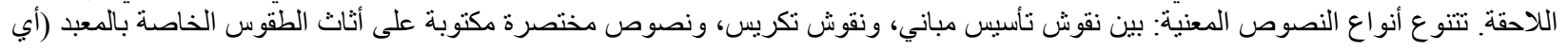




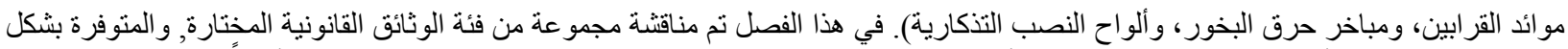

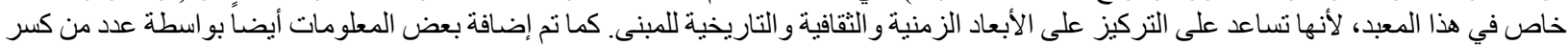

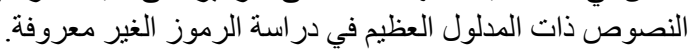

$$
\text { 5. معبد عثر ذو قبض في بر اقش. المعثور ات| بقلم: سابينا انطونيتي. }
$$

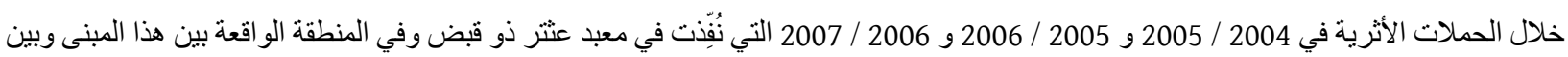

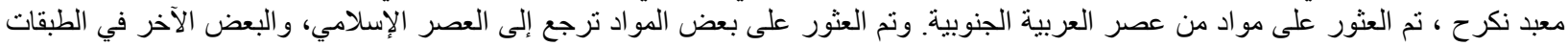

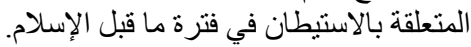

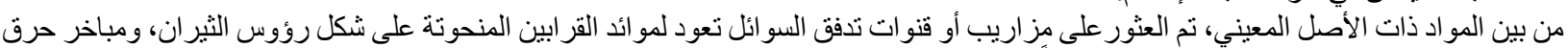

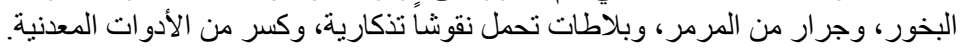

6. التخزين المؤقت للأوبسيديان [الزجاج البركاني] من معبد عثر ذو قبض في بر اقش| بقلم: فر انشيسكو ج. فيديله

تم وصف ومناقثة مجمو عة استثنائية لستة قطع من الأوبسيديان [الزجاج البركاني] من أسفل أرضية المقصورة [غرفة قدس الأقداس]، واحدة منها قطر ها

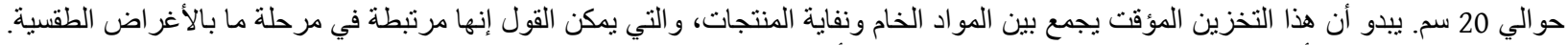

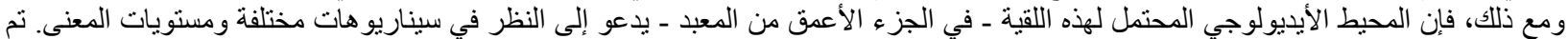

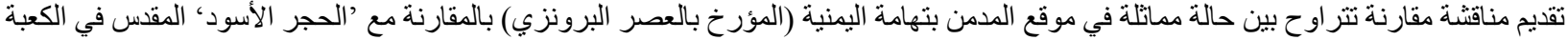

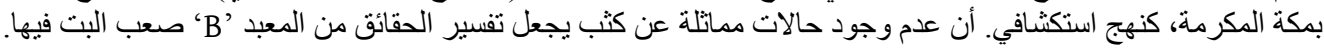

$$
\text { 7. }
$$

$$
\text { 8. التنقيب خار ج الجدران 444/24في بر اقش | بقلم: سابينا انطونيني بالتعاون مع ر. فالنتيني }
$$

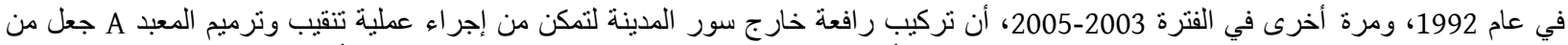

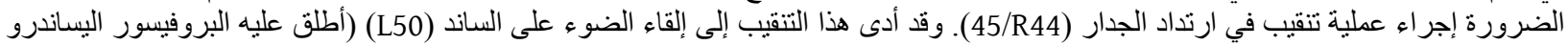

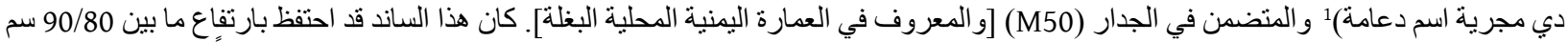

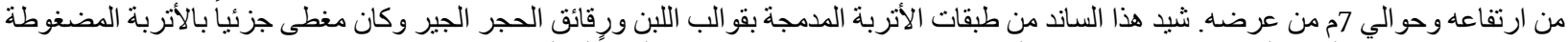

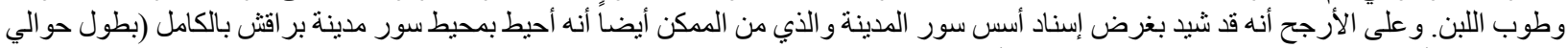

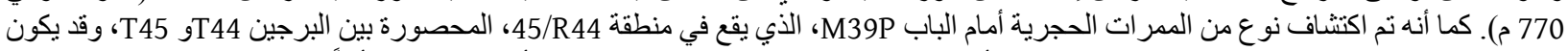

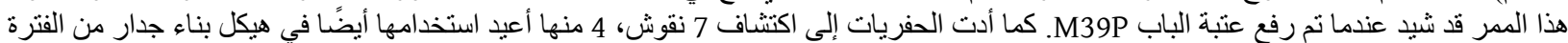

الإسلامية.

${ }^{1}$ Part in round brackets added by the translator. The Yemeni Arabic word al-baghlah, 'mule', was employed in Medieval architecture and is still traditionally used to indicate a short wall (or similar element) reinforcing ordinary masonry.

$$
\text { 9. التنقيب خارج الجران /R44 } 54 \text { في بر اقش , النقوش| بقلم اليسيو أغوستيني }
$$

أدى تنظيف المنطقة أمام T24 T45 (الفصل 8) إلى تسليط الضوء على الئى بعض القطع من النقوش المتعلقة بو اجهة جدران المدينة. تم العثور على بعضها

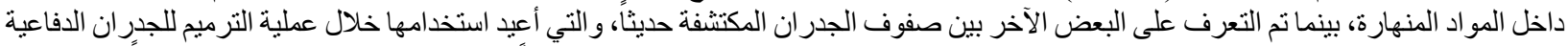

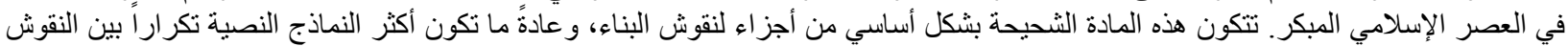

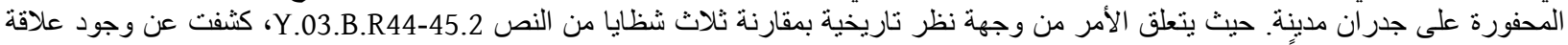

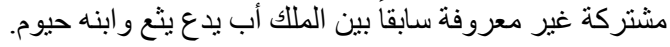

10. الهندسة المعمارية لمعبدي نكرح و عثر ذو قبص ببر اقش| بقلم كرستيان دارلس

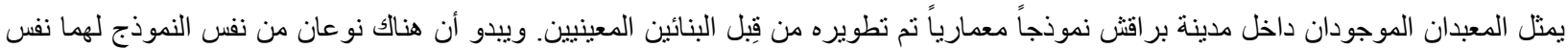

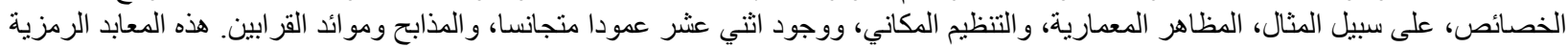


هي أمثلة على الهندسة المعمارية المتميزة، الغنية بالرموز، و التي تم تصدير ها إلى يحا، في إثيوبيا.

$$
\text { 11. أثاث الطقوس الدينية في معبد نكرح في بر اقش | بقلم: سولين ماريون دي بروسي }
$$

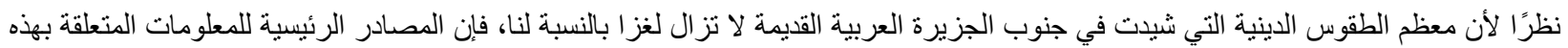

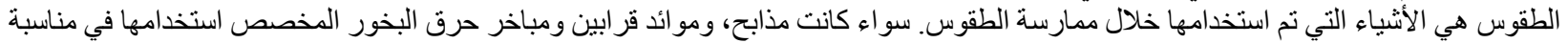

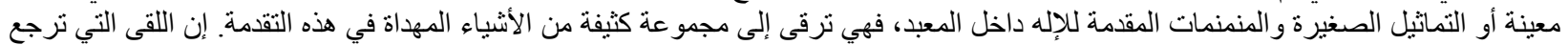

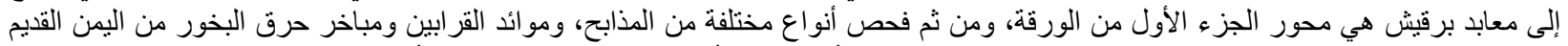

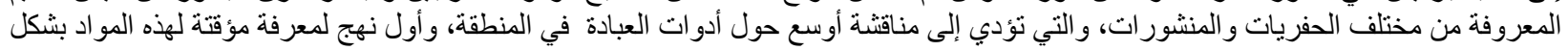

12. استخدام الطوب اللبن في سور مدينة بر اقش| بقلم: كرستيان دارلس

استخدام الطوب اللبن كمادة بناء أمر شائع في جميع أنحاء اليمن منذ العصور القديمة، وكان بمثابة عنصر في بناء الهياكل العمودية. في هذا الفصل سيتم

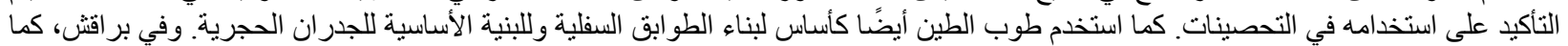

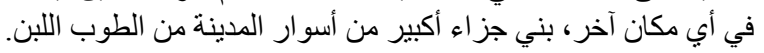

13. الصيانة و الترميم الإنشائي للعناصر المعمارية لمعبد نكرح في بر اقش (الجمهورية اليمنية) | بقلم: سافريو برونو سجليانو و اليساندرا بالادينو

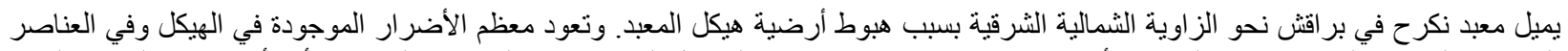

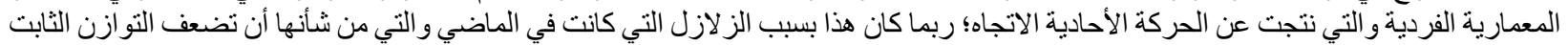

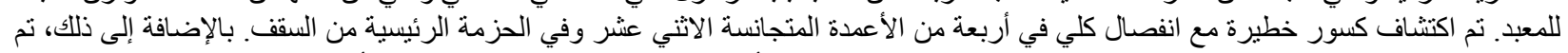

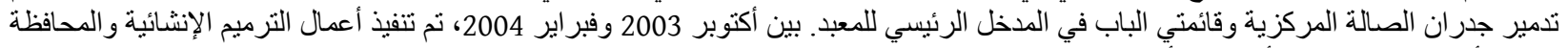

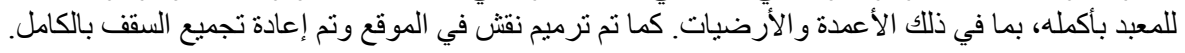

14. ترميم العناصر المعمارية لمعبد عثثر ذو قبض في بر اقش (الجمهورية اليمنية) ، و التعامل معها وتأمينها

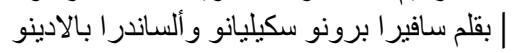

لوحظ في معبد عثر ذو قبض وجود ضعف في الطبقة الأرضية، مع ميل واضح لجميع العناصر المعمارية، بشكل رئيسي نحو الثمال. كانت التذخلات

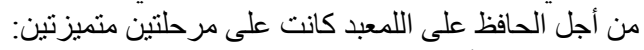

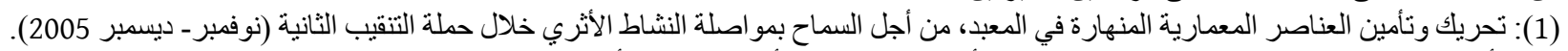

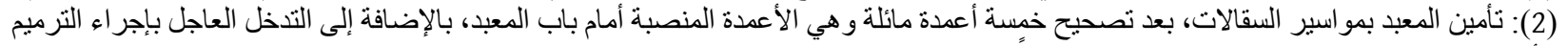

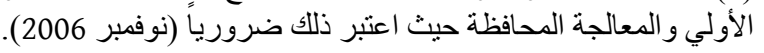

15. الحفر الاستكشافي في بر اقش ، 1987 و 1990| بقلم: فر انشيسكو ج. فيديله

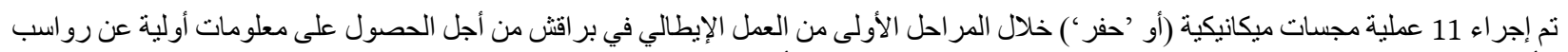

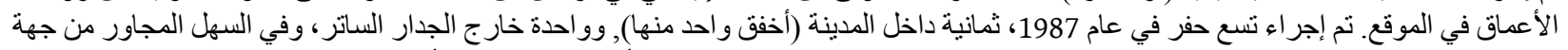

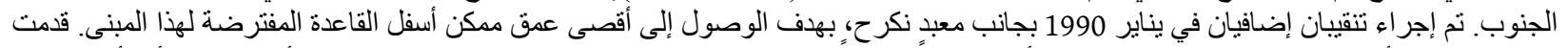

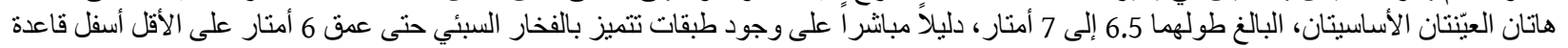

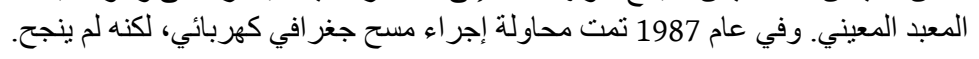

16. تقدير ات الكربون المشع 1987-2006): المحاور، المعبدان A وB، المنطقة D ـ مسح و إعادة تقييم | بقلم: فرانشيسكو ج. فيديله

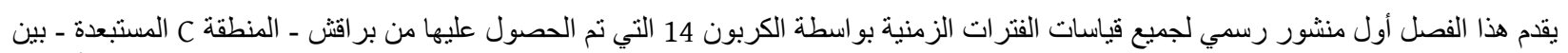

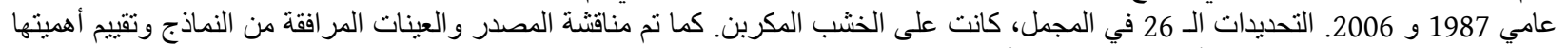
الزمنية. يبرز الجدول (الجدول 3) أهمية وقيود هذه الأعمار من الكربون المشع لتو لتواريخ مر احل معبد نكرح. 
المجلا 2

Volume 2

17. الحفريات خارج سور المدينة في المنطقة C. المحيط، والتراصف الطبقي, و الجيولوجيا| بقلم فر انشيسكو ج. فيديله

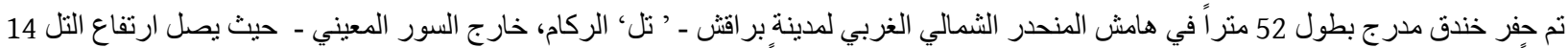

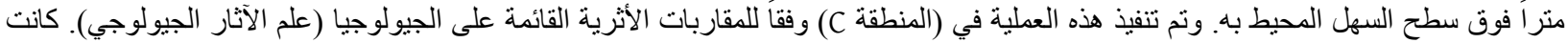

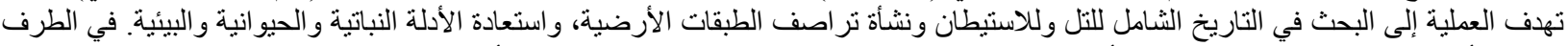

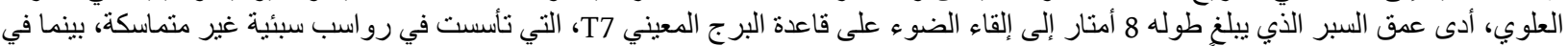

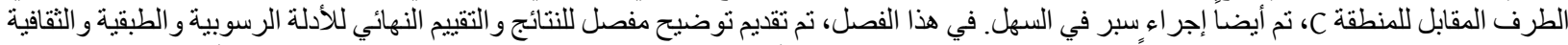

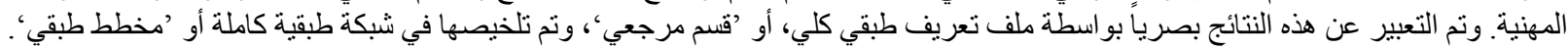

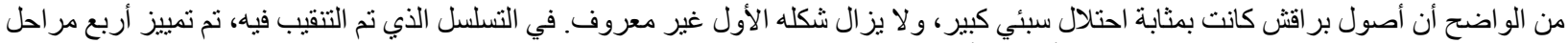

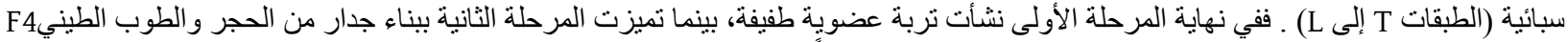

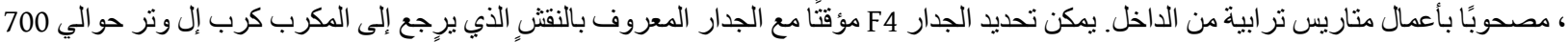

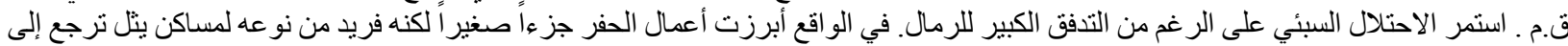

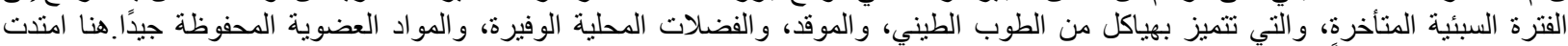

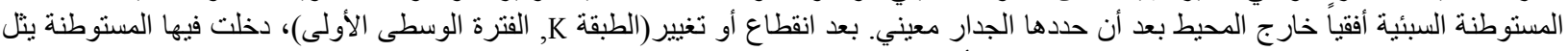

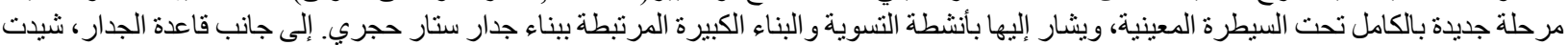

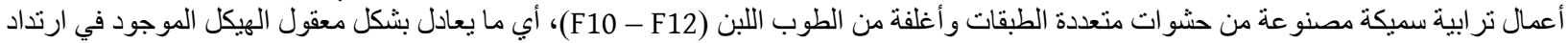

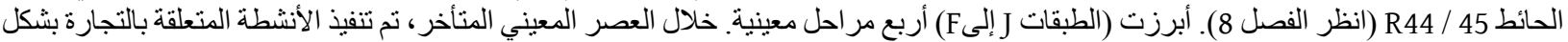

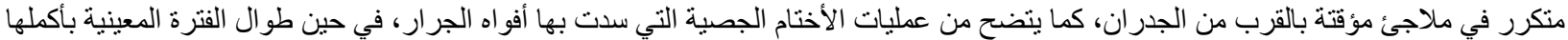

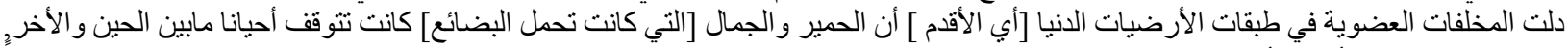

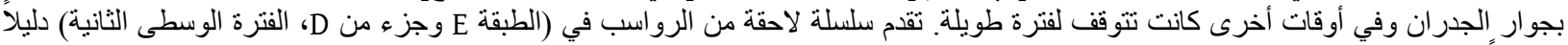

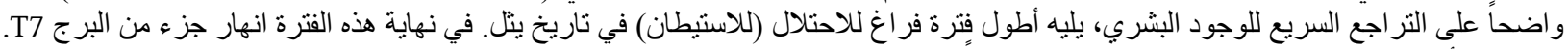

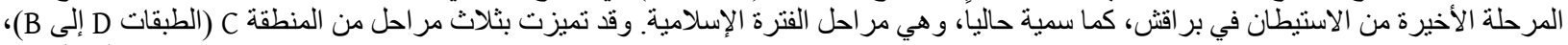

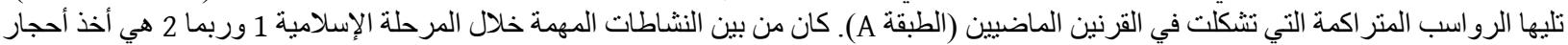

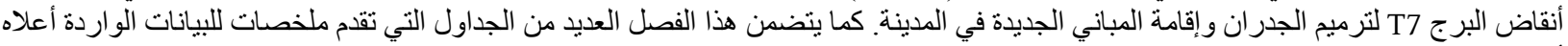

أو مواد داعمة لها.

18. الحفريات خارج سور المدينة في المنطقة C ـ التسلسل الزمني و التسلسل التاريخي| بقلم: فرانشيسكو ج. فيديله

يتناولٍ القسم الأول في هذا الفصل تاريخ التتابع والتسلسل الزمني للطبقات و المر احل و الفترات الموصوفة في الفصل 17. تم الحصول على تسعة عشر

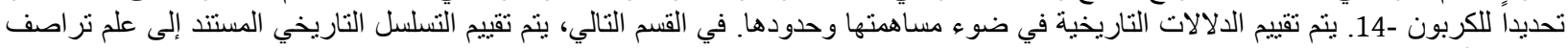

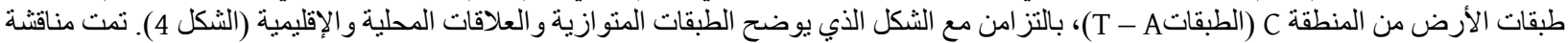

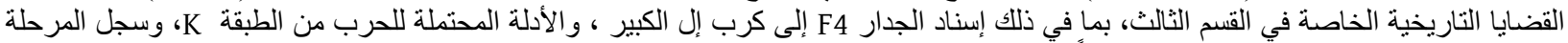

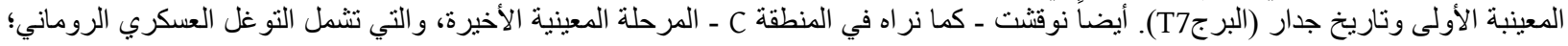
و هجر مدينة يثل في الفترة المتوسطة الثانية؛ و المشاكل الكبيرة المرتبطة بربط السجل الفئل الإسلامي من المنطقة C مع تسلسل منطقة المعبد الداخلي.

19. الحفريات خارج سور المدينة في المنطقة C. الاقتصاد والتجارة والبيئة| بقلم: فر انشيسكو ج. فيديله

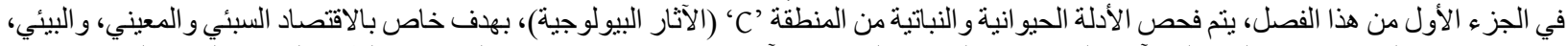

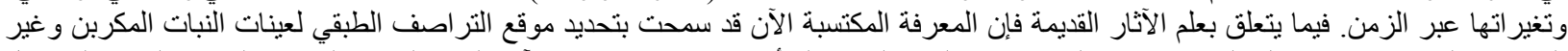

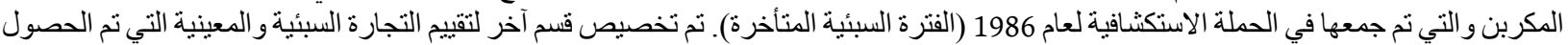

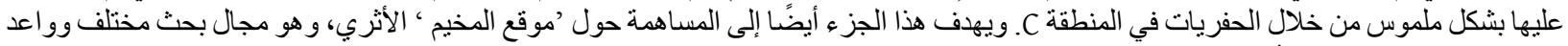

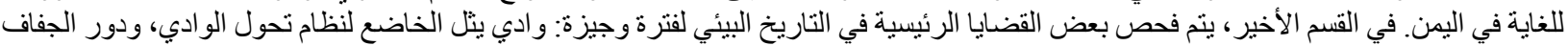
المناخي. ومن الواضح أن هناك حاجة إلى قدر كبير من العمل الميداني على مستويات مختلفة للفئ.

20. اللقي الأثرية من خارج سور المدينة في المنطقة C كتالوج المجموعة الأثرية من المنطقة C و الأعمال ذات الصلة| بقلم: ف. ج. فيديله . يستهل هذا القمم القصير مقدمة للفصل 21، ويتعلق باللقي المكتشفة في المنطقة C. وتحديد طبيعة وتكوين المجموعة الأثرية وتوفير إرشادات لاستخدام

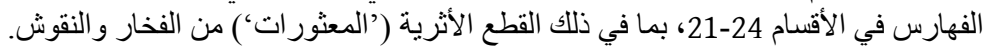


تم وصف 240 قطعة أثرية من الحفريات في المنطقة C، تمثل حوالي 10 في المائة من إجمالي القطع المسترجعة. تم ترنيب الإدخالات الموجودة في

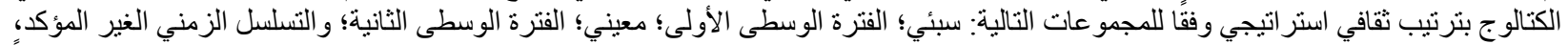
أب الفترة الأثرية الغير محددة أو البحث غئ غير المطابق. تم ترتيب اللقي المكتشفة ضمن كل مجموعة زمنية وثقافية ومن ثم في فئات نموذجية تعتمد جزئياً

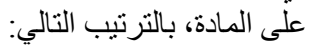

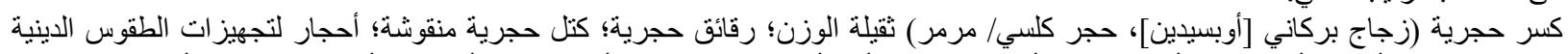

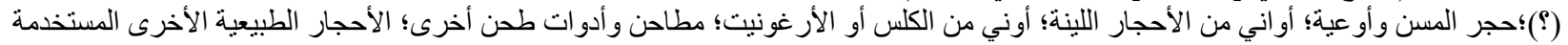

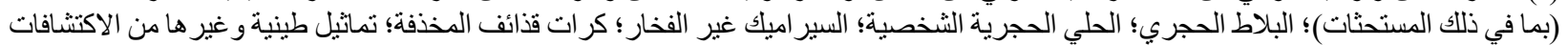

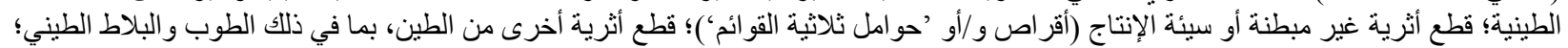

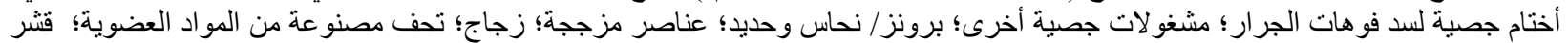

بيض النعام؛ أصداف بحرية (الحلي الثخصية) قو اقع بحرية.

22. المنطقة C. الفخار المعيني| بقلم: فيتوريا بوفا. انظر الملخصات الفصل 22.

23. المنطقة C. ملاحظات على الفخار السبئي| بقلم فر انشيسكوا ج. فيديله

يقدم هذا القسم فقط عرضاً أولياً عاماً لمجمو عة الفخار السبئي، حيث لا يمكن تتفيذ الوصف الكامل والرسومات الشكلية. الهدف من ذلك هو تحديد وفهم

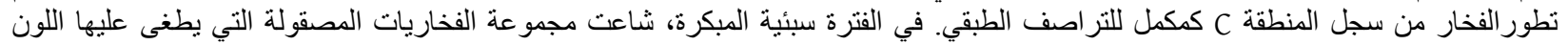

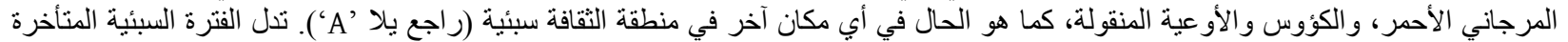

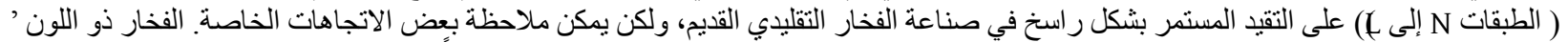

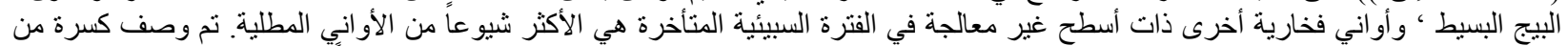

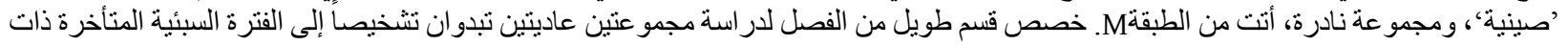

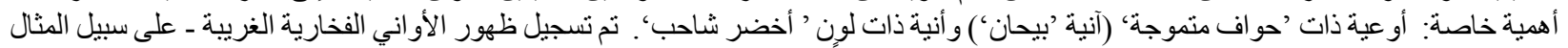

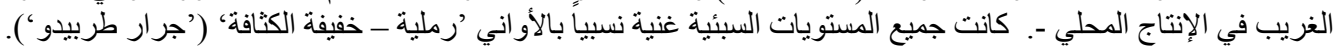

24. المنطقة C : النقوش| بقلم: اليسيو أغوستيني

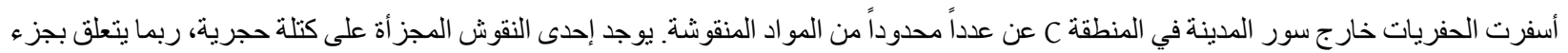

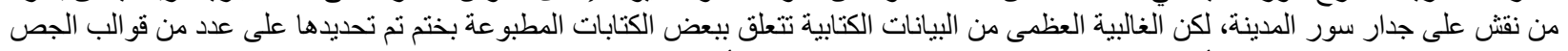

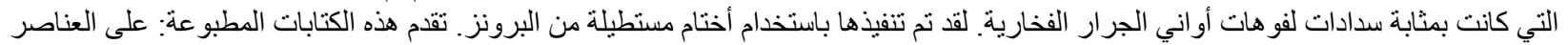

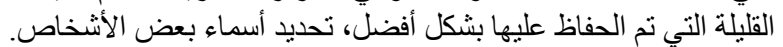

25. التصنيف النمطي للفخار المعيني من معبد عثر ذو قبض والتنقيبات خارج سور مدينة بر اقش المنطقة C | بقلم ف. بوفا

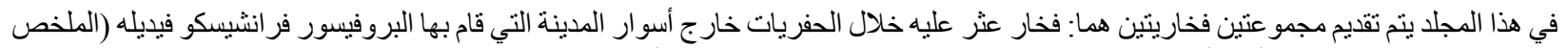

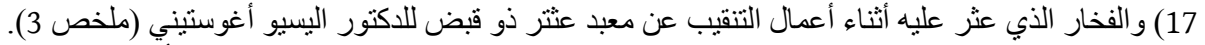

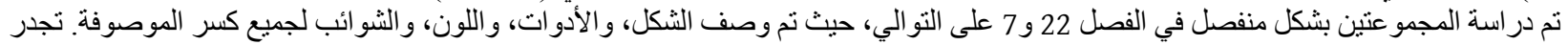

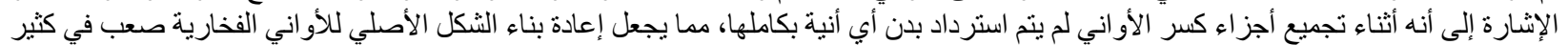

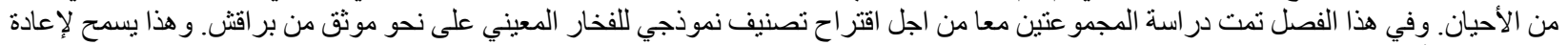

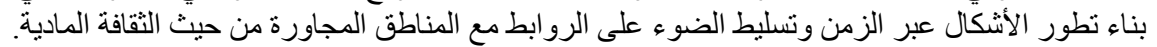

26. لمحة عن 'يثل الكبرى': المستوطنة السبئية والتطور |بقلم: فر انسشيسكو ج. فيديله

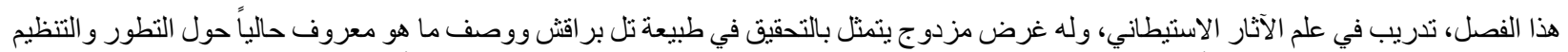

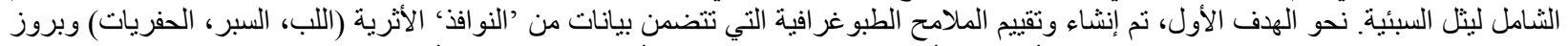

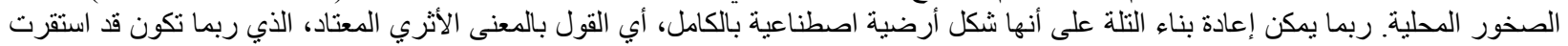

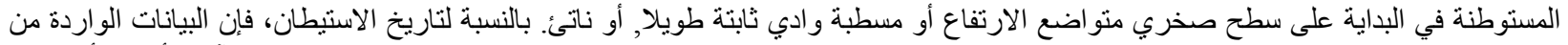

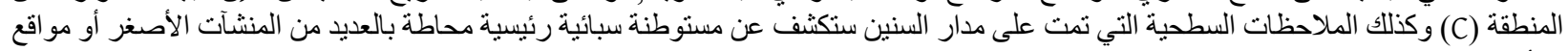

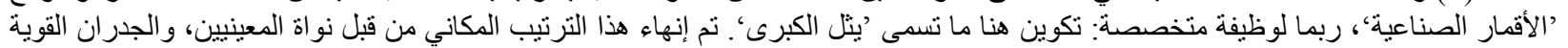




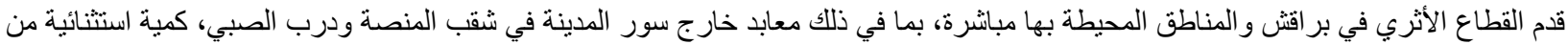

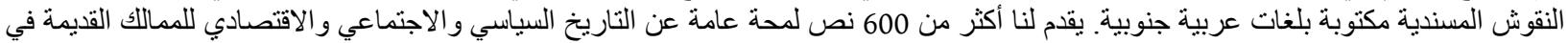

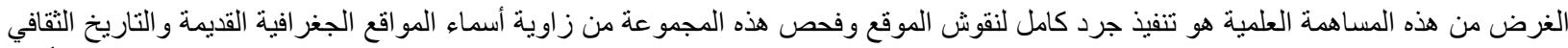

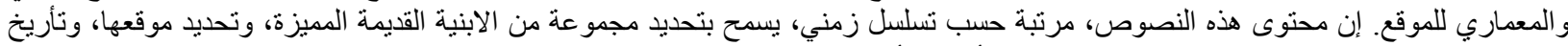

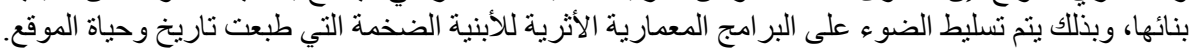

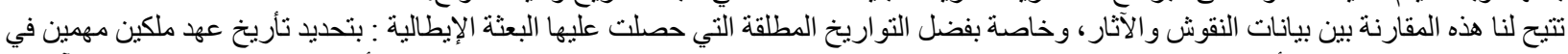

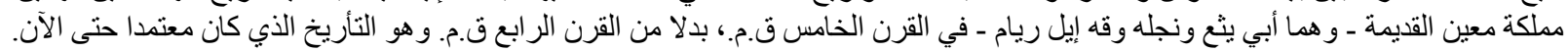

$$
\text { 28. نتائج مسح سطح موقع درب الصبي| بقلم : ر. فالنتيني }
$$

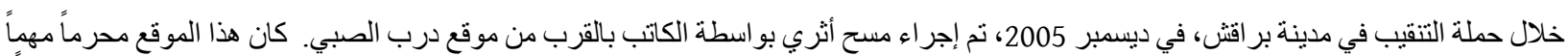

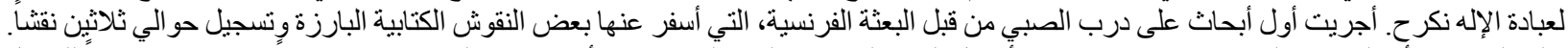

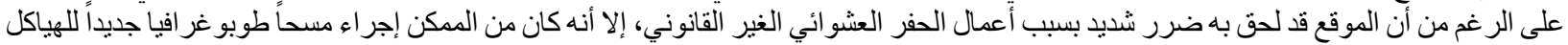

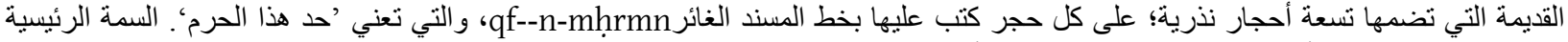

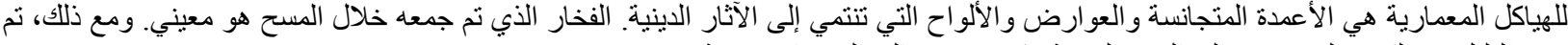
جمع القليل من الكسر التي ترجع إلى الفترة السبئية وكسر ترجع إلى الفئ الفترة الإسلامية. 


\section{Bibliography for Volume 2}

In this book the references of the individual chapters were brought together in a unified bibliography. In order to facilitate consultation, however, the bibliographic entries pertaining to the chapters in each volume have been separated. Only the references related to the chapters in the present volume are listed below.

Arabic names with prefixed definite article (al-) are listed according to the first letter of the name following the article.

\section{AGI [American Geological Institute]}

1984 Dictionary of geological terms, 3rd (pocket) edition. New York: Anchor Press/Doubleday.

Agostini, A.

2010a Building materials in South Arabian inscriptions: observations on some problems concerning the study of architectural lexicography, Proceedings of the Seminar for Arabian Studies 40, 85-97.

2010b Funerary stelae from Barāqish: study of the onomastics, in S. Antonini and A. Agostini (eds) 2010a, 49-73.

2011 Two new inscriptions from the recently excavated temple of 'Athtar dhū-Qabḍ in Barāqish (Ancient Minaean Yathill). In memoriam Alessandro de Maigret, Arabian Archaeology and Epigraphy 22 (1), 48-58.

2012 New perspectives on Minaean expiatory texts, Proceedings of the Seminar for Arabian Studies 42, 1-12.

2015 The excavation of the temple of 'Athtar dhuQabḍ in Barāqish. Stratigraphic data and historical reconstruction, Proceedings of the Seminar for Arabian Studies 45, 1-14.

2016 Seal impressions on pottery, in A. de Maigret and C.J. Robin (eds) 2016, 340.

2018a The Jawf Valley as a crossroad: some observations about the tribe of Amir in South Arabia, ARAM. Ancient churches, Greek culture and the Arabs before Islam 30 (1-2), 355-368.

2018b Il rito di espiazione sudarabico antico: uno sguardo ai nuovi dati da Barāqish (Yemen), in M. Betrò, S. De Martino, G. Miniaci and F. Pinnock (eds), Egitto e Vicino Oriente antichi: tra passato e futuro. Studi e ricerche sull'Egitto e il Vicino Oriente in Italia. I convegno nazionale, Pisa, 5-6 giugno 2017, 85-95. Pisa: Pisa University Press.

Aitken, M.J.

1990 Science-based dating in archaeology. London and New York: Longman.

Akkermans, P.M.M.G.

1993 Villages in the steppe. Later Neolithic settlement and subsistence in the Balikh Valley, northern Syria
(Archaeological Series 5). Ann Arbor (MI): International Monographs in Prehistory.

Akkermans, P.M.M.G. and G.M. Schwartz

2003 The archaeology of Syria. From complex huntergatherers to early urban societies (c. 16,000-300 BC) (Cambridge World Archaeology). Cambridge: Cambridge University Press.

Al-Ansary, A.R. ['Abd al-Rahmān al-Ṭayyib al-'Anșārī]

1982 Qaryat al-Fau. A portrait of pre-Islamic civilisation in Saudi Arabia. London: Croom Helm. New York: St. Martin's Press.

2010 Qaryat al-Fâw, in A.I. al-Ghabban et al. (eds) 2010, 310-363.

al-Așma'ī, al-Așmaciyyāt

al-Așma'ī, Abū Sa'īd 'Abd al-Malik b. Qarīb b. 'Alī b. Așma'. Al-așma'iyyāt. Edited by A.M. Shākir et A.M. Hārūn, Cairo: Dār al-Macārif, 7th edition, 1993.

Albright, F.P.

1953 The Chronology of the Minaean Kings of Arabia, Bulletin of the American School of Oriental Research 129, 20-24.

1958 Catalogue of objects found in Mârib excavations, in R.LeB. Bowen, Jr and F.P. Albright [and contributors] 1958, 269-286.

Albright, W.F.

1974 The Lachish cosmetic burner and Esther 2:12, in H.N. Bream, R.D. Heim and C.A. Moore (eds), A light unto my path. Old Testament studies in honor of Jacob $\mathrm{M}$. Myers, 25-32. Philadelphia: Temple University Press. Andrefsky, W., Jr

2005 Lithics. Macroscopic approaches to analysis, 2nd edition. Cambridge: Cambridge University Press.

Antonini, S.

1988 Nuovi incensieri iscritti yemeniti, Oriens Antiquus 27 (1-2), 133-141.

1999 Statuettes from the excavations of the temple of Nakrah (Temple A) at Barāqish (Republic of Yemen), Arabian Archaeology and Epigraphy 10 (1), 58-68.

2005 Alcune stele inedite dal Jawf (Yemen), in A.S. Sedov and I.M. Smiljanskaja (eds), Arabia Vitalis, Studies in honour of Vitalij Naumkin in occasion of his 60th anniversary, 308-313. Moscow: Rossijskaja Akademija Nauk / Moskovskij Gosudarstvennyj Universitet. Moscow: Institut Vostokovedenija RAM.

2010a The excavation, in S. Antonini and A. Agostini 2010a, 11-14.

$2010 \mathrm{~b}$ The archaeological materials, in S. Antonini and A. Agostini 2010a, 15-48.

2015 The world of women, in L. Carioni and D. Dasara (coord.), Searching for the Queen of Sheba, 86-97. Florence: Contemporanea Progetti.

2016a Lo scavo delle tombe T1, T2, T3, T4, in A. de Maigret and C.J. Robin (eds) 2016, 345-392. 
2016b Lo scavo delle tombe T5, T6, T7, T8, in A. de Maigret and C.J. Robin (eds) 2016, 393-422.

2016c The pottery found in the houses of the 'Market square' in Tamna', in A. de Maigret and C.J. Robin (eds) 2016, 451-456.

Antonini de Maigret, S.

2012 South Arabian Art. Art History in Pre-Islamic Yemen (Orient \& Méditerranée 10). Paris: De Boccard.

Antonini, S. and A. Agostini

2010a A Minaean necropolis at Barāqish (Jawf, Republic of Yemen). Preliminary report of the 2005-2006 archaeological campaigns. With an appendix by Paola Pagano (Reports and Memoirs n. s. 9). Rome: Istituto Italiano per l'Africa e l'Oriente.

2010b Excavations of the Italian Archaeological Mission in Yemen: A Minaean Necropolis at Barāqish (Wadi Jawf) and the Qatabanian Necropolis of Hayd bin 'Aqīl (Wadi Bayhān), in Ll. Weeks (ed.), Death and burial in Arabia and beyond. Multidisciplinary perspectives (BAR International Series 2107; Society for Arabian Studies Monographs 10), 215-224. Oxford: Archaeopress.

Antonini, S. and V. Buffa

2016 The typological classification, in A. de Maigret and C.J. Robin (eds) 2016, 457-476.

Arbach, M.

1993 Le madhābien: Lexique, Onomastique et Grammaire d'une langue de l'Arabie méridionale préislamique. $\mathrm{PhD}$ dissertation, Université de Provence Aix Marseille I, Aix en Provence.

1994 Inscriptions sudarabiques, Raydān. Journal of Ancient Yemeni Antiquities and Epigraphy 6, 5-16.

2009 Un lion en bronze avec un nouveau synchronisme minéo-qatabānite, in A.M. Sholan et al. (eds) 2009, 21-33. [Originally published Naples and $\operatorname{Ṣan}^{(\bar{a})}$, 2005.]

$2011 \mathrm{La}$ découverte du temple intra-muros de Nakrah à Ma'īn, l'antique Qarnā, Arabian Archaeology and Epigraphy 22, 201-14.

2018 L'Arabie du Sud : de la Cité-État au royaume (VIII $\mathrm{VI}^{\mathrm{e}}$ s. av. J.-C.), Mémoire d'Habilitation à Diriger des Recherches, Paris: Université Paris 1.

2019 Les mots de la guerre en Arabie du Sud au I ${ }^{\text {er }}$ millénaire avant l'ère chrétienne, in J.-F. Breton and F. Villeneuve (eds) 2019, 21-41.

Arbach, M. and R. Audouin

2007 San $\left.^{(} \hat{a}\right)$ National Museum. Collection of epigraphic and archaeological artefacts from al-Jawf sites - Part II (UNESCO Social Fund for Development, Republic of Yemen). San' $\bar{a}$ ': National Museum.

Arbach, M. and I. Rossi

2012 From city-state to kingdom: history and chronology of Ma'in between the VIII and the VI centuries BC, Orientalia 81 (4), 318-339.

Arbach, M. and J. Schiettecatte

2006 Catalogue des pièces archéologiques \& épigraphiques du Jawf au Musée national de San' $\hat{a}^{\prime}$ (UNESCO Social Fund for Development, Republic of Yemen). Șan( $\bar{a})$ :
National Museum and Centre français d'archéologie et de sciences sociales.

Arbach, M. and J. Schiettecatte

2017 Premiers échos de l'expédition romaine d'Ælius Gallus dans la documentation sudarabique, Académie des Inscriptions et Belles-Lettres, Comptes rendus des séances de l'année 2017161 (2), 675-700. [Published April 2018.]

Arramond, J.-C.

2011 La céramique, in J.-F. Breton (ed.) 2011, 79-89.

Arsebük, G. and M. Korfmann

1976 An assemblage of sling-pellets from Tülintepe, 1972, in S. Pekman (ed.), Keban Project 1972 activities (Keban Project Publications series 1, 5), 163-172. Ankara: Middle East Technical University.

Aston, B.G., J.A. Harrell and I. Shaw

2000 Stone, in P.T. Nicholson and I. Shaw (eds) 2000, 5-77.

Avanzini, A.

1995 As-Sawd $\bar{a}^{\text {' (Inventaire des inscriptions sudarabiques }}$

4). Paris: Académie des inscriptions et belles-lettres. Rome: Istituto italiano per il Medio ed Estremo Oriente. [Distribution: Diffusion de Boccard, Paris; Herder, Rome.]

2004 Corpus of South Arabian Inscriptions I-III. Qatabanic, Marginal Qatabanic, Awsanite Inscriptions. Arabia Antica 2. Pisa: Edizioni Plus.

2015 Qatabanian jars in the port of Sumhuram: notes on the trade by sea in South Arabia, in M. Arbach and J. Schiettecatte (eds), Pre-Islamic South Arabia and its neighbours: new developments of research (British Foundation for the Study of Arabia. Monographs 16), 13-20. Oxford: Archaeopress.

2016 By land and by sea: a history of South Arabia before Islam recounted from inscriptions. Rome: 'L'Erma' di Bretschneider.

Avanzini, A. (ed.)

1997 Profumi d'Arabia. Atti del convegno (Saggi di storia antica 11). Rome: 'L'Erma' di Bretschneider. [Atti del convegno di Pisa, 19-21 ottobre 1995.]

2008 A port in Arabia between Rome and the Indian Ocean ( $3^{\text {rd }}$ C. BC- $5^{\text {th }}$ C. AD). Khor Rori report 2 (Arabia Antica 5, Archaeological studies). Rome: 'L'Erma' di Bretschneider.

Ayoub, S.

2007 Die Keramik aus dem Bar’ān-Temple in Mārib (Archäologische Berichte aus dem Yemen 11), 307347, Tafeln 1-78. Mainz: Verlag Philipp von Zabern. Ayyad, S., K. Krzywinski and R. Pierce

1991 Mudbrick as a bearer of agricultural information: an archaeopalynological study, Norwegian Archaeological Review 24 (2), 77-96.

Badre, L.

1992 Le sondage stratigraphique de Shabwa 1976-1981, in J.-F. Breton (ed.) 1992a, 229-314.

Bagg, A.M.

2018 Untersuchungen zu den 'Arabischen' Toponymen und zur Rezeption der 'Araber' in den historischen 
Quellen der Assyrer, in A. Hausleiter et al. (eds) 2018, 246-267.

Baker, H.D.

2009 A waste of space? Unbuilt land in the Babylonian cities of the first millennium BC, Iraq 71, 89-98.

2012 The Neo-Babylonian empire, in D.T. Potts (ed.) 2012, 914-930.

Balfet, H., M.-F. Fauvet-Berthelot and S. Monzon

1989 Lexique et typologie des poteries. Pour la normalisation de la description des poteries (CNRS Plus). Paris: Presses du CNRS.

Barca, D., G. Lucarini and F.G. Fedele

2012 The provenance of obsidian artefacts from the Wādī ath-Thayyilah 3 Neolithic site (eastern Yemen Plateau) by LA-ICP-MS, Archaeometry 54 (4), 603622.

Barnard, H. and W. Wendrich (eds)

2008 The archaeology of mobility. Old World and New World nomadism (Cotsen Advanced Seminars 4). Los Angeles: Cotsen Institute of Archaeology, University of California.

Bar-Yosef, O. and A. Khazanov (eds)

1992 Pastoralism in the Levant. Archaeological materials in anthropological perspectives. Madison: Prehistory Press.

Bar-Yosef Mayer, D.E. (ed.)

2005 Archaeomalacology. Molluscs in former environments of human behaviour (Proceedings of the 9th Conference of the International Council of Archaeozoology, Durham, August 2002). Oxford and Oakville (CT): Oxbow Books.

Bar-Yosef Mayer, D.E. and L. Kolska Horwitz (eds)

2015 Malacological studies from the past and present. A special volume in honor of Henk K. Mienis, Quaternary International 390, 1-146.

Bates, R.L. and J.A. Jackson (eds)

1987 Glossary of geology, 3rd edition. Alexandria (VA): American Geological Institute.

Bauer, G.M. et A. Lundin

1998 Ǔžnaâ Araviâ. Pamâtniki drevnej istorii i kul'tury. vypusk 2, čast' 2, Èpigrafičeskie pamâtniki drevnego Jemena. Saint Petersburg: Centr 'Peterburgskoe vostokovedenie'.

Beaucamp, J. and C. Robin

1981 Le christianisme dans la péninsule Arabique d'après l'épigraphie et l'archéologie, Hommage à $M$. Paul Lemerle (Travaux et Mémoires [de l'UMR 8167 Orient \& Méditerranée] 8) 45-61. Paris: Éditions de Boccard.

Bednarik, R.G.

2017 Scientific investigations into Saudi Arabian rock art: a review, Mediterranean Archaeology and Archaeometry 17 (4), 43-59.

Bednarik, R.G. and M. Khan

2005 Scientific studies of Saudi Arabian rock art, Rock Art Research 22, 49-81.
Beech, M., M. Mashkour, M. Huels and A. Zazzo

2009 Prehistoric camels in south-eastern Arabia: the discovery of a new site in Abu Dhabi's Western Region, United Arab Emirates, Proceedings of the Seminar for Arabian Studies 39, 17-30.

Beeston, A.F.L.

1976 Warfare in ancient South Arabia (2nd-3rd centuries AD) (Qahtan, Studies in Old South Arabian Epigraphy 3). London: Luzac.

Bennett, W.J., Jr and J.A. Blakely

1989 (K.G. O'Connell, SJ with F.L. Horton, Jr, volume eds) Tell el-Hesi: the Persian period (Stratum V) (The Joint Archaeological Expedition to Tell el-Hesi 3; American Schools of Oriental Research excavation reports). Winona Lake (IN): Eisenbrauns.

Berger, J.-F., J.-P. Bravard, L. Purdue, A. Benoist, M. Mouton and F. Braemer

2012 Rivers of the Hadramawt watershed (Yemen) during the Holocene: clues of late functioning, Quaternary International 266 (Geoarchaeology of Egypt and the Mediterranean: reconstructing Holocene landscapes and human occupation history), 142-161. [M. Ghilardi and Y. Tristant, guest eds.]

Bessac, J.-C.

1998a Techniques de construction, de gravure et d'ornementation en pierre dans le Jawf, in J.-F. Breton (ed.) 1998, 173-230.

Betts, A.

2008 Things to do with sheep and goats: Neolithic hunter-forager-herders in North Arabia, in $\mathrm{H}$. Barnard and W. Wendrich (eds) 2008, 25-42.

Biagetti, S.

2014 Ethnoarchaeology of the Kel Tadrart Tuareg. Pastoralism and resilience in central Sahara (SpringerBriefs in Archaeology). Cham, Heidelberg, and New York: Springer.

Bienkowski, P. and A. Millard (eds)

2000 Dictionary of the ancient Near East. London: British Museum Press.

Biffi, N. (trans., commentary, and introduction)

2002 Il Medio Oriente di Strabone. Libro XVI della Geografia (Quaderni di 'Invigilata lucernis' 19). Bari: Edipuglia. Blakely, J.A.

1985 The stratigraphic probe at Hajar at-Tamrah, in J.A. Blakely et al. 1985, 55-126, 133-145.

Blakely, J. and W.D. Glanzman

1996 Fron clay to stone? Cooking bowls of South Arabia, in J.D. Seger (ed.) 1996a, 3-26.

Blakely, J.A. and L.E. Toombs

1980 (K.G. O'Connell, volume ed.) The Tell el-Hesi field manual (The Joint Archaeological Expedition to Tell el-Hesi 1; American Schools of Oriental Research excavation reports). Cambridge (MA): American Schools of Oriental Research.

Blakely, J.A., J.A. Sauer, M.R. Toplyn [and contributors] 1985 (L.J. Tiede, volume ed.) The Wadi al-Jubah Archaeological Project. 2: Site reconnaissance in North 
Yemen, 1983. Washington (DC): The American Foundation for the Study of Man.

Bosch, D.T., S.P. Dance, R.G. Moolenbeek and P.G. Oliver 1995 (S.P. Dance, volume ed.) Seashells of eastern Arabia.

Dubai, Abu Dhabi and London: Motivate Publishing. Bosch, D. and E. Bosch

1989 Seashells of southern Arabia. Dubai (UAE): Motivate

Publishing. [English and Arabic.]

Boschian, G.

2017 Pastoral sites, in A.S. Gilbert (ed.) 2017, 644-652. Bourdieu, P.

1977 Outline of a theory of practice. Cambridge and New York: Cambridge University Press.

Bowen, R.LeB., Jr

1958 Appendix IV. Dating the Huraidha irrigation ruins, in R.LeB. Bowen, Jr and F.P. Albright [and contributors] 1958, 149-153.

Bowen, R.LeB., Jr and F.P. Albright [and contributors]

1958 Archaeological discoveries in South Arabia

(Publications of the American Foundation for the

Study of Man 2). Baltimore (MD): The Johns Hopkins Press.

Bowersock, G.W.

1983 Roman Arabia. Cambridge (MA) and London: Harvard University Press. [Paperback ed. 1994.]

1984 The bilingual inscription from Barāqish, in A.R.T. Al-Ansary ['Abd al-Rahmān T. al-Ansārī] (ed.), Studies in the history of Arabia. 2: Pre-Islamic Arabia, 103-106. Riyadh: King Saud University Press.

Bradley, R.J.

1992 Nomads in the archaeological record. Case studies in the northern provinces of the Sudan (Meroitica 13). Berlin: Akademie Verlag.

Brereton, G. (ed.)

2018 I am Ashurbanipal, king of the world, king of Assyria. The BP exhibition. London: Thames and Hudson, in collaboration with the British Museum.

Breton, J.-F.

1991 À propos de Najrân, in Études sud-arabes. Recueil offert à Jacques Ryckmans (Publications de l'Institut orientaliste de Louvain 39), 59-85. Louvain-laNeuve: Université Catholique de Louvain, Institut orientaliste.

1992b Conclusion: Shabwa et les capitales sud-arabiques ( $\mathrm{I}^{\mathrm{er}}-\mathrm{IV} \mathrm{V}^{\mathrm{e}}$ siècle de notre ère), in J.-F. Breton (ed.) 1992a, 419-431.

1994 Les fortifications d'Arabie méridionale du $7^{e}$ au $1^{\text {er }}$ siècle avant notre ère (Archäologische Berichte aus dem Yemen 8). Mainz: Verlag Philipp von Zabern.

1999 Arabia Felix from the time of the queen of Sheba. Eighth century B.C. to first century A.D. Notre Dame (IN): University of Notre Dame Press. [French edition 1988, trans. A. LaFarge.]

2001 Les villes du Yémen antique, Dossiers d'Archéologie 263 (May), 22-29.

2002 Architecture, in Queen of Sheba 2002, 142-148.
Breton, J.-F. (ed.)

1992a Fouilles de Shabwa II. Rapports préliminaires (Institut Français d'Archéologie du Proche-Orient [IFAPO], Publications hors série 19). Paris: Librairie orientaliste Paul Geuthner. [Reissue as a volume from Syria. Revue d'Art oriental et d'Archéologie 68 (1991).]

1998 Fouilles de Shabwa III. Architecture et techniques de construction (Bibliothèque archéologique et historique 154). Beirut: Institut français d'archéologie du Proche Orient.

Breton, J.-F. and A. Bațayā̄ [Aḥmed Bāțāyic]

1992 Les autels de Shabwa, in J.-F. Breton (ed.) 1992a, 365-378.

Breton, J.-F., A.M. McMahon and D.A. Warburton

1998 Two seasons at Hajar am-Dhaybiyya, Yemen, Arabian Archaeology and Epigraphy 9 (1), 90-111.

Breton, J.-F., C.J. Robin and R. Audouin

1979 Prospection archéologique et épigraphique de la Mission Archéologique Française au Yémen du Nord (oct-déc. 1978), Syria. Revue d'Art oriental et d'Archéologie 56, 417-27.

Breton, J.-F., C. Darles, C. Robin and J.L. Swauger

1997 Le grand monument de Tamna ${ }^{c}$ (Yémen): architecture et identification, Syria. Revue d'Art oriental et d'Archéologie 74, 33-72.

Breton, J.-F., C. Darles, J.-C. Roux and C. Cammas

2010 Une nouvelle stratigraphie à Shabwa, capitale du royaume antique du Hadramawt (Yémen), (XIII ${ }^{\mathrm{e}}$ siècle av. n. è.-IV ${ }^{e}$ siècle de n.è.), Arabia. Revue de sabéologie 4 (2007-2010), 11-66, 165-204.

Breton, J.-F. and F. Villeneuve (eds)

2019 La guerre en Arabie antique. Actes des $22^{e}$ Rencontres sabéennes Paris, 21-23 juin 2018. Paris: S. N. Librairie orientaliste Paul Geuthner.

Bridey, F.

2018 Susa and the kingdom of Elam in the Neo-Elamite period, in G. Brereton (ed.) 2018, 180-193.

Brinkmann, R.

1996 Pedological characteristics of anthrosols in the alJadidah Basin of Wadi al-Jubah, and native sediments in Wadi al-Ajwirah, Yemen Arab Republic, in M.J. Grolier et al. 1996, 45-211.

Broderick, L.G. and M. Wallace

2016 Manure: valued by farmers, undervalued by zooarchaeologists, in L.G. Broderick (ed.), Perspectives \& studies in ethnozooarchaeology, 34-41. Oxford and Philadelphia: Oxbow Books.

Bron, F.

1998 Inventaire des inscriptions sudarabiques. Tome 3 : Macin. Paris: Académie des inscriptions et belleslettres. Rome: Istituto Italiano per il Medio ed Estremo Oriente.

2019 À propos de l'inscription minéenne Gl $1145=$ RES $3562=$ M $348=$ HSM 1936.1.19, Semitica et Classica 12, 241-244. 
Bronk Ramsey, C.

2009 Bayesian analysis of radiocarbon dates, Radiocarbon 51 (1), 337-360.

Brothwell, D.R. and A.M. Pollard (eds)

2001 Handbook of archaeological sciences. Chichester: John Wiley \& Sons.

Brown III, M.R. and E.C. Harris

1993 Interfaces in archaeological stratigraphy, in E.C. Harris, M.R. Brown III and G.J. Brown (eds), Practices of archaeological stratigraphy, 7-20. London and San Diego (CA): Academic Press.

Brunner, U.

1983 Die Erforschung der antiken Oase von Ma'rib mit Hilfe geomorphologischer Untersuchungsmethoden (Archäologische Berichte aus dem Yemen 2). Mainz am Rhein: Verlag Philipp von Zabern.

1997a Geography and human settlements in ancient Southern Arabia, Arabian Archaeology and Epigraphy 8, 190-202.

1997b The history of irrigation in the Wādī Marhah'sic, in Proceedings of the Seminar for Arabian Studies 27, 75-85. [Published 1998.]

Buffa, V.

1996 Note per una tipologia delle tecniche costruttive del periodo sud-arabico antico, in C.J. Robin and I. Gajda (eds) 1996, 165-177.

2007 Malayba et l'Âge du Bronze du Yémen (Archäologische Berichte aus dem Yemen 12). Wiesbaden: Reichert Verlag.

2015 Shape versus ware. The South Arabian straw tempered ovoid storage jars 3 rd cent. BC - 5th cent. AD, in I. Gerlach (ed.) 2015, 47-61.

2016a Building B, the sounding in room L11-L12, in A. de Maigret and C.J. Robin (eds) 2016, 325-339.

2016b Naming types, defining shapes: the case of the typological study of the pottery assemblage from Tamna', in A. de Maigret and C.J. Robin (eds) 2016, 447-450.

Bull, I.D. and R.P. Evershed

2012 Organic geochemical signatures of ancient manure use, in R. Jones (ed.) 2012, 61-77.

Bull, I.D., I.A. Simpson, P.F. van Bergen and R.P. Evershed 1999 Muck 'n' molecules: organic geochemical methods for detecting ancient manuring, Antiquity 73 (279), 86-96.

Burke, A.A.

2008 Walled up to heaven. The evolution of Middle Bronze Age fortification strategies in the Levant (Harvard Semitic Museum Publications. Studies in the archaeology and history of the Levant 4). Winona Lake (IN): Eisenbrauns.

Buschmann, K.

1991 Motiv und Ziel des Aelius-Gallus-Zuges nach Südarabien, Die Welt des Orients 22, 85-93.

Butzer, K.W.

1976 Geomorphology from the earth (Harper \& Row Series in Geography). New York and London: Harper International Edition (Harper \& Row, Publishers).
1982 Archaeology as human ecology. Method and theory for a contextual approach. Cambridge: Cambridge University Press.

Çakırlar, C.

2009 Problems in determining the chain of production in shell 'objects'. Observations on shell assemblages from coastal sites in the Eastern Mediterranean, in R. de Beauclair, S. Münzel and H. Napierala (eds), Knochen pflastern ihren Weg. Festschrift für Margarethe und Hans-Peter Uerpmann (BioArchaeologica 5), 4549. Rahden (Westf.): Verlag Marie Leidorf GmbH.

Calvet, Y. and C. Robin, with F. Briquel-Chatonnet and M. Pic

1997 Arabie heureuse, Arabie déserte. Les antiquités arabiques du Musée du Louvre (Notes et documents des musées de France). Paris: Éditions de la Réunion des musées nationaux.

Canti, M. and D.J. Huisman

2015 Scientific advances in geoarchaeology during the last twenty years, Journal of Archaeological Science 56 (1), 96-108.

Carannante, A., R. Fattovich and C. Pepe

2016 Marine resource exploitation at Mersa/Wadi Gawasis (Red Sea, Egypt). The harbour of the Pharaohs to the land of Punt, in K. Szabó et al. (eds), 121-134.

Carenti, G. and B. Wilkens

2008 Terrestrial fauna and marine produce in Sumhuram, in A. Avanzini (ed.) 2008, 477-547.

Carruthers, D.

1922 The Arabian ostrich, The Ibis [1922], 471-474.

Carver, M.

1995 Digging for data: principles and procedures for evaluation, excavation and post-excavation in towns, in P. Urbańczyk (ed.) 1995, 255-302.

Casanova, $\mathrm{M}$.

2018 Alabaster vessels: manufacture, function and distribution (4th to 2nd millennia BC), in C.S. Phillips and St J. Simpson (eds) 2018a, 70-78.

Caton-Thompson, $\mathrm{G}$.

1944 The tombs and moon temple of Hureidha (Hadhramaut) (Reports of the Research Committee of the Society of Antiquaries of London 13). Oxford: University Press.

Chang, C. and H.A. Koster

1986 Beyond bones: toward an archaeology of pastoralism, in M.B. Schiffer (ed.), Advances in archaeological method and theory. Vol. 9, 97-148. Orlando: Academic Press (Harcourt Brace Jovanovich, Publishers).

Chapman, J.C. and B.I. Gaydarska

2007 Parts and wholes. Fragmentation in prehistoric context. Oxford: Oxbow Books.

Charles, M.P.

1998 Fodder from dung: the recognition and interpretation of dung-derived plant material from archaeological sites, Environmental Archaeology 1, 111-122. 
Charvát, $\mathrm{P}$.

2005 The ancient Sumerians in the tides of time, in S. Pollock and R. Bernbeck (eds), 271-285.

Christie, A.C., A. Grant and A. Haour

2019 Cataloging cowries: a standardized strategy to record six key species of cowrie shell from the West African archaeological record, African Archaeological Review 36, 479-504.

Chugunov, K.V., V.A. Dergachev, A. Nagler, H. Parzinger, G. Possnert, A.A. Sementsov, E.M. Scott, B. Van Geel, J. van der Plicht, S.S. Vasiliev and G.I. Zaitseva

2004 First chronological data for the unique Tsar burial mound Arzhan-2 in Tuva, Central Asia, in T. Higham, C. Bronk Ramsey and C. Owen (eds), Radiocarbon and archaeology. Fourth International Symposium. St Catherine's College, Oxford. 9-14 April 2002, 171-175. Oxford: Oxford University School of Archaeology.

Claassen, $C$.

1998 Shells (Cambridge Manuals in Archaeology). Cambridge: Cambridge University Press.

Cleuziou, S. and M. Tosi

1997 Evidence for the use of aromatics in the Early Bronze Age of Oman: period III at RJ-2 (2300-2200 BC), in A. Avanzini (ed.) 1997, 57-81.

$2000 \mathrm{Ra}^{2} \mathrm{~s}$ al Jinz and the prehistoric coastal cultures of the Ja'alan, Journal of Oman Studies 11, 19-73.

Cleuziou S., M.-L. Inizan and B. Marcolongo

1992 Le peuplement pré- et protohistorique du système fluviatile fossile du Jawf-Hadramawt au Yémen (d'après l'interprétation d'images satellite, de photographies aériennes et de prospections), Paléorient 18 (2), 5-29.

Cleuziou, S., M. Tosi and J. Zarins (eds)

2002 Essays on the late prehistory of the Arabian peninsula. Proceedings of the First international conference on the Conservation and exploitation of the archaeological heritage of the Arabian Peninsula held in the Palazzo Brancaccio, Rome, by IsMEO on 28th-30th May 1991. Rome: Istituto Italiano per l'Africa e l'Oriente.

Cleveland, R.L.

1965 An ancient South Arabian necropolis. Objects from the second campaign (1951) in the Timna' cemetery (Publications of the American Foundation for the Study of Man 4). Baltimore: The Johns Hopkins Press.

Colledge, $\mathrm{S}$.

2003 Plants and people, in R. Matthews (ed.) 2003a, 388-416.

Condoluci, C., M. Degli Esposti and C. Phillips

2014 Iron Age settlement patterns at Salūt c. 1300-300

BC, Proceedings of the Seminar for Arabian Studies 44, 99-120.

Cooley, A.E. (trans. and ed.)

2009 Res Gestae Divi Augusti. Text, translation, and commentary. Cambridge: Cambridge University Press.
Coque-Delhuille, B. and P. Gentelle

1998 Aeolian dust and superficial formations in the arid part of Yemen, in A.S. Alsharhan, K.W. Glennie, G.L. Whittle and G.G. StC. Kendall (eds), Quaternary deserts and climatic change. Proceedings of the International conference on Quaternary deserts and climatic change: al Ain, United Arab Emirates, 9-11 December 1995, 199-208. Rotterdam and Brookfield (VT): A.A. Balkema.

Costa, P.M.

1977 A Latin-Greek inscription from the Jawf of the Yemen, Proceedings of the Seminar for Arabian Studies 7, 69-72.

1986 Further comments on the bilingual inscription from Baraqish, Proceedings of the Seminar for Arabian Studies 16, 33-36.

1991 South Arabian jar sealings, Proceedings of the Seminar for Arabian Studies 21, 41-48.

Costantini, L.

1986 Paleobotanical research, in de Maigret et al. 1986, 465.

Costantini, L. and L. Costantini Biasini

1986 Laboratory of Bioarchaeology. Palaeoethnobotanical investigations in the Middle East and Arabian Peninsula, 1986, East and West 36 (4), 354365.

Coulombel, A.

1994 Coquillages de Djibouti. Aix-en-Provence: Édisud.

Cramp, S. (chief ed.)

1977 Handbook of the birds of Europe, the Middle East and North Africa. The birds of the Western Palearctic. 1: Ostrich to ducks. Oxford: Oxford University Press and Royal Society for the Protection of Birds.

Crassard, R.

2008 La préhistoire du Yémen. Diffusions et diversités locales, à travers l'étude d'industries lithiques du Hadramawt (BAR International Series 1842). Oxford: Archaeopress.

Creasman, P.P. and K. Yamamoto

2019 The African incense trade and its impacts in Pharaonic Egypt, African Archaeological Review 36, 347-365.

Cribb, R.L.D.

1991 Mobile villagers: the structure and organisation of nomadic pastoral campsites in the Near East, in C.S. Gamble and W.A. Boismier (eds) 1991, 371-393.

2004 Nomads in archaeology. Cambridge: Cambridge University Press. [Reprint; originally published 1991.]

CSAI

2019 Corpus of South Arabian inscriptions, in DASI. <http://dasi.cnr.it/index.php?id=42\&prjId=1\& corId $=0$ \& colId $=0$ \&navId $=0>$, accessed 1 December 2019. [CSAI is a project of DASI.]

Cuvigny, $\mathrm{H}$.

1997 L'Arabie heureuse des classiques: naissance d'un mythe, in Yémen 1997, 67-69. 
Dafni, A., S. Levy and E. Lev

2005 The ethnobotany of Christ's Thorn Jujube (Ziziphus spina-christi) in Israel, Journal of Ethnobiology and Ethnomedicine 1 (8), 1-11.

DASI

2019 Digital archive for the study of pre-Islamic Arabian inscriptions, A. Avanzini (project dir.). Pisa: Università degli studi di Pisa, and Scuola Normale Superiore. Rome: Consiglio Nazionale delle Ricerche. <http:// dasi.cnr.it/>, accessed 1 December 2019.

David, $\mathrm{H}$.

2002 Soft stone mining evidence in the Oman Peninsula and its relation to Mesopotamia, in S. Cleuziou et al. (eds) 2002, 317-335.

David, N. and C. Kramer

2001 Ethnoarchaeology in action (Cambridge World Archaeology). Cambridge: Cambridge University Press.

Davidson, D.A.

1976 Processes of tell formation and erosion, in D.A. Davidson and M.L. Shackley (eds) 1976, 255-266.

Davidson, D.A. and M.L. Shackley (eds)

1976 Geoarchaeology. Earth sciences and the past. London: Duckworth.

Daum, W. (ed.)

1988 Yemen. 3000 years of art and civilisation in Arabia Felix. Innsbruck: Pinguin-Verlag. Frankfurt am Main: Umschau-Verlag. [Original edition 1987 (German).] de Maigret, A.

1986 Sabaean-Minaean culture. A: Archaeological studies, in A. de Maigret et al. 1986, 384-394.

1988b Archaeological survey on the Wādi Yalā antiquities, in A. de Maigret (ed.) 1988a, 1-20.

1991a Gli scavi della Missione Archeologica nella città minea di Barāqish. Con una nota di G. Gnoli (Conferenze IsMEO 3). Rome: Istituto per il Medio ed Estremo Oriente. [Contains Gnoli 1991, q.v.]

1991b The excavations of the temple of Nakrah at Barāqish (Yemen), Proceedings of the Seminar for Arabian Studies 21, 159-172.

1993 La seconda campagna di scavi della Missione Archeologica Italiana a Barāqish (Yemen 1992). Con una nota di G. Gnoli (Conferenze IsMEO 6). Rome: Istituto per il Medio ed Estremo Oriente. [Contains Gnoli 1993a, q.v.]

1997a Yathill, in Yémen 1997, 138-139.

1997b The frankincense road from Najrān to Ma'ān: a hypothetical itinerary, in A. Avanzini (ed.) 1997, 315331. [Reprinted in de Maigret 2012, article XII.]

1998c Review of J.-F. Breton, J.-C. Arramond, B. CoqueDelhuille and P. Gentelle, 1998, 'Une vallée aride du Yémen antique. Le wâdî Bayhân', Annali dell'Istituto Universitario Orientale di Napoli 58, 568-571. [Reprinted in de Maigret 2012, article XXVI.]

2003 La ceramica sabea. Specificità e sviluppi da uno studio delle forme, Arabia. Revue de sabéologie 1, 8996, 217-244. [Reprinted in de Maigret 2012, article VII.] 2004a Barāqish, Minaean Yathill. Excavation and restoration of the temple of Nakrah (YICAR Papers 1). Șan'ā [sic]: Yemeni-Italian Centre for Archaeological Research. [Printed and distributed by Il Torcoliere, Naples.]

$2005 \mathrm{~b}$ Restoration work on the Temple of Nakrah at Barāqish (and related excavations), in Sāleh 'Alī Bāsurrah (ed.) Șan' $(\bar{a})$. History and cultural heritage. Proceedings of the Fifth International Conference on Yemeni Civilization. Vol. 1, 33-41. Șan'ā’) University of Sanaa; Al-Metha.

2005c Excavations of the Turret Tombs of Jabal alMakhdarah, in A. de Maigret and S. Antonini (eds) 2005, 11-40.

2006 Excavations of the Italian Archaeological Mission in the second temple at Barāqish (2004-2005), in C.J. Robin and M.`A. al-R. Jāzim (eds), Le pèlerin des forteresses du savoir. Hommage au qādị Ismā'īl b. 'Alī alAkwa' à l'occasion de son $85^{\circ}$ anniversaire, 81-92. Șan'ā') Centre français d'archéologie et de sciences sociales de Sanaa. [Reprinted in de Maigret 2012, article XIV.]

2009a Arabia Felix. Anexploration of the archaeological history of Yemen. Reprinted with a foreword by Professor T. J. Wilkinson. London: Stacey International. [First published 1999, reprinted 2002.]

2009b The excavations of the Italian Archaeological Mission at Barâqish (Republic of Yemen), Newsletter Archeologia (CISA) 0, 50-90. Also available online: <http://www.unior.it/userfiles/workarea_231/file/ Articoli/De\%20Maigret\%2050-90.pdf>, accessed 1 December 2019.

2010a A Sabaean stratigraphy from Barāqish, Arabia. Revue de sabéologie 4 [2007-2010], 67-95, 205-240 (figs 66-127). [Reprinted in de Maigret 2012, article XVI.]

2010b Il grande tempio di Yéha (Etiopia) ed i templi minei di Barāqish (Yemen), in F. Mazzei and P. Carioti (eds) Oriente, Occidente e dintorni... Scritti in onore di Adolfo Tamburello. Vol. 2, 773-781. Naples: Università di Napoli 'L'Orientale', Dipartimento di Studi asiatici. Rome: Istituto Italiano per l'Africa e l'Oriente.

2010c Foreword, in S. Antonini and A. Agostini 2010a, 7-8.

2012 Saba', Ma'în et Qatabân. Contributions à l'archéologie et à l'histoire de l'Arabie ancienne. Choix d'articles scientifiques préparés par $\mathrm{S}$. Antonini de Maigret and C.J. Robin (Orient \& Méditerranée 8). Paris: Éditions de Boccard.

2016 Il tempio di Athirat. Rapporto finale degli scavi 1999-2000, in A. de Maigret and C.J. Robin (eds) 2016, 107-257.

de Maigret, A. (ed.)

1988a The Sabaean archaeological complex in the Wādi Yalā (eastern Hawlān aț-Tìyāl, Yemen Arab Republic). A preliminary report (Reports and memoirs 21). Rome: IsMEO / Istituto Italiano per il Medio ed Estremo Oriente. [In English and Arabic.] 
1990a The Bronze Age culture of Hawlān at-Tiyāl and AlHada (Republic of Yemen). A first general report (Reports and Memoirs 24). Rome: IsMEO/Istituto Italiano per il Medio ed Estremo Oriente.

de Maigret, A. and S. Antonini (eds)

2005 South Arabian necropolises. Italian excavations at AlMakhdarah and Kharibat al-Ahjur (Republic of Yemen) (Reports and Memoirs n.s. 4). Rome: Istituto Italiano per l'Africa e l'Oriente.

de Maigret, A. and C. Robin

1989 Les fouilles italiennes de Yalâ (Yémen du Nord): nouvelles données sur la chronologie de l'Arabie du Sud préislamique, Académie des Inscriptions et BellesLettres, Comptes rendus des séances de l'année 1989133 (2), 255-291. [Reprinted in de Maigret 2012, article VI.]

1993 Le temple de Nakrah à Yathill (aujourd'hui Barāqish), Yémen, résultats des deux premières campagnes de fouilles de la Mission italienne, Académie des Inscriptions et Belles-Lettres, Comptes rendus des séances de l'année 1993137 (2), 427-496. [Reprinted in de Maigret 2012, article XIII.]

de Maigret, A. and C.J. Robin (eds)

2016 Gli scavi italo-francesi di Tamna' (Repubblica dello Yemen). Rapporto finale (Orient \& Méditerranée 20). Paris: Éditions de Boccard.

de Maigret, A., G.M. Bulgarelli, L. Costantini, M. Cucarzi, P. Cuneo, F. Di Mario, F.G. Fedele, V. Francaviglia, G. Gnoli, B. Marcolongo, A.M. Palmieri, G. Pettinato, U. Scerrato, M. Tosi and G. Ventrone

1986 Archaeological activities in the Yemen Arab Republic, 1986, East and West 36 (4), 376-470.

de Maigret A., F.G. Fedele, V. Francaviglia, G. Gnoli, G. Pettinato, M. Tosi, U. Scerrato [et al.]

1987 Cooperation activities of the Italian Archaeological Mission in the Yemen Arab Republic. 1987 Report [of] activities. MAIRAY/IsMEO, unpublished report submitted to the General Organization for Antiquities and Museums, San' $\bar{a}^{\bar{a}}$, Republic of Yemen.

de Moulins, D., C. Phillips and N. Durrani

2003 The archaeobotanical record of Yemen and the question of Afro-Asian contacts, in K. Neumann, A. Butler and S. Kahlheber (eds), Food, fuel and fields. Progress in African archaeobotany (Africa Praehistorica 15), 213-228. Köln: Heinrich-Barth-Institut.

Dekker, $\mathrm{H}$.

2000 The Neritidae (Gastropoda) from the circumarabian seas, with the description of two new species, a new subgenus and a new genus, Vita Marina 47 (2), 29-64. [In English and Dutch.]

Dekker, H. and F.G. de Ceuninck van Capelle

1994 Survey of Yemen Red Sea shells collected by the Tibia-I Expedition, 1993, De Kreukel 30 (7-10), 79-147. Demange, $F$.

2010a Les caravanes de l'encens, in A.I. al-Ghabban et al. (eds) 2010, 132-135. 2010b Sur la route des caravanes, L'Archéo-Théma 9, 2023.

Dickson, $\mathrm{H}$.

1951 The Arab of the desert. A glimpse into Bedouin life in Kuwait and Saudi Arabia. London: Allen \& Unwin.

Di Mario, F., L. Costantini, F.G. Fedele, F. Gravina and C. Smriglio

1989 The western ar-Rub` al-Khālī 'Neolithic': new data from the Ramlat Sab'atayn (Yemen Arab Republic), Annali, Istituto Universitario Orientale 49 (2), 109-148.

Doe, D.B.

1983 Monuments of South Arabia (Arabia past and present 12). Santa Maria la Bruna (Naples): The Falcon Press. Cambridge and New York: The Oleander Press.

Drewes, A.J. and J. Ryckmans

2016 (P. Stein and H. Stroomer eds) Les inscriptions sudarabes sur bois dans la collection de l'Oosters Instituut conservée dans la bibliothèque universitaire de Leiden. Text revised and adapted by Peter Stein. Wiesbaden: Harrassowitz Verlag.

Dubin, L.S.

1987 The history of beads. From 30,000 B.C. to the present. London: Thames and Hudson.

Dunbar, C.O. and J. Rodgers

1957 Principles of stratigraphy. New York, London, Sydney, and Toronto: John Wiley \& Sons, Inc.

Durrani, N.

2005 The Tihamah coastal plain of south-west Arabia in its regional context c.6000 BC-AD 600 (Society for Arabian Studies Monographs 4; BAR International Series 1456). Oxford: Archaeopress.

Edens, C. and T.J. Wilkinson

1998 Southwest Arabia during the Holocene: recent archaeological developments, Journal of World Prehistory 12 (1), 55-119.

Edgell, H.S.

2006 Arabian deserts. Nature, origin, and evolution. Dordrecht (NL): Springer.

Eichhorst, T.E.

2016 Neritidae of the World. Vol. 1. Hackenheim: ConchBooks.

Eichmann, R. and H. Hitgen

2003 Marib, Hauptstadt des Sabäischen Reiches / Marib, capital of the Sabaean kingdom, in I. Gerlach (ed.) 2003a, 52-61.

Eiland, $\mathrm{M}$.

2003 Ceramics and society, in R. Matthews (ed.) 2003a, 321-362.

Eisenmann, V.

1980 Les Chevaux (Equus sensu lato) fossiles et actuels: crânes et dents jugales supérieures (Cahiers de Paléontologie). Paris: Éditions du CNRS.

Eisenstein, $\mathrm{H}$.

2010 Das Kamel in der arabischen Kulturgeschichte, in U. Pietruschka, M.P. Streck and B. Eschment (eds) 2010, 169-188. 
Eph'al, I.

1974 'Arabs' in Babylonia in the 8th century B.C., Journal of the American Oriental Society 94 (1), 108-115.

Evershed, R.P., S.N. Dudd, M.J. Lockheart and S. Jim

2001 Lipids in archaeology, in D.R. Brothwell and A.M. Pollard (eds) 2001, 331-349.

Fairbridge, R.W.

1976 Effects of Holocene climatic change on some typical geomorphic processes, Quaternary Research 6, 529-556.

Fakhry, A. [Ahmad Fakhrī] and G. Ryckmans

1951-1952 An archaeological journey to Yemen (March-May 1947), 3 vols. Part I [text] (1952); Part II, Epigraphical texts, by G. Ryckmans [in French] (1952); Part III, Plates (1951). Cairo: Service des Antiquités de l'Égypte/Mașlahat al-Āthār, Goverment Press.

FAO

1988 Traditional food plants. A resource book for promoting the exploitation and consumption of food plants in arid, semi-arid and sub-humid lands of Eastern Africa (FAO Food and nutrition paper 42). Rome: Food and Agricultural Organization of the United Nations.

Farrand, W.R.

2000 Excavations at Franchthi Cave, Greece. Fasc. 12: Depositional history of Franchthi Cave. Sediments, stratigraphy, and chronology. Bloomington (IN): Indiana University Press.

Fedele, F.G.

1973 Una stazione Vaso a bocca quadrata sul Monfenera, Valsesia (scavi 1969-72). Rapporto preliminare, Preistoria Alpina 9, 151-222.

1976 Sediments as palaeo-land segments: the excavation side of study, in D.A. Davidson and M.L. Shackley (eds) 1976, 23-48.

1984 Towards an analytical stratigraphy: stratigraphic reasoning and excavation, Stratigraphica Archaeologica 1, 7-15.

1990a Bronze Age faunal collections from North Yemen, in A. de Maigret (ed.) 1990a, 149-185.

1990b Radiocarbon dates, in A. de Maigret (ed.) 1990a, 205-212. [The bibliography, mistakenly omitted from the printed volume, is available at http:// www.researchgate.net/profile/F_Fedele.]

1995 Archaeological stratification and the logic of excavation, in P. Urbańczyk (ed.) 1995, 81-106.

2008 Wādì at-Tayyilah 3, a Neolithic and Pre-Neolithic occupation on the eastern Yemen Plateau, and its archaeofaunal information, Proceedings of the Seminar for Arabian Studies 38, 153-171.

2009 Sabaean animal economy and household consumption at Yalā, eastern Khawlān al-Ṭiyāl, Yemen, Proceedings of the Seminar for Arabian Studies 39, 135-154.

2010 Barāqish, over-wall excavations 2005-2006: stratigraphy, environment and economy of the Sabaean-Islamic sequence, Arabia. Revue de sabéologie 4 [2007-2010], 97-161, 241-257 (figs 128-145). 2011a The wall and talus at Barāqish, ancient Yathill (alJawf, Yemen): a Minaean stratigraphy, Proceedings of the Seminar for Arabian Studies 41, 101-120.

$2011 \mathrm{~b}$ In memoriam. Alessandro de Maigret, Proceedings of the Seminar for Arabian Studies 41, xi-xiii.

2013 Neolithic settlement of the eastern Yemen Plateau: an exploration of locational choice and land use, Arabian Archaeology and Epigraphy 24 (1), 44-50.

2014 Camels, donkeys and caravan trade: an emerging context from Barāqish, ancient Yathill (Wādī alJawf, Yemen), Anthropozoologica 49 (2), 177-194.

$2017 \mathrm{New}$ data on domestic and wild camels (Camelus dromedarius and Camelus sp.) in Sabaean and Minaean Yemen, in M. Mashkour and M. Beech (eds) 2017, 286-311.

2019 First millennium BC archaeofaunas from Yemen: Italian studies at Yalā and Barāqish, in M. Baldi, R. Dan, M. Delle Donne, G. Lucarini and G. Mutri (eds), Archaeology of food. New data from international missions in Africa and Asia. Proceedings of the 1st Workshop on the Archaeology of Food - Rome, 26 May 2016 (ISMEO, Serie Orientale Roma n.s. 17), 187-211. Rome: Scienze e Lettere.

in press Rethinking the Highland Bronze Age of Yemen, in C. Darles, L. Khalidi, M. Arbach and M. BarretAudouin (eds), Arabie du Sud et Corne de l'Afrique: échanges et relations de l'Age du Bronze à l'Islam. Actes des 21es Rencontres Sabéennes tenues à Toulouse en juin 2017 en hommage à Rémy Audouin (Sites et Cités $\mathrm{d}$ 'Afrique series). Toulouse: Presse Universitaire $d u$ Midi.

Felli, C.

2003 Developing complexity. Early to mid fourthmillennium investigations: the Northern Middle Uruk period, in R. Matthews (ed.) 2003a, 53-95.

Ferguson, N.

2011 Civilization. The West and the Rest. London: Allen Lane.

Field, $\mathrm{H}$.

1952 The ostrich in south-western Asia, Man 52, 48.

1958 The ostrich in south-western Asia: a further note, Man 58, 67.

Fleitmann, D. and A. Matter

2009 The speleothem record of climate variability in Southern Arabia, Comptes Rendus Geoscience 341 (89), 633-642.

Fleitmann, D., S.J. Burns, A. Mangini, M. Mudelsee, J. Kramers, I. Villa, U. Neff, A.A. Al-Subbary, A. Buettner, D. Hippler and A. Matter

2007 Holocene ITCZ and Indian monsoon dynamics recorded in stalagmites from Oman and Yemen (Socotra), Quaternary Science Reviews 26, 170-188.

Fleitmann, D., S.J. Burns, M. Pekala, A. Mangini, A. AlSubbary, M. Al-Aowah, J. Kramers and A. Matter

2011 Holocene and Pleistocene pluvial periods in Yemen, southern Arabia, Quaternary Science Reviews 30 (7-8), 783-787. 
Fontaine, H. and M. Arbach

2006 Yémen. Cités d'écritures. Manosque: Editions Le Bec en l'air.

Fowler, M.D.

1984 Excavated incense burners, in Biblical Archaeologist 47 (3), 183-186.

1985 Excavated incense burners: a case for identifying a site as sacred?, Palestine Exploration Quarterly 117 (1), 25-29.

Frahm, E.

1997 Einleitung in die Sanherib-Inschriften (Archiv für Orientforschung Beiheft 26). Wien: Institut für Orientalistik der Universität Wien.

2001 Perlen von den Rändern der Welt, in K. Van Lerberghe and G. Voet (eds), Languages and cultures in contact. At the crossroads of civilizations in the SyroMesopotamian realm (Compte rendu, Rencontre Assyriologique Internationale 42; Orientalia Lovaniensia Analecta 96), 79-99. Leuven: Peeters.

Francaviglia, V.

1987 Geoarchaeological survey at Barāqish, Y.A.R., in de Maigret et al. 1987, 19-20. [Unpublished report dated 7 September 1987.]

1990 Obsidian sources in ancient Yemen, in A. de Maigret (ed.) 1990a, 129-136.

1996 Il existait déjà au Néolithique un commerce d'obsidienne à travers la mer Rouge, in L'Archéométrie dans les pays européens de langue latine et l'implication de l'archéométrie dans les grands travaux de sauvetage archéologique. Actes du colloque d'Archéométrie 1995 (Supplément à la 'Revue d'Archéométrie'), 65-70. Perigueux: Pole Editorial Archéologique de l'Ouest (P.E.A.O.).

2002 Some remarks on the irrigation systems of Ancient Yemen, in S. Cleuziou et al. (eds) 2002, 111-144.

Frantsouzoff, S.A.

2006 A Minaic inscription on the pedestal of an ibex figurine from the British Museum, Proceedings of the Seminar for Arabian Studies 36, 69-77.

Freestone, I.C.

1991 Technical examination of Neo-Assyrian glazed wall plaques, Iraq 53, 55-58.

French, C.A.I.

2003 The Dhamar region, central highlands, Yemen, in C. French (ed.), Geoarchaeology in action. Studies in soil micromorphology and landscape evolution, 224-234. London: Routledge.

Frendo, A.J.

1996 The capabilities and limitations of ancient Near Eastern nomadic archaeology, Orientalia 65, 1-23.

Frevel, C. and K. Pyschny

2014 Perserzeitliche Räucherkästchen: zu einer wenig beachteten Fundgattung im Kontext der These Ephraim Sterns, in C. Frevel, K. Pyschny and I. Cornelius (eds), A 'religious revolution' in Yehûd? The material culture of the Persian period as a test case (Orbis Biblicus et Orientalis 267), 111-220. Fribourg:
Academic Press Fribourg. Göttingen: Vandenhoeck \& Ruprecht.

Gajda, I.

2012 Liens entre symboles et divinités dans les inscriptions sudarabiques, in I. Sachet (ed.) [En collaboration avec Christian Julien Robin], Dieux et déesses d'Arabie. Images et représentations, 447-459. Actes de la table ronde tenue au Collège de France (Paris) le 1er et 2 octobre 2007. Paris: Éditions de Boccard.

Gale, R., P. Gasson, N. Hepper and G. Killen

2000 Wood, in P.T. Nicholson and I. Shaw (eds) 2000, 334-371.

Galli, C.

2014-2019 Worldwide Mollusc Species Data Base [WMSDB]. <http://www.bagniliggia.it/WMSD/WMSDhome. htm>, accessed 1 November 2019. [Individual citations refer to the latest update for the family concerned, e.g. 2015 for Arcidae.]

Gamble, C.S. and W.A. Boismier (eds)

1991 Ethnoarchaeological approaches to mobile campsites. Hunter-gatherer and pastoralist case studies (Ethnoarchaeological Series 1). Ann Arbor: International Monographs in Prehistory.

Garbini, G.

1974 Iscrizioni sudarabiche. I: Iscrizioni minee (Pubblicazioni del Seminario di Semitistica, Istituto Orientale di Napoli, Ricerche 10). Naples: Istituto Universitario Orientale.

Gasche, H. and Ö. Tunca

1983 Guide to archaeostratigraphic classification and terminology: definitions and principles, Journal of Field Archaeology 10, 325-335.

Gauthier-Pilters, H. and A.I. Dagg

1981 The camel. Its evolution, ecology, behavior, and relationship to man. Chicago and London: The University of Chicago Press. [Photography by $\mathrm{H}$. Gauthier-Pilters.]

Gentelle, P.

1997 Le recul des terres cultivées au VI ${ }^{\mathrm{e}}$ siècle, in Yémen 1997, 220.

Genz, H.

2012 The northern Levant, in D.T. Potts (ed.) 2012, 607628.

Gerlach, I.

2003c Un relief en bronze sabéen d'inspiration procheorientale, Chroniques Yéménites 11. <http://journals. openedition.org/cy/159>, accessed 20 October 2019.

Gerlach, I. (ed.)

2003a 25 Jahre Ausgrabungen und Forschungen im Jemen 1978-2003 / 25 years excavations and research in Yemen 1978-2003. (Hefte zur Kulturgeschichte des Jemen 1). Șan' $\bar{a}$ ') and Berlin: Deutsches Archäologisches Institut, Orient-Abteilung, Aussenstelle Sanaa.

2015 South Arabia and its neighbours. Phenomena of intercultural contacts. 14. Rencontres Sabéennes (Archäologische Berichte aus dem Yemen 14). Wiesbaden: Dr Ludwig Reichert Verlag. 
al-Ghabban, A.I., B. André-Salvini, F. Demange, C. Juvin and M. Cotty (eds)

2010 Routes d'Arabie. Archéologie et histoire du Royaume d'Arabie Saoudite. Paris: Louvre éditions; and Somogy éditions d'art. [Exhibition catalogue: Paris, Musée du Louvre, 14 July-27 September 2010.]

Gibson, A. and A. Woods

1990 Prehistoric pottery for the archaeologist. Leicester, London and New York: Leicester University Press (a division of Pinter Publishers Ltd).

Gifford-Gonzales, D.

2009 Preface, in G. Grupe et al. (eds) 2009, 11-16.

Gilbert, A.S.

1975 Modern nomads and prehistoric pastoralists: the limits of analogy, The Journal of the Ancient Near Eastern Society of Columbia University 7, 53-71.

Gilbert, A.S. (ed.)

2017 Encyclopedia of geoarchaeology (Encyclopedia of Earth Sciences series). Dordrecht: Springer (Science+Business Media).

Glanzman, W.D.

1987a Ceramics, in W.D. Glanzman and A.O. Ghaleb 1987a, 67-126.

1987b Steatite vessels, in W.D. Glanzman and A.O. Ghaleb 1987a, 131-138.

1987c Metallurgical debris, in W.D. Glanzman and A.O. Ghaleb 1987a, 145-148.

1987d Plaster and cement, in W.D. Glanzman and A.O. Ghaleb 1987a, 157-160.

1987e Conclusions, in W.D. Glanzman and A.O. Ghaleb 1987a, 207-208.

1994 Toward a classification and chronology of pottery from HR3 (Hajar ar-Rayhani), Wadi al-Jubah, Republic of Yemen. Unpublished PhD dissertation, University of Pennsylvania. [Available as UMI no. 9521036 from ProQuest LLC, Ann Arbor (MI).]

2004a Beyond their borders: a common potting tradition and ceramic horizon within South Arabia during the later first millennium $\mathrm{BC}$ through the early first millennium AD, Proceedings of the Seminar for Arabian Studies 34, 121-138.

2004b Ancient South Arabia's camel caravans: a reassessment of the evidence, and the road ahead. Paper and abstract presented at the Seminar for Arabian Studies, held at the British Museum, London, 22 July 2004.

2005 'Is your cup half empty, or half full?'. The function and significance of the Wavy Rim Bowl in preIslamic South Arabia, Bulletin of the Society for Arabian Studies 10, 15-19, 37.

2018 The steatite cooking bowl of the 1st millennium BC and early 1st millennium AD in South Arabia: archaeological views and cultural dynamics, in C.S. Phillips and St J. Simpson (eds) 2018a, 124-136.

Glanzman, W.D. and A.O. Ghaleb

1987b The stratigraphic probe at Hajar ar-Rayhani, in W.D. Glanzman and A.O. Ghaleb 1987a, 5-63.

Glanzman, W.D. and A.O. Ghaleb [and contributors] 1987a (L.J. Tiede and S.J. Fleming, volume eds) The Wadi al-Jubah Archaeological Project, 3. Site reconnaissance in the Yemen Arab Republic, 1984: the stratigraphic probe at Hajar ar-Rayhani. Washington (DC): American Foundation for the Study of Man.

Glaser, E.

1913 (D.H. von Müller and N. Rhodokanakis eds) Reise nach Mārib; nebst 4 kartographischen und topographischen Beilagen und 3 Skizzen der Dammbauten bei Marib. Vienna: Verlag Alfred Hölder.

Gnoli, G.

1993a Sulle nuove iscrizioni di Baraqish, in de Maigret (ed.) 1993, 23-33.

1993b Shaqab al-Manașșa (Inventaire des inscriptions sudarabiques 2). Paris: Académie des inscriptions et belles-lettres. Rome: Istituto italiano per il Medio ed Estremo Oriente. [Distribution: Diffusion de Boccard, Paris; Herder, Rome.]

1996b Il sincronismo mineo-persiano, in C.J. Robin and I. Gajda (eds) 1996, 23-34.

2009 Ancora sui 'Medi' in RES 3022, in A.M. Sholan et al. (eds) 2009, 295-300. [Originally published Naples and Șan' $(\bar{a}), 2005$.]

Gnoli, G. and C.J. Robin

1992 Nouveaux documents sabéens de Barāqish, in Yemen. Studi archeologici, storici e filologici sull'Arabia meridionale 1, 93-98. Rome: Istituto italiano per il Medio ed Estremo Oriente.

Goodman, S.M., P.F. Houlihan and I. Helmy

1984 Recent records of the ostrich Struthio camelus in Egypt, Bulletin of the British Ornithologists' Club 104, 39-44.

Goudie, A.S.

1989 Weathering processes, in D.S.G. Thomas (ed.) 1989a, 11-24.

2013 Arid and semi-arid geomorphology. Cambridge: Cambridge University Press.

Goulder, J.R.

2018 Modern development studies as a resource for understanding working animal use in later human prehistory: the example of 4th-3rd millennium BC Mesopotamia. 1-2. PhD dissertation, UCL Institute of Archaeology, London. <http://discovery.ucl. ac.uk/id/eprint/10053639/>, accessed 25 October 2019.

2019 Working donkeys in 4th-3rd millennium BC Mesopotamia. Insights from modern development studies (UCL Institute of Archaeology Publications). London: Routledge.

Grohmann, A.

1914 Göttersymbole und Symboltiere auf Südarabischen Denkmälern (Denkschriften der Kaiserlichen Akademie der Wissenschaften in Wien. Philosophisch-historische Klasse 58/1). Vienna (In Kommission bei Alfred Hölder).

Grolier, M.J.

1988 Geomorphology of the al-Jubah quadrangle, Y. A. R.: a guide to the interpretation of landforms in 
the basin of Wadi al-Jubah, in W.C. Overstreet et al. 1988a, 289-357.

Grolier, M.J. and W.C. Overstreet

1978 Geologic map of the Yemen Arab Republic (San' 'a')

(USGS Miscellaneous investigations series, Map

I-1143 B). Washington (DC): U.S. Geological Survey. [Scale 1:500,000.]

Grolier, M.J., R. Brinkmann and J.A. Blakely [and contributors]

1996 (W.C. Overstreet and J.A. Blakely, volume eds) The Wadi al-Jubah Archaeological Project, 5. Environmental research in support of archaeological investigations in the Yemen Arab Republic, 1982-1987. Washington (DC): American Foundation for the Study of Man.

Grupe, G., G. McGlynn and J. Peters (eds)

2009 Tracking down the past. Ethnohistory meets archaeozoology (Documenta Archaeobiologiae: Jahrbuch der Staatssammlung für Anthropologie und Paläoanatomie München 7). Rahden (Westf.): Verlag Marie Leidorf $\mathrm{GmbH}$.

Habshūsh, Hayyim

2018 A vision of Yemen by Ḥayyim Ḥabshūsh translated from the original Hebrew and Judeo-Arabic, in A. Verskin 2018a, 61-212, 230-248.

Halévy, J.

1872a Rapport sur une mission archéologique dans le Yémen, Journal Asiatique $6^{\mathrm{e}}$ série 19, 5-98, 129-266, 489-547. [Published in the January, FebruaryMarch, and June issues.]

al-Hamdānī, al-Iklīl

al-Hamdānī, al-Hasan ibn Ahmad ibn Ya'qūb Ibn al-Hầ'ik. The Antiquities of South Arabia, Being a Translation from the Arabic with Linguistic, Geographic, and Historic Notes of the Eighth Book of al-Hamdanni's alIklil. Edited by N.A. Faris. Princeton, 1938.

Harris, E.C.

1989 Principles of archaeological stratigraphy, 2nd edition. London: Academic Press.

Harvey, S.P.

2003 Interpreting Punt: geographic, cultural and artistic landscapes, in D. O'Connor and S. Quirke (eds), Mysterious lands, 81-91. London: UCL Press.

Hassanzadeh,Y. and J. Curtis

2018 Western Iran in the Iron Ages, in G. Brereton (ed.) 2018, 166-179.

Hassell, J.

2002 Cuboid incense-burning altars from South Arabia in the collection of the American Foundation for the Study of Man: some unpublished aspects, Arabian Archaeology and Epigraphy 13 (2), 157-192.

Hauser, S.R.

2006b Zur Einleitung: Archäologische Annäherungen an Nomaden, in S.R. Hauser (ed.) 2006a, 1-26.

Hauser, S.R. (ed.)

2006a Die Sichtbarkeit von Nomaden und saisonaler Besiedlung in der Archäologie. Multidisziplinäre Annäherungen an ein methodisches Problem (Mitteilungen des SFB 'Differenz und Integration'
9; Orientwissenschaftliche Hefte 21). Halle (Saale): OWZ.

Hausleiter, A.

2010 L'oasis de Taymāc [sic], in A.I. al-Ghabban et al. (eds) 2010, 218-239, 240-261 (catalogue).

2012 North Arabian kingdoms, in D.T. Potts (ed.) 2012, 816-832.

Hausleiter, A. and R. Eichmann

2018 The archaeological exploration of the oasis of Taymā', in A. Hausleiter et al. (eds) 2018, 2-58.

Hausleiter, A., R. Eichmann and M. al-Najem (eds)

2018 Taym $\bar{a}$ ' I. Archaeological exploration, palaeoenvironment, cultural contacts (Taymā'). Multidisciplinary series on the results of the Saudi-German archaeological project). Oxford: Archaeopress Publishing [for Deutsches Archäologisches Institut, Orient-Abteilung, and Saudi Commission for Tourism and National Heritage].

Head, D.

1992 The Achaemenid Persian army. Stockport: Montvert Publications.

Hehmeyer, I.

2018 A history of water engineering and management in Yemen. Material remains and textual foundations (Handbook of Oriental studies/Handbuch der Orientalistik, Section One, 'The Near and Middle East', 129). Leiden: E.J. Brill.

Hehmeyer, I. and J. Schmidt

1991 Antike Technologie-Die sabäische Wasserwirtschaft von Mārib. 1 (Archäologische Berichte aus dem Yemen

5). Mainz am Rhein: Verlag Philipp von Zabern.

Heinrichs, W.

1998 Al-Sharqī b. al-Qutāmī and his etiologies of proverbs, in S. Leder (ed.), Story-telling in the framework of non-fictional Arabic literature, 282-308. Wiesbaden: Harrassowitz.

Heller, J.

2015 Sea snails. A natural history. Cham, Heidelberg, New York [etc.]: Springer.

Henderson, $\mathrm{J}$.

2001 Glass and glazes, in D.R. Brothwell and A.M. Pollard (eds) 2001, 471-482.

Henkelman, W.F.M.

2012 The Achaemenid heartland: an archaeologicalhistorical perspective, in D.T. Potts (ed.) 2012, 931962.

Henrickson, E.F. and I. Thuesen (eds)

1989 Upon this foundation: the 'Ubaid reconsidered. Proceedings from the 'Ubaid Symposium, Elsinore, May 30th-June 1st 1988. Copenhagen: Museum Tusculanum Press.

Henry, D.O., C.E. Cordova, M. Portillo, R.-M. Albert, R. DeWitt and A. Emery-Barbier

2017 Blame it on the goats? Desertification in the Near East during the Holocene, The Holocene 27 (5), 625637. 
Herles, M.

2010 Kamele in assyrischen Quellen - Ein Exot wird zur Selbstverständlichkeit, in U. Pietruschka, M.P. Streck and B. Eschment (eds) 2010, 127-167.

Heron, C.

2001 Geochemical prospecting, in D.R. Brothwell and A.M. Pollard (eds) 2001, 565-573.

Hesse, B.

1996a The Hajar ar-Rayhani fauna: a first look at Yemen's Iron Age pastoral economy, in J.D. Seger (ed.) 1996a, 103-122.

1996b The Hajar ar-Rayhani fauna: variation in the animal economy in Iron-Age Yemen, in M.J. Grolier et al. 1996, 263-292.

Hill, H.D., T. Jacobsen and P. Delougaz

1990 Old Babylonian public buildings in the Diyala region. Part One: Excavations at Ishchali. Part Two: Khafajah Mounds B, C, and D. (Oriental Institute Publications 98). Chicago: The Oriental Institute, The University of Chicago. [With contributions by T. A. Holland and A. McMahon.]

Hislop, M.

2013 How to read castles. A crash course in understanding fortifications. London: Bloomsbury Publishing.

Hodos, T., C.R. Cartwright, J. Montgomery, G. Nowell, K. Crowder, A.C. Fletcher and Y. Gönster

2020 The origins of decorated ostrich eggs in the ancient Mediterranean and Middle East, Antiquity 94 (374), 381-400.

Hole, F.

1978 Pastoral nomadism in western Iran, in R.A. Gould (ed.), Explorations in ethnoarchaeology (School of American Research Advanced Seminar Series), 127167. Albuquerque: University of New Mexico Press.

1979 Re-discovering the past in the present: ethnoarchaeology in Luristan, Iran, in C. Kramer (ed.), Ethnoarchaeology: implications of ethnography for archaeology, 192-218. New York: Columbia University Press.

1980 The prehistory of herding: some suggestions from ethnography, in M.T. Barrelet (ed.), L'Archéologie de l'Iraq du début de l'époque Néolithique à 333 avant notre ère, 119-130. Paris: Éditions du CNRS.

2009 Pastoral mobility as an adaptation, in J. Szuchman (ed.) 2009, 261-283.

Huzayyin, S.A.

1935 Changement historique du climat et du paysage d'Arabie du Sud, University of Egypt, Bulletin of the Faculty of Arts 3 (1), 19-23.

Ilan, D.

1998 The dawn of internationalism-the Middle Bronze Age, in T.E. Levy (ed.) 1998, 297-319.

2012 Review of 'Walled up to heaven. The evolution of Middle Bronze Age fortification strategies in the Levant' by A.A. Burke (2008), Journal of Near Eastern Studies 71 (1), 164-167.

Irwin, R.

2010 Camel (Animal series). London: Reaktion Books.
Iserlis, $\mathrm{M}$.

2009 Khirbet Kerak Ware at Bet Yerah: segregation and integration through technology, Tel Aviv 36 (2), 181195.

Jackson, J.W.

1916 XIII. The use of cowry-shells for the purposes of currency, amulets, and charms, Memoirs and Proceedings of the Manchester Literary and Philosophical Society (Manchester Memoirs) 60, 1-72. [Issued 30 November 1916. Vol. 60 of the journal, 1915-1916, was completed in 1917.]

1917 Shells as evidence of the migrations of early culture (Publications of the University of Manchester 112, Ethnological Series 11). Manchester: Manchester University Press. London [etc.]: Longmans, Green \& Co. [From papers originally published in Memoirs and Proceedings of the Manchester Literary and Philosophical Society 60 (1915-1916).]

1944 Report on marine shells, in G. Caton Thompson 1944, 104-105.

Jacobsen, T. and R.McC. Adams

1958 Salt and silt in ancient Mesopotamian agriculture, Science 128 (3334), 1251-1258.

Jameson, S.

1968 Chronology of the campaigns of Aelius Gallus and C. Petronius, The Journal of Roman Studies 58 (1-2), 71-84.

Jamme, A.

1953 Les expéditions archéologiques américaines en Arabie du Sud (1950-1953). (Avec une brève étude sur l'estampage en latex), Oriente Moderno 33 (3), 133-157.

Japp, S.

2007 Anhang: Bemerkungen zum Artikel "Die Keramik aus dem Bar̉ān-Temple in Mārib" von Saad Ayoub, in Archäologische Berichte aus dem Yemen 11, 348-352. Mainz: Verlag Philipp von Zabern.

Jasmin, M.

2005 Les conditions d'émergence de la route de l'encens à la fin du $\mathrm{II}^{\mathrm{e}}$ millénaire avant notre ère', Syria. Revue d'Art oriental et d'Archéologie 82, 49-62.

Jazem, M.A. [Mohammad 'Abd al-Raḥmān Jāzim] and B. Leclercq-Neveu

2001 L'organisation des caravanes au Yémen selon alHamdânî (Xe siècle), Chroniques yéménites 9,2-9. Also available online: <https://journals.openedition. org/cy/32>, accessed 15 September 2019.

Jemen

1998 Jemen. Kunst und Archäologie im Land der Königin von Saba'. Milan: Skira. [Exhibition catalogue: Eine Ausstellung des Kunsthistorischen Museums Wien in Zusammenarbeit mit der Generalinstitution für Altertümer, Museen und Handschriften, Ministerium für Kultur und Tourismus der Republik Jemen. Vienna, Künstlerhaus, 9. November 1998-21 February 1999. W. Seipel, ed.] 
Jesse, F.

2006 Spurlose Wanderschaft? - Zur archäologischen Sichtbarkeit von Pastoralnomaden in der südlichen Libyischen Wüste, in S.R. Hauser (ed.) 2006a, 65-86.

Joannès, F. and C. Michel (eds)

2001 Dictionnaire de la civilisation mésopotamienne (Collection Bouquins). Paris: Éditions Robert Laffont. Jones, R. (ed.)

2012 Manure matters. Historical, archaeological and ethnographic perspectives. Farnham: Ashgate.

Kelso, J.L. and J.P. Thorley

1943 The potter's technique at Tell Beit Mirsim, particularly in Stratum A, in W.F. Albright 1943, The excavation of Tell Beit Mirsim. 3: The Iron Age (The Annual of the American Schools of Oriental Research 21-22, for 1941-1943), 86-143. New Haven: American Schools of Oriental Research. [Volume ed. for ASOR by M. Burrows and E.A. Speiser.]

Kemp, B.

2000 Soil (including mud-brick architecture), in P.T. Nicholson and I. Shaw (eds) 2000, 78-103.

Khalidi, L.

2005 The prehistoric and early historic settlement patterns on the Tihāmah coastal plain (Yemen): preliminary findings of the Tihāmah Coastal Survey 2003, Proceedings of the Seminar for Arabian Studies 35, 115-127.

Khan, M.

1998 A critical review of rock art studies in Saudi Arabia, East and West n.s. 48 (3-4), p. 427-437.

2012 (1433 H.) The Arabian horse, origin, development and history / al-Hișān al-'arabi, al-așl wa-'l-tațawwur wa-'lta'rikh. Riyadh: Z Company for Advertising \& Public Relations. [With contributions by R. Bednarik and M. Macdonald.]

Kirkby, A. and M.J. Kirkby

1976 Geomorphic processes and the surface survey of archaeological sites in semi-arid areas, in D.A. Davidson and M.L. Shackley (eds) 1976, 229-253.

Kitchen, K.A.

1994 Documentation for Ancient Arabia. Part I. Chronological framework and historical sources. Liverpool: Liverpool University Press.

1999 Three unusual Sabaean inscriptions in bronze, Proceedings of the Seminar for Arabian Studies 28, 149156. [PSAS for 1998.]

Kohl, P.L., G. Harbottle and E.V. Sayre

1979 Physical and chemical analyses of soft stone vessels from southwest Asia, Archaeometry 21, 131-160.

Kohler, S.

1995 Vielfältige Nutzung des 'ilb-Baumes, Jemen-Report $26(2), 12-14$

Köpp, H.

2013 Desert travel and transport in ancient Egypt. An overview based on epigraphic, pictorial and archaeological evidence, in H. Riemer and F. Förster (eds), Desert road archaeology in ancient Egypt and beyond (Africa Praehistorica 26), 107-133. Köln: Heinrich-Barth-Institut.

Korfmann, M.

1972 Schleuder und Bogen in Südwestasien. Von den frühesten Belegen bis zum Beginn der historischen Stadtstaaten (Antiquitas. Abhandlungen zur Vorund Frühgeschichte, zur klassischen und provinzialrömischen Archäologie und zur Geschichte des Altertums, series 3, 13). Bonn: Rudolf Habelt Verlag. Kovács, L.

2008 Vulvae, eyes, snake heads. Archeological finds of cowrie amulets. With malacological identifications by Gyula Radócz (BAR International Series 1846). Oxford: Archaeopress.

Krautwurst, R.

2007 Die Keramik vom Tempel des Waddum DūMasma'im, in Archäologische Berichte aus dem Yemen 11, 23-116. Mainz am Rhein: Verlag Philipp von Zabern.

Kruck, W., U. Schäffer and J. Thiele

1996 Explanatory notes on the Geological map of the Republic of Yemen - Western part - (former Yemen Arab Republic), Geologisches Jahrbuch ser. B, 87, 3-105. [With 8 maps 1:250,000.]

Lafont, B., P. Villard and C. Castel

2001 Armement, in F. Joannès and C. Michel (eds) 2001, 75-78.

Lancelotti, C. and M. Madella

2012 The 'invisible' product: developing markers for identifying dung in archaeological contexts, Journal of Archaeological Science 39, 953-963.

Lanfranchi, G.B.

2004 Mesopotamia e Arabia nelle iscrizioni reali assire, in F.M. Fales and D. Morandi Bonacossi (eds), Mesopotamia e Arabia. Scavi archeologici e studi territoriali delle università trivenete (1994-1998), 217253. Venice: Istituto Veneto di Scienze, Lettere e Arti.

Laufer, B.

1926 Ostrich egg-shell cups of Mesopotamia and the ostrich in ancient and modern times (Anthropology Leaflet 23). Chicago: Field Museum of Natural History.

Lawrence, D. and T.J. Wilkinson

2015 Hubs and upstarts: pathways to urbanism in the northern Fertile Crescent, Antiquity 89 (344), 328344.

Layard, A.H.

1853 Discoveries in the ruins of Nineveh and Babylon; with travels in Armenia, Kurdistan and the Desert. Being the result of a second expedition undertaken for the Trustees of the British Museum. London: John Murray.

Lemaire, A.

1996 Histoire du Proche-Orient et chronologie sudarabique avant Alexandre, in C. J. Robin and I. Gajda (eds) 1996, 35-48. 
Lesur, J.

2007 Chasse et élevage dans la Corne de l'Afrique entre le Néolithique et les temps historiques (Cambridge Monographs in African Archaeology 68; BAR International Series 1602). Oxford: BAR Publishing. Lesur-Gebremariam, J.

2010 Domesticates and wild game in the Western Egyptian desert at the end of the 5th millennium BC: results from KS 43 (oasis of Kharga, Egypt). Poster presented at the 11th ICAZ Conference, Paris, 23-28 August 2010, session 51.1 'Archaeozoology of Holocene Africa'.

Levine, M.A.

1982 The use of crown height measurements and eruption-wear sequences to age horse teeth, in B. Wilson, C. Grigson and S. Payne (eds), Ageing and sexing animal bones from archaeological sites (BAR British Series 109), 223-250. Oxford: B.A.R.

Levy, T.E. (ed.)

1998 The archaeology of society in the Holy Land, 2nd edition. With a new introduction by Kent Flannery. London and Washington: Leicester University Press.

Lézine, A.-M., J.J. Tiercelin, C. Robert, J.-F. Saliège, S. Cleuziou, M.-L. Inizan and F. Braemer

2007 Centennial to millennial-scale variability of the Indian monsoon during the early Holocene from a sediment, pollen and isotope record from the desert of Yemen, Palaeogeography Palaeoclimatology Palaeoecology 243 (3-4), 235-249.

Lézine, A.-M., F. Bassinot and J.-Y. Peterschmitt

2014 Orbitally-induced changes of the Atlantic and Indian monsoons over the past 20,000 years: new insights based on the comparison of continental and marine records, Bulletin de la Société Géologique de France 185 (1), 3-12.

Lombardi, A., V. Buffa and A. Pavan

2008 Small finds, in A. Avanzini (ed.) 2008, 317-475.

London, G.

1981 Dung-tempered clay, in Journal of Field Archaeology 8 (2), 189-195.

Lönnqvist, M., M. Törmä and K. Lönnqvist

2011 A window to 'living archaeology': bedouin camps and villages, in M. Lönnqvist, M. Törmä, K. Lönnqvist and M. Nuñez (eds), Jebel Bishri in focus. Remote sensing, archaeological surveying, mapping and GIS studies of Jebel Bishri in central Syria by the Finnish project SYGIS (BAR International Series 2230), 371397. Oxford: Archaeopress.

Lorenz, F.

2017a Cowries. A guide to the gastropod family Cypraeidae. 1: Biology and systematics. Hackenheim: ConchBooks.

2017b A new subspecies of Erronea caurica (Linnaeus 1758) from West Thailand (Gastropoda: Cypraeidae), Acta Conchyliorum 16, 29-37.

2018 Cowries. A guide to the gastropod family Cypraeidae. 2: Shells and animals. Hackenheim: ConchBooks.
Lorenz, F. and A. Hubert

2000 A guide to worldwide cowries, 2nd enlarged and completely revised edition. Hackenheim: ConchBooks.

Loreto, R.

2009 House and household: a contextual approach to the study of South Arabian domestic architecture. A case study from seventh- to sixth-century BC Yalā/ ad-Durayb, Proceedings of the Seminar for Arabian Studies 39, 255-269.

2011 L'architettura domestica e i palazzi reali di epoca sud arabica $^{\text {sic }}$ nello Yemen pre-islamico (VII sec. a.C.-VI sec. d.C.) (Università degli studi di Napoli 'L'Orientale', Dissertationes 7). Naples: Università degli studi di Napoli 'L'Orientale'.

2016 Il grande tempio. Gli oggetti, in A. de Maigret and C.J. Robin (eds) 2016, 297-323.

2019 The Assyrians in Arabia - The archaeological evidence, in J.-F. Breton and F. Villeneuve (eds) 2019, 133-144.

Loreto, R. and R. Valentini

2012 Il santuario rupestre del dio Nakrah presso Darb aș-Șabī (Barāqiš, antica Yațill), Newsletter di Archeologia (CISA) 3, 265-311. Also available online: <http://www.unior.it/userfiles/workarea_231/file/ Newsletter Archeologia\%20numero\%203/5_\%20 Loreto-Valentini\%202012.pdf>, accessed 15 May 2018.

Ludwig, A.

2015 Kameldarstellungen aus Metall im vorislamischen Südarabien. Eine archäologische Fallstudie zu den Kulturkontakten zwischen Arabia Felix und der Mittelmeerwelt (Jenaer Archäologische Schriften 1). Wiesbaden: Reichert Verlag.

Lüning, S. and F. Vahrenholt

2019 Holocene climate development of North Africa and the Arabian Peninsula, in A. Bendaoud, Z. Hamimi, M. Hamoudi, S. Djemai and B. Zoheir (eds), The geology of the Arab world-An overview (Springer Geology), 507-546. Cham: Springer.

Luther, A.

1999 Medo nectis catenas? Die Expedition des Aelius Gallus im Rahmen der augusteischen Partherpolitik, Orbis Terrarum 5, 157-182.

Magee, $\mathrm{P}$.

1996 The chronology of the Southeast Arabian Iron Age, Arabian Archaeology and Epigraphy 7, 240-252.

Mandel, R.D., P. Goldberg and V.T. Holliday

2017 Site formation processes, in A.S. Gilbert (ed.) 2017, 797-817.

Maraqten, $\mathrm{M}$.

1994 Typen altsüdarabischer Altäre, in N. Nebes (ed.) 1994, 160-177.

2015 Hunting in pre-Islamic Arabia in light of the epigraphic evidence, Arabian Archaeology and Epigraphy 26 (2), 208-234. 
Marcolongo, B.

1994 Le périmètre irrigué, grenier de l'antique Yathill, et les déplacements du wâdî Majzir, Saba. Art littérature - histoire - Arabie Méridionale 1 (Parfums d'Arabie), 60-62. [Contained in Robin and de Maigret 1994, q.v.]

1996 Modelli di utilizzo delle risorse idriche nello Yemen interno dall'età del Bronzo al periodo sudarabico, in C.J. Robin and I. Gajda (eds) 1996, 179-187.

1997 Les systèmes irrigués de Barāqish, in Yémen 1997, 78.

2000 L'oasi di Barâqish, in Yemen 2000, 137-139.

Marcolongo, B. and D. Morandi Bonacossi

1997 L'abandon du système d'irrigation qatabanite dans la vallée du wadi Bayhan (Yémen): analyse géoarchéologique, Comptes rendus de l'Académie des Sciences 325, 79-86.

Marcolongo, B. and A.M. Palmieri

1986 Palaeoenvironmental conditions in the areas of Wādī at-Tayyilah and Barāqiš: preliminary report, in A. de Maigret et al. 1986, 461-464.

Marek, C.

1993 Die Expedition des Aelius Gallus nach Arabien im Jahre 25 v. Chr., Chiron. Mitteilungen der Kommission für Alte Geschichte und Epigraphik des Deutschen Archäologischen Instituts 23, 121-156.

1994 Der römische Inschriftenstein von Barāqiš, in N. Nebes (ed.) 1994, 178-190.

Marshall, F.

2007 African pastoral perspectives on domestication of the donkey: a first synthesis, in T.P. Denham, J. Iriarte and L. Vrydaghs (eds), Rethinking agriculture. Archaeological and ethnoarchaeological perspectives (One World Archaeology 51), 537-594. Walnut Creek (CA): Left Coast Press.

Marshall, F. and L. Weissbrod

2009 The consequences of women's use of donkeys for pastoral flexibility: Maasai ethnoarchaeology, in G. Grupe et al. (eds) 2009, 59-79.

Martin, C.

2005 The shell material from Suwayh I (Oman, Neolithic), in D.E. Bar-Yosef Mayer (ed.) 2005, 166-173.

Marzahn, J.

2008 Koldewey's Babylon, in I.L. Finkel and M.J. Seymour (eds), Babylon. Myth and reality, 46-53. London: The British Museum Press.

Mashkour, M. and K. Abdi

2002 The question of mobile pastoralist campsites in archaeology: the case of Tuwah Khoshkeh, in $\mathrm{H}$. Buitenhuis, A.M. Choyke, M. Mashkour and A.H. Al-Shiyab (eds), Archaeozoology of the Near East V. Proceedings of the fifth international symposium on the archaeozoology of southwestern Asia and adjacent areas (ARC-Publicaties 62), 211-227. Groningen: ARC-bv.

Mashkour, M. and M. Beech (eds)

2017 Archaeozoology of the Near East 9. In honour of HansPeter Uerpmann and François Poplin. 1-2. Oxford and Philadelphia: Oxbow Books.
Matthews, R.

2003b Traces of early complexity. Late fifth- to early fourth-millennia investigations: the Early Northern Uruk period, in R. Matthews (ed.) 2003a, 25-51.

2003c A chiefdom on the northern plains. Early thirdmillennium investigations: the Ninevite 5 period, in R. Matthews (ed.) 2003a, 97-191.

Matthews, R. (ed.)

2003a Excavations at Tell Brak. 4: Exploring an Upper Mesopotamian regional centre, 1994-1996 (McDonald Institute Monographs). London: British School of Archaeology in Iraq. Cambridge: McDonald Institute for Archaeological Research.

Matthews, W.

2017 Tells, in A.S. Gilbert (ed.) 2017, 951-972.

McCorriston, J. and Z. Johnson

1998 Agriculture and animal husbandry at Ziyadid Zabid, Yemen, Proceedings of the Seminar for Arabian Studies 28, 175-188. [Published 1999.]

McDonald, $\mathrm{H}$.

2003 Art and artefact: sealings from the HP ash dump, in R. Matthews (ed.) 2003a, 212-227.

McDonald, H. and N. Jackson

2003 A house on the hill. Second-millennium investigations: the Middle Bronze Age, in $\mathrm{R}$. Matthews (ed.) 2003a, 271-319.

McDonald, M.

1998 Early African pastoralism: view from Dakhleh Oasis (South Central Egypt), Journal of Anthropological Archaeology 17, 124-142.

Meadow, R.H. and H.-P. Uerpmann (eds)

1991 Equids in the ancient world. Volume 2 (Beihefte zum Tübinger Atlas des Vorderen Orients, series A, 19/2). Wiesbaden: Dr. Ludwig Reichert Verlag.

Meinertzhagen, Colonel R.

1954 Birds of Arabia. Edinburgh and London: Oliver and Boyd.

Middleton, N.J.

1989 Desert dust, in D.S.G. Thomas (ed.) 1989a, 262-283. Miller, N.F.

1999 Interpreting ancient environment and patterns of land use: seeds, charcoal and archaeological context, Tüba-Ar. Turkish Academy of Sciences Journal of Archaeology 2, 15-29.

2020 An idiosyncratic and not exhaustive bibliography for animal dung and archaeology. <http:// www. sas.upenn.edu/ nmillero/dung.html>, accessed 5 March 2020.

Miller, N.F. and T.L. Smart

1984 Intentional burning of dung as fuel: a mechanism for the incorporation of charred seeds into the archaeological record, Journal of Ethnobiology 4, 1528.

Mitchell, P.

2018 The donkey in human history. An archaeological perspective. Oxford: Oxford University Press. 
MNHN

2019 Muséum national d'Histoire naturelle, Paris, France. Collection Mollusques (IM). <http://science. mnhn.fr/institution/mnhn/collection/im/item/ search>, accessed 30 October 2019.

MolluscaBase

2019 MolluscaBase, R. Bank et al. (eds). Database hosted by the Flanders Marine Institute (VLIZ), Oostende. <http://www.molluscabase.org>, accessed 30 October 2019. [The taxa are accessible via AphiaID number.]

Monkhouse, F.J.

1974 A dictionary of geography. 2nd edition, reprinted with corrections. London: Edward Arnold.

Moorey, P.R.S.

1994 Ancient Mesopotamian materials and industries. The archaeological evidence. Oxford: Clarendon Press of Oxford University Press. New York: Oxford University Press.

Mortensen, $\mathrm{P}$.

1972 Seasonal camps and early villages in the Zagros, in P.J. Ucko, R. Tringham and W. Dimbleby (eds), Man, settlement and urbanism, 293-298. London: Gerald Duckworth \& Co.

Muchawsky-Schnapper, E.

2018 Yemeni stone vessels: a different perspective. The use and interpretation of stone vessels by the Jews of Yemen, in C.S. Phillips and St J. Simpson (eds) 2018a, 238-245.

Müller, W.W.

1982 Bemerkungen zu einigen von der YemenExpedition 1977 des Deutschen Archäologischen Instituts aufgenommenen Inschriften aus dem Raum Mārib und Barāqiš, in Archäologische Berichte aus dem Yemen 1, 129-134. Mainz am Rhein: Verlag Philipp von Zabern.

1988 Outline of the history of ancient Southern Arabia, in W. Daum (ed.) 1988, 49-54.

1997 Namen von Aromata im antiken Südarabien, in A. Avanzini (ed.) 1997, 193-210.

Multhoff, A.

2019 Merchant and marauder - The adventures of a Sabaean clansman, Arabian Archaeology and Epigraphy, 30 (2), 239-262.

Munsell 1994

Munsell soil color charts, 1994 revised ed., New Windsor, NY (Munsell ${ }^{\circledR}$ Color, Macbeth Division of Kollmorgen Instruments Corporation).

Murphy, M.A. and A. Salvador (eds)

1999 International Stratigraphic Guide [International Subcommission on Stratigraphic Classification of IUGS-International Commission on Stratigraphy]. An abridged edition, Episodes 22 (4), 255-271.

Murray, M.A.

2000 Fruits, vegetables, pulses and condiments, in P.T. Nicholson and I. Shaw (eds) 2000, 609-655.
Nadali, D.

2006 Esarhaddon's glazed bricks from Nimrud: the Egyptian campaign depicted, Iraq 68, 109-119.

Nāmī, Kh.Y. [Khalīl Yahyā]

1954 Nuqūš hirbat Barāqiš 'alā ḍaw' majmū'at Muhammad Tawfīq, Majallat kulliyat al-'Ā'āb 16, 1-21.

1955 Nuqūš hirbat Barāqiš 'alā daw' majmū'at Muhammad Tawfīq, Majallat kulliyat al'’̄̄dāb 17, 1-22.

1956 Nuqūš hirbat Barāqiš 'alā daw' majmū'at Muhammad Tawfīq, Majallat kulliyat al-'̄Adāb 18, 1-36.

1957 Nuqūš hirbat Barāqiě ‘alā daw' majmū'at Muhammad Tawfīq, Majallat kulliyat al-'Ādāb 19, 93-124.

Nappo, D.

2010 On the location of Leuke Kome, Journal of Roman Archaeology 23, 335-348.

Nebes, N.

1997 Karib’̂̂l Watâr, premier unificateur du Yémen, in Yémen 1997, 95-97.

2007 Ita'amar der Sabäer: zur Datierung der Monumentalinschrift des Yita'amar Watar aus Șirwāh, Arabian Archaeology and Epigraphy 18 (1), 25-33.

2016 Der Tatenbericht des Yata $a^{('}$ amar Watar bin Yakrubmalik aus Șirwāh. (Jemen).Zur Geschichte Südarabiens im frühen 1.Jahrtausend vor Christus. Mit einem archäologischen Beitrag von Iris Gerlach und Mike Schnelle (DAI, Orient-Abteilung, Epigraphische Forschungen auf der Arabischen Halbinsel 7). Tübingen and Berlin: Ernst Wasmuth Verlag.

Nebes, N. (ed.)

1994 Arabia Felix. Beiträge zur Sprache und Kultur des vorislamischen Arabien. Festschrift Walter W. Müller zum 60. Geburtstag. Wiesbaden: Harrassowitz Verlag. [Edited by N. Nebes with collaboration by R. Richter, I. Kottsieper, M. Maraqten.]

Nelson, K. and Associates

2002 Holocene settlement of the Egyptian Sahara. 2: The pottery of Nabta Playa. New York etc: Kluwer Academic/Plenum Publishers.

Nicholson, P.T. with E. Peltenburg

2000 Egyptian fayence, in P.T. Nicholson and I. Shaw (eds) 2000, 177-194.

Nicholson, P.T. and I. Shaw (eds)

2000 Ancient Egyptian materials and technology. Cambridge: Cambridge University Press. [5th printing 2009.]

Nickling, W.G. and C. McKenna Neuman

2009 Aeolian sediment transport, in A.J. Parsons and A.D. Abrahams (eds) 2009, 517-555.

Nunn, A.

1988 Die Wandmalerei und der glasierte Wandschmuck im alten Orient (Handbuch der Orientalistik, Part 7, Vol. 1, section 2, B6). Leiden, New York, Copenhagen, and Köln: E.J. Brill. 
Ochsenschlager, E.

1974 Mud objects from Al-Hiba. A study in ancient and modern technology, Archaeology 27 (3), 162-174.

Oliver, P.G.

1992 Bivalved seashells of the Red Sea. Wiesbaden: Verlag Christa Hemmen. Cardiff: National Museum of Wales.

1995 Bivalves (Bivalvia), in D.T. Bosch et al. 1995, 194281.

Oliver, P.G. and H.C.G. Chesney

1994 Taxonomy of Arabian bivalves. Part 1. Arcoidea, Journal of Conchology 35 (1), 17-31.

Oppenheim, A.L., R.H. Brill, D. Barag and A. von Saldern 1970 Glass and glassmaking in ancient Mesopotamia. New York: Corning Museum of Glass.

Overstreet, W.C. and M.J. Grolier

1988a Reconnaissance geology of the al-Jubah quadrangle, Y. A. R., in W.C. Overstreet et al. 1988a, 155-288.

1996 Summary of environmental background for the human occupation of the al-Jadidah basin in Wadi al-Jubah, Yemen Arab Republic, in M.J. Grolier et al. 1996, 337-438.

Overstreet, W.C., M.J. Grolier and M.R. Toplyn [and contributors]

1988a (D.M. Kinney and A.L. Dilonardo, volume eds) The Wadi al-Jubah Archaeological Project, 4. Geological and archaeological reconnaissance in the Yemen Arab Republic, 1985. Washington (DC): American Foundation for the Study of Man.

Overstreet, W.C., D.E. Detra, T. Botinelly, M.J. Grolier, D.B. Stoeser and D.L. Schmidt

1988b Mineral resources of the al-Jubah quadrangle, Yemen Arab Republic, in W.C. Overstreet et al. 1988a, 359-417.

Pachur, H.J.

1991 Tethering stones as palaeoenvironmental indicators, Sahara 4, 13-32.

Pagano, $\mathrm{P}$.

2010 Appendix. Funerary stelae and other objects from the Barāqish area (MAIRY collection), in Antonini and Agostini 2010a, 75-83.

Parker, A.G. and A.S. Goudie

2008 Geomorphological and palaeoenvironmental investigations in the southeastern Arabian Gulf region and the implication for the archaeology of the region, Geomorphology 101 (3), 458-470.

Parsons, A.J. and A.D. Abrahams (eds)

2009 Geomorphology of desert environments, 2nd edition. Berlin, Heidelberg, and New York: Springer Science+Business Media B.V.

Payne, S.

1991 Early Holocene equids from Tall-i-Mushki (Iran) and Can Hasan III (Turkey), in R.H. Meadow and H.P. Uerpmann (eds) 1991, 132-177.
Pevsner, N.

2016 Pevsner's architectural glossary, 2nd edition. Foreword by Simon Bradley. New Haven and London: Yale University Press. [No stated editor.]

Philby, H.St J.B.

1952 Arabian highlands (The Middle East Institute publications). Ithaca (NY): Cornell University Press.

Phillips, C. and St J. Simpson

2018b Introduction, in C.S. Phillips and St J. Simpson (eds) 2018a, 2-54.

2018c Ancient South Arabian softstone vessels in the British Museum, in C.S. Phillips and St J. Simpson (eds) 2018a, 167-179.

Phillips, C.S. and St J. Simpson (eds)

2018a Softstone. Approaches to the study of chlorite and calcite vessels in the Middle East and Central Asia from prehistory to the present (British Foundation for the Study of Arabia Monographs 20). Oxford: Archaeopress.

Phillips, W.G.

1955 Qataban and Sheba. Exploring the ancient kingdoms of the Biblical spice routes of Arabia. New York: Harcourt, Brace and Company. London: Victor Gollancz.

Piamenta, M.

1997 A dictionary of post-classical Arabic. 2. Leiden: E. J. Brill.

Pietruschka, U., M.P. Streck and B. Eschment (eds)

2010 Symbolische Repräsentation und Wirklichkeit nomadischen Lebens (Nomaden und Sesshafte 12). Wiesbaden: Dr. Ludwig Reichert Verlag.

Pietsch, D., P. Kühn, T. Scholten, U. Brunner, H. Hitgen and I. Gerlach

2010 Holocene soils and sediments around Ma'rib Oasis, Yemen: further Sabaean treasures?, The Holocene 20 (5), 785-799.

Pietsch, D., K. Schenk, S. Japp and M. Schnelle

2013 Standardised recording of sediments in the excavation of the Sabaean town of Sirwah, Yemen, Journal of Archaeological Science 40, 2430-2445.

Pirenne, J.

1956 Paléographie des inscriptions sud-arabes: contribution à la chronologie et à l'histoire de l'Arabie du sud antique. 1: Des origines jusqu'à l'époque himyarite. Brussel: Paleis der Academien.

1961 Le royaume sud-arabe de Qatabân et sa datation, d'après l'Archéologie et les sources classiques jusqu'au Périple de la mer Erythrée (Bibliothèque du Muséon 48). Louvain: Publications universitaires - Institut orientaliste.

Pollock, S. and R. Bernbeck (eds)

2005 Archaeologies of the Middle East. Critical perspectives (Blackwell Studies in Global archaeology 4). Oxford, Malden (MA), and Carlton (AU): Blackwell Publishing. [Republished in Wiley-Blackwell studies in global archaeology series, Wiley-Blackwell, Hoboken (NJ).] 
Porter, A.

2004 Amphora trade between South Arabia and East Africa in the first millennium BC: a re-examination of the evidence, Proceedings of the Seminar for Arabian Studies 34, 261-275.

2018 The distribution and provenance of ancient South Arabian steatite-tempered pottery: a thin-section analysis, in C.S. Phillips and St J. Simpson (eds) 2018a, 137-166.

Porter, A., R. Stacey and B. Derham

2009 The function of ceramic jar Type 4100: a preliminary organic residue analysis, Proceedings of the Seminar for Arabian Studies 39, 337-349.

Posey, S.

1994 Yemeni pottery: the Littlewood collection. London: British Museum Press.

Postgate, J.N.

2000 The Assyrian army in Zamua, Iraq 62, 89-108.

Potts, D.T.

1988 Trans-Arabian routes of the Pre-Islamic period, in J.-F. Salles (ed.), L'Arabie et ses mers bordières. 1. Itinéraires et voisinages. Séminaire de recherche 1985-1986 (Travaux de la Maison de l'Orient méditerranéen 16), 127-162. Lyon: GIS Maison de l'Orient et Presses Universitaires de Lyon.

1994 Augustus, Aelius Gallus and the Periplus: a reinterpretation of the coinage of San' $(\bar{a})$ Class B, in N. Nebes (ed.) 1994, 212-222.

1998 Some issues in the study of the pre-Islamic weaponry of southeastern Arabia, Arabian Archaeology and Epigraphy 9 (2), 182-208.

2001 Ostrich distribution and exploitation in the Arabian peninsula, Antiquity 75 (287), 182-190.

2003 The mukarrib and his beads: Karib'il Watar's Assyrian diplomacy in the early 7th century B.C., Isimu. Revista sobre Oriente Próximo y Egipto en la antigüedad 6 (Assur und sein Umland), 197-206.

2007 Babylonian sources of exotic raw materials, in G. Leick (ed.), The Babylonian world (The Routledge Worlds), 124-140. New York and London: Routledge. Potts, D.T. (ed.)

2012 A companion to the archaeology of the ancient Near East. 1-2. Chichester: Wiley-Blackwell.

Prat, F.

1966 Les Équidés, in R. Lavocat (ed.), Atlas de Préhistoire. 3: Faunes et flores préhistoriques de l'Europe occidentale (L'Homme et ses origines), 194-215. Paris: Éditions N. Boubée et Cie.

Prater, S.H.

1921 The Arabian ostrich, Journal of the Bombay Natural History Society 27, 602-605. [Republished 1923 in A survey of the fauna of Iraq etc., Bombay, Basra and Baghdad, London.]

Prioletta, A.

2012 Evidence from a new inscription regarding the goddess $\mathrm{t} t(\mathrm{t}) \mathrm{rm}$ and some remarks on the gender of deities in South Arabia, Proceedings of the Seminar for Arabian Studies 42, 309-318.
Pritchard, J.B.

1972 An incense burner from Tell es-Sacidiyeh, Jordan Valley, in J.W. Wevers and D.B. Redford (eds), Studies on the ancient Palestinian world, presented to Prof. F. V. Winnett, 3-17. Toronto: University of Toronto Press. Queen of Sheba

2002 Queen of Sheba. Treasures from ancient Yemen. London: The British Museum Press. [Exhibition catalogue: St J. Simpson, ed.]

Radies, D., F. Preusser, A. Matter and M. Mange

2004 Eustatic and climatic controls on the development of the Wahiba Sand Sea, Sultanate of Oman, Sedimentology 51, 1359-1385.

Rapp, G.R. and C.H. Hill

2006 Geoarchaeology. The earth-science approach to archaeological interpretation, 2nd edition. New Haven: Yale University Press.

Reade, J.E.

1972 The Neo-Assyrian court and army: evidence from the sculptures, Iraq 34, 87-112.

1979 Assyrian architectural decoration: techniques and subject-matter, Baghdader Mitteilungen 10, 17-49.

1987 Field observations of glass and glazed materials, in M. Bimson and I.C. Freestone (eds), Early vitreous materials (British Museum Occasional Papers 56), 31-38. London: The British Museum.

1995 The Khorsabad glazed bricks and their symbolism, in A. Caubet (ed.), Khorsabad. Le palais de Sargon II, roi d'Assyrie. Actes du colloque organisé au musée du Louvre par le Service culturel les 21 et 22 janvier 1994 (Louvre conférences et colloques), 225-251. Paris: La Documentation française.

2018 Ashurbanipal's palace at Niniveh, in G. Brereton (ed.) 2018, 20-33.

Regourd, A.

2013 Divination by dropping shells (wad') in Șan' $(\bar{a})$, Yemen, in Magic, Ritual, and Witchcraft 8 (2), 171-193. Regourd, A. and A. Julliard

2003 Le jet de coquillages divinatoire en Islam arabe et en Afrique subsaharienne: première contribution à une étude comparative, Journal of Oriental and African Studies 11 [2000-2002], 133-149.

Reid, I. and L.E. Frostick

1989 Channel form, flows and sediments in deserts, in D.S.G. Thomas (ed.) 1989a, 117-135.

Reimer, P.J., E. Bard, A. Bayliss, J.W. Beck, P.G. Blackwell, C. Bronk Ramsey, C.E. Buck, H. Cheng, R.L. Edwards, M. Friedrich, P.M. Grootes, T.P. Guilderson, H. Haflidason, I. Hajdas, C. Hatté, T.J. Heaton, D.L. Hoffmann, A.G. Hogg, K.A. Hughen, K.F. Kaiser, B. Kromer, S.W. Manning, M. Niu, R.W. Reimer, D.A. Richards, E.M. Scott, J.R. Southon, R.A. Staff, C.S.M. Turney and J. van der Plicht

2013 IntCal13 and Marine13 radiocarbon age calibration curves 0-50,000 years cal BP, Radiocarbon 55 (4), 1869-1887. [With online supplementary material, figs S1-S25.] 
Retsö, J.

2003 The Arabs in antiquity. Their history from the Assyrians to the Umayyads. Abingdon (Oxon.) and New York: RoutledgeCurzon.

Rhodokanakis, $\mathrm{N}$.

1927 Altsabäische Texte I (Sitzungsberichte der Akademie der Wissenschaften in Wien, PhilosophischHistorische Klasse 206, 2. Abhandlung). Wien and Leipzig: Hölder-Pichler-Tempsky.

Ribechini, E. and M.P. Colombini

2008 Chemical investigation of the resinous material from Sumhuram, in A. Avanzini (ed.) 2008, 687-688.

Ridout-Sharpe, J.

2015 Changing lifestyles in the northern Levant: Late Epipalaeolithic and early Neolithic shells from Tell Abu Hureyra, in D.E. Bar-Yosef Mayer and L. Kolska Horwitz (eds) 2015, 102-116.

2017 Shell ornaments, icons and other artefacts from the eastern Mediterranean and Levant, in M.J. Allen (ed.), Molluscs in archaeology: methods, approaches and applications (Studying Scientific Archaeology 3), 290-307. Oxford and Philadelphia: Oxbow Books.

Riemer, H., F. Förster, M. Herb and N. Pöllath (eds)

2009 Desert animals in the eastern Sahara: status, economic significance, and cultural reflection in antiquity (Colloquium Africanum 4). Köln: Heinrich-BarthInstitut e.V.

Roaf , M.

1989 Social organization and social activities at Tell Madhhur, in E.F. Henrickson and I. Thuesen (eds) 1989, 91-146.

Robin, C.J.

1979a Mission archéologique et épigraphique française au Yémen du Nord en automne 1978, Académie des Inscriptions et Belles-Lettres, Comptes rendus des séances de l'année 1979123 (2), 174-202.

1979b À propos des inscriptions in situ de Barāqish, l'antique Yțl (Nord-Yémen), Proceedings of the Seminar for Arabian Studies 9, 102-112.

1984 La cité et l'organisation sociale à Ma'īn: l'exemple de YTL (aujourd'hui Barāqish), in A.M. 'Abdallāh, S. al-Sakkar and R. Mortel (eds), Studies in the History of Arabia. II: Pre-Islamic Arabia, 157-162 [general ed. 'A.R.T. al-Anșārī]. Riyaḍ: King Saud University Press. [Arabic summary, 163-164, uncorrected.]

1987 Trois inscriptions sabéennes découvertes près de Barāqish (République Arabe du Yémen), Proceedings of the Seminar for Arabian Studies 17, 165-177.

1988 Quelques observations sur la date de construction et la chronologie de la 1ère digue de Marib d'après les inscriptions, Proceedings of the Seminar for Arabian Studies 18, 95-113.

1991c Quelques épisodes marquants de l'histoire sudarabique, in C. Robin (ed.) 1991a, 55-70.

1991d La pénétration des Arabes nomades au Yémen, in C. Robin (ed.) 1991a, 71-88.

1992 Inabba', Haram, al-Kāfir, Kamna et al-Harāshif (Inventaire des inscriptions sudarabiques 1). Paris:
Académie des inscriptions et belles-lettres. Rome: Istituto Italiano per il Medio ed Estremo Oriente. [Distribution: Diffusion de Boccard, Paris; Herder, Rome.]

1994 Les plantes aromatiques que brûlaient les Sabéens, Saba. Art - littérature - histoire - Arabie Méridionale 1 (Parfums d'Arabie), 25-31, 81 [bibliography].

1996a Les premiers États du Jawf et la civilisation sudarabique, in C. J. Robin et I. Gajda (eds) 1996, 49-65.

1996b Sheba. II. Dans les inscriptions d'Arabie du Sud, in J. Brend, E. Cothenet, H. Cazelles and A. Feuillet (eds), Supplément au Dictionnaire de la Bible. Fasc. 70: Sexualité-Sichem, cols 1047-1254. Paris: Letouzey.

1997a Le mythe de l' 'Arabie heureuse', in Y. Calvet et. al. 1997, 42-47.

1998 La fin du royaume de Ma'in, in R. Gyselen and F. Aubaile-Sallenave [et al.] (assembled by), Parfums d'Orient (Res Orientales 11), 177-188. Bures-surYvette: Groupe pour l'Étude de la Civilisation du Moyen-Orient. Leuven: Peeters.

2010a L'Antiquité, in A.I. al-Ghabban et al. (eds) 2010, 80-99.

2012 Matériaux pour une typologie des divinités arabiques et de leurs représentations, in I. Sachet and C.J. Robin (eds) 2012, 7-118.

2016b Tamna' et Qatabān: l'état des lieux. [I-IV], in A. de Maigret and C.J. Robin (eds) 2016, 21-97.

2019a À propos de l'armement des troupes himyarites $\mathrm{au} \mathrm{VI}^{\mathrm{e}}$ siècle de l'ère chrétienne, in J.-F. Breton and $\mathrm{F}$. Villeneuve (eds) 2019, 145-173.

2019b Les silences d'Aelius Gallus. L'hypothèse d'une brève occupation romaine et nabatéenne du royaume de Saba', in A.V. Sedov and E.A. Rezvan (eds), Ex Oriente lux. Collected papers to mark the 75th anniversary of Mikhail Borisovich Piotrovsky, 234-262. Saint Petersburg: The State Hermitage Publishers. Robin, C. (ed.) ['sous la responsabilité de']

1991a L'Arabie antique de Karib'îl à Mahomet. Nouvelles données sur l'histoire des Arabes grâce aux inscriptions, Revue du Monde musulman et de la Méditerranée 61 (3), 9-166.

Robin, C.J. and A. de Maigret

1994 Yathill, appelée aujourd'hui Barâqish, Saba. Art - littérature - histoire - Arabie Méridionale 1 (Parfums d'Arabie), 46-60, 62-69. [Contains Marcolongo 1994, q.v.]

2009 Le royaume sudarabique de Ma'în: nouvelles données grâce aux fouilles italiennes de Barâqish (l'antique Yathill). With a 'Note complémentaire sur la guerre entre la Chaldée et l'Ionie' by S. Anthonioz, Académie des Inscriptions et Belles-Lettres, Comptes rendus des séances de l'année 2009153 (1), 57-96. [Reprinted in de Maigret 2012, article XV.]

Robin, C.J. and I. Gajda (eds)

1996 Arabia antiqua. Early origins of South Arabian states. Proceedings of the First international conference on the Conservation and exploitation of the archaeological 
heritage of the Arabian Peninsula held in the Palazzo Brancaccio, Rome, by IsMEO on 28th-30th May 1991 (Serie Orientale Roma 70, 1). Rome: Istituto per il Medio ed Estremo Oriente.

Robin, C.J., S. Antonini et F. Bron

2007 Nouveautés épigraphiques, Arabia. Revue de sabéologie 3, 273-280.

Robin C., J.-F Breton and J. Ryckmans

1981 Le sanctuaire minéen de Nkrh à Darb aș-Ṣabī (environs de Barāqish). Rapport préliminaire (première partie), Raydān. Journal of Ancient Yemeni Antiquities and Epigraphy 4, 249-262.

Robin, C.J., J. Ryckmans and J.-F. Breton

1988 Le sanctuaire minéen de Nkrh à Darb aș-Ṣabī (environs de Barāqish). Rapport préliminaire (seconde partie). Étude des inscriptions, Raydān. Journal of Ancient Yemeni Antiquities and Epigraphy 5, 91-159.

Roller, D.W.

2014 The Geography of Strabo. An English translation, with introduction and notes. Cambridge: Cambridge University Press.

2015 Ancient geography. The discovery of the world in classical Greece and Rome. London and New York: I.B. Tauris \& Co.

Romer, J.

2016 A history of ancient Egypt. 2: From the Great Pyramid to the fall of the Middle Kingdom. London: Allen Lane (Penguin Books).

Rosen, A.M.

1986 Cities of clay. The geoarcheology of tells. Chicago and London: The University of Chicago Press.

Rosen, S.A.

1992 Nomads in archaeology: a response to Finkelstein and Perevolotsky, Bulletin of the American Schools of Oriental Research 287, 75-85.

1993 A Roman period pastoral tent camp in the Negev, Israel, Journal of Field Archaeology 20, 441-451.

2003 Early multi-resource nomadism: excavations at the Camel site in the central Negev, Antiquity 77 (298), 750-761.

2011 An investigation into early desert pastoralism. Excavations at the Camel Site, Negev (Monograph 69). Los Angeles: Cotsen Institute of Archaeology.

Rosen, S.A. and B.A. Saidel

2010 The camel and the tent: an exploration of technological change among early pastoralists, Journal of Near Eastern Studies 69 (1), 63-77.

Rosen, S.A., A.B. Savinetsky, Y. Plakht, N.K. Kisseleva, B.F. Khassanov, A.M. Pereladov and M. Haiman

2005 Dung in the desert: preliminary results of the Negev Holocene Ecology Project, Current Anthropology 46 (2), 317-327.

Rothenberg, B.

2003 Egyptian chariots, Midianites from Hijaz/Midian (Northwest Arabia) and Amalekites from the Negev in the Timna Mines. Rock drawings in the Ancient Copper Mines of the Arabah - new aspects of the region's history II, iams - Institute for ArchaeoMetallurgical Studies 23, 9-14.

Rothenberg, B. and J. Glass

1983 The Midianite pottery, in J.F.A. Sawyer and D.J.A. Clines (eds), Midian, Moab and Edom. The history and archaeology of Late Bronze and Iron Age Jordan and North-west Arabia (Journal for the Study of the old Testament Supplement series 24), 65-124. Sheffield: JSOT Press.

Russell, J.M.

1991 Sennacherib's palace without a rival at Nineveh. Chicago: The University of Chicago Press.

Ryckmans, J.

1963 De quelque divinités sud-arabes, Ephemerides Theologicae Lovanienses 39, 463.

1989 Le panthéon de l'Arabie du sud préislamique: état des problèmes et brève synthèse, Revue de l'histoire des religions 206 (2), 151-169.

Saggs, H.W.F.

1963 Assyrian warfare in the Sargonid period, Iraq 25, 145-154.

Saidel, B.A.

2009 Pitching camp: ethnoarchaeological investigations of inhabited tent camps in the Wadi Hisma, Jordan, in J. Szuchman (ed.) 2009, 87-104.

Saied, A.S., J. Gebauer, K. Hammer and A. Buerkert

2008 Ziziphus spina-christi (L.) Willd.: a multipurpose fruit tree, Genetic Resources and Crop Evolution 55, 929-937.

Sauer, J.A., A.O. Ghaleb and S. al-Hakimi

1996 Interview with Sheik al-Bahrî of Jubah al-Jadidah, Yemen Arab Republic, in M.J. Grolier et al. 1996, 9-12. Sauvage, M.

2001 Fortifications, in F. Joannès and C. Michel (eds) 2001, 338-341.

Schiettecatte, J.

2006b L'évolution de l'armature urbaine en Arabie du Sud: la vallée du Jawf du VIII e siècle av. au VI siècle apr. J.-C., M@ppemonde 84 (4), 1-17. Online <http:// mappemonde-archive.mgm.fr/num12/articles/ art06404.html>, accessed 20 May 2018.

2010a L'Arabie à la veille de l'islam, L'Archéo-Théma 9, 46-49.

2010b Why did the cities of the Jawf valley collapse? An archaeogeographical approach, in H. Alarashi, M.-L. Chambrade, S. Gondet, A. Jouvenel, C. Sauvage and H. Tronchère (eds), Regards croisés sur l'étude archéologique des paysages anciens. Nouvelles recherches dans le Bassin méditerranéen, en Asie Centrale et au Proche et au Moyen-Orient (Travaux de la Maison de l'Orient 56), 149-161. Lyon: Maison de l'Orient et de la Méditerranée Jean Pouilloux.

2011 D'Aden à Zafar. Villes d'Arabie du Sud préislamique (Orient \& Méditerranée / Archéologie 6). Paris: Éditions de Boccard.

Schiettecatte, J. (ed.)

2019a Barāqish, in DASI. <http://dasi.cnr.it/index. php? id=dasi_prj_ sit\&prjId $=1 \&$ corId $=0 \quad \&$ colId $=0 \&$ 
navId=143714431 \&recId=243>, accessed 1 December 2019.

Schiffer, M.B.

1996 Formation processes of the archaeological record. Salt Lake City: University of Utah Press. [Originally published 1987, Albuquerque: University of New Mexico Press.]

Schnelle, M.

2016 Sirwah-The urban topography of a Sabaean town. Paper presented at the 20th Rencontres Sabéennes, held at Auditorium Santa Cecilia, Perugia, 9-11 June 2016.

Schoch, R.M.

1989 Stratigraphy. Principles and methods. New York: Van Nostrand Reinhold.

Schönig, $\mathrm{H}$.

1998 Vielfältige Nutzung des cilb-Baumes. Ein Nachtrag, Jemen-Report 29 (1-2), 22-23.

Scoging, $\mathrm{H}$.

1989 Runoff generation and sediment mobilisation by water, in D.S.G. Thomas (ed.) 1989a, 87-116.

Seger, J.D.

1996b The point one principle: a case study from the Halif Terrace, in J.D. Seger (ed.) 1996a, 245-268.

Seger, J.D. (ed.)

1996a Retrieving the past. Essays on archaeological research and methodology in honor of Gus W. Van Beek. Winona Lake (IN): Eisenbrauns [for Cobb Institute of Archaeology, Mississippi State University].

Sekunda, N. and S. Chew

1992 The Persian army 560-330 BC. London: Osprey Publishing. [S. Chew, illustrator.]

Serjeant, R.B.

1976 South Arabian hunt. London: Luzac \& Company. Serpico, M.

2000 Resins, amber and bitumen (with a contribution by Raymond White), in P.T. Nicholson and I. Shaw (eds) 2000, 430-474.

Shahack-Gross, R.

2011 Herbivorous livestock dung: formation, taphonomy, methods for identification, and archaeological significance, Journal of Archaeological Science 38, 205-218.

Shahack-Gross, R., A. Simons and S.H. Ambrose

2008 Identification of pastoral sites using stable nitrogen and carbon isotopes from bulk sediment samples: a case study in modern and archaeological pastoral settlements in Kenya, Journal of Archaeological Science 35 (4), 983-990.

Shahīd, I.

1984 Byzantium and the Arabs in the fourth century

(Dumbarton Oaks Monographs). Washington (DC):

Dumbarton Oaks. [Paperback ed. 2018.]

Shea, J.J.

2013 Stone tools in the Paleolithic and Neolitic Near East. A guide. Cambridge: Cambridge University Press.
Shea, M.O'D.

1980 The small cuboid incense-burners of the Near East in the first millennium $\mathrm{BC}$, Bulletin of the Institute of Archaeology 17, 130. [In 'Summaries of M.A. and M.Sc. reports for $1978 / 79$ '.]

1983 The small cuboid incense-burner of the ancient Near East, Levant. The Journal of the Council for British Research in the Levant 15 (1), 76-109.

1987 A small cube-shaped incense-burner from Tell Fara in southern Palestine, University of London Institute of Archaeology Bulletin 23 (1986), 161-169.

Sholan, A.M. ['Amīda Shu'lān], S. Antonini and M. Arbach (eds)

2009 Sabaean studies. Archaeological, epigraphical and historical studies in honour of Yūsuf M. 'Abdalläh, Alessandro de Maigret and Christian J. Robin on the occasion of their sixtieth birthdays (Orient \& Méditerranée 4). Paris: De Boccard. [Originally published Naples and Șan' $(\bar{a}), 2005$.]

Sidebotham, S.E.

1986a Aelius Gallus and Arabia, Latomus 45 (3), 590-602. 1986b Roman economic policy in the Erythra Thalassa, 30 B.C.-A.D. 217 (Mnemosyne, Bibliotheca Classica Batava, suppl. 91). Leiden: E.J. Brill.

Sima, A.

2000 Tiere, Pflanzen, Steine und Metalle in den altsüdarabischen Inschriften. Eine lexikalische und realienkundliche Untersuchungen (Akademie der Wissenschaften und der Literatur (Mainz), Veröffentlichungen der Orientalischen Kommission 46). Wiesbaden: Harrassowitz Verlag.

Simon, R.

2002 Aelius Gallus' campaign and the Arab trade in the Augustan age, Acta Orientalia Academiae Scientiarum Hungaricae 55 (4), 309-318.

Simpson, I.A., P.F. van Bergen, V. Perret, M.M. Elhmmali, D.J. Roberts and R.P. Evershed

1999 Lipid biomarkers of manuring practice in relict anthropogenic soils, The Holocene 9 (2), 223-229.

Simpson, St J.

2018 'Of cooking pots let him choose those made of stone': the manufacture, circulation and function of chlorite cooking pots and other objects in the Middle East and Central Asia during the Sasanian and medieval periods, in C.S. Phillips and St J. Simpson (eds) 2018a, 180-206.

Skibo, J.M. and M.B. Schiffer

1987 The effects of water on processes of ceramic abrasion, Journal of Archaeological Science 14, 83-96.

Skibo, J.M., T.C. Butts and M.B. Schiffer

1997 Ceramic surface treatment and abrasion resistance: an experimental study, Journal of Archaeological Science 24, 311-317.

Skibo, J.M., M.B. Schiffer and K.C. Reid

1989 Organic-tempered pottery: an experimental study, American Antiquity 54 (1), 122-146. 
Sørensen, S.L. et K. Geus

2019 A Sabaean eyewitness to the war of Euagoras against the Persians. Synchronising Greek and ancient South Arabian sources, Zeitschrift für Papyrologie und Epigraphik 209, 196-204.

Speidel, M. A.

2015 'Almaqah in Rom? Zu den Beziehungen zwischen dem kaiserzeitlichen Imperium Romanum und Südarabien im Spiegel der dokumentarischen Überlieferung, Zeitschrift für Papyrologie und Epigraphik 194, 241-258.

Spengler, R.N., III

2019 Dung burning in the archaeobotanical record of West Asia: where are we now?, Vegetation History and Archaeobotany 28, 215-227.

Stark, F.

1936 The southern gates of Arabia. A journey in the Hadhramaut. London: John Murray. New York: E.P. Dutton \& Co.

Steadman, S.R.

2000 Spatial patterning and social complexity on prehistoric Near Eastern 'tell' sites: models for mounds, Journal of Anthropological Archaeology 19, 164-199.

2005 Reliquaries on the landscape: mounds as matrices of human cognition, in S. Pollock and R. Bernbeck (eds) 2005, 286-307.

Steele, C., H. McDonald, R Matthews and J. Black

2003 Impact of empire. Later third-millennium investigations: the late Early Dynastic and Akkadian periods, in R. Matthews (ed.) 2003a, 193-269.

Stein, J. K.

1987 Deposits for archaeologists, in M.B. Schiffer (ed.), Advances in archaeological method and theory 11, 337395. London: Academic Press.

2001 Archaeological sediments in cultural environments, in J.K. Stein and W.R. Farrand (eds) 2001, 1-28.

Stein, J.K. and V.T. Holliday

2017 Archaeological stratigraphy, in A.S. Gilbert (ed.) 2017, 33-39.

Stein, J.K. and W.R. Farrand (eds)

2001 Sediments in archaeological context. Salt Lake City: University of Utah Press.

Stein, J.K., J.N. Deo and L.S. Phillips

2003 Big sites/short time: accumulation rates in archaeological sites, Journal of Archaeological Science 30, 297-316.

Stout, M.E.

1977 Clay sling-bullets from Tell Sweyhat, Levant. The Journal of the Council for British Research in the Levant 9, 63-65.

Stow, D.A.V.

2005 Sedimentary rocks in the field. A colour guide. London: Manson Publishing. [Second impression 2006.]
Strabo

1930 (trans. H.L. Jones) Geography, Books 15-16 (Loeb Classical Library, Strabo 7). Cambridge (MA) and London: Harvard University Press. [Reprinted 2000.] Sweet, L.E.

1965 Camel pastoralism in north Arabia and the minimal camping unit, in A. Leeds and A.P. Vayda (eds), Man, culture, and animals. The role of animals in human ecological adjustments (AAAS Publication 78), 129-152. Washington (DC): American Association for the Advancement of Science.

Szabó, K.A.

2005 Technique and practice: shell-working in the western Pacific and island Southeast Asia. Unpublished $\mathrm{PhD}$ dissertation, The Australian National University, Canberra.

Szabó, K., C. Dupont, V. Dimitrijević, L. Gómez Gastélum and N. Serrand (eds)

2016 Archaeomalacology. Shells in the archaeological record (BAR International Series 2666). Oxford: BAR Publishing. [Originally published 2014.]

Szuchman, J. (ed.)

2009 Nomads, tribes, and the state in the ancient Near East. Cross-disciplinary perspectives (Oriental Institute Seminars 5). Chicago: The Oriental Institute of the University of Chicago.

Tebes, J.M.

2014 The symbolic and social world of the Qurayyah pottery iconography, in J.M. Tebes (ed.), Unearthing the wilderness. Studies on the history and archaeology of the Negev and Edom in the Iron Age (Ancient Near Eastern Studies supplement 45), 163-202. Leuven: Peeters Publishers.

Thomas, D.S.G.

1989b Reconstructing ancient arid environments, in D.S.G. Thomas (ed.) 1989a, 311-334.

Thomas, D.S.G. (ed.)

1989a Arid zone geomorphology. London: Belhaven Press (Pinter Publishers). New York and Toronto: Halsted Press (John Wiley \& Sons).

2011 Arid zone geomorphology. Process, form and change in drylands, 3rd edition. Chichester: John Wiley \& Sons.

Thoms, A.V.

2017 Burned-rock features, in A.S. Gilbert (ed.) 2017, 89-94.

Tiede, L. J.

1987 Miscellaneous objects, in W.D. Glanzman and A.O. Ghaleb 1987a, 149-156.

Tobi, Y.

2005 An unknown study by Joseph Halévy on his journey to Yemen, Proceedings of the Seminar for Arabian Studies 35, 287-292.

Toplyn, M.R.

1985 Faunal evidence, in J.A. Blakely et al. 1985, 127-128.

Tsuneki, A. and Y. Miyake (eds)

1998 Excavations at Tell Umm Qseir in middle Khabur Valley, North Syria. Report of the 1996 season. Tsukuba: University of Tsukuba. 
Uerpmann, H.-P.

1991 Equus africanus in Arabia, in R.H. Meadow and H-P.

Uerpmann (eds) 1991, 12-33.

Uerpmann, H.-P. and M. Uerpmann

2002 The appearance of the domestic camel in southeast Arabia, The Journal of Oman Studies 12, 235-260.

Uerpmann, M. and H.-P. Uerpmann

2017 The Iron Age site of Muweilah (Sharjah, UAE) and the problems of dromedary domestication, in $\mathrm{M}$. Mashkour and M. Beech (eds) 2017, 312-319.

Urbańczyk, P. (ed.)

1995 Theory and practice of archaeological research. 2: Acquisition of field data at multi-strata sites. Warsaw: Institute of Archaeology and Ethnology, Polish Academy of Sciences.

Van Beek, G.W.

1958 Marginally drafted, pecked masonry, in R.LeB. Bowen, Jr and F.P. Albright [and contributors] 1958, 287-299.

1969 Hajar Bin Humeid. Investigations at a Pre-Islamic site in South Arabia (Publications of the American Foundation for the Study of Man 5). Baltimore (MD): The Johns Hopkins Press.

van Geel, B., J. van der Plicht, M.R. Kilian, E.R. Klaver, J.H.M. Kouwenberg, H. Renssen, I. Reynaud-Farrera and H.T. Waterbolk

1998 The sharp rise of $\Delta{ }^{14} \mathrm{C} c a .800 \mathrm{cal} \mathrm{BC}$ : possible causes, related climatic teleconnections and the impact on human environments, Radiocarbon 40 (1) (Proceedings of the 16 th Intl ${ }^{14} \mathrm{C}$ Conference), 535550. [W.G. Mook and J. van der Plicht, issue eds.]

van Lemmen, $\mathrm{H}$.

20135000 years of tiles. London: The British Museum Press.

van Rampelbergh M., D. Fleitmann, S. Verheyden, H. Cheng, L. Edwards, P. De Geest, D. De Vleeschouwer, S.J. Burns, A. Matter, P. Claeys and E. Keppens

2013 Mid- to late Holocene Indian Ocean Monsoon variability recorded in four speleothems from Socotra Island, Yemen, Quaternary Science Reviews 65, 129-142.

Vermeij, G.J.

1993 A natural history of shells. Princeton (NJ) and Chichester: Princeton University Press.

Verskin, A.

2018a A vision of Yemen. The travels of a European orientalist and his native guide. A translation of Hayyim Habshush's travelogue. Stanford (CA): Stanford University Press.

Viljoen, R., M. Viljoen and C. Anhaeusser (eds)

2016 Africa's top geological sites. 35th International Geological Congress commemorative volume. Cape Town: Penguin Random House South Africa.

Villeneuve F., C. Phillips and W. Facey

2002 Une inscription latine de l'archipel Farasān (sud de la mer Rouge) et son contexte archéologique et historique, Arabia. Revue de sabéologie 2, 143-192, 229-232. von den Driesch, A.

1976 A guide to the measurement of animal bones from archaeological sites as developed by the Institut für Palaeoanatomie, Domestikationsforschung und Geschichte der Tiermedizin of the University of Munich (Peabody Museum Bulletin 1). Cambridge (MA): Peabody Museum of Archaeology and Ethnology, Harvard University. [6th printing, with Addenda, 2004.]

2001 Eine Aufsammlung von Tierknochen aus einer pharaonischen Bergwerk-Station auf dem Gebel Zeit am Roten Meer, in H. Buitenhuis and W. Prummel (eds), Animals and man in the past. Essays in honour of Dr. A. T. Clason Emeritus Professor of Archaeozoology Rijksuniversiteit Groningen, The Netherlands (ARCPublicatie 41), 346-356. Groningen: ARC/ Archaeological Research and Consultancy.

von Müller, D.H.

1896a Athlula, in Paulys Realencyclopädie der classischen Altertumswissenschaft. 2 (2), col. 2065. Stuttgart: J.B. Metzler'sche Verlagsbuchhandlung.

1896b Athrula, in Paulys Realencyclopädie der classischen Altertumswissenschaft. 2(2), col. 2071-2072. Stuttgart: J.B. Metzler'sche Verlagsbuchhandlung.

von Wissmann, $\mathrm{H}$.

1968 Zur Archäologie und antiken Geographie von Südarabien. Hadramaut, Qatabān und das 'Aden-Gebiet in der Antike (Uitgaven van het Nederlands HistorischArchaeologisch Instituut te İstanbul 24). Istanbul: Nederlands Historisch-Archaeologisch Instituut in het Nabije Oosten.

1976 Die Geschichte des Sabäerreichs und der Feldzug des Ælius Gallus, in H. Temporini (ed.), Aufstieg und Niedergang der römischen Welt. Geschichte und Kultur Roms im Spiegel der neueren Forschung. 2: Principat, 9, Part 1, 308-544. Berlin and New York: de Gruyter.

Wallace, M. and M. Charles

2013 What goes in does not always come out: the impact of the ruminant digestive system of sheep on plant material, and its importance for the interpretation of dung-derived archaeobotanical assemblages, Environmental Archaeology 18, 18-30.

Watkin, D.

2011 A history of western architecture, 5th edition. London: Laurence King Publishing.

Watson, A.

1989 Desert crusts and rock varnish, in D.S.G. Thomas (ed.) 1989a, 25-55.

Weir, S.

2018 The contemporary softstone industry in Jabal Rāzih, north-west Yemen, in C.S. Phillips and St J. Simpson (eds) 2018a, 246-251.

Wendrich, $\mathrm{W}$.

2008 From objects to agents: the Ababda nomads and the interpretation of the past, in H. Barnard and W. Wendrich (eds) 2008, 509-542. 
Wiegels, R.

2015 Fern von Germanien. Römische Grenzpolitik in Ägypten und Arabien zu Beginn der Herrschaft des Augustus, in G.A. Lehmann and R. Wiegels (eds), 'Über die Alpen und über den Rhein...': Beiträge zu den Anfängen und zum Verlauf der römischen Expansion nach Mitteleuropa (Abhandlungen der Akademie der Wissenschaften zu Göttingen, Neue Folge 37), 9-67. Berlin and Boston: De Gruyter Akademie Forschung. Wikipedia

2019a Cowrie-shell divination. <https://en.wikipedia. org/wiki/Cowrie-shell_divination> (last edited 11.9. 2019), accessed 30 October 2019.

Wilkens, B.

2005 The use of marine shells at Sumhuram, Oman, in D.E. Bar-Yosef Mayer (ed.) 2005, 159-165.

Wilkinson, T.J., B.H. Monahan and D.J. Tucker

1996 Khanijdal East: a small Ubaid site in northern Iraq, Iraq 58, 17-50.

Wilson, R.T.

1984 The camel. London: Longman International Education/Longman Group. New York: AddisonWesley Longman.

Winnett, F.V.

1939 The place of the Mineans in the History of preIslamic Arabia, Bulletin of the American School of Oriental Research 73, 3-9. (February)

Winter, I.J.

2002 Defining 'aesthetics' for non-western studies: the case of ancient Mesopotamia, in M.A. Holly and K. Moxey (eds), Art history, aesthetics, visual studies (Clark Studies in the Visual Arts), 3-28. New Haven and London: Yale University Press.

WMSDB: see Galli 2014-2019.

Wood, J.R.I.

1997 A handbook of the Yemen flora. Kew: Royal Botanic Gardens.

Woolley, Sir L. [C.L.]

1962 Ur excavations. 9: The Neo-Babylonian and Persian periods. With a contribution by Professor M.E.L. Mallowan (Publications of the Joint Expedition of the British Museum and of the University Museum, University of Pennsylvania, Philadelphia, to Mesopotamia). London: The Trustees of the British Museum and the University Museum, University of Pennsylvania.

WoRMS [WoRMS Editorial Board]

2019 World register of marine species. Database hosted by the Flanders Marine Institute (VLIZ), Oostende. <http://www.marinespecies.org>, accessed 30 October 2019. [Taxa are accessible via AphiaID number.]

Wright, G.R.H.

1987 Some preliminary observations on the masonry work at Mārib, in Archäologische Berichte aus dem Yemen 4, 63-78. Mainz am Rhein: Verlag Philipp von Zabern.
Yang, B.

2019 Cowrie shells and cowrie money. A global history (Routledge approaches to history). Abingdon (Oxon.) and New York: Routledge.

Yāqūt, Mu'jam al-buldān, 1

Yāqūt ibn 'Abd Allāh al-Hamawī. Jacut's geographisches Wörterbuch, aus den Handschriften zu Berlin, St. Petersburg und Paris. Erster Band I-ث. Edited by Ferdinand Wüstenfeld. Vol. 3. Leipzig : Brockhaus, 1866.

Yekutieli, Y.

2009 The Har Hemar site: a northern outpost on the desert margin?, Tel Aviv 36 (2), 218-240.

Yemen

2000 Yemen. Nel paese della regina di Saba. Milan: Skira.

[Exhibition catalogue: Rome, Palazzo Ruspoli, Fondazione Memmo, 6 April-30 June 2000.]

Yémen

1997 Yémen, au pays de la reine de Saba'. Exposition présentée à l'Institut du monde arabe du 25 octobre 1997 au 28 février 1998. Paris: Flammarion. [Exhibition catalogue: C.J. Robin and B. Vogt, scientific coordinators.]

Yon, M.

1981 Dictionnaire illustré multilingue de la céramique du Proche-Orient ancien (Collection de la Maison de l'Orient Méditerranéen 10, série archéologique 7). Lyons: Maison de l'Orient.

Zaitseva, G.I., K.V. Chugunov, V.A. Dergachev, A. Nagler, G. Parzinger, E.M. Scott, A.A. Sementsov, S. Vasiliev, B. van Geel, J. van der Plicht and L.M. Lebedeva

2004 Chronological studies of the Arzhan-2 Scythian monument in Tuva (Russia), Radiocarbon 46 (1), 277284.

al-Zahranī al-Subali, A.A., Sa’ad al-Mishari and Abdulaziz al-Nafisa

2001 Preliminary report on the excavations of alUkhdoud, Najran. Second Season 1417 A.H., Atlal. The Journal of Saudi Arabian Archaeology 16, 13-21 (English), 13-35 (Arabic).

al-Zahranī al-Subali, A.A., Sa’ad al-Mishari and Abdulaziz al-Yahya

2005 Al-Ukhdoud excavation (Najran). 4th Season 1422 A.H./2003 A.C., Atlal. The Journal of Saudi Arabian Archaeology 18, 11-17 (English), 11-33 (Arabic).

Zarins, J.

1978 Steatite vessels in the Riyadh Museum, Atlal. The Journal of Saudi Arabian Archaeology 2, 65-93.

1989 Pastoralism in southwest Asia: the second millennium $\mathrm{BC}$, in J. Clutton-Brock (ed.), The walking larder. Patterns of domestication, pastoralism, and predation (One World Archaeology 2), 127-155. London: Unwin Hyman.

Zarins, J., 'A.R. Kabawi ['Abdul Rahman Kabawi], 'A.J.S. Murad ['Abdul Jawad S. Murad] and S. Rashad

1983 Preliminary report on the Najrān/Ukhdūd survey and excavations 1982/1402 AH, Atlal. The Journal of Saudi Arabian Archaeology 7, 22-40. 
Zayadine, F.

1995 Cosmetic techniques: a historical and botanical approach, in Kh. 'Amr, F. Zayadine and M. Zaghloul (eds), Studies in the history and archaeology of Jordan. 5: Art and technology throughout the ages, 67-75. Amman: Department of Antiquities of Jordan.

Ziegler, L.

1942 Tonkästchen aus Uruk, Babylon und Assur, Zeitschrift für Assyriologie und Vorderasiatische Archäologie 47 (3), 224-240.

Zimmerle, W.G.

2014a Aromatics of all kinds: cuboid incense burners in the ancient Near East from the late third to the late first millennia BC. PhD dissertation, University of Pennsylvania. [Published 2015, UMI no. 3671000, Ann Arbor (MI): ProQuest LLC.]

2014b Ethnographic light on the form, function, and decoration of 'Arabian-style' cuboid incense burners from first-millennium BC Nippur, Proceedings of the Seminar for Arabian Studies 44, 337-351.

Zohary, M.

1972 Flora Palaestina. Part Two: Platanaceae to Umbelliferae. Jerusalem: The Israel Academy of Science and Humanities.

Zuschin, M. and P.G. Oliver

2003 Bivalves and bivalve habitats in the northern Red Sea. The northern Bay of Safaga (Red Sea, Egypt): an actuopalaeontological approach. 6: Bivalvia. Wien: Naturhistorisches Museum Wien.

Zuschin, M., M. Stachowitsch and R.J. Stanton, Jr 2003 Patterns and processes of shell fragmentation in modern and ancient marine environments, Earth Science Reviews 63, 33-82. 